\title{
Hanford Double-Shell Tank Thermal and Seismic Project - Seismic Analysis in support of Increased Liquid Level in 241-AP Tank Farms
}

\author{
Author: TC Mackey \\ WRPS \\ Richland, WA 99352 \\ U.S. Department of Energy Contract DE-AC27-08RV14800 \\ $\begin{array}{lrl}\text { EDT/ECN: } & \text { ECN-725882-R0 } & \text { UC: } \\ \text { Cost Center: } & & \text { Charge Code: } \\ \text { B\&R Code: } & & \text { Total Pages: } 784\end{array}$
}

Key Words: DST, Double-Shell Tanks, dynamic response, waste elastic properties, increased fluid level, sludge level, DST comments

Abstract: The essential difference between Revision 1 and the original issue of this report is in the spring constants used to model the anchor bolt response for the anchor bolts that tie the steel dome of the primary tank to the concrete tank dome. Consequently, focus was placed on the changes in the anchor bolt responses, and a full reevaluation of alltank components was judged to be unnecessary. To confirm this judgment, primary tank stresses from the revised analysis of the BES-BEC case are compared to the original analysis and it was verified thatthe changes are small, as expected. .

TRADEMARK DISCLAIMER. Reference herein to any specific commercial product, process, or service by trade name, trademark, manufacturer, or otherwise, does not necessarily constitute or imply its endorsement, recommendation, or favoring by the United States Government or any agency thereof or its contractors or subcontractors.

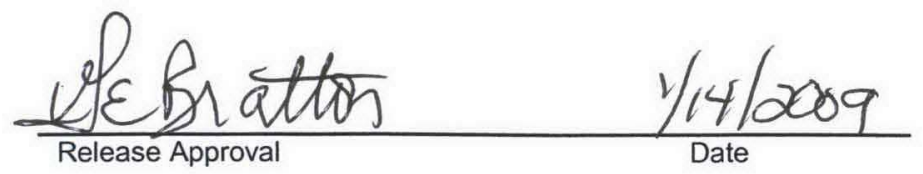

Approved For Public Release

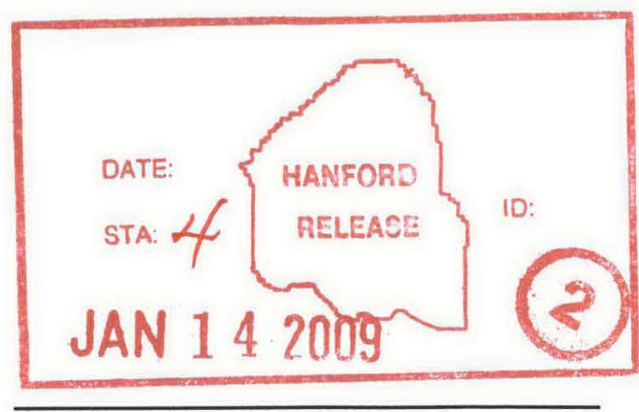

Release Stamp 


\begin{tabular}{|c|c|c|c|}
\hline \multicolumn{2}{|r|}{$\begin{array}{l}\text { Tank Farm Contractor (TFC) } \\
\text { RECORD OF REVISION }\end{array}$} & $\begin{array}{l}\text { (1) Document Number: } \\
\text { RPP-RPT-32239 }\end{array}$ & Page 1 \\
\hline \multicolumn{4}{|l|}{$\begin{array}{l}\text { (2) Title: } \\
\text { Seismic }\end{array}$} \\
\hline \multicolumn{4}{|c|}{ Change Control Record } \\
\hline \multirow{2}{*}{$\begin{array}{c}(3) \\
\text { Revision }\end{array}$} & \multirow{2}{*}{ (4) Description of Change - Replace, Add, and Delete Pages } & \multicolumn{2}{|c|}{ Authorized for Release } \\
\hline & & (5) Resp. Engr. (print/sign/date) & (6) Resp. Mgr. (print/sign/date) \\
\hline 1 RS & Incorporate ECN 725882 Rev. 0 & T.C. Mackey & $\begin{array}{l}\text { D.J. Washenfelder } \\
\text { Dg washenfelde } \\
0,108109\end{array}$ \\
\hline
\end{tabular}




\section{Pacific Northwest} National Laboratory

Operated by Battelle for the U.S. Department of Energy

\section{Hanford Double-Shell Tank Thermal and Seismic Project - Seismic Analysis in Support of Increased Liquid Level in 241-AP Tank Farms}

F. G. Abatt

M. W. Rinker

January 2008

Prepared for

CH2M HILL Hanford Group, Inc.

in Support of the

Double-Shell Tank Integrity Program

Sponsored by the U.S. Department of Energy under Contract DE-AC05-76RL01830 


\title{
DISCLAIMER
}

This report was prepared as an account of work sponsored by an agency of the United States Government. Neither the United States Government nor any agency thereof, nor Battelle Memorial Institute, nor any of their employees, makes any warranty, express or implied, or assumes any legal liability or responsibility for the accuracy, completeness, or usefulness of any information, apparatus, product, or process disclosed, or represents that its use would not infringe privately owned rights. Reference herein to any specific commercial product, process, or service by trade name, trademark, manufacturer, or otherwise does not necessarily constitute or imply its endorsement, recommendation, or favoring by the United States Government or any agency thereof, or Battelle Memorial Institute. The views and opinions of authors expressed herein do not necessarily state or reflect those of the United States Government or any agency thereof.

\author{
PACIFIC NORTHWEST NATIONAL LABORATORY \\ operated by \\ BATTELLE \\ for the \\ UNITED STATES DEPARTMENT OF ENERGY \\ under Contract DE-AC05-76RL01830
}

This document was printed on recycled paper. 


\title{
Hanford Double-Shell Tank Thermal and Seismic Project - Seismic Analysis in Support of Increased Liquid Level in 241-AP Tank Farms
}

\author{
F. G. Abatt ${ }^{(\mathrm{a})}$
}

M. W. Rinker

January 2008

Prepared for

CH2M HILL Hanford Group, Inc.

in Support of the Double-Shell Tank Integrity Program

Pacific Northwest National Laboratory

Richland, Washington 99352

(a) M\&D Professional Services, Richland, Washington. 
RPP-RPT-32239, Rev. 1

M\&D-2008-005-CALC-001, Rev. 1

Intentionally left blank. 


\title{
Seismic Analysis in Support of Increased Liquid Level in 241-AP Tank Farm

\author{
F.G. Abatt
}

January 2008

\author{
Prepared by \\ M\&D Professional Services, Inc. \\ for \\ Pacific Northwest National Laboratory
}
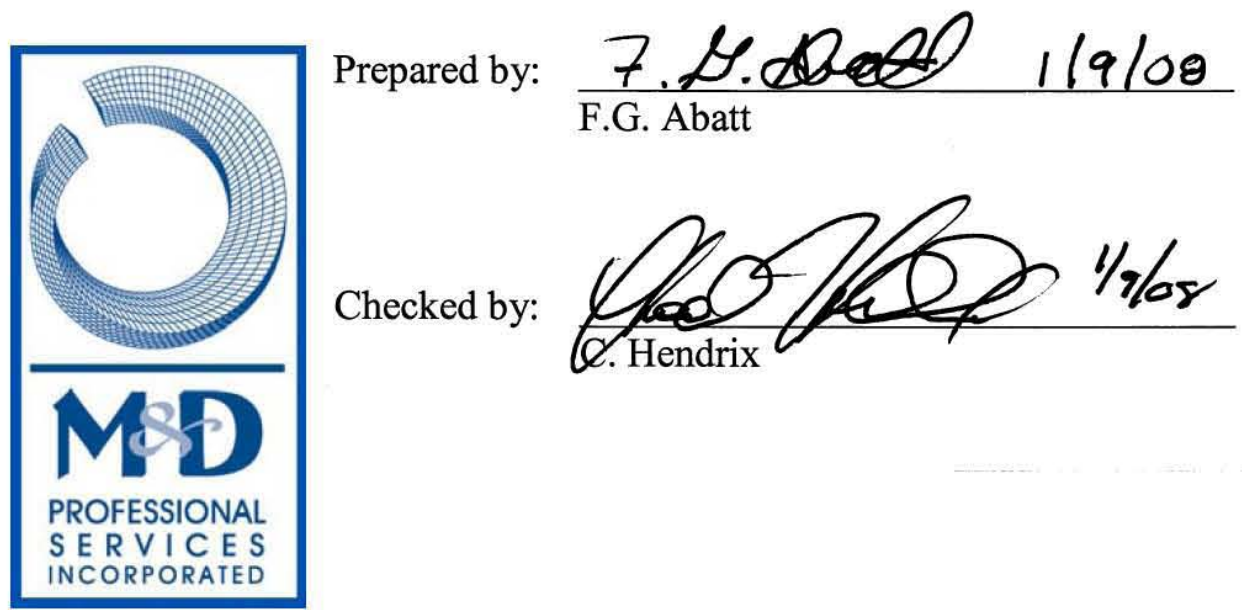
RPP-RPT-32239, Rev. 1

M\&D-2008-005-CALC-001, Rev. 1

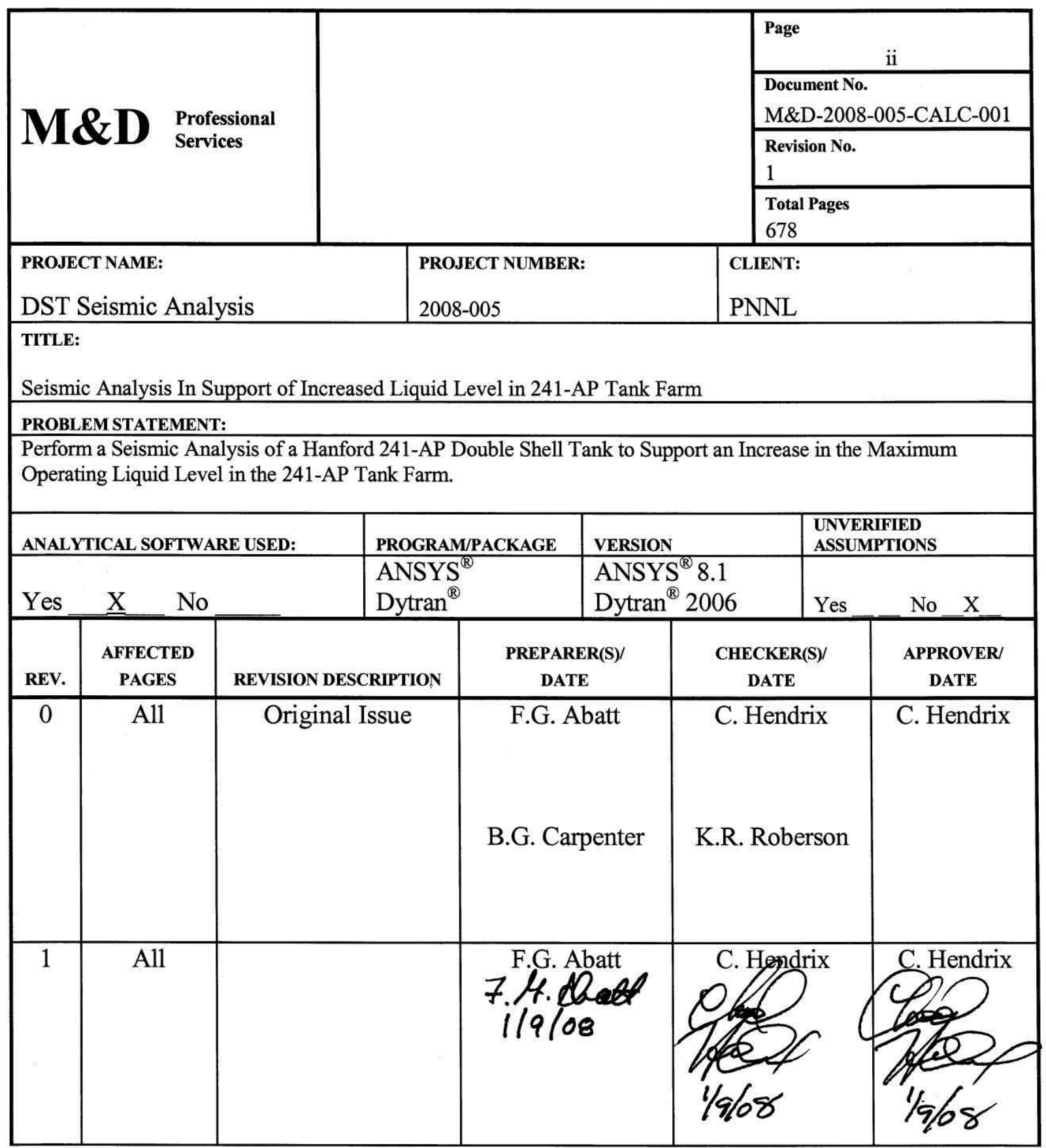




\section{RPP-RPT-32239, Rev. 1 \\ M\&D-2008-005-CALC-001, Rev. 1}

\section{Executive Summary}

The work presented in this report is an extension of the baseline seismic analysis documented in Deibler et al. (2007a) and Rinker et al. (2006c). The baseline analysis was for a bounding generic tank configuration based on the 241-AY tanks having a bulk waste specific gravity of 1.7 and a waste level of 422 inches. In this analysis, the bulk specific gravity and waste level were increased to 1.83 and 460 inches, respectively. The previously developed models were used with minor modifications to represent the 241-AP tanks. Earlier studies documented in Rinker and Abatt (2006a, 2006b) and Rinker et al. (2006a, 2006b) provide the justification for the basic models and analysis techniques.

The fundamental difference between this analysis and the baseline liquid level analysis reported in Deibler et al. (2007a) and Rinker et al. (2006c) is increased interaction between the liquid waste and the tank dome (i.e., more complex sloshing response). To address the more complex fluid-structure interaction analysis at the increased liquid level, sub-models of the primary tank were created in both Dytran ${ }^{\circledR}$ and $\mathrm{ANSYS}^{\circledR 1}$ and the results were compared. The Dytran ${ }^{\otimes 2}$ sub-model analysis served as an alternate calculation for evaluating the stresses in the primary tank due to fluid-structure interaction. However, the seismic evaluation of all tank components was based directly on the results of the global ANSYS ${ }^{\circledR}$ model, just as in the baseline seismic analysis.

In the concrete shell, the ANSYS ${ }^{\circledR}$ global model showed that forces and moments are generally highest for the lower bound soil load case. Due to the higher relative stiffness of the tank as compared to the soil for the lower bound soil, loads are transmitted through the stiffer path. The lowest forces and moments are generally found in the fully cracked concrete case. In this case, the concrete is much more compliant and the load path is retained through the soil.

In the primary tank, the highest stresses occur for the upper bound soil case near the middle of the primary tank wall. The lowest stresses in the primary tank occur for the lower bound soil case. Primary tank stresses correlate well to the free-field soil response at the bottom of the double-shell tank ( $57 \mathrm{ft}$ below grade). The free-field soil seismic response at the level of the bottom of the tank shows a pronounced drop in the lower bound soil for frequencies corresponding to the impulsive natural frequency of the tank/fluid system.

The primary tank sub-model study showed that the stresses in the primary tank are very similar for the $\operatorname{Dytran}^{\circledR}$ and ANSYS $^{\circledR}$ sub-models except near the liquid-free surface, which was the expected result based on earlier studies. Some differences also existed in the knuckle region of the primary tank, but these were at least partly due to a configurational difference between the two models in the knuckle region.

Agreement between the ANSYS ${ }^{\circledR}$ and Dytran ${ }^{\circledR}$ sub-models occurs in the majority of the tank because the total stresses are dominated by gravity loading, which should be captured sufficiently by either model, and the seismic stresses are dominated by the impulsive response, which is adequately captured by either model. Although the ANSYS ${ }^{\circledR}$ model is deficient in its ability to properly simulate the convective effects of the contained liquid, this convective response is not a major contributor to the demands on the primary

\footnotetext{
${ }^{1}$ ANSYS $^{\circledR}$ is a registered trademark of ANSYS, Inc., Canonsburg, Pennsylvania.

${ }^{2} \operatorname{Dytran}^{\circledR}$ is a registered trademark of MSC.Software Corporation, Santa Ana, California.
} 
RPP-RPT-32239, Rev. 1

M\&D-2008-005-CALC-001, Rev. 1

tank. Moreover, ANSYS $^{\circledR}$ tends to overpredict the stress magnitudes near the free surface, so the results are conservative relative to the more accurate Dytran ${ }^{\circledR}$ solution. Given the available stress margins in the primary tank, it was acceptable to use the seismic demands from the global ANSYS ${ }^{\circledR}$ model for the ASME code evaluation of the 241-AP primary tank reported in Deibler et al. (2008).

The essential difference between Revision 1 and the original issue of this report is in the spring constants used to model the anchor bolt response for the anchor bolts that tie the steel dome of the primary tank to the concrete tank dome. In the original report (Revision 0 ), the nominal values of the anchor bolt shear and axial stiffness were $139,000 \mathrm{lbf} / \mathrm{in}$. and $189,800 \mathrm{lbf} / \mathrm{in}$., respectively. In the current revision, the stiffnesses have been reduced to $65,000 \mathrm{lbf} / \mathrm{in}$. for both shear and axial response. The motivation for modifying the anchor bolt properties and the development of the new values is discussed in Appendix B of Deibler et al. (2008).

The four seismic cases of best-estimate soil, best-estimate concrete (BES-BEC), lower-bound soil, bestestimate concrete (LBS-BEC), upper-bound soil, best-estimate concrete (UBS-BEC), and best-estimate soil, fully cracked concrete (BES-FCC) were rerun using the modified anchor bolt response. Because the significant change to the models consisted of reducing the anchor bolt stiffnesses, the significant effects on the response of the overall tank model are expected to be limited local changes. That is, the forces and displacements of the anchor bolts are expected to change, but the differences in the response of the other tank components such as the primary tanks stresses, secondary liner strains, and concrete tank forces and moments are expected to be small.

Consequently, focus was placed on the changes in the anchor bolt responses, and a full reevaluation of all tank components was judged to be unnecessary. To confirm this judgment, primary tank stresses from the revised analysis of the BES-BEC case are compared to the original analysis and it was verified that the changes are small, as expected. 
RPP-RPT-32239, Rev. 1

M\&D-2008-005-CALC-001, Rev. 1

\section{Acronyms and Abbreviations}

$\begin{array}{ll}\text { B } & \text { Bulk Modulus } \\ \text { BEC } & \text { Best-Estimate Concrete } \\ \text { BES } & \text { Best-Estimate Soil } \\ \text { BNL } & \text { Brookhaven National Laboratory } \\ \text { DST } & \text { Double-Shell Tank } \\ \text { E } & \text { Elastic Modulus } \\ \text { FCC } & \text { Fully Cracked Concrete } \\ \text { G } & \text { Shear Modulus } \\ \text { g } & \text { Acceleration of Gravity } \\ \text { Hz } & \text { Hertz (cycles per second) } \\ \text { LBS } & \text { Lower Bound Soil } \\ \text { M\&D } & \text { M\&D Professional Services, Inc } \\ \text { PNNL } & \text { Pacific Northwest National Laboratory } \\ \text { psi } & \text { Pound per Square Inch } \\ \text { SRSS } & \text { Square Root of the Sum of the Squares } \\ \text { SSI } & \text { Soil Structure Interaction } \\ \text { TOLA } & \text { Thermal and Operating Loads Analysis } \\ \text { UBS } & \text { Upper Bound Soil } \\ \phi & \text { Soil Internal Angle of Friction } \\ \rho & \text { Mass Density } \\ v & \text { Poisson's Ratio } \\ \sigma & \text { Stress }\end{array}$


RPP-RPT-32239, Rev. 1

M\&D-2008-005-CALC-001, Rev. 1

Intentionally left blank. 
RPP-RPT-32239, Rev. 1

M\&D-2008-005-CALC-001, Rev. 1

\section{Contents}

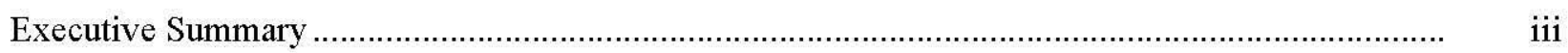

Acronyms and Abbreviations ..........................................................................................

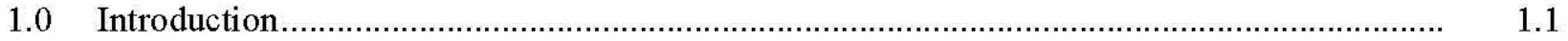

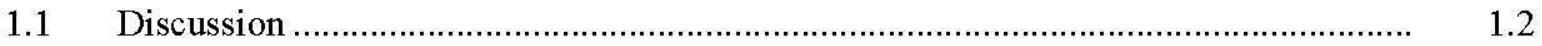

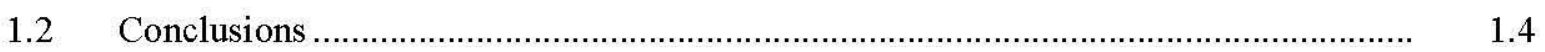

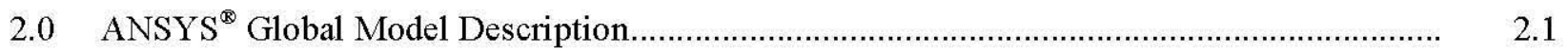

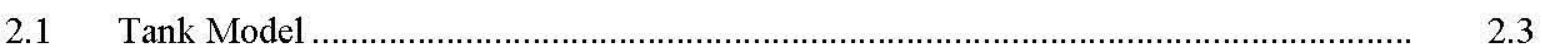

2.1.1 Concrete Shell .................................................................................... $\quad 2.3$

2.1.2 Primary Tank ................................................................................. 2.10

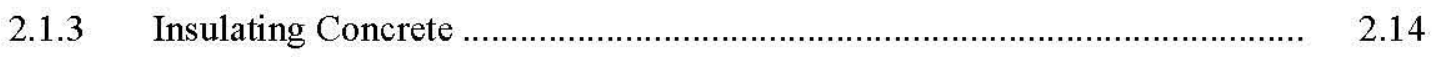

2.1.4 Anchor Bolts .............................................................................. $\quad 2.14$

2.1.5 Secondary Liner ............................................................................... 2.16

2.1.6 Waste...................................................................................... 2.17

2.1.7 Primary Tank and Concrete Dome Interface ............................................. $\quad 2.19$

2.1.8 Primary Tank/Insulating Concrete Interface ........................................... 2.20

2.1.9 Insulating Concrete/Secondary Liner Interface..................................... 2.20

2.1.10 Interface Between Concrete Shell and Soil ............................................... $\quad 2.21$

2.1.11 Interface Between Excavated Soil and Native Soil.................................... 2.23

2.1.12 Interface Between Primary Tank and Waste............................................. 2.23

2.1.13 Interface Between Concrete Wall and Tank Footing .................................. 2.24

2.1.14 Surface Loads ....................................................................................... 2.25

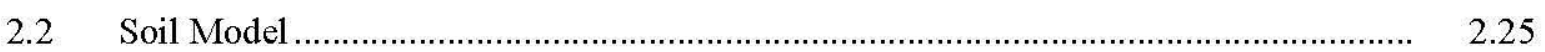

2.2.1 Soil Properties ............................................................................... 2.25

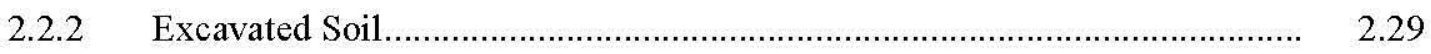

2.2.3 Native Soil................................................................................ $\quad 2.30$

$2.3 \quad$ Boundary Conditions...................................................................................... 2.31

2.3.1 Soil Boundary Conditions .................................................................. 2.31

2.3.2 Tank Boundary Conditions ............................................................ 2.34

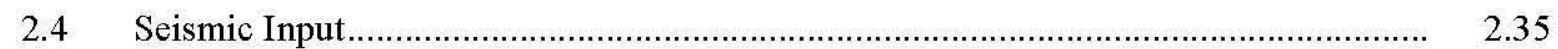

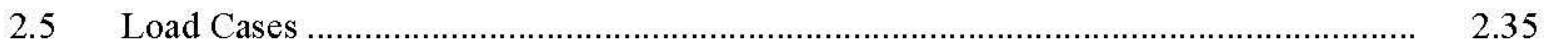

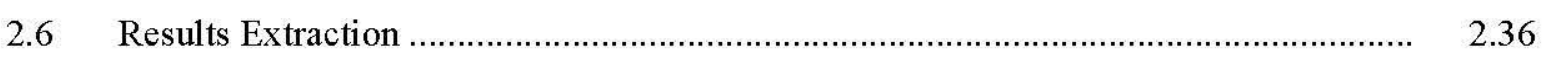

3.0 Dytran ${ }^{\circledR}$ Primary Tank Sub-Model Description ............................................................... 3.1

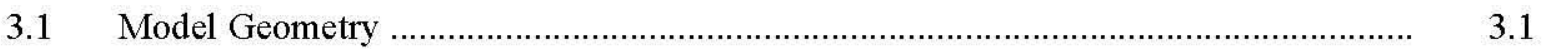

3.2 Material Properties and Element Types ............................................................ 3.9

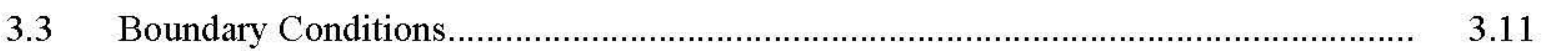

3.4 Initial Conditions ....................................................................................... 
RPP-RPT-32239, Rev. 1

M\&D-2008-005-CALC-001, Rev. 1

3.5 Seismic Input.

3.6 Differences from Earlier Dytran ${ }^{\circledR}$ Models.

4.0 Results from Dytran ${ }^{\circledR}$ Primary Tank Sub-Models.

4.1 Characterization of Damping in Dytran ${ }^{\circledR}$ Sub-Model ............................................. 4.1

4.2 Hydrodynamic Forces from Dytran ${ }^{\circledR}$ Sub-Model.................................................... 4.2

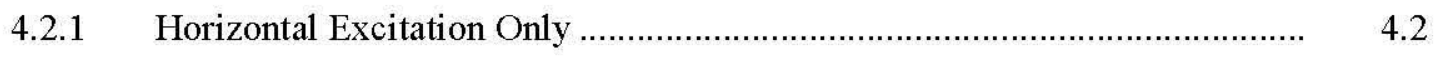

4.2.2 Vertical Excitation Only ................................................................... 4.4

4.2.3 Two-Component Motion .......................................................................... 4.4

4.3 Waste Pressures from Dytran ${ }^{\circledR}$ Sub-Model ........................................................... 4.6

4.3.1 Horizontal Excitation Only ................................................................ 4.7

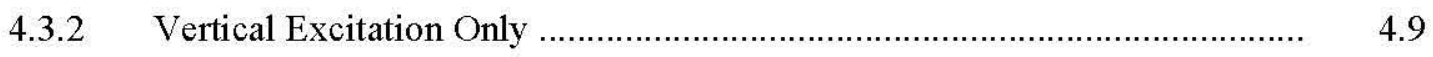

4.3.3 Two-Component Motion ..................................................................... 4.11

4.4 Maximum Slosh Height Results from Dytran ${ }^{\circledR}$ Sub-Model .................................... 4.13

4.5 Primary Tank Stresses from Dytran ${ }^{\circledR}$ Sub-Model ................................................. 4.13

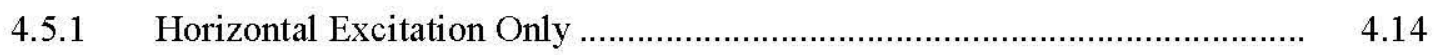

4.5.2 Vertical Excitation ....................................................................... 4.18

4.5.3 Two-Component Motion........................................................................ $\quad 4.20$

$5.0 \quad$ ANSYS $^{\circledR}$ Primary Tank Sub-Model Description ......................................................... 5.1

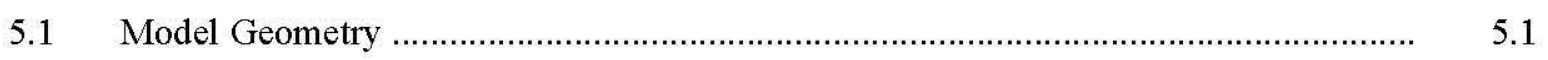

5.2 Damping Characterization and Frequency Tuning with the Dytran ${ }^{\circledR}$ Model ............... $\quad 5.4$

6.0 Results from ANSYS ${ }^{\circledR}$ Primary Tank Sub-Models.............................................................

6.1 Hydrodynamic Forces from ANSYS ${ }^{\circledR}$ Sub-Model............................................... $\quad 6.1$

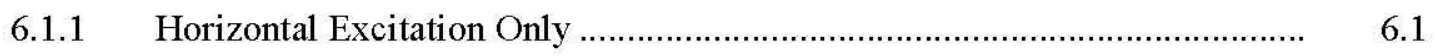

6.1.2 Vertical Excitation Only ………........................................................ 6.2

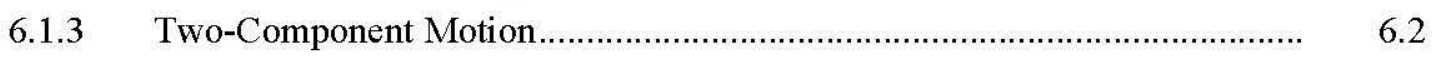

6.2 Waste Pressures from ANSYS ${ }^{\circledR}$ Sub-Model .............................................................. $\quad 6.4$

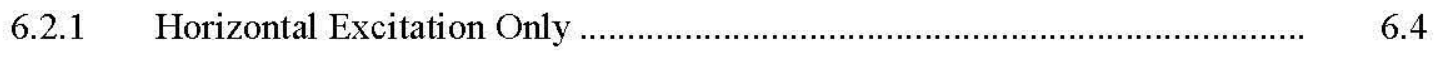

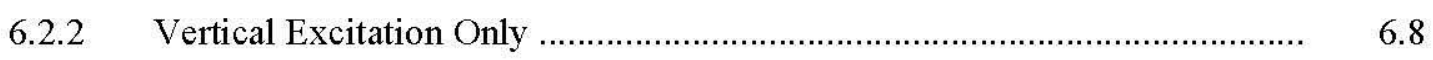

6.2.3 Two-Component Motion..................................................................... $\quad 6.10$

6.3 Primary Tank Stresses from ANSYS ${ }^{\circledR}$ Sub-Model ….......................................... $\quad 6.14$

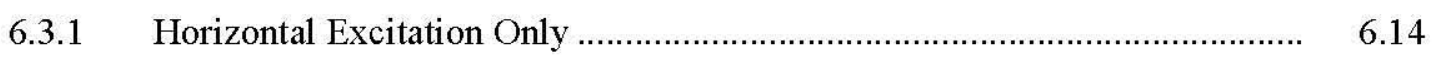

6.3.2 Vertical Excitation Only ............................................................... 6.18

6.3.3 Two-Component Motion .................................................................... $\quad 6.20$

7.0 ANSYS $^{\circledR}$ to Dytran ${ }^{\circledR}$ Comparisons for Primary Tank Sub-Models ..................................... 7.1

$7.1 \quad$ Frequency Comparisons ...............................................................................

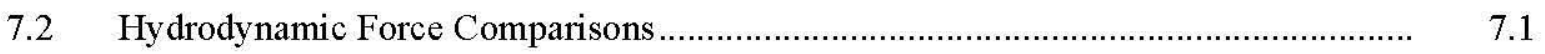

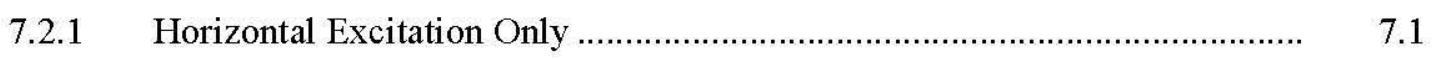

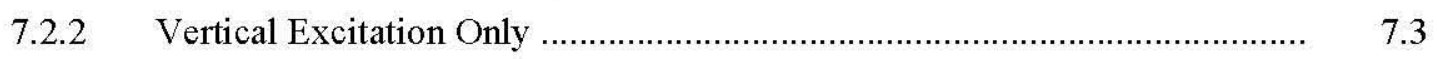

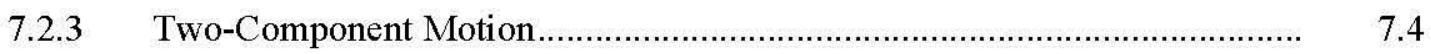


RPP-RPT-32239, Rev. 1

M\&D-2008-005-CALC-001, Rev. 1

7.3 Waste Pressure Comparisons ………...................................................................

$7.4 \quad$ Stress Comparisons .......................................................................................

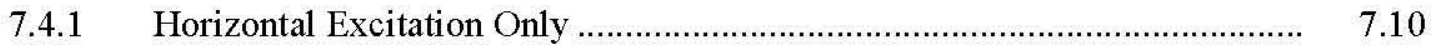

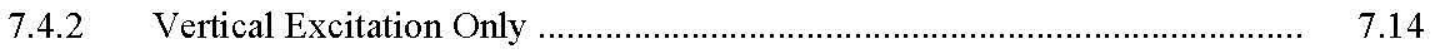

7.4.3 Two-Component Motion...................................................................... $\quad 7.16$

7.4.4 Two-Component Motion Comparisons for Various Models ......................... $\quad 7.20$

7.5 Uncertainties Associated with Waste Characterization.............................................. $\quad 7.22$

8.0 $\quad$ ANSYS $^{\circledR}$ Global Model Free-Field Spectra ................................................................

$8.1 \quad$ Lower Bound Soil, Best-Estimate Concrete...............................................................

8.2 Best-Estimate Soil, Best-Estimate Concrete …................................................... $\quad 8.4$

8.3 Upper Bound Soil, Best-Estimate Concrete _......................................................... $\quad 8.6$

8.4 Best-Estimate Soil, Fully Cracked Concrete ........................................................... $\quad 8.8$

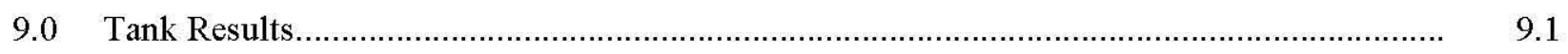

9.1 Concrete Shell Results for Revision 0 Model ....................................................... 9.1

9.2 Primary Tank Results for Revision 0 Model ......................................................... 9.11

9.3 Comparison of Primary Tank Stresses Between the Revision 0 and Revision 1

Models for the BES-BEC Case ............................................................................... 9.19

9.4 Anchor Bolt Results for the Revision 1 Model ..................................................... 9.24

9.5 Comparison of Anchor Bolt Results Between the Revision 0 and Revision 1 Models for the BES-BEC Case ......................................................................... $\quad 9.30$

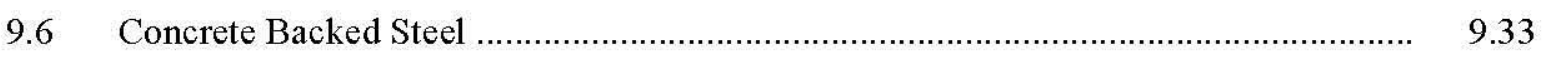

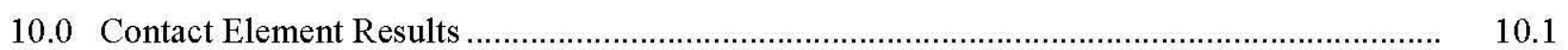

10.1 Concrete Footing Contact Results for the Revision 0 Model .................................... 10.1

10.2 Soil Contact Results for the Revision 0 Model ..................................................... 10.11

10.3 Dome Contact Results for the Revision 1 Model ................................................... 10.22

10.4 Primary Tank/Insulating Concrete Contact Results for the Revision 0 Model ............ 10.28

10.5 Insulating Concrete/Secondary Liner Contact Results from the Revision 0 Model...... 10.35

11.0 Waste Results from the Revision 0 Model................................................................. 11.1

$11.1 \quad$ Lower Bound Soil ................................................................................................... 11.3

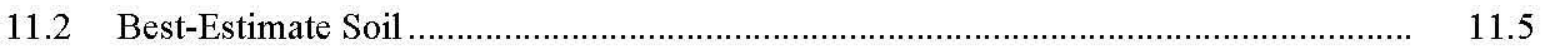

$11.3 \quad$ Upper Bound Soil ...................................................................................... 11.7

11.4 Best-Estimate Soil, Fully Cracked Concrete ........................................................... 11.9

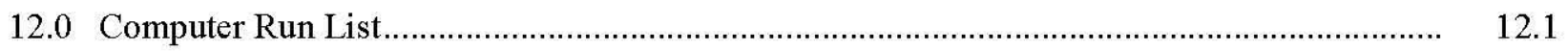

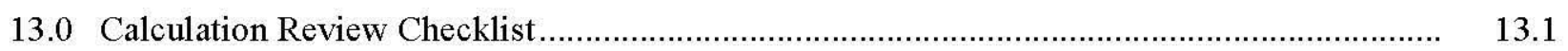

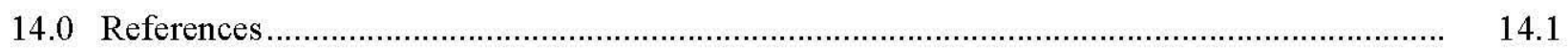

Appendix A - Dytran ${ }^{\circledR}$ Input Files for Primary Tank Sub-Models................................................ A. A

Appendix B - Stress Time History Plots for Dytran ${ }^{\circledR}$ Primary Tank Sub-Models .......................... B. B

Appendix C - Common ANSYS ${ }^{\circledR}$ Sub-Model Files Listing ......................................................... C.1

Appendix D - Sub-Model Best-Estimate Soil Best-Estimate Concrete Results File Listing ............ D.1 
RPP-RPT-32239, Rev. 1

M\&D-2008-005-CALC-001, Rev. 1

Appendix E - Common ANSYS ${ }^{\circledR}$ Files Listing

E.1

Appendix F - Lower Bound Soil, Best-Estimate Concrete Results Load Case Specific Input

Files File Listing

Appendix G - Best-Estimate Soil, Best-Estimate Concrete Results Load Case Specific Input Files File Listing.

Appendix H - Upper Bound Soil, Best-Estimate Concrete Results Load Case Specific Input Files File Listing

Appendix I - Best-Estimate Soil, Fully Cracked Concrete Results Load Case Specific Input Files File Listing. 
RPP-RPT-32239, Rev. 1

M\&D-2008-005-CALC-001, Rev. 1

Figures

2-1 Composite Tank Model Detail ........................................................................................

2-2 241-AP Primary Tank Dimensions ..................................................................................... 2.2

2-3 Concrete Shell Profile Including Shell Thickness ........................................................... 2.9

2-4 Concrete Shell Model Detail..................................................................................... 2.10

2-5 Primary/Concrete Shell Node Geometry ....................................................................... 2.10

2-6 Primary Tank Model Detail .......................................................................................... 2.13

2-7 Primary Tank Model Detail - Knuckle Region .............................................................. 2.13

2-8 Insulating Concrete Model Detail ......................................................................... 2.14

2-9 Anchor Bolt Model Detail ............................................................................................... 2.16

2-10 Spring Elements - Anchor Bolts to Primary Tank ......................................................... 2.16

2-11 Secondary Liner Model Detail ............................................................................. 2.17

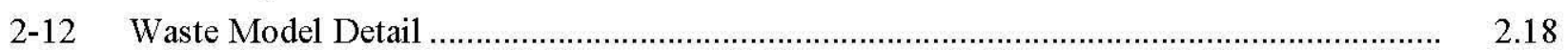

2-13 Waste Model Detail, Interface with Tank Dome …......................................................... 2.19

2-14 Contact Elements - Primary Tank to Concrete Dome ........................................................ 2.20

2-15 Contact Elements - Insulating Concrete Top and Bottom .................................................. 2.21

2-16 Contact Elements - Soil to Concrete Shell …............................................................... 2.22

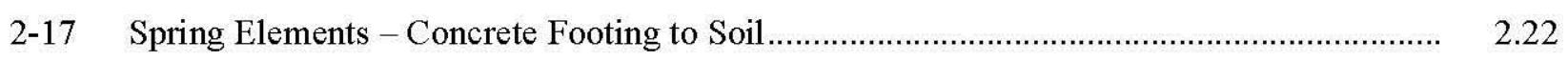

2-18 Contact Elements - Near Soil to Far Soil ......................................................................... 2.23

2-19 Contact Elements - Waste to Primary Tank ........................................................................ 2.24

2-20 Contact Elements - Concrete Wall to Footing ............................................................ 2.24

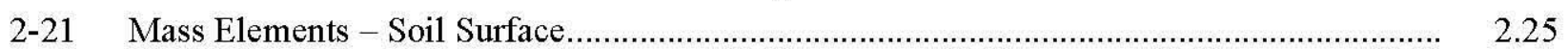

2-22 Excavated Soil Model Detail ........................................................................................... 2.29

2-23 Excavated Soil - Softened Soil Zones .............................................................................. 2.29

2-24 Detail Plot of ANSYS ${ }^{\circledR}$ Global Model Showing Soil Zones ................................................ $\quad 2.30$

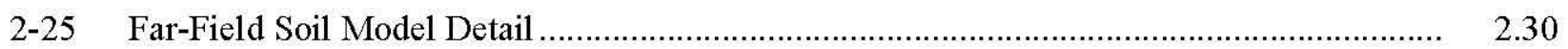

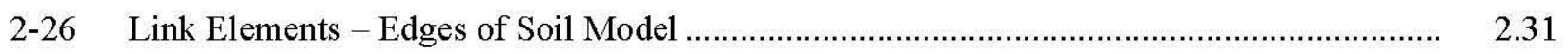

2-27 Boundary Conditions - Soil Base ............................................................................... 2.32

2-28 Boundary Conditions - Typical Soil Layer ...................................................................... 2.32

2-29 Boundary Conditions - Slaved Boundary Conditions .................................................... 2.33

2-30 Boundary Conditions - Symmetry Plane ........................................................................ 2.33

2-31 Boundary Condition - Concrete Shell .......................................................................... 2.34

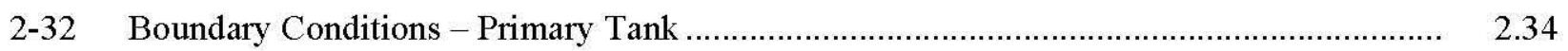

2-33 Boundary Conditions - Secondary Liner...................................................................... 2.35

3-1 241-AY Tank Dimensions .................................................................................... 3.2

3-2 241-AP Tank Dimensions ..........................................................................................

3-3 Plot of Dytran ${ }^{\circledR}$ Primary Tank and Base Model ............................................................ 3.4 
RPP-RPT-32239, Rev. 1

M\&D-2008-005-CALC-001, Rev. 1

3-4 Plot of Dytran ${ }^{\circledR}$ Tank, Waste, and Air Elements at 460-Inch Waste Level

3-5 Top View of Dytran ${ }^{\circledR}$ Primary Tank Sub-Model Showing the Angular Locations of Fluid Elements at Which Pressures Were Monitored...

3-6 Elevation View of Dytran ${ }^{\circledR}$ Tank Mesh Showing the Locations of "Plusx_els", "Cent_press", and "Minusx_els" Fluid Element Sets at Which Pressures Were Monitored.

3-7 Waste Element Numbering for Element Sets "Plusx_els"," Minusx_els", and Cent_press"

3-8 Elevation View of Dytran ${ }^{\circledR}$ Tank Mesh Showing the Locations of "Press45" and "Plusz_els", Fluid Element Sets at Which Pressures Were Monitored.

3-9 Waste Element Numbering for Dytran ${ }^{\circledR}$ Element Sets "Press_45" and Plusz_els".

3-10 Shell Element Numbering for Dytran ${ }^{\otimes}$ Tank Wall Stress Results at $\theta=0^{\circ}$ and $\theta=90^{\circ} \ldots \ldots \ldots . . .$.

3-11 Shell Element Numbering for Dytran ${ }^{\circledR}$ Tank Wall Stress Results at $\theta=45^{\circ}$ and $\theta=180^{\circ} \ldots \ldots$.

3-12 Plot of Dytran ${ }^{\circledR}$ Primary Tank Mesh with Different Colors Representing Different Wall Thicknesses

3-13 Rigid Regions of the Dytran ${ }^{\circledR}$ Primary Tank Model for Horizontal Excitation Only ............

3-14 Plot of Junction of Concrete Wall and Concrete Basemat from Global ANSYS ${ }^{\circledR}$ Model Showing Node 495 from Which Sub-Model Input Time Histories Were Extracted.

3-15 Detailed Plot of Junction of Concrete Wall and Concrete Basemat from Global ANSYS $^{\circledR}$ Model Showing Node 495 from Which Sub-Model Input Time Histories Were Extracted

3-16 Tank With Hinged Top Boundary Condition per BNL (1995).

3-17 Horizontal Acceleration Time History Used as Input to the Primary Tank Sub-Models ......

3-18 Vertical Acceleration Time History Used as Input to the Primary Tank Sub-Models

3-19 Velocity Time Histories - Vertical Time History Used as Input to the Dytran ${ }^{\circledR}$ Primary Tank Sub-Model

3-20 Displacement Time Histories Corresponding to Primary Tank Sub-Model Input.

3-21 4\% Damped Response Spectra for Acceleration Time Histories Extracted from ANSYS $^{\circledR}$ Model

4-1 Horizontal Displacement of Tank Wall Node 523 vs. Time During Initial Gravity Loading.

4-2 Horizontal Coupling Surface Reaction Force vs. Time for Horizontal Seismic Excitation

4-3 Horizontal Coupling Surface Reaction Force vs. Time for Horizontal Seismic Excitation During the Final Free Vibration Phase

4-4 Vertical Coupling Surface Reaction Force vs. Time for Vertical Seismic Excitation.

4-5 Horizontal Coupling Surface Reaction Force vs. Time for Two-Component Seismic Excitation

4-6 Horizontal Coupling Surface Reaction Force vs. Time for Two-Component Seismic Excitation During the Final Free Vibration Phase

4-7 Vertical Coupling Surface Reaction Force vs. Time for Two-Component Seismic Excitation 
RPP-RPT-32239, Rev. 1

M\&D-2008-005-CALC-001, Rev. 1

4-8 Waste Pressure Time Histories for Fluid Elements at $\theta=0^{\circ}$ Subjected to Horizontal

Seismic Excitation Only

4-9 Waste Pressure Time Histories for Fluid Elements at $\theta=45^{\circ}$ Subjected to Horizontal Seismic Excitation Only

4-10 Waste Pressure Time Histories for Fluid Elements at $\theta=90^{\circ}$ Subjected to Horizontal Seismic Excitation Only

4-11 Waste Pressure Time Histories for Fluid Elements at $\theta=0^{\circ}$ Subjected to Vertical Seismic Excitation Only

4-12 Waste Pressure Time Histories for Fluid Elements at $\theta=45^{\circ}$ Subjected to Vertical Seismic Excitation Only

4-13 Waste Pressure Time Histories for Fluid Elements at $\theta=0^{\circ}$ Subjected to TwoComponent Seismic Excitation.

4-14 Waste Pressure Time Histories for Fluid Elements at $\theta=45^{\circ}$ Subjected to TwoComponent Seismic Excitation.

4-15 Waste Pressure Time Histories for Fluid Elements at $\theta=90^{\circ}$ Subjected to TwoComponent Seismic Excitation.

4-16 Maximum Slosh Height Time-History for Horizontal, Vertical, and Two-Component Seismic Excitation

4-17 Maximum and Minimum Hoop Stress vs. Path Length for Element Set

"Plusx_Outstrip" at $\theta=0^{\circ}$ for Horizontal Seismic Excitation Only

4-18 Maximum and Minimum Meridional Stress vs. Path Length for Element Set

"Plusx_Outstrip" at $\theta=0^{\circ}$ for Horizontal Seismic Excitation Only

4-19 Maximum and Minimum Shear Stress vs. Path Length for Element Set

"Plusx_Outstrip" at $\theta=0^{\circ}$ for Horizontal Seismic Excitation Only

4-20 Maximum and Minimum Hoop Stress vs. Path Length for Element Set

"Press 45 Outstrip" at $\theta=45^{\circ}$ for Horizontal Seismic Excitation Only

4-21 Maximum and Minimum Meridional Stress vs. Path Length for Element Set

"Press 45 Outstrip" at $\theta=45^{\circ}$ for Horizontal Seismic Excitation Only

4-22 Maximum and Minimum Shear Stress vs. Path Length for Element Set

"Press 45 Outstrip" at $\theta=45^{\circ}$ for Horizontal Seismic Excitation Only

4-23 Maximum and Minimum Shear Stress vs. Path Length for Element Set

"Plusz_Outstrip" at $\theta=90^{\circ}$ for Horizontal Seismic Excitation Only

4-24 Maximum and Minimum Hoop Stress vs. Path Length for Element Set

"Plusx_Outstrip" at $\theta=0^{\circ}$ for Vertical Seismic Excitation Only .....

4-25 Maximum and Minimum Meridional Stress vs. Path Length for Element Set

"Plusx_Outstrip" at $\theta=0^{\circ}$ for Vertical Seismic Excitation Only.

4-26 Maximum and Minimum Shear Stress vs. Path Length for Element Set

"Plusx_Outstrip" at $\theta=0^{\circ}$ for Vertical Seismic Excitation Only.

4-27 Maximum and Minimum Hoop Stress vs. Path Length for Element Set

"Plusx_Outstrip" at $\theta=0^{\circ}$ for Two-Component Seismic Excitation

4-28 Maximum and Minimum Meridional Stress vs. Path Length for Element Set

"Plusx_Outstrip" at $\theta=0^{\circ}$ for Two-Component Seismic Excitation

4-29 Maximum and Minimum Shear Stress vs. Path Length for Element Set

"Plusx_Outstrip" at $\theta=0^{\circ}$ for Two-Component Seismic Excitation 


\section{RPP-RPT-32239, Rev. 1 \\ M\&D-2008-005-CALC-001, Rev. 1}

4-30 Maximum and Minimum Hoop Stress vs. Path Length for Element Set

"Press45_Outstrip" at $\theta=45^{\circ}$ for Two-Component Seismic Excitation.

4-31 Maximum and Minimum Meridional Stress vs. Path Length for Element Set

"Press 45 Outstrip" at $\theta=45^{\circ}$ for Two-Component Seismic Excitation

4-32 Maximum and Minimum Shear Stress vs. Path Length for Element Set

"Press 45 Outstrip" at $\theta=45^{\circ}$ for Two-Component Seismic Excitation.

4-33 Maximum and Minimum Shear Stress vs. Path Length for Element Set

"Plusz_Outstrip" at $\theta=90^{\circ}$ for Two-Component Seismic Excitation

5-1 Plot of ANSYS ${ }^{\circledR}$ Primary Tank Sub-Model

5-2 Slice Plot Showing Rigid Regions of the ANSYS ${ }^{\circledR}$ Primary Tank Sub-Model.

5-3 Plot of Flexible Primary Tank of ANSYS ${ }^{\circledR}$ Sub-Model ......

5-4 Shell Element Numbering for Tank Wall Stress Results at $\theta=0^{\circ}$ and $\theta=90^{\circ}$

5-5 Shell Element Numbering for Tank Wall Stress Results at $\theta=45^{\circ}$ and $\theta=180^{\circ}$...

5-6 Free Horizontal Oscillation Total Reaction

5-7 Total Reaction from ANSYS ${ }^{\circledR}$ Primary Tank Sub-Model for Free Horizontal Oscillation

5-8 Total Reaction Force Comparison Between Rigid and Flexible ANSYS ${ }^{\circledR}$ Primary

Tank Sub-Models for Free Horizontal Oscillation ....

5-9 Total Reaction Force for ANSYS ${ }^{\circledR}$ Primary Tank Sub-Model for Free Vertical Oscillation...

6-1 Horizontal Coupling Surface Reaction Force vs. Time from ANSYS ${ }^{\circledR}$ Primary

Tank Sub-Model for Horizontal Seismic Excitation.

6-2 Vertical Reaction Force vs. Time from ANSYS ${ }^{\circledR}$ Primary Tank Sub-Model for Vertical Seismic Excitation.

6-3 Horizontal Reaction Force vs. Time from ANSYS ${ }^{\circledR}$ Primary Tank Sub-Model for Two-Component Seismic Excitation

6-4 Vertical Reaction Force vs. Time from ANSYS ${ }^{\circledR}$ Primary Tank Sub-Model for Two-Component Seismic Excitation

6-5 Waste Pressure Time Histories from ANSYS ${ }^{\circledR}$ Primary Tank Sub-Model for Fluid Elements at $\theta=0^{\circ}$ Subjected to Horizontal Seismic Excitation Only

6-6 Maximum and Minimum Waste Pressures vs. Normalized Height from Tank Bottom from ANSYS ${ }^{\otimes}$ Primary Tank Sub-Model for Waste Elements at $\theta=0^{\circ}$ Subjected to Horizontal Seismic Excitation Only.

6-7 Waste Pressure Time Histories from ANSYS ${ }^{\circledR}$ Primary Tank Sub-Model for Fluid Elements at $\theta=45^{\circ}$ Subjected to Horizontal Seismic Excitation Only .

6-8 Waste Pressure Variation from ANSYS ${ }^{\circledR}$ Primary Tank Sub-Model for Waste Elements at $\theta=45^{\circ}$ Subjected to Horizontal Seismic Excitation Only...

6-9 Waste Pressure Time Histories from ANSYS ${ }^{\circledR}$ Primary Tank Sub-Model for Fluid Elements at $\theta=90^{\circ}$ Subjected to Horizontal Seismic Excitation Only .

6-10 Waste Pressure Variation from ANSYS ${ }^{\circledR}$ Primary Tank Sub-Model for Waste Elements at $\theta=90^{\circ}$ Subjected to Horizontal Seismic Excitation Only

6-11 Waste Pressure Time Histories from ANSYS ${ }^{\circledR}$ Primary Tank Sub-Model for Fluid Elements at $\theta=0^{\circ}$ Subjected to Vertical Seismic Excitation Only 
RPP-RPT-32239, Rev. 1

M\&D-2008-005-CALC-001, Rev. 1

6-12 Waste Pressure Variation from ANSYS ${ }^{\circledR}$ Primary Tank Sub-Model for Waste

Elements at $\theta=0^{\circ}$ Subjected to Vertical Seismic Excitation Only

6-13 Waste Pressure Time Histories from ANSYS ${ }^{\circledR}$ Primary Tank Sub-Model for Fluid

Elements at $\theta=45^{\circ}$ Subjected to Vertical Seismic Excitation Only

6-14 Waste Pressure Variation from ANSYS ${ }^{\circledR}$ Primary Tank Sub-Model for Waste

Elements at $\theta=45^{\circ}$ Subjected to Vertical Seismic Excitation Only

6-15 Waste Pressure Time Histories from ANSYS ${ }^{\circledR}$ Primary Tank Sub-Model for Fluid Elements at $\theta=0^{\circ}$ Subjected to Two-Component Seismic Excitation

6-16 Waste Pressure Variation from ANSYS ${ }^{\circledR}$ Primary Tank Sub-Model for Waste Elements at $\theta=0^{\circ}$ Subjected to Two-Component Seismic Excitation

6-17 Waste Pressure Time Histories from ANSYS ${ }^{\circledR}$ Primary Tank Sub-Model for Fluid Elements at $\theta=45^{\circ}$ Subjected to Two-Component Seismic Excitation

6-18 Waste Pressure Variation from ANSYS ${ }^{\circledR}$ Primary Tank Sub-Model for Waste Elements at $\theta=45^{\circ}$ Subjected to Two-Component Seismic Excitation

6-19 Waste Pressure Time Histories from ANSYS ${ }^{\circledR}$ Primary Tank Sub-Model for Fluid Elements at $\theta=90^{\circ}$ Subjected to Two-Component Seismic Excitation

6-20 Waste Pressure Variation from ANSYS ${ }^{\circledR}$ Primary Tank Sub-Model for Waste Elements at $\theta=90^{\circ}$ Subjected to Two-Component Seismic Excitation.

6-21 Maximum and Minimum Hoop Stress vs. Path Length at $\theta=0^{\circ}$ for Horizontal Seismic Excitation Only

6-22 Maximum and Minimum Meridional Stress vs. Path Length at $\theta=0^{\circ}$ for Horizontal Seismic Excitation Only

6-23 Maximum and Minimum Shear Stress vs. Path Length at $\theta=0^{\circ}$ for Horizontal Seismic Excitation Only

6-24 Maximum and Minimum Hoop Stress vs. Path Length at $\theta=45^{\circ}$ for Horizontal Seismic Excitation Only

6-25 Maximum and Minimum Meridional Stress vs. Path Length at $\theta=45^{\circ}$ for Horizontal Seismic Excitation Only

6-26 Maximum and Minimum Shear Stress vs. Path Length at $\theta=45^{\circ}$ for Horizontal Seismic Excitation Only

6-27 Maximum and Minimum Shear Stress vs. Path Length at $\theta=90^{\circ}$ for Horizontal Seismic Excitation Only

6-28 Maximum and Minimum Hoop Stress vs. Path Length at $\theta=0^{\circ}$ for Vertical Seismic Excitation Only

6-29 Maximum and Minimum Meridional Stress vs. Path Length at $\theta=0^{\circ}$ for Vertical Seismic Excitation Only

6-30 Maximum and Minimum Shear Stress vs. Path Length at $\theta=0^{\circ}$ for Vertical Seismic Excitation Only

6-31 Maximum and Minimum Hoop Stress vs. Path Length at $\theta=0^{\circ}$ for Two-Component Seismic Excitation

6-32 Maximum and Minimum Meridional Stress vs. Path Length at $\theta=0^{\circ}$ for TwoComponent Seismic Excitation.

6-33 Maximum and Minimum Shear Stress vs. Path Length at $\theta=0^{\circ}$ for Two-Component Seismic Excitation 
RPP-RPT-32239, Rev. 1

M\&D-2008-005-CALC-001, Rev. 1

6-34 Maximum and Minimum Hoop Stress vs. Path Length at $\theta=45^{\circ}$ for Two-Component

Seismic Excitation

6-35 Maximum and Minimum Meridional Stress vs. Path Length at $\theta=45^{\circ}$ for TwoComponent Seismic Excitation.

6-36 Maximum and Minimum Shear Stress vs. Path Length at $\theta=45^{\circ}$ for Two-Component Seismic Excitation

6-37 Maximum and Minimum Shear Stress vs. Path Length at $\theta=90^{\circ}$ for Two-Component Seismic Excitation

7-1 Comparison of Horizontal Reaction Forces Between ANSYS ${ }^{\circledR}$ and Dytran ${ }^{\circledR}$ Primary Tank Sub-Models for Horizontal Excitation Only - ES-BEC Time History....

7-2 Comparison of Horizontal Reaction Forces Between ANSYS ${ }^{\circledR}$ and Dytran ${ }^{\circledR}$ Primary Tank Sub-Models for Horizontal Excitation During Strong Motion Portion of Excitation - BES-BEC Time History

7-3 Comparison of Vertical Reaction Forces Between ANSYS ${ }^{\circledR}$ and Dytran ${ }^{\circledR}$ Primary Tank Sub-Models for Vertical Excitation Only - BES-BEC Time History ....

7-4 Comparison of Vertical Reaction Forces Between ANSYS ${ }^{\circledR}$ and Dytran ${ }^{\circledR}$ Primary Tank Sub-Models for Vertical Excitation During Strong Motion Portion of Excitation - BES-BEC Time History

7-5 Comparison of Horizontal Reaction Forces Between ANSYS ${ }^{\circledR}$ and Dytran ${ }^{\circledR}$ Primary Tank Sub-Models for Two-Component Seismic Excitation - BES-BEC Time History ........

7-6 Comparison of Horizontal Reaction Forces Between ANSYS ${ }^{\circledR}$ and Dytran ${ }^{\circledR}$ Primary Tank Sub-Models for Two-Component Seismic Excitation During Strong Motion Portion of Excitation - BES-BEC Time History

7-7 Comparison of Vertical Reaction Forces Between ANSYS ${ }^{\circledR}$ and Dytran ${ }^{\circledR}$ Primary Tank Sub-Models for Two-Component Seismic Excitation - BES-BEC Time History ........

7-8 Comparison of Vertical Reaction Forces Between ANSYS ${ }^{\circledR}$ and Dytran ${ }^{\circledR}$ Primary Tank Sub-Models for Two-Component Seismic Excitation During Strong Motion Portion of Excitation - BES-BEC Time History

7-9 Comparison of Selected ANSYS ${ }^{\circledR}$ and Dytran ${ }^{\circledR}$ Waste Pressures at $\theta=0^{\circ}$ for Horizontal Excitation Only

7-10 Comparison of Selected ANSYS ${ }^{\circledR}$ and Dytran ${ }^{\circledR}$ Waste Pressures at $\theta=0^{\circ}$ for Vertical Excitation Only

7-11 Comparison of Selected ANSYS ${ }^{\circledR}$ and Dytran ${ }^{\circledR}$ Waste Pressures at $\theta=0^{\circ}$ for TwoComponent Seismic Excitation

7-12 Comparison of Dytran ${ }^{\circledR}$ and ANSYS ${ }^{\circledR}$ Mid-Surface Hoop Stresses at $\theta=0^{\circ}$ for Horizontal Seismic Excitation

7-13 Comparison of Dytran ${ }^{\circledR}$ and ANSYS $^{\circledR}$ Outside and Inside Surface Meridional Stresses at $\theta=0^{\circ}$ for Horizontal Seismic Excitation

7-14 Comparison of Dytran ${ }^{\circledR}$ and ANSYS ${ }^{\circledR}$ Mid-Surface In-Plane Shear Stresses at $\theta=0^{\circ}$ for Horizontal Seismic Excitation..

7-15 Comparison of Dytran ${ }^{\circledR}$ and ANSYS ${ }^{\circledR}$ Mid-Surface Hoop Stresses at $\theta=45^{\circ}$ for Horizontal Seismic Excitation

7-16 Comparison of Dytran ${ }^{\circledR}$ and ANSYS ${ }^{\circledR}$ Outside and Inside Surface Meridional Stresses at $\theta=45^{\circ}$ for Horizontal Seismic Excitation 
RPP-RPT-32239, Rev. 1

M\&D-2008-005-CALC-001, Rev. 1

7-17 Comparison of Dytran ${ }^{\circledR}$ and ANSYS ${ }^{\circledR}$ Mid-Surface In-Plane Shear Stresses at $\theta=45^{\circ}$

for Horizontal Seismic Excitation.

7-18 Comparison of Dytran ${ }^{\circledR}$ and ANSYS $^{\circledR}$ Mid-Surface In-Plane Shear Stresses at $\theta=90^{\circ}$ for Horizontal Seismic Excitation

7-19 Comparison of Dytran ${ }^{\circledR}$ and ANSYS ${ }^{\circledR}$ Mid-Surface Hoop Stresses at $\theta=0^{\circ}$ for Vertical Seismic Excitation

7-20 Comparison of Dytran ${ }^{\circledR}$ and ANSYS $^{\circledR}$ Outside and Inside Surface Meridional Stresses at $\theta=0^{\circ}$ for Vertical Seismic Excitation

7-21 Comparison of Dytran ${ }^{\circledR}$ and ANSYS ${ }^{\circledR}$ Mid-Surface In-Plane Shear Stresses at $\theta=0^{\circ}$ for Vertical Seismic Excitation

7-22 Comparison of Dytran ${ }^{\circledR}$ and ANSYS ${ }^{\circledR}$ Mid-Surface Hoop Stresses at $\theta=0^{\circ}$ for TwoComponent Seismic Excitation.

7-23 Comparison of Dytran ${ }^{\circledR}$ and ANSYS ${ }^{\circledR}$ Outside and Inside Surface Meridional Stresses at $\theta=0^{\circ}$ for Two-Component Seismic Excitation

7-24 Comparison of Dytran ${ }^{\circledR}$ and ANSYS ${ }^{\circledR}$ Mid-Surface In-Plane Shear Stresses at $\theta=0^{\circ}$ for Two-Component Seismic Excitation.

7-25 Comparison of Dytran ${ }^{\circledR}$ and ANSYS ${ }^{\circledR}$ Mid-Surface Hoop Stresses at $\theta=45^{\circ}$ for TwoComponent Seismic Excitation.

7-26 Comparison of Dytran ${ }^{\circledR}$ and ANSYS ${ }^{\circledR}$ Outside and Inside Surface Meridional Stresses at $\theta=45^{\circ}$ for Two-Component Seismic Excitation

7-27 Comparison of Dytran ${ }^{\circledR}$ and ANSYS ${ }^{\circledR}$ Mid-Surface In-Plane Shear Stresses at $\theta=45^{\circ}$ for Two-Component Seismic Excitation.

7-28 Comparison of Dytran ${ }^{\circledR}$ and ANSYS ${ }^{\circledR}$ Mid-Surface In-Plane Shear Stresses at $\theta=90^{\circ}$ for Two-Component Seismic Excitation.

7-29 Primary Tank Maximum Mid-Surface Hoop Stress Comparisons for Various Models at $\theta=0^{\circ}$

7-30 Primary Tank Maximum Mid-Surface Meridional Stress Comparisons for Various Models at $\theta=0^{\circ}$.

7-31 Primary Tank Maximum Mid-Surface Shear Stress Comparisons for Various Models at $\theta=0^{\circ}$.

7-32 Comparison of Maximum Waste from the ANSYS ${ }^{\circledR}$ Primary Tank Sub-Model for Waste Elements at $\theta=0^{\circ}$ Subjected to Horizontal Seismic Excitation Only to Maximum Waste Pressures for the $100 \%$ Impulsive Case

8-1 5\% Damped Horizontal Response Spectra Comparison, Surface (LBS-BEC).

8-2 5\% Damped Horizontal Response Spectra, Tank Bottom (LBS-BEC)

8-4 5\% Damped Vertical Response Spectra, Tank Bottom (LBS-BEC) .

8-5 5\% Damped Horizontal Response Spectra Comparison, Surface (BES-BEC).....................

8-6 5\% Damped Horizontal Response Spectra, Tank Bottom (BES-BEC)...

8-7 5\% Damped Vertical Response Spectra Comparison, Surface (BES-BEC) ........................

8-8 5\% Damped Vertical Response Spectra, Tank Bottom (BES-BEC)

8-9 5\% Damped Horizontal Response Spectra Comparison, Surface (UBS-BEC) ....................

8-10 5\% Damped Horizontal Response Spectra, Tank Bottom (UBS-BEC) 
RPP-RPT-32239, Rev. 1

M\&D-2008-005-CALC-001, Rev. 1

8-11 5\% Damped Vertical Response Spectra Comparison, Surface (UBS-BEC) ....................... $\quad 8.7$

8-12 5\% Damped Vertical Response Spectra, Tank Bottom (UBS-BEC) ................................ $\quad 8.8$

8-13 5\% Damped Horizontal Response Spectra Comparison, Surface (BES-FCC) .................... 8.9

8-14 5\% Damped Horizontal Response Spectra, Tank Bottom (BES-FCC) ............................. 8.9

8-15 5\% Damped Vertical Response Spectra Comparison, Surface (BES-FCC) ........................ $\quad 8.10$

8-16 5\% Damped Vertical Response Spectra, Tank Bottom (BES-FCC) .................................... $\quad 8.10$

9-1 Concrete Shell Element Retrieval Sequence Starting Numbers ...................................... 9.2

9-2 Concrete Shell Hoop Forces - Gravity Only ............................................................. 9.2

9-3 Concrete Shell Hoop Forces - Gravity Plus Seismic .......................................................... 9.3

9-4 Concrete Shell Hoop Forces - Seismic Only ............................................................

9-5 Concrete Shell Meridional Forces - Gravity Only …................................................. 9.4

9-6 Concrete Shell Meridional Forces - Gravity Plus Seismic ................................................ 9.4

9-7 Concrete Shell Meridional Forces - Seismic Only ......................................................

9-8 Concrete Shell Hoop Moments - Gravity Only …........................................................ $\quad 9.5$

9-9 Concrete Shell Hoop Moments - Gravity Plus Seismic ................................................ 9.6

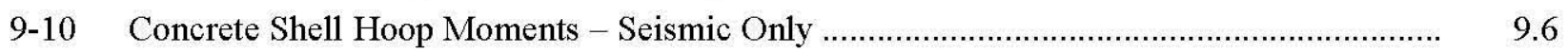

9-11 Concrete Shell Meridional Moments - Gravity Only …....................................................... $\quad 9.7$

9-12 Concrete Shell Meridional Moments - Gravity Plus Seismic ............................................ 9.7

9-13 Concrete Shell Meridional - Seismic Only ................................................................. 9.8

9-14 Concrete Shell In-Plane Shear Forces - Gravity Only ................................................... 9.8

9-15 Concrete Shell In-Plane Shear Forces - Gravity Plus Seismic ..........................................

9-16 Concrete Shell In-Plane Shear Forces - Seismic Only ................................................ 9.9

9-17 Concrete Shell Through-Wall Shear Forces - Gravity Only ............................................... 9.10

9-18 Concrete Shell Through-Wall Shear Forces - Gravity Plus Seismic................................... 9.10

9-19 Concrete Shell Through-Wall Shear Forces - Seismic Only .......................................... 9.11

9-20 Primary Tank Element Retrieval Sequence Starting Numbers ............................................ 9.12

9-21 Primary Hoop Stress (Middle) - Gravity Only ........................................................... 9.13

9-22 Primary Tank Hoop Stress (Middle) - Gravity Plus Seismic ............................................ 9.13

9-23 Primary Tank Hoop Stress (Middle) - Seismic Only …................................................... 9.14

9-24 Primary Meridional Stress (Inside) - Gravity Only ........................................................ 9.14

9-25 Primary Tank Meridional Stress (Inside) - Gravity Plus Seismic .................................... 9.15

9-26 Primary Tank Meridional Stress (Inside) - Seismic Only .................................................. 9.15

9-27 Primary Meridional Stress (Outside) - Gravity Only ..................................................... 9.16

9-28 Primary Tank Meridional Stress (Outside) - Gravity Plus Seismic ..................................... 9.16

9-29 Primary Tank Meridional Stress (Outside) - Seismic Only .................................................. 9.17

9-30 Primary Tank In-Plane Shear Stress (Middle) - Gravity Only ........................................ 9.17

9-31 Primary Tank In-Plane Shear Stress (Middle) - Gravity Plus Seismic ............................. 9.18

9-32 Primary Tank In-Plane Shear Stress (Middle) - Seismic Only .......................................... 9.18 
RPP-RPT-32239, Rev. 1

M\&D-2008-005-CALC-001, Rev. 1

9-33 Comparison of Hoop Stresses at the Outside Surface of the Primary Tank for the Updated and Original Models - Seismic Only

9-34 Comparison of Hoop Stresses at the Mid-Surface of the Primary Tank for the Updated and Original Models - Seismic Only

9-35 Comparison of Hoop Stresses at the Inside Surface of the Primary Tank for the Updated and Original Models - Seismic Only

9-36 Comparison of Meridional Stresses at the Outside Surface of the Primary Tank for the Updated and Original Models - Seismic Only

9-37 Comparison of Meridional Stresses at the Mid-Surface of the Primary Tank for the Updated and Original Models - Seismic Only

9-38 Comparison of Meridional Stresses at the Inside Surface of the Primary Tank for the Updated and Original Models - Seismic Only

9-39 Comparison of In-Plane Shear Stresses at the Outside Surface of the Primary Tank for the Updated and Original Models - Seismic Only .

9-40 Comparison of In-Plane Shear Stresses at the Mid-Surface of the Primary Tank for the Updated and Original Models - Seismic Only

9-41 Comparison of In-Plane Shear Stresses at the Inside Surface of the Primary Tank for the Updated and Original Models - Seismic Only

9-42 Anchor Bolt Element Retrieval Sequence Starting Numbers ..........................................

9.25

9-43 Anchor Bolts - Maximum Axial Force - Gravity Only ................................................

9.25

9-44 Anchor Bolts - Minimum Axial Force - Gravity Only ….............................................

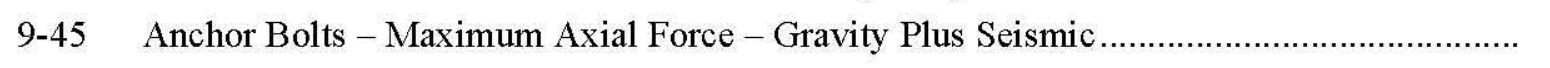

9.26

9-46 Anchor Bolts - Minimum Axial Force - Gravity Plus Seismic.........................................

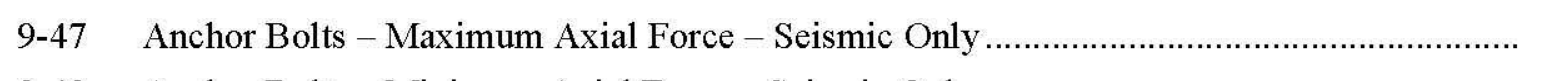

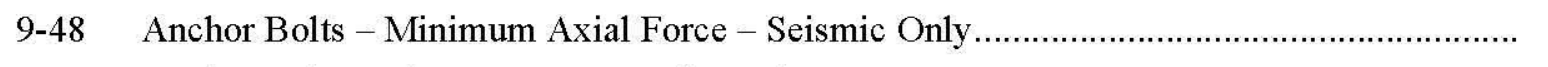

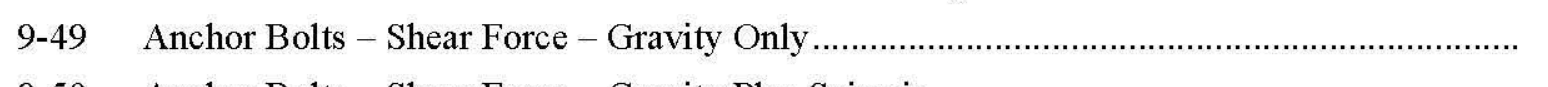

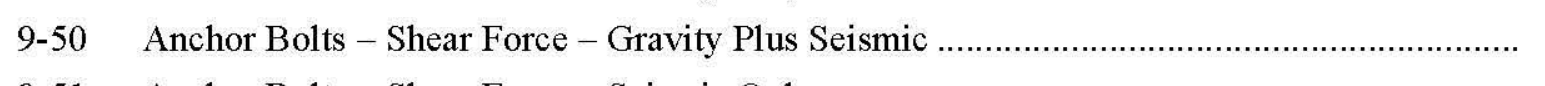

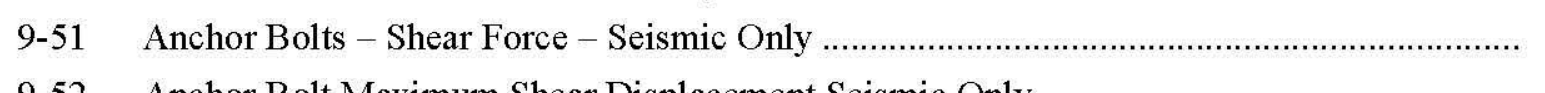

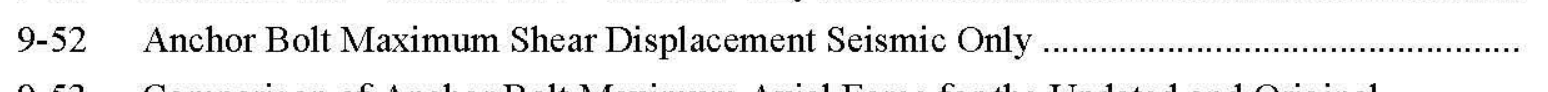

9-53 Comparison of Anchor Bolt Maximum Axial Force for the Updated and Original Models - Seismic Only BES-BEC

9.26

9.27

9.27

9.28

9.28

9.29

9.29

9.30

9-54 Comparison of Anchor Bolt Minimum Axial Force for the Updated and Original Models - Seismic Only BES-BEC

9-55 Comparison of Anchor Bolt Maximum Shear Force for the Updated and Original Models - Seismic Only BES-BEC ...................................................................... 9.32

9-56 Comparison of Anchor Bolt Maximum Shear Displacement for the Updated and Original Models - Seismic Only BES-BEC ................................................................ 9.32

9-57 Element Retrieval Sequence Starting Numbers for Strain ........................................... 9.34

9-58 Element Retrieval Sequence Starting Numbers for Strain (Detail) .................................. 9.34

9-59 Concrete Backed Steel Strain, Principal 1, Gravity Only ….......................................... 9.35

9-60 Concrete Backed Steel Strain, Principal 1, Min, Gravity Plus Seismic................................ 9.35

9-61 Concrete Backed Steel Strain, Principal 1, Max, Gravity Plus Seismic ............................ 9.36 
RPP-RPT-32239, Rev. 1

M\&D-2008-005-CALC-001, Rev. 1

9-62 Concrete Backed Steel Strain, Principal 1, Min, Seismic Only ......................................... 9.36

9-63 Concrete Backed Steel Strain, Principal 1, Max, Seismic Only ........................................ 9.37

9-64 Concrete Backed Steel Strain, Principal 2, Gravity Only .................................................. 9.37

9-65 Concrete Backed Steel Strain, Principal 2, Min, Gravity Plus Seismic ............................... 9.38

9-66 Concrete Backed Steel Strain, Principal 2, Max, Gravity Plus Seismic ............................... 9.38

9-67 Concrete Backed Steel Strain, Principal 2, Min, Seismic Only .......................................... $\quad 9.39$

9-68 Concrete Backed Steel Strain, Principal 2, Max, Seismic Only ....................................... 9.39

9-69 Concrete Backed Steel Strain, Principal 3, Gravity Only ................................................... 9.40

9-70 Concrete Backed Steel Strain, Principal 3, Min, Gravity Plus Seismic ................................ $\quad 9.40$

9-71 Concrete Backed Steel Strain, Principal 3, Max, Gravity Plus Seismic ............................ 9.41

9-72 Concrete Backed Steel Strain, Principal 3, Min, Seismic Only ........................................... 9.41

9-73 Concrete Backed Steel Strain, Principal 3, Max, Seismic Only .......................................... 9.42

10-1 Footing Contact Element Retrieval Numbers ............................................................. 10.2

10-2 Concrete Footing Contact Force - Gravity Only …........................................................ 10.2

10-3 Maximum Concrete Footing Contact Force - Gravity Plus Seismic ................................. $\quad 10.3$

10-4 Minimum Concrete Footing Contact Force - Gravity Plus Seismic.................................. 10.3

10-5 Maximum Concrete Footing Contact Force - Seismic Only ….......................................... 10.4

10-6 Minimum Concrete Footing Contact Force - Seismic Only ........................................... $\quad 10.4$

10-7 Concrete Footing Contact Shear - Gravity Only …..................................................... 10.5

10-8 Concrete Footing Contact Shear - Gravity Plus Seismic.................................................... 10.5

10-9 Concrete Footing Contact Shear - Seismic Only ............................................................ 10.6

10-10 Concrete Footing Time History, $\theta=9^{\circ}$ - LBS-BEC …................................................ 10.7

10-11 Concrete Footing Time History, $\theta=90^{\circ}$ - LBS-BEC .................................................... 10.7

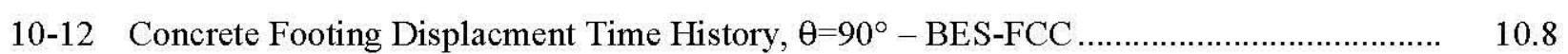

10-13 Concrete Footing Time History, $\theta=9^{\circ}$ - BES-BEC ...................................................... 10.8

10-14 Concrete Footing Time History, $\theta=90^{\circ}-$ BES-BEC ................................................... 10.9

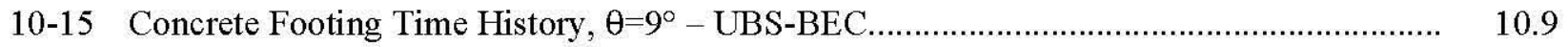

10-16 Concrete Footing Time History, $\theta=90^{\circ}-$ UBS-BEC ...................................................... 10.10

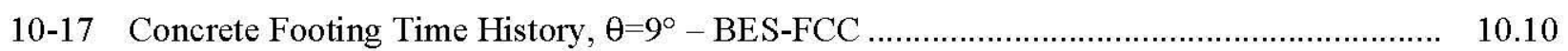

10-18 Concrete Footing Time History, $\theta=90^{\circ}-$ BES-FCC …................................................. 10.11

10-19 Soil/Concrete Contact Element Retrieval Sequence Starting Numbers............................. 10.12

10-20 Soil/Concrete Contact Element Normal Pressure - Gravity Only .................................... 10.13

10-21 Soil/Concrete Contact Element Maximum Normal Pressure - Gravity Plus Seismic ........... 10.13

10-22 Soil/Concrete Contact Element Minimum Normal Pressure - Gravity Plus Seismic........... 10.14

10-23 Soil/Concrete Contact Element Maximum Normal Pressure - Seismic Only ..................... 10.14

10-24 Soil/Concrete Contact Element Minimum Normal Pressure - Seismic Only ..................... 10.15

10-25 Soil/Concrete Contact Element Meridional Shear - Gravity Only …............................... 10.15

10-26 Soil/Concrete Contact Element Meridional Shear - Gravity Plus Seismic ........................ 10.16 
RPP-RPT-32239, Rev. 1

M\&D-2008-005-CALC-001, Rev. 1

10-27 Soil/Concrete Contact Element Meridional Shear - Seismic Only ................................. 10.16

10-28 Soil/Concrete Contact Element Tangential Shear - Gravity Only .................................. 10.17

10-29 Soil/Concrete Contact Element Tangential Shear - Gravity Plus Seismic ........................ 10.17

10-30 Soil/Concrete Contact Element Gap Tangential Shear - Seismic Only ............................ 10.18

10-31 Soil/Concrete Contact Element Gap Lateral Displacement (Slide) - Gravity Only ............ 10.18

10-32 Soil/Concrete Contact Element Gap Lateral Displacement (Slide) - Gravity Plus Seismic

10-33 Soil/Concrete Contact Element Gap Lateral Displacement (Slide) - Seismic Only ............ 10.19

10-34 Seismic Soil Pressure Comparison to Scaled Gravity Soil Pressures, LBS-BEC................ 10.20

10-35 Seismic Soil Pressure Comparison to Scaled Gravity Soil Pressures, BES-BEC ................ 10.21

10-36 Seismic Soil Pressure Comparison to Scaled Gravity Soil Pressures, UBS-BEC ............... 10.21

10-37 Seismic Soil Pressure Comparison to Scaled Gravity Soil Pressures, BES-FCC ................. 10.22

10-38 Primary Tank Dome Contact Element Retrieval Sequence Starting Numbers .................... 10.23

10-39 Primary Tank/Concrete Dome Contact Element Maximum Contact Pressure Gravity Only

10.24

10-40 Primary Tank/Concrete Dome Contact Element Maximum Contact Pressure Gravity Plus Seismic.

10-41 Primary Tank/Concrete Dome Contact Element Maximum Contact Pressure Seismic Only.

10-42 Primary Tank/Concrete Dome Contact Element Maximum Contact Gap Gravity Only

10-43 Primary Tank/Concrete Dome Contact Element Maximum Contact Gap Gravity Plus Seismic.

10-44 Primary Tank/Concrete Dome Contact Element Maximum Contact Gap Seismic Only....

10-45 Primary Tank/Concrete Dome Contact Element Maximum Contact Lateral Displacement (Slide) - Gravity Only

10-46 Primary Tank/Concrete Dome Contact Element Maximum Contact Lateral Displacement (Slide) - Gravity Plus Seismic

10-47 Primary Tank/Concrete Dome Contact Element Maximum Contact Lateral Displacement (Slide) - Seismic Only

10-48 Primary Tank Bottom Contact Element Retrieval Sequence Starting Numbers

10-49 Primary Tank/Insulating Concrete Contact Element Contact Pressure - Gravity Only ........

10-50 Primary Tank/Insulating Concrete Contact Element Maximum Contact Pressure Gravity Plus Seismic

10-51 Primary Tank/Insulating Concrete Contact Element Minimum Contact Pressure Gravity Plus Seismic

10-52 Primary Tank/Insulating Concrete Contact Element Maximum Contact Pressure Seismic Only

10-53 Primary Tank/Insulating Concrete Contact Element Minimum Contact Pressure Seismic Only. 


\section{RPP-RPT-32239, Rev. 1 \\ M\&D-2008-005-CALC-001, Rev. 1}

10-54 Primary Tank/Insulating Concrete Contact Element Maximum Contact Gap Gravity Only

10-55 Primary Tank/Insulating Concrete Contact Element Maximum Contact Gap Gravity Plus Seismic.

10-56 Primary Tank/Insulating Concrete Contact Element Maximum Contact Gap Seismic Only

10-57 Primary Tank/Insulating Concrete Contact Element Maximum Contact Lateral Displacement (Slide) - Gravity Only

10-58 Primary Tank/Insulating Concrete Contact Element Maximum Contact Lateral Displacement (Slide) - Gravity Plus Seismic

10-59 Primary Tank/Insulating Concrete Contact Element Maximum Contact Lateral Displacement (Slide) - Seismic Only

10-60 Insulating Concrete Contact Element Retrieval Sequence Starting Numbers

10-61 Insulating Concrete/Secondary Liner Contact Element Contact Pressure Gravity Only

10-62 Insulating Concrete/Secondary Liner Contact Element Maximum Contact Pressure Gravity Plus Seismic..

10-63 Insulating Concrete/Secondary Liner Contact Element Minimum Contact Pressure Gravity Plus Seismic....

10-64 Insulating Concrete/Secondary Liner Contact Element Maximum Contact Pressure Seismic Only

10-65 Insulating Concrete/Secondary Liner Contact Element Minimum Contact Pressure Seismic Only

10-66 Insulating Concrete/Secondary Liner Contact Element Maximum Contact Lateral Displacement (Slide) - Gravity Only

10-67 Insulating Concrete/Secondary Liner Contact Element Maximum Contact Lateral Displacement (Slide) - Gravity Plus Seismic

10-68 Insulating Concrete/Secondary Liner Contact Element Maximum Contact Lateral Displacement (Slide) - Seismic Only

11-1 Waste Contact Element Retrieval Sequence Starting Element Numbers

11-2 Waste Pressure Distribution, LBS-BEC .

11-3 Waste-Free Surface Displacement, LBS-BEC.

11-4 Waste Pressure Distribution, BES-BEC .

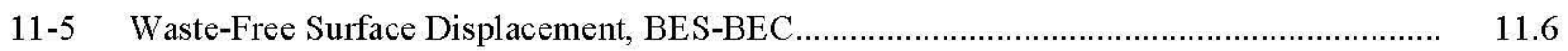

11-6 Waste Pressure Distribution, UBS-BEC ........................................................................ 11.8

11-7 Waste-Free Surface Displacement, UBS-BEC ........................................................ 11.8

11-8 Waste Pressure Distribution, BES-FCC …........................................................... 11.10

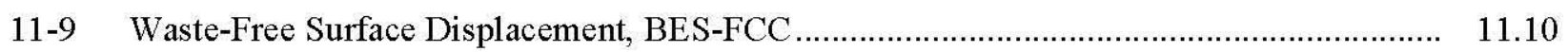


RPP-RPT-32239, Rev. 1

M\&D-2008-005-CALC-001, Rev. 1

Tables

2-1 $\quad$ ANSYS $^{\circledR}$ Model Input File Description........................................................................ 2.3

2-2 Concrete Shell Centerline Coordinates ............................................................................. 2.4

2-3 Best-Estimate Concrete Properties, $250^{\circ} \mathrm{F}$....................................................................... 2.6

2-4 Fully Cracked Concrete Properties ………………………………………………........ 2.8

2-5 Primary Tank Dome Coordinate Calculation.................................................................... $\quad 2.12$

2-6 Anchor Bolt Area Calculations .................................................................................... 2.15

2-7 Best-Estimate Native Soil Iterated Soil Properties ........................................................... 2.26

2-8 Best-Estimate Excavated Soil Iterated Soil Properties ....................................................... 2.26

2-9 Upper Bound Native Soil Iterated Soil Properties ............................................................. 2.27

2-10 Upper Bound Excavated Soil Iterated Soil Properties ....................................................... 2.27

2-11 Lower Bound Native Soil Iterated Soil Properties.............................................................. 2.28

2-12 Lower Bound Excavated Soil Iterated Soil Properties....................................................... 2.28

4-1 Theoretical Hydrostatic Pressures for Selected Fluid Elements from the Dytran ${ }^{\otimes}$

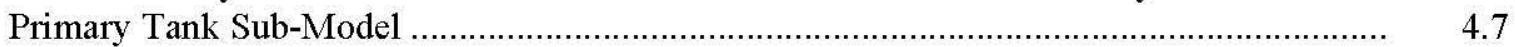

4-2 Primary Tank Regions Parameterized by Path Length from Dome Apex and Elevation from Tank Bottom ....................................................................................... 4.14

6-1 Theoretical Hydrostatic Pressures for Selected Fluid Elements from ANSYS ${ }^{\circledR}$ Primary Tank Sub-Model ….......................................................................................... 6.4

7-1 Comparison of ANSYS ${ }^{\circledR}$ and Dytran ${ }^{\circledR}$ Frequencies for Primary Tank Sub-Models ............. 7.1

7-2 Summary of Peak Reaction Forces from Primary Tank Sub-Models ..................................... $\quad 7.7$

11-1 Theoretical Waste Pressures, LBS-BEC ............................................................................. 11.3

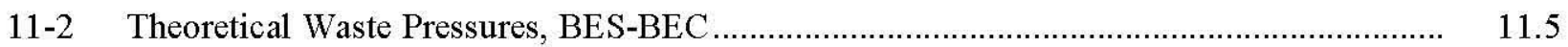

11-3 Theoretical Waste Pressures, UBS-BEC …………….................................................... 11.7

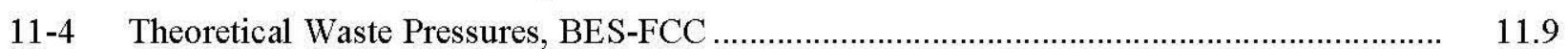


RPP-RPT-32239, Rev. 1

M\&D-2008-005-CALC-001, Rev. 1

Intentionally left blank.

xxiv 


\section{RPP-RPT-32239, Rev. 1 \\ M\&D-2008-005-CALC-001, Rev. 1}

\subsection{Introduction}

A seismic analysis of the Hanford double-shell tanks (DSTs) for a bounding generic configuration at the baseline liquid level of 422 inches was reported in Deibler et al. (2007a) and Rinker et al. (2006c). This analysis extends that work and was performed in support of a proposed liquid level increase for the 241-AP tanks. The baseline seismic analysis was for a bounding generic tank configuration based on the 241-AY tanks having a bulk waste specific gravity of 1.7 and a waste level of 422 inches. In this analysis, the bulk specific gravity and waste level were increased to 1.83 and 460 inches, respectively. The previously developed models were used with minor modifications to represent the 241-AP tanks.

The biggest difference between the baseline seismic analysis and the original seismic analysis for the proposed increased liquid level that was reported on Revision 0 of this document is the increased interaction between the waste and tank dome during a seismic event (i.e., more complex sloshing response). To address this more complex fluid-structure interaction behavior, sub-models of the primary tank were created and analyzed using both Dytran ${ }^{\circledR 1}$ and ANSYS ${ }^{\circledR 2}{ }^{2}$ Development of the supporting methodologies and benchmarking of solutions is documented in Rinker and Abatt (2006a, 2006b) and Rinker et al. (2006a, 2006b, 2006c).

As in the baseline seismic analysis, the following four load cases were considered:

- Lower Bound Soil Properties, Best-Estimate Concrete (LBS-BEC)

- Best-Estimate Soil Properties, Best-Estimate Concrete (BES-BEC)

- Upper Bound Soil Properties, Best-Estimate Concrete (UBS-BEC)

- Best-Estimate Soil Properties, Fully Cracked Concrete (BES-FCC)

The significant difference between the current revision (Revision 1) of this report and the original issue (Revision 0 ) is that the stiffnesses of the anchor bolts that tie the steel dome of the primary tank to the concrete tank dome have been reduced. The original values of the shear and axial stiffnesses were $139,000 \mathrm{lbf} / \mathrm{in}$. and 189,800 lbf/in., respectively. The current anchor bolt stiffness is $65,000 \mathrm{lbf} / \mathrm{in}$. in all directions. The reduced stiffnesses represent the secant shear stiffness (equivalent linear shear stiffness) of the embedded anchor bolts. The reduced shear stiffness was introduced into the models to credit the finite shear deformation that occurs in the connection prior to failure. It also serves to distribute the shear load more evenly between the outer and inner rows of anchor bolts. The motivation for modifying the anchor bolt properties and the development of the new values is discussed in Appendix B of Deibler et al. (2008).

The reduced stiffnesses simulate the secant shear modulus (equivalent linear shear modulus) of the anchor bolts. Setting the axial stiffness of the anchor bolts equal to the shear stiffness in the seismic models is insignificant because the anchor bolts essentially remain in compression under the combination of seismic and thermal and operating loads (Deibler et al. 2008), and the active load path in compression is the contact elements at the steel and concrete dome interface.

\footnotetext{
${ }^{1}$ Dytran $^{\circledR}$ is a registered trademark of MSC.Software Corporation, Santa Ana, California.

${ }^{2}$ ANSYS $^{\circledR}$ is a registered trademark of ANSYS, Inc., Canonsburg, Pennsylvania.
} 


\section{RPP-RPT-32239, Rev. 1 \\ M\&D-2008-005-CALC-001, Rev. 1}

The four seismic cases of best-estimate soil, best-estimate concrete (BES-BEC), lower-bound soil, bestestimate concrete (LBS-BEC), upper-bound soil, best-estimate concrete (UBS-BEC), and best-estimate soil, fully cracked concrete (BES-FCC) were rerun using the modified anchor bolt response. Because the significant change to the models was a reduction in the anchor bolt stiffnesses, the significant effects on the response of the overall tank model are expected to be limited local changes. That is, the forces and displacements of the anchor bolts are expected to change, but the differences in the response of the other tank components such as the primary tanks stresses, secondary liner strains, and concrete tank forces and moments are expected to be small. The second change to the analysis in the current revision (Revision 1) relative to the original issue (Revision 0 ) is a slight increase in the normal contact stiffness between the steel and concrete dome. This is described in more detail in Section 2.1.7.

Consequently, focus was placed on the changes in the anchor bolt responses, and a full reevaluation of all tank components was judged to be unnecessary. To confirm this judgment, primary tank stresses from the revised analysis of the BES-BEC case are compared to the original analysis, and it was verified that the changes are small, as expected.

The significant updates to Revision 1 of this report appear in Sections 1.0, 1.1, 1.2, 2.1.4, 9.3, 9.4, and 10.3. Sections 3.0 through 8.0 and the associated sub-sections are unchanged except for a few minor editorial corrections.

\subsection{Discussion}

The work presented in Revision 0 of this report was an extension of the baseline seismic analysis documented in Deibler et al. (2007a) and Rinker et al. (2006c). Earlier studies documented in Rinker and Abatt (2006a, 2006b) and Rinker et al. (2006a, 2006b) provide the justification for the basic models and analysis techniques. The fundamental difference between this analysis and the baseline liquid level analysis reported in Deibler et al. (2007a) and Rinker et al. (2006c) is interaction between the liquid waste and the tank dome.

Based on the earlier studies, the global ANSYS ${ }^{\circledR}$ model is expected to give sufficiently accurate results for all tank components except for portions of the primary tank. The limit on the ability of the global ANSYS $^{\circledR}$ model to accurately predict the convective response of the tank waste is recognized and has been documented in the earlier reports.

The earlier reports also contain extensive benchmarking of the ability of Dytran ${ }^{\circledR}$ to adequately capture the fluid-structure interaction behavior in the tanks including convective effects. To address the more complex fluid-structure interaction analysis at the increased liquid level, sub-models of the primary tank were created in both Dytran ${ }^{\circledR}$ and ANSYS ${ }^{\circledR}$ and the results were compared.

As discussed in Section 1.0 of this report, the anchor bolt stiffnesses were reduced in the reanalysis performed in support of the current revision (Revision 1) of this report. Because this modification did not require a complete reevaluation of the seismic demand on all tank components, the remainder of this Section (Section 1.1) is unchanged from Revision 0, except that the maximum displacement reported between the primary tank and concrete dome has been increased from 0.063 inch to 0.096 inch to reflect the softer anchor bolts. 


\section{RPP-RPT-32239, Rev. 1 \\ M\&D-2008-005-CALC-001, Rev. 1}

Forces and moments in the concrete shell are generally highest for the lower bound soil case. Due to the higher stiffness of the concrete shell compared to the soil for the lower bound soil, loads are transmitted through the stiffer path. The lowest forces and moments in the concrete shell are generally found in the fully cracked concrete case. In this case, the concrete is much more compliant and the load path is retained through the soil.

The highest stresses occur in the primary tank for the upper bound soil case near the middle of the primary tank wall. The lowest stresses in the primary tank occur for the lower bound soil case. Primary tank stresses correlate well to the free-field soil response at the bottom of the DST ( $57 \mathrm{ft}$ below grade). The free-field soil seismic response at the level of the bottom of the tank shows a pronounced drop in the lower bound soil case for frequencies corresponding to the impulsive natural frequency of the tank/fluid system.

Of the contact surfaces used in the model, only two were shown to be important. The first is the contact interface between the soil and the concrete shell, which controls how the forces and displacements of the surrounding soil are transferred to the concrete shell. The second is the interface between the primary tank and the inside face of the concrete dome, where the presence of the contact interface is critical to obtaining the correct load path. Where the concrete dome and primary tank are in contact and the load path is in compression, the contact elements are in compression and transmit the load between these surfaces. Where separation occurs, the forces are transmitted through the anchor bolt connections only.

The results also show that the displacement between the bottom of concrete wall and the tank footing (basemat) due to seismic loading is insignificant. The reason is twofold: the axial load in the wall generates a significant normal force between the wall and the footing, and the wall cylinder is stiff enough to prevent local displacements where higher shear forces occur (i.e., the average shear at the interface does not exceed the friction capacity, even though localized shear forces may exceed localized friction capacities).

No significant sliding occurs at the interfaces between the concrete wall and the footing, primary tank and concrete dome, primary tank and insulating concrete, or insulating concrete and secondary liner. The maximum displacements are as follows:

- Concrete Wall/Footing

- Primary Tank/Concrete Dome

- Primary Tank/Insulating Concrete

- Insulating Concrete/Secondary Liner

$$
\begin{aligned}
& 0.00103 \text { inch } \\
& 0.096 \text { inch } \\
& 0.076 \text { inch } \\
& 0.025 \text { inch }
\end{aligned}
$$

While the sliding displacement between the primary tank and concrete dome is small, the inclusion of this contact surface is critical to obtaining the correct load path.

The primary tank sub-model study showed that the stresses in the primary tank are very similar for the Dytran $^{\circledR}$ and ANSYS ${ }^{\circledR}$ sub-models except near the liquid-free surface, which was the expected result based on earlier studies. Some differences also existed in the knuckle region of the primary tank, but these were at least partly due to a configurational difference between the two models in the knuckle region. 
RPP-RPT-32239, Rev. 1

M\&D-2008-005-CALC-001, Rev. 1

Near the liquid-free surface, the ANSYS ${ }^{\circledR}$ sub-model consistently predicted hoop stresses and meridional stresses of higher magnitude than the Dytran ${ }^{\circledR}$ sub-model. The shear stresses from the two models were very similar and of low magnitude.

Agreement between the ANSYS ${ }^{\circledR}$ and Dytran ${ }^{\circledR}$ sub-models occurs in the majority of the tank because the total stresses are dominated by gravity loading, which should be captured sufficiently by either model, and the seismic stresses are dominated by the impulsive response, which is adequately captured by either model. Although the ANSYS ${ }^{\circledR}$ model is deficient in its ability to properly simulate the convective effects of the contained liquid, this convective response is not a major contributor to the demands on the primary tank. Moreover, ANSYS ${ }^{\circledR}$ tends to overpredict the stress magnitudes near the free surface, so the results are conservative relative to the more accurate Dytran ${ }^{\circledR}$ solution. Given the available stress margins in the primary tank, it was acceptable to use the seismic demands from the global ANSYS ${ }^{\circledR}$ model for the ASME code evaluation of the primary tank reported in Deibler et al. (2007b).

\subsection{Conclusions}

Conclusions on the behavior of the DST to seismic and combined dead load and seismic loading are presented in this section. Overall conclusions regarding the evaluation of the 241-AP tanks for the proposed liquid level increase are presented in Deibler et al. (2007b).

1. Two of the contact surfaces used in the global ANSYS ${ }^{\circledR}$ model were shown to be important. The first is the contact interface between the soil and the concrete shell, which controls how the forces and displacements of the surrounding soil are transferred to the concrete shell. The second is the interface between the primary tank and the inside face of the concrete dome, where the presence of the contact interface is critical to obtaining the correct load path.

2. Other contact surfaces included in the model did not show significant non-linear behavior such as sliding; however, their behavior under higher loading cannot be predicted based on the current excitation levels.

3. The primary tank stresses are adequately predicted by the global ANSYS ${ }^{\circledR}$ model, except near the waste-free surface, where the stress predictions were conservative.

4. Given the generally low stresses in the primary tank near the waste-free surface, the primary tank can be successfully qualified for service using the conservative stresses reported by ANSYS $^{\circledR}$.

5. The stresses in the primary tank are dominated by gravity loading.

6. The reduction of anchor bolt stiffnesses had the expected effect of decreasing peak shear loads on the anchor bolts, increasing peak shear displacements of the anchor bolts, and more evenly spreading the load among the anchor bolts.

7. The reduction of the anchor bolt stiffness had very little effect on the primary tank stresses. 


\section{RPP-RPT-32239, Rev. 1 \\ M\&D-2008-005-CALC-001, Rev. 1 \\ 2.0 $\quad$ ANSYS $^{\circledR}$ Global Model Description}

The model used for the evaluation of the 241-AP tank configuration and increased liquid level is based on the model developed for the 241-AY tank and a liquid level of 422 inches (Rinker et al. 2006c). Key differences in the increased liquid level and the 241-AY model are as follows:

- 241-AP tank geometry used (geometry and wall thicknesses)

- Waste level increased to 460 inches

- Waste specific gravity increased to 1.83

- Number of contact areas used for waste/primary tank interface increased.

For completeness, a detailed description of the model development is provided below.

A model of a Hanford DST was created and analyzed using version 8.1 of the general-purpose finite element program ANSYS ${ }^{\circledR}$. A half-symmetry model of the DST, including the concrete shell, primary tank, secondary liner, anchor bolts, waste, and surrounding soil was developed to evaluate the seismic loading on the DST. Figure 2-1 shows the complete model. Details for each part of the model are discussed in the following sections.

The tank model geometry was based on the 241-AP tank configuration shown in Hanford Drawing Number H-2-90534. The primary tank has a 450 -inch radius, and a nominal height of the vertical wall is 422.3125 inches. The nominal dome apex is 561.5 inches above the bottom of the tank. The models were run using a waste depth of 460 inches. An excerpt from Drawing Number H-2-90534 is shown as Figure 2-2. The complete model, including the DST and surrounding soil is shown in Figure 2-1.

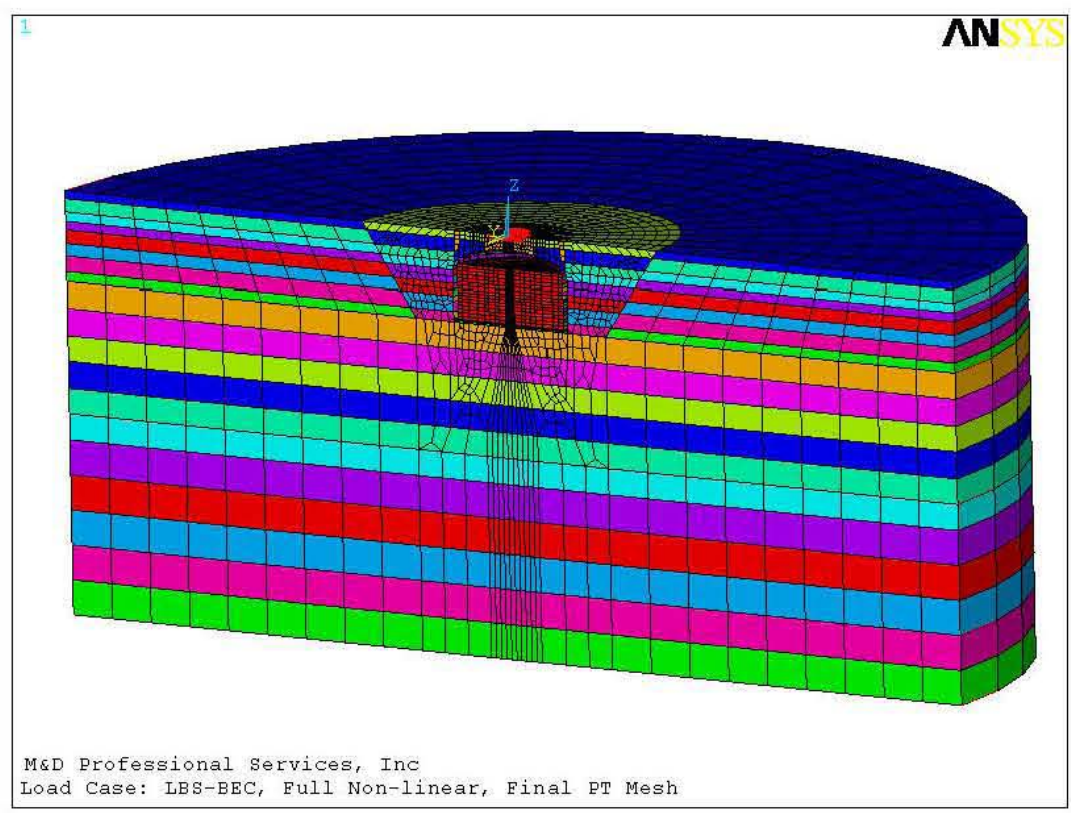

Figure 2-1. Composite Tank Model Detail 
RPP-RPT-32239, Rev. 1

M\&D-2008-005-CALC-001, Rev. 1

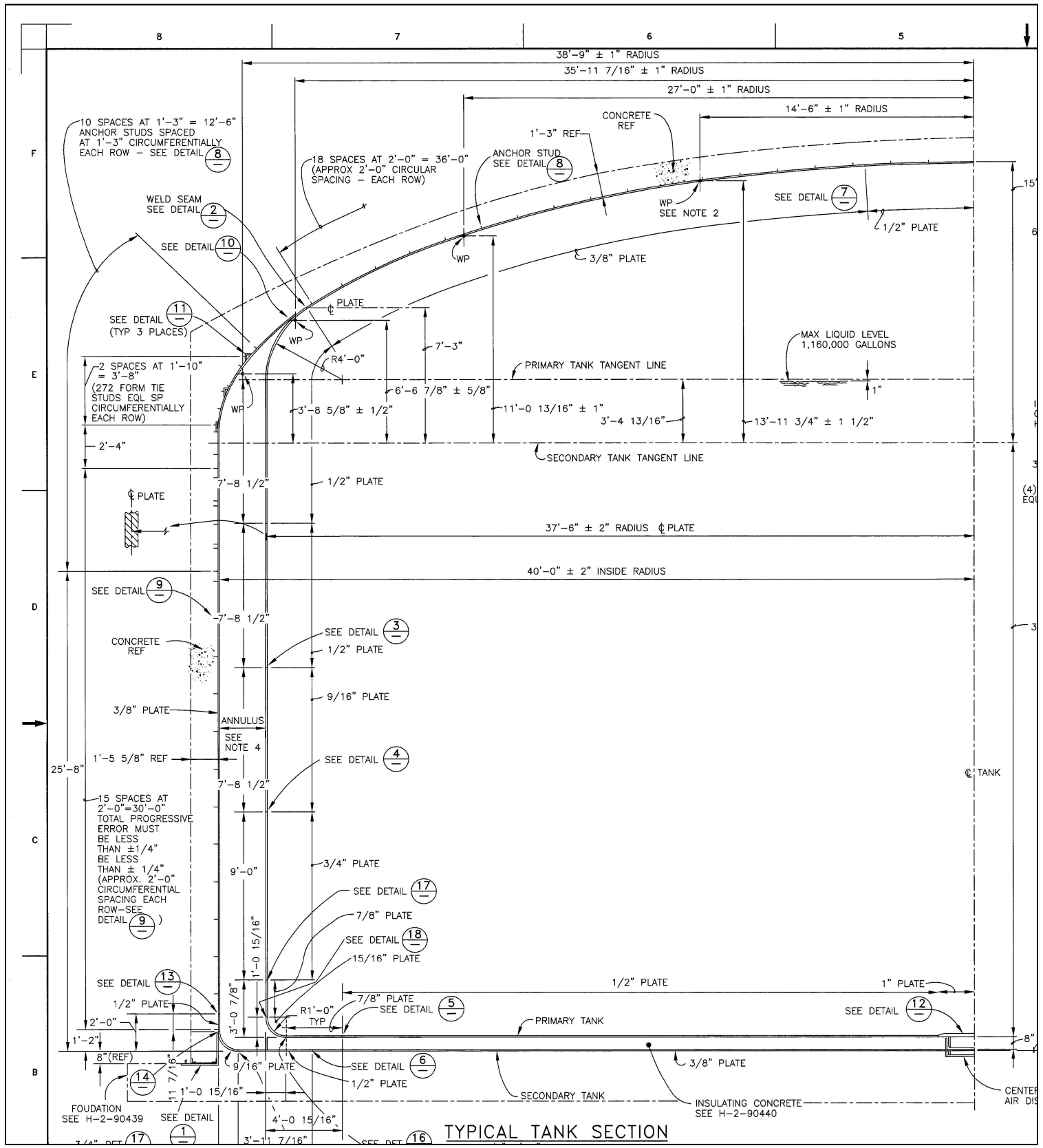

Figure 2-2. 241-AP Primary Tank Dimensions

The detailed ANSYS ${ }^{\circledR}$ model was developed based on coordinates used in the Thermal and Operating Loads Analysis (TOLA) model. A series of input files were used to break the model creation into manageable parts. The files used and a short description is provided in Table 2-1. Files that are common to all load cases are provided in Appendix E. Files that are unique to a specific load case are provided in the appendix for each load case. 
RPP-RPT-32239, Rev. 1

M\&D-2008-005-CALC-001, Rev. 1

Table 2-1. $\operatorname{ANSYS}^{\circledR}$ Model Input File Description

\begin{tabular}{|c|c|}
\hline File Name & Description \\
\hline Run-Tank.txt & Calls each input for development of model. \\
\hline Tank-Coordinates-AP.txt & $\begin{array}{l}\text { Defines key geometry and model parameters. Concrete geometry set to } \\
\text { match PNNL section cut locations. }\end{array}$ \\
\hline Tank-Props-\#\#.txt & $\begin{array}{l}\text { Defines concrete material and real properties for model. Uses properties } \\
\text { based on best-estimate or fully cracked conditions. Each tank layer can be } \\
\text { assigned unique properties. }\end{array}$ \\
\hline Tank-Mesh1.txt & Creates concrete shell mesh. Foundation and wall are separate entities \\
\hline Primary-Props-AP.txt & Defines primary tank material and real properties. \\
\hline Primary.txt & Creates primary tank mesh. Primary tank is not connected to concrete shell. \\
\hline Insulate.txt & $\begin{array}{l}\text { Creates insulating concrete mesh. Uses existing geometry from concrete } \\
\text { and primary tanks, but is not connected. }\end{array}$ \\
\hline Waste-Solid-AP.txt & $\begin{array}{l}\text { Creates model of waste. Uses Solid } 45 \text { elements with low shear modulus. } \\
\text { Uses primary tank geometry. }\end{array}$ \\
\hline Interfacel.txt & Creates interface connections or contacts between pieces of model. \\
\hline Interface-gap1.txt & Creates interface connections or contacts between pieces of model. \\
\hline Bolts-friction.txt & $\begin{array}{l}\text { Creates elements for anchor bolts and contact surface between the primary } \\
\text { tank and concrete shell in the dome. }\end{array}$ \\
\hline Liner.txt & Creates elements for Secondary Liner. \\
\hline Near-Soil-1.txt & $\begin{array}{l}\text { Creates soil model for excavated region around tank. Merges coincident } \\
\text { nodes with concrete shell. }\end{array}$ \\
\hline Soil-Props-\#\#-Geo.txt & $\begin{array}{l}\text { Defines all soil geometry and material properties. Excavated region and } \\
\text { native soil have different material properties. Unique files are used for each } \\
\text { soil condition (UB, BE, LB). }\end{array}$ \\
\hline Far-Soil.txt & $\begin{array}{l}\text { Creates far-field/native soil to a radius of } 320 \mathrm{ft} \text { and depth of } 266 \mathrm{ft} \text {. Merges } \\
\text { coincident nodes with near soil and concrete shell. Places large mass at } \\
\text { bottom of model for excitation force. }\end{array}$ \\
\hline Fix-Soil.txt & $\begin{array}{l}\text { Creates the contact interface between the excavated soil and native soil } \\
\text { portions of the model. }\end{array}$ \\
\hline Slave.txt & Creates slaved boundary conditions around exterior of model. \\
\hline Boundary.txt & $\begin{array}{l}\text { Creates boundary conditions for symmetry. Does not set boundary } \\
\text { conditions for solution phase. }\end{array}$ \\
\hline Live_Load.txt & Applies surface concentrated load over center of dome. \\
\hline Outer-Spar.txt & Creates spar elements at edge of soil model to control shear behavior. \\
\hline
\end{tabular}

All components of the model are based on $9^{\circ}$ slices over the half model, for a total of twenty slices. The following model description will address the tank components first, then the surrounding soil.

\subsection{Tank Model}

\subsubsection{Concrete Shell}

The first component developed in the model is the concrete shell and footing. Thirty-three sections are used between the dome and center of the floor for each $9^{\circ}$ slice. In the detailed TOLA model documented 
RPP-RPT-32239, Rev. 1

M\&D-2008-005-CALC-001, Rev. 1

in Rinker et al. (2004), seventy sections were identified and used for extracting forces and moments. Using the profile coordinates for these seventy sections, a subset of 33 sections was developed for the profile of the ANSYS ${ }^{\circledR}$ seismic model (see Table 2-2). Based on the need to allow for connecting other portions of the full model, some coordinates were adjusted relative to the TOLA model.

Table 2-2. Concrete Shell Centerline Coordinates

\begin{tabular}{|c|c|c|c|c|c|c|c|}
\hline & \multirow[b]{2}{*}{ Section } & \multicolumn{3}{|c|}{ Coordinates } & \multicolumn{3}{|c|}{ ANSYS $^{\circledR}$} \\
\hline & & $\begin{array}{c}\mathrm{R} \\
\text { (in.) }\end{array}$ & $\begin{array}{c}\mathbf{H} \\
\text { (in.) }\end{array}$ & $\begin{array}{c}\mathbf{t} \\
\text { (in.) }\end{array}$ & $\mathrm{X}$ & $\mathrm{Z}$ & Set \# \\
\hline & & $\overline{0}$ & $\bar{~} 568.6$ & 15 & 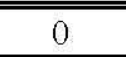 & $\overline{508.8}$ & $\bar{~} 1$ \\
\hline Dome & 1 & 30.2 & 568.6 & 15 & & & \\
\hline & & & & 15 & 45 & 568 & 2 \\
\hline Dome & 2 & 61.4 & 567.5 & 15 & & & \\
\hline Dome & 3 & 90.4 & 565.8 & 15 & 90.4 & 565.8 & 3 \\
\hline Dome & 4 & 120.72 & 563.21 & 15 & 120.72 & 563.21 & 4 \\
\hline Dome & 5 & 152.9 & 559.7 & 15 & 152.9 & 559.7 & 5 \\
\hline Dome & 6 & 184.14 & 555.34 & 15 & & & \\
\hline Dome & 7 & 211.4 & 550.7 & 15 & 211.4 & 550.7 & 6 \\
\hline Dome & 8 & 239.1 & 545.2 & 15 & 239.1 & 545.2 & 7 \\
\hline Dome & 9 & 271.85 & 537.45 & 15 & & & \\
\hline Dome & 10 & 306.63 & 527.68 & 15 & 306.63 & 527.68 & 8 \\
\hline Dome & 11 & 316.22 & 524.68 & 15 & & & \\
\hline Dome & 12 & 335.6 & 518.2 & 15 & 335.6 & 518.2 & 9 \\
\hline Dome & 13 & 356.7 & 510.37 & 15 & & & \\
\hline Dome & 14 & 371.86 & 504.24 & 15 & & & \\
\hline Dome & 15 & 393.7 & 494.5 & 15 & 393.7 & 494.5 & 10 \\
\hline Dome & 16 & 404.5 & 489.3 & 18.92 & & & \\
\hline Haunch & 17 & 415.2 & 483.7 & 20.31 & & & \\
\hline Haunch & 18 & 428.7 & 476.2 & 22.58 & 428.7 & 476.2 & 11 \\
\hline Haunch & 19 & 441.8 & 468.2 & 25.56 & & & \\
\hline Haunch & 20 & 454.5 & 459.5 & 29.46 & & & \\
\hline Haunch & 21 & 469.9 & 447.4 & 36.36 & 469.9 & 447.4 & 12 \\
\hline Haunch & 22 & 483.8 & 423.18 & 29.71 & & & \\
\hline Haunch & 23 & 486.9 & 407.1 & 22.52 & 486.9 & 407.1 & 13 \\
\hline Haunch & 24 & 488.47 & 393.5 & 19.07 & & & \\
\hline Wall & 25 & 489 & 382.1 & 18 & 489 & 374.1 & 14 \\
\hline Wall & 26 & 489 & 360.8 & 18 & & & \\
\hline Wall & 27 & 489 & 345.6 & 18 & & & \\
\hline Wall & 28 & 489 & 335 & 18 & 489 & 327 & 15 \\
\hline Wall & 29 & 489 & 321 & 18 & & & \\
\hline Wall & 30 & 489 & 306 & 18 & & & \\
\hline Wall & 31 & 489 & 300 & 18 & & & \\
\hline Wall & 32 & 489 & 281 & 18 & 489 & 273 & 16 \\
\hline Wall & 33 & 489 & 260.5 & 18 & & & \\
\hline Wall & 34 & 489 & 236 & 18 & 489 & 228.5 & 17 \\
\hline
\end{tabular}


RPP-RPT-32239, Rev. 1

M\&D-2008-005-CALC-001, Rev. 1

Table 2-2. (contd)

\begin{tabular}{|c|c|c|c|c|c|c|c|}
\hline & \multirow[b]{2}{*}{ Section } & \multicolumn{3}{|c|}{ Coordinates } & \multicolumn{3}{|c|}{ ANSYS $^{\circledR}$} \\
\hline & & $\begin{array}{c}\mathrm{R} \\
\text { (in.) } \\
\end{array}$ & $\begin{array}{c}\mathbf{H} \\
\text { (in.) } \\
\end{array}$ & $\begin{array}{c}\mathbf{t} \\
\text { (in.) } \\
\end{array}$ & $\mathrm{X}$ & $\mathrm{Z}$ & Set \# \\
\hline Wall & 35 & 489 & 210.5 & 18 & & & \\
\hline Wall & 36 & 489 & 201 & 18 & & & \\
\hline Wall & 37 & 489 & 186.8 & 18 & 489 & 178.8 & 18 \\
\hline Wall & 38 & 489 & 171 & 18 & & & \\
\hline Wall & 39 & 489 & 150.5 & 18 & & & \\
\hline Wall & 40 & 489 & 145.5 & 18 & 489 & 137.5 & 19 \\
\hline Wall & 41 & 489 & 120.5 & 18 & & & \\
\hline Wall & 42 & 489 & 100.5 & 18 & & & \\
\hline Wall & 43 & 489 & 80 & 18 & & & \\
\hline Wall & 44 & 489 & 60 & 18 & 489 & 62.0 & 20 \\
\hline Wall & 45 & 489 & 39.9 & 18 & & & \\
\hline Wall & 46 & 489 & 21 & 18 & 489 & 12 & 21 \\
\hline \multirow[t]{3}{*}{ Wall } & 47 & 489 & -4.5 & 18 & & & \\
\hline & & & & & 489 & -12.0 & 22 \\
\hline & & & & & 531 & -12.0 & 23 \\
\hline Slab & 48 & 517 & -18.4 & 23.5 & & & \\
\hline Slab & 49 & 508.5 & -18.4 & 23.5 & & & \\
\hline Slab & 50 & 503 & -18.4 & 23.5 & & & \\
\hline Slab & 51 & 496.8 & -19.1 & 23.5 & & & \\
\hline Slab & 52 & 493 & -19.1 & 23.5 & & & \\
\hline Slab & 53 & 489 & -19.1 & 22 & 489 & -12.0 & 24 \\
\hline Slab & 54 & 485.1 & -19.1 & 22 & & & \\
\hline Slab & 55 & 481 & -19.1 & 22 & & & \\
\hline Slab & 56 & 477 & -19.1 & 22 & & & \\
\hline Slab & 57 & 471 & -19.1 & 22 & & & \\
\hline Slab & 58 & 465 & -19.1 & 22 & & & \\
\hline Slab & 59 & 440 & -19.1 & 19.38 & 438 & -12.0 & 25 \\
\hline \multirow[t]{2}{*}{ Slab } & 60 & 421.4 & -17.9 & 17.05 & 423 & & \\
\hline & & & & & 400 & -12.0 & 26 \\
\hline Slab & 61 & 390 & -15.9 & 13.12 & & & \\
\hline Slab & 62 & 358 & -13.9 & 9.13 & 340 & -12.0 & 27 \\
\hline Slab & 63 & 338 & -13.4 & 8 & & & \\
\hline Slab & 64 & 277.7 & -13.4 & 8 & 280 & -12.0 & 28 \\
\hline Slab & 65 & 218.5 & -13.4 & 8 & 220 & -12.0 & 29 \\
\hline Slab & 66 & 180 & -13.4 & 8 & 160 & -12.0 & 30 \\
\hline Slab & 67 & 129.9 & -13.4 & 8 & & -12.0 & 31 \\
\hline Slab & 68 & 95.7 & -13.4 & 8 & 100 & -12.0 & 32 \\
\hline \multirow[t]{2}{*}{ Slab } & 69 & 54 & -17.1 & 15.43 & & & \\
\hline & & & & & 36 & -12.0 & 33 \\
\hline \multirow[t]{2}{*}{ Slab } & 70 & 20 & -20.1 & 21.5 & & & \\
\hline & & & & & 0 & -12.0 & 34 \\
\hline
\end{tabular}


RPP-RPT-32239, Rev. 1

M\&D-2008-005-CALC-001, Rev. 1

The geometry of the concrete shell is based on a combination of data from drawings and the TOLA model. The basic geometry is based on drawings H-2-90534 and H-2-64306. Nodal locations were selected to correspond reasonably well to the TOLA model. This was done to simplify load combinations. Table 2-2 provides a listing comparison of nodal coordinates for the ANSYS ${ }^{\circledR}$ seismic model and TOLA model.

Input file "Tank-Coordinates-AP.txt" is used to read coordinate data for the concrete shell.

Element stiffnesses are also based on the TOLA model for best-estimate concrete conditions for a maximum temperature of $250^{\circ} \mathrm{F}$. Common properties for all concrete sections are provided below.

Poisson's Ratio $(v)=0.18$

Damping $=7 \%$

Input file "Tank-Props-BEC-250.txt" defines the concrete shell material properties and real constants (thickness) for the best-estimate concrete. Input file "Tank-Props-BEC-Crack.txt" defines the concrete shell material properties and real constants (thickness) for the fully cracked concrete. Table 2-3 provides a complete listing of section properties based on the TOLA model. Table 2-4 provides concrete section properties assuming all sections are cracked.

Table 2-3. Best-Estimate Concrete Properties, $250^{\circ} \mathrm{F}$

\begin{tabular}{|c|c|c|c|c|c|c|c|c|}
\hline \multirow{2}{*}{$\begin{array}{c}\begin{array}{c}\text { Is Section } \\
\text { Cracked? }\end{array} \\
\text { Y/N } \\
\end{array}$} & \multicolumn{2}{|c|}{ Eshl } & \multicolumn{2}{|c|}{$\begin{array}{c}\text { Shell } \\
\text { Thickness } \\
\text { t-shl }\end{array}$} & \multicolumn{2}{|c|}{$\begin{array}{c}\text { Shell } \\
\text { Density, } \\
\text { Rho-shl }\end{array}$} & \multirow{2}{*}{$\begin{array}{c}\text { M\&D } \\
\text { Section } \\
\text { No. }\end{array}$} & \multirow{2}{*}{$\begin{array}{c}\text { PNNL } \\
\text { Section } \\
\text { No. } \\
\end{array}$} \\
\hline & (psi) & (ksf) & (in.) & (ft) & $\left(\mathrm{lb} / \mathrm{in}^{3}\right)$ & $\left(\mathrm{lbf} / \mathrm{ft}^{3}\right)$ & & \\
\hline $\mathrm{N}$ & $4.502 \mathrm{E}+06$ & 648,297 & 15.35 & 1.28 & 0.08484 & 147 & & 1 \\
\hline $\mathrm{N}$ & $4.352 \mathrm{E}+06$ & 626,754 & 15.18 & 1.26 & 0.08578 & 148 & 1 & 2 \\
\hline $\mathrm{N}$ & $4.306 \mathrm{E}+06$ & 620,114 & 15.12 & 1.26 & 0.08609 & 149 & 2 & 3 \\
\hline $\mathrm{N}$ & $4.282 \mathrm{E}+06$ & 616,594 & 15.09 & 1.26 & 0.08627 & 149 & 3 & 4 \\
\hline $\mathrm{N}$ & $4.262 \mathrm{E}+06$ & 613,774 & 15.15 & 1.26 & 0.08595 & 149 & & 5 \\
\hline $\mathrm{N}$ & $4.243 \mathrm{E}+06$ & 610,922 & 15.13 & 1.26 & 0.08609 & 149 & 4 & 6 \\
\hline $\mathrm{N}$ & $4.315 \mathrm{E}+06$ & 621,305 & 15.21 & 1.27 & 0.08559 & 148 & 5 & 7 \\
\hline $\mathrm{N}$ & $4.295 \mathrm{E}+06$ & 618,475 & 15.19 & 1.27 & 0.08572 & 148 & & 8 \\
\hline $\mathrm{N}$ & $4.216 \mathrm{E}+06$ & 607,093 & 15.17 & 1.26 & 0.08583 & 148 & 6 & 9 \\
\hline $\mathrm{N}$ & $4.201 \mathrm{E}+06$ & 604,939 & 15.15 & 1.26 & 0.08594 & 148 & & 10 \\
\hline $\mathrm{N}$ & $4.439 \mathrm{E}+06$ & 639,237 & 15.39 & 1.28 & 0.08463 & 146 & 7 & 11 \\
\hline $\mathrm{N}$ & $4.425 \mathrm{E}+06$ & 637,265 & 15.34 & 1.28 & 0.08487 & 147 & & 12 \\
\hline $\mathrm{N}$ & $4.405 \mathrm{E}+06$ & 634,338 & 15.32 & 1.28 & 0.08497 & 147 & 8 & 13 \\
\hline $\mathrm{N}$ & $4.392 \mathrm{E}+06$ & 632,441 & 15.31 & 1.28 & 0.08504 & 147 & & 14 \\
\hline $\mathrm{N}$ & $4.316 \mathrm{E}+06$ & 621,503 & 15.30 & 1.28 & 0.08510 & 147 & & 15 \\
\hline $\mathrm{N}$ & $4.406 \mathrm{E}+06$ & 634,531 & 19.32 & 1.61 & 0.08499 & 147 & & 16 \\
\hline $\mathrm{N}$ & $4.366 \mathrm{E}+06$ & 628,756 & 20.73 & 1.73 & 0.08505 & 147 & 9 & 17 \\
\hline $\mathrm{N}$ & $4.323 \mathrm{E}+06$ & 622,528 & 22.99 & 1.92 & 0.08527 & 147 & & 18 \\
\hline $\mathrm{Y}$ & $1.655 \mathrm{E}+06$ & 238,350 & 26.72 & 2.23 & 0.08302 & 143 & & 19 \\
\hline $\mathrm{Y}$ & $1.345 \mathrm{E}+06$ & 193,677 & 26.78 & 2.23 & 0.09548 & 165 & 10 & 20 \\
\hline $\mathrm{N}$ & $4.000 \mathrm{E}+06$ & 575,959 & 37.86 & 3.15 & 0.08337 & 144 & 11 & 21 \\
\hline
\end{tabular}


RPP-RPT-32239, Rev. 1

M\&D-2008-005-CALC-001, Rev. 1

Table 2-3. (contd)

\begin{tabular}{|c|c|c|c|c|c|c|c|c|}
\hline \multirow{2}{*}{$\begin{array}{c}\text { Is Section } \\
\text { Cracked? } \\
\text { Y/N }\end{array}$} & \multicolumn{2}{|c|}{ Eshl } & \multicolumn{2}{|c|}{$\begin{array}{c}\text { Shell } \\
\text { Thickness } \\
\text { t-shl }\end{array}$} & \multicolumn{2}{|c|}{$\begin{array}{c}\text { Shell } \\
\text { Density, } \\
\text { Rho-shl }\end{array}$} & \multirow{2}{*}{$\begin{array}{c}\text { M\&D } \\
\text { Section } \\
\text { No. }\end{array}$} & \multirow{2}{*}{$\begin{array}{c}\text { PNNL } \\
\text { Section } \\
\text { No. }\end{array}$} \\
\hline & (psi) & (ksf) & (in.) & (ft) & $\left(\mathrm{lb} / \mathrm{in}^{3}\right)$ & $\left(\mathrm{lbf} / \mathrm{ft}^{3}\right)$ & & \\
\hline $\mathrm{N}$ & $3.960 \mathrm{E}+06$ & 570,283 & 30.93 & 2.58 & 0.08339 & 144 & & 22 \\
\hline $\bar{Y}$ & $1.264 \mathrm{E}+06$ & 182,025 & 21.60 & 1.80 & 0.09052 & 156 & & 23 \\
\hline $\mathrm{Y}$ & $1.409 \mathrm{E}+06$ & 202,953 & 18.00 & 1.50 & 0.09197 & 159 & 12 & 24 \\
\hline $\mathrm{Y}$ & $1.120 \mathrm{E}+06$ & 161,221 & 15.28 & 1.27 & 0.10227 & 177 & & 25 \\
\hline $\mathrm{Y}$ & $1.093 \mathrm{E}+06$ & 157,426 & 15.36 & 1.28 & 0.10170 & 176 & 13 & 26 \\
\hline $\mathrm{Y}$ & $1.076 \mathrm{E}+06$ & 155,010 & 15.42 & 1.28 & 0.10133 & 175 & & 27 \\
\hline Y & $1.068 \mathrm{E}+06$ & 153,784 & 14.00 & 1.17 & 0.11163 & 193 & & 28 \\
\hline $\mathrm{Y}$ & $1.068 \mathrm{E}+06$ & 153,784 & 14.00 & 1.17 & 0.11163 & 193 & & 29 \\
\hline $\mathrm{Y}$ & $1.068 \mathrm{E}+06$ & 153,784 & 14.00 & 1.17 & 0.11163 & 193 & 14 & 30 \\
\hline $\mathrm{Y}$ & $9.490 \mathrm{E}+05$ & 136,651 & 13.53 & 1.13 & 0.11552 & 200 & & 31 \\
\hline $\mathrm{Y}$ & $9.490 \mathrm{E}+05$ & 136,651 & 13.53 & 1.13 & 0.11552 & 200 & & 32 \\
\hline $\mathrm{Y}$ & $9.490 \mathrm{E}+05$ & 136,651 & 13.53 & 1.13 & 0.11552 & 200 & 15 & 33 \\
\hline Y & $9.490 \mathrm{E}+05$ & 136,651 & 13.53 & 1.13 & 0.11552 & 200 & & 34 \\
\hline $\mathrm{Y}$ & $9.490 \mathrm{E}+05$ & 136,651 & 13.53 & 1.13 & 0.11552 & 200 & 16 & 35 \\
\hline $\mathrm{Y}$ & $9.490 \mathrm{E}+05$ & 136,651 & 13.53 & 1.13 & 0.11552 & 200 & & 36 \\
\hline $\mathrm{Y}$ & $9.490 \mathrm{E}+05$ & 136,651 & 13.53 & 1.13 & 0.11552 & 200 & & 37 \\
\hline $\mathrm{N}$ & $9.589 \mathrm{E}+05$ & 138,084 & 14.89 & 1.24 & 0.10496 & 181 & 17 & 38 \\
\hline $\mathrm{N}$ & $3.467 \mathrm{E}+06$ & 499,310 & 18.08 & 1.51 & 0.08644 & 149 & & 39 \\
\hline $\mathrm{Y}$ & $3.435 \mathrm{E}+06$ & 494,646 & 18.06 & 1.50 & 0.08652 & 150 & & 40 \\
\hline $\mathrm{Y}$ & $8.568 \mathrm{E}+05$ & 123,378 & 12.89 & 1.07 & 0.12123 & 209 & 18 & 41 \\
\hline $\mathrm{Y}$ & $8.568 \mathrm{E}+05$ & 123,378 & 12.89 & 1.07 & 0.12123 & 209 & & 42 \\
\hline $\mathrm{Y}$ & $8.655 \mathrm{E}+05$ & 124,633 & 14.21 & 1.18 & 0.10997 & 190 & 19 & 43 \\
\hline $\mathrm{Y}$ & $8.655 \mathrm{E}+05$ & 124,633 & 14.21 & 1.18 & 0.10997 & 190 & & 44 \\
\hline $\mathrm{Y}$ & $8.568 \mathrm{E}+05$ & 123,378 & 12.89 & 1.07 & 0.12123 & 209 & & 45 \\
\hline $\mathrm{Y}$ & $8.638 \mathrm{E}+05$ & 124,388 & 12.86 & 1.07 & 0.12149 & 210 & 20 & 46 \\
\hline $\mathrm{Y}$ & $8.871 \mathrm{E}+05$ & 127,746 & 14.12 & 1.18 & 0.11067 & 191 & & 47 \\
\hline $\mathrm{N}$ & $3.810 \mathrm{E}+06$ & 548,683 & 23.64 & 1.97 & 0.09606 & 166 & 21 & 48 \\
\hline $\mathrm{N}$ & $3.764 \mathrm{E}+06$ & 542,010 & 23.65 & 1.97 & 0.09604 & 166 & & 49 \\
\hline $\mathrm{Y}$ & $1.038 \mathrm{E}+06$ & 149,405 & 20.05 & 1.67 & 0.10680 & 185 & & 50 \\
\hline $\mathrm{Y}$ & $1.054 \mathrm{E}+06$ & 151,733 & 20.06 & 1.67 & 0.10674 & 184 & & 51 \\
\hline $\mathrm{Y}$ & $1.075 \mathrm{E}+06$ & 154,870 & 20.12 & 1.68 & 0.10643 & 184 & 22 & 52 \\
\hline $\mathrm{Y}$ & $7.157 \mathrm{E}+05$ & 103,055 & 14.04 & 1.17 & 0.13627 & 235 & & 53 \\
\hline $\mathrm{N}$ & $3.571 \mathrm{E}+06$ & 514,287 & 17.19 & 1.43 & 0.09959 & 172 & 23 & 54 \\
\hline $\mathrm{N}$ & $3.570 \mathrm{E}+06$ & 514,043 & 13.20 & 1.10 & 0.10383 & 179 & & 55 \\
\hline $\mathrm{Y}$ & $1.140 \mathrm{E}+06$ & 164,113 & 6.14 & 0.51 & 0.16690 & 288 & 24 & 56 \\
\hline $\mathrm{N}$ & $3.632 \mathrm{E}+06$ & 522,946 & 7.94 & 0.66 & 0.11656 & 201 & 25 & 57 \\
\hline $\mathrm{Y}$ & $1.349 \mathrm{E}+06$ & 194,254 & 4.96 & 0.41 & 0.18649 & 322 & 26 & 58 \\
\hline $\mathrm{Y}$ & $1.387 \mathrm{E}+06$ & 199,783 & 7.02 & 0.58 & 0.16289 & 281 & 27 & 59 \\
\hline $\mathrm{Y}$ & $1.129 \mathrm{E}+06$ & 162,553 & 6.61 & 0.55 & 0.17280 & 299 & 28 & 60 \\
\hline $\mathrm{Y}$ & $1.393 \mathrm{E}+06$ & 200,531 & 5.01 & 0.42 & 0.22800 & 394 & 29 & 61 \\
\hline $\mathrm{Y}$ & $1.163 \mathrm{E}+06$ & 167,538 & 4.81 & 0.40 & 0.23765 & 411 & 30 & 62 \\
\hline $\mathrm{Y}$ & $8.719 \mathrm{E}+05$ & 125,560 & 12.28 & 1.02 & 0.14557 & 252 & & 63 \\
\hline
\end{tabular}


RPP-RPT-32239, Rev. 1

M\&D-2008-005-CALC-001, Rev. 1

Table 2-4. Fully Cracked Concrete Properties

\begin{tabular}{|c|c|c|c|c|c|c|c|c|}
\hline \multirow{2}{*}{$\begin{array}{c}\begin{array}{c}\text { Is Section } \\
\text { Cracked? }\end{array} \\
\text { Y/N } \\
\end{array}$} & \multicolumn{2}{|c|}{ Eshl } & \multicolumn{2}{|c|}{$\begin{array}{c}\text { Shell } \\
\text { Thickness } \\
\text { t-shl }\end{array}$} & \multicolumn{2}{|c|}{$\begin{array}{c}\text { Shell } \\
\text { Density, } \\
\text { Rho-shl }\end{array}$} & \multirow{2}{*}{$\begin{array}{c}\text { M\&D } \\
\text { Section } \\
\text { No. }\end{array}$} & \multirow{2}{*}{$\begin{array}{c}\text { PNNL } \\
\text { Section } \\
\text { No. }\end{array}$} \\
\hline & (psi) & (ksf) & (in.) & (ft) & $\left(\mathbf{l b} / \mathbf{i n}^{3}\right)$ & $\left(\mathrm{lbf} / \mathrm{ft}^{3}\right)$ & & \\
\hline $\bar{Y}$ & $1.435 \mathrm{E}+06$ & 206,708 & 14.64 & 1.22 & 0.08893 & 154 & & 1 \\
\hline $\mathrm{Y}$ & $1.084 \mathrm{E}+06$ & 156,131 & 13.21 & 1.10 & 0.09854 & 170 & 1 & 2 \\
\hline $\mathrm{Y}$ & $9.438 \mathrm{E}+05$ & 135,907 & 12.40 & 1.03 & 0.10504 & 182 & 2 & 3 \\
\hline $\mathrm{Y}$ & $8.552 \mathrm{E}+05$ & 123,148 & 11.78 & 0.98 & 0.11053 & 191 & 3 & 4 \\
\hline $\mathrm{Y}$ & $9.951 \mathrm{E}+05$ & 143,289 & 12.81 & 1.07 & 0.10168 & 176 & & 5 \\
\hline $\mathrm{Y}$ & $9.318 \mathrm{E}+05$ & 134,181 & 12.41 & 1.03 & 0.10491 & 181 & 4 & 6 \\
\hline $\mathrm{Y}$ & $1.141 \mathrm{E}+06$ & 164,239 & 13.58 & 1.13 & 0.09590 & 166 & 5 & 7 \\
\hline $\mathrm{Y}$ & $1.089 \mathrm{E}+06$ & 156,781 & 13.32 & 1.11 & 0.09774 & 169 & & 8 \\
\hline $\mathrm{Y}$ & $1.029 \mathrm{E}+06$ & 148,115 & 13.08 & 1.09 & 0.09951 & 172 & 6 & 9 \\
\hline $\mathrm{Y}$ & $9.768 \mathrm{E}+05$ & 140,657 & 12.53 & 1.04 & 0.10391 & 180 & & 10 \\
\hline $\mathrm{Y}$ & $1.512 \mathrm{E}+06$ & 217,769 & 14.64 & 1.22 & 0.08897 & 154 & 7 & 11 \\
\hline $\mathrm{Y}$ & $1.482 \mathrm{E}+06$ & 213,340 & 14.39 & 1.20 & 0.09048 & 156 & & 12 \\
\hline $\mathrm{Y}$ & $1.443 \mathrm{E}+06$ & 207,751 & 14.28 & 1.19 & 0.09119 & 158 & 8 & 13 \\
\hline $\mathrm{Y}$ & $1.417 \mathrm{E}+06$ & 204,062 & 14.20 & 1.18 & 0.09168 & 158 & & 14 \\
\hline $\mathrm{Y}$ & $1.371 \mathrm{E}+06$ & 197,485 & 14.12 & 1.18 & 0.09219 & 159 & & 15 \\
\hline $\mathrm{Y}$ & $1.544 \mathrm{E}+06$ & 222,339 & 18.42 & 1.53 & 0.08916 & 154 & & 16 \\
\hline $\mathrm{Y}$ & $1.474 \mathrm{E}+06$ & 212,206 & 19.67 & 1.64 & 0.08962 & 155 & 9 & 17 \\
\hline $\mathrm{Y}$ & $1.394 \mathrm{E}+06$ & 200,772 & 21.66 & 1.81 & 0.09047 & 156 & & 18 \\
\hline $\mathrm{Y}$ & $1.531 \mathrm{E}+06$ & 220,469 & 27.13 & 2.26 & 0.08177 & 141 & & 19 \\
\hline $\mathrm{Y}$ & $1.240 \mathrm{E}+06$ & 178,532 & 27.37 & 2.28 & 0.09343 & 161 & 10 & 20 \\
\hline $\mathrm{Y}$ & $1.046 \mathrm{E}+06$ & 150,644 & 34.88 & 2.91 & 0.09050 & 156 & 11 & 21 \\
\hline $\mathrm{Y}$ & $1.270 \mathrm{E}+06$ & 182,924 & 32.31 & 2.69 & 0.07982 & 138 & & 22 \\
\hline $\mathrm{Y}$ & $1.163 \mathrm{E}+06$ & 167,483 & 22.03 & 1.84 & 0.08873 & 153 & & 23 \\
\hline $\mathrm{Y}$ & $1.302 \mathrm{E}+06$ & 187,438 & 18.31 & 1.53 & 0.09041 & 156 & 12 & 24 \\
\hline $\mathrm{Y}$ & $1.028 \mathrm{E}+06$ & 147,988 & 15.59 & 1.30 & 0.10025 & 173 & & 25 \\
\hline $\mathrm{Y}$ & $1.004 \mathrm{E}+06$ & 144,559 & 15.67 & 1.31 & 0.09972 & 172 & 13 & 26 \\
\hline $\mathrm{Y}$ & $9.887 \mathrm{E}+05$ & 142,377 & 15.72 & 1.31 & 0.09937 & 172 & & 27 \\
\hline $\mathrm{Y}$ & $9.808 \mathrm{E}+05$ & 141,234 & 14.29 & 1.19 & 0.10936 & 189 & & 28 \\
\hline $\mathrm{Y}$ & $9.808 \mathrm{E}+05$ & 141,234 & 14.29 & 1.19 & 0.10936 & 189 & & 29 \\
\hline $\mathrm{Y}$ & $9.808 \mathrm{E}+05$ & 141,234 & 14.29 & 1.19 & 0.10936 & 189 & 14 & 30 \\
\hline $\mathrm{Y}$ & $8.690 \mathrm{E}+05$ & 125,131 & 13.83 & 1.15 & 0.11297 & 195 & & 31 \\
\hline $\mathrm{Y}$ & $8.690 \mathrm{E}+05$ & 125,131 & 13.83 & 1.15 & 0.11297 & 195 & & 32 \\
\hline $\mathrm{Y}$ & $8.690 \mathrm{E}+05$ & 125,131 & 13.83 & 1.15 & 0.11297 & 195 & 15 & 33 \\
\hline $\mathrm{Y}$ & $8.690 \mathrm{E}+05$ & 125,131 & 13.83 & 1.15 & 0.11297 & 195 & & 34 \\
\hline $\mathrm{Y}$ & $8.690 \mathrm{E}+05$ & 125,131 & 13.83 & 1.15 & 0.11297 & 195 & 16 & 35 \\
\hline $\mathrm{Y}$ & $8.690 \mathrm{E}+05$ & 125,131 & 13.83 & 1.15 & 0.11297 & 195 & & 36 \\
\hline $\mathrm{Y}$ & $8.690 \mathrm{E}+05$ & 125,131 & 13.83 & 1.15 & 0.11297 & 195 & & 37 \\
\hline $\mathrm{Y}$ & $8.782 \mathrm{E}+05$ & 126,463 & 15.21 & 1.27 & 0.10273 & 178 & 17 & 38 \\
\hline $\mathrm{Y}$ & $8.690 \mathrm{E}+05$ & 125,131 & 13.83 & 1.15 & 0.11297 & 195 & & 39 \\
\hline $\mathrm{Y}$ & $7.828 \mathrm{E}+05$ & 112,717 & 13.20 & 1.10 & 0.11839 & 205 & & 40 \\
\hline $\mathrm{Y}$ & $7.828 \mathrm{E}+05$ & 112,717 & 13.20 & 1.10 & 0.11839 & 205 & 18 & 41 \\
\hline $\mathrm{Y}$ & $7.828 \mathrm{E}+05$ & 112,717 & 13.20 & 1.10 & 0.11839 & 205 & & 42 \\
\hline $\mathrm{Y}$ & $7.908 \mathrm{E}+05$ & 113,881 & 14.54 & 1.21 & 0.10747 & 186 & 19 & 43 \\
\hline $\mathrm{Y}$ & $7.908 \mathrm{E}+05$ & 113,881 & 14.54 & 1.21 & 0.10747 & 186 & & 44 \\
\hline $\mathrm{Y}$ & $7.828 \mathrm{E}+05$ & 112,717 & 13.20 & 1.10 & 0.11839 & 205 & & 45 \\
\hline $\mathrm{Y}$ & $7.891 \mathrm{E}+05$ & 113,629 & 13.17 & 1.10 & 0.11864 & 205 & 20 & 46 \\
\hline
\end{tabular}


RPP-RPT-32239, Rev. 1

M\&D-2008-005-CALC-001, Rev. 1

Table 2-4. (contd)

\begin{tabular}{|c|c|c|c|c|c|c|c|c|}
\hline \multirow{2}{*}{$\begin{array}{c}\text { Is Section } \\
\text { Cracked? } \\
\mathrm{Y} / \mathrm{N}\end{array}$} & \multicolumn{2}{|c|}{ Eshl } & \multicolumn{2}{|c|}{$\begin{array}{c}\text { Shell } \\
\text { Thickness } \\
\text { t-shl }\end{array}$} & \multicolumn{2}{|c|}{$\begin{array}{c}\text { Shell } \\
\text { Density, } \\
\text { Rho-shl }\end{array}$} & \multirow{2}{*}{$\begin{array}{c}\text { M\&D } \\
\text { Section } \\
\text { No. }\end{array}$} & \multirow{2}{*}{$\begin{array}{c}\text { PNNL } \\
\text { Section } \\
\text { No. }\end{array}$} \\
\hline & (psi) & (ksf) & (in.) & (ft) & $\left(\mathrm{lb} / \mathrm{in}^{3}\right)$ & $\left(\mathrm{lbf} / \mathrm{ft}^{3}\right)$ & & \\
\hline $\mathrm{Y}$ & $8.104 \mathrm{E}+05$ & 116,693 & 14.45 & 1.20 & 0.10813 & 187 & & 47 \\
\hline $\mathrm{Y}$ & $9.322 \mathrm{E}+05$ & 134,235 & 21.54 & 1.79 & 0.10546 & 182 & 21 & 48 \\
\hline $\mathrm{Y}$ & $9.324 \mathrm{E}+05$ & 134,263 & 21.66 & 1.80 & 0.10488 & 181 & & 49 \\
\hline $\mathrm{Y}$ & $9.504 \mathrm{E}+05$ & 136,857 & 20.46 & 1.71 & 0.10463 & 181 & & 50 \\
\hline$Y$ & $9.659 \mathrm{E}+05$ & 139,096 & 20.46 & 1.71 & 0.10465 & 181 & & 51 \\
\hline $\mathrm{Y}$ & $9.861 \mathrm{E}+05$ & 141,998 & 20.52 & 1.71 & 0.10436 & 180 & 22 & 52 \\
\hline $\mathrm{Y}$ & $6.510 \mathrm{E}+05$ & 93,743 & 14.43 & 1.20 & 0.13263 & 229 & & 53 \\
\hline $\mathrm{Y}$ & $7.229 \mathrm{E}+05$ & 104,097 & 14.13 & 1.18 & 0.12109 & 209 & 24 & 54 \\
\hline $\mathrm{Y}$ & $8.420 \mathrm{E}+05$ & 121,245 & 11.21 & 0.93 & 0.12227 & 211 & & 55 \\
\hline$Y$ & $1.048 \mathrm{E}+06$ & 150,866 & 6.25 & 0.52 & 0.16372 & 283 & 24 & 56 \\
\hline $\mathrm{Y}$ & $1.147 \mathrm{E}+06$ & 165,097 & 4.93 & 0.41 & 0.18777 & 324 & 25 & 57 \\
\hline $\mathrm{Y}$ & $1.246 \mathrm{E}+06$ & 179,441 & 5.05 & 0.42 & 0.18346 & 317 & 26 & 58 \\
\hline $\mathrm{Y}$ & $1.283 \mathrm{E}+06$ & 184,804 & 7.11 & 0.59 & 0.16072 & 278 & 27 & 59 \\
\hline $\mathrm{Y}$ & $1.038 \mathrm{E}+06$ & 149,438 & 6.73 & 0.56 & 0.16977 & 293 & 28 & 60 \\
\hline$Y$ & $1.288 \mathrm{E}+06$ & 185,420 & 5.09 & 0.42 & 0.22441 & 388 & 29 & 61 \\
\hline $\mathrm{Y}$ & $1.070 \mathrm{E}+06$ & 154,101 & 4.90 & 0.41 & 0.23326 & 403 & 30 & 62 \\
\hline$Y$ & $7.964 \mathrm{E}+05$ & 114,687 & 12.57 & 1.05 & 0.14218 & 246 & & 63 \\
\hline
\end{tabular}

Input file "Tank-Mesh1.txt" develops the concrete shell model. Element type SHELL143 is used for the concrete shell to be able to extract through-wall shear forces.

Figure 2-3 and Figure 2-4 show the profile and full concrete shell model, respectively.

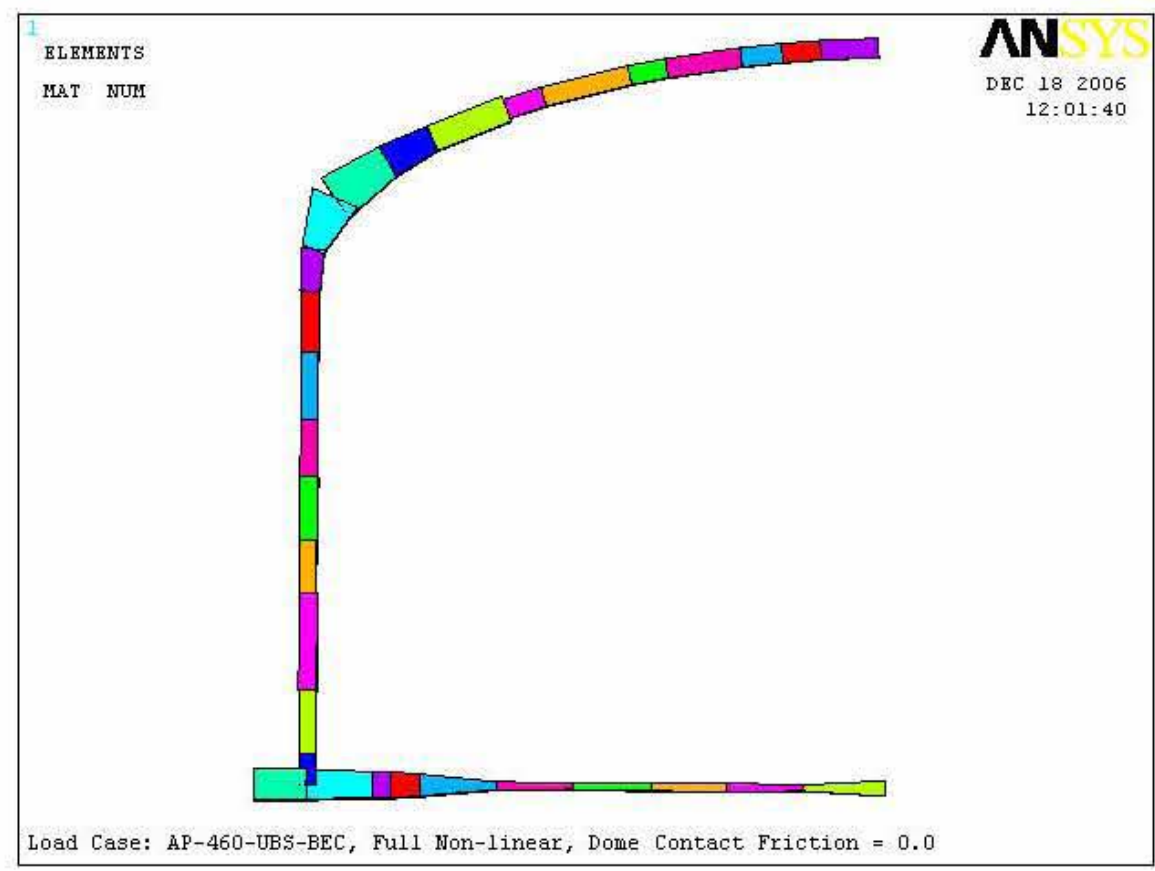

Figure 2-3. Concrete Shell Profile Including Shell Thickness 
RPP-RPT-32239, Rev. 1

M\&D-2008-005-CALC-001, Rev. 1

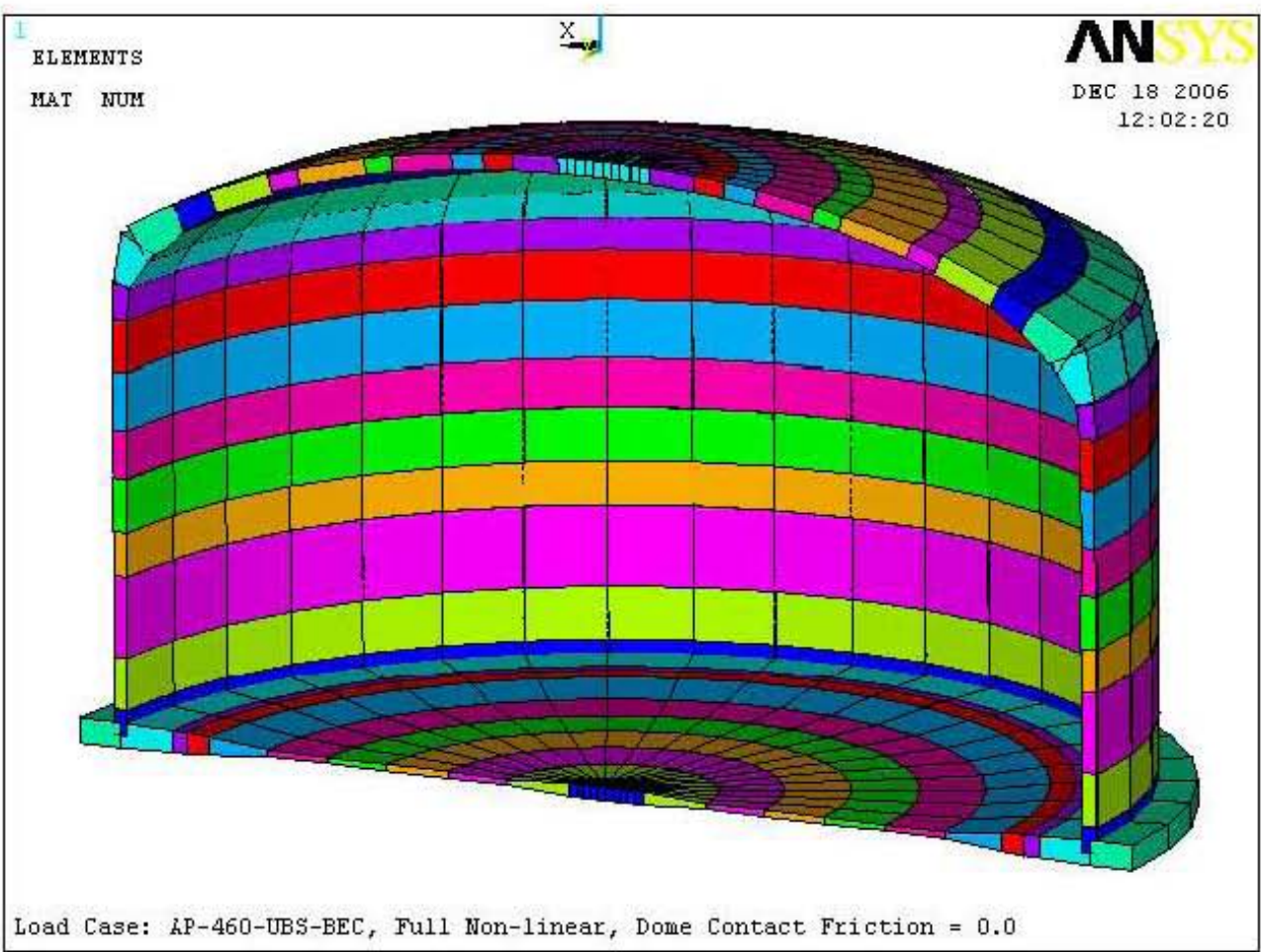

Figure 2-4. Concrete Shell Model Detail

\subsubsection{Primary Tank}

The geometry of the primary tank is based on drawing H-2-90534. To ensure that the anchor bolt elements are perpendi cular to the primary tank, the primary tank dome coordinates were calculated based on the location of the corresponding concrete shell coordinate, taking into account the concrete shell thickness, and normal to the primary tank (see Figure 2-5). The concrete shell thi ckness used is based on the nominal concrete thickness.

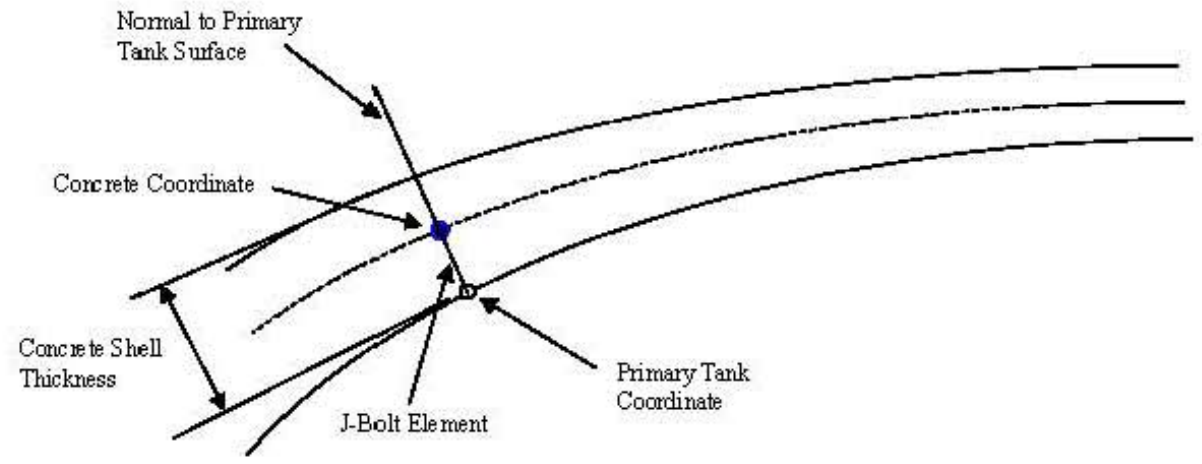

Figure 2-5. Primary/Concrete Shell Node Geometry 
RPP-RPT-32239, Rev. 1

M\&D-2008-005-CALC-001, Rev. 1

The location of the primary tank nodes was iteratively determined as follows:

Select a value for $\mathrm{x}$ (radial distance from center of the tank).

Calculate the respective location for y' based on the defined shape of the primary tank. The primary tank is an ellipse with a major axis of $80 \mathrm{ft}$ and minor axis of $30 \mathrm{ft}$. The equation for the location of $\mathrm{y}^{\prime}$ is as follows:

$$
\begin{aligned}
& y^{\prime}=a \sqrt{1-\frac{x^{2}}{b^{2}}}-a, \text { where } \\
& a=\text { Minor Radius }=180 \text { inches } \\
& b=\text { Major Radius }=480 \text { inches } \\
& x=\text { Test Location for } x \\
& \text { For } x=61.0398, y^{\prime}=180 \sqrt{1-\frac{61.0398^{2}}{480^{2}}-180}=-1.46
\end{aligned}
$$

The slope of the ellipse can be calculated by taking the derivative of the equation for $y^{\prime}$.

$$
\frac{d}{d x}\left(a \sqrt{1-\frac{x^{2}}{b^{2}}}\right)=-\frac{x \frac{a}{b}}{\sqrt{b^{2}-x^{2}}}
$$

For $\mathrm{x}=61.0398$ inches, the slope of the ellipse is -0.048 radians. The corresponding angle is the arctangent of the slope, or in this case, -0.048 radians. The length of line connecting the centerline of the concrete to the primary tank is half the thickness of the tank at that point. Therefore, to check the accuracy of the assumed $x$-location of the primary tank, back-calculate the location of the concrete coordinates. If the back-calculated concrete location is the same as the known location, the $x$-location of the primary tank must be correct, otherwise, reselect $\mathrm{x}$ until it is correct.

Following the example, for concrete location of (61.4 inches), the $x$-location of the primary tank is 61.0398 inches. $y^{\prime}$ was determined to be -1.46 inches. Adjusting this to value for the vertical location of the center of the ellipse, add 561.45 inches (elevation of the primary tank at the apex). For this case, $\mathrm{y}=559.99$ inches. The check is as follows:

$$
\begin{aligned}
& X_{\text {conc }}=X_{\text {primary }}+\frac{t}{2} \sin (\theta), \text { where } \theta \text { is the angle of the slope from horizontal } \\
& X_{\text {conc }}=61.0398+\frac{15}{2} \sin (0.048)=61.39966 \approx 61.4 \text { inches } \\
& Y_{\text {conc }}=Y_{\text {primary }}+\frac{t}{2} \cos (\theta)=559.99+\frac{15}{2} \cos (0.048)=567.48136 \approx 567.5 \text { inches }
\end{aligned}
$$

The primary tank dome coordinates are listed in Table 2-5. 
RPP-RPT-32239, Rev. 1

M\&D-2008-005-CALC-001, Rev. 1

Table 2-5. Primary Tank Dome Coordinate Calculation

\begin{tabular}{|c|c|c|c|c|c|c|c|c|c|c|c|}
\hline \multicolumn{2}{|c|}{ Concrete } & \multirow[b]{2}{*}{$\mathbf{t}$} & & \multicolumn{2}{|c|}{ Primary Tank } & \multirow[b]{2}{*}{$\mathbf{y}^{*}$} & \multirow[b]{2}{*}{ Slope } & \multirow[b]{2}{*}{$\begin{array}{c}\text { Angle } \\
\text { (rad) }\end{array}$} & \multirow[b]{2}{*}{$\begin{array}{l}\text { Angle } \\
\text { (Deg) }\end{array}$} & & \\
\hline $\mathbf{x}$ & $\mathbf{y}$ & & & $\mathbf{x}$ & $\mathbf{y}$ & & & & & & \\
\hline 0 & 568.95 & 15 & $0 \%$ & 0 & 561.30 & 0.00 & 0.000 & 0.000 & 0.000 & 7.500 & 0.000 \\
\hline 45 & 568.2 & 15 & $0 \%$ & 44.7369 & $560 . .50$ & -0.78 & -0.035 & -0.035 & -2.010 & 7.495 & -0.263 \\
\hline 90.4 & 565.8 & 15 & $0 \%$ & 89.8653 & 558.32 & -1.46 & -0.048 & -0.048 & -2.753 & 7.491 & -0.360 \\
\hline 120.72 & 563.21 & 15 & $0 \%$ & 119.9972 & 555.74 & -5.72 & -0.097 & -0.097 & -5.530 & 7.465 & -0.723 \\
\hline 152.9 & 559.7 & 15 & $0 \%$ & 151.9685 & 552.26 & -9.26 & -0.125 & -0.125 & -7.134 & 7.442 & -0.931 \\
\hline 211.4 & 550.7 & 15 & $0 \%$ & 210.0535 & 543.32 & -18.15 & -0.183 & -0.181 & -10.343 & 7.378 & -1.347 \\
\hline 239.1 & 545.2 & 15 & $0 \%$ & 237.5336 & 537.86 & -23.59 & -0.214 & -0.210 & -12.055 & 7.335 & -1.566 \\
\hline 306.63 & 527.68 & 15 & $0 \%$ & 304.4248 & 520.51 & -40.83 & -0.308 & -0.298 & -17.099 & 7.169 & -2.205 \\
\hline 335.6 & 518.2 & 15 & $0 \%$ & 333.0513 & 511.15 & -50.38 & -0.361 & -0.347 & -19.866 & 7.054 & -2.549 \\
\hline 393.7 & 494.5 & 15 & $0 \%$ & 390.2214 & 487.86 & -75.18 & -0.524 & \begin{tabular}{l|}
-0.482 \\
\end{tabular} & -27.633 & 6.645 & -3.479 \\
\hline 428.7 & 476.2 & 22.58 & $0 \%$ & 422.2643 & 466.93 & -94.41 & -0.694 & -0.607 & -34.752 & 9.276 & -6.436 \\
\hline & & & & 432 & 460.20 & -101.54 & -0.774 & \begin{tabular}{|l|}
-0.659 \\
\end{tabular} & -37.750 & 0.000 & 0.000 \\
\hline & & & & 440 & 453.39 & -108.06 & -0.860 & -0.710 & -40.700 & 0.000 & 0.000 \\
\hline $\mathrm{a}$ & 180 & & & & & & & & & & \\
\hline b & 480 & & & & & & & & & & \\
\hline
\end{tabular}

Element thicknesses are based on the drawing H-2-90534 but with reduction of 0.06 inch for corrosion. General steel properties are used and are as follows:

Elastic Modulus $(\mathrm{E})=4,176,200 \mathrm{kip} / \mathrm{ft}^{2}$

Poisson's Ratio $(v)=0.30$

Mass Density $(\rho)=0.001522 \mathrm{kip}-\mathrm{sec}^{2} / \mathrm{ft}^{4}=\left(\left(0.490 \mathrm{kip} / \mathrm{ft}^{3}\right) /\left(32.2 \mathrm{ft} / \mathrm{sec}^{2}\right)\right)$

Damping $=2 \%$

Tank coordinates are developed in the model from input file "Tank-Coordinates-AP.txt." Tank element properties are from input file "Primary-Props-AP." The tank mesh is generated using "Primary.txt" and uses SHELL143 elements.

Figure 2-6 shows the full primary tank model, and Figure 2-7 shows the detail in the knuckle region at the bottom of the tank. 
RPP-RPT-32239, Rev. 1

M\&D-2008-005-CALC-001, Rev. 1

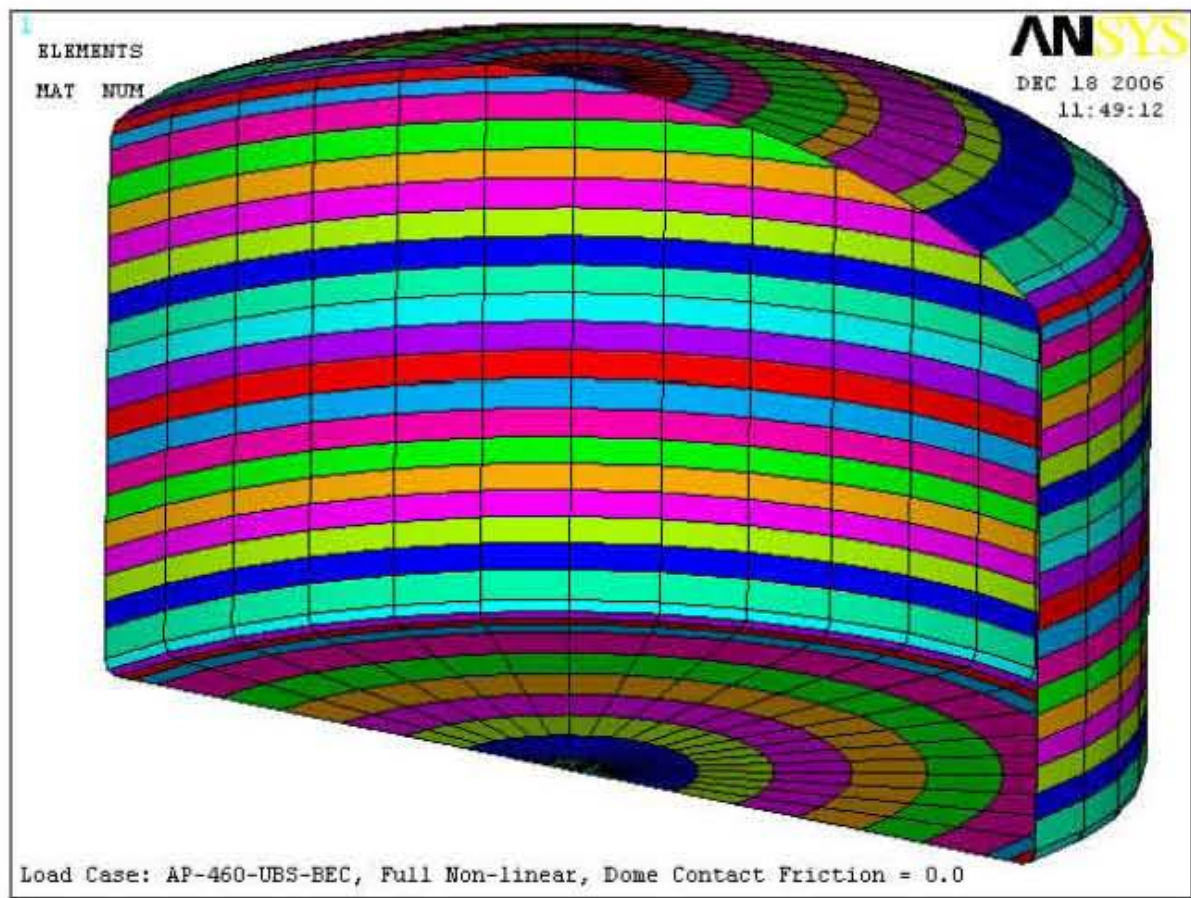

Figure 2-6. Primary Tank Model Detail

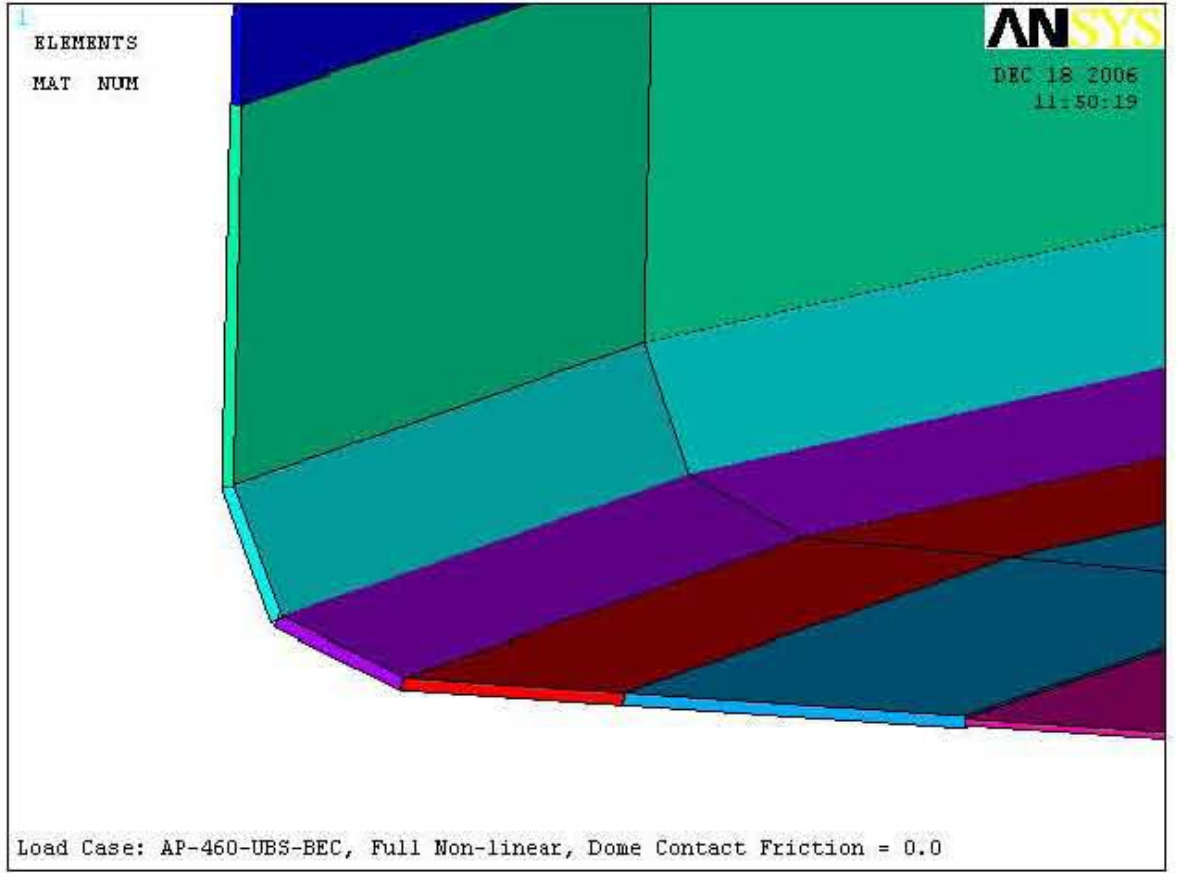

Figure 2-7. Primary Tank Model Detail - Knuckle Region 
RPP-RPT-32239, Rev. 1

M\&D-2008-005-CALC-001, Rev. 1

\subsubsection{Insulating Concrete}

The insulating concrete uses the geometry defined for the concrete and primary tanks and fills in the open volume with solid element (SOLID45). Concrete properties are taken from Rinker et al. (2004).

Elastic Modulus $(\mathrm{E})=23,760 \mathrm{kip} / \mathrm{ft}^{2}$

Poisson's Ratio $(v)=0.15$

Mass Density $(\rho)=0.00155 \mathrm{kip}-\mathrm{sec}^{2} / \mathrm{ft}^{4}=\left(\left(0.050 \mathrm{kip} / \mathrm{ft}^{3}\right) /\left(32.2 \mathrm{ft} / \mathrm{sec}^{2}\right)\right)$

Damping $=7 \%$

Material properties for the insulating concrete are in the file "Tank-Props-BEC-250.txt." The element mesh is generated using "Insulate.txt." Figure 2-8 shows the insulating concrete elements.

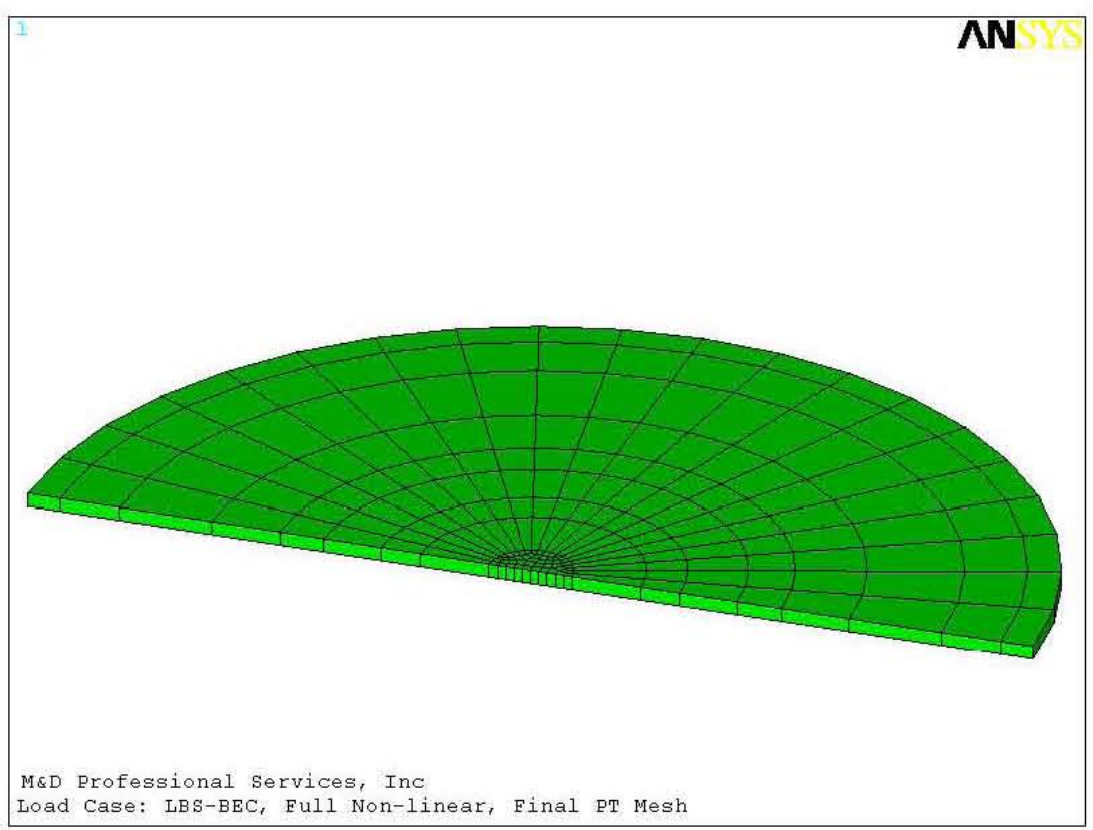

Figure 2-8. Insulating Concrete Model Detail

\subsubsection{Anchor Bolts}

The anchor bolts connecting the primary tank to the concrete shell are modeled using beam elements (BEAM4) and spring elements (COMBIN14). Based on drawing H-2-64310, the anchor bolts are spaced on an average of $2 \mathrm{ft}$ in each direction. Therefore, the contributing area of the bolts in the model is based on the number of $4 \mathrm{ft}^{2}$ areas associated with the element. The required area is calculated based on the number of bolts to be represented and the thickness of the concrete at the bolt location. The anchor bolt area calculations are presented in Table 2-6. 
RPP-RPT-32239, Rev. 1

M\&D-2008-005-CALC-001, Rev. 1

Table 2-6. Anchor Bolt Area Calculations

\begin{tabular}{|c|c|c|c|c|c|c|c|c|c|c|c|}
\hline Ring No. & 1 & 2 & 3 & 4 & 5 & 6 & 7 & 8 & 9 & 10 & 11 \\
\hline $\mathrm{x}$ & 0.00 & 44.72 & 89.87 & 120.00 & 151.97 & 210.05 & 237.53 & 304.42 & 333.05 & 390.22 & 422.26 \\
\hline $\mathrm{y}$ & 561.45 & 560.77 & 558.37 & 555.83 & 552.29 & 543.40 & 537.96 & 520.72 & 511.17 & 486.37 & 467.14 \\
\hline & 0.00 & 0.68 & 3.08 & 5.62 & 9.16 & 18.05 & 23.49 & 40.73 & 50.28 & 75.08 & 94.31 \\
\hline Delta Y & 0.00 & 0.68 & 2.40 & 2.53 & 3.54 & 8.89 & 5.43 & 17.25 & 9.55 & 24.80 & 19.23 \\
\hline $\mathrm{x}^{\prime}$ & 0.00 & 44.72 & 89.92 & 120.13 & 152.24 & 210.83 & 238.69 & 307.14 & 336.83 & 397.38 & 432.67 \\
\hline $\mathrm{x}^{\prime \prime}$ & 0.00 & 44.72 & 89.93 & 120.17 & 152.34 & 211.10 & 239.11 & 308.19 & 338.37 & 400.69 & 438.06 \\
\hline \begin{tabular}{|l|} 
Horizontal \\
Midpoint
\end{tabular} & 22.36 & 67.33 & 105.05 & 136.26 & 181.72 & 225.11 & 273.65 & 323.28 & 369.53 & 419.37 & 443.88 \\
\hline Ring Area & 785.52 & 6335.32 & 10214.81 & 11827.27 & 22708.34 & 27726.13 & 38033.10 & 46534.03 & 50329.54 & 61766.66 & 41420.22 \\
\hline \begin{tabular}{|l|} 
Number of \\
Bolts in Ring \\
\end{tabular} & 1.36 & 11.00 & 17.73 & 20.53 & 39.42 & 48.14 & 66.03 & 80.79 & 87.38 & 107.23 & 71.91 \\
\hline $\begin{array}{l}\text { Bolts per } \\
\text { element } \\
(20 \text { Sections })\end{array}$ & 1.36 & 0.55 & 0.89 & 1.03 & 1.97 & 2.41 & 3.30 & 4.04 & 4.37 & 5.36 & 3.60 \\
\hline
\end{tabular}

The BEAM4 elements are modeled as essentially rigid, and are oriented normal to the tank dome. Attached to the base of each beam element are three orthogonal springes oriented in the directions of the global coordinate system. Because the beams are rigid, the springs define the response of the anchor bolts in the model.

The stiffness of a single anchor bolt was set to $780 \mathrm{kip} / \mathrm{ft}(65,000 \mathrm{lbf} / \mathrm{in}$.) in all three directions. This stiffness represents the secant shear modulus for the anchor bolts that is documented in Deibler et al. (2008). This formulation will underestimate the axial stiffness of an anchor bolt and thus conservatively overestimate the total deformation of the bolt. Not only does this modeling assumption err on the conservative side, but the axial response of the anchor bolts in the seismic model is essentially inconsequential when combined with the results of the TOLA model.

The anchor bolt model is developed using input file "Bolt-Friction.txt". See Figure 2-9 for the distribution of anchor bolts. Figure 2-10 shows the locations of spring elements connecting the end of each anchor bolt to the primary tank. 
RPP-RPT-32239, Rev. 1

M\&D-2008-005-CALC-001, Rev. 1

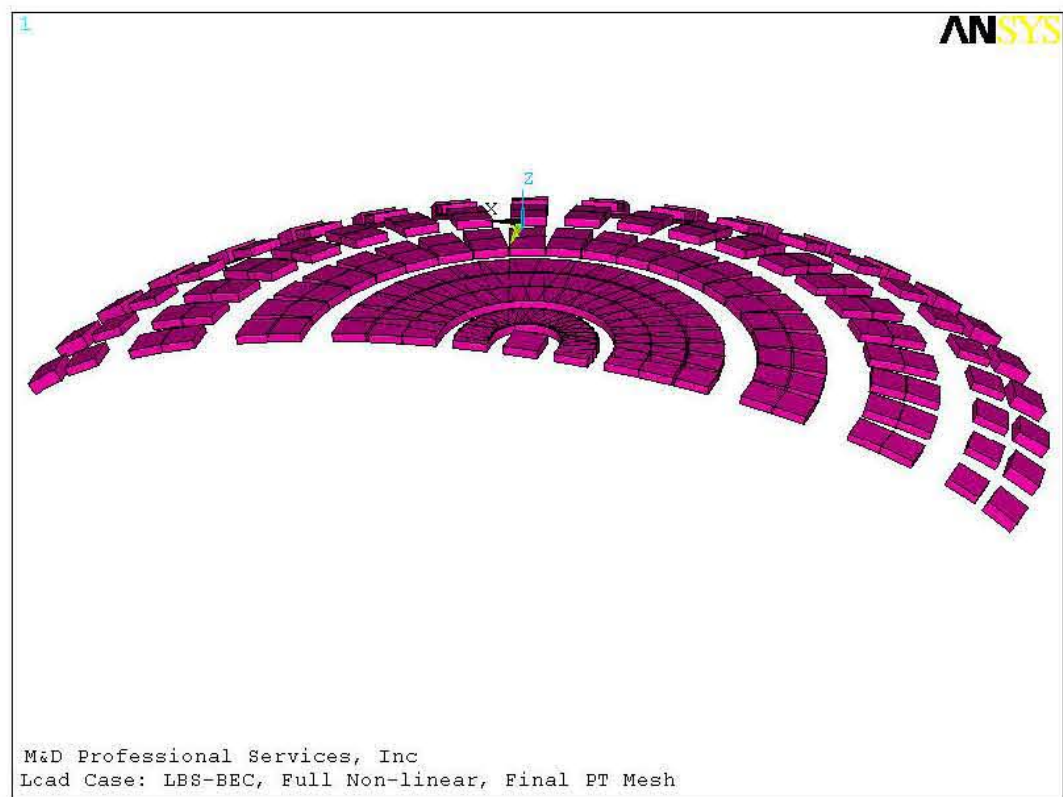

Figure 2-9. Anchor Bolt Model Detail

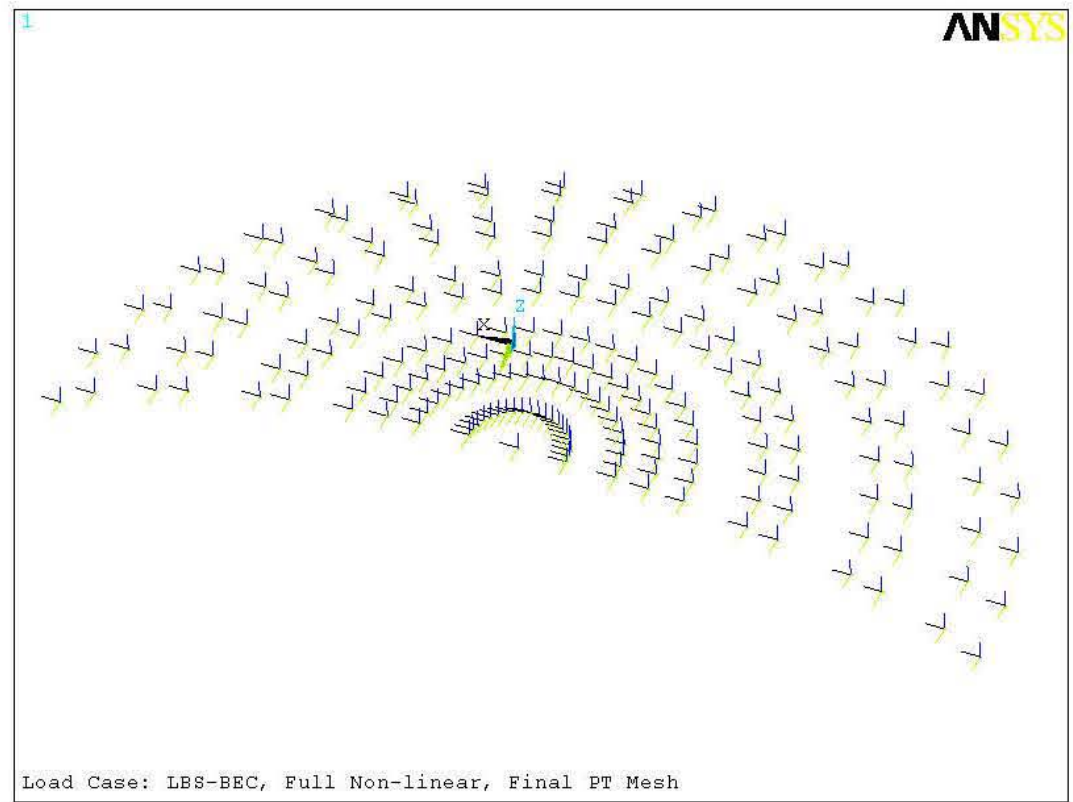

Figure 2-10. Spring Elements - Anchor Bolts to Primary Tank

\subsubsection{Secondary Liner}

The secondary liner is modeled using SHELL143 elements and its geometry is taken from drawing H-2-64449. The steel thickness is 0.25 inch throughout the liner. The model stops after the first full wall element coincident with the liner (Figure 2-11). 
RPP-RPT-32239, Rev. 1

M\&D-2008-005-CALC-001, Rev. 1

Input file "Liner.txt" develops the model for the liner using the geometry defined for the concrete shell in "Tank-Coordinates.txt." The following material properties are used for the steel liner.

Elastic Modulus $(\mathrm{E})=4,176,200 \mathrm{kip} / \mathrm{ft}^{2}$

Poisson's Ratio $(v)=0.30$

Mass Density $(\rho)=0.001522 \mathrm{kip}-\mathrm{sec}^{2} / \mathrm{ft}^{4}=\left(\left(0.490 \mathrm{kip} / \mathrm{ft}^{3}\right) /\left(32.2 \mathrm{ft} / \mathrm{sec}^{2}\right)\right)$

Damping $=2 \%$

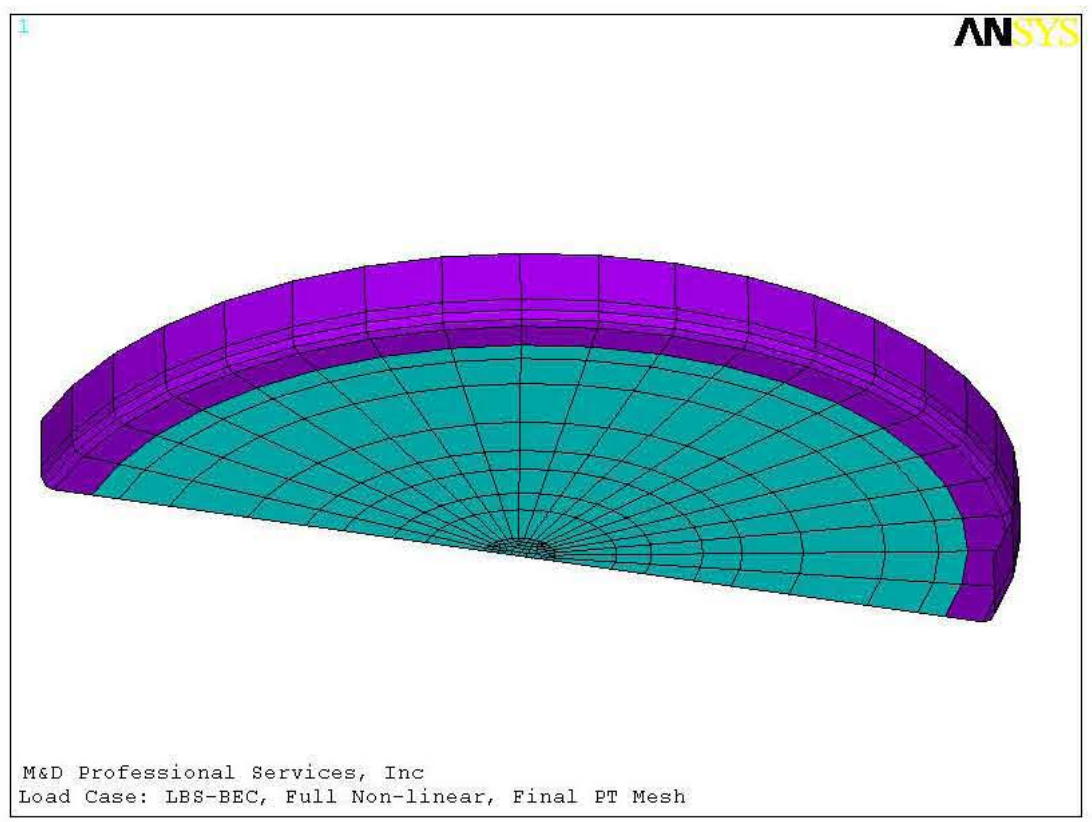

Figure 2-11. Secondary Liner Model Detail

\subsubsection{Waste}

The waste is modeled using solid elements (SOLD45) with material properties defined to simulate a liquid. The waste elements are meshed such that there are no common nodes with the primary tank; however, those on the exterior (at the primary tank) are coincident with the primary tank nodes. Contact elements are used for the interface between the waste and the primary tank. The material properties are as follows:

Elastic Modulus $(\mathrm{E})=2.592 \mathrm{kip} / \mathrm{ft}^{2}$

Poisson's Ratio $(v)=0.49999$

Mass Density $(\rho)=0.00355 \mathrm{kip}-\mathrm{sec}^{2} / \mathrm{ft}^{4}=\left(\left(1.83 * 0.0624 \mathrm{kip} / \mathrm{ft}^{3}\right) /\left(32.2 \mathrm{ft} / \mathrm{sec}^{2}\right)\right)$

Damping $=0$

Shear Modulus $(\mathrm{G})=0.216 \mathrm{kip} / \mathrm{ft}^{2}$ 
The elastic modulus was calculated based on the bulk modulus of water $(\sim 300,000 \mathrm{psi})$. Using a value of $v$ close to $0.5(0.49990)$, the value of $E$ can be calculated.

$$
\begin{aligned}
& \mathrm{B}=E /[3(1-2 v)] \text { or } \\
& E=\mathrm{B}[3(1-2 v)]=300,000[3(1-2(0.49999))]=18 \mathrm{lb} / \mathrm{in}^{2}=2.592 \mathrm{k} / \mathrm{ft}^{2}
\end{aligned}
$$

The shear modulus can then be calculated based on $\mathrm{E}$ and $v, \mathrm{G}=\mathrm{E} /[2(1+v)]$. For the values shown above, this gives a value for $\mathrm{G}$ of $0.864 \mathrm{kip} / \mathrm{ft}^{2}$. However, because a fluid cannot carry shear, a smaller value is used. The value was selected such that the solution remains mathematically stable, but does not transmit significant shear energy. Plots of the waste elements are shown in Figure 2-12 and Figure 2-13.

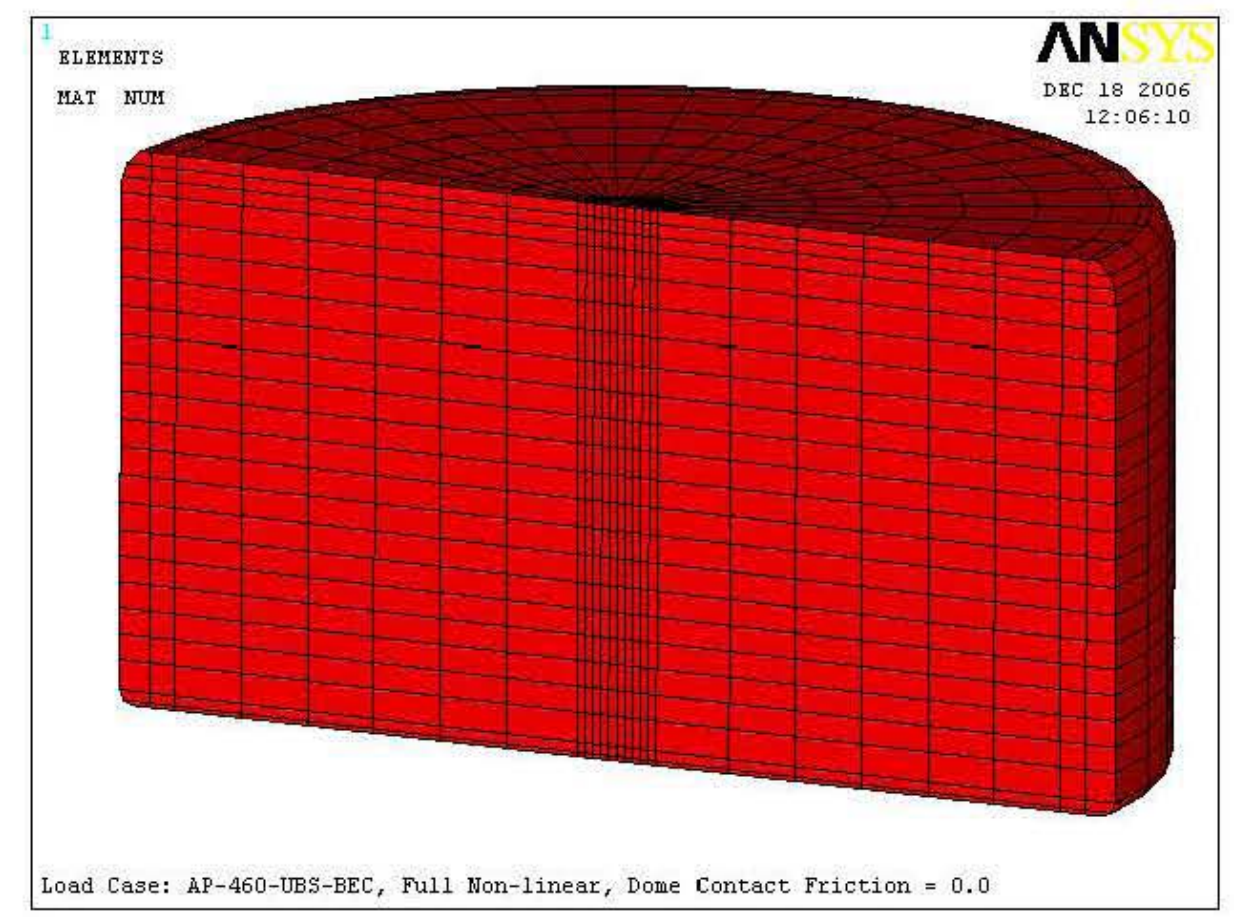

Figure 2-12. Waste Model Detail 
RPP-RPT-32239, Rev. 1

M\&D-2008-005-CALC-001, Rev. 1

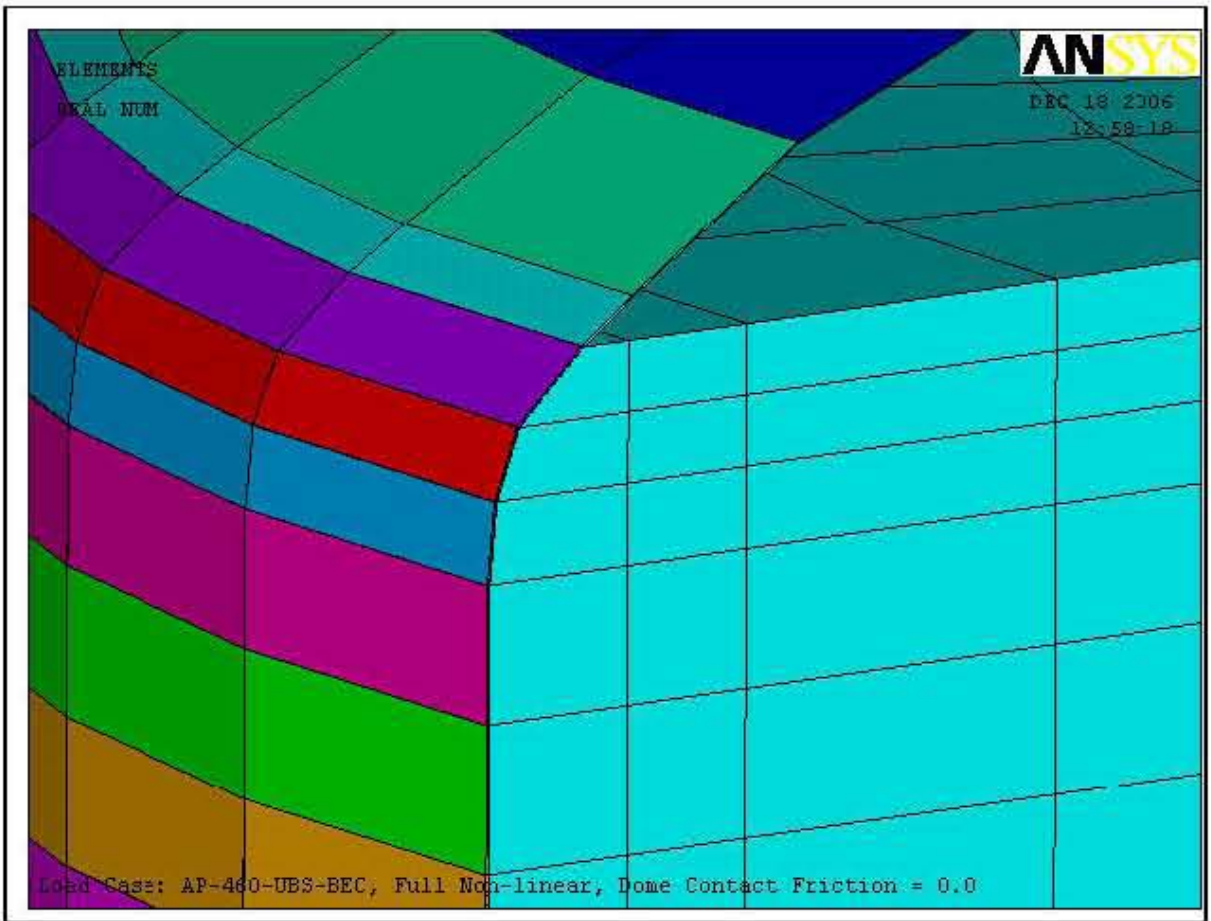

Figure 2-13. Waste Model Detail, Interface with Tank Dome

\subsubsection{Primary Tank and Concrete Dome Interface}

A combination of TARGE170 and CONTA173 elements are used to model the interface between the top of the primary tank and the inside face of the concrete dome. Key-option controls are used to place the interface location at the inside face of the concrete (or bottom of the concrete shell element). A coefficient of friction of 0.01 was used for the contact surface. A low friction value results in the primary load path for shear between the primary tank and the dome to be through the anchor bolts. The small positive value is used to improve model solution stability without significantly affecting the solution.

The contact normal stiffness was set to 0.025 , which is consistent with the value used in Rinker et al. (2006c) for the AY Tank baseline analysis, but is greater than the value of 0.01 used in Revision 0 of this report for the AP Tank Liquid Level Increase. The increase in the contact stiffness was inadvertent, and had the effect of introducing some unwanted contact "chatter" back into the solution. This is a rather unimportant technical detail, and it was verified that this discrepancy had essentially no effect on any significant results.

The contact surface is developed using input file "bolt-friction.txt." Figure 2-14 shows the contact and target elements comprising the dome contact surface. 
RPP-RPT-32239, Rev. 1

M\&D-2008-005-CALC-001, Rev. 1

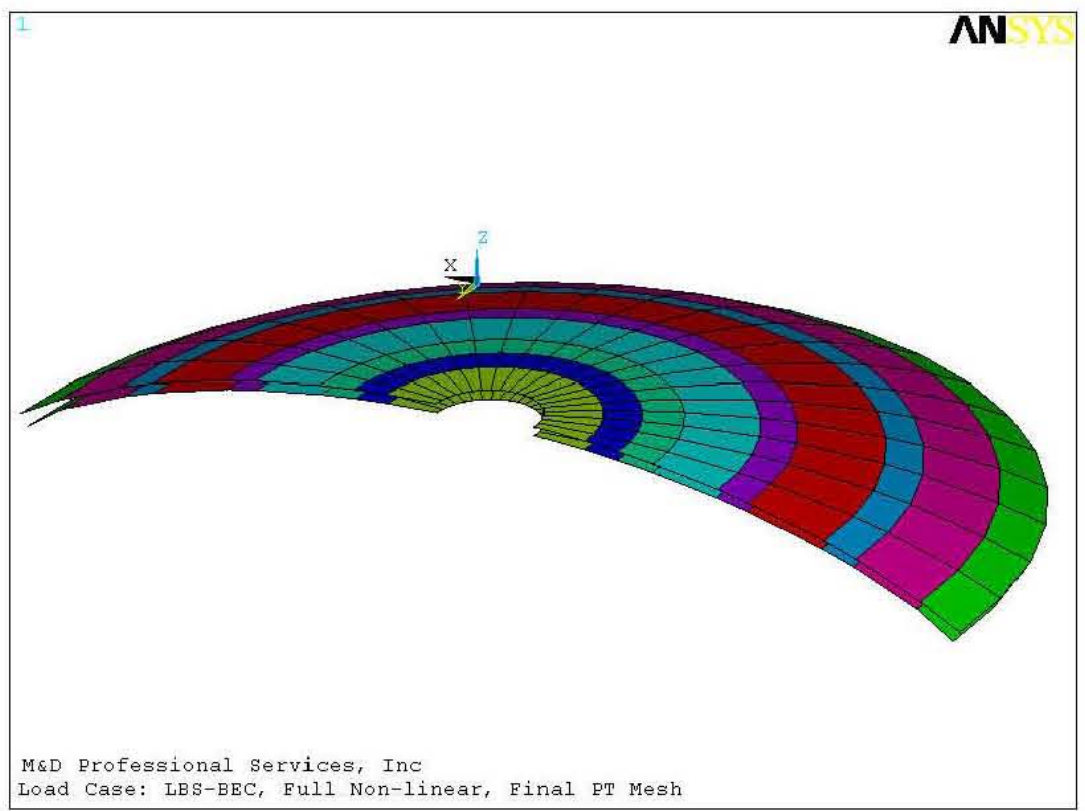

Figure 2-14. Contact Elements - Primary Tank to Concrete Dome

\subsubsection{Primary Tank/Insulating Concrete Interface}

A combination of TARGE170 and CONTA173 elements are used to model the interface between the bottom of the primary tank and the top of the insulating concrete. The contact and target surfaces are modeled as coincident (i.e., no offsets are included for shell thicknesses). A coefficient of friction of 0.4 was used for the contact surface. The contact surface is developed using input file "interfacel.txt." Figure 2-15 shows the contact elements (top layer of elements).

\subsubsection{Insulating Concrete/Secondary Liner Interface}

A combination of TARGE170 and CONTA173 elements are used to model the interface between the bottom of the primary tank and the top of the insulating concrete. The contact and target surfaces are modeled as coincident (i.e., no offsets are included for shell thicknesses). A coefficient of friction of 0.4 was used for the contact surface. The contact surface is developed using input file "interface1.txt." Figure 2-15 shows the contact elements (bottom layer of elements). 
RPP-RPT-32239, Rev. 1

M\&D-2008-005-CALC-001, Rev. 1

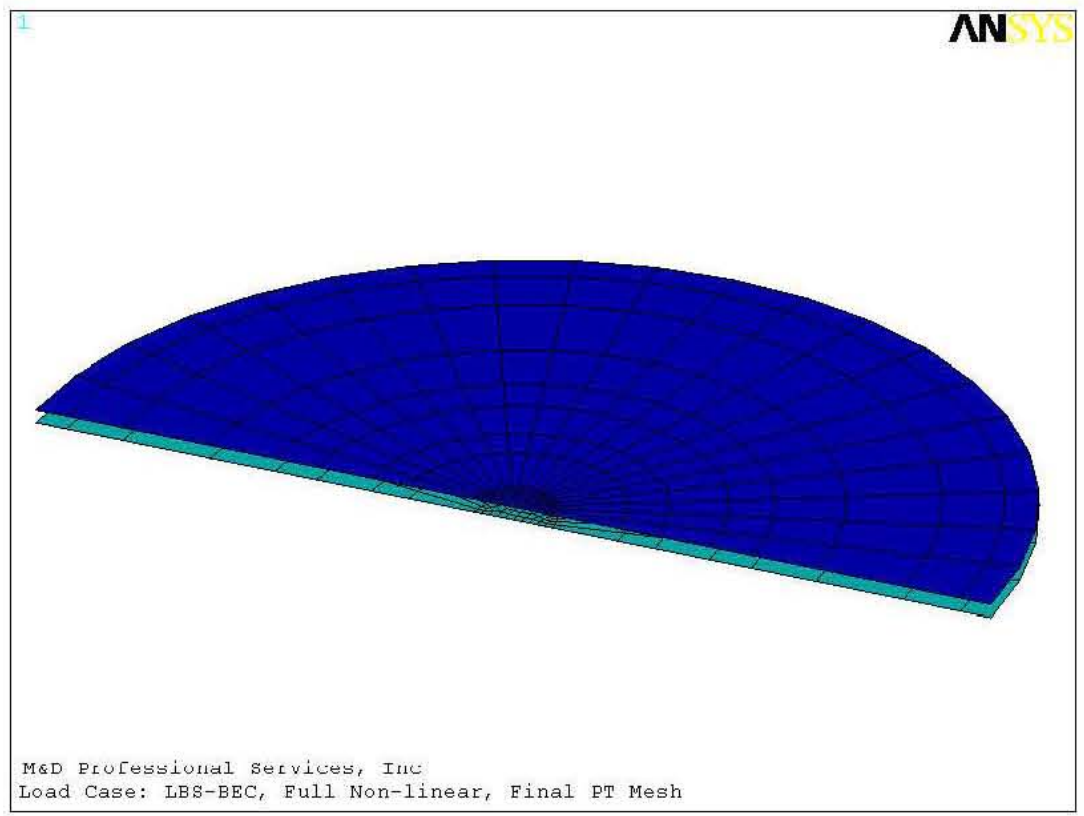

Figure 2-15. Contact Elements - Insulating Concrete Top and Bottom

\subsubsection{Interface Between Concrete Shell and Soil}

A combination of TARGE170 and CONTA173 elements are used to model the interface between the soil and the concrete shell, and for the interface plane between the native and excavated soils. A coefficient of friction of 0.2 was used for the contact surface between the soil and the concrete shell during the static gravity loading to realistically simulate the distribution of geostatic loads. The friction coefficient was then increased to 0.6 for the transient portion of the solution to simulate the dynamic frictional response at this interface (see Rinker et al. [2006c] for additional discussion of soil friction). See Figure 2-16 for the contact surface model.

For the interface between the bottom of the footing and the native soil, COMBIN14 (spring) elements were used. Arbitrary high stiffness values were applied to these springs because the flexibility at the interface is already included in the material properties for the concrete and soil. See Figure 2-17. 
RPP-RPT-32239, Rev. 1

M\&D-2008-005-CALC-001, Rev. 1

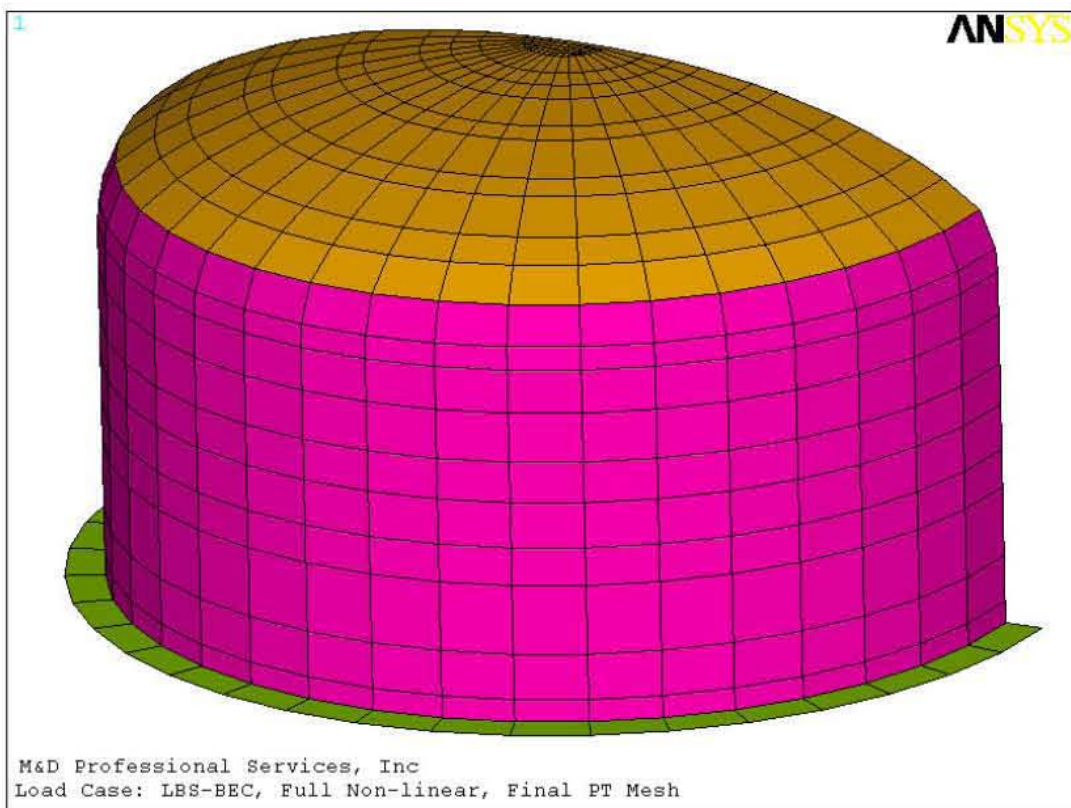

Figure 2-16. Contact Elements - Soil to Concrete Shell

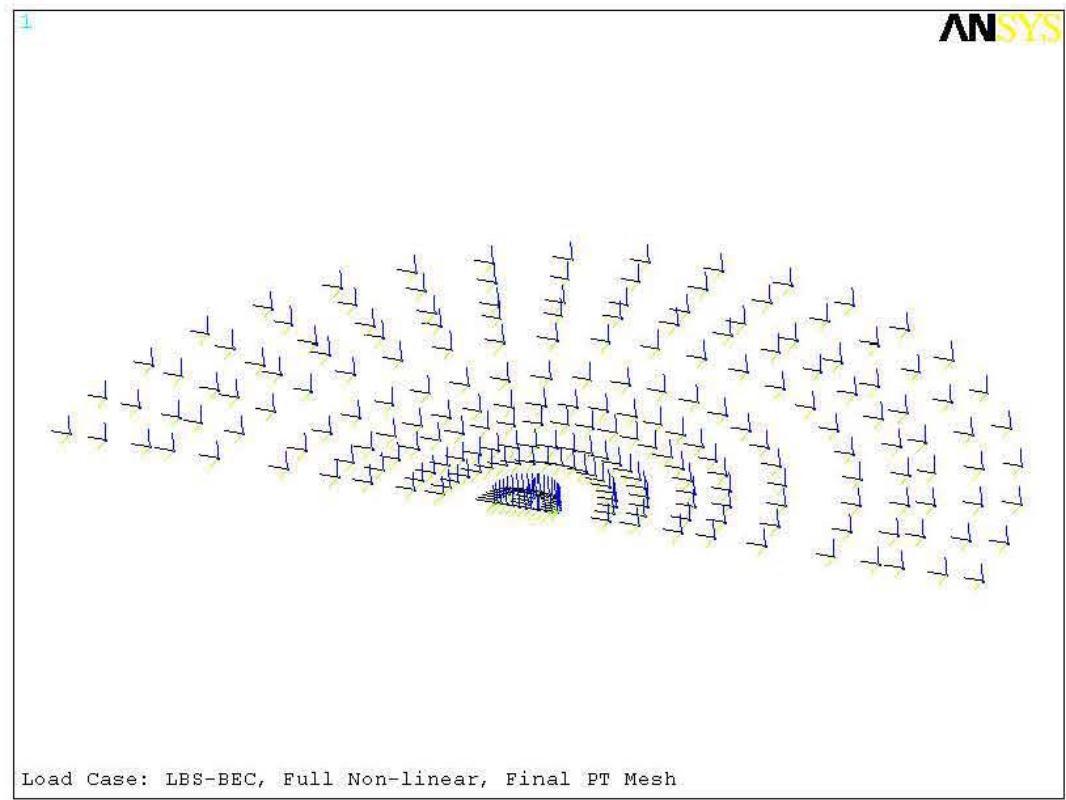

Figure 2-17. Spring Elements - Concrete Footing to Soil 
RPP-RPT-32239, Rev. 1

M\&D-2008-005-CALC-001, Rev. 1

\subsubsection{Interface Between Excavated Soil and Native Soil}

A combination of TARGE170 and CONTA173 elements are used to model the interface between the native and excavated soils. An initial coefficient of friction for the soil-to-soil interface of 0.3 is used for the gravity (static) analysis. The coefficient of friction is changed to 0.7 for the transient analysis. This surface is included to improve the initial conditions for the transient analysis by allowing an initial displacement between the native and excavated soil but located far enough away that it does not have a significant affect on the tank behavior. The soil contact elements are shown in Figure 2-18.

This surface is developed using the input file "fix-soil.txt".

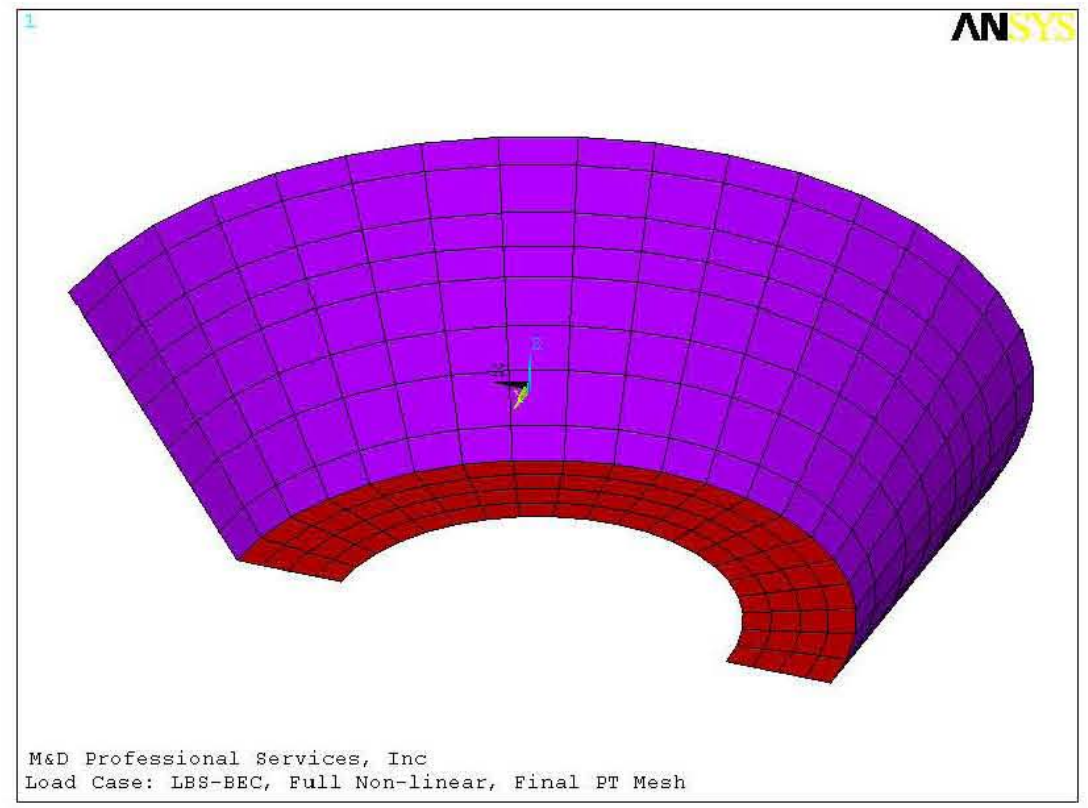

Figure 2-18. Contact Elements - Near Soil to Far Soil

\subsubsection{Interface Between Primary Tank and Waste}

A combination of TARGE170 and CONTA173 elements are used to model the interface between waste and primary tank. No friction is included for this surface. A high stiffness was defined for this contact to obtain the correct hydrostatic pressure on the tank. The high stiffness of the contact was needed because the waste model was very soft. Excessive displacements occur without modifying the contact stiffness. The contact surface is divided into multiple zones to enhance the performance of the contacts. This approach captures more realistic waste pressures in areas of higher curvature (dome and knuckle regions). The contact between the primary tank and waste is shown in Figure 2-19. The contact surface is developed using input file "Waste-Soild-AP.txt." 
RPP-RPT-32239, Rev. 1

M\&D-2008-005-CALC-001, Rev. 1

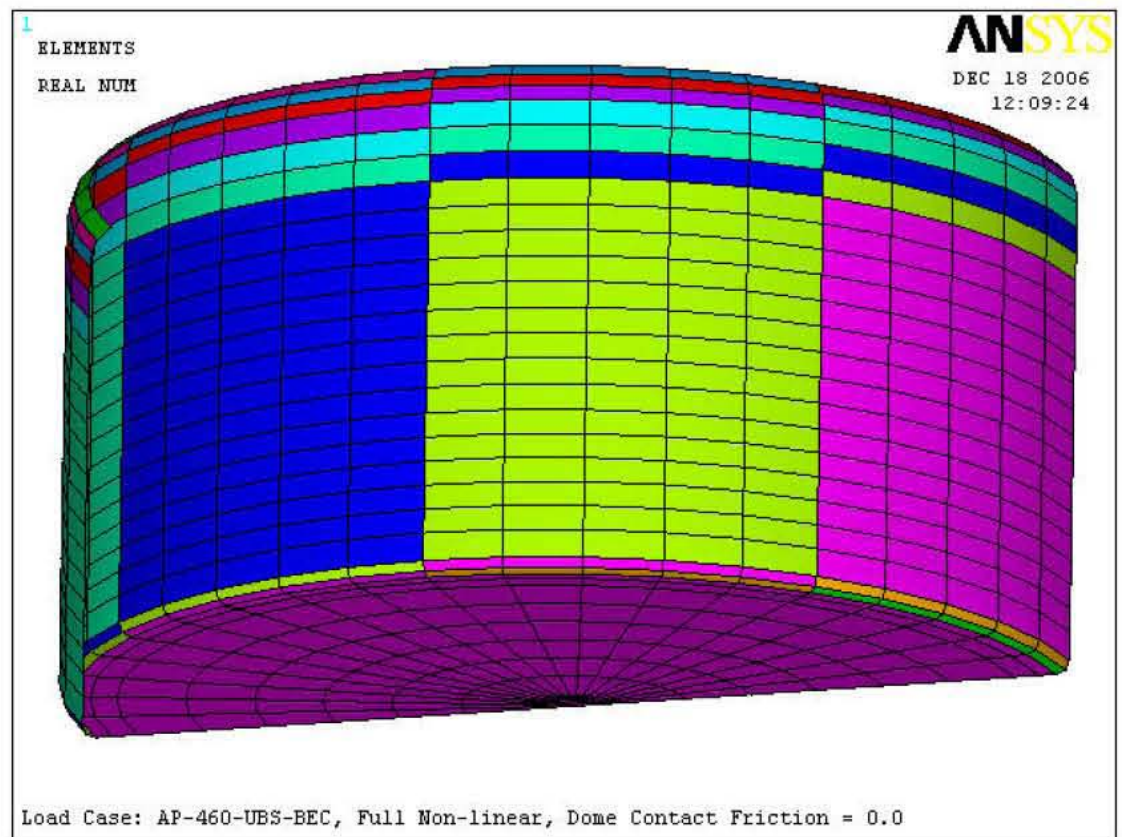

Figure 2-19. Contact Elements - Waste to Primary Tank

\subsubsection{Interface Between Concrete Wall and Tank Footing}

The contact at the bottom of the wall was modeled using CONTA178 elements (see Figure 2-20). A friction coefficient of 0.2 was used for this contact to reflect the steel on steel interface. Use of contact elements for this interface will be used to establish if displacement can occur during a seismic event. The contact elements allow only normal and shear forces (no moments) to be transferred to the footing.

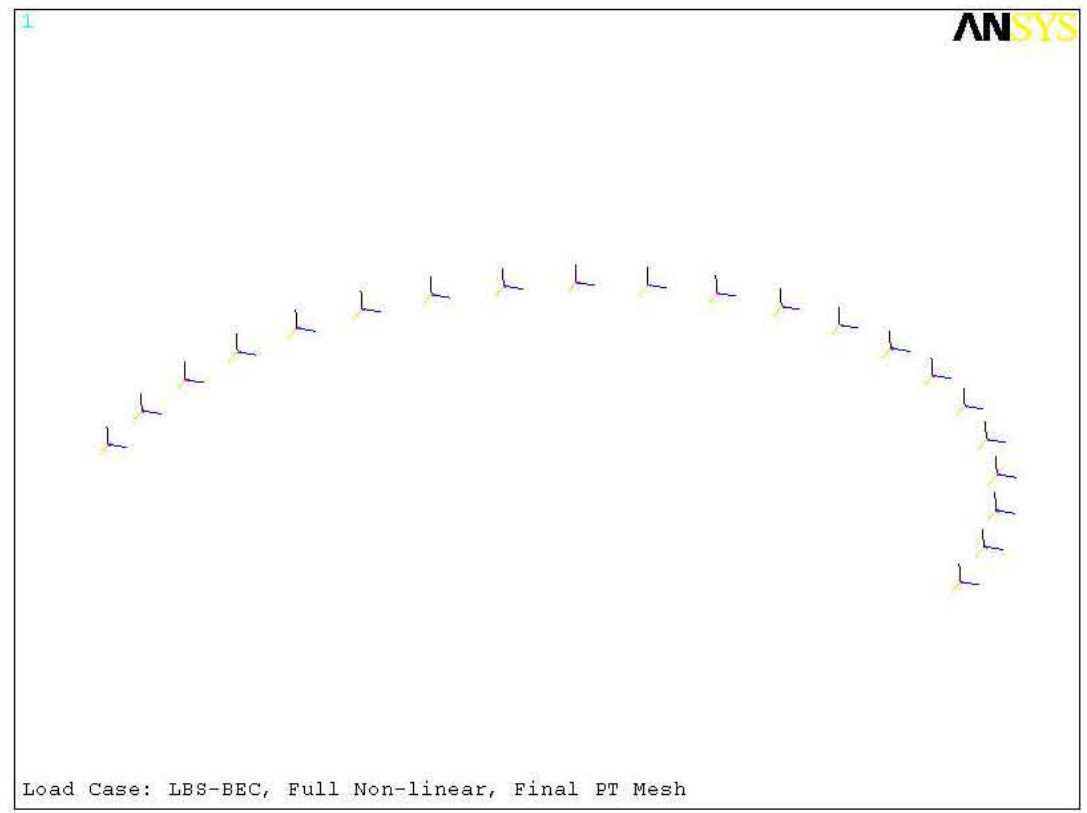

Figure 2-20. Contact Elements - Concrete Wall to Footing 


\section{RPP-RPT-32239, Rev. 1 \\ M\&D-2008-005-CALC-001, Rev. 1}

\subsubsection{Surface Loads}

MASS21 elements (see Figure 2-21) were added to the soil surface over the center of the dome to create a "live load" over the tank dome. The mass provides an equivalent weight of $200,000 \mathrm{lbf}$. Mass elements were used in lieu of forces to capture the dynamic participation of equipment that creates this load.

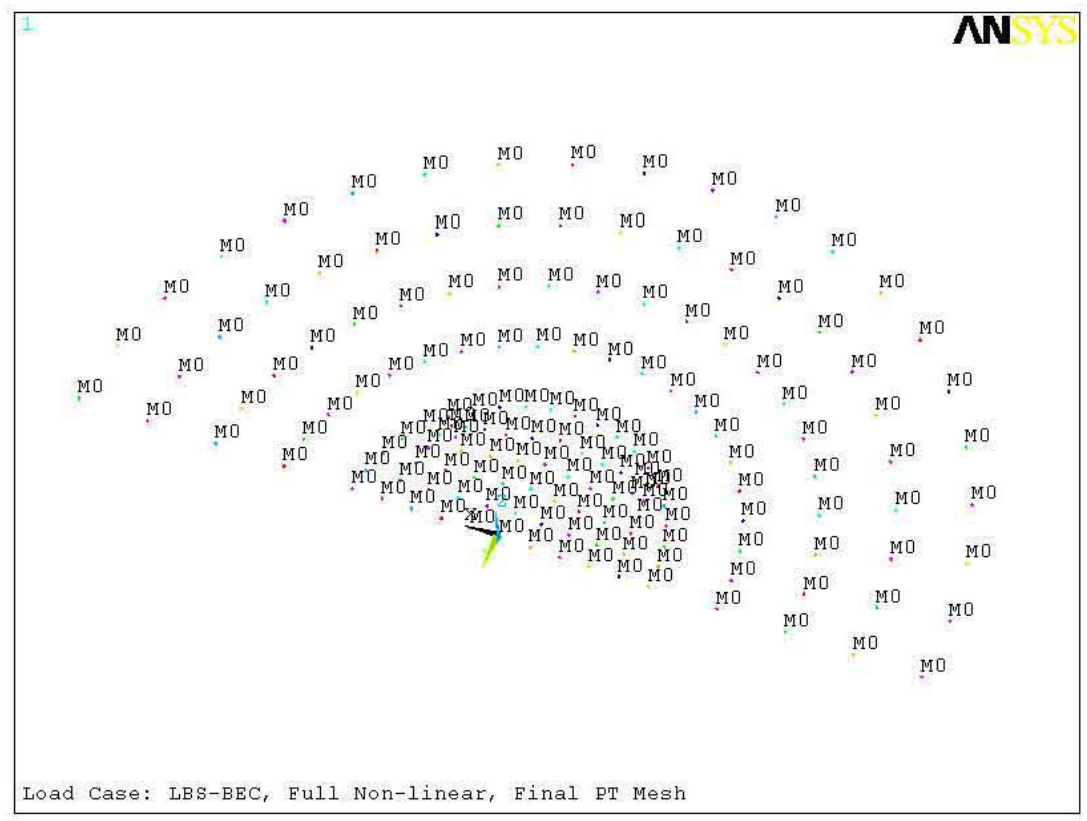

Figure 2-21. Mass Elements - Soil Surface

\subsection{Soil Model}

\subsubsection{Soil Properties}

The soil surrounding the tank is modeled in two groups, the excavated soil and the far-field soil. The excavated soil fills the volume outside the concrete shell and bounded by the slope matching the soil removed during construction. The far-field soil is comprised of all other soil out to a radius of $320 \mathrm{ft}$ and a depth of $266 \mathrm{ft}$. Both regions are modeled using SOLID45 elements.

Two SHAKE analyses were performed for each soil condition to obtain soil properties for the layering used in the model described in Rinker et al. (2006a). One run used the native soil properties and is used for the far-field soil material properties. The second run used material properties associated with structural backfill, and the results are used for the material properties in the excavated soil region.

Soil properties used for the model are listed in the following tables:

- Table 2-7. Best-Estimate Native Soil Iterated Soil Properties

- Table 2-8. Best-Estimate Excavated Soil Iterated Soil Properties

- Table 2-9. Upper Bound Native Soil Iterated Soil Properties

- Table 2-10. Upper Bound Excavated Soil Iterated Soil Properties 
RPP-RPT-32239, Rev. 1

M\&D-2008-005-CALC-001, Rev. 1

- Table 2-11. Lower Bound Native Soil Iterated Soil Properties

- Table 2-12. Lower Bound Excavated Soil Iterated Soil Properties

Table 2-7. Best-Estimate Native Soil Iterated Soil Properties

\begin{tabular}{|c|c|c|c|c|c|c|}
\hline $\begin{array}{c}\text { Layer } \\
\text { Depth } \\
\text { (ft) } \\
\end{array}$ & Damping & $\begin{array}{c}\mathbf{G} \\
\left(\mathrm{kip} / \mathrm{ft}^{2}\right) \\
\end{array}$ & $\begin{array}{c}\text { Poisson's } \\
\text { Ratio } \\
\end{array}$ & $\mathrm{E}\left(\mathrm{kip} / \mathrm{ft}^{2}\right)$ & $\begin{array}{l}\text { Density } \\
\left(\mathbf{l b f} / \mathrm{ft}^{\mathbf{3}}\right)\end{array}$ & $\begin{array}{c}\text { Material } \\
\text { Property } \\
\text { No. } \\
\end{array}$ \\
\hline 2.5 & 0.017 & 6622.3 & 0.24 & 16,423 & 110 & 901 \\
\hline 9.2 & 0.025 & 6241.7 & 0.24 & 15,479 & 110 & 902 \\
\hline 16.4 & 0.034 & 5839.1 & 0.24 & 14,481 & 110 & 903 \\
\hline 22.1 & 0.028 & 5930.4 & 0.24 & 14,707 & 110 & 904 \\
\hline 29 & 0.032 & 5724.9 & 0.19 & 13,625 & 110 & 905 \\
\hline 37.2 & 0.033 & 6494.2 & 0.19 & 15,456 & 110 & 906 \\
\hline 44.7 & 0.033 & 7366.4 & 0.19 & 17,532 & 110 & 907 \\
\hline 52.9 & 0.025 & 8811.9 & 0.19 & 20,972 & 110 & 908 \\
\hline 65.5 & 0.026 & 9851.5 & 0.19 & 23,447 & 110 & 909 \\
\hline 82 & 0.027 & 9721.9 & 0.19 & 23,138 & 110 & 910 \\
\hline 98.8 & 0.029 & 9560.1 & 0.19 & 22,753 & 110 & 911 \\
\hline 115.5 & 0.033 & 9272.5 & 0.19 & 22,069 & 110 & 912 \\
\hline 132 & 0.025 & 10831.8 & 0.19 & 25,780 & 110 & 913 \\
\hline 148.3 & 0.027 & 10644 & 0.19 & 25,333 & 110 & 914 \\
\hline 167.5 & 0.022 & 13867.4 & 0.28 & 35,501 & 120 & 915 \\
\hline 189.5 & 0.021 & 15416 & 0.28 & 39,465 & 120 & 916 \\
\hline 211.5 & 0.023 & 15064.3 & 0.28 & 38,565 & 120 & 917 \\
\hline 233.5 & 0.025 & 14732.5 & 0.28 & 37,715 & 120 & 918 \\
\hline 255.5 & 0.024 & 16209.2 & 0.28 & 41,496 & 120 & 919 \\
\hline
\end{tabular}

Table 2-8. Best-Estimate Excavated Soil Iterated Soil Properties

\begin{tabular}{|c|c|c|c|c|c|c|}
\hline $\begin{array}{c}\text { Layer } \\
\text { Depth } \\
\text { (ft) } \\
\end{array}$ & Damping & $\begin{array}{c}\mathbf{G} \\
\left(\mathrm{kip} / \mathrm{ft}^{2}\right) \\
\end{array}$ & $\begin{array}{c}\text { Poisson's } \\
\text { Ratio } \\
\end{array}$ & E (kip/ft $\left.{ }^{2}\right)$ & $\begin{array}{c}\text { Density } \\
\left(\mathbf{l b f} / \mathrm{ft}^{3}\right) \\
\end{array}$ & $\begin{array}{c}\text { Material } \\
\text { Property } \\
\text { No. } \\
\end{array}$ \\
\hline 2.5 & 0.019 & 3920.4 & 0.27 & 9,958 & 125 & 801 \\
\hline 9.2 & 0.035 & 3463.4 & 0.27 & 8,797 & 125 & 802 \\
\hline 16.4 & 0.048 & 3088.5 & 0.27 & 7,845 & 125 & 803 \\
\hline 22.1 & 0.039 & 3231.8 & 0.27 & 8,209 & 125 & 804 \\
\hline 29 & 0.048 & 3005.6 & 0.27 & 7,634 & 125 & 805 \\
\hline 37.2 & 0.055 & 2829.8 & 0.27 & 7,188 & 125 & 806 \\
\hline 44.7 & 0.059 & 2729.6 & 0.27 & 6,933 & 125 & 807 \\
\hline 52.9 & 0.045 & 3018.4 & 0.27 & 7,667 & 125 & 808 \\
\hline
\end{tabular}


RPP-RPT-32239, Rev. 1

M\&D-2008-005-CALC-001, Rev. 1

Table 2-9. Upper Bound Native Soil Iterated Soil Properties

\begin{tabular}{|c|c|c|c|c|c|c|}
\hline $\begin{array}{c}\text { Layer } \\
\text { Depth } \\
\text { (ft) } \\
\end{array}$ & Damping & $\begin{array}{c}\mathrm{G} \\
\left.\text { (kip/fte }{ }^{2}\right) \\
\end{array}$ & $\begin{array}{c}\text { Poisson's } \\
\text { Ratio } \\
\end{array}$ & E (kip/ft $\left.t^{2}\right)$ & $\begin{array}{l}\text { Density } \\
\left(\mathbf{l b f} / \mathrm{ft}^{\mathbf{3}}\right)\end{array}$ & $\begin{array}{c}\text { Material } \\
\text { Property } \\
\text { No. } \\
\end{array}$ \\
\hline 2.5 & 0.016 & 10004.3 & 0.24 & 24,811 & 110 & 901 \\
\hline 9.2 & 0.022 & 9607.3 & 0.24 & 23,826 & 110 & 902 \\
\hline 16.4 & 0.027 & 9268.4 & 0.24 & 22,986 & 110 & 903 \\
\hline 22.1 & 0.022 & 9383.3 & 0.24 & 23,271 & 110 & 904 \\
\hline 29 & 0.026 & 9068.8 & 0.19 & 21,584 & 110 & 905 \\
\hline 37.2 & 0.027 & 10289.2 & 0.19 & 24,488 & 110 & 906 \\
\hline 44.7 & 0.028 & 11649.1 & 0.19 & 27,725 & 110 & 907 \\
\hline 52.9 & 0.022 & 13709.7 & 0.19 & 32,629 & 110 & 908 \\
\hline 65.5 & 0.022 & 15284.2 & 0.19 & 36,376 & 110 & 909 \\
\hline 82 & 0.024 & 15035.4 & 0.19 & 35,784 & 110 & 910 \\
\hline 98.8 & 0.025 & 14863.1 & 0.19 & 35,374 & 110 & 911 \\
\hline 115.5 & 0.026 & 14746.3 & 0.19 & 35,096 & 110 & 912 \\
\hline 132 & 0.02 & 16982.4 & 0.19 & 40,418 & 110 & 913 \\
\hline 148.3 & 0.021 & 16838.8 & 0.19 & 40,076 & 110 & 914 \\
\hline 167.5 & 0.019 & 21821.5 & 0.28 & 55,863 & 120 & 915 \\
\hline 189.5 & 0.019 & 23910.6 & 0.28 & 61,211 & 120 & 916 \\
\hline 211.5 & 0.02 & 23673.5 & 0.28 & 60,604 & 120 & 917 \\
\hline 233.5 & 0.02 & 23525 & 0.28 & 60,224 & 120 & 918 \\
\hline 255.5 & 0.019 & 25917.8 & 0.28 & 66,350 & 120 & 919 \\
\hline
\end{tabular}

Table 2-10. Upper Bound Excavated Soil Iterated Soil Properties

\begin{tabular}{||c|c|c|c|c|c|c||}
\hline $\begin{array}{c}\text { Layer } \\
\text { Depth (ft) }\end{array}$ & Damping & $\begin{array}{c}\mathbf{G} \\
\text { (kip/ft }^{\mathbf{2}} \text { ) }\end{array}$ & $\begin{array}{c}\text { Poisson's } \\
\text { Ratio }\end{array}$ & $\begin{array}{c}\mathbf{E} \\
\text { (kip/ft }^{\mathbf{2}} \text { ) }\end{array}$ & $\begin{array}{c}\text { Density } \\
\text { (lbf/ft }^{\mathbf{3}} \text { ) }\end{array}$ & $\begin{array}{c}\text { Material } \\
\text { Property } \\
\text { No. }\end{array}$ \\
\hline \hline 2.5 & 0.017 & 5956.9 & 0.27 & 15,131 & 125 & 801 \\
\hline 9.2 & 0.027 & 5554.3 & 0.27 & 14,108 & 125 & 802 \\
\hline 16.4 & 0.039 & 5041.9 & 0.27 & 12,806 & 125 & 803 \\
\hline 22.1 & 0.031 & 5191.5 & 0.27 & 13,186 & 125 & 804 \\
\hline 29 & 0.035 & 5005.7 & 0.27 & 12,714 & 125 & 805 \\
\hline 37.2 & 0.042 & 4747.8 & 0.27 & 12,059 & 125 & 806 \\
\hline 44.7 & 0.047 & 4551.9 & 0.27 & 11,562 & 125 & 807 \\
\hline 52.9 & 0.037 & 4864.9 & 0.27 & 12,357 & 125 & 808 \\
\hline
\end{tabular}


RPP-RPT-32239, Rev. 1

M\&D-2008-005-CALC-001, Rev. 1

Table 2-11. Lower Bound Native Soil Iterated Soil Properties

\begin{tabular}{|c|c|c|c|c|c|c|}
\hline $\begin{array}{c}\text { Layer } \\
\text { Depth (ft) }\end{array}$ & Damping & $\begin{array}{c}\mathbf{G} \\
\left(\mathrm{kip} / \mathrm{ft}^{2}\right)\end{array}$ & $\begin{array}{c}\text { Poisson's } \\
\text { Ratio }\end{array}$ & E $\left(\mathrm{kip} / \mathrm{ft}^{2}\right)$ & $\begin{array}{l}\text { Density } \\
\left(\mathbf{l b f} / \mathrm{ft}^{\mathbf{3}}\right)\end{array}$ & $\begin{array}{c}\text { Material } \\
\text { Property } \\
\text { No }\end{array}$ \\
\hline 2.5 & 0.018 & 4382.9 & 0.24 & 10,870 & 110 & 901 \\
\hline 9.2 & 0.03 & 4004 & 0.24 & 9,930 & 110 & 902 \\
\hline 16.4 & 0.043 & 3590.3 & 0.24 & 8,904 & 110 & 903 \\
\hline 22.1 & 0.034 & 3739.6 & 0.24 & 9,274 & 110 & 904 \\
\hline 29 & 0.04 & 3551.3 & 0.19 & 8,452 & 110 & 905 \\
\hline 37.2 & 0.042 & 4004.4 & 0.19 & 9,530 & 110 & 906 \\
\hline 44.7 & 0.042 & 4561.5 & 0.19 & 10,856 & 110 & 907 \\
\hline 52.9 & 0.03 & 5629.7 & 0.19 & 13,399 & 110 & 908 \\
\hline 65.5 & 0.03 & 6331 & 0.19 & 15,068 & 110 & 909 \\
\hline 82 & 0.035 & 6066.4 & 0.19 & 14,438 & 110 & 910 \\
\hline 98.8 & 0.039 & 5831.4 & 0.19 & 13,879 & 110 & 911 \\
\hline 115.5 & 0.043 & 5633.7 & 0.19 & 13,408 & 110 & 912 \\
\hline 132 & 0.032 & 6786.7 & 0.19 & 16,152 & 110 & 913 \\
\hline 148.3 & 0.032 & 6763.3 & 0.19 & 16,097 & 110 & 914 \\
\hline 167.5 & 0.028 & 8619.5 & 0.28 & 22,066 & 120 & 915 \\
\hline 189.5 & 0.028 & 9445.3 & 0.28 & 24,180 & 120 & 916 \\
\hline 211.5 & 0.029 & 9314.8 & 0.28 & 23,846 & 120 & 917 \\
\hline 233.5 & 0.029 & 9320.7 & 0.28 & 23,861 & 120 & 918 \\
\hline 255.5 & 0.026 & 10588.1 & 0.28 & 27,106 & 120 & 919 \\
\hline 279 & 0.014 & 29929.7 & 0.3 & 77,817 & 125 & 920 \\
\hline 304 & 0.014 & 29856.3 & 0.3 & 77,626 & 125 & 921 \\
\hline 329 & 0.015 & 29714.3 & 0.3 & 77,257 & 125 & 922 \\
\hline 354 & 0.015 & 29602.2 & 0.3 & 76,966 & 125 & 923 \\
\hline
\end{tabular}

Table 2-12. Lower Bound Excavated Soil Iterated Soil Properties

\begin{tabular}{|c|c|c|c|c|c|c|}
\hline $\begin{array}{c}\text { Layer } \\
\text { Depth (ft) }\end{array}$ & Damping & G (kip/ft $\left.{ }^{2}\right)$ & $\begin{array}{c}\text { Poisson's } \\
\text { Ratio }\end{array}$ & $\begin{array}{c}E \\
\left.\text { (kip/ft }{ }^{2}\right) \\
\end{array}$ & $\begin{array}{l}\text { Density } \\
\left(\mathbf{l b f} / \mathbf{f t}^{\mathbf{3}}\right)\end{array}$ & $\begin{array}{c}\text { Material } \\
\text { Property } \\
\text { No } \\
\end{array}$ \\
\hline 2.5 & 0.023 & 2547.2 & 0.27 & 6,470 & 125 & 801 \\
\hline 9.2 & 0.044 & 2126.7 & 0.27 & 5,402 & 125 & 802 \\
\hline 16.4 & 0.066 & 1782.2 & 0.27 & 4,527 & 125 & 803 \\
\hline 22.1 & 0.053 & 1910.9 & 0.27 & 4,854 & 125 & 804 \\
\hline 29 & 0.061 & 1777 & 0.27 & 4,514 & 125 & 805 \\
\hline 37.2 & 0.067 & 1689.3 & 0.27 & 4,291 & 125 & 806 \\
\hline 44.7 & 0.07 & 1628.4 & 0.27 & 4,136 & 125 & 807 \\
\hline 52.9 & 0.056 & 1815.9 & 0.27 & 4,612 & 125 & 808 \\
\hline
\end{tabular}




\section{RPP-RPT-32239, Rev. 1 \\ M\&D-2008-005-CALC-001, Rev. 1}

\subsubsection{Excavated Soil}

The excavated soil portion of the soil is developed using the input file "Near-Soil-1.txt." Figure 2-22 shows the detail of the excavated region of soil. Two zones in the soil above the dome are softened (see Figure 2-23) to break the potential arching that can occur in the soil model. This arching effect can occur because linear elastic properties are used for soil, which means that the soil as modeled can carry tension. For a detailed discussion of the development of these softened zones, see Rinker et al. (2006c). The global soil model with the tank in place is shown in Figure 2-24.

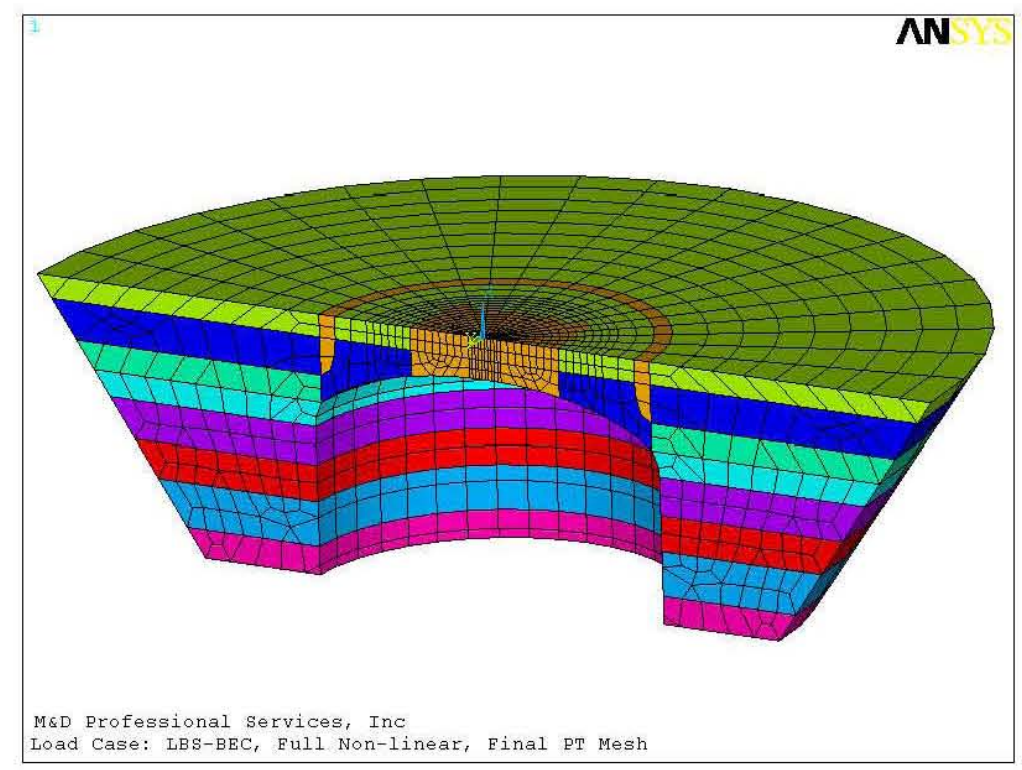

Figure 2-22. Excavated Soil Model Detail

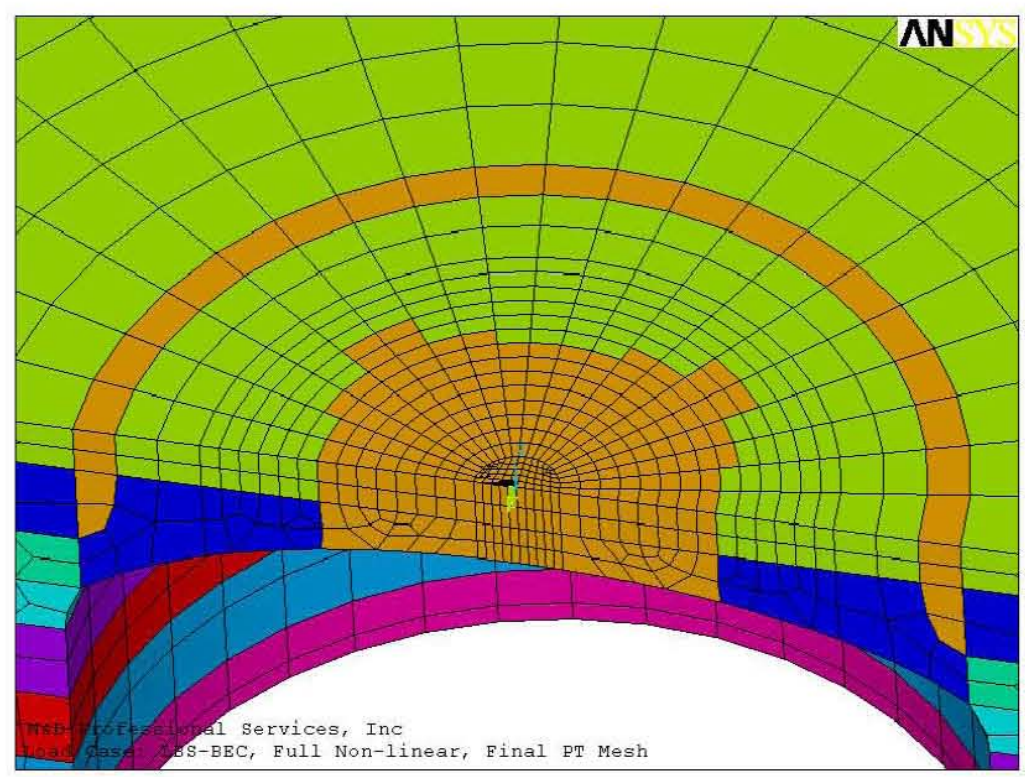

Figure 2-23. Excavated Soil - Softened Soil Zones 
RPP-RPT-32239, Rev. 1

M\&D-2008-005-CALC-001, Rev. 1

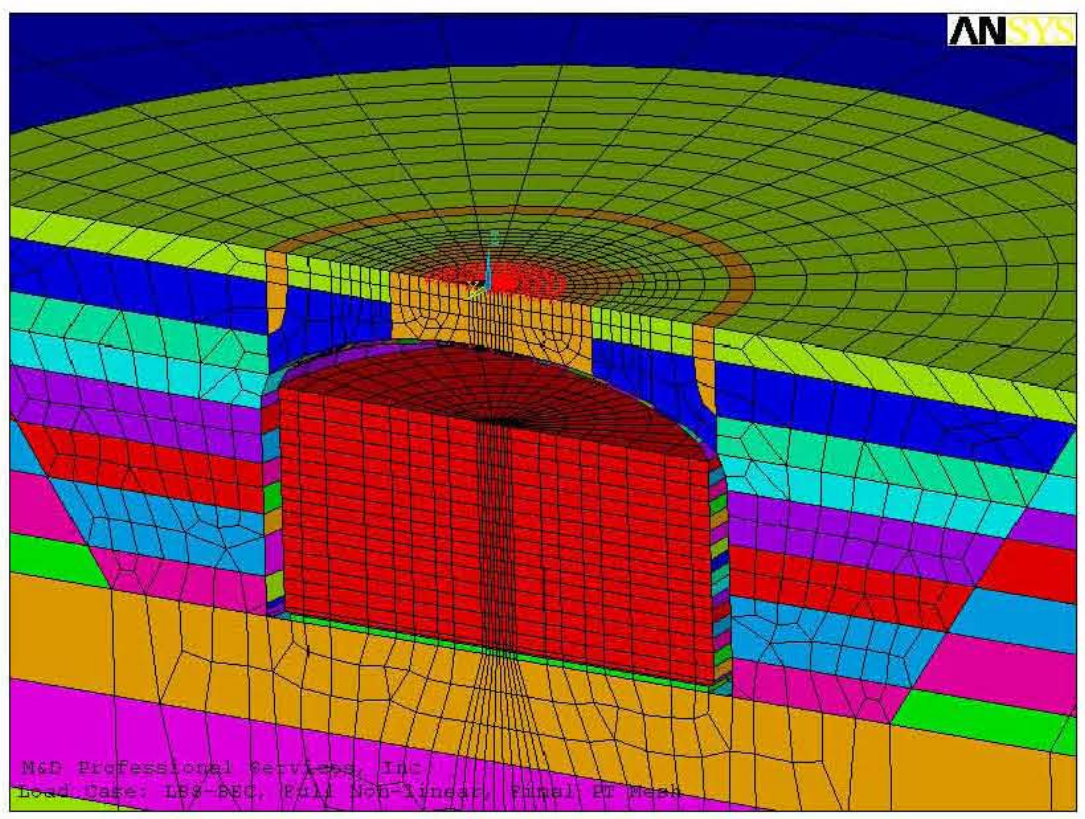

Figure 2-24. Detail Plot of ANSYS ${ }^{\circledR}$ Global Model Showing Soil Zones

\subsubsection{Native Soil}

The native soil region of the model is developed using input file "Far-Soil.txt." SOLID45 elements are used, and the material properties are discussed above. Figure 2-25 shows the native soil portion of the model.

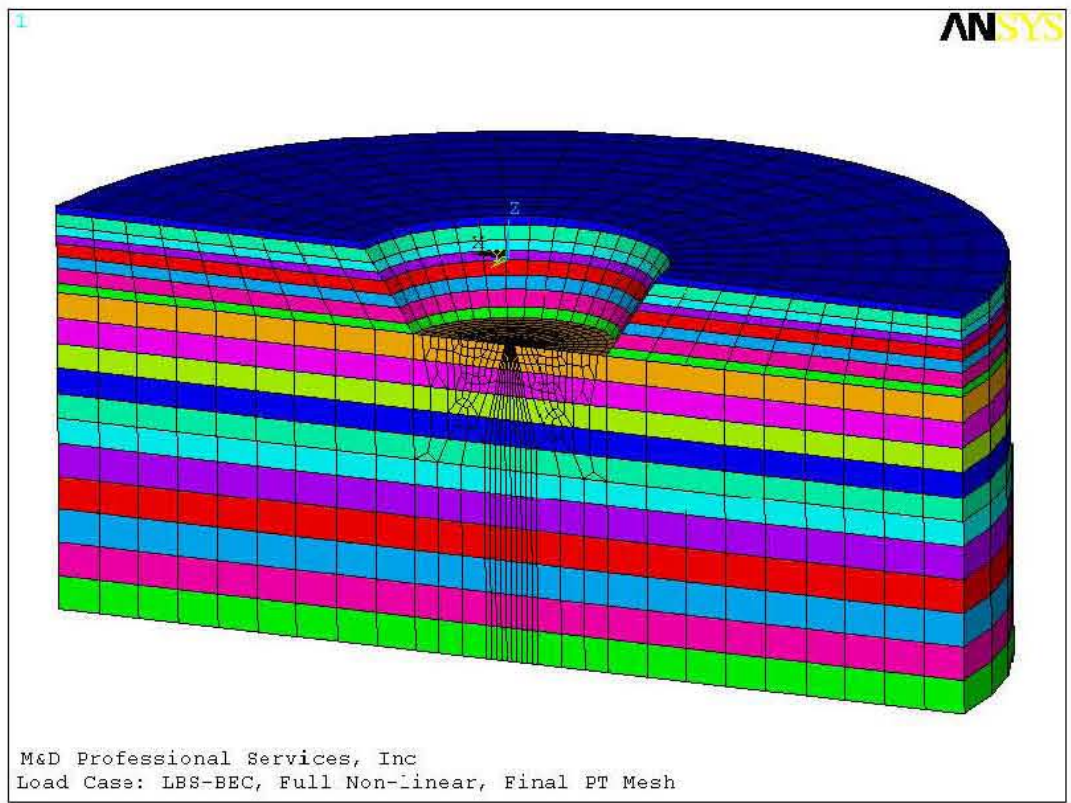

Figure 2-25. Far-Field Soil Model Detail 
LINK8 elements are used to connect the native soil slaved nodes on each layer to the symmetry plane. These are required because the slaved node of a couple cannot have a boundary condition applied to it. Therefore, to maintain the desired soil behavior, the link elements effectively complete the coupling of the outside soil node at each layer. Figure 2-26 shows the locations of the link elements. Input file "Outer-Spar.txt" develops these elements.

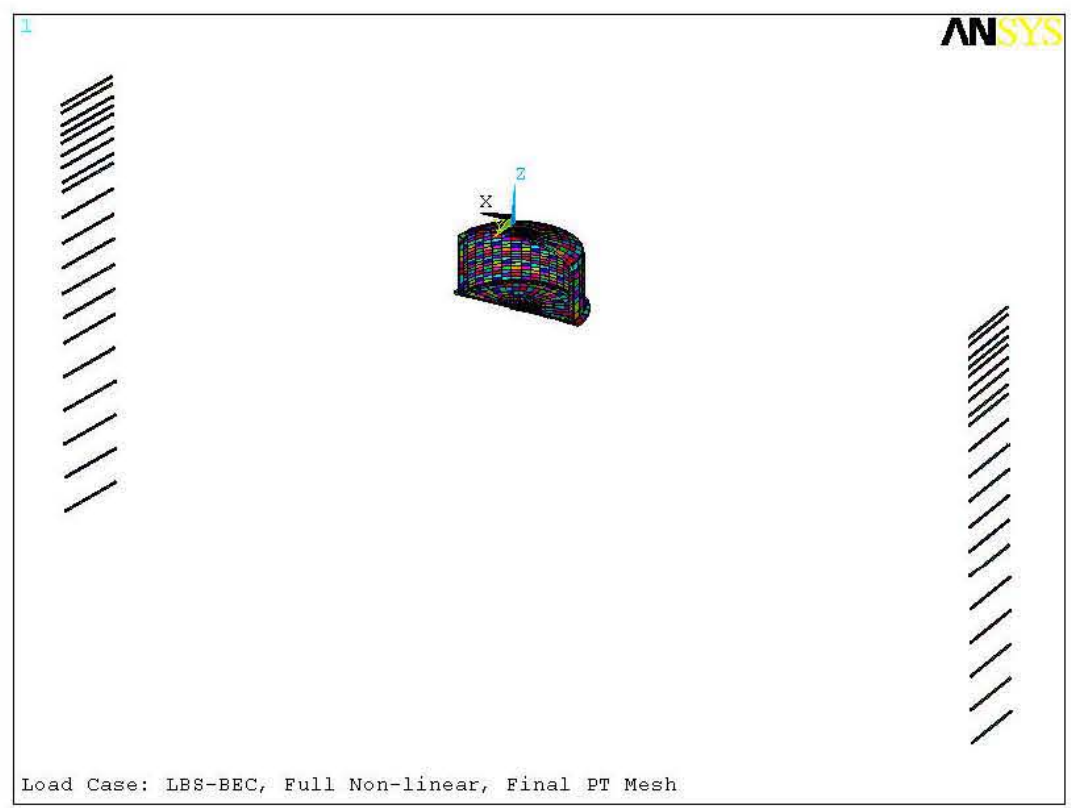

Figure 2-26. Link Elements - Edges of Soil Model

\subsection{Boundary Conditions}

\subsubsection{Soil Boundary Conditions}

All nodes on the outside edge (radius $=320 \mathrm{ft}$ ) have been "slaved" to a single node at each layer. Couples are used in each of the three translations to force the soil to behave essentially as a shear beam. This approach is used to create the appropriate conditions for vertical and horizontal waves to pass through the model (see Figure 2-28 and Figure 2-29). The effectiveness of this approach is documented in Rinker et al. (2006a). All nodes on the bottom of the model ( $-266 \mathrm{ft})$ are coupled together to create a rigid foundation (see Figure 2-27). The symmetry plane for the soil has all nodes fixed for y-translation, see Figure 2-30. 


\section{RPP-RPT-32239, Rev. 1}

M\&D-2008-005-CALC-001, Rev. 1

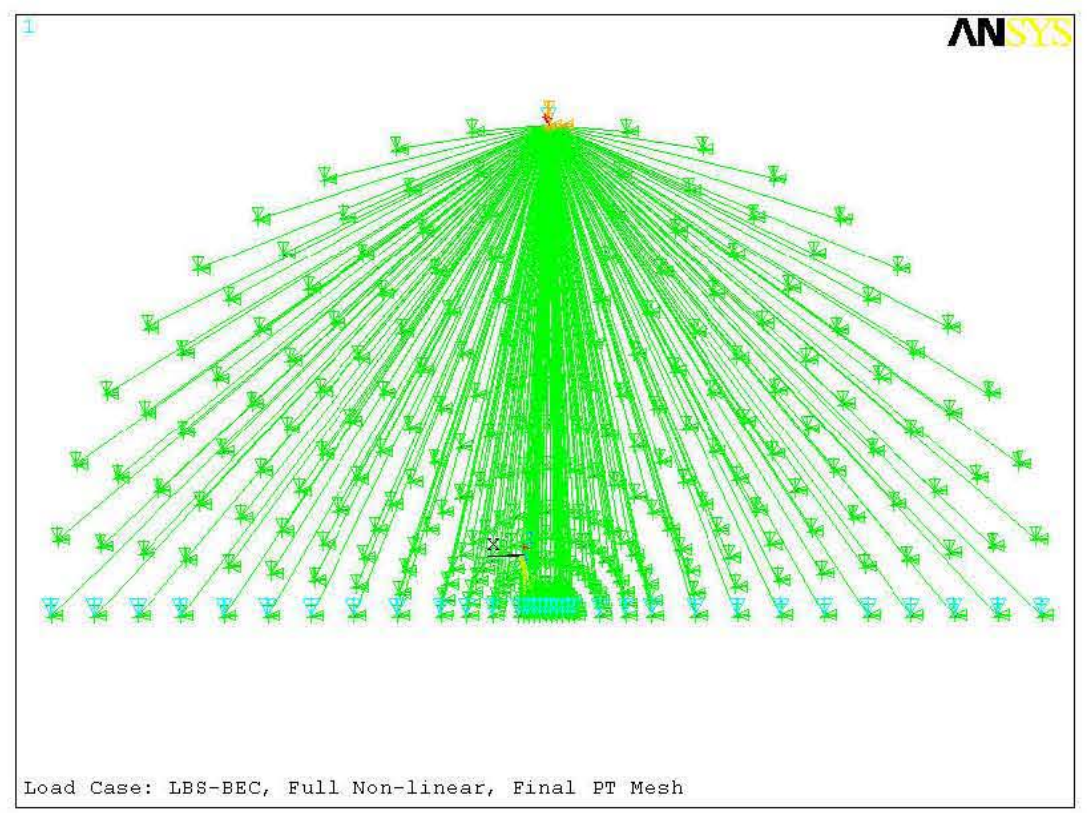

Figure 2-27. Boundary Conditions - Soil Base

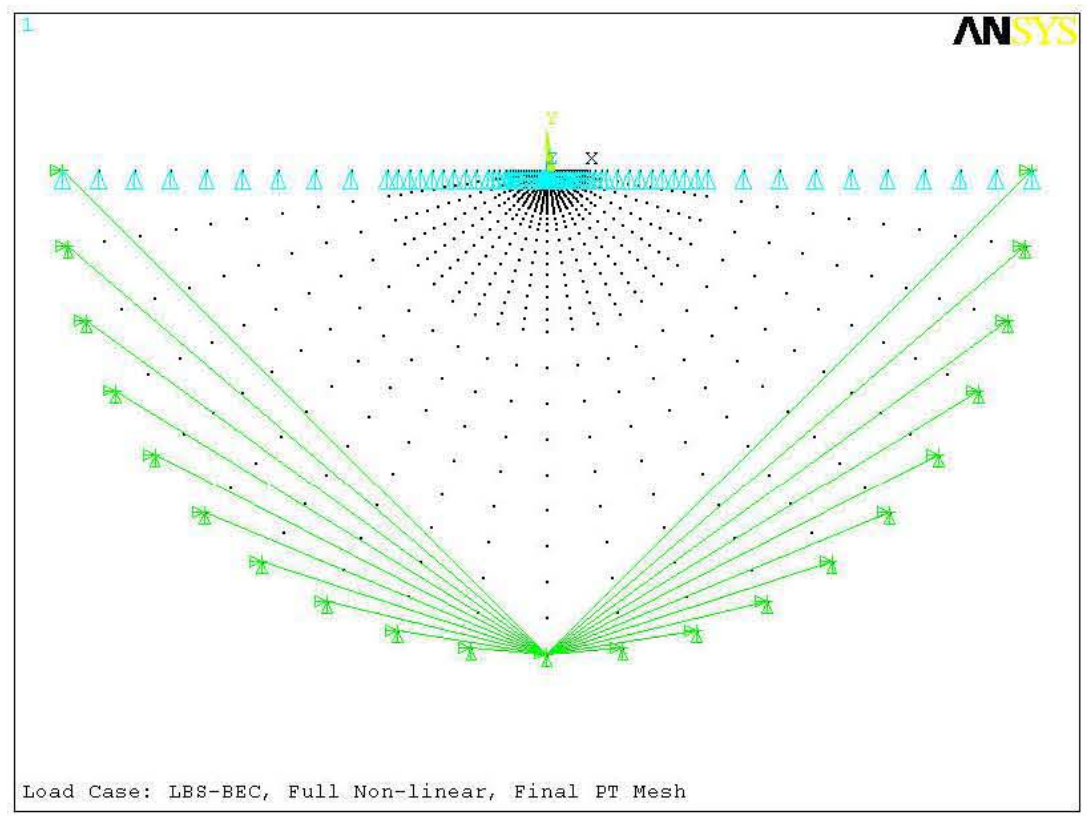

Figure 2-28. Boundary Conditions - Typical Soil Layer 


\section{RPP-RPT-32239, Rev. 1}

M\&D-2008-005-CALC-001, Rev. 1

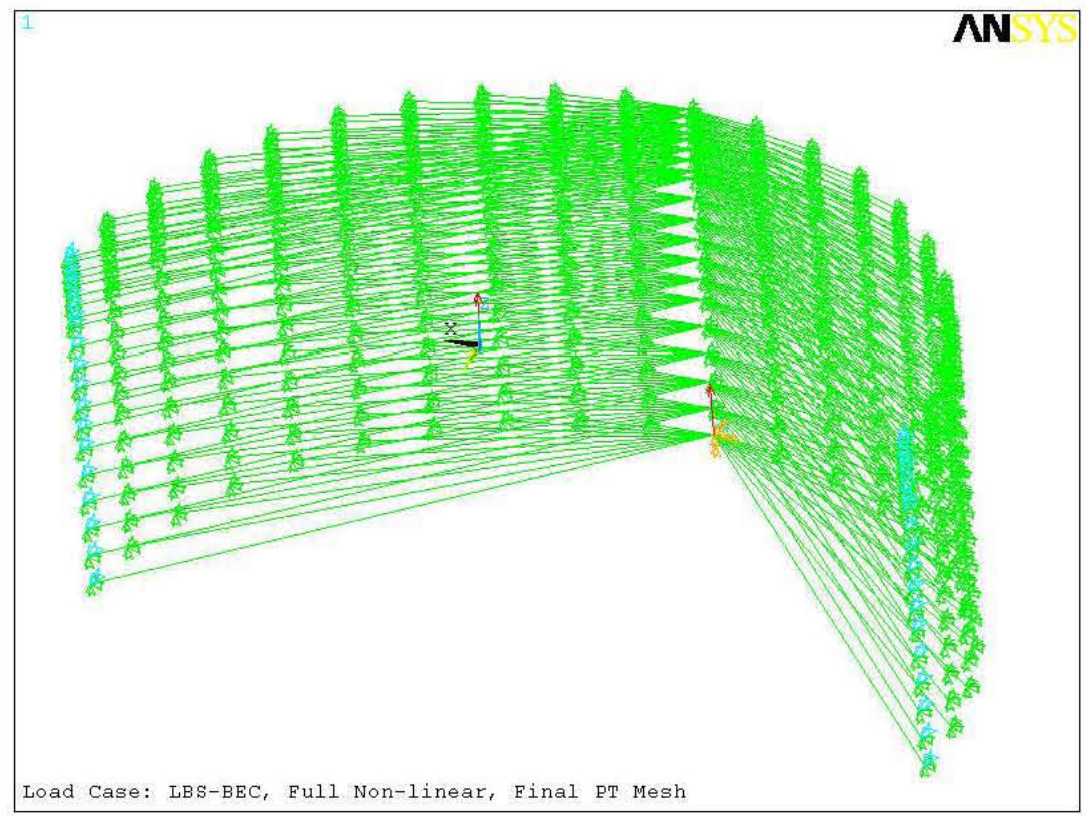

Figure 2-29. Boundary Conditions - Slaved Boundary Conditions

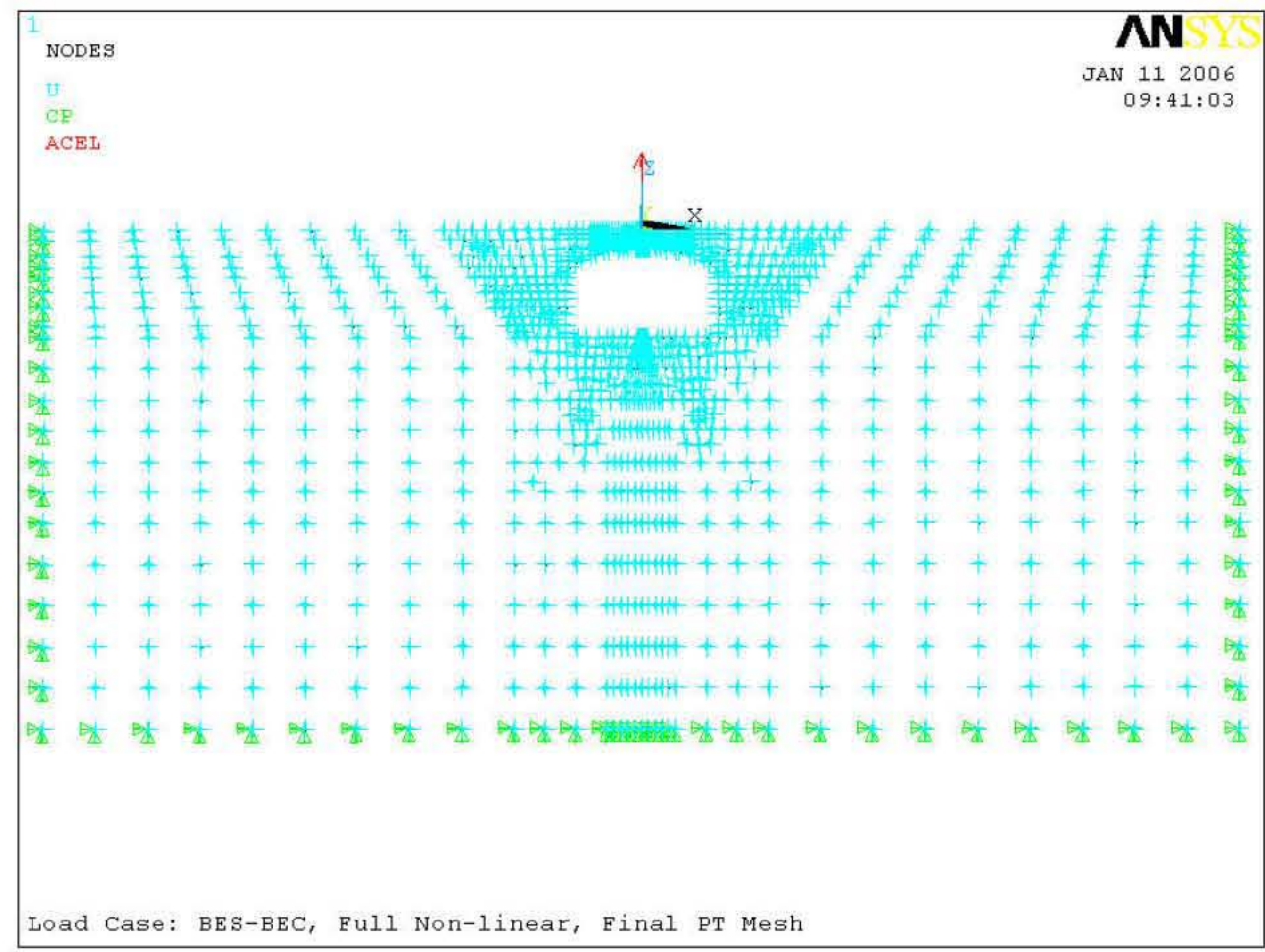

Figure 2-30. Boundary Conditions - Symmetry Plane 
RPP-RPT-32239, Rev. 1

M\&D-2008-005-CALC-001, Rev. 1

\subsubsection{Tank Boundary Conditions}

The tank model has all nodes on the symmetry plane fixed in the $\mathrm{y}$-translation, $\mathrm{x}$-rotation and z-rotation (see Figure 2-31 and Figure 2-32). Couples have been used between some components to ensure that compatible displacements occur. Where no common nodes exist between the concrete shell and secondary liner, couples are used to control the deformation of the secondary liner where it is in contact with the concrete shell. This ensures that the secondary liner does not "pass through" the concrete on the footing and on the walls (See Figure 2-33).

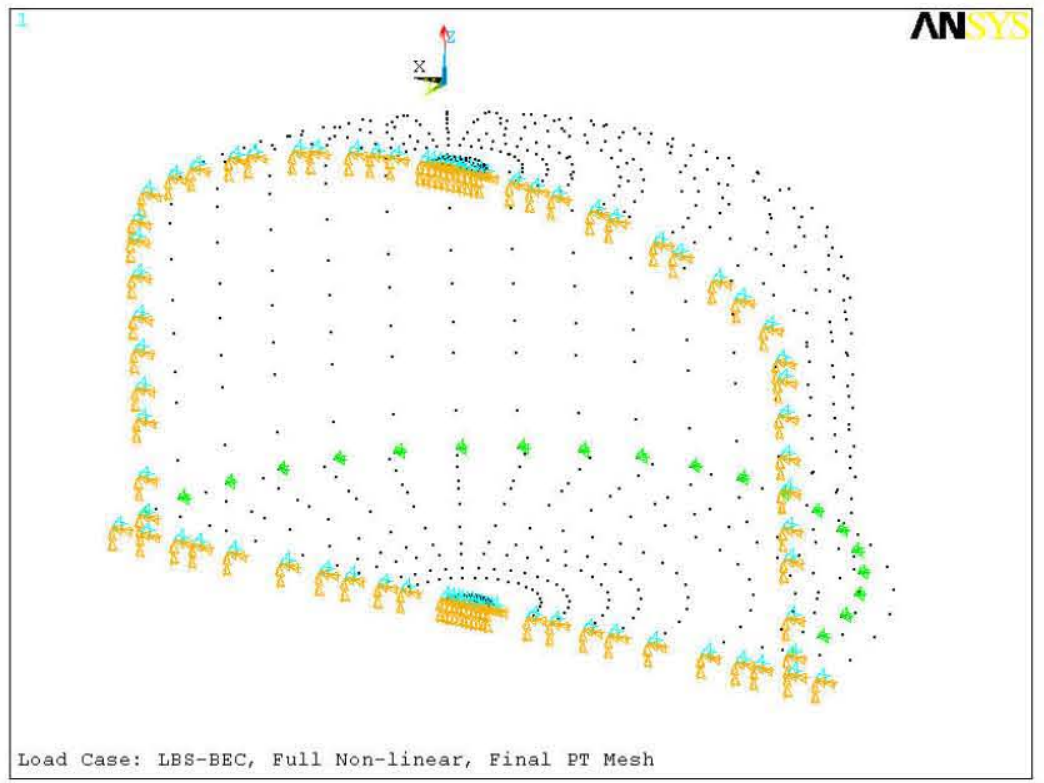

Figure 2-31. Boundary Condition - Concrete Shell

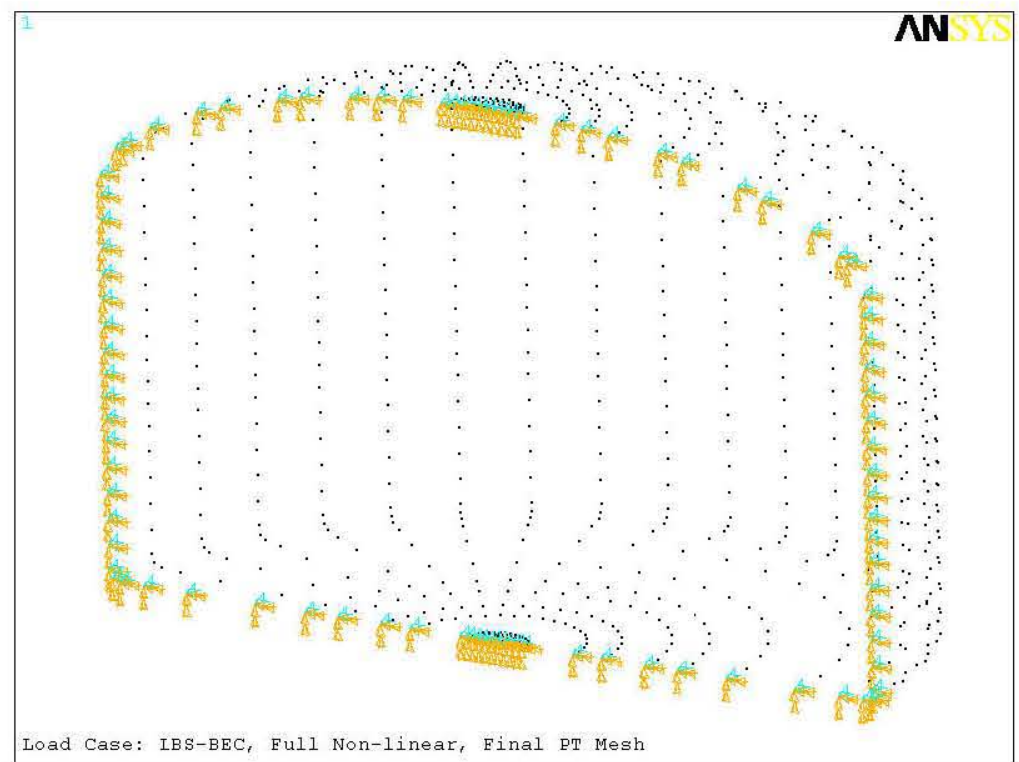

Figure 2-32. Boundary Conditions - Primary Tank 


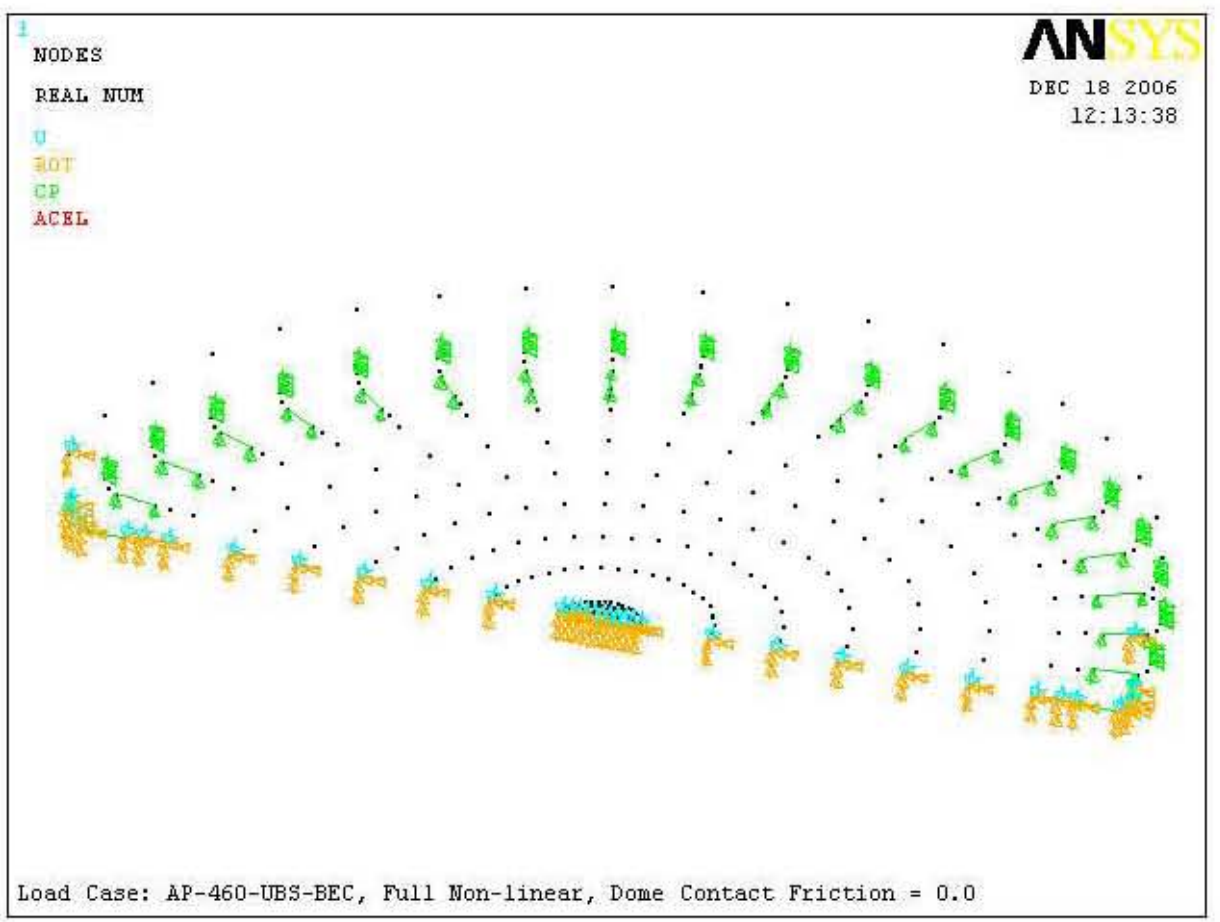

Figure 2-33. Boundary Conditions - Secondary Liner

\subsection{Seismic Input}

The time histories used as input to the global ANSYS $^{\text {(2) }}$ model are the same as used for the baseline analysis described in Deibler et al. (2007a) and Rinker et al. (2006c). As in the baseline analyses, the time histories are applied at the base of the model corresponding to a depth of $266 \mathrm{ft}$ below grade. Horizontal and vertical time histories are applied at the base of the global model, and different time histories are used to represent mean, lower bound, and upper bound soil properties. A large mass element is located at the bottom of the soil model $(-266 \mathrm{ft})$ and a force is applied to that node. The force is the product of the point mass and the acceleration for that time step of the time history. The point mass used is greater than 100 times the mass of the full global model to faithfully reflect the seismic input.

\subsection{Load Cases}

Four separate load cases have been considered in this analysis. These cases are:

- Lower Bound Soil (LBS), Best-Estimate Concrete (BEC) Properties

- Best-Estimate Soil (BES), Best-Estimate Concrete Properties

- Upper Bound Soil (UBS), Best-Estimate Concrete Properties

- Best-Estimate Soil, Fully Cracked Concrete (FCC) Properties

These four cases are intended to cover the most significant areas of uncertainty for response of the DSTs to seismic loading. The three variations in soil properties address the variability and uncertainty in soil properties. The fully cracked concrete case addresses uncertainty in the concrete condition. 


\section{RPP-RPT-32239, Rev. 1 \\ M\&D-2008-005-CALC-001, Rev. 1}

Each load case consists of two analyses. First a gravity case is analyzed. Results from the gravity-only case will be used to determine the seismic-only results from the non-linear transient analysis. The second analysis for each case is a non-linear time history analysis. Two input motions (horizontal and vertical) have been defined as acceleration time histories consisting of 2,048 time steps to simulate the seismic motion.

\subsection{Results Extraction}

The following data are recorded for the gravity and transient analyses using the global model.

- Nodes

- Reactions

- Concrete Shell

- Primary Tank

- Secondary Liner

- Insulating Concrete

- Anchor bolts

- Soil Contacts

- Waste Contacts

- Primary tank contacts

- Liner contacts

- Footing contact

- Excavated Soil

- Excavated Soil Contacts

- Native Soil

- Waste
All active degrees of freedom

All reactions

All element results

Element stresses

Element strains

Element stresses

All element results

All element results

All element results

All element results

All element results

All element results

Element stresses

All element results

Element stresses near tank

Displacements Only

The following results have been extracted from the global ANSYS ${ }^{\circledR}$ model.

- Nodes

- Reactions

- Concrete Shell

- Primary Tank

- Secondary Liner

- Insulating Concrete

- Anchor bolts

- Soil Contacts

- Waste Contacts

- Primary tank contacts

- Liner contacts

- Footing contact

- Excavated Soil

- Excavated Soil Contacts

- Native Soil

- Waste
Displacements at selected locations

None

Element Forces and Moment and Selected Strains

Element stresses (top, middle, bottom)

Element strains (top, middle bottom)

None

Selected element forces

Pressures, displacements, status

Pressures, displacements, status

Pressures, displacements, status

Pressures, displacements, status

Pressures, displacements, status

None

None

None

Displacements at free surface 
RPP-RPT-32239, Rev. 1

M\&D-2008-005-CALC-001, Rev. 1

For each of the results listed above, all time history results have been extracted into text files. Minima and maxima data were also obtained for all the above-listed results. In general, only the result minima and maxima data are used in this report. Results are obtained throughout the model and then summarized around the circumference for presentation. 
RPP-RPT-32239, Rev. 1

M\&D-2008-005-CALC-001, Rev. 1

Intentionally left blank. 
RPP-RPT-32239, Rev. 1

M\&D-2008-005-CALC-001, Rev. 1

\subsection{Dytran ${ }^{\circledR}$ Primary Tank Sub-Model Description}

A simplified sub-model of a Hanford double-shell tank (DST) primary tank was created using the 2005 version of MSC.Patran ${ }^{\mathbb{B}}$, and was analyzed using the Dytran ${ }^{\mathbb{B}} 2006$ Development Version.

The purpose of the Dytran ${ }^{\mathbb{B}}$ sub-model analysis was to investigate the fluid-structure interaction behavior within the primary tank during seismic excitation. Based on earlier studies (Rinker and Abatt 2006a, 2006b; Rinker et al. 2006c) it is expected that the global ANSYS ${ }^{\circledR}$ model will not accurately capture the convective response of the fluid within the primary tank during a seismic event. In particular, the pressures and stresses in the region of the primary tank near the liquid-free surface may not be accurately predicted with the global ANSYS ${ }^{\mathbb{B}}$ model. However, the Dytran ${ }^{\mathbb{B}}$ sub-model is expected to give accurate results for the stresses in the tank, and the Dytran ${ }^{\mathbb{B}}$ sub-model analysis serves as an alternate calculation for evaluating the stresses in the primary tank due to fluid-structure interaction.

The fundamental difference between this analysis and the earlier analysis at the baseline liquid level of 422 inches (Rinker et al. 2006c) is increased interaction between the contained waste and the curved dome area of the primary tank. Thus, the stresses induced by the interaction of the liquid and the dome are of particular interest. The results from the Dytran ${ }^{\mathbb{B}}$ sub-model analysis are compared to the results of a similar ANSYS $^{\circledR}$ sub-model of a primary tank, as well as to the results from the global ANSYS ${ }^{\circledR}$ models.

The Dytran ${ }^{\mathbb{B}}$ models are full three-dimensional (3D) representations of the tanks. Applied loads include gravity loading and seismic loading, with seismic loading applied in the horizontal and vertical directions both as separate load cases and simultaneously.

\subsection{Model Geometry}

The Dytran ${ }^{\mathbb{B}}$ sub-model geometry was based on the 241-AY tank configuration shown in Hanford Drawing Number H-2-64449. However, the primary tank wall thicknesses were representative of the 241-AP tank configuration shown in Hanford Drawing Number H-2-90534. The rationale for using the 241-AY tank configuration as a bounding idealization is discussed in Chapter 2 of Rinker et a1. (2004) and also in Deibler et al. (2007a). However, the primary tank thicknesses and material properties for the 241-AP tanks were incorporated into the models because those are the tanks being considered for an increased operating liquid level.

The primary tank has a 450 -inch radius and the height of the vertical wall is 424 inches. The dome apex is 561.5 inches above the bottom of the tank. Excerpts from drawings H-2-64449 and H-2-90534 are shown as Figure 3-1 and Figure 3-2, respectively. Two dimensions of interest for the Dytran ${ }^{\circledR}$ primary tank sub-model are the elevation of the primary tank tangent line at 424.3125 inches above the bottom of the primary tank (drawing H-2-64449), and the elevation of the first row of anchor bolts at 467 inches above the bottom of the primary tank (estimated from drawings H-2-64449 and H-2-90534). 
RPP-RPT-32239, Rev. 1

M\&D-2008-005-CALC-001, Rev. 1

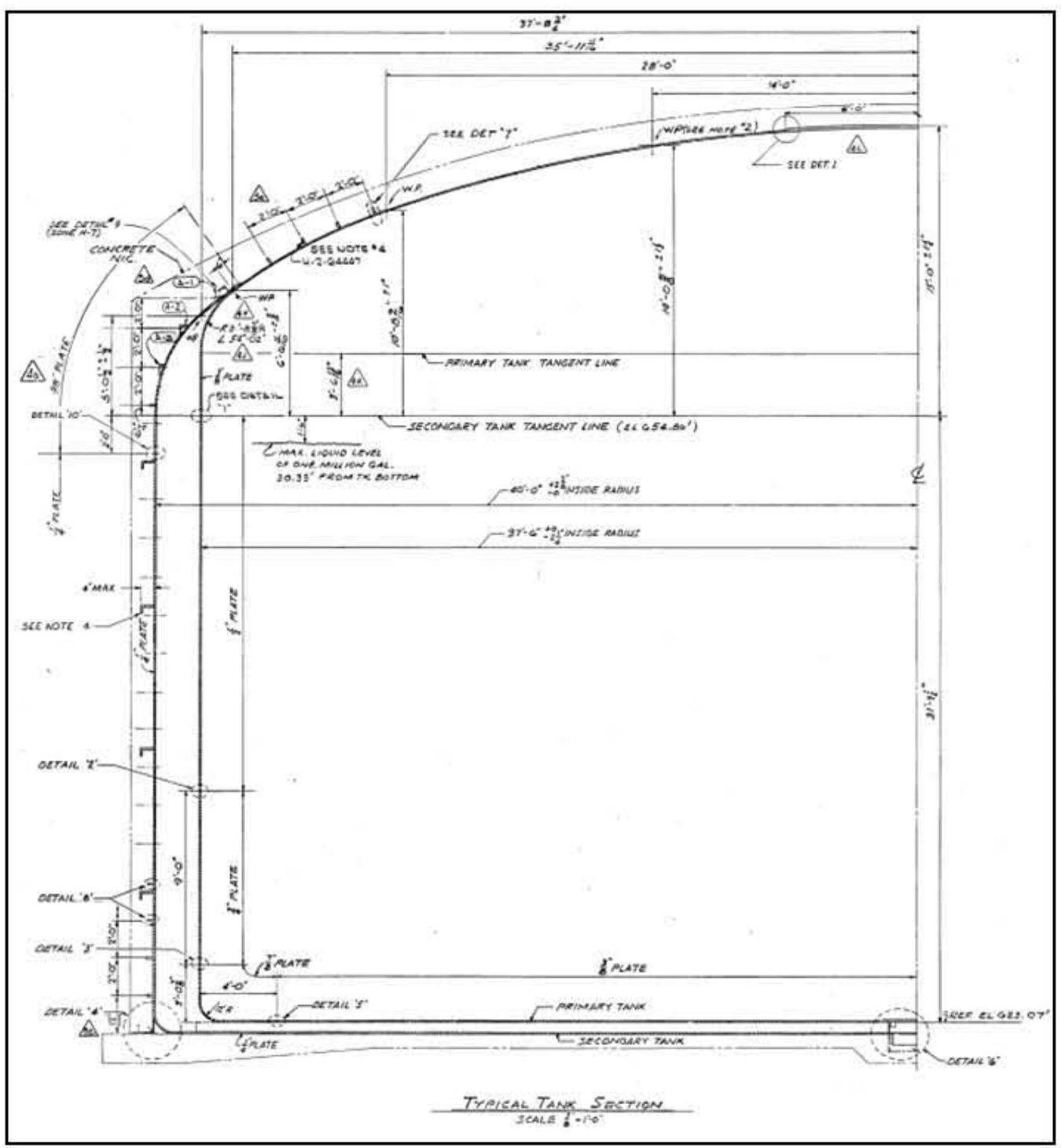

Figure 3-1. 241-AY Tank Dimensions

When the Dytran ${ }^{\text {(1) }}$ model is subjected to horizontal excitation only, the bottom of the primary tank is supported vertically by a fixed rigid base plate in contact with the tank bottom as shown in Figure 3-3. The purpose of the base plate is to provide the vertical support to the bottom of the primary tank model that is provided by the insulating concrete in the actual tank. The base is not present in the model when vertical excitation is applied.

A notable difference between the Dytran ${ }^{\text {(2) }}$ primary tank model and the actual tank as shown in Figure 3-3 is that the junction between the vertical wall and the tank bottom is modeled as a right angle. Consequently, the details of the tank lower knuckle region and its support by the insulating concrete have not been captured by this simplified Dytran ${ }^{\circledR}$ sub-model. 
RPP-RPT-32239, Rev. 1

M\&D-2008-005-CALC-001, Rev. 1

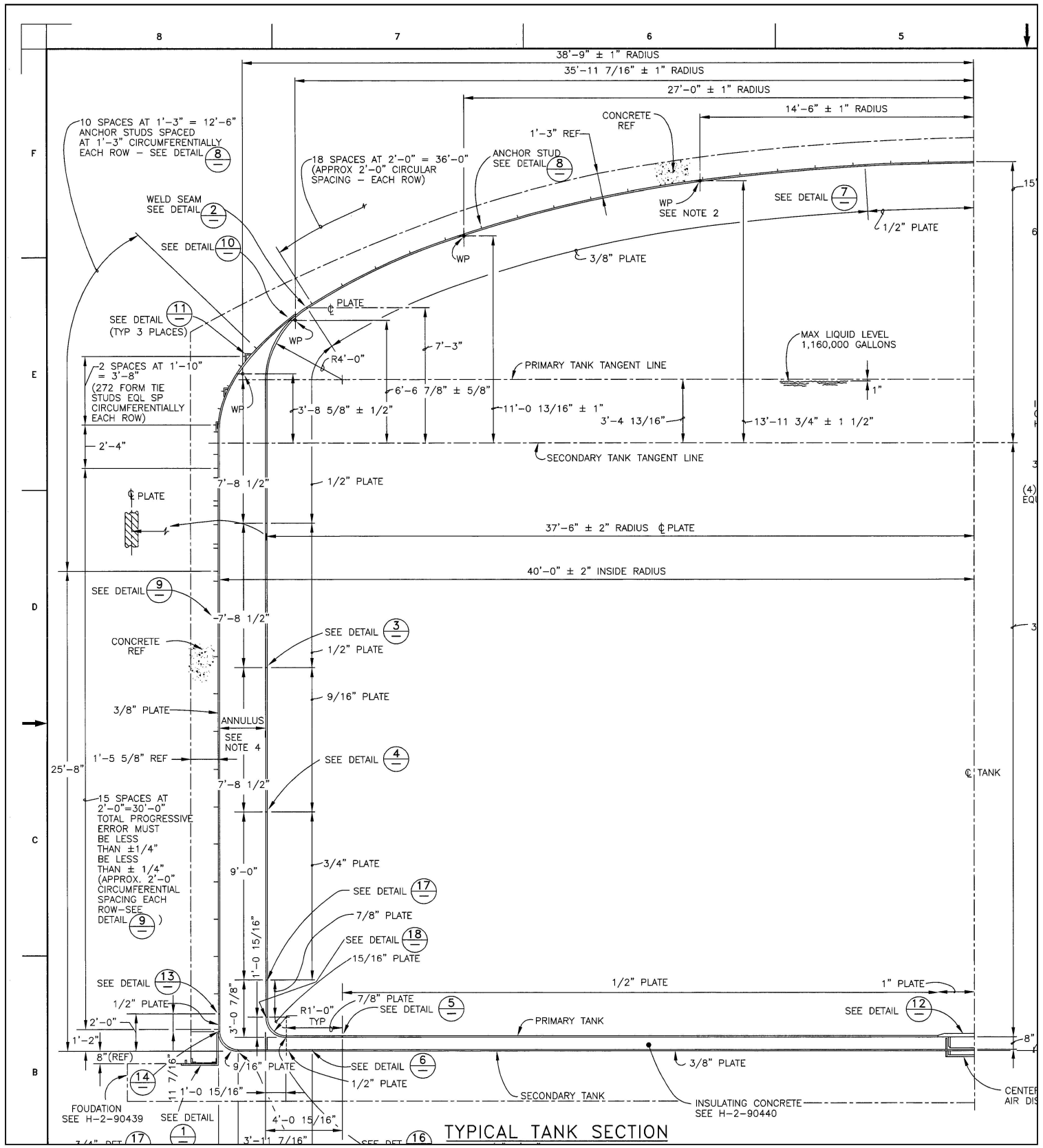

Figure 3-2. 241-AP Tank Dimensions

The relative height of the waste to the tank for the 460-inch waste level is shown in Figure 3-4. The tank floor and walls form what is known as a Dytran ${ }^{\circledR}$ coupling surface with the water. The coupling surface allows the Eulerian waste mesh to interact with the Lagrangian structural mesh, and although the Eulerian mesh extends beyond the tank boundary, all the fluid dynamics occur inside the tank. 


\section{RPP-RPT-32239, Rev. 1 \\ M\&D-2008-005-CALC-001, Rev. 1}

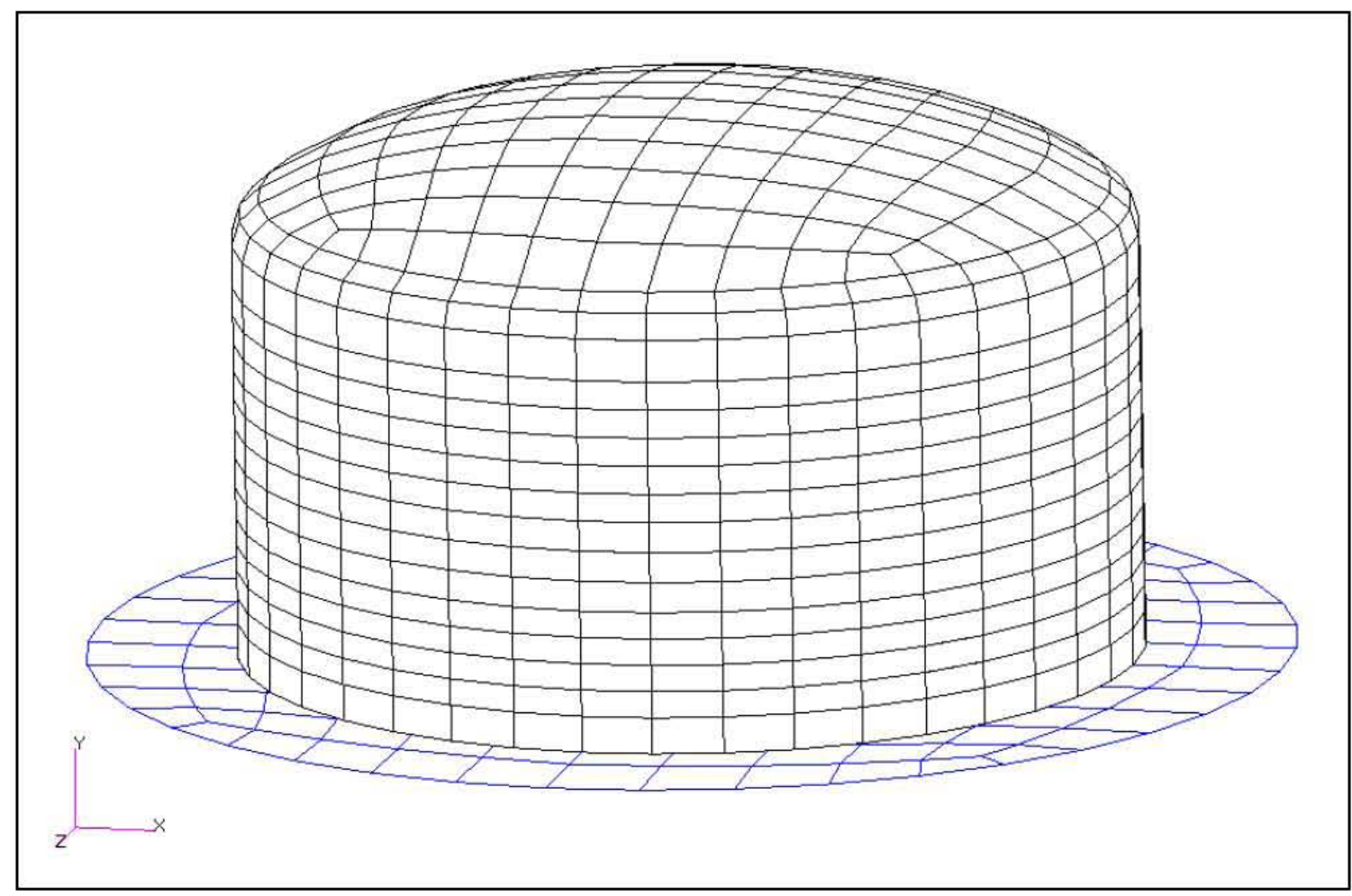

Figure 3-3. Plot of Dytran ${ }^{\circledR}$ Primary Tank and Base Model (base not present when vertical excitation is applied)

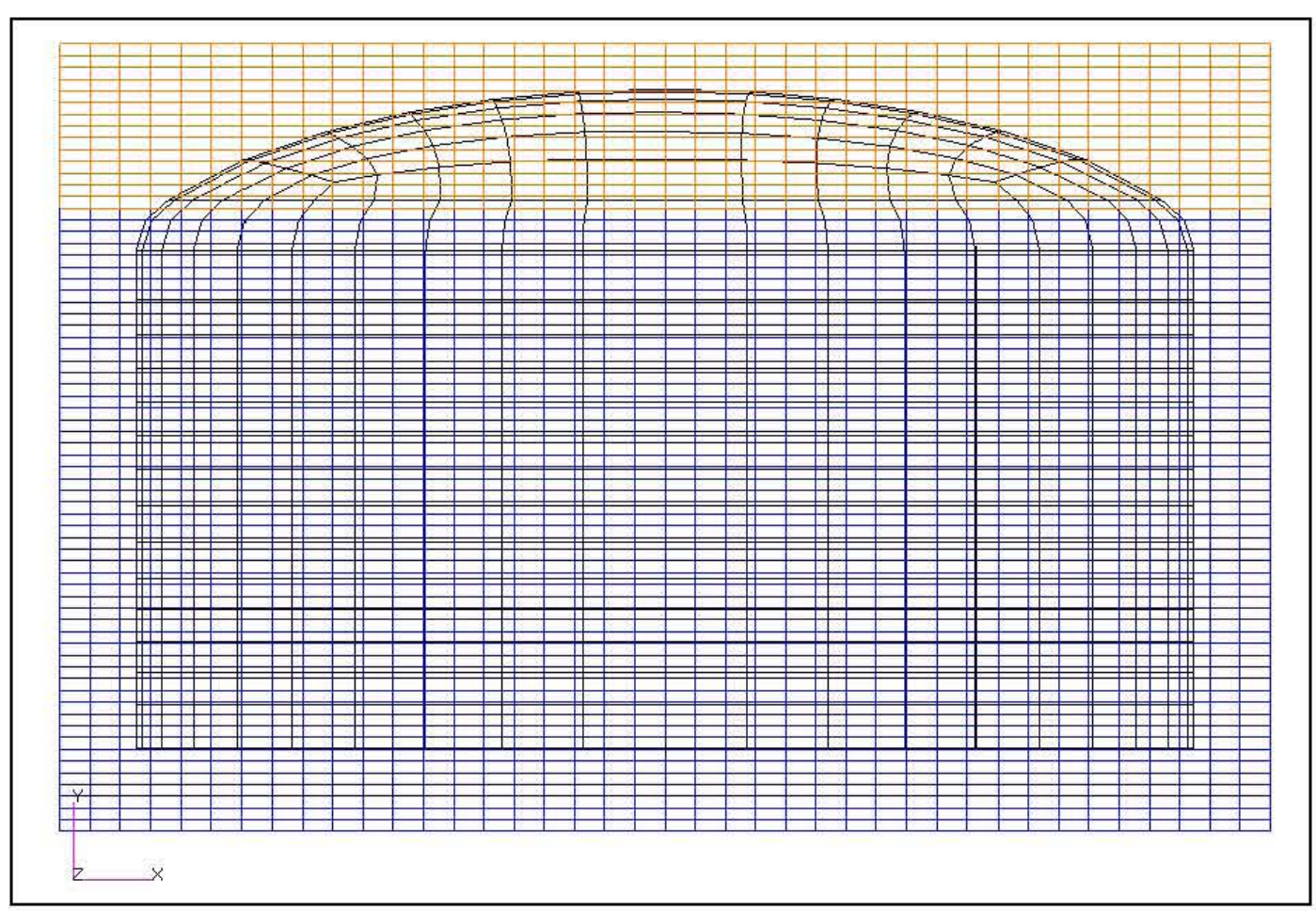

Figure 3-4. Plot of Dytran ${ }^{1}$ Tank, Waste, and Air Elements at 460-Inch Waste Level 
RPP-RPT-32239, Rev. 1

M\&D-2008-005-CALC-001, Rev. 1

Dynamic waste pressures are a function of depth, angular location and radial location of the fluid element. Waste pressures were extracted from five sets of fluid elements throughout the tank as shown in Figure 3-5. The element set "plusx_els" is located near the tank wall in the positive $\mathrm{x}$-direction $(\theta=0)$ in the plane of the seismic excitation. Note that the angle $\theta$ is measured from the positive $x$-axis to the positive $z$-axis to describe the angular position of elements in the model. Element sets "press_45" and "plusz_els" are located near the tank wall at $45^{\circ}$ (approximately) and $90^{\circ}$ from the excitation direction. Element set "minusx_els" is near the tank wall in the negative x-direction, and the set "cent_press" is near the center of the tank at a radial location of approximately zero. As can be seen in Figure 3-5, there are 40 elements circumferentially in the tank wall, or 10 elements in each $90^{\circ}$ sector.

Figure 3-6 and Figure 3-7 are elevation views that show the location and numbering of fluid element sets "plusx_els", "cent_press" and "minusx_els". Figure 3-8 and Figure 3-9 are elevation views showing the location and numbering of fluid element sets "press_45" and "plusx_els".

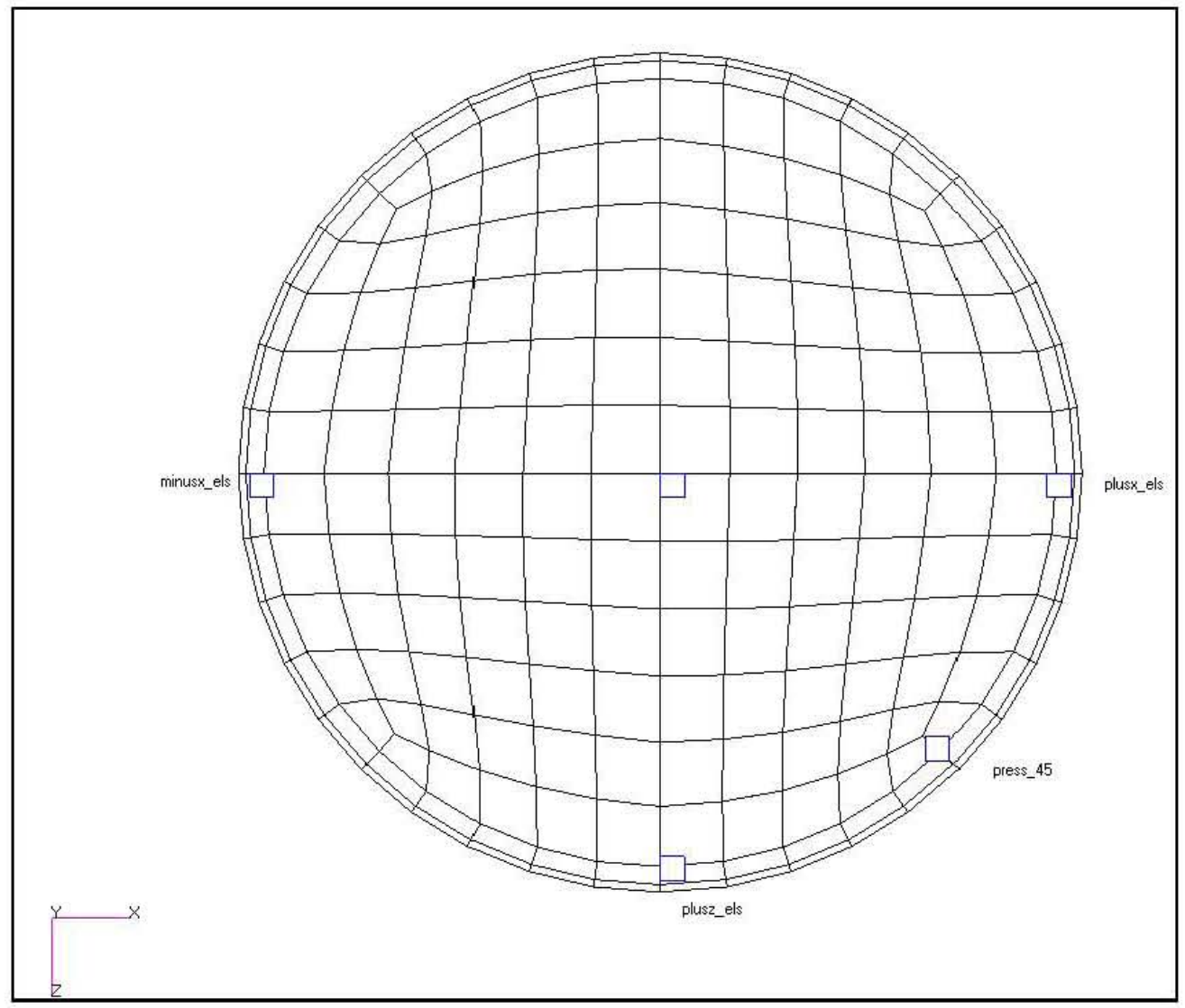

Figure 3-5. Top View of Dytran ${ }^{(1)}$ Primary Tank Sub-Model Showing the Angular Locations of Fluid Elements at Which Pressures Were Monitored 
RPP-RPT-32239, Rev. 1

M\&D-2008-005-CALC-001, Rev. 1

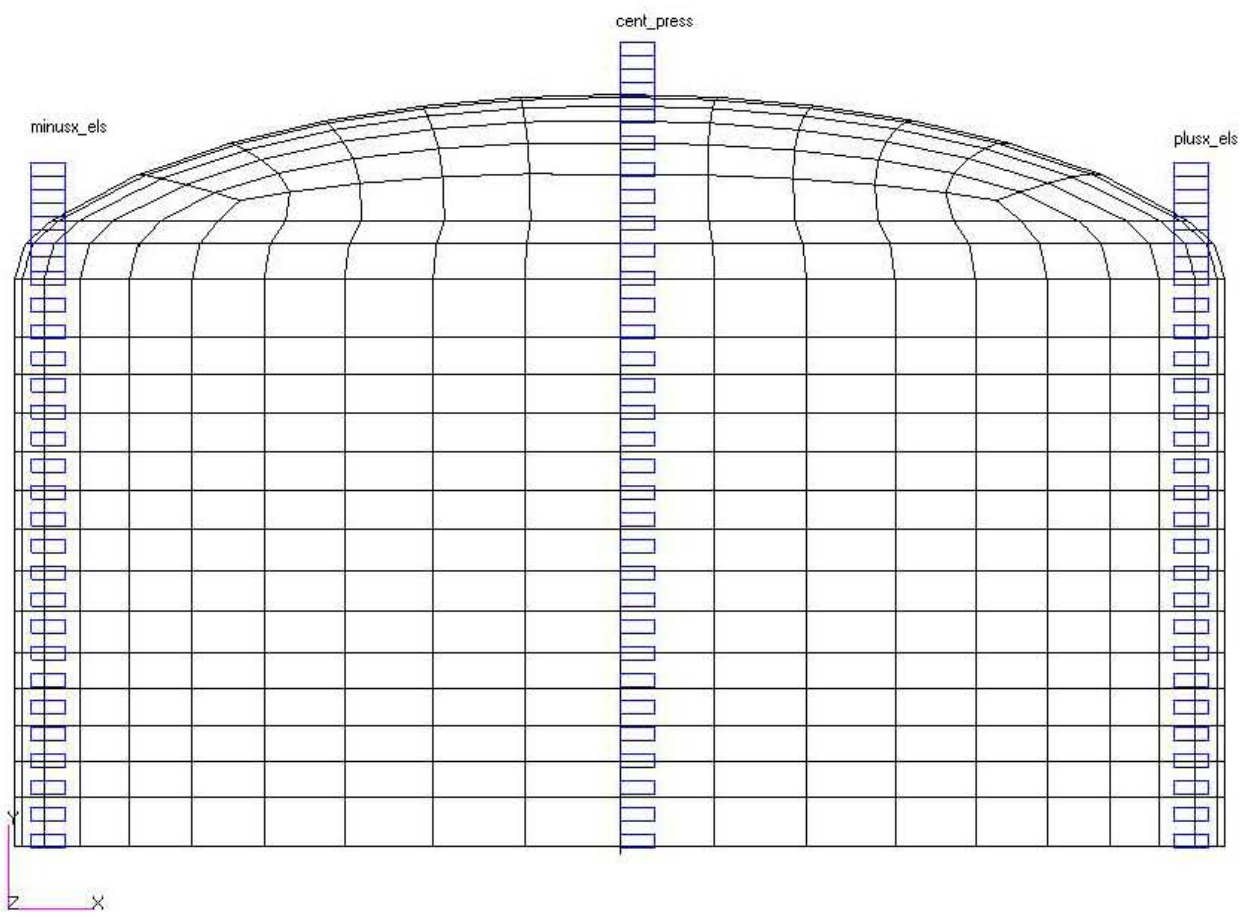

Figure 3-6. Elevation View of Dytran ${ }^{\circledR}$ Tank Mesh Showing the Locations of "Plusx_els", "Cent_press", and "Minusx els" Fluid Element Sets at Which Pressures Were Monitored

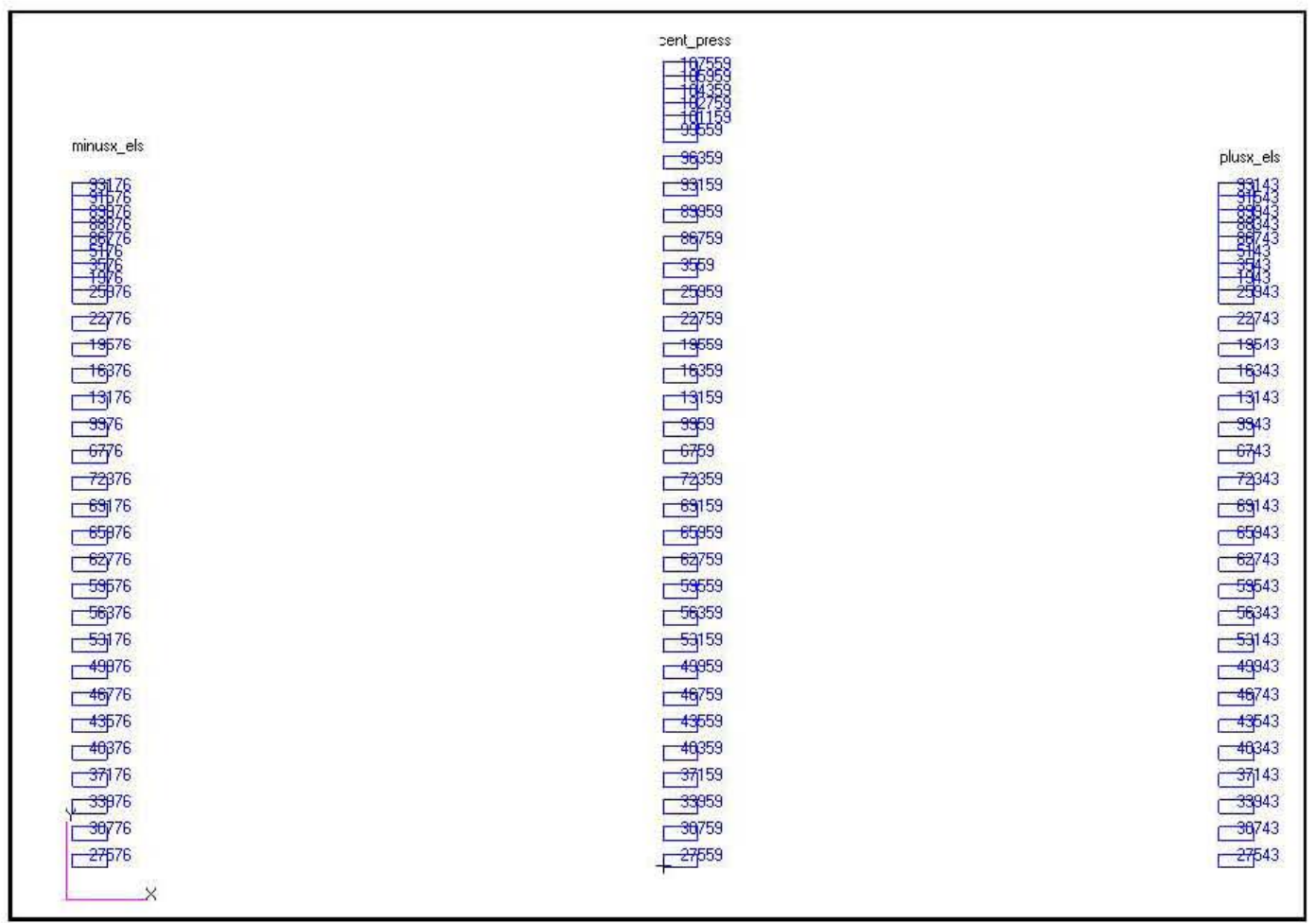

Figure 3-7. Waste Element Numbering for Element Sets "Plusx_els"," Minusx_els", and Cent press" 
RPP-RPT-32239, Rev. 1

M\&D-2008-005-CALC-001, Rev. 1

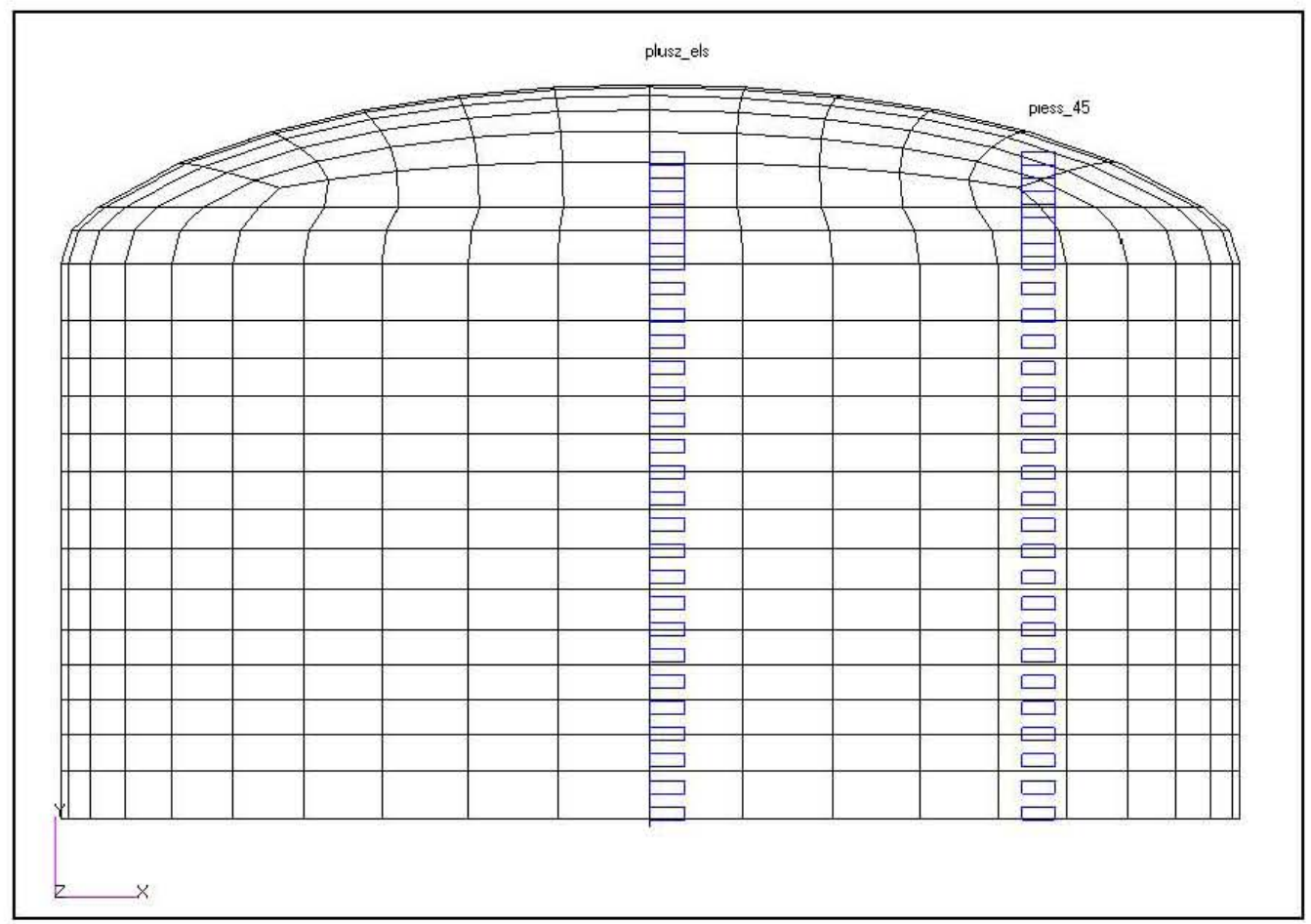

Figure 3-8. Elevation View of Dytran ${ }^{\circledR}$ Tank Mesh Showing the Locations of "Press45" and "Plusz_els", Fluid Element Sets at Which Pressures Were Monitored

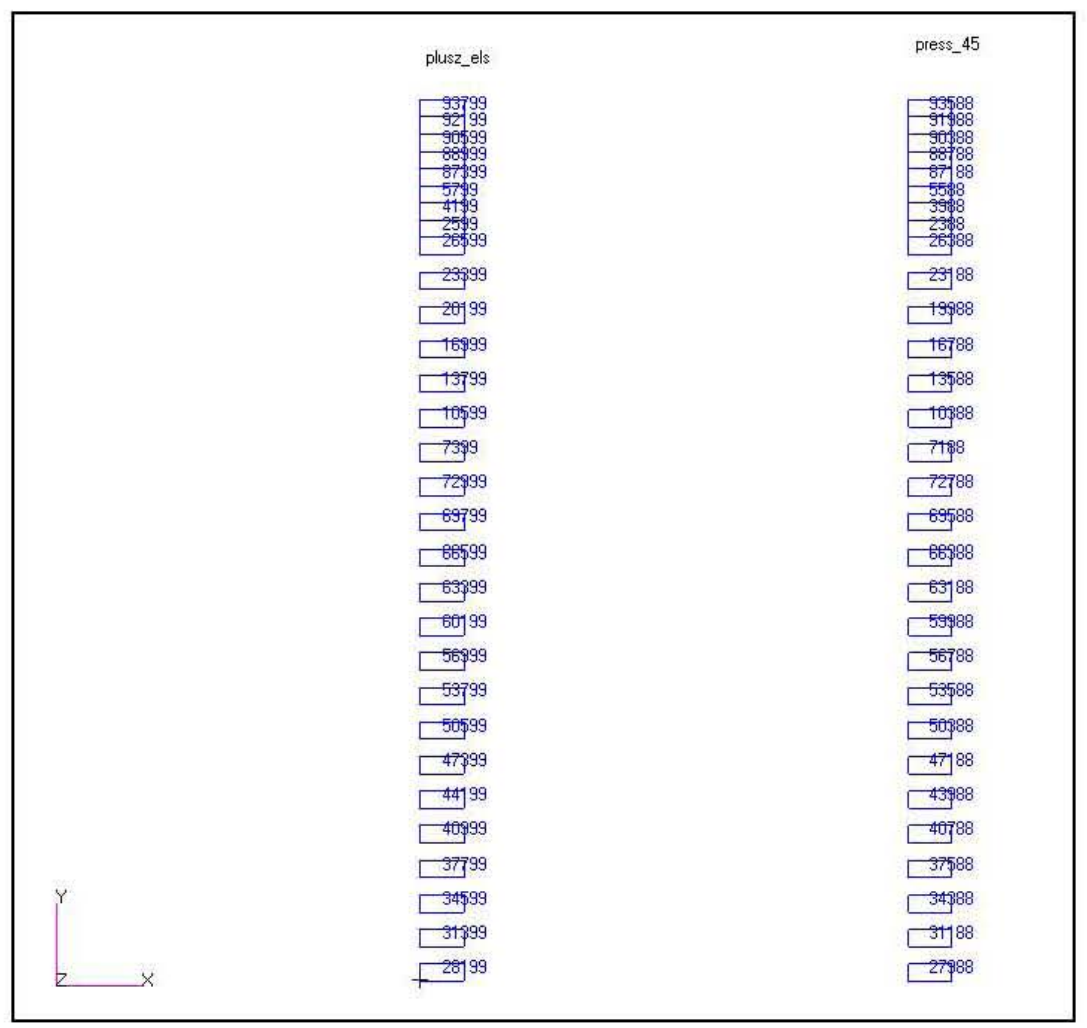

Figure 3-9. Waste Element Numbering for Dytran ${ }^{\circledR}$ Element Sets "Press_45" and Plusz_els" 
Tank wall stresses were extracted at angular locations of $\theta=0,45,90$, and $180^{\circ}$. The shell element numbering for the $\theta=0^{\circ}$ and $\theta=90^{\circ}$ sets is shown in Figure 3-10, with the elements at $\theta=0^{\circ}$ and on the right, and the elements at $\theta=90^{\circ}$ on the left. The numbering for the $\theta=45^{\circ}$ and $\theta=180^{\circ}$ sets is shown in Figure $3-11$, with the elements at $\theta=45^{\circ}$ and on the right, and the elements at $\theta=180^{\circ}$ on the left.

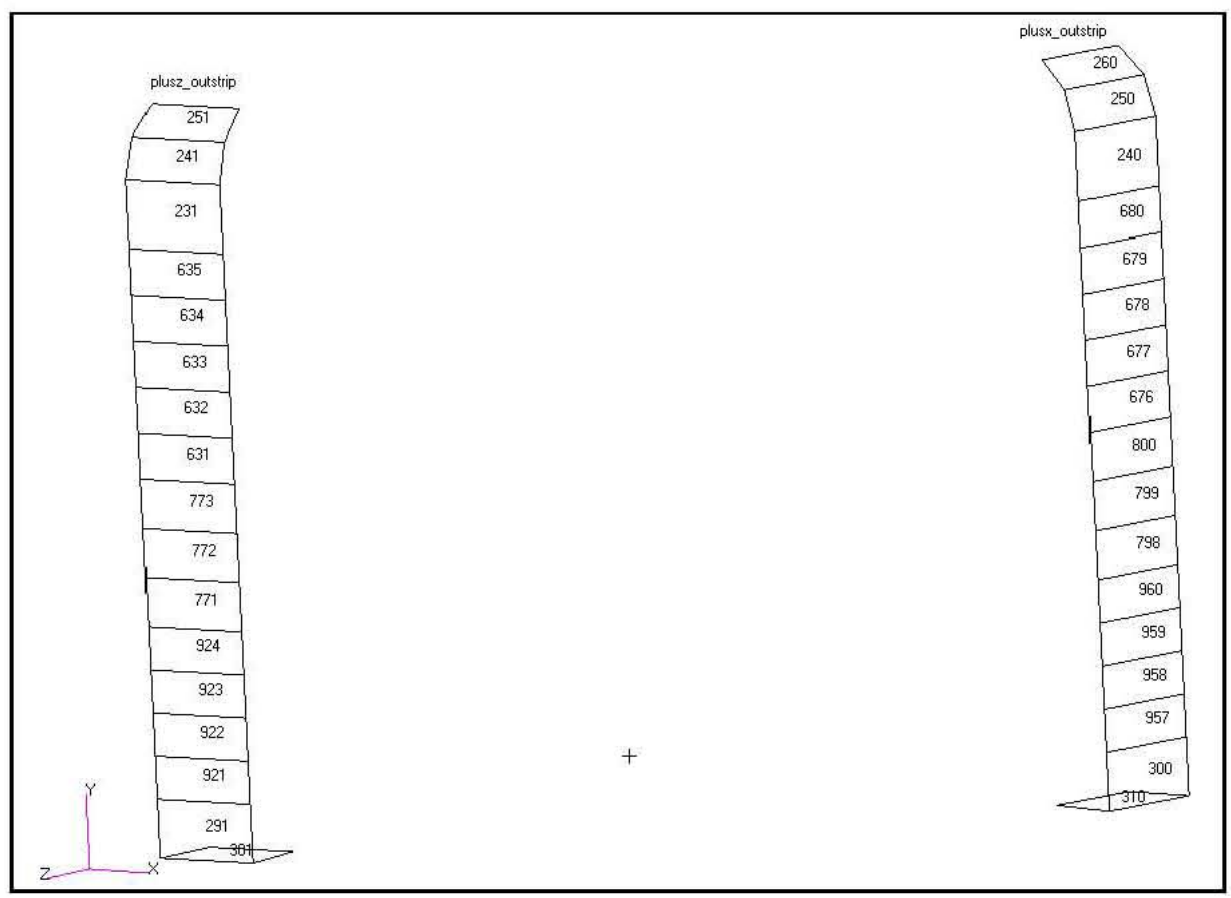

Figure 3-10. Shell Element Numbering for Dytran ${ }^{\circledR}$ Tank Wall Stress Results at $\theta=0^{\circ}$ and $\theta=90^{\circ}$

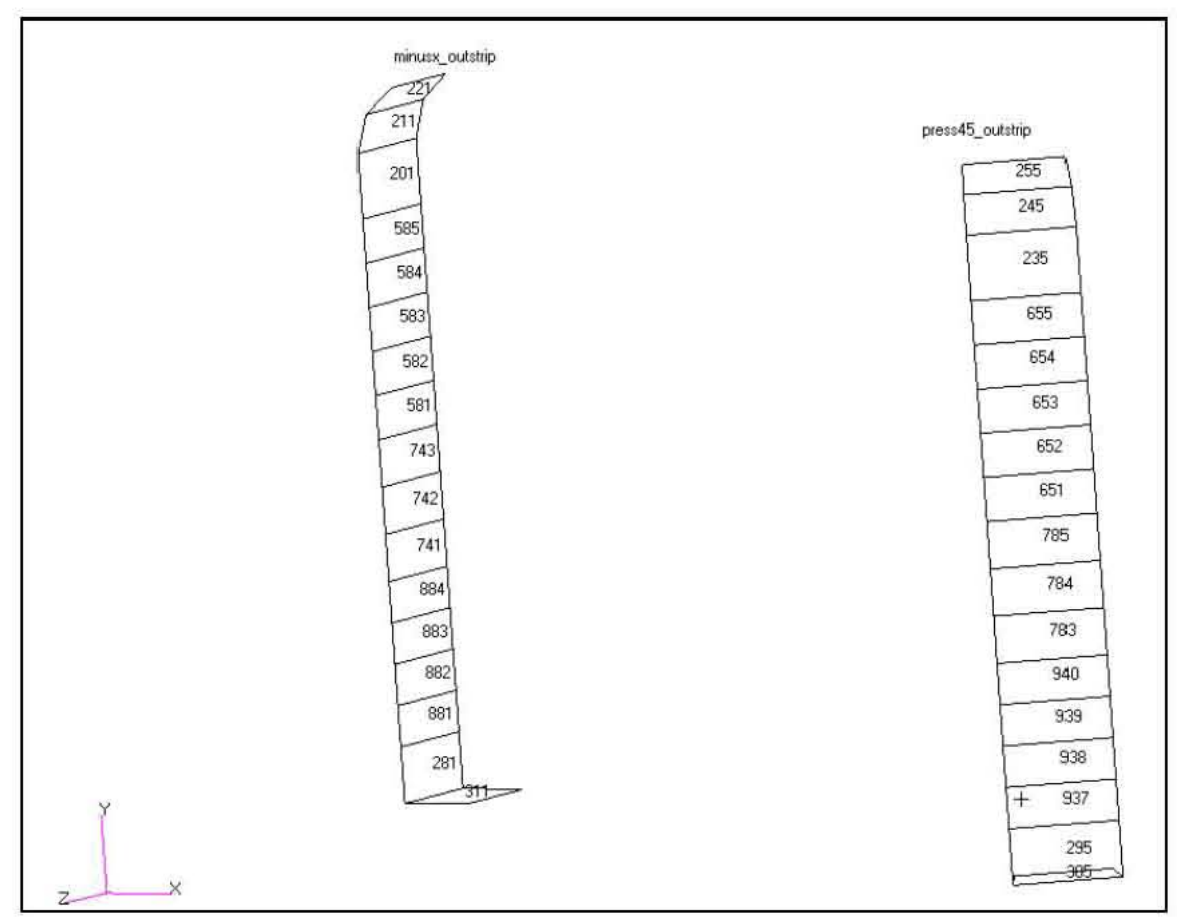

Figure 3-11. Shell Element Numbering for Dytran ${ }^{\circledR}$ Tank Wall Stress Results at $\theta=45^{\circ}$ and $\theta=180^{\circ}$ 
RPP-RPT-32239, Rev. 1

M\&D-2008-005-CALC-001, Rev. 1

\subsection{Material Properties and Element Types}

The primary tank was modeled in Dytran ${ }^{\circledR}$ using CQUAD4 shell elements. The elastic modulus, Poisson's ratio, and specific weight of the steel walls were set to $28.8 \times 10^{6} \mathrm{lbf} / \mathrm{in}^{2}, 0.3$, and $0.284 \mathrm{lbf} / \mathrm{in}^{3}$, respectively. The steel properties are for the 241-AP tanks per Section 3.3 of Rinker et al. (2004). The tank wall thicknesses are for the 241-AP tanks and are from Drawing H-2-90534, Rev. 4. The general configuration of the primary tank wall thickness is shown in Figure 3-12. In that plot, the blue band at the bottom represents the 7/8-inch-thick portion of the wall, the green band represents the 3/4-inch-thick portion of the wall, the red represents the 9/16-inch-thick portion of the wall, and the light blue represents the $1 / 2$-inch-thick portion of the wall. The black portion of the dome is modeled as rigid. It can be seen in Figure 3-12 that there are 16 elements vertically in the flexible portion of the tank wall giving an average element height of approximately 29 inches.

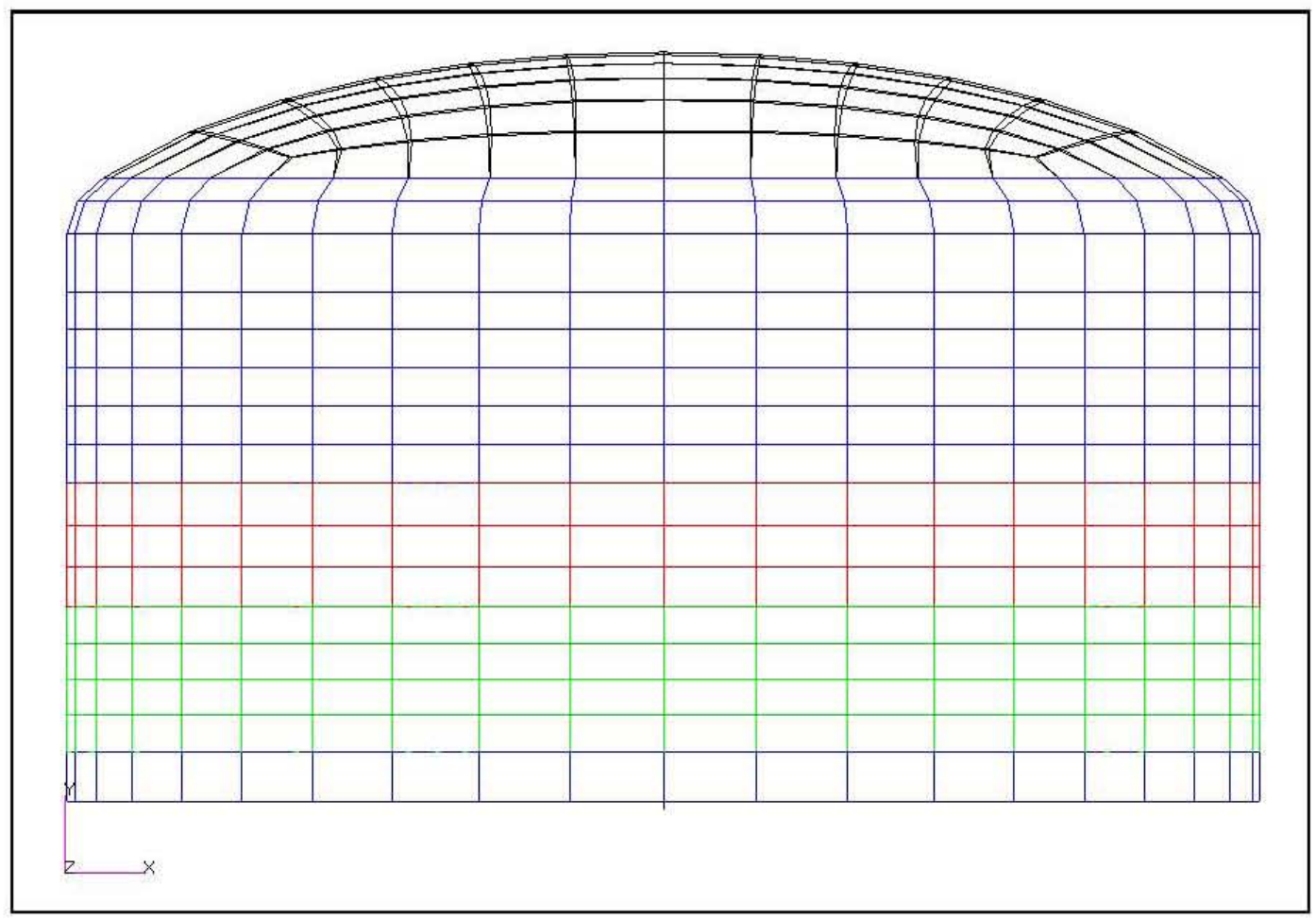

Figure 3-12. Plot of Dytran ${ }^{\circledR}$ Primary Tank Mesh with Different Colors Representing Different Wall Thicknesses

The dome was kept rigid above the attachment point of the first row of anchor bolts (estimated at 467 inch above the floor of the primary tank per Drawing H-2-90534, Rev. 4). A rigid region was also defined for the bottom of the tank. In the case of horizontal excitation only, the central portion of the primary tank bottom was kept rigid and the outer ring of elements in the tank bottom was left flexible and assigned normal steel properties with a thickness of $1 / 2$ inch. Both of the rigid regions were assigned artificially high mass density to faithfully reflect the applied seismic motion. In the case of horizontal excitation only, the rigid regions are those shown in black in Figure 3-13. The flexible outer ring of elements in the tank floor is shown in blue. For the cases of vertical excitation only and two-component motion with horizontal and vertical excitation, the outer ring of elements in the floor was also specified as 
RPP-RPT-32239, Rev. 1

M\&D-2008-005-CALC-001, Rev. 1

rigid, and the rigid base shown in blue in Figure 3-3 was removed from the model to allow for vertical motion. With the rigid base present, there are 1,100 CQUAD4 elements in the model. Without the rigid base, the number of CQUAD4 elements is reduced to 960.

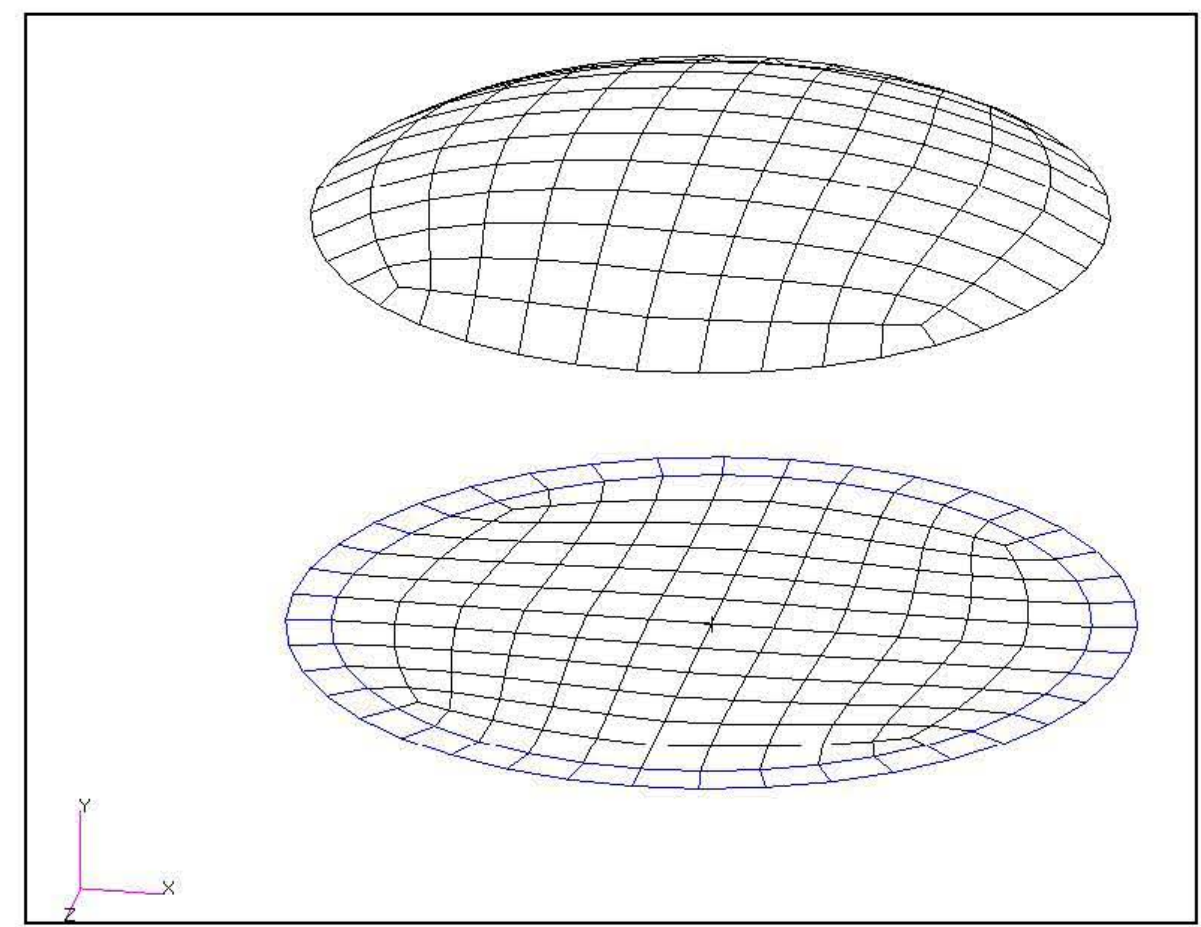

Figure 3-13. Rigid Regions of the Dytran ${ }^{\circledR}$ Primary Tank Model (shown in black) for Horizontal Excitation Only

The waste and air in the dome space were modeled using 107,200 8-node CHEXA Eulerian solid elements. Because two fluids are present, the Eulerian elements were assigned multi-material hydrodynamic material properties (MMHYDRO). Both the air and the waste were modeled as homogeneous, inviscid, fluids.

The waste was modeled using a polynomial equation of state (EOSPOL) that requires the initial mass density and the bulk modulus of the fluid as input. The initial density of the waste was set to $1.71 \times 10^{4}$ $1 \mathrm{bf}-\mathrm{sec}^{2} / \mathrm{in}^{4}$ (specific gravity=1.83). The bulk modulus of the waste was set to $305,000 \mathrm{lbf} / \mathrm{in}^{2}$, which is a typical bulk modulus for water. However, the results are expected to be insensitive to the value of the bulk modulus since fluid compressibility is not critical to the response in this problem.

The air was modeled using the gamma law equation of state (EOSGAM), where the pressure is a function of the mass density $\rho$, the specific internal energy per unit mass $e$, and the ideal gas ratio of specific heats $\gamma$ via $p=(\gamma-1) \rho e$. The mass density of air is $1.167 \times 10^{-7} \mathrm{lbf}-\mathrm{sec}^{2} / \mathrm{in}^{4}$, and the ratio of constantpressure specific heat to constant-volume specific heat is 1.4 . The specific internal energy per unit mass of the air was set to $3.15 \times 10^{8} \mathrm{in}^{2} / \mathrm{sec}^{2}$, which corresponds to an air pressure of $14.7 \mathrm{lbf} / \mathrm{in}^{2}$. 


\section{RPP-RPT-32239, Rev. 1 \\ M\&D-2008-005-CALC-001, Rev. 1}

\subsection{Boundary Conditions}

In the case of horizontal seismic excitation only, the rigid regions were free in the $\mathrm{x}$-direction, and fixed in the other five degrees-of-freedom. The rigid regions are those shown in black in Figure 3-13 and the rigid base shown in blue in Figure 3-3 was present in the model. In the cases of vertical excitation only and two-component motion (simultaneous horizontal and vertical excitation), the rigid regions included all elements shown in Figure 3-13. In these two cases, the rigid base shown in Figure 3-3 was removed from the model to allow for vertical motions. In the case of vertical motion, the rigid regions were excited in the vertical direction and were fixed in the other five degrees-of-freedom. For two-component motion, the rigid regions were excited in the $\mathrm{x}$ and $\mathrm{y}$-directions and fixed in the other four degrees-offreedom.

The Dytran ${ }^{\mathbb{B}}$ general coupling algorithm was used to allow the Eulerian waste mesh to interact with the Lagrangian structural mesh. The problem was set up to take advantage of the "fast coupling" option in Dytran $^{\mathbb{Q}}$.

\subsection{Initial Conditions}

All Dytran ${ }^{\circledR}$ simulations were performed at absolute pressure so that the initial air pressure was set to the atmospheric pressure of $14.7 \mathrm{lbf} / \mathrm{in}^{2}$ in the parameters section of the input file. The specific internal energy per unit mass of the air was set to $3.15 \times 10^{8} \mathrm{in}^{2} / \mathrm{sec}^{2}$ according to the gamma law equation of state

$$
e=\frac{p}{(\gamma-1) \rho}
$$

As a convenience, a balancing pressure of $14.7 \mathrm{lbf} / \mathrm{in}^{2}$ was applied to the outside of the tank using the Dytran ${ }^{\mathbb{B}}$ COUOPT command (MSC 2005) to keep the tank stresses in terms of gage pressures.

\subsection{Seismic Input}

The seismic time histories used to excite the primary tank sub-models (both Dytran ${ }^{\circledR}$ and ANSYS ${ }^{\circledR}$ ) were output from the global ANSYS ${ }^{\mathbb{B}}$ model of the DST and surrounding soil described in Section 2.0. The time histories used as input to the primary tank sub-models were taken from node 495 in the concrete basemat of the global ANSYS ${ }^{\circledR}$ model as shown in Figure 3-14 and Figure 3-15. As shown in those figures, node 495 lies at the junction between the bottom of the concrete wall and the basemat $90^{\circ}$ from the plane of horizontal excitation in the negative y-direction. Note that in Figure 3-14 and Figure 3-15, the tank wall elements near node 495 have been unselected for ease of visualization.

The extracted time histories consisted of 2,048 points defined at 0.01 -second intervals giving seismic records with durations of 20.48 second. In all three cases, the seismic excitation was preceded by a 6-second quiet period to allow sufficient time for the gravity loading to equilibrate.

In the case of horizontal (x-direction) excitation, the seismic time histories were applied as body force accelerations per unit mass on the nodes of the rigid portions of the tank that have artificially high mass. The vertical seismic time history was applied as a velocity time history to the rigid portions of the tank. The reason that the vertical input was applied as a velocity rather than an acceleration time history is that 
RPP-RPT-32239, Rev. 1

M\&D-2008-005-CALC-001, Rev. 1

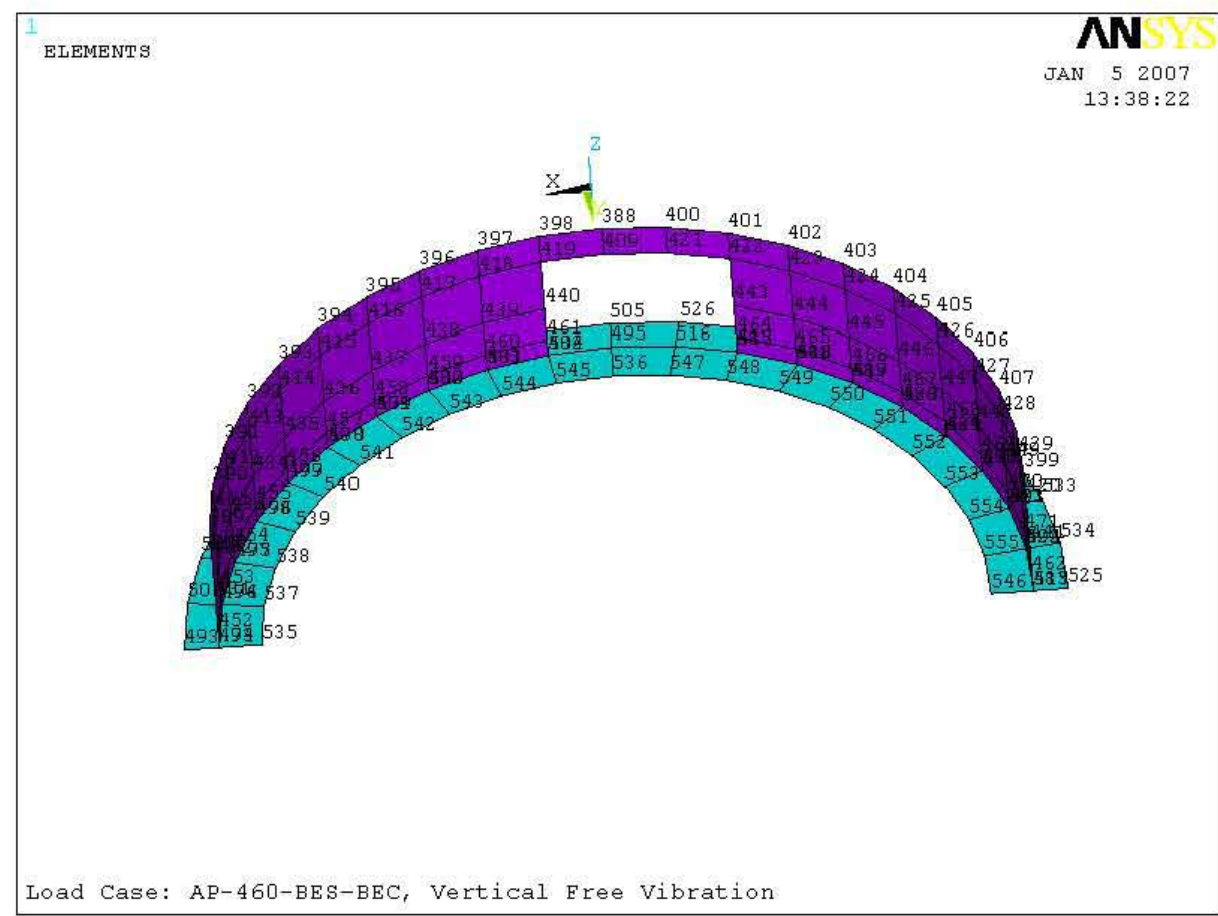

Figure 3-14. Plot of Junction of Concrete Wall and Concrete Basemat from Global ANSYS ${ }^{\circledR}$ Model Showing Node 495 from Which Sub-Model Input Time Histories Were Extracted

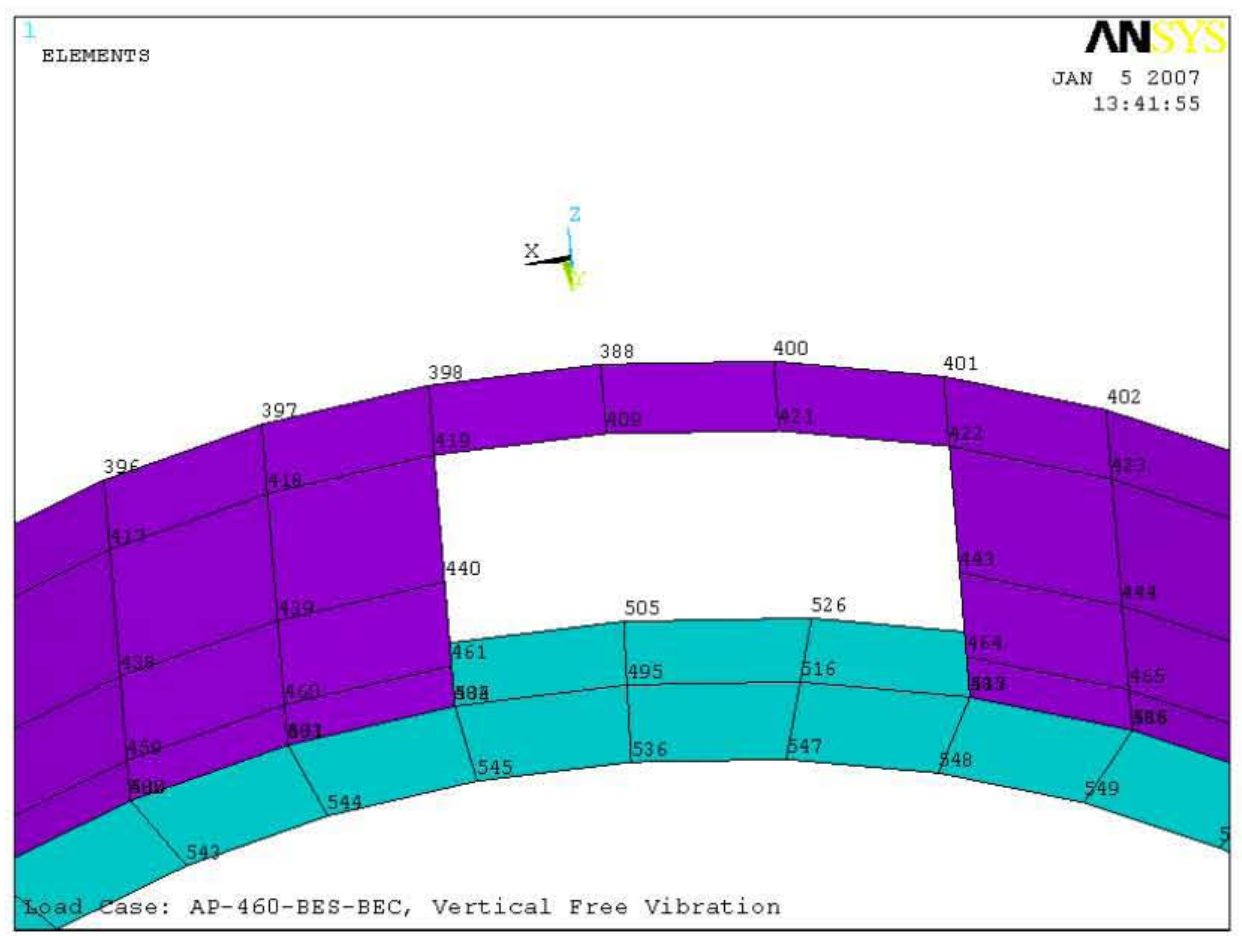

Figure 3-15. Detailed Plot of Junction of Concrete Wall and Concrete Basemat from Global ANSYS ${ }^{\circledR}$ Model Showing Node 495 from Which Sub-Model Input Time Histories Were Extracted 
RPP-RPT-32239, Rev. 1

M\&D-2008-005-CALC-001, Rev. 1

this approach precludes having to exactly balance the vertical gravity load with the vertical acceleration time history, thus preventing any vertical drift. In all cases, the same excitations were applied to all rigid elements simultaneously. That is, the top and bottom of the tank were excited together with the same seismic time histories. This represents the hinged top boundary condition discussed in BNL (1995) and shown in Figure 3-16.

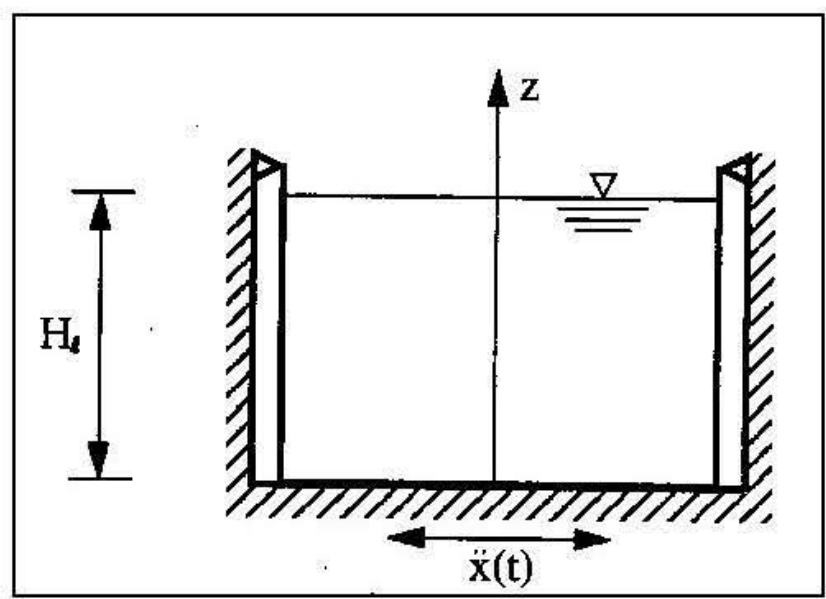

Figure 3-16. Tank With Hinged Top Boundary Condition per BNL (1995)

The horizontal acceleration, vertical acceleration, and the velocity and displacement time histories for horizontal and vertical input are shown in Figure 3-17, Figure 3-18, Figure 3-19, and, Figure 3-20, respectively. The $4 \%$ damped response spectra for the horizontal and vertical time histories are shown in Figure 3-21.

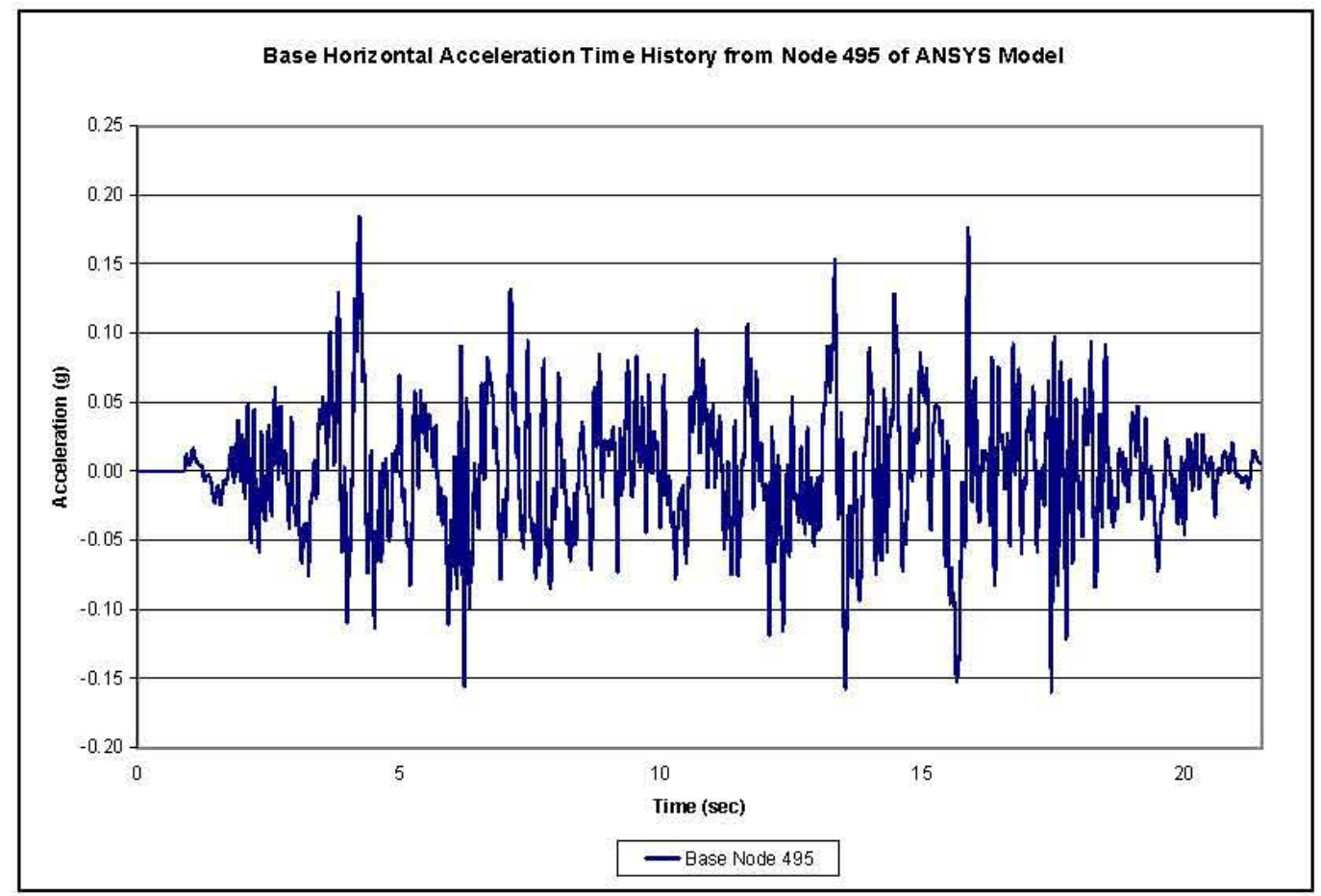

Figure 3-17. Horizontal Acceleration Time History Used as Input to the Primary Tank Sub-Models 
RPP-RPT-32239, Rev. 1

M\&D-2008-005-CALC-001, Rev. 1

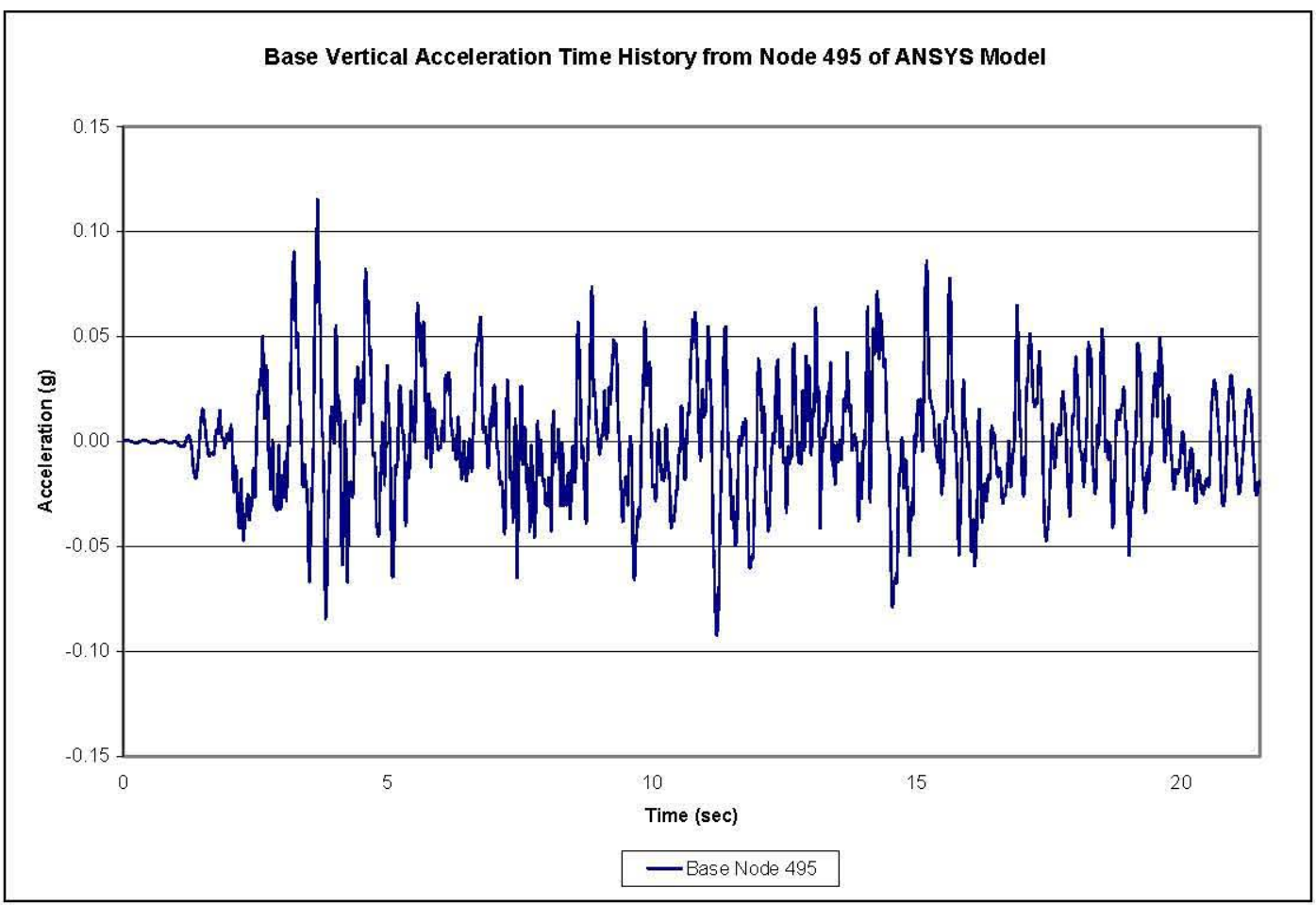

Figure 3-18. Vertical Acceleration Time History Used as Input to the Primary Tank Sub-Models

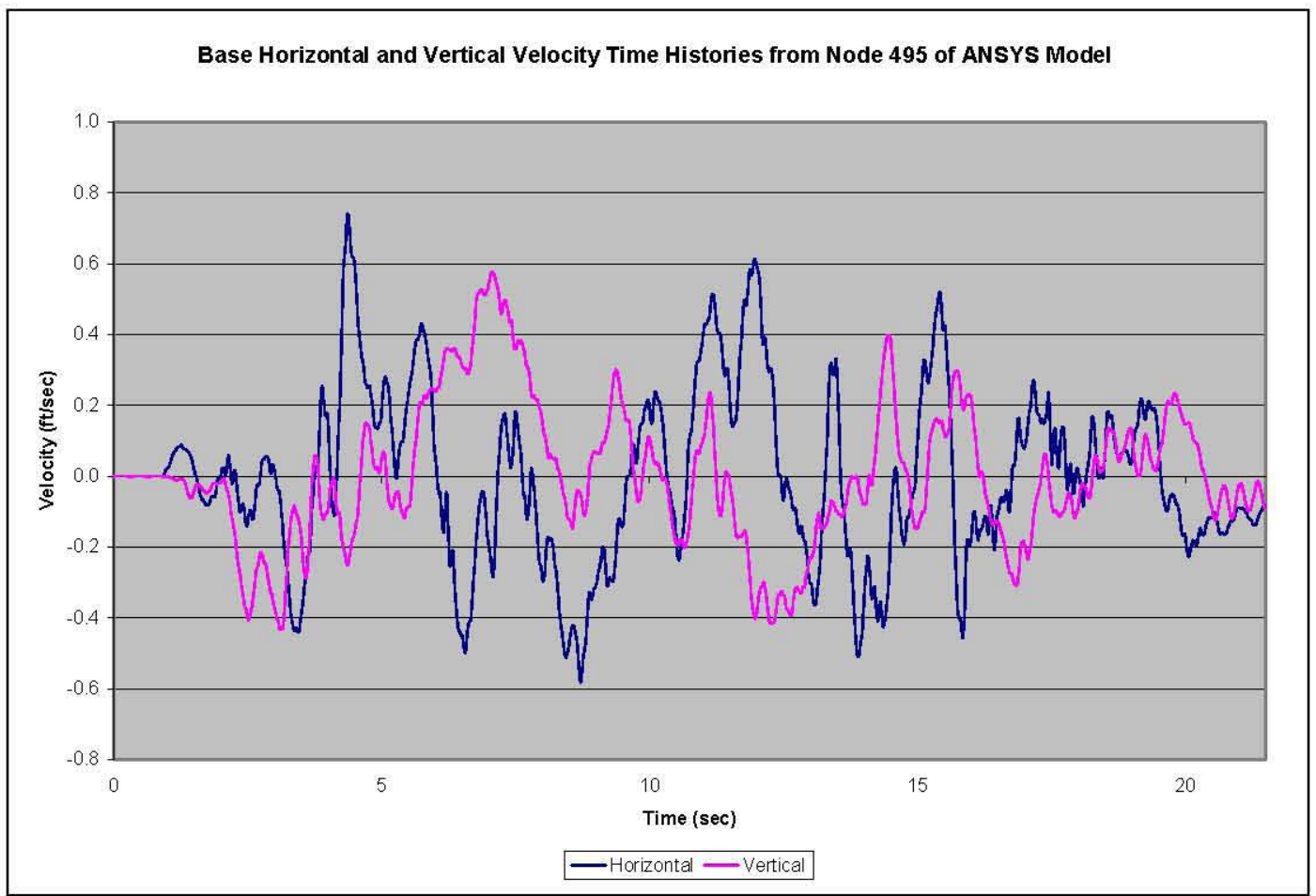

Figure 3-19. Velocity Time Histories - Vertical Time History Used as Input to the Dytran ${ }^{\mathbb{B}}$ Primary Tank Sub-Model 
RPP-RPT-32239, Rev. 1

M\&D-2008-005-CALC-001, Rev. 1

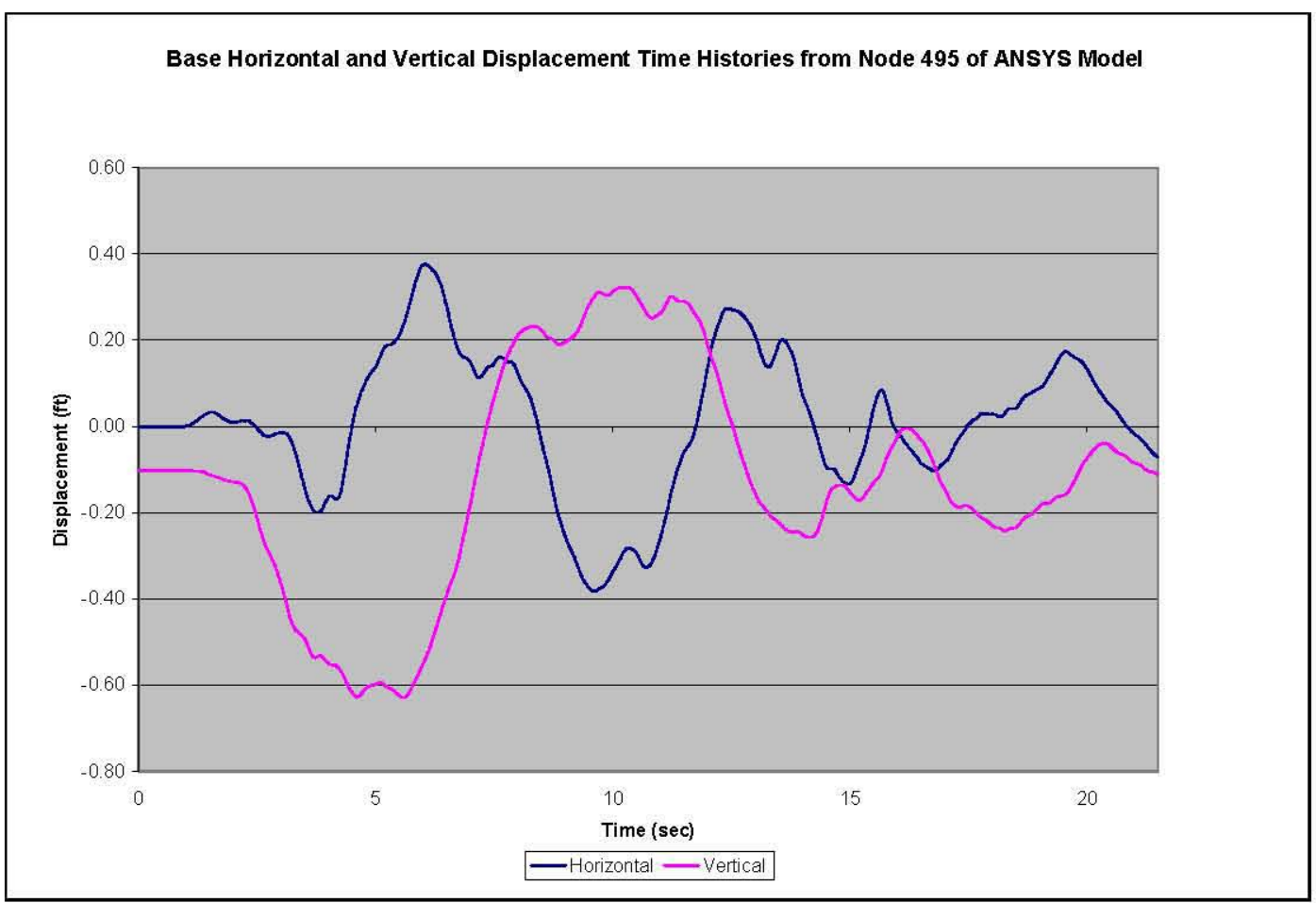

Figure 3-20. Displacement Time Histories Corresponding to Primary Tank Sub-Model Input

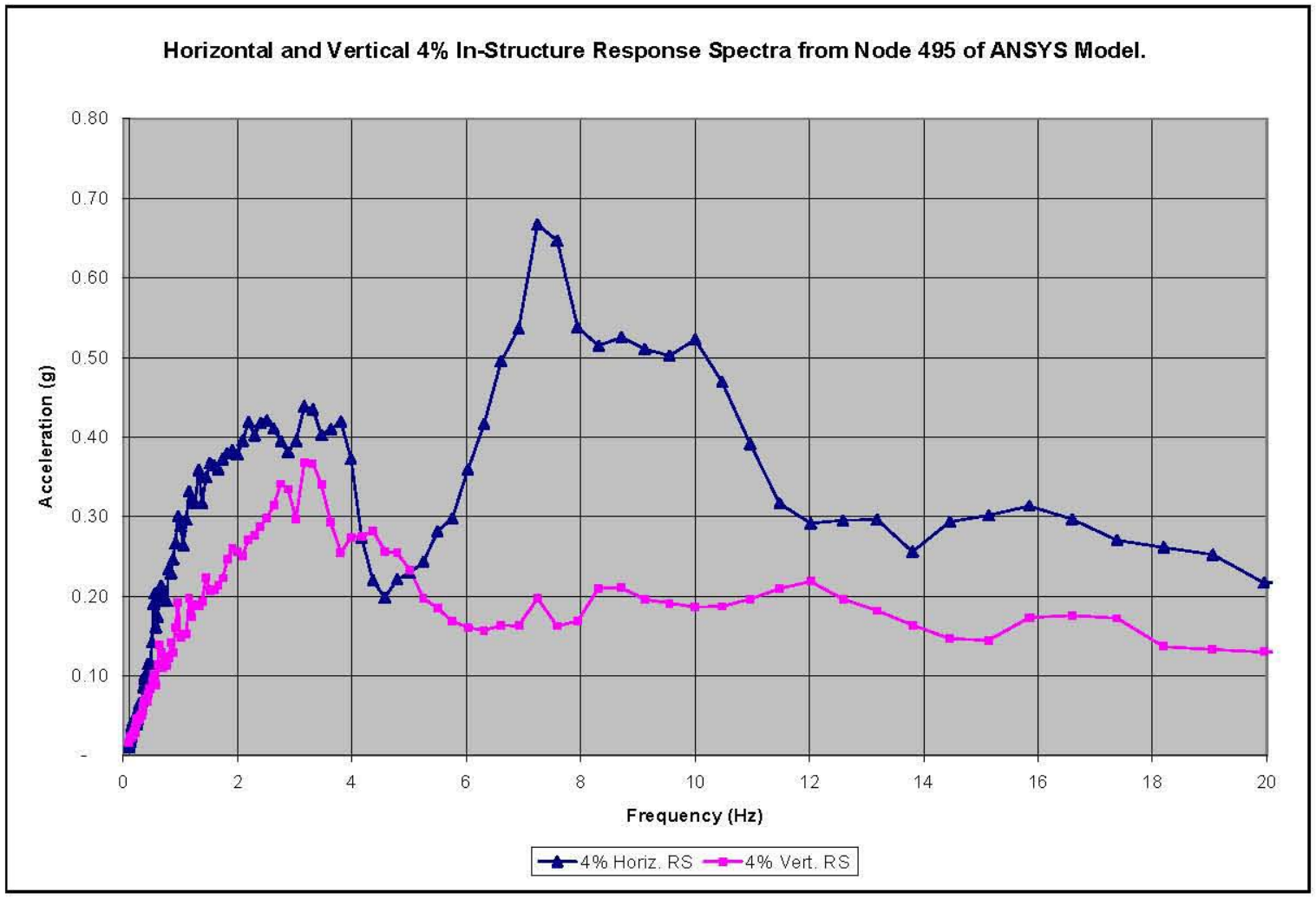

Figure 3-21. 4\% Damped Response Spectra for Acceleration Time Histories Extracted from ANSYS ${ }^{\circledR}$ Model 
RPP-RPT-32239, Rev. 1

M\&D-2008-005-CALC-001, Rev. 1

\subsection{Differences from Earlier Dytran ${ }^{\circledR}$ Models}

The Dytran ${ }^{\mathbb{B}}$ models described in this report differ from the Dytran ${ }^{\mathbb{B}}$ flexible primary tank sub-models at the 460-inch liquid level described in Rinker and Abatt (2006a) in the following respects:

1. The non-uniform wall thickness representative of the 241-AP tanks is incorporated in the present models.

2. The transition from flexible elements to rigid elements has been shifted up from approximately 458 inches to 467 inches to more accurately represent the elevation of the first row of anchor bolts.

3. The time history input records used are different having been extracted from the tank base of the global ANSYS ${ }^{\circledR}$ model at the 460 -inch waste level instead of from the dome of the global ANSYS ${ }^{\circledR}$ model at the 422 -inch waste level.

4. The dynamic relaxation parameter was increased from 0.02 to 0.025 to achieve the desired effective damping.

5. The boundary conditions at the bottom of the tank in the presence of vertical excitation have been changed as described in Section 3.3.

6. Two-component motion (simultaneous horizontal and vertical seismic excitation) is incorporated in the present models.

7. The elastic modulus was reduced from $29.0 \times 10^{6} \mathrm{lbf} / \mathrm{in}^{2}$ to $28.8 \times 10^{6} \mathrm{lbf} / \mathrm{in}^{2}$. 
RPP-RPT-32239, Rev. 1

M\&D-2008-005-CALC-001, Rev. 1

\subsection{Results from Dytran ${ }^{\circledR}$ Primary Tank Sub-Models}

Results from horizontal seismic excitation only, vertical seismic excitation only, and simultaneous application of horizontal and vertical seismic excitation (two-component motion) are described in this chapter.

Impulsive and convective frequencies, global reaction forces, waste pressures, maximum slosh heights, and primary tank stresses will be reported. Extensive benchmarking of Dytran ${ }^{\mathbb{B}}$ tank models was performed and reported in Rinker and Abatt (2006a, 2006b). In those reports, much emphasis was placed on documenting that the frequencies, reaction forces and waste pressures matched well to known solutions. In this report, there is less emphasis on frequencies, reaction forces, and waste pressures, and more emphasis on primary tank stresses. Thus, although frequencies, reaction forces, waste pressures, and slosh heights are reported to provide a basic check of the results, the primary tank stresses are of the most interest. Furthermore, due to the extensive data produced by the Dytran ${ }^{\mathbb{B}}$ simulations, not all results are shown in the body of this report. Additional results are included in Appendix B.

\subsection{Characterization of Damping in Dytran ${ }^{\circledR}$ Sub-Model}

The intent of introducing dynamic relaxation (damping) into the solution is to achieve realistic effective damping values for the impulsive and convective response of the tank and waste system.

The target values are $2-4 \%$ for the impulsive response and $0.5 \%$ for the convective response of the tank and liquid system per DOE (2002). The value of the dynamic relaxation factor was set to 0.025 based on the initial decay of the vertical coupling surface reaction force during gravity loading. The initial decay of the vertical reaction force actually represents the effective damping of the breathing mode response of the system, but this was expected to be a good indicator of the impulsive response of the system. Based on the decay of the breathing mode response, the effective impulsive damping is approximately $3.5 \%$ of critical.

A more direct (but much more time-consuming) way of determining the effective damping for the impulsive response is to quantify the decay of the horizontal reaction force immediately following the cessation of the seismic excitation. With this approach, the effective damping for the impulsive response is approximately $4.3 \%$ of critical damping. Based on the data displayed in Figure 4-2 and Figure 4-5, the effective damping for the convective response is approximately $0.6 \%$. Both values are slightly higher than desired, but further reductions in the dynamic relaxation parameter introduced undesired noise and instabilities into the solution.

The artificial viscosities implemented in Dytran $^{(\mathbb{B}}$ are referred to as the linear (BULKL) and quadratic (BULKQ) bulk viscosities. The bulk viscosities act to control the formation of shock waves by introducing viscosity to the bulk straining of the fluid. Experience with earlier models (Rinker and Abatt 2006a, 2006b) has shown that it is necessary to increase the bulk viscosity coefficients relative to the

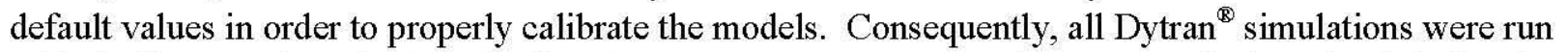
with the linear and quadratic bulk viscosity parameters set to 0.2 and 1.1 , respectively. The default values for the bulk viscosity coefficients are 0.0 for the linear coefficient and 1.0 for the quadratic coefficient. 
RPP-RPT-32239, Rev. 1

M\&D-2008-005-CALC-001, Rev. 1

\subsection{Hydrodynamic Forces from Dytran ${ }^{\circledR}$ Sub-Model}

\subsubsection{Horizontal Excitation Only}

The horizontal displacement of node 523 near the mid-height of the tank wall shown in Figure 4-1 during the initial equilibration phase exhibits a breathing mode frequency of $5.07 \mathrm{~Hz}$. Also shown in the plot are decay curves representing $3 \%, 3.5 \%$, and $4 \%$ critical damping. The best match appears to be from the $3.5 \%$ damping curve.

The peak horizontal hydrodynamic force is $3.05 \times 10^{6} \mathrm{lbf}$, as shown in Figure 4-2, along with the convective response, which shows a fundamental frequency of $0.207 \mathrm{~Hz}$. The convective response in Figure 4-2 shows an approximately $10 \%$ decay during the three cycles, from 29 to 44 seconds, giving an effective damping of approximately $0.6 \%$ for the convective response. The "noise" in the horizontal reaction force trace between approximately 32 and 43 seconds is numerically spurious data, with no significant effect on the solution. The signal could have been smoothed by increasing the dynamic relaxation (damping), but this would have been counterproductive, since the effective damping for the impulsive response is already slightly greater than desired.

Figure 4-3 shows the horizontal reaction force time history during the second free vibration period beginning at 26.5 seconds. According to that plot, the impulsive frequency is approximately $5.7 \mathrm{~Hz}$, and the effective damping for the impulsive response is slightly greater than $4 \%$ of critical.

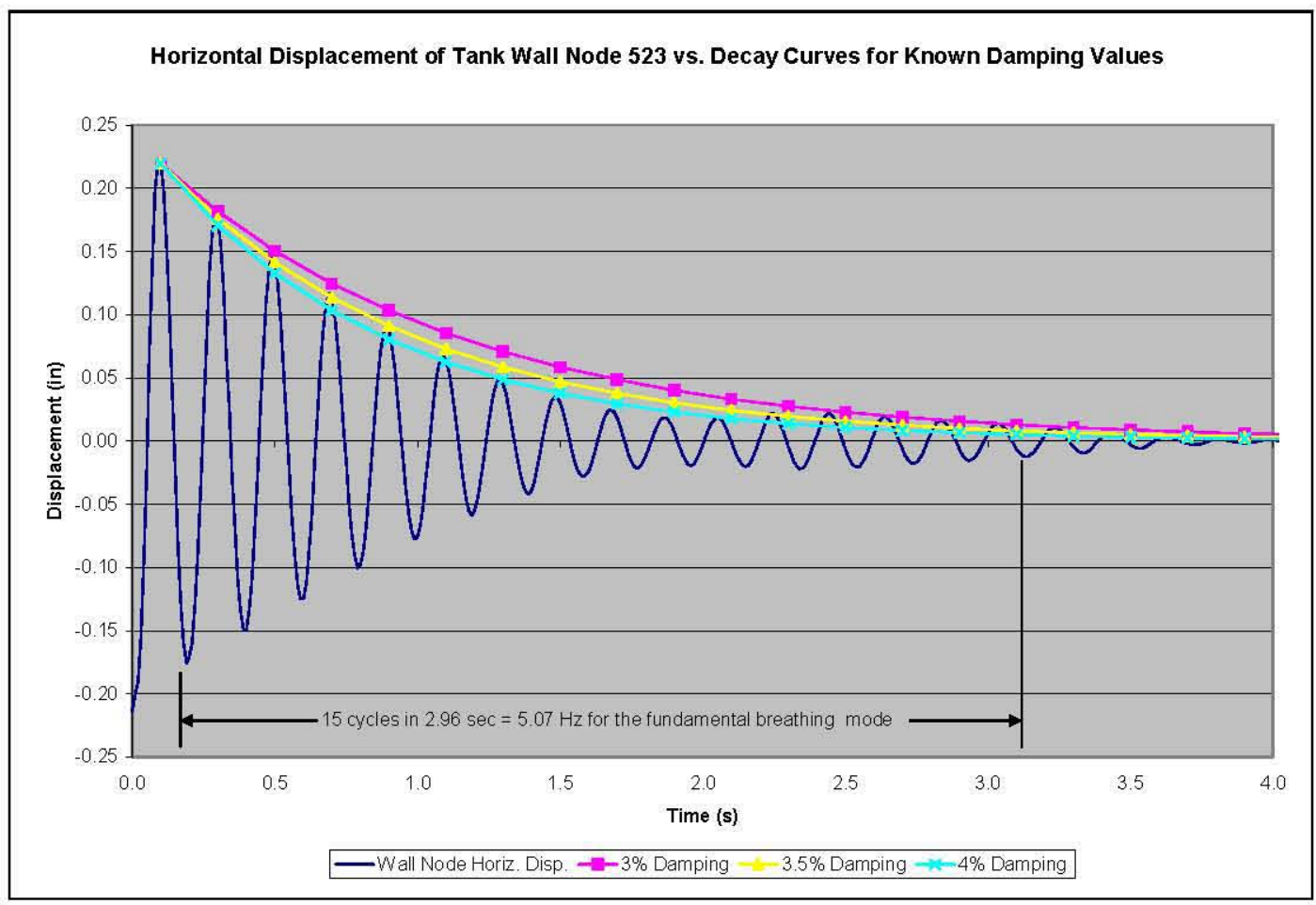

Figure 4-1. Horizontal Displacement of Tank Wall Node 523 (Mid-Height) vs. Time During Initial Gravity Loading 
RPP-RPT-32239, Rev. 1

M\&D-2008-005-CALC-001, Rev. 1

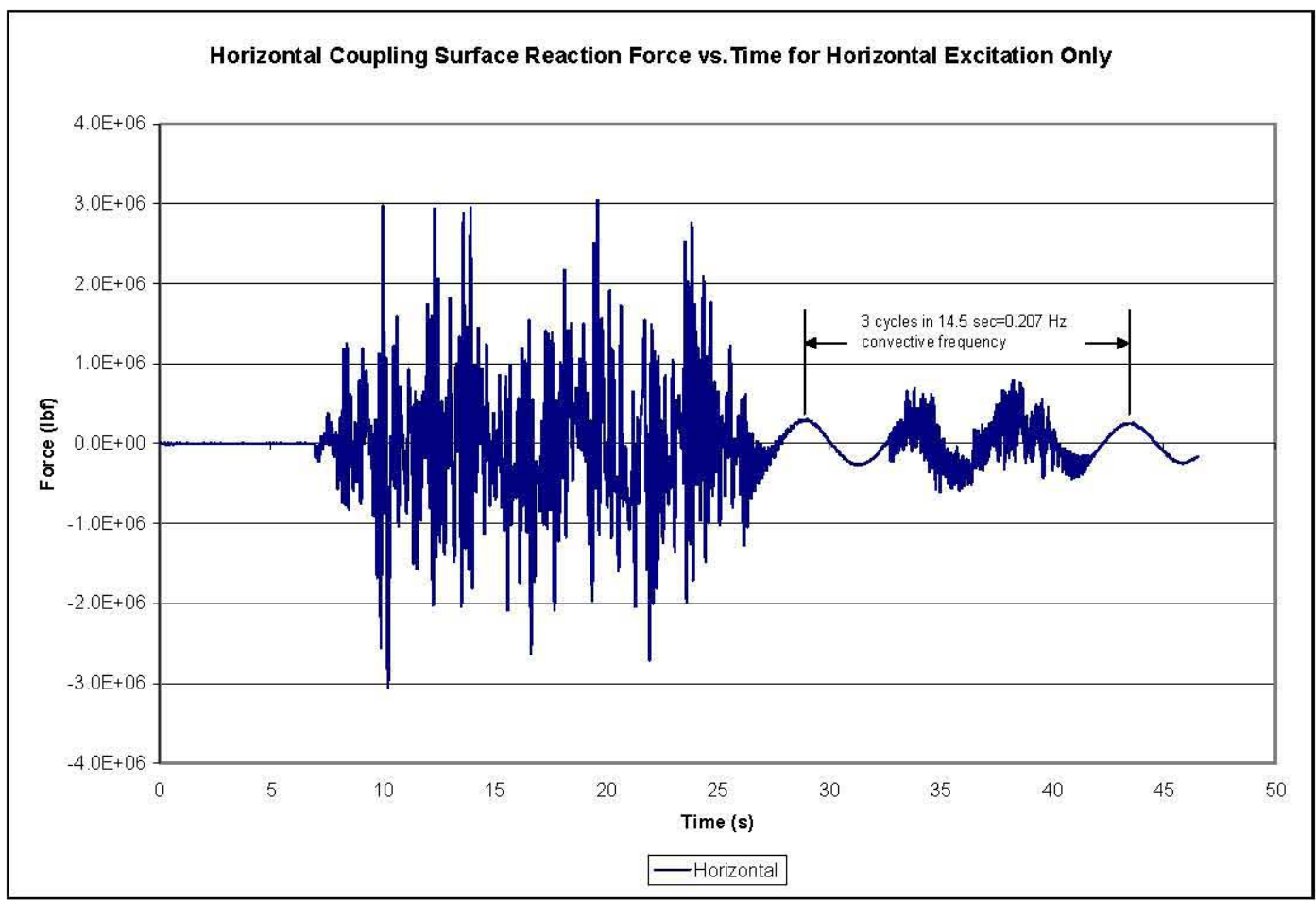

Figure 4-2. Horizontal Coupling Surface Reaction Force vs. Time for Horizontal Seismic Excitation

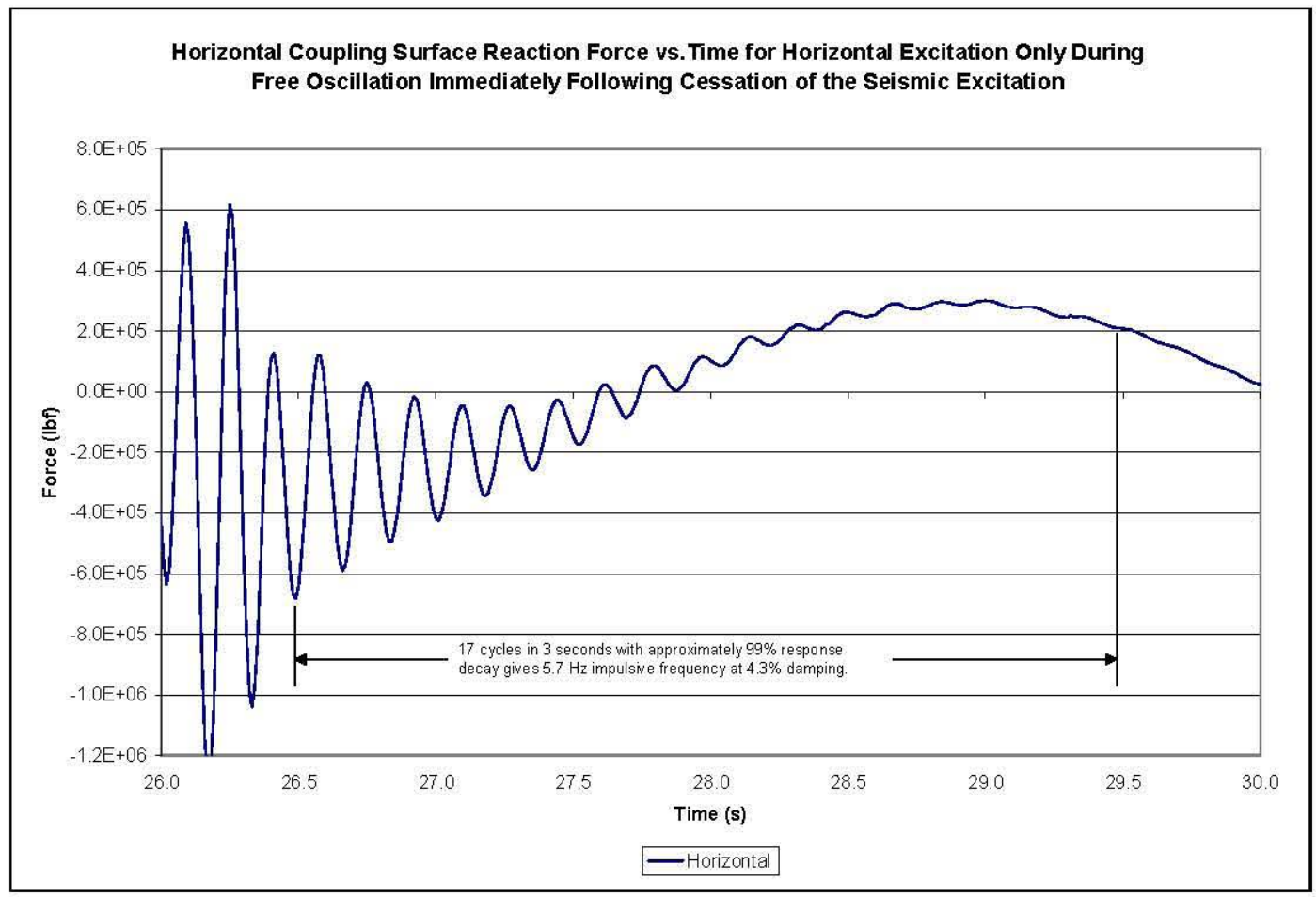

Figure 4-3. Horizontal Coupling Surface Reaction Force vs. Time for Horizontal Seismic Excitation During the Final Free Vibration Phase 


\subsubsection{Vertical Excitation Only}

As shown in Figure 4-4, the vertical reaction force varies between $-1.65 \times 10^{7} \mathrm{lbf}$ and $-2.28 \times 10^{7} \mathrm{lbf}$. The weight of the contained fluid is $1.92 \times 10^{7} \mathrm{lbf}$, so that the maximum dynamic component of the vertical reaction force is $3.6 \times 10^{6} \mathrm{lbf}$ (difference between peak reaction force and weight of fluid), which is greater than for horizontal excitation only.

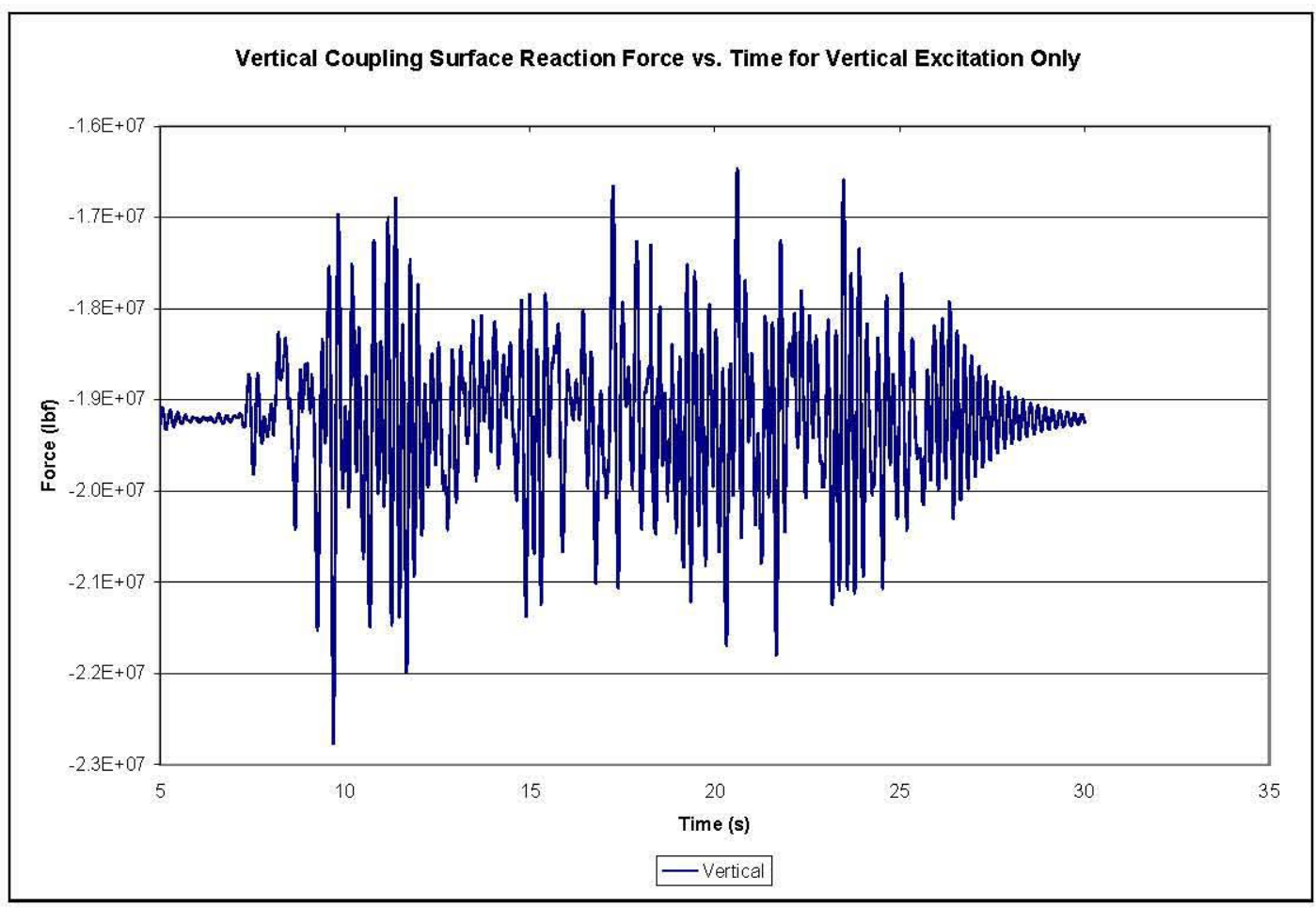

Figure 4-4. Vertical Coupling Surface Reaction Force vs. Time for Vertical Seismic Excitation

\subsubsection{Two-Component Motion}

The horizontal reaction force time history for two-component motion is shown in Figure 4-5. The maximum horizontal reaction force is $3.7 \times 10^{6} \mathrm{lbf}$, which is $21 \%$ greater than for horizontal motion only. The fundamental convective frequency is $0.207 \mathrm{~Hz}$ - the same as for horizontal excitation only.

The impulsive response and decay for the system is shown in Figure 4-6. In contrast to the case of horizontal motion only, the apparent impulsive frequency has increased from $5.7 \mathrm{~Hz}$ to $5.88 \mathrm{~Hz}$. Depending on how peaks are counted, the effective damping for the impulsive response is between $3.9 \%$ and $5.2 \%$ of critical.

In the case of two-component motion, Figure 4-7 shows that the vertical reaction force varies between $-1.65 \times 10^{7} \mathrm{lbf}$ and $-2.28 \times 10^{7} \mathrm{lbf}-$ exactly the same as for vertical seismic excitation only. Based on the reaction forces, the presence of the vertical input couples in such a way as to increase the maximum horizontal reaction force, but the presence of the horizontal input has no effect on the peak vertical reaction force. 
RPP-RPT-32239, Rev. 1

M\&D-2008-005-CALC-001, Rev. 1

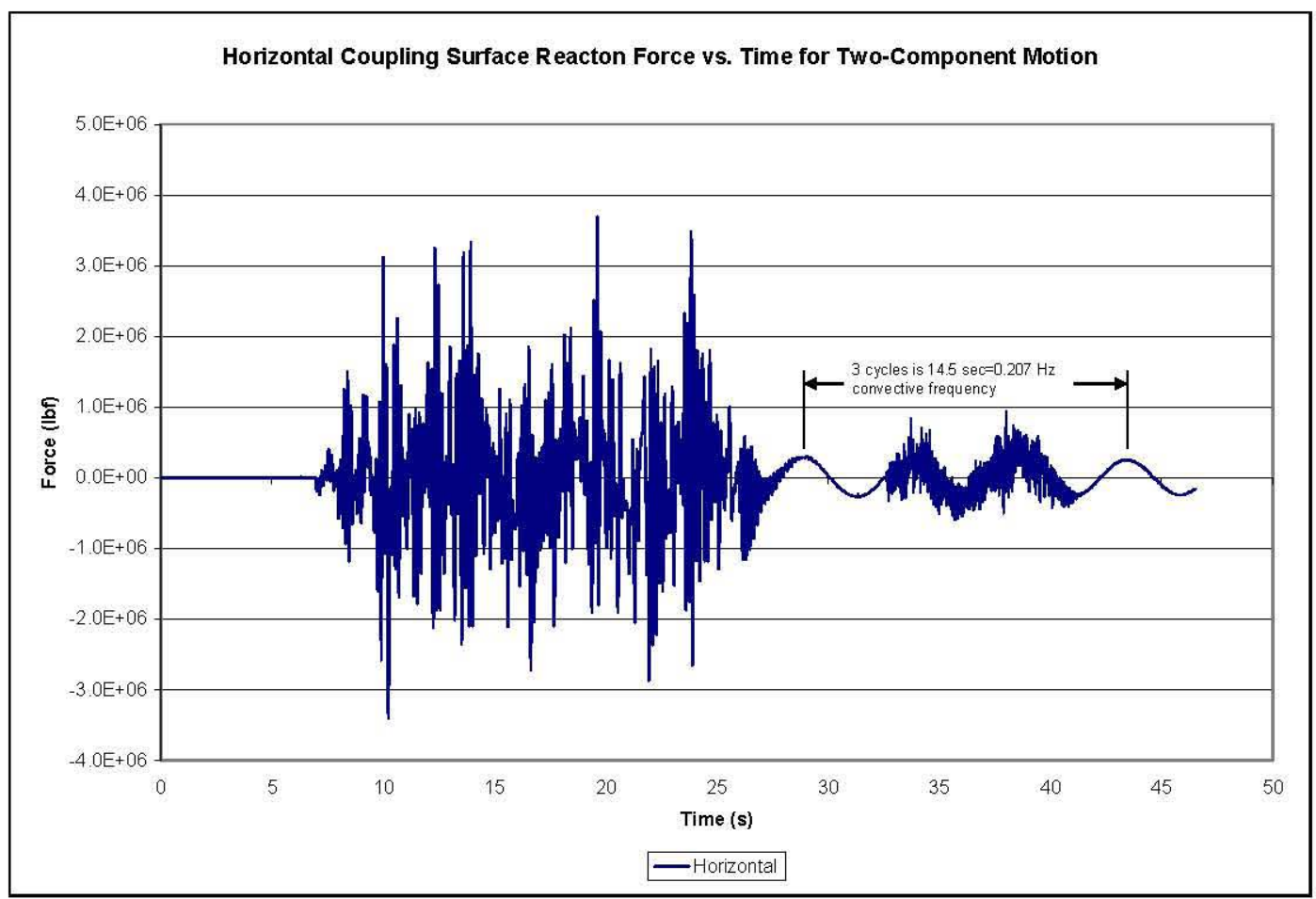

Figure 4-5. Horizontal Coupling Surface Reaction Force vs. Time for Two-Component Seismic Excitation

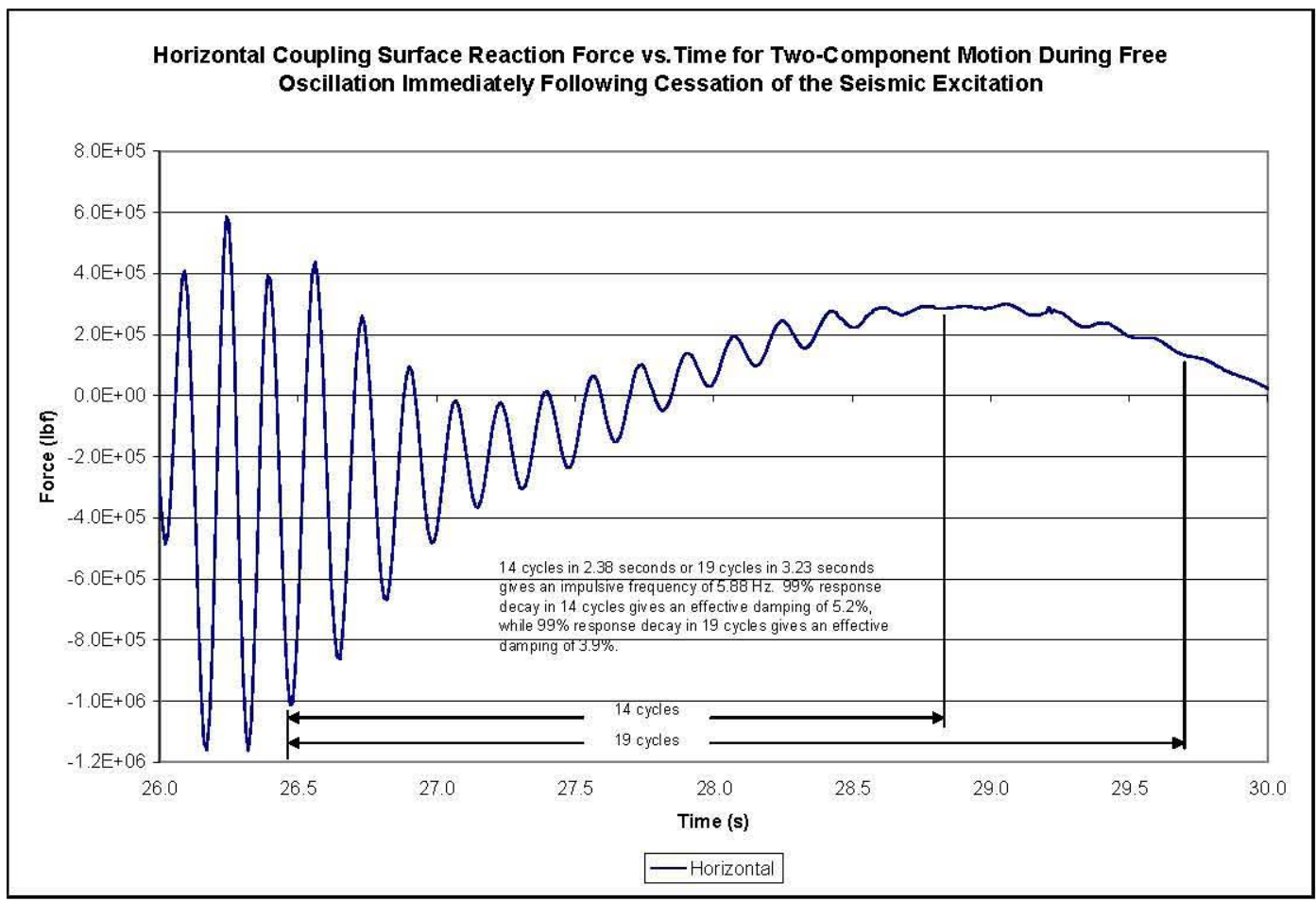

Figure 4-6. Horizontal Coupling Surface Reaction Force vs. Time for Two-Component Seismic Excitation During the Final Free Vibration Phase 
RPP-RPT-32239, Rev. 1

M\&D-2008-005-CALC-001, Rev. 1

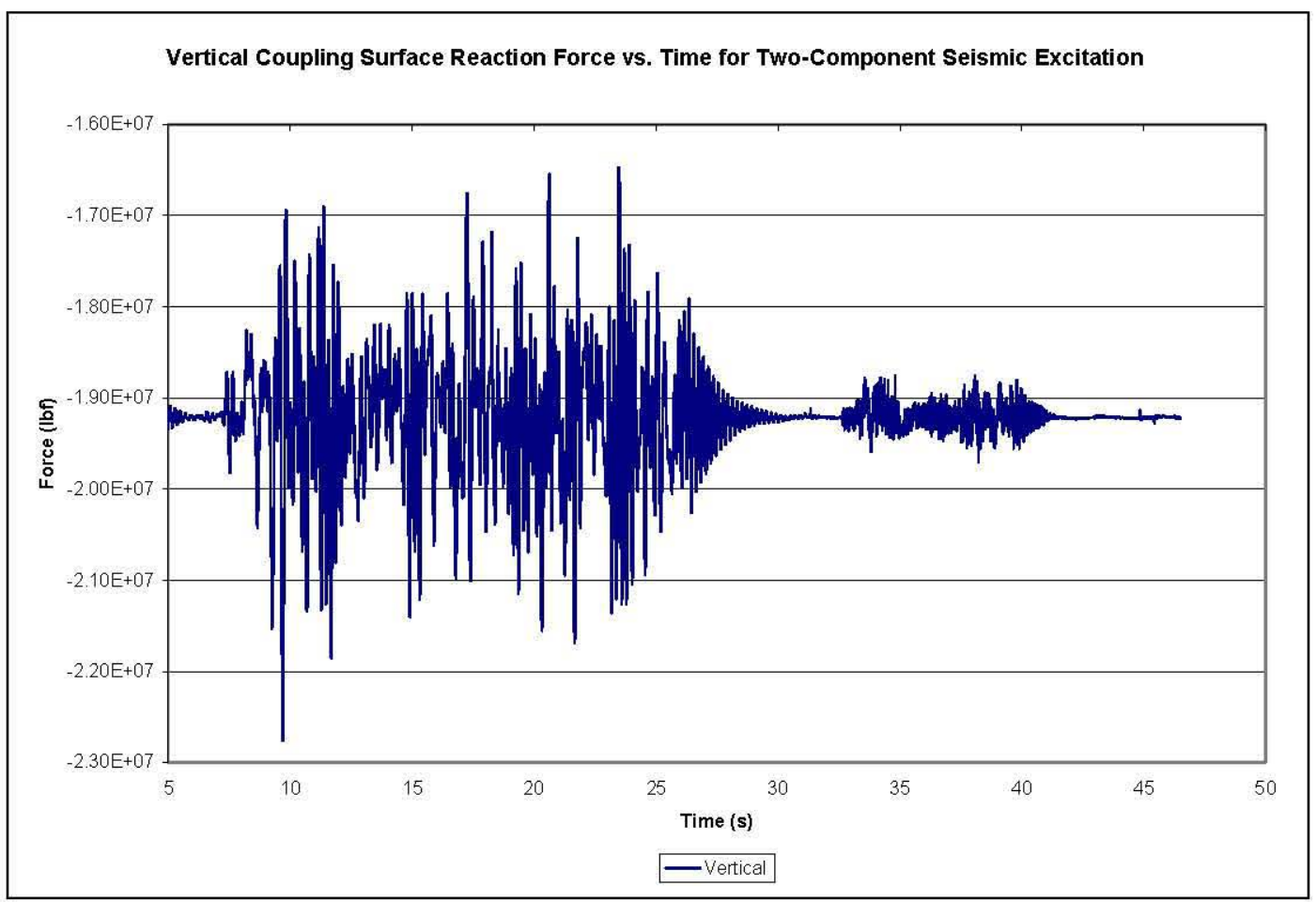

Figure 4-7. Vertical Coupling Surface Reaction Force vs. Time for Two-Component Seismic Excitation

\subsection{Waste Pressures from Dytran ${ }^{\circledR}$ Sub-Model}

The total pressures are the sum of the hydrostatic pressures and the hydrodynamic pressures. The theoretical hydrostatic pressures for the elements in the sets "plusx_els", "press_45", "plusz_els", "cent_press" and "minusx_els" are shown in Table 4-1. 
RPP-RPT-32239, Rev. 1

M\&D-2008-005-CALC-001, Rev. 1

Table 4-1. Theoretical Hydrostatic Pressures for Selected Fluid Elements from the Dytran ${ }^{\mathbb{B}}$ Primary Tank Sub-Model

\begin{tabular}{||c|c|c|c|c|c||}
\hline "Plusx_els" & "Press_45" & "Plusz_els" & "Cent_press" & "Minusx_els" & $\begin{array}{c}\text { Theoretical } \\
\text { Hydrostatic } \\
\text { Pressure } \\
\text { (psi absolute) }\end{array}$ \\
\hline 5143 & Element & Element & Element & Element & 15.0 \\
\hline 3543 & 5588 & 5799 & 89959 & 86776 & 15.7 \\
\hline 1943 & 3988 & 4199 & 86759 & 5176 & 16.4 \\
\hline 25943 & 2388 & 2599 & 3559 & 3576 & 17.0 \\
\hline 22743 & 23188 & 23399 & 22759 & 22776 & 18.3 \\
\hline 19543 & 19988 & 20199 & 19559 & 19576 & 19.7 \\
\hline 16343 & 16788 & 16999 & 16359 & 16376 & 21.0 \\
\hline 13143 & 13588 & 13799 & 13159 & 13176 & 22.3 \\
\hline 9943 & 10388 & 10599 & 9959 & 9976 & 23.6 \\
\hline 6743 & 7188 & 7399 & 6759 & 6776 & 24.9 \\
\hline 72343 & 72788 & 72399 & 72359 & 72376 & 26.3 \\
\hline 69143 & 69588 & 69799 & 69159 & 69176 & 27.6 \\
\hline 65943 & 66388 & 66599 & 65959 & 65876 & 28.9 \\
\hline 62743 & 63188 & 63399 & 62759 & 62776 & 30.2 \\
\hline 59543 & 59988 & 60199 & 59559 & 59576 & 31.6 \\
\hline 56343 & 56788 & 56999 & 56359 & 56376 & 32.9 \\
\hline 53143 & 53588 & 53799 & 53159 & 53176 & 34.2 \\
\hline 49943 & 50388 & 50599 & 49959 & 49876 & 35.5 \\
\hline 46743 & 47188 & 47399 & 46759 & 46776 & 36.9 \\
\hline 43543 & 43988 & 44199 & 43559 & 43576 & 38.2 \\
\hline 40343 & 40788 & 40999 & 40359 & 40376 & 39.5 \\
\hline 37143 & 37588 & 37799 & 37159 & 37176 & 40.9 \\
\hline 33943 & 34388 & 34599 & 33959 & 33876 & 42.2 \\
\hline 30743 & 31188 & 31399 & 30759 & 30776 & 43.5 \\
\hline 27543 & 27988 & 28199 & 27559 & 27576 & 44.8 \\
\hline & & & & & \\
\hline
\end{tabular}

\subsubsection{Horizontal Excitation Only}

The pressure time histories for the elements adjacent to the tank wall at $\theta=0,45$, and $90^{\circ}$ are shown in Figure 4-8, Figure 4-9, and Figure 4-10, respectively. In each plot, the hydrostatic pressures are stable and fall between approximately 16 and $44 \mathrm{lbf} / \mathrm{in}^{2}$, in agreement with the values in Table $4-1$. It is apparent that the pressure in the elements near the bottom of the tank is dominated by impulsive effects while the pressure in fluid elements near the free surface is dominated by convective effects, as expected.

It may also be observed that the highest dynamic pressures occur in the plane of excitation $\left(\theta=0^{\circ}\right)$, and the minimum dynamic pressures occur normal to the plane of excitation $\left(\theta=90^{\circ}\right)$, as expected. The dynamic pressures at $\theta=45^{\circ}$ lie between the two extremes. 
RPP-RPT-32239, Rev. 1

M\&D-2008-005-CALC-001, Rev. 1

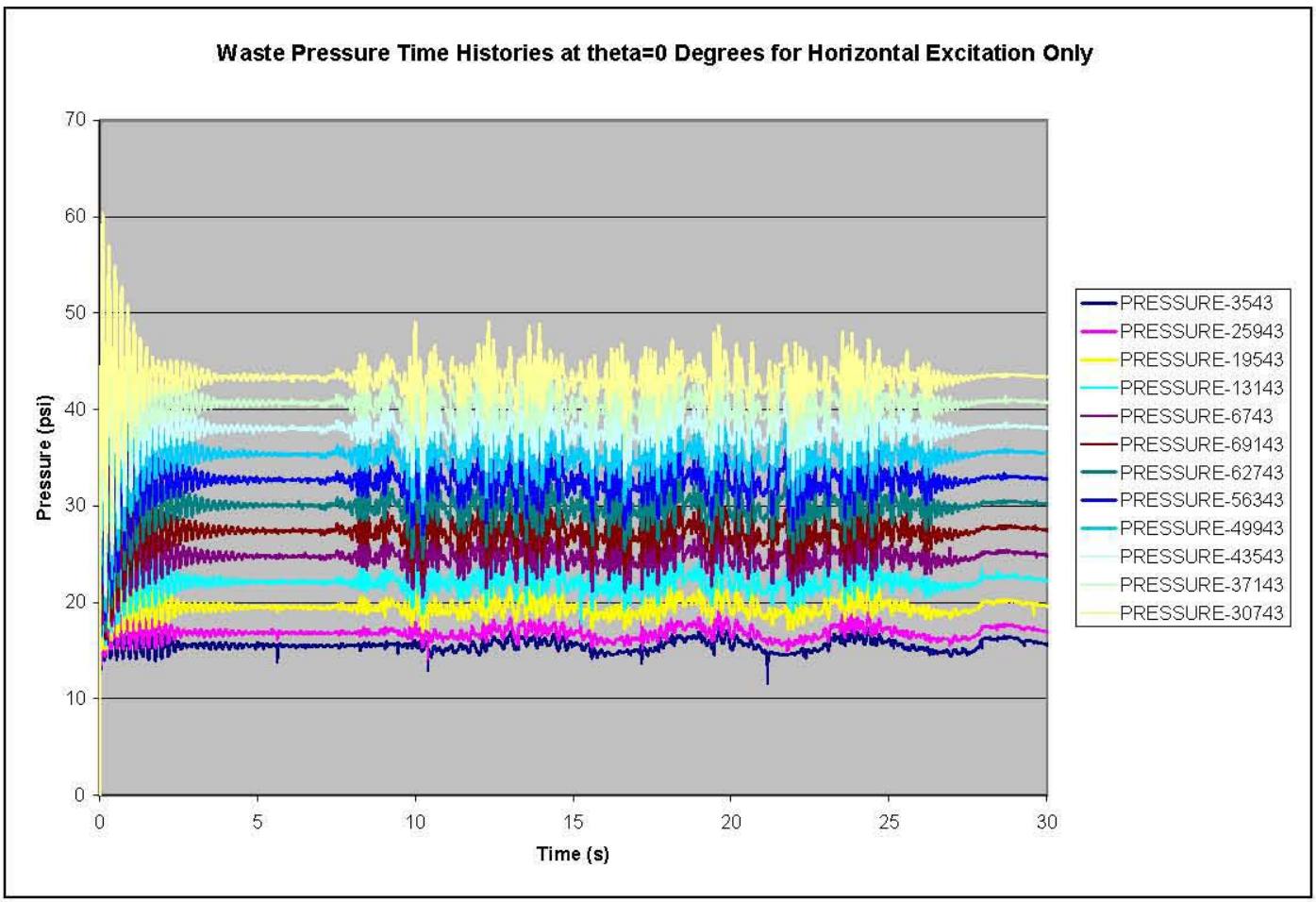

Figure 4-8. Waste Pressure Time Histories for Fluid Elements at $\theta=0^{\circ}$ (Plusx_els) Subjected to Horizontal Seismic Excitation Only

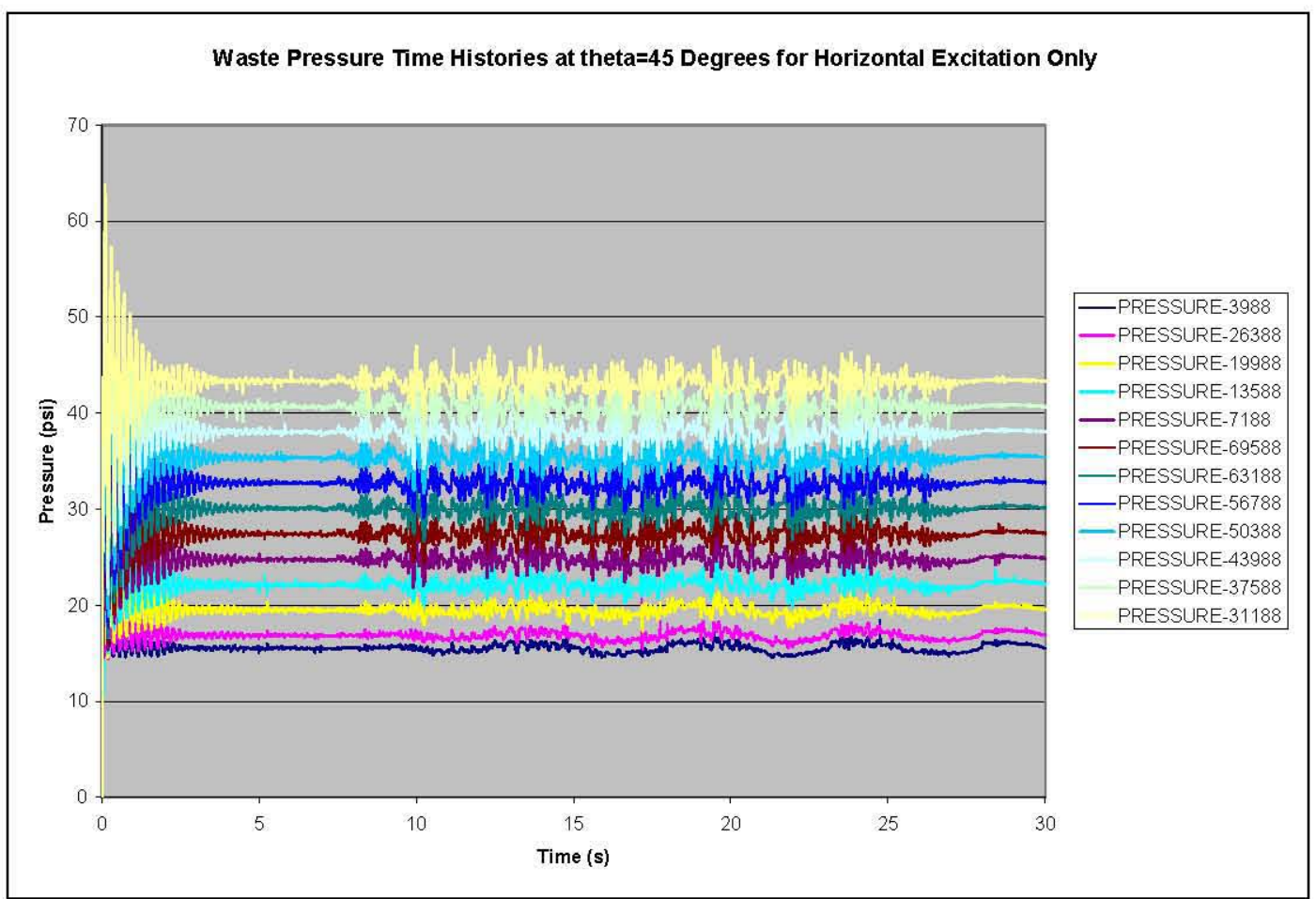

Figure 4-9. Waste Pressure Time Histories for Fluid Elements at $\theta=45^{\circ}$ (Press 45) Subjected to Horizontal Seismic Excitation Only 
RPP-RPT-32239, Rev. 1

M\&D-2008-005-CALC-001, Rev. 1

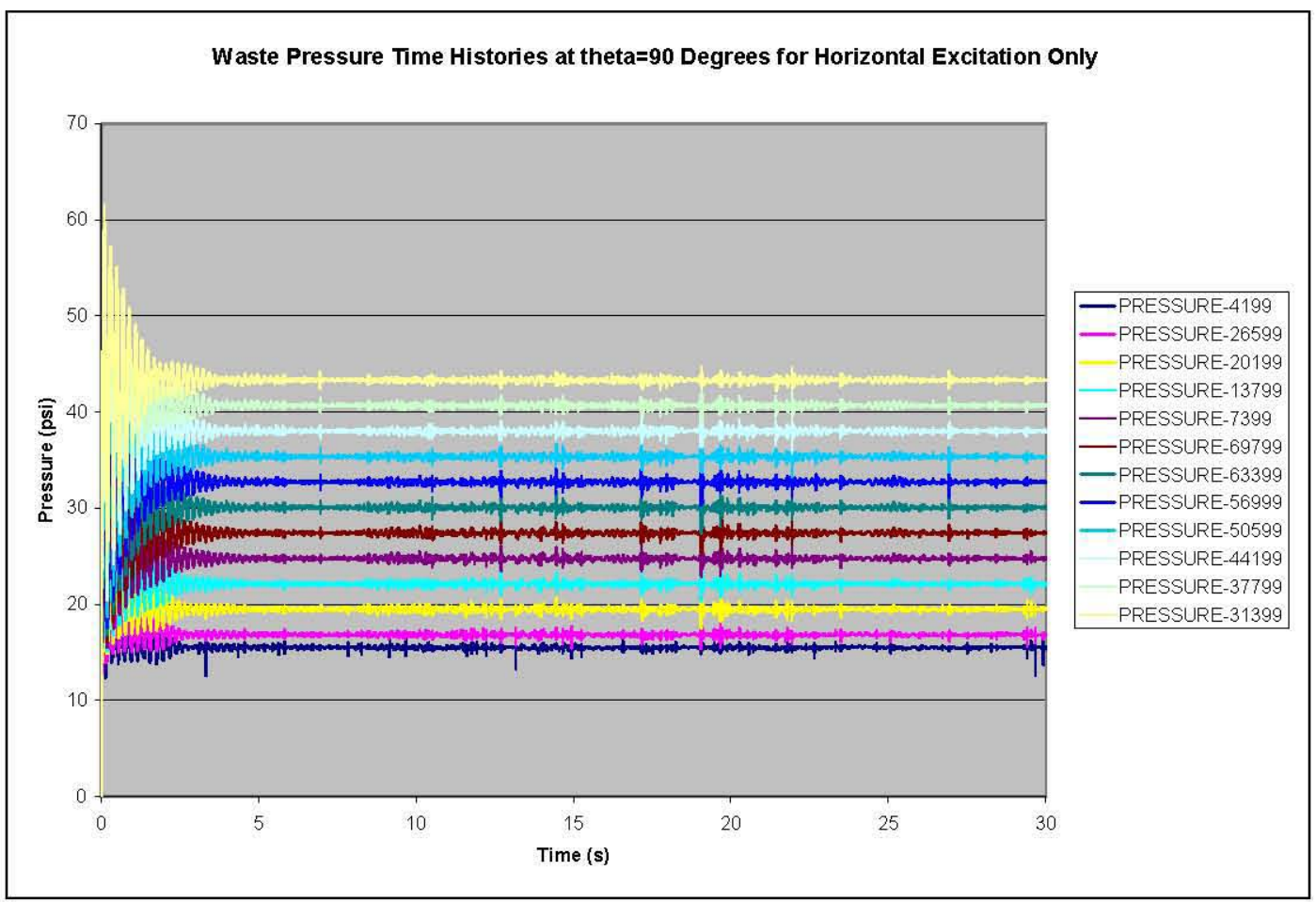

Figure 4-10. Waste Pressure Time Histories for Fluid Elements at $\theta=90^{\circ}$ (Plusz_els) Subjected to Horizontal Seismic Excitation Only

\subsubsection{Vertical Excitation Only}

The pressure time histories for the waste elements adjacent to the tank wall at $\theta=0^{\circ}$ and at $\theta=45^{\circ}$ are shown in Figure 4-11 and Figure 4-12, respectively. The two plots are essentially the same, indicating that the solution for vertical excitation is independent of the angular position, as expected. 
RPP-RPT-32239, Rev. 1

M\&D-2008-005-CALC-001, Rev. 1

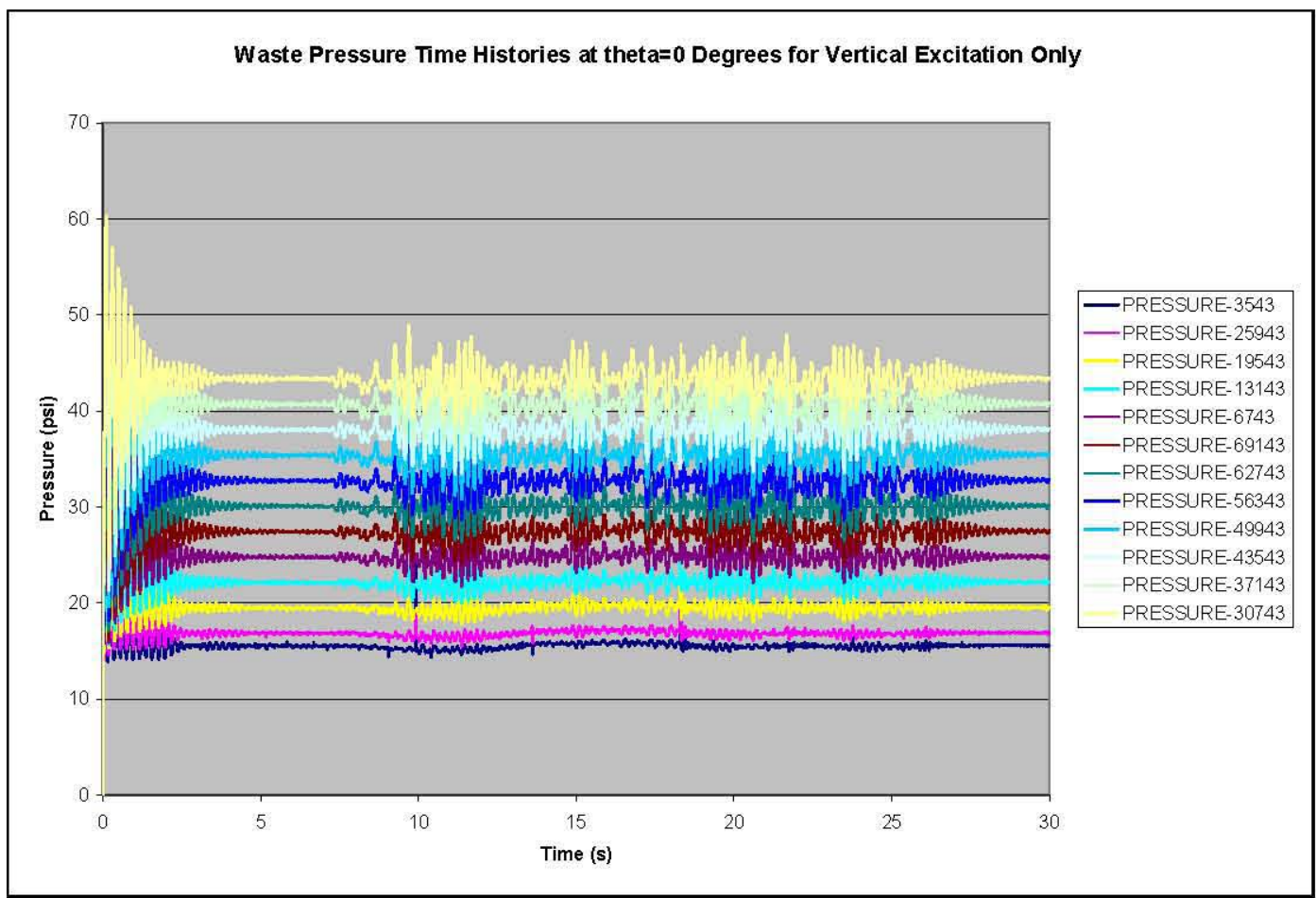

Figure 4-11. Waste Pressure Time Histories for Fluid Elements at $\theta=0^{\circ}$ (Plusx_els) Subjected to Vertical Seismic Excitation Only

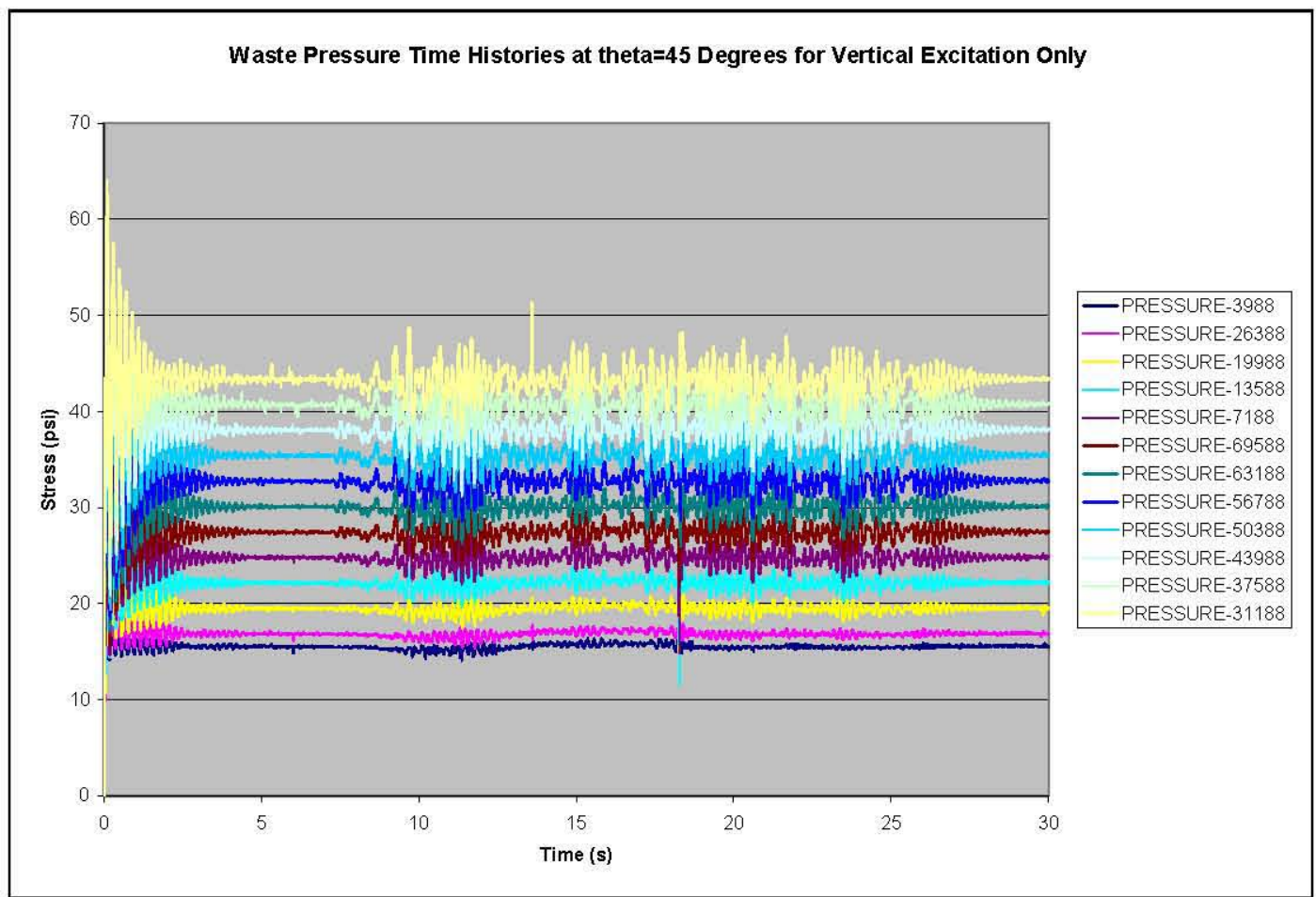

Figure 4-12. Waste Pressure Time Histories for Fluid Elements at $\theta=45^{\circ}$ (Press_45) Subjected to Vertical Seismic Excitation Only 


\section{RPP-RPT-32239, Rev. 1 \\ M\&D-2008-005-CALC-001, Rev. 1}

\subsubsection{Two-Component Motion}

Waste pressure time histories for fluid elements located along the tank wall at $\theta=0^{\circ}, 45^{\circ}$, and $90^{\circ}$ when subjected to two-component seismic excitation are shown in Figure 4-13, Figure 4-14, and Figure 4-15, respectively. The plots show that the peak dynamic pressures are greater for the case of two-component motion than for either horizontal or vertical motion acting alone. The dynamic pressures for twocomponent motion appear to be consistent with square-root-sum-of-the squares (SRSS) combination of the dynamic pressures from the horizontal and vertical cases. For example, the peak dynamic pressure (difference between peak total pressure and hydrostatic pressure) for element 30473 shown in Figure 4-8 for horizontal excitation only is approximately $5.5-6 \mathrm{lbf} / \mathrm{in}^{2}$. The peak dynamic pressure for that element for vertical excitation only is also approximately $5.5-6 \mathrm{lbf} / \mathrm{in}^{2}$ (Figure $4-11$ ). The peak dynamic pressure for that element for two-component motion is approximately $8 \mathrm{lbf} / \mathrm{in}^{2}$ as shown in Figure 4-13, which is consistent with an SRSS directional combination.

The traces show that the peak pressures for two-component motion occur later in the event than the peaks for horizontal or vertical motion acting alone. That is, the timing of the peaks changes when horizontal and vertical motion are combined. As expected, the magnitude of the dynamic pressures decreases as the angle from the plane of excitation increases. The data also illustrate that the waste pressure time history at $\theta=90^{\circ}$ for two-component motion (Figure 4-15) is very similar to the pressure time histories for vertical excitation only (Figure 4-11 and Figure 4-12). This also is expected since the contribution from the horizontal component of motion should be negligible in the plane normal to the plane of excitation.

In Figure 4-14 and Figure 4-15 a few isolated peaks occur that are characteristic of a high-frequency response that may be due to spurious numerics, and that in any case are unimportant to the structural analysis. This phenomenon is discussed in greater detail in Rinker and Abatt (2006a, 2006b).

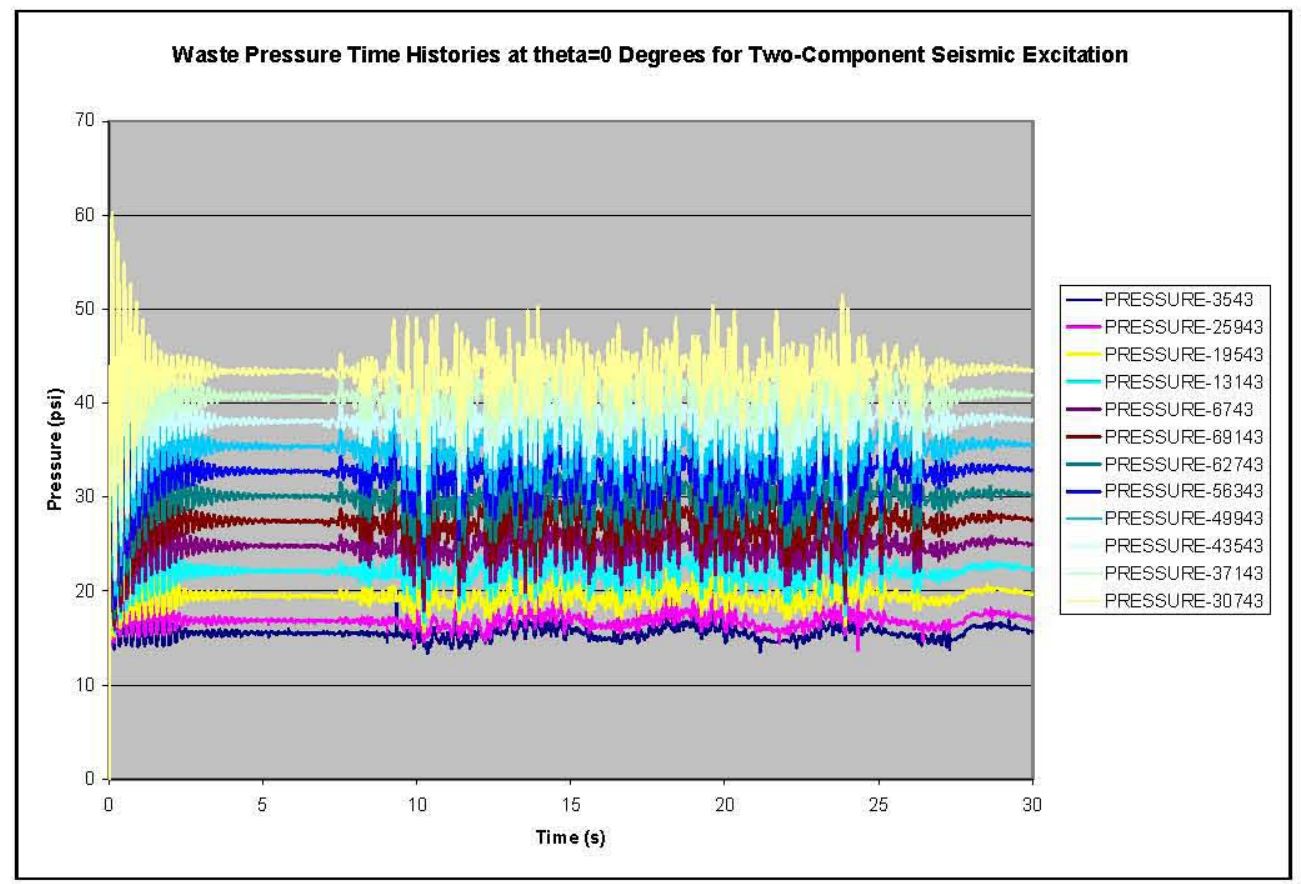

Figure 4-13. Waste Pressure Time Histories for Fluid Elements at $\theta=0^{\circ}$ (Plusx_els) Subjected to TwoComponent Seismic Excitation 
RPP-RPT-32239, Rev. 1

M\&D-2008-005-CALC-001, Rev. 1

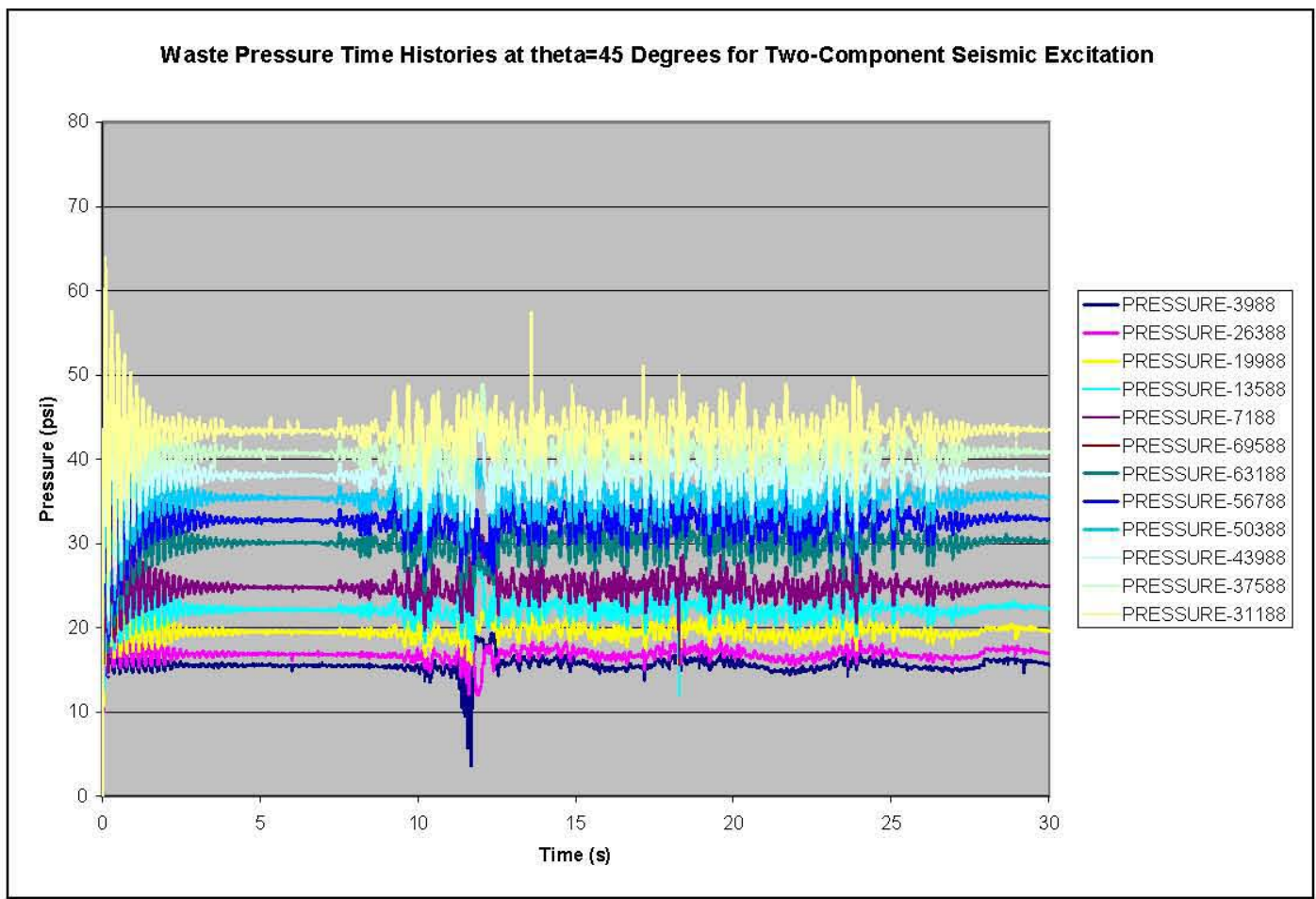

Figure 4-14. Waste Pressure Time Histories for Fluid Elements at $\theta=45^{\circ}$ (Press_45) Subjected to TwoComponent Seismic Excitation

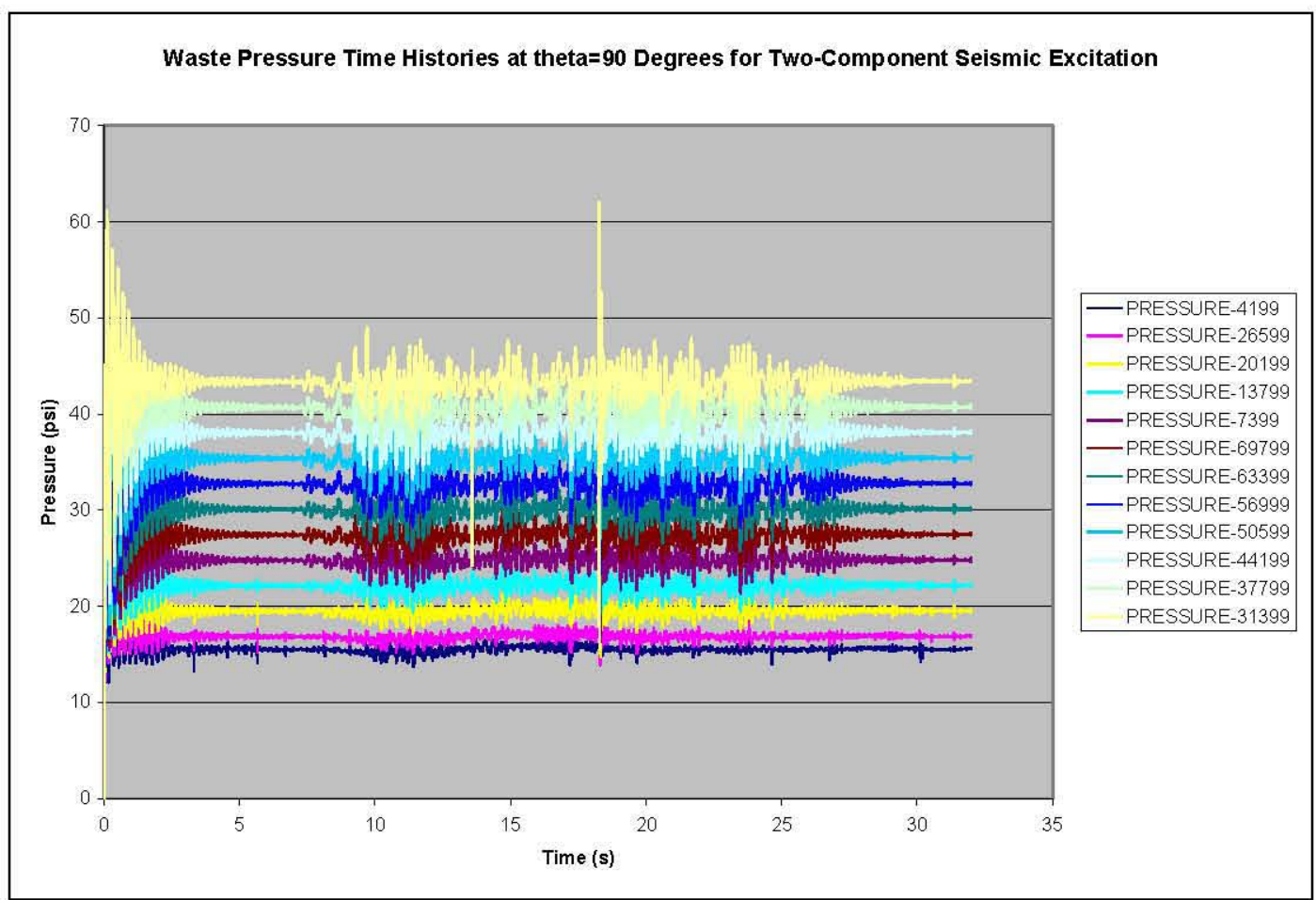

Figure 4-15. Waste Pressure Time Histories for Fluid Elements at $\theta=90^{\circ}$ (Plusz_els) Subjected to TwoComponent Seismic Excitation 
RPP-RPT-32239, Rev. 1

M\&D-2008-005-CALC-001, Rev. 1

\subsection{Maximum Slosh Height Results from Dytran ${ }^{\circledR}$ Sub-Model}

Plots of the maximum free-surface height vs. time for horizontal, vertical, and two-component motion are presented in Figure 4-16. The traces for the vertical motion and two-component motion input have had the vertical displacement of the tank subtracted out so that the net slosh height is depicted. The peak slosh height for horizontal or two-component motion is approximately 25 inches. The maximum slosh height associated with vertical motion only is less than 1 inch.

The maximum theoretical slosh height for an open top tank without a dome is also shown in the plot. Note that the presence of the curved dome acts to increase the maximum slosh height in the tank relative to the open top solution.

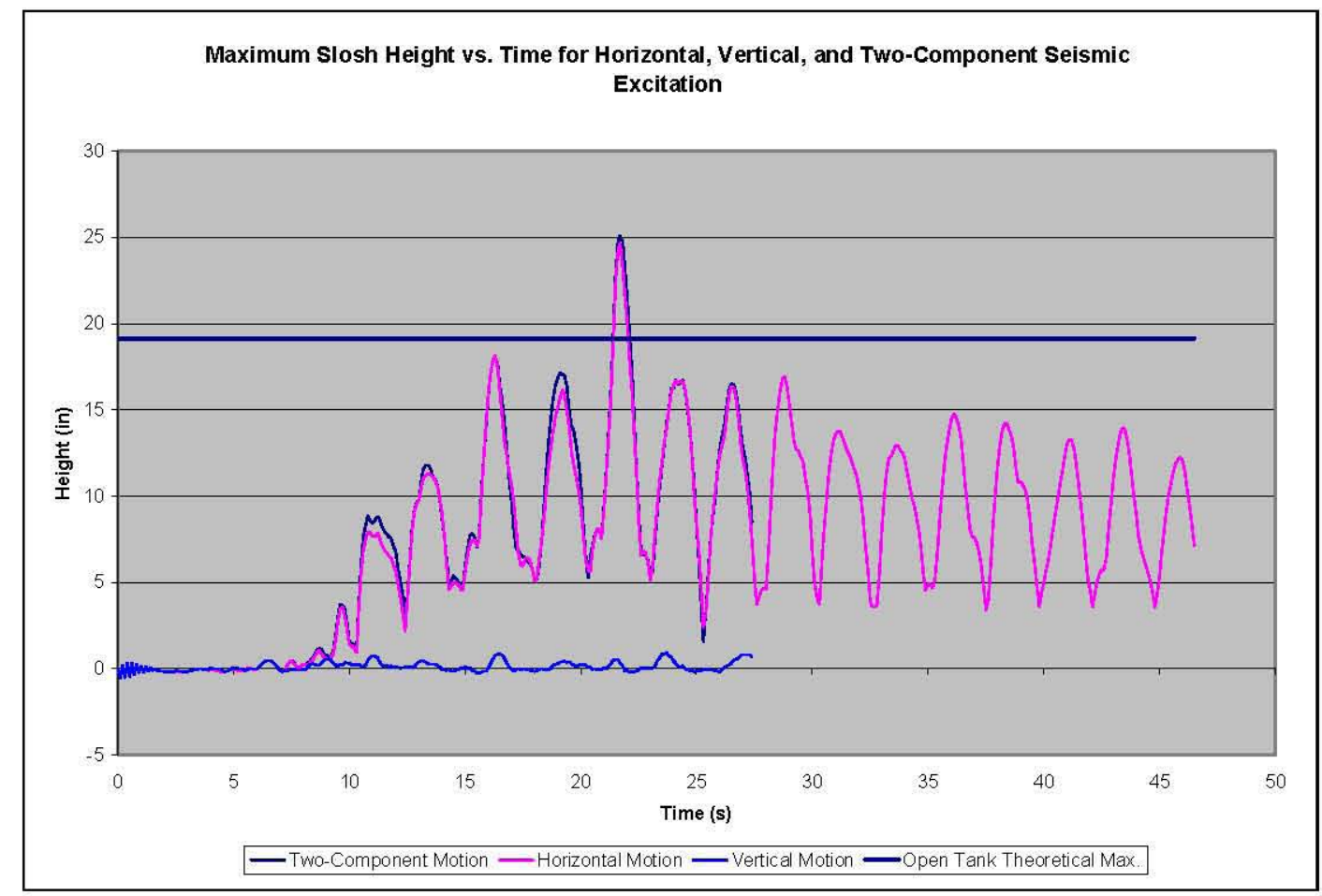

Figure 4-16. Maximum Slosh Height Time-History for Horizontal, Vertical, and Two-Component Seismic Excitation

\subsection{Primary Tank Stresses from Dytran ${ }^{\circledR}$ Sub-Model}

The following three sections present primary tank stress distributions for the Dytran ${ }^{\mathbb{B}}$ sub-model when subjected to horizontal, vertical, and two-component motion. The plots show maximum and minimum stresses vs. path length from the dome apex. Important values of the path length are the beginning of the flexible portion of the tank at 438.1 inches, the top of the vertical portion of the tank wall at 490.9 inches, and the bottom of the tank wall at 915.2 inches (zero elevation). A summary of the tank regions by path length and elevation is provided in Table 4-2. 
RPP-RPT-32239, Rev. 1

M\&D-2008-005-CALC-001, Rev. 1

Table 4-2. Primary Tank Regions Parameterized by Path Length from Dome Apex and Elevation from Tank Bottom

\begin{tabular}{||c|c|c|c||}
\hline $\begin{array}{c}\text { Path Length from } \\
\text { Dome Apex (in.) }\end{array}$ & $\begin{array}{c}\text { Elevation from } \\
\text { Tank Bottom (in.) }\end{array}$ & Tank Region & $\begin{array}{c}\text { Wall } \\
\text { Thickness (in.) }\end{array}$ \\
\hline \hline 0 to 438.1 & 467.0 to 561.5 & Rigid dome & Rigid \\
\hline 438.1 to 490.9 & 424.3 to 467.0 & Haunch portion of flexible wall & $1 / 2$ \\
\hline 490.9 to 677.3 & 237.9 to 424.3 & Vertical portion of wall & $1 / 2$ \\
\hline 677.3 to 770.3 & 144.9 to 237.9 & Vertical portion of wall & $9 / 16$ \\
\hline 770.3 to 878.3 & 36.9 to 144.9 & Vertical portion of wall & $3 / 4$ \\
\hline 878.3 to 915.2 & 0 to 36.9 & Vertical portion of wall & $7 / 8$ \\
\hline
\end{tabular}

\subsubsection{Horizontal Excitation Only}

Hoop, meridional, and shear stress distributions for the tank shell elements at $\theta=0^{\circ}$ are presented as Figure 4-17, Figure 4-18, and Figure 4-19, respectively. The hoop stresses shown in Figure 4-17 indicate that the hoop response is dominated by membrane stresses with little contribution from bending. The meridional stress distributions shown in Figure 4-18 indicate that the meridional stresses are low in the majority of the tank wall, but higher in the haunch and bottom of the wall. The meridional response is dominated by bending in the haunch and bottom of the wall, but consists primarily of membrane stress in the majority of the wall. The mid-surface in-plane shear stresses are low, as shown in Figure 4-19.

The hoop stresses at $45^{\circ}$ from the plane of excitation are approximately $10 \%$ lower than at $\theta=0^{\circ}$, as shown in Figure 4-20. Likewise, the meridional stresses at $\theta=45^{\circ}$ are 5 to $10 \%$ lower than at $\theta=0^{\circ}$, as seen in Figure 4-21. In contrast, the mid-surface shear stresses are approximately 10 times higher at $\theta=45^{\circ}$ than at $\theta=0^{\circ}$ (Figure 4-22), and the peak shear stresses occur at $\theta=90^{\circ}$, as expected and shown Figure 4-23.

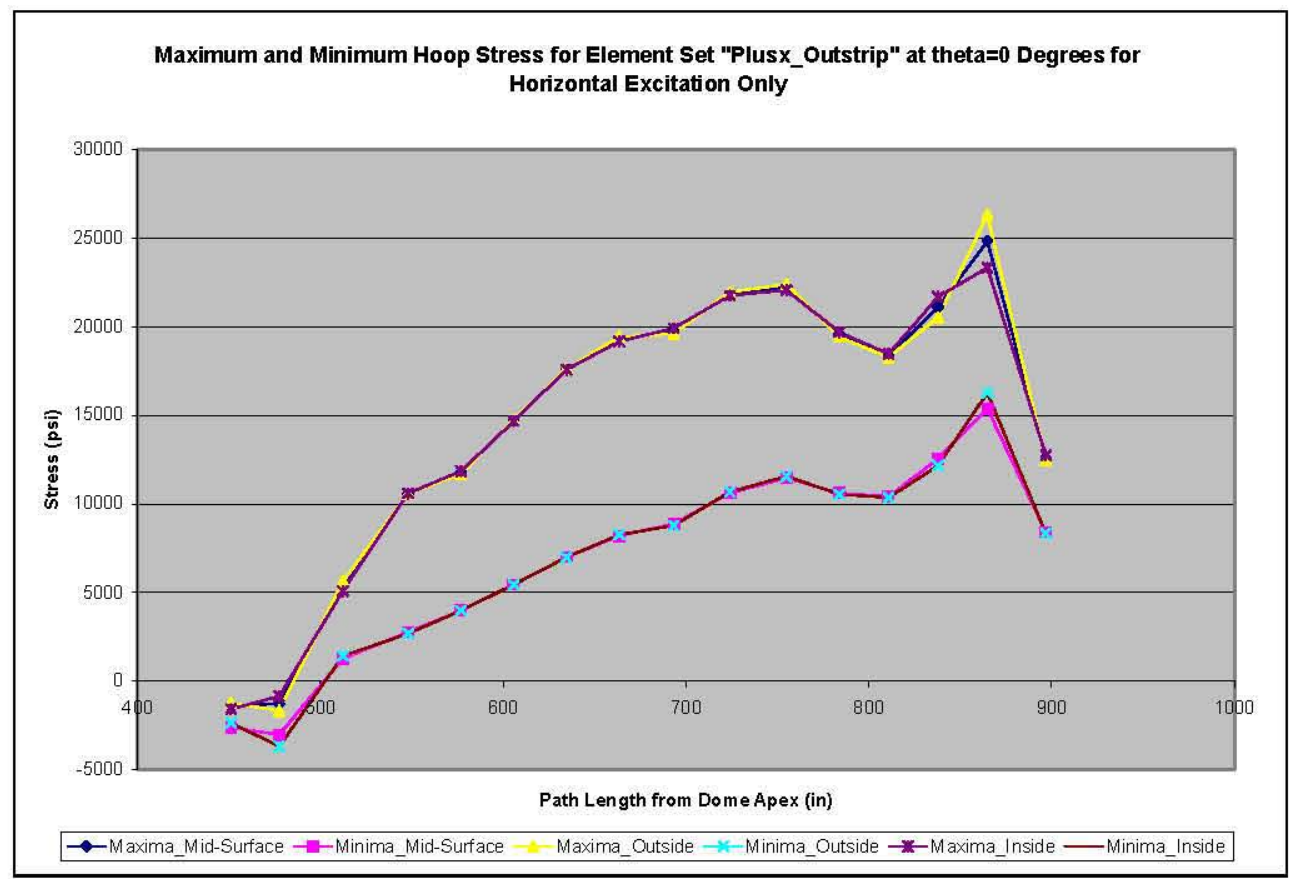

Figure 4-17. Maximum and Minimum Hoop Stress vs. Path Length for Element Set "Plusx_Outstrip" at $\theta=0^{\circ}$ for Horizontal Seismic Excitation Only 
RPP-RPT-32239, Rev. 1

M\&D-2008-005-CALC-001, Rev. 1

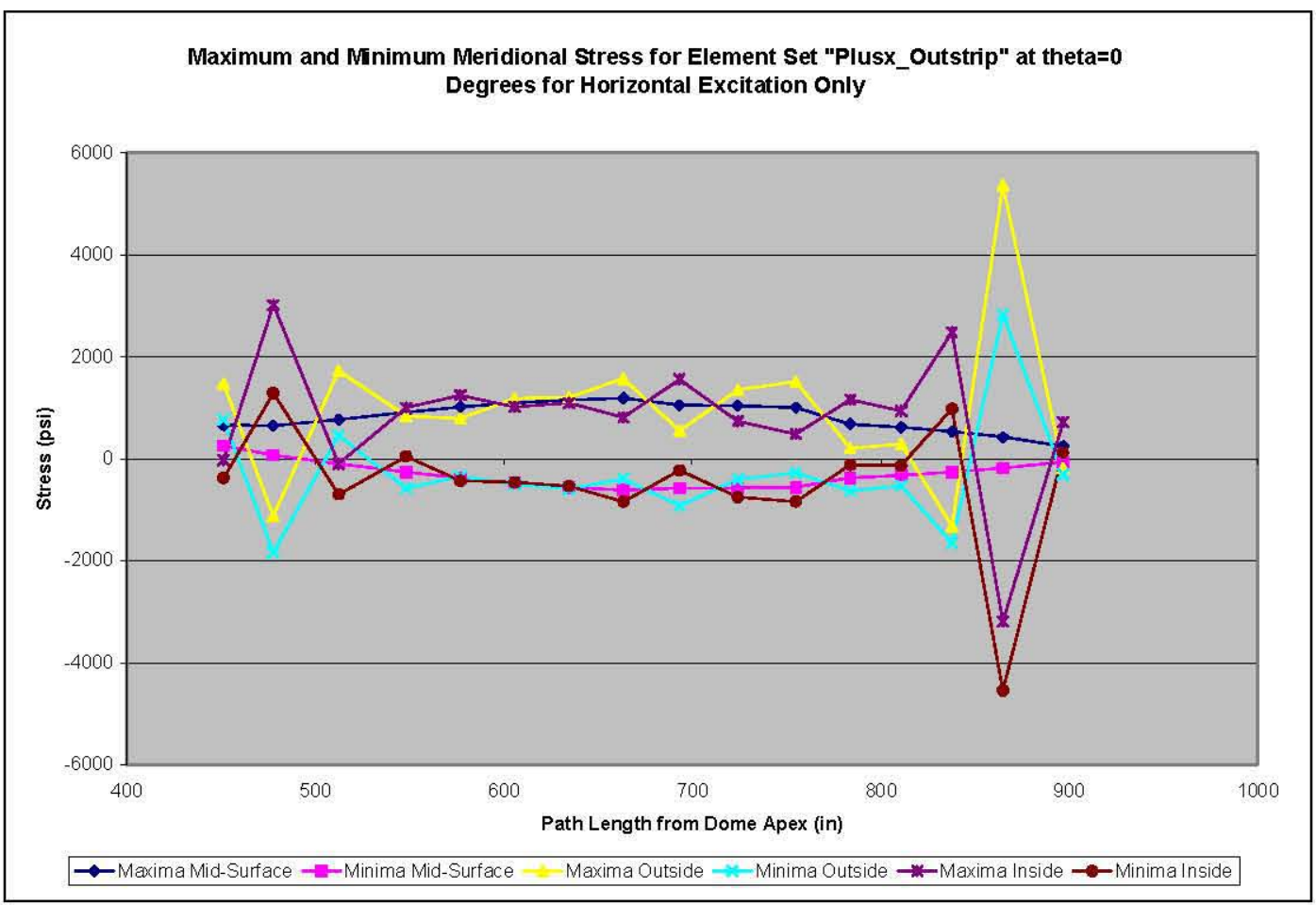

Figure 4-18. Maximum and Minimum Meridional Stress vs. Path Length for Element Set "Plusx_Outstrip" at $\theta=0^{\circ}$ for Horizontal Seismic Excitation Only

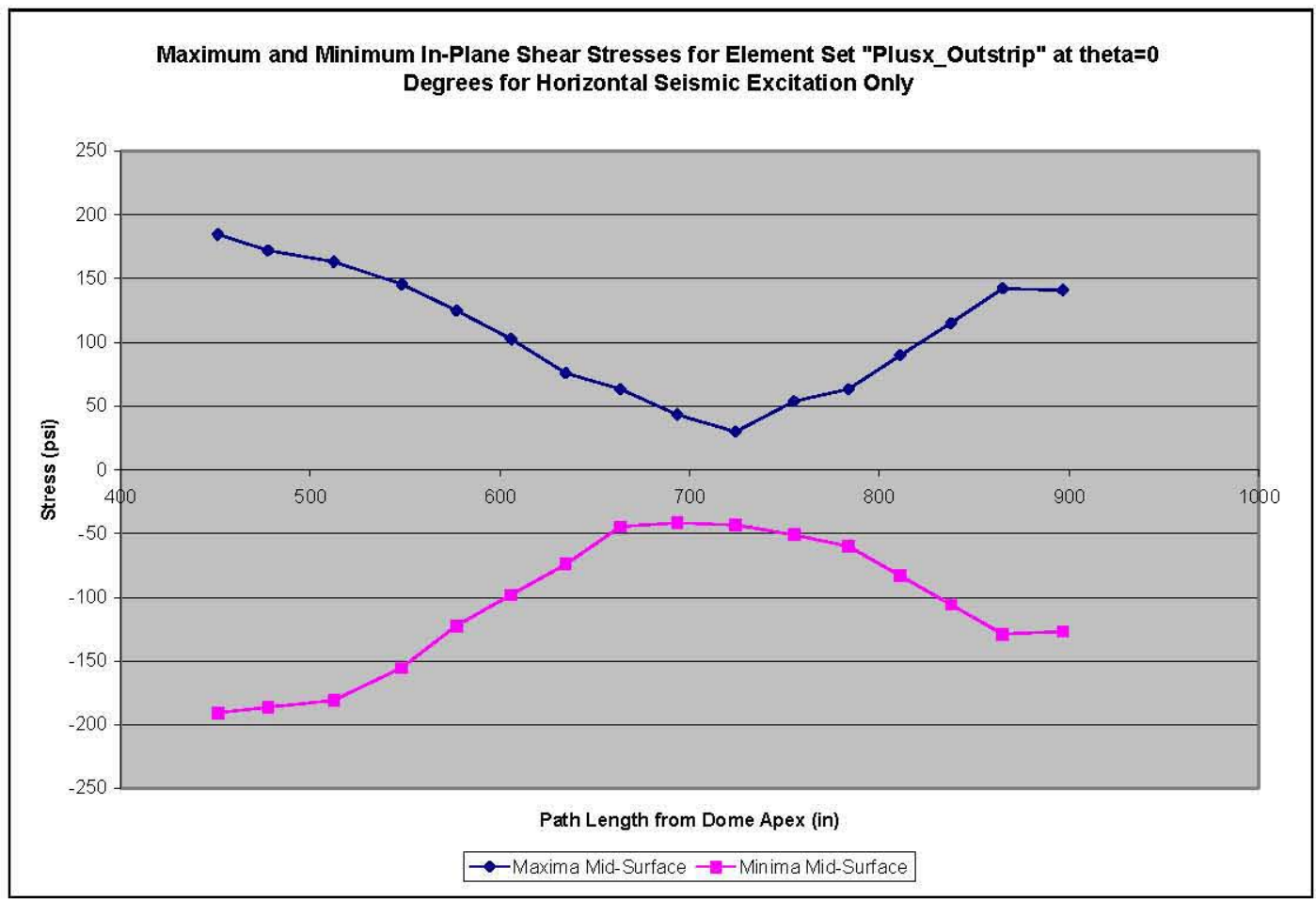

Figure 4-19. Maximum and Minimum Shear Stress vs. Path Length for Element Set "Plusx_Outstrip" at $\theta=0^{\circ}$ for Horizontal Seismic Excitation Only 
RPP-RPT-32239, Rev. 1

M\&D-2008-005-CALC-001, Rev. 1

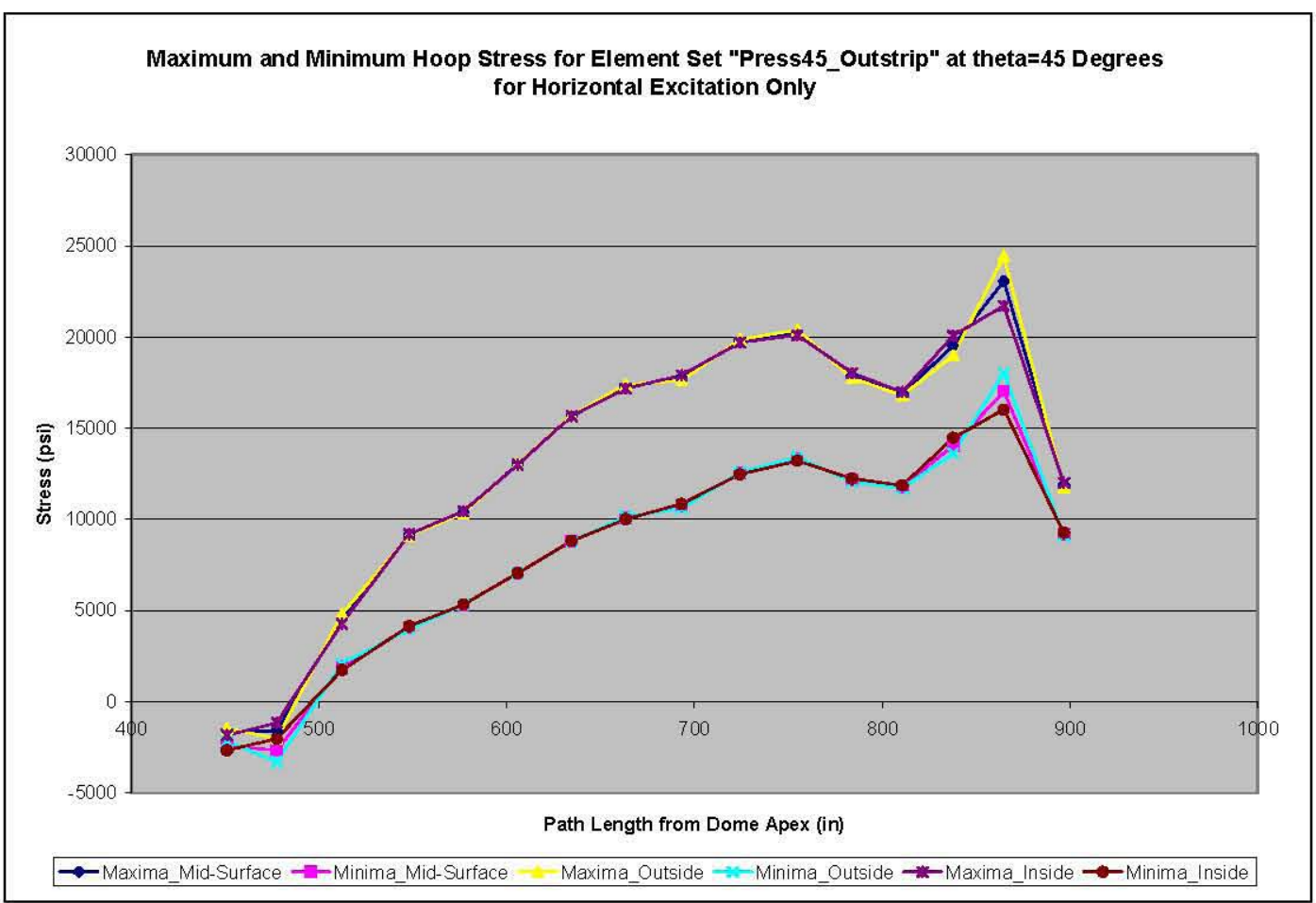

Figure 4-20. Maximum and Minimum Hoop Stress vs. Path Length for Element Set "Press45_Outstrip" at $\theta=45^{\circ}$ for Horizontal Seismic Excitation Only

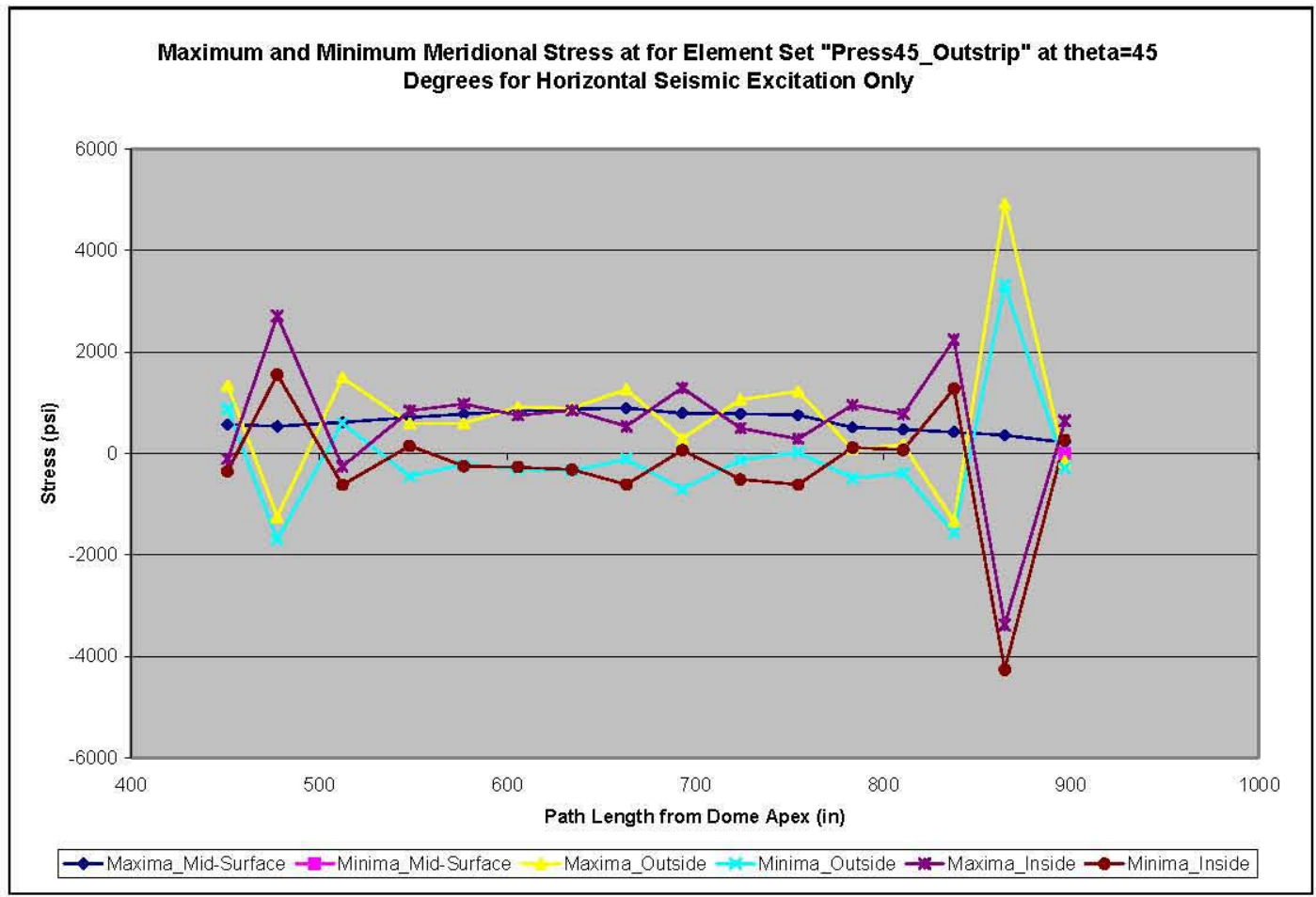

Figure 4-21. Maximum and Minimum Meridional Stress vs. Path Length for Element Set "Press 45 Outstrip" at $\theta=45^{\circ}$ for Horizontal Seismic Excitation Only 
RPP-RPT-32239, Rev. 1

M\&D-2008-005-CALC-001, Rev. 1

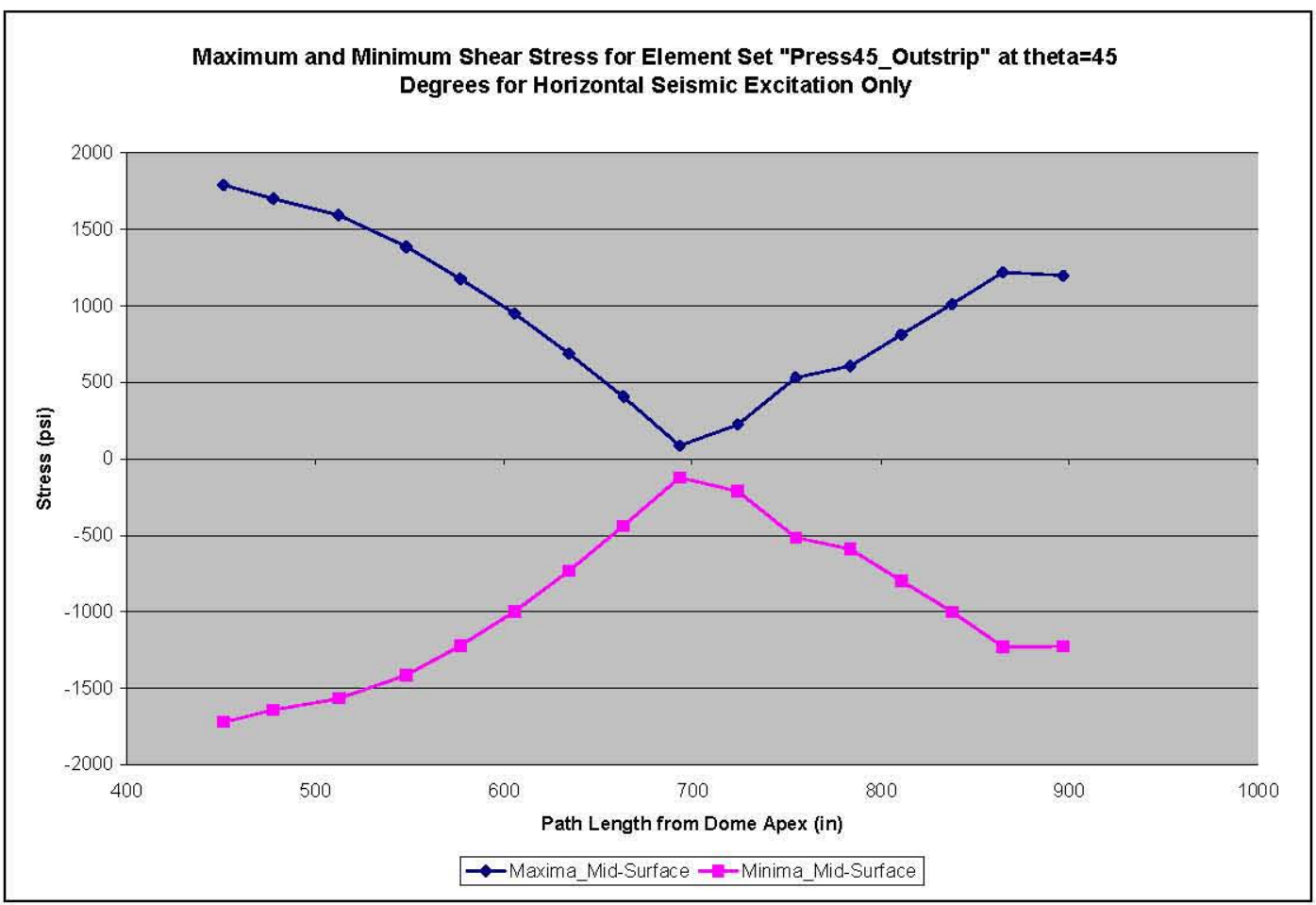

Figure 4-22. Maximum and Minimum Shear Stress vs. Path Length for Element Set "Press45_Outstrip" at $\theta=45^{\circ}$ for Horizontal Seismic Excitation Only

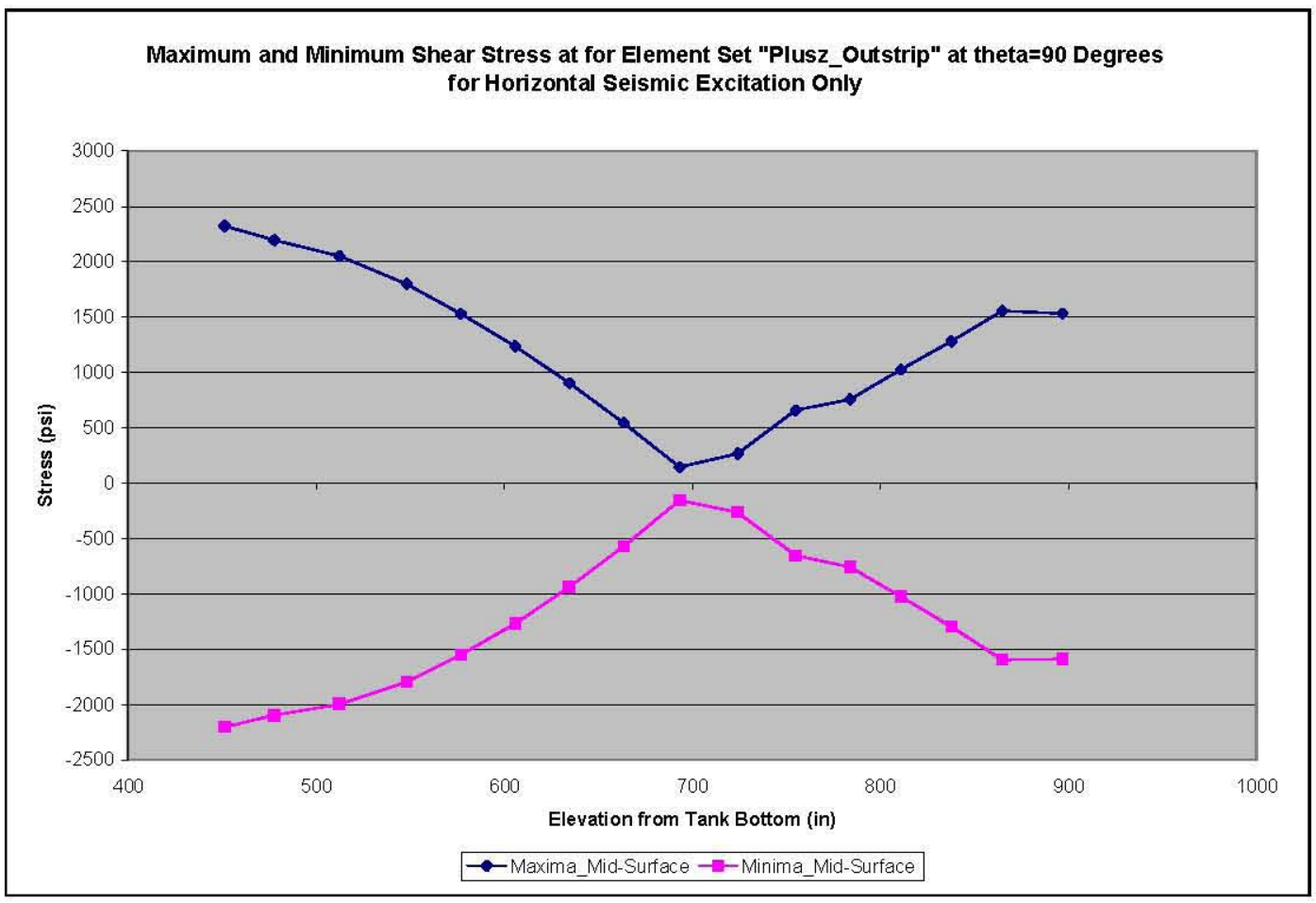

Figure 4-23. Maximum and Minimum Shear Stress vs. Path Length for Element Set "Plusz_Outstrip" at $\theta=90^{\circ}$ for Horizontal Seismic Excitation Only 
RPP-RPT-32239, Rev. 1

M\&D-2008-005-CALC-001, Rev. 1

\subsubsection{Vertical Excitation}

The hoop, meridional, and shear stress distributions at $\theta=0^{\circ}$ for vertical excitation only are shown in Figure 4-24, Figure 4-25, and Figure 4-26, respectively. The plots indicate that the hoop stress is dominated by the membrane response, the hoop and meridional stress distributions and magnitudes are similar to that for horizontal excitation, and the shear stress is negligible. Plots at other angular locations are not shown due to the axisymmetric response for vertical excitation.

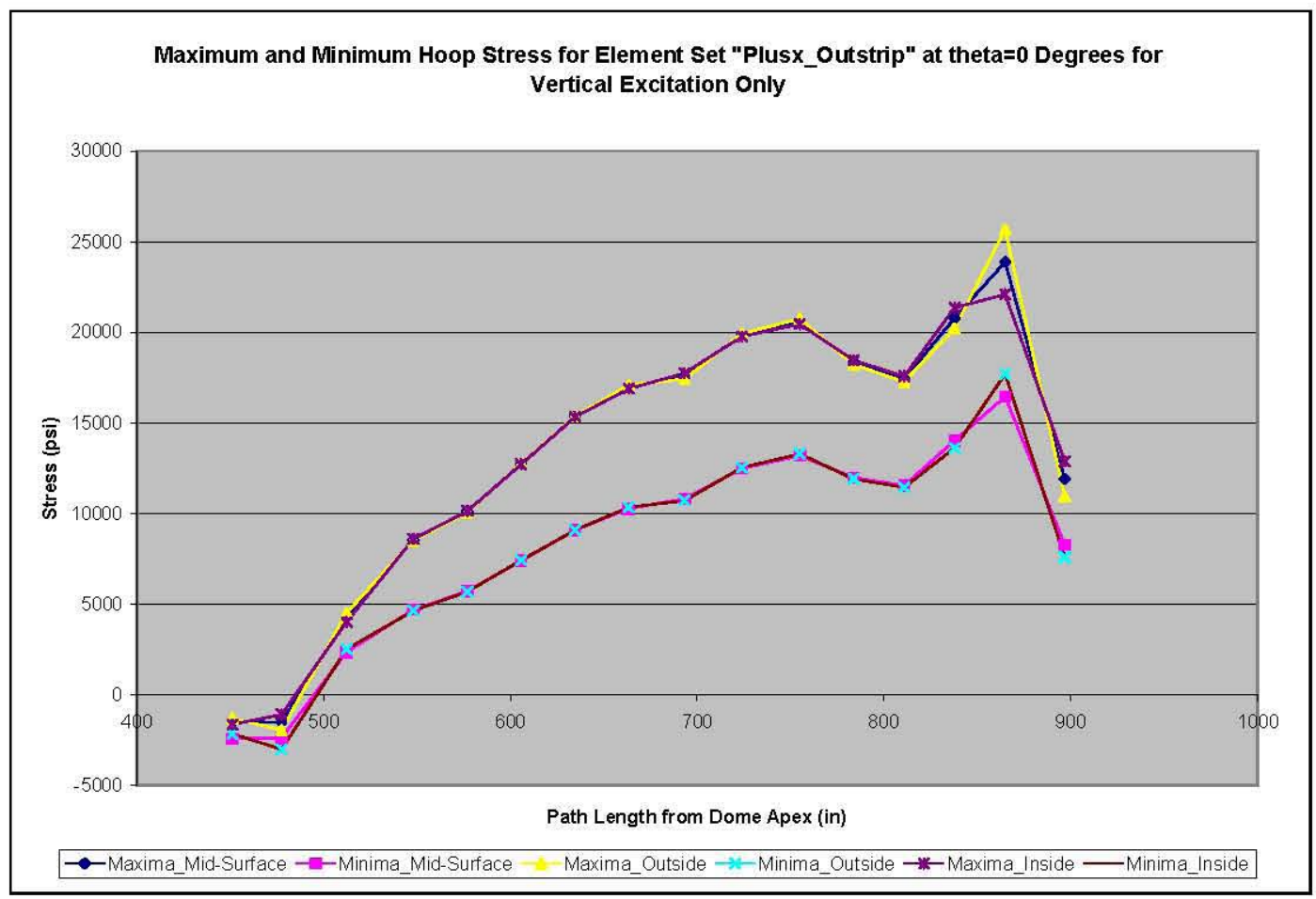

Figure 4-24. Maximum and Minimum Hoop Stress vs. Path Length for Element Set "Plusx_Outstrip" at $\theta=0^{\circ}$ for Vertical Seismic Excitation Only 
RPP-RPT-32239, Rev. 1

M\&D-2008-005-CALC-001, Rev. 1

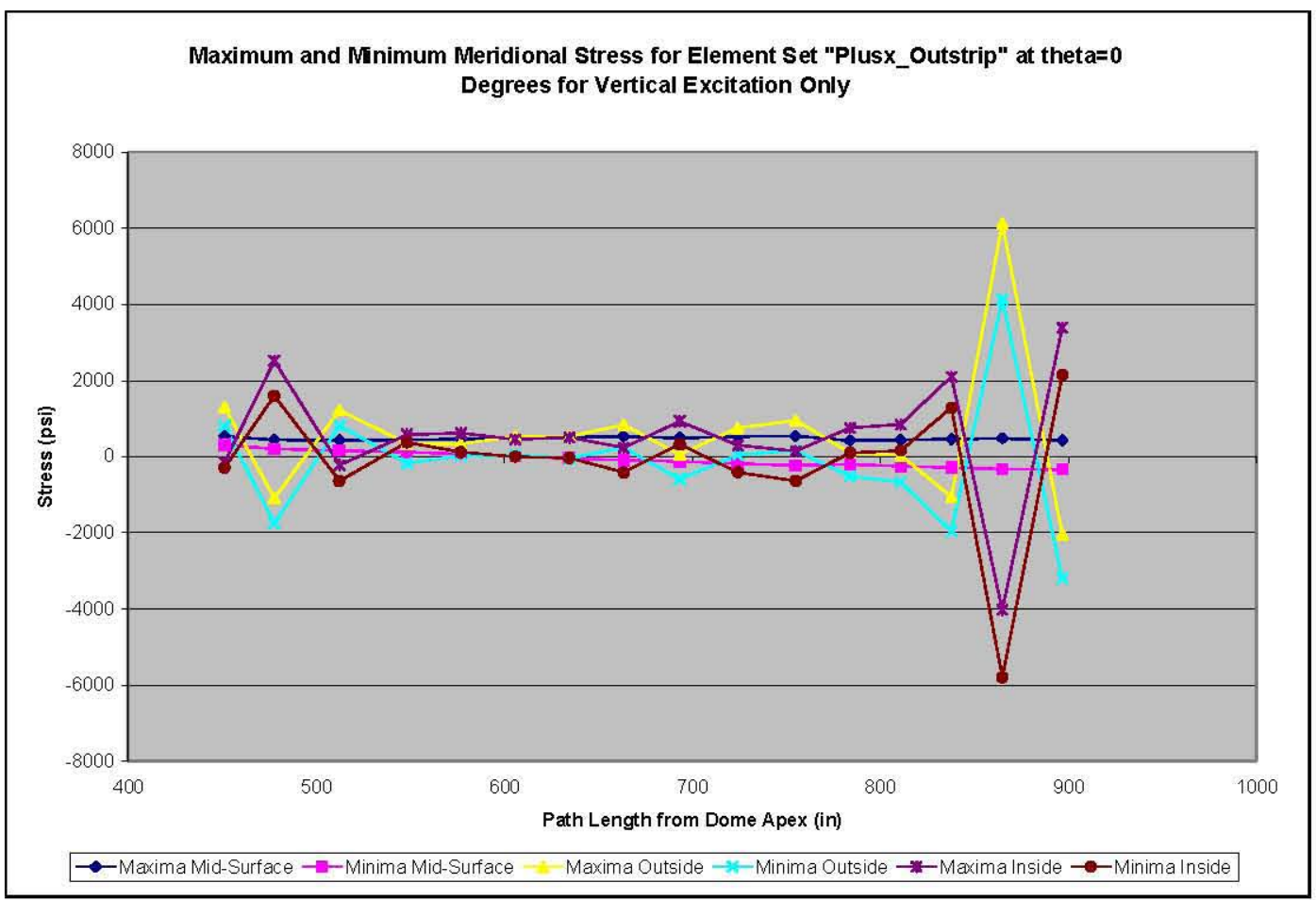

Figure 4-25. Maximum and Minimum Meridional Stress vs. Path Length for Element Set "Plusx_Outstrip" at $\theta=0^{\circ}$ for Vertical Seismic Excitation Only

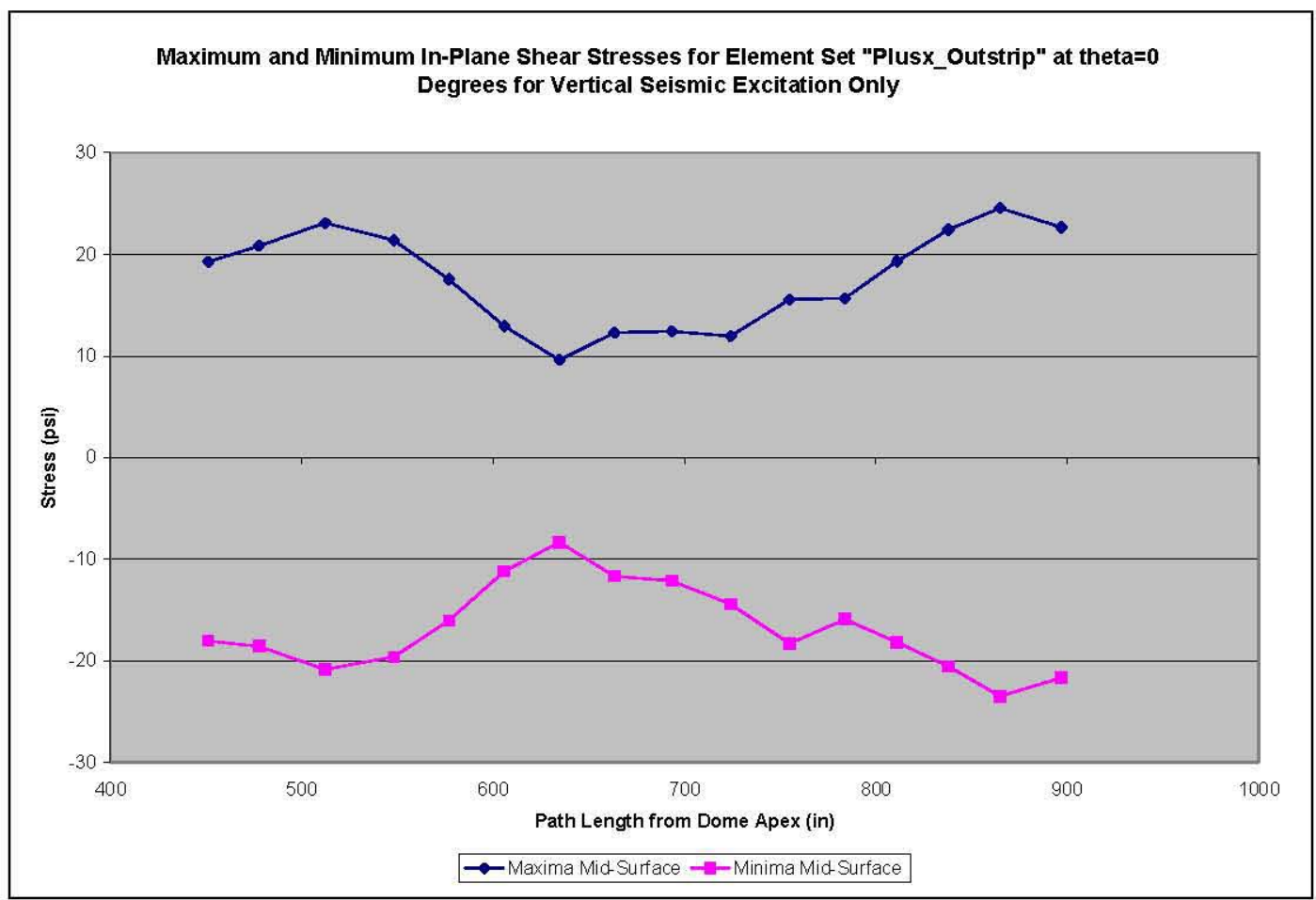

Figure 4-26. Maximum and Minimum Shear Stress vs. Path Length for Element Set "Plusx_Outstrip" at $\theta=0^{\circ}$ for Vertical Seismic Excitation Only 


\subsubsection{Two-Component Motion}

Hoop, meridional, and shear stress distributions at $\theta=0^{\circ}$ are presented in Figure 4-27, Figure 4-28, and Figure 4-29, respectively. The stress distributions at $\theta=45^{\circ}$ are shown in Figure 4-30, Figure 4-31, and Figure 4-32. The shear stress distribution at $\theta=90^{\circ}$ is shown in Figure 4-33.

In general, the hoop stress distributions for two-component motion are similar to those for horizontal excitation only, but the magnitudes are somewhat higher. As in the cases of horizontal motion and vertical motion only, the hoop stress is dominated by the membrane response. The meridional stress distributions for two-component motion also are similar to those for horizontal excitation only, but with somewhat higher peak stress, especially near the bottom of the tank wall.

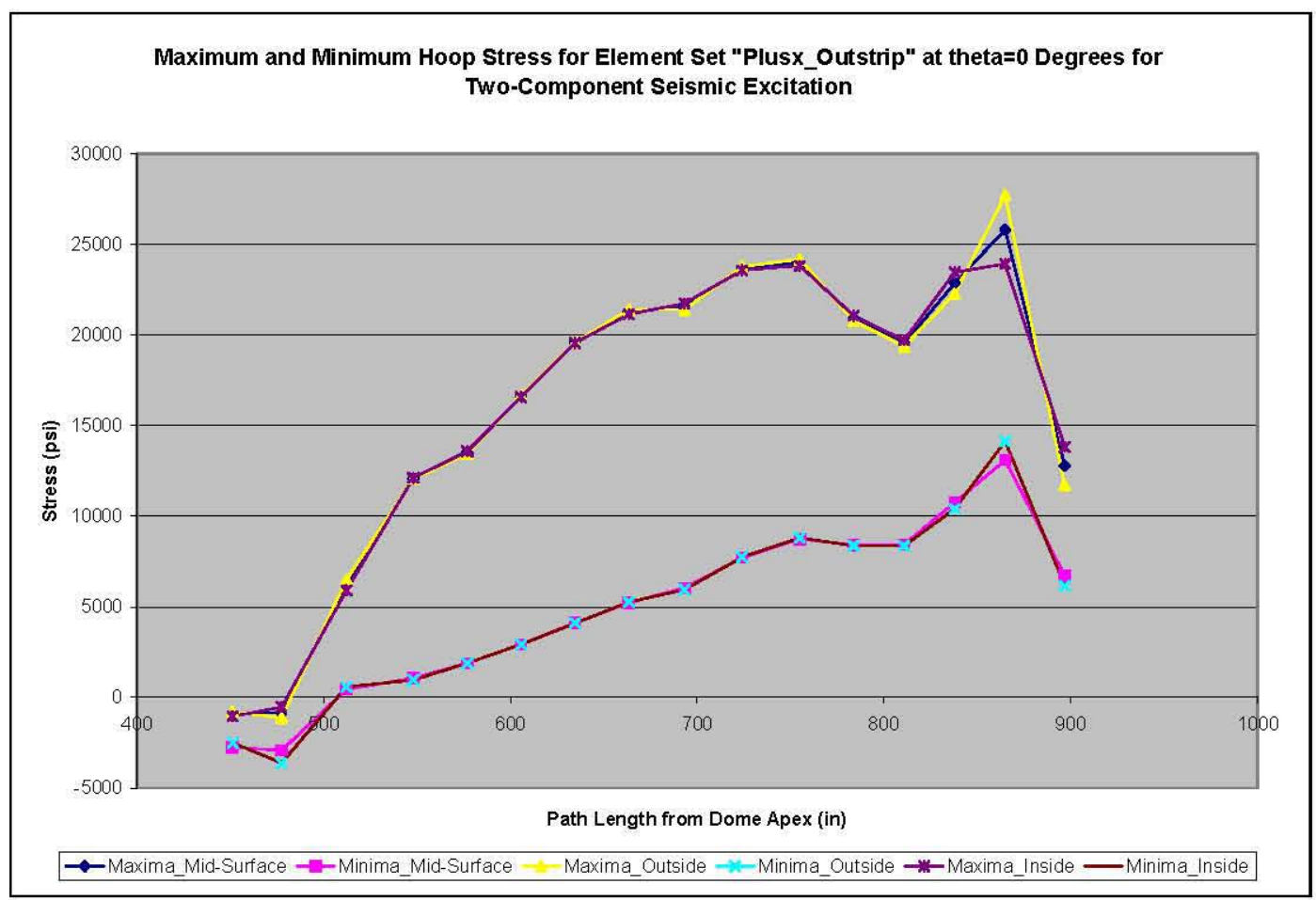

Figure 4-27. Maximum and Minimum Hoop Stress vs. Path Length for Element Set "Plusx_Outstrip" at $\theta=0^{\circ}$ for Two-Component Seismic Excitation 
RPP-RPT-32239, Rev. 1

M\&D-2008-005-CALC-001, Rev. 1

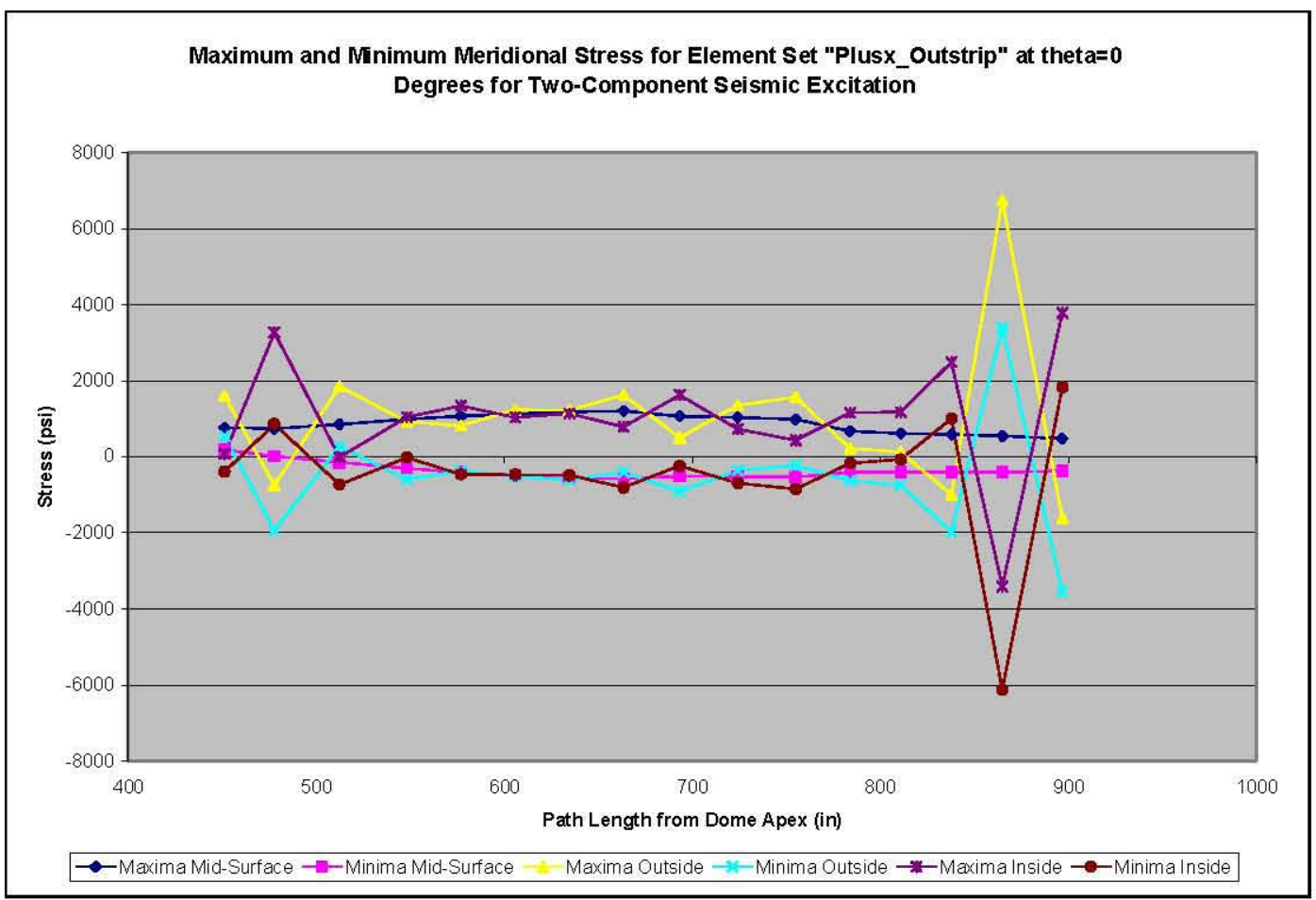

Figure 4-28. Maximum and Minimum Meridional Stress vs. Path Length for Element Set "Plusx_Outstrip" at $\theta=0^{\circ}$ for Two-Component Seismic Excitation

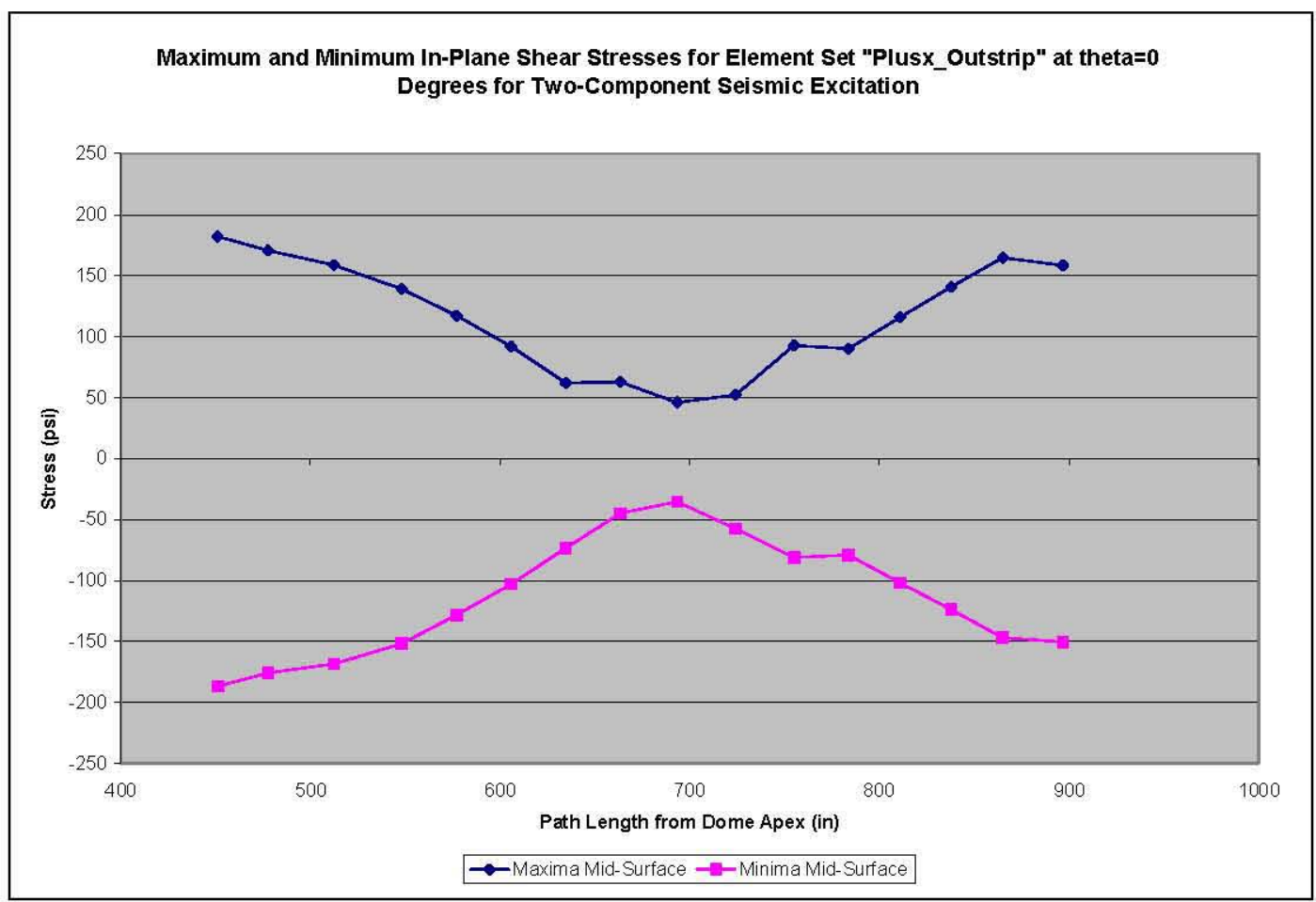

Figure 4-29. Maximum and Minimum Shear Stress vs. Path Length for Element Set "Plusx_Outstrip" at $\theta=0^{\circ}$ for Two-Component Seismic Excitation 
RPP-RPT-32239, Rev. 1

M\&D-2008-005-CALC-001, Rev. 1

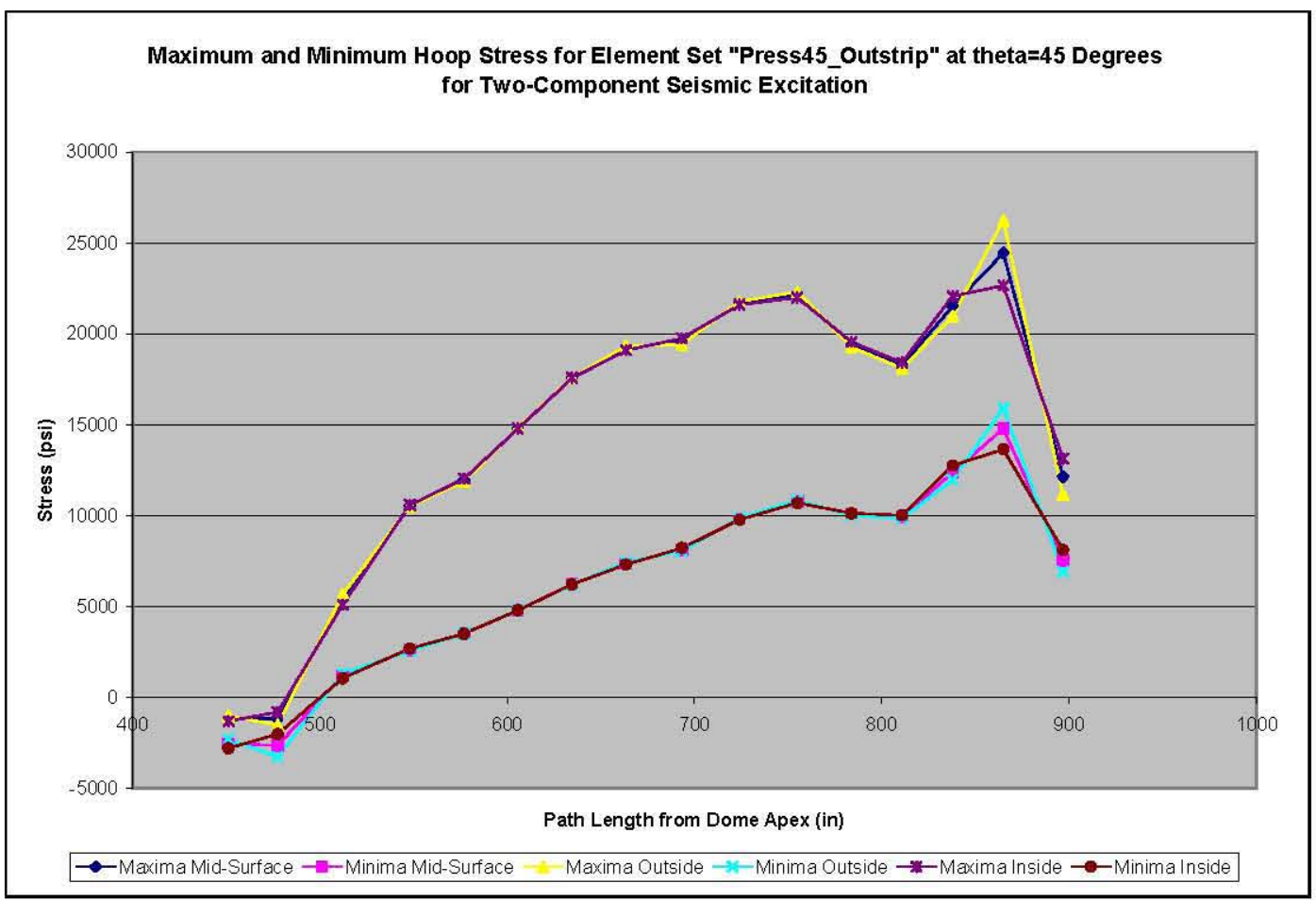

Figure 4-30. Maximum and Minimum Hoop Stress vs. Path Length for Element Set "Press45_Outstrip" at $\theta=45^{\circ}$ for Two-Component Seismic Excitation

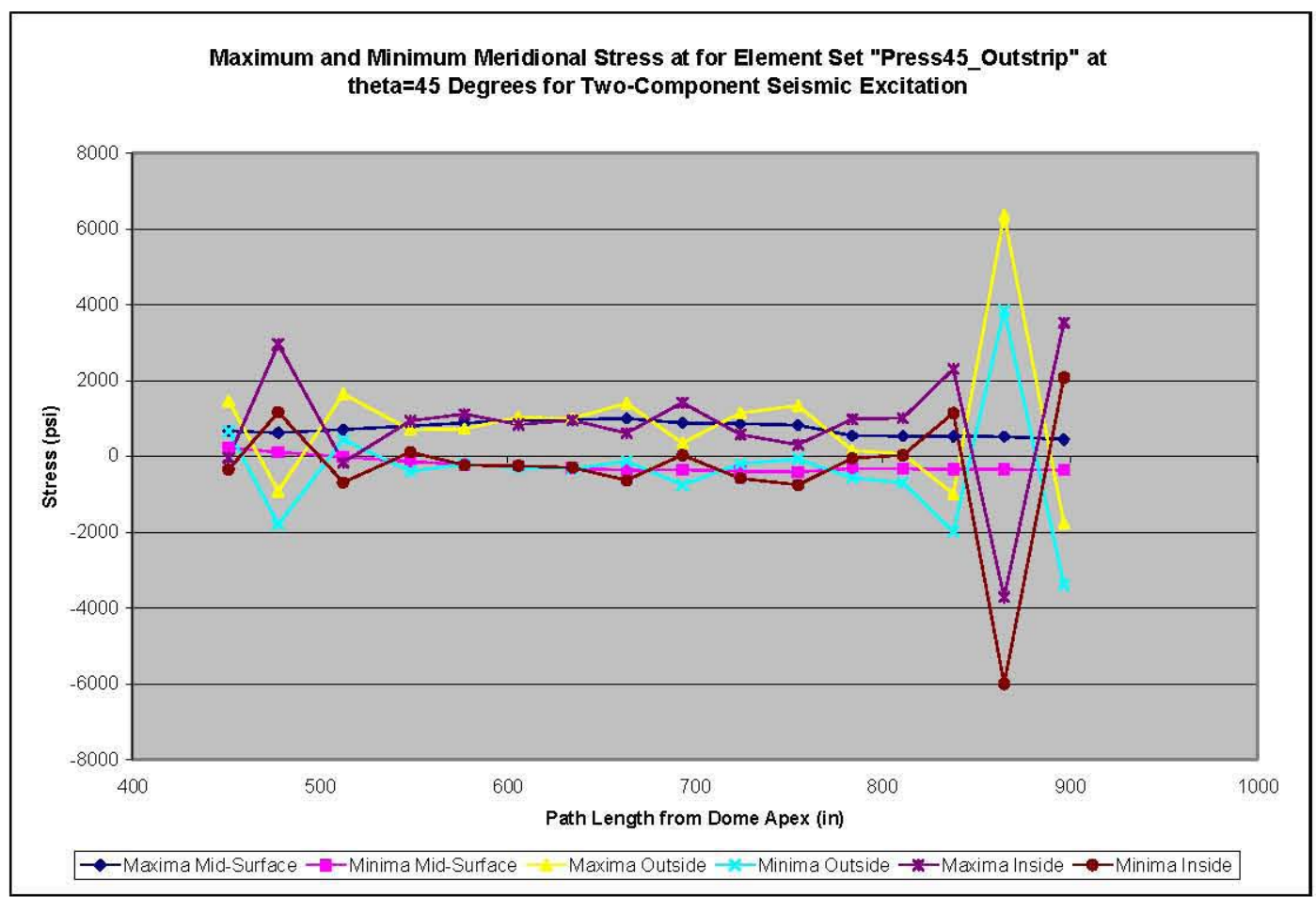

Figure 4-31. Maximum and Minimum Meridional Stress vs. Path Length for Element Set "Press45_Outstrip" at $\theta=45^{\circ}$ for Two-Component Seismic Excitation 
RPP-RPT-32239, Rev. 1

M\&D-2008-005-CALC-001, Rev. 1

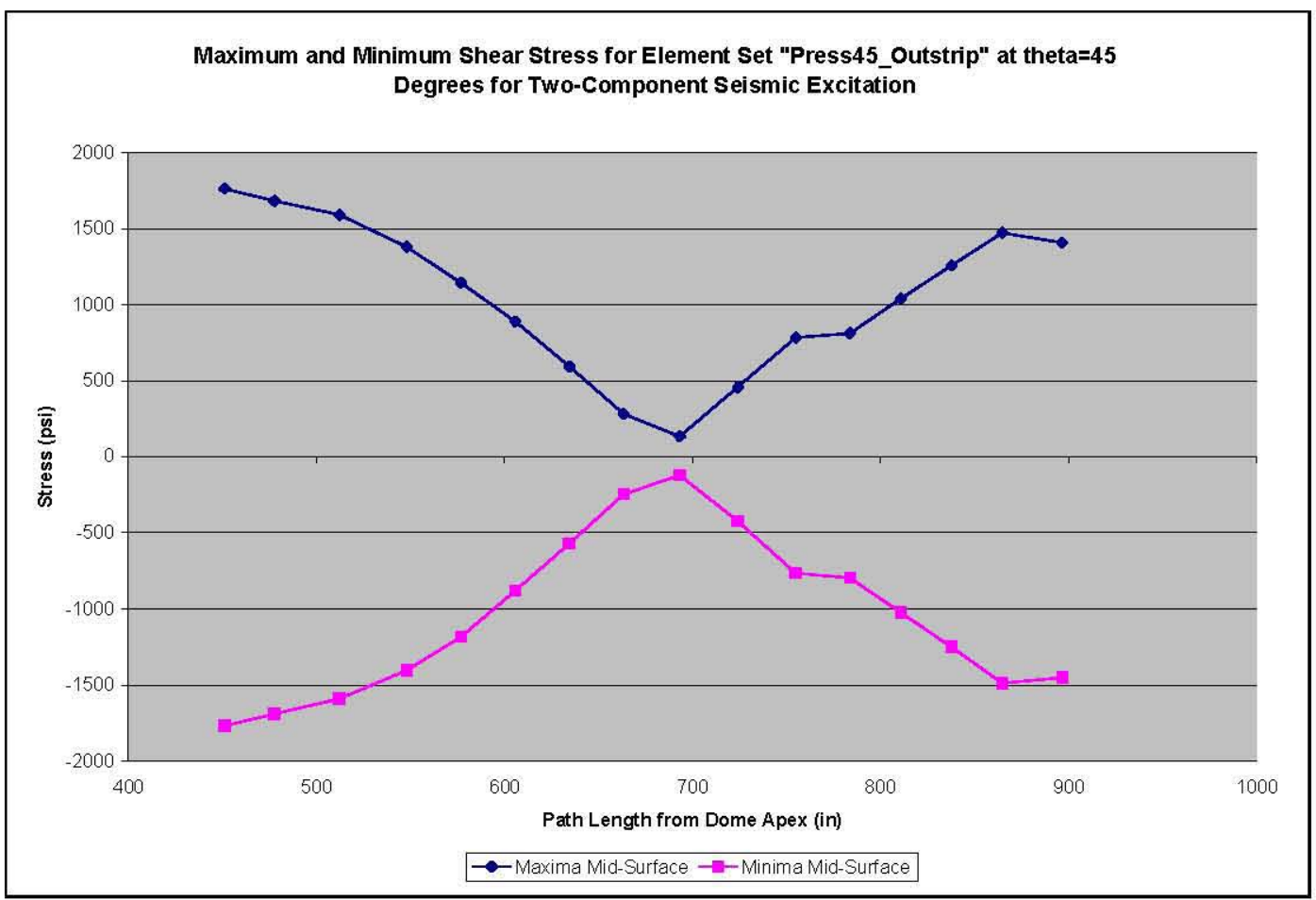

Figure 4-32. Maximum and Minimum Shear Stress vs. Path Length for Element Set "Press45_Outstrip" at $\theta=45^{\circ}$ for Two-Component Seismic Excitation

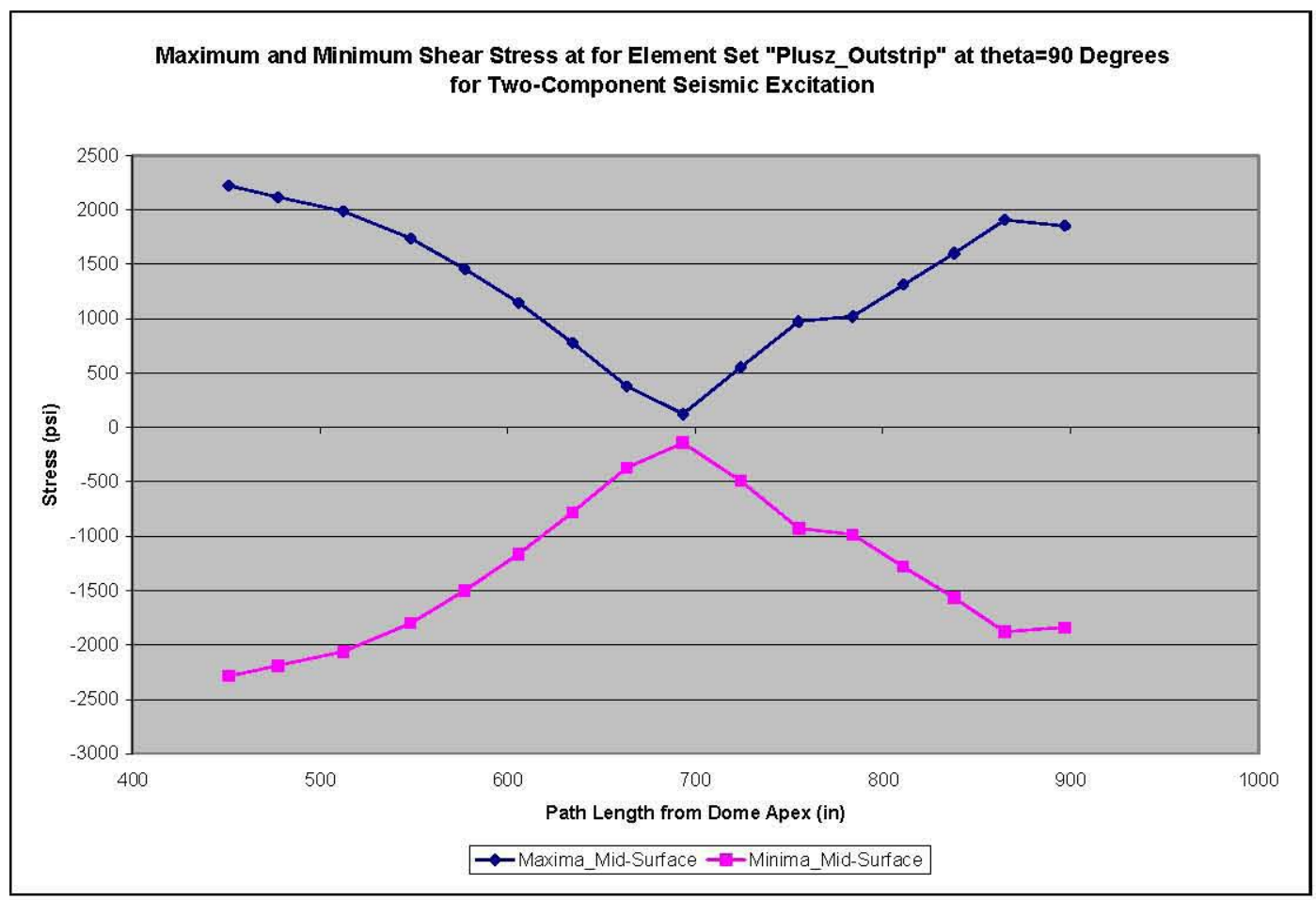

Figure 4-33. Maximum and Minimum Shear Stress vs. Path Length for Element Set "Plusz_Outstrip" at $\theta=90^{\circ}$ for Two-Component Seismic Excitation 
RPP-RPT-32239, Rev. 1

M\&D-2008-005-CALC-001, Rev. 1

Inspection of the primary tank stresses for the previous cases shows that the hoop and meridional stresses are similar in magnitude and distribution for horizontal, vertical, and two-component motion. The shear stresses are similar for horizontal and two-component motion, but negligible for vertical. These

observations support the conclusion that the stresses in the primary tank sub-models are dominated by dead weight loading. 
RPP-RPT-32239, Rev. 1

M\&D-2008-005-CALC-001, Rev. 1

\subsection{ANSYS ${ }^{\circledR}$ Primary Tank Sub-Model Description}

The global ANSYS ${ }^{\mathbb{B}}$ model was used as the starting point for the development of the primary tank submodel. Those features not needed for the sub-model were unselected. For the elements used, properties and element options were changed as needed to obtain a model with geometry and dynamic characteristic similar to the Dytran ${ }^{\mathbb{B}}$ sub-model. The key modifications to the full model are described below.

All elements related to the modeling of the soil were unselected for the sub-model. This includes the soil (element types 8,9,90, and 91), contact elements between the soil and the concrete shell (element types, 60 through 63), spring elements between the concrete basemat and the underlying soil (element types 21 , 22 , and 23), the links used at the exterior surface of the soil (element type 30), and the mass elements used for applying the surface load (element type 10).

For the concrete shell elements, the modulus of elasticity was increased by a factor of 10,000 to obtain "rigid" behavior. The same increase in stiffness was also applied to the insulating concrete elements. This will ensure that the full sub-model is excited uniformly top and bottom, consistent with the Dytran ${ }^{\mathbb{B}}$ sub-model.

The geometry and properties for the majority of the primary tank were not changed in the sub-model. The only changes were to the elements in the dome region, where the modulus of elasticity was increased by a factor of 10,000 . The geometry of the knuckle region for the ANSYS ${ }^{\mathbb{B}}$ and Dytran ${ }^{\mathbb{B}}$ models is different. The ANSYS ${ }^{\circledR}$ model explicitly includes the curvature of the knuckle, whereas the Dytran ${ }^{\circledR}$ model does not. Retaining the curvature in the ANSYS $^{\circledR}$ model provided a better match of the impulsive frequencies of the two models than using a square corner. It also improved the solution behavior for the contact element in the knuckle region.

The liner, anchor bolts, and contact elements associated with the dome, primary tank to insulating concrete, and insulating concrete to liner were all modified to obtain "rigid" behavior. For the liner and anchor bolt elements, the modulus of elasticity was increased by a factor of 10,000 . The contact element key options were modified to obtain bonded behavior (i.e., they are "locked" together). Bonding the contact surfaces creates the same condition as if the nodes on the two surfaces were merged.

No changes were made to the waste elements or to the waste to primary tank contact elements.

A large mass is required at the location of excitation to properly simulate the seismic excitation. This mass was located at the apex of the concrete shell. The boundary conditions of the node at the apex are adjusted depending on the direction of excitation.

\subsection{Model Geometry}

A plot of the ANSYS ${ }^{\mathbb{B}}$ primary tank sub-model is shown in Figure 5-1. Although the concrete portion of the DST is shown in the plot, the concrete was effectively rigid as stated in the previous section. A slice plot of the rigid regions of the model is shown in Figure 5-2. Flexible portions of the primary tank are shown in Figure 5-3, though the portion of the primary tank bottom in contact with the underlying insulation concrete is effectively rigid. 
RPP-RPT-32239, Rev. 1

M\&D-2008-005-CALC-001, Rev. 1

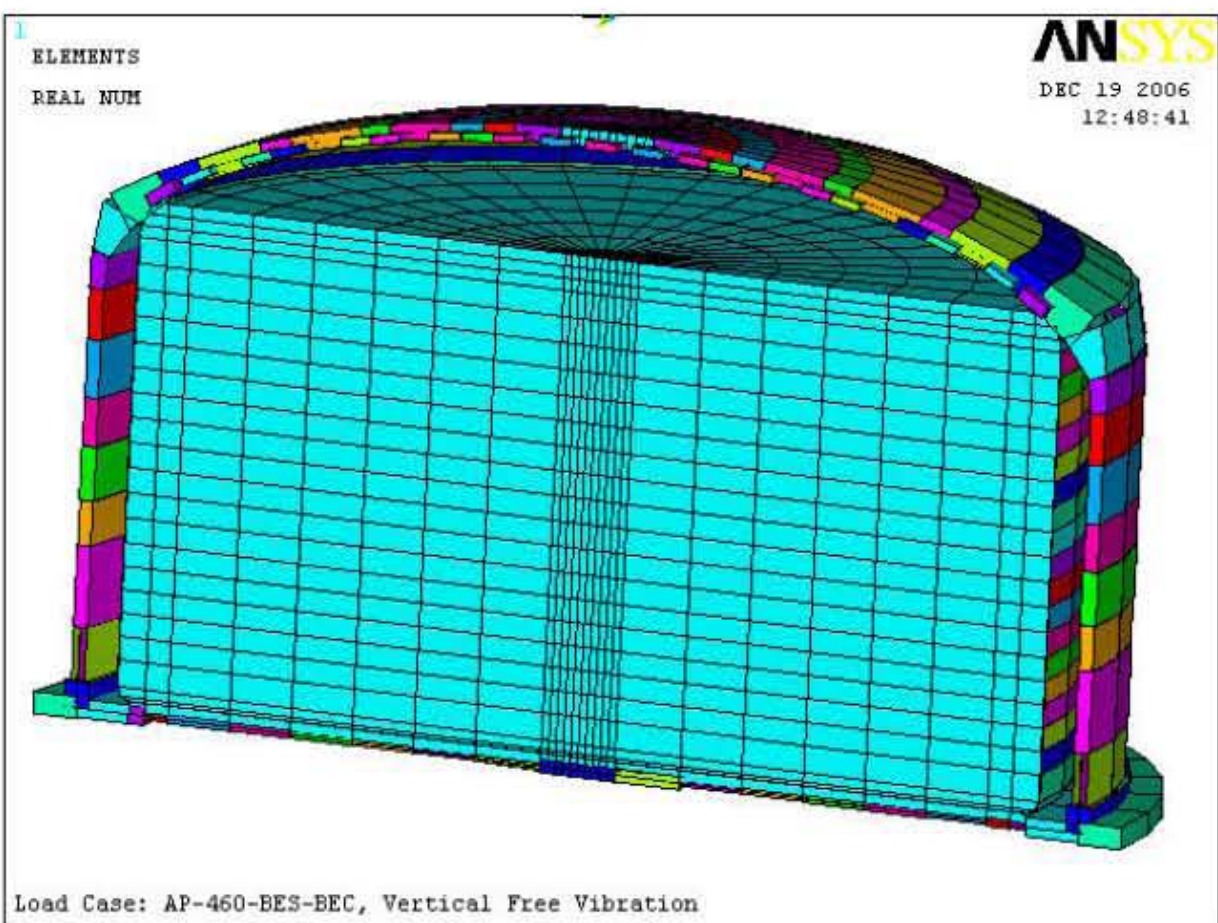

Figure 5-1. Plot of ANSYS ${ }^{\text {פ }}$ Primary Tank Sub-Model

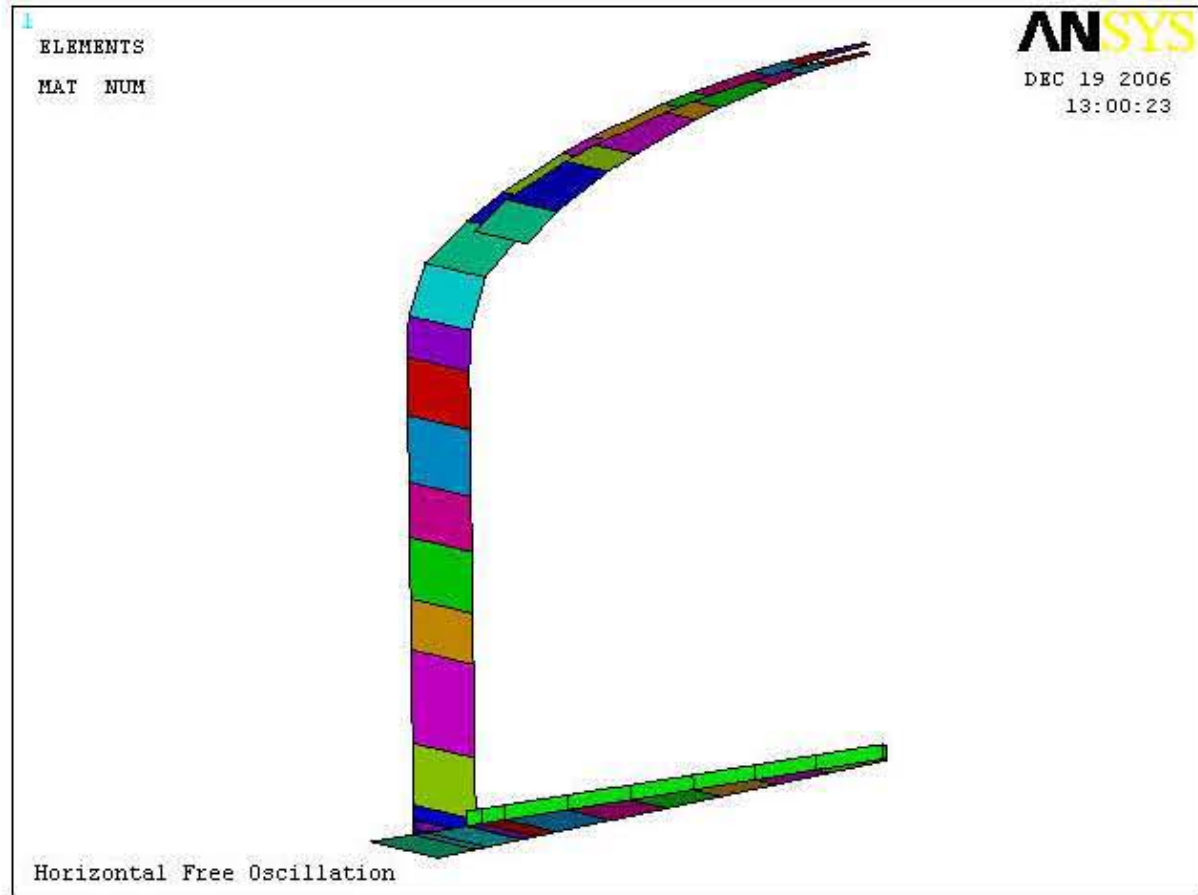

Figure 5-2. Slice Plot Showing Rigid Regions of the ANSYS ${ }^{\circledR}$ Primary Tank Sub-Model 
RPP-RPT-32239, Rev. 1

M\&D-2008-005-CALC-001, Rev. 1

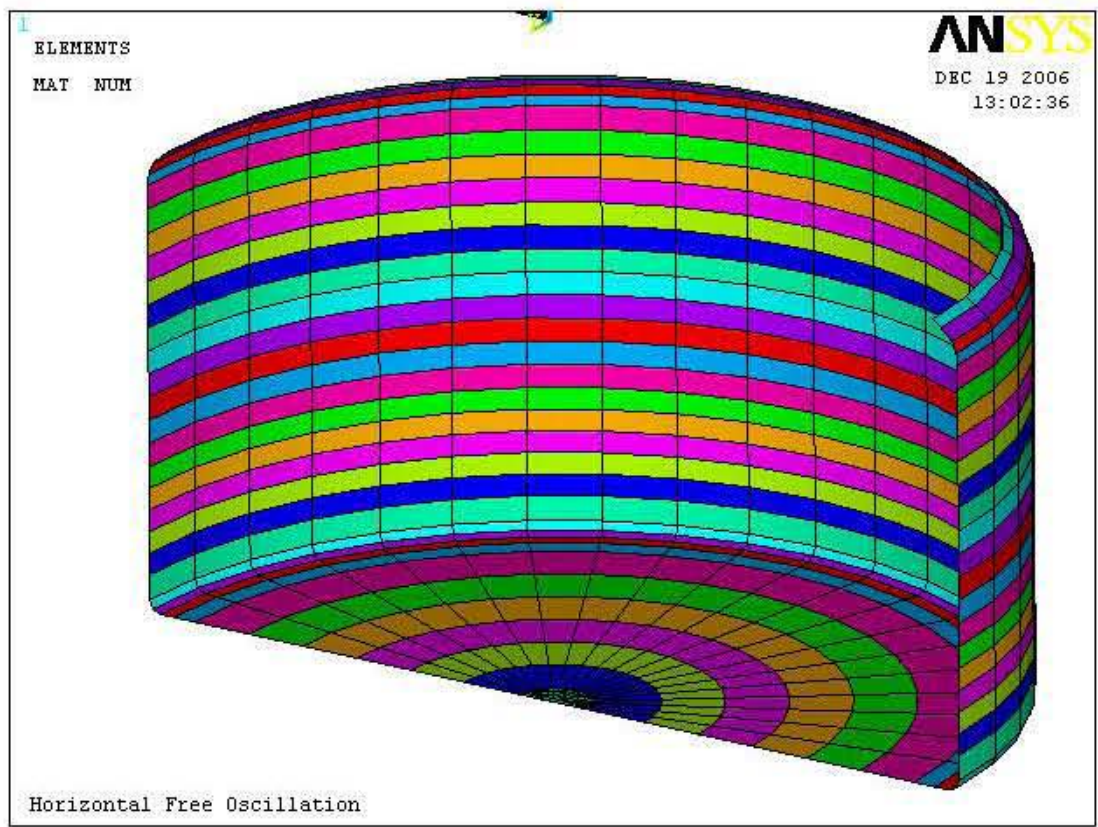

Figure 5-3. Plot of Flexible Primary Tank of ANSYS ${ }^{(2)}$ Sub-Model

Shell element numbers at locations for which primary tank stresses are extracted are shown in Figure 5-4 and Figure 5-5.

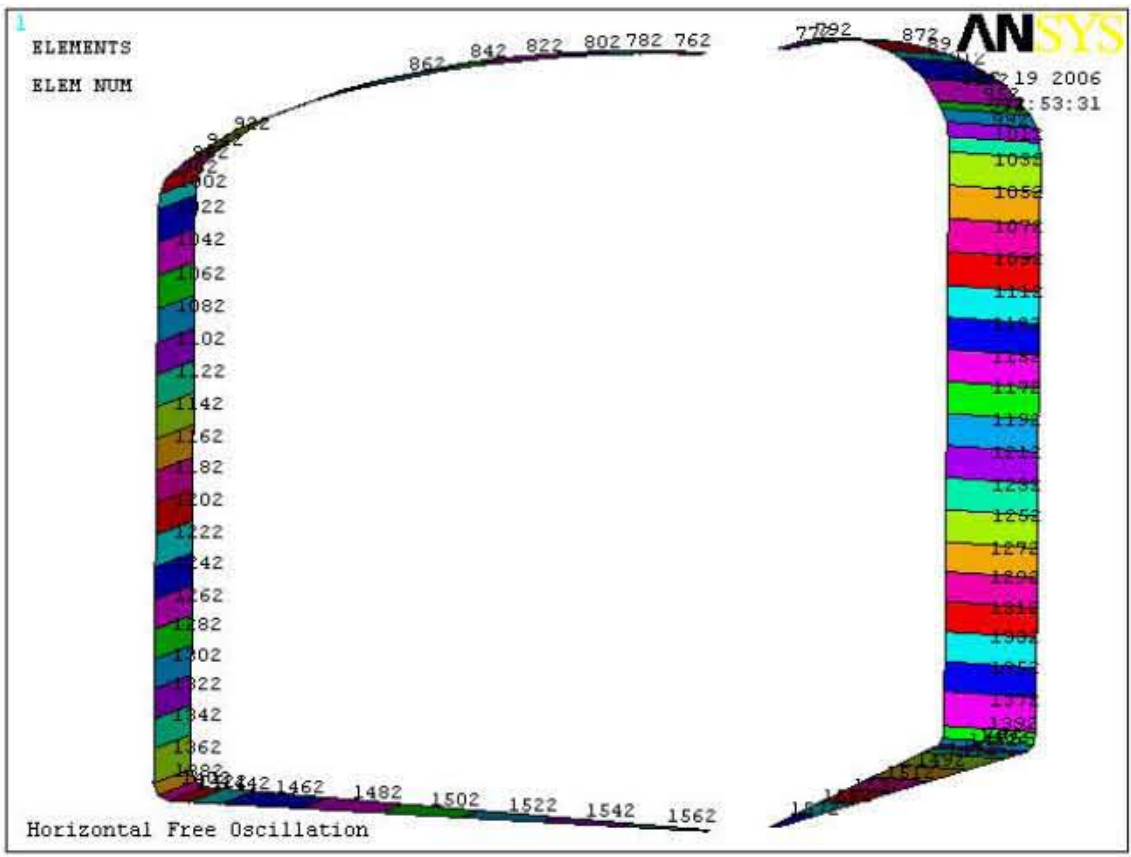

Figure 5-4. Shell Element Numbering for Tank Wall Stress Results at $\theta=0^{\circ}$ and $\theta=90^{\circ}$ 
RPP-RPT-32239, Rev. 1

M\&D-2008-005-CALC-001, Rev. 1

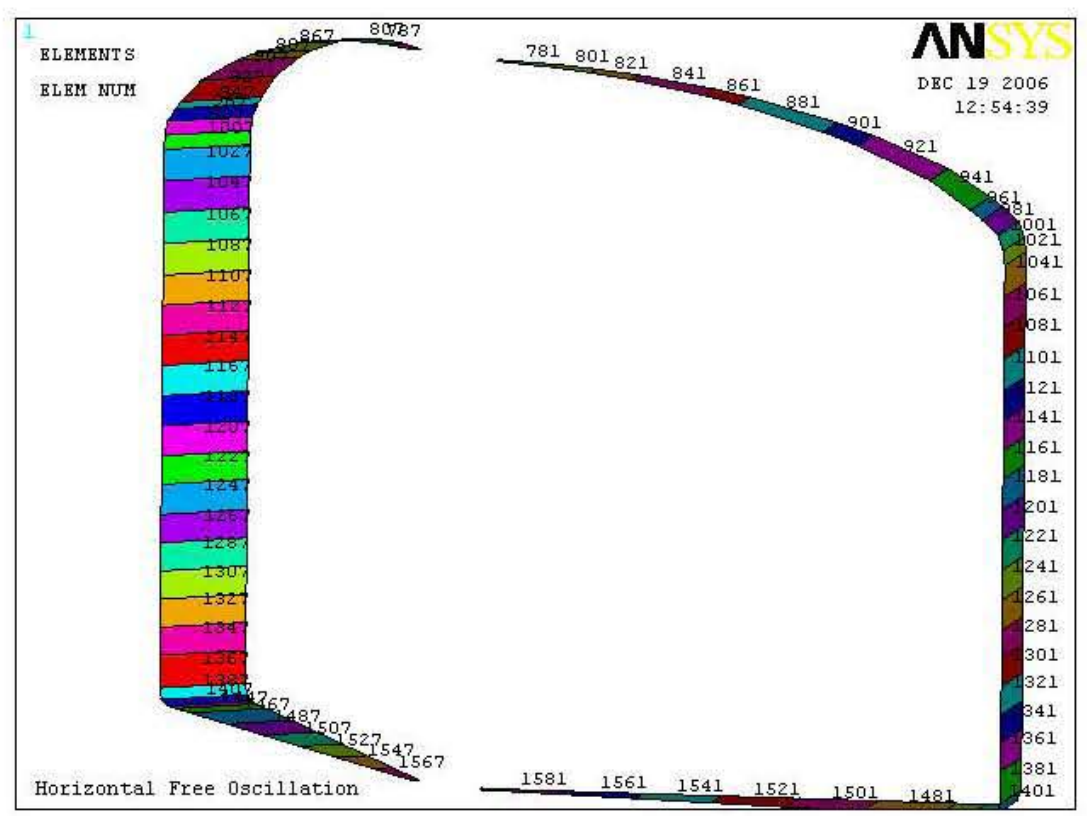

Figure 5-5. Shell Element Numbering for Tank Wall Stress Results at $\theta=45^{\circ}$ and $\theta=180^{\circ}$

\subsection{Damping Characterization and Frequency Tuning with the Dytran Model}

The objective of frequency tuning was to obtain an impulsive frequency for the tank/waste system as close as practical to that of the Dytran ${ }^{\text {(2) }}$ sub-model so that the input time histories would have essentially the same effect on both models. That is, the goal was that both sub-models should be experiencing the same spectral accelerations.

Tuning of the ANSYS ${ }^{(\text {i }}$ sub-model was performed by activating or de-activating various features from the full global model. Model features tested included the anchor bolts, contact behavior in the dome and at the bottom, presence of the radius on the knuckle, and the inclusion of tank floor flexibility.

The configuration providing the best match was essentially the same as the Dytran ${ }^{\text {s }}$ sub-model except for the inclusion of the knuckle curvature at the bottom of the primary tank, as shown in Figure 5-3,

Figure 5-4, and Figure 5-5. In this configuration, the ANSYS ${ }^{\circledR}$ sub-model displayed a horizontal impulsive frequency of $5.78 \mathrm{~Hz}$, and an associated effective damping of $3.77 \%$.

The convective and impulsive fundamental frequencies were determined in a two-step process. A rigid primary tank model is used in the first step and a flexible primary tank model is used in the second. For each step, the sub-model was solved in the initial time step with a $0.05 \mathrm{~g}$ lateral acceleration applied. This induced an initial displacement in the sub-model. The lateral acceleration was then removed and the submodel allowed to oscillate freely. The total hydrodynamic response is tracked for each step. The waste convective frequency was determined with the primary tank modeled as "rigid." A combined response, convective and impulsive, is determined with the flexible model. The impulsive portion of the total response is the difference between the flexible model total response and the rigid model total response. 
RPP-RPT-32239, Rev. 1

M\&D-2008-005-CALC-001, Rev. 1

Figure 5-6 shows the total hydrodynamic response for free oscillation initiated by the $0.05 g$ horizontal accelerations with the primary tank modeled as "rigid." From this, a fundamental convective frequency of $0.21 \mathrm{~Hz}$ can be determined $(2 /(13.9-4.45)=0.21 \mathrm{~Hz})$.

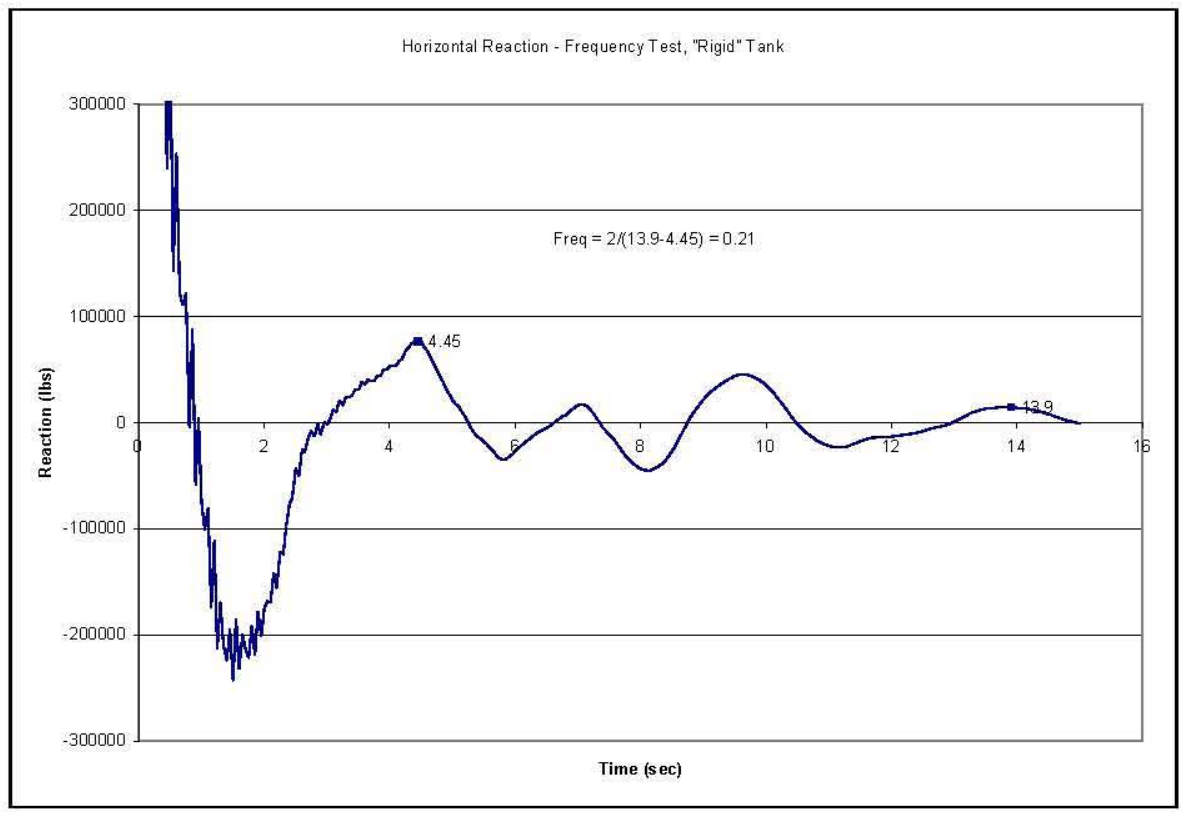

Figure 5-6. Free Horizontal Oscillation Total Reaction

Figure $5-7$ shows the total hydrodynamic response for free oscillation initiated by the $0.05 \mathrm{~g}$ horizontal acceleration for the flexible-wall model. The response shows 5 cycles in 0.87 seconds, for a frequency of $5.78 \mathrm{~Hz}$.

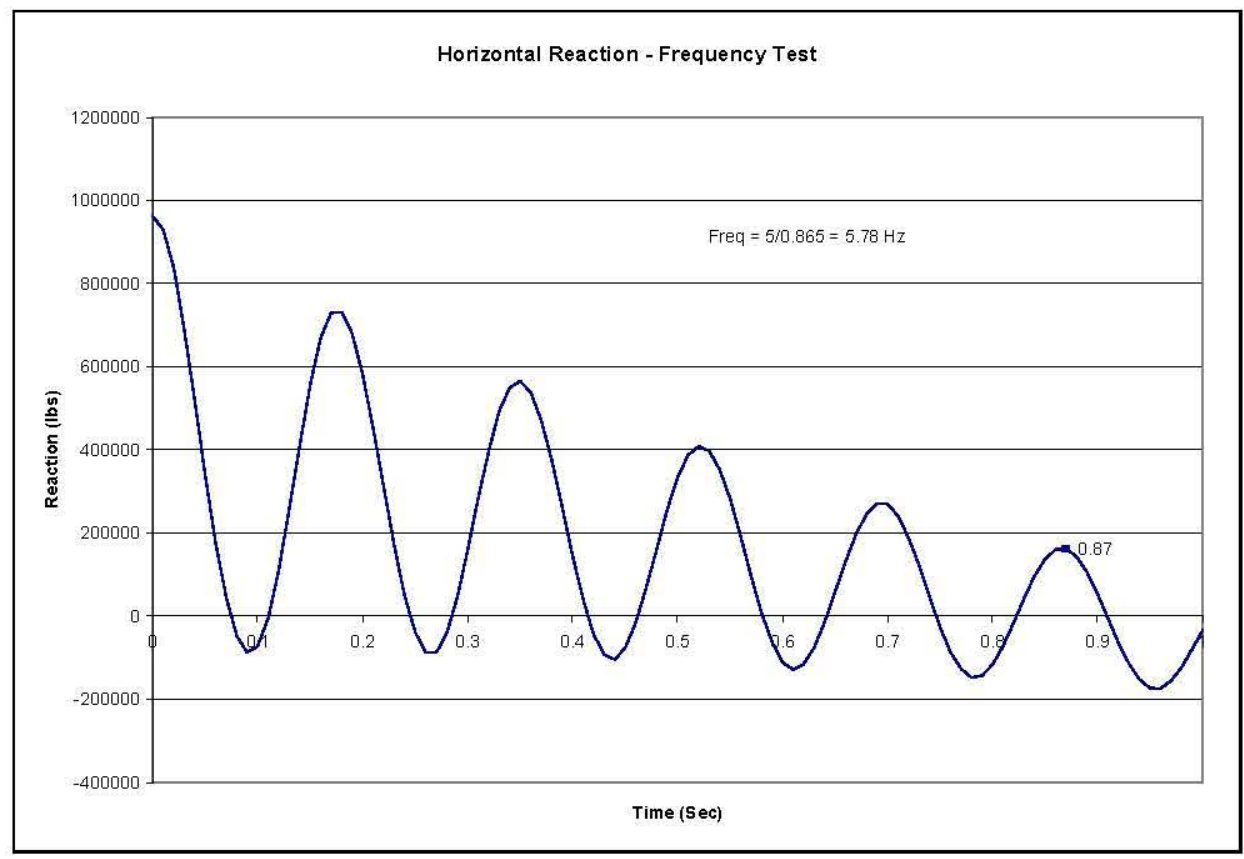

Figure 5-7. Total Reaction from ANSYS ${ }^{\circledR}$ Primary Tank Sub-Model for Free Horizontal Oscillation 
RPP-RPT-32239, Rev. 1

M\&D-2008-005-CALC-001, Rev. 1

Figure 5-8 shows three lines, the total hydrodynamic response of the flexible-wall sub-model, the response of the rigid sub-model, and the difference between the two - that is, the impulsive portion of the reaction. From this difference, the damping can be calculated based on the decrease in response over three cycles. A damping value of $3.77 \%$ corresponds well with the Dytran ${ }^{\mathbb{B}}$ damping of $4.3 \%$.

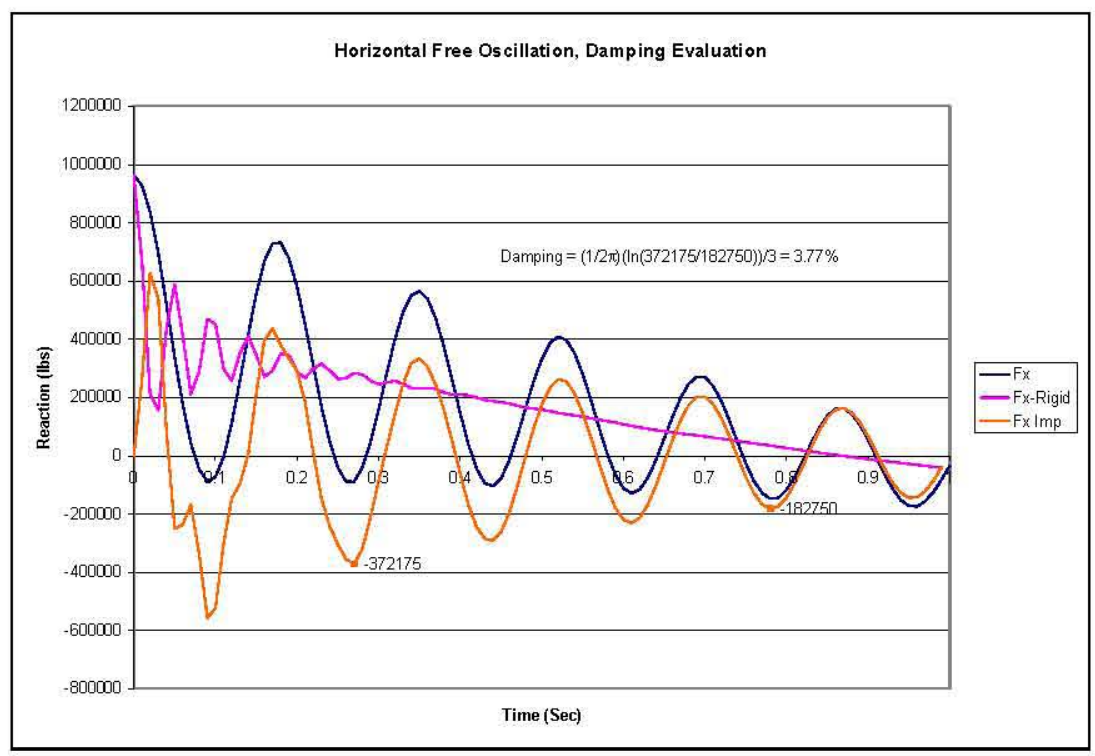

Figure 5-8. Total Reaction Force Comparison Between Rigid and Flexible ANSYS ${ }^{\mathbb{B}}$ Primary Tank SubModels for Free Horizontal Oscillation

Figure 5-9 shows the total hydrodynamic response for free oscillation initiated by a $0.05 g$ vertical acceleration. The response shows 3 cycles in 0.8 seconds, for a frequency of $5.0 \mathrm{~Hz}$ (vs. $5.07 \mathrm{~Hz}$ for Dytran ${ }^{\mathbb{B}}$ ). The damping associated with the "breathing" mode can be calculated based on the decrease in response over three cycles. A damping value of $2.6 \%$ is less than shown in Dytran ${ }^{\mathbb{B}}$ with a damping of $3.5 \%$.

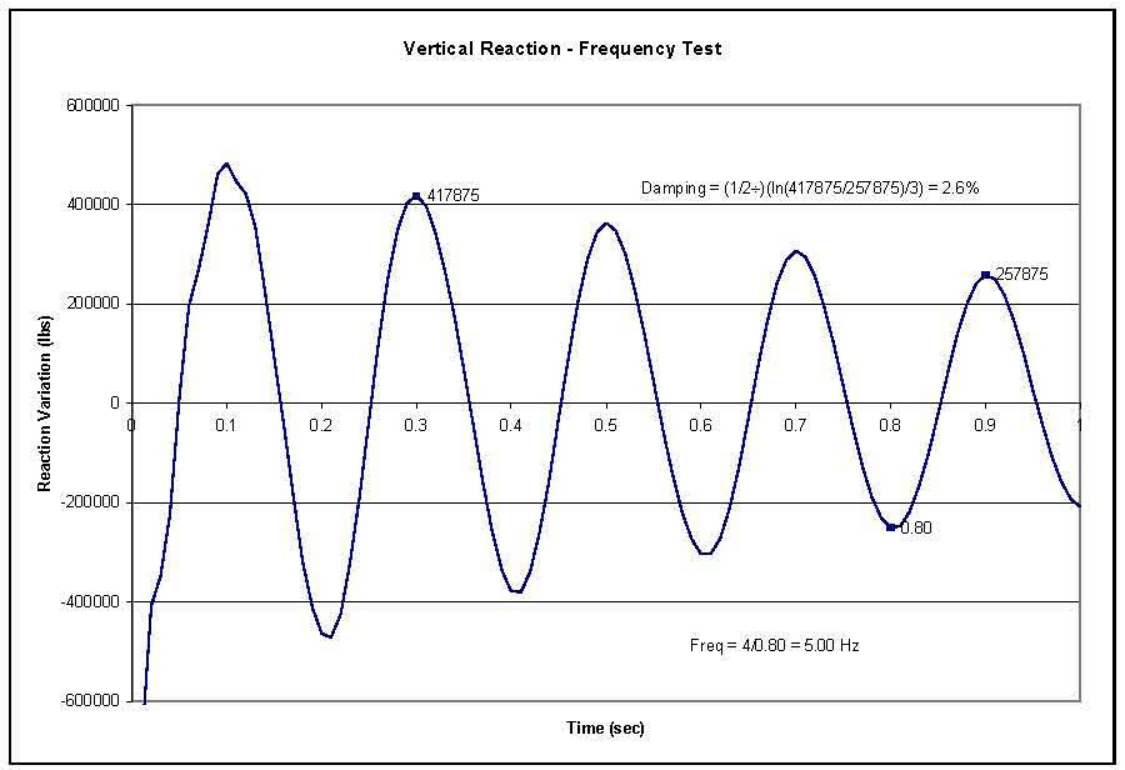

Figure 5-9. Total Reaction Force for ANSYS ${ }^{\mathbb{B}}$ Primary Tank Sub-Model for Free Vertical Oscillation 
RPP-RPT-32239, Rev. 1

M\&D-2008-005-CALC-001, Rev. 1

\subsection{Results from ANSYS ${ }^{\circledR}$ Primary Tank Sub-Models}

Results from horizontal seismic excitation only, vertical seismic excitation only, and simultaneous application of horizontal and vertical seismic excitation (two-component motion) are described in this chapter.

Impulsive and convective frequencies, global reaction forces, waste pressures, maximum slosh heights, and primary tank stresses will be reported. Benchmarking of ANSYS ${ }^{\mathbb{B}}$ primary tank sub-models was performed and reported in Rinker et al. (2006b). Thus, although frequencies, reaction forces, waste pressures, and slosh heights are reported to provide a basic check of the results, the primary tank stresses are of the most interest. Furthermore, due to the extensive data produced by the ANSYS ${ }^{\circledR}$ simulations, some results appear in Appendix D rather than in the main body of this report.

\subsection{Hydrodynamic Forces from ANSYS ${ }^{\circledR}$ Sub-Model}

The total horizontal and vertical reaction forces for horizontal excitation, vertical excitation, and twocomponent motion are presented in the following sections.

\subsubsection{Horizontal Excitation Only}

The maximum reaction force for horizontal excitation only is $3.47 \times 10^{6} \mathrm{lbf}$, as shown in Figure 6-1. This is approximately $14 \%$ greater than the value of $3.05 \times 10^{6} \mathrm{lbf}$ from the Dytran ${ }^{B}$ model. This is consistent with a reduced convective response and increased impulsive response for the ANSYS ${ }^{\circledR}$ sub-model.

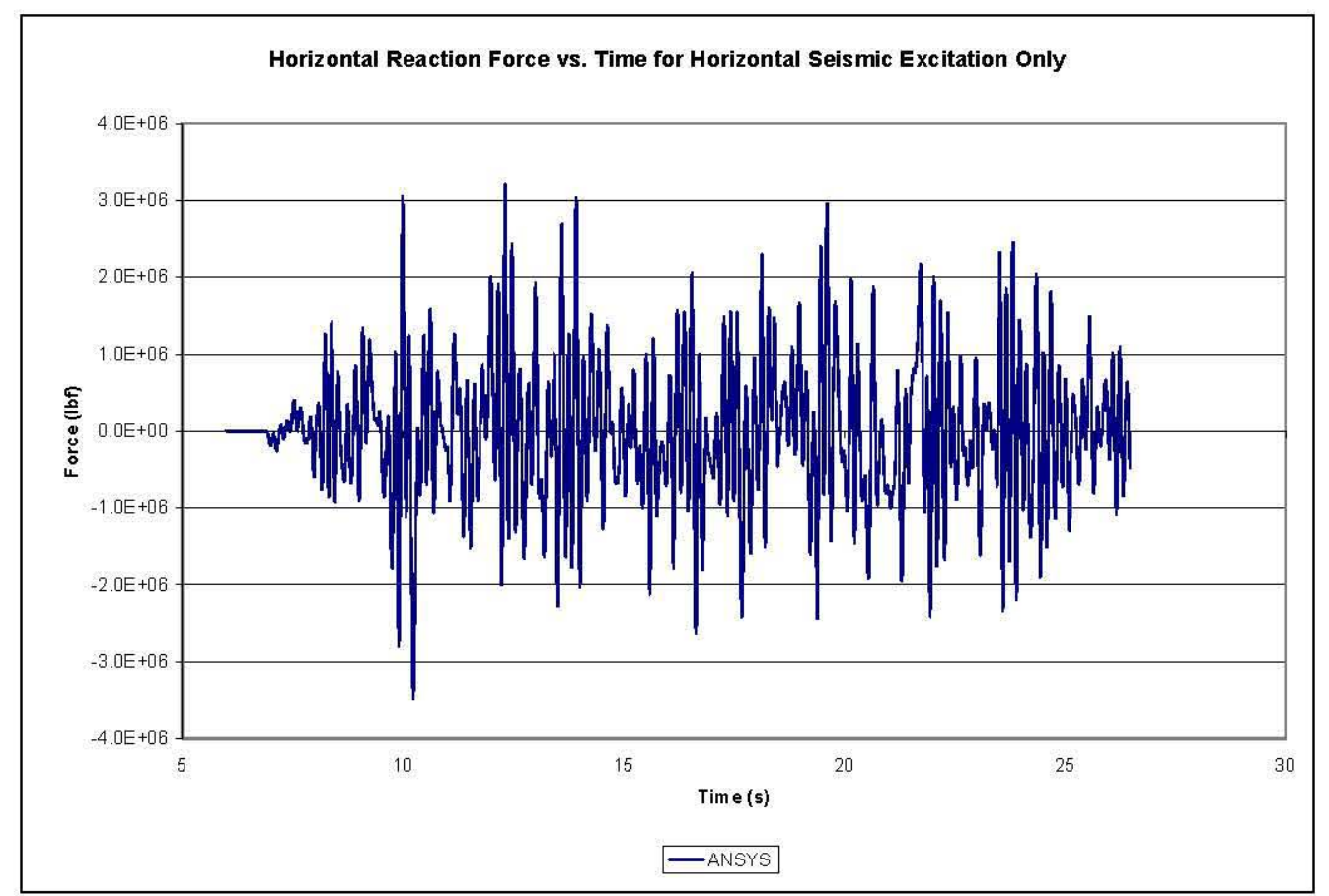

Figure 6-1. Horizontal Coupling Surface Reaction Force vs. Time from ANSYS ${ }^{\circledR}$ Primary Tank SubModel for Horizontal Seismic Excitation 


\subsubsection{Vertical Excitation Only}

According to Figure 6-2, the vertical reaction force varies between $-1.65 \times 10^{7} \mathrm{lbf}$ and $-2.29 \times 10^{7} \mathrm{lbf}$. The weight of the contained fluid is $1.92 \times 10^{7} \mathrm{lbf}$, so that the maximum dynamic component of the vertical reaction force is $3.7 \times 10^{6} \mathrm{lbf}$, which is greater than for horizontal excitation only, and nearly the same as the value of $3.6 \times 10^{6} \mathrm{lbf}$ from the Dytran ${ }^{\mathbb{B}}$ model. Good agreement between the ANSYS ${ }^{\mathbb{B}}$ and Dytran ${ }^{\circledR}$ sub-models is expected for vertical excitation since the response does not involve fluid sloshing.

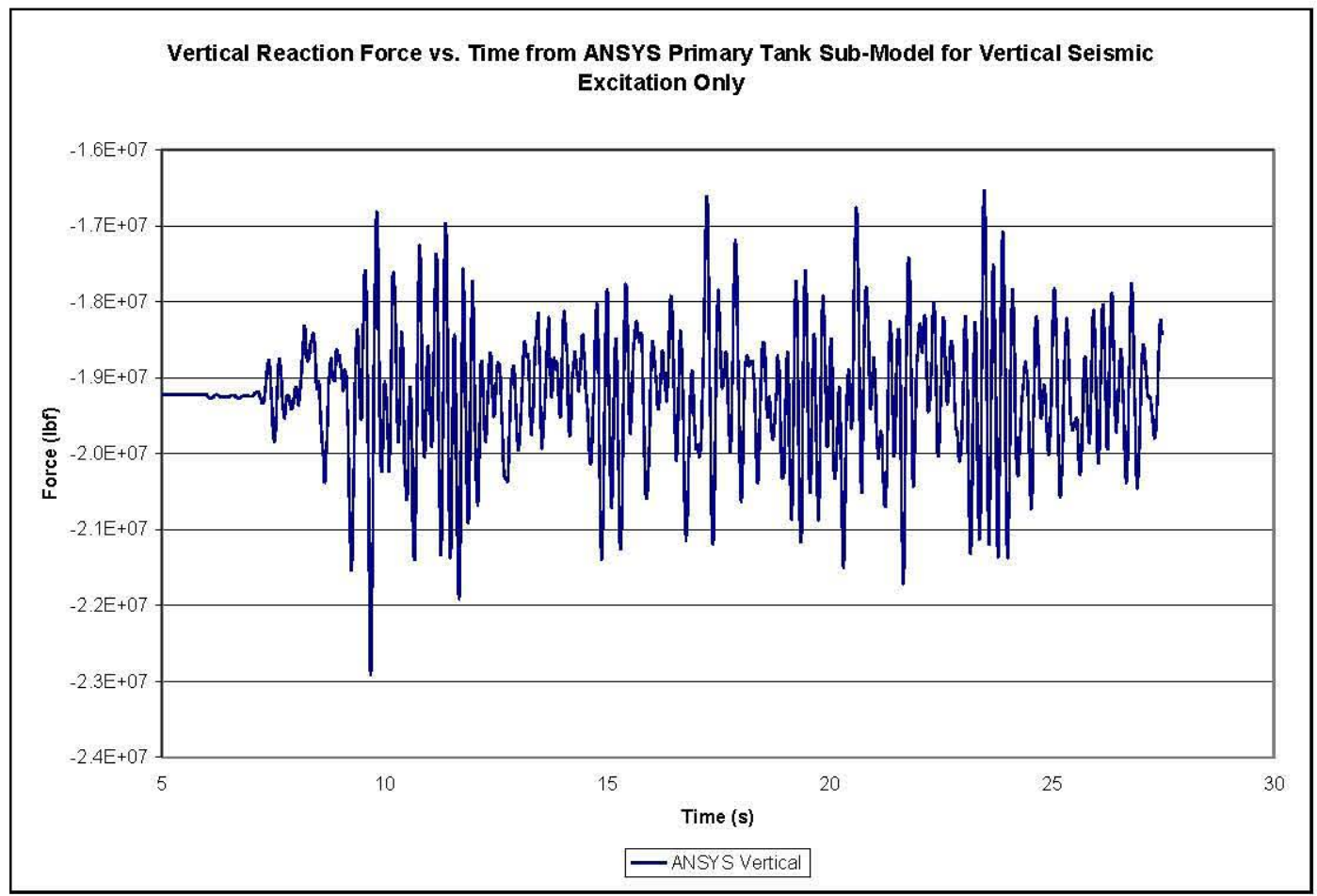

Figure 6-2. Vertical Reaction Force vs. Time from ANSYS ${ }^{\circledR}$ Primary Tank Sub-Model for Vertical Seismic Excitation

\subsubsection{Two-Component Motion}

The horizontal reaction force time-history plot presented as Figure 6-3 shows that the maximum horizontal force is $3.47 \times 10^{6} \mathrm{lbf}$, exactly the same as for horizontal motion only. Similarly, Figure 6-4 shows that the vertical reaction force varies between $-1.65 \times 10^{7} \mathrm{lbf}$ and $-2.29 \times 10^{7} \mathrm{lbf}-$ the same as for vertical excitation only, giving a maximum dynamic component of the vertical reaction force of $3.7 \times 10^{6} \mathrm{lbf}$, as before. That is, the peak reaction forces for two-component motion are the same as for the individual component directions run separately. 
RPP-RPT-32239, Rev. 1

M\&D-2008-005-CALC-001, Rev. 1

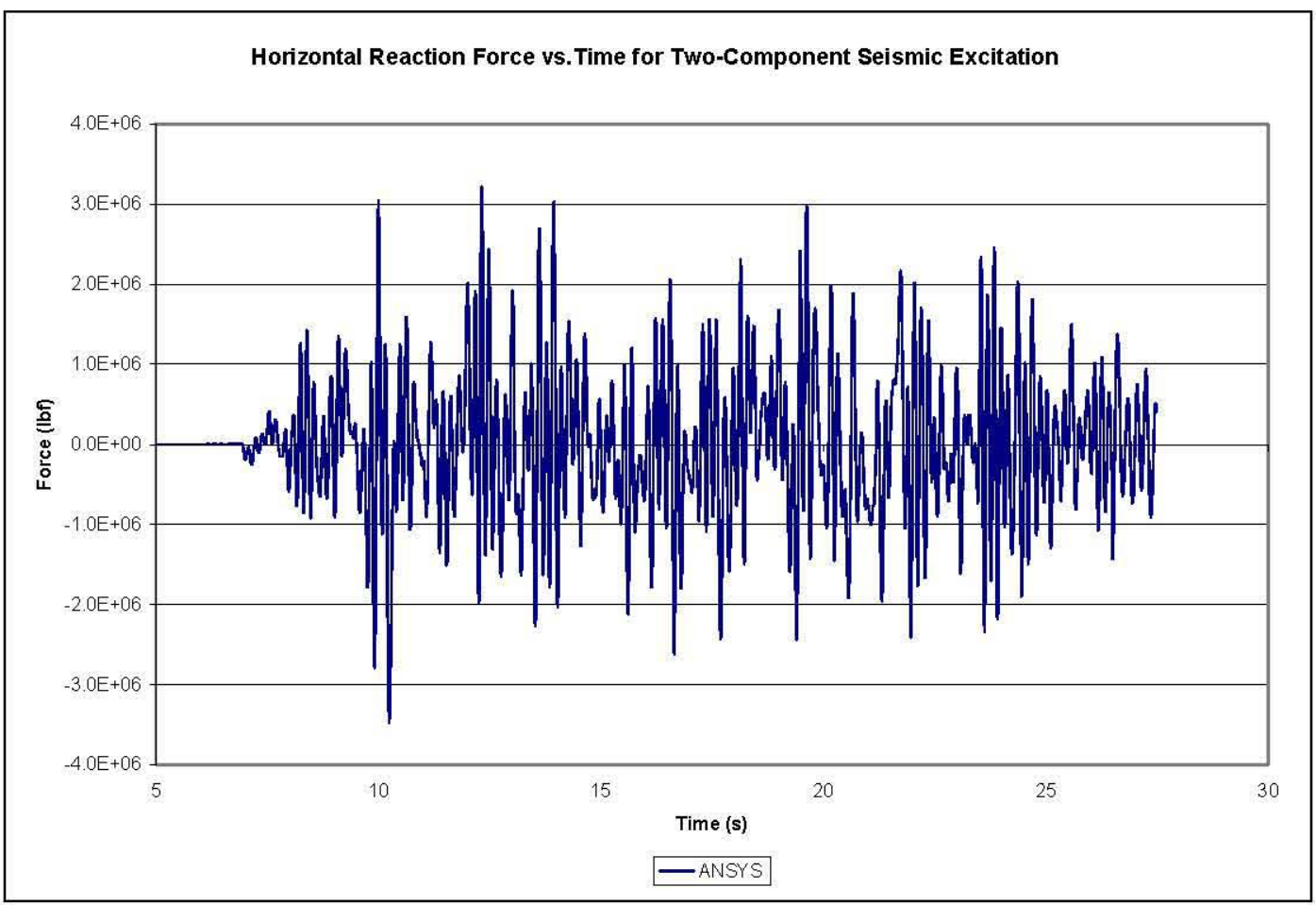

Figure 6-3. Horizontal Reaction Force vs. Time from ANSYS ${ }^{\circledR}$ Primary Tank Sub-Model for TwoComponent Seismic Excitation

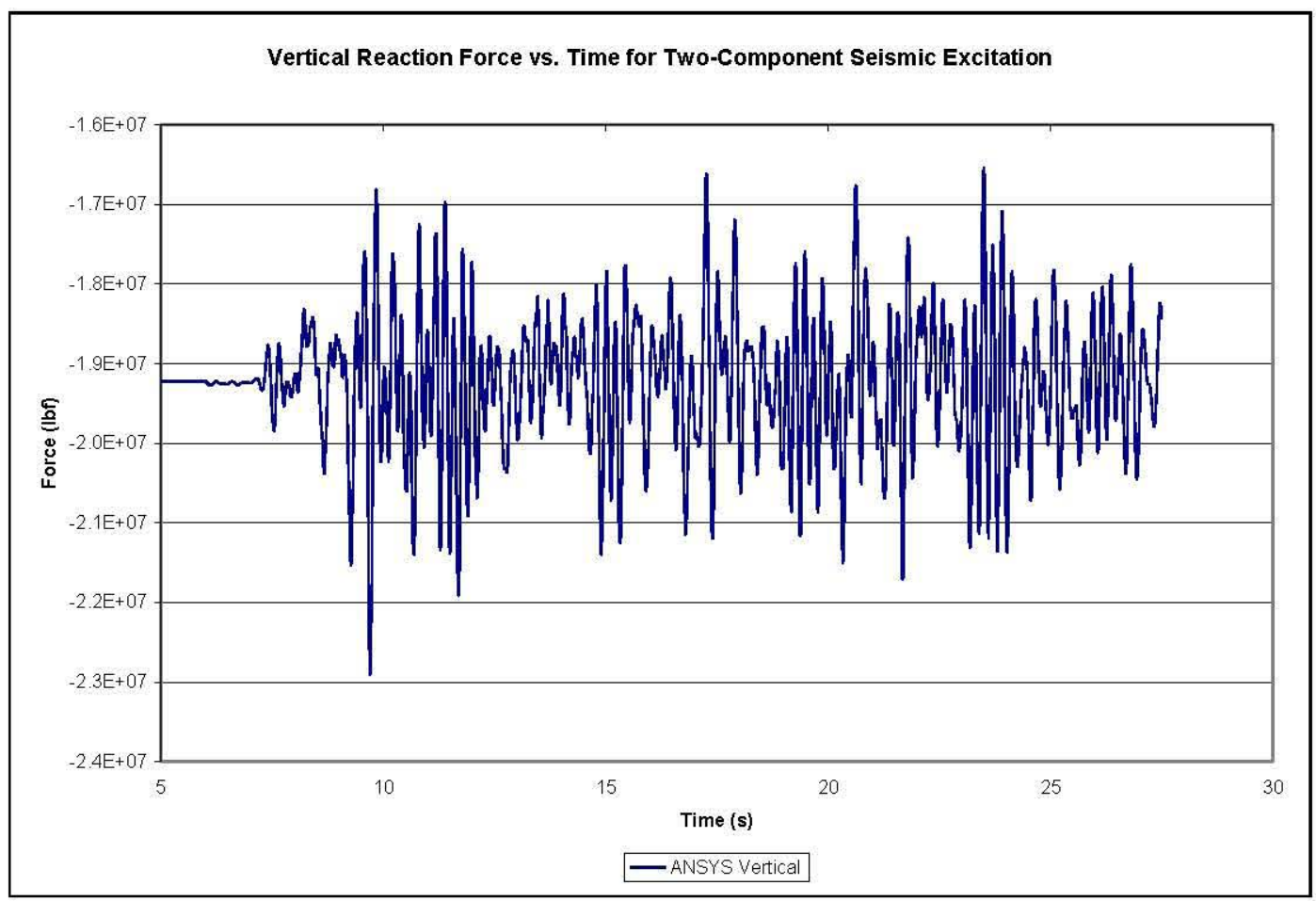

Figure 6-4. Vertical Reaction Force vs. Time from ANSYS ${ }^{\circledR}$ Primary Tank Sub-Model for TwoComponent Seismic Excitation 
RPP-RPT-32239, Rev. 1

M\&D-2008-005-CALC-001, Rev. 1

\subsection{Waste Pressures from ANSYS ${ }^{\circledR}$ Sub-Model}

The theoretical hydrostatic pressures for the waste elements at $\theta=0,45$, and $90^{\circ}$ from the plane of excitation are shown in Table 6-1. The hydrostatic pressures from the sub-model simulations are reflected in the initial portion of the waste pressure time-history plots.

Table 6-1. Theoretical Hydrostatic Pressures for Selected Fluid Elements from ANSYS ${ }^{\circledR}$ Primary Tank Sub-Model

\begin{tabular}{||c|c|c|c||}
\hline Element & Element & Element & $\begin{array}{c}\text { Theoretical } \\
\text { Hydrostatic } \\
\text { Pressure } \\
\text { (psi absolute) }\end{array}$ \\
\hline \hline 7722 & 7727 & 7732 & 15.1 \\
\hline 8382 & 8387 & 8392 & 15.8 \\
\hline 9042 & 9047 & 9052 & 16.6 \\
\hline 9702 & 9707 & 9712 & 17.7 \\
\hline 10362 & 10367 & 10372 & 19.3 \\
\hline 11022 & 11027 & 11032 & 20.9 \\
\hline 12482 & 12557 & 12632 & 22.5 \\
\hline 12487 & 12562 & 12637 & 24.1 \\
\hline 12492 & 12567 & 12642 & 25.6 \\
\hline 12497 & 12572 & 12647 & 27.1 \\
\hline 12502 & 12577 & 12562 & 28.6 \\
\hline 12507 & 12582 & 12657 & 30.2 \\
\hline 12512 & 12587 & 12662 & 31.7 \\
\hline 12517 & 12592 & 12667 & 33.2 \\
\hline 12522 & 12597 & 12672 & 34.8 \\
\hline 12527 & 12602 & 12677 & 36.2 \\
\hline 12532 & 12607 & 12682 & 37.7 \\
\hline 12537 & 12612 & 12687 & 39.1 \\
\hline 12542 & 12617 & 12692 & 40.5 \\
\hline 12547 & 12622 & 12697 & 41.9 \\
\hline 12552 & 12627 & 12702 & 43.5 \\
\hline 13102 & 13107 & 13112 & 44.6 \\
\hline 13522 & 13527 & 13532 & 45.0 \\
\hline & & & \\
\hline & & & $\mathbf{0}^{\circ}$ \\
\hline
\end{tabular}

\subsubsection{Horizontal Excitation Only}

Pressure time histories and maximum and minimum pressure plots for horizontal excitation only are shown in Figure 6-5 through Figure 6-10. The hydrostatic pressures match well with the theoretical values shown in Table 6-1. Comparisons to the pressure time history plots from the Dytran ${ }^{\mathbb{B}}$ sub-model are presented in Section 7.3. 
RPP-RPT-32239, Rev. 1

M\&D-2008-005-CALC-001, Rev. 1

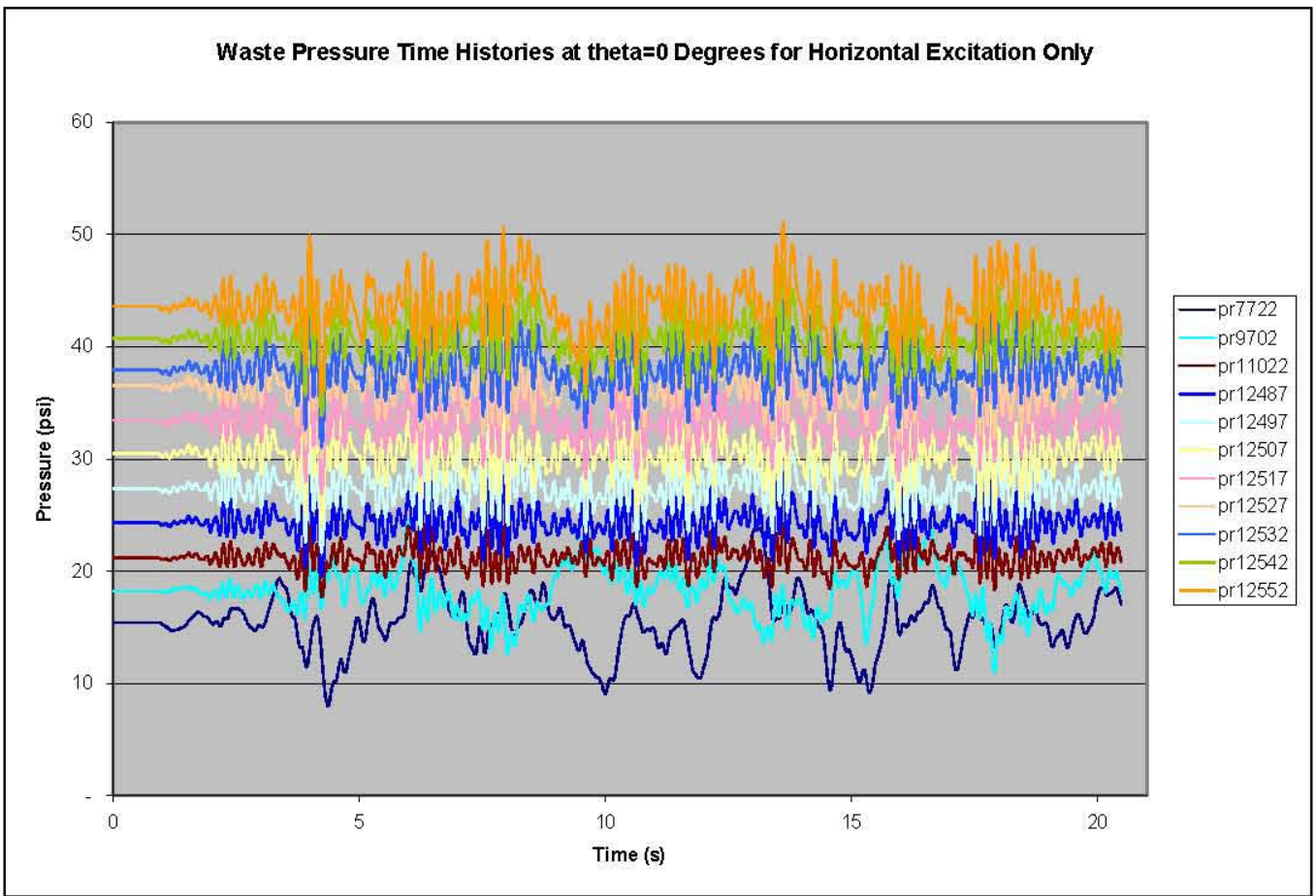

Figure 6-5. Waste Pressure Time Histories from ANSYS ${ }^{\circledR}$ Primary Tank Sub-Model for Fluid Elements at $\theta=0^{\circ}$ Subjected to Horizontal Seismic Excitation Only

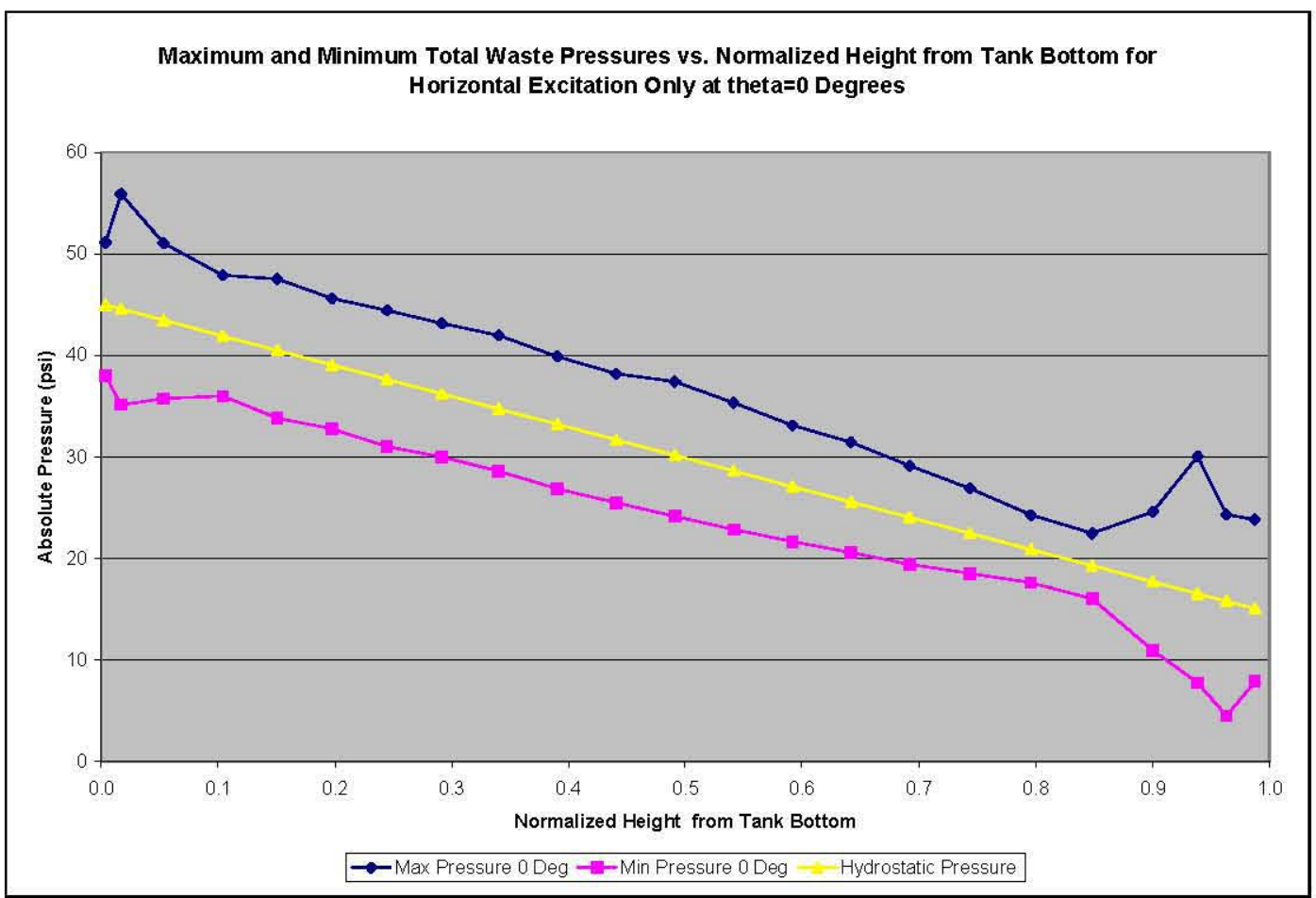

Figure 6-6. Maximum and Minimum Waste Pressures vs. Normalized Height from Tank Bottom from ANSYS $^{\mathscr{B}}$ Primary Tank Sub-Model for Waste Elements at $\theta=0^{\circ}$ Subjected to Horizontal Seismic Excitation Only 
RPP-RPT-32239, Rev. 1

M\&D-2008-005-CALC-001, Rev. 1

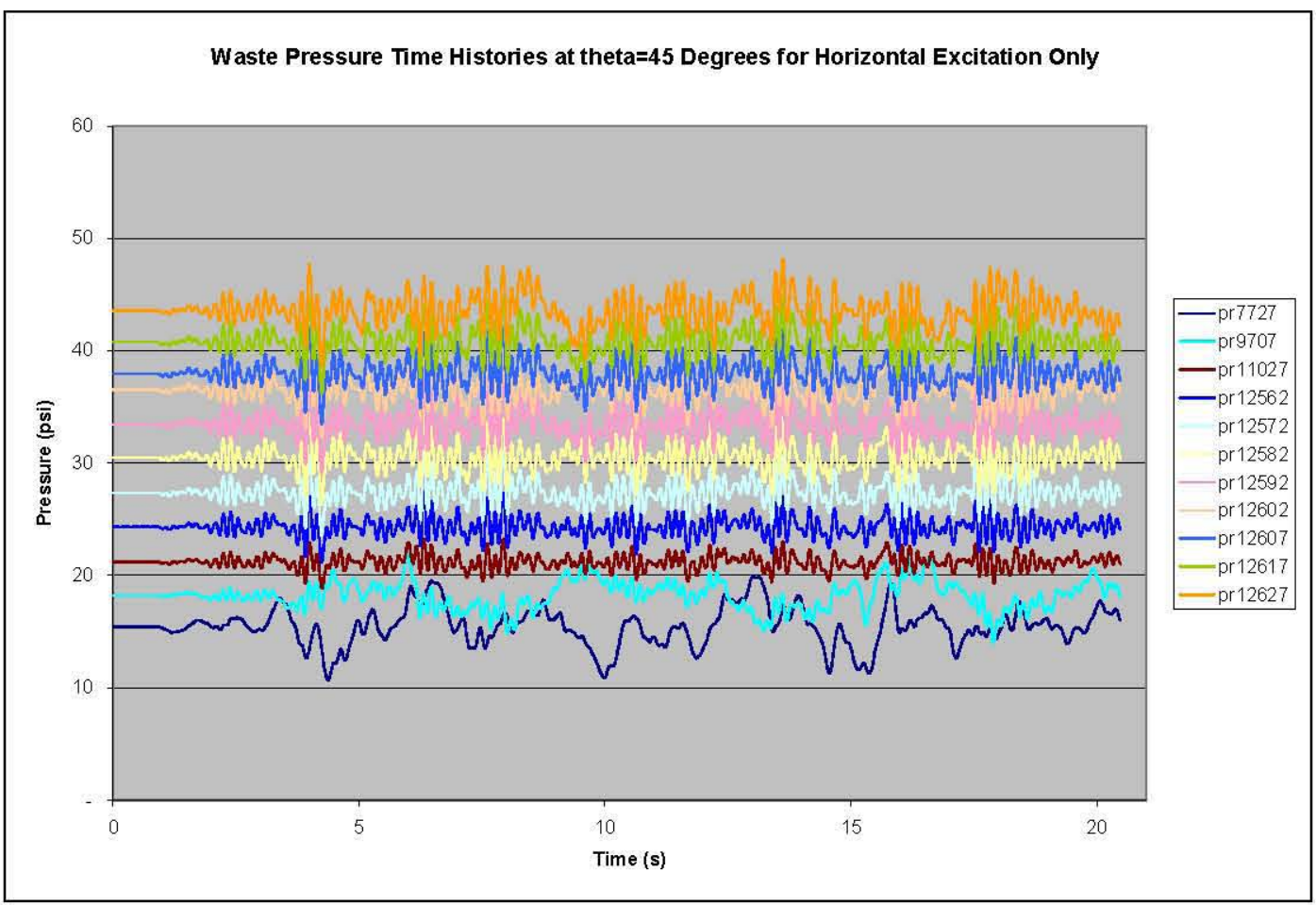

Figure 6-7. Waste Pressure Time Histories from ANSYS ${ }^{\mathbb{B}}$ Primary Tank Sub-Model for Fluid Elements at $\theta=45^{\circ}$ Subjected to Horizontal Seismic Excitation Only

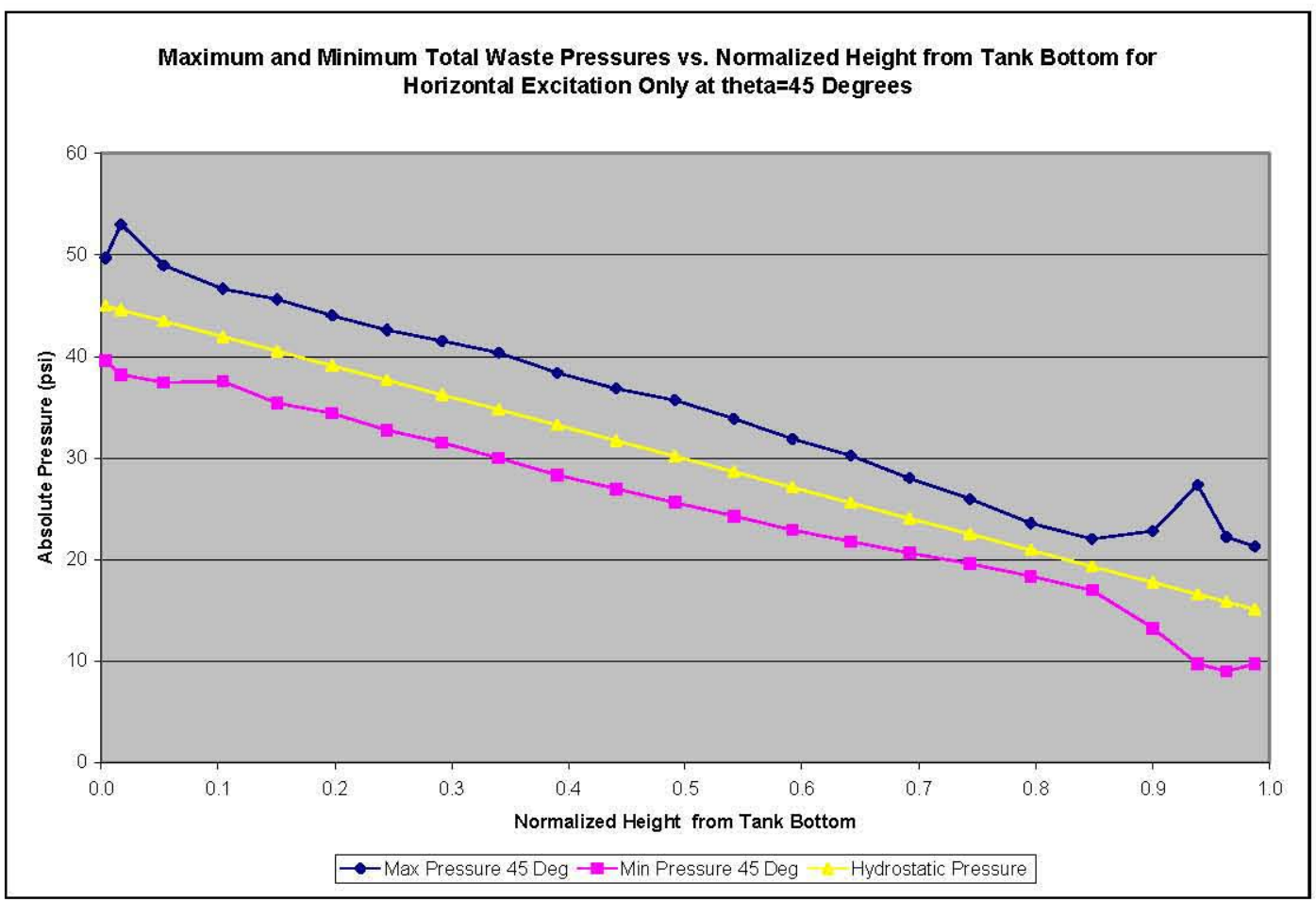

Figure 6-8. Waste Pressure Variation from ANSYS ${ }^{\circledR}$ Primary Tank Sub-Model for Waste Elements at $\theta=45^{\circ}$ Subjected to Horizontal Seismic Excitation Only 
RPP-RPT-32239, Rev. 1

M\&D-2008-005-CALC-001, Rev. 1

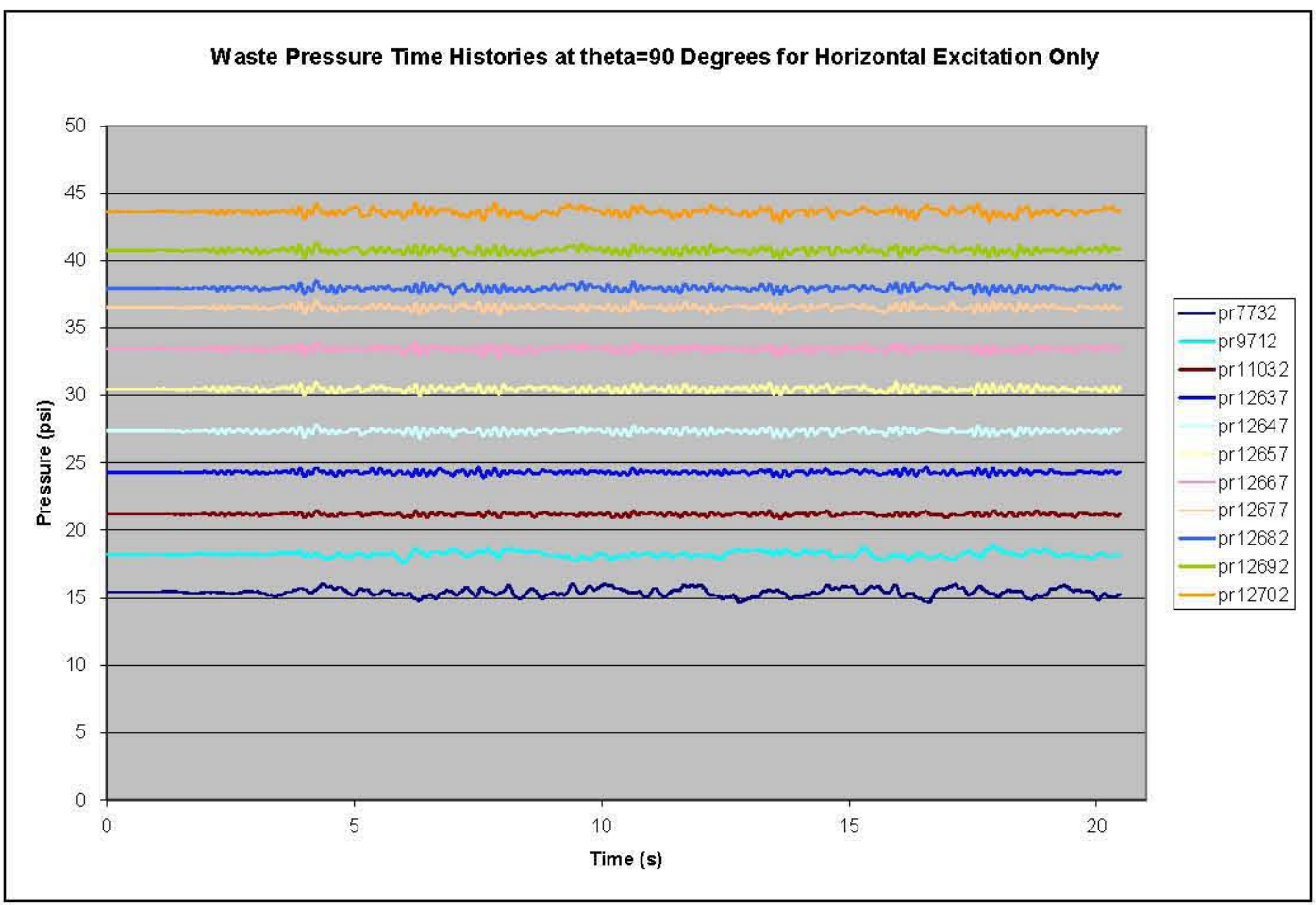

Figure 6-9. Waste Pressure Time Histories from ANSYS ${ }^{\mathbb{B}}$ Primary Tank Sub-Model for Fluid Elements at $\theta=90^{\circ}$ Subjected to Horizontal Seismic Excitation Only

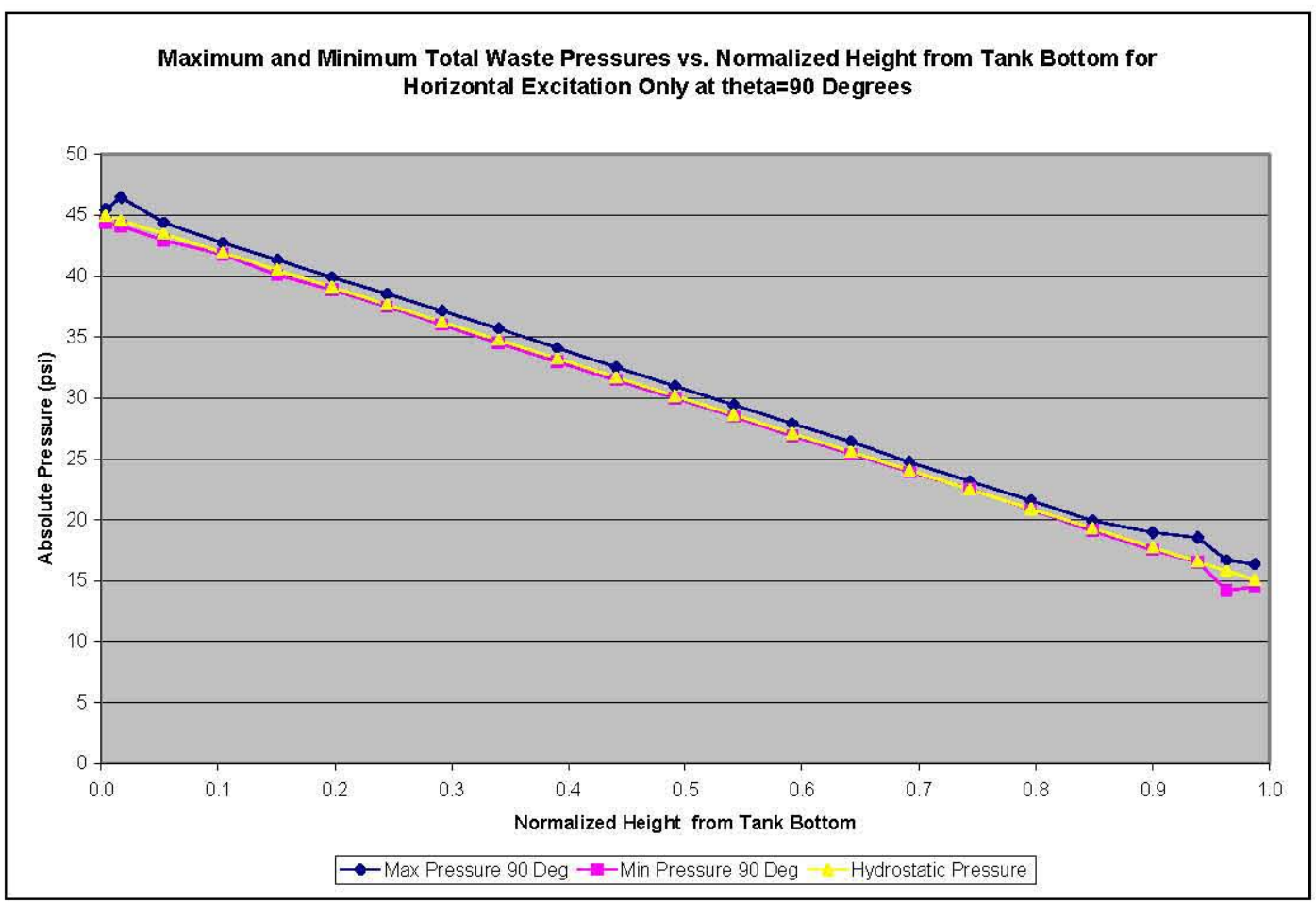

Figure 6-10. Waste Pressure Variation from ANSYS ${ }^{\mathbb{B}}$ Primary Tank Sub-Model for Waste Elements at $\theta=90^{\circ}$ Subjected to Horizontal Seismic Excitation Only 


\subsubsection{Vertical Excitation Only}

Plots of waste pressure time histories and maximum and minimum stresses at $\theta=0^{\circ}$ and $\theta=45^{\circ}$ are shown in Figure 6-11, Figure 6-12, Figure 6-13, and Figure 6-14. The stress distributions are independent of the angular location and the dynamic pressures increase with depth, both of which are required for vertical excitation only. Figure 6-11 and Figure 6-13 appear very similar to Figure 4-11 and Figure 4-12 from the Dytran ${ }^{\mathbb{B}}$ sub-model simulation for vertical excitation.

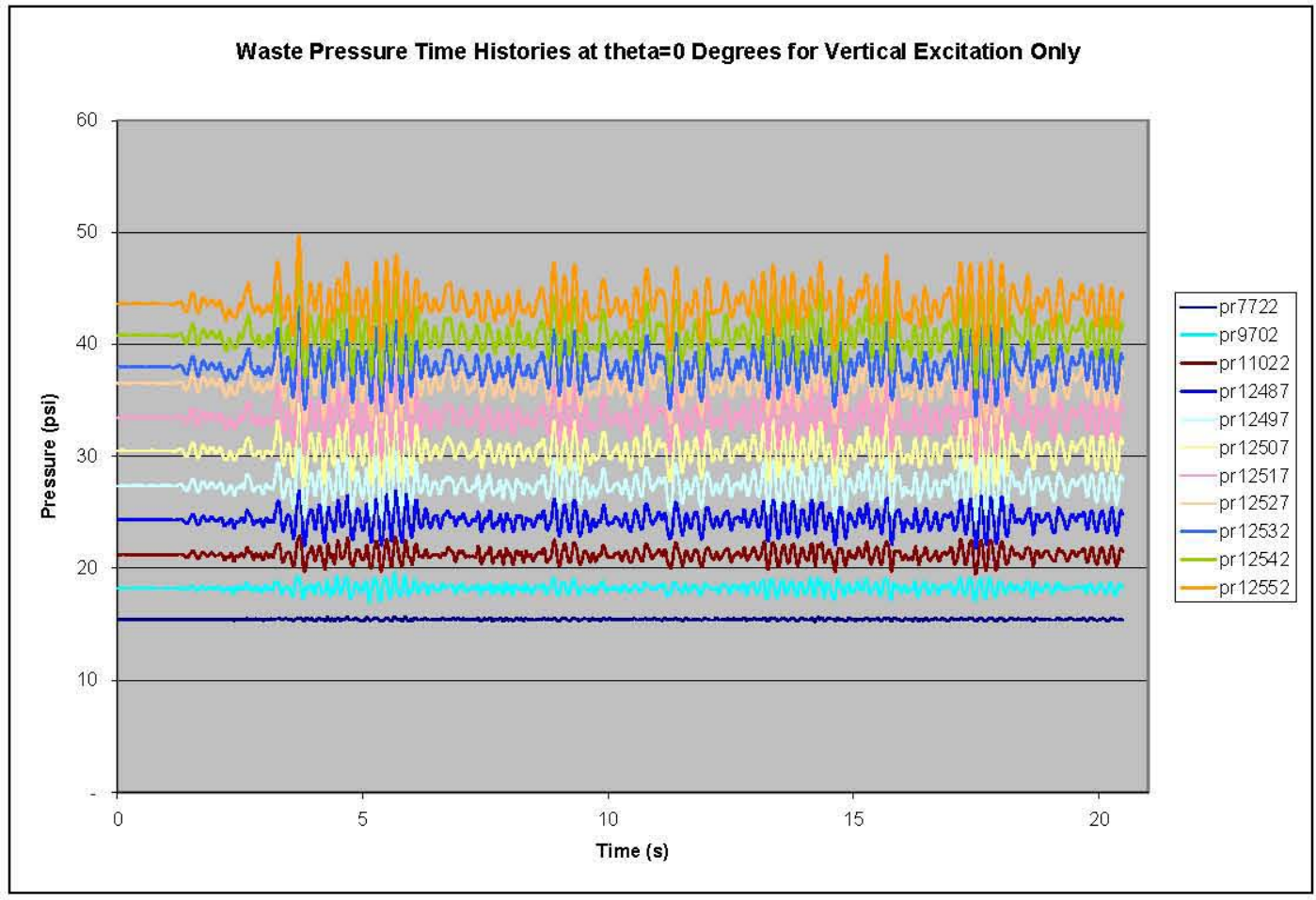

Figure 6-11. Waste Pressure Time Histories from ANSYS ${ }^{\circledR}$ Primary Tank Sub-Model for Fluid Elements at $\theta=0^{\circ}$ Subjected to Vertical Seismic Excitation Only 
RPP-RPT-32239, Rev. 1

M\&D-2008-005-CALC-001, Rev. 1

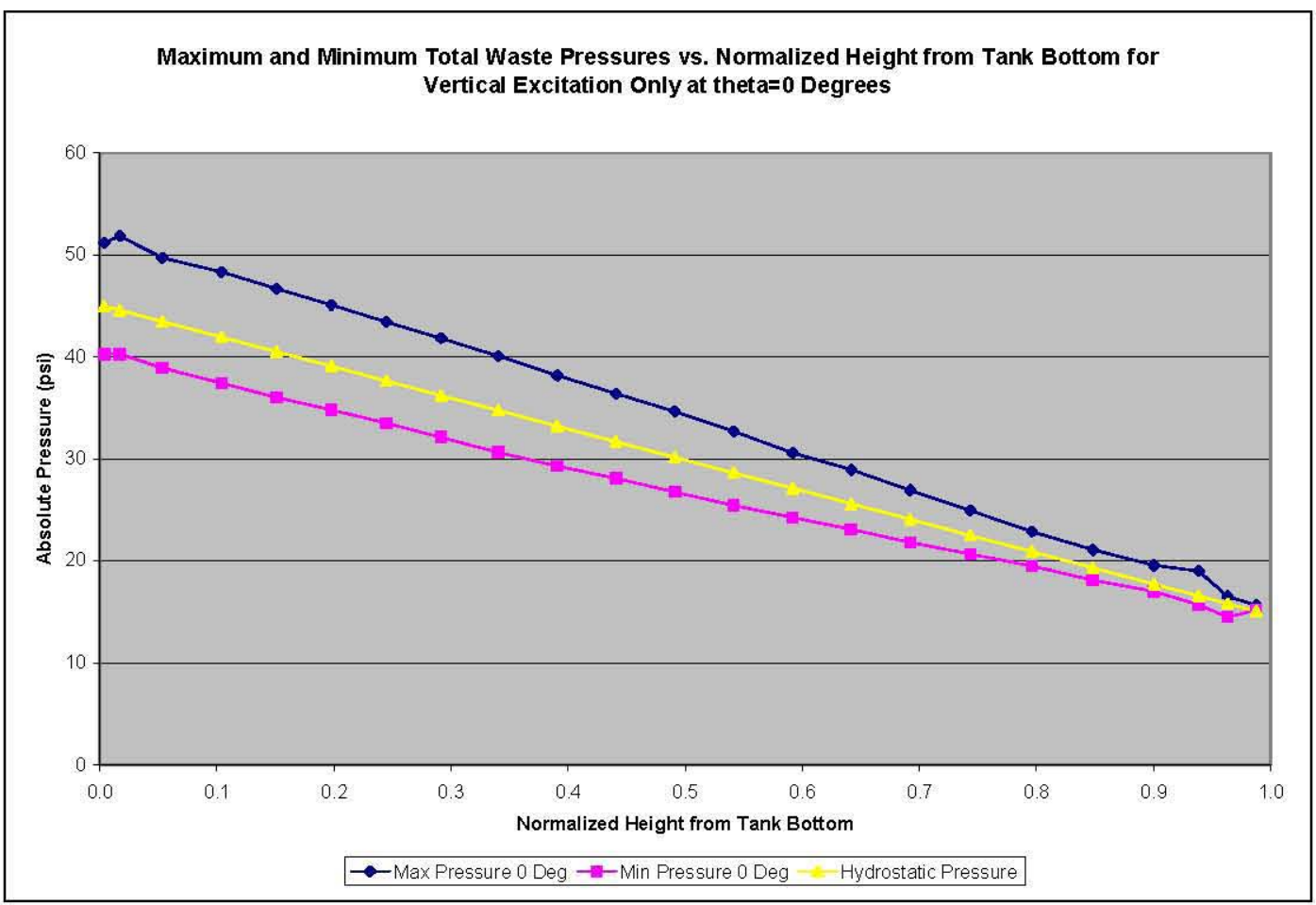

Figure 6-12. Waste Pressure Variation from ANSYS ${ }^{\mathbb{B}}$ Primary Tank Sub-Model for Waste Elements at $\theta=0^{\circ}$ Subjected to Vertical Seismic Excitation Only

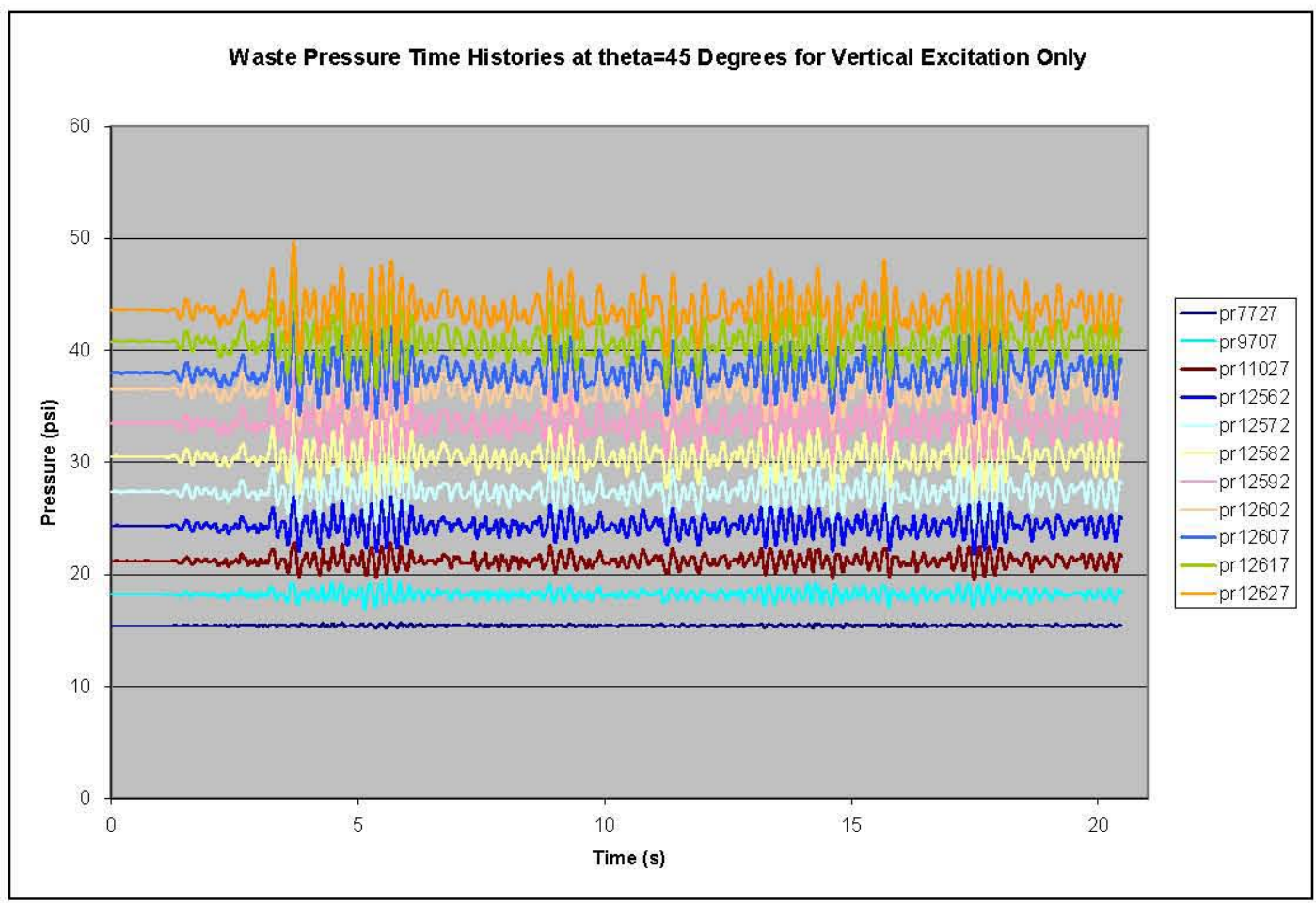

Figure 6-13. Waste Pressure Time Histories from ANSYS ${ }^{\mathbb{B}}$ Primary Tank Sub-Model for Fluid Elements at $\theta=45^{\circ}$ Subjected to Vertical Seismic Excitation Only 
RPP-RPT-32239, Rev. 1

M\&D-2008-005-CALC-001, Rev. 1

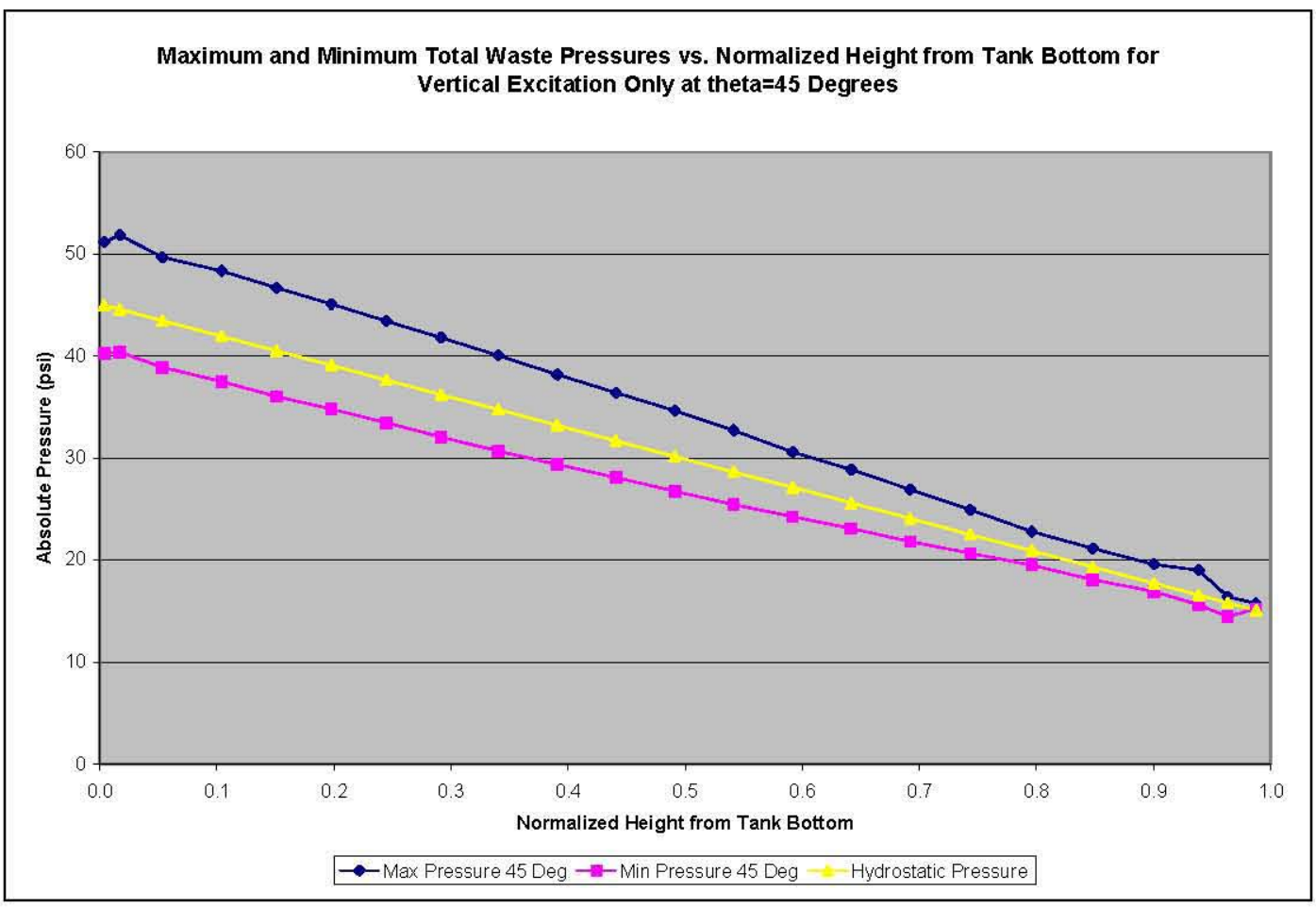

Figure 6-14. Waste Pressure Variation from ANSYS $^{\circledR}$ Primary Tank Sub-Model for Waste Elements at $\theta=45^{\circ}$ Subjected to Vertical Seismic Excitation Only

\subsubsection{Two-Component Motion}

Waste pressure time histories for fluid elements located along the tank wall at $\theta=0^{\circ}, 45^{\circ}$, and $90^{\circ}$ when subjected to two-component seismic excitation are shown in Figure 6-15, Figure 6-17, and Figure 6-19, respectively. Maximum and minimum pressure distributions are shown in Figure 6-16, Figure 6-18, and Figure 6-20, respectively. The peak pressures are higher for two-component motion than for either horizontal motion or vertical motion separately and the timing of the peaks is different. The waste pressure time histories at $\theta=90^{\circ}$ are nearly the same as for vertical motion only, as expected, since the contribution to dynamic pressure from horizontal excitation is nearly zero at $\theta=90^{\circ}$. 
RPP-RPT-32239, Rev. 1

M\&D-2008-005-CALC-001, Rev. 1

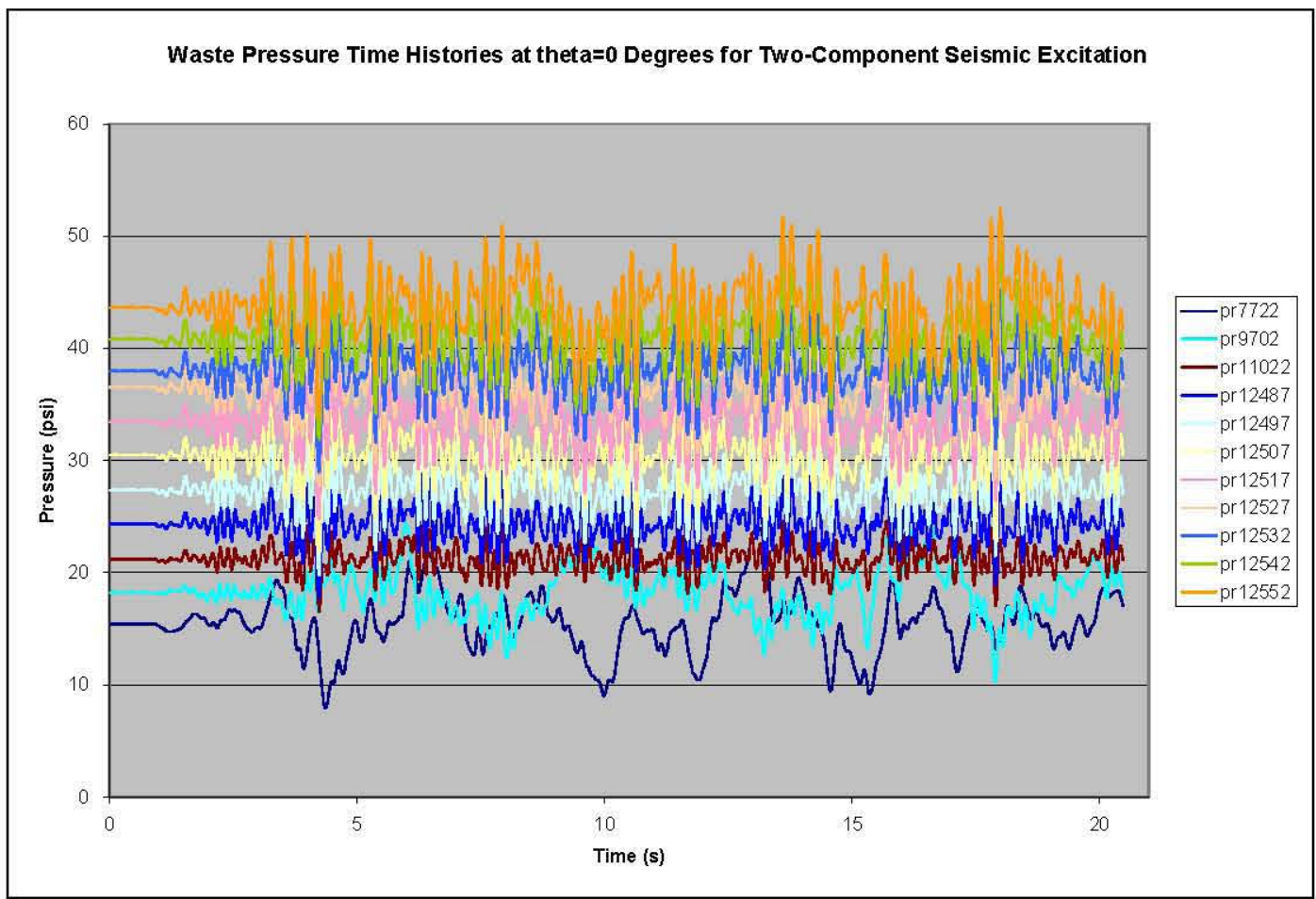

Figure 6-15. Waste Pressure Time Histories from ANSYS ${ }^{\circledR}$ Primary Tank Sub-Model for Fluid Elements at $\theta=0^{\circ}$ Subjected to Two-Component Seismic Excitation

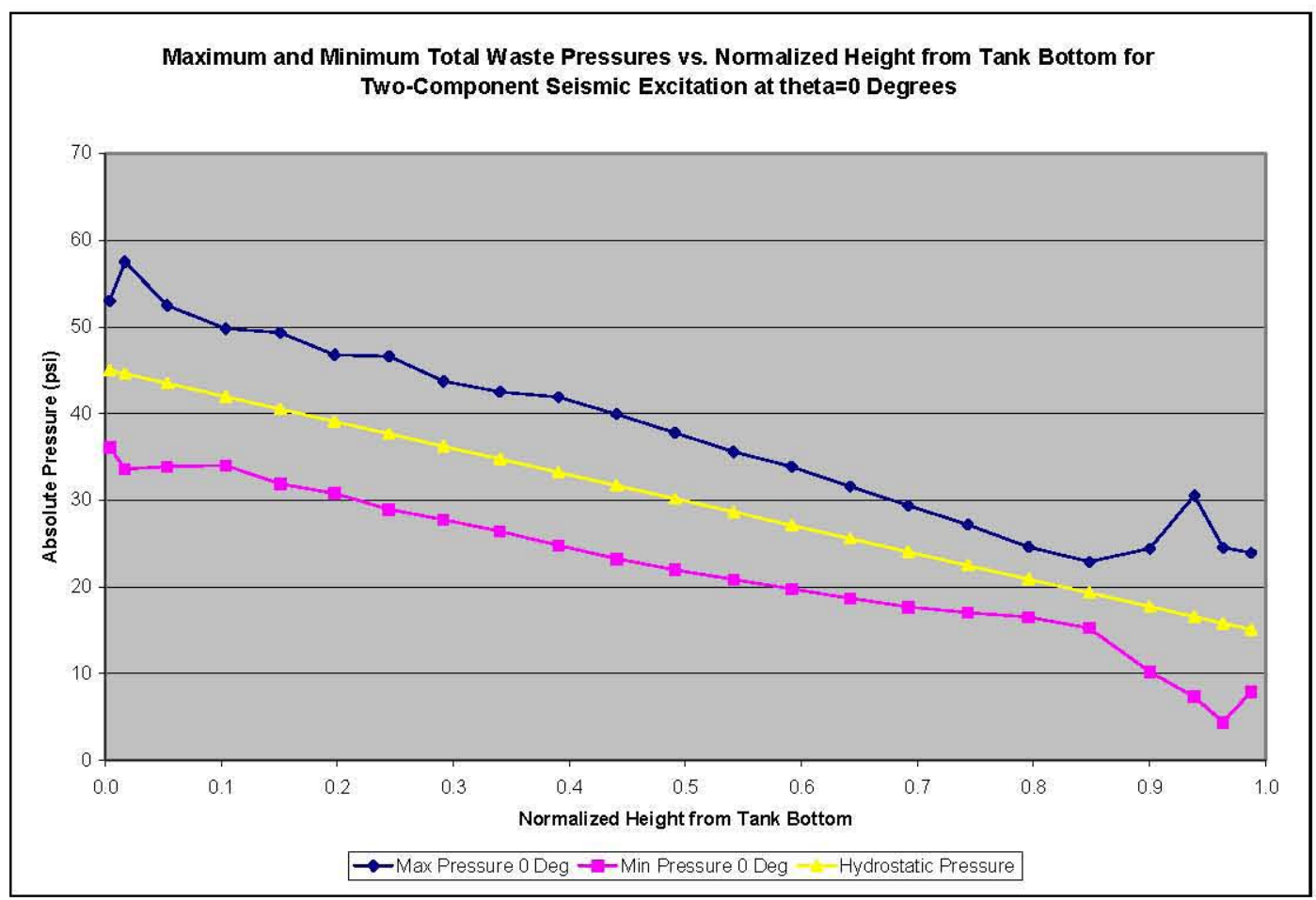

Figure 6-16. Waste Pressure Variation from ANSYS $^{\mathbb{B}}$ Primary Tank Sub-Model for Waste Elements at $\theta=0^{\circ}$ Subjected to Two-Component Seismic Excitation 
RPP-RPT-32239, Rev. 1

M\&D-2008-005-CALC-001, Rev. 1

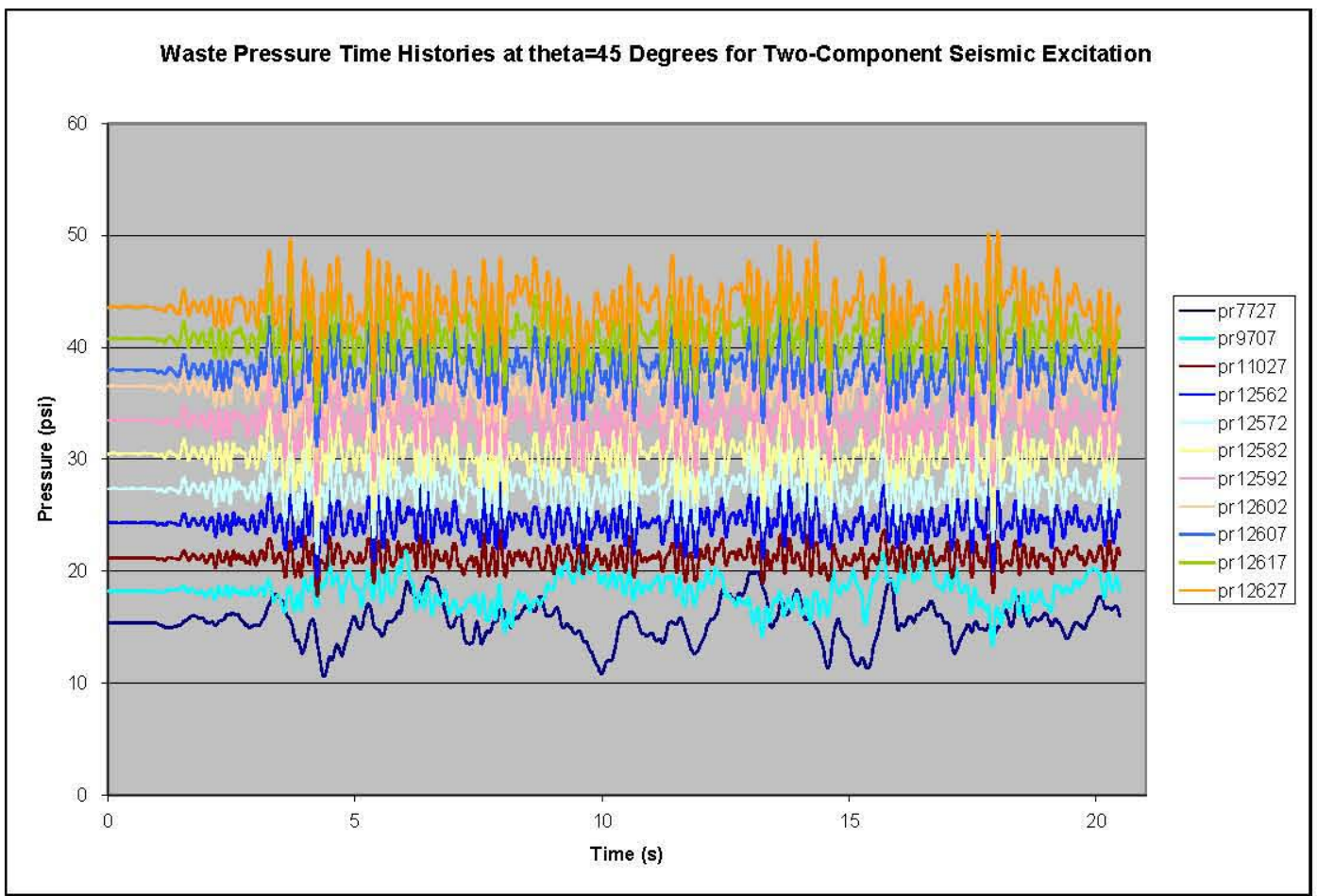

Figure 6-17. Waste Pressure Time Histories from ANSYS ${ }^{\circledR}$ Primary Tank Sub-Model for Fluid Elements at $\theta=45^{\circ}$ Subjected to Two-Component Seismic Excitation

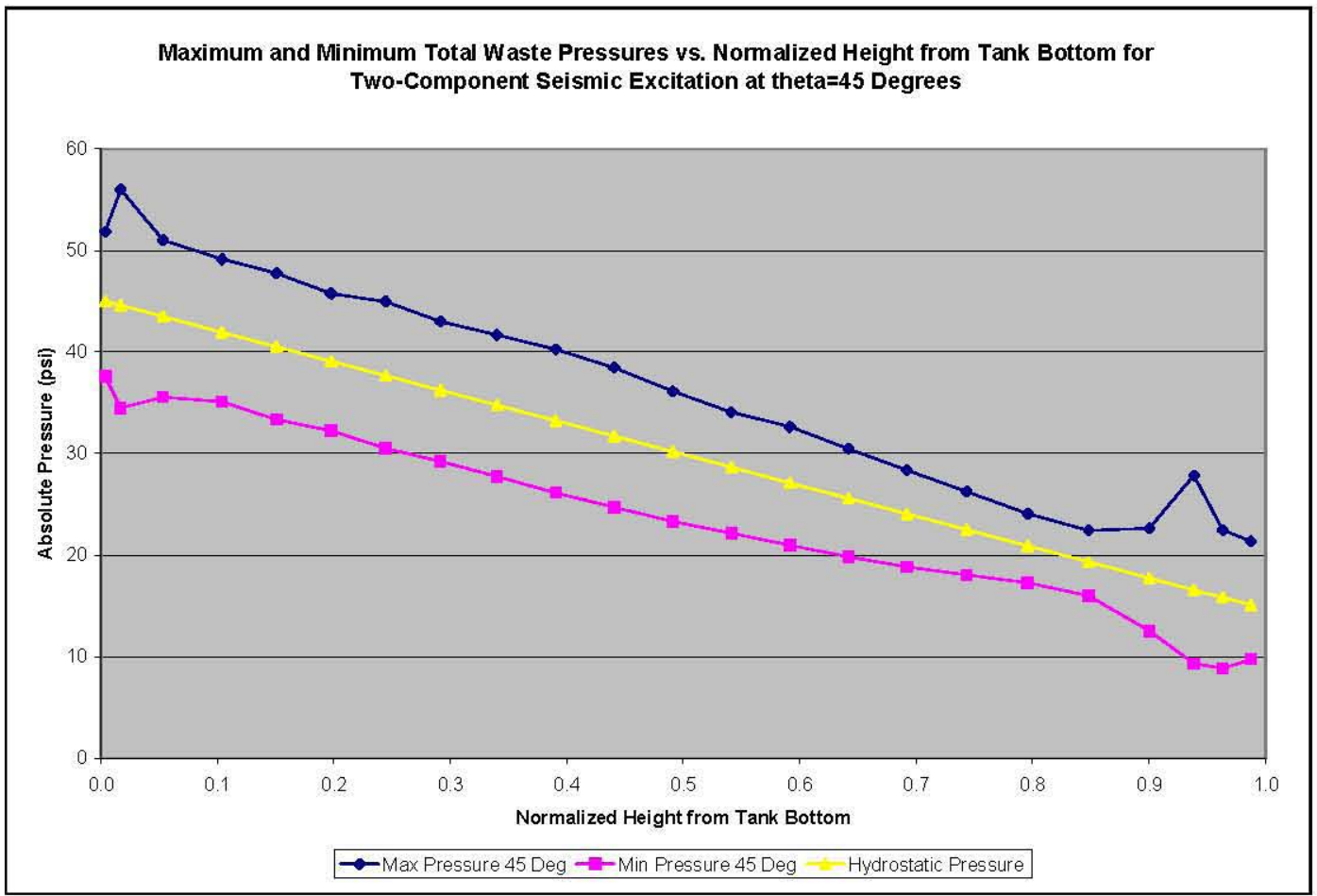

Figure 6-18. Waste Pressure Variation from ANSYS ${ }^{\circledR}$ Primary Tank Sub-Model for Waste Elements at $\theta=45^{\circ}$ Subjected to Two-Component Seismic Excitation 
RPP-RPT-32239, Rev. 1

M\&D-2008-005-CALC-001, Rev. 1

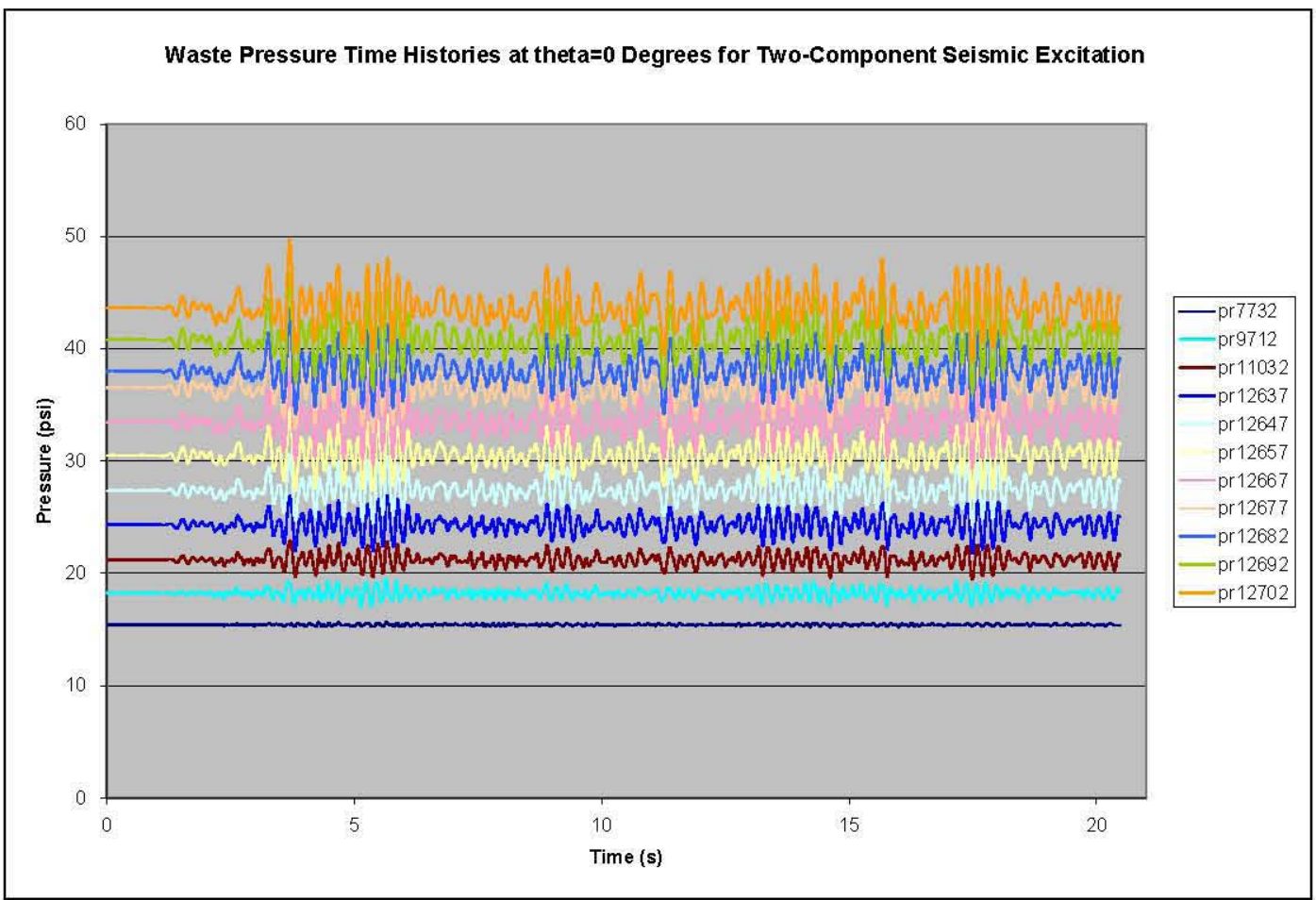

Figure 6-19. Waste Pressure Time Histories from ANSYS ${ }^{\circledR}$ Primary Tank Sub-Model for Fluid Elements at $\theta=90^{\circ}$ Subjected to Two-Component Seismic Excitation

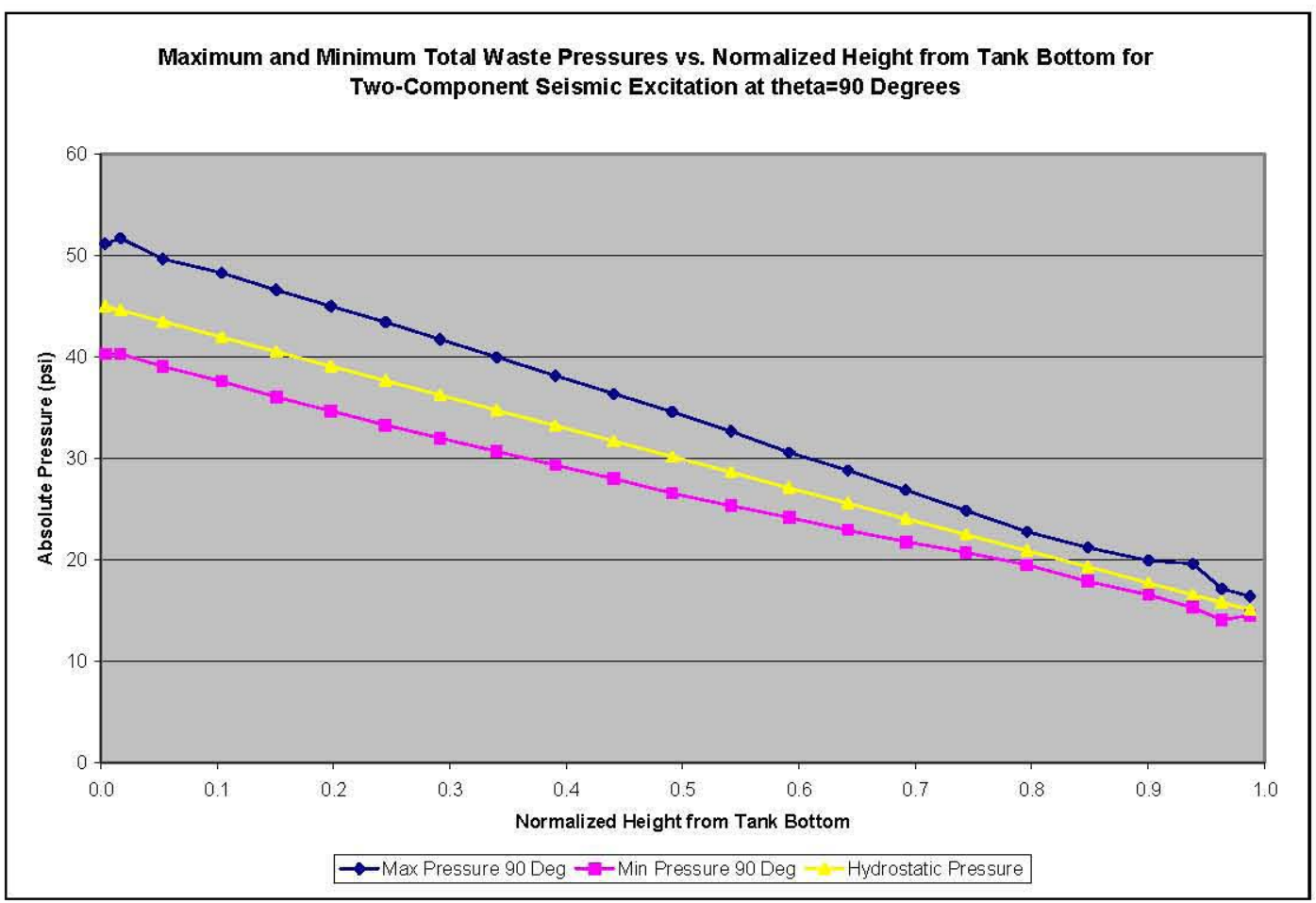

Figure 6-20. Waste Pressure Variation from ANSYS ${ }^{\mathbb{B}}$ Primary Tank Sub-Model for Waste Elements at $\theta=90^{\circ}$ Subjected to Two-Component Seismic Excitation 
RPP-RPT-32239, Rev. 1

M\&D-2008-005-CALC-001, Rev. 1

\subsection{Primary Tank Stresses from ANSYS ${ }^{\circledR}$ Sub-Model}

Primary tank stresses from the ANSYS ${ }^{\circledR}$ sub-model for horizontal excitation, vertical excitation, and twocomponent excitation are presented and discussed in the next three sections.

\subsubsection{Horizontal Excitation Only}

Maximum and minimum stresses in the primary tank for horizontal excitation only are plotted in Figure 6-21 through Figure 6-27. The plots show that there is very little bending in the hoop response at $\theta=0^{\circ}$ and $45^{\circ}$ except near the free-surface. The data also show that the meridional stresses are fairly low and are dominated by membrane response, except near free surface and knuckle. The shear stresses are low in the plane of excitation and increase with increasing angle from the plane of excitation, as expected.

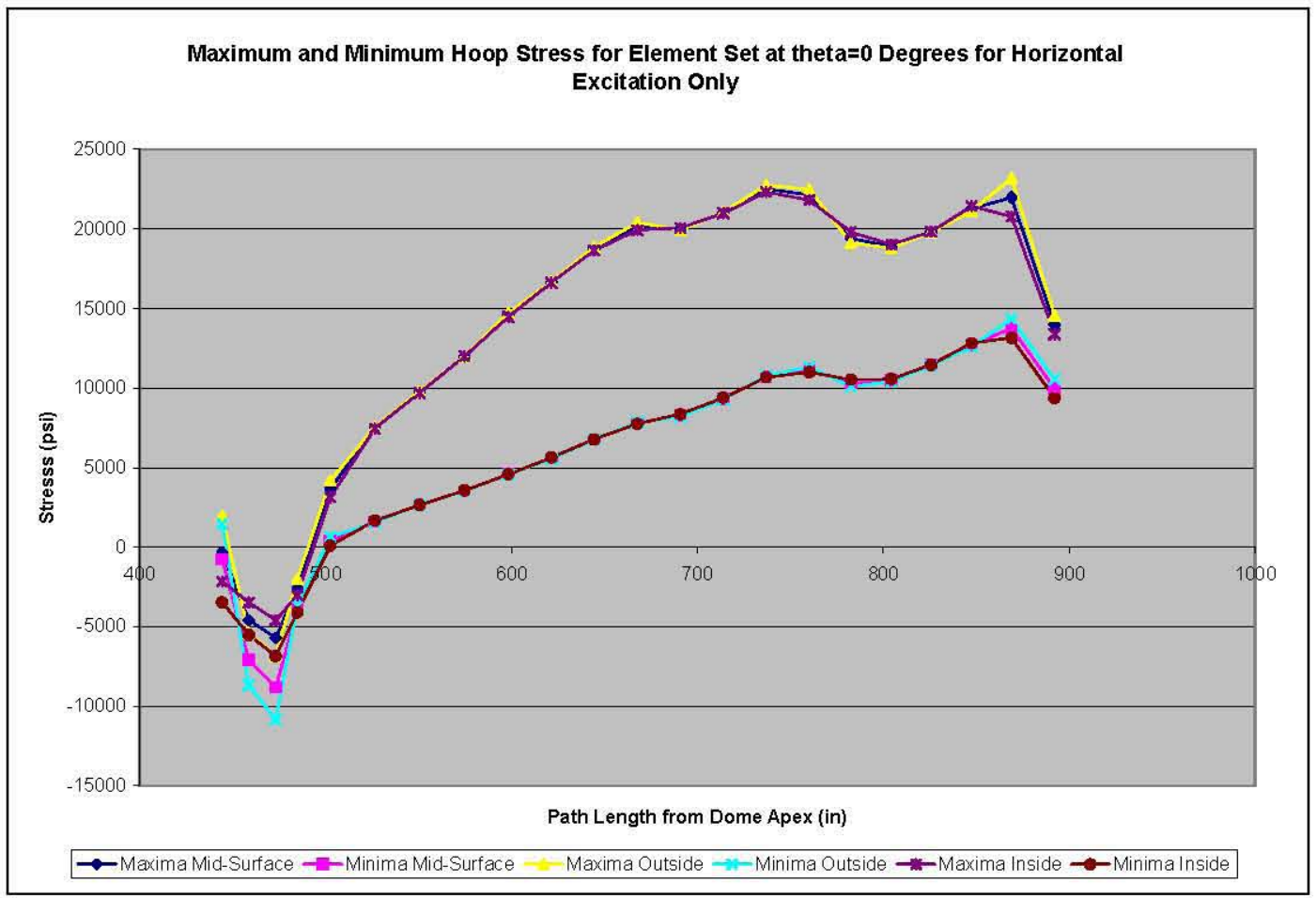

Figure 6-21. Maximum and Minimum Hoop Stress vs. Path Length at $\theta=0^{\circ}$ for Horizontal Seismic Excitation Only 
RPP-RPT-32239, Rev. 1

M\&D-2008-005-CALC-001, Rev. 1

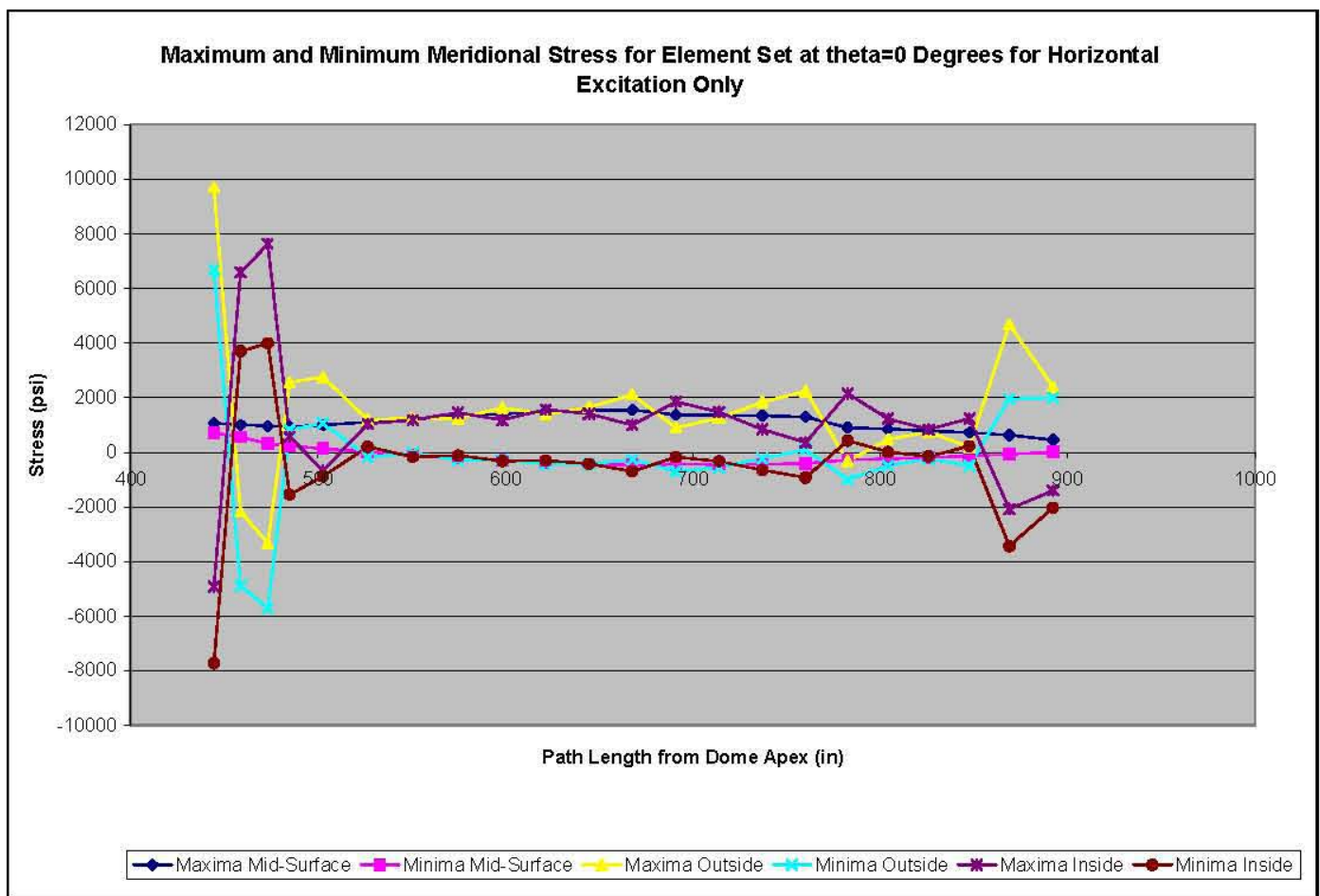

Figure 6-22. Maximum and Minimum Meridional Stress vs. Path Length at $\theta=0^{\circ}$ for Horizontal Seismic Excitation Only

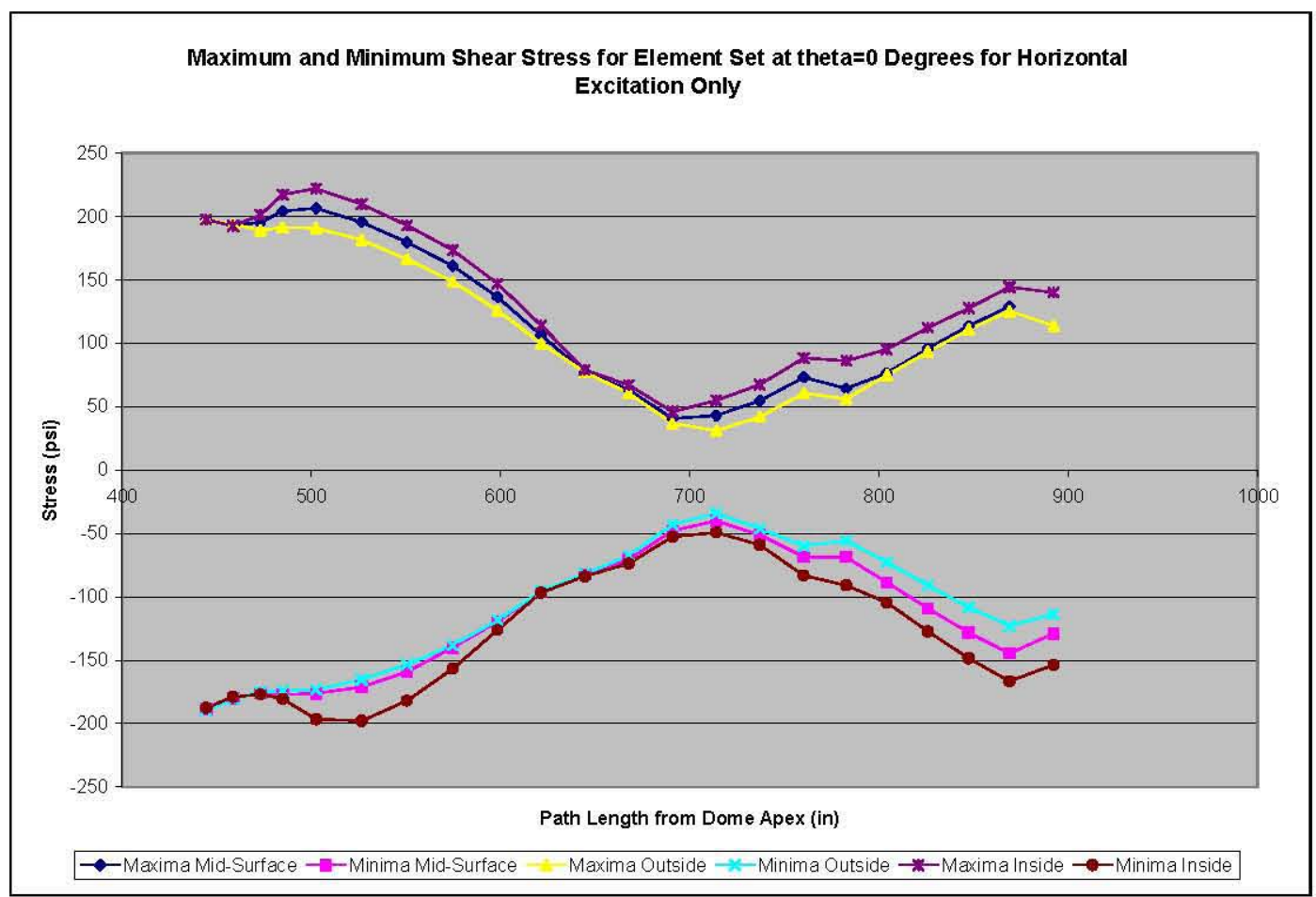

Figure 6-23. Maximum and Minimum Shear Stress vs. Path Length at $\theta=0^{\circ}$ for Horizontal Seismic Excitation Only 
RPP-RPT-32239, Rev. 1

M\&D-2008-005-CALC-001, Rev. 1

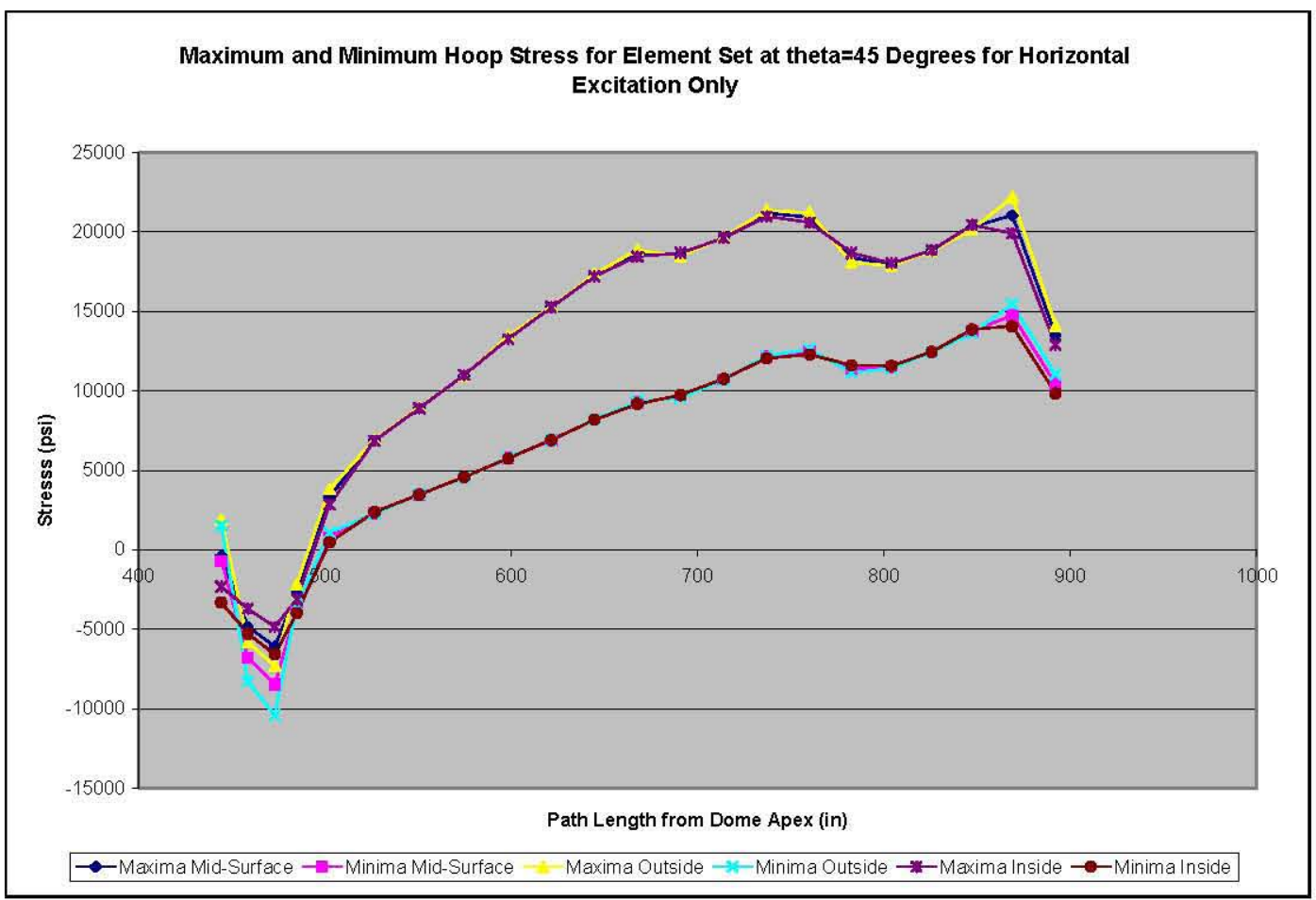

Figure 6-24. Maximum and Minimum Hoop Stress vs. Path Length at $\theta=45^{\circ}$ for Horizontal Seismic Excitation Only

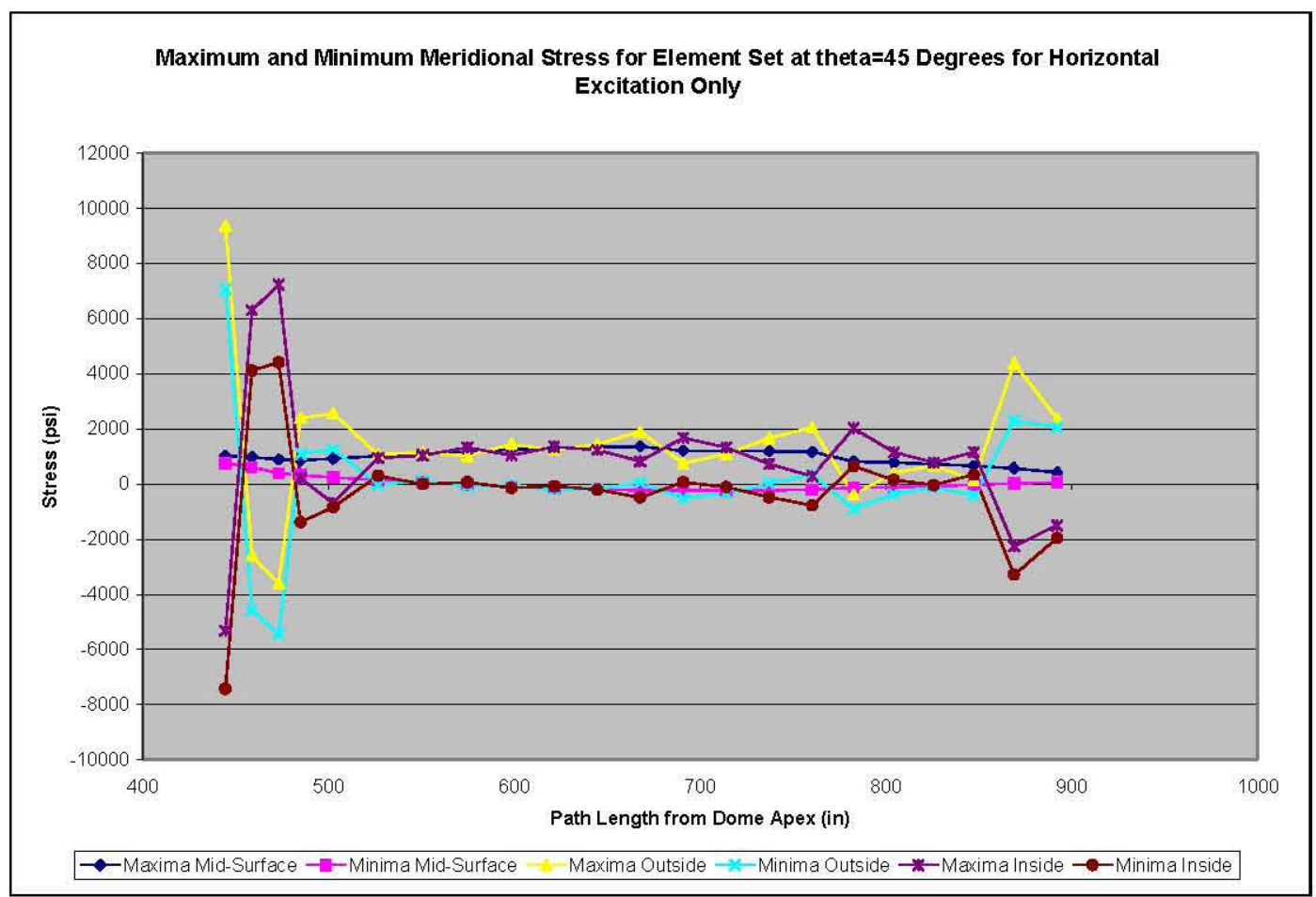

Figure 6-25. Maximum and Minimum Meridional Stress vs. Path Length at $\theta=45^{\circ}$ for Horizontal Seismic Excitation Only 
RPP-RPT-32239, Rev. 1

M\&D-2008-005-CALC-001, Rev. 1

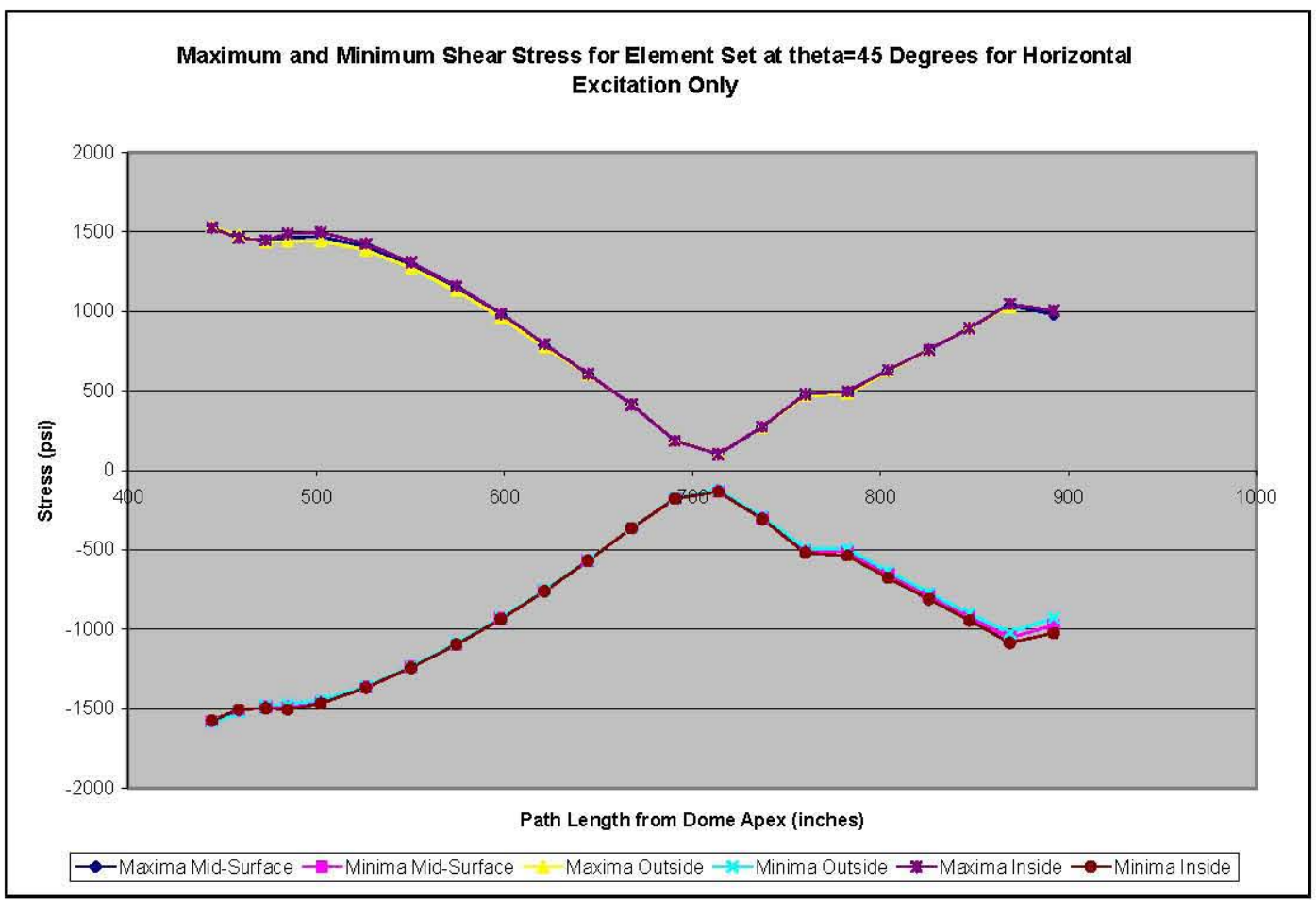

Figure 6-26. Maximum and Minimum Shear Stress vs. Path Length at $\theta=45^{\circ}$ for Horizontal Seismic Excitation Only

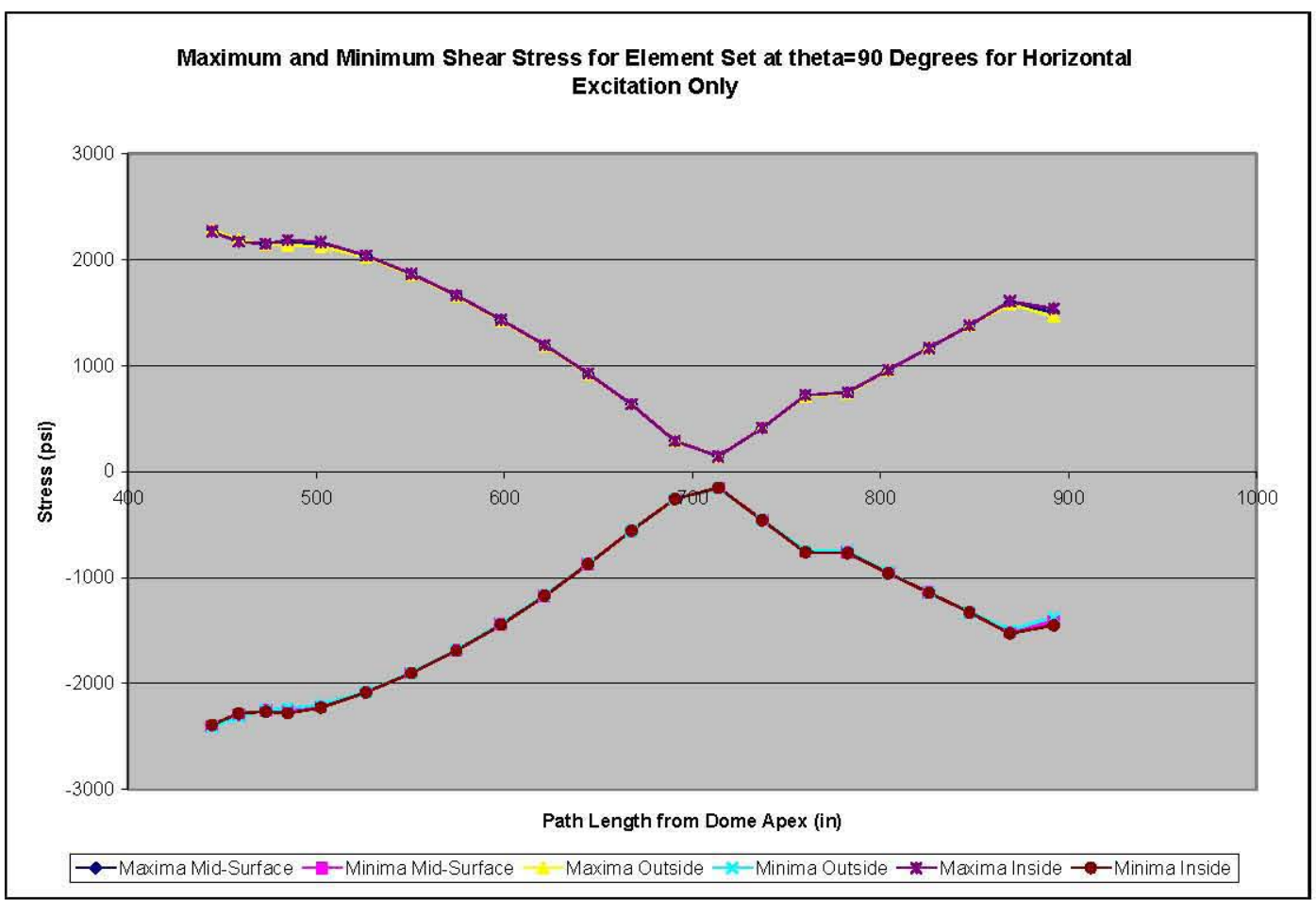

Figure 6-27. Maximum and Minimum Shear Stress vs. Path Length at $\theta=90^{\circ}$ for Horizontal Seismic Excitation Only 
RPP-RPT-32239, Rev. 1

M\&D-2008-005-CALC-001, Rev. 1

\subsubsection{Vertical Excitation Only}

In the case of vertical excitation only, maximum and minimum stress distributions for hoop, meridional, and shear components at $\theta=0^{\circ}$ are shown in Figure 6-28, Figure 6-29, and Figure 6-30. The stress distributions for vertical excitation only are very similar to those for horizontal excitation only, except that shear stresses are negligible for the vertical case. This indicates that primary tank stresses are dominated by gravity loading.

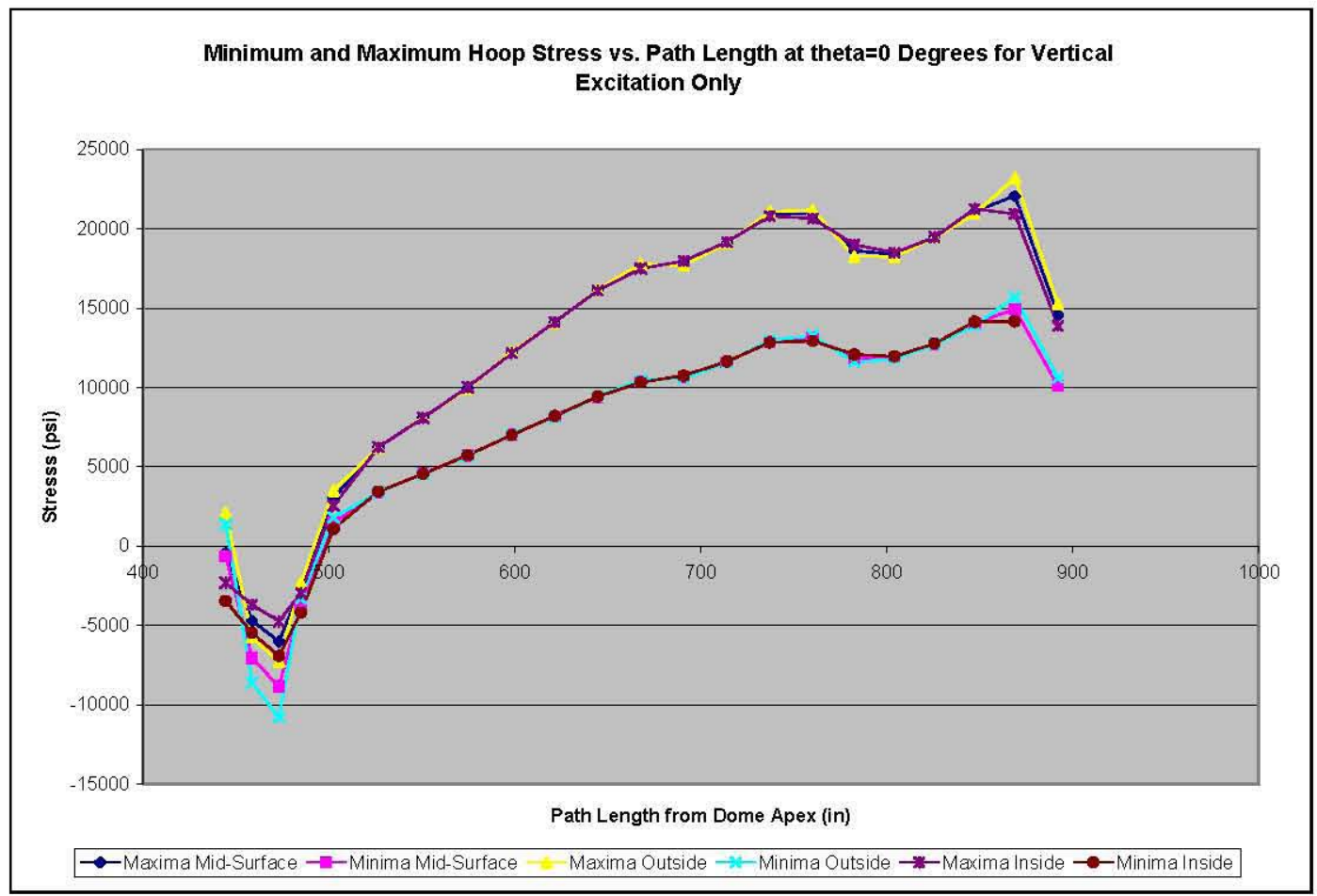

Figure 6-28. Maximum and Minimum Hoop Stress vs. Path Length at $\theta=0^{\circ}$ for Vertical Seismic Excitation Only 
RPP-RPT-32239, Rev. 1

M\&D-2008-005-CALC-001, Rev. 1

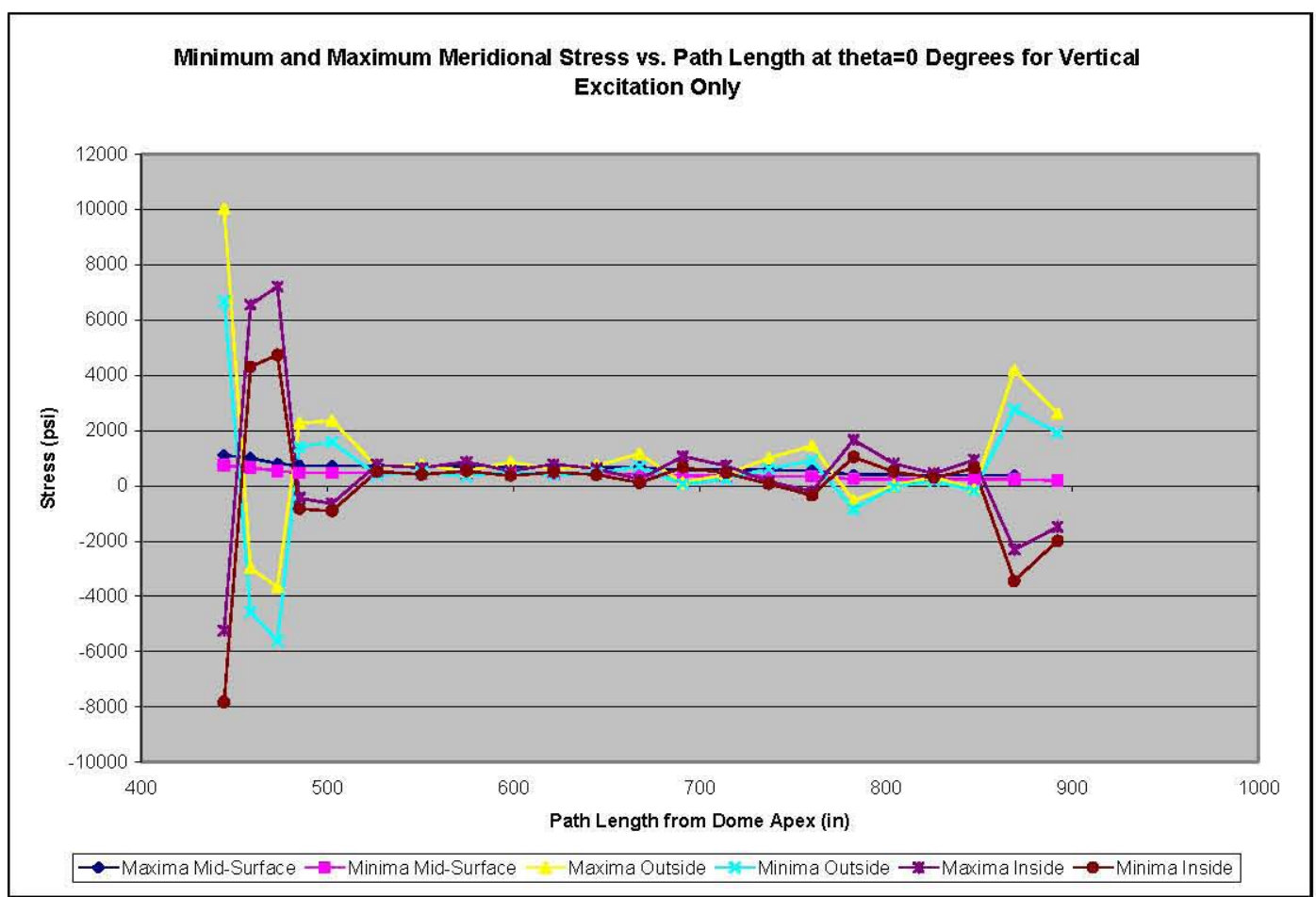

Figure 6-29. Maximum and Minimum Meridional Stress vs. Path Length at $\theta=0^{\circ}$ for Vertical Seismic Excitation Only

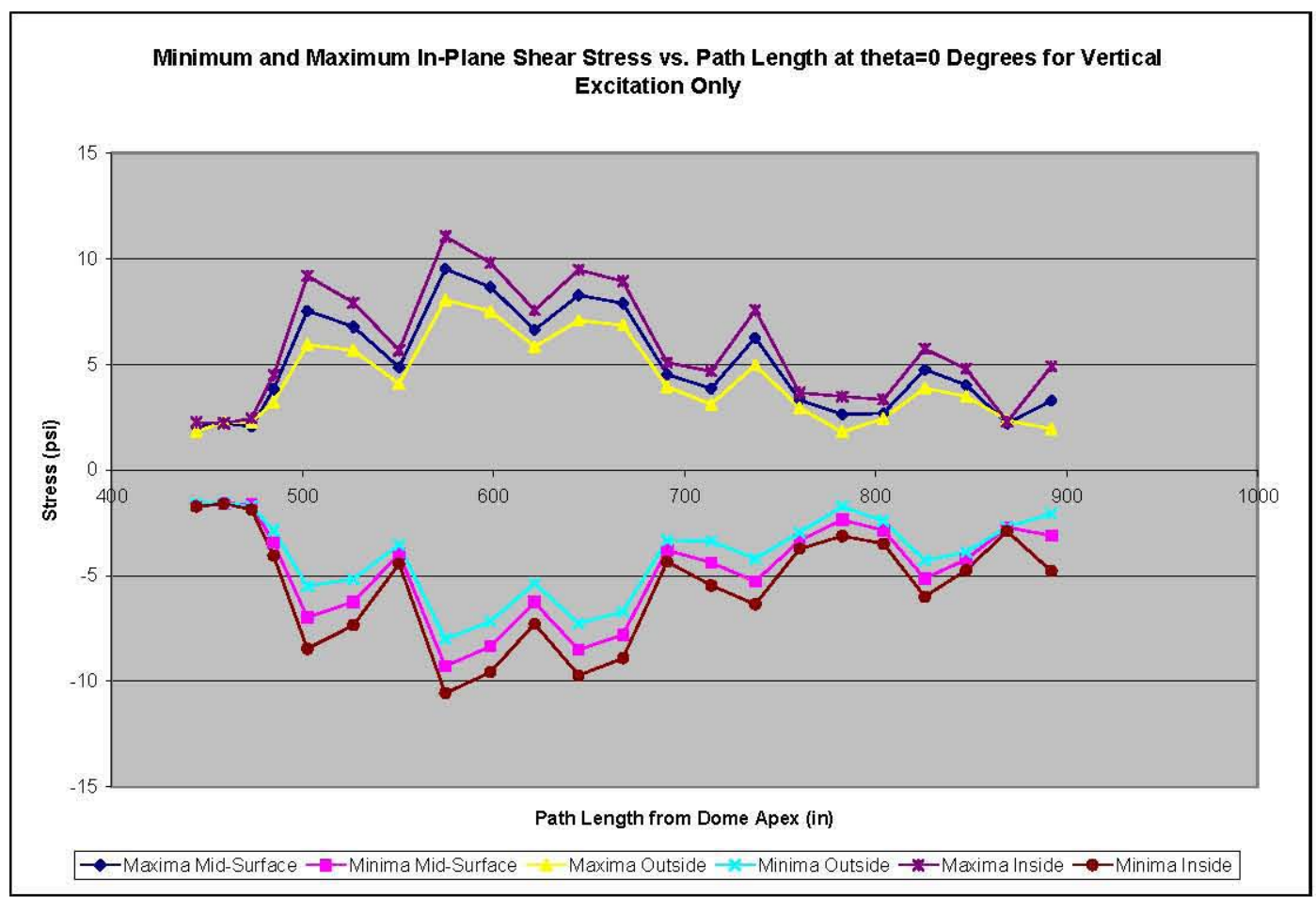

Figure 6-30. Maximum and Minimum Shear Stress vs. Path Length at $\theta=0^{\circ}$ for Vertical Seismic Excitation Only 
RPP-RPT-32239, Rev. 1

M\&D-2008-005-CALC-001, Rev. 1

\subsubsection{Two-Component Motion}

Maximum and minimum stress distributions for the case of two-component motion are shown in Figure 6-31 through Figure 6-37. In general, the plots show that the hoop and meridional stress distributions are very similar in character to those for horizontal and vertical excitation only, but the magnitudes are slightly higher. The shear stresses are essentially the same as for the horizontal case, which makes sense because the shear stresses were negligible in the case of vertical excitation only.

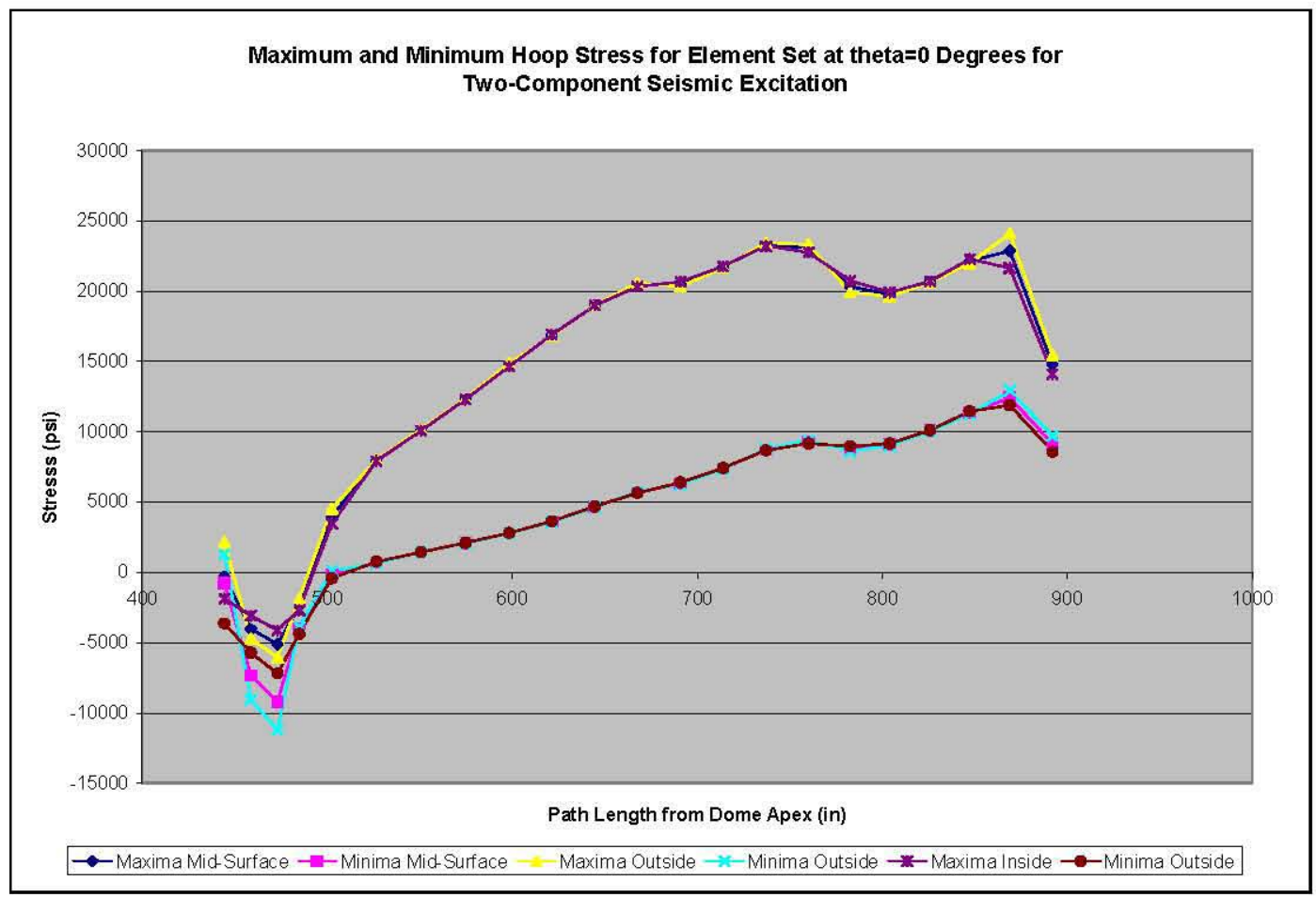

Figure 6-31. Maximum and Minimum Hoop Stress vs. Path Length at $\theta=0^{\circ}$ for Two-Component Seismic Excitation 
RPP-RPT-32239, Rev. 1

M\&D-2008-005-CALC-001, Rev. 1

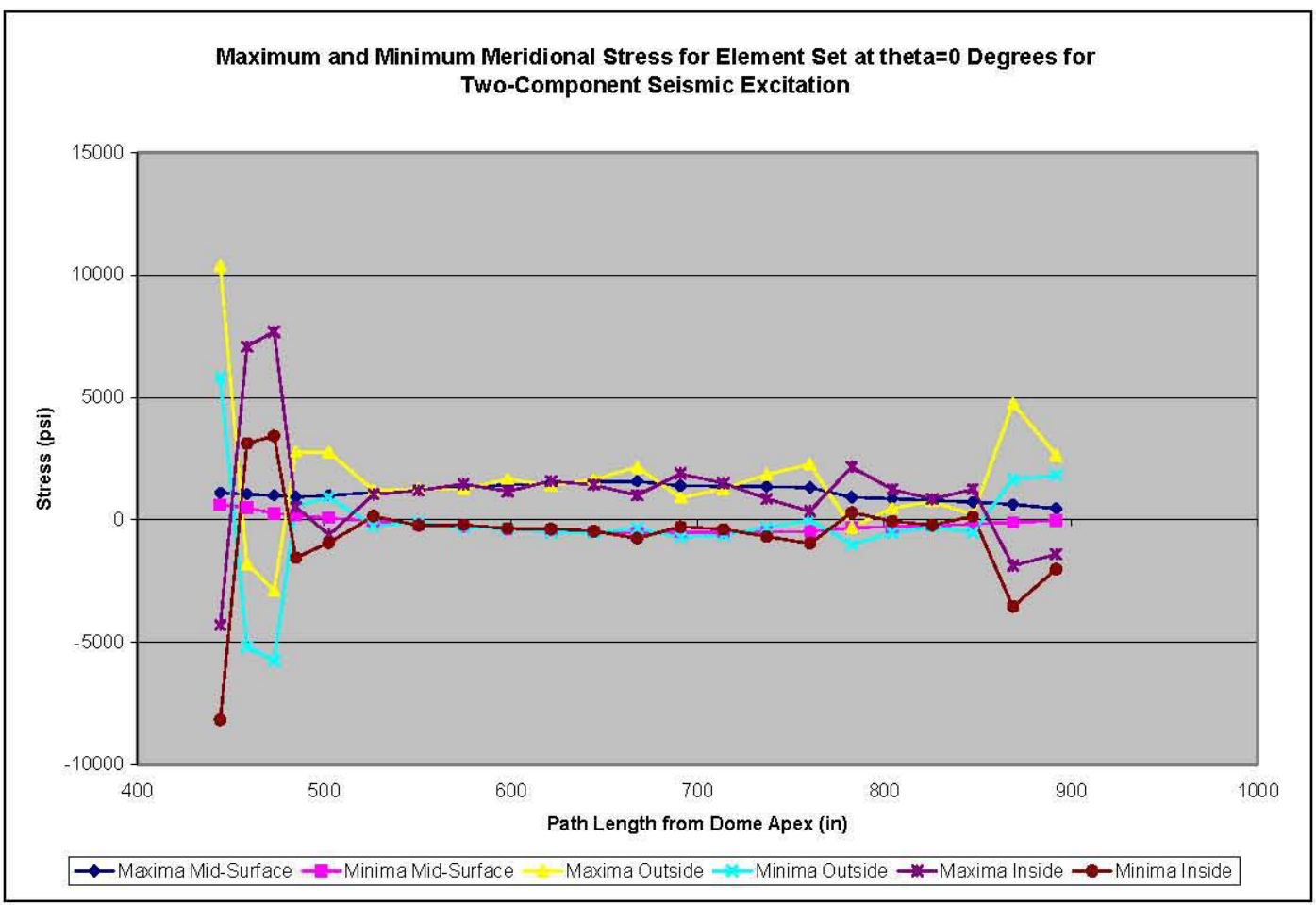

Figure 6-32. Maximum and Minimum Meridional Stress vs. Path Length at $\theta=0^{\circ}$ for Two-Component Seismic Excitation

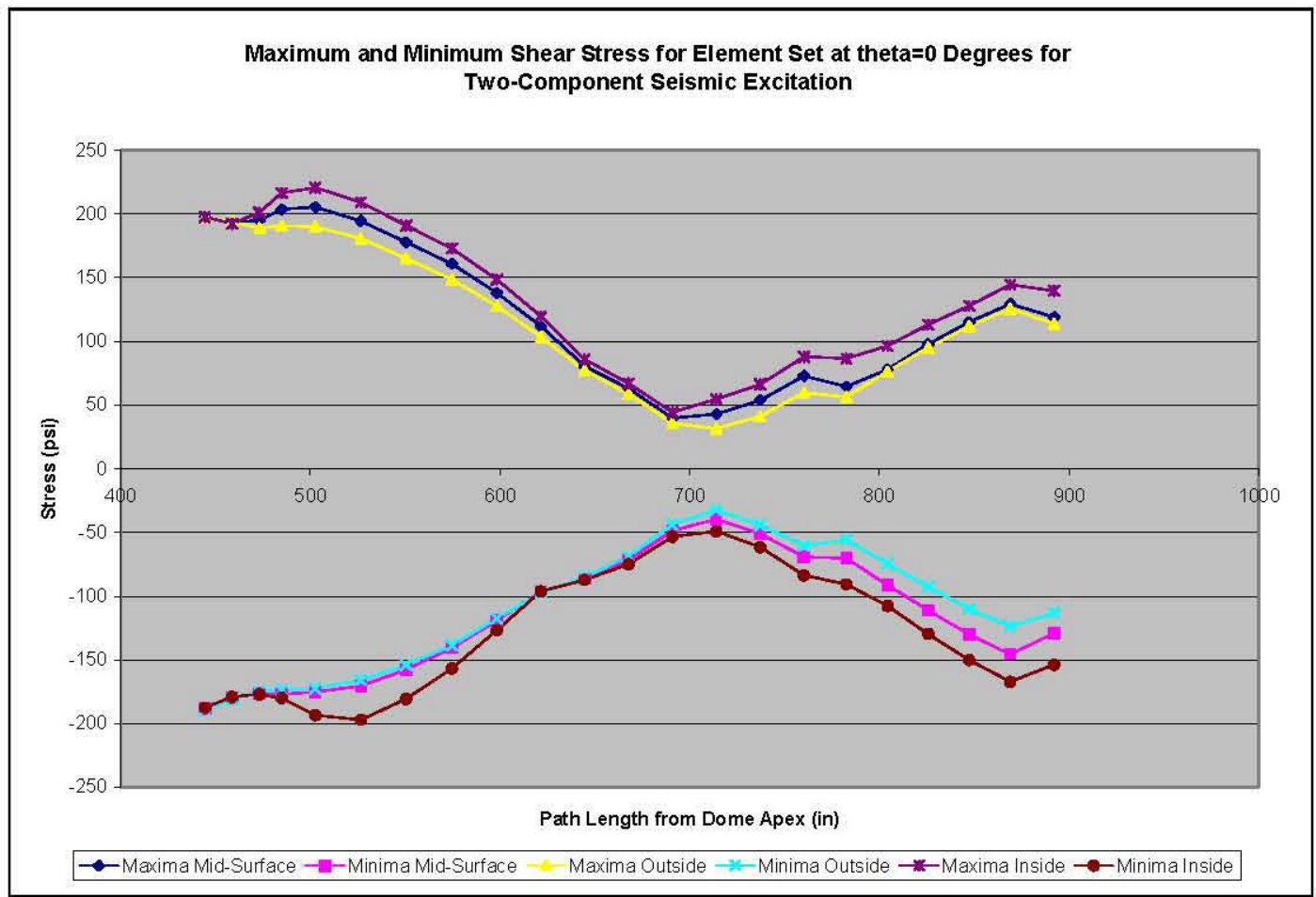

Figure 6-33. Maximum and Minimum Shear Stress vs. Path Length at $\theta=0^{\circ}$ for Two-Component Seismic Excitation 
RPP-RPT-32239, Rev. 1

M\&D-2008-005-CALC-001, Rev. 1

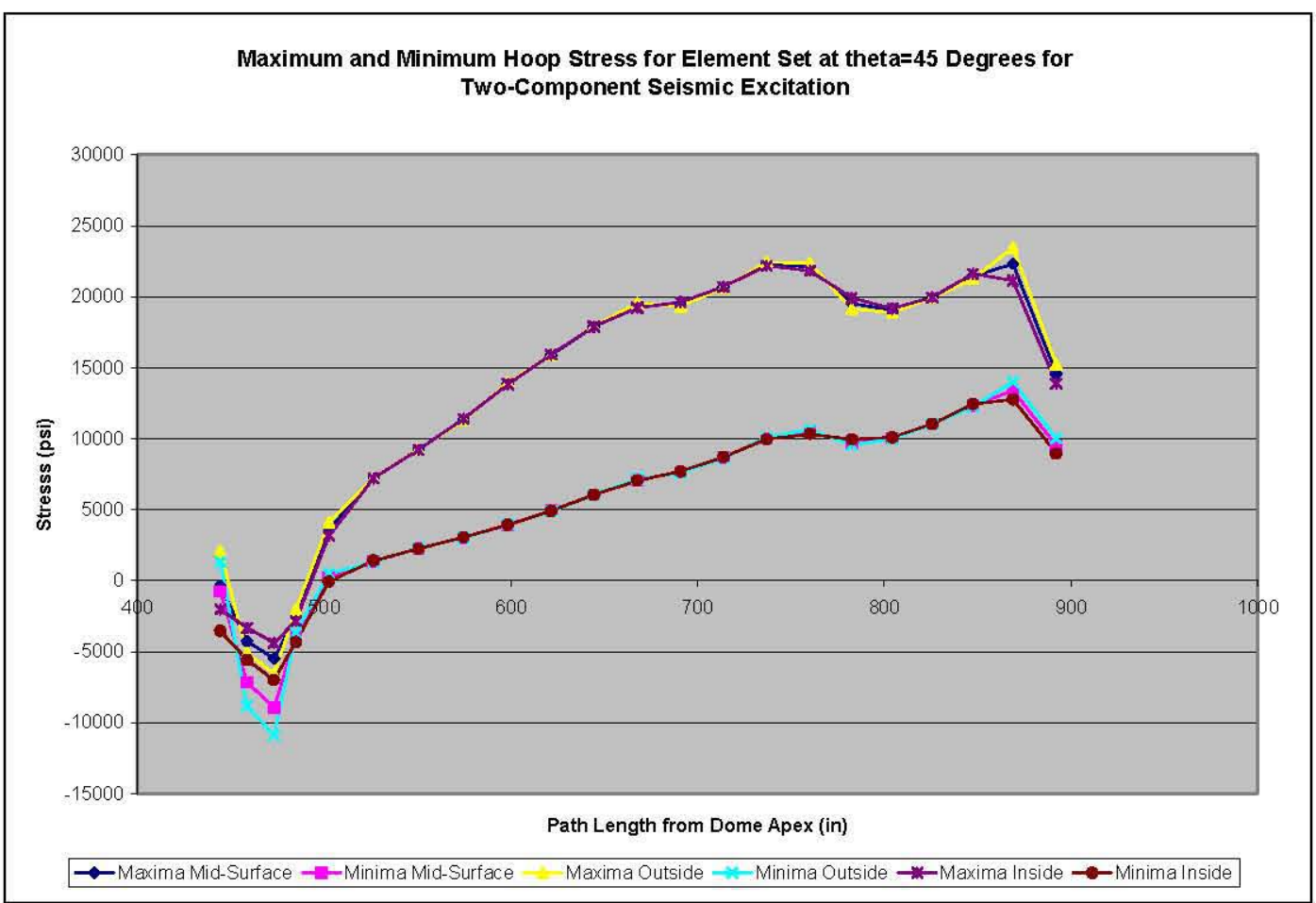

Figure 6-34. Maximum and Minimum Hoop Stress vs. Path Length at $\theta=45^{\circ}$ for Two-Component Seismic Excitation

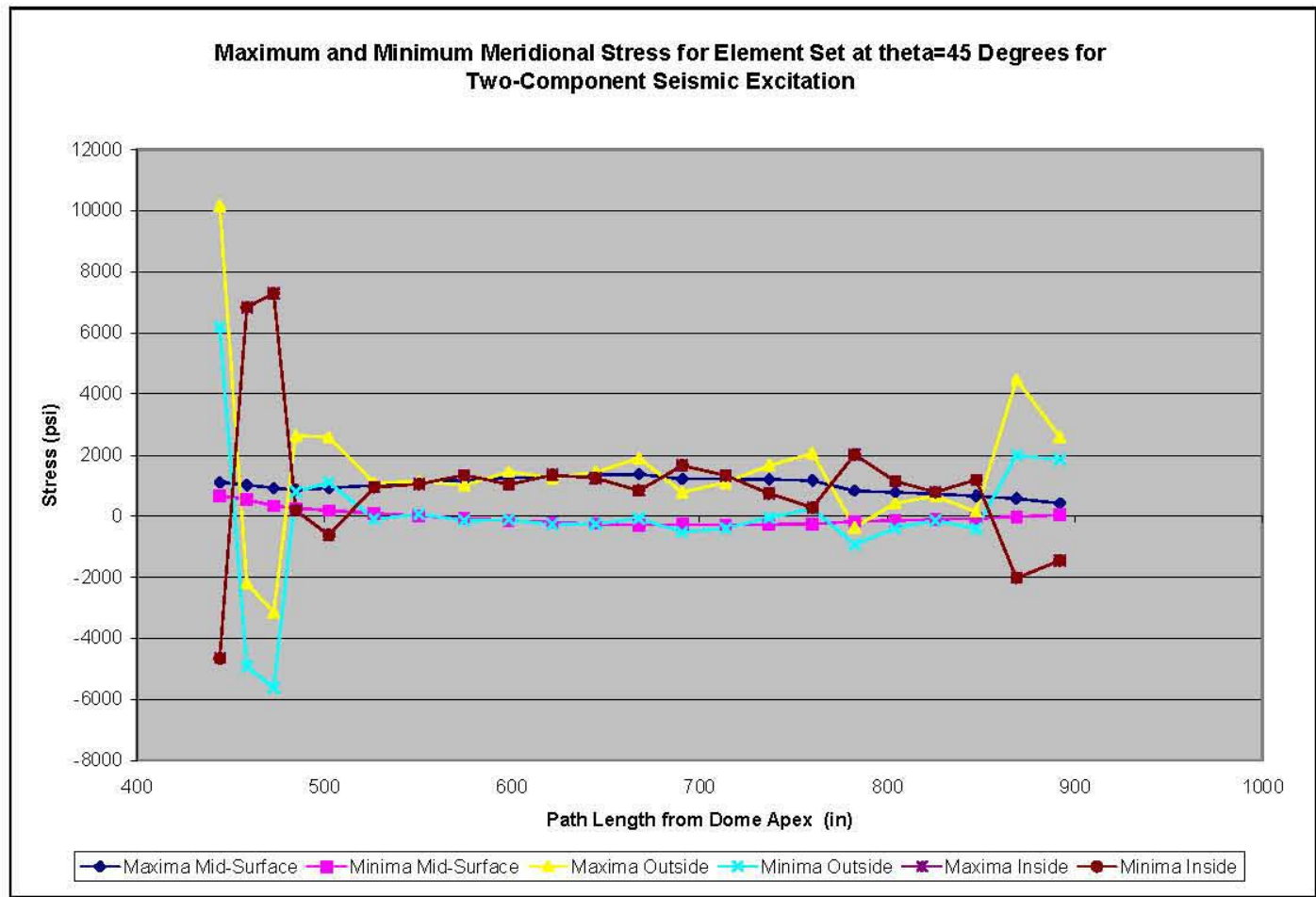

Figure 6-35. Maximum and Minimum Meridional Stress vs. Path Length at $\theta=45^{\circ}$ for Two-Component Seismic Excitation 
RPP-RPT-32239, Rev. 1

M\&D-2008-005-CALC-001, Rev. 1

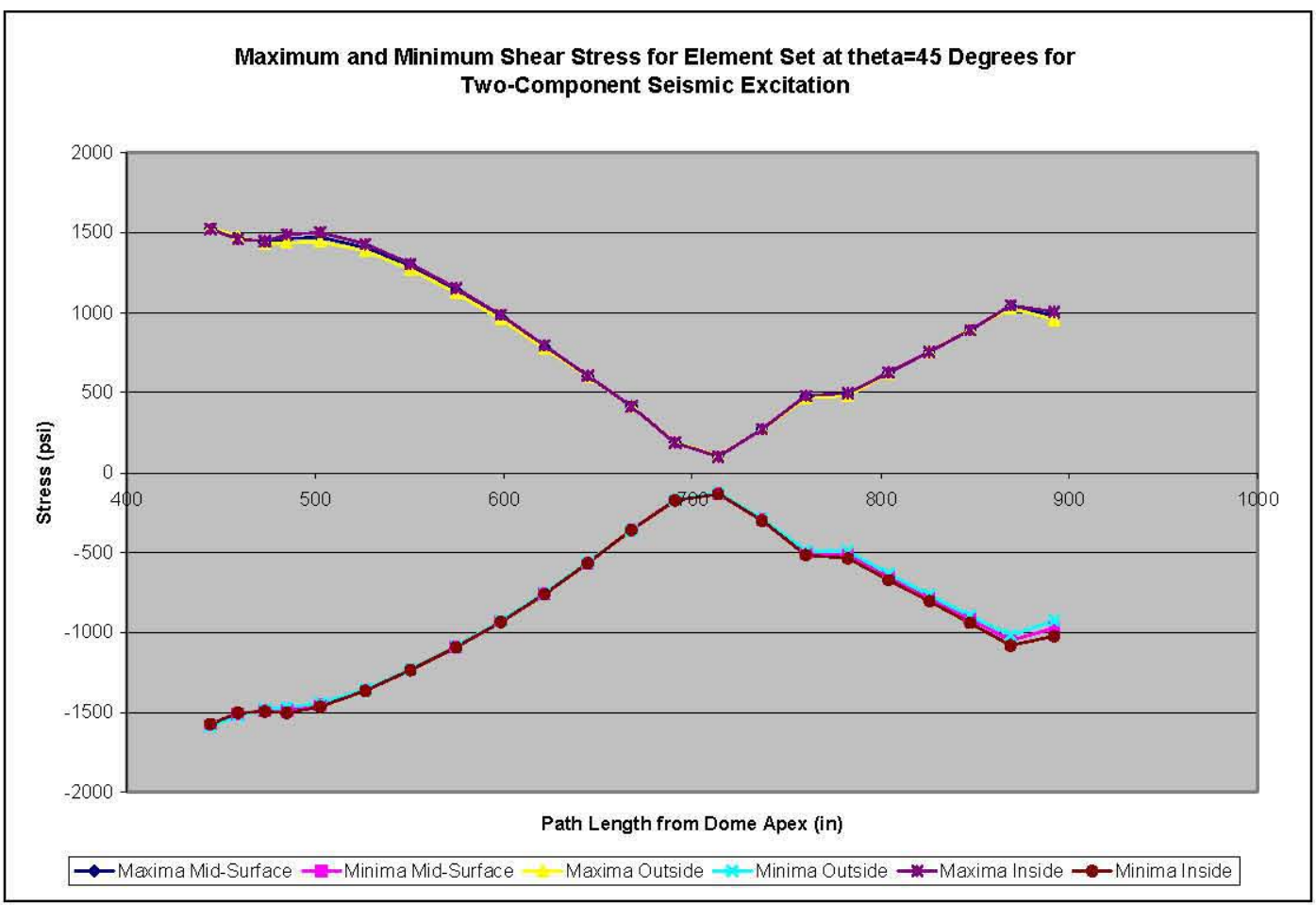

Figure 6-36. Maximum and Minimum Shear Stress vs. Path Length at $\theta=45^{\circ}$ for Two-Component Seismic Excitation

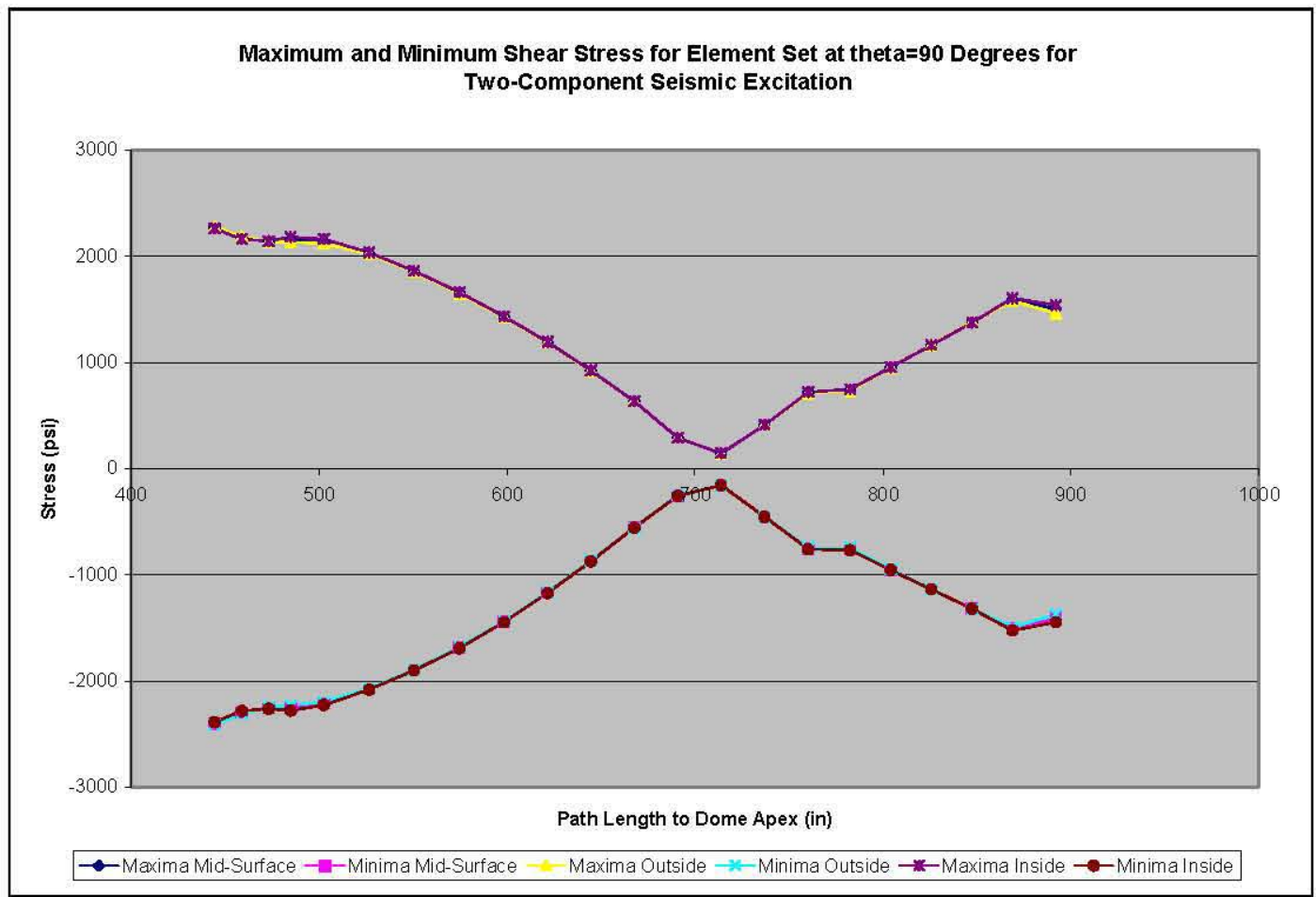

Figure 6-37. Maximum and Minimum Shear Stress vs. Path Length at $\theta=90^{\circ}$ for Two-Component Seismic Excitation 
RPP-RPT-32239, Rev. 1

M\&D-2008-005-CALC-001, Rev. 1

Intentionally left blank. 
RPP-RPT-32239, Rev. 1

M\&D-2008-005-CALC-001, Rev. 1

\subsection{ANSYS $^{\circledR}$ to Dytran ${ }^{\circledR}$ Comparisons for Primary Tank Sub-Models}

In the following sections, comparisons of frequencies, hydrodynamic forces, waste pressures, and tank stresses are presented for the ANSYS ${ }^{\circledR}$ and Dytran ${ }^{\mathbb{B}}$ sub-models. Comparisons with stresses predicted by the global ANSYS ${ }^{\mathbb{B}}$ model are presented in Section 7.4.4. The intent of the comparisons is to show that the stresses predicted by the ANSYS ${ }^{\mathbb{B}}$ models are either nearly the same as the Dytran ${ }^{\mathbb{B}}$ model, are small in magnitude, or small relative to the available margin.

\subsection{Frequency Comparisons}

A summary of fundamental frequencies predicted by both ANSYS $^{\mathbb{B}}$ and Dytran ${ }^{\mathbb{B}}$ is given in Table 7-1. The convective, impulsive, and breathing mode frequencies are within approximately $1 \%$ between the $\mathrm{ANSYS}^{\mathbb{B}}$ and Dytran ${ }^{\mathbb{B}}$ models.

Table 7-1. Comparison of ANSYS ${ }^{\mathbb{B}}$ and $\operatorname{Dytran}^{\mathbb{B}}$ Frequencies for Primary Tank Sub-Models

\begin{tabular}{|c|c|c|c|c|c|c|}
\hline \multicolumn{2}{|c|}{$\begin{array}{c}\text { First Convective } \\
\text { Mode Frequency (Hz) }\end{array}$} & \multicolumn{3}{|c|}{ Impulsive Mode Frequency $(\mathrm{Hz})$} & \multicolumn{2}{|c|}{$\begin{array}{l}\text { Breathing Mode } \\
\text { Frequency (Hz) }\end{array}$} \\
\hline Dytran $^{(3)}$ & ANSYS $^{(\mathbb{B}}$ & $\begin{array}{c}\text { Dytran }^{\circledR} \\
\text { Horizontal } \\
\text { Excitation }\end{array}$ & $\begin{array}{c}\text { Dytran }^{(1)} \text { Two- } \\
\text { Component } \\
\text { Motion }\end{array}$ & ANSYS $^{\circledR}$ & Dytran $^{\circledR}$ & ANSYS $^{\circledR}$ \\
\hline 0.207 & 0.21 & 5.7 & 5.88 & 5.78 & 5.07 & 5.0 \\
\hline
\end{tabular}

\subsection{Hydrodynamic Force Comparisons}

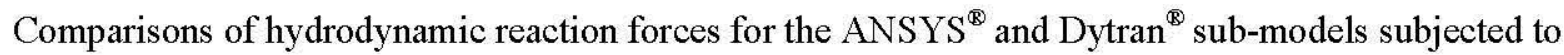
horizontal excitation, vertical excitation, and two-component excitation are presented in the following three sections.

\subsubsection{Horizontal Excitation Only}

Figure 7-1 and Figure 7-2 show a comparison of Dytran ${ }^{\circledR}$ and $\mathrm{ANSYS}^{\circledR}$ horizontal reaction force time histories for horizontal excitation only. The Dytran ${ }^{\mathbb{B}}$ and $\mathrm{ANSYS}^{\mathbb{B}}$ traces are quite similar with the $\mathrm{ANSYS}^{\circledR}$ reaction force time history tending to have slightly higher peaks than the Dytran ${ }^{\circledR}$ time history. 
RPP-RPT-32239, Rev. 1

M\&D-2008-005-CALC-001, Rev. 1

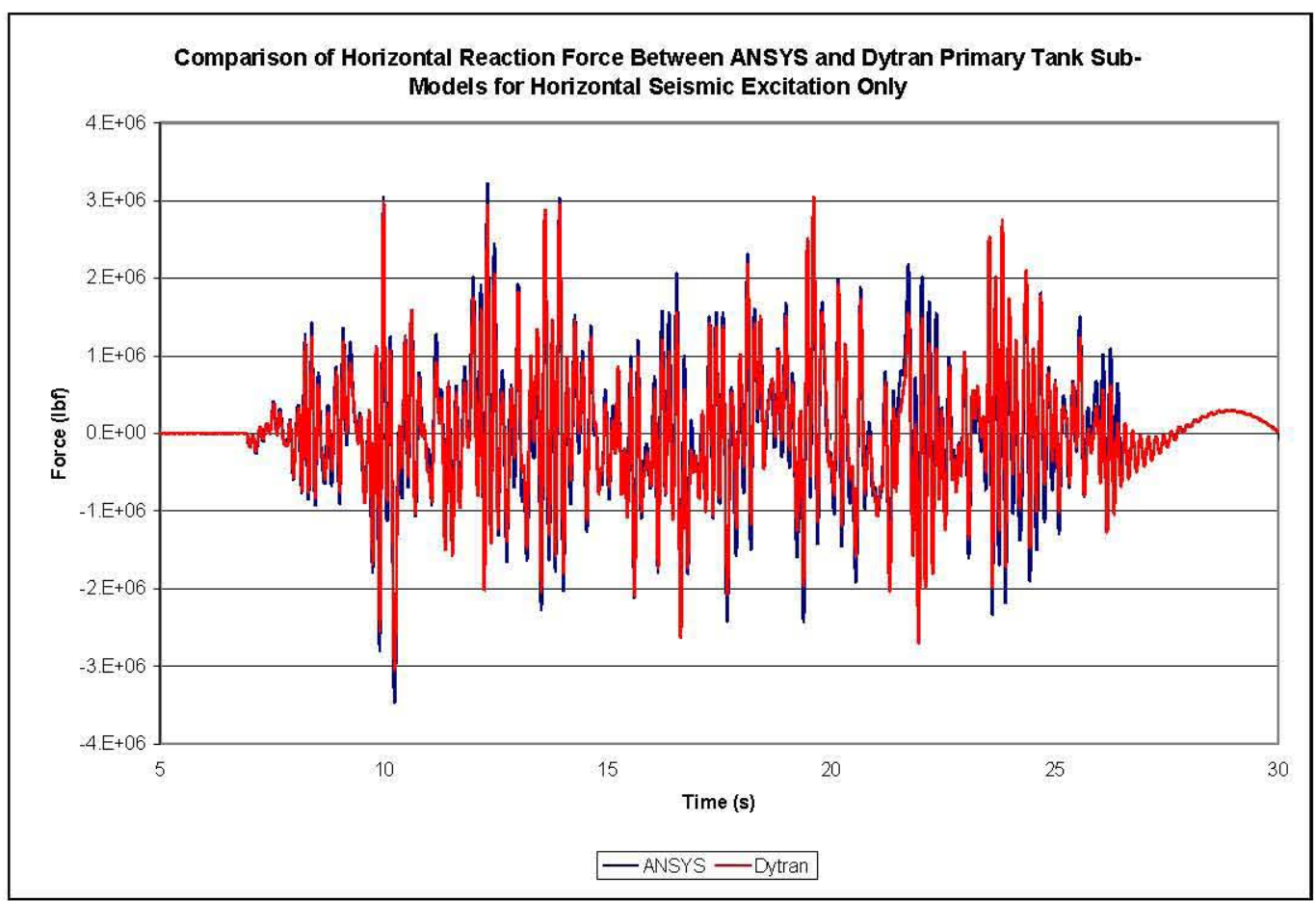

Figure 7-1. Comparison of Horizontal Reaction Forces Between ANSYS ${ }^{\mathbb{B}}$ and Dytran ${ }^{\mathbb{B}}$ Primary Tank Sub-Models for Horizontal Excitation Only - ES-BEC Time History

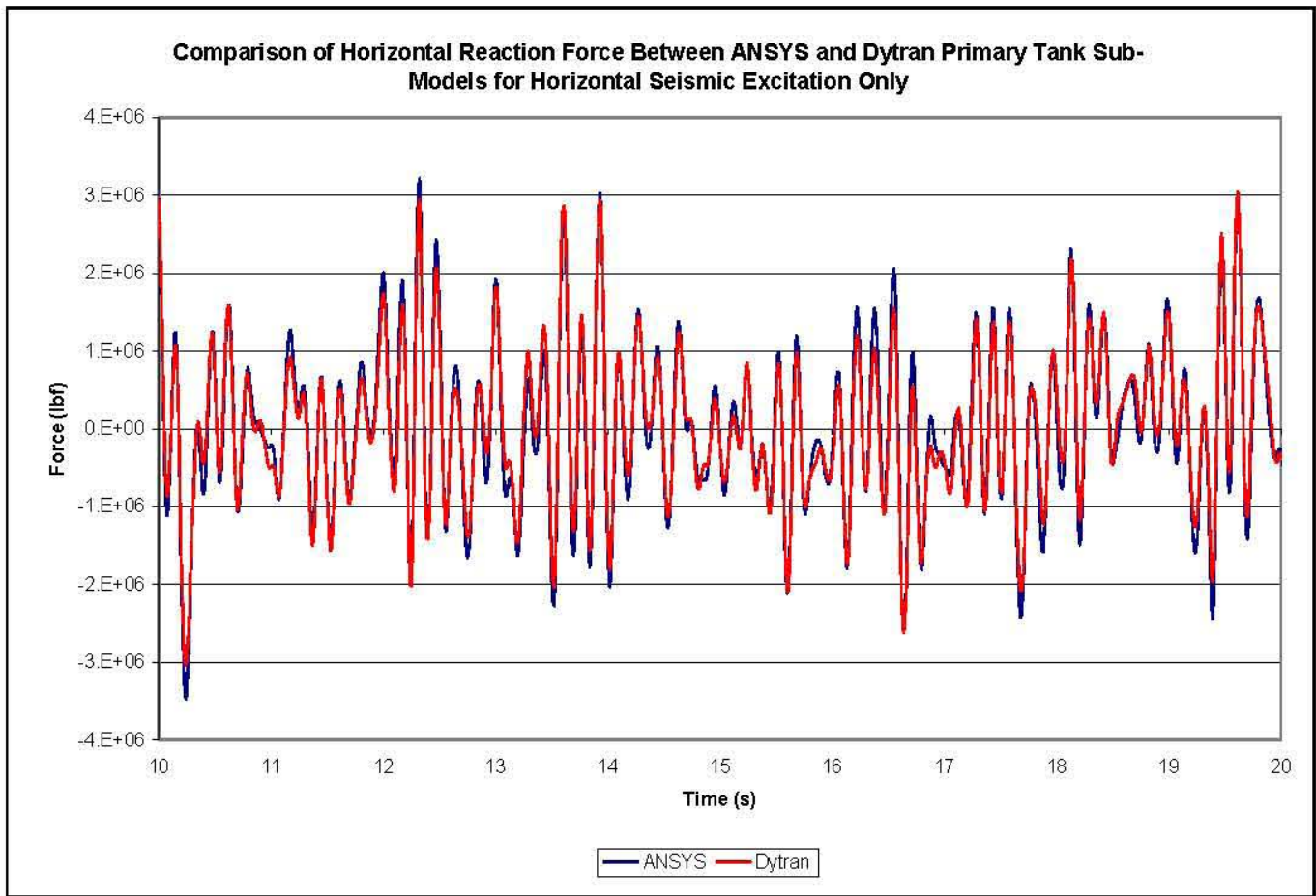

Figure 7-2. Comparison of Horizontal Reaction Forces Between ANSYS ${ }^{\circledR}$ and Dytran ${ }^{\circledR}$ Primary Tank Sub-Models for Horizontal Excitation During Strong Motion Portion of Excitation BES-BEC Time History 
RPP-RPT-32239, Rev. 1

M\&D-2008-005-CALC-001, Rev. 1

\subsubsection{Vertical Excitation Only}

The time history comparisons of the vertical reaction force for vertical excitation only are shown in Figure 7-3 and Figure 7-4. As in the case of the horizontal reaction forces, the Dytran ${ }^{\mathbb{B}}$ and ANSYS ${ }^{\mathbb{B}}$ reaction force time histories are quite similar. Neither the Dytran ${ }^{\mathbb{B}}$ nor the ANSYS $^{\circledR}$ model exhibits peaks that are consistently higher than the other model.

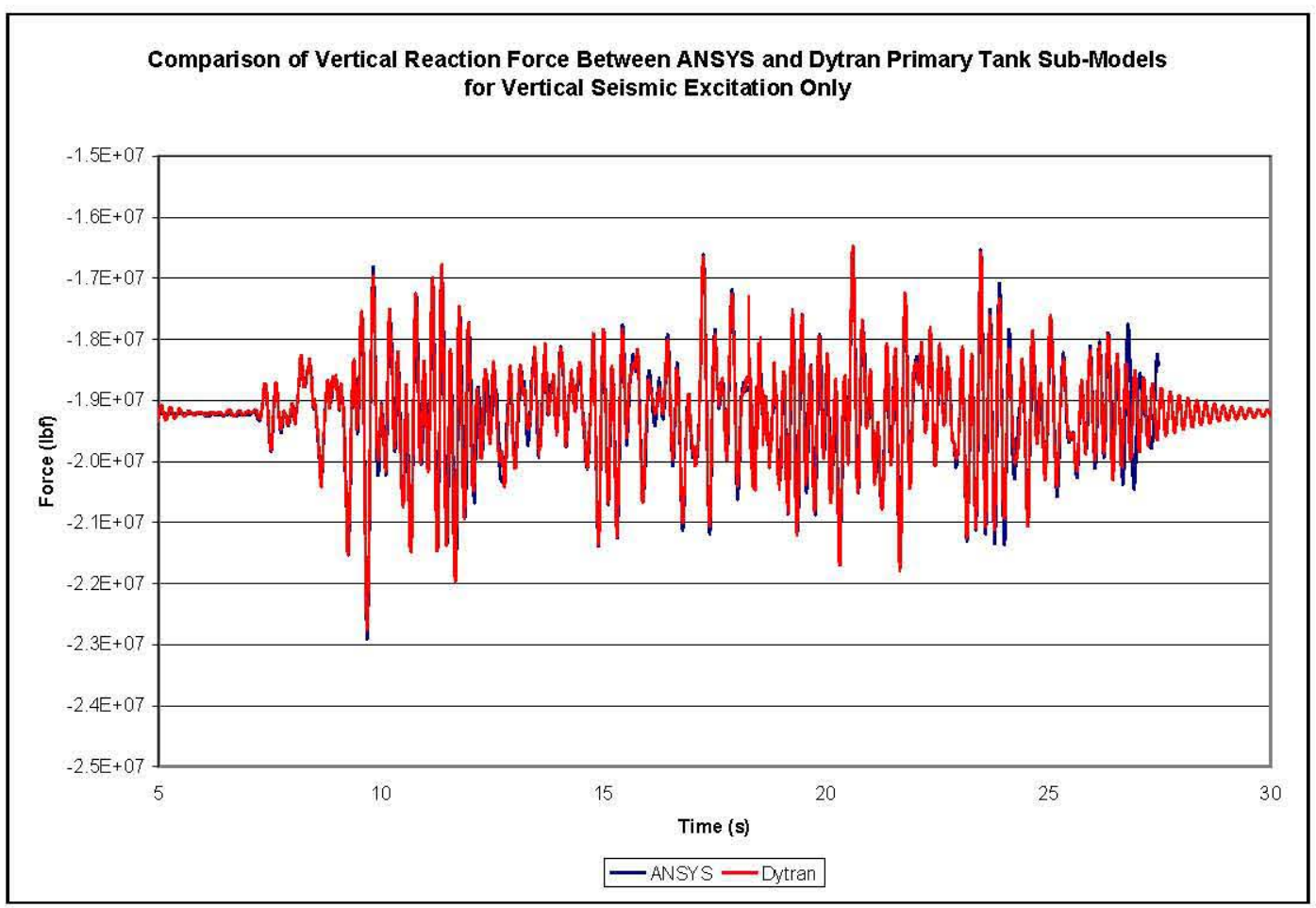

Figure 7-3. Comparison of Vertical Reaction Forces Between $\mathrm{ANSYS}^{\mathbb{B}}$ and Dytran ${ }^{\mathbb{B}}$ Primary Tank SubModels for Vertical Excitation Only - BES-BEC Time History 
RPP-RPT-32239, Rev. 1

M\&D-2008-005-CALC-001, Rev. 1

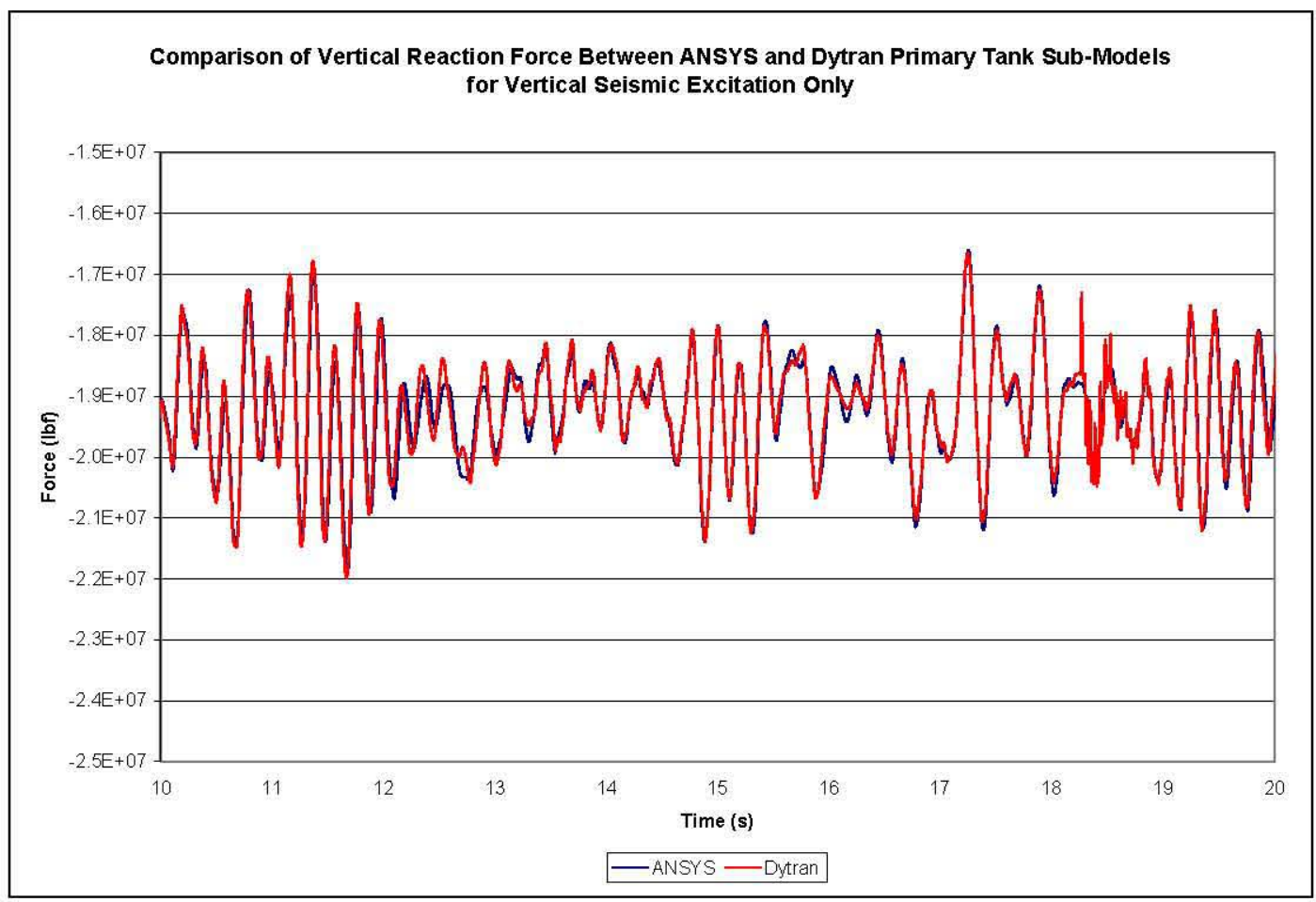

Figure 7-4. Comparison of Vertical Reaction Forces Between ANSYS ${ }^{\circledR}$ and Dytran ${ }^{\circledR}$ Primary Tank SubModels for Vertical Excitation During Strong Motion Portion of Excitation - BES-BEC Time History

\subsubsection{Two-Component Motion}

In the case of two-component motion, both the horizontal and vertical reaction forces are compared for the Dytran ${ }^{\mathbb{B}}$ and ANSYS ${ }^{\mathbb{B}}$ sub-models. The comparisons of the horizontal reaction forces are shown in Figure 7-5 and Figure 7-6, and the comparisons of the vertical reaction force are presented in Figure 7-7 and Figure 7-8.

The peak reaction forces indicate that directional coupling exists in the Dytran ${ }^{\mathbb{B}}$ model in the sense that the peak horizontal reaction force for two-component motion is higher than for the case of horizontal excitation only. That is, the presence of vertical motion increases the peak horizontal reaction force. However, the presence of horizontal motion has no effect on the peak vertical reaction force, since that value is the same for two-component motion as it is in the case of vertical excitation only.

On the other hand, the results from the $\mathrm{ANSYS}^{\mathbb{B}}$ sub-model show that the peak horizontal and vertical reaction forces are the same for two-component motion as they are when the seismic excitations are applied in one direction at a time. The complete independence of the horizontal and vertical responses in two-component motion does not seem plausible, and it suggests an inability of the ANSYS ${ }^{\mathbb{B}}$ model to resolve the responses in sufficient detail to capture any directional coupling in the reaction forces.

Because of the directional coupling in Dytran ${ }^{\mathbb{B}}$, the peak horizontal reaction force from the Dytran ${ }^{\mathbb{B}}$ model subjected to two-component excitation is higher than for ANSYS ${ }^{\mathbb{Q}}$, even though the individual direction components are higher from the $\mathrm{ANSYS}^{\mathbb{B}}$ model when the excitations are applied separately. 
RPP-RPT-32239, Rev. 1

M\&D-2008-005-CALC-001, Rev. 1

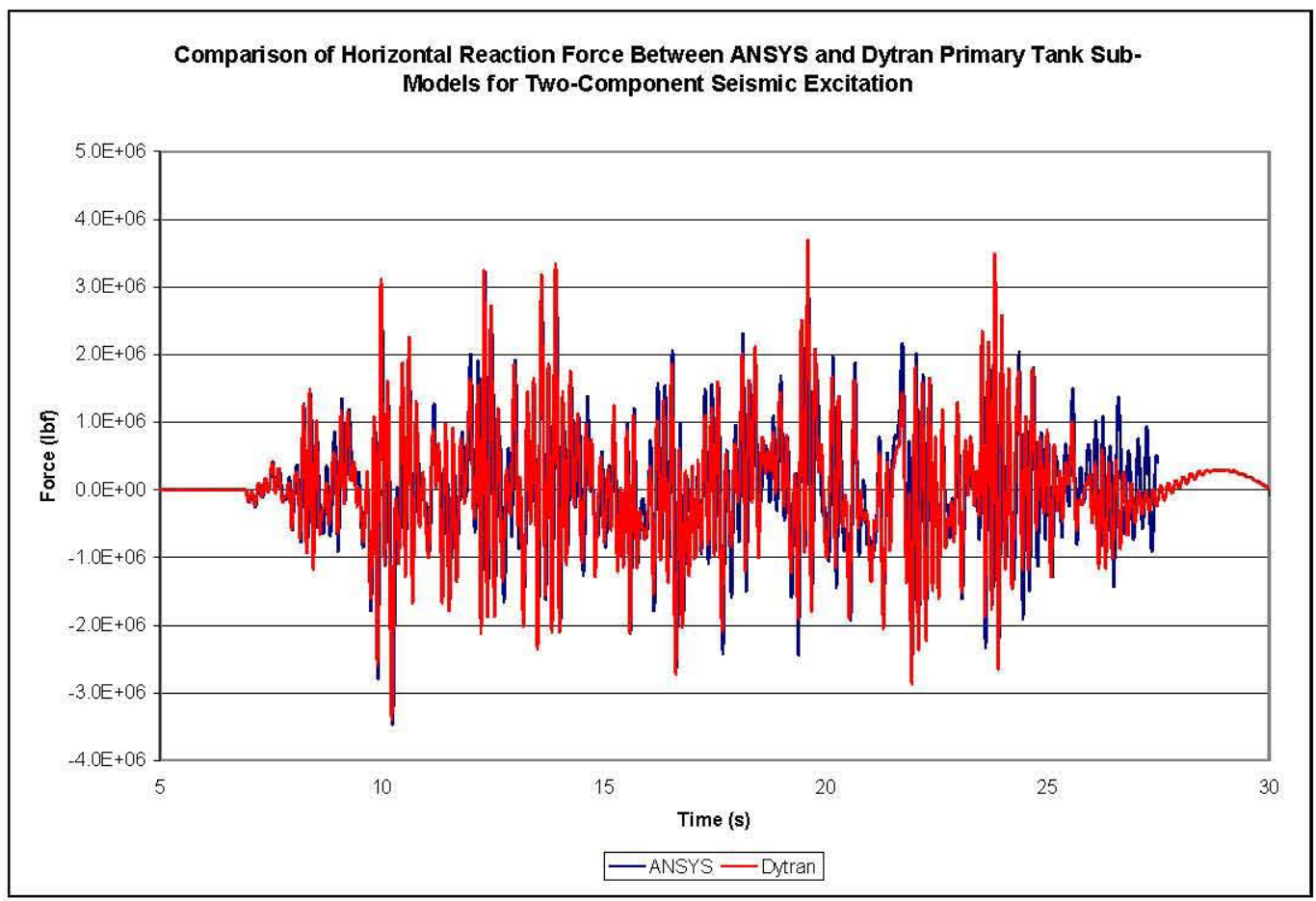

Figure 7-5. Comparison of Horizontal Reaction Forces Between ANSYS ${ }^{\mathbb{B}}$ and Dytran ${ }^{\mathbb{B}}$ Primary Tank Sub-Models for Two-Component Seismic Excitation - BES-BEC Time History

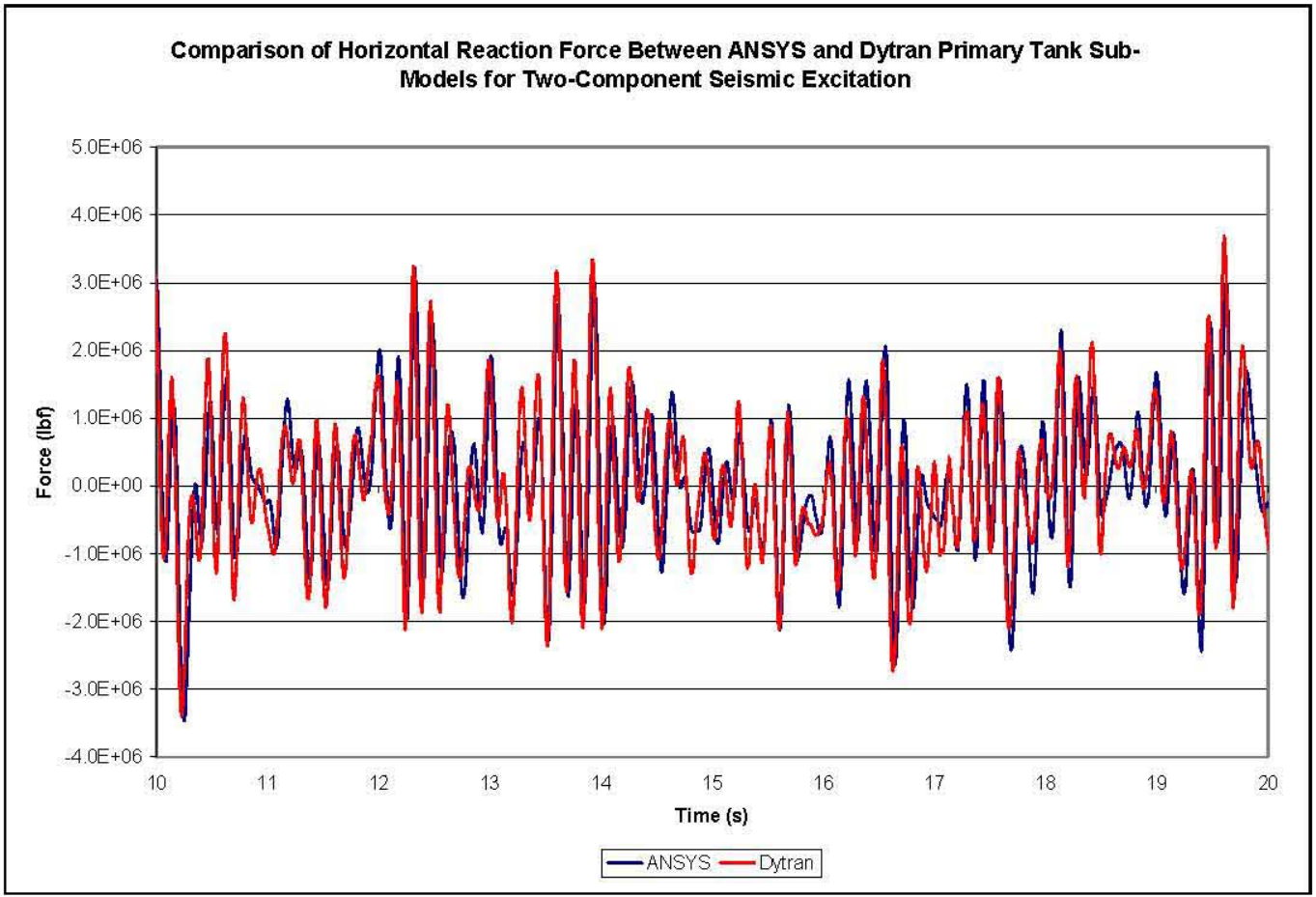

Figure 7-6. Comparison of Horizontal Reaction Forces Between ANSYS ${ }^{\circledR}$ and Dytran ${ }^{\circledR}$ Primary Tank Sub-Models for Two-Component Seismic Excitation During Strong Motion Portion of Excitation - BES-BEC Time History 
RPP-RPT-32239, Rev. 1

M\&D-2008-005-CALC-001, Rev. 1

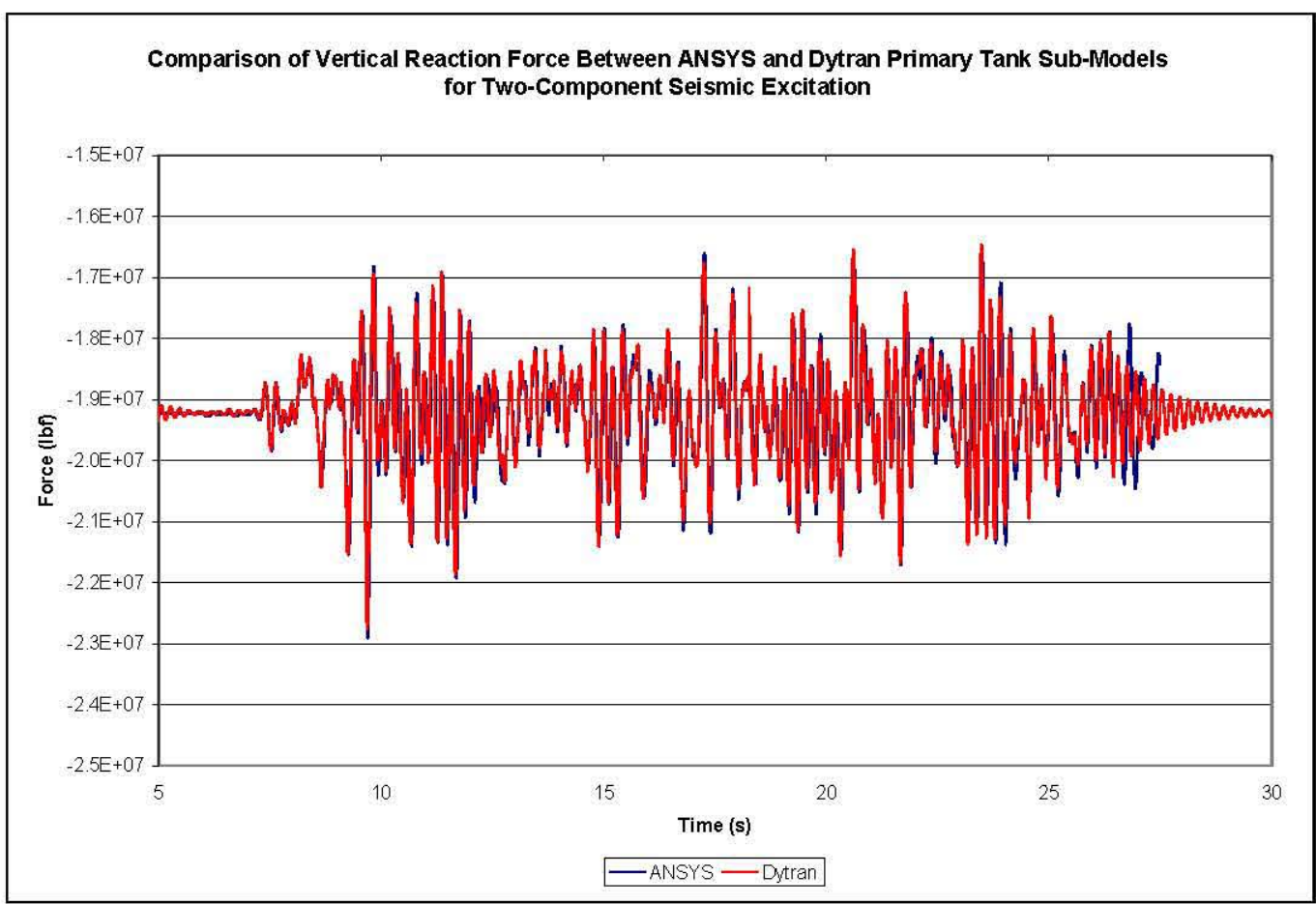

Figure 7-7. Comparison of Vertical Reaction Forces Between $\mathrm{ANSYS}^{\mathbb{B}}$ and Dytran ${ }^{\mathbb{B}}$ Primary Tank SubModels for Two-Component Seismic Excitation - BES-BEC Time History

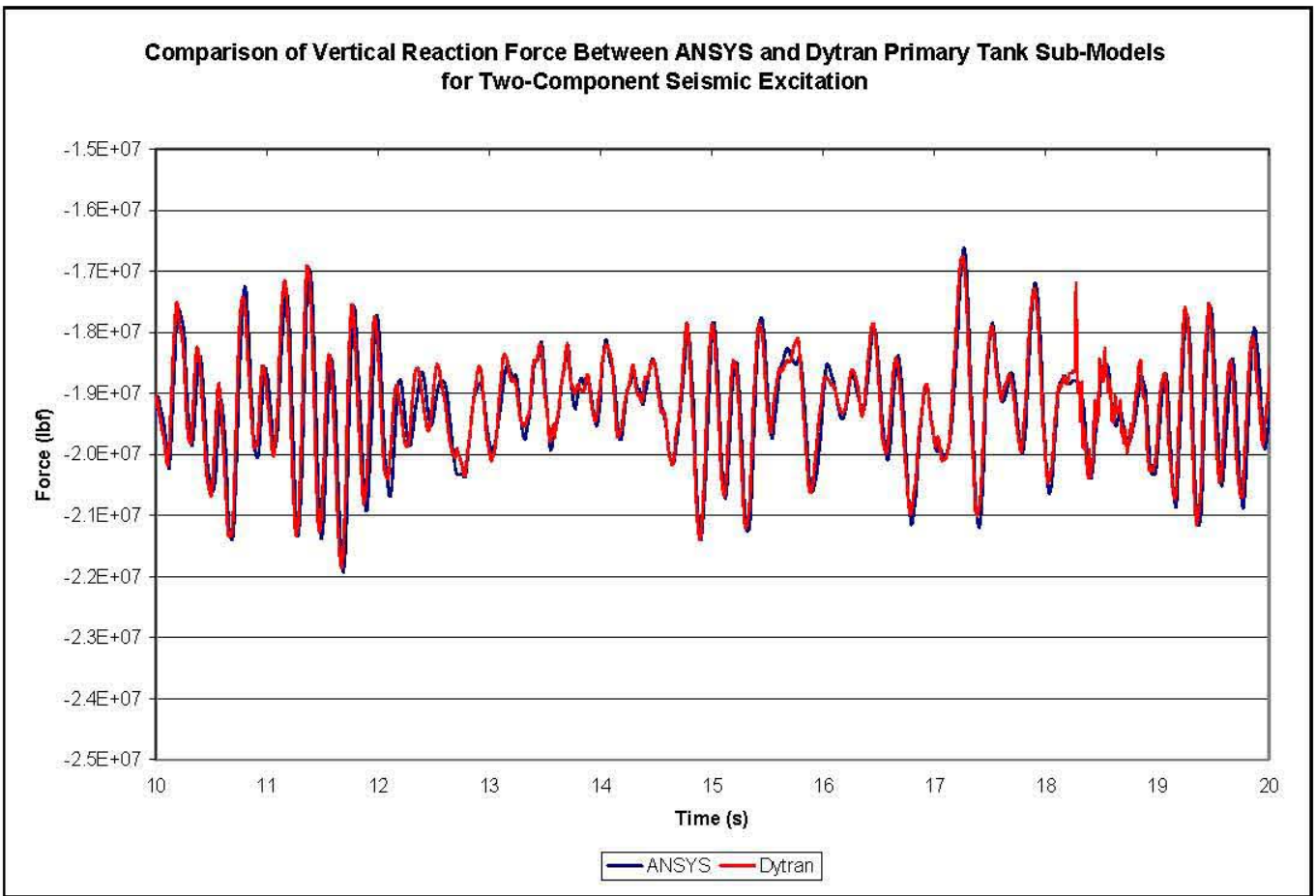

Figure 7-8. Comparison of Vertical Reaction Forces Between ANSYS ${ }^{\circledR}$ and Dytran ${ }^{\circledR}$ Primary Tank SubModels for Two-Component Seismic Excitation During Strong Motion Portion of Excitation - BES-BEC Time History 
RPP-RPT-32239, Rev. 1

M\&D-2008-005-CALC-001, Rev. 1

A summary of the peak reaction forces from the various simulations is given as Table 7-2.

Table 7-2. Summary of Peak Reaction Forces from Primary Tank Sub-Models

\begin{tabular}{||l|c|c|c|c||}
\hline \multirow{2}{*}{ Excitation Direction(s) } & \multicolumn{2}{|c|}{$\begin{array}{c}\text { Peak Horizontal Reaction } \\
\text { Force (lbf) }\end{array}$} & \multicolumn{2}{c||}{$\begin{array}{c}\text { Peak Vertical Reaction Force } \\
\text { (lbf) }\end{array}$} \\
\cline { 2 - 5 } & Dytran $^{\circledR}$ & ANSYS $^{\circledR}$ & Dytran $^{\circledR}$ & ANSYS $^{(\mathbb{B}}$ \\
\hline \hline Horizontal Only & $3.05 \times 10^{6}$ & $3.47 \times 10^{6}$ & Not Calculated & Not Calculated \\
\hline Vertical Only & Not Calculated & Not Calculated & $3.6 \times 10^{6}$ & $3.7 \times 10^{6}$ \\
\hline Two-Component Motion & $3.7 \times 10^{6}$ & $3.47 \times 10^{6}$ & $3.6 \times 10^{6}$ & $3.7 \times 10^{6}$ \\
\hline \hline
\end{tabular}

\subsection{Waste Pressure Comparisons}

Comparisons of selected waste pressure time histories from the $\mathrm{ANSYS}^{\mathbb{Q}}$ and Dytran ${ }^{\mathbb{Q}}$ sub-models for horizontal excitation only, vertical excitation only, and two-component excitation are shown in Figure 7-9, Figure 7-10, and Figure 7-11, respectively. The centroidal elevation of the upper two elements (Dytran ${ }^{\mathbb{B}}$ element 5143 and ANSYS $^{\mathbb{B}}$ element 7722 ) is approximately 455 inches from the tank bottom, giving a normalized height of 0.99 . The centroidal elevation of the lower two elements (Dytran ${ }^{\mathbb{B}}$ element 30743 and ANSYS $^{\circledR}$ element 12552) is approximately 24 inches from the tank bottom, giving a normalized height of 0.05 .

In the case of horizontal excitation only, the pressures predicted by ANSYS $^{\circledR}$ near the bottom of the tank appear to be slightly higher than those predicted by Dytran ${ }^{\mathbb{B}}$ as shown in Figure 7-9. In the case of vertical motion only, the pressures predicted by ANSYS $^{\mathbb{B}}$ near the bottom of the tank appear to be slightly less than those predicted by Dytran ${ }^{\mathbb{B}}$ (Figure 7-10). In the case of two-component motion, the peak pressures near the bottom of the tank are similar from the two models, but the character of the time histories is noticeably different.

The most striking difference between the ANSYS ${ }^{\circledR}$ and Dytran ${ }^{\circledR}$ results is the pressures near the freesurface when horizontal excitation is present. In those two cases the peak pressures predicted by $\mathrm{ANSYS}^{\mathbb{B}}$ are significantly higher than those predicted by Dytran ${ }^{\mathbb{B}}$ as shown in Figure 7-9 and Figure 7-11. Some of the difference between the pressures in Dytran ${ }^{(\mathbb{B}}$ element 5143 and ANSYS $^{(\mathbb{B}}$ element 7722 can be attributed to the fact that the Dytran ${ }^{\mathbb{B}}$ pressure results are in the Eulerian formulation, while the $\mathrm{ANSYS}^{\circledR}$ results are in the Lagrangian formulation — but the two results are still significantly different.

In the case of vertical motion only, the ANSYS ${ }^{\mathbb{E}}$ sub-model predicts nearly zero dynamic pressure near the free surface, while the Dytran ${ }^{\mathbb{B}}$ sub-model shows dynamic pressures of approximately $\pm 1 \mathrm{lbf} / \mathrm{in}^{2}$ as shown in Figure 7-10. 
RPP-RPT-32239, Rev. 1

M\&D-2008-005-CALC-001, Rev. 1

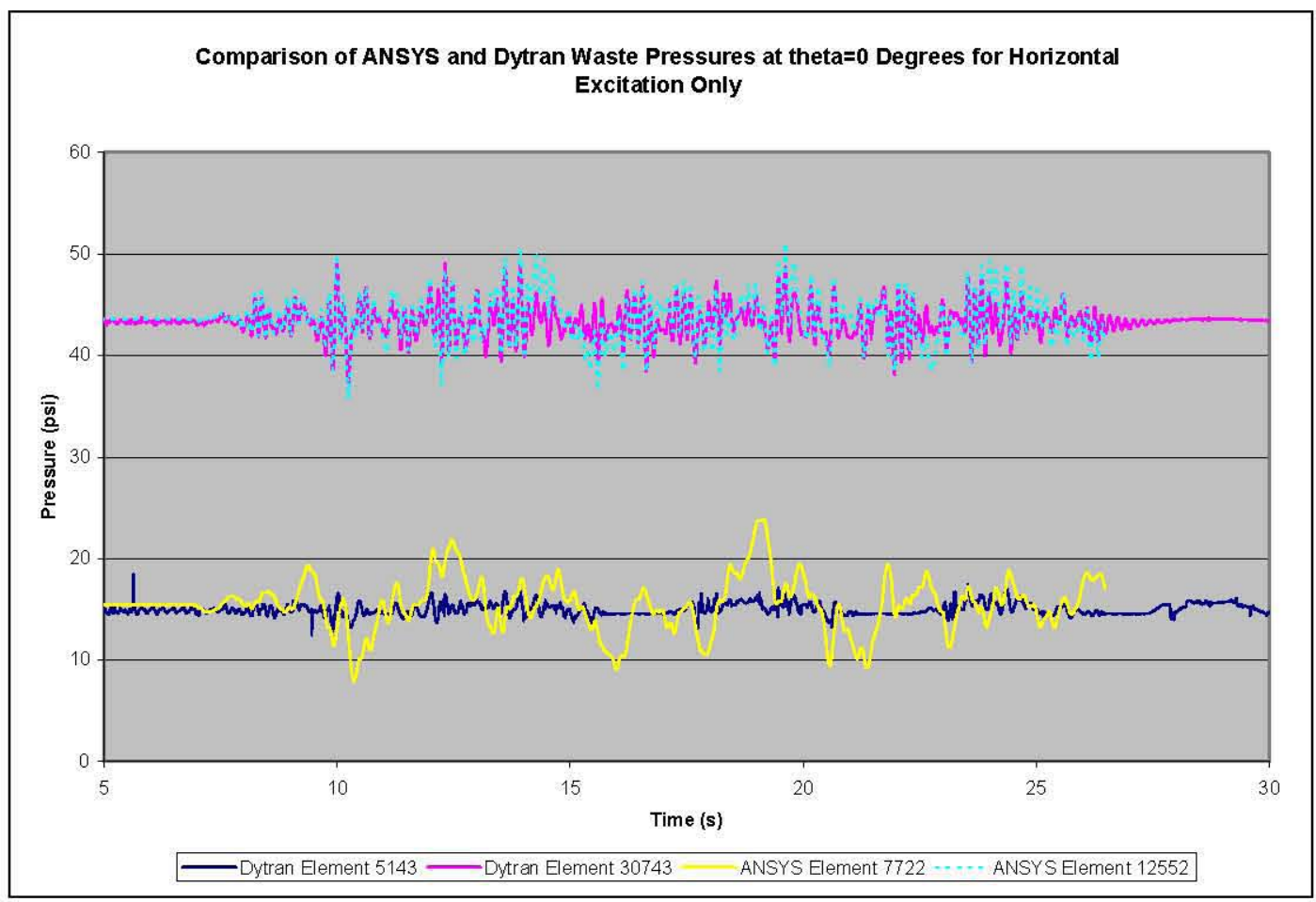

Figure 7-9. Comparison of Selected $\mathrm{ANSYS}^{\circledR}$ and Dytran ${ }^{\circledR}$ Waste Pressures at $\theta=0^{\circ}$ for Horizontal Excitation Only

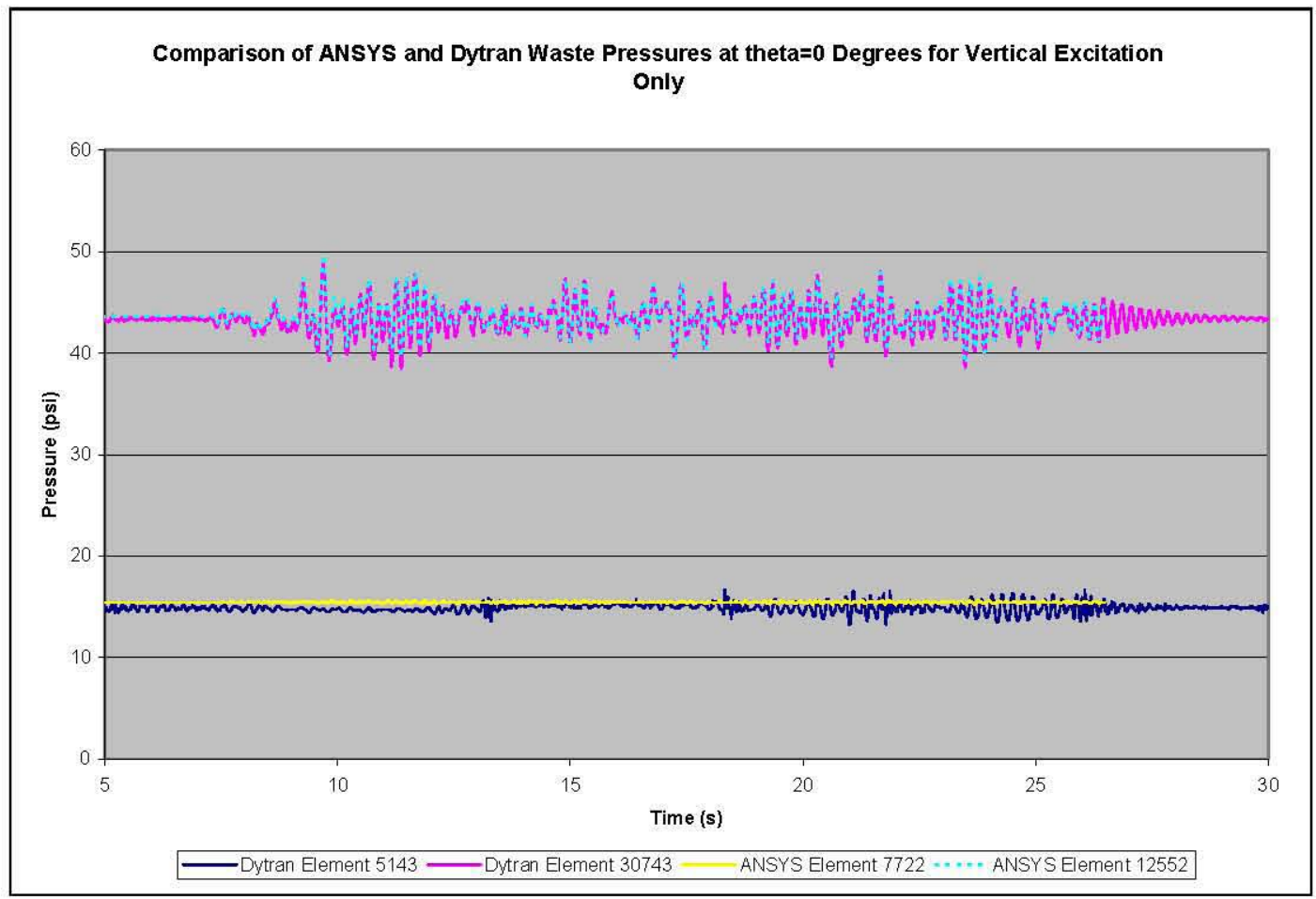

Figure 7-10. Comparison of Selected ANSYS ${ }^{\mathbb{Q}}$ and Dytran ${ }^{\mathbb{B}}$ Waste Pressures at $\theta=0^{\circ}$ for Vertical Excitation Only 
RPP-RPT-32239, Rev. 1

M\&D-2008-005-CALC-001, Rev. 1

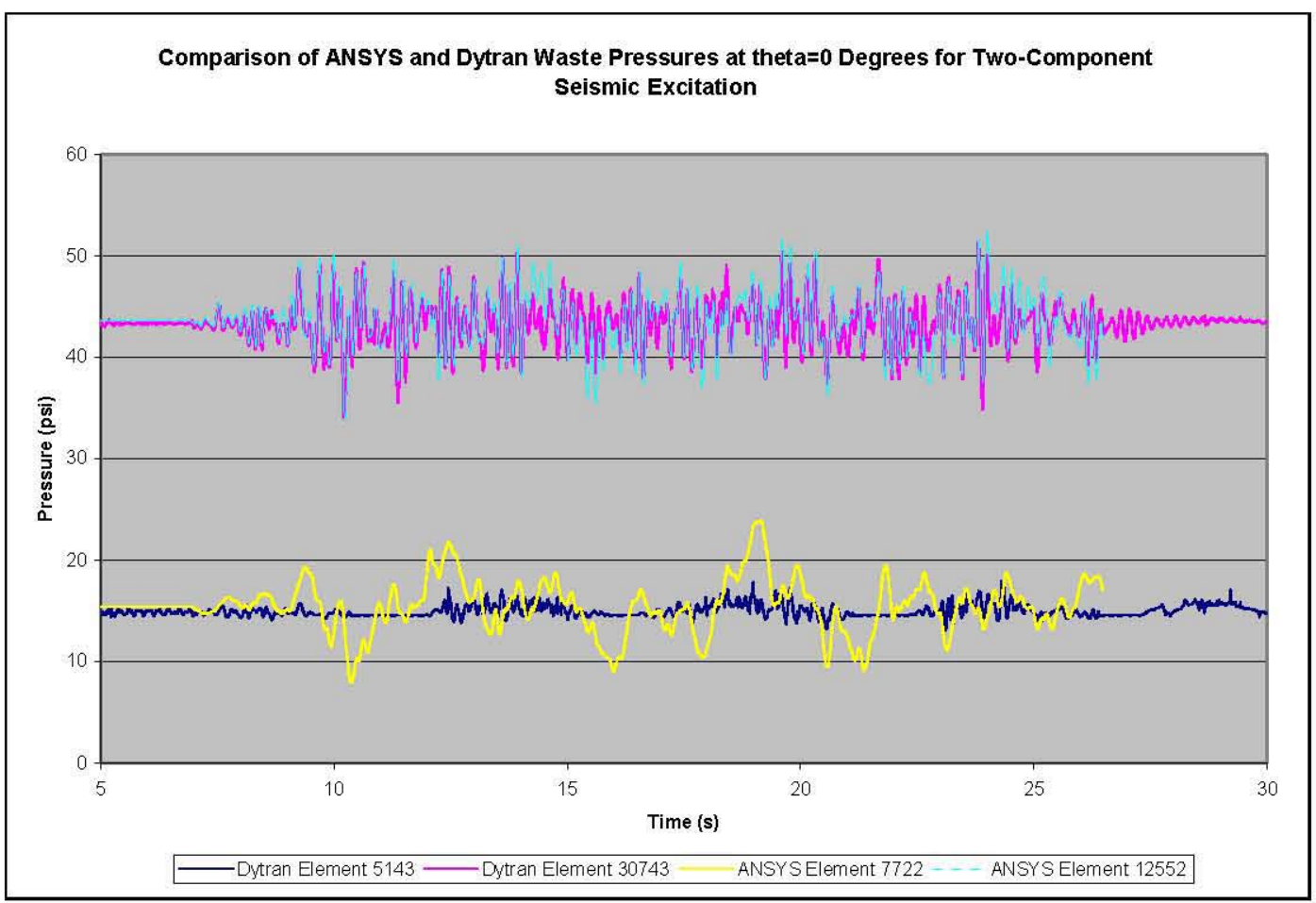

Figure 7-11. Comparison of Selected ANSYS ${ }^{\mathbb{B}}$ and Dytran ${ }^{\mathbb{B}}$ Waste Pressures at $\theta=0^{\circ}$ for TwoComponent Seismic Excitation

\subsection{Stress Comparisons}

The following three sections include comparisons of maximum and minimum stress distributions for the ANSYS $^{\circledR}$ and Dytran ${ }^{\circledR}$ primary tank sub-models. Section 7.4.4 also includes stress results from the global ANSYS ${ }^{\circledR}$ model. The data show that the stresses predicted by the two sub-models are very similar except near the free surface and to some degree near the tank knuckle.

Based on earlier studies documented in Rinker and Abatt (2006a) and in Rinker et al. (2006b), it is expected that the convective response of the contained liquid will not be captured properly by the ANSYS $^{\mathbb{B}}$ model. Thus, differences in the stresses near the liquid-free surface are expected. Some differences in the stresses between the ANSYS ${ }^{\mathbb{Q}}$ and Dytran ${ }^{\mathbb{B}}$ models are also expected in the tank knuckle if for no other reason than the fact that in the Dytran ${ }^{(\mathbb{B}}$ sub-model the junction of the wall with the floor is a right angle, as shown in Figure 3-10 and Figure 3-11, while in the ANSYS ${ }^{\circledR}$ sub-model the knuckle radius is approximated with two elements, as shown in Figure 5-3, Figure 5-4, and Figure 5-5.

Although the convective response may not be captured properly by the ANSYS ${ }^{\circledR}$ sub-model, it is expected that the impulsive response will be represented with sufficient accuracy, and will tend to be overpredicted by the ANSYS ${ }^{\circledR}$ model due to the constitutive model for the waste. Because the total response is dominated by the impulsive response, it is expected that the stresses from the ANSYS ${ }^{\circledR}$ submodel should be very similar to those from the Dytran ${ }^{\mathbb{B}}$ sub-model in the majority of the tank wall. Another point to note is that the stresses from the primary tank sub-models are due to combined effects of gravity loading and seismic loading. Because the demands from gravity loading tend to dominate those 
RPP-RPT-32239, Rev. 1

M\&D-2008-005-CALC-001, Rev. 1

from seismic loading only, and the models are expected to give very similar results for gravity loading, the differences in the predictions for seismic stresses only will be less apparent in the stress plots.

In the stress comparison plots, only mid-surface stresses are plotted for the hoop and shear components, since bending is not a significant contributor to these components. In the case of the meridional component, the stresses on the inside and outside surface of the primary tank are plotted.

\subsubsection{Horizontal Excitation Only}

Comparison plots of the maximum and minimum hoop, meridional, and shear stress distributions in the plane of excitation at $\theta=0^{\circ}$ for horizontal excitation only are shown in Figure 7-12, Figure 7-13, and Figure $7-14$, respectively. Plots of the same stress components at $\theta=45^{\circ}$ are shown in Figure $7-15$, Figure 7-16, and Figure 7-17. The mid-surface shear stress distribution at $\theta=90^{\circ}$ is shown as Figure 7-18.

The plots show that the hoop stresses from the two sub-models are very similar, except at the waste-free surface, as expected. The meridional stresses are similar in the majority of the tank wall, but differ somewhat in the knuckle region, and especially near the waste-free surface. The shear stresses are nearly the same or are of negligible magnitude.

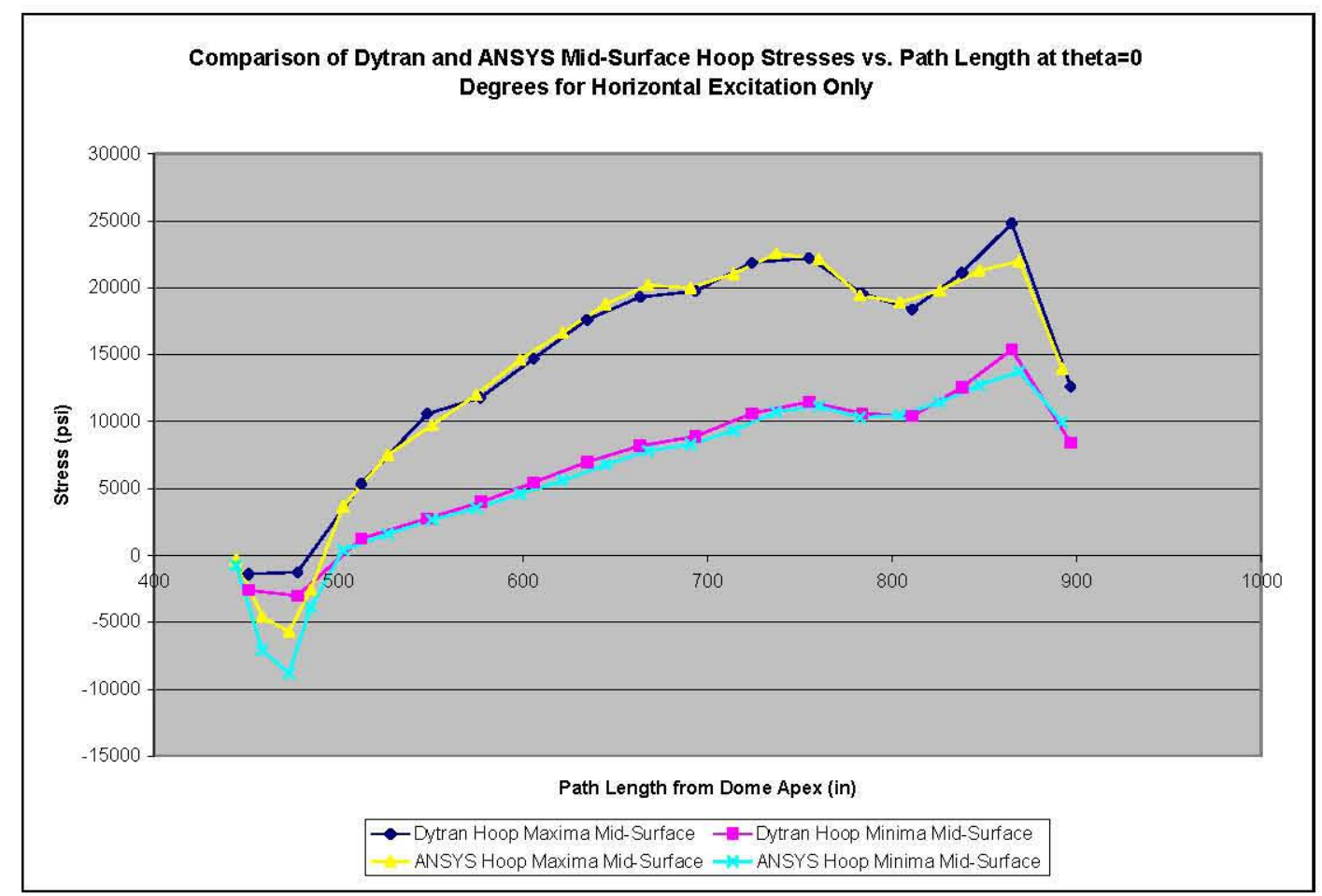

Figure 7-12. Comparison of Dytran ${ }^{\mathbb{B}}$ and $\operatorname{ANSYS}^{\mathbb{B}}$ Mid-Surface Hoop Stresses at $\theta=0^{\circ}$ for Horizontal Seismic Excitation 
RPP-RPT-32239, Rev. 1

M\&D-2008-005-CALC-001, Rev. 1

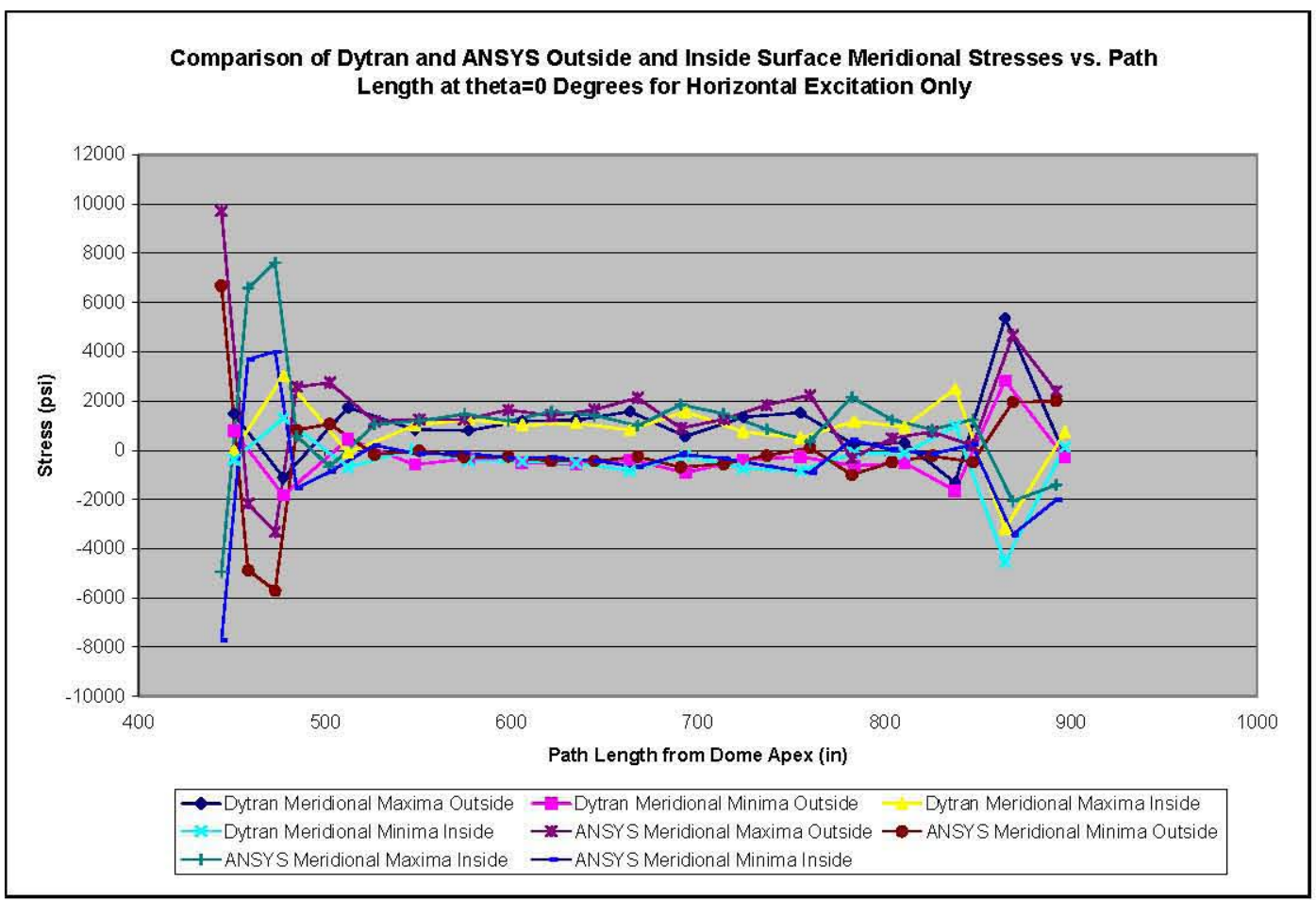

Figure 7-13. Comparison of Dytran ${ }^{\mathbb{B}}$ and $\operatorname{ANSYS}^{\mathbb{B}}$ Outside and Inside Surface Meridional Stresses at $\theta=0^{\circ}$ for Horizontal Seismic Excitation

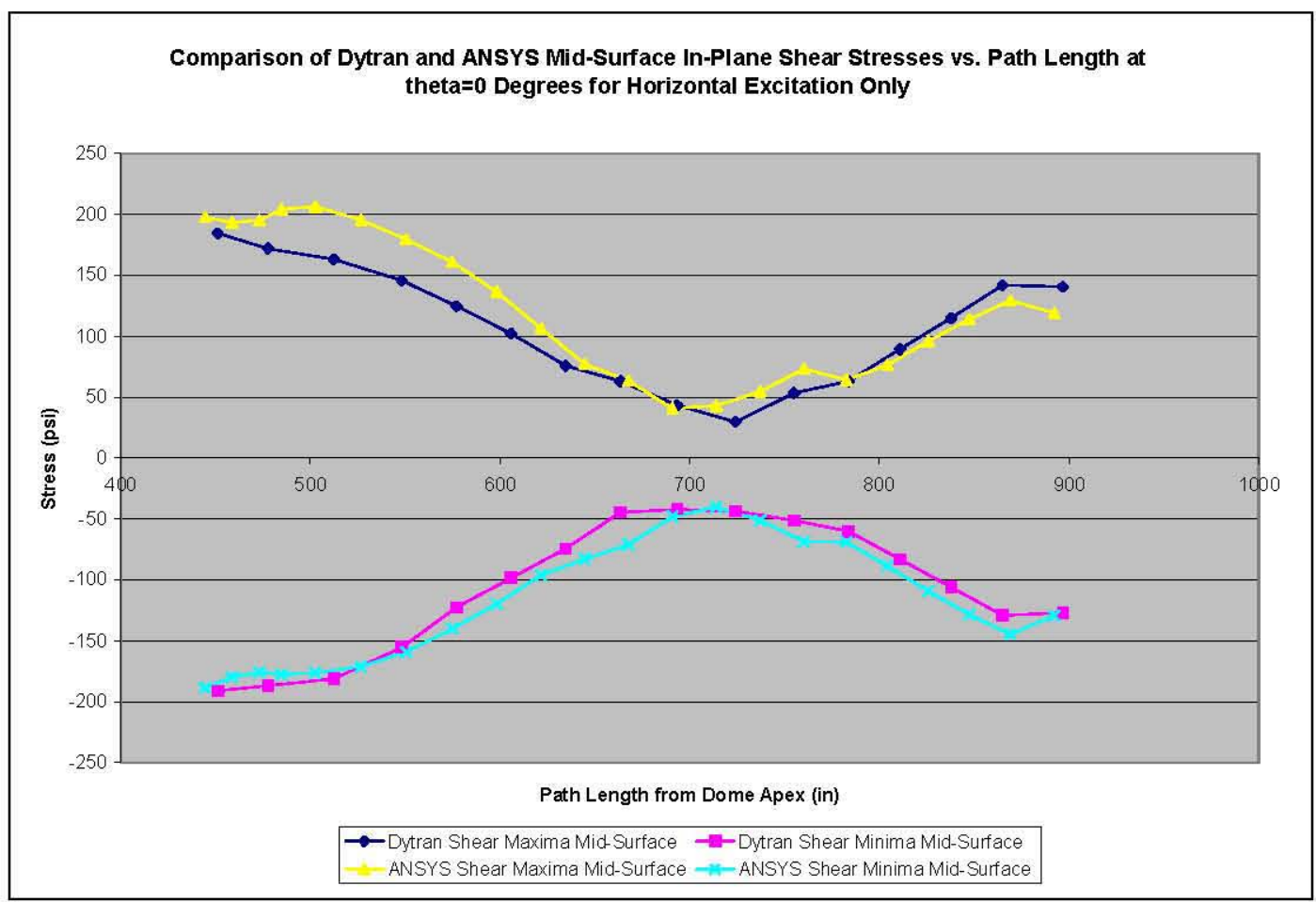

Figure 7-14. Comparison of Dytran ${ }^{\circledR}$ and $\operatorname{ANSYS}^{\circledR}$ Mid-Surface In-Plane Shear Stresses at $\theta=0^{\circ}$ for Horizontal Seismic Excitation 
RPP-RPT-32239, Rev. 1

M\&D-2008-005-CALC-001, Rev. 1

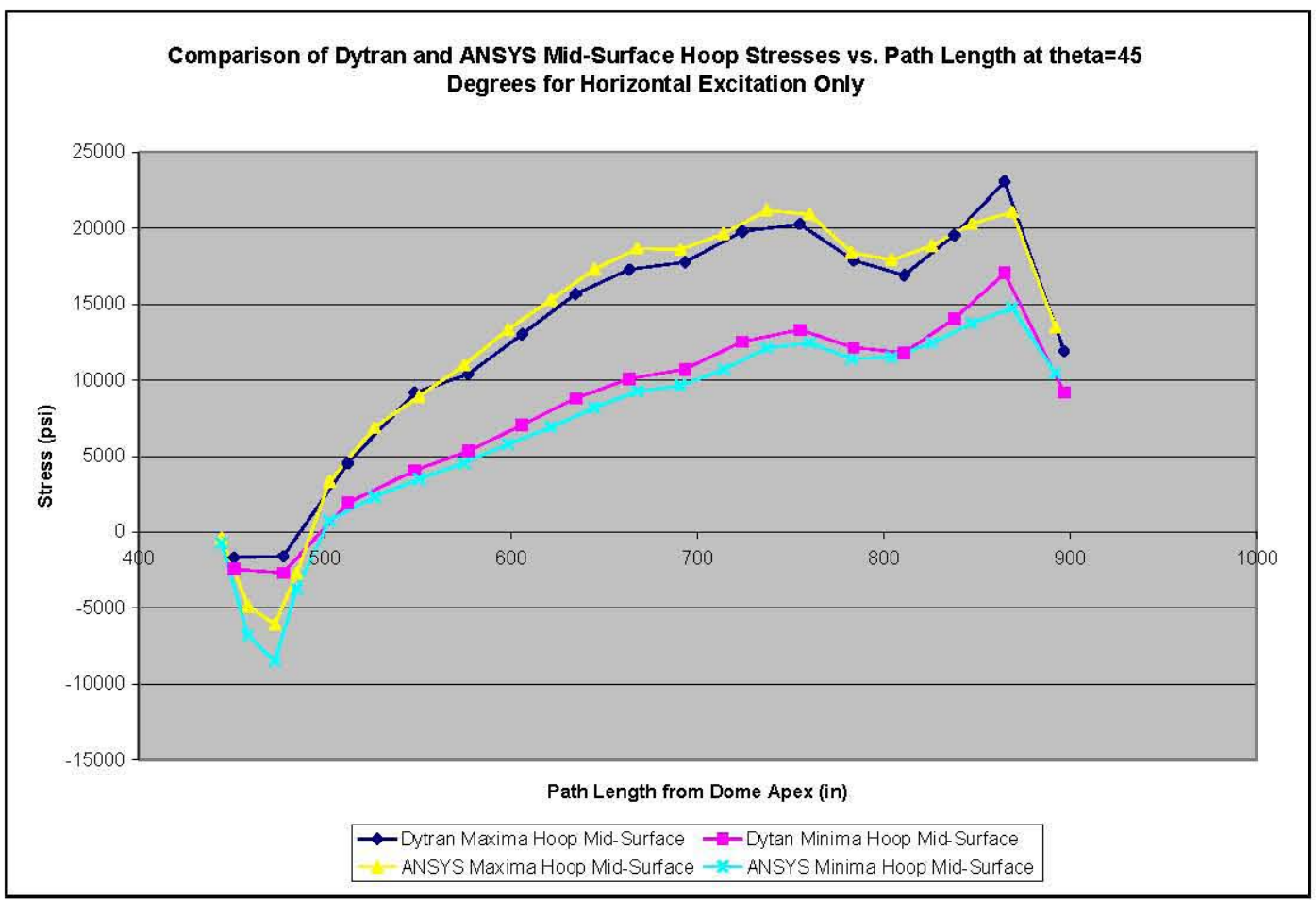

Figure 7-15. Comparison of Dytran ${ }^{\mathbb{B}}$ and $\operatorname{ANSYS}^{\circledR}$ Mid-Surface Hoop Stresses at $\theta=45^{\circ}$ for Horizontal Seismic Excitation

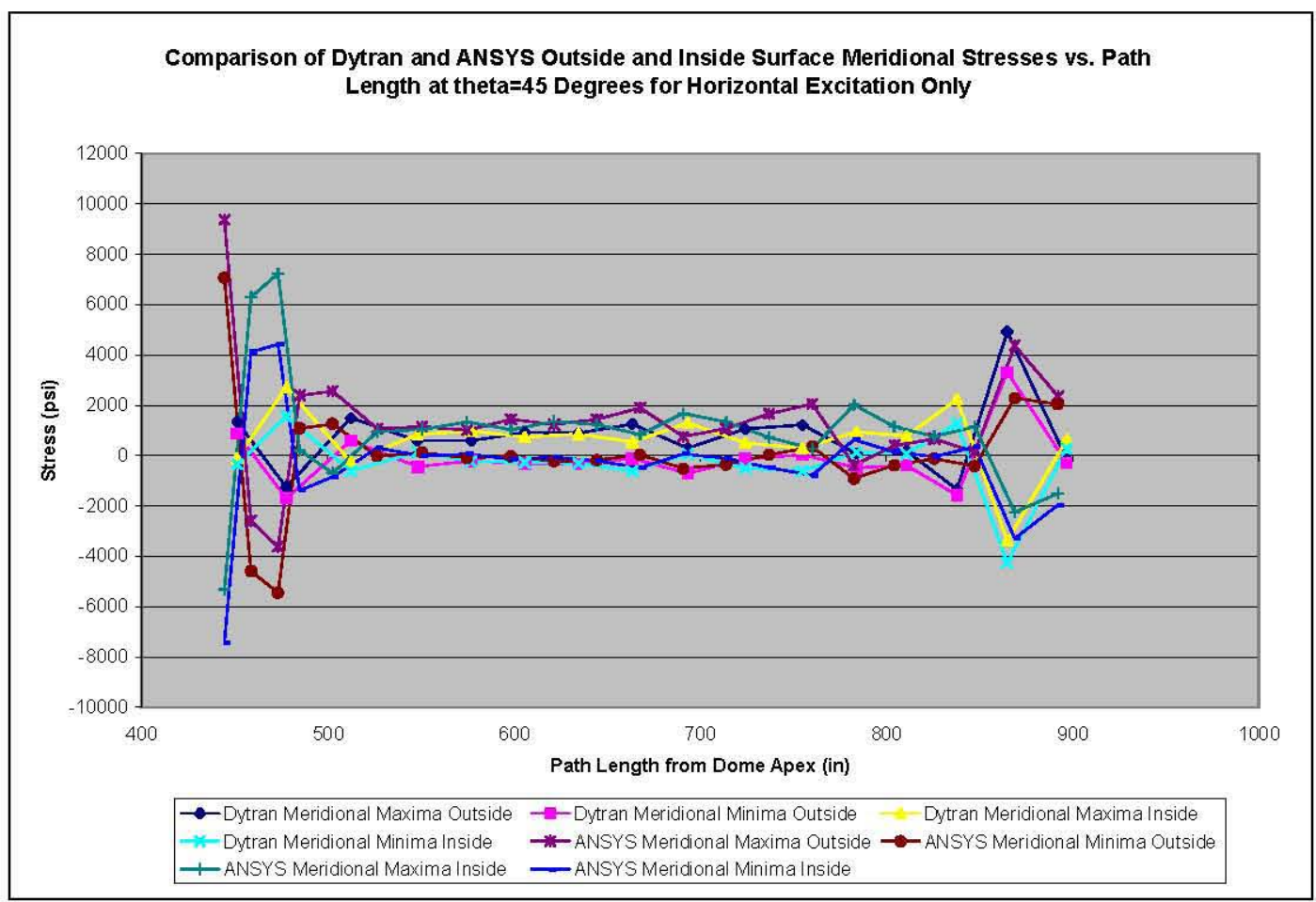

Figure 7-16. Comparison of Dytran ${ }^{\circledR}$ and $\operatorname{ANSYS}^{\circledR}$ Outside and Inside Surface Meridional Stresses at $\theta=45^{\circ}$ for Horizontal Seismic Excitation 
RPP-RPT-32239, Rev. 1

M\&D-2008-005-CALC-001, Rev. 1

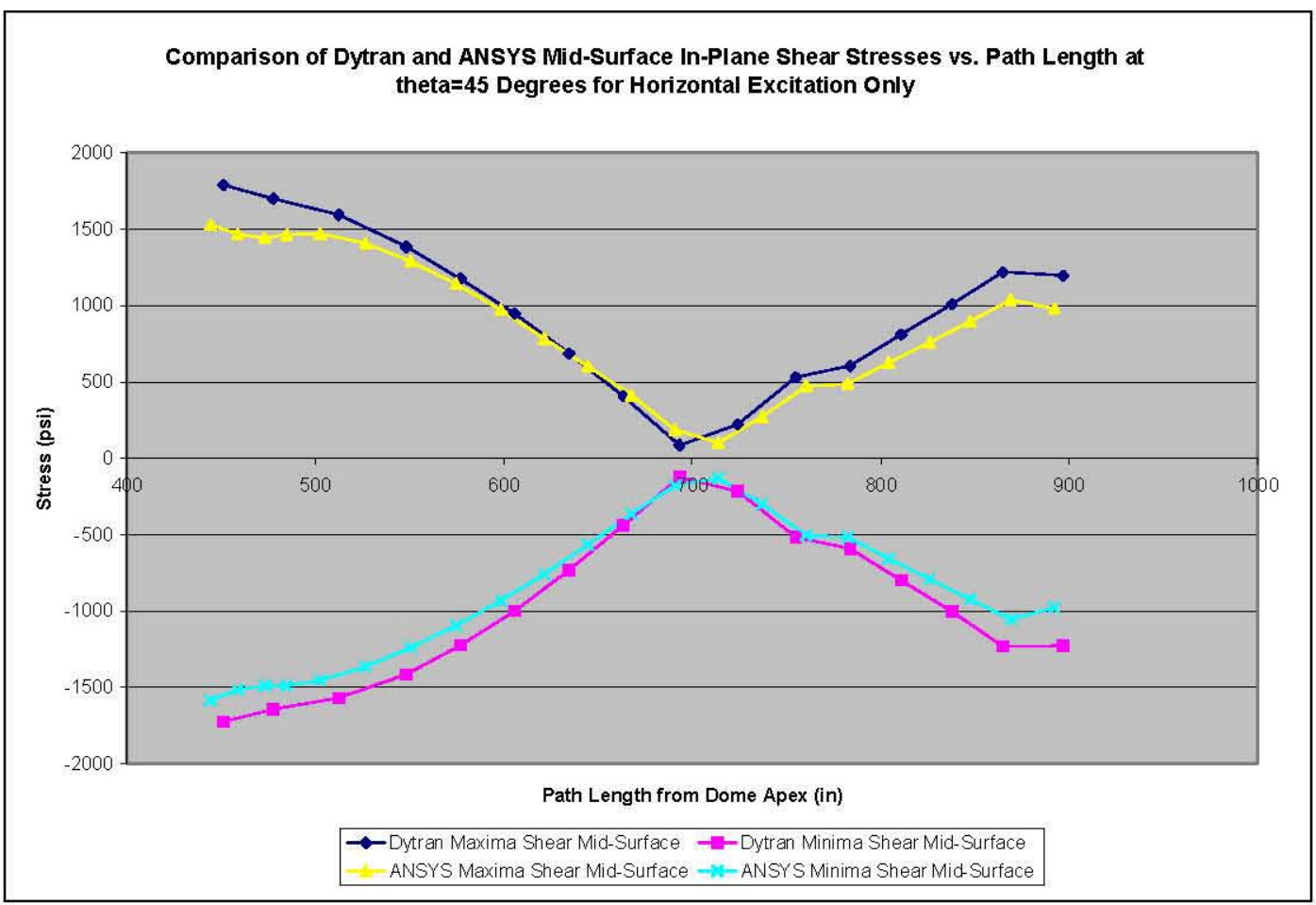

Figure 7-17. Comparison of Dytran ${ }^{\mathbb{B}}$ and $\mathrm{ANSYS}^{\mathbb{B}}$ Mid-Surface In-Plane Shear Stresses at $\theta=45^{\circ}$ for Horizontal Seismic Excitation

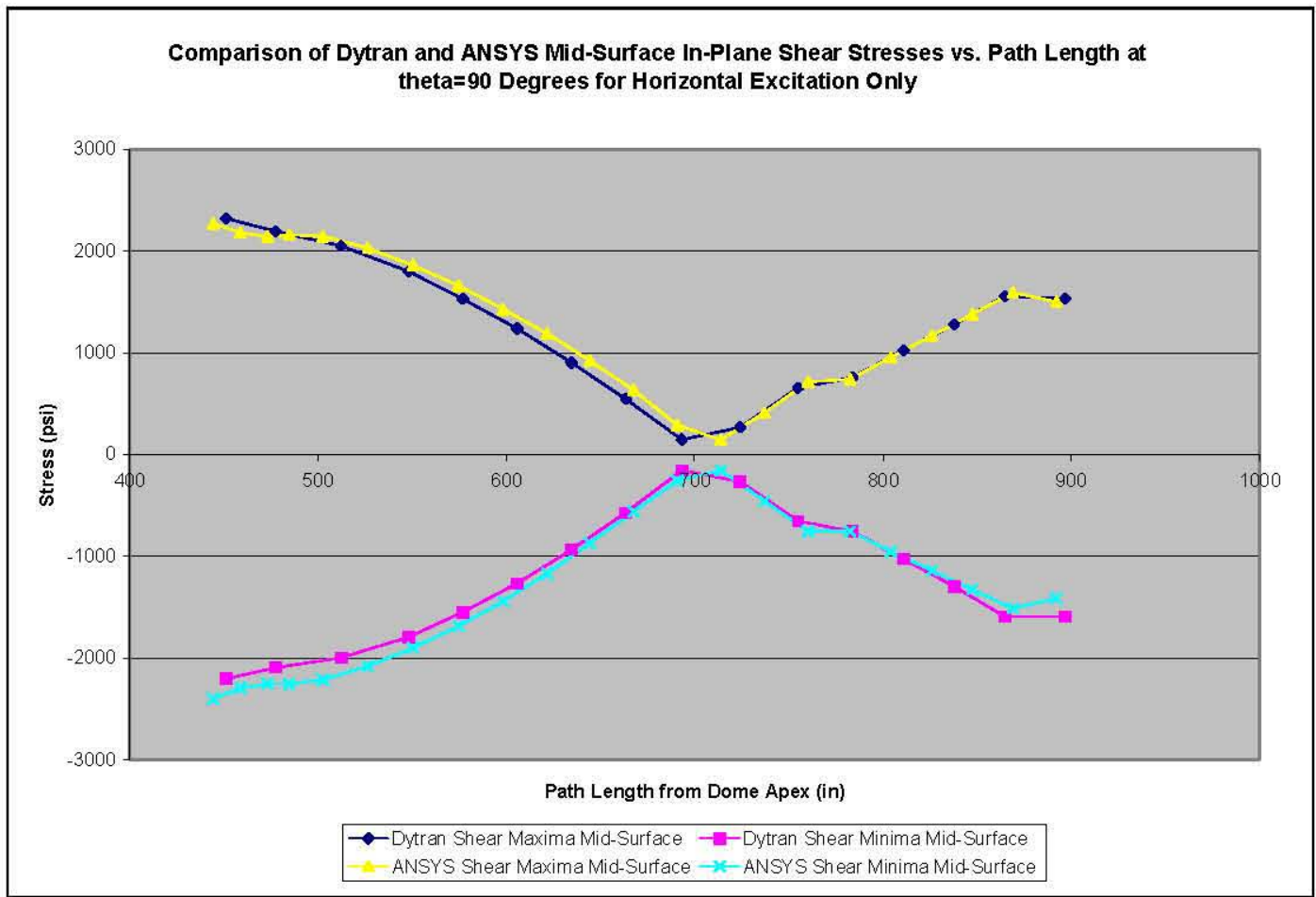

Figure 7-18. Comparison of Dytran ${ }^{\mathbb{B}}$ and $\mathrm{ANSYS}^{\mathbb{Q}}$ Mid-Surface In-Plane Shear Stresses at $\theta=90^{\circ}$ for Horizontal Seismic Excitation 
RPP-RPT-32239, Rev. 1

M\&D-2008-005-CALC-001, Rev. 1

\subsubsection{Vertical Excitation Only}

Plots of the hoop, meridional, and shear stress distributions at $\theta=0^{\circ}$ for vertical excitation only are shown in Figure 7-19, Figure 7-20, and Figure 7-21, respectively. The same observations made for the case of horizontal excitation only apply in this case.

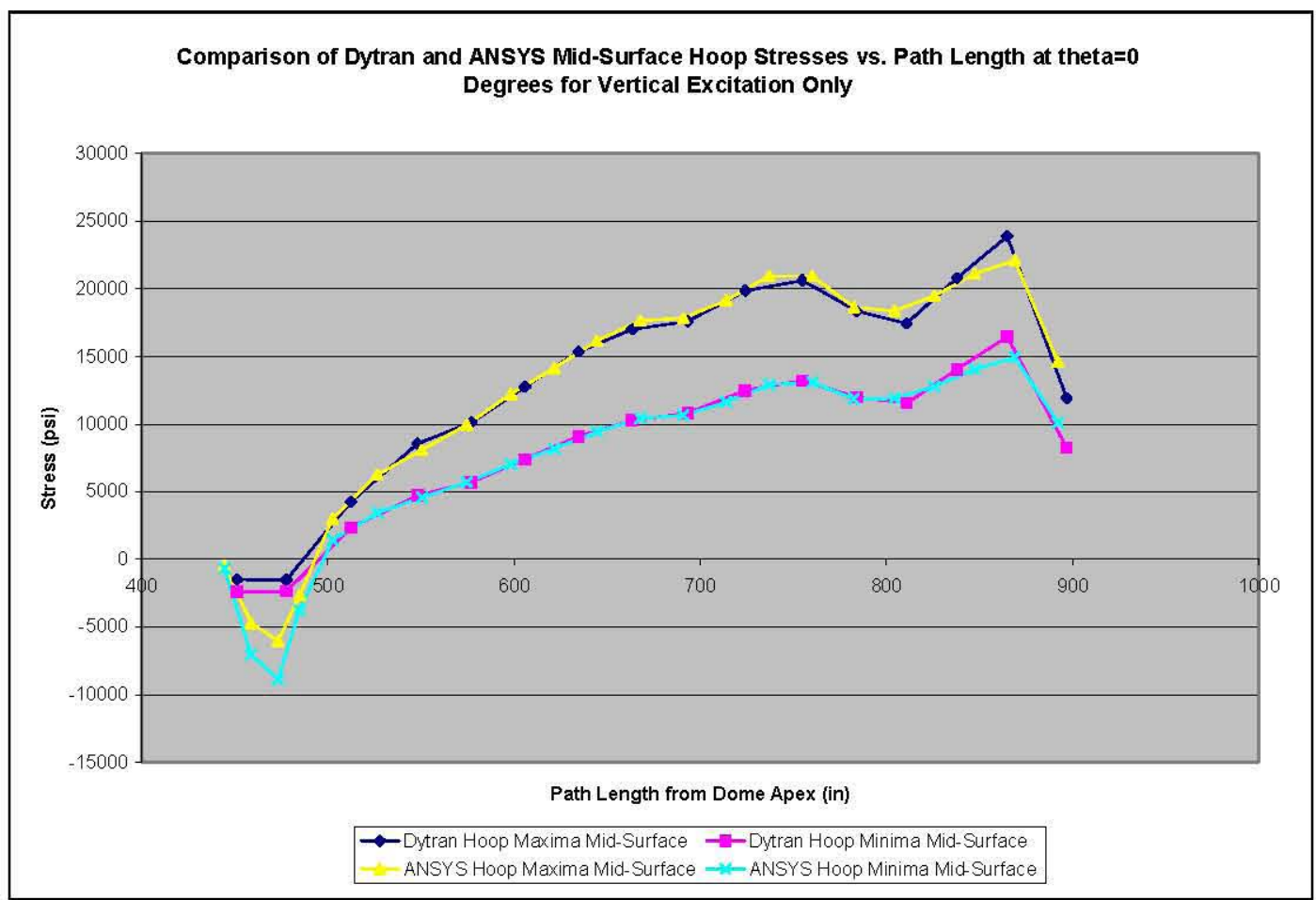

Figure 7-19. Comparison of Dytran ${ }^{\mathbb{B}}$ and $\operatorname{ANSYS}^{\mathbb{B}}$ Mid-Surface Hoop Stresses at $\theta=0^{\circ}$ for Vertical Seismic Excitation 
RPP-RPT-32239, Rev. 1

M\&D-2008-005-CALC-001, Rev. 1

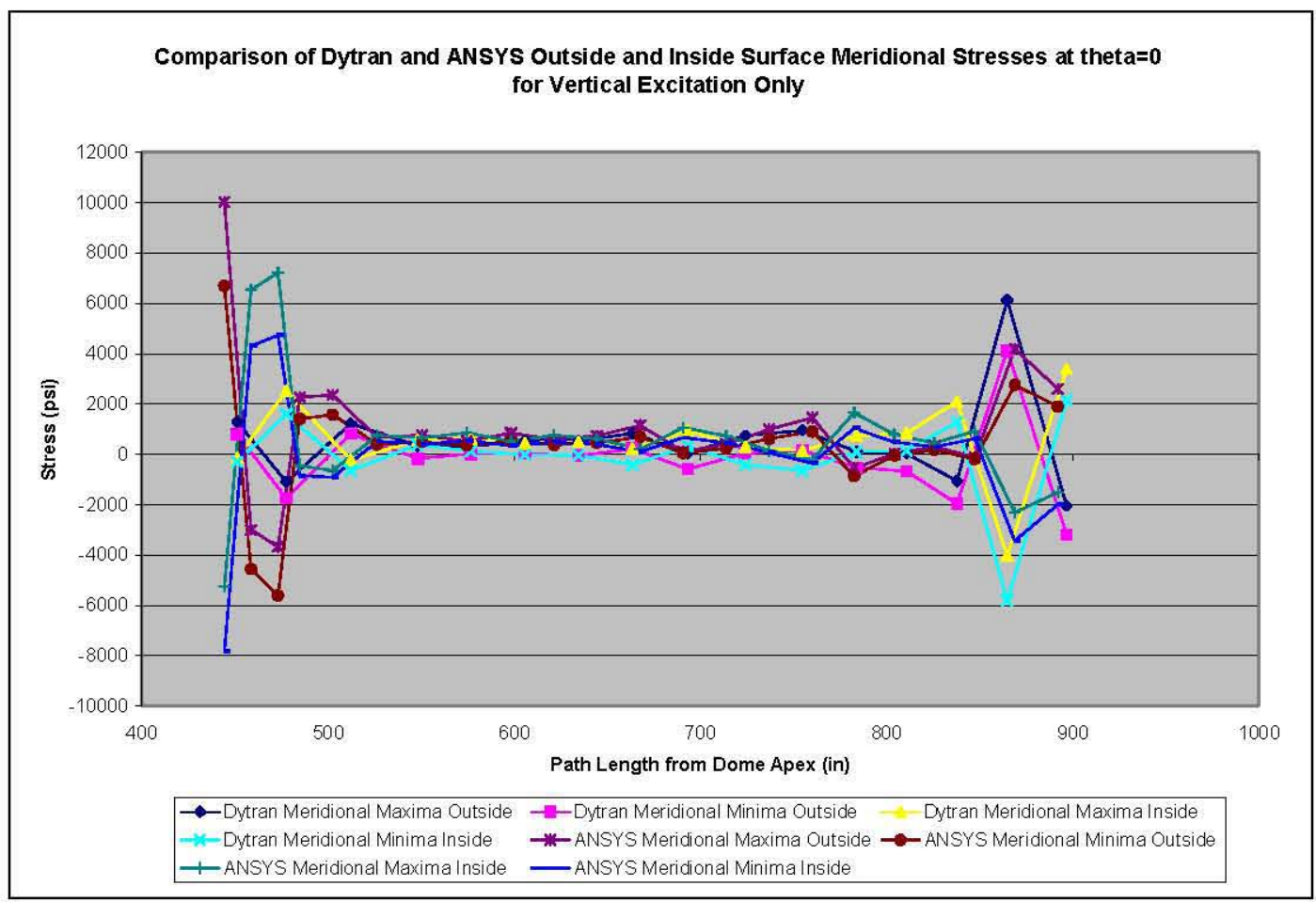

Figure 7-20. Comparison of Dytran ${ }^{\mathbb{B}}$ and $\mathrm{ANSYS}^{\circledR}$ Outside and Inside Surface Meridional Stresses at $\theta=0^{\circ}$ for Vertical Seismic Excitation

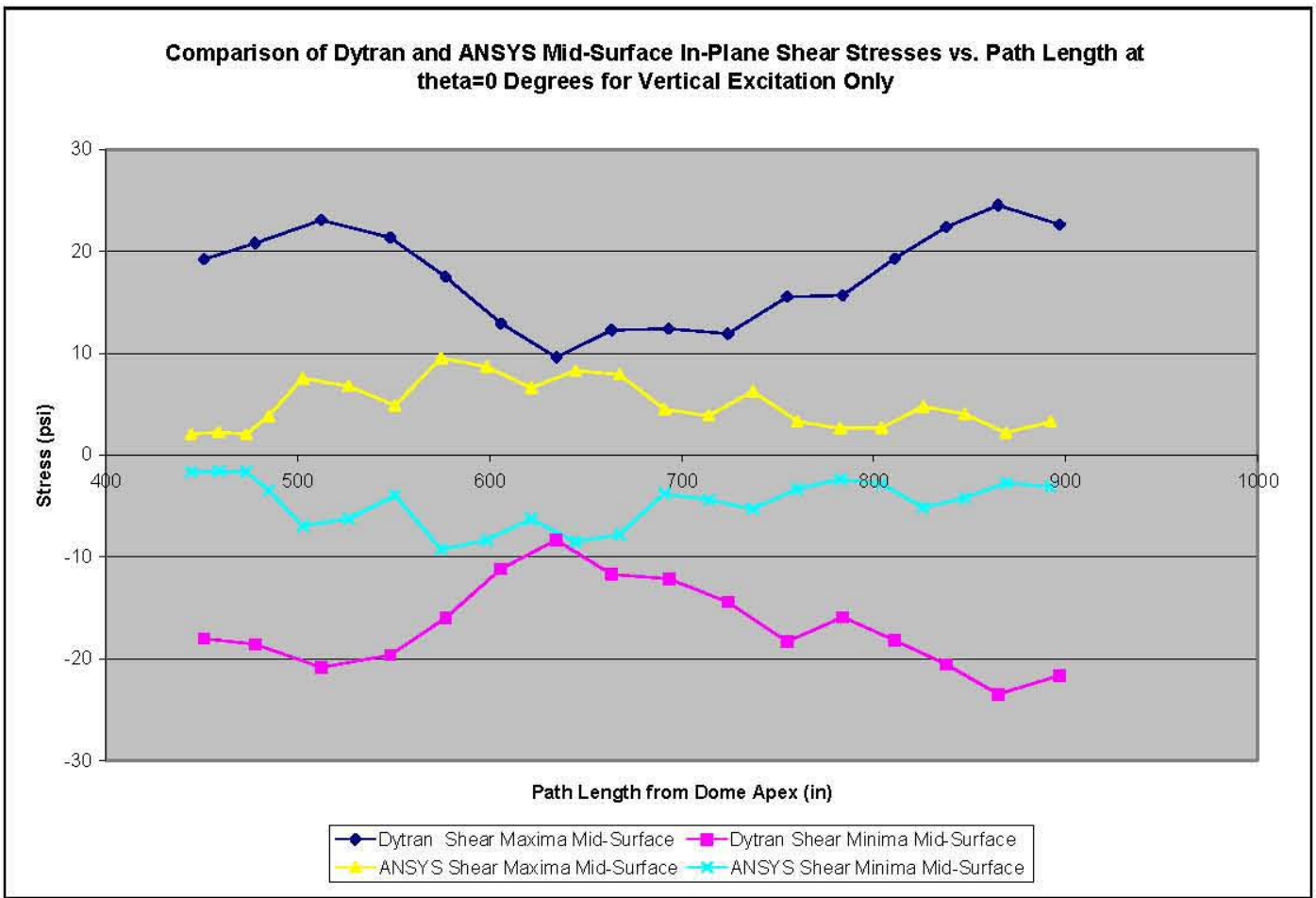

Figure 7-21. Comparison of Dytran ${ }^{\circledR}$ and $\operatorname{ANSYS}^{\circledR}$ Mid-Surface In-Plane Shear Stresses at $\theta=0^{\circ}$ for Vertical Seismic Excitation 
RPP-RPT-32239, Rev. 1

M\&D-2008-005-CALC-001, Rev. 1

\subsubsection{Two-Component Motion}

Comparison plots of the maximum and minimum hoop, meridional, and shear stress distributions in the plane of excitation at $\theta=0^{\circ}$ for horizontal excitation only are shown in Figure 7-22, Figure 7-23, and Figure $7-24$, respectively. Plots of the same stress components at $\theta=45^{\circ}$ are shown in Figure $7-25$, Figure 7-26, and Figure 7-27. The mid-surface shear stress distribution at $\theta=90^{\circ}$ is shown as Figure 7-28.

The same observations made for the cases of horizontal excitation only and vertical excitation only apply to the case of two-component excitation.

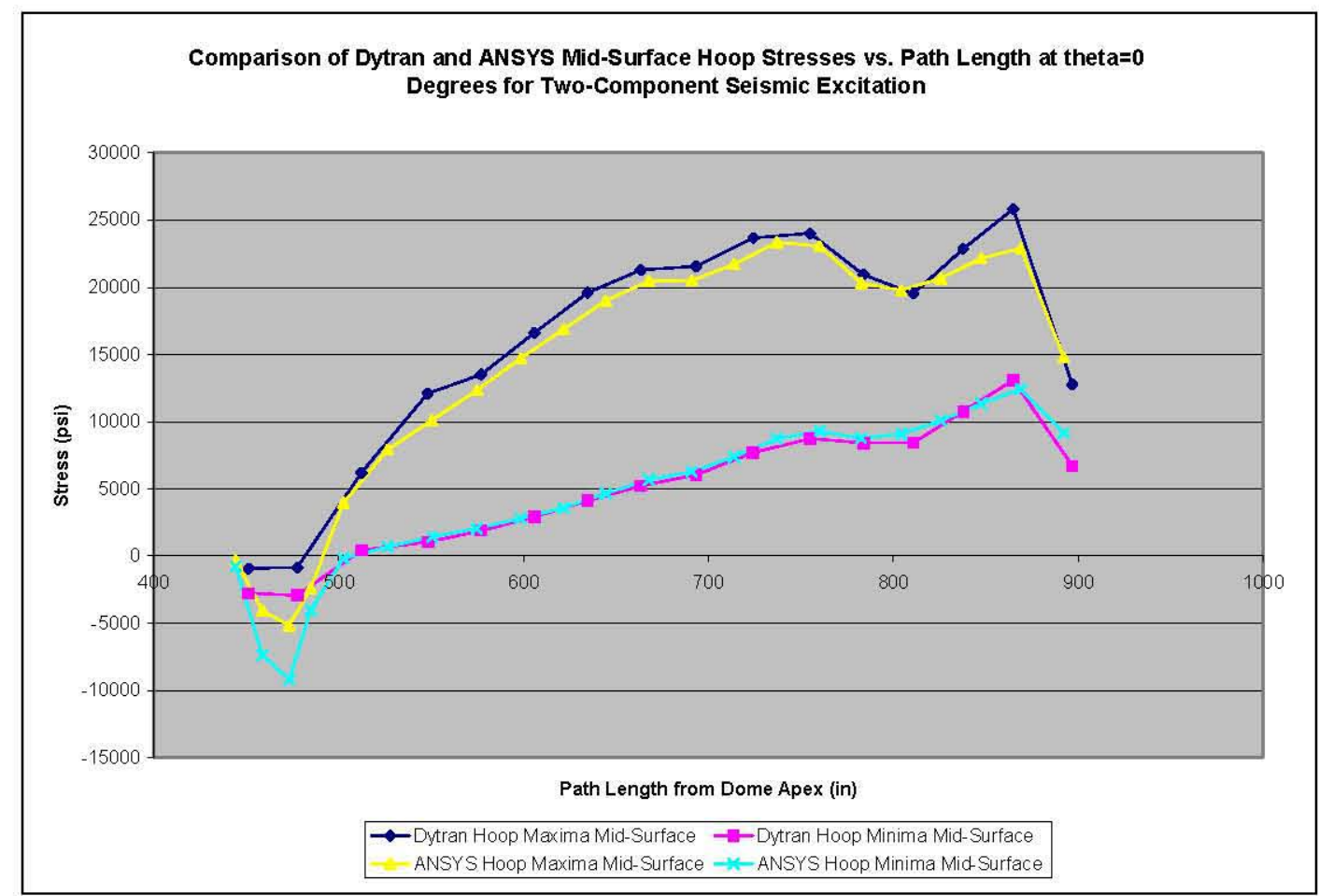

Figure 7-22. Comparison of Dytran ${ }^{\circledR}$ and ANSYS ${ }^{\circledR}$ Mid-Surface Hoop Stresses at $\theta=0^{\circ}$ for TwoComponent Seismic Excitation 
RPP-RPT-32239, Rev. 1

M\&D-2008-005-CALC-001, Rev. 1

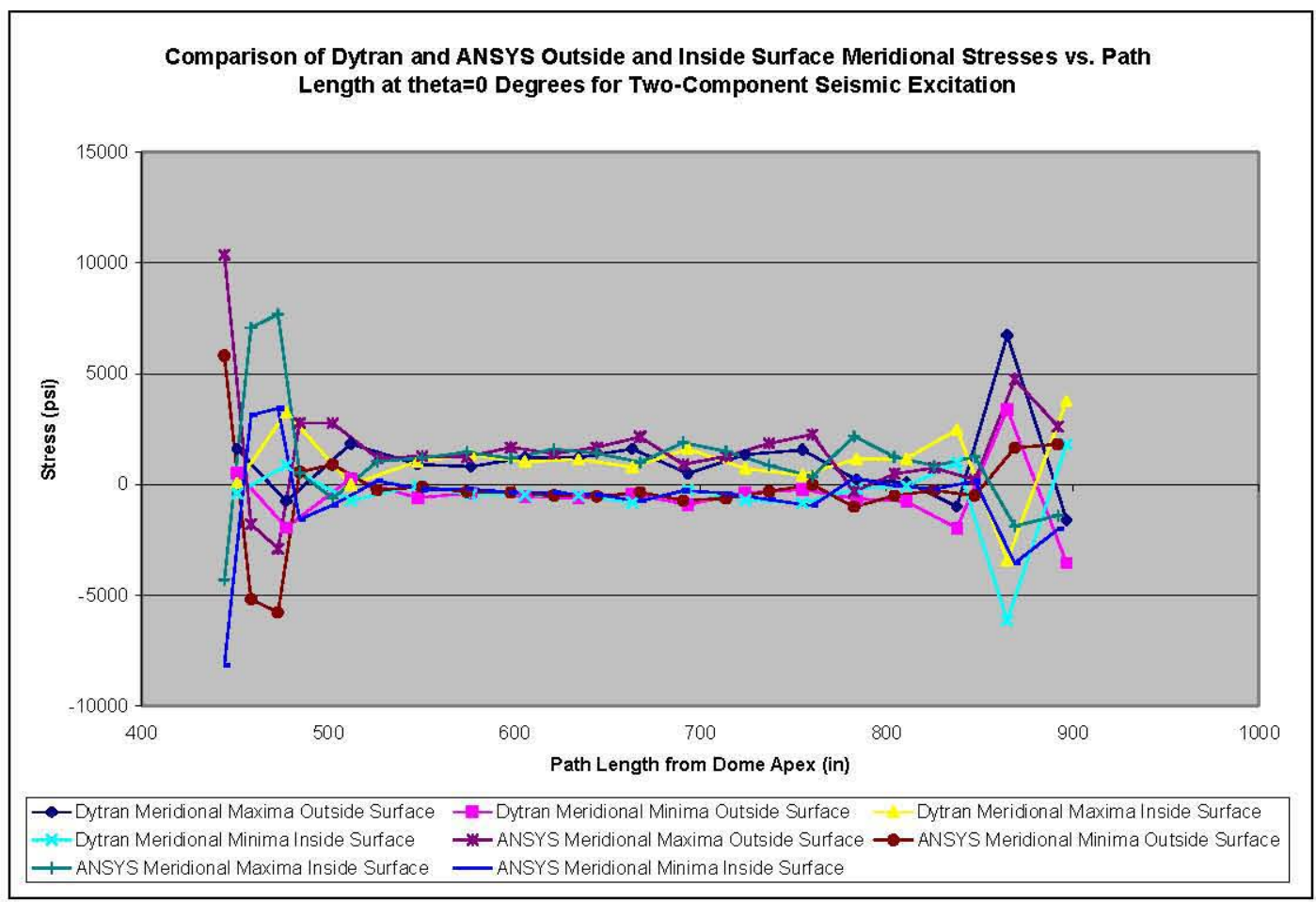

Figure 7-23. Comparison of Dytran ${ }^{\mathbb{B}}$ and $\mathrm{ANSYS}^{\circledR}$ Outside and Inside Surface Meridional Stresses at $\theta=0^{\circ}$ for Two-Component Seismic Excitation

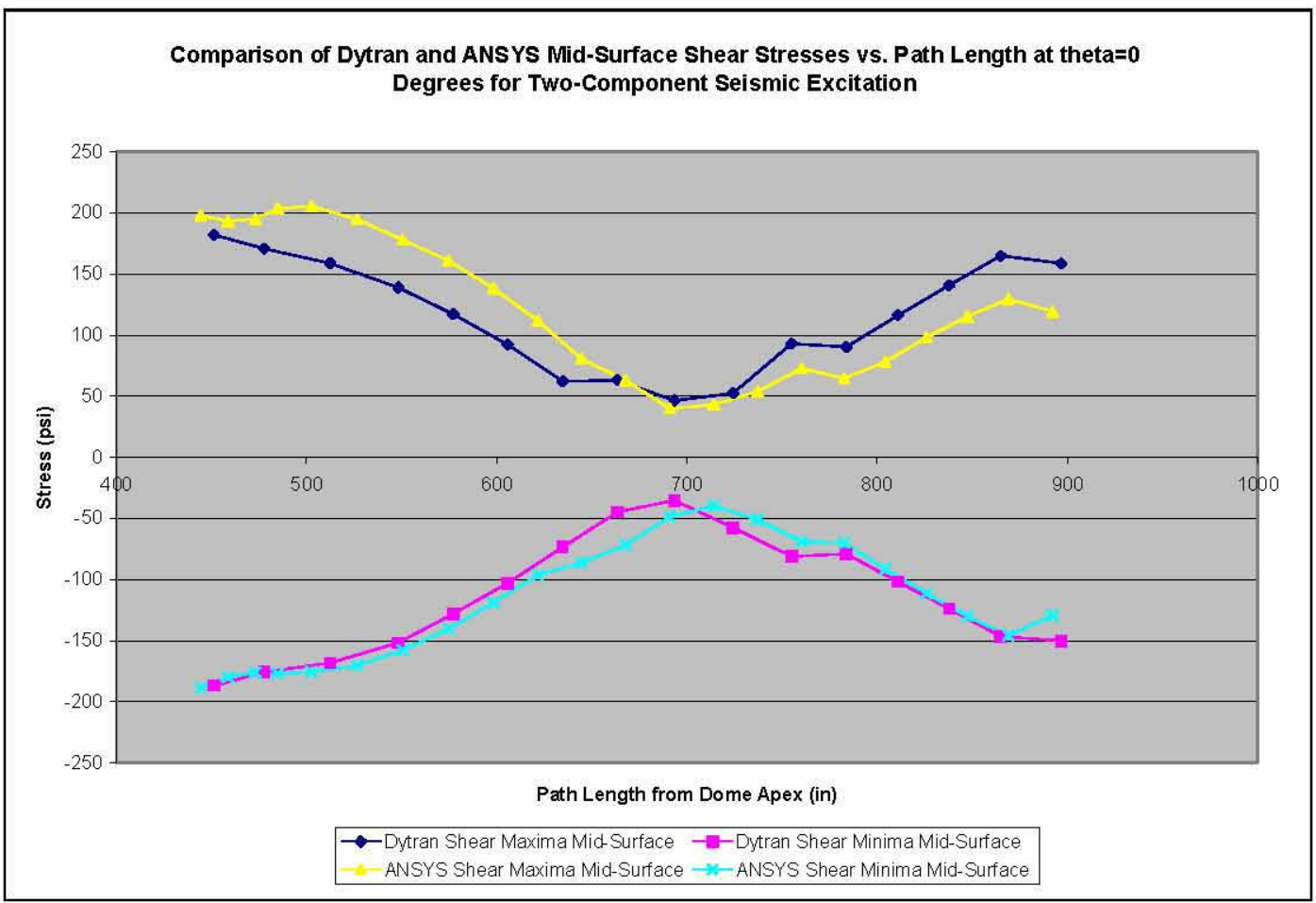

Figure 7-24. Comparison of Dytran ${ }^{\circledR}$ and $\operatorname{ANSYS}^{\circledR}$ Mid-Surface In-Plane Shear Stresses at $\theta=0^{\circ}$ for Two-Component Seismic Excitation 
RPP-RPT-32239, Rev. 1

M\&D-2008-005-CALC-001, Rev. 1

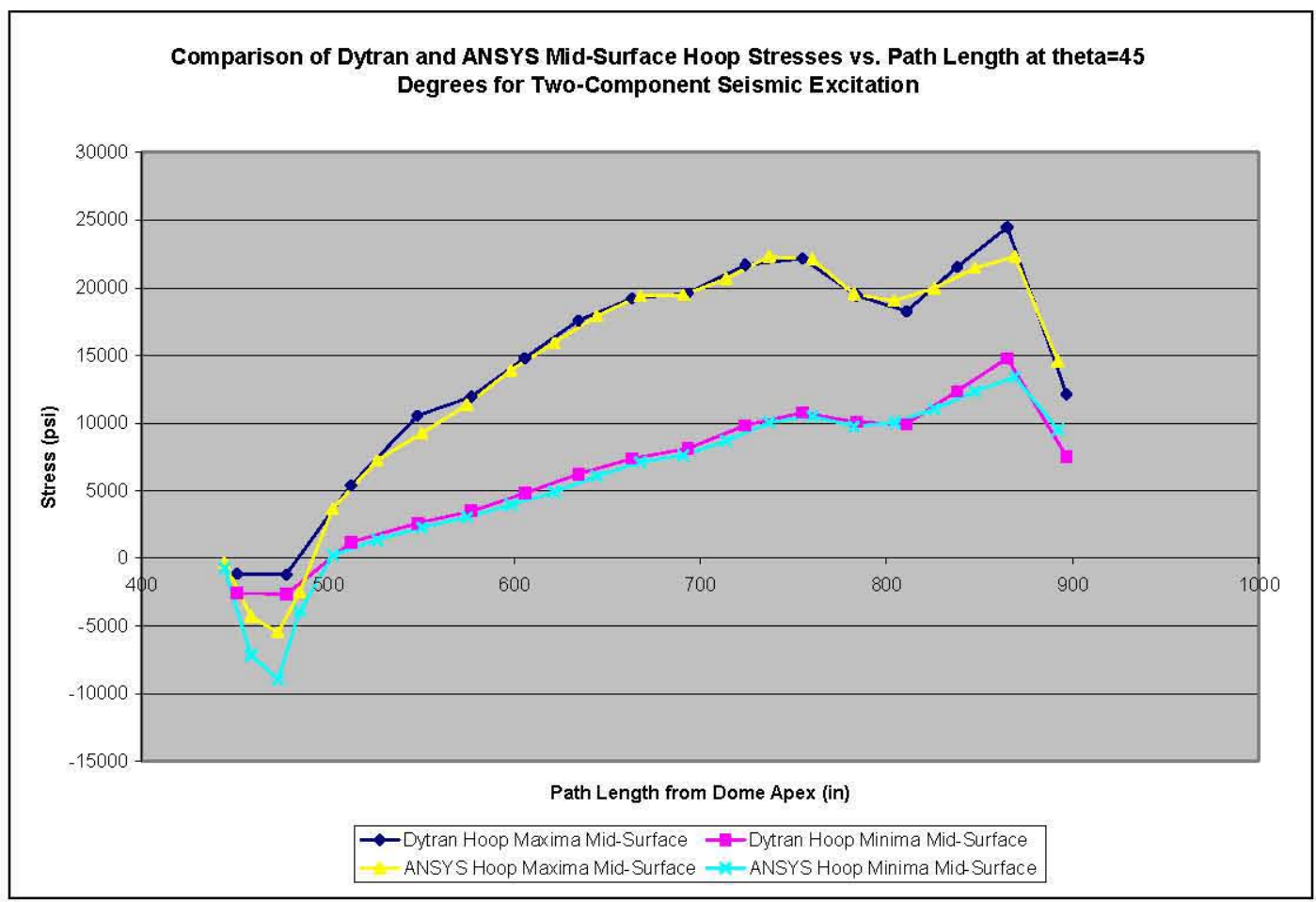

Figure 7-25. Comparison of Dytran ${ }^{\circledR}$ and ANSYS ${ }^{\circledR}$ Mid-Surface Hoop Stresses at $\theta=45^{\circ}$ for TwoComponent Seismic Excitation

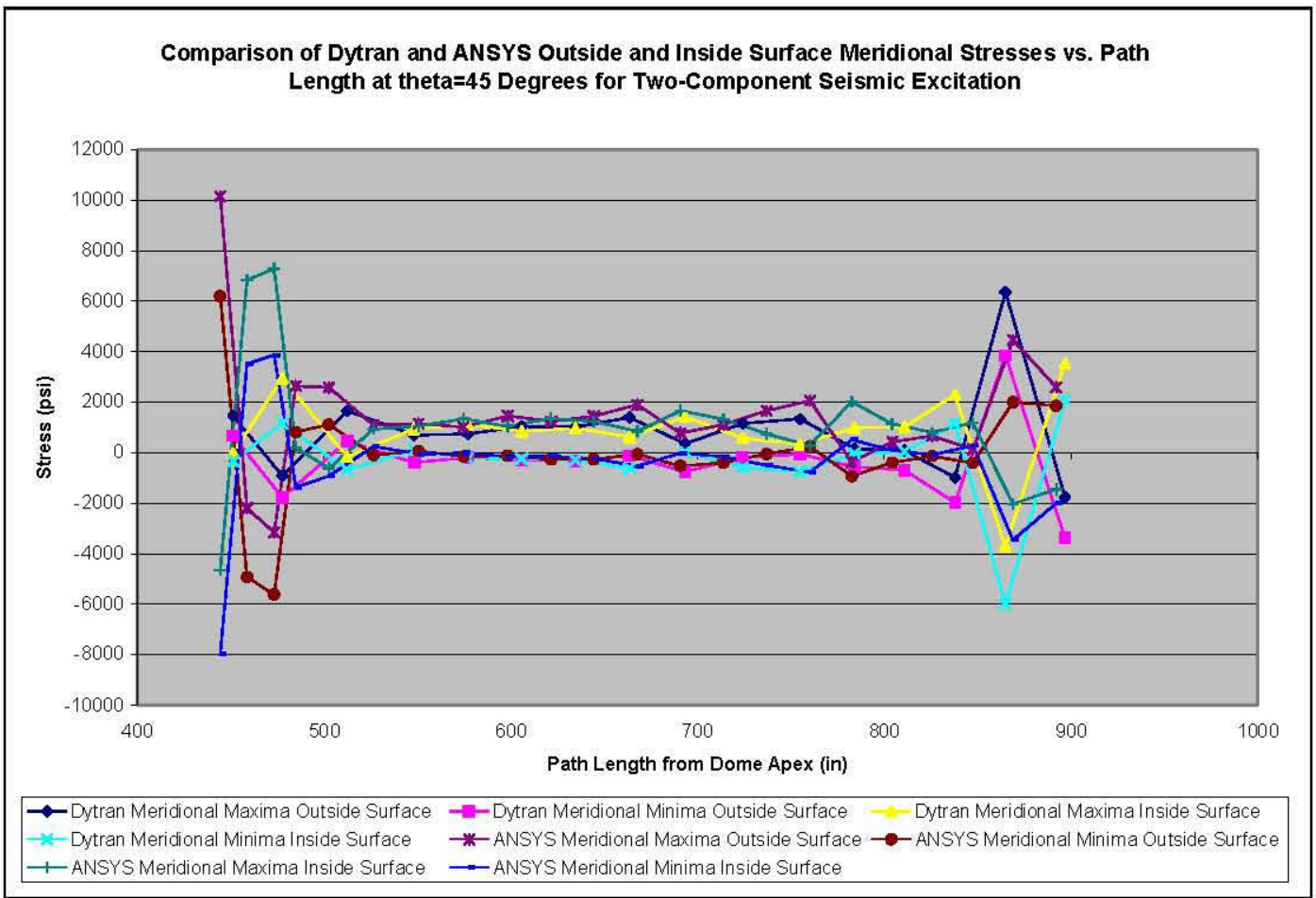

Figure 7-26. Comparison of Dytran ${ }^{\circledR}$ and $\mathrm{ANSYS}^{\circledR}$ Outside and Inside Surface Meridional Stresses at $\theta=45^{\circ}$ for Two-Component Seismic Excitation 
RPP-RPT-32239, Rev. 1

M\&D-2008-005-CALC-001, Rev. 1

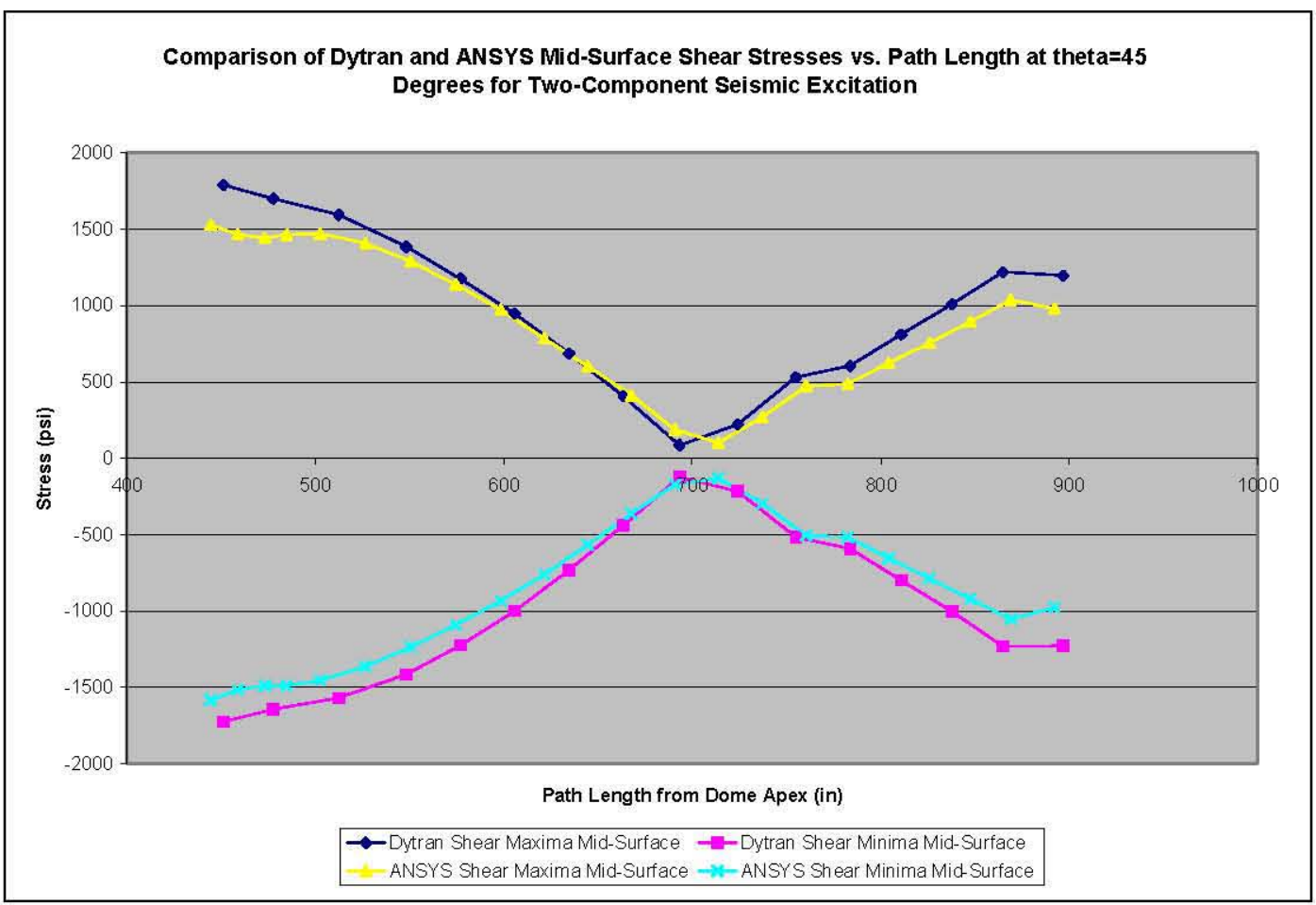

Figure 7-27. Comparison of Dytran ${ }^{\mathbb{B}}$ and $\mathrm{ANSYS}^{\mathbb{B}}$ Mid-Surface In-Plane Shear Stresses at $\theta=45^{\circ}$ for Two-Component Seismic Excitation

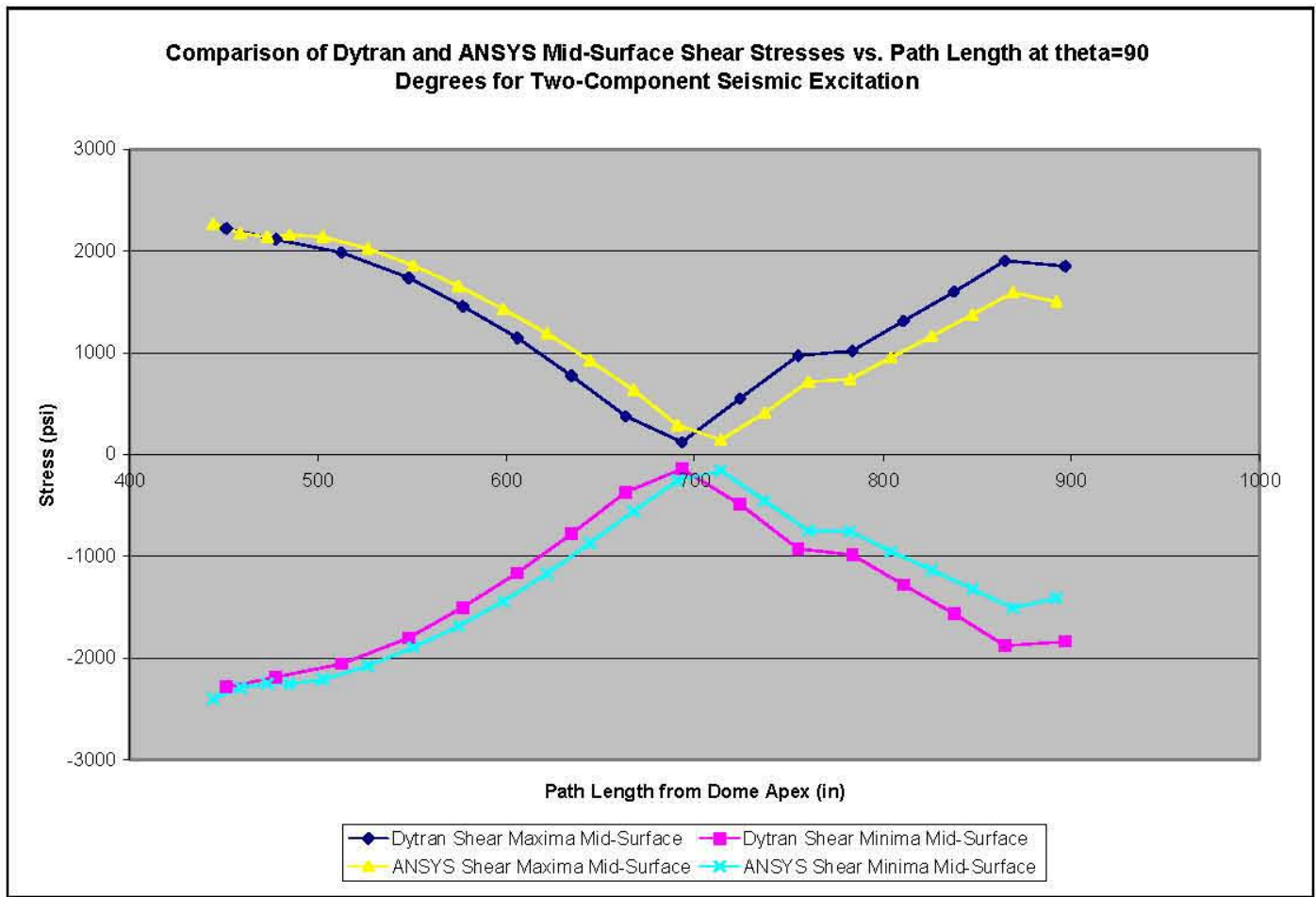

Figure 7-28. Comparison of Dytran ${ }^{\mathbb{B}}$ and $\mathrm{ANSYS}^{\mathbb{Q}}$ Mid-Surface In-Plane Shear Stresses at $\theta=90^{\circ}$ for Two-Component Seismic Excitation 
RPP-RPT-32239, Rev. 1

M\&D-2008-005-CALC-001, Rev. 1

\subsubsection{Two-Component Motion Comparisons for Various Models}

The data in this section are presented to illustrate the differences in stress results that are attributable to the differences between the global model and the sub-models, and to differences in primary tank stresses due to different soil and concrete conditions. Differences between the global ANSYS ${ }^{\circledR}$ model and the sub-models include the method of excitation, a slight shifting of fundamental impulsive frequency between the models, and model configuration differences including anchor bolts, soil, and the lack of or presence of rigid regions.

A minor point that was considered while reviewing the ANSYS ${ }^{\mathbb{B}}$ data presented in Figure 7-29 and Figure 7-30 is that the maximum stresses shown actually represent the maximum signed magnitude of the stresses extracted from the ANSYS $^{\mathbb{B}}$ model. That is, in regions where the ANSYS ${ }^{\mathbb{B}}$ stresses are negative, the ANSYS $^{\circledR}$ traces could represent the minimum rather than the maximum stress. This potential inconsistency does not appear in the stress distributions used for the actual primary tank evaluation, and it does not affect the data in Figure 7-31 because all those stresses are positive.

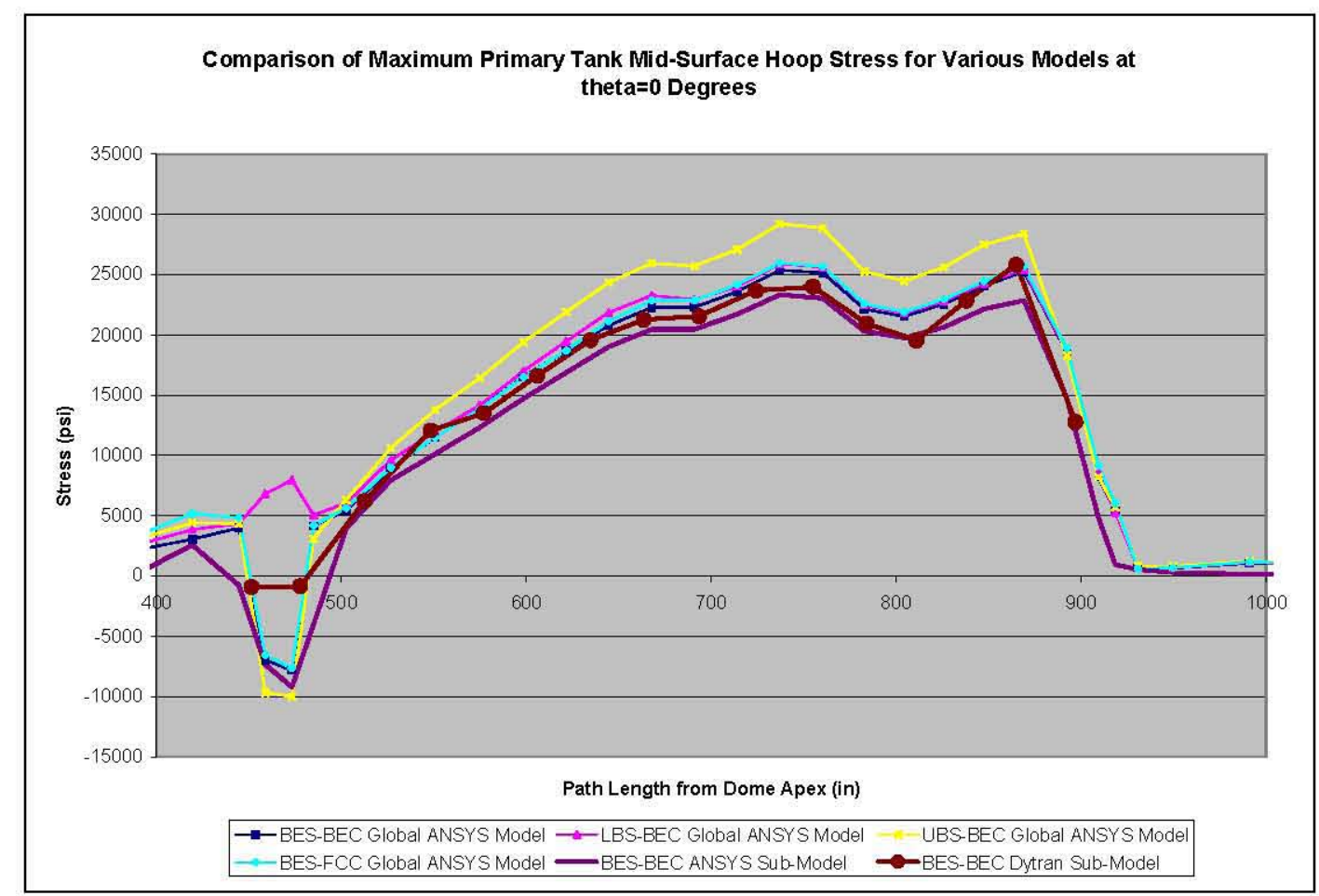

Figure 7-29. Primary Tank Maximum Mid-Surface Hoop Stress Comparisons for Various Models at $\theta=0^{\circ}$ 
RPP-RPT-32239, Rev. 1

M\&D-2008-005-CALC-001, Rev. 1

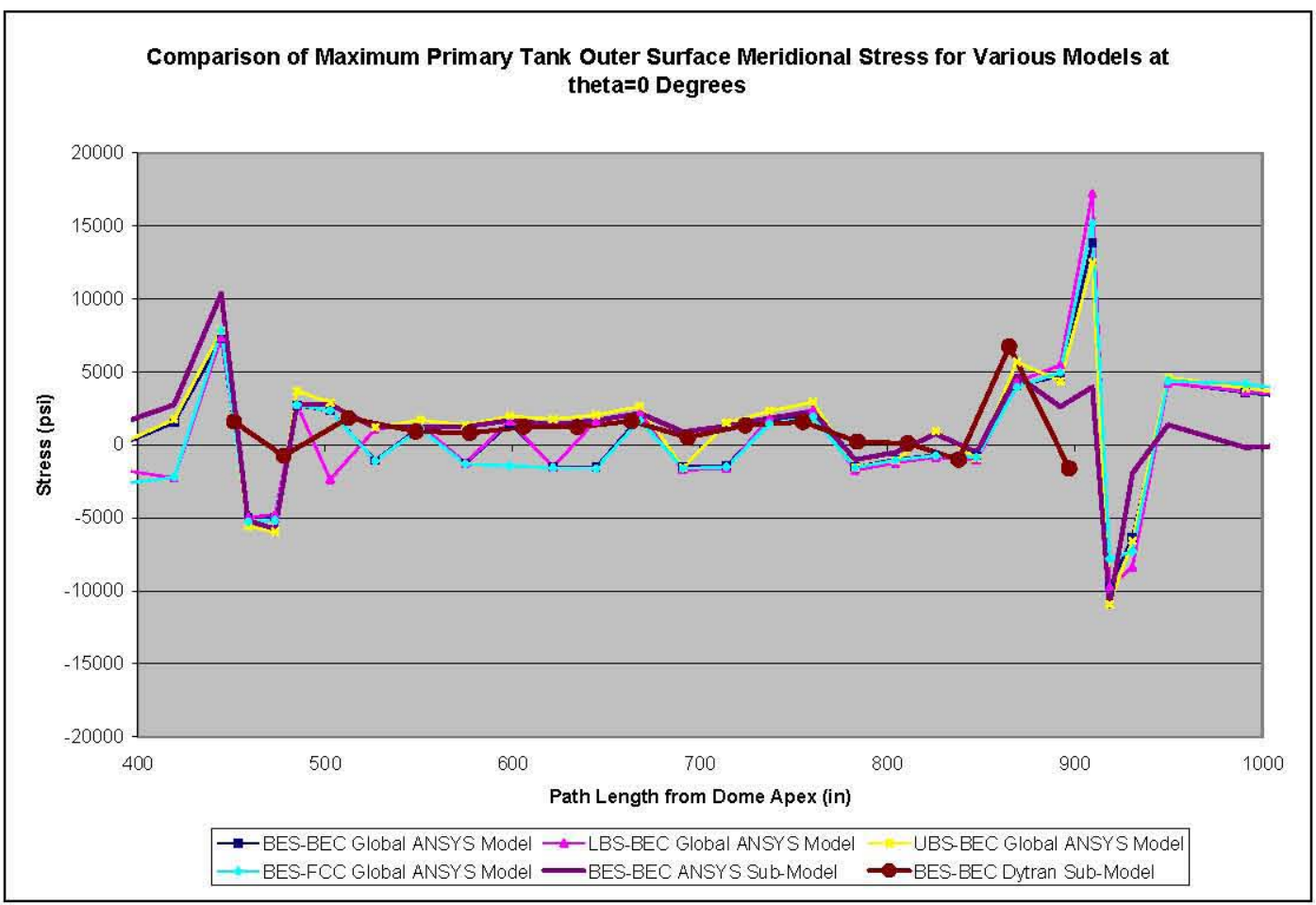

Figure 7-30. Primary Tank Maximum Mid-Surface Meridional Stress Comparisons for Various Models at $\theta=0^{\circ}$

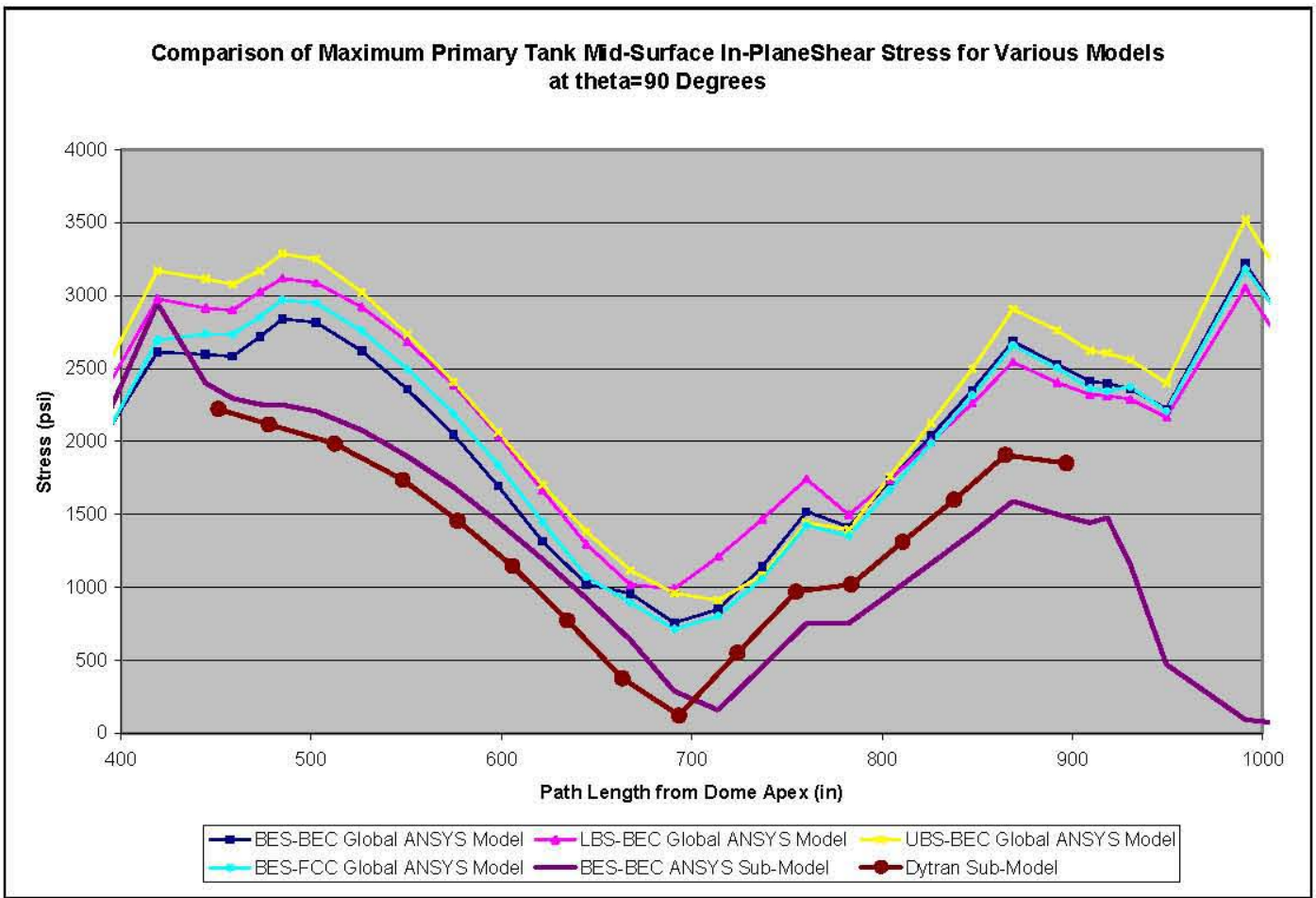

Figure 7-31. Primary Tank Maximum Mid-Surface Shear Stress Comparisons for Various Models at $\theta=0^{\circ}$ 


\section{RPP-RPT-32239, Rev. 1 \\ M\&D-2008-005-CALC-001, Rev. 1}

\subsection{Uncertainties Associated with Waste Characterization}

In the Dytran ${ }^{\mathbb{B}}$ analysis of the AP tanks, the waste was modeled as a homogeneous, nearly incompressible, inviscid liquid with a bulk specific gravity of 1.83 . In the $\mathrm{ANSYS}^{\circledR}$ analysis, the waste was modeled as a homogeneous, nearly incompressible deformable solid with very low shear resistance, also with a bulk specific gravity of 1.83 . During a project review meeting held in June 2007, one review comment stated that there are fundamental uncertainties in idealizing the tank waste as a homogeneous liquid (see Appendix A of Deibler et al. 2008). The technical issue of concern is that hydrodynamic effects for a tank storing a solid-like material may be larger than for a liquid-containing tank.

The potential for an increased response from a tank containing a solid-like material relative to a tank containing a liquid arises from two mechanisms. First, the solid-like material will have reduced sloshing response relative to a liquid, so a higher portion of the mass responds impulsively, thereby increasing some response parameters. Second, depending on the excitation, as well the structural characteristics and geometrical configuration of the tank and contained waste, it is possible for the response of the tank to amplify the response of the tank walls (Veletsos and Younan [1998]).

The second phenomenon can occur when the natural frequencies of contained material are "in tune" with the natural frequencies of the tank. This also depends on the ratio of the waste height to the tank radius (slenderness ratio), and the characteristics of the forcing function. For this to occur, the contained material must be "solid" in the sense that it has structural frequencies and mode shapes independent of the tank itself. This characterization appears to be inconsistent with Hanford DST waste properties and will not be discussed further. Depending on the DST waste composition, the first phenomenon may occur to some degree.

When the waste is completely liquid, the mass of the waste in the DSTs that responds in the impulsive and convective modes is roughly the same, with somewhat greater than half the waste mass responding in the impulsive mode (BNL 1995).

If it is assumed conservatively that the lower one-third of the waste is a sludge layer of specific gravity of 1.83 that responds $100 \%$ impulsively, and that the upper two-thirds of the waste is liquid specific gravity of 1.83 , which responds equally in the impulsive and convective modes, then two-thirds of the total waste mass responds impulsively. This gives an approximate increase of $1 / 6(16.7 \%)$ in the portion of the waste responding impulsively. The increase in impulsive mass will affect both the demands on the anchor bolts and the waste pressures in the primary tank.

Some simple conservative estimates of the effects of a sludge layer at the bottom of the tank can be made based on the equations in Chapter 4 of BNL (1995) and Rinker and Abatt (2006b).

As a first approximation, it is assumed that the increase in the maximum horizontal hydrodynamic reaction force is proportional to the increase in the impulsive mass of the waste. That is, the increase in the maximum horizontal reaction force is estimated to be $16.7 \%$. The increased shear reaction is split between the bottom of the primary tank (contact interface with the insulating concrete) and the top of the primary tank (anchor bolts and normal and shear forces between steel and concrete dome).

With several load paths available to accommodate the increased shear force, not all of the additional shear will be reacted by the anchor bolts. Moreover, a significant portion of the anchor bolt demand (roughly 


\section{RPP-RPT-32239, Rev. 1 \\ M\&D-2008-005-CALC-001, Rev. 1}

one-third) is from thermal and operating loads, which are largely unaffected by the presence of a sludge layer. With the above considerations in mind, the increase in the anchor bolt demands from this conservative estimate appears to be less than $10 \%$. This upper bound estimate of the increase in anchor bolt loads is exclusive of several other notable conservative factors in the analysis, including the following:

- The most recent site response analyses performed at the Hanford Site Waste Treatment Plant (WTP) show that the currently published design spectra for the WTP Site are significantly lower than the interim spectra published in 2005 (PNNL 2007). This indicates that the governing spectra being used for the DST analysis are likely to be conservative.

- The TOLA and seismic demands reported for the AP tanks do not credit any friction between the concrete dome and the steel tank. Initial indications are that the benefit of friction may reduce the demands by approximately $5 \%$.

- So far, a simplified routine that smears spatial and temporal results has been used to calculate peak seismic demands. Use of a more refined methodology is estimated to reduce the seismic demand by approximately $5-10 \%$.

- The assumption of a bulk modulus of 1.83 is conservative.

In lieu of further, more detailed analysis, it appears that for a sludge height not exceeding one-third of the primary tank height, the potential increase in anchor bolt loads due to increased impulsive response is offset by the increase in capacity associated with the conservatisms inherent to the analysis.

Due to the margins available in the primary tank stresses that are shown in Deibler et al. (2008), an even more conservative argument suffices to show that the increased dynamic pressures in the primary tank are acceptable. For this estimate, assume that all of the tank waste responds impulsively. In this case, the peak hydrodynamic wall is independent of the vertical position along the tank wall and is given by

$$
p_{\text {wall }}(\theta)=\rho_{w} \cdot R \cdot\left(S_{A}\right)_{i} \cdot \cos (\theta)
$$

The spectral acceleration for the impulsive mode of the primary tank and waste can be estimated from the impulsive mode frequency and in-structure response spectrum at the base of the primary tank.

The ANSYS ${ }^{\circledR}$ simulation for the increase liquid level shows an impulsive frequency of $5.78 \mathrm{~Hz}$. The Dytran $^{\circledR}$ simulations show 5.7 and $5.88 \mathrm{~Hz}$, depending on whether the input is single- or two-component motion. The effective impulsive damping from either model is in the range of $4 \%$ of critical damping. Based on the horizontal response spectrum shown in Figure 3-20, an upper bound estimate of the spectral acceleration for the impulsive mode of the primary tank is $0.35 \mathrm{~g}$. The corresponding peak dynamic wall pressure along the plane of excitation $(\theta=0)$ is $10.4 \mathrm{lbf} / \mathrm{in}^{2}$.

Figure 7-32 is a reproduction of Figure 6-6 with the predicted waste pressures for the $100 \%$ impulsive response included. In the critical middle third of the primary tank, the increase in total gage pressure (stress-producing pressure) is $10-15 \%$. Although the percentage increase in the dynamic pressure is higher, the waste pressures are dominated by the gravity-induced hydrostatic pressure over the majority of the tank, and the increase in dynamic pressures associated with the increase in the impulsive response is 
RPP-RPT-32239, Rev. 1

M\&D-2008-005-CALC-001, Rev. 1

mitigated by the superimposed static pressure. Thus, even with highly conservative assumptions, increases in the AP tank waste pressures and tank stresses are easily accommodated with the present analysis.

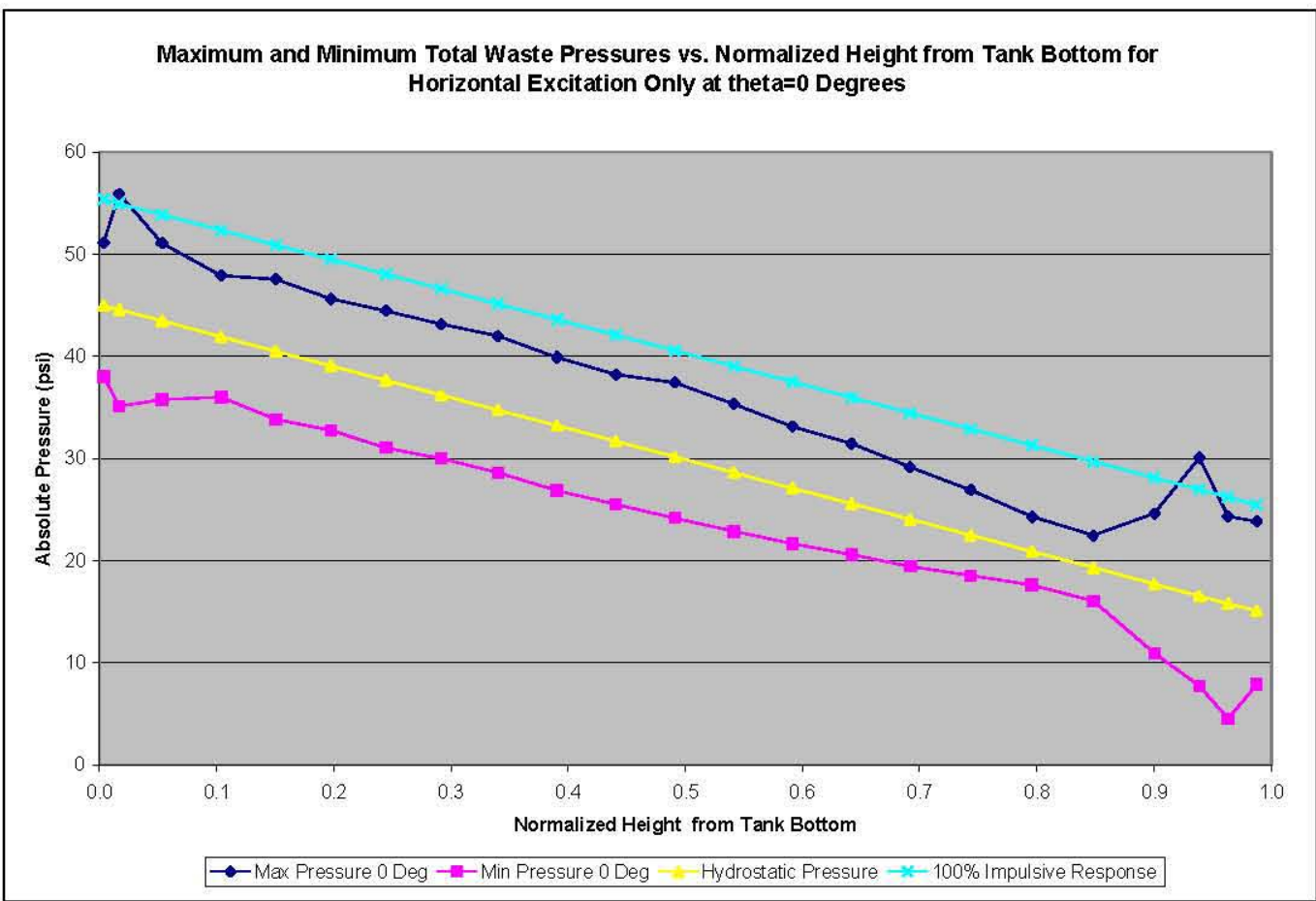

Figure 7-32. Comparison of Maximum Waste from the ANSYS ${ }^{\circledR}$ Primary Tank Sub-Model for Waste Elements at $\theta=0^{\circ}$ Subjected to Horizontal Seismic Excitation Only to Maximum Waste Pressures for the $100 \%$ Impulsive Case 
RPP-RPT-32239, Rev. 1

M\&D-2008-005-CALC-001, Rev. 1

\section{0 $\quad$ ANSYS $^{\circledR}$ Global Model Free-Field Spectra}

This section presents a comparison between response spectra extracted at the lateral boundary of the global model and the free-field spectra from SHAKE. The intent is to demonstrate that the spectra extracted from the global ANSYS ${ }^{\circledR}$ model meet the spectral requirements discussed in Deibler et al. (2007a) and Rinker et al. (2006a, 2006c) and that the lateral boundary of the global model is sufficiently far from the tank structure to essentially reproduce the free-field response. Further discussion of the extent of the lateral boundary of the model is presented in Rinker et al. (2006a).

Similar spectral comparisons are presented in Rinker et al. (2006c) for the baseline liquid level of 422 inches at a specific gravity of 1.7 , but the spectra shown in the following sections are from the global model with the increased liquid level of 460 inches and the increased specific gravity of 1.83 .

Due to the large amount of data, only plots summarizing the results are presented in this section. For more detailed results, see the following appendixes:

- Lower Bound Soil, Best-Estimate Concrete

- Best-Estimate Soil, Best-Estimate Concrete

- Upper Bound Soil, Best-Estimate Concrete

- Best-Estimate Soil, Fully Cracked Concrete
Appendix F

Appendix G

Appendix $\mathrm{H}$

Appendix I

All data were extracted for the full transient analysis (gravity loading plus 2,048 step seismic loading) and summarized using ANSYS ${ }^{\mathbb{B}}$ to obtain the minimum and maximum values. Both the full-time history data and summary data are available electronically.

As discussed in Section 2.5, four separate load cases have been run. One check to ensure that the correct loading was applied during the transient analysis is to compare the response spectra at the edge of the model to the free-field, or design basis response spectra. For each load case, horizontal and vertical spectra have been extracted at both the surface and at $-57 \mathrm{ft}$ (base of tank) for comparison.

\subsection{Lower Bound Soil, Best-Estimate Concrete}

For the lower bound soil case, the ANSYS ${ }^{\circledR}$ spectra are compared to the SHAKE spectra at the surface and tank base. In the lower bound soil, the time histories at the base of the model have been increased by scale factors of 1.175 and 1.12 for horizontal and vertical accelerations respectively in order to meet the minimum spectral requirements. Further discussion of scale factors and requirements for the response spectra is presented in the baseline seismic analysis reported in Deibler et al. (2007a) and Rinker et al. (2006a, 2006c). As can be seen in Figure 8-1 through Figure 8-4, there is a good match between the ANSYS $^{\mathscr{B}}$ model free-field response and the free-field response from SHAKE. This demonstrates that the desired ground motions occur in the ANSYS $^{\circledR}$ model. 
RPP-RPT-32239, Rev. 1

M\&D-2008-005-CALC-001, Rev. 1

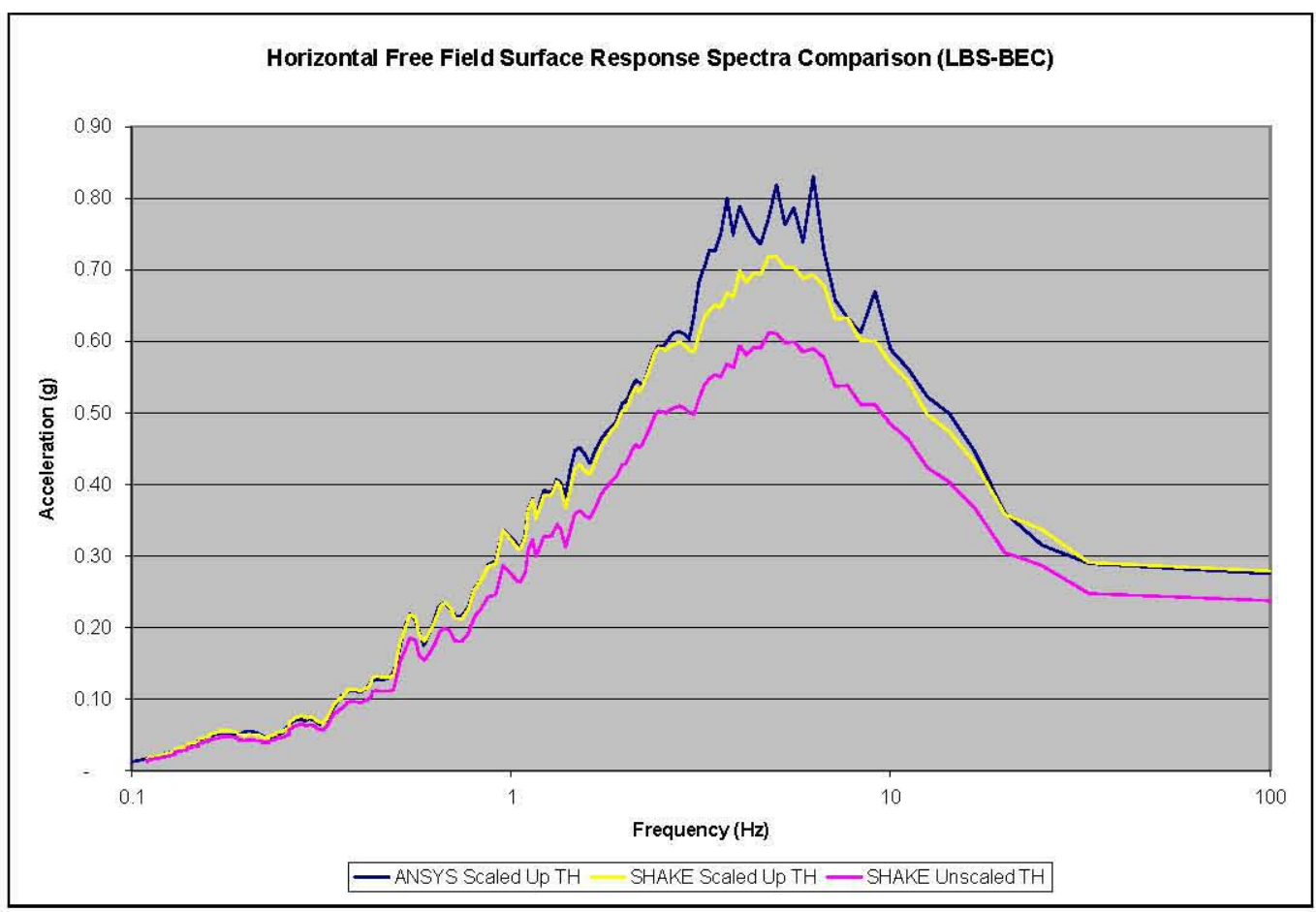

Figure 8-1. 5\% Damped Horizontal Response Spectra Comparison, Surface (LBS-BEC)

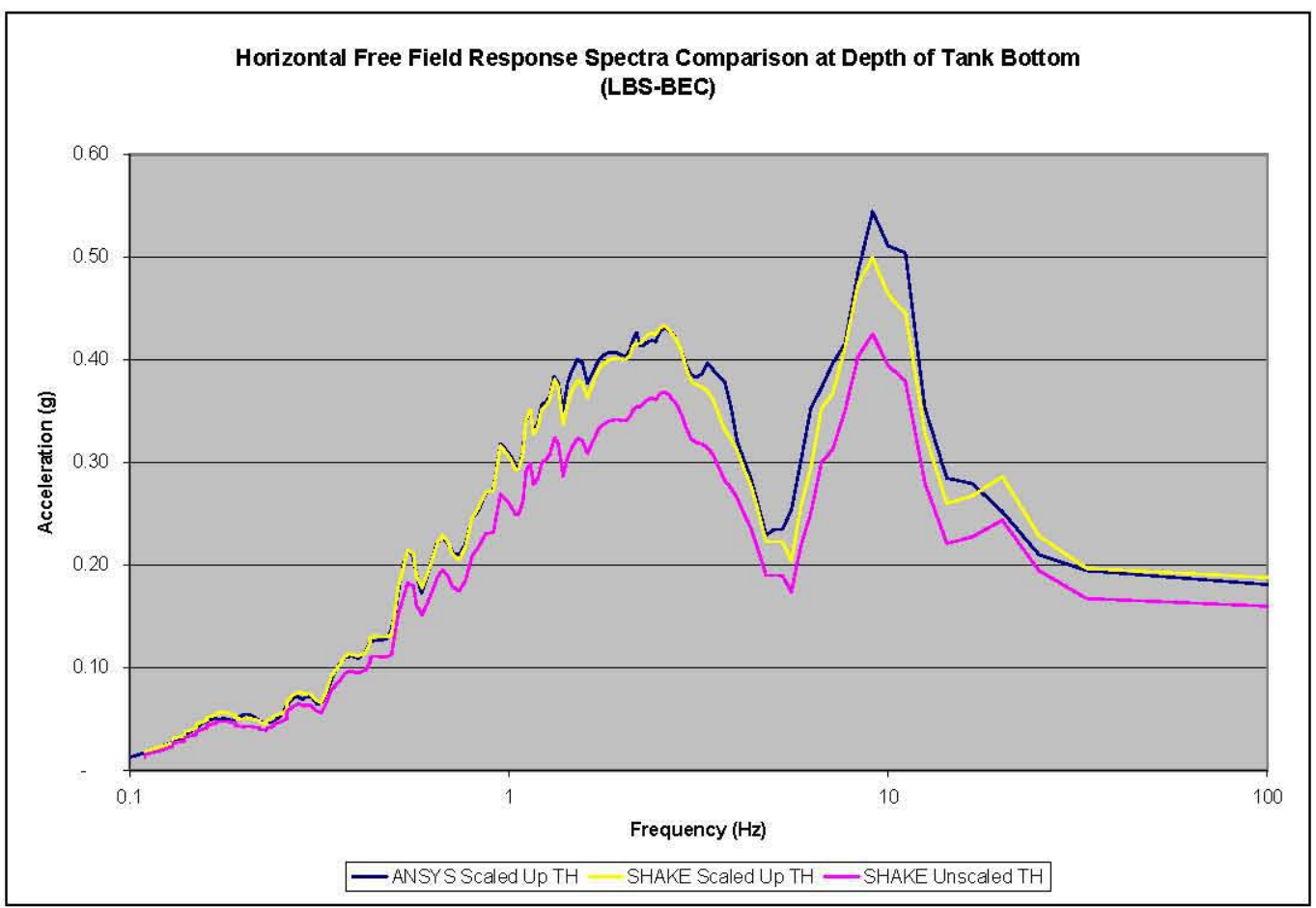

Figure 8-2. 5\% Damped Horizontal Response Spectra, Tank Bottom (LBS-BEC) 
RPP-RPT-32239, Rev. 1

M\&D-2008-005-CALC-001, Rev. 1

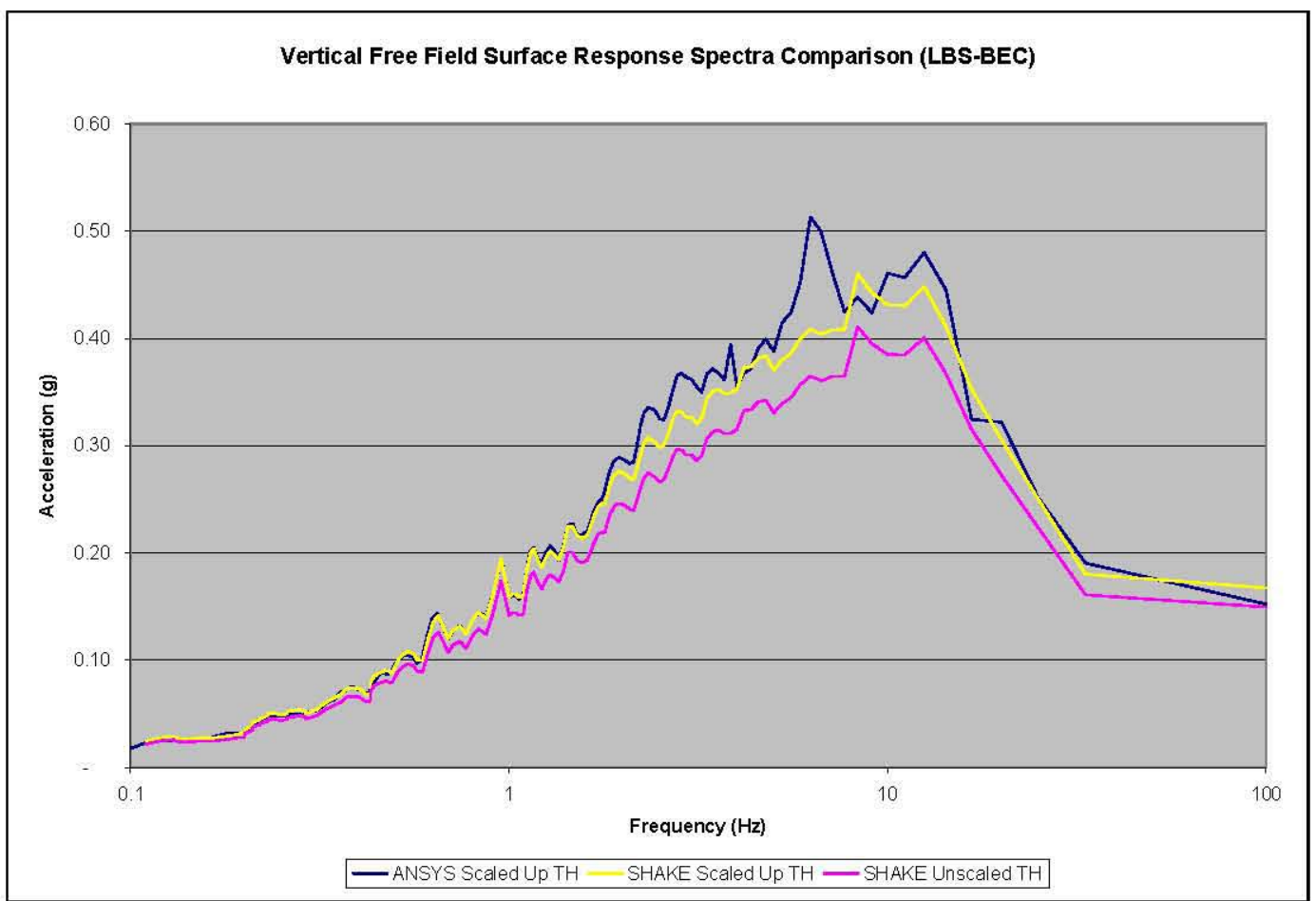

Figure 8-3. 5\% Damped Vertical Response Spectra Comparison, Surface (LBS-BEC)

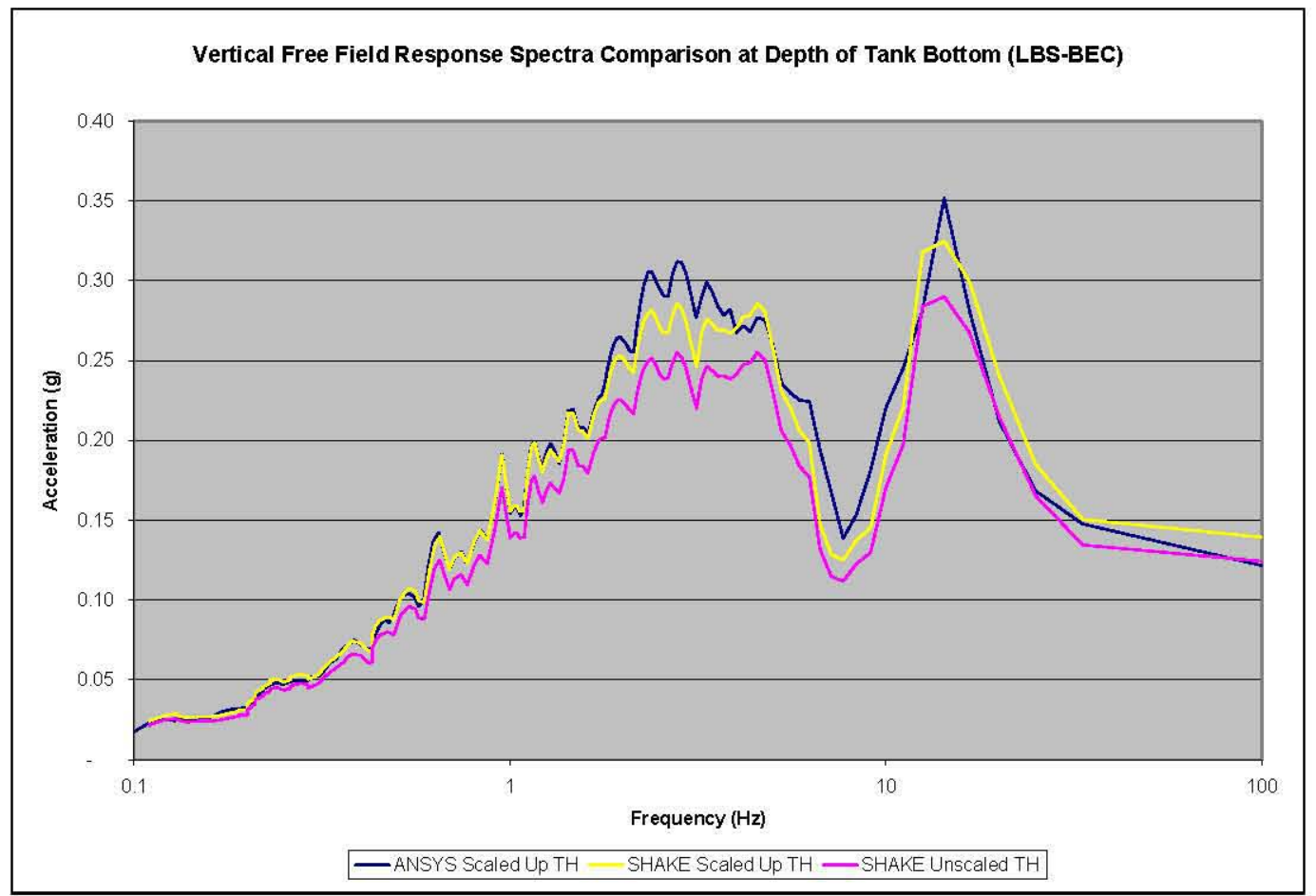

Figure 8-4. 5\% Damped Vertical Response Spectra, Tank Bottom (LBS-BEC) 
RPP-RPT-32239, Rev. 1

M\&D-2008-005-CALC-001, Rev. 1

\subsection{Best-Estimate Soil, Best-Estimate Concrete}

For the best-estimate soil, no scale factors have been applied to the base acceleration time histories. As can be seen in Figure 8-5 through Figure 8-8, there is a good match between the free-field response from the ANSYS ${ }^{\circledR}$ model and the free-field response from SHAKE.

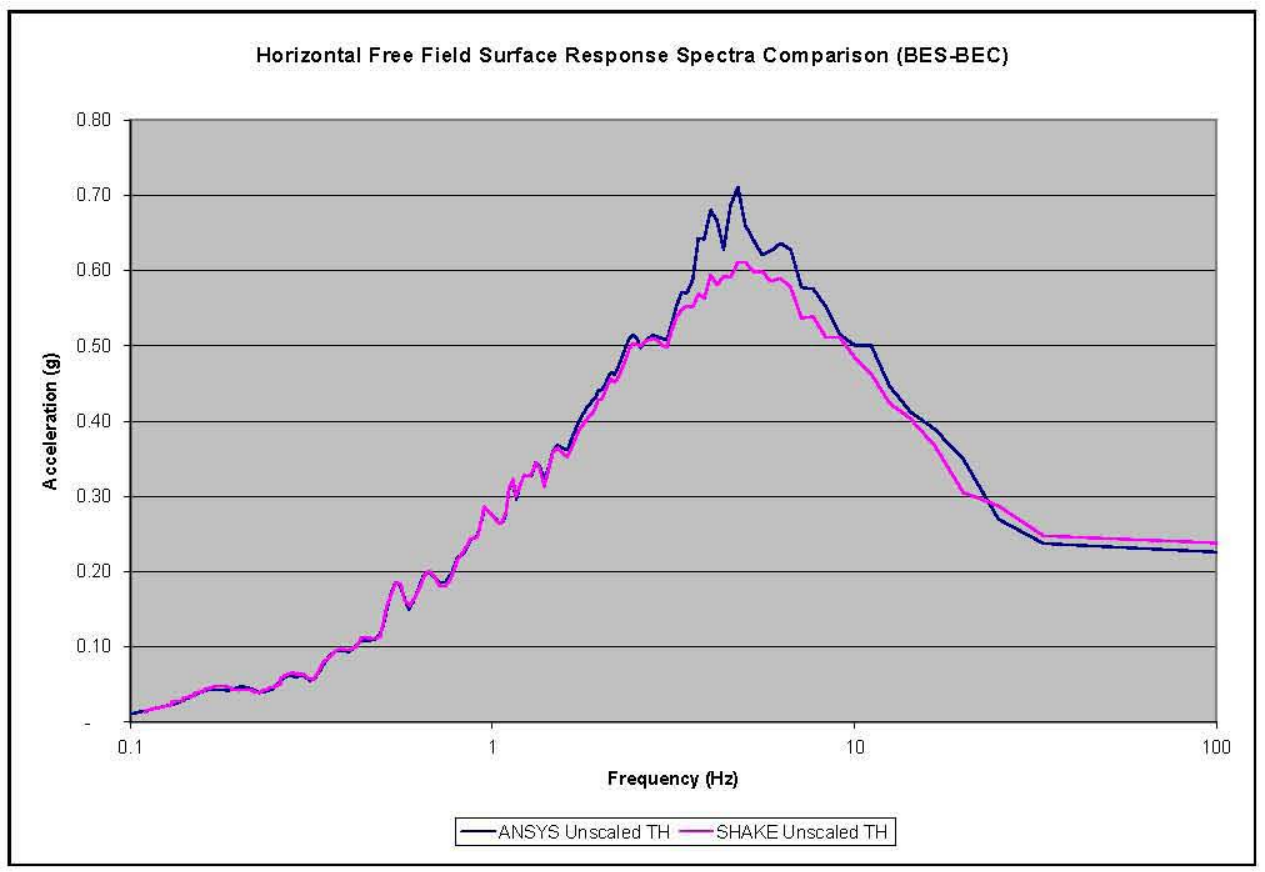

Figure 8-5. 5\% Damped Horizontal Response Spectra Comparison, Surface (BES-BEC)

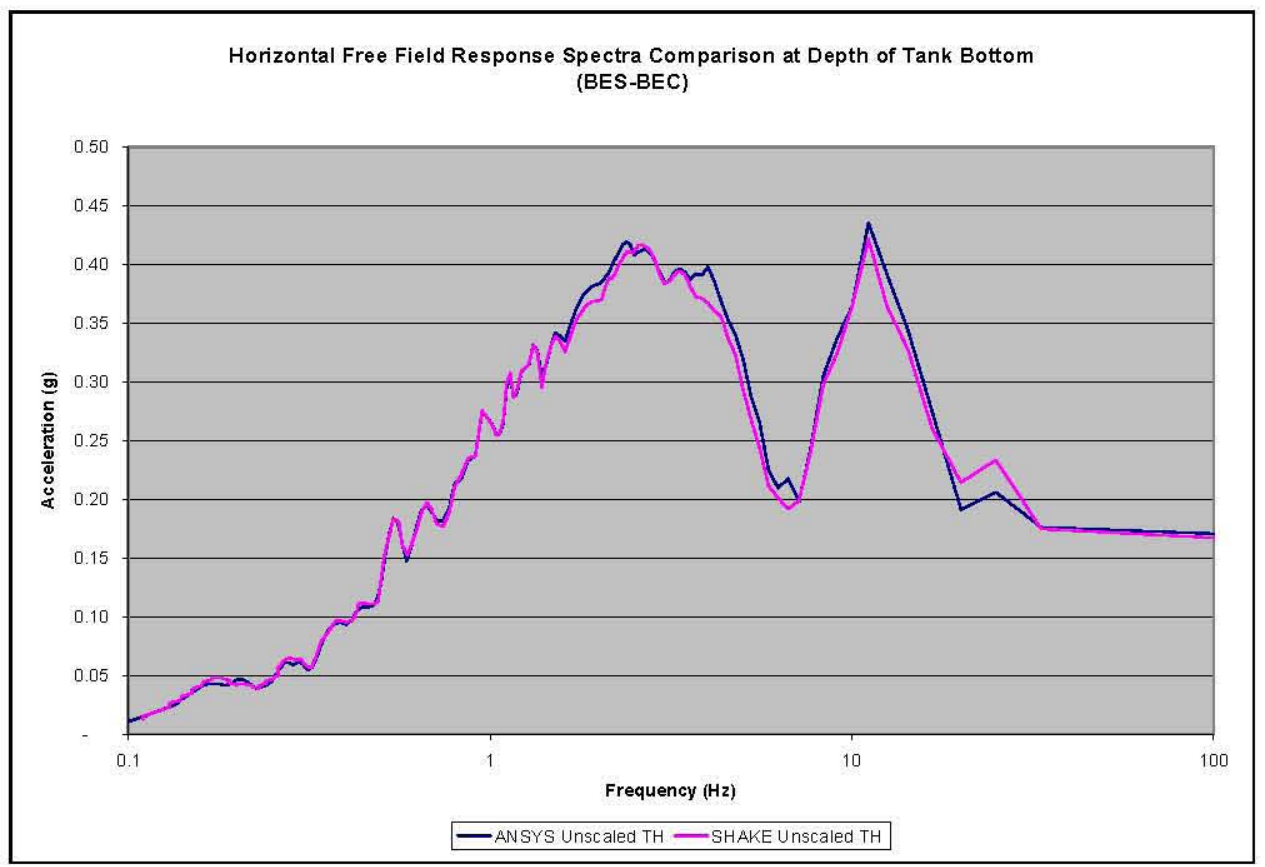

Figure 8-6. 5\% Damped Horizontal Response Spectra, Tank Bottom (BES-BEC) 
RPP-RPT-32239, Rev. 1

M\&D-2008-005-CALC-001, Rev. 1

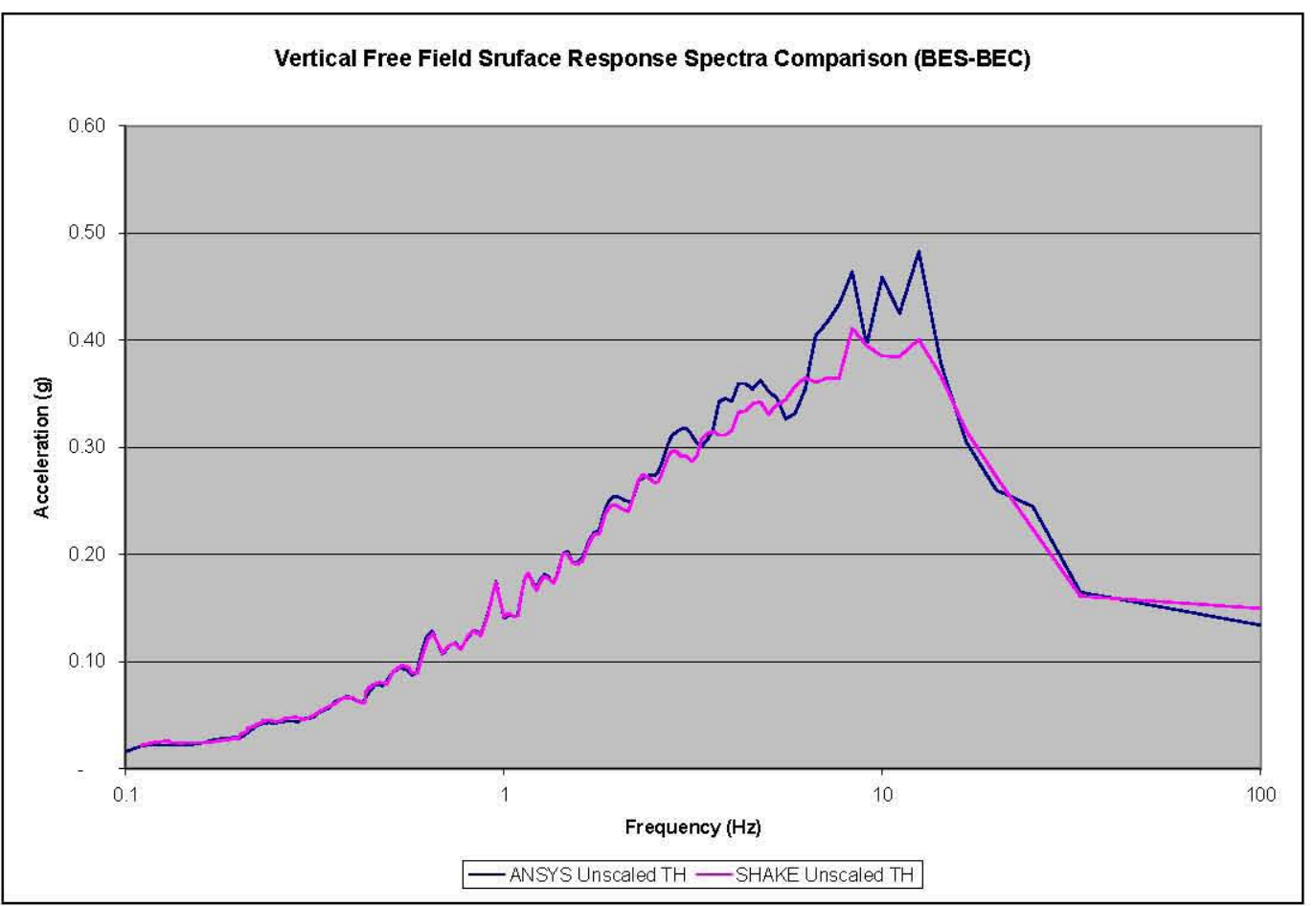

Figure 8-7. 5\% Damped Vertical Response Spectra Comparison, Surface (BES-BEC)

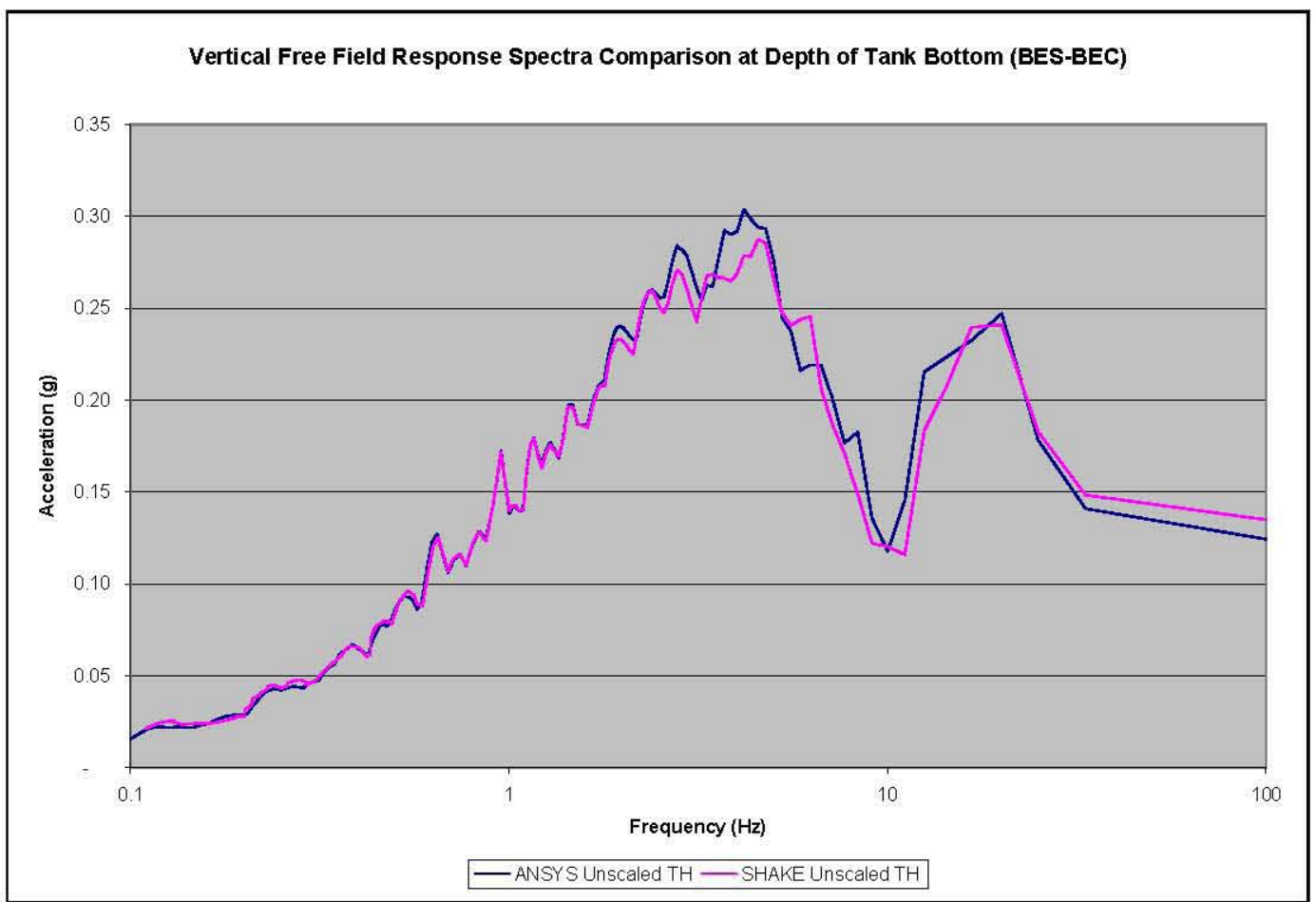

Figure 8-8. 5\% Damped Vertical Response Spectra, Tank Bottom (BES-BEC) 
RPP-RPT-32239, Rev. 1

M\&D-2008-005-CALC-001, Rev. 1

\subsection{Upper Bound Soil, Best-Estimate Concrete}

For the upper bound soil case, the ANSYS ${ }^{\circledR}$ spectra are compared to the SHAKE spectra at the surface and tank base. In the upper bound soil, the time histories at the base of the model have been increased by scale factors of 1.12 and 1.19 for horizontal and vertical accelerations respectively in order to meet the minimum spectral requirements. Further discussion of scale factors and requirements for the response spectra is presented in the baseline seismic analysis reported in Deibler et al. (2007a) and Rinker et al. (2006a, 2006c). As can be seen in Figure 8-9 through Figure 8-12, there is a good match between the ANSYS $^{\mathbb{B}}$ model free-field response and the free-field response from SHAKE. This demonstrates that the desired ground motions occur in the ANSYS $^{\mathbb{B}}$ model.

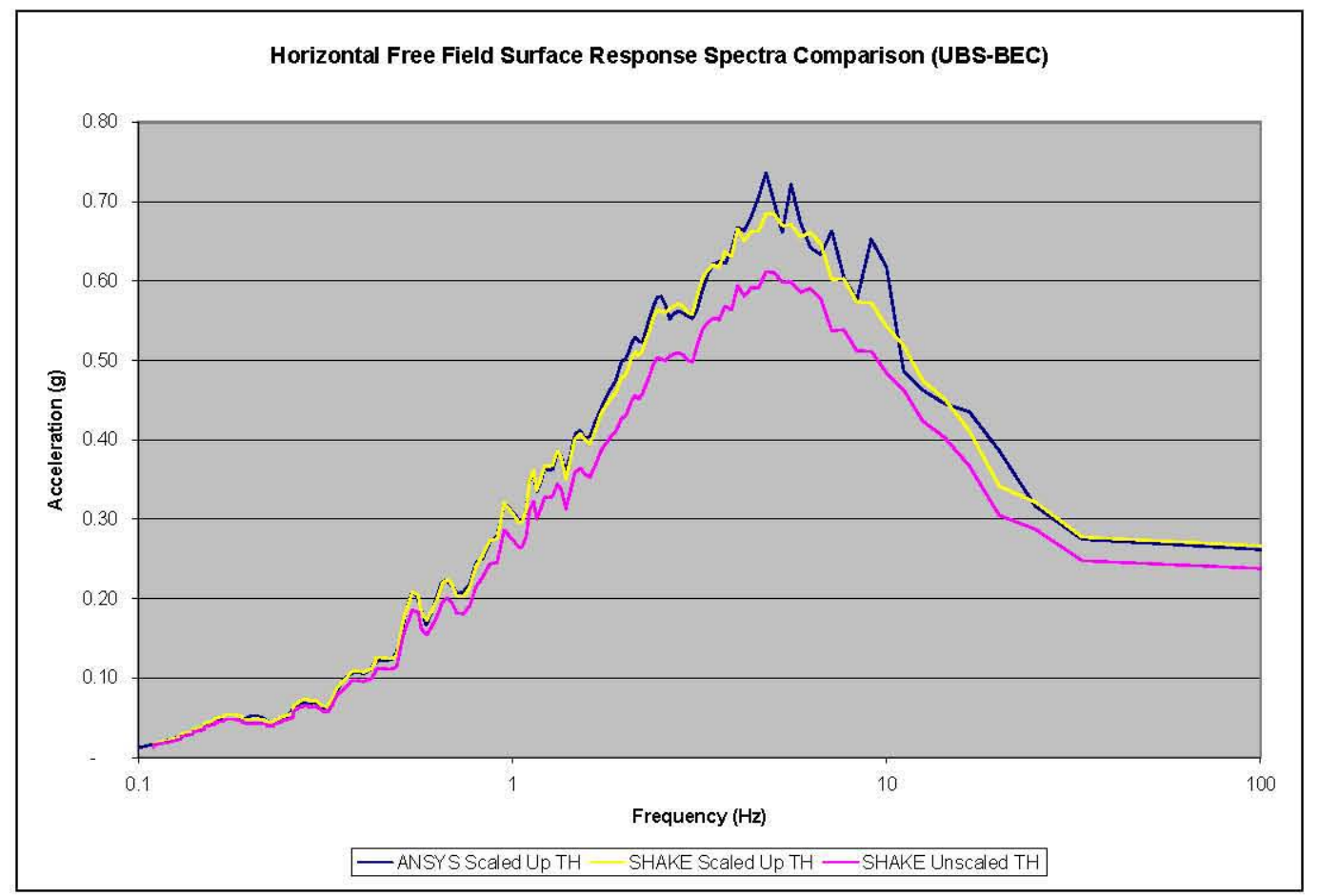

Figure 8-9. 5\% Damped Horizontal Response Spectra Comparison, Surface (UBS-BEC) 
RPP-RPT-32239, Rev. 1

M\&D-2008-005-CALC-001, Rev. 1

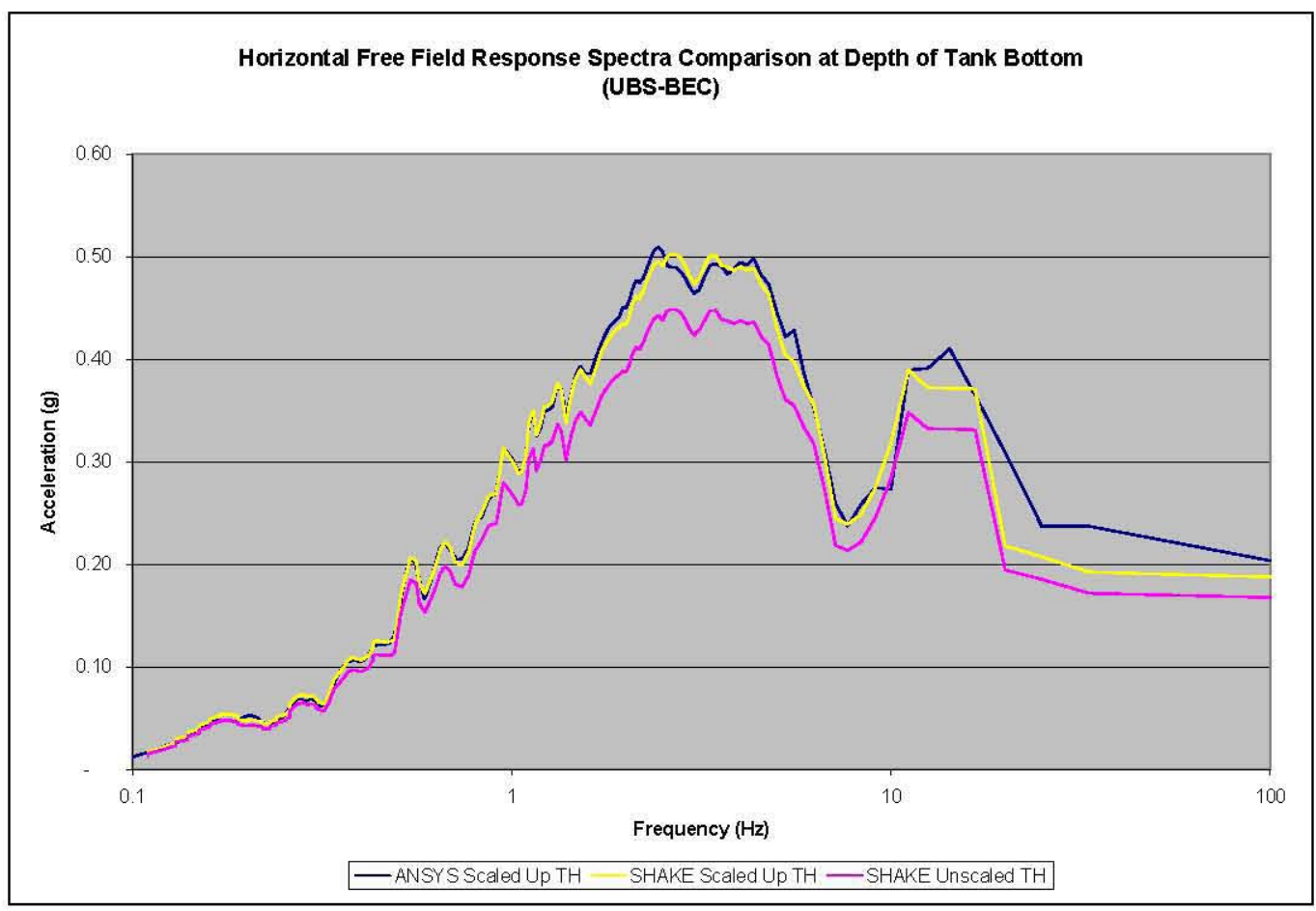

Figure 8-10. 5\% Damped Horizontal Response Spectra, Tank Bottom (UBS-BEC)

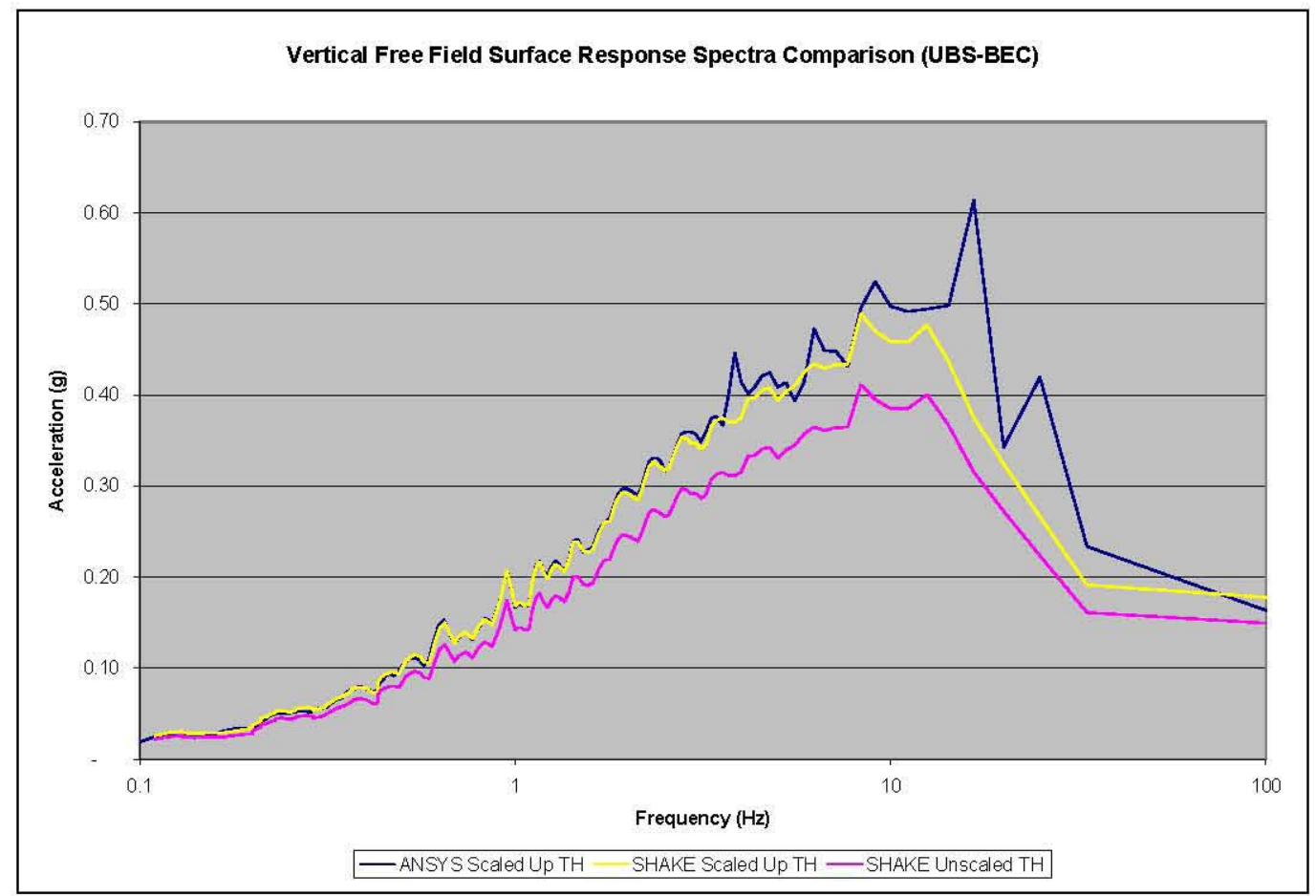

Figure 8-11. 5\% Damped Vertical Response Spectra Comparison, Surface (UBS-BEC) 
RPP-RPT-32239, Rev. 1

M\&D-2008-005-CALC-001, Rev. 1

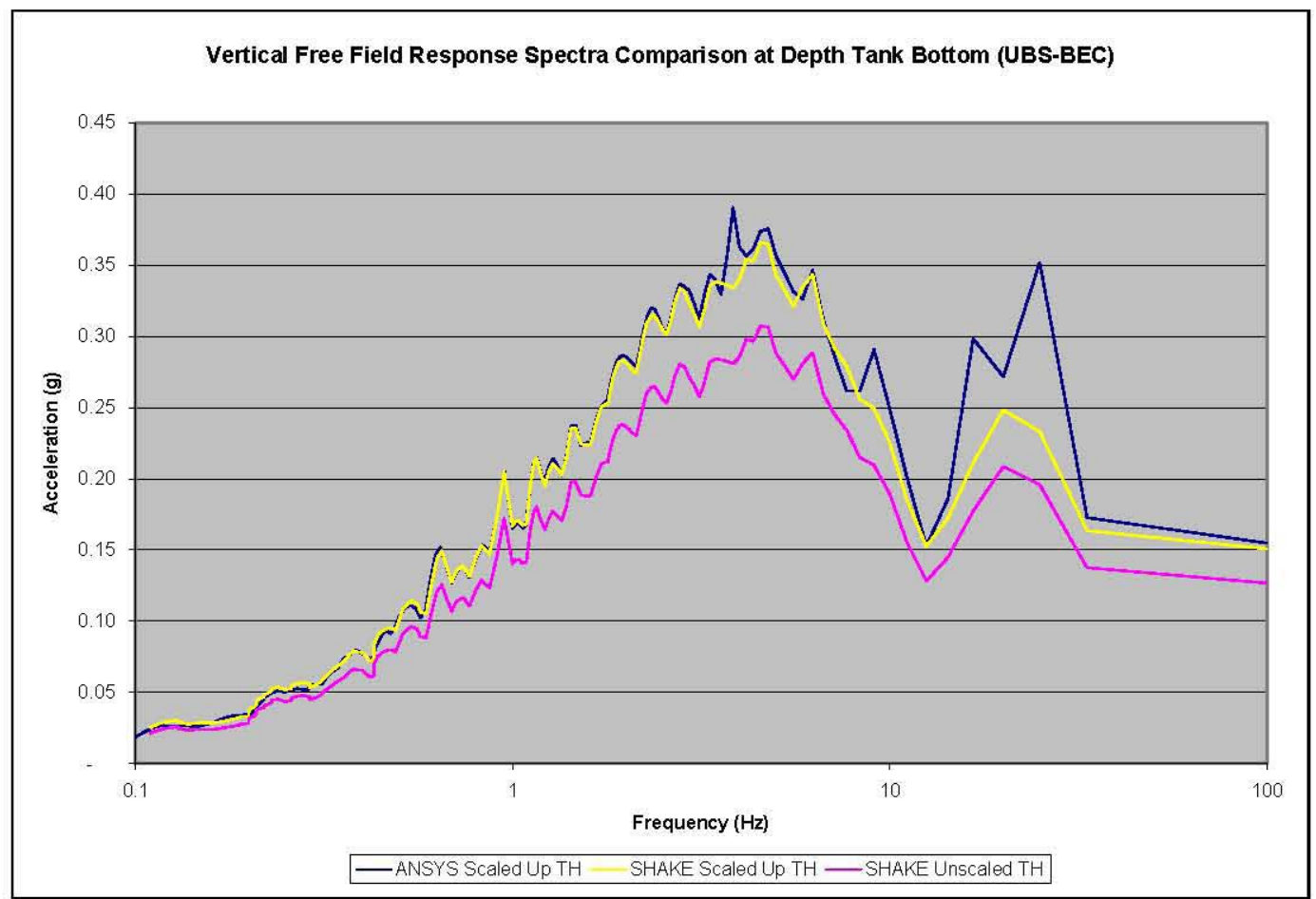

Figure 8-12. 5\% Damped Vertical Response Spectra, Tank Bottom (UBS-BEC)

\subsection{Best-Estimate Soil, Fully Cracked Concrete}

For the best-estimate soil case, the spectra are compared against the surface and tank base spectra with the appropriate scale factors applied. For the best-estimate soil, no scale factors have been applied to the base acceleration time history. As can be seen in Figure 8-13 through Figure 8-16, there is a good match between the model response and the response of the free field as developed by SHAKE. This demonstrates that the size of the soil model is sufficient to capture appropriate behavior and that the desired ground motions occur throughout the model. 
RPP-RPT-32239, Rev. 1

M\&D-2008-005-CALC-001, Rev. 1

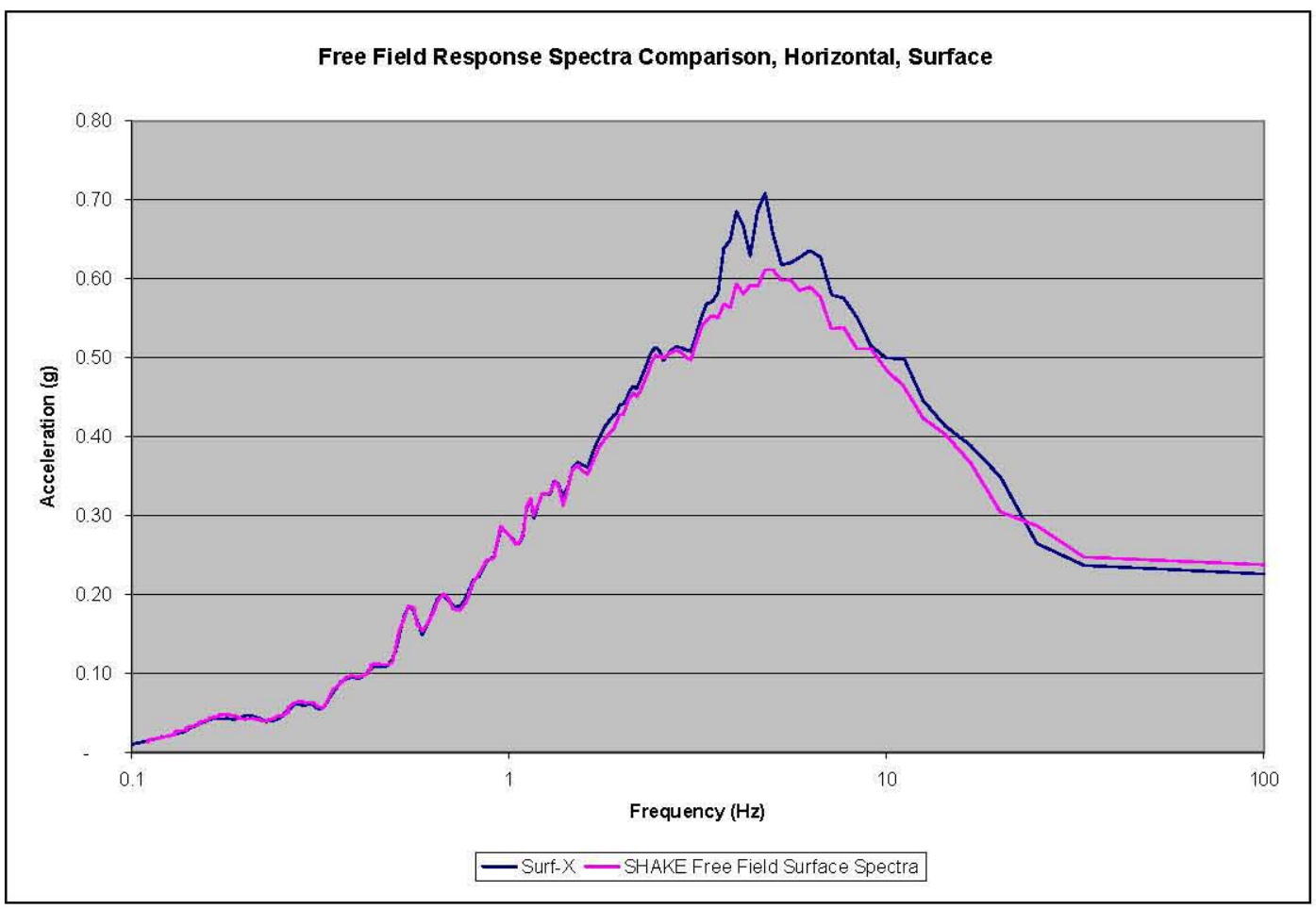

Figure 8-13. 5\% Damped Horizontal Response Spectra Comparison, Surface (BES-FCC)

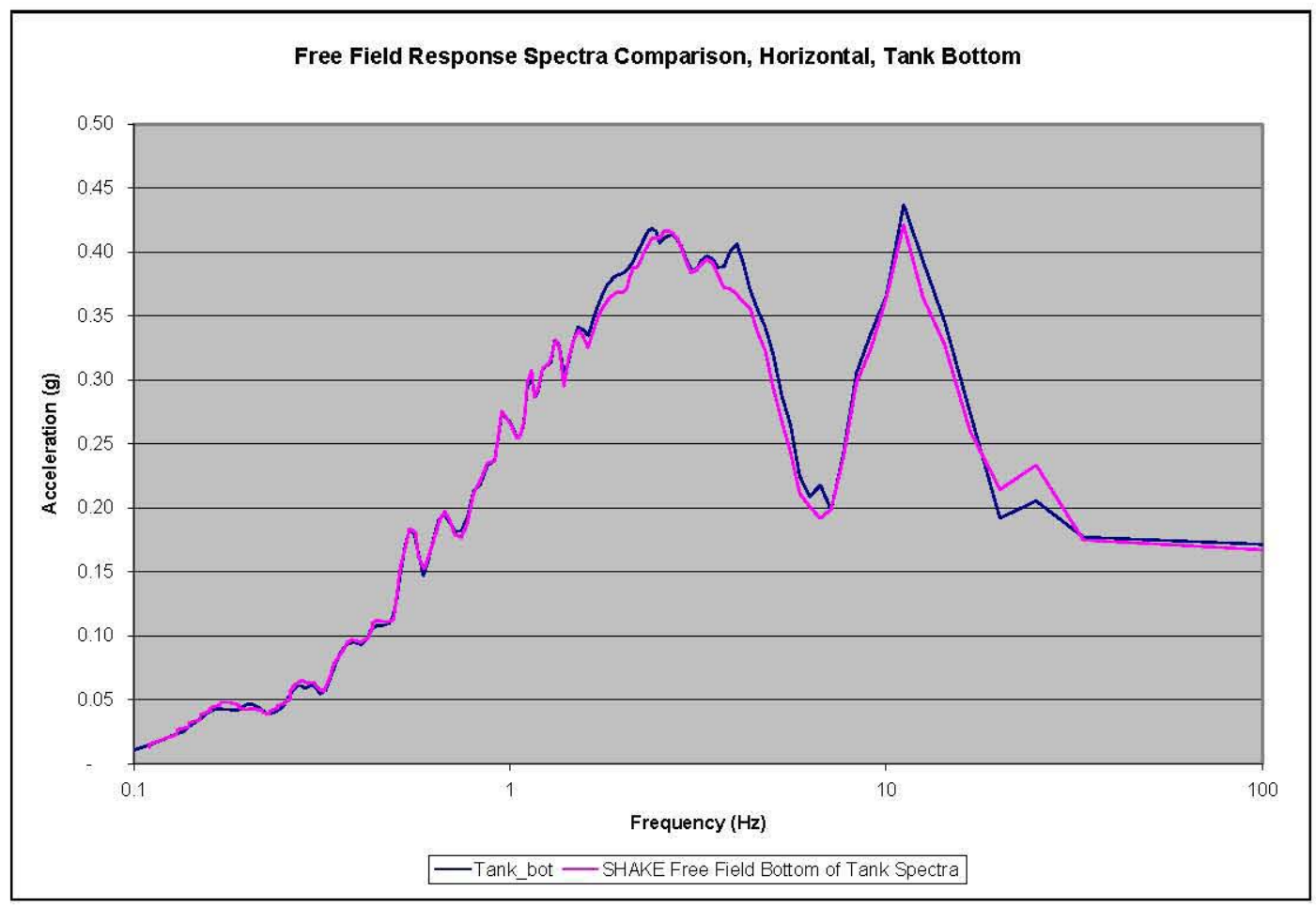

Figure 8-14. 5\% Damped Horizontal Response Spectra, Tank Bottom (BES-FCC) 
RPP-RPT-32239, Rev. 1

M\&D-2008-005-CALC-001, Rev. 1

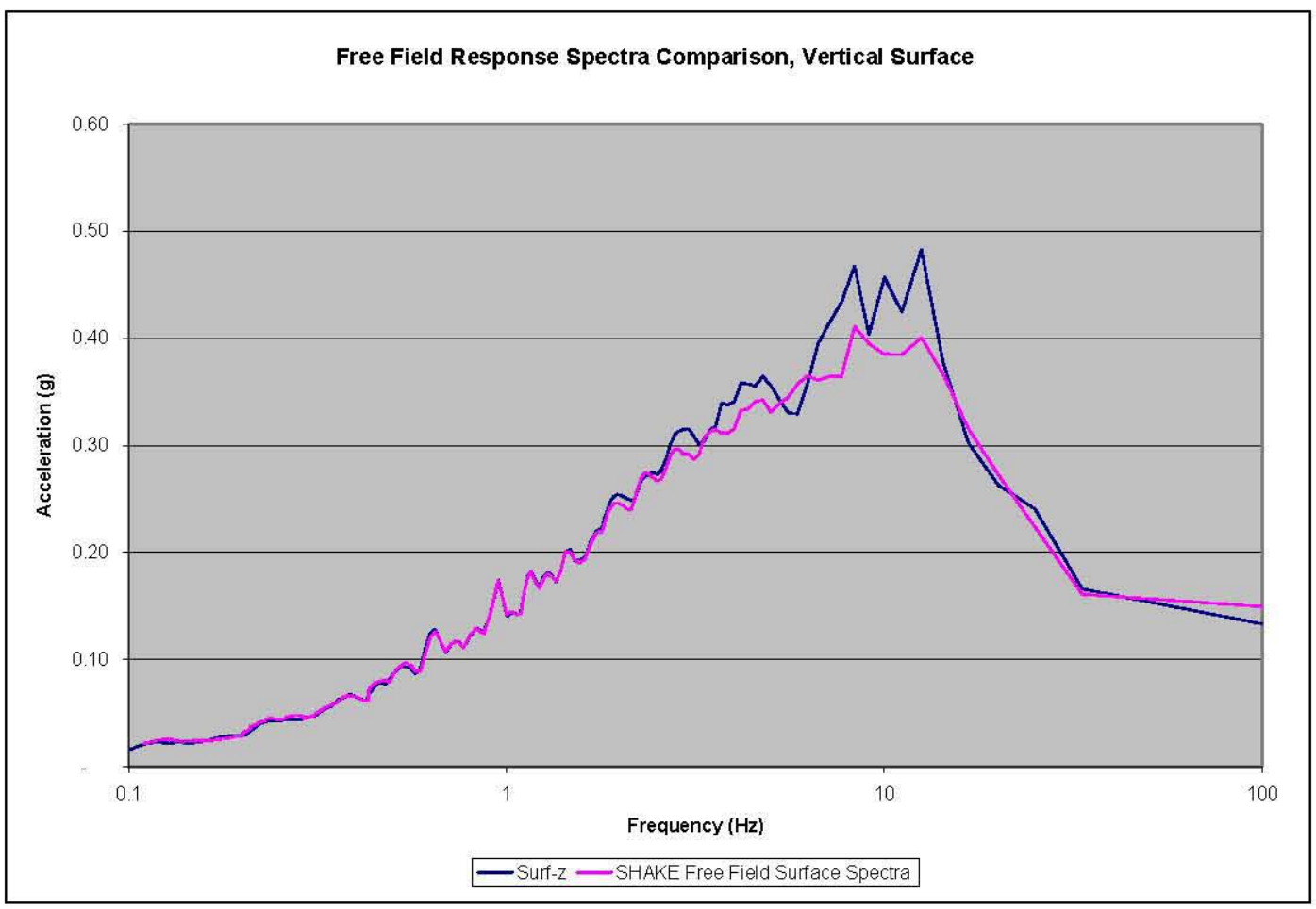

Figure 8-15. 5\% Damped Vertical Response Spectra Comparison, Surface (BES-FCC)

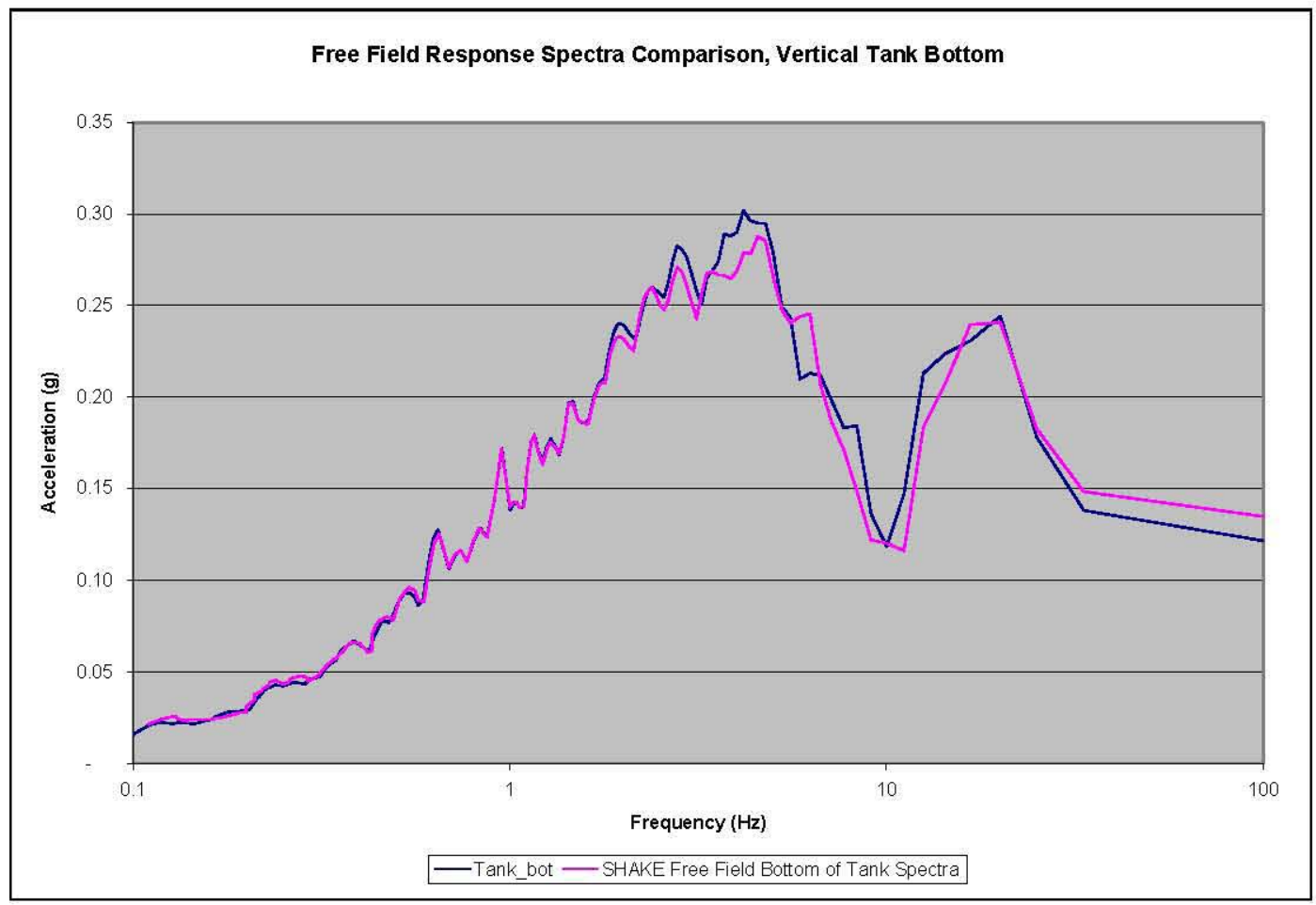

Figure 8-16. 5\% Damped Vertical Response Spectra, Tank Bottom (BES-FCC) 
RPP-RPT-32239, Rev. 1

M\&D-2008-005-CALC-001, Rev. 1

\subsection{Tank Results}

\subsection{Concrete Shell Results for Revision 0 Model}

Concrete shell forces and moments are extracted from the model in $9^{\circ}$ slices, starting near the top of the dome and moving down the wall and across the footing from the outside to the center of the tank. Figure 9-1 show the first slice, with element numbers. Each of the subsequent figures shows one component of force or moment, comparing the results from each load case. The results presented for the concrete forces and moments are enveloped minima/maxima around the circumference of the tank.

The following forces/moments for SHELL143 elements were extracted from the model

- SMISC1 Hoop force (Meridional in footing)

- SMISC2 Meridional force (Hoop in footing)

- SMISC3 In-Plane shear force

- SMISC4 Hoop Moment (Meridional in footing)

- SMISC5 Meridional Moment (Hoop in footing)

- SMISC6 Twisting Moment

- SMISC7 Through Wall Shear Force (XZ)

- SMISC8 Through Wall Shear Force (YZ)

Figures are grouped in sets showing the force or moment for gravity only first, total demand from the transient analysis (gravity plus seismic), and then only the seismic portion. The seismic only load is simply the difference between the full transient loading and gravity only. The forces and moments are plotted against a "path" which starts at 0 at the top of the dome, increasing to the center of the footing. Forces and moment have been enveloped circumferentially for these plots. Concrete force/moment plots are as follows:

- Figure 9-1. Concrete Shell Element Retrieval Sequence Starting Numbers

- Figure 9-2. Concrete Shell Hoop Forces - Gravity Only

- Figure 9-3. Concrete Shell Hoop Forces - Gravity Plus Seismic

- Figure 9-4. Concrete Shell Hoop Forces - Seismic Only

- Figure 9-5. Concrete Shell Meridional Forces - Gravity Only

- Figure 9-6. Concrete Shell Meridional Forces - Gravity Plus Seismic

- Figure 9-7. Concrete Shell Meridional Forces - Seismic Only

- Figure 9-8. Concrete Shell Hoop Moments - Gravity Only

- Figure 9-9. Concrete Shell Hoop Moments - Gravity Plus Seismic

- Figure 9-10. Concrete Shell Hoop Moments - Seismic Only

- Figure 9-11. Concrete Shell Meridional Moments - Gravity Only

- Figure 9-12. Concrete Shell Meridional Moments - Gravity Plus Seismic

- Figure 9-13. Concrete Shell Meridional - Seismic Only

- Figure 9-14. Concrete Shell In-Plane Shear Forces - Gravity Only

- Figure 9-15. Concrete Shell In-Plane Shear Forces - Gravity Plus Seismic 
RPP-RPT-32239, Rev. 1

M\&D-2008-005-CALC-001, Rev. 1

- Figure 9-16. Concrete Shell In-Plane Shear Forces - Seismic Only

- Figure 9-17. Concrete Shell Through-Wall Shear Forces - Gravity Only

- Figure 9-18. Concrete Shell Through-Wall Shear Forces - Gravity Plus Seismic

- Figure 9-19. Concrete Shell Through-Wall Shear Forces - Seismic Only

Results for Through-Wall Shear Forces are the envelope of SMISC7 and SMISC8. No results are presented for SMISC6, the element XY moment.

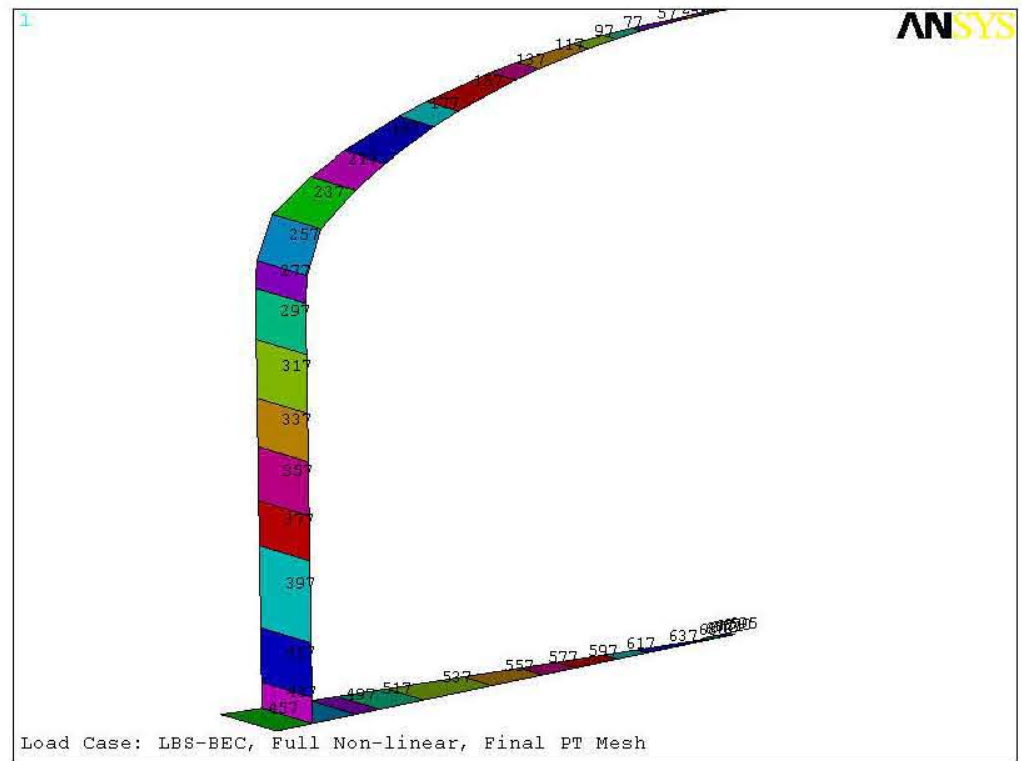

Figure 9-1. Concrete Shell Element Retrieval Sequence Starting Numbers

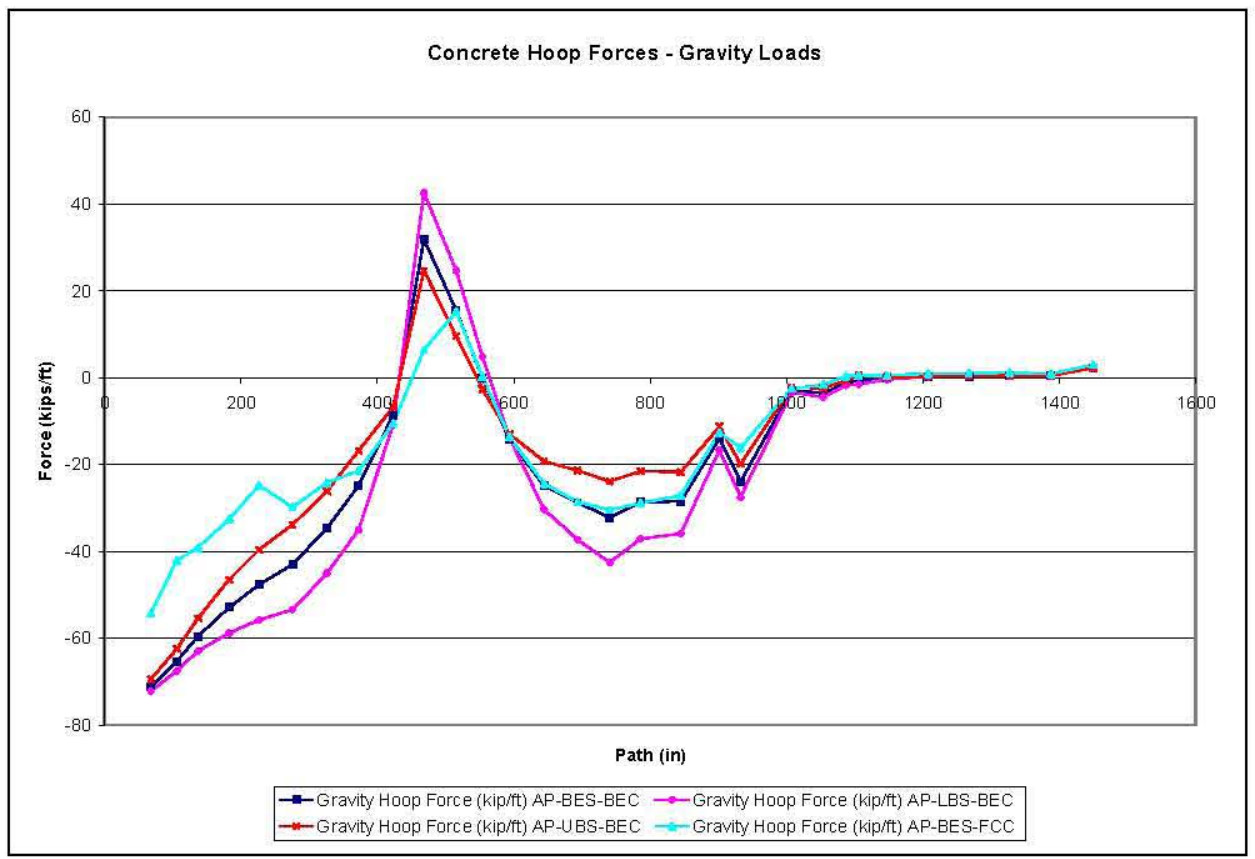

Figure 9-2. Concrete Shell Hoop Forces - Gravity Only 
RPP-RPT-32239, Rev. 1

M\&D-2008-005-CALC-001, Rev. 1

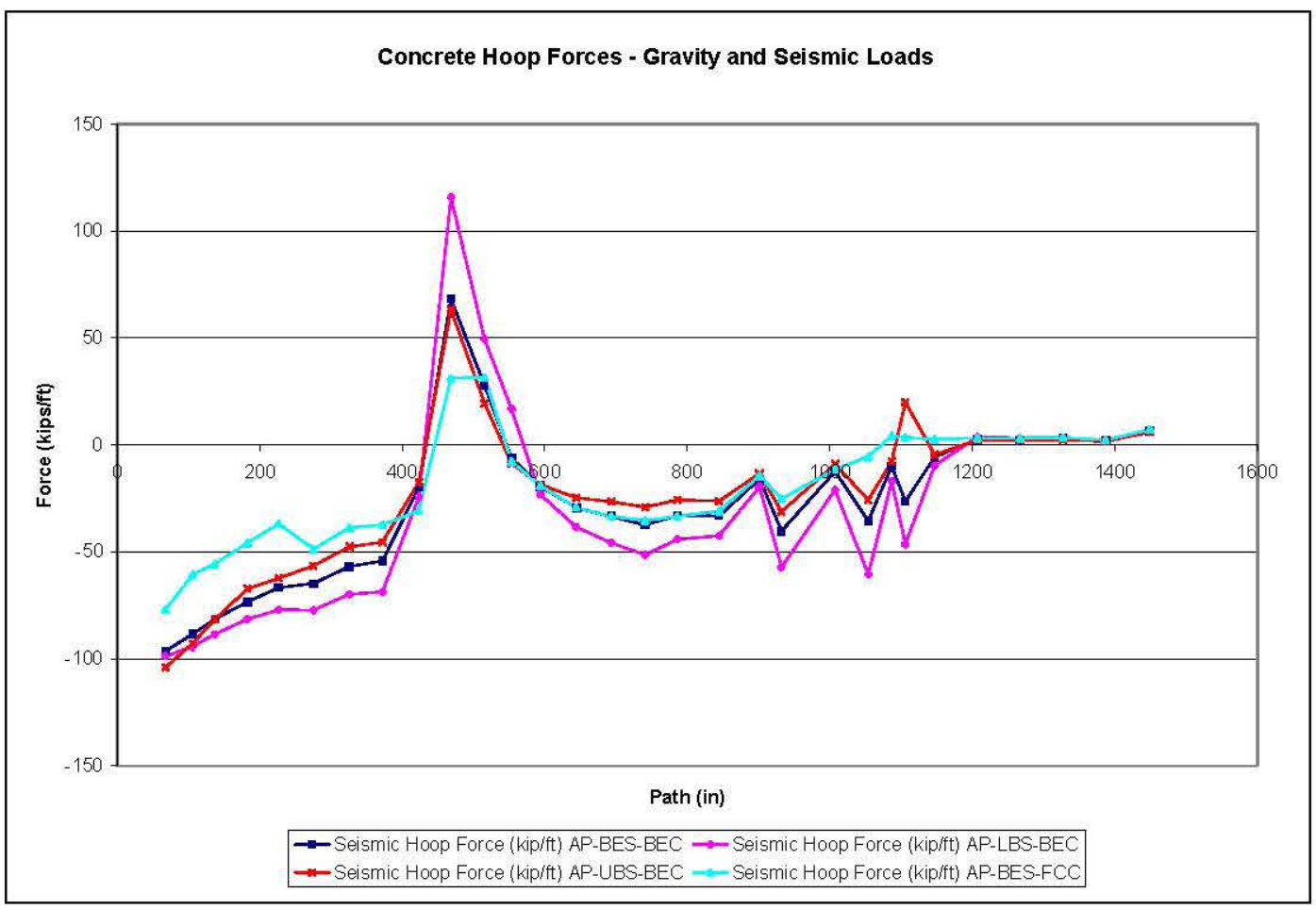

Figure 9-3. Concrete Shell Hoop Forces - Gravity Plus Seismic

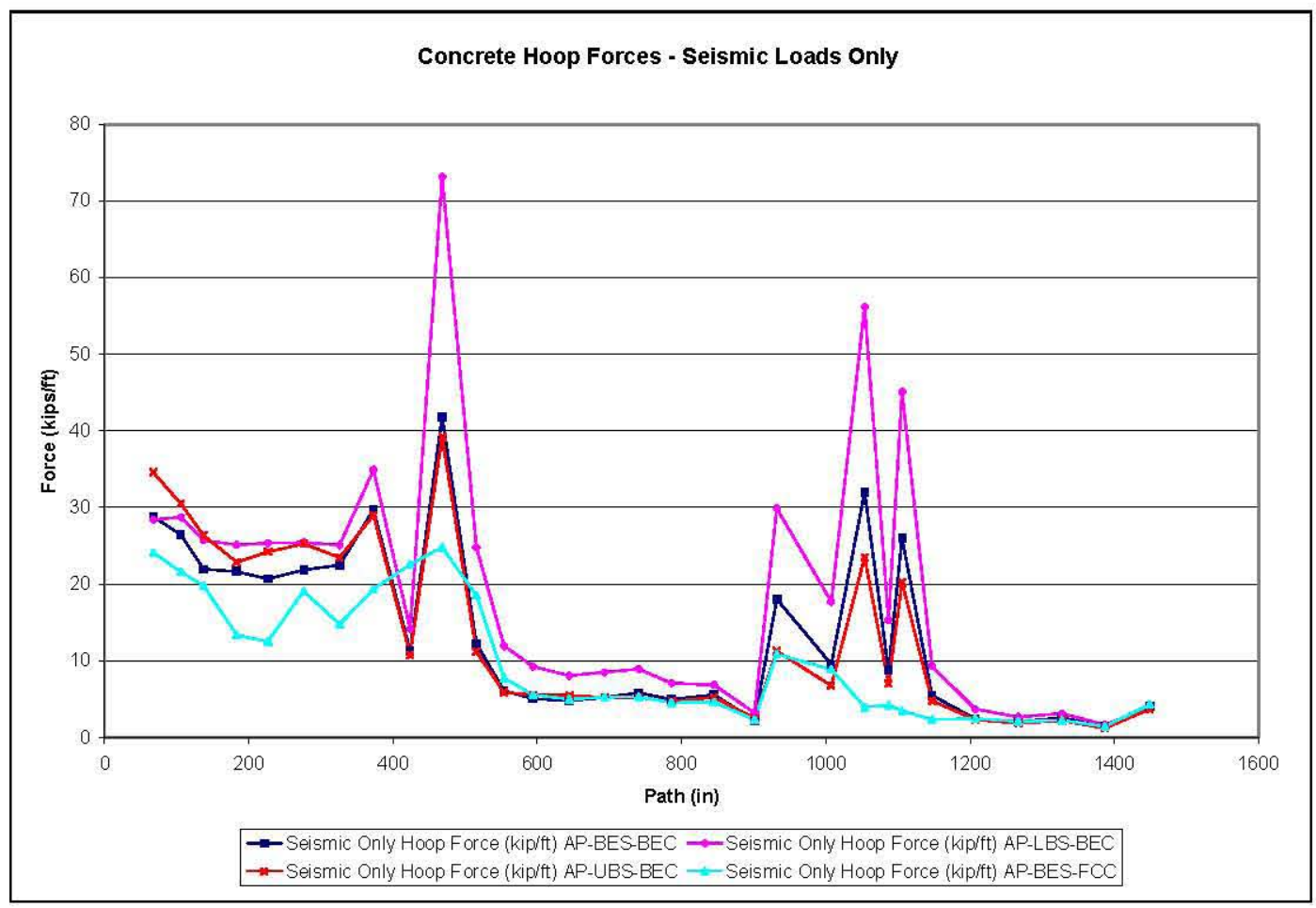

Figure 9-4. Concrete Shell Hoop Forces - Seismic Only 
RPP-RPT-32239, Rev. 1

M\&D-2008-005-CALC-001, Rev. 1

Concrete Meridional Forces - Gravity Loads

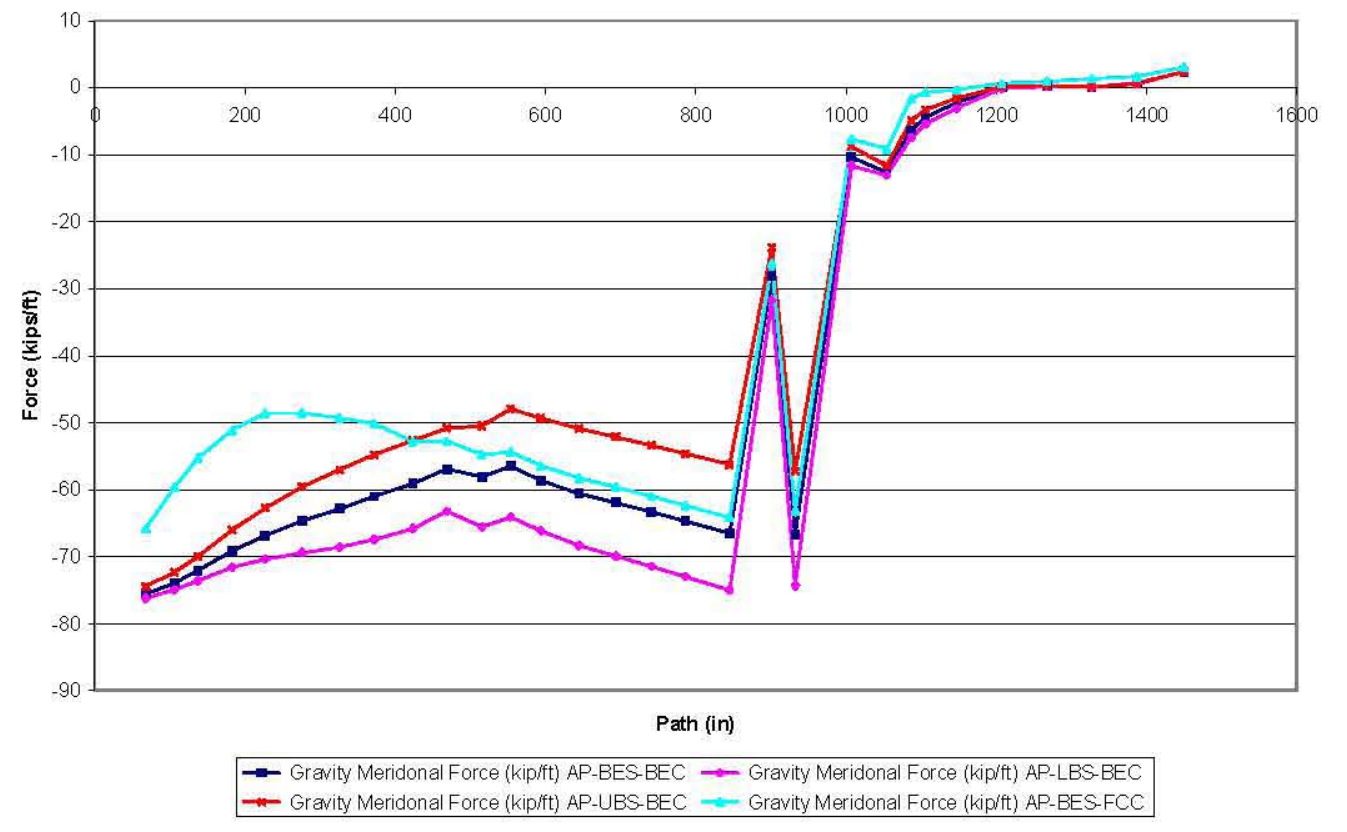

Figure 9-5. Concrete Shell Meridional Forces - Gravity Only

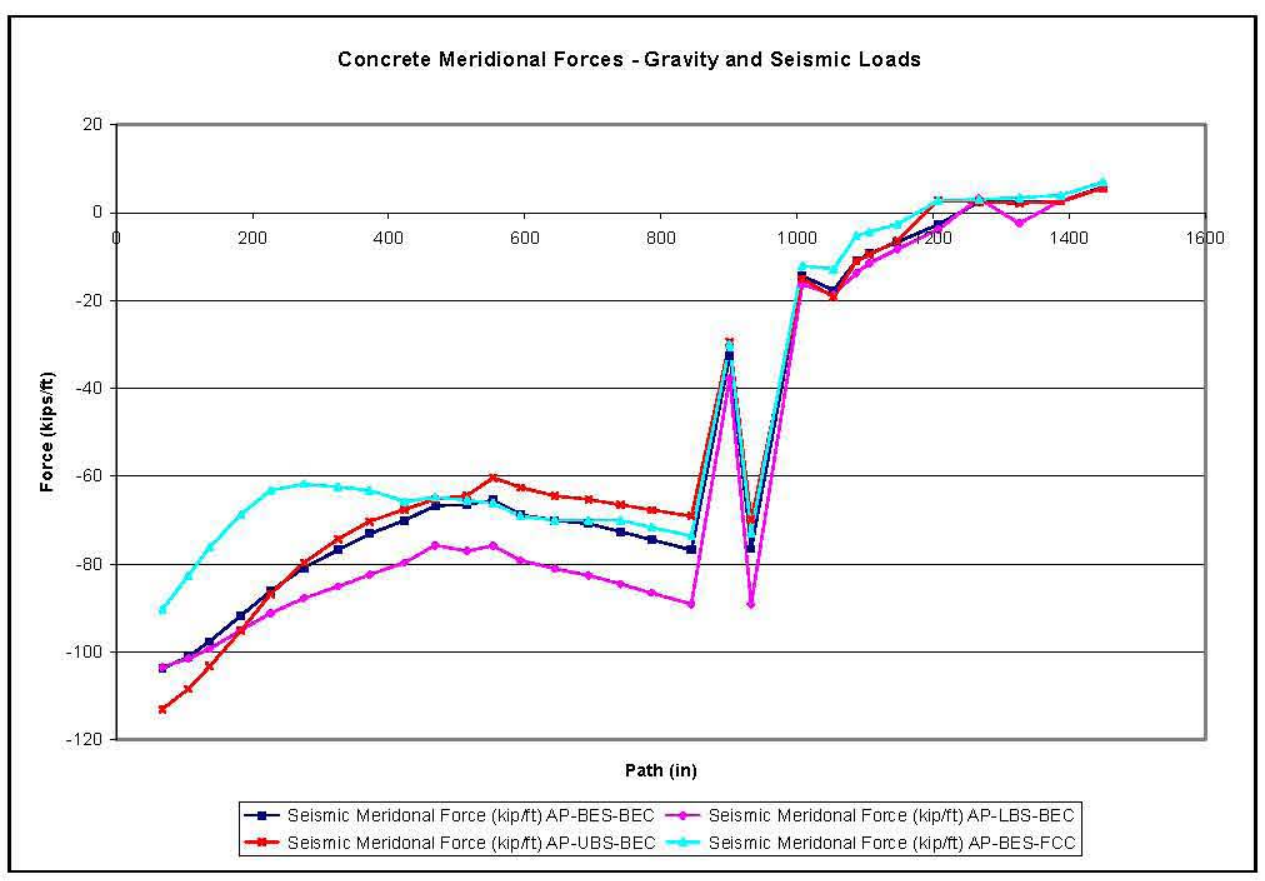

Figure 9-6. Concrete Shell Meridional Forces - Gravity Plus Seismic 
RPP-RPT-32239, Rev. 1

M\&D-2008-005-CALC-001, Rev. 1

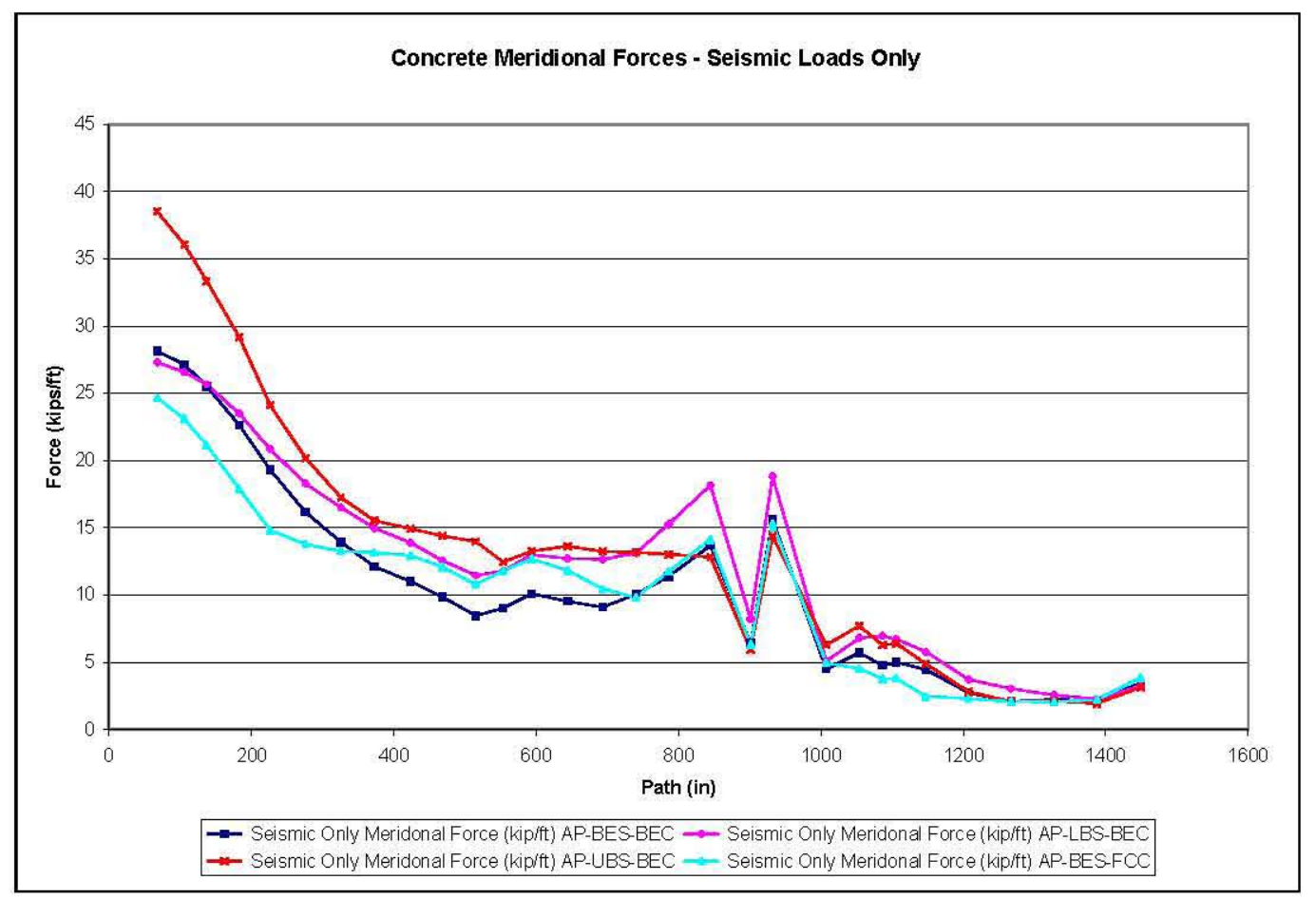

Figure 9-7. Concrete Shell Meridional Forces - Seismic Only

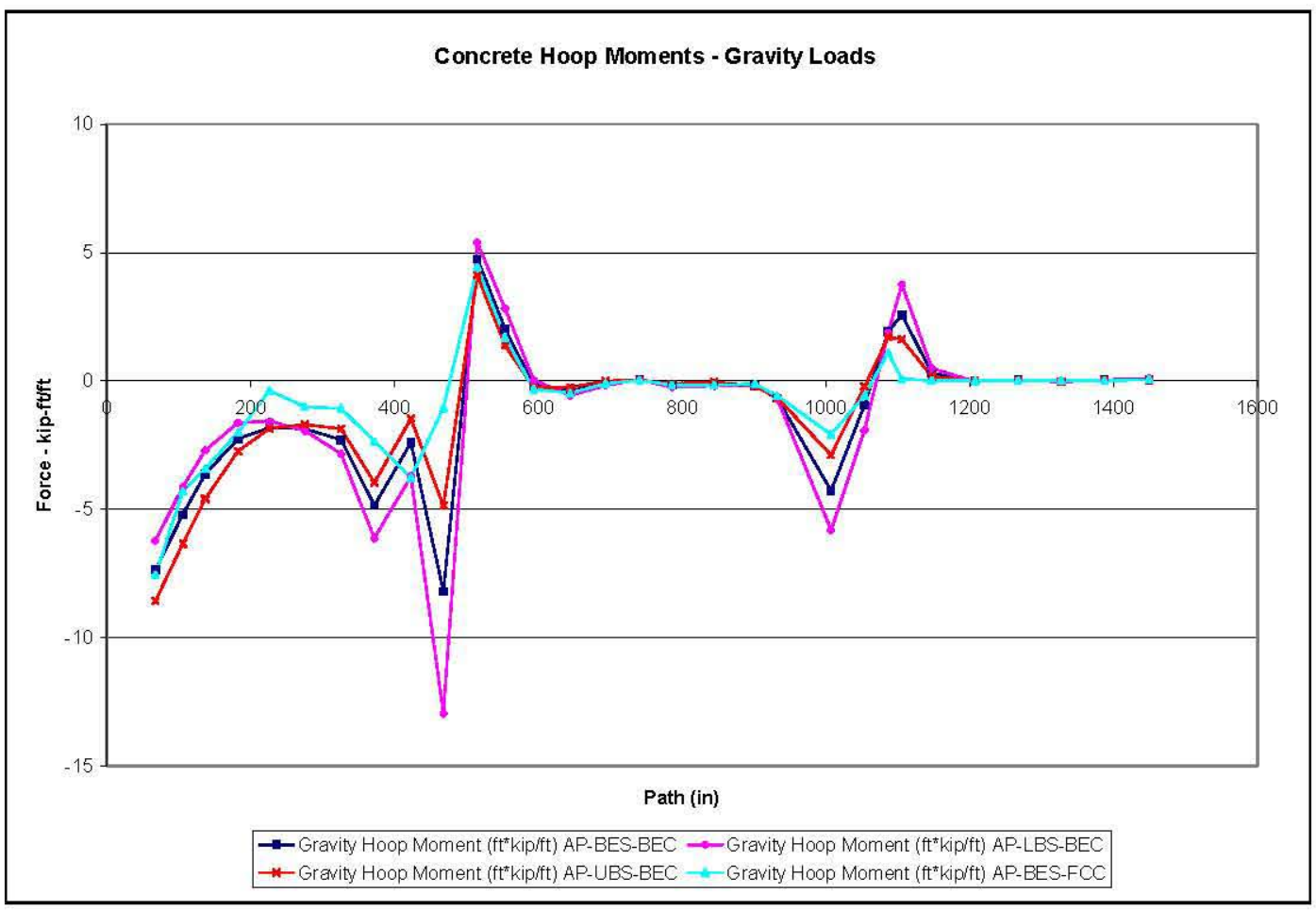

Figure 9-8. Concrete Shell Hoop Moments - Gravity Only 
RPP-RPT-32239, Rev. 1

M\&D-2008-005-CALC-001, Rev. 1

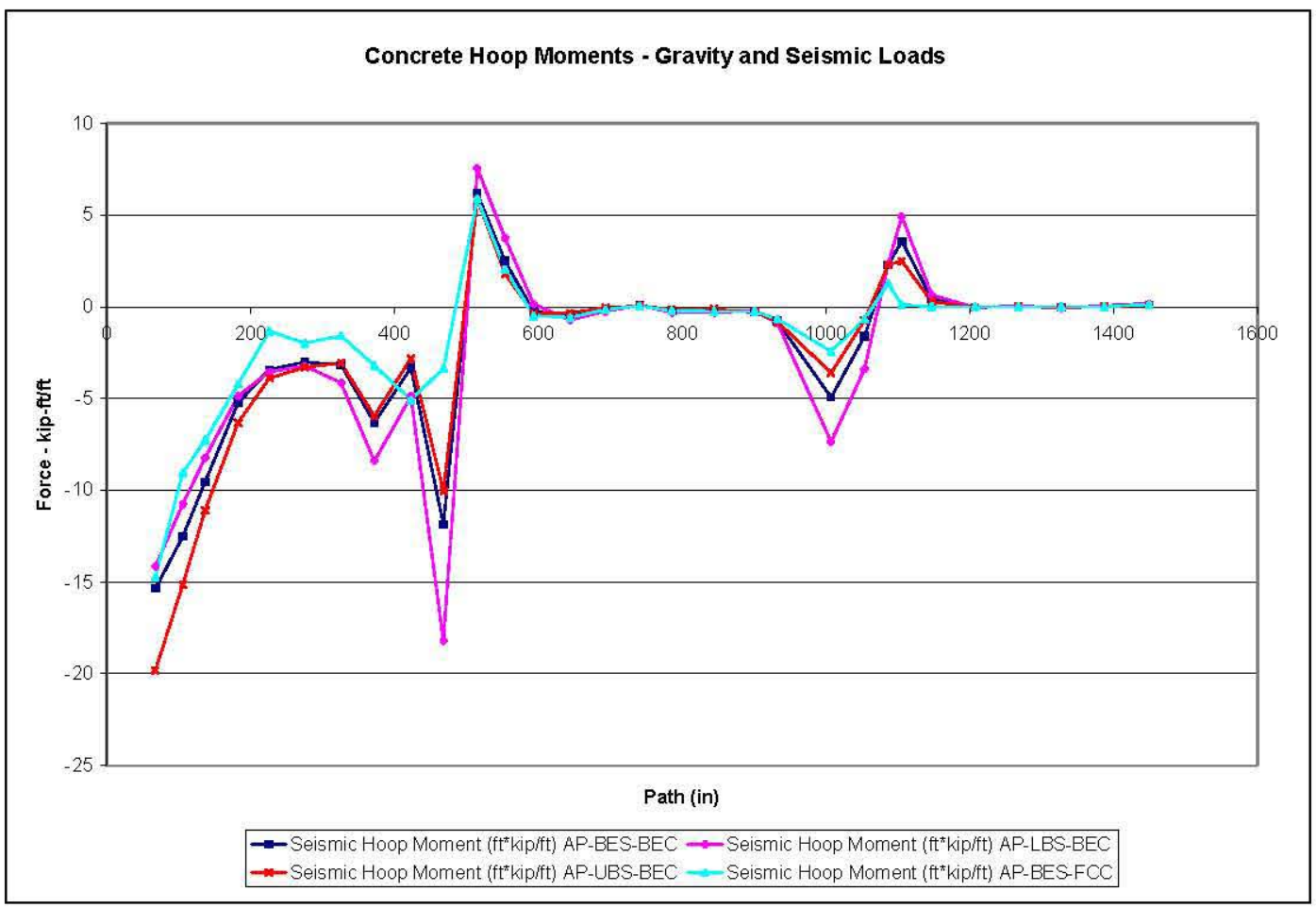

Figure 9-9. Concrete Shell Hoop Moments - Gravity Plus Seismic

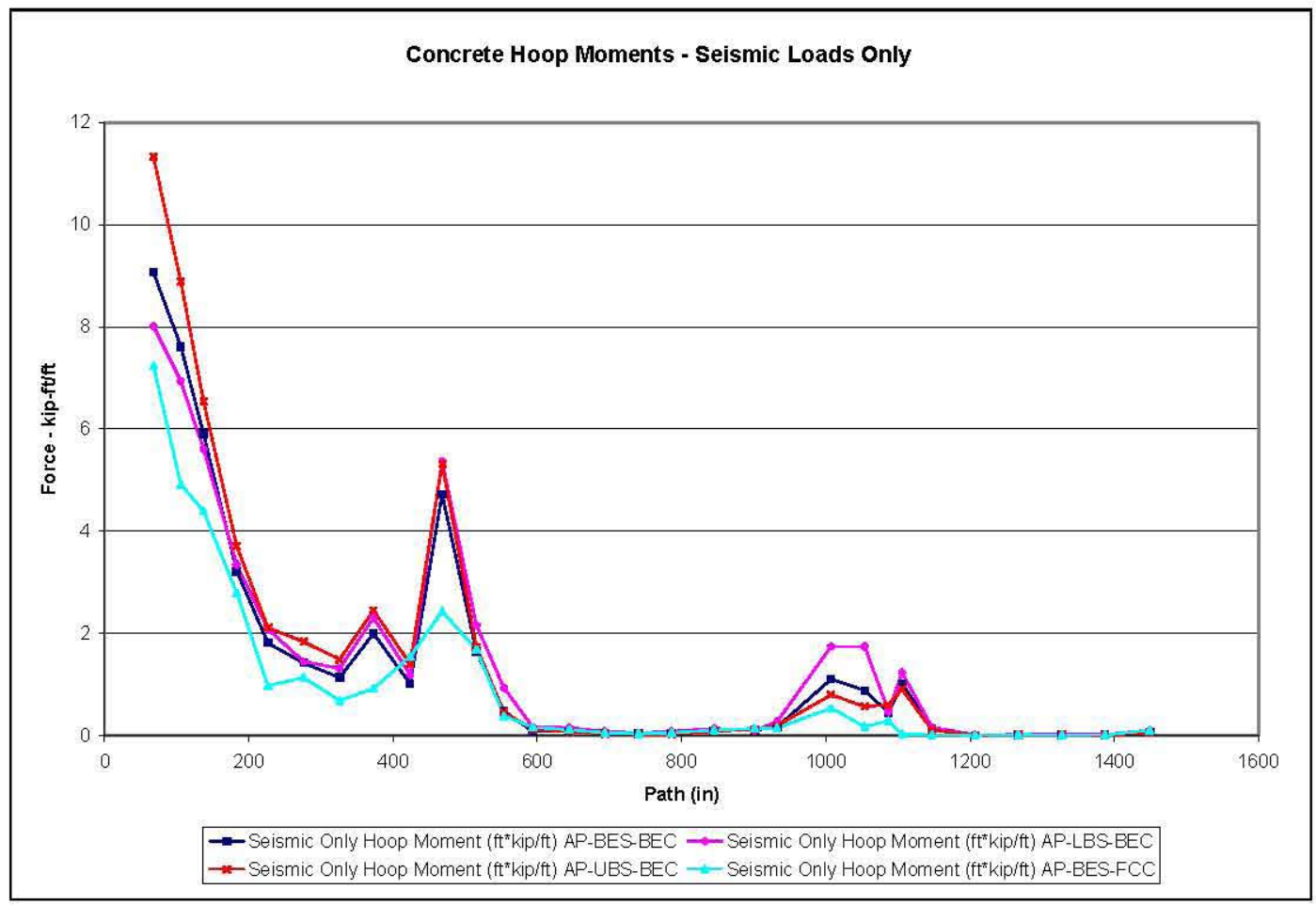

Figure 9-10. Concrete Shell Hoop Moments - Seismic Only 
RPP-RPT-32239, Rev. 1

M\&D-2008-005-CALC-001, Rev. 1

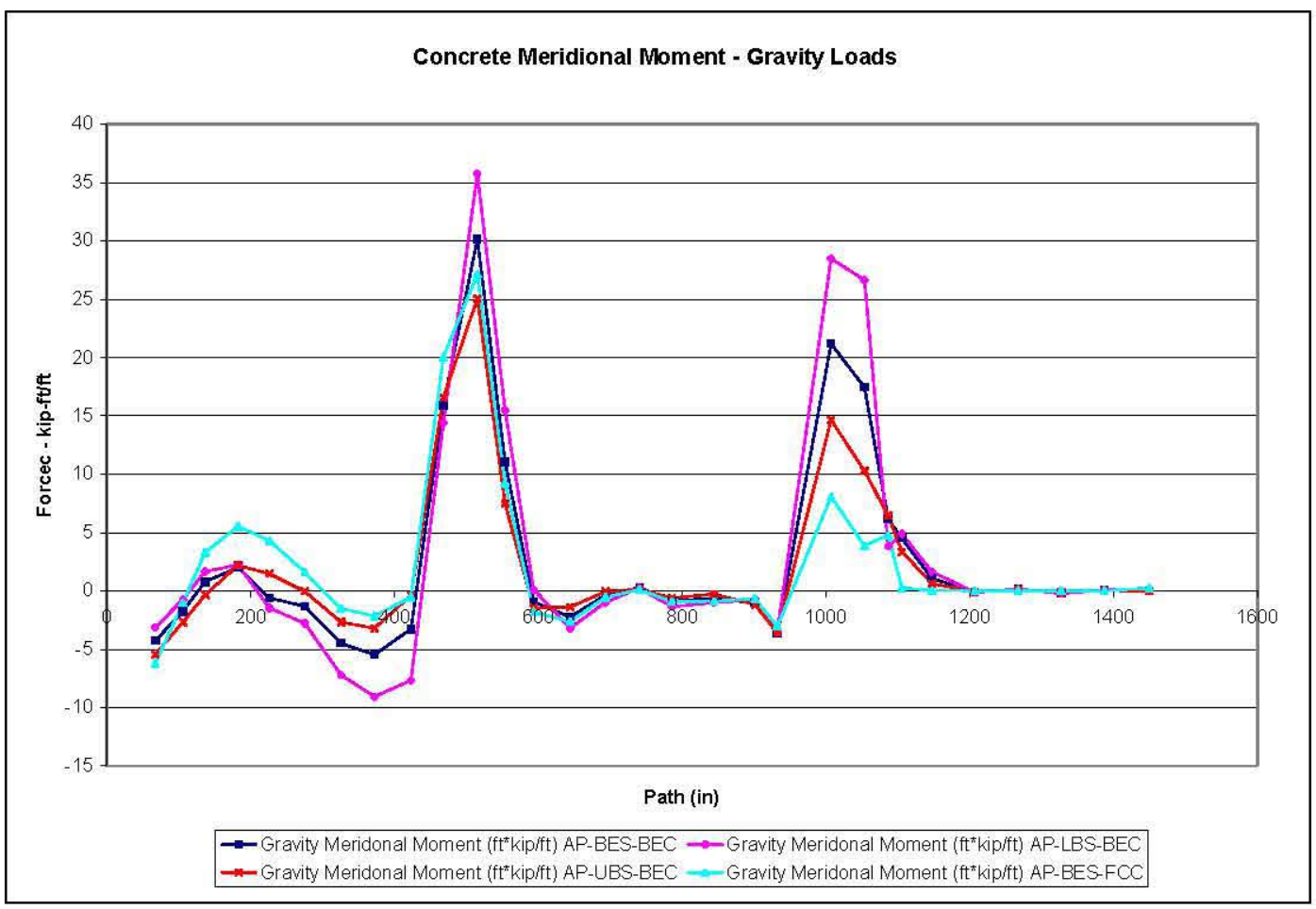

Figure 9-11. Concrete Shell Meridional Moments - Gravity Only

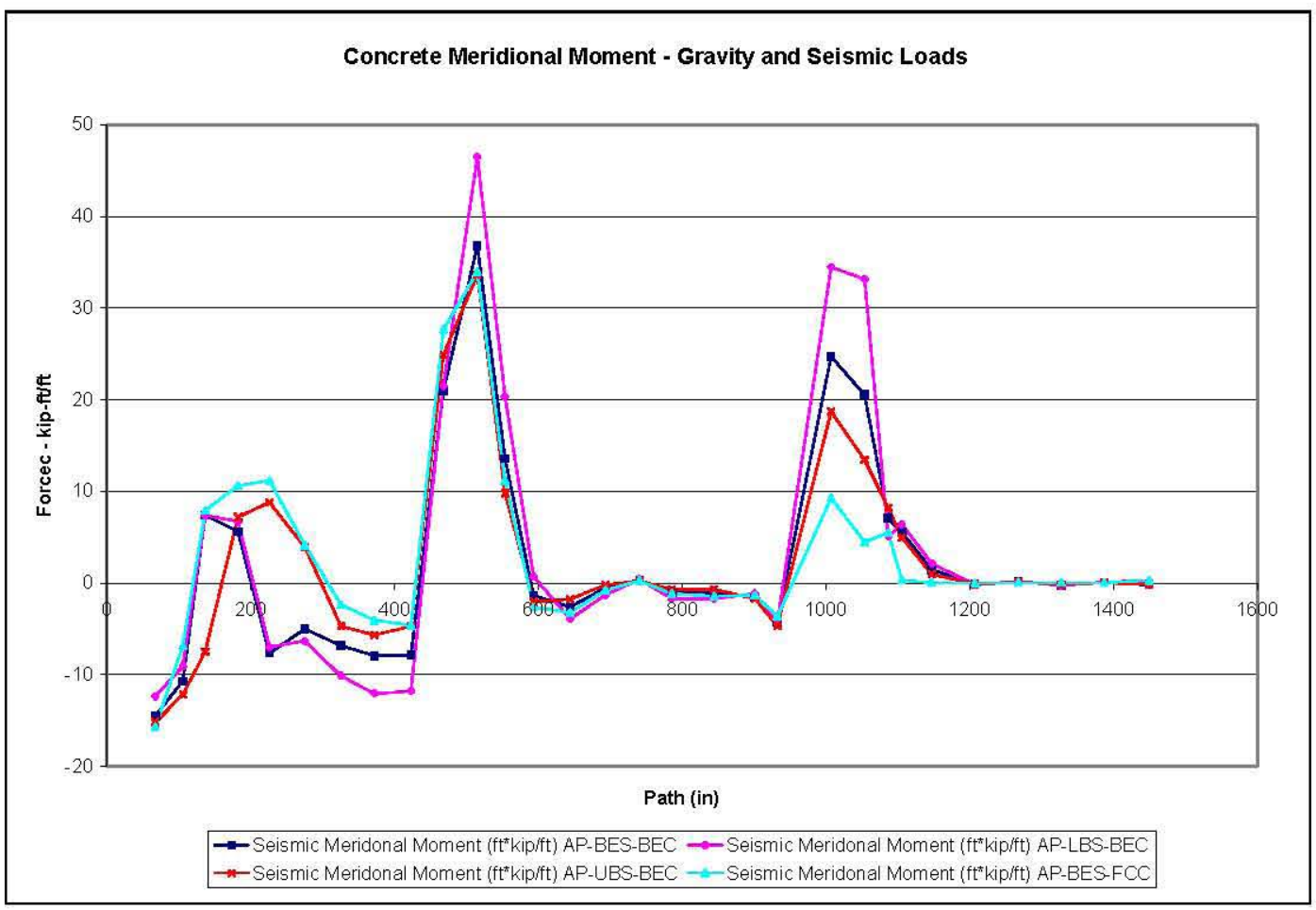

Figure 9-12. Concrete Shell Meridional Moments - Gravity Plus Seismic 
RPP-RPT-32239, Rev. 1

M\&D-2008-005-CALC-001, Rev. 1

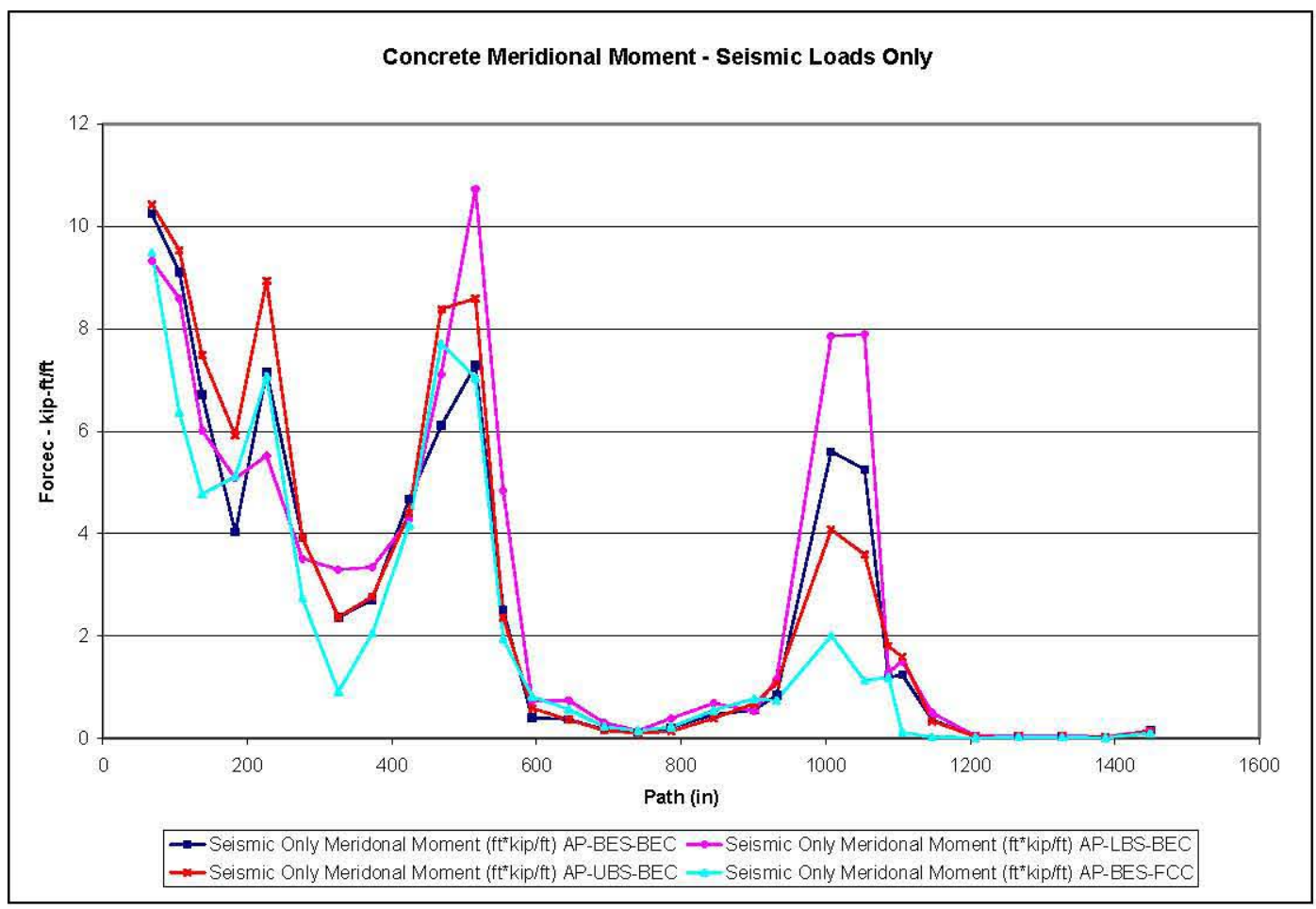

Figure 9-13. Concrete Shell Meridional - Seismic Only

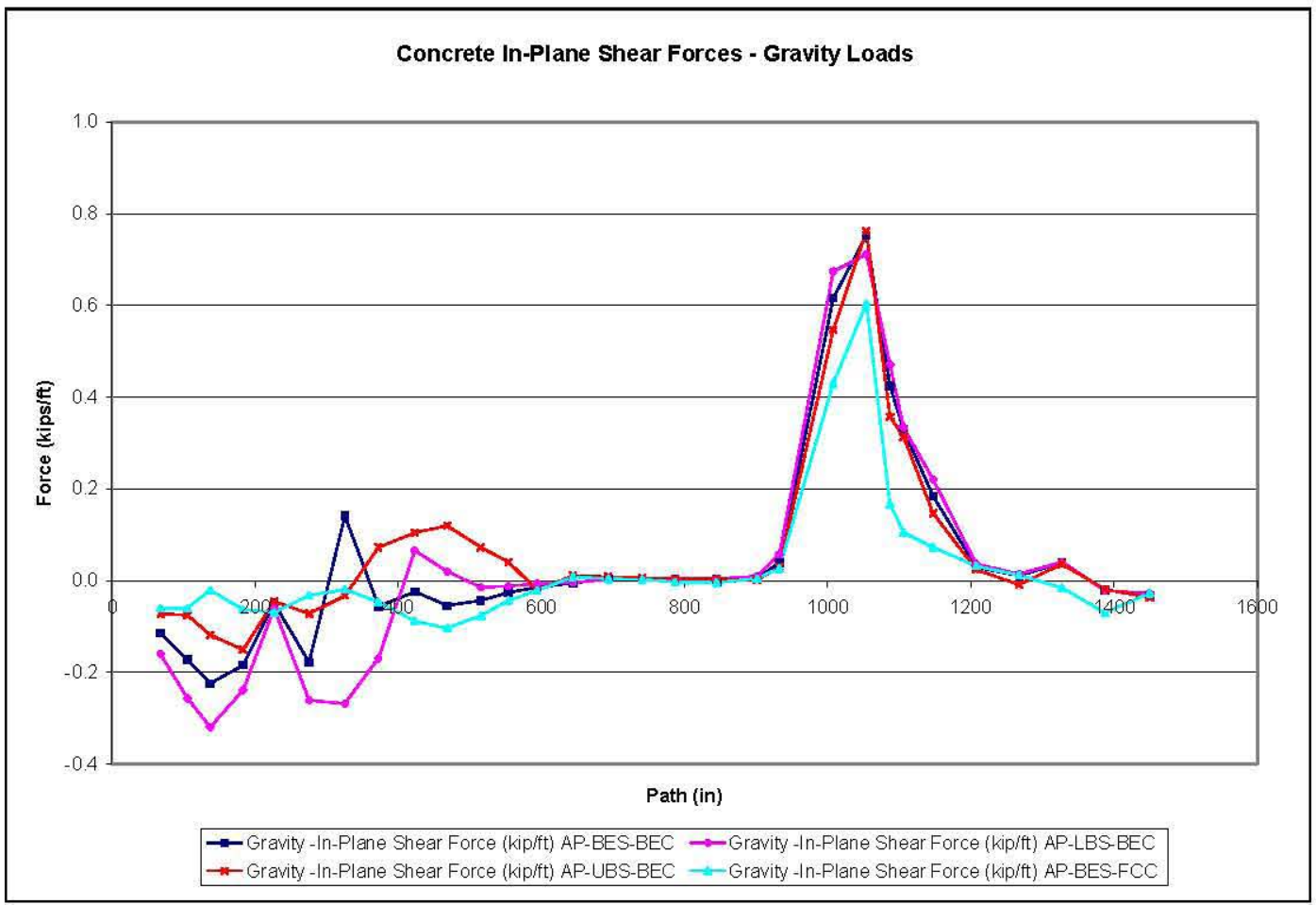

Figure 9-14. Concrete Shell In-Plane Shear Forces - Gravity Only 
RPP-RPT-32239, Rev. 1

M\&D-2008-005-CALC-001, Rev. 1

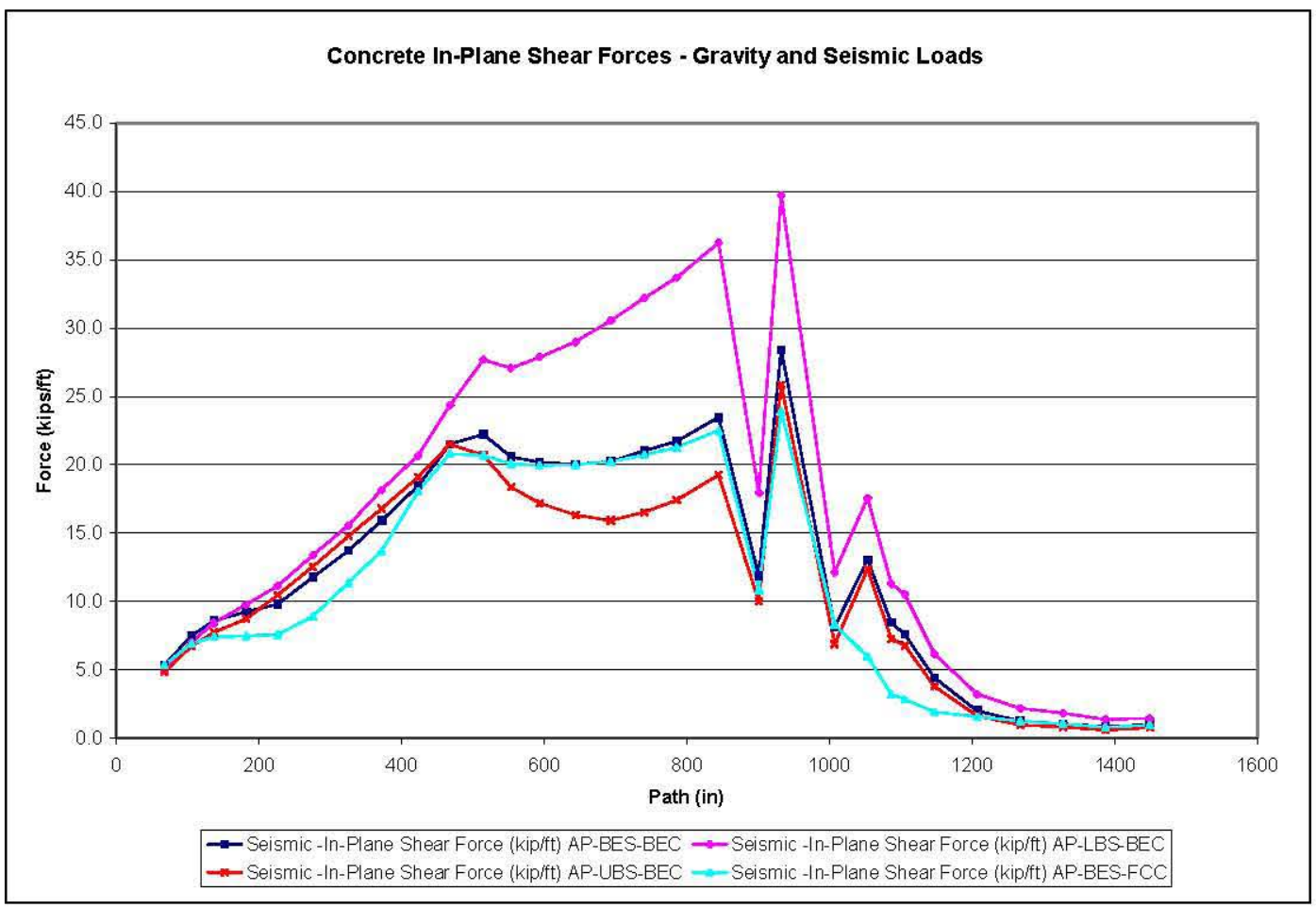

Figure 9-15. Concrete Shell In-Plane Shear Forces - Gravity Plus Seismic

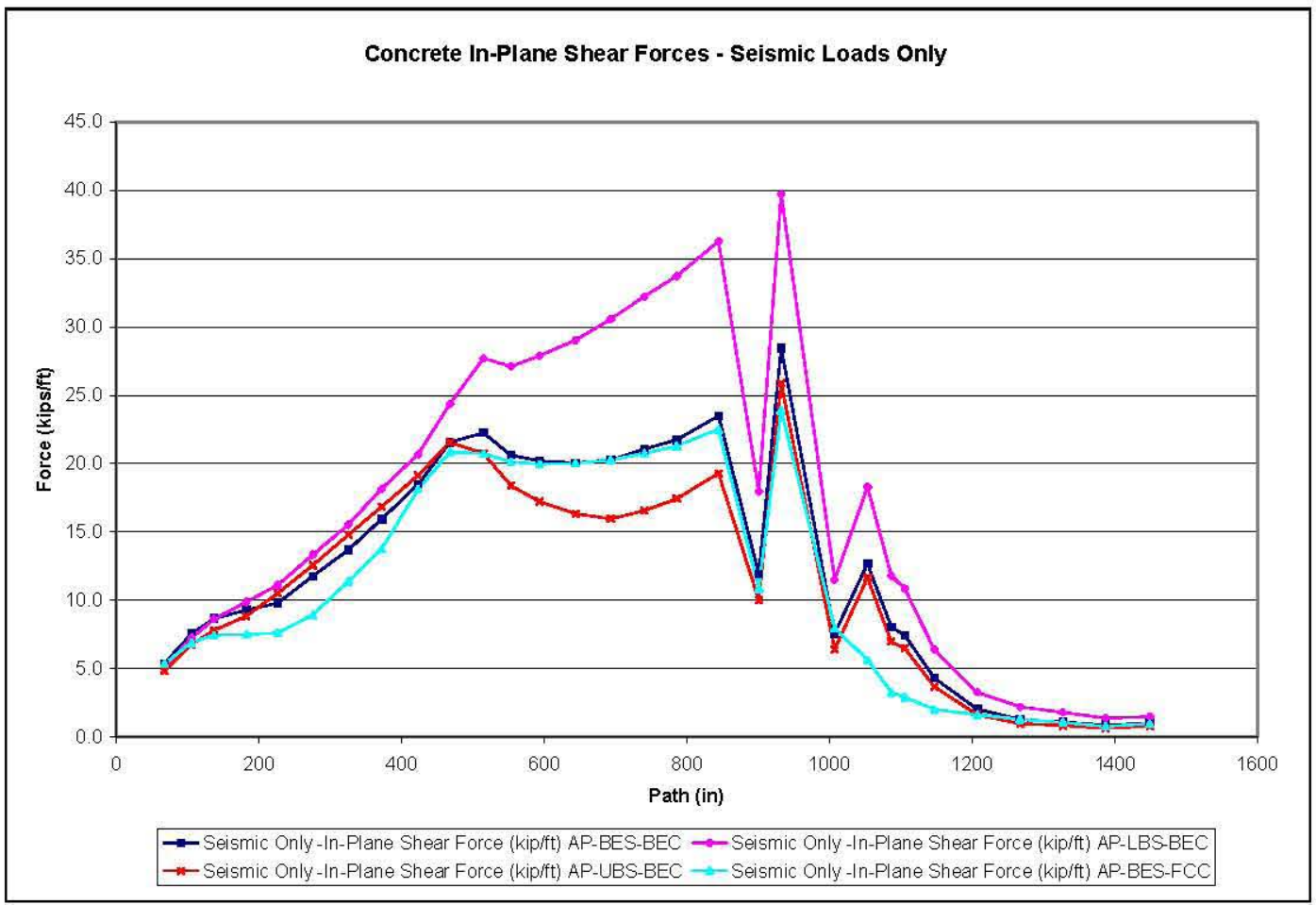

Figure 9-16. Concrete Shell In-Plane Shear Forces - Seismic Only 
RPP-RPT-32239, Rev. 1

M\&D-2008-005-CALC-001, Rev. 1

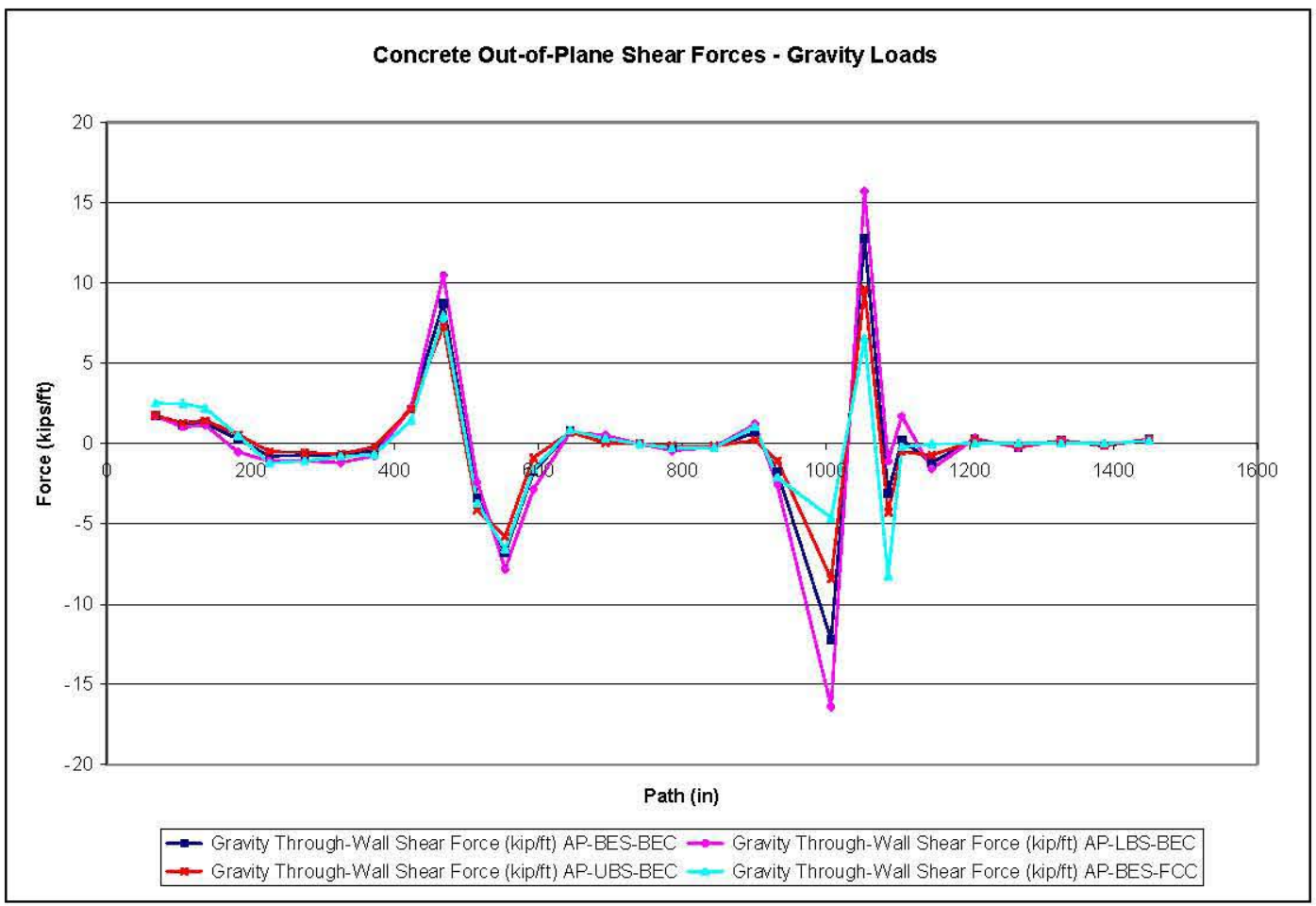

Figure 9-17. Concrete Shell Through-Wall Shear Forces - Gravity Only

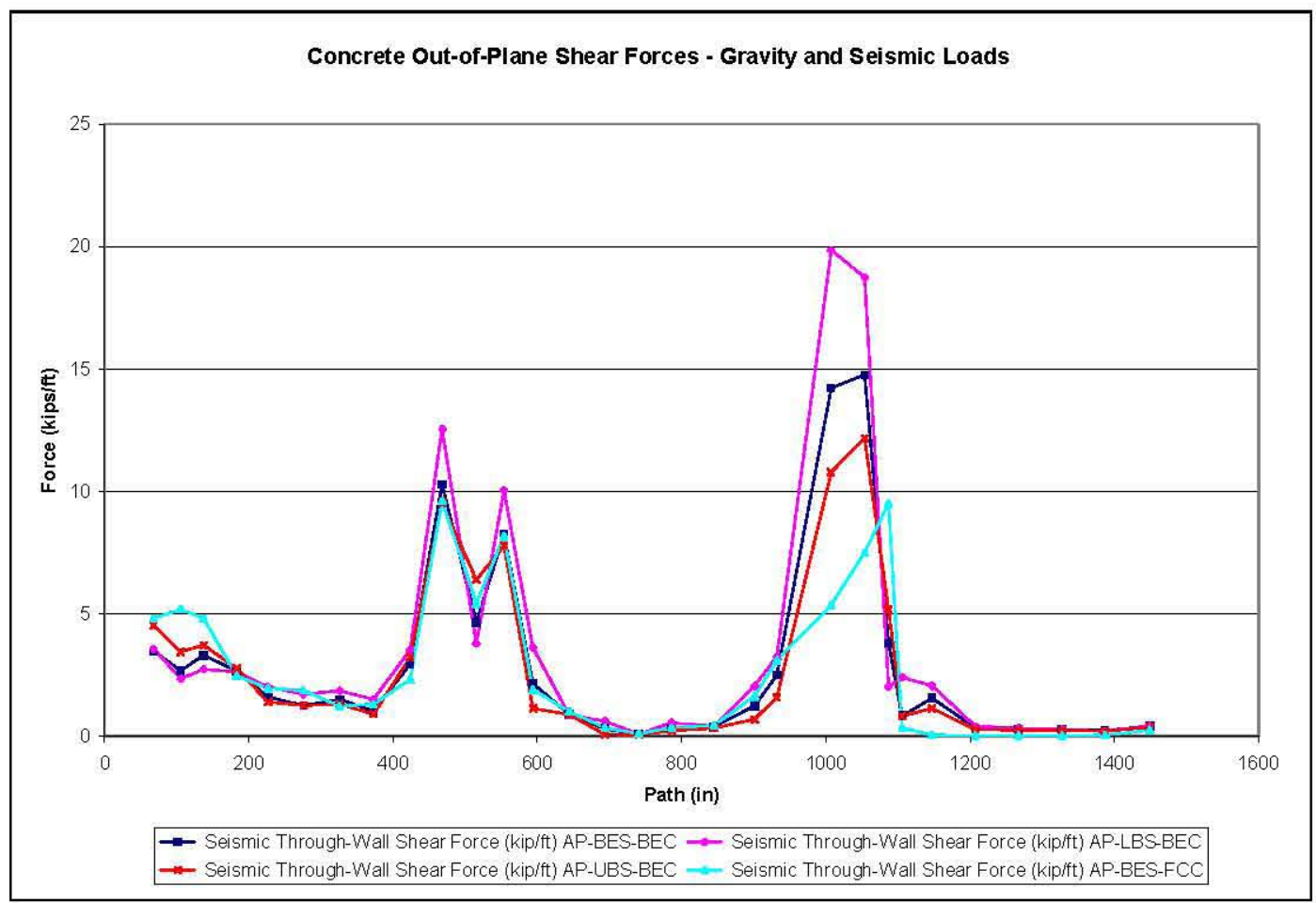

Figure 9-18. Concrete Shell Through-Wall Shear Forces - Gravity Plus Seismic 
RPP-RPT-32239, Rev. 1

M\&D-2008-005-CALC-001, Rev. 1

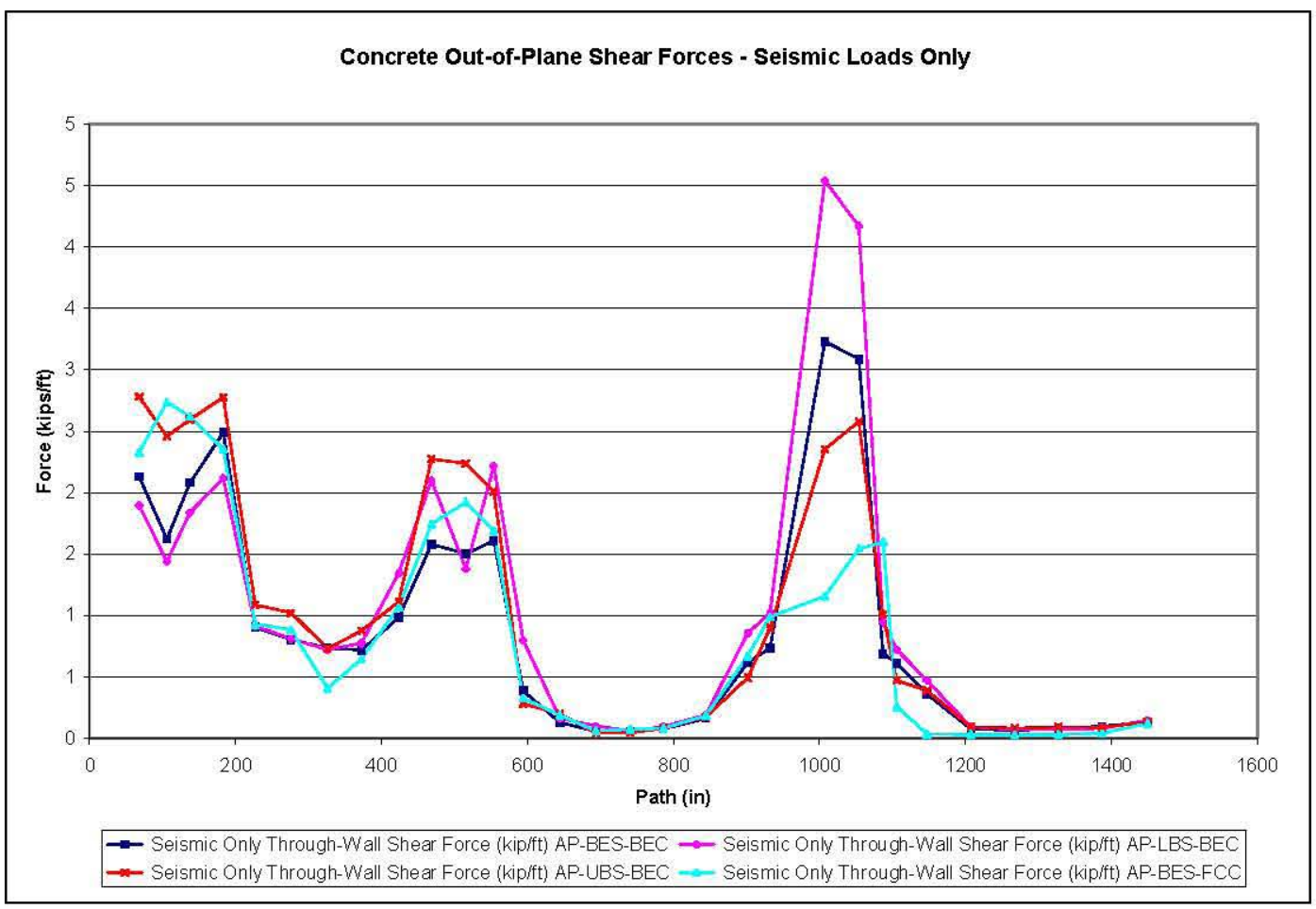

Figure 9-19. Concrete Shell Through-Wall Shear Forces - Seismic Only

\subsection{Primary Tank Results for Revision 0 Model}

Primary tank stresses are extracted from the model in $9^{\circ}$ slices, starting near the top of the dome and moving down the wall and around the lower knuckle to the center of the tank. Stresses were extracted for the top, middle, and bottom of each shell element. Figure 9-20 shows the first slice, with element numbers. Each of the subsequent figures shows one component of stress, comparing the results from each load case. The results presented for the primary tank stresses are enveloped minima/maxima around the circumference of the tank. The gravity comparison includes a comparison to the TOLA model. This comparison demonstrates that for the majority of the primary tank, the model provides very similar results to the more detailed model. The meridional stresses in the knuckle are under-predicted in the global model. This is due to the lack of resolution in the knuckle.

The following stresses are extracted for the primary tank SHELL143 elements at the top, middle, and bottom for each element.

- SX Hoop Stress (Meridional in floor)

- SY Meridional Stress (Hoop in floor)

- SINT Stress Intensity

- SXY In-Plane Shear Stress

- SYZ Shear Stress

- SXZ Shear Stress

Figures are grouped in sets showing the stress for gravity only first, total demand from the transient analysis (gravity plus seismic), and then only the seismic portion. The seismic only load is simply the 
RPP-RPT-32239, Rev. 1

\section{M\&D-2008-005-CAL C-001, Rev. 1}

difference between the full transient loading and gravity only. For the primary tank, hoop stresses at the shell middle, Meridional stresses at the shell top and bottom, and in-plane shear stresses at the shell middle are presented in the following figures.

- Figure 9-21. Primary Hoop Stress (Middle) - Gravity Only

- Figure 9-22. Primary Tank Hoop Stress (Middle) - Gravity Plus Seismic

- Figure 9-23. Primary Tank Hoop Stress (Middle) - Seismic Only

- Figure 9-24. Primary Meridional Stress (Inside) - Gravity Only

- Figure 9-25. Primary Tank Meridional Stress (Inside) - Gravity Plus Seismic

- Figure 9-26. Primary Tank Meridional Stress (Inside) - Seismic Only

- Figure 9-27. Primary Meridional Stress (Outside) - Gravity Only

- Figure 9-28. Primary Tank Meridional Stress (Outside)-Gravity Plus Seismic

- Figure 9-29. Primary Tank Meridional Stress (Outside) - Seismic Only

- Figure 9-30. Primary Tank In-Plane Shear Stress (Middle) - Gravity Only

- Figure 9-31. Primary Tank In-Plane Shear Stress (Middle) - Gravity Plus Seismic

- Figure 9-32. Primary Tank In-Plane Shear Stress (Middle) - Seismic Only

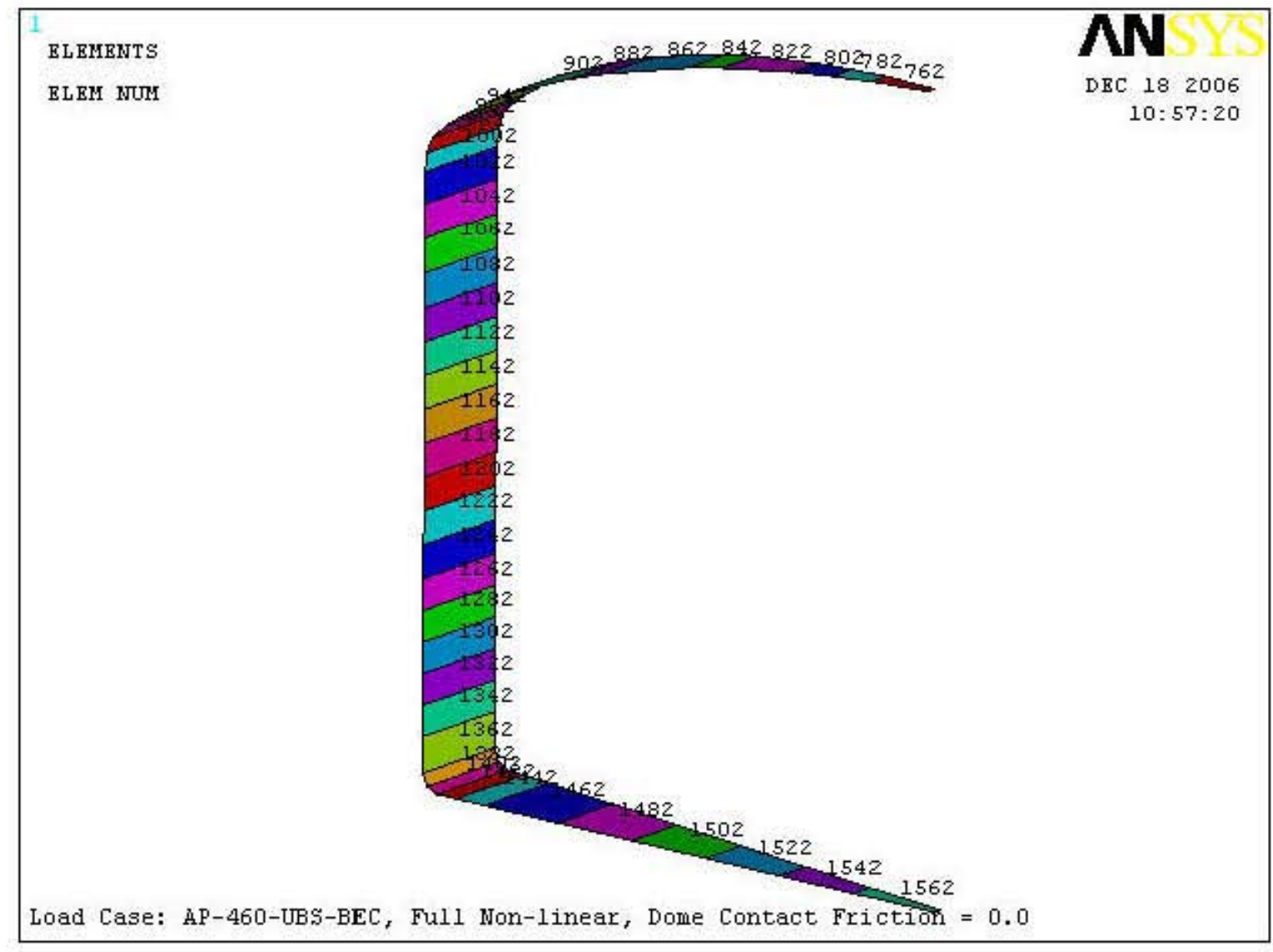

Figure 9-20. Primary Tank Element Retrieval Sequence Starting Numbers 
RPP-RPT-32239, Rev. 1

M\&D-2008-005-CALC-001, Rev. 1

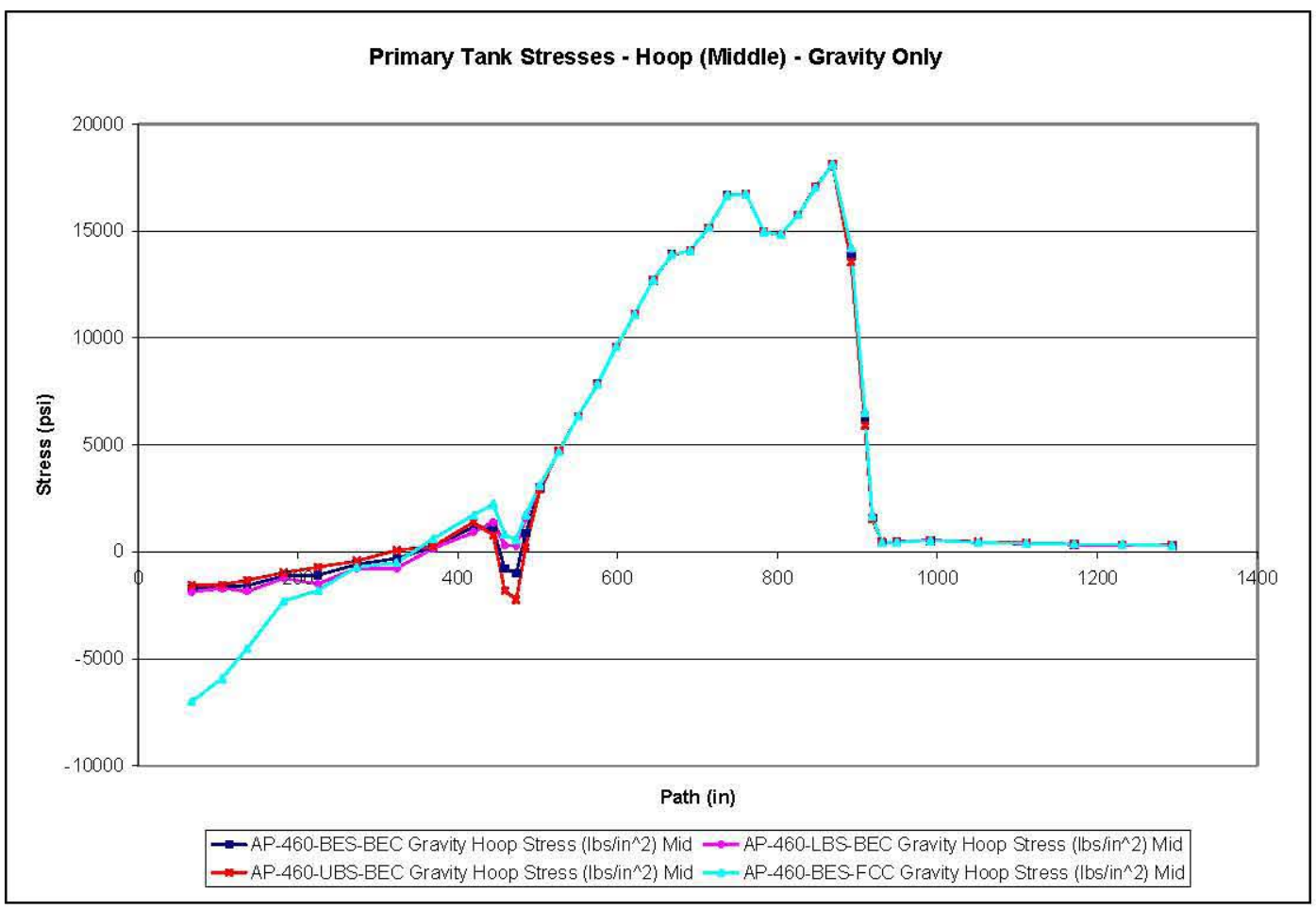

Figure 9-21. Primary Hoop Stress (Middle) - Gravity Only

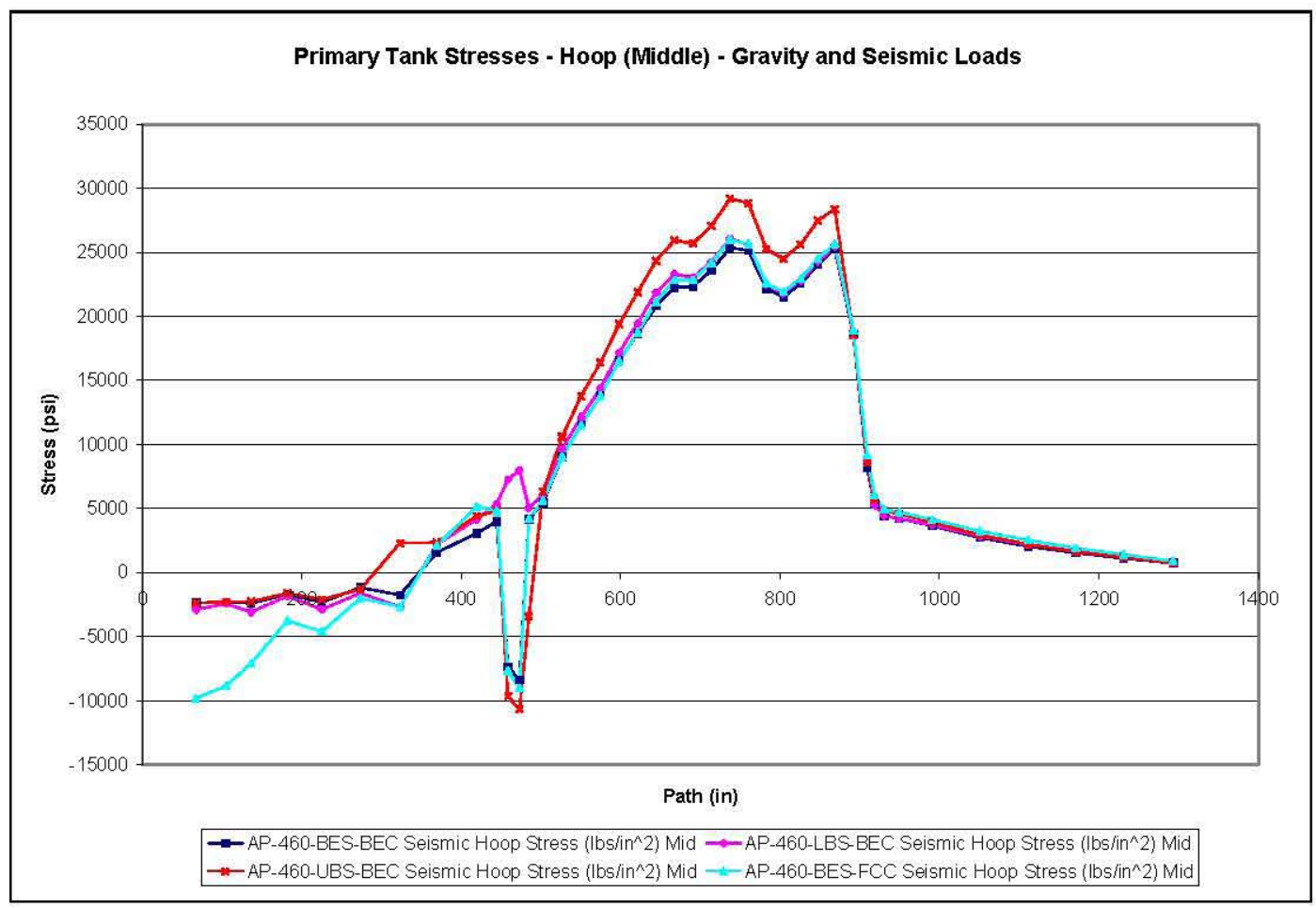

Figure 9-22. Primary Tank Hoop Stress (Middle) - Gravity Plus Seismic 
RPP-RPT-32239, Rev. 1

M\&D-2008-005-CALC-001, Rev. 1

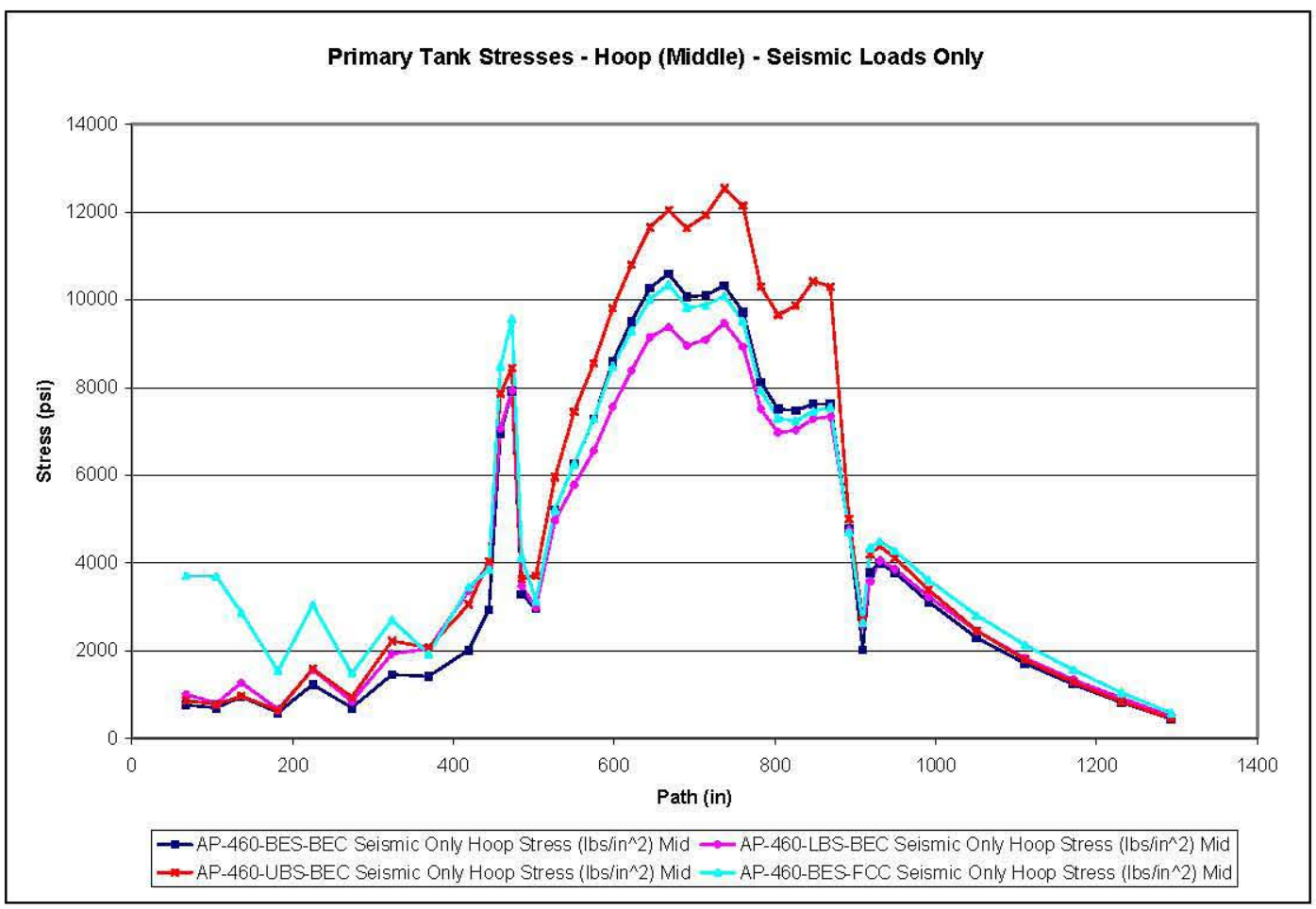

Figure 9-23. Primary Tank Hoop Stress (Middle) - Seismic Only

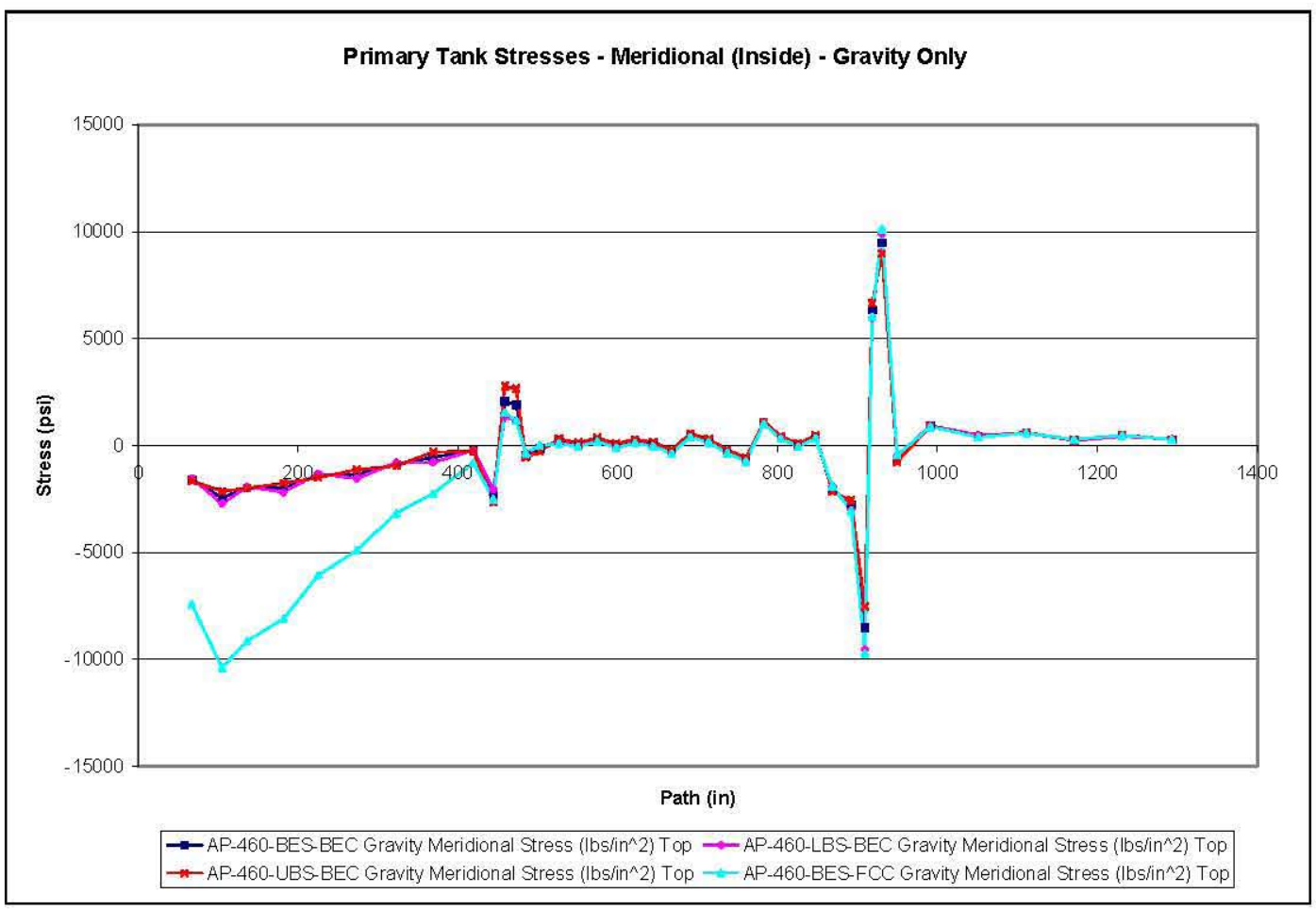

Figure 9-24. Primary Meridional Stress (Inside) - Gravity Only 
RPP-RPT-32239, Rev. 1

M\&D-2008-005-CALC-001, Rev. 1

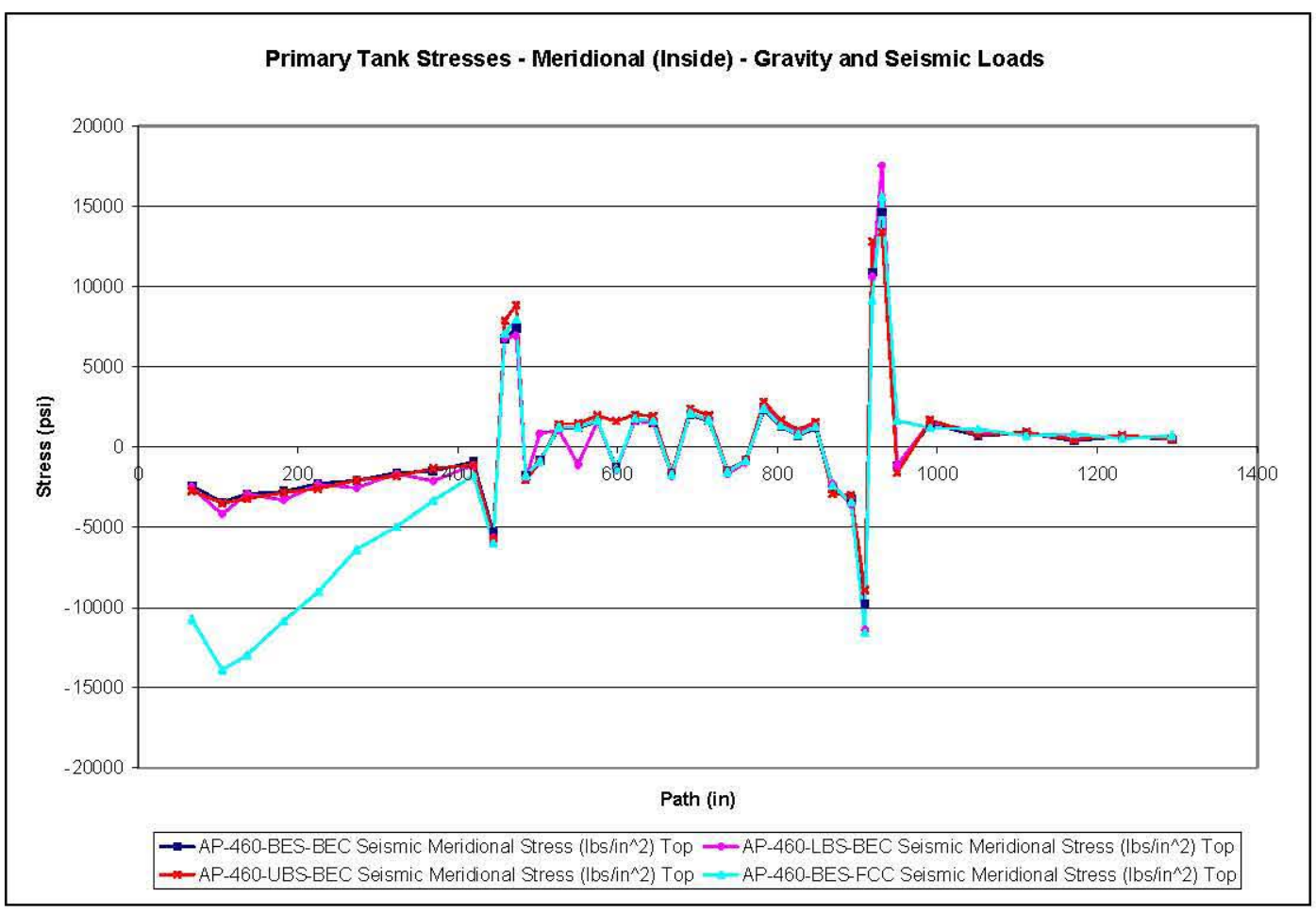

Figure 9-25. Primary Tank Meridional Stress (Inside) - Gravity Plus Seismic

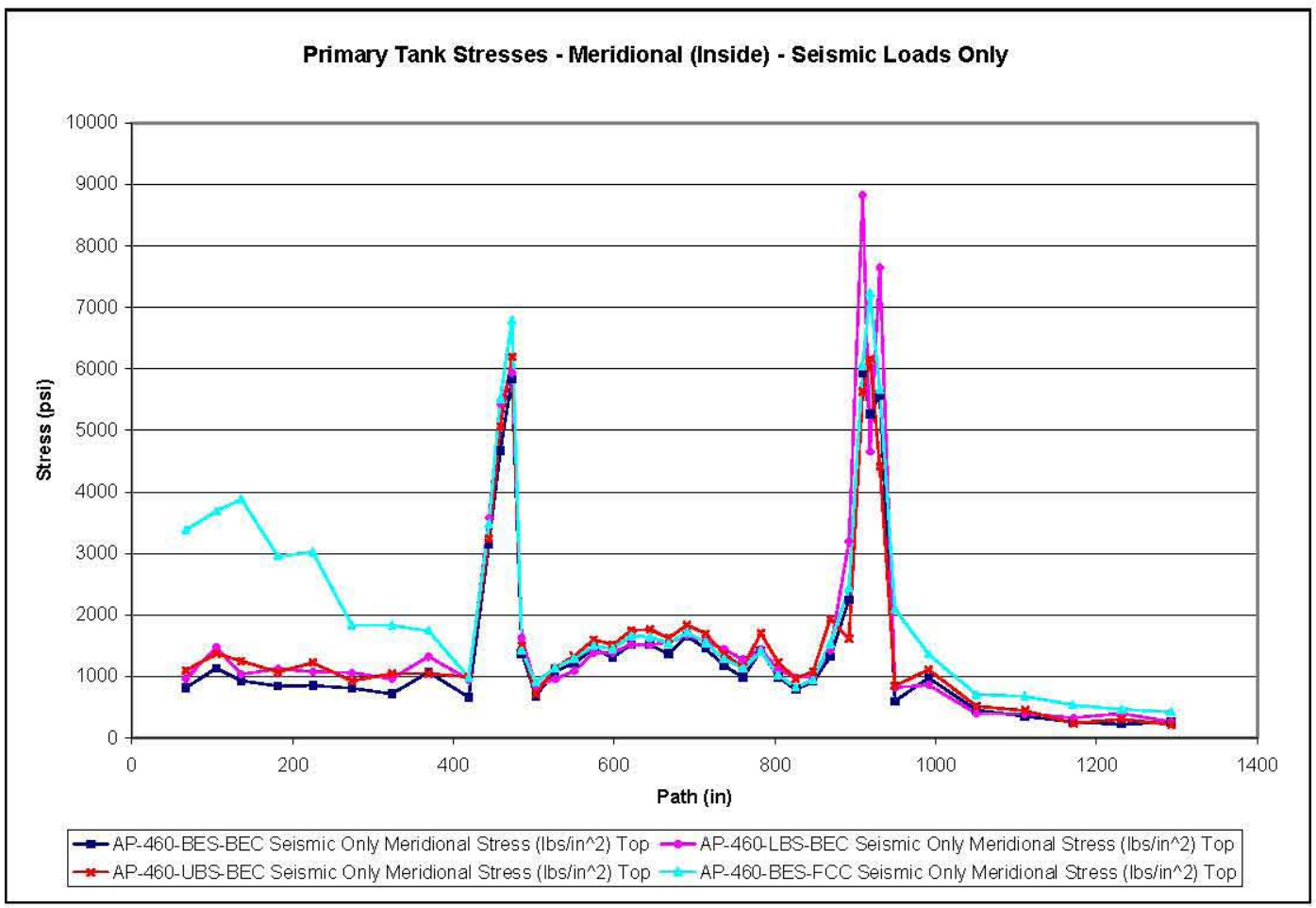

Figure 9-26. Primary Tank Meridional Stress (Inside) - Seismic Only 
RPP-RPT-32239, Rev. 1

M\&D-2008-005-CALC-001, Rev. 1

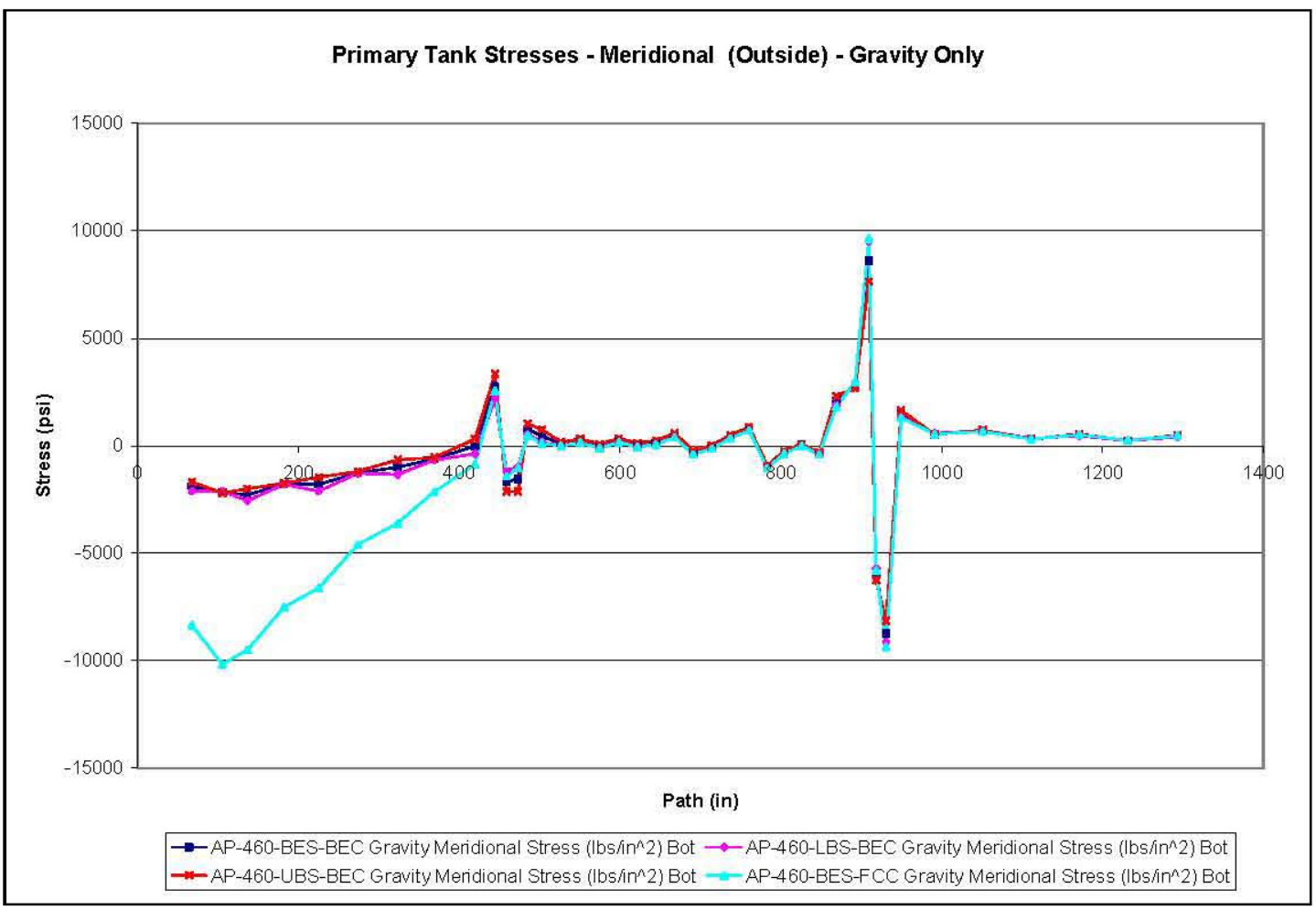

Figure 9-27. Primary Meridional Stress (Outside) - Gravity Only

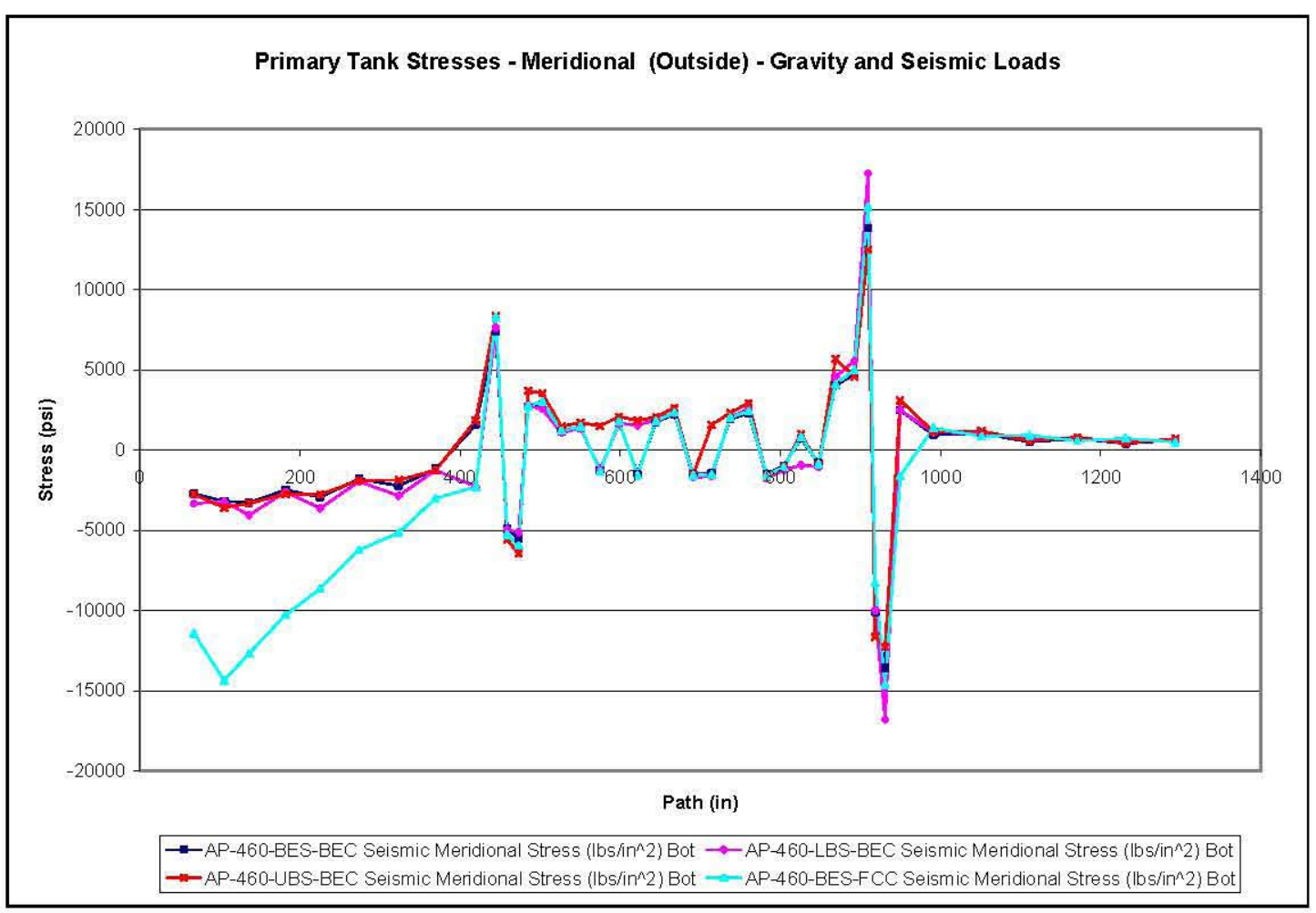

Figure 9-28. Primary Tank Meridional Stress (Outside) - Gravity Plus Seismic 
RPP-RPT-32239, Rev. 1

M\&D-2008-005-CALC-001, Rev. 1

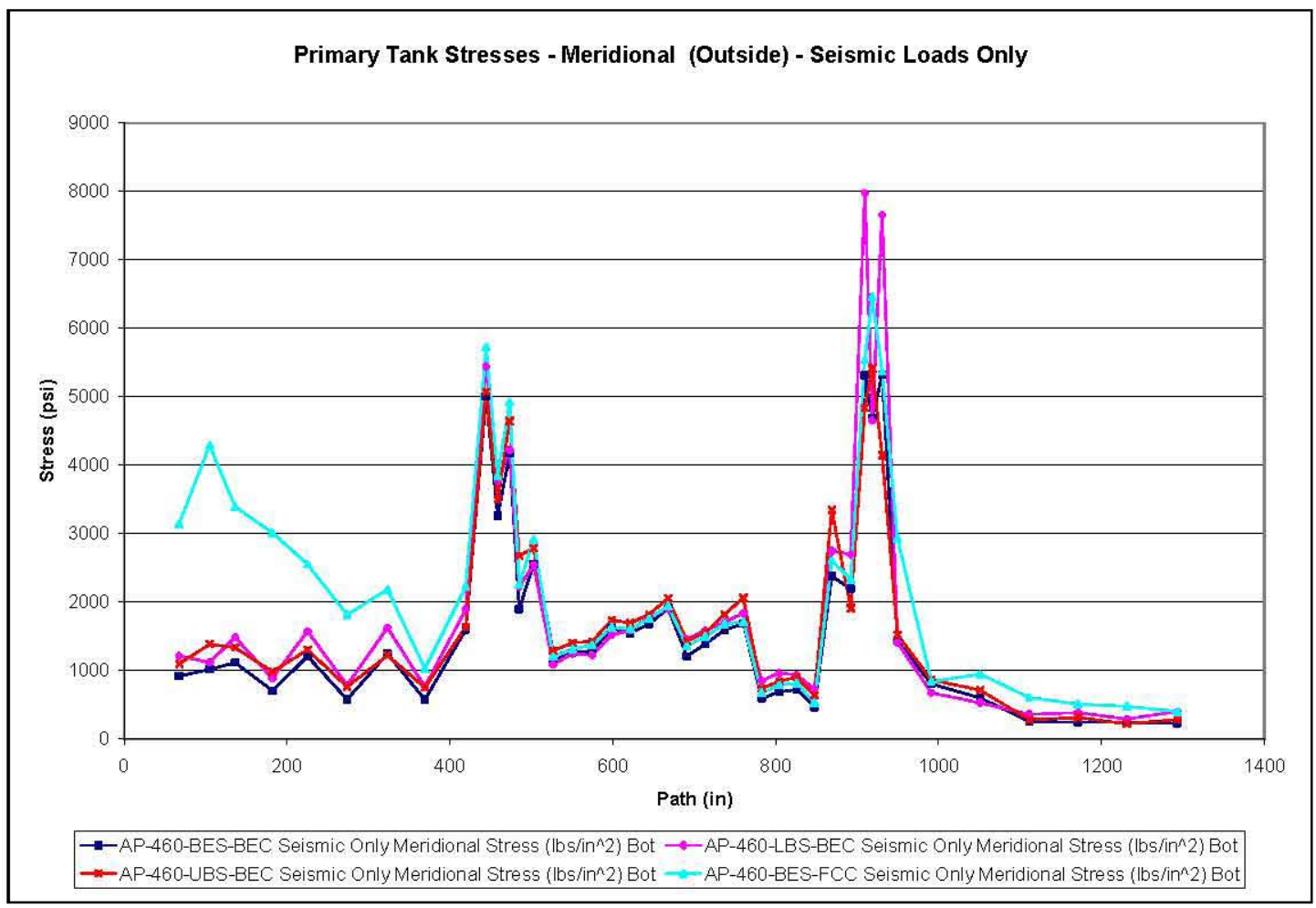

Figure 9-29. Primary Tank Meridional Stress (Outside) - Seismic Only

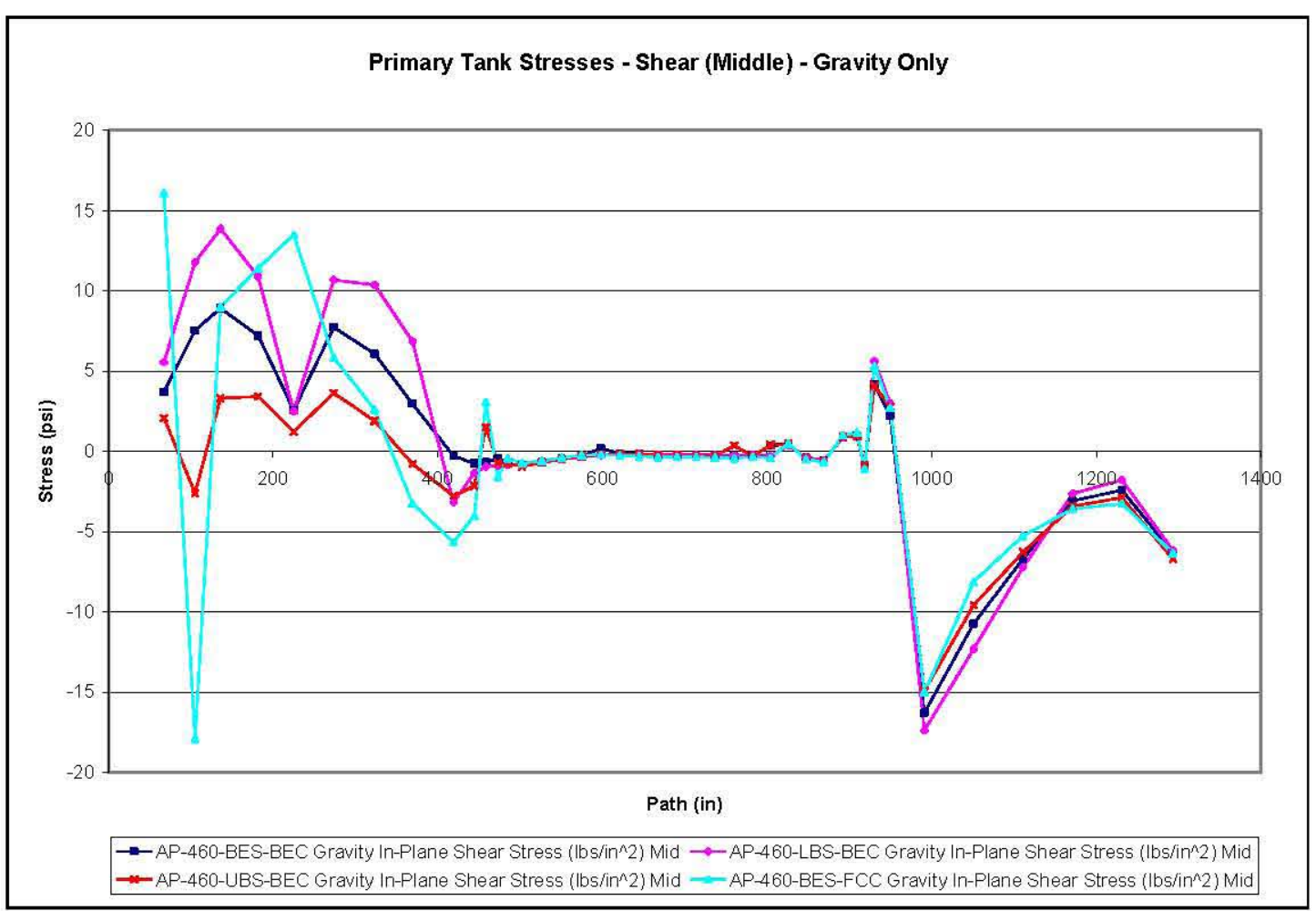

Figure 9-30. Primary Tank In-Plane Shear Stress (Middle) - Gravity Only 
RPP-RPT-32239, Rev. 1

M\&D-2008-005-CALC-001, Rev. 1

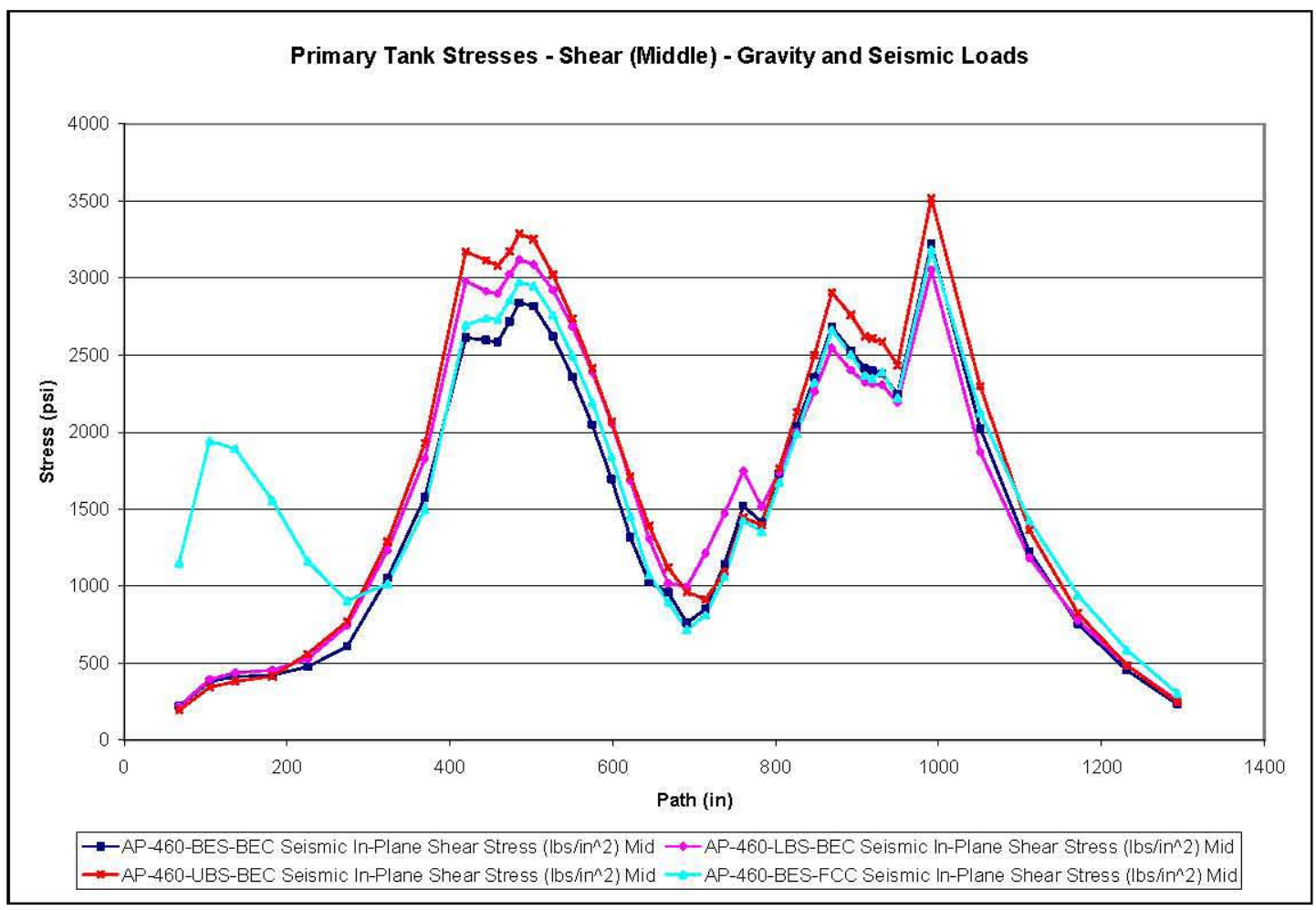

Figure 9-31. Primary Tank In-Plane Shear Stress (Middle) - Gravity Plus Seismic

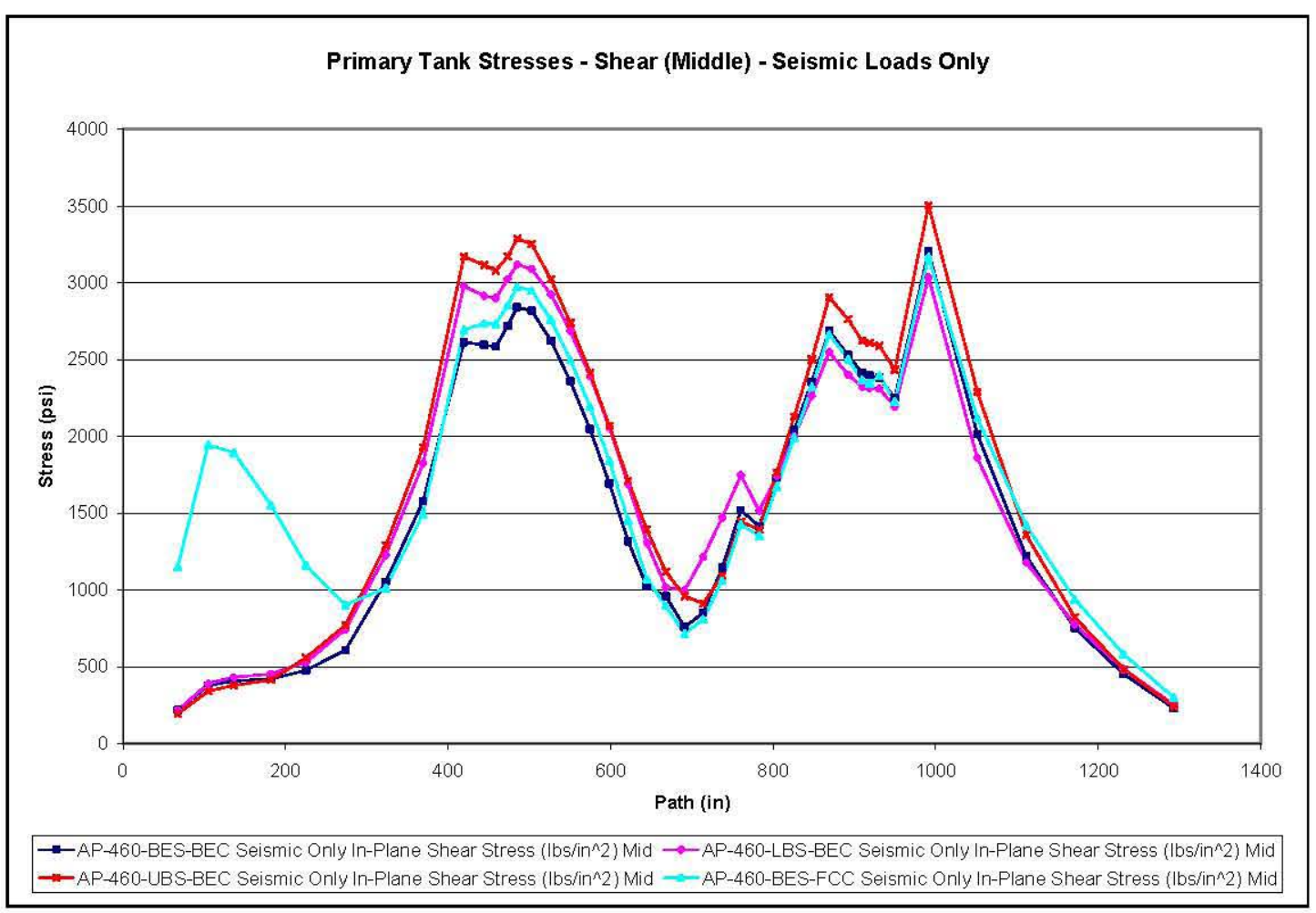

Figure 9-32. Primary Tank In-Plane Shear Stress (Middle) - Seismic Only 
RPP-RPT-32239, Rev. 1

M\&D-2008-005-CALC-001, Rev. 1

\subsection{Comparison of Primary Tank Stresses Between the Revision 0 and Revision 1 Models for the BES-BEC Case}

Figure 9-33 through Figure 9-41 show comparisons of stress components in the primary tank under seismic loading only for the updated (Revision 1) model with the secant stiffness for the anchor bolts and the original (Revision 0) model in the BES-BEC case. As expected, the plots show that the differences in the primary tank stress components are minor and that a full reevaluation of all tank components is not required.

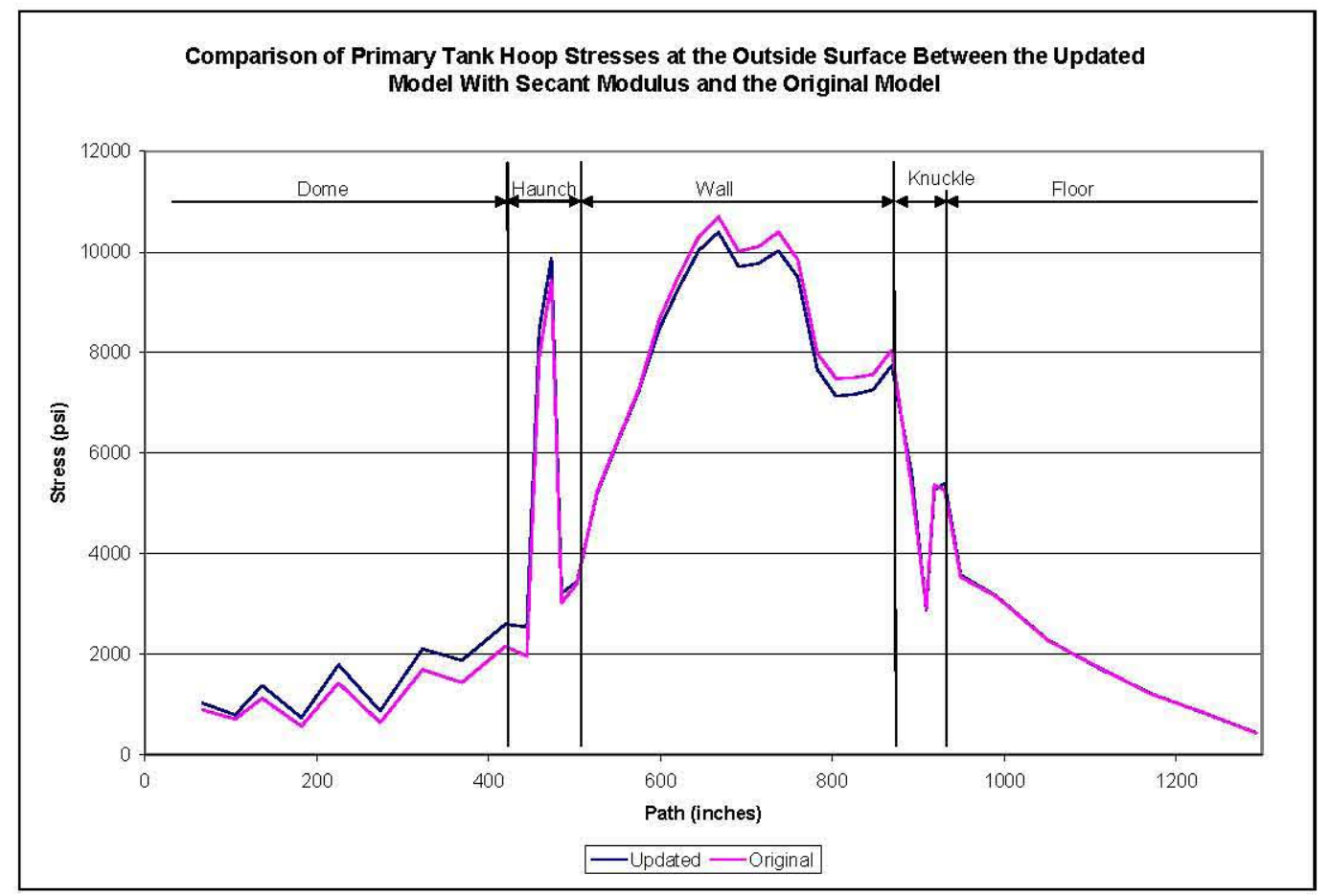

Figure 9-33. Comparison of Hoop Stresses at the Outside Surface of the Primary Tank for the Updated and Original Models - Seismic Only 
RPP-RPT-32239, Rev. 1

M\&D-2008-005-CALC-001, Rev. 1

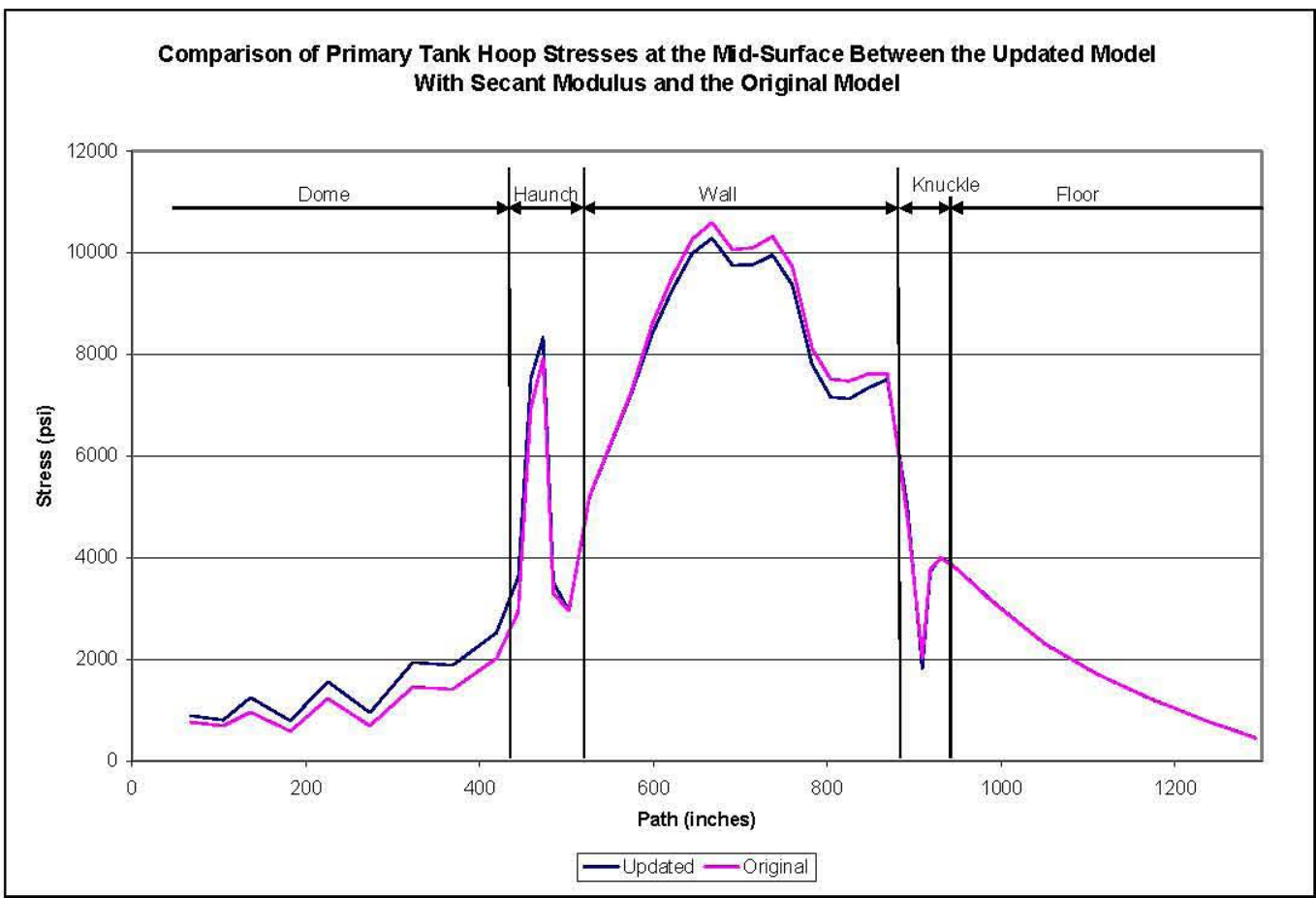

Figure 9-34. Comparison of Hoop Stresses at the Mid-Surface of the Primary Tank for the Updated and Original Models - Seismic Only

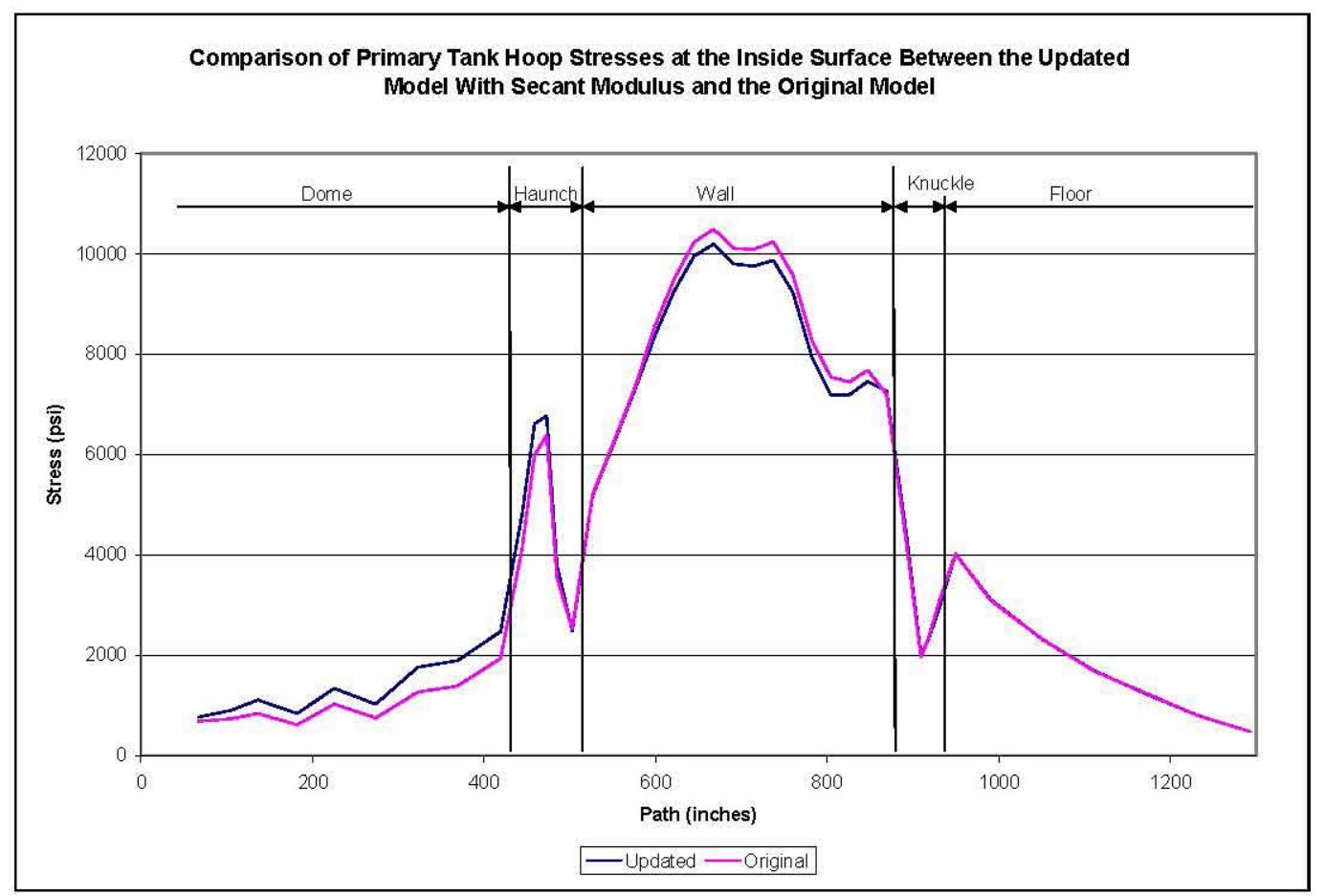

Figure 9-35. Comparison of Hoop Stresses at the Inside Surface of the Primary Tank for the Updated and Original Models - Seismic Only 
RPP-RPT-32239, Rev. 1

M\&D-2008-005-CALC-001, Rev. 1

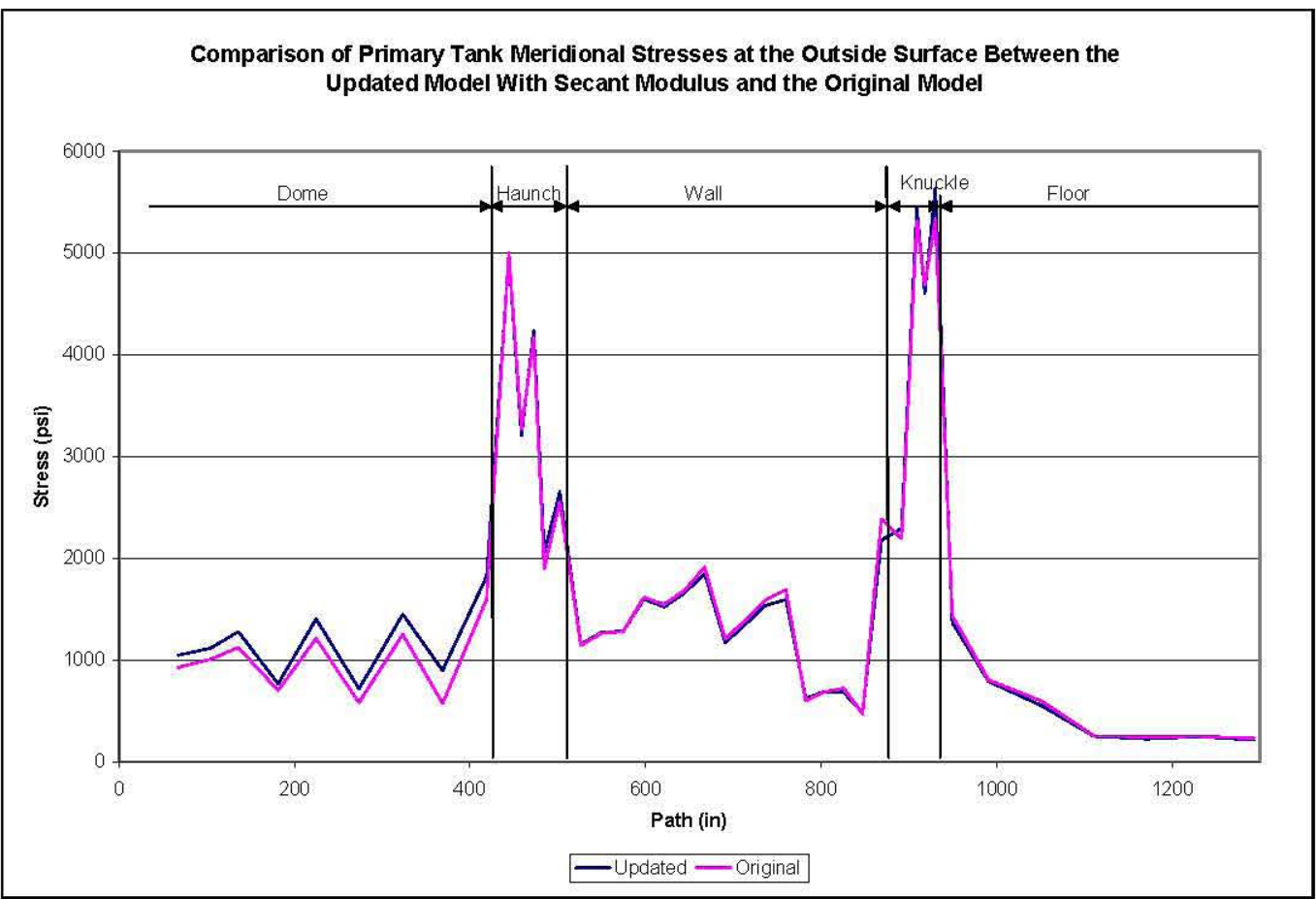

Figure 9-36. Comparison of Meridional Stresses at the Outside Surface of the Primary Tank for the Updated and Original Models - Seismic Only

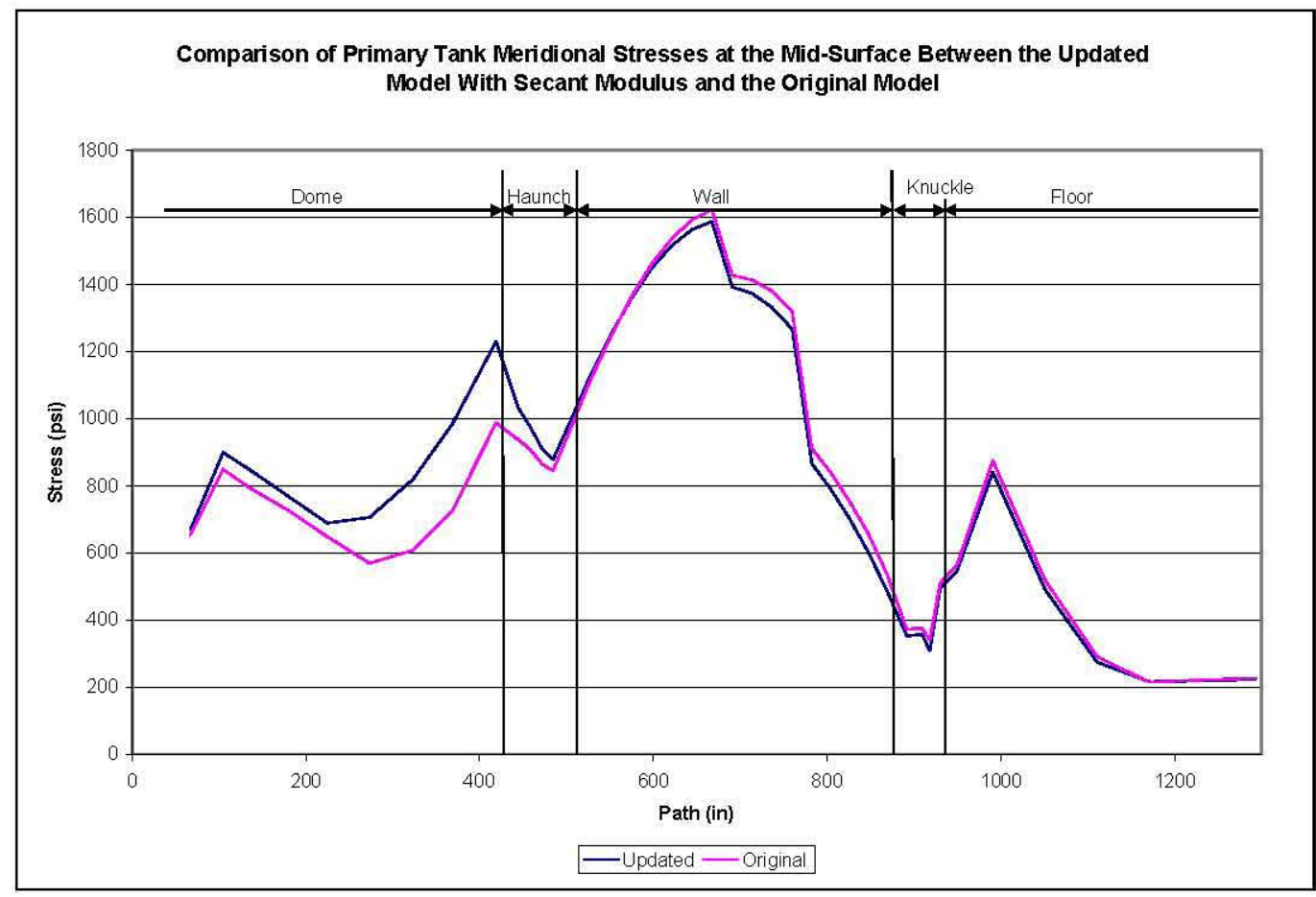

Figure 9-37. Comparison of Meridional Stresses at the Mid-Surface of the Primary Tank for the Updated and Original Models - Seismic Only 
RPP-RPT-32239, Rev. 1

M\&D-2008-005-CALC-001, Rev. 1

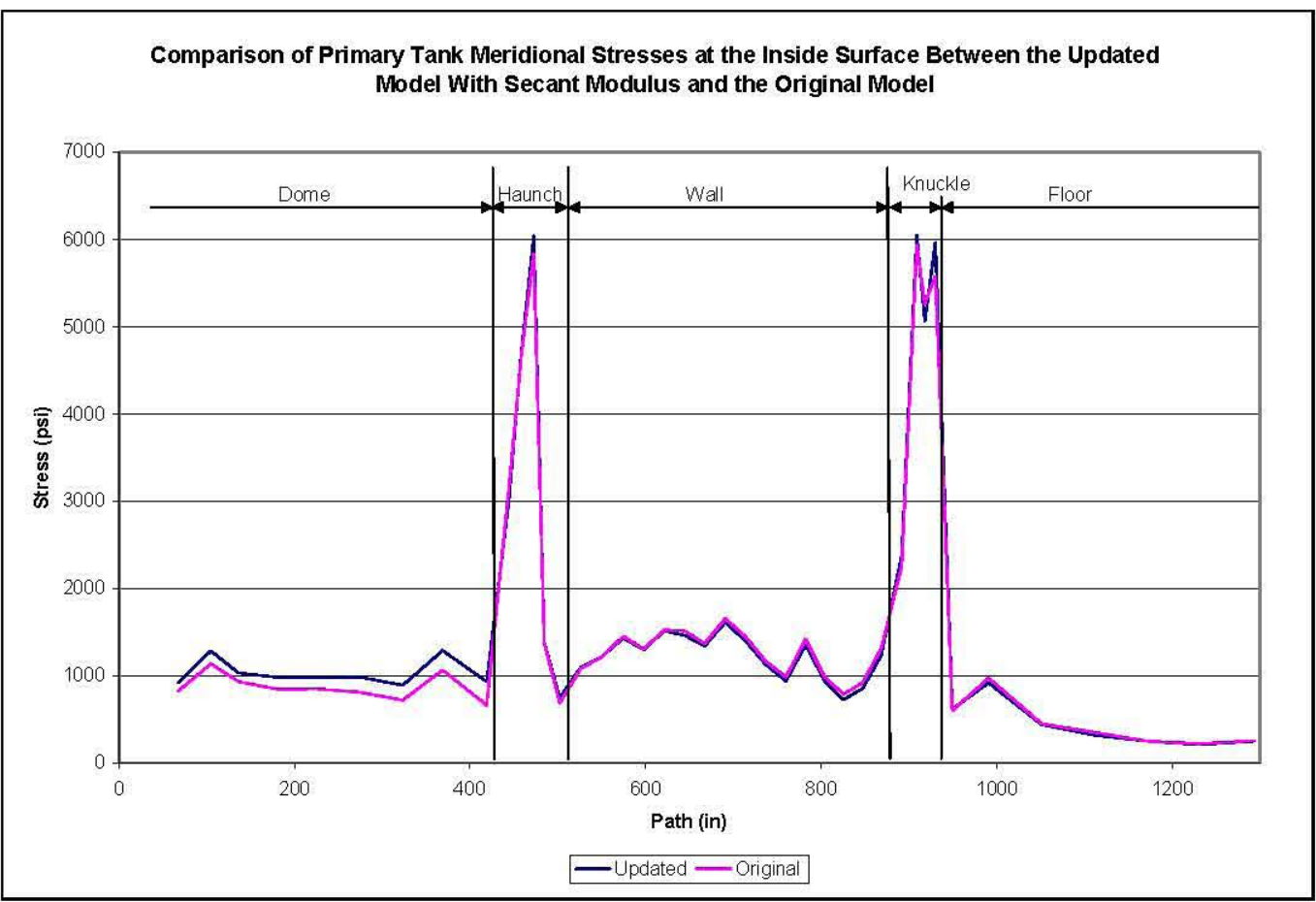

Figure 9-38. Comparison of Meridional Stresses at the Inside Surface of the Primary Tank for the Updated and Original Models - Seismic Only

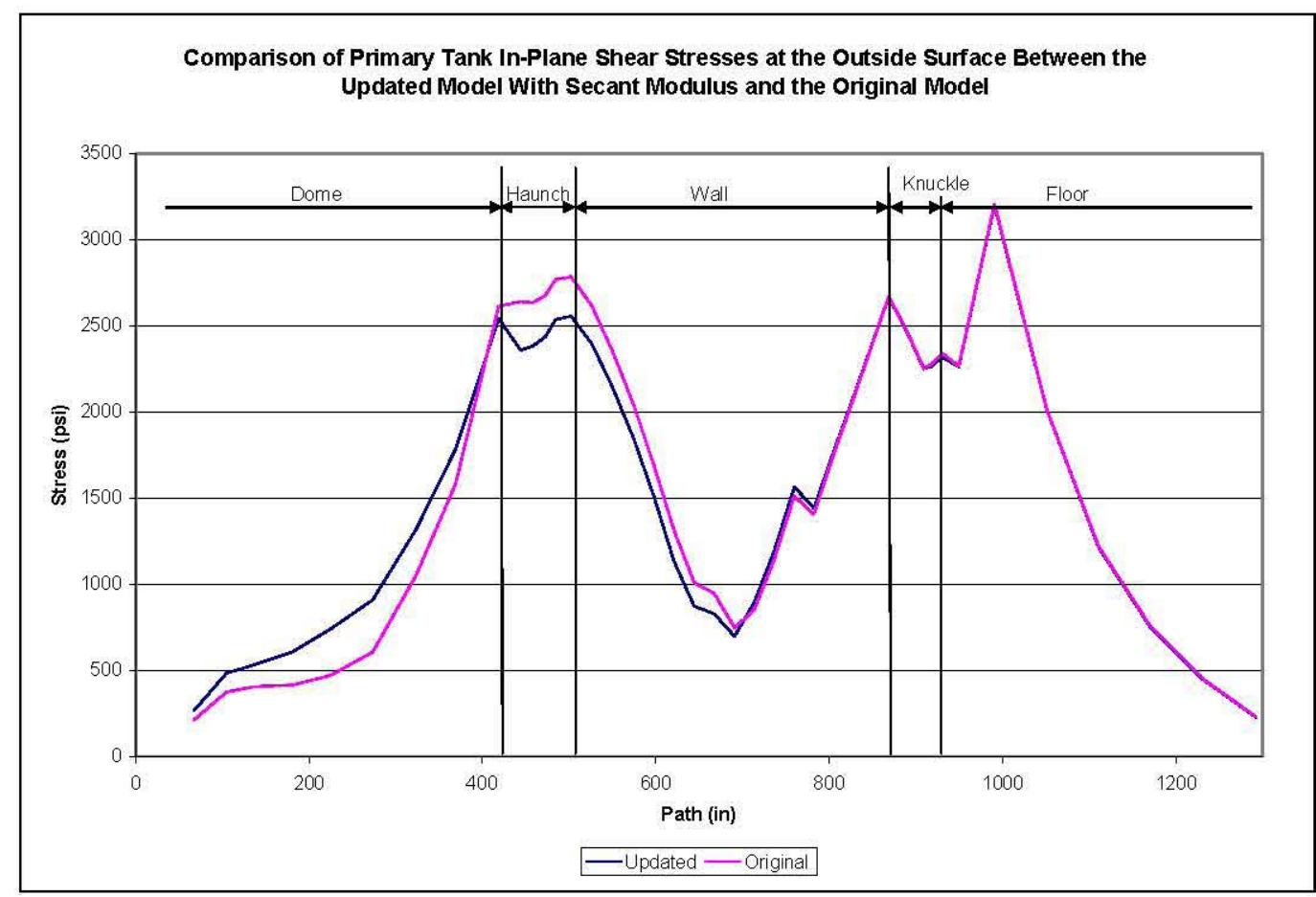

Figure 9-39. Comparison of In-Plane Shear Stresses at the Outside Surface of the Primary Tank for the Updated and Original Models - Seismic Only 
RPP-RPT-32239, Rev. 1

M\&D-2008-005-CALC-001, Rev. 1

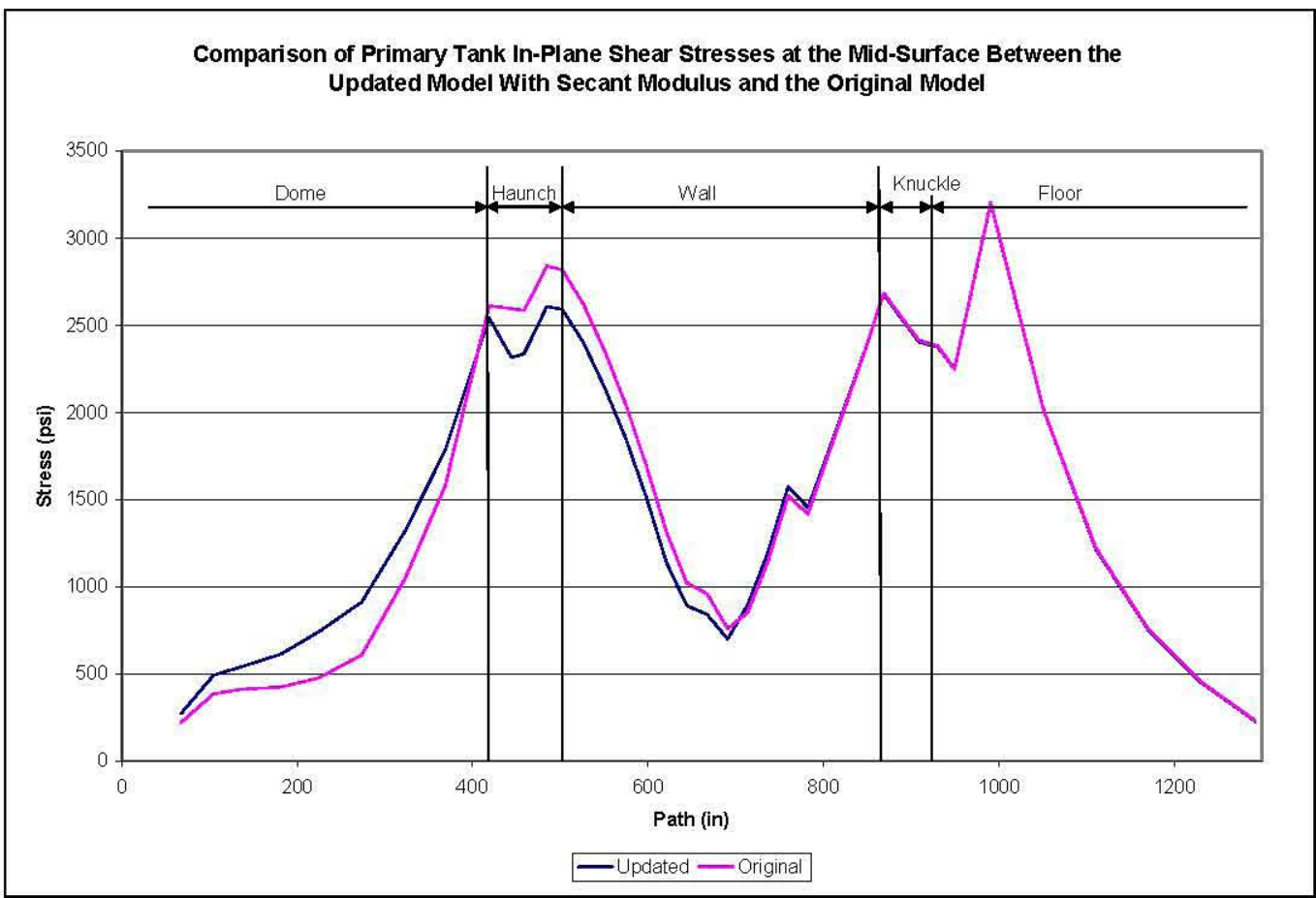

Figure 9-40. Comparison of In-Plane Shear Stresses at the Mid-Surface of the Primary Tank for the Updated and Original Models - Seismic Only

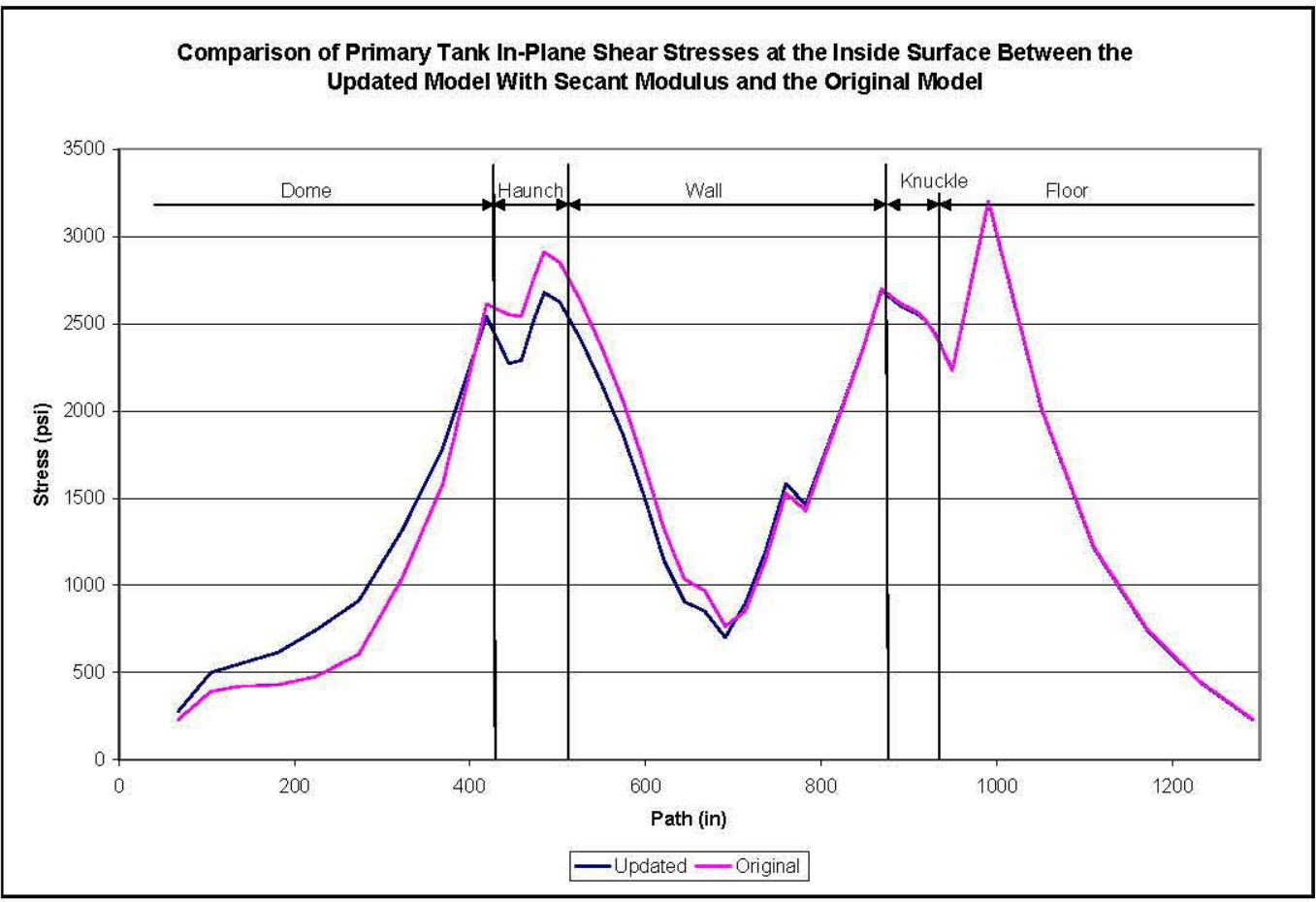

Figure 9-41. Comparison of In-Plane Shear Stresses at the Inside Surface of the Primary Tank for the Updated and Original Models - Seismic Only 
RPP-RPT-32239, Rev. 1

M\&D-2008-005-CALC-001, Rev. 1

\subsection{Anchor Bolt Results for the Revision 1 Model}

Axial and shear forces were extracted for the anchor bolt elements. Figure 9-42 shows the element numbers for the first five sets of anchor bolts. Because anchor bolt elements are placed at the edges of each slice, a total of twenty-one sets are extracted, but are extracted by radius instead of angle as was done for the concrete and primary tank. The following forces were extracted from the BEAM4 element results.

- SMISC7 Axial force (Element X)

- SMISC8 Shear force (Element Y)

- SMISC9 Shear force (Element Z)

After enveloping the forces around the circumference of the tank, the forces are reallocated on a per-bolt basis using the information from Figure 2-6. The total shear force is calculated by combining the two orthogonal shears extracted from the model by the SRSS method. The results are presented in the following figures:

- Figure 9-43. Anchor Bolts - Maximum Axial Force - Gravity Only

- Figure 9-44. Anchor Bolts - Minimum Axial Force-Gravity Only

- Figure 9-45. Anchor Bolts - Maximum Axial Force-Gravity Plus Seismic

- Figure 9-46. Anchor Bolts - Minimum Axial Force-Gravity Plus Seismic

- Figure 9-47. Anchor Bolts - Maximum Axial Force-Seismic Only

- Figure 9-48. Anchor Bolts - Minimum Axial Force-Seismic Only

- Figure 9-49. Anchor Bolts - Shear Force - Gravity Only

- Figure 9-50. Anchor Bolts - Shear Force-Gravity Plus Seismic

- Figure 9-51. Anchor Bolts - Shear Force-Seismic Only

- Figure 9-52. Anchor Bolt Maximum Shear Displacement Seismic Only 
RPP-RPT-32239, Rev. 1

M\&D-2008-005-CALC-001, Rev. 1

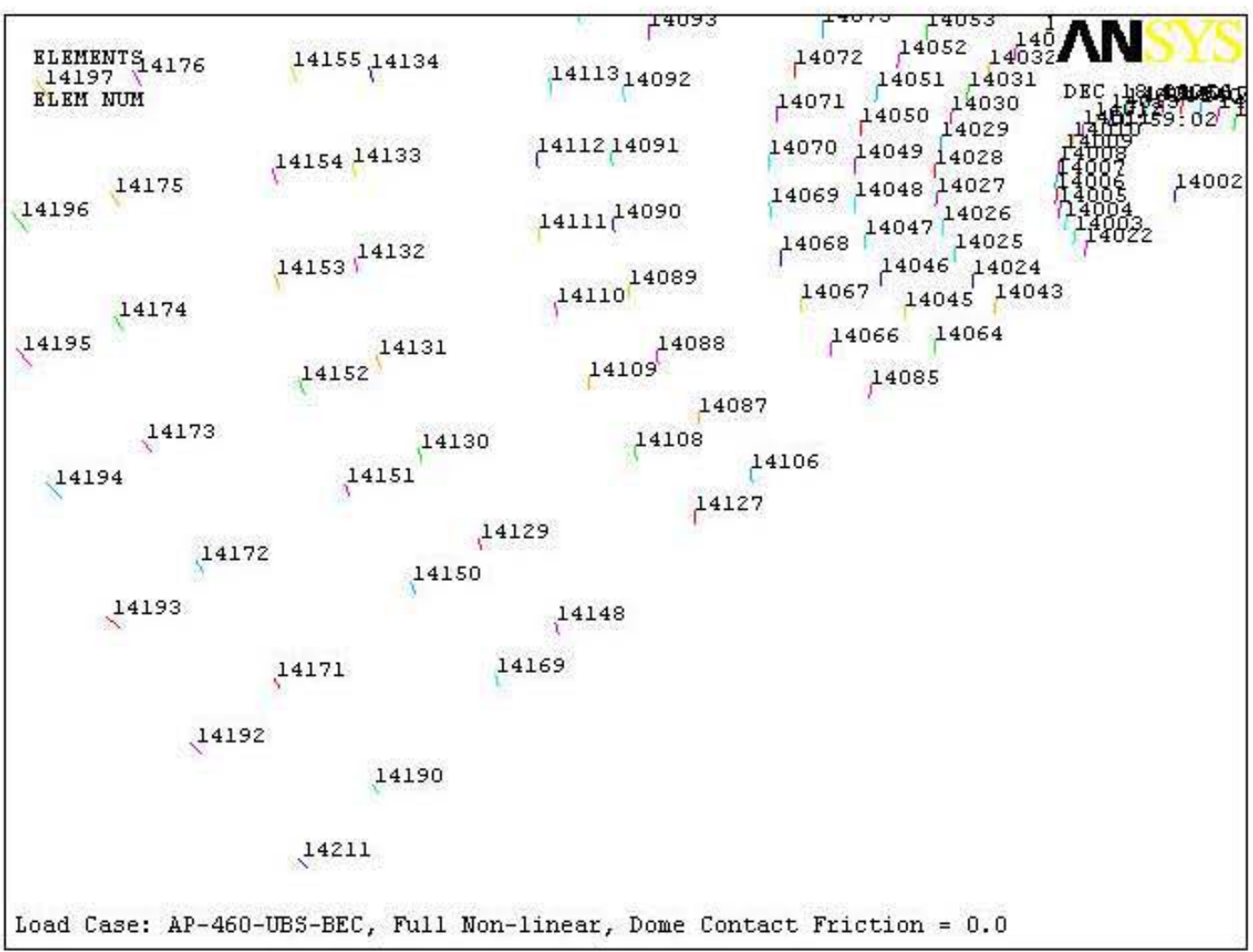

Figure 9-42. Anchor Bolt Element Retrieval Sequence Starting Numbers

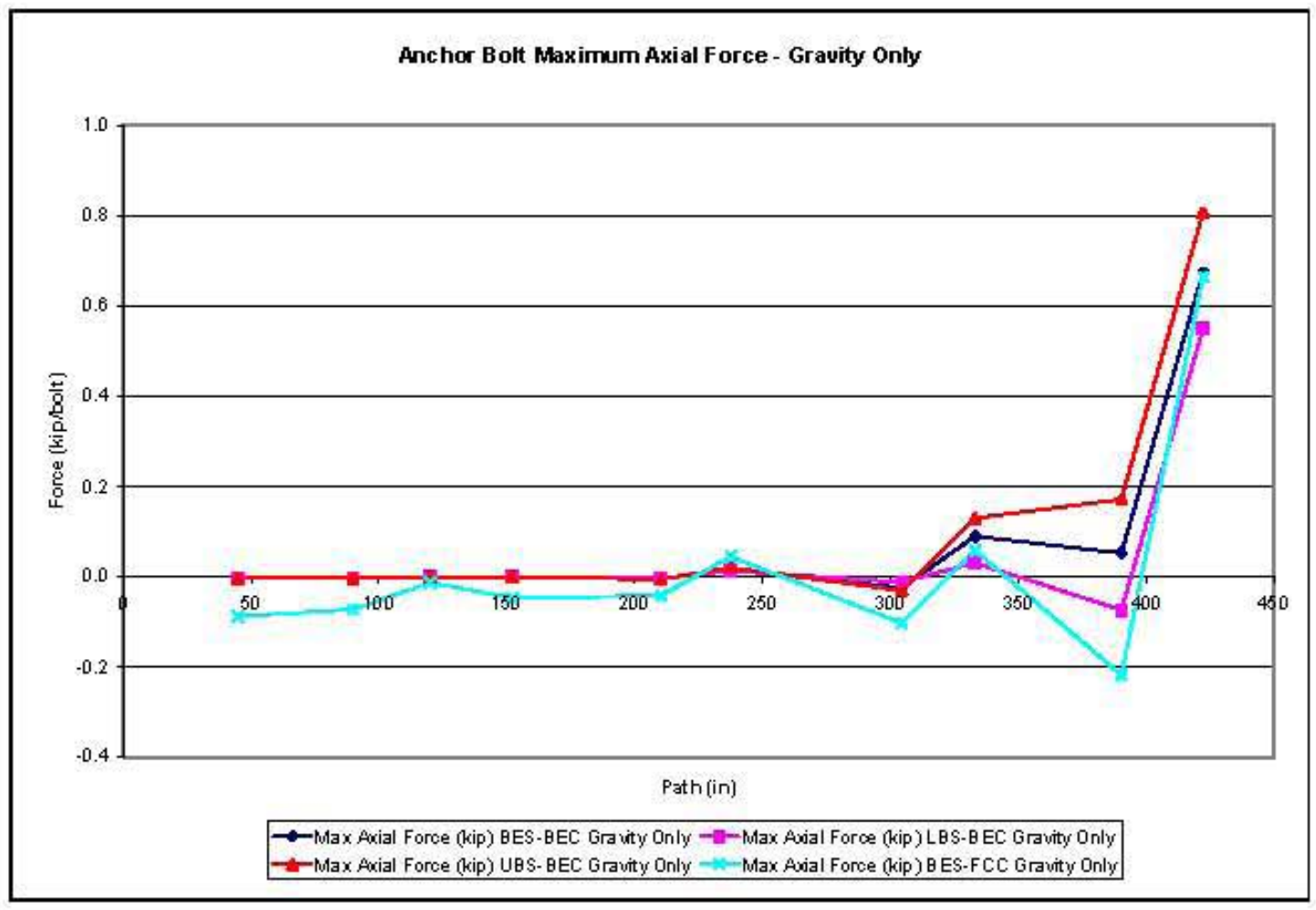

Figure 9-43. Anchor Bolts - Maximum Axial Force - Gravity Only 
RPP-RPT-32239, Rev. 1

M\&D-2008-005-CALC-001, Rev. 1

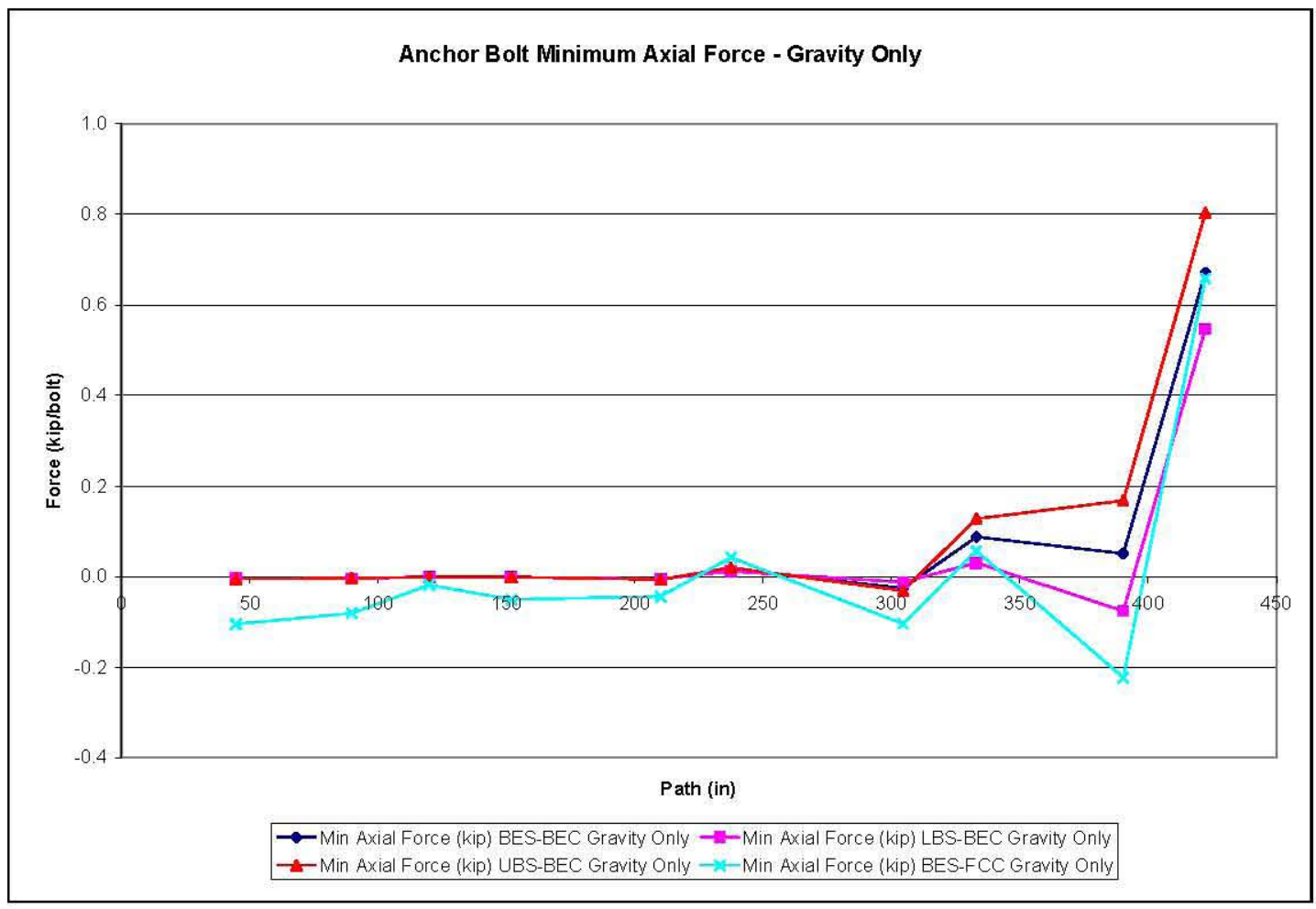

Figure 9-44. Anchor Bolts - Minimum Axial Force - Gravity Only

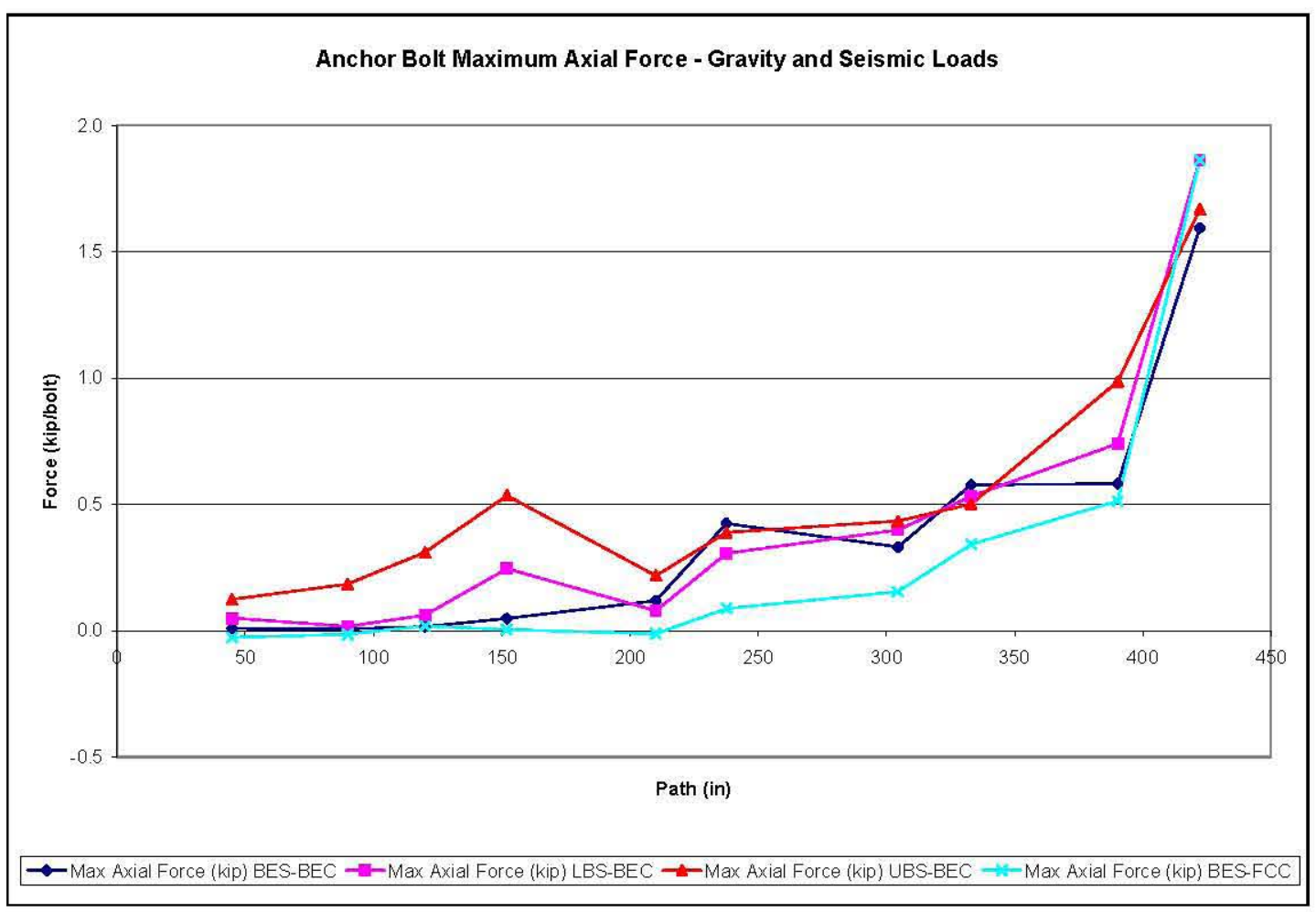

Figure 9-45. Anchor Bolts - Maximum Axial Force - Gravity Plus Seismic 
RPP-RPT-32239, Rev. 1

M\&D-2008-005-CALC-001, Rev. 1

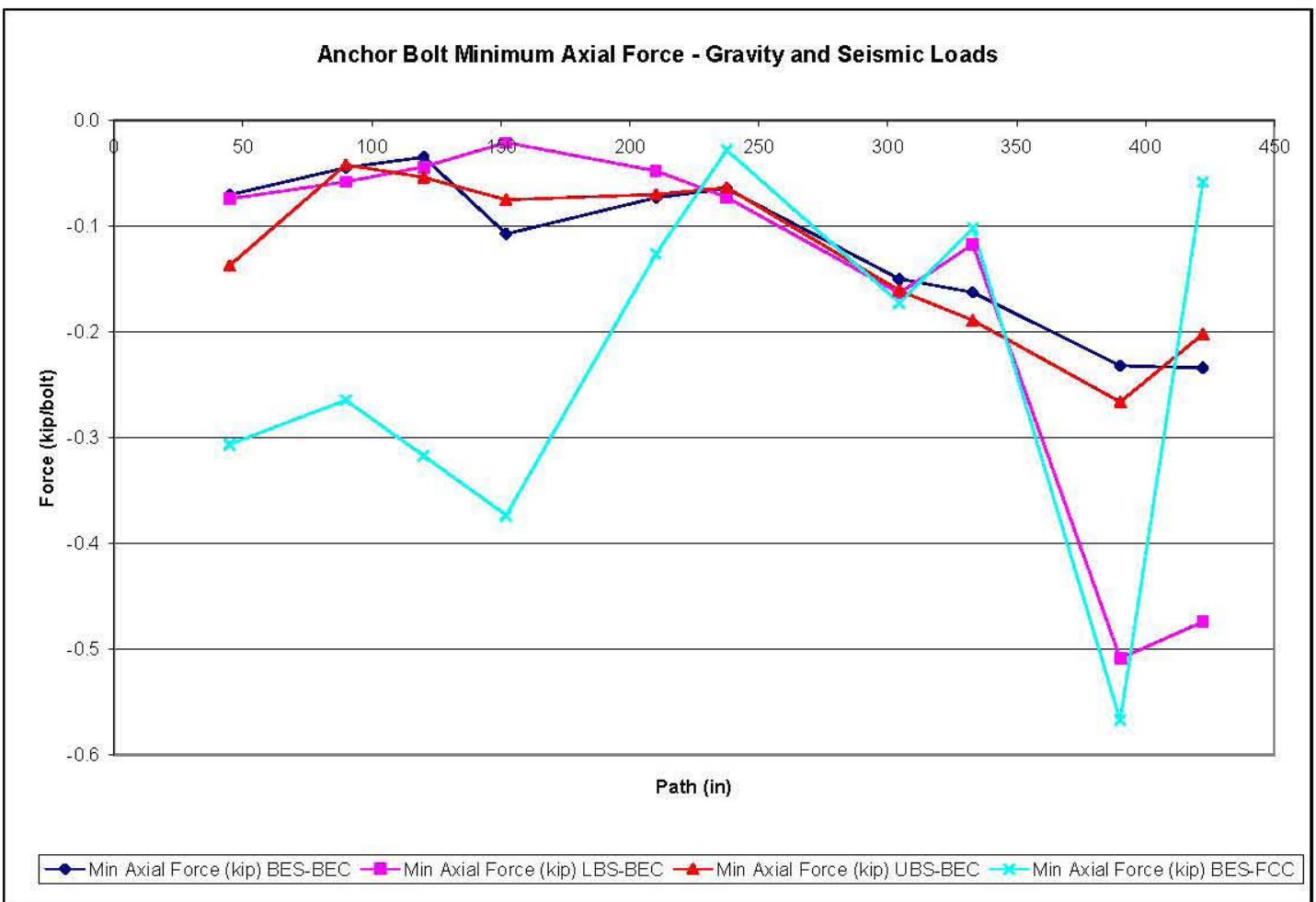

Figure 9-46. Anchor Bolts - Minimum Axial Force - Gravity Plus Seismic

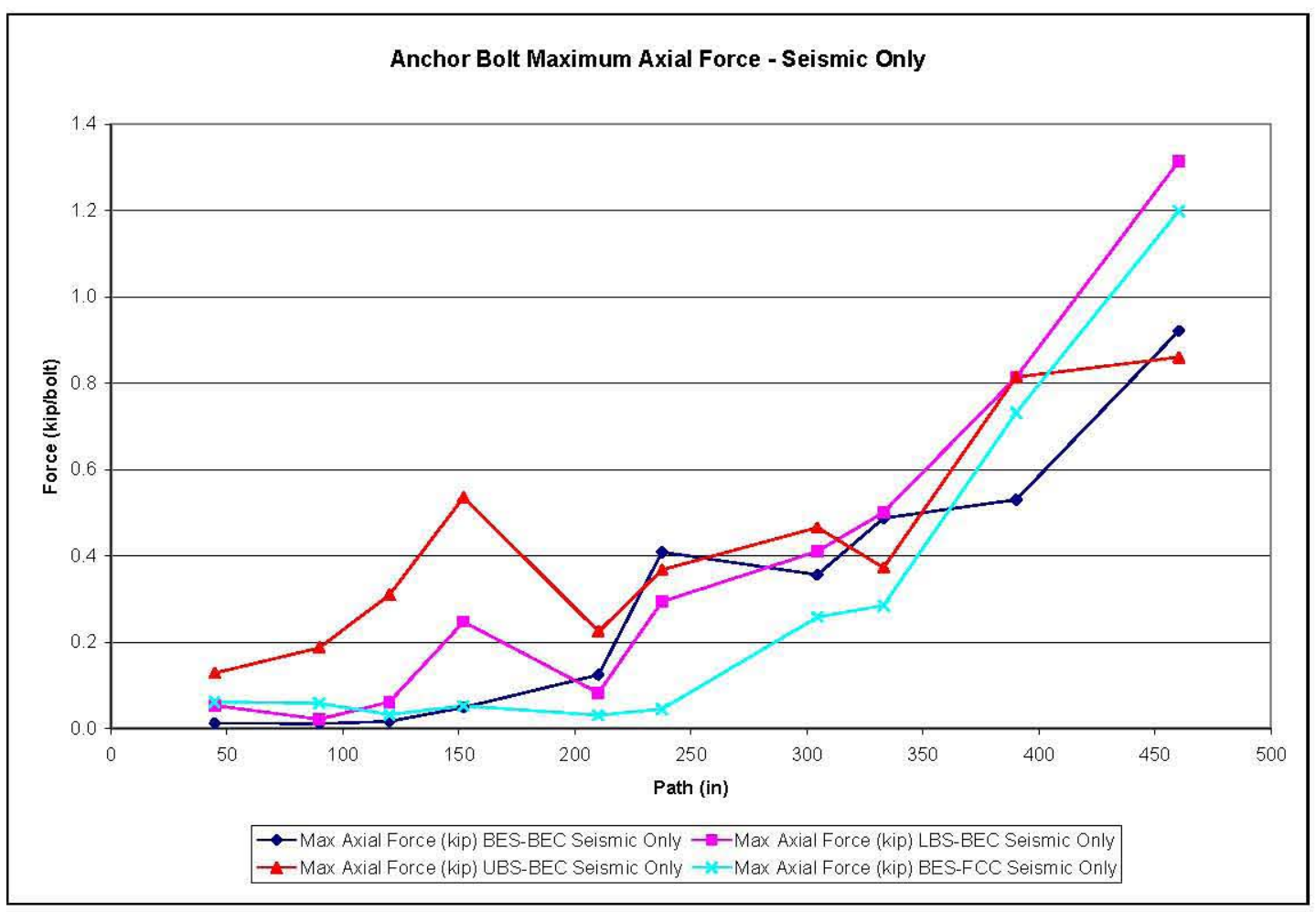

Figure 9-47. Anchor Bolts - Maximum Axial Force - Seismic Only 
RPP-RPT-32239, Rev. 1

M\&D-2008-005-CALC-001, Rev. 1

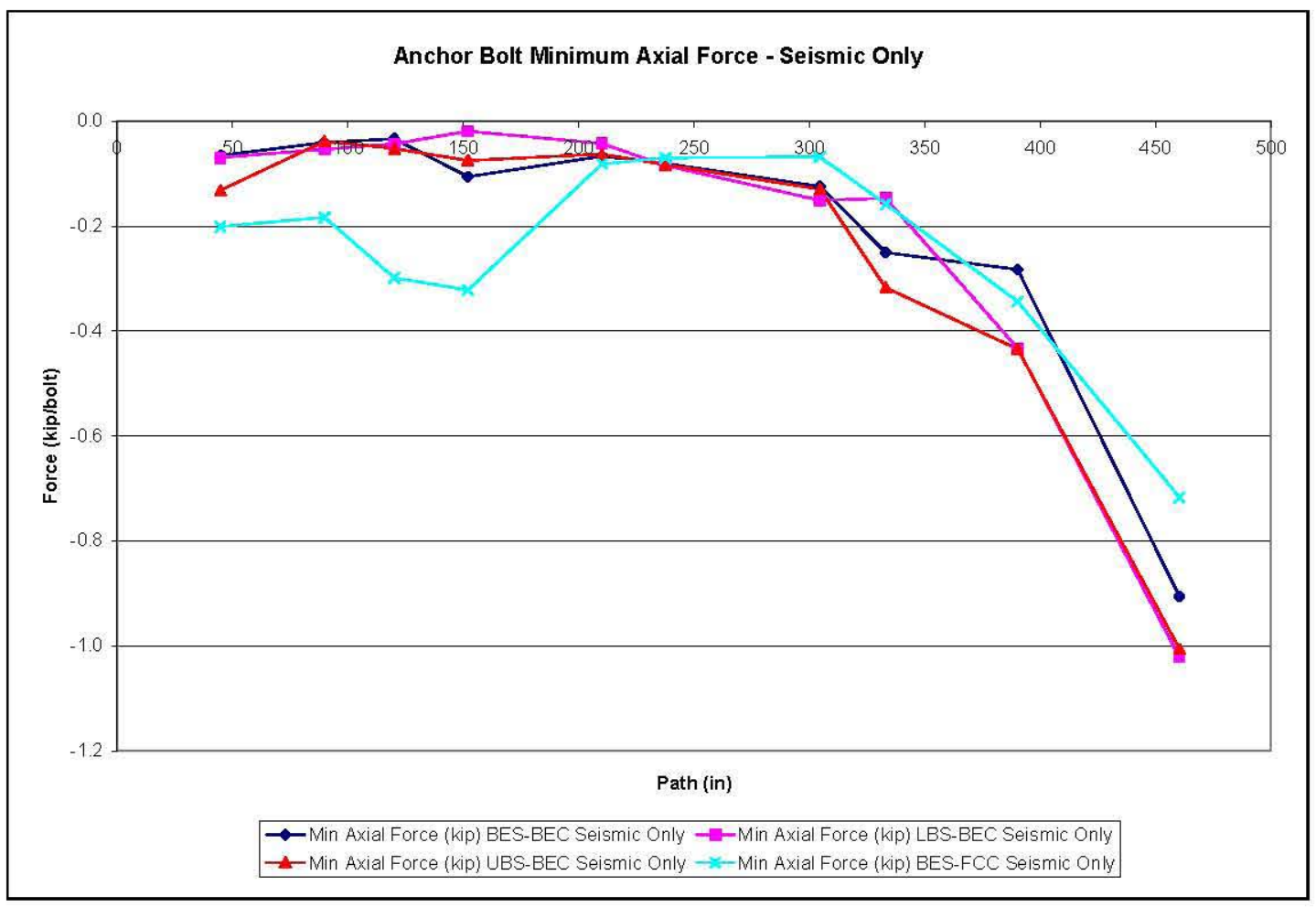

Figure 9-48. Anchor Bolts - Minimum Axial Force - Seismic Only

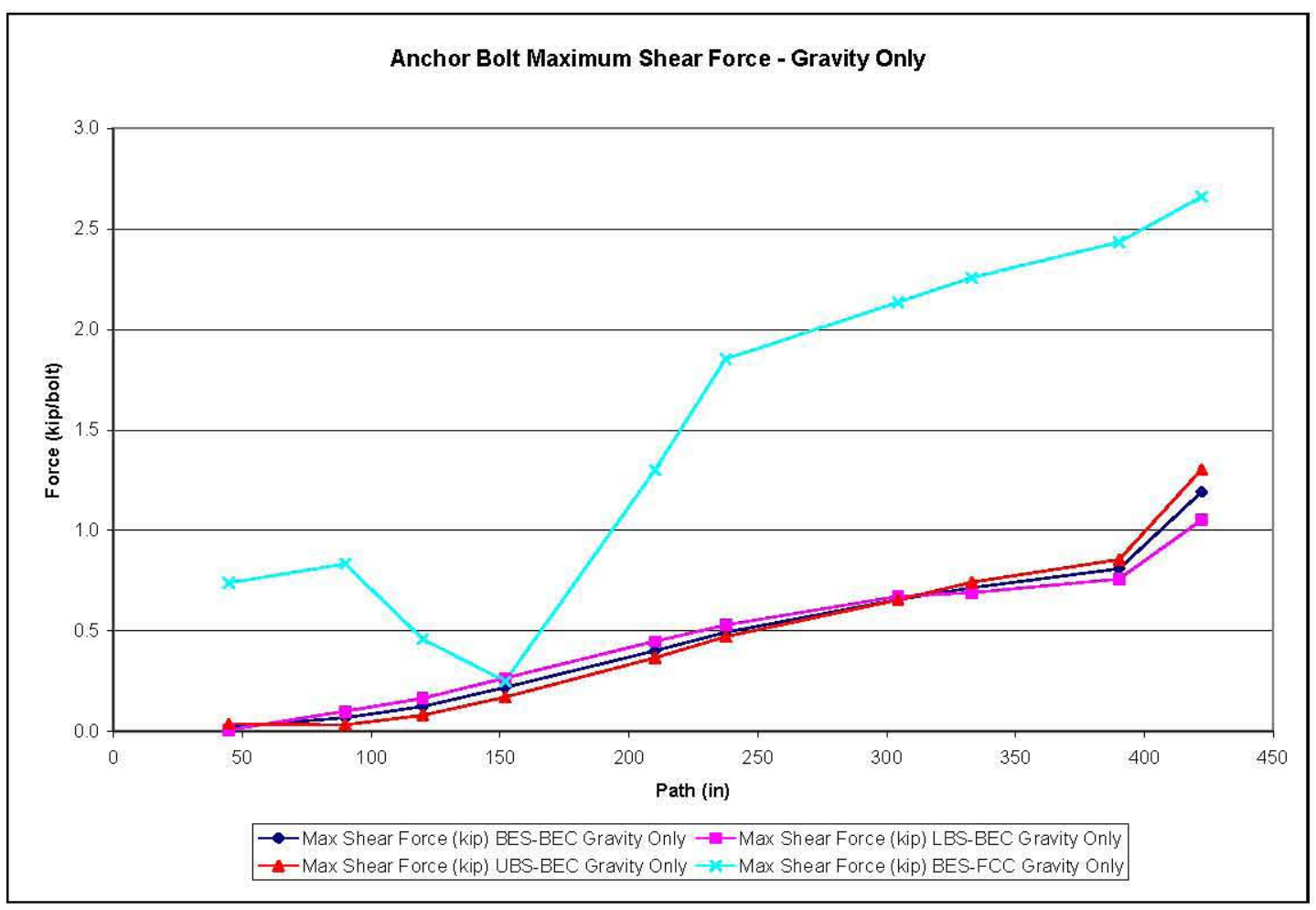

Figure 9-49. Anchor Bolts - Shear Force - Gravity Only 
RPP-RPT-32239, Rev. 1

M\&D-2008-005-CALC-001, Rev. 1

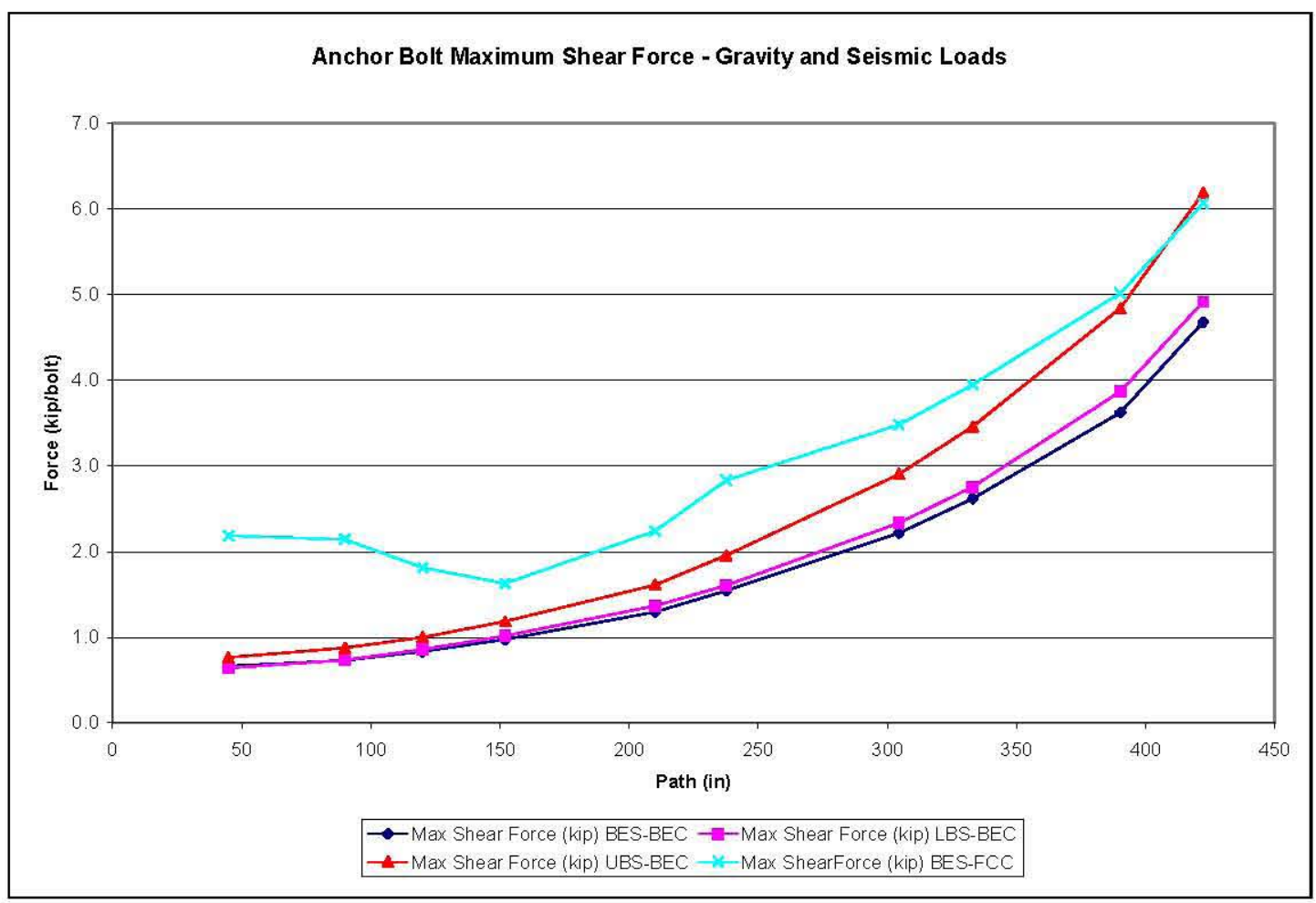

Figure 9-50. Anchor Bolts - Shear Force - Gravity Plus Seismic

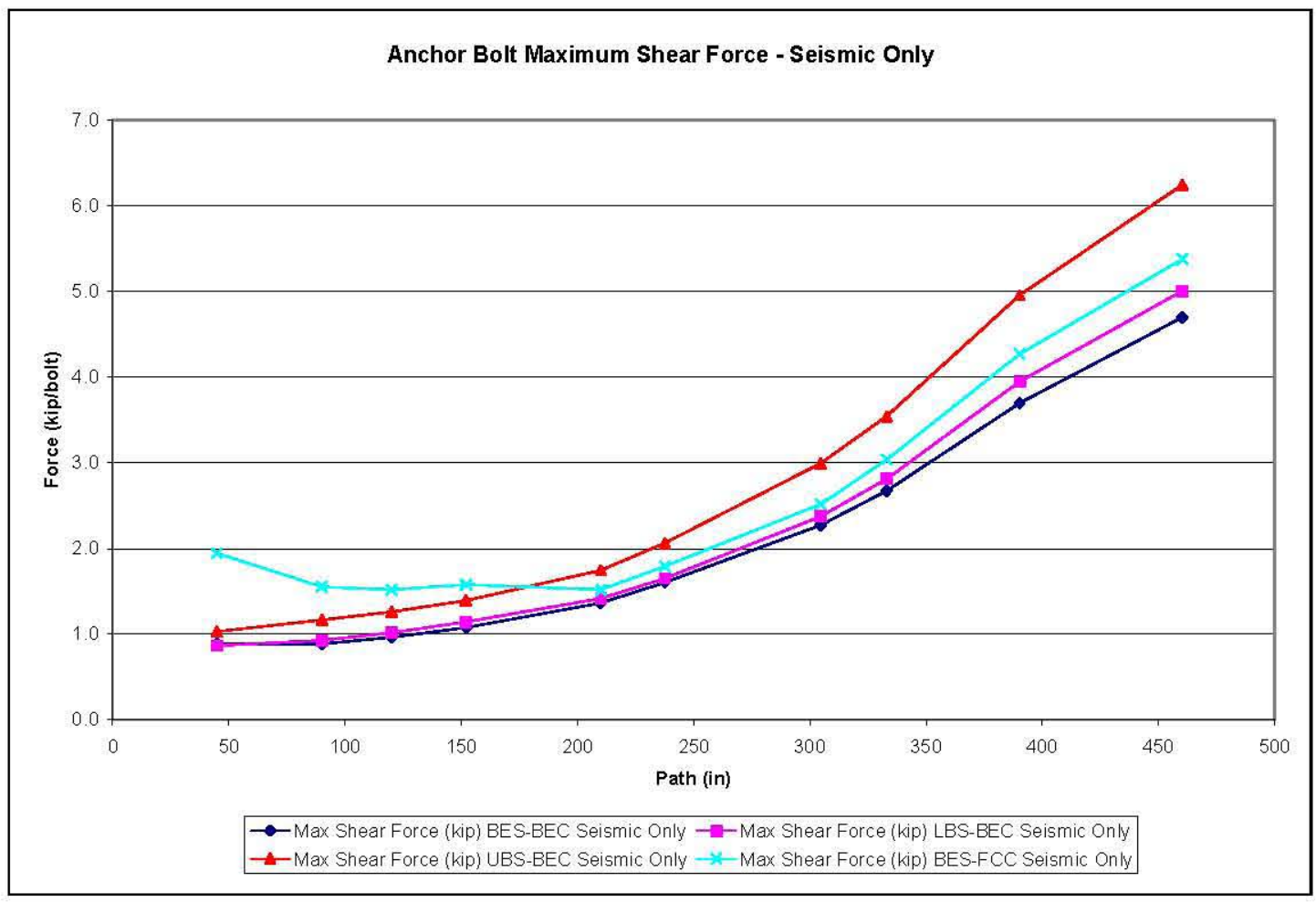

Figure 9-51. Anchor Bolts - Shear Force-Seismic Only 
RPP-RPT-32239, Rev. 1

M\&D-2008-005-CALC-001, Rev. 1

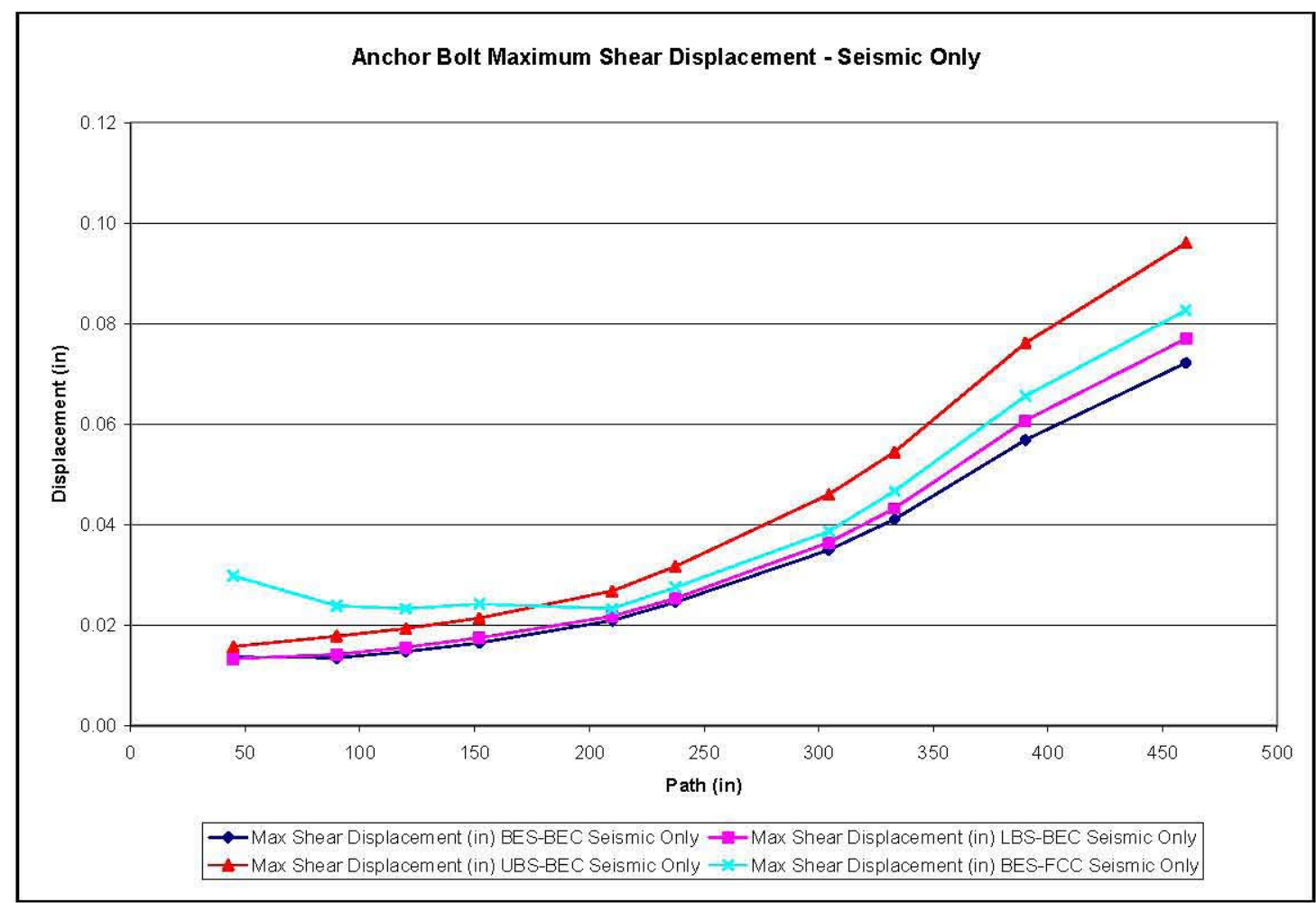

Figure 9-52. Anchor Bolt Maximum Shear Displacement Seismic Only

\subsection{Comparison of Anchor Bolt Results Between the Revision 0 and Revision 1 Models for the BES-BEC Case}

Figure 9-53 and Figure 9-54 show comparisons of anchor bolt demands under seismic loading only for the updated (Revision 1) model with the secant stiffness for the anchor bolts and the original (Revision 0 ) model in the BES-BEC case. Figure 9-55 and Figure 9-56 show only minor differences between the anchor bolt axial forces for the updated and original models. Of more interest is the comparisons of shear forces and shear displacements in Figure 9-57 and Figure 9-58. The reduction in the anchor bolt stiffnesses had the expected effect of reducing the peak shear forces and more evenly distributing the shear force among the anchor bolts. The change also resulted in higher shear displacements as shown in Figure 9-59. 
RPP-RPT-32239, Rev. 1

M\&D-2008-005-CALC-001, Rev. 1

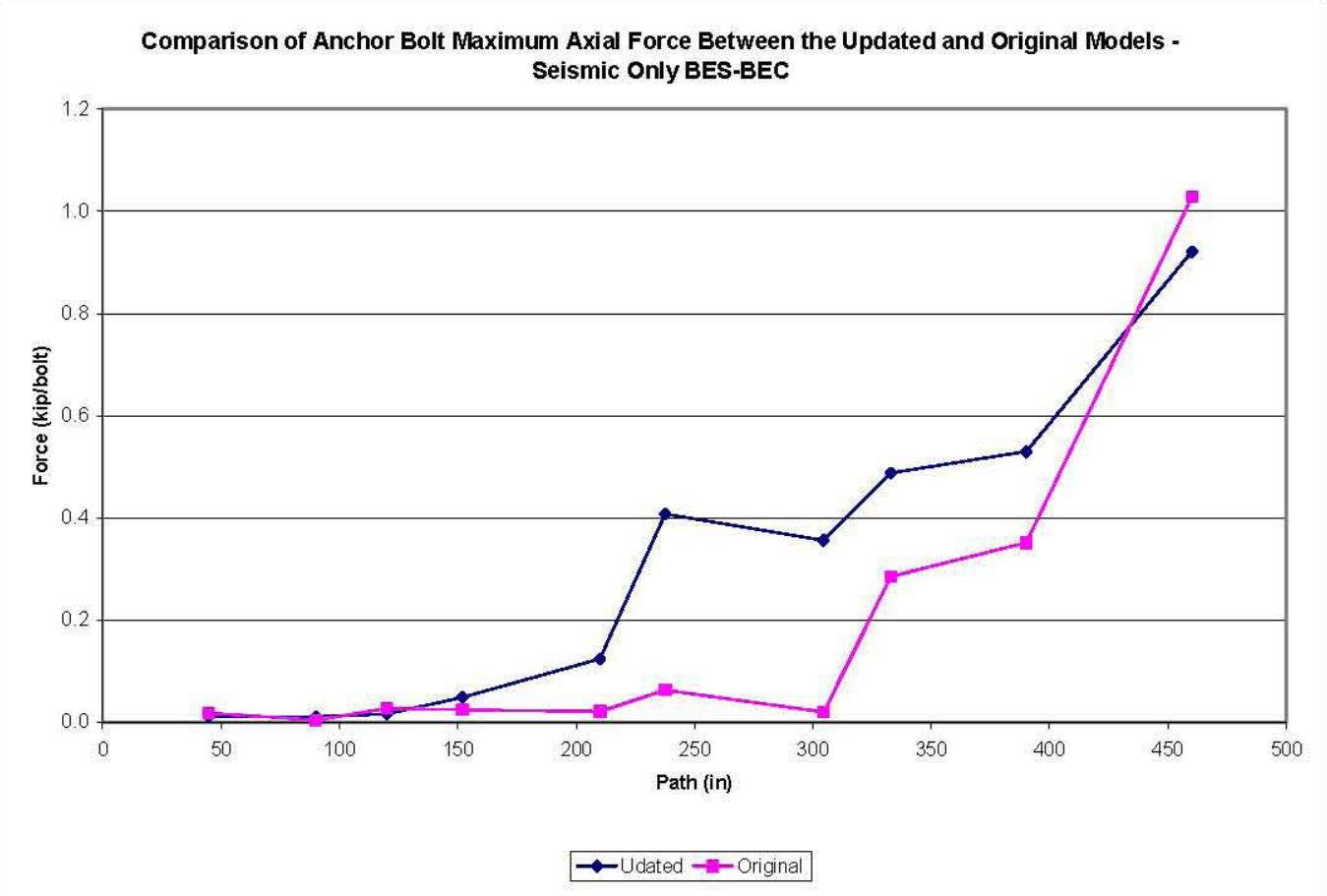

Figure 9-53. Comparison of Anchor Bolt Maximum Axial Force for the Updated and Original Models Seismic Only BES-BEC

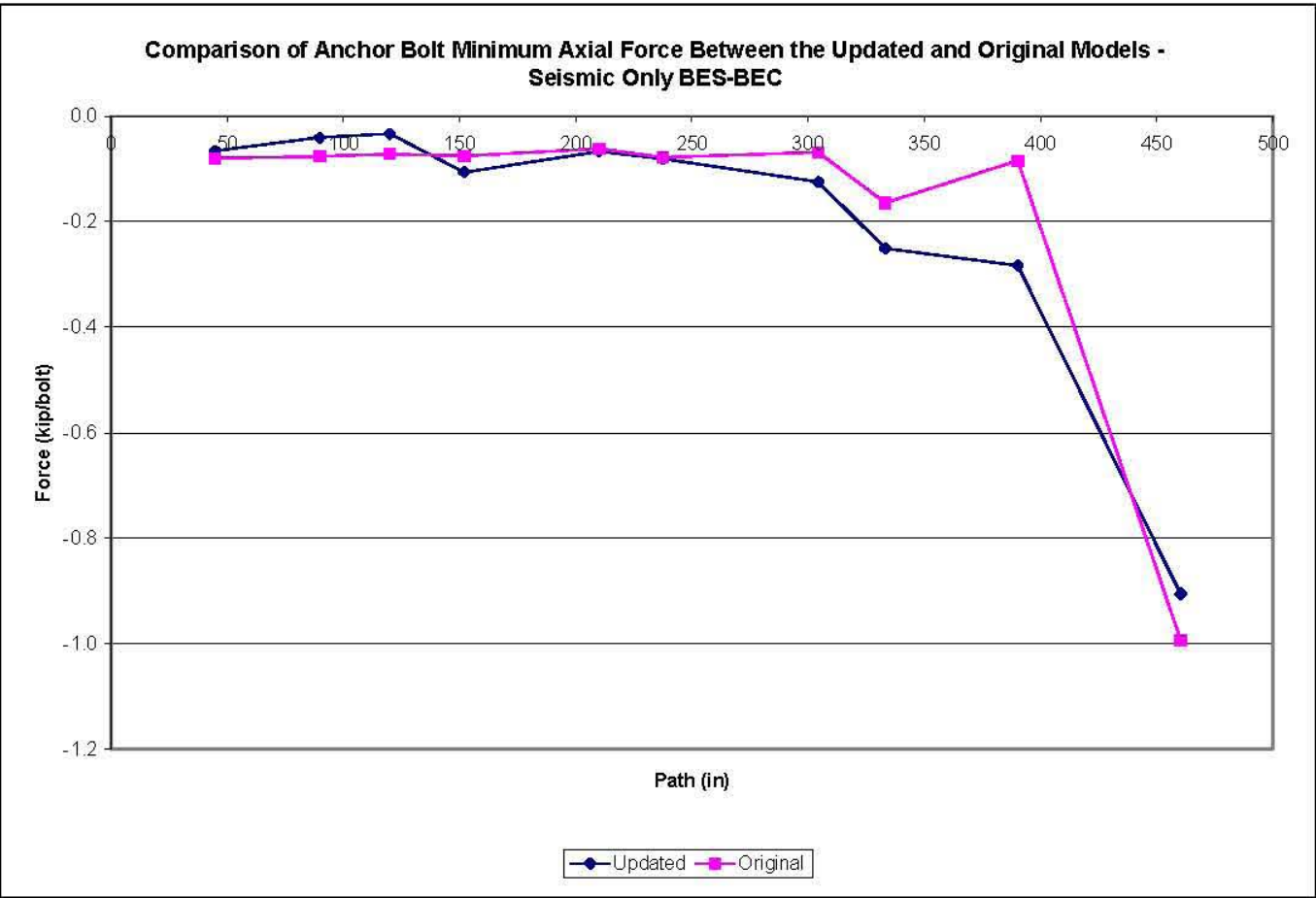

Figure 9-54. Comparison of Anchor Bolt Minimum Axial Force for the Updated and Original Models Seismic Only BES-BEC 
RPP-RPT-32239, Rev. 1

M\&D-2008-005-CALC-001, Rev. 1

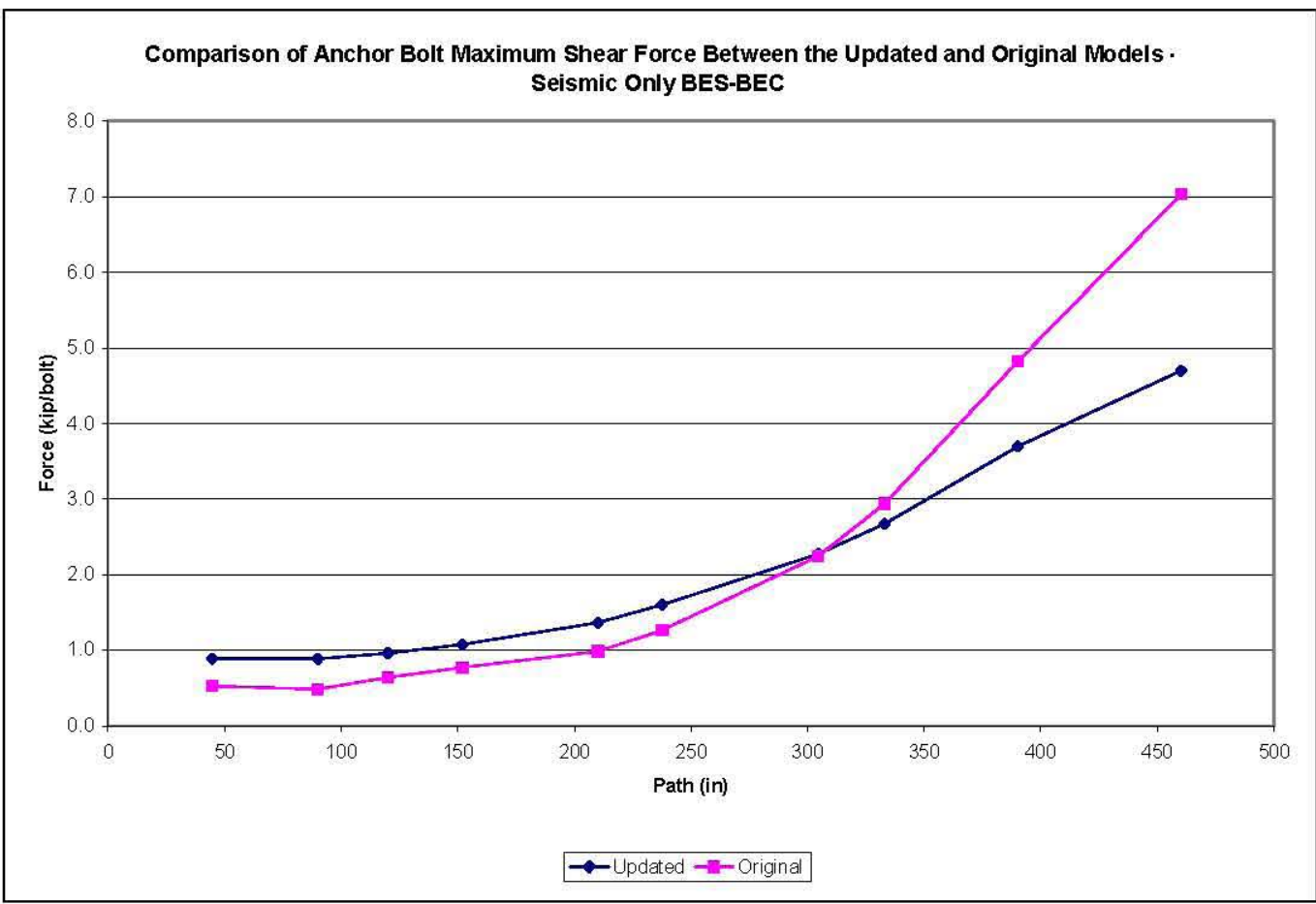

Figure 9-55. Comparison of Anchor Bolt Maximum Shear Force for the Updated and Original Models Seismic Only BES-BEC

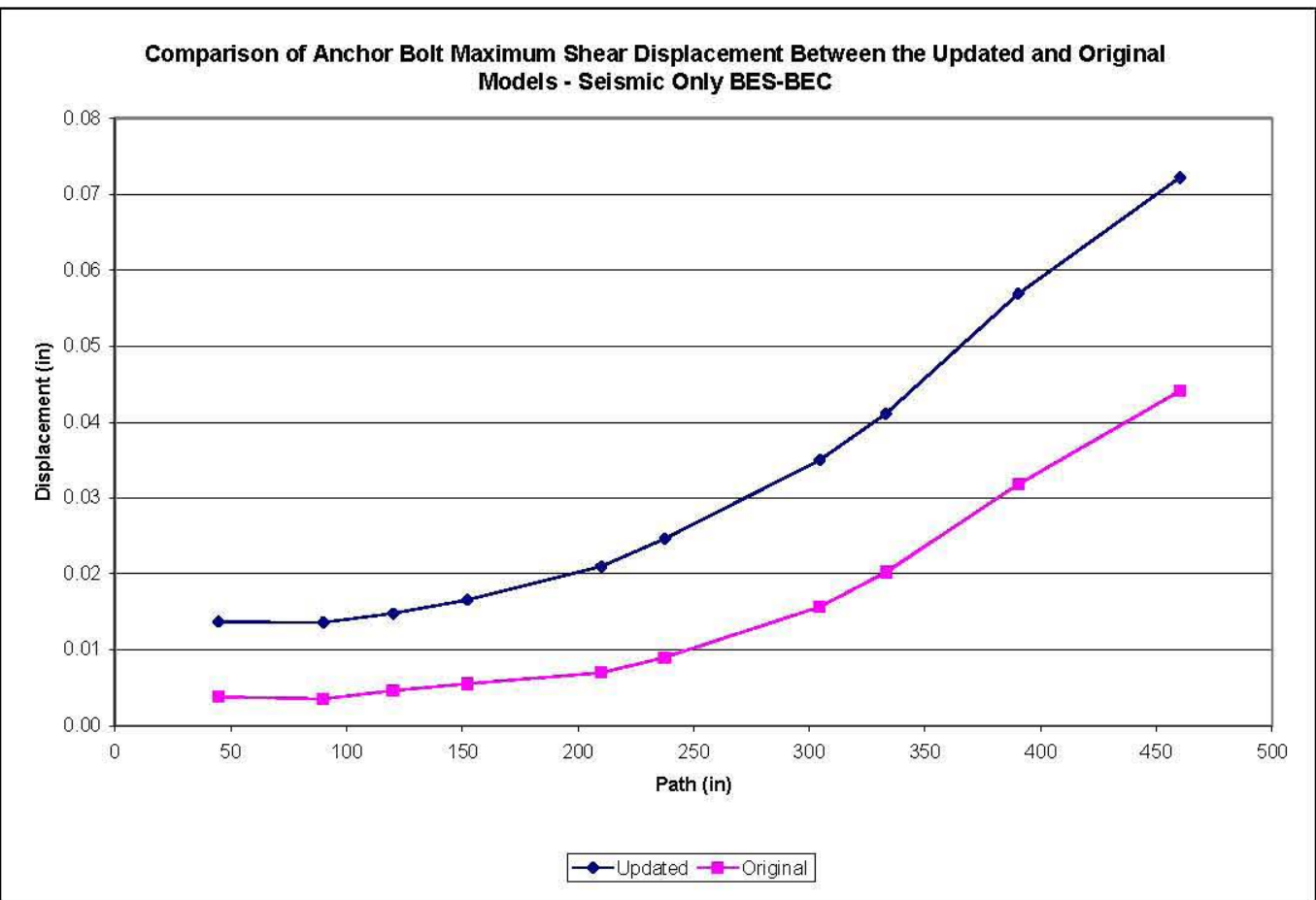

Figure 9-56. Comparison of Anchor Bolt Maximum Shear Displacement for the Updated and Original Models - Seismic Only BES-BEC 


\section{RPP-RPT-32239, Rev. 1 \\ M\&D-2008-005-CALC-001, Rev. 1}

\subsection{Concrete Backed Steel}

Concrete backed steel strains are extracted from the model in $9^{\circ}$ slices, starting near the center of the dome, down the wall and across the footing from the outside to the center of the liner. However, to obtain strains for all concrete backed steel, results were extracted from different groups of elements, including the primary tank, concrete, and liner elements. Principal strains were extracted for the top, middle, and bottom of each shell element representing the primary tank in the dome region. Principal strains were extracted for the inside face of the concrete shell elements in the haunch, wall, and floor. These strains will be considered to be mid-plane strains for the liner. Principal strains were extracted from the secondary liner where it was explicitly modeled at the footing/wall interface. Figure 9-57 and Figure 9-58 show the first slice, with element numbers.

The following strains were extracted for the SHELL143 primary tank dome and the secondary liner elements for the top, middle, and bottom of each element.

- EPEL1 $\quad 1^{\text {st }}$ Principal Strain (Top, Middle, Bottom)

- EPEL2 $22^{\text {nd }}$ Principal Strain (Top, Middle, Bottom)

- EPEL3 $\quad 3^{\text {rd }}$ Principal Strain (Top, Middle, Bottom)

The following strains were extracted for the SHELL143 concrete shell elements for the bottom of each element in the wall and the top of each element in the floor

- EPEL1 1 st Principal Strain

- EPEL2 $22^{\text {nd }}$ Principal Strain

- EPEL3 $\quad 3^{\text {rd }}$ Principal Strain

Figures are grouped in sets showing the strain for gravity only first, total demand from the transient analysis (gravity plus seismic), and then only the seismic portion. The seismic only load is simply the difference between the full transient loading and gravity only. For the concrete backed steel, each of the three principal strains is shown in the following figures:

- Figure 9-57. Element Retrieval Sequence Starting Numbers for Strain

- Figure 9-58. Element Retrieval Sequence Starting Numbers for Strain (Detail)

- Figure 9-59. Concrete Backed Steel Strain, Principal 1, Gravity Only

- Figure 9-60. Concrete Backed Steel Strain, Principal 1, Min, Gravity Plus Seismic

- Figure 9-61. Concrete Backed Steel Strain, Principal 1, Max, Gravity Plus Seismic

- Figure 9-62. Concrete Backed Steel Strain, Principal 1, Min, Seismic Only

- Figure 9-63. Concrete Backed Steel Strain, Principal 1, Max, Seismic Only

- Figure 9-64. Concrete Backed Steel Strain, Principal 2, Gravity Only

- Figure 9-65. Concrete Backed Steel Strain, Principal 2, Min, Gravity Plus Seismic

- Figure 9-66. Concrete Backed Steel Strain, Principal 2, Max, Gravity Plus Seismic

- Figure 9-67. Concrete Backed Steel Strain, Principal 2, Min, Seismic Only

- Figure 9-68. Concrete Backed Steel Strain, Principal 2, Max, Seismic Only

- Figure 9-69. Concrete Backed Steel Strain, Principal 3, Gravity Only

- Figure 9-70. Concrete Backed Steel Strain, Principal 3, Min, Gravity Plus Seismic

- Figure 9-71. Concrete Backed Steel Strain, Principal 3, Max, Gravity Plus Seismic 
RPP-RPT-32239, Rev. 1

M\&D-2008-005-CALC-001, Rev. 1

- Figure 9-72. Concrete Backed Steel Strain, Principal 3, Min, Seismic Only

- Figure 9-73. Concrete Backed Steel Strain, Principal 3, Max, Seismic Only

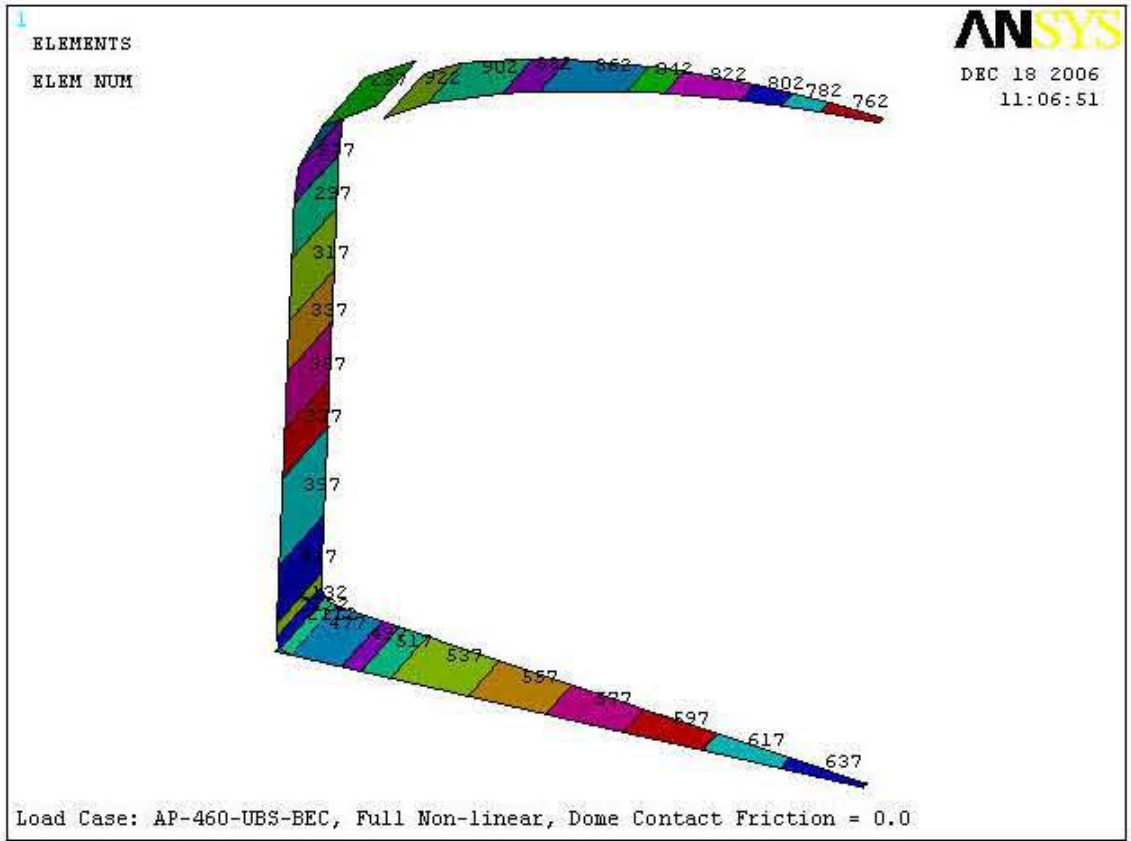

Figure 9-57. Element Retrieval Sequence Starting Numbers for Strain

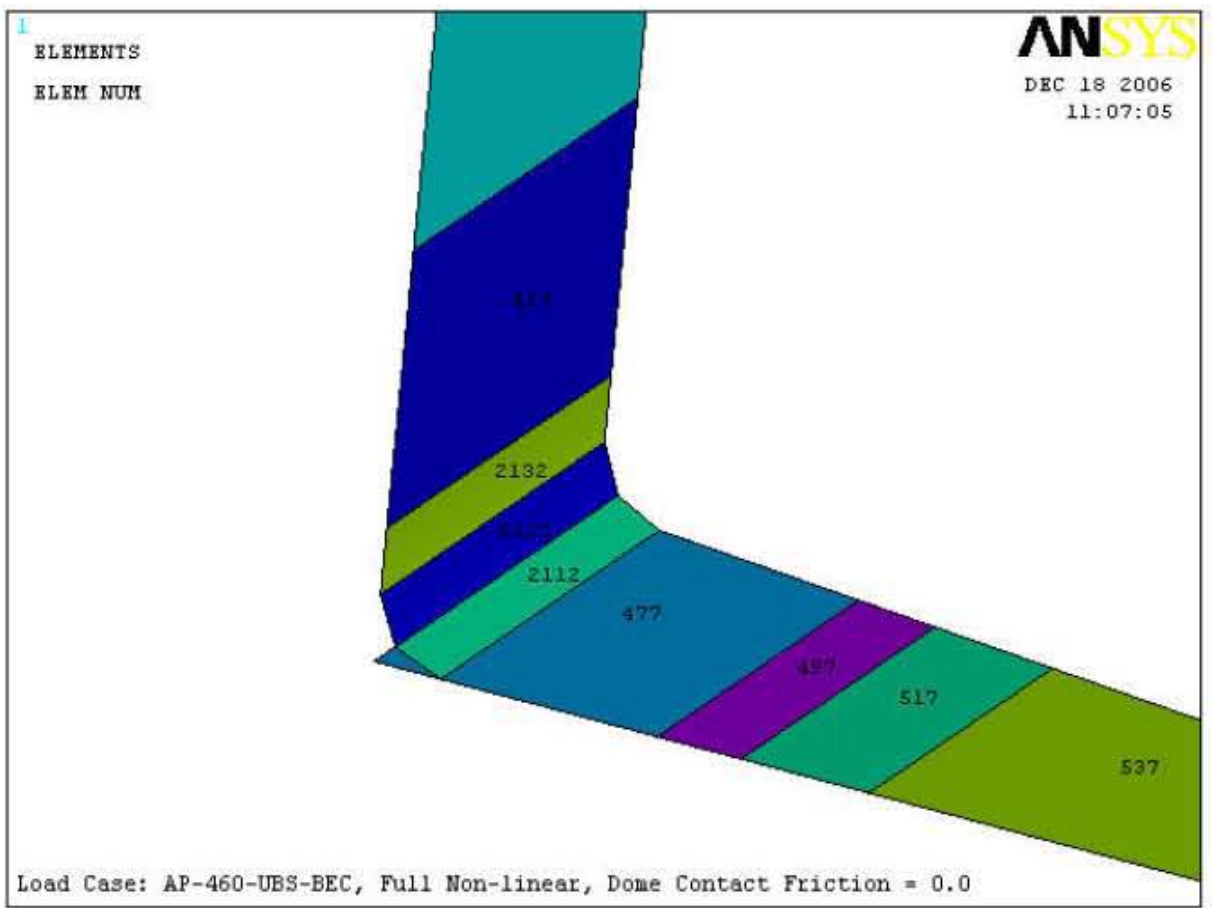

Figure 9-58. Element Retrieval Sequence Starting Numbers for Strain (Detail) 
RPP-RPT-32239, Rev. 1

M\&D-2008-005-CALC-001, Rev. 1

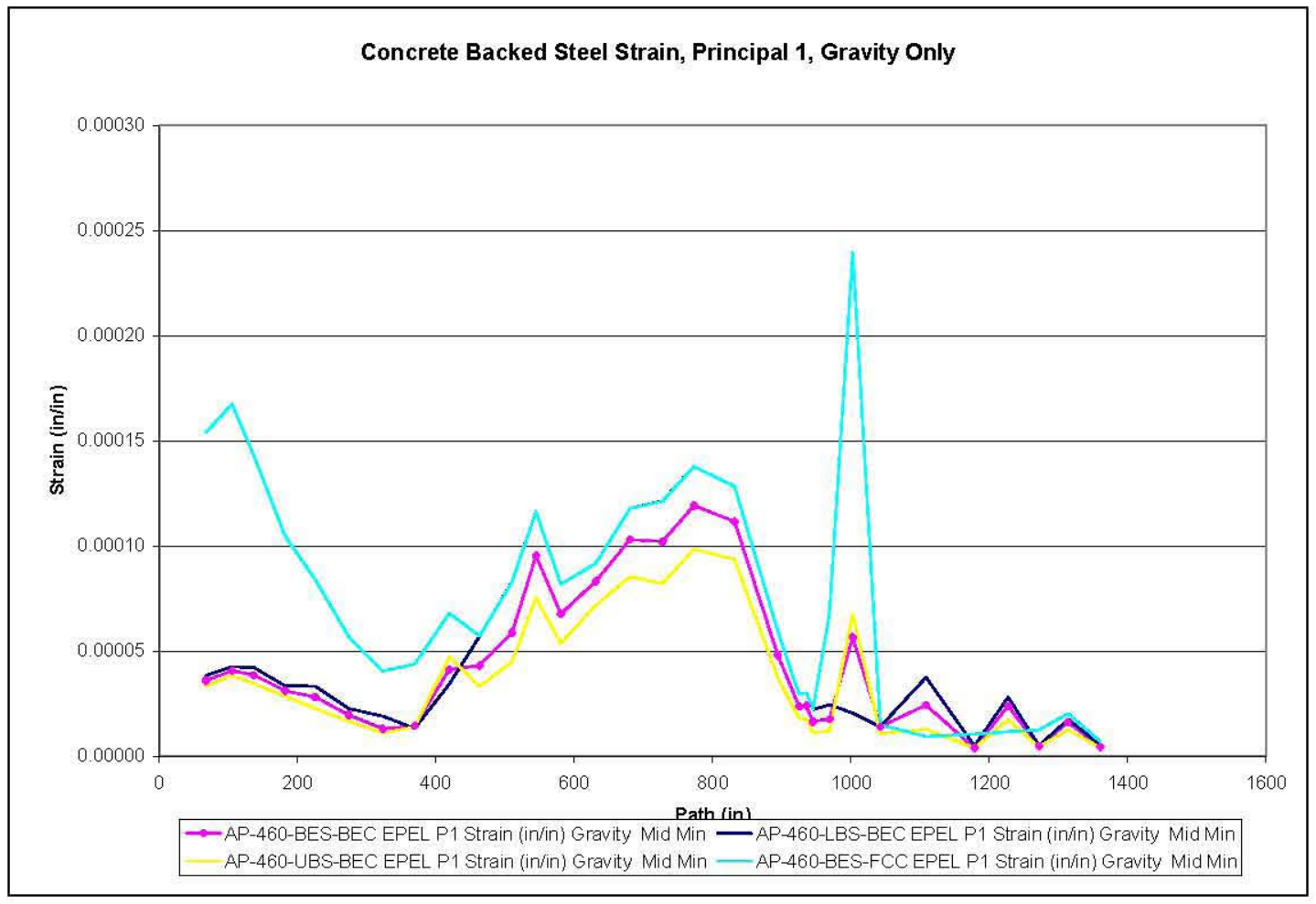

Figure 9-59. Concrete Backed Steel Strain, Principal 1, Gravity Only

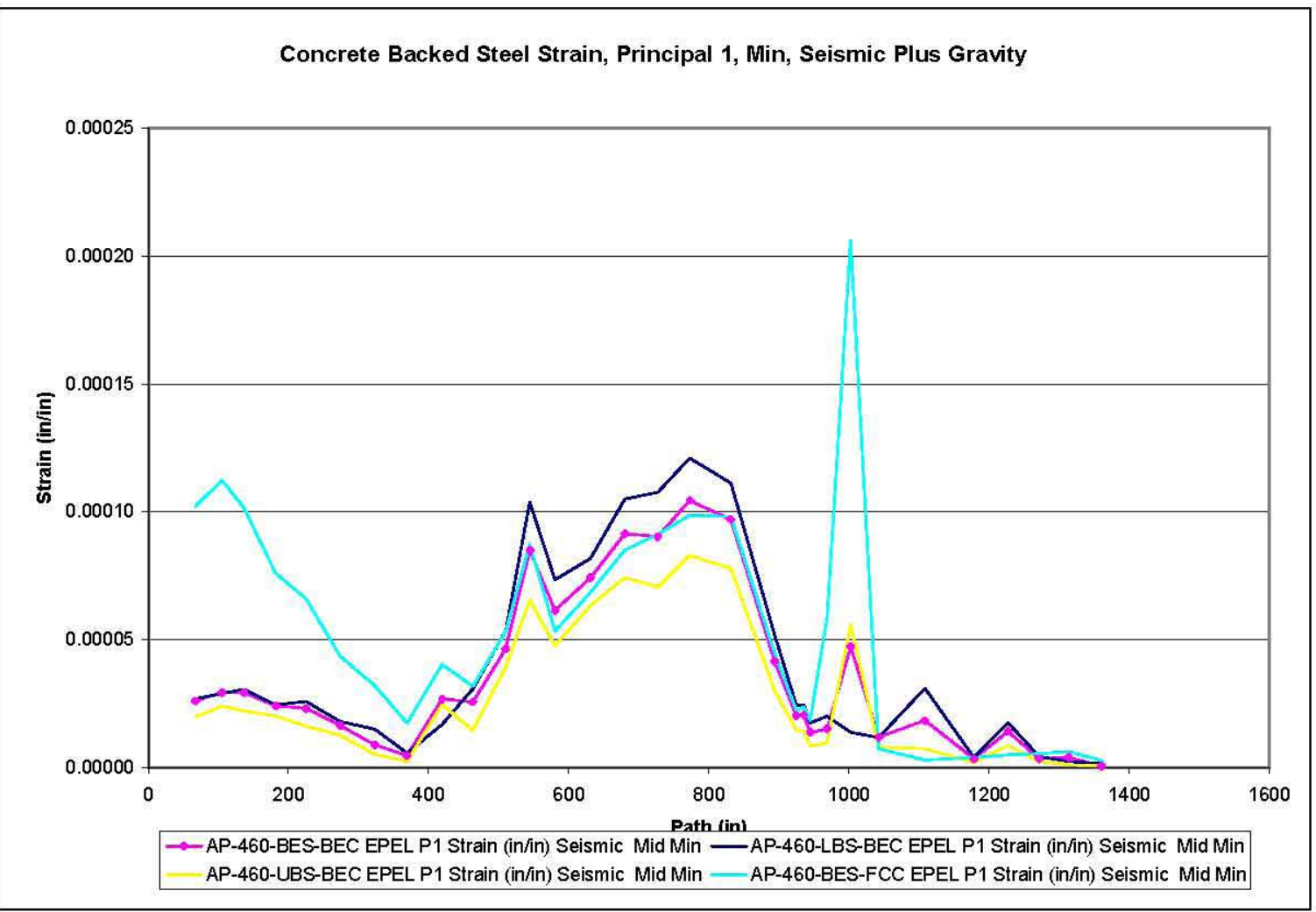

Figure 9-60. Concrete Backed Steel Strain, Principal 1, Min, Gravity Plus Seismic 
RPP-RPT-32239, Rev. 1

M\&D-2008-005-CALC-001, Rev. 1

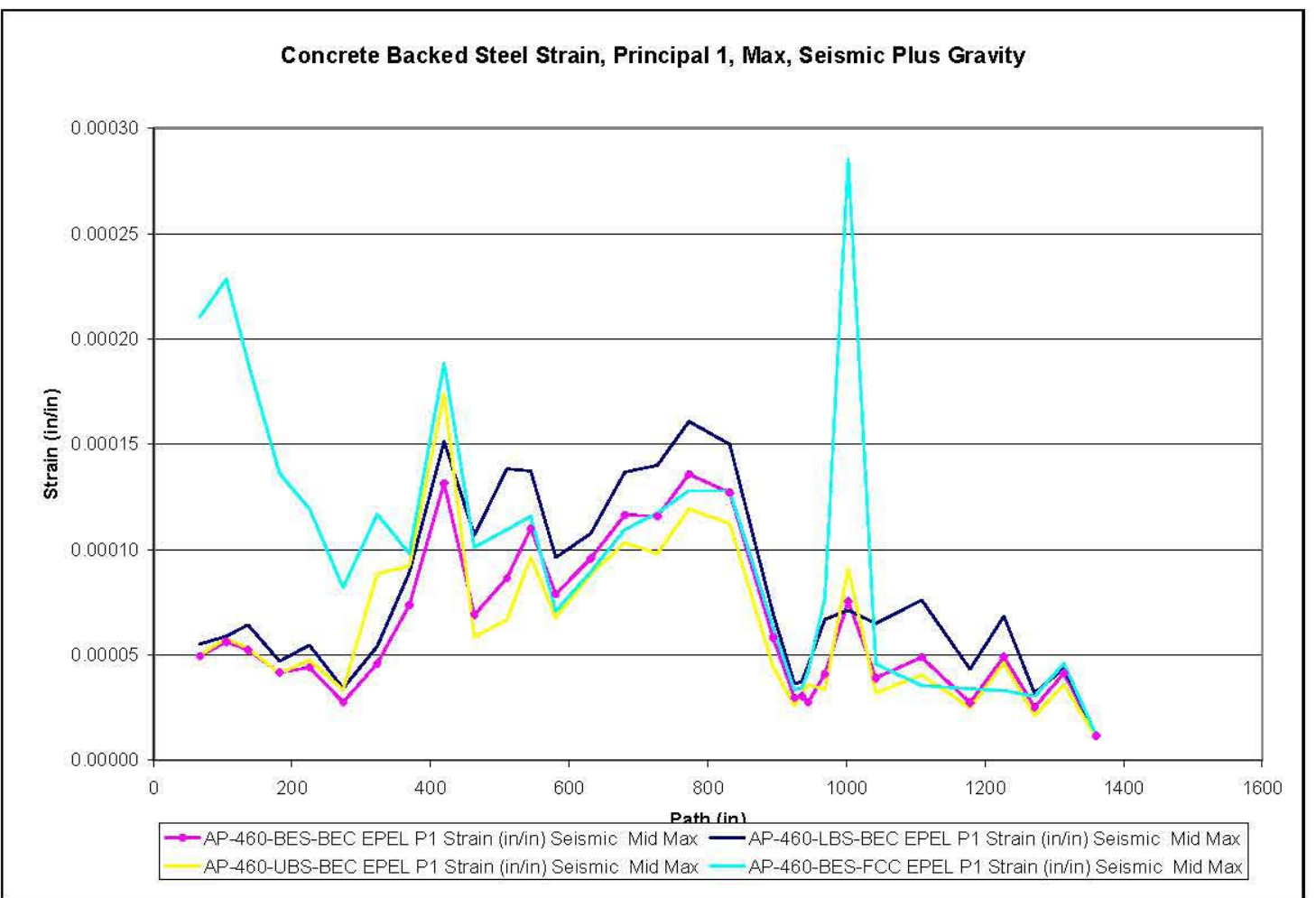

Figure 9-61. Concrete Backed Steel Strain, Principal 1, Max, Gravity Plus Seismic

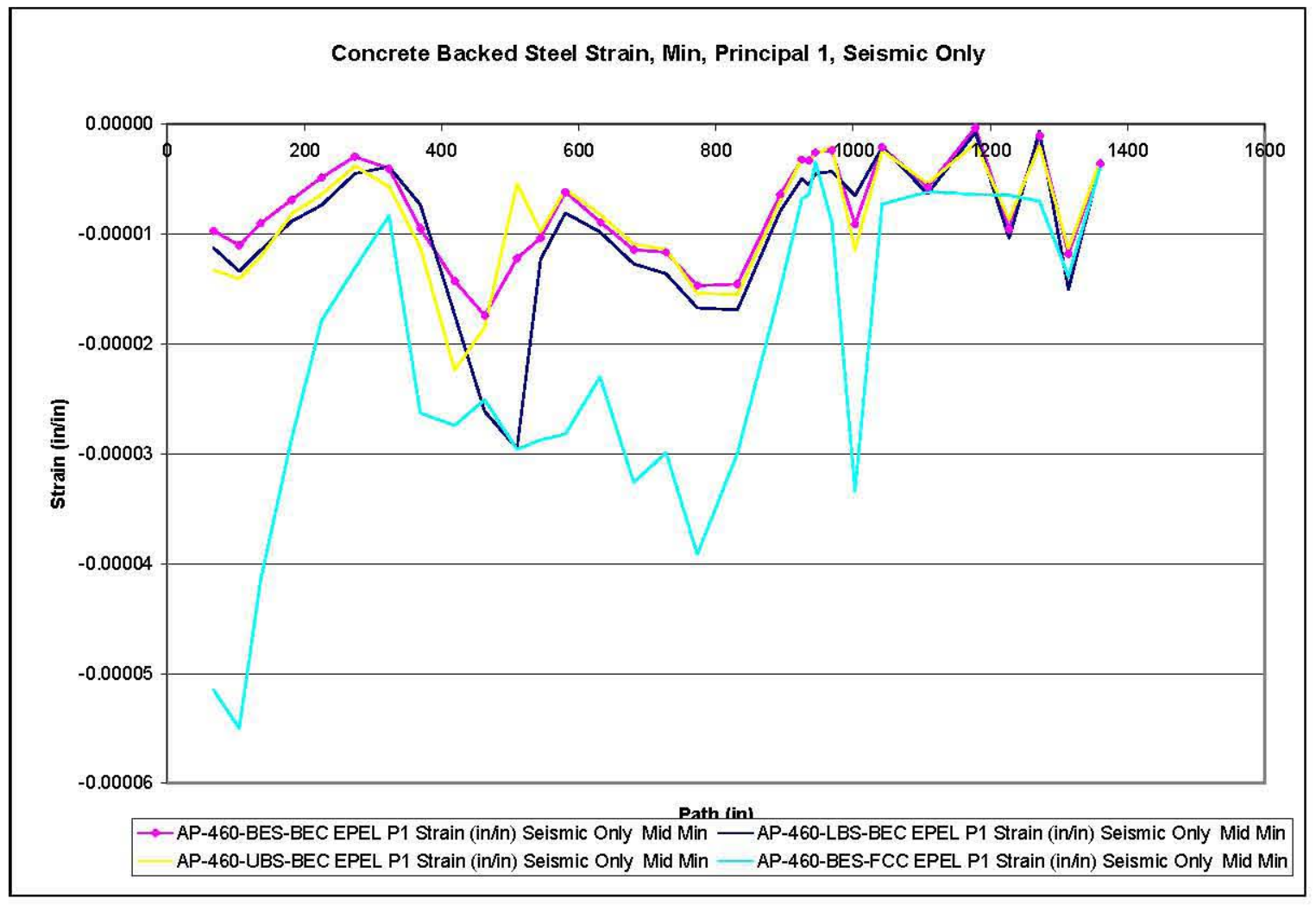

Figure 9-62. Concrete Backed Steel Strain, Principal 1, Min, Seismic Only 
RPP-RPT-32239, Rev. 1

M\&D-2008-005-CALC-001, Rev. 1

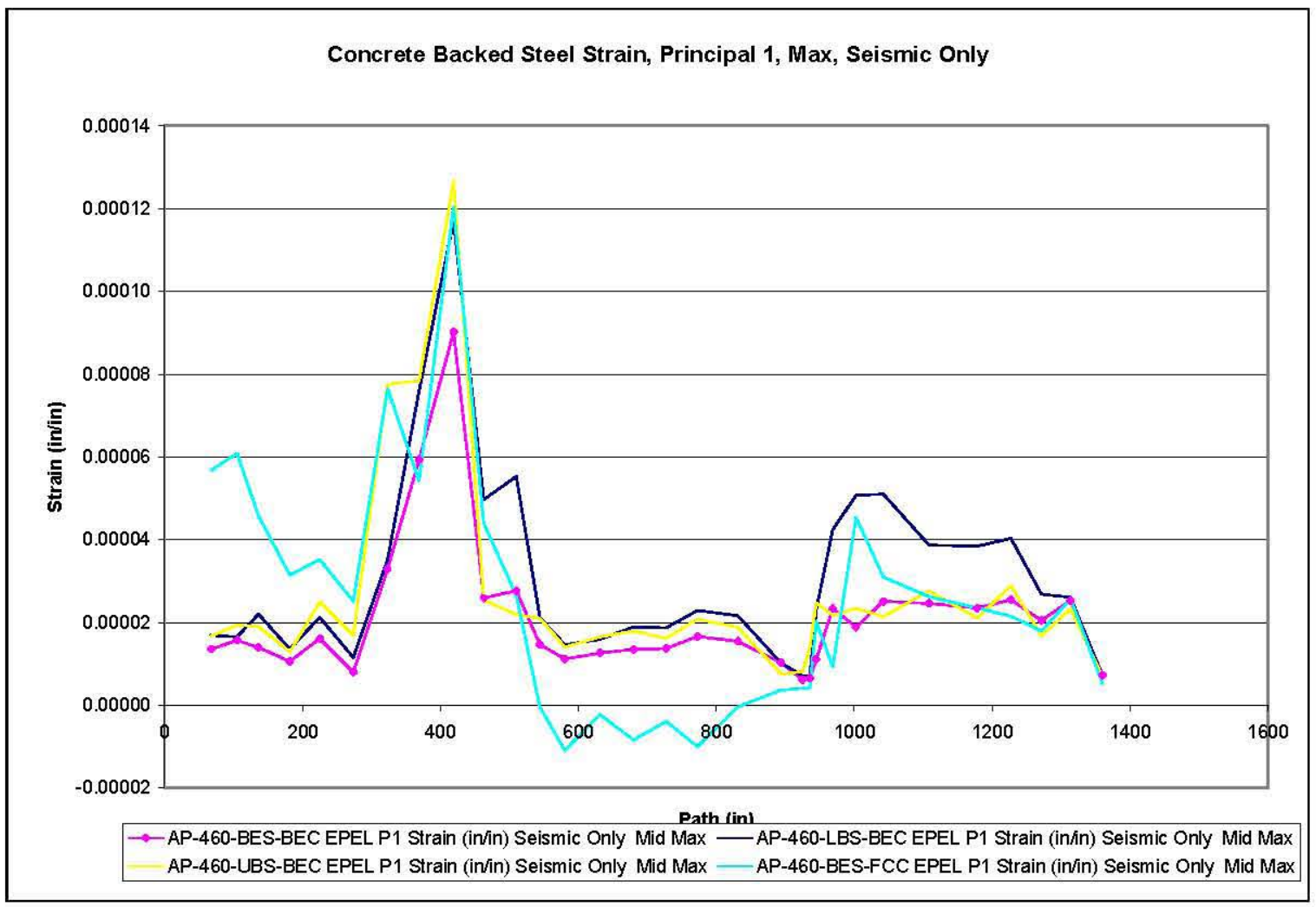

Figure 9-63. Concrete Backed Steel Strain, Principal 1, Max, Seismic Only

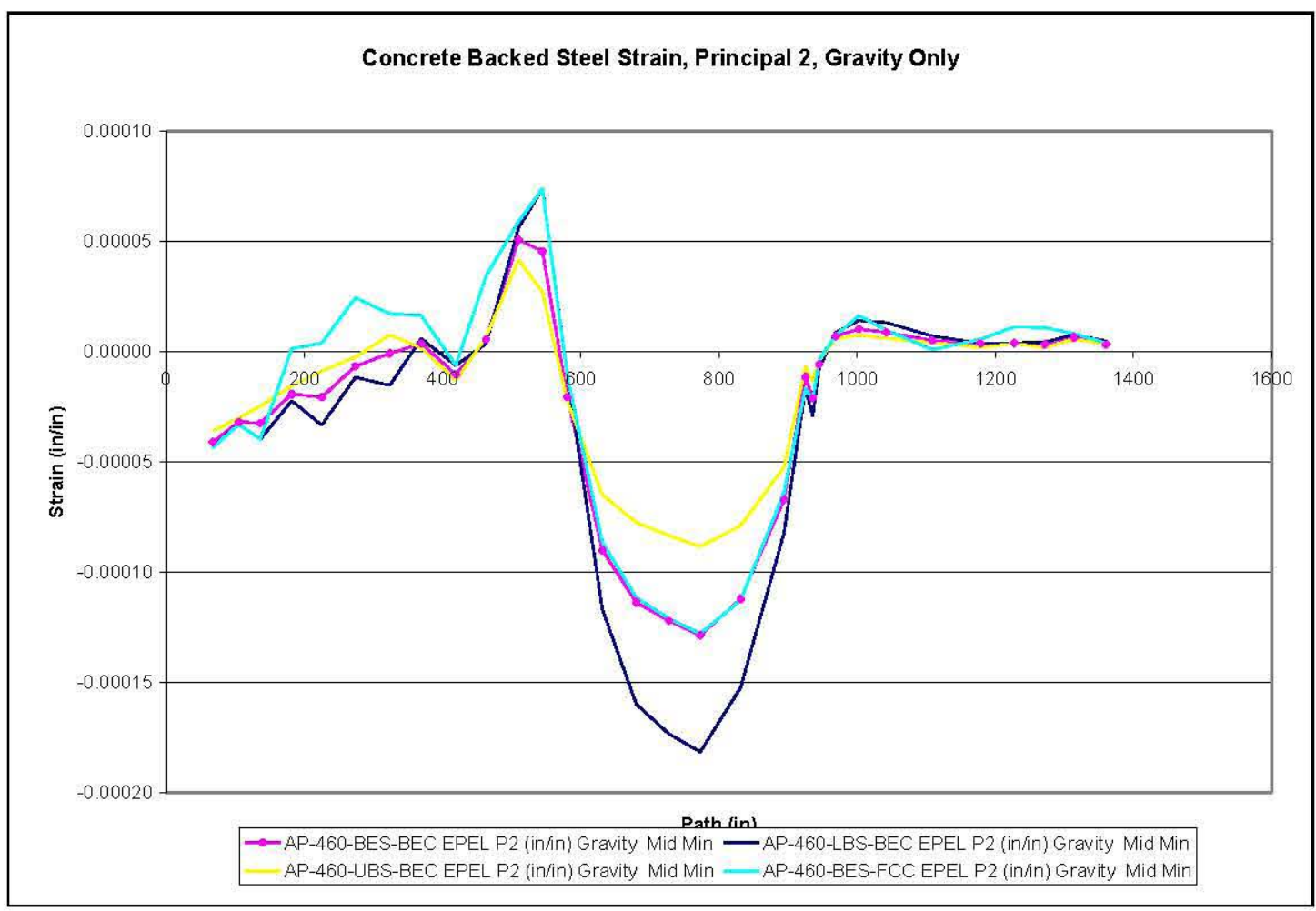

Figure 9-64. Concrete Backed Steel Strain, Principal 2, Gravity Only 
RPP-RPT-32239, Rev. 1

M\&D-2008-005-CALC-001, Rev. 1

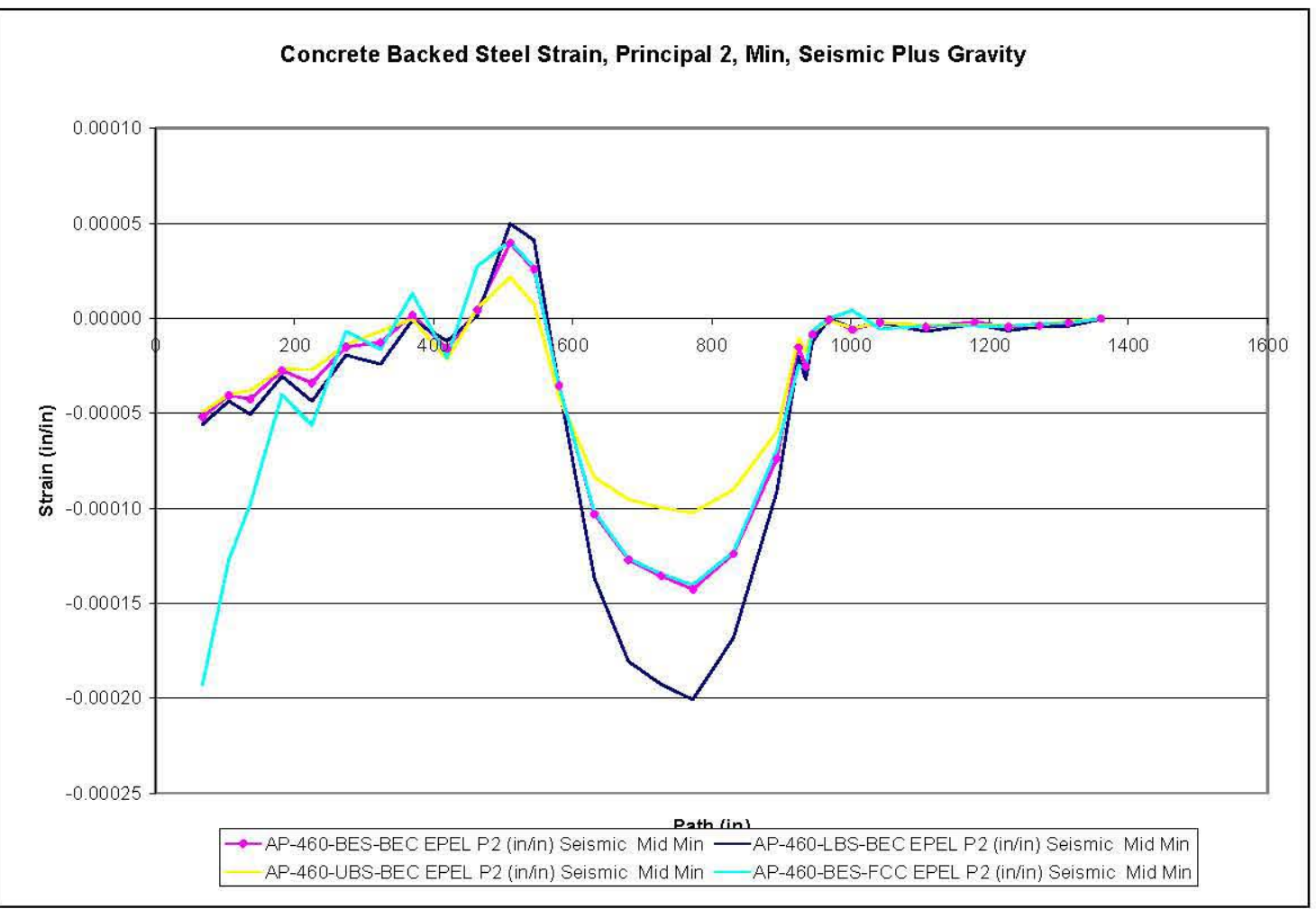

Figure 9-65. Concrete Backed Steel Strain, Principal 2, Min, Gravity Plus Seismic

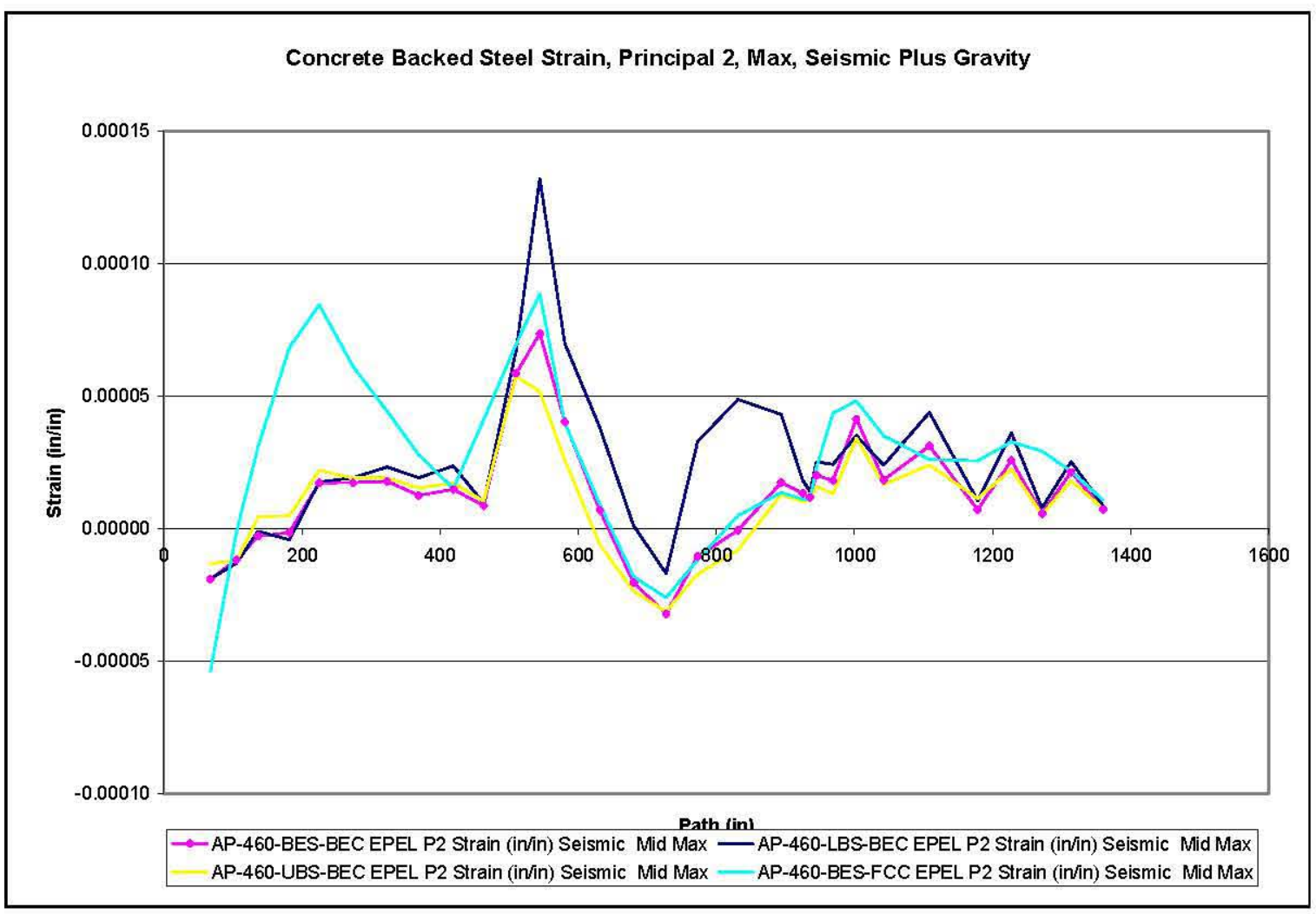

Figure 9-66. Concrete Backed Steel Strain, Principal 2, Max, Gravity Plus Seismic 
RPP-RPT-32239, Rev. 1

M\&D-2008-005-CALC-001, Rev. 1

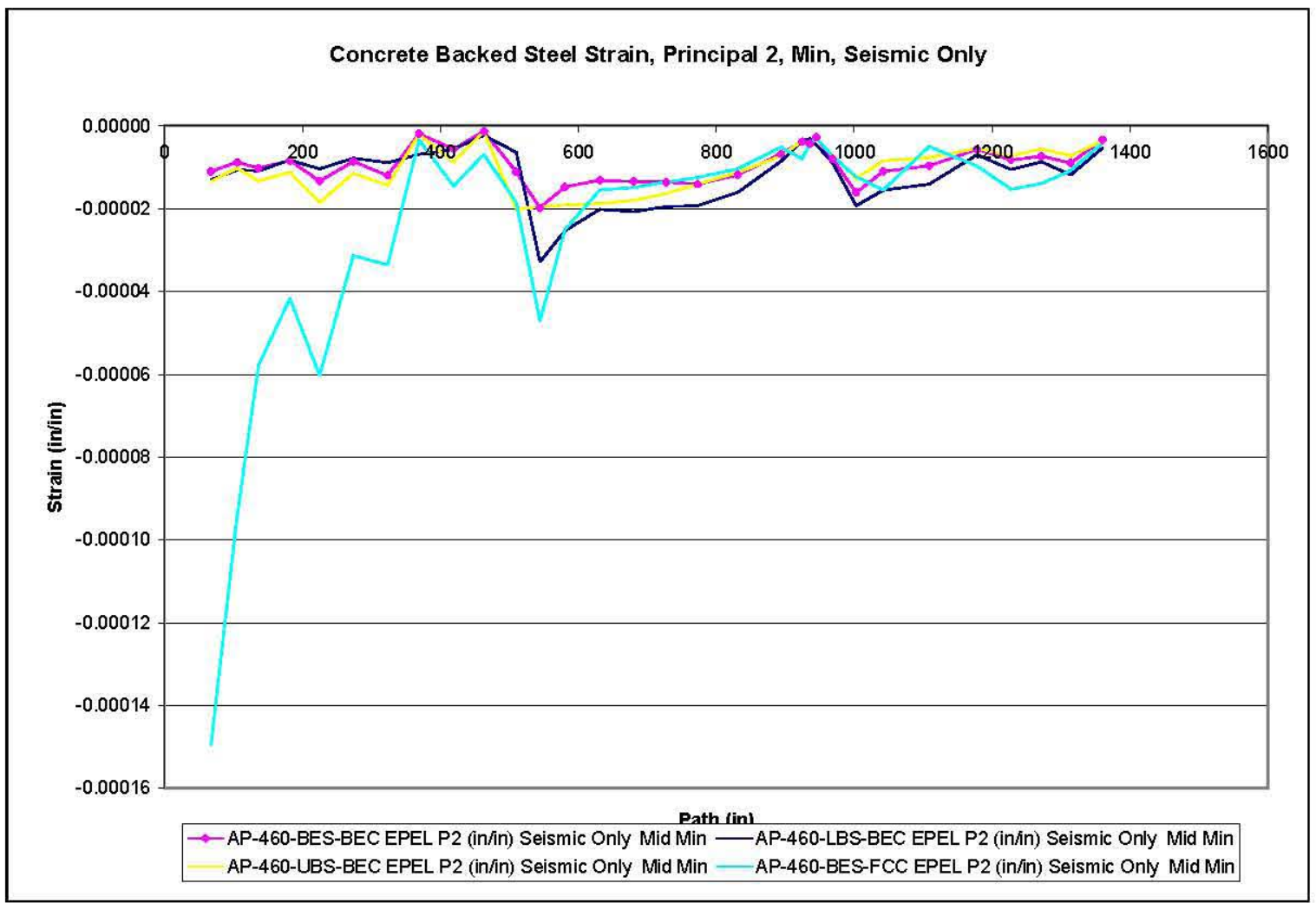

Figure 9-67. Concrete Backed Steel Strain, Principal 2, Min, Seismic Only

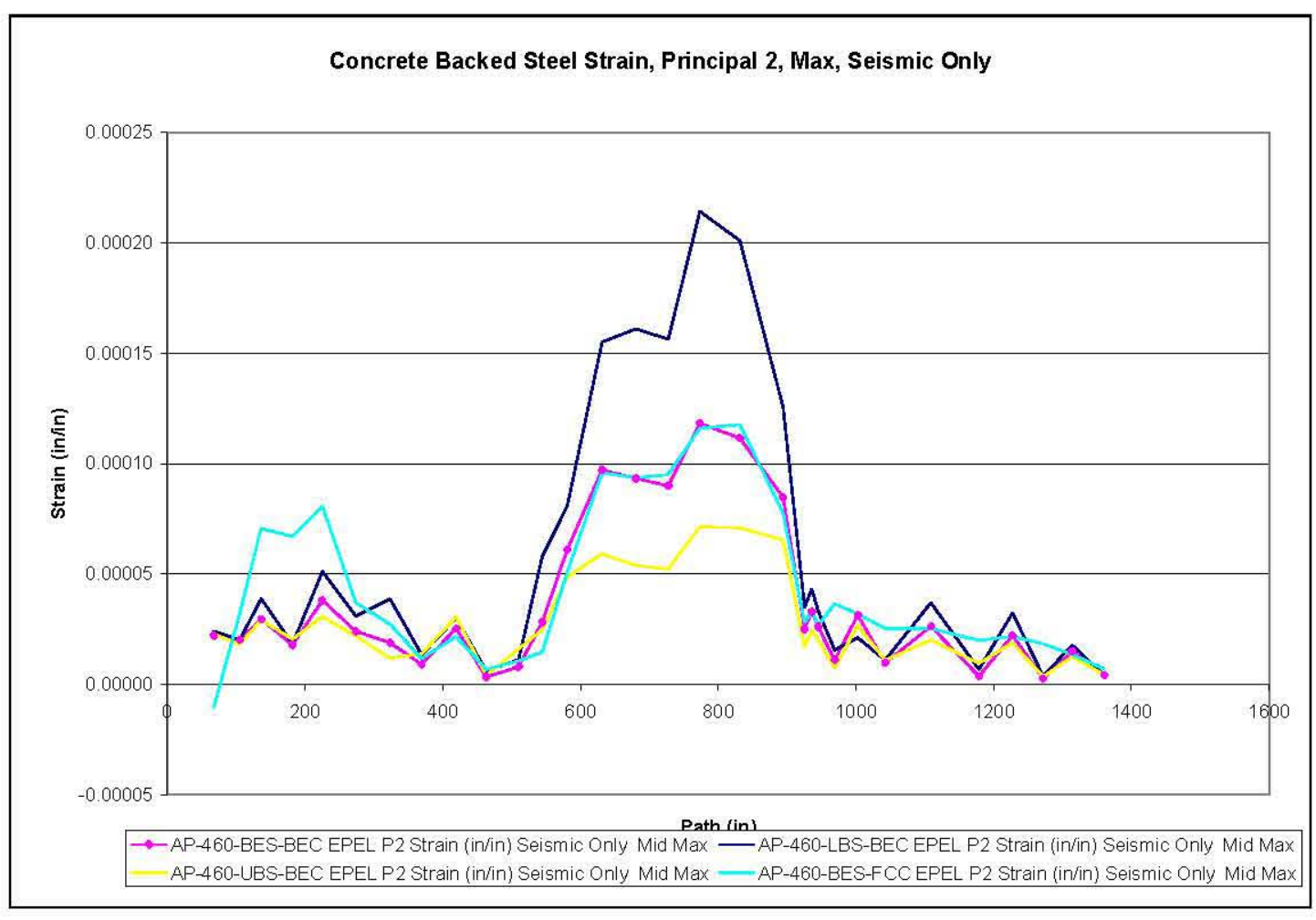

Figure 9-68. Concrete Backed Steel Strain, Principal 2, Max, Seismic Only 
RPP-RPT-32239, Rev. 1

M\&D-2008-005-CALC-001, Rev. 1

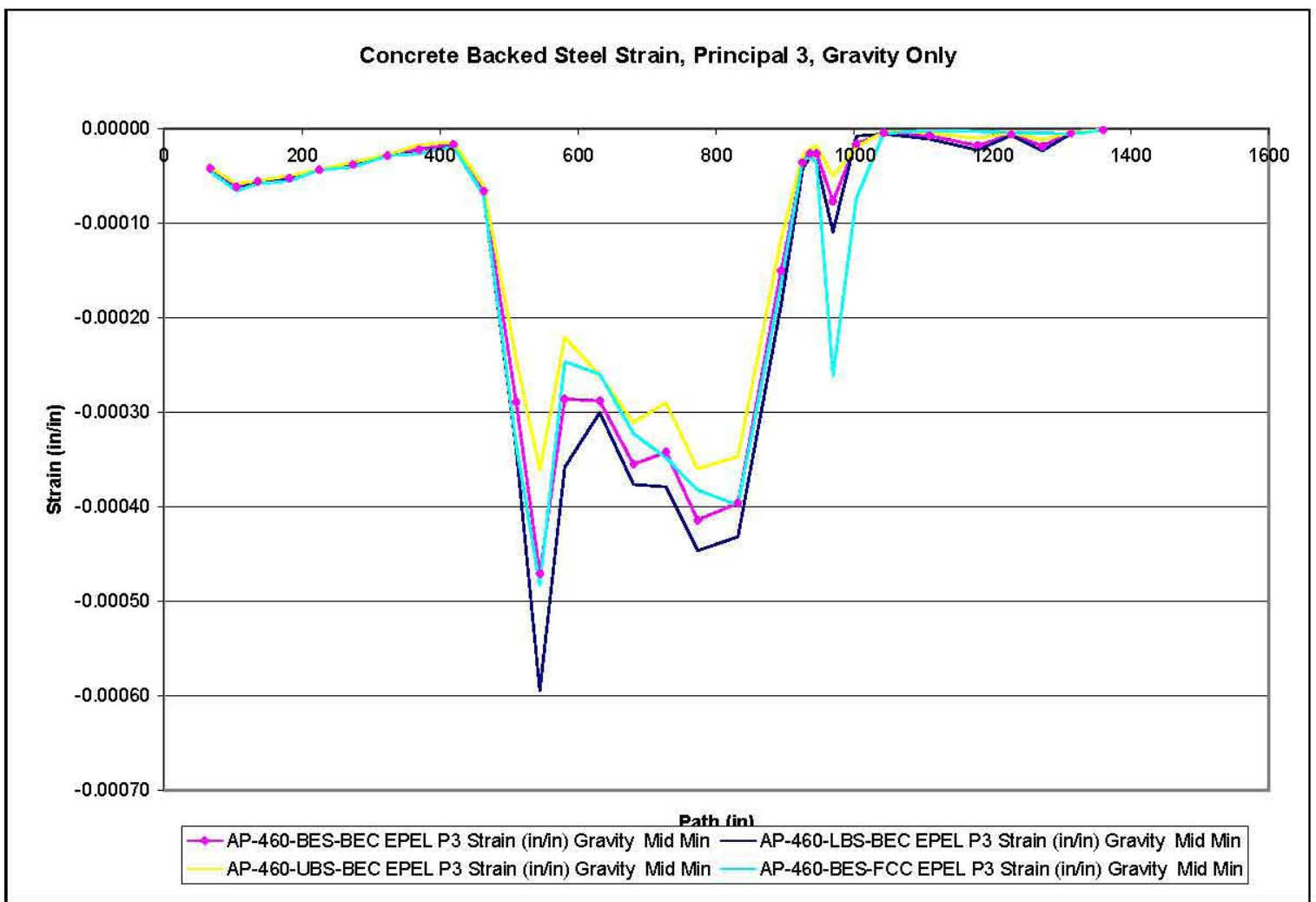

Figure 9-69. Concrete Backed Steel Strain, Principal 3, Gravity Only

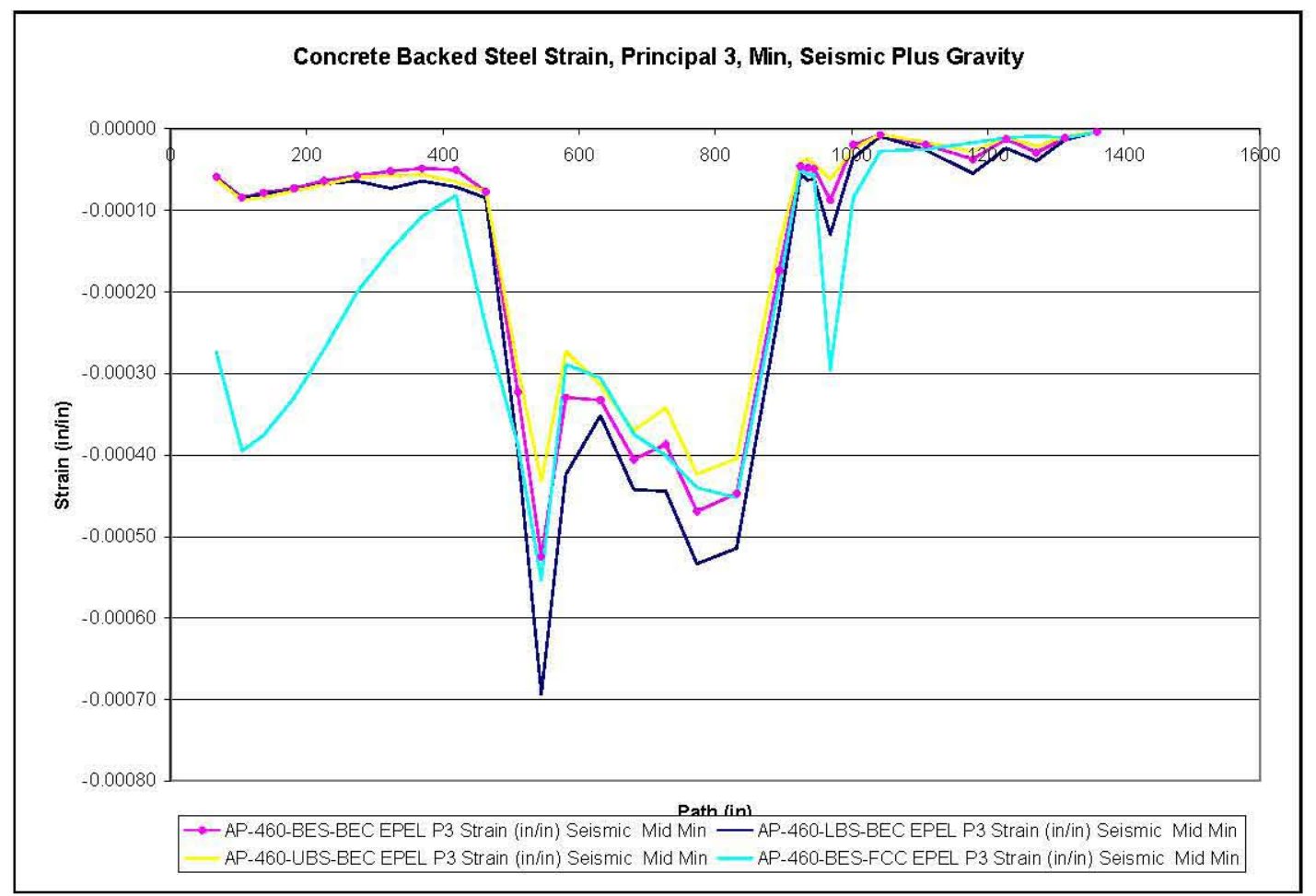

Figure 9-70. Concrete Backed Steel Strain, Principal 3, Min, Gravity Plus Seismic 
RPP-RPT-32239, Rev. 1

M\&D-2008-005-CALC-001, Rev. 1

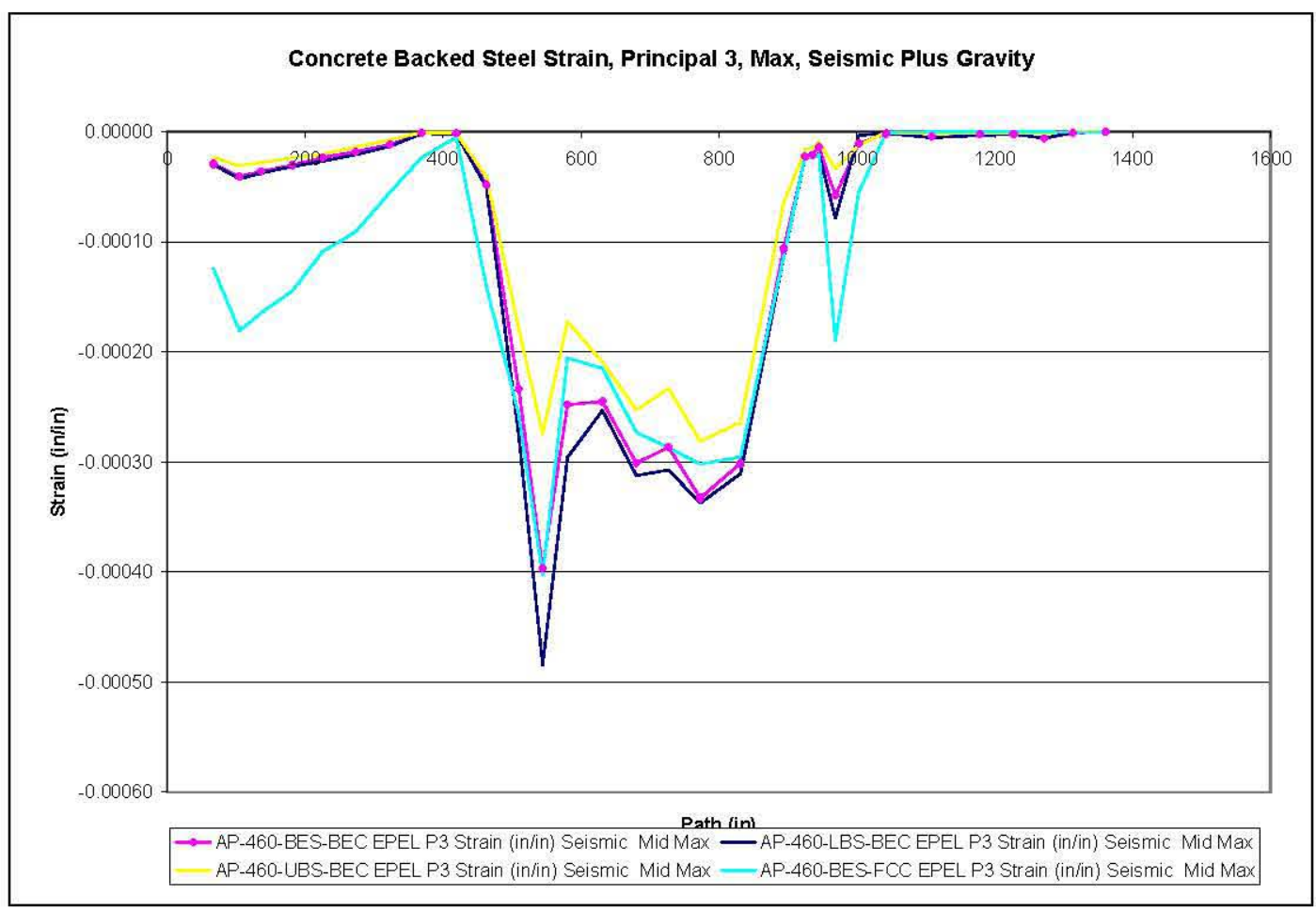

Figure 9-71. Concrete Backed Steel Strain, Principal 3, Max, Gravity Plus Seismic

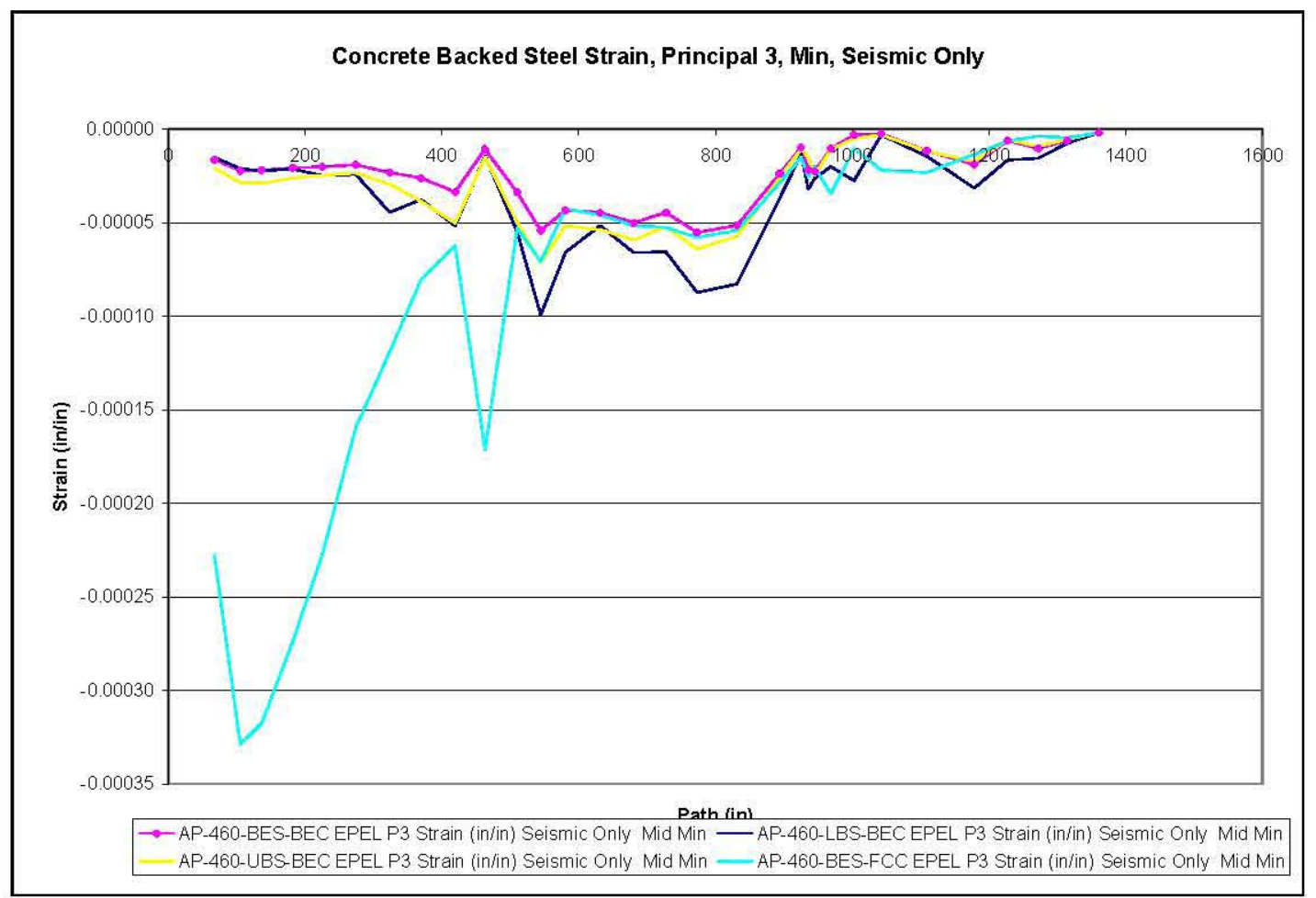

Figure 9-72. Concrete Backed Steel Strain, Principal 3, Min, Seismic Only 
RPP-RPT-32239, Rev. 1

M\&D-2008-005-CALC-001, Rev. 1

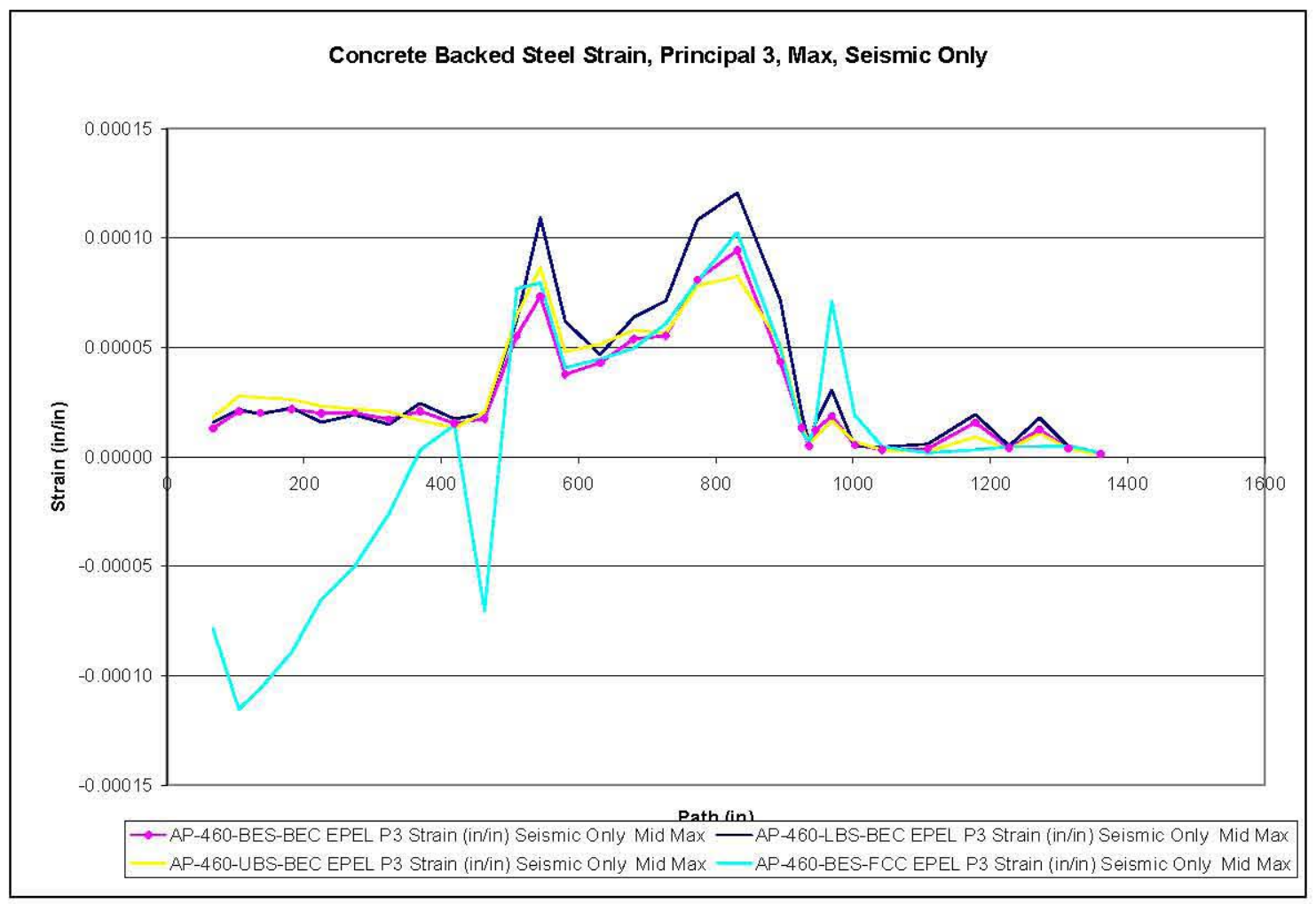

Figure 9-73. Concrete Backed Steel Strain, Principal 3, Max, Seismic Only 
RPP-RPT-32239, Rev. 1

M\&D-2008-005-CALC-001, Rev. 1

\subsection{Contact Element Results}

\subsection{Concrete Footing Contact Results for the Revision 0 Model}

Contact normal and shear forces, and other contact data were extracted for the interface between the bottom of the concrete wall and the footing. Data for each of the twenty-one contact elements were extracted. Figure 10-1 shows the location and element numbers for each contact element.

The following contact data were extracted for each of the CONTAC178 elements.

- SMISC1

- CONT-SLIDE

- CONT-GAP

- CONT-STAT

- SMISC2

- $\mathrm{SMISC} 3$
Normal contact force

Contact lateral displacement

Contact gap distance

Contact status (open, closed, sliding)

Shear force (element Y)

Shear force (element $Z$ )

Results for the contacts were then calculated on a force-per-foot basis for evaluation and plotting. The following figures present the footing contact data.

- Figure 10-1. Footing Contact Element Retrieval Numbers

- Figure 10-2. Concrete Footing Contact Force - Gravity Only

- Figure 10-3. Maximum Concrete Footing Contact Force - Gravity Plus Seismic

- Figure 10-4. Minimum Concrete Footing Contact Force-Gravity Plus Seismic

- Figure 10-5. Maximum Concrete Footing Contact Force - Seismic Only

- Figure 10-6. Minimum Concrete Footing Contact Force - Seismic Only

- Figure 10-7. Concrete Footing Contact Shear - Gravity Only

- Figure 10-8. Concrete Footing Contact Shear - Gravity Plus Seismic

- Figure 10-9. Concrete Footing Contact Shear - Seismic Only 
RPP-RPT-32239, Rev. 1

M\&D-2008-005-CALC-001, Rev. 1

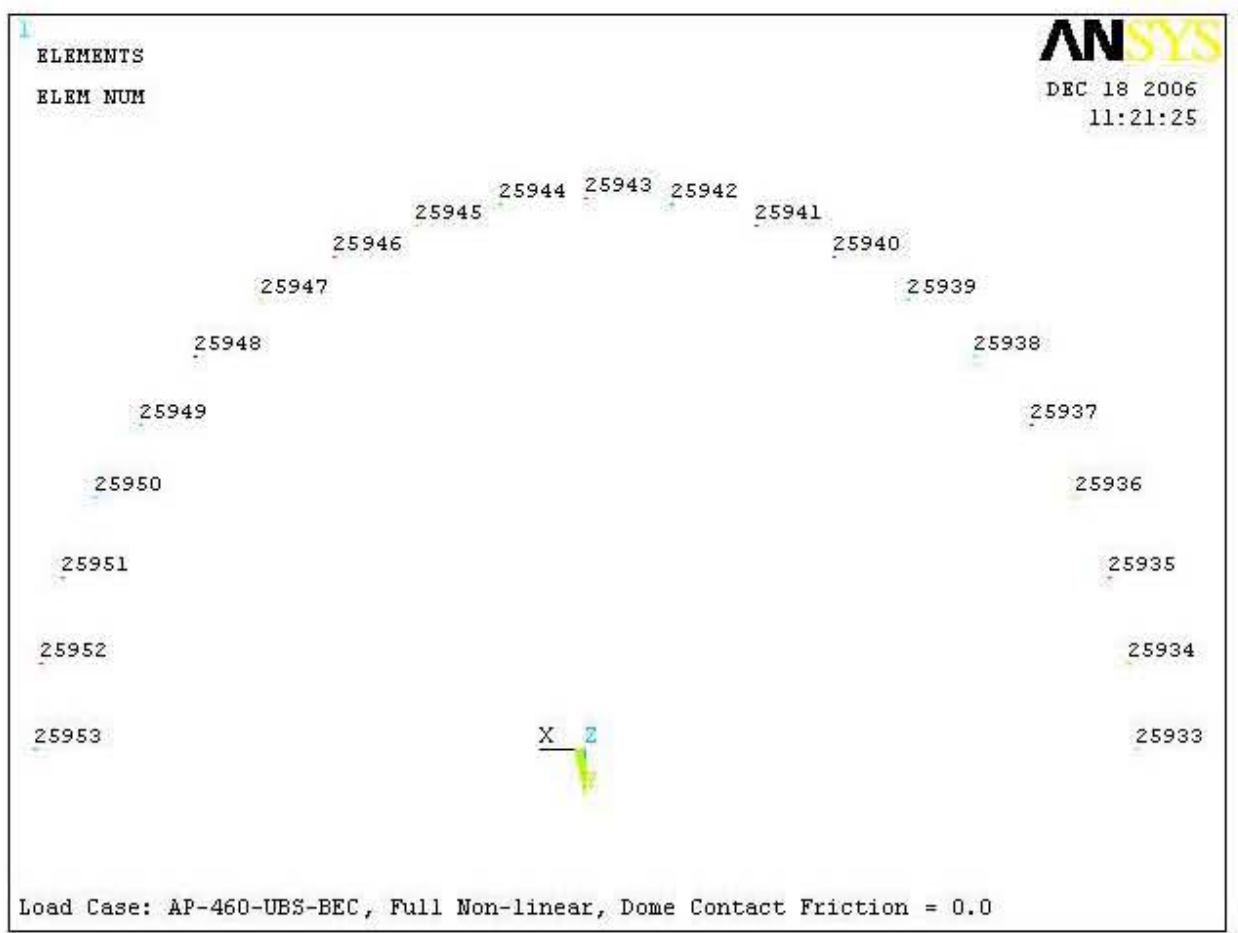

Figure 10-1. Footing Contact Element Retrieval Numbers

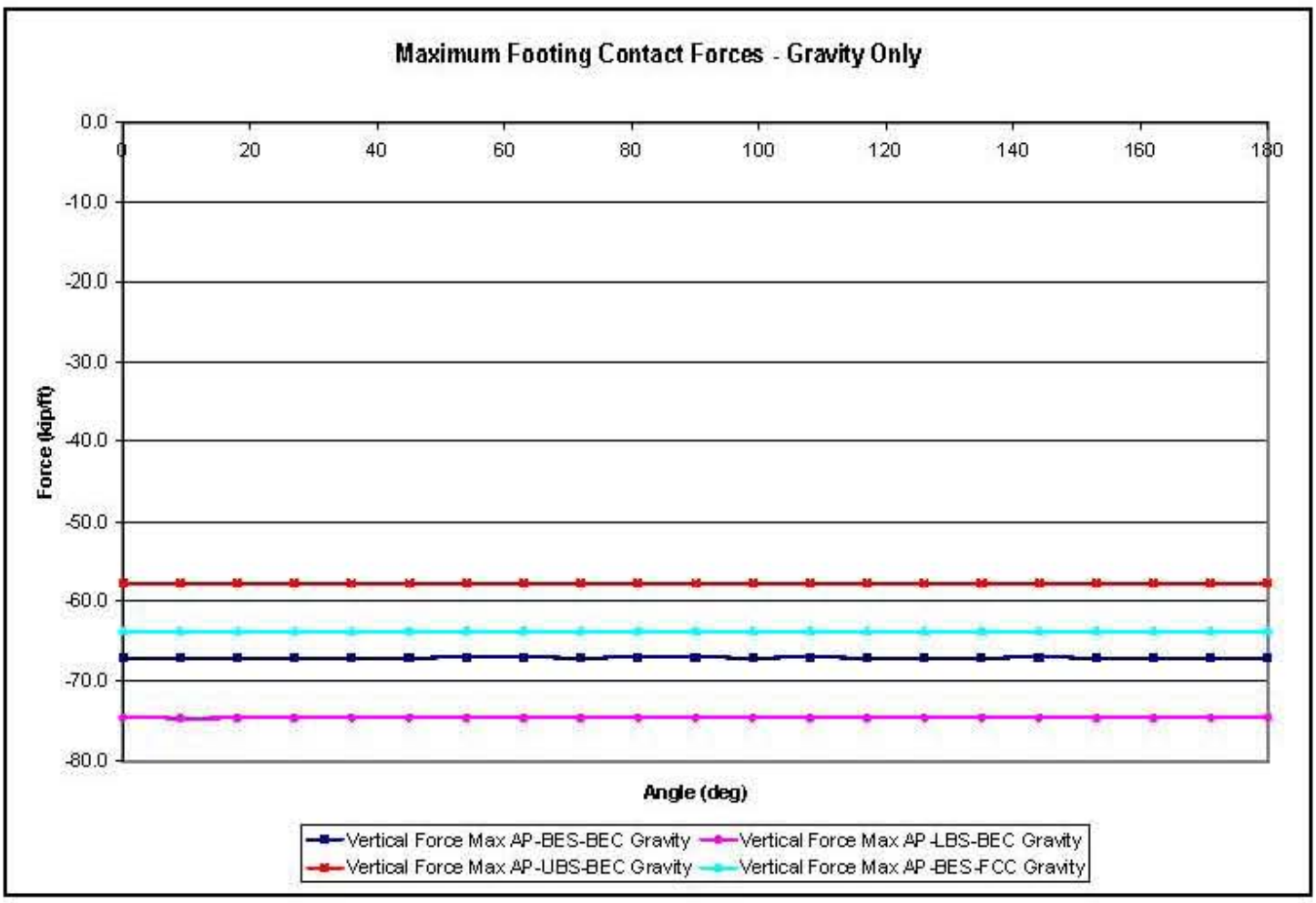

Figure 10-2. Concrete Footing Contact Force - Gravity Only 
RPP-RPT-32239, Rev. 1

M\&D-2008-005-CALC-001, Rev. 1

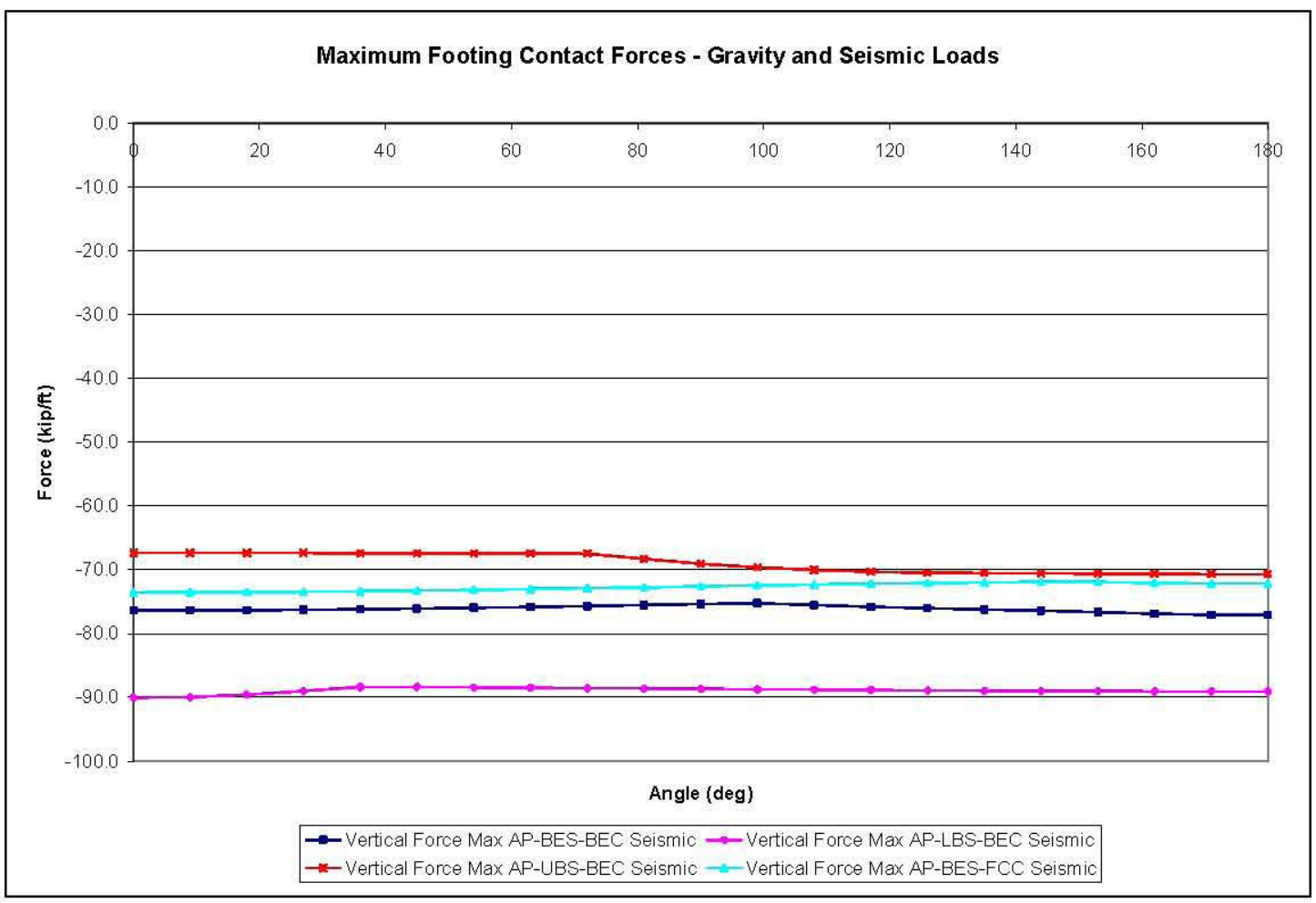

Figure 10-3. Maximum Concrete Footing Contact Force - Gravity Plus Seismic

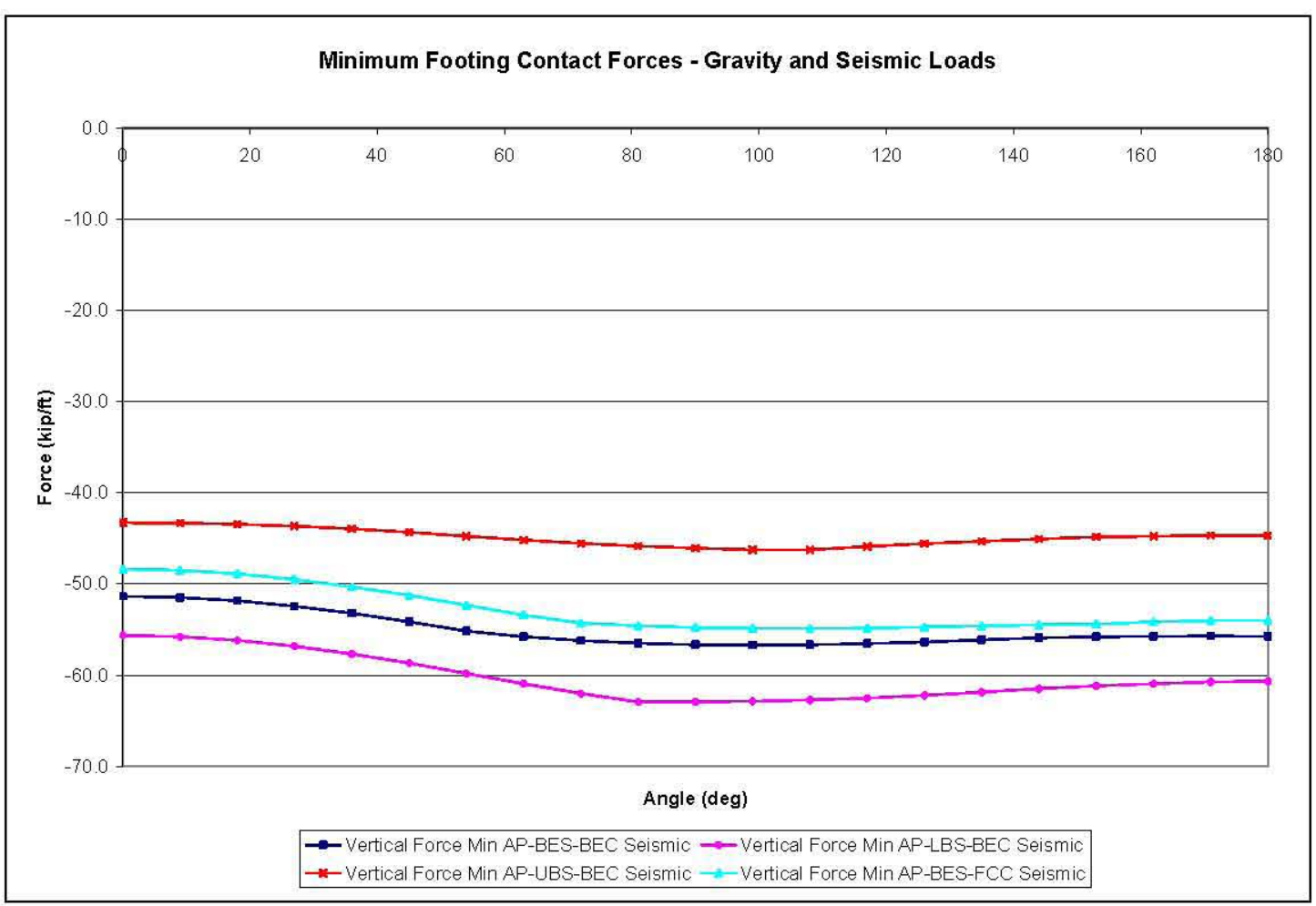

Figure 10-4. Minimum Concrete Footing Contact Force - Gravity Plus Seismic 
RPP-RPT-32239, Rev. 1

M\&D-2008-005-CALC-001, Rev. 1

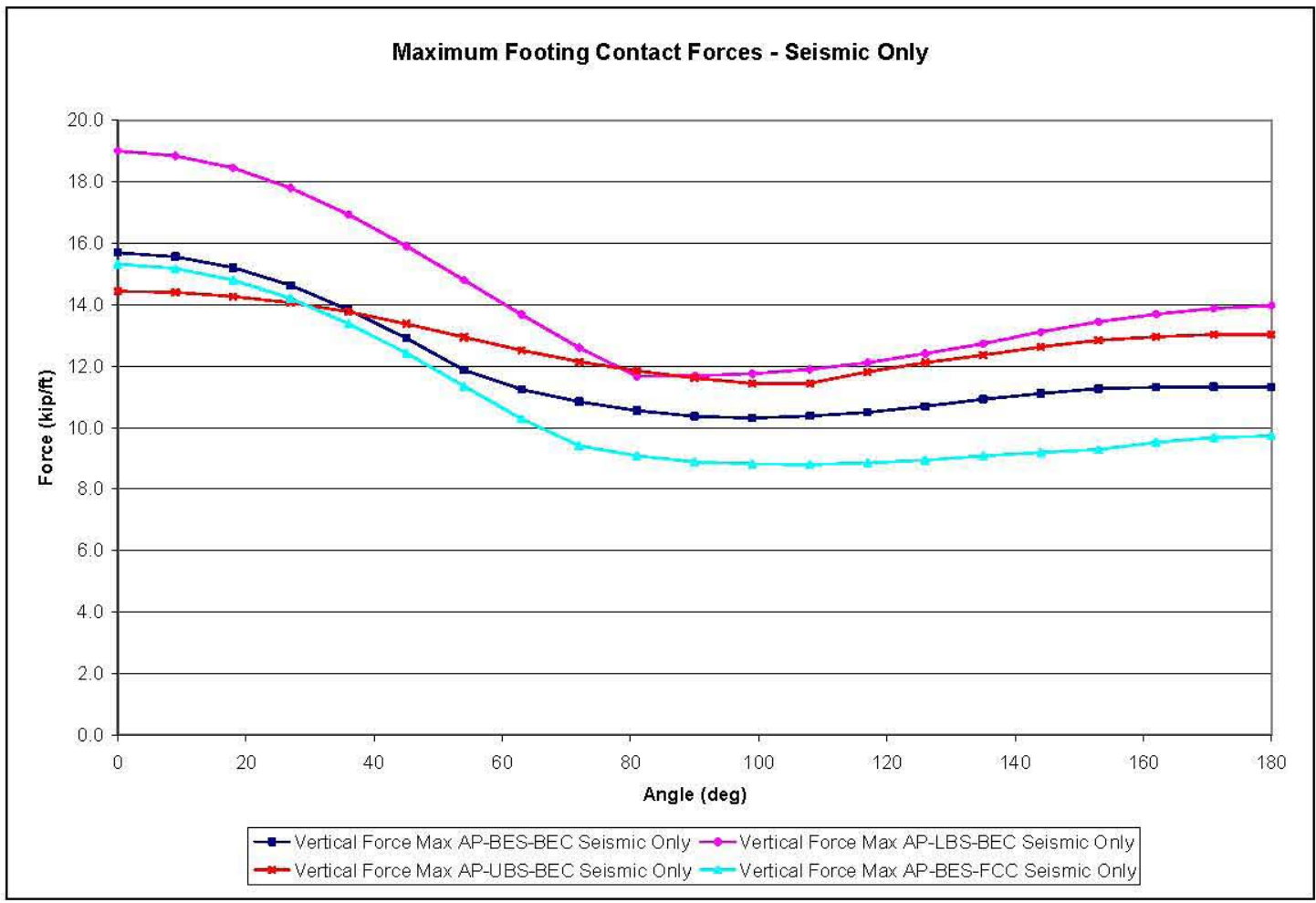

Figure 10-5. Maximum Concrete Footing Contact Force - Seismic Only

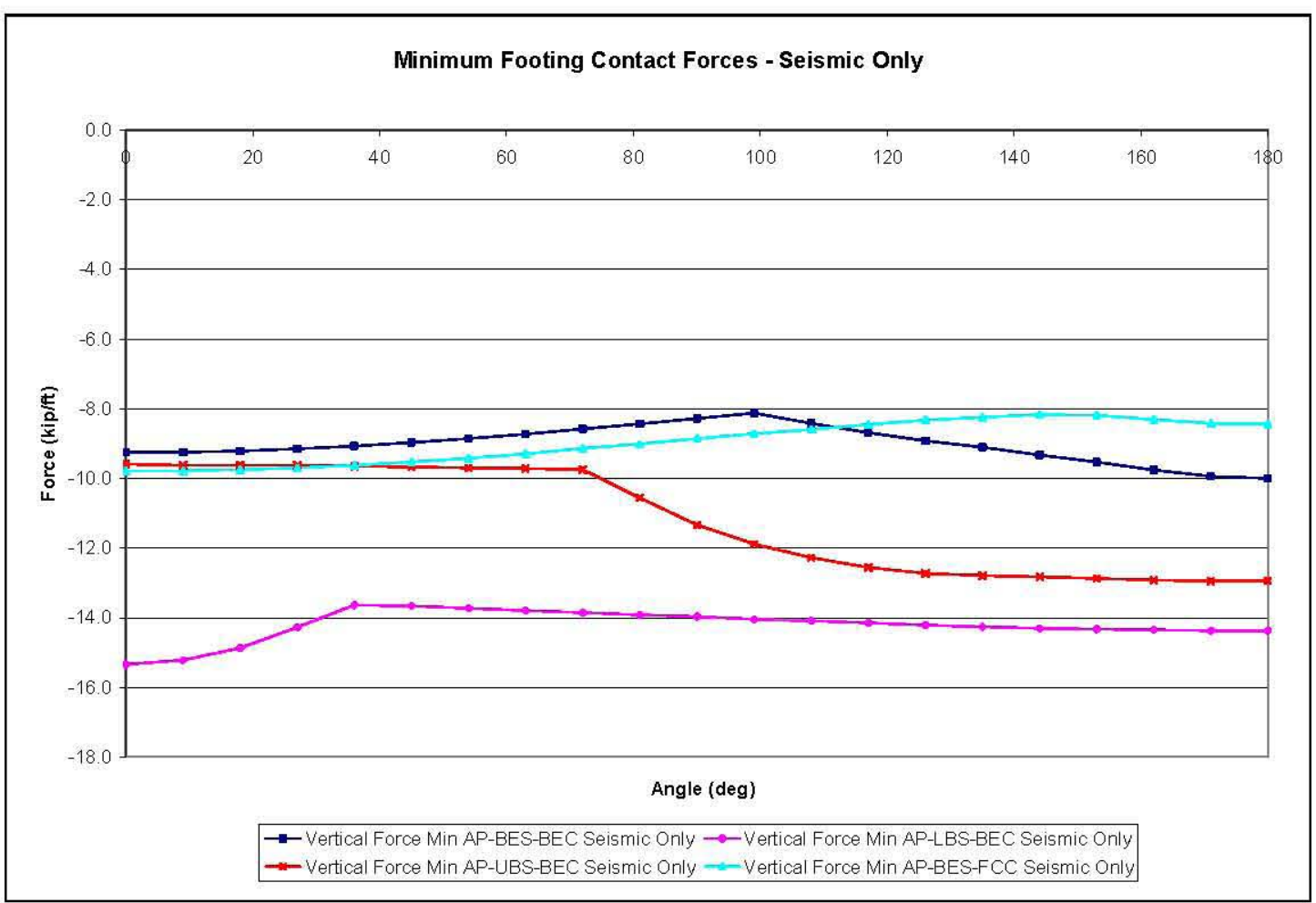

Figure 10-6. Minimum Concrete Footing Contact Force - Seismic Only 
RPP-RPT-32239, Rev. 1

M\&D-2008-005-CALC-001, Rev. 1

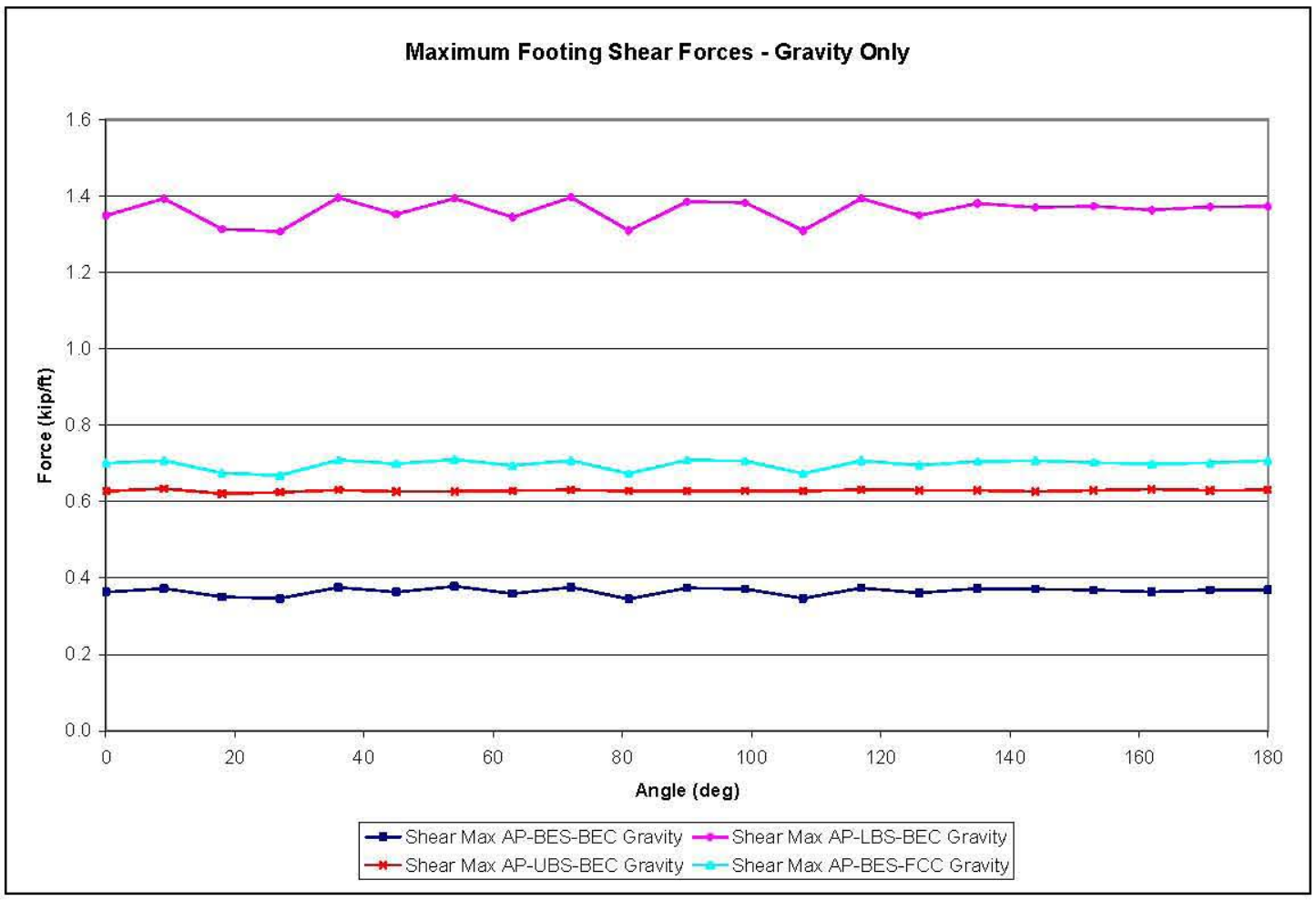

Figure 10-7. Concrete Footing Contact Shear - Gravity Only

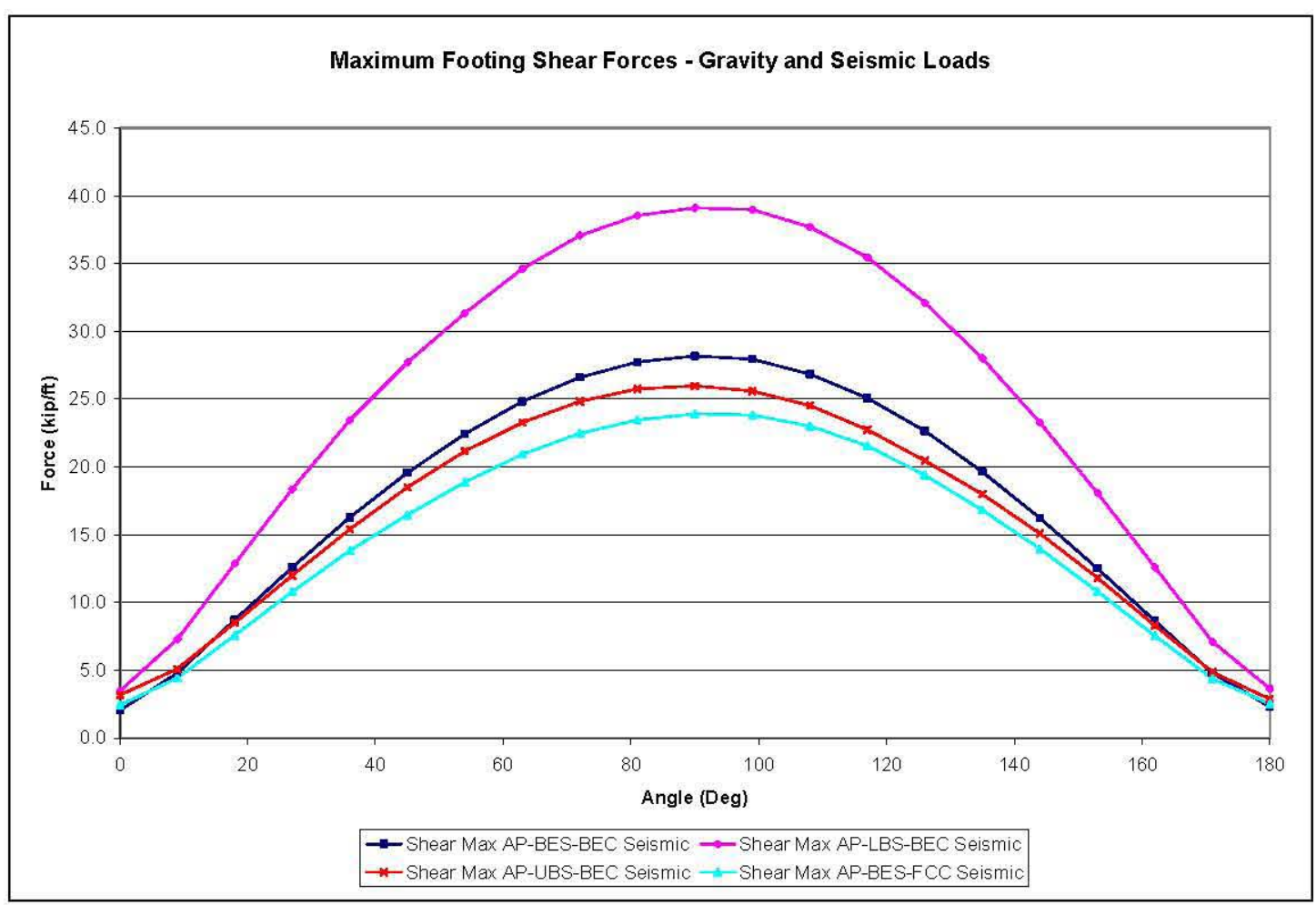

Figure 10-8. Concrete Footing Contact Shear - Gravity Plus Seismic 
RPP-RPT-32239, Rev. 1

M\&D-2008-005-CALC-001, Rev. 1

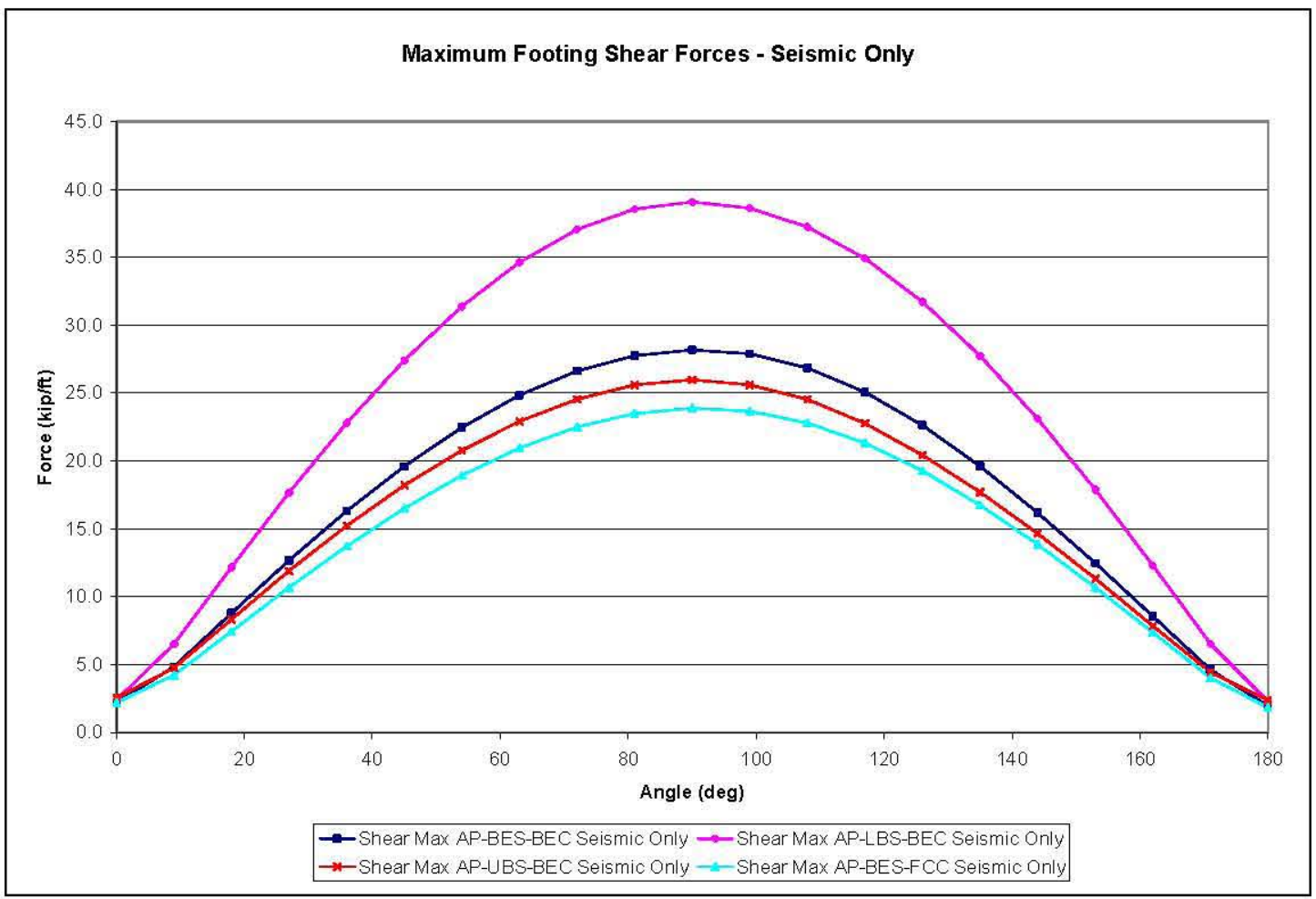

Figure 10-9. Concrete Footing Contact Shear - Seismic Only

Time history results were evaluated for the contact elements located at $9^{\circ}$ and $180^{\circ}$. The resultant shear and normal forces were compared over the full-time history to determine the potential for sliding. There were no cases in which ANSYS ${ }^{\mathbb{B}}$ showed any sliding to occur. It is noted that at times during the transient analysis, the shear force exceeded the friction capacity of the contact element. This is because the total displacement occurring at any time did not meet the ANSYS $^{\circledR}$ criteria for sliding to occur. The maximum elastic displacement for any load case was 0.00009 inch (Best-Estimate Soil, Fully Cracked Concrete). Each plot comparing the shear force and normal force includes the contact normal force (pr\# in plots), the shear force, and the ratio of the shear to normal force $(\mathrm{V} / \mathrm{N})$. The following figures are provided for the time histories.

- Figure 10-10. Concrete Footing Time History, $\theta=9^{\circ}-$ LBS-BEC

- Figure 10-11. Concrete Footing Time History, $\theta=90^{\circ}-$ LBS-BEC

- Figure 10-12. Concrete Footing Displacment Time History, $\theta=90^{\circ}-\mathrm{BES}-\mathrm{FCC}$

- Figure 10-13. Concrete Footing Time History, $\theta=9^{\circ}-$ BES-BEC

- Figure 10-14. Concrete Footing Time History, $\theta=90^{\circ}-\mathrm{BES}-\mathrm{BEC}$

- Figure 10-15. Concrete Footing Time History, $\theta=9^{\circ}$ - UBS-BEC

- Figure 10-16. Concrete Footing Time History, $\theta=90^{\circ}-\mathrm{UBS}-\mathrm{BEC}$

- Figure 10-17. Concrete Footing Time History, $\theta=9^{\circ}-$ BES-FCC

- Figure 10-18. Concrete Footing Time History, $\theta=90^{\circ}-\mathrm{BES}-\mathrm{FCC}$ 
RPP-RPT-32239, Rev. 1

M\&D-2008-005-CALC-001, Rev. 1

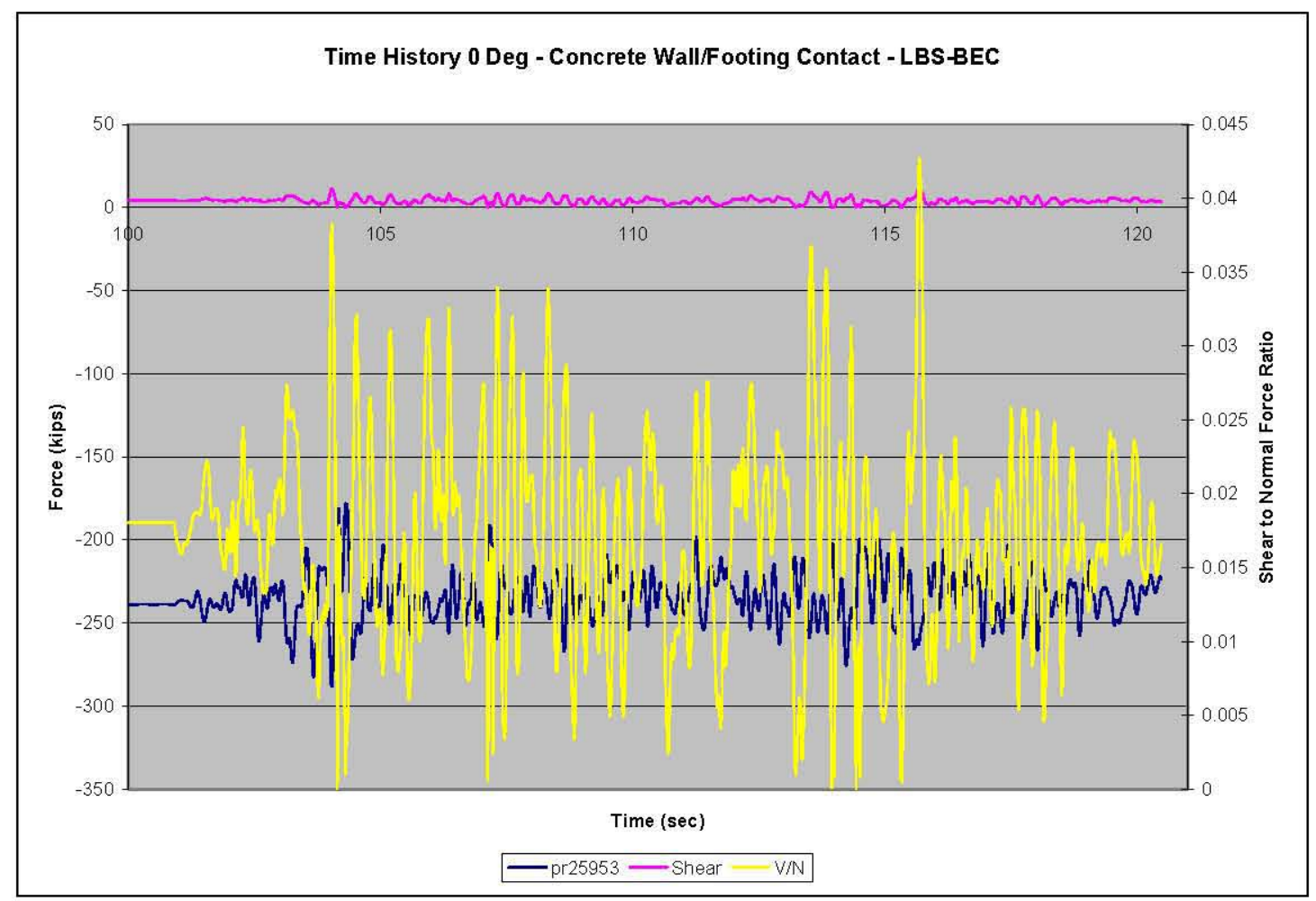

Figure 10-10. Concrete Footing Time History, $\theta=9^{\circ}-\mathrm{LBS}-\mathrm{BEC}$

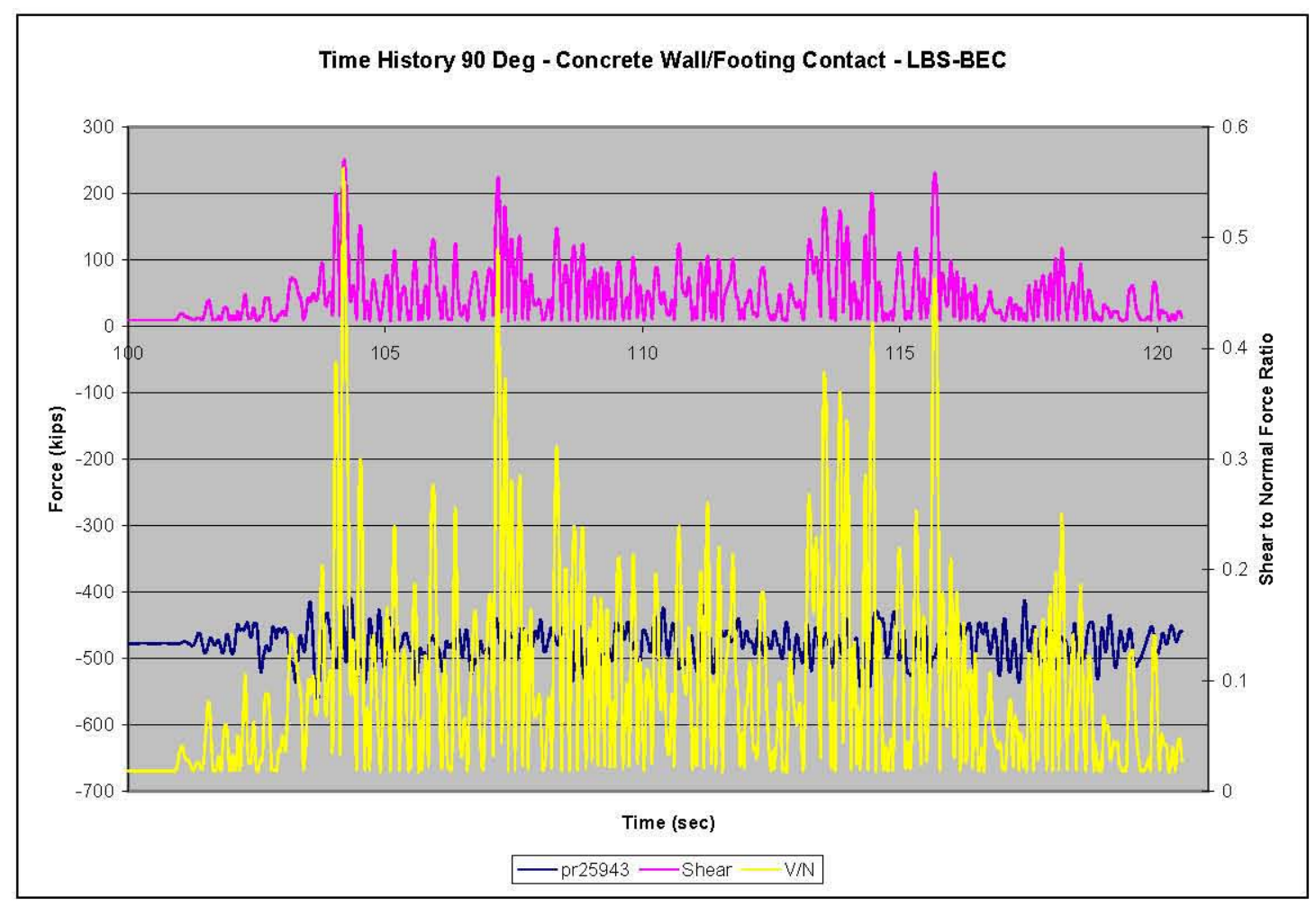

Figure 10-11. Concrete Footing Time History, $\theta=90^{\circ}-$ LBS-BEC 
RPP-RPT-32239, Rev. 1

M\&D-2008-005-CALC-001, Rev. 1

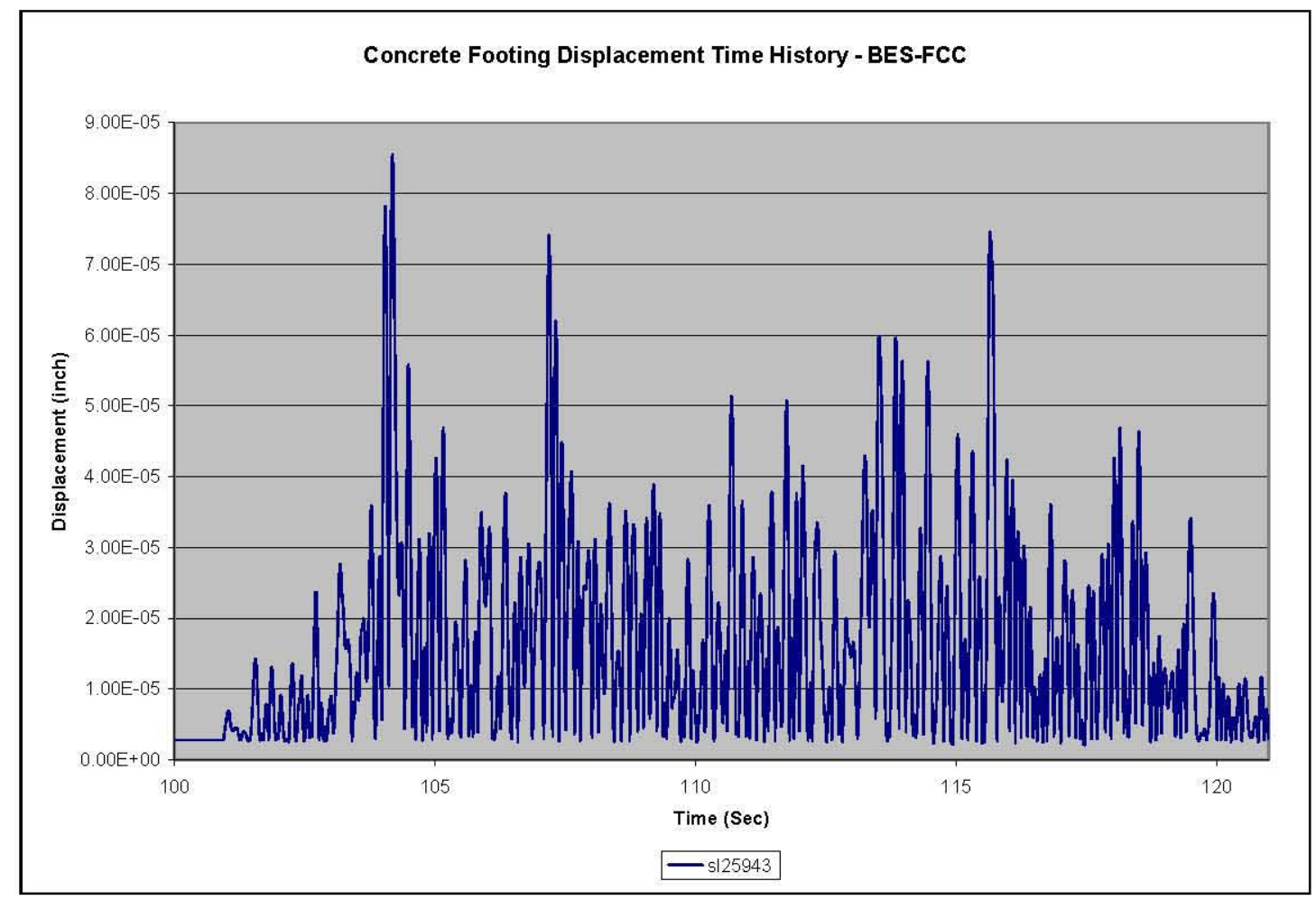

Figure 10-12. Concrete Footing Displacment Time History, $\theta=90^{\circ}-\mathrm{BES}-\mathrm{FCC}$

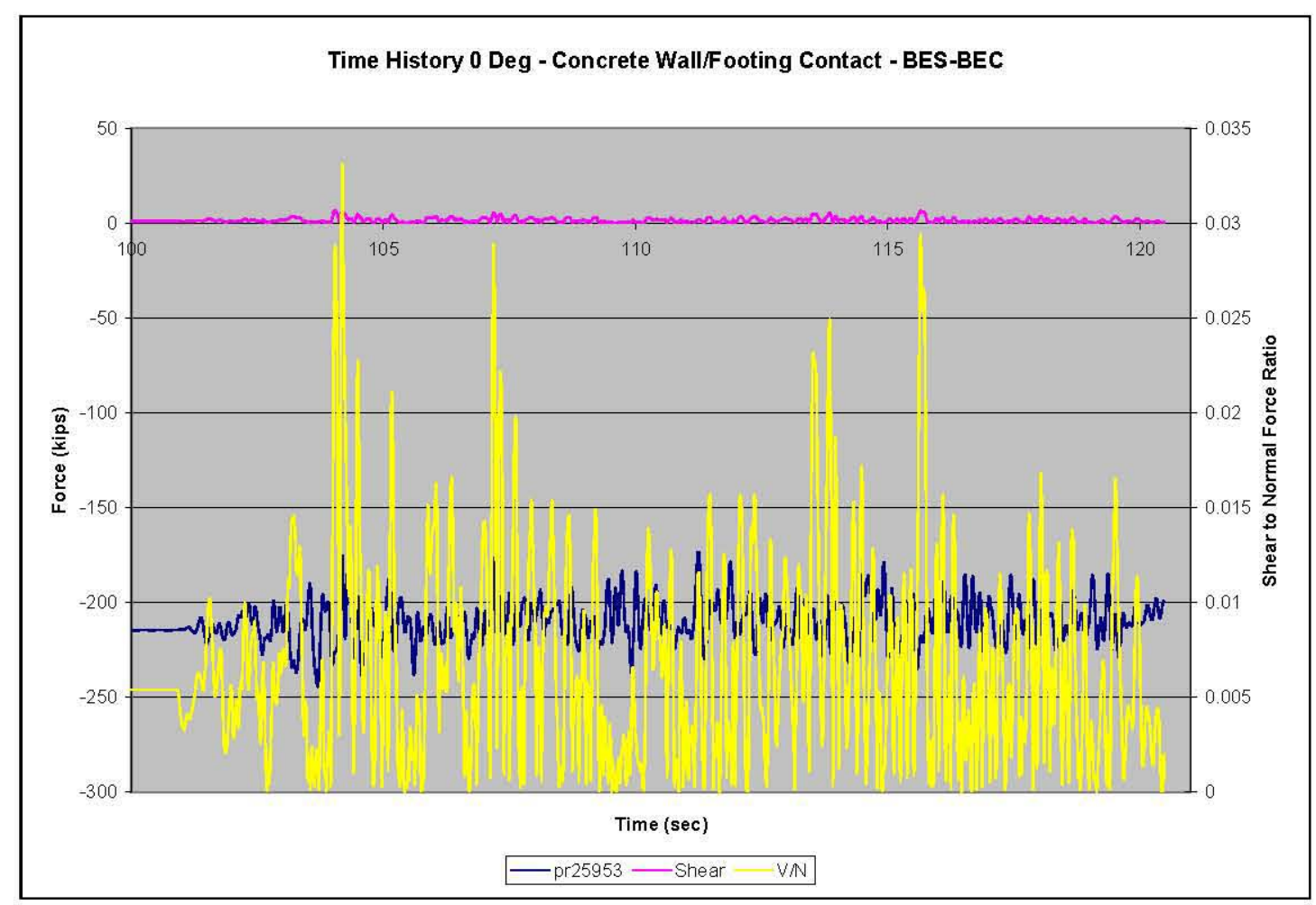

Figure 10-13. Concrete Footing Time History, $\theta=9^{\circ}-\mathrm{BES}-\mathrm{BEC}$ 
RPP-RPT-32239, Rev. 1

M\&D-2008-005-CALC-001, Rev. 1

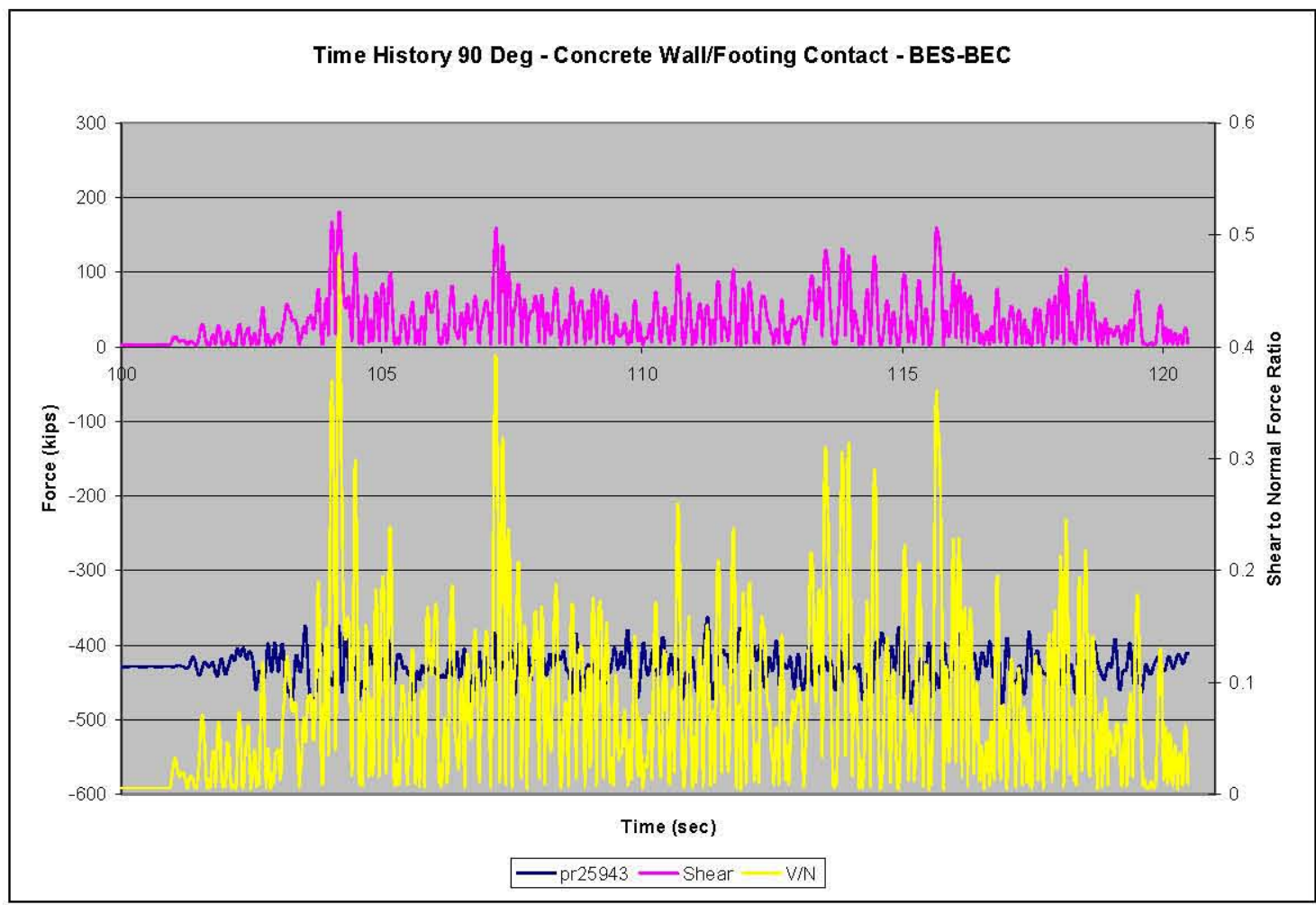

Figure 10-14. Concrete Footing Time History, $\theta=90^{\circ}-\mathrm{BES}-\mathrm{BEC}$

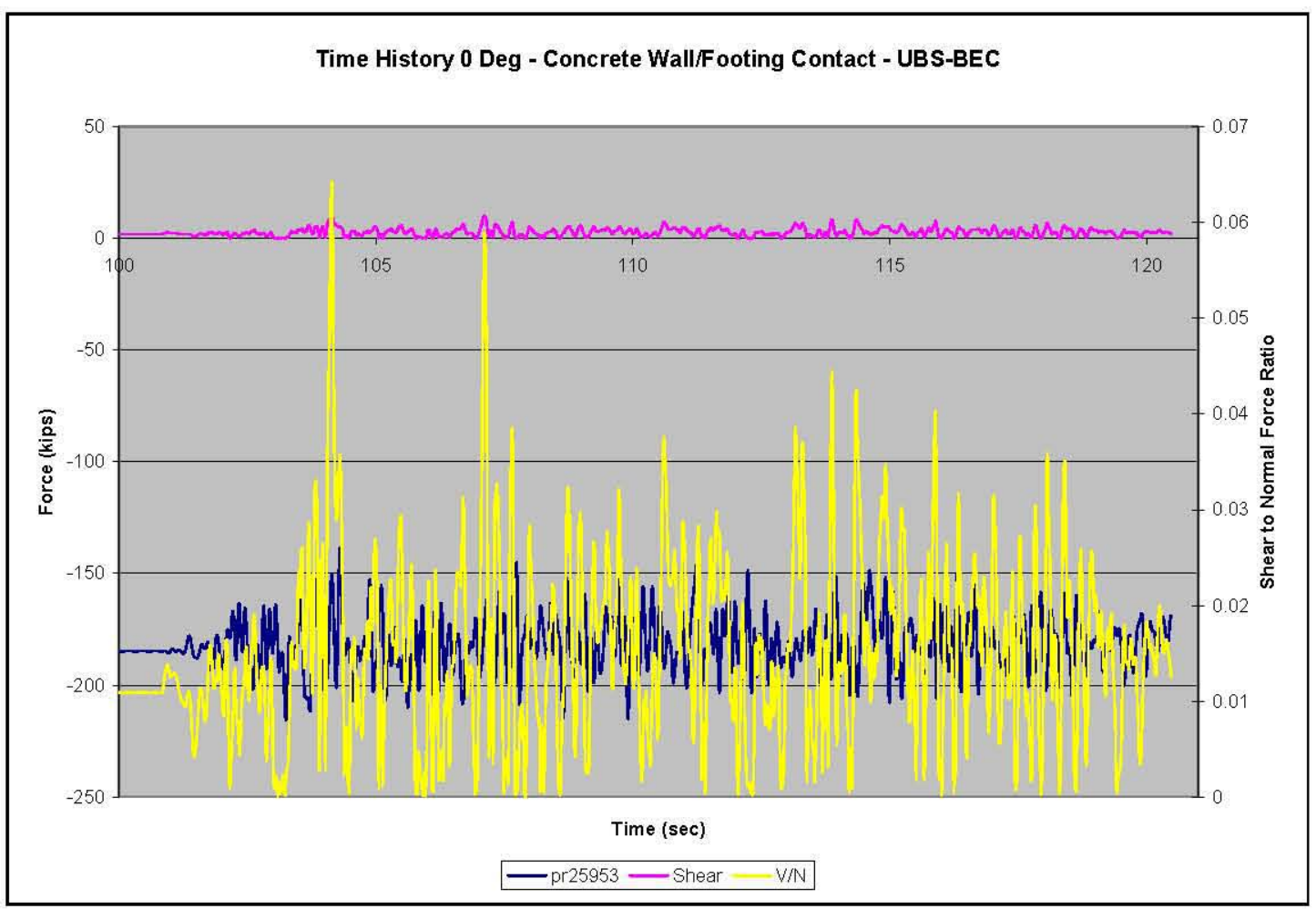

Figure 10-15. Concrete Footing Time History, $\theta=9^{\circ}-$ UBS-BEC 
RPP-RPT-32239, Rev. 1

M\&D-2008-005-CALC-001, Rev. 1

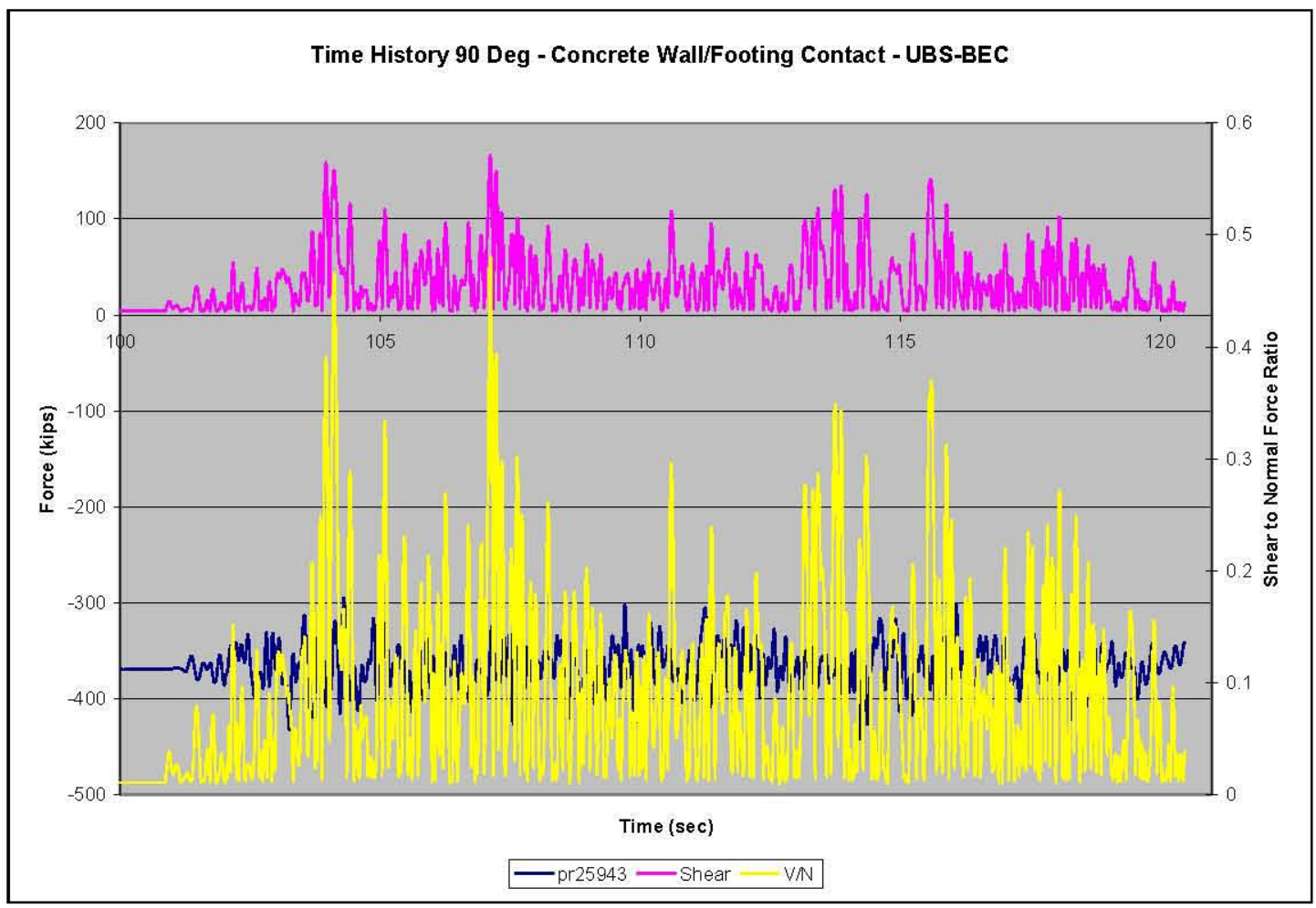

Figure 10-16. Concrete Footing Time History, $\theta=90^{\circ}-\mathrm{UBS}-\mathrm{BEC}$

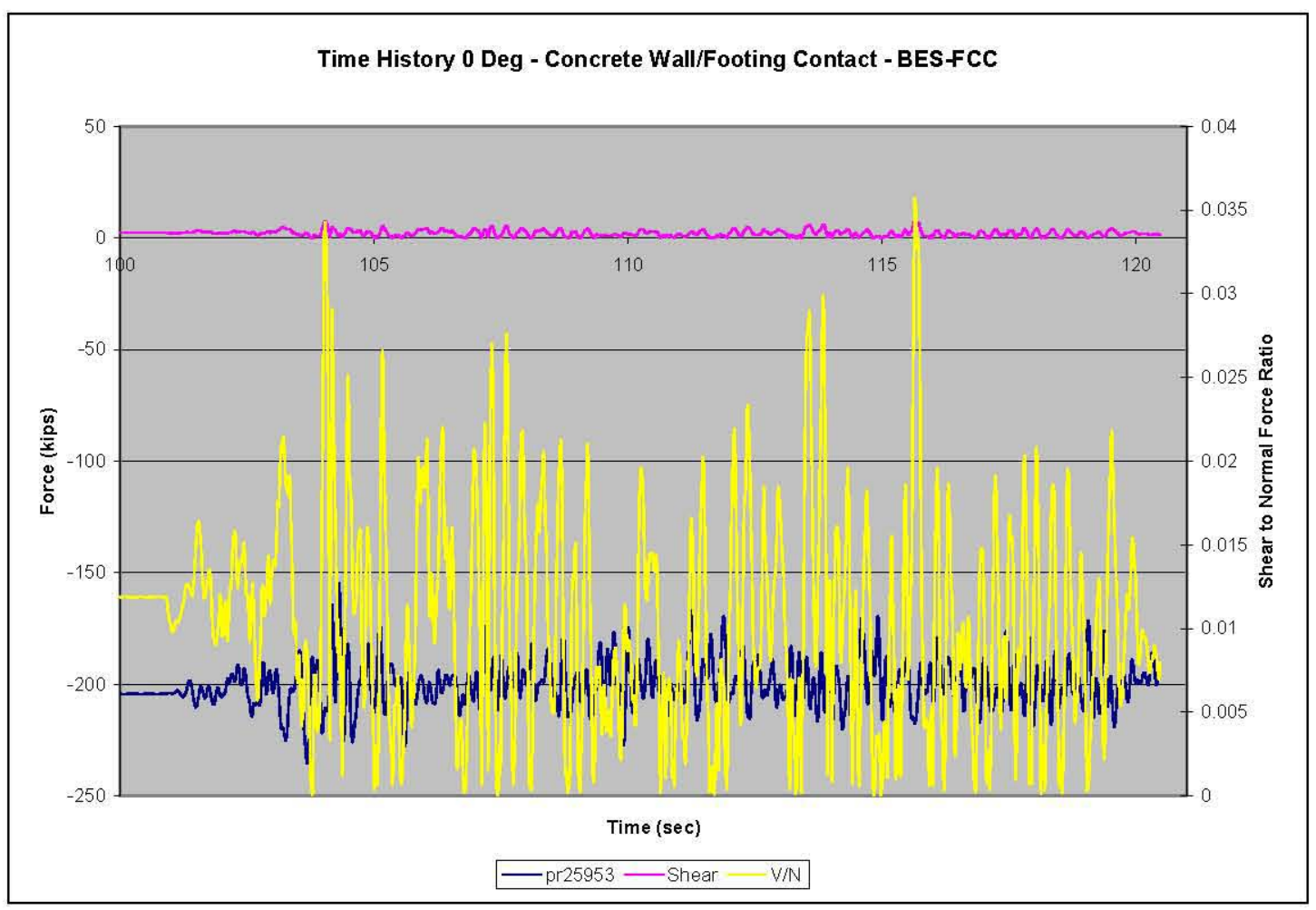

Figure 10-17. Concrete Footing Time History, $\theta=9^{\circ}-\mathrm{BES}-\mathrm{FCC}$ 
RPP-RPT-32239, Rev. 1

M\&D-2008-005-CALC-001, Rev. 1

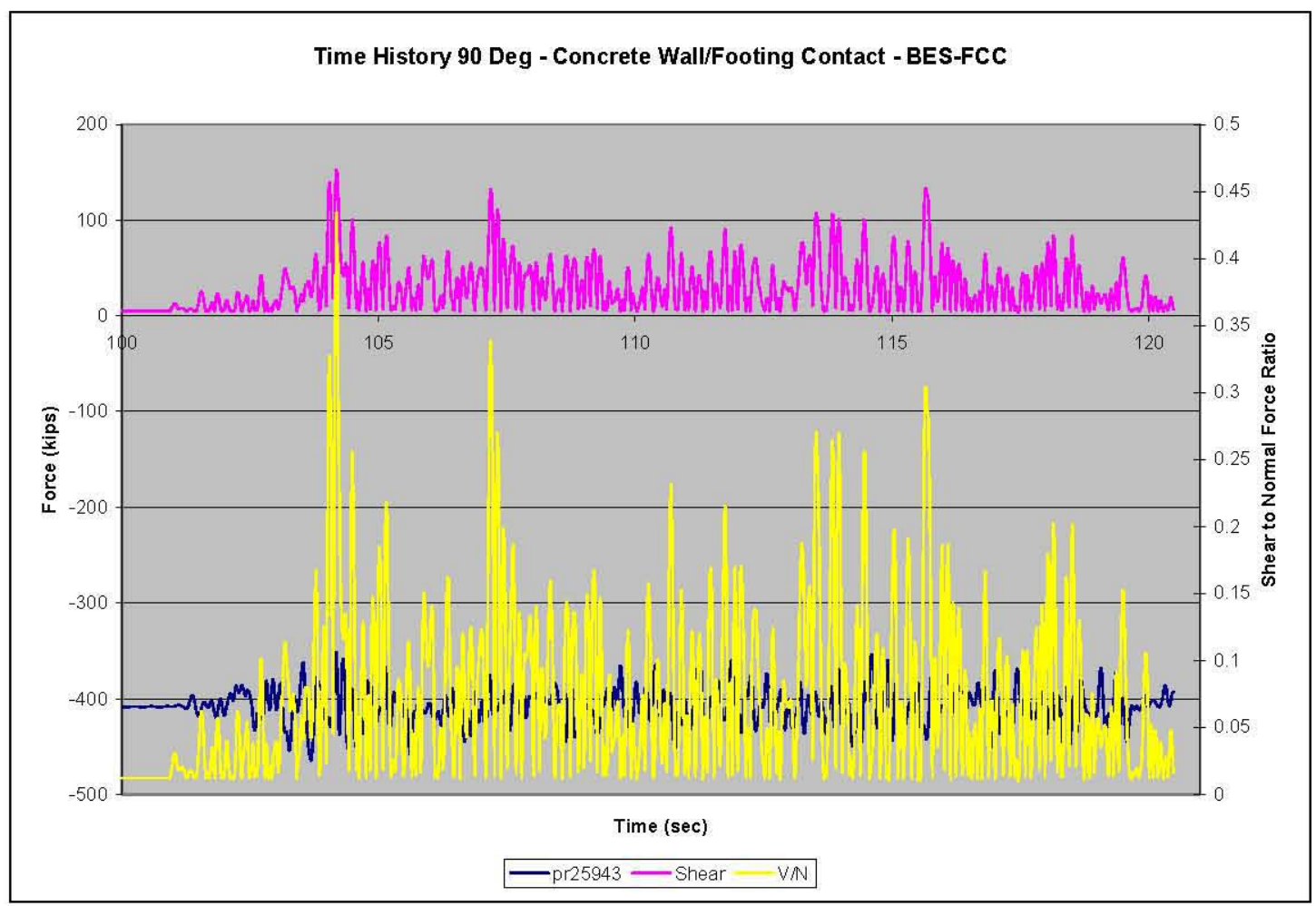

Figure 10-18. Concrete Footing Time History, $\theta=90^{\circ}-\mathrm{BES}-\mathrm{FCC}$

Based on the results presented above for the contact interface between the concrete wall and footing, no displacements are expected to occur. Therefore, future models of the DSTs do not need to incorporate this feature.

\subsection{Soil Contact Results for the Revision 0 Model}

Soil contact data are extracted from the model in $9^{\circ}$ slices, starting near the top of the dome and moving down the wall. Contact normal and shear forces, and other contact data were extracted for the interface between soil and the concrete shell. Figure 10-19 shows the location and element numbers for first slice of contact elements. The following data were extracted for each CONTA173 element:

- CONT-PRES

- CONT-SLIDE

- CONT-GAP

- CONT-STAT

- SMISC8

- $\mathrm{SMISC12}$
Normal Contact Pressure

Contact Lateral Displacement

Contact Gap Distance

Contact Status (Open, Closed, Sliding)

Tangential Friction (Element Y)

Tangential Friction (Element Z) 
RPP-RPT-32239, Rev. 1

M\&D-2008-005-CALC-001, Rev. 1

For each load case, the minimum and maximum contact pressure, tangential shear pressures, and lateral displacements are compared. The figures for each component are grouped by gravity only, gravity plus seismic, and seismic only. For the soil contact interface, the following figures are provided.

- Figure 10-20. Soil/Concrete Contact Element Normal Pressure - Gravity Only

- Figure 10-21. Soil/Concrete Contact Element Maximum Normal Pressure - Gravity Plus Seismic

- Figure 10-22. Soil/Concrete Contact Element Minimum Normal Pressure - Gravity Plus Seismic

- Figure 10-23. Soil/Concrete Contact Element Maximum Normal Pressure - Seismic Only

- Figure 10-24. Soil/Concrete Contact Element Minimum Normal Pressure - Seismic Only

- Figure 10-25. Soil/Concrete Contact Element Meridional Shear-Gravity Only

- Figure 10-26. Soil/Concrete Contact Element Meridional Shear-Gravity Plus Seismic

- Figure 10-27. Soil/Concrete Contact Element Meridional Shear-Seismic Only

- Figure 10-28. Soil/Concrete Contact Element Tangential Shear-Gravity Only

- Figure 10-29. Soil/Concrete Contact Element Tangential Shear-Gravity Plus Seismic

- Figure 10-30. Soil/Concrete Contact Element Gap Tangential Shear-Seismic Only

- Figure 10-31. Soil/Concrete Contact Element Gap Lateral Displacement (Slide) - Gravity Only

- Figure 10-32. Soil/Concrete Contact Element Gap Lateral Displacement (Slide) - Gravity Plus Seismic

- Figure 10-33. Soil/Concrete Contact Element Gap Lateral Displacement (Slide) - Seismic Only

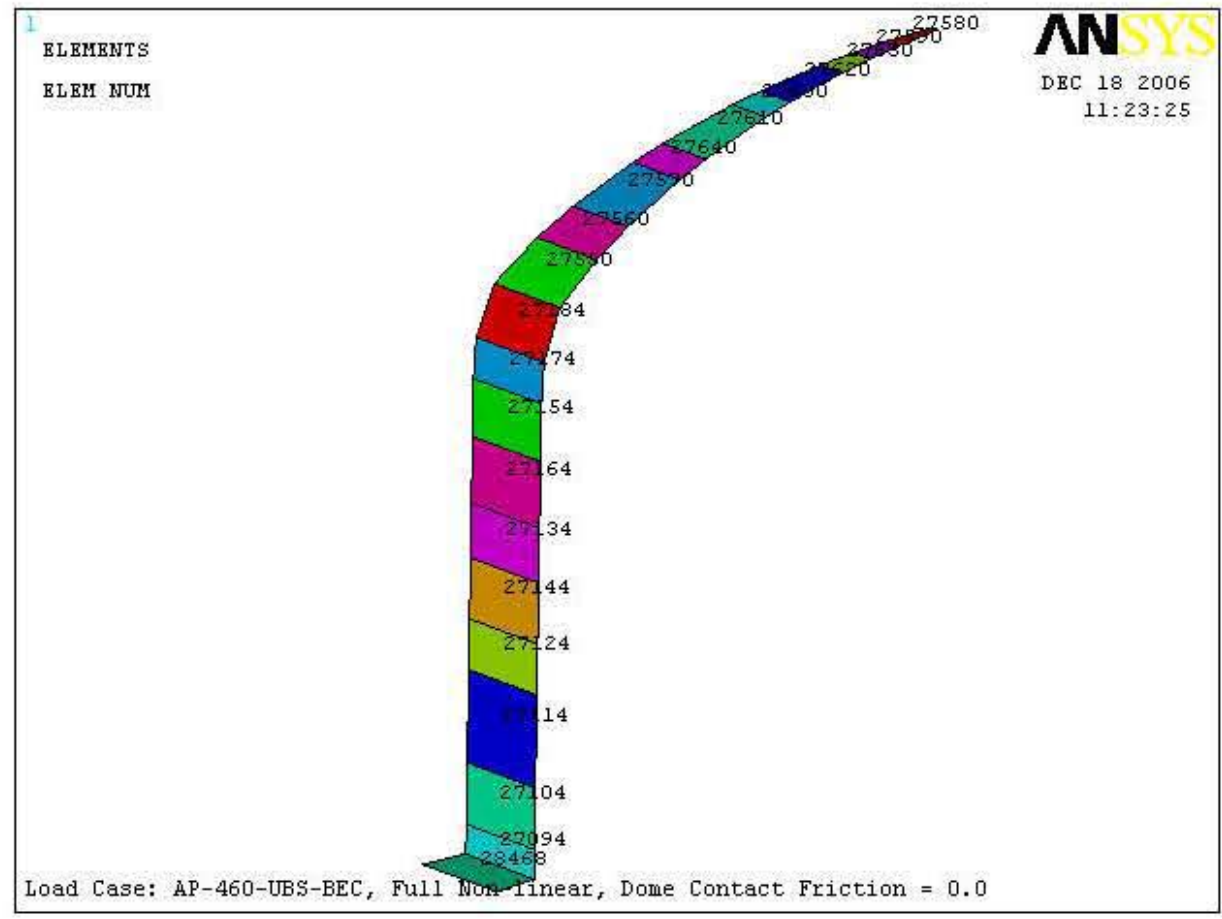

Figure 10-19. Soil/Concrete Contact Element Retrieval Sequence Starting Numbers 
RPP-RPT-32239, Rev. 1

M\&D-2008-005-CALC-001, Rev. 1

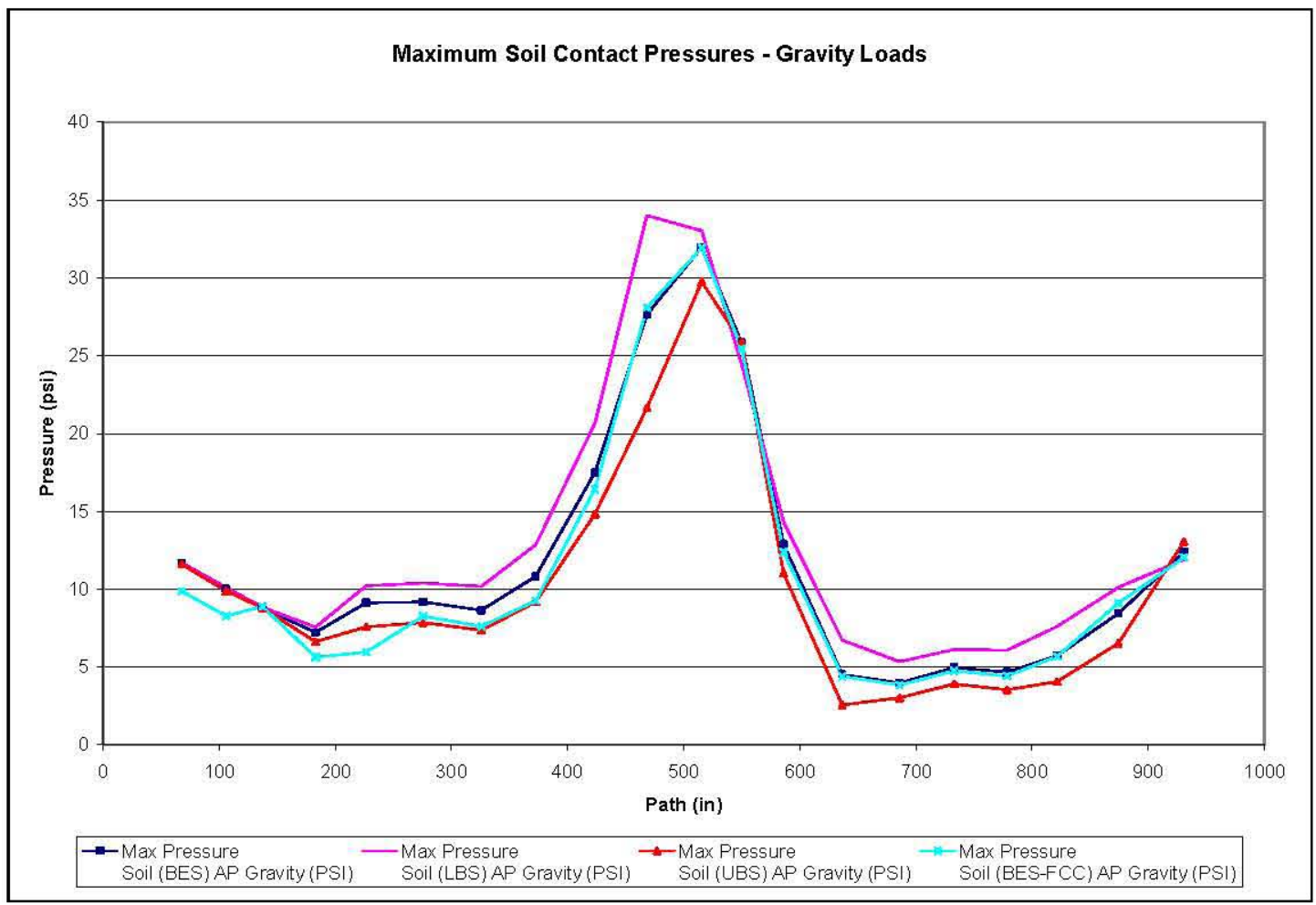

Figure 10-20. Soil/Concrete Contact Element Normal Pressure - Gravity Only

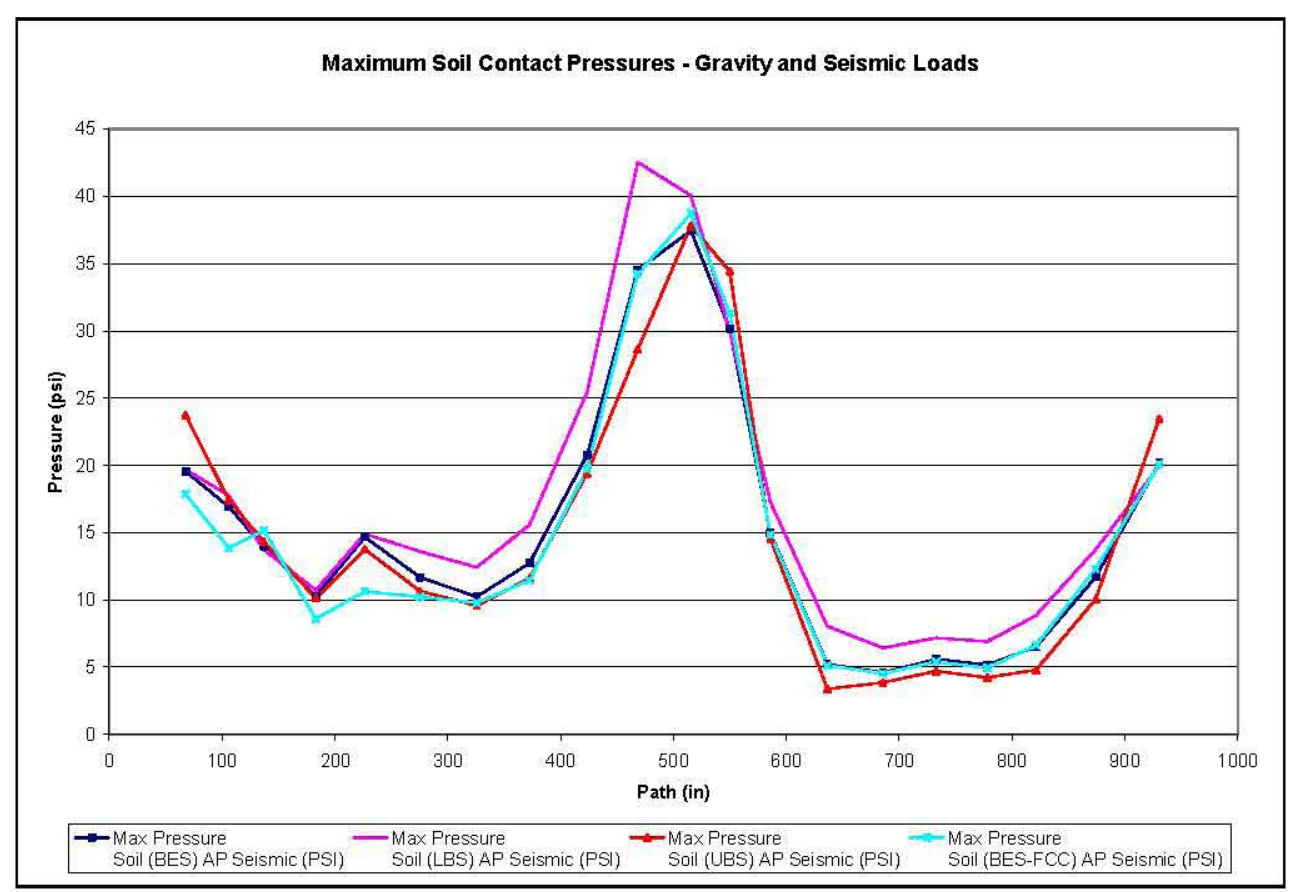

Figure 10-21. Soil/Concrete Contact Element Maximum Normal Pressure - Gravity Plus Seismic 
RPP-RPT-32239, Rev. 1

M\&D-2008-005-CALC-001, Rev. 1

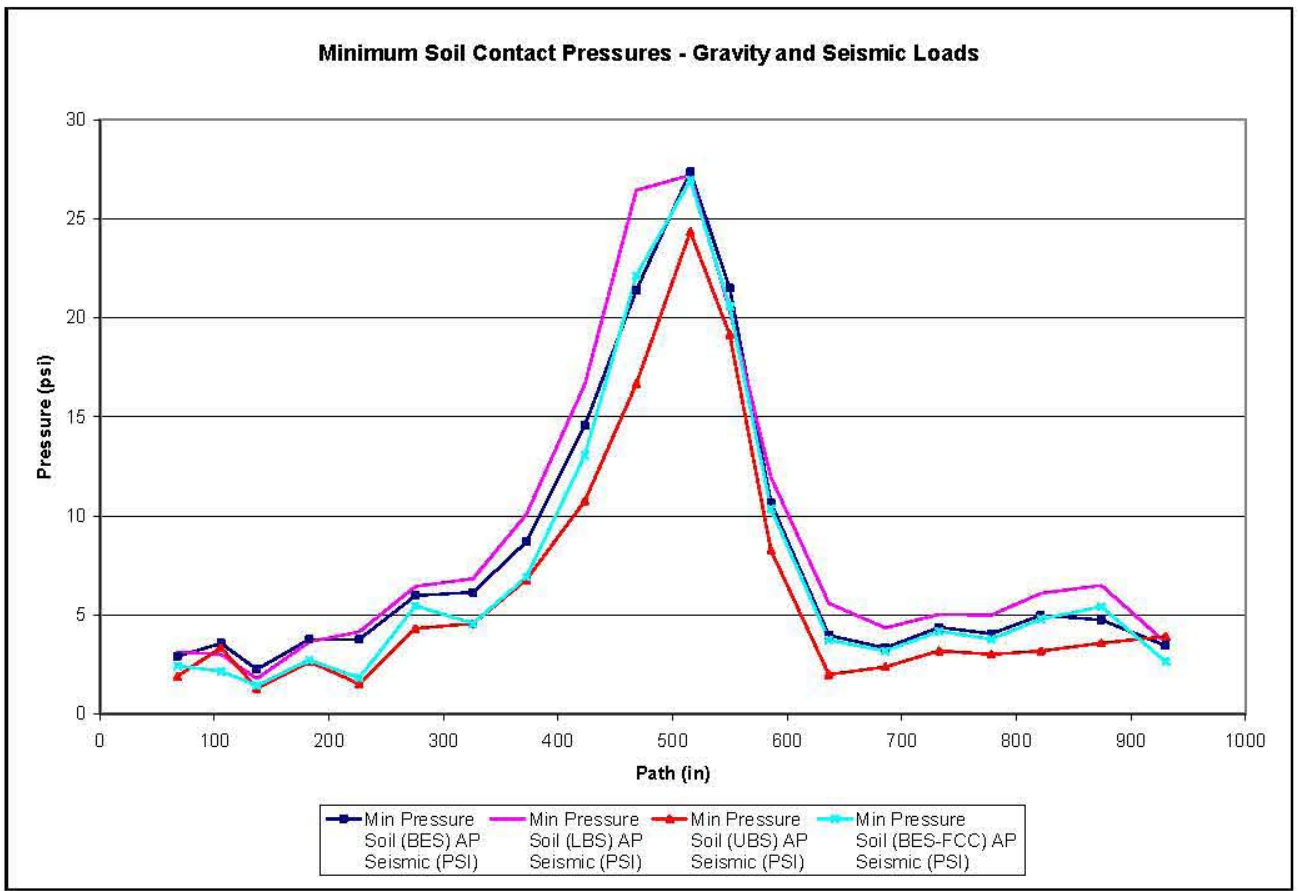

Figure 10-22. Soil/Concrete Contact Element Minimum Normal Pressure - Gravity Plus Seismic

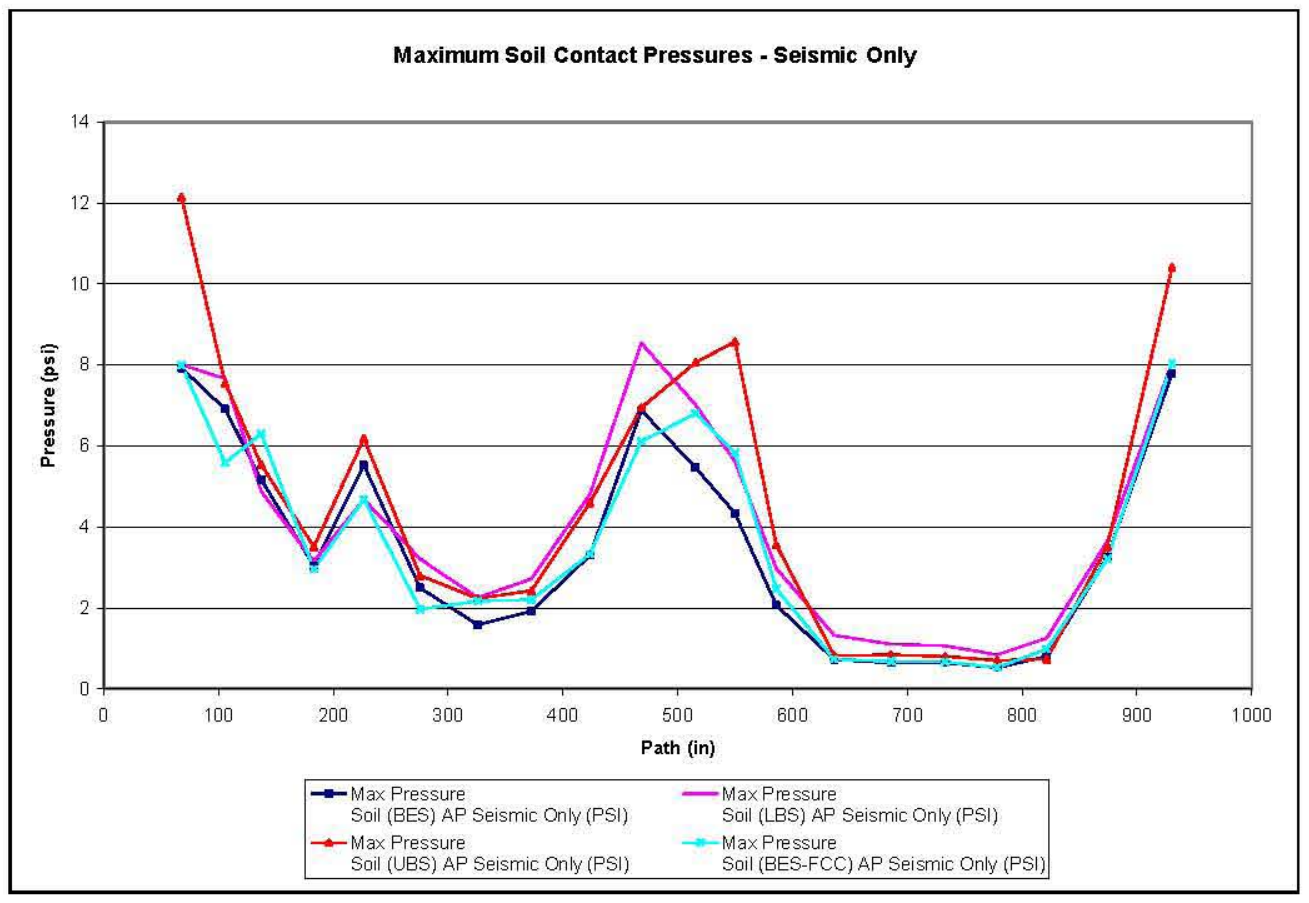

Figure 10-23. Soil/Concrete Contact Element Maximum Normal Pressure - Seismic Only 
RPP-RPT-32239, Rev. 1

M\&D-2008-005-CALC-001, Rev. 1

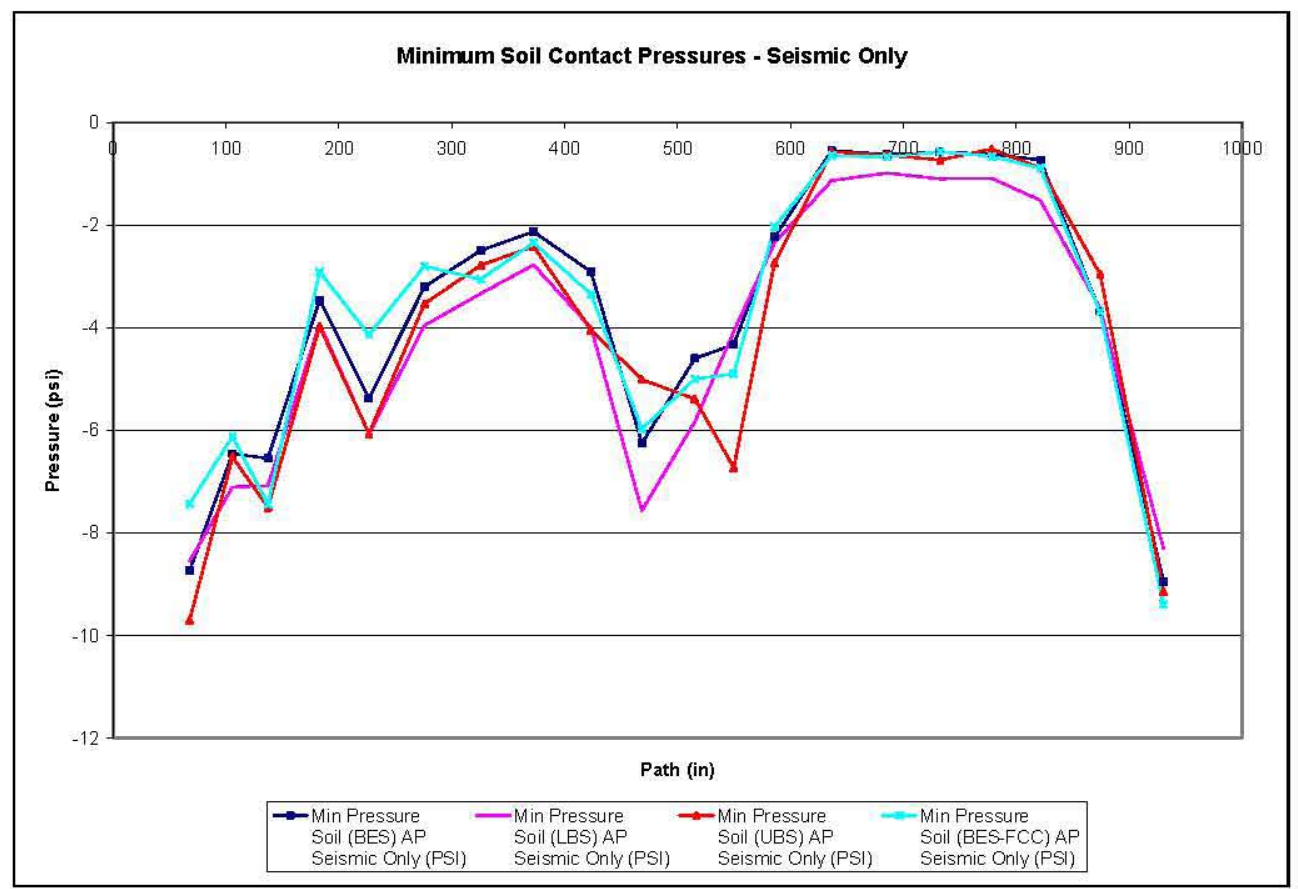

Figure 10-24. Soil/Concrete Contact Element Minimum Normal Pressure - Seismic Only

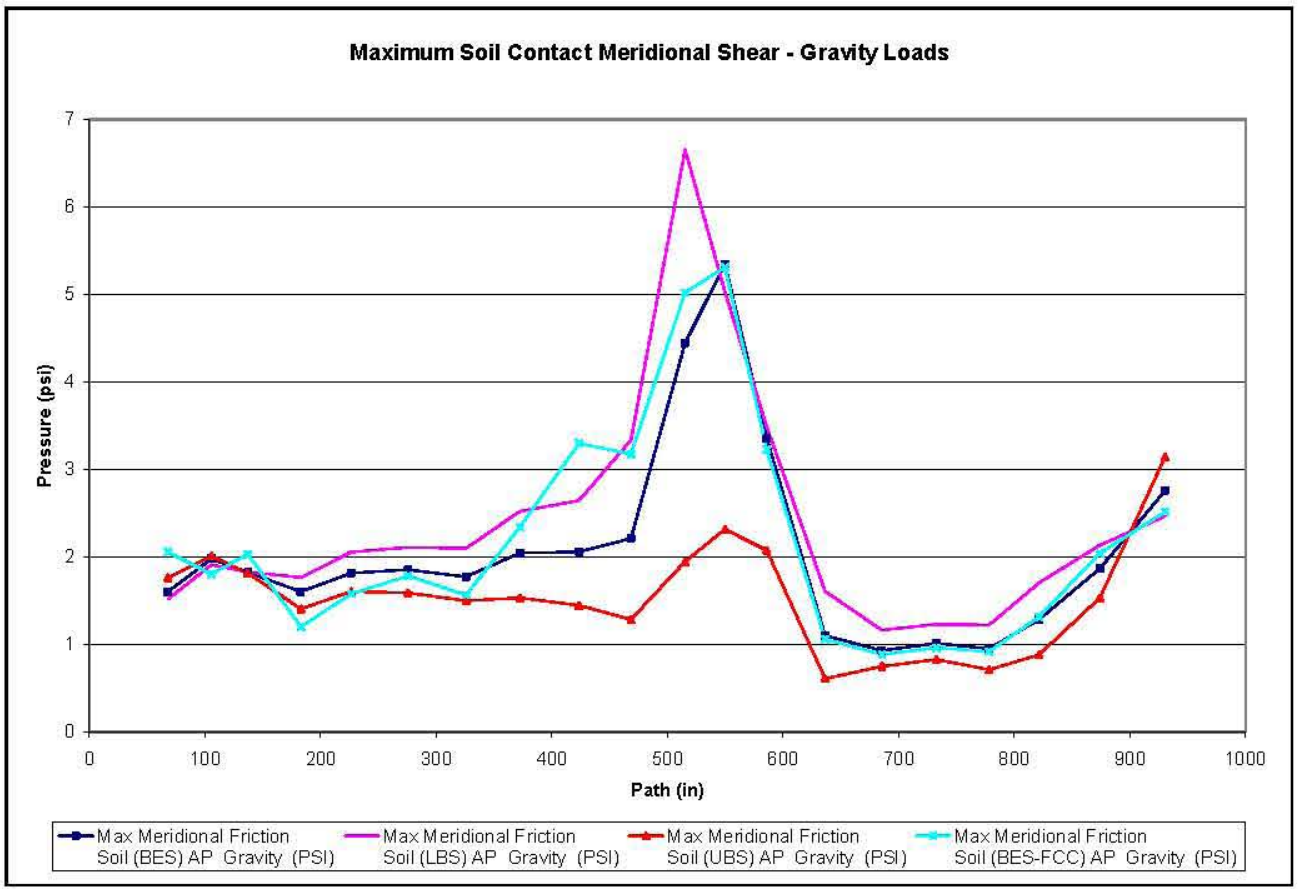

Figure 10-25. Soil/Concrete Contact Element Meridional Shear - Gravity Only 
RPP-RPT-32239, Rev. 1

M\&D-2008-005-CALC-001, Rev. 1

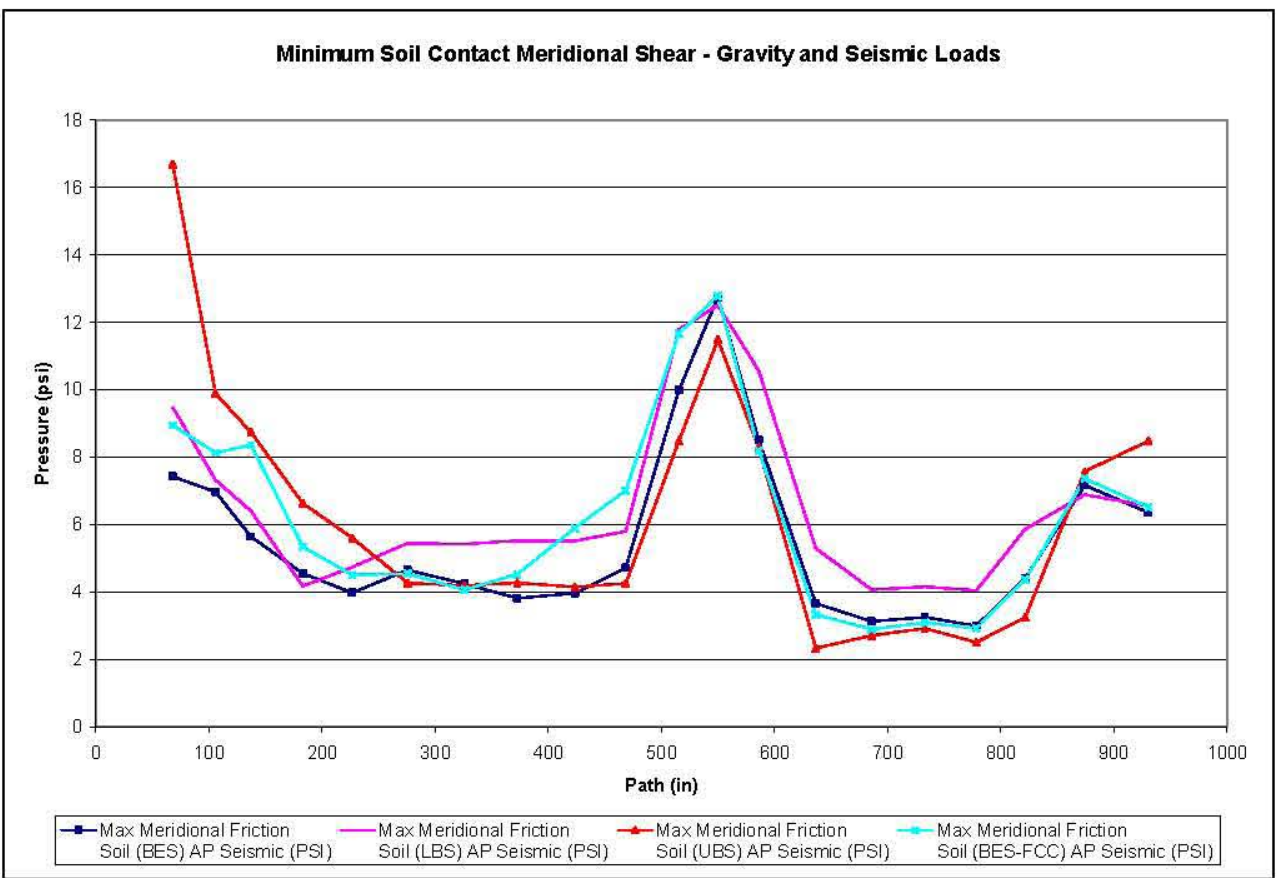

Figure 10-26. Soil/Concrete Contact Element Meridional Shear - Gravity Plus Seismic

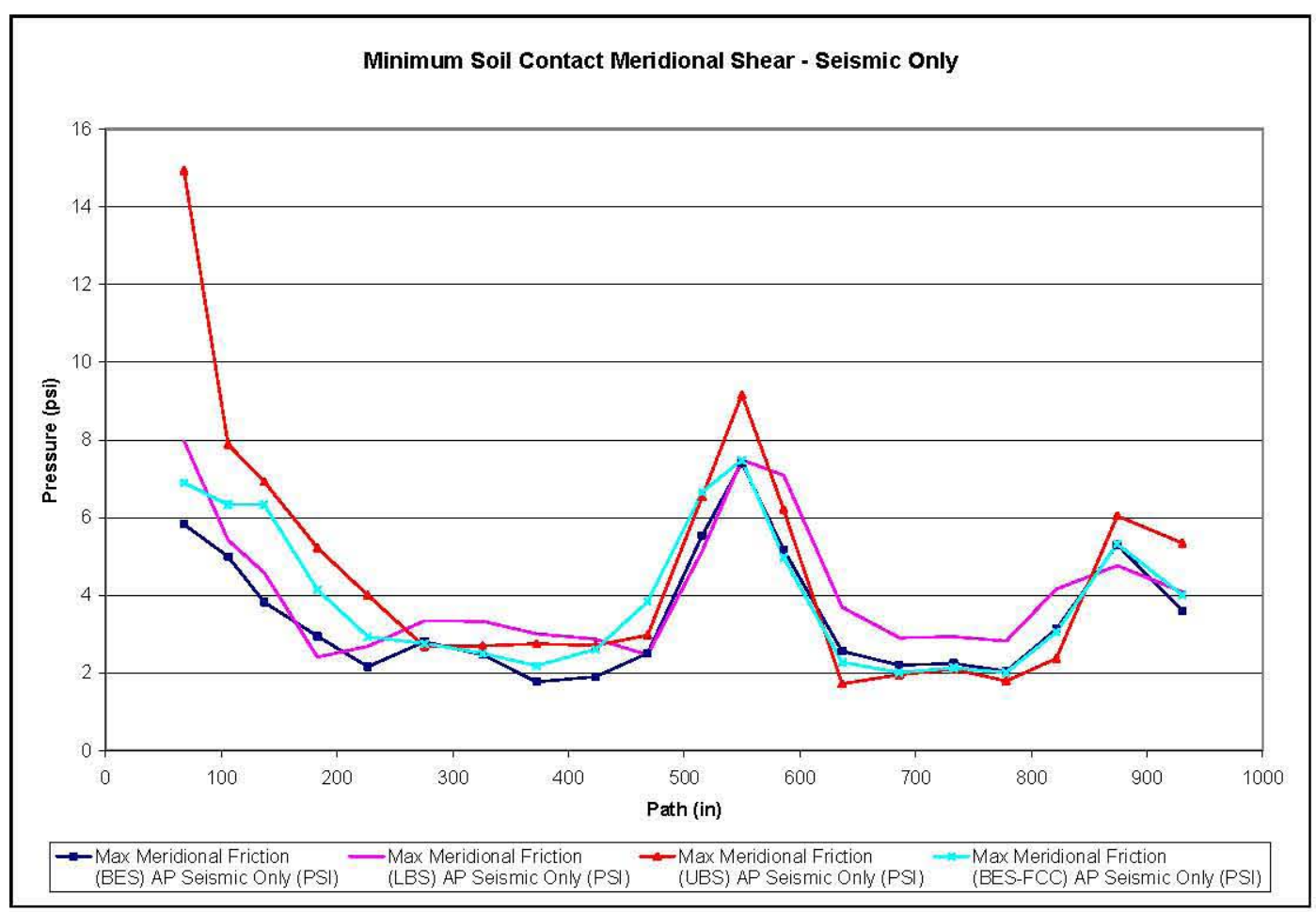

Figure 10-27. Soil/Concrete Contact Element Meridional Shear - Seismic Only 
RPP-RPT-32239, Rev. 1

M\&D-2008-005-CALC-001, Rev. 1

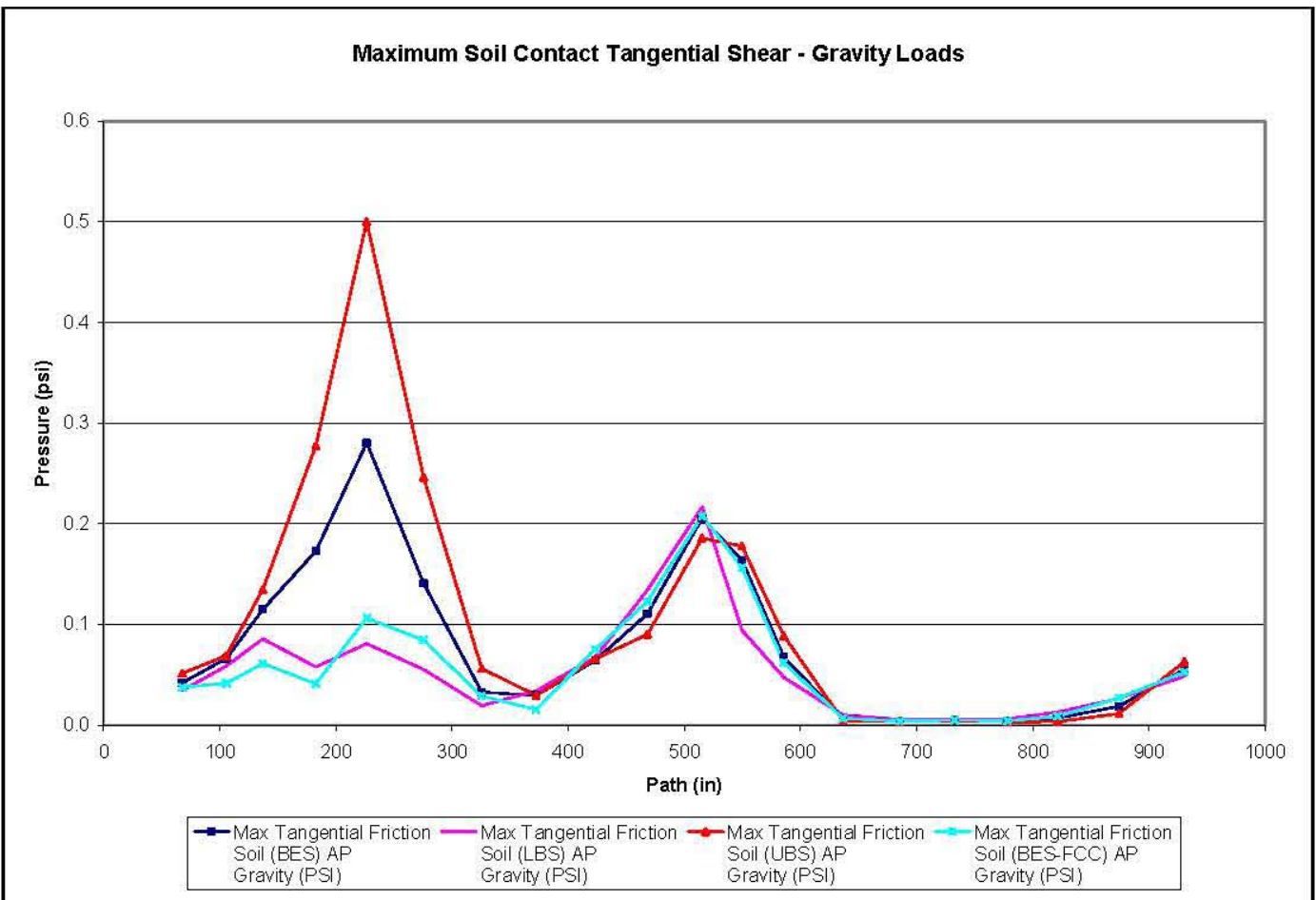

Figure 10-28. Soil/Concrete Contact Element Tangential Shear - Gravity Only

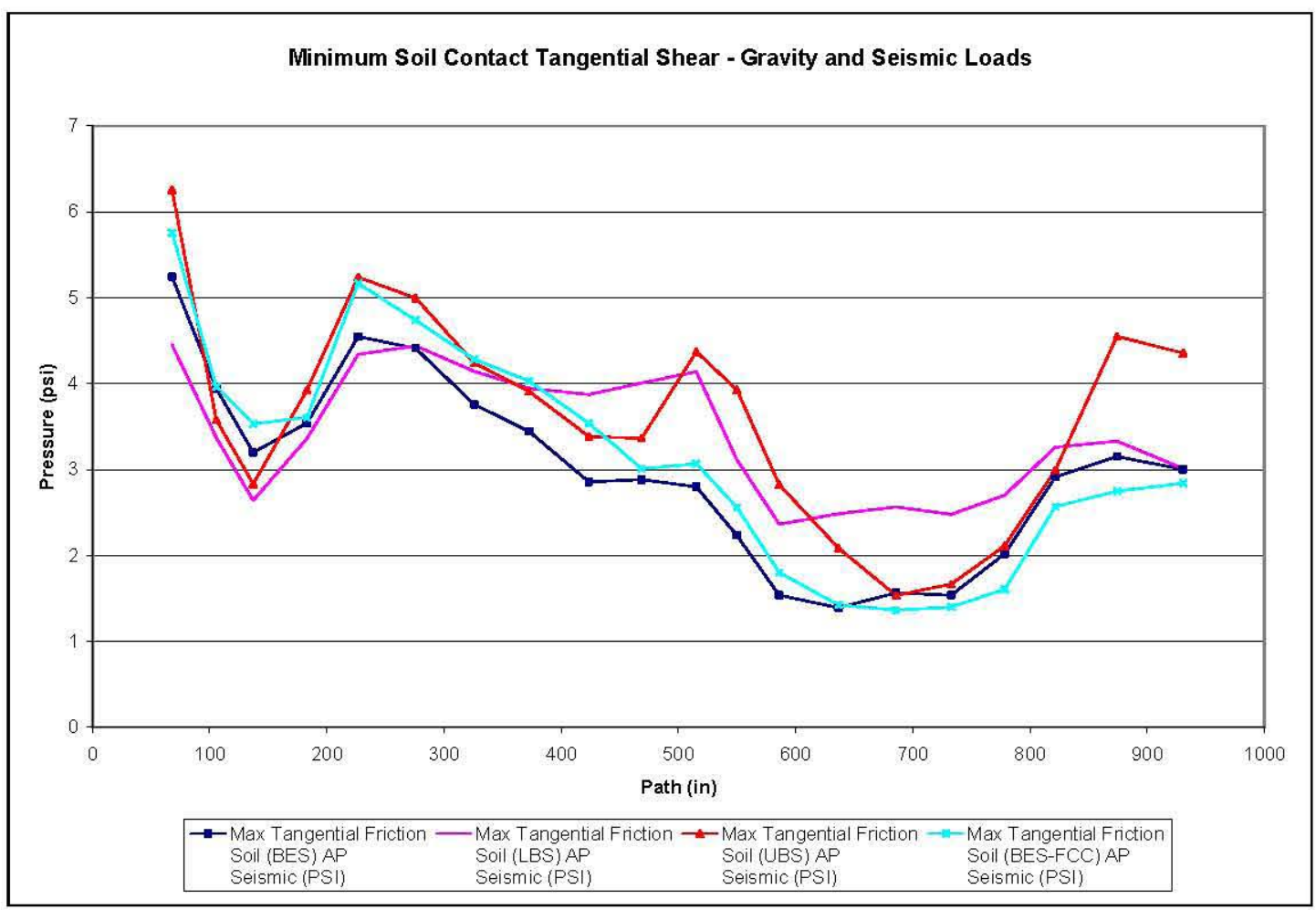

Figure 10-29. Soil/Concrete Contact Element Tangential Shear - Gravity Plus Seismic 
RPP-RPT-32239, Rev. 1

M\&D-2008-005-CALC-001, Rev. 1

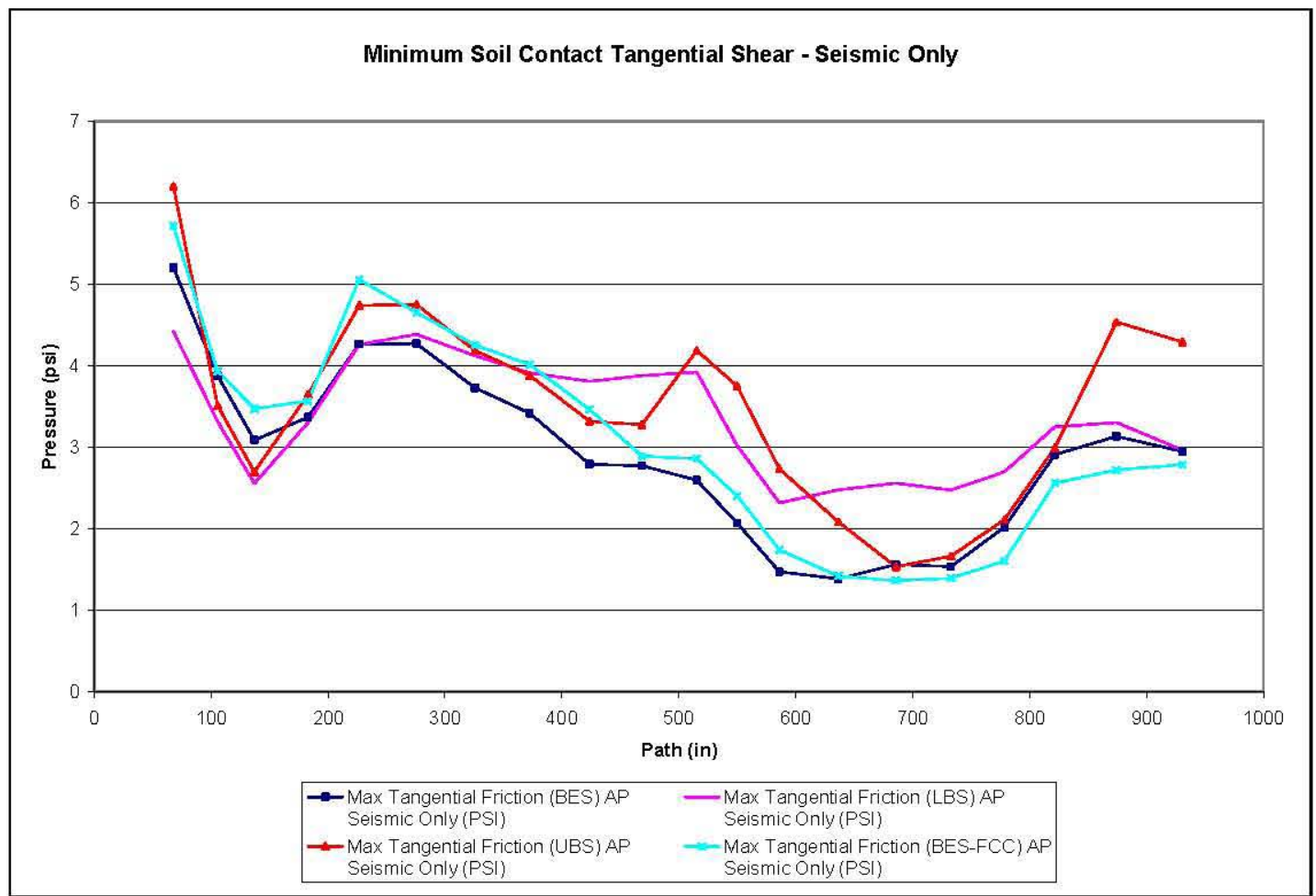

Figure 10-30. Soil/Concrete Contact Element Gap Tangential Shear - Seismic Only

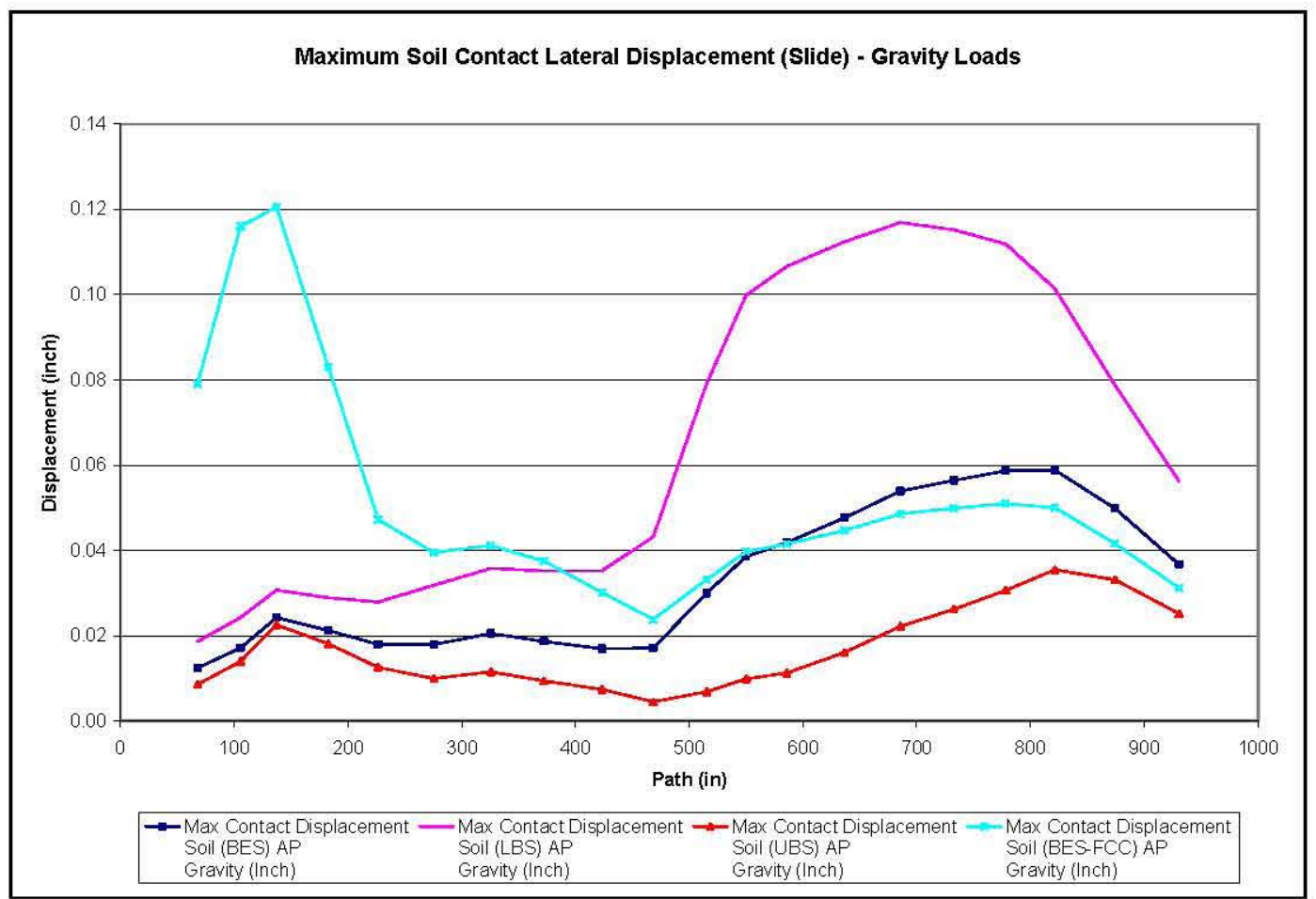

Figure 10-31. Soil/Concrete Contact Element Gap Lateral Displacement (Slide) - Gravity Only 
RPP-RPT-32239, Rev. 1

M\&D-2008-005-CALC-001, Rev. 1

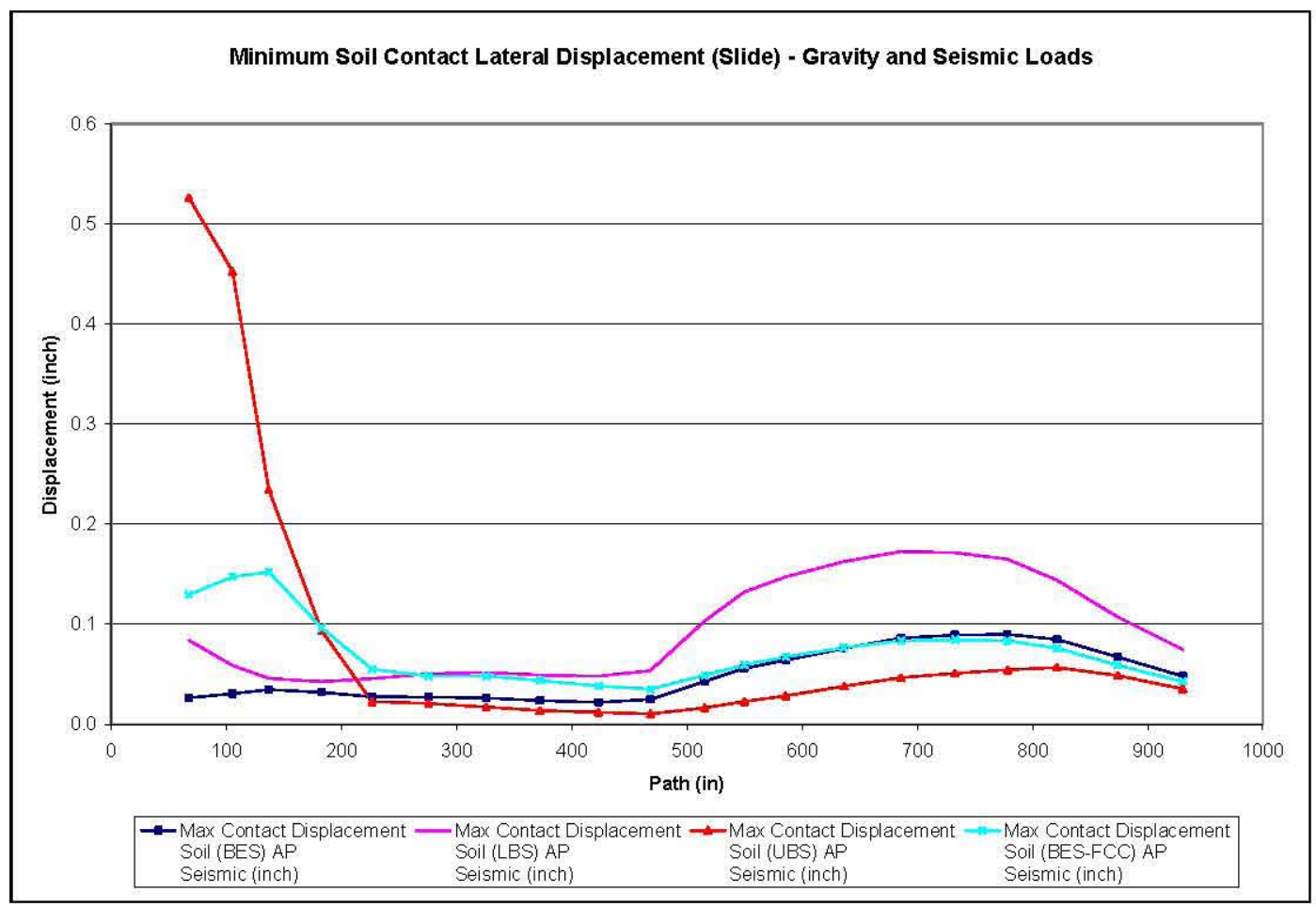

Figure 10-32. Soil/Concrete Contact Element Gap Lateral Displacement (Slide) - Gravity Plus Seismic

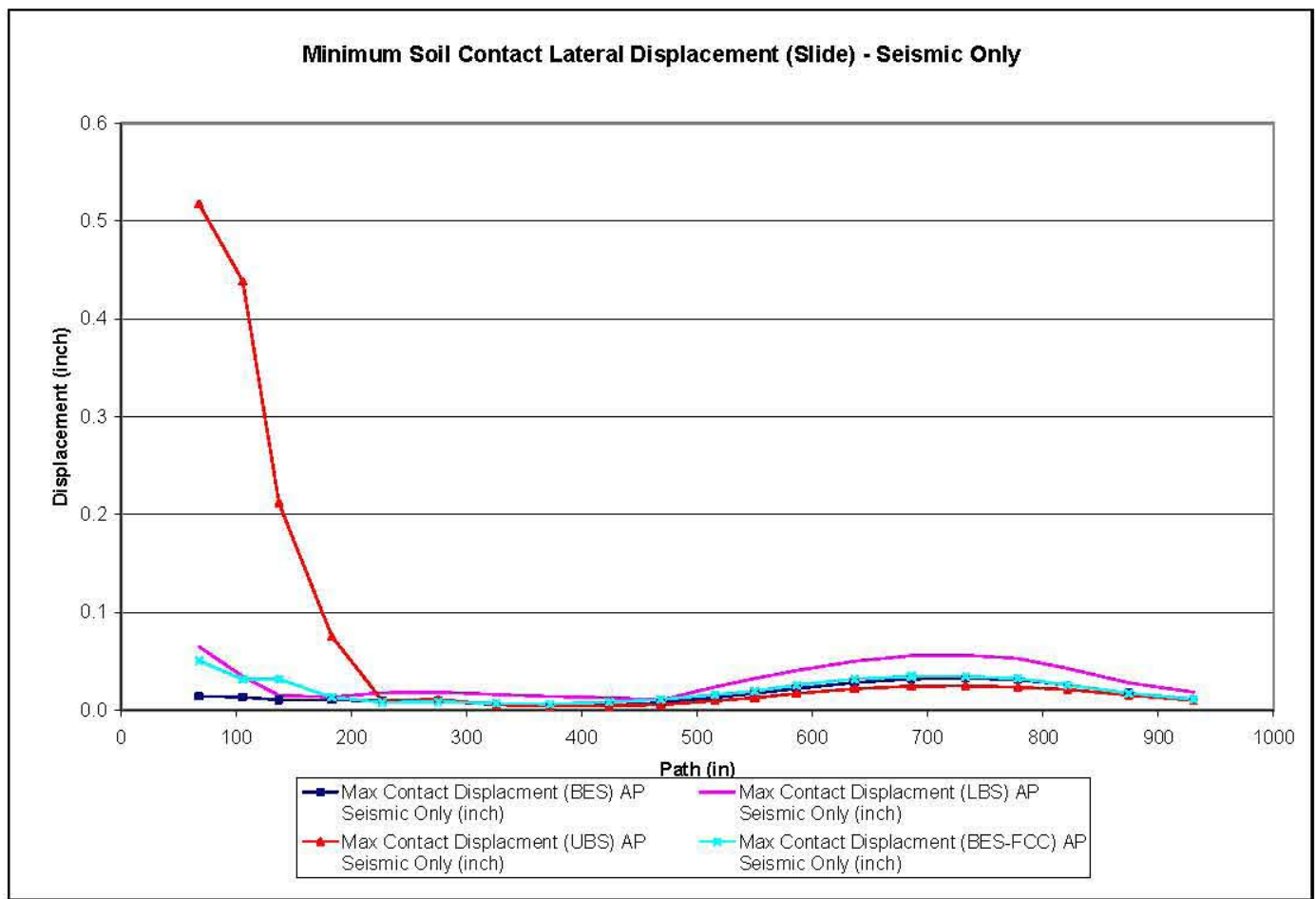

Figure 10-33. Soil/Concrete Contact Element Gap Lateral Displacement (Slide) - Seismic Only 
RPP-RPT-32239, Rev. 1

M\&D-2008-005-CALC-001, Rev. 1

To evaluate the soil loads on the concrete dome due to seismic loading, a comparison was made between the seismic soil pressure and gravity only soil pressures scaled by accelerations taken from the dome. For this comparison, soil pressures due to gravity load only were scaled by the vertical spectral accelerations at a frequency of $20 \mathrm{~Hz}$ taken at the haunch and center of the dome. The scaled gravity pressures provide an approximation of the pressure on the dome due to vertical excitation. The center of the dome can be expected to see a pressure associated with the acceleration at the center of the dome, decreasing toward the haunch. At the haunch and on the vertical wall, the pressures should correspond to the spectral acceleration at the haunch. Figure 10-34 through Figure 10-37 show this comparison for each load case. These comparisons demonstrate that there is not significant arching in the soil.

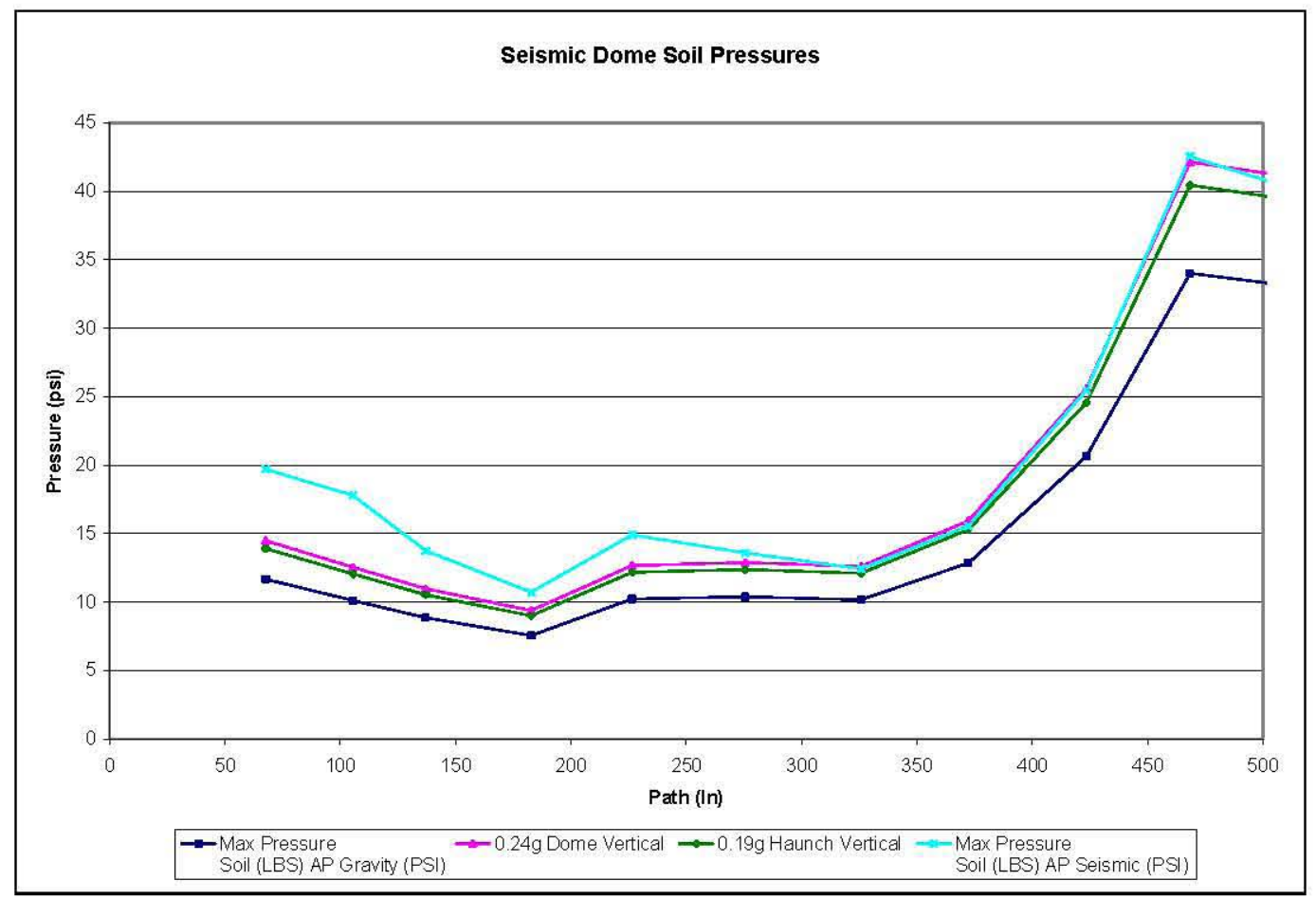

Figure 10-34. Seismic Soil Pressure Comparison to Scaled Gravity Soil Pressures, LBS-BEC 
RPP-RPT-32239, Rev. 1

M\&D-2008-005-CALC-001, Rev. 1

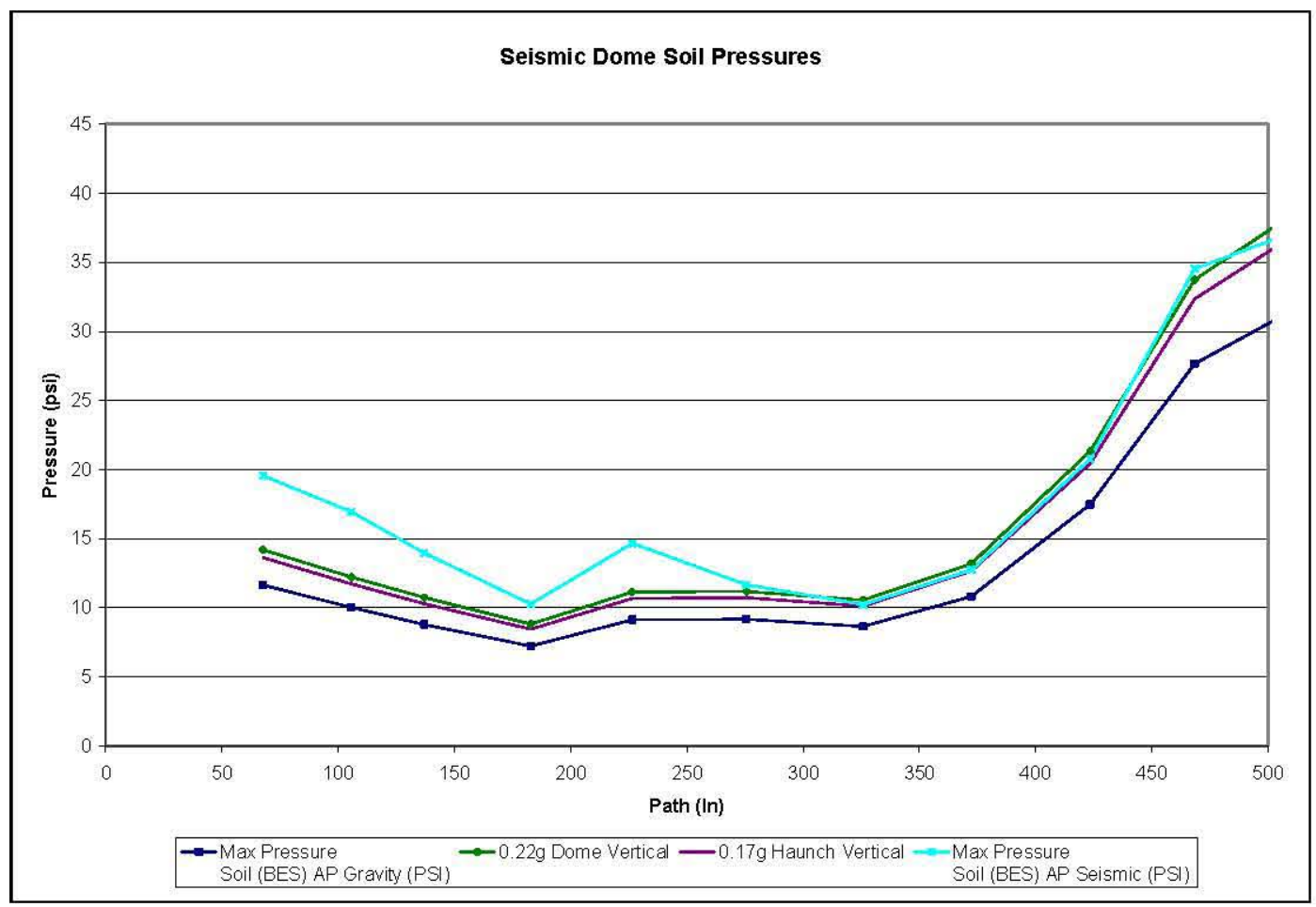

Figure 10-35. Seismic Soil Pressure Comparison to Scaled Gravity Soil Pressures, BES-BEC

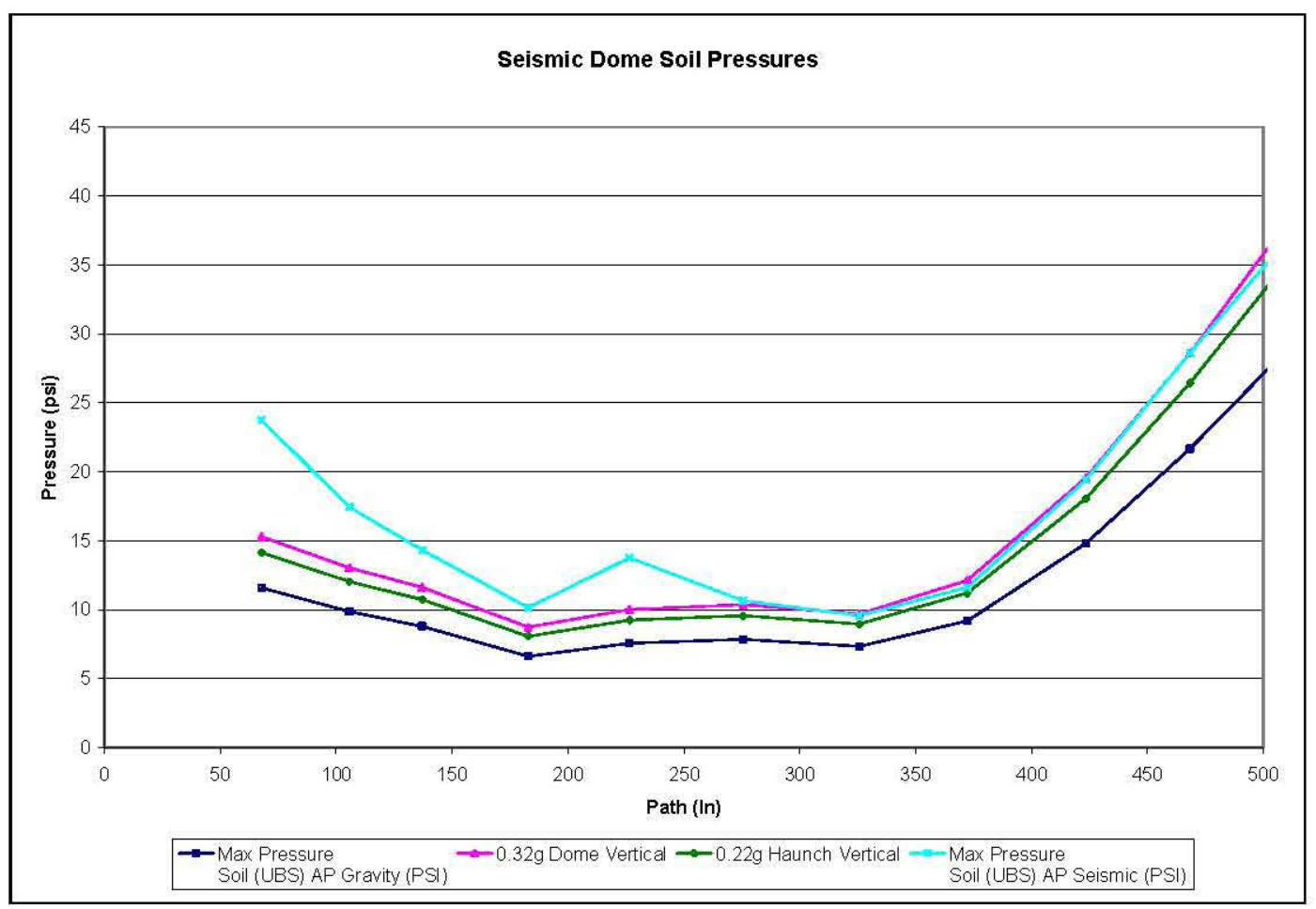

Figure 10-36. Seismic Soil Pressure Comparison to Scaled Gravity Soil Pressures, UBS-BEC 
RPP-RPT-32239, Rev. 1

M\&D-2008-005-CALC-001, Rev. 1

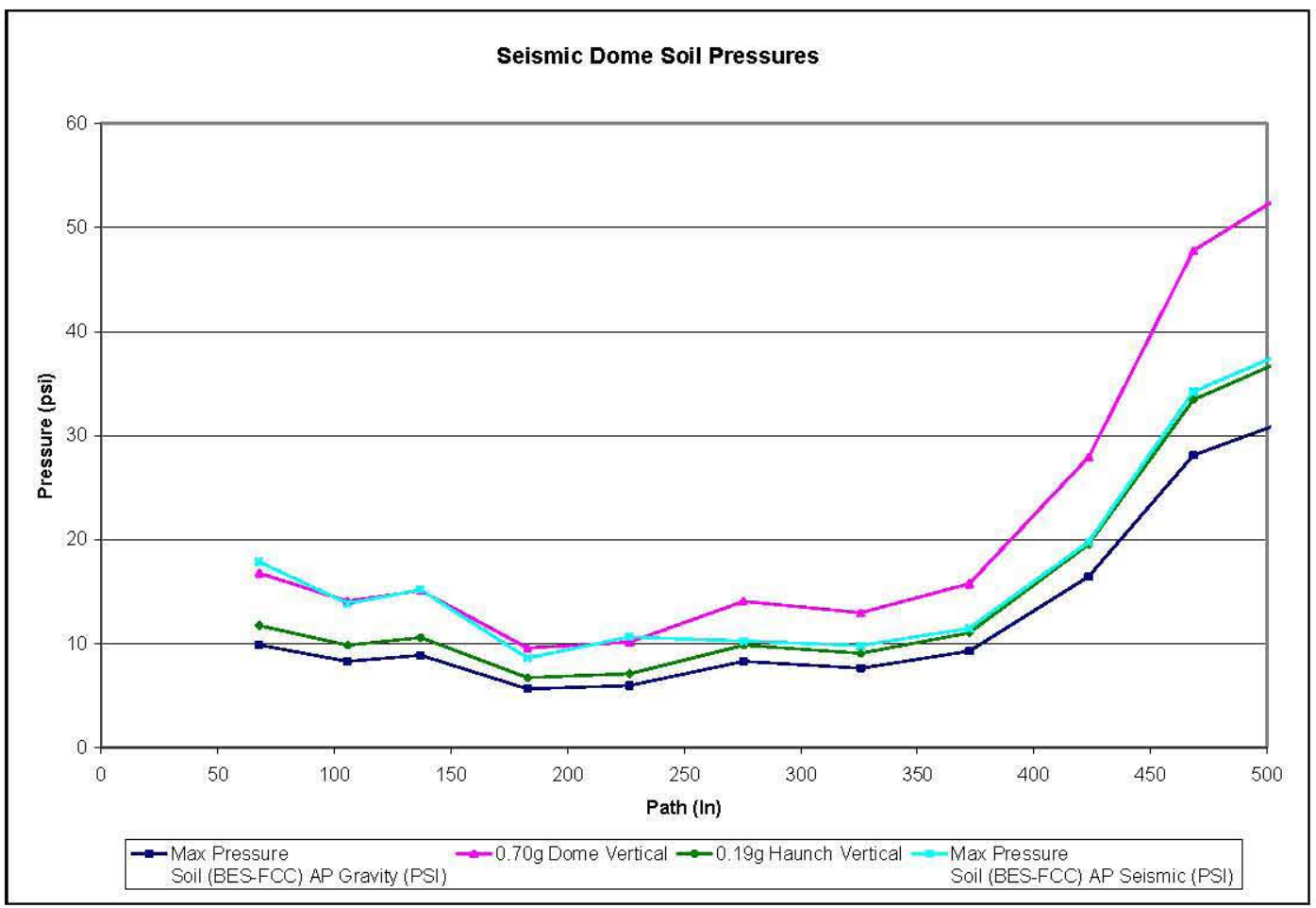

Figure 10-37. Seismic Soil Pressure Comparison to Scaled Gravity Soil Pressures, BES-FCC

\subsection{Dome Contact Results for the Revision 1 Model}

Dome contact data are extracted from the model in $9^{\circ}$ slices, starting near the top of the dome and moving out to the tangent point of the primary tank. Contact normal and other contact data were extracted for the interface between primary tank and concrete dome. Figure 10-38 shows the location and element numbers for first slice of contact elements. The following data were extracted for each CONTA173 element

- CONT-PRES Normal Contact Pressure

- CONT-SLIDE Contact Lateral Displacement

- CONT-GAP Contact Gap Distance

- CONT-STAT Contact Status (Open, Closed, Sliding)

For each load case, the minimum and maximum contact pressure, lateral displacements, and gaps are compared. The figures for each component are grouped by gravity only, gravity plus seismic, and seismic only. For the dome contact interface, the following figures are provided.

- Figure 10-39. Primary Tank/Concrete Dome Contact Element Maximum Contact Pressure Gravity Only

- Figure 10-40. Primary Tank/Concrete Dome Contact Element Maximum Contact Pressure Gravity Plus Seismic

- Figure 10-41. Primary Tank/Concrete Dome Contact Element Maximum Contact Pressure Seismic 
RPP-RPT-32239, Rev. 1

M\&D-2008-005-CALC-001, Rev. 1

- Figure 10-42. Primary Tank/Concrete Dome Contact Element Maximum Contact Gap - Gravity Only

- Figure 10-43. Primary Tank/Concrete Dome Contact Element Maximum Contact Gap - Gravity Plus Seismic

- Figure 10-44. Primary Tank/Concrete Dome Contact Element Maximum Contact Gap - Seismic Only

- Figure 10-45. Primary Tank/Concrete Dome Contact Element Maximum Contact Lateral Displacement (Slide) - Gravity Only

- Figure 10-46. Primary Tank/Concrete Dome Contact Element Maximum Contact Lateral Displacement (Slide) - Gravity Plus Seismic

- Figure 10-47. Primary Tank/Concrete Dome Contact Element Maximum Contact Lateral Displacement (Slide) - Seismic Only

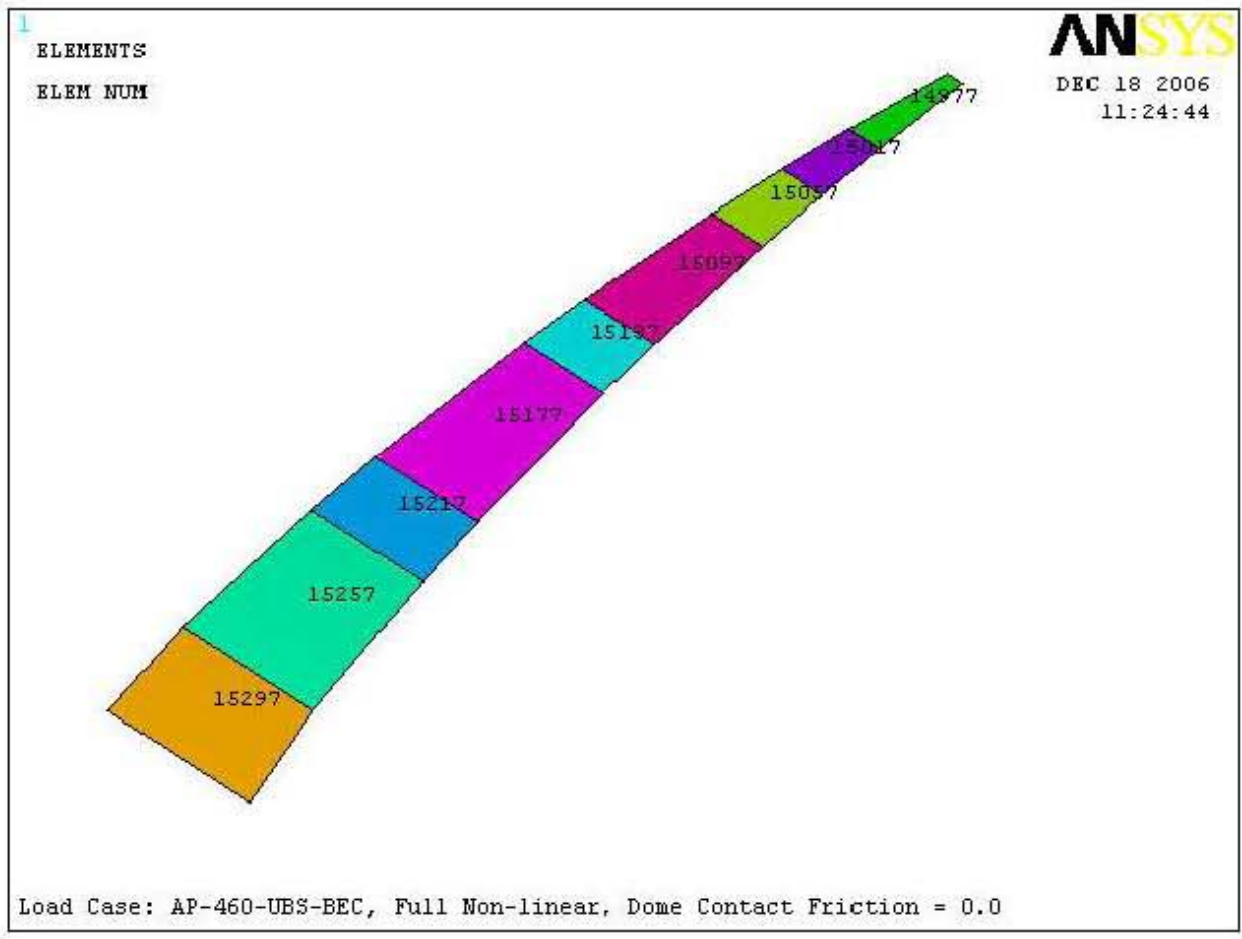

Figure 10-38. Primary Tank Dome Contact Element Retrieval Sequence Starting Numbers 
RPP-RPT-32239, Rev. 1

M\&D-2008-005-CALC-001, Rev. 1

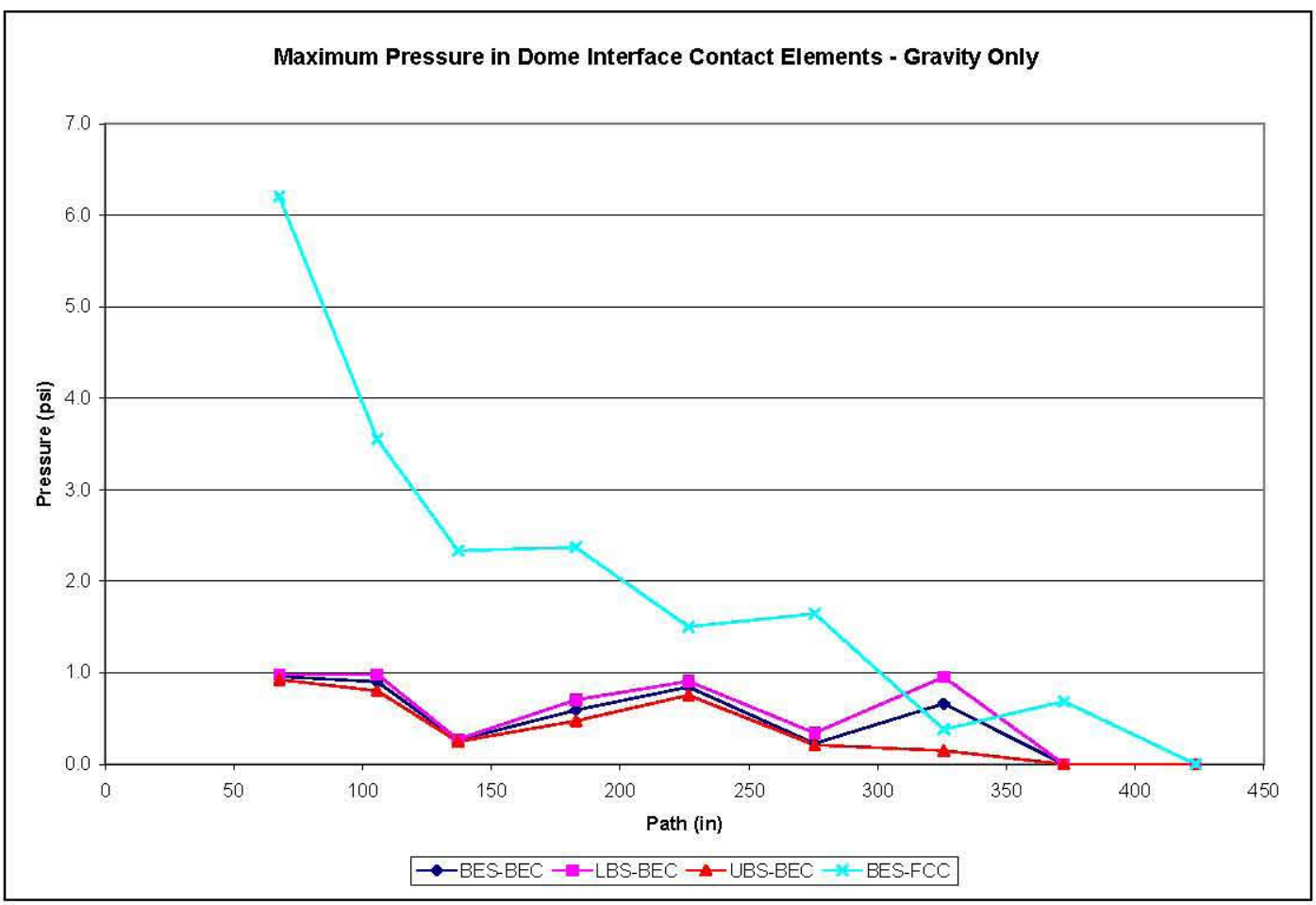

Figure 10-39. Primary Tank/Concrete Dome Contact Element Maximum Contact Pressure - Gravity Only

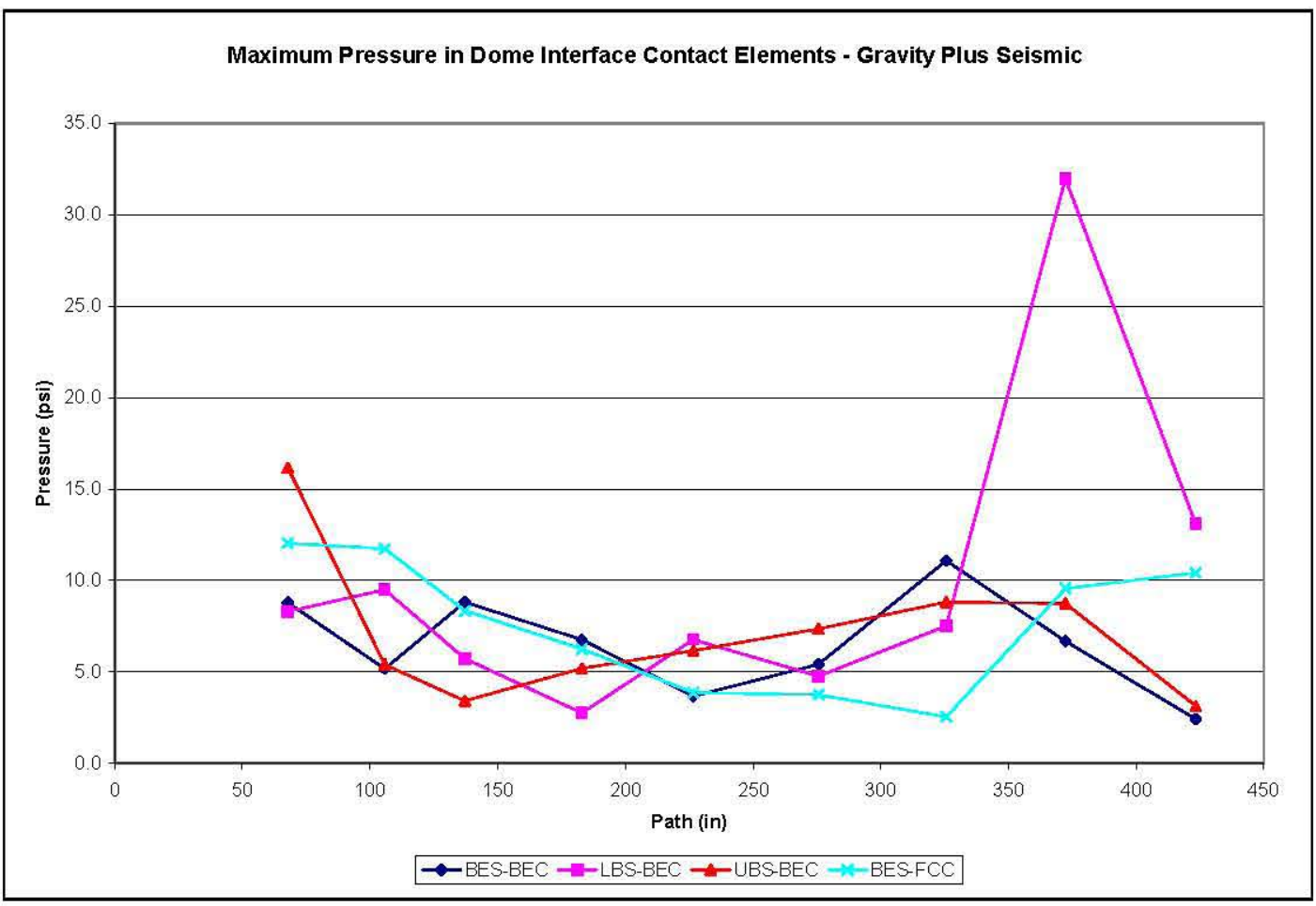

Figure 10-40. Primary Tank/Concrete Dome Contact Element Maximum Contact Pressure - Gravity Plus Seismic 
RPP-RPT-32239, Rev. 1

M\&D-2008-005-CALC-001, Rev. 1

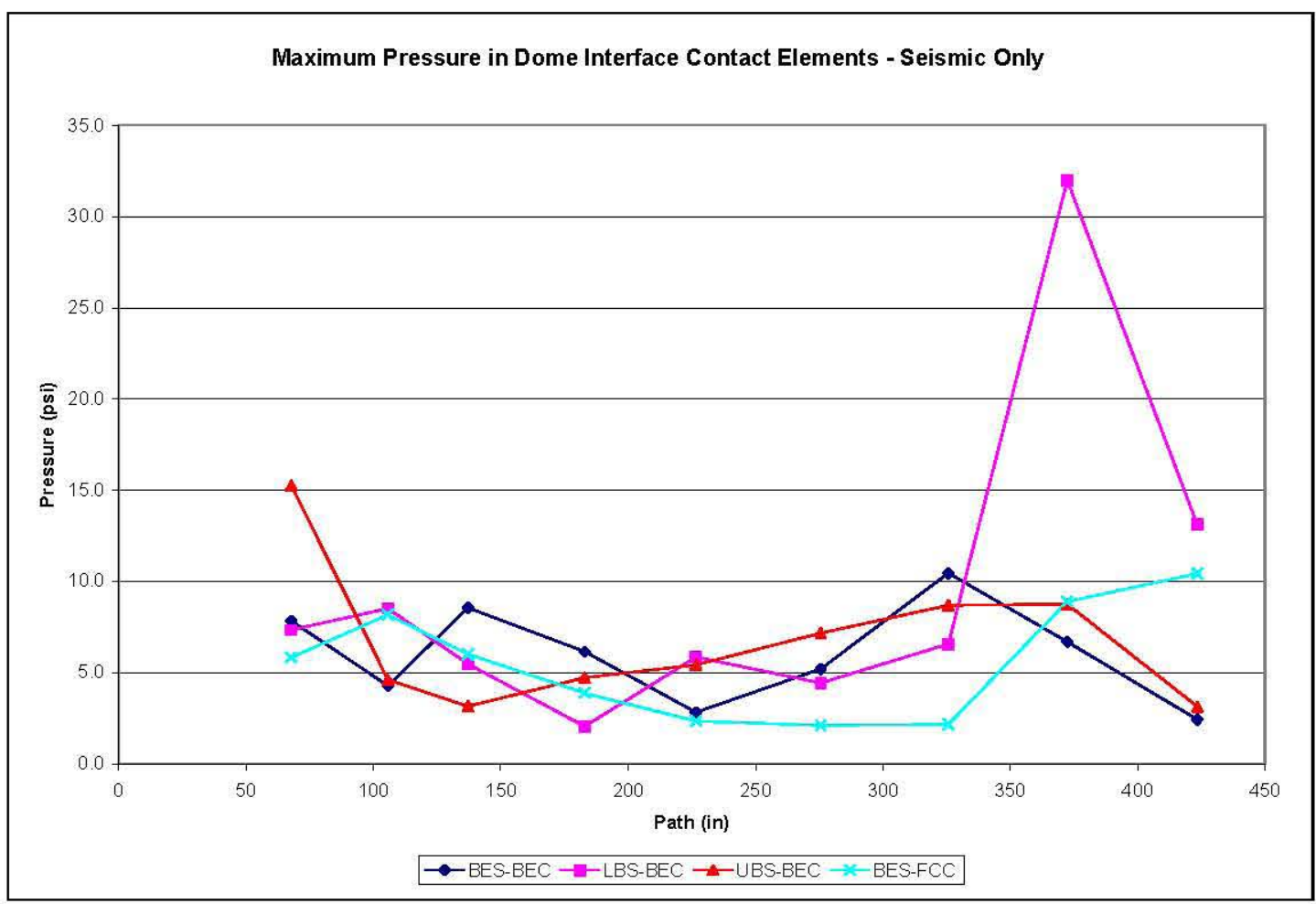

Figure 10-41. Primary Tank/Concrete Dome Contact Element Maximum Contact Pressure - Seismic Only

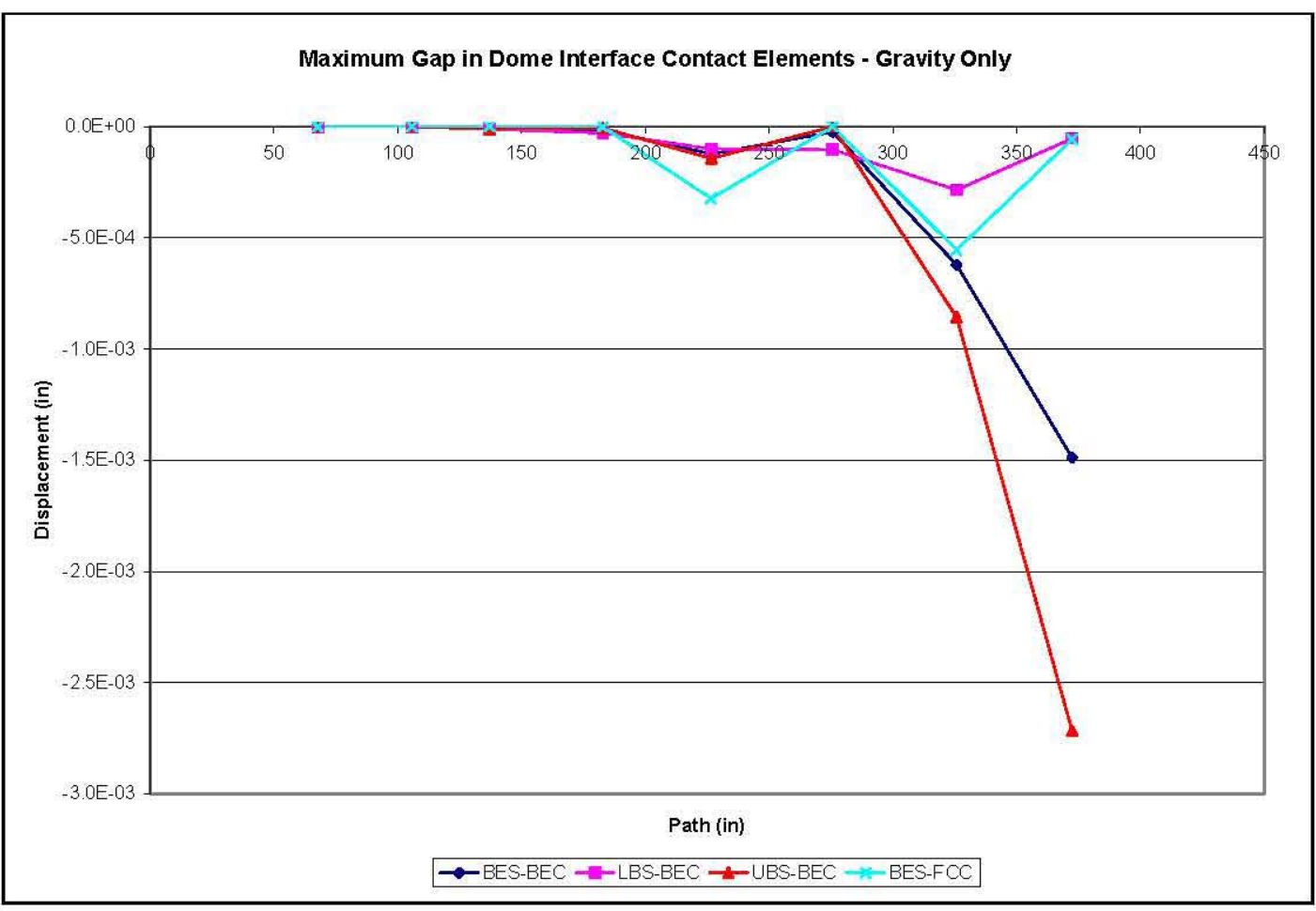

Figure 10-42. Primary Tank/Concrete Dome Contact Element Maximum Contact Gap - Gravity Only 
RPP-RPT-32239, Rev. 1

M\&D-2008-005-CALC-001, Rev. 1

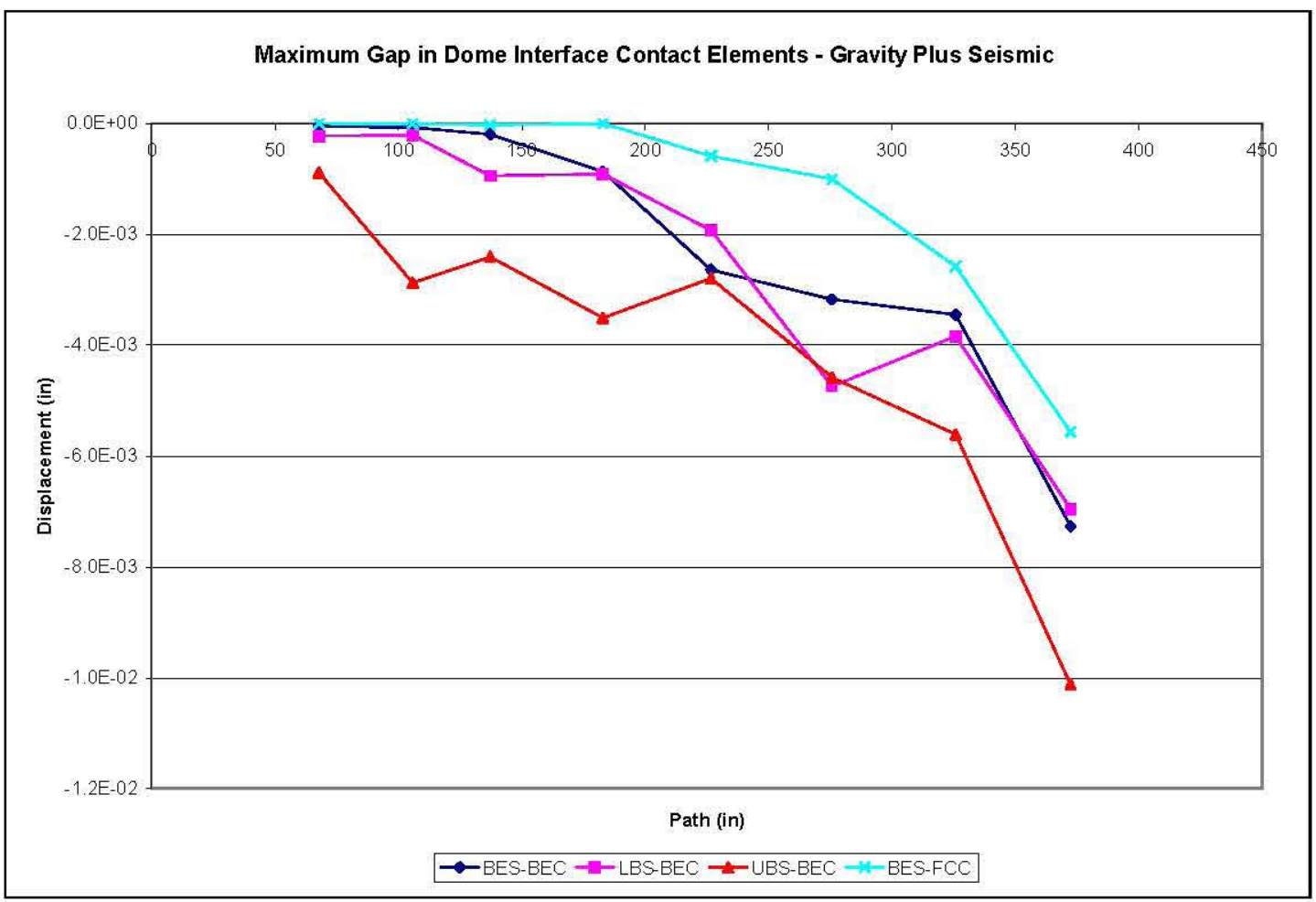

Figure 10-43. Primary Tank/Concrete Dome Contact Element Maximum Contact Gap - Gravity Plus Seismic

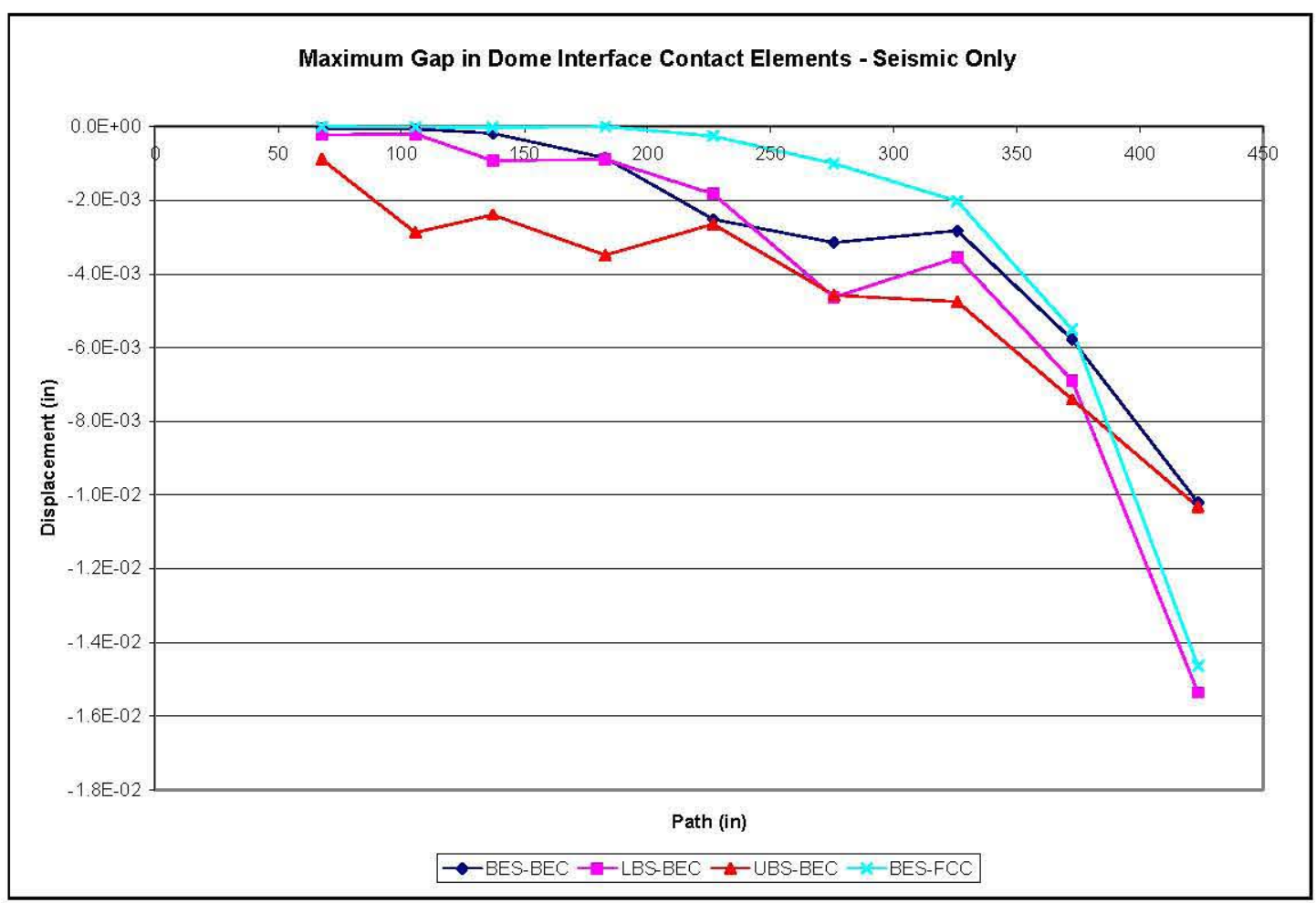

Figure 10-44. Primary Tank/Concrete Dome Contact Element Maximum Contact Gap - Seismic Only 
RPP-RPT-32239, Rev. 1

M\&D-2008-005-CALC-001, Rev. 1

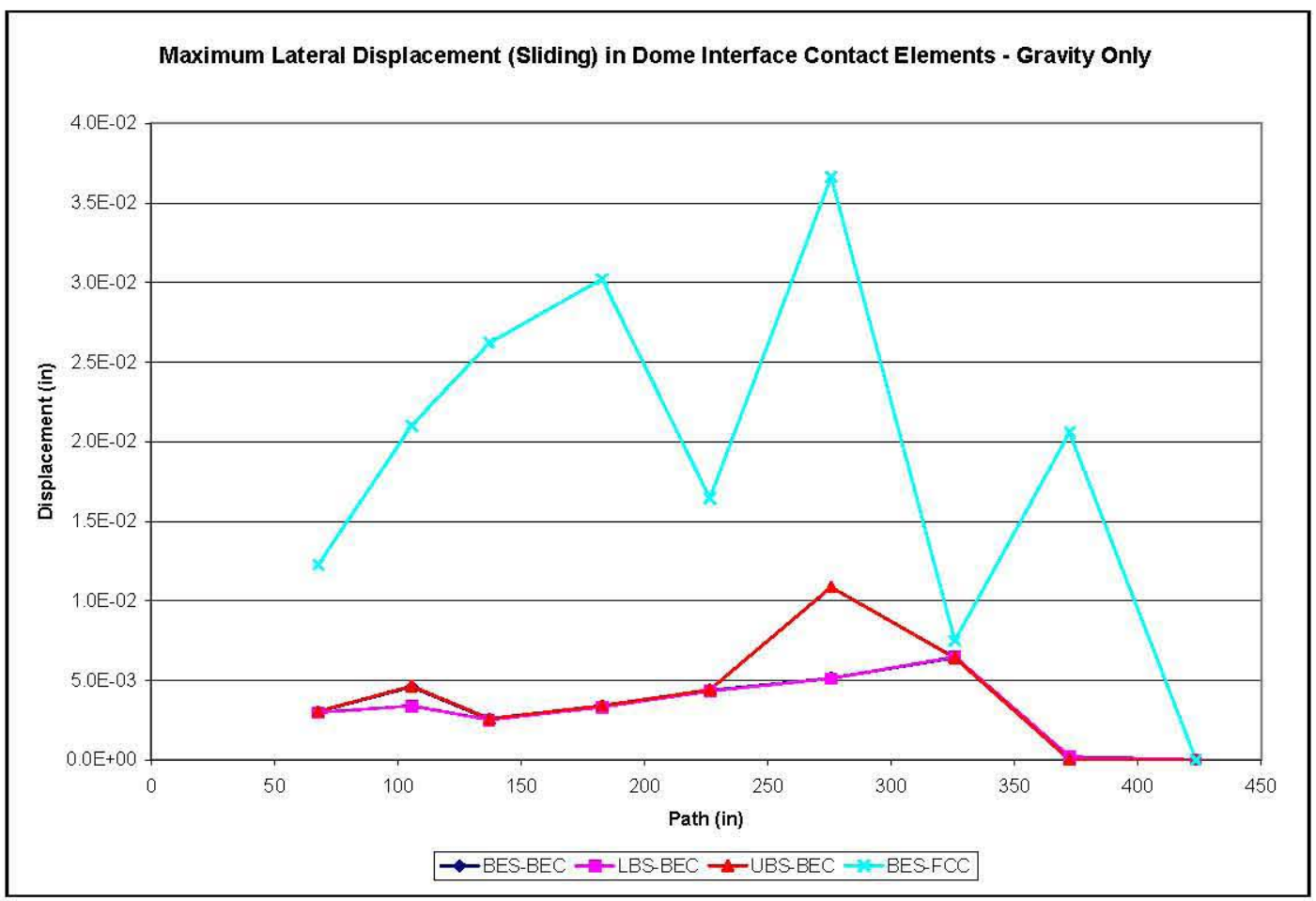

Figure 10-45. Primary Tank/Concrete Dome Contact Element Maximum Contact Lateral Displacement (Slide) - Gravity Only

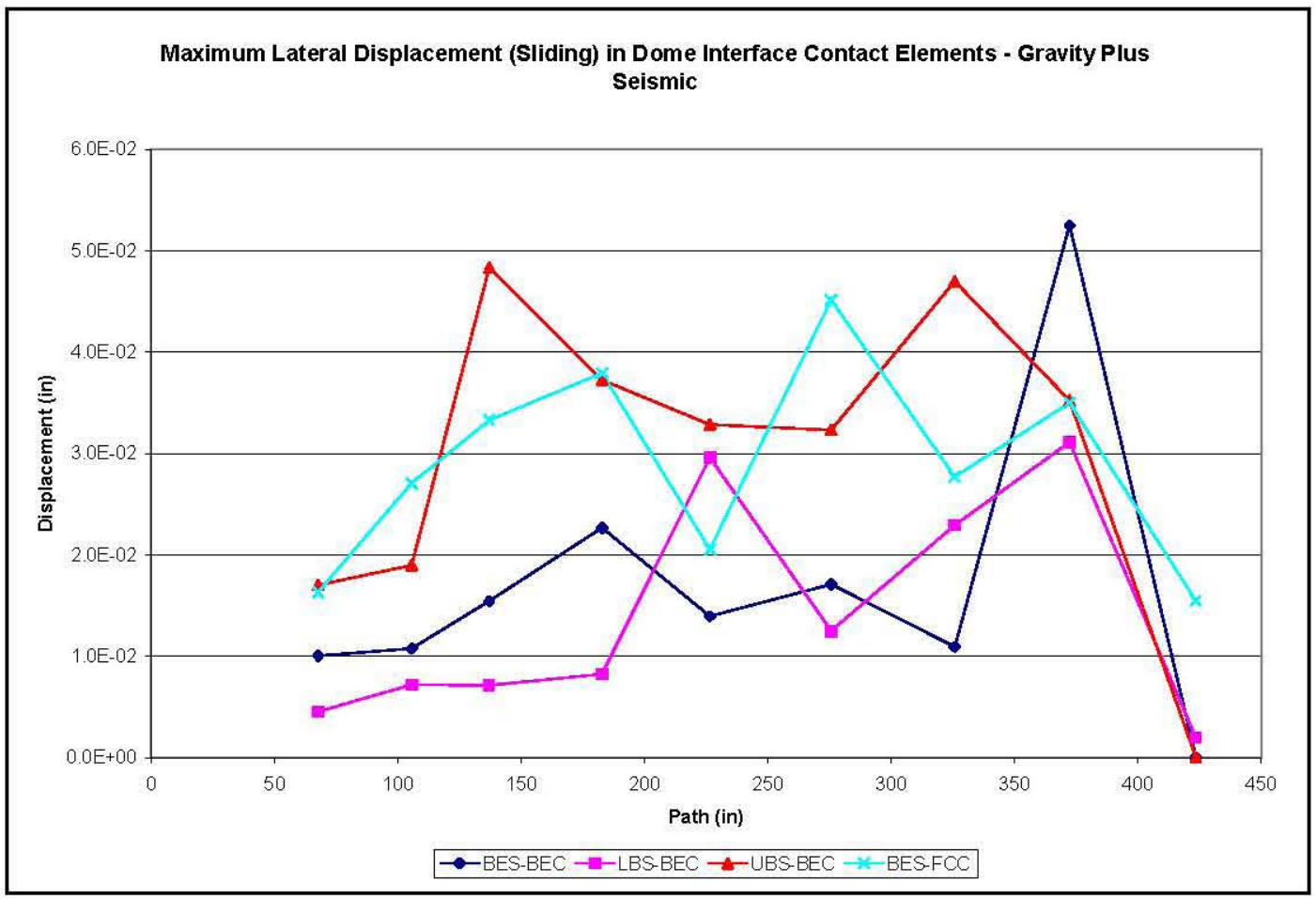

Figure 10-46. Primary Tank/Concrete Dome Contact Element Maximum Contact Lateral Displacement (Slide) - Gravity Plus Seismic 
RPP-RPT-32239, Rev. 1

M\&D-2008-005-CALC-001, Rev. 1

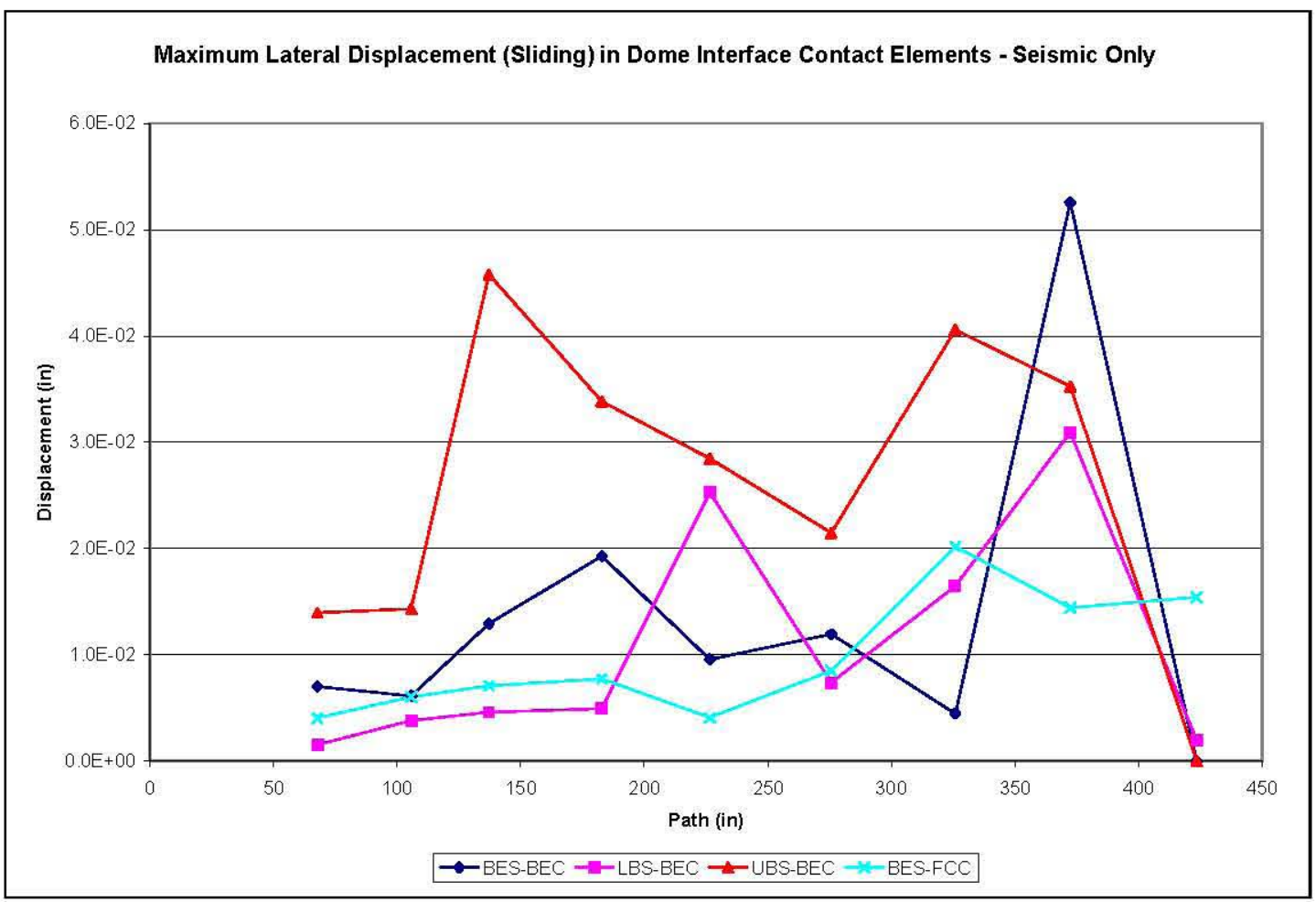

Figure 10-47. Primary Tank/Concrete Dome Contact Element Maximum Contact Lateral Displacement (Slide) - Seismic Only

\subsection{Primary Tank/Insulating Concrete Contact Results for the Revision 0 Model}

Primary Tank/Insulating Concrete contact data are extracted from the model in $9^{\circ}$ slices, starting at the outside radius of the primary tank, moving in toward the center. Contact normal and other contact data were extracted for the interface between primary tank and insulating concrete. Figure 10-48 shows the location and element numbers for first slice of contact elements. The following data were extracted for each CONTA173 element

- CONT-PRES

- CONT-SLIDE

- CONT-GAP

- CONT-STAT
Normal Contact Pressure

Contact Lateral Displacement

Contact Gap Distance

Contact Status (Open, Closed, Sliding)

For each load case, the minimum and maximum contact pressure, lateral displacements, and gaps are compared. The figures for each component are grouped by gravity only, gravity plus seismic, and seismic only. For the primary tank/insulating concrete contact interface, the following figures are provided.

- Figure 10-49. Primary Tank/Insulating Concrete Contact Element Contact Pressure - Gravity Only

- Figure 10-50. Primary Tank/Insulating Concrete Contact Element Maximum Contact Pressure Gravity Plus Seismic 
RPP-RPT-32239, Rev. 1

M\&D-2008-005-CALC-001, Rev. 1

- Figure 10-51. Primary Tank/Insulating Concrete Contact Element Minimum Contact Pressure Gravity Plus Seismic

- Figure 10-52. Primary Tank/Insulating Conerete Contact Element Maximum Contact Pressure Seismic Only

- Figure 10-53. Primary Tank/Insulating Conerete Contact Element Minimum Contact Pressure Seismic Only

- Figure 10-54. Primary Tank/Insulating Concrete Contact Element Maximum Contact Gap Gravity Only

- Figure 10-55. Primary Tank/Insulating Concrete Contact Element Maximum Contact Gap Gravity Plus Seismic

- Figure 10-56. Primary Tank/Insulating Concrete Contact Element Maximum Contact Gap Seismic Only

- Figure 10-57. Primary Tank/Insulating Conerete Contact Element Maximum Contact Lateral Displacement (Slide) - Gravity Only

- Figure 10-58. Primary Tank/Insulating Concrete Contact Element Maximum Contact Lateral Displacement (Slide) - Gravity Plus Seismic

- Figure 10-59. Primary Tank/Insulating Concrete Contact El ement Maximum Contact Lateral Displacement (Slide) - Seismic Only

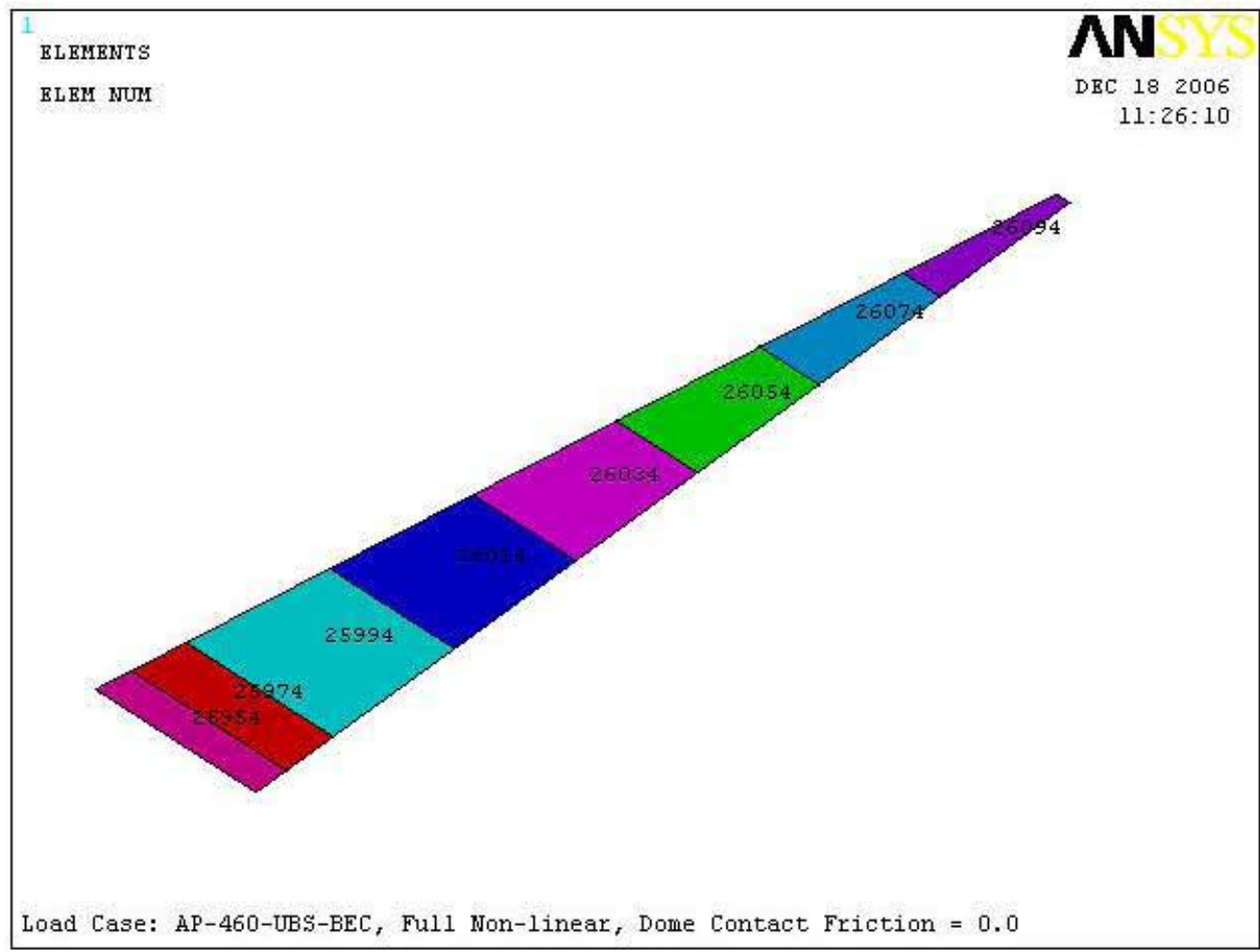

Figure 10-48. Primary Tank Bottom Contact Element Retrieval Sequence Starting Numbers 
RPP-RPT-32239, Rev. 1

M\&D-2008-005-CALC-001, Rev. 1

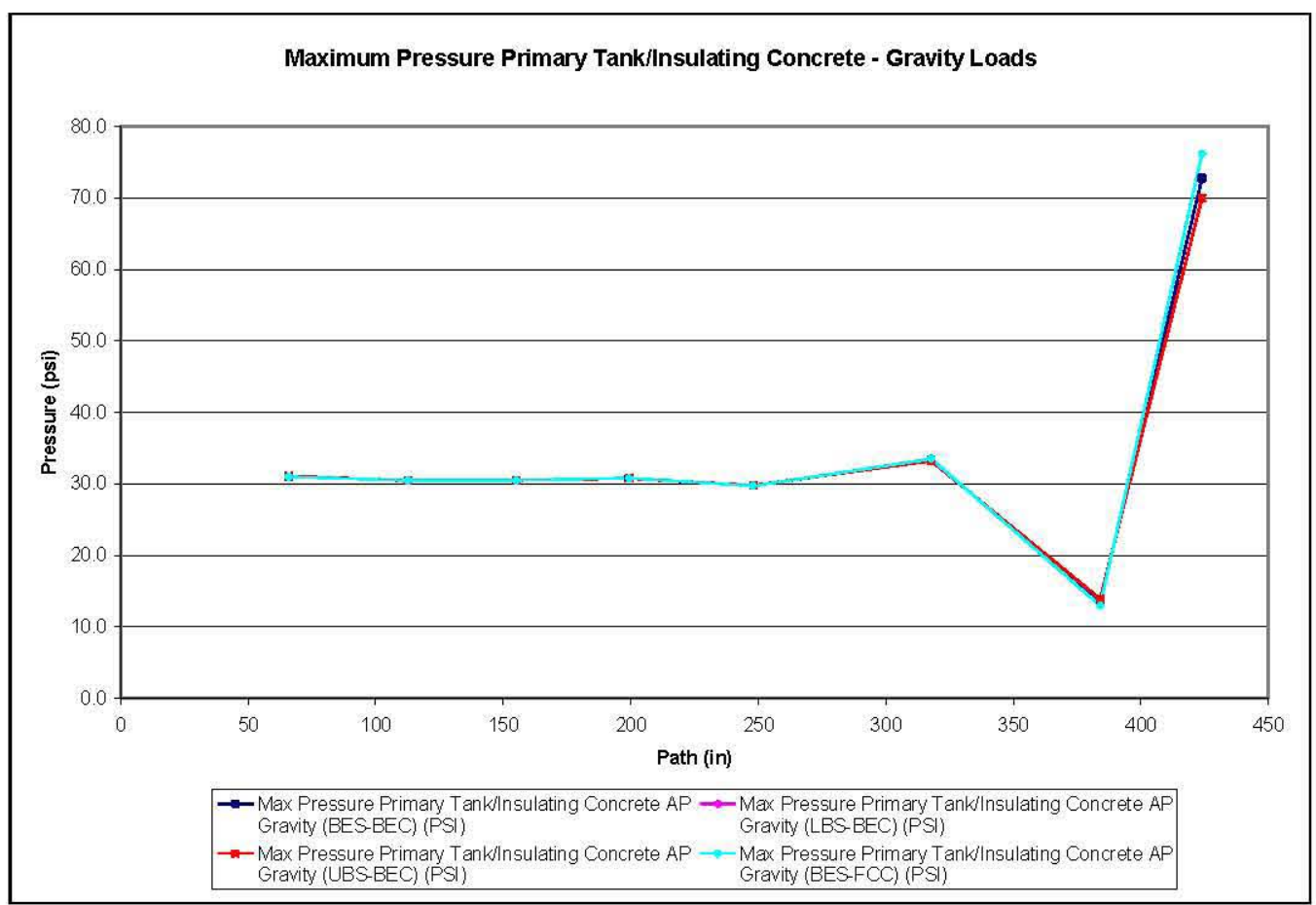

Figure 10-49. Primary Tank/Insulating Concrete Contact Element Contact Pressure - Gravity Only

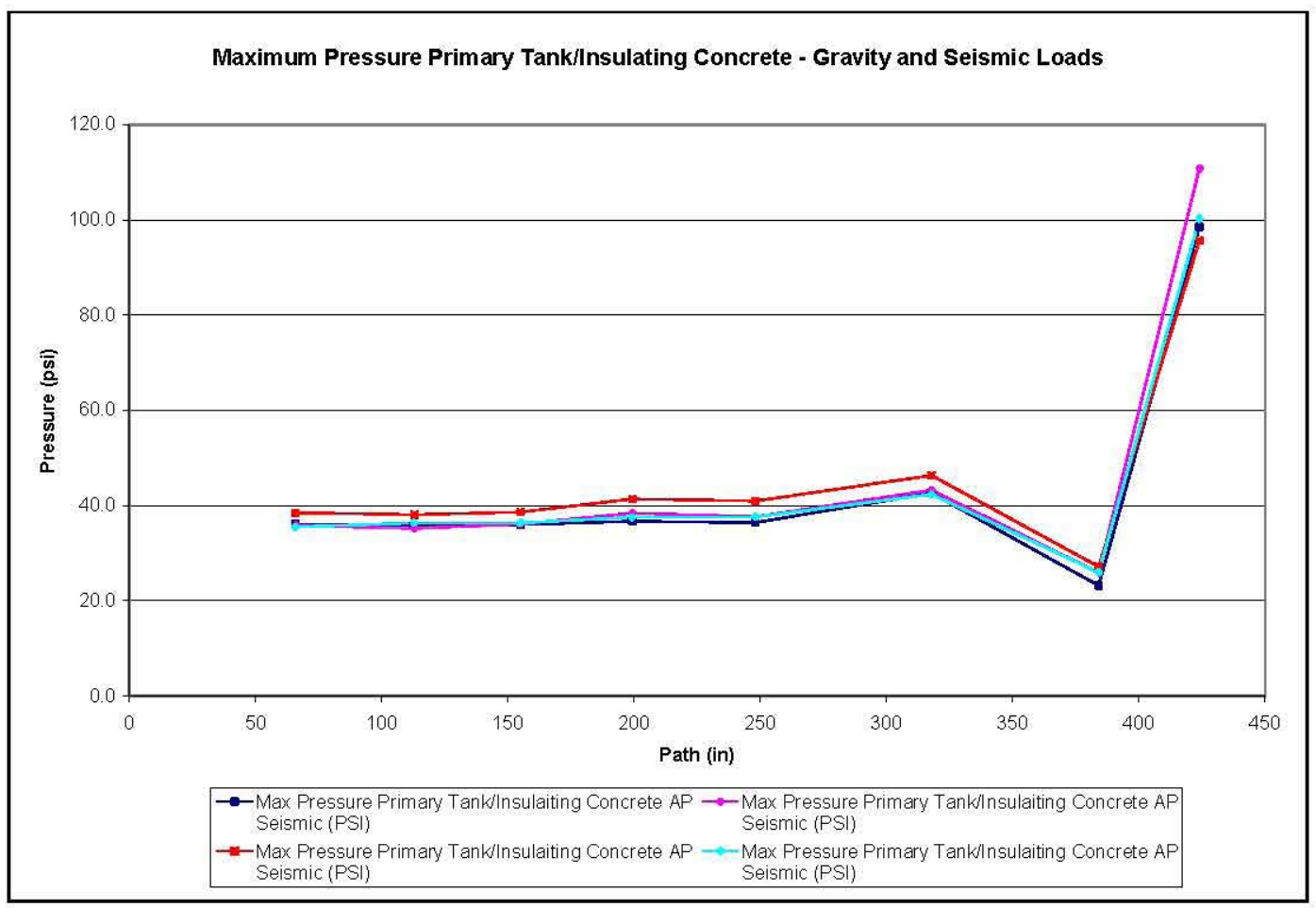

Figure 10-50. Primary Tank/Insulating Concrete Contact Element Maximum Contact Pressure Gravity Plus Seismic 
RPP-RPT-32239, Rev. 1

M\&D-2008-005-CALC-001, Rev. 1

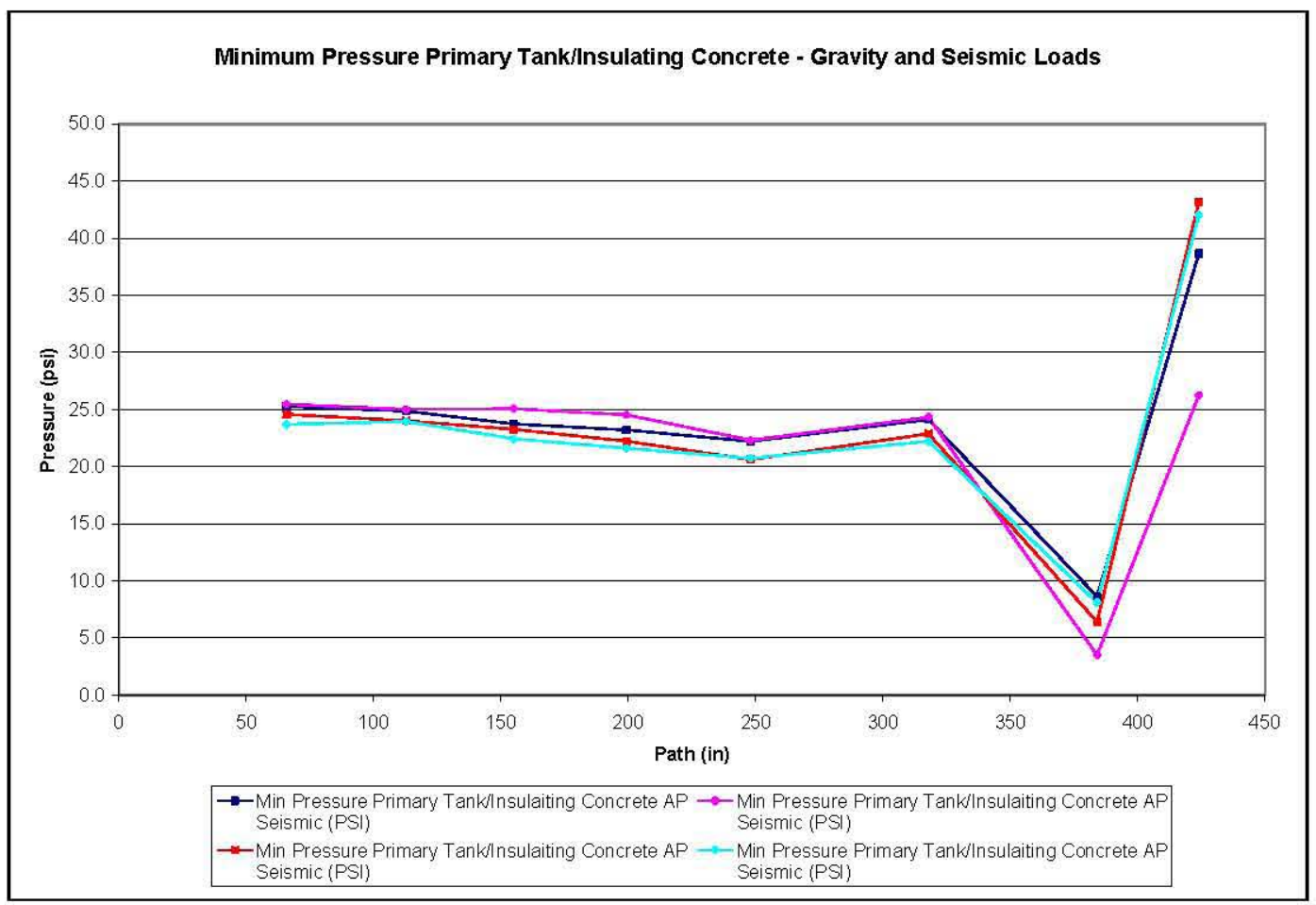

Figure 10-51. Primary Tank/Insulating Concrete Contact Element Minimum Contact Pressure - Gravity Plus Seismic

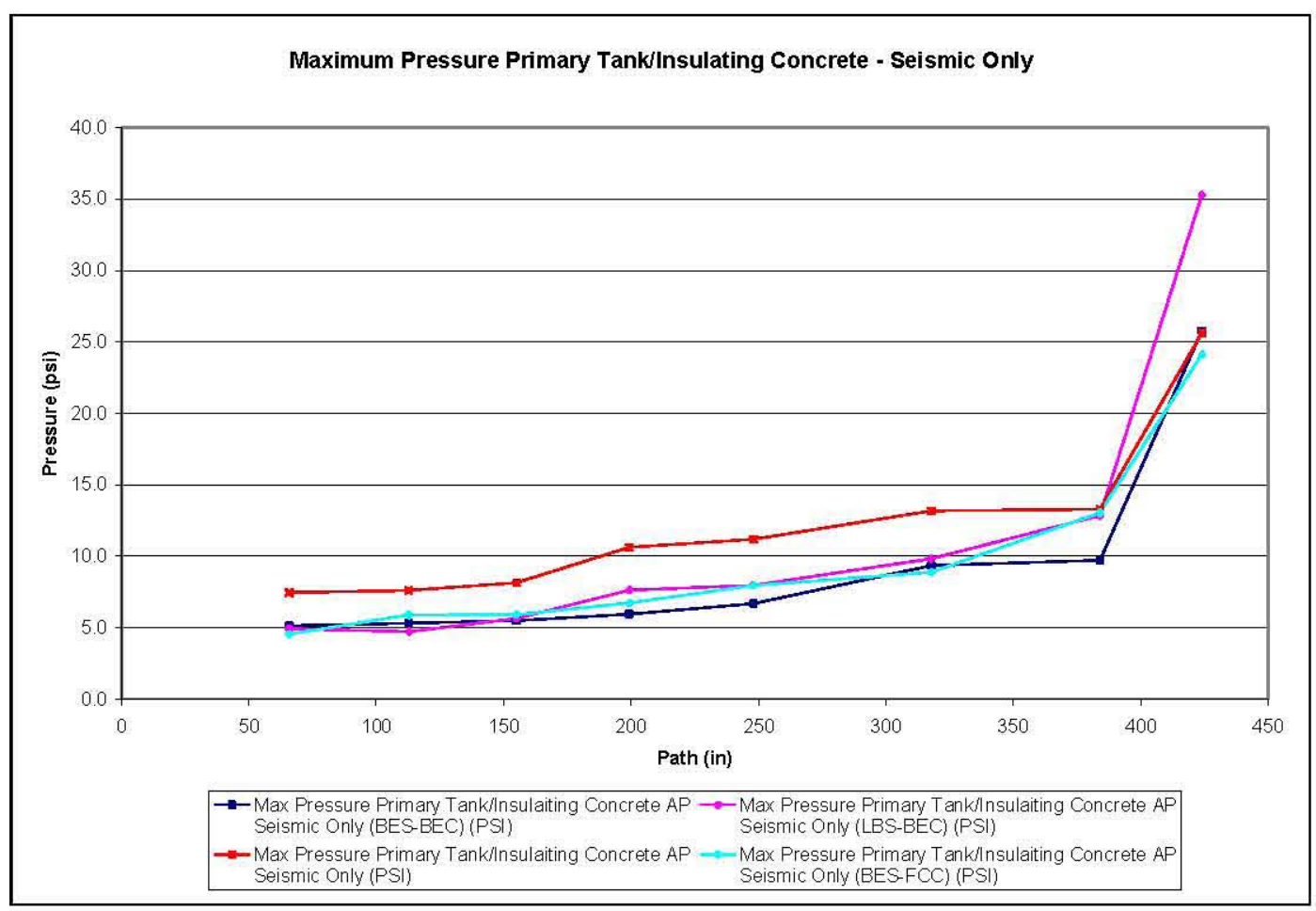

Figure 10-52. Primary Tank/Insulating Concrete Contact Element Maximum Contact Pressure Seismic Only 
RPP-RPT-32239, Rev. 1

M\&D-2008-005-CALC-001, Rev. 1

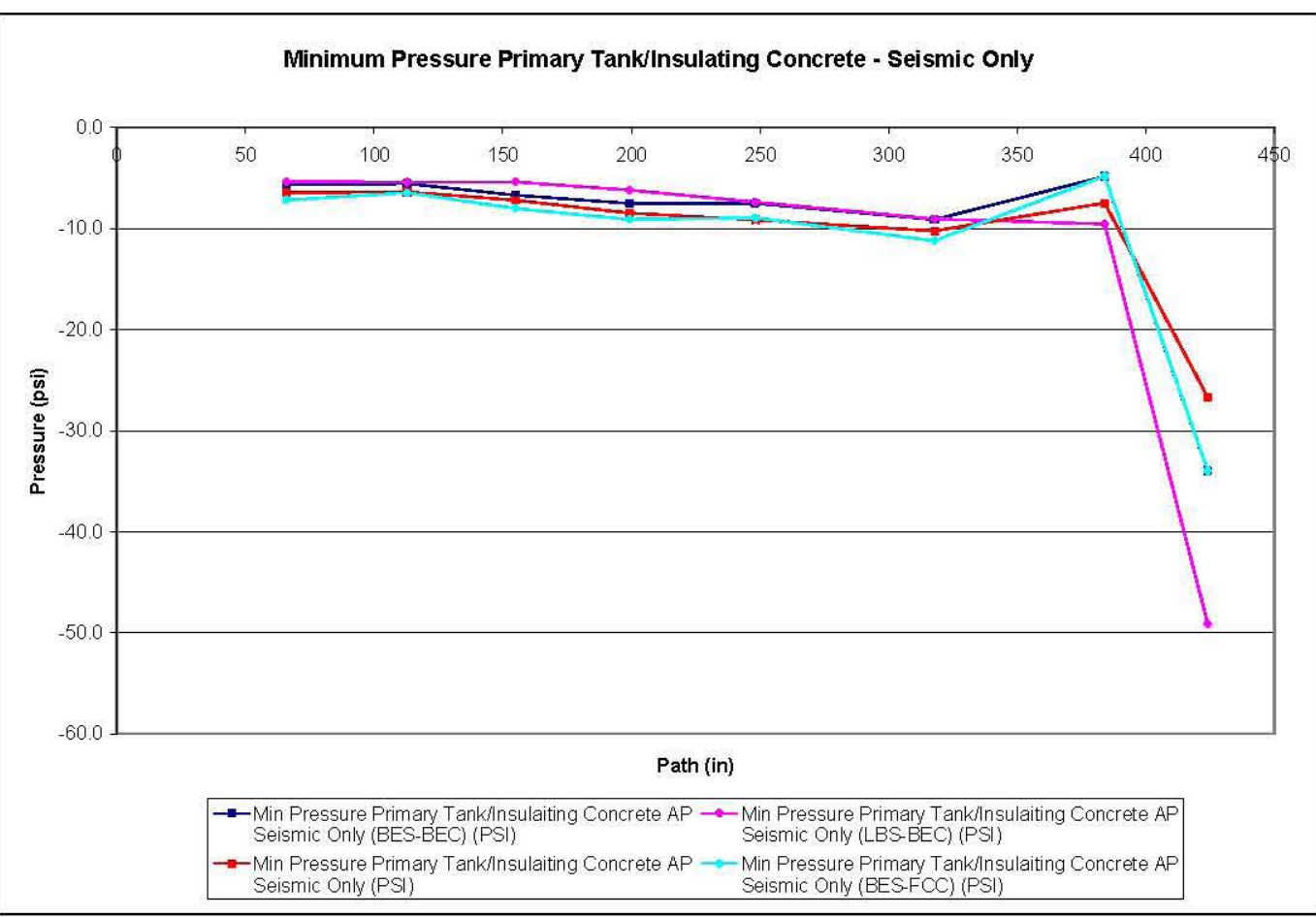

Figure 10-53. Primary Tank/Insulating Concrete Contact Element Minimum Contact Pressure Seismic Only

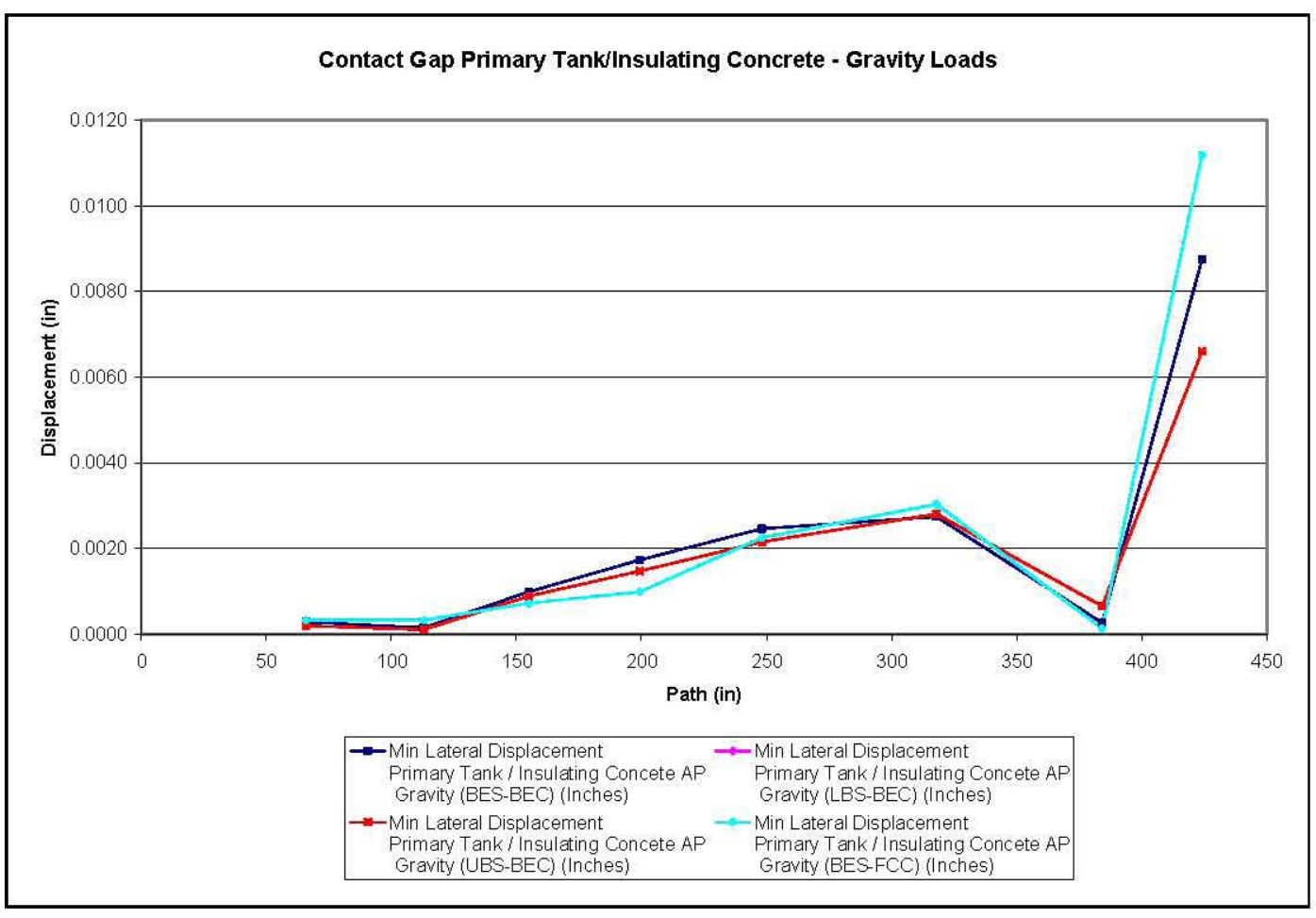

Figure 10-54. Primary Tank/Insulating Concrete Contact Element Maximum Contact Gap - Gravity Only 
RPP-RPT-32239, Rev. 1

M\&D-2008-005-CALC-001, Rev. 1

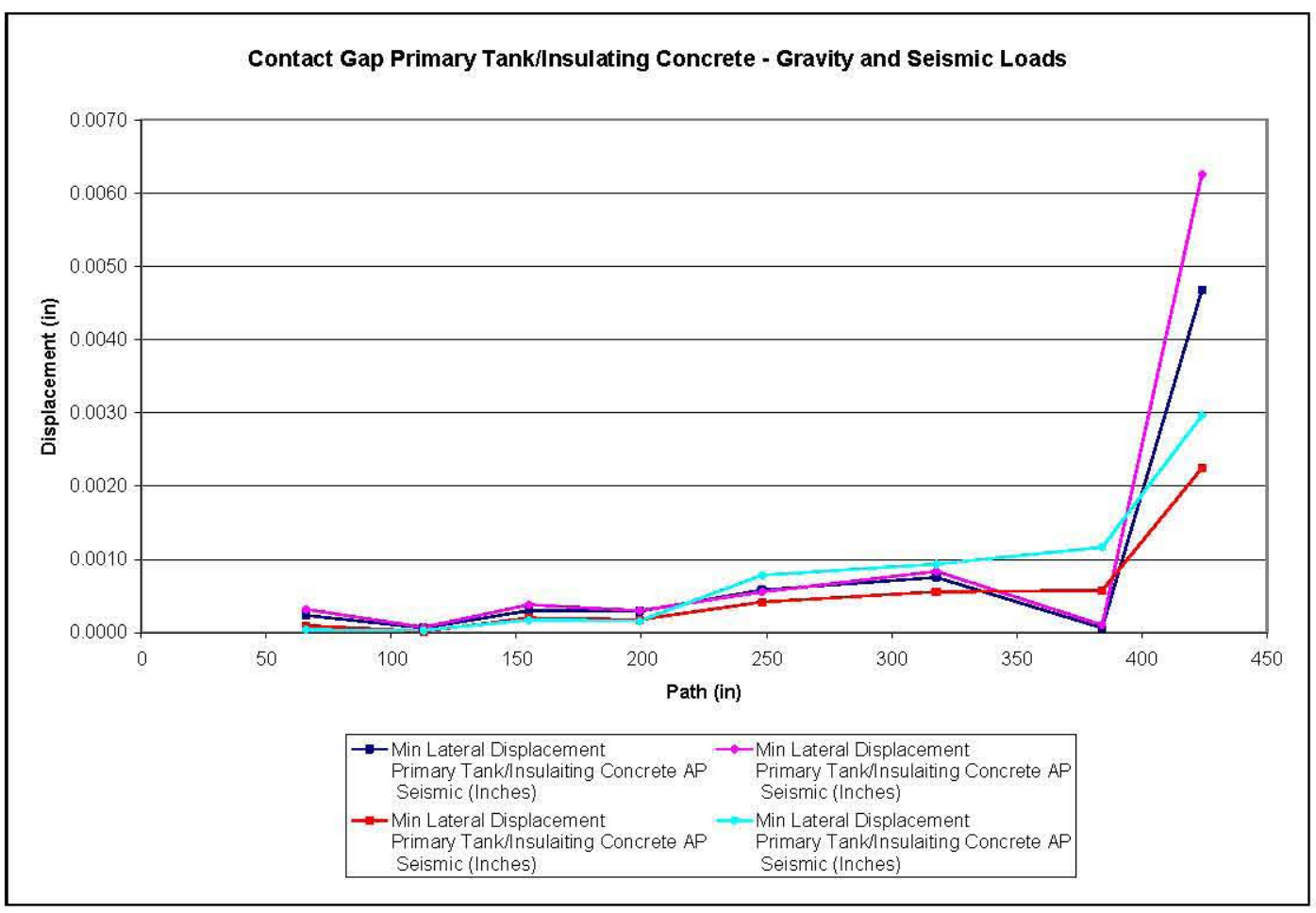

Figure 10-55. Primary Tank/Insulating Concrete Contact Element Maximum Contact Gap - Gravity Plus Seismic

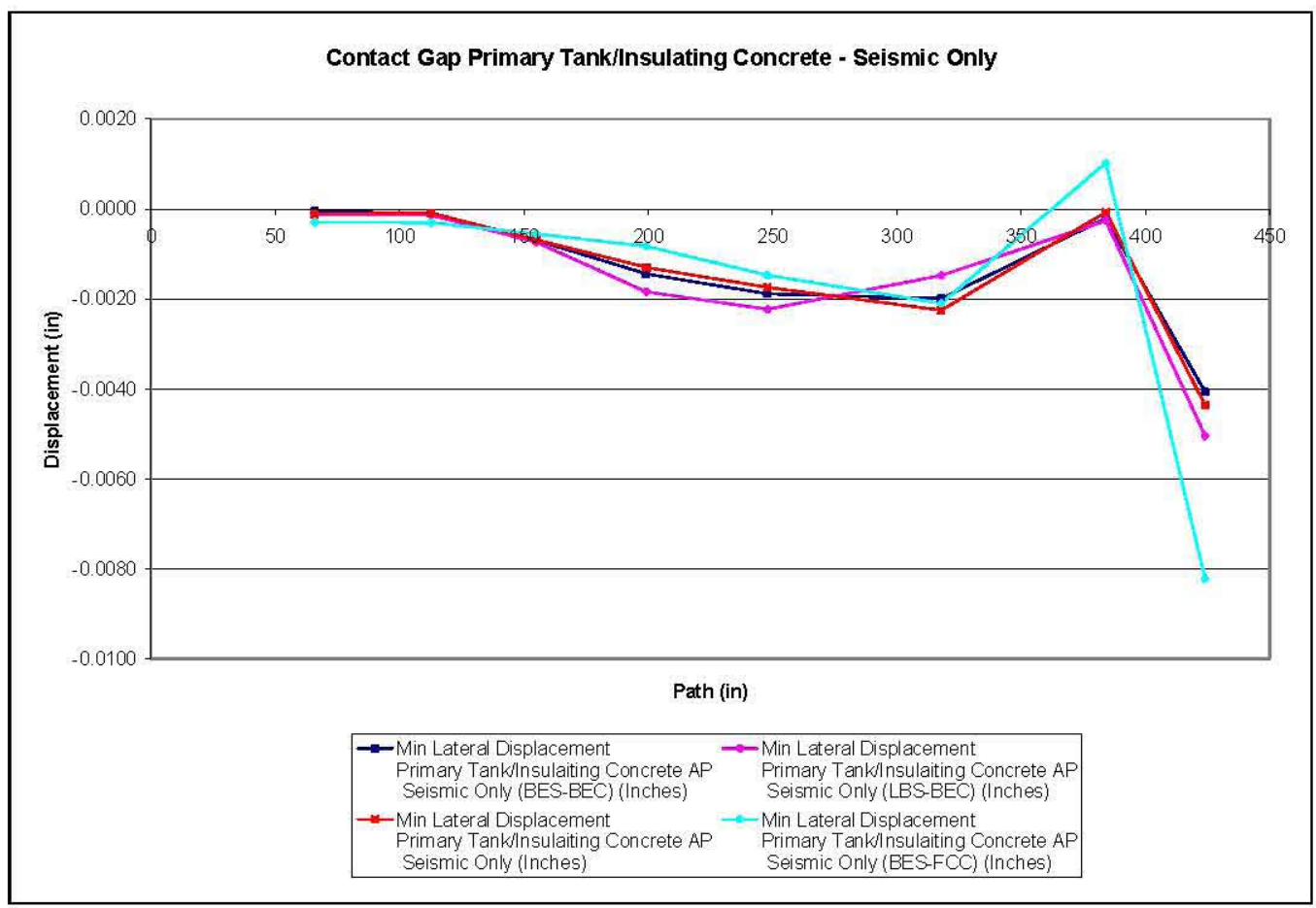

Figure 10-56. Primary Tank/Insulating Concrete Contact Element Maximum Contact Gap - Seismic Only 
RPP-RPT-32239, Rev. 1

M\&D-2008-005-CALC-001, Rev. 1

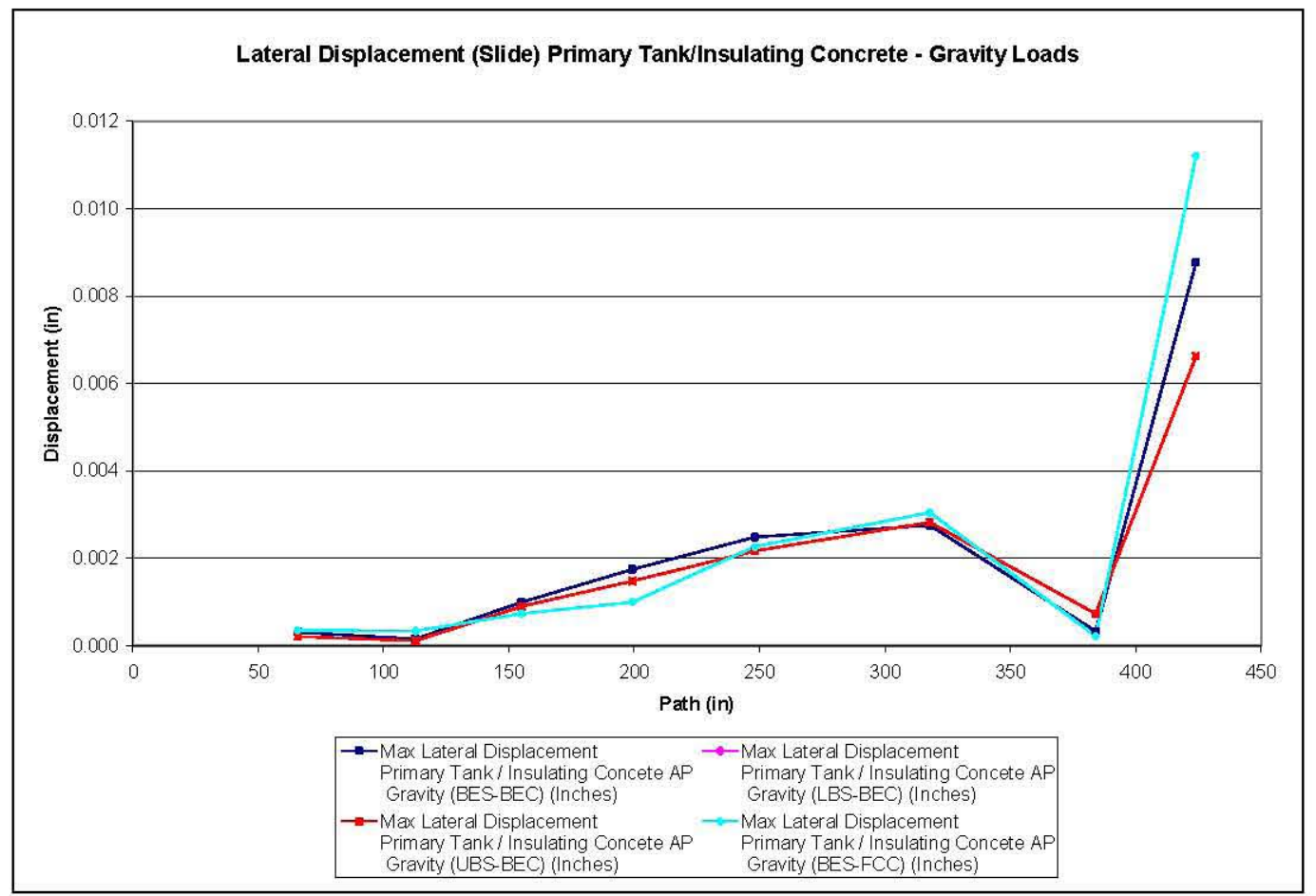

Figure 10-57. Primary Tank/Insulating Concrete Contact Element Maximum Contact Lateral Displacement (Slide) - Gravity Only

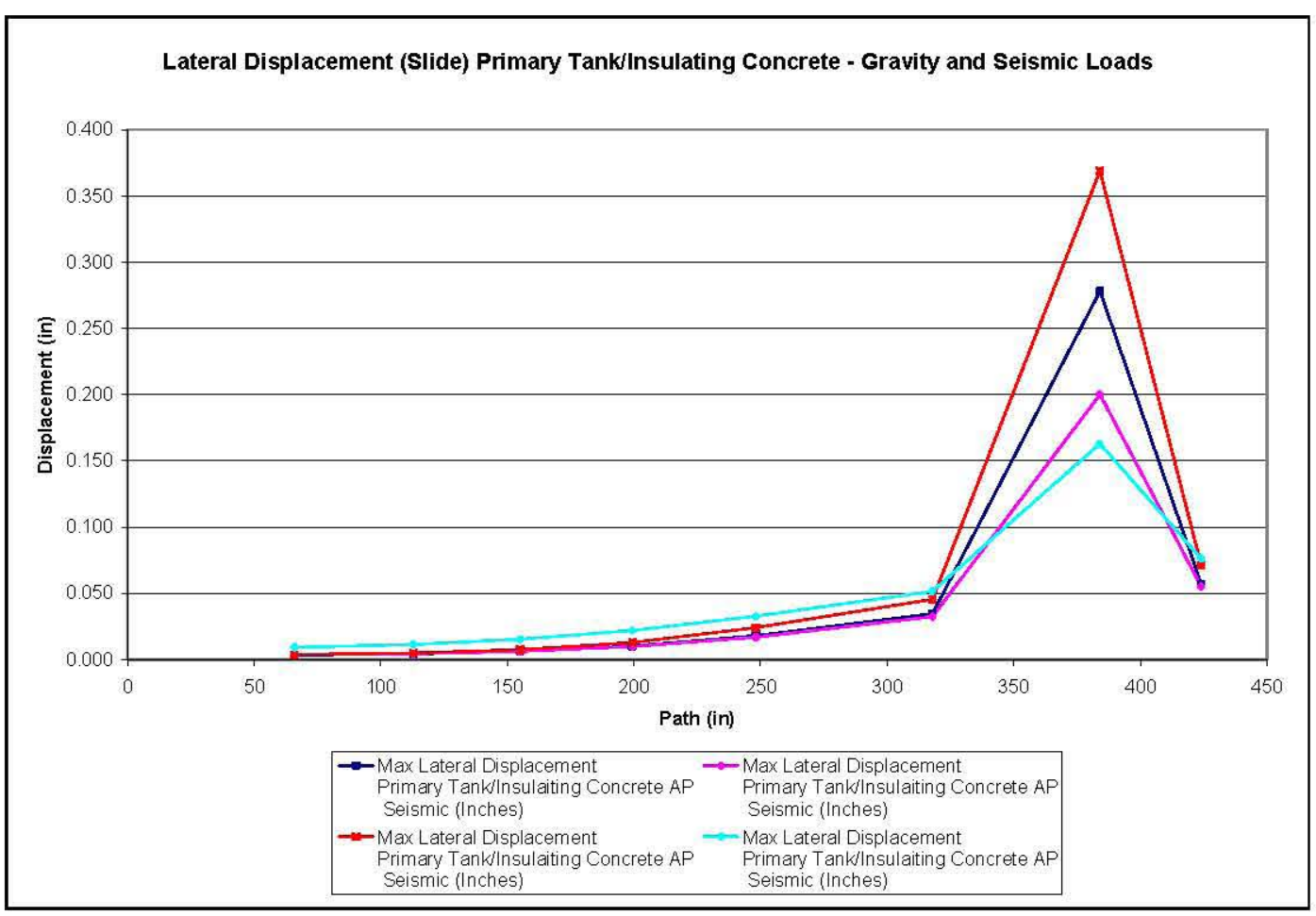

Figure 10-58. Primary Tank/Insulating Concrete Contact Element Maximum Contact Lateral Displacement (Slide) - Gravity Plus Seismic 
RPP-RPT-32239, Rev. 1

M\&D-2008-005-CALC-001, Rev. 1

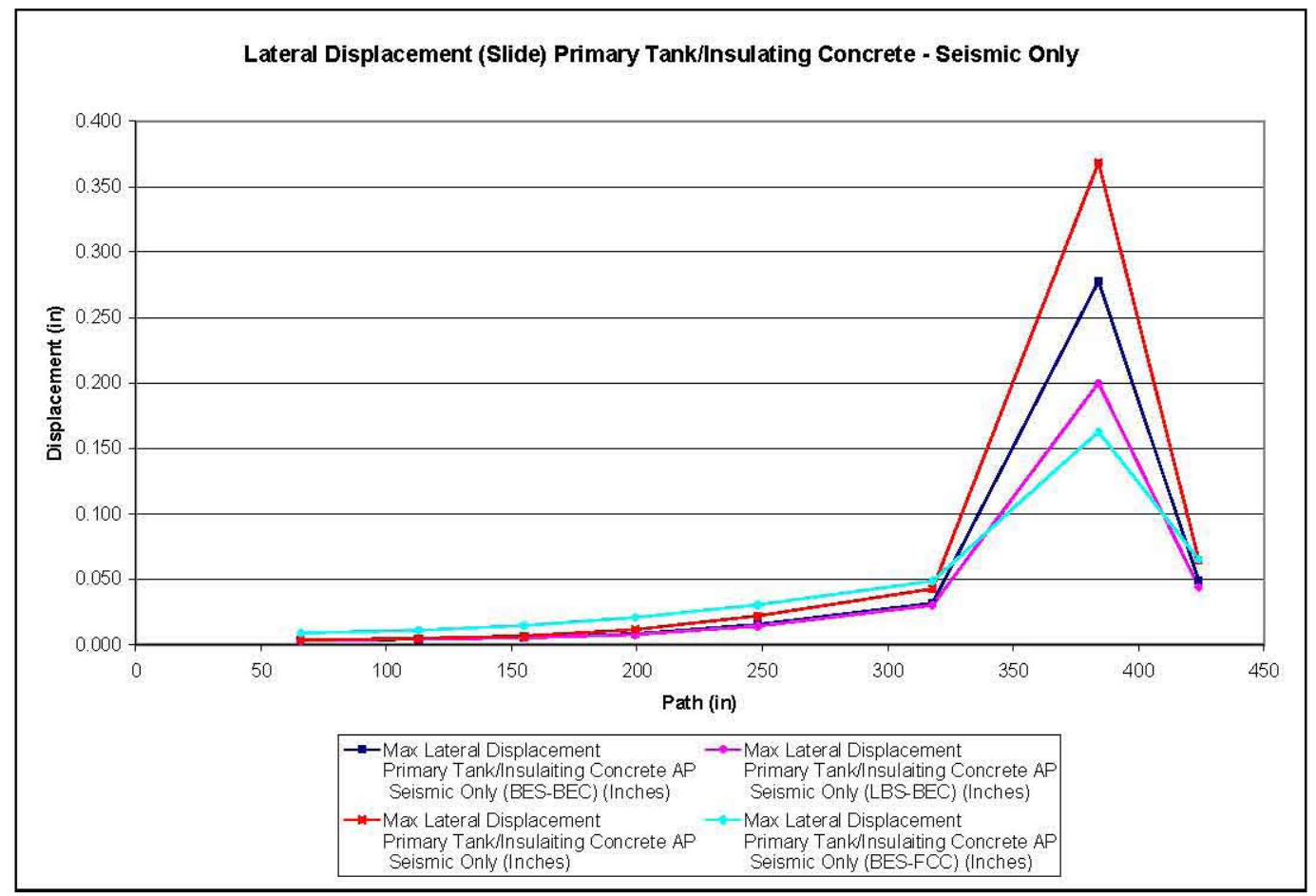

Figure 10-59. Primary Tank/Insulating Concrete Contact Element Maximum Contact Lateral Displacement (Slide) - Seismic Only

Figure 10-58 and Figure 10-59 show high sliding displacements for a radius of 384 inches. These displacements are very localized and occur in regions of low contact pressures. When separation occurs on an ANSYS $^{\mathbb{B}}$ contact element, relative displacements, or sliding is not tracked. The apparent high local displacements are due to separation, not to real relative displacements.

\subsection{Insulating Concrete/Secondary Liner Contact Results from the Revision 0 Model}

Insulating concrete/secondary liner contact data are extracted from the model in $9^{\circ}$ slices, starting at the outside radius of the insulating concrete, moving in toward the center. Contact normal and other contact data were extracted for the interface between insulating concrete and secondary liner. Figure 10-60 shows the location and element numbers for first slice of contact elements. The following data were extracted for each CONTA173 element:

- CONT-PRES Normal Contact Pressure

- CONT-SLIDE Contact Lateral Displacement

- CONT-GAP Contact Gap Distance

- CONT-STAT Contact Status (Open, Closed, Sliding)

For each load case, the minimum and maximum contact pressure, lateral displacements, and gaps are compared. The figures for each component are grouped by gravity only, gravity plus seismic, and seismic only. For the insulating concrete/secondary liner contact interface, the following figures are provided. 
RPP-RPT-32239, Rev. 1

M\&D-2008-005-CALC-001, Rev. 1

- Figure 10-61. Insulating Concrete/Secondary Liner Contact Element Contact Pressure - Gravity Only

- Figure 10-62. Insulating Concrete/Secondary Liner Contact Element Maximum Contact Pressure Gravity Plus Seismic

- Figure 10-63. Insulating Concrete/Secondary Liner Contact Element Minimum Contact Pressure Gravity Plus Seismic

- Figure 10-64. Insulating Concrete/Secondary Liner Contact Element Maximum Contact Pressure Seismic Only

- Figure 10-65. Insulating Concrete/Secondary Liner Contact Element Minimum Contact Pressure Seismic Only

- Figure 10-66. Insulating Concrete/Secondary Liner Contact Element Maximum Contact Lateral Displacement (Slide) - Gravity Only

- Figure 10-67. Insulating Concrete/Secondary Liner Contact Element Maximum Contact Lateral Displacement (Slide) - Gravity Plus Seismic

- Figure 10-68. Insulating Concrete/Secondary Liner Contact Element Maximum Contact Lateral Displacement (Slide) - Seismic Only

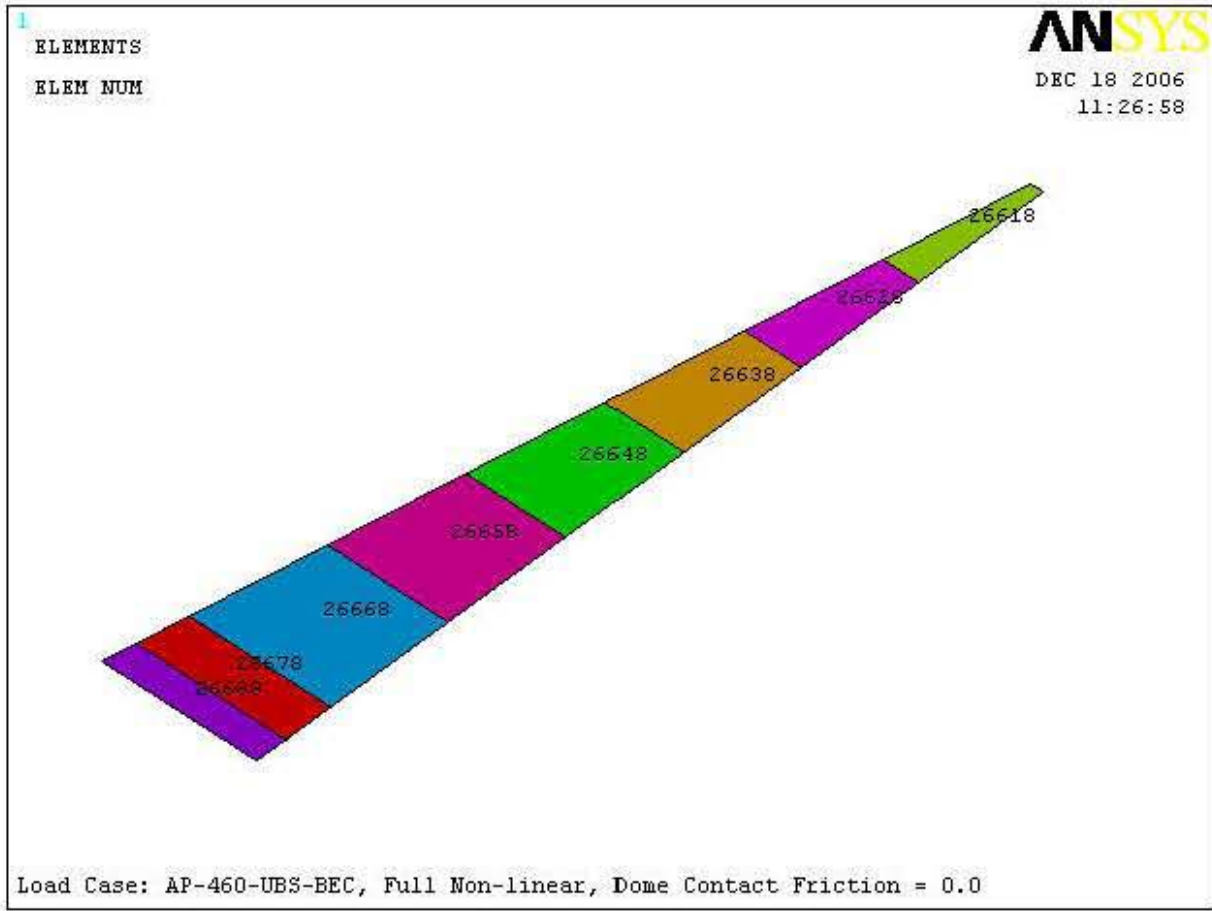

Figure 10-60. Insulating Concrete Contact Element Retrieval Sequence Starting Numbers 
RPP-RPT-32239, Rev. 1

M\&D-2008-005-CALC-001, Rev. 1

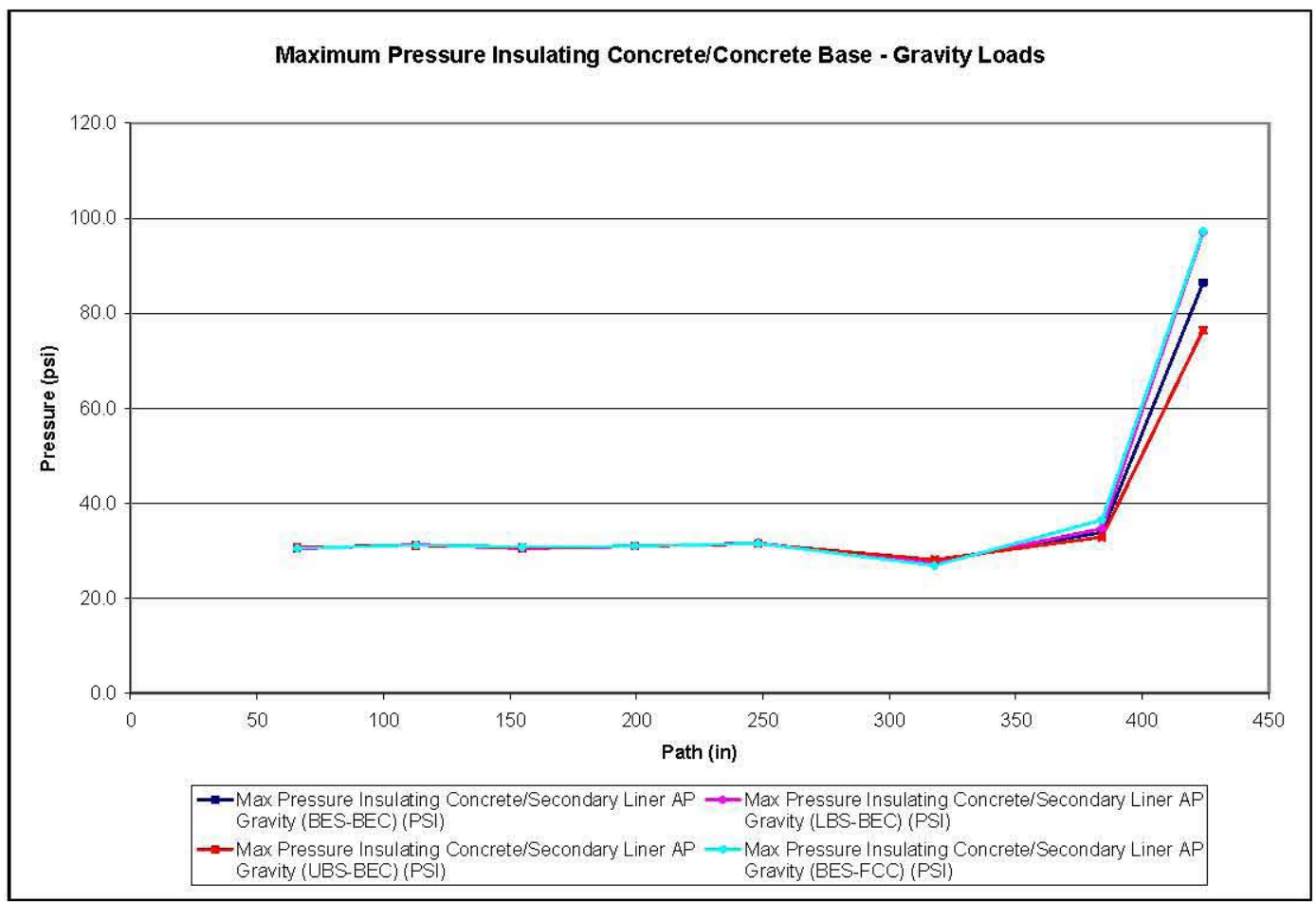

Figure 10-61. Insulating Concrete/Secondary Liner Contact Element Contact Pressure - Gravity Only

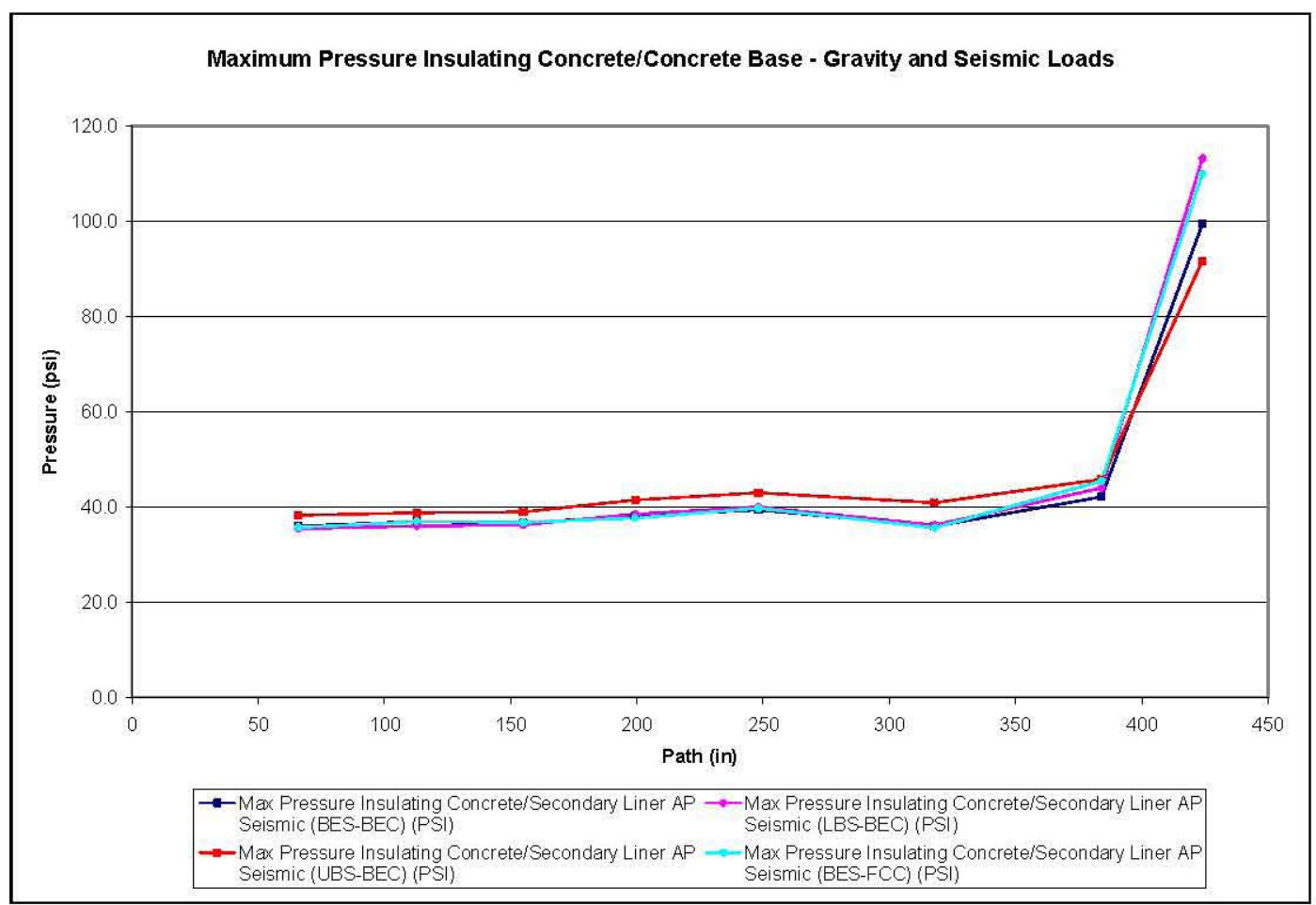

Figure 10-62. Insulating Concrete/Secondary Liner Contact Element Maximum Contact Pressure Gravity Plus Seismic 
RPP-RPT-32239, Rev. 1

M\&D-2008-005-CALC-001, Rev. 1

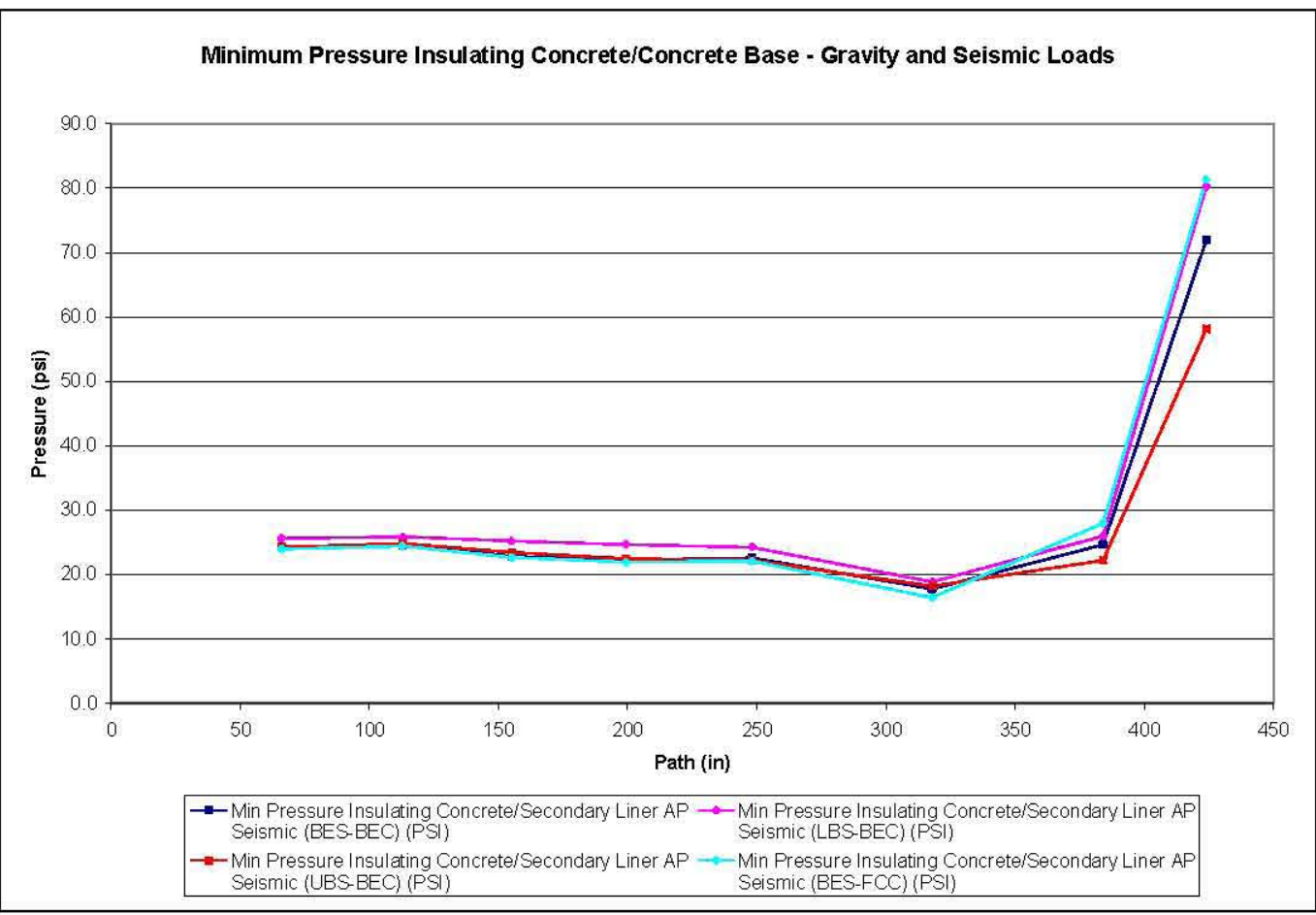

Figure 10-63. Insulating Concrete/Secondary Liner Contact Element Minimum Contact Pressure Gravity Plus Seismic

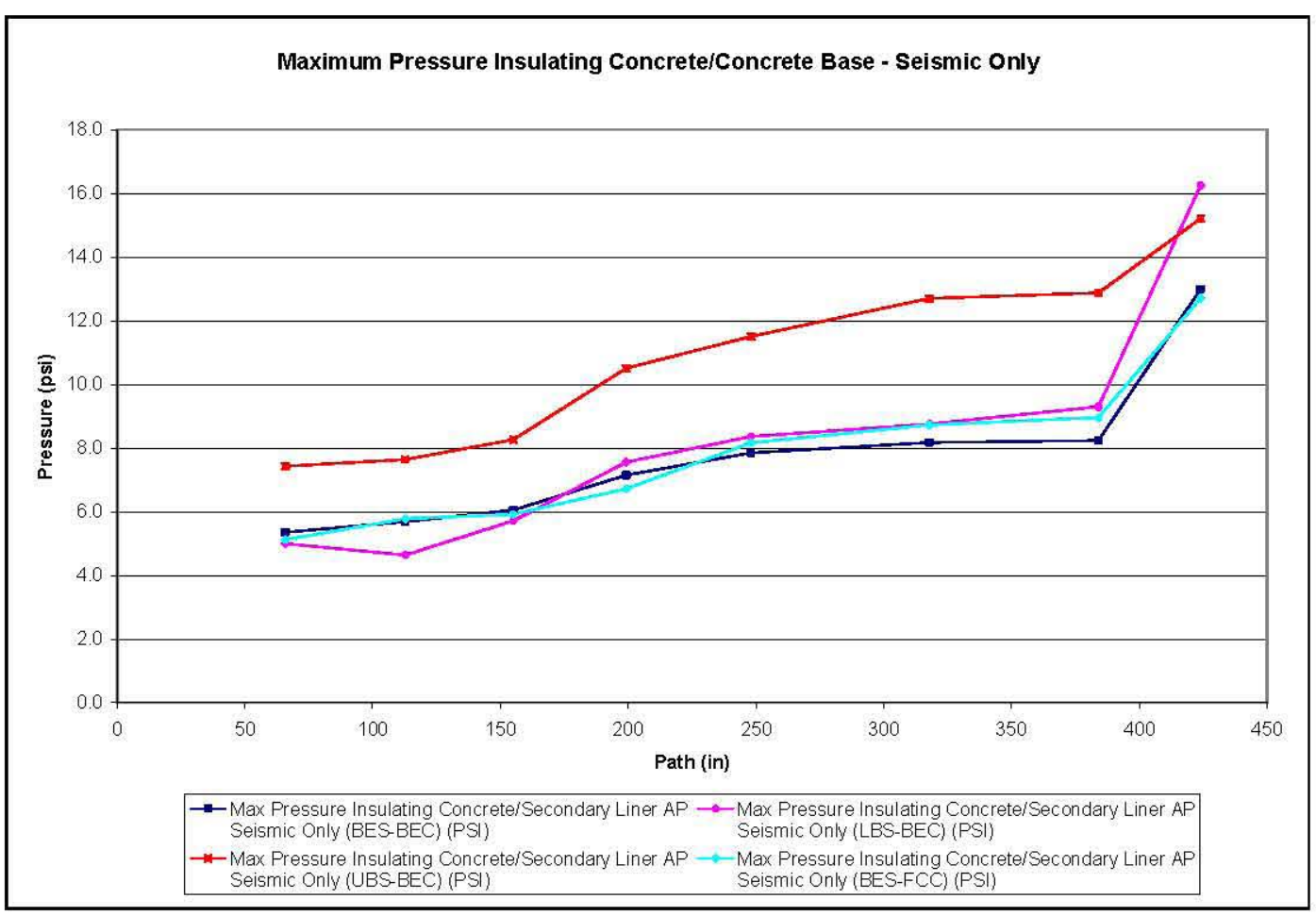

Figure 10-64. Insulating Concrete/Secondary Liner Contact Element Maximum Contact Pressure Seismic Only 
RPP-RPT-32239, Rev. 1

M\&D-2008-005-CALC-001, Rev. 1

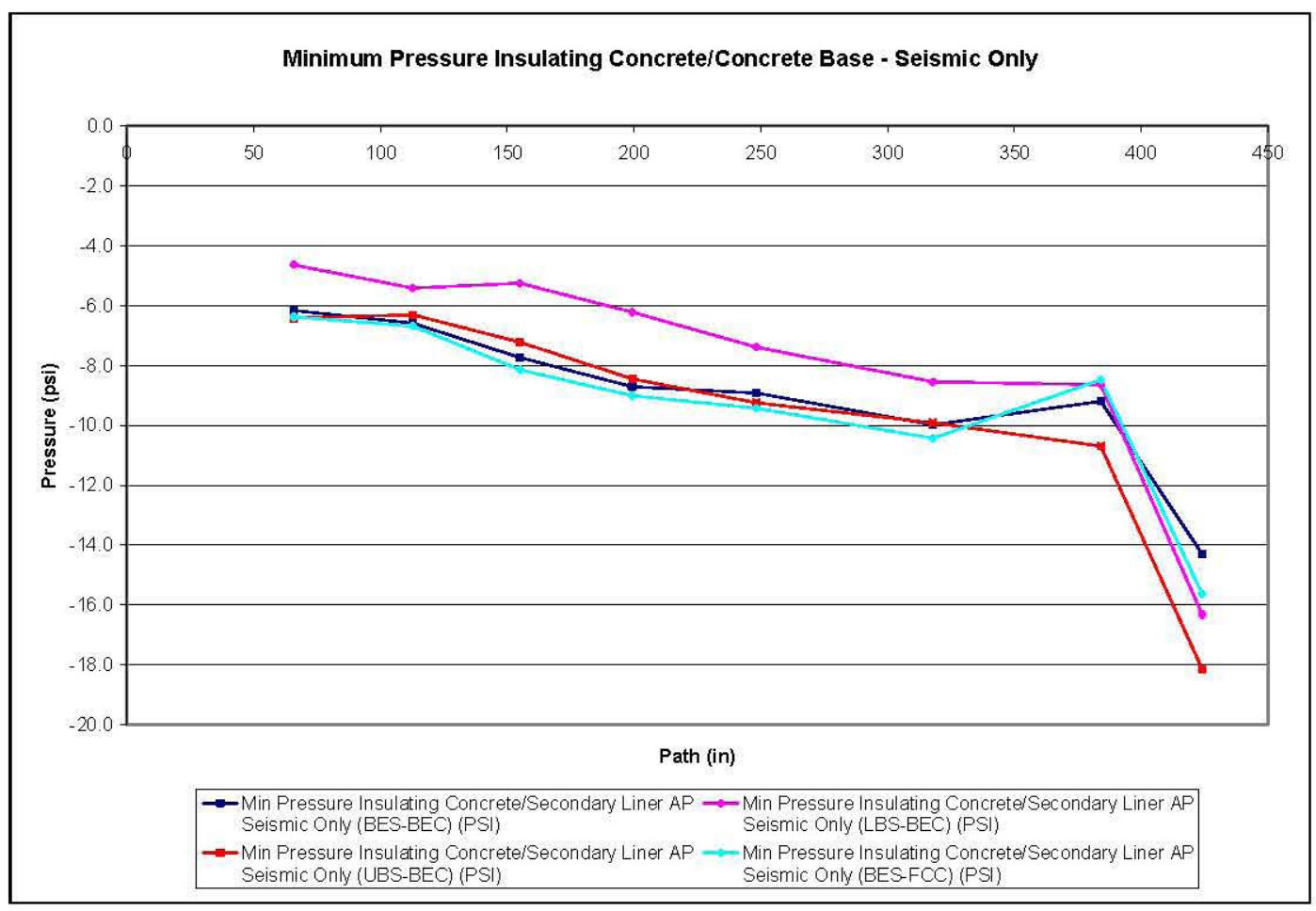

Figure 10-65. Insulating Concrete/Secondary Liner Contact Element Minimum Contact Pressure-Seismic Only

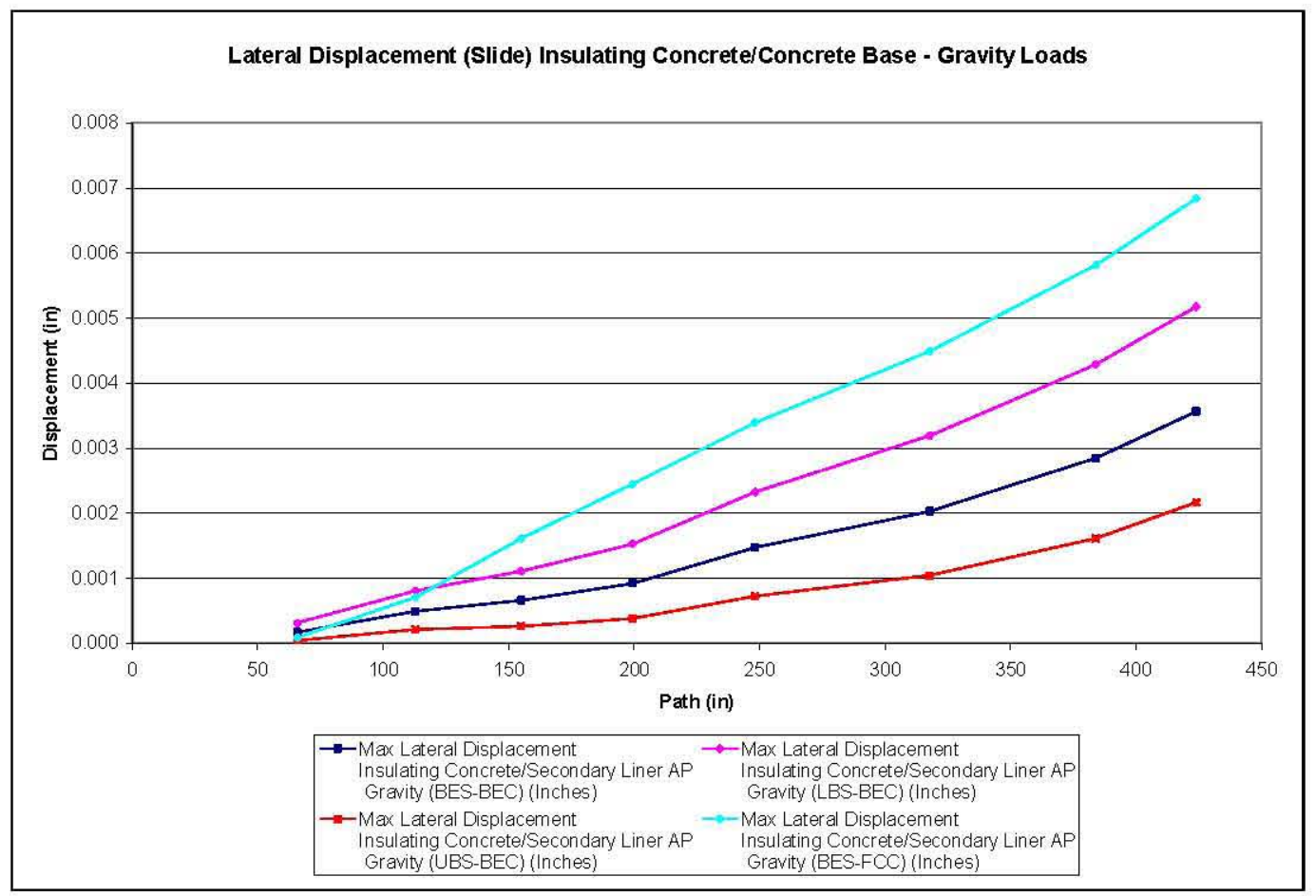

Figure 10-66. Insulating Concrete/Secondary Liner Contact Element Maximum Contact Lateral Displacement (Slide) - Gravity Only 
RPP-RPT-32239, Rev. 1

M\&D-2008-005-CALC-001, Rev. 1

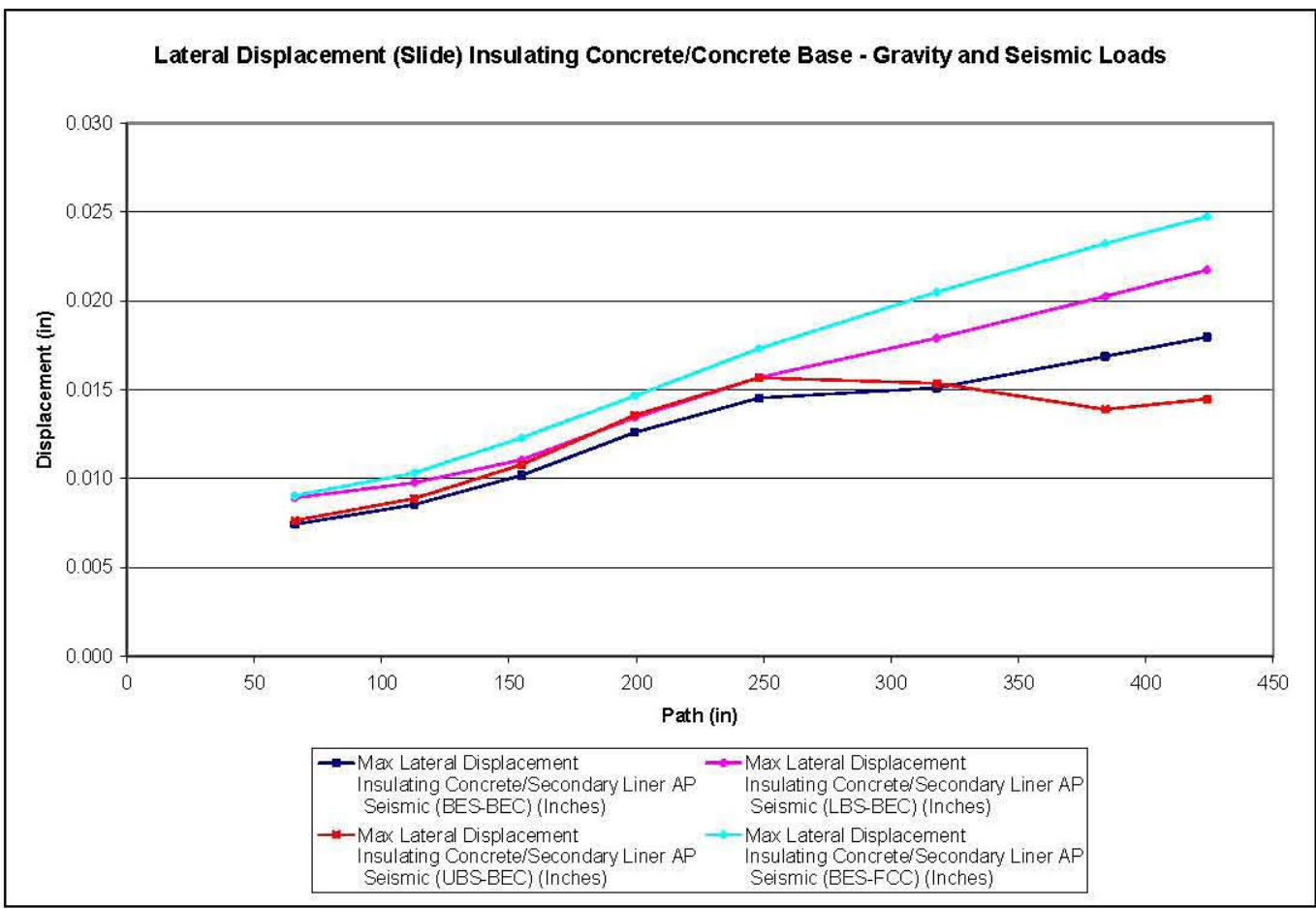

Figure 10-67. Insulating Concrete/Secondary Liner Contact Element Maximum Contact Lateral Displacement (Slide) - Gravity Plus Seismic

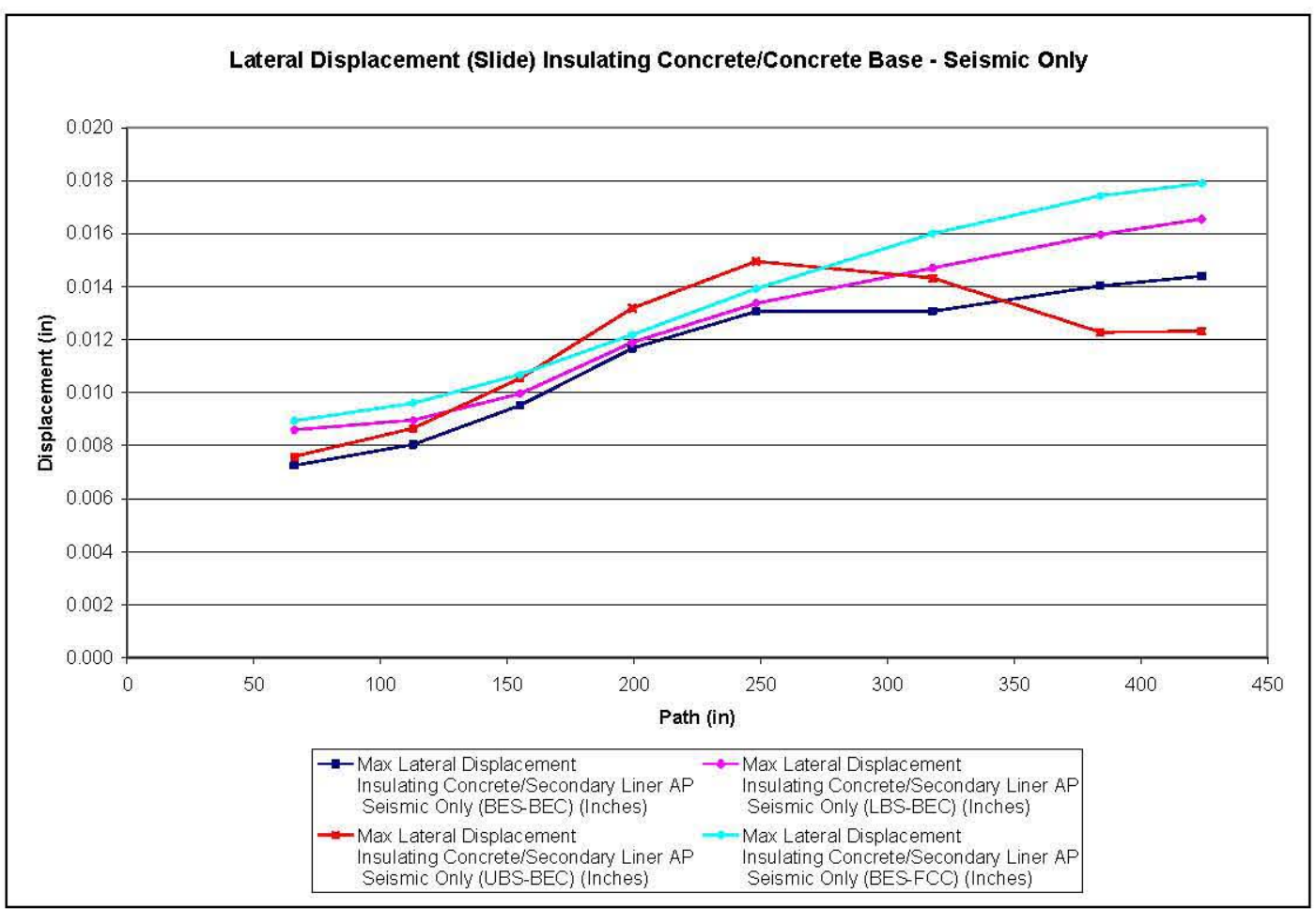

Figure 10-68. Insulating Concrete/Secondary Liner Contact Element Maximum Contact Lateral Displacement (Slide) - Seismic Only 
RPP-RPT-32239, Rev. 1

M\&D-2008-005-CALC-001, Rev. 1

\subsection{Waste Results from the Revision 0 Model}

Waste pressure distributions were extracted from the model for comparison against a theoretical solution. This comparison helps demonstrate that the seismic motions were correctly transmitted to the waste. Theoretical waste pressures were calculated using a horizontal spectral acceleration for the impulsive mode of the tank/waste system using a horizontal response spectrum from the center bottom of the concrete wall at $90^{\circ}$. Theoretical vertical waste pressures were calculated using a vertical spectral acceleration for the impulsive mode of the tank/waste system using a vertical response spectrum from the bottom of the concrete shell wall. Theoretical waste pressures were developed for an open-top tank with a radius of 450 inches, a waste depth of 460 inches, and a uniform wall thickness of 0.65 inch (average thickness for AY tank used). While the theoretical solution does not address the influence of the interaction with the dome or the variable primary tank wall thickness, it does provide a reasonable basis for comparison to see that the hydrodynamic forces are correct.

Waste/Primary tank contact data are extracted from the model in $9^{\circ}$ slices, starting at the free surface of the waste, moving down the wall and then in toward the center. Contact normal and other contact data were extracted for the interface between waste and the primary tank. Figure 11-1 shows the location and element numbers for first slice of contact elements. The following data were extracted for each CONTA173 element

- CONT-PRES

- CONT-SLIDE

- CONT-GAP

- CONT-STAT
Normal Contact Pressure

Contact Lateral Displacement

Contact Gap Distance

Contact Status (Open, Closed, Sliding) 
RPP-RPT-32239, Rev. 1

M\&D-2008-005-CALC-001, Rev. 1

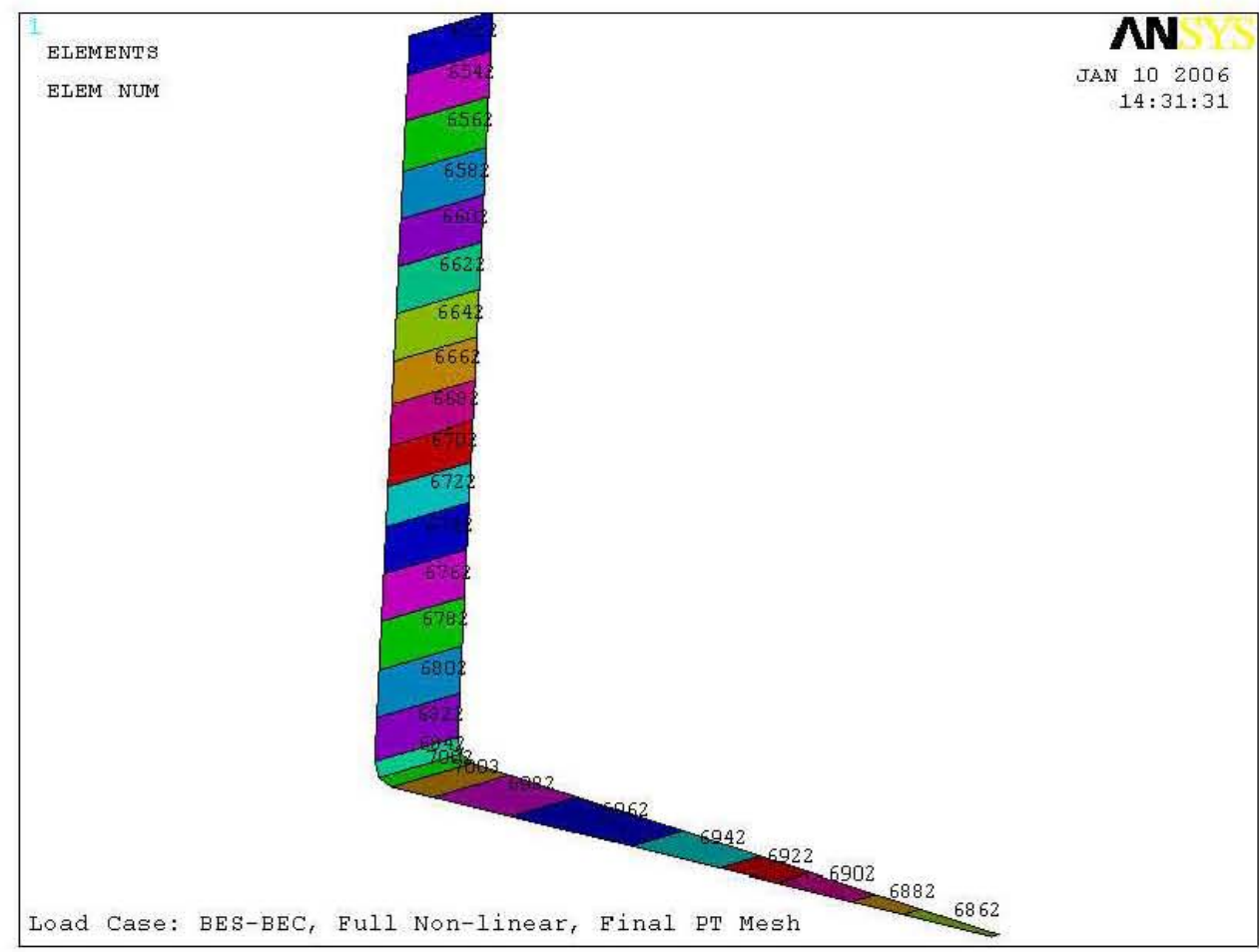

Figure 11-1. Waste Contact Element Retrieval Sequence Starting Element Numbers

The hydrodynamic pressures in the tank are caused by impulsive and convective components and depend on the location of the fluid element within the tank. In the case of horizontal excitation, both the impulsive and convective components vary in the circumferential direction as the cosine of the angle $\theta$, with the maximum values occurring at $\theta=0$ measured from the plane of excitation, and decreasing to zero hydrodynamic pressure at $\theta=90^{\circ}$ to the plane of excitation. The impulsive hydrodynamic pressure increases with depth, while the convective dynamic pressure is a maximum at the top of the waste.

In the case of an open-top tank with no dome, the theoretical peak hydrodynamic pressures due to horizontal excitation are given by Equation 4.24 of BNL (1995). The maximum hydrodynamic pressures induced by the waste on the tank wall due to vertical excitation depend on the vertical location in the waste and are given by Equation 4.52 of BNL (1995). The total pressures are the sum of the hydrostatic pressures and the hydrodynamic pressures. Details for the calculation of theoretical waste pressures are provided in Appendixes F through I.

For comparison, the theoretical hydrodynamic pressures for an open-top tank with a waste depth of 460 inches and a radius of 450 inches are shown. The hydrostatic, peak hydrodynamic, and peak total pressures for the elements located on the plane of excitation are shown in Table 11-1 through Table 11-4. The waste pressure distribution is shown in Figure 11-2, Figure 11-4, Figure 11-6, and Figure 11-8 for each load case.

The maximum slosh height over all surface waste elements is evaluated. According to Equation 4.60 of BNL (1995), the maximum predicted slosh height due to horizontal excitation is 23.7 inches for all load cases. Plots of the surface free-field response are provided for both horizontal and vertical excitation for each load case in Figure 11-3, Figure 11-5, Figure 11-7, and Figure 11-9. 
RPP-RPT-32239, Rev. 1

M\&D-2008-005-CALC-001, Rev. 1

\subsection{Lower Bound Soil}

$\mathrm{S}_{\text {ah }}=0.32 g$ (Horizontal Spectral Acceleration)

$\mathrm{S}_{\mathrm{av}}=0.29 g$ (Vertical Spectra Acceleration)

Table 11-1. Theoretical Waste Pressures, LBS-BEC

\begin{tabular}{||c|c|c|c|c|c|c|c|c||}
\hline $\begin{array}{c}\text { Waste } \\
\text { Height }\end{array}$ & $\mathbf{n u}$ & $\begin{array}{c}\text { Horiz } \\
\text { Conv } \\
\text { (psi) }\end{array}$ & $\begin{array}{c}\text { Horiz } \\
\text { Imp } \\
\mathbf{p s i}\end{array}$ & $\begin{array}{c}\text { Vert } \\
\text { (psi) }\end{array}$ & $\begin{array}{c}\text { SRSS } \\
\text { (psi) }\end{array}$ & $\begin{array}{c}\text { Static } \\
\text { (psi) }\end{array}$ & $\begin{array}{c}\text { Theor } \\
\text { Min } \\
\text { (psi) }\end{array}$ & $\begin{array}{c}\text { Theor } \\
\text { Max } \\
\text { (psi) }\end{array}$ \\
\hline \hline 454.35 & 0.99 & 1.58 & 0.84 & 0.14 & 1.79 & 0.37 & 0 & 2.16 \\
\hline 443.05 & 0.96 & 1.51 & 1.30 & 0.41 & 2.03 & 1.12 & 0 & 3.15 \\
\hline 431.7625 & 0.94 & 1.44 & 1.73 & 0.68 & 2.35 & 1.87 & 0 & 4.21 \\
\hline 414.125 & 0.90 & 1.34 & 2.33 & 1.10 & 2.91 & 3.03 & 0.13 & 5.94 \\
\hline 390.125 & 0.85 & 1.22 & 3.05 & 1.67 & 3.69 & 4.62 & 0.93 & 8.30 \\
\hline 366.125 & 0.80 & 1.12 & 3.68 & 2.22 & 4.44 & 6.20 & 1.77 & 10.64 \\
\hline 342 & 0.74 & 1.02 & 4.22 & 2.77 & 5.15 & 7.80 & 2.65 & 12.94 \\
\hline 318.325 & 0.69 & 0.94 & 4.68 & 3.28 & 5.80 & 9.36 & 3.57 & 15.16 \\
\hline 295.225 & 0.64 & 0.86 & 5.08 & 3.76 & 6.38 & 10.89 & 4.50 & 17.27 \\
\hline 272.125 & 0.59 & 0.80 & 5.43 & 4.22 & 6.93 & 12.41 & 5.49 & 19.34 \\
\hline 248.975 & 0.54 & 0.74 & 5.74 & 4.65 & 7.43 & 13.94 & 6.52 & 21.37 \\
\hline 225.825 & 0.49 & 0.69 & 6.01 & 5.06 & 7.89 & 15.47 & 7.59 & 23.36 \\
\hline 202.725 & 0.44 & 0.65 & 6.25 & 5.43 & 8.30 & 17.00 & 8.70 & 25.30 \\
\hline 179.625 & 0.39 & 0.61 & 6.45 & 5.77 & 8.67 & 18.53 & 9.85 & 27.20 \\
\hline 156.475 & 0.34 & 0.57 & 6.62 & 6.07 & 9.00 & 20.06 & 11.06 & 29.05 \\
\hline 134.075 & 0.29 & 0.55 & 6.76 & 6.33 & 9.28 & 21.54 & 12.26 & 30.81 \\
\hline 112.475 & 0.24 & 0.53 & 6.88 & 6.54 & 9.50 & 22.96 & 13.46 & 32.46 \\
\hline 90.875 & 0.20 & 0.51 & 6.97 & 6.71 & 9.69 & 24.39 & 14.70 & 34.08 \\
\hline 69.275 & 0.15 & 0.49 & 7.04 & 6.86 & 9.84 & 25.82 & 15.98 & 35.66 \\
\hline 47.7375 & 0.10 & 0.48 & 7.09 & 6.96 & 9.95 & 27.24 & 17.29 & 37.19 \\
\hline 24.5 & 0.05 & 0.48 & 7.13 & 7.03 & 10.02 & 28.78 & 18.76 & 38.79 \\
\hline 7.755 & 0.02 & 0.47 & 7.14 & 7.05 & 10.04 & 29.88 & 19.84 & 39.92 \\
\hline 1.755 & 0.00 & 0.47 & 7.14 & 7.05 & 10.04 & 30.28 & 20.23 & 40.32 \\
\hline See Appendix F, Table 41, for calculation of theoretical waste pressures. & & & \\
\hline
\end{tabular}


RPP-RPT-32239, Rev. 1

M\&D-2008-005-CALC-001, Rev. 1

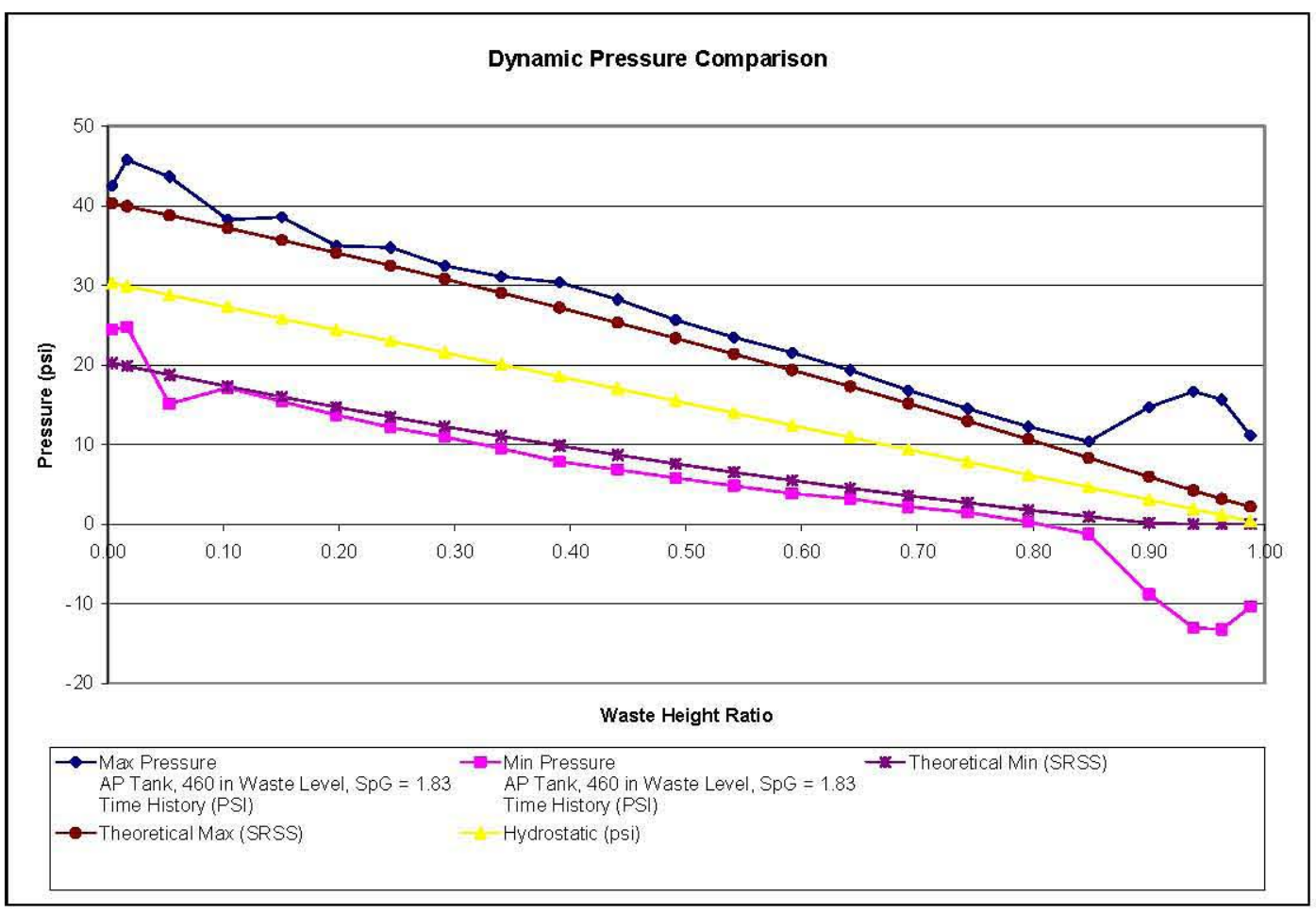

Figure 11-2. Waste Pressure Distribution, LBS-BEC

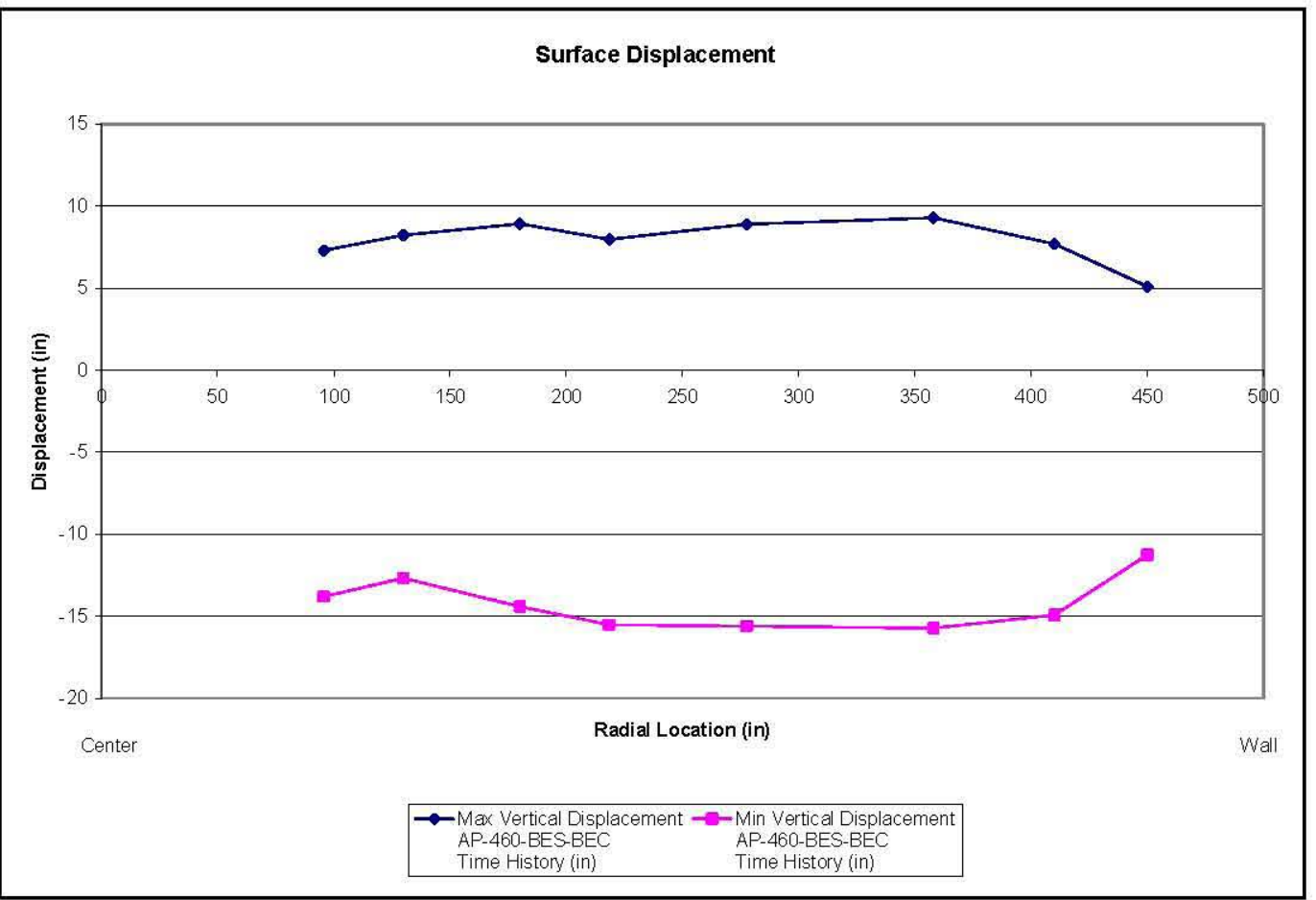

Figure 11-3. Waste-Free Surface Displacement, LBS-BEC 
RPP-RPT-32239, Rev. 1

M\&D-2008-005-CALC-001, Rev. 1

\subsection{Best-Estimate Soil}

$\mathrm{S}_{\text {ah }}=0.28 g$

$\mathrm{S}_{\mathrm{av}}=0.26 \mathrm{~g}$

Table 11-2. Theoretical Waste Pressures, BES-BEC

\begin{tabular}{||c|c|c|c|c|c|c|c|c||}
\hline $\begin{array}{c}\text { Waste } \\
\text { Height }\end{array}$ & $\mathbf{n u}$ & $\begin{array}{c}\text { Horiz } \\
\text { Conv } \\
\text { (psi) }\end{array}$ & $\begin{array}{c}\text { Horiz } \\
\text { Imp } \\
\mathbf{p s i}\end{array}$ & $\begin{array}{c}\text { Vert } \\
\text { (psi) }\end{array}$ & $\begin{array}{c}\text { SRSS } \\
\text { (psi) }\end{array}$ & $\begin{array}{c}\text { Static } \\
\text { (psi) }\end{array}$ & $\begin{array}{c}\text { Theor } \\
\text { Min } \\
\text { (psi) }\end{array}$ & $\begin{array}{c}\text { Theor } \\
\text { Max } \\
\text { (psi) }\end{array}$ \\
\hline \hline 454.35 & 0.99 & 1.58 & 0.73 & 0.12 & 1.74 & 0.37 & 0 & 2.12 \\
\hline 443.05 & 0.96 & 1.51 & 1.14 & 0.37 & 1.92 & 1.12 & 0 & 3.04 \\
\hline 431.7625 & 0.94 & 1.44 & 1.51 & 0.61 & 2.17 & 1.87 & 0 & 4.04 \\
\hline 414.125 & 0.90 & 1.34 & 2.04 & 0.99 & 2.63 & 3.03 & 0.40 & 5.66 \\
\hline 390.125 & 0.85 & 1.22 & 2.67 & 1.49 & 3.30 & 4.62 & 1.32 & 7.91 \\
\hline 366.125 & 0.80 & 1.12 & 3.22 & 1.99 & 3.94 & 6.20 & 2.26 & 10.15 \\
\hline 342 & 0.74 & 1.02 & 3.69 & 2.48 & 4.56 & 7.80 & 3.23 & 12.36 \\
\hline 318.325 & 0.69 & 0.94 & 4.10 & 2.94 & 5.13 & 9.36 & 4.23 & 14.49 \\
\hline 295.225 & 0.64 & 0.86 & 4.45 & 3.37 & 5.65 & 10.89 & 5.24 & 16.54 \\
\hline 272.125 & 0.59 & 0.80 & 4.75 & 3.78 & 6.13 & 12.41 & 6.29 & 18.54 \\
\hline 248.975 & 0.54 & 0.74 & 5.02 & 4.17 & 6.57 & 13.94 & 7.37 & 20.52 \\
\hline 225.825 & 0.49 & 0.69 & 5.26 & 4.53 & 6.98 & 15.47 & 8.49 & 22.45 \\
\hline 202.725 & 0.44 & 0.65 & 5.46 & 4.87 & 7.35 & 17.00 & 9.65 & 24.35 \\
\hline 179.625 & 0.39 & 0.61 & 5.64 & 5.17 & 7.68 & 18.53 & 10.85 & 26.20 \\
\hline 156.475 & 0.34 & 0.57 & 5.79 & 5.44 & 7.97 & 20.06 & 12.09 & 28.02 \\
\hline 134.075 & 0.29 & 0.55 & 5.92 & 5.67 & 8.21 & 21.54 & 13.32 & 29.75 \\
\hline 112.475 & 0.24 & 0.53 & 6.02 & 5.86 & 8.42 & 22.96 & 14.55 & 31.38 \\
\hline 90.875 & 0.20 & 0.51 & 6.10 & 6.02 & 8.58 & 24.39 & 15.81 & 32.97 \\
\hline 69.275 & 0.15 & 0.49 & 6.16 & 6.15 & 8.72 & 25.82 & 17.10 & 34.53 \\
\hline 47.7375 & 0.10 & 0.48 & 6.20 & 6.24 & 8.81 & 27.24 & 18.43 & 36.05 \\
\hline 24.5 & 0.05 & 0.48 & 6.23 & 6.30 & 8.88 & 28.78 & 19.90 & 37.65 \\
\hline 7.755 & 0.02 & 0.47 & 6.24 & 6.32 & 8.90 & 29.88 & 20.98 & 38.78 \\
\hline 1.755 & 0.00 & 0.47 & 6.25 & 6.32 & 8.90 & 30.28 & 21.38 & 39.18 \\
\hline See Appendix G, Table 41, for calculation of theoretical waste pressures. & & \\
\hline
\end{tabular}


RPP-RPT-32239, Rev. 1

M\&D-2008-005-CALC-001, Rev. 1

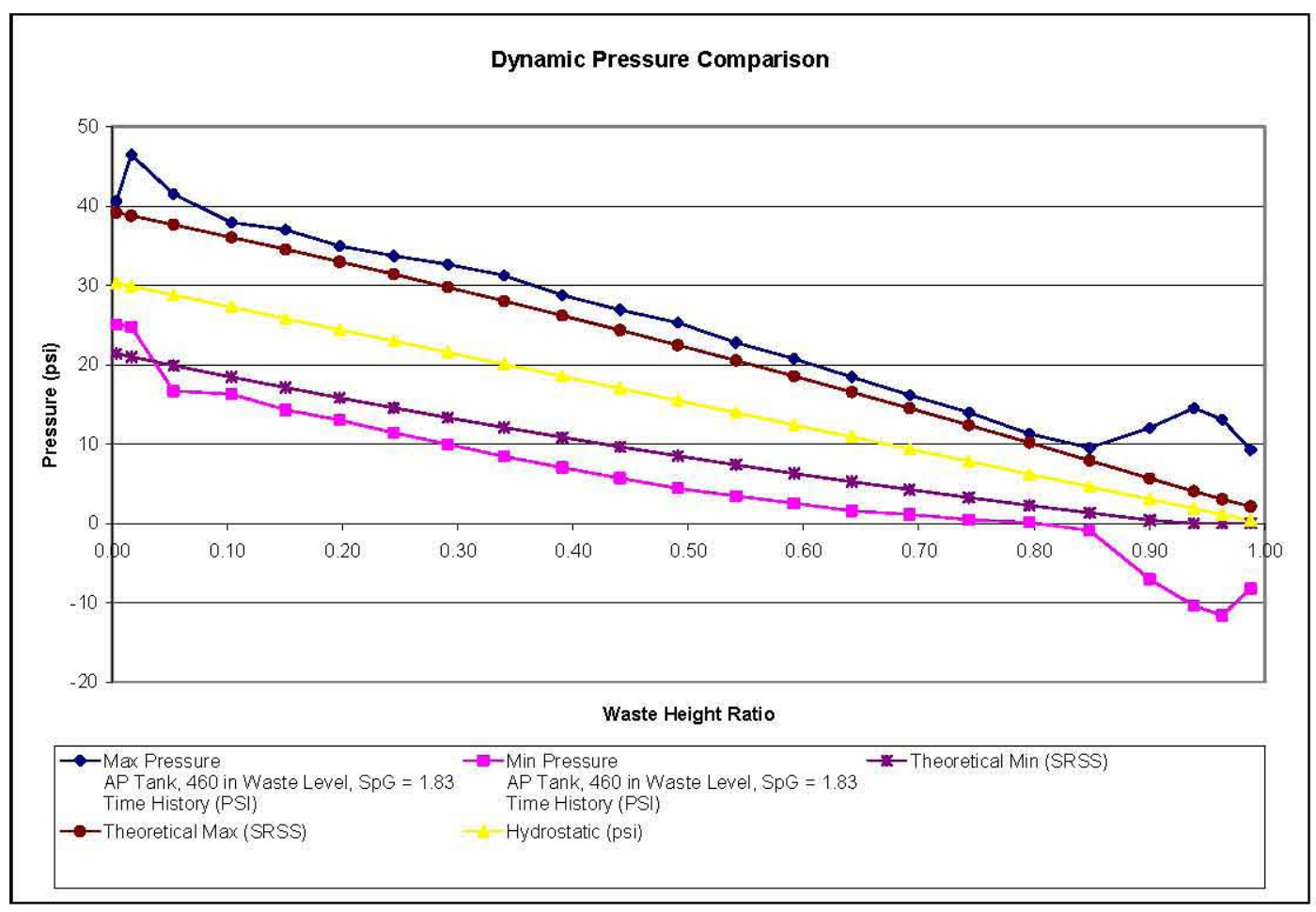

Figure 11-4. Waste Pressure Distribution, BES-BEC

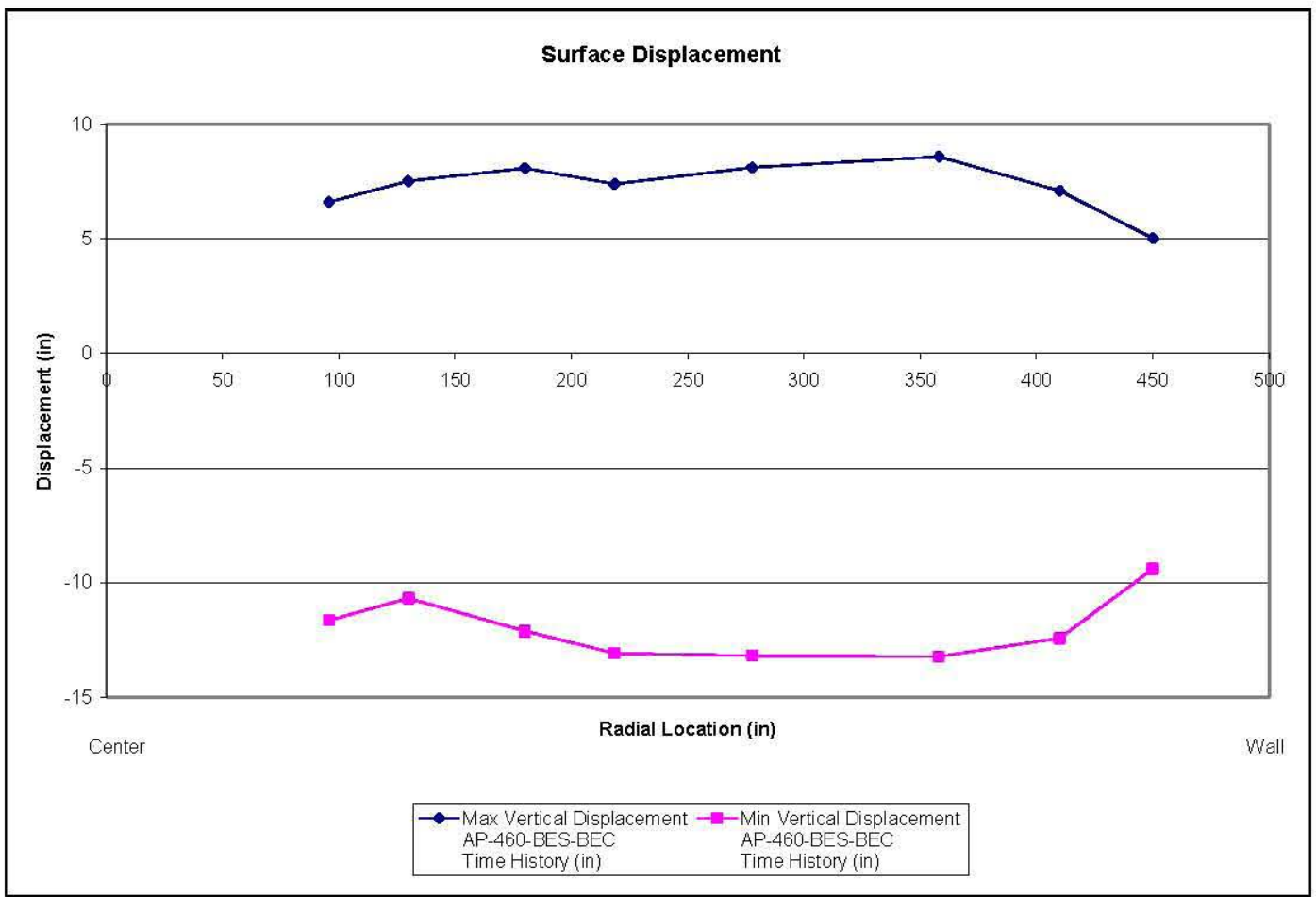

Figure 11-5. Waste-Free Surface Displacement, BES-BEC 
RPP-RPT-32239, Rev. 1

M\&D-2008-005-CALC-001, Rev. 1

\subsection{Upper Bound Soil}

$\mathrm{S}_{\mathrm{ah}}=0.36 \mathrm{~g}$

$\mathrm{S}_{\mathrm{av}}=0.32 g$

Table 11-3. Theoretical Waste Pressures, UBS-BEC

\begin{tabular}{||c|c|c|c|c|c|c|c|c||}
\hline $\begin{array}{c}\text { Waste } \\
\text { Height }\end{array}$ & nu & $\begin{array}{c}\text { Horiz } \\
\text { Conv } \\
\text { (psi) }\end{array}$ & $\begin{array}{c}\text { Horiz } \\
\text { Imp } \\
\text { (psi) }\end{array}$ & $\begin{array}{c}\text { Vert } \\
\text { (psi) }\end{array}$ & $\begin{array}{c}\text { SRSS } \\
\text { (psi) }\end{array}$ & $\begin{array}{c}\text { Static } \\
\text { (psi) }\end{array}$ & $\begin{array}{c}\text { Theor } \\
\text { Min } \\
\text { (psi) }\end{array}$ & $\begin{array}{c}\text { Theor } \\
\text { Max } \\
\text { (psi) }\end{array}$ \\
\hline \hline 454.35 & 0.99 & 1.58 & 0.94 & 0.15 & 1.84 & 0.37 & 0 & 2.22 \\
\hline 443.05 & 0.96 & 1.51 & 1.46 & 0.45 & 2.15 & 1.12 & 0 & 3.27 \\
\hline 431.7625 & 0.94 & 1.44 & 1.94 & 0.75 & 2.53 & 1.87 & 0 & 4.40 \\
\hline 414.125 & 0.90 & 1.34 & 2.62 & 1.21 & 3.19 & 3.03 & 0.00 & 6.22 \\
\hline 390.125 & 0.85 & 1.22 & 3.43 & 1.84 & 4.08 & 4.62 & 0.53 & 8.70 \\
\hline 366.125 & 0.80 & 1.12 & 4.13 & 2.45 & 4.93 & 6.20 & 1.27 & 11.14 \\
\hline 342 & 0.74 & 1.02 & 4.75 & 3.05 & 5.73 & 7.80 & 2.06 & 13.53 \\
\hline 318.325 & 0.69 & 0.94 & 5.27 & 3.62 & 6.46 & 9.36 & 2.90 & 15.82 \\
\hline 295.225 & 0.64 & 0.86 & 5.72 & 4.15 & 7.12 & 10.89 & 3.77 & 18.01 \\
\hline 272.125 & 0.59 & 0.80 & 6.11 & 4.66 & 7.73 & 12.41 & 4.69 & 20.14 \\
\hline 248.975 & 0.54 & 0.74 & 6.46 & 5.13 & 8.28 & 13.94 & 5.66 & 22.23 \\
\hline 225.825 & 0.49 & 0.69 & 6.76 & 5.58 & 8.79 & 15.47 & 6.68 & 24.27 \\
\hline 202.725 & 0.44 & 0.65 & 7.03 & 5.99 & 9.26 & 17.00 & 7.74 & 26.25 \\
\hline 179.625 & 0.39 & 0.61 & 7.25 & 6.36 & 9.67 & 18.53 & 8.86 & 28.19 \\
\hline 156.475 & 0.34 & 0.57 & 7.45 & 6.70 & 10.03 & 20.06 & 10.02 & 30.09 \\
\hline 134.075 & 0.29 & 0.55 & 7.61 & 6.98 & 10.34 & 21.54 & 11.20 & 31.87 \\
\hline 112.475 & 0.24 & 0.53 & 7.74 & 7.21 & 10.59 & 22.96 & 12.37 & 33.55 \\
\hline 90.875 & 0.20 & 0.51 & 7.84 & 7.41 & 10.80 & 24.39 & 13.59 & 35.19 \\
\hline 69.275 & 0.15 & 0.49 & 7.92 & 7.56 & 10.96 & 25.82 & 14.85 & 36.78 \\
\hline 47.7375 & 0.10 & 0.48 & 7.98 & 7.68 & 11.08 & 27.24 & 16.16 & 38.32 \\
\hline 24.5 & 0.05 & 0.48 & 8.02 & 7.75 & 11.16 & 28.78 & 17.61 & 39.94 \\
\hline 7.755 & 0.02 & 0.47 & 8.03 & 7.78 & 11.19 & 29.88 & 18.69 & 41.07 \\
\hline 1.755 & 0.00 & 0.47 & 8.03 & 7.78 & 11.19 & 30.28 & 19.09 & 41.47 \\
\hline See Appendix H, Table 41, for calculation of theoreticalwaste pressures. & & & \\
\hline
\end{tabular}


RPP-RPT-32239, Rev. 1

M\&D-2008-005-CALC-001, Rev. 1

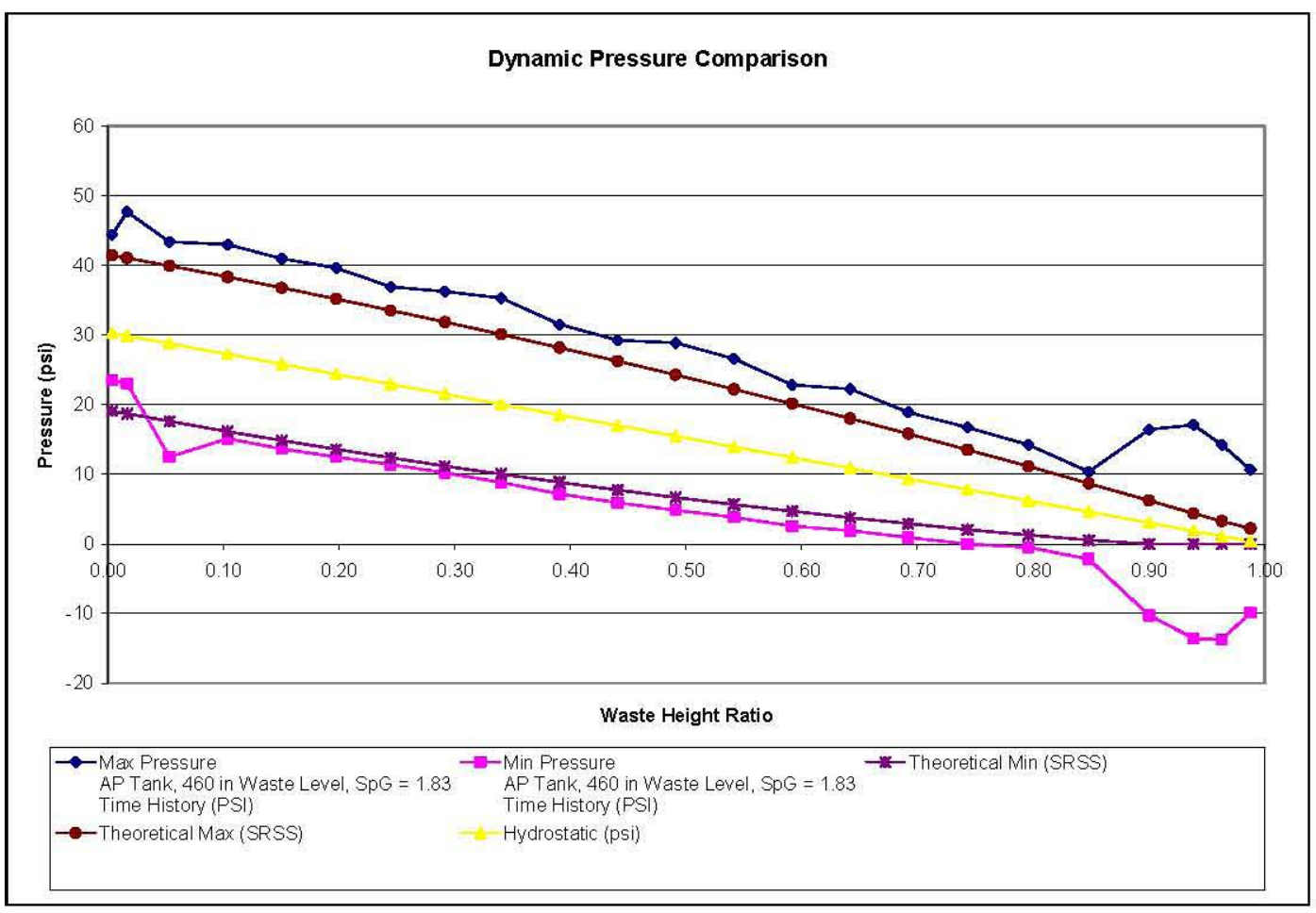

Figure 11-6. Waste Pressure Distribution, UBS-BEC

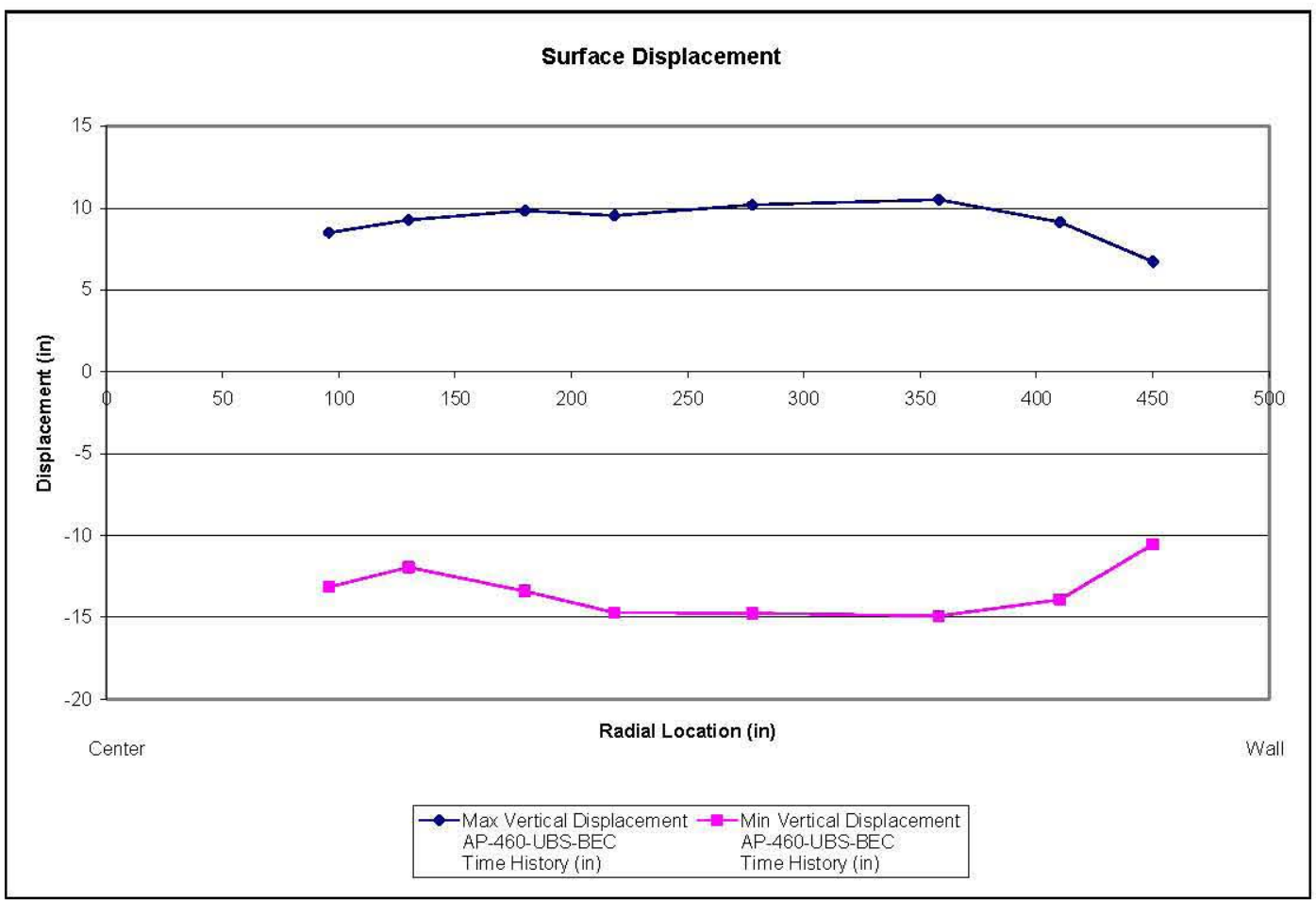

Figure 11-7. Waste-Free Surface Displacement, UBS-BEC 
RPP-RPT-32239, Rev. 1

M\&D-2008-005-CALC-001, Rev. 1

\subsection{Best-Estimate Soil, Fully Cracked Concrete}

$\mathrm{S}_{\mathrm{ah}}=0.29 g$

$\mathrm{S}_{\mathrm{av}}=0.25 \mathrm{~g}$

Table 11-4. Theoretical Waste Pressures, BES-FCC

\begin{tabular}{||c|c|c|c|c|c|c|c|c||}
\hline $\begin{array}{c}\text { Waste } \\
\text { Height }\end{array}$ & nu & $\begin{array}{c}\text { Horiz } \\
\text { Conv } \\
\text { (psi) }\end{array}$ & $\begin{array}{c}\text { Horiz } \\
\text { Imp } \\
\text { (psi) }\end{array}$ & $\begin{array}{c}\text { Vert } \\
\text { (psi) }\end{array}$ & $\begin{array}{c}\text { SRSS } \\
\text { (psi) }\end{array}$ & $\begin{array}{c}\text { Static } \\
\text { (psi) }\end{array}$ & $\begin{array}{c}\text { Theor } \\
\text { Min } \\
\text { (psi) }\end{array}$ & $\begin{array}{c}\text { Theor } \\
\text { Max } \\
\text { (psi) }\end{array}$ \\
\hline \hline 454.35 & 0.99 & 1.58 & 0.76 & 0.12 & 1.75 & 0.37 & 0 & 2.13 \\
\hline 443.05 & 0.96 & 1.51 & 1.18 & 0.35 & 1.94 & 1.12 & 0 & 3.06 \\
\hline 431.7625 & 0.94 & 1.44 & 1.56 & 0.59 & 2.20 & 1.87 & 0 & 4.07 \\
\hline 414.125 & 0.90 & 1.34 & 2.11 & 0.95 & 2.68 & 3.03 & 0.35 & 5.71 \\
\hline 390.125 & 0.85 & 1.22 & 2.77 & 1.44 & 3.35 & 4.62 & 1.27 & 7.97 \\
\hline 366.125 & 0.80 & 1.12 & 3.33 & 1.92 & 4.00 & 6.20 & 2.20 & 10.20 \\
\hline 342 & 0.74 & 1.02 & 3.82 & 2.38 & 4.62 & 7.80 & 3.18 & 12.42 \\
\hline 318.325 & 0.69 & 0.94 & 4.25 & 2.83 & 5.19 & 9.36 & 4.17 & 14.55 \\
\hline 295.225 & 0.64 & 0.86 & 4.61 & 3.24 & 5.70 & 10.89 & 5.19 & 16.59 \\
\hline 272.125 & 0.59 & 0.80 & 4.92 & 3.64 & 6.17 & 12.41 & 6.24 & 18.59 \\
\hline 248.975 & 0.54 & 0.74 & 5.20 & 4.01 & 6.61 & 13.94 & 7.33 & 20.56 \\
\hline 225.825 & 0.49 & 0.69 & 5.45 & 4.36 & 7.01 & 15.47 & 8.46 & 22.48 \\
\hline 202.725 & 0.44 & 0.65 & 5.66 & 4.68 & 7.37 & 17.00 & 9.63 & 24.37 \\
\hline 179.625 & 0.39 & 0.61 & 5.84 & 4.97 & 7.70 & 18.53 & 10.83 & 26.22 \\
\hline 156.475 & 0.34 & 0.57 & 6.00 & 5.23 & 7.98 & 20.06 & 12.07 & 28.04 \\
\hline 134.075 & 0.29 & 0.55 & 6.13 & 5.45 & 8.22 & 21.54 & 13.31 & 29.76 \\
\hline 112.475 & 0.24 & 0.53 & 6.23 & 5.64 & 8.42 & 22.96 & 14.54 & 31.38 \\
\hline 90.875 & 0.20 & 0.51 & 6.31 & 5.79 & 8.58 & 24.39 & 15.81 & 32.97 \\
\hline 69.275 & 0.15 & 0.49 & 6.38 & 5.91 & 8.71 & 25.82 & 17.11 & 34.53 \\
\hline 47.7375 & 0.10 & 0.48 & 6.43 & 6.00 & 8.80 & 27.24 & 18.44 & 36.04 \\
\hline 24.5 & 0.05 & 0.48 & 6.46 & 6.06 & 8.87 & 28.78 & 19.91 & 37.64 \\
\hline 7.755 & 0.02 & 0.47 & 6.47 & 6.08 & 8.89 & 29.88 & 20.99 & 38.77 \\
\hline 1.755 & 0.00 & 0.47 & 6.47 & 6.08 & 8.89 & 30.28 & 21.39 & 39.17 \\
\hline See Appendix I, Table 41, for calculation of theoretical waste pressures. & & \\
\hline
\end{tabular}


RPP-RPT-32239, Rev. 1

M\&D-2008-005-CALC-001, Rev. 1

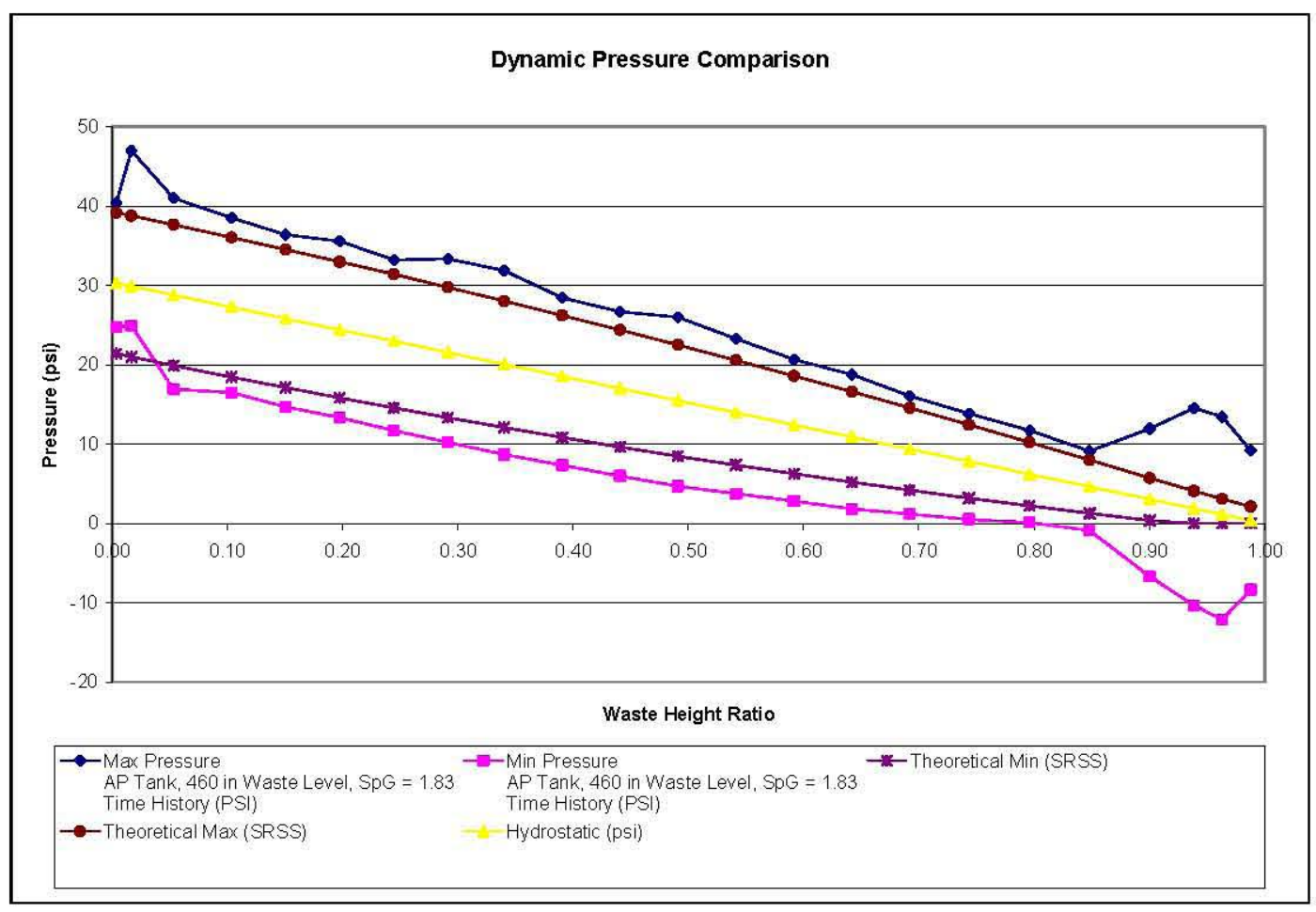

Figure 11-8. Waste Pressure Distribution, BES-FCC

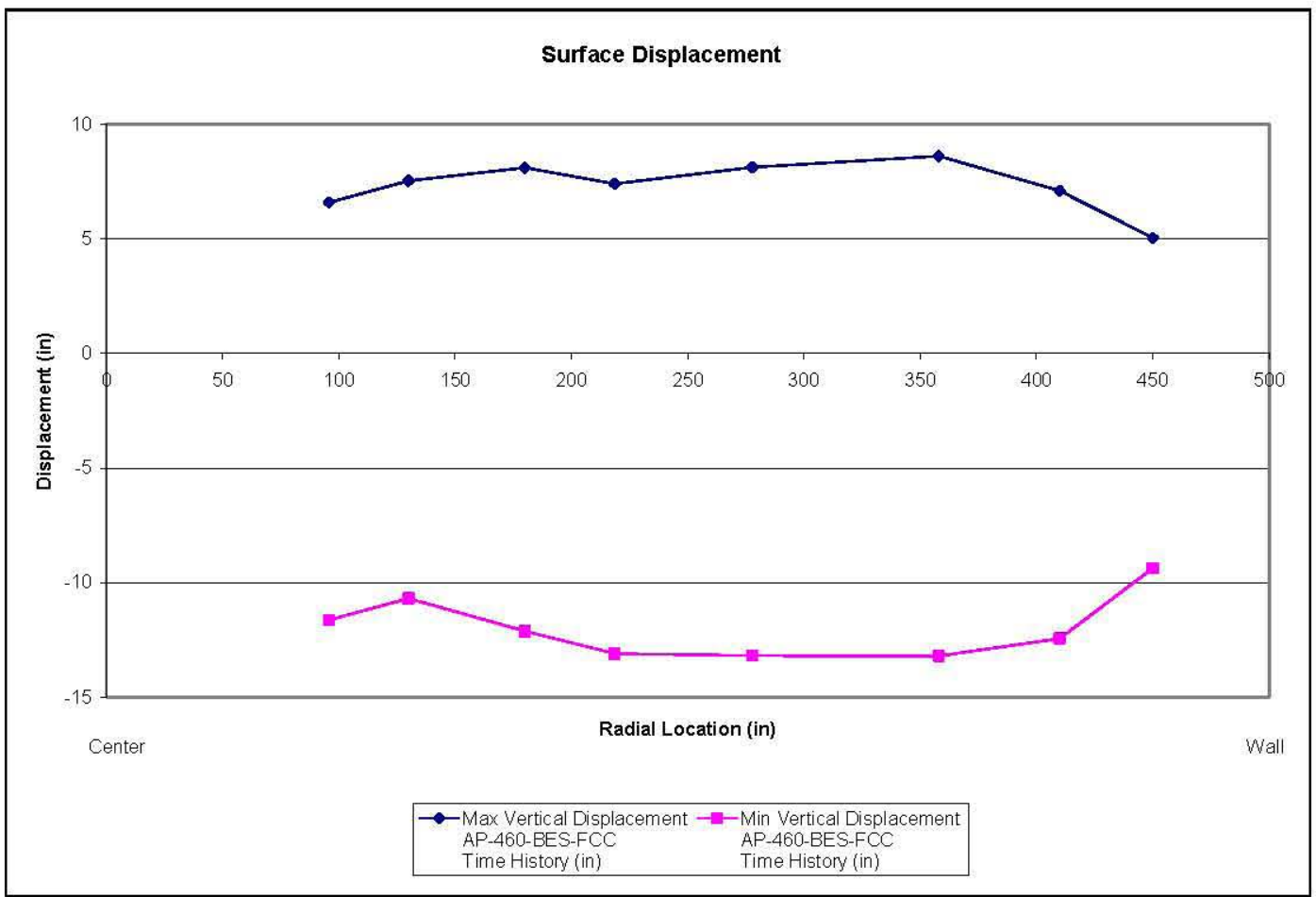

Figure 11-9. Waste-Free Surface Displacement, BES-FCC 
RPP-RPT-32239, Rev. 1

M\&D-2008-005-CALC-001, Rev. 1

\subsection{Computer Run List}

\section{Computer File Listing}

Program Used:

Version Used: $\underline{8.1}$

V\&V Reference: M\&D-V\&V-ANS-81-001, Revision 2

Workstation used:

Error Report Reviewed for Applicability: $\quad$ YES _ $\mathrm{X}_{-} \quad \mathrm{NO}$

Due to the large number of input and output files associated with each run, file listings are included in the appendix containing load case or study results data. The appendixes are as follows:

- Appendix F Lower Bound Soil, Best-Estimate Concrete

- Appendix G Best-Estimate Soil, Best-Estimate Concrete

- Appendix H Upper Bound Soil, Best-Estimate Concrete

- Appendix I Best-Estimate Soil, Fully Cracked Concrete 
RPP-RPT-32239, Rev. 1

M\&D-2008-005-CALC-001, Rev. 1

Intentionally left blank. 
RPP-RPT-32239, Rev. 1

M\&D-2008-005-CALC-001, Rev. 1

\subsection{Calculation Review Checklist}

\section{Calculation Review Checklist}

\begin{tabular}{|c|c|c|c|}
\hline Yes & No & N/A & \\
\hline $\mathrm{X}$ & & & 1. Objective is clearly stated. \\
\hline $\mathrm{X}$ & & & $\begin{array}{l}\text { 2. Design inputs and their sources are clearly identified, including revision and date of the } \\
\text { source. }\end{array}$ \\
\hline $\mathrm{X}$ & & & 3. Assumptions are listed and identified as unverified as appropriate. \\
\hline $\mathrm{X}$ & & & 4. Analytical approach is described and appropriate to satisfy the stated objectives. \\
\hline $\mathrm{X}$ & & & 5. Software used is identified, including revision and workstation used. \\
\hline $\mathrm{X}$ & & & $\begin{array}{l}\text { 6. Computer File Listing has been included and completed if software has been used } \\
\text { (separate listing for each program and version used). }\end{array}$ \\
\hline $\mathrm{X}$ & & & 7. Results are technically correct and consistent with design input and assumptions. \\
\hline $\mathrm{X}$ & & & $\begin{array}{l}\text { 8. Calculations are sufficiently detailed that a technically qualified person can understand } \\
\text { and verify the methodology without requiring outside or unreferenced information. }\end{array}$ \\
\hline \multirow[t]{3}{*}{$\mathrm{X}$} & & & 9. Results and conclusions address all points in the objective. \\
\hline & & $\mathrm{X}$ & $\begin{array}{l}\text { 10. Each page in body of calculation identifies the calculation number, page number, } \\
\text { preparer and checker. (Preparer and Checker have signed or initialed each page.) }\end{array}$ \\
\hline & & $\mathrm{X}$ & $\begin{array}{l}\text { 11. Each page in appendixes or attachments identifies the calculation number and page } \\
\text { number, and the first page identifies the preparer and checker. (Preparer and Checker } \\
\text { have signed or initialed first page.) }\end{array}$ \\
\hline \multirow[t]{3}{*}{$\mathrm{X}$} & & & 12. Total number of pages, including attachments or appendixes has been included. \\
\hline & & $\mathrm{X}$ & 13. Alternate calculations, if used by the checker, have been included. \\
\hline & & $\mathrm{X}$ & $\begin{array}{l}\text { 14. Revised information has been clearly identified by use of markers such as clouds or } \\
\text { revision bars, and a revision history included that describes the changes made and } \\
\text { identifies pages changed. }\end{array}$ \\
\hline
\end{tabular}


RPP-RPT-32239, Rev. 1

M\&D-2008-005-CALC-001, Rev. 1

Intentionally left blank. 


\section{RPP-RPT-32239, Rev. 1 \\ M\&D-2008-005-CALC-001, Rev. 1}

\subsection{References}

BNL. 1995. Seismic Design and Evaluation Guidelines for the Department of Energy High Level Waste Storage Tanks and Appurtenances. Report No. 52361, October, 1995, Engineering Research and Applications Division, Department of Advanced Technology, Brookhaven National Laboratory, Associated Universities, Inc., Upton, New York.

Deibler JE, JD Holberry, KI Johnson, and MW Rinker. 2004. DST Primary Tank Settlement Evaluation. PNNL-14706, Pacific Northwest National Laboratory, Richland, Washington.

Deibler JE, KI Johnson, NK Karri, SP Pilli, MW Rinker, FG Abatt, BG Carpenter, and C Hendrix. 2007a. Hanford Double-Shell Tank Thermal and Seismic Project-Summary of Combined Thermal and Operating Loads with Seismic Analysis. RPP-RPT-28968, Rev. 0A, Pacific Northwest National Laboratory, Richland, Washington.

Deibler JE, KI Johnson, SP Pilli, NK Karri, MW Rinker, FG Abatt, and BG Carpenter. 2007b. Hanford Double-Shell Tank Thermal and Seismic Project - Increased Liquid Level Analysis for 241-AP Tank Farms. RPP-RPT-32237, Rev. 0, Pacific Northwest National Laboratory, Richland, Washington.

Deibler JE, KI Johnson, SP Pilli, MW Rinker, FG Abatt, and NK Karri. 2008. Hanford Double-Shell Tank Thermal and Seismic Project - Increased Liquid Level Analysis for 241-AP Tank Farm. RPP-RPT-32237, Rev. 1, Pacific Northwest National Laboratory, Richland, Washington.

DOE. 2002. Natural Phenomena Hazards Design and Evaluation Criteria for Department of Energy Facilities. DOE-STD-1020-2002, U.S. Department of Energy, Washington, D.C.

Hanford Drawing H-2-64306, Rev. 4, dated 12/4/1968, Tank Foundation Plan, Building 241-AY, Vitro Hanford Engineering Services, Richland, Washington.

Hanford Drawing H-2-64310, Rev. 1, dated 3/24/1970, Concrete Tank Section and Details, Building 241-AY, Vitro Hanford Engineering Services, Richland, Washington.

Hanford Drawing H-2-64449, Rev. 6, dated 5/12/1970, Tank Elevation and Details, 241-AY, Vitro Hanford Engineering Services, Richland, Washington.

Hanford Drawing H-2-90534, Rev. 4, dated 7/14/1998, Tank Cross Section 241-AP Tanks, Lockheed Martin Hanford Corporation, Richland, Washington.

MSC. 2005. MSC.Dytran Reference Manual, Version 2005. MSC Software Corporation, Santa Ana, California.

PNNL. 2007. Updated Site Response Analyses for the Waste Treatment Plant, DOE Hanford Site, Washington. PNNL-16653/GMX-9995.002-001, prepared by RR Youngs of Geomatrix Consultants, Inc. for the Pacific Northwest National Laboratory, Richland, Washington. 
RPP-RPT-32239, Rev. 1

M\&D-2008-005-CALC-001, Rev. 1

Rinker MW, JE Deibler, KI Johnson, SP Pilli, CE Guzman-Leong, and OD Mullen. 2004. Hanford Double-Shell Tank Thermal and Seismic Project - Thermal and Operating Loads Analysis.

RPP-RPT-23308, Rev. 0, Pacific Northwest National Laboratory, Richland, Washington.

Rinker MW and FG Abatt. 2006a. Dytran ${ }^{\circledR}$ Benchmark Analysis of Seismically Induced Fluid-Structure Interaction in a Hanford Double Shell Primary Tank. RPP RPT-28963, Rev. 0A, prepared by M\&D Professional Services, Inc. for Pacific Northwest National Laboratory, Richland, Washington.

Rinker MW and FG Abatt. 2006b. Dytran ${ }^{\circledR}$ Benchmark Analysis of Seismically Induced Fluid-Structure Interaction in Flat-Top Tanks. RPP-RPT-30807, Rev. 0, prepared by M\&D Professional Services, Inc. for Pacific Northwest National Laboratory, Richland, Washington.

Rinker MW, FG Abatt, BG Carpenter, and CA Hendrix. 2006a. Establishment of Methodology for Time Domain Soil-Structure Interaction Analysis of a Hanford Double Shell Tank. RPP-RPT-28964, Rev. 0, prepared by M\&D Professional Services, Inc. for Pacific Northwest National Laboratory, Richland, Washington.

Rinker MW, BG Carpenter, and FG Abatt. 2006b. ANSYS Benchmark Analysis of Seismically Induced Fluid-Structure Interaction in a Hanford Double Shell Primary Tank. RPP-RPT-28965, Rev. 0, prepared by M\&D Professional Services, Inc. for Pacific Northwest National Laboratory, Richland, Washington.

Rinker MW, BG Carpenter, CA Hendrix, and FG Abatt. 2006c. ANSYS ${ }^{\circledR}$ Seismic Analysis of Hanford Double Shell Tank. RPP-RPT-28966, Rev. 0, prepared by M\&D Professional Services, Inc. for Pacific Northwest National Laboratory, Richland, Washington.

Veletsos AS and AH Younan. 1998. "Dynamics of Solid-Containing Tanks. II: Flexible Tanks." Journal of Structural Engineering (124):62-70. 
RPP-RPT-32239, Rev. 1

M\&D-2008-005-CALC-001, Rev. 1

\section{Appendix A}

\section{Dytran $^{\circledR}$ Input Files for Primary Tank Sub-Models}


RPP-RPT-32239, Rev. 1

M\&D-2008-005-CALC-001, Rev. 1

Intentionally left blank 
RPP-RPT-32239, Rev. 1

M\&D-2008-005-CALC-001, Rev. 1

Appendix A

\section{Dytran ${ }^{\circledR}$ Input Files for Primary Tank Sub-Models}

\section{Dytran Input File Horizontal Excitation Only}

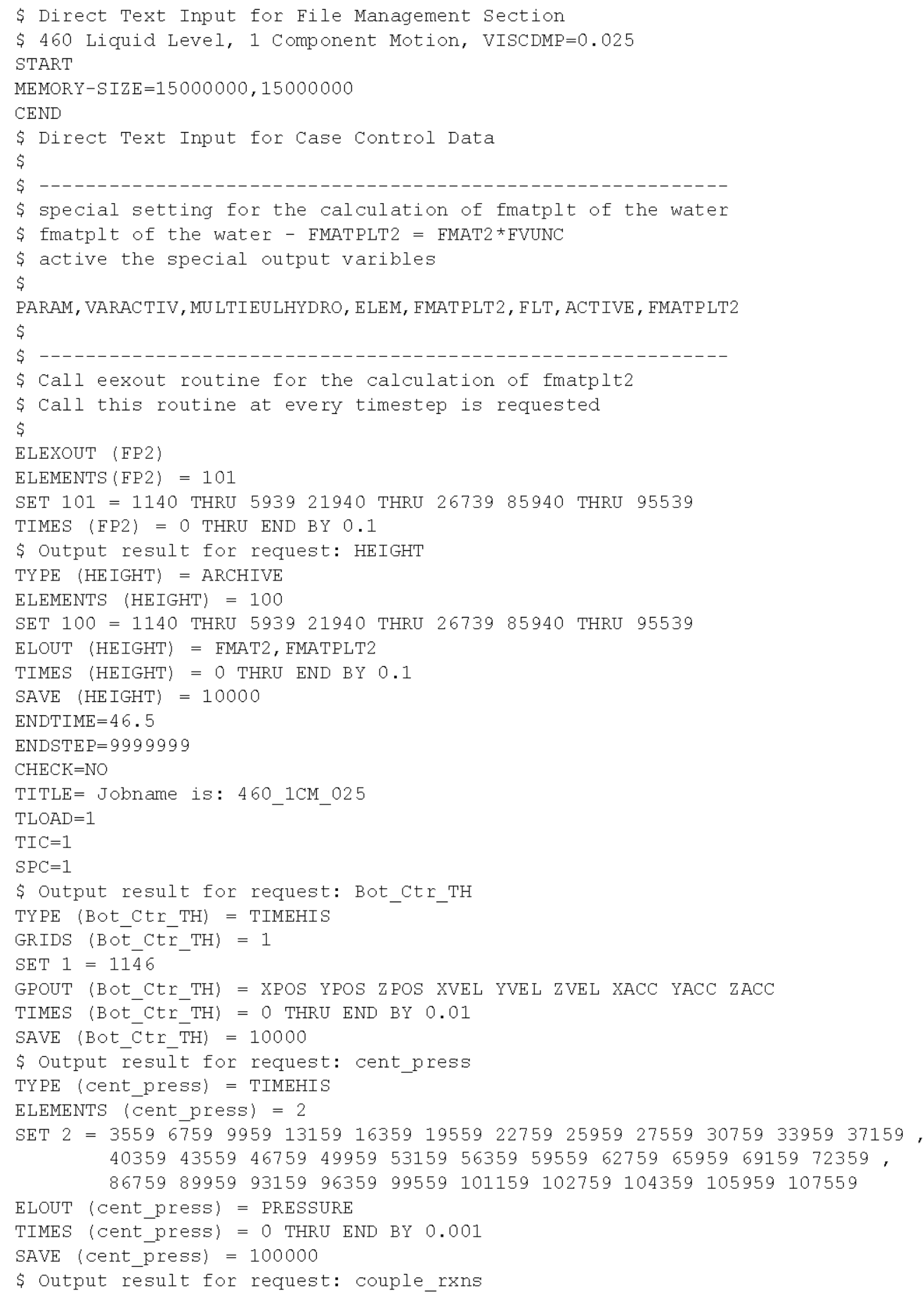




\section{RPP-RPT-32239, Rev. 1 \\ M\&D-2008-005-CALC-001, Rev. 1}

TYPE (couple_rxns) = TIMEHIS

CPLSURFS (couple_rxns) $=3$

SET $3=1$

CPLSOUT (COUple_rXns) = XFORCE YFORCE ZFORCE

TIMES (couple_rXns) $=0$ THRU END BY 0.01

SAVE (couple_rxns) $=10000$

\$ Output result for request: couple_rxns_001

TYPE (couple rXns 001) = TIMEHIS

CPLSURFS (couple_rxns_001) $=4$

$\mathrm{SET} 4=1$

CPLSOUT (COuple_rXnS_001) = XFORCE YFORCE

TIMES (couple_rXns_001) $=0$ THRU END BY 0.001

SAVE (couple_rxns_on $=100000$

\$ Output result for request: euler_height_out

TYPE (euler height out) = ARCHIVE

ELEMENTS (eüler height out) $=5$

SET $5=1140$ THRU 593921940 THRU 2673985940 THRU 95539

ELOUT (euler_height_out) = FMATPLT

TIMES (euler_height_out) $=0$ THRU END BY 0.1

SAVE (euler_height_out) $=10000$

\$ Output result for request: minuss_outstrip

TYPE (minusx_outstrip) = TIMEHIS

ELEMENTS (miñus outstrip) $=6$

SET $6=201211221281311581582583584 \quad 585741742743881882883884$

ELOUT (minusX_outstrip) $=$ TXX-MID TXX-OUT TXX-IN TYY-MID TYY-OUT TYY-IN

TIMES (minusx_outstrip) $=0$ THRU END BY 0.01

SAVE (minusx_outstrip) $=10000$

\$ Output result for request: minusx press

TYPE (minusX_press) = TIMEHIS

ELEMENTS (minusx press) $=7$

SET $7=1976357 \overline{6} 5176 \quad 6776997613176163761957622776259762757630776$ ， 3397637176403764357646776499765317656376595766277665976 ， 69176723768677688376899769157693176

ELOUT (minusx_press) $=$ PRESSURE

TIMES (minusx_press) $=0$ THRU END BY 0.001

SAVE (minusx_press) $=100000$

\$ Output result for request: minusx_shear

TYPE (minusx_shear) = TIMEHIS

ELEMENTS (minusx_shear) $=8$

SET $8=201211 \overline{2} 21281311581582583584 \quad 585741 \quad 742 \quad 743 \quad 881882 \quad 883884$

ELOUT (minusx_shear) $=$ TXY-MID

TIMES (minusx_shear) $=0$ THRU END BY 0.01

SAVE (minusx shear) $=10000$

$\$$ Output result for request: plusx_outstrip

TYPE (plusX outstrip) = TIMEHIS

ELEMENTS (p Iusx outstrip) $=9$

SET $9=240 \quad 250 \quad 260 \quad 300 \quad 310676 \quad 677 \quad 678 \quad 679680798 \quad 799 \quad 800 \quad 957958 \quad 959 \quad 960$

ELOUT (plusx outstrip) $=$ TXX-MID TXX-OUT TXX-IN TYY-MID TYY-OUT TYY-IN

TIMES (plusx_outstrip) $=0$ THRU END BY 0.01

SAVE (plusx_outstrip) $=10000$

\$ Output result for request: plusx_press

TYPE (plusX_press) = TIMEHIS

ELEMENTS (plusx_press) $=10$

SET $10=19433 \overline{543} 51436743994313143163431954322743259432754330743$ ， 3394337143403434354346743499435314356343595436274365943 , 69143723438674388343899439154393143

ELOUT (plusx_press) = PRESSURE

TIMES (plusx press) $=0$ THRU END BY 0.01

SAVE (plusx_press) $=10000$

\$ Output result for request: plusx_press_001

TYPE (plusX_press_001) = TIMEHIS

ELEMENTS (plusx_press_001) = 11

SET $11=1943 \quad \overline{5} 4351 \overline{4} 367439943131431634319543227432594327543 \quad 30743$, 3394337143403434354346743499435314356343595436274365943 , 69143723438674388343899439154393143 


\section{RPP-RPT-32239, Rev. 1 \\ M\&D-2008-005-CALC-001, Rev. 1}

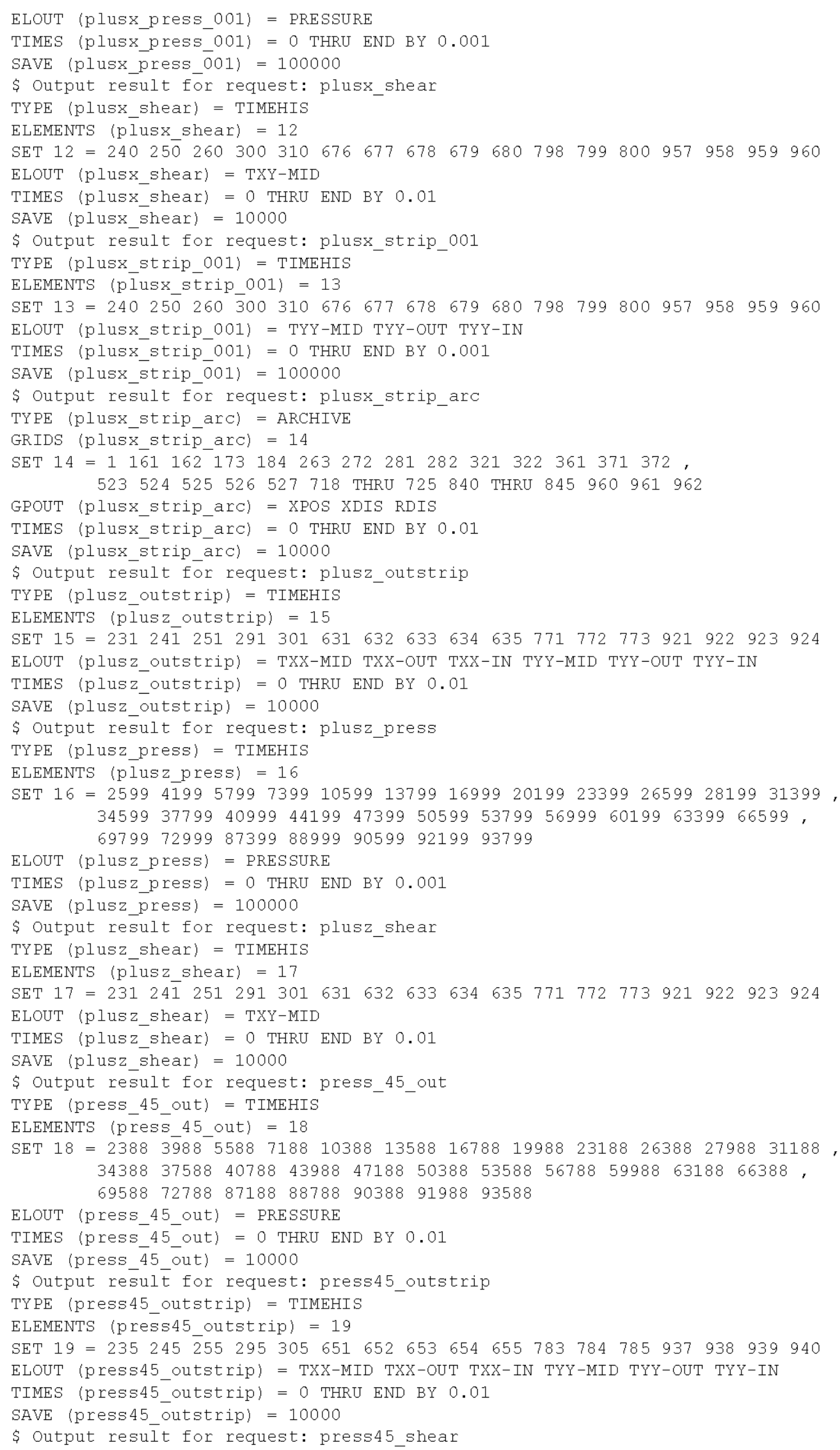




\section{RPP-RPT-32239, Rev. 1 \\ M\&D-2008-005-CALC-001, Rev. 1}

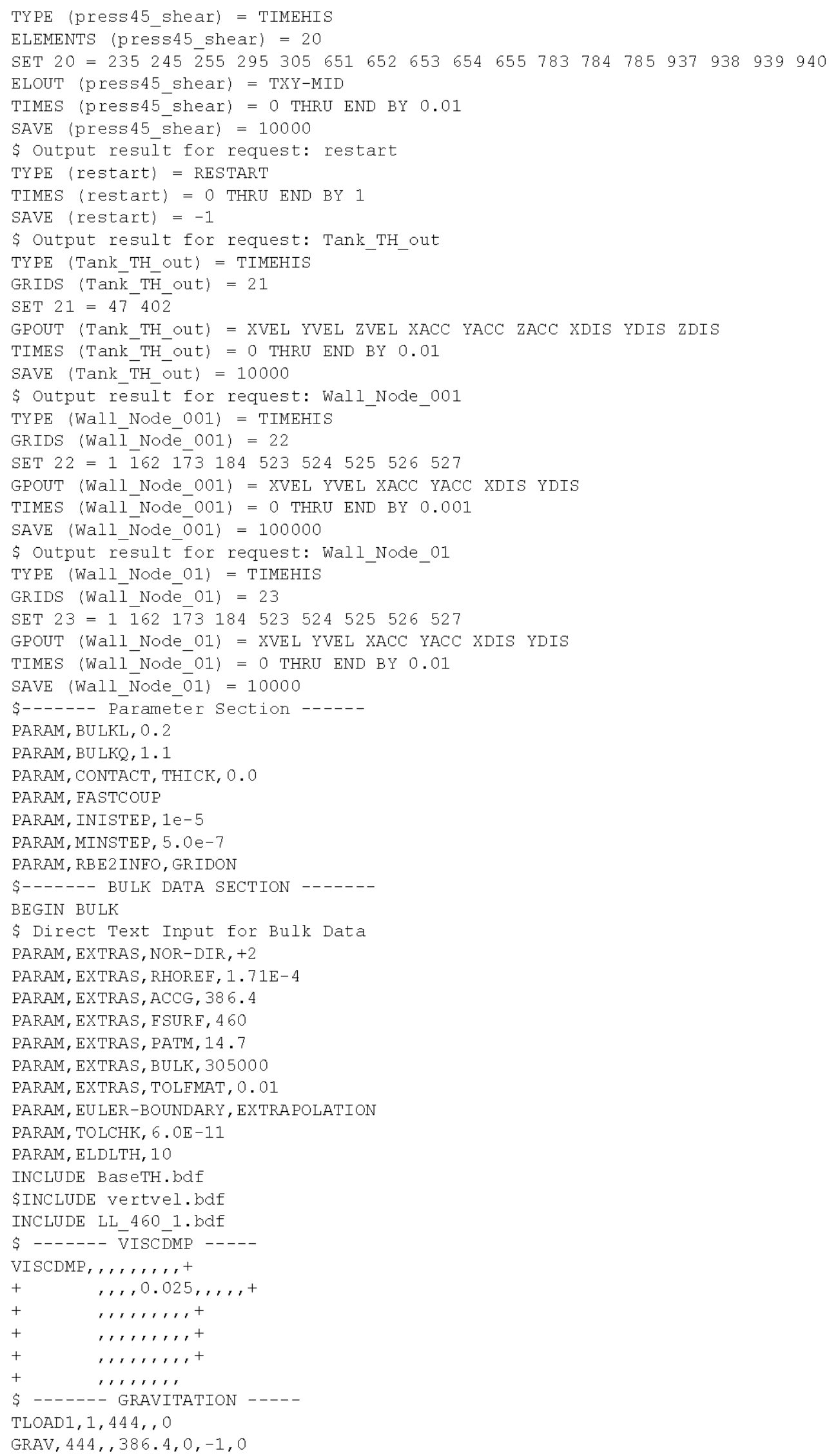


RPP-RPT-32239, Rev. 1

M\&D-2008-005-CALC-001, Rev. 1

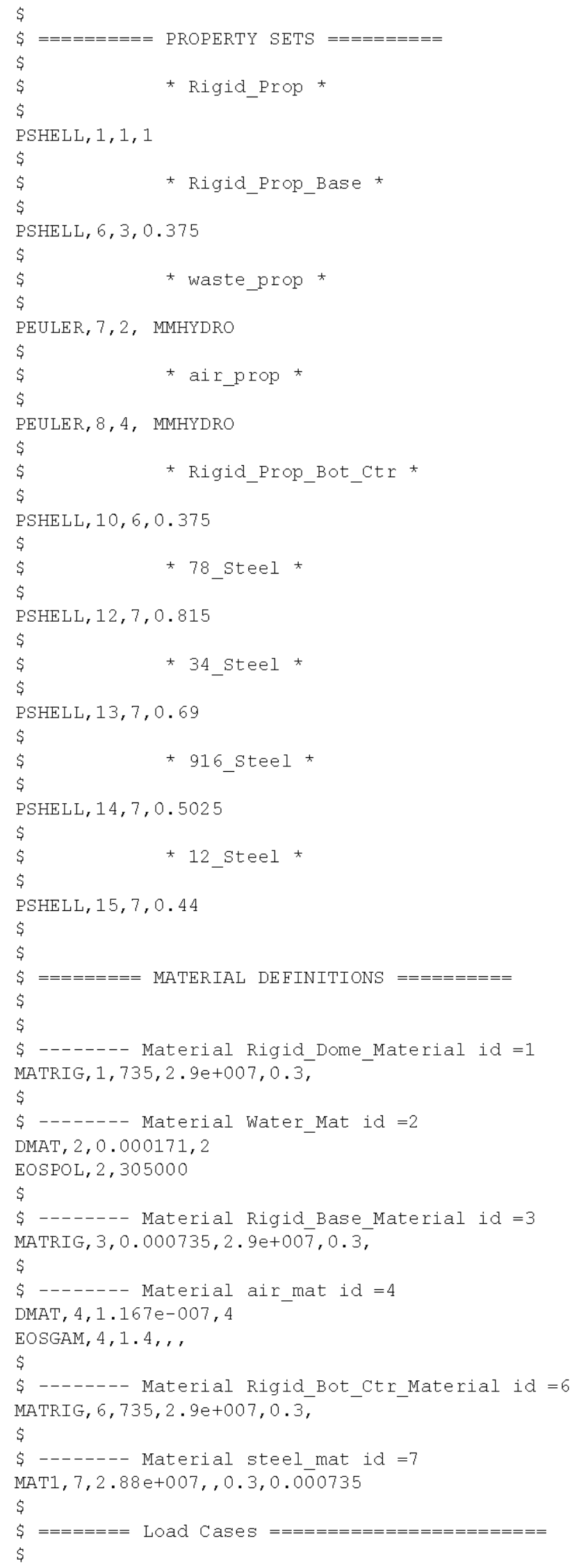




\section{RPP-RPT-32239, Rev. 1 M\&D-2008-005-CALC-001, Rev. 1}

$\$$

$\$-----$ Rigid Body object Rigid_Tank -----

$\$$--- No reference node is used.

TLOAD $1,1,2,12$

FORCE , 2, MR1, $0,0,0$

TLOAD $1,1,1002,12$

MOMENT, 1002, MR1, , 0, 0, 0, 0

$\$$

$\$$----- TICEL BC air_init_set ----

SET1, 24, 85940, THRU, $864 \overline{6} 6,10 \overline{7} 985$, THRU, $108339,107579,+$

$+\quad$, THRU, 107984, 107173, THRU, 107578, 106767, THRU, 107172, +

$+\quad, 106361$, THRU, 106766,105955, THRU, 106360, 105549, THRU, +

$+\quad, 105954,105143$, THRU, 105548, 104737, THRU, 105142,104331, +

$+\quad$, THRU, 104736, 103925, THRU, 104330, 103519, THRU, 103924, +

$+\quad, 103113$, THRU , 103518, 102707, THRU, 103112, 102301, THRU, +

$+\quad, 102706,101895$, THRU, 102300, 101489, THRU, 101894, 101083,+

$+\quad$, THRU, 101488, 100677, THRU, 101082, 100271, THRU, 100676, +

$+\quad, 99865$, THRU, 100270,99459, THRU, 99864,99053, THRU , +

$+\quad, 99458,98647$, THRU, 99052,98241, THRU, $98646,97835,+$

$+\quad$, THRU, 98240,97429 , THRU, 97834,97023, THRU, $97428,+$

$+\quad, 96617$, THRU, 97022,96211, THRU, 96616,95805, THRU , +

$+\quad, 96210,95399$, THRU, 95804,94993, THRU, $95398,94587,+$

$+\quad$, THRU, 94992,94181, THRU, 94586,93775, THRU, $94180,+$

$+\quad, 93369$, THRU, 93774,92963, THRU, 93368,92557, THRU , +

$+\quad, 92962,92151$, THRU, 92556,91745, THRU, $92150,91339,+$

$+\quad$, THRU, 91744,90933, THRU, 91338,90527, THRU, $90932,+$

$+\quad$,90121, THRU, 90526,89715, THRU, 90120,89309, THRU, +

$+\quad, 89714,88903$, THRU, 89308, 88497, THRU, 88902,88091, +

$+\quad$, THRU, 88496,87685, THRU, 88090,87279, THRU , $87684,+$

$+\quad, 86873$, THRU, 87278,86467, THRU, 86872

TICEL , 1, 24, DENSITY, 1.167e-007, SIE, $3.15 \mathrm{e}+008$

$\$$

$\$-----$ TICEL BC wat init set ----

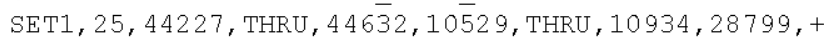

$+\quad$, THRU, 29204, 28393, THRU, 28798, 27987, THRU, 28392,+

$+\quad, 27581$, THRU, 27986, 27175, THRU, 27580, 26769, THRU, +

$+\quad, 27174,26363$, THRU, 26768, 25957, THRU, 26362, 25551,+

$+\quad$, THRU, 25956,25145, THRU, 25550,24739 , THRU , 25144, +

$+\quad, 24333$, THRU, 24738,23927, THRU, 24332, 23521, THRU, +

$+\quad$,23926,23115, THRU, 23520, 22709, THRU, 23114, 22303,+ , 21085, THRU, 21490, 20679, THRU, 21084, 20273 , THRU, + ,20678,19867, THRU, 20272,19461, THRU, 19866, 19055,+ , THRU, 19460, 18649, THRU, 19054, 18243, THRU, 18648 , + , 17837, THRU, 18242, 17431, THRU, 17836, 17025, THRU , + ,17430,16619, THRU, 17024, 16213, THRU, 16618, 15807,+ , THRU, 16212, 15401, THRU, 15806, 14995, THRU , 15400,+ , 14589, THRU, 14994, 14183, THRU, 14588, 13777, THRU , + , 14182, 13371, THRU, 13776, 12965, THRU, 13370, 12559,+ , THRU, 12964,12153 , THRU, 12558, 11747, THRU, 12152,+ , 11341, THRU, 11746, 10935, THRU, 11340, 10123, THRU , + , 10528, 9717, THRU, 10122,9311, THRU, 9716, 8905,+ , THRU, 9310, 8499, THRU, 8904,8093, THRU, 8498,+ , 7687, THRU, 8092,7281 , THRU, 7686, 6875, THRU, + ,7280, 6469, THRU, 6874, 6063, THRU, 6468, 5657,+ , THRU, 6062, 5251, THRU, 5656, 4845, THRU, 5250,+ , 4439, THRU, 4844, 4033, THRU, 4438, 3627, THRU, + , 4032, 3221 , THRU, 3626,2815 , THRU, $3220,2409,+$ , THRU, 2814, 2003, THRU, 2408, 1597, THRU, 2002,+ , 1191, THRU, 1596, 1140, THRU, 1190, 43821, THRU, + , 44226,43415, THRU, 43820, 43009, THRU, 43414, 42603,+ , THRU, 43008, 42197, THRU, 42602,41791, THRU, 42196,+ ,41385, THRU, 41790, 40979, THRU, 41384, 40573 , THRU , + ,40978,40167, THRU, 40572, 39761, THRU, 40166, 39355,+ , THRU, 39760,38949 , THRU, 39354, 38543, THRU, 38948 ,+ 


\section{RPP-RPT-32239, Rev. 1 \\ M\&D-2008-005-CALC-001, Rev. 1}

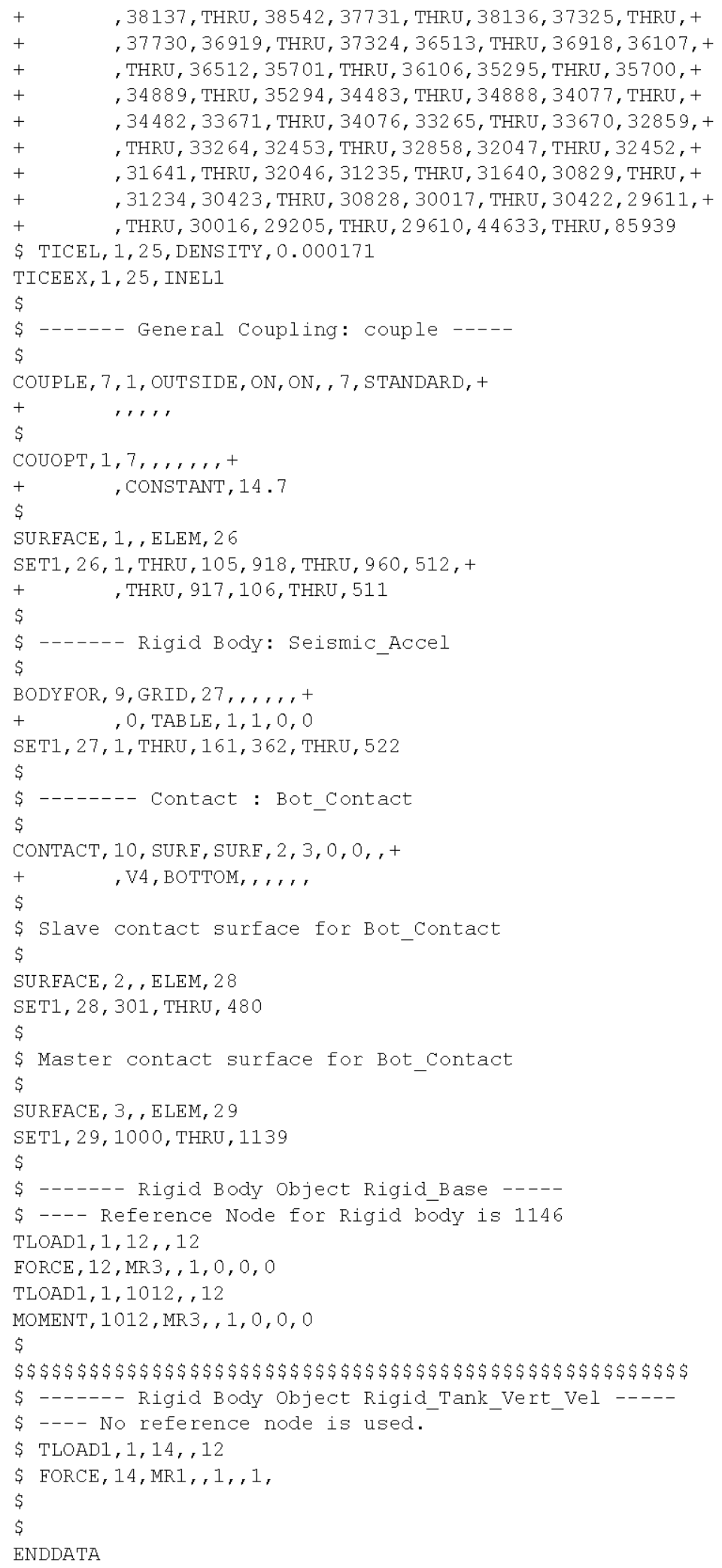




\section{RPP-RPT-32239, Rev. 1 \\ M\&D-2008-005-CALC-001, Rev. 1}

\section{Dytran Input File Vertical Excitation Only}

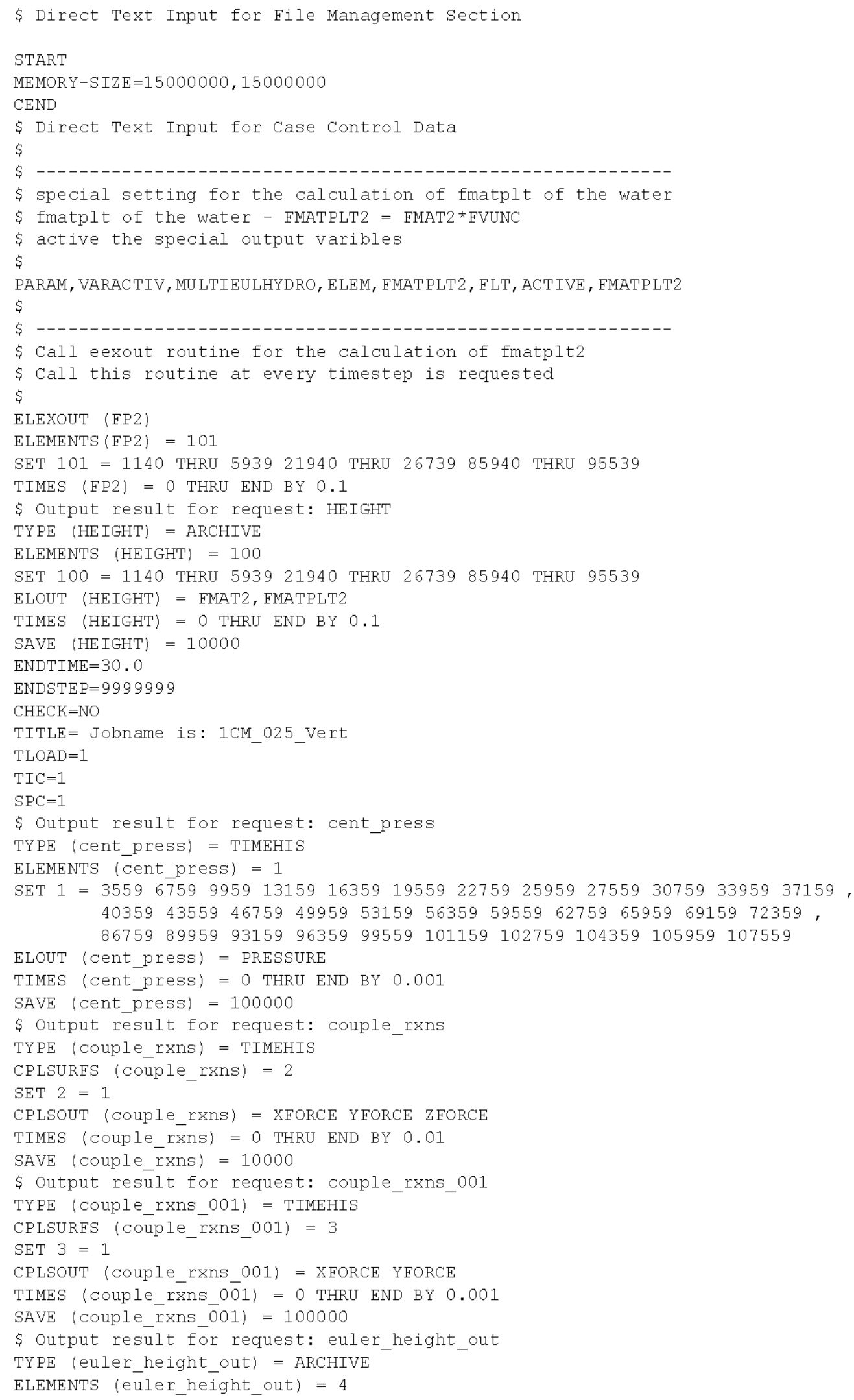




\section{RPP-RPT-32239, Rev. 1 \\ M\&D-2008-005-CALC-001, Rev. 1}

SET $4=1140$ THRU 593921940 THRU 2673985940 THRU 95539

ELOUT (euler_height_out) $=$ FMATRLT

TIMES (euler height out) $=0$ THRU END BY 0.1

SAVE (euler_height_out) $=10000$

\$ Output result for request: minusx_outstrip

TYPE (minusX outstrip) = TIMEHIS

ELEMENTS (miñusX_outstrip) $=5$

SET $5=201211 \overline{2} 21281311581582583584 \quad 585741 \quad 742 \quad 743 \quad 881882 \quad 883884$

ELOUT (minusX_outstrip) $=$ TXX-MID TXX-OUT TXX-IN TYY-MID TYY-OUT TYY-IN

TIMES (minusx_outstrip) $=0$ THRU END BY 0.01

SAVE (minusx_outstrip) $=10000$

$\$$ Output result for request: minusx_press

TYPE (minusX press) = TIMEHIS

ELEMENTS (minusx_press) $=6$

SET $6=1976357651766776997613176163761957622776259762757630776$ ， 3397637176403764357646776499765317656376595766277665976 , 69176723768677688376899769157693176

ELOUT (minusx press) $=$ PRESSURE

TIMES (minusx_press) $=0$ THRU END BY 0.01

SAVE (minusx press) $=10000$

\$ Output result for request: minusx_press_001

TYPE (minusX_press_001) = TIMEHIS

ELEMENTS (minusx_press_001) $=7$

SET $7=1976357651766776997613176163761957622776259762757630776$ ， $33976371764037643576467764997653176 \quad 56376595766277665976$, 69176723768677688376899769157693176

ELOUT (minusX_press_001) $=$ PRESSURE

TIMES (minusX press 001) $=0$ THRU END BY 0.001

SAVE (minusx_press_ō01) $=100000$

\$ Output result for request: minusx shear

TYPE (minusx_shear) = TIMEHIS

ELEMENTS (minusx_shear) $=8$

SET $8=201211 \overline{2} 21281311581582583 \quad 584 \quad 585741742 \quad 743 \quad 881882883884$

ELOUT (minusX_shear) $=$ TXY-MID

TIMES (minusx_shear) $=0$ THRU END BY 0.01

SAVE (minusx_shear) $=10000$

\$ Output result for request: plusx_outstrip

TYPE (plusx outstrip) = TIMEHIS

ELEMENTS (pI ISx_outstrip) = 9

SET $9=240 \quad 250^{-} 260 \quad 300 \quad 310 \quad 676 \quad 677 \quad 678 \quad 679 \quad 680 \quad 798 \quad 799 \quad 800 \quad 957 \quad 958 \quad 959 \quad 960$

ELOUT (plusx_outstrip) $=$ TXX-MID TXX-OUT TXX-IN TYY-MID TYY-OUT TYY-IN

TIMES (plusx_outstrip) $=0$ THRU END BY 0.01

SAVE (plusx outstrip) $=10000$

\$ Output result for request: plusx_press

TYPE (plusx press) = TIMEHIS

ELEMENTS (plusx press) $=10$

SET $10=1943354351436743994313143163431954322743259432754330743$, 3394337143403434354346743499435314356343595436274365943 , 69143723438674388343899439154393143

ELOUT (plusx press) = PRESSURE

TIMES (plusx press) $=0$ THRU END BY 0.01

SAVE (plusx_press) $=10000$

\$ Output result for request: plusx_press 001

TYPE (plusX_press_001) = TIMEHIS

ELEMENTS (plusx press 001) $=11$

$\mathrm{SET} 11=19433 \overline{5} 4351 \overline{4} 36743994313143163431954322743259432754330743$ ， 3394337143403434354346743499435314356343595436274365943 ， $69143 \quad 72343 \quad 86743 \quad 88343 \quad 89943 \quad 91543 \quad 93143$

ELOUT (plusx_press_001) = PRESSURE

TIMES (plusx press 001) $=0$ THRU END BY 0.001

SAVE (plusx_press_001) $=100000$

\$ Output result for request: plusx shear

TYPE (plusx_shear) = TIMEHIS

ELEMENTS (plusx_shear) $=12$

SET $12=240250 \quad 260 \quad 300310 \quad 676 \quad 677 \quad 678 \quad 679680798 \quad 799 \quad 800 \quad 957 \quad 958 \quad 959960$ 


\section{RPP-RPT-32239, Rev. 1 \\ M\&D-2008-005-CALC-001, Rev. 1}

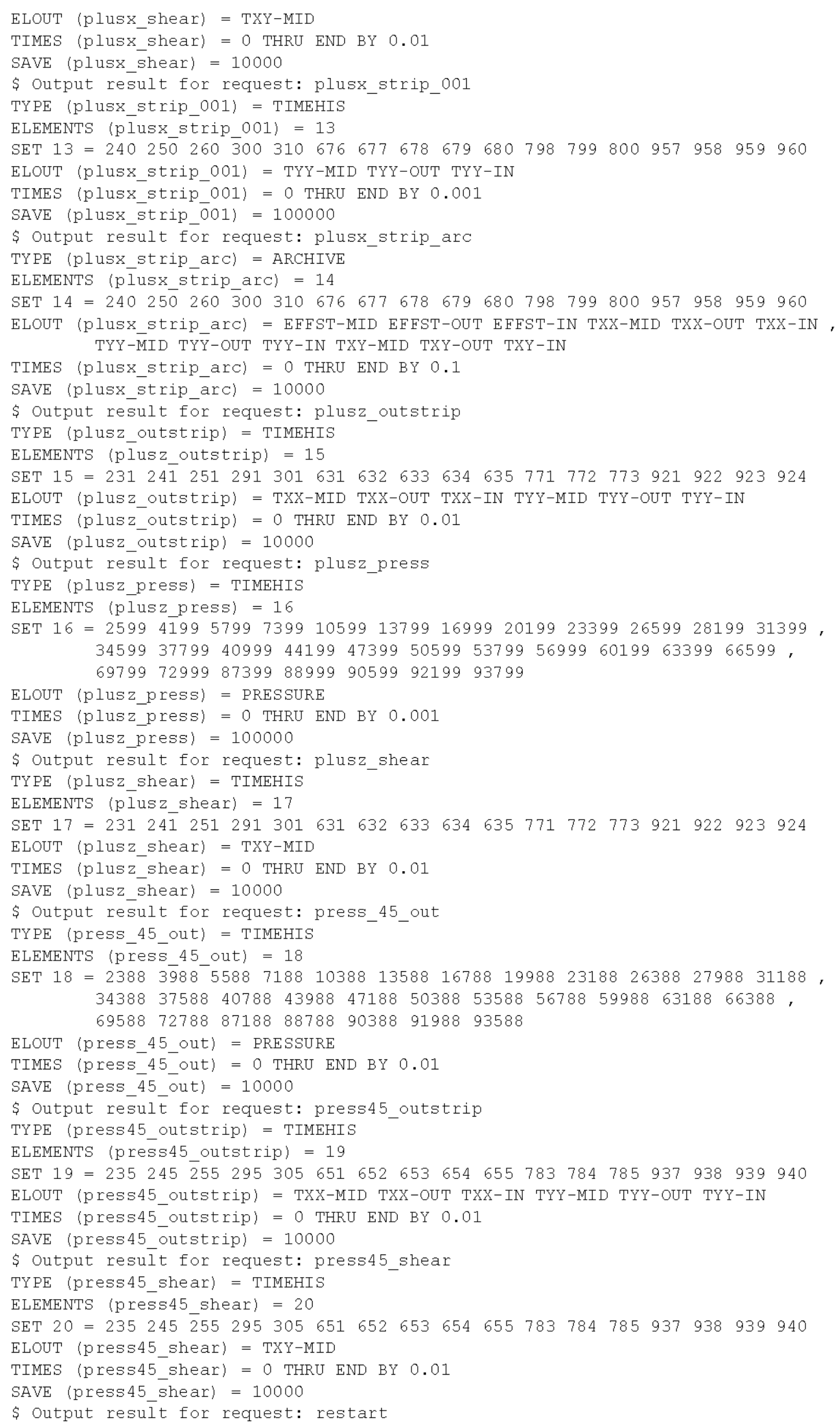




\section{RPP-RPT-32239, Rev. 1 \\ M\&D-2008-005-CALC-001, Rev. 1}

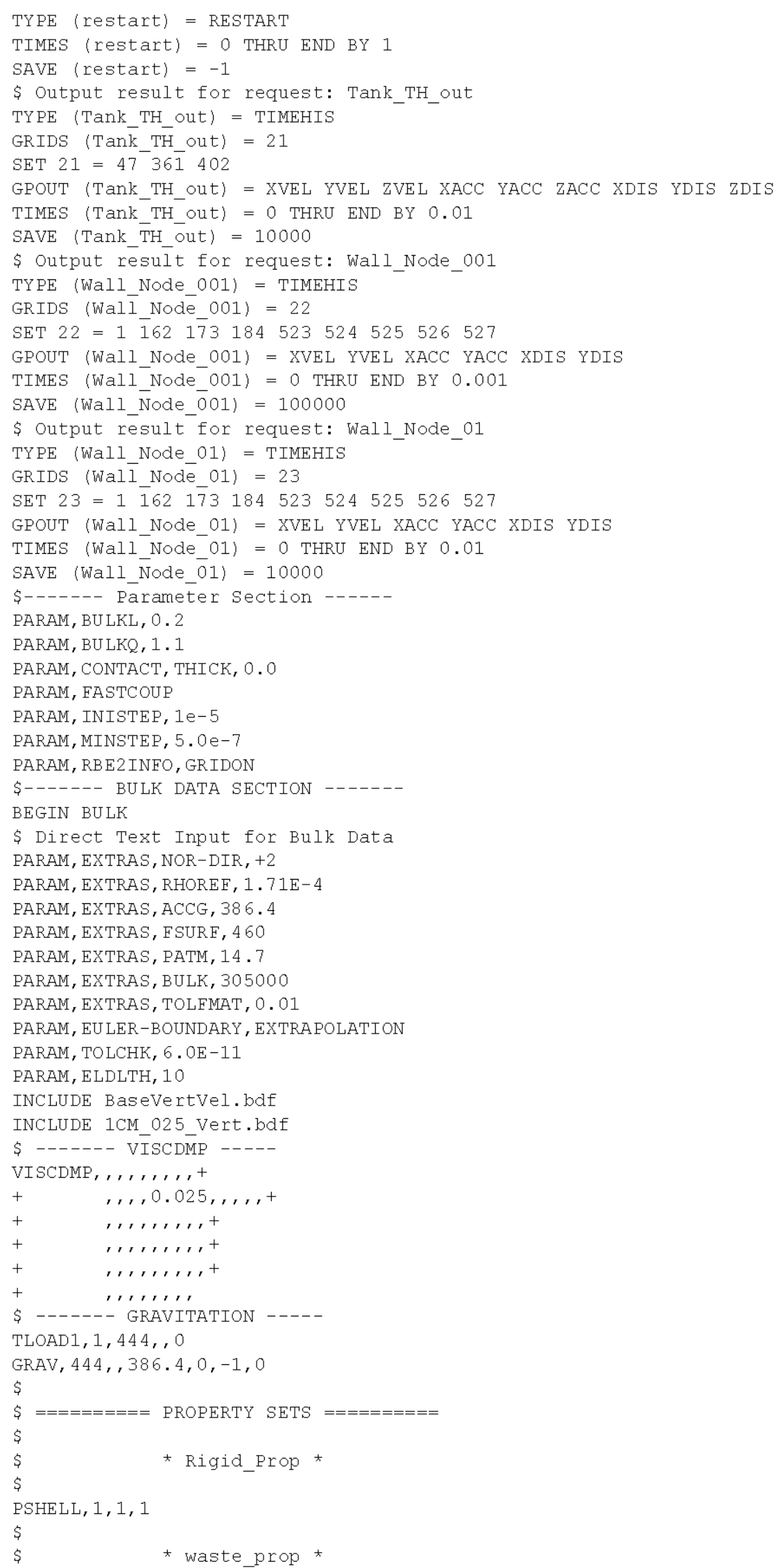




\section{RPP-RPT-32239, Rev. 1 \\ M\&D-2008-005-CALC-001, Rev. 1}

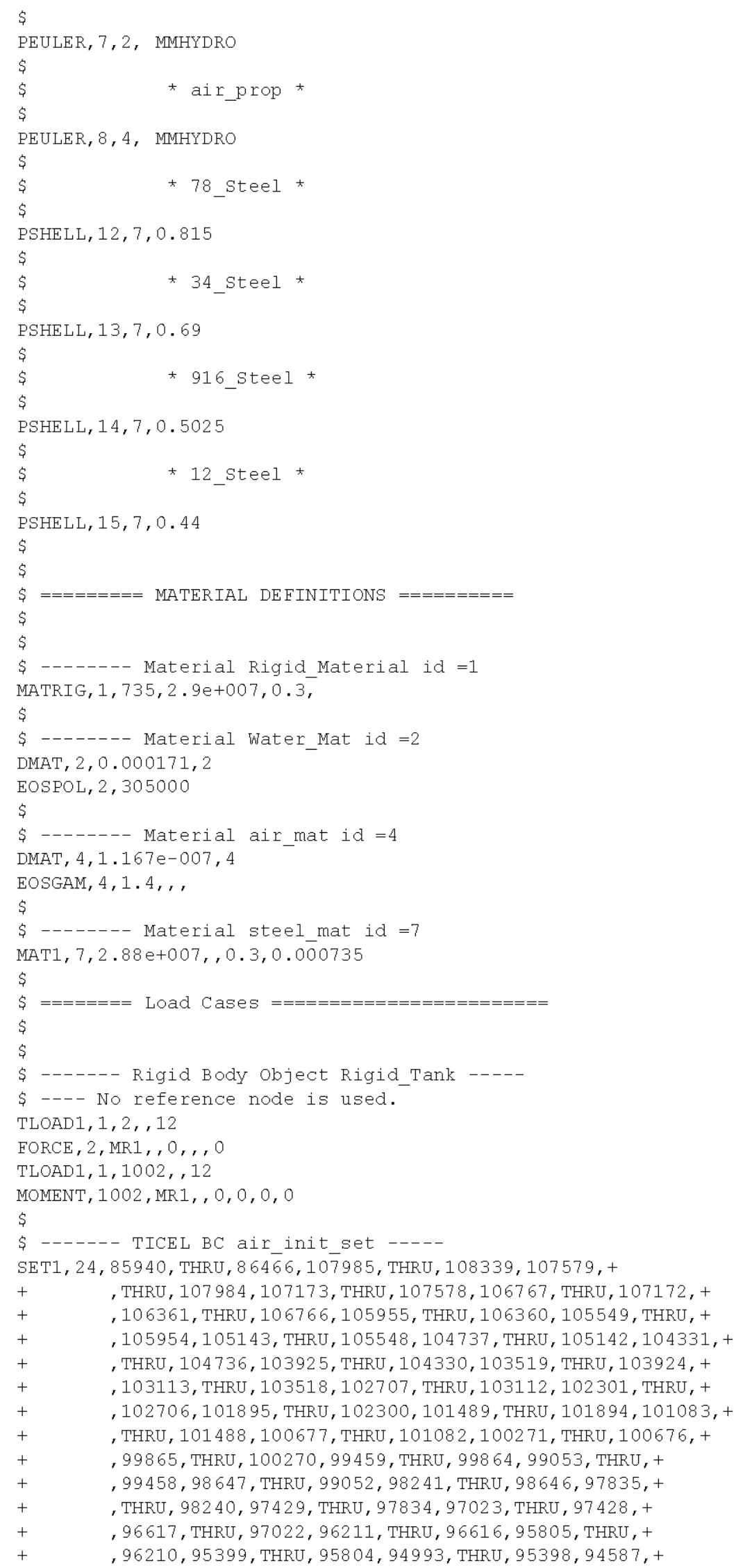

A. 12 


\section{RPP-RPT-32239, Rev. 1 M\&D-2008-005-CALC-001, Rev. 1}

$+\quad$, THRU, 94992,94181, THRU, 94586,93775, THRU , 94180,+ $+\quad, 93369$, THRU, 93774,92963, THRU, 93368, 92557, THRU , + $+\quad, 92962,92151$, THRU, 92556, 91745, THRU, 92150,91339, + $+\quad$, THRU, 91744,90933, THRU, 91338, 90527, THRU, 90932,+ $+\quad$,90121, THRU, 90526,89715, THRU, 90120,89309, THRU , + $+\quad, 89714,88903$, THRU, 89308, 88497, THRU, 88902,88091, + $+\quad$, THRU , 88496,87685, THRU , 88090,87279, THRU , $87684,+$ $+\quad, 86873, \mathrm{THRU}, 87278,86467, \mathrm{THRU}, 86872$

TICEL $, 1,24$, DENSITY, $1.167 \mathrm{e}-007$, SIE, $3.15 \mathrm{e}+008$

$\$$ $\$$----- TICEL BC wat init set --.--

SET1, 25, 44227, THRU, $446 \overline{3} 2,10 \overline{5} 29$, THRU , 10934, 28799,+

$+\quad$, THRU, 29204, 28393, THRU, 28798, 27987, THRU, 28392,+

$+\quad, 27581$, THRU, 27986,27175, THRU, 27580,26769, THRU , +

$+\quad, 27174,26363$, THRU, 26768,25957, THRU, 26362, 25551, + $+\quad$, THRU, 25956,25145, THRU, 25550,24739, THRU, 25144,+ $+\quad$,24333, THRU, 24738, 23927, THRU, 24332, 23521, THRU, +

$+\quad, 23926,23115$, THRU, 23520, 22709, THRU, 23114, 22303,+ $+\quad$, THRU, 22708,21897, THRU, 22302, 21491, THRU, 21896, + $+\quad$,21085, THRU, 21490,20679, THRU, 21084, 20273, THRU, + $+\quad \quad, 20678,19867$, THRU, 20272,19461, THRU, 19866,19055,+ $+\quad$, THRU, 19460,18649, THRU, 19054, 18243, THRU, 18648, + $+\quad, 17837$, THRU, 18242,17431, THRU, 17836, 17025, THRU , + $+\quad, 17430,16619$, THRU, 17024, 16213, THRU, 16618, 15807,+ $+\quad$, THRU, 16212,15401, THRU, 15806, 14995, THRU , 15400,+ $+\quad, 14589$, THRU, 14994, 14183, THRU, 14588, 13777, THRU, + $+\quad, 14182,13371$, THRU, 13776, 12965, THRU, 13370, 12559, + $+\quad$, THRU, 12964,12153, THRU, 12558, 11747, THRU, 12152,+ $+\quad, 11341$, THRU, 11746, 10935, THRU, 11340,10123, THRU, + $+\quad, 10528,9717$, THRU $, 10122,9311$, THRU, 9716, 8905, + $+\quad$, THRU, 9310,8499, THRU, 8904, 8093, THRU, 8498, + $+\quad, 7687$, THRU $, 8092,7281$, THRU, 7686,6875, THRU,+ $+\quad, 7280,6469, \mathrm{THRU}, 6874,6063, \mathrm{THRU}, 6468,5657,+$ $+\quad$, THRU, 6062, 5251, THRU, 5656, 4845, THRU, 5250,+ $+\quad, 4439$, THRU, 4844,4033, THRU $, 4438,3627$, THRU , + $+\quad, 4032,3221$, THRU $, 3626,2815$, THRU, $3220,2409,+$ $+\quad$,THRU, 2814,2003, THRU, 2408, 1597, THRU, 2002,+ $+\quad, 1191$, THRU $, 1596,1140$, THRU $, 1190,43821$, THRU,+ $+\quad, 44226,43415$, THRU, 43820,43009, THRU, 43414, 42603,+ $+\quad$, THRU, 43008,42197, THRU, 42602, 41791, THRU, 42196, + $+\quad$ 4 41385, THRU, 41790,40979, THRU, 41384,40573, THRU, + $+\quad, 40978,40167$, THRU, 40572, 39761, THRU, 40166, 39355,+ $+\quad$, THRU, 39760,38949, THRU, 39354, 38543, THRU, 38948,+ $+\quad$, 38137, THRU, 38542, 37731, THRU, 38136, 37325, THRU, + $+\quad, 37730,36919$, THRU, 37324, 36513, THRU, 36918, 36107, + $+\quad$, THRU, 36512, 35701, THRU, 36106, 35295, THRU, 35700,+ $+\quad, 34889$, THRU, 35294, 34483, THRU, 34888, 34077, THRU, + $+\quad, 34482,33671$, THRU, 34076, 33265, THRU, 33670, 32859,+ $+\quad$, THRU, 33264, 32453, THRU, 32858, 32047, THRU, 32452,+ $+\quad, 31641$, THRU, 32046,31235, THRU, 31640,30829, THRU , + $+\quad, 31234,30423$, THRU, 30828, 30017, THRU, 30422, 29611, + $+\quad$, THRU, 30016, 29205, THRU, 29610, 44633, THRU, 85939 \$ TICEL, 1, 25, DENSITY, 0.000171 


\section{RPP-RPT-32239, Rev. 1 \\ M\&D-2008-005-CALC-001, Rev. 1}

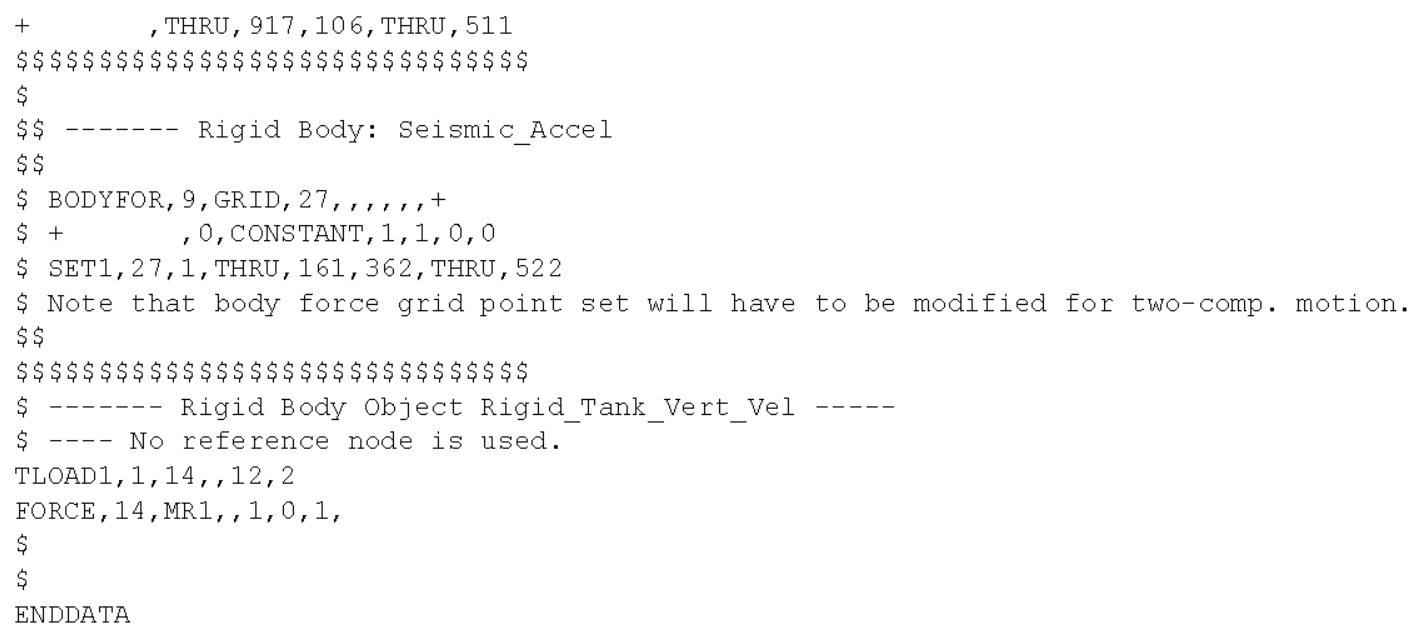

\section{Dytran Input File Two-Component Motion (Horizontal and Vertical)}

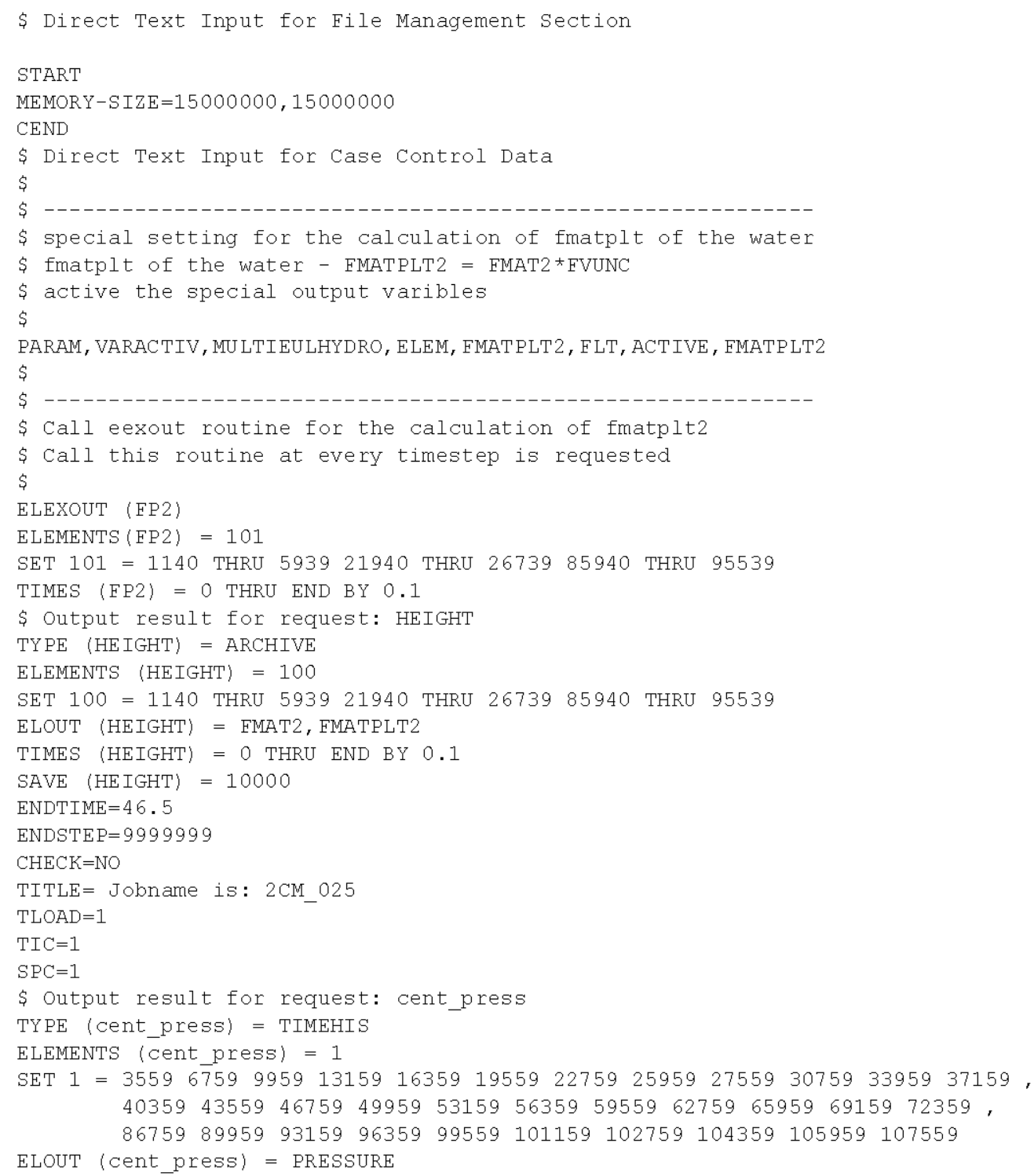




\section{RPP-RPT-32239, Rev. 1 \\ M\&D-2008-005-CALC-001, Rev. 1}

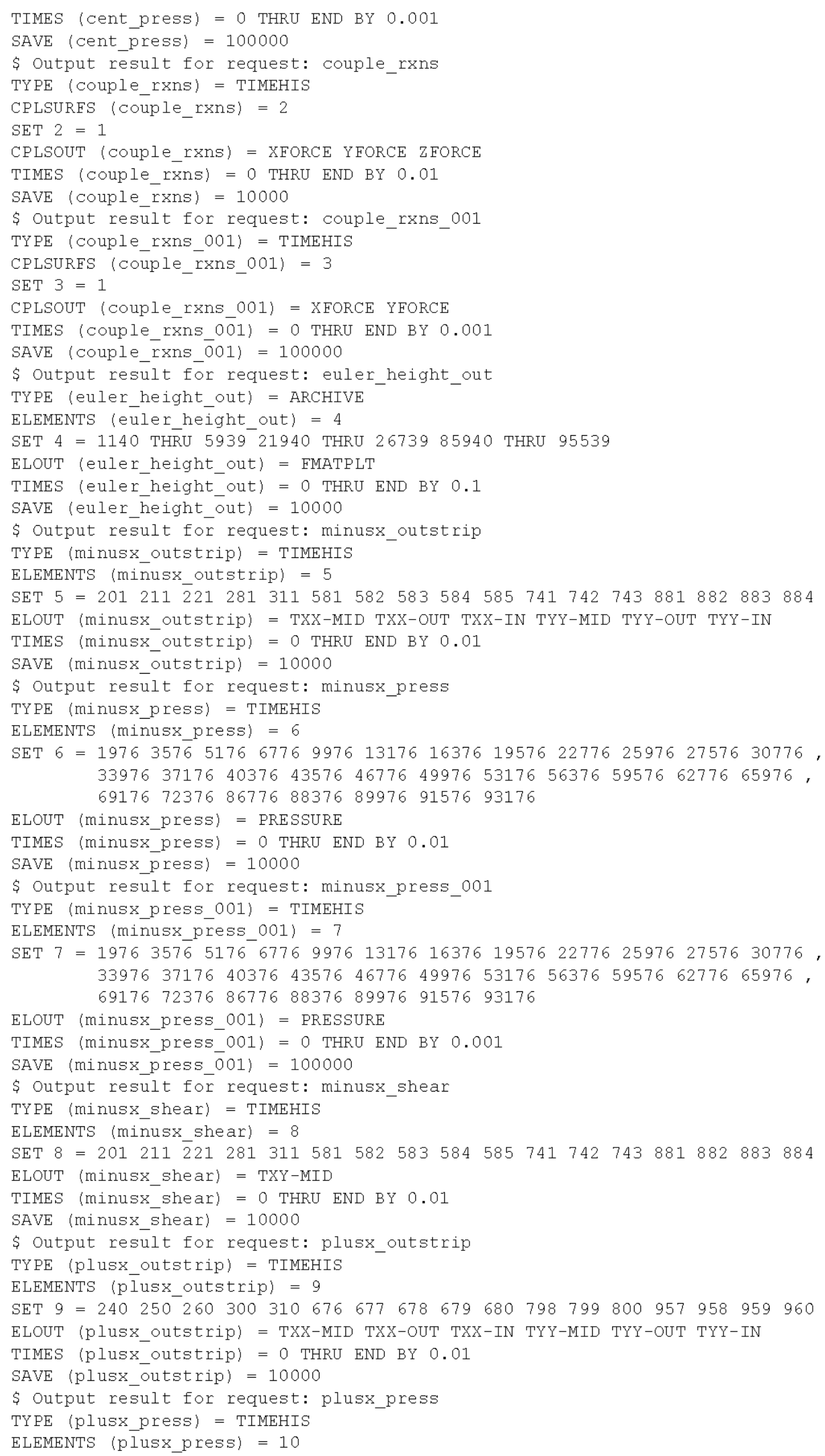




\section{RPP-RPT-32239, Rev. 1 M\&D-2008-005-CALC-001, Rev. 1}

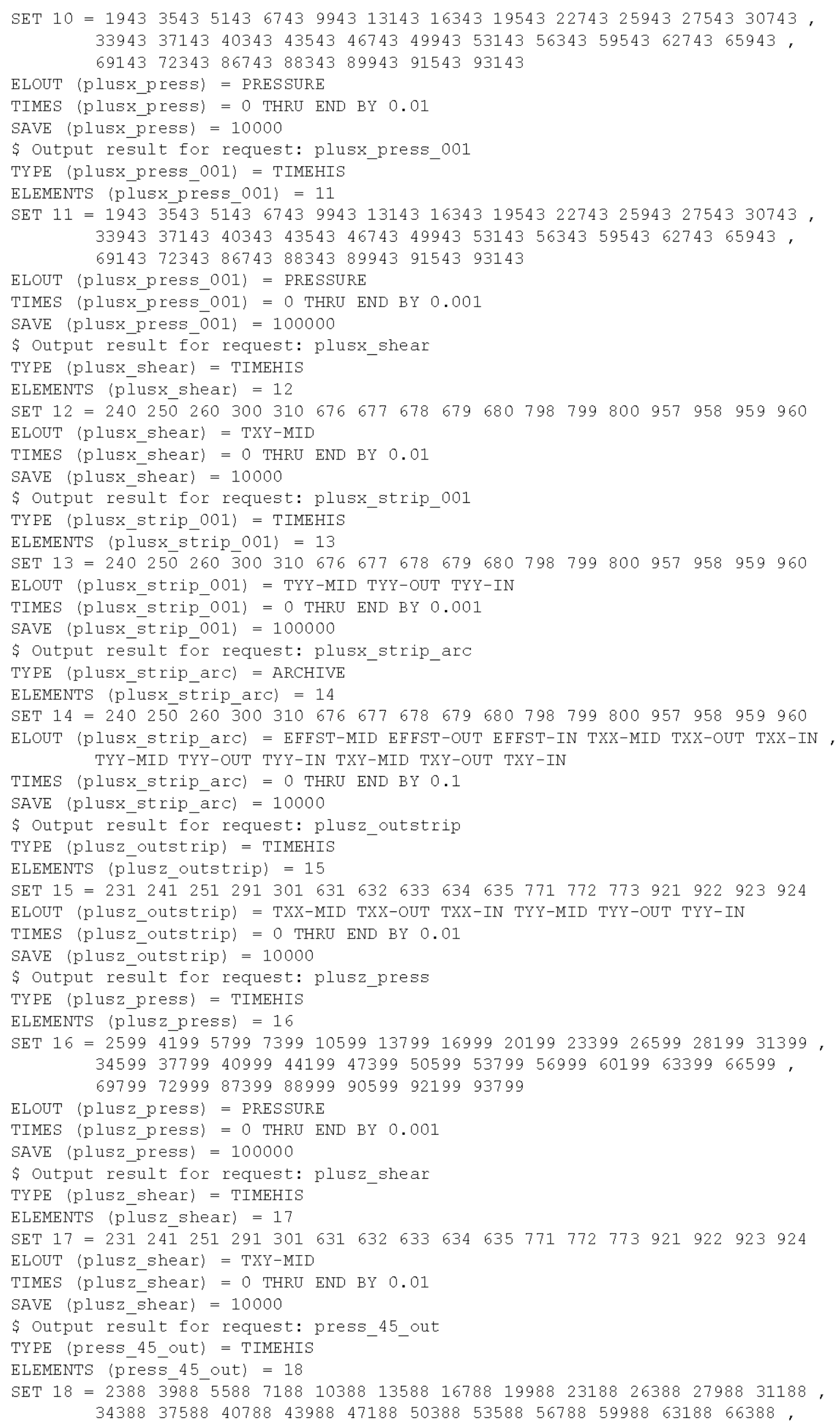




\section{RPP-RPT-32239, Rev. 1 \\ M\&D-2008-005-CALC-001, Rev. 1}

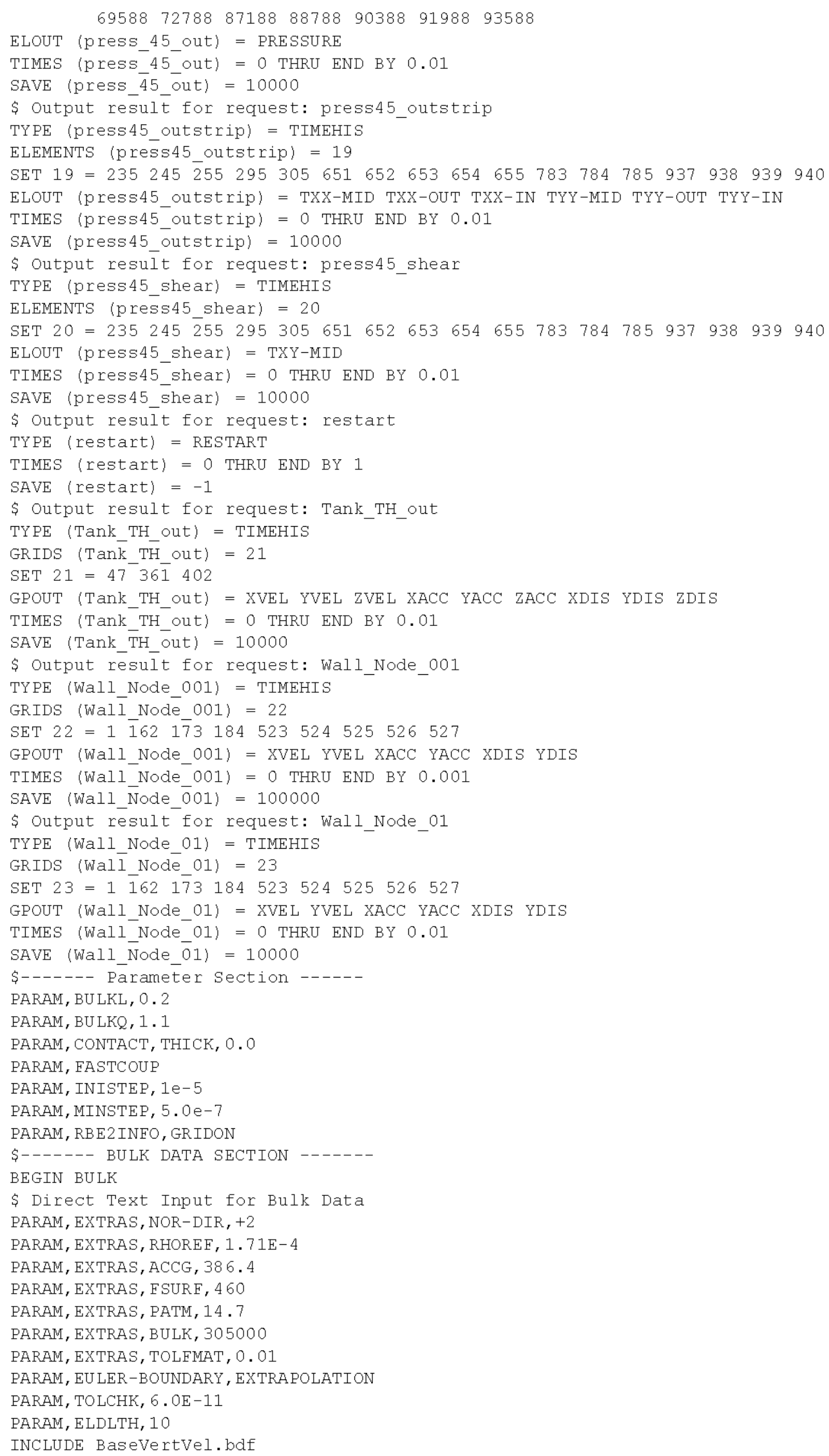


RPP-RPT-32239, Rev. 1

M\&D-2008-005-CALC-001, Rev. 1

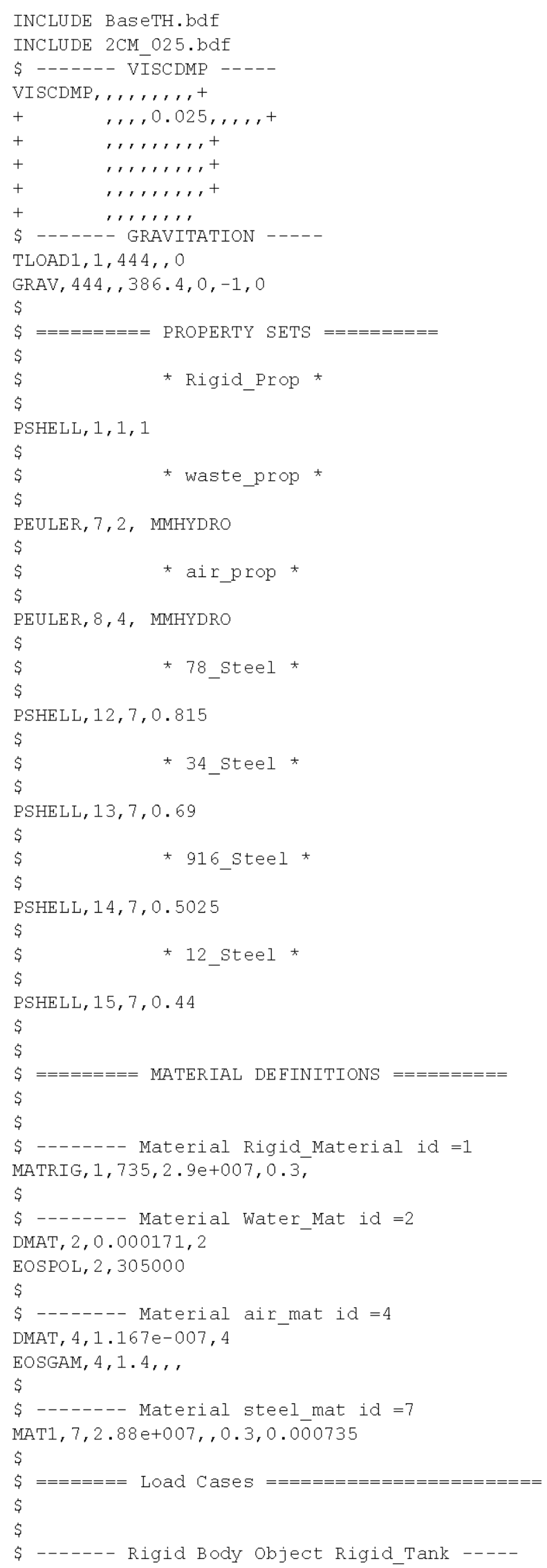




\section{RPP-RPT-32239, Rev. 1 \\ M\&D-2008-005-CALC-001, Rev. 1}

$\$$---- No reference node is used.

TLOAD $1,1,2,12$

FORCE $, 2, M R 1,0, \ldots$

TLOAD $1,1,1002,12$

MOMENT, 1002, MR1, $0,0,0,0$

$\$$

$\$$------ TICEL BC air_init_set -----

SET1, 24, 85940, THRU, $864 \overline{6} 6,10 \overline{7} 985$, THRU $, 108339,107579,+$

$+\quad$, THRU, 107984, 107173, THRU, 107578, 106767, THRU, 107172, +

$+\quad, 106361$, THRU, 106766,105955, THRU, 106360, 105549, THRU, +

$+\quad, 105954,105143$, THRU, 105548, 104737, THRU, 105142,104331,+

$+\quad$, THRU, 104736, 103925, THRU, 104330, 103519, THRU, 103924,+

$+\quad, 103113$, THRU , 103518, 102707, THRU, 103112, 102301, THRU, +

$+\quad, 102706,101895$, THRU, 102300, 101489, THRU, 101894,101083,+

$+\quad$, THRU, 101488,100677 , THRU , 101082, 100271, THRU, 100676, +

$+\quad, 99865$, THRU, 100270,99459, THRU, 99864,99053, THRU,+

$+\quad, 99458,98647$, THRU, 99052,98241, THRU, $98646,97835,+$

$+\quad$, THRU, 98240,97429, THRU, 97834,97023, THRU $, 97428,+$

$+\quad \quad, 96617$, THRU, 97022,96211, THRU, 96616,95805, THRU , +

$+\quad, 96210,95399$, THRU, 95804, 94993, THRU, 95398, 94587,+

$+\quad$, THRU, 94992,94181, THRU, 94586,93775, THRU, $94180,+$

$+\quad, 93369$, THRU $, 93774,92963$, THRU, 93368,92557, THRU , +

$+\quad \quad, 92962,92151$, THRU, 92556, 91745, THRU, 92150,91339,+

$+\quad$, THRU, 91744, 90933, THRU, 91338, 90527, THRU, 90932,+

$+\quad, 90121$, THRU, 90526, 89715, THRU, 90120,89309, THRU, +

$+\quad$,89714,88903, THRU, 89308, 88497, THRU, 88902,88091, +

$+\quad$, THRU, 88496,87685, THRU, 88090,87279, THRU , $87684,+$

$+\quad, 86873$, THRU, 87278,86467, THRU, 86872

TICEL $, 1,24$, DENSITY, $1.167 \mathrm{e}-007$, SIE, $3.15 \mathrm{e}+008$

$\$$

$\$-----$ TICEL BC wat init set ----

SET1, 25, 44227, THRU, 44632, 10529, THRU, 10934, 28799,+

$+\quad$, THRU, 29204,28393, THRU , 28798, 27987, THRU , $28392,+$

$+\quad, 27581$, THRU, 27986, 27175, THRU, 27580,26769, THRU, +

$+\quad, 27174,26363$, THRU, 26768,25957, THRU, 26362, 25551,+ , THRU, 25956, 25145, THRU, 25550, 24739 , THRU , 25144 ,+ , 24333, THRU, 24738, 23927, THRU, 24332, 23521, THRU, + $, 23926,23115$, THRU, 23520, 22709, THRU, 23114, 22303,+ , THRU, 22708, 21897, THRU, 22302,21491, THRU, 21896,+ ,21085, THRU, 21490,20679, THRU, 21084, 20273, THRU ,+ ,20678,19867, THRU, 20272, 19461, THRU, 19866, 19055,+ , THRU, 19460, 18649, THRU, 19054, 18243, THRU , 18648 ,+ ,17837, THRU, 18242,17431, THRU, 17836,17025, THRU , + $, 17430,16619$, THRU, 17024, 16213, THRU, 16618, 15807,+ , THRU , 16212, 15401, THRU, 15806, 14995, THRU , 15400,+ ,14589, THRU, 14994, 14183, THRU, 14588, 13777, THRU , + , 14182,13371, THRU, 13776, 12965, THRU, 13370, 12559,+ , THRU, 12964,12153, THRU , 12558, 11747, THRU, 12152,+ , 11341, THRU, 11746, 10935, THRU, 11340, 10123, THRU ,+ , 10528, 9717, THRU, 10122, 9311, THRU, 9716, 8905,+ , THRU, 9310, 8499, THRU, 8904, 8093, THRU, 8498, + , 7687, THRU, 8092,7281, THRU, 7686,6875, THRU,+ $, 7280,6469$, THRU $, 6874,6063$, THRU $, 6468,5657,+$ , THRU, 6062, 5251, THRU, 5656, 4845, THRU, 5250,+ ,4439, THRU, 4844, 4033, THRU, 4438,3627, THRU ,+ ,4032, 3221, THRU, 3626, 2815, THRU, 3220, 2409,+ , THRU, 2814, 2003, THRU, 2408, 1597, THRU, 2002,+ ,1191, THRU, 1596, 1140, THRU, 1190, 43821, THRU, + ,44226,43415, THRU, 43820, 43009, THRU, 43414, 42603,+ , THRU, 43008, 42197, THRU, 42602, 41791, THRU, 42196,+ , 41385, THRU, 41790, 40979, THRU, 41384, 40573, THRU ,+ ,40978,40167, THRU, 40572, 39761, THRU, $40166,39355,+$ , THRU, 39760,38949 , THRU, 39354,38543 , THRU, $38948,+$ , 38137, THRU, 38542, 37731, THRU, 38136, 37325, THRU , + , 37730, 36919, THRU, 37324, 36513, THRU, 36918, 36107, + 


\section{RPP-RPT-32239, Rev. 1 \\ M\&D-2008-005-CALC-001, Rev. 1}

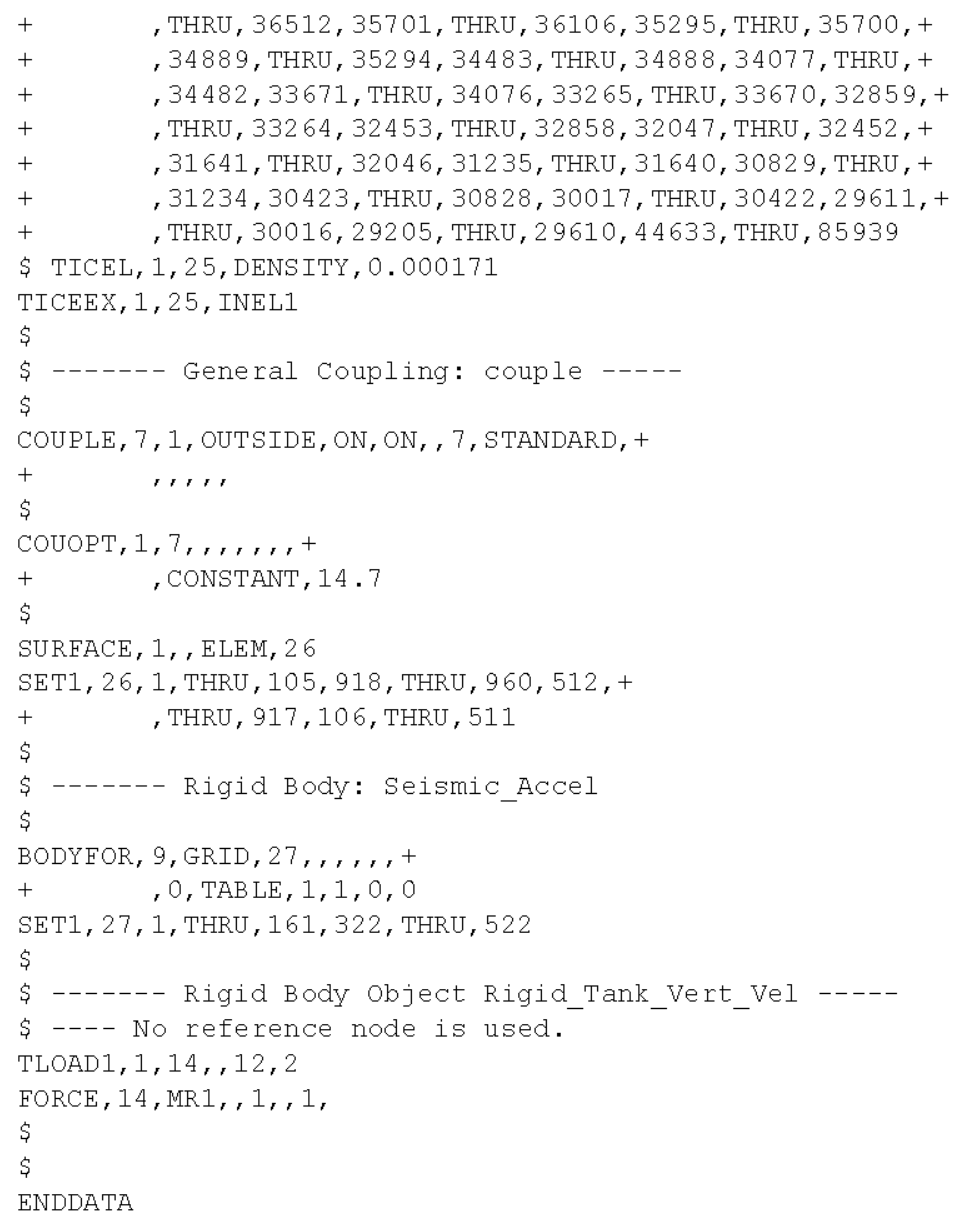


RPP-RPT-32239, Rev. 1

M\&D-2008-005-CALC-001, Rev. 1

\section{Appendix B}

Stress Time History Plots for Dytran ${ }^{\circledR}$ Primary Tank Sub-Models 
RPP-RPT-32239, Rev. 1

M\&D-2008-005-CALC-001, Rev. 1

Intentionally left blank 


\section{Stress Time History Plots for Dytran ${ }^{\circledR}$ Primary Tank Sub-Models}

\section{Figures}

B.1 Mid-Plane Hoop Stress Time Histories for Element Set "Plusx_Outstrip" at $\theta=0^{\circ}$

for Horizontal Seismic Excitation Only

B.2 Mid-Plane Meridional Stress Time Histories for Element Set "Plusx_Outstrip" at $\theta=0^{\circ}$ for Horizontal Excitation Only

B.3 Shear Stress Time Histories for Element Set "Plusx_Outstrip" at $\theta=0^{\circ}$ for Horizontal Excitation Only.

B.4 Mid-Plane Hoop Stress Time Histories for Element Set "Press 45 " at $\theta=45^{\circ}$ for Horizontal Seismic Excitation Only

B.5 Mid-Plane Meridional Stress Time Histories for Element Set "Press45" at $\theta=45^{\circ}$ for Horizontal Seismic Excitation Only

B.6 Shear Stress Time Histories for Element Set "Press 45 " at $\theta=45^{\circ}$ for Horizontal Seismic Excitation Only

B.7 Mid-Plane Hoop Stress Time Histories for Element Set "Plusz_Outstrip" at $\theta=90^{\circ}$ for Horizontal Seismic Excitation Only

B.8 Mid-Plane Meridional Stress Time Histories for Element Set "Plusz_Outstrip" at $\theta=90^{\circ}$ for Horizontal Seismic Excitation Only

B.9 Shear Stress Time Histories for Element Set "Plusz_Outstrip" at $\theta=90^{\circ}$ for Horizontal Seismic Excitation Only

B.10 Mid-Plane Hoop Stress Time Histories for Element Set "Plusx_Outstrip" at $\theta=0^{\circ}$ for Vertical Seismic Excitation Only

B.11 Mid-Plane Meridional Stress Time Histories for Element Set "Plusx_Outstrip" at $\theta=0^{\circ}$ for Vertical Excitation Only

B.12 Shear Stress Time Histories for Element Set "Plusx_Outstrip" at $\theta=0^{\circ}$ for Vertical Excitation Only.

B.13 Mid-Plane Hoop Stress Time Histories for Element Set "Plusx_Outstrip" at $\theta=0^{\circ}$ for Two-Component Seismic Excitation

B.14 Mid-Plane Meridional Stress Time Histories for Element Set "Plusx_Outstrip" at $\theta=0^{\circ}$ for Two-Component Seismic Excitation.

B.15 Mid-Plane Shear Stress Time Histories for Element Set "Plusx_Outstrip" at $\theta=0^{\circ}$ for Two-Component Seismic Excitation

B.16 Mid-Plane Hoop Stress Time Histories for Element Set "Press45_Outstrip" at $\theta=45^{\circ}$ for Two-Component Seismic Excitation 
RPP-RPT-32239, Rev. 1

M\&D-2008-005-CALC-001, Rev. 1

B.17 Mid-Plane Meridional Stress Time Histories for Element Set "Press45_Outstrip" at $\theta=45^{\circ}$ for Two-Component Seismic Excitation.

B.18 Mid-Plane Shear Stress Time Histories for Element Set "Press45_Outstrip" at $\theta=45^{\circ}$ for Two-Component Seismic Excitation

B.19 Mid-Plane Hoop Stress Time Histories for Element Set "Plusz_Outstrip" at $\theta=90^{\circ}$ for Two-Component Seismic Excitation

B.20 Mid-Plane Meridional Stress Time Histories for Element Set "Plusz_Outstrip" at $\theta=90^{\circ}$ for Two-Component Seismic Excitation.

B.21 Mid-Plane Shear Stress Time Histories for Element Set "Plusz_Outstrip" at $\theta=90^{\circ}$ for Two-Component Seismic Excitation

B.22 Mid-Plane Hoop Stress Time Histories for Element Set "Minusx_Outstrip" at $\theta=180^{\circ}$ for Two-Component Seismic Excitation

B.23 Mid-Plane Meridional Stress Time Histories for Element Set "Minusx_Outstrip" at $\theta=180^{\circ}$ for Two-Component Seismic Excitation.

B.24 Mid-Plane Shear Stress Time Histories for Element Set "Minusx_Outstrip" at $\theta=180^{\circ}$ for Two-Component Seismic Excitation 
RPP-RPT-32239, Rev. 1

M\&D-2008-005-CALC-001, Rev. 1

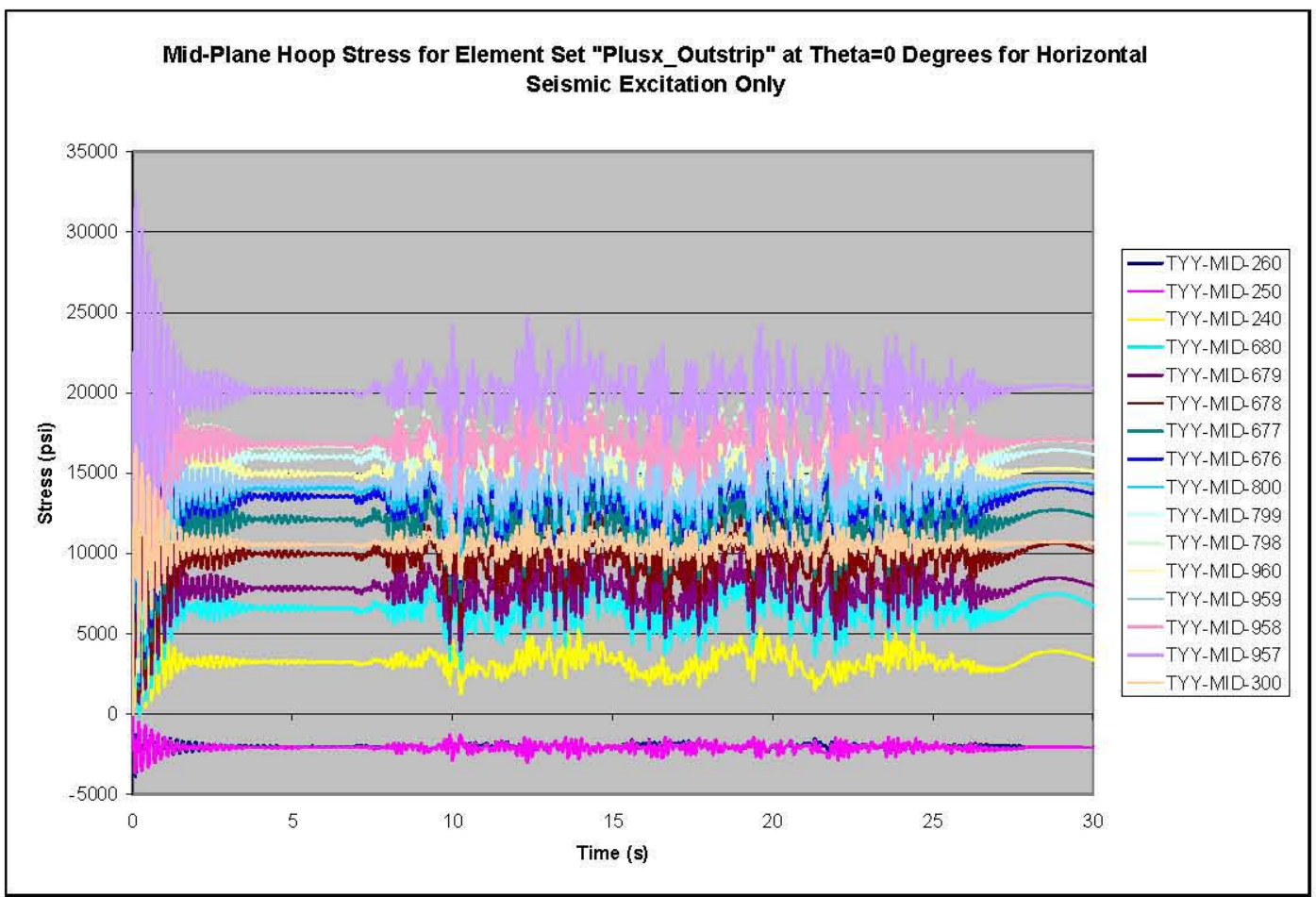

Figure B.1. Mid-Plane Hoop Stress Time Histories for Element Set "Plusx Outstrip" at $\theta=0^{\circ}$ for Horizontal Seismic Excitation Only

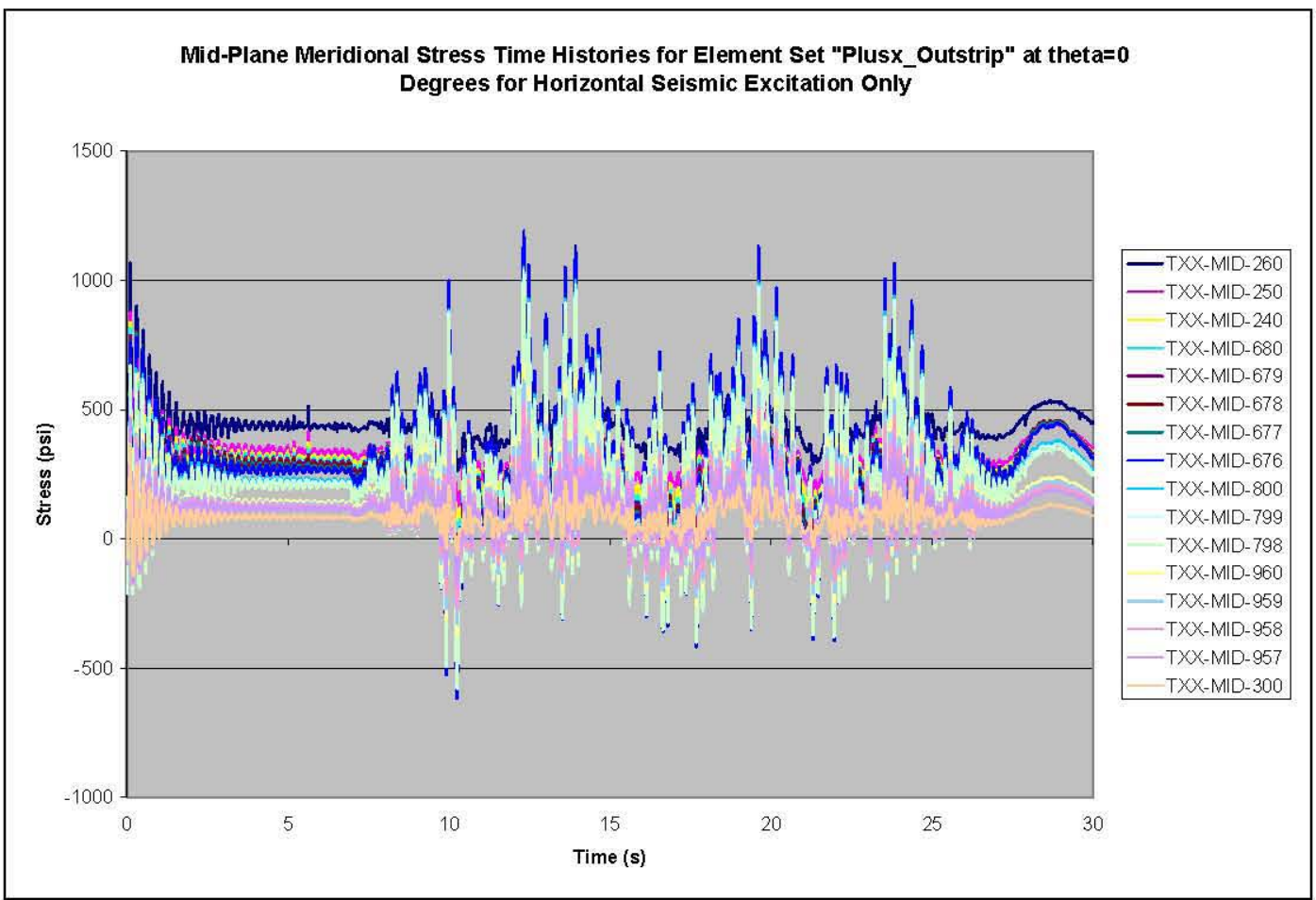

Figure B.2. Mid-Plane Meridional Stress Time Histories for Element Set "Plusx_Outstrip" at $\theta=0^{\circ}$ for Horizontal Excitation Only 
RPP-RPT-32239, Rev. 1

M\&D-2008-005-CALC-001, Rev. 1

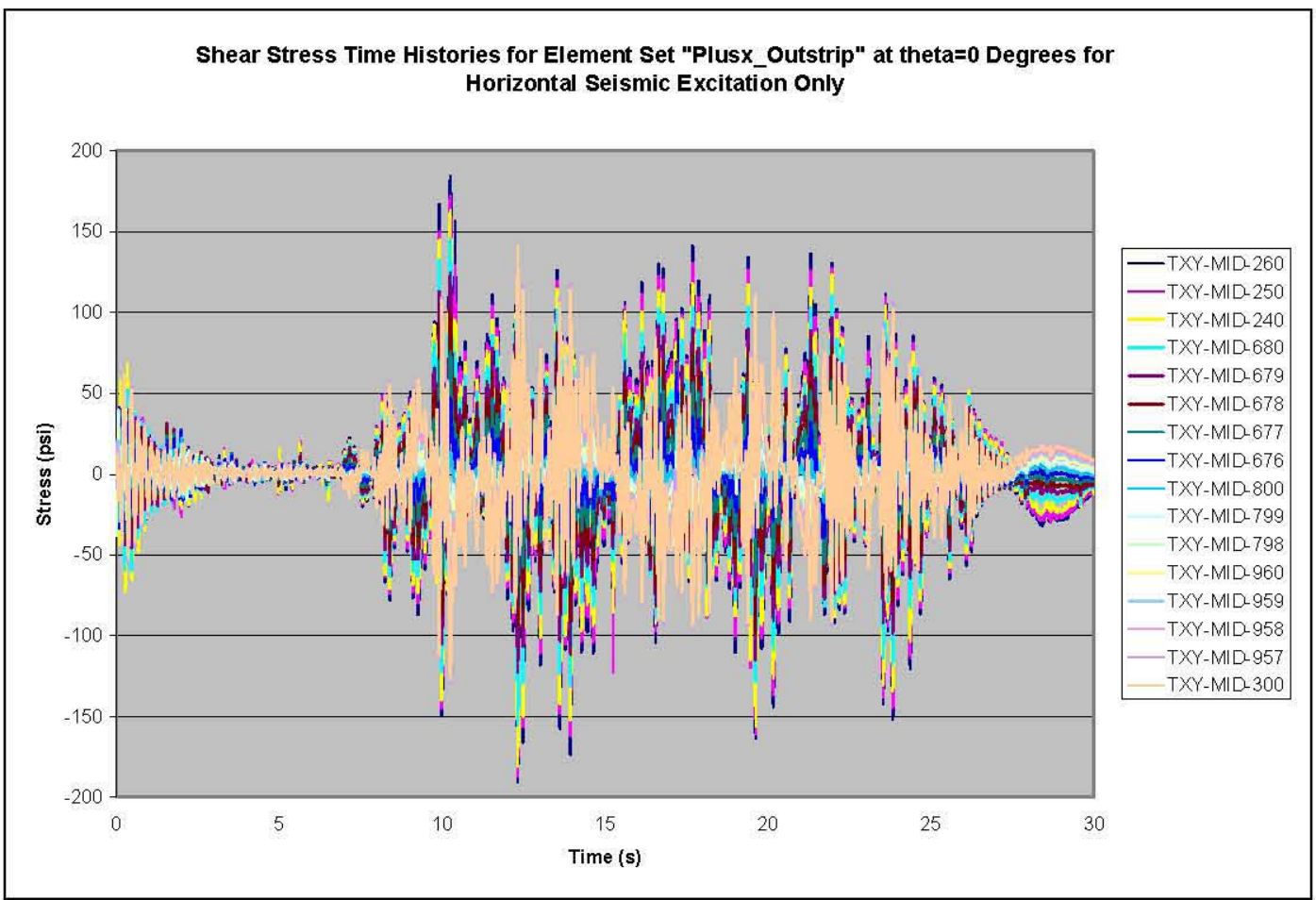

Figure B.3. Shear Stress Time Histories for Element Set "Plusx_Outstrip" at $\theta=0^{\circ}$ for Horizontal Excitation Only

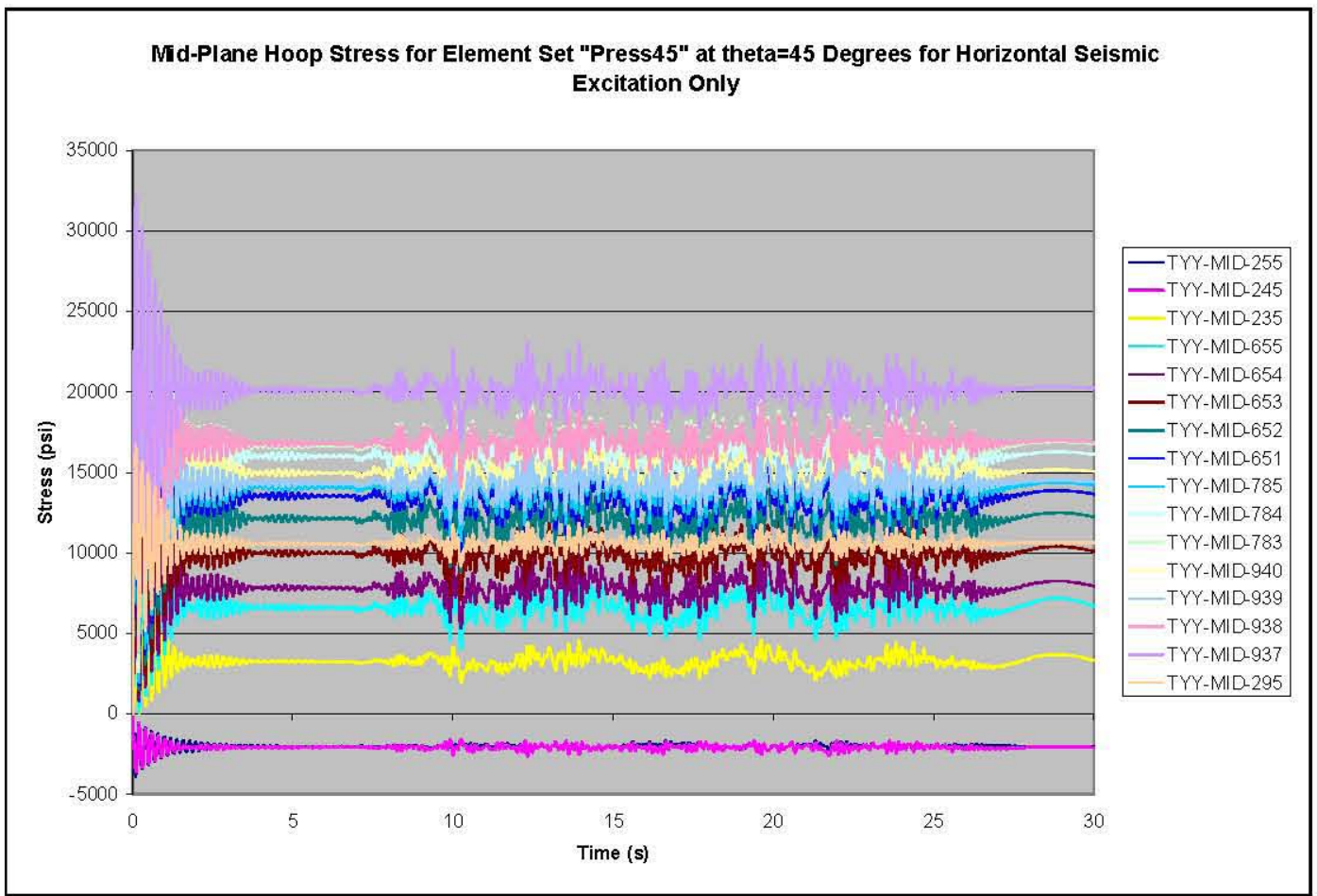

Figure B.4. Mid-Plane Hoop Stress Time Histories for Element Set "Press 45 " at $\theta=45^{\circ}$ for Horizontal Seismic Excitation Only 
RPP-RPT-32239, Rev. 1

M\&D-2008-005-CALC-001, Rev. 1

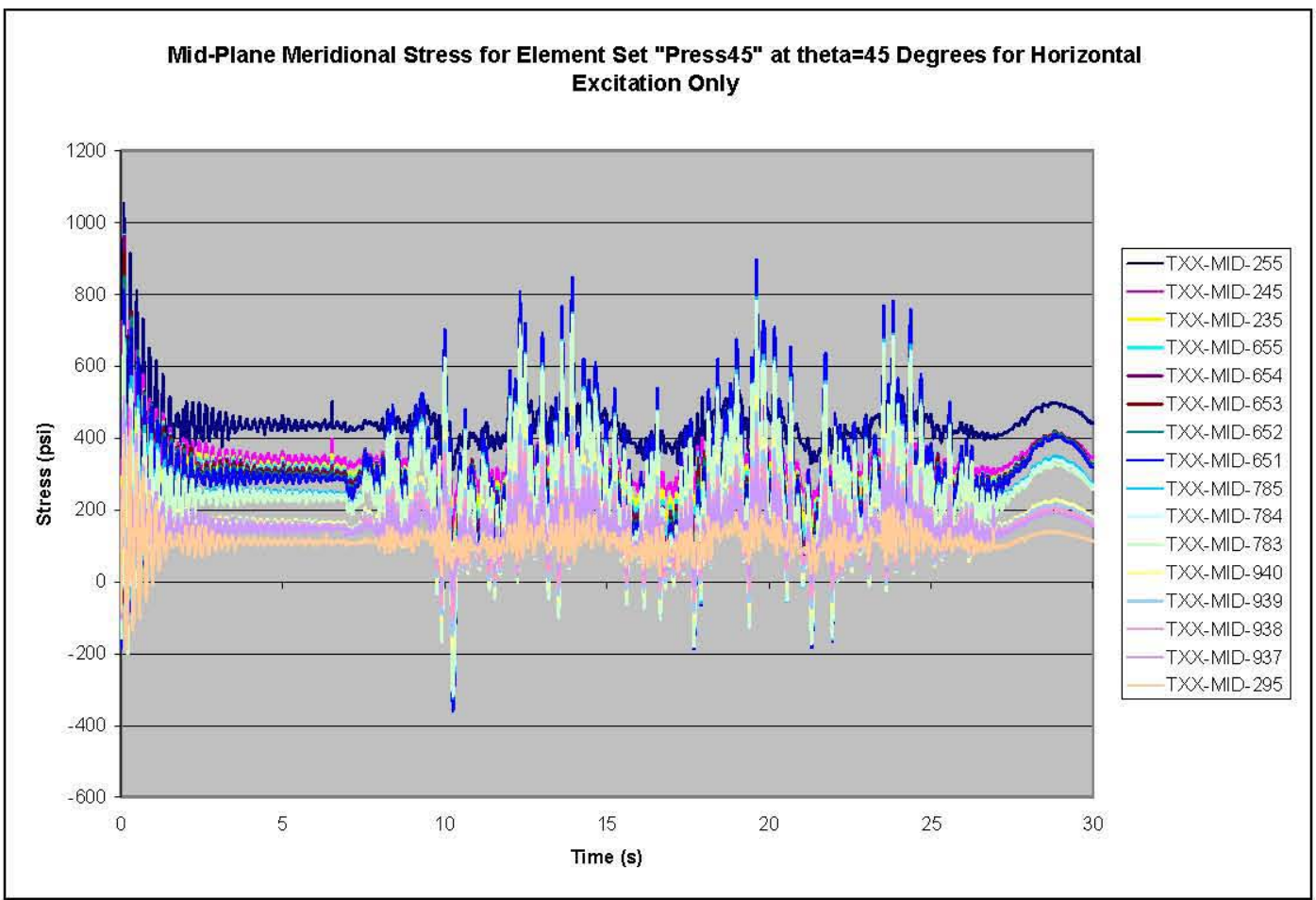

Figure B.5. Mid-Plane Meridional Stress Time Histories for Element Set "Press $45^{\prime \prime}$ at $\theta=45^{\circ}$ for Horizontal Seismic Excitation Only

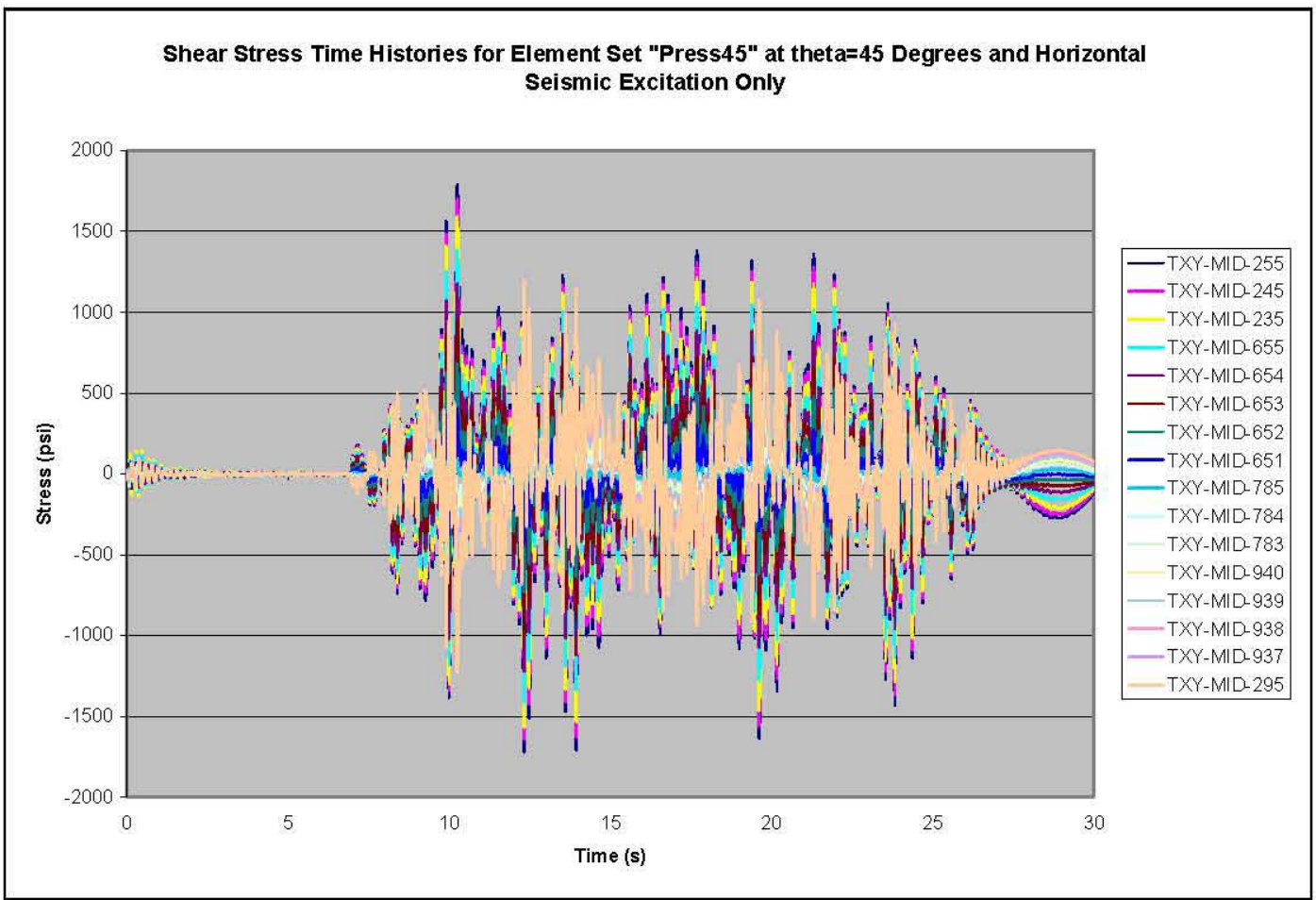

Figure B.6. Shear Stress Time Histories for Element Set "Press $45^{\prime}$ " at $\theta=45^{\circ}$ for Horizontal Seismic Excitation Only 
RPP-RPT-32239, Rev. 1

M\&D-2008-005-CALC-001, Rev. 1

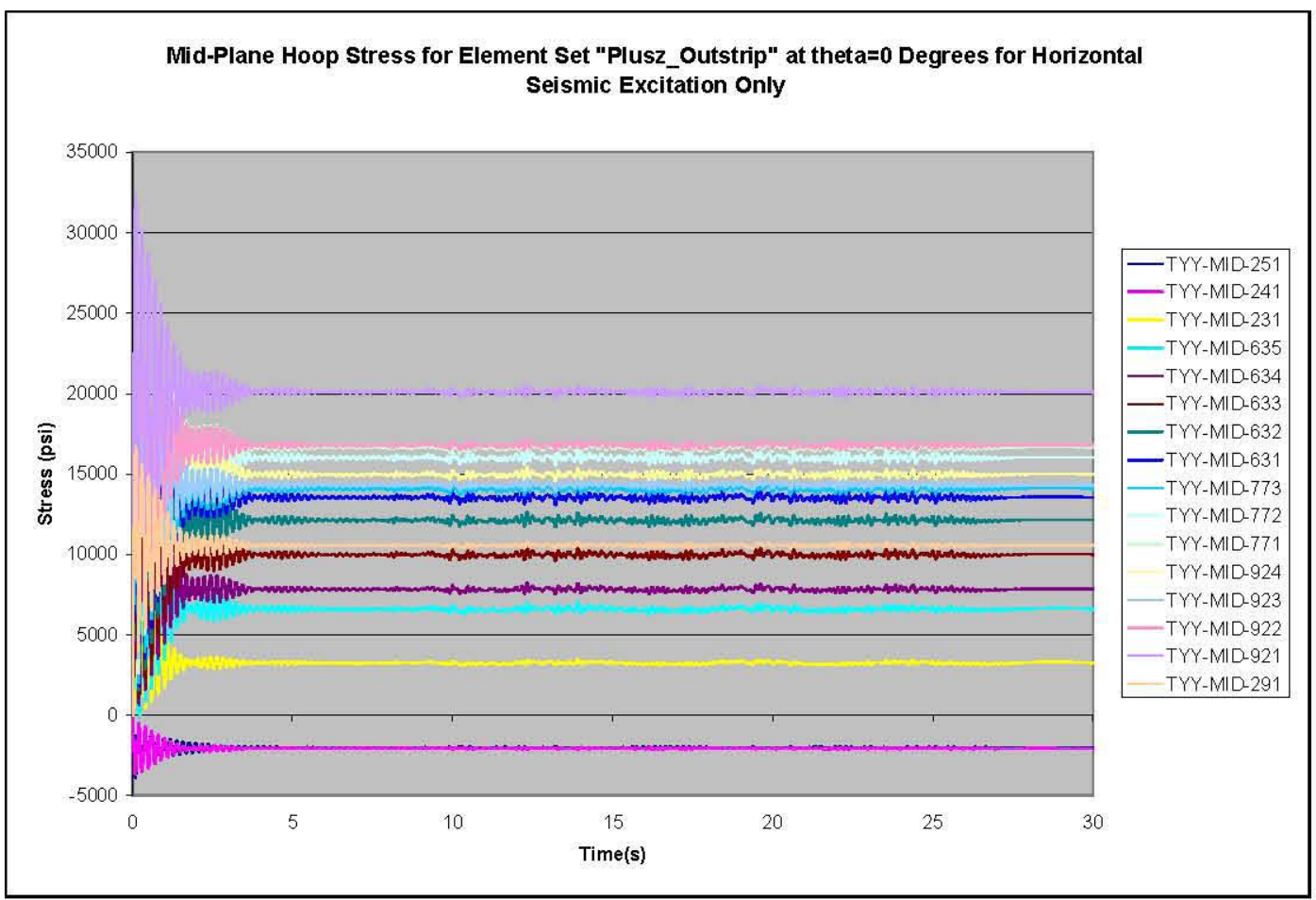

Figure B.7. Mid-Plane Hoop Stress Time Histories for Element Set "Plusz_Outstrip" at $\theta=90^{\circ}$ for Horizontal Seismic Excitation Only

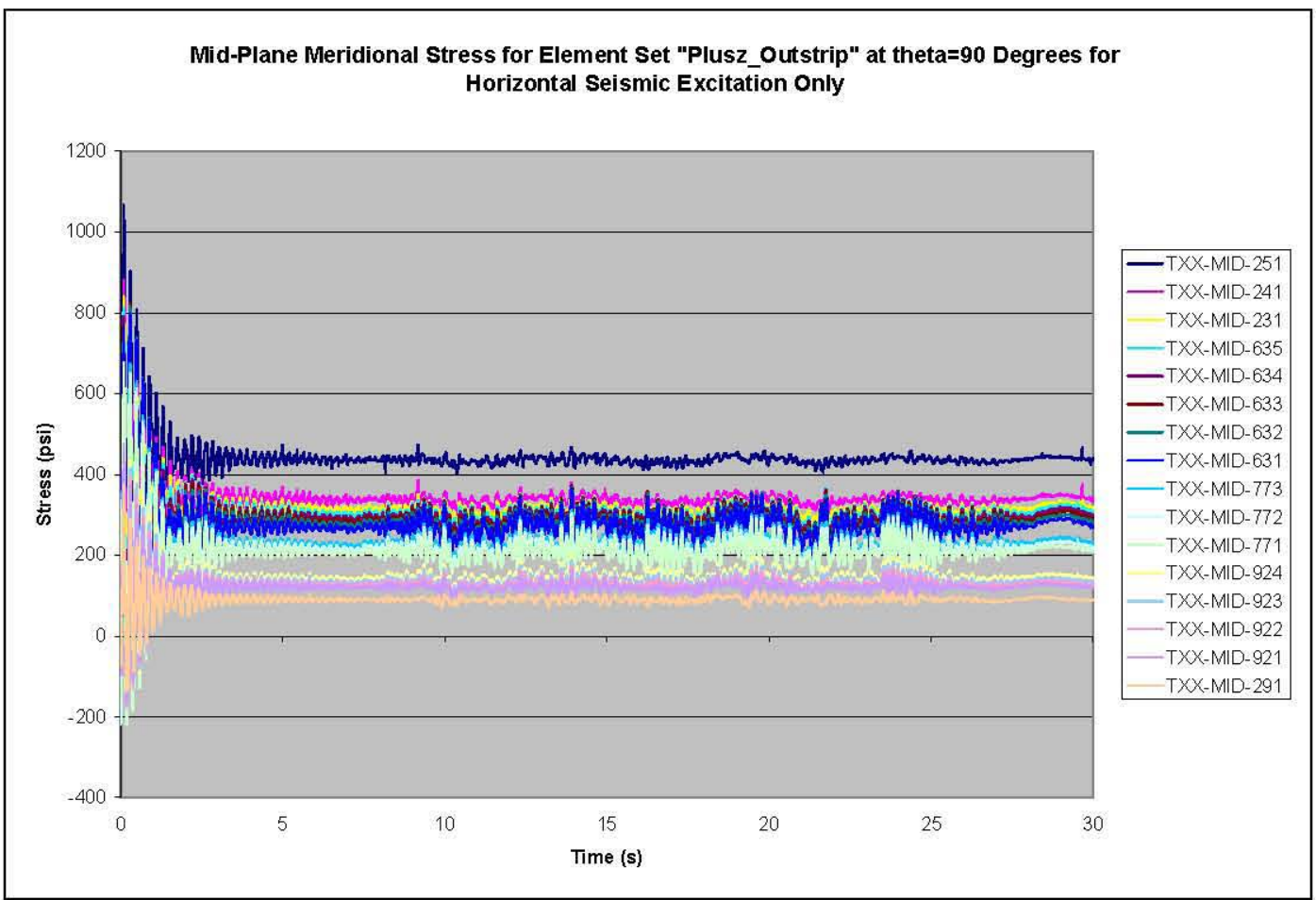

Figure B.8. Mid-Plane Meridional Stress Time Histories for Element Set "Plusz_Outstrip" at $\theta=90^{\circ}$ for Horizontal Seismic Excitation Only 
RPP-RPT-32239, Rev. 1

M\&D-2008-005-CALC-001, Rev. 1

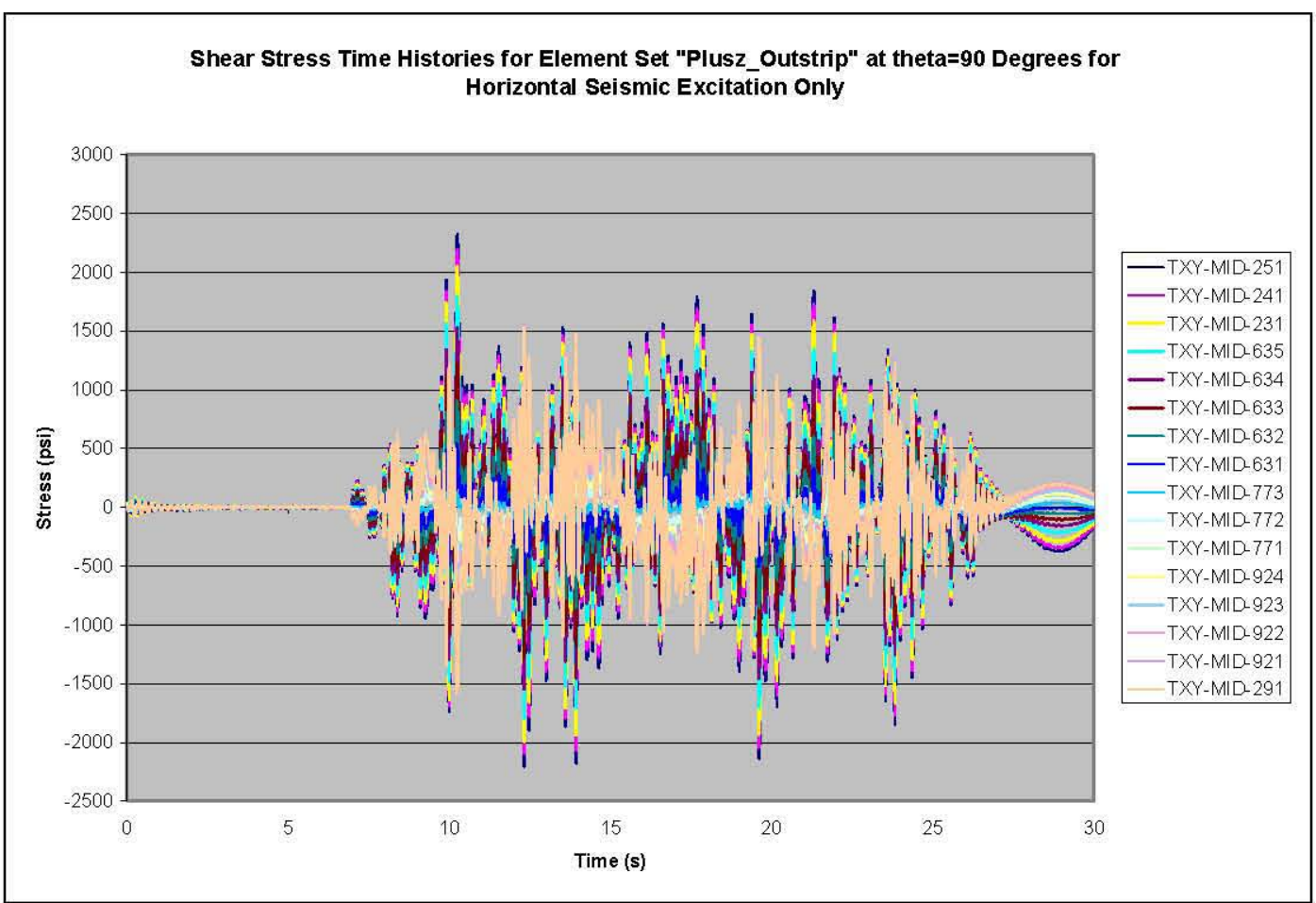

Figure B.9. Shear Stress Time Histories for Element Set "Plusz_Outstrip" at $\theta=90^{\circ}$ for Horizontal Seismic Excitation Only

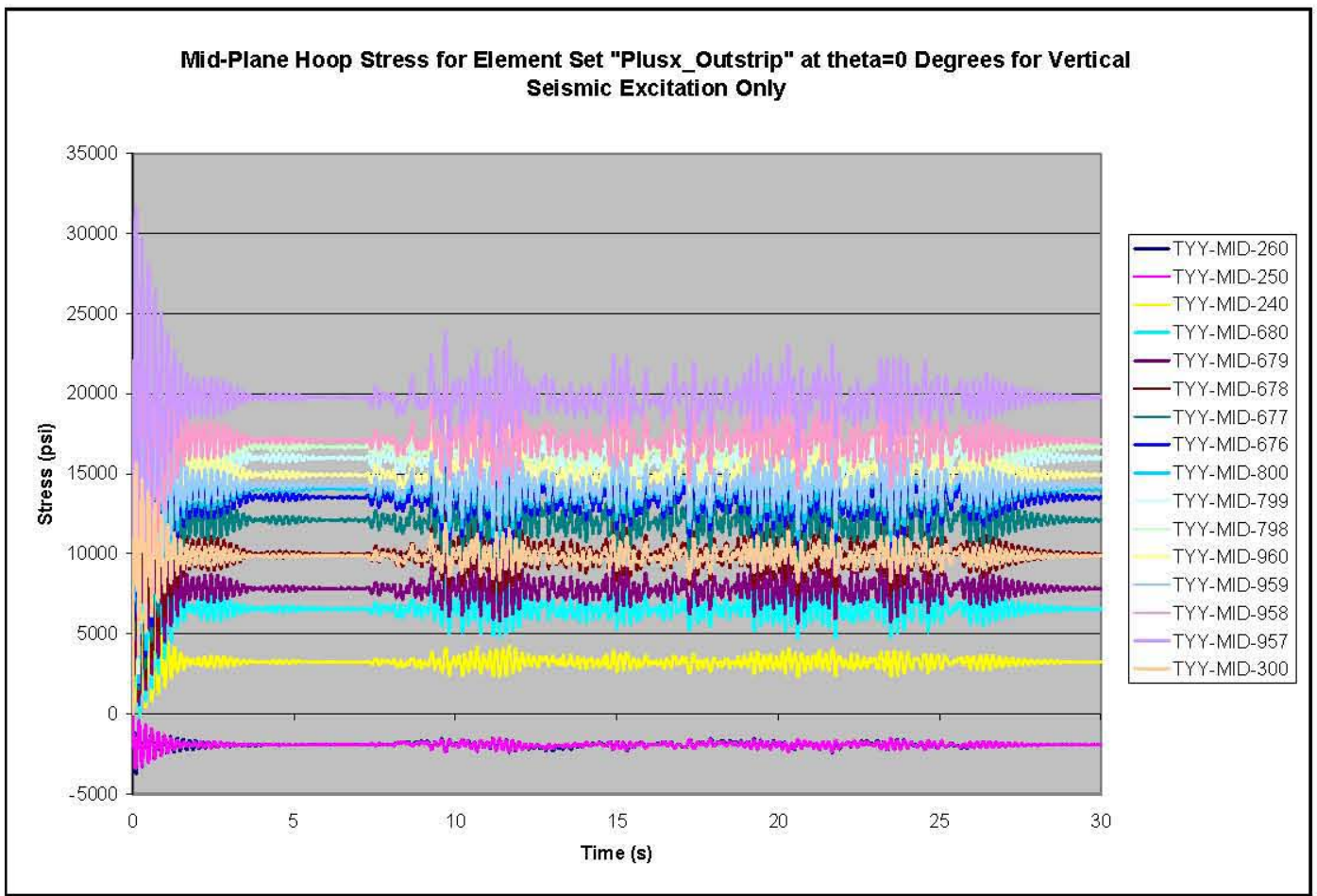

Figure B.10. Mid-Plane Hoop Stress Time Histories for Element Set "Plusx_Outstrip" at $\theta=0^{\circ}$ for Vertical Seismic Excitation Only 
RPP-RPT-32239, Rev. 1

M\&D-2008-005-CALC-001, Rev. 1

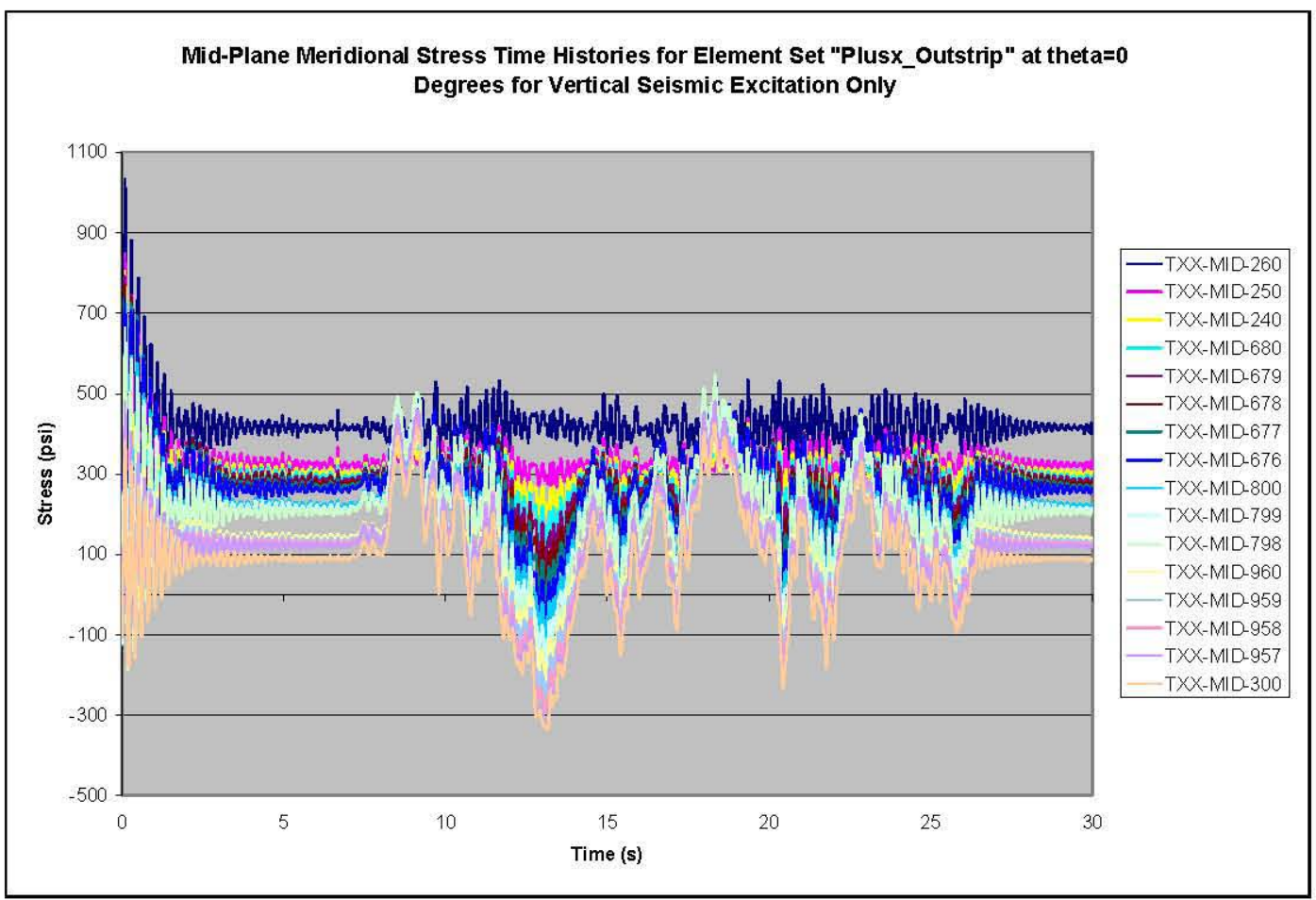

Figure B.11. Mid-Plane Meridional Stress Time Histories for Element Set "Plusx_Outstrip" at $\theta=0^{\circ}$ for Vertical Excitation Only

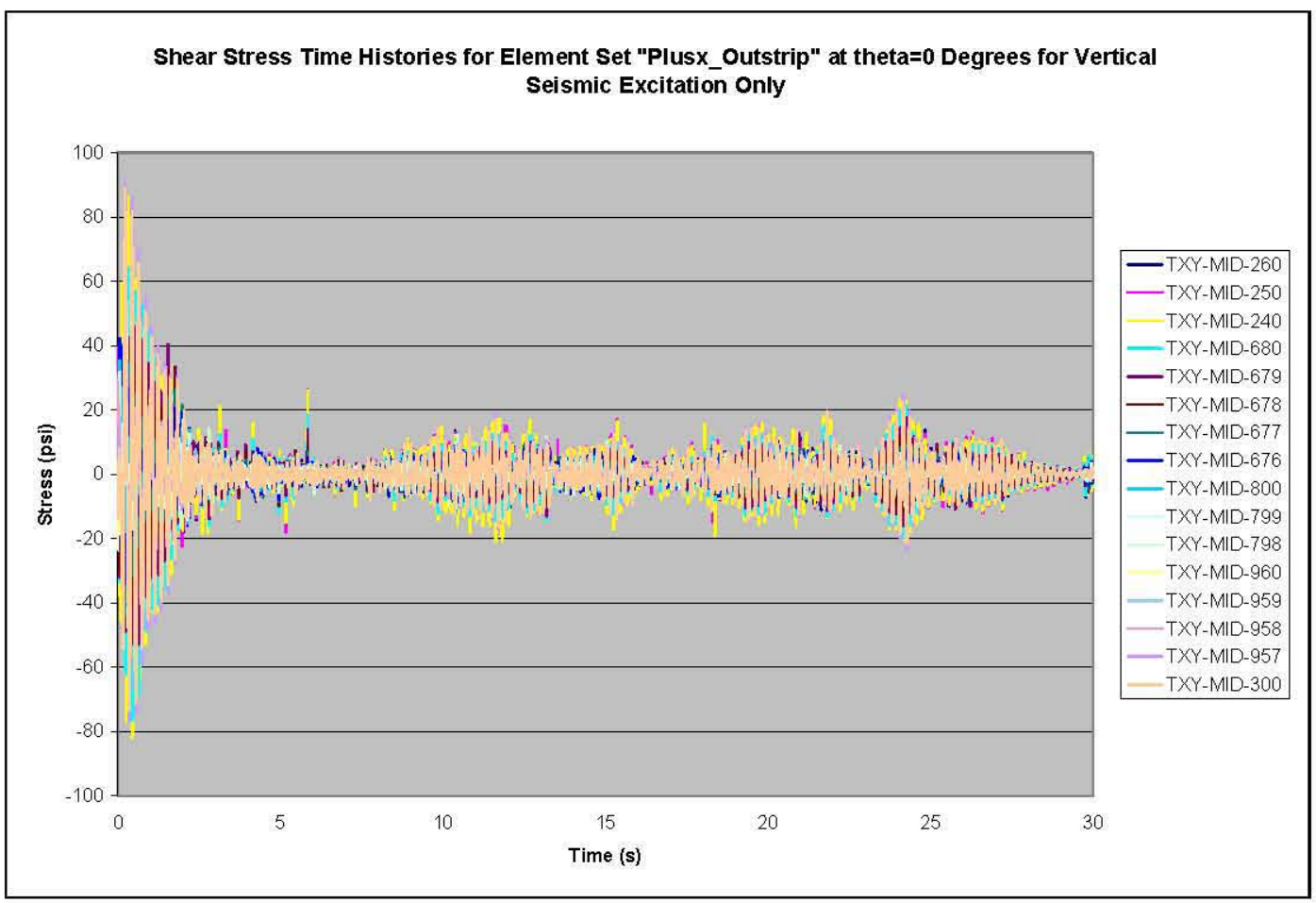

Figure B.12. Shear Stress Time Histories for Element Set "Plusx_Outstrip" at $\theta=0^{\circ}$ for Vertical Excitation Only 
RPP-RPT-32239, Rev. 1

M\&D-2008-005-CALC-001, Rev. 1

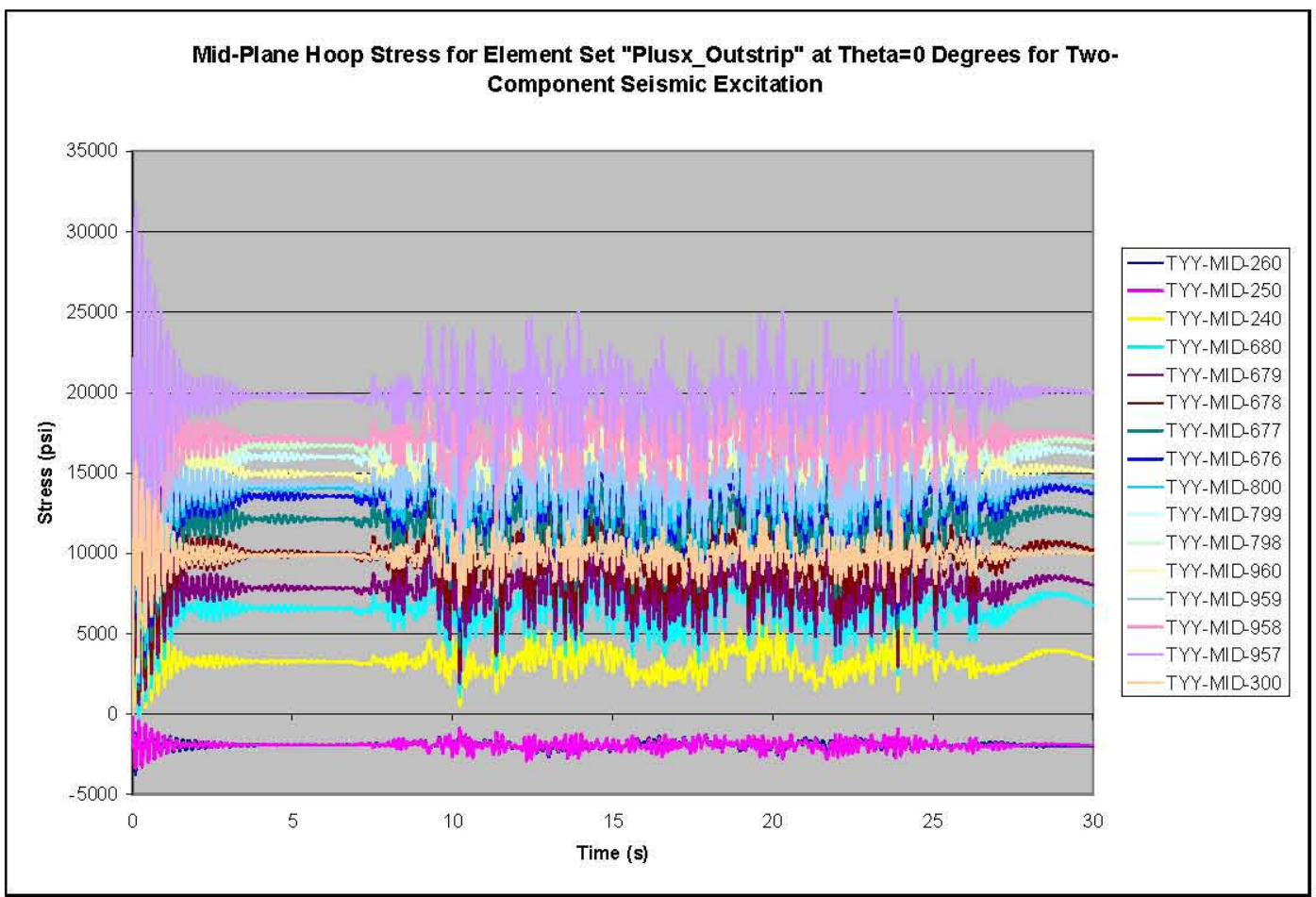

Figure B.13. Mid-Plane Hoop Stress Time Histories for Element Set "Plusx_Outstrip" at $\theta=0^{\circ}$ for Two-Component Seismic Excitation

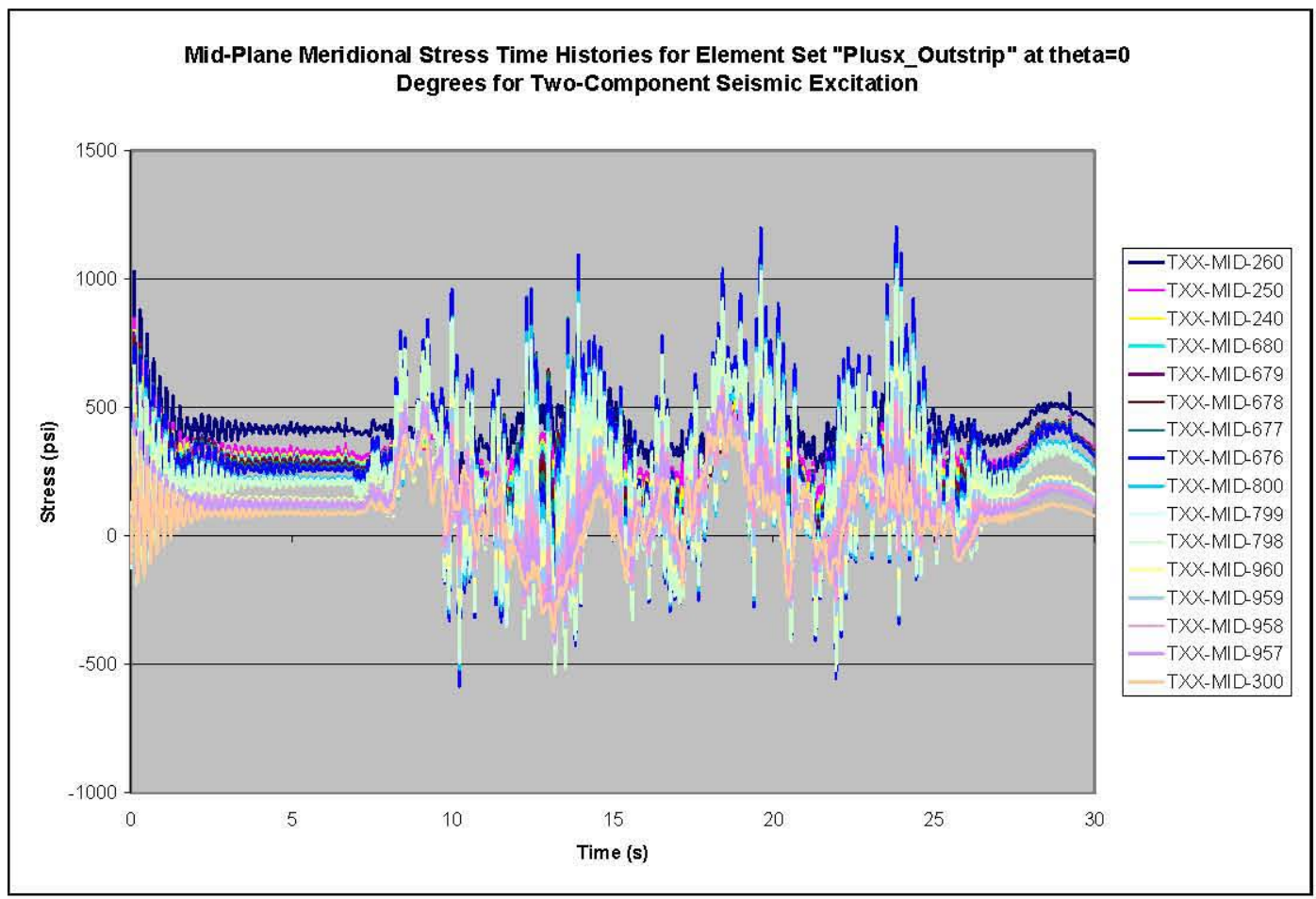

Figure B.14. Mid-Plane Meridional Stress Time Histories for Element Set "Plusx_Outstrip" at $\theta=0^{\circ}$ for Two-Component Seismic Excitation 
RPP-RPT-32239, Rev. 1

M\&D-2008-005-CALC-001, Rev. 1

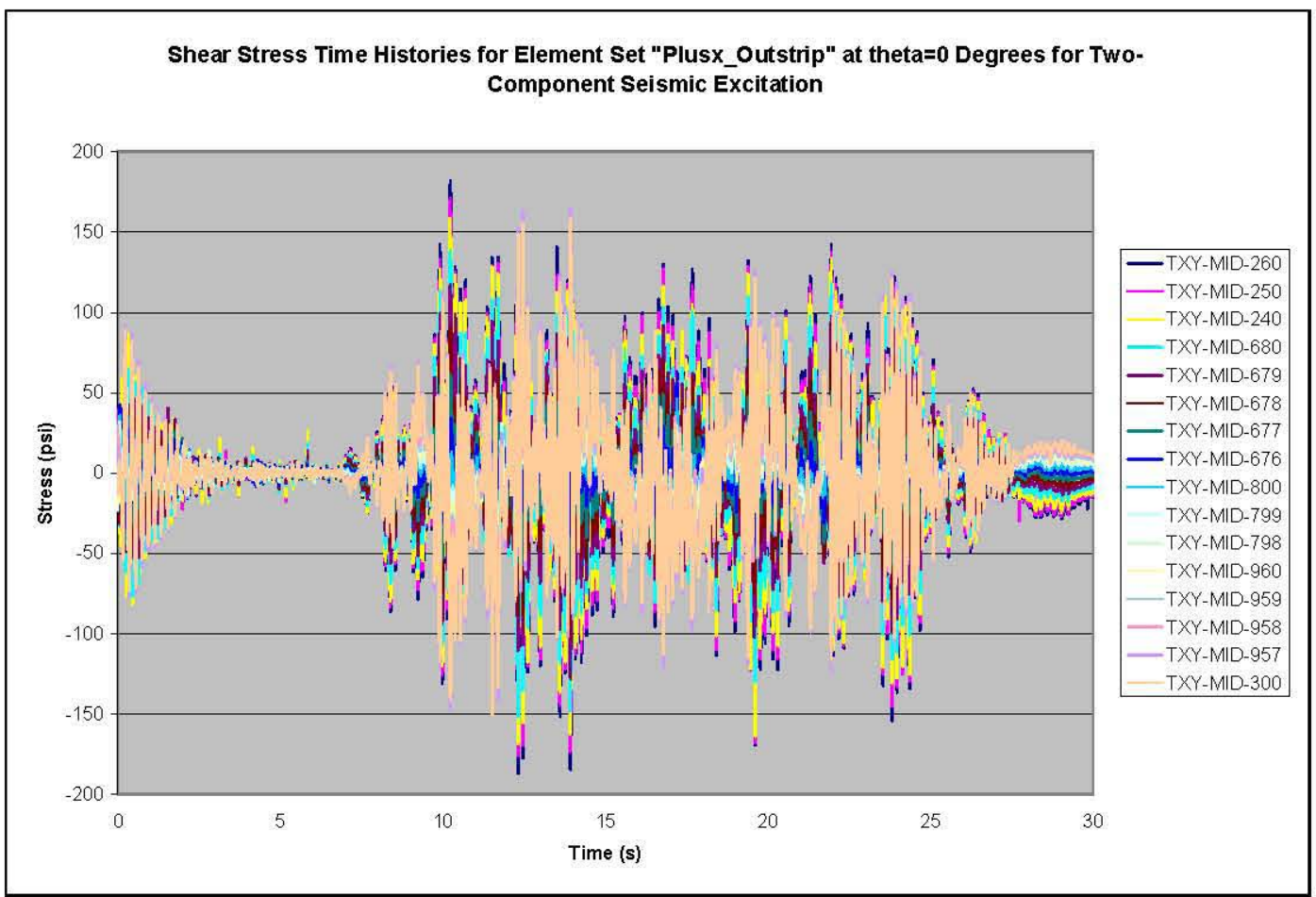

Figure B.15. Mid-Plane Shear Stress Time Histories for Element Set "Plusx_Outstrip" at $\theta=0^{\circ}$ for Two-Component Seismic Excitation

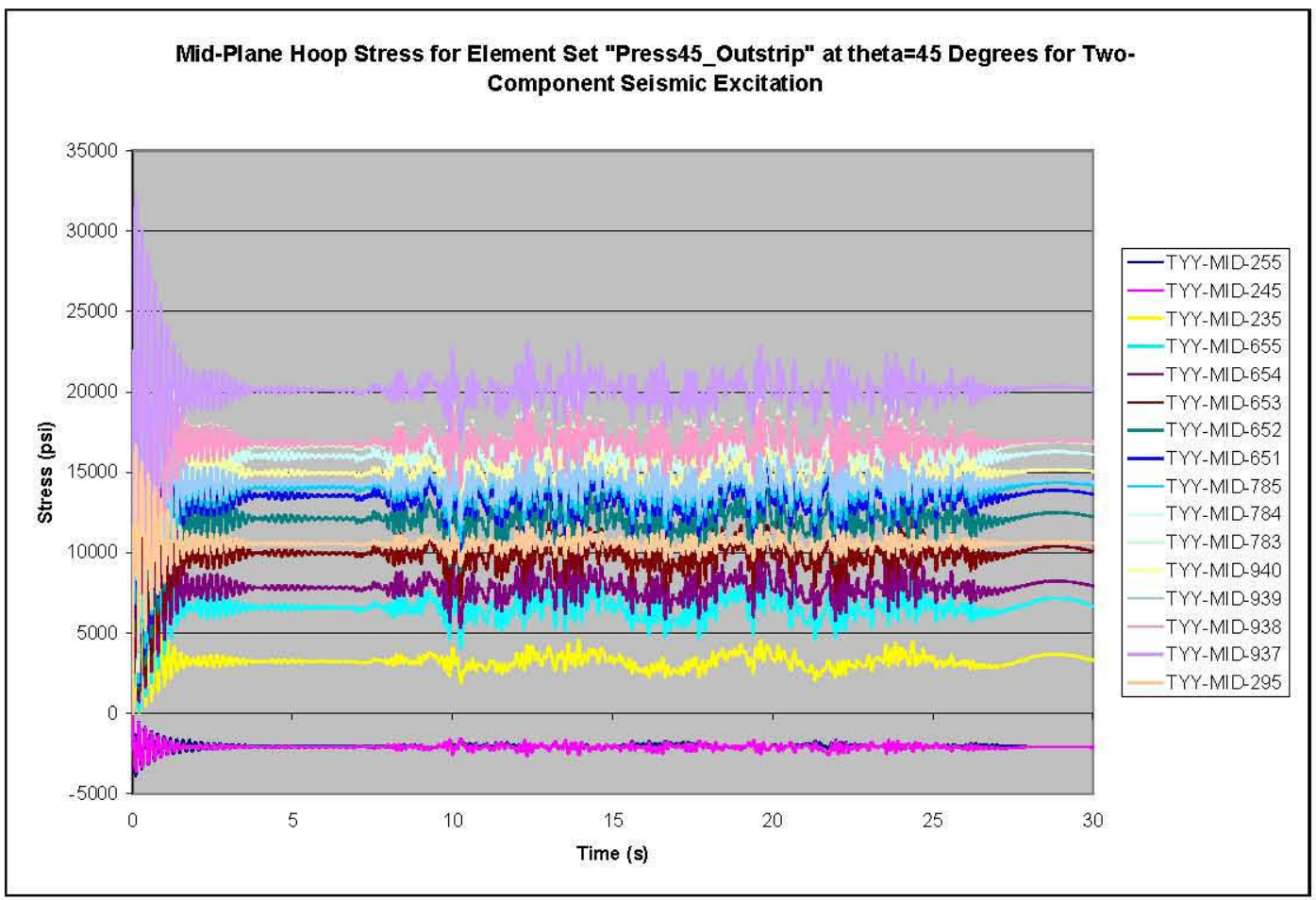

Figure B.16. Mid-Plane Hoop Stress Time Histories for Element Set "Press 45 _Outstrip" at $\theta=45^{\circ}$ for Two-Component Seismic Excitation 
RPP-RPT-32239, Rev. 1

M\&D-2008-005-CALC-001, Rev. 1

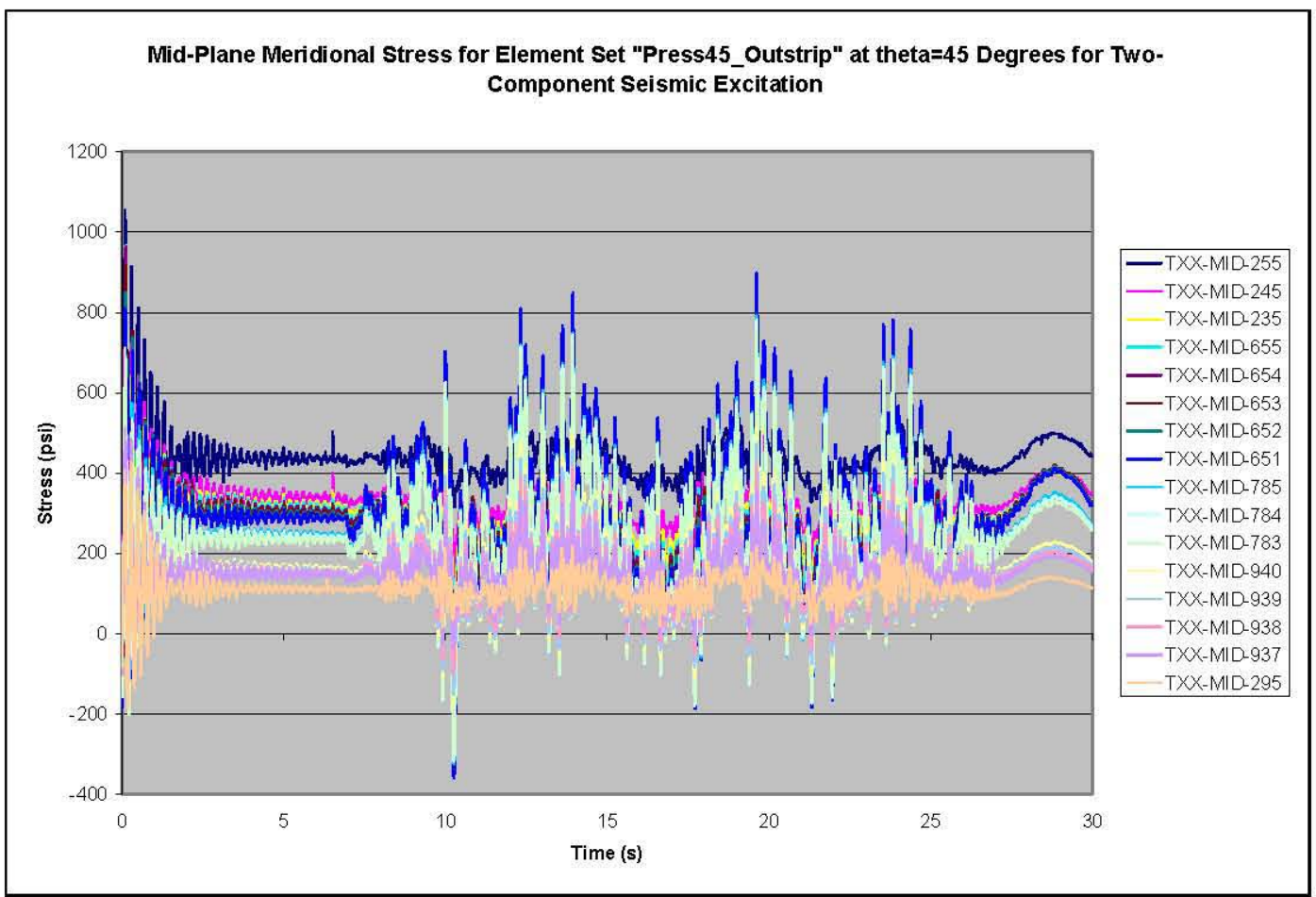

Figure B.17. Mid-Plane Meridional Stress Time Histories for Element Set "Press45_Outstrip" at $\theta=45^{\circ}$ for Two-Component Seismic Excitation

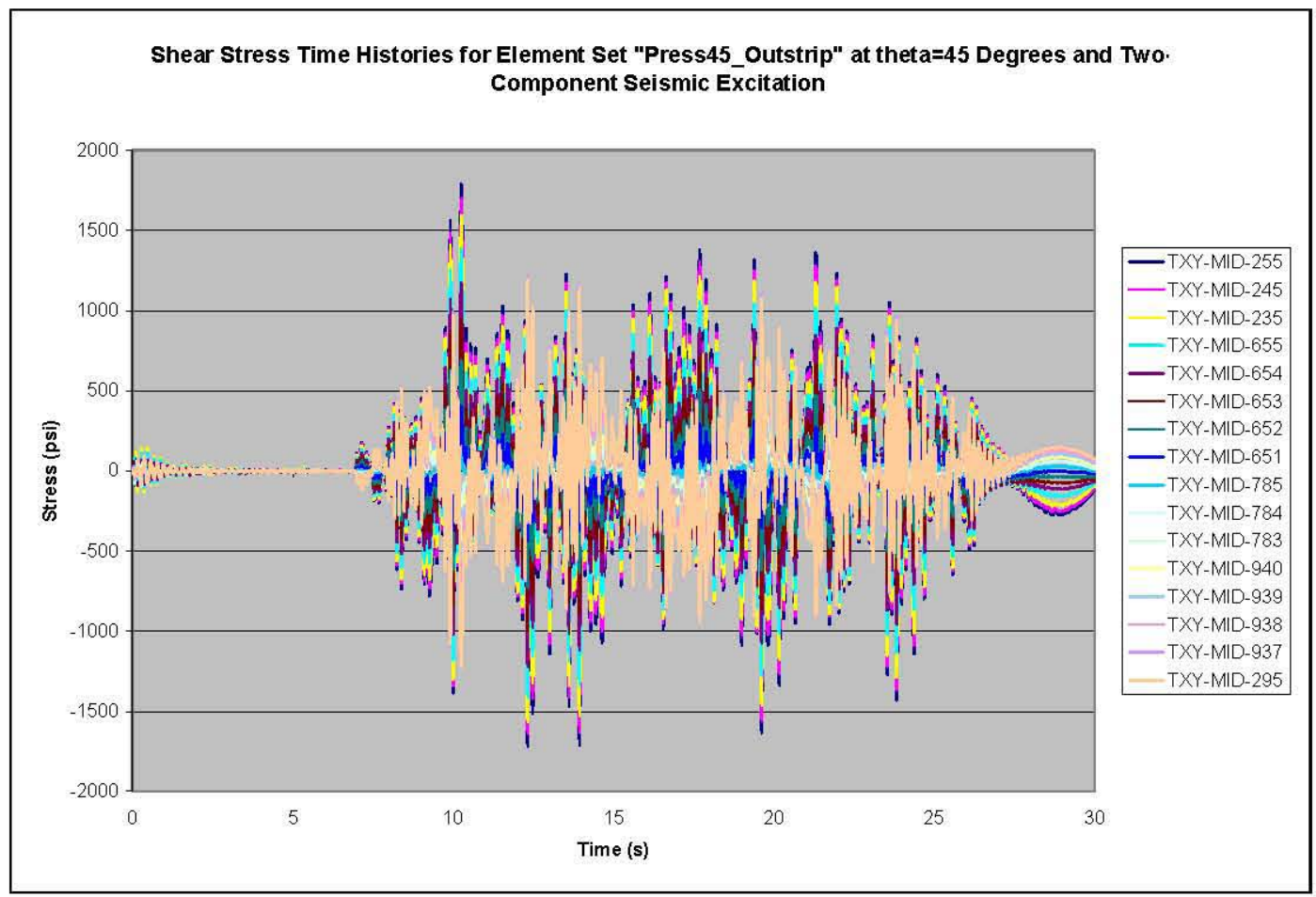

Figure B.18. Mid-Plane Shear Stress Time Histories for Element Set "Press 45 _Outstrip" at $\theta=45^{\circ}$ for Two-Component Seismic Excitation 
RPP-RPT-32239, Rev. 1

M\&D-2008-005-CALC-001, Rev. 1

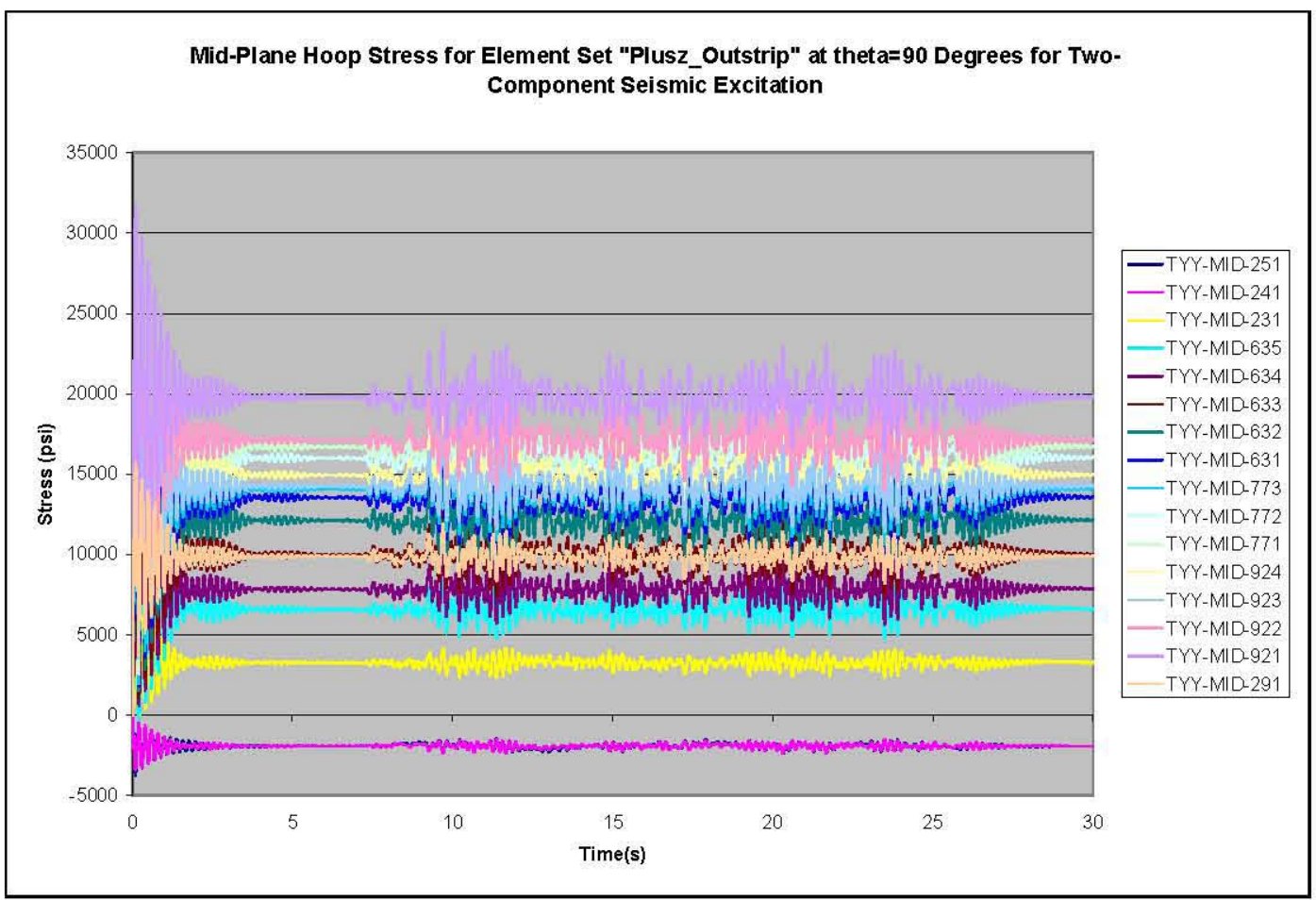

Figure B.19. Mid-Plane Hoop Stress Time Histories for Element Set "Plusz_Outstrip" at $\theta=90^{\circ}$ for Two-Component Seismic Excitation

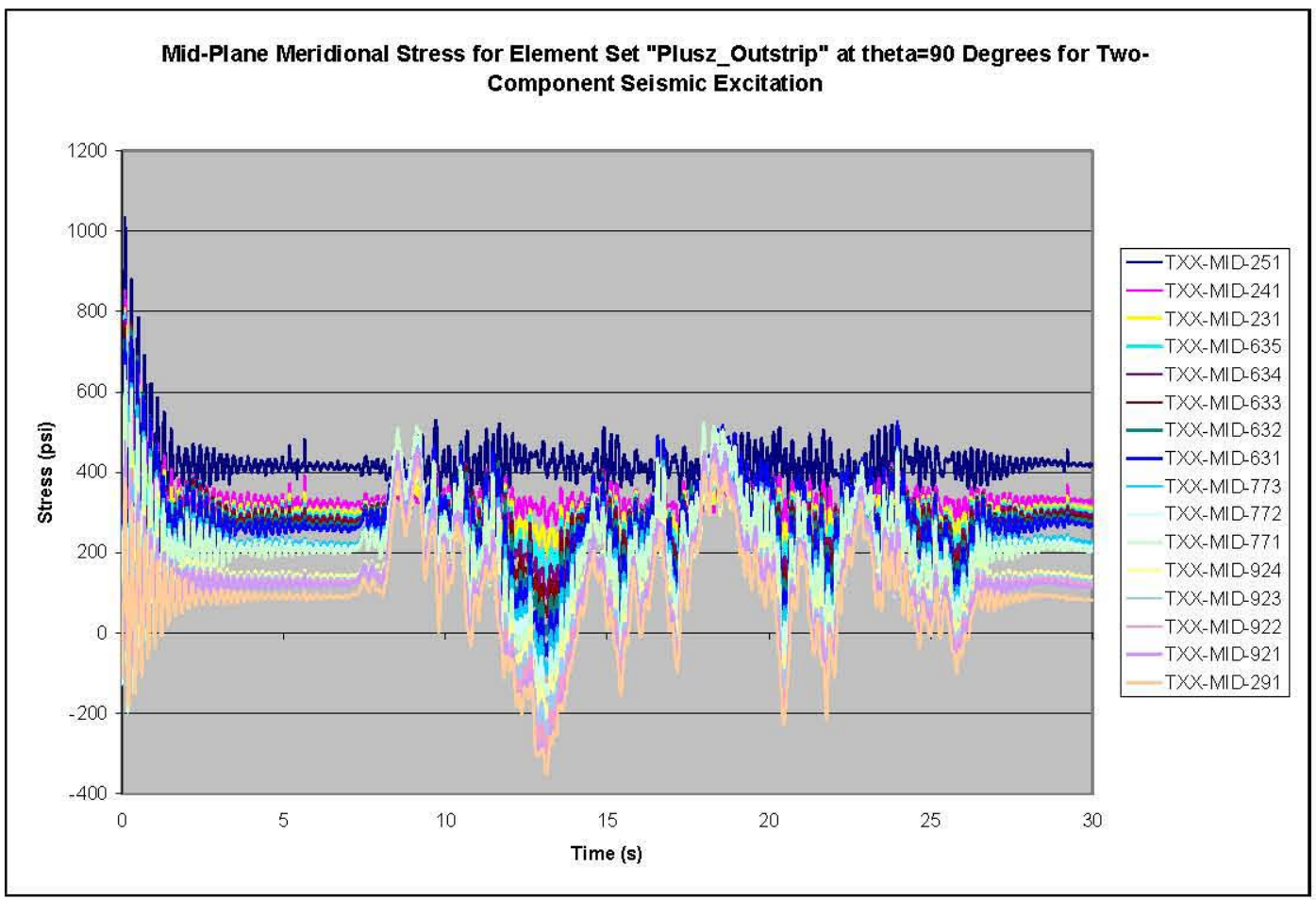

Figure B.20. Mid-Plane Meridional Stress Time Histories for Element Set "Plusz_Outstrip" at $\theta=90^{\circ}$ for Two-Component Seismic Excitation 
RPP-RPT-32239, Rev. 1

M\&D-2008-005-CALC-001, Rev. 1

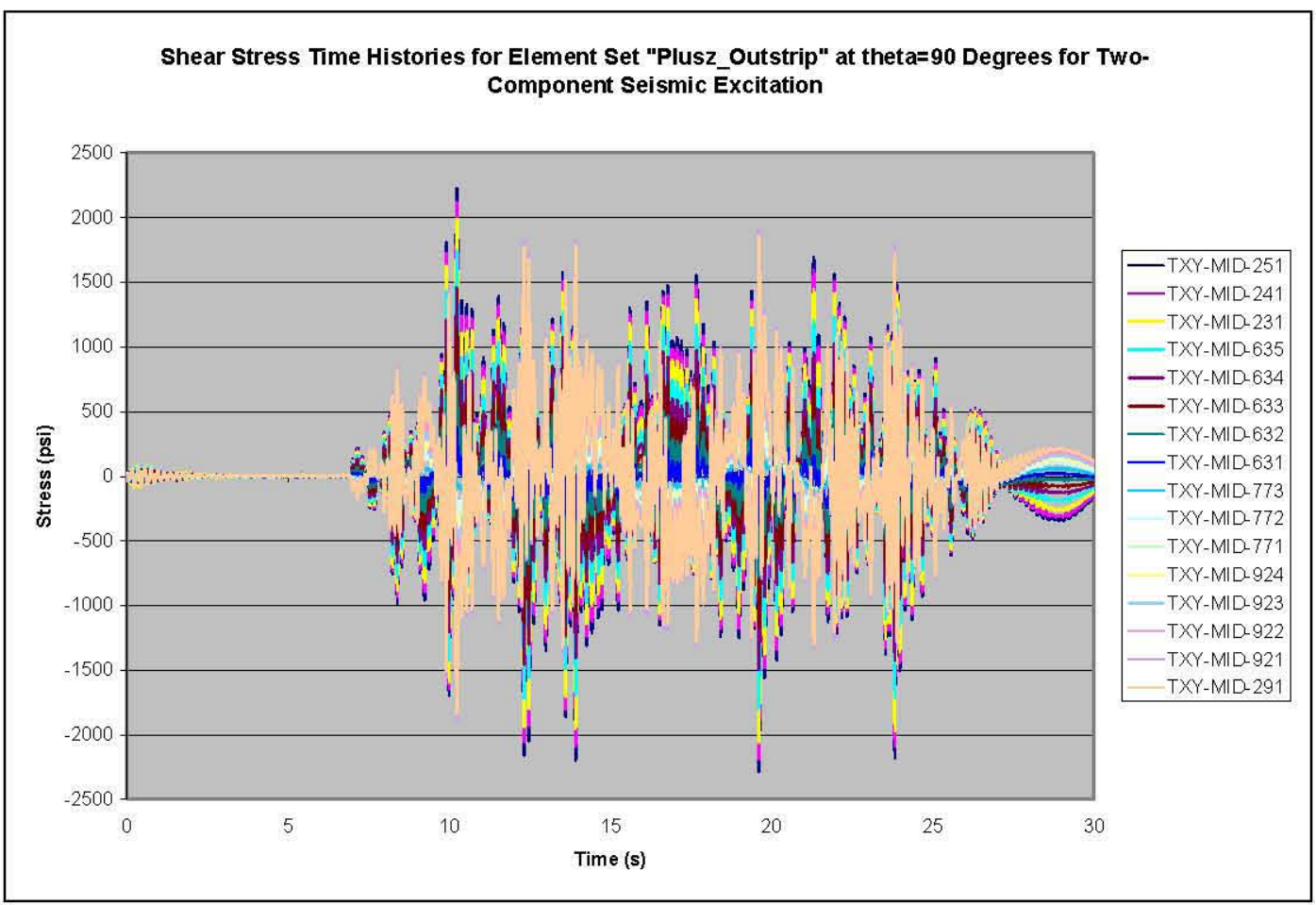

Figure B.21. Mid-Plane Shear Stress Time Histories for Element Set "Plusz_Outstrip" at $\theta=90^{\circ}$ for Two-Component Seismic Excitation

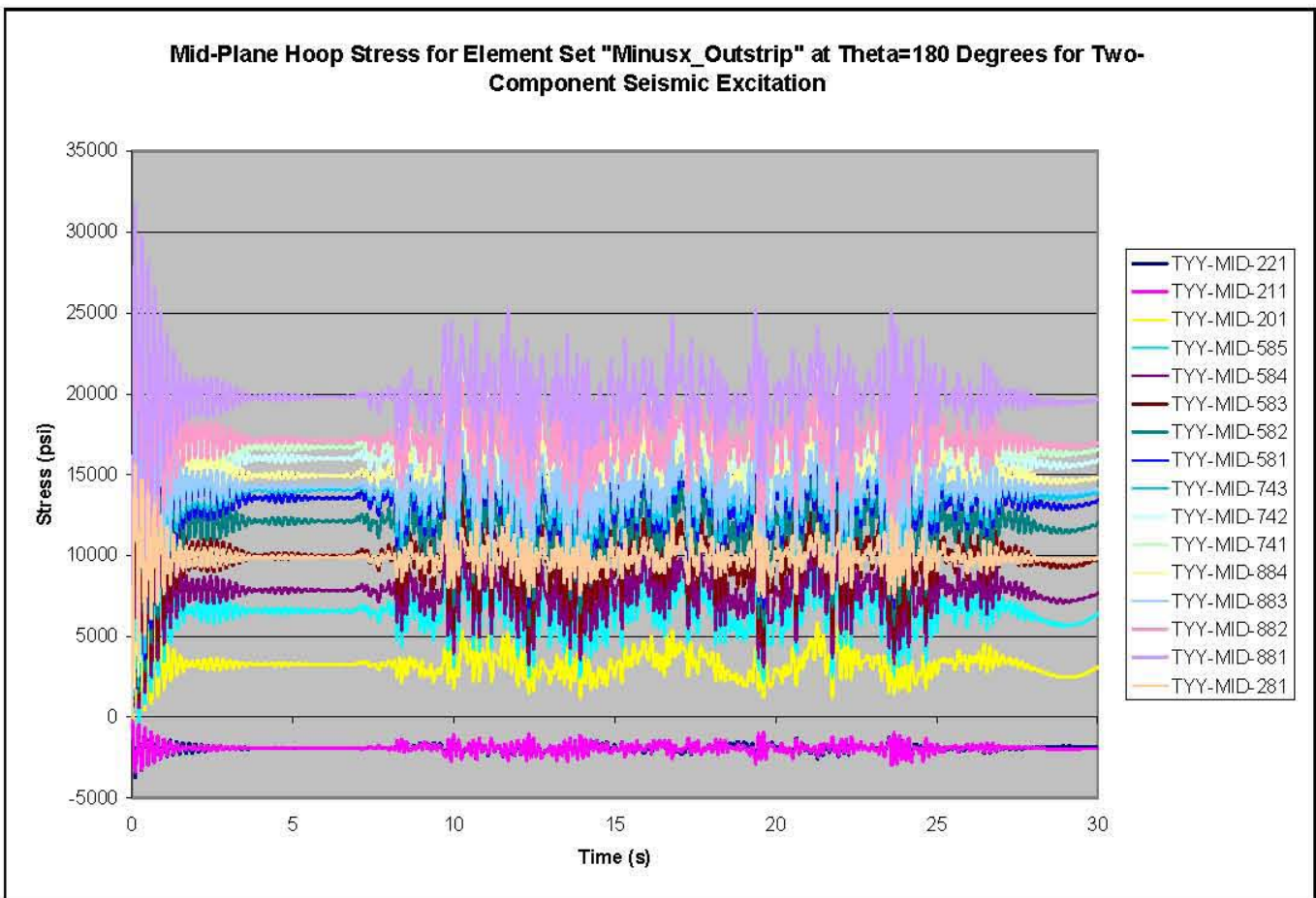

Figure B.22. Mid-Plane Hoop Stress Time Histories for Element Set "Minusx_Outstrip" at $\theta=180^{\circ}$ for Two-Component Seismic Excitation 
RPP-RPT-32239, Rev. 1

M\&D-2008-005-CALC-001, Rev. 1

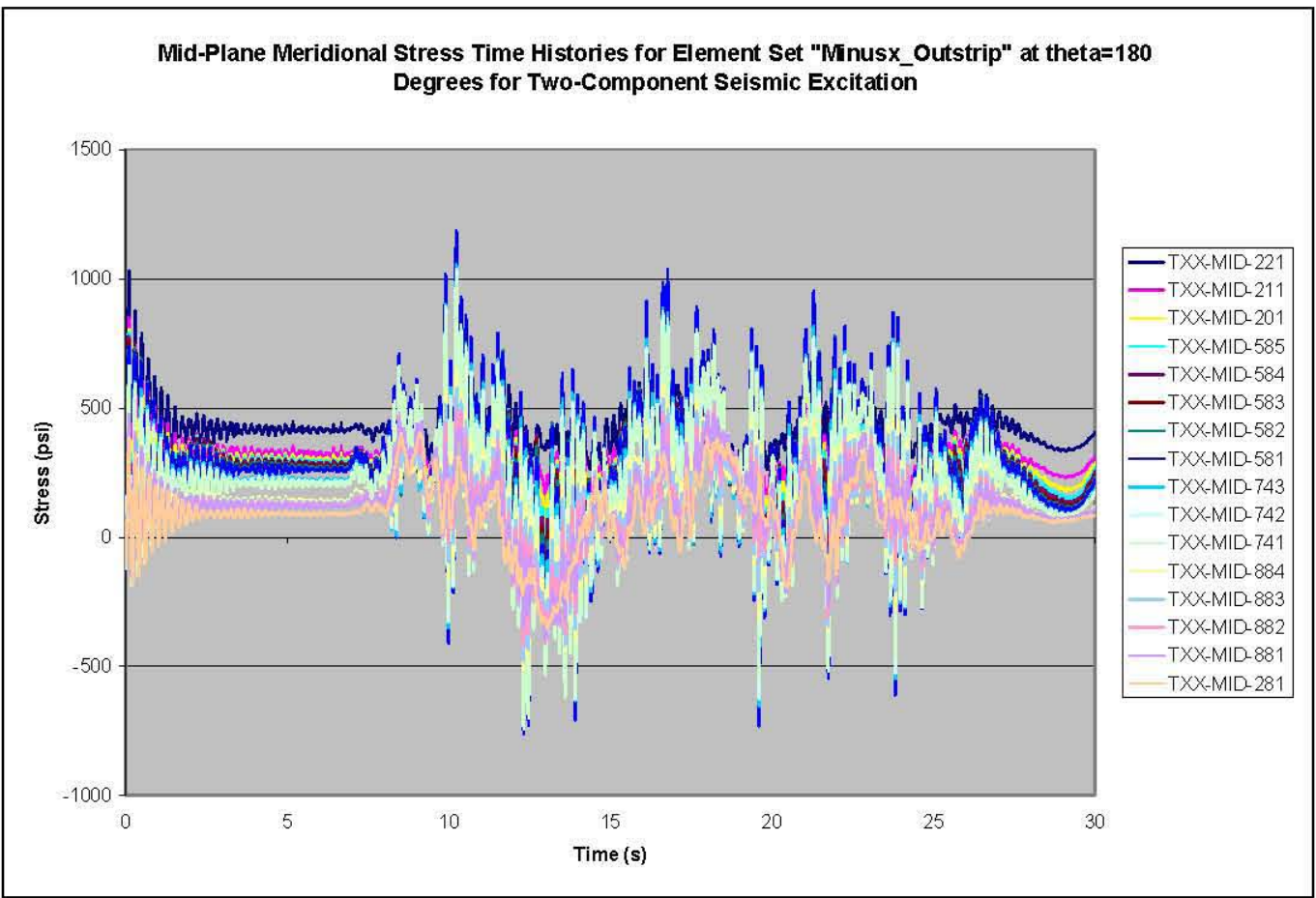

Figure B.23. Mid-Plane Meridional Stress Time Histories for Element Set "Minusx_Outstrip" at $\theta=180^{\circ}$ for Two-Component Seismic Excitation

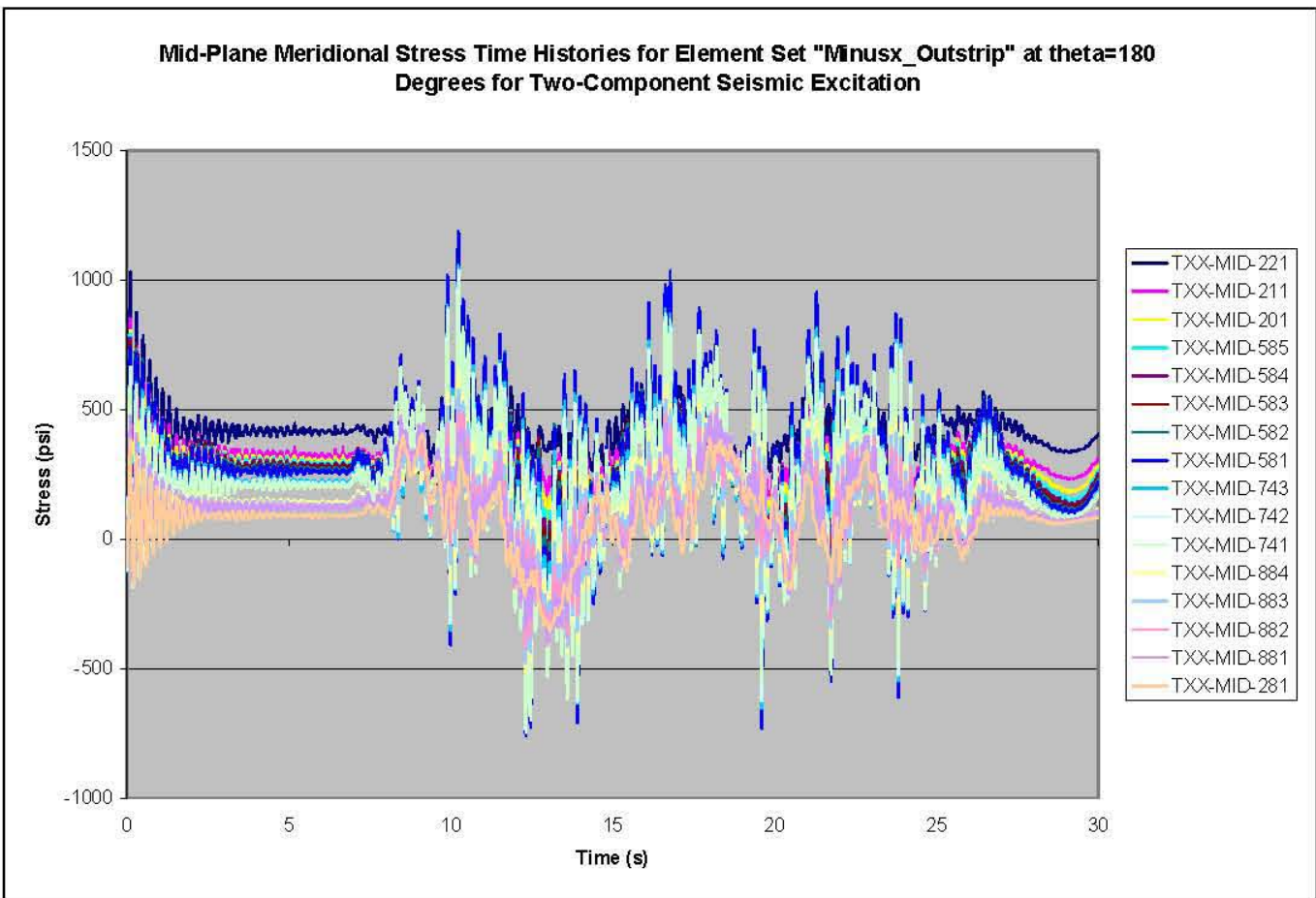

Figure B.24. Mid-Plane Shear Stress Time Histories for Element Set "Minusx_Outstrip" at $\theta=180^{\circ}$ for Two-Component Seismic Excitation 
RPP-RPT-32239, Rev. 1

M\&D-2008-005-CALC-001, Rev. 1

\section{Appendix C}

Common ANSYS ${ }^{\circledR}$ Sub-Model Files Listing 
RPP-RPT-32239, Rev. 1

M\&D-2008-005-CALC-001, Rev. 1

Intentionally left blank 
RPP-RPT-32239, Rev. 1

M\&D-2008-005-CALC-001, Rev. 1

Appendix C

\title{
Common ANSYS ${ }^{\circledR}$ Sub-Model Files Listing
}

\begin{abstract}
All-Forces.txt
!/input, force-c, txt

/input, stress-Primary, txt

/input, Force-J bolt, txt

!/input, strain-liner, txt
\end{abstract}

\section{Bolts-Friction.txt}

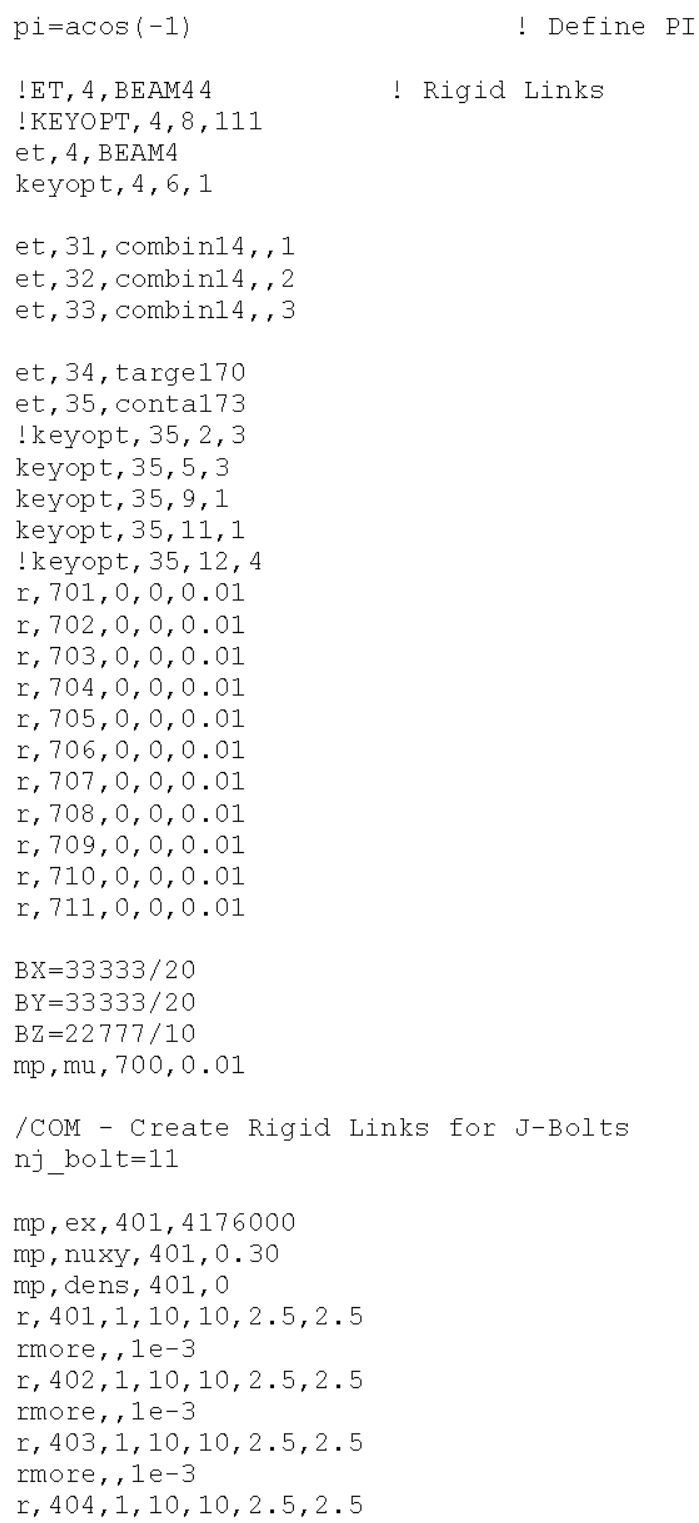


RPP-RPT-32239, Rev. 1

M\&D-2008-005-CALC-001, Rev. 1

rmore,, $1 \mathrm{e}-3$

$r, 405,1,10,10,2.5,2.5$

rmore,, $1 \mathrm{e}-3$

$r, 406,1,10,10,2.5,2.5$

rmore,, $1 \mathrm{e}-3$

$r, 407,1,10,10,2.5,2.5$

rmore,, $1 \mathrm{e}-3$

$r, 408,1,10,10,2.5,2.5$

rmore, , 1e-3

$r, 409,1,10,10,2.5,2.5$

rmore,, $1 \mathrm{e}-3$

$r, 410,1,10,10,2.5,2.5$

rmore,, $1 \mathrm{e}-3$

$r, 411,1,10,10,2.5,2.5$

rmore, , $1 \mathrm{e}-3$

$r, 421,1 / 2,10,10,2.5,2.5$

rmore,, $1 \mathrm{e}-3$

$r, 422,1 / 2,10,10,2.5,2.5$

rmore,, $1 \mathrm{e}-3$

$r, 423,1 / 2,10,10,2.5,2.5$

rmore,, $1 \mathrm{e}-3$

$r, 424,1 / 2,10,10,2.5,2.5$

rmore,, $1 \mathrm{e}-3$

$r, 425,1 / 2,10,10,2.5,2.5$

rmore,, $1 \mathrm{e}-3$

$r, 426,1 / 2,10,10,2.5,2.5$

rmore,, $1 \mathrm{e}-3$

$r, 427,1 / 2,10,10,2.5,2.5$

rmore, $1 \mathrm{e}-3$

$r, 428,1 / 2,10,10,2 \cdot 5,2.5$

rmore, $1 \mathrm{e}-3$

$r, 429,1 / 2,10,10,2 \cdot 5,2.5$

rmore,, $1 \mathrm{e}-3$

$r, 430,1 / 2,10,10,2.5,2.5$

rmore,, $1 \mathrm{e}-3$

$r, 431,1 / 2,10,10,2.5,2.5$

rmore,, $1 \mathrm{e}-3$

$r, 501,1.364 * \mathrm{BX}$

$\mathrm{r}, 502,0.550 * \mathrm{BX}$

$\mathrm{r}, 503,0.887^{*} \mathrm{BX}$

$\mathrm{r}, 504,1.027^{\star} \mathrm{BX}$

$\mathrm{r}, 505,1.971{ }^{\star \mathrm{BX}}$

$r, 506,2.407 \star^{\mathrm{BX}}$

$\mathrm{r}, 507,3.301 * \mathrm{BX}$

$\mathrm{r}, 508,4.039{ }^{*} \mathrm{BX}$

$\mathrm{r}, 509,4.369 * \mathrm{BX}$

$\mathrm{r}, 510,5.362{ }^{\star} \mathrm{BX}$

$r, 511,3.596 \star^{\mathrm{BX}}$

$\mathrm{r}, 521,1.364 \star_{\mathrm{BY}}$

$r, 522,0.550 * \mathrm{BY}$

$r, 523,0.887^{*} \mathrm{BY}$

$\mathrm{r}, 524,1.027 * \mathrm{BY}$

$\mathrm{r}, 525,1.971{ }^{*} \mathrm{BY}$

$\mathrm{r}, 526,2.407{ }^{*} \mathrm{BY}$

$\mathrm{r}, 527,3.301{ }^{\mathrm{BY}}$

$\mathrm{r}, 528,4.039 * \mathrm{BY}$

$r, 529,4.369 \star^{\mathrm{BY}}$

$r, 530,5.362 * \mathrm{BY}$

$\mathrm{r}, 531,3.596{ }^{\star} \mathrm{BY}$

$\mathrm{r}, 541,1.364 * \mathrm{BZ}$

$r, 542,0.550{ }^{*} \mathrm{BZ}$

$\mathrm{r}, 543,0.887{ }^{*} \mathrm{BZ}$

$\mathrm{r}, 544,1.027{ }^{*} \mathrm{BZ}$

$\mathrm{r}, 545,1.971{ }^{\star} \mathrm{BZ}$

$\mathrm{r}, 546,2.407{ }^{\star} \mathrm{BZ}$

$\mathrm{r}, 547,3.301 * \mathrm{BZ}$

$\mathrm{r}, 548,4.039 \star_{\mathrm{BZ}}$ 
RPP-RPT-32239, Rev. 1

M\&D-2008-005-CALC-001, Rev. 1

$r, 549,4.369 * \mathrm{BZ}$

$\mathrm{r}, 550,5.362 * \mathrm{BZ}$

$\mathrm{r}, 551,3.596^{\star} \mathrm{BZ}$

$\mathrm{R}, 601,1.364{ }^{\star} \mathrm{BX} / 2$

$\mathrm{R}, 602,0.550{ }^{*} \mathrm{BX} / 2$

$\mathrm{R}, 603,0.887{ }^{\star} \mathrm{BX} / 2$

$\mathrm{R}, 604,1.0277^{*} \mathrm{BX} / 2$

$\mathrm{R}, 605,1.971 * \mathrm{BX} / 2$

$\mathrm{R}, 606,2.407^{\star} \mathrm{BX} / 2$

$\mathrm{R}, 607,3.301 * \mathrm{BX} / 2$

$\mathrm{R}, 608,4.039 \star_{\mathrm{BX} / 2}$

$\mathrm{R}, 609,4.369 * \mathrm{BX} / 2$

$\mathrm{R}, 610,5.362 * \mathrm{BX} / 2$

$\mathrm{R}, 611,3.596 * \mathrm{BX} / 2$

$\mathrm{R}, 621,1.364 * \mathrm{BY} / 2$

$\mathrm{R}, 622,0.550{ }^{\mathrm{BY}} / 2$

$\mathrm{R}, 623,0.887{ }^{*} \mathrm{BY} / 2$

$\mathrm{R}, 624,1.027^{\star} \mathrm{BY} / 2$

$\mathrm{R}, 625,1.971^{*} \mathrm{BY} / 2$

$\mathrm{R}, 626,2.407^{*} \mathrm{BY} / 2$

$\mathrm{R}, 627,3.301 * \mathrm{BY} / 2$

$\mathrm{R}, 628,4.039{ }^{\mathrm{BY}} / 2$

$\mathrm{R}, 629,4.369{ }^{*} \mathrm{BY} / 2$

$\mathrm{R}, 630,5.362 \star_{\mathrm{BY}} / 2$

$\mathrm{R}, 631,3.596{ }^{\star} \mathrm{BY} / 2$

$\mathrm{R}, 641,1.364{ }^{\star} \mathrm{BZ} / 2$

$\mathrm{R}, 642,0.550 * \mathrm{BZ} / 2$

$\mathrm{R}, 643,0.887^{\star} \mathrm{BZ} / 2$

$\mathrm{R}, 644,1.027^{*} \mathrm{BZ} / 2$

$\mathrm{R}, 645,1.971 * \mathrm{BZ} / 2$

$\mathrm{R}, 646,2.407{ }^{*} \mathrm{BZ} / 2$

$\mathrm{R}, 647,3.301 * \mathrm{BZ} / 2$

$\mathrm{R}, 648,4.039{ }^{\star} \mathrm{BZ} / 2$

$\mathrm{R}, 649,4.369 * \mathrm{BZ} / 2$

$\mathrm{R}, 650,5.362 * \mathrm{BZ} / 2$

$\mathrm{R}, 651,3.596{ }^{*} \mathrm{BZ} / 2$

cmsel, s, primary-tank

nsle

nsel, r, loc, z,ptz (1), ptz (11)

$\mathrm{cm}$, bolt-primary-n, node

nsel, none

$\mathrm{n},, 0,0, \mathrm{ptz}(1)$

${ }^{*} \mathrm{do}, i, 2, \mathrm{nj}$ bolt

${ }^{*} \mathrm{do}, j, 0,18 \overline{0} / \operatorname{arcsize}$

angley $=-j *$ arcsize

$\mathrm{n}, \operatorname{ptx}(i)$, angley, ptz(i)

*enddo

*enddo

$\mathrm{cm}$, bolt-node, node

/COM - Create link at top center of tanks

type, 4

mat, 401

real, 401

nsel, s, loc, $x, 0$

nsel, r, loc, z, ptz (1), $\operatorname{ctz}(1)$

!nsel, u, node, , 1

cmsel, u, bolt-primary-n

eintf, 10

Csys, 1

/COM - Create links for J-Bolts

${ }^{*} \mathrm{do}, \mathrm{i}, 2, \mathrm{nj}$ jbolt

REAL, $400+i$

${ }^{*}$ do, $j, 1,180 / \operatorname{arcsize}-1$
! Select nodes on model origin

! Reselect nodes on concrete and primary tanks

! Place link at dome center

! Cycle by radius

! Cycle by model slice 


\section{RPP-RPT-32239, Rev. 1 \\ M\&D-2008-005-CALC-001, Rev. 1}

angley $=-j *$ arcsize

nsel, s, loc, $x, \operatorname{ctx}(i), \operatorname{ptx}(i)$

nsel, r, loc, $z, \operatorname{ctz}(i), p t z(i)$

nsel, $r, l \circ c, y$, angley

cmsel, u, bolt-primary-n

cmsel, u, waste-n

eintf, 10

*enddo

real, $420+i$

nsel, s, loc, $x, \operatorname{ctx}(i), p t x(i)$

nsel, r, loc, z, ctz(i), ptz(i)

nsel, $r, l \circ c, y, 0$

cmsel, u, bolt-primary-n

cmsel, u, waste-n

eintf, 10

nsel, s, loc, $x, \operatorname{ctx}(i), \operatorname{ptx}(i)$

nsel, r, loc, z, ctz(i), ptz(i)

nsel, $r, 100, y, 180$

cmsel, u, bolt-primary-n

cmsel, u, waste-n

eintf, 10

*enddo

esel, s, type, 4

$\mathrm{cm}, j$ bolts, elem

allsel
! Define angle for node selection

! Select nodes at radius

! Reselect nodes at angle "anlgey"

! Create rigid link

! Select nodes at radius

! Reselect nodes at angle 0

! Create rigid link

! Select nodes at radius

! Reselect nodes at angle 180

! Create rigid link

! Create component for J-Bolt rigid links

/COM - Create link at top center of tanks

nsel, $R, 100, x, 0$

nsel, r, loc, z, ptz(1), ptz (1)

TYPE, 31

REAL, 501

eintf

TYPE, 32

REAL, 521

eintf

TYPE, 33

REAL, 541

eintf

Csys, 1

/COM - Create links for J-Bolts

$\star d o, j, 0,2$

type, $31+j$

${ }^{*}$ do, $i, 2$, nj bolt

REAL, $500+2 \overline{0} * j+i$

${ }^{*}$ do $, \mathrm{k}, 1,180 /$ arcsize-1

angley $=-k^{*}$ arcsize

nsel, s, loc, $x, p t x(i), p t x(i)$

nsel, r, loc, z,ptz(i),ptz(i)

nsel, $r$, loc, $y$, angley

cmsel, u, waste-n

eintf

*enddo

real, $600+j * 20+i$

nsel, s, loc, $x, p t x(i), p t x$ (i)

nsel, r, loc, z,ptz(i),ptz(i)

nsel, $r, 1 \circ c, y, 0$

cmsel, u, waste-n

eintf

nsel, s, loc, $x, p t x(i), p t x(i)$

nsel, r, loc, z,ptz(i),ptz(i)

nsel, $r, 100, y, 180$

cmsel, u, waste-n

eintf

tenddo

*enddo
! Select nodes on model origin

! Reselect nodes on concrete and primary tanks

! Place link at dome center

! Place link at dome center

! Place link at dome center

! Cycle by radius

! Cycle by model slice

! Define angle for node selection

! Select nodes at radius

! Select nodes at radius

! Reselect nodes at angle "anlgey"

! Create rigid link

! Select nodes at radius

! Select nodes at radius

! Reselect nodes at angle 0

! Create rigid link

! select nodes at radius

! Select nodes at radius

! Reselect nodes at angle 180

! Create rigid link 
RPP-RPT-32239, Rev. 1

M\&D-2008-005-CALC-001, Rev. 1

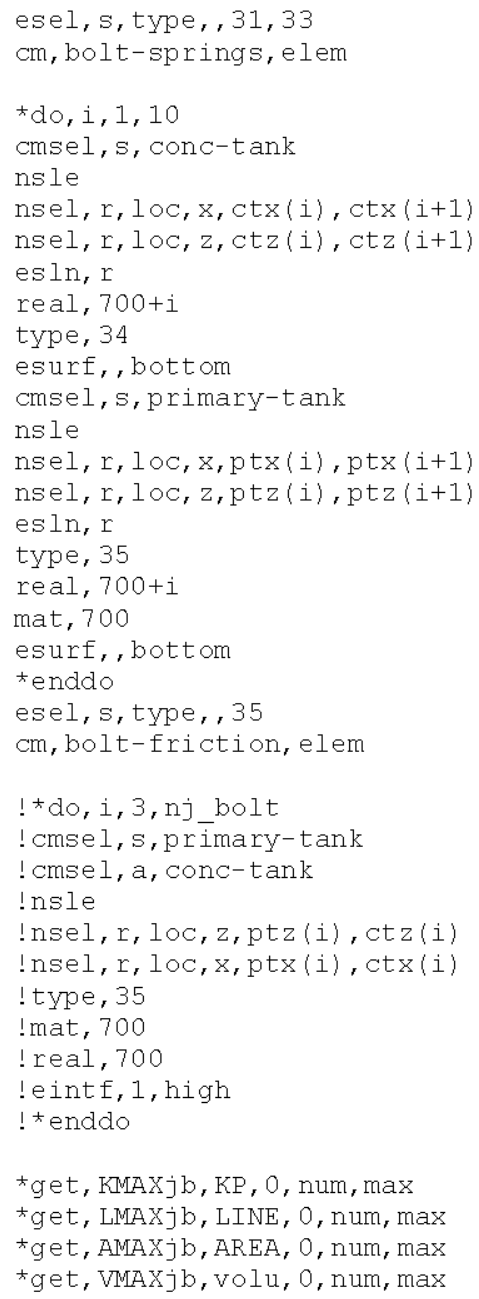

\section{Boundary.txt}

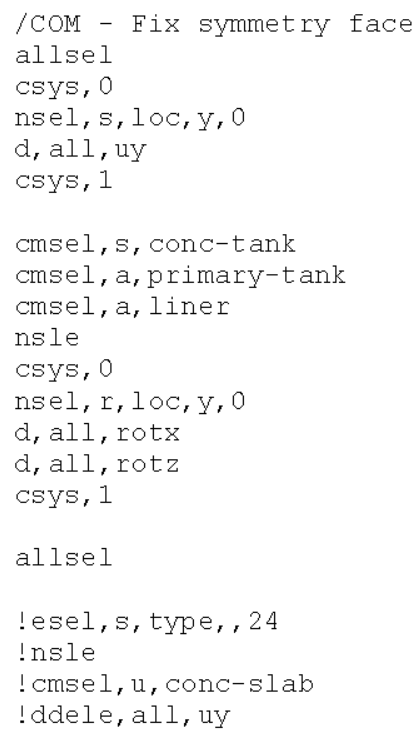


RPP-RPT-32239, Rev. 1

M\&D-2008-005-CALC-001, Rev. 1

!allsel

\section{Contact-AP.txt}

/input, waste-reaction, txt /input, contact-waste-ap, txt

! / input, contact-insul, txt

!/ input, contact-primary, txt

!/ input, contact-j-bolts, txt

! / input, contact-soil, txt

! / input, waste-surface-ap, txt

! / input, contact-footing, txt

\section{Contact-Waste-AP.txt}

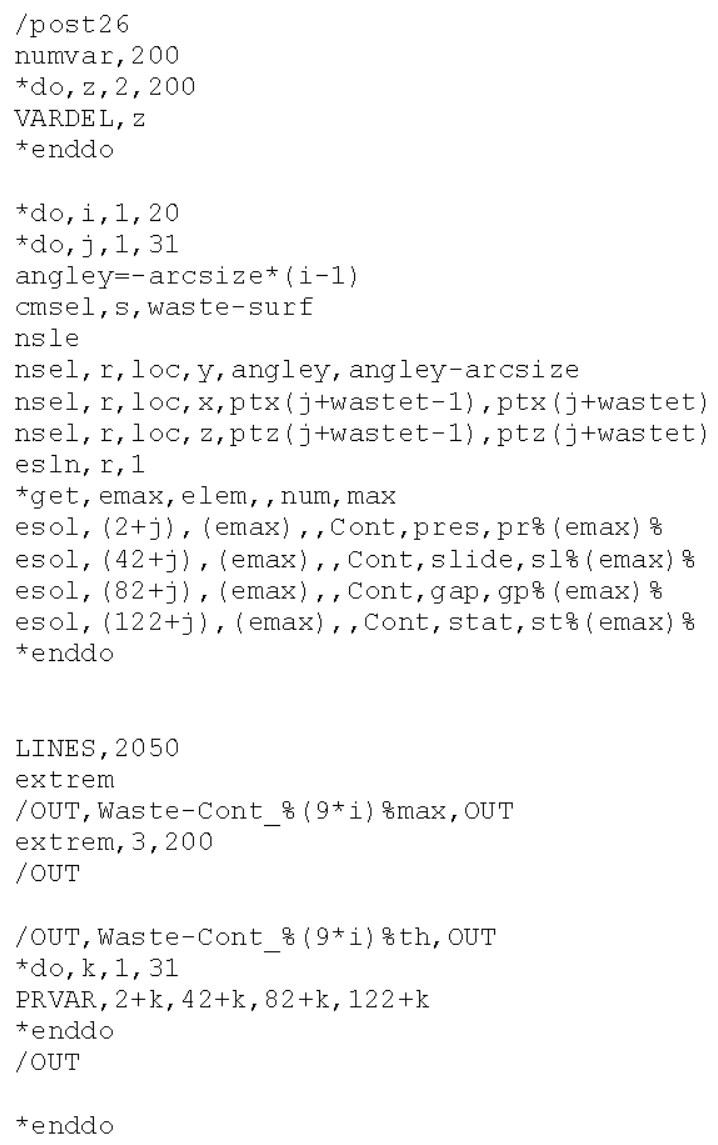

\section{Far-Soil.txt}

et, 9 , solid 45

et, $10, \operatorname{mass} 21$

$r, 1001$, mass, mass, mass

type, 9

asel, none

vsel, none

lsel, none

nsel, none

ksel, none

esel, none 


\section{RPP-RPT-32239, Rev. 1 \\ M\&D-2008-005-CALC-001, Rev. 1}

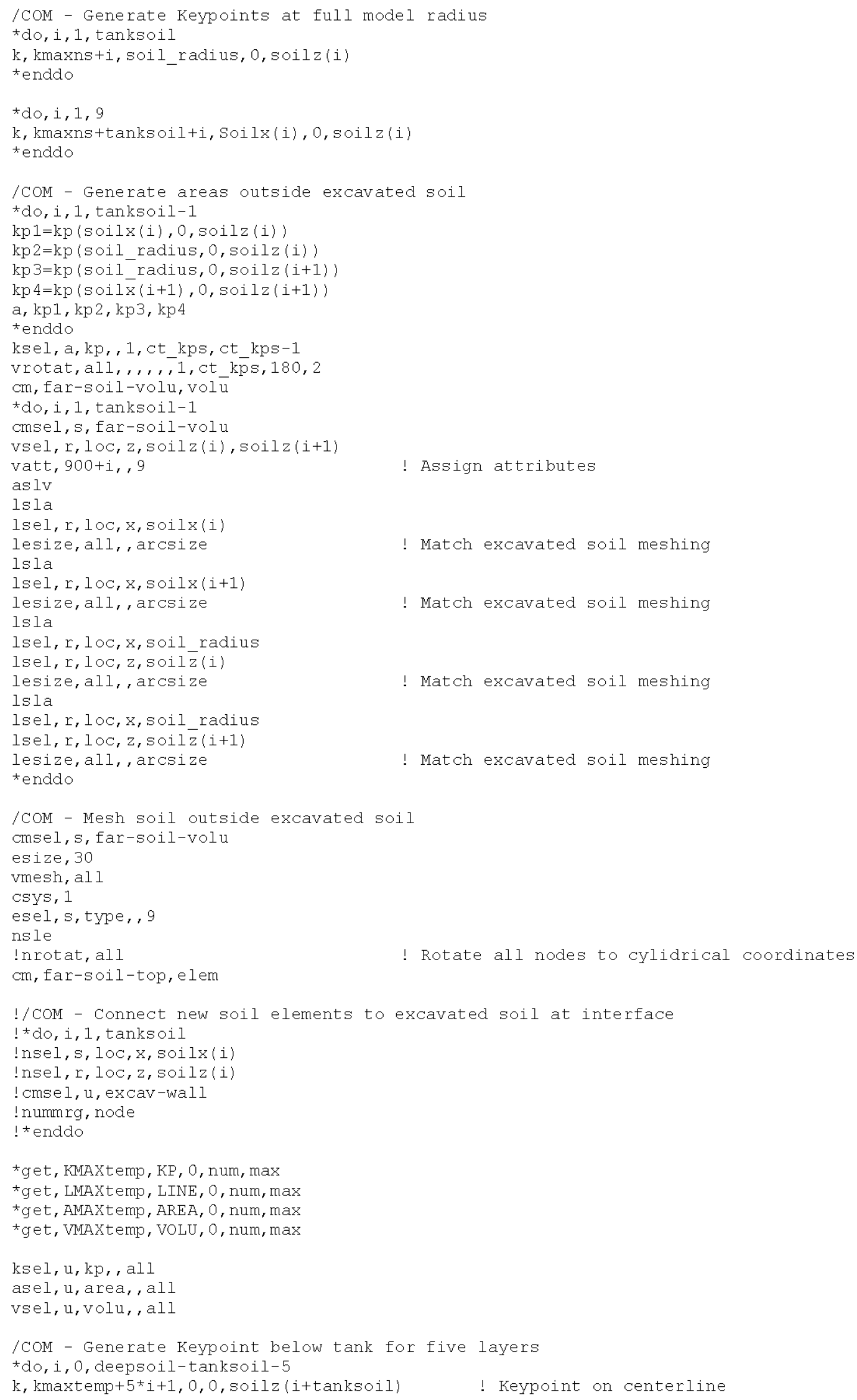




\section{RPP-RPT-32239, Rev. 1 M\&D-2008-005-CALC-001, Rev. 1}

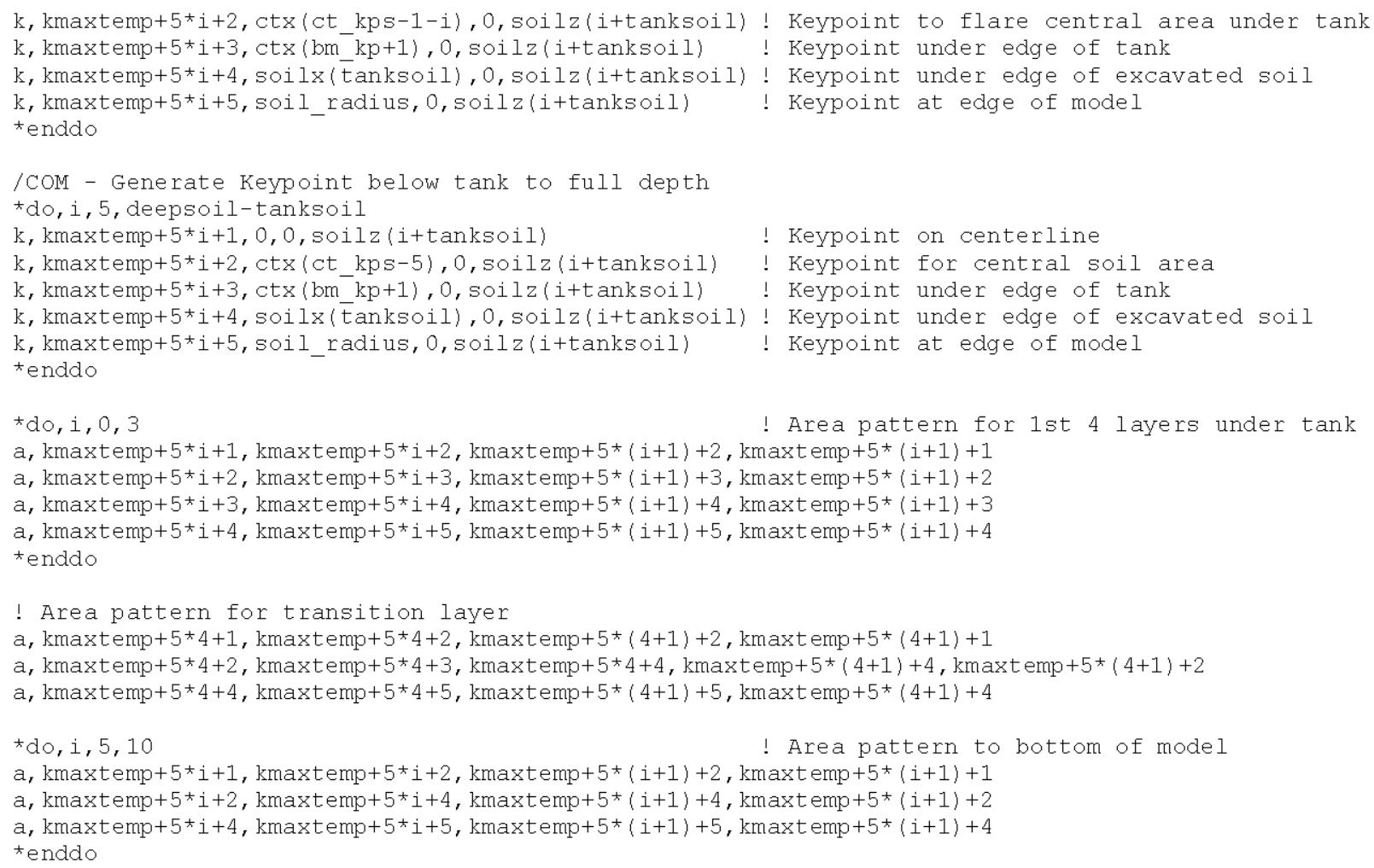




\section{RPP-RPT-32239, Rev. 1 \\ M\&D-2008-005-CALC-001, Rev. 1}

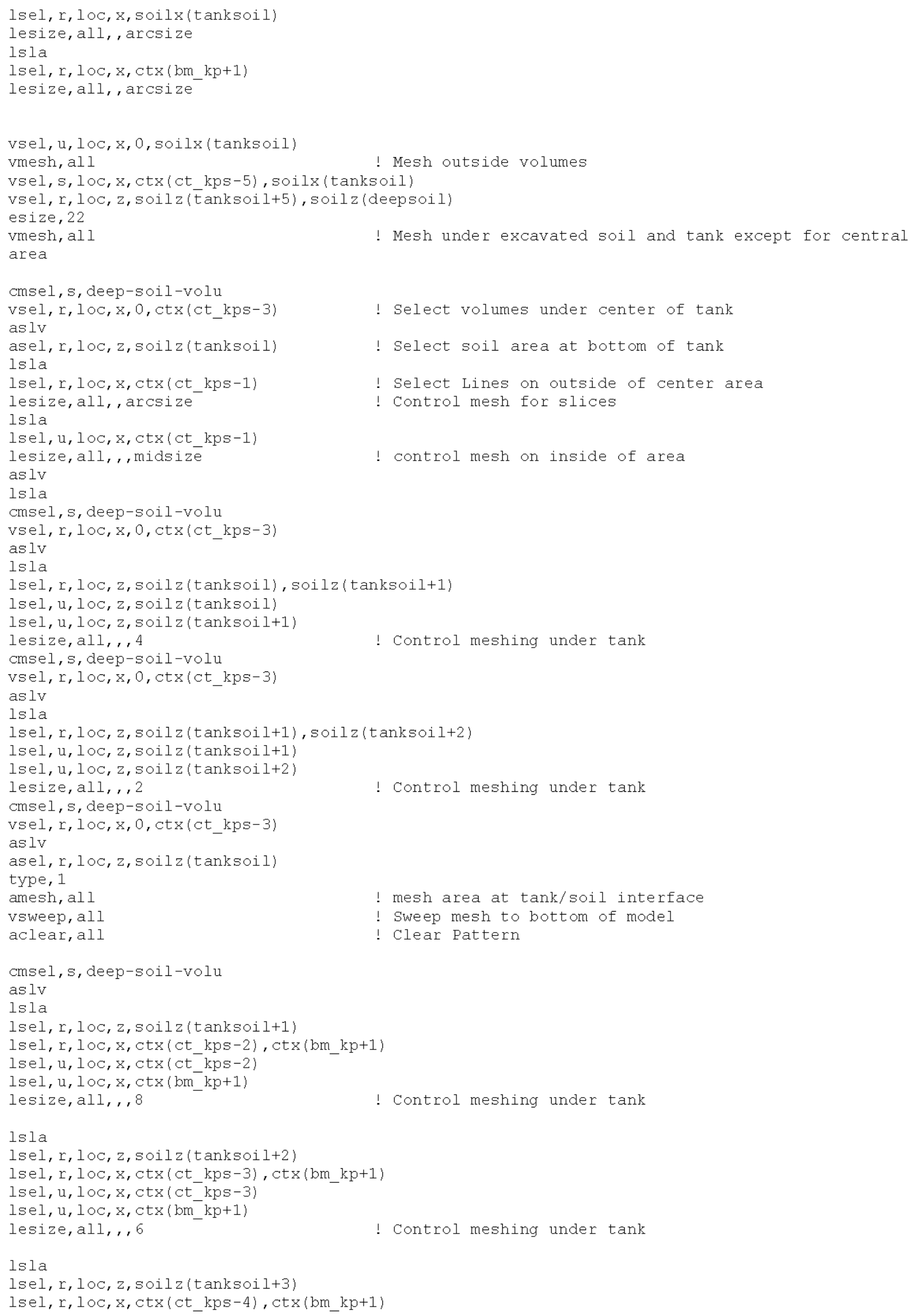




\section{RPP-RPT-32239, Rev. 1 \\ M\&D-2008-005-CALC-001, Rev. 1}

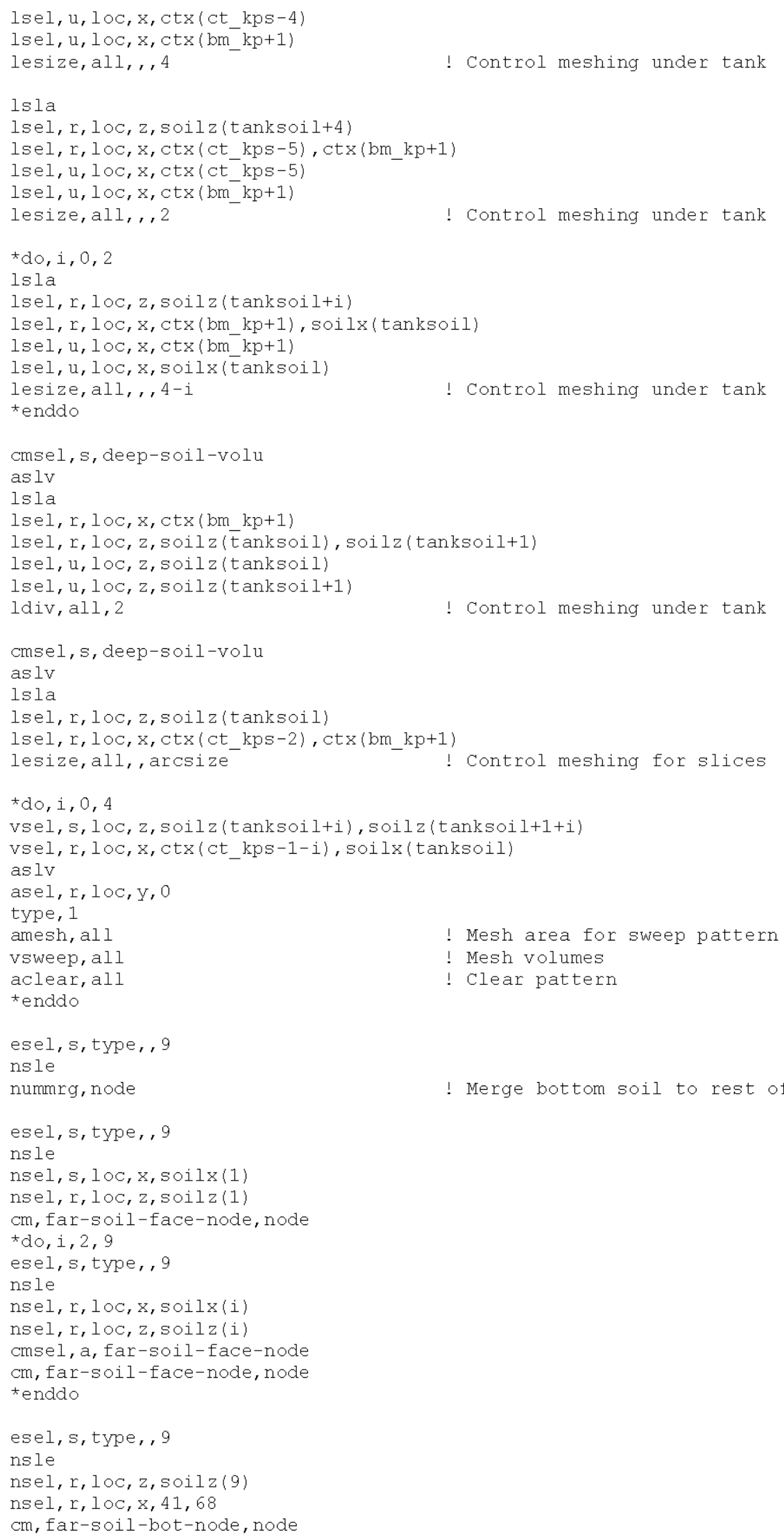


RPP-RPT-32239, Rev. 1

M\&D-2008-005-CALC-001, Rev. 1

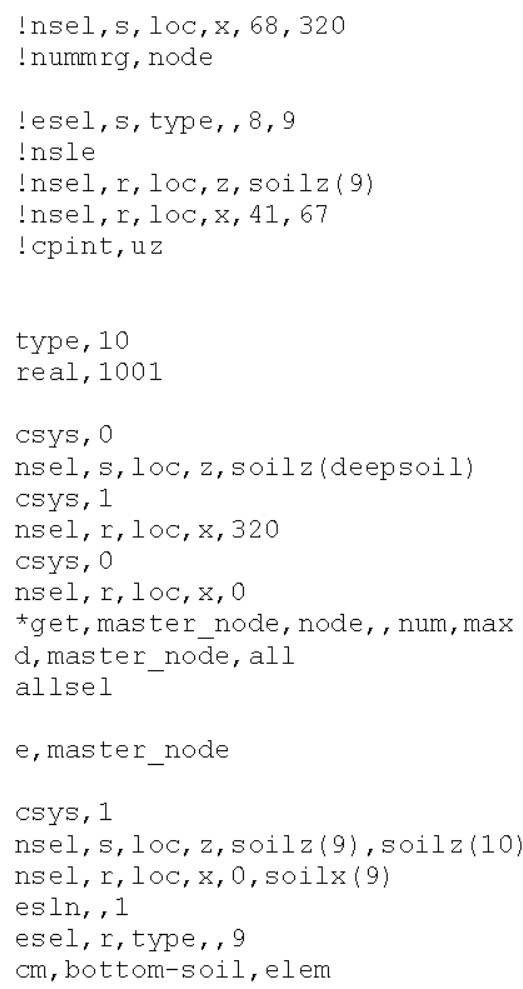

\section{Fix-Soil.txt}

! esel, s, type, , 8, 9

!nsle

!nsel, r, loc, z, soilz (9)

!nsel, r, loc, $x, \operatorname{ctx}(21)+1,68$

! nummrg, node

et, 90, targe 170

et, 91 , conta173

keyopt, $91,9,1$

$\mathrm{mp}, \mathrm{mu}, 90,0.3$

mp , mu, $91,0.7$

$\mathrm{mp}, \mathrm{mu}, 92,0.7$

$r, 90,0.1$

$r, 91,, 0.1$

esel, s, type, 9

cmsel,s, far-soil-face-node

esln, $r$

type, 90

real, 90

mat, 90

esurf

esel, s, type, 8

cmsel, s, near-soil-face-node

esln, $r$

type, 91

esurf

esel, s, type, 9

cmsel, s, far-soil-bot-node

esln, $r$

type, 90

real, 91

mat, 91

esurf 
RPP-RPT-32239, Rev. 1

M\&D-2008-005-CALC-001, Rev. 1

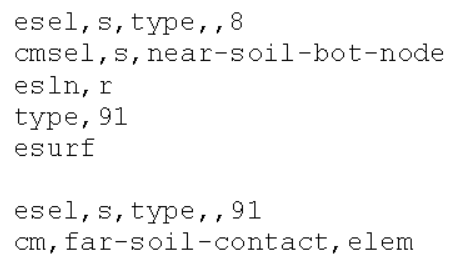

\section{Insulate.txt}

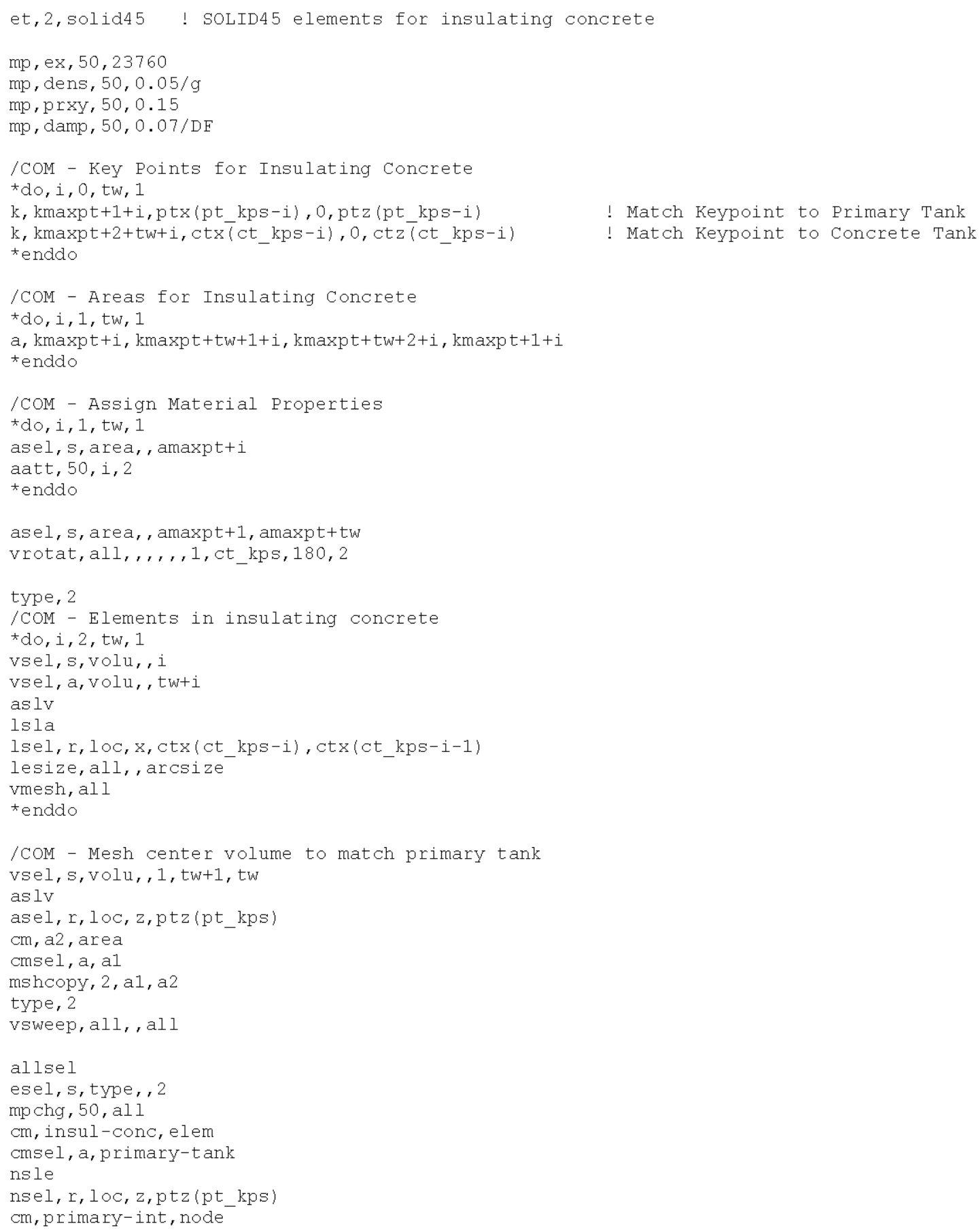

! Match Keypoint to Primary Tank

! Match Keypoint to Concrete Tank 
RPP-RPT-32239, Rev. 1

M\&D-2008-005-CALC-001, Rev. 1

allsel

cmsel, s, conc-tank

esel, a, type, , 2

nsle

nsel, r, loc, z, ctz (ct_kps)

nsel,r, loc, x, ctx (ct_kps-tw), ctx(ct_kps)

cm, insul-vol, volu

cm, insul-int, node

cmsel, s, a2

aclear, all

allsel

*get, KMAXic, KP, 0, num, max

*get, LMAXic, LINE, 0, num, max

! Get maximum Keypoint Number

*get, AMAXic, AREA, 0, num, max

! Get maximum Line Number

*get, VMAXic, VOLU, 0, num, max

! Get maximum Area Number

! Get maximum Volume Number

cmsel, s, insul-conc

nsle

nsel, r, loc, z, ptz (pt_kps)

nsel, r, loc, $x, p t x$ (pt kps-tw)

csys, 1

!nrotat, all

allsel

\section{interface-gap1.txt}

/CoM, Create components for wall and dome of concrete tank and excavated soil for interface coupling

Csys, 1

cmsel, s, conc-dome wall-n

nsel, r, loc, $x, \operatorname{ctx}(\overline{1} 2), \operatorname{ctx}(14)+.1$

esln, s, 1

cmsel, u, liner

$\mathrm{cm}$, conc-wall-e, elem

$\mathrm{cm}$, conc-wall-n, node

cmsel, s, conc-dome wall-e

cmsel, s, conc-dome wall-n

cmsel, u, conc-wall-e

nsle, s, 1

nsel, u, loc, z, etz(13), ctz(14)

esln, r, 1

$\mathrm{cm}$, conc-dome-e, elem

$\mathrm{cm}$, conc-dome-n, node

cmsel, s, excav-soil

nsle, $s, 1$

nsel, r, loc, $x, \operatorname{ctx}(12), \operatorname{ctx}(14)$

nsel, r, loc, z, ctz (12), ctz(22)

esln, s

$\mathrm{cm}$, excav-wall-e, elem

$\mathrm{cm}$, excav-wall-n, node

cmsel, s, excav-soil

nsle, s, 1

$\mathrm{CM}, \mathrm{EXCAV}-\mathrm{SOIL}-\mathrm{N}, \mathrm{NODE}$

!nsel, r, loc, x, 0, ctx (14)

!nsel, u, loc, z, 0, soilz (3)

!nsel, u, loc, $z, \operatorname{ctz}(14), \operatorname{ctz}(22)$

! cm, ntemp, node

!nsel, r, loc $, \mathrm{z},-11,-13.4$

!nsel, u, loc, $x, 0,28$

! cm, ntemp1, node 


\section{RPP-RPT-32239, Rev. 1 \\ M\&D-2008-005-CALC-001, Rev. 1}

! cmsel, s, ntemp

! cmse 1, u, ntemp 1

CMSEL, S, EXCAV-SOIL-N

NSEL, R, LOC, X, CTX (1), CTX (2)

NSEL, R, LOC, Z, CTZ (1), CTZ (2)

$\mathrm{cm}$, excav-dome-n, node

${ }^{\star} \mathrm{DO}, \mathrm{I}, 3,12$

CMSEL, S, EXCAV-SOIL-N

NSEL, R, LOC, X, CTX (I)

NSEL, R, LOC, Z, CTZ (I)

CMSEL, A, EXCAV-DOME-N

$\mathrm{cm}$, excav-dome-n, node

$\star \mathrm{ENDDO}$

esln,

$\mathrm{cm}$, excav-dome-e, elem

/COM, Create wall soil to concrete tank interface elements

cmsel, s, conc-wall-n

cmsel, a, excav-wall-n

$\mathrm{cm}$, conc-excav-wall-int, node

cmsel, s, conc-dome-n

cmsel, a, excav-dome-n

$\mathrm{cm}$, conc-excav-dome-int, node

/COM, Define contact properteis

et, 61, conta 173

keyopt, $61,5,3$

et, 60 , targe 170

! keyopt, 60, 8, 2

surface and al

permitted)

! keyopt, $61,2,3$

et, 63, conta173

keyopt, $63,5,3$

et, 62, targe 170

! keyopt, $62,8,2$

! keyopt, $63,12,4$

! keyopt, $63,2,3$

$\mathrm{mp}, \mathrm{mu}, 60,0.2$

! Coefficient of Friction between excavated soil and

concrete tank wall

$\mathrm{MP}$, damp, 60,0.07/DF

$r, 60,, 0.05$

$\mathrm{mp}, \mathrm{mu}, 62,0.2$

! Contact Surface - Concrete Tank

! Type of constriant - Shell/Solid contact normal direction

! Contact Element - Excavated Soil

! Asymmetric contact selection (all contact elements on one target elements on the other surface)

! Behavior of contact surface (no seperation, sliding

concrete tank dome

MP, damp, 62,0.07/DF

$r, 62,, 0.05$

$r, 61,, 0.05$

$r, 63,, 0.025$

$\mathrm{mp}, \mathrm{mu}, 64,0.6$

concrete tank dome

MP , damp, 64, 0.07/DF

! add wall interface elements

! concrete tank surface target

cmsel, s, conc-wall-e

nsle, $s, 1$

type, 60

real, 60

mat, 60

esurf

esel, s, type, 60

nsle

nsel, r, loc, z, ctz(12), $\operatorname{ctz}(14)$

esln, r, 1

! Coefficient of Friction between excavated soil and

! Coefficient of Friction between excavated soil and 
RPP-RPT-32239, Rev. 1

M\&D-2008-005-CALC-001, Rev. 1

emodif, all, real, 61

esel, s, type, , 61

cmsel, u, conc-wall-e

$\mathrm{cm}$, conc-target, elem

type, 61

cmsel, s, excav-wall-e

cmsel, a, excav-wall-n

esurf

esel, s, type, , 61

nsle

nsel, r, loc, z, ctz (12), ctz (14)

esln, $r, 1$

emodif, all, real, 61

esel, s, type, ,61

cmsel, u, excav-wall-e

cmsel, u, excav-wall-n

$\mathrm{cm}$, excav-contact, elem

cmsel, s, conc-target

cmsel, a, excav-contact

$\mathrm{cm}$, conc-excav-wall-gap, elem

! add dome interface elements

! concrete tank surface target

cmsel, s, conc-dome-e

nsle, s, 1

type, 62

real, 62

mat, 62

esurf

esel, s, type,, 62

nsle

nsel, r, loc, z, ctz(12), ctz(14)

esln, $r, 1$

emodif, all, real, 62

esel, s, type,, 62

cmsel, u, conc-dome-e

$\mathrm{cm}$, conc-dome-target, elem

type, 63

cmsel, s, excav-dome-e

esel, u, type, , 1

cmsel, s, excav-dome-n

esurf

cmsel, u, excav-dome-e

$\mathrm{cm}$, excav-dome-contact, elem

cmsel, s, conc-dome-target

cmsel, a, excav-dome-cont act

$\mathrm{cm}$, conc-excav-dome-gap, elem

allsel

/COM, Create concrete slab to soil interface elments

! spring constants

! slab

$r, 307,1 e 8$

$r, 308,1 \mathrm{e} 8$

$r, 309,1 e 8$

esel, none

esel, s, type, 9

nsle

nsel, r, loc, z, ctz(23)

nsel, $r, 100, x, 0, \operatorname{ctx}(23)$

$\mathrm{cm}$, soil-slab, node

allsel

esel, none

cmsel, s, conc-slab

cmsel, a, soil-slab

type, 21 
RPP-RPT-32239, Rev. 1

M\&D-2008-005-CALC-001, Rev. 1

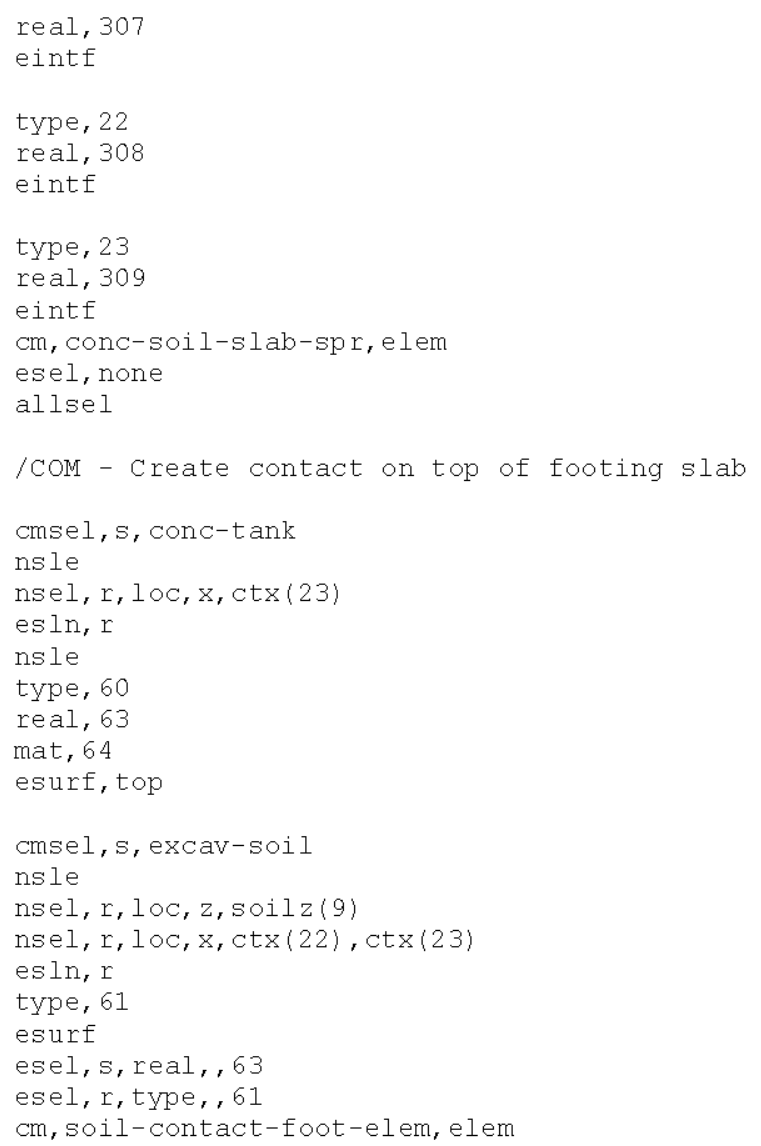

\section{interface1.txt}

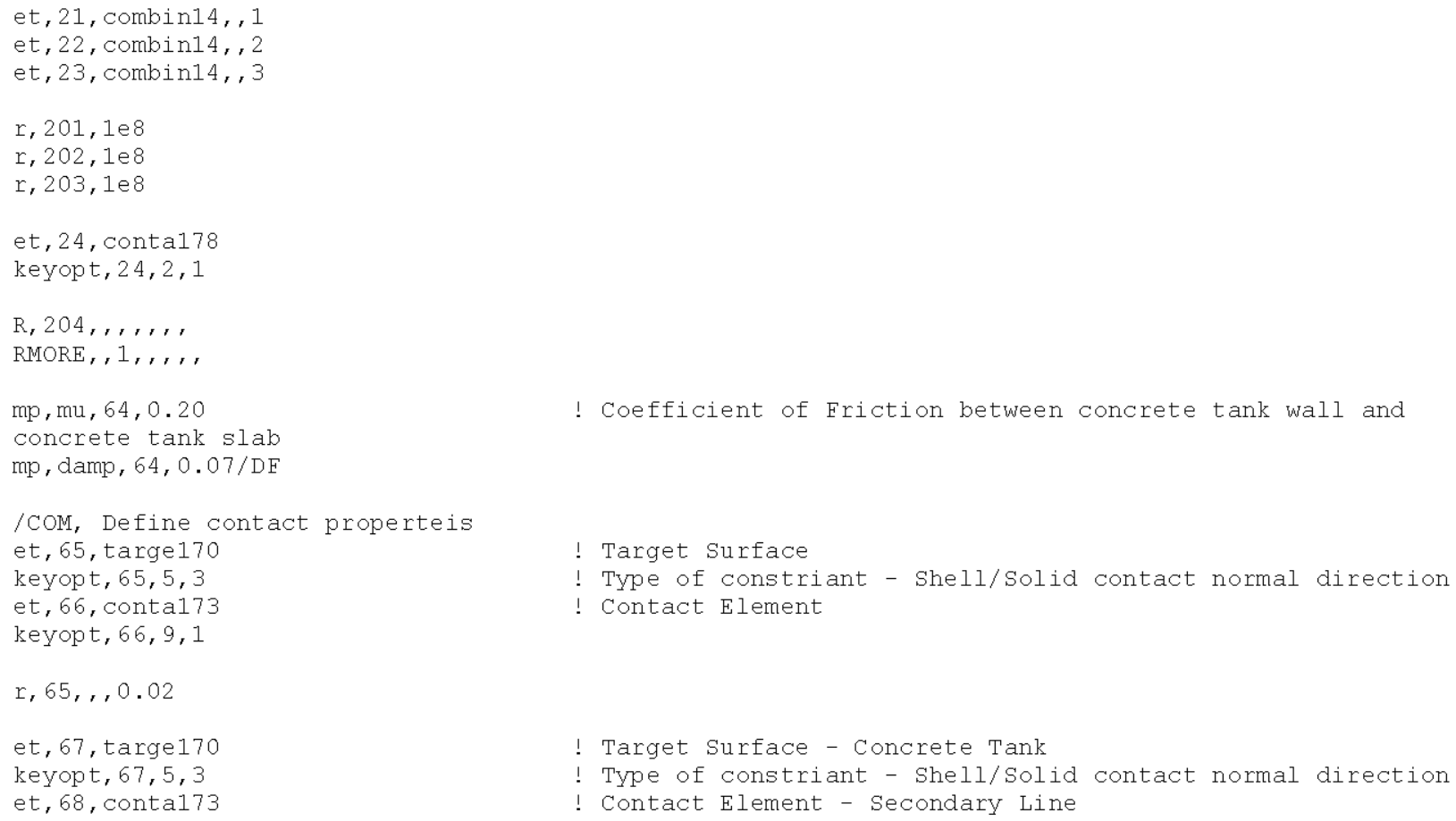

! Coefficient of Friction between concrete tank wall and 


\section{RPP-RPT-32239, Rev. 1 \\ M\&D-2008-005-CALC-001, Rev. 1}

keyopt, $68,9,1$

$r, 67,, 0.01$

$\mathrm{mp}, \mathrm{mu}, 65,0.40$

! Coefficient of Friction between primary tank and

insulating concrete (PNNL values)

MP , damp, 65, 0.3/DF

$\mathrm{mp}, \mathrm{mu}, 67,0.40$

concrete tank basemat (PNNL values)

MP, damp, 67, 0.3/DF

esel, none

/COM - Create Interface Elements at Bottom of Concrete Wall

cmsel, s, wall-int

type, 24

real, 204

mat, 64

eintf, , high

cm, wall-int-gap, elem

esel, none

/COM - Create Interface Elements between primary tank and insulating concrete

cmsel, s, primary-tank

Csys, 1

nsle

nsel, r, loc, z, ptz (40)

!nsel, r, loc, x, ptx (41), ptx (39)

$\mathrm{cm}$, primary-int $-\mathrm{n}$, node

esln, $r, 1$

$\mathrm{cm}$, primary-int-e, elem

cmsel, s, insul-conc

nsle

nsel, r, loc, z, ptz (40)

!nsel, r, loc, x, ptx (31), ptx (39)

$\mathrm{cm}$, insul-int-n, node

cmsel, s, primary-int-e

cmsel, s, primary-int-n

type, 66

real, 65

mat, 65

esurf, , bottom

cmsel, u, primary-int-e

$\mathrm{cm}$, pri-target, elem

cmsel, s, insul-conc

cmsel, s, insul-int-n

type, 65

real, 65

esurf

cmsel, u, insul-conc

$\mathrm{cm}$, insul-contact, elem

cmsel,s,pri-target

cmsel, a, insul-contact

cm,primary-int-gap, elem

esel, none

!nsel, s, 10c, z, ptz (34)

!nsel, r, loc, x, ptx (39)-.1, ptx (40)

! cpint, uz

/COM - Create Interface Elements between concrete tank and insulating concrete

cmsel, s, conc-tank

cmsel, a, liner

cmsel, a, insul-int

esln, $r, 1$

$\mathrm{cm}$, etemp, elem

cmsel, s, etemp 
RPP-RPT-32239, Rev. 1

M\&D-2008-005-CALC-001, Rev. 1

esel, u, real, 51

$\mathrm{cm}$, conc-temp, elem

cmsel, s, etemp

esel, r, real,, 51

$\mathrm{cm}$, liner-temp, elem

cmsel, s, conc-temp

nsle

type, 67

real, 67

mat, 67

esurf, top

cmsel, u, conc-temp

$\mathrm{cm}$, conc-target, elem

cmsel, s, liner-temp

nsle

type, 68

real, 67

esurf, , bottom

cmsel, u, liner-temp

$\mathrm{cm}$, liner-contact, elem

cmsel, s, conc-target

cmsel, a, liner-contact

$\mathrm{cm}$, conc-liner-gap, elem

\section{Liner.txt}

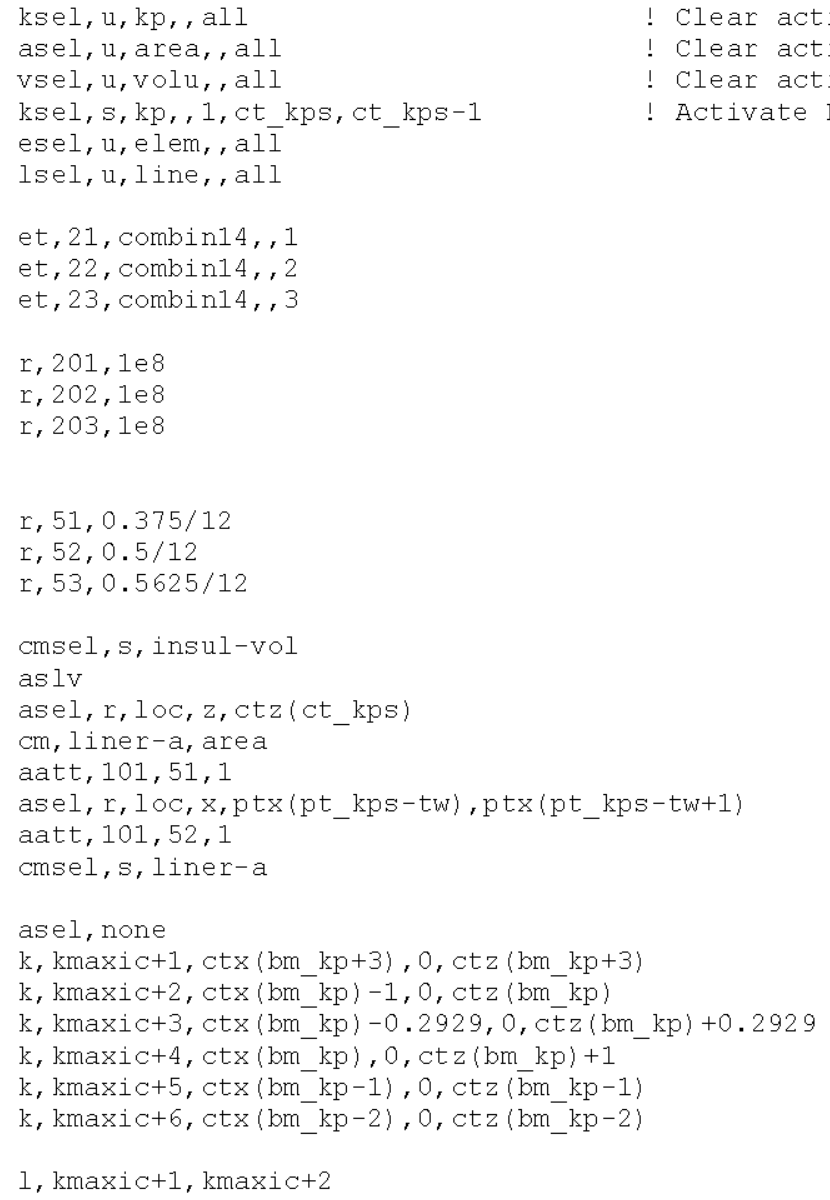


RPP-RPT-32239, Rev. 1

M\&D-2008-005-CALC-001, Rev. 1

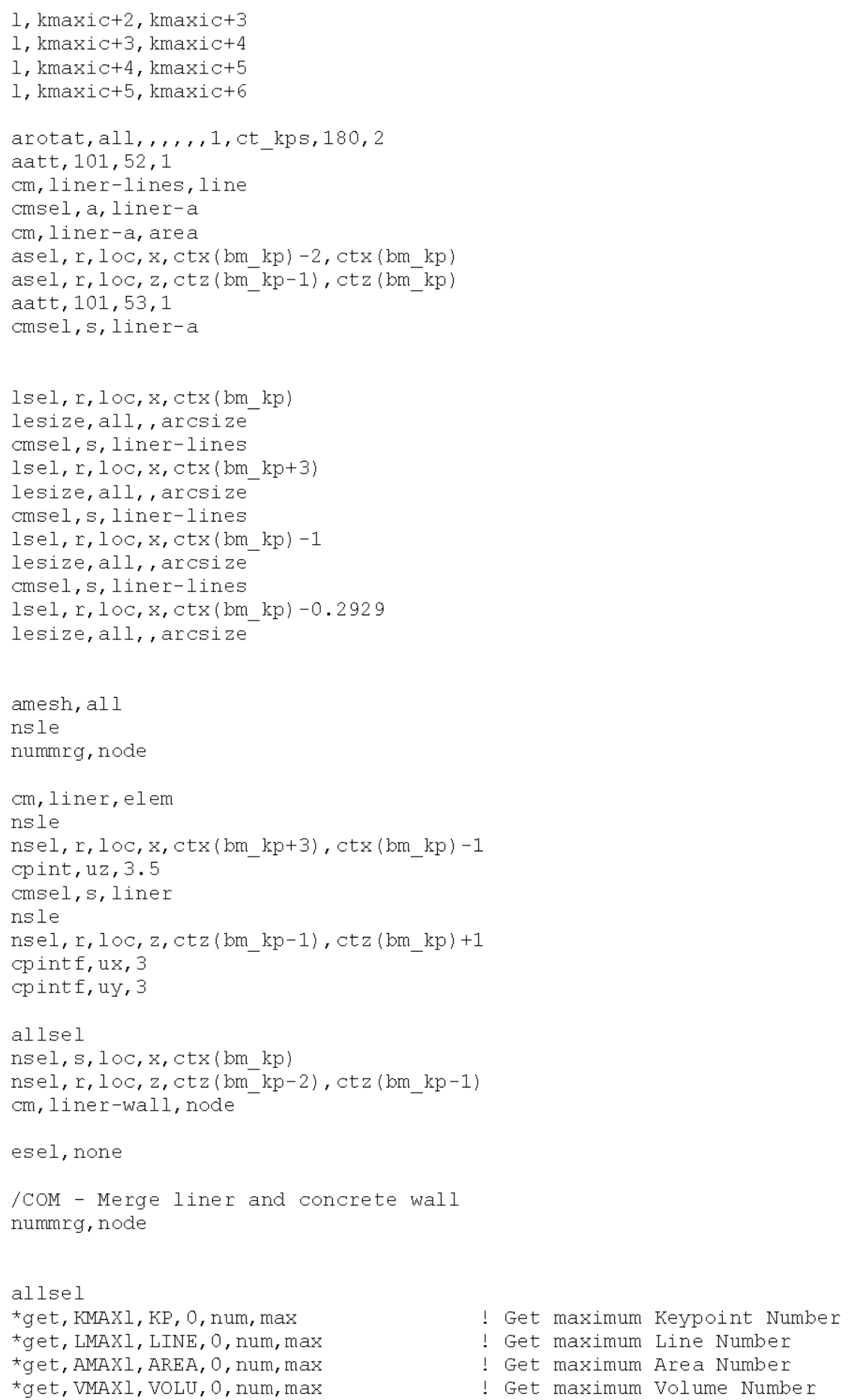

\section{live load.txt}

! select nodes to apply concentrated live load over - 10 ft radius allsel

nsel, s, loc, $z, 0$

nsel, $r, 10 \mathrm{c}, \mathrm{x}, 0,11$

$\mathrm{cm}, \mathrm{n}$-live, node

*get, nodes, node, count ! count the number of nodes selected

*get, nstart, node, num, min ! get min node number 


\section{RPP-RPT-32239, Rev. 1 \\ M\&D-2008-005-CALC-001, Rev. 1}

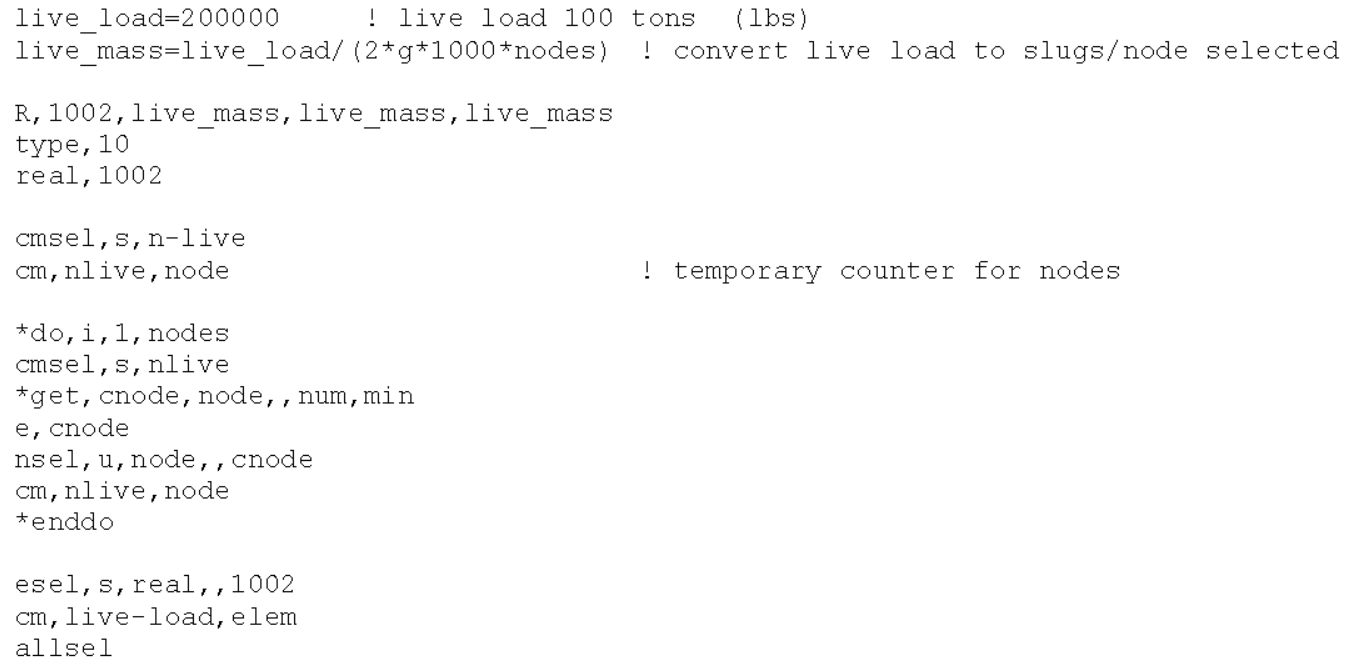

Near-Soil-1.txt

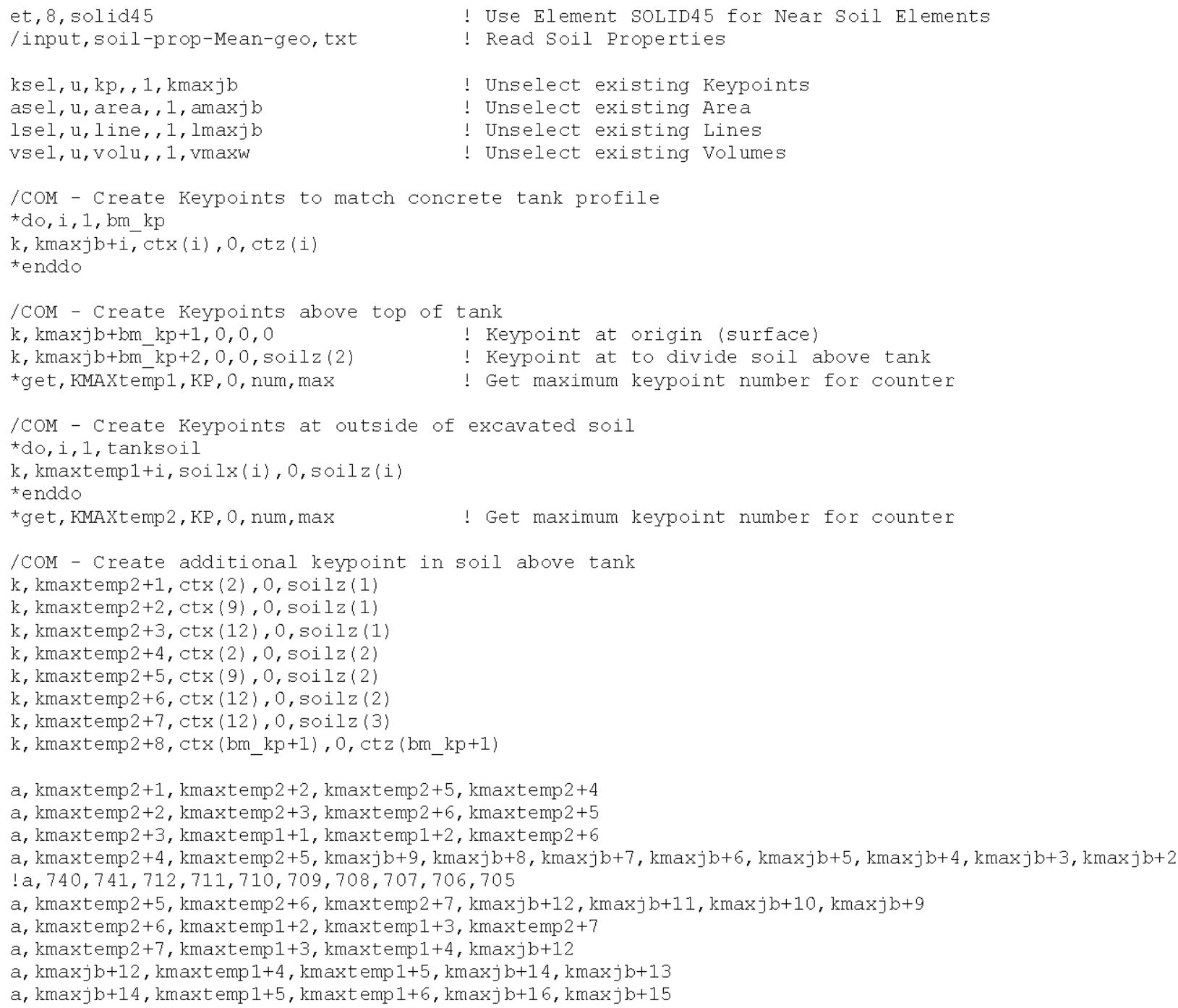


RPP-RPT-32239, Rev. 1

M\&D-2008-005-CALC-001, Rev. 1

$a, k \max j b+16, k \max t e m p 1+6, k \max t \operatorname{emp} 1+7, \operatorname{kmaxj} b+18, k \max j \mathrm{~b}+17$

a, kmaxj $b+18, \operatorname{kmaxt} \operatorname{emp} 1+7, \operatorname{kmaxt} \operatorname{emp} 1+8, \operatorname{kmaxj} b+20, k \max j \mathrm{~b}+19$

a, kmaxj $b+20, k \max t \operatorname{emp} 1+8, \operatorname{kmax} t \operatorname{emp} 1+9, \operatorname{kmaxt} \operatorname{emp} 2+8, \operatorname{kmaxj} b+22, k \max j \mathrm{~b}+21$

cm,top-soil-area, area

lsla

$\mathrm{cm}$, top-soil, line

type, 1

real, 1

/COM - Define line divisions to control meshing

lsel, s, loc, z, soilz(1), soilz(2)

lsel, $r, 1 \circ c, x, \operatorname{ctx}(3), \operatorname{ctx}(8)$

lesize, all, , 14

! soil above tank top, match tank meshing

lsel, s, loc, z, soilz $(1), \operatorname{sollz}(2)$

lsel, r, loc, $x, \operatorname{ctx}(10), \operatorname{ctx}(11)$

lesize, all, , 3

cmsel, s, top-soil

lsel, r, loc, $x, \operatorname{ctx}(2)$

lesize, all, , 2

cmsel, s, top-soil

lsel, s, loc, $x, \operatorname{ctx}(9)$

lesize, all, , 2

cmsel, s, top-soil

lsel, r, loc, $x, \operatorname{ctx}(12)$

lesize, all, , 2

cmsel,s, top-soil

lsel, r, loc, z, ctz $(2), \operatorname{ctz}(12)$

lsel, r, loc, $x, \operatorname{ctx}(2), \operatorname{ctx}(12)$

lesize, all, , 1

lsel, s, line, $, 1 \max j b+8, l \operatorname{maxj} b+10,2$

lsel, a, line, , 1 maxj $b+26, l \operatorname{maxj} b+28,2$

lsel, a, line, $, 1 \max j b+30, l \operatorname{maxj} b+38,4$

lesize, all, , 9

lsel, s, line, , $l \operatorname{maxj} b+42, l \operatorname{maxj} b+42,4$

lesize, all, , 7

lsel, s, line,, $1 \operatorname{maxj} b+9$

lsel, a, line, , $l \max j b+25, l \operatorname{maxj} b+27,2$

lsel, a, line, $, \operatorname{lmaxjb} b+29, l \operatorname{maxj} b+45,4$

lesize, all, , 1

lsel, s, line, , 1 maxj $b+6$

lsel, $a, l i n e,, l \max j b+20, l \max j b+21$

lsel, a, line, , $l \operatorname{maxj} b+32, l \operatorname{maxj} b+44,4$

lsel, a, line, , $l$ maxj $b+31, l \max j b+43,4$

lsel, a, line, , lmaxjb+47, lmaxjb+49

lesize, all, , 1

lsel, s, line, , lmaxjb+46

lesize, all, , 4

! soil above tank top, match tank meshing

! Reselect lines in near soil

! Control vertical element size, above tank

! Control vertical element size, above tank

! Control vertical element size, above tank

! Control vertical element size, outside excavation mesh

cmsel, s, top-soil-area

amesh, all

! Control horizontal meshing in soil

! Control horizontal meshing in soil

! Control meshing to match tank

! Control mesh size at bottom of excavated soil

type, 8

$\mathrm{ksel}, \mathrm{a}, \mathrm{kp}, \mathrm{r}$

ksel, a, kp, , ct kps

vrotat, all, , , , 1, ct_kps, 180,2

lsla

lsel, $r, 100, x, \operatorname{ctx}(2)$

lesize, all, , arcsize

Isla

lsel, $r, 1 \circ \mathrm{c}, \mathrm{x}, \operatorname{ctx}(9)$

lesize, all, , arcsize

lsla

lsel, $r, 100, x, \operatorname{ctx}(12)$

lesize, all, arcsize

vsweep, all

aclear, all

cm, top-soil-vol, volu

! Mesh area to develop pattern for volume meshing

! Select Keypoint for rotation axis

! Select Keypoint for rotation axis

! Generate Volumes for excavated soil

! Define meshing for slices

! Define meshing for slices

! Define meshing for slices

! Sweep pattern into volume

! Delete elements used for sweep 


\section{RPP-RPT-32239, Rev. 1 \\ M\&D-2008-005-CALC-001, Rev. 1}

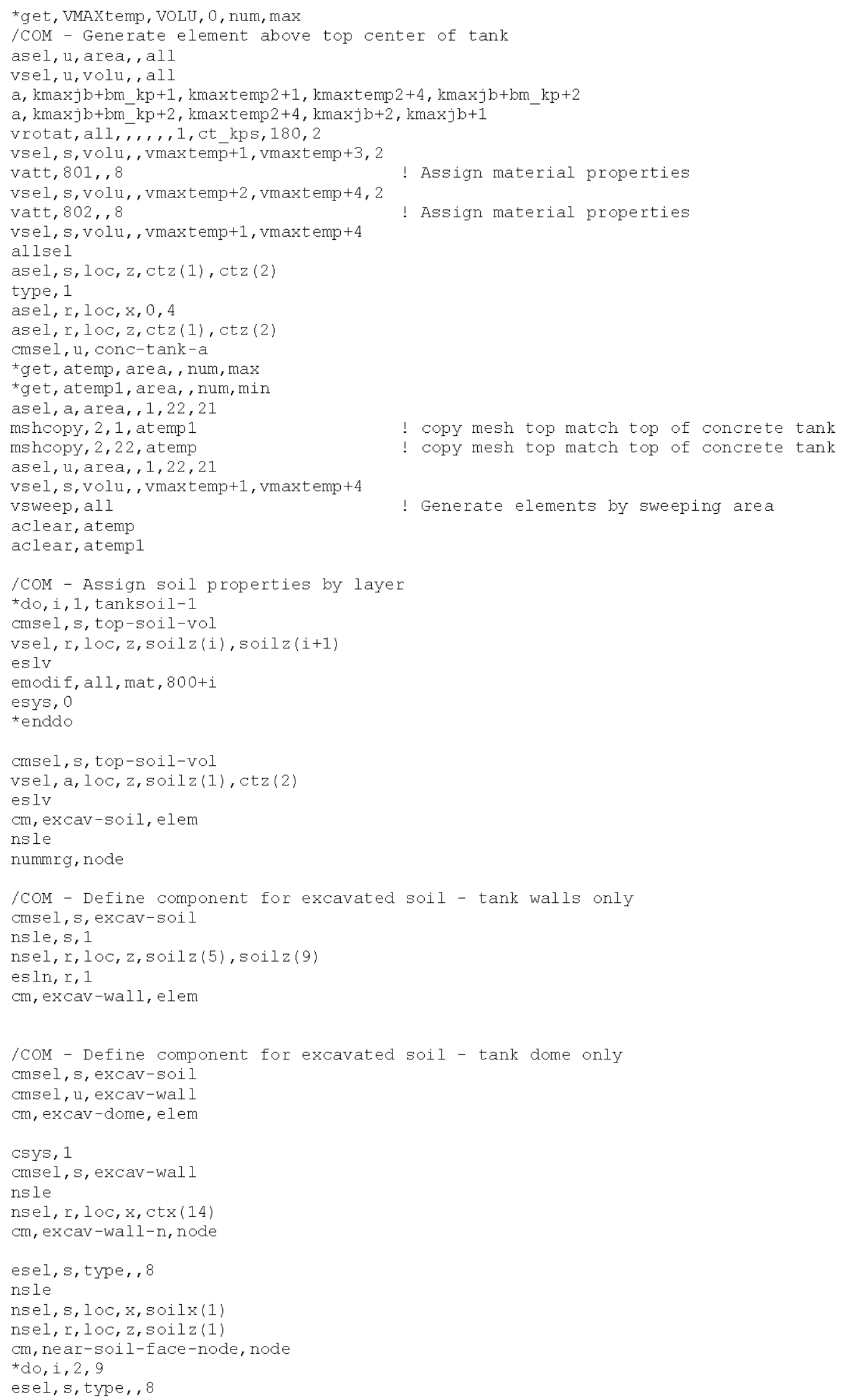




\section{RPP-RPT-32239, Rev. 1 \\ M\&D-2008-005-CALC-001, Rev. 1}

nsle

nsel, $r, 100, x, \operatorname{soilx}(i)$

nsel, r, loc, $z$, soilz (i)

cmsel, a, near-soil-face-node

$\mathrm{cm}$, near-soil-face-node, node

*enddo

esel, s, type, 8

nsle

nsel, r, loc, z, soilz (9)

nsel, $r, 100, x, 41,68$

$\mathrm{cm}$, near-soil-bot-node, node

allsel

${ }^{*}$ get, KMAXns, KP, 0, num, max

*get, LMAXns, LINE, 0, num, max

! Get maximum Keypoint number

*get, AMAXns, AREA, 0, num, max

! Get maximum line number

*get, vMAXns, volu, 0, num, max

! Get maximum Area number

! Get maximum Volume number

\section{outer-spar.txt}

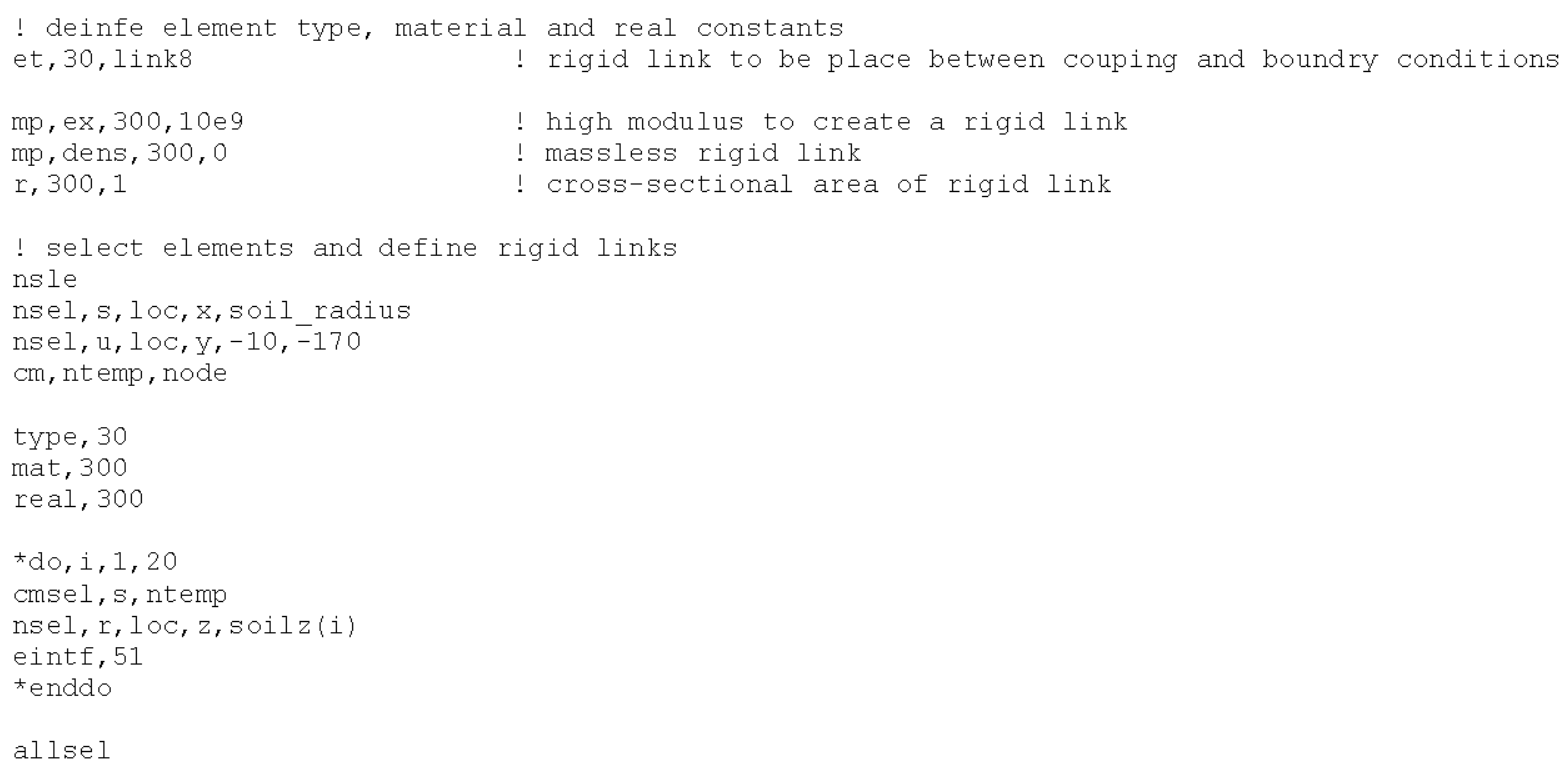

\section{Post-Tank.txt}

/input, contact-ap, txt

! / input, force-c, txt

/input, stress-Primary, txt

!/input, Force-J_bolt, txt

\section{Primary-Props-AP.txt}

/COM - Material Definitions

/COM - Material 101, Tank Steel

mp, ex, $101,4248000 * 1$ e 4

mp, nuxy, $101,0.30$

mp, dens, $101,490 /\left(1000^{*} \mathrm{~g}\right)$

mp , damp, 101, 0.00135 
RPP-RPT-32239, Rev. 1

M\&D-2008-005-CALC-001, Rev. 1

/COM - Material 102, Tank steel mp , ex, $102,4248000 * 1$ e 4

mp, nuxy, $102,0.30$

mp , dens, 102,490/(1000*g)

mp , damp, 102, 0.00135

/COM - Material 103, Tank steel

mp, ex, 103,4248000*1e4

mp, nuxy, 103, 0.30

$\mathrm{mp}$, dens, $103,490 /\left(1000^{\star} \mathrm{g}\right)$

mp , damp, 103, 0.00135

/COM - Material 104, Tank steel

mp, ex, 104, 4248000*1e4

mp, nuxy, 104, 0.30

mp, dens, $104,490 /\left(1000^{\star} \mathrm{g}\right)$

mp , damp, 104, 0.00135

/COM - Material 105, Tank steel

mp, ex, $105,4248000 * 1$ e 4

mp, nuxy, 105, 0.30

mp , dens, $105,490 /\left(1000^{\star} \mathrm{g}\right)$

mp, damp, 105, 0.00135

/COM - Material 106, Tank steel mp, ex, $106,4248000 * 1 e 4$

mp, nuxy, 106,0.30

$\mathrm{mp}$, dens, $106,490 /\left(1000^{\star} \mathrm{g}\right)$

mp , damp, 106, 0.00135

/COM - Material 107, Tank steel

mp, ex, $107,4248000 * 1 \mathrm{e} 4$

mp, nuxy, 107, 0.30

$\mathrm{mp}$, dens, $107,490 /\left(1000^{\star} \mathrm{g}\right)$

mp , damp, 107, 0.00135

/COM - Material 108, Tank Steel

mp , ex, $108,4248000 * 1$ e 4

mp, nuxy, $108,0.30$

mp, dens, $108,490 /\left(1000^{\star} \mathrm{g}\right)$

mp, damp, 108, 0.00135

/COM - Material 109, Tank Steel mp , ex, 109,4248000*1e4

mp, nuxy, 109, 0.30

mp, dens, 109,490/(1000*g)

mp , damp, 109, 0.00135

/COM - Material,110, Tank Steel

mp , ex, $110,4248000 * 1 \mathrm{e} 4$

mp, nuxy, $110,0.30$

$\mathrm{mp}$, dens, $110,490 /\left(1000^{\star} \mathrm{g}\right)$

mp , damp, 110, 0.00135

/COM - Material,111, Tank steel mp, ex, 111,4248000

mp, nuxy, 111, 0.30

$\mathrm{mp}$, dens, $111,490 /\left(1000^{\star} \mathrm{g}\right)$

mp , damp, 111, 0.00135

/COM - Material,112, Tank steel mp, ex, 112, 4248000

mp, nuxy, $112,0.30$

mp, dens, $112,490 /\left(1000^{\star} \mathrm{g}\right)$

mp , damp, $112,0.00135$

/COM - Material,113, Tank steel mp, ex, 113, 4248000

mp, nuxy, 113,0.30

mp, dens, $113,490 /\left(1000^{\star} \mathrm{g}\right)$

mp , damp, 113, 0.00135 
RPP-RPT-32239, Rev. 1

M\&D-2008-005-CALC-001, Rev. 1

/COM - Material,114, Tank Steel

mp, ex, 114,4248000

mp, nuxy, $114,0.30$

$\mathrm{mp}$, dens, $114,490 /\left(1000^{*} \mathrm{~g}\right)$

$\mathrm{mp}$, damp, 114, 0.00135

/COM - Material,115, Tank Steel

mp, ex, 115, 4248000

mp, nuxy, $115,0.30$

$\mathrm{mp}$, dens, $115,490 /\left(1000{ }^{*} \mathrm{~g}\right)$

mp, damp, 115, 0.00135

/COM - Material,116, Tank Steel mp, ex, 116,4248000

mp, nuxy, 116, 0.30

$\mathrm{mp}$, dens, $116,490 /\left(1000^{*} \mathrm{~g}\right)$

mp, damp, $116,0.00135$

/COM - Material,117, Tank Steel mp, ex, 117,4248000

mp, nuxy, 117, 0.30

$\mathrm{mp}$, dens, $117,490 /\left(1000^{\star} \mathrm{g}\right)$

$\mathrm{mp}$, damp, 117, 0.00135

/COM - Material,118, Tank Steel $\mathrm{mp}, \mathrm{ex}, 118,4248000$

mp, nuxy, $118,0.30$

mp, dens, $118,490 /\left(1000^{*} \mathrm{~g}\right)$

mp, damp, $118,0.00135$

/COM - Material,119, Tank Steel mp, ex, 119,4248000

mp, nuxy, $119,0.30$

mp, dens, $119,490 /\left(1000^{*} \mathrm{~g}\right)$

$\mathrm{mp}$, damp, 119,0.00135

/COM - Material,120, Tank Steel mp, ex, 120,4248000

mp, nuxy, $120,0.30$

$\mathrm{mp}$, dens, $120,490 /\left(1000^{*} \mathrm{~g}\right)$

mp, damp, $120,0.00135$

/COM - Material,121, Tank Steel mp, ex, 121,4248000

mp, nuxy, $121,0.30$

mp, dens, $121,490 /\left(1000^{*} \mathrm{~g}\right)$

$\mathrm{mp}$, damp, $121,0.00135$

/COM - Material,122, Tank Steel mp, ex, 122,4248000

mp, nuxy, $122,0.30$

mp, dens, $122,490 /\left(1000^{*} \mathrm{~g}\right)$

mp , damp, $122,0.03 / \mathrm{df}$

/COM - Material,123, Tank Steel $\mathrm{mp}, \mathrm{ex}, 123,4248000$

mp, nuxy, $123,0.30$

$\mathrm{mp}$, dens, $123,490 /(1000 * \mathrm{~g})$

mp, damp, 123,0.00135

/COM - Material,124, Tank Steel mp , ex, 124,4248000

mp, nuxy, $124,0.30$

$\mathrm{mp}$, dens, $124,490 /\left(1000^{*} \mathrm{~g}\right)$

$\mathrm{mp}$, damp, $124,0.00135$

/COM - Material,125, Tank steel mp, ex, 125,4248000

mp, nuxy, $125,0.30$

mp, dens, $125,490 /\left(1000^{*} \mathrm{~g}\right)$ 
RPP-RPT-32239, Rev. 1

M\&D-2008-005-CALC-001, Rev. 1

mp , damp, 125, 0.00135

/COM - Material,126, Tank Steel mp, ex, 126,4248000

mp, nuxy, $126,0.30$

$\mathrm{mp}$, dens, $126,490 /\left(1000^{*} \mathrm{~g}\right)$

mp, damp, 126, 0.00135

/COM - Material,127, Tank Steel mp, ex, 127,4248000

mp, nuxy, $127,0.30$

$\mathrm{mp}$, dens, $127,490 /\left(1000^{*} \mathrm{~g}\right)$

mp , damp, 127, 0.00135

/COM - Material,128, Tank Steel mp, ex, 128,4248000

mp, nuxy, $128,0.30$

$\mathrm{mp}$, dens, $128,490 /\left(1000^{*} \mathrm{~g}\right)$

mp , damp, $128,0.00135$

/COM - Material,129, Tank Steel mp, ex, 129,4248000

mp, nuxy, $129,0.30$

mp, dens, $129,490 /(1000 * \mathrm{~g})$

mp, damp, $129,0.00135$

/COM - Material,130, Tank Steel mp, ex, 130,4248000

mp, nuxy, $130,0.30$

$\mathrm{mp}$, dens, $130,490 /\left(1000^{*} \mathrm{~g}\right)$

$\mathrm{mp}$, damp, 130,0.00135

/COM - Material,131, Tank Steel mp, ex, 131,4248000

mp, nuxy, $131,0.30$

$\mathrm{mp}$, dens, $131,490 /\left(1000{ }^{*} \mathrm{~g}\right)$

$\mathrm{mp}$, damp, 131, 0.00135

/COM - Material,132, Tank Steel mp, ex, 132,4248000

mp, nuxy, $132,0.30$

$\mathrm{mp}$, dens, $132,490 /(1000 * \mathrm{~g})$

mp, damp, $132,0.00135$

/COM - Material,133, Tank Steel mp, ex, 133,4248000

mp, nuxy, $133,0.30$

$\mathrm{mp}$, dens, $133,490 /\left(1000^{*} \mathrm{~g}\right)$

mp, damp, 133, 0.00135

/COM - Material,134, Tank Steel mp, ex, 134,4248000

mp, nuxy, $134,0.30$

$\mathrm{mp}$, dens, $134,490 /\left(1000^{*} \mathrm{~g}\right)$

$\mathrm{mp}$, damp, $134,0.00135$

/COM - Material,135, Tank Steel mp, ex, 135, 4248000

mp, nuxy, $135,0.30$

$\mathrm{mp}$, dens, $135,490 /\left(1000^{\star} \mathrm{g}\right)$

mp , damp, 135, 0.00135

/COM - Material,136, Tank Steel mp, ex, 136,4248000

mp, nuxy, $136,0.30$

$\mathrm{mp}$, dens, $136,490 /\left(1000^{*} \mathrm{~g}\right)$

$\mathrm{mp}$, damp, 136, 0.00135

/COM - Material,137, Tank steel $\mathrm{mp}, \mathrm{ex}, 137,4248000$

mp, nuxy, 137, 0.30 
RPP-RPT-32239, Rev. 1

M\&D-2008-005-CALC-001, Rev. 1

$\mathrm{mp}$, dens, $137,490 /\left(1000^{*} \mathrm{~g}\right)$

mp, damp, 137, 0.00135

/COM - Material,138, Tank Steel mp, ex, 138,4248000

mp, nuxy, $138,0.30$

mp, dens, $138,490 /\left(1000^{\star} \mathrm{g}\right)$

$\mathrm{mp}$, damp, $138,0.00135$

/COM - Material,139, Tank Steel mp, ex, 139, 4248000

mp, nuxy, $139,0.30$

$\mathrm{mp}$, dens, $139,490 /(1000 * \mathrm{~g})$

$\mathrm{mp}$, damp, 139, 0.00135

/COM - Material,140, Tank Steel $\mathrm{mp}, \mathrm{ex}, 140,4248000$

mp, nuxy, 140, 0.30

$\mathrm{mp}$, dens, $140,490 /\left(1000^{*} \mathrm{~g}\right)$

mp, damp, 140, 0.00135

/COM - Material,141, Tank Steel mp, ex, 141,4248000

mp, nuxy, $141,0.30$

mp, dens, $141,490 /\left(1000^{*} \mathrm{~g}\right)$

$\mathrm{mp}$, damp, $141,0.00135$

/COM - Material,142, Tank Steel mp, ex, 142,4248000

mp, nuxy, 142, 0.30

$\mathrm{mp}$, dens, $142,490 /\left(1000^{*} \mathrm{~g}\right)$

mp, damp, 142, 0.00135

/COM - Material,143, Tank Steel mp, ex, 143,4248000

mp, nuxy, 143,0.30

$\mathrm{mp}$, dens, $143,490 /\left(1000^{*} \mathrm{~g}\right)$

mp, damp, 143, 0.00135

$r, 101,(0.5-0.06) / 12$

$r, 102,(0.5-0.06) / 12$

$r, 103,(0.375-0.06) / 12$

$r, 104,(0.375-0.06) / 12$

$r, 105,(0.375-0.06) / 12$

$r, 106,(0.375-0.06) / 12$

$r, 107,(0.375-0.06) / 12$

$r, 108,(0.375-0.06) / 12$

$r, 109,(0.375-0.06) / 12$

$r, 110,(0.375-0.06) / 12$

$r, 111,(0.5-0.06) / 12$

$r, 112,(0.5-0.06) / 12$

$r, 113,(0.5-0.06) / 12$

$r, 114,(0.5-0.06) / 12$

$r, 115,(0.5-0.06) / 12$

$r, 116,(0.5-0.06) / 12$

$r, 117,(0.5-0.06) / 12$

$r, 118,(0.5-0.06) / 12$

$r, 119,(0.5-0.06) / 12$

$r, 120,(0.5-0.06) / 12$

$r, 121,(0.5-0.06) / 12$

$r, 122,(0.5-0.06) / 12$

$r, 123,(0.5625-0.06) / 12$

$r, 124,(0.5625-0.06) / 12$

$r, 125,(0.5625-0.06) / 12$

$r, 126,(0.5625-0.06) / 12$

$r, 127,(0.75-0.06) / 12$

$r, 128,(0.75-0.06) / 12$

$r, 129,(0.75-0.06) / 12$

$r, 130,(0.75-0.06) / 12$

$r, 131,(0.75-0.06) / 12$

$r, 132,(0.875-0.06) / 12$ 
RPP-RPT-32239, Rev. 1

M\&D-2008-005-CALC-001, Rev. 1

$r, 133,(0.9375-0.06) / 12$

$r, 134,(0.9375-0.06) / 12$

$r, 135,(0.875-0.06) / 12$

$r, 136,(0.875-0.06) / 12$

$r, 137,(0.5-0.06) / 12$

$r, 138,(0.5-0.06) / 12$

$r, 139,(0.5-0.06) / 12$

$r, 140,(0.5-0.06) / 12$

$r, 141,(0.5-0.06) / 12$

$r, 142,(0.5-0.06) / 12$

$r, 143,(0.5-0.06) / 12$

\section{Primary.txt}

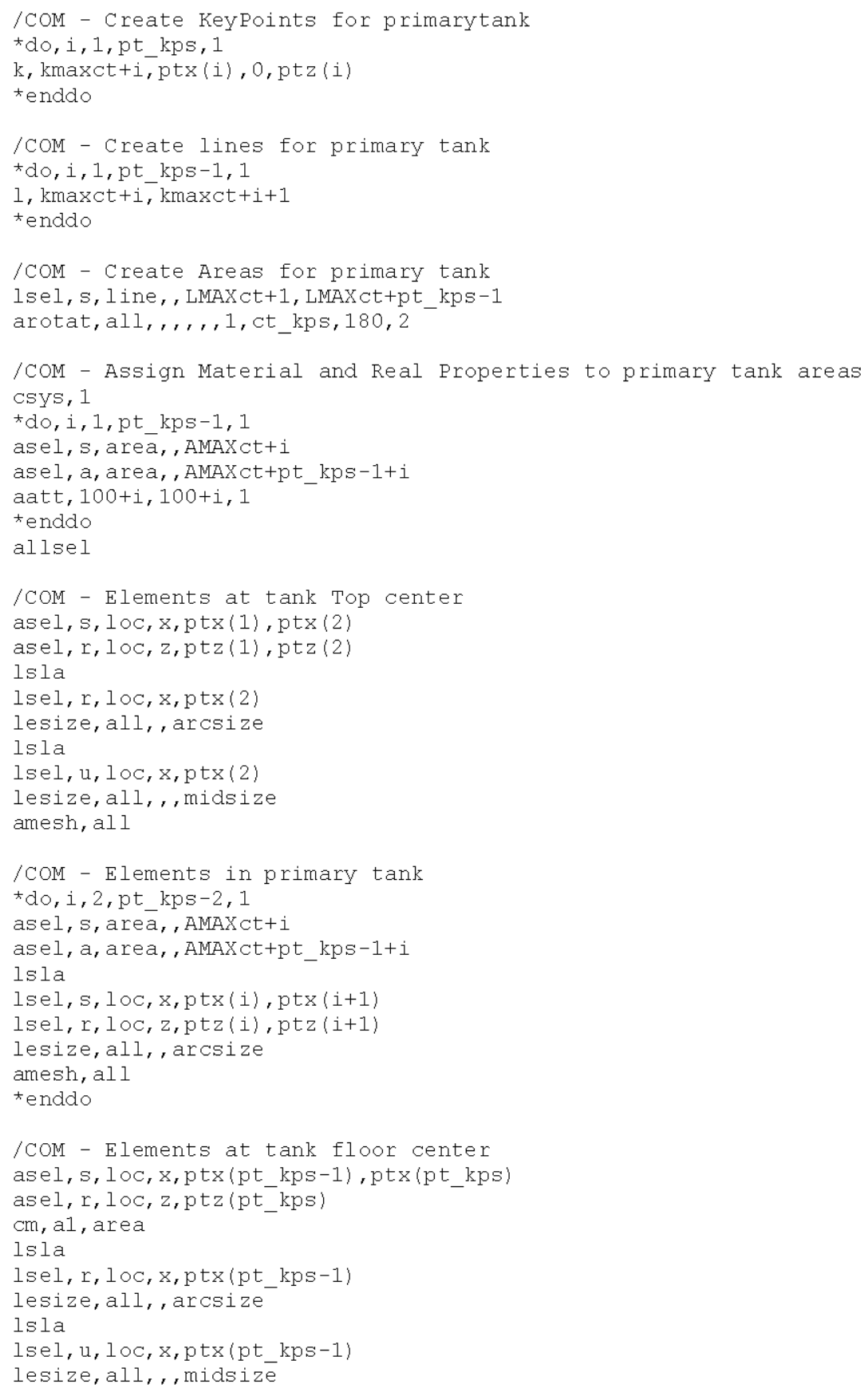


RPP-RPT-32239, Rev. 1

M\&D-2008-005-CALC-001, Rev. 1

amesh, all

asel, r, loc, y, 0, -90

$\mathrm{cm}, \mathrm{al}$, area

! Component for mesh mapping

cmsel, $\mathrm{s}, \mathrm{al}$

cmsel, u, ala

$\mathrm{cm}, \mathrm{alb}$, area

allsel

cmsel, u, conc-tank

*get, emax, elem, num, maxd

enorm, emax

$\mathrm{cm}$, primary-tank, elem

allsel

*get, KMAXpt, KP, 0, num, max

*get, LMAXpt, LINE, 0, num, max

! Compoment for mesh mapping

*get, AMAXpt, AREA, 0, num, max

! Get maximum Keypoint number

! Get maximum Line Number

! Get maximum Area Number

\section{Soil-Props-Mean-Geo.txt}

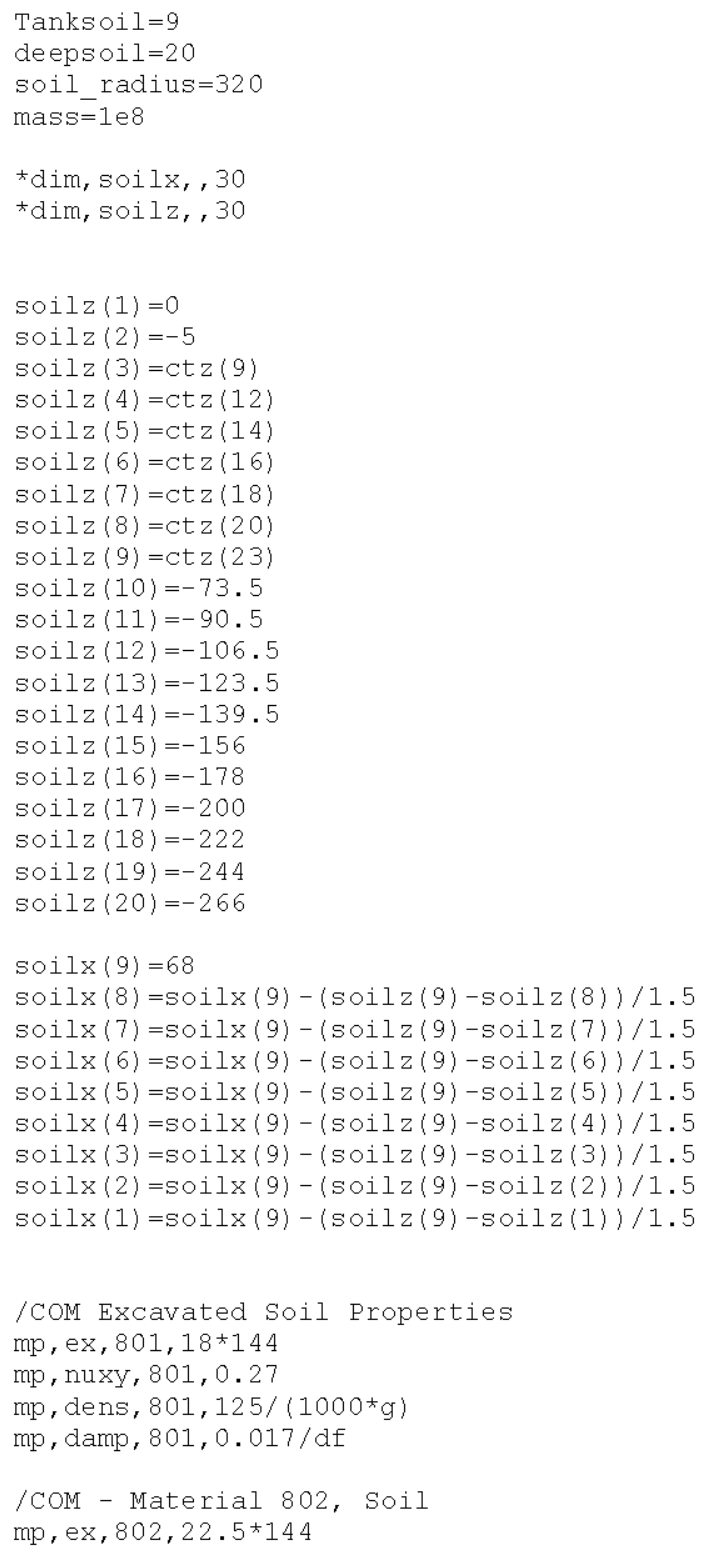


RPP-RPT-32239, Rev. 1

M\&D-2008-005-CALC-001, Rev. 1

mp, nuxy, $802,0.27$

$\mathrm{mp}$, dens, $802,125 /\left(1000^{\star} \mathrm{g}\right)$

$\mathrm{mp}$, damp, 802, 0.027/df

/COM - Material 803, Soil

mp, ex, $803,29.25 \star 144$

mp, nuxy, $803,0.27$

$\mathrm{mp}$, dens, $803,125 /\left(1000^{*} \mathrm{~g}\right)$

$\mathrm{mp}$, damp, 803,0.039/df

/COM - Material 804, Soil

$\mathrm{mp}, \mathrm{ex}, 804,36 \star 144$

mp, nuxy, $804,0.27$

$\mathrm{mp}$, dens, $804,125 /\left(1000^{*} \mathrm{~g}\right)$

mp, damp, 804, 0.031/df

/COM - Material 805, Soil

mp, ex, $805,42 * 144$

mp, nuxy, $805,0.27$

$\mathrm{mp}$, dens, $805,125 /\left(1000{ }^{\circ} \mathrm{g}\right)$

mp , damp, 805, 0. 035/df

/COM - Material 806, Soil

$\mathrm{mp}, \mathrm{ex}, 806,48.75 * 144$

mp, nuxy, 806, 0.27

$\mathrm{mp}$, dens, $806,125 /\left(1000^{\star} \mathrm{g}\right)$

mp , damp, 806, 0.042/df

/COM - Material 807, Soil

$\mathrm{mp}, \mathrm{ex}, 807,55.5 * 144$

mp, nuxy, $807,0.27$

$\mathrm{mp}$, dens, $807,125 /\left(1000^{*} \mathrm{~g}\right)$

$\mathrm{mp}$, damp, 807, 0.047/df

/COM - Material 808, Soil

$\mathrm{mp}, \mathrm{ex}, 808,60 * 144$

mp, nuxy, $808,0.27$

$\mathrm{mp}$, dens, $808,125 /\left(1000^{*} \mathrm{~g}\right)$

$\mathrm{mp}$, damp, 808, 0.037/df

/COM - Material 810, Soil

mp, ex, 810,250

mp, nuxy, $810,0.27$

$\mathrm{mp}$, dens, $810,125 /\left(1000^{*} \mathrm{~g}\right)$

$\mathrm{mp}$, damp, 810,0.037/df

/COM - Material Definitions

/COM - Material 811, Soil

mp , ex, 811,9958

$\mathrm{mp}$, nuxy, $811,0.27$

$\mathrm{mp}$, dens, $811,125 /\left(1000^{*} \mathrm{~g}\right)$

$\mathrm{mp}$, damp, 811, 0.019/df

/COM - Material 812, Soil

mp, ex, 812,8797

$\mathrm{mp}, \mathrm{nuxy}, 812,0.27$

$\mathrm{mp}$, dens, $812,125 /\left(1000^{*} \mathrm{~g}\right)$

mp , damp, 812, 0.035/df

/COM - Material 813, Soil

$\mathrm{mp}, \mathrm{ex}, 813,7845$

mp, nuxy, $813,0.27$

mp, dens, $813,125 /\left(1000{ }^{\circ} g\right)$

$\mathrm{mp}$, damp, $813,0.048 / \mathrm{df}$

/COM - Material 814, Soil

mp, ex, 814,8209

mp, nuxy, 814, 0.27

$\mathrm{mp}$, dens, $814,125 /\left(1000^{*} \mathrm{~g}\right)$

mp, damp, 814,0.039/df 
RPP-RPT-32239, Rev. 1

M\&D-2008-005-CALC-001, Rev. 1

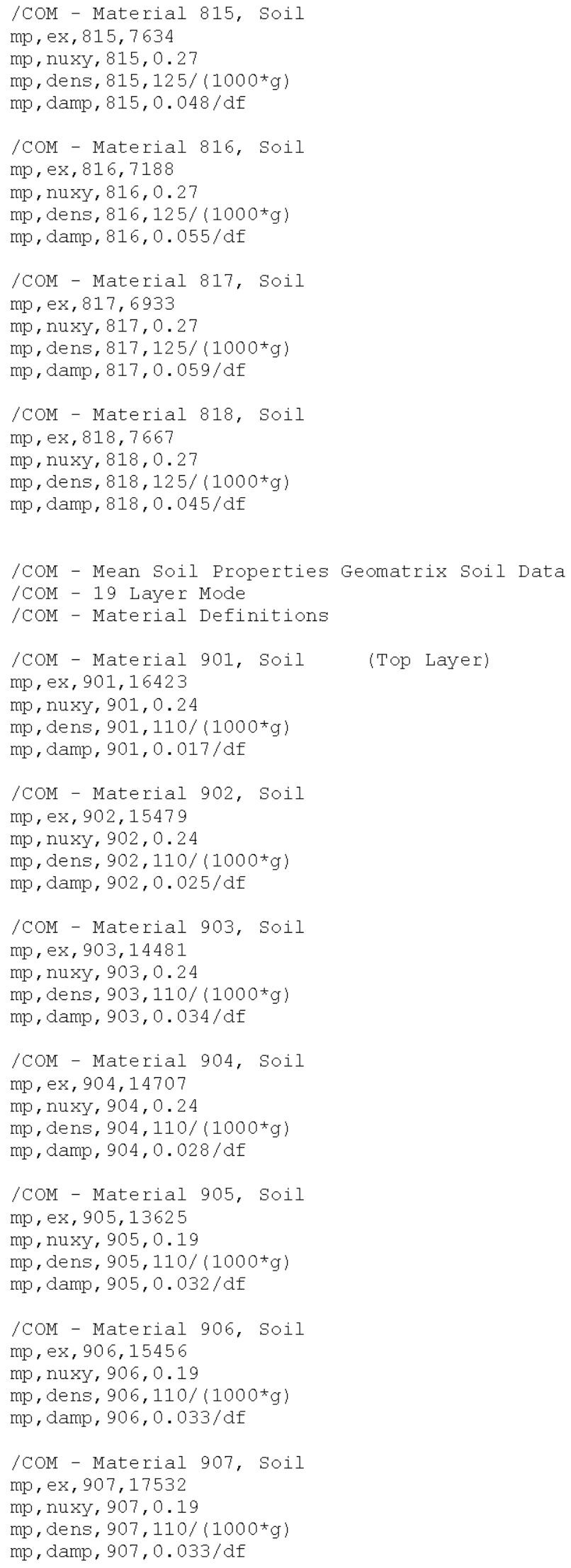


RPP-RPT-32239, Rev. 1

M\&D-2008-005-CALC-001, Rev. 1

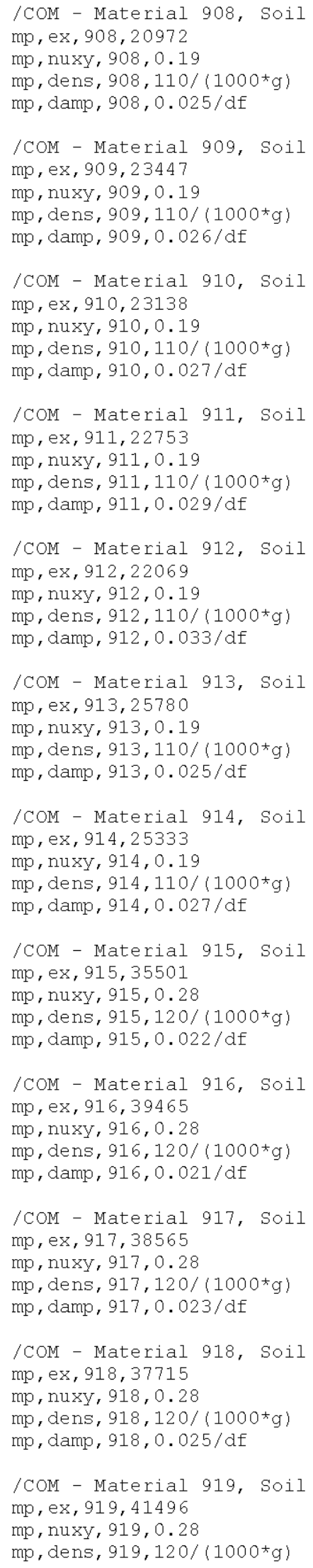


RPP-RPT-32239, Rev. 1

M\&D-2008-005-CALC-001, Rev. 1

mp , damp, 919,0.024/df

\section{Slave.txt}

/COM - Develop Slave Boundarz Conditions

/COM - 20 Layer Model

csys, 1

*get, CPMAX, CP, 0, num, max

! Set Cylindrical Coordinates

nsel, s, loc, $x$, soil_radius

! Counter for Couple set Numbers

csys, 0

nrotat, all

nsel,s, loc, z, soilz (deepsoil)

nrotat, all

! Select soil exterior surface nodes

! Set Cartesian Coordinates

! Rotate into Global Cartesian Coordinates

! Select all Base nodes

! Rotate into Global Cartesian Coordinates

Csys, 1

${ }^{\star}$ do, i, 1, deepsoil-1, 1

nsel, $s, 10 c, x$, soil radius

nsel, r, loc, z, soilz $(i)$

$\mathrm{cp}, 3^{*} i-2+\mathrm{cpmax}, \mathrm{ux}$, all

$\mathrm{cp}, 3^{\star} i+\mathrm{cpmax}, \mathrm{u}, \mathrm{all}$

! Set Cylindrical Coordinates

! Cycle through each soil layer

! Select all exterior nodes

! Select nodes by layer

! Couple in $\mathrm{X}$

! Couple in $Z$

nsel, u, loc, y, o

nsel, $u, 100, y, 180$

$\mathrm{cp}, 3 * i-1+\mathrm{cpmax}, \mathrm{uy}$, all

*enddo

! Unselect nodes on symmetry Plane

nsel, s, loc, z, soilz (deepsoil)

nsel, u, loc, z, 320-.1,320+.1

$\mathrm{cp}$, deepsoil*10+1+cpmax, ux, all

! Couple in $\mathrm{Y}$

cp, deepsoil*10+2+cpmax, uy, all

cp, deepsoil*10+3+cpmax, uz, all

! Select base nodes

allsel

! Couple in $\mathrm{X}$

! Couple in $\mathrm{Y}$

! Couple in $Z$

\section{stress-compb.txt}

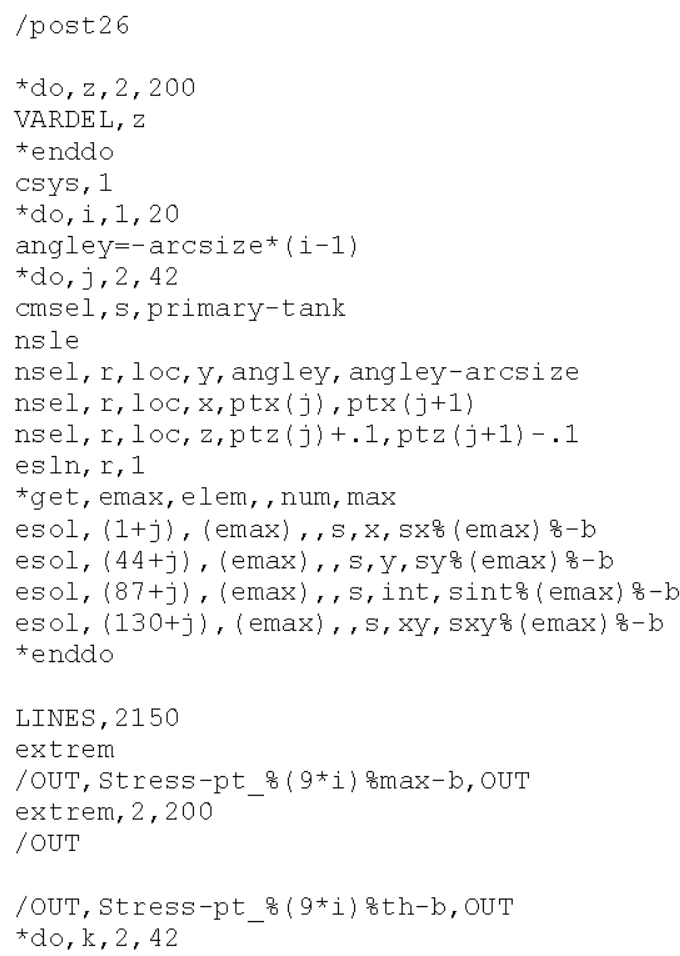


RPP-RPT-32239, Rev. 1

M\&D-2008-005-CALC-001, Rev. 1

PRVAR, $1+k, 44+k, 87+k, 130+k$

*enddo

/OUT

*enddo

\section{stress-compm.txt}

/post 26

numvar, 200

$\star$ do $, \mathrm{z}, 2,200$

VARDE L, $z$

tenddo

csys, 1

*do, $i, 1,20$

angley $=-\operatorname{arcsize}(i-1)$

*do,j, 2,42

cmsel, s, primary-tank

nsle

nsel, r, loc, y, angley, angley-arcsize

nsel, r, loc, $x, p t x(j), p t x(j+1)$

nsel, r, loc, z,ptz $(j)+.1, \operatorname{ptz}(j+1)-.1$

esln, r, 1

*get, emax, elem, , num, max

esol, $(1+j),($ emax) $, 5, x, 5 x 8$ (emax) $8-m$

esol, $(44+j),($ emax) , s,y, syo (emax) $8-m$

esol, $(87+j),($ emax), s, int, sinto (emax) $8-m$

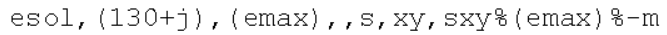

tenddo

LINES, 2150

extrem

/OUT, stress-pt_o (9*i) 8 max $-m$, OUT

extrem, 2,200

/OUT

/OUT, stress-pt_o( $9 * i) \% t h-m$, OUT

*do, $\mathrm{k}, 2,42$

PRVAR, 1+k, 44+k, $87+\mathrm{k}, 130+\mathrm{k}$

tenddo

/OUT

tenddo

\section{stress-compt.txt}

/post 26

*do, $\mathrm{z}, 2,200$

VARDEL, z

tenddo

csys, 1

$\star$ do, i, 1,20

angley $=-\operatorname{arcsize}(i-1)$

$\star \mathrm{do}, \mathrm{j}, 2,42$

cmsel, s, primary-tank

nsle

nsel, r, loc, y, angley, angley-arcsize

nsel, r, loc, $x, p t x(j), p t x(j+1)$

nsel, r, loc, z, ptz $(j)+.1, p t z(j+1)-.1$

esln, r, 1

*get, emax, elem, num, max

esol, $(1+j),($ emax) $, s, x, s x \%$ (emax) $8-t$

esol, $(43+j),($ emax) $, 5, y$, syo (emax) $8-t$

esol, $(87+j),($ emax), s, int, sinto (emax) $8-t$

esol, $(130+j),\left(\right.$ emax) $, 5, x y$, sxyo (emax) $\frac{}{8}-t$

*enddo 


\section{RPP-RPT-32239, Rev. 1 \\ M\&D-2008-005-CALC-001, Rev. 1}

LINES, 2150

extrem

/OUT, Stress-pt 8 (9*i) 8 max-t, OUT

extrem, 2,200

/OUT

/OUT, Stress-pt_o(9*i) 8 th-t, OUT

$\star \mathrm{do}, \mathrm{k}, 2,42$

PRVAR, $1+k, 44+k, 87+k, 130+k$

*enddo

/OUT

*enddo

\section{Stress-Primary.txt}

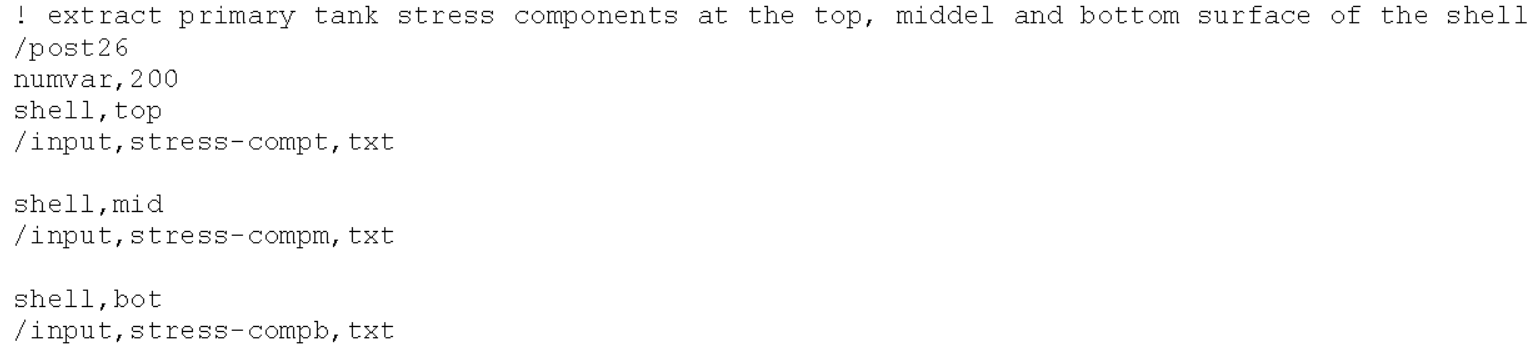

\section{Tank-Coordinates-AP.txt}

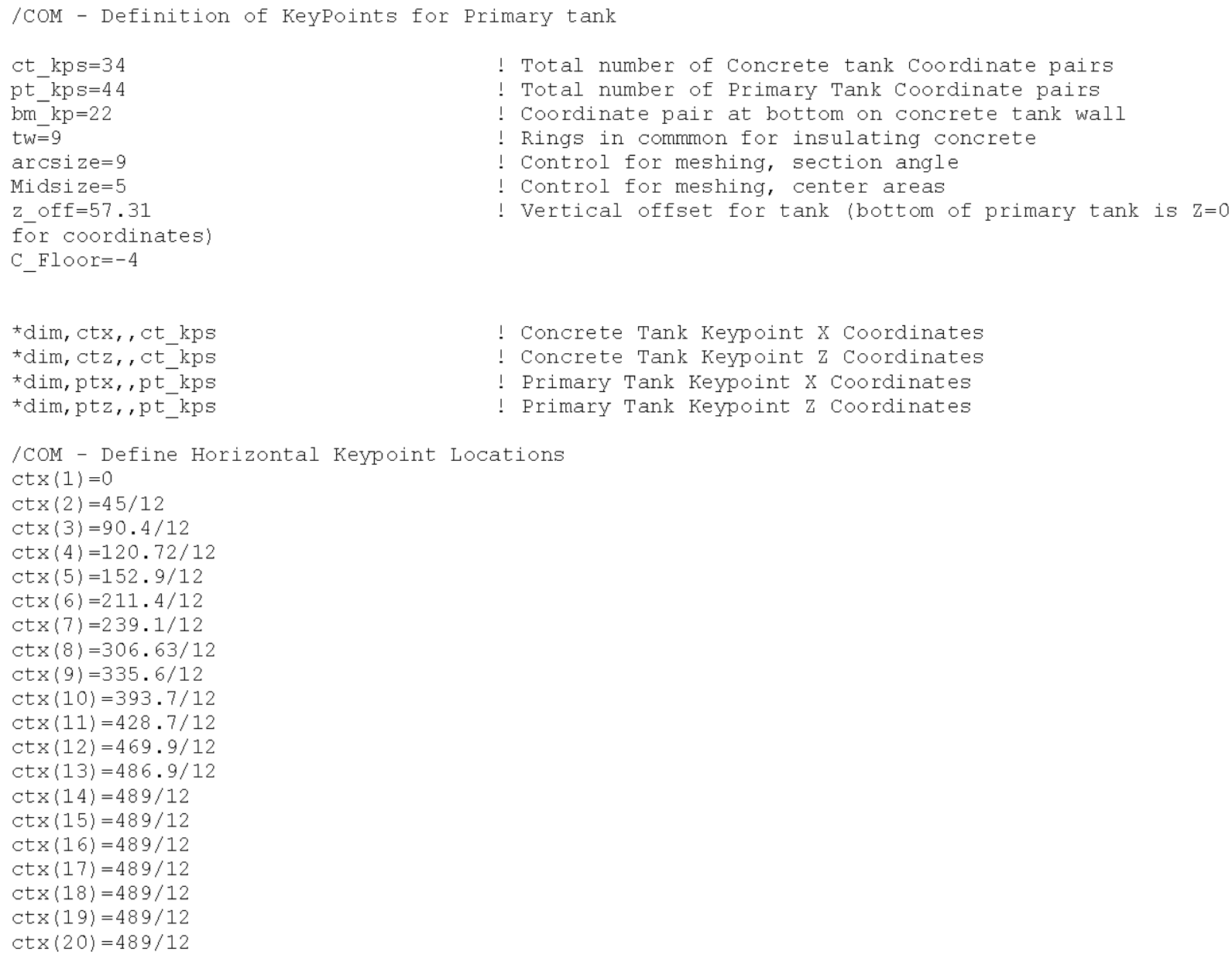


RPP-RPT-32239, Rev. 1

M\&D-2008-005-CALC-001, Rev. 1

$\operatorname{ctx}(21)=489 / 12$

$\operatorname{ctx}(22)=489 / 12$

$\operatorname{ctx}(23)=531 / 12$

$\operatorname{ctx}(24)=489 / 12$

$\operatorname{ctx}(25)=438 / 12$

$\operatorname{ctx}(26)=423 / 12$

$\operatorname{ctx}(27)=400 / 12$

$\operatorname{ctx}(28)=340 / 12$

$\operatorname{ctx}(29)=280 / 12$

$\operatorname{ctx}(30)=220 / 12$

$\operatorname{ctx}(31)=160 / 12$

$\operatorname{ctx}(32)=100 / 12$

$\operatorname{ctx}(33)=36 / 12$

$\operatorname{ctx}(34)=0$

/COM - Define Vertical Keypoint Locations

ctz $(1)=576.8 / 12-z$ off

$\operatorname{ct} z(2)=576 / 12-z$ off

ctz $(3)=573.8 / 12-z$ off

ct $z(4)=571.21 / 12-\bar{z}$ off

$\operatorname{ctz}(5)=567.7 / 12-z$ off

ctz $(6)=558.7 / 12-z$ off

ct $z(7)=553.2 / 12-z$ off

ctz $(8)=535.68 / 12-\bar{z}$ off

ctz $(9)=526.2 / 12-z$ off

$\operatorname{ctz}(10)=502 \cdot 5 / 12-\bar{z}$ off

$\operatorname{ctz}(11)=484.2 / 12-z$ off

ctz $(12)=455.4 / 12-z_{-}$off

$\operatorname{ctz}(13)=415 \cdot 1 / 12-z$ off

$\operatorname{ctz}(14)=382 \cdot 1 / 12-z_{\text {off }}$

ctz $(15)=335 / 12-z$ off

ct $z(16)=281 / 12-z$ off

ct $z(17)=236.5 / 12-z$ off

$\operatorname{ctz}(18)=186.8 / 12-z$ off

$\operatorname{ctz}(19)=145.5 / 12-z_{-}^{-}$off

$\operatorname{ctz}(20)=70 / 12-z$ of $\bar{f}$

Ctz $(21)=($ C_Floor +24$) / 12-z$ off

Ctz $(22)=\mathrm{C} \overline{\mathrm{F}}$ loor $/ 12-z$ off

Ctz (23) $=\mathrm{C}^{-} \mathrm{Floor} / 12-z^{-}$off

Ctz $(24)=\mathrm{C}^{-} \mathrm{Fl}$ loor $/ 12-z^{-}$off

Ctz $(25)=$ C Floor $/ 12-z$ off

Ctz $(26)=\mathrm{C}^{-} \mathrm{Fl}$ loor $/ 12-z^{-}$off

Ctz (27) $=$ C_Floor $/ 12-z$ off

Ctz $(28)=\mathrm{C}^{-}$Floor $/ 12-z$ off

Ctz $(29)=\mathrm{C}$ Floor $/ 12-z$ off

Ctz $(30)=C_{-}^{-}$Floor $/ 12-z_{-}$off

Ctz $(31)=\mathrm{C}$ Floor $/ 12-z$ off

ctz $(32)=\mathrm{C}^{-} \mathrm{Floor} / 12-z^{-}$off

Ctz $(33)=\mathrm{C}$ Floor $/ 12-z$ off

Ctz $(34)=C_{-}^{-}$Floor/12-z_off

$\operatorname{ptx}(1)=0$

$\operatorname{ptx}(2)=44.73689 / 12$

$\operatorname{ptx}(3)=89.86533 / 12$

$\operatorname{ptx}(4)=119.99721 / 12$

$\operatorname{ptx}(5)=151.96854 / 12$

$\operatorname{ptx}(6)=210.05344 / 12$

$\operatorname{ptx}(7)=237.53366 / 12$

ptx $(8)=304.42488 / 12$

$\operatorname{ptx}(9)=333.05132 / 12$

$\operatorname{ptx}(10)=390.22141 / 12$

$\operatorname{ptx}(11)=422.26434 / 12$

$\operatorname{ptx}(12)=432 / 12$

$\operatorname{ptx}(13)=444.36 / 12$

$\operatorname{ptx}(14)=448.66 / 12$

$\operatorname{ptx}(15)=450 / 12$

$\operatorname{ptx}(16)=450 / 12$

$\operatorname{ptx}(17)=450 / 12$

$\operatorname{ptx}(18)=450 / 12$

$\operatorname{ptx}(19)=450 / 12$ 
RPP-RPT-32239, Rev. 1

M\&D-2008-005-CALC-001, Rev. 1

$\operatorname{ptx}(20)=450 / 12$

$\operatorname{ptx}(21)=450 / 12$

$\operatorname{ptx}(22)=450 / 12$

$\operatorname{ptx}(23)=450 / 12$

$\operatorname{ptx}(24)=450 / 12$

$\operatorname{ptx}(25)=450 / 12$

$\operatorname{ptx}(26)=450 / 12$

$\operatorname{ptx}(27)=450 / 12$

$\operatorname{ptx}(28)=450 / 12$

$\operatorname{ptx}(29)=450 / 12$

$\operatorname{ptx}(30)=450 / 12$

$\operatorname{ptx}(31)=450 / 12$

$\operatorname{ptx}(32)=450 / 12$

$\operatorname{ptx}(33)=450 / 12$

$\operatorname{ptx}(34)=446.49 / 12$

$\operatorname{ptx}(35)=438 / 12$

$\operatorname{ptx}(36)=423 / 12$

$\operatorname{ptx}(37)=400 / 12$

$\operatorname{ptx}(38)=340 / 12$

$\operatorname{ptx}(39)=280 / 12$

$\operatorname{ptx}(40)=220 / 12$

$\operatorname{ptx}(41)=160 / 12$

$\operatorname{ptx}(42)=100 / 12$

$\operatorname{ptx}(43)=36 / 12$

$\operatorname{ptx}(44)=0$

ptz $(1)=569.30000 / 12-z$ off ptz $(2)=568.50462 / 12-z$ off ptz $(3)=566.31908 / 12-z$ off ptz $(4)=563.74491 / 12-z$ off ptz $(5)=560.25807 / 12-z$ off ptz $(6)=551.32187 / 12-z$ off ptz $(7)=545.86539 / 12-z$ off ptz $(8)=528.51150 / 12-z$ off Ptz $(9)=519.14633 / 12-z$ off ptz $(10)=495.85550 / 12-\bar{z}$ off ptz $(11)=474.92388 / 12-z$ off ptz $(12)=468 / 12-z$ off ptz $(13)=456.7 / 12-z$ off ptz $(14)=445.4 / 12-z$ off ptz $(15)=432 \cdot 3125 / 1 \overline{2}-z$ off ptz $(16)=410.125 / 12-z$ off ptz $(17)=386.125 / 12-z$ off ptz $(18)=362.125 / 12-z$ off ptz $(19)=337.875 / 12-z$ off ptz $(20)=314.775 / 12-z$ off ptz $(21)=291.675 / 12-z$ off $\operatorname{ptz}(22)=268.575 / 12-z$ off ptz $(23)=245.375 / 12-z$ off ptz $(24)=222.275 / 12-z$ off ptz $(25)=199.175 / 12-z$ off ptz $(26)=176.075 / 12-z$ off ptz $(27)=152.875 / 12-z$ off ptz $(28)=131.275 / 12-z$ off ptz $(29)=109.675 / 12-z$ off ptz $(30)=88.075 / 12-z$ off ptz $(31)=66.475 / 12-z$ off ptz $(32)=45 / 12-z$ off $\operatorname{ptz}(33)=20 / 12-z$ off ptz $(34)=11.51 / 1 \overline{2}-z$ off ptz $(35)=8 / 12-z$ off ptz $(36)=8 / 12-z_{-}$off ptz $(37)=8 / 12-z$ off ptz $(38)=8 / 12-z$ off ptz $(39)=8 / 12-z$ off ptz $(40)=8 / 12-z$ off ptz $(41)=8 / 12-z$ off ptz $(42)=8 / 12-z$ off ptz $(43)=8 / 12-z$ off ptz $(44)=8 / 12-z^{-}$off 


\section{RPP-RPT-32239, Rev. 1 \\ M\&D-2008-005-CALC-001, Rev. 1}

\section{Tank-Mesh1.txt}

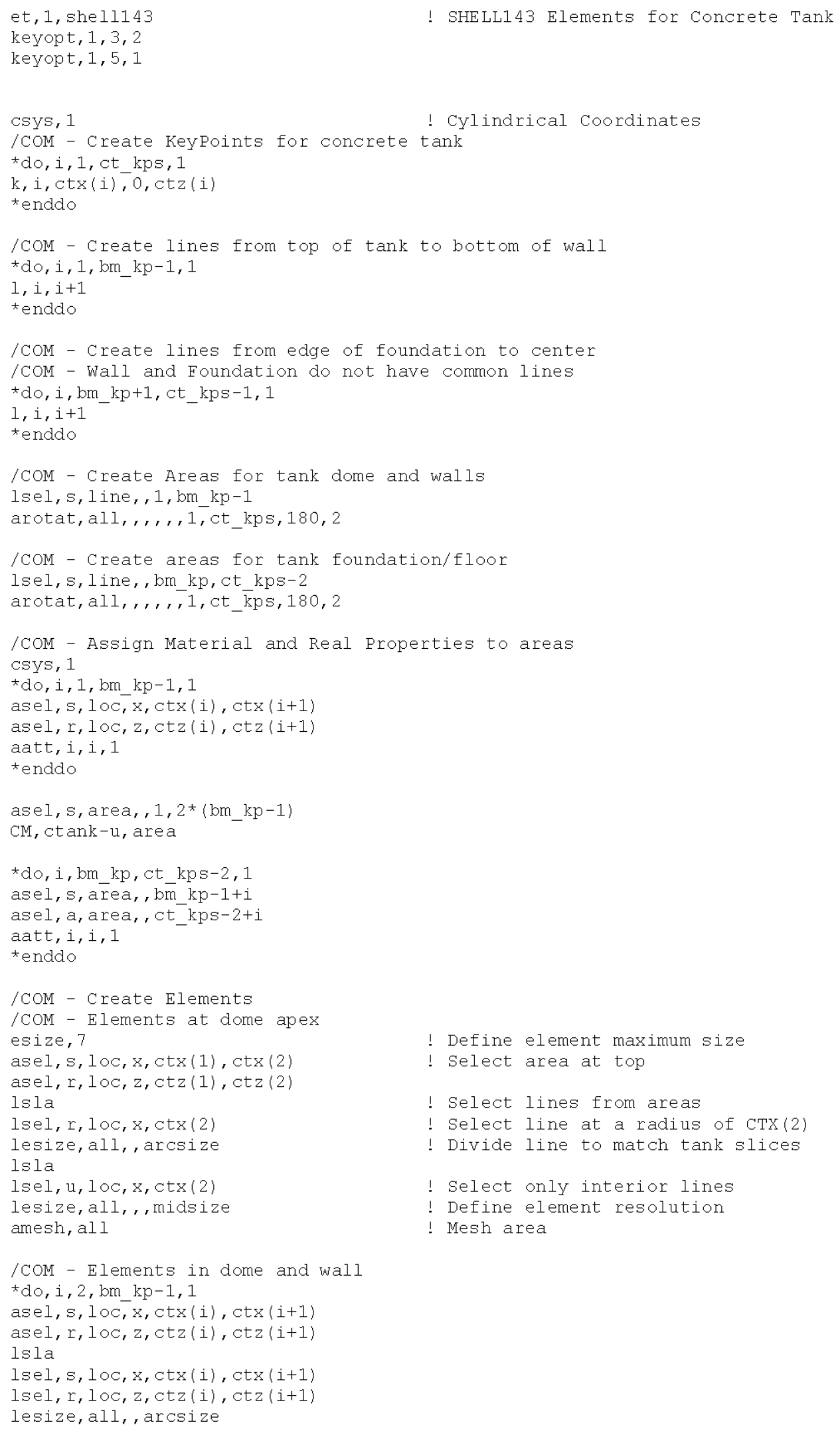


RPP-RPT-32239, Rev. 1

M\&D-2008-005-CALC-001, Rev. 1

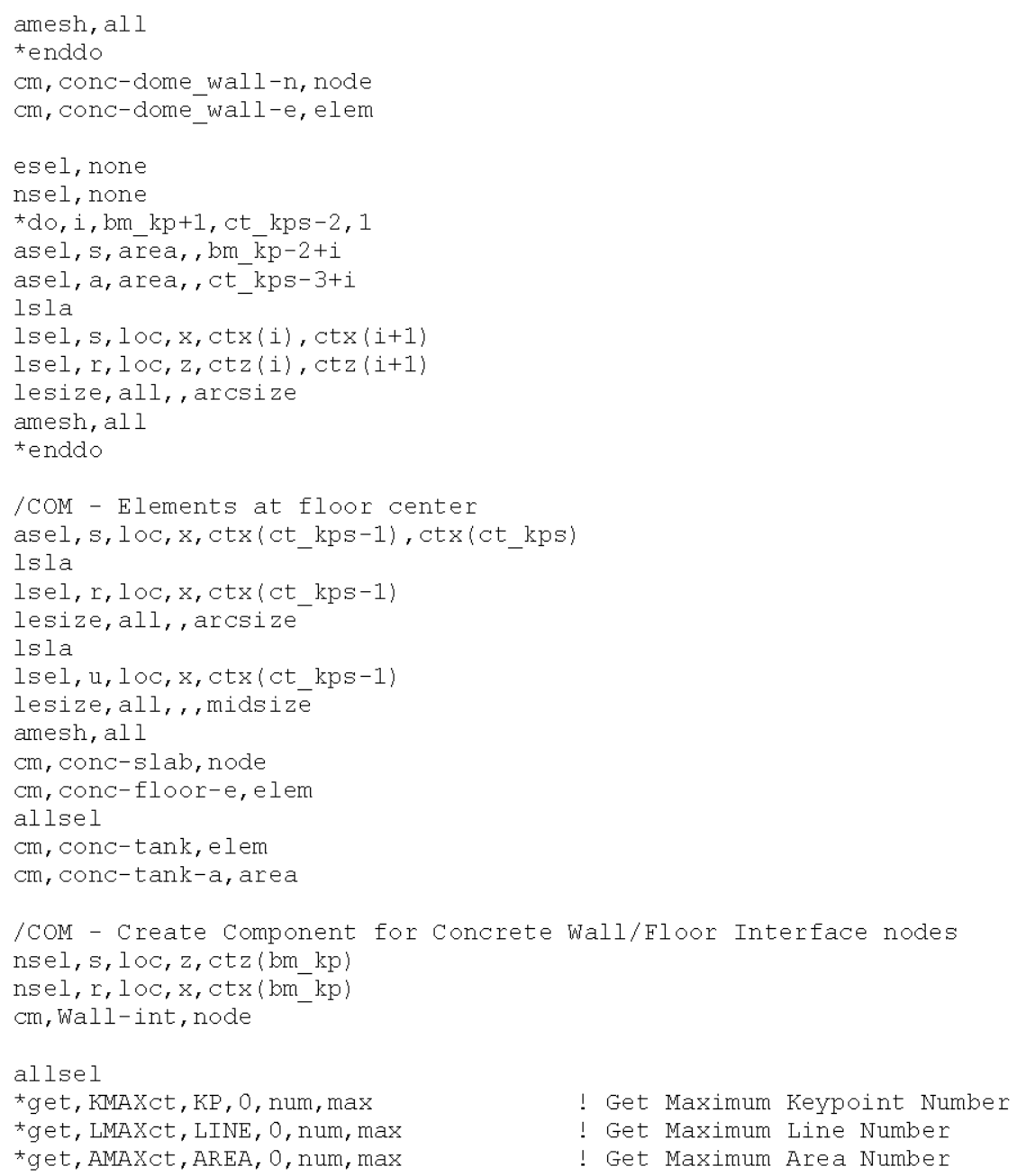

\section{Tank-Props-Rigid.txt}

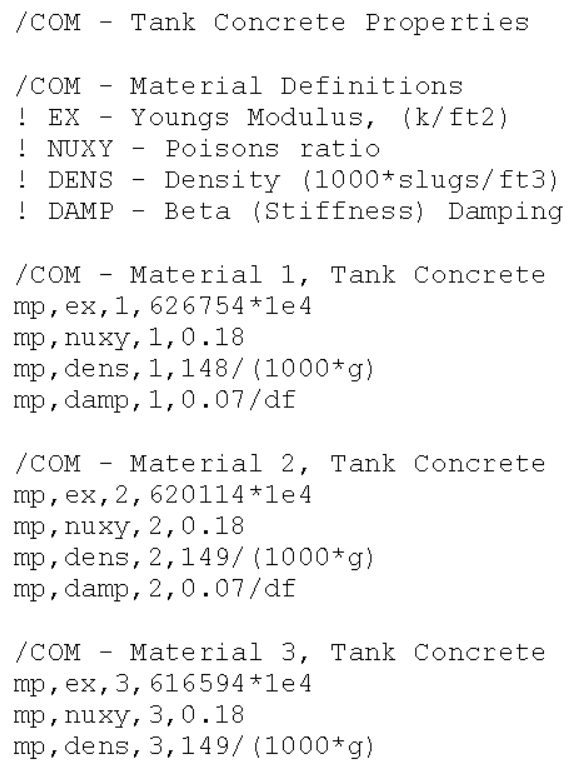


RPP-RPT-32239, Rev. 1

M\&D-2008-005-CALC-001, Rev. 1

$\mathrm{mp}$, damp, 3,0.07/df

/COM - Material 4, Tank Concrete $\mathrm{mp}, \mathrm{ex}, 4,610922 * 1 \mathrm{e} 4$

mp, nuxy, 4, 0.18

$\mathrm{mp}$, dens, $4,149 /\left(100{ }^{*} \mathrm{~g}\right)$

mp, damp, 4, 0.07/df

/COM - Material 5, Tank Concrete

$\mathrm{mp}, \mathrm{ex}, 5,612305^{\star} 1 \mathrm{e} 4$

mp, nuxy, 5, 0.18

$\mathrm{mp}$, dens, $5,148 /\left(1000^{*} \mathrm{~g}\right)$

mp , damp, 5, 0.07/df

/COM - Material 6, Tank Concrete

$\mathrm{mp}, \mathrm{ex}, 6,607093 \star 1 \mathrm{e} 4$

$\mathrm{mp}$, nuxy, $6,0.18$

$\mathrm{mp}$, dens, $6,148 /\left(1000{ }^{*} \mathrm{~g}\right)$

$\mathrm{mp}$, damp, 6, 0.07/df

/COM - Material 7, Tank Concrete $\mathrm{mp}, \mathrm{ex}, 7,639237 \star 1 \mathrm{e} 4$

mp, nuxy, $7,0.18$

$\mathrm{mp}$, dens, $7,146 /(1000 * \mathrm{~g})$

mp, damp, 7, 0.07/df

/COM - Material 8, Tank Concrete

mp, ex, 8, 634338*1e 4

mp, nuxy, $8,0.18$

$\mathrm{mp}$, dens, $8,147 /\left(1000^{*} \mathrm{~g}\right)$

mp, damp, 8, 0.07/df

/COM - Material 9, Tank Concrete

$\mathrm{mp}, \mathrm{ex}, 9,628756 * 1 \mathrm{e} 4$

mp, nuxy, $9,0.18$

$\mathrm{mp}$, dens, $9,147 /\left(1000{ }^{*} \mathrm{~g}\right)$

mp, damp, 9, 0.07/df

/COM - Material,10, Tank Concrete $\mathrm{mp}, \mathrm{ex}, 10,193677 \star 1 \mathrm{e} 4$

$\mathrm{mp}, \mathrm{nuxy}, 10,0.18$

$\mathrm{mp}$, dens, $10,165 /\left(1000^{*} \mathrm{~g}\right)$

$\mathrm{mp}$, damp, 10,0.07/df

/COM - Material,11, Tank Concrete $\mathrm{mp}, \mathrm{ex}, 11,575959 * 1 \mathrm{e} 4$

$\mathrm{mp}$, nuxy, $11,0.18$

$\mathrm{mp}$, dens, $11,144 /\left(1000^{*} \mathrm{~g}\right)$

$\mathrm{mp}$, damp, $11,0.07 / \mathrm{df}$

/COM - Material,12, Tank Concrete mp, ex, $12,202953 * 1$ e4

$\mathrm{mp}$, nuxy, $12,0.18$

$\mathrm{mp}$, dens, $12,159 /\left(1000^{\star} \mathrm{g}\right)$

$\mathrm{mp}$, damp, $12,0.07 / \mathrm{df}$

/COM - Material,13, Tank Concrete mp, ex, 13, 157426*1e4

mp, nuxy, $13,0.18$

mp, dens, $13,176 /\left(1000^{*} \mathrm{~g}\right)$

$\mathrm{mp}$, damp, $13,0.07 / \mathrm{df}$

/COM - Material,14, Tank Concrete mp, ex, 14,153784 * 1 e4

mp, nuxy, $14,0.18$

mp, dens, $14,193 /\left(1000^{*} \mathrm{~g}\right)$

$\mathrm{mp}$, damp, 14,0.07/df

/COM - Material,15, Tank Concrete $\mathrm{mp}, \mathrm{ex}, 15,136651 * 1 \mathrm{e} 4$

$\mathrm{mp}, \mathrm{nuxy}, 15,0.18$ 
RPP-RPT-32239, Rev. 1

M\&D-2008-005-CALC-001, Rev. 1

$\mathrm{mp}$, dens, $15,200 /\left(1000^{*} \mathrm{~g}\right)$

mp, damp, 15, 0.07/df

/COM - Material,16, Tank Concrete

$\mathrm{mp}, \mathrm{ex}, 16,136651 * 1 \mathrm{e} 4$

$\mathrm{mp}, \mathrm{nuxy}, 16,0.18$

$\mathrm{mp}$, dens, $16,200 /\left(1000^{\star} \mathrm{g}\right)$

$\mathrm{mp}$, damp, $16,0.07 / \mathrm{df}$

/COM - Material,17, Tank Concrete

mp, ex, 17,138084 * $1 \mathrm{e} 4$

mp, nuxy, 17, 0.18

$\mathrm{mp}$, dens, $17,181 /\left(1000{ }^{*} \mathrm{~g}\right)$

$\mathrm{mp}$, damp, 17, 0.07/df

/COM - Material,18, Tank Concrete mp, ex, 18, 123378*1e4

mp, nuxy, $18,0.18$

$\mathrm{mp}$, dens, $18,209 /\left(1000^{\star} \mathrm{g}\right)$

$\mathrm{mp}$, damp, $18,0.07 / \mathrm{df}$

/COM - Material,19, Tank Concrete

mp, ex, $19,124633^{\star} 1 \mathrm{e} 4$

mp, nuxy, $19,0.18$

$\mathrm{mp}$, dens, $19,190 /\left(1000^{*} \mathrm{~g}\right)$

$\mathrm{mp}$, damp, 19,0.07/df

/COM - Material,20, Tank Concrete mp, ex, 20, 124388*1e4

$\mathrm{mp}, \mathrm{nuxy}, 20,0.18$

$\mathrm{mp}$, dens, $20,210 /(1000 * \mathrm{~g})$

$\mathrm{mp}$, damp, 20,0.07/df

/COM - Material,21, Tank Concrete mp , ex, $21,548683 * 1 e 4$

$\mathrm{mp}, \mathrm{nuxy}, 21,0.18$

$\mathrm{mp}$, dens, $21,166 /\left(1000^{\star} \mathrm{g}\right)$

$\mathrm{mp}$, damp, $21,0.07 / \mathrm{df}$

/COM - Material,22, Tank Concrete $\mathrm{mp}, \mathrm{ex}, 22,154870 * 1 \mathrm{e} 4$

$\mathrm{mp}$, nuxy, $22,0.18$

$\mathrm{mp}$, dens, $22,184 /\left(1000^{*} \mathrm{~g}\right)$

mp, damp, 22, 0.07/df

/COM - Material,23, Tank Concrete $\mathrm{mp}, \mathrm{ex}, 23,514287^{\star} 1 \mathrm{e} 4$

mp, nuxy, $23,0.18$

mp, dens, $23,172 /(1000 * g)$

mp , damp, 23, 0.060/df

/COM - Material,24, Tank Concrete $\mathrm{mp}, \mathrm{ex}, 24,164113 * 1 \mathrm{e} 4$

$\mathrm{mp}, \mathrm{nuxy}, 24,0.18$

mp, dens, $24,288 /\left(1000^{*} \mathrm{~g}\right)$

$\mathrm{mp}$, damp, 24,0.07/df

/COM - Material,25, Tank Concrete $\mathrm{mp}, \mathrm{ex}, 25,522946 * 1 \mathrm{e} 4$

mp, nuxy, 25, 0.18

$\mathrm{mp}$, dens, $25,201 /\left(1000{ }^{*} \mathrm{~g}\right)$

mp , damp, 25,0.07/df

/COM - Material,26, Tank Concrete mp, ex, 26, 194254*1e4

mp, nuxy, $26,0.18$

$\mathrm{mp}$, dens, $26,322 /\left(1000^{*} \mathrm{~g}\right)$

$\mathrm{mp}$, damp, $26,0.07 / \mathrm{df}$

/COM - Material,27, Tank Concrete mp, ex, 27, 199783*1e4 
RPP-RPT-32239, Rev. 1

M\&D-2008-005-CALC-001, Rev. 1

mp, nuxy, 27, 0.18

$\mathrm{mp}$, dens, $27,281 /\left(1000^{*} \mathrm{~g}\right)$

mp, damp, 27,0.07/df

/COM - Material,28, Tank Concrete

$\mathrm{mp}, \mathrm{ex}, 28,162553 * 1 \mathrm{e} 4$

mp, nuxy, $28,0.18$

$\mathrm{mp}$, dens, $28,299 /\left(1000^{*} \mathrm{~g}\right)$

$\mathrm{mp}$, damp, $28,0.07 / \mathrm{df}$

/COM - Material,29, Tank Concrete

$\mathrm{mp}, \mathrm{ex}, 29,200531 * 1 \mathrm{e} 4$

$\mathrm{mp}, \mathrm{nuxy}, 29,0.18$

$\mathrm{mp}$, dens, $29,3894 /\left(1000^{*} \mathrm{~g}\right)$

$\mathrm{mp}$, damp, 29,0.07/df

/COM - Material,30, Tank Concrete

mp, ex, 30, 167538*1e4

mp, nuxy, 30, 0.18

$\mathrm{mp}$, dens, $30,411 /\left(1000^{*} \mathrm{~g}\right)$

$\mathrm{mp}$, damp, 30,0.07/df

/COM - Material,31, Tank Concrete mp, ex, 31, 731952*1e4

$\mathrm{mp}$, nuxy, $31,0.18$

$\mathrm{mp}$, dens, $31,150 /\left(100{ }^{*} \mathrm{~g}\right)$

$\mathrm{mp}$, damp, 31, 0.07/df

/COM - Material,32, Tank Concrete $\mathrm{mp}, \mathrm{ex}, 32,731952 * 1 \mathrm{e} 4$

$\mathrm{mp}$, nuxy, $32,0.18$

$\mathrm{mp}$, dens, $32,150 /\left(1000^{*} \mathrm{~g}\right)$

$\mathrm{mp}$, damp, 32,0.07/df

!/COM - Material, 33, Tank Concrete !mp, ex, 33, 731952*1e4

!mp, nuxy, 33, 0.18

!mp, dens, 33, 150/(1000*g)

!mp, damp, 33,0.07/df

!/COM - Material, 34, Tank Concrete ! mp, ex, 34, 731952*1e4

!mp, nuxy, $34,0.18$

! mp, dens, $34,150 /\left(1000^{*} \mathrm{~g}\right)$

!mp, damp, 34, 0.07/df

!/COM - Material, 35, Tank Concrete ! mp, ex, 35, 731952*1e4

!mp, nuxy, 35, 0.18

! mp, dens, $35,150 /\left(1000^{\star} \mathrm{g}\right)$

!mp , damp, 35, 0.07/df

!/COM - Material, 36, Tank Concrete

!mp, ex, 36, 731952*1e4

!mp, nuxy, $36,0.18$

! mp, dens, 36, 150/(1000*g)

!mp, damp, $36,0.07 / d f$

!/COM - Material, 37, Tank Concrete

!mp, ex, 37, 731952*1e4

!mp, nuxy, $37,0.18$

!mp, dens, 37, 150/(1000*g)

!mp, damp , 37, 0.07/df

/COM - Concrete Real Values, $t$ in $\mathrm{ft}$ $r, 1,1.26$

$r, 2,1.26$

$r, 3,1.26$

$r, 4,1.26$

$r, 5,1.27$

$r, 6,1.26$

! 15 in

! 15 in

! 15 in

! 15 in

! 15 in

! 15 in 
RPP-RPT-32239, Rev. 1

M\&D-2008-005-CALC-001, Rev. 1

$r, 7,1.28$

! 15 in

$r, 8,1.28$

! 15 in

$r, 9,1.73$

$r, 10,1.73,1.73,2.23,2.23$

$r, 11,2.23,2.22,3.15,3.15$

$r, 12,3.15,3.15,1.50,1.50$

$r, 13,1.50,1.50,1.28,1.28$

$r, 14,1.17$

$r, 15,1.13$

$r, 16,1.13$

$r, 17,1.24$

$r, 18,1.07$

$r, 19,1.18$

$r, 20,1.07$

$r, 21,1.97$

$r, 22,1.68$

$r, 23,1.43$

$r, 24,1.43,1.43,0.51,0.51$

$r, 25,0.51,0.51,0.66,0.66$

$r, 26,0.66,0.66,0.41,0.41$

$r, 27,0.58$

$r, 28,0.55$

$r, 29,0.42$

$r, 30,0.40$

$r, 31,0.40,0.40,1.02,1.02$

! 15 in

! 15 in to

$r, 32,1.02$

! $r, 34,1$

! $r, 35,1$

!r, 36, 1

!r, 37, 1

!r, 39, 1

18 in

! 18 in

! 18 in

! 18 in

! 18 in

! 18 in

! 18 in

! 18 in

! 18 in

! 18 in

!

!

! 8 in

! 8 in

! 8 in

! 8 in

! 8 in to

/COM - Material,50, Insulating Concrete

mp, ex, 50,23760

mp, nuxy, 50, 0.15

$\mathrm{mp}$, dens, $50,50 /\left(1000^{*} \mathrm{~g}\right)$

mp, damp, 50, 0.07/df

\section{Waste-Reaction.txt}

/post 1

*dim, REACTX, , 2149

*dim, REACTZ, , 2149

cmsel, s, waste

cmsel, a, waste-surf

nsle

*do, i, 1, 2149

set, $i$

fsum, cont

*get, REACTX (i), FSUM, 0, ITEM, FX

*get, reactz (i), FSUM, 0, ITEM, FZ

*enddo

/out, Waste-Reaction-460-SD3, out

*vwrite

("Total Waste Forces")

tvwrite

('Fx FZ')

*vwrite, reactx(1), reactz(1)

(f10.1, f10.1)

lout

\section{Waste-solid-AP-S.txt}

et, 3, solid4 5

Waste $t=12$
! Solid45 Elements

! Primary tank coordinate for top of waste (460 in for AP Tanks) 


\section{RPP-RPT-32239, Rev. 1 \\ M\&D-2008-005-CALC-001, Rev. 1}

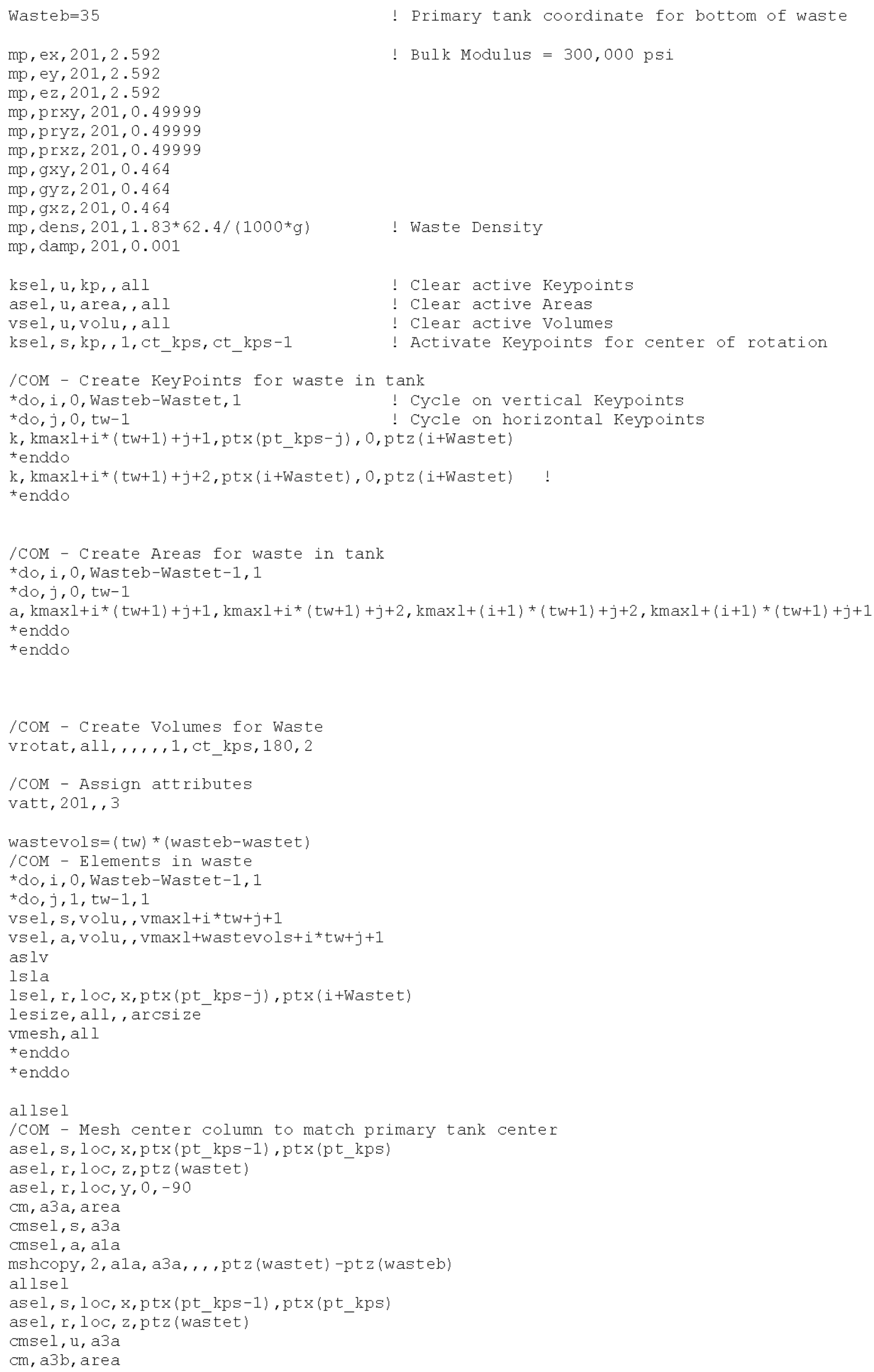


RPP-RPT-32239, Rev. 1

M\&D-2008-005-CALC-001, Rev. 1

cmsel, $a, a 1 b$

mshcopy, 2, a1b, a3b, , , ptz (wastet) -ptz (wasteb)

vsel, s, volu, , vmaxl+1, vmaxl+2* was tevols +1 , tw

vsweep, all, all

cmsel, u, alb

cmsel, a, a3a

aclear, all

esel, s, type,, 3

$\mathrm{cm}$, waste, elem

nsle

$\mathrm{cm}$, waste $-\mathrm{n}$, node

/COM - Couple waste to primary tank

csys, 1

allsel

et, 44, targe 170

et, 45 , conta173

et, 46 , conta173

$r, 800,, 400 / 1.5$

$r, 801,, 400 / 1.5$

$r, 802,400 / 1.5$

$r, 803,, 400 / 1.5$

$r, 804, \ldots 380 / 1.5$

$r, 805,, 360 / 1.5$

$r, 806,, 340 / 1.5$

$r, 807,, 320 / 1.5$

$r, 808,, 300 / 1.5$

$r, 809,, 280 / 1.5$

$r, 810,, 400 / 1.5$

$r, 811,, 400 / 1.5$

$r, 812, \ldots, 400 / 1.5$

$r, 813,, 400 / 1.5$

$r, 814, \ldots, 380 / 1.5$

$r, 815, \ldots, 360 / 1.5$

$r, 816,, 340 / 1.5$

$r, 817,,, 320 / 1.5$

$r, 818,, 300 / 1.5$

$r, 819,, 280 / 1.5$

$r, 820,, 400 / 1.5$

$r, 821,, 400 / 1.5$

$r, 822,, 400 / 1.5$

$r, 823,, 400 / 1.5$

$r, 824, \ldots, 380 / 1.5$

$r, 825,, 360 / 1.5$

$r, 826,, 340 / 1.5$

$r, 827, \ldots, 320 / 1.5$

$r, 828, r, 300 / 1.5$

$r, 829,, 280 / 1.5$

$r, 830,, 400 / 1.5$

$r, 831,, 400 / 1.5$

$r, 832,, 400 / 1.5$

$r, 833,, 400 / 1.5$

$r, 834, \ldots 380 / 1.5$

$r, 835,, 360 / 1.5$

$r, 836,, 340 / 1.5$

$r, 837,, 320 / 1.5$

$r, 838,, 300 / 1.5$

$r, 839, \ldots 280 / 1.5$

keyopt, 45, 12, 4

keyopt $, 46,12,4$ 
RPP-RPT-32239, Rev. 1

M\&D-2008-005-CALC-001, Rev. 1

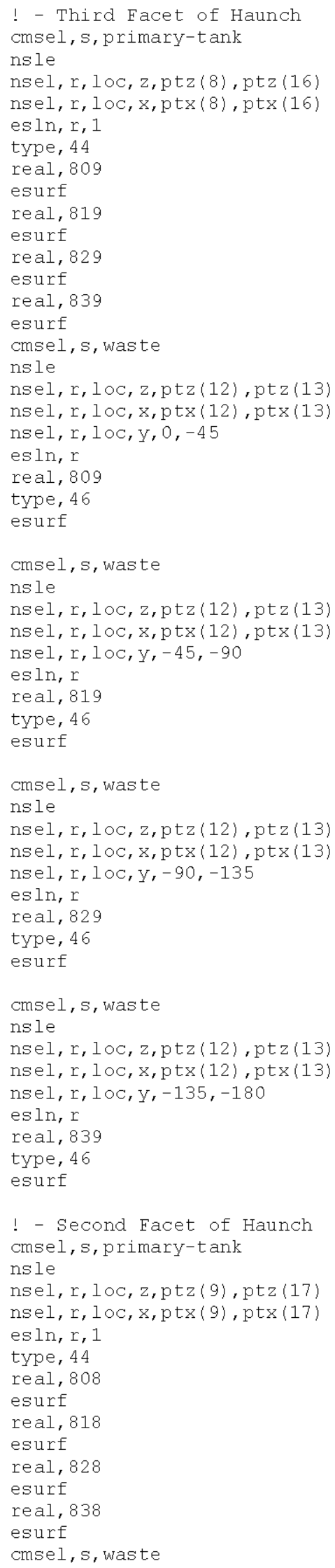


RPP-RPT-32239, Rev. 1

M\&D-2008-005-CALC-001, Rev. 1

nsle

nsel, r, loc, z, ptz (13), ptz (14)

nsel, r, loc, x,ptx(13), ptx (14)

nsel, $r, 1 \circ c, y, 0,-45$

esln, $r$

real, 808

type, 46

esurf

cmsel, s, waste

nsle

nsel, r, loc, z, ptz (13), ptz(14)

nsel, r, loc, x, ptx (13), ptx (14)

nsel, $r, 1 \circ 0, y,-45,-90$

esln, $r$

real, 818

type, 46

esurf

cmsel, s, waste

nsle

nsel, r, loc, z, ptz (13), ptz (14)

nsel, r, loc, $x, p t x(13), p t x(14)$

nsel, r, loc, y, $-90,-135$

esln, $r$

real, 828

type, 46

esurf

cmsel, s, waste

nsle

nsel, r, loc, z,ptz (13), ptz (14)

nsel, r, loc, x, ptx (13), ptx(14)

nsel, r, loc, y, $-135,-180$

esln, $r$

real, 838

type, 46

esurf

! - First Facet of Haunch

cmsel, s, primary-tank

nsle

nsel, r, loc, z, ptz (10), ptz(18)

nsel, r, loc, $x, p t x(10), \operatorname{ptx}(18)$

esln, $r, 1$

type, 44

real, 807

esurf

real, 817

esurf

real, 827

esurf

real, 837

esurf

cmsel, s, waste

nsle

nsel, r, loc, z, ptz (14), ptz(15)

nsel, r, loc, x, ptx (14), ptx(15)

nsel, $r, 1 \circ c, y, 0,-45$

esln, $r$

real, 807

type, 46

esurf

cmsel, s, waste

nsle

nsel, r, loc, z,ptz (14), ptz (15)

nsel, r, loc, x, ptx(14), ptx(15)

nsel, $r, 100, y,-45,-90$

esln, $r$

real, 817 
RPP-RPT-32239, Rev. 1

M\&D-2008-005-CALC-001, Rev. 1

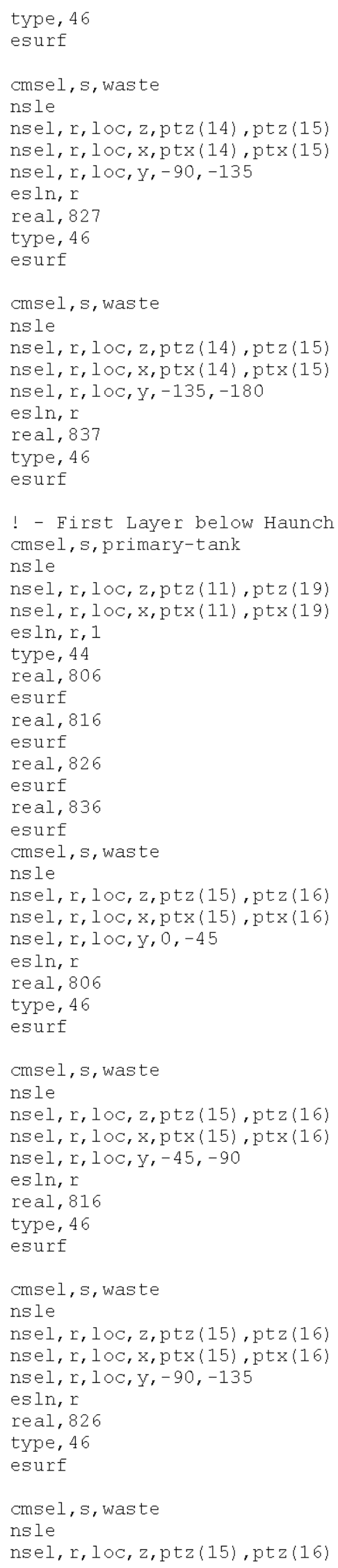


RPP-RPT-32239, Rev. 1

M\&D-2008-005-CALC-001, Rev. 1

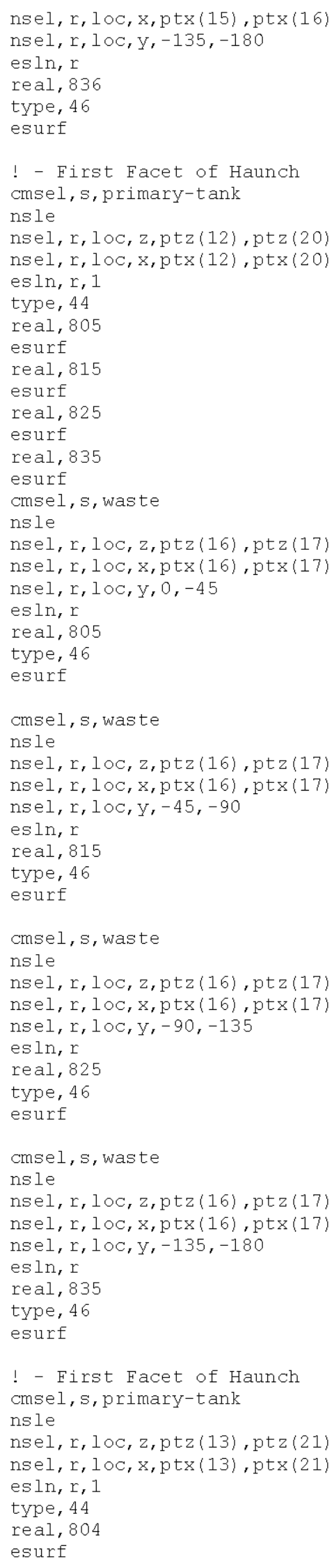


RPP-RPT-32239, Rev. 1

M\&D-2008-005-CALC-001, Rev. 1

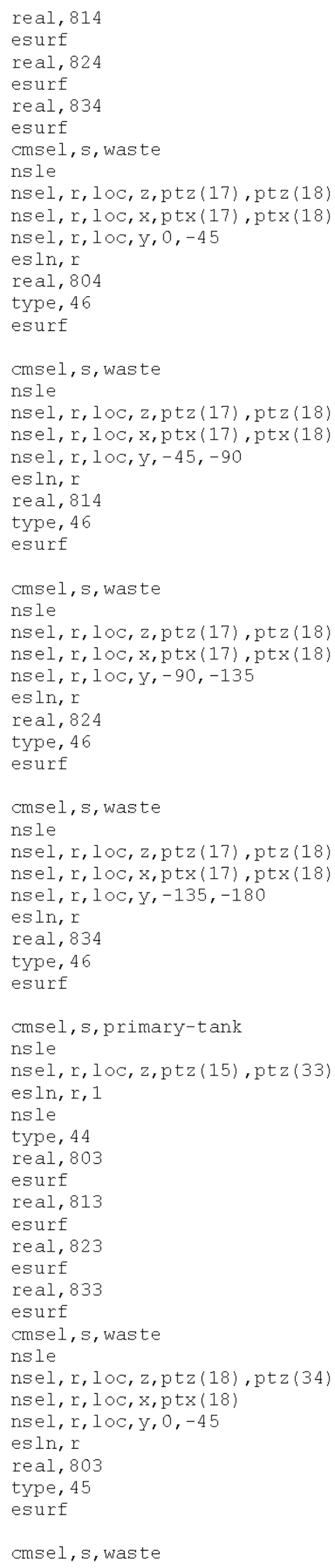


RPP-RPT-32239, Rev. 1

M\&D-2008-005-CALC-001, Rev. 1

nsle

nsel, r, loc, z, ptz (18), ptz(34)

nsel, r, loc, $x, p t x(18)$

nsel, $r, 100, y,-45,-90$

esln, $r$

real, 813

type, 45

esurf

cmsel, s, waste

nsle

nsel, r, loc, z, ptz (18), ptz (34)

nsel, r, loc, $x, p t x(18)$

nsel, $r, 100, y,-90,-135$

esln, $r$

real, 823

type, 45

esurf

cmsel, s, waste

nsle

nsel, r, loc, z, ptz (18), ptz (34)

nsel, r, loc, $x, p t x(18)$

nsel, r, loc, y, $-135,-180$

esln, $r$

real, 833

type, 45

esurf

! - Second Facet of Knuckle

cmsel, s, primary-tank

nsle

nsel, r, loc, z, ptz(32), ptz(36)

nsel, r, loc, $x, p t x(32), \operatorname{ptx}(36)$

esln, $r, 1$

type, 44

real, 802

esurf

real, 812

esurf

real, 822

esurf

real, 832

esurf

cmsel, s, waste

nsle

nsel, r, loc, z, ptz (33), ptz (34)

nsel, r, loc, $x, p t x(33), p t x(34)$

nsel, $r, 1 \circ c, y, 0,-45$

esln, $r$

real, 802

type, 46

esurf

cmsel, s, waste

nsle

nsel, r, loc, z, ptz (33), ptz (34)

nsel, r, loc, x, ptx (33), ptx (34)

nsel, $r, 1 \circ 0, y,-45,-90$

esln, $r$

real, 812

type, 46

esurf

cmsel, s, waste

nsle

nsel, r, loc, z, ptz (33), ptz (34)

nsel, r, loc, x, ptx (33), ptx (34)

nsel, $r, 100, y,-90,-135$

esln, $r$

real, 822 
RPP-RPT-32239, Rev. 1

M\&D-2008-005-CALC-001, Rev. 1

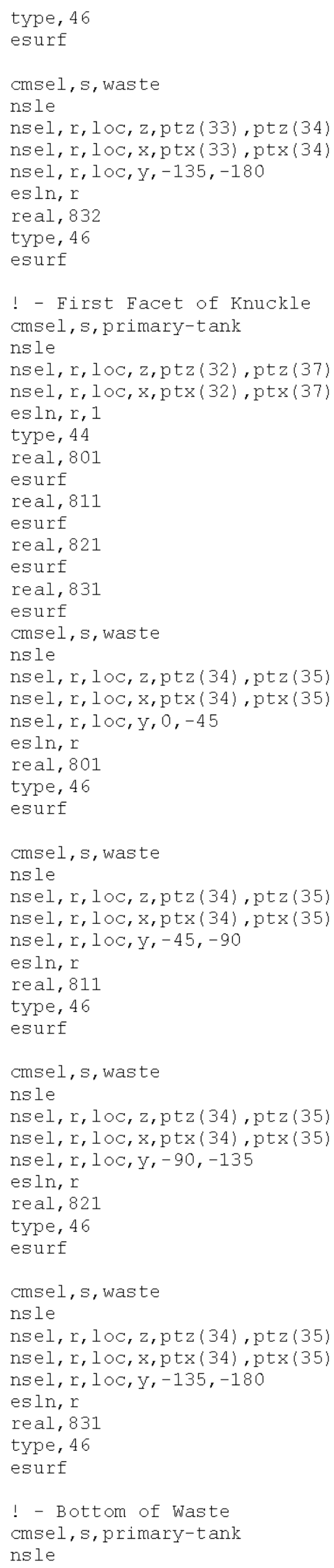




\section{RPP-RPT-32239, Rev. 1 \\ M\&D-2008-005-CALC-001, Rev. 1}

nsel, r, loc, z, ptz (33), ptz (36)

esln, r, 1

type, 44

real, 800

esurf

cmsel, s, waste

nsle

nsel, r, loc, z,ptz (36)

esln, $r$

type, 45

esurf

esel, s, type, , 45, 46

$\mathrm{cm}$, waste-surf, elem

!cmsel, s, waste-n

!nsel, r, loc, z, ptz (wastet+2), ptz (wastet)

!nsel, r, loc, $x, p t x(36), p t x(21)$

!esln, r, 1

!emodif, mat, , 202

! cmse l, s, waste

!nsle

!nsel, r, loc, z, ptz (wastet)

allsel

*get, KMAXw, KP, 0, num, max

*get, LMAXW, LINE, 0, num, max

! Get maximum Keypoint number

*get, AMAXW, AREA, 0, num, max

! Get maximum Line number

*get, VMAXw, VOLU, 0, num, max

! Get maximum Area number

! Get maximum volume number

\section{Horizontal Excitation Only}

\section{Run-Tank.txt}

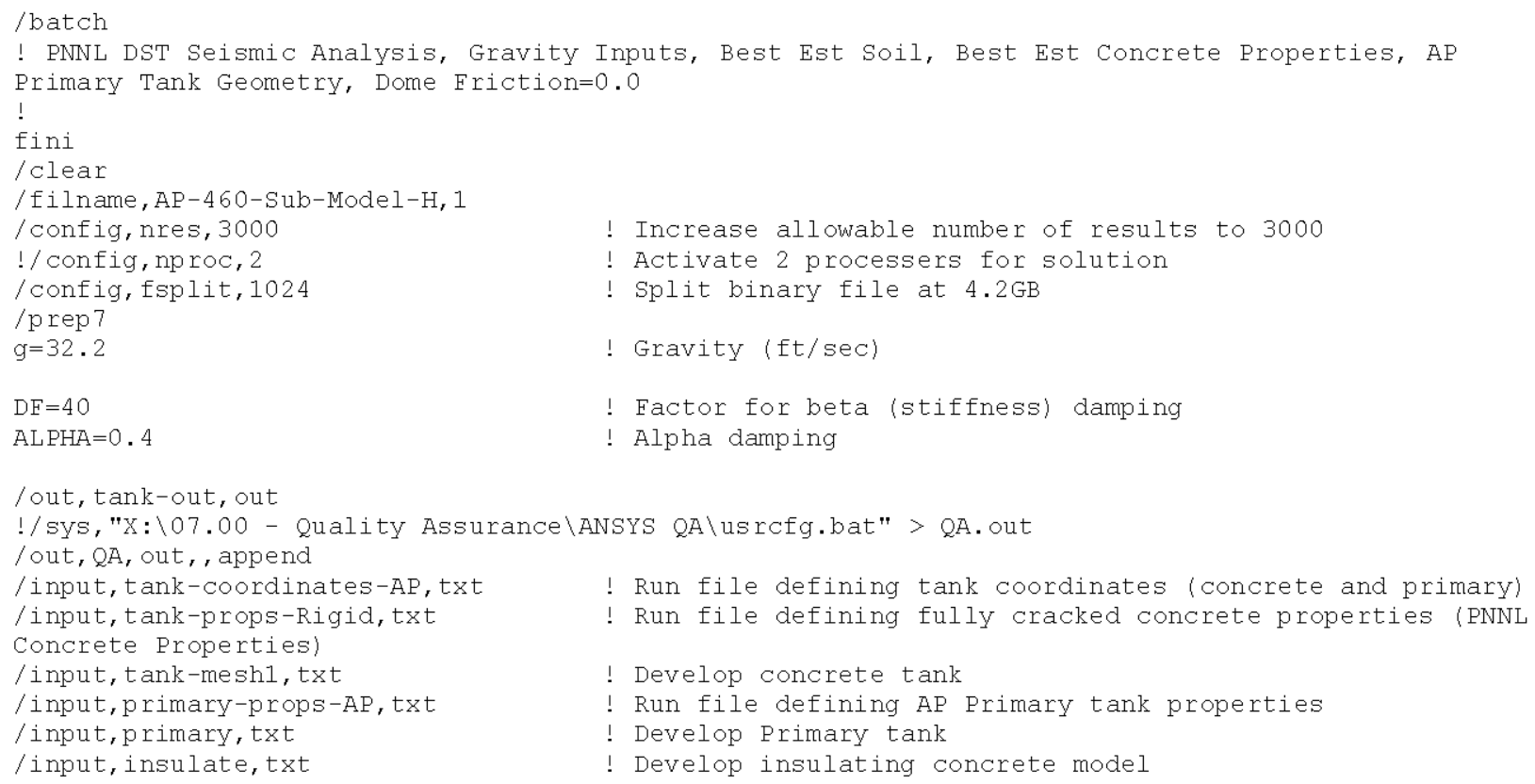


RPP-RPT-32239, Rev. 1

M\&D-2008-005-CALC-001, Rev. 1

/input, liner, txt

/input, waste-solid-AP-S, txt

/input, bolts-friction, txt

/input, near-soil-1, txt

/input, far-soil, txt

/input, interfacel, txt

/input, interface-gap1, txt

/input, slave, txt

/input, boundary, txt

/input, outer-spar, txt

/input, live_load, txt

/input,fix-soil,txt

lout

ALLSEL

lout, Tank-th, out

save

!/input, solve-slosh-flex, txt

/input, solve-sub-horiz, txt

/input, contact-waste-ap, txt

/input, waste-reaction, txt

lout

/exit

\section{Solve-Sub-Horiz.txt}

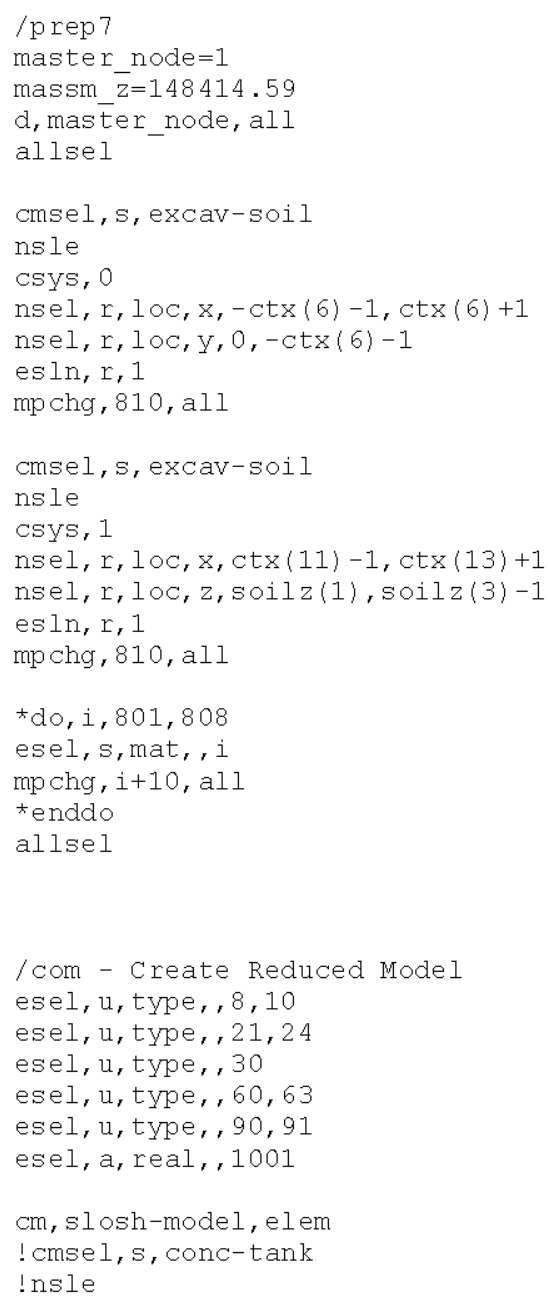


RPP-RPT-32239, Rev. 1

M\&D-2008-005-CALC-001, Rev. 1

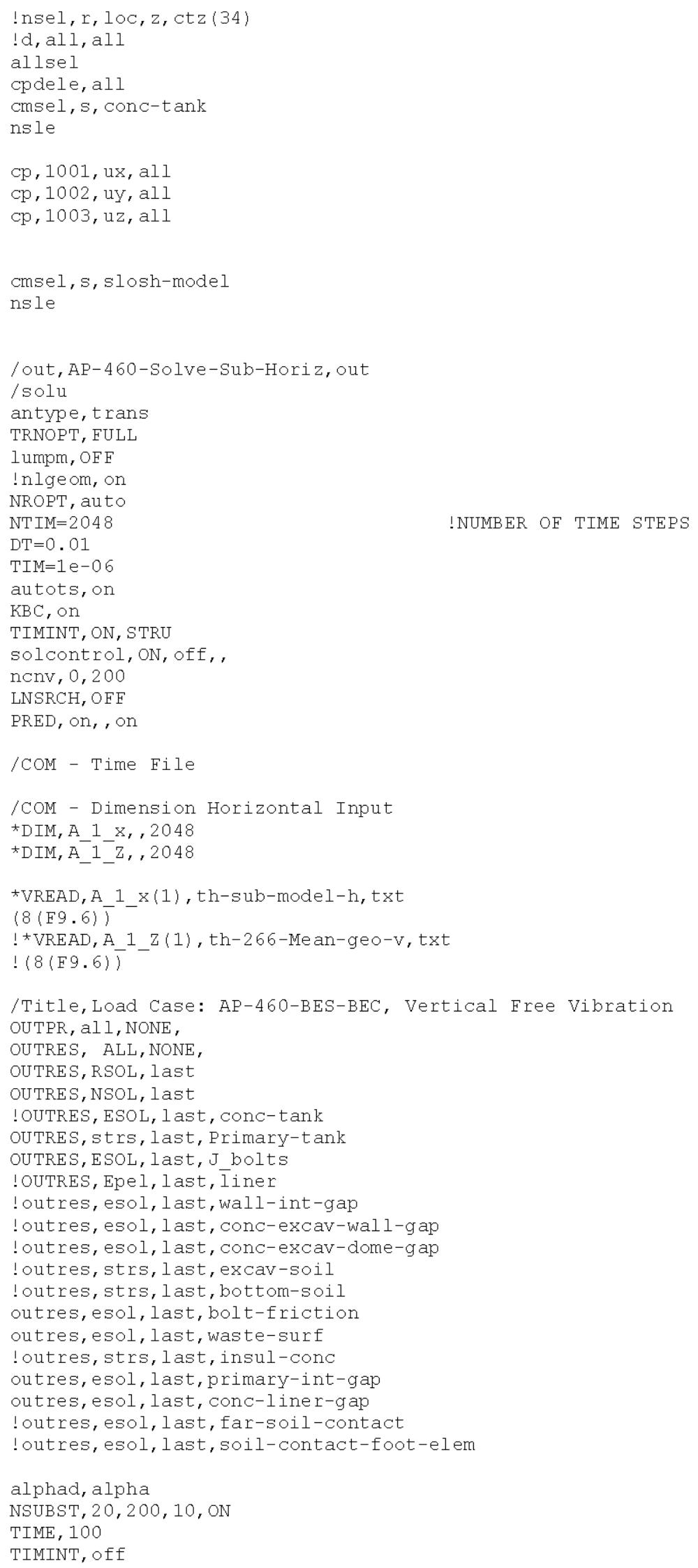




\title{
RPP-RPT-32239, Rev. 1 \\ M\&D-2008-005-CALC-001, Rev. 1
}

\author{
acel, $0,0,9$ \\ SOLVE \\ SAVE \\ TIMINT, on \\ $\operatorname{ITIM}=1$ \\ $\mathrm{DS}=\mathrm{TIM}$ \\ NSUBST, $1,20,1$, ON \\ ddele, 1 , ux \\ acel, $0,0,0$ \\ ${ }^{*} \mathrm{DO}, \mathrm{ITIM}, 1, \mathrm{NTIM}, 1$ \\ $\mathrm{TIM}=\mathrm{DT} \mathrm{T}^{\star} \mathrm{ITIM}$ \\ TIME, TIM+100 \\ $\mathrm{F}$, master node, $\mathrm{FX}, \mathrm{A} 1 \mathrm{X}$ (itim) ${ }^{*} \mathrm{mass}^{\star} \mathrm{g}$

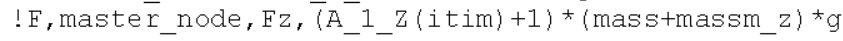 \\ SOLVE \\ SAVE \\ $\star$ ENDDO \\ FINISH \\ lout
}

\section{Vertical Excitation Only}

\section{Run-tank.txt}

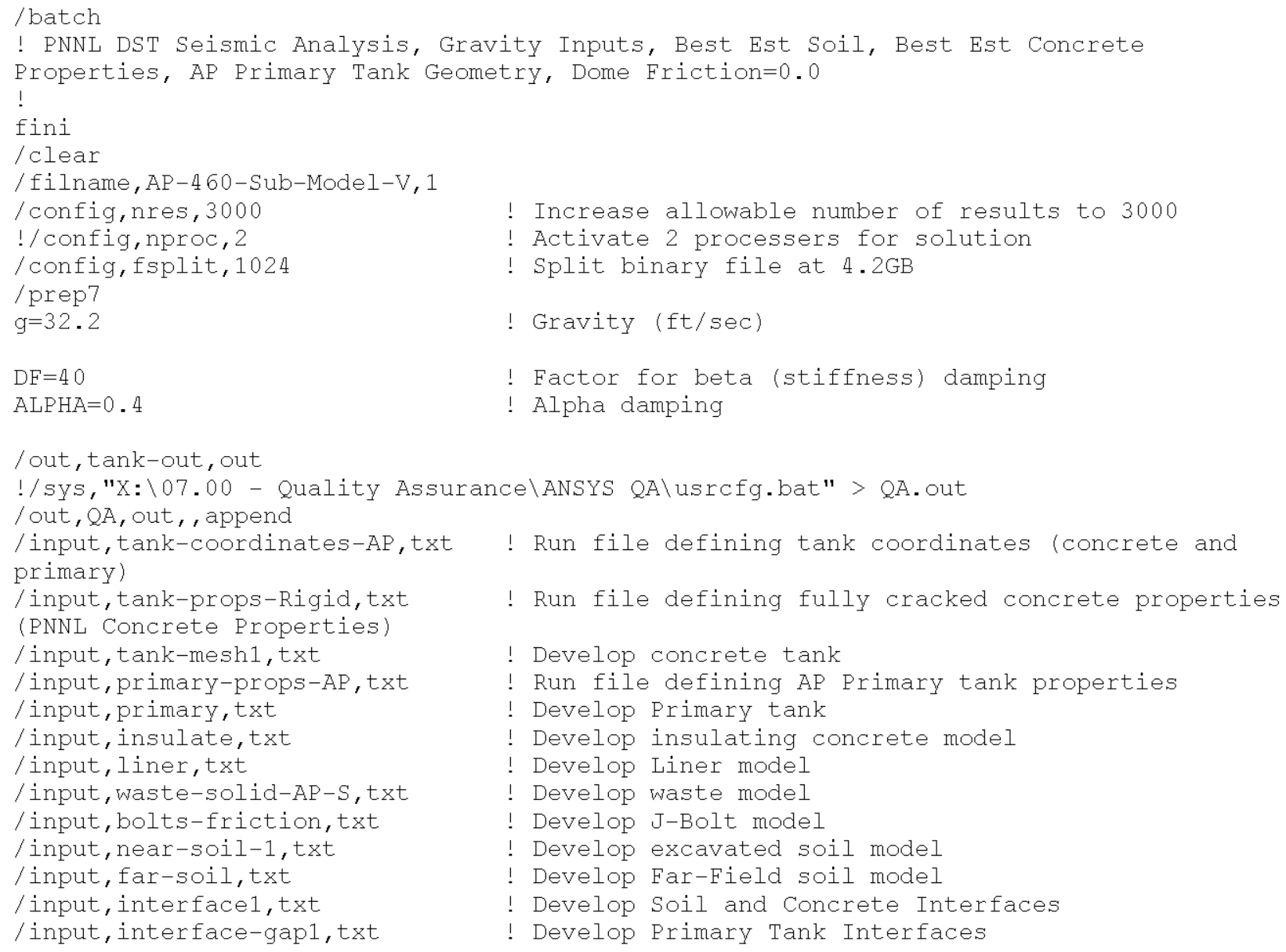


RPP-RPT-32239, Rev. 1

M\&D-2008-005-CALC-001, Rev. 1

/ input, slave, txt

/input, boundary, txt

/input, outer-spar, txt

/input, live load, txt

/input,fix-soil,txt

/ out

ALLSEL

/ out, Tank-th, out

save

! / input, solve-slosh-flex, txt / input, solve-sub-vert, txt /input, contact-waste-ap, txt /input, waste-reaction, txt /input, stress-primary,txt

/ out

/exit

\section{Solve-Sub-Vert.txt}

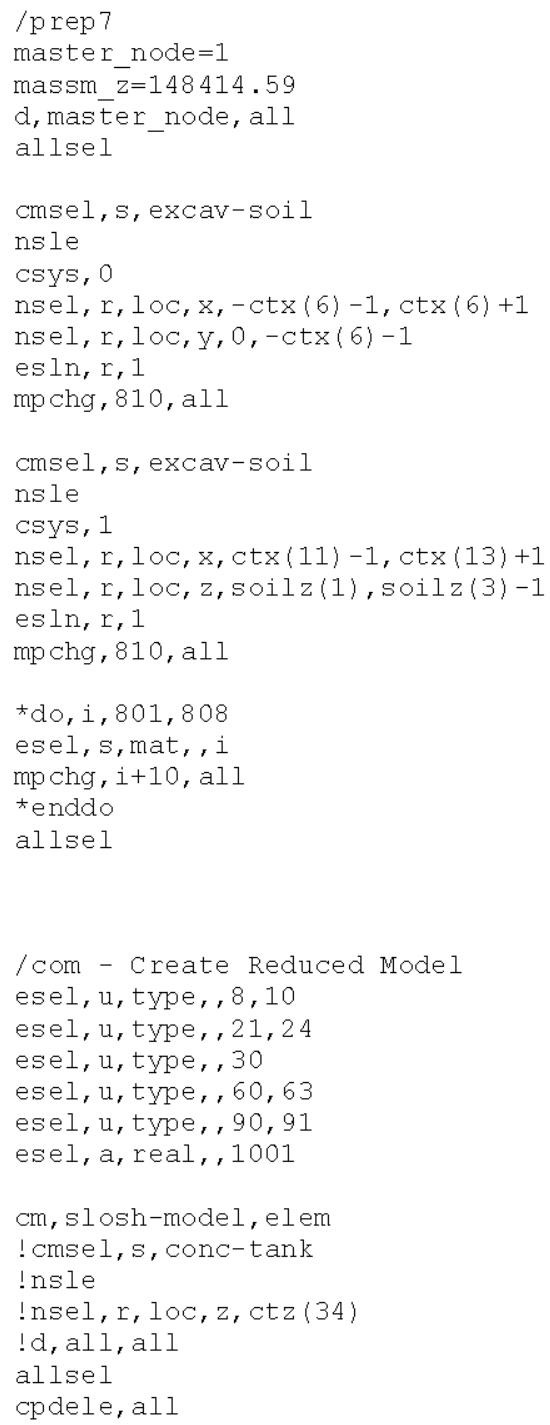

! Develop slaved boundary conditions

! Place base and symmetry boundary conditions

! Connect soil model to symmetry plane

! Apply live load over a $10 \mathrm{ft}$ radius over dome center
! Run solution Phase!/input, post-sub, txt 


\section{RPP-RPT-32239, Rev. 1 \\ M\&D-2008-005-CALC-001, Rev. 1}

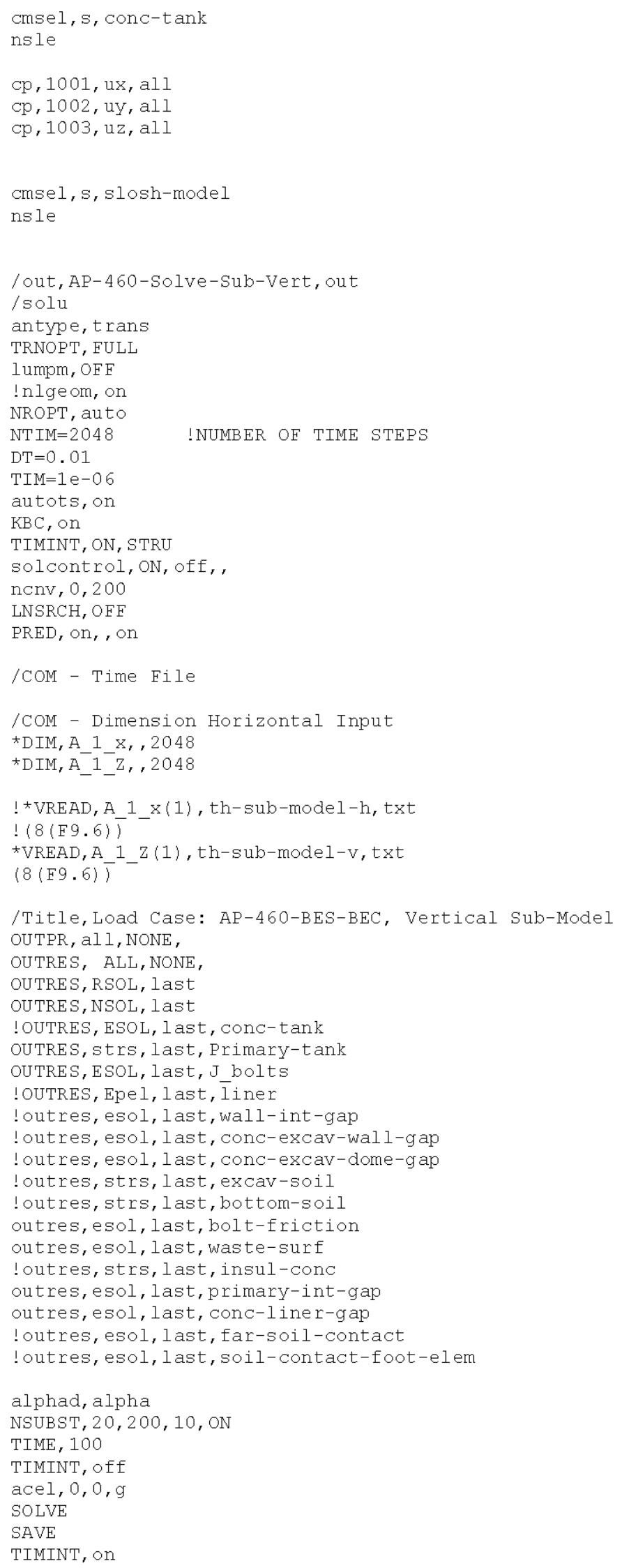




\section{RPP-RPT-32239, Rev. 1 \\ M\&D-2008-005-CALC-001, Rev. 1}

ITIM $=1$

$\mathrm{DS}=\mathrm{TIM}$

NSUBST, $1,20,1$, ON

ddele, 1 , uz

acel, $0,0,9$

${ }^{\star}$ DO, ITIM, 1 , NTIM, 1

$\mathrm{TIM}=\mathrm{DT} \mathrm{T}^{\star} \mathrm{ITIM}$

TIME, TIM +100

! F, master node, FX, A 1 X (itim) *mass* $g$

F, master_ñode, Fz, (A_1_z (itim) +1$) *$ (mass+massm_z) ${ }^{*} g$

SOLVE

SAVE

*ENDDO

FINISH

lout

\section{Horizontal and Vertical Excitation}

\section{Run-Tank.txt}

/batch

! PNNL DST Seismic Analysis, Gravity Inputs, Best Est Soil, Best Est Concrete Properties, AP Primary Tank Geometry, Dome Friction $=0.0$

!

fini

/clear

/filname, AP-460-Sub-Model-HV, 1

/ config, nres, 3000

! Increase allowable number of results to 3000

! / config, nproc, 2

! Activate 2 processers for solution

/config, fsplit, 1024

$/$ prep 7

$g=32.2$

! Split binary file at $4.2 \mathrm{~GB}$

$\mathrm{DF}=40$

! Gravity (ft/sec)

ALPHA $=0.4$

! Factor for beta (stiffness) damping

! Alpha damping

lout, tank-out, out

!/sys, "X: $\backslash 07.00$ - Quality Assurance $\backslash$ ANSYS QA $\backslash$ usrefg.bat" > QA. out

lout, $Q A$, out, , append

/input, tank-coordinates-AP, txt

! Run file defining tank coordinates (concrete and primary)

/input, tank-props-Rigid, txt

Concrete Properties)

/input, tank-mesh1, txt

/input, primary-props-AP, txt

/input, primary, txt

/input, insulate, txt

/input, liner, txt

/input, waste-solid-AP-S, txt

/input, bolts-friction, txt

/input, near-soil-1, txt

/input, far-soil, txt

/input, interfacel, txt

/input, interface-gap1, txt

/input, slave, txt

/input, boundary, txt

/input, outer-spar, txt

/input, live load, txt

/input, fix-soil, txt

! Run file defining fully cracked concrete properties (PNNL

lout

ALLSEL

lout, Tank-th, out 
RPP-RPT-32239, Rev. 1

M\&D-2008-005-CALC-001, Rev. 1

save

!/input, solve-slosh-flex, txt / input, solve-sub-HV, txt /input, contact-waste-ap, txt / input, waste-reaction, txt /input, stress-primary, txt lout

/exit

\section{Solve-Sub-HV.txt}

/prep 7

master node $=1$

massm $\bar{z}=148414.59$

d, master node, all

allsel

cmsel, s, excav-soil

nsle

csys, 0

nsel, $r, 10 \mathrm{c}, \mathrm{x},-\operatorname{ctx}(6)-1, \operatorname{ctx}(6)+1$

nsel, r, loc, y, 0,-ctx (6)-1

esln, r, 1

mpchg, 810, all

cmsel, s, excav-soil

nsle

csys, 1

nsel, r, loc, x, $\operatorname{ctx}(11)-1, \operatorname{ctx}(13)+1$

nsel, r, loc, z, soilz(1), soilz (3)-1

esln, $r, 1$

mpchg, 810 , all

tdo, i, 801,808

esel, s, mat, , i

mp chg, $i+10$, all

*enddo

allsel

/com - Create Reduced Model

esel, u, type, , 8, 10

esel, u, type, ,21,24

esel, u, type, 30

esel, u, type, $, 60,63$

esel, u, type, ,90,91

esel, a, real, 1001

cm, slosh-model, elem

! cmse l, s, conc-tank

!nsle

!nsel, r, loc, z, ctz (34)

!d, all, all

allsel

cpdele, all

cmsel, s, conc-tank

nsle

$\mathrm{cp}, 1001, \mathrm{ux}, \mathrm{all}$

cp, 1002, uy, all

$\mathrm{cp}, 1003, \mathrm{uz}, \mathrm{all}$

cmsel, s, slosh-model

nsle
! Run solution Phase!/input, post-sub, txt 
RPP-RPT-32239, Rev. 1

M\&D-2008-005-CALC-001, Rev. 1

lout,AP-460-Solve-Sub-HV, out

/solu

antype, trans

TRNOPT, FULL

lumpm, $\mathrm{OFF}$

!nlgeom, on

NROPT, auto

NTIM $=2048$

!NUMBER OF TIME STEPS

$\mathrm{DT}=0.01$

TIM $=1 e-06$

autots, on

$\mathrm{KBC}$, on

TIMINT, ON, STRU

solcontrol, on, off,

nenv, 0,200

LNSRCH, OFE

PRED, on, on

/COM - Time File

/COM - Dimension Horizontal Input

${ }^{\star}$ DIM, A_1_x, 2048

${ }^{*} \mathrm{DIM}, \mathrm{A}-1-\mathrm{Z}, 2048$

*VREAD, A_1_x(1), th-sub-model-h, txt

$(8(\mathrm{~F} 9.6))$

*VREAD, A 1 Z(1), th-sub-model-v, txt

$(8(\mathrm{~F} 9.6))$

/Title, Load Case: AP-460-BES-BEC, Sub-Model 2 Direction Input OUTPR, all, NONE,

OUTRES, ALL, NONE,

OUTRES, RSOL, last

OUTRES, NSOL, last

!OUTRES, ESOL, last, conc-tank

OUTRES, strs, last, Primary-tank

OUTRES, ESOL, last, J bolts

! OUTRES, Epel, last, Iiner

!outres, esol, last, wall-int-gap

! outres, esol, last, conc-excav-wall-gap

!outres, esol, last, conc-excav-dome-gap

!outres, strs, last, excav-soil

!outres, strs, last, bottom-soil

outres, esol, last, bolt-friction

outres, esol, last, waste-surf

!outres, strs, last, insul-cono

outres, esol, last, primary-int-gap

outres, esol, last, conc-liner-gap

!outres, esol, last, far-soil-contact

!outres, esol, last, soil-contact-foot-elem

alphad, alpha

NSUBST, 20, 200, 10, ON

TIME, 100

TIMINT, off

acel, 0, 0, g

SOLVE

SAVE

TIMINT, on

ITIM $=1$

$\mathrm{DS}=\mathrm{TIM}$

NSUBST $, 1,20,1$, ON

ddele, 1 , ux

ddele, 1 , uz

acel, $0,0,9$

${ }^{\star}$ DO , ITIM, 1, NTIM, 1

$\mathrm{TIM}=\mathrm{DT}^{*}$ I TIM

TIME, TIM+100 
RPP-RPT-32239, Rev. 1

M\&D-2008-005-CALC-001, Rev. 1

F, master_node, FX, A_1_X (itim) ${ }^{*}$ mass ${ }^{\star} \mathrm{g}$

$\mathrm{F}$, master_node, $\mathrm{Fz},\left(\overline{\mathrm{A}}{ }_{-}{ }^{-}{ } \mathrm{Z}(\mathrm{itim})+1\right){ }^{*}(\operatorname{mass}+\operatorname{massm} \mathrm{z}){ }^{*} \mathrm{~g}$

SOLVE

SAVE

*ENDDO

FINISH

lout

\section{Horizontal Frequency Check}

\section{Run-Tank.txt}

/ batch

! PNNL DST Seismic Analysis, Gravity Inputs, Best Est Soil, Best Est Concrete Properties, AP Primary Tank Geometry, Dome Friction=0.0

fini

/clear

/filname, AP-460-Sub-Model-H, 1

/ config, nres, 3000

! Increase allowable number of results to 3000

! config, nproc, 2

/ config, fsplit, 1024

! Activate 2 processers for solution

$1 \mathrm{prep} 7$

$g=32.2$

! Split binary file at $4.2 \mathrm{~GB}$

$\mathrm{DF}=40$

! Gravity (ft/sec)

$\mathrm{ALPHA}=0.4$

! Factor for beta (stiffness) damping

! Alpha damping

/out, tank-out, out

!/sys, "X: $\backslash 07.00$ - Quality Assurance $\backslash$ ANSYS QA $\backslash$ usrcfg.bat" > QA. out

/out, QA, out, append

/ input, tank-coordinates-AP, txt

! Run file defining tank coordinates (concrete and primary)

/input, tank-props-Rigid, txt

Concrete Properties)

/input, tank-meshl, txt

/input, primary-props-AP, txt

/input, primary, txt

/input, insulate, txt

/input, liner, txt

/ input, waste-solid-AP-S, txt

/input, bolts-friction, txt

/input, near-soil-1, txt

/input, far-soil, txt

/input, interfacel, txt

/ input, interface-gap 1, txt

/input, slave, txt

/input, boundary, txt

/input, outer-spar, txt

/input, live load, txt

/input, fix-soil, txt

! Run file defining fully cracked concrete properties (PNNL

lout

ALLSEL

lout, Tank-th, out

save

/input, solve-slosh-flex, txt

! / input, solve-sub-horiz, txt

! / input, contact-waste-ap, txt

! Develop concrete tank

! Run file defining AP Primary tank properties

! Develop Primary tank

! Develop insulating concrete model

! Develop Liner model

! Develop waste model

! Develop J-Bolt model

! Develop excavated soil model

! Develop Far-Field soil model

! Develop Soil and Concrete Interfaces

! Develop Primary Tank Interfaces

! Develop slaved boundary conditions

! Place base and symmetry boundary conditions

! Connect soil model to symmetry plane

! Apply live load over a loft radius over dome center

/input, waste-reaction, txt

lout

lexit

! Run solution Phase!/input, post-sub, txt 
RPP-RPT-32239, Rev. 1

M\&D-2008-005-CALC-001, Rev. 1

\section{Solve-Slosh-Flex.txt}

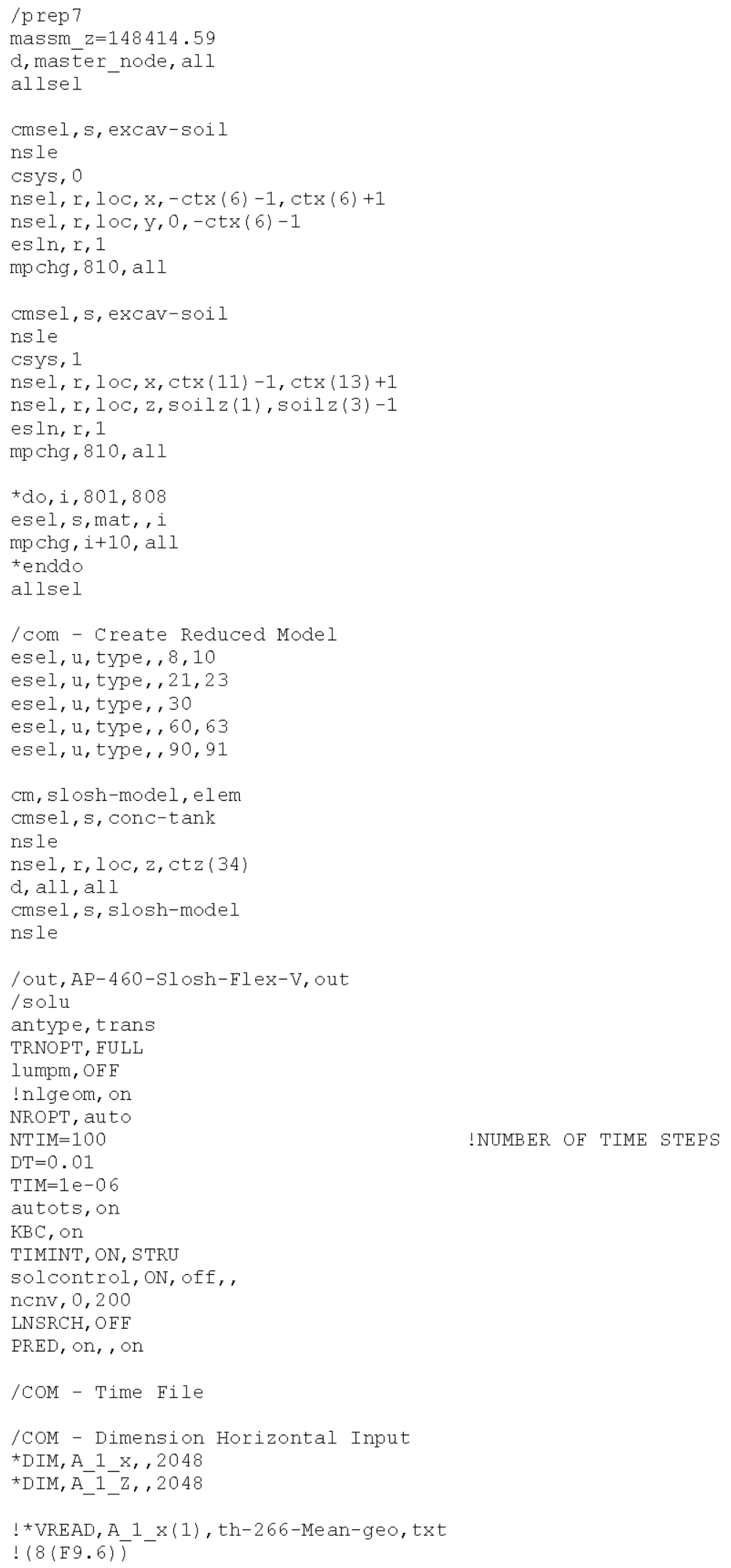


RPP-RPT-32239, Rev. 1

M\&D-2008-005-CALC-001, Rev. 1

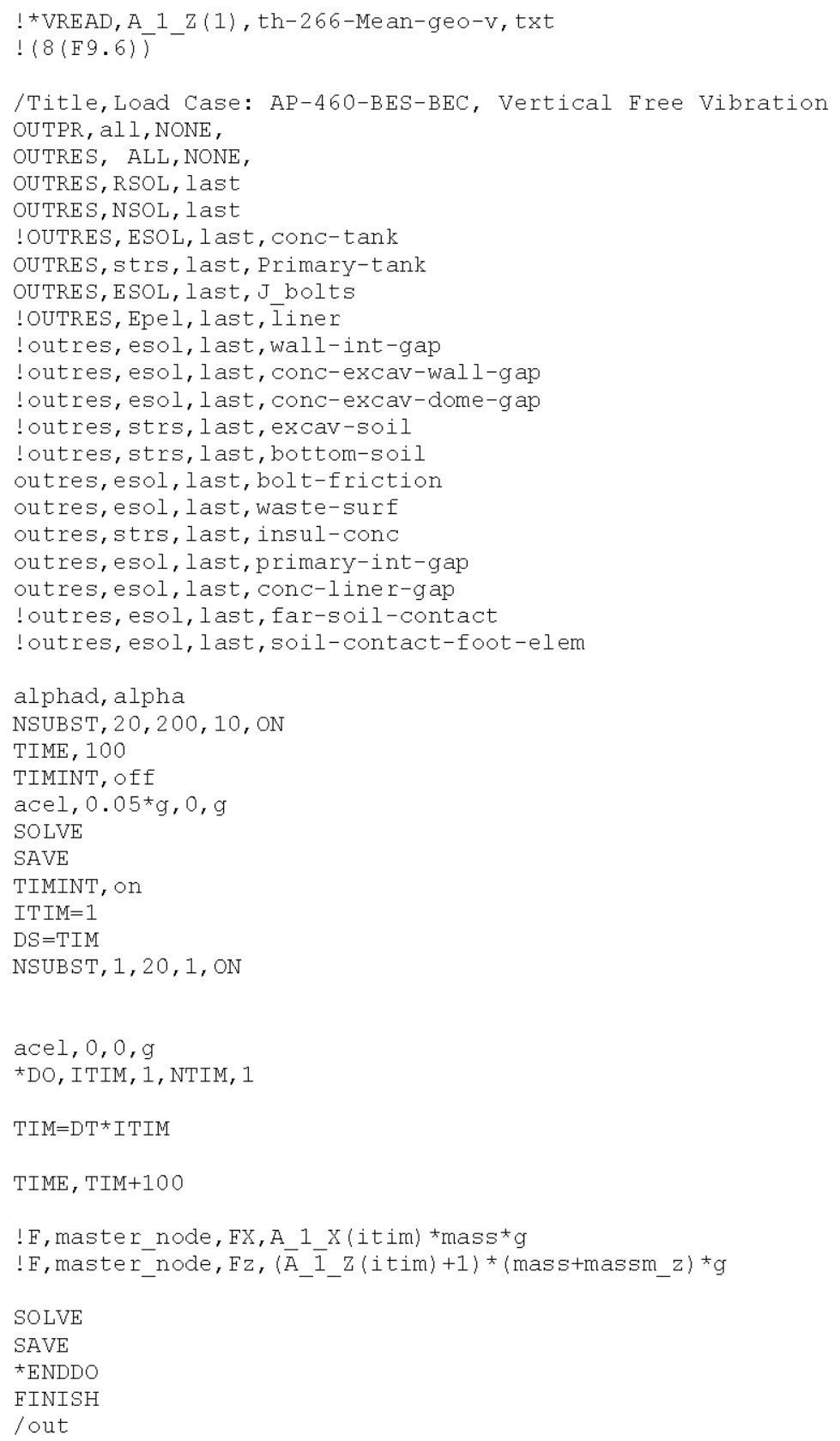

\section{Vertical Frequency Check}

\section{Run-Tank.txt}

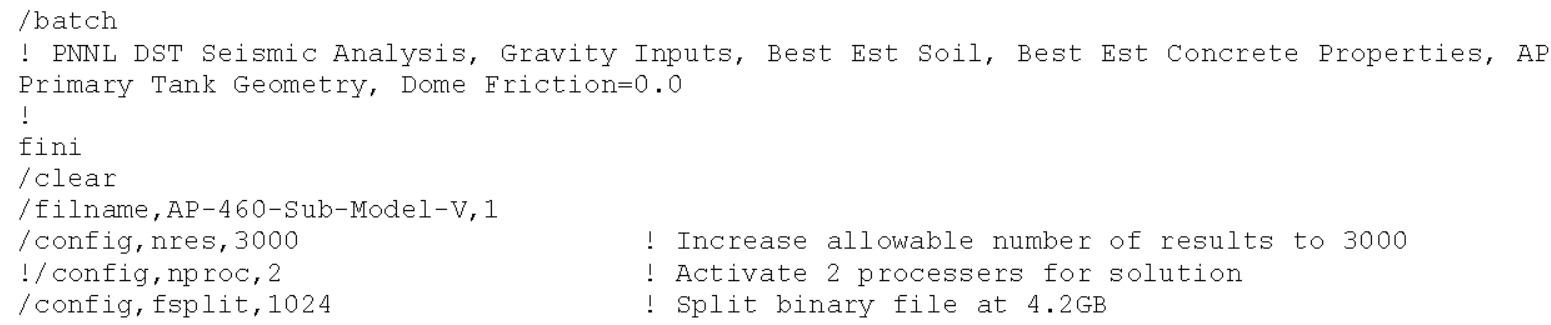




\section{RPP-RPT-32239, Rev. 1 \\ M\&D-2008-005-CALC-001, Rev. 1}

$/$ prep 7

$g=32.2$

! Gravity (ft/sec)

$\mathrm{DF}=40$

! Factor for beta (stiffness) damping

AL PHA $=0.4$

! Alpha damping

lout, tank-out, out

!/sys, "X: $\backslash 07.00$ - Quality Assurance $\backslash$ ANSYS $Q A \backslash$ usrefg.bat" > QA. out

/ out, QA, out, , append

/input, tank-coordinates-AP, txt

! Run file defining tank coordinates (concrete and primary)

/input, tank-props-Rigid, txt

! Run file defining fully cracked concrete properties (PNNL

Concrete Properties)

/input, tank-mesh1, txt

/input, primary-props-AP, txt

/input, primary, txt

/input, insulate, txt

/input, liner, txt

/input, waste-solid-AP-S, txt

/input, bolts-friction, txt

/input, near-soil-1, txt

/input, far-soil, txt

/input, interface1, txt

/input, interface-gap 1, txt

/input, slave, txt

/input, boundary, txt

/input, outer-spar, txt

/input, live load, txt

/input, fix-soil,txt

lout

ALLSEL

lout, Tank-th, out

save

/input, solve-slosh-vert, txt

!/input, solve-sub-horiz, txt

!/input, contact-waste-ap, txt

! Develop concrete tank

! Run file defining AP Primary tank properties

! Develop Primary tank

! Develop insulating concrete model

! Develop Liner model

! Develop waste model

! Develop J-Bolt model

! Develop excavated soil model

! Develop Far-Field soil model

! Develop Soil and Concrete Interfaces

! Develop Primary Tank Interfaces

! Develop slaved boundary conditions

! Place base and symmetry boundary conditions

! Connect soil model to symmetry plane

! Apply live load over a loft radius over dome center

/input, waste-reaction, txt

lout

/exit

\section{Solve-Slosh-Vert.txt}

/prep 7

massm $z=148414.59$

d, master_node, all

allsel

cmsel, s, excav-soil

nsle

csys, 0

nsel, $x, 10 c, x,-\operatorname{ctx}(6)-1, \operatorname{ctx}(6)+1$

nsel, $r, 100, y, 0,-\operatorname{ctx}(6)-1$

esln, $r, 1$

mpchg , 810, all

cmsel, s, excav-soil

nsle

Csys, 1

nsel, r, loc, $x, \operatorname{ctx}(11)-1, \operatorname{ctx}(13)+1$

nsel, r, loc, z, soilz(1), soilz(3)-1

esln, $r, 1$

mpchg, 810, all

${ }^{*} \mathrm{do}, \mathrm{i}, 801,808$

esel, s, mat, , i

mpchg, i+10, all

*enddo

allsel

! Run solution Phase!/input, post-sub, txt 
RPP-RPT-32239, Rev. 1

M\&D-2008-005-CALC-001, Rev. 1

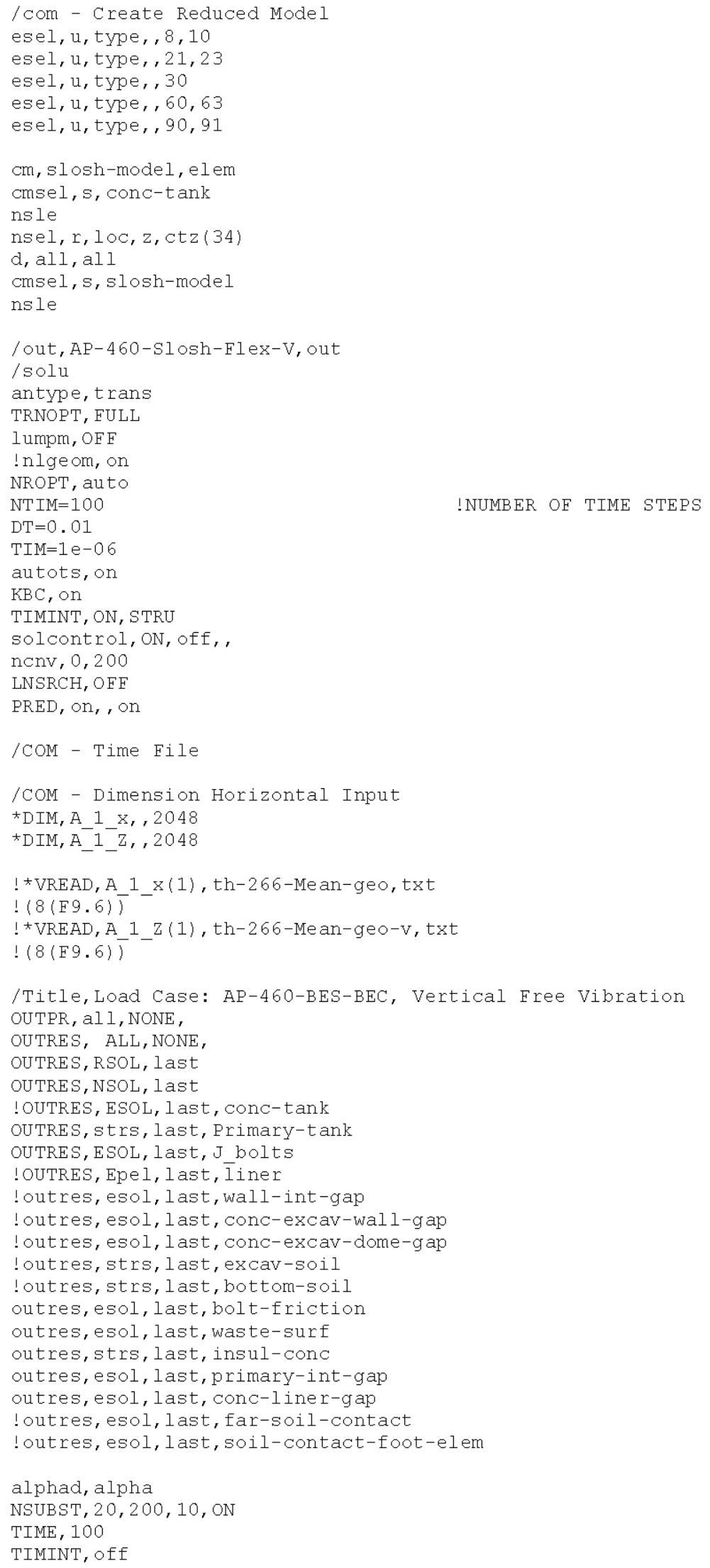




\section{RPP-RPT-32239, Rev. 1 \\ M\&D-2008-005-CALC-001, Rev. 1}

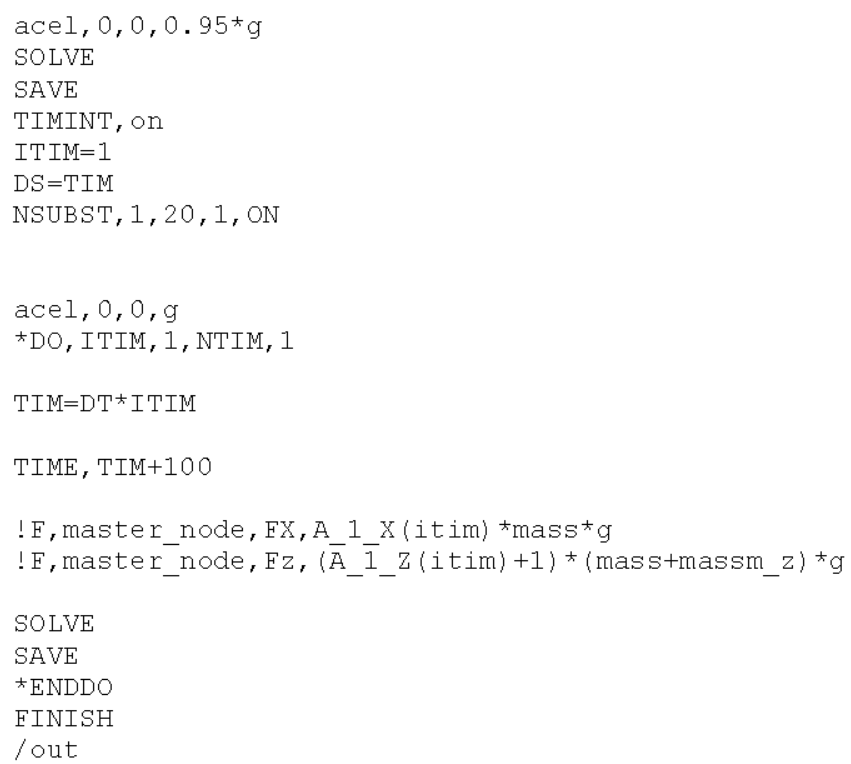

\section{Convective Mode Frequency Check}

\section{Run-Tank.txt}

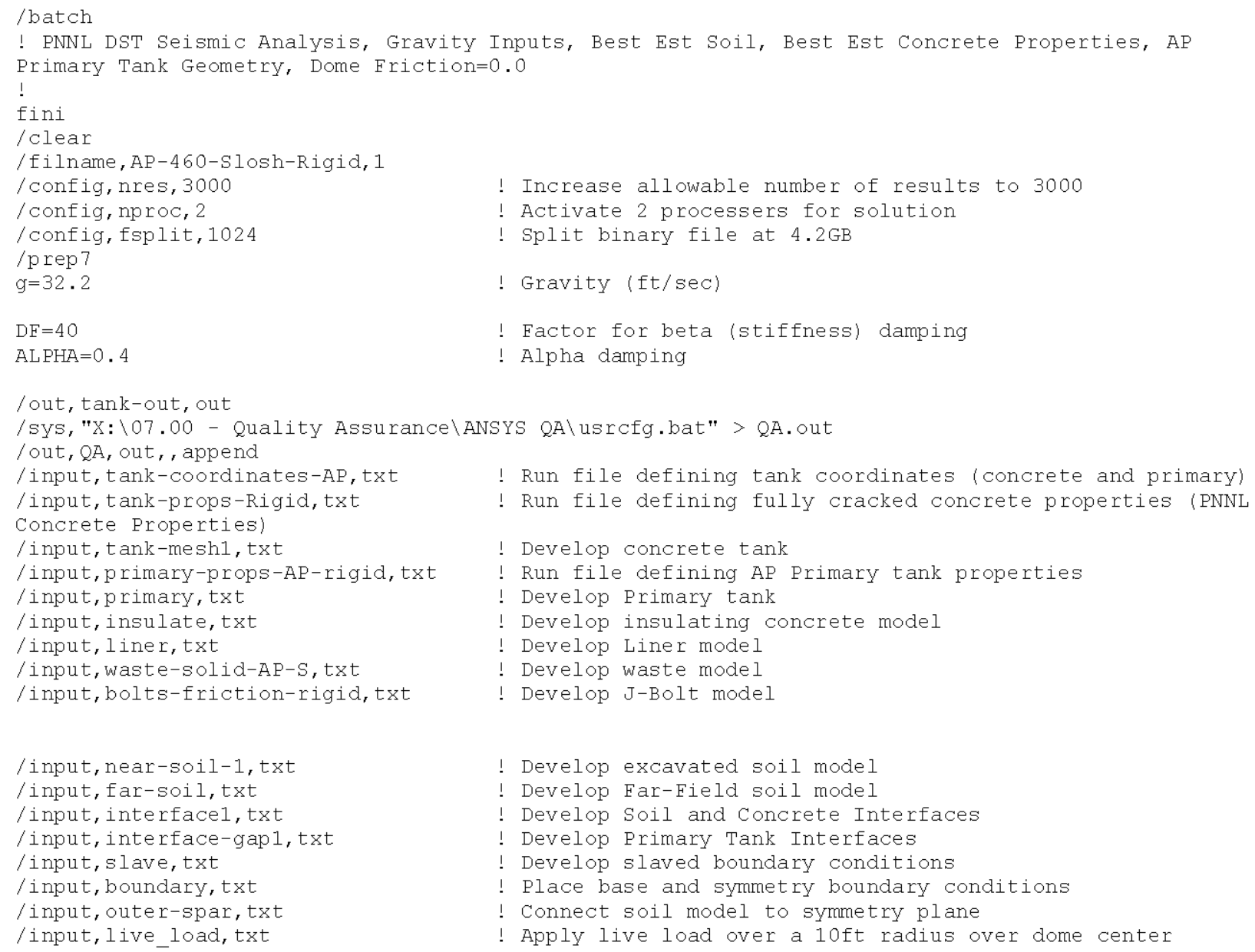


RPP-RPT-32239, Rev. 1

M\&D-2008-005-CALC-001, Rev. 1

/input, fix-soil, txt

lout

ALLSEL

lout, Tank-th, out

save

/input, solve-Slosh-rigid, txt

/ input, contact-waste-ap, txt

/input, waste-reaction, txt

lout

lexit

\section{Solve-Slosh-Rigid.txt}

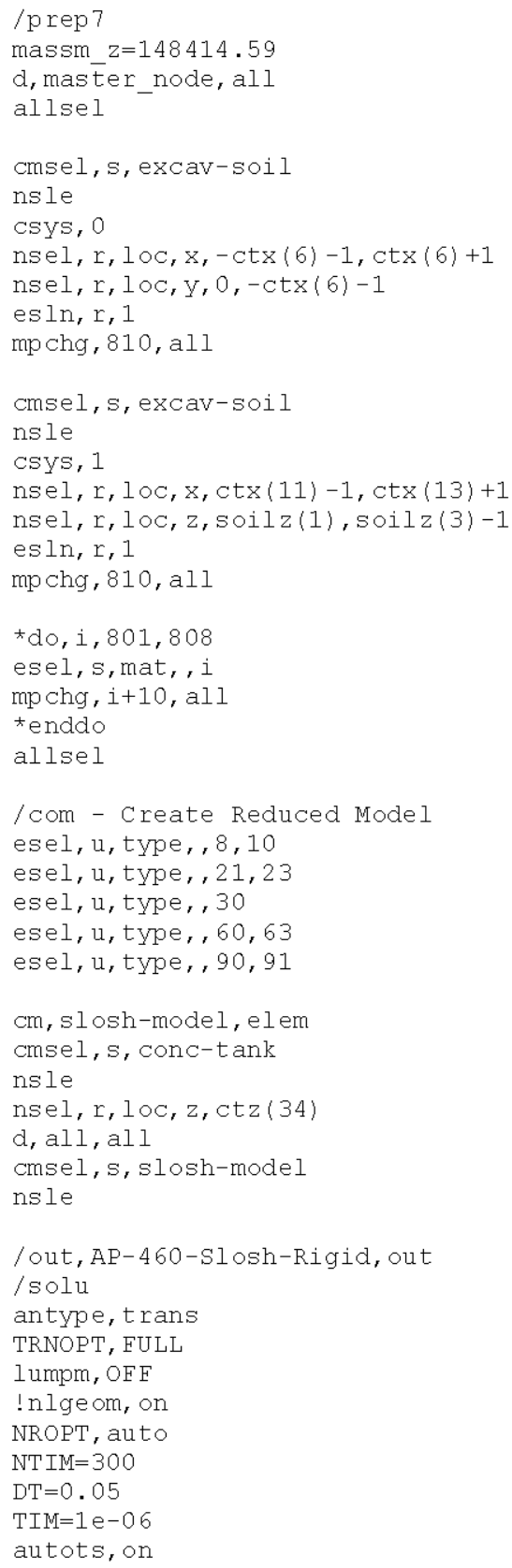


RPP-RPT-32239, Rev. 1

M\&D-2008-005-CALC-001, Rev. 1

$\mathrm{KBC}$, on

TIMINT, ON, STRU

solcontrol, on, off, ,

nenv, 0,200

LNSRCH, OFF

PRED, on, on

/COM - Time File

/COM - Dimension Horizontal Input

*DIM, A_1_x, 2048

${ }^{*}$ DIM, A $1-2,2048$

*VREAD, A_1_x(1), th-266-Mean-geo, txt

$(8(\mathrm{~F} 9.6))$

*VREAD, A_1_Z(1), th-266-Mean-geo-v, txt

$(8(\mathrm{~F} 9.6))$

/Title, Load Case: AP-460-BES-BEC, Gravity, Dome Friction =0.00, OUTPR, all, NONE,

OUTRES, ALL, NONE,

OUTRES, RSOL, last

OUTRES, NSOL, last

!OUTRES, ESOL, last, conc-tank

OUTRES, strs, last, Primary-tank

OUTRES, ESOL, last, J bolts

!OUTRES, Epel, last, Iiner

!outres, esol, last, wall-int-gap

!outres, esol, last, conc-excav-wall-gap

loutres, esol, last, conc-excav-dome-gap

!outres, strs, last, excav-soil

loutres, strs, last, bottom-soil

outres, esol, last, bolt-friction

outres, esol, last, waste-surf

outres, strs, last, insul-conc

outres, esol, last, primary-int-gap

outres, esol, last, conc-liner-gap

!outres, esol, last, far-soil-contact

!outres, esol, last, soil-contact-foot-elem

alphad, alpha

NSUBST, 20,200, 10, ON

TIME, 100

TIMINT, off

acel $, 0.08 * 9,0,9$

SOLVE

SAVE

TIMINT, on

ITIM $=1$

$\mathrm{DS}=\mathrm{TIM}$

NSUBST, $1,20,1$, ON

acel, 0, 0, g

${ }^{\star}$ DO , ITIM, 1 , NTIM, 1

$\mathrm{TIM}=\mathrm{DT} \mathrm{T}^{\star} \mathrm{ITIM}$

TIME, TIM+100

! , master_node, FX, A_1 X (itim) ${ }^{*}$ mass $^{\star} g$

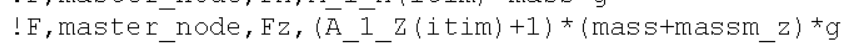

SOLVE

SAVE

*ENDDO

FINISH

lout 
RPP-RPT-32239, Rev. 1

M\&D-2008-005-CALC-001, Rev. 1

\section{TH-Sub-Model-h.txt}

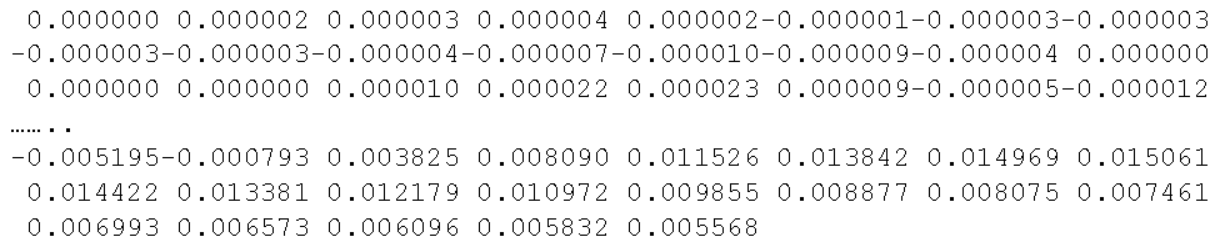

\section{TH-Sub-Model-v.txt}

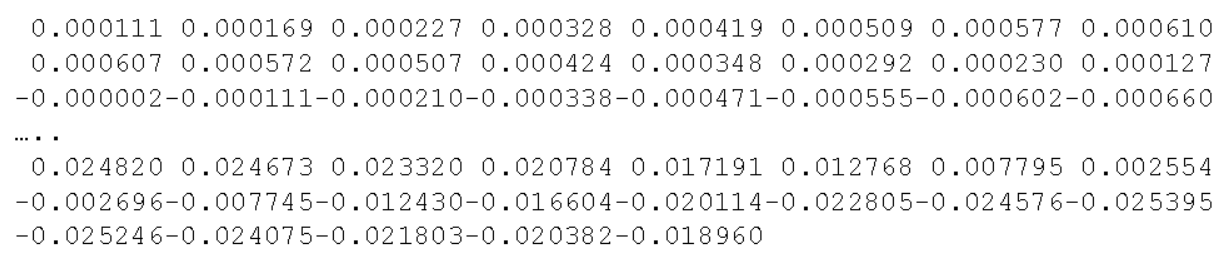


RPP-RPT-32239, Rev. 1

M\&D-2008-005-CALC-001, Rev. 1

\section{Appendix D}

\section{Sub-Model Best Estimate Soil, Best Estimate Concrete Results File Listing}


RPP-RPT-32239, Rev. 1

M\&D-2008-005-CALC-001, Rev. 1

Intentionally left blank 


\section{Sub-Model Best Estimate Soil, Best Estimate Concrete Results File Listing}

\section{Tables}

D.1 Sub-Model, Primary Tank Stresses, Shell Top, Gravity Plus Seismic Load, Horizontal and Vertical Excitation

D.2 Sub-Model, Primary Tank Stresses, Shell Middle, Gravity Plus Seismic Load, Horizontal and Vertical Excitation

D.3 Sub-Model, Primary Tank Stresses, Shell Bottom, Gravity Plus Seismic Load, Horizontal and Vertical Excitation

D.4 Sub-Model, Waste Contact Pressure, Gravity Plus Seismic, Horizontal and Vertical Excitation

D.5 Sub-Model, Primary Tank Stresses, Shell Top, Gravity Plus Seismic Load, Horizontal Excitation

D.6 Sub-Model, Primary Tank Stresses, Shell Middle, Gravity Plus Seismic Load, Horizontal Excitation.

D.7 Sub-Model, Primary Tank Stresses, Shell Bottom, Gravity Plus Seismic Load, Horizontal Excitation.

D.8 Sub-Model, Waste Contact Pressure, Gravity Plus Seismic, Horizontal Excitation.

D.9 Sub-Model, Primary Tank Stresses, Shell Top, Gravity Plus Seismic Load, Vertical Excitation

D.10 Sub-Model, Primary Tank Stresses, Shell Middle, Gravity Plus Seismic Load, Vertical Excitation

D.11 Sub-Model, Primary Tank Stresses, Shell Bottom, Gravity Plus Seismic Load, Vertical Excitation. 
RPP-RPT-32239, Rev. 1

M\&D-2008-005-CALC-001, Rev. 1

Table D.1. Sub-Model, Primary Tank Stresses, Shell Top, Gravity Plus Seismic Load, Horizontal and Vertical Excitation

AP Primary Tank Sub Model, Best Estimate Soil, Horizontal and Vertical Seismic, Best Estimate Tank Sub Model Concrete, 460 in. Waste Level at $1.83 \mathrm{SpG}$

\begin{tabular}{|c|c|c|c|c|c|}
\hline \multirow[b]{2}{*}{$\begin{array}{c}\text { M\&D } \\
\text { Starting } \\
\text { M\&D } \\
\text { Element } \\
\text { No. }\end{array}$} & \multirow[b]{2}{*}{ Path (in.) } & \multicolumn{4}{|c|}{ Shell Top Surface (inside - waste side) } \\
\hline & & $\begin{array}{c}\text { AP-460-Sub-H\&V } \\
\text { Seismic Hoop Stress } \\
\text { (Ibs/in^²) Top }\end{array}$ & $\begin{array}{c}\text { AP-460-Sub-H\&V } \\
\text { Seismic Meridional } \\
\text { Stress (lbs/in^2) Top }\end{array}$ & $\begin{array}{c}\text { AP-460-Sub-H\&V } \\
\text { Seismic Stress } \\
\text { Intensity (lbs/in^2) } \\
\text { Top }\end{array}$ & $\begin{array}{c}\text { AP-460-Sub-H\&V } \\
\text { Seismic In-Plane } \\
\text { Shear Stress } \\
(\text { lbs/in^2) Top }\end{array}$ \\
\hline 762 & 67.33 & 172.01 & -345.35 & 736.81 & 4.80 \\
\hline 782 & 105.04 & 16.38 & 764.58 & 773.61 & 8.23 \\
\hline 802 & 136.24 & 130.63 & -324.65 & 684.03 & 9.26 \\
\hline 822 & 181.83 & -202.71 & 464.38 & 80972 & 18.62 \\
\hline 842 & 225.10 & 197.22 & -434.72 & 909.03 & 58.49 \\
\hline 862 & 273.66 & -329.03 & 647.71 & 1204.17 & 179.03 \\
\hline 882 & 323.27 & 661.18 & -372.36 & 1365.28 & 523.06 \\
\hline 902 & 369.20 & 354.24 & 1581.25 & 3368.75 & 1376.39 \\
\hline 922 & 419.20 & 2385.42 & 497.29 & 601736 & 2769.44 \\
\hline 942 & 444.31 & -231181 & -5249.31 & 8291.67 & 2269.44 \\
\hline 962 & 458.66 & -3703.47 & 7250.00 & 12937.50 & 2174.31 \\
\hline 982 & 473.08 & -4763.89 & 7750.00 & 1495139 & 2160.42 \\
\hline 1002 & 484.80 & -298194 & 530.97 & 5456.94 & 2205.56 \\
\hline 1022 & 502.48 & 3696.53 & -648.61 & 5127.08 & 2192.36 \\
\hline 1042 & 526.48 & 7965.28 & 104653 & 7965.28 & 2064.58 \\
\hline 1062 & 550.48 & 10069.44 & 1206.94 & 10076.39 & 1885.42 \\
\hline 1082 & 574.60 & 12305.56 & 1463.89 & 12305.56 & 1672.92 \\
\hline 1102 & 598.28 & 14944.44 & 1178.47 & 1495139 & 1440.28 \\
\hline 1122 & 621.38 & 17312.50 & 1593.06 & 17312.50 & 1201.39 \\
\hline 1142 & 644.48 & 19555.56 & 1427.78 & 19555.56 & 932.64 \\
\hline 1162 & 667.63 & 20993.06 & 1006.94 & 20993.06 & 639.10 \\
\hline 1182 & 690.78 & 21305.56 & 1884.72 & 21305.56 & 288.40 \\
\hline 1202 & 713.88 & 22381.94 & 1505.56 & 22381.94 & 156.46 \\
\hline 1222 & 736.98 & 23861.11 & 870.14 & 23861.11 & 417.43 \\
\hline 1242 & 760.13 & 23347.22 & 381.04 & 23347.22 & 730.56 \\
\hline 1262 & 782.53 & 21173.61 & 2177.78 & 21173.61 & 755.56 \\
\hline 1282 & 804.13 & 2029861 & 1253.47 & 2029861 & 96111 \\
\hline 1302 & 825.73 & 21090.28 & 848.61 & 21090.28 & 1163.19 \\
\hline 1322 & 847.33 & 22736.11 & 1261.11 & 22736.11 & 1374.31 \\
\hline 1342 & 868.87 & 21993.06 & -1872.92 & 25590.28 & 1606.94 \\
\hline 1362 & 892.10 & 14291.67 & -1284.72 & 16222.22 & 1539.58 \\
\hline 1382 & 909.20 & 4289.58 & -813.89 & 6965.28 & 1484.03 \\
\hline 1402 & 918.38 & 4629.17 & 12270.83 & 12277.78 & 1496.53 \\
\hline 1460 & 930.48 & 2353.47 & 7513.89 & 7576.39 & 718.75 \\
\hline 1442 & 949.48 & -755.56 & -2779.86 & 3830.56 & 605.00 \\
\hline 1462 & 990.98 & 302.64 & 95972 & 965.28 & -36.31 \\
\hline 1482 & 1050.98 & -156.46 & -556.81 & 733.33 & 4753 \\
\hline 1502 & 1110.98 & 221.32 & 729.86 & 733.33 & -29.83 \\
\hline 1522 & 1170.98 & -137.71 & -51625 & 708.33 & 41.53 \\
\hline 1542 & 1230.98 & 199.38 & 684.72 & 687.92 & -31.23 \\
\hline 1562 & 1292.98 & -88.06 & -450.00 & 618.89 & 59.04 \\
\hline
\end{tabular}


RPP-RPT-32239, Rev. 1

M\&D-2008-005-CALC-001, Rev. 1

Table D.2. Sub-Model, Primary Tank Stresses, Shell Middle, Gravity Plus Seismic Load, Horizontal and Vertical Excitation

AP Primary Tank Sub Model, Best Estimate Soil, Horizontal and

Vertical Seismic, Best Estimate Tank Sub Model Concrete, 460

in. Waste Level at $1.83 \mathrm{SpG}$

\begin{tabular}{|c|c|c|c|c|c|}
\hline \multirow[b]{2}{*}{$\begin{array}{c}\text { M\&D } \\
\text { Starting } \\
\text { M\&D } \\
\text { Element } \\
\text { No. }\end{array}$} & \multirow[b]{2}{*}{ Path (in.) } & \multicolumn{4}{|c|}{ Shell Mid-Plane } \\
\hline & & $\begin{array}{c}\text { AP-460-Sub-H\&V } \\
\text { Seismic Hoop Stress } \\
\text { (lbs/in^2) Mid }\end{array}$ & $\begin{array}{l}\text { AP-460-Sub-H\&V } \\
\text { Seismic Meridional } \\
\text { Stress (lbs/in^2) Mid }\end{array}$ & $\begin{array}{c}\text { AP-460-Sub-H\&V } \\
\text { Seismic Stress } \\
\text { Intensity (lbs/in^2) } \\
\text { Mid }\end{array}$ & $\begin{array}{c}\text { AP-460-Sub-H\&V } \\
\text { Seismic In-Plane } \\
\text { Shear Stress } \\
\text { (lbs/in^2) Mid }\end{array}$ \\
\hline 762 & 67.33 & 332.64 & 45.22 & 333.33 & 5.94 \\
\hline 782 & 105.04 & -120.63 & 104.31 & 302.43 & 8.02 \\
\hline 802 & 136.24 & 326.88 & 128.47 & 329.58 & 9.27 \\
\hline 822 & 181.83 & -271.46 & 134.17 & 542.15 & 18.58 \\
\hline 842 & 225.10 & 417.71 & 202.57 & 426.18 & 58.26 \\
\hline 862 & 273.66 & -404.72 & 327.92 & 931.94 & 178.96 \\
\hline 882 & 323.27 & 932.64 & 550.28 & 1165.97 & 523.19 \\
\hline 902 & 369.20 & -470.07 & 946.53 & 3223.61 & 1375.69 \\
\hline 922 & 419.20 & 2729.86 & 130069 & 5913.89 & 2770.83 \\
\hline 942 & 444.31 & -454.10 & 1136.81 & 4988.89 & 2276.39 \\
\hline 962 & 458.66 & -4741.67 & 1056.94 & 8541.67 & 2187.50 \\
\hline 982 & 473.08 & -6043.06 & 1002.08 & 10180.56 & 2154.86 \\
\hline 1002 & 484.80 & -2661.81 & 939.58 & 5865.97 & 2178.47 \\
\hline 1022 & 502.48 & 4202.78 & 1001.39 & 4595.83 & 2168.06 \\
\hline 1042 & 526.48 & 8006.94 & 1121.53 & 8006.94 & 2053.47 \\
\hline 1062 & 550.48 & 10118.06 & 1238.89 & 10125.00 & 1878.47 \\
\hline 1082 & 574.60 & 12326.39 & 1339.58 & 12333.33 & 1665.97 \\
\hline 1102 & 598.28 & 14965.28 & 1425.69 & 14965.28 & 1433.33 \\
\hline 1122 & 621.38 & 17236.11 & 149722 & 17236.11 & 1195.83 \\
\hline 1142 & 644.48 & 19527.78 & 154792 & 19527.78 & 927.78 \\
\hline 1162 & 667.63 & 21104.17 & 1581.25 & 21104.17 & 638.75 \\
\hline 1182 & 690.78 & 21083.33 & 1395.83 & 21083.33 & 289.38 \\
\hline 1202 & 713.88 & 22270.83 & 1386.81 & 22270.83 & 150.76 \\
\hline 1222 & 736.98 & 23951.39 & 1362.50 & 2395139 & 416.60 \\
\hline 1242 & 760.13 & 23590.28 & 1318.75 & 23590.28 & 723.61 \\
\hline 1262 & 782.53 & 20694.44 & 920.83 & 20694.44 & 746.53 \\
\hline 1282 & 804.13 & 20111.11 & 866.67 & 2011111 & 959.72 \\
\hline 1302 & 825.73 & 21034.72 & 802.08 & 21034.72 & 1164.58 \\
\hline 1322 & 847.33 & 22548.61 & 727.08 & 22548.61 & 1377.08 \\
\hline 1342 & 868.87 & 23236.11 & 637.99 & 23236.11 & 1593.75 \\
\hline 1362 & 892.10 & 14979.17 & 463.19 & 14986.11 & 1501.39 \\
\hline 1382 & 909.20 & 4998.61 & 430.35 & 5109.72 & 1443.06 \\
\hline 1402 & 918.38 & 938.89 & 535.28 & 3014.58 & 1477.78 \\
\hline 1460 & 930.48 & 363.13 & 621.04 & 2371.53 & 1039.58 \\
\hline 1442 & 949.48 & 182.78 & 333.61 & 958.33 & 416.46 \\
\hline 1462 & 990.98 & 62.43 & 156.74 & 200.49 & 72.36 \\
\hline 1482 & 1050.98 & 3.44 & 6.33 & 39.64 & 12.40 \\
\hline 1502 & 1110.98 & 0.86 & 2.30 & 39.64 & 2.10 \\
\hline 1522 & 1170.98 & 0.34 & 2.35 & 44.50 & 0.20 \\
\hline 1542 & 1230.98 & 0.23 & 2.11 & 57.35 & 0.32 \\
\hline 1562 & 1292.98 & 0.07 & 1.65 & 95.00 & 0.27 \\
\hline
\end{tabular}

Note 1: Meridonal, Hoop, and Shear Stresses are Reversed in Highlighted Sections

(Floor) 
RPP-RPT-32239, Rev. 1

M\&D-2008-005-CALC-001, Rev. 1

Table D.3. Sub-Model, Primary Tank Stresses, Shell Bottom, Gravity Plus Seismic Load, Horizontal and Vertical Excitation

AP Primary Tank Sub Model, Best Estimate Soil, Horizontal and Vertical Seismic, Best Estimate Tank Sub Model Concrete, 460 in. Waste Level at 1.83 SpG

\begin{tabular}{|c|c|c|c|c|c|}
\hline \multirow[b]{2}{*}{$\begin{array}{c}\text { M\&D } \\
\text { Starting } \\
\text { M\&D } \\
\text { Element } \\
\text { No. }\end{array}$} & \multirow[b]{2}{*}{ Path (in.) } & \multicolumn{4}{|c|}{ Shell Bottom Surface (outside - away from waste) } \\
\hline & & $\begin{array}{c}\text { AP-460-Sub-H\&V } \\
\text { Seismic Hoop Stress } \\
\text { (Ibs/in^2) Bot }\end{array}$ & $\begin{array}{l}\text { AP-460-Sub-H\&V } \\
\text { Seismic Meridional } \\
\text { Stress (lbs/in^2) Bot }\end{array}$ & $\begin{array}{c}\text { AP-460-Sub-H\&V } \\
\text { Seismic Stress } \\
\text { Intensity (lbs/in^2) } \\
\text { Bot }\end{array}$ & $\begin{array}{c}\text { AP-460-Sub-H\&V } \\
\text { Seismic In-Plane } \\
\text { Shear Stress } \\
\text { (lbs/in^ } 2 \text { ) Bot }\end{array}$ \\
\hline 762 & 67.33 & 494.86 & 653.47 & 653.61 & 7.57 \\
\hline 782 & 105.04 & -242.08 & -346.04 & 582.57 & 788 \\
\hline 802 & 136.24 & 523.68 & 765.97 & 76667 & 9.28 \\
\hline 822 & 181.83 & -340.28 & -168.06 & 576.46 & 18.53 \\
\hline 842 & 225.10 & 683.13 & 1009.03 & 101181 & 58.05 \\
\hline 862 & 273.66 & -480.28 & 86.74 & 877.78 & 178.89 \\
\hline 882 & 323.27 & 1206.25 & 1542.36 & 1655.56 & 523.33 \\
\hline 902 & 369.20 & -607.01 & 506.18 & 3106.94 & 1375.00 \\
\hline 922 & 419.20 & 3073.61 & 2749.31 & 5907.64 & 2772.22 \\
\hline 942 & 444.31 & 2163.19 & 10465.28 & 10472.22 & 2283.33 \\
\hline 962 & 458.66 & -5780.56 & -3004.17 & 926389 & 2201.39 \\
\hline 982 & 473.08 & -7319.44 & -3680.56 & 11375.00 & 2149.31 \\
\hline 1002 & 484.80 & -2355.56 & 2975.00 & 6375.00 & 2150.69 \\
\hline 1022 & 502.48 & 4709.03 & 2770.83 & 4834.72 & 2143.75 \\
\hline 1042 & 526.48 & 8048.61 & 1204.17 & 8048.61 & 2043.06 \\
\hline 1062 & 550.48 & 10166.67 & 1270.83 & 10166.67 & 1871.53 \\
\hline 1082 & 574.60 & 12354.17 & 1253.47 & 12354.17 & 1659.03 \\
\hline 1102 & 598.28 & 15041.67 & 1672.92 & 1504861 & 1426.39 \\
\hline 1122 & 621.38 & 17222.22 & 1401.39 & 17229.17 & 1190.28 \\
\hline 1142 & 644.48 & 19555.56 & 1668.06 & 19555.56 & 923.61 \\
\hline 1162 & 667.63 & 21270.83 & 2155.56 & 21270.83 & 638.40 \\
\hline 1182 & 690.78 & 20937.50 & 906.94 & 20937.50 & 290.35 \\
\hline 1202 & 713.88 & 22243.06 & 1267.36 & 22243.06 & 147.29 \\
\hline 1222 & 736.98 & 24104.17 & 1854.86 & 24104.17 & 415.83 \\
\hline 1242 & 760.13 & 23875.00 & 2269.44 & 23875.00 & 715.97 \\
\hline 1262 & 782.53 & 20298.61 & -512.78 & 20861.11 & 73750 \\
\hline 1282 & 804.13 & 19972.22 & 482.92 & 19972.22 & 958.33 \\
\hline 1302 & 825.73 & 20979.17 & 755.56 & 20986.11 & 1166.67 \\
\hline 1322 & 847.33 & 22361.11 & 211.18 & 22361.11 & 1379.17 \\
\hline 1342 & 868.87 & 24479.17 & 4768.75 & 24479.17 & 1579.86 \\
\hline 1362 & 892.10 & 1566667 & 2659.03 & 1566667 & 1463.89 \\
\hline 1382 & 909.20 & 5747.22 & 3965.28 & 5768.06 & 1402.78 \\
\hline 1402 & 918.38 & -1927.78 & -7756.94 & 1127083 & 1459.03 \\
\hline 1460 & 930.48 & -139653 & -4703.47 & 6522.22 & 1359.72 \\
\hline 1442 & 949.48 & 1390.97 & 4424.31 & 4451.39 & 227.99 \\
\hline 1462 & 990.98 & -137.36 & -491.53 & 671.18 & 109.17 \\
\hline 1482 & 1050.98 & 233.40 & 763.89 & 733.33 & -29.88 \\
\hline 1502 & 1110.98 & -161.32 & -534.31 & 733.33 & 41.81 \\
\hline 1522 & 1170.98 & 211.25 & 705.56 & 708.33 & -30.12 \\
\hline 1542 & 1230.98 & -144.65 & -501.04 & 687.85 & 43.26 \\
\hline 1562 & 1292.98 & 160.14 & 615.76 & 618.96 & -40.85 \\
\hline
\end{tabular}


RPP-RPT-32239, Rev. 1

M\&D-2008-005-CALC-001, Rev. 1

Table D.4. Sub-Model, Waste Contact Pressure, Gravity Plus Seismic, Horizontal and Vertical Excitation

Tank AY, 460 Inch Waste Level

$\mathrm{SpG}=1.83$

Sub Model

Horizontal and Vertical Input

\begin{tabular}{|c|c|c|c|c|c|c|c|}
\hline $\begin{array}{l}\text { Waste } \\
\text { Height } \\
\text { Ratio }\end{array}$ & Waste Height & $\begin{array}{l}\text { Max Pressure } \\
\text { AP Tank, } 460 \text { in } \\
\text { Waste Level, } \\
\text { SpG }=1.83 \\
\text { Time History } \\
\text { (PSI) }\end{array}$ & $\begin{array}{c}\text { Min Pressure } \\
\text { AP Tank, } 460 \text { in } \\
\text { Waste Level, } \\
\text { SpG }=1.83 \\
\text { Time History } \\
\text { (PSI) }\end{array}$ & $\begin{array}{l}\text { Hydrostatic } \\
\text { (psi) }\end{array}$ & $\begin{array}{l}\text { Hydro- } \\
\text { dyanmic (psi) }\end{array}$ & $\begin{array}{l}\text { Theoretical } \\
\text { Min (SRSS) }\end{array}$ & $\begin{array}{l}\text { Theoretical } \\
\text { Max (SRSS) }\end{array}$ \\
\hline 0.99 & 454.35 & 8.931 & -7.708 & 0.37 & 1.65 & 0.00 & 2.02 \\
\hline 0.96 & 443.05 & 11.771 & -10.604 & 1.12 & 1.69 & 0.00 & 2.81 \\
\hline 0.94 & 431.7625 & 15.521 & -10.847 & 1.87 & 1.77 & 0.10 & 3.64 \\
\hline 0.90 & 414.125 & 9.882 & -4.788 & 3.03 & 195 & 1.08 & 4.98 \\
\hline 0.85 & 390.125 & 8.174 & 0.200 & 4.62 & 2.25 & 2.37 & 6.86 \\
\hline 0.80 & 366.125 & 9.833 & 1.484 & 6.20 & 2.56 & 3.64 & 8.76 \\
\hline 0.74 & 342 & 12.236 & 2.042 & 7.80 & 2.87 & 4.93 & 10.67 \\
\hline 0.69 & 318.325 & 14.771 & 2.693 & 9.36 & 3.16 & 6.20 & 12.52 \\
\hline 0.64 & 295.225 & 17.410 & 3.688 & 10.89 & 3.42 & 7.46 & 14.31 \\
\hline 0.59 & 272.125 & 19.118 & 4.612 & 12.41 & 3.67 & 8.75 & 16.08 \\
\hline 0.54 & 248.975 & 21.472 & 5.807 & 13.94 & 3.89 & 10.05 & 17.84 \\
\hline 0.49 & 225.825 & 23.438 & 6.951 & 15.47 & 4.10 & 11.37 & 19.57 \\
\hline 0.44 & 202.725 & 24.910 & 8.250 & 17.00 & 4.28 & 12.71 & 21.28 \\
\hline 0.39 & 179.625 & 26.979 & 9.674 & 18.53 & 4.45 & 14.08 & 22.98 \\
\hline 0.34 & 156.475 & 28.549 & 11.424 & 20.06 & 4.60 & 15.46 & 24.65 \\
\hline 0.29 & 134.075 & 29.396 & 12.750 & 21.54 & 4.72 & 16.82 & 26.25 \\
\hline 0.24 & 112.475 & 31.590 & 13.931 & 22.96 & 4.82 & 18.14 & 27.78 \\
\hline 0.20 & 90.875 & 32.028 & 15.785 & 24.39 & 4.90 & 19.49 & 29.29 \\
\hline 0.15 & 69.275 & 34.354 & 16.910 & 25.82 & 4.97 & 20.85 & 3078 \\
\hline 0.10 & 47.738 & 34.785 & 19.007 & 27.24 & 5.01 & 22.23 & 32.25 \\
\hline 0.05 & 24.500 & 37.458 & 18.868 & 28.78 & 5.05 & 23.73 & 33.82 \\
\hline 0.02 & 7.755 & 42.681 & 25.306 & 29.88 & 5.06 & 24.82 & 34.94 \\
\hline 0.00 & 1.755 & 37.979 & 25.389 & 30.28 & 5.06 & 25.22 & 35.34 \\
\hline
\end{tabular}


RPP-RPT-32239, Rev. 1

M\&D-2008-005-CALC-001, Rev. 1

Table D.5. Sub-Model, Primary Tank Stresses, Shell Top, Gravity Plus Seismic Load, Horizontal Excitation

AP Primary Tank Sub Model, Best Estimate Soil, Horizontal Seismic, Best Estimate Tank Sub Model Concrete, 460 in. Waste Level at $1.83 \mathrm{SpG}$

\begin{tabular}{|c|c|c|c|c|c|}
\hline \multirow[b]{2}{*}{$\begin{array}{c}\text { M\&D } \\
\text { Starting } \\
\text { M\&D } \\
\text { Element } \\
\text { No. }\end{array}$} & \multirow[b]{2}{*}{ Path (in.) } & \multicolumn{4}{|c|}{ Shell Top Surface (inside - waste side) } \\
\hline & & $\begin{array}{l}\text { AP-460-Sub-Horiz } \\
\text { Seismic Hoop Stress } \\
\text { (Ibs/in^2) Top }\end{array}$ & $\begin{array}{l}\text { AP-460-Sub-Horiz } \\
\text { Seismic Meridional } \\
\text { Stress (lbs/in^2) Top }\end{array}$ & $\begin{array}{l}\text { AP-460-Sub-Horiz } \\
\text { Seismic Stress } \\
\text { Intensity (lbs/in^2) } \\
\text { Top }\end{array}$ & $\begin{array}{c}\text { AP-460-Sub-Horiz } \\
\text { Seismic In-Plane } \\
\text { Shear Stress } \\
\text { (lbs/in^2) Top }\end{array}$ \\
\hline 762 & 67.33 & 158.89 & -407.57 & 679.03 & 4.77 \\
\hline 782 & 105.04 & 17.44 & 704.86 & 711.11 & 8.25 \\
\hline 802 & 136.24 & 129.17 & -383.54 & 635.00 & 9.18 \\
\hline 822 & 181.83 & -239.17 & 437.57 & 742.36 & 18.60 \\
\hline 842 & 225.10 & 196.60 & -509.79 & 845.14 & 58.50 \\
\hline 862 & 273.66 & -384.86 & 632.50 & 1143.06 & 179.31 \\
\hline 882 & 323.27 & 660.28 & -419.38 & 1403.47 & 523.96 \\
\hline 902 & 369.20 & -379.31 & 1373.61 & 3440.28 & 1379.17 \\
\hline 922 & 419.20 & 2379.17 & 493.54 & 6040.28 & 2776.39 \\
\hline 942 & 444.31 & -2761.81 & -6286.11 & 7861.11 & 2275.69 \\
\hline 962 & 458.66 & -438681 & 68.38 .19 & 1204861 & 2180.56 \\
\hline 982 & 473.08 & -5584.03 & 7770.83 & 1450694 & 2167.36 \\
\hline 1002 & 484.80 & -3424.31 & 574.10 & 5395.83 & 2213.19 \\
\hline 1022 & 502.48 & 353681 & -713.19 & 5273.61 & 220069 \\
\hline 1042 & 526.48 & 7979.17 & 1040.28 & 7979.17 & 2071.53 \\
\hline 1062 & 550.48 & 9979.17 & 1213.89 & 9986.11 & 1887.50 \\
\hline 1082 & 574.60 & 12138.89 & 1497.22 & 12138.89 & 1673.61 \\
\hline 1102 & 598.28 & 14513.89 & 1184.03 & 1452083 & 1440.28 \\
\hline 1122 & 621.38 & 16611.11 & 156111 & 1661111 & 1201.39 \\
\hline 1142 & 644.48 & 18652.78 & 1422.92 & 18652.78 & 932.64 \\
\hline 1162 & 667.63 & 19930.56 & 1013.19 & 19930.56 & 639.10 \\
\hline 1182 & 690.78 & 20083.33 & 1897.92 & 20083.33 & 287.64 \\
\hline 1202 & 713.88 & 2101389 & 1522.22 & 2101389 & 155.49 \\
\hline 1222 & 736.98 & 22458.33 & 858.33 & 22458.33 & 418.40 \\
\hline 1242 & 760.13 & 22013.89 & 387.64 & 22020.83 & 731.94 \\
\hline 1262 & 782.53 & 19986.11 & 2227.08 & 19986.11 & 75694 \\
\hline 1282 & 804.13 & 19222.22 & 1279.86 & 19222.22 & 961.81 \\
\hline 1302 & 825.73 & 20055.56 & 878.47 & 20055.56 & 1166.67 \\
\hline 1322 & 847.33 & 21736.11 & 1295.83 & 21736.11 & 1377.78 \\
\hline 1342 & 868.87 & 21069.44 & -2079.17 & 24611.11 & 1607.64 \\
\hline 1362 & 892.10 & 1345139 & -1385.42 & 14916.67 & 1538.89 \\
\hline 1382 & 909.20 & 3997.22 & -922.92 & 6783.33 & 1484.72 \\
\hline 1402 & 918.38 & 4131.25 & 11493.06 & 11500.00 & 1496.53 \\
\hline 1460 & 930.48 & 2144.44 & 6756.25 & 6777.78 & 720.83 \\
\hline 1442 & 949.48 & -818.75 & -3109.72 & 3440.97 & 604.44 \\
\hline 1462 & 990.98 & 268.06 & 846.53 & 847.22 & -37.59 \\
\hline 1482 & 1050.98 & -176.53 & -618.47 & 650.28 & 47.80 \\
\hline 1502 & 1110.98 & 196.53 & 647.15 & 650.28 & -33.24 \\
\hline 1522 & 1170.98 & -155.21 & -572.64 & 630.21 & 37.10 \\
\hline 1542 & 1230.98 & 177.22 & 603.61 & 606.74 & -35.14 \\
\hline 1562 & 1292.98 & -98.40 & -500.21 & 549.58 & 51.98 \\
\hline
\end{tabular}

Note 1: Meridonal, Hoop, and Shear Stresses are Reversed in Highlighted Sections (Floor) 
RPP-RPT-32239, Rev. 1

M\&D-2008-005-CALC-001, Rev. 1

Table D.6. Sub-Model, Primary Tank Stresses, Shell Middle, Gravity Plus Seismic Load, Horizontal Excitation

AP Primary Tank Sub Model, Best Estimate Soil, Horizontal Seismic, Best Estimate Tank Sub Model Concrete, 460 in. Waste Level at $1.83 \mathrm{SpG}$

\begin{tabular}{|c|c|c|c|c|c|}
\hline $\begin{array}{c}\text { M\&D } \\
\text { Starting } \\
\text { M\&D } \\
\text { Element } \\
\text { No. }\end{array}$ & Path (in.) & \multicolumn{4}{|c|}{ Shell Mid-Plane } \\
\hline 762 & 67.33 & 306.94 & 44.99 & 307.50 & 5.96 \\
\hline 782 & 105.04 & -141.67 & 103.33 & 277.71 & 8.06 \\
\hline 802 & 136.24 & 302.92 & 128.06 & 305.42 & 9.19 \\
\hline 822 & 181.83 & -321.53 & 134.10 & 496.32 & 18.56 \\
\hline 842 & 225.10 & 411.18 & 202.22 & 415.00 & 58.28 \\
\hline 942 & 444.31 & -530.56 & 1090.28 & 5025.00 & 2283.33 \\
\hline 962 & 458.66 & -5656.94 & 1063.89 & 8319.44 & 2194.44 \\
\hline 982 & 473.08 & -7125.00 & 988.19 & 9840.28 & 2161.81 \\
\hline 1002 & 484.80 & -304792 & 955.56 & 5886.11 & 2186.11 \\
\hline 1022 & 502.48 & 406736 & 1029.86 & 4757.64 & 217639 \\
\hline 1042 & 526.48 & 8013.89 & 1136.11 & 8013.89 & 2060.42 \\
\hline 1062 & 550.48 & 9986.11 & 1234.72 & 9993.06 & 1881.25 \\
\hline 1082 & 574.60 & 12090.28 & 1322.92 & 1209722 & 1666.67 \\
\hline 1102 & 598.28 & 14590.28 & 1406.94 & 14590.28 & 1433.33 \\
\hline 1122 & 621.38 & 16645.83 & 1475.69 & 16645.83 & 119583 \\
\hline 1142 & 644.48 & 18750.00 & 1525.00 & 18750.00 & 928.47 \\
\hline 1302 & 825.73 & 20041.67 & 806.25 & 20041.67 & 1167.36 \\
\hline 1322 & 847.33 & 21576.39 & 737.50 & 21576.39 & 1379.86 \\
\hline 1342 & 868.87 & 22333.33 & 652.57 & 22333.33 & 1593.75 \\
\hline 1362 & 892.10 & 14013.89 & 475.56 & 14020.83 & 1501.39 \\
\hline 1382 & 909.20 & 4393.75 & 444.44 & 4913.89 & 1443.75 \\
\hline 1402 & 918.38 & 902.78 & 547.15 & 3017.36 & 1477.78 \\
\hline 1460 & 930.48 & 375.56 & 618.54 & 2382.64 & 1038.89 \\
\hline 1442 & 949.48 & 18965 & 329.03 & 965.28 & 41729 \\
\hline 1462 & 990.98 & 63.21 & 140.76 & 204.79 & 72.43 \\
\hline 1482 & 1050.98 & 3.37 & 6.15 & 35.10 & 12.76 \\
\hline 1502 & 1110.98 & 0.88 & 2.30 & 35.10 & 2.12 \\
\hline 1522 & 1170.98 & 0.35 & 2.35 & 39.43 & 0.20 \\
\hline 1542 & 1230.98 & 0.24 & 2.11 & 50.93 & 0.32 \\
\hline 1562 & 1292.98 & 0.07 & 1.65 & 84.86 & 0.27 \\
\hline
\end{tabular}

Note 1: Meridonal, Hoop, and Shear Stresses are Reversed in Highlighted Sections (Floor) 
RPP-RPT-32239, Rev. 1

M\&D-2008-005-CALC-001, Rev. 1

Table D.7. Sub-Model, Primary Tank Stresses, Shell Bottom, Gravity Plus Seismic Load, Horizontal Excitation

AP Primary Tank Sub Model, Best Estimate Soil, Horizontal Seismic, Best Estimate Tank Sub Model Concrete, 460 in. Waste Level at $1.83 \mathrm{SpG}$

\begin{tabular}{|c|c|c|c|c|c|}
\hline \multirow[b]{2}{*}{$\begin{array}{c}\text { M\&D } \\
\text { Starting } \\
\text { M\&D } \\
\text { Element } \\
\text { No. }\end{array}$} & \multirow[b]{2}{*}{ Path (in.) } & \multicolumn{4}{|c|}{ Shell Bottom Surface (outside - away from waste) } \\
\hline & & $\begin{array}{c}\text { AP-460-Sub-Horiz } \\
\text { Seismic Hoop Stress } \\
\text { (lbs/in^2) Bot }\end{array}$ & $\begin{array}{l}\text { AP-460-Sub-Horiz } \\
\text { Seismic Meridional } \\
\text { Stress (lbs/in^^2) Bot }\end{array}$ & $\begin{array}{l}\text { AP-460-Sub-Horiz } \\
\text { Seismic Stress } \\
\text { Intensity (lbs/in^2) } \\
\text { Bot }\end{array}$ & $\begin{array}{c}\text { AP-460-Sub-Horiz } \\
\text { Seismic In-Plane } \\
\text { Shear Stress } \\
\text { (lbs/in^2) Bot }\end{array}$ \\
\hline 762 & 67.33 & 456.11 & 602.08 & 602.15 & 7.58 \\
\hline 782 & 105.04 & -285.35 & -40764 & 54771 & 791 \\
\hline 802 & 136.24 & 483.82 & 705.56 & 706.25 & 9.26 \\
\hline 822 & 181.83 & -403.96 & -193.54 & 550.76 & 18.52 \\
\hline 842 & 225.10 & 632.08 & 927.78 & 929.86 & 58.07 \\
\hline 862 & 273.66 & -565.49 & 80.97 & 859.03 & 179.10 \\
\hline 882 & 323.27 & 1200.00 & 1407.64 & 1658.33 & 524.24 \\
\hline 902 & 369.20 & -690.28 & 517.99 & 3134.03 & 1377.78 \\
\hline 922 & 419.20 & 3063.19 & 2502.78 & 5910.42 & 2779.17 \\
\hline 942 & 444.31 & 1963.89 & 9708.33 & 9715.28 & 2290.28 \\
\hline 962 & 458.66 & -6905.56 & -36.11 .11 & 8736.11 & 2207.64 \\
\hline 982 & 473.08 & -8673.61 & -4475.00 & 10861.11 & 2156.25 \\
\hline 1002 & 484.80 & -2664.58 & 283681 & 6459.72 & 2158.33 \\
\hline 1022 & 502.48 & 4597.92 & 2795.83 & 4989.58 & 2151.39 \\
\hline 1042 & 526.48 & 8048.61 & 1245.83 & 8048.61 & 2049.31 \\
\hline 1062 & 550.48 & 1000000 & 1256.25 & 10000.00 & 1874.31 \\
\hline 1082 & 574.60 & 12041.67 & 1229.17 & 12048.61 & 1660.42 \\
\hline 1102 & 598.28 & 14701.39 & 1637.50 & 14708.33 & 1426.39 \\
\hline 1122 & 621.38 & 16680.56 & 1390.97 & 16680.56 & 1190.28 \\
\hline 1142 & 644.48 & 18847.22 & 1641.67 & 18847.22 & 923.61 \\
\hline 1162 & 667.63 & 20409.72 & 2111.11 & 20409.72 & 638.33 \\
\hline 1182 & 690.78 & 19923.61 & 897.22 & 19923.61 & 289.72 \\
\hline 1202 & 713.88 & 21062.50 & 1250.00 & 21062.50 & 147.22 \\
\hline 1222 & 736.98 & 22777.78 & 1842.36 & 22777.78 & 416.60 \\
\hline 1242 & 760.13 & 22597.22 & 2234.72 & 22597.22 & 717.36 \\
\hline 1262 & 782.53 & 19222.22 & -573.68 & 19618.06 & 738.89 \\
\hline 1282 & 804.13 & 19000.00 & 473.26 & 19000.00 & 959.03 \\
\hline 1302 & 825.73 & 20027.78 & 742.36 & 20034.72 & 1168.06 \\
\hline 1322 & 847.33 & 21416.67 & 203.40 & 21416.67 & 1381.25 \\
\hline 1342 & 868.87 & 23597.22 & 4843.06 & 23597.22 & 1580.56 \\
\hline 1362 & 892.10 & 14583.33 & 2403.47 & 14583.33 & 1463.89 \\
\hline 1382 & 909.20 & 5115.28 & 3990.97 & 5611.11 & 1403.47 \\
\hline 1402 & 918.38 & -2222.92 & -9006.94 & 10479.17 & 1459.03 \\
\hline 1460 & 930.48 & -1565.28 & -523958 & 5862.50 & 1356.25 \\
\hline 1442 & 949.48 & 1240.28 & 3961.11 & 3965.28 & 230.21 \\
\hline 1462 & 990.98 & -155.83 & -540.28 & 611.04 & 109.17 \\
\hline 1482 & 1050.98 & 20875 & 678.61 & 653.26 & -33.12 \\
\hline 1502 & 1110.98 & -180.28 & -592.92 & 653.26 & 37.47 \\
\hline 1522 & 1170.98 & 187.36 & 623.26 & 626.18 & -33.87 \\
\hline 1542 & 1230.98 & -163.13 & -555.97 & 610.49 & 38.66 \\
\hline 1562 & 1292.98 & 143.96 & 542.78 & 546.39 & -47.18 \\
\hline
\end{tabular}

Note 1: Meridonal, Hoop, and Shear Stresses are Reversed in Highlighted Sections (Floor) 
RPP-RPT-32239, Rev. 1

M\&D-2008-005-CALC-001, Rev. 1

Table D.8. Sub-Mode1, Waste Contact Pressure, Gravity Plus Seismic, Horizontal Excitation

Tank AY, 460 Inch Waste Level

$\mathrm{SpG}=1.83$

Best Estimate Soil

Best Estimate Concrete

\begin{tabular}{|c|c|c|c|c|c|c|c|}
\hline $\begin{array}{l}\text { Waste } \\
\text { Height } \\
\text { Ratio }\end{array}$ & Waste Height & $\begin{array}{l}\text { Max Pressure } \\
\text { AP Tank, } 460 \text { in } \\
\text { Waste Level, } \\
\text { SpG =1.83 } \\
\text { Time History } \\
\text { (PSI) }\end{array}$ & $\begin{array}{l}\text { Min Pressure } \\
\text { AP Tank, } 460 \text { in } \\
\text { Waste Level, } \\
\text { SpG = 1.83 } \\
\text { Time History } \\
\text { (PSI) }\end{array}$ & $\left|\begin{array}{l}\text { Hydrostatic } \\
\text { (psi) }\end{array}\right|$ & $\begin{array}{l}\text { Hydrodynamic } \\
\text { (psi) }\end{array}$ & $\mid \begin{array}{l}\text { Theoretical } \\
\text { Min (SRSS) }\end{array}$ & \begin{tabular}{|l|} 
Theoretical \\
Max (SRSS)
\end{tabular} \\
\hline 099 & 454.35 & 8.847 & -7.722 & 0.37 & 1.65 & 0.00 & 2.02 \\
\hline 096 & 443.05 & 11.313 & -10.486 & 1.12 & 1.68 & 0.00 & 2.80 \\
\hline 094 & 431.7625 & 15.090 & -10.299 & 1.87 & 1.75 & 0.12 & 3.61 \\
\hline 0.90 & 414.125 & 10.326 & -4.045 & 3.03 & 1.90 & 1.13 & 4.93 \\
\hline 0.85 & 390.125 & 8.035 & 1.046 & 4.62 & 2.14 & 2.48 & 6.76 \\
\hline 0.80 & 366.125 & 9.757 & 2.586 & 6.20 & 2.39 & 3.81 & 8.59 \\
\hline 0.74 & 342 & 12.174 & 3.535 & 7.80 & 2.63 & 5.16 & 10.43 \\
\hline 0.69 & 318.325 & 14.188 & 4.442 & 9.36 & 2.85 & 6.51 & 12.21 \\
\hline 0.64 & 295.225 & 16.479 & 5.202 & 10.89 & 3.05 & 7.84 & 13.94 \\
\hline 0.59 & 272.125 & 18.174 & 6.298 & 12.41 & 3.23 & 9.19 & 15.64 \\
\hline 0.54 & 248.975 & 20.417 & 7.486 & 13.94 & 3.38 & 10.56 & 17.33 \\
\hline 0.49 & 225.825 & 22.444 & 8.743 & 15.47 & 3.52 & 11.95 & 19.00 \\
\hline 0.44 & 202.725 & 23.472 & 10.507 & 17.00 & 3.65 & 13.35 & 20.65 \\
\hline 0.39 & 179.625 & 25.208 & 11.882 & 18.53 & 3.76 & 14.77 & 22.28 \\
\hline 0.34 & 156.475 & 27.014 & 13.313 & 20.06 & 3.85 & 16.21 & 23.91 \\
\hline 0.29 & 134.075 & 28.174 & 15.014 & 21.54 & 3.93 & 17.61 & 25.46 \\
\hline 0.24 & 112.475 & 29.889 & 16.049 & 22.96 & 3.99 & 18.97 & 26.95 \\
\hline 0.20 & 90.875 & 30.764 & 17.785 & 24.39 & 4.04 & 20.35 & 28.43 \\
\hline 0.15 & 69.275 & 32.896 & 18.854 & 25.82 & 4.08 & 21.74 & 29.89 \\
\hline 0.10 & 47.738 & 33.333 & 21.014 & 27.24 & 4.11 & 23.13 & 31.35 \\
\hline 0.05 & 24.500 & 36.389 & 20.757 & 28.78 & 4.12 & 24.65 & 32.90 \\
\hline 0.02 & 7.755 & 41.014 & 29.222 & 29.88 & 4.13 & 25.75 & 34.01 \\
\hline 0.00[ & 1.755 & 36.958 & 29.472 & 30.28 & 4.13 & 26.15 & 34.41 \\
\hline
\end{tabular}


RPP-RPT-32239, Rev. 1

M\&D-2008-005-CALC-001, Rev. 1

Table D.9. Sub-Model, Primary Tank Stresses, Shell Top, Gravity Plus Seismic Load, Vertical Excitation

AP Primary Tank Sub Model, Best Estimate Soil, Vertical Seismic, Best Estimate Tank Sub Model Concrete, 460 in. Waste Level at $1.83 \mathrm{SpG}$

\begin{tabular}{|c|c|c|c|c|c|}
\hline \multirow[b]{2}{*}{$\begin{array}{c}\text { M\&D } \\
\text { Starting } \\
\text { M\&D } \\
\text { Element } \\
\text { No. }\end{array}$} & \multirow[b]{2}{*}{ Path (in.) } & \multicolumn{4}{|c|}{ Shell Top Surface (inside - waste side) } \\
\hline & & $\begin{array}{c}\text { AP-460-Sub-Vert } \\
\text { Seismic Hoop Stress } \\
\text { (lbs/in^2) Top }\end{array}$ & $\begin{array}{c}\text { AP-460-Sub-Vert } \\
\text { Seismic Meridional } \\
\text { Stress (lbs/in^2) Top }\end{array}$ & $\begin{array}{c}\text { AP-460-Sub-Vert } \\
\text { Seismic Stress } \\
\text { Intensity (lbs/in^2) } \\
\text { Top }\end{array}$ & $\begin{array}{c}\text { AP-460-Sub-Vert } \\
\text { Seismic In-Plane } \\
\text { Shear Stress } \\
\text { (lbs/in^2) Top }\end{array}$ \\
\hline 762 & 67.33 & \begin{tabular}{|c|}
168.75 \\
\end{tabular} & -34215 & 676.53 & 0.71 \\
\hline 782 & 105.04 & 1.10 & 698.61 & 700.00 & 0.23 \\
\hline 802 & 136.24 & 123.40 & -322.99 & 607.01 & 0.21 \\
\hline 822 & 181.83 & -202.43 & 439.17 & 743.06 & 0.17 \\
\hline 842 & 225.10 & 145.42 & -431.25 & 793.75 & 0.26 \\
\hline 862 & 273.66 & -329.17 & 627.78 & 1122.22 & 0.43 \\
\hline 882 & 323.27 & 428.40 & -370.69 & 989.58 & 1.05 \\
\hline 902 & 369.20 & -355.76 & 1543.06 & 2078.47 & 2.57 \\
\hline 922 & 419.20 & 1410.42 & -89.51 & 1575.00 & 8.15 \\
\hline 942 & 444.31 & -2302.08 & -5234.03 & 7840.28 & 8.32 \\
\hline 962 & 458.66 & -3687.50 & 6544.44 & 12020.83 & 8.83 \\
\hline 982 & 473.08 & -4757.64 & 7215.28 & 14131.94 & 12.32 \\
\hline 1002 & 484.80 & -2971.53 & -451.11 & 4197.22 & 12.44 \\
\hline 1022 & 502.48 & 2567.36 & -646.74 & 3440.97 & 12.85 \\
\hline 1042 & 526.48 & 6236.81 & 755.56 & 6236.81 & 12.85 \\
\hline 1062 & 550.48 & 8083.33 & 654.72 & 8083.33 & 9.90 \\
\hline 1082 & 574.60 & 10034.72 & 867.36 & 10034.72 & 16.76 \\
\hline 1102 & 598.28 & 12166.67 & 525.35 & 12166.67 & 13.84 \\
\hline 1122 & 621.38 & 14138.89 & 772.92 & 14138.89 & 13.56 \\
\hline 1142 & 644.48 & 16118.06 & 625.07 & 16118.06 & 13.40 \\
\hline 1162 & 667.63 & 17506.94 & 210.69 & 17506.94 & 12.72 \\
\hline 1182 & 690.78 & 17979.17 & 1061.81 & 17979.17 & 9.98 \\
\hline 1202 & 713.88 & 19180.56 & 731.94 & 19180.56 & 11.65 \\
\hline 1222 & 736.98 & 20805.56 & 147.36 & 20805.56 & 10.57 \\
\hline 1242 & 760.13 & 20652.18 & -201.53 & 21000.00 & 9.51 \\
\hline 1262 & 782.53 & 19006.94 & 1657.64 & 1900694 & 8.85 \\
\hline 1282 & 804.13 & 18493.06 & 800.69 & 18493.06 & 7.72 \\
\hline 1302 & 825.73 & 19479.17 & 444.58 & 19479.17 & 11.76 \\
\hline 1322 & 847.33 & 21270.83 & 927.08 & 2127083 & 9.82 \\
\hline 1342 & 868.87 & 20944.44 & -2313.19 & 24388.89 & 7.99 \\
\hline 1362 & 892.10 & 13881.94 & -1487.50 & 15881.94 & 9.10 \\
\hline 1382 & 909.20 & 4162.50 & -2091.67 & 6894.44 & 7.42 \\
\hline 1402 & 918.38 & 4571.53 & 11979.17 & 11993.06 & 7.23 \\
\hline 1460 & 930.48 & 233681 & 7493.06 & 7548.61 & -297.78 \\
\hline 1442 & 949.48 & -81111 & -2747.22 & 3827.08 & 219.72 \\
\hline 1462 & 990.98 & 301.25 & 959.03 & 963.89 & -40.04 \\
\hline 1482 & 1050.98 & -160.63 & -548.19 & 735.42 & 42.97 \\
\hline 1502 & 1110.98 & 221.11 & 731.94 & 735.42 & -30.06 \\
\hline 1522 & 1170.98 & -141.11 & -50875 & 710.42 & 41.44 \\
\hline 1542 & 1230.98 & 199.24 & 686.39 & 689.65 & -30.97 \\
\hline 1562 & 1292.98 & -89.72 & -444.10 & 620.42 & 58.71 \\
\hline
\end{tabular}

Note 1: Meridonal, Hoop, and Shear Stresses are Reversed in Highlighted Sections (Floor) 
RPP-RPT-32239, Rev. 1

M\&D-2008-005-CALC-001, Rev. 1

Table D.10. Sub-Model, Primary Tank Stresses, Shell Middle, Gravity Plus Seismic Load, Vertical Excitation

AP Primary Tank Sub Model, Best Estimate Soil, Vertical Seismic, Best Estimate Tank Sub Model Concrete, 460 in. Waste Level at $1.83 \mathrm{SpG}$

\begin{tabular}{|c|c|c|c|c|c|}
\hline $\begin{array}{c}\text { M\&D } \\
\text { Starting } \\
\text { M\&D } \\
\text { Element } \\
\text { No. }\end{array}$ & Path (in.) & \multicolumn{4}{|c|}{ Shell Mid-Plane } \\
\hline 762 & 67.33 & 312.78 & 39.80 & 313.26 & 0.40 \\
\hline 782 & 105.04 & -120.00 & 93.61 & 275.63 & 0.17 \\
\hline 802 & 136.24 & 300.14 & 109.58 & 302.29 & 0.16 \\
\hline 822 & 181.83 & -270.83 & 95.00 & 502.43 & 0.17 \\
\hline 842 & 225.10 & 384.93 & 147.01 & 390.97 & 0.25 \\
\hline 882 & 323.27 & 738.89 & 467.57 & 745.14 & 1.03 \\
\hline 902 & 369.20 & -484.79 & 912.50 & 1641.67 & 2.60 \\
\hline 922 & 419.20 & 1835.42 & 1255.56 & 1839.58 & 8.20 \\
\hline 942 & 444.31 & -451.94 & 1099.31 & 1788.89 & 8.48 \\
\hline 962 & 458.66 & -4718.75 & 991.67 & 8041.67 & 8.95 \\
\hline 982 & 473.08 & -6031.25 & 802.08 & 9673.61 & 11.58 \\
\hline 1002 & 484.80 & -2668.75 & 732.64 & 4481.94 & 11.53 \\
\hline 1022 & 502.48 & 3038.89 & 718.75 & 3039.58 & 11.47 \\
\hline 1042 & 526.48 & 6231.25 & 711.81 & 6231.25 & 11.59 \\
\hline 1062 & 550.48 & 8097.22 & 704.17 & 8097.22 & 8.77 \\
\hline 1082 & 574.60 & 998611 & 696.53 & 9986.11 & 14.81 \\
\hline 1102 & 598.28 & 12222.22 & 689.03 & 12222.22 & 12.33 \\
\hline 1122 & 621.38 & 14111.11 & 681.11 & 14111.11 & 11.69 \\
\hline 1142 & 644.48 & 16138.89 & 673.89 & 16138.89 & 11.84 \\
\hline 1162 & 667.63 & 17652.78 & 666.11 & 17652.78 & 11.44 \\
\hline 1182 & 690.78 & 17833.33 & 576.46 & 17833.33 & 8.78 \\
\hline 1202 & 713.88 & 19131.94 & 568.75 & 19131.94 & 9.56 \\
\hline 1222 & 736.98 & 20937.50 & 561.04 & 2093750 & 8.65 \\
\hline 1242 & 760.13 & 20923.61 & 553.61 & 2092361 & 1.99 \\
\hline 1262 & 782.53 & 18631.94 & 39708 & 18631.94 & 6.46 \\
\hline 1282 & 804.13 & 18368.06 & 389.93 & 18368.06 & 6.09 \\
\hline 1302 & 825.73 & 19465.28 & 382.78 & 19465.28 & 9.10 \\
\hline 1322 & 847.33 & 21104.17 & 375.76 & 21104.17 & 8.13 \\
\hline 1342 & 868.87 & 22083.33 & 368.82 & 22090.28 & 6.60 \\
\hline 1362 & 892.10 & 14569.44 & 305.90 & 14576.39 & 6.87 \\
\hline 1382 & 909.20 & 4953.47 & 311.32 & 5063.19 & 5.87 \\
\hline 1402 & 918.38 & 914.58 & 472.08 & 1013.89 & 6.89 \\
\hline 1460 & 930.48 & 199.24 & 518.96 & 802.08 & -20.92 \\
\hline 1442 & 949.48 & 125.14 & 320.49 & 351.39 & -17.01 \\
\hline 1462 & 990.98 & 55.91 & 156.74 & 160.49 & -8.33 \\
\hline 1482 & 1050.98 & 1.29 & 2.20 & 39.40 & 0.23 \\
\hline 1502 & 1110.98 & 0.11 & 0.21 & 39.40 & 0.04 \\
\hline 1522 & 1170.98 & 0.07 & 0.06 & 44.22 & 0.01 \\
\hline 1542 & 1230.98 & 0.04 & 0.03 & 56.96 & 0.00 \\
\hline 1562 & 1292.98 & 0.02 & 0.02 & 94.44 & 0.00 \\
\hline
\end{tabular}

Note 1: Meridonal, Hoop, and Shear Stresses are Reversed in Highlighted Sections

(Floor) 
RPP-RPT-32239, Rev. 1

M\&D-2008-005-CALC-001, Rev. 1

Table D.11. Sub-Model, Primary Tank Stresses, Shell Bottom, Gravity Plus Seismic Load, Vertical Excitation

\section{AP Primary Tank Sub Model, Best Estimate Soil, Vertical Seismic, Best Estimate Tank Sub Model Concrete, 460 in. Waste Level at $1.83 \mathrm{SpG}$}

\begin{tabular}{|c|c|c|c|c|c|}
\hline \multirow[b]{2}{*}{$\begin{array}{c}\text { M\&D } \\
\text { Starting } \\
\text { M\&D } \\
\text { Element } \\
\text { No. }\end{array}$} & \multirow[b]{2}{*}{ Path (in.) } & \multicolumn{4}{|c|}{ Shell Bottom Surface (outside - away from waste) } \\
\hline & & $\begin{array}{c}\text { AP-460-Sub-Vert } \\
\text { Seismic Hoop Stress } \\
\text { (lbs/in^2) Bot }\end{array}$ & $\begin{array}{c}\text { AP-460-Sub-Vert } \\
\text { Seismic Meridional } \\
\text { Stress (lbs/in^2) Bot }\end{array}$ & $\begin{array}{c}\text { AP-460-Sub-Vert } \\
\text { Seismic Stress } \\
\text { Intensity (lbs/in^2) } \\
\text { Bot }\end{array}$ & $\begin{array}{l}\text { AP-460-Sub-Vert } \\
\text { Seismic In-Plane } \\
\text { Shear Stress } \\
\text { (lbs/in^2) Bot }\end{array}$ \\
\hline 762 & 67.33 & 459.31 & 588.19 & 588.26 & 0.57 \\
\hline 782 & 105.04 & -239.72 & -342.71 & 512.22 & 0.29 \\
\hline 802 & 136.24 & 477.01 & 702.08 & 702.78 & 0.16 \\
\hline 822 & 181.83 & -339.24 & -166.67 & 509.31 & 0.20 \\
\hline 842 & 225.10 & 624.44 & 940.28 & 941.67 & 0.26 \\
\hline 862 & 273.66 & -479.10 & -74.10 & 722.22 & 0.40 \\
\hline 882 & 323.27 & 1049.31 & 1489.58 & 1493.75 & 1.00 \\
\hline 902 & 369.20 & -614.03 & 281.18 & 1207.64 & 2.62 \\
\hline 922 & 419.20 & 2261.11 & 2645.83 & 2649.31 & 8.26 \\
\hline 942 & 444.31 & 2096.53 & 10027.78 & 10034.72 & 8.63 \\
\hline 962 & 458.66 & -5751.39 & -2992.36 & 8625.00 & 9.08 \\
\hline 982 & 473.08 & -7305.56 & -3677.78 & 10805.56 & 10.84 \\
\hline 1002 & 484.80 & -2359.72 & 2282.64 & 5568.75 & 10.89 \\
\hline 1022 & 502.48 & 3511.11 & 2358.33 & 3511.11 & 10.16 \\
\hline 1042 & 526.48 & 6225.69 & 675.90 & 6225.69 & 10.59 \\
\hline 1062 & 550.48 & 8111.11 & 763.19 & 8111.11 & 7.76 \\
\hline 1082 & 574.60 & 9951.39 & 536.18 & 995139 & 12.86 \\
\hline 1102 & 598.28 & 12270.83 & 855.56 & 12270.83 & 10.81 \\
\hline 1122 & 621.38 & 14083.33 & 594.79 & 14083.33 & 9.83 \\
\hline 1142 & 644.48 & 16152.78 & 731.25 & 1615278 & 10.34 \\
\hline 1162 & 667.63 & 17798.61 & 1155.56 & 17798.61 & 10.17 \\
\hline 1182 & 690.78 & 17694.44 & 112.71 & 17694.44 & 7.57 \\
\hline 1202 & 713.88 & 19083.33 & 407.29 & 19083.33 & 7.47 \\
\hline 1222 & 736.98 & 21069.44 & 1002.08 & 21069.44 & 6.74 \\
\hline 1242 & 760.13 & 21194.44 & 1450.69 & 21194.44 & 7.15 \\
\hline 1262 & 782.53 & 18256.94 & -546.81 & 19118.06 & 4.41 \\
\hline 1282 & 804.13 & 18250.00 & 10.06 & 18270.83 & 4.57 \\
\hline 1302 & 825.73 & 19444.44 & 324.17 & 19444.44 & 6.68 \\
\hline 1322 & 847.33 & 2093750 & -136.04 & 2111111 & 6.79 \\
\hline 1342 & 868.87 & 23229.17 & 4181.25 & 23229.17 & 5.83 \\
\hline 1362 & 892.10 & 15263.89 & 2604.17 & 15263.89 & 5.44 \\
\hline 1382 & 909.20 & 5744.44 & 3346.53 & 5758.33 & 5.45 \\
\hline 1402 & 918.38 & -1943.75 & -7798.61 & 11048.61 & 6.55 \\
\hline 1460 & 930.48 & -1403.47 & -4665.97 & 6513.19 & 364.03 \\
\hline 1442 & 949.48 & 1379.86 & 4419.44 & 4440.28 & -179.31 \\
\hline 1462 & 990.98 & -140.69 & -483.47 & 672.15 & 41.66 \\
\hline 1482 & 1050.98 & 232.78 & 765.28 & 735.42 & -31.04 \\
\hline 1502 & 1110.98 & -159.10 & -526.53 & 735.42 & 41.78 \\
\hline 1522 & 1170.98 & 21090 & 706.94 & 710.42 & -29.82 \\
\hline 1542 & 1230.98 & -143.26 & -493.89 & 689.58 & 43.05 \\
\hline 1562 & 1292.98 & 160.49 & 617.22 & 620.42 & -42.18 \\
\hline
\end{tabular}

Note 1: Meridonal, Hoop, and Shear Stresses are Reversed in Highlighted Sections (Floor) 
RPP-RPT-32239, Rev. 1

M\&D-2008-005-CALC-001, Rev. 1

Table D.12. Sub-Model, Waste Contact Pressure, Gravity Plus Seismic, Vertical Excitation

Tank AY, 460 Inch Waste Level

$\mathrm{SpG}=1.83$

Sub-Model Vertical

\begin{tabular}{|c|c|c|c|c|c|c|c|}
\hline $\begin{array}{l}\text { Waste } \\
\text { Height } \\
\text { Ratio }\end{array}$ & Waste Height & $\begin{array}{l}\text { Max Pressure } \\
\text { AP Tank, } 460 \text { in } \\
\text { Waste Level, } \\
\text { SpG }=1.83 \\
\text { Time History } \\
\text { (PSI) }\end{array}$ & $\begin{array}{c}\text { Min Pressure } \\
\text { AP Tank, } 460 \text { in } \\
\text { Waste Level, } \\
\text { SpG }=1.83 \\
\text { Time History } \\
\text { (PSI) }\end{array}$ & $\mid \begin{array}{l}\text { Hydrostatic } \\
\text { (psi) }\end{array}$ & $\begin{array}{l}\text { Hydrodynami } \\
\text { c (psi) }\end{array}$ & $\mid \begin{array}{l}\text { Theoretical } \\
\text { Min (SRSS) }\end{array}$ & $\begin{array}{l}\text { Theoretical } \\
\text { Max (SRSS) }\end{array}$ \\
\hline 0.99 & 454.35 & 0805 & 0.191 & 0.37 & 0.06 & 0.32 & 0.43 \\
\hline 0.96 & 443.05 & 1.632 & -0.566 & 1.12 & 0.17 & 0.95 & 1.29 \\
\hline 0.94 & 431.7625 & 4.026 & 0.599 & 1.87 & 0.28 & 1.58 & 2.15 \\
\hline 0.90 & 414.125 & 4.615 & 1.868 & 3.03 & 0.46 & 2.58 & 3.49 \\
\hline 0.85 & 390.125 & 6.233 & 3.053 & 4.62 & 0.69 & 3.93 & 5.31 \\
\hline 0.80 & 366.125 & 7.944 & 4.492 & 6.20 & 0.92 & 5.28 & 7.12 \\
\hline 0.74 & 342 & 10.014 & 5.637 & 7.80 & 1.14 & 6.65 & 8.94 \\
\hline 0.69 & 318.325 & 11.979 & 6.735 & 9.36 & 1.36 & 8.00 & 10.72 \\
\hline 0.64 & 295.225 & 13.938 & 7.944 & 10.89 & 1.56 & 9.33 & 12.44 \\
\hline 0.59 & 272.125 & 15.750 & 9.181 & 12.41 & 175 & 10.67 & 14.16 \\
\hline 0.54 & 248.975 & 17.771 & 10.424 & 13.94 & 1.93 & 12.02 & 15.87 \\
\hline 0.49 & 225.825 & 19.701 & 11.688 & 15.47 & 2.09 & 13.38 & 17.57 \\
\hline 0.44 & 202.725 & 21.417 & 12.938 & 17.00 & 2.25 & 14.75 & 19.25 \\
\hline 0.39 & 179.625 & 23.264 & 14.292 & 18.53 & 2.39 & 16.14 & 20.91 \\
\hline 0.34 & 156.475 & 25.153 & 15.639 & 20.06 & 2.51 & 17.54 & 22.57 \\
\hline 0.29 & 134.075 & 26.861 & 17.056 & 21.54 & 2.62 & 18.92 & 24.15 \\
\hline 0.24 & 112.475 & 28.458 & 18.361 & 22.96 & 2.71 & 20.26 & 25.67 \\
\hline 0.20 & 90.875 & 30.083 & 19.750 & 24.39 & 2.78 & 21.61 & 27.17 \\
\hline 0.15 & 69.275 & 31.736 & 21.007 & 25.82 & 2.84 & 22.98 & 28.65 \\
\hline 0.10 & 47.738 & 33.424 & 22.438 & 27.24 & 2.88 & 24.36 & 30.12 \\
\hline 0.05 & 24.500 & 34.701 & 23.799 & 28.78 & 2.91 & 25.87 & 31.68 \\
\hline 0.02 & 7.755 & 36.896 & 25.417 & 29.88 & 2.92 & 26.96 & 32.80 \\
\hline 0.00 & 1.755 & 36.243 & 25.313 & 30.28 & 2.92 & 27.36 & 33.20 \\
\hline
\end{tabular}




\section{RPP-RPT-32239, Rev. 1 \\ M\&D-2008-005-CALC-001, Rev. 1}

\section{Sub-Model File Listing, Horizontal and Vertical Excitation}

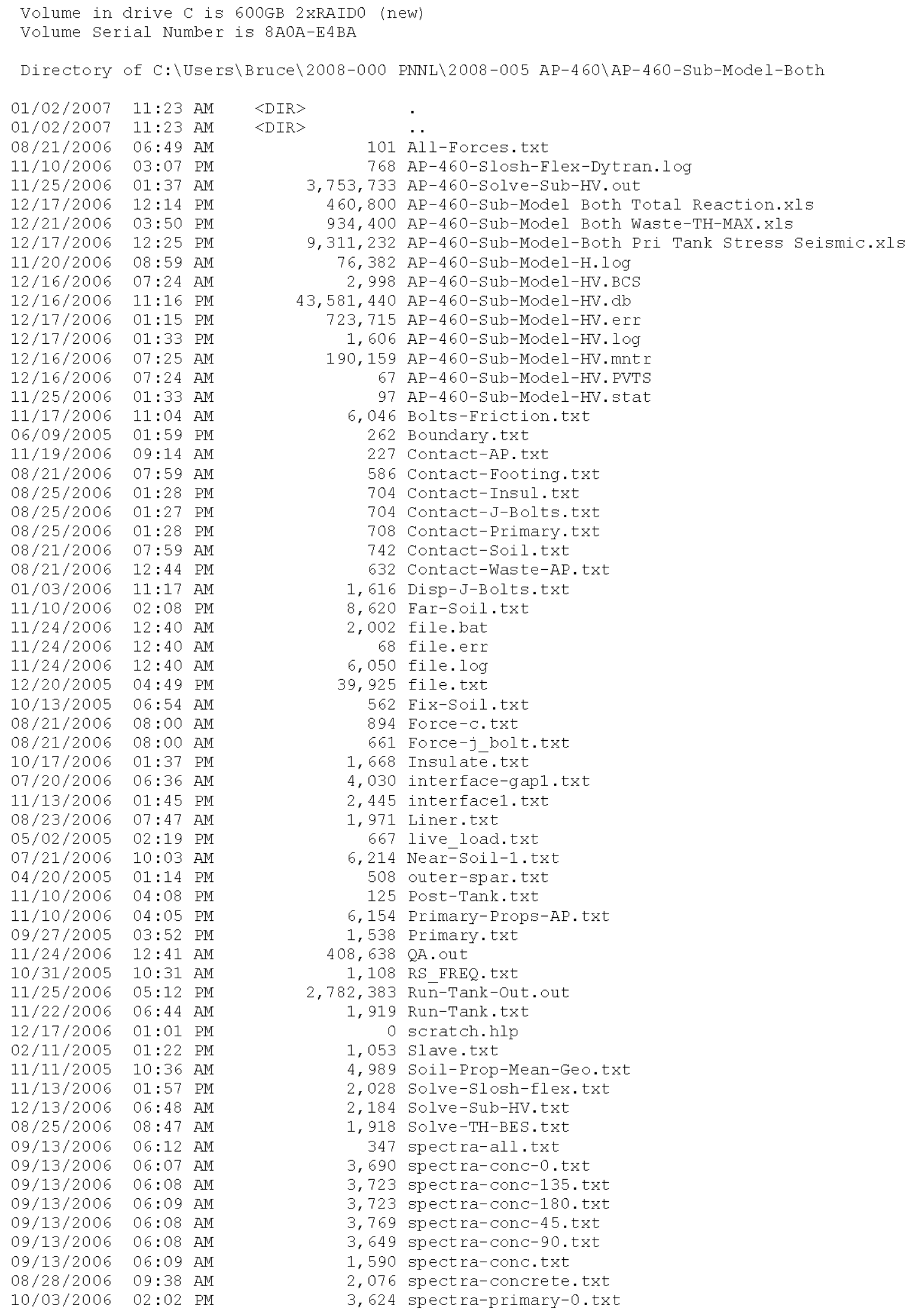




\section{RPP-RPT-32239, Rev. 1 M\&D-2008-005-CALC-001, Rev. 1}

$10 / 03 / 2006$ $09 / 13 / 2006$ $10 / 03 / 2006$ $10 / 03 / 2006$ $09 / 13 / 2006$ $06 / 20 / 2005$ $06 / 20 / 2005$ $12 / 17 / 2006$ $12 / 17 / 2006$ $12 / 17 / 2006$ $12 / 17 / 2006$ $12 / 17 / 2006$ $12 / 17 / 2006$ $09 / 05 / 2006$ $08 / 21 / 2006$ $08 / 16 / 2006$ $08 / 21 / 2006$ $08 / 21 / 2006$ $08 / 16 / 2006$ $08 / 21 / 2006$ $08 / 21 / 2006$ $08 / 16 / 2006$ $08 / 21 / 2006$ $08 / 21 / 2006$ $01 / 05 / 2006$ $08 / 21 / 2006$ $08 / 16 / 2006$ $08 / 16 / 2006$ $08 / 16 / 2006$ $08 / 21 / 2006$ $08 / 21 / 2006$ $08 / 21 / 2006$ $08 / 21 / 2006$ $08 / 21 / 2006$ $08 / 24 / 2006$ $08 / 17 / 2006$ $08 / 24 / 2006$ $12 / 16 / 2006$ $12 / 16 / 2006$ $12 / 16 / 2006$ $12 / 16 / 2006$ $12 / 16 / 2006$ $12 / 16 / 2006$ $12 / 16 / 2006$ $12 / 16 / 2006$ $12 / 16 / 2006$ $12 / 16 / 2006$ $12 / 16 / 2006$ $12 / 16 / 2006$ $12 / 16 / 2006$ $12 / 16 / 2006$ $12 / 16 / 2006$ $12 / 16 / 2006$ $12 / 16 / 2006$ $12 / 16 / 2006$ $12 / 16 / 2006$ $12 / 16 / 2006$ $12 / 16 / 2006$ $12 / 16 / 2006$ $12 / 16 / 2006$ $12 / 16 / 2006$ $12 / 16 / 2006$ $12 / 16 / 2006$ $12 / 16 / 2006$ $12 / 16 / 2006$ $12 / 16 / 2006$ $12 / 16 / 2006$ $12 / 16 / 2006$ $12 / 16 / 2006$ $12 / 16 / 2006$ $12 / 16 / 2006$
02:04 PM $06: 15 \mathrm{AM}$ 02:03 PM 02:03 PM $06: 15$ AM 09:04 AM $08: 52$ AM $12: 22 \mathrm{PM}$ $12: 22$ PM $12: 22 \mathrm{PM}$ $12: 23 \mathrm{PM}$ $12: 23 \mathrm{PM}$ $12: 23 \mathrm{PM}$ $02: 00$ PM 08:01 AM 01:59 PM 08:01 AM 08:02 AM 02:00 PM $08: 01$ AM 08:02 AM 02:00 PM 08:02 AM 08:02 AM $03: 14$ PM $08: 02$ AM 03:01 PM 02:01 PM $02: 19 \mathrm{PM}$ $08: 02$ AM 08:02 AM 08:03 AM 08:03 AM $08: 03$ AM 03:19 PM $11: 19$ AM $12: 05 \mathrm{PM}$ $09: 38$ PM $05: 30 \mathrm{PM}$ $01: 22 \mathrm{PM}$ $09: 38$ PM 05:30 PM $01: 22$ PM 09:50 PM $05: 42$ PM $01: 34 \mathrm{PM}$ 09:50 PM $05: 42 \mathrm{PM}$ $01: 34 \mathrm{PM}$ 10:02 PM 05:55 PM $01: 47 \mathrm{PM}$ 10:02 PM $05: 55$ PM $01: 47 \mathrm{PM}$ $10: 15 \mathrm{PM}$ 06:07 PM $01: 59 \mathrm{PM}$ 10:15 PM 06:07 PM $01: 59 \mathrm{PM}$ 10:27 PM $06: 19$ PM $02: 12 \mathrm{PM}$ $10: 27$ PM 06:19 PM $02: 12 \mathrm{PM}$ 10:39 PM $06: 32 \mathrm{PM}$ $02: 24 \mathrm{PM}$ $10: 39 \mathrm{PM}$
3,777 spectra-primary-135.txt

3,777 spectra-primary-180.txt

3,703 spectra-primary -45 .txt

3,703 spectra-primary-90.txt

3,801 spectra-soil.txt

647 spectra-wall.txt

679 spectra-waste.txt

279,040 str-comp 0-90b.xls

284,160 str-comp-0-90m.xls

279,040 str-comp 0-90t.xls

279,040 str-comp_99-180b.xls

284,160 str-comp_99-180m.xls

279,040 str-comp 99-180t.xls

2,588 strain-backed. txt

566 strain-compb-p.txt

621 strain-compb-primary.txt

693 strain-compb.txt

566 strain-compm-p.txt

621 strain-compm-primary.txt

705 strain-compm.txt

578 strain-compt-p.txt

621 strain-compt-primary.txt

720 strain-compt.txt

730 Strain-Liner-floor.txt

550 Strain-Liner-p.txt

962 Strain-Liner-wall.txt

545 Strain-Liner.txt

292 Strain-Primary.txt

273 strain.txt

554 stress-compb-p.txt

598 stress-compb.txt

554 stress-compm-p.txt

608 stress-compm.txt

554 stress-compt-p.txt

598 stress-compt.txt

207 Stress-Primary-M.txt

224 Stress-Primary.txt

13,519 Stress-pt_108max-b.OUT

13,519 Stress-pt $108 \mathrm{max}-\mathrm{m}$. OUT

13,519 Stress-pt $108 \mathrm{max}-\mathrm{t}$.OUT

$6,143,768$ stress-pt ${ }^{-} 108 \mathrm{th}-\mathrm{b}$. OUT

$6,143,768$ stress-pt 108 th-m.OUT

$6,115,040$ Stress-pt $108 \mathrm{th}-\mathrm{t}$. OUT

13,519 Stress-pt $117 \mathrm{max}-\mathrm{b}$.OUT

13,519 Stress-pt_117max-m.OUT

13,519 stress-pt $117 \mathrm{max}-t$.OUT

$6,143,768$ stress-pt_117th-b.OUT

$6,143,768$ stress-pt $117 \mathrm{th}-\mathrm{m}$.OUT

$6,115,040$ stress-pt_117th-t.OUT

13,519 Stress-pt $126 \mathrm{max}-\mathrm{b}$.OUT

13,519 stress-pt $126 \mathrm{max}-\mathrm{m}$. OUT

13,519 stress-pt $126 \mathrm{max}-\mathrm{t}$.OUT

$6,143,768$ stress-pt $126 \mathrm{th}-\mathrm{b}$. OUT

$6,143,768$ stress-pt $126 \mathrm{th}-\mathrm{m}$. OUT

6,115,040 stress-pt 126th-t.OUT

13,519 Stress-pt_135max-b.OUT

13,519 stress-pt 135max-m.OUT

13,519 Stress-pt_135max-t.OUT

$6,143,768$ Stress-pt $135 \mathrm{th}-\mathrm{b}$. OUT

$6,143,768$ Stress-pt $135 \mathrm{th}-\mathrm{m}$. OUT

$6,115,040$ stress-pt $135 \mathrm{th}-\mathrm{t}$. OUT

13,519 Stress-pt_144max-b.OUT

13,519 stress-pt $144 \mathrm{max}-\mathrm{m}$. OUT

13,519 Stress-pt $144 \mathrm{max}-t$.OUT

$6,143,768$ stress-pt_144th-b. OUT

$6,143,768$ stress-pt 144 th-m. OUT

$6,115,040$ stress-pt_144th-t.OUT

13,519 Stress-pt 153max-b. OUT

13,519 Stress-pt_153max-m.OUT

13,519 Stress-pt $153 \mathrm{max}-t$.OUT

$6,143,768$ stress-pt_153th-b.OUT 


\section{RPP-RPT-32239, Rev. 1 M\&D-2008-005-CALC-001, Rev. 1}

12/16/2006 06:32 PM $12 / 16 / 2006 \quad 02: 24 \mathrm{PM}$ $12 / 16 / 2006 \quad 10: 52 \mathrm{PM}$ 12/16/2006 06:44 PM $12 / 16 / 2006 \quad 02: 37 \mathrm{PM}$ $12 / 16 / 2006 \quad 10: 52 \mathrm{PM}$ 12/16/2006 06:44 PM $12 / 16 / 2006 \quad 02: 37 \mathrm{PM}$ 12/16/2006 11:04 PM $12 / 16 / 2006 \quad 06: 57 \mathrm{PM}$ $12 / 16 / 2006 \quad 02: 49 \mathrm{PM}$ 12/16/2006 11:04 PM 12/16/2006 06:57 PM $12 / 16 / 2006 \quad 02: 49$ PM $12 / 16 / 2006 \quad 11: 16 \mathrm{PM}$ 12/16/2006 07:09 PM 12/16/2006 03:01 PM 12/16/2006 11:16 PM 12/16/2006 07:09 PM 12/16/2006 03:01 PM 12/16/2006 07:34 PM 12/16/2006 03:26 PM 12/16/2006 11:18 AM 12/16/2006 07:34 PM 12/16/2006 03:26 PM $12 / 16 / 2006 \quad 11: 18$ AM 12/16/2006 07:46 PM 12/16/2006 03:38 PM $12 / 16 / 2006 \quad 11: 30$ AM 12/16/2006 07:46 PM $12 / 16 / 2006 \quad 03: 38 \mathrm{PM}$ 12/16/2006 11:30 AM 12/16/2006 07:58 PM 12/16/2006 03:50 PM $12 / 16 / 2006 \quad 11: 42$ AM 12/16/2006 07:58 PM $12 / 16 / 2006 \quad 03: 50 \mathrm{PM}$ 12/16/2006 11:42 AM $12 / 16 / 2006 \quad 08: 10 \mathrm{PM}$ 12/16/2006 04:02 PM 12/16/2006 11:55 AM 12/16/2006 08:10 PM 12/16/2006 04:03 PM 12/16/2006 11:55 AM $12 / 16 / 2006 \quad 08: 22$ PM $12 / 16 / 2006 \quad 04: 15 \mathrm{PM}$ $12 / 16 / 2006 \quad 12: 07$ PM $12 / 16 / 2006 \quad 08: 22 \mathrm{PM}$ 12/16/2006 04:15 PM $12 / 16 / 2006 \quad 12: 07 \mathrm{PM}$ 12/16/2006 08:36 PM $12 / 16 / 2006 \quad 04: 28 \mathrm{PM}$ $12 / 16 / 2006 \quad 12: 20 \mathrm{PM}$ $12 / 16 / 2006 \quad 08: 36$ PM $12 / 16 / 2006 \quad 04: 28 \quad \mathrm{PM}$ $12 / 16 / 2006 \quad 12: 20 \mathrm{PM}$ $12 / 16 / 2006 \quad 08: 48 \mathrm{PM}$ $12 / 16 / 2006 \quad 04: 40 \mathrm{PM}$ $12 / 16 / 2006 \quad 12: 32 \mathrm{PM}$ $12 / 16 / 2006 \quad 08: 48 \mathrm{PM}$ $12 / 16 / 2006 \quad 04: 40 \quad \mathrm{PM}$ $12 / 16 / 2006 \quad 12: 32 \mathrm{PM}$ 12/16/2006 09:00 PM $12 / 16 / 2006 \quad 04: 52 \quad \mathrm{PM}$ $12 / 16 / 2006 \quad 12: 45 \mathrm{PM}$ 12/16/2006 09:00 PM $12 / 16 / 2006 \quad 04: 53 \mathrm{PM}$ $12 / 16 / 2006 \quad 12: 45 \mathrm{PM}$ 12/16/2006 09:13 PM 12/16/2006 05:05 PM $12 / 16 / 2006 \quad 12: 57 \mathrm{PM}$
$6,143,768$ Stress-pt 153th-m.OUT $6,115,040$ stress-pt 153th-t.OUT

13,519 Stress-pt $162 \mathrm{max}-\mathrm{b}$. OUT 13,519 Stress-pt $162 \mathrm{max}-\mathrm{m}$. OUT

13,519 stress-pt_162max-t.OUT $6,143,768$ Stress-pt 162th-b.OUT $6,143,768$ stress-pt_162th-m. OUT $6,115,040$ stress-pt 162 th-t.OUT

13,521 Stress-pt_171max-b.OUT

13,521 Stress-pt 171max-m.OUT

13,521 Stress-pt_171max-t.OUT $6,143,768$ Stress-pt_171th-b.OUT $6,143,768$ stress-pt 171th-m. OUT $6,115,040$ Stress-pt_171th-t.OUT

13,521 stress-pt 180max-b.OUT

13,521 Stress-pt_180max-m.OUT

13,521 stress-pt $180 \mathrm{max}-t$.OUT $6,143,768$ Stress-pt_180th-b.OUT $6,143,768$ stress-pt 180 th-m.OUT 6,115,040 Stress-pt_180th-t.oUT

13,519 stress-pt 18max-b. OUT

13,519 Stress-pt_18max-m.OUT

13,519 Stress-pt $18 \mathrm{max}-\mathrm{t}$. OUT $6,143,768$ stress-pt 18 th-b. OUT $6,143,768$ Stress-pt_18th-m. OUT $6,115,040$ stress-pt 18th-t. OUT 13,519 stress-pt_27max-b.OUT 13,519 Stress-pt $27 \mathrm{max}-\mathrm{m}$.OUT 13,519 Stress-pt_27max-t.OUT $6,143,768$ stress-pt 27 th-b. OUT $6,143,768$ stress-pt_27th-m. OUT $6,115,040$ stress-pt 27 th-t.OUT

13,519 Stress-pt $36 \mathrm{max}-\mathrm{b}$.OUT

13,519 Stress-pt $36 \mathrm{max}-\mathrm{m}$. OUT

13,519 Stress-pt $36 \mathrm{max}-t$.OUT

$6,143,768$ Stress-pt_36th-b. OUT $6,143,768$ stress-pt 36 th-m. OUT 6,115,040 Stress-pt_36th-t.OUT

13,519 Stress-pt $45 \mathrm{max}-\mathrm{b}$. OUT

13,519 Stress-pt $45 \mathrm{max}-\mathrm{m}$. OUT

13,519 Stress-pt $45 \mathrm{max}-\mathrm{t}$.OUT $6,143,768$ stress-pt_45th-b. OUT $6,143,768$ stress-pt ${ }^{-} 45 \mathrm{th}-\mathrm{m}$. OUT 6,115,040 Stress-pt 45th-t. OUT

13,519 Stress-pt 54 max-b. OUT 13,519 Stress-pt 54max-m.OUT 13,519 stress-pt_54max-t.oUT $6,143,768$ stress-pt 54 th-b. OUT $6,143,768$ stress-pt 54 th-m. OUT $6,115,040$ stress-pt 54 th-t. OUT

13,519 stress-pt_63max-b. OUT

13,519 Stress-pt ${ }^{-} 63 \mathrm{max}-\mathrm{m}$. OUT

13,519 stress-pt $63 \mathrm{max}-\mathrm{t}$. OUT $6,143,768$ stress-pt 63 th-b. OUT $6,143,768$ stress-pt 63 th-m. OUT 6,115,040 stress-pt 63th-t. OUT

13,519 Stress-pt $72 \mathrm{max}-\mathrm{b}$. OUT 13,519 stress-pt_ $72 \mathrm{max}-\mathrm{m}$.OUT 13,519 Stress-pt $72 \mathrm{max}-\mathrm{t}$.OUT $6,143,768$ Stress-pt 72 th-b. OUT $6,143,768$ stress-pt 72 th-m. OUT $6,115,040$ stress-pt ${ }^{-} 72$ th-t. OUT

13,519 stress-pt $81 \mathrm{max}-\mathrm{b}$.OUT 13,519 stress-pt-81max-m.OUT 13,519 Stress-pt_81max-t.OUT $6,143,768$ Stress-pt 81 th-b. OUT $6,143,768$ stress-pt_81th-m. OUT $6,115,040$ stress-pt 81 th-t. OUT 13,519 Stress-pt_90max-b.OUT 13,519 Stress-pt $90 \mathrm{max}-\mathrm{m}$.OUT 13,519 stress-pt_90max-t.OUT 


\section{RPP-RPT-32239, Rev. 1 M\&D-2008-005-CALC-001, Rev. 1}

12/16/2006 09:13 PM 12/16/2006 05:05 PM $12 / 16 / 2006 \quad 12: 57$ PM 12/16/2006 09:25 PM 12/16/2006 05:18 PM $12 / 16 / 2006 \quad 01: 10 \mathrm{PM}$ 12/16/2006 09:25 PM $12 / 16 / 2006 \quad 05: 18 \mathrm{PM}$ 12/16/2006 01:10 PM 12/16/2006 07:21 PM 12/16/2006 03:14 PM 12/16/2006 11:05 AM 12/16/2006 07:21 PM $12 / 16 / 2006 \quad 03: 14$ PM 12/16/2006 11:05 AM 01/02/2007 11:24 AM 08/02/2006 06:15 AM 05/25/2005 03:32 PM 12/15/2006 07:28 AM 10/17/2006 12:18 PM 12/15/2006 07:29 AM $11 / 10 / 2006 \quad 02: 17$ PM $11 / 10 / 2006 \quad 02: 19 \mathrm{PM}$ $11 / 22 / 2006 \quad 08: 27$ AM 12/19/2006 03:21 PM 12/19/2006 03:23 PM 12/19/2006 03:14 PM 12/16/2006 09:24 AM 12/16/2006 09:25 AM 12/16/2006 09:34 AM $12 / 16 / 2006 \quad 09: 34$ AM 12/16/2006 09:44 AM 12/16/2006 09:44 AM 12/16/2006 09:54 AM 12/16/2006 09:54 AM 12/16/2006 10:05 AM 12/16/2006 10:05 AM 12/16/2006 10:14 AM $12 / 16 / 2006 \quad 10: 14$ AM 12/16/2006 10:23 AM 12/16/2006 10:23 AM $12 / 16 / 2006 \quad 10: 34$ AM $12 / 16 / 2006 \quad 10: 34$ AM $12 / 16 / 2006 \quad 10: 44$ AM $12 / 16 / 2006 \quad 10: 44$ AM $12 / 16 / 2006 \quad 07: 45$ AM 12/16/2006 07:45 AM 12/16/2006 07:56 AM $12 / 16 / 2006 \quad 07: 56$ AM 12/16/2006 08:06 AM 12/16/2006 08:06 AM 12/16/2006 08:16 AM $12 / 16 / 2006 \quad 08: 16$ AM $12 / 16 / 2006 \quad 08: 26$ AM $12 / 16 / 2006 \quad 08: 26$ AM $12 / 16 / 2006 \quad 08: 35$ AM $12 / 16 / 2006 \quad 08: 35$ AM 12/16/2006 08:44 AM $12 / 16 / 2006 \quad 08: 44$ AM $12 / 16 / 2006 \quad 08: 54$ AM $12 / 16 / 2006 \quad 08: 54$ AM 12/16/2006 09:04 AM 12/16/2006 09:04 AM 12/16/2006 09:14 AM 12/16/2006 09:14 AM 12/16/2006 07:34 AM 12/16/2006 07:34 AM 12/16/2006 10:53 AM 09/25/2006 10:41 AM 11/14/2006 07:33 AM 12/17/2006 01:06 PM
$6,143,768$ stress-pt 90th-b. OUT $6,143,768$ Stress-pt 90 th-m. OUT $6,115,040$ stress-pt 90 th-t.OUT

13,519 Stress-pt $99 \mathrm{max}-\mathrm{b}$.OUT

13,519 Stress-pt_-99max-m.OUT

13,519 Stress-pt $99 \mathrm{max}-t$. OUT $6,143,768$ stress-pt_99th-b. OUT $6,143,768$ stress-pt 99 th-m. OUT 6,115,040 stress-pt -99th-t. OUT

13,519 Stress-pt 9 max-b. OUT

13,519 stress-pt_9max-m. OUT

13,519 Stress-pt_9max-t. OUT $6,143,896$ stress-pt 9 th-b.OUT $6,143,896$ Stress-pt_9th-m. OUT $6,115,168$ stress-pt 9 th-t.OUT o Sub-Model-Both-Files.txt

4,008 Tank-Coordinates-AP.txt

2,512 Tank-Mesh1.txt

25 tank-out.out

5,554 Tank-Props-Rigid.txt

7,787 Tank-th. out

22, 588 TH-Sub-Modal-Column. txt

19,879 TH-Sub-Model-h.txt

19,879 TH-Sub-Model-v.txt

10,996, 224 Waste Pressure 0 deg.xls $11,942,400$ waste Pressure 45 deg.xls $11,920,384$ Waste Pressure 90 deg.xls 10, 180 Waste-Cont $108 \mathrm{max}$. OUT

4,643,118 Waste-Cont ${ }^{-108 \text { th. OUT }}$ 10,180 waste-Cont $117 \mathrm{max}$. OUT

4,643,118 waste-Cont_117th. OUT 10,180 waste-Cont_126max.OUT

4,643,118 waste-Cont 126th. OUT 10,180 Waste-Cont $135 \mathrm{max}$. OUT

4,643,118 Waste-Cont 135 th. OUT 10,180 waste-Cont_144max.OUT

4,643,118 waste-Cont $144 \mathrm{th}$. OUT 10,180 Waste-Cont_153max.OUT

4,643,118 waste-Cont 153 th. OUT 10,180 Waste-Cont $162 \mathrm{max}$.OUT

4,643,118 Waste-Cont_162th. OUT 10, 180 Waste-Cont 171 max.OUT

$4,643,118$ Waste-Cont ${ }^{-171}$ th. OUT 10,180 Waste-Cont 180 max. OUT

4,643,118 Waste-Cont_180th. OUT 10,180 waste-Cont $18 \mathrm{max}$. OUT

4,643,118 Waste-Cont_18th. OUT 10,180 waste-Cont $27 \mathrm{max}$. OUT

4,643,118 Waste-Cont_27th.OUT 10,180 waste-Cont $36 \mathrm{max}$. OUT

4,643,118 waste-Cont_36th.OUT 10,180 Waste-Cont_45max. OUT

4, 643,118 waste-Cont 45th. OUT 10,180 Waste-Cont $54 \mathrm{max}$. OUT

4,643,118 waste-Cont 54th. OUT 10,180 Waste-Cont_63max. OUT

4,643,118 waste-Cont 63th. OUT 10,180 waste-Cont_ $72 \mathrm{max}$. OUT

4,643,118 waste-Cont ${ }^{-} 72$ th. OUT 10,180 Waste-Cont $81 \mathrm{max}$. OUT

4,643,118 waste-Cont 81 th. OUT 10,180 waste-Cont 90 max. OUT

4,643,118 Waste-Cont_90th.OUT 10,180 waste-Cont 99 max. OUT

4,643,118 waste-Cont-99th.OUT 10,180 Waste-Cont 9 max. OUT

4,643,246 waste-Cont_9th.OUT

45,117 Waste-Reaction-460-SD3. out 340 waste-Reaction.txt

10,553 Waste-solid-AP-S.txt 683 Waste-Surface-AP.txt 


\section{RPP-RPT-32239, Rev. 1 M\&D-2008-005-CALC-001, Rev. 1}

\begin{tabular}{|c|c|c|c|c|}
\hline $12 / 17 / 2006$ & $01: 07$ & PM & 1,027 & Waste-Surf_Omax.OUT \\
\hline $12 / 17 / 2006$ & $01: 07$ & PM & 572,693 & Waste-Surf_oth.oUT \\
\hline $12 / 17 / 2006$ & $01: 12$ & PM & 1,027 & Waste-Surf_-108max.OUT \\
\hline $12 / 17 / 2006$ & $01: 12$ & PM & 572,693 & Waste-Surf_-108th.OUT \\
\hline $2 / 17 / 2006$ & $01: 12$ & PM & 1,027 & Waste-Surf_117max.OUT \\
\hline $12 / 17 / 2006$ & $01: 12$ & PM & 572,693 & Waste-Surf_-117th.OUT \\
\hline $2 / 17 / 2006$ & $01: 13$ & PM & 1,027 & Waste-Surf_126max.OUT \\
\hline $2 / 17 / 2006$ & $01: 13$ & PM & 572,693 & Waste-Surf-126th.OUT \\
\hline $2 / 17 / 2006$ & $01: 13$ & $\mathrm{PM}$ & 1,027 & Waste-Surf_-135max.OUT \\
\hline $12 / 17 / 2006$ & $01: 13$ & PM & 572,693 & Waste-Surf-135th.OUT \\
\hline $12 / 17 / 2006$ & $01: 14$ & PM & 1,027 & Waste-Surf_144max.OUT \\
\hline $2 / 17 / 2006$ & $01: 14$ & PM & 572,693 & Waste-Surf-144th.OUT \\
\hline $2 / 17 / 2006$ & $01: 14$ & $\mathrm{PM}$ & 1,027 & Waste-Surf_-153max.oUT \\
\hline $12 / 17 / 2006$ & $01: 14$ & PM & 572,693 & Waste-Surf_-153th.OUT \\
\hline $12 / 17 / 2006$ & $01: 14$ & $\mathrm{PM}$ & 1,027 & Waste-Surf_-162max.OUT \\
\hline $12 / 17 / 2006$ & $01: 14$ & PM & 572,693 & Waste-Surf_-162th.OUT \\
\hline $12 / 17 / 2006$ & $01: 15$ & PM & 1,027 & Waste-Surf_-171max.OUT \\
\hline $2 / 17 / 2006$ & $01: 15$ & PM & 572,693 & Waste-Surf_-171th.OUT \\
\hline $12 / 17 / 2006$ & $01: 15$ & PM & 1,027 & Waste-Surf-180max.OUT \\
\hline $2 / 17 / 2006$ & $01: 15$ & PM & 572,693 & Waste-Surf_-180th.OUT \\
\hline $12 / 17 / 2006$ & $01: 15$ & PM & 1,027 & Waste-Surf-189max.oUT \\
\hline $12 / 17 / 2006$ & $01: 15$ & PM & 572,693 & Waste-Surf_-189th.OUT \\
\hline $12 / 17 / 2006$ & $01: 08$ & PM & 1,027 & Waste-Surf_-18max.OUT \\
\hline $12 / 17 / 2006$ & $01: 08$ & PM & 572,693 & Waste-Surf_-18th.oUT \\
\hline $12 / 17 / 2006$ & $01: 08$ & PM & 1,027 & Waste-Surf_-27max.OUT \\
\hline $12 / 17 / 2006$ & $01: 08$ & $\mathrm{PM}$ & 572,693 & Waste-Surf-27th.OUT \\
\hline $12 / 17 / 2006$ & $01: 09$ & PM & 1,027 & Waste-Surf_-36max.OUT \\
\hline $12 / 17 / 2006$ & $01: 09$ & PM & 572,693 & Waste-Surf_-36th.OUT \\
\hline $12 / 17 / 2006$ & $01: 09$ & PM & 1,027 & Waste-Surf_- $45 \mathrm{max}$.OUT \\
\hline $12 / 17 / 2006$ & $01: 09$ & $\mathrm{PM}$ & 572,693 & Waste-Surf_45th.OUT \\
\hline $12 / 17 / 2006$ & $01: 09$ & PM & 1,027 & Waste-Surf_-54max.OUT \\
\hline $12 / 17 / 2006$ & $01: 09$ & $\mathrm{PM}$ & 572,693 & Waste-Surf_54th.OUT \\
\hline $12 / 17 / 2006$ & $01: 10$ & PM & 1,027 & Waste-Surf_-63max.OUT \\
\hline $12 / 17 / 2006$ & $01: 10$ & $\mathrm{PM}$ & 572,693 & Waste-Surf_-63th.OUT \\
\hline $12 / 17 / 2006$ & $01: 10$ & PM & 1,027 & Waste-Surf-72max.OUT \\
\hline $12 / 17 / 2006$ & $01: 10$ & PM & 572,693 & Waste-Surf-72th.OUT \\
\hline $12 / 17 / 2006$ & $01: 11$ & $\mathrm{PM}$ & 1,027 & Waste-Surf_-81max.OUT \\
\hline $12 / 17 / 2006$ & $01: 11$ & PM & 572,693 & Waste-Surf_81th.oUT \\
\hline $12 / 17 / 2006$ & $01: 11$ & PM & 1,027 & Waste-Surf_-90max.OUT \\
\hline $12 / 17 / 2006$ & $01: 11$ & $\mathrm{PM}$ & 572,693 & Waste-Surf_-90th.OUT \\
\hline $12 / 17 / 2006$ & $01: 11$ & PM & 1,027 & Waste-Surf_-99max.OUT \\
\hline $12 / 17 / 2006$ & $01: 11$ & PM & 572,693 & Waste-Surf_-99th.OUT \\
\hline $12 / 17 / 2006$ & $01: 07$ & $\mathrm{PM}$ & 1,027 & Waste-Surf_9max.oUT \\
\hline $12 / 17 / 2006$ & $01: 07$ & PM & 572,693 & Waste-Surf_9th.oUT \\
\hline $12 / 17 / 2006$ & $12: 17$ & $\mathrm{PM}$ & 229,888 & waste_0-90.xls \\
\hline $12 / 17 / 2006$ & $\begin{array}{c}12: 17 \\
320\end{array}$ & $\begin{array}{l}\text { PM } \\
\text { File (s) } \\
\operatorname{Dir}(\mathrm{s})\end{array}$ & $\begin{array}{r}229,888 \\
74,095,02\end{array}$ & $\begin{array}{l}\text { waste } 99-180 . x 1 s \\
6 \text { bytes } \\
60 \text { bytes free }\end{array}$ \\
\hline
\end{tabular}

\section{Sub-Model File Listing, Horizontal Excitation}

\footnotetext{
Volume in drive $C$ is $600 \mathrm{~GB} 2 \mathrm{xRAIDO}$ (new)

Volume serial Number is $8 \mathrm{AOA}-\mathrm{E} 4 \mathrm{BA}$

Directory of C: \Users $\backslash$ Bruce $\backslash 2008-000$ PNNL $\backslash 2008-005$ AP-460 $\backslash$ AP-460-Sub-Model-Horiz

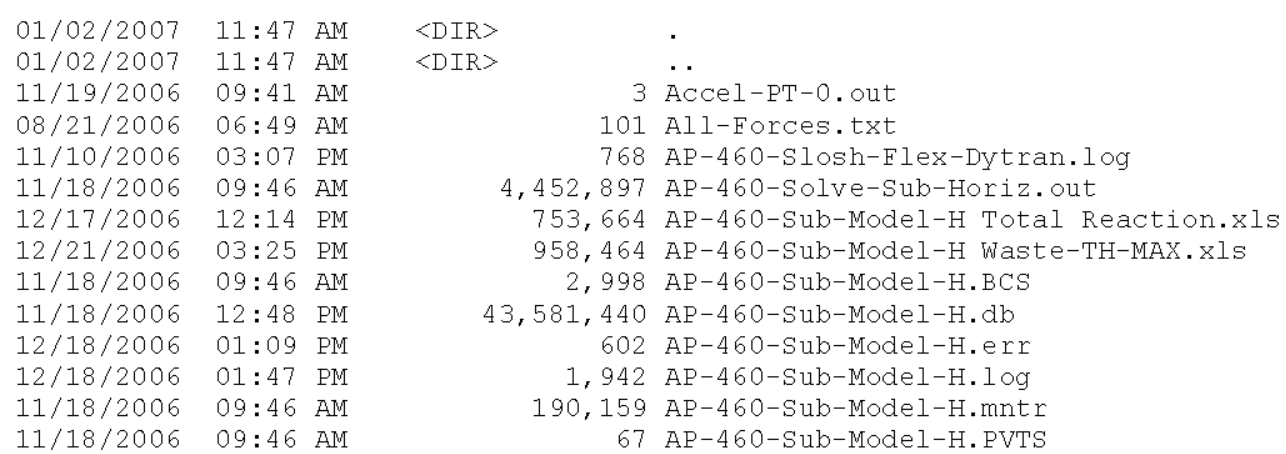




\section{RPP-RPT-32239, Rev. 1 \\ M\&D-2008-005-CALC-001, Rev. 1}

11/16/2006 01:10 PM 11/27/2006 03:08 PM 11/17/2006 11:04 AM 06/09/2005 01:59 PM 11/19/2006 09:14 AM 08/21/2006 07:59 AM 08/25/2006 01:28 PM 08/25/2006 01:27 PM 08/25/2006 01:28 PM 08/21/2006 07:59 AM $08 / 21 / 2006 \quad 12: 44 \quad \mathrm{PM}$ 01/03/2006 11:17 AM 11/19/2006 09:41 AM 11/10/2006 02:08 PM 11/17/2006 10:53 AM 11/17/2006 10:53 AM $12 / 20 / 2005 \quad 04: 49 \mathrm{PM}$ 10/13/2005 06:54 AM 08/21/2006 08:00 AM 08/21/2006 08:00 AM 01/02/2007 11:07 AM 10/17/2006 01:37 PM 07/20/2006 06:36 AM 11/13/2006 01:45 PM 08/23/2006 07:47 AM 05/02/2005 02:19 PM 07/21/2006 10:03 AM 04/20/2005 01:14 PM 11/10/2006 04:08 PM 11/10/2006 04:05 PM 09/27/2005 03:52 PM 11/17/2006 11:14 AM 11/19/2006 09:41 AM 10/31/2005 10:31 AM 11/14/2006 07:38 AM 12/17/2006 01:33 PM 02/11/2005 01:22 PM $11 / 11 / 2005 \quad 10: 36$ AM 11/13/2006 01:57 PM 11/17/2006 11:14 AM 08/25/2006 08:47 AM 09/13/2006 06:12 AM 09/13/2006 06:07 AM 09/13/2006 06:08 AM 09/13/2006 06:09 AM 09/13/2006 06:08 AM 09/13/2006 06:08 AM 09/13/2006 06:09 AM 08/28/2006 09:38 AM 10/03/2006 02:02 PM 10/03/2006 02:04 PM 09/13/2006 06:15 AM 10/03/2006 02:03 PM 10/03/2006 02:03 PM 09/13/2006 06:15 AM 06/20/2005 09:04 AM 06/20/2005 08:52 AM 11/27/2006 09:23 AM 11/27/2006 09:23 AM 11/27/2006 09:23 AM 11/27/2006 09:24 AM $11 / 27 / 2006 \quad 09: 24$ AM $11 / 27 / 2006 \quad 09: 24$ AM 09/05/2006 02:00 PM $08 / 21 / 2006 \quad 08: 01$ AM $08 / 16 / 2006 \quad 01: 59 \mathrm{PM}$ 08/21/2006 08:01 AM $08 / 21 / 2006 \quad 08: 02$ AM 08/16/2006 02:00 PM 08/21/2006 08:01 AM 08/21/2006 08:02 AM
0 AP-460-Sub-Model-H.sda

9,269,760 AP-460-Sub-Model-Horiz Pri Tank Stress Seismic.xls 6,046 Bolts-Friction.txt

262 Boundary.txt

227 Contact-AP.txt

586 Contact-Footing.txt

704 Contact-Insul. txt

704 Contact-J-Bolts.txt

708 Contact-Primary.txt

742 Contact-Soil.txt

632 Contact-Waste-AP. txt

1,616 Disp-J-Bolts.txt

535, 476 Disp-PT-0.out

8,620 Far-Soil.txt

287 FILE.err

5,822 file. $\log$

39, 925 file.txt

562 Fix-Soil.txt

894 Force-c.txt

661 Force-j_bolt.txt Freq Test

1,668 Insulate.txt

4,030 interface-gap1.txt

2,445 interfacel.txt

1,971 Liner.txt

667 live load.txt

6,214 Near-Soil-1.txt

508 outer-spar.txt

125 Post-Tank.txt

6,154 Primary-Props-AP.txt

1,538 Primary.txt

902,478 QA. out

47,121 RS-PT-0. out

1,108 RS FREQ.txt

1,894 Run-Tank.txt

0 scratch.hlp

1,053 slave.txt

4,989 Soil-Prop-Mean-Geo.txt

2,028 Solve-Slosh-flex.txt

2,177 Solve-Sub-Horiz.txt

1,918 Solve-TH-BES.txt

347 spectra-all.txt

3,690 spectra-conc-0.txt

3,723 spectra-conc-135. txt

3,723 spectra-conc-180.txt

3,769 spectra-conc-45.txt

3,649 spectra-conc-90.txt

1,590 spectra-conc.txt

2,076 spectra-concrete.txt

3,624 spectra-primary-0.txt

3,777 spectra-primary-135.txt

3,777 spectra-primary-180.txt

3,703 spectra-primary -45 .txt

3,703 spectra-primary-90.txt

3,801 spectra-soil.txt

647 spectra-wall.txt

679 spectra-waste.txt

279,040 str-comp_0-90b.xls

284,672 str-comp-0-90m.xls

279,040 str-comp_o-90t.xls

279,552 str-comp $99-180 \mathrm{~b} . \mathrm{xls}$

284,160 str-comp_99-180m.xls

279,040 str-comp 99-180t.xls

2,588 strain-backed.txt

566 strain-compb-p.txt

621 strain-compb-primary.txt

693 strain-compb.txt

566 strain-compm-p.txt

621 strain-compm-primary.txt

705 strain-compm.txt

578 strain-compt-p.txt 


\section{RPP-RPT-32239, Rev. 1 M\&D-2008-005-CALC-001, Rev. 1}

$08 / 16 / 2006$ $08 / 21 / 2006$ $08 / 21 / 2006$ $01 / 05 / 2006$ $08 / 21 / 2006$ $08 / 16 / 2006$ $08 / 16 / 2006$ $08 / 16 / 2006$ $08 / 21 / 2006$ $08 / 21 / 2006$ $08 / 21 / 2006$ $08 / 21 / 2006$ $08 / 21 / 2006$ $08 / 24 / 2006$ $08 / 17 / 2006$ $08 / 24 / 2006$ $11 / 19 / 2006$ $11 / 19 / 2006$ $11 / 19 / 2006$ $11 / 19 / 2006$ $11 / 19 / 2006$ $11 / 19 / 2006$ $11 / 19 / 2006$ $11 / 19 / 2006$ $11 / 19 / 2006$ $11 / 19 / 2006$ $11 / 19 / 2006$ $11 / 19 / 2006$ $11 / 19 / 2006$ $11 / 19 / 2006$ $11 / 19 / 2006$ $11 / 19 / 2006$ $11 / 19 / 2006$ $11 / 19 / 2006$ $11 / 19 / 2006$ $11 / 19 / 2006$ $11 / 19 / 2006$ $11 / 19 / 2006$ $11 / 19 / 2006$ $11 / 19 / 2006$ $11 / 19 / 2006$ $11 / 19 / 2006$ $11 / 19 / 2006$ $11 / 19 / 2006$ $11 / 19 / 2006$ $11 / 19 / 2006$ $11 / 19 / 2006$ $11 / 19 / 2006$ $11 / 19 / 2006$

$11 / 19 / 2006$

$11 / 19 / 2006$

$11 / 19 / 2006$

$11 / 19 / 2006$

$11 / 19 / 2006$

$11 / 19 / 2006$

$11 / 19 / 2006$

$11 / 19 / 2006$

$11 / 19 / 2006$

$11 / 19 / 2006$

$11 / 19 / 2006$

$11 / 19 / 2006$

$11 / 19 / 2006$

$11 / 19 / 2006$

$11 / 19 / 2006$

$11 / 19 / 2006$

$11 / 19 / 2006$

$11 / 19 / 2006$

$11 / 19 / 2006$

$11 / 19 / 2006$

$11 / 19 / 2006$

$11 / 19 / 2006$
02:00 PM 08:02 AM 08:02 AM 03:14 PM $08: 02$ AM 03:01 PM 02:01 PM $02: 19$ PM 08:02 AM $08: 02$ AM 08:03 AM 08:03 AM 08:03 AM $03: 19$ PM $11: 19$ AM 12:05 PM 07:15 PM 04:00 PM $12: 45 \mathrm{PM}$ 07:15 PM $04: 00 \mathrm{PM}$ $12: 45 \mathrm{PM}$ $07: 24$ PM $04: 10 \mathrm{PM}$ $12: 55 \mathrm{PM}$ 07:24 PM $04: 10$ PM $12: 55 \mathrm{PM}$ $07: 34 \mathrm{PM}$ 04:19 PM 01:04 PM $07: 34 \mathrm{PM}$ $04: 19 \mathrm{PM}$ 01:04 PM $07: 44 \quad \mathrm{PM}$ $04: 29$ PM $01: 14 \mathrm{PM}$ $07: 44 \mathrm{PM}$ $04: 29$ PM $01: 14$ PM $07: 53 \mathrm{PM}$ $04: 39 \mathrm{PM}$ $01: 24$ PM $07: 53 \mathrm{PM}$ $04: 39 \mathrm{PM}$ $01: 24 \mathrm{PM}$ $08: 03 \mathrm{PM}$ $04: 49 \mathrm{PM}$ $01: 34 \mathrm{PM}$ $08: 03 \mathrm{PM}$ $04: 49 \mathrm{PM}$ $01: 34 \mathrm{PM}$ $08: 13 \mathrm{PM}$ $04: 58$ PM $01: 44 \quad \mathrm{PM}$ $08: 13 \mathrm{PM}$ $04: 59 \mathrm{PM}$ $01: 44 \mathrm{PM}$ $08: 22 \mathrm{PM}$ 05:08 PM $01: 53 \mathrm{PM}$ $08: 22 \mathrm{PM}$ $05: 08$ PM $01: 53 \mathrm{PM}$ $08: 32 \mathrm{PM}$ $05: 17 \mathrm{PM}$ $02: 03 \mathrm{PM}$ $08: 32 \mathrm{PM}$ $05: 17 \mathrm{PM}$ $02: 03 \mathrm{PM}$ $05: 37 \mathrm{PM}$
621 strain-compt-primary.txt

720 strain-compt.txt

730 strain-Liner-floor.txt

550 Strain-Liner-p.txt

962 Strain-Liner-wall.txt

545 Strain-Liner.txt

292 Strain-Primary.txt

273 strain.txt

554 stress-compb-p.txt

598 stress-compb.txt

554 stress-compm-p.txt

608 stress-compm.txt

554 stress-compt-p.txt

598 stress-compt.txt

207 Stress-Primary-M.txt

224 Stress-Primary.txt

13,519 Stress-pt 108max-b. OUT

13,519 Stress-pt_108max-m.OUT

13,519 Stress-pt 108max-t.OUT

$6,143,768$ Stress-pt_108th-b.OUT

$6,143,768$ stress-pt $108 \mathrm{th}-\mathrm{m}$. OUT

$6,115,040$ stress-pt $108 \mathrm{th}-\mathrm{t}$. OUT

13,519 Stress-pt $117 \mathrm{max}-\mathrm{b}$.OUT

13,519 Stress-pt $117 \mathrm{max}-\mathrm{m}$.OUT

13,519 Stress-pt_117max-t.OUT

$6,143,768$ stress-pt $117 \mathrm{th}-\mathrm{b}$. OUT $6,143,768$ stress-pt_117th-m.OUT $6,115,040$ stress-pt 117th-t.OUT

13,519 Stress-pt $126 \mathrm{max}-\mathrm{b}$.OUT

13,519 Stress-pt $126 \mathrm{max}-\mathrm{m}$.OUT

13,519 Stress-pt $126 \mathrm{max}-t$. OUT $6,143,768$ stress-pt 126 th-b. OUT $6,143,768$ stress-pt 126th-m.OUT $6,115,040$ Stress-pt $126 \mathrm{th}-\mathrm{t}$. OUT

13,519 Stress-pt 135max-b. OUT

13,519 stress-pt_135max-m.OUT

13,519 stress-pt 135max-t.OUT $6,143,768$ Stress-pt_135th-b.OUT $6,143,768$ Stress-pt $135 \mathrm{th}-\mathrm{m}$. OUT 6,115,040 stress-pt_135th-t.OUT

13,519 Stress-pt $144 \mathrm{max}-\mathrm{b}$.OUT

13,519 Stress-pt $144 \mathrm{max}-\mathrm{m}$.OUT

13,519 Stress-pt $144 \mathrm{max}-\mathrm{t}$.OUT $6,143,768$ stress-pt 144th-b.OUT $6,143,768$ Stress-pt_144th-m.OUT $6,115,040$ stress-pt 144th-t.OUT

13,519 Stress-pt_153max-b.OUT

13,519 Stress-pt 153max-m.OUT

13,519 Stress-pt ${ }^{-} 153 \mathrm{max}-\mathrm{t}$.OUT $6,143,768$ stress-pt 153th-b.OUT $6,143,768$ stress-pt $153 \mathrm{th}-\mathrm{m}$. OUT $6,115,040$ stress-pt 153 th-t.OUT

13,519 Stress-pt ${ }^{-} 162 \mathrm{max}-\mathrm{b}$. OUT

13,519 Stress-pt_162max-m.OUT

13,519 Stress-pt $162 \mathrm{max}-t$.OUT $6,143,768$ Stress-pt_162th-b.OUT $6,143,768$ stress-pt 162th-m.OUT 6,115,040 Stress-pt_162th-t.OUT

13,521 Stress-pt 171max-b.OUT

13,521 Stress-pt $171 \mathrm{max}-\mathrm{m}$.OUT

13,521 Stress-pt 171max-t.OUT $6,143,768$ stress-pt 171 th-b.OUT $6,143,768$ stress-pt $171 \mathrm{th}-\mathrm{m}$. OUT 6,115,040 stress-pt 171th-t.OUT

13,521 Stress-pt_180max-b.OUT

13,521 Stress-pt-180max-m.OUT

13,521 stress-pt $180 \mathrm{max}-\mathrm{t}$.OUT $6,143,768$ Stress-pt 180 th-b.OUT $6,143,768$ stress-pt_180th-m.OUT 6,115,040 stress-pt 180 th-t.OUT

13,519 stress-pt_18max-b.OUT 


\section{RPP-RPT-32239, Rev. 1 M\&D-2008-005-CALC-001, Rev. 1}

11/19/2006 02:22 PM 11/19/2006 11:05 AM 11/19/2006 05:37 PM $11 / 19 / 2006 \quad 02: 22 \mathrm{PM}$ 11/19/2006 11:05 AM 11/19/2006 05:46 PM 11/19/2006 02:32 PM $11 / 19 / 2006 \quad 11: 15$ AM 11/19/2006 05:46 PM $11 / 19 / 2006 \quad 02: 32 \mathrm{PM}$ 11/19/2006 11:15 AM $11 / 19 / 2006 \quad 05: 56 \mathrm{PM}$ $11 / 19 / 2006 \quad 02: 41 \mathrm{PM}$ 11/19/2006 11:25 AM 11/19/2006 05:56 PM $11 / 19 / 2006 \quad 02: 41 \mathrm{PM}$ 11/19/2006 11:25 AM 11/19/2006 06:06 PM $11 / 19 / 2006 \quad 02: 51 \quad \mathrm{PM}$ 11/19/2006 11:36 AM 11/19/2006 06:06 PM $11 / 19 / 2006 \quad 02: 51 \quad \mathrm{PM}$ 11/19/2006 11:36 AM 11/19/2006 06:15 PM 11/19/2006 03:01 PM $11 / 19 / 2006 \quad 11: 45$ AM 11/19/2006 06:15 PM 11/19/2006 03:01 PM $11 / 19 / 2006 \quad 11: 45$ AM 11/19/2006 06:25 PM 11/19/2006 03:11 PM 11/19/2006 11:56 AM 11/19/2006 06:25 PM 11/19/2006 03:11 PM 11/19/2006 11:56 AM 11/19/2006 06:35 PM 11/19/2006 03:20 PM $11 / 19 / 2006 \quad 12: 05 \mathrm{PM}$ 11/19/2006 06:35 PM 11/19/2006 03:20 PM $11 / 19 / 2006 \quad 12: 05$ PM 11/19/2006 06:45 PM 11/19/2006 03:30 PM 11/19/2006 12:15 PM 11/19/2006 06:45 PM 11/19/2006 03:30 PM $11 / 19 / 2006 \quad 12: 15 \mathrm{PM}$ 11/19/2006 06:55 PM 11/19/2006 03:40 PM $11 / 19 / 2006 \quad 12: 25 \mathrm{PM}$ 11/19/2006 06:55 PM 11/19/2006 03:40 PM $11 / 19 / 2006 \quad 12: 25 \mathrm{PM}$ 11/19/2006 07:05 PM 11/19/2006 03:50 PM $11 / 19 / 2006 \quad 12: 35 \mathrm{PM}$ 11/19/2006 07:05 PM 11/19/2006 03:50 PM $11 / 19 / 2006 \quad 12: 35 \mathrm{PM}$ 11/19/2006 05:27 PM $11 / 19 / 2006 \quad 02: 13 \mathrm{PM}$ 11/19/2006 10:55 AM 11/19/2006 05:27 PM $11 / 19 / 2006 \quad 02: 13 \mathrm{PM}$ $11 / 19 / 2006 \quad 10: 55$ AM 01/02/2007 11:47 AM 08/02/2006 06:15 AM 05/25/2005 03:32 PM 11/17/2006 11:13 AM 10/17/2006 12:18 PM 11/17/2006 11:14 AM
13,519 Stress-pt 18max-m. OUT 13,519 Stress-pt $18 \mathrm{max}-t$.OUT $6,143,768$ Stress-pt 18 th-b. OUT $6,143,768$ stress-pt 18 th-m. OUT 6,115,040 Stress-pt_18th-t. OUT

13,519 Stress-pt 27max-b.OUT

13,519 Stress-pt_27max-m.OUT

13,519 Stress-pt $27 \mathrm{max}-\mathrm{t}$.OUT $6,143,768$ stress-pt 27 th-b. OUT $6,143,768$ stress-pt 27 th-m. OUT 6,115,040 Stress-pt_27th-t.OUT

13,519 stress-pt $36 \mathrm{max}-\mathrm{b}$. OUT

13,519 Stress-pt $36 \mathrm{max}-\mathrm{m}$. OUT

13,519 Stress-pt_36max-t.OUT $6,143,768$ stress-pt 36 th-b. OUT $6,143,768$ Stress-pt_36th-m. OUT $6,115,040$ stress-pt 36th-t. OUT

13,519 Stress-pt_45max-b.OUT

13,519 Stress-pt $45 \mathrm{max}-\mathrm{m}$.OUT

13,519 Stress-pt_45max-t.OUT $6,143,768$ Stress-pt 45 th-b. OUT $6,143,768$ stress-pt 45 th-m. OUT 6,115,040 stress-pt 45 th-t. OUT

13,519 Stress-pt $54 \mathrm{max}-\mathrm{b}$.OUT

13,519 Stress-pt_54max-m.OUT

13,519 Stress-pt $54 \mathrm{max}-\mathrm{t}$.OUT $6,143,768$ Stress-pt_54th-b. OUT $6,143,768$ Stress-pt 54 th-m. OUT 6,115,040 stress-pt 54 th-t. OUT

13,519 stress-pt $63 \mathrm{max}-\mathrm{b}$. OUT

13,519 Stress-pt $63 \mathrm{max}-\mathrm{m}$. OUT

13,519 stress-pt ${ }^{-} 63 \mathrm{max}-\mathrm{t}$.OUT $6,143,768$ stress-pt 63th-b. OUT $6,143,768$ stress-pt ${ }^{-} 63 \mathrm{th}-\mathrm{m}$. OUT $6,115,040$ stress-pt 63th-t. OUT

13,519 Stress-pt_72max-b.OUT

13,519 Stress-pt $72 \mathrm{max}-\mathrm{m}$.OUT

13,519 Stress-pt_ $72 \mathrm{max}-t$. OUT $6,143,768$ Stress-pt ${ }^{-} 72$ th-b. OUT $6,143,768$ Stress-pt 72 th-m. OUT $6,115,040$ stress-pt ${ }^{-} 72$ th-t. OUT

13,519 stress-pt_81max-b.OUT

13,519 Stress-pt $81 \mathrm{max}-\mathrm{m}$.OUT

13,519 Stress-pt $81 \mathrm{max}-t$.OUT $6,143,768$ Stress-pt-81th-b. OUT $6,143,768$ stress-pt 81 th-m. OUT $6,115,040$ stress-pt_81th-t.OUT

13,519 Stress-pt 90 max-b. OUT

13,519 Stress-pt $90 \mathrm{max}-\mathrm{m}$. OUT

13,519 Stress-pt $90 \mathrm{max}-t$.OUT $6,143,768$ stress-pt_90th-b. OUT $6,143,768$ stress-pt 90 th-m. OUT $6,115,040$ stress-pt_90th-t. OUT

13,519 stress-pt-99max-b. OUT

13,519 Stress-pt $99 \mathrm{max}-\mathrm{m}$.OUT

13,519 Stress-pt_99max-t.OUT $6,143,768$ stress-pt 99 th-b. OUT $6,143,768$ Stress-pt_99th-m. OUT $6,115,040$ Stress-pt $99 \mathrm{th}-\mathrm{t}$. OUT

13,519 Stress-pt 9 max-b. OUT

13,519 Stress-pt ${ }^{-} 9$ max-m. OUT

13,519 stress-pt_9max-t. OUT $6,143,896$ Stress-pt_9th-b.OUT $6,143,896$ stress-pt_9th-m.OUT $6,115,168$ stress-pt_9th-t.OUT

o Sub-Model-Horiz-files.txt

4,008 Tank-Coordinates-AP. txt

2,512 Tank-Mesh1.txt

25 tank-out.out

5, 554 Tank-Props-Rigid.txt

7,943 Tank-th. out 


\section{RPP-RPT-32239, Rev. 1 M\&D-2008-005-CALC-001, Rev. 1}

11/10/2006 02:17 PM $11 / 10 / 2006 \quad 02: 19 \mathrm{PM}$ 11/27/2006 10:40 AM 11/27/2006 09:58 AM $11 / 27 / 2006 \quad 10: 40$ AM 11/19/2006 09:41 AM 12/19/2006 02:55 PM 12/19/2006 03:11 PM 12/19/2006 03:10 PM 11/18/2006 11:36 AM $11 / 18 / 2006 \quad 11: 36$ AM 11/18/2006 11:45 AM 11/18/2006 11:45 AM 11/18/2006 11:53 AM 11/18/2006 11:53 AM $11 / 18 / 2006 \quad 12: 02 \mathrm{PM}$ 11/18/2006 12:02 PM 11/18/2006 12:12 PM $11 / 18 / 2006 \quad 12: 12$ PM $11 / 18 / 2006 \quad 12: 20 \mathrm{PM}$ $11 / 18 / 2006 \quad 12: 20 \mathrm{PM}$ $11 / 18 / 2006 \quad 12: 29 \mathrm{PM}$ $11 / 18 / 2006 \quad 12: 29 \mathrm{PM}$ $11 / 18 / 2006 \quad 12: 38 \quad \mathrm{PM}$ $11 / 18 / 2006 \quad 12: 38$ PM $11 / 18 / 2006 \quad 12: 48 \quad \mathrm{PM}$ $11 / 18 / 2006 \quad 12: 48 \mathrm{PM}$ 11/18/2006 10:05 AM $11 / 18 / 2006 \quad 10: 05$ AM $11 / 18 / 2006 \quad 10: 15$ AM 11/18/2006 10:15 AM $11 / 18 / 2006 \quad 10: 24$ AM $11 / 18 / 2006 \quad 10: 24 \mathrm{AM}$ $11 / 18 / 2006 \quad 10: 33$ AM 11/18/2006 10:33 AM 11/18/2006 10:42 AM $11 / 18 / 2006 \quad 10: 42$ AM 11/18/2006 10:50 AM $11 / 18 / 2006 \quad 10: 50$ AM $11 / 18 / 2006 \quad 10: 59$ AM $11 / 18 / 2006 \quad 10: 59$ AM 11/18/2006 11:08 AM 11/18/2006 11:08 AM 11/18/2006 11:17 AM $11 / 18 / 2006 \quad 11: 17$ AM 11/18/2006 11:26 AM 11/18/2006 11:26 AM 11/18/2006 09:55 AM 11/18/2006 09:55 AM 11/19/2006 09:24 AM 09/25/2006 10:41 AM 11/14/2006 07:33 AM 12/17/2006 01:06 PM 12/17/2006 01:35 PM 12/17/2006 01:35 PM 12/17/2006 01:40 PM $12 / 17 / 2006 \quad 01: 40 \mathrm{PM}$ 12/17/2006 01:41 PM 12/17/2006 01:41 PM 12/17/2006 01:41 PM $12 / 17 / 2006 \quad 01: 41 \mathrm{PM}$ 12/17/2006 01:41 PM 12/17/2006 01:41 PM 12/17/2006 01:42 PM 12/17/2006 01:42 PM $12 / 17 / 2006 \quad 01: 42 \mathrm{PM}$ $12 / 17 / 2006 \quad 01: 42 \mathrm{PM}$ $12 / 17 / 2006 \quad 01: 43 \mathrm{PM}$ 12/17/2006 01:43 PM $12 / 17 / 2006 \quad 01: 43 \mathrm{PM}$ 12/17/2006 01:43 PM
22,588 TH-Sub-Modal-Column. txt 19,879 TH-Sub-Model-h.txt 6,813,184 Time History - Bot.xls 6,813,184 Time History - Mid.xls 6,813,184 Time History - Top.xls 535,476 Vel-PT-0.out

$11,706,368$ waste Pressure 0 deg.x1s $11,939,328$ waste Pressure 45 deg.xls 10,744,320 waste Pressure 90 deg.xls 10,180 Waste-Cont $108 \mathrm{max}$. OUT

4,643,118 waste-Cont_108th. OUT 10,180 waste-Cont_ $117 \mathrm{max}$. OUT

4,643,118 waste-Cont 117th. OUT 10,180 Waste-Cont_126max.OUT

4,643,118 Waste-Cont 126 th. OUT 10,180 Waste-Cont_135max.OUT

4,643,118 Waste-Cont 135th. OUT 10,180 waste-Cont_ $144 \mathrm{max}$. OUT

4,643,118 waste-Cont 144 th. OUT 10,180 Waste-Cont_153max. OUT

4,643,118 Waste-Cont_153th. OUT 10,180 Waste-Cont_162max.OUT

$4,643,118$ Waste-Cont ${ }^{-162}$ th. OUT 10,180 Waste-Cont $171 \mathrm{max}$.OUT

4,643,118 waste-Cont_171th. OUT 10,180 Waste-Cont $180 \mathrm{max}$.OUT

4,643,118 Waste-Cont_180th. OUT 10,180 Waste-Cont $18 \mathrm{max}$. OUT

4,643,118 waste-Cont_18th. OUT 10,180 waste-Cont $27 \mathrm{max}$. OUT

4,643,118 Waste-Cont_27th.OUT 10,180 Waste-Cont_36max.OUT

4,643,118 waste-Cont_36th.OUT 10,180 Waste-Cont $45 \mathrm{max}$. OUT

4,643,118 Waste-Cont 45th. OUT 10,180 waste-Cont_54max. OUT

4,643,118 waste-Cont 54th.OUT 10,180 Waste-Cont_63max.OUT

4,643,118 Waste-Cont 63th. OUT 10,180 Waste-Cont $72 \mathrm{max}$. OUT

$4,643,118$ waste-Cont 72 th. OUT 10,180 Waste-Cont_81max.OUT

4,643,118 Waste-Cont_81th. OUT 10,180 waste-Cont 90max. OUT

4,643,118 Waste-Cont 90 th. OUT 10,180 waste-Cont $99 \mathrm{max}$. OUT

4,643,118 waste-Cont-99th.OUT 10,180 waste-Cont 9 max. OUT

4,643,246 waste-Cont_9th.OUT

45,117 Waste-Reaction-460-SD3. out 340 waste-Reaction.txt

10, 553 Waste-solid-AP-S.txt 683 waste-Surface-AP. txt 946 Waste-Surf Omax. OUT

509,333 Waste-Surf ${ }^{-}$oth. OUT 946 Waste-Surf $108 \mathrm{max}$.OUT

509,205 Waste-Surf $108 \mathrm{th}$. OUT 946 waste-Surf_117max. OUT

509,205 Waste-Surf 117 th. OUT 946 Waste-Surf $126 \max$.OUT

509,205 Waste-Surf 126 th. OUT 946 waste-Surf $135 \mathrm{max}$. OUT

509,205 waste-Surf 135 th. OUT 946 Waste-Surf $144 \mathrm{max}$.OUT

509,205 Waste-Surf 144 th. OUT 946 Waste-Surf 153max.OUT

509, 205 waste-Surf_153th. OUT 946 Waste-Surf $162 \mathrm{max}$. OUT

509,205 Waste-Surf_162th. OUT 946 waste-Surf $171 \mathrm{max}$.OUT

509,205 Waste-Surf_171th. OUT 


\section{RPP-RPT-32239, Rev. 1 \\ M\&D-2008-005-CALC-001, Rev. 1}

12/17/2006 01:43 PM 12/17/2006 01:43 PM 12/17/2006 01:43 PM 12/17/2006 01:43 PM 12/17/2006 01:36 PM 12/17/2006 01:36 PM 12/17/2006 01:37 PM 12/17/2006 01:37 PM 12/17/2006 01:37 PM $12 / 17 / 2006 \quad 01: 37$ PM $12 / 17 / 2006 \quad 01: 37$ PM 12/17/2006 01:37 PM $12 / 17 / 2006 \quad 01: 38 \mathrm{PM}$ 12/17/2006 01:38 PM 12/17/2006 01:38 PM 12/17/2006 01:38 PM $12 / 17 / 2006 \quad 01: 39 \mathrm{PM}$ 12/17/2006 01:39 PM 12/17/2006 01:39 PM 12/17/2006 01:39 PM 12/17/2006 01:39 PM 12/17/2006 01:39 PM $12 / 17 / 2006 \quad 01: 40 \mathrm{PM}$ 12/17/2006 01:40 PM 12/17/2006 01:36 PM 12/17/2006 01:36 PM 11/27/2006 09:21 AM

11/27/2006 09:21 AM 323 File(s)
946 Waste-Surf 180max. OUT

509,205 Waste-Surf 180th. OUT

946 Waste-Surf $189 \mathrm{max}$.OUT

509,205 Waste-Surf $189 \mathrm{th}$. OUT 946 Waste-Surf 18max. OUT

509, 205 Waste-Surf 18 th. OUT 946 Waste-Surf_27max. OUT

509, 205 Waste-Surf 27 th. OUT 946 waste-Surf $36 \mathrm{max}$. OUT

509, 205 Waste-Surf 36 th. OUT 946 Waste-Surf_45max. OUT

509,205 Waste-Surf 45th.OUT 946 Waste-Surf 54 max. OUT

509,205 Waste-Surf 54 th. OUT 946 Waste-Surf 63max. OUT

509,205 Waste-Surf-63th.OUT 946 Waste-Surf 72 max. OUT

509,205 Waste-Surf-72th. OUT 946 waste-Surf $-81 \mathrm{max}$. OUT

509,205 Waste-Surf-81th.OUT 946 waste-Surf 90 max. OUT

509,205 Waste-Surf-90th.OUT 946 Waste-Surf 99 max. OUT

509, 205 Waste-Surf 99 th. OUT 946 waste-Surf_9max.OUT

509,205 Waste-Surf 9 th. OUT

229,888 waste_0-90.xls

229,888 waste $99-180 . \times 1$ s $591,651,351$ bytes

Directory of C: \Users \Bruce $\backslash 2008-000$ PNNL $\backslash 2008-005$ AP-460 $\backslash$ AP-460-Sub-Model-Horiz $\backslash$ Freq Test

$01 / 02 / 2007$ $01 / 02 / 2007$ $08 / 21 / 2006$ $11 / 10 / 2006$ $12 / 19 / 2006$ $12 / 19 / 2006$ $12 / 19 / 2006$ $12 / 19 / 2006$ $12 / 19 / 2006$ $12 / 19 / 2006$ $12 / 19 / 2006$ $12 / 19 / 2006$ $12 / 19 / 2006$ $12 / 19 / 2006$ $12 / 19 / 2006$ $12 / 19 / 2006$ $12 / 19 / 2006$ $12 / 19 / 2006$ $12 / 19 / 2006$ $11 / 19 / 2006$ $12 / 19 / 2006$ $12 / 19 / 2006$ $12 / 19 / 2006$ $12 / 19 / 2006$ $12 / 19 / 2006$ $12 / 19 / 2006$ $12 / 19 / 2006$ $11 / 17 / 2006$ $06 / 09 / 2005$ $11 / 19 / 2006$ $08 / 21 / 2006$ $08 / 25 / 2006$ $08 / 25 / 2006$ $08 / 25 / 2006$ $08 / 21 / 2006$ $08 / 21 / 2006$ $01 / 03 / 2006$ $11 / 10 / 2006$ $11 / 17 / 2006$

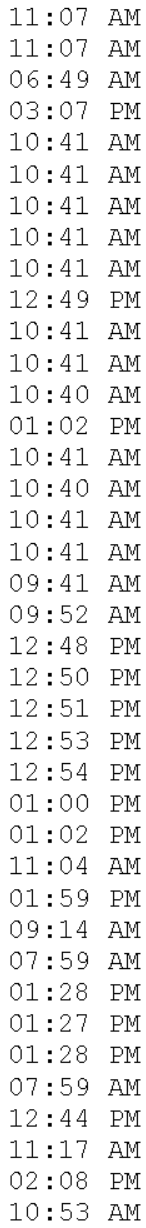

$\langle\mathrm{DIR}\rangle$ $<$ DIR> .

101 All-Forces.txt

768 AP-460-Slosh-Flex-Dytran.log

309, 512 AP-460-Slosh-Flex-V. out

2,998 AP-460-Sub-Model-H.BCS

$43,646,976$ AP-460-Sub-Model-H.db

$53,084,160$ AP-460-Sub-Model-H. dbb

$11,730,944$ AP-460-Sub-Model-H. emat

200,318 AP-460-Sub-Model-H.err

$50,462,720$ AP-460-Sub-Model-H. esav

$12,845,056$ AP-460-Sub-Model-H.full

$15,299,480$ AP-460-Sub-Model-H. Idhi

96, 922 AP-460-Sub-Model-H.log

10, 943 AP-460-Sub-Model-H.mntr

$50,462,720$ AP-460-Sub-Model-H. osav

67 AP-460-Sub-Model-H. PVTS

$50,987,008$ AP-460-Sub-Model-H. r001

$43,646,976$ AP-460-Sub-Model-H.rdb

0 AP-460-Sub-Model-H.sda

140,667 AP-460-Sub-Model-H000.jpg

37,344 AP-460-Sub-Model-H001.jpg

36,448 AP-460-Sub-Model-H002.jpg

51,532 AP-460-Sub-Model-H003.jpg

51, 017 AP-460-Sub-Model-H004.jpg

33, 346 AP-460-Sub-Model-H005.jpg

120,459 AP-460-Sub-Model-H006.jpg

6,046 Bolts-Friction.txt

262 Boundary.txt

227 Contact-AP. txt

586 Contact-Footing.txt

704 Contact-Insul.txt

704 Contact-J-Bolts.txt

708 Contact-Primary.txt

742 Contact-Soil.txt

632 Contact-Waste-AP.txt

1,616 Disp-J-Bolts.txt

8,620 Far-Soil.txt

5,822 file. log 


\section{RPP-RPT-32239, Rev. 1 \\ M\&D-2008-005-CALC-001, Rev. 1}

$12 / 20 / 2005$ $10 / 13 / 2005$ $08 / 21 / 2006$ $08 / 21 / 2006$ $10 / 17 / 2006$ $07 / 20 / 2006$ $11 / 13 / 2006$ $08 / 23 / 2006$ $05 / 02 / 2005$ $07 / 21 / 2006$ $04 / 20 / 2005$ $11 / 10 / 2006$ $11 / 10 / 2006$ $09 / 27 / 2005$ $12 / 19 / 2006$ $10 / 31 / 2005$ $11 / 19 / 2006$ $12 / 19 / 2006$ $02 / 11 / 2005$

$11 / 11 / 2005$

$11 / 13 / 2006$

$11 / 17 / 2006$

$08 / 25 / 2006$

$09 / 13 / 2006$

$09 / 13 / 2006$

$09 / 13 / 2006$

$09 / 13 / 2006$

$09 / 13 / 2006$

$09 / 13 / 2006$

$09 / 13 / 2006$

$08 / 28 / 2006$

$10 / 03 / 2006$

$10 / 03 / 2006$

$09 / 13 / 2006$

$10 / 03 / 2006$

$10 / 03 / 2006$

$09 / 13 / 2006$

$06 / 20 / 2005$

$06 / 20 / 2005$

$09 / 05 / 2006$

$08 / 21 / 2006$

$08 / 16 / 2006$

$08 / 21 / 2006$

$08 / 21 / 2006$

$08 / 16 / 2006$

$08 / 21 / 2006$

$08 / 21 / 2006$

$08 / 16 / 2006$

$08 / 21 / 2006$

$08 / 21 / 2006$

$01 / 05 / 2006$

$08 / 21 / 2006$

$08 / 16 / 2006$

$08 / 16 / 2006$

$08 / 16 / 2006$

$08 / 21 / 2006$

$08 / 21 / 2006$

$08 / 21 / 2006$

$08 / 21 / 2006$

$08 / 21 / 2006$

$08 / 24 / 2006$

$08 / 17 / 2006$

$08 / 24 / 2006$

$08 / 02 / 2006$

$05 / 25 / 2005$

$12 / 19 / 2006$

$10 / 17 / 2006$

$12 / 19 / 2006$

$11 / 10 / 2006$

$11 / 10 / 2006$

$12 / 19 / 2006$
$04: 49 \mathrm{PM}$ $06: 54$ AM 08:00 AM 08:00 AM $01: 37$ PM 06:36 AM $01: 45$ PM $07: 47$ AM 02:19 PM 10:03 AM $01: 14$ PM $04: 08$ PM $04: 05$ PM $03: 52$ PM 09:41 AM 10:31 AM 09:49 AM $09: 40$ AM $01: 22$ PM 10:36 AM $01: 57 \mathrm{PM}$ $11: 14$ AM $08: 47$ AM 06:12 AM 06:07 AM 06:08 AM 06:09 AM 06:08 AM 06:08 AM 06:09 AM $09: 38$ AM $02: 02 \mathrm{PM}$ $02: 04 \mathrm{PM}$ $06: 15$ AM 02:03 PM 02:03 PM 06:15 AM 09:04 AM $08: 52$ AM 02:00 PM $08: 01$ AM 01:59 PM $08: 01$ AM 08:02 AM 02:00 PM 08:01 AM 08:02 AM 02:00 PM $08: 02 \mathrm{AM}$ $08: 02 \mathrm{AM}$ $03: 14 \mathrm{PM}$ $08: 02$ AM 03:01 PM $02: 01 \mathrm{PM}$ $02: 19 \mathrm{PM}$ $08: 02$ AM $08: 02 \mathrm{AM}$ $08: 03$ AM $08: 03$ AM $08: 03 \mathrm{AM}$ $03: 19 \mathrm{PM}$ $11: 19$ AM $12: 05 \mathrm{PM}$ $06: 15$ AM $03: 32$ PM $09: 40$ AM $12: 18 \mathrm{PM}$ $09: 41$ AM $02: 17 \mathrm{PM}$ $02: 19 \mathrm{PM}$ $12: 34 \mathrm{PM}$
39,925 file.txt

562 Fix-Soil.txt

894 Force-c.txt

661 Force-j bolt.txt

1,668 Insulate.txt

4,030 interface-gap $1 . t x t$

2,445 interface1.txt

1,971 Liner.txt

667 live load.txt

6,214 Near-Soil-1.txt

508 outer-spar.txt

125 Post-Tank.txt

6,154 Primary-Props-AP.txt

1,538 Primary.txt

$1,353,717$ QA. out

1,108 RS_FREQ.txt

1,893 Run-Tank.txt

0 scratch.hlp

1,053 slave.txt

4,989 Soil-Prop-Mean-Geo.txt

2,028 Solve-Slosh-flex.txt

2,177 Solve-Sub-Horiz.txt

1,918 Solve-TH-BES.txt

347 spectra-all.txt

3,690 spectra-conc-0.txt

3,723 spectra-conc-135.txt

3,723 spectra-conc-180.txt

3,769 spectra-conc-45.txt

3,649 spectra-conc-90.txt

1,590 spectra-conc.txt

2,076 spectra-concrete.txt

3,624 spectra-primary-0.txt

3,777 spectra-primary-135.txt

3,777 spectra-primary-180.txt

3,703 spectra-primary-45.txt

3,703 spectra-primary-90.txt

3,801 spectra-soil.txt

647 spectra-wall.txt

679 spectra-waste.txt

2,588 strain-backed.txt

566 strain-compb-p.txt

621 strain-compb-primary.txt

693 strain-compb.txt

566 strain-compm-p.txt

621 strain-compm-primary.txt

705 strain-compm.txt

578 strain-compt-p.txt

621 strain-compt-primary.txt

720 strain-compt.txt

730 Strain-Liner-floor.txt

550 Strain-Liner-p.txt

962 strain-Liner-wall.txt

545 Strain-Liner.txt

292 Strain-Primary.txt

273 Strain.txt

554 stress-compb-p.txt

598 stress-compb.txt

554 stress-compm-p.txt

608 stress-compm.tixt

554 stress-compt-p.txt

598 stress-compt.txt

207 Stress-Primary-M.txt

224 Stress-Primary.txt

4,008 Tank-Coordinates-AP. txt

2,512 Tank-Mesh1.txt

25 tank-out.out

5, 554 Tank-Props-Rigid.txt

6,711 Tank-th. out

22, 588 TH-Sub-Modal-Column.txt

19,879 TH-Sub-Model-h.txt

45,117 Waste-Reaction-460-SD3. out 


\section{RPP-RPT-32239, Rev. 1 M\&D-2008-005-CALC-001, Rev. 1}

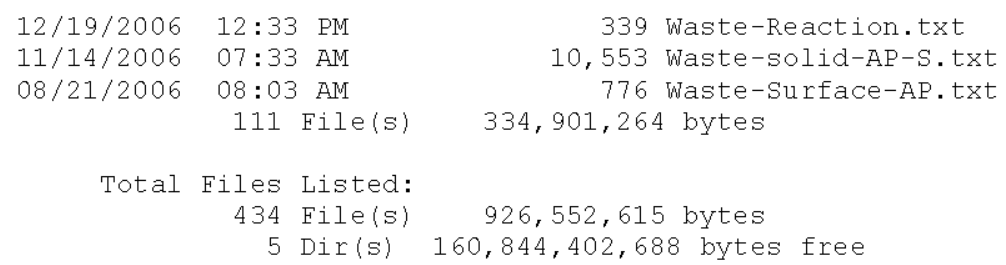

\section{Sub-Model File Listing, Vertical Excitation}

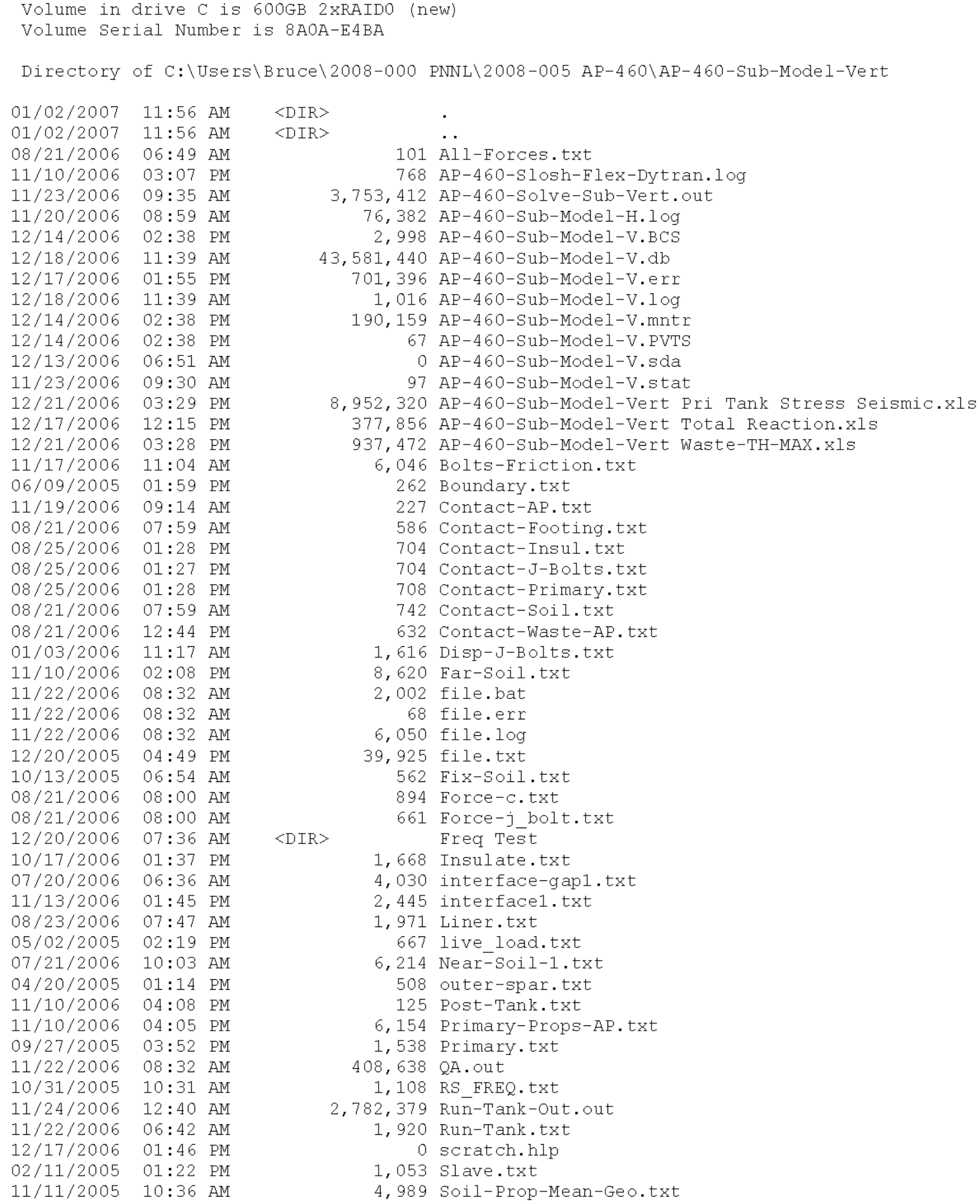




\section{RPP-RPT-32239, Rev. 1 M\&D-2008-005-CALC-001, Rev. 1}

$11 / 13 / 2006$ $12 / 13 / 2006$ $08 / 25 / 2006$ $09 / 13 / 2006$ $09 / 13 / 2006$ $09 / 13 / 2006$ $09 / 13 / 2006$ $09 / 13 / 2006$ $09 / 13 / 2006$ $09 / 13 / 2006$ $08 / 28 / 2006$ $10 / 03 / 2006$ $10 / 03 / 2006$ $09 / 13 / 2006$ $10 / 03 / 2006$ $10 / 03 / 2006$ $09 / 13 / 2006$ $06 / 20 / 2005$ $06 / 20 / 2005$ $12 / 15 / 2006$ $12 / 15 / 2006$ $12 / 15 / 2006$ $12 / 15 / 2006$ $12 / 15 / 2006$ $12 / 15 / 2006$ $09 / 05 / 2006$ $08 / 21 / 2006$ $08 / 16 / 2006$ $08 / 21 / 2006$ $08 / 21 / 2006$ $08 / 16 / 2006$ $08 / 21 / 2006$ $08 / 21 / 2006$ $08 / 16 / 2006$ $08 / 21 / 2006$ $08 / 21 / 2006$ $01 / 05 / 2006$ $08 / 21 / 2006$ $08 / 16 / 2006$ $08 / 16 / 2006$ $08 / 16 / 2006$ $08 / 21 / 2006$ $08 / 21 / 2006$ $08 / 21 / 2006$ $08 / 21 / 2006$ $08 / 21 / 2006$ $08 / 24 / 2006$ $08 / 17 / 2006$ $08 / 24 / 2006$ $12 / 15 / 2006$ $12 / 14 / 2006$ $12 / 14 / 2006$ $12 / 15 / 2006$ $12 / 14 / 2006$ $12 / 14 / 2006$ $12 / 15 / 2006$ $12 / 14 / 2006$ $12 / 14 / 2006$ $12 / 15 / 2006$ $12 / 14 / 2006$ $12 / 14 / 2006$ $12 / 15 / 2006$ $12 / 15 / 2006$ $12 / 14 / 2006$ $12 / 15 / 2006$ $12 / 15 / 2006$ $12 / 14 / 2006$ $12 / 15 / 2006$ $12 / 15 / 2006$ $12 / 14 / 2006$ $12 / 15 / 2006$
$01: 57 \mathrm{PM}$ $06: 48$ AM $08: 47$ AM 06:12 AM 06:07 AM 06:08 AM 06:09 AM 06:08 AM 06:08 AM 06:09 AM $09: 38$ AM 02:02 PM 02:04 PM 06:15 AM $02: 03 \mathrm{PM}$ 02:03 PM 06:15 AM 09:04 AM $08: 52$ AM 07:10 AM 07:11 AM 07:11 AM 07:11 AM 07:11 AM 07:12 AM 02:00 PM 08:01 AM 01:59 PM 08:01 AM 08:02 AM 02:00 PM 08:01 AM 08:02 AM 02:00 PM 08:02 AM $08: 02$ AM $03: 14 \mathrm{PM}$ 08:02 AM 03:01 PM 02:01 PM $02: 19 \mathrm{PM}$ 08:02 AM $08: 02$ AM 08:03 AM 08:03 AM $08: 03 \mathrm{AM}$ 03:19 PM $11: 19$ AM $12: 05 \mathrm{PM}$ $03: 27 \mathrm{AM}$ 11:43 PM 07:58 PM $03: 27 \mathrm{AM}$ $11: 43$ PM 07:58 PM $03: 38$ AM 11:54 PM 08:09 PM $03: 38$ AM $11: 54$ PM 08:09 PM $03: 49$ AM $12: 05$ AM $08: 21 \mathrm{PM}$ $03: 49$ AM $12: 05 \mathrm{AM}$ $08: 21 \mathrm{PM}$ $04: 00 \mathrm{AM}$ $12: 16$ AM $08: 32 \mathrm{PM}$ 04:01 AM
2,028 Solve-Slosh-flex.txt

2,168 Solve-Sub-Vert.txt

1,918 Solve-TH-BES.txt

347 spectra-all.txt

3,690 spectra-conc-0.txt

3,723 spectra-conc-135.txt

3,723 spectra-conc-180.txt

3,769 spectra-conc-45.txt

3,649 spectra-conc-90.txt

1,590 spectra-conc.txt

2,076 spectra-concrete.txt

3,624 spectra-primary-0.txt

3,777 spectra-primary-135.txt

3,777 spectra-primary-180.txt

3,703 spectra-primary $-45 . t x t$

3,703 spectra-primary-90.txt

3,801 spectra-soil.txt

647 spectra-wall.txt

679 spectra-waste.txt

286,720 str-comp 0-90b.xls

291,840 str-comp-0-90m.xls

292,864 str-comp-0-90t.xls

293,376 str-comp $99-180 \mathrm{~b} . \mathrm{xls}$

298,496 str-comp $99-180 \mathrm{~m} . \mathrm{xls}$

292,864 str-comp_99-180t.xls

2,588 strain-backed.txt

566 strain-compb-p.txt

621 strain-compb-primary.txt

693 strain-compb.txt

566 strain-compm-p.txt

621 strain-compm-primary.txt

705 strain-compm.txt

578 strain-compt-p.txt

621 strain-compt-primary.txt

720 strain-compt.txt

730 strain-Liner-floor.txt

550 Strain-Liner-p.txt

962 Strain-Liner-wall.txt

545 Strain-Liner.txt

292 Strain-Primary.txt

273 strain.txt

554 stress-compb-p.txt

598 stress-compb.txt

554 stress-compm-p.txt

608 stress-compm.txt

554 stress-compt-p.txt

598 stress-compt.txt

207 Stress-Primary-M.txt

224 Stress-Primary.txt

13,519 Stress-pt 108max-b.OUT

13,519 Stress-pt_108max-m.OUT

13,519 Stress-pt $108 \mathrm{max}-\mathrm{t}$.OUT

$6,143,768$ stress-pt 108 th-b.OUT

$6,143,768$ stress-pt 108 th-m.OUT

$6,115,040$ stress-pt 108th-t.OUT

13,519 Stress-pt_117max-b.OUT

13,519 stress-pt 117max-m.OUT

13,519 Stress-pt_117max-t.OUT

$6,143,768$ stress-pt $117 \mathrm{th}-\mathrm{b}$.OUT

$6,143,768$ stress-pt_117th-m.OUT

$6,115,040$ stress-pt 117 th-t.OUT

13,519 Stress-pt_126max-b.OUT

13,519 stress-pt $126 \mathrm{max}-\mathrm{m}$. OUT

13,519 stress-pt $126 \mathrm{max}-\mathrm{t}$. OUT

$6,143,768$ Stress-pt_126th-b.OUT

$6,143,768$ stress-pt 126th-m. OUT

6,115,040 stress-pt_126th-t.OUT

13, 519 Stress-pt $135 \mathrm{max}-\mathrm{b}$.OUT

13,519 Stress-pt_135max-m.OUT

13,519 Stress-pt ${ }^{-} 135 \mathrm{max}-\mathrm{t}$.OUT

$6,143,768$ stress-pt_135th-b.OUT 


\section{RPP-RPT-32239, Rev. 1 M\&D-2008-005-CALC-001, Rev. 1}

$12 / 15 / 2006$ $12 / 14 / 2006$ $12 / 15 / 2006$ $12 / 15 / 2006$ $12 / 14 / 2006$ $12 / 15 / 2006$ $12 / 15 / 2006$ $12 / 14 / 2006$ $12 / 15 / 2006$ $12 / 15 / 2006$ $12 / 14 / 2006$ $12 / 15 / 2006$ $12 / 15 / 2006$ $12 / 14 / 2006$ $12 / 15 / 2006$ $12 / 15 / 2006$ $12 / 14 / 2006$ $12 / 15 / 2006$ $12 / 15 / 2006$ $12 / 14 / 2006$ $12 / 15 / 2006$ $12 / 15 / 2006$ $12 / 14 / 2006$ $12 / 15 / 2006$ $12 / 15 / 2006$ $12 / 14 / 2006$ $12 / 15 / 2006$ $12 / 15 / 2006$ $12 / 14 / 2006$ $12 / 15 / 2006$ $12 / 15 / 2006$ $12 / 14 / 2006$ $12 / 15 / 2006$ $12 / 14 / 2006$ $12 / 14 / 2006$ $12 / 15 / 2006$ $12 / 14 / 2006$ $12 / 14 / 2006$ $12 / 15 / 2006$ $12 / 14 / 2006$ $12 / 14 / 2006$ $12 / 15 / 2006$ $12 / 14 / 2006$ $12 / 14 / 2006$ $12 / 15 / 2006$ $12 / 14 / 2006$ $12 / 14 / 2006$ $12 / 15 / 2006$ $12 / 14 / 2006$ $12 / 14 / 2006$ $12 / 15 / 2006$ $12 / 14 / 2006$ $12 / 14 / 2006$ $12 / 15 / 2006$ $12 / 14 / 2006$ $12 / 14 / 2006$ $12 / 15 / 2006$ $12 / 14 / 2006$ $12 / 14 / 2006$ $12 / 15 / 2006$ $12 / 14 / 2006$ $12 / 14 / 2006$ $12 / 15 / 2006$ $12 / 14 / 2006$ $12 / 14 / 2006$ $12 / 15 / 2006$ $12 / 14 / 2006$ $12 / 14 / 2006$ $12 / 15 / 2006$ $12 / 14 / 2006$ $12 / 14 / 2006$
$12: 16 \mathrm{AM}$ $08: 32 \mathrm{PM}$ $04: 12$ AM $12: 28$ AM $08: 43 \mathrm{PM}$ $04: 12$ AM $12: 28$ AM $08: 43 \mathrm{PM}$ $04: 23$ AM $12: 39$ AM $08: 54 \mathrm{PM}$ $04: 23$ AM $12: 39 \mathrm{AM}$ $08: 54$ PM $04: 34 \mathrm{AM}$ $12: 50$ AM 09:06 PM $04: 34$ AM $12: 50 \mathrm{AM}$ 09:06 PM $04: 45$ AM 01:01 AM $09: 17 \mathrm{PM}$ $04: 45 \mathrm{AM}$ 01:01 AM 09:17 PM $04: 56$ AM $01: 12$ AM $09: 28$ PM $04: 56$ AM $01: 12$ AM $09: 28$ PM $01: 35$ AM 09:51 PM 06:06 PM $01: 35$ AM 09:51 PM 06:06 PM $01: 45$ AM 10:02 PM 06:17 PM $01: 45$ AM 10:02 PM $06: 17 \mathrm{PM}$ $01: 56$ AM $10: 13 \mathrm{PM}$ 06:28 PM $01: 56$ AM $10: 13 \mathrm{PM}$ $06: 28 \mathrm{PM}$ $02: 08$ AM $10: 24 \mathrm{PM}$ 06:40 PM $02: 08$ AM $10: 24 \mathrm{PM}$ 06:40 PM $02: 19$ AM $10: 35 \mathrm{PM}$ 06:50 PM $02: 19 \mathrm{AM}$ $10: 35 \mathrm{PM}$ 06:50 PM $02: 31$ AM $10: 47 \mathrm{PM}$ 07:02 PM $02: 31 \mathrm{AM}$ $10: 47 \mathrm{PM}$ 07:02 PM $02: 41$ AM 10:58 PM $07: 13 \mathrm{PM}$
$6,143,768$ stress-pt $135 \mathrm{th}-\mathrm{m}$. OUT $6,115,040$ stress-pt ${ }^{-} 135 \mathrm{th}-\mathrm{t}$. OUT 13,519 Stress-pt_144max-b.OUT 13,519 Stress-pt $144 \mathrm{max}-\mathrm{m}$. OUT 13,519 stress-pt_144max-t.OUT $6,143,768$ Stress-pt 144th-b.OUT $6,143,768$ stress-pt_144th-m.OUT $6,115,040$ stress-pt $144 \mathrm{th}-\mathrm{t}$.OUT

13,519 Stress-pt $153 \mathrm{max}-\mathrm{b}$.OUT

13,519 stress-pt 153max-m.OUT

13,519 stress-pt 153max-t. OUT $6,143,768$ stress-pt_153th-b.OUT $6,143,768$ stress-pt 153th-m.OUT $6,115,040$ Stress-pt_153th-t.oUT

13,519 Stress-pt 162max-b. OUT 13,519 Stress-pt_162max-m.OUT

13,519 stress-pt 162max-t.OUT $6,143,768$ Stress-pt_162th-b.OUT $6,143,768$ stress-pt 162 th-m. OUT $6,115,040$ stress-pt 162 th-t.OUT

13,521 stress-pt 171max-b.OUT 13,521 Stress-pt 171max-m.OUT

13,521 stress-pt $171 \mathrm{max}-\mathrm{t}$.OUT $6,143,768$ stress-pt 171th-b. OUT $6,143,768$ stress-pt_171th-m.OUT $6,115,040$ stress-pt 171th-t.OUT

13,521 Stress-pt_180max-b.OUT

13,521 Stress-pt 180max-m.OUT

13,521 stress-pt ${ }^{-} 180 \mathrm{max}-\mathrm{t}$.OUT $6,143,768$ stress-pt 180 th-b.OUT $6,143,768$ stress-pt 180th-m.OUT $6,115,040$ stress-pt 180 th-t.OUT 13,519 stress-pt 18max-b. OUT 13,519 Stress-pt $18 \mathrm{max}-\mathrm{m}$. OUT 13,519 Stress-pt $18 \mathrm{max}-\mathrm{t}$.OUT $6,143,768$ Stress-pt_18th-b. OUT $6,143,768$ stress-pt 18th-m. OUT 6,115,040 Stress-pt_18th-t. OUT

13,519 Stress-pt $27 \mathrm{max}-\mathrm{b}$. OUT

13,519 Stress-pt_27max-m.OUT

13,519 Stress-pt $27 \mathrm{max}-t$.OUT $6,143,768$ stress-pt 27 th-b. OUT $6,143,768$ stress-pt 27 th-m. OUT $6,115,040$ stress-pt 27 th-t. OUT 13,519 Stress-pt $36 \mathrm{max}-\mathrm{b}$. OUT 13,519 Stress-pt 36max-m.OUT 13,519 Stress-pt_36max-t.OUT $6,143,768$ Stress-pt 36 th-b. OUT $6,143,768$ stress-pt_36th-m. OUT $6,115,040$ stress-pt 36 th-t. OUT

13,519 stress-pt $45 \mathrm{max}-\mathrm{b}$. OUT

13,519 stress-pt $45 \mathrm{max}-\mathrm{m}$. OUT

13,519 stress-pt ${ }^{-} 45 \mathrm{max}-\mathrm{t}$. OUT $6,143,768$ stress-pt 45 th-b. OUT $6,143,768$ stress-pt 45 th-m. OUT 6,115,040 stress-pt 45 th-t. OUT 13,519 stress-pt 54max-b. OUT 13,519 Stress-pt_54max-m.OUT 13,519 Stress-pt 54max-t.OUT $6,143,768$ stress-pt_54th-b. OUT $6,143,768$ stress-pt 54 th-m. OUT 6,115,040 Stress-pt 54th-t. OUT

13,519 stress-pt $63 \mathrm{max}-\mathrm{b}$. OUT 13,519 Stress-pt $63 \mathrm{max}-\mathrm{m}$. OUT

13,519 Stress-pt $63 \mathrm{max}-\mathrm{t}$. OUT $6,143,768$ Stress-pt 63 th-b. OUT $6,143,768$ stress-pt_63th-m. OUT $6,115,040$ stress-pt 63th-t. OUT 13,519 Stress-pt_ $72 \mathrm{max}-\mathrm{b}$. OUT 13,519 stress-pt $72 \mathrm{max}-\mathrm{m}$. OUT 13,519 stress-pt_ $72 \mathrm{max}-t$. OUT 


\section{RPP-RPT-32239, Rev. 1 M\&D-2008-005-CALC-001, Rev. 1}

$12 / 15 / 2006 \quad 02: 41$ AM 12/14/2006 10:58 PM $12 / 14 / 2006 \quad 07: 13 \mathrm{PM}$ $12 / 15 / 2006 \quad 02: 53$ AM 12/14/2006 11:09 PM 12/14/2006 07:24 PM 12/15/2006 02:53 AM 12/14/2006 11:09 PM 12/14/2006 07:24 PM 12/15/2006 03:04 AM 12/14/2006 11:20 PM 12/14/2006 07:36 PM 12/15/2006 03:04 AM 12/14/2006 11:20 PM 12/14/2006 07:36 PM 12/15/2006 03:16 AM 12/14/2006 11:32 PM 12/14/2006 07:47 PM 12/15/2006 03:16 AM 12/14/2006 11:32 PM 12/14/2006 07:47 PM 12/15/2006 01:23 AM 12/14/2006 09:39 PM 12/14/2006 05:55 PM 12/15/2006 01:24 AM 12/14/2006 09:39 PM 12/14/2006 05:55 PM 01/02/2007 11:57 AM 08/02/2006 06:15 AM 05/25/2005 03:32 PM $11 / 22 / 2006 \quad 08: 32$ AM 10/17/2006 12:18 PM $11 / 22 / 2006 \quad 08: 32$ AM $11 / 10 / 2006 \quad 02: 17$ PM $11 / 10 / 2006 \quad 02: 19 \mathrm{PM}$ 11/22/2006 08:27 AM $12 / 19 / 2006 \quad 03: 13 \mathrm{PM}$ 12/19/2006 03:13 PM $12 / 19 / 2006 \quad 03: 14 \mathrm{PM}$ 12/14/2006 04:26 PM 12/14/2006 04:26 PM 12/14/2006 04:35 PM 12/14/2006 04:35 PM 12/14/2006 04:44 PM $12 / 14 / 2006 \quad 04: 44 \quad \mathrm{PM}$ 12/14/2006 04:53 PM $12 / 14 / 2006 \quad 04: 53 \mathrm{PM}$ 12/14/2006 05:02 PM 12/14/2006 05:02 PM 12/14/2006 05:10 PM 12/14/2006 05:10 PM 12/14/2006 05:19 PM $12 / 14 / 2006 \quad 05: 19 \mathrm{PM}$ 12/14/2006 05:28 PM 12/14/2006 05:28 PM $12 / 14 / 2006 \quad 05: 37 \mathrm{PM}$ $12 / 14 / 2006 \quad 05: 37 \mathrm{PM}$ $12 / 14 / 2006 \quad 02: 57$ PM $12 / 14 / 2006 \quad 02: 57 \mathrm{PM}$ 12/14/2006 03:06 PM 12/14/2006 03:06 PM 12/14/2006 03:16 PM 12/14/2006 03:16 PM $12 / 14 / 2006 \quad 03: 25 \mathrm{PM}$ 12/14/2006 03:25 PM 12/14/2006 03:34 PM 12/14/2006 03:34 PM 12/14/2006 03:42 PM 12/14/2006 03:42 PM 12/14/2006 03:51 PM 12/14/2006 03:51 PM
$6,143,768$ stress-pt 72 th-b. OUT $6,143,768$ stress-pt ${ }^{-} 72$ th-m. OUT 6,115,040 stress-pt_72th-t. OUT 13,519 Stress-pt $81 \mathrm{max}-\mathrm{b}$.OUT 13,519 Stress-pt_81max-m.OUT 13,519 Stress-pt $81 \mathrm{max}-\mathrm{t}$. OUT $6,143,768$ stress-pt_81th-b. OUT $6,143,768$ stress-pt 81 th-m. OUT $6,115,040$ stress-pt_81th-t.oUT

13,519 stress-pt $90 \mathrm{max}-\mathrm{b}$. OUT

13,519 stress-pt_90max-m.OUT

13,519 Stress-pt_90max-t. OUT $6,143,768$ Stress-pt 90 th-b. OUT $6,143,768$ stress-pt_90th-m. OUT $6,115,040$ stress-pt 90 th-t. OUT

13,519 Stress-pt_99max-b.OUT

13,519 Stress-pt $99 \mathrm{max}-\mathrm{m}$.OUT

13,519 stress-pt_99max-t.OUT $6,143,768$ Stress-pt 99 th-b. OUT $6,143,768$ stress-pt_99th-m. OUT 6,115,040 stress-pt_99th-t. OUT 13,519 Stress-pt_9max-b. OUT 13,519 Stress-pt 9 max-m. OUT 13,519 Stress-pt 9 max-t. OUT $6,143,896$ Stress-pt_9th-b.OUT $6,143,896$ stress-pt 9 th-m. OUT $6,115,168$ stress-pt_9th-t.oUT

0 Sub-Model-Vert-Files.txt

4,008 Tank-Coordinates-AP. txt

2,512 Tank-Meshl.txt

25 tank-out.out

5, 554 Tank-Props-Rigid.txt 7,639 Tank-th. out

22, 588 TH-Sub-Modal-Column.txt

19,879 TH-Sub-Model-h.txt

19,879 TH-Sub-Model-v.txt

$11,696,640$ waste Pressure 0 deg.xls $11,919,872$ Waste Pressure 45 deg.xls $11,920,384$ Waste Pressure 90 deg.xls 10,180 Waste-Cont_108max.OUT

4,643,118 waste-Cont ${ }^{-108 \text { th. OUT }}$ 10,180 Waste-Cont $117 \mathrm{max}$. OUT

$4,643,118$ Waste-Cont ${ }^{-117 t h}$. OUT 10,180 Waste-Cont $126 \mathrm{max}$.OUT

4,643,118 Waste-Cont_126th. OUT 10,180 Waste-Cont 135max.OUT

4,643,118 Waste-Cont_135th. OUT 10,180 waste-Cont $144 \mathrm{max}$.OUT

4,643,118 Waste-Cont_144th. OUT 10,180 waste-Cont 153 max. OUT

4,643,118 Waste-Cont 153 th. OUT 10,180 Waste-Cont $162 \mathrm{max}$. OUT

4,643,118 Waste-Cont_162th. OUT 10,180 Waste-Cont $171 \mathrm{max}$.OUT

4,643,118 Waste-Cont 171 th. OUT 10,180 Waste-Cont $180 \mathrm{max}$.OUT

$4,643,118$ Waste-Cont 180th. OUT 10,180 Waste-Cont_18max. OUT

4,643,118 Waste-Cont $18 \mathrm{th}$. OUT 10,180 Waste-Cont $27 \mathrm{max}$. OUT

4,643,118 waste-Cont $27 \mathrm{th}$.OUT 10,180 waste-Cont $36 \mathrm{max}$. OUT

4,643,118 Waste-Cont-36th.OUT 10,180 waste-Cont $45 \mathrm{max}$. OUT

4,643,118 waste-Cont 45 th. OUT 10,180 waste-Cont 54max. OUT

$4,643,118$ waste-Cont 54 th. OUT 10,180 waste-Cont $63 \mathrm{max}$. OUT

4,643,118 waste-Cont_63th. OUT 10,180 Waste-Cont ${ }^{-} 72 \mathrm{max}$.OUT

4,643,118 Waste-Cont_ 72 th.OUT 


\section{RPP-RPT-32239, Rev. 1 M\&D-2008-005-CALC-001, Rev. 1}

12/14/2006 03:59 PM 12/14/2006 03:59 PM 12/14/2006 04:08 PM 12/14/2006 04:08 PM $12 / 14 / 2006 \quad 04: 17 \mathrm{PM}$ $12 / 14 / 2006 \quad 04: 17 \mathrm{PM}$ $12 / 14 / 2006 \quad 02: 47$ PM $12 / 14 / 2006 \quad 02: 47 \mathrm{PM}$ 12/14/2006 05:43 PM 09/25/2006 10:41 AM 11/14/2006 07:33 AM 12/17/2006 01:06 PM 12/17/2006 01:47 PM $12 / 17 / 2006 \quad 01: 47$ PM 12/17/2006 01:52 PM 12/17/2006 01:52 PM 12/17/2006 01:53 PM 12/17/2006 01:53 PM 12/17/2006 01:53 PM 12/17/2006 01:53 PM 12/17/2006 01:53 PM 12/17/2006 01:53 PM $12 / 17 / 2006 \quad 01: 54$ PM $12 / 17 / 2006 \quad 01: 54 \mathrm{PM}$ 12/17/2006 01:54 PM 12/17/2006 01:54 PM 12/17/2006 01:55 PM 12/17/2006 01:55 PM $12 / 17 / 2006 \quad 01: 55 \mathrm{PM}$ 12/17/2006 01:55 PM 12/17/2006 01:55 PM 12/17/2006 01:55 PM 12/17/2006 01:55 PM 12/17/2006 01:55 PM $12 / 17 / 2006 \quad 01: 48 \quad \mathrm{PM}$ 12/17/2006 01:48 PM $12 / 17 / 2006 \quad 01: 48 \quad \mathrm{PM}$ $12 / 17 / 2006 \quad 01: 48 \mathrm{PM}$ $12 / 17 / 2006 \quad 01: 49 \mathrm{PM}$ 12/17/2006 01:49 PM 12/17/2006 01:49 PM $12 / 17 / 2006 \quad 01: 49 \mathrm{PM}$ 12/17/2006 01:50 PM 12/17/2006 01:50 PM 12/17/2006 01:50 PM 12/17/2006 01:50 PM 12/17/2006 01:50 PM 12/17/2006 01:50 PM 12/17/2006 01:51 PM 12/17/2006 01:51 PM 12/17/2006 01:51 PM 12/17/2006 01:51 PM 12/17/2006 01:52 PM 12/17/2006 01:52 PM $12 / 17 / 2006 \quad 01: 48 \mathrm{PM}$ 12/17/2006 01:48 PM 12/15/2006 07:15 AM 12/15/2006 07:15 AM 321 File(s)
10,180 waste-Cont $81 \mathrm{max}$. OUT $4,643,118$ waste-Cont_81th.OUT 10,180 Waste-Cont 90 max. OUT 4,643,118 waste-Cont 90th. OUT 10,180 waste-Cont_99max. OUT 4,643,118 Waste-Cont 99th.OUT 10,180 waste-Cont_9max.OUT 4,643,246 Waste-Cont 9 th. OUT

45,117 Waste-Reaction-460-SD3. out 340 Waste-Reaction.txt

10, 553 waste-solid-AP-S.txt 683 waste-Surface-AP. txt 1,027 Waste-Surf Omax.OUT 572,821 Waste-Surf_oth.OUT 1,027 Waste-Surf $108 \mathrm{max}$. OUT 572,693 Waste-Surf 108 th. OUT 1,027 Waste-Surf 117max.OUT 572,693 Waste-Surf 117 th. OUT 1,027 Waste-Surf ${ }^{-} 126 \mathrm{max}$. OUT

572,693 Waste-Surf 126 th. OUT

1,027 Waste-Surf $135 \mathrm{max}$. OUT

572,693 Waste-Surf 135 th. OUT

1, 027 Waste-Surf $144 \mathrm{max}$. OUT

572,693 Waste-Surf 144 th. OUT

1,027 Waste-Surf_153max. OUT

572,693 Waste-Surf 153th. OUT

1,027 Waste-Surf $162 \mathrm{max}$.OUT

572,693 Waste-Surf 162 th. OUT

1,027 Waste-Surf $171 \mathrm{max}$.OUT

572,693 waste-Surf ${ }^{-171}$ th. OUT

1,027 Waste-Surf 180max. OUT

572,693 Waste-Surf-180th. OUT

1,027 Waste-Surf 189max. OUT

572,693 Waste-Surf 189 th. OUT

1,027 Waste-Surf 18max. OUT

572,693 waste-Surf 18 th.OUT

1,027 Waste-Surf $27 \mathrm{max}$. OUT

572,693 Waste-Surf 27th.OUT

1,027 Waste-Surf $36 \mathrm{max}$. OUT

572,693 Waste-Surf 36 th. OUT

1,027 Waste-Surf $45 \mathrm{max}$. OUT

572,693 Waste-Surf 45 th. OUT

1, 027 Waste-Surf $54 \mathrm{max}$. OUT

572,693 Waste-Surf_54th.OUT

1, 027 Waste-Surf 63 max. OUT

572,693 Waste-Surf 63th. OUT

1,027 Waste-Surf-72max. OUT

572,693 Waste-Surf $72 \mathrm{th}$.OUT

1,027 Waste-Surf 81 max. OUT

572,693 Waste-Surf ${ }^{-} 81$ th. OUT

1,027 Waste-Surf 90 max. OUT

572,693 Waste-Surf-90th.OUT

1,027 waste-Surf 99max. OUT

572,693 waste-Surf $99 \mathrm{th}$.OUT

1, 027 waste-Surf 9 max. OUT

572,693 Waste-Surf 9 th. OUT

229,888 waste $0-90.81$ s

229,888 waste_99-180.xls $574,382,541$ bytes

Directory of C: \Users $\backslash$ Bruce $\backslash 2008-000$ PNNL $\backslash 2008-005$ AP-460 $\backslash$ AP-460-Sub-Model-Vert $\backslash$ Freq Test

$12 / 20 / 2006$ $12 / 20 / 2006$ $08 / 21 / 2006$ $11 / 10 / 2006$ $12 / 19 / 2006$ $12 / 19 / 2006$ $12 / 19 / 2006$ $12 / 19 / 2006$ $12 / 19 / 2006$

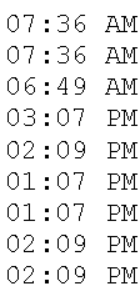

$\langle\mathrm{DIR}\rangle$ $\langle\mathrm{DIR}>$

101 All-Forces.txt

768 AP-460-Slosh-Flex-Dytran.log

323,726 AP-460-Slosh-Flex-V. out

136 AP-460-Sub-Model-H.err

77, 418 AP-460-Sub-Model-H. log

2,998 AP-460-Sub-Model-V.BCS

$43,646,976$ AP-460-Sub-Model-V.db 


\section{RPP-RPT-32239, Rev. 1 M\&D-2008-005-CALC-001, Rev. 1}

$12 / 19 / 2006$ $12 / 19 / 2006$ $12 / 20 / 2006$ $12 / 19 / 2006$ $12 / 19 / 2006$ $12 / 19 / 2006$ $12 / 20 / 2006$ $12 / 19 / 2006$ $12 / 19 / 2006$ $12 / 19 / 2006$ $12 / 19 / 2006$ $12 / 19 / 2006$ $12 / 19 / 2006$ $11 / 17 / 2006$ $06 / 09 / 2005$ $11 / 19 / 2006$ $08 / 21 / 2006$ $08 / 25 / 2006$ $08 / 25 / 2006$ $08 / 25 / 2006$ $08 / 21 / 2006$ $08 / 21 / 2006$ $01 / 03 / 2006$ $11 / 10 / 2006$ $11 / 17 / 2006$ $12 / 20 / 2005$ $10 / 13 / 2005$ $08 / 21 / 2006$ $08 / 21 / 2006$ $10 / 17 / 2006$ $07 / 20 / 2006$ $11 / 13 / 2006$ $08 / 23 / 2006$ $05 / 02 / 2005$ $07 / 21 / 2006$ $04 / 20 / 2005$ $11 / 10 / 2006$ $11 / 10 / 2006$ $09 / 27 / 2005$ $12 / 19 / 2006$ $10 / 31 / 2005$ $12 / 19 / 2006$ $12 / 19 / 2006$ $02 / 11 / 2005$ $11 / 11 / 2005$ $12 / 19 / 2006$ $11 / 17 / 2006$ $08 / 25 / 2006$ $09 / 13 / 2006$ $09 / 13 / 2006$ $09 / 13 / 2006$ $09 / 13 / 2006$ $09 / 13 / 2006$ $09 / 13 / 2006$ $09 / 13 / 2006$ $08 / 28 / 2006$ $10 / 03 / 2006$ $10 / 03 / 2006$ $09 / 13 / 2006$ $10 / 03 / 2006$ $10 / 03 / 2006$ $09 / 13 / 2006$ $06 / 20 / 2005$ $06 / 20 / 2005$ $09 / 05 / 2006$ $08 / 21 / 2006$ $08 / 16 / 2006$ $08 / 21 / 2006$ $08 / 21 / 2006$ $08 / 16 / 2006$ $08 / 21 / 2006$
02:09 PM 02:09 PM $07: 36$ AM 02:09 PM 02:09 PM 02:08 PM $07: 36$ AM 02:09 PM $02: 08$ PM 02:09 PM 02:09 PM 01:08 PM 02:09 PM $11: 04$ AM $01: 59 \mathrm{PM}$ $09: 14$ AM 07:59 AM 01:28 PM $01: 27$ PM $01: 28$ PM $07: 59 \mathrm{AM}$ $12: 44 \mathrm{PM}$ $11: 17$ AM $02: 08 \mathrm{PM}$ 10:53 AM $04: 49$ PM $06: 54$ AM 08:00 AM 08:00 AM $01: 37 \mathrm{PM}$ 06:36 AM $01: 45 \mathrm{PM}$ $07: 47$ AM $02: 19 \mathrm{PM}$ 10:03 AM $01: 14$ PM 04:08 PM 04:05 PM 03:52 PM 01:08 PM $10: 31 \mathrm{AM}$ 09:50 AM 01:07 PM 01:22 PM $10: 36$ AM 09:50 AM $11: 14$ AM $08: 47$ AM 06:12 AM 06:07 AM 06:08 AM 06:09 AM 06:08 AM 06:08 AM 06:09 AM 09:38 AM 02:02 PM 02:04 PM $06: 15 \mathrm{AM}$ $02: 03 \mathrm{PM}$ 02:03 PM $06: 15$ AM $09: 04$ AM $08: 52$ AM $02: 00 \mathrm{PM}$ $08: 01 \mathrm{AM}$ $01: 59 \mathrm{PM}$ $08: 01$ AM $08: 02$ AM $02: 00 \mathrm{PM}$ $08: 01 \mathrm{AM}$
$53,084,160$ AP-460-Sub-Model-V.dbb $11,730,944$ AP-460-Sub-Model-V. emat 48,725 AP-460-Sub-Model-V.err $50,462,720$ AP-460-Sub-Model-V. esav $12,845,056$ AP-460-Sub-Model-V.full $15,299,480$ AP-460-Sub-Model-V.ldhi 2,948 AP-460-Sub-Model-V.log 10,943 AP-460-Sub-Model-V.mntr $50,462,720$ AP-460-Sub-Model-V. osav 67 AP-460-Sub-Model-V.PVTS

$50,987,008$ AP-460-Sub-Model-V.r001 $43,646,976$ AP-460-Sub-Model-V.rdb $610,467,840$ AP-460-Sub-Model-V.rst 6,046 Bolts-Friction.txt

262 Boundary.txt

227 Contact-AP.txt

586 Contact-Footing.txt

704 Contact-Insul.txt

704 Contact-J-Bolts.txt

708 Contact-Primary.txt

742 Contact-Soil.txt

632 Contact-Waste-AP.txt

1,616 Disp-J-Bolts.txt

8,620 Far-Soil.txt

5,822 file.log

39,925 file.txt

562 Fix-Soil.txt

894 Force-c.txt

661 Force-j_bolt.txt

1,668 Insulate.txt

4,030 interface-gap1.txt

2,445 interface1.txt

1,971 Liner.txt

667 live load.txt

6,214 Near-Soil-1.txt

508 outer-spar.txt

125 Post-Tank.txt

6,154 Primary-Props-AP.txt

1,538 Primary.txt

451,239 QA. out

1, 108 RS FREQ. txt

1,893 Run-Tank.txt

0 scratch.hlp

1,053 Slave.txt

4,989 Soil-Prop-Mean-Geo.txt

2,028 Solve-Slosh-vert.txt

2,177 Solve-Sub-Horiz.txt

1,918 Solve-TH-BES.txt

347 spectra-all.txt

3,690 spectra-conc-0.txt

3,723 spectra-conc-135.txt

3,723 spectra-conc-180. txt

3,769 spectra-conc -45. txt

3,649 spectra-conc-90.txt

1,590 spectra-conc.txt

2,076 spectra-concrete.txt

3,624 spectra-primary-0.txt

3,777 spectra-primary-135.txt

3,777 spectra-primary-180.txt

3,703 spectra-primary-45.txt

3,703 spectra-primary-90.txt

3,801 spectra-soil.txt

647 spectra-wall.txt

679 spectra-waste.txt

2,588 strain-backed.txt

566 strain-compb-p.txt

621 strain-compb-primary.txt

693 strain-compb.txt

566 strain-compm-p.txt

621 strain-compm-primary.txt

705 strain-compm.txt 
RPP-RPT-32239, Rev. 1

M\&D-2008-005-CALC-001, Rev. 1

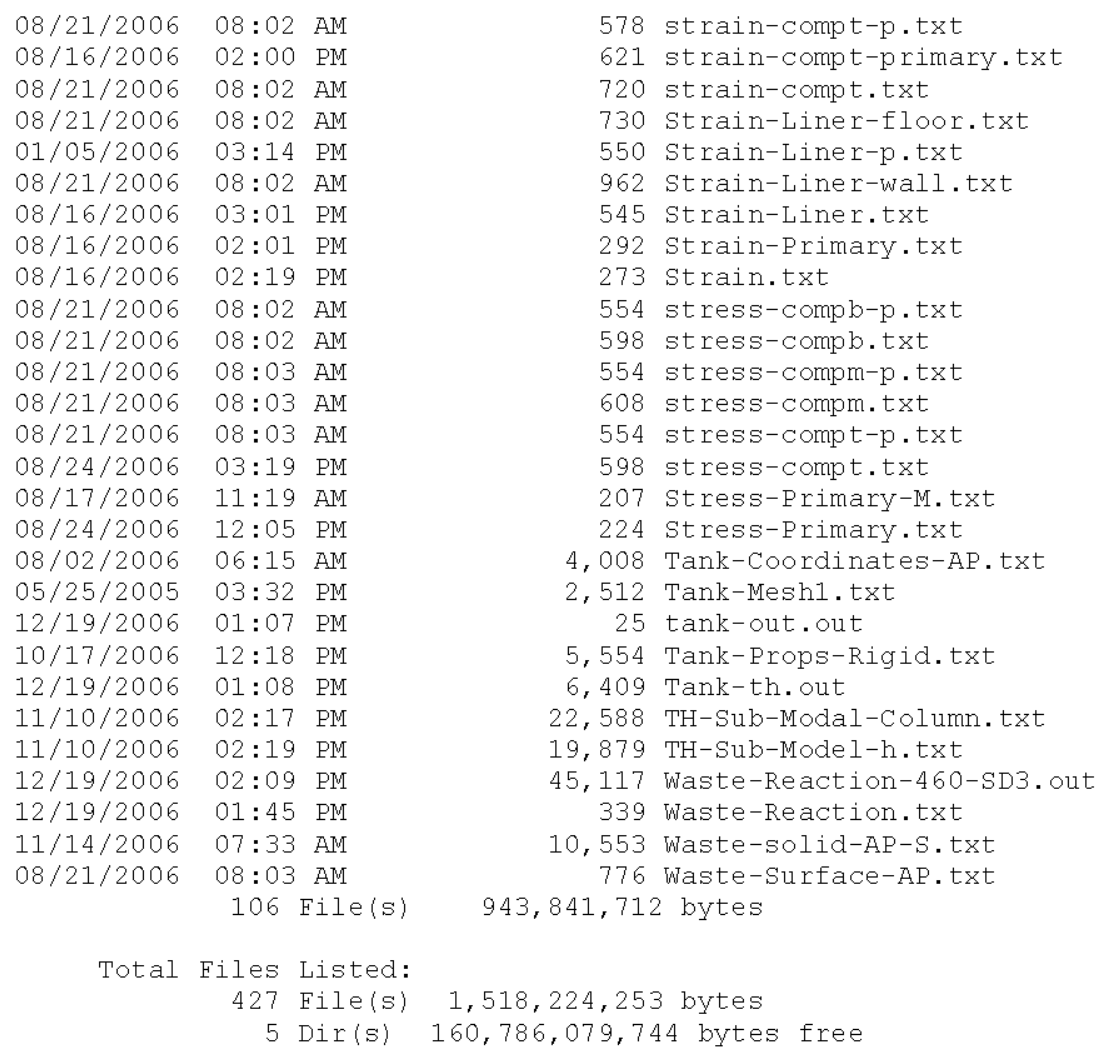


RPP-RPT-32239, Rev. 1

M\&D-2008-005-CALC-001, Rev. 1

Intentionally left blank.

D.32 
RPP-RPT-32239, Rev. 1

M\&D-2008-005-CALC-001, Rev. 1

\section{Appendix E}

Common ANSYS ${ }^{\circledR}$ Files Listing 
RPP-RPT-32239, Rev. 1

M\&D-2008-005-CALC-001, Rev. 1

Intentionally left blank 
RPP-RPT-32239, Rev. 1

M\&D-2008-005-CALC-001, Rev. 1

Appendix E

\title{
Common ANSYS ${ }^{\circledR}$ Files Listing
}

\begin{abstract}
All-Forces.txt
/input, force-c, txt

/input, stress-Primary, txt

/input, Force-J bolt, txt

/input, strain-liner, txt
\end{abstract}

\section{Bolts-Friction.txt}

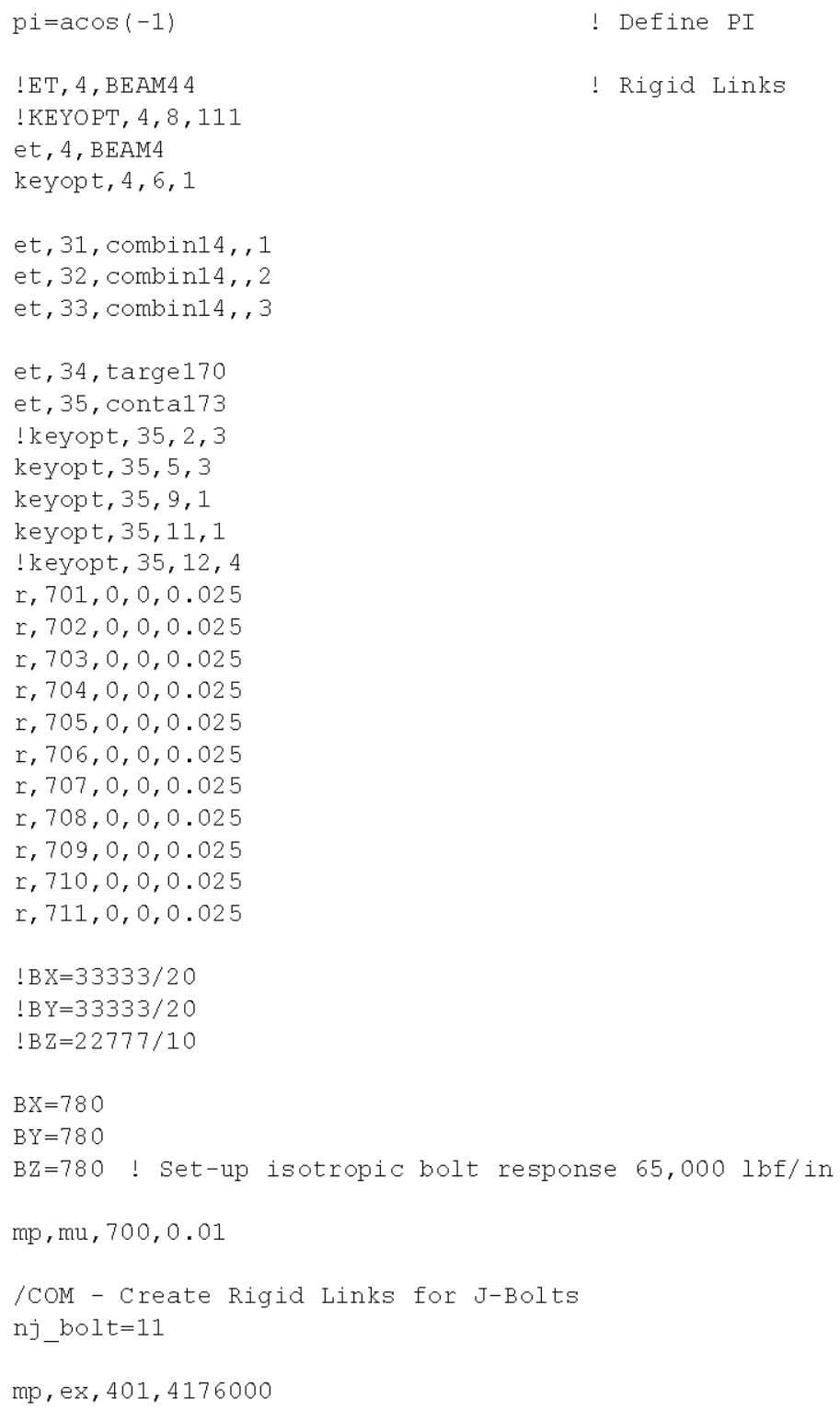


RPP-RPT-32239, Rev. 1

M\&D-2008-005-CALC-001, Rev. 1

mp, nuxy, 401, 0.30

mp, dens, 401, 0

$r, 401,1,10,10,2.5,2.5$

rmore, , $1 \mathrm{e}-3$

$r, 402,1,10,10,2.5,2.5$

rmore, $1 \mathrm{e}-3$

$r, 403,1,10,10,2.5,2.5$

rmore,, $1 \mathrm{e}-3$

$r, 404,1,10,10,2.5,2.5$

rmore,, $1 \mathrm{e}-3$

$r, 405,1,10,10,2.5,2.5$

rmore,, $1 \mathrm{e}-3$

$r, 406,1,10,10,2.5,2.5$

rmore, , $1 \mathrm{e}-3$

$r, 407,1,10,10,2.5,2.5$

rmore,, $1 \mathrm{e}-3$

$r, 408,1,10,10,2.5,2.5$

rmore, $1 \mathrm{e}-3$

$r, 409,1,10,10,2.5,2.5$

rmore, , $1 \mathrm{e}-3$

$r, 410,1,10,10,2.5,2.5$

rmore, , $1 \mathrm{e}-3$

$r, 411,1,10,10,2.5,2.5$

rmore, , 1e-3

$r, 421,1 / 2,10,10,2 \cdot 5,2.5$

rmore,, $1 \mathrm{e}-3$

$r, 422,1 / 2,10,10,2.5,2.5$

rmore,, $1 \mathrm{e}-3$

$r, 423,1 / 2,10,10,2.5,2.5$

rmore,, $1 e-3$

$r, 424,1 / 2,10,10,2 \cdot 5,2.5$

rmore,, $1 \mathrm{e}-3$

$r, 425,1 / 2,10,10,2.5,2.5$

rmore, , 1e-3

$r, 426,1 / 2,10,10,2.5,2.5$

rmore,, $1 \mathrm{e}-3$

$r, 427,1 / 2,10,10,2.5,2.5$

rmore,, $1 \mathrm{e}-3$

$r, 428,1 / 2,10,10,2 \cdot 5,2.5$

rmore,, $1 e-3$

$r, 429,1 / 2,10,10,2 \cdot 5,2.5$

rmore,, $1 \mathrm{e}-3$

$r, 430,1 / 2,10,10,2.5,2.5$

rmore,, $1 \mathrm{e}-3$

$r, 431,1 / 2,10,10,2.5,2.5$

rmore,, $1 \mathrm{e}-3$

$r, 501,1.364{ }^{*} \mathrm{BX}$

$\mathrm{r}, 502,0.550{ }^{*} \mathrm{BX}$

$r, 503,0.887^{\star} \mathrm{BX}$

$\mathrm{r}, 504,1.027^{\star} \mathrm{BX}$

$\mathrm{r}, 505,1.971 \star_{\mathrm{BX}}$

$\mathrm{r}, 506,2.407 * \mathrm{BX}$

$\mathrm{r}, 507,3.301 * \mathrm{BX}$

$r, 508,4.039 \star_{\mathrm{BX}}$

$r, 509,4.369 * \mathrm{BX}$

$\mathrm{r}, 510,5.362 \star_{\mathrm{BX}}$

$r, 511,3.596{ }^{\star} \mathrm{BX}$

$\mathrm{r}, 521,1.364 \star_{\mathrm{BY}}$

$r, 522,0.550 * \mathrm{BY}$

$\mathrm{r}, 523,0.887^{*} \mathrm{BY}$

$\mathrm{r}, 524,1.027^{\star} \mathrm{BY}$

$r, 525,1.971^{\star} \mathrm{BY}$ 
RPP-RPT-32239, Rev. 1

M\&D-2008-005-CALC-001, Rev. 1

$r, 526,2.407 * \mathrm{BY}$

$r, 527,3.301 * \mathrm{BY}$

$\mathrm{r}, 528,4.039{ }^{\mathrm{BY}}$

$\mathrm{r}, 529,4.369 * \mathrm{BY}$

$r, 530,5.362{ }^{*} \mathrm{BY}$

$r, 531,3.596 * \mathrm{BY}$

$\mathrm{r}, 541,1.364{ }^{*} \mathrm{BZ}$

$\mathrm{r}, 542,0.550 * \mathrm{BZ}$

$\mathrm{r}, 543,0.887^{\star} \mathrm{BZ}$

$\mathrm{r}, 544,1.027^{\star} \mathrm{BZ}$

$\mathrm{r}, 545,1.971{ }^{\star} \mathrm{BZ}$

$\mathrm{r}, 546,2.407^{*} \mathrm{BZ}$

$\mathrm{r}, 547,3.301 * \mathrm{BZ}$

$\mathrm{r}, 548,4.039 * \mathrm{BZ}$

$\mathrm{r}, 549,4.369{ }^{*} \mathrm{BZ}$

$\mathrm{r}, 550,5.362{ }^{\star} \mathrm{BZ}$

$\mathrm{r}, 551,3.596{ }^{\star} \mathrm{BZ}$

$\mathrm{R}, 601,1.364{ }^{\star} \mathrm{BX} / 2$

$\mathrm{R}, 602,0.550 * \mathrm{BX} / 2$

$\mathrm{R}, 603,0.887^{\star} \mathrm{BX} / 2$

$\mathrm{R}, 604,1.027 * \mathrm{BX} / 2$

$\mathrm{R}, 605,1.971^{\star} \mathrm{BX} / 2$

$\mathrm{R}, 606,2.407{ }^{\star} \mathrm{BX} / 2$

$\mathrm{R}, 607,3.301 * \mathrm{BX} / 2$

$\mathrm{R}, 608,4.039 * \mathrm{BX} / 2$

$\mathrm{R}, 609,4.369{ }^{\mathrm{BXX}} / 2$

$\mathrm{R}, 610,5.362{ }^{*} \mathrm{BX} / 2$

$\mathrm{R}, 611,3.596{ }^{\star} \mathrm{BX} / 2$

$\mathrm{R}, 621,1.364{ }^{*} \mathrm{BY} / 2$

$\mathrm{R}, 622,0.550 * \mathrm{BY} / 2$

$\mathrm{R}, 623,0.887^{*} \mathrm{BY} / 2$

$\mathrm{R}, 624,1.027{ }^{\star} \mathrm{BY} / 2$

$\mathrm{R}, 625,1.971 * \mathrm{BY} / 2$

$\mathrm{R}, 626,2.407 * \mathrm{BY} / 2$

$\mathrm{R}, 627,3.301 * \mathrm{BY} / 2$

$\mathrm{R}, 628,4.039{ }^{*} \mathrm{BY} / 2$

$\mathrm{R}, 629,4.369 * \mathrm{BY} / 2$

$\mathrm{R}, 630,5.362{ }^{*} \mathrm{BY} / 2$

$\mathrm{R}, 631,3.596{ }^{\star} \mathrm{BY} / 2$

$\mathrm{R}, 641,1.364 * \mathrm{BZ} / 2$

$\mathrm{R}, 642,0.550{ }^{*} \mathrm{BZ} / 2$

$\mathrm{R}, 643,0.887^{\star} \mathrm{BZ} / 2$

$\mathrm{R}, 644,1.027{ }^{\star} \mathrm{BZ} / 2$

$\mathrm{R}, 645,1.971^{\star} \mathrm{BZ} / 2$

$\mathrm{R}, 646,2.407^{\star} \mathrm{BZ} / 2$

$\mathrm{R}, 647,3.301 * \mathrm{BZ} / 2$

$\mathrm{R}, 648,4.039{ }^{*} \mathrm{BZ} / 2$

$\mathrm{R}, 649,4.369{ }^{\mathrm{BZ}} / 2$

$\mathrm{R}, 650,5.362 * \mathrm{BZ} / 2$

$\mathrm{R}, 651,3.596^{*} \mathrm{BZ} / 2$

cmsel, s, primary-tank

nsle

nsel, r, loc, z,ptz(1), ptz (11)

$\mathrm{cm}$, bolt-primary-n, node

nsel, none

$\mathrm{n}, 0,0, \mathrm{ptz}(1)$

$\star$ do, i, 2, nj bolt

${ }^{*} \mathrm{do}, j, 0,18 \overline{0} / \operatorname{arcsize}$

angley $=-j *$ arcsize

n, ptx(i), angley,ptz(i) 


\section{RPP-RPT-32239, Rev. 1 \\ M\&D-2008-005-CALC-001, Rev. 1}

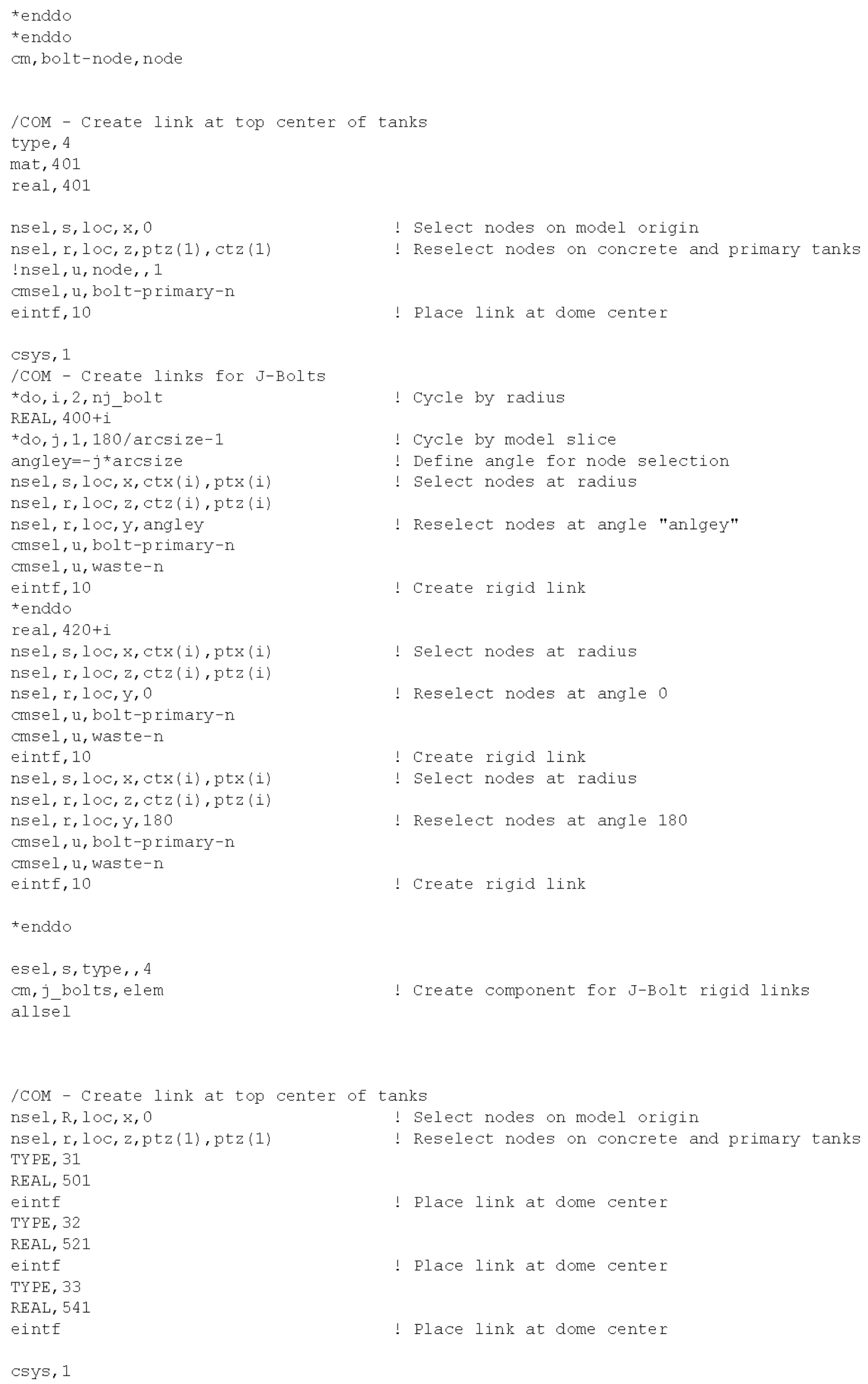


RPP-RPT-32239, Rev. 1

M\&D-2008-005-CALC-001, Rev. 1

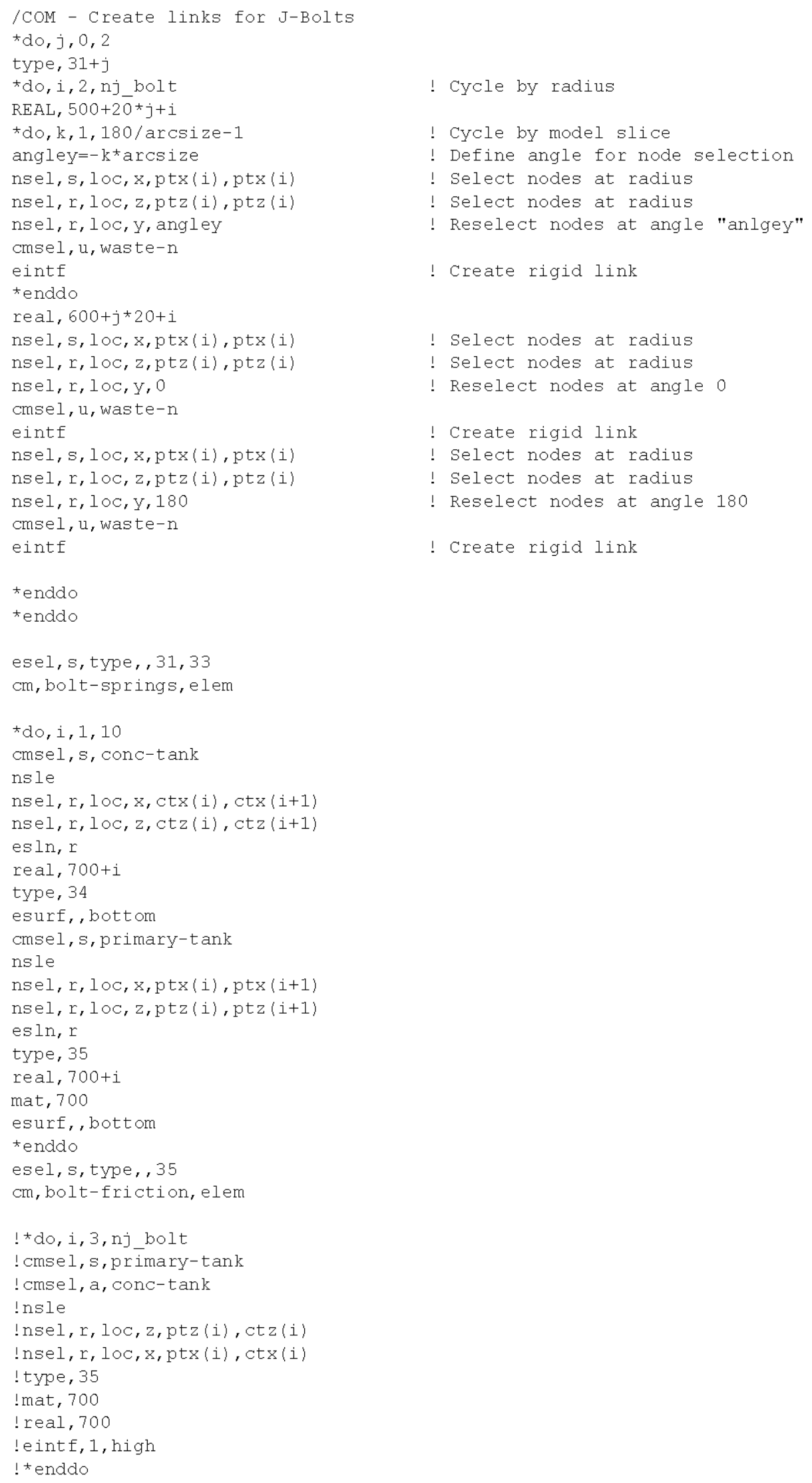

! Cycle by radius

! Cycle by model slice

! Define angle for node selection

! Select nodes at radius

! Select nodes at radius

! Reselect nodes at angle "anlgey"

! Create rigid link

! Select nodes at radius

! Select nodes at radius

! Reselect nodes at angle 0

! Create rigid link

! Select nodes at radius

! Select nodes at radius

! Reselect nodes at angle 180

! Create rigid link 
RPP-RPT-32239, Rev. 1

M\&D-2008-005-CALC-001, Rev. 1

*get, KMAXjb, KP, 0, num, max *get, LMAXjb, LINE, 0, num, max ${ }^{\star}$ get, AMAXjb, AREA, 0, num, max *get, VMAXjb, volu, 0, num, max
! Get maximum keypoint number

! Get maximum line number

( Get maximum area number

! Get maximum volume number

\section{Boundary.txt}

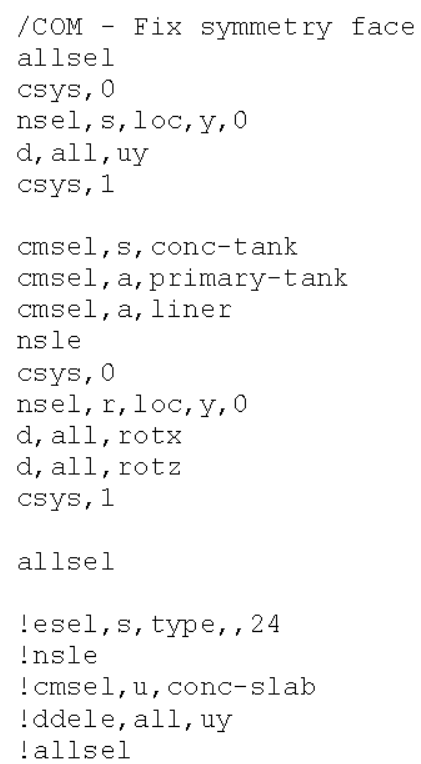

\section{Contact-AP.txt}

/ input, waste-reaction, txt /input, contact-waste-ap, txt / input, contact-insul, txt / input, contact-primary, txt / input, contact-j-bolts, txt /input, contact-soil, txt /input, waste-surface-ap, txt /input, contact-footing, txt

\section{Contact-Footing.txt}

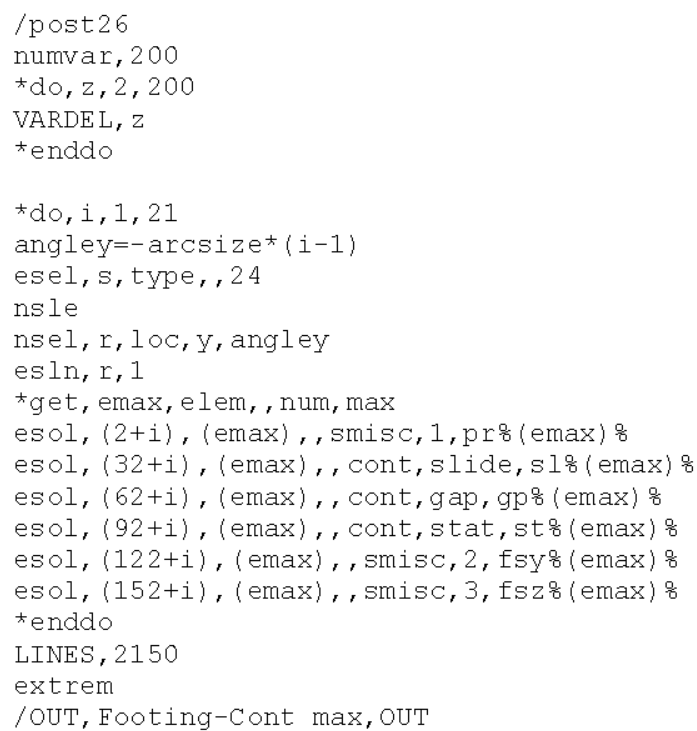


RPP-RPT-32239, Rev. 1

M\&D-2008-005-CALC-001, Rev. 1

extrem, 3,200

/OUT

/OUT, Footing-Cont_th, OUT

${ }^{*} \mathrm{do}, \mathrm{k}, 1,20$

PRVAR, $2+k, 32+k, 62+k, 92+k, 122+k, 152+k$

*enddo

/OUT

\section{Contact-Insul.txt}

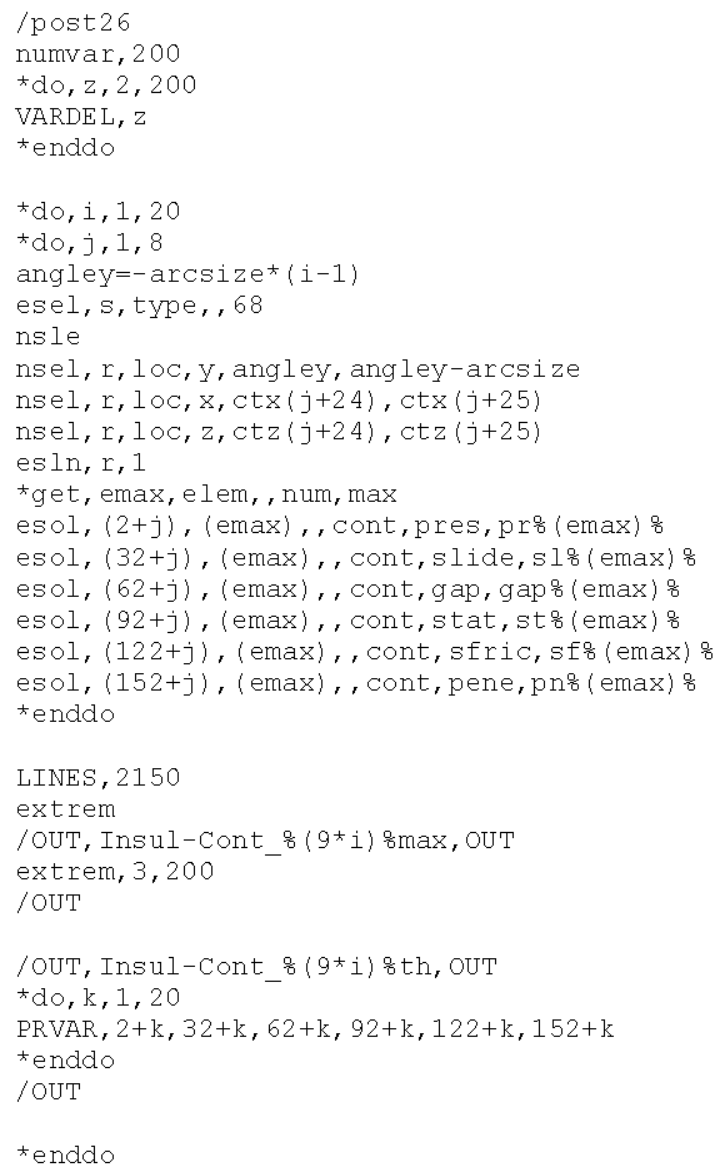

\section{Contact-J-Bolts.txt}

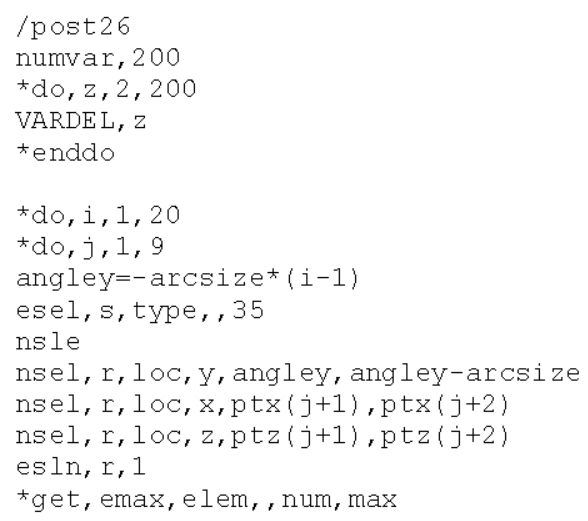


RPP-RPT-32239, Rev. 1

M\&D-2008-005-CALC-001, Rev. 1

esol, $(2+j)$, (emax), , cont, pres, pro (emax) 8 esol, $(32+j),($ emax), , cont, slide, slo(emax) 8 esol, $(62+j)$, (emax), , cont, gap, gap 8 (emax) $\%$ esol, $(92+j)$, (emax), , cont, stat, stato (emax) o esol, (122+j), (emax), , cont, sfric, sfo (emax) esol, $(152+j),($ emax), , cont, pene, pno (emax) 응 *enddo

LINES, 2150

extrem

/OUT, J-Bolt-Cont_o ( $9 * i)$ omax, OUT

extrem, 3,200

/OUT

/OUT, J-Bolt-Cont_\&( 9 *i) 8 th, OUT

${ }^{*} \mathrm{do}, \mathrm{k}, 1,21$

PRVAR, $2+k, 32+k, 62+k, 92+k .122+k, 152+k$

*enddo

/OUT

*enddo

\section{Contact-Primary.txt}

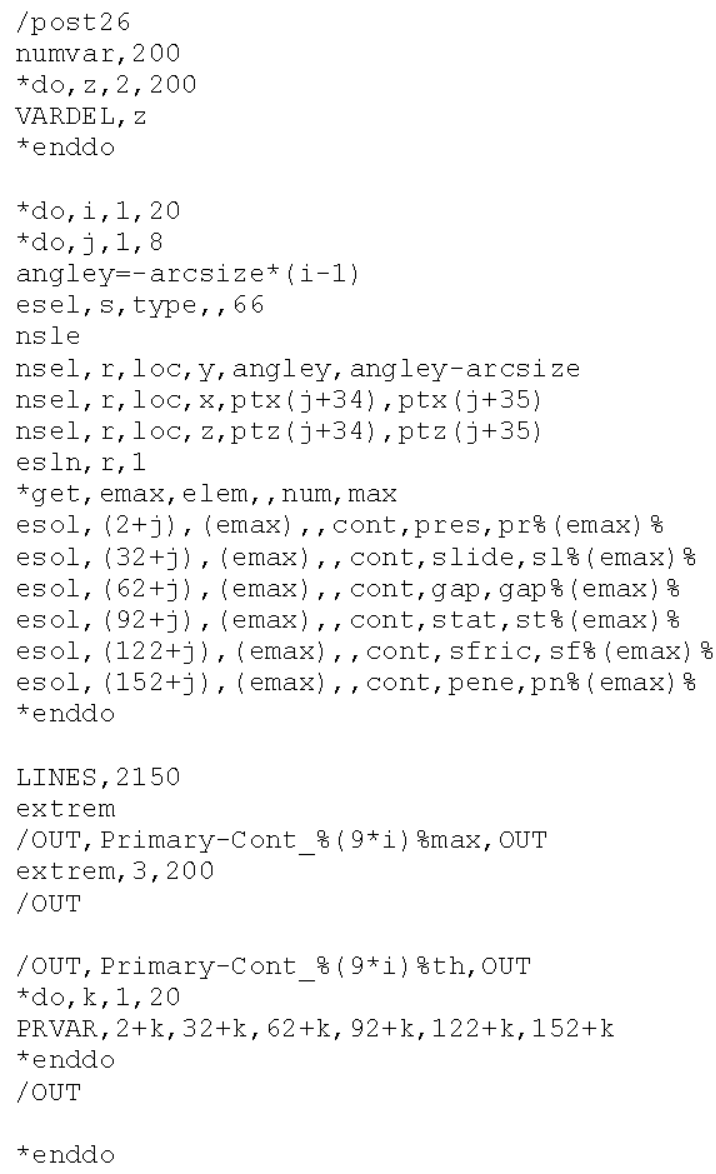

\section{Contact-Soil.txt}

/post26

numvar, 200

$\star$ do, $z, 2,200$

VARDE L, $z$ 
RPP-RPT-32239, Rev. 1

M\&D-2008-005-CALC-001, Rev. 1

*enddo

$*$ do, $i, 1,20$

$\star \mathrm{do}, j, 1,20$

angley $=-\operatorname{arcsize}(i-1)$

esel, s, type, $, 61,63,2$

nsle

nsel, $r, l o c, y$, angley, angley-arcsize

nsel, $r, l o c, x, \operatorname{ctx}(j+1), \operatorname{ctx}(j+2)$

nsel, r, loc, $z, \operatorname{ctz}(j+1), \operatorname{ctz}(j+2)$

esln, $r, 1$

*get, emax, elem, num, max

*get, nmax, node, , num, mas

esol, $(2+j)$, (emax), , cont, pres, pro (emax) $\frac{8}{8}$

esol, $(32+j)$, (emax), , cont, slide, pro (emax) \&

esol, $(62+j),($ emax), , cont, gap, pro (emax) $\%$

esol, $(92+j)$, (emax), cont, stat, pro (emax) :

esol, $(122+j),\left(\right.$ emax), nmax, smisc, $8, \operatorname{taur} 8$ (emax) $\frac{8}{8}$

esol, (152+j), (emax), nmax, smisc, 12, tauso (emax) 음

*enddo

LINES, 2150

extrem

/OUT, Soil-Contact 8 (9*i) 8 max, OUT

extrem, 3,200

/OUT

/OUT, Soil-Contact $\frac{\circ}{8}(9 * i) \frac{8}{8}$ th, OUT

${ }^{\star} \mathrm{do}, \mathrm{k}, 1,21$

PRVAR, $2+k, 32+k, 62+k, 92+k, 122+k, 152+k$

*enddo

/OUT

*enddo

\section{Contact-Waste-AP.txt}

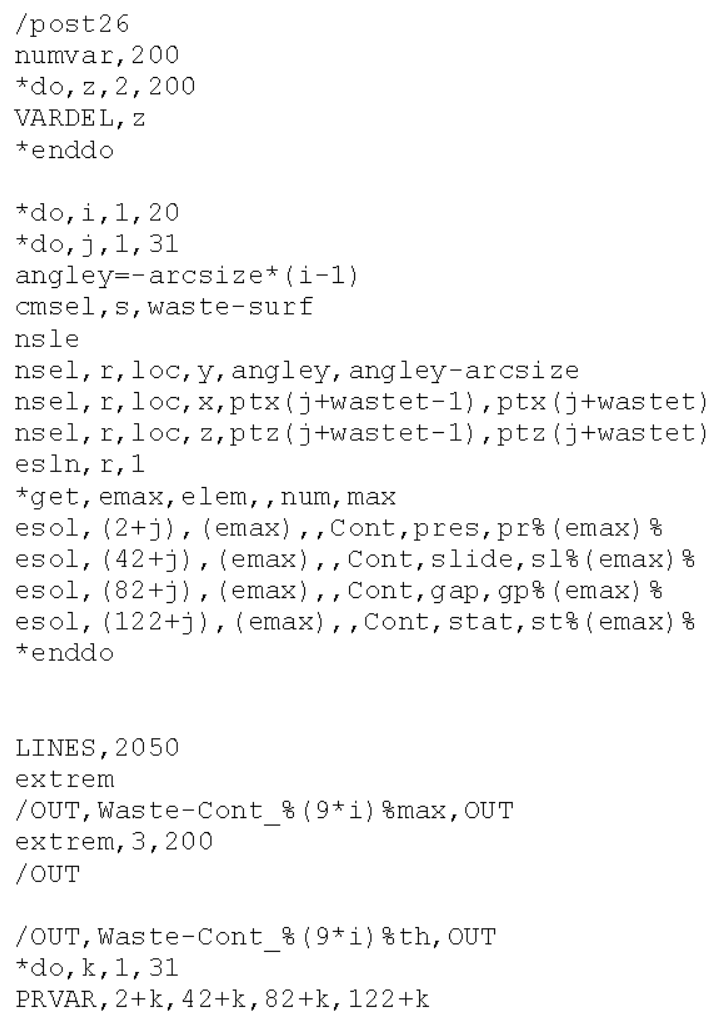


RPP-RPT-32239, Rev. 1

M\&D-2008-005-CALC-001, Rev. 1

*enddo

/OUT

*enddo

\section{Far-Soil.txt}

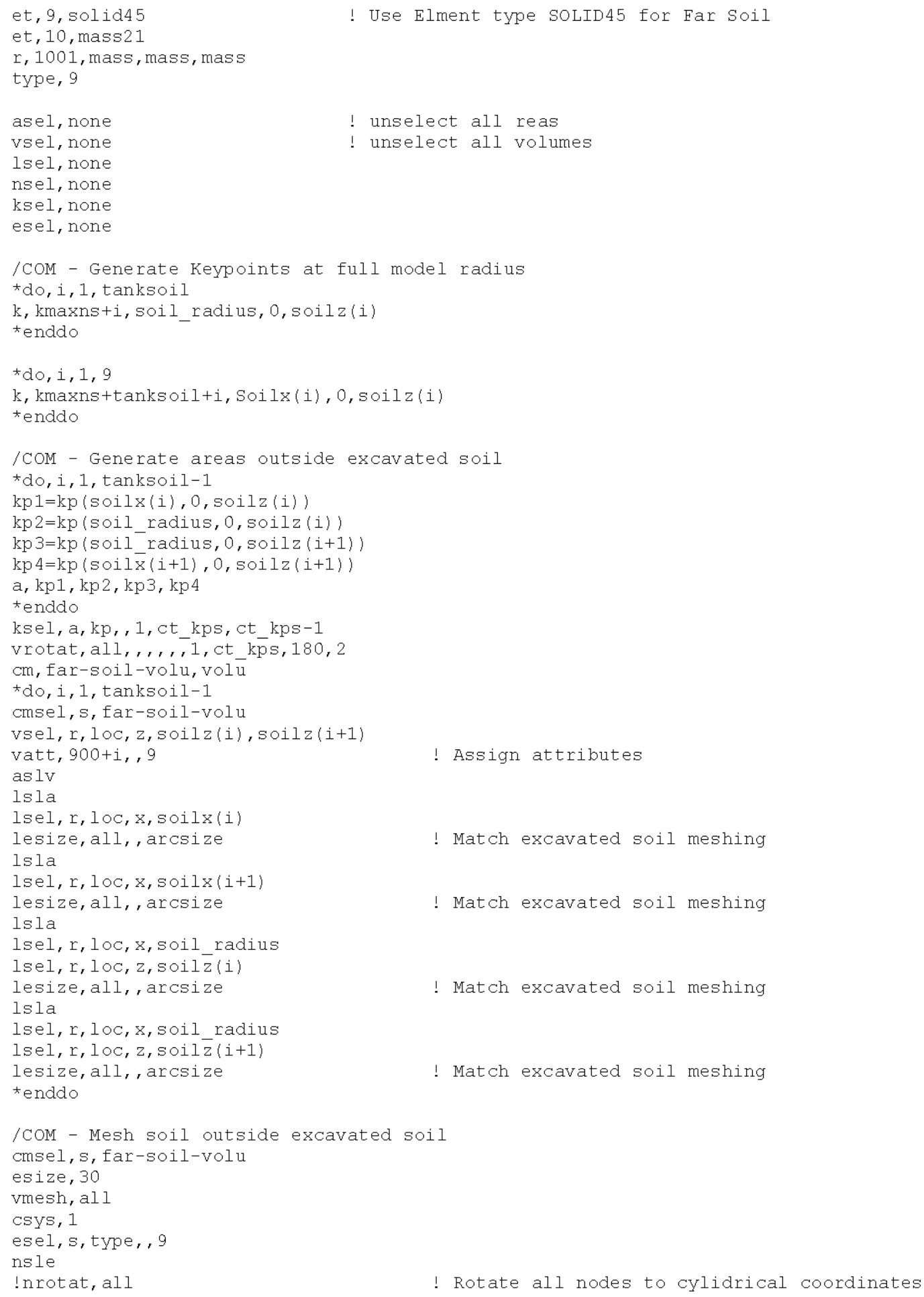




\section{RPP-RPT-32239, Rev. 1 M\&D-2008-005-CALC-001, Rev. 1}

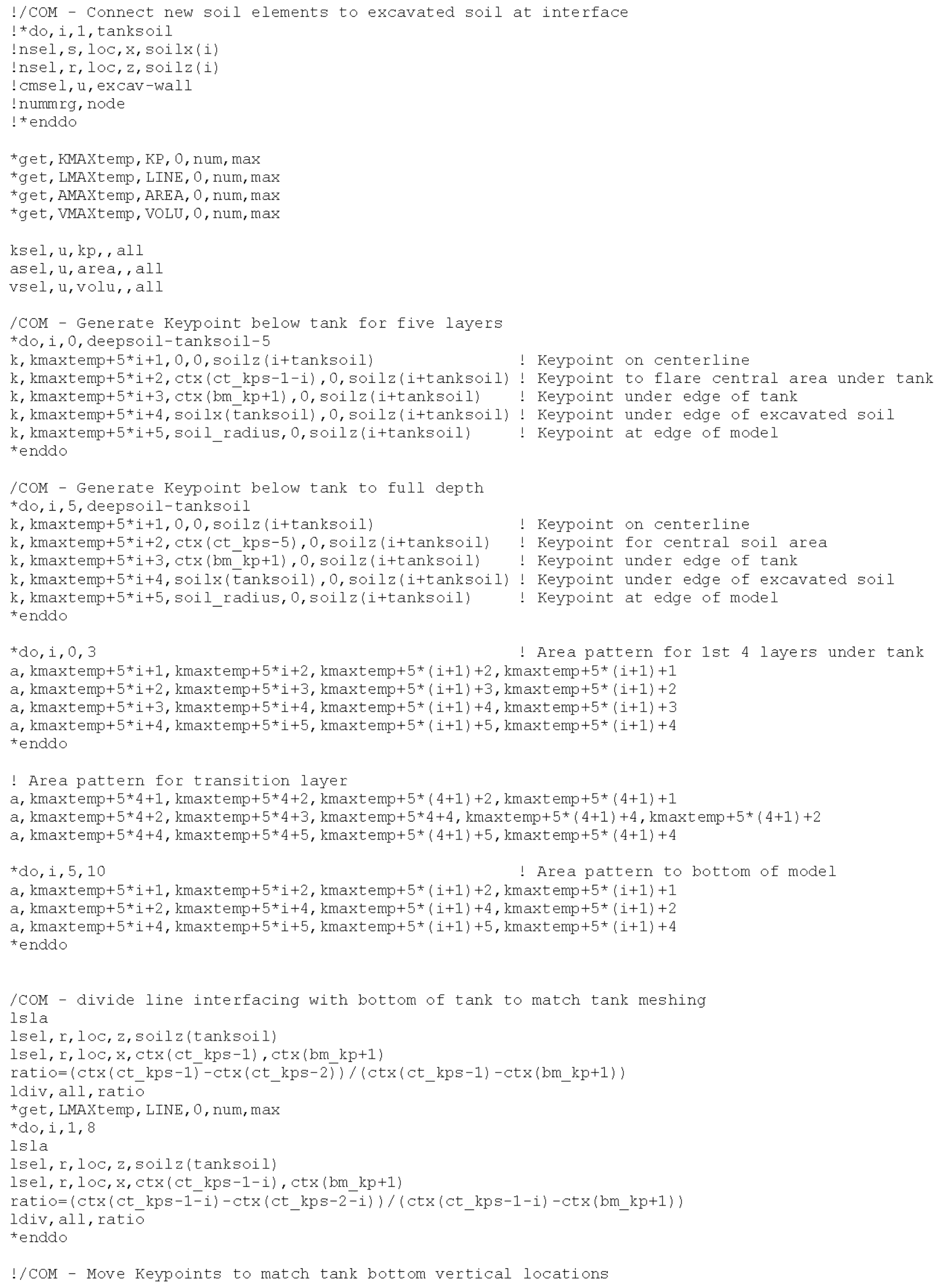




\section{RPP-RPT-32239, Rev. 1 \\ M\&D-2008-005-CALC-001, Rev. 1}

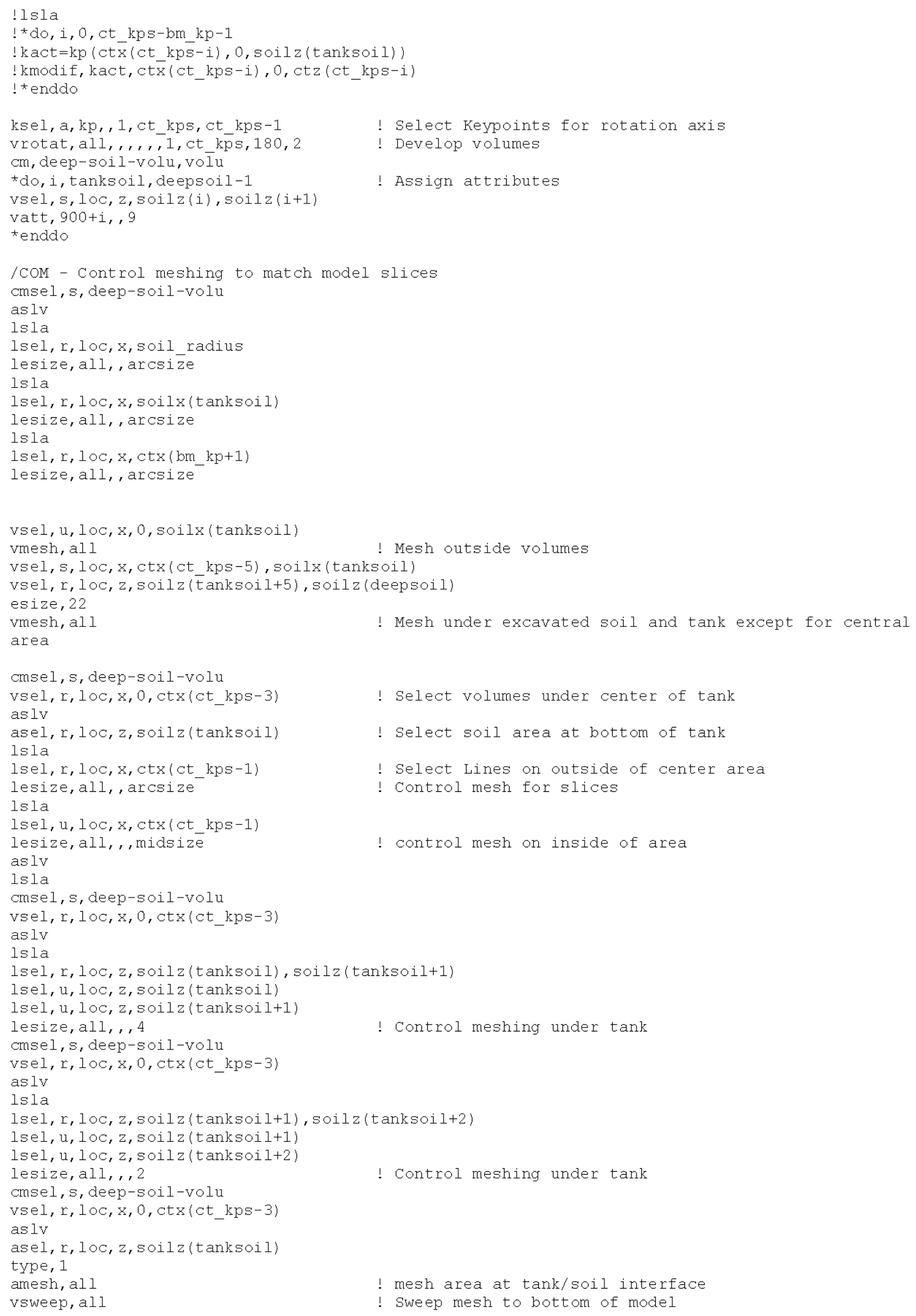

! Sweep mesh to bottom of model 


\section{RPP-RPT-32239, Rev. 1 \\ M\&D-2008-005-CALC-001, Rev. 1}

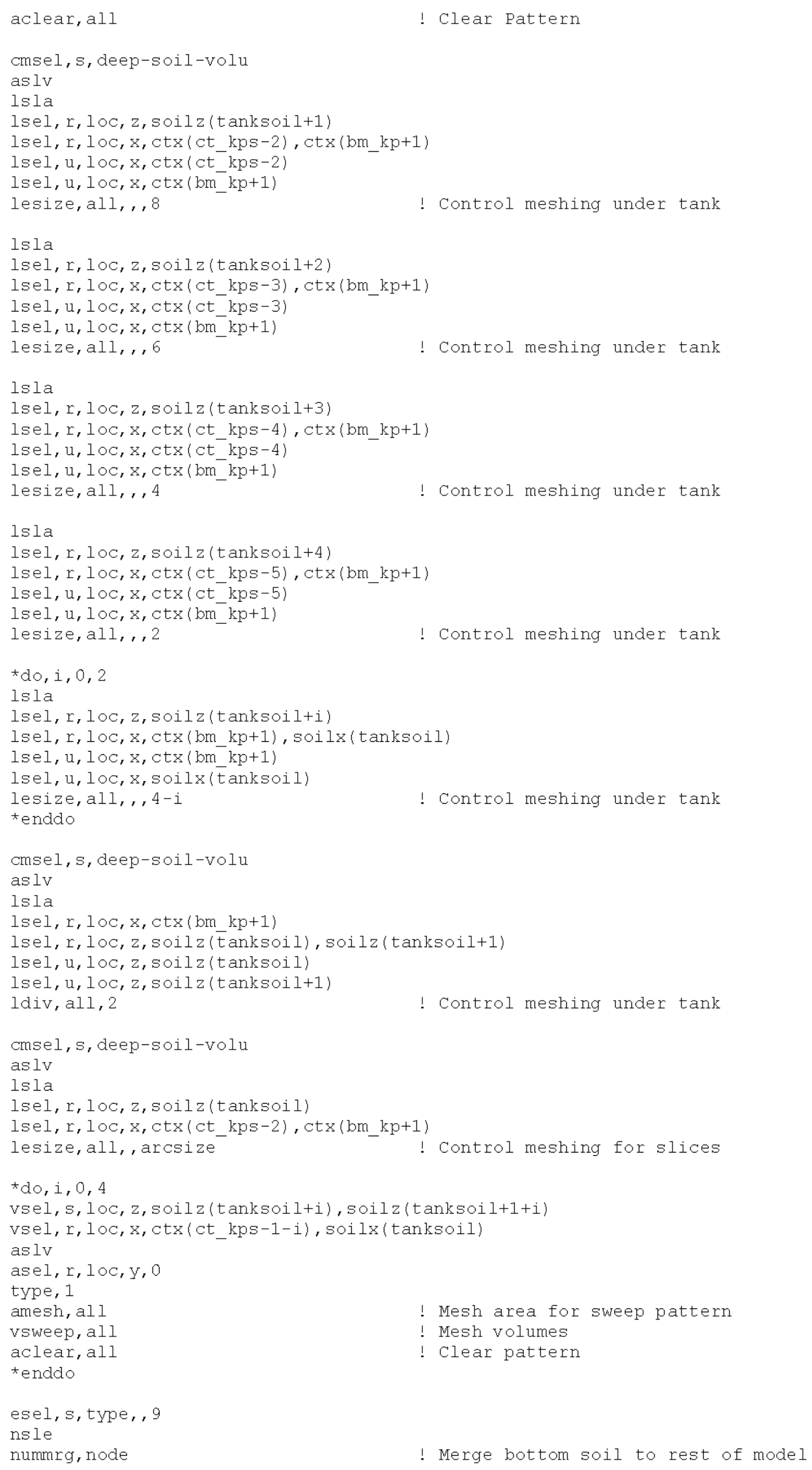


RPP-RPT-32239, Rev. 1

M\&D-2008-005-CALC-001, Rev. 1

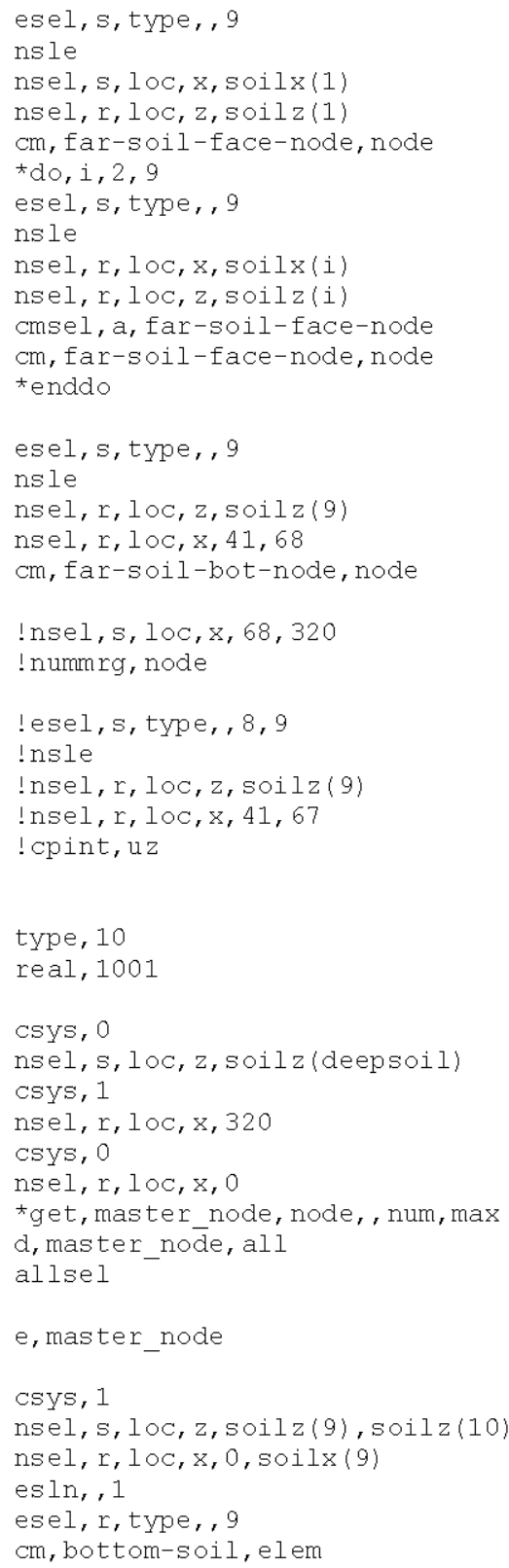

\section{Fix-Soil.txt}

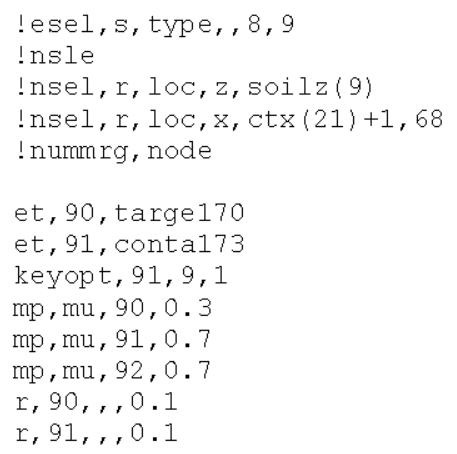


RPP-RPT-32239, Rev. 1

M\&D-2008-005-CALC-001, Rev. 1

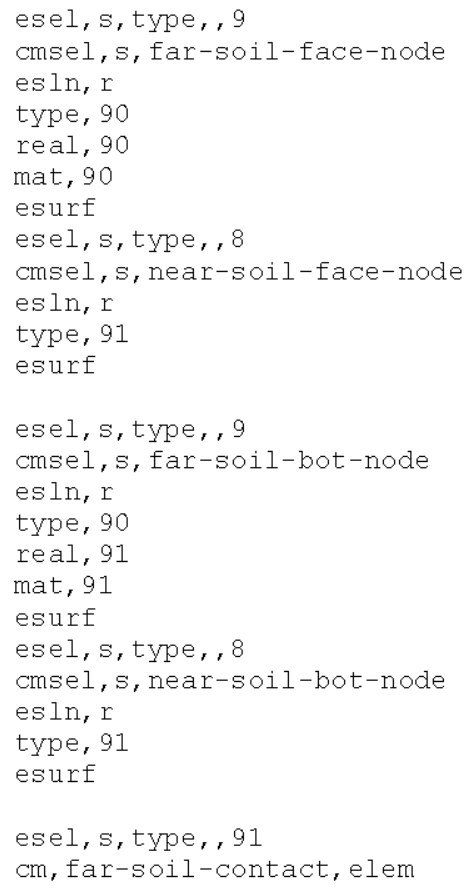

\section{Force-c.txt}

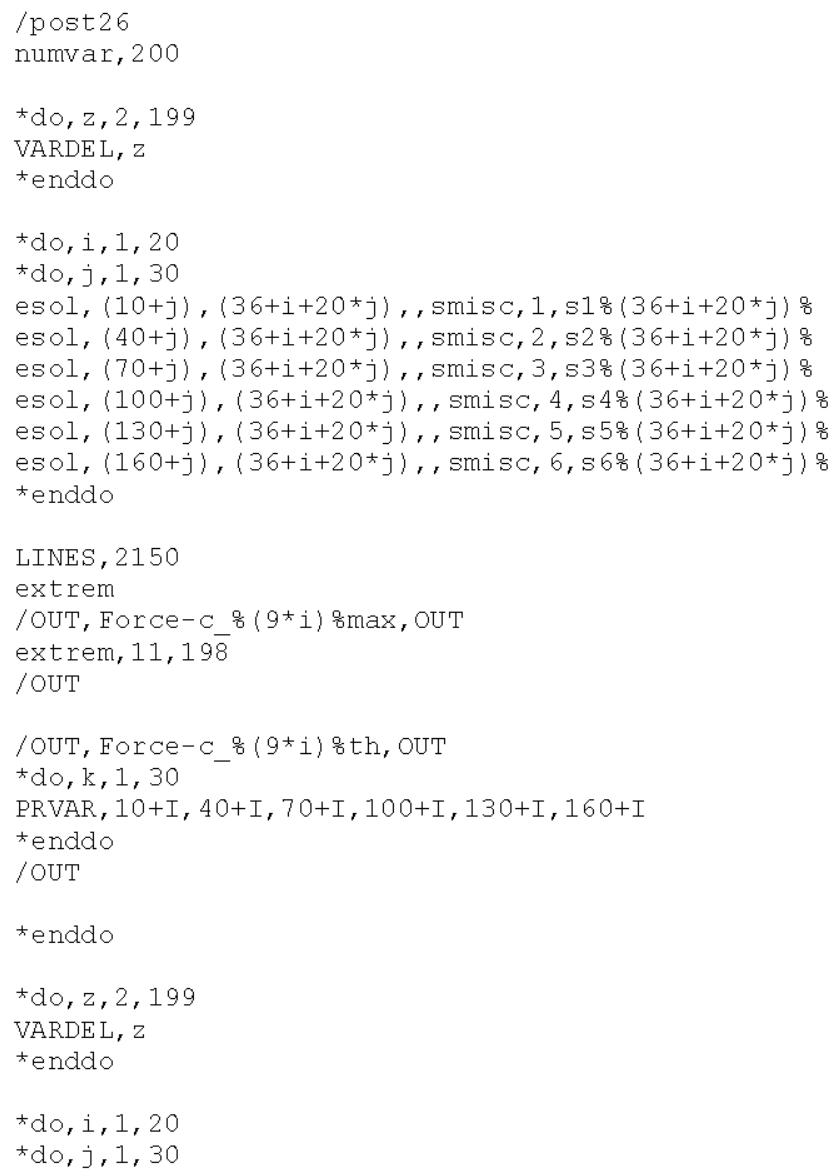


RPP-RPT-32239, Rev. 1

M\&D-2008-005-CALC-001, Rev. 1

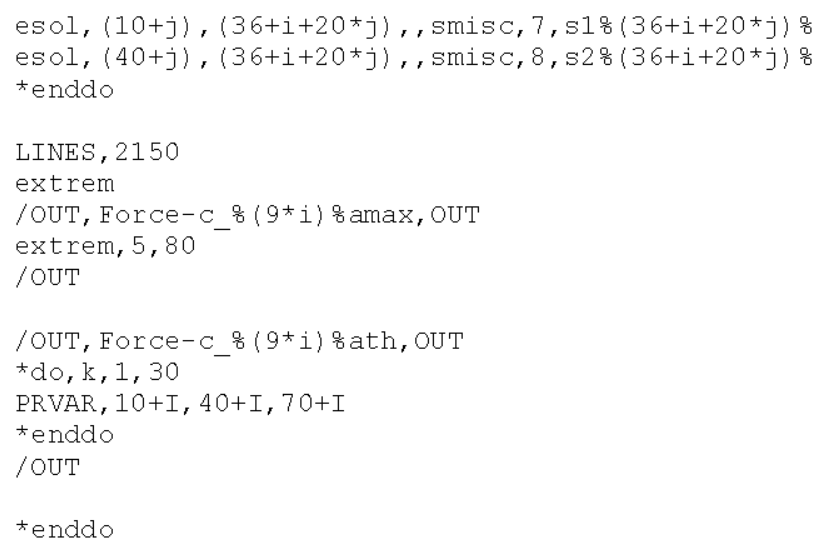

\section{Force-j_bolt.txt}

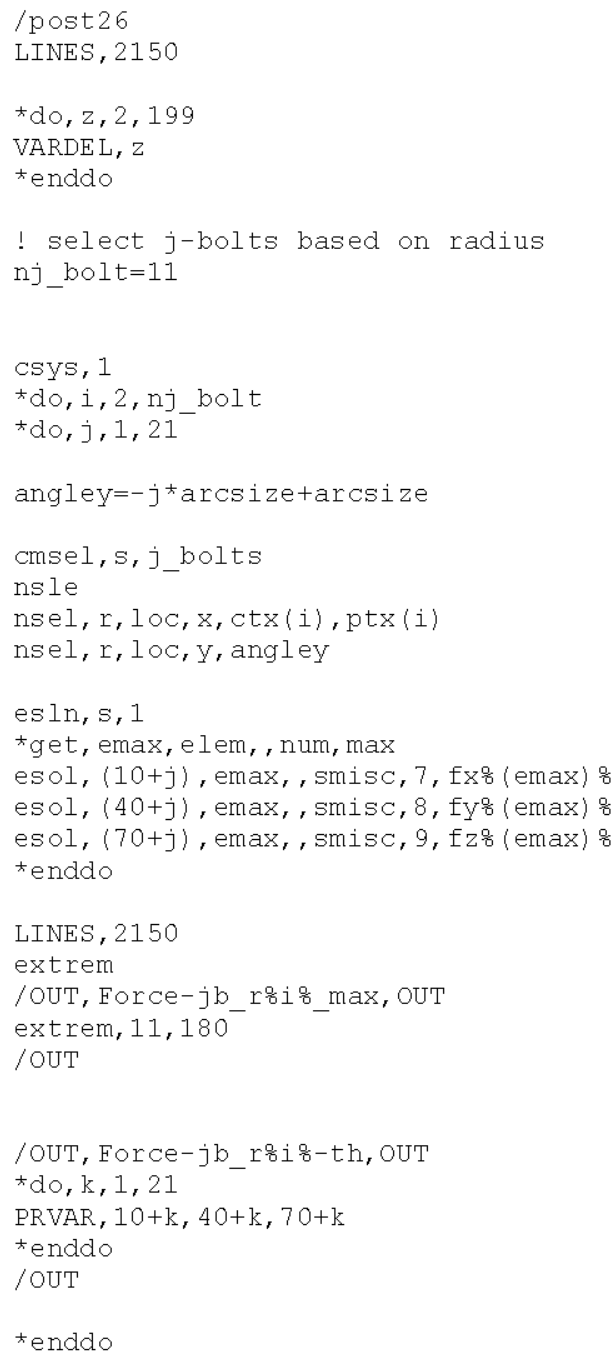

\section{Insulate.txt}


RPP-RPT-32239, Rev. 1

M\&D-2008-005-CALC-001, Rev. 1

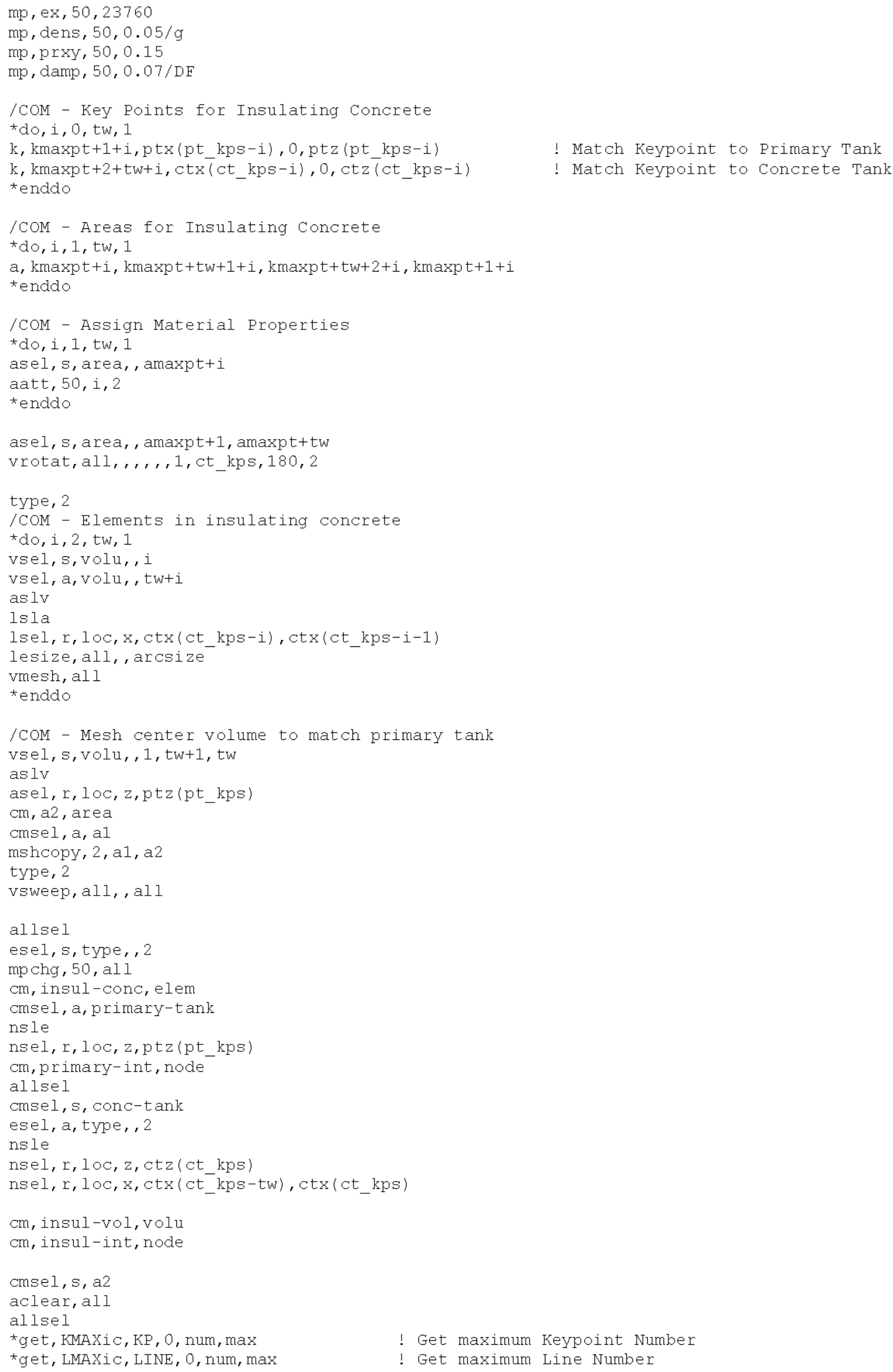




\section{RPP-RPT-32239, Rev. 1 \\ M\&D-2008-005-CALC-001, Rev. 1}

*get, AMAXic, AREA, 0, num, max *get, VMAXic, VOLU, 0, num, max
! Get maximum Area Number

! Get maximum Volume Number

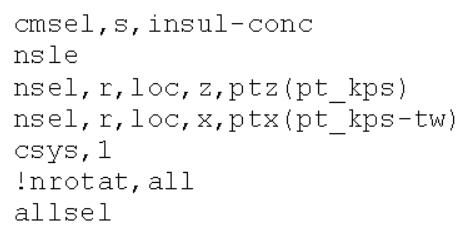

interface-gap1.txt

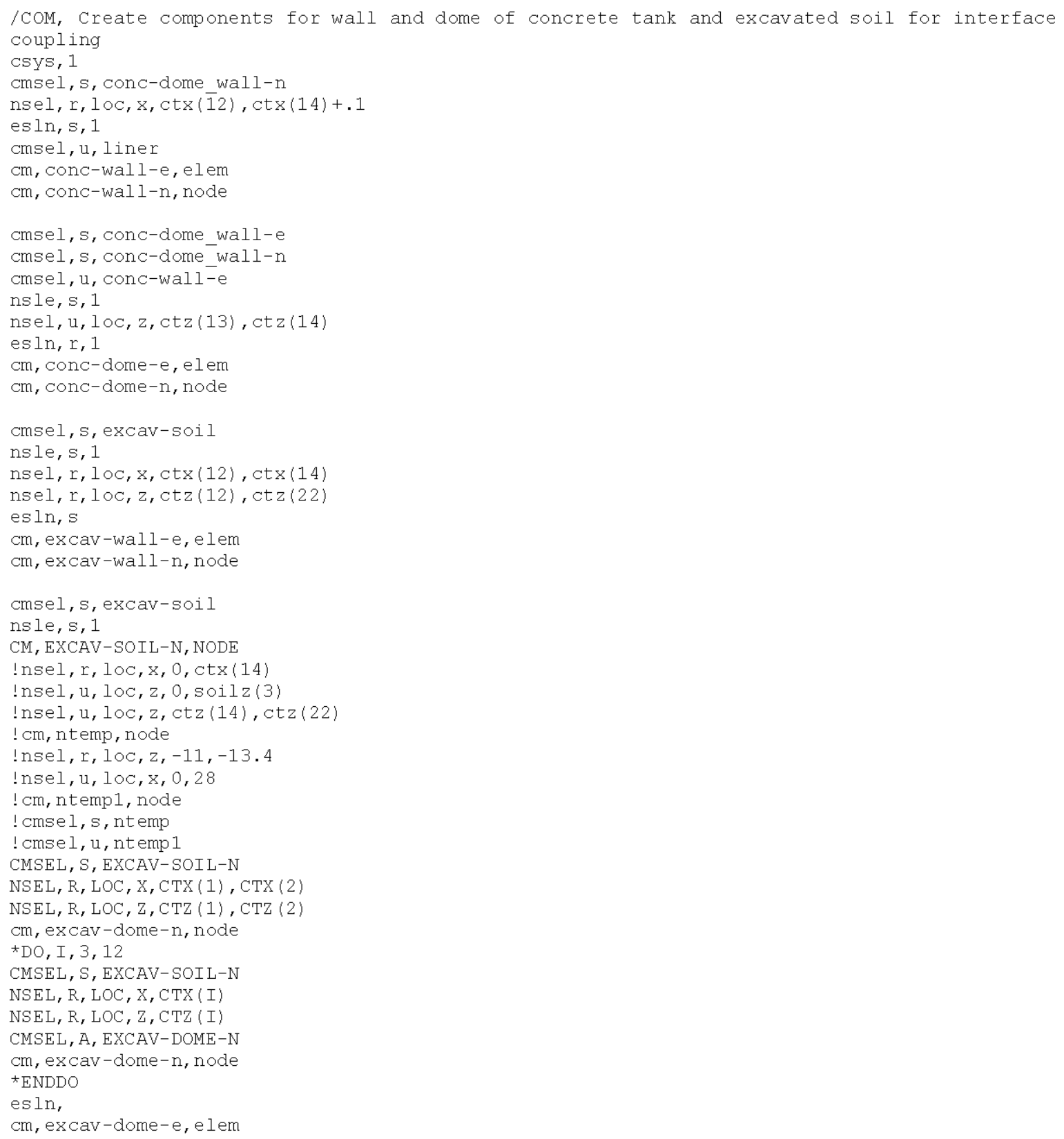


RPP-RPT-32239, Rev. 1

M\&D-2008-005-CALC-001, Rev. 1

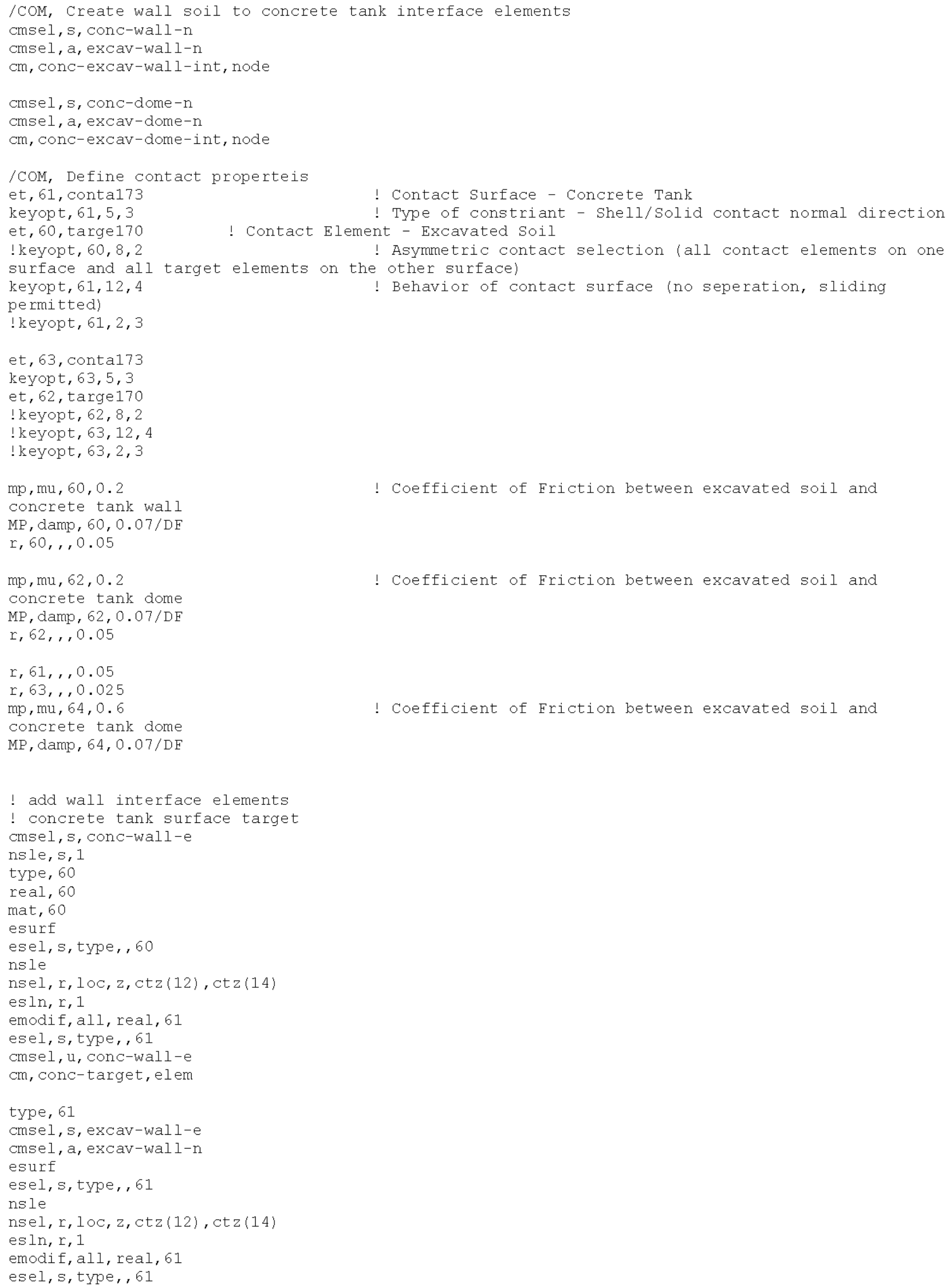


RPP-RPT-32239, Rev. 1

M\&D-2008-005-CALC-001, Rev. 1

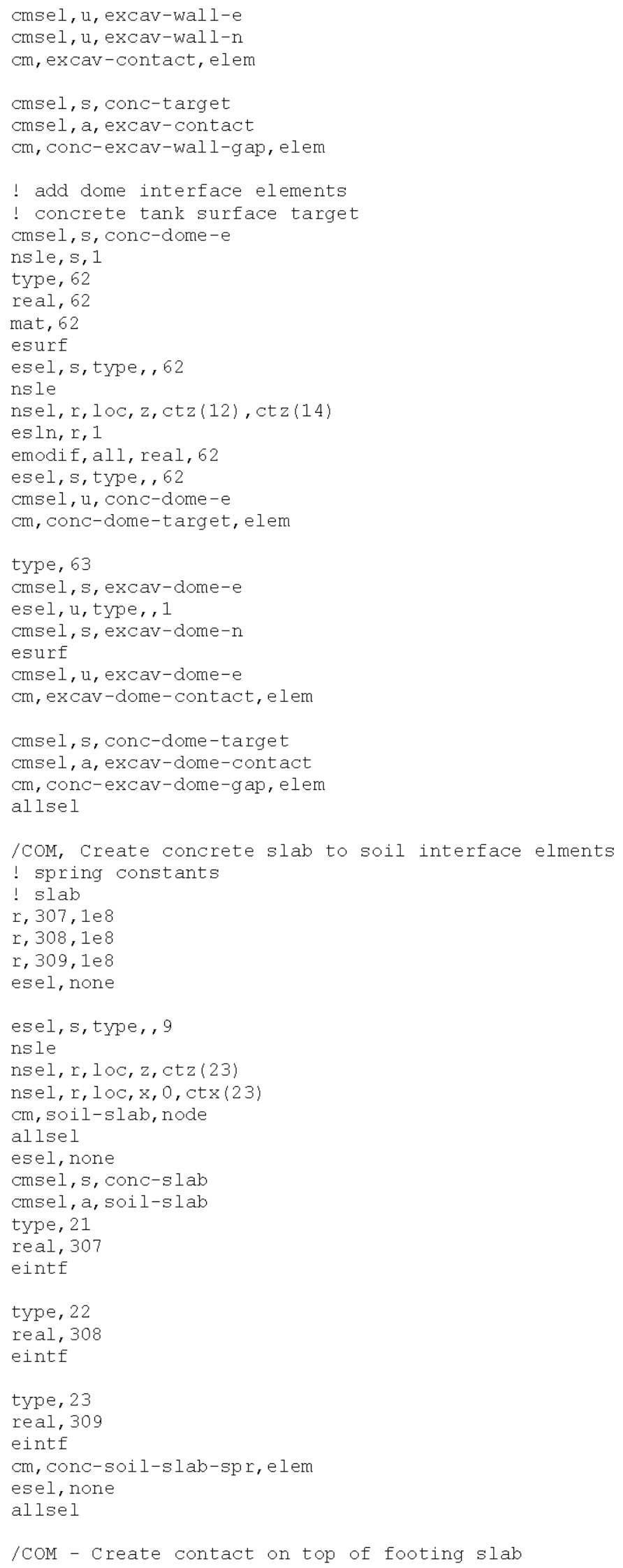


RPP-RPT-32239, Rev. 1

M\&D-2008-005-CALC-001, Rev. 1

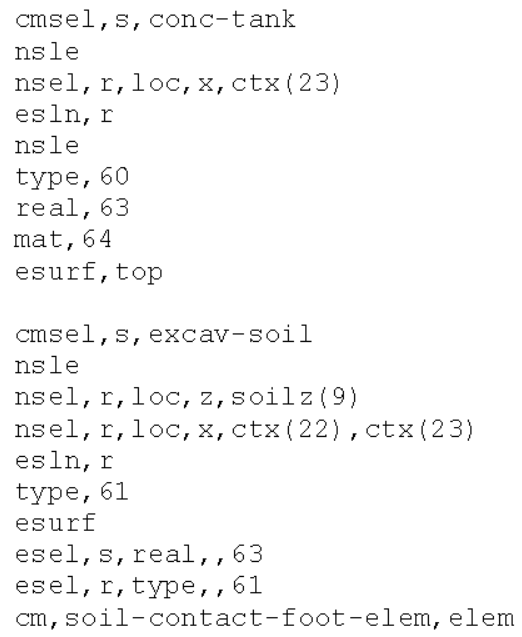

\section{interface1.txt}

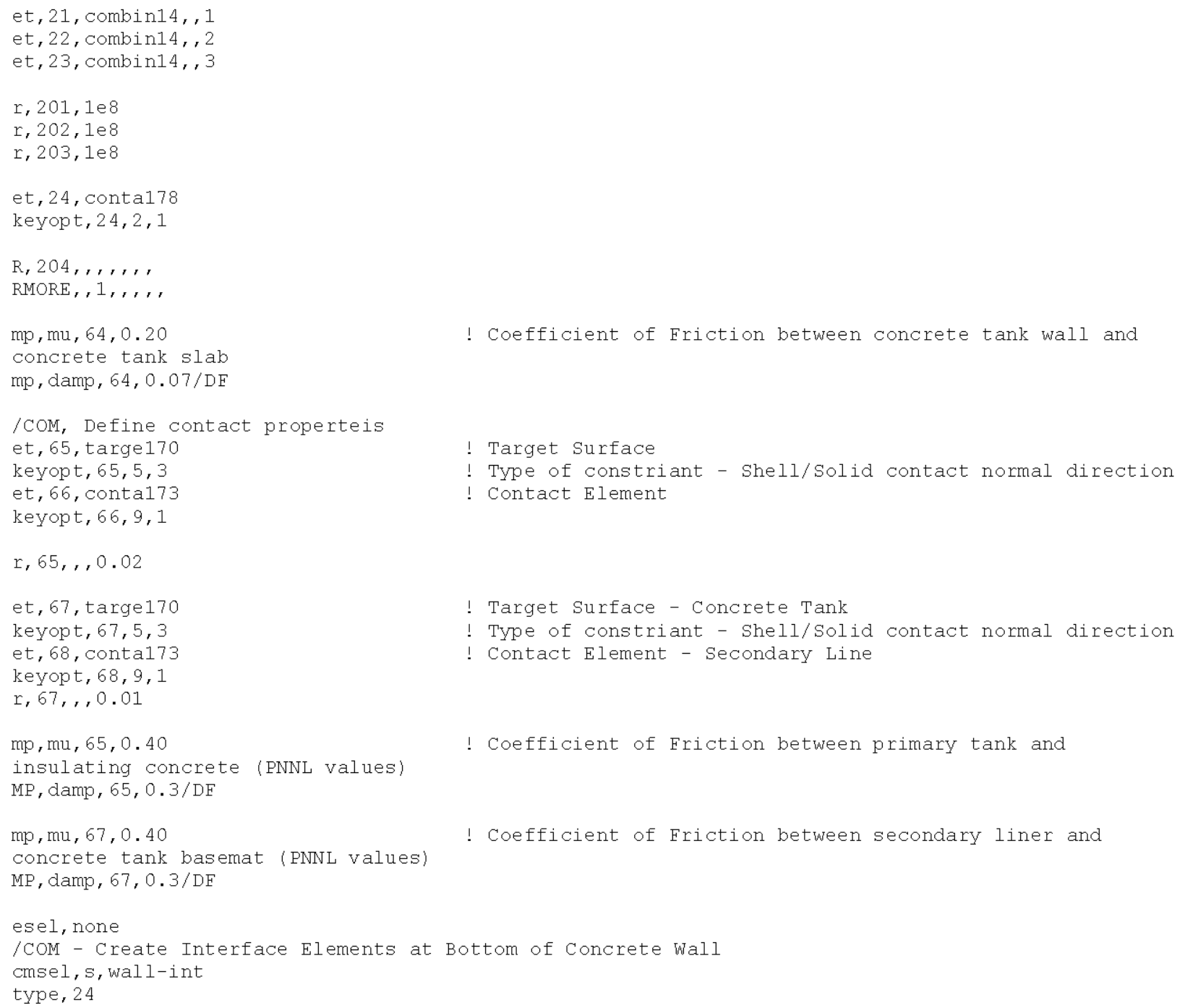


RPP-RPT-32239, Rev. 1

M\&D-2008-005-CALC-001, Rev. 1

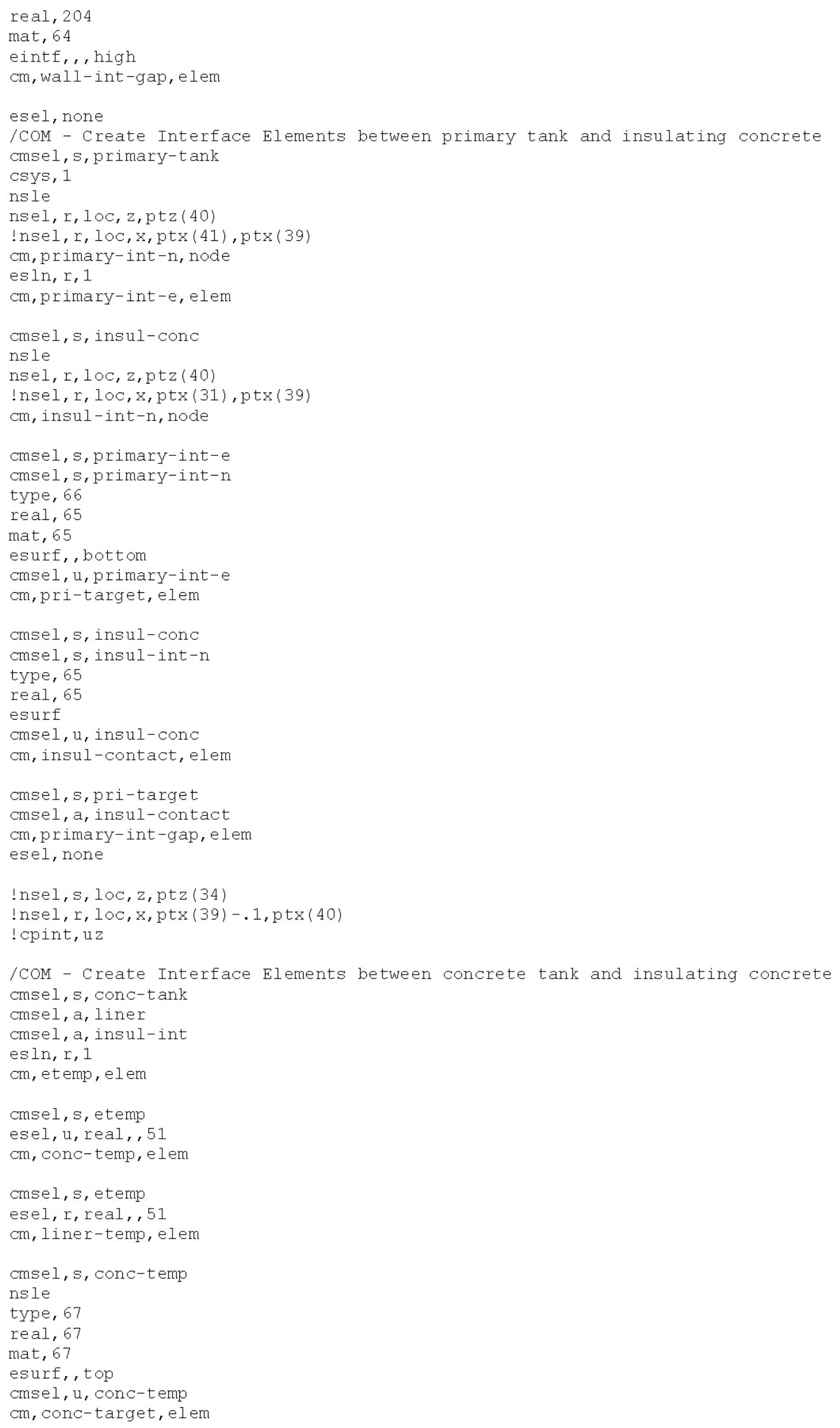




\section{RPP-RPT-32239, Rev. 1 \\ M\&D-2008-005-CALC-001, Rev. 1}

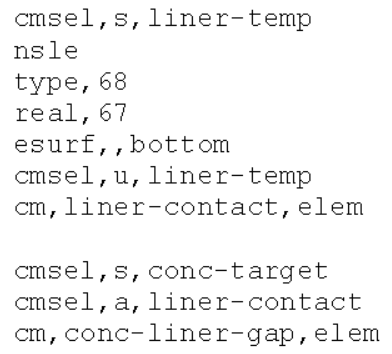

\section{Liner.txt}

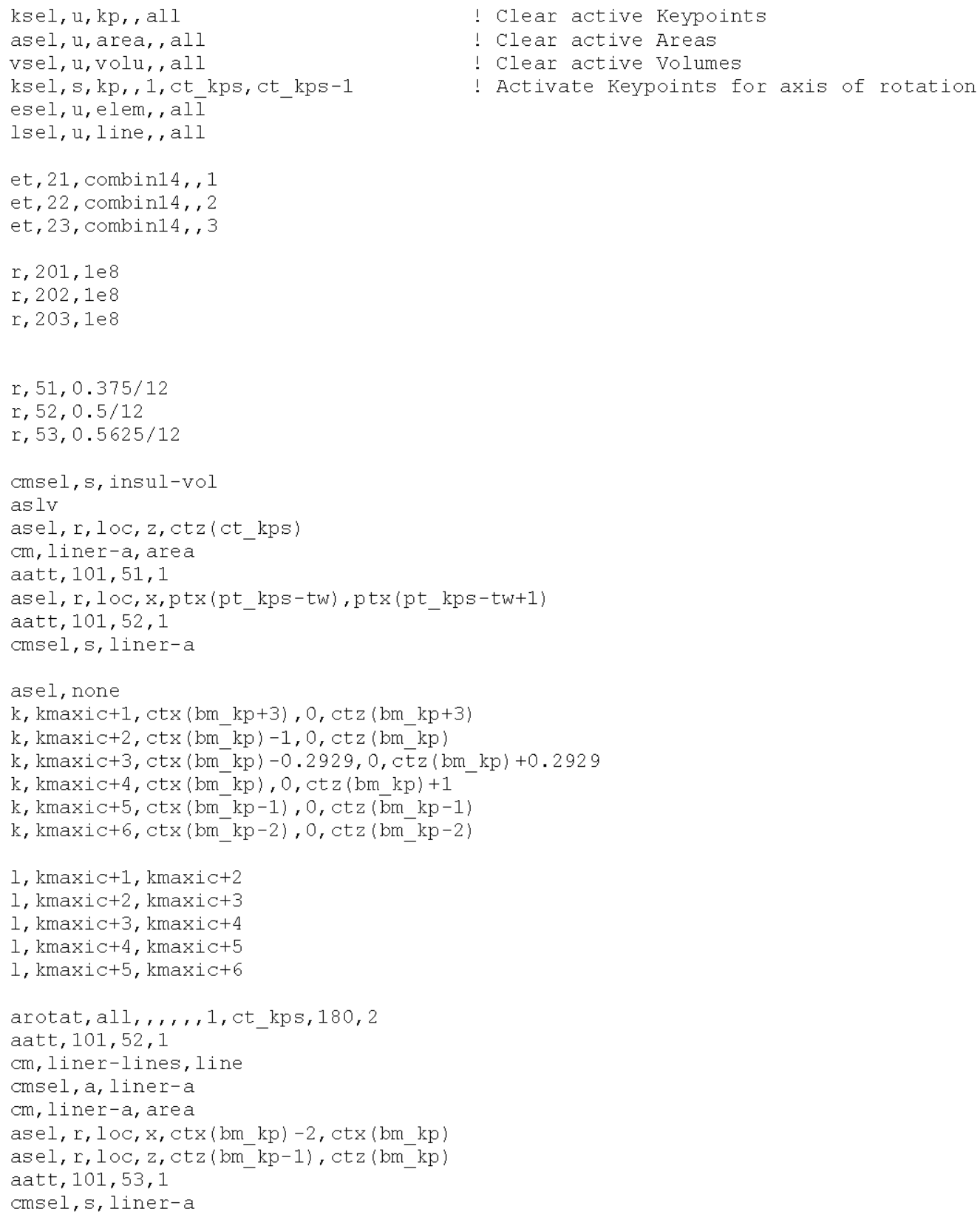


RPP-RPT-32239, Rev. 1

M\&D-2008-005-CALC-001, Rev. 1

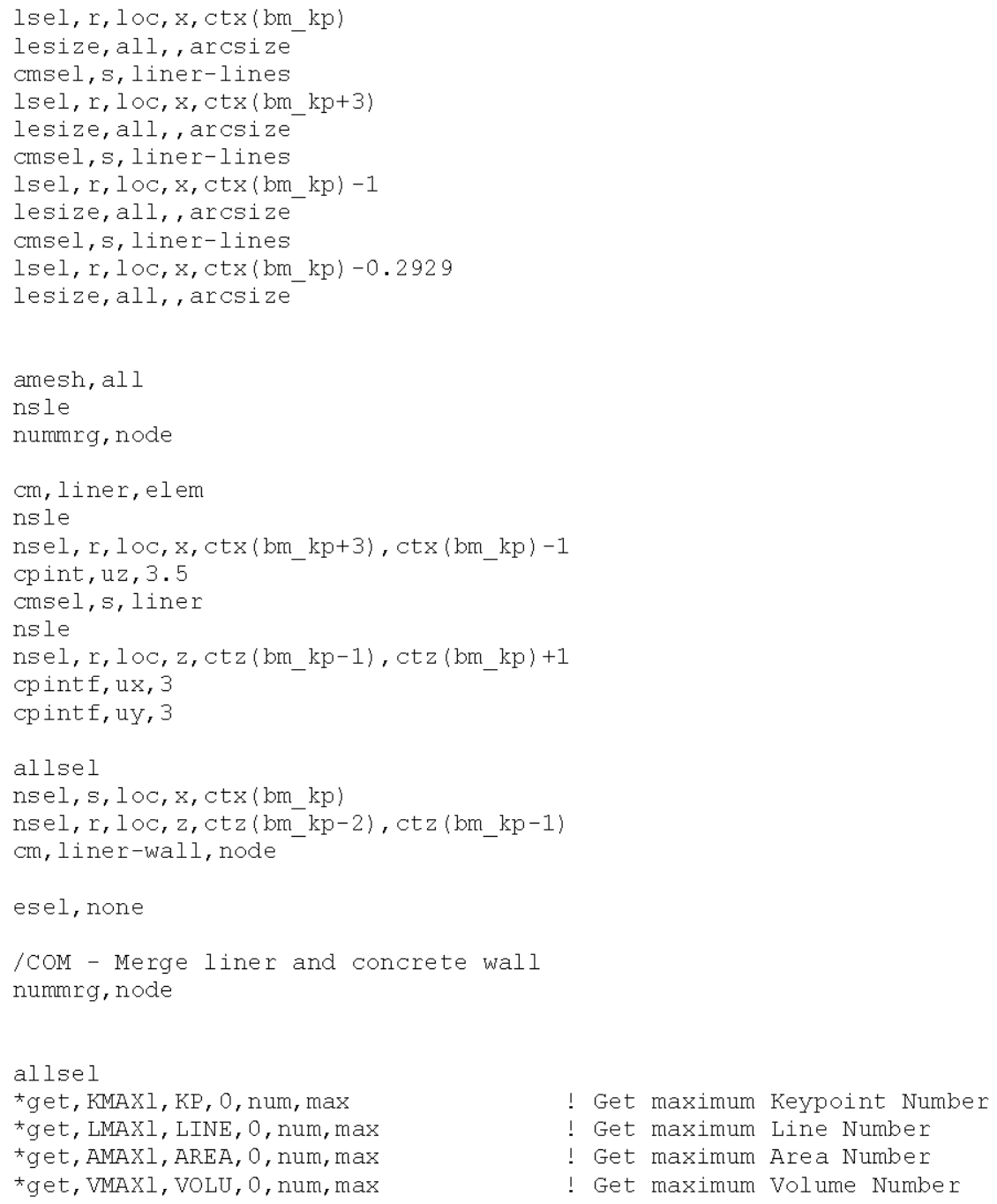

\section{live_load.txt}

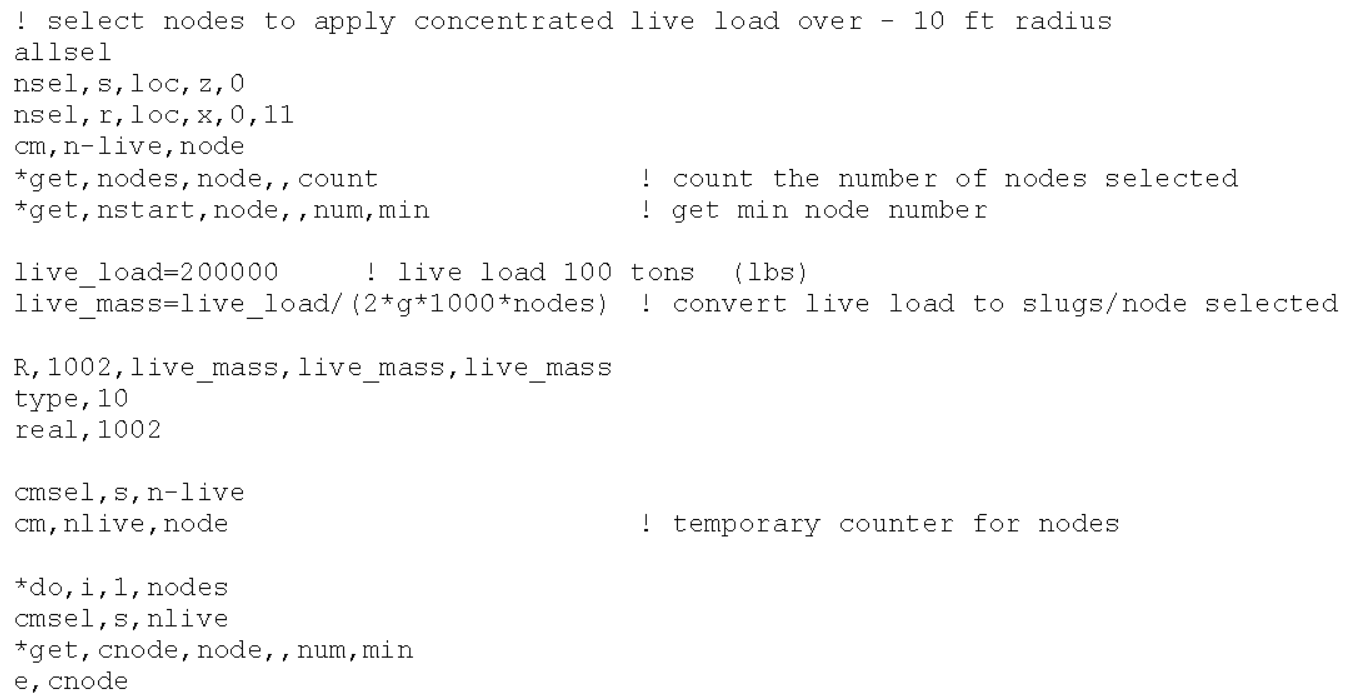


RPP-RPT-32239, Rev. 1

M\&D-2008-005-CALC-001, Rev. 1

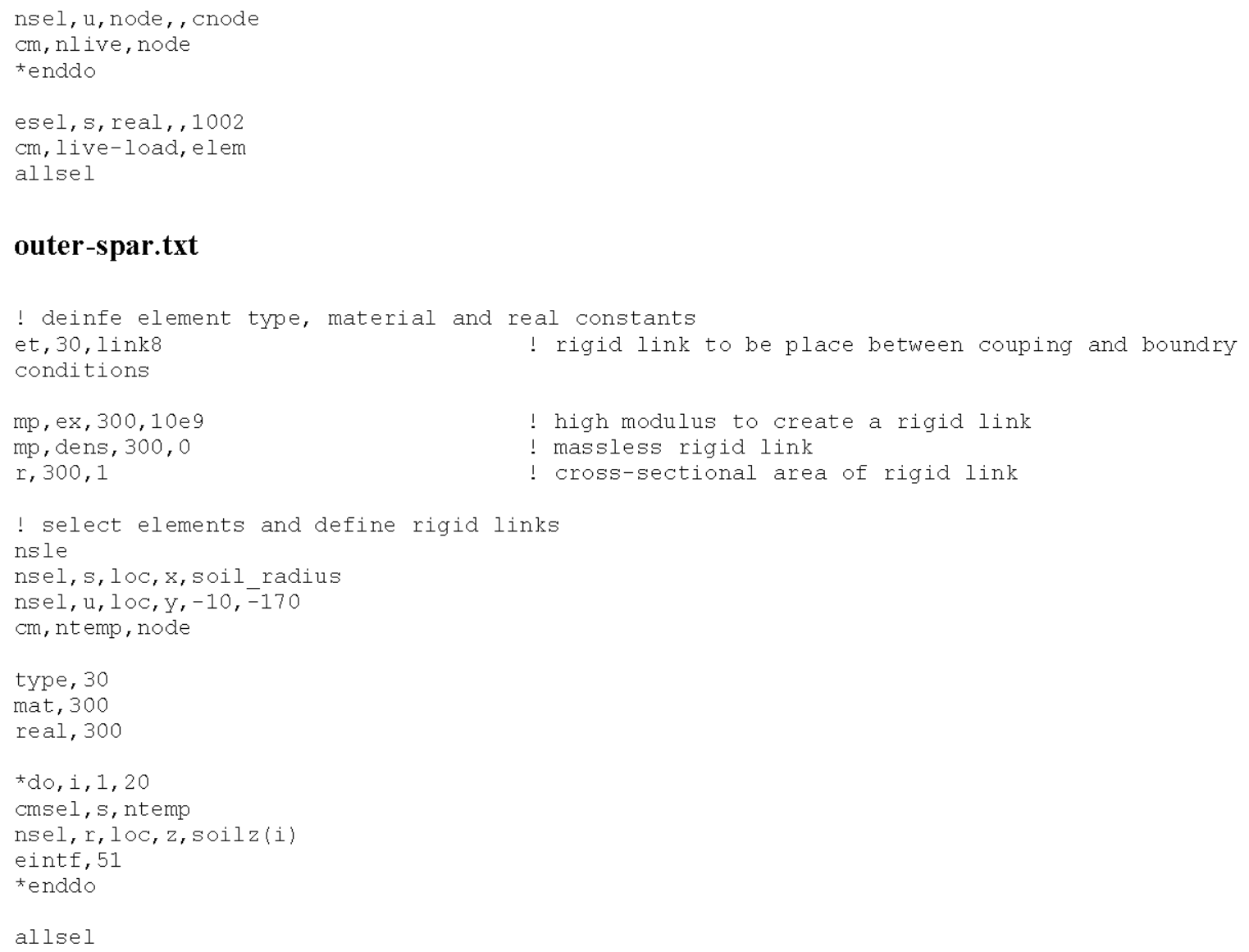

\section{Post-Tank.txt}

/input, spectra-all, txt

/input, contact-ap, txt

/input, force-c, txt

/input, stress-Primary, txt

/input, Force-J_bolt, txt

\section{Primary-Props-AP.txt}

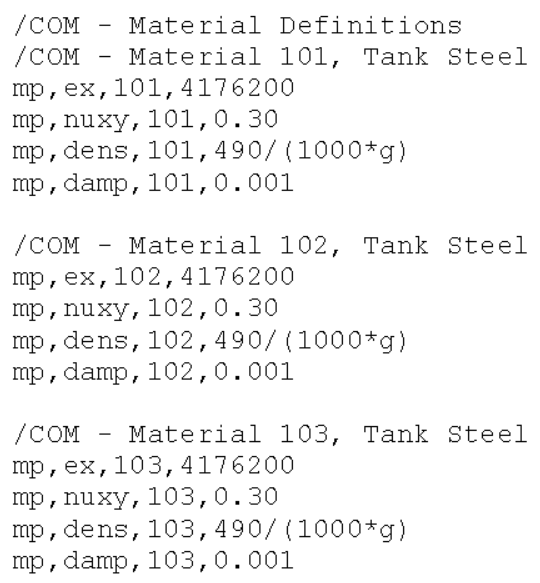


RPP-RPT-32239, Rev. 1

M\&D-2008-005-CALC-001, Rev. 1

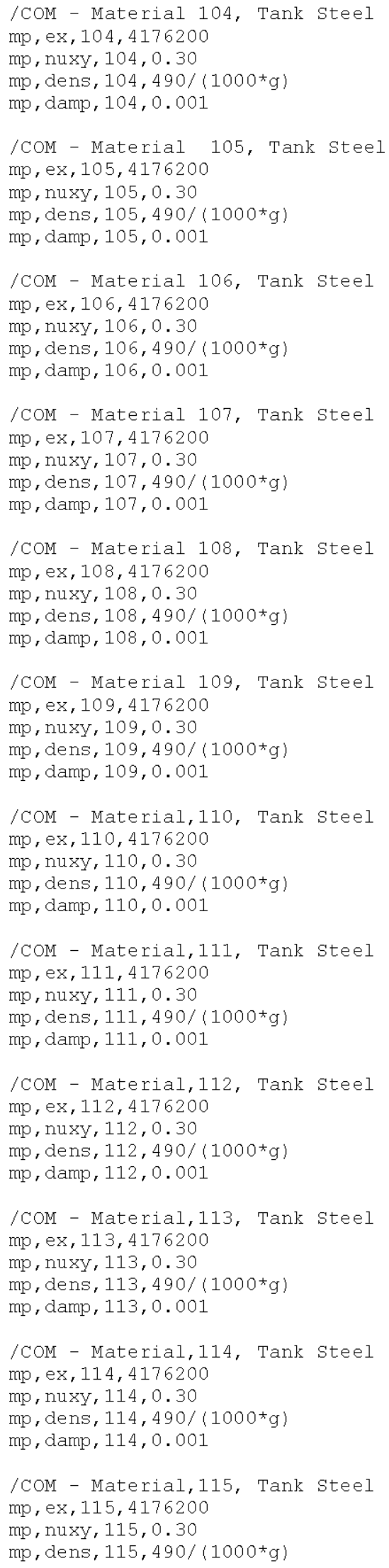


RPP-RPT-32239, Rev. 1

M\&D-2008-005-CALC-001, Rev. 1

mp , damp, 115, 0.001

/COM - Material,116, Tank Steel mp, ex, 116,4176200

$\mathrm{mp}$, nuxy, $116,0.30$

$\mathrm{mp}$, dens, $116,490 /\left(1000^{\star} \mathrm{g}\right)$

mp, damp, 116, 0.001

/COM - Material,117, Tank Steel mp, ex, 117,4176200

mp, nuxy, $117,0.30$

$\mathrm{mp}$, dens, $117,490 /\left(1000^{*} \mathrm{~g}\right)$

mp, damp, 117, 0.001

/COM - Material,118, Tank Steel mp, ex, 118,4176200

$\mathrm{mp}, \mathrm{nuxy}, 118,0.30$

mp, dens, $118,490 /(1000 * g)$

mp , damp, $118,0.001$

/COM - Material,119, Tank Steel mp, ex, 119,4176200

mp, nuxy, $119,0.30$

mp, dens, $119,490 /\left(1000^{*} \mathrm{~g}\right)$

mp, damp, 119, 0.001

/COM - Material,120, Tank Steel mp, ex, 120,4176200

mp, nuxy, 120, 0.30

$\mathrm{mp}$, dens, $120,490 /\left(1000^{*} \mathrm{~g}\right)$

mp, damp, 120, 0.001

/COM - Material,121, Tank Steel mp, ex, 121,4176200

mp, nuxy, $121,0.30$

$\mathrm{mp}$, dens, 121, 490/(1000*g)

mp , damp, 121, 0.001

/COM - Material,122, Tank Steel mp , ex, 122,4176200

mp, nuxy, $122,0.30$

mp, dens, $122,490 /\left(1000^{*} \mathrm{~g}\right)$

mp, damp, $122,0.03 / \mathrm{df}$

/COM - Material,123, Tank Steel mp, ex, 123,4176200

mp, nuxy, $123,0.30$

$\mathrm{mp}$, dens, $123,490 /\left(1000^{*} \mathrm{~g}\right)$

mp, damp, 123, 0.001

/COM - Material,124, Tank Steel mp , ex, 124,4176200

mp, nuxy, $124,0.30$

$\mathrm{mp}$, dens, $124,490 /\left(1000^{\star} \mathrm{g}\right)$

mp , damp, 124, 0.001

/COM - Material,125, Tank Steel mp, ex, 125,4176200

mp, nuxy, $125,0.30$

mp, dens, $125,490 /\left(1000^{*} \mathrm{~g}\right)$

mp, damp, 125, 0.001

/COM - Material,126, Tank Steel mp, ex, 126,4176200

mp, nuxy, $126,0.30$

$\mathrm{mp}$, dens, $126,490 /(1000 * \mathrm{~g})$

mp, damp, $126,0.001$

/COM - Material,127, Tank steel mp, ex, 127,4176200

$\mathrm{mp}, \mathrm{nuxy}, 127,0.30$ 
RPP-RPT-32239, Rev. 1

M\&D-2008-005-CALC-001, Rev. 1

mp, dens, $127,490 /\left(1000^{*} \mathrm{~g}\right)$

mp, damp, 127, 0.001

/COM - Material,128, Tank Steel

mp, ex, 128,4176200

mp, nuxy, $128,0.30$

mp, dens, $128,490 /\left(1000^{\star} \mathrm{g}\right)$

mp , damp, $128,0.001$

/COM - Material,129, Tank Steel

mp, ex, 129,4176200

mp, nuxy, $129,0.30$

mp, dens, $129,490 /(1000 * \mathrm{~g})$

mp, damp, $129,0.001$

/COM - Material,130, Tank Steel $\mathrm{mp}, \mathrm{ex}, 130,4176200$

mp, nuxy, $130,0.30$

$\mathrm{mp}$, dens, $130,490 /\left(1000^{*} \mathrm{~g}\right)$

mp, damp, 130, 0.001

/COM - Material,131, Tank Steel mp, ex, 131, 4176200

mp, nuxy, $131,0.30$

mp, dens, 131,490/(1000*g)

mp , damp, 131, 0.001

/COM - Material,132, Tank Steel mp, ex, 132,4176200

$\mathrm{mp}, \mathrm{nuxy}, 132,0.30$

$\mathrm{mp}$, dens, $132,490 /\left(1000^{*} \mathrm{~g}\right)$

mp, damp, $132,0.001$

/COM - Material,133, Tank Steel mp, ex, 133, 4176200

mp, nuxy, $133,0.30$

$\mathrm{mp}$, dens, $133,490 /\left(1000^{*} \mathrm{~g}\right)$

mp, damp, 133, 0.001

/COM - Material,134, Tank Steel mp, ex, 134,4176200

mp, nuxy, 134, 0.30

$\mathrm{mp}$, dens, $134,490 /\left(1000^{*} \mathrm{~g}\right)$

mp, damp, 134, 0.001

/COM - Material,135, Tank Steel $\mathrm{mp}, \mathrm{ex}, 135,4176200$

mp, nuxy, $135,0.30$

mp, dens, $135,490 /\left(1000{ }^{*} \mathrm{~g}\right)$

mp , damp, 135, 0.001

/COM - Material,136, Tank Steel mp, ex, 136,4176200

mp, nuxy, $136,0.30$

$\mathrm{mp}$, dens, $136,490 /\left(1000^{*} \mathrm{~g}\right)$

mp, damp, 136, 0.001

/COM - Material,137, Tank steel $\mathrm{mp}, \mathrm{ex}, 137,4176200$

mp, nuxy, 137, 0.30

$\mathrm{mp}$, dens, $137,490 /\left(1000^{*} \mathrm{~g}\right)$

$\mathrm{mp}$, damp, 137, 0.001

/COM - Material,138, Tank Steel $\mathrm{mp}, \mathrm{ex}, 138,4176200$

mp, nuxy, $138,0.30$

$\mathrm{mp}$, dens, $138,490 /\left(1000^{\star} \mathrm{g}\right)$

mp , damp, $138,0.001$

/COM - Material,139, Tank Steel mp, ex, 139,4176200 
RPP-RPT-32239, Rev. 1

M\&D-2008-005-CALC-001, Rev. 1

mp, nuxy, $139,0.30$

mp, dens, $139,490 /\left(1000^{*} \mathrm{~g}\right)$

mp, damp, 139, 0.001

/COM - Material,140, Tank Steel mp, ex, 140,4176200

mp, nuxy, $140,0.30$

$\mathrm{mp}$, dens, $140,490 /\left(1000^{*} \mathrm{~g}\right)$

mp, damp, 140, 0.001

/COM - Material,141, Tank Steel mp, ex, 141, 4176200

mp, nuxy, 141,0.30

$\mathrm{mp}$, dens, 141,490/(1000*g)

mp, damp, 141, 0.001

/COM - Material,142, Tank Steel mp, ex, 142,4176200

mp, nuxy, $142,0.30$

mp, dens, $142,490 /\left(1000^{\star} \mathrm{g}\right)$

mp , damp, $142,0.001$

/COM - Material,143, Tank Steel mp, ex, 143,4176200

mp, nuxy, $143,0.30$

$\mathrm{mp}$, dens, $143,490 /\left(1000^{*} \mathrm{~g}\right)$

mp , damp, 143, 0.001

$r, 101,(0.5-0.06) / 12$

$r, 102,(0.5-0.06) / 12$

$r, 103,(0.375-0.06) / 12$

$r, 104,(0.375-0.06) / 12$

$r, 105,(0.375-0.06) / 12$

$r, 106,(0.375-0.06) / 12$

$r, 107,(0.375-0.06) / 12$

$r, 108,(0.375-0.06) / 12$

$r, 109,(0.375-0.06) / 12$

$r, 110,(0.375-0.06) / 12$

$r, 111,(0.5-0.06) / 12$

$r, 112,(0.5-0.06) / 12$

$r, 113,(0.5-0.06) / 12$

$r, 114,(0.5-0.06) / 12$

$r, 115,(0.5-0.06) / 12$

$r, 116,(0.5-0.06) / 12$

$r, 117,(0.5-0.06) / 12$

$r, 118,(0.5-0.06) / 12$

$r, 119,(0.5-0.06) / 12$

$r, 120,(0.5-0.06) / 12$

$r, 121,(0.5-0.06) / 12$

$r, 122,(0.5-0.06) / 12$

$r, 123,(0.5625-0.06) / 12$

$r, 124,(0.5625-0.06) / 12$

$r, 125,(0.5625-0.06) / 12$

$r, 126,(0.5625-0.06) / 12$

$r, 127,(0.75-0.06) / 12$

$r, 128,(0.75-0.06) / 12$

$r, 129,(0.75-0.06) / 12$

$r, 130,(0.75-0.06) / 12$

$r, 131,(0.75-0.06) / 12$

$r, 132,(0.875-0.06) / 12$

$r, 133,(0.9375-0.06) / 12$

$r, 134,(0.9375-0.06) / 12$

$r, 135,(0.875-0.06) / 12$

$r, 136,(0.875-0.06) / 12$

$r, 137,(0.5-0.06) / 12$

$r, 138,(0.5-0.06) / 12$

$r, 139,(0.5-0.06) / 12$

$r, 140,(0.5-0.06) / 12$

$r, 141,(0.5-0.06) / 12$

$r, 142,(0.5-0.06) / 12$

$r, 143,(1-0.06) / 12$ 
RPP-RPT-32239, Rev. 1

M\&D-2008-005-CALC-001, Rev. 1

\section{Primary.txt}

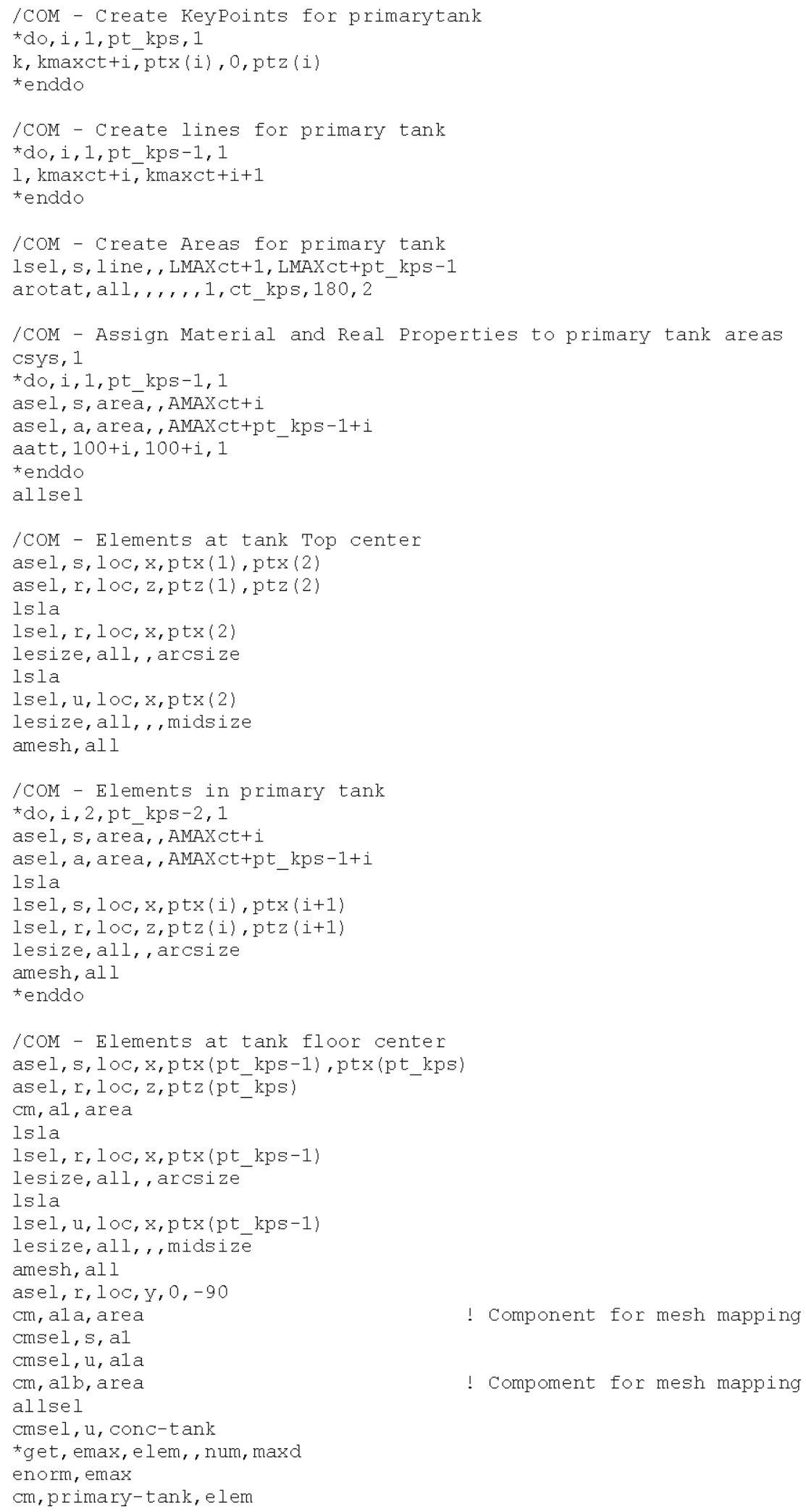


RPP-RPT-32239, Rev. 1

M\&D-2008-005-CALC-001, Rev. 1

allsel

*get, kMAXpt, KP, 0, num, max

* get, LMAXpt, LINE, 0, num, max

*get, AMAXpt, AREA, 0, num, max

\section{RS_FREQ.txt}

data, 2, 1, 152, 1, frequency

(f7.3)

0.100

0.105

0.111

0.118

0.125

0.128

0.132

0.135

0.139

0.143

0.147

0.152

0.156

0.161

0.167

0.172

0.179

0.185

0.192

0.196

0.200

0.204

0.208

0.213

0.217

0.222

0.227

0.233

0.238

0.244

0.250

0.256

0.263

0.270

0.278

0.286

0.294

0.303

0.313

0.323

0.333

0.345

0.357

0.370

0.385

0.400

0.417

0.426

0.435

0.444

0.455

0.465

0.476

0.488

0.500

0.513

0.526

0.541
! Get maximum Keypoint number

! Get maximum Area Number 
RPP-RPT-32239, Rev. 1

M\&D-2008-005-CALC-001, Rev. 1

0.556

0.571

0.588

0.606

0.625

0.645

0.667

0.690

0.714

0.741

0.769

0.800

0.833

0.870

0.909

0.952

1.000

1.020

1.042

1.064

1.087

1.111

1.136

1.163

1.190

1.220

1.250

1.282

1.316

1.351

1.389

1.429

1.471

1.515

1.563

1.613

1.667

1.724

1.754

1.786

1.818

1.852

1.887

1.923

1.961

2.000

2.041

2.083

2.128

2.174

2. 222

2.273

2. 326

2.381

2.439

2.500

2.564

2.632

2.703

2.778

2.857

2. 941

3.030

3.125

3.226

3.333

3.448

3.571

3.704

3.846

4.000 
RPP-RPT-32239, Rev. 1

M\&D-2008-005-CALC-001, Rev. 1

4.167

4.348

4.545

4.762

5.000

5.263

5.556

5.882

6.250

6.667

7.143

7.692

8.333

9.091

10.000

11.111

12.500

14.286

16.667

20.000

25.000

33.333

100.000

\section{Slave.txt}

/COM - Develop Slave Boundarz Conditions

/COM - 20 Layer Model

Csys, 1

*get, CPMAX, CP, 0, num, max

! Set Cylindrical Coordinates

nsel, $s, 10 c, x$, soil radius

! Counter for Couple Set Numbers

csys, 0

nrotat, all

nsel,s, loc, z, soilz (deepsoil)

- Select soil exterior surface nodes

! Set Cartesian Coordinates

! Rotate into Global Cartesian Coordinates

nrotat, all

! Select all Base nodes

! Rotate into Global Cartesian Coordinates

Csys, 1

*do, i, 1, deepsoil-1, 1

! Set Cylindrical Coordinates

nsel, s, loc, $x$, soil radius

Cycle through each soil layer

nsel, $r, l \circ c, z, \operatorname{soll} z$ (i)

$\mathrm{cp}, 3^{*} i-2+\mathrm{cpmax}, \mathrm{ux}$, all

! Select all exterior nodes

! Select nodes by layer

$\mathrm{cp}, 3 * i+\mathrm{cpmax}, \mathrm{u}, \mathrm{all}$

! Couple in $\mathrm{X}$

! Couple in 7

nsel, u, loc, y, 0

! Unselect nodes on Symmetry Plane

nsel, u, loc, $y, 180$

$\mathrm{cp}, 3 * i-1+\mathrm{cpmax}, \mathrm{uy}$, all

! Couple in $\mathrm{Y}$

*enddo

nsel,s,loc, z, soilz(deepsoil) ! select base nodes

nsel, u, loc, $z, 320-.1,320+.1$

$\mathrm{cp}$, deepsoil*10+1+cpmax, ux, all ! Couple in $\mathrm{X}$

cp, deepsoil*10+2+cpmax, uy, all ! Couple in $\mathrm{Y}$

cp, deepsoil*10+3+cpmax, uz, all ! Couple in $\mathrm{z}$

allsel

\section{spectra-all.txt}

/input, spectra-conc, txt /input, spectra-conc-0, txt /input, spectra-conc-45, txt /input, spectra-conc-90, txt /input, spectra-conc-135, txt /input, spectra-conc-180, txt /input, spectra-primary-0, txt /input, spectra-primary-45, txt /input, spectra-primary-90, txt

/input, spectra-primary-135, txt 
RPP-RPT-32239, Rev. 1

M\&D-2008-005-CALC-001, Rev. 1

/input, spectra-primary-180, txt

/input, spectra-soil, txt

spectra-conc- 0. txt

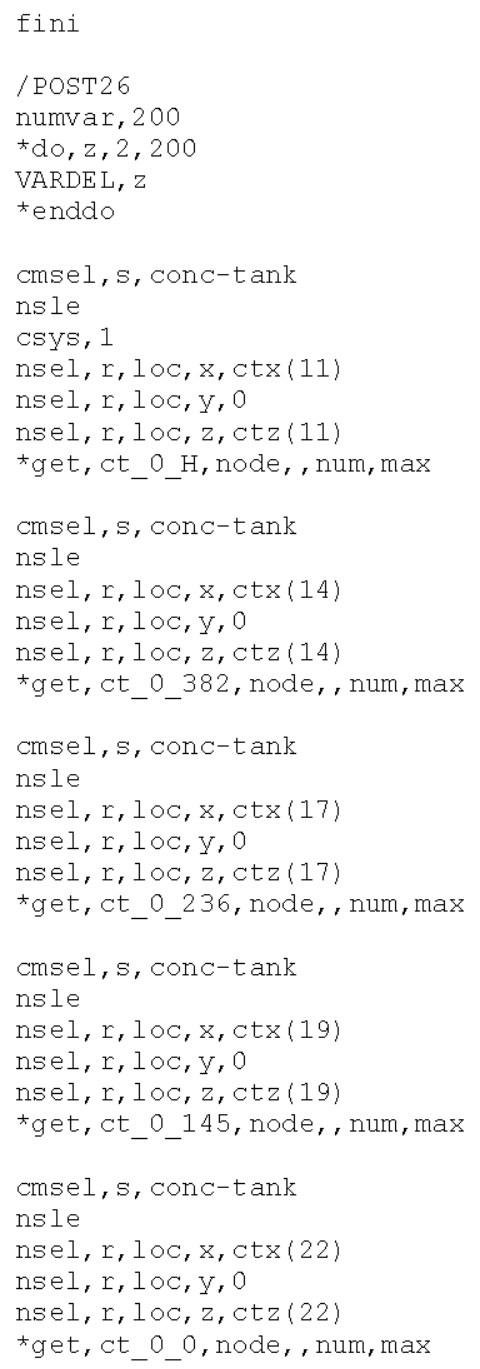

/input,rs_freq, txt 
RPP-RPT-32239, Rev. 1

M\&D-2008-005-CALC-001, Rev. 1

resp, 31, 2,3,3,0.033,0.01,100,120.48 resp, $32,2,4,3,0.033,0.01,100,120.48$ resp, 33, 2, 5, 3,0.033,0.01,100,120.48 resp, $34,2,6,3,0.033,0.01,100,120.48$ resp, 35,2,7,3,0.033,0.01,100,120.48 resp, 41,2,13,3,0.033,0.01,100,120.48 resp, $42,2,14,3,0.033,0.01,100,120.48$ resp, 43,2,15,3,0.033,0.01,100,120.48 resp, $44,2,16,3,0.033,0.01,100,120.48$ resp $, 45,2,17,3,0.033,0.01,100,120.48$ resp, 51,2,23,3,0.033,0.01,100,120.48 resp $, 52,2,24,3,0.033,0.01,100,120.48$ resp, 53,2,25,3,0.033,0.01,100,120.48 resp, $54,2,26,3,0.033,0.01,100,120.48$ resp, 55,2,27,3,0.033,0.01,100,120.48

prod, 61,31, , rs_o (ct_O_H) $8-X_{1}, 1 / 9$ prod, 62, 32, , rs_o (ct_o-382) $8-\mathrm{X}^{-}, 1,1 / \mathrm{g}$ prod, 63, 33, , , rs 8 ( $\left.\mathrm{ct}^{-} \mathrm{O}^{-} 236\right) 8-\mathrm{x}, 1,1 / \mathrm{g}$ prod, 64, 34, , rs_o (ct_0_145) $8-X_{1}, 1 / 9$ prod, 65,35, , rs 8 (ct 0 o) $8-X_{1}, 11 / 9$

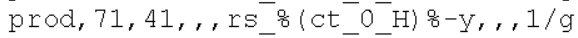
prod, 72,42, , rs ${ }^{-} 8\left(\mathrm{ct}_{-}^{-}{ }^{-} 382\right) \mathrm{o}^{-} \mathrm{y}_{1}, 1 / \mathrm{g}$

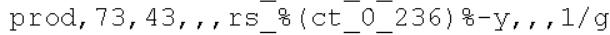

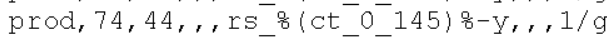
prod, 75, 45, , rs ${ }^{-}$( ct ct $\left.^{-}{ }^{-} 0\right)$ 응-y, , , 1/g prod, 81,51, , rs_o (ct_o_H) $8-z, 1,1 / 9$ prod $, 82,52,1$, rs $^{-} 8\left(\mathrm{ct}_{-}^{-}{ }^{-} 382\right) 8-z_{1}, 1 / \mathrm{g}$ prod, 83, 53, , rs ro (ct_o_236) g-z, 1 - $1 / 9$ prod, 84, 54, , rs ${ }^{-} 8\left(\mathrm{ct}^{-} \mathrm{O}^{-} 145\right) 8-z, 1,1 / 9$ prod, 85,55, , rs_o $\left(\mathrm{ct}_{-}{ }^{-}{ }_{-} 0\right) 8-2,14,1 / 9$

lines, 200

/out, RS-ct-0, out

prvar $, 2,61,62,63,64,65$

prvar, $2,71,72,73,74,75$

prvar $, 2,81,82,83,84,85$

lout

deriv, $91,3,1$, vx3

deriv, $92,4,1$, , vx 4

deriv, $93,5,1$, , vx 5

deriv, $94,6,1$, vx 6

deriv, 95, 7, 1, , vx 7

deriv, 101, 13,1, , vy13

deriv, 102,14,1, ,vy14

deriv, 103,15,1, ,vy15

deriv, 104,16,1, ,vy16

deriv, 105, 71, 1, , vy17

deriv, 111,23,1, vz23

deriv, 112, 24,1, vz24

deriv, 113,25, 1, vz25

deriv, 114,26,1, , vz26

deriv, 115, 27, 1, ,vz27

deriv, $121,91,1$, a $\frac{0}{8}$ (ct $0 \mathrm{H}$ ) $\frac{\mathrm{g}}{\mathrm{r}}-\mathrm{x}, 1,1 / \mathrm{g}$

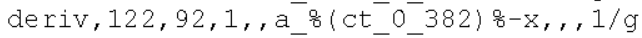
deriv, $123,93,1$, a 8 (ct $\left.{ }^{-} 236\right) 8-x, 1,1 / 9$ deriv, 124,94,1, a a ${ }^{-}\left(\mathrm{ct}_{-}^{-}{ }^{-}{ }^{-} 145\right) \mathrm{g}-\mathrm{x}, 1,1 / \mathrm{g}$ deriv $, 125,95,1$, a_o $^{-}\left(\mathrm{ct}_{-}^{-}{ }^{-}{ }_{-} 0\right) \mathrm{g}-\mathrm{x}, 1,1 / 9$

deriv, 131, 101, 1, a_ 8 (ct_0_H) $8-y_{1}, 1 / 9$ deriv, 132, 102, 1, , a_o (ct_o_382) $8-y, 1,1 / 9$ deriv, 133,103,1, a_o (ct_o_236) $8-\mathrm{y}_{1}, 1,1 / \mathrm{g}$ deriv, 134, 104, 1, a o (ct 0 145) 음 -y, , 1/g deriv $, 135,105,1$, a $_{-}^{-} 8\left(\mathrm{ct}_{-}^{-}{ }^{-}{ }_{-} 0\right) 8-\mathrm{g}-\mathrm{y}, 1,1 / \mathrm{g}$

deriv $, 141,111,1$, , a_o (ct_O_H) $8-z, 1,1 / 9$ 
RPP-RPT-32239, Rev. 1

M\&D-2008-005-CALC-001, Rev. 1

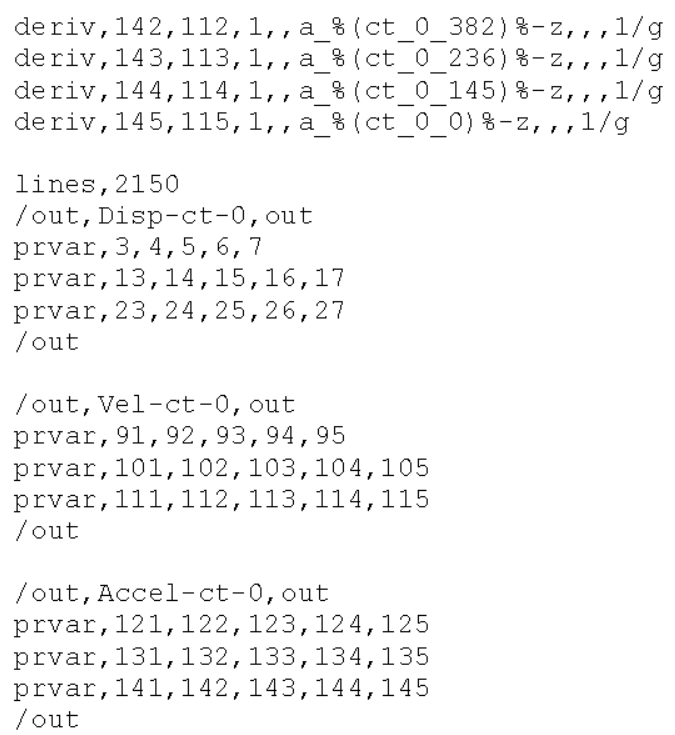

spectra-conc-135.txt

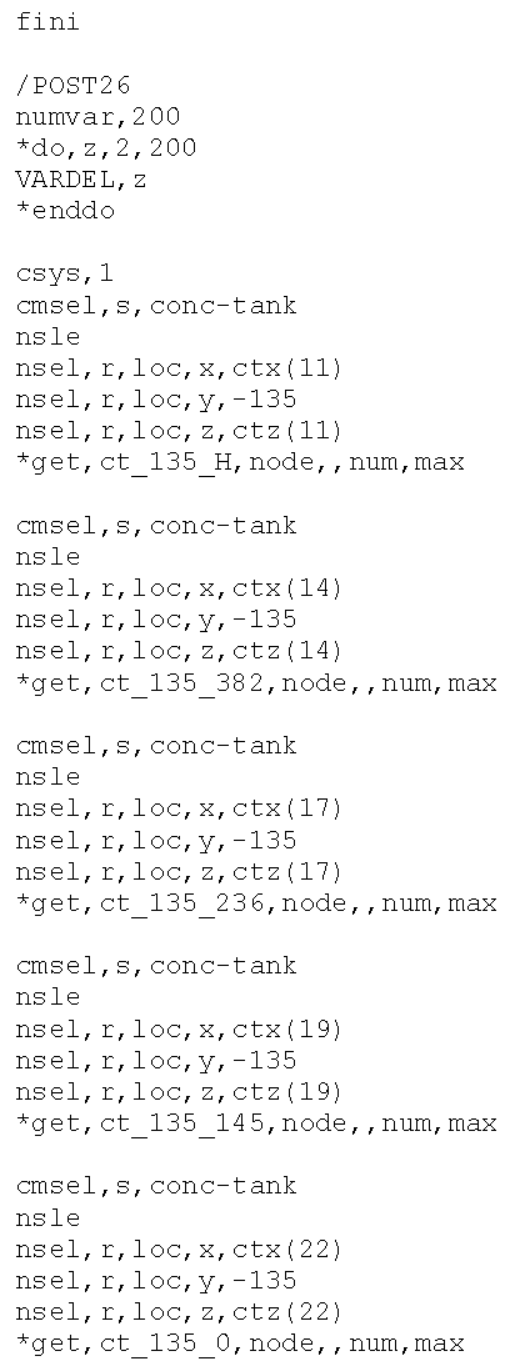


RPP-RPT-32239, Rev. 1

M\&D-2008-005-CALC-001, Rev. 1

nsol, 3, ct_135_H, u, r, N_8 (ct_135_H) $8 \mathrm{X}$

$\mathrm{nsol}, 4, \mathrm{ct}{ }^{-} 135-382, \mathrm{u}, \mathrm{x}, \mathrm{N}$ - 8 ( $\overline{\mathrm{c}} \mathrm{C} \_1 \overline{3} 5$ 382) $8 \mathrm{x}$ $\mathrm{nsol}, 5, \mathrm{ct}^{-} 135^{-} 236, \mathrm{u}, \mathrm{x}, \mathrm{N}^{-} \mathrm{o}$ ( ct $\left.\mathrm{ct}^{-} 135^{-} 236\right)$ ) $8 \mathrm{x}$ nsol, 6, ct_135_145, u, x, N_o (ct ${ }^{-}{ }^{-} 135^{-}$145) 8 x

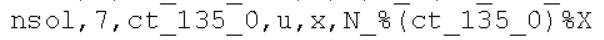

nsol, 13, ct $135 \mathrm{H}, \mathrm{u}, \mathrm{y}, \mathrm{N}$ \% (ct $135 \mathrm{H}$ ) $8 \mathrm{y}$

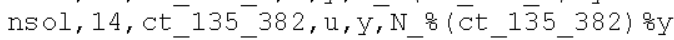
$\mathrm{nsol}, 15, \mathrm{ct} 135$ 236, u, y, N 8 (ct 135 236) 8y

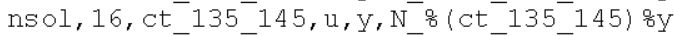

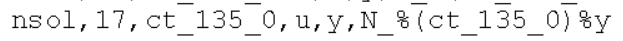

nsol, 23, ct_135_H, u, z, N_o (ct_135_H) $8 \mathrm{z}$ nsol, 24, ct 135 382, u, z, N o (ct $1 \overline{3} 5382$ ) 号z nsol, 25, ct ${ }^{-} 135-236, u, z, N_{-}^{-}$( $\left.\mathrm{ct}^{-} 135^{-} 236\right) \% \mathrm{z}$ nsol, 26, ct 135 145, u, z,N o (ct 135 145) $8 \mathrm{z}$

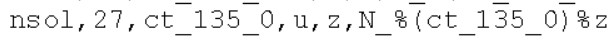

/input,rs_freq, txt

resp, 31, 2,3,3,0.033,0.01,100,120.48 resp, $32,2,4,3,0.033,0.01,100,120.48$ resp, $33,2,5,3,0.033,0.01,100,120.48$ resp, $34,2,6,3,0.033,0.01,100,120.48$ resp, 35, 2,7,3,0.033,0.01,100,120.48 resp, 41,2,13,3,0.033,0.01,100,120.48 resp, 42, 2,14,3,0.033,0.01,100,120.48 resp $, 43,2,15,3,0.033,0.01,100,120.48$ resp $, 44,2,16,3,0.033,0.01,100,120.48$ resp, 45,2,17,3,0.033,0.01,100,120.48 resp, 51,2,23,3,0.033,0.01,100,120.48 resp $, 52,2,24,3,0.033,0.01,100,120.48$ resp $, 53,2,25,3,0.033,0.01,100,120.48$ resp, $54,2,26,3,0.033,0.01,100,120.48$ resp $, 55,2,27,3,0.033,0.01,100,120.48$

prod, 61, 31, ,rs_ct_135_H-X, , 1/g prod, 62,32, rs ct $135-382-x_{1}, 1 / g$ prod, 63,33, , rs_ct_135_236-X, , 1/g prod, 64,34, , rs ct $135^{-} 145-\mathrm{x}, 1,1 / \mathrm{g}$ prod, 65, 35, , rs_ct ${ }^{-135} 0-\mathrm{X}, 1,1 / \mathrm{g}$ prod, $71,41,, \mathrm{rs}^{-} \mathrm{Ct}^{-} 135^{-} \mathrm{H}-\mathrm{y}, 1,1 / \mathrm{g}$ prod, 72,42, ,rs_ct_135_382-y, , 1/g prod, $73,43,1$, ss_ct $^{-} 135^{-} 236-\mathrm{y}, 1,1 / \mathrm{g}$ prod, $74,44,$, rs ct $135145-\mathrm{y}, 1,1 / \mathrm{g}$ prod, $75,45,$, rs_ct_135_0-y, , $1 / \mathrm{g}$ prod, $81,51, \ldots$ rs ct $135 \mathrm{H}-\mathrm{z}, 1,1 / \mathrm{g}$ prod, $82,52,$, rs ${ }_{-}{ }^{-} t_{-} 135-382-z,, 1 / 9$ prod, $83,53,1$, rs $^{-} \mathrm{Ct}^{-} 135^{-} 236-2,1,1 / \mathrm{g}$ prod, 84,54, , rs ${ }^{-} \mathrm{Ct}^{-} 135-145-2,1,1 / \mathrm{g}$ prod, 85, 55, , rs_ct_135_0-z, , 1/g

lines, 200

lout, RS-ct-135, out prvar, $2,61,62,63,64,65$ prvar $, 2,71,72,73,74,75$ prvar $, 2,81,82,83,84,85$ lout

deriv, $91,3,1$, , vx3 deriv, $92,4,1,, \mathrm{vx} 4$ deriv, $93,5,1$, , vx 5 deriv, $94,6,1$, , vx 6 deriv, 95, 7, 1, , vx 7

deriv, 101, 13,1, , vy13 deriv, 102,14,1, ,vy14 deriv, 103, 15, 1, , vy15 deriv, 104,16,1, , vy16 
RPP-RPT-32239, Rev. 1

M\&D-2008-005-CALC-001, Rev. 1

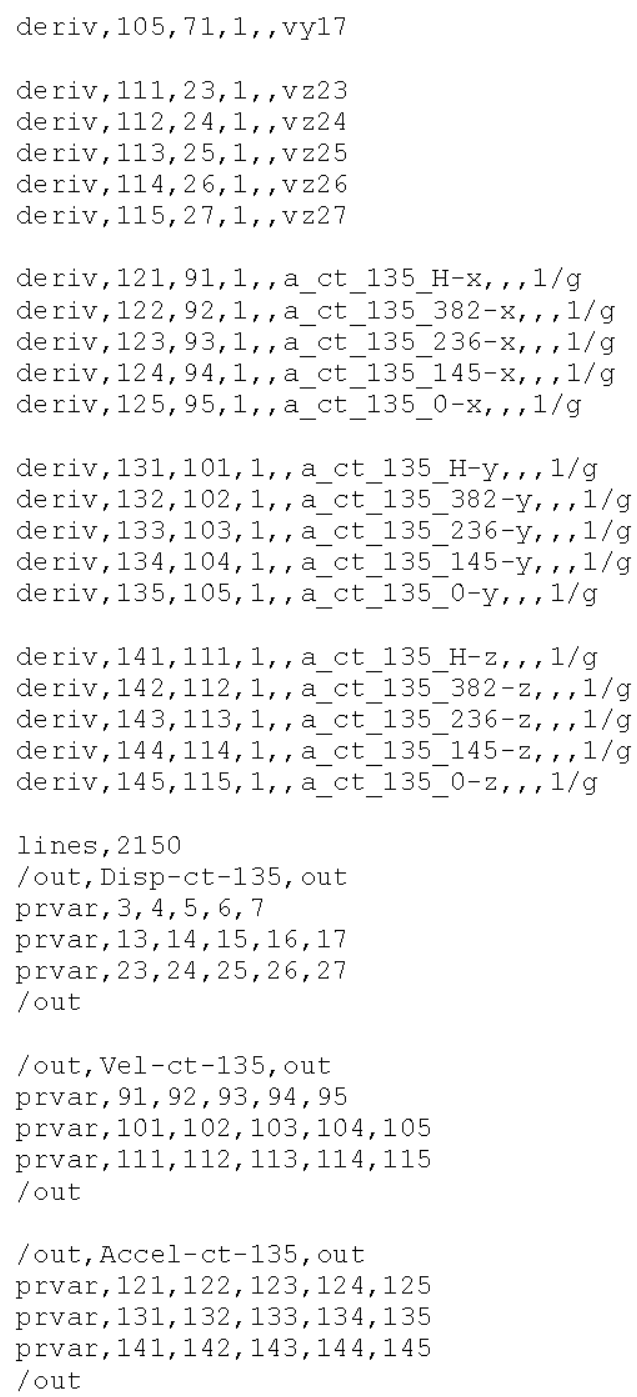

\section{spectra-conc-180.txt}

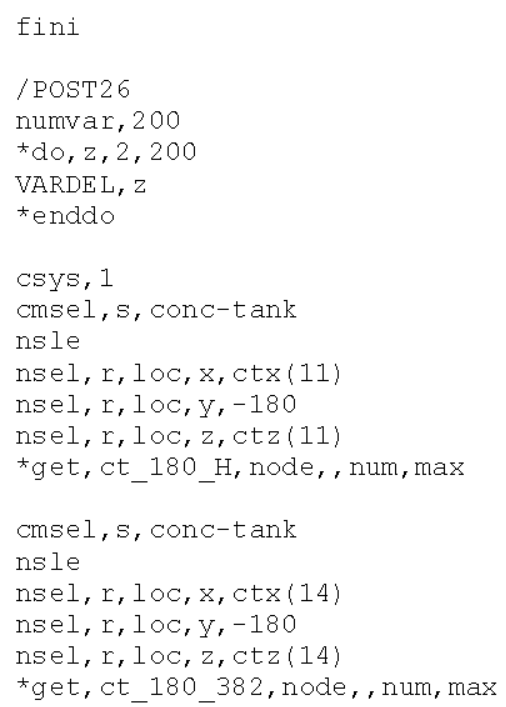




\section{RPP-RPT-32239, Rev. 1 \\ M\&D-2008-005-CALC-001, Rev. 1}

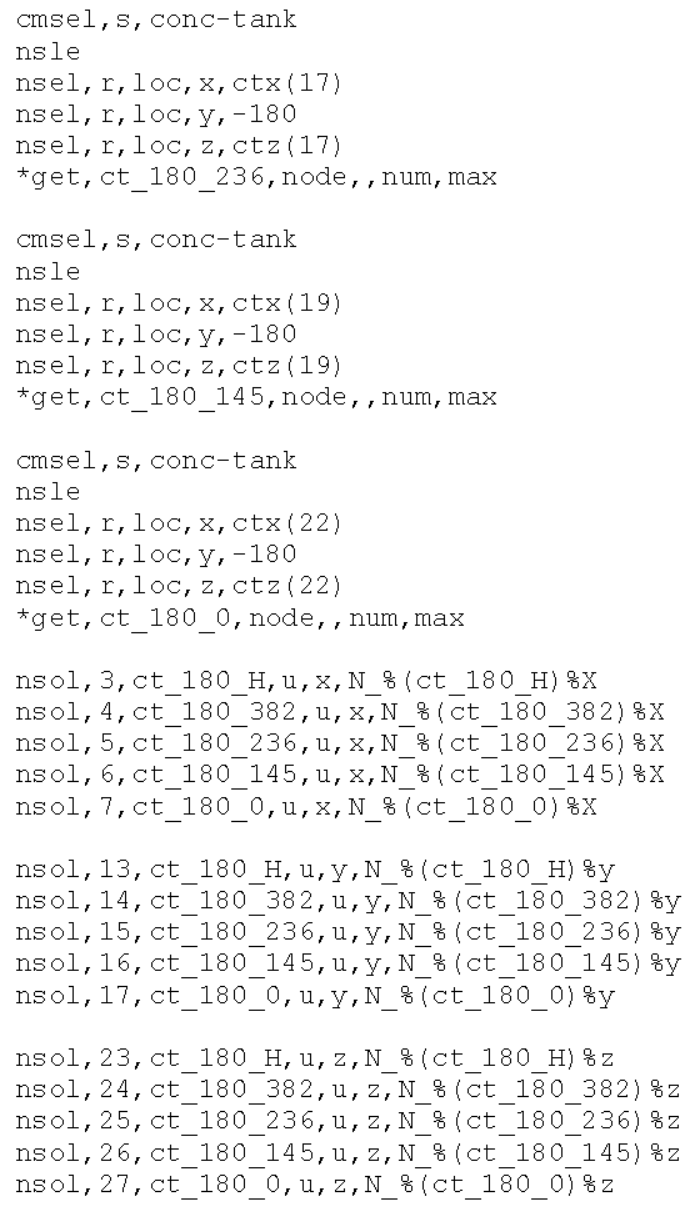


RPP-RPT-32239, Rev. 1

M\&D-2008-005-CALC-001, Rev. 1

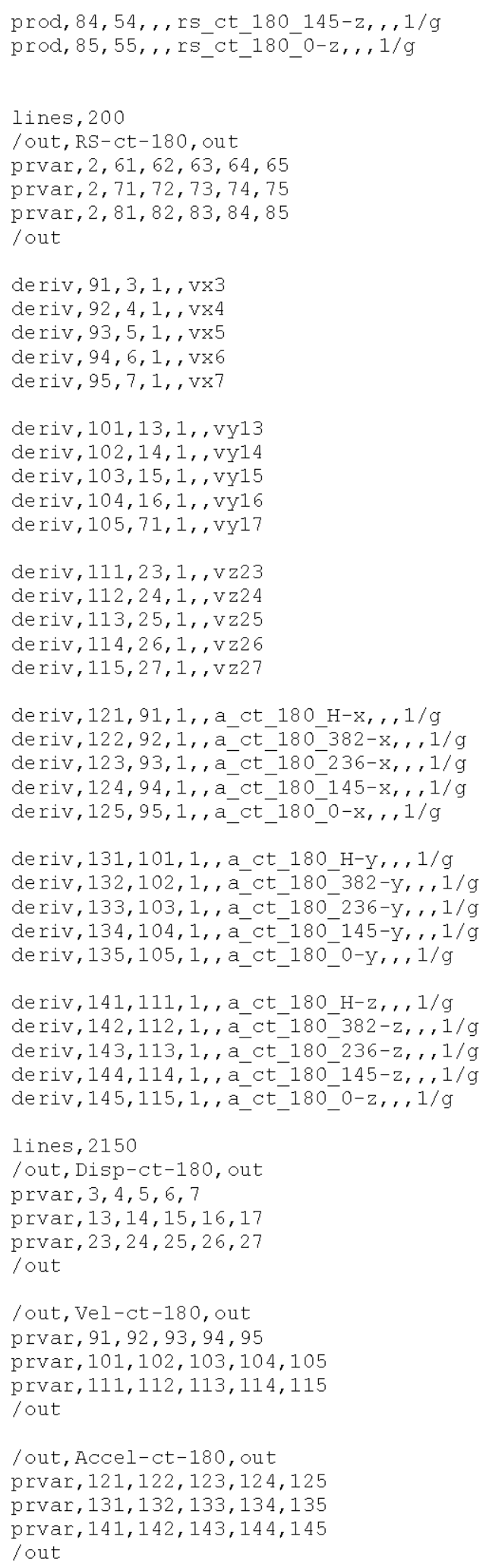


RPP-RPT-32239, Rev. 1

M\&D-2008-005-CALC-001, Rev. 1

\section{spectra-conc-45.txt}

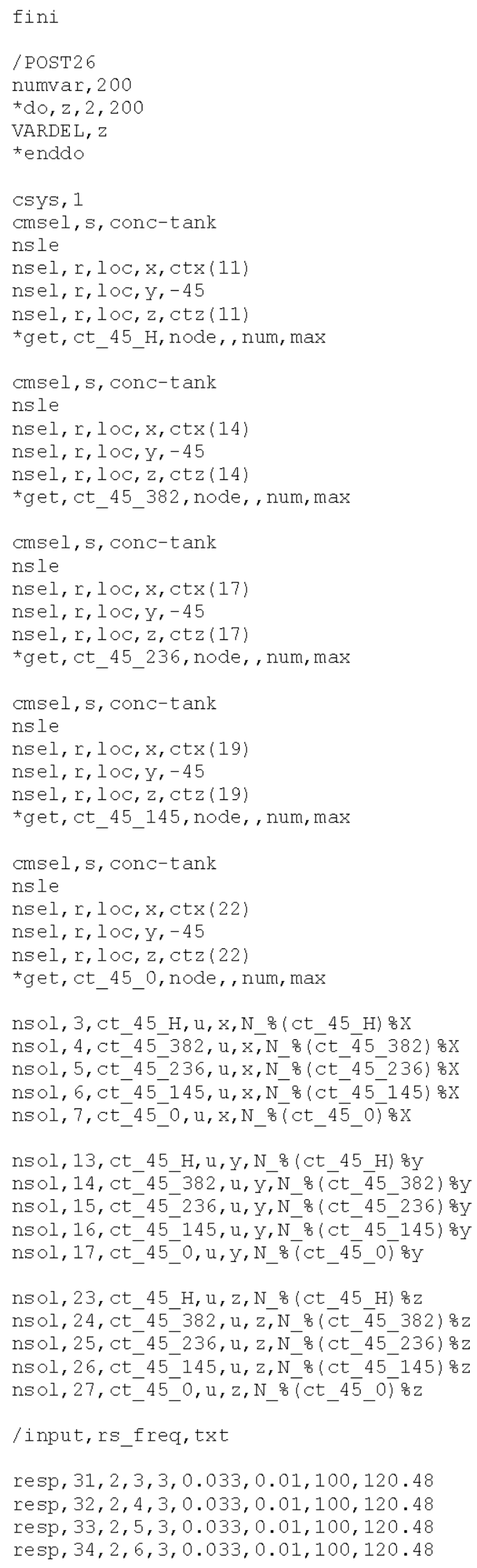


RPP-RPT-32239, Rev. 1

M\&D-2008-005-CALC-001, Rev. 1

resp, $35,2,7,3,0.033,0.01,100,120.48$ resp, 41,2,13,3,0.033,0.01,100,120.48 resp $, 42,2,14,3,0.033,0.01,100,120.48$ resp, 43,2,15,3,0.033,0.01,100,120.48 resp, $44,2,16,3,0.033,0.01,100,120.48$ resp, 45,2,17,3,0.033,0.01,100,120.48 resp, $51,2,23,3,0.033,0.01,100,120.48$ resp, $52,2,24,3,0.033,0.01,100,120.48$ resp, 53,2,25,3,0.033,0.01,100,120.48 resp, $54,2,26,3,0.033,0.01,100,120.48$ resp, 55,2,27,3,0.033,0.01,100,120.48

prod, 61, 31, , rs_o(ct_45_H) $8-\mathrm{X}, 1,1 / \mathrm{g}$ prod, 62, 32, , rs ${ }^{-} 8\left(\mathrm{ct}_{-}^{-} 45_{-}^{-} 382\right) 8-\mathrm{X}_{1}, 1 / \mathrm{g}$ prod, 63,33, ,rs_8(ct_45_236) $8-X_{1}, 1 / 9$ prod, 64, 34, , rs ${ }^{-} 8\left(\mathrm{ct}_{-}^{-} 45_{-}^{-} 145\right) \mathrm{g}-\mathrm{X}, 1,1 / \mathrm{g}$ prod, 65, 35, , rs 8 (ct 45 o) $8-X, 1,1 / g$ prod, 71, 41, , rs s $^{-}\left(\mathrm{ct}_{-}^{-} 45_{-}^{-} \mathrm{H}\right) \mathrm{g}-\mathrm{y},, 1 / \mathrm{g}$ prod, 72,42, , rs ${ }^{-} 8\left(\mathrm{ct}^{-} 45^{-} 382\right) 8-\mathrm{y}, 1,1 / \mathrm{g}$ prod, 73,43, ,rs_8 (ct_45_236) $8-y, 1,1 / 9$ prod, 74, 44, , rs 8 (ct 45 145) $8-y, 1,1 / 9$

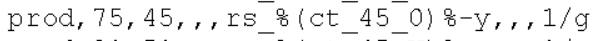
prod, 81, 51, , rs 8 ( $\left.\mathrm{ct}^{-} 45-\mathrm{H}\right) \mathrm{8}-\mathrm{z}, 1,1 / \mathrm{g}$ prod, 82,52, , rs_o (ct_45_382) $8-2,1,1 / \mathrm{g}$ prod $, 83,53,1$, rs_o $_{-}\left(\mathrm{ct}_{-}^{-} 45_{-}^{-} 236\right) 8-2,1,1 / 9$ prod, 84,54, , rs_o(ct_45_145) g $-2,1,1 / g$

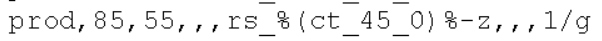

lines, 200

lout, RS-ct-45, out

prvar, $2,61,62,63,64,65$ prvar, $2,71,72,73,74,75$ prvar, $2,81,82,83,84,85$ lout

deriv, $91,3,1$, vx3 deriv, $92,4,1$, vx 4 deriv, $93,5,1$, vx 5 deriv, $94,6,1$, vx 6 deriv, 95, 7, 1, ,vx7

deriv, 101, 13,1, , vy13 deriv, 102,14,1, , vy14 deriv, 103,15, 1, , vy15 deriv, 104,16,1, ,vy16 deriv, 105, 71, 1, , vy17

deriv, 111, 23,1, ,vz23 deriv, $112,24,1$, , vz24 deriv, 113,25,1, vz25 deriv, $114,26,1$, vz26 deriv, 115, 27, 1, , vz27

deriv, 121, 91, 1, a_o (ct_45_H) $8-\mathrm{x}, 1,1 / \mathrm{g}$

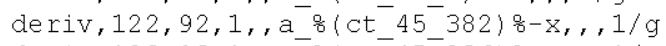
deriv, 123,93,1, a-g (ct_45_236) $8-8,1,1 / 9$ deriv, 124,94,1, a_o (ct_45_145) 마-x, , 1/g

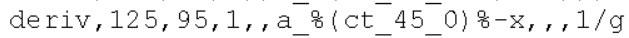

deriv, 131, 101, 1, a 8 (ct 45 H) $8-y, 1,1 / 9$

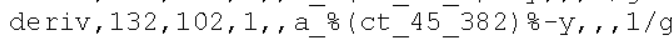
deriv, 133,103,1, a a $^{-}$ct $\left.^{-} 45^{-} 236\right)$ ) $-\mathrm{y}_{1}, 1,1 / 9$ deriv, 134,104,1, a- a $\left(\mathrm{ct}_{-} 45_{-}{ }^{-} 45\right) \mathrm{8}-\mathrm{y}, 1,1 / \mathrm{g}$ deriv $, 135,105,1$, a_o $^{-}\left(\mathrm{ct}_{-}^{-} 45_{-}^{-} 0\right)$ o-y, $1,1 / \mathrm{g}$

deriv, $141,111,1$, , a_o (ct_45_H) $8-z, 1,1 / 9$ deriv, 142, 112, 1, a 8 (ct 45382 ) $8-z, 1,1 / g$ deriv, 143,113,1, a_o(ct_45_236) $8-z, r, 1 / 9$ deriv, 144,114,1, a $\mathrm{a}^{-}\left(\mathrm{ct}^{-} 45^{-}\right.$145) $8-\mathrm{z}, 1,1 / \mathrm{g}$ deriv $, 145,115,1, a_{-}{ }^{-}\left(c_{-} 45_{-} 0\right) 8-z_{1}, 1 / 9$ 
RPP-RPT-32239, Rev. 1

M\&D-2008-005-CALC-001, Rev. 1

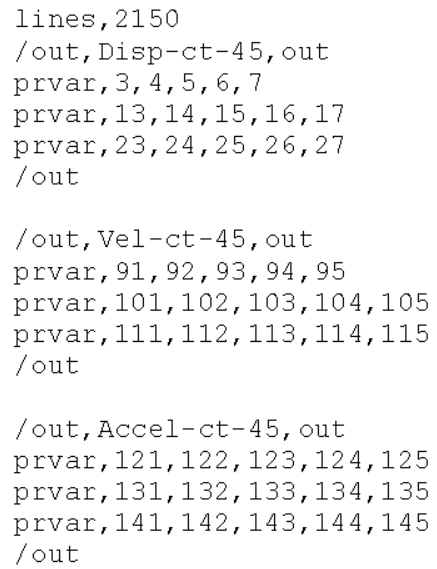

\section{spectra-conc-90.txt}

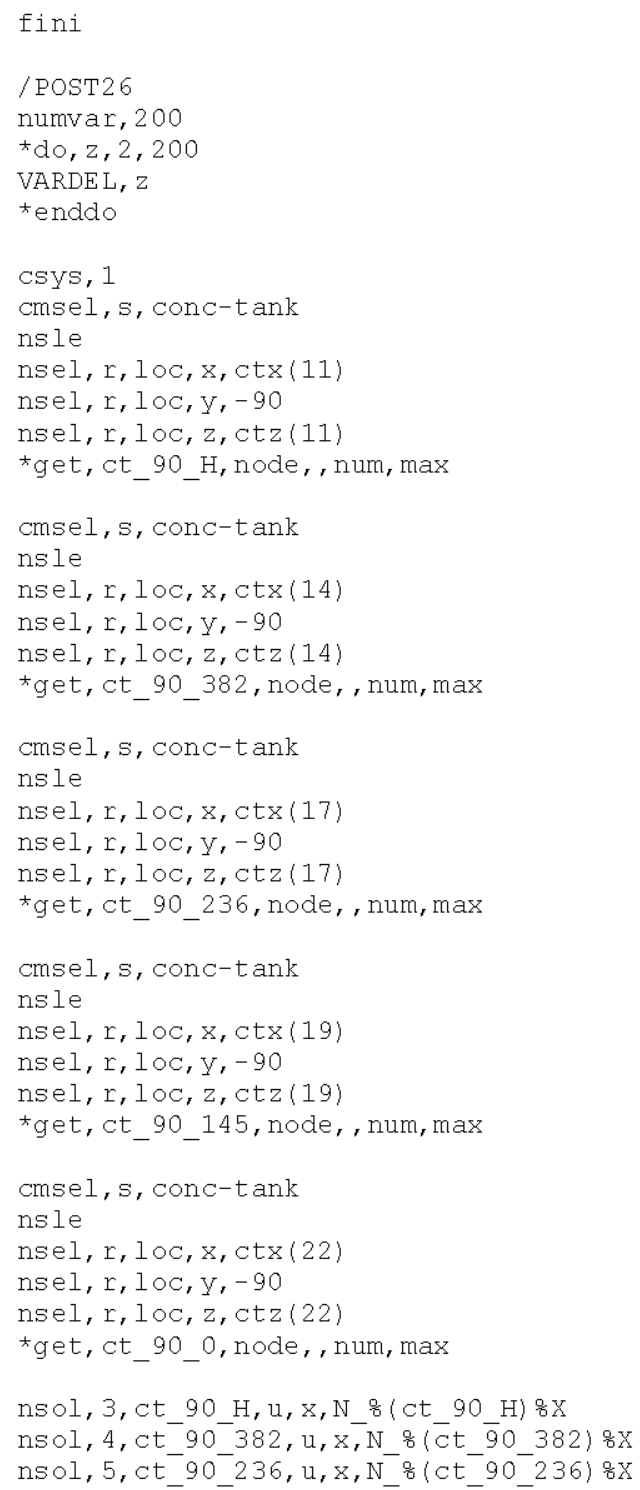


RPP-RPT-32239, Rev. 1

M\&D-2008-005-CALC-001, Rev. 1

nsol, 6, ct $90145, u, x, N$ \% (ct 90 145) $8 x$

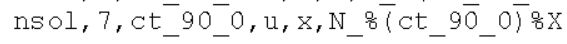

nsol, 13, ct $90 \mathrm{H}, \mathrm{u}, \mathrm{y}, \mathrm{N}$ ( ct $90 \mathrm{H}$ ) $8 \mathrm{y}$

nsol, 14, ct_90_382, u, y, N_o (ct $\overline{9} 0$ 382) $8 \mathrm{y}$ nsol, 15, ct 90 236, u, y, N o (ct 90 236) $8 \mathrm{y}$ nsol, 16, ct ${ }^{-} 90^{-} 145, u_{1}, N_{-}^{-}$( ct $\left.{ }^{-} 90^{-} 145\right)$ \%y

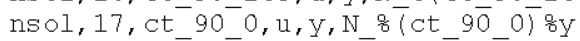

nsol, 23, ct $90 \mathrm{H}, \mathrm{u}, \mathrm{z}, \mathrm{N}$ \% (ct $90 \mathrm{H}$ ) $8 \mathrm{z}$ $\mathrm{nsol}, 24, \mathrm{ct} 9 \mathrm{o}^{-} 382, \mathrm{u}, \mathrm{z}, \mathrm{N}$ \% ( $\left.\mathrm{ct} \overline{90} 382\right) \mathrm{zz}$ nsol, 25, ct $90^{-} 236, u, z, N^{-}$( ct $\left.\mathrm{ct}^{-} 90^{-} 236\right) \mathrm{gz}$ nsol, 26, ct $\mathrm{ct}^{-} \mathrm{O}^{-} 145, \mathrm{u}, \mathrm{z}, \mathrm{N}^{-} \mathrm{g}$ ( $\left.\mathrm{ct}^{-} 90^{-} 145\right) \mathrm{gz}$

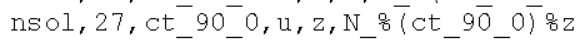

/input,rs_freq, txt

resp, $31,2,3,3,0.033,0.01,100,120.48$ resp, $32,2,4,3,0.033,0.01,100,120.48$ resp, 33,2,5,3,0.033,0.01,100,120.48 resp, 34, 2,6,3,0.033,0.01,100,120.48 resp, 35,2,7,3,0.033,0.01,100,120.48 resp, $41,2,13,3,0.033,0.01,100,120.48$ resp, 42,2,14,3,0.033,0.01,100,120.48 resp, 43,2,15,3,0.033,0.01,100,120.48 resp, 44, 2, 16,3,0.033,0.01,100,120.48 resp, 45,2,17,3,0.033,0.01,100,120.48 resp, $51,2,23,3,0.033,0.01,100,120.48$ resp, 52, 2,24,3,0.033,0.01,100,120.48 resp $, 53,2,25,3,0.033,0.01,100,120.48$ resp, 54,2,26,3,0.033,0.01,100,120.48 resp $, 55,2,27,3,0.033,0.01,100,120.48$

prod, 61,31, , rs ct $90 \mathrm{H}-\mathrm{X}, 1,1 / \mathrm{g}$ prod, 62, 32, , rs_ct_90_382-X, , 1/g prod, 63, 33, , rs_ct_90_236-X, , , 1/g prod, 64, 34, , rs_ct $90-145-\mathrm{X}, 1,1 / \mathrm{g}$ prod, 65, 35, , rs_ct_90_0-X, , , 1/g prod, 71,41, , rs ct $90^{-} \mathrm{H}-\mathrm{y}, 1,1 / \mathrm{g}$ prod, 72, 42, , rs_ct_90_382-y, , , 1/g prod, 73,43, , rs ct $90-236-y, 1,1 / 9$ prod, 74, 44, , rs_ct_90_145-y, , , 1/g prod, 75,45, , rs ct $90^{-} 0-y, 1,1 / \mathrm{g}$ prod, 81, 51, , rs_ct_90_H-z, , $1 / \mathrm{g}$ prod, 82, 52, , rs_ct $90-382-z, 1 / \mathrm{g}$ prod, 83, 53, , rs_ct_90_236-z, , , 1/g prod, 84,54, , rs_ct_90_145-z, , , 1/g prod, 85, 55, , rs_ct_90_0-z, , , 1/g

lines, 200

/out, RS-ct-90, out prvar, $2,61,62,63,64,65$ prvar, $2,71,72,73,74,75$ prvar $, 2,81,82,83,84,85$ lout

deriv, $91,3,1$, , vx3 deriv, $92,4,1$, vx 4 deriv, $93,5,1$, , vx 5 deriv, $94,6,1$, , vx 6 deriv, $95,7,1$, , vx 7

deriv, 101, 13, 1, , vy13 deriv, 102, 14, 1, , vy14 deriv, 103, 15, 1, , vy15 deriv, 104, 16, 1, , vy16 deriv, 105, 71, 1, , vy17

deriv, 111, 23, 1, vz23 deriv, $112,24,1$, , vz24 
RPP-RPT-32239, Rev. 1

M\&D-2008-005-CALC-001, Rev. 1

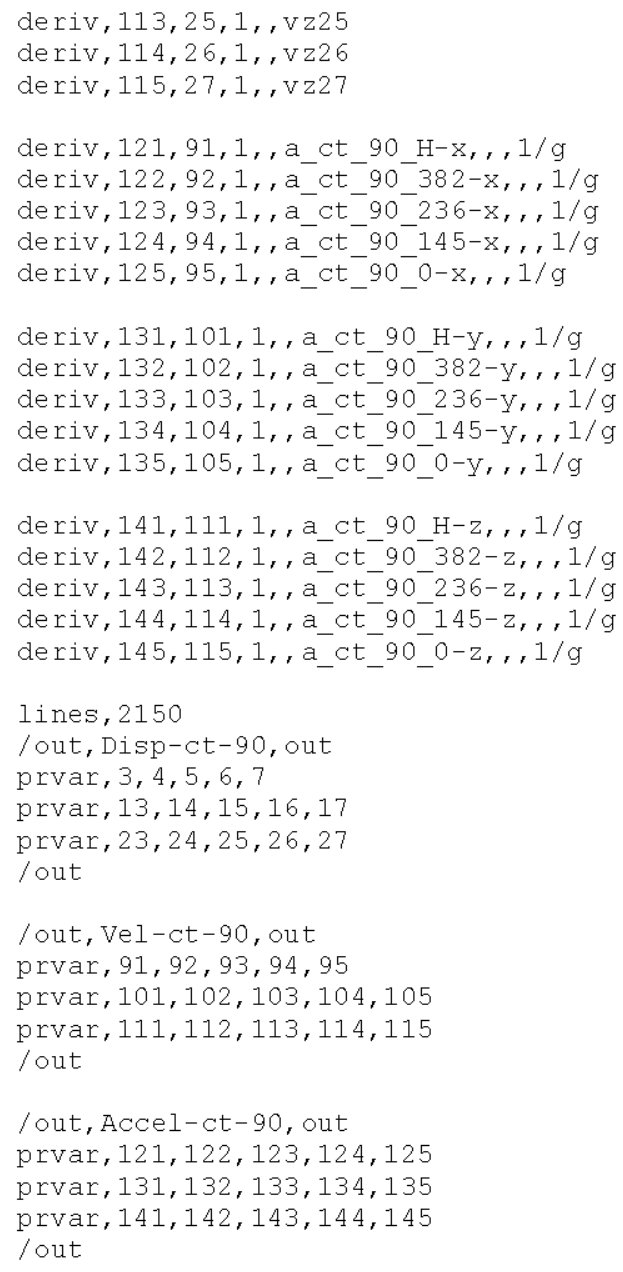

\section{spectra-conc.txt}

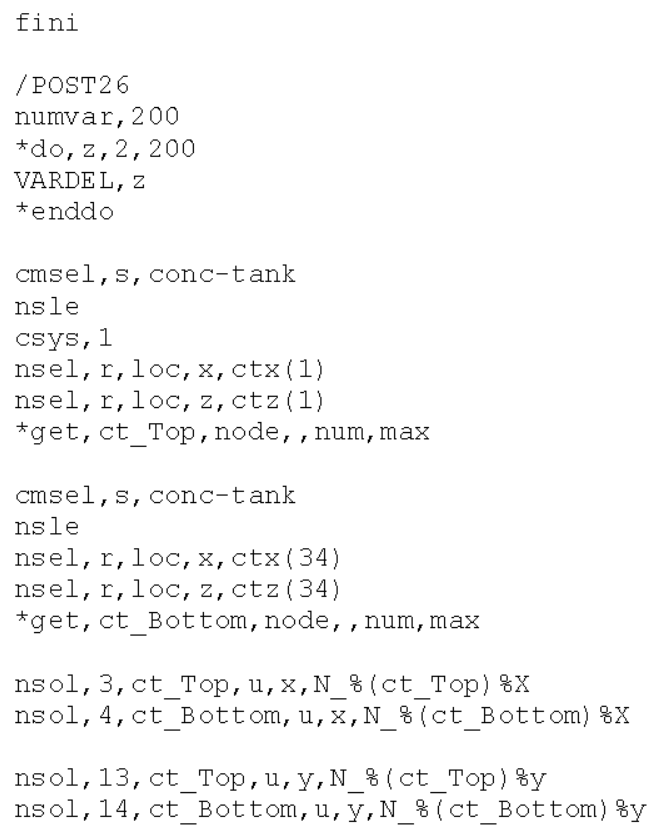


RPP-RPT-32239, Rev. 1

M\&D-2008-005-CALC-001, Rev. 1

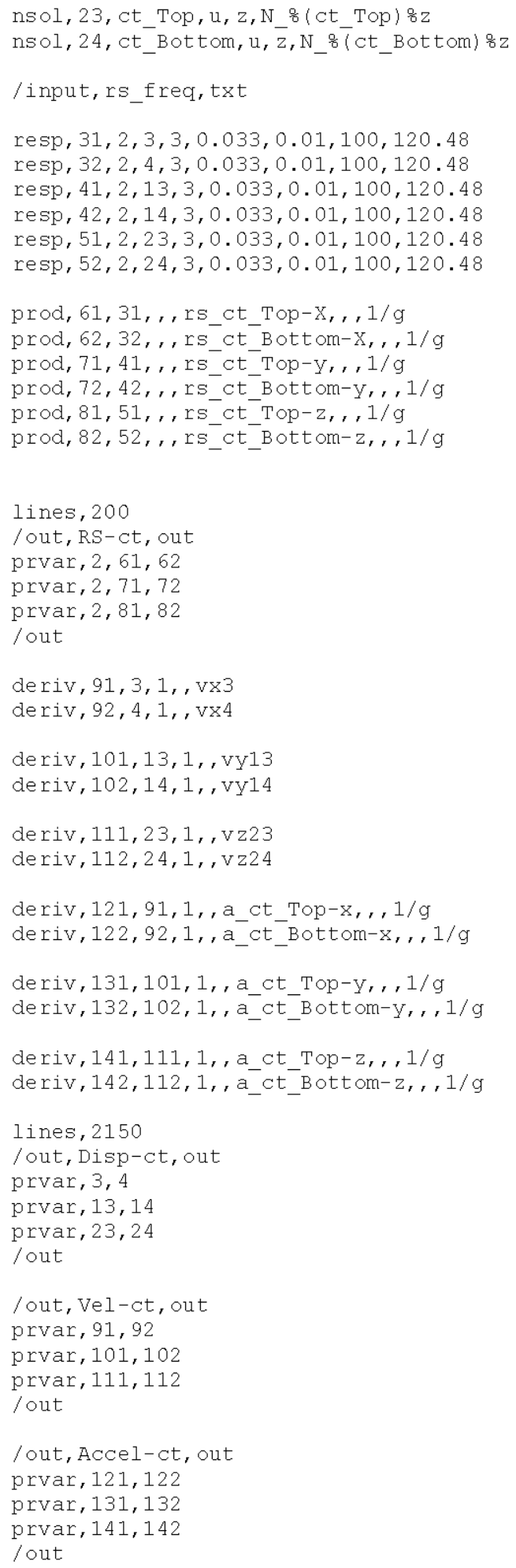


RPP-RPT-32239, Rev. 1

M\&D-2008-005-CALC-001, Rev. 1

spectra-concrete.txt

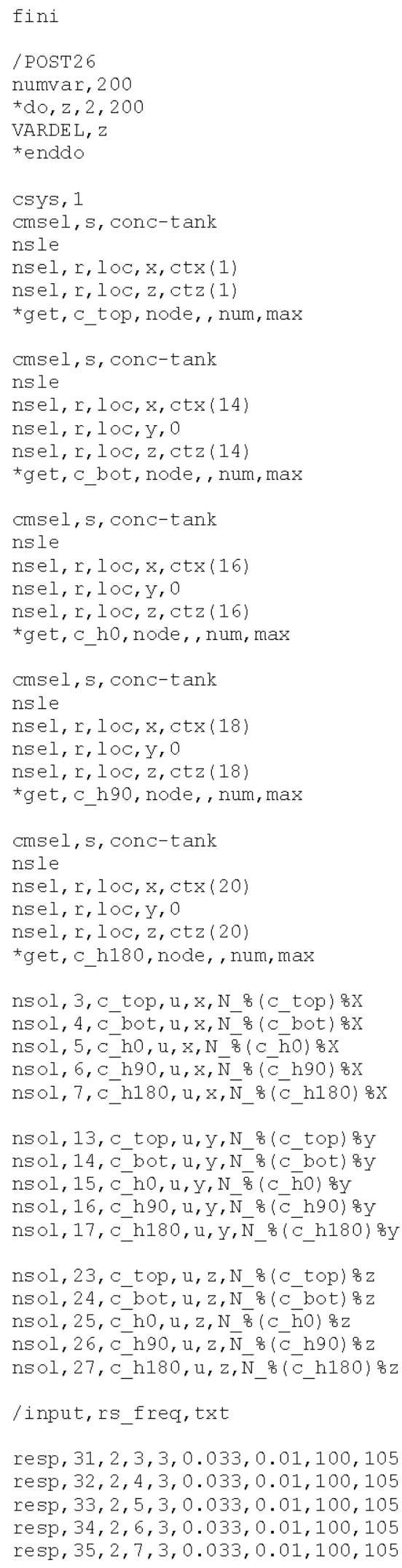


RPP-RPT-32239, Rev. 1

M\&D-2008-005-CALC-001, Rev. 1

resp, 41,2,13,3,0.033,0.01,100,105 resp, 42,2,14,3,0.033,0.01,100,105 resp $, 43,2,15,3,0.033,0.01,100,105$ resp, 44,2,16,3,0.033,0.01,100,105 resp, $45,2,17,3,0.033,0.01,100,105$ resp, $51,2,23,3,0.033,0.01,100,105$ resp, 52,2,24,3,0.033,0.01,100,105 resp, 53,2,25,3,0.033,0.01,100,105 resp, 54,2,26,3,0.033,0.01,100,105 resp $, 55,2,27,3,0.033,0.01,100,105$

prod, $61,31, \ldots, 1 / 9$ prod, $62,32, \ldots, 1,1 / 9$ prod, $63,33,1,1,1 / 9$ prod, $64,34, \ldots, 1 / 9$ prod, $65,35, \ldots, 1,1 / 9$ prod, $71,41,1,1,1 / 9$ prod, $72,42,,, 1,1 / 9$ prod, $73,43, \ldots, 1,1 / 9$ prod, $74,44,, 1,1 / 9$ prod, $75,45,1,1,1 / 9$ prod, $81,51, \ldots, 1,1 / 9$ prod, $82,52, \ldots, 1,1 / 9$ prod, $83,53, \ldots, 1 / 1 / 9$ prod, $84,54,1,1,1 / 9$ prod, $85,55, \ldots, 1 / 9$

lines, 200

/ out, RS-OUT-Concrete, txt prvar, $2,61,62,63,64,65$ prvar, $2,71,72,73,74,75$ prvar $, 2,81,82,83,84,85$ lout

spectra-primary-0.txt

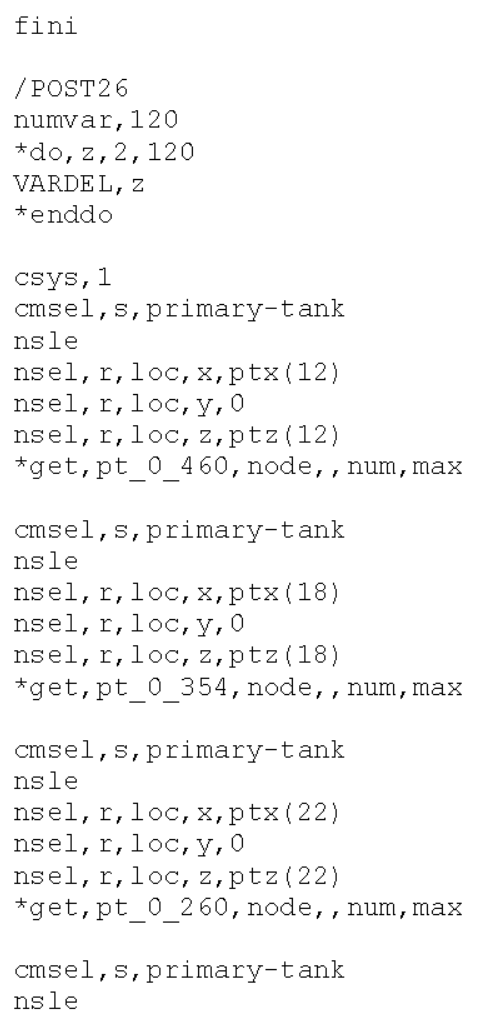




\section{RPP-RPT-32239, Rev. 1 \\ M\&D-2008-005-CALC-001, Rev. 1}

nsel, r, loc, $x, p t x(28)$

nsel, r, loc, y, 0

nsel, r, loc, z, ptz (28)

*get, pt_0_123, node, num, max

cmsel, s, primary-tank

nsle

nsel, r, loc, $x, p t x$ (33)

nsel, r, loc, y, 0

nsel, r, loc, z, ptz (33)

${ }^{\star}$ get, pt_o_12, node, num, max

nsol, 3, pt 0 460, u, x, N g (pt 0 460) $8 x$ $\mathrm{nsol}, 4, \mathrm{pt}^{-} \mathrm{o}^{-} 354, \mathrm{u}, \mathrm{x}, \mathrm{N}^{-} \mathrm{g}\left(\mathrm{pt}_{-}^{-}{ }^{-}-354\right) \% \mathrm{x}$ $\mathrm{nsol}, 5, \mathrm{pt} \mathrm{O}^{-} 260, \mathrm{u}, \mathrm{x}, \mathrm{N}^{-} \mathrm{g}\left(\mathrm{pt} \mathrm{O}^{-} 260\right) \mathrm{gx}$ $\mathrm{nsol}, 6, \mathrm{pt}^{-} \mathrm{O}^{-} 123, \mathrm{u}, \mathrm{x}, \mathrm{N}^{-} \mathrm{g}\left(\mathrm{pt}^{-} \mathrm{O}^{-} 123\right) \mathrm{gx}$ $\mathrm{nsol}, 7, \mathrm{pt}{ }_{-}{ }^{-} 12, \mathrm{u}, \mathrm{x}, \mathrm{N}_{-} \overline{\mathrm{g}}\left(\mathrm{pt} \mathrm{p}_{-}{ }_{-} \overline{1} 2\right) \% \mathrm{x}$

nsol, 13, pt $0460, u, y, N$ o (pt 0460$) \% y$ $\mathrm{nsol}, 14, \mathrm{pt}{ }_{-}^{-}{ }^{-} 354, \mathrm{u}, \mathrm{y}, \mathrm{N}_{-}^{-} \mathrm{g}\left(\mathrm{pt}_{-}^{-}{ }^{-}{ }_{-}^{-} 354\right) \% \mathrm{y}$ nsol, 15, pt o 260, u, y, N 8 (pt o 260) \%y nsol, 16, pt_o_123, u, y, N_o (pt_o-123) ${ }^{-} \mathrm{y}$

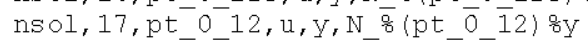

$\mathrm{nsol}, 23, \mathrm{pt}{ }_{0}{ }_{-} 460, \mathrm{u}, \mathrm{z}_{2} \mathrm{~N}_{-} \mathrm{o}\left(\mathrm{pt} \mathrm{p}_{-}{ }_{-} 460\right) \% \mathrm{z}$ $\mathrm{nsol}, 24, \mathrm{pt} \mathrm{o}^{-} 354, \mathrm{u}, \mathrm{z}, \mathrm{N}^{-} \mathrm{g}\left(\mathrm{pt}_{-}^{-} \mathrm{O}_{-}^{-} 354\right) \% \mathrm{z}$ $\mathrm{nsol}, 25, \mathrm{pt}{ }_{-}{ }^{-} 260, \mathrm{u}, \mathrm{z}, \mathrm{N}_{-}^{-} \mathrm{o}\left(\mathrm{pt} \mathrm{p}_{-}{ }^{-} 260\right) \% \mathrm{z}$ nsol, 26, pt $0^{-} 123, u, z, N^{-} \%\left(p^{-} 0^{-} 123\right) \% z$

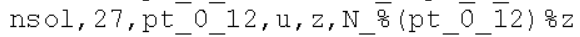

/input,rs_freq, txt

resp $, 31,2,3,3,0.033,0.01,100,112.48$ resp, $32,2,4,3,0.033,0.01,100,112.48$ resp, $33,2,5,3,0.033,0.01,100,112.48$ resp $, 34,2,6,3,0.033,0.01,100,112.48$ resp, $35,2,7,3,0.033,0.01,100,112.48$ resp, $41,2,13,3,0.033,0.01,100,112.48$ resp, 42, 2,14,3,0.033,0.01,100,112.48 resp, 43,2,15,3,0.033,0.01,100,112.48 resp, 44, 2,16,3,0.033,0.01,100,112.48 resp, 45,2,17,3,0.033,0.01,100,112.48 resp, $51,2,23,3,0.033,0.01,100,112.48$ resp $, 52,2,24,3,0.033,0.01,100,112.48$ resp $, 53,2,25,3,0.033,0.01,100,112.48$ resp $, 54,2,26,3,0.033,0.01,100,112.48$ resp, 55,2,27,3,0.033,0.01,100,112.48

prod, 61, 31, , rs_pt_0_460-X, , 1/g prod, 62, 32, , rs pt 0 354-X, , $1 / \mathrm{g}$ prod, 63, 33, , rs_pt_o_260-X, r, 1/g prod, 64, 34, , rs pt $0^{-} 123-\mathrm{X}, 1,1 / \mathrm{g}$ prod, 65, 35, , rs_pto r $12-\mathrm{X}, 1,1 / \mathrm{g}$ prod, 71, 41, , rs pt $0-460-y, r, 1 / \mathrm{g}$ prod, 72, 42, , rs pt $0^{-} 354-\mathrm{y}, 1,1 / \mathrm{g}$ prod, 73,43, , rs_pt_o_260-y,, $1 / 9$ prod, 74, 44, , rs pt $0-123-y, 1,1 / \mathrm{g}$ prod, 75, 45, , rs_pt_o_12-y, , $1 / \mathrm{g}$ prod, 81,51, , rs pt $0^{-} 460-z, 1,1 / \mathrm{g}$ prod, 82, 52, , rs_pt_o_354-z, , $1 / \mathrm{g}$ prod, 83, 53, r, rs pt 0 260-z, , $1 / \mathrm{g}$ prod, 84, 54, , rs_pt_o_123-z, , 1/g prod, 85,55, , rs_pt_o_12-z,, $1 / \mathrm{g}$

lines, 200

/ out, RS-PT-0, out prvar, $2,61,62,63,64,65$ prvar $, 2,71,72,73,74,75$ prvar $, 2,81,82,83,84,85$ lout 
RPP-RPT-32239, Rev. 1

M\&D-2008-005-CALC-001, Rev. 1

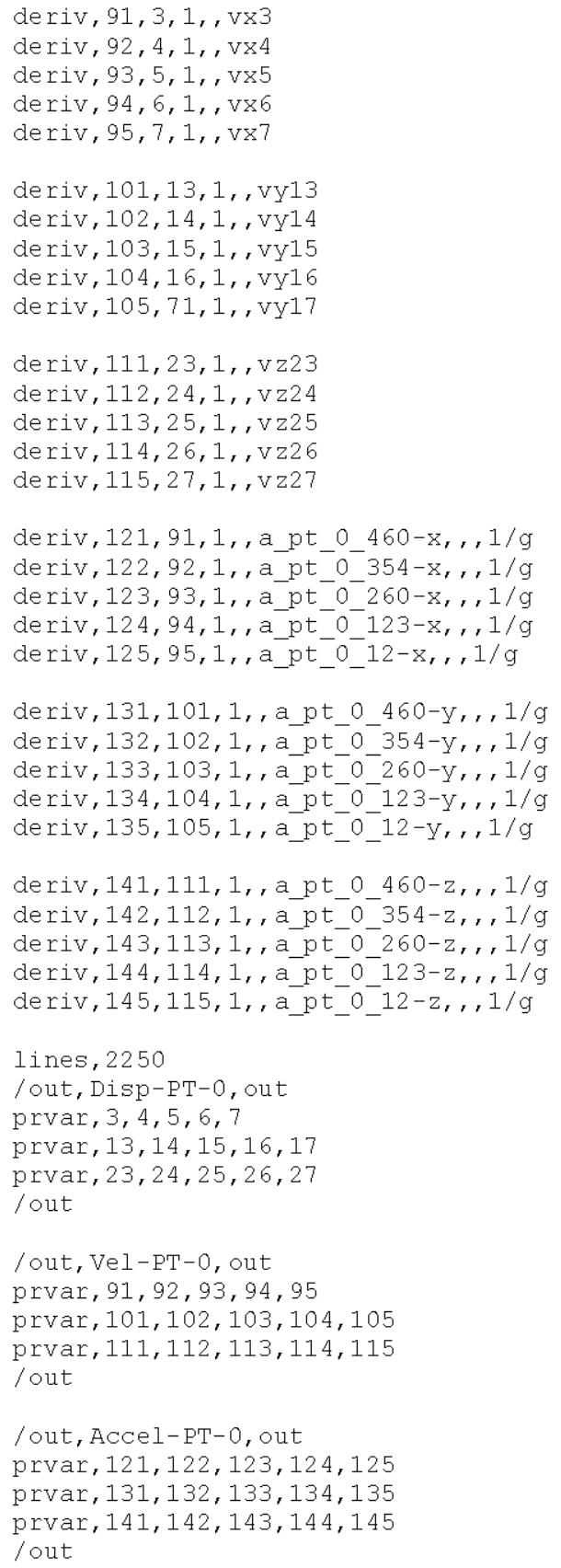

spectra-primary-135.txt

fini

/POST26

numvar, 120

$\star d o, z, 2,120$

VARDE L, $z$

*enddo

Csys, 1

cmsel,s,primary-tank

nsle 


\section{RPP-RPT-32239, Rev. 1 \\ M\&D-2008-005-CALC-001, Rev. 1}

nsel, $r, 1 \circ, x, p t x(12)$

nsel, $r, 100, y,-135$

nsel, r, loc, $z, p t z(12)$

*get,pt_135_460, node, num, max

cmsel, s, primary-tank

nsle

nsel, r, loc, $x, p t x(18)$

nsel, r, loc, y, -135

nsel, r, loc, z, ptz (18)

*get, pt_135_354, node, num, max

cmsel, s, primary-tank

nsle

nsel, r, loc, $x, p t x(22)$

nsel, $r, 100, y,-135$

nsel, r, loc, z, ptz (22)

*get,pt_135_260, node, num, max

cmsel, s, primary-tank

nsle

nsel, r, loc, $x, p t x(28)$

nsel, r, loc, y, -135

nsel, r, loc, z, ptz (28)

*get, pt_135_123, node, num, max

cmsel, s, primary-tank

nsle

nsel, r, loc, $x, p t x(33)$

nsel, $r, 100, y,-135$

nsel, r, loc, z, ptz (33)

*get,pt_135_12, node, , num, max

nsol, 3,pt 135 460, u, x,N 8 (pt 135 460) $8 \mathrm{x}$ nsol, 4,pt 135 354, u, x,N 8 (pt 135 354) $8 \mathrm{x}$ $\mathrm{nsol}, 5, \mathrm{pt}{ }^{-} 135-260, \mathrm{u}, \mathrm{x}, \mathrm{N}^{-} \mathrm{o}\left(\mathrm{pt}_{-}{ }^{-} 135^{-} 260\right)$ \% $\mathrm{x}$ nsol, 6, pt 135 123, u, x,N \& (pt 135 123) $8 x$ nsol, 7, pt_135_12, u, x, N_o ${ }^{-}\left(\mathrm{pt}_{-} \overline{1} 35 \_\overline{1} 2\right) \mathrm{gx}$

nsol, 13,pt_135_460,u,y, N_o (pt_135_460) 8y nsol, 14,pt 135 354,u,y, N 8 (pt 135354 ) $8 \mathrm{y}$ nsol, 15, pt_135_260,u,y, N_o (pt_135_260) 豆y $\mathrm{nsol}, 16, \mathrm{pt}^{-} 135^{-} 123, \mathrm{u}, \mathrm{y}, \mathrm{N}^{-} \mathrm{o}\left(\mathrm{pt}^{-} 135^{-} 123\right)$ 8y

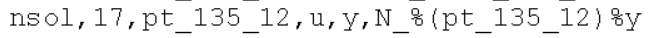

$\mathrm{nsol}, 23, \mathrm{pt} 135460, \mathrm{u}, \mathrm{z}, \mathrm{N}$ \% (pt 135460$) \% \mathrm{z}$ nsol, 24, pt_135_354,u, z, N_o pt_135_354) $8 \mathrm{z}$ $\mathrm{nsol}, 25, \mathrm{pt}^{-} 135^{-} 260, \mathrm{u}, \mathrm{z}, \mathrm{N}^{-} \mathrm{g}\left(\mathrm{pt}^{-} 135^{-} 260\right) \% \mathrm{z}$ $\mathrm{nsol}, 26, \mathrm{pt}^{-} 135^{-} 123, \mathrm{u}, \mathrm{z}, \mathrm{N}^{-} \mathrm{q}\left(\mathrm{pt}^{-} 135^{-} 123\right) \% \mathrm{z}$

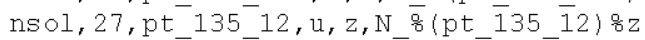

/input,rs_freq, txt

resp, $31,2,3,3,0.033,0.01,100,112.48$ resp, 32,2,4,3,0.033,0.01,100,112.48 resp, 33,2,5,3,0.033,0.01,100,112.48 resp, $34,2,6,3,0.033,0.01,100,112.48$ resp $, 35,2,7,3,0.033,0.01,100,112.48$ resp, 41,2,13,3,0.033,0.01,100,112.48 resp $, 42,2,14,3,0.033,0.01,100,112.48$ resp $, 43,2,15,3,0.033,0.01,100,112.48$ resp, 44,2,16,3,0.033,0.01,100,112.48 resp $, 45,2,17,3,0.033,0.01,100,112.48$ resp $, 51,2,23,3,0.033,0.01,100,112.48$ resp $, 52,2,24,3,0.033,0.01,100,112.48$ resp $, 53,2,25,3,0.033,0.01,100,112.48$ resp, $54,2,26,3,0.033,0.01,100,112.48$ resp, 55,2,27,3,0.033,0.01,100,112.48

prod, 61,31, , rs pt $135460-\mathrm{X}, 1,1 / \mathrm{g}$ prod, 62, 32, , rs_pt_135_354-X, , 1/9 
RPP-RPT-32239, Rev. 1

M\&D-2008-005-CALC-001, Rev. 1

prod, $63,33,1$, rs pt $135260-X_{1}, 1 / 9$ prod, 64,34, , rs_pt_135_123-X, , 1/g prod, 65, 35, , rs_pt_135_12-X, , 1/g prod, 71, 41, , rs_pt_135_460-y, , 1/g prod, 72, 42, , rs_pt_135_354-y, , $1 / 9$ prod, 73,43, , rs_pt 135 260-y, , 1/g prod, 74, 44, , rs_pt_135_123-y, , 1/9 prod, 75,45, , rs pt $135^{-} 12-\mathrm{y}, 1,1 / \mathrm{g}$ prod, 81,51, , rs_pt_135_460-z, , 1/g prod, 82,52, , rs pt $135354-z,, 1 / 9$ prod, 83,53, , rs_pt_135_260-z, , 1/g prod, 84,54, , rs pt $135^{-} 123-z, 1,1 / 9$ prod, 85, 55, , rs_pt_135_12-z, , 1/g

lines, 200

lout, RS-PT-135, out

prvar, $2,61,62,63,64,65$ prvar $, 2,71,72,73,74,75$ prvar $, 2,81,82,83,84,85$ lout

deriv, $91,3,1$, vx3 deriv, $92,4,1$, , vx 4 deriv, $93,5,1$, , vx 5 deriv, $94,6,1$, vx 6 deriv, $95,7,1$, , vx 7

deriv, 101, 13, 1, , vy13 deriv, 102, 14,1, , vy14 deriv, 103,15,1, , vy15 deriv, 104,16,1, , vy16 deriv, 105, 71, 1, , vy17

deriv, $111,23,1$, , vz23 deriv, 112, 24, 1, vz24 deriv, $113,25,1$, , vz25 deriv, $114,26,1$, , vz26 deriv, $115,27,1$, , vz27

deriv, $121,91,1$, a pt $135460-x, 1,1 / \mathrm{g}$ deriv, 122, 92,1, a_pt_135_354-x, , 1/g deriv, $123,93,1$, a pt $135-260-x, 1,1 / 9$ deriv, 124,94,1, a_pt_135_123-x, , 1/g deriv, 125,95,1, a_pt_135_12-x, , 1/g

deriv, 131, 101, 1, a_pt_135_460-y, , 1/g deriv, 132,102,1, a_pt_135_354-y, , 1/g deriv, 133,103,1, a_pt_135_260-y, , 1/g deriv $, 134,104,1$, a pt $135^{-} 123-y, 1 / \mathrm{g}$ deriv, 135,105,1, a_pt_135_12-y, , 1/g

deriv, 141,111,1, a_pt_135_460-z, , 1/g deriv, $142,112,1$, a pt $135-354-z, 1,1 / \mathrm{g}$ deriv, 143,113,1, a_pt_135_260-z, , 1/g deriv $, 144,114,1$, a_pt $135-123-z, 1,1 / 9$ deriv, 145,115,1, a_pt_135_12-z, , 1/g

lines, 2250

/out, Disp-PT-135, out

prvar $, 3,4,5,6,7$

prvar $, 13,14,15,16,17$

prvar $, 23,24,25,26,27$

lout

/out, Vel-PT-135, out

prvar, $91,92,93,94,95$

prvar, 101, 102,103,104,105

prvar, 111, 112, 113,114, 115

lout 
RPP-RPT-32239, Rev. 1

M\&D-2008-005-CALC-001, Rev. 1

lout, Accel-PT-135, out prvar, 121, 122, 123, 124,125 prvar $, 131,132,133,134,135$ prvar, 141,142,143,144,145 lout

spectra-primary-180.txt

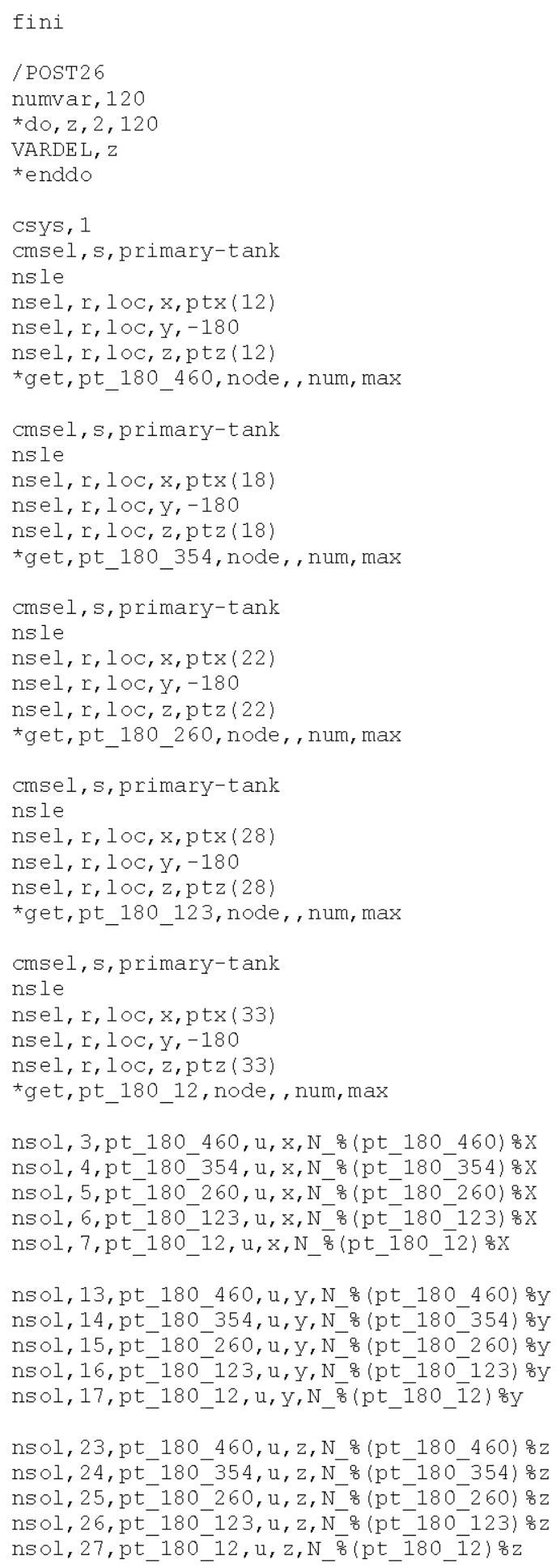


RPP-RPT-32239, Rev. 1

M\&D-2008-005-CALC-001, Rev. 1

/input,rs_freq, txt

resp, 31,2,3,3,0.033,0.01,100,112.48 resp, 32, 2, 4,3,0.033,0.01,100,112.48 resp, 33,2,5,3,0.033,0.01,100,112.48 resp, 34,2,6,3,0.033,0.01,100,112.48 resp, 35,2, 7,3,0.033,0.01,100,112.48 resp, 41,2,13,3,0.033,0.01,100,112.48 resp, 42,2,14,3,0.033,0.01,100,112.48 resp, 43,2,15,3,0.033,0.01,100,112.48 resp, $44,2,16,3,0.033,0.01,100,112.48$ resp $, 45,2,17,3,0.033,0.01,100,112.48$ resp $, 51,2,23,3,0.033,0.01,100,112.48$ resp, $52,2,24,3,0.033,0.01,100,112.48$ resp, $53,2,25,3,0.033,0.01,100,112.48$ resp, 54,2,26,3,0.033,0.01,100,112.48 resp, 55,2,27,3,0.033,0.01,100,112.48

prod, 61,31, , rs_pt_180_460-X, , $1 / 9$ prod, 62, 32, , rs pt $180354-\mathrm{X}, 1,1 / \mathrm{g}$ prod, 63, 33, , rs pt $180^{-} 260-x_{1}, 1 / 9$ prod, $64,34,1, \mathrm{rs}^{-} \mathrm{pt}^{-} 180^{-} 123-\mathrm{X}, 1,1 / \mathrm{g}$ prod, 65, 35, , rs_pt $180^{-} 12-\mathrm{X}, 1,1 / \mathrm{g}$ prod, 71,41, , rs_pt_180_460-y,, $1 / \mathrm{g}$ prod, 72, 42, , rs pt $180354-\mathrm{y},, 1 / \mathrm{g}$ prod, 73,43, , rs pt_180_260-y, , 1/g prod, $74,44,$, rs pt $180-123-\mathrm{y}, 1,1 / \mathrm{g}$ prod, 75,45, , rs_pt_180_12-y, , 1/g prod, $81,51,$, rs pt $180^{-} 460-z, 1,1 / 9$ prod, 82,52, , rs_pt_180_354-z, , $1 /$ g prod, $83,53,1$, rs pt $^{-} 180^{-} 260-2,1,1 / \mathrm{g}$ prod, 84,54, , rs_pt_180_123-z, , 1/g prod, 85,55, , rs_pt_180_12-z, , 1/g

lines, 200

lout, RS-PT-180, out prvar $, 2,61,62,63,64,65$ prvar, $2,71,72,73,74,75$ prvar $, 2,81,82,83,84,85$ lout

deriv, $91,3,1$, , vx3 deriv, $92,4,1$, , vx4 deriv, $93,5,1$, , vx 5 deriv $, 94,6,1$, vx 6 deriv, 95, 7, 1, , vx 7

deriv, 101, 13,1, , vy13 deriv, 102,14,1, ,vy14 deriv, 103,15,1, vy15 deriv, 104,16,1, , vy16 deriv, 105, 71, 1, , vy17

deriv, $111,23,1$, , vz23

deriv, $112,24,1$, vz24

deriv, $113,25,1$, , vz25

deriv, $114,26,1$, , vz26

deriv, 115,27,1, vz27

deriv, 121,91,1, a_pt_180_460-x, , 1/g deriv, 122,92,1, a pt $180^{-} 354-x_{1}, 1 / 9$ deriv, 123,93,1, a_pt_180_260-x, , 1/g deriv, $124,94,1$, a_pt $180-123-x, 1,1 / 9$ deriv, 125,95,1, a_pt_180_12-x, , 1/g

deriv, 131,101,1, a_pt_180_460-y, , 1/g deriv, 132,102,1, a_pt_180_354-y, , 1/g deriv, 133,103,1, a pt $180-260-y_{1}, 11 / 9$ deriv $, 134,104,1$, a_pt_180_123-y, , 1/9 
RPP-RPT-32239, Rev. 1

M\&D-2008-005-CALC-001, Rev. 1

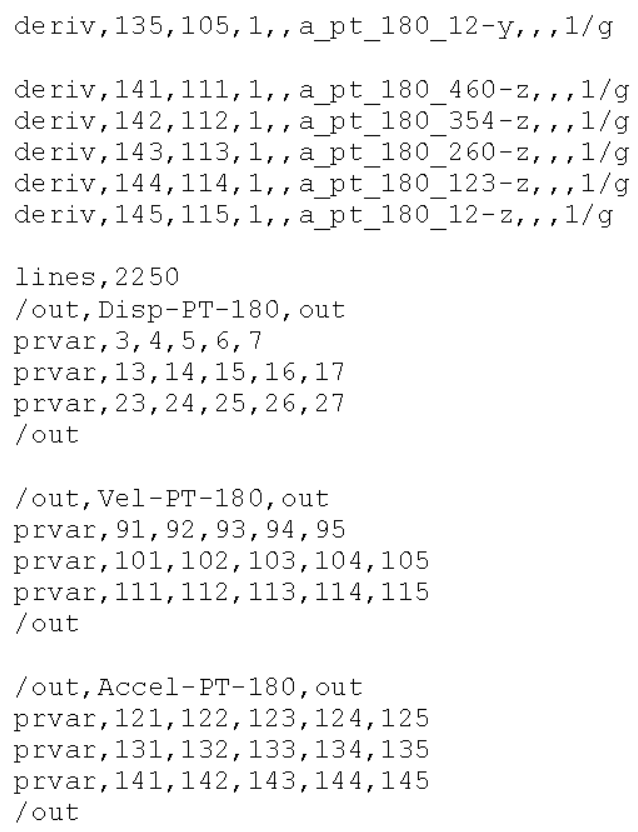

spectra-primary-45.txt

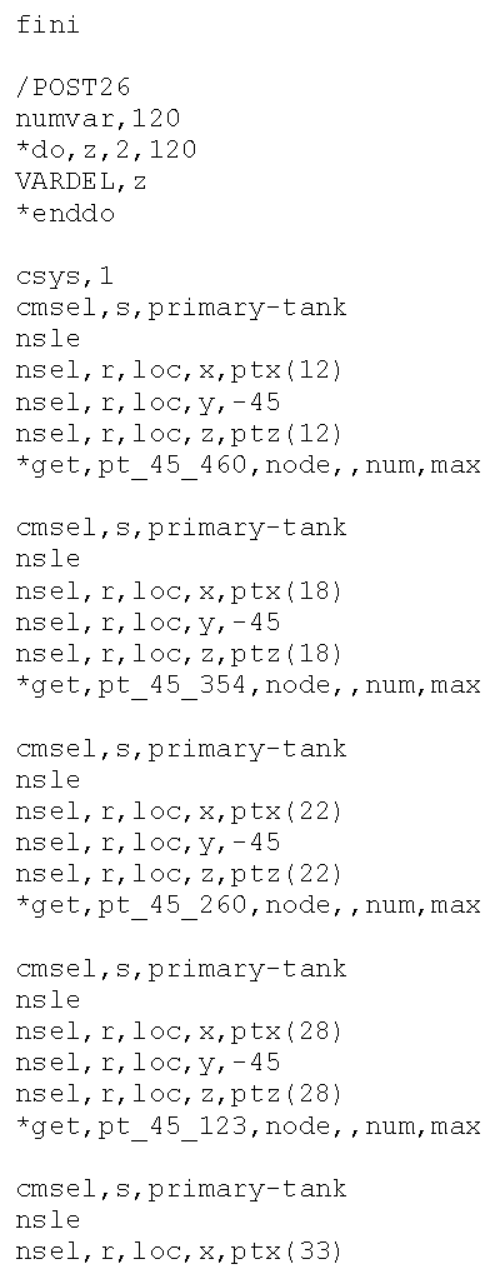




\section{RPP-RPT-32239, Rev. 1 \\ M\&D-2008-005-CALC-001, Rev. 1}

nsel, $r, 100, y,-45$

nsel, r, loc, z,ptz (33)

${ }^{*}$ get, pt_45_12, node, num, max

$\mathrm{nsol}, 3, \mathrm{pt}$ 45_460, u, x, N_o (pt_45_460) $8 \mathrm{x}$ $\mathrm{nsol}, 4, \mathrm{pt}^{-} 45^{-} 354, \mathrm{u}, \mathrm{x}, \mathrm{N}^{-} 8\left(\mathrm{pt}^{-} 45^{-} 354\right) \% \mathrm{x}$ $\mathrm{nsol}, 5, \mathrm{pt}^{-} 45^{-} 260, \mathrm{u}, \mathrm{x}, \mathrm{N}_{-}^{-} 8\left(\mathrm{pt}_{-}^{-} 45_{-}^{-} 260\right) 8 \mathrm{x}$ $\mathrm{nsol}, 6, \mathrm{pt} 45^{-} 123, \mathrm{u}, \mathrm{x}, \mathrm{N}^{-} \mathrm{o}\left(\mathrm{pt}^{-} 45^{-} 123\right) \% \mathrm{x}$

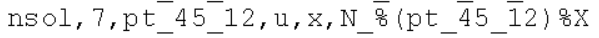

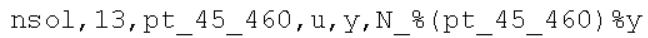
$\mathrm{nsol}, 14, \mathrm{pt}^{-} 45^{-} 354, \mathrm{u}, \mathrm{y}, \mathrm{N}^{-} \mathrm{8}\left(\mathrm{pt}^{-} 45^{-} 354\right)$ 8y $\mathrm{nsol}, 15, \mathrm{pt}^{-} 45^{-} 260, \mathrm{u}, \mathrm{y}, \mathrm{N}^{-} \mathrm{g}\left(\mathrm{pt}^{-} 45^{-} 260\right)$ 8y $\mathrm{nsol}, 16, \mathrm{pt}_{-}^{-} 5^{-} 123, \mathrm{u}, \mathrm{Y}, \mathrm{N}^{-} \mathrm{8}\left(\mathrm{pt}^{-} 45^{-} 123\right)$ 8y

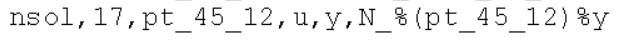

nsol, 23, pt $45460, u, z, N$ \% (pt 45460 ) $8 z$ $\mathrm{nsol}, 24, \mathrm{pt}_{-}^{-} 45_{-} 354, \mathrm{u}, \mathrm{z}, \mathrm{N}_{-}^{-} \mathrm{o}\left(\mathrm{pt}_{-}^{-} 45^{-} 354\right) \% \mathrm{z}$ nsol, 25, pt $45^{-} 260, u, z, N^{-}$( pt $\left.{ }^{-} 45^{-} 260\right) \% z$ nsol, 26, pt_45_123,u, z, N-8 (pt $\left.45^{-} 123\right): \mathrm{z}$ $\mathrm{nsol}, 27, \mathrm{pt}{ }_{-} 45_{-}{ }^{-} 12, \mathrm{u}, \mathrm{z}, \mathrm{N}_{-} \overline{\mathrm{g}}\left(\mathrm{pt} \mathrm{p}_{-} 5_{-} \overline{1} 2\right) \mathrm{g} \mathrm{z}$

/input,rs_freq, txt

resp, 31,2,3,3,0.033,0.01,100,112.48 resp, 32, 2, 4, 3, 0.033,0.01,100,112.48 resp, 33,2,5,3,0.033,0.01,100,112.48 resp, 34, 2,6,3,0.033,0.01,100,112.48 resp, $35,2,7,3,0.033,0.01,100,112.48$ resp, $41,2,13,3,0.033,0.01,100,112.48$ resp, 42,2,14,3,0.033,0.01,100,112.48 resp, 43,2,15,3,0.033,0.01,100,112.48 resp $, 44,2,16,3,0.033,0.01,100,112.48$ resp $, 45,2,17,3,0.033,0.01,100,112.48$ resp, $51,2,23,3,0.033,0.01,100,112.48$ resp $, 52,2,24,3,0.033,0.01,100,112.48$ resp $, 53,2,25,3,0.033,0.01,100,112.48$ resp $, 54,2,26,3,0.033,0.01,100,112.48$ resp $, 55,2,27,3,0.033,0.01,100,112.48$

prod, $61,31, \ldots$, rs pt $45460-x, 1,1 / g$ prod, 62, 32, , rs_pt_45_354-X, , 1/g prod, $63,33,1, r s p t-45^{-} 260-\mathrm{X}, 1,1 / \mathrm{g}$ prod, 64,34, ,rs_pt_45_123-X, , 1/g prod, 65, 35, , rs_pt_45_12-X, , 1/g prod, 71,41, , rs_pt_45_460-y, , 1/g prod, 72,42, ,rs_pt_45_354-y, , , 1/g prod, 73,43, , rs_pt_45_260-y, , 1/g prod, 74,44, , rs_pt_45_123-y, , 1/g prod, 75, 45, , rs pt $4512-\mathrm{y}, 1,1 / \mathrm{g}$ prod, 81, 51, , rs_pt_45_460-z, , 1/g prod, 82,52, , rs pt $45-354-z, 1,1 / 9$ prod, 83,53, ,rs_pt_45_260-z, , , 1/g prod, 84,54, , rs pt $45^{-} 123-z, 1,1 / 9$ prod, 85,55, ,rs_pt_45_12-z, , 1/g

lines, 200

/out, RS-PT-45, out prvar, $2,61,62,63,64,65$ prvar, $2,71,72,73,74,75$ prvar $, 2,81,82,83,84,85$ cout

deriv, $91,3,1$, , vx3

deriv, $92,4,1$, vx 4

deriv, $93,5,1$, , vx 5

deriv, $94,6,1$, vx 6

deriv, $95,7,1$, , vx 7

deriv, 101, 13, 1, , vy13 
RPP-RPT-32239, Rev. 1

M\&D-2008-005-CALC-001, Rev. 1

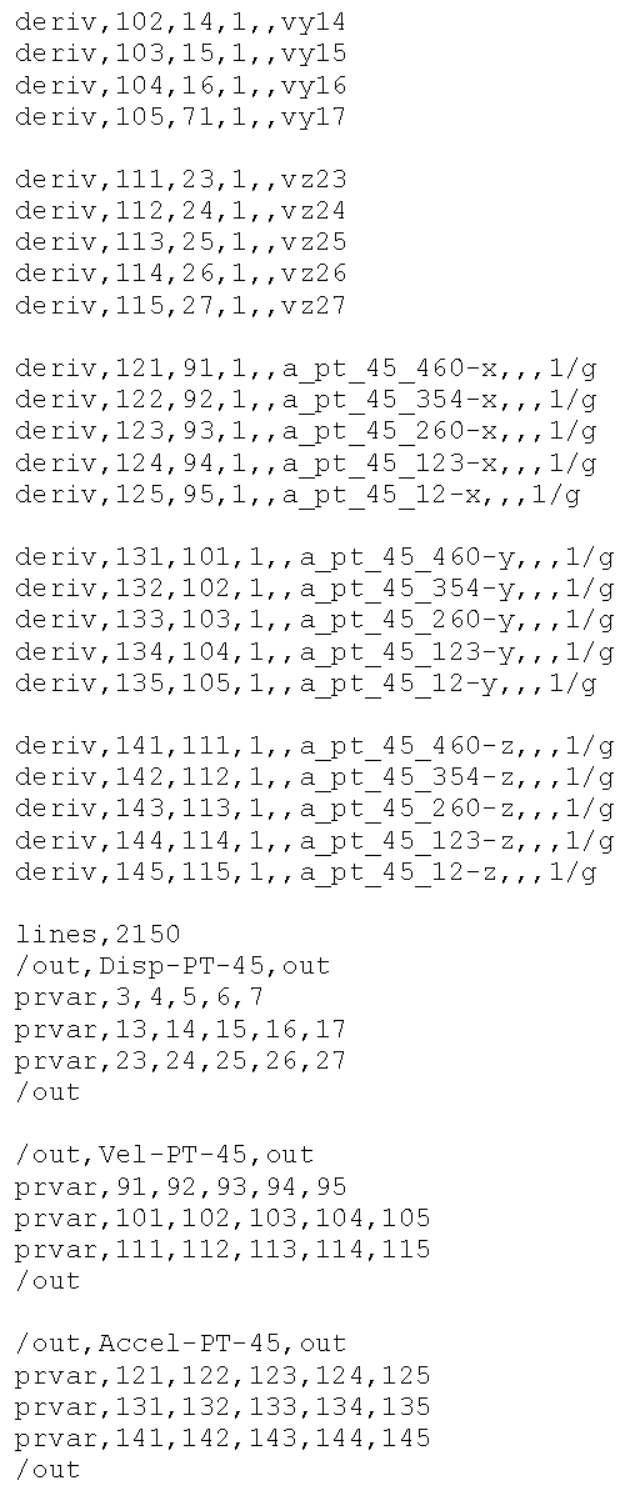

spectra-primary-90.txt

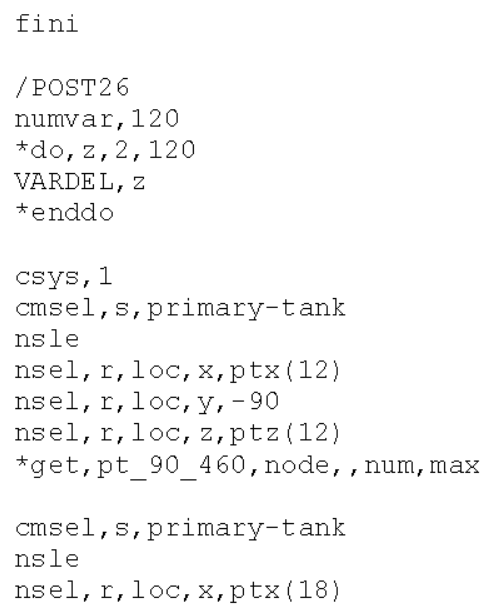




\section{RPP-RPT-32239, Rev. 1 \\ M\&D-2008-005-CALC-001, Rev. 1}

nsel, $r, 1 \circ c, y,-90$

nsel, r, loc, z, ptz (18)

*get, pt_90_354, node, , num, max

cmsel, s, primary-tank

nsle

nsel, r, loc, $x, p t x(22)$

nsel, r, loc, y, -90

nsel, r, loc, z, ptz (22)

*get, pt 90_260, node, , num, max

cmsel,s,primary-tank

nsle

nsel, $r, 1 \circ c, x, p t x(28)$

nsel, $r, 100, y,-90$

nsel, r, loc, z, ptz (28)

${ }^{*}$ get, pt_90_123, node, , num, max

cmsel, s, primary-tank

nsle

nsel, r, loc, $x, p t x(33)$

nsel, $r, 100, y,-90$

nsel, r, loc, z, ptz (33)

*get, pt_90_12, node, , num, max

nsol, 3,pt $90460, u, x, N$ \& (pt 90460$) 8 x$ nsol, 4, pt_90_354, u, x, N-8 (pt_90_354) $8 x$ $\mathrm{nsol}, 5, \mathrm{pt}^{-} 90^{-} 260, \mathrm{u}, \mathrm{x}, \mathrm{N}^{-} \mathrm{g}\left(\mathrm{pt}^{-} 90^{-} 260\right) \% \mathrm{x}$

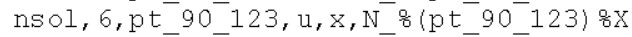
$\mathrm{ns} 01,7, \mathrm{pt}_{-} 90_{-} 12, \mathrm{u}, \mathrm{x}_{1} \mathrm{~N}_{-} \overline{\mathrm{g}}\left(\mathrm{pt} \mathrm{pt}_{-} \mathrm{g} \overline{1}_{-}\right) \mathrm{gx}$

$\mathrm{ns} 01,13, \mathrm{pt} 990 \_460, \mathrm{u}, \mathrm{y}, \mathrm{N} \_\mathrm{8}$ (pt_90_460) $8 \mathrm{y}$ nsol, 14, pt_90_354,u,y, N_o (pt-90_354) $8 \mathrm{y}$ nsol, 15, pt_90_260, u,y, N-8 (pt_90_260) $8 \mathrm{y}$ $\mathrm{nsol}, 16, \mathrm{pt}^{-} 90^{-} 123, \mathrm{u}, \mathrm{y}^{-} \mathrm{N}^{-} \mathrm{o}\left(\mathrm{pt}^{-} 90^{-} 123\right) 8 \mathrm{y}$ $\mathrm{nsol}, 17, \mathrm{pt}_{-}^{-} 90_{-}^{-} 12, \mathrm{u}, \mathrm{y}, \mathrm{N}_{-} \overline{\mathrm{g}}\left(\mathrm{pt} \mathrm{pt}_{-} \mathrm{g}_{-} \overline{1} 2\right) 8 \mathrm{y}$

nsol, 23,pt_90_460,u, z,N_8 (pt_90_460) $8 \mathrm{z}$ nsol, $24, \mathrm{pt}^{-} 90^{-} 354, \mathrm{u}, \mathrm{z}, \mathrm{N}^{-} \mathrm{o}\left(\mathrm{pt}^{-} 90^{-} 354\right) \% \mathrm{z}$ nsol, 25, pt_90_260,u, z, N_o (pt-90_260) $8 z$ nsol, 26, pt $90^{-} 123, \mathrm{u}, \mathrm{z}, \mathrm{N}^{-} \mathrm{8}\left(\mathrm{pt} 90^{-} 123\right) \% \mathrm{z}$ $\mathrm{nsol}, 27, \mathrm{pt}_{-} 9 \mathrm{~g}_{-} 12, \mathrm{u}, \mathrm{z}, \mathrm{N}_{-} \overline{\mathrm{g}}\left(\mathrm{pt} \mathrm{pt}_{-} \mathrm{g}_{-} \overline{1} 2\right) \mathrm{gz}$

/input,rs_freq, txt

resp, 31,2,3,3,0.033,0.01,100,112.48 resp $, 32,2,4,3,0.033,0.01,100,112.48$ resp, 33, 2, 5,3,0.033,0.01,100,112.48 resp, $34,2,6,3,0.033,0.01,100,112.48$ resp, 35,2,7,3,0.033,0.01,100,112.48 resp, 41,2,13,3,0.033,0.01,100,112.48 resp $, 42,2,14,3,0.033,0.01,100,112.48$ resp $, 43,2,15,3,0.033,0.01,100,112.48$ resp $, 44,2,16,3,0.033,0.01,100,112.48$ resp, $45,2,17,3,0.033,0.01,100,112.48$ resp $, 51,2,23,3,0.033,0.01,100,112.48$ resp, $52,2,24,3,0.033,0.01,100,112.48$ resp $, 53,2,25,3,0.033,0.01,100,112.48$ resp $, 54,2,26,3,0.033,0.01,100,112.48$ resp, $55,2,27,3,0.033,0.01,100,112.48$

prod, 61, 31, , rs_pt_90_460-X, , $1 / \mathrm{g}$ prod, $62,32, \ldots$, rs pt $90-354-x_{1}, 1 / 9$ prod, 63,33, , rs_pt_90_260-X, , 1/g prod, 64, 34, , rs_pt_90-123-X, , 1/9 prod, $65,35,1$, rs_pt $90^{-} 12-\mathrm{X}, 1,1 / \mathrm{g}$ prod, $71,41,1$, rs_pt_90_460-y,, $1 / \mathrm{g}$ prod, 72,42, , rs_pt_90_354-y, , 1/g prod, $73,43, \ldots$, rs_pt_90_260-y, , 1/g prod, 74, 44, , rs pt $90^{-} 123-y_{1}, 1 / 9$ prod, $75,45, \ldots, r s \_p t+90 \_12-y, \cdots 1 / 9$ 
RPP-RPT-32239, Rev. 1

M\&D-2008-005-CALC-001, Rev. 1

prod, $81,51,$, rs_pt_90 $460-z,, 1 / 9$ prod, 82, 52, ,rs_pt_90_354-z, , 1/g prod, 83,53, , rs pt $90^{-} 260-z, 1,1 / \mathrm{g}$ prod, 84,54, , rs_pt_90_123-z, , 1/g prod, 85, 55, , rs_pt_90_12-z,, $1 / \mathrm{g}$

lines, 200

/ out, RS-PT-90, out

prvar, $2,61,62,63,64,65$

prvar $, 2,71,72,73,74,75$

prvar $, 2,81,82,83,84,85$

lout

deriv, $91,3,1$, vx3

deriv, $92,4,1$, , vx 4

deriv, $93,5,1$, , vx5

deriv, $94,6,1$, , vx 6

deriv $, 95,7,1$, vx 7

deriv, 101, 13,1, , vy13

deriv, 102,14,1, ,vy14

deriv, 103,15,1, ,vy15

deriv, 104,16,1, vy16

deriv $, 105,71,1$, ,vy17

deriv, 111, 23,1, ,vz23

deriv, 112, 24, 1, ,vz24

deriv, 113,25, 1, vz25

deriv, $114,26,1$, , vz26

deriv, 115,27,1, vz27

deriv, 121,91,1, a_pt_90_460-x, , 1/g deriv, 122,92,1, a_pt_90-354-x, $1,1 / 9$ deriv, 123,93,1, a_pt_90_260-x,, $1 / \mathrm{g}$ deriv $, 124,94,1$, a_pt_90_123-x,, $1 / 9$ deriv $, 125,95,1$, a_pt_90_12-x,, $1 / 9$

deriv, 131, 101,1, a_pt_90_460-y, , 1/9 deriv, 132,102,1, a_pt_90_354-y, , 1/g deriv, 133,103,1, a pt $90^{-} 260-\mathrm{y}_{1}, 1 / \mathrm{g}$ deriv, 134,104,1, a_pt_90_123-y, , 1/9 deriv $, 135,105,1$, a_pt_90_12-y, , 1/g

deriv, $141,111,1$, a_pt_90_460-z,, $1 / 9$ deriv $, 142,112,1$, a_pt $90-354-z, 1,1 / 9$ deriv $, 143,113,1$, a_pt_90_260-z, , 1/g deriv, 144,114,1, a_pt_90_123-z, , 1/g deriv, 145,115,1, a_pt_90_12-z, , 1/g

lines, 2250

lout, Disp-PT-90, out

prvar, $3,4,5,6,7$

prvar $, 13,14,15,16,17$

prvar, $23,24,25,26,27$

lout

lout, Vel-PT-90, out

prvar, $91,92,93,94,95$

prvar, 101,102,103,104,105

prvar, 111,112,113,114,115

lout

lout, Accel-PT-90, out

prvar, 121, 122, 123,124, 125

prvar, 131, 132, 133,134,135

prvar, 141,142,143,144,145

lout 


\section{RPP-RPT-32239, Rev. 1 \\ M\&D-2008-005-CALC-001, Rev. 1}

\section{spectra-soil.txt}

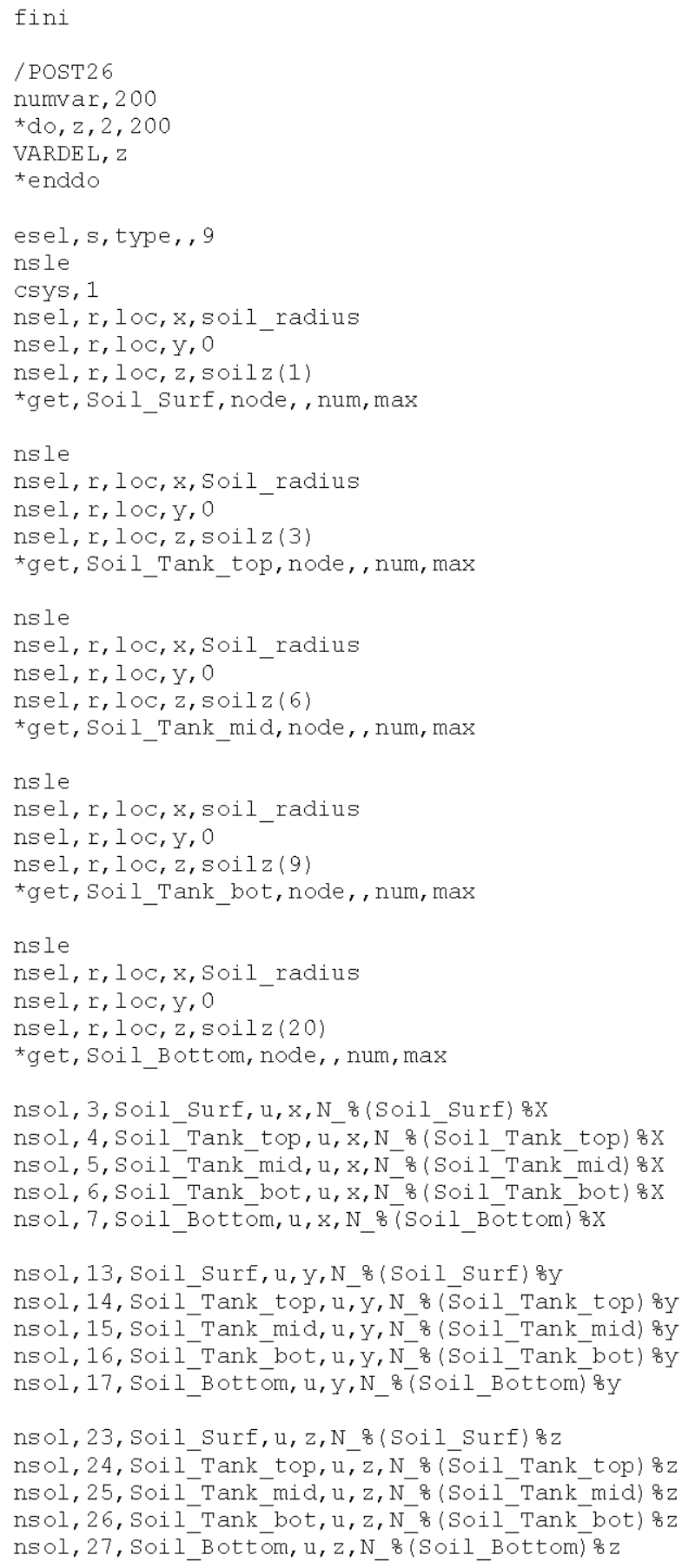


RPP-RPT-32239, Rev. 1

M\&D-2008-005-CALC-001, Rev. 1

resp, 44,2,16,3,0.05,0.01,100,120.48

resp, 45,2,17,3,0.05,0.01,100,120.48

resp, $51,2,23,3,0.05,0.01,100,120.48$

resp, 52,2,24,3,0.05,0.01,100,120.48

resp $, 53,2,25,3,0.05,0.01,100,120.48$

resp, 54,2,26,3,0.05,0.01,100,120.48

resp, $55,2,27,3,0.05,0.01,100,120.48$

prod, 61,31, ,rs_Soil_Surf-X, , 1/g

prod, 62, 32, , rs Soil Tank top-X, , $1 / \mathrm{g}$

prod, 63,33, ,rs_Soil_Tank_mid-X,, $1 / 9$

prod, 64,34,,rs_Soil_Tank_bot-X, , , 1/g

prod, 65,35, ,rs_Soil_Bottom-X, , 1/g

prod, 71,41, , rs_Soil_Surf-y, , 1/g

prod, 72,42,,rs_Soil_Tank_top-y, , 1/g

prod, 73,43, ,rs_Soil_Tank_mid-y, , $1 / 9$

prod, 74,44,,,rs_Soil_Tank_bot-y, , , 1/9

prod, 75, 45, ,rs_Soil_Bottom-y, , 1/g

prod, 81, 51, , rs Soil Surf-z, , 1/g

prod, 82, 52, ,rs_Soil_Tank_top-z, , 1/g

prod, 83,53, ,rs_Soil_Tank_mid-z, , $1 / 9$

prod, 84,54,,rs_Soil_Tank_bot-z, , 1/9

prod, 85, 55, , rs_Soil_Bottom-z,, $1 / 9$

lines, 200

/ out, RS-SOil, out

prvar, $2,61,62,63,64,65$

prvar $, 2,71,72,73,74,75$

prvar $, 2,81,82,83,84,85$

lout

deriv, $91,3,1$, , vx3

deriv, $92,4,1$, vx 4

deriv, $93,5,1$, , vx5

deriv, $94,6,1$, , vx 6

deriv, $95,7,1$, , vx 7

deriv, 101, 13,1, , vy13

deriv, 102,14,1, ,vy14

deriv, 103, 15, 1, , vy15

deriv, 104,16,1, ,vy16

deriv, 105, 71, 1, , vy17

deriv, $111,23,1$, ,vz23

deriv, 112, 24, 1, , vz24

deriv, $113,25,1$, , vz25

deriv, $114,26,1$, , vz26

deriv, 115,27,1, vz27

deriv, 121,91,1, a_Soil_Surf-x, , 1/g

deriv, $122,92,1$, a Soil Tank top-x,, $1 / \mathrm{g}$

deriv, 123,93,1, a_Soil_Tank_mid-x, , 1/g

deriv, 124,94,1, a Soil Tank bot-x,, $1 / 9$

deriv, 125, 95,1, a_Soil_Bottom-x, , 1/g

deriv, 131, 101, 1, a Soil Surf-y, , 1/g

deriv, 132,102,1, a Soil Tank top-y, , 1/g deriv, 133,103,1, a_Soil_Tank_mid-y, , , 1/9 deriv, 134,104,1, a_Soil_Tank_bot-y, , 1/9 deriv, 135,105,1, a_Soil_Bottom-y, , 1/9

deriv, 141,111, 1, a Soil_Surf-z, , 1/9

deriv, 142,112,1, a_Soil_Tank_top-z, , 1/g

deriv, 143,113,1, a_Soil_Tank_mid-z, , $1 / 9$

deriv, 144,114,1, a Soil Tank bot-z, , 1/g

deriv, 145,115,1, a_Soil_Bottom-z, , 1/g

lines, 2150

lout, Disp-Soil, out

prvar, $3,4,5,6,7$ 


\section{RPP-RPT-32239, Rev. 1 \\ M\&D-2008-005-CALC-001, Rev. 1}

prvar $, 13,14,15,16,17$

prvar, $23,24,25,26,27$

lout

lout, vel-Soil, out

prvar, $91,92,93,94,95$

prvar, 101,102,103,104,105

prvar, 111,112,113,114,115

lout

/out,Accel-SOil, out

prvar, $121,122,123,124,125$

prvar, 131, 132, 133,134,135

prvar, 141,142,143,144,145

lout

\section{strain-backed-principle-bot.txt}

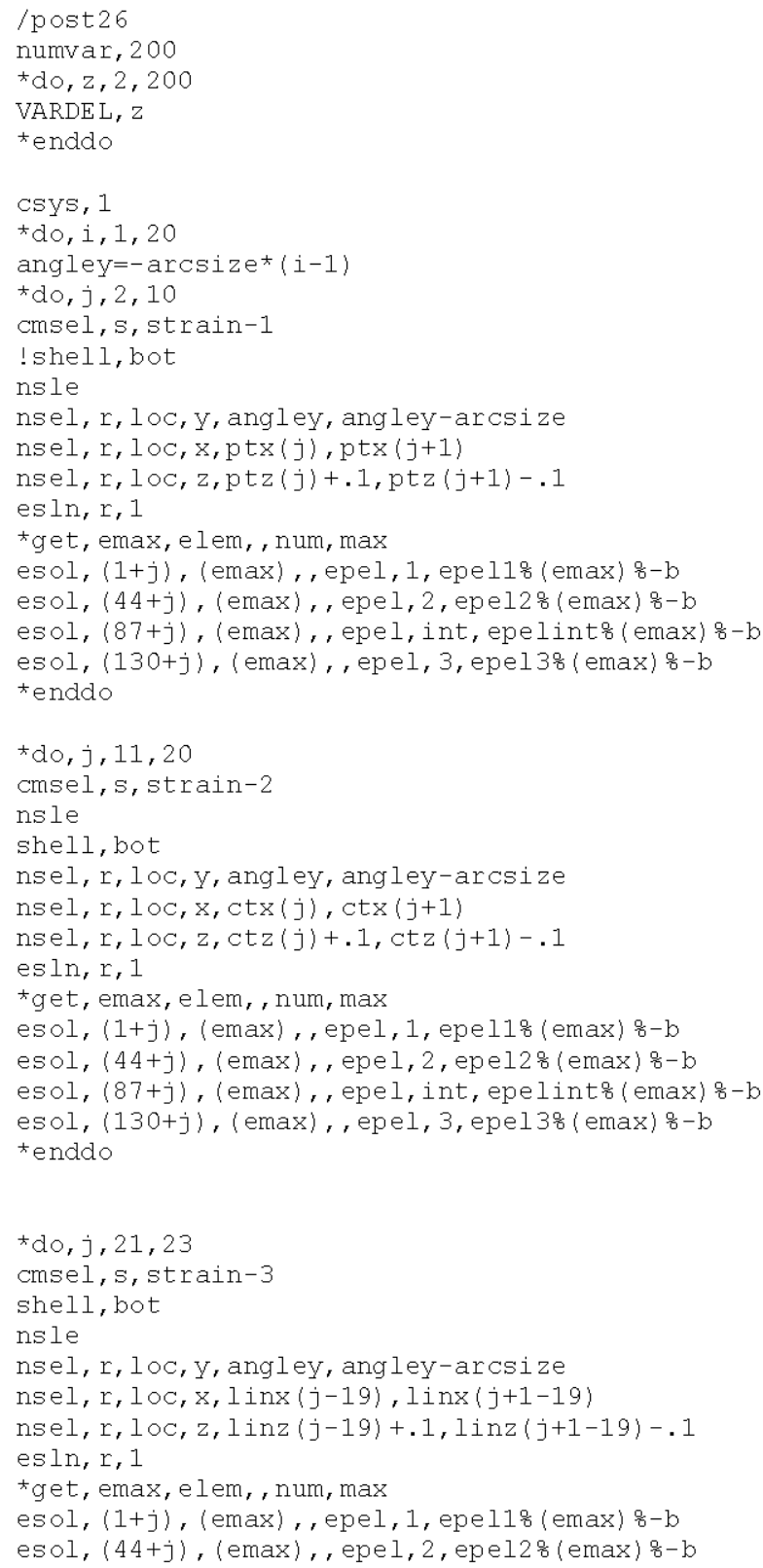


RPP-RPT-32239, Rev. 1

M\&D-2008-005-CALC-001, Rev. 1

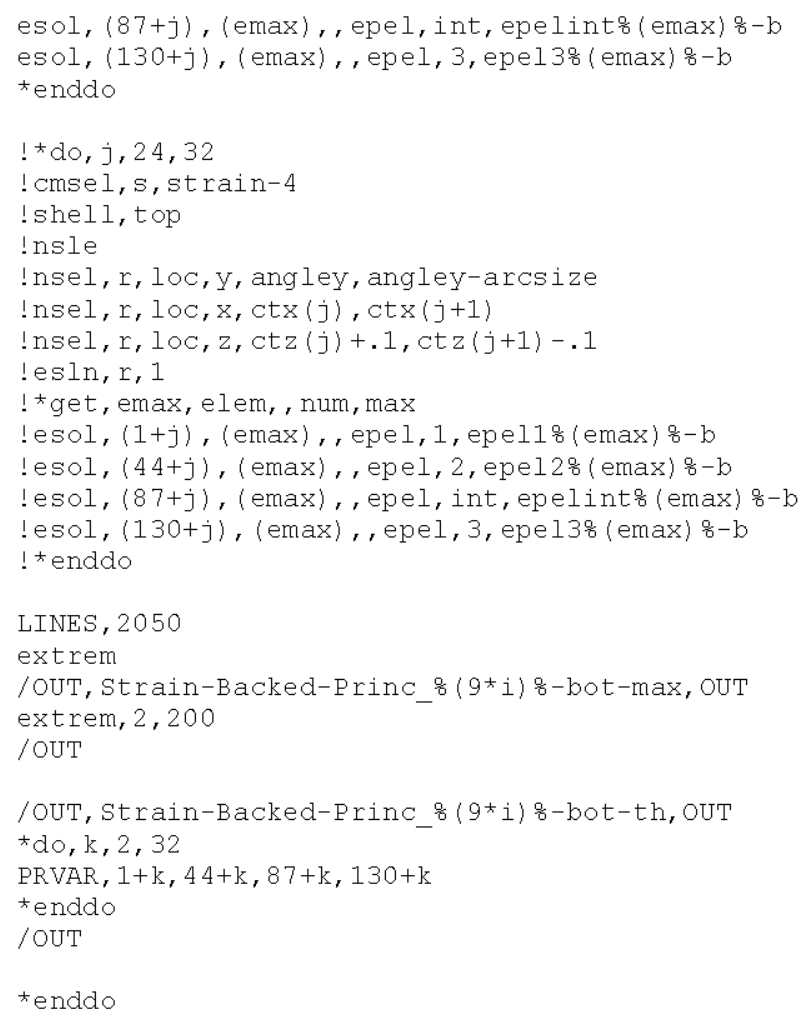

\section{strain-backed-principle-mid.txt}

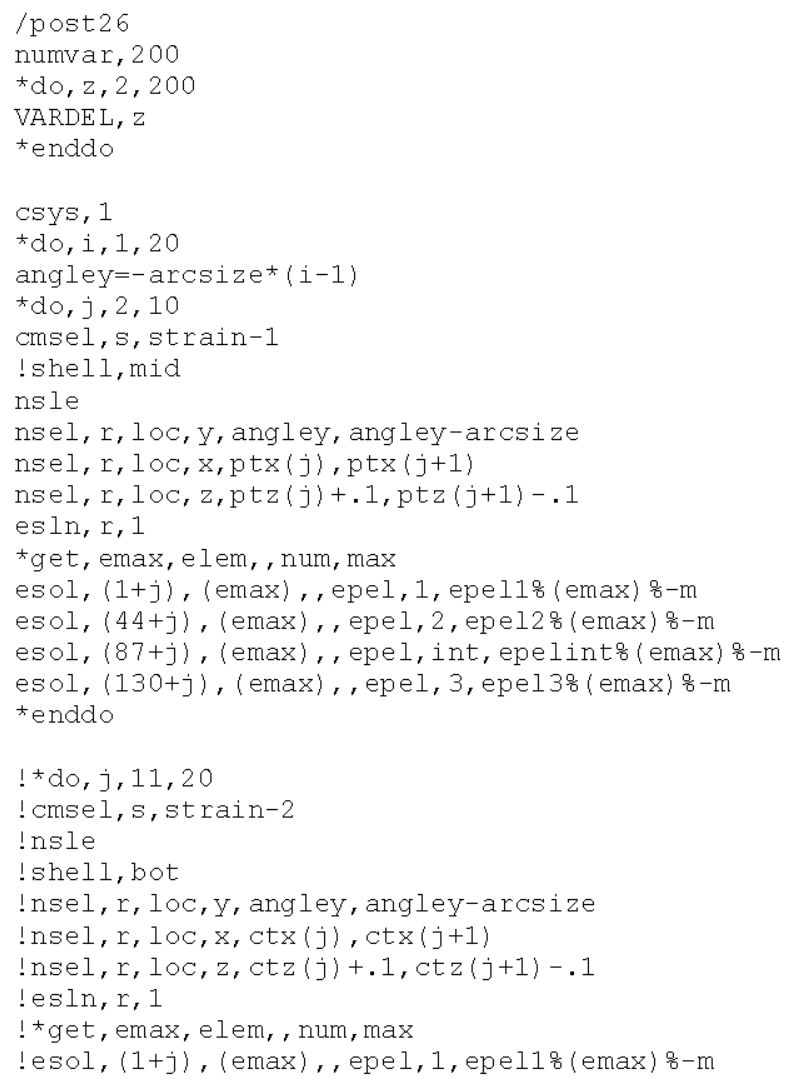


RPP-RPT-32239, Rev. 1

M\&D-2008-005-CALC-001, Rev. 1

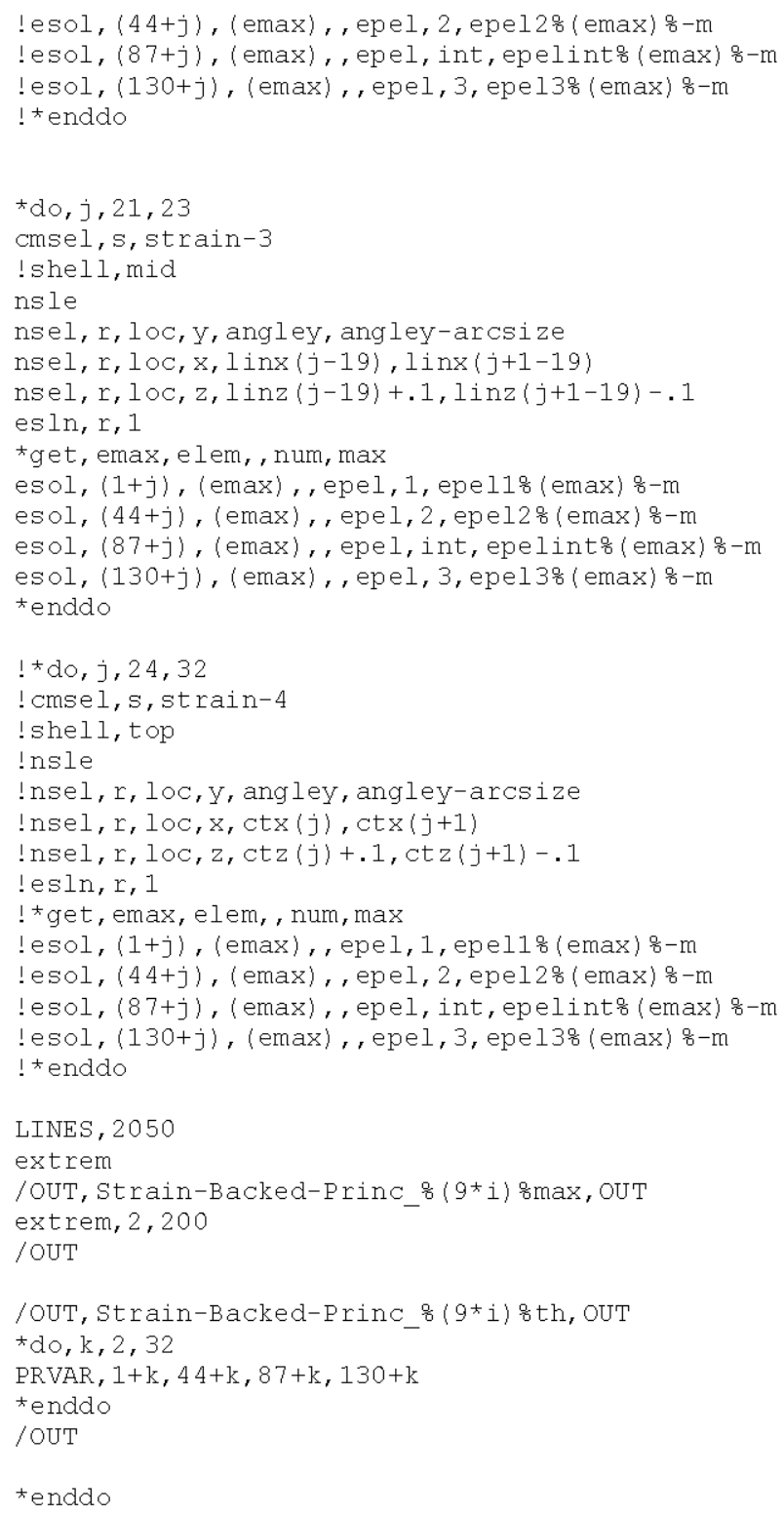

\section{strain-backed-principle-top.txt}

$/$ post 26

numvar, 200

tdo, $z, 2,200$

VARDEL, $z$

tenddo

Csys, 1

*do, $i, 1,20$

angley=-arcsize* $(i-1)$

$\star \mathrm{do}, \mathrm{j}, 2,10$

cmsel, s, strain-1

!shell, top

nsle

nsel, r, loc, y, angley, angley-arcsize

nsel, $r, l \circ c, x, p t x(j), \operatorname{ptx}(j+1)$

nsel, r, loc, z,ptz $(j)+.1, p t z(j+1)-.1$

esln, r, 1 
RPP-RPT-32239, Rev. 1

M\&D-2008-005-CALC-001, Rev. 1

*get, emax, elem, num, max

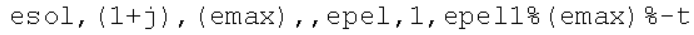

esol, $(44+j),($ emax), , epel, 2 , epel2 8 (emax) $8-t$

esol, $(87+j),($ emax), , epel, int, epelinto (emax) $8-t$

esol, $(130+j),($ emax), , epel, 3 , epel $3 \%$ (emax) $8-t$

*enddo

!*do, j, 11,20

! cmsel, s, strain-2

!nsle

! shell, bot

!nsel, r, loc, y, angley, angley-arcsize

!nsel, r, loc, $x, \operatorname{ctx}(j), \operatorname{ctx}(j+1)$

!nsel, r, loc, $z, \operatorname{ctz}(j)+.1, \operatorname{ctz}(j+1)-.1$

! esln, r, 1

! *get, emax, elem, num, max

!esol, (1+j), (emax), , epel, 1, epel18 (emax) $8-t$

!esol, $(44+j),($ emax), , epel, 2 , epel2 2 (emax) $8-t$

!esol, $(87+j),($ emax), , epel, int, epelinto (emax) 8 -t

! esol, $(130+j),($ emax), , epel, 3 , epel3 (emax) 8 -t

! * enddo

$\star d o, j, 21,23$

cmsel, s, strain-3

!shell, top

nsle

nsel, r, loc, y, angley, angley-arcsize

nsel, r, loc, x, linx $(j-19), \operatorname{linx}(j+1-19)$

nsel, r, loc, $z, \operatorname{linz}(j-19)+.1, \operatorname{linz}(j+1-19)-.1$

esln, r, 1

*get, emax, elem, num, max

esol, $(1+j),($ emax), , epel, 1, epel18 (emax) $8-t$

esol, $(44+j),($ emax), , epel, 2 , epel2 8 (emax) $8-t$

esol, $(87+j),($ emax), , epel, int, epelints (emax) 8 -t

esol, $(130+j),($ emax), , epel, 3 , epel3\% (emax) $8-t$

tenddo

$\star d o, j, 24,32$

cmsel, s, strain-4

! shell, top

nsle

nsel, r, loc, y, angley, angley-arcsize

nsel, r, loc, $x, \operatorname{ctx}(j), \operatorname{ctx}(j+1)$

nsel, r, loc, $z, \operatorname{ctz}(j)+.1, \operatorname{ctz}(j+1)-.1$

esln, $r, 1$

*get, emax, elem, , num, max

esol, (1+j), (emax), , epel, 1, epel1\% (emax) $8-t$

esol, $(44+j),($ emax), , epel, 2 , epel2 8 (emax) $8-t$

esol, $(87+j),($ emax), , epel, int, epelinto (emax) 8 -t

esol, $(130+j),($ emax), , epel, 3, epel3\% (emax) $8-t$

tenddo

LINES, 2050

extrem

/OUT, Strain-Backed-Princ_号 (9*i) 号-Top-max, OUT

extrem, 2,200

/OUT

/OUT, Strain-Backed-Princ_o(9*i) 8 -Top-th, OUT

*do, $\mathrm{k}, 2,32$

PRVAR, 1+k, 44+k, $87+k, 130+k$

tenddo

/OUT

tenddo

\section{strain-backed-principle.txt}




\section{RPP-RPT-32239, Rev. 1 \\ M\&D-2008-005-CALC-001, Rev. 1}

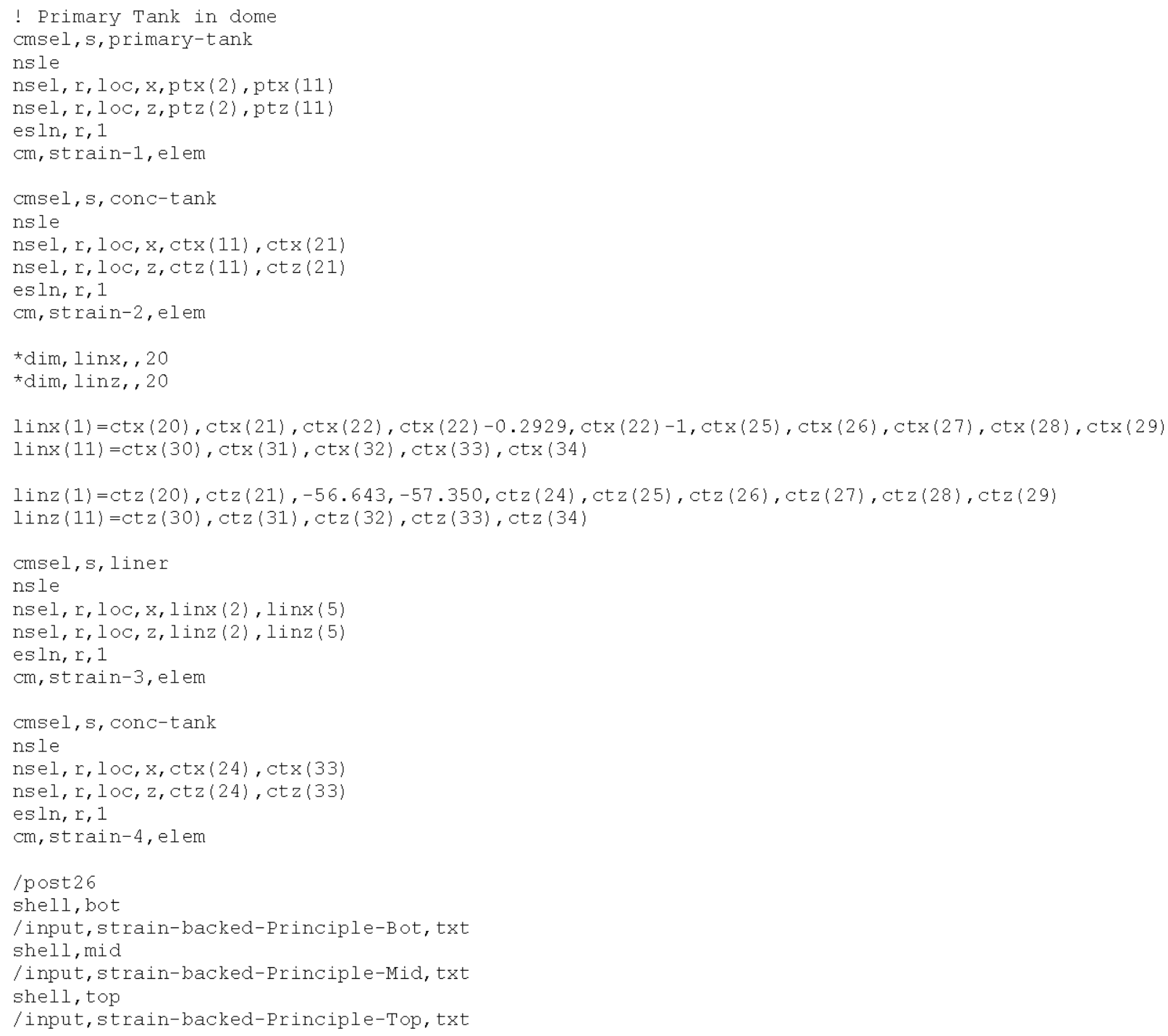

stress-compb.txt

/post26

$*$ do, $z, 2,200$

VARDE L, $z$

*enddo

csys, 1

$\star$ do, $i, 1,20$

angley $=-\operatorname{arcsize} e^{*}(i-1)$

$\star d o, j, 2,42$

cmsel, s, primary-tank

nsle

nsel, $r, l o c, y$, angley, angley-arcsize

nsel, r, loc, $x, p t x(j), p t x(j+1)$

nsel, r, loc, $z, p t z(j)+.1, p t z(j+1)-.1$

esln, $r, 1$

*get, emax, elem, num, max

esol, $(1+j),(\operatorname{emax}),, 5, x, 5 x$ o (emax) $\frac{0}{8}-b$

esol, $(44+j),\left(\right.$ emax), , s,y, syo (emax) $\frac{\circ}{b}-b$

esol, $(87+j),($ emax), , s, int, sinto (emax) $8-b$

esol, $(130+j),(\operatorname{emax}),, 5, x y$, sxy 8 (emax) $8-b$

*enddo 
RPP-RPT-32239, Rev. 1

M\&D-2008-005-CALC-001, Rev. 1

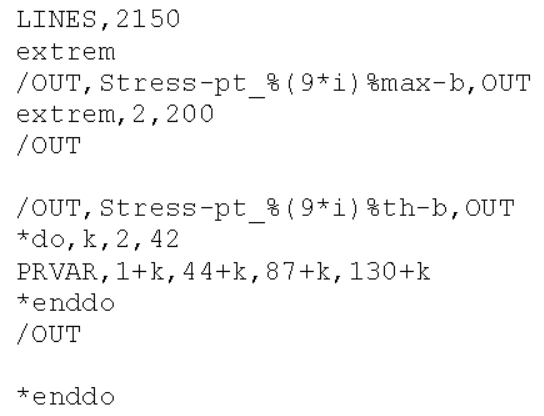

\section{stress-compm.txt}

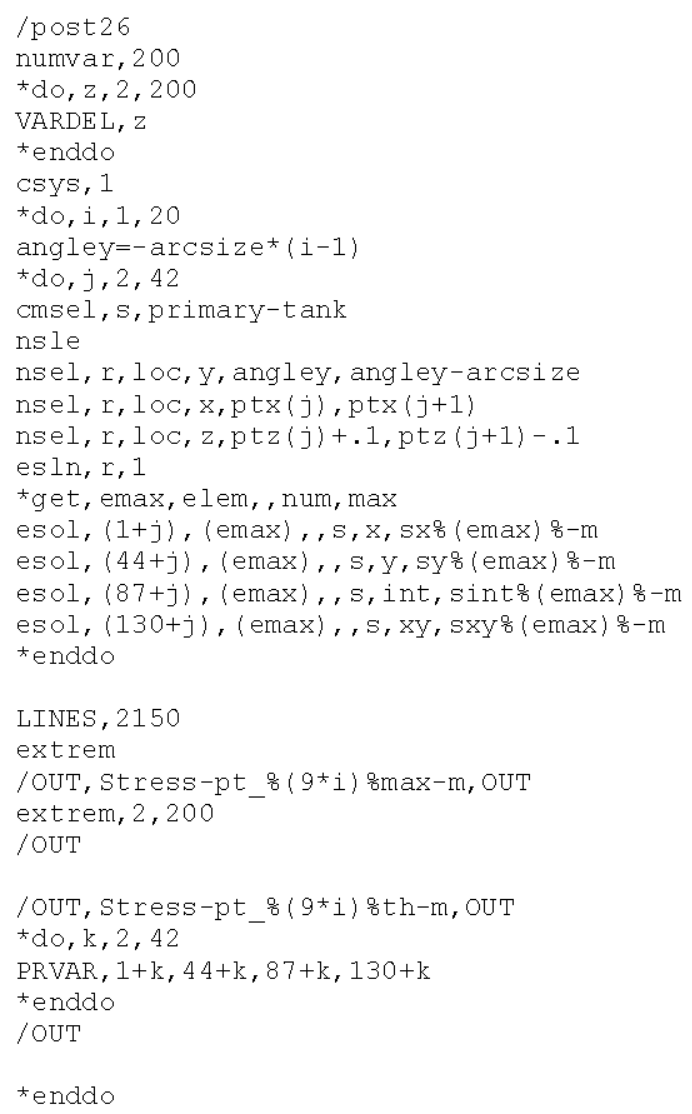

\section{stress-compt.txt}

/post26

$\star$ do, $z, 2,200$

VARDE L, $z$

tenddo

csys, 1

${ }^{*} \mathrm{do}, \mathrm{i}, 1,20$

angley $=-\operatorname{arcsize}(i-1)$

$\star \mathrm{do}, j, 2,42$

cmsel, s, primary-tank

nsle

nsel, r, loc, $y$, angley, ang ley-arcsize

nsel, $r, l \circ c, x, p t x(j), p t x(j+1)$ 
RPP-RPT-32239, Rev. 1

M\&D-2008-005-CALC-001, Rev. 1

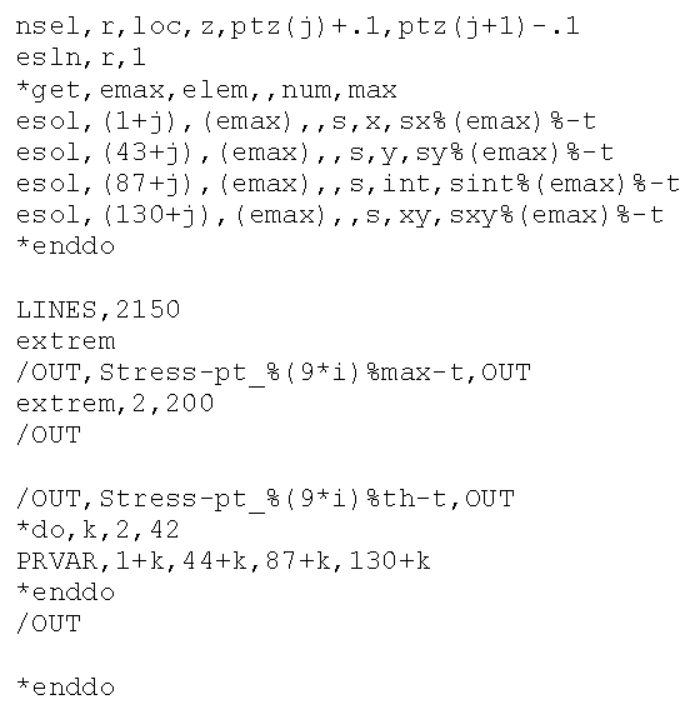

\section{Stress-Primary.txt}

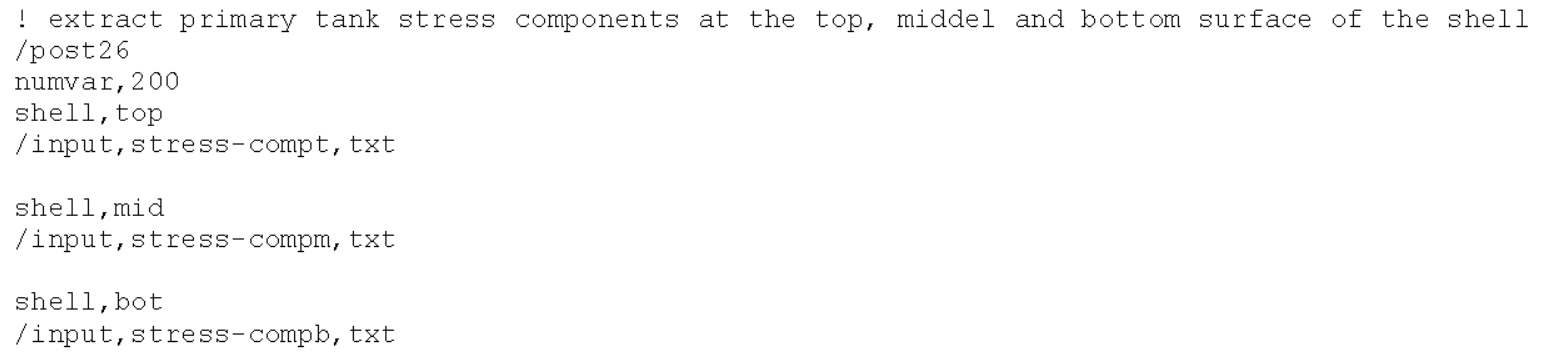

\section{Tank-Coordinates-AP.txt}

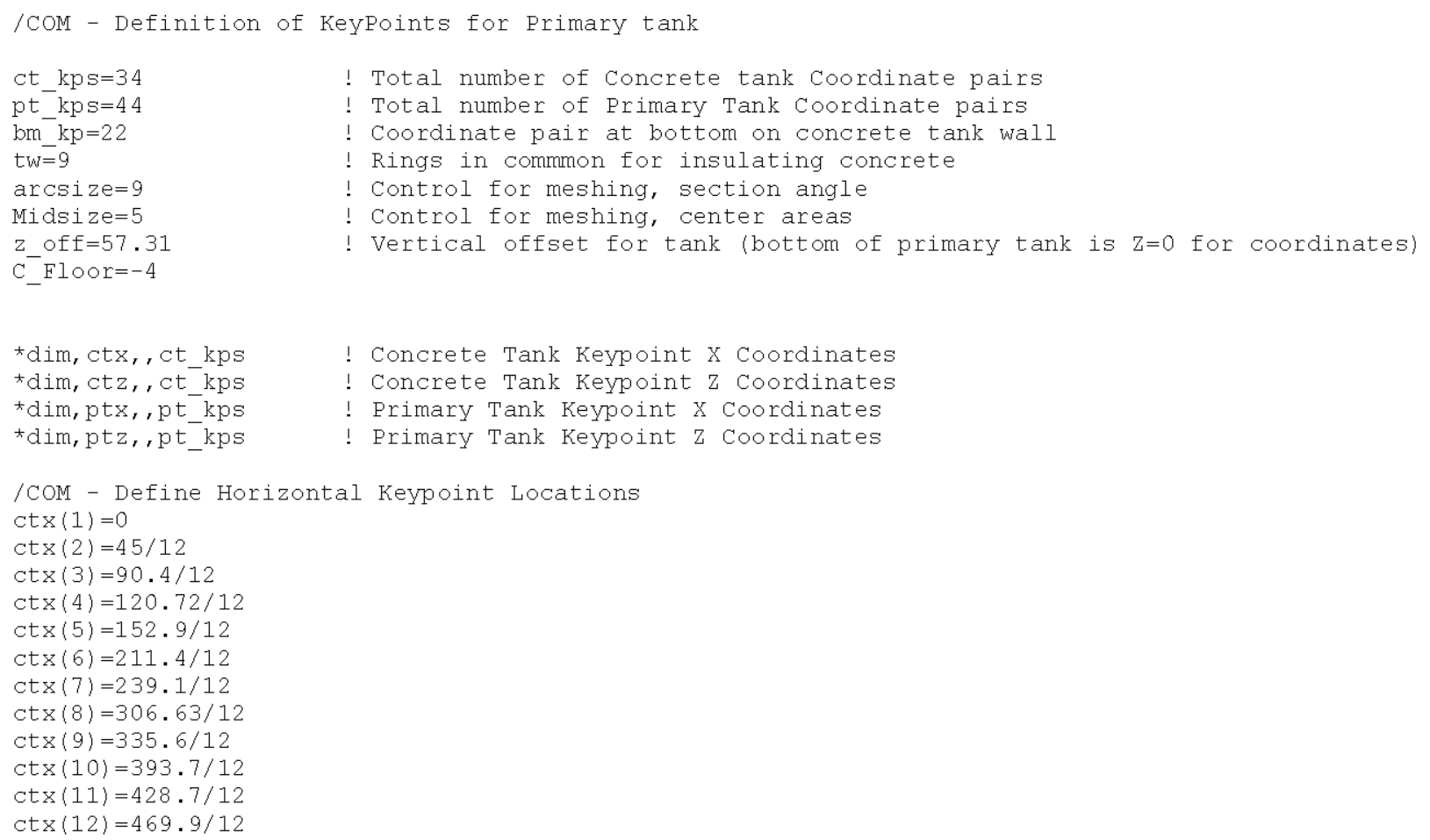


RPP-RPT-32239, Rev. 1

M\&D-2008-005-CALC-001, Rev. 1

$\operatorname{ctx}(13)=486.9 / 12$

$\operatorname{ctx}(14)=489 / 12$

$\operatorname{ctx}(15)=489 / 12$

$\operatorname{ctx}(16)=489 / 12$

$\operatorname{ctx}(17)=489 / 12$

$\operatorname{ctx}(18)=489 / 12$

$\operatorname{ctx}(19)=489 / 12$

$\operatorname{ctx}(20)=489 / 12$

$\operatorname{ctx}(21)=489 / 12$

$\operatorname{ctx}(22)=489 / 12$

$\operatorname{ctx}(23)=531 / 12$

$\operatorname{ctx}(24)=489 / 12$

$\operatorname{ctx}(25)=438 / 12$

$\operatorname{ctx}(26)=423 / 12$

$\operatorname{ctx}(27)=400 / 12$

$\operatorname{ctx}(28)=340 / 12$

$\operatorname{ctx}(29)=280 / 12$

$\operatorname{ctx}(30)=220 / 12$

$\operatorname{ctx}(31)=160 / 12$

$\operatorname{ctx}(32)=100 / 12$

$\operatorname{ctx}(33)=36 / 12$

$\operatorname{ctx}(34)=0$

/COM - Define Vertical Keypoint Locations

$\operatorname{ctz}(1)=576.8 / 12-z$ off

ctz $(2)=576 / 12-z$ off

$\operatorname{ctz}(3)=573.8 / 12-z$ off

ctz $(4)=571.21 / 12-\bar{z}$ off

ctz $(5)=567.7 / 12-z$ off

ctz $(6)=558.7 / 12-z$ off

$\operatorname{ctz}(7)=553.2 / 12-z^{-}$off

ct $z(8)=535.68 / 12-\bar{z}$ off

ctz $(9)=526 \cdot 2 / 12-z$ off

$\operatorname{ctz}(10)=502 \cdot 5 / 12-\bar{z}$ off

ctz $(11)=484.2 / 12-z$ off

$\operatorname{ctz}(12)=455.4 / 12-z$ off

ct $z(13)=415 \cdot 1 / 12-z$ off

$\operatorname{ctz}(14)=382.1 / 12-z$ off

ctz $(15)=335 / 12-z$ of $\bar{f}$

ctz $(16)=281 / 12-z$ off

ct $z(17)=236.5 / 12-z$ off

Ct $z(18)=186.8 / 12-z$ off

$\operatorname{ctz}(19)=145.5 / 12-z$ off

ctz $(20)=70 / 12-z$ _of $\bar{f}$

ctz $(21)=(\mathrm{CFloor}+24) / 12-z$ off

$\operatorname{ctz}(22)=C_{-} \overline{\mathrm{F}} 100 \mathrm{r} / 12-z$ off

Ct $z(23)=C$ Floor $/ 12-z$ off

Ctz $(24)=\mathrm{C}_{-}^{-} \mathrm{Fl}$ loor $/ 12-z_{\text {- off }}$

Ctz $(25)=\mathrm{C}$ Floor $/ 12-z$ off

Ctz $(26)=\mathrm{C}^{-} \mathrm{F}$ loor $/ 12-z_{\text {_off }}$

Ct $z(27)=\mathrm{C}^{-} \mathrm{Floor} / 12-z^{-}$off

Ctz $(28)=\mathrm{C}$ Floor $/ 12-z$ off

Ctz $(29)=\mathrm{C}^{-} \mathrm{Floor} / 12-z^{-}$off

Ctz $(30)=\mathrm{C}^{-} \mathrm{Fl}$ loor/12-z off

Ctz $(31)=C_{-}^{-}$Floor $/ 12-z$ off

Ctz $(32)=\mathrm{C}$ Floor $/ 12-z$ off

Ctz $(33)=\mathrm{C}^{-} \mathrm{F}$ loor $/ 12-z_{-}^{-}$off

Ctz $(34)=\mathrm{C}^{-} \mathrm{Fl}$ loor $/ 12-\mathrm{z}_{\text {_off }}$

$\operatorname{ptx}(1)=0$

$\operatorname{ptx}(2)=44.73689 / 12$

$\operatorname{ptx}(3)=89.86533 / 12$

$\operatorname{ptx}(4)=119.99721 / 12$

$\operatorname{ptx}(5)=151.96854 / 12$

$\operatorname{ptx}(6)=210.05344 / 12$

$\operatorname{ptx}(7)=237.53366 / 12$

$\operatorname{ptx}(8)=304.42488 / 12$

$\operatorname{ptx}(9)=333.05132 / 12$

$\operatorname{ptx}(10)=390.22141 / 12$

$\operatorname{ptx}(11)=422.26434 / 12$ 
RPP-RPT-32239, Rev. 1

M\&D-2008-005-CALC-001, Rev. 1

$\operatorname{ptx}(12)=432 / 12$

$\operatorname{ptx}(13)=444.36 / 12$

$\operatorname{ptx}(14)=448.66 / 12$

$\operatorname{ptx}(15)=450 / 12$

$\operatorname{ptx}(16)=450 / 12$

$\operatorname{ptx}(17)=450 / 12$

$\operatorname{ptx}(18)=450 / 12$

$\operatorname{ptx}(19)=450 / 12$

$\operatorname{ptx}(20)=450 / 12$

$\operatorname{ptx}(21)=450 / 12$

$\operatorname{ptx}(22)=450 / 12$

$\operatorname{ptx}(23)=450 / 12$

$\operatorname{ptx}(24)=450 / 12$

$\operatorname{ptx}(25)=450 / 12$

$\operatorname{ptx}(26)=450 / 12$

$\operatorname{ptx}(27)=450 / 12$

$\operatorname{ptx}(28)=450 / 12$

$\operatorname{ptx}(29)=450 / 12$

$\operatorname{ptx}(30)=450 / 12$

$\operatorname{ptx}(31)=450 / 12$

$\operatorname{ptx}(32)=450 / 12$

$\operatorname{ptx}(33)=450 / 12$

$\operatorname{ptx}(34)=446.49 / 12$

$\operatorname{ptx}(35)=438 / 12$

$\operatorname{ptx}(36)=423 / 12$

$\operatorname{ptx}(37)=400 / 12$

$\operatorname{ptx}(38)=340 / 12$

$\operatorname{ptx}(39)=280 / 12$

$\operatorname{ptx}(40)=220 / 12$

$\operatorname{ptx}(41)=160 / 12$

$\operatorname{ptx}(42)=100 / 12$

$\operatorname{ptx}(43)=36 / 12$

$\operatorname{ptx}(44)=0$

ptz $(1)=569.30000 / 12-z$ off ptz $(2)=568.50462 / 12-z$ off ptz $(3)=566.31908 / 12-z$ off ptz $(4)=563.74491 / 12-z$ off ptz $(5)=560.25807 / 12-z$ off ptz $(6)=551.32187 / 12-z$ off ptz $(7)=545.86539 / 12-z$ off ptz $(8)=528.51150 / 12-z$ off Ptz $(9)=519.14633 / 12-z$ off ptz $(10)=495.85550 / 12-\bar{z}$ off ptz $(11)=474.92388 / 12-z_{-}$off ptz $(12)=468 / 12-z$ off

ptz $(13)=456.7 / 12-z$ off

ptz $(14)=445.4 / 12-z$ off

ptz $(15)=432 \cdot 3125 / 1 \overline{2}-z$ off

ptz $(16)=410.125 / 12-z$ off

ptz $(17)=386.125 / 12-z$ off

ptz $(18)=362.125 / 12-z$ off

ptz $(19)=337.875 / 12-z$ off ptz $(20)=314.775 / 12-z$ off ptz $(21)=291.675 / 12-z$ off ptz $(22)=268.575 / 12-z$ off ptz $(23)=245.375 / 12-z$ off ptz (24) $=222.275 / 12-z$ off $\operatorname{ptz}(25)=199.175 / 12-z$ off ptz $(26)=176.075 / 12-z$ off ptz $(27)=152.875 / 12-z$ off ptz $(28)=131.275 / 12-z$ off ptz $(29)=109.675 / 12-z$ off ptz $(30)=88.075 / 12-z$ off ptz $(31)=66.475 / 12-z$ off ptz $(32)=45 / 12-z$ off ptz $(33)=20 / 12-z$ off ptz $(34)=11.51 / 1 \overline{2}-z$ off ptz $(35)=8 / 12-z$ off ptz $(36)=8 / 12-z$ off ptz $(37)=8 / 12-z_{-}$off 


\section{RPP-RPT-32239, Rev. 1 \\ M\&D-2008-005-CALC-001, Rev. 1}

ptz $(38)=8 / 12-z$ off

ptz $(39)=8 / 12-z$ off

ptz $(40)=8 / 12-z$ off

ptz $(41)=8 / 12-z^{-}$off

ptz $(42)=8 / 12-z_{-}$off

ptz $(43)=8 / 12-z$ off

$\operatorname{ptz}(44)=8 / 12-z_{-}$off

\section{Tank-Mesh1.txt}

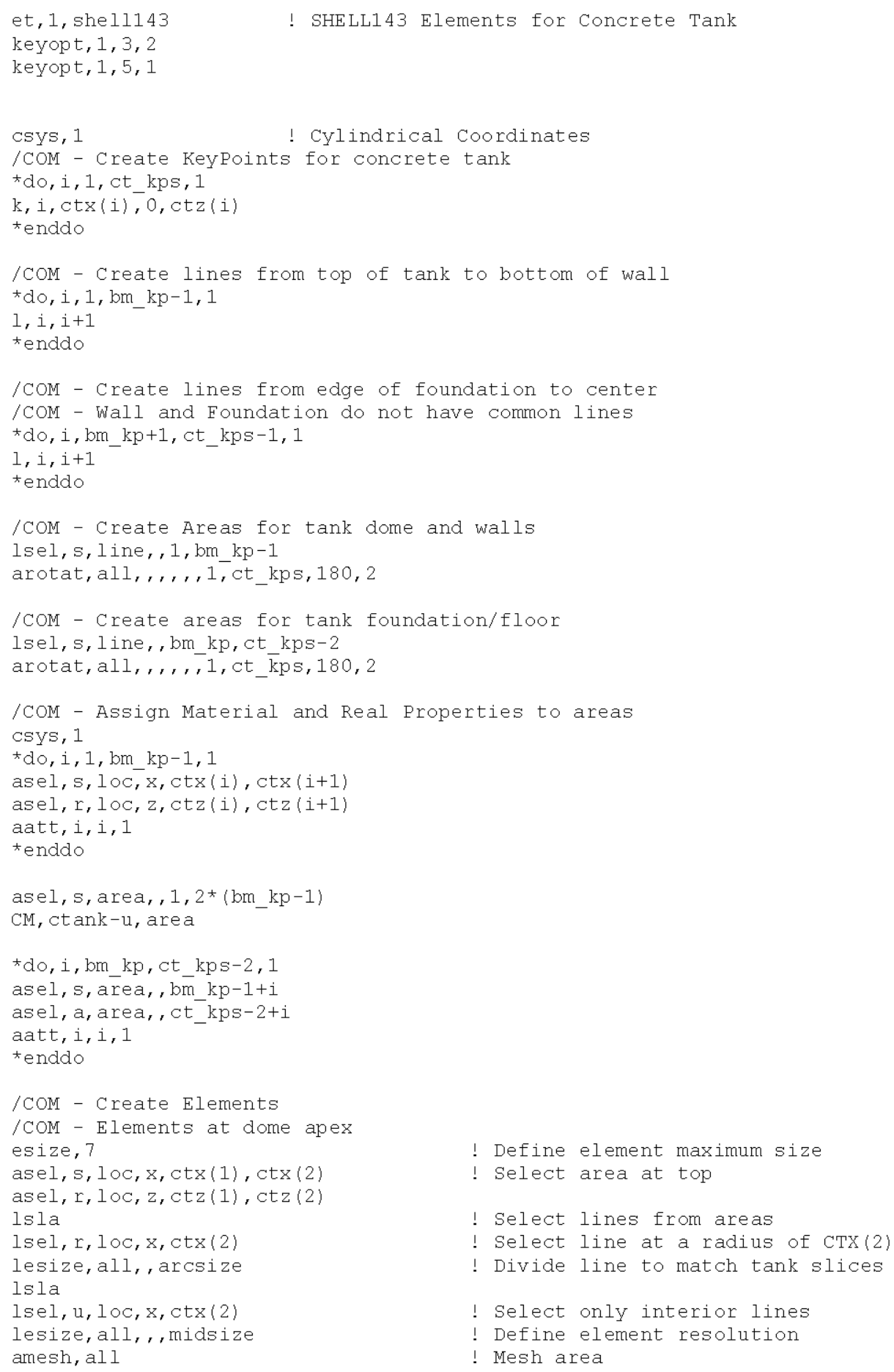


RPP-RPT-32239, Rev. 1

M\&D-2008-005-CALC-001, Rev. 1

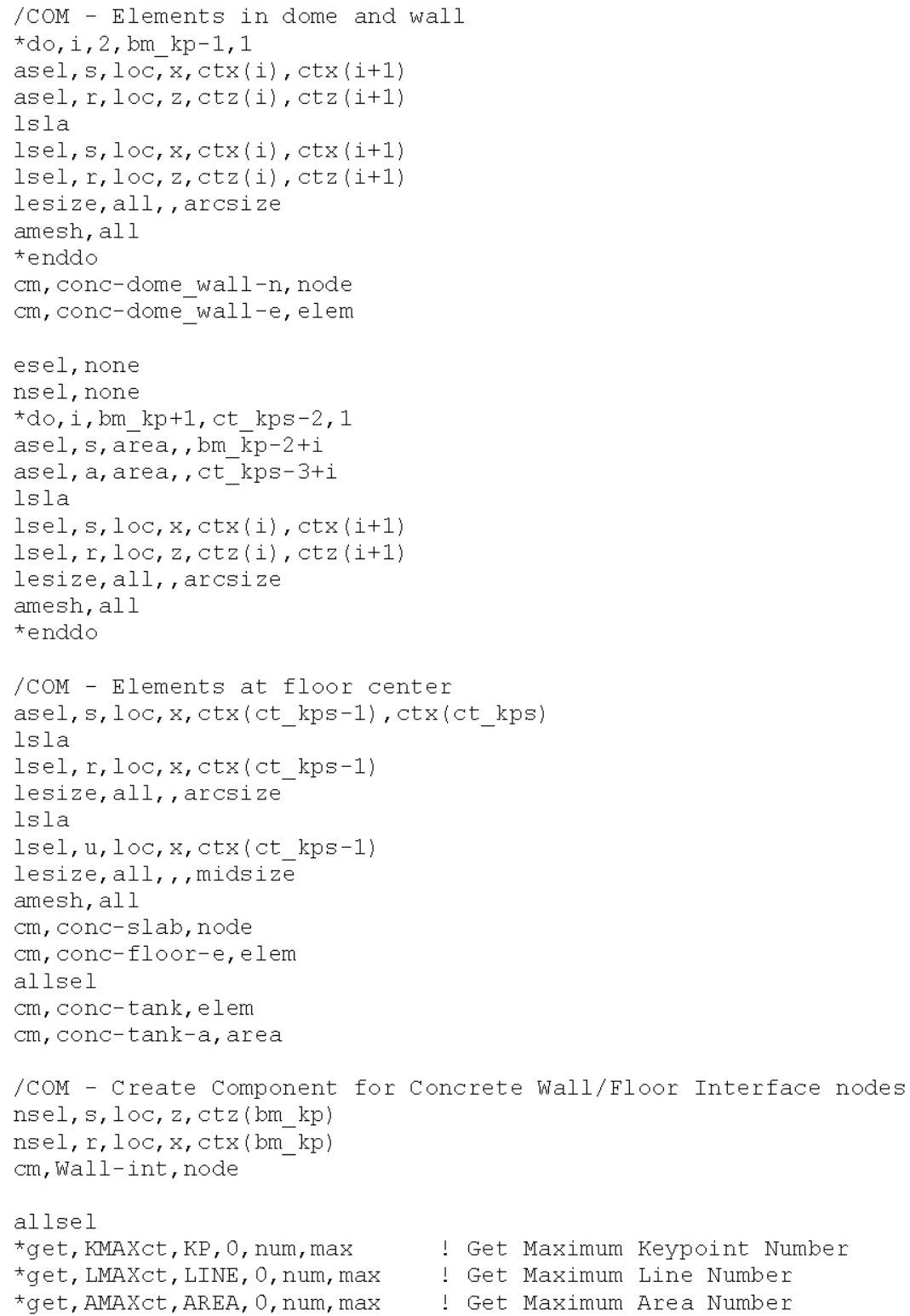

\section{Waste-Reaction.txt}

$/$ post 1

*dim, REACTX, 2149

*dim, REACTZ, , 2149

cmsel, s, waste

cmsel, a, waste-surf

nsle

$\star$ do, i, 1, 2149

set, $i$

fsum, cont

*get, REACTX (i) , FSUM, 0, ITEM, FX

*get, reactz (i), FSUM, 0, ITEM, EZ

*enddo

lout, Waste-Reaction-460-SD3, out 


\section{RPP-RPT-32239, Rev. 1 \\ M\&D-2008-005-CALC-001, Rev. 1}

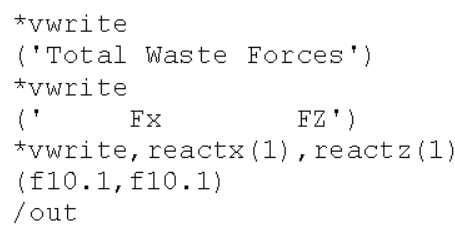

\section{Waste-solid-AP-S.txt}

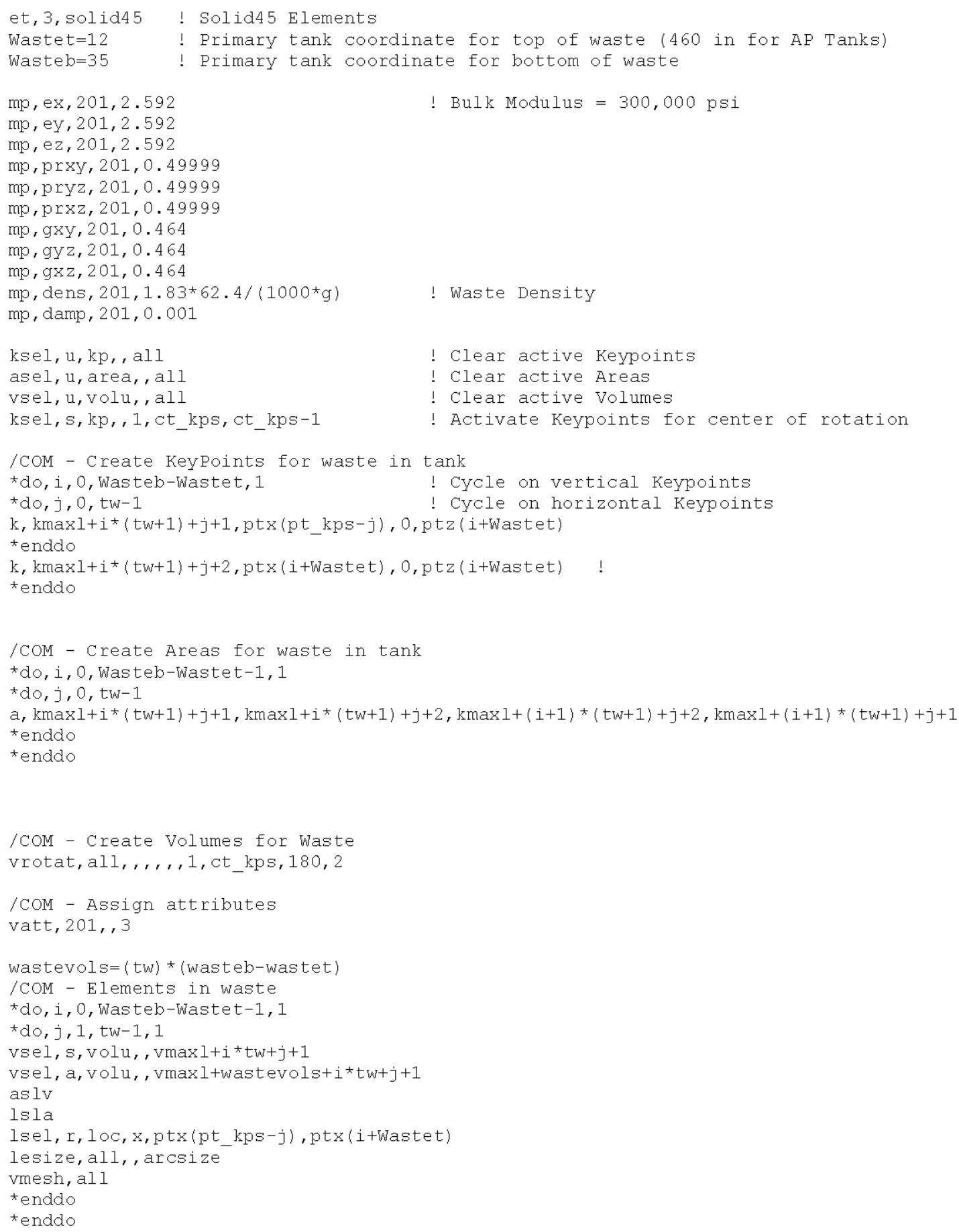


RPP-RPT-32239, Rev. 1

M\&D-2008-005-CALC-001, Rev. 1

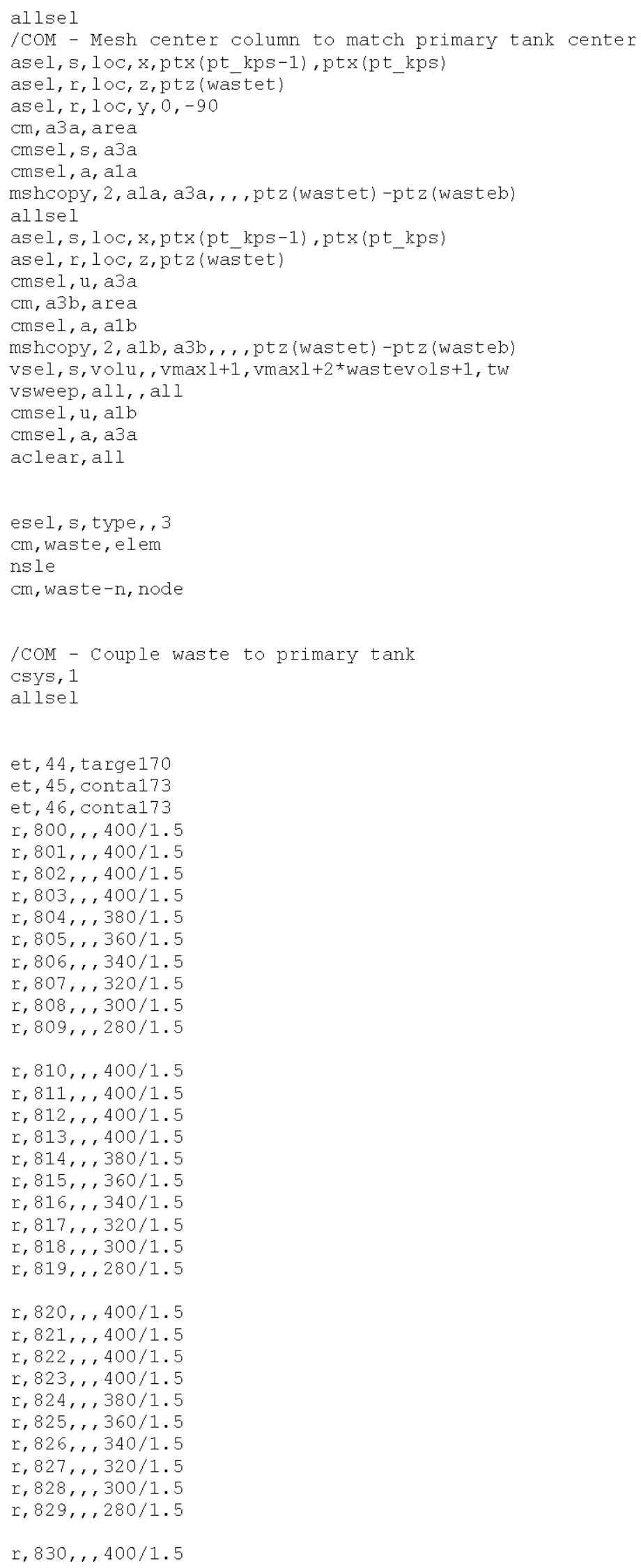


RPP-RPT-32239, Rev. 1

M\&D-2008-005-CALC-001, Rev. 1

$r, 831,, 400 / 1.5$
$r, 832, r, 400 / 1.5$
$r, 833, r, 400 / 1.5$
$r, 834, r 380 / 1.5$
$r, 835, r 360 / 1.5$
$r, 836, r 340 / 1.5$
$r, 837, r, 320 / 1.5$
$r, 838, m, 300 / 1.5$
$r, 839,, 280 / 1.5$
keyopt, $45,12,4$
keyopt, $46,12,4$

! - Third Facet of Haunch

cmsel,s,primary-tank

nsle

nsel, r, loc, z,ptz (8), ptz (16)

nsel, r, loc, $x, p t x(8), p t x(16)$

esln, $r, 1$

type, 44

real, 809

esurf

real, 819

esurf

real, 829

esurf

real, 839

esurf

cmsel, s, waste

nsle

nsel, r, loc, z,ptz (12), ptz (13)

nsel, r, loc, x, ptx (12), ptx(13)

nsel, $r, 1 \circ c, y, 0,-45$

esln, $r$

real, 809

type, 46

esurf

cmsel, s, waste

nsle

nsel, r, loc, z, ptz (12), ptz (13)

nsel, r, loc, $x, p t x(12), p t x(13)$

nsel, $r, 1 \circ 0, y,-45,-90$

esln, $r$

real, 819

type, 46

esurf

cmsel, s, waste

nsle

nsel, r, loc, z, ptz (12), ptz(13)

nsel, r, loc, x, ptx(12), ptx(13)

nsel, $r, 100, y,-90,-135$

esln, $r$

real, 829

type, 46

esurf

cmsel, s, waste

nsle

nsel, r, loc, z, ptz (12), ptz (13)

nsel, r, loc, $x, p t x(12), p t x(13)$

nsel, r, loc, y, $-135,-180$

esln, $r$

real, 839

type, 46

esurf

! - Second Facet of Haunch

cmsel, s, primary-tank 
RPP-RPT-32239, Rev. 1

M\&D-2008-005-CALC-001, Rev. 1

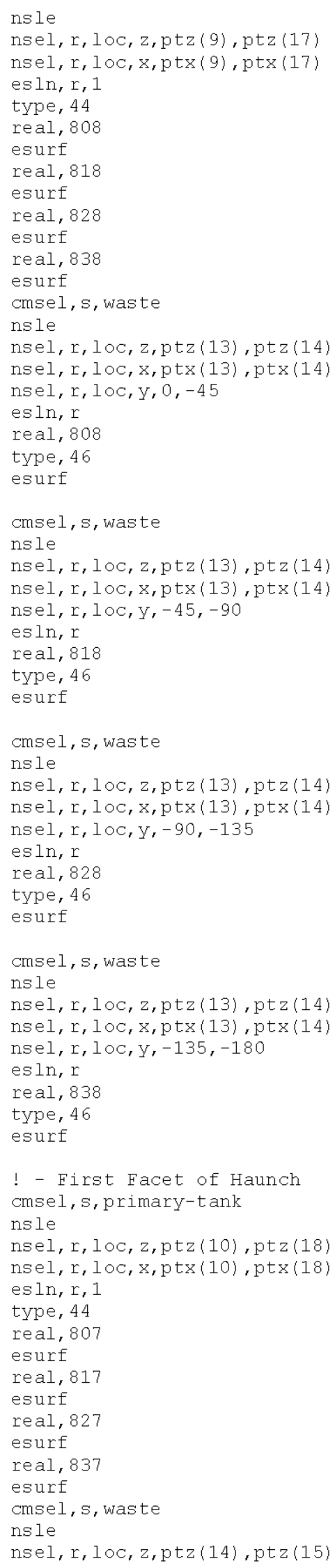


RPP-RPT-32239, Rev. 1

M\&D-2008-005-CALC-001, Rev. 1

nsel, r, loc, x, ptx (14), ptx(15)

nsel, $r, 1 \circ c, y, 0,-45$

esln, $r$

real, 807

type, 46

esurf

cmsel, s, waste

nsle

nsel, r, loc, z,ptz(14),ptz(15)

nsel, r, loc, x, ptx (14), ptx (15)

nsel, $r, 100, y,-45,-90$

esln, $r$

real, 817

type, 46

esurf

cmsel, s, waste

nsle

nsel, r, loc, z, ptz (14), ptz (15)

nsel, r, loc, x, ptx (14), ptx (15)

nsel, $r, 10 c, y,-90,-135$

esln, r

real, 827

type, 46

esurf

cmsel, s, waste

nsle

nsel, r, loc, z, ptz (14),ptz(15)

nsel, r, loc, x, ptx (14), ptx (15)

nsel, $r, 100, y,-135,-180$

esln, $r$

real, 837

type, 46

esurf

! - First Layer below Haunch cmsel, s, primary-tank

nsle

nsel, r, loc, z, ptz (11), ptz(19)

nsel, r, loc, x, ptx (11), ptx (19)

esln, $r, 1$

type, 44

real, 806

esurf

real, 816

esurf

real, 826

esurf

real, 836

esurf

cmsel, s, waste

nsle

nsel, r, loc, z, ptz(15),ptz(16)

nsel, $r, 10 c, x, p t x(15), p t x(16)$

nsel, $r, 1 \circ c, y, 0,-45$

esln, $r$

real, 806

type, 46

esurf

cmsel, s, waste

nsle

nsel, r, loc, $z, p t z(15), p t z(16)$

nsel, r, loc, x, ptx (15), ptx (16)

nsel, $r, 100, y,-45,-90$

esln, $r$

real, 816

type, 46

esurf 
RPP-RPT-32239, Rev. 1

M\&D-2008-005-CALC-001, Rev. 1

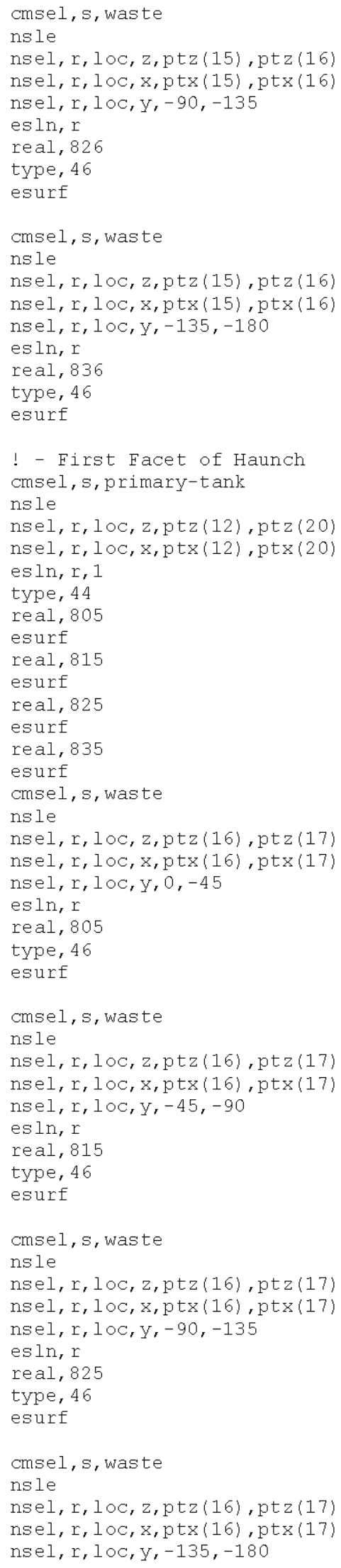


RPP-RPT-32239, Rev. 1

M\&D-2008-005-CALC-001, Rev. 1

esln, $r$

real, 835

type, 46

esurf

! - First Facet of Haunch

cmsel, s, primary-tank

nsle

nsel, r, loc, z, ptz (13), ptz (21)

nsel, r, loc, $x, p t x(13), p t x(21)$

esln, $r, 1$

type, 44

real, 804

esurf

real, 814

esurf

real, 824

esurf

real, 834

esurf

cmsel, s, waste

nsle

nsel, r, loc, z,ptz (17), ptz (18)

nsel, r, loc, $x, p t x(17), p t x(18)$

nsel, $r, 100, y, 0,-45$

esln, $r$

real, 804

type, 46

esurf

cmsel, s, waste

nsle

nsel, r, loc, z,ptz(17), ptz(18)

nsel, r, loc, $x, p t x(17), p t x(18)$

nsel, $r, 1 \circ 0, y,-45,-90$

esln, $r$

real, 814

type, 46

esurf

cmsel, s, waste

nsle

nsel, r, loc, z, ptz (17), ptz (18)

nsel, r, loc, x,ptx(17), ptx(18)

nsel, $r, 100, y,-90,-135$

esln, $r$

real, 824

type, 46

esurf

cmsel, s, waste

nsle

nsel, r, loc, z, ptz (17), ptz(18)

nsel, r, loc, $x, p t x(17), p t x(18)$

nsel, $r, 100, y,-135,-180$

esln, $r$

real, 834

type, 46

esurf

cmsel, s, primary-tank

nsle

nsel, r, loc, z, ptz (15), ptz(33)

esln, $r, 1$

nsle

type, 44

real, 803

esurf

real, 813

esurf

real, 823 
RPP-RPT-32239, Rev. 1

M\&D-2008-005-CALC-001, Rev. 1

esurf

real, 833

esurf

cmsel, s, waste

nsle

nsel, r, loc, z, ptz (18), ptz(34)

nsel, r, loc, $x, p t x(18)$

nsel, $r, 10 c, y, 0,-45$

esln, $r$

real, 803

type, 45

esurf

cmsel, s, waste

nsle

nsel, r, loc, z, ptz (18), ptz (34)

nsel, r, loc, $x, p t x(18)$

nsel, $r, 100, y,-45,-90$

esln, $r$

real, 813

type, 45

esurf

cmsel, s, waste

nsle

nsel, r, loc, z, ptz (18), ptz(34)

nsel, r, loc, $x, p t x(18)$

nsel, r, loc, y, -90,-135

esln, $r$

real, 823

type, 45

esurf

cmsel, s, waste

nsle

nsel, r, loc, z,ptz (18), ptz (34)

nsel, r, loc, $x, p t x(18)$

nsel, $r, 100, y,-135,-180$

esln, $r$

real, 833

type, 45

esurf

! - Second Facet of Knuckle

cmsel, s, primary-tank

nsle

nsel, r, loc, z, ptz (32), ptz (36)

nsel, r, loc, $x, p t x(32), p t x(36)$

esln, r, 1

type, 44

real, 802

esurf

real, 812

esurf

real, 822

esurf

real, 832

esurf

cmsel, s, waste

nsle

nsel, r, loc, z, ptz (33), ptz (34)

nsel, r, loc, $x, p t x(33), p t x(34)$

nsel, $r, 1 \circ 0, y, 0,-45$

esln, r

real, 802

type, 46

esurf

cmsel, s, waste

nsle

nsel, r, loc, z, ptz(33), ptz(34) 
RPP-RPT-32239, Rev. 1

M\&D-2008-005-CALC-001, Rev. 1

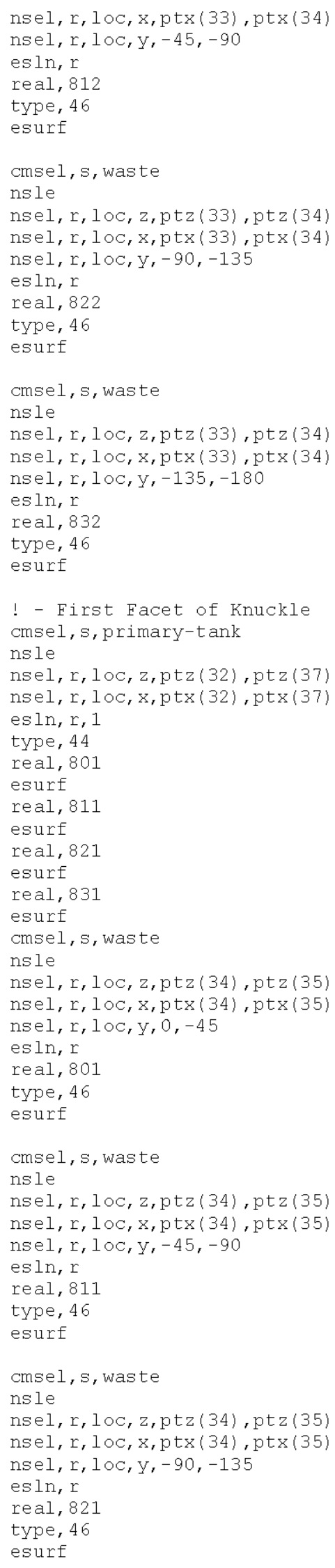


RPP-RPT-32239, Rev. 1

M\&D-2008-005-CALC-001, Rev. 1

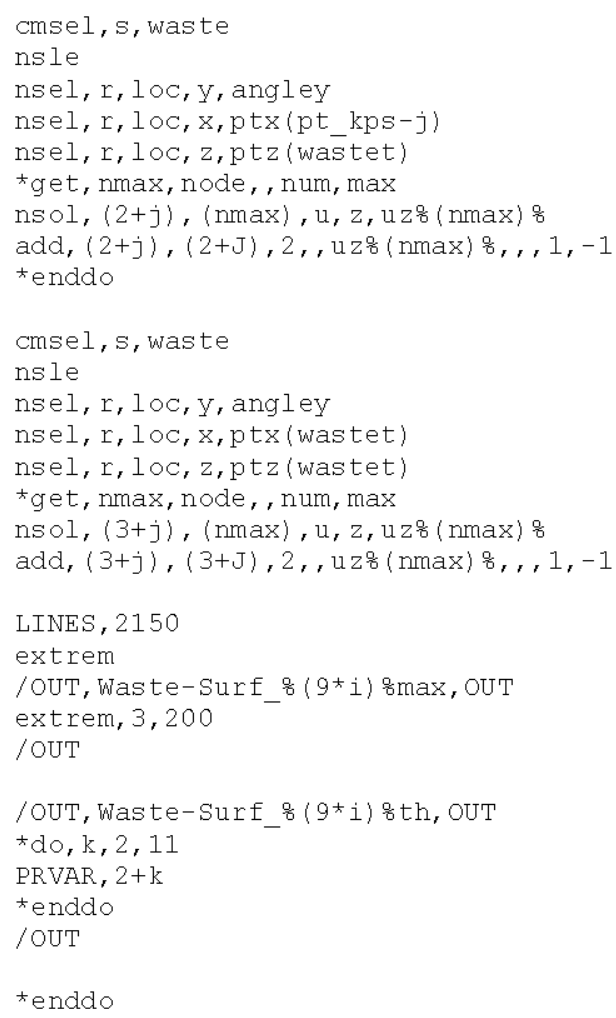


RPP-RPT-32239, Rev. 1

M\&D-2008-005-CALC-001, Rev. 1

Intentionally left blank.

E. 84 
RPP-RPT-32239, Rev. 1

M\&D-2008-005-CALC-001, Rev. 1

\title{
Appendix F
}

\author{
Lower Bound Soil, \\ Best Estimate Concrete
}

\author{
Results \\ Load Case Specific Input Files
}

File Listing 
RPP-RPT-32239, Rev. 1

M\&D-2008-005-CALC-001, Rev. 1

Intentionally left blank 
RPP-RPT-32239, Rev. 1

M\&D-2008-005-CALC-001, Rev. 1

\section{Appendix F}

\section{Lower Bound Soil, Best Estimate Concrete}

\section{Results \\ Load Case Specific Input Files File Listing}

List of Tables Updated in Revision 1:

Table F.13
Table F.14
Table F.15
Table F.31
Table F.32
Table F.33 
RPP-RPT-32239, Rev. 1

M\&D-2008-005-CALC-001, Rev. 1

Tables

F.1 LBS-BEC Concrete Forces and Moment, Gravity Load Only …..................................... F.4

F.2 LBS-BEC Concrete Forces and Moments, Gravity Plus Seismic Load ................................ F.5

F.3 LBS-BEC Concrete Forces and Moments, Seismic Only …........................................... F.

F.4 LBS-BEC Primary Tank Stresses, Shell Top, Gravity Load Only ……............................. F. F

F.5 LBS-BEC Primary Tank Stresses, Shell Middle, Gravity Load Only ................................... F F.8

F.6 LBS-BEC Primary Tank Stresses, Shell Bottom, Gravity Load Only ................................ F.9

F.7 LBS-BEC Primary Tank Stresses, Shell Top, Gravity Plus Seismic Load ......................... $\quad$ F.10

F.8 LBS-BEC Primary Tank Stresses, Shell Middle, Gravity Plus Seismic Load ...................... F F.11

F.9 LBS-BEC Primary Tank Stresses, Shell Bottom, Gravity Plus Seismic Load...................... $\quad$ F.12

F.10 LBS-BEC Primary Tank Stresses, Shell Top, Seismic Load Only .................................... F.13

F.11 LBS-BEC Primary Tank Stresses, Shell Bottom, Seismic Load Only ................................. F. F.15

F.12 LBS-BEC Anchor Bolt Forces, Gravity Load Only …................................................ F. F.16

F.13 LBS-BEC Anchor Bolt Forces, Gravity Plus Seismic Loads .......................................... F. F.17

F.14 LBS-BEC Anchor Bolt Forces, Seismic Load Only ....................................................... F. F.18

F.15 LBS-BEC Concrete Backed Steel Strain, Shell Top, Gravity Load Only ............................ F. F.19

F.16 LBS-BEC Concrete Backed Steel Strain, Shell Middle, Gravity Load Only ……............... F F.20

F.17 LBS-BEC Concrete Backed Steel Strain, Shell Bottom, Gravity Load Only ...................... $\quad$ F.21

F.18 LBS-BEC Concrete Backed Steel Strain, Shell Top, Gravity Plus Seismic Load ................ $\quad$ F.22

F.19 LBS-BEC Concrete Backed Steel Strain, Shell Middle, Gravity Plus Seismic Load ............ $\quad$ F.23

F.20 LBS-BEC Concrete Backed Steel Strain, Shell Bottom, Gravity Plus Seismic Load............ F F.24

F.21 LBS-BEC Concrete Backed Steel Strain, Shell Top, Seismic Load Only .......................... F. F.25

F.22 LBS-BEC Concrete Backed Steel Strain, Shell Middle, Seismic Load Only ...................... F. F.26

F.23 LBS-BEC Concrete Backed Steel Strain, Shell Bottom, Seismic Load Only ....................... F. F.27

F.24 LBS-BEC Concrete Wall/Footing Contact Forces, Gravity Only …….............................. F F.28

F.25 LBS-BEC Concrete Wall/Footing Contact Forces, Gravity Plus Seismic .......................... F F.29

F.26 LBS-BEC Concrete Wall/Footing Contact Forces, Seismic Only ..................................... F. F.30

F.27 LBS-BEC Soil/Concrete Tank Contact Forces, Gravity Only ........................................ F. F.31

F.28 LBS-BEC Soil/Concrete Tank Contact Forces, Gravity Plus Seismic ................................ F. F.32

F.29 LBS-BEC Soil/Concrete Tank Contact Forces, Seismic Only …...................................... F. F.33

F.30 LBS-BEC Primary Tank/Concrete Dome Contact Data, Gravity Only ….......................... F. F.34

F.31 LBS-BEC Primary Tank/Concrete Dome Contact Data, Gravity Plus Seismic .................... F. F.35

F.32 LBS-BEC Primary Tank/Concrete Dome Contact Data, Seismic Only ............................... F. F.36

F.33 LBS-BEC Primary Tank/Insulating Concrete Contact Forces, Gravity Only ...................... F F.37

F.34 LBS-BEC Primary Tank/ Insulating Concrete Contact Data, Gravity Plus Seismic.............. F F.38

F.35 LBS-BEC Primary Tank/Insulating Concrete Contact Forces, Seismic Only ...................... F F.39

F.36 LBS-BEC Insulating Concrete/Concrete Backed Steel Contact Data, Gravity Only ............. F. F.40 
RPP-RPT-32239, Rev. 1

M\&D-2008-005-CALC-001, Rev. 1

F.37 LBS-BEC Insulating Concrete/Concrete Backed Steel Contact Data, Gravity Plus Seismic . F.41

F.38 LBS-BEC Insulating Concrete/Concrete Backed Steel Contact Data, Seismic Only ............ F. F.42

F.39 LBS-BEC Waste Contact Pressure, Gravity Plus Seismic ……........................................ F. F.43

F.40 LBS-BEC Waste Contact Pressure, Theoretical Pressures.................................................. F.44

F.41 LBS-BEC Waste Surface Displacement, Gravity Plus Seismic ............................................ F. F 
RPP-RPT-32239, Rev. 1

M\&D-2008-005-CALC-001, Rev. 1

Table F.1. LBS-BEC Concrete Forces and Moment, Gravity Load Only

\section{AP Primary Tank, Lower Bound Soil (Geomatrix), Gravity Only, Best Estimate Concrete, 460 in. Waste Level at 1.83 SpG}

\begin{tabular}{|c|c|c|c|c|c|c|c|}
\hline $\begin{array}{l}\text { PNNL } \\
\text { Section } \\
\text { No. }\end{array}$ & Path (in.) & $\begin{array}{c}\text { Gravity Hoop } \\
\text { Force (kip/ft) AP } \\
\text { LBS-BEC }\end{array}$ & $\begin{array}{c}\text { Gravity } \\
\text { Meridonal } \\
\text { Force (kip/ft) } \\
\text { AP-LBS-BEC }\end{array}$ & $\begin{array}{l}\text { Gravity-ln- } \\
\text { Plane Shear } \\
\text { Force (kip/ft) } \\
\text { AP-LBS-BEC }\end{array}$ & $\begin{array}{c}\text { Gravity Hoop } \\
\text { Moment } \\
\text { (ft*kip/ft) AP- } \\
\text { LBS-BEC }\end{array}$ & $\begin{array}{c}\text { Gravity Meridonal } \\
\text { Moment (ft*kip/ft) } \\
\text { AP-LBS-BEC }\end{array}$ & $\begin{array}{c}\text { Gravity } \\
\text { Through-Wall } \\
\text { Shear Force } \\
\text { (kip/ft) AP-LBS } \\
\text { BEC }\end{array}$ \\
\hline 2 & 67.734 & -72.190 & -76.220 & -0.160 & -6.222 & 3.128 & 1.712 \\
\hline 3 & 105.676 & -67.460 & -74.910 & -0.257 & -4.144 & -0.764 & 1.013 \\
\hline 4 & 137.076 & -63.000 & -73.590 & -0.320 & -2.707 & 1.656 & 1.139 \\
\hline 6 & 182.856 & -58.820 & -71570 & -0.239 & -1.631 & 2.216 & -0.527 \\
\hline 8 & 226.570 & -55.770 & -70.340 & -0.061 & -1.573 & -1.478 & -1.101 \\
\hline 9 & 275.574 & -53.430 & -69.430 & -0.261 & -1.939 & -2.809 & -1.097 \\
\hline 11 & 325.697 & -45.010 & -68.610 & -0.268 & -2.843 & -7.213 & -1.192 \\
\hline 13 & 372.312 & 35.110 & -67.460 & -0.169 & -6.118 & -9.082 & -0.772 \\
\hline 17 & 423.434 & -10.880 & -65.800 & 0.065 & 3.728 & -7.689 & 2.217 \\
\hline 20 & 468.315 & 42.570 & -63.200 & 0.019 & -12.950 & 14.350 & 10.470 \\
\hline 22 & 515.319 & 24.640 & -65.570 & -0.015 & 5.384 & 35.730 & -2.411 \\
\hline 24 & 553.722 & 4.816 & -64.080 & -0.012 & 2.814 & 15.480 & -7.823 \\
\hline 26 & 593.805 & -13.870 & -66.160 & -0.007 & 0.025 & 0.136 & -2.836 \\
\hline 30 & 644.355 & 30.340 & -68.310 & -0.004 & -0.577 & 3.205 & 0.709 \\
\hline 33 & 693.605 & 37.280 & -69.900 & 0.003 & -0.176 & -0.978 & 0.523 \\
\hline 35 & 740.705 & -42.540 & -71.450 & 0.003 & 0.043 & 0.239 & -0.034 \\
\hline 38 & 786.205 & 37.090 & -72.970 & 0.003 & -0.244 & -1.357 & -0.466 \\
\hline 41 & 844.605 & 35.910 & -75.000 & 0.004 & -0.184 & -1.020 & -0.224 \\
\hline 43 & 901.355 & -16.710 & -31.660 & 0.010 & -0.131 & -0.720 & 1.196 \\
\hline 46 & 932.355 & -27.450 & -74.280 & 0.058 & -0.700 & 3.476 & -2.551 \\
\hline 48 & 1007.355 & 3.424 & -11.680 & 0.674 & -5.823 & 28.450 & -16.400 \\
\hline 51 & 1053.855 & -4.459 & -13.040 & 0.711 & -1.921 & 26.630 & 15.710 \\
\hline 53 & 1086.855 & -1.691 & -7.447 & 0.472 & 1.868 & 3.811 & -1.096 \\
\hline 55 & 1105.855 & -1.448 & -5.416 & 0.334 & 3.753 & 4.877 & 1.687 \\
\hline 57 & 1147.355 & -0.396 & 3.032 & 0.220 & 0.487 & 1.631 & -1.588 \\
\hline 58 & 1207.355 & 0.239 & -0.143 & 0.036 & -0.021 & -0.149 & 0.327 \\
\hline 59 & 1267.355 & 0.313 & 0.230 & 0.014 & 0.033 & 0.163 & -0.259 \\
\hline 60 & 1327.355 & 0.486 & 0.075 & 0.040 & -0.039 & -0.244 & 0.211 \\
\hline 61 & 1387.355 & 0.484 & 0.674 & -0.022 & 0.033 & 0.068 & -0.121 \\
\hline 62 & 1449.355 & 2.307 & 2417 & -0.027 & 0.088 & 0.085 & 0.281 \\
\hline
\end{tabular}

Note: Meridonal/Hoop Forces and Meridonal/Hoop Moments are Reversed in Highlighted Sections. 
RPP-RPT-32239, Rev. 1

M\&D-2008-005-CALC-001, Rev. 1

Table F.2. LBS-BEC Concrete Forces and Moments, Gravity Plus Seismic Load

AP- Primary Tank, Lower Bound Soil (Geomatrix), Best Estimate Concrete,

\begin{tabular}{|c|c|c|c|c|c|c|c|}
\hline $\begin{array}{l}\text { PNNL } \\
\text { Section } \\
\text { No. }\end{array}$ & Path (in.) & $\begin{array}{l}\text { Seismic Hoop } \\
\text { Force (kip/ft) } \\
\text { AP-LBS-BEC }\end{array}$ & $\begin{array}{c}\text { Seismic } \\
\text { Meridonal } \\
\text { Force (kip/ft) } \\
\text { AP-LBS-BEC }\end{array}$ & $\begin{array}{l}\text { Seismic -ln- } \\
\text { Plane Shear } \\
\text { Force (kip/ft) } \\
\text { AP-LBS-BEC }\end{array}$ & $\begin{array}{c}\text { Seismic Hoop } \\
\text { Moment } \\
\text { (ft*kip/ft) AP- } \\
\text { LBS-BEC }\end{array}$ & $\begin{array}{c}\text { Seismic Meridonal } \\
\text { Moment (ft*kip/ft) } \\
\text { AP-LBS-BEC }\end{array}$ & $\begin{array}{c}\text { Seismic } \\
\text { Through-Wall } \\
\text { Shear Force } \\
\text { (kip/ft) AP-LBS } \\
\text { BEC }\end{array}$ \\
\hline 2 & 67.734 & -98.830 & -103.500 & 4.949 & -14.140 & -12.350 & 3.582 \\
\hline 3 & 105.676 & -94.430 & -101500 & 7.021 & -10.770 & -9.063 & 2.352 \\
\hline 4 & 137.076 & -88.460 & -99.280 & 8.423 & -8.239 & 7.385 & 2.735 \\
\hline 6 & 182.856 & -81550 & -95.050 & 9.777 & -4.853 & 6.732 & 2.625 \\
\hline 8 & 226.570 & -77.210 & -91.170 & 11.130 & -3.541 & -6.991 & 2.015 \\
\hline 9 & 275.574 & -77.340 & -87.730 & 13.380 & -3.232 & -6.305 & 1.709 \\
\hline 11 & 325.697 & -69.820 & -85.120 & 15.590 & -4.145 & -10.110 & 1.855 \\
\hline 13 & 372.312 & -68710 & -82.440 & 18.180 & -8.406 & -12.050 & 1.514 \\
\hline 17 & 423.434 & -24.530 & -79.710 & 20.680 & -4.879 & -11.790 & 3.520 \\
\hline 20 & 468.315 & 115.700 & -75.760 & 24.360 & -18.220 & 21.460 & 12.540 \\
\hline 22 & 515.319 & 49.410 & -77.010 & 27.690 & 7540 & 46.460 & 3.792 \\
\hline 24 & 553.722 & 16.710 & -75.860 & 27.090 & 3.738 & 20.310 & 10.040 \\
\hline 26 & 593.805 & -23.100 & -79.150 & 27.870 & 0.149 & 0.739 & 3.633 \\
\hline 30 & 644.355 & -38.380 & -81.020 & 29.010 & -0.728 & -3.947 & 0.873 \\
\hline 33 & 693.605 & -45.790 & -82550 & 30560 & -0.254 & -1280 & 0.623 \\
\hline 35 & 740.705 & -51440 & -84.580 & 32.210 & 0.082 & 0.391 & 0.094 \\
\hline 38 & 786.205 & -44.090 & -86.540 & 33.700 & -0.317 & -1714 & 0.559 \\
\hline 41 & 844.605 & -42.540 & -89.120 & 36.260 & -0.321 & -1.709 & 0.414 \\
\hline 43 & 901.355 & -19560 & -37.710 & 17.950 & -0.206 & -1.146 & 2.047 \\
\hline 46 & 932.355 & -57.260 & -89.170 & 39.730 & -0.872 & -4.364 & 3.257 \\
\hline 48 & 1007.355 & -21.090 & -16.390 & 12.130 & -7.356 & 34,450 & 19.860 \\
\hline 51 & 1053.855 & -60.570 & -18.680 & 17.580 & -3.392 & 33.120 & 18.730 \\
\hline 53 & 1086.855 & -16.970 & -13.830 & 11.320 & 2.330 & 5.081 & 2.040 \\
\hline 55 & 1105.855 & -46.410 & -11.590 & 10.520 & 4.925 & 6.378 & 2.403 \\
\hline 57 & 1147.355 & -9.667 & -8.374 & 6.165 & 0.642 & 2.128 & 2.060 \\
\hline 58 & 1207.355 & 3.810 & -3.875 & 3.206 & -0.028 & -0.193 & 0.420 \\
\hline 59 & 1267.355 & 2.999 & 3.141 & 2193 & 0.045 & 0.215 & 0.330 \\
\hline 60 & 1327.355 & 3.613 & -2.481 & 1.831 & -0.055 & -0.299 & 0.285 \\
\hline 61 & 1387.355 & 2.108 & 2.712 & 1.363 & 0.044 & 0.099 & 0.202 \\
\hline 62 & 1449.355 & 6.171 & 5.432 & 1.477 & 0.190 & 0.220 & 0.424 \\
\hline
\end{tabular}


RPP-RPT-32239, Rev. 1

M\&D-2008-005-CALC-001, Rev. 1

Table F.3. LBS-BEC Concrete Forces and Moments, Seismic Only

AP- Primary Tank, Lower Bound Soil (Geomatrix), Best Estimate Concrete, $460 \mathrm{in}$. Waste Level at $1.83 \mathrm{SpG}$

\begin{tabular}{|c|c|c|c|c|c|c|c|}
\hline $\begin{array}{c}\text { PNNL } \\
\text { Section } \\
\text { No. }\end{array}$ & Path (in.) & $\begin{array}{c}\text { Seismic Only } \\
\text { Hoop Force } \\
\text { (kip/ft) AP-LBS- } \\
\text { BEC }\end{array}$ & $\begin{array}{c}\text { Seismic Only } \\
\text { Meridonal } \\
\text { Force (kip/ft) } \\
\text { AP-LBS-BEC }\end{array}$ & \begin{tabular}{|c|} 
Seismic Only- \\
In-Plane Shear \\
Force (kip/ft) \\
AP-LBS-BEC \\
\end{tabular} & $\begin{array}{c}\text { Seismic Only } \\
\text { Hoop Moment } \\
\text { (ft*kip/ft) AP- } \\
\text { LBS-BEC } \\
\end{array}$ & $\begin{array}{c}\text { Seismic Only } \\
\text { Meridonal Moment } \\
\text { (ftkip/ft) AP-LBS- } \\
\text { BEC }\end{array}$ & $\begin{array}{c}\text { Seismic Only } \\
\text { Through-Wall } \\
\text { Shear Force } \\
\text { (kip/ft) AP-LBS } \\
\text { BEC }\end{array}$ \\
\hline 2 & 67.734 & 28.410 & 27.280 & 5.026 & 8.007 & 9.328 & 1.895 \\
\hline 3 & 105.676 & 28.760 & 26.590 & 7.202 & 6.934 & 8.591 & 1.441 \\
\hline 4 & 137.076 & 25.730 & 25.690 & 8.584 & 5.602 & 6.011 & 1.837 \\
\hline 6 & 182.856 & 25.140 & 23.480 & 9.875 & 3.348 & 5.084 & 2.117 \\
\hline 8 & 226.570 & 25.340 & 20.830 & 11.102 & 2.079 & 5.515 & 0.917 \\
\hline 9 & 275.574 & 25.430 & 18.300 & 13.323 & 1.444 & 3.511 & 0.810 \\
\hline 11 & 325.697 & 25.100 & 16.510 & 15.527 & 1.309 & 3.293 & 0.723 \\
\hline 13 & 372.312 & 34.915 & 14.980 & 18.140 & 2.300 & 3.340 & 0.774 \\
\hline 17 & 423.434 & 14181 & 13910 & 20664 & 1185 & 4269 & 1344 \\
\hline 20 & 468.315 & 73.130 & 12560 & 24.358 & 5.370 & 7.110 & 2.100 \\
\hline 22 & 515.319 & 24.770 & 11450 & 27.695 & 2.157 & 10.730 & 1381 \\
\hline 24 & 553.722 & 11.912 & 11790 & 27094 & 0.926 & 4.840 & 2.217 \\
\hline 26 & 593.805 & 9230 & 12990 & $27 B / 3$ & 0156 & 0741 & 0799 \\
\hline 30 & 644.355 & 8.040 & 12.710 & 29.012 & 0.151 & 0.742 & 0.164 \\
\hline 33 & 693.605 & 8.510 & 12.650 & 30.562 & 0.078 & 0.303 & 0.101 \\
\hline 35 & 740.705 & 8.900 & 13.130 & 32.212 & 0.053 & 0.152 & 0.061 \\
\hline $3 B$ & 786.205 & 7070 & 15260 & 33702 & 0076 & 0394 & 0097 \\
\hline 41 & 844.605 & 6870 & 18.140 & 36.263 & 0.137 & 0.690 & 0.191 \\
\hline 43 & 901.355 & 3.230 & 8.220 & 17.952 & 0.094 & 0.530 & 0855 \\
\hline 46 & 932.355 & $29 \mathrm{BEO}$ & $18 B 20$ & 39720 & 0268 & 1167 & 1021 \\
\hline 48 & 1007.355 & 17689 & 5082 & 11.488 & 1.743 & 7.860 & 4540 \\
\hline 51 & 1053.855 & 56204 & 6798 & 18.290 & 1.738 & 7890 & 4.170 \\
\hline 53 & 1086.855 & 15.311 & 6.952 & 11.777 & 0.469 & 1289 & 0.945 \\
\hline 55 & 1105.855 & 45073 & 6723 & $10 B 40$ & 1228 & $150 \mathrm{~B}$ & 0722 \\
\hline 57 & 1147.355 & 9299 & 5777 & 6374 & 0161 & $049 B$ & 0473 \\
\hline 58 & 1207.355 & 3.671 & 3.735 & 3.235 & 0,008 & 0,044 & 0094 \\
\hline 59 & 1267.355 & 2.687 & 3.026 & 2.186 & 0.015 & 0.052 & 0072 \\
\hline 60 & 1327.355 & 3.128 & 2.536 & 1.796 & 0019 & 0.056 & 0076 \\
\hline 61 & 1387.355 & 1625 & 2252 & $137 \mathrm{~B}$ & 0011 & 0031 & $00 B 2$ \\
\hline 62 & 1449.355 & 3.973 & 3.214 & 1.463 & 0.101 & 0.151 & 0.149 \\
\hline
\end{tabular}


RPP-RPT-32239, Rev. 1

M\&D-2008-005-CALC-001, Rev. 1

Table F.4. LBS-BEC Primary Tank Stresses, Shell Top, Gravity Load Only

AP Primary Tank, Lower Bound Soil, Gravity Only, Best Estimate Tank Concrete, 460 in. Waste Level at 1.83 SpG

\begin{tabular}{|c|c|c|c|c|c|}
\hline \multirow[b]{2}{*}{$\begin{array}{l}\text { M\&D } \\
\text { Starting } \\
\text { Element } \\
\text { No. }\end{array}$} & \multirow[b]{2}{*}{ Path (in.) } & \multicolumn{4}{|c|}{ Shell Top Surface (inside - waste side) } \\
\hline & & $\begin{array}{c}\text { AP-460-LBS-BEC } \\
\text { Gravity Hoop Stress } \\
\text { (lbs/in^2) Top }\end{array}$ & $\begin{array}{l}\text { AP-460-LBS-BEC } \\
\text { Gravity Meridional } \\
\text { Stress (lbs/in^2) Top }\end{array}$ & $\begin{array}{c}\text { AP-460-LBS-BEC } \\
\text { Gravity Stress } \\
\text { Intensity (lbs/in^2) } \\
\text { Top }\end{array}$ & $\begin{array}{c}\text { AP-460-LBS-BEC } \\
\text { Gravity In-Plane } \\
\text { Shear Stress } \\
\text { (lbs/in^2) Top }\end{array}$ \\
\hline 762 & 67.33 & -1781.94 & -1527.78 & 1781.94 & 6.02 \\
\hline 782 & 105.04 & -1776.39 & -2723.61 & 2724.31 & 12.41 \\
\hline 802 & 136.24 & -1736.81 & -1931.94 & 1932.64 & 14.94 \\
\hline 822 & 181.83 & -1300.69 & -2182.64 & 2182.64 & 11.91 \\
\hline 842 & 225.10 & -1373.61 & -1329.86 & 1373.61 & 2.92 \\
\hline 862 & 273.66 & -797.22 & -1549.31 & 1549.31 & 11.38 \\
\hline 882 & 323.27 & -680.90 & -796.53 & 797.92 & 10.77 \\
\hline 902 & 369.20 & 150.07 & -794.44 & 944.44 & 7.01 \\
\hline 922 & 419.20 & 934.72 & -220.07 & 1155.56 & -3.17 \\
\hline 942 & 444.31 & 745.14 & -2059.72 & 2804.86 & -1.32 \\
\hline 962 & 458.66 & 683.40 & 1363.89 & 1363.89 & -0.90 \\
\hline 982 & 473.08 & 608.68 & 1151.39 & 1151.39 & -0.88 \\
\hline 1002 & 484.80 & 1454.86 & -383.82 & 1838.89 & -0.88 \\
\hline 1022 & 502.48 & 3062.50 & -12.06 & 3079.86 & -0.85 \\
\hline 1042 & 526.48 & 4693.75 & 112.57 & 4693.75 & -0.76 \\
\hline 1062 & 550.48 & 6315.28 & -36.29 & 6352.78 & -0.54 \\
\hline 1082 & 574.60 & 7881.94 & 192.99 & 7881.94 & -0.38 \\
\hline 1102 & 598.28 & 9569.44 & -83.82 & 9652.78 & -0.25 \\
\hline 1122 & 621.38 & 11125.00 & 115.49 & 11125.00 & -0.19 \\
\hline 1142 & 644.48 & 12694.44 & -12.06 & 12708.33 & -0.17 \\
\hline 1162 & 667.63 & 13791.67 & -360.76 & 14152.78 & -0.22 \\
\hline 1182 & 690.78 & 14201.39 & 409.86 & 14201.39 & -0.22 \\
\hline 1202 & 713.88 & 15201.39 & 146.88 & 15201.39 & -0.21 \\
\hline 1222 & 736.98 & 16562.50 & -348.06 & 1690972 & -0.24 \\
\hline 1242 & 760.13 & 16506.94 & -729.17 & 17236.11 & -0.28 \\
\hline 1262 & 782.53 & 15270.83 & 1013.89 & 15270.83 & -0.24 \\
\hline 1282 & 804.13 & 14930.56 & 327.99 & 14930.56 & 0.30 \\
\hline 1302 & 825.73 & 15770.83 & -31.66 & 15805.56 & 0.38 \\
\hline 1322 & 847.33 & 17138.89 & 348.54 & 17138.89 & -0.35 \\
\hline 1342 & 868.87 & 17541.67 & -1929.17 & 19472.22 & -0.73 \\
\hline 1362 & 892.10 & 13256.94 & -3013.19 & 16277.78 & 1.10 \\
\hline 1382 & 909.20 & 3752.08 & -9562.50 & 13326.39 & 1.33 \\
\hline 1402 & 918.38 & 3770.83 & 5961.81 & 6009.03 & -1.79 \\
\hline 1460 & 930.48 & 3492.36 & 990972 & 9958.33 & -508.47 \\
\hline 1442 & 949.48 & 192.85 & -497.22 & 695.83 & 54.65 \\
\hline 1462 & 990.98 & 605.28 & 93750 & 939.58 & -26.92 \\
\hline 1482 & 1050.98 & 422.78 & 487.78 & 583.26 & -6.02 \\
\hline 1502 & 1110.98 & 419.65 & 582.36 & 583.26 & -13.95 \\
\hline 1522 & 1170.98 & 29764 & 233.75 & 298.06 & 6.37 \\
\hline 1542 & 1230.98 & 351.53 & 416.60 & 417.01 & -6.35 \\
\hline 1562 & 1292.98 & 286.39 & 306.60 & 307.01 & -2.99 \\
\hline
\end{tabular}

Note 1: Meridonal, Hoop, and Shear Stresses are Reversed in Highlighted Sections

(Floor) 
RPP-RPT-32239, Rev. 1

M\&D-2008-005-CALC-001, Rev. 1

Table F.5. LBS-BEC Primary Tank Stresses, Shell Middle, Gravity Load Only

\begin{tabular}{|c|c|c|c|c|c|}
\hline \multirow[b]{2}{*}{$\begin{array}{l}\text { M\&D } \\
\text { Starting } \\
\text { Element } \\
\text { No. }\end{array}$} & \multirow[b]{2}{*}{ Path (in.) } & \multicolumn{4}{|c|}{$\begin{array}{l}\text { AP Primary Tank, Lower Bound Soi } \\
\text { Estimate Tank Concrete, } 460 \text { in. Was } \\
\text { Shell Mid-Plane }\end{array}$} \\
\hline & & $\begin{array}{l}\text { AP-460-LBS-BEC } \\
\text { Gravity Hoop Stress } \\
\text { (lbs/in^2) Mid }\end{array}$ & $\begin{array}{l}\text { AP-460-LBS-BEC } \\
\text { Gravity Meridional } \\
\text { Stress (lbs/in^2) Mid }\end{array}$ & $\begin{array}{l}\text { AP-460-LBS-BEC } \\
\text { Gravity Stress } \\
\text { Intensity (lbs/in^2) } \\
\text { Mid }\end{array}$ & $\begin{array}{l}\text { AP-460-LBS-BEC } \\
\text { Gravity In-Plane } \\
\text { Shear Stress } \\
\text { (lbs/in^2) Mid }\end{array}$ \\
\hline 762 & 67.33 & -1885.42 & -1821.53 & 1885.42 & 5.55 \\
\hline 782 & 105.04 & -1700.69 & -2415.28 & 2415.28 & 11.76 \\
\hline 802 & 136.24 & -1842.36 & -2250.69 & 2251.39 & 13.85 \\
\hline \begin{tabular}{l|l|}
822 \\
\end{tabular} & 181.83 & -1247.22 & -1988.19 & 1988.19 & 10.88 \\
\hline 842 & 225.10 & -1495.83 & -1725.69 & 1725.69 & 2.48 \\
\hline 862 & 273.66 & -764.58 & -1418.75 & 1418.75 & 10.67 \\
\hline 882 & 323.27 & -765.28 & -1068.75 & 1070.14 & 10.36 \\
\hline 902 & 369.20 & 161.94 & -729.17 & 89167 & 6.85 \\
\hline 922 & 419.20 & 906.25 & -298.26 & 1204.86 & -3.20 \\
\hline 942 & 444.31 & 1394.44 & 65.06 & 1409.72 & -1.35 \\
\hline 962 & 458.66 & 314.31 & 86.88 & 314.93 & -0.96 \\
\hline 982 & 473.08 & 281.88 & 80.69 & 283.68 & -0.90 \\
\hline 1002 & 484.80 & 1590.28 & 76.60 & 1592.36 & -0.86 \\
\hline 1022 & 502.48 & 3087.50 & 72.43 & 3088.89 & -0.78 \\
\hline 1042 & 526.48 & 4679.17 & 65.99 & 4679.86 & -0.69 \\
\hline 1062 & 550.48 & 6343.75 & 59.24 & 6344.44 & -0.50 \\
\hline 1082 & 574.60 & 7840.28 & 52.47 & 7840.28 & -0.36 \\
\hline 1102 & 598.28 & 9611.11 & 45.78 & 9611.11 & -0.24 \\
\hline 1122 & 621.38 & 11097.22 & 39.27 & 11097.22 & -0.19 \\
\hline 1142 & 644.48 & 12701.39 & 32.75 & 12708.33 & -0.16 \\
\hline 1162 & 667.63 & 13909.72 & 26.19 & 13909.72 & -0.20 \\
\hline 1182 & 690.78 & 14083.33 & 16.78 & 14083.33 & -0.19 \\
\hline 1202 & 713.88 & 15159.72 & 10.22 & 15159.72 & -0.19 \\
\hline 1222 & 736.98 & 16666.67 & 3.67 & 16680.56 & -0.23 \\
\hline 1242 & 760.13 & 16722.22 & -3.90 & 16729.17 & -0.28 \\
\hline 1262 & 782.53 & 14965.28 & -8.31 & 14979.17 & -0.21 \\
\hline 1282 & 804.13 & 14826.39 & -14.41 & 14840.28 & -0.29 \\
\hline 1302 & 825.73 & 15770.83 & -20.58 & 15791.67 & 0.36 \\
\hline 1322 & 847.33 & 17027.78 & -26.76 & 17048.61 & -0.36 \\
\hline 1342 & 868.87 & 18111.11 & -32.76 & 18159.72 & -0.58 \\
\hline 1362 & 892.10 & 14152.78 & -33.93 & 14201.39 & 0.87 \\
\hline 1382 & 909.20 & 6488.89 & -44.09 & 6660.42 & 1.05 \\
\hline 1402 & 918.38 & 1690.28 & 122.43 & 2010.42 & -1.12 \\
\hline 1460 & 930.48 & 448.82 & 384.86 & 570.21 & 5.61 \\
\hline 1442 & 949.48 & 464.79 & 431.46 & 465.56 & 2.98 \\
\hline 1462 & 990.98 & 543.26 & 755.56 & 756.94 & -1738 \\
\hline 1482 & 1050.98 & 454.17 & 597.50 & 459.58 & -12.31 \\
\hline 1502 & 1110.98 & 381.39 & 459.10 & 459.58 & -7.23 \\
\hline 1522 & 1170.98 & 331.25 & 349.24 & 34938 & -2.64 \\
\hline 1542 & 1230.98 & 317.71 & 324.38 & 324.58 & -1.79 \\
\hline 1562 & 1292.98 & 296.60 & 358.19 & 358.82 & -6.17 \\
\hline
\end{tabular}


RPP-RPT-32239, Rev. 1

M\&D-2008-005-CALC-001, Rev. 1

Table F.6. LBS-BEC Primary Tank Stresses, Shell Bottom, Gravity Load Only

\begin{tabular}{|c|c|c|c|c|c|}
\hline \multirow[b]{2}{*}{$\begin{array}{l}\text { M\&D } \\
\text { Starting } \\
\text { Element } \\
\text { No. }\end{array}$} & \multirow[b]{2}{*}{ Path (in.) } & \multicolumn{4}{|c|}{$\begin{array}{l}\text { AP Primary Tank, Lower Bound Soil, Gravity Only, } \\
\text { Estimate Tank Concrete, } 460 \text { in. Waste Level at } 1.8 \\
\text { Shell Bottom Surface (outside - away from waste) }\end{array}$} \\
\hline & & $\begin{array}{l}\text { AP-460-LBS-BEC } \\
\text { Gravity Hoop Stress } \\
\text { (lbs/in^2) Bot }\end{array}$ & $\begin{array}{l}\text { AP-460-LBS-BEC } \\
\text { Gravity Meridional } \\
\text { Stress (lbs/in^2) Bot }\end{array}$ & $\begin{array}{c}\text { AP-460-LBS-BEC } \\
\text { Gravity Stress } \\
\text { Intensity (lbs/in^2) } \\
\text { Bot }\end{array}$ & $\begin{array}{c}\text { AP-460-LBS-BEC } \\
\text { Gravity In-Plane } \\
\text { Shear Stress } \\
\text { (lbs/in^^2) Bot }\end{array}$ \\
\hline 762 & 67.33 & -1996.53 & -2115.28 & 211528 & 5.93 \\
\hline 782 & 105.04 & -1624.31 & -2106.25 & 2106.94 & -11.19 \\
\hline 802 & 136.24 & -194722 & -256944 & 2570.14 & 13.06 \\
\hline 822 & 181.83 & -1193.75 & -179375 & 179375 & -10.11 \\
\hline 842 & 225.10 & -1618.75 & -2122.22 & 2122.22 & 2.20 \\
\hline 862 & 273.66 & -731.94 & -1288.19 & 1288.19 & 9.97 \\
\hline 882 & 323.27 & -850.00 & -1340.97 & 1342.36 & 9.95 \\
\hline 902 & 369.20 & 173.82 & -664.38 & 838.19 & 6.69 \\
\hline 922 & 419.20 & 878.47 & -376.46 & 1254.86 & -3.23 \\
\hline 942 & 444.31 & 2043.06 & 2188.19 & 218889 & -1.37 \\
\hline 962 & 458.66 & -62.10 & -1190.28 & 1190.97 & -1.02 \\
\hline 982 & 473.08 & -49.34 & -98958 & 99028 & -0.93 \\
\hline 1002 & 484.80 & 1726.39 & 536.18 & 1726.39 & -0.84 \\
\hline 1022 & 502.48 & 3112.50 & 15660 & 3113.19 & -0.71 \\
\hline 1042 & 526.48 & 4665.97 & 19.58 & 4668.06 & -0.62 \\
\hline 1062 & 550.48 & 6372.22 & 154.03 & 6372.92 & -0.47 \\
\hline 1082 & 574.60 & 7798.61 & -89.03 & 7888.89 & -0.34 \\
\hline 1102 & 598.28 & 9645.83 & 174.44 & 9645.83 & -0.23 \\
\hline 1122 & 621.38 & 11076.39 & -38.00 & 11118.06 & -0.19 \\
\hline 1142 & 644.48 & 12715.28 & 76.46 & 12715.28 & -0.16 \\
\hline 1162 & 667.63 & 14027.78 & 41215 & 14027.78 & -0.19 \\
\hline 1182 & 690.78 & 13965.28 & -37736 & 14340.28 & -0.17 \\
\hline 1202 & 713.88 & 15118.06 & -127.36 & 15243.06 & -0.19 \\
\hline 1222 & 736.98 & 1677778 & 354.72 & 16777.78 & -0.22 \\
\hline 1242 & 760.13 & 16937.50 & 722.92 & 1693750 & -0.27 \\
\hline 1262 & 782.53 & 1465972 & -1029.86 & 1568750 & -0.22 \\
\hline 1282 & 804.13 & 14722.22 & -356.32 & 15076.39 & -0.28 \\
\hline 1302 & 825.73 & 15777.78 & -8.72 & 15784.72 & 0.35 \\
\hline 1322 & 847.33 & 16909.72 & -40125 & 17312.50 & -0.37 \\
\hline 1342 & 868.87 & 18680.56 & 1867.36 & 18680.56 & -0.43 \\
\hline 1362 & 892.10 & 15048.61 & 2948.61 & 15048.61 & 0.63 \\
\hline 1382 & 909.20 & 9229.17 & 9479.17 & 9486.11 & 0.76 \\
\hline 1402 & 918.38 & -393.13 & -5716.67 & 5766.67 & -0.50 \\
\hline 1460 & 930.48 & -2600.69 & -9138.89 & 918750 & 518.47 \\
\hline 1442 & 949.48 & 73750 & 1358.33 & 136250 & -49.54 \\
\hline 1462 & 990.98 & 48139 & 574.65 & 575.28 & -7.85 \\
\hline 1482 & 1050.98 & 485.83 & 708.33 & 343.40 & -18.61 \\
\hline 1502 & 1110.98 & 343.33 & 33736 & 343.40 & 1.64 \\
\hline 1522 & 1170.98 & 365.14 & 46653 & 46708 & -9.22 \\
\hline 1542 & 1230.98 & 284.58 & 234.31 & 284.93 & 5.36 \\
\hline 1562 & 1292.98 & 308.13 & 412.15 & 41285 & -9.89 \\
\hline
\end{tabular}


RPP-RPT-32239, Rev. 1

M\&D-2008-005-CALC-001, Rev. 1

Table F.7. LBS-BEC Primary Tank Stresses, Shell Top, Gravity Plus Seismic Load

AP Primary Tank, Lower Bound Soil, Horizontal and Vertical Seismic, Best Estimate Tank Concrete, 460 in. Waste Level at 1.83 SpG

\begin{tabular}{|c|c|c|c|c|c|}
\hline \multirow[b]{2}{*}{$\begin{array}{c}\text { M\&D } \\
\text { Starting } \\
\text { M\&D } \\
\text { Element } \\
\text { No. }\end{array}$} & \multirow[b]{2}{*}{ Path (in.) } & \multicolumn{4}{|c|}{ Shell Top Surface (inside - waste side) } \\
\hline & & $\begin{array}{c}\text { AP-460-LBS-BEC } \\
\text { Seismic Hoop Stress } \\
\text { (Ibsin`^2) Top }\end{array}$ & $\begin{array}{l}\text { AP-460-LBS-BEC } \\
\text { Seismic Meridional } \\
\text { Stress (lbs/in^2) Top }\end{array}$ & $\begin{array}{l}\text { AP-460-LBS-BEC } \\
\text { Seismic Stress } \\
\text { Intensity (lbs/in^2) } \\
\text { Top }\end{array}$ & $\begin{array}{c}\text { AP-460-LBS-BEC } \\
\text { Seismic In-Plane } \\
\text { Shear Stress } \\
(\text { lbs/in^2) Top }\end{array}$ \\
\hline 762 & 67.33 & -2589.58 & -2490.97 & 2590.28 & -217.99 \\
\hline 782 & 105.04 & -2638.19 & -4195.83 & 4197.22 & -398.89 \\
\hline 802 & 136.24 & -2787.50 & -2940.28 & 2940.28 & -440.56 \\
\hline 822 & 181.83 & -1931.94 & -3304.86 & 3305.56 & -458.40 \\
\hline 842 & 225.10 & -2497.22 & -2348.61 & 2498.61 & 528.96 \\
\hline 862 & 273.66 & -1672.92 & -2555.56 & 2555.56 & -741.67 \\
\hline 882 & 323.27 & -2430.56 & -1672.92 & 2702.78 & 1228.47 \\
\hline 902 & 369.20 & 2236.81 & -2111.81 & 3995.83 & 1826.39 \\
\hline 922 & 419.20 & 415139 & -1132.64 & 6142.36 & 2977.08 \\
\hline 942 & 444.31 & 5570.14 & -5634.03 & 6727.08 & 2870.83 \\
\hline 962 & 458.66 & 6760.42 & 6794.44 & 11680.56 & 2870.14 \\
\hline 982 & 473.08 & 679722 & 6912.50 & 12368.06 & 3075.69 \\
\hline 1002 & 484.80 & 5085.42 & -2000.00 & 6875.00 & 3179.17 \\
\hline 1022 & 502.48 & 5620.14 & 831.25 & 7180.56 & 3113.89 \\
\hline 1042 & 526.48 & 9631.94 & 1054.17 & 9638.89 & 2927.78 \\
\hline 1062 & 550.48 & 12083.33 & -1122.92 & 12083.33 & 2690.28 \\
\hline 1082 & 574.60 & 14458.33 & 1574.31 & 14465.28 & 2397.92 \\
\hline 1102 & 598.28 & 17083.33 & -1417.36 & 17083.33 & 2067.36 \\
\hline 1122 & 621.38 & 19479.17 & 163.3 .33 & 19479.17 & 1693.06 \\
\hline 1142 & 644.48 & 21784.72 & 1498.61 & 21784.72 & -1311.11 \\
\hline 1162 & 667.63 & 23083.33 & -1811.81 & 23083.33 & 1018.06 \\
\hline 1182 & 690.78 & 23201.39 & 2072.92 & 23201.39 & 1000.00 \\
\hline 1202 & 713.88 & 24291.67 & 1713.19 & 24291.67 & 1215.28 \\
\hline 1222 & 736.98 & 25881.94 & -1696.53 & 25881.94 & 1472.92 \\
\hline 1242 & 760.13 & 25256.94 & -953.47 & 25375.00 & 1765.97 \\
\hline 1262 & 782.53 & 22868.06 & 2377.08 & 22868.06 & 1541.67 \\
\hline 1282 & 804.13 & 21902.78 & 1436.81 & 21902.78 & 1755.56 \\
\hline 1302 & 825.73 & 22756.94 & 950.69 & 22756.94 & 1997.22 \\
\hline 1322 & 847.33 & 24437.50 & 1340.97 & 24444.44 & 2259.03 \\
\hline 1342 & 868.87 & 24465.28 & -2303.47 & 27347.22 & 2551.39 \\
\hline 1362 & 892.10 & 17284.72 & -360000 & 22770.83 & 2466.67 \\
\hline 1382 & 909.20 & 5804.86 & -11416.67 & 20895.83 & 2491.67 \\
\hline 1402 & 918.38 & 5911.11 & 10611.11 & 10638.89 & 2483.33 \\
\hline 1460 & 930.48 & 6288.19 & 17541.67 & 17625.00 & -2960.42 \\
\hline 1442 & 949.48 & 4259.72 & -1142.36 & 4614.58 & -2118.75 \\
\hline 1462 & 990.98 & 3768.75 & 1581.25 & 6131.94 & -3061.11 \\
\hline 1482 & 1050.98 & 2843.06 & 881.94 & 2379.86 & -1863.19 \\
\hline 1502 & 1110.98 & 2218.06 & 812.50 & 2379.86 & -1189.58 \\
\hline 1522 & 1170.98 & 1658.33 & 553.96 & 1660.42 & -768.06 \\
\hline 1542 & 1230.98 & 1253.47 & 629.93 & 1254.86 & -491.11 \\
\hline 1562 & 1292.98 & 80903 & 544.17 & 809.03 & -252.43 \\
\hline
\end{tabular}


RPP-RPT-32239, Rev. 1

M\&D-2008-005-CALC-001, Rev. 1

Table F.8. LBS-BEC Primary Tank Stresses, Shell Middle, Gravity Plus Seismic Load

\begin{tabular}{|c|c|c|c|c|c|}
\hline \multirow[b]{3}{*}{$\begin{array}{c}\text { M\&D } \\
\text { Starting } \\
\text { M\&D } \\
\text { Element } \\
\text { No. }\end{array}$} & \multirow[b]{3}{*}{ Path (in.) } & \multicolumn{4}{|c|}{$\begin{array}{c}\text { AP Primary Tank, Lower Bound Soil, Horizontal and Vertical } \\
\text { Seismic, Best Estimate Tank Concrete, } 460 \text { in. Waste Level at } \\
1.83 \mathrm{SpG}\end{array}$} \\
\hline & & \multicolumn{4}{|c|}{ Shell Mid-Plane } \\
\hline & & $\begin{array}{c}\text { AP-460-LBS-BEC } \\
\text { Seismic Hoop Stress } \\
\text { (lbs/in^2) Mid }\end{array}$ & $\begin{array}{c}\text { AP-460-LBS-BEC } \\
\text { Seismic Meridional } \\
\text { Stress (lbs/in^2) Mid }\end{array}$ & $\begin{array}{l}\text { AP-460-LBS-BEC } \\
\text { Seismic Stress } \\
\text { Intensity (lbs/in^2) } \\
\text { Mid }\end{array}$ & $\begin{array}{l}\text { AP-460-LBS-BEC } \\
\text { Seismic In-Plane } \\
\text { Shear Stress } \\
\text { (lbs/in^2) Mid }\end{array}$ \\
\hline 762 & 67.33 & -288750 & -247361 & 2888.19 & -218.47 \\
\hline 782 & 105.04 & -2431.25 & -3298.61 & 3360.00 & -393.82 \\
\hline 802 & 136.24 & -3097.22 & -3110.42 & 3163.89 & -436.18 \\
\hline 822 & 181.83 & -1827.08 & -2778.47 & 2778.47 & -454.44 \\
\hline 842 & 225.10 & -287292 & -2459.03 & 2876.39 & -527.78 \\
\hline 862 & 273.66 & -1611.81 & -214236 & 2142.36 & $-f 40.9 f$ \\
\hline 882 & 323.27 & -2690.28 & -1870.83 & $26 \mathrm{C5} 14$ & 1229.86 \\
\hline 902 & 369.20 & 2203.47 & -1663.89 & 3947.22 & 1825.69 \\
\hline 922 & 419.20 & 4165.28 & -1413.19 & 6178.47 & 2979.17 \\
\hline 942 & 444.31 & 5346.53 & 1000.00 & 6381.25 & 2913.89 \\
\hline 962 & 458.66 & 7277.78 & 988.19 & 7902.78 & 2899.31 \\
\hline 982 & 473.08 & 7986.11 & 922.92 & 8784.72 & 3024.31 \\
\hline 1002 & 484.80 & 5050.00 & 865.28 & 6704.17 & 3117.36 \\
\hline 1022 & 502.48 & 6075.69 & 938.89 & 7076.39 & 3088.19 \\
\hline 1042 & 526.48 & 9645.83 & 1052.08 & 9645.83 & 2921.53 \\
\hline 1062 & 550.48 & 12118.06 & 118681 & 12125.00 & 2684.72 \\
\hline 1082 & 574.60 & 14395.83 & 1338.89 & 14402.78 & 2390.97 \\
\hline 1102 & 598.28 & 17166.67 & 1475.69 & 17173.61 & 2059.03 \\
\hline 1122 & 621.38 & 19472.22 & 1590.28 & 19472.22 & 1686.11 \\
\hline 1142 & 644.48 & 21840.28 & 1682.64 & 21840.28 & -1306.94 \\
\hline 1162 & 667.63 & 23284.72 & 1753.47 & 23284.72 & 1018.06 \\
\hline 1182 & 690.78 & 23034.72 & 1572.92 & 23034.72 & 996.53 \\
\hline 1202 & 713.88 & 24250.00 & 158681 & 24256.94 & 121389 \\
\hline 1222 & 736.98 & 26069.44 & 1576.39 & 26069.44 & 1470.83 \\
\hline 1242 & 760.13 & 25611.11 & 1536.11 & 25611.11 & 1747.22 \\
\hline 1262 & 782.53 & 22479.17 & 1078.47 & 22479.17 & 1515.28 \\
\hline 1282 & 804.13 & 21798.61 & 1015.97 & 21798.61 & 1740.97 \\
\hline 1302 & 825.73 & 22798.61 & 934.03 & 22798.61 & 1998.61 \\
\hline 1322 & 847.33 & 24305.56 & 834.72 & 24305.56 & 2263.89 \\
\hline 1342 & 868.87 & 25444.44 & -706.25 & 25451.39 & 2546.53 \\
\hline 1362 & 892.10 & 18756.94 & -514.72 & 18868.06 & 2402.08 \\
\hline 1382 & 909.20 & 8715.28 & -494.38 & 9145.83 & 2320.83 \\
\hline 1402 & 918.38 & 526389 & 517.71 & 5650.00 & 2313.19 \\
\hline 1460 & 930.48 & 4431.94 & 846.53 & 4701.39 & -2305.56 \\
\hline 1442 & 949.48 & 4218.06 & 861.81 & 4424.31 & -2190.97 \\
\hline 1462 & 990.98 & 372222 & 1319.44 & 6122.22 & -3052.78 \\
\hline 1482 & 1050.98 & 2847.22 & 902.08 & 2374.31 & -1870.14 \\
\hline 1502 & 1110.98 & 2193.06 & 654.10 & 2374.31 & -1184.03 \\
\hline 1522 & 1170.98 & 1670.14 & 519.72 & 1672.22 & -775.69 \\
\hline 1542 & 1230.98 & 1235.42 & 487.29 & 1236.81 & -485.83 \\
\hline 1562 & 1292.98 & 806.94 & 533.26 & 806.94 & -255.56 \\
\hline
\end{tabular}


RPP-RPT-32239, Rev. 1

M\&D-2008-005-CALC-001, Rev. 1

Table F.9. LBS-BEC Primary Tank Stresses, Shell Bottom, Gravity Plus Seismic Load

AP Primary Tank, Lower Bound Soil, Horizontal and Vertical Seismic, Best Estimate Tank Concrete, 460 in. Waste Level at $1.83 \mathrm{SpG}$

\begin{tabular}{|c|c|c|c|c|c|}
\hline \multirow[b]{2}{*}{$\begin{array}{l}\text { M\&D } \\
\text { Starting } \\
\text { M\&D } \\
\text { Element } \\
\text { No. }\end{array}$} & \multirow[b]{2}{*}{ Path (in.) } & \multicolumn{4}{|c|}{ Shell Bottom Surface (outside - away from waste) } \\
\hline & & $\begin{array}{l}\text { AP-460-LBS-BEC } \\
\text { Seismic Hoop Stress } \\
\text { (lbs/in^2) Bot }\end{array}$ & $\begin{array}{l}\text { AP-460-LBS-BEC } \\
\text { Seismic Meridional } \\
\text { Stress (lbs/in^2) Bot }\end{array}$ & $\begin{array}{l}\text { AP-460-LBS-BEC } \\
\text { Seismic Stress } \\
\text { Intensity (lbs/in^^2) } \\
\text { Bot }\end{array}$ & $\begin{array}{c}\text { AP-460-LBS-BEC } \\
\text { Seismic In-Plane } \\
\text { Shear Stress } \\
(\text { lbs/in^2) Bot }\end{array}$ \\
\hline 762 & 67.33 & -3185.42 & -3328.47 & 3328.47 & -219.58 \\
\hline 782 & 105.04 & -2347.92 & $-3218,06$ & 3218.75 & -388.68 \\
\hline 802 & 136.24 & -340694 & -4052.78 & 4054.86 & -431.81 \\
\hline 822 & 181.83 & -1738.89 & -2603.47 & 2604.17 & -450.49 \\
\hline 842 & 225.10 & -3248.61 & -3630.56 & 3634.03 & -526.94 \\
\hline 862 & 273.66 & -1551.39 & -1970.14 & 1986.11 & -740.28 \\
\hline 882 & 323.27 & -2950.00 & -2849.31 & 2955.56 & 1230.56 \\
\hline 902 & 369.20 & 2170.14 & -1271.53 & 3902.08 & 1825.00 \\
\hline 922 & 419.20 & 4179.86 & -2270.14 & 6228.47 & 2981.94 \\
\hline 942 & 444.31 & 5568.06 & 7631.94 & 7631.94 & 2956.94 \\
\hline 962 & 458.66 & -8375.00 & -4968.75 & 8375.00 & 2928.47 \\
\hline 982 & 473.08 & -9388.89 & -5129.17 & 9395.83 & 2972.92 \\
\hline 1002 & 484.80 & 5075.00 & 2765.28 & 6566.67 & 3055.56 \\
\hline 1022 & 502.48 & 653125 & 2556.94 & 7020.83 & 3062.50 \\
\hline 1042 & 526.48 & 9652.78 & 1090.97 & 9659.72 & 2915.28 \\
\hline 1062 & 550.48 & 12159.72 & 1359.03 & 12159.72 & 2679.86 \\
\hline 1082 & 574.60 & 14333.33 & -1239.58 & 14333.33 & 2384.03 \\
\hline 1102 & 598.28 & 17256.94 & 1661.81 & 17256.94 & 2050.69 \\
\hline 1122 & 621.38 & 19465.28 & 1546.53 & 19472.22 & 1679.17 \\
\hline 1142 & 644.48 & 21902.78 & 1865.97 & 21902.78 & -1302.78 \\
\hline 1162 & 667.63 & 23493.06 & 2309.03 & 23493.06 & 1018.06 \\
\hline 1182 & 690.78 & 22861.11 & -1718.06 & 22861.11 & 993.06 \\
\hline 1202 & 713.88 & 24215.28 & -1627.08 & 24215.28 & 1212.50 \\
\hline 1222 & 736.98 & 26256.94 & 2054.17 & 26256.94 & 1468.75 \\
\hline 1242 & 760.13 & 25993.06 & 2539.58 & 25993.06 & 1740.97 \\
\hline 1262 & 782.53 & 22090.28 & -1786.11 & 22819.44 & 1488.19 \\
\hline 1282 & 804.13 & 21694.44 & -1235.42 & 21701.39 & 1738.89 \\
\hline 1302 & 825.73 & 22840.28 & -944.44 & 22840.28 & 2000.69 \\
\hline 1322 & 847.33 & 24166.67 & -1052.08 & 24291.67 & 2268.06 \\
\hline 1342 & 868.87 & 26423.61 & 4566.67 & 26423.61 & 2542.36 \\
\hline 1362 & 892.10 & 20444.44 & 5553.47 & 20451.39 & 233681 \\
\hline 1382 & 909.20 & 13333.33 & 17229.17 & 17229.17 & 2152.08 \\
\hline 1402 & 918.38 & -5414.58 & -9993.06 & 10069.44 & 2151.39 \\
\hline 1460 & 930.48 & -8708.33 & -16791.67 & 16875.00 & 2659.72 \\
\hline 1442 & 949.48 & 4232.64 & 2478.47 & 5154.17 & -2262.50 \\
\hline 1462 & 990.98 & 3676.39 & 1100.69 & 6115.28 & -3044.44 \\
\hline 1482 & 1050.98 & 285694 & 1075.69 & 2377.78 & -1877.08 \\
\hline 1502 & 1110.98 & 2170.14 & 697.22 & 2377.78 & -1178.47 \\
\hline 1522 & 1170.98 & 168194 & 672.99 & 1684.03 & -783.33 \\
\hline 1542 & 1230.98 & 1218.06 & 523.68 & 1219.44 & -480.56 \\
\hline 1562 & 1292.98 & 80625 & 621.81 & 807.64 & -258.75 \\
\hline
\end{tabular}

Note 1: Meridonal, Hoop, and Shear Stresses are Reversed in Highlighted Sections

(Floor) 
RPP-RPT-32239, Rev. 1

M\&D-2008-005-CALC-001, Rev. 1

Table F.10. LBS-BEC Primary Tank Stresses, Shell Top, Seismic Load Only

AP Primary Tank, Lower Bound Soil, Horizontal and Vertical Seismic, Best Estimate Tank Concrete, 460 in. Waste Level at 1.83 SpG

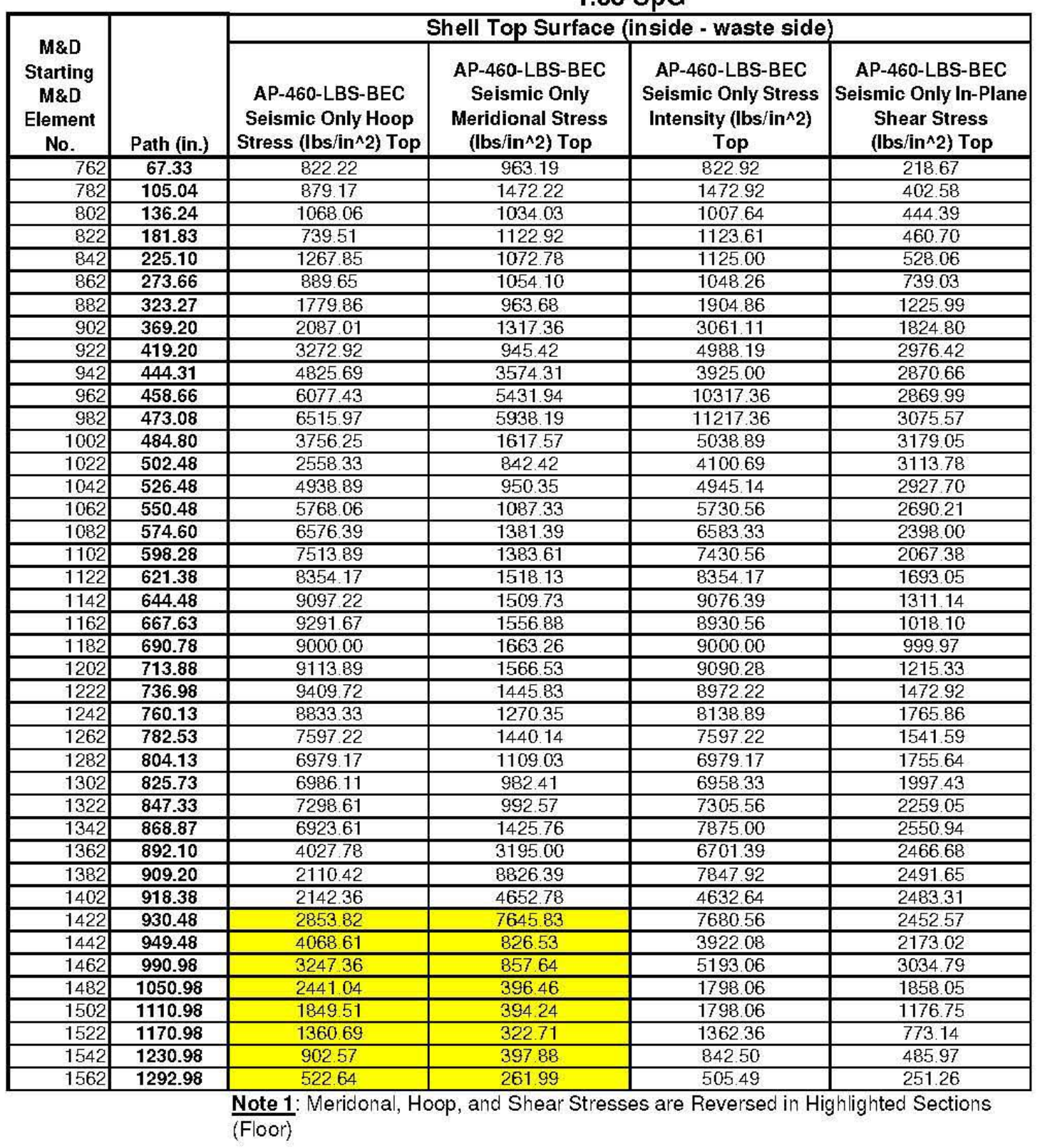


RPP-RPT-32239, Rev. 1

M\&D-2008-005-CALC-001, Rev. 1

Table F.11. LBS-BEC Primary Tank Stresses, Shell Middle, Seismic Load Only

AP Primary Tank, Lower Bound Soil, Horizontal and Vertical Seismic, Best Estimate Tank Concrete, 460 in. Waste Level at $1.83 \mathrm{SpG}$

\begin{tabular}{|c|c|c|c|c|c|}
\hline \multirow[b]{2}{*}{$\begin{array}{c}\text { M\&D } \\
\text { Starting } \\
\text { M\&D } \\
\text { Element } \\
\text { No. }\end{array}$} & \multirow[b]{2}{*}{ Path (in.) } & \multicolumn{4}{|c|}{ Shell Mid-Plane } \\
\hline & & $\begin{array}{l}\text { AP-460-LBS-BEC } \\
\text { Seismic Only Hoop } \\
\text { Stress (lbs/in^2) Mid }\end{array}$ & $\begin{array}{l}\text { AP-460-LBS-BEC } \\
\text { Seismic Only } \\
\text { Meridional Stress } \\
\text { (lbs/in^2) Mid }\end{array}$ & $\begin{array}{c}\text { AP-460-LBS-BEC } \\
\text { Seismic Only Stress } \\
\text { Intensity (lbs/in^2) } \\
\text { Mid }\end{array}$ & $\begin{array}{c}\text { AP-460-LBS-BEC } \\
\text { Seismic Only In-Plane } \\
\text { Shear Stress } \\
\text { (lbs:in^2) Mid }\end{array}$ \\
\hline 762 & 67.33 & 1009.72 & 652.08 & 1010.42 & 219.52 \\
\hline 782 & 105.04 & 795.14 & 883.33 & 884.72 & 397.11 \\
\hline 802 & 136.24 & 1270.83 & 859.72 & 934.03 & 439.95 \\
\hline 822 & 181.83 & 662.71 & 790.28 & 790.28 & 456.57 \\
\hline 842 & 225.10 & 1562.86 & 733.33 & 1150.69 & 527.06 \\
\hline 862 & 273.66 & 847.92 & 723.61 & 723.61 & 738.44 \\
\hline 882 & 323.27 & 1925.69 & 802.08 & 1625.00 & 1227.48 \\
\hline 902 & 369.20 & 204181 & 934.72 & 3065.28 & 1824.12 \\
\hline 922 & 419.20 & 336181 & 1114.93 & 4974.31 & 2978.50 \\
\hline 942 & 444.31 & 3952.78 & 979.13 & 4976.39 & 2913.69 \\
\hline 962 & 458.66 & 7061.11 & 933.75 & 7588.40 & 2899.13 \\
\hline 982 & 473.08 & 7932.15 & 870.76 & 8501.04 & 3024.17 \\
\hline 1002 & 484.80 & 3460.42 & 818.75 & 5113.19 & 3117.24 \\
\hline 1022 & 502.48 & 2988.89 & 891.04 & 3988.19 & 3088.09 \\
\hline 1042 & 526.48 & 4966.67 & 997.01 & 4965.97 & 2921.44 \\
\hline 1062 & 550.48 & 5774.31 & 1127.72 & 5780.56 & 2684.65 \\
\hline 1082 & 574.60 & 6555.56 & 1286.65 & 6562.50 & 2391.04 \\
\hline 1102 & 598.28 & 7555.56 & 1430.15 & 7562.50 & 205905 \\
\hline 1122 & 621.38 & 8375.00 & 1551.24 & 8375.00 & 1686.11 \\
\hline 1142 & 644.48 & 9138.89 & 1650.13 & 9131.94 & 1306.96 \\
\hline 1162 & 667.63 & 9375.00 & 1727.52 & 9375,00 & 1018.09 \\
\hline 1182 & 690.78 & 8951.39 & 1556.32 & 8951.39 & 996.52 \\
\hline 1202 & 713.88 & 9090.28 & 1576.75 & 9097.22 & 1213.93 \\
\hline 1222 & 736.98 & 9465.28 & 1572.93 & 9388.89 & 1470.83 \\
\hline 1242 & 760.13 & 8923.61 & 1539.23 & 8881.94 & 174714 \\
\hline 1262 & 782.53 & 7513.89 & 1086.20 & 7506.94 & 1515.23 \\
\hline 1282 & 804.13 & 6972.22 & 1029.85 & 6958.33 & 1741.04 \\
\hline 1302 & 825.73 & 7027.78 & 954.05 & 7006.94 & 1998.75 \\
\hline 1322 & 847.33 & 7277.78 & 860.89 & 7256.94 & 2263.88 \\
\hline 1342 & 868.87 & 7333.33 & 735.28 & 7291.67 & 2546.21 \\
\hline 1362 & 892.10 & 4750.00 & 520.01 & 4784.72 & 2402.10 \\
\hline 1382 & 909.20 & 258681 & 480.90 & 2668.75 & 2320.86 \\
\hline 1402 & 918.38 & 3575.00 & 395.49 & 3640.28 & 2313.23 \\
\hline 1422 & 930.48 & 4052.43 & 46167 & 4131.32 & 2310.35 \\
\hline 1442 & 949.48 & 3855.28 & 501.53 & 3960.83 & 2193.64 \\
\hline 1462 & 990.98 & 3234.93 & 716.50 & 5365.28 & 3035.92 \\
\hline 1482 & 1050.98 & 2446.74 & 423.40 & 1914.72 & 1858.76 \\
\hline 1502 & 1110.98 & 1835.76 & 304.93 & 1914.72 & 1177.85 \\
\hline 1522 & 1170.98 & 1338.96 & 302.61 & 1325.21 & 774.26 \\
\hline 1542 & 1230.98 & 917.71 & 286.72 & 914.93 & 485.29 \\
\hline 1562 & 1292.98 & 510.35 & 263.13 & 451.32 & 250.70 \\
\hline
\end{tabular}


RPP-RPT-32239, Rev. 1

M\&D-2008-005-CALC-001, Rev. 1

Table F.12. LBS-BEC Primary Tank Stresses, Shell Bottom, Seismic Load Only

AP Primary Tank, Lower Bound Soil, Horizontal and Vertical Seismic, Best Estimate Tank Concrete, 460 in. Waste Level at

1.83 SpG

\begin{tabular}{|c|c|c|c|c|c|}
\hline \multirow[b]{2}{*}{$\begin{array}{c}\text { M\&D } \\
\text { Starting } \\
\text { M\&D } \\
\text { Element } \\
\text { No. }\end{array}$} & \multirow[b]{2}{*}{ Path (in.) } & \multicolumn{4}{|c|}{ Shell Bottom Surface (outside - away from waste) } \\
\hline & & $\begin{array}{l}\text { AP-460-LBS-BEC } \\
\text { Seismic Only Hoop } \\
\text { Stress (lbs/in^2) Bot }\end{array}$ & $\begin{array}{l}\text { AP-460-LBS-BEC } \\
\text { Seismic Only } \\
\text { Meridional Stress } \\
\text { (lbs/in^2) Bot }\end{array}$ & $\begin{array}{c}\text { AP-460-LBS-BEC } \\
\text { Seismic Only Stress } \\
\text { Intensity (lbs/in^2) } \\
\text { Bot }\end{array}$ & $\begin{array}{c}\text { AP-460-LBS-BEC } \\
\text { Seismic Only In-Plane } \\
\text { Shear Stress } \\
\text { (lbsin^^2) Bot }\end{array}$ \\
\hline 762 & 67.33 & 1197.92 & 1213.89 & 1213.19 & 221.30 \\
\hline 782 & 105.04 & 776.39 & 1118.75 & 1116.67 & 391.57 \\
\hline 802 & 136.24 & 1476.04 & 1483.33 & 1485.42 & 435.51 \\
\hline 822 & 181.83 & 585.21 & 884.03 & 810.42 & 452.44 \\
\hline 842 & 225.10 & 1857.15 & 1572.29 & 1511.81 & 526.39 \\
\hline 862 & 273.66 & 819.44 & 784.17 & 704.86 & 737.84 \\
\hline 882 & 323.27 & 2201.39 & 1622.85 & 1613.19 & 1228.27 \\
\hline 902 & 369.20 & 1996.67 & 763.06 & 3069.44 & 1823.43 \\
\hline 922 & 419.20 & 3472.22 & 1893.68 & 4976.39 & 2981.27 \\
\hline 942 & 444.31 & 3525.00 & 5444.44 & 5443.75 & 2956.72 \\
\hline 962 & 458.66 & 8317.75 & 3779.17 & 7184.72 & 2928.27 \\
\hline 982 & 473.08 & 9341.40 & 4222.22 & 8406.25 & 2972.76 \\
\hline 1002 & 484.80 & 3350.00 & 2230.49 & 4841.67 & 3055.43 \\
\hline 1022 & 502.48 & 3419.44 & 2544.58 & 3908.33 & 3062.39 \\
\hline 1042 & 526.48 & 498750 & 1084.67 & 4991.67 & 2915.18 \\
\hline 1062 & 550.48 & 5787.50 & 1247.36 & 578750 & 2679.78 \\
\hline 1082 & 574.60 & 6534.72 & 1224.86 & 6444.44 & 2384.08 \\
\hline 1102 & 598.28 & 761111 & 1519.79 & 7611.11 & 2050.72 \\
\hline 1122 & 621.38 & 8388.89 & 1583.63 & 8361.11 & 1679.18 \\
\hline 1142 & 644.48 & 9187.50 & 1789.86 & 918750 & 1302.78 \\
\hline 1162 & 667.63 & 9465.28 & 1897.15 & 9465.28 & 1018.09 \\
\hline 1182 & 690.78 & 8895.83 & 1456.04 & 8520.83 & 993.06 \\
\hline 1202 & 713.88 & 9097.22 & 1586.25 & 8972.22 & 1212.53 \\
\hline 1222 & 736.98 & 9520.83 & 1699.72 & 9486.11 & 1468.75 \\
\hline 1242 & 760.13 & 9055.56 & 1838.89 & 9055.56 & 1740.92 \\
\hline 1262 & 782.53 & 7430.56 & 852.99 & 7131.94 & 1488.17 \\
\hline 1282 & 804.13 & 6972.22 & 962.92 & 6625.00 & 1739.00 \\
\hline 1302 & 825.73 & 7062.50 & 936.06 & 7055.56 & 2000.84 \\
\hline 1322 & 847.33 & 7256.94 & 729.86 & 6979.17 & 2268.18 \\
\hline 1342 & 868.87 & 7743.06 & 2747.92 & 7743.06 & 2542.49 \\
\hline 1362 & 892.10 & 5541.67 & 2696.25 & 5534.72 & 2336.83 \\
\hline 1382 & 909.20 & 4164.58 & 7976.39 & 7750.00 & 2152.15 \\
\hline 1402 & 918.38 & 5023.40 & 4653.47 & 4306.25 & 2151.49 \\
\hline 1422 & 930.48 & 6111.81 & 7659.72 & 7694.44 & 2214.10 \\
\hline 1442 & 949.48 & 3665.97 & 1407.90 & 3795.14 & 2213.51 \\
\hline 1462 & 990.98 & 3222.43 & 673.33 & 5540.00 & 3037.05 \\
\hline 1482 & 1050.98 & 2451.74 & 528.61 & 2036.74 & 1859.49 \\
\hline 1502 & 1110.98 & 1826.81 & 362.57 & 2036.74 & 1178.94 \\
\hline 1522 & 1170.98 & 1340.83 & 386.60 & 1220.90 & 775.38 \\
\hline 1542 & 1230.98 & 933.47 & 292.15 & 934.51 & 484.61 \\
\hline 1562 & 1292.98 & 523.33 & 400.88 & 398.68 & 250.22 \\
\hline
\end{tabular}


RPP-RPT-32239, Rev. 1

M\&D-2008-005-CALC-001, Rev. 1

Table F.13. LBS-BEC Anchor Bolt Forces, Gravity Load Only

\begin{tabular}{|c|c|c|c|c|c|c|c|c|c|c|c|}
\hline \multicolumn{12}{|c|}{$\begin{array}{l}\text { AP Primary Tank, Lowe } \\
\text { ANSYS MAXIMUMS BY RADIUS }\end{array}$} \\
\hline $\begin{array}{c}\text { M\&D } \\
\text { J-Bolt } \\
\text { Radius No. }\end{array}$ & $\begin{array}{l}\text { Mean } \\
\text { J-Bolt } \\
\text { Radius }\end{array}$ & $\begin{array}{c}\text { Radius } \\
\text { Inc } \\
\min \end{array}$ & $\begin{array}{l}\text { J-Bolts } \\
\text { ded } \\
\max \end{array}$ & $\begin{array}{l}\text { Average } \\
\text { Bolts per } \\
\text { Element }\end{array}$ & $\begin{array}{c}\text { Min Axial } \\
\text { Force (kip) } \\
\text { LBS-BEC } \\
\text { Gravity } \\
\text { Only }\end{array}$ & $\begin{array}{c}\text { Max Axial } \\
\text { Force (kip) } \\
\text { LBS-BEC } \\
\text { Gravity } \\
\text { Only }\end{array}$ & $\begin{array}{c}\text { Shear } \\
\text { Force1 } \\
\text { (kip) LBS- } \\
\text { BEC } \\
\text { Gravity } \\
\end{array}$ & $\begin{array}{c}\text { Maximum } \\
\text { Shear Force1 } \\
\text { Model Angle }\end{array}$ & $\begin{array}{c}\text { Shear Force2 } \\
\text { (kip) LBS- } \\
\text { BEC Gravity } \\
\text { Only }\end{array}$ & \begin{tabular}{|c|} 
Maximum \\
Shear Force2 \\
Model Angle
\end{tabular} & $\begin{array}{c}\text { Total } \\
\text { Shear } \\
\text { (kip) LBS } \\
\text { BEC } \\
\text { Gravity }\end{array}$ \\
\hline Radius 2 & $=44.72$ & $\overline{22.36}$ & $\begin{array}{l}67.29 \\
\end{array}$ & 0.55 & -0.005 & $=0.004$ & 0.001 & 45 & 0.007 & 90 & 0.007 \\
\hline Radius 3 & 89.87 & 67.29 & 104.93 & 0.89 & -0.005 & -0.004 & 0.002 & 27 & 0.100 & 180 & 0.100 \\
\hline Radius 4 & 120.00 & 104.93 & 135.98 & 1.03 & -0.001 & 0.000 & 0.003 & 153 & 0.165 & 180 & 0.165 \\
\hline Radius 5 & 151.97 & 135.98 & 181.01 & 1.97 & -0.002 & -0.001 & 0.007 & 153 & 0.265 & 90 & 0.265 \\
\hline Radius 6 & 210.05 & 181.01 & 223.79 & 2.41 & -0.005 & -0.005 & 0.012 & 153 & 0.447 & 81 & 0.447 \\
\hline Radius 7 & 237.53 & 223.79 & 270.98 & 3.30 & 0.011 & 0.012 & 0.011 & 153 & 0.529 & 135 & 0.529 \\
\hline Radius 8 & 304.43 & 270.98 & 318.74 & 4.04 & -0.012 & -0.012 & 0.004 & 153 & 0.672 & 135 & 0.672 \\
\hline Radius 9 & 333.05 & 318.74 & 361.64 & 4.37 & 0.030 & 0.030 & 0.001 & 153 & 0.690 & 45 & 0.690 \\
\hline Radius 10 & 390.22 & 361.64 & 406.24 & 5.36 & -0.076 & -0.074 & 0.000 & 144 & 0.759 & 45 & 0.759 \\
\hline Radius 11 & 422.26 & 406.24 & 431.63 & 3.60 & 0.547 & 0.549 & 0.001 & 117 & 1.050 & 171 & 1.050 \\
\hline $\begin{array}{c}\text { M\&D } \\
\text { J-Bolt } \\
\text { Radius No. }\end{array}$ & $\begin{array}{l}\text { Mean } \\
\text { J-Bolt } \\
\text { Radius }\end{array}$ & $\begin{array}{r}\text { Radius } \\
\text { Inc }\end{array}$ & $\begin{array}{l}\text { J-Bolts } \\
\text { ded }\end{array}$ & $\begin{array}{l}\text { Average } \\
\text { Bolts per } \\
\text { Element }\end{array}$ & $\begin{array}{l}\text { Bolt Angle } \\
\text { (Rad) }\end{array}$ & $\begin{array}{l}\text { Shear } \\
\text { Stiffness } \\
\text { (kip/f) }\end{array}$ & $\begin{array}{l}\text { Axial } \\
\text { Stiffness } \\
\text { (kip/ft) }\end{array}$ & $\begin{array}{c}\text { Shear } \\
\text { Displacement } \\
\text { LBS-BEC- } \\
\text { Gravity Only }\end{array}$ & $\begin{array}{l}\text { Axial Min } \\
\text { Displacement } \\
\text { LBS-BEC- } \\
\text { Gravity Only }\end{array}$ & $\begin{array}{c}\text { Axial Max } \\
\text { Displacement } \\
\text { LBS-BEC- } \\
\text { Gravity Only }\end{array}$ & \\
\hline Radius 2 & $4 \quad 44.72$ & 22.36 & $\begin{array}{l}67.29 \\
\end{array}$ & 0.55 & $\begin{array}{l}0.0351 \\
\end{array}$ & 780 & 780 & 0.00010 & -0.00007 & -0.00005 & \\
\hline Radius 3 & 89.87 & 67.29 & 104.93 & 0.89 & 0.0715 & 780 & 780 & 0.00154 & -0.00008 & -0.00007 & \\
\hline Radius 4 & 120.00 & 104.93 & 135.98 & 1.03 & 0.0968 & 780 & 780 & 0.00254 & -0.00001 & 0.00000 & \\
\hline Radius 5 & 151.97 & 135.98 & 181.01 & 1.97 & 0.1252 & 780 & 780 & 0.00408 & -0.00003 & -0.00002 & \\
\hline Radius 6 & 210.05 & 181.01 & 223.79 & 2.41 & $\begin{array}{l}0.1825 \\
\end{array}$ & 780 & 780 & 0.00688 & -0.00008 & -0.00007 & \\
\hline Radius 7 & 237.53 & 223.79 & 270.98 & 3.30 & 0.2136 & 780 & 780 & 0.00814 & 0.00018 & 0.00019 & \\
\hline Radius 8 & 304.43 & 270.98 & 318.74 & 4.04 & 0.3076 & 780 & 780 & 0.01034 & -0.00019 & -0.00018 & \\
\hline Radius 9 & 333.05 & 318.74 & 361.64 & 4.37 & 0.3613 & 780 & 780 & 0.01062 & 0.00046 & 0.00047 & \\
\hline Radius 10 & 390.22 & 361.64 & 406.24 & 5.36 & 0.5235 & 780 & 780 & 0.01167 & -0.00117 & -0.00115 & \\
\hline Radius 11 & 460.26 & 406.24 & 431.63 & 3.60 & 0.6938 & 780 & 780 & 0.01616 & 0.00842 & 0.00845 & \\
\hline
\end{tabular}


RPP-RPT-32239, Rev. 1

M\&D-2008-005-CALC-001, Rev. 1

Table F.14. LBS-BEC Anchor Bolt Forces, Gravity Plus Seismic Loads

\begin{tabular}{|c|c|c|c|c|c|c|c|c|c|c|c|}
\hline \multicolumn{12}{|c|}{$\begin{array}{l}\text { AP Primary Tank, Lowe } \\
\text { ANSYS MAXIMUMS BY RADIUS }\end{array}$} \\
\hline $\begin{array}{c}\text { M\&D } \\
\text { J-Bolt } \\
\text { Radius No. }\end{array}$ & $\begin{array}{l}\text { Mean } \\
\text { J-Bolt } \\
\text { Radius }\end{array}$ & $\begin{array}{r}\text { Radius } 0 \\
\text { Inclu }\end{array}$ & $\begin{array}{l}\text { of J-Bolts } \\
\text { Jded }\end{array}$ & $\begin{array}{l}\text { Average } \\
\text { Bolts per } \\
\text { Element }\end{array}$ & $\begin{array}{c}\text { Min Axial } \\
\text { Force (kip) } \\
\text { LBS-BEC }\end{array}$ & $\begin{array}{c}\text { Max Axial } \\
\text { Force (kip) } \\
\text { LBS-BEC }\end{array}$ & $\begin{array}{c}\text { Shear } \\
\text { Force1 (kip) } \\
\text { LBS-BEC }\end{array}$ & $\begin{array}{c}\text { Maximum } \\
\text { Shear Force1 } \\
\text { Model Angle }\end{array}$ & $\begin{array}{c}\text { Shear Force2 } \\
\text { (kip) LBS-BEC }\end{array}$ & $\begin{array}{c}\text { Maximum } \\
\text { Shear Force2 } \\
\text { Model Angle }\end{array}$ & $\begin{array}{c}\text { Total } \\
\text { Shear } \\
\text { (kip) LBS } \\
\text { BEC }\end{array}$ \\
\hline Radius 2 & $=44.72$ & 22.36 & $\overline{67.29}$ & 0.55 & $=0.074$ & 0.050 & 0.627 & 90 & 0.604 & 0 & 0.642 \\
\hline Radius 3 & 89.87 & 67.29 & \begin{tabular}{|c|}
104.93 \\
\end{tabular} & 0.89 & -0.058 & 0.017 & 0.690 & 90 & 0.720 & 180 & 0.735 \\
\hline Radius 4 & 120.00 & 104.93 & \begin{tabular}{|l|}
135.98 \\
\end{tabular} & 1.03 & -0.044 & 0.061 & 0.781 & 90 & 0.820 & 180 & 0.854 \\
\hline Radius 5 & 151.97 & 135.98 & 181.01 & 1.97 & -0.021 & 0.246 & 0.914 & 90 & 0.958 & 180 & 1.017 \\
\hline Radius 6 & 210.05 & 181.01 & \begin{tabular}{|l|}
223.79 \\
\end{tabular} & 2.41 & -0.048 & 0.078 & 1.233 & 90 & 1.165 & 0 & 1.366 \\
\hline Radius 7 & 237.53 & 223.79 & \begin{tabular}{|l|}
270.98 \\
\end{tabular} & 3.30 & -0.073 & 0.306 & 1.483 & 90 & 1.269 & 0 & 1.606 \\
\hline Radius 8 & 304.43 & 270.98 & \begin{tabular}{|l|}
318.74 \\
\end{tabular} & 4.04 & -0.163 & 0.399 & 2.204 & 90 & 1.556 & 0 & 2.332 \\
\hline Radius 9 & 333.05 & 318.74 & \begin{tabular}{|l|}
361.64 \\
\end{tabular} & 4.37 & -0.118 & 0.531 & 2.635 & 90 & 1.678 & 180 & 2.757 \\
\hline Radius 10 & 390.22 & 361.64 & \begin{tabular}{|l|}
406.24 \\
\end{tabular} & 5.36 & -0.509 & 0.739 & 3.760 & 90 & 1.965 & 0 & 3.864 \\
\hline Radius 11 & 422.26 & 406.24 & 431.63 & 3.60 & -0.474 & 1.864 & 4.750 & 90 & 2.627 & 180 & 4.915 \\
\hline $\begin{array}{c}\text { M\&D } \\
\text { J-Bolt } \\
\text { Radius No. }\end{array}$ & $\begin{array}{l}\text { Mean } \\
\text { J-Bolt } \\
\text { Radius }\end{array}$ & $\begin{array}{r}\text { Radius } 0 \\
\text { Inclu }\end{array}$ & $\begin{array}{l}\text { f J-Bolts } \\
\text { Ided }\end{array}$ & $\begin{array}{l}\text { Average } \\
\text { Bolts per } \\
\text { Element }\end{array}$ & $\begin{array}{l}\text { Bolt Angle } \\
\text { (Rad) }\end{array}$ & $\begin{array}{l}\text { Shear } \\
\text { Stiffness } \\
\text { (kip/ft) }\end{array}$ & $\begin{array}{l}\text { Axial } \\
\text { Stiffness } \\
\text { (kipft) }\end{array}$ & $\begin{array}{l}\text { Shear Disp } \\
\text { LBS-BEC- } \\
\text { Seismic }\end{array}$ & $\begin{array}{c}\text { Axial Min Disp } \\
\text { LBS-BEC- } \\
\text { Seismic }\end{array}$ & $\begin{array}{l}\text { Axial Max Disp } \\
\text { LBS-BEC- } \\
\text { Seismic }\end{array}$ & \\
\hline Radius 2 & $=44.72$ & 22.36 & 67.29 & 0.55 & \begin{tabular}{l|l|}
0.0351 \\
\end{tabular} & 780 & 780 & 0.00987 & -0.00115 & 0.00077 & \\
\hline Radius 3 & 89.87 & 67.29 & 104.93 & 0.89 & 0.0715 & 780 & 780 & 0.01130 & -0.00090 & 0.00026 & \\
\hline Radius 4 & 120.00 & \begin{tabular}{|l|}
104.93 \\
\end{tabular} & 135.98 & 1.03 & 0.0968 & 78 & 780 & 0.01314 & -0.00068 & 0.00094 & \\
\hline Radius 5 & 151.97 & \begin{tabular}{|l|}
135.98 \\
\end{tabular} & 181.01 & 1.97 & 0.1252 & 780 & 780 & 0.01564 & -0.00033 & 0.00378 & \\
\hline Radius 6 & 210.05 & \begin{tabular}{|l|}
181.01 \\
\end{tabular} & 223.79 & 2.41 & \begin{tabular}{l|l|}
0.1825 \\
\end{tabular} & 78 & 780 & 0.02101 & -0.00074 & 0.00120 & \\
\hline Radius 7 & 237.53 & \begin{tabular}{|l|}
223.79 \\
\end{tabular} & 270.98 & 3.30 & 0.2136 & 780 & 780 & 0.02471 & -0.00113 & 0.00471 & \\
\hline Radius 8 & 304.43 & \begin{tabular}{|l|}
270.98 \\
\end{tabular} & 318.74 & 4.04 & 0.3076 & 780 & 780 & 0.03588 & -0.00251 & 0.00613 & \\
\hline Radius 9 & 333.05 & \begin{tabular}{|l|}
318.74 \\
\end{tabular} & 361.64 & 4.37 & 0.3613 & 780 & 780 & 0.04241 & -0.00181 & 0.00817 & \\
\hline Radius 10 & 390.22 & \begin{tabular}{|l|}
361.64 \\
\end{tabular} & 406.24 & 5.36 & 0.5235 & 780 & 780 & 0.05945 & -0.00783 & 0.01137 & \\
\hline Radius 11 & 460.26 & 406.24 & \begin{tabular}{|l|}
431.63 \\
\end{tabular} & 3.60 & 0.6938 & 780 & 780 & 0.07562 & -0.00730 & 0.02868 & \\
\hline
\end{tabular}


RPP-RPT-32239, Rev. 1

M\&D-2008-005-CALC-001, Rev. 1

Table F.15. LBS-BEC Anchor Bolt Forces, Seismic Load Only

\begin{tabular}{|c|c|c|c|c|c|c|c|c|c|c|c|}
\hline \multicolumn{12}{|c|}{$\begin{array}{l}\text { AP Primary Tank, Low } \\
\text { ANSYS MAXIMUMS BY RADIUS }\end{array}$} \\
\hline $\begin{array}{c}\text { M\&D } \\
\text { J-Bolt } \\
\text { Radius } \\
\text { No. } \\
\end{array}$ & $\begin{array}{c}\text { Mean } \\
\text { J-Bolt } \\
\text { Radius } \\
\end{array}$ & $\begin{array}{r}\text { Radius } 0 \\
\text { Incl }\end{array}$ & $\begin{array}{l}\text { f J-Bolts } \\
\text { Ided }\end{array}$ & $\begin{array}{c}\text { Average } \\
\text { Bolts per } \\
\text { Element }\end{array}$ & \begin{tabular}{|c|} 
Min Axial \\
Force (kip) \\
LBS-BEC- \\
Seismic \\
Only \\
\end{tabular} & $\begin{array}{c}\text { Max Axial } \\
\text { Force (kip) } \\
\text { LBS-BEC- } \\
\text { Seismic } \\
\text { Only } \\
\end{array}$ & $\begin{array}{l}\text { Shear } \\
\text { Force1 (kip) } \\
\text { LBS-BEC- } \\
\text { Seismic Only } \\
\end{array}$ & \begin{tabular}{|c|} 
Maximum \\
Shear Force1 \\
Model Angle \\
\end{tabular} & \begin{tabular}{|c|} 
Shear Force2 \\
(kip) LBS- \\
BEC-Seismic \\
Only \\
\end{tabular} & $\begin{array}{c}\text { Maximum } \\
\text { Shear Force2 } \\
\text { Model Angle } \\
\end{array}$ & $\begin{array}{l}\text { Total Shear } \\
\text { (kip) LBS- } \\
\text { BEC- } \\
\text { Seismic } \\
\text { Only } \\
\end{array}$ \\
\hline $\begin{array}{l}\text { Radius } 2 \\
\end{array}$ & $4 \quad 44.72$ & 22.36 & 67.29 & 0.55 & -0.070 & 0.053 & 0.626 & 108 & 0.598 & $\overline{0}$ & 0.866 \\
\hline Radius 3 & 89.87 & 67.29 & 104.93 & 0.89 & -0.053 & 0.022 & 0.688 & 108 & 0.620 & 0 & 0.926 \\
\hline Radius 4 & 120.00 & 104.93 & 135.98 & 1.03 & -0.044 & 0.062 & 0.778 & 108 & 0.655 & 0 & 1.017 \\
\hline Radius 5 & 151.97 & 135.98 & 181.01 & 1.97 & -0.019 & 0.247 & 0.907 & 108 & 0.692 & 0 & 1.141 \\
\hline Radius 6 & 210.05 & 181.01 & 223.79 & 2.41 & -0.043 & 0.082 & 1.221 & 108 & 0.717 & 144 & 1.416 \\
\hline Radius 7 & 237.53 & 223.79 & 270.98 & 3.30 & -0.085 & 0.294 & 1.472 & 90 & 0.739 & 135 & 1.647 \\
\hline \begin{tabular}{l|} 
Radius 8 \\
\end{tabular} & 304.43 & 270.98 & 318.74 & 4.04 & -0.151 & 0.411 & 2.200 & 117 & 0.883 & 117 & 2.371 \\
\hline Radius 9 & 333.05 & 318.74 & 361.64 & 4.37 & -0.147 & 0.501 & 2.633 & 117 & 0.987 & 117 & 2.812 \\
\hline Radius 10 & 390.22 & 361.64 & 406.24 & 5.36 & -0.433 & 0.813 & 3.760 & 108 & 1.207 & 0 & 3.948 \\
\hline Radius 11 & 460.26 & 406.24 & 431.63 & 3.60 & -1.021 & 1.315 & 4.750 & 108 & 1.577 & 0 & 5.005 \\
\hline $\begin{array}{c}\text { M\&D } \\
\text { J-Bolt } \\
\text { Radius } \\
\text { No. }\end{array}$ & $\begin{array}{l}\text { Mean } \\
\text { J-Bolt } \\
\text { Radius }\end{array}$ & $\begin{array}{r}\text { Radius } \\
\text { Inclt }\end{array}$ & $\begin{array}{l}\text {-Bolts } \\
\text { d }\end{array}$ & $\begin{array}{l}\text { Average } \\
\text { Bolts per } \\
\text { Element }\end{array}$ & $\begin{array}{l}\text { Bolt Angle } \\
\text { (Rad) }\end{array}$ & $\begin{array}{l}\text { Shear } \\
\text { Stiffness } \\
\text { (kip/f) }\end{array}$ & $\begin{array}{c}\text { Axial } \\
\text { Stiffness } \\
\text { (kip/t) }\end{array}$ & \begin{tabular}{|c|} 
Shear Disp \\
LBS-BEC- \\
Seismic Only
\end{tabular} & $\begin{array}{c}\text { Axial Min Disp } \\
\text { LBS-BEC- } \\
\text { Seismic Only }\end{array}$ & \begin{tabular}{|c|} 
Axial Max Disp \\
LBS-BEC- \\
Seismic Only
\end{tabular} & \\
\hline \begin{tabular}{|l|} 
Radius 2 \\
\end{tabular} & $\overline{444.72}$ & 22.36 & 67.29 & 0.55 & 0.0351 & 780 & 780 & 0.01332 & 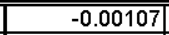 & 0.00082 & \\
\hline Radius 3 & 89.87 & 67.29 & 104.93 & 0.89 & 0.0715 & 780 & 780 & 0.01 & -0.00082 & & \\
\hline Radius 4 & 120.00 & 104.93 & 135.98 & 1.03 & 0.0968 & 780 & 780 & 0.01564 & -0.00067 & 0.00095 & \\
\hline Radius 5 & 151.97 & 135.98 & 181.01 & 1.97 & 0.1252 & 780 & 78 & 0.01756 & -0.00030 & 0.00380 & \\
\hline Radius 6 & 210.05 & 181.01 & 223.79 & 2.41 & 0.1825 & 780 & 780 & 0.02179 & -0.00066 & 0.00127 & \\
\hline Radius 7 & 237.53 & 223.79 & 270.98 & 3.30 & 0.2136 & 780 & 78 & 0.02534 & -0.00130 & 0.00452 & \\
\hline Radius 8 & 304.43 & 270.98 & 318.74 & 4.04 & 0.3076 & 780 & 780 & 0.03647 & -0.00232 & 0.00632 & \\
\hline Radius 9 & 333.05 & \begin{tabular}{|l|}
318.74 \\
\end{tabular} & 361.64 & 4.37 & 0.3613 & 780 & 780 & 0.04 & -0.00227 & 0.00770 & \\
\hline Radius 10 & 390.22 & 361.64 & 406.24 & 5.36 & 0.5235 & 780 & 780 & 0.06075 & -0.00666 & 0.01251 & \\
\hline Radius 11 & 460.26 & 406.24 & 431.63 & 3.60 & 0.6938 & 780 & 780 & 0.07699 & -0.01571 & 0.02023 & \\
\hline
\end{tabular}


RPP-RPT-32239, Rev. 1

M\&D-2008-005-CALC-001, Rev. 1

Table F.16. LBS-BEC Concrete Backed Steel Strain, Shell Top, Gravity Load Only

AP Backed Steel, Lower Bound Soil, Gravity Only, Best Es timate Tank Concrete, 460 In Waste Level at 1.83SpG

\begin{tabular}{|c|c|c|c|c|c|c|c|}
\hline \multirow[b]{2}{*}{$\begin{array}{c}\text { M\&D } \\
\text { Starting } \\
\text { M\&D } \\
\text { Element } \\
\text { No. }\end{array}$} & \multirow[b]{2}{*}{ Path (in) } & \multicolumn{6}{|c|}{ Shell Top Surface (inside - towards waste) Gravity } \\
\hline & & $\begin{array}{l}\text { AP-460-LBS-BEC } \\
\text { EPEL P1 Strain (in/in } \\
\text { Gravity Top Min }\end{array}$ & \begin{tabular}{|c|} 
AP-460-LBS-BEC \\
EPEL P1 Strain (in/in) \\
Gravity Top Max \\
\end{tabular} & $\begin{array}{l}\text { AP-460-LBS-BEC } \\
\text { EPEL P2 (in/in) } \\
\text { Gravity Top Min }\end{array}$ & \begin{tabular}{|} 
AP-460-LBS-BEC \\
EPEL P2 Strain (in/in) \\
Gravity Top Max
\end{tabular} & $\begin{array}{c}\text { AP-460-LBS-BEC } \\
\text { EPEL P3 Strain (in/in) } \\
\text { Gravity Top Min }\end{array}$ & $\begin{array}{c}\text { AP-460-LBS-BEC } \\
\text { EPEL P3 Strain (in/in) } \\
\text { Gravity Top Max }\end{array}$ \\
\hline 762 & 67.33 & $3.42 \mathrm{E}-05$ & $3.42 \mathrm{E}-05$ & $-3.40 \mathrm{E}-05$ & $-3.40 \mathrm{E}-05$ & $-4.51 \mathrm{E}-05$ & $-4.51 \mathrm{E}-05$ \\
\hline 782 & 105.04 & $4.63 \mathrm{E}-05$ & $4.64 \mathrm{E}-05$ & $-3.25 \mathrm{E}-05$ & $-3.25 \mathrm{E}-05$ & $-7.43 \mathrm{E}-05$ & $-7.42 \mathrm{E}-05$ \\
\hline 802 & 136.24 & $3.78 \mathrm{E}-05$ & $3.78 \mathrm{E}-05$ & $-3.93 \mathrm{E}-05$ & $-3.93 \mathrm{E}-05$ & $-4.74 \mathrm{E}-05$ & $-4.74 \mathrm{E}-05$ \\
\hline 822 & 181.71 & $3.59 \mathrm{E}-05$ & $3.60 \mathrm{E}-05$ & $-2.21 \mathrm{E}-05$ & $-2.20 \mathrm{E}-05$ & $-6.04 \mathrm{E}-05$ & $-6.03 E-05$ \\
\hline 842 & 225.10 & $2.79 \mathrm{E}-05$ & $2.80 \mathrm{E}-05$ & $-3.07 \mathrm{E}-05$ & $-3.06 \mathrm{E}-05$ & $-3.33 E-05$ & $-3.33 \mathrm{E}-05$ \\
\hline 862 & 273.66 & $2.43 \mathrm{E}-05$ & $2.43 \mathrm{E}-05$ & $-1.14 \mathrm{E}-05$ & $-1.14 \mathrm{E}-05$ & $-4.42 E-05$ & $-4.41 \mathrm{E}-05$ \\
\hline 882 & 323.27 & $1.53 \mathrm{E}-05$ & $1.53 \mathrm{E}-05$ & $-1.52 \mathrm{E}-05$ & $-1.52 \mathrm{E}-05$ & $-1.98 \mathrm{E}-05$ & $-1.98 \mathrm{E}-05$ \\
\hline 902 & 369.20 & $1.34 \mathrm{E}-05$ & $1.34 \mathrm{E}-05$ & $6.67 \mathrm{E}-06$ & $6.67 \mathrm{E}-06$ & $-2.85 \mathrm{E}-05$ & $-2.84 \mathrm{E}-05$ \\
\hline 922 & 419.20 & $3.45 \mathrm{E}-05$ & $3.45 \mathrm{E}-05$ & $-7.31 \mathrm{E}-06$ & $-7.30 \mathrm{E}-06$ & $-1.71 \mathrm{E}-05$ & $-1.71 \mathrm{E}-05$ \\
\hline 237 & 463.02 & & & & & & \\
\hline 257 & 510.03 & & & & & & \\
\hline 277 & 544.44 & & & & & & \\
\hline 297 & 580.53 & & & & & & \\
\hline 317 & 631.08 & & & & & & \\
\hline 337 & 680.34 & & & & & & \\
\hline 357 & 727.44 & & & & & & \\
\hline 377 & 772.93 & & & & & & \\
\hline 397 & 831.34 & & & & & & \\
\hline 417 & 894.09 & & & & & & \\
\hline 2132 & 925.08 & $3.46 \mathrm{E}-05$ & $3.47 \mathrm{E}-05$ & $-3.25 E-05$ & $-3.25 \mathrm{E}-05$ & $-4.24 \mathrm{E}-05$ & $-4.24 \mathrm{E}-05$ \\
\hline 2122 & 935.67 & $7.56 \mathrm{E}-05$ & $7.57 \mathrm{E}-05$ & $-2.12 \mathrm{E}-05$ & $-2.12 \mathrm{E}-05$ & $-3.10 \mathrm{E}-05$ & $-3.10 \mathrm{E}-05$ \\
\hline 2112 & 944.86 & $9.60 \mathrm{E}-05$ & $9.61 \mathrm{E}-05$ & $-7.77 \mathrm{E}-06$ & $-7.76 \mathrm{E}-06$ & $-2.13 \mathrm{E}-04$ & $-2.13 \mathrm{E}-04$ \\
\hline 477 & 968.95 & & & & & & \\
\hline 497 & 1002.45 & & & & & & \\
\hline 517 & 1042.45 & & & & & & \\
\hline 537 & 1108.60 & & & & & & \\
\hline 557 & 1178.35 & & & & & & \\
\hline 577 & 1227.20 & & & & & & \\
\hline 597 & 1271.50 & & & & & & \\
\hline 617 & 1313.65 & & & & & & \\
\hline 637 & 1360.60 & & & & & & \\
\hline
\end{tabular}


RPP-RPT-32239, Rev. 1

M\&D-2008-005-CALC-001, Rev. 1

Table F.17. LBS-BEC Concrete Backed Steel Strain, Shell Middle, Gravity Load Only

AP Backed Steel, Lower Bound Soil, Gravity Only, Best Estimate Tank Concrete, 460 In Waste Level at 1.83SpG

\begin{tabular}{|c|c|c|c|c|c|c|c|}
\hline \multirow{2}{*}{$\begin{array}{c}\text { M\&D } \\
\text { Starting } \\
\text { M\&D } \\
\text { Element } \\
\text { No. }\end{array}$} & \multirow[b]{2}{*}{ Path (in) } & \multicolumn{6}{|c|}{ Shell Mid-Plane } \\
\hline & & $\begin{array}{c}\text { AP-460-LBS-BEC } \\
\text { EPEL P1 Strain (in/in) } \\
\text { Gravity Mid Min }\end{array}$ & $\begin{array}{c}\text { AP-460-LBS-BEC } \\
\text { EPEL P1 Strain (in/in) } \\
\text { Gravity Mid Max }\end{array}$ & $\begin{array}{l}\text { AP-460-LBS-BEC } \\
\text { EPEL P2 (in/in) } \\
\text { Gravity Mid Min }\end{array}$ & $\begin{array}{c}\text { AP-460-LBS-BEC } \\
\text { EPEL P2 Strain (in/in) } \\
\text { Gravity Mid Max }\end{array}$ & $\begin{array}{c}\text { AP-460-LBS-BEC } \\
\text { EPEL P3 Strain (in/in) } \\
\text { Gravity Mid Min }\end{array}$ & $\begin{array}{c}\text { AP-460-LBS-BEC } \\
\text { EPEL P3 Strain (in/in) } \\
\text { Gravity Mid Max }\end{array}$ \\
\hline 762 & 67.33 & $3.82 \mathrm{E}-05$ & $3.83 E-05$ & $-4.29 E-05$ & $-4.29 \mathrm{E}-05$ & $-4.59 E-05$ & $-4.59 \mathrm{E}-05$ \\
\hline 782 & 105.04 & $4.24 \mathrm{E}-05$ & $4.24 \mathrm{E}-05$ & $-3.30 \mathrm{E}-05$ & $-3.30 \mathrm{E}-05$ & $-6.47 \mathrm{E}-05$ & $-6.47 \mathrm{E}-05$ \\
\hline 802 & 136.24 & $4.22 \mathrm{E}-05$ & $4.22 \mathrm{E}-05$ & $-3.97 E-05$ & $-3.97 \mathrm{E}-05$ & $-5.73 E-05$ & $-5.72 E-05$ \\
\hline 822 & 181.71 & $3.34 \mathrm{E}-05$ & $3.34 \mathrm{E}-05$ & $-2.23 E-05$ & $-2.23 \mathrm{E}-05$ & $-5.42 E-05$ & $-5.42 \mathrm{E}-05$ \\
\hline 842 & 225.10 & 3.33E-05 & 3.33E-05 & $-3.33 E-05$ & $-3.33 E-05$ & $-4.28 \mathrm{E}-05$ & $-4.28 \mathrm{E}-05$ \\
\hline 862 & 273.66 & $2.26 \mathrm{E}-05$ & $2.26 \mathrm{E}-05$ & $-1.16 \mathrm{E}-05$ & $-1.16 \mathrm{E}-05$ & $-4.01 E-05$ & -4.00 E- 05 \\
\hline 882 & 323.27 & $1.90 \mathrm{E}-05$ & $1.90 \mathrm{E}-05$ & $-1.53 \mathrm{E}-05$ & $-1.53 \mathrm{E}-05$ & $-2.83 E-05$ & $-2.83 E-05$ \\
\hline 902 & 369.20 & $1.31 \mathrm{E}-05$ & 1.31E-05 & $5.88 \mathrm{E}-06$ & $5.88 \mathrm{E}-06$ & $-2.64 E-05$ & $-2.64 \mathrm{E}-05$ \\
\hline 922 & 419.20 & $3.43 \mathrm{E}-05$ & $3.43 \mathrm{E}-05$ & $-6.23 E-06$ & $-6.22 E-06$ & $-1.95 \mathrm{E}-05$ & $-1.95 \mathrm{E}-05$ \\
\hline 237 & 463.02 & $5.70 \mathrm{E}-05$ & $5.71 \mathrm{E}-05$ & $3.65 \mathrm{E}-06$ & $3.66 \mathrm{E}-06$ & $-7.06 \mathrm{E}-05$ & $-7.05 E-05$ \\
\hline 257 & 510.03 & $8.29 E-05$ & $8.30 \mathrm{E}-05$ & $5.61 \mathrm{E}-05$ & $5.62 \mathrm{E}-05$ & $-3.38 \mathrm{E}-04$ & $-3.38 \mathrm{E}-04$ \\
\hline 277 & 544.44 & $1.16 \mathrm{E}-04$ & 1.16E-04 & $7.40 \mathrm{E}-05$ & $7.42 E-05$ & $-5.94 \mathrm{E}-04$ & $-5.94 \mathrm{E}-04$ \\
\hline 297 & 580.53 & $8.16 \mathrm{E}-05$ & $8.16 \mathrm{E}-05$ & $-1.08 \mathrm{E}-05$ & $-1.07 \mathrm{E}-05$ & $-3.58 E-04$ & $-3.58 \mathrm{E}-04$ \\
\hline 317 & 631.08 & $9.16 \mathrm{E}-05$ & $9.17 \mathrm{E}-05$ & $-1.17 \mathrm{E}-04$ & $-1.17 \mathrm{E}-04$ & $-3.00 \mathrm{E}-04$ & $-3.00 \mathrm{E}-04$ \\
\hline 337 & 680.34 & $1.18 \mathrm{E}-04$ & $1.18 \mathrm{E}-04$ & $-1.60 \mathrm{E}-04$ & $-1.60 \mathrm{E}-04$ & $-3.77 \mathrm{E}-04$ & $-3.76 \mathrm{E}-04$ \\
\hline 357 & 727.44 & $1.21 \mathrm{E}-04$ & $1.21 \mathrm{E}-04$ & $-1.73 E-04$ & $-1.73 \mathrm{E}-04$ & $-3.79 E-04$ & $-3.79 E-04$ \\
\hline 377 & 772.93 & $1.38 \mathrm{E}-04$ & $1.38 \mathrm{E}-04$ & $-1.82 E-04$ & $-1.81 \mathrm{E}-04$ & $-4.46 \mathrm{E}-04$ & $-4.46 \mathrm{E}-04$ \\
\hline 397 & 831.34 & $1.28 \mathrm{E}-04$ & $1.28 \mathrm{E}-04$ & $-1.52 E-04$ & $-1.52 \mathrm{E}-04$ & $-4.32 E-04$ & $-4.31 \mathrm{E}-04$ \\
\hline 417 & 894.09 & $5.96 \mathrm{E}-05$ & $5.97 E-05$ & $-8.25 E-05$ & $-8.24 E-05$ & $-1.86 \mathrm{E}-04$ & $-1.86 \mathrm{E}-04$ \\
\hline 2132 & 925.08 & $2.92 \mathrm{E}-05$ & $2.92 \mathrm{E}-05$ & $-1.67 \mathrm{E}-05$ & $-1.67 \mathrm{E}-05$ & $-4.25 E-05$ & $-4.24 \mathrm{E}-05$ \\
\hline 2122 & 935.67 & $3.02 E-05$ & $3.02 E-05$ & $-2.90 \mathrm{E}-05$ & $-2.90 \mathrm{E}-05$ & $-3.07 \mathrm{E}-05$ & $-3.07 \mathrm{E}-05$ \\
\hline 2112 & 944.86 & $2.20 \mathrm{E}-05$ & $2.20 \mathrm{E}-05$ & $-7.73 E-06$ & $-7.73 E-06$ & $-3.54 \mathrm{E}-05$ & $-3.54 \mathrm{E}-05$ \\
\hline 477 & 968.95 & $2.44 E-05$ & $2.45 E-05$ & $8.71 \mathrm{E}-06$ & $8.72 E-06$ & $-1.09 E-04$ & $-1.09 \mathrm{E}-04$ \\
\hline 497 & 1002.45 & $2.04 \mathrm{E}-05$ & $2.04 \mathrm{E}-05$ & $1.43 \mathrm{E}-05$ & $1.43 \mathrm{E}-05$ & $-8.17 \mathrm{E}-06$ & $-8.16 \mathrm{E}-06$ \\
\hline 517 & 1042.45 & 1.39E-05 & $1.40 \mathrm{E}-05$ & $1.32 E-05$ & $1.32 E-05$ & $-6.15 E-06$ & $-6.14 E-06$ \\
\hline 537 & 1108.60 & $3.74 \mathrm{E}-05$ & $3.74 \mathrm{E}-05$ & $7.10 \mathrm{E}-06$ & 7.12E-06 & $-1.14 \mathrm{E}-05$ & $-1.14 \mathrm{E}-05$ \\
\hline 557 & 1178.35 & $4.77 \mathrm{E}-06$ & $4.77 \mathrm{E}-06$ & $3.89 \mathrm{E}-06$ & $3.90 \mathrm{E}-06$ & $-2.31 E-05$ & $-2.30 \mathrm{E}-05$ \\
\hline 577 & 1227.20 & $2.80 \mathrm{E}-05$ & $2.80 \mathrm{E}-05$ & $3.92 \mathrm{E}-06$ & $3.93 \mathrm{E}-06$ & $-7.30 \mathrm{E}-06$ & $-7.29 E-06$ \\
\hline 597 & 1271.50 & $5.03 E-06$ & $5.04 \mathrm{E}-06$ & $4.31 E-06$ & $4.31 \mathrm{E}-06$ & $-2.38 E-05$ & $-2.38 E-05$ \\
\hline 617 & 1313.65 & $1.75 \mathrm{E}-05$ & $1.75 \mathrm{E}-05$ & $7.74 \mathrm{E}-06$ & $7.75 \mathrm{E}-06$ & $-5.57 \mathrm{E}-06$ & $-5.56 \mathrm{E}-06$ \\
\hline 637 & 1360.60 & $5.09 \mathrm{E}-06$ & $5.09 \mathrm{E}-06$ & $4.74 \mathrm{E}-06$ & $4.75 \mathrm{E}-06$ & $-2.02 E-06$ & $-2.01 \mathrm{E}-06$ \\
\hline
\end{tabular}


RPP-RPT-32239, Rev. 1

M\&D-2008-005-CALC-001, Rev. 1

Table F.18. LBS-BEC Concrete Backed Steel Strain, Shell Bottom, Gravity Load Only

AP Backed Steel, Lower Bound Soil, Gravity Only, Best Estimate Tank Concrete, 460 In Waste

Level at $1.83 \mathrm{SpG}$

\begin{tabular}{|c|c|c|c|c|c|c|c|}
\hline \multirow[b]{2}{*}{$\begin{array}{c}\text { M\&D } \\
\text { Starting } \\
\text { M\&D } \\
\text { Element } \\
\text { No. }\end{array}$} & \multirow[b]{2}{*}{ Path (in) } & \multicolumn{6}{|c|}{ Shell Bottom Surface (outside - away from waste) Gravity } \\
\hline & & $\begin{array}{c}\text { AP-460-LBS-BEC } \\
\text { EPEL P1 Strain (in/in) } \\
\text { Gravity Bot Min }\end{array}$ & $\begin{array}{c}\text { AP-460-LBS-BEC } \\
\text { EPEL P1 Strain (in/in) } \\
\text { Gravity Bot Max }\end{array}$ & $\begin{array}{l}\text { AP-460-LBS-BEC } \\
\text { EPEL P2 (in/in) } \\
\text { Gravity Bot Min }\end{array}$ & $\begin{array}{c}\text { AP-460-LBS-BEC } \\
\text { EPEL P2 Strain (in/in) } \\
\text { Gravity Bot Max }\end{array}$ & $\begin{array}{c}\text { AP-460-LBS-BEC } \\
\text { EPEL P3 Strain (in/in) } \\
\text { Gravity Bat Min }\end{array}$ & $\begin{array}{c}\text { AP-460-LBS-BEC } \\
\text { EPEL P3 Strain (in/in) } \\
\text { Gravity Bat Max }\end{array}$ \\
\hline 762 & 67.33 & $4.24 \mathrm{E}-05$ & $4.24 \mathrm{E}-05$ & $-4.66 \mathrm{E}-05$ & $-4.65 \mathrm{E}-05$ & $-5.17 \mathrm{E}-05$ & $-5.16 \mathrm{E}-05$ \\
\hline 782 & 105.04 & $3.84 \mathrm{E}-05$ & $3.84 \mathrm{E}-05$ & $-3.35 \mathrm{E}-05$ & $-3.35 \mathrm{E}-05$ & $-5.50 \mathrm{E}-05$ & $-5.50 \mathrm{E}-05$ \\
\hline 802 & 136.24 & $4.66 \mathrm{E}-05$ & $4.66 \mathrm{E}-05$ & $-4.01 \mathrm{E}-05$ & $-4.01 \mathrm{E}-05$ & $-6.71 \mathrm{E}-05$ & $-6.70 \mathrm{E}-05$ \\
\hline 822 & 181.71 & $3.09 \mathrm{E}-05$ & 3.09E-05 & $-2.26 \mathrm{E}-05$ & $-2.26 \mathrm{E}-05$ & $-4.80 \mathrm{E}-05$ & $-4.80 \mathrm{E}-05$ \\
\hline 842 & 225.10 & $3.87 \mathrm{E}-05$ & 3.87E-05 & $-3.33 E-05$ & $-3.33 E-05$ & $-5.49 E-05$ & $-5.48 E-05$ \\
\hline 862 & 273.66 & 2.09E-05 & 2.09E-05 & $-1.19 \mathrm{E}-05$ & $-1.19 \mathrm{E}-05$ & $-3.59 \mathrm{E}-05$ & $-3.59 \mathrm{E}-05$ \\
\hline 882 & 323.27 & 2.27E-05 & $2.27 \mathrm{E}-05$ & $-1.54 \mathrm{E}-05$ & $-1.54 \mathrm{E}-05$ & $-3.68 \mathrm{E}-05$ & $-3.68 \mathrm{E}-05$ \\
\hline 902 & 369.20 & $1.28 \mathrm{E}-05$ & $1.29 \mathrm{E}-05$ & $5.10 \mathrm{E}-06$ & $5.10 \mathrm{E}-06$ & $-2.43 E-05$ & $-2.43 E-05$ \\
\hline 922 & 419.20 & $3.41 \mathrm{E}-05$ & $3.42 \mathrm{E}-05$ & $-5.13 \mathrm{E}-06$ & $-5.13 E-06$ & $-2.19 \mathrm{E}-05$ & $-2.18 \mathrm{E}-05$ \\
\hline 237 & 463.02 & & & & & & \\
\hline 257 & 510.03 & & & & & & \\
\hline 277 & 544.44 & & & & & & \\
\hline 297 & 580.53 & & & & & & \\
\hline 317 & 631.08 & & & & & & \\
\hline 337 & 680.34 & & & & & & \\
\hline 357 & 727.44 & & & & & & \\
\hline 377 & 772.93 & & & & & & \\
\hline 397 & 831.34 & & & & & & \\
\hline 417 & 894.09 & & & & & & \\
\hline 2132 & 925.08 & $2.79 \mathrm{E}-05$ & $2.80 \mathrm{E}-05$ & $-4.82 E-06$ & $-4.82 \mathrm{E}-06$ & $-4.25 \mathrm{E}-05$ & $-4.24 \mathrm{E}-05$ \\
\hline 2122 & 935.67 & $6.42 \mathrm{E}-05$ & $6.43 \mathrm{E}-05$ & $-3.03 E-05$ & $-3.03 E-05$ & $-1.16 \mathrm{E}-04$ & $-1.16 \mathrm{E}-04$ \\
\hline 2112 & 944.86 & $1.56 \mathrm{E}-04$ & $1.56 \mathrm{E}-04$ & $-7.70 \mathrm{E}-06$ & $-7.70 \mathrm{E}-06$ & $-6.33 \mathrm{E}-05$ & $-6.32 \mathrm{E}-05$ \\
\hline 477 & 968.95 & & & & & & \\
\hline 497 & 1002.45 & & & & & & \\
\hline 517 & 1042.45 & & & & & & \\
\hline 537 & 1108.60 & & & & & & \\
\hline 557 & 1178.35 & & & & & & \\
\hline 577 & 1227.20 & & & & & & \\
\hline 597 & 1271.50 & & & & & & \\
\hline 617 & 1313.65 & & & & & & \\
\hline 637 & 1360.60 & & & & & & \\
\hline
\end{tabular}


RPP-RPT-32239, Rev. 1

M\&D-2008-005-CALC-001, Rev. 1

Table F.19. LBS-BEC Concrete Backed Steel Strain, Shell Top, Gravity Plus Seismic Load

AP Backed Steel, Lower Bound Soil, Seismic Only, Best Estimate Tank Concrete, 460 In Waste Level at 1.83SpG

\begin{tabular}{|c|c|c|c|c|c|c|c|}
\hline \multirow{2}{*}{$\begin{array}{c}\text { M\&D } \\
\text { Starting } \\
\text { M\&D } \\
\text { Element } \\
\text { No. }\end{array}$} & \multirow[b]{2}{*}{ Path (in) } & \multicolumn{6}{|c|}{ Shell Top Surface (inside - towards waste) Seismic } \\
\hline & & $\begin{array}{l}\text { AP-460-LBS-BEC } \\
\text { EPEL P1 Strain (in/in) } \\
\text { Seismic Tap Min }\end{array}$ & $\begin{array}{c}\text { AP-460-LBS-BEC } \\
\text { EPEL P1 Strain (in/in) } \\
\text { Seismic Tap Max }\end{array}$ & $\begin{array}{l}\text { AP-460-LBS-BEC } \\
\text { EPEL P2 (in/in) } \\
\text { Seismic Top Min }\end{array}$ & $\begin{array}{c}\text { AP-460-LBS-BEC } \\
\text { EPEL P2 Strain (in/in) } \\
\text { Seismic Top Max }\end{array}$ & $\begin{array}{l}\text { AP-460-LBS-BEC } \\
\text { EPEL P3 Strain (in/in) } \\
\text { Seismic Tap Min }\end{array}$ & $\begin{array}{l}\text { AP-460-LBS-BEC } \\
\text { EPEL P3 Strain (in/in) } \\
\text { Seismic Tap Max }\end{array}$ \\
\hline 762 & 67.33 & $2.28 \mathrm{E}-05$ & $4.61 \mathrm{E}-05$ & $-4.91 \mathrm{E}-05$ & $-5.64 \mathrm{E}-06$ & $-5.89 \mathrm{E}-05$ & $-2.77 \mathrm{E}-05$ \\
\hline 782 & 105.04 & $3.37 E-05$ & $7.07 E-05$ & $-4.27 \mathrm{E}-05$ & $-1.31 \mathrm{E}-05$ & $-9.45 \mathrm{E}-05$ & $-3.49 \mathrm{E}-05$ \\
\hline 802 & 136.24 & $2.59 \mathrm{E}-05$ & $5.13 E-05$ & $-4.99 E-05$ & $-3.86 \mathrm{E}-07$ & $-7.37 \mathrm{E}-05$ & $-3.07 \mathrm{E}-05$ \\
\hline 822 & 181.71 & $2.70 \mathrm{E}-05$ & $5.42 \mathrm{E}-05$ & $-3.06 \mathrm{E}-05$ & $-3.90 \mathrm{E}-06$ & $-8.10 \mathrm{E}-05$ & $-3.13 \mathrm{E}-05$ \\
\hline 842 & 225.10 & $2.12 \mathrm{E}-05$ & $3.83 E-05$ & $-3.64 \mathrm{E}-05$ & $2.04 \mathrm{E}-05$ & $-6.13 E-05$ & $-2.42 E-05$ \\
\hline 862 & 273.66 & 1.94E-05 & 3.89E-05 & $-1.93 E-05$ & 1.89E-05 & $-6.95 E-05$ & $-1.43 \mathrm{E}-05$ \\
\hline 882 & 323.27 & $1.28 \mathrm{E}-05$ & $5.44 \mathrm{E}-05$ & $-1.87 \mathrm{E}-05$ & $2.36 \mathrm{E}-05$ & $-7.22 \mathrm{E}-05$ & $-1.16 \mathrm{E}-05$ \\
\hline 902 & 369.20 & $6.02 \mathrm{E}-06$ & $8.86 \mathrm{E}-05$ & $-9.00 \mathrm{E}-07$ & $2.08 \mathrm{E}-05$ & $-7.17 \mathrm{E}-05$ & $-1.50 \mathrm{E}-06$ \\
\hline 922 & 419.20 & $1.74 \mathrm{E}-05$ & $1.52 \mathrm{E}-04$ & $-1.13 E-05$ & $1.78 \mathrm{E}-05$ & $-7.55 \mathrm{E}-05$ & $-4.46 \mathrm{E}-07$ \\
\hline 237 & 463.02 & & & & & & \\
\hline 257 & 510.03 & & & & & & \\
\hline 277 & 544.44 & & & & & & \\
\hline 297 & 580.53 & & & & & & \\
\hline 317 & 631.08 & & & & & & \\
\hline 337 & 680.34 & & & & & & \\
\hline 357 & 727.44 & & & & & & \\
\hline 377 & 772.93 & & & & & & \\
\hline 397 & 831.34 & & & & & & \\
\hline 417 & 894.09 & & & & & & \\
\hline 2132 & 925.08 & $2.90 \mathrm{E}-05$ & $4.70 \mathrm{E}-05$ & $-3.72 E-05$ & $2.01 \mathrm{E}-05$ & $-5.92 E-05$ & $-3.31 E-05$ \\
\hline 2122 & 935.67 & $6.48 \mathrm{E}-05$ & $1.18 \mathrm{E}-04$ & $-2.40 \mathrm{E}-05$ & $1.11 \mathrm{E}-05$ & $-4.83 E-05$ & $-1.97 \mathrm{E}-05$ \\
\hline 2112 & 944.86 & $7.25 \mathrm{E}-05$ & $1.60 \mathrm{E}-04$ & $-1.34 \mathrm{E}-05$ & $4.54 \mathrm{E}-05$ & $-2.52 \mathrm{E}-04$ & $-5.00 \mathrm{E}-05$ \\
\hline 477 & 968.95 & & & & & & \\
\hline 497 & 1002.45 & & & & & & \\
\hline 517 & 1042.45 & & & & & & \\
\hline 537 & 1108.60 & & & & & & \\
\hline 557 & 1178.35 & & & & & & \\
\hline 577 & 1227.20 & & & & & & \\
\hline 597 & 1271.50 & & & & & & \\
\hline 617 & 1313.65 & & & & & & \\
\hline 637 & 1360.60 & & & & & & \\
\hline
\end{tabular}


RPP-RPT-32239, Rev. 1

M\&D-2008-005-CALC-001, Rev. 1

Table F.20. LBS-BEC Concrete Backed Steel Strain, Shell Middle, Gravity Plus Seismic Load

AP Backed Steel, Lower Bound Soil, Seismic Only, Best Estimate Tank Concrete, 460 In Waste Level at 1.83SpG

\begin{tabular}{|c|c|c|c|c|c|c|c|}
\hline \multirow{2}{*}{$\begin{array}{l}\text { M\&D } \\
\text { Starting } \\
\text { M\&D } \\
\text { Element } \\
\text { No. }\end{array}$} & \multirow[b]{2}{*}{ Path (in) } & \multicolumn{6}{|c|}{ Shell Mid-Plane } \\
\hline & & $\begin{array}{l}\text { AP-460-LBS-BEC } \\
\text { EPEL P1 Strain (in/in) } \\
\text { Seismic Mid Min }\end{array}$ & $\begin{array}{l}\text { AP-460-LBS-BEC } \\
\text { EPEL P1 Strain (in/in) } \\
\text { Seismic Mid Max }\end{array}$ & $\begin{array}{l}\text { AP-460-LBS-BEC } \\
\text { EPEL P2 (in/in) } \\
\text { Seismic Mid Min }\end{array}$ & $\begin{array}{c}\text { AP-460-LBS-BEC } \\
\text { EPEL P2 Strain (in/in) } \\
\text { Seismic Mid Max } \\
\end{array}$ & $\begin{array}{c}\text { AP-460-LBS-BEC } \\
\text { EPEL P3 Strain (in/in) } \\
\text { Seismic Mid Min }\end{array}$ & $\begin{array}{l}\text { AP-460-LBS-BEC } \\
\text { EPEL P3 Strain (in/in) } \\
\text { Seismic Mid Max }\end{array}$ \\
\hline 762 & 67.33 & $2.70 \mathrm{E}-05$ & $5.52 \mathrm{E}-05$ & $-5.60 \mathrm{E}-05$ & $-1.89 \mathrm{E}-05$ & $-6.11 E-05$ & $-3.01 \mathrm{E}-05$ \\
\hline 782 & 105.04 & $2.90 \mathrm{E}-05$ & 5.89E-05 & $-4.37 \mathrm{E}-05$ & $-1.30 \mathrm{E}-05$ & $-8.58 \mathrm{E}-05$ & $-4.30 \mathrm{E}-05$ \\
\hline 802 & 136.24 & $3.07 \mathrm{E}-05$ & $6.42 \mathrm{E}-05$ & $-5.06 \mathrm{E}-05$ & $-9.42 \mathrm{E}-07$ & $-7.96 \mathrm{E}-05$ & $-3.77 \mathrm{E}-05$ \\
\hline 822 & 181.71 & $2.46 \mathrm{E}-05$ & $4.70 \mathrm{E}-05$ & $-3.06 \mathrm{E}-05$ & $-4.11 \mathrm{E}-06$ & $-7.54 \mathrm{E}-05$ & $-3.18 \mathrm{E}-05$ \\
\hline 842 & 225.10 & $2.60 \mathrm{E}-05$ & $5.46 \mathrm{E}-05$ & $-4.37 \mathrm{E}-05$ & $1.77 \mathrm{E}-05$ & $-6.76 \mathrm{E}-05$ & $-2.70 \mathrm{E}-05$ \\
\hline 862 & 273.66 & $1.81 \mathrm{E}-05$ & $3.42 \mathrm{E}-05$ & $-1.94 \mathrm{E}-05$ & $1.92 \mathrm{E}-05$ & $-6.42 \mathrm{E}-05$ & $-2.09 \mathrm{E}-05$ \\
\hline 882 & 323.27 & $1.51 \mathrm{E}-05$ & $5.42 \mathrm{E}-05$ & $-2.42 \mathrm{E}-05$ & $2.33 \mathrm{E}-05$ & $-7.27 \mathrm{E}-05$ & $-1.35 \mathrm{E}-05$ \\
\hline 902 & 369.20 & $5.79 \mathrm{E}-06$ & $8.91 \mathrm{E}-05$ & $-1.03 E-06$ & $1.92 \mathrm{E}-05$ & $-6.39 E-05$ & $-1.87 \mathrm{E}-06$ \\
\hline 922 & 419.20 & $1.70 \mathrm{E}-05$ & $1.51 \mathrm{E}-04$ & $-1.19 \mathrm{E}-05$ & $2.38 \mathrm{E}-05$ & $-7.11 \mathrm{E}-05$ & $-2.13 E-06$ \\
\hline 237 & 463.02 & $3.09 \mathrm{E}-05$ & $1.07 \mathrm{E}-04$ & $1.40 \mathrm{E}-06$ & $9.62 \mathrm{E}-06$ & $-8.48 E-05$ & $-5.07 \mathrm{E}-05$ \\
\hline 257 & 510.03 & $5.33 \mathrm{E}-05$ & $1.38 \mathrm{E}-04$ & 4.97E-05 & $6.74 \mathrm{E}-05$ & $-3.93 E-04$ & $-2.76 \mathrm{E}-04$ \\
\hline 277 & 544.44 & $1.04 \mathrm{E}-04$ & 1.37E-04 & $4.12 \mathrm{E}-05$ & $1.32 \mathrm{E}-04$ & $-6.94 \mathrm{E}-04$ & $-4.85 \mathrm{E}-04$ \\
\hline 297 & 580.53 & $7.35 \mathrm{E}-05$ & $9.62 \mathrm{E}-05$ & $-3.62 E-05$ & $7.01 \mathrm{E}-05$ & $-4.24 E-04$ & $-2.96 \mathrm{E}-04$ \\
\hline 317 & 631.08 & $8.18 \mathrm{E}-05$ & $1.08 \mathrm{E}-04$ & $-1.37 \mathrm{E}-04$ & $3.83 \mathrm{E}-05$ & $-3.52 E-04$ & $-2.53 \mathrm{E}-04$ \\
\hline 337 & 680.34 & $1.05 \mathrm{E}-04$ & $1.37 \mathrm{E}-04$ & $-1.81 \mathrm{E}-04$ & 1.13E-06 & $-4.43 E-04$ & $-3.13 E-04$ \\
\hline 357 & 727.44 & $1.08 \mathrm{E}-04$ & $1.40 \mathrm{E}-04$ & $-1.93 E-04$ & $-1.68 E-05$ & $-4.45 E-04$ & $-3.07 \mathrm{E}-04$ \\
\hline 377 & 772.93 & $1.21 \mathrm{E}-04$ & $1.61 \mathrm{E}-04$ & $-2.01 E-04$ & $3.29 \mathrm{E}-05$ & $-5.34 E-04$ & $-3.38 E-04$ \\
\hline 397 & 831.34 & 1.11E-04 & $1.50 \mathrm{E}-04$ & $-1.68 E-04$ & $4.88 \mathrm{E}-05$ & $-5.15 E-04$ & $-3.11 \mathrm{E}-04$ \\
\hline 417 & 894.09 & $5.17 \mathrm{E}-05$ & $6.98 \mathrm{E}-05$ & $-9.10 \mathrm{E}-05$ & 4.32E-05 & $-2.23 E-04$ & $-1.15 \mathrm{E}-04$ \\
\hline 2132 & 925.08 & $2.43 \mathrm{E}-05$ & 3.63E-05 & $-2.02 \mathrm{E}-05$ & $1.83 \mathrm{E}-05$ & $-5.58 \mathrm{E}-05$ & $-2.28 \mathrm{E}-05$ \\
\hline 2122 & 935.67 & $2.47 \mathrm{E}-05$ & 3.73E-05 & $-3.21 \mathrm{E}-05$ & $1.41 \mathrm{E}-05$ & $-6.30 \mathrm{E}-05$ & $-2.42 E-05$ \\
\hline 2112 & 944.86 & $1.75 \mathrm{E}-05$ & $4.52 \mathrm{E}-05$ & $-1.23 \mathrm{E}-05$ & $2.53 \mathrm{E}-05$ & $-6.15 \mathrm{E}-05$ & $-2.01 \mathrm{E}-05$ \\
\hline 477 & 968.95 & $2.01 \mathrm{E}-05$ & 6.69E-05 & $-3.01 \mathrm{E}-07$ & $2.42 \mathrm{E}-05$ & $-1.29 E-04$ & $-7.87 \mathrm{E}-05$ \\
\hline 497 & 1002.45 & 1.39E-05 & $7.12 \mathrm{E}-05$ & $-5.04 \mathrm{E}-06$ & $3.52 \mathrm{E}-05$ & $-3.57 \mathrm{E}-05$ & $-3.55 \mathrm{E}-06$ \\
\hline 517 & 1042.45 & $1.18 \mathrm{E}-05$ & $6.50 \mathrm{E}-05$ & $-2.38 E-06$ & $2.40 \mathrm{E}-05$ & $-9.20 \mathrm{E}-06$ & $-1.58 E-06$ \\
\hline 537 & 1108.60 & $3.11 \mathrm{E}-05$ & 7.61E-05 & $-6.99 \mathrm{E}-06$ & $4.40 \mathrm{E}-05$ & $-2.58 \mathrm{E}-05$ & $-5.62 E-06$ \\
\hline 557 & 1178.35 & $4.04 \mathrm{E}-06$ & 4.32E-05 & $-3.10 \mathrm{E}-06$ & $1.06 \mathrm{E}-05$ & $-5.45 \mathrm{E}-05$ & $-3.61 \mathrm{E}-06$ \\
\hline 577 & 1227.20 & $1.76 \mathrm{E}-05$ & $6.83 E-05$ & $-6.63 E-06$ & $3.61 \mathrm{E}-05$ & $-2.38 \mathrm{E}-05$ & $-2.39 \mathrm{E}-06$ \\
\hline 597 & 1271.50 & $4.40 \mathrm{E}-06$ & $3.18 \mathrm{E}-05$ & $-4.37 E-06$ & $7.93 \mathrm{E}-06$ & $-3.93 E-05$ & $-6.00 \mathrm{E}-06$ \\
\hline 617 & 1313.65 & $2.46 \mathrm{E}-06$ & 4.36E-05 & $-4.13 E-06$ & $2.54 \mathrm{E}-05$ & $-1.32 E-05$ & $-8.19 \mathrm{E}-07$ \\
\hline 637 & 1360.60 & $1.59 \mathrm{E}-06$ & $1.20 \mathrm{E}-05$ & $-5.59 \mathrm{E}-07$ & 8.53E-06 & $-3.67 \mathrm{E}-06$ & $-3.00 \mathrm{E}-07$ \\
\hline
\end{tabular}


RPP-RPT-32239, Rev. 1

M\&D-2008-005-CALC-001, Rev. 1

Table F.21. LBS-BEC Concrete Backed Steel Strain, Shell Bottom, Gravity Plus Seismic Load

AP Backed Steel, Lower Bound Soil, Seismic Only, Best Estimate Tank Concrete, 460 In Waste

Level at 1.83SpG

\begin{tabular}{|c|c|c|c|c|c|c|c|}
\hline \multirow{2}{*}{$\begin{array}{c}\text { M\&D } \\
\text { Starting } \\
\text { M\&D } \\
\text { Element } \\
\text { No. }\end{array}$} & \multirow[b]{2}{*}{ Path (in) } & \multicolumn{6}{|c|}{ Shell Bottom Surface (outside - away from waste) Seismic } \\
\hline & & $\begin{array}{l}\text { AP-460-LBS-BEC } \\
\text { EPEL P1 Strain (in/in) } \\
\text { Seismic Bot Min }\end{array}$ & $\begin{array}{c}\text { AP-460-LBS-BEC } \\
\text { EPEL P1 Strain (in/in) } \\
\text { Seismic Bot Max }\end{array}$ & $\begin{array}{l}\text { AP-460-LBS-BEC } \\
\text { EPEL P2 (in/in) } \\
\text { Seismic Bot Min }\end{array}$ & $\begin{array}{c}\text { AP-460-LBS-BEC } \\
\text { EPEL P2 Strain (in/in) } \\
\text { Seismic Bot Max }\end{array}$ & \begin{tabular}{|} 
AP-460-LBS-BEC \\
EPEL P3 Strain (in/in) \\
Seismic Bat Min
\end{tabular} & $\begin{array}{c}\text { AP-460-LBS-BEC } \\
\text { EPEL P3 Strain (in/in) } \\
\text { Seismic Bot Max }\end{array}$ \\
\hline 762 & 67.33 & $3.10 \mathrm{E}-05$ & $6.74 \mathrm{E}-05$ & $-5.95 \mathrm{E}-05$ & $-1.96 \mathrm{E}-05$ & $-6.68 \mathrm{E}-05$ & $-2.42 \mathrm{E}-05$ \\
\hline 782 & 105.04 & $2.43 \mathrm{E}-05$ & $5.56 \mathrm{E}-05$ & $-4.45 \mathrm{E}-05$ & $-1.29 \mathrm{E}-05$ & $-7.87 \mathrm{E}-05$ & $-2.40 \mathrm{E}-05$ \\
\hline 802 & 136.24 & $3.53 \mathrm{E}-05$ & $7.72 \mathrm{E}-05$ & $-5.09 E-05$ & $-1.50 \mathrm{E}-06$ & $-8.77 \mathrm{E}-05$ & $-3.43 E-05$ \\
\hline 822 & 181.71 & $2.14 \mathrm{E}-05$ & $4.12 \mathrm{E}-05$ & $-3.08 E-05$ & $-4.32 \mathrm{E}-06$ & $-7.06 \mathrm{E}-05$ & $-2.70 \mathrm{E}-05$ \\
\hline 842 & 225.10 & $3.02 \mathrm{E}-05$ & $7.11 \mathrm{E}-05$ & $-4.93 E-05$ & $1.38 \mathrm{E}-05$ & $-7.90 \mathrm{E}-05$ & $-2.05 E-05$ \\
\hline 862 & 273.66 & $1.66 \mathrm{E}-05$ & 2.99E-05 & $-1.94 \mathrm{E}-05$ & 1.99E-05 & $-6.15 \mathrm{E}-05$ & $-1.97 \mathrm{E}-05$ \\
\hline 882 & 323.27 & $1.68 \mathrm{E}-05$ & $5.53 \mathrm{E}-05$ & $-2.71 E-05$ & $2.58 \mathrm{E}-05$ & $-7.57 \mathrm{E}-05$ & $-3.65 \mathrm{E}-06$ \\
\hline 902 & 369.20 & $5.53 \mathrm{E}-06$ & $8.96 \mathrm{E}-05$ & $-1.14 \mathrm{E}-06$ & $1.81 \mathrm{E}-05$ & $-6.05 E-05$ & $-6.78 \mathrm{E}-06$ \\
\hline 922 & 419.20 & $1.64 \mathrm{E}-05$ & $1.51 \mathrm{E}-04$ & $-1.27 \mathrm{E}-05$ & $3.03 E-05$ & $-7.82 E-05$ & $-1.85 E-06$ \\
\hline 237 & 463.02 & & & & & & \\
\hline 257 & 510.03 & & & & & & \\
\hline 277 & 544.44 & & & & & & \\
\hline 297 & 580.53 & & & & & & \\
\hline 317 & 631.08 & & & & & & \\
\hline 337 & 680.34 & & & & & & \\
\hline 357 & 727.44 & & & & & & \\
\hline 377 & 772.93 & & & & & & \\
\hline 397 & 831.34 & & & & & & \\
\hline 417 & 894.09 & & & & & & \\
\hline 2132 & 925.08 & $2.46 \mathrm{E}-05$ & $3.43 E-05$ & $-8.41 E-06$ & $1.60 \mathrm{E}-05$ & $-5.31 E-05$ & $-1.68 \mathrm{E}-05$ \\
\hline 2122 & 935.67 & 5.31E-05 & 9.24E-05 & $-3.64 \mathrm{E}-05$ & $9.63 \mathrm{E}-06$ & $-1.39 E-04$ & $-4.79 \mathrm{E}-05$ \\
\hline 2112 & 944.86 & $1.18 \mathrm{E}-04$ & $2.73 \mathrm{E}-04$ & $-1.82 \mathrm{E}-05$ & $4.49 \mathrm{E}-05$ & $-7.44 \mathrm{E}-05$ & $-2.64 \mathrm{E}-05$ \\
\hline 477 & 968.95 & & & & & & \\
\hline 497 & 1002.45 & & & & & & \\
\hline 517 & 1042.45 & & & & & & \\
\hline 537 & 1108.60 & & & & & & \\
\hline 557 & 1178.35 & & & & & & \\
\hline 577 & 1227.20 & & & & & & \\
\hline 597 & 1271.50 & & & & & & \\
\hline 617 & 1313.65 & & & & & & \\
\hline 637 & 1360.60 & & & & & & \\
\hline
\end{tabular}


RPP-RPT-32239, Rev. 1

M\&D-2008-005-CALC-001, Rev. 1

Table F.22. LBS-BEC Concrete Backed Steel Strain, Shell Top, Seismic Load Only

AP Backed Steel, Lower Bound Soil, Seismic Only, Best Estimate Tank Concrete, 460 In Waste Level at 1.83SpG

\begin{tabular}{|c|c|c|c|c|c|c|c|}
\hline \multirow[b]{2}{*}{$\begin{array}{c}\text { M\&D } \\
\text { Starting } \\
\text { M\&D } \\
\text { Element } \\
\text { No. }\end{array}$} & \multirow[b]{2}{*}{ Path (in) } & \multicolumn{6}{|c|}{ Shell Top Surface (inside - towards waste) Seismic } \\
\hline & & $\begin{array}{c}\text { AP-460-LBS-BEC } \\
\text { EPEL P1 Strain (in/in) } \\
\text { Seismic Only Top } \\
\text { Min }\end{array}$ & $\begin{array}{c}\text { AP-460-LBS-BEC } \\
\text { EPEL P1 Strain (in/in) } \\
\text { Seismic Only Top } \\
\text { Max }\end{array}$ & $\begin{array}{l}\text { AP-460-LBS-BEC } \\
\text { EPEL P2 (in/in) } \\
\text { Seismic Only Tap } \\
\text { Min }\end{array}$ & $\begin{array}{c}\text { AP-460-LBS-BEC } \\
\text { EPEL P2 Strain (in/in) } \\
\text { Seismic Only Top } \\
\text { Max }\end{array}$ & $\begin{array}{c}\text { AP-460-LBS-BEC } \\
\text { EPEL P3 Strain } \\
\text { (in/in) Seismic Only } \\
\text { Top Min }\end{array}$ & $\begin{array}{c}\text { AP-460-LBS-BEC } \\
\text { EPEL P3 Strain (in/in) } \\
\text { Seismic Only Tap } \\
\text { Max }\end{array}$ \\
\hline 762 & 67.33 & $-1.14 \mathrm{E}-05$ & 1.19E-05 & $-1.51 \mathrm{E}-05$ & $2.83 E-05$ & $-1.37 \mathrm{E}-05$ & $1.74 \mathrm{E}-05$ \\
\hline 782 & 105.04 & $-1.27 \mathrm{E}-05$ & $2.43 \mathrm{E}-05$ & $-1.03 \mathrm{E}-05$ & $1.94 \mathrm{E}-05$ & $-2.02 \mathrm{E}-05$ & $3.93 \mathrm{E}-05$ \\
\hline 802 & 136.24 & $-1.18 \mathrm{E}-05$ & $1.35 \mathrm{E}-05$ & $-1.06 \mathrm{E}-05$ & $3.89 \mathrm{E}-05$ & $-2.63 E-05$ & $1.66 \mathrm{E}-05$ \\
\hline 822 & 181.71 & $-8.90 \mathrm{E}-06$ & $1.82 \mathrm{E}-05$ & $-8.51 \mathrm{E}-06$ & $1.81 \mathrm{E}-05$ & $-2.07 \mathrm{E}-05$ & $2.90 \mathrm{E}-05$ \\
\hline 842 & 225.10 & $-6.77 \mathrm{E}-06$ & $1.04 \mathrm{E}-05$ & $-5.68 \mathrm{E}-06$ & $5.11 \mathrm{E}-05$ & $-2.80 \mathrm{E}-05$ & $9.04 \mathrm{E}-06$ \\
\hline 862 & 273.66 & $-4.85 \mathrm{E}-06$ & $1.46 \mathrm{E}-05$ & $-7.94 \mathrm{E}-06$ & $3.03 E-05$ & $-2.53 E-05$ & 2.99E-05 \\
\hline 882 & 323.27 & $-2.47 \mathrm{E}-06$ & $3.91 \mathrm{E}-05$ & $-3.54 \mathrm{E}-06$ & $3.88 \mathrm{E}-05$ & $-5.24 \mathrm{E}-05$ & $8.21 \mathrm{E}-06$ \\
\hline 902 & 369.20 & $-7.34 \mathrm{E}-06$ & $7.52 \mathrm{E}-05$ & $-7.57 \mathrm{E}-06$ & $1.41 \mathrm{E}-05$ & $-4.32 \mathrm{E}-05$ & 2.69E-05 \\
\hline 922 & 419.20 & $-1.71 \mathrm{E}-05$ & $1.18 \mathrm{E}-04$ & $-3.99 E-06$ & $2.51 \mathrm{E}-05$ & $-5.84 E-05$ & $1.66 \mathrm{E}-05$ \\
\hline 237 & 463.02 & & & & & & \\
\hline 257 & 510.03 & & & & & & \\
\hline 277 & 544.44 & & & & & & \\
\hline 297 & 580.53 & & & & & & \\
\hline 317 & 631.08 & & & & & & \\
\hline 337 & 680.34 & & & & & & \\
\hline 357 & 727.44 & & & & & & \\
\hline 377 & 772.93 & & & & & & \\
\hline 397 & 831.34 & & & & & & \\
\hline 417 & 894.09 & & & & & & \\
\hline 2062 & 925.08 & $-5.68 \mathrm{E}-06$ & $1.24 \mathrm{E}-05$ & $-4.68 \mathrm{E}-06$ & $5.26 \mathrm{E}-05$ & $-1.68 \mathrm{E}-05$ & 9.37E-06 \\
\hline 2052 & 935.67 & $-1.08 \mathrm{E}-05$ & $4.21 \mathrm{E}-05$ & $-2.83 E-06$ & $3.23 \mathrm{E}-05$ & $-1.73 E-05$ & 1.13E-05 \\
\hline 2042 & 944.86 & $-2.35 E-05$ & $6.37 \mathrm{E}-05$ & $-5.64 \mathrm{E}-06$ & $5.32 \mathrm{E}-05$ & $-3.87 \mathrm{E}-05$ & 1.63E-04 \\
\hline 477 & 968.95 & & & & & & \\
\hline 497 & 1002.45 & & & & & & \\
\hline 517 & 1042.45 & & & & & & \\
\hline 537 & 1108.60 & & & & & & \\
\hline 557 & 1178.35 & & & & & & \\
\hline 577 & 1227.20 & & & & & & \\
\hline 597 & 1271.50 & & & & & & \\
\hline 617 & 1313.65 & & & & & & \\
\hline 637 & 1360.60 & & & & & & \\
\hline
\end{tabular}


RPP-RPT-32239, Rev. 1

M\&D-2008-005-CALC-001, Rev. 1

Table F.23. LBS-BEC Concrete Backed Steel Strain, Shell Middle, Seismic Load Only

AP Backed Steel, Lower Bound Soil, Seismic Only, Best Estimate Tank Concrete, 460 In Waste Level at 1.83SpG

\begin{tabular}{|c|c|c|c|c|c|c|c|}
\hline \multirow[b]{2}{*}{$\begin{array}{c}\text { M\&D } \\
\text { Starting } \\
\text { M\&D } \\
\text { Element } \\
\mathrm{No.}\end{array}$} & \multirow[b]{2}{*}{ Path (in) } & \multicolumn{6}{|c|}{ Shell Mid-Plane } \\
\hline & & $\begin{array}{l}\text { AP-46u-LBS- } \\
\text { BEC EPEL P1 } \\
\text { Strain (in/in) } \\
\text { Seismic Only } \\
\text { Mid Min }\end{array}$ & $\begin{array}{c}\text { AP-460-LBS-BEC } \\
\text { EPEL P1 Strain (in/in) } \\
\text { Seismic Only Mid } \\
\text { Max }\end{array}$ & $\begin{array}{l}\text { AP-460-LBS-BEC } \\
\text { EPEL P2 (in/in) } \\
\text { Seismic Only Mid } \\
\text { Min }\end{array}$ & $\begin{array}{c}\text { AP-460-LBS-BEC } \\
\text { EPEL P2 Strain (in/in) } \\
\text { Seismic Only Mid } \\
\text { Max }\end{array}$ & $\begin{array}{c}\text { AP-460-LBS-BEC } \\
\text { EPEL P3 Strain (in/in) } \\
\text { Seismic Only Mid } \\
\text { Min }\end{array}$ & $\begin{array}{c}\text { AP-460-LBS-BEC } \\
\text { EPEL P3 Strain (in/in) } \\
\text { Seismic Only Mid } \\
\text { Max }\end{array}$ \\
\hline 762 & 67.33 & $-1.12 \mathrm{E}-05$ & $1.69 \mathrm{E}-05$ & $-1.31 E-05$ & $2.40 \mathrm{E}-05$ & $-1.52 \mathrm{E}-05$ & $1.57 \mathrm{E}-05$ \\
\hline 782 & 105.04 & $-1.34 \mathrm{E}-05$ & $1.65 \mathrm{E}-05$ & $-1.07 \mathrm{E}-05$ & $2.00 \mathrm{E}-05$ & $-2.10 \mathrm{E}-05$ & 2.17E-05 \\
\hline 802 & 136.24 & $-1.15 E-05$ & $2.20 \mathrm{E}-05$ & $-1.09 \mathrm{E}-05$ & 3.87E-05 & $-2.24 \mathrm{E}-05$ & $1.95 \mathrm{E}-05$ \\
\hline 822 & 181.71 & $-8.82 \mathrm{E}-06$ & $1.36 \mathrm{E}-05$ & $-8.28 \mathrm{E}-06$ & $1.82 \mathrm{E}-05$ & $-2.12 \mathrm{E}-05$ & $2.24 \mathrm{E}-05$ \\
\hline 842 & 225.10 & $-7.35 \mathrm{E}-06$ & $2.12 \mathrm{E}-05$ & $-1.04 \mathrm{E}-05$ & $5.10 \mathrm{E}-05$ & $-2.48 E-05$ & $1.58 \mathrm{E}-05$ \\
\hline 862 & 273.66 & $-4.47 \mathrm{E}-06$ & $1.16 \mathrm{E}-05$ & $-7.80 \mathrm{E}-06$ & 3.09E-05 & $-2.41 E-05$ & $1.91 \mathrm{E}-05$ \\
\hline 882 & 323.27 & $-3.86 \mathrm{E}-06$ & $3.52 \mathrm{E}-05$ & $-8.91 \mathrm{E}-06$ & $3.86 \mathrm{E}-05$ & $-4.44 \mathrm{E}-05$ & $1.48 \mathrm{E}-05$ \\
\hline 902 & 369.20 & $-7.31 \mathrm{E}-06$ & 7.59E-05 & $-6.91 E-06$ & 1.33E-05 & $-3.75 \mathrm{E}-05$ & $2.45 \mathrm{E}-05$ \\
\hline 922 & 419.20 & $-1.73 \mathrm{E}-05$ & 1.17E-04 & $-5.70 \mathrm{E}-06$ & $3.00 \mathrm{E}-05$ & $-5.16 \mathrm{E}-05$ & $1.73 \mathrm{E}-05$ \\
\hline 237 & 463.02 & $-2.61 \mathrm{E}-05$ & 4.97E-05 & $-2.25 \mathrm{E}-06$ & $5.96 \mathrm{E}-06$ & $-1.42 E-05$ & $1.98 \mathrm{E}-05$ \\
\hline 257 & 510.03 & $-2.95 E-05$ & $5.53 \mathrm{E}-05$ & $-6.41 E-06$ & $1.12 \mathrm{E}-05$ & $-5.49 \mathrm{E}-05$ & $6.24 \mathrm{E}-05$ \\
\hline 277 & 544.44 & $-1.23 \mathrm{E}-05$ & $2.11 \mathrm{E}-05$ & $-3.28 \mathrm{E}-05$ & $5.80 \mathrm{E}-05$ & $-9.93 E-05$ & $1.09 \mathrm{E}-04$ \\
\hline 297 & 580.53 & $-8.07 \mathrm{E}-06$ & $1.46 \mathrm{E}-05$ & $-2.54 \mathrm{E}-05$ & $8.08 \mathrm{E}-05$ & $-6.58 \mathrm{E}-05$ & 6.19E-05 \\
\hline 317 & 631.08 & $-9.80 E-06$ & 1.59E-05 & $-2.02 E-05$ & $1.55 \mathrm{E}-04$ & $-5.15 E-05$ & $4.67 \mathrm{E}-05$ \\
\hline 337 & 680.34 & $-1.27 \mathrm{E}-05$ & $1.89 \mathrm{E}-05$ & $-2.07 E-05$ & $1.61 \mathrm{E}-04$ & $-6.59 \mathrm{E}-05$ & $6.37 \mathrm{E}-05$ \\
\hline 357 & 727.44 & $-1.36 \mathrm{E}-05$ & 1.87E-05 & $-1.95 \mathrm{E}-05$ & 1.56E-04 & $-6.56 \mathrm{E}-05$ & $7.13 \mathrm{E}-05$ \\
\hline 377 & 772.93 & $-1.67 \mathrm{E}-05$ & $2.29 \mathrm{E}-05$ & $-1.93 \mathrm{E}-05$ & $2.14 \mathrm{E}-04$ & $-8.73 E-05$ & $1.08 \mathrm{E}-04$ \\
\hline 397 & 831.34 & $-1.69 \mathrm{E}-05$ & $2.16 \mathrm{E}-05$ & $-1.61 E-05$ & $2.01 \mathrm{E}-04$ & $-8.27 E-05$ & $1.21 \mathrm{E}-04$ \\
\hline 417 & 894.09 & $-7.86 \mathrm{E}-06$ & $1.02 \mathrm{E}-05$ & $-8.54 \mathrm{E}-06$ & $1.26 \mathrm{E}-04$ & $-3.67 E-05$ & $7.15 \mathrm{E}-05$ \\
\hline 2062 & 925.08 & $-4.95 \mathrm{E}-06$ & $7.07 \mathrm{E}-06$ & $-3.54 \mathrm{E}-06$ & $3.50 \mathrm{E}-05$ & $-1.33 \mathrm{E}-05$ & $1.97 \mathrm{E}-05$ \\
\hline 2052 & 935.67 & $-5.49 \mathrm{E}-06$ & $7.15 \mathrm{E}-06$ & $-3.09 E-06$ & $4.31 \mathrm{E}-05$ & $-3.22 E-05$ & $6.52 \mathrm{E}-06$ \\
\hline 2042 & 944.86 & $-4.48 \mathrm{E}-06$ & $2.31 \mathrm{E}-05$ & $-4.55 \mathrm{E}-06$ & $3.30 \mathrm{E}-05$ & $-2.62 \mathrm{E}-05$ & $1.52 \mathrm{E}-05$ \\
\hline 477 & 968.95 & $-4.30 \mathrm{E}-06$ & $4.24 \mathrm{E}-05$ & $-9.01 E-06$ & $1.55 \mathrm{E}-05$ & $-2.00 \mathrm{E}-05$ & $3.05 E-05$ \\
\hline 497 & 1002.45 & $-6.48 E-06$ & $5.07 \mathrm{E}-05$ & $-1.93 \mathrm{E}-05$ & $2.10 \mathrm{E}-05$ & $-2.75 \mathrm{E}-05$ & $4.61 \mathrm{E}-06$ \\
\hline 517 & 1042.45 & $-2.09 \mathrm{E}-06$ & $5.10 \mathrm{E}-05$ & $-1.56 \mathrm{E}-05$ & $1.08 \mathrm{E}-05$ & $-3.05 \mathrm{E}-06$ & $4.56 \mathrm{E}-06$ \\
\hline 537 & 1108.60 & $-6.31 \mathrm{E}-06$ & 3.87E-05 & $-1.41 \mathrm{E}-05$ & $3.68 \mathrm{E}-05$ & $-1.44 \mathrm{E}-05$ & $5.76 \mathrm{E}-06$ \\
\hline 557 & 1178.35 & $-7.31 \mathrm{E}-07$ & $3.84 \mathrm{E}-05$ & $-6.98 \mathrm{E}-06$ & $6.67 \mathrm{E}-06$ & $-3.15 \mathrm{E}-05$ & $1.94 \mathrm{E}-05$ \\
\hline 577 & 1227.20 & $-1.04 \mathrm{E}-05$ & $4.03 \mathrm{E}-05$ & $-1.06 \mathrm{E}-05$ & $3.22 \mathrm{E}-05$ & $-1.65 \mathrm{E}-05$ & $4.90 \mathrm{E}-06$ \\
\hline 597 & 1271.50 & $-6.29 E-07$ & $2.68 \mathrm{E}-05$ & $-8.68 \mathrm{E}-06$ & $3.62 \mathrm{E}-06$ & $-1.55 \mathrm{E}-05$ & $1.78 \mathrm{E}-05$ \\
\hline 617 & 1313.65 & $-1.50 \mathrm{E}-05$ & $2.61 \mathrm{E}-05$ & $-1.19 \mathrm{E}-05$ & $1.76 \mathrm{E}-05$ & -7.60 E-06 & $4.74 \mathrm{E}-06$ \\
\hline 637 & 1360.60 & $-3.50 \mathrm{E}-06$ & $6.88 \mathrm{E}-06$ & $-5.30 \mathrm{E}-06$ & $3.79 \mathrm{E}-06$ & $-1.65 \mathrm{E}-06$ & $1.71 \mathrm{E}-06$ \\
\hline
\end{tabular}


RPP-RPT-32239, Rev. 1

M\&D-2008-005-CALC-001, Rev. 1

Table F.24. LBS-BEC Concrete Backed Steel Strain, Shell Bottom, Seismic Load Only

AP Backed Steel, Lower Bound Soil, Seismic Only, Best Estimate Tank Concrete, 460 In Waste

Level at $1.83 \mathrm{SpG}$

\begin{tabular}{|c|c|c|c|c|c|c|c|}
\hline \multirow[b]{2}{*}{$\begin{array}{c}\text { M\&D } \\
\text { Starting } \\
\text { M\&D } \\
\text { Element } \\
\text { No. }\end{array}$} & \multirow[b]{2}{*}{ Path (in) } & \multicolumn{6}{|c|}{ Shell Bottom Surface (outside - away from waste) Seismic } \\
\hline & & $\begin{array}{c}\text { AP-460-LBS-BEC } \\
\text { EPEL P1 Strain (in/in) } \\
\text { Seismic Only Bot } \\
\text { Min }\end{array}$ & $\begin{array}{c}\text { AP-460-LBS-BEC } \\
\text { EPEL P1 Strain (in/in) } \\
\text { Seismic Only Bot } \\
\text { Max }\end{array}$ & $\begin{array}{c}\text { AP-460-LBS-BEC } \\
\text { EPEL P2 (in/in) } \\
\text { Seismic Only Bot } \\
\text { Min }\end{array}$ & $\begin{array}{c}\text { AP-460-LBS-BEC } \\
\text { EPEL P2 Strain (in/in) } \\
\text { Seismic Only Bot } \\
\text { Max }\end{array}$ & $\begin{array}{c}\text { AP-460-LBS-BEC } \\
\text { EPEL P3 Strain (in/in) } \\
\text { Seismic Only Bot } \\
\text { Min }\end{array}$ & $\begin{array}{c}\text { AP-460-LBS-BEC } \\
\text { EPEL P3 Strain (in/in) } \\
\text { Seismic Only Bot } \\
\text { Max }\end{array}$ \\
\hline 762 & 67.33 & $-1.14 \mathrm{E}-05$ & $2.49 \mathrm{E}-05$ & $-1.30 \mathrm{E}-05$ & $2.69 \mathrm{E}-05$ & $-1.51 \mathrm{E}-05$ & $2.74 \mathrm{E}-05$ \\
\hline 782 & 105.04 & $-1.41 \mathrm{E}-05$ & $1.72 \mathrm{E}-05$ & $-1.10 \mathrm{E}-05$ & $2.07 \mathrm{E}-05$ & $-2.36 \mathrm{E}-05$ & $3.10 \mathrm{E}-05$ \\
\hline 802 & 136.24 & $-1.12 \mathrm{E}-05$ & $3.06 \mathrm{E}-05$ & $-1.08 \mathrm{E}-05$ & $3.86 \mathrm{E}-05$ & $-2.07 \mathrm{E}-05$ & $3.27 \mathrm{E}-05$ \\
\hline 822 & 181.71 & $-9.46 \mathrm{E}-06$ & $1.03 E-05$ & $-8.18 \mathrm{E}-06$ & $1.83 \mathrm{E}-05$ & $-2.25 \mathrm{E}-05$ & $2.10 \mathrm{E}-05$ \\
\hline 842 & 225.10 & $-8.46 \mathrm{E}-06$ & $3.24 \mathrm{E}-05$ & $-1.60 \mathrm{E}-05$ & $4.71 \mathrm{E}-05$ & $-2.41 E-05$ & $3.43 \mathrm{E}-05$ \\
\hline 862 & 273.66 & $-4.28 \mathrm{E}-06$ & $8.97 \mathrm{E}-06$ & $-7.51 E-06$ & $3.17 \mathrm{E}-05$ & $-2.56 \mathrm{E}-05$ & $1.62 \mathrm{E}-05$ \\
\hline 882 & 323.27 & $-5.87 E-06$ & $3.27 E-05$ & $-1.16 \mathrm{E}-05$ & $4.12 \mathrm{E}-05$ & $-3.89 E-05$ & 3.31E-05 \\
\hline 902 & 369.20 & $-7.31 E-06$ & $7.67 \mathrm{E}-05$ & $-6.24 \mathrm{E}-06$ & $1.30 \mathrm{E}-05$ & $-3.62 E-05$ & $1.75 \mathrm{E}-05$ \\
\hline 922 & 419.20 & $-1.77 \mathrm{E}-05$ & 1.17E-04 & $-7.55 \mathrm{E}-06$ & $3.54 \mathrm{E}-05$ & $-5.63 E-05$ & $2.00 \mathrm{E}-05$ \\
\hline 237 & 463.02 & & & & & & \\
\hline 257 & 510.03 & & & & & & \\
\hline 277 & 544.44 & & & & & & \\
\hline 297 & 580.53 & & & & & & \\
\hline 317 & 631.08 & & & & & & \\
\hline 337 & 680.34 & & & & & & \\
\hline 357 & 727.44 & & & & & & \\
\hline 377 & 772.93 & & & & & & \\
\hline 397 & 831.34 & & & & & & \\
\hline 417 & 894.09 & & & & & & \\
\hline 2062 & 925.08 & $-3.35 \mathrm{E}-06$ & $6.36 \mathrm{E}-06$ & $-3.59 \mathrm{E}-06$ & $2.08 \mathrm{E}-05$ & $-1.06 \mathrm{E}-05$ & $2.56 \mathrm{E}-05$ \\
\hline 2052 & 935.67 & $-1.12 \mathrm{E}-05$ & $2.82 \mathrm{E}-05$ & $-6.12 \mathrm{E}-06$ & $3.99 \mathrm{E}-05$ & $-2.32 E-05$ & $6.81 \mathrm{E}-05$ \\
\hline 2042 & 944.86 & $-3.80 \mathrm{E}-05$ & 1.17E-04 & $-1.05 E-05$ & $5.26 \mathrm{E}-05$ & $-1.11 \mathrm{E}-05$ & $3.68 \mathrm{E}-05$ \\
\hline 477 & 968.95 & & & & & & \\
\hline 497 & 1002.45 & & & & & & \\
\hline 517 & 1042.45 & & & & & & \\
\hline 537 & 1108.60 & & & & & & \\
\hline 557 & 1178.35 & & & & & & \\
\hline 577 & 1227.20 & & & & & & \\
\hline 597 & 1271.50 & & & & & & \\
\hline 617 & 1313.65 & & & & & & \\
\hline 637 & 1360.60 & & & & & & \\
\hline
\end{tabular}


RPP-RPT-32239, Rev. 1

M\&D-2008-005-CALC-001, Rev. 1

Table F.25. LBS-BEC Concrete Wall/Footing Contact Forces, Gravity Only

\begin{tabular}{|c|c|c|c|c|c|c|c|c|c|c|c|}
\hline \multirow[b]{4}{*}{ Angle } & Vertical & Vertical & Shear Y & Shear $Y$ & Shear $X$ & Shear X & Shear $Y$ & Shear X & Shear & & \\
\hline & Min AP. & Max AP- & Min AP- & Max AP- & Min AP- & Max AP. & Max AP. & Max AP- & Max AP- & Vertical Force & Vertical Force \\
\hline & LBS-BEC & LBS-BEC & LBS-BEC & LBS-BEC & LBS-BEC & LBS-BEC & LBS-BEC & LBS-BEC & LBS-BEC & Max AP-LBS- & Min AP-LBS- \\
\hline & Gravity & Gravity & Gravity & Gravity & Gravity & Gravity & Gravity & Gravity & Gravity & BEC Gravity & BEC Gravity \\
\hline 0 & -239.10 & -238.90 & 0.00 & 0.00 & -4.32 & -4.31 & 0.00 & 1.35 & 1.35 & -74.72 & -74.66 \\
\hline 9 & -478.40 & -477.80 & -1.59 & -1.58 & -8.78 & -8.76 & 0.25 & 1.37 & 1.39 & -74.75 & -74.66 \\
\hline 18 & -478.30 & -477.80 & -2.28 & -2.28 & -8.09 & -8.08 & 0.36 & 1.26 & 1.31 & -74.73 & -74.66 \\
\hline 27 & -478.30 & -477.70 & -3.43 & -3.43 & -7.63 & -7.61 & 0.54 & 1.19 & 1.31 & -74.73 & -74.64 \\
\hline 36 & -478.30 & -477.80 & -5.30 & -5.29 & -7.19 & -7.18 & 0.83 & 1.12 & 1.40 & -74.73 & -74.66 \\
\hline 45 & -478.20 & -477.60 & -6.13 & -6.12 & -6.11 & -6.10 & 0.96 & 0.95 & 1.35 & -74.72 & -74.63 \\
\hline 54 & -478.20 & -477.60 & -7.19 & -7.18 & -5.28 & -5.27 & 1.12 & 0.83 & 1.39 & -74.72 & -74.63 \\
\hline 63 & -478.20 & -477.60 & -7.65 & -7.64 & -3.93 & -3.93 & 1.20 & 0.61 & 1.34 & -74.72 & -74.63 \\
\hline 72 & -478.30 & -477.70 & -8.52 & -8.51 & -2.70 & -2.70 & 1.33 & 0.42 & 1.40 & -74.73 & -74.64 \\
\hline 81 & -478.10 & -477.60 & -8.26 & -8.25 & -1.43 & -1.42 & 1.29 & 0.22 & 1.31 & -74.70 & -74.63 \\
\hline 90 & -478.20 & -477.60 & -8.87 & -8.86 & 0.04 & 0.04 & 1.39 & 0.01 & 1.39 & -74.72 & -74.63 \\
\hline 99 & -478.20 & -477.70 & -8.73 & -8.72 & 1.44 & 1.44 & 1.36 & 0.23 & 1.38 & -74.72 & -74.64 \\
\hline 108 & -478.20 & -477.60 & -8.02 & -8.01 & 2.43 & 2.43 & 1.25 & 0.38 & 1.31 & -74.72 & -74.63 \\
\hline 117 & -478.30 & -477.70 & -7.93 & -7.92 & 4.07 & 4.07 & 1.24 & 0.64 & 1.39 & -74.73 & -74.64 \\
\hline 126 & -478.20 & -477.70 & -6.95 & -6.94 & 5.11 & 5.12 & 1.09 & 0.80 & 1.35 & -74.72 & -74.64 \\
\hline 135 & -478.20 & -477.60 & -6.18 & -6.17 & 6.31 & 6.31 & 0.97 & 0.99 & 1.38 & -74.72 & -74.63 \\
\hline 144 & -478.10 & -477.60 & -5.13 & -5.12 & 7.11 & 7.12 & 0.80 & 1.11 & 1.37 & -74.70 & -74.63 \\
\hline 153 & -478.20 & -477.60 & -4.01 & -4.00 & 7.81 & 7.82 & 0.63 & 1.22 & 1.37 & -74.72 & -74.63 \\
\hline 162 & -478.20 & -477.70 & -2.67 & -2.66 & 8.29 & 8.31 & 0.42 & 1.30 & 1.36 & -74.72 & -74.64 \\
\hline 171 & -478.20 & -477.70 & -1.33 & -1.32 & 8.66 & 8.68 & 0.21 & 1.36 & 1.37 & -74.72 & -74.64 \\
\hline 180 & -239.10 & -238.90 & 0.00 & 0.00 & 4.39 & 4.39 & 0.00 & 1.37 & 1.37 & -74.72 & -74.66 \\
\hline
\end{tabular}

Table F.26. LBS-BEC Concrete Wall/Footing Contact Forces, Gravity Plus Seismic

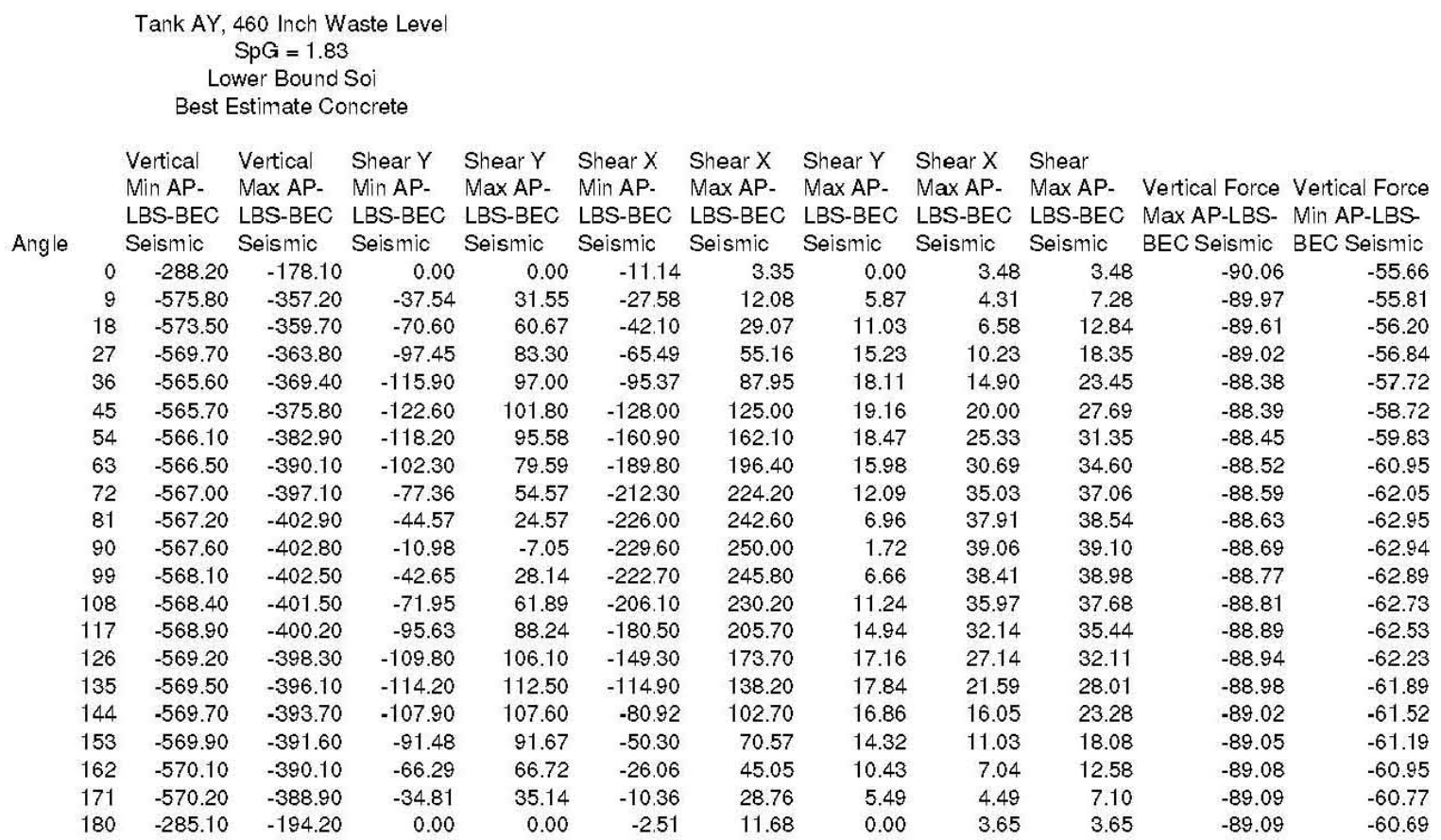


RPP-RPT-32239, Rev. 1

M\&D-2008-005-CALC-001, Rev. 1

Table F.27. LBS-BEC Concrete Wall/Footing Contact Forces, Seismic Only

Tank AY, 460 Inch Waste Level

$\mathrm{SpG}=1.83$

Lower Bound So

Best Estimate Concrete

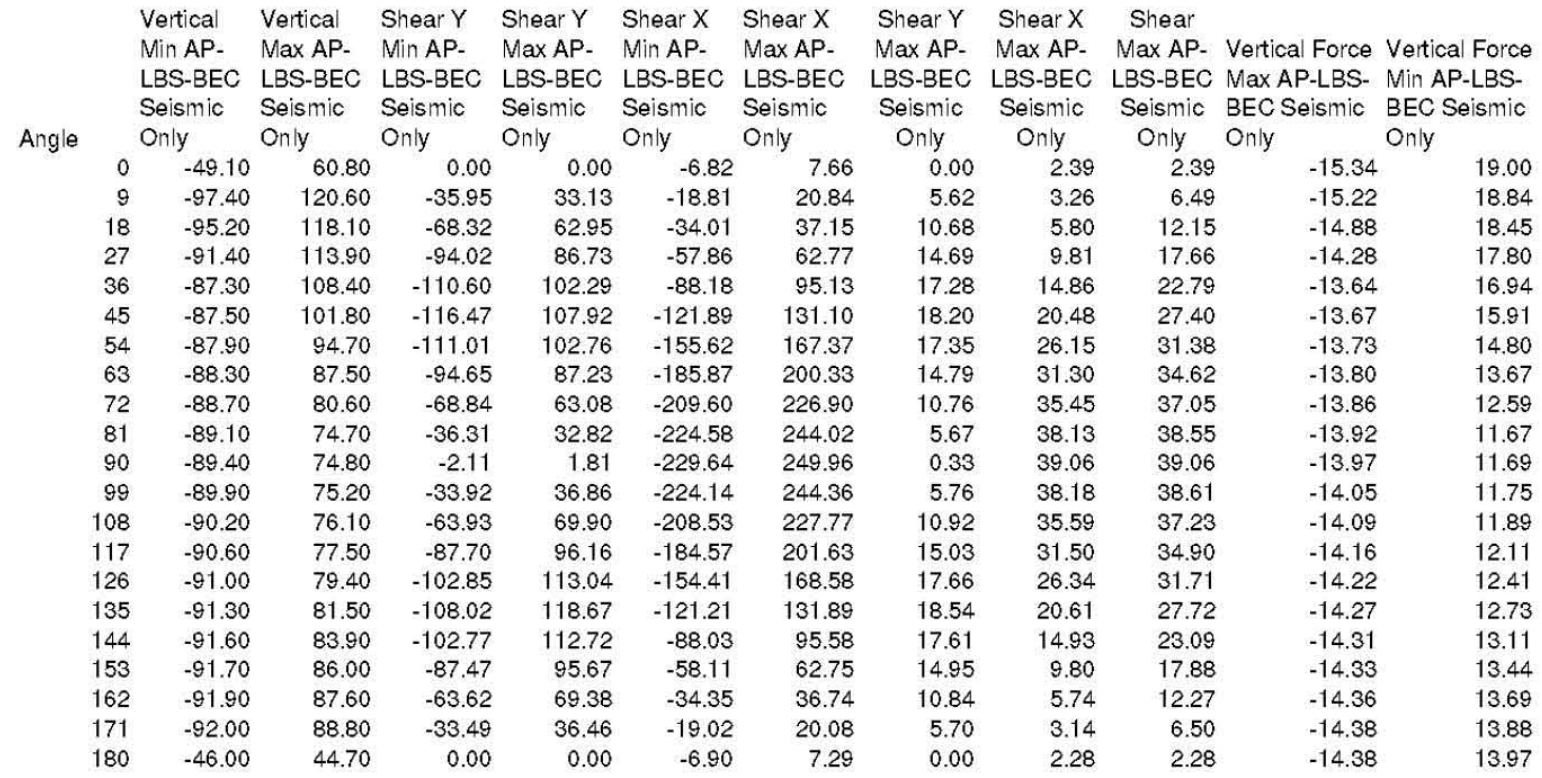

Table F.28. LBS-BEC Soil/Concrete Tank Contact Forces, Gravity Only

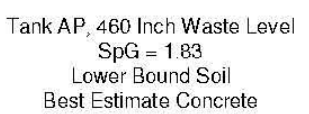

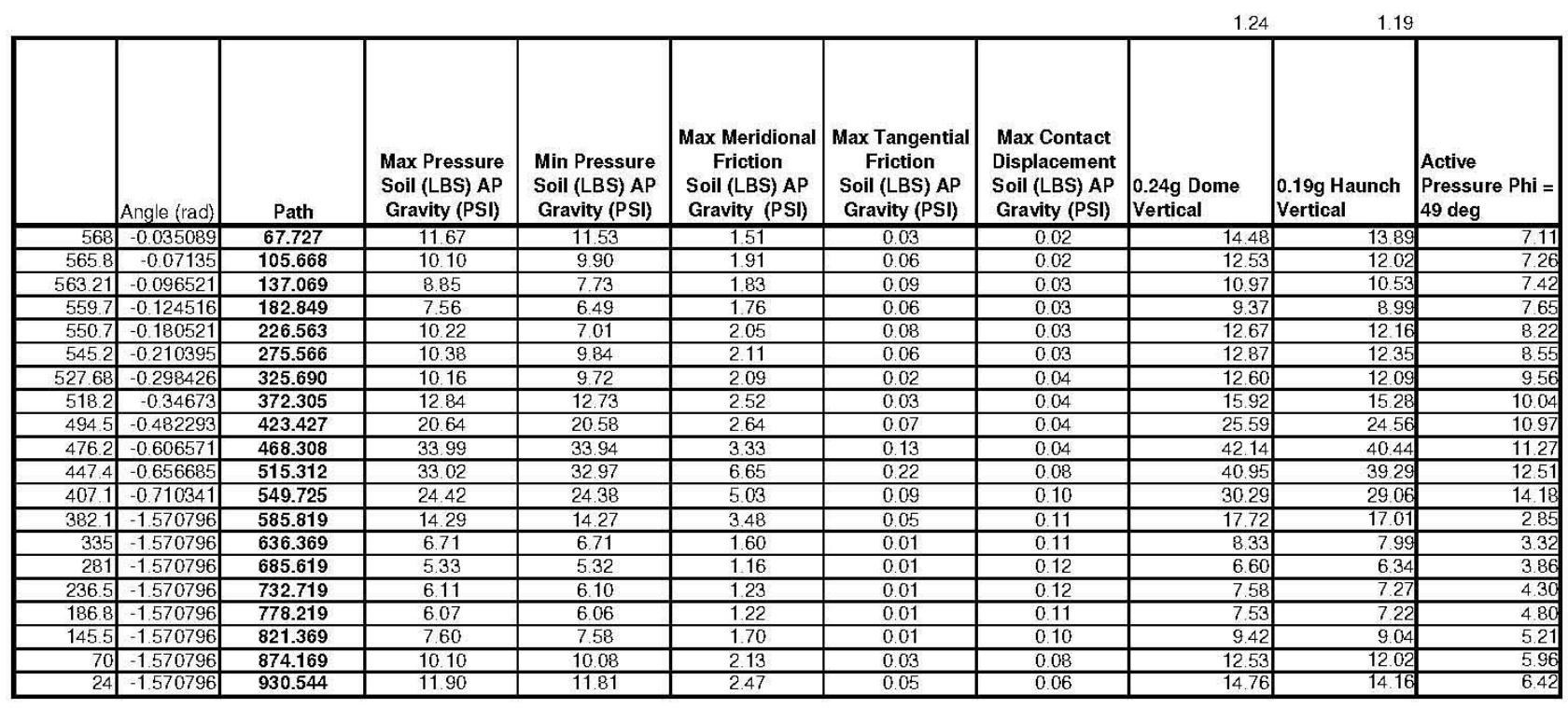


RPP-RPT-32239, Rev. 1

M\&D-2008-005-CALC-001, Rev. 1

Table F.29. LBS-BEC Soil/Concrete Tank Contact Forces, Gravity Plus Seismic

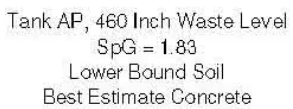

\begin{tabular}{|c|c|c|c|c|c|c|c|c|c|c|}
\hline & Angle (rad) & Path & $\begin{array}{l}\text { Max Pressure } \\
\text { Soil (LBS) AP } \\
\text { Seismic (PSI) }\end{array}$ & $\begin{array}{l}\text { Min Pressure } \\
\text { Soil (LBS) AP } \\
\text { Seismic (PSI) }\end{array}$ & $\begin{array}{l}\text { Max Meridianal } \\
\text { Friction } \\
\text { Soil (LBS) AP } \\
\text { Seismic (PSI) }\end{array}$ & $\begin{array}{c}\text { Max Tangential } \\
\text { Friction } \\
\text { Soil (LBS) AP } \\
\text { Seismic (PSI) }\end{array}$ & $\begin{array}{l}\text { Max Contact } \\
\text { Displacement } \\
\text { Sail (LBS) AP } \\
\text { Seismic (inch) }\end{array}$ & $\begin{array}{l}\text { Vertical } \\
\text { Pressure }\end{array}$ & $\begin{array}{l}\text { Active } \\
\text { Pressure Phi = } \\
\text { 33 deg }\end{array}$ & $\begin{array}{l}\text { Active } \\
\text { Pressure Phi = } \\
49 \text { deg }\end{array}$ \\
\hline 568 & -0.035089 & 67.727 & 19.68 & 3.13 & 9.48 & 4.45 & 0.08 & 7.12 & 7.11 & 7.11 \\
\hline 565.8 & -0.07135 & 105.668 & 17.76 & 3.00 & 7.32 & 3.37 & 0.06 & 7.27 & 7.26 & 7.26 \\
\hline 563.21 & -0.096521 & 137.069 & 13.73 & 1.77 & 6.40 & 2.64 & 0.05 & 7.46 & 7.43 & 7.42 \\
\hline 559.7 & -0.124516 & 182.849 & 10.70 & 3.63 & 4.17 & 3.36 & 0.04 & 7.71 & 7.65 & 7.65 \\
\hline 550.7 & -0.180521 & 226.563 & 14.90 & 4.14 & 4.73 & 4.34 & 0.05 & 8.35 & 8.23 & 8.22 \\
\hline 545.2 & -0.210395 & 275.566 & 13.59 & 6.43 & 5.44 & 4.44 & 0.05 & 8.74 & 8.57 & 8.55 \\
\hline 527.68 & -0.298426 & 325.690 & 12.41 & 6.83 & 5.42 & 4.14 & 0.05 & 9.99 & 9.59 & 9.56 \\
\hline 518.2 & -0.34673 & 372.305 & 15.56 & 10.06 & 5.52 & 3.95 & 0.05 & 10.66 & 10.09 & 10.04 \\
\hline 494.5 & -0.482293 & 423.427 & 25.44 & 16.64 & 5.51 & 3.87 & 0.05 & 12.35 & 11.07 & 10.97 \\
\hline 476.2 & -0.606571 & 468.308 & 42.53 & 26.42 & 5.80 & 4.01 & 0.05 & 13.65 & 11.45 & 11.27 \\
\hline 447.4 & -0.656685 & 515.312 & 40.03 & 27.19 & 11.78 & 4.14 & 0.10 & 15.70 & 12.75 & 12.51 \\
\hline 407.1 & -0.710341 & 549.725 & 30.04 & 20.35 & 12.51 & 3.11 & 0.13 & 18.57 & 14.53 & 14.18 \\
\hline 382.1 & \begin{tabular}{|l|l|}
-1.570796 \\
\end{tabular} & 585.819 & 17.26 & 11.94 & 10.56 & 2.36 & 0.15 & 20.35 & 6.00 & 2.85 \\
\hline 335 & -1.570796 & 636.369 & 8.03 & 5.59 & 5.30 & 2.48 & 0.16 & 23.70 & 6.99 & 3.32 \\
\hline 281 & -1.570796 & 685.619 & 6.43 & 4.34 & 4.06 & 2.56 & 0.17 & 27.55 & 8.13 & 3.86 \\
\hline 236.5 & -1.570796 & 732.719 & 7.17 & 5.01 & 4.15 & 2.48 & 0.17 & 30.71 & 9.06 & 4.30 \\
\hline 186.8 & -1.570796 & 778.219 & 6.91 & 4.98 & 4.04 & 2.70 & 0.16 & 34.25 & 10.10 & 4.80 \\
\hline 145.5 & -1.570796 & 821.369 & 8.85 & 6.08 & 5.86 & 3.26 & 0.14 & 37.19 & 10.97 & 5.21 \\
\hline 70 & -1.570796 & 874.169 & 13.75 & 6.49 & 6.89 & 3.33 & 0.11 & 42.57 & 12.56 & 5.96 \\
\hline 24 & -1.570796 & 930.544 & 19.95 & 3.60 & 6.55 & 3.01 & 0.07 & 45.84 & 13.52 & 6.42 \\
\hline
\end{tabular}


RPP-RPT-32239, Rev. 1

M\&D-2008-005-CALC-001, Rev. 1

Table F.30. LBS-BEC Soil/Concrete Tank Contact Forces, Seismic Only

Tank AP, 460 Inch Waste Level

$$
\mathrm{SpG}=1.83
$$

Lower Bound Soil

Best Estimate Concrete

\begin{tabular}{|c|c|c|c|c|c|c|c|}
\hline & Angle (rad) & Path & $\begin{array}{c}\text { Max Pressure } \\
\text { Soil (LBS) AP } \\
\text { Seismic Only } \\
\text { (PSI) }\end{array}$ & $\begin{array}{c}\text { Min Pressure } \\
\text { Soil (LBS) AP } \\
\text { Seismic Only } \\
\text { (PSI) }\end{array}$ & $\begin{array}{l}\text { Max } \\
\text { Meridional } \\
\text { Friction } \\
\text { (LBS) AP } \\
\text { Seismic Only } \\
\text { (PSI) }\end{array}$ & $\begin{array}{c}\text { Max } \\
\text { Tangential } \\
\text { Friction (LBS) } \\
\text { AP } \\
\text { Seismic Only } \\
\text { (PSI) }\end{array}$ & $\begin{array}{l}\text { Max Contact } \\
\text { Displacment } \\
\text { (LBS) AP } \\
\text { Seismic Only } \\
\text { (inch) }\end{array}$ \\
\hline 568 & -0.035089 & 67.727 & 8.01 & -8.55 & 7.97 & 4.42 & 0.07 \\
\hline 565.8 & -0.07135 & 105.668 & 7.66 & -7.10 & 5.41 & 3.31 & 0.03 \\
\hline 563.21 & -0.096521 & 137.069 & 4.88 & -7.08 & 4.57 & 2.55 & 0.02 \\
\hline 559.7 & -0.124516 & 182.849 & 3.15 & -3.92 & 2.40 & 3.30 & 0.01 \\
\hline 550.7 & -0.180521 & 226.563 & 4.68 & -6.07 & 2.68 & 4.26 & 0.02 \\
\hline 545.2 & -0.210395 & 275.566 & 3.21 & -3.96 & 3.34 & 4.38 & 0.02 \\
\hline 527.68 & -0.298426 & 325.690 & 2.25 & -3.33 & 3.33 & 4.12 & 0.02 \\
\hline 518.2 & -0.34673 & 372.305 & 2.72 & -2.78 & 3.00 & 3.91 & 0.01 \\
\hline 494.5 & -0.482293 & 423.427 & 4.81 & -4.00 & 2.87 & 3.81 & 0.01 \\
\hline 476.2 & -0.606571 & 468.308 & 8.54 & -7.56 & 2.46 & 3.88 & 0.01 \\
\hline 447.4 & -0.656685 & 515.312 & 7.01 & -5.83 & 5.12 & 3.92 & 0.02 \\
\hline 407.1 & -0.710341 & 549.725 & 5.62 & -4.07 & 7.48 & 3.02 & 0.03 \\
\hline 382.1 & -1.570796 & 585.819 & 2.97 & -2.35 & 7.08 & 2.32 & 0.04 \\
\hline 335 & -1.570796 & 636.369 & 1.32 & -1.13 & 3.69 & 2.47 & 0.05 \\
\hline 281 & -1.570796 & 685.619 & 1.10 & -0.99 & 2.90 & 2.56 & 0.06 \\
\hline 236.5 & -1.570796 & 732.719 & 1.06 & -1.10 & 2.92 & 2.47 & 0.06 \\
\hline 186.8 & -1.570796 & 778.219 & 0.84 & -1.09 & 2.82 & 2.70 & 0.05 \\
\hline 145.5 & -1.570796 & 821.369 & 1.25 & -1.52 & 4.15 & 3.25 & 0.04 \\
\hline 70 & -1.570796 & 874.169 & 3.65 & -3.62 & 4.76 & 3.30 & 0.03 \\
\hline 24 & -1.570796 & 930.544 & 8.05 & -8.31 & 4.08 & 2.96 & 0.02 \\
\hline
\end{tabular}


RPP-RPT-32239, Rev. 1

M\&D-2008-005-CALC-001, Rev. 1

Table F.31. LBS-BEC Primary Tank/Concrete Dome Contact Data, Gravity Only

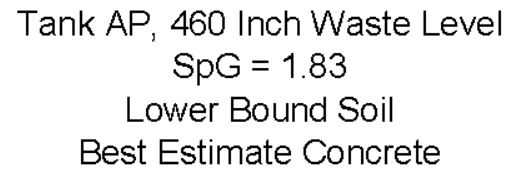

\begin{tabular}{|c|c|c|c|c|}
\hline & $\begin{array}{c}\text { Max Pressure } \\
\text { Primary } \\
\text { Tank/Concrete } \\
\text { Tank Dome AP } \\
\text { Gravity (PSI) }\end{array}$ & $\begin{array}{c}\text { Min Pressure } \\
\text { Primary } \\
\text { Tank/Concrete } \\
\text { Tank Dome AP } \\
\text { Gravity (PSI) }\end{array}$ & $\begin{array}{c}\text { Max Gap } \\
\text { Lateral } \\
\text { Displacement } \\
\text { Primary Tank } \\
\text { /Concrete } \\
\text { Tank Dome } \\
\text { Gravity (in) }\end{array}$ & $\begin{array}{c}\text { Max Gap Displacement } \\
\text { Primary Tank/Concete Tank } \\
\text { Dome AP } \\
\text { Gravity (Inches) }\end{array}$ \\
\hline Radius & 0.981 & 0.937 & 0.002978 & 0.000000 \\
\hline $\mathbf{6 7 . 7 2 7}$ & 0.983 & 0.967 & 0.003391 & 0.000000 \\
\hline $\mathbf{1 0 5 . 6 6 8}$ & 0.270 & 0.250 & 0.002503 & -0.000012 \\
\hline $\mathbf{1 3 7 . 0 6 9}$ & 0.701 & 0.691 & 0.003308 & -0.000028 \\
\hline $\mathbf{1 8 2 . 8 4 9}$ & 0.907 & 0.856 & 0.004315 & -0.000102 \\
\hline $\mathbf{2 2 6 . 5 6 3}$ & 0.343 & 0.324 & 0.005107 & -0.000104 \\
\hline $\mathbf{2 7 5 . 5 6 6}$ & 0.952 & 0.928 & 0.006469 & -0.000285 \\
\hline $\mathbf{3 2 5 . 6 9 0}$ & 0.000 & 0.000 & 0.000188 & -0.000054 \\
\hline $\mathbf{3 7 2 . 3 0 5}$ & 0.000 & 0.000 & 0.000000 & -1.058760 \\
\hline $\mathbf{4 2 3 . 4 2 7}$ & & & & \\
\hline
\end{tabular}


RPP-RPT-32239, Rev. 1

M\&D-2008-005-CALC-001, Rev. 1

Table F.32. LBS-BEC Primary Tank/Concrete Dome Contact Data, Gravity Plus Seismic

$$
\begin{gathered}
\text { Tank AP, } 460 \text { Inch Waste Level } \\
\text { SpG }=1.83 \\
\text { Lower Bound Soil } \\
\text { Best Estimate Concrete }
\end{gathered}
$$

\begin{tabular}{|c|c|c|c|c|}
\hline & $\begin{array}{c}\text { Max Pressure } \\
\text { Primary } \\
\text { Tank/Concrete } \\
\text { Tank Dome AP } \\
\text { Seismic (PSI) }\end{array}$ & $\begin{array}{c}\text { Min Pressure } \\
\text { Primary } \\
\text { Tank/Concrete } \\
\text { Tank Dome AP } \\
\text { Seismic (PSI) }\end{array}$ & $\begin{array}{c}\text { Max Gap } \\
\text { Lateral } \\
\text { Displacement } \\
\text { Primary Tank } \\
\text { /Concrete } \\
\text { Tank Dome } \\
\text { Seismic (in) }\end{array}$ & $\begin{array}{c}\text { Max Gap Displacement } \\
\text { Primary Tank/Concete Tank } \\
\text { Dome AP } \\
\text { Seismic (Inches) }\end{array}$ \\
\hline Radius & 8.306 & 0.110 & 0.011134 & -0.000231 \\
\hline $\mathbf{6 7 . 7 2 7}$ & 9.500 & 0.000 & 0.018240 & -0.000209 \\
\hline $\mathbf{1 0 5 . 6 6 8}$ & 5.744 & 0.000 & 0.047772 & -0.000946 \\
\hline $\mathbf{1 3 7 . 0 6 9}$ & 2.745 & 0.000 & 0.046452 & -0.000915 \\
\hline $\mathbf{1 8 2 . 8 4 9}$ & 6.760 & 0.000 & 0.030888 & -0.001931 \\
\hline $\mathbf{2 2 6 . 5 6 3}$ & 4.763 & 0.000 & 0.036312 & -0.004744 \\
\hline $\mathbf{2 7 5 . 5 6 6}$ & 7.521 & 0.000 & 0.034296 & -0.003840 \\
\hline $\mathbf{3 2 5 . 6 9 0}$ & 31.979 & 0.000 & 0.074472 & -0.007304 \\
\hline $\mathbf{3 7 2 . 3 0 5}$ & 13.097 & 0.000 & 0.001961 & -1.074120 \\
\hline $\mathbf{4 2 3 . 4 2 7}$ & & & & \\
\hline
\end{tabular}


RPP-RPT-32239, Rev. 1

M\&D-2008-005-CALC-001, Rev. 1

Table F.33. LBS-BEC Primary Tank/Concrete Dome Contact Data, Seismic Only

Tank AP, 460 Inch Waste Level

$\mathrm{SpG}=1.83$

Lower Bound Soil

Best Estimate Concrete

\begin{tabular}{|c|c|c|c|c|}
\hline & $\begin{array}{c}\text { Max Pressure } \\
\text { Primary } \\
\text { Tank/Concrete } \\
\text { Tank Dome AP } \\
\text { Seismic Only } \\
\text { (PSI) }\end{array}$ & $\begin{array}{c}\text { Min Pressure } \\
\text { Primary } \\
\text { Tank/Concrete } \\
\text { Tank Dome AP } \\
\text { Seismic Only } \\
\text { (PSI) }\end{array}$ & $\begin{array}{c}\text { Max Gap } \\
\text { Lateral } \\
\text { Displacement } \\
\text { Primary Tank } \\
\text { /Concrete } \\
\text { Tank Dome } \\
\text { Seismic Only } \\
\text { (in) }\end{array}$ & $\begin{array}{c}\text { Max Gap Displacement } \\
\text { Primary Tank/Concete Tank } \\
\text { Dome AP } \\
\text { Seismic Only (Inches) }\end{array}$ \\
\hline $\mathbf{6 7 . 7 2 7}$ & 7.324 & -0.827 & 0.008155 & -0.000231 \\
\hline $\mathbf{1 0 5 . 6 6 8}$ & 8.517 & -0.967 & 0.014849 & -0.000209 \\
\hline $\mathbf{1 3 7 . 0 6 9}$ & 5.474 & -0.250 & 0.045269 & -0.000934 \\
\hline $\mathbf{1 8 2 . 8 4 9}$ & 2.044 & -0.691 & 0.043144 & -0.000886 \\
\hline $\mathbf{2 2 6 . 5 6 3}$ & 5.853 & -0.856 & 0.026573 & -0.001829 \\
\hline $\mathbf{2 7 5 . 5 6 6}$ & 4.420 & -0.324 & 0.031205 & -0.004640 \\
\hline $\mathbf{3 2 5 . 6 9 0}$ & 6.569 & -0.928 & 0.027827 & -0.003555 \\
\hline $\mathbf{3 7 2 . 3 0 5}$ & 31.979 & 0.000 & 0.074284 & -0.007251 \\
\hline $\mathbf{4 2 3 . 4 2 7}$ & 13.097 & 0.000 & 0.001961 & -0.015360 \\
\hline
\end{tabular}

Table F.34. LBS-BEC Primary Tank/Insulating Concrete Contact Forces, Gravity Only

Tank AP, 460 Inch Waste Level

$\mathrm{SpG}=1.83$

Lower Bound Soil

Best Estimate Concrete

\begin{tabular}{|c|c|c|c|c|}
\hline & $\begin{array}{c}\text { Max Pressure } \\
\text { Primary } \\
\text { Tank/nsulating } \\
\text { Concrete AP } \\
\text { Gravity (PSI) }\end{array}$ & $\begin{array}{c}\text { Min Pressure } \\
\text { Primary } \\
\text { Tank/nsulating } \\
\text { Concrete AP } \\
\text { Gravity (PSI) }\end{array}$ & $\begin{array}{c}\text { Max Lateral } \\
\text { Displacement } \\
\text { Primary Tank/ } \\
\text { Insulating Concete AP } \\
\text { Gravity (Inches) }\end{array}$ & $\begin{array}{c}\text { Min Lateral } \\
\text { Primary Tank/Insulating } \\
\text { Concete AP } \\
\text { Cisplacement } \\
\text { Gravity (Inches) }\end{array}$ \\
\hline 4 Radius & 75.486 & 75.347 & 0.011330 & 0.011302 \\
\hline 384.00 & 13.069 & 13.049 & 0.000375 & 0.000368 \\
\hline 317.85 & 33.403 & 33.368 & 0.002321 & 0.002309 \\
\hline $\mathbf{2 4 8 . 1 0}$ & 29.701 & 29.674 & 0.002796 & 0.002785 \\
\hline $\mathbf{1 9 9 . 2 5}$ & 30.764 & 30.736 & 0.002148 & 0.002140 \\
\hline $\mathbf{1 5 4 . 9 5}$ & 30.479 & 30.444 & 0.001122 & 0.001116 \\
\hline $\mathbf{1 1 2 . 8 0}$ & 30.479 & 30.438 & 0.000217 & 0.000208 \\
\hline $\mathbf{6 5 . 8 5}$ & 30.896 & 30.799 & 0.000469 & 0.000452 \\
\hline
\end{tabular}


RPP-RPT-32239, Rev. 1

M\&D-2008-005-CALC-001, Rev. 1

Table F.35. LBS-BEC Primary Tank/ Insulating Concrete Contact Data, Gravity Plus Seismic

Tank AP, 460 Inch Waste Level

$\mathrm{SpG}=1.83$

Lower Bound Soil

Best Estimate Concrete

\begin{tabular}{|c|c|c|c|c|}
\hline & $\begin{array}{c}\text { Max Pressure } \\
\text { Primary } \\
\text { Tank/nsulaiting } \\
\text { Concrete AP } \\
\text { Seismic (PSI) }\end{array}$ & $\begin{array}{c}\text { Min Pressure } \\
\text { Primary } \\
\text { Tank/nsulaiting } \\
\text { Concrete AP } \\
\text { Seismic (PSI) }\end{array}$ & $\begin{array}{c}\text { Max Lateral } \\
\text { Displacement } \\
\text { Primary } \\
\text { Tank/nsulaiting } \\
\text { Concrete AP } \\
\text { Seismic (Inches) }\end{array}$ & $\begin{array}{c}\text { Min Lateral } \\
\text { Displacement } \\
\text { Primary Tank/nsulaiting } \\
\text { Concrete AP } \\
\text { Seismic (Inches) }\end{array}$ \\
\hline $\mathbf{4 2 4 . 0 0}$ & 110.764 & 26.257 & 0.055104 & 0.006257 \\
\hline $\mathbf{3 8 4 . 0 0}$ & 25.903 & 3.496 & 0.200160 & 0.000102 \\
\hline $\mathbf{3 1 7 . 8 5}$ & 43.215 & 24.319 & 0.032280 & 0.000832 \\
\hline $\mathbf{2 4 8 . 1 0}$ & 37.646 & 22.299 & 0.016752 & 0.000552 \\
\hline $\mathbf{1 9 9 . 2 5}$ & 38.375 & 24.549 & 0.009676 & 0.000295 \\
\hline $\mathbf{1 5 4 . 9 5}$ & 36.111 & 25.063 & 0.006120 & 0.000376 \\
\hline $\mathbf{1 1 2 . 8 0}$ & 35.181 & 25.014 & 0.004398 & 0.000069 \\
\hline $\mathbf{6 5 . 8 5}$ & 35.819 & 25.451 & 0.003653 & 0.000314 \\
\hline
\end{tabular}

Table F.36. LBS-BEC Primary Tank/Insulating Concrete Contact Forces, Seismic Only

Tank AP, 460 Inch Waste Level

$\mathrm{SpG}=1.83$

Lower Bound Soil

Best Estimate Concrete

\begin{tabular}{|c|c|c|c|c|}
\hline & $\begin{array}{c}\text { Max Pressure } \\
\text { Primary } \\
\text { Tank/nsulaiting } \\
\text { Concrete AP } \\
\text { Seismic Only } \\
\text { (PSI) }\end{array}$ & $\begin{array}{c}\text { Min Pressure } \\
\text { Primary } \\
\text { Tank/nsulaiting } \\
\text { Concrete AP } \\
\text { Seismic Only } \\
\text { (PSI) }\end{array}$ & $\begin{array}{c}\text { Max Lateral } \\
\text { Displacement } \\
\text { Primary } \\
\text { Tank/nsulaiting } \\
\text { Concrete AP } \\
\text { Seismic Only (Inches) }\end{array}$ & $\begin{array}{c}\text { Min Lateral } \\
\text { Primary Tank/nsulaiting } \\
\text { Concrete AP } \\
\text { Sismic Only (Inches) }\end{array}$ \\
\hline 424.00 & 35.278 & -49.090 & 0.044 & -0.005 \\
\hline 384.00 & 12.833 & -9.553 & 0.200 & 0.000 \\
\hline 317.85 & 9.813 & -9.049 & 0.030 & -0.001 \\
\hline $\mathbf{2 4 8 . 1 0}$ & 7.944 & -7.375 & 0.014 & -0.002 \\
\hline 199.25 & 7.611 & -6.188 & 0.008 & -0.002 \\
\hline 154.95 & 5.632 & -5.382 & 0.005 & -0.001 \\
\hline 112.80 & 4.701 & -5.424 & 0.004 & 0.000 \\
\hline 65.85 & 4.924 & -5.347 & 0.003 & 0.000 \\
\hline
\end{tabular}


RPP-RPT-32239, Rev. 1

M\&D-2008-005-CALC-001, Rev. 1

Table F.37. LBS-BEC Insulating Concrete/Concrete Backed Steel Contact Data, Gravity Only

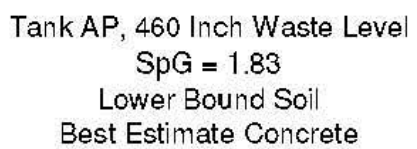

\begin{tabular}{|c|c|c|c|c|}
\hline & $\begin{array}{c}\text { Max Pressure } \\
\text { Insulating } \\
\text { Concrete/Secondary } \\
\text { Liner AP } \\
\text { Gravity (PSI) }\end{array}$ & $\begin{array}{c}\text { Min Pressure } \\
\text { Insulating } \\
\text { Concrete/Secondary } \\
\text { Liner AP } \\
\text { Gravity (PSI) }\end{array}$ & $\begin{array}{c}\text { Max Lateral } \\
\text { Concrete/Secondary } \\
\text { Insulating } \\
\text { Liner AP } \\
\text { Gravity (Inches) }\end{array}$ & $\begin{array}{c}\text { Min Lateral } \\
\text { Displacement } \\
\text { Insulating } \\
\text { Concrete/Secondary } \\
\text { Liner AP } \\
\text { Gravity (Inches) }\end{array}$ \\
\hline 424.00 & 96.944 & 96.597 & 0.005172 & 0.005129 \\
\hline 384.00 & 34.653 & 34.563 & 0.004285 & 0.004247 \\
\hline 317.85 & 27.389 & 27.354 & 0.003188 & 0.003155 \\
\hline $\mathbf{2 4 8 . 1 0}$ & 31.625 & 31.597 & 0.002322 & 0.002297 \\
\hline 199.25 & 30.882 & 30.840 & 0.001525 & 0.001510 \\
\hline 154.95 & 30.486 & 30.438 & 0.001106 & 0.001097 \\
\hline 112.80 & 31.313 & 31.222 & 0.000803 & 0.000800 \\
\hline 65.85 & 30.424 & 30.188 & 0.000313 & 0.000307 \\
\hline
\end{tabular}

Table F.38. LBS-BEC Insulating Concrete/Concrete Backed Steel Contact Data, Gravity Plus Seismic

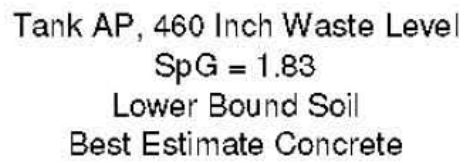

\begin{tabular}{|c|c|c|c|c|}
\hline & $\begin{array}{c}\text { Max Pressure } \\
\text { Insulating } \\
\text { Concrete/Secon } \\
\text { dary Liner AP } \\
\text { Seismic (PSI) }\end{array}$ & $\begin{array}{c}\text { Min Pressure } \\
\text { Insulating } \\
\text { Concrete/Secon } \\
\text { dary Liner AP } \\
\text { Seismic (PSI) }\end{array}$ & $\begin{array}{c}\text { Max Lateral } \\
\text { Displacement } \\
\text { Insulating } \\
\text { Concrete/Secondary } \\
\text { Liner AP } \\
\text { Seismic (Inches) }\end{array}$ & $\begin{array}{c}\text { Min Lateral } \\
\text { Displacement } \\
\text { Insulating } \\
\text { Concrete/Secondary } \\
\text { Liner AP } \\
\text { Seismic (Inches) }\end{array}$ \\
\hline Radius & 113.194 & 80.278 & 0.021720 & 0.000214 \\
\hline 424.00 & 43.944 & 25.917 & 0.020244 & 0.000346 \\
\hline 384.00 & 36.146 & 18.813 & 0.017892 & 0.000140 \\
\hline $\mathbf{3 1 7 . 8 5}$ & 39.986 & 24.208 & 0.015684 & 0.000072 \\
\hline $\mathbf{2 4 8 . 1 0}$ & 38.438 & 24.618 & 0.013416 & 0.000090 \\
\hline $\mathbf{1 9 9 . 2 5}$ & 36.194 & 25.181 & 0.011056 & 0.000060 \\
\hline $\mathbf{1 5 4 . 9 5}$ & 35.944 & 25.806 & 0.009767 & 0.000050 \\
\hline $\mathbf{1 1 2 . 8 0}$ & 35.417 & 25.542 & 0.008903 & 0.000099 \\
\hline $\mathbf{6 5 . 8 5}$ & & & & \\
\hline
\end{tabular}


RPP-RPT-32239, Rev. 1

M\&D-2008-005-CALC-001, Rev. 1

Table F.39. LBS-BEC Insulating Concrete/Concrete Backed Steel Contact Data, Seismic Only

Tank AP, 460 lnch Waste Level

$\mathrm{SpG}=1.83$

Lower Bound Soil

Best Estimate Concrete

\begin{tabular}{|c|c|c|c|c|}
\hline & $\begin{array}{c}\text { Max Pressure } \\
\text { Insulating } \\
\text { Concrete/Secon } \\
\text { dary Liner AP } \\
\text { Seismic Only } \\
\text { (PSI) }\end{array}$ & $\begin{array}{c}\text { Min Pressure } \\
\text { Insulating } \\
\text { Concrete/Secon } \\
\text { dary Liner AP } \\
\text { Seismic Only } \\
\text { (PSI) }\end{array}$ & $\begin{array}{c}\text { Max Lateral } \\
\text { Displacement } \\
\text { Insulating } \\
\text { Concrete/Secondary } \\
\text { Liner AP } \\
\text { Seismic Only (Inches) }\end{array}$ & $\begin{array}{c}\text { Min Lateral } \\
\text { Displacement } \\
\text { Insulating } \\
\text { Concrete/Secondary } \\
\text { Liner AP } \\
\text { Seismic Only (Inches) }\end{array}$ \\
\hline 424.00 & 16.250 & -16.319 & 0.017 & -0.005 \\
\hline $\mathbf{3 8 4 . 0 0}$ & 9.292 & -8.646 & 0.016 & -0.004 \\
\hline $\mathbf{3 1 7 . 8 5}$ & 8.757 & -8.542 & 0.015 & -0.003 \\
\hline $\mathbf{2 4 8 . 1 0}$ & 8.361 & -7.389 & 0.013 & -0.002 \\
\hline $\mathbf{1 9 9 . 2 5}$ & 7.556 & -6.222 & 0.012 & -0.001 \\
\hline $\mathbf{1 5 4 . 9 5}$ & 5.708 & -5.257 & 0.010 & -0.001 \\
\hline $\mathbf{1 1 2 . 8 0}$ & 4.632 & -5.417 & 0.009 & -0.001 \\
\hline $\mathbf{6 5 . 8 5}$ & 4.993 & -4.646 & 0.009 & 0.000 \\
\hline
\end{tabular}


RPP-RPT-32239, Rev. 1

M\&D-2008-005-CALC-001, Rev. 1

Table F.40. LBS-BEC Waste Contact Pressure, Gravity Plus Seismic

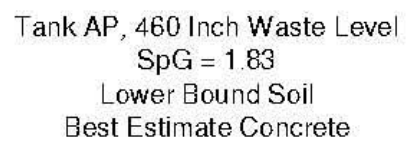

\begin{tabular}{|c|c|c|c|c|c|c|c|}
\hline $\begin{array}{l}\text { Waste } \\
\text { Height } \\
\text { Ratio }\end{array}$ & Waste Height & $\begin{array}{c}\text { Max Pressure } \\
\text { AP Tank, } 460 \text { in } \\
\text { Waste Level, } \\
\text { SpG }=1.83 \\
\text { Time History } \\
\text { (PSI) }\end{array}$ & $\begin{array}{c}\text { Min Pressure } \\
\text { AP Tank, } 460 \text { in } \\
\text { Waste Level, } \\
\text { SpG }=1.83 \\
\text { Time History } \\
\text { (PSI) }\end{array}$ & \begin{tabular}{|l} 
Hydrostatic \\
(psi)
\end{tabular} & $\begin{array}{l}\text { Hydrodynamic } \\
\text { (psi) }\end{array}$ & $\begin{array}{l}\text { Theoretical } \\
\text { Min (SRSS) }\end{array}$ & $\begin{array}{l}\text { Theoretical } \\
\text { Max (SRSS) }\end{array}$ \\
\hline 0.99 & 454.35 & 11.153 & -10.382 & 0.37 & 1.79 & 0.00 & 2.16 \\
\hline 0.96 & 443.05 & 15.646 & -13.264 & 1.12 & 2.03 & 0.00 & 3.15 \\
\hline 0.94 & 431.7625 & 16.660 & -13.042 & 1.87 & 2.35 & 0.00 & 4.21 \\
\hline 0.90 & 414.125 & 14.694 & -8.833 & 3.03 & 2.91 & 0.13 & 5.94 \\
\hline 0.85 & 390.125 & 10.396 & -1.240 & 4.62 & 3.69 & 0.93 & 8.30 \\
\hline 0.80 & 366.125 & 12.222 & 0.239 & 6.20 & 4.44 & 1.77 & 10.64 \\
\hline 0.74[ & 342 & 14.486 & 1.451 & 7.80 & 5.15 & 2.65 & 12.94 \\
\hline 0.69 & 318.325 & 16.799 & 2.137 & 9.36 & 5.80 & 3.57 & 15.16 \\
\hline 0.64[ & 295.225 & 19.319 & 3.182 & 10.89 & 6.38 & 4.50 & 17.27 \\
\hline 0.59 & 272.125 & 21.528 & 3.831 & 12.41 & 6.93 & 5.49 & 19.34 \\
\hline 0.54 & 248.975 & 23.458 & 4.776 & 13.94 & 7.43 & 6.52 & 21.37 \\
\hline 0.49 & 225.825 & 25.646 & 5.795 & 15.47 & 7.89 & 7.59 & 23.36 \\
\hline 0.44 & 202.725 & 28.215 & 6840 & 17.00 & 8.30 & 8.70 & 25.30 \\
\hline 0.39 & 179.625 & 30.361 & 7819 & 18.53 & 8.67 & 9.85 & 27.20 \\
\hline 0.34 & 156.475 & 31.104 & 9.500 & 20.06 & 9.00 & 11.06 & 29.05 \\
\hline 0.29 & 134.075 & 32.458 & 10.944 & 21.54 & 9.28 & 12.26 & 3081 \\
\hline 0.24 & 112.475 & 34.750 & 12.153 & 22.96 & 9.50 & 13.46 & 32.46 \\
\hline 0.20 & 90.875 & 34.965 & 13.736 & 24.39 & 9.69 & 14.70 & 34.08 \\
\hline 0.15 & 69.275 & 38.563 & 15.389 & 25.82 & 9.84 & 15.98 & 35.66 \\
\hline 0.10 & 47.738 & 38.250 & 17.097 & 27.24 & 9.95 & 17.29 & 37.19 \\
\hline 0.05 & 24.500 & 43.639 & 15.104 & 28.78 & 10.02 & 18.76 & 38.79 \\
\hline 0.02 & 7.755 & 45.778 & 24.743 & 29.88 & 10.04 & 19.84 & 39.92 \\
\hline 0.00 & 1.755 & 42.493 & 24.465 & 30.28 & 10.04 & 20.23 & 40.32 \\
\hline
\end{tabular}


RPP-RPT-32239, Rev. 1

M\&D-2008-005-CALC-001, Rev. 1

Table F.41. LBS-BEC Waste Contact Pressure, Theoretical Pressures

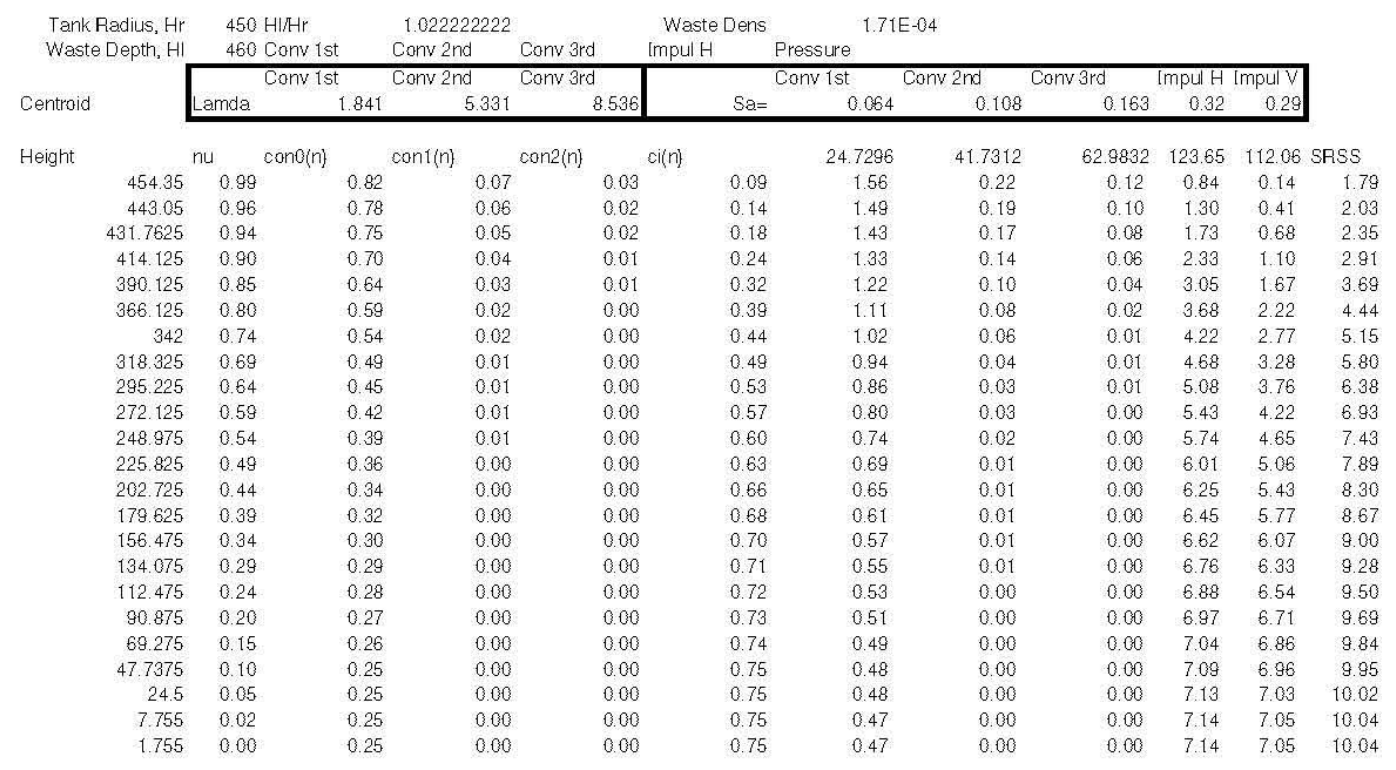


RPP-RPT-32239, Rev. 1

M\&D-2008-005-CALC-001, Rev. 1

Table F.42. LBS-BEC Waste Surface Displacement, Gravity Plus Seismic

Tank AP, 460 Inch Waste Level

$\mathrm{SpG}=1.83$

Lower Bound Soil

Best Estimate Concrete

\begin{tabular}{|r|c|c|}
\hline & $\begin{array}{c}\text { Max Vertical } \\
\text { Displacement } \\
\text { AP-460-BES- } \\
\text { BEC } \\
\text { Time History } \\
\text { (in) }\end{array}$ & $\begin{array}{c}\text { Min Vertical } \\
\text { Displacement } \\
\text { AP-460-BES- } \\
\text { BEC } \\
\text { Time History } \\
\text { (in) }\end{array}$ \\
\hline 95.7 & 7.30 & -13.81 \\
\hline 129.9 & 8.22 & -12.68 \\
\hline 180 & 8.92 & -14.41 \\
\hline 218.5 & 7.96 & -15.54 \\
\hline 277.7 & 8.88 & -15.61 \\
\hline 358 & 9.27 & -15.74 \\
\hline 410 & 7.69 & -14.93 \\
\hline 450 & 5.10 & -11.27 \\
\hline & & \\
\hline
\end{tabular}




\section{RPP-RPT-32239, Rev. 1 \\ M\&D-2008-005-CALC-001, Rev. 1}

\section{Near-Soil-1.txt}

et, 8, solid 45

/input, soil-prop-LB-geo, txt

$\mathrm{ksel}, \mathrm{u}, \mathrm{kp}, \mathrm{,}, \mathrm{k}, \mathrm{maxj} \mathrm{b}$

asel, $u$, area, , $1, \operatorname{amaxj} \mathrm{b}$

lsel, u, line, , 1, lmaxjb

vsel, u, volu, , 1, vmaxw
! Use Element SOLID45 for Near Soil Elements

! Read Soil Properties

! Unselect existing Keypoints

! Unselect existing Area

! Unselect existing Lines

! Unselect existing Volumes

/COM - Create Keypoints to match concrete tank profile

${ }^{*} \mathrm{do}, \mathrm{i}, 1, \mathrm{bm}$ kp

$k, \operatorname{kmaxj} b+i, \operatorname{ctx}(i), 0, \operatorname{ctz}(i)$

*enddo

/COM - Create Keypoints above top of tank

$\mathrm{k}, \mathrm{kmaxj}_{\mathrm{b}}+\mathrm{bm} \mathrm{k}_{\mathrm{k}} \mathrm{p}+1,0,0,0$

! Keypoint at origin (surface)

$k, \operatorname{kmaxj} b+b{ }^{-} k p+2,0,0, \operatorname{soilz}(2)$

! Keypoint at to divide soil above tank

*get, KMAXtemp1, KP, 0, num, max

! Get maximum keypoint number for counter

/COM - Create Keypoints at outside of excavated soil

$\star$ do, $i, 1, \operatorname{tanksoil}$

$k$, kmaxtemp $1+i, \operatorname{soilx}(i), 0, \operatorname{soilz}(i)$

tenddo

${ }^{*}$ get, KMAXtemp2, KP , 0, num, max

! Get maximum keypoint number for counter

/COM - Create additional keypoint in soil above tank

$k, \operatorname{kmaxtemp} 2+1, \operatorname{ctx}(2), 0, \operatorname{soilz}(1)$

k, kmaxtemp $2+2, \operatorname{ctx}(9), 0, \operatorname{soilz}(1)$

$\mathrm{k}, \operatorname{kmax}$ temp $2+3, \operatorname{ctx}(12), 0, \operatorname{soilz}(1)$

$k$, kmaxtemp $2+4, \operatorname{ctx}(2), 0, \operatorname{soilz}(2)$

$k$, kmaxtemp $2+5, \operatorname{ctx}(9), 0, \operatorname{soilz}(2)$

$\mathrm{k}, \operatorname{kmaxtemp} 2+6, \operatorname{ctx}(12), 0, \operatorname{soilz}(2)$

$\mathrm{k}$, kmaxtemp $2+7, \operatorname{ctx}(12), 0, \operatorname{soilz}(3)$

$\mathrm{k}, \operatorname{kmax} t e m p 2+8, \operatorname{ctx}\left(\mathrm{bm} \_\mathrm{kp}+1\right), 0, \operatorname{ctz}\left(\mathrm{bm} \_\mathrm{kp}+1\right)$

a, kmaxtemp $2+1$, kmaxtemp $2+2$, kmaxtemp $2+5$, kmaxtemp $2+4$

a, kmaxtemp $2+2$, kmaxtemp $2+3$, kmaxtemp $2+6$, kmaxtemp $2+5$

a, kmaxtemp $2+3$, kmaxtemp $1+1$, kmaxtemp $1+2$, kmaxtemp $2+6$

a, kmaxtemp 2+4, kmaxtemp2 +5, kmaxj $b+9, k \max j b+8, k \max j b+7, k \max j b+6, k \max j b+5, k \max j b+4, k \max j b+3, k \max j b+2$

!a, $740,741,712,711,710,709,708,707,706,705$

a, kmaxtemp 2+5, kmaxtemp $2+6, \operatorname{kmaxtemp} 2+7, \operatorname{kmaxj} b+12, \operatorname{kmaxj} b+11, k \max j \mathrm{~b}+10, k \operatorname{kax} j b+9$

a, kmaxtemp $2+6$, kmaxtemp $1+2$, kmaxtemp $1+3$, kmaxtemp $2+7$

a, kmaxtemp $2+7, \operatorname{kmaxtemp} 1+3, \operatorname{kmaxtemp} 1+4, \operatorname{kmaxj} \mathrm{b}+12$

a, $\operatorname{kmaxj} \mathrm{b}+12, \operatorname{kmaxt} \operatorname{emp} 1+4, \operatorname{kmaxt} \operatorname{emp} 1+5, \operatorname{kmaxj} \mathrm{b}+14, \operatorname{kmax} j \mathrm{~b}+13$

a, kmaxj b+14, kmaxt emp 1+5, kmaxt emp $1+6, \operatorname{kmaxj} b+16, \operatorname{kmax} j b+15$

$a, k \operatorname{maxj} b+16, \operatorname{kmaxt} \operatorname{emp} 1+6, \operatorname{kmaxt} \operatorname{emp} 1+7, \operatorname{kmaxj} \mathrm{b}+18, \operatorname{kmax} j \mathrm{~b}+17$

a, $k \operatorname{maxj} \mathrm{b}+18, k \operatorname{kax} t e m p 1+7, \operatorname{kmax} t \operatorname{emp} 1+8, k \operatorname{maxj} \mathrm{b}+20, k \max j \mathrm{~b}+19$

$a, k \max j b+20, k \operatorname{kax} t \operatorname{emp} 1+8, \operatorname{kmax} t \operatorname{emp} 1+9, \operatorname{kmaxt} \operatorname{emp} 2+8, \operatorname{kmaxj} b+22, \operatorname{kmaxj} b+21$

cm, top-soil-area, area

lsla

$\mathrm{cm}$, top-soil, line

type, 1

real, 1

/COM - Define line divisions to control meshing

lsel, s, loc, $z, \operatorname{soilz}(1), \operatorname{soilz}(2)$

lsel, $r, 1 \circ c, x, \operatorname{ctx}(3), \operatorname{ctx}(8)$

lesize, all, , 14

lsel, s, loc, $z, \operatorname{soilz}(1), \operatorname{soilz}(2)$

lsel, r, loc, $\mathrm{x}, \operatorname{ctx}(10), \operatorname{ctx}(11)$

lesize, all, , 3

cmsel, s, top-soil

lsel, $r, 100, x, \operatorname{ctx}(2)$

lesize, all, , 2

cmsel, s, top-soil

lsel, s, loc, $x, \operatorname{ctx}(9)$

lesize, all, , 2

! soil above tank top, match tank meshing

! soil above tank top, match tank meshing

! Reselect lines in near soil

! Control vertical element size, above tank

! Control vertical element size, above tank 


\section{RPP-RPT-32239, Rev. 1 M\&D-2008-005-CALC-001, Rev. 1}

cmsel, s, top-soil

lsel, r, loc, $x, \operatorname{ctx}(12)$

lesize, all,, 2

cmsel, s, top-soil

lsel, r, loc, z, ctz(2), ctz(12)

lsel, r, loc, $x, \operatorname{ctx}(2), \operatorname{ctx}(12)$

lesize, all, , 1

lsel,, , line, $, 1 \max j b+8, l \max j b+10,2$

lsel, $a, l i n e,, l \max j b+26, l \operatorname{maxj} b+28,2$

lsel, a, line, , 1 maxj $b+30, l \operatorname{maxj} b+38,4$

lesize, all, , 9

lsel, s, line, , $l$ maxj $b+42, l \operatorname{maxj} b+42,4$

lesize, all, , 7

lsel, s, line, , lmaxjb+9

lsel, $a, l i n e,, l \max j b+25, l \max j b+27,2$

lsel, a, line, , lmaxjb+29, lmaxj b+45, 4

lesize, all, , 1

lsel, s, line, $1 \operatorname{maxj} b+6$

lsel, a, line, , $l \max j b+20, l \max j b+21$

lsel, a, line, , $l \max j b+32, l \operatorname{maxj} b+44,4$

lsel, a, line, $, 1 \max j b+31, l \operatorname{maxj} b+43,4$

lsel, a, line, , $l \operatorname{maxj} b+47, l \operatorname{maxj} b+49$

lesize, all, , 1

lsel, s, line, , lmaxjb+46

lesize, all, , 4

! Control meshing to match tank

cmsel, s, top-soil-area

! Control mesh size at bottom of excavated soil

amesh, all

! Mesh area to develop pattern for volume meshing

type, 8

ksel, a, kp, 1

ksel, a, kp, , ct_kps

vrotat, all, $, 1,1$, ct_kps, 180,2

lsla

lsel, $r, 1 \circ \mathrm{c}, \mathrm{x}, \operatorname{ctx}(2)$

lesize, all, , arcsize

lsla

lsel, r, loc, $x, \operatorname{ctx}(9)$

lesize, all, , arcsize

lsla

lsel, r, loc, $x, \operatorname{ctx}(12)$

! Control vertical element size, above tank

! Control vertical element size, outside excavation mesh

! Control horizontal meshing in soil

! Control horizontal meshing in soil

lesize, all, arcsize

vsweep, all

aclear, all

cm, top-soil-vol, volu

! Select Keypoint for rotation axis

! Select Keypoint for rotation axis

! Generate Volumes for excavated soil

! Define meshing for slices

! Define meshing for slices

! Define meshing for slices

! Sweep pattern into volume

! Delete elements used for sweep

*get, vMAXtemp, vOLU, o, num, max

/COM - Generate element above top center of tank

asel, u, area, , all

vsel, u, volu, , all

$a, k m a x j b+b m k p+1, k m a x t e m p 2+1, k \max t e m p 2+4, k \operatorname{maxj} b+b m k p+2$

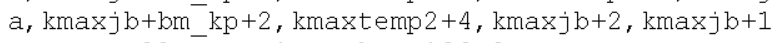

vrotat, all,,,, 1, , ct kps, 180,2

vsel, s, volu, , vmaxtemp +1 , vmaxtemp $+3,2$

vatt, 801,8

vsel, s, volu, , vmaxtemp +2, vmaxt emp $+4,2$

vatt, 802,8

! Assign material properties

vsel, s, volu, , vmaxtemp+1, vmaxtemp +4

allsel

asel, s, loc, $z, \operatorname{ctz}(1), \operatorname{ctz}(2)$

type, 1

asel, $r, 100, x, 0,4$

asel, r, loc, $z, \operatorname{ctz}(1), \operatorname{ctz}(2)$

cmsel, u, conc-tank-a

${ }^{*}$ get, atemp, area, , num, max

${ }^{\star}$ get, atemp1, area, num, min

asel, a, area, $1,22,21$

mshcopy, 2, 1, at emp 1

mshcopy, 2, 22, atemp

asel, u, area, $1,22,21$ 
RPP-RPT-32239, Rev. 1

M\&D-2008-005-CALC-001, Rev. 1

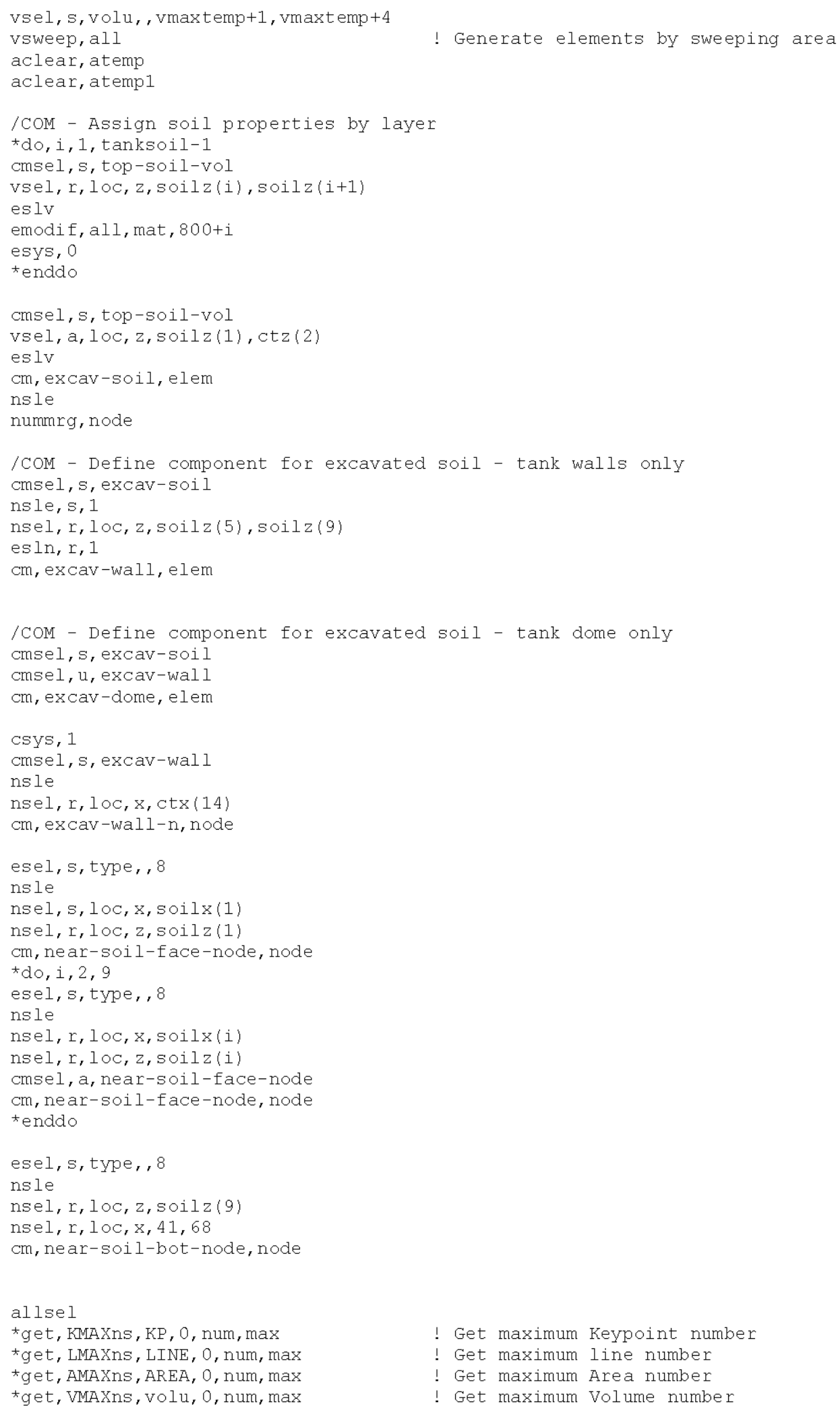


RPP-RPT-32239, Rev. 1

M\&D-2008-005-CALC-001, Rev. 1

\section{Run-Tank.txt}

! batch

! PNNL DST Seismic Analysis, Gravity Inputs, Lower Bound Soil, Best Est Concrete Properties, AP Primary Tank Geometry, Dome Friction=0.0

!

fini

/clear

/filname, AP-460-LBS-BEC-Seismic, 1

/config, nres, 3000

/config, nproc, 2

! Increase allowable number of results to 3000

/ config, fsplit, 1024

! Activate 2 processers for solution

$/ \mathrm{prep} 7$

$g=32.2$

! Split binary file at $4.2 \mathrm{~GB}$

$\mathrm{DF}=40$

! Gravity (ft/sec)

$\mathrm{ALPHA}=0.4$

! Factor for beta (stiffness) damping

! Alpha damping

lout, tank-out, out

/sys, "X: $\backslash 07.00$ - Quality Assurance $\backslash$ ANSYS QA \usrcfg.bat" > QA. out

lout, QA, out, , append

/ input, tank-coordinates-AP, txt

! Run file defining tank coordinates (concrete and primary)

/ input, tank-props-bec-250, txt

! Run file defining fully cracked concrete properties (PNNL

Concrete Properties)

/input, tank-mesh1, txt

! Develop concrete tank

/input, primary-props-AP, txt

/input, primary, txt

/input, insulate, txt

/input, liner, txt

/input, waste-solid-AP-s, txt

/input, bolts-friction, txt

/input, near-soil-1, txt

/input, far-soil, txt

/input, interfacel, txt

/input, interface-gap 1, txt

/input, slave, txt

! Run file defining AP Primary tank properties

! Develop Primary tank

! Develop insulating concrete model

! Develop Liner model

! Develop waste model

! Develop J-Bolt model

! Develop excavated soil model

! Develop Far-Field soil model

! Develop soil and Concrete Interfaces

! Develop Primary Tank Interfaces

! Develop slaved boundary conditions

/input, boundary, txt

/input, outer-spar, txt

! Place base and symmetry boundary conditions

! Connect soil model to symmetry plane

/input, live_load, txt

/input, fix-soil, txt

/out

ALLSEL

lout, Tank-th, out

save

/ input, solve-TH-LBS, txt

! Run solution Phase

/input,post-tank, txt

lout

/exit

\section{Soil-Prop-LB-Geo.txt}

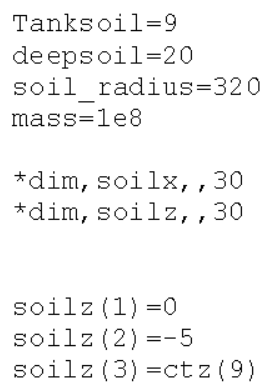


RPP-RPT-32239, Rev. 1

M\&D-2008-005-CALC-001, Rev. 1

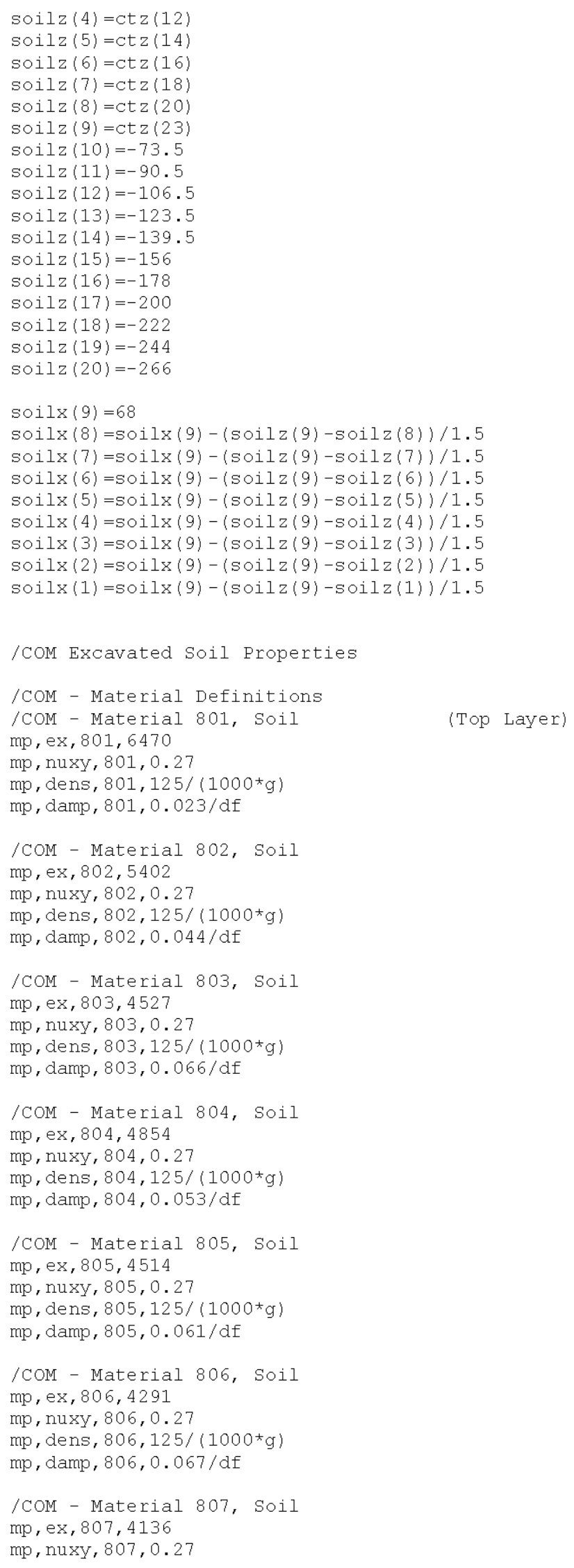


RPP-RPT-32239, Rev. 1

M\&D-2008-005-CALC-001, Rev. 1

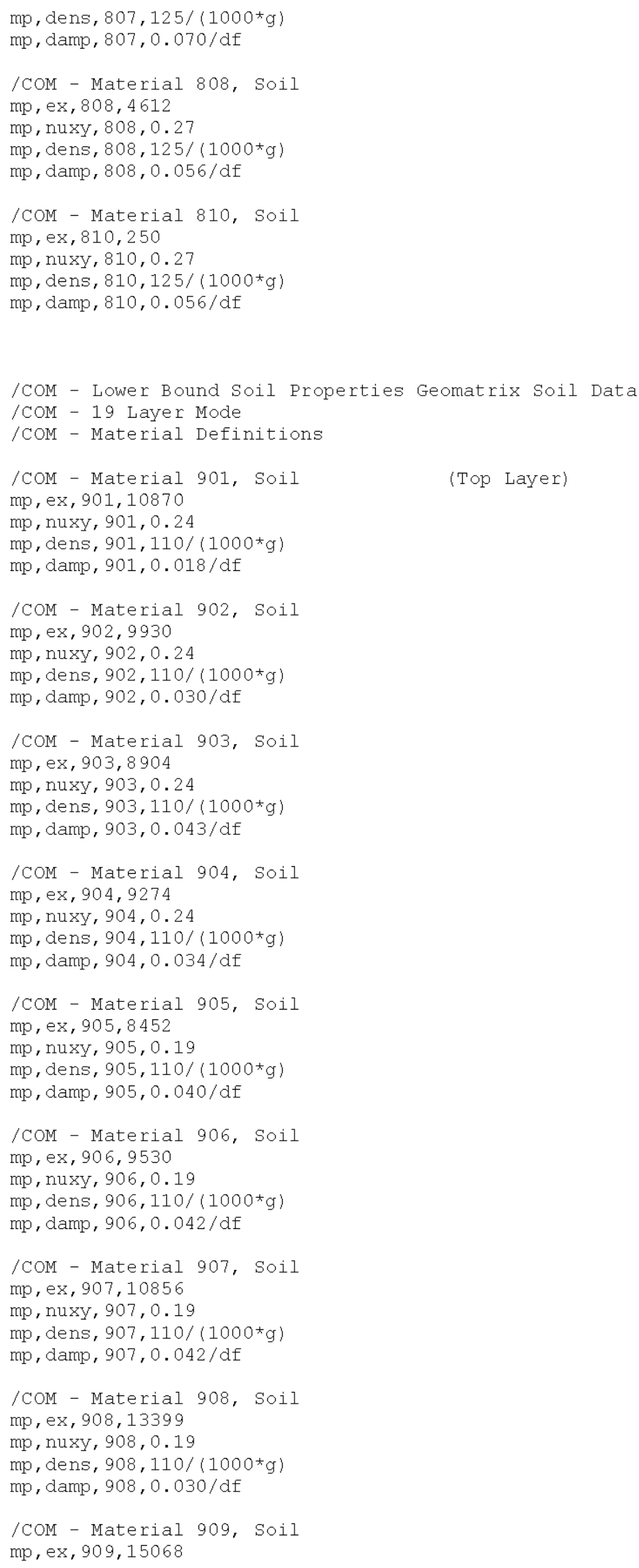


RPP-RPT-32239, Rev. 1

M\&D-2008-005-CALC-001, Rev. 1

mp, nuxy, 909, 0.19

$\mathrm{mp}$, dens, $909,110 /\left(1000^{\star} \mathrm{g}\right)$

mp , damp, 909, 0.030/df

/COM - Material 910, Soil

mp, ex, 910,14438

mp, nuxy, 910, 0.19

mp, dens, $910,110 /\left(1000^{*} \mathrm{~g}\right)$

mp , damp, 910,0.035/df

/COM - Material 911, Soil

$\mathrm{mp}, \mathrm{ex}, 911,13879$

mp, nuxy, 911,0.19

$\mathrm{mp}$, dens, $911,110 /\left(1000^{\star} \mathrm{g}\right)$

mp, damp, 911, 0.039/df

/COM - Material 912, Soil

mp, ex, 912, 13408

mp, nuxy, 912, 0.19

$\mathrm{mp}$, dens, $912,110 /\left(1000^{*} \mathrm{~g}\right)$

mp , damp, 912, 0.043/df

/COM - Material 913, Soil mp, ex, 913, 16152

mp, nuxy, 913, 0.19

$\mathrm{mp}$, dens, $913,110 /\left(1000^{*} \mathrm{~g}\right)$

mp, damp, 913,0.032/df

/COM - Material 914, Soil

$\mathrm{mp}, \mathrm{ex}, 914,16097$

mp, nuxy, 914, 0.19

$\mathrm{mp}$, dens, $914,110 /\left(1000^{\star} \mathrm{g}\right)$

mp , damp, 914, 0.032/df

/COM - Material 915, Soil

$\mathrm{mp}, \mathrm{ex}, 915,22066$

mp, nuxy, 915, 0.28

mp, dens, $915,120 /\left(1000^{*} \mathrm{~g}\right)$

mp, damp, 915, 0.028/df

/COM - Material 916, Soil

mp, ex, 916,24180

mp, nuxy, $916,0.28$

mp, dens, $916,120 /\left(1000^{*} \mathrm{~g}\right)$

mp , damp, 916, 0.028/df

/COM - Material 917, Soil

$\mathrm{mp}, \mathrm{ex}, 917,23846$

mp, nuxy, $917,0.28$

mp, dens, 917, 120/(1000*g)

mp , damp, 917, 0.029/df

/COM - Material 918, Soil

$\mathrm{mp}, \mathrm{ex}, 918,23861$

mp, nuxy, $918,0.28$

$\mathrm{mp}$, dens, $918,120 /\left(1000^{*} \mathrm{~g}\right)$

mp , damp, $918,0.029 / \mathrm{df}$

/COM - Material 919, Soil

$\mathrm{mp}, \mathrm{ex}, 919,27106$

mp, nuxy, 919, 0.28

mp, dens, $919,120 /\left(1000 *^{\circ}\right)$

mp , damp, $919,0.026 / d f$

\section{Solve-Gravity-LBS.txt}

/prep 7

massm $z=148414.59$

d, master_node, all 
RPP-RPT-32239, Rev. 1

M\&D-2008-005-CALC-001, Rev. 1

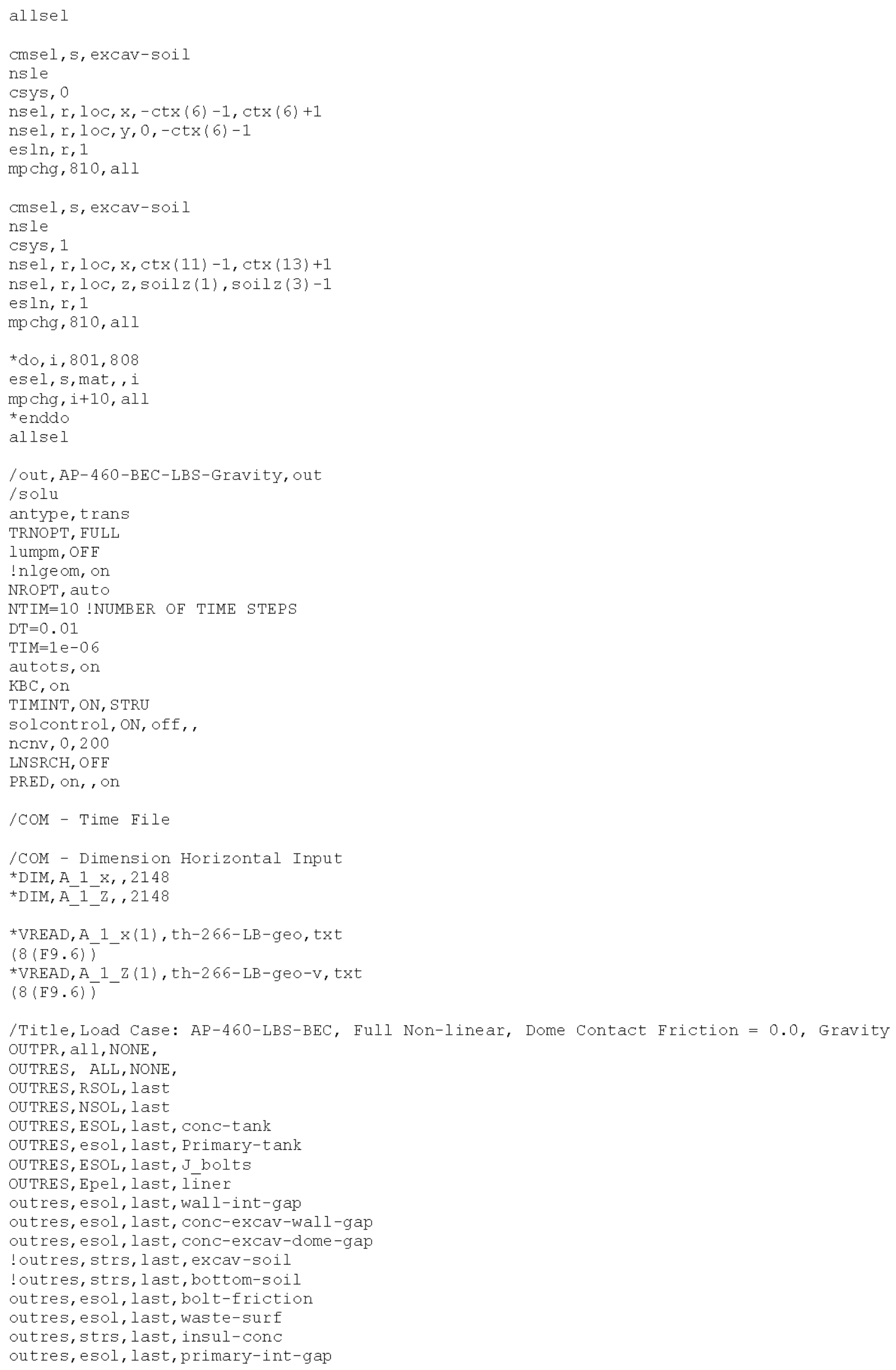


RPP-RPT-32239, Rev. 1

M\&D-2008-005-CALC-001, Rev. 1

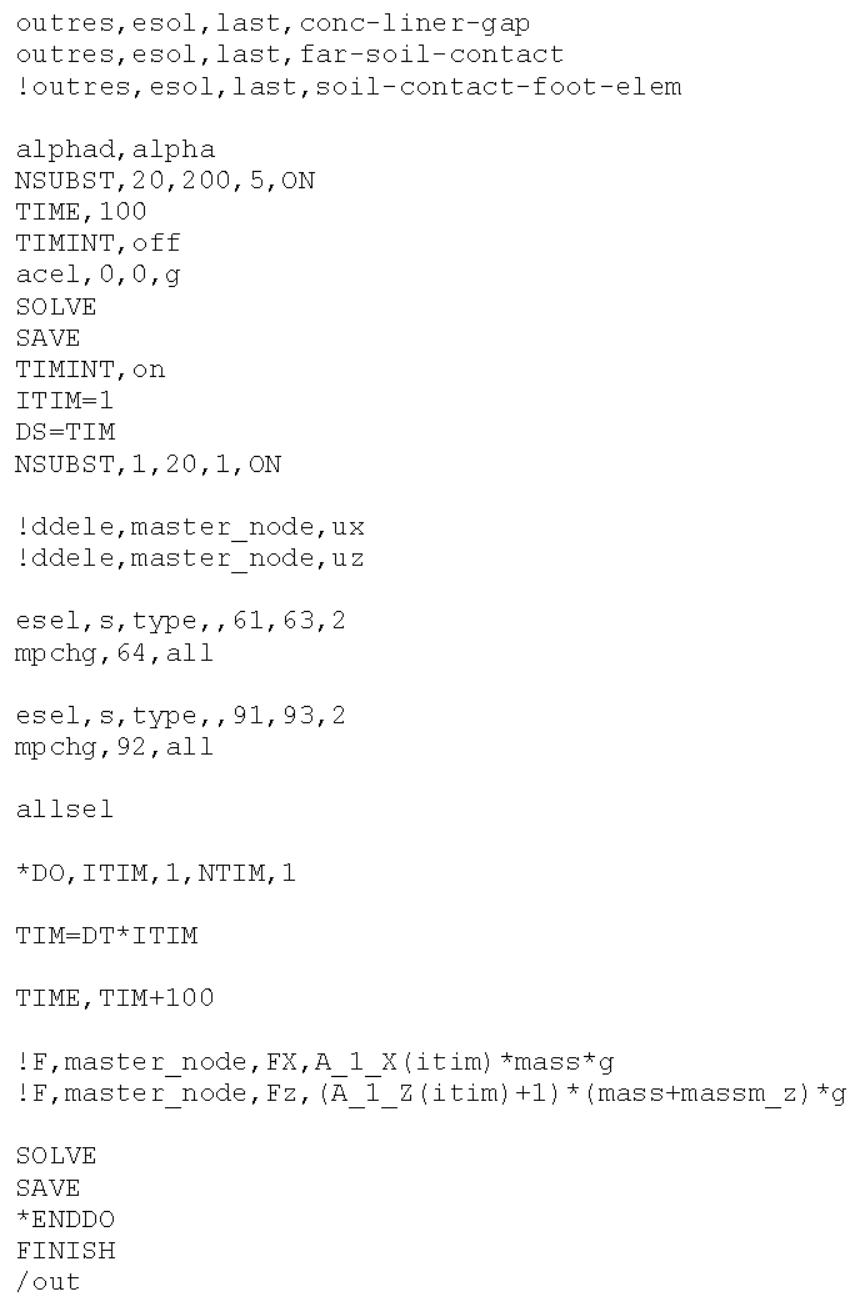

\section{Solve-TH-LBS}

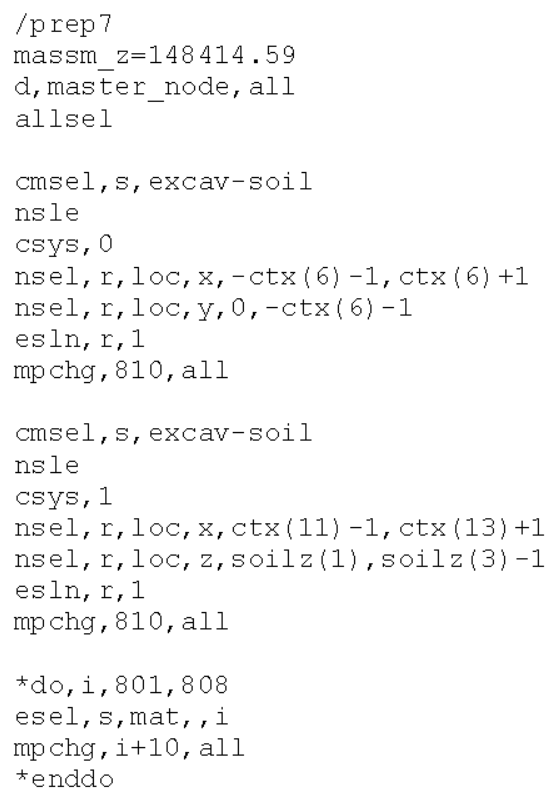




\section{RPP-RPT-32239, Rev. 1 \\ M\&D-2008-005-CALC-001, Rev. 1}

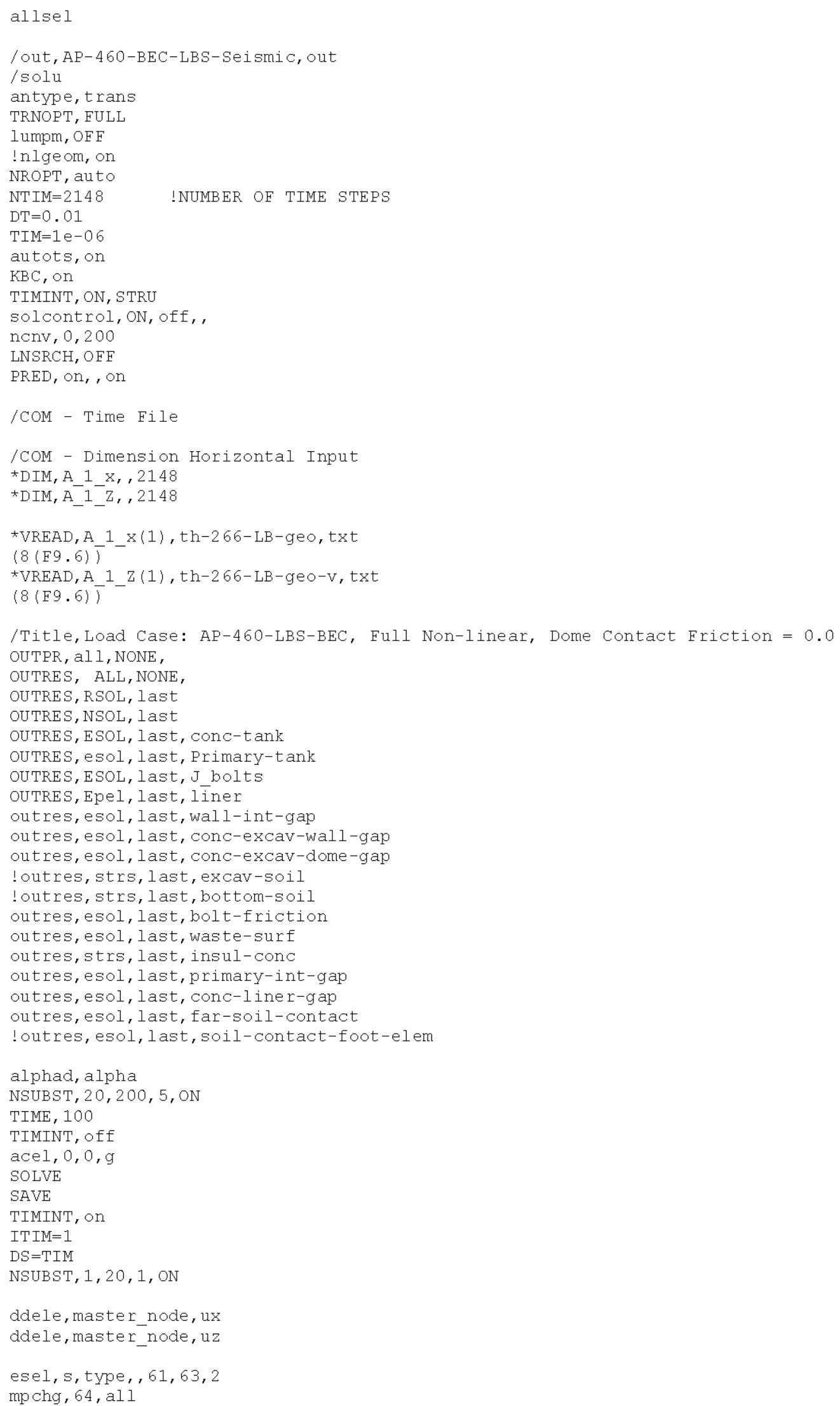


RPP-RPT-32239, Rev. 1

M\&D-2008-005-CALC-001, Rev. 1

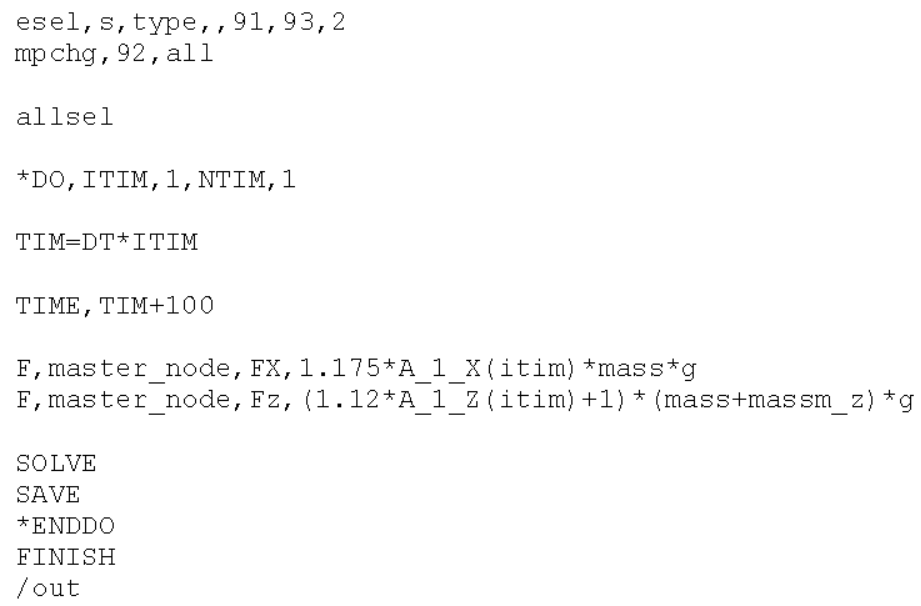

\section{Tank-Props-BEC-250}

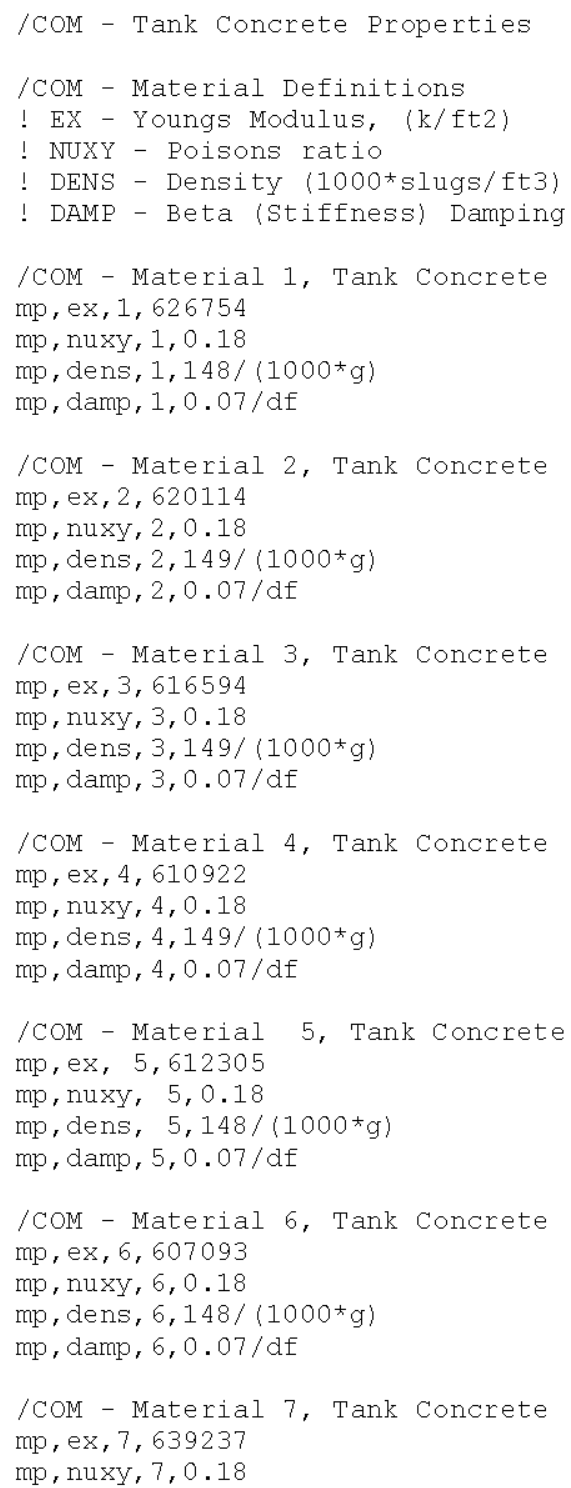


RPP-RPT-32239, Rev. 1

M\&D-2008-005-CALC-001, Rev. 1

$\mathrm{mp}$, dens, $7,146 /\left(1000^{*} \mathrm{~g}\right)$

mp, damp, 7,0.07/df

/COM - Material 8, Tank Concrete

mp, ex, 8,634338

mp, nuxy, $8,0.18$

$\mathrm{mp}$, dens, $8,147 /\left(1000^{*} \mathrm{~g}\right)$

mp , damp, 8, 0.07/df

/COM - Material 9, Tank Concrete

mp, ex, 9, 628756

mp, nuxy, 9, 0.18

$\mathrm{mp}$, dens, $9,147 /(1000 * \mathrm{~g})$

mp, damp, 9, 0.07/df

/COM - Material,10, Tank Concrete $\mathrm{mp}, \mathrm{ex}, 10,193677$

$\mathrm{mp}$, nuxy, $10,0.18$

$\mathrm{mp}$, dens, $10,165 /(1000 * \mathrm{~g})$

$\mathrm{mp}$, damp, 10, 0.07/df

/COM - Material,11, Tank Concrete

$\mathrm{mp}, \mathrm{ex}, 11,575959$

mp, nuxy, 11, 0.18

$\mathrm{mp}$, dens, $11,144 /\left(1000^{*} \mathrm{~g}\right)$

$\mathrm{mp}$, damp, 11, 0.07/df

/COM - Material,12, Tank Concrete $\mathrm{mp}, \mathrm{ex}, 12,202953$

mp, nuxy, 12, 0.18

mp, dens, $12,159 /\left(1000{ }^{*} \mathrm{~g}\right)$

$\mathrm{mp}$, damp, $12,0.07 / \mathrm{df}$

/COM - Material,13, Tank Concrete $\mathrm{mp}, \mathrm{ex}, 13,157426$

mp, nuxy, $13,0.18$

$\mathrm{mp}$, dens, $13,176 /\left(1000^{\star} \mathrm{g}\right)$

$\mathrm{mp}$, damp, 13,0.07/df

/COM - Material,14, Tank Concrete $\mathrm{mp}, \mathrm{ex}, 14,153784$

mp, nuxy, 14, 0.18

mp, dens, $14,193 /\left(1000^{*} \mathrm{~g}\right)$

$\mathrm{mp}$, damp, 14, 0.07/df

/COM - Material,15, Tank Concrete $\mathrm{mp}, \mathrm{ex}, 15,136651$

mp, nuxy, 15, 0.18

$\mathrm{mp}$, dens, $15,200 /\left(1000^{*} \mathrm{~g}\right)$

$\mathrm{mp}$, damp, 15, 0.07/df

/COM - Material,16, Tank Concrete $\mathrm{mp}, \mathrm{ex}, 16,136651$

mp, nuxy, $16,0.18$

$\mathrm{mp}$, dens, $16,200 /\left(1000^{*} \mathrm{~g}\right)$

$\mathrm{mp}$, damp, 16,0.07/df

/COM - Material,17, Tank Concrete $\mathrm{mp}, \mathrm{ex}, 17,138084$

mp, nuxy, $17,0.18$

$\mathrm{mp}$, dens, $17,181 /\left(1000^{*} \mathrm{~g}\right)$

$\mathrm{mp}$, damp, 17, 0.07/df

/COM - Material,18, Tank Concrete $\mathrm{mp}, \mathrm{ex}, 18,123378$

mp, nuxy, 18, 0.18

$\mathrm{mp}$, dens, $18,209 /\left(1000^{*} \mathrm{~g}\right)$

$\mathrm{mp}$, damp, $18,0.07 / \mathrm{df}$

/COM - Material,19, Tank Concrete mp , ex, 19, 124633 
RPP-RPT-32239, Rev. 1

M\&D-2008-005-CALC-001, Rev. 1

$\mathrm{mp}, \mathrm{nuxy}, 19,0.18$

mp, dens, $19,190 /\left(1000^{*} \mathrm{~g}\right)$

$\mathrm{mp}$, damp, 19,0.07/df

/COM - Material,20, Tank Concrete mp, ex, 20, 124388

$\mathrm{mp}$, nuxy, $20,0.18$

$\mathrm{mp}$, dens, 20, 210/(1000*g)

$\mathrm{mp}$, damp, 20,0.07/df

/COM - Material,21, Tank Concrete mp, ex, 21,548683

mp, nuxy, 21, 0.18

$\mathrm{mp}$, dens, $21,166 /\left(1000^{*} \mathrm{~g}\right)$

$\mathrm{mp}$, damp, $21,0.07 / \mathrm{df}$

/COM - Material,22, Tank Concrete $\mathrm{mp}, \mathrm{ex}, 22,154870$

mp, nuxy, 22, 0.18

$\mathrm{mp}$, dens, $22,184 /\left(1000^{*} \mathrm{~g}\right)$

$\mathrm{mp}$, damp, 22,0.07/df

/COM - Material,23, Tank Concrete $\mathrm{mp}, \mathrm{ex}, 23,514287$

mp, nuxy, $23,0.18$

$\mathrm{mp}$, dens, $23,172 /\left(1000^{*} \mathrm{~g}\right)$

mp, damp, 23,0.060/df

/COM - Material,24, Tank Concrete $\mathrm{mp}, \mathrm{ex}, 24,164113$

mp, nuxy, 24, 0.18

$\mathrm{mp}$, dens, $24,288 /\left(1000^{*} \mathrm{~g}\right)$

mp , damp, 24, 0.07/df

/COM - Material,25, Tank Concrete $\mathrm{mp}, \mathrm{ex}, 25,522946$

mp, nuxy, 25, 0.18

mp, dens, $25,201 /(1000 * \mathrm{~g})$

$\mathrm{mp}$, damp, 25, 0.07/df

/COM - Material,26, Tank Concrete mp, ex, 26, 194254

mp, nuxy, $26,0.18$

$\mathrm{mp}$, dens, $26,322 /\left(1000{ }^{*} \mathrm{~g}\right)$

$\mathrm{mp}$, damp, 26, 0.07/df

/COM - Material,27, Tank Concrete $\mathrm{mp}, \mathrm{ex}, 27,199783$

$\mathrm{mp}$, nuxy, $27,0.18$

$\mathrm{mp}$, dens, $27,281 /\left(1000^{\star} \mathrm{g}\right)$

mp, damp, 27,0.07/df

/COM - Material,28, Tank Concrete $\mathrm{mp}, \mathrm{ex}, 28,162553$

mp, nuxy, 28, 0.18

$\mathrm{mp}$, dens, $28,299 /\left(1000^{*} \mathrm{~g}\right)$

$\mathrm{mp}$, damp, $28,0.07 / \mathrm{df}$

/COM - Material,29, Tank Concrete $\mathrm{mp}, \mathrm{ex}, 29,200531$

mp, nuxy, 29, 0.18

mp, dens, 29, 3894/(1000*g)

$\mathrm{mp}$, damp, 29,0.07/df

/COM - Material,30, Tank Concrete $\mathrm{mp}, \mathrm{ex}, 30,167538$

mp, nuxy, 30, 0.18

$\mathrm{mp}$, dens, $30,411 /\left(1000^{*} \mathrm{~g}\right)$

$\mathrm{mp}$, damp, 30,0.07/df

/COM - Material,31, Tank Concrete 
RPP-RPT-32239, Rev. 1

M\&D-2008-005-CALC-001, Rev. 1

$\mathrm{mp}, \mathrm{ex}, 31,731952$

$\mathrm{mp}$, nuxy, $31,0.18$

$\mathrm{mp}$, dens, $31,150 /\left(1000^{*} \mathrm{~g}\right)$

mp, damp, 31, 0.07/df

/COM - Material,32, Tank Concrete

$\mathrm{mp}, \mathrm{ex}, 32,731952$

mp, nuxy, 32, 0.18

mp, dens, 32, 150/(1000*g)

$\mathrm{mp}$, damp, 32,0.07/df

!/COM - Material, 33, Tank Concrete !mp, ex, 33, 731952

!mp, nuxy, $33,0.18$

! mp, dens, $33,150 /\left(1000^{\star} \mathrm{g}\right)$

!mp, damp , 33,0.07/df

!/COM - Material, 34, Tank Concrete !mp, ex, 34, 731952

!mp, nuxy, $34,0.18$

!mp, dens, 34, 150/(1000*g)

!mp, damp, 34,0.07/df

!/COM - Material, 35, Tank Concrete !mp, ex, 35, 731952

!mp, nuxy, 35, 0.18

! mp, dens, 35, 150/(1000*g)

!mp, damp, 35,0.07/df

!/COM - Material, 36, Tank Concrete !mp, ex, 36, 731952

!mp, nuxy, $36,0.18$

! mp, dens, $36,150 /\left(1000^{\star} \mathrm{g}\right)$

! mp, damp, 36, 0.07/df

!/COM - Material, 37, Tank Concrete !mp, ex, 37, 731952

!mp, nuxy, $37,0.18$

!mp, dens, $37,150 /\left(1000^{*} \mathrm{~g}\right)$

! mp, damp, $37,0.07 / d f$

/COM - Concrete Real Values, $t$ in $\mathrm{ft}$ $r, 1,1.26$

$r, 2,1.26$

! 15 in

$r, 3,1.26$

$r, 4,1.26$

$r, 5,1.27$

$r, 6,1.26$

$r, 7,1.28$

$r, 8,1.28$

$r, 9,1.73$

$r, 10,1.73,1.73,2.23,2.23$

$r, 11,2.23,2.22,3.15,3.15$

$r, 12,3.15,3.15,1.50,1.50$

$r, 13,1.50,1.50,1.28,1.28$

$r, 14,1.17$

$r, 15,1.13$

$r, 16,1.13$

$r, 17,1.24$

$r, 18,1.07$

$r, 19,1.18$

$r, 20,1.07$

$r, 21,1.07$

$r, 22,1.97$

$r, 23,1.97,1.67,1.67,1.97$

$r, 24,1.67$

$r, 25,1.68,1.43,1.43,1.68$

$r, 26,1.43,0.51,0.51,1.43$

$r, 27,0.51,0.41,0.41,0.51$

$r, 28,0.41,0.55,0.55,0.41$

! 15 in

! 15 in

! 15 in

! 15 in

! 15 in

! 15 in

! 15 in

! 15 in to

!

!

$r, 29,0.55$ 
RPP-RPT-32239, Rev. 1

M\&D-2008-005-CALC-001, Rev. 1

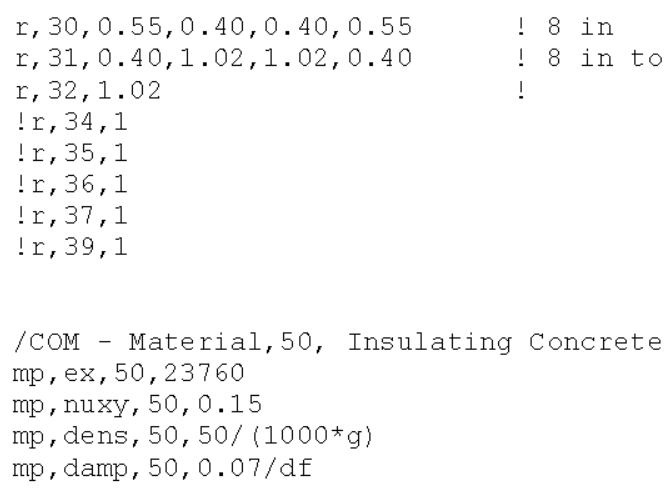

\section{TH-266-LB-Geo-V.txt}

$\begin{array}{llll}-0.000173-0.000255 & 0.000174 & 0.000257-0.000174-0.0002580 .0001760 .000261 & 1\end{array}$ $-0.000176-0.0002620 .0001780 .000264-0.000178-0.0002650 .0001800 .000268 \quad 2$ $-0.000180-0.0002690 .0001820 .000272-0.000182-0.0002730 .0001840 .000277 \quad 3$

\section{TH-266-LB-Geo.txt}

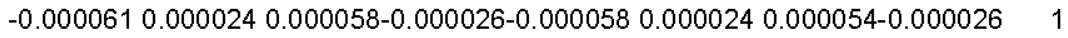
$\begin{array}{llll}-0.0000540 .000024 & 0.000050-0.000026-0.0000510 .0000240 .000045-0.000027 & 2\end{array}$ $\begin{array}{llllll}-0.000046 & 0.000023 & 0.000040-0.000027-0.000041 & 0.000023 & 0.000034-0.000028 & 3\end{array}$ $\ldots \ldots \ldots$

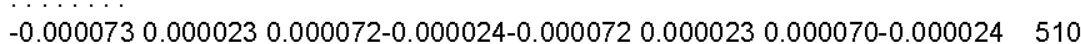

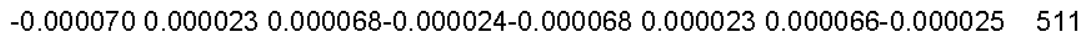

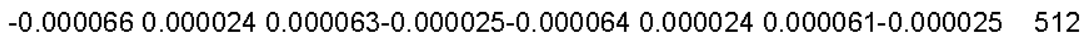

\section{LBS-BEC Seismic File Listing}

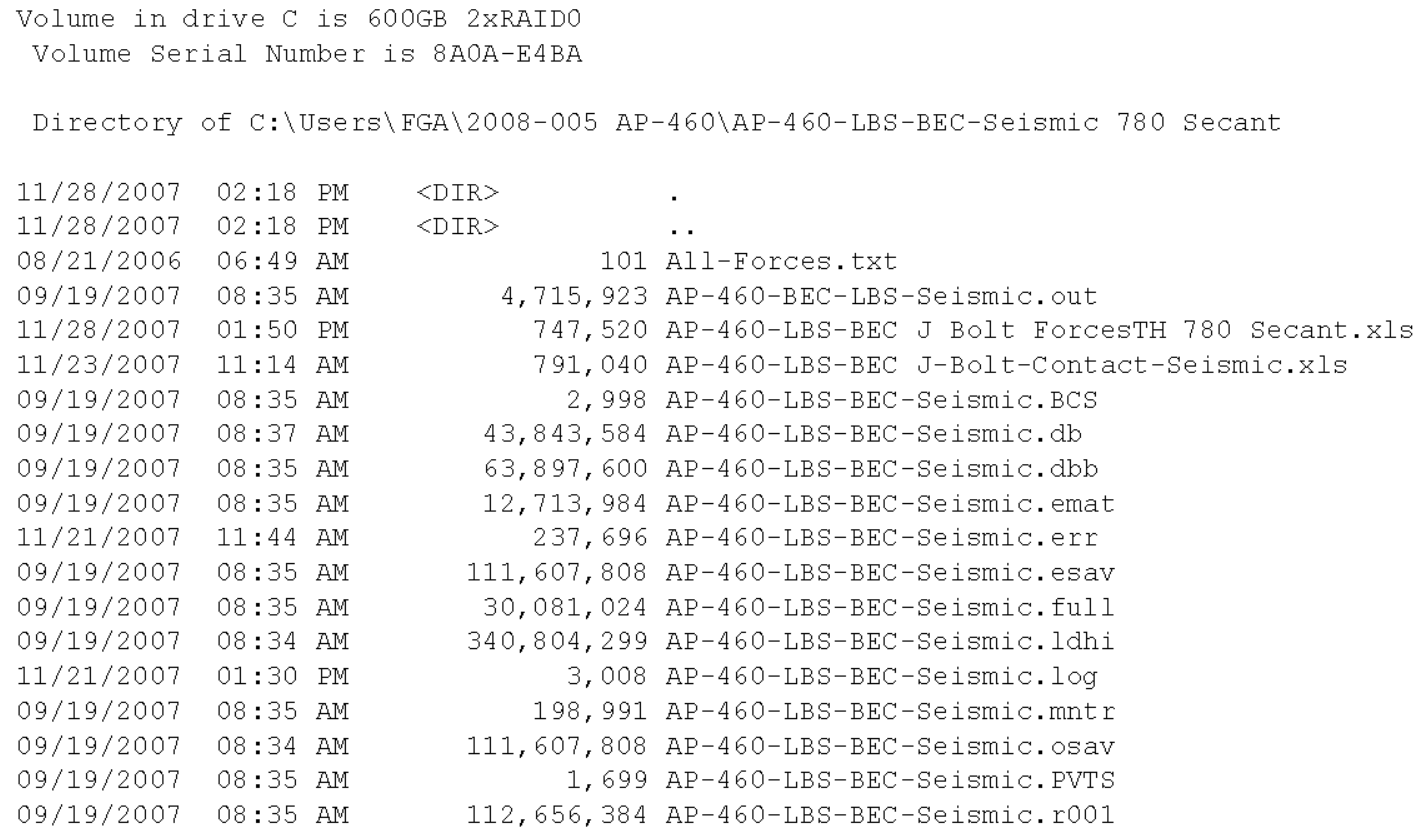




\section{RPP-RPT-32239, Rev. 1 M\&D-2008-005-CALC-001, Rev. 1}

09/17/2007 04:06 PM 09/19/2007 08:35 AM 09/18/2007 01:14 AM 09/18/2007 05:55 AM 09/18/2007 10:41 AM 09/18/2007 03:34 PM 09/18/2007 08:35 PM 09/19/2007 01:40 AM 09/19/2007 06:54 AM 09/19/2007 08:35 AM 08/15/2007 10:18 AM 09/08/2006 02:54 PM 08/25/2006 08:48 AM 08/21/2006 07:59 AM 08/25/2006 01:28 PM 08/25/2006 01:27 PM 08/25/2006 01:28 PM 08/21/2006 07:59 AM $08 / 21 / 2006 \quad 12: 44 \quad \mathrm{PM}$ 11/28/2007 02:18 PM 01/03/2006 11:17 AM 05/08/2006 01:31 PM 01/09/2007 06:41 AM 10/13/2005 06:54 AM 08/21/2006 08:00 AM $11 / 19 / 2007$ 02:53 PM 09/19/2007 12:02 PM 09/19/2007 12:02 PM 09/19/2007 12:03 PM 09/19/2007 12:03 PM 09/19/2007 11:55 AM 09/19/2007 11:55 AM 09/19/2007 11:56 AM 09/19/2007 11:55 AM 09/19/2007 11:56 AM 09/19/2007 11:56 AM 09/19/2007 11:57 AM 09/19/2007 11:57 AM 09/19/2007 11:58 AM 09/19/2007 11:58 AM 09/19/2007 11:59 AM 09/19/2007 11:59 AM 09/19/2007 12:00 PM 09/19/2007 12:00 PM 09/19/2007 12:01 PM 09/19/2007 12:01 PM 09/19/2007 11:52 AM 11/23/2007 11:13 AM 09/01/2005 10:27 AM 07/20/2006 06:36 AM 08/23/2006 07:55 AM 11/23/2007 11:02 AM 11/23/2007 11:14 AM 11/21/2007 12:01 PM $11 / 21 / 2007 \quad 12: 01 \quad \mathrm{PM}$ $11 / 21 / 2007 \quad 12: 03 \mathrm{PM}$ $11 / 21 / 2007 \quad 12: 03 \mathrm{PM}$ $11 / 21 / 2007 \quad 12: 04$ PM 11/21/2007 12:04 PM 11/21/2007 12:06 PM $11 / 21 / 2007 \quad 12: 06 \mathrm{PM}$ $11 / 21 / 2007 \quad 12: 06 \mathrm{PM}$ $11 / 21 / 2007 \quad 12: 06 \mathrm{PM}$ $11 / 21 / 2007 \quad 12: 06 \mathrm{PM}$ 11/21/2007 12:06 PM
$43,974,656$ AP-460-LBS-BEC-Seismic.rdb $4,294,967,296$ AP-460-LBS-BEC-Seismic.rst $4,294,967,296$ AP-460-LBS-BEC-Seismic.rst02 $4,294,967,296$ AP-460-LBS-BEC-Seismic.rst03 $4,294,967,296$ AP-460-LBS-BEC-Seismic.rst04 $4,294,967,296$ AP-460-LBS-BEC-Seismic.rst05 $4,294,967,296$ AP-460-LBS-BEC-Seismic.rst06 $4,294,967,296 \mathrm{AP}-460-\mathrm{LBS}-\mathrm{BEC}-\mathrm{Se}$ ismic.rst07 $4,294,967,296$ AP-460-LBS-BEC-Seismic.rst08 $1,388,445,696$ AP-460-LBS-BEC-Seismic.rst09

6, 120 Bolts-Friction.txt

277 Boundary.txt

220 Contact-AP. txt

586 Contact-Footing.txt

704 Contact-Insul.txt

704 Contact-J-Bolts.txt

708 Contact-Primary.txt

742 Contact-Soil.txt

632 Contact-Waste-AP. txt

0 dir_listing.txt

1,616 Disp-J-Bolts.txt

8,616 Far-Soil.txt

50,448 file-list.txt

562 Fix-Soil.txt

894 Force-c.txt

135,680 force-jb.xls

$2,666,244$ Force-jb_r10-th. OUT

5,239 Force-jb r10 max. OUT

$2,666,244$ Force-jb_r11-th. OUT

5,239 Force-jb_rl1_max. OUT

$2,666,372$ Force-jb r2-th. OUT

5,239 Force-jb_r2_max. OUT

$2,666,244$ Force-jb r3-th. OUT

5,239 Force-jb_r3_max. OUT

$2,666,244$ Force-jb_r4-th. OUT

5,239 Force-jb_r4 max. OUT

$2,666,244$ Force-jb_r5-th. OUT

5,239 Force-jb r5 max. OUT

$2,666,244$ Force-jb_r6-th. OUT

5,239 Force-jb r6 max. OUT

$2,666,244$ Force-jb r7-th. OUT

5,239 Force-jb_r7_max.OUT

$2,666,244$ Force-jbr8-th. OUT

5,239 Force-jb_r8_max. OUT

$2,666,244$ Force-jb r9-th. OUT

5,239 Force-jb r9 max. OUT

675 Force-j_bolt.txt

Gravity

1,664 Insulate.txt

4,030 interface-gap 1.txt

2,411 interfacel.txt

$116,224 \mathrm{~J}$-Bolt-Contact_0-90.xls

$116,224 \mathrm{~J}-$ Bolt-Contact $99-180 . x 1 \mathrm{~s}$

4, 519 J-Bolt-Cont $108 \mathrm{max}$. OUT

$1,685,484 \mathrm{~J}$-Bolt-Cont 108th.OUT

4,519 J-Bolt-Cont_117max.OUT

$1,685,484 \mathrm{~J}$-Bolt-Cont $117 \mathrm{th}$. OUT

4,519 J-Bolt-Cont $126 \mathrm{max}$. OUT

$1,685,484 \mathrm{~J}-\mathrm{Bolt}$-Cont $126 \mathrm{th}$. OUT

4,519 J-Bolt-Cont $135 \mathrm{max}$. OUT

$1,685,484 \mathrm{~J}$-Bolt-Cont $135 \mathrm{th}$.OUT

4,519 J-Bolt-Cont 144 max. OUT

$1,685,484 \mathrm{~J}$-Bolt-Cont_144th.OUT

4,519 J-Bolt-Cont 153max. OUT

1,685,484 J-Bolt-Cont 153th. OUT 


\section{RPP-RPT-32239, Rev. 1 M\&D-2008-005-CALC-001, Rev. 1}

11/21/2007 12:07 PM 11/21/2007 12:07 PM 11/21/2007 12:09 PM $11 / 21 / 2007 \quad 12: 09 \mathrm{PM}$ $11 / 21 / 2007 \quad 12: 10 \mathrm{PM}$ $11 / 21 / 2007 \quad 12: 10 \mathrm{PM}$ 11/21/2007 11:49 AM 11/21/2007 11:49 AM 11/21/2007 11:50 AM 11/21/2007 11:50 AM 11/21/2007 11:52 AM 11/21/2007 11:52 AM 11/21/2007 11:54 AM $11 / 21 / 2007 \quad 11: 54$ AM 11/21/2007 11:55 AM $11 / 21 / 2007 \quad 11: 55$ AM 11/21/2007 11:56 AM 11/21/2007 11:56 AM 11/21/2007 11:56 AM 11/21/2007 11:56 AM 11/21/2007 11:58 AM 11/21/2007 11:58 AM $11 / 21 / 2007 \quad 12: 00 \mathrm{PM}$ $11 / 21 / 2007 \quad 12: 00 \mathrm{PM}$ $11 / 21 / 2007 \quad 12: 00 \mathrm{PM}$ 11/21/2007 12:00 PM 11/21/2007 11:48 AM 11/21/2007 11:48 AM 12/22/2006 08:33 AM 08/23/2006 07:47 AM 05/02/2005 02:19 PM 09/01/2006 06:03 AM 04/20/2005 01:14 PM 09/17/2007 04:05 PM 10/12/2006 02:28 PM 09/27/2005 03:52 PM 09/17/2007 04:06 PM 10/31/2005 10:31 AM 09/01/2006 06:03 AM 11/21/2007 11:44 AM 02/11/2005 01:22 PM 09/20/2005 02:46 PM 09/11/2006 09:46 AM 09/13/2006 06:12 AM 09/13/2006 06:07 AM 09/13/2006 06:08 AM 09/13/2006 06:09 AM 09/13/2006 06:08 AM 09/13/2006 06:08 AM 09/13/2006 06:09 AM 08/28/2006 09:38 AM 09/13/2006 06:13 AM 09/13/2006 06:14 AM 09/13/2006 06:15 AM 09/13/2006 06:13 AM 09/13/2006 06:14 AM 09/13/2006 06:15 AM 06/20/2005 09:04 AM 06/20/2005 08:52 AM 01/03/2007 03:40 PM 01/03/2007 03:40 PM 01/03/2007 03:41 PM 01/03/2007 04:02 PM 08/21/2006 08:02 AM 08/21/2006 08:03 AM
4,519 J-Bolt-Cont 162max. OUT

1,685,484 J-Bolt-Cont_162th.OUT

4,519 J-Bolt-Cont $171 \mathrm{max}$. OUT

$1,685,484 \mathrm{~J}$-Bolt-Cont_171th.OUT

4,519 J-Bolt-Cont 18 max. OUT

$1,685,484 \mathrm{~J}$-Bolt-Cont 180th.OUT

4,519 J-Bolt-Cont_18max.OUT

$1,685,484 \mathrm{~J}$-Bolt-Cont $18 \mathrm{th}$. OUT

$4,519 \mathrm{~J}$-Bolt-Cont_27max.OUT

$1,685,484 \mathrm{~J}$-Bolt-Cont_27th. OUT

4,519 J-Bolt-Cont $36 \mathrm{max}$. OUT

$1,685,484 \mathrm{~J}$-Bolt-Cont $36 \mathrm{th}$. OUT

4,519 J-Bolt-Cont_45max.OUT

$1,685,484 \mathrm{~J}-\mathrm{Bolt}$-Cont_45th. OUT

4, $519 \mathrm{~J}$-Bolt-Cont $54 \mathrm{max}$. OUT

$1,685,484 \mathrm{~J}$-Bolt-Cont_54th. OUT

$4,519 \mathrm{~J}$-Bolt-Cont_63max. OUT

$1,685,484 \mathrm{~J}$-Bolt-Cont $63 \mathrm{th}$. OUT

$4,519 \mathrm{~J}$-Bolt-Cont_ $72 \max$.OUT

$1,685,484 \mathrm{~J}$-Bolt-Cont $72 \mathrm{th}$. OUT

4, $519 \mathrm{~J}$-Bolt-Cont_81max. OUT

$1,685,484 \mathrm{~J}$-Bolt-Cont_81th. OUT

$4,519 \mathrm{~J}$-Bolt-Cont $90 \mathrm{max}$. OUT

$1,685,484 \mathrm{~J}$-Bolt-Cont_90th. OUT

4,519 J-Bolt-Cont $99 \max$. OUT

$1,685,484 \mathrm{~J}$-Bolt-Cont_99th. OUT

4,519 J-Bolt-Cont_9max. OUT

$1,685,612 \mathrm{~J}$-Bolt-Cont 9 th. OUT

52, 949 LBS-BEC-SeismiC-File-List.txt

1,971 Liner.txt

667 live load.txt

6,212 Near-Soil-1.txt

508 outer-spar.txt

162 Post-Tank.txt

6,028 Primary-Props-AP.txt

1,538 Primary.txt

448,180 QA. out

1,108 RS_FREQ.tXt

1,819 Run-Tank.txt

0 scratch.hlp

1,053 Slave.txt

4,106 Soil-Prop-LB-Geo.txt

1,925 Solve-TH-LBS.txt

347 spectra-all.txt

3,690 spectra-conc-0.txt

3,723 spectra-conc-135.txt

3,723 spectra-conc-180.txt

3,769 spectra-conc-45.txt

3,649 spectra-conc-90.txt

1,590 spectra-conc.txt

2,076 spectra-concrete.txt

3,609 spectra-primary-0.txt

3,762 spectra-primary-135.txt

3,777 spectra-primary-180.txt

3,688 spectra-primary -45. txt

3,688 spectra-primary-90.txt

3,801 spectra-soil.txt

647 spectra-wall.txt

679 spectra-waste.txt

1,823 strain-backed-principle-bot.txt

1,828 strain-backed-principle-mid.txt

1,825 strain-backed-principle-top.txt

966 strain-backed-principle.txt

598 stress-complo.txt

608 stress-compm.txt 
RPP-RPT-32239, Rev. 1

M\&D-2008-005-CALC-001, Rev. 1
08/24/2006 03:19 PM
08/24/2006 12:05 PM
$10 / 12 / 2006 \quad 02: 29 \mathrm{PM}$
05/25/2005 03:32 PM
09/17/2007 04:05 PM
08/25/2006 07:52 AM
09/17/2007 04:06 PM
05/16/2005 03:41 PM
05/16/2005 08:44 AM
$08 / 25 / 2006 \quad 08: 47$ AM
10/12/2006 02:27 PM
$08 / 21 / 2006$
598 stress-compt.txt
224 Stress-Primary.txt
4,009 Tank-Coordinates-AP. txt
2,512 Tank-Mesh1.txt
102 tank-out.out
5,450 Tank-Props-BEC-250.txt
6,495 Tank-th. out
41, 470 TH-266-LB-Geo-V.txt
41, $472 \mathrm{TH}-266-\mathrm{LB}-\mathrm{Geo}$.txt
340 Waste-Reaction.txt
10,266 Waste-solid-AP-S.txt
$08: 03 \mathrm{AM}$
776 waste-Surface-AP.txt
158 File(s) $36,687,730,876$ bytes
$3 \operatorname{Dir}(\mathrm{s}) \quad 111,055,118,336$ bytes free 
RPP-RPT-32239, Rev. 1

M\&D-2008-005-CALC-001, Rev. 1

\title{
Appendix G
}

\author{
Best Estimate Soil,
} Best Estimate Concrete

\author{
Results \\ Load Case Specific Input Files
}

File Listing 
RPP-RPT-32239, Rev. 1

M\&D-2008-005-CALC-001, Rev. 1

Intentionally left blank 
RPP-RPT-32239, Rev. 1

M\&D-2008-005-CALC-001, Rev. 1

\section{Appendix G}

\section{Best Estimate Soil, Best Estimate Concrete}

\section{Results \\ Load Case Specific Input Files File Listing}

List of Tables Updated in Revision 1:

Table G.4

Table G. 5

Table G.6

Table G.7

Table G. 8

Table G.9

Table G. 10

Table G.11

Table G.12

Table G.13

Table G.14

Table G. 15

Table G.31

Table G.32

Table G.33 
RPP-RPT-32239, Rev. 1

M\&D-2008-005-CALC-001, Rev. 1

Tables

G.1 BES-BEC Concrete Forces and Moment, Gravity Load Only

G.2 BES-BEC Concrete Forces and Moments, Gravity Plus Seismic Load .

G.5

G.3 BES-BEC Concrete Forces and Moments, Seismic Only

G.4 BES-BEC Primary Tank Stresses, Shell Top, Gravity Load Only

G.5 BES-BEC Primary Tank Stresses, Shell Middle, Gravity Load Only

G.6 BES-BEC Primary Tank Stresses, Shell Bottom, Gravity Load Only ....

G.7 BES-BEC Primary Tank Stresses, Shell Top, Gravity Plus Seismic Load

G.10

G.8 BES-BEC Primary Tank Stresses, Shell Middle, Gravity Plus Seismic Load

G.11

G.9 BES-BEC Primary Tank Stresses, Shell Bottom, Gravity Plus Seismic Load..

G.12

G.10 BES-BEC Primary Tank Stresses, Shell Top, Seismic Load Only

G.13

G.11 BES-BEC Primary Tank Stresses, Shell Middle, Seismic Load Only

G.14

G.12 BES-BEC Primary Tank Stresses, Shell Bottom, Seismic Load Only

G.15

G.13 BES-BEC Anchor Bolt Forces, Gravity Load Only

G.16

G.14 BES-BEC Anchor Bolt Forces, Gravity Plus Seismic Loads.

G.15 BES-BEC Anchor Bolt Forces, Seismic Load Only

G.18

G.16 BES-BEC Concrete Backed Steel Strain, Shell Top, Gravity Load Only

G.19

G.17 BES-BEC Concrete Backed Steel Strain, Shell Middle, Gravity Load Only

G.20

G.18 BES-BEC Concrete Backed Steel Strain, Shell Bottom, Gravity Load Only .

G.21

G.19 BES-BEC Concrete Backed Steel Strain, Shell Top, Gravity Plus Seismic Load ....

G.22

G.20 BES-BEC Concrete Backed Steel Strain, Shell Middle, Gravity Plus Seismic Load

G.23

G.21 BES-BEC Concrete Backed Steel Strain, Shell Bottom, Gravity Plus Seismic Load.

G. 24

G.22 BES-BEC Concrete Backed Steel Strain, Shell Top, Seismic Load Only

G. 25

G.23 BES-BEC Concrete Backed Steel Strain, Shell Middle, Seismic Load Only ...

G.26

G.24 BES-BEC Concrete Backed Steel Strain, Shell Bottom, Seismic Load Only...

G.27

G.25 BES-BEC Concrete Wall/Footing Contact Forces, Gravity Only .

G.28

G.26 BES-BEC Concrete Wall/Footing Contact Forces, Gravity Plus Seismic

G.29

G.27 BES-BEC Concrete Wall/Footing Contact Forces, Seismic Only

G.30

G.28 BES-BEC Soil/Concrete Tank Contact Forces, Gravity Only

G.31

G.29 BES-BEC Soil/Concrete Tank Contact Forces, Gravity Plus Seismic....

G.32

G.30 BES-BEC Soil/Concrete Tank Contact Forces, Seismic Only

G.33

G.31 BES-BEC Primary Tank/Concrete Dome Contact Data, Gravity Only

G.34

G.32 BES-BEC Primary Tank/Concrete Dome Contact Data, Gravity Plus Seismic

G.35

G.33 BES-BEC Primary Tank/Concrete Dome Contact Data, Seismic Only

G.36

G.34 BES-BEC Primary Tank/Insulating Concrete Contact Forces, Gravity Only

G.37 
RPP-RPT-32239, Rev. 1

M\&D-2008-005-CALC-001, Rev. 1

G.35 BES-BEC Primary Tank/Insulating Concrete Contact Data, Gravity Plus Seismic............... G.38

G.36 BES-BEC Primary Tank/Insulating Concrete Contact Forces, Seismic Only..................... G. G.39

G.37 BES-BEC Insulating Concrete/Concrete Backed Steel Contact Data, Gravity Only ............ G G.40

G.38 BES-BEC Insulating Concrete/Concrete Backed Steel Contact Data, Gravity Plus Seismic

G.41

G.39 BES-BEC Insulating Concrete/Concrete Backed Steel Contact Data, Seismic Only ............ G.42

G.40 BES-BEC Waste Contact Pressure, Gravity Plus Seismic ............................................... G.43

G.41 BES-BEC Waste Contact Pressure, Theoretical Pressures.................................................. G.44

G.42 BES-BEC Waste Surface Displacement, Gravity Plus Seismic ........................................ G.45 
RPP-RPT-32239, Rev. 1

M\&D-2008-005-CALC-001, Rev. 1

Table G.1. BES-BEC Concrete Forces and Moment, Gravity Load Only

\section{AP Primary Tank, Best Estimate Soil (Geomatrix), Gravity Only, Best Estimate Concrete, $460 \mathrm{in}$. Waste Level at $1.83 \mathrm{SpG}$}

\begin{tabular}{|c|c|c|c|c|c|c|c|}
\hline $\begin{array}{l}\text { PNNL } \\
\text { Section } \\
\text { No. }\end{array}$ & Path (in.) & $\begin{array}{l}\text { Gravity Hoop } \\
\text { Force (kip/ft) } \\
\text { AP-BES-BEC }\end{array}$ & $\begin{array}{c}\text { Gravity } \\
\text { Meridonal } \\
\text { Force (kip/ft) } \\
\text { AP-BES-BEC }\end{array}$ & $\begin{array}{l}\text { Gravity -In- } \\
\text { Plane Shear } \\
\text { Force (kip/ft) } \\
\text { AP-BES-BEC }\end{array}$ & $\begin{array}{l}\text { Gravity Hoop } \\
\text { Moment } \\
\text { (ft* }{ }^{*} \text { kip } / \mathrm{ft} \text { ) AP- } \\
\text { BES-BEC }\end{array}$ & $\begin{array}{c}\text { Gravity Meridonal } \\
\text { Moment (ft }{ }^{*} \mathrm{kip} / \mathrm{ft} \text { ) } \\
\text { AP-BES-BEC }\end{array}$ & $\begin{array}{c}\text { Gravity } \\
\text { Through-Wall } \\
\text { Shear Force } \\
\text { (kip/ft) AP-BES } \\
\text { BEC }\end{array}$ \\
\hline 2 & 67.734 & -71.110 & -75.640 & -0.115 & -7.359 & -4.269 & 1.725 \\
\hline 3 & 105.676 & -65.280 & -73.940 & -0.172 & -5.205 & -1.763 & 1115 \\
\hline 4 & 137.076 & -59.520 & -72.100 & -0.224 & -3.637 & 0.778 & 1.262 \\
\hline 6 & 182.856 & -52.840 & -69.090 & -0.184 & -2.253 & 1.984 & 0.273 \\
\hline 8 & 226.570 & -47.630 & -66.820 & -0.049 & -1.825 & -0.616 & -0.795 \\
\hline 9 & 275.574 & -42.980 & -64.660 & -0.178 & -1.864 & -1.317 & -0.734 \\
\hline 11 & 325.697 & -34.650 & -62.850 & 0.141 & -2.292 & -4.489 & -0.803 \\
\hline 13 & 372.312 & -24.800 & -61.000 & -0.056 & -4.864 & -5.474 & -0.438 \\
\hline 17 & 423.434 & -8.647 & -59.050 & -0.024 & -2.396 & -3.279 & 2.161 \\
\hline 20 & 468.315 & 31.900 & -56.900 & -0.055 & -8.195 & 15.940 & 8.741 \\
\hline 22 & 515.319 & 15.520 & -58.080 & -0.044 & 4.760 & 30.140 & -3.421 \\
\hline 24 & 553.722 & -0.166 & -56.480 & -0.026 & 2.016 & 11.050 & -6.813 \\
\hline 26 & 593.805 & -14.320 & -58.640 & -0.014 & -0.170 & -0.937 & -1.767 \\
\hline 30 & 644.355 & -24.810 & -60.520 & -0.006 & -0.405 & -2.248 & 0.770 \\
\hline 33 & 693.605 & -28.700 & -61.900 & 0.004 & -0.065 & -0.362 & 0.261 \\
\hline 35 & 740.705 & -32.290 & -63.310 & 0.003 & 0.045 & 0.247 & -0.041 \\
\hline 38 & 786.205 & -28.640 & -64.690 & 0.003 & -0.161 & -0.893 & -0.290 \\
\hline 41 & 844.605 & -28.470 & -66.490 & -0.004 & -0.114 & -0.629 & -0.222 \\
\hline 43 & 901.355 & -14.020 & -28.120 & 0.004 & -0.187 & -1.035 & 0.678 \\
\hline 46 & 932.355 & -23.880 & -66.640 & 0.039 & -0.678 & -3.632 & -1.768 \\
\hline 48 & 1007.355 & -2.856 & -10.330 & 0.617 & -4.280 & 21.190 & -12.210 \\
\hline 51 & 1053.855 & -3.510 & -12.650 & 0.753 & -0.938 & 17.440 & 12.750 \\
\hline 53 & 1086.855 & -1.228 & -6.325 & 0.425 & 1.922 & 6.127 & -3.114 \\
\hline 55 & 1105.855 & -0.545 & -4.383 & 0.329 & 2.571 & 4.504 & 0.226 \\
\hline 57 & 1147.355 & -0.136 & -2.277 & 0.184 & 0.305 & 1.091 & -1.199 \\
\hline 58 & 1207.355 & 0.292 & 0.039 & 0.030 & -0.019 & -0.127 & 0.285 \\
\hline 59 & 1267.355 & 0.328 & 0.294 & 0.011 & 0.026 & 0.131 & -0.233 \\
\hline 60 & 1327.355 & 0.480 & 0.107 & 0.038 & -0.033 & -0.194 & 0.208 \\
\hline 61 & 1387.355 & 0.468 & 0.635 & -0.021 & 0.024 & 0.059 & -0.146 \\
\hline 62 & 1449.355 & 2.289 & 2.414 & -0.032 & 0.034 & -0.044 & 0.279 \\
\hline
\end{tabular}


RPP-RPT-32239, Rev. 1

M\&D-2008-005-CALC-001, Rev. 1

Table G.2. BES-BEC Concrete Forces and Moments, Gravity Plus Seismic Load

AP- Primary Tank, Best Estimate Soil (Geomatrix), Best Estimate Concrete, 460 in. Waste Level at $1.83 \mathrm{SpG}$

ANSYS MAXIMUMS BY PATH

\begin{tabular}{|c|c|c|c|c|c|c|c|}
\hline $\begin{array}{l}\text { PNNL } \\
\text { Section } \\
\text { No. }\end{array}$ & Path (in.) & $\begin{array}{l}\text { Seismic Hoop } \\
\text { Force (kip/ft) } \\
\text { AP-BES-BEC }\end{array}$ & $\begin{array}{c}\text { Seismic } \\
\text { Meridanal } \\
\text { Force (kip/ft) } \\
\text { AP-BES-BEC }\end{array}$ & $\begin{array}{l}\text { Seismic -ln- } \\
\text { Plane Shear } \\
\text { Force (kip/ft) } \\
\text { AP-BES-BEC }\end{array}$ & $\begin{array}{c}\text { Seismic Hoop } \\
\text { Moment } \\
\left(\mathrm{ft}^{*} \text { kip/ft) AP- }\right. \\
\text { BES-BEC }\end{array}$ & $\begin{array}{l}\text { Seismic Meridanal } \\
\text { Moment }\left(\mathrm{ft}^{*} \mathrm{kip} / \mathrm{ft} \text { ) }\right. \\
\text { AP-BES-BEC }\end{array}$ & $\begin{array}{c}\text { Seismic } \\
\text { Through-Wall } \\
\text { Shear Force } \\
\text { (kip/ft) AP-BES } \\
\text { BEC }\end{array}$ \\
\hline 2 & 67.734 & -96.440 & -103.800 & 5.353 & -15.350 & -14.470 & 3.477 \\
\hline 3 & 105.676 & -88.430 & -101.100 & 7.498 & -12.520 & -10.690 & 2.686 \\
\hline 4 & 137.076 & -81.280 & -97.610 & 8.596 & -9.537 & 7.415 & 3.311 \\
\hline 6 & 182.856 & -73.450 & -91.730 & 9.255 & -5.238 & 5.605 & 2.666 \\
\hline 8 & 226.570 & -66.750 & -86.140 & 9.807 & -3.423 & -7.668 & 1.606 \\
\hline 9 & 275.574 & -64.820 & -80.840 & 11.780 & -3.009 & -5.030 & 1.250 \\
\hline 11 & 325.697 & -56.930 & -76.780 & 13.720 & -3.158 & -6.846 & 1.503 \\
\hline 13 & 372.312 & -54.220 & -73.110 & 15.940 & -6.309 & -7.928 & 1.026 \\
\hline 17 & 423.434 & -19.820 & -70.070 & 18.480 & -3.318 & -7.832 & 2.956 \\
\hline 20 & 468.315 & 68.280 & -66.760 & 21.530 & -11.860 & 20.960 & 10.290 \\
\hline 22 & 515.319 & 27.650 & -66.500 & 22.230 & 6.166 & 36.750 & 4.649 \\
\hline 24 & 553.722 & -6.263 & -65.470 & 20.600 & 2.479 & 13.540 & 8.250 \\
\hline 26 & 593.805 & -19.360 & 68.740 & 20.190 & $-0.25 i$ & -1.344 & $2.15 i$ \\
\hline 30 & 644.355 & -29.250 & -70.050 & 20.030 & -0.478 & -2.618 & 0.898 \\
\hline 33 & 693.605 & -33.400 & -70.790 & 20.250 & -0.106 & -0.535 & 0.310 \\
\hline 35 & 740.705 & -37.390 & -72.550 & 21.040 & 0.070 & 0.368 & 0.099 \\
\hline 38 & 786.205 & -33.060 & -74.480 & 21.730 & -0.203 & -1.100 & 0.365 \\
\hline 41 & 844.605 & -33.070 & -76.790 & 23.470 & -0.200 & -1.063 & 0.385 \\
\hline 43 & 901.355 & -15.980 & -32.500 & 11.900 & -0.287 & -1.585 & 1.237 \\
\hline 46 & 932.355 & -40.250 & -76.550 & 28.440 & -0.781 & -4.292 & 2.501 \\
\hline 48 & 1007.355 & -12.370 & -14.460 & 8.134 & -4.936 & 24.690 & 14.220 \\
\hline $5 i$ & 1053.855 & -35.450 & -17.660 & 13.060 & -1.602 & 20.540 & 14.760 \\
\hline 53 & 1086.855 & -10.000 & -11.080 & 8.448 & 2.280 & 7.062 & 3.796 \\
\hline 55 & 1105.855 & -26.420 & -9.378 & 7.597 & 3.577 & 5.514 & 0.832 \\
\hline 57 & 1147.355 & -5.582 & -6.731 & 4.422 & 0.435 & 1.458 & 1.559 \\
\hline 58 & 1207.355 & 2.624 & -2.730 & 1.997 & -0.024 & -0.160 & 0.361 \\
\hline 59 & 1267.355 & 2.340 & 2.360 & 1.257 & 0.038 & 0.165 & 0.297 \\
\hline 60 & 1327.355 & 3.044 & 2.318 & 1.060 & -0.043 & -0.230 & 0.289 \\
\hline 61 & 1387.355 & 1.962 & 2.510 & 0.875 & 0.031 & 0.081 & 0.242 \\
\hline 62 & 1449.355 & 6.335 & 5.830 & 1.007 & 0.104 & -0.200 & 0.400 \\
\hline
\end{tabular}


RPP-RPT-32239, Rev. 1

M\&D-2008-005-CALC-001, Rev. 1

Table G.3. BES-BEC Concrete Forces and Moments, Seismic Only

\section{AP- Primary Tank, Best Estimate Soil (Geomatrix), Best Estimate Concrete, $460 \mathrm{in.}$. Waste Level at $1.83 \mathrm{SpG}$}

ANSYS MAXIMUMS BY PATH

\begin{tabular}{|c|c|c|c|c|c|c|c|}
\hline $\begin{array}{l}\text { PNNL } \\
\text { Section } \\
\text { No. }\end{array}$ & Path (in.) & $\begin{array}{c}\text { Seismic Only } \\
\text { Hoop Force } \\
\text { (kip/ft) AP-BES- } \\
\text { BEC }\end{array}$ & $\begin{array}{l}\text { Seismic Only } \\
\text { Meridonal } \\
\text { Force (kip/ft) } \\
\text { AP-BES-BEC }\end{array}$ & $\begin{array}{c}\text { Seismic Only - } \\
\text { In-Plane Shear } \\
\text { Force (kip/ft) } \\
\text { AP-BES-BEC }\end{array}$ & $\begin{array}{c}\text { Seismic Only } \\
\text { Hoop Moment } \\
\text { (ft*kip/ft) AP- } \\
\text { BES-BEC }\end{array}$ & $\begin{array}{c}\text { Seismic Only } \\
\text { Meridonal Moment } \\
\text { (ft*kip/ft) AP-BES- } \\
\text { BEC }\end{array}$ & $\begin{array}{c}\text { Seismic Only } \\
\text { Through-Wall } \\
\text { Shear Force } \\
\text { (kip/ft) AP-BES } \\
\text { BEC }\end{array}$ \\
\hline 2 & 67.734 & 28.810 & 28.160 & 5.365 & 9.065 & 10.250 & 2.132 \\
\hline 3 & 105.676 & 26.430 & 27.160 & 7.538 & 7.611 & 9.112 & 1.623 \\
\hline 4 & 137.076 & 21.960 & 25.510 & 8.651 & 5.900 & 6.716 & 2.083 \\
\hline 6 & 182.856 & 21.650 & 22.640 & 9.292 & 3.215 & 4.025 & 2.489 \\
\hline 8 & 226.570 & 20.710 & 19.320 & 9.799 & 1.812 & 7.157 & 0.906 \\
\hline 9 & 275.574 & 21.860 & 16.180 & 11.746 & 1416 & 3.930 & 0.805 \\
\hline 11 & 325.697 & 22.450 & 13.930 & 13.690 & 1.138 & 2.360 & 0.737 \\
\hline 13 & 372.312 & 29.710 & 12.110 & 15.931 & 1.980 & 2.713 & 0.719 \\
\hline 17 & 423.434 & 11.282 & 11.020 & 18.487 & 1.005 & 4.676 & 0.983 \\
\hline 20 & 468.315 & 41.840 & 9.860 & 21.545 & 4.720 & 6.110 & 1.582 \\
\hline 22 & 515.319 & 12.220 & 8.450 & 22.241 & 1.639 & 7.290 & 1.502 \\
\hline 24 & 553.722 & 6.097 & 9.000 & 20.607 & 0.478 & 2.510 & 1.608 \\
\hline 26 & 593.805 & 5.040 & 10.110 & 20.194 & 0.081 & 0.408 & 0.388 \\
\hline 30 & 644.355 & 4.750 & 9.530 & 20.032 & 0.073 & 0.372 & 0.132 \\
\hline 33 & 603.605 & 5.190 & 9.110 & 20.250 & 0.040 & 0.175 & 0.058 \\
\hline 35 & 740.705 & 5.810 & 10.040 & 21.040 & 0.028 & 0.120 & 0.058 \\
\hline 38 & 786.205 & 4.960 & 11.370 & 21.730 & 0.042 & 0.207 & 0.078 \\
\hline 41 & 844.605 & 5.570 & 13.690 & 23.470 & 0.092 & 0.468 & 0.163 \\
\hline 43 & 901.355 & 2.220 & 6.420 & 11.901 & 0.102 & 0.557 & 0.617 \\
\hline 46 & 932.355 & 18.039 & 15.610 & 28.432 & 0.161 & 0.848 & 0.735 \\
\hline 48 & 1007.355 & 9.539 & 4.496 & 7.551 & 1.107 & 5.600 & 3.231 \\
\hline $5 i$ & 1053.855 & 32.038 & 5.710 & 12.672 & 0.877 & 5.260 & 3.087 \\
\hline 53 & 1086.855 & 8.802 & 4.756 & 8.043 & 0.449 & 1.190 & 0.688 \\
\hline 55 & 1105.855 & 25.990 & 4.995 & 7.421 & 1.010 & 1.244 & 0.614 \\
\hline 57 & 1147.355 & 5.478 & 4.454 & 4.300 & 0.130 & 0.367 & 0.361 \\
\hline 58 & 1207.355 & 2.431 & 2.744 & 2.017 & 0.005 & 0.034 & 0.077 \\
\hline 59 & 1267.355 & 2.012 & 2.087 & 1.254 & 0.012 & 0.034 & 0.065 \\
\hline 60 & 1327.355 & 2.564 & 2.234 & 1.066 & 0.012 & 0.036 & 0.083 \\
\hline 61 & 1387.355 & 1.495 & 2. 144 & 0.862 & 0.007 & 0.023 & 0.098 \\
\hline 62 & 1449.355 & 4.050 & 3.459 & 0.992 & 0.070 & 0.163 & 0.135 \\
\hline
\end{tabular}


RPP-RPT-32239, Rev. 1

M\&D-2008-005-CALC-001, Rev. 1

Table G.4. BES-BEC Primary Tank Stresses, Shell Top, Gravity Load Only

\begin{tabular}{|c|c|c|c|c|c|}
\hline \multirow[b]{2}{*}{$\begin{array}{c}\text { M\&D } \\
\text { Starting } \\
\text { Element } \\
\text { No. }\end{array}$} & \multirow[b]{2}{*}{ Path (in.) } & \multicolumn{4}{|c|}{ Shell Top Surface (inside - waste side) } \\
\hline & & $\begin{array}{c}\text { AP-460-BES-BEC } \\
\text { Gravity Hoop Stress } \\
\text { (lbs/in^2) Top }\end{array}$ & $\begin{array}{c}\text { AP-460-BES-BEC } \\
\text { Gravity Meridional } \\
\text { Stress (Ibs/in^2) Top }\end{array}$ & $\begin{array}{c}\text { AP-460-BES-BEC } \\
\text { Gravity Stress } \\
\text { Intensity (Ibs/in^2) } \\
\text { Top }\end{array}$ & $\begin{array}{c}\text { AP-460-BES-BEC } \\
\text { Gravity In-Plane } \\
\text { Shear Stress } \\
\text { (Ibs/in^2) Top }\end{array}$ \\
\hline 762 & 67.33 & -1272.22 & -1369.44 & 1369.44 & -3.76 \\
\hline 782 & 105.04 & -1247.22 & -1814.58 & 1814.58 & 7.28 \\
\hline 802 & 136.24 & -1081.94 & -1628.47 & 1629.17 & 8.82 \\
\hline 822 & 181.83 & -781.94 & -1445.83 & 1445.83 & 7.51 \\
\hline 842 & 225.10 & -592.08 & -1179.17 & 1179.17 & 2.95 \\
\hline 862 & 273.66 & -288.19 & -925.69 & 925.69 & 7.91 \\
\hline 882 & 323.27 & 99.31 & -737.50 & 837.50 & -6.02 \\
\hline 902 & 369.20 & 456.94 & -280.97 & 738.19 & 3.06 \\
\hline 922 & 419.20 & 1305.56 & -253.54 & 1559.72 & 0.33 \\
\hline 942 & 444.31 & 407.64 & -1658.33 & 2065.97 & 0.68 \\
\hline 962 & 458.66 & -119.79 & 1870.14 & 1988.89 & -0.65 \\
\hline 982 & 473.08 & -214.51 & 1607.64 & 1821.53 & -0.59 \\
\hline 1002 & 484.80 & 920.83 & -461.81 & 1383.33 & -0.89 \\
\hline 1022 & 502.48 & 2954.17 & -101.18 & 3055.56 & -0.94 \\
\hline 1042 & 526.48 & 4704.86 & 180.28 & 4705.56 & -0.75 \\
\hline 1062 & 550.48 & 6313.19 & 26.81 & 6315.28 & -0.50 \\
\hline 1082 & 574.60 & 7881.94 & 252.29 & 7881.94 & -0.34 \\
\hline 1102 & 598.28 & 9569.44 & -23.74 & 9590.28 & 0.21 \\
\hline 1122 & 621.38 & 11118.06 & 175.49 & 11118.06 & -0.16 \\
\hline 1142 & 644.48 & 12687.50 & 49.22 & 12687.50 & -0.16 \\
\hline 1162 & 667.63 & 13791.67 & -300.42 & 14090.28 & -0.22 \\
\hline 1182 & 690.78 & 14194.44 & 461.94 & 14194.44 & -0.22 \\
\hline 1202 & 713.88 & 15201.39 & 199.44 & 15201.39 & -0.21 \\
\hline 1222 & 736.98 & 16562.50 & -295.42 & 16854.17 & -0.25 \\
\hline 1242 & 760.13 & 16506.94 & -675.49 & 17180.56 & 0.32 \\
\hline 1262 & 782.53 & 15270.83 & 1050.69 & 15270.83 & -0.26 \\
\hline 1282 & 804.13 & 14923.61 & 365.00 & 14923.61 & 0.36 \\
\hline 1302 & 825.73 & 15770.83 & 14.14 & 15770.83 & 0.44 \\
\hline 1322 & 847.33 & 17152.78 & 395.28 & 17152.78 & -0.37 \\
\hline 1342 & 868.87 & 17493.06 & -2025.00 & 19520.83 & -0.74 \\
\hline 1362 & 892.10 & 13062.50 & -2853.47 & 15916.67 & 1.15 \\
\hline 1382 & 909.20 & 3731.94 & -8770.83 & 12513.89 & 1.25 \\
\hline 1402 & 918.38 & 3771.53 & 6309.03 & 6349.31 & -1.44 \\
\hline 1460 & 930.48 & 3376.39 & 9611.11 & 9659.72 & -493.96 \\
\hline 1442 & 949.48 & 136.11 & -624.03 & 767.36 & 60.24 \\
\hline 1462 & 990.98 & 582.08 & 900.69 & 902.78 & -25.90 \\
\hline 1482 & 1050.98 & 397.50 & 422.85 & 585.14 & -3.02 \\
\hline 1502 & 1110.98 & 419.72 & 584.24 & 585.14 & -14.28 \\
\hline 1522 & 1170.98 & 295.56 & 225.42 & 296.11 & 7.03 \\
\hline 1542 & 1230.98 & 355.49 & 440.21 & 440.69 & -8.19 \\
\hline 1562 & 1292.98 & 275.90 & 279.17 & 279.72 & -1.98 \\
\hline
\end{tabular}


RPP-RPT-32239, Rev. 1

M\&D-2008-005-CALC-001, Rev. 1

Table G.5. BES-BEC Primary Tank Stresses, Shell Middle, Gravity Load Only

\begin{tabular}{|c|c|c|c|c|c|}
\hline \multirow[b]{3}{*}{$\begin{array}{l}\text { M\&D } \\
\text { Starting } \\
\text { Element } \\
\text { No. }\end{array}$} & \multirow[b]{3}{*}{ Path (in.) } & \multicolumn{4}{|c|}{$\begin{array}{l}\text { AP Primary Tank, Best Estimate Soil, Gravity Only, Best } \\
\text { Estimate Tank Concrete, } 460 \text { in. Waste Level at } 1.83 \text { SpG }\end{array}$} \\
\hline & & \multicolumn{4}{|c|}{ Shell Mid-Plane } \\
\hline & & $\begin{array}{c}\text { AP-460-BES-BEC } \\
\text { Gravity Hoop Stress } \\
\text { (Ibs/in^2) Mid }\end{array}$ & $\begin{array}{c}\text { AP-460-BES-BEC } \\
\text { Gravity Meridional } \\
\text { Stress (lbs/in^2) Mid }\end{array}$ & $\begin{array}{c}\text { AP-460-BES-BEC } \\
\text { Gravity Stress } \\
\text { Intensity (lbs/in^2) } \\
\text { Mid }\end{array}$ & $\begin{array}{c}\text { AP-460-BES-BEC } \\
\text { Gravity In-Plane } \\
\text { Shear Stress } \\
\text { (Ibs/in^2) Mid }\end{array}$ \\
\hline 762 & 67.33 & -1313.19 & -1400.00 & 1400.00 & 3.26 \\
\hline 782 & 105.04 & -1265.28 & -1811.11 & 1811.11 & 6.90 \\
\hline 802 & 136.24 & -1102.78 & -1652.78 & 1652.78 & 8.15 \\
\hline 822 & 181.83 & -784.03 & -1423.61 & 1423.61 & 6.71 \\
\hline 842 & 225.10 & -602.99 & -1197.22 & 1197.92 & 2.62 \\
\hline 862 & 273.66 & -299.24 & -940.97 & 940.97 & 7.23 \\
\hline 882 & 323.27 & 121.60 & -653.33 & 775.69 & 5.79 \\
\hline 902 & 369.20 & 424.10 & -371.60 & 795.83 & 2.98 \\
\hline 922 & 419.20 & 1371.53 & -29.13 & 1402.08 & 0.38 \\
\hline 942 & 444.31 & 984.03 & 172.99 & 990.97 & -0.51 \\
\hline 962 & 458.66 & -609.31 & 174.79 & 784.72 & -0.51 \\
\hline 982 & 473.08 & -659.93 & 148.19 & 810.42 & -0.50 \\
\hline 1002 & 484.80 & 1097.22 & 137.36 & 1098.61 & -0.78 \\
\hline 1022 & 502.48 & 3023.61 & 132.57 & 3024.31 & -0.83 \\
\hline 1042 & 526.48 & 4688.89 & 126.04 & 4688.89 & -0.68 \\
\hline 1062 & 550.48 & 6340.97 & 119.38 & 6340.97 & -0.47 \\
\hline 1082 & 574.60 & 7840.28 & 112.64 & 7840.28 & -0.32 \\
\hline 1102 & 598.28 & 9604.17 & 105.90 & 9604.17 & 0.21 \\
\hline 1122 & 621.38 & 11097.22 & 99.38 & 11097.22 & -0.16 \\
\hline 1142 & 644.48 & 12701.39 & 92.78 & 12701.39 & -0.14 \\
\hline 1162 & 667.63 & 13909.72 & 86.25 & 13909.72 & -0.19 \\
\hline 1182 & 690.78 & 14076.39 & 69.35 & 14076.39 & -0.19 \\
\hline 1202 & 713.88 & 15159.72 & 62.78 & 15159.72 & -0.20 \\
\hline 1222 & 736.98 & 16666.67 & 56.18 & 16666.67 & -0.24 \\
\hline 1242 & 760.13 & 16722.22 & 49.59 & 16722.22 & -0.29 \\
\hline 1262 & 782.53 & 14965.28 & 30.62 & 14965.28 & -0.24 \\
\hline 1282 & 804.13 & 14819.44 & 24.51 & 14826.39 & 0.34 \\
\hline 1302 & 825.73 & 15770.83 & 18.46 & 15770.83 & 0.42 \\
\hline 1322 & 847.33 & 17041.67 & 12.38 & 17041.67 & -0.38 \\
\hline 1342 & 868.87 & 18104.17 & 6.32 & 18131.94 & -0.59 \\
\hline 1362 & 892.10 & 13916.67 & -1.40 & 13937.50 & 0.88 \\
\hline 1382 & 909.20 & 6245.14 & -10.08 & 6400.00 & 0.97 \\
\hline 1402 & 918.38 & 1611.81 & 151.18 & 1899.31 & -0.94 \\
\hline 1460 & 930.48 & 441.67 & 394.31 & 576.25 & 4.22 \\
\hline 1442 & 949.48 & 453.47 & 429.03 & 454.38 & 2.22 \\
\hline 1462 & 990.98 & 522.78 & 718.75 & 720.14 & -16.15 \\
\hline 1482 & 1050.98 & 437.64 & 558.40 & 445.14 & -10.64 \\
\hline 1502 & 1110.98 & 376.88 & 444.65 & 445.14 & -6.64 \\
\hline 1522 & 1170.98 & 333.96 & 354.72 & 354.93 & -3.07 \\
\hline 1542 & 1230.98 & 318.68 & 330.07 & 330.28 & -2.39 \\
\hline 1562 & 1292.98 & 293.40 & 353.47 & 354.24 & -6.27 \\
\hline & & $\frac{\text { Vote 1: }}{\text { Floor) }}$ & id Shear & Reversec & ed Sections \\
\hline
\end{tabular}


RPP-RPT-32239, Rev. 1

M\&D-2008-005-CALC-001, Rev. 1

Table G.6. BES-BEC Primary Tank Stresses, Shell Bottom, Gravity Load Only

\begin{tabular}{|c|c|c|c|c|c|}
\hline \multirow[b]{3}{*}{$\begin{array}{c}\text { M\&D } \\
\text { Starting } \\
\text { Element } \\
\text { No. }\end{array}$} & \multirow[b]{3}{*}{ Path (in.) } & \multicolumn{4}{|c|}{$\begin{array}{l}\text { AP Primary Tank, Best Estimate Soil, Gravity Only, Best } \\
\text { Estimate Tank Concrete, } 460 \text { in. Waste Level at } 1.83 \text { SpG }\end{array}$} \\
\hline & & \multicolumn{4}{|c|}{ Shell Bottom Surface (outside - away from waste) } \\
\hline & & $\begin{array}{c}\text { AP-460-BES-BEC } \\
\text { Gravity Hoop Stress } \\
\text { (Ibs/in^2) Bot }\end{array}$ & $\begin{array}{c}\text { AP-460-BES-BEC } \\
\text { Gravity Meridional } \\
\text { Stress (Ibs/in^2) Bot }\end{array}$ & $\begin{array}{c}\text { AP-460-BES-BEC } \\
\text { Gravity Stress } \\
\text { Intensity (lbs/in^2) } \\
\text { Bot }\end{array}$ & $\begin{array}{c}\text { AP-460-BES-BEC } \\
\text { Gravity In-Plane } \\
\text { Shear Stress } \\
\text { (Ibs/in^2) Bot }\end{array}$ \\
\hline 762 & 67.33 & -1359.72 & -1431.94 & 1431.94 & 3.56 \\
\hline 782 & 105.04 & -1283.33 & -1807.64 & 1807.64 & -6.60 \\
\hline 802 & 136.24 & -1124.31 & -1677.08 & 1677.08 & 7.62 \\
\hline 822 & 181.83 & -786.81 & -1400.69 & 1400.69 & -6.08 \\
\hline 842 & 225.10 & -613.89 & -1215.97 & 1215.97 & 2.29 \\
\hline 862 & 273.66 & -310.35 & -956.94 & 956.94 & 6.55 \\
\hline 882 & 323.27 & 143.96 & -568.96 & 713.19 & 5.57 \\
\hline 902 & 369.20 & 391.25 & -462.15 & 853.47 & 2.91 \\
\hline 922 & 419.20 & 1436.81 & 196.39 & 1436.81 & 0.43 \\
\hline 942 & 444.31 & 1559.72 & 2004.17 & 2005.56 & -0.34 \\
\hline 962 & 458.66 & -1098.61 & -1520.83 & 1520.83 & -0.37 \\
\hline 982 & 473.08 & -1105.56 & -1311.11 & 1311.81 & -0.42 \\
\hline 1002 & 484.80 & 1273.61 & 735.42 & 1273.61 & -0.67 \\
\hline 1022 & 502.48 & 3093.75 & 366.11 & 3093.75 & -0.71 \\
\hline 1042 & 526.48 & 4672.92 & 72.15 & 4673.61 & -0.61 \\
\hline 1062 & 550.48 & 6368.75 & 212.15 & 6369.44 & -0.45 \\
\hline 1082 & 574.60 & 7798.61 & -28.39 & 7826.39 & -0.31 \\
\hline 1102 & 598.28 & 9645.83 & 234.44 & 9645.83 & 0.21 \\
\hline 1122 & 621.38 & 11076.39 & 23.42 & 11076.39 & -0.15 \\
\hline 1142 & 644.48 & 12715.28 & 136.60 & 12715.28 & -0.13 \\
\hline 1162 & 667.63 & 14020.83 & 471.81 & 14020.83 & -0.16 \\
\hline 1182 & 690.78 & 13958.33 & -324.31 & 14284.72 & -0.17 \\
\hline 1202 & 713.88 & 15118.06 & -74.93 & 15194.44 & -0.21 \\
\hline 1222 & 736.98 & 16770.83 & 407.15 & 16770.83 & -0.24 \\
\hline 1242 & 760.13 & 16937.50 & 775.00 & 16937.50 & -0.28 \\
\hline 1262 & 782.53 & 14659.72 & -990.28 & 15645.83 & -0.23 \\
\hline 1282 & 804.13 & 14722.22 & -316.88 & 15034.72 & 0.33 \\
\hline 1302 & 825.73 & 15770.83 & 23.08 & 15777.78 & 0.40 \\
\hline 1322 & 847.33 & 16923.61 & -371.32 & 17298.61 & -0.38 \\
\hline 1342 & 868.87 & 18715.28 & 2039.58 & 18715.28 & 0.47 \\
\hline 1362 & 892.10 & 14770.83 & 2853.47 & 14770.83 & 0.63 \\
\hline 1382 & 909.20 & 8756.94 & 8756.94 & 8763.89 & 0.70 \\
\hline 1402 & 918.38 & -551.04 & -6007.64 & 6049.31 & -0.53 \\
\hline 1460 & 930.48 & -2497.92 & -8819.44 & 8868.06 & 501.32 \\
\hline 1442 & 949.48 & 771.53 & 1480.56 & 1485.42 & -56.49 \\
\hline 1462 & 990.98 & 463.89 & 538.13 & 538.61 & -6.46 \\
\hline 1482 & 1050.98 & 478.19 & 695.83 & 334.65 & -18.30 \\
\hline 1502 & 1110.98 & 334.44 & 307.08 & 334.65 & 3.46 \\
\hline 1522 & 1170.98 & 372.85 & 486.11 & 486.74 & -10.38 \\
\hline 1542 & 1230.98 & 282.57 & 222.50 & 283.06 & 6.41 \\
\hline 1562 & 1292.98 & 312.08 & 430.49 & 431.32 & -11.42 \\
\hline \multicolumn{6}{|c|}{$\frac{\text { Note 1: }}{\text { (Floor) }}$ Meridonal, Hoop, and Shear Stresses are Reversed in Highlighted Sections } \\
\hline
\end{tabular}


RPP-RPT-32239, Rev. 1

M\&D-2008-005-CALC-001, Rev. 1

Table G.7. BES-BEC Primary Tank Stresses, Shell Top, Gravity Plus Seismic Load

\begin{tabular}{|c|c|c|c|c|c|}
\hline \multirow[b]{3}{*}{$\begin{array}{c}\text { M\&D } \\
\text { Starting } \\
\text { M\&D } \\
\text { Element } \\
\text { No. }\end{array}$} & \multirow[b]{3}{*}{ Path (in.) } & \multicolumn{4}{|c|}{$\begin{array}{l}\text { AP Primary Tank, Best Estimate Soil, Horizontal and Vertical } \\
\text { Seismic, Best Estimate Tank Concrete, } 460 \text { in. Waste Level at } \\
1.83 \mathrm{SpG}\end{array}$} \\
\hline & & \multicolumn{4}{|c|}{ Shell Top Surface (inside - waste side) } \\
\hline & & $\begin{array}{l}\text { AP-460-BES-BEC } \\
\text { Seismic Hoop Stress } \\
\text { (Ibs/in^2) Top }\end{array}$ & $\begin{array}{l}\text { AP-460-BES-BEC } \\
\text { Seismic Meridional } \\
\text { Stress (Ibs/in^2) Top }\end{array}$ & $\begin{array}{l}\text { AP-460-BES-BEC } \\
\text { Seismic Stress } \\
\text { Intensity (lbs/in^2) } \\
\text { Top }\end{array}$ & $\begin{array}{l}\text { AP-460-BES-BEC } \\
\text { Seismic In-PIane } \\
\text { Shear Stress } \\
\text { (lbs/in^2) Top }\end{array}$ \\
\hline 762 & 67.33 & -1979.86 & -2286.11 & 2287.50 & -276.60 \\
\hline 782 & 105.04 & -2059.72 & -2946.53 & 2946.53 & -499.58 \\
\hline 802 & 136.24 & -2120.83 & -2656.25 & 2657.64 & -549.72 \\
\hline 822 & 181.83 & -1608.33 & -2292.36 & 2292.36 & -617.15 \\
\hline 842 & 225.10 & -1761.81 & -2152.78 & 2747.22 & -745.14 \\
\hline 862 & 273.66 & -1178.47 & -1757.64 & 2112.50 & -914.58 \\
\hline 882 & 323.27 & 1866.67 & -1627.78 & 3393.75 & -1321.53 \\
\hline 902 & 369.20 & 2257.64 & -1345.83 & 3791.67 & -1785.42 \\
\hline 922 & 419.20 & 3761.11 & -1186.11 & 5418.06 & -2539.58 \\
\hline 942 & 444.31 & 5225.69 & -4339.58 & 5232.64 & -2271.53 \\
\hline 962 & 458.66 & 6493.06 & 6580.56 & 12451.39 & -2289.58 \\
\hline 982 & 473.08 & 6569.44 & 7180.56 & 13631.94 & -2521.53 \\
\hline 1002 & 484.80 & 4723.61 & -1836.11 & 5711.11 & -2677.78 \\
\hline 1022 & 502.48 & 5224.31 & -819.44 & 6156.25 & -2623.61 \\
\hline 1042 & 526.48 & 8944.44 & 1163.89 & 8944.44 & -2407.64 \\
\hline 1062 & 550.48 & 11375.00 & -1191.67 & 11381.94 & -2152.08 \\
\hline 1082 & 574.60 & 13798.61 & 1548.61 & 13798.61 & -1859.72 \\
\hline 1102 & 598.28 & 16368.06 & -1318.06 & 16368.06 & -1518.75 \\
\hline 1122 & 621.38 & 18750.00 & 1605.56 & 18750.00 & -1142.36 \\
\hline 1142 & 644.48 & 21104.17 & 1454.86 & 21104.17 & -909.03 \\
\hline 1162 & 667.63 & 22680.56 & -1637.50 & 22680.56 & -853.47 \\
\hline 1182 & 690.78 & 23083.33 & 1930.56 & 23083.33 & 702.78 \\
\hline 1202 & 713.88 & 24236.11 & 1502.08 & 24236.11 & 896.53 \\
\hline 1222 & 736.98 & 25840.28 & -1423.61 & 25840.28 & 1195.83 \\
\hline 1242 & 760.13 & 25326.39 & -862.50 & 25770.83 & 1583.33 \\
\hline 1262 & 782.53 & 23055.56 & 2210.42 & 23055.56 & 1463.89 \\
\hline 1282 & 804.13 & 22118.06 & 1170.14 & 22118.06 & 1752.08 \\
\hline 1302 & 825.73 & 22965.28 & 664.93 & 22965.28 & 2045.14 \\
\hline 1322 & 847.33 & 24611.11 & 1084.72 & 24611.11 & 2352.08 \\
\hline 1342 & 868.87 & 24763.89 & -2556.25 & 27513.89 & 2691.67 \\
\hline 1362 & 892.10 & 17465.28 & -3325.00 & 22333.33 & 2596.53 \\
\hline 1382 & 909.20 & 5411.11 & -10069.44 & 17222.22 & 2559.03 \\
\hline 1402 & 918.38 & 5891.67 & 10694.44 & 10736.11 & 2522.92 \\
\hline 1460 & 930.48 & 6323.61 & 15131.94 & 15208.33 & -2936.11 \\
\hline 1442 & 949.48 & 4151.39 & -1133.33 & 4781.94 & -2173.61 \\
\hline 1462 & 990.98 & 3684.72 & 1426.39 & 6450.69 & -3222.92 \\
\hline 1482 & 1050.98 & 2707.64 & 713.19 & 2450.69 & -2015.28 \\
\hline 1502 & 1110.98 & 2077.08 & 844.44 & 2450.69 & -1225.00 \\
\hline 1522 & 1170.98 & 1522.22 & 401.74 & 1523.61 & -743.06 \\
\hline 1542 & 1230.98 & 1140.28 & 632.64 & 1140.97 & -455.35 \\
\hline 1562 & 1292.98 & 757.64 & 474.58 & 757.64 & -226.11 \\
\hline & & \multicolumn{4}{|c|}{$\frac{\text { Note 1: }}{\text { (Floor) }}$ Meridonal, Hoop, and Shear Stresses are Reversed in Highlighted Sections } \\
\hline
\end{tabular}


RPP-RPT-32239, Rev. 1

M\&D-2008-005-CALC-001, Rev. 1

Table G.8. BES-BEC Primary Tank Stresses, Shell Middle, Gravity Plus Seismic Load

\begin{tabular}{|c|c|c|c|c|c|}
\hline \multirow[b]{3}{*}{$\begin{array}{c}\text { M\&D } \\
\text { Starting } \\
\text { M\&D } \\
\text { Element } \\
\text { No. }\end{array}$} & \multirow[b]{3}{*}{ Path (in.) } & \multicolumn{4}{|c|}{$\begin{array}{c}\text { AP Primary Tank, Best Estimate Soil, Horizontal and Vertical } \\
\text { Seismic, Best Estimate Tank Concrete, } 460 \text { in. Waste Level at } \\
1.83 \mathrm{SpG}\end{array}$} \\
\hline & & \multicolumn{4}{|c|}{ Shell Mid-Plane } \\
\hline & & $\begin{array}{l}\text { AP-460-BES-BEC } \\
\text { Seismic Hoop Stress } \\
\text { (Ibs/in^2) Mid }\end{array}$ & $\begin{array}{c}\text { AP-460-BES-BEC } \\
\text { Seismic Meridional } \\
\text { Stress (Ibs/in^2) Mid }\end{array}$ & $\begin{array}{l}\text { AP-460-BES-BEC } \\
\text { Seismic Stress } \\
\text { Intensity (lbs/in^2) } \\
\text { Mid }\end{array}$ & $\begin{array}{l}\text { AP-460-BES-BEC } \\
\text { Seismic In-Plane } \\
\text { Shear Stress } \\
\text { (lbs/in^2) Mid }\end{array}$ \\
\hline 762 & 67.33 & -2085.42 & -2069.44 & 2095.14 & -271.04 \\
\hline 782 & 105.04 & -2028.47 & -2654.86 & 2655.56 & -490.49 \\
\hline 802 & 136.24 & -2281.94 & -2408.33 & 2409.03 & -540.90 \\
\hline 822 & 181.83 & -1550.69 & -2100.69 & 2100.69 & -612.15 \\
\hline 842 & 225.10 & -1982.64 & -1824.31 & 2285.42 & -740.97 \\
\hline 862 & 273.66 & -1143.75 & -1552.08 & 2127.08 & -913.19 \\
\hline 882 & 323.27 & 2056.25 & -1418.75 & 2931.94 & -1320.14 \\
\hline 902 & 369.20 & 2238.89 & -1328.47 & 3804.17 & -1784.03 \\
\hline 922 & 419.20 & 3894.44 & -1259.72 & 5403.47 & -2540.97 \\
\hline 942 & 444.31 & 4600.69 & 1131.25 & 5440.97 & -2315.28 \\
\hline 962 & 458.66 & -7618.06 & 1075.00 & 8708.33 & -2336.11 \\
\hline 982 & 473.08 & -8333.33 & 980.56 & 9326.39 & -2479.86 \\
\hline 1002 & 484.80 & 4602.78 & 933.33 & 5551.39 & -2607.64 \\
\hline 1022 & 502.48 & 5626.39 & 1018.75 & 5854.17 & -2589.58 \\
\hline 1042 & 526.48 & 8916.67 & 1140.97 & 8916.67 & -2402.08 \\
\hline 1062 & 550.48 & 11402.78 & 1248.61 & 11402.78 & -2147.22 \\
\hline 1082 & 574.60 & 13715.28 & 1354.17 & 13715.28 & -1852.08 \\
\hline 1102 & 598.28 & 16402.78 & 1440.28 & 16402.78 & -1512.50 \\
\hline 1122 & 621.38 & 18680.56 & 1508.33 & 18680.56 & -1138.19 \\
\hline 1142 & 644.48 & 21076.39 & 1552.78 & 21076.39 & -890.97 \\
\hline 1162 & 667.63 & 22798.61 & 1571.53 & 22798.61 & -840.97 \\
\hline 1182 & 690.78 & 22833.33 & 1372.92 & 22833.33 & 700.00 \\
\hline 1202 & 713.88 & 24097.22 & 1341.67 & 24097.22 & 895.83 \\
\hline 1222 & 736.98 & 25895.83 & 1286.11 & 25895.83 & 1195.14 \\
\hline 1242 & 760.13 & 25562.50 & -1216.67 & 25562.50 & 1574.31 \\
\hline 1262 & 782.53 & 22493.06 & -835.42 & 22493.06 & 1452.78 \\
\hline 1282 & 804.13 & 21854.17 & -767.36 & 21861.11 & 1751.39 \\
\hline 1302 & 825.73 & 22895.83 & -684.86 & 22895.83 & 2047.92 \\
\hline 1322 & 847.33 & 24381.94 & -590.63 & 24388.89 & 2356.94 \\
\hline 1342 & 868.87 & 25611.11 & -482.15 & 25618.06 & 2679.86 \\
\hline 1362 & 892.10 & 18909.72 & 351.81 & 18944.44 & 2519.44 \\
\hline 1382 & 909.20 & 8048.61 & 348.96 & 8534.72 & 2404.17 \\
\hline 1402 & 918.38 & 5303.47 & 417.01 & 5787.50 & 2390.97 \\
\hline 1460 & 930.48 & 4448.61 & 774.31 & 4832.64 & -2371.53 \\
\hline 1442 & 949.48 & 4219.44 & 786.81 & 4605.56 & -2246.53 \\
\hline 1462 & 990.98 & 3648.61 & 1203.47 & 6438.19 & -3213.89 \\
\hline 1482 & 1050.98 & 2721.53 & 870.14 & 2451.39 & -2023.61 \\
\hline 1502 & 1110.98 & 2056.25 & 676.25 & 2451.39 & -1218.06 \\
\hline 1522 & 1170.98 & 1531.94 & 545.14 & 1533.33 & -750.00 \\
\hline 1542 & 1230.98 & 1127.08 & 493.89 & 1128.47 & -449.58 \\
\hline 1562 & 1292.98 & 751.39 & 500.14 & 751.39 & -230.83 \\
\hline \multicolumn{6}{|c|}{ Note 1: Meridonal, Hoop, and Shear Stresses are Reversed in Highlighted Sections } \\
\hline
\end{tabular}


RPP-RPT-32239, Rev. 1

M\&D-2008-005-CALC-001, Rev. 1

Table G.9. BES-BEC Primary Tank Stresses, Shell Bottom, Gravity Plus Seismic Load

\begin{tabular}{|c|c|c|c|c|c|}
\hline \multirow[b]{3}{*}{$\begin{array}{c}\text { M\&D } \\
\text { Starting } \\
\text { M\&D } \\
\text { Element } \\
\text { No. }\end{array}$} & \multirow[b]{3}{*}{ Path (in.) } & \multicolumn{4}{|c|}{$\begin{array}{c}\text { AP Primary Tank, Best Estimate Soil, Horizontal and Vertical } \\
\text { Seismic, Best Estimate Tank Concrete, } 460 \text { in. Waste Level at } \\
1.83 \mathrm{SpG}\end{array}$} \\
\hline & & \multicolumn{4}{|c|}{ Shell Bottom Surface (outside - away from waste) } \\
\hline & & $\begin{array}{l}\text { AP-460-BES-BEC } \\
\text { Seismic Hoop Stress } \\
\text { (Ibs/in^2) Bot }\end{array}$ & $\begin{array}{l}\text { AP-460-BES-BEC } \\
\text { Seismic Meridional } \\
\text { Stress (Ibs/in^2) Bot }\end{array}$ & $\begin{array}{l}\text { AP-460-BES-BEC } \\
\text { Seismic Stress } \\
\text { Intensity (lbs/in^2) } \\
\text { Bot }\end{array}$ & $\begin{array}{l}\text { AP-460-BES-BEC } \\
\text { Seismic In-Plane } \\
\text { Shear Stress } \\
\text { (Ibs/in^2) Bot }\end{array}$ \\
\hline 762 & 67.33 & -2242.36 & -2348.61 & 2348.61 & -265.49 \\
\hline 782 & 105.04 & -2067.36 & -2923.61 & 2927.08 & -481.32 \\
\hline 802 & 136.24 & -2443.06 & -2779.17 & 2779.86 & -532.01 \\
\hline 822 & 181.83 & -1493.06 & -2168.75 & 2169.44 & -607.15 \\
\hline 842 & 225.10 & -2203.47 & -2487.50 & 2488.89 & -739.58 \\
\hline 862 & 273.66 & -1109.03 & -1672.92 & 2154.86 & -911.81 \\
\hline 882 & 323.27 & 2245.83 & -1950.00 & 2878.47 & -1318.06 \\
\hline 902 & 369.20 & 2220.83 & -1359.03 & 3818.75 & -1782.64 \\
\hline 922 & 419.20 & 4028.47 & 2017.36 & 5388.89 & -2542.36 \\
\hline 942 & 444.31 & 4000.00 & 6545.83 & 7229.17 & -2359.03 \\
\hline 962 & 458.66 & -9145.83 & -4723.61 & 9145.83 & -2383.33 \\
\hline 982 & 473.08 & -10229.17 & -5237.50 & 10236.11 & -2438.89 \\
\hline 1002 & 484.80 & 4482.64 & 2787.50 & 5598.61 & -2537.50 \\
\hline 1022 & 502.48 & 6027.78 & 2822.92 & 6029.86 & -2555.56 \\
\hline 1042 & 526.48 & 8895.83 & 1125.69 & 8895.83 & -2396.53 \\
\hline 1062 & 550.48 & 11423.61 & 1369.44 & 11423.61 & -2142.36 \\
\hline 1082 & 574.60 & 13631.94 & -1311.11 & 13631.94 & -1845.14 \\
\hline 1102 & 598.28 & 16430.56 & 1656.94 & 16430.56 & -1506.25 \\
\hline 1122 & 621.38 & 18611.11 & -1496.53 & 18611.11 & -1133.33 \\
\hline 1142 & 644.48 & 21048.61 & 1650.69 & 21048.61 & -872.22 \\
\hline 1162 & 667.63 & 22916.67 & 2145.14 & 22916.67 & -829.17 \\
\hline 1182 & 690.78 & 22638.89 & -1495.14 & 22638.89 & 697.92 \\
\hline 1202 & 713.88 & 24055.56 & -1422.92 & 24055.56 & 895.83 \\
\hline 1222 & 736.98 & 26090.28 & 1824.31 & 26097.22 & 1195.14 \\
\hline 1242 & 760.13 & 25958.33 & 2193.75 & 25958.33 & 1565.28 \\
\hline 1262 & 782.53 & 22131.94 & -1551.39 & 23076.39 & 1440.97 \\
\hline 1282 & 804.13 & 21777.78 & -1006.94 & 21819.44 & 1750.69 \\
\hline 1302 & 825.73 & 22937.50 & -660.56 & 22944.44 & 2050.69 \\
\hline 1322 & 847.33 & 24180.56 & -817.36 & 24500.00 & 2362.50 \\
\hline 1342 & 868.87 & 26451.39 & 3852.08 & 26451.39 & 2668.75 \\
\hline 1362 & 892.10 & 20361.11 & 4879.86 & 20361.11 & 2443.06 \\
\hline $\begin{array}{l}1302 \\
1382\end{array}$ & 909.20 & 11388.89 & 13993.06 & 14000.00 & 2249.31 \\
\hline $\begin{array}{l}1002 \\
1402\end{array}$ & 918.38 & -5659.03 & -10000.00 & 10076.39 & 2264.58 \\
\hline 1460 & 930.48 & -7770.83 & -14055.56 & 14138.89 & 2375.00 \\
\hline 1442 & 949.48 & 4288.19 & 2384.72 & 5330.56 & -2318.75 \\
\hline 1462 & 990.98 & 3612.50 & 979.86 & 6427.78 & -3204.86 \\
\hline 1482 & 1050.98 & 2735.42 & 1036.11 & 2455.56 & -2031.94 \\
\hline 1502 & 1110.98 & 2034.72 & 520.28 & 2455.56 & -1211.11 \\
\hline 1522 & 1170.98 & 1547.92 & 706.25 & 1549.31 & -756.94 \\
\hline 1542 & 1230.98 & 1114.58 & 398.82 & 1115.97 & -443.82 \\
\hline 1562 & 1292.98 & 748.61 & 599.93 & 750.69 & -235.63 \\
\hline & & \multicolumn{4}{|c|}{$\frac{\text { Note 1: }}{\text { (Floor) }}$ Meridonal, Hoop, and Shear Stresses are Reversed in Highlighted Sections } \\
\hline
\end{tabular}


RPP-RPT-32239, Rev. 1

M\&D-2008-005-CALC-001, Rev. 1

Table G.10. BES-BEC Primary Tank Stresses, Shell Top, Seismic Load Only

\begin{tabular}{|c|c|c|c|c|c|}
\hline \multirow[b]{3}{*}{$\begin{array}{c}\text { M\&D } \\
\text { Starting } \\
\text { M\&D } \\
\text { Element } \\
\text { No. }\end{array}$} & \multirow[b]{3}{*}{ Path (in.) } & \multicolumn{4}{|c|}{$\begin{array}{c}\text { AP Primary Tank, Best Estimate Soil, Horizontal and Vertical } \\
\text { Seismic, Best Estimate Tank Concrete, } 460 \text { in. Waste Level at } \\
1.83 \mathrm{SpG}\end{array}$} \\
\hline & & \multicolumn{4}{|c|}{ Shell Top Surface (inside - waste side) } \\
\hline & & $\begin{array}{l}\text { AP-460-BES-BEC } \\
\text { Seismic Only Hoop } \\
\text { Stress (lbs/in^2) Top }\end{array}$ & $\begin{array}{l}\text { AP-460-BES-BEC } \\
\text { Seismic Only } \\
\text { Meridional Stress } \\
\text { (Ibs/in^2) Top }\end{array}$ & $\begin{array}{l}\text { AP-460-BES-BEC } \\
\text { Seismic Only Stress } \\
\text { Intensity (lbs/in^2) } \\
\text { Top }\end{array}$ & $\begin{array}{l}\text { AP-460-BES-BEC } \\
\text { Seismic Only In- } \\
\text { Plane Shear Stress } \\
\text { (Ibs/in^2) Top }\end{array}$ \\
\hline 762 & 67.33 & 769.58 & 918.06 & 919.44 & 276.51 \\
\hline 782 & 105.04 & 903.33 & 1283.82 & 1274.38 & 501.68 \\
\hline 802 & 136.24 & 1107.65 & 1029.17 & 1031.94 & 549.07 \\
\hline 822 & 181.83 & 842.66 & 981.67 & 980.14 & 618.25 \\
\hline 842 & 225.10 & 1335.28 & 974.31 & 1568.06 & 746.01 \\
\hline 862 & 273.66 & 1023.68 & 985.58 & 1193.75 & 912.99 \\
\hline 882 & 323.27 & 1767.36 & 890.28 & 2556.25 & 1322.78 \\
\hline 902 & 369.20 & 1893.47 & 1288.19 & 3059.72 & 1784.81 \\
\hline 922 & 419.20 & 2477.78 & 932.78 & 3861.81 & 2539.52 \\
\hline 942 & 444.31 & 4818.06 & 2999.31 & 3166.67 & 2271.28 \\
\hline 962 & 458.66 & 6610.69 & 4711.81 & 10464.58 & 2289.47 \\
\hline 982 & 473.08 & 6781.67 & 6039.58 & 11813.19 & 2521.58 \\
\hline 1002 & 484.80 & 3806.25 & 1375.35 & 4330.56 & 2677.91 \\
\hline 1022 & 502.48 & 2480.56 & 749.93 & 3100.69 & 2623.75 \\
\hline 1042 & 526.48 & 5180.97 & 1092.99 & 4239.58 & 2407.74 \\
\hline 1062 & 550.48 & 6196.81 & 1218.35 & 5066.67 & 2152.16 \\
\hline 1082 & 574.60 & 7243.19 & 1430.56 & 6039.58 & 1859.68 \\
\hline 1102 & 598.28 & 8335.42 & 1295.53 & 7031.94 & 1518.78 \\
\hline 1122 & 621.38 & 9247.92 & 1511.53 & 7931.94 & 1142.36 \\
\hline 1142 & 644.48 & 9952.78 & 1464.37 & 8545.83 & 909.01 \\
\hline 1162 & 667.63 & 10189.58 & 1338.13 & 8903.47 & 853.44 \\
\hline 1182 & 690.78 & 9801.39 & 1613.61 & 8888.89 & 702.82 \\
\hline 1202 & 713.88 & 9752.78 & 1397.22 & 9041.67 & 896.61 \\
\hline 1222 & 736.98 & 9873.61 & 1128.75 & 8986.11 & 1195.80 \\
\hline 1242 & 760.13 & 9236.11 & 938.89 & 8590.28 & 1583.42 \\
\hline 1262 & 782.53 & 7930.56 & 1348.40 & 7784.72 & 1463.96 \\
\hline 1282 & 804.13 & 7194.44 & 942.08 & 7194.44 & 1752.16 \\
\hline 1302 & 825.73 & 7194.44 & 723.12 & 7194.44 & 2045.25 \\
\hline 1322 & 847.33 & 7458.33 & 853.75 & 7458.33 & 2352.08 \\
\hline 1342 & 868.87 & 7270.83 & 1231.94 & 7993.06 & 2691.21 \\
\hline 1362 & 892.10 & 4402.78 & 2378.47 & 6416.67 & 2596.55 \\
\hline 1382 & 909.20 & 1997.22 & 6050.69 & 5125.00 & 2559.04 \\
\hline 1402 & 918.38 & 2340.97 & 5061.11 & 4389.58 & 2522.93 \\
\hline 1422 & 930.48 & 2948.61 & 5965.97 & 5562.50 & 2442.92 \\
\hline 1442 & 949.48 & 4016.67 & 616.48 & 4016.67 & 2233.34 \\
\hline 1462 & 990.98 & 3102.99 & 916.10 & 5548.61 & 3197.68 \\
\hline 1482 & 1050.98 & 2310.42 & 442.28 & 1867.36 & 2013.24 \\
\hline 1502 & 1110.98 & 1690.56 & 315.07 & 1867.36 & 1212.04 \\
\hline 1522 & 1170.98 & 1235.97 & 247.71 & 1227.50 & 748.61 \\
\hline 1542 & 1230.98 & 806.25 & 206.67 & 705.90 & 448.70 \\
\hline 1562 & 1292.98 & 481.74 & 251.02 & 481.39 & 226.24 \\
\hline & & \multicolumn{4}{|c|}{$\frac{\text { Note 1: Meridonal, Hoop, and Shear Stresses are Reversed in Highlighted Sections }}{\text { (Floor) }}$} \\
\hline
\end{tabular}


RPP-RPT-32239, Rev. 1

M\&D-2008-005-CALC-001, Rev. 1

Table G.11. BES-BEC Primary Tank Stresses, Shell Middle, Seismic Load Only

\begin{tabular}{|c|c|c|c|c|c|}
\hline \multirow[b]{3}{*}{$\begin{array}{c}\text { M\&D } \\
\text { Starting } \\
\text { M\&D } \\
\text { Element } \\
\text { No. }\end{array}$} & \multirow[b]{3}{*}{ Path (in.) } & \multicolumn{4}{|c|}{$\begin{array}{l}\text { AP Primary Tank, Best Estimate Soil, Horizontal and Vertical } \\
\text { Seismic, Best Estimate Tank Concrete, } 460 \text { in. Waste Level at } \\
1.83 \mathrm{SpG}\end{array}$} \\
\hline & & \multicolumn{4}{|c|}{ Shell Mid-Plane } \\
\hline & & $\begin{array}{l}\text { AP-460-BES-BEC } \\
\text { Seismic Only Hoop } \\
\text { Stress (Ibs/in^2) Mid }\end{array}$ & $\begin{array}{l}\text { AP-460-BES-BEC } \\
\text { Seismic Only } \\
\text { Meridional Stress } \\
\text { (lbs/in^2) Mid }\end{array}$ & $\begin{array}{l}\text { AP-460-BES-BEC } \\
\text { Seismic Only Stress } \\
\text { Intensity (lbs/in^2) } \\
\text { Mid }\end{array}$ & $\begin{array}{l}\text { AP-460-BES-BEC } \\
\text { Seismic Only In- } \\
\text { Plane Shear Stress } \\
\text { (Ibs/in^2) Mid }\end{array}$ \\
\hline 762 & 67.33 & 887.92 & 669.44 & 700.00 & 271.49 \\
\hline 782 & 105.04 & 807.99 & 898.61 & 897.22 & 492.31 \\
\hline 802 & 136.24 & 1242.29 & 846.53 & 845.14 & 540.51 \\
\hline 822 & 181.83 & 787.73 & 765.49 & 764.17 & 613.13 \\
\hline 842 & 225.10 & 1560.76 & 688.96 & 1087.50 & 741.71 \\
\hline 862 & 273.66 & 944.65 & 705.14 & 1200.69 & 911.66 \\
\hline 882 & 323.27 & 1934.65 & 820.35 & 2158.33 & 1321.34 \\
\hline 902 & 369.20 & 1881.46 & 983.82 & 3014.58 & 1783.42 \\
\hline 922 & 419.20 & 2522.92 & 1230.81 & 4004.86 & 2540.92 \\
\hline 942 & 444.31 & 3616.67 & 1033.13 & 4450.69 & 2315.09 \\
\hline 962 & 458.66 & 7525.14 & 973.82 & 7925.00 & 2336.03 \\
\hline 982 & 473.08 & 8331.25 & 908.33 & 8518.06 & 2479.90 \\
\hline 1002 & 484.80 & 3509.03 & 878.82 & 4453.47 & 2607.75 \\
\hline 1022 & 502.48 & 2957.85 & 979.58 & 2830.56 & 2589.71 \\
\hline 1042 & 526.48 & 5196.25 & 1121.74 & 4227.78 & 2402.19 \\
\hline 1062 & 550.48 & 6214.86 & 1246.39 & 5061.81 & 2147.31 \\
\hline 1082 & 574.60 & 7233.61 & 1357.64 & 5964.58 & 1852.05 \\
\hline 1102 & 598.28 & 8390.97 & 1448.19 & 7042.36 & 1512.54 \\
\hline 1122 & 621.38 & 9259.72 & 1515.35 & 7865.97 & 1138.20 \\
\hline 1142 & 644.48 & 9991.67 & 1562.92 & 8540.28 & 890.96 \\
\hline 1162 & 667.63 & 10289.58 & 1586.88 & 8888.89 & 840.94 \\
\hline 1182 & 690.78 & 9751.39 & 1392.94 & 8756.94 & 699.96 \\
\hline 1202 & 713.88 & 9761.81 & 1373.17 & 8937.50 & 895.91 \\
\hline 1222 & 736.98 & 9947.92 & 1331.82 & 9229.17 & 1195.10 \\
\hline 1242 & 760.13 & 9361.11 & 1266.19 & 8840.28 & 1574.40 \\
\hline 1262 & 782.53 & 7798.61 & 866.01 & 7527.78 & 1452.86 \\
\hline 1282 & 804.13 & 7152.78 & 791.78 & 7034.72 & 1751.49 \\
\hline 1302 & 825.73 & 7125.00 & 703.13 & 7125.00 & 2048.05 \\
\hline 1322 & 847.33 & 7340.28 & 602.68 & 7347.22 & 2356.91 \\
\hline 1342 & 868.87 & 7506.94 & 487.85 & 7486.11 & 2679.53 \\
\hline 1362 & 892.10 & 4993.06 & 352.83 & 5006.94 & 2519.47 \\
\hline 1382 & 909.20 & 1809.72 & 358.08 & 2135.42 & 2404.21 \\
\hline 1402 & 918.38 & 3725.00 & 308.19 & 3888.89 & 2391.02 \\
\hline 1422 & 930.48 & 4008.61 & 494.79 & 4256.67 & 2375.10 \\
\hline 1442 & 949.48 & 3776.04 & 546.94 & 4152.78 & 2248.48 \\
\hline 1462 & 990.98 & 3125.90 & 841.04 & 5718.06 & 3198.32 \\
\hline 1482 & 1050.98 & 2294.86 & 490.08 & 2006.25 & 2014.01 \\
\hline 1502 & 1110.98 & 1699.38 & 274.86 & 2006.25 & 1212.65 \\
\hline 1522 & 1170.98 & 1224.51 & 215.76 & 1181.25 & 748.34 \\
\hline 1542 & 1230.98 & 815.83 & 219.31 & 801.39 & 448.67 \\
\hline 1562 & 1292.98 & 457.99 & 223.54 & 400.90 & 226.10 \\
\hline & & $\frac{\text { ote 1: }}{\text { loor) }}$ & d Shear & Reversed & ighted Sections \\
\hline
\end{tabular}


RPP-RPT-32239, Rev. 1

M\&D-2008-005-CALC-001, Rev. 1

Table G.12. BES-BEC Primary Tank Stresses, Shell Bottom, Seismic Load Only

\begin{tabular}{|c|c|c|c|c|c|}
\hline \multirow[b]{3}{*}{$\begin{array}{c}\text { M\&D } \\
\text { Starting } \\
\text { M\&D } \\
\text { Element } \\
\text { No. }\end{array}$} & \multirow[b]{3}{*}{ Path (in.) } & \multicolumn{4}{|c|}{$\begin{array}{l}\text { AP Primary Tank, Best Estimate Soil, Horizontal and Vertical } \\
\text { Seismic, Best Estimate Tank Concrete, } 460 \text { in. Waste Level at } \\
1.83 \mathrm{SpG}\end{array}$} \\
\hline & & \multicolumn{4}{|c|}{ Shell Bottom Surface (outside - away from waste) } \\
\hline & & $\begin{array}{l}\text { AP-460-BES-BEC } \\
\text { Seismic Only Hoop } \\
\text { Stress (lbs/in^2) Bot }\end{array}$ & $\begin{array}{l}\text { AP-460-BES-BEC } \\
\text { Seismic Only } \\
\text { Meridional Stress } \\
\text { (lbs/in^2) Bot }\end{array}$ & $\begin{array}{l}\text { AP-460-BES-BEC } \\
\text { Seismic Only Stress } \\
\text { Intensity (lbs/in^2) } \\
\text { Bot }\end{array}$ & $\begin{array}{l}\text { AP-460-BES-BEC } \\
\text { Seismic Only In- } \\
\text { Plane Shear Stress } \\
\text { (Ibs/in^2) Bot }\end{array}$ \\
\hline 762 & 67.33 & 1024.10 & 1046.53 & 1044.31 & 266.48 \\
\hline 782 & 105.04 & 796.53 & 1118.75 & 1122.22 & 482.87 \\
\hline 802 & 136.24 & 1376.94 & 1276.74 & 1222.50 & 532.01 \\
\hline 822 & 181.83 & 732.80 & 768.06 & 768.75 & 608.02 \\
\hline 842 & 225.10 & 1785.56 & 1401.39 & 1272.92 & 738.98 \\
\hline 862 & 273.66 & 865.63 & 715.97 & 1215.97 & 910.32 \\
\hline 882 & 323.27 & 2101.88 & 1448.82 & 2170.14 & 1319.20 \\
\hline 902 & 369.20 & 1869.44 & 896.88 & 2974.31 & 1782.02 \\
\hline 922 & 419.20 & 2591.67 & 1821.67 & 3954.86 & 2542.31 \\
\hline 942 & 444.31 & 2541.67 & 4972.92 & 5225.00 & 2358.90 \\
\hline 962 & 458.66 & 8443.75 & 3204.17 & 7625.69 & 2383.29 \\
\hline 982 & 473.08 & 9880.56 & 4238.89 & 8925.00 & 2438.92 \\
\hline 1002 & 484.80 & 3213.19 & 2052.78 & 4328.47 & 2537.59 \\
\hline 1022 & 502.48 & 3435.83 & 2653.06 & 2936.81 & 2555.68 \\
\hline 1042 & 526.48 & 5212.22 & 1152.64 & 4222.22 & 2396.64 \\
\hline 1062 & 550.48 & 6232.92 & 1273.61 & 5121.53 & 2142.46 \\
\hline 1082 & 574.60 & 7224.03 & 1283.99 & 5917.36 & 1845.12 \\
\hline 1102 & 598.28 & 8453.47 & 1600.76 & 7080.56 & 1506.30 \\
\hline 1122 & 621.38 & 9279.17 & 1519.74 & 7792.36 & 1133.35 \\
\hline 1142 & 644.48 & 10030.56 & 1661.46 & 8541.67 & 872.22 \\
\hline 1162 & 667.63 & 10388.89 & 1846.39 & 9013.89 & 829.14 \\
\hline 1182 & 690.78 & 9700.69 & 1171.88 & 8551.39 & 697.90 \\
\hline 1202 & 713.88 & 9764.58 & 1349.03 & 8868.06 & 895.83 \\
\hline 1222 & 736.98 & 10021.53 & 1534.58 & 9326.39 & 1195.10 \\
\hline 1242 & 760.13 & 9486.11 & 1595.14 & 9020.83 & 1565.38 \\
\hline 1262 & 782.53 & 7659.72 & 621.81 & 7430.56 & 1441.07 \\
\hline 1282 & 804.13 & 7131.94 & 690.76 & 6784.72 & 1750.81 \\
\hline 1302 & 825.73 & 7166.67 & 682.98 & 7173.61 & 2050.84 \\
\hline 1322 & 847.33 & 7256.94 & 481.67 & 7201.39 & 2362.63 \\
\hline 1342 & 868.87 & 7736.11 & 2177.64 & 7736.11 & 2668.87 \\
\hline 1362 & 892.10 & 5590.28 & 2292.01 & 5590.28 & 2443.09 \\
\hline 1382 & 909.20 & 2868.75 & 5440.97 & 5243.06 & 2249.38 \\
\hline 1402 & 918.38 & 5263.26 & 4604.86 & 4029.17 & 2264.68 \\
\hline 1422 & 930.48 & 5396.53 & 5638.89 & 5277.78 & 2320.00 \\
\hline 1442 & 949.48 & 3572.22 & 1366.94 & 3850.69 & 2262.88 \\
\hline 1462 & 990.98 & 3148.89 & 790.56 & 5889.17 & 3198.96 \\
\hline 1482 & 1050.98 & 2281.67 & 551.04 & 2123.82 & 2014.78 \\
\hline 1502 & 1110.98 & 1708.89 & 251.76 & 2123.82 & 1213.26 \\
\hline 1522 & 1170.98 & 1213.06 & 224.44 & 1067.43 & 748.06 \\
\hline 1542 & 1230.98 & 832.01 & 244.28 & 832.92 & 448.63 \\
\hline 1562 & 1292.98 & 437.29 & 213.19 & 324.24 & 226.03 \\
\hline \multicolumn{6}{|c|}{$\frac{\text { Note 1: Meridonal, Hoop, and Shear Stresses are Reversed in Highlighted Sections }}{\text { (Floor) }}$} \\
\hline
\end{tabular}


RPP-RPT-32239, Rev. 1

M\&D-2008-005-CALC-001, Rev. 1

Table G.13. BES-BEC Anchor Bolt Forces, Gravity Load Only

\begin{tabular}{|c|c|c|c|c|c|c|c|c|c|c|c|}
\hline \multicolumn{12}{|c|}{$\begin{array}{l}\text { AP Primary Tank, Best } \\
\text { ANSYS MAXIMUMS BY RADIUS }\end{array}$} \\
\hline $\begin{array}{c}\text { M\&D } \\
\text { J-Bolt } \\
\text { Radius No. }\end{array}$ & $\begin{array}{c}\text { Mean } \\
\text { J-Bolt } \\
\text { Radius } \\
\end{array}$ & $\begin{array}{c}\text { Radius } \\
\text { Inclt } \\
\min \\
\end{array}$ & $\begin{array}{l}\text { J-Bolts } \\
\text { ded } \\
\max \\
\end{array}$ & $\begin{array}{l}\text { Average } \\
\text { Bolts per } \\
\text { Element } \\
\end{array}$ & \begin{tabular}{|c|} 
VIIn AXIaI \\
Force (kip) \\
BES-BEC \\
Gravity \\
Only \\
\end{tabular} & $\begin{array}{c}\text { TylaxAXIal } \\
\text { Force (kip) } \\
\text { BES-BEC } \\
\text { Gravity } \\
\text { Only } \\
\end{array}$ & $\begin{array}{c}\text { Shear } \\
\text { Force1 } \\
\text { (kip) BES- } \\
\text { BEC } \\
\text { Gravity } \\
\end{array}$ & $\begin{array}{c}\text { Maximum } \\
\text { Shear Force1 } \\
\text { Model Angle } \\
\end{array}$ & $\begin{array}{c}\text { Shear Force2 } \\
\text { (kip) BES- } \\
\text { BEC Gravity } \\
\text { Only } \\
\end{array}$ & \begin{tabular}{|c|} 
Maximum \\
Shear Force2 \\
Model Angle \\
\end{tabular} & $\begin{array}{l}\text { Total } \\
\text { Shear } \\
\text { (kip) BES } \\
\text { BEC } \\
\text { Gravity } \\
\end{array}$ \\
\hline Radius 2 & 44.72 & 22.36 & 67.29 & 0.55 & -0.005 & -0.004 & 0.001 & 45 & 0.021 & 90 & 0.021 \\
\hline Radius 3 & 89.87 & 67.29 & 104.93 & 0.89 & -0.004 & -0.004 & 0.001 & 36 & 0.068 & 0 & 0.068 \\
\hline Radius 4 & 120.00 & 104.93 & 135.98 & 1.03 & -0.001 & -0.001 & 0.002 & 27 & 0.125 & 180 & 0.125 \\
\hline Radius 5 & 151.97 & 135.98 & 181.01 & 1.97 & -0.001 & -0.001 & 0.005 & 153 & 0.218 & 90 & 0.218 \\
\hline Radius 6 & 210.05 & 181.01 & 223.79 & 2.41 & -0.006 & -0.006 & 0.009 & 144 & 0.401 & 81 & 0.401 \\
\hline Radius 7 & 237.53 & 223.79 & 270.98 & 3.30 & 0.016 & 0.016 & 0.008 & 144 & 0.492 & 45 & 0.492 \\
\hline Radius 8 & 304.43 & 270.98 & 318.74 & 4.04 & -0.026 & -0.025 & 0.002 & 153 & 0.656 & 45 & 0.656 \\
\hline Radius 9 & 333.05 & 318.74 & 361.64 & 4.37 & 0.088 & 0.089 & 0.001 & 144 & 0.714 & 45 & 0.714 \\
\hline Radius 10 & 390.22 & 361.64 & 406.24 & 5.36 & 0.051 & 0.052 & 0.001 & 117 & 0.810 & 0 & 0.810 \\
\hline Radius 11 & 422.26 & 406.24 & 431.63 & 3.60 & 0.671 & 0.674 & 0.001 & 54 & 1.191 & 0 & 1.191 \\
\hline $\begin{array}{c}\text { M\&D } \\
\text { J-Bolt } \\
\text { Radius No. }\end{array}$ & $\begin{array}{l}\text { Mean } \\
\text { J-Bolt } \\
\text { Radius }\end{array}$ & $\begin{array}{r}\text { Radius } 0 \\
\text { Incl }\end{array}$ & $\begin{array}{l}\text { I-Bolts } \\
\text { ed }\end{array}$ & $\begin{array}{l}\text { Average } \\
\text { Bolts per } \\
\text { Element }\end{array}$ & $\begin{array}{l}\text { Bolt Angle } \\
\text { (Rad) }\end{array}$ & $\begin{array}{c}\text { Shear } \\
\text { Stiffness } \\
\text { (kip/t) }\end{array}$ & $\begin{array}{c}\text { Axial } \\
\text { Stiffness } \\
\text { (kip/t) }\end{array}$ & $\begin{array}{l}\text { Shear } \\
\text { Displacement } \\
\text { BES-BEC- } \\
\text { Gravity Only }\end{array}$ & $\begin{array}{c}\text { Axial Min } \\
\text { Displacement } \\
\text { BES-BEC- } \\
\text { Gravity Only }\end{array}$ & $\begin{array}{c}\text { Axial Max } \\
\text { Displacement } \\
\text { BES-BEC- } \\
\text { Gravity Only }\end{array}$ & \\
\hline Radius 2 & 444.72 & 22.36 & $\begin{array}{l}67.29 \\
\end{array}$ & 0.55 & |0.0351| & 780 & 780 & 0.00033 & \begin{tabular}{c|}
-0.00008 \\
\end{tabular} & $\begin{array}{c}-0.00006 \\
\end{array}$ & \\
\hline Radius 3 & 89.87 & 67.29 & 104.93 & 0.89 & 0.0715 & 780 & 780 & 0.00 & -0.00007 & -0.00006 & \\
\hline Radius 4 & 120.00 & 104.93 & 135.98 & 1.03 & 0.0968 & 780 & 780 & 0.00192 & -0.00002 & -0.00001 & \\
\hline Radius 5 & 151.97 & 135.98 & 181.01 & 1.97 & 0.1252 & 780 & 780 & 0.00335 & -0.00002 & -0.00002 & \\
\hline Radius 6 & 210.05 & 181.01 & 223.79 & 2.41 & 0.1825 & 780 & 780 & 0.00617 & -0.00010 & -0.00009 & \\
\hline Radius 7 & 237.53 & 223.79 & 270.98 & 3.30 & 0.2136 & 780 & 780 & 0.00757 & 0.00025 & 0.00025 & \\
\hline Radius 8 & 304.43 & 270.98 & 318.74 & 4.04 & 0.3076 & 780 & 780 & 0.01009 & -0.00039 & -0.00038 & \\
\hline Radius 9 & 333.05 & 318.74 & 361.64 & 4.37 & 0.3613 & 780 & 780 & 0.01098 & 0.00135 & 0.00138 & \\
\hline Radius 10 & 390.22 & 361.64 & 406.24 & 5.36 & 0.5235 & 780 & 780 & 0.01246 & 0.00078 & 0.00080 & \\
\hline Radius 11 & 460.26 & 406.24 & 431.63 & 3.60 & 0.6938 & 780 & 780 & 0.01833 & 0.01032 & 0.01037 & \\
\hline
\end{tabular}


RPP-RPT-32239, Rev. 1

M\&D-2008-005-CALC-001, Rev. 1

Table G.14. BES-BEC Anchor Bolt Forces, Gravity Plus Seismic Loads

\begin{tabular}{|c|c|c|c|c|c|c|c|c|c|c|c|}
\hline \multicolumn{12}{|c|}{$\begin{array}{l}\text { AP Primary Tank, Bes } \\
\text { Estimate T } \\
\text { ANSYS MAXIMUMS BY RADIUS }\end{array}$} \\
\hline $\begin{array}{c}\text { M\&D } \\
\text { J-Bolt } \\
\text { Radius No. }\end{array}$ & $\begin{array}{l}\text { Mean } \\
\text { J-Bolt } \\
\text { Radius }\end{array}$ & $\begin{array}{r}\text { Radius of } \\
\text { Inclu }\end{array}$ & f J-Bolts & $\begin{array}{l}\text { Average } \\
\text { Bolts per } \\
\text { Element }\end{array}$ & $\begin{array}{c}\text { Min Axial } \\
\text { Force (kip) } \\
\text { BES-BEC }\end{array}$ & $\begin{array}{c}\text { Max Axial } \\
\text { Force (kip) } \\
\text { BES-BEC }\end{array}$ & $\begin{array}{c}\text { Shear } \\
\text { Force1 (kip) } \\
\text { BES-BEC }\end{array}$ & $\begin{array}{c}\text { Maximum } \\
\text { Shear Force1 } \\
\text { Model Angle }\end{array}$ & \begin{tabular}{|} 
Shear Force2 \\
(kip) BES-BEC
\end{tabular} & \begin{tabular}{|c|} 
Maximum \\
Shear Force2 \\
Model Angle \\
\end{tabular} & $\begin{array}{c}\text { Total } \\
\text { Shear } \\
\text { (kip) BES } \\
\text { BEC } \\
\end{array}$ \\
\hline Radius 2 & "44.72 & 22.36 & 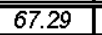 & 0.55 & -0.071 & 0.008 & "0.618 & $\overline{90}$ & 0.663 & $\overline{0}$ & 0.663 \\
\hline Radius 3 & 89.87 & 67.29 & 104.93 & 0.89 & -0.045 & 0.007 & 0.691 & 90 & 0.621 & 180 & 0.729 \\
\hline Radius 4 & 120.00 & 104.93 & 135.98 & 1.03 & -0.035 & 0.015 & 0.783 & 90 & 0.685 & 180 & 0.834 \\
\hline Radius 5 & 151.97 & 135.98 & 181.01 & 1.97 & -0.107 & 0.048 & 0.909 & 90 & 0.802 & 180 & 0.975 \\
\hline Radius 6 & 210.05 & 181.01 & 223.79 & 2.41 & -0.073 & 0.118 & 1.194 & 90 & 1.073 & 180 & 1.293 \\
\hline Radius 7 & 237.53 & 223.79 & 270.98 & 3.30 & -0.065 & 0.425 & 1.423 & 90 & 1.239 & 180 & 1.542 \\
\hline Radius 8 & 304.43 & 270.98 & 318.74 & 4.04 & -0.150 & 0.331 & 2.083 & 90 & 1.573 & 180 & 2.217 \\
\hline Radius 9 & 333.05 & 318.74 & 361.64 & 4.37 & -0.163 & 0.577 & 2.479 & 90 & 1.708 & 180 & 2.617 \\
\hline Radius 10 & 390.22 & 361.64 & 406.24 & 5.36 & -0.232 & 0.582 & 3.497 & 90 & 2.010 & 180 & 3.623 \\
\hline Radius 11 & 422.26 & 406.24 & 431.63 & 3.60 & -0.234 & 1.595 & 4.458 & 90 & 2.665 & 180 & 4.676 \\
\hline $\begin{array}{c}\text { M\&D } \\
\text { J-Bolt } \\
\text { Radius No. }\end{array}$ & $\begin{array}{l}\text { Mean } \\
\text { J-Bolt } \\
\text { Radius }\end{array}$ & $\begin{array}{r}\text { Radius of } \\
\text { Inclu }\end{array}$ & $\begin{array}{l}\text { J-Bolts } \\
\text { ded }\end{array}$ & $\begin{array}{l}\text { Average } \\
\text { Bolts per } \\
\text { Element }\end{array}$ & $\begin{array}{c}\text { Bolt Angle } \\
\text { (Rad) }\end{array}$ & $\begin{array}{c}\text { Shear } \\
\text { Stiffness } \\
\text { (kip/ft) }\end{array}$ & $\begin{array}{c}\text { Axial } \\
\text { Stiffness } \\
\text { (kip/ft) }\end{array}$ & $\begin{array}{c}\text { Shear Disp } \\
\text { BES-BEC- } \\
\text { Seismic }\end{array}$ & \begin{tabular}{|c|} 
Axial Min Disp \\
BES-BEC- \\
Seismic
\end{tabular} & $\begin{array}{c}\text { Axial Max Disp } \\
\text { BES-BEC- } \\
\text { Seismic }\end{array}$ & \\
\hline Radius 2 & 44.72 & 22.36 & 67.29 & 0.55 & 0.0351 & 780 & 780 & 0.01019 & -0.00109 & 0.00013 & \\
\hline Radius 3 & 89.87 & 67.29 & 104.93 & 0.89 & 0.0715 & 780 & 780 & 0.01122 & -0.00069 & 0.00011 & \\
\hline Radius 4 & 120.00 & 104.93 & 135.98 & 1.03 & 0.0968 & 780 & 780 & 0.01283 & -0.00053 & 0.00024 & \\
\hline Radius 5 & 151.97 & 135.98 & 181.01 & 1.97 & 0.1252 & 780 & 780 & 0.01500 & \begin{tabular}{l|l}
-0.00165 \\
\end{tabular} & 0.00074 & \\
\hline Radius 6 & 210.05 & 181.01 & 223.79 & 2.41 & 0.1825 & 780 & 780 & 0.01989 & -0.00113 & 0.00182 & \\
\hline Radius 7 & 237.53 & 223.79 & 270.98 & 3.30 & 0.2136 & 780 & 780 & 0.02373 & -0.00100 & 0.00653 & \\
\hline Radius 8 & 304.43 & 270.98 & 318.74 & 4.04 & 0.3076 & 780 & 780 & 0.03410 & -0.00231 & 0.00509 & \\
\hline Radius 9 & 333.05 & 318.74 & 361.64 & 4.37 & 0.3613 & 780 & 780 & 0.04026 & -0.00251 & 0.00887 & \\
\hline Radius 10 & 390.22 & 361.64 & 406.24 & 5.36 & 0.5235 & 780 & 780 & 0.05574 & -0.00357 & 0.00895 & \\
\hline Radius 11 & 460.26 & 406.24 & 431.63 & 3.60 & 0.6938 & 780 & 780 & 0.07195 & -0.00360 & 0.02453 & \\
\hline
\end{tabular}


RPP-RPT-32239, Rev. 1

M\&D-2008-005-CALC-001, Rev. 1

Table G.15. BES-BEC Anchor Bolt Forces, Seismic Load Only

\begin{tabular}{|c|c|c|c|c|c|c|c|c|c|c|c|}
\hline \multicolumn{12}{|c|}{$\begin{array}{l}\text { AP Primary Tank, Best Estimate Soil, Horizontal and Vertical Seismic Input, Best } \\
\text { Estimate Tank Concrete, } 460 \text { in. Waste Level at } 1.83 \mathrm{SpG} \text { Seismic Only } \\
\text { ANSYS MAXIMUMS BY RADIUS }\end{array}$} \\
\hline $\begin{array}{l}\text { M\&D } \\
\text { J-Bolt } \\
\text { Radius } \\
\text { No. }\end{array}$ & $\begin{array}{l}\text { Mean } \\
\text { J-Bolt } \\
\text { Radius }\end{array}$ & $\begin{array}{r}\text { Radius } \\
\text { Incl }\end{array}$ & $\begin{array}{l}\text { J-Bolts } \\
\text { ded }\end{array}$ & $\begin{array}{l}\text { Average } \\
\text { Bolts per } \\
\text { Element }\end{array}$ & $\begin{array}{l}\text { Min Axial } \\
\text { Force (kip) } \\
\text { BES-BEC- } \\
\text { Seismic } \\
\text { Only }\end{array}$ & $\begin{array}{l}\text { Max Axial } \\
\text { Force (kip) } \\
\text { BES-BEC- } \\
\text { Seismic } \\
\text { Only }\end{array}$ & \begin{tabular}{|} 
Shear \\
Force1 (kip) \\
BES-BEC- \\
Seismic Only
\end{tabular} & $\begin{array}{c}\text { Maximum } \\
\text { Shear Force1 } \\
\text { Model Angle }\end{array}$ & $\begin{array}{c}\text { Shear Force2 } \\
\text { (kip) BES- } \\
\text { BEC-Seismic } \\
\text { Only }\end{array}$ & $\begin{array}{c}\text { Maximum } \\
\text { Shear Force2 } \\
\text { Model Angle }\end{array}$ & $\begin{array}{c}\text { Total Shear } \\
\text { (kip) BES- } \\
\text { BEC- } \\
\text { Seismic } \\
\text { Only }\end{array}$ \\
\hline Radius 2 & 44.72 & 22.36 & 67.29 & 0.55 & -0.066 & 0.012 & 0.617 & 108 & 0.641 & $\overline{0}$ & 0.890 \\
\hline Radius 3 & 89.87 & 67.29 & 104.93 & 0.89 & -0.040 & 0.011 & 0.690 & 108 & 0.553 & 0 & 0.884 \\
\hline Radius 4 & 120.00 & 104.93 & 135.98 & 1.03 & -0.034 & 0.016 & 0.781 & 108 & 0.560 & 0 & 0.961 \\
\hline Radius 5 & 151.97 & 135.98 & 181.01 & 1.97 & -0.106 & 0.049 & 0.904 & 108 & 0.584 & 0 & 1.076 \\
\hline Radius 6 & 210.05 & 181.01 & 223.79 & 2.41 & -0.067 & 0.124 & 1.186 & 108 & 0.672 & 144 & 1.363 \\
\hline Radius 7 & 237.53 & 223.79 & 270.98 & 3.30 & -0.081 & 0.408 & 1.415 & 90 & 0.747 & 135 & 1.600 \\
\hline Radius 8 & 304.43 & 270.98 & 318.74 & 4.04 & -0.125 & 0.356 & 2.081 & 117 & 0.917 & 117 & 2.274 \\
\hline Radius 9 & 333.05 & 318.74 & 361.64 & 4.37 & -0.251 & 0.487 & 2.478 & 117 & 0.994 & 117 & 2.670 \\
\hline Radius 10 & 390.22 & 361.64 & 406.24 & 5.36 & -0.283 & 0.529 & 3.496 & 108 & 1.200 & 0 & 3.696 \\
\hline Radius 11 & 460.26 & 406.24 & 431.63 & 3.60 & -0.905 & 0.921 & 4.458 & 108 & 1.474 & 0 & 4.695 \\
\hline $\begin{array}{l}\text { M\&D } \\
\text { J-Bolt } \\
\text { Radius } \\
\text { No. } \\
\end{array}$ & $\begin{array}{l}\text { Mean } \\
\text { J-Bolt } \\
\text { Radius }\end{array}$ & $\begin{array}{r}\text { Radius } \\
\text { Incl }\end{array}$ & $\begin{array}{l}\text { J-Bolts } \\
\text { ed }\end{array}$ & $\begin{array}{l}\text { Average } \\
\text { Bolts per } \\
\text { Element }\end{array}$ & $\begin{array}{c}\text { Bolt Angle } \\
\text { (Rad) }\end{array}$ & $\begin{array}{l}\text { Shear } \\
\text { Stiffness } \\
\text { (kip/tt) }\end{array}$ & $\begin{array}{c}\text { Axial } \\
\text { Stiffness } \\
\text { (kip/ft) }\end{array}$ & $\begin{array}{l}\text { Shear Disp } \\
\text { BES-BEC- } \\
\text { Seismic Only }\end{array}$ & $\begin{array}{l}\text { Axial Min Disp } \\
\text { BES-BEC- } \\
\text { Seismic Only }\end{array}$ & $\begin{array}{c}\text { Axial Max Disp } \\
\text { BES-BEC- } \\
\text { Seismic Only }\end{array}$ & \\
\hline Radius 2 & 44.72 & 22.36 & 67.29 & 0.55 & 0.0351 & 780 & 780 & 0.01369 & -0.00101 & 0.00019 & \\
\hline Radius 3 & 89.87 & 67.29 & 104.93 & 0.89 & 0.0715 & 780 & 780 & 0.01360 & -0.00062 & 0.00017 & \\
\hline Radius 4 & 120.00 & 104.93 & 135.98 & 1.03 & 0.0968 & 780 & 780 & 0.01478 & -0.00052 & 0.00025 & \\
\hline Radius 5 & 151.97 & 135.98 & 181.01 & 1.97 & 0.1252 & 780 & 780 & 0.01655 & -0.00163 & 0.00076 & \\
\hline Radius 6 & 210.05 & 181.01 & 223.79 & 2.41 & 0.1825 & 780 & 780 & 0.02097 & -0.00103 & 0.00191 & \\
\hline Radius 7 & 237.53 & 223.79 & 270.98 & 3.30 & 0.2136 & 780 & 780 & 0.02462 & -0.00124 & 0.00628 & \\
\hline Radius 8 & 304.43 & 270.98 & 318.74 & 4.04 & 0.3076 & 780 & 780 & 0.03498 & -0.00192 & 0.00548 & \\
\hline Radius 9 & 333.05 & 318.74 & 361.64 & 4.37 & 0.3613 & 780 & 780 & 0.04108 & -0.00386 & 0.00750 & \\
\hline Radius 10 & 390.22 & 361.64 & 406.24 & 5.36 & 0.5235 & 780 & 780 & 0.05687 & -0.00435 & 0.00814 & \\
\hline Radius 11 & 460.26 & 406.24 & 431.63 & 3.60 & 0.6938 & 780 & 780 & 0.07223 & -0.01393 & 0.01417 & \\
\hline
\end{tabular}


RPP-RPT-32239, Rev. 1

M\&D-2008-005-CALC-001, Rev. 1

Table G.16. BES-BEC Concrete Backed Steel Strain, Shell Top, Gravity Load Only

AP Backed Steel, Best Estimate Soil, Gravity Only, Best Estimate Tank Concrete, 460 In Waste Level at $1.83 \mathrm{SpG}$

\begin{tabular}{|c|c|c|c|c|c|c|c|}
\hline \multirow[b]{2}{*}{$\begin{array}{c}\text { M\&D } \\
\text { Starting } \\
\text { M\&D } \\
\text { Element } \\
\text { No. }\end{array}$} & \multirow[b]{2}{*}{ Path (in) } & \multicolumn{6}{|c|}{ Shell Top Surface (inside - towards waste) Gravity } \\
\hline & & $\begin{array}{l}\text { AP-460-BES-BEC } \\
\text { EPEL P1 Strain (in/in) } \\
\text { Gravity Tap Min }\end{array}$ & $\begin{array}{l}\text { AP-460-BES-BEC } \\
\text { EPEL P1 Strain (in/in) } \\
\text { Gravity Tap Max }\end{array}$ & $\begin{array}{l}\text { AP-460-BES-BEC } \\
\text { EPEL P2 (in/in) } \\
\text { Gravity Top Min }\end{array}$ & $\begin{array}{l}\text { AP-460-BES-BEC } \\
\text { EPEL P2 Strain (in/in) } \\
\text { Gravity Top Max }\end{array}$ & $\begin{array}{c}\text { AP-460-BES-BEC } \\
\text { EPEL P3 Strain (in/in) } \\
\text { Gravity Top Min }\end{array}$ & $\begin{array}{l}\text { AP-460-BES-BEC } \\
\text { EPEL P3 Strain (in/in) } \\
\text { Gravity Top Max }\end{array}$ \\
\hline 762 & 67.33 & $3.36 \mathrm{E}-05$ & $3.37 \mathrm{E}-05$ & $-3.81 \mathrm{E}-05$ & $-3.81 \mathrm{E}-05$ & $-3.99 \mathrm{E}-05$ & $-3.99 \mathrm{E}-05$ \\
\hline 782 & 105.04 & $4.21 \mathrm{E}-05$ & $4.21 \mathrm{E}-05$ & $-3.12 E-05$ & $-3.12 \mathrm{E}-05$ & $-6.62 E-05$ & $-6.61 \mathrm{E}-05$ \\
\hline 802 & 136.24 & $3.62 \mathrm{E}-05$ & $3.62 \mathrm{E}-05$ & $-3.18 \mathrm{E}-05$ & $-3.18 \mathrm{E}-05$ & $-5.17 \mathrm{E}-05$ & $-5.17 \mathrm{E}-05$ \\
\hline 822 & 181.71 & $3.22 \mathrm{E}-05$ & $3.23 \mathrm{E}-05$ & $-1.89 \mathrm{E}-05$ & $-1.88 \mathrm{E}-05$ & $-5.55 \mathrm{E}-05$ & $-5.54 \mathrm{E}-05$ \\
\hline 842 & 225.10 & $2.56 \mathrm{E}-05$ & $2.56 \mathrm{E}-05$ & $-2.06 \mathrm{E}-05$ & $-2.06 \mathrm{E}-05$ & $-3.82 E-05$ & $-3.82 \mathrm{E}-05$ \\
\hline 862 & 273.66 & $2.01 \mathrm{E}-05$ & $2.01 \mathrm{E}-05$ & $-6.25 \mathrm{E}-06$ & $-6.25 \mathrm{E}-06$ & $-4.00 \mathrm{E}-05$ & $-3.99 \mathrm{E}-05$ \\
\hline 882 & 323.27 & $1.22 \mathrm{E}-05$ & $1.22 \mathrm{E}-05$ & $-7.65 \mathrm{E}-07$ & $-7.54 \mathrm{E}-07$ & $-2.72 E-05$ & $-2.72 E-05$ \\
\hline 902 & 369.20 & $1.45 \mathrm{E}-05$ & $1.45 \mathrm{E}-05$ & $3.10 \mathrm{E}-06$ & $3.10 \mathrm{E}-06$ & $-2.14 \mathrm{E}-05$ & $-2.14 \mathrm{E}-05$ \\
\hline 922 & 419.20 & $4.13 \mathrm{E}-05$ & $4.13 \mathrm{E}-05$ & $-8.89 \mathrm{E}-06$ & $-8.88 \mathrm{E}-06$ & $-2.03 \mathrm{E}-05$ & $-2.03 \mathrm{E}-05$ \\
\hline 237 & 463.02 & & & & & & \\
\hline 257 & 510.03 & & & & & & \\
\hline 277 & 544.44 & & & & & & \\
\hline 297 & 580.53 & & & & & & \\
\hline 317 & 631.08 & & & & & & \\
\hline 337 & 680.34 & & & & & & \\
\hline 357 & 727.44 & & & & & & \\
\hline 377 & 772.93 & & & & & & \\
\hline 397 & 831.34 & & & & & & \\
\hline 417 & 894.09 & & & & & & \\
\hline 2132 & 925.08 & $2.84 \mathrm{E}-05$ & $2.84 \mathrm{E}-05$ & $-2.59 \mathrm{E}-05$ & $-2.59 \mathrm{E}-05$ & $-3.60 \mathrm{E}-05$ & $-3.60 \mathrm{E}-05$ \\
\hline 2122 & 935.67 & $7.02 \mathrm{E}-05$ & $7.02 E-05$ & $-1.99 \mathrm{E}-05$ & $-1.99 \mathrm{E}-05$ & $-2.67 \mathrm{E}-05$ & $-2.67 \mathrm{E}-05$ \\
\hline 2112 & 944.86 & $7.35 \mathrm{E}-05$ & $7.36 \mathrm{E}-05$ & $-5.93 \mathrm{E}-06$ & $-5.93 \mathrm{E}-06$ & $-1.63 \mathrm{E}-04$ & $-1.63 \mathrm{E}-04$ \\
\hline 477 & 968.95 & & & & & & \\
\hline 497 & 1002.45 & & & & & & \\
\hline 517 & 1042.45 & & & & & & \\
\hline 537 & 1108.60 & & & & & & \\
\hline 557 & 1178.35 & & & & & & \\
\hline 577 & 1227.20 & & & & & & \\
\hline 597 & 1271.50 & & & & & & \\
\hline 617 & 1313.65 & & & & & & \\
\hline 637 & 1360.60 & & & & & & \\
\hline
\end{tabular}


RPP-RPT-32239, Rev. 1

M\&D-2008-005-CALC-001, Rev. 1

Table G.17. BES-BEC Concrete Backed Steel Strain, Shell Middle, Gravity Load Only

AP Backed Steel, Best Estimate Soil, Gravity Only, Best Estimate Tank Concrete, 460 In Waste Level at 1.83SpG

\begin{tabular}{|c|c|c|c|c|c|c|c|}
\hline \multirow{2}{*}{$\begin{array}{c}\text { M\&D } \\
\text { Starting } \\
\text { M\&D } \\
\text { Element } \\
\text { No. }\end{array}$} & \multirow[b]{2}{*}{ Path (in) } & \multicolumn{6}{|c|}{ Shell Mid-Plane } \\
\hline & & $\begin{array}{c}\text { AP-460-BES-BEC } \\
\text { EPEL P1 Strain (in/in) } \\
\text { Gravity Mid Min }\end{array}$ & $\begin{array}{c}\text { AP-460-BES-BEC } \\
\text { EPEL P1 Strain (in/in) } \\
\text { Gravity Mid Max }\end{array}$ & $\begin{array}{l}\text { AP-460-BES-BEC } \\
\text { EPEL P2 (in/in) } \\
\text { Gravity Mid Min }\end{array}$ & $\begin{array}{c}\text { AP-460-BES-BEC } \\
\text { EPEL P2 Strain (in/in) } \\
\text { Gravity Mid Max }\end{array}$ & $\begin{array}{c}\text { AP-460-BES-BEC } \\
\text { EPEL P3 Strain (in/in) } \\
\text { Gravity Mid Min }\end{array}$ & $\begin{array}{c}\text { AP-460-BES-BEC } \\
\text { EPEL P3 Strain (in/in) } \\
\text { Gravity Mid Max }\end{array}$ \\
\hline 762 & 67.33 & $3.58 \mathrm{E}-05$ & $3.59 E-05$ & $-4.10 \mathrm{E}-05$ & $-4.10 \mathrm{E}-05$ & $-4.23 E-05$ & $-4.23 E-05$ \\
\hline 782 & 105.04 & $4.05 E-05$ & $4.05 \mathrm{E}-05$ & $-3.19 \mathrm{E}-05$ & $-3.18 \mathrm{E}-05$ & $-6.20 \mathrm{E}-05$ & $-6.19 \mathrm{E}-05$ \\
\hline 802 & 136.24 & $3.84 \mathrm{E}-05$ & $3.84 \mathrm{E}-05$ & $-3.24 \mathrm{E}-05$ & $-3.23 \mathrm{E}-05$ & $-5.64 \mathrm{E}-05$ & $-5.64 \mathrm{E}-05$ \\
\hline 822 & 181.71 & $3.10 \mathrm{E}-05$ & $3.11 \mathrm{E}-05$ & $-1.92 \mathrm{E}-05$ & $-1.92 \mathrm{E}-05$ & $-5.24 \mathrm{E}-05$ & $-5.23 E-05$ \\
\hline 842 & 225.10 & $2.80 \mathrm{E}-05$ & $2.81 \mathrm{E}-05$ & $-2.07 E-05$ & $-2.07 \mathrm{E}-05$ & $-4.37 E-05$ & $-4.36 \mathrm{E}-05$ \\
\hline 862 & 273.66 & $1.95 \mathrm{E}-05$ & $1.95 \mathrm{E}-05$ & $-6.50 \mathrm{E}-06$ & $-6.49 \mathrm{E}-06$ & $-3.85 E-05$ & $-3.84 \mathrm{E}-05$ \\
\hline 882 & 323.27 & $1.30 \mathrm{E}-05$ & $1.30 \mathrm{E}-05$ & $-8.69 \mathrm{E}-07$ & $-8.58 \mathrm{E}-07$ & $-2.90 \mathrm{E}-05$ & $-2.89 \mathrm{E}-05$ \\
\hline 902 & 369.20 & $1.43 \mathrm{E}-05$ & $1.43 \mathrm{E}-05$ & $3.61 \mathrm{E}-06$ & $3.61 \mathrm{E}-06$ & $-2.24 \mathrm{E}-05$ & $-2.23 E-05$ \\
\hline 922 & 419.20 & $4.12 E-05$ & $4.12 \mathrm{E}-05$ & $-1.04 \mathrm{E}-05$ & $-1.03 E-05$ & $-1.67 \mathrm{E}-05$ & $-1.67 \mathrm{E}-05$ \\
\hline 237 & 463.02 & $4.30 \mathrm{E}-05$ & $4.31 \mathrm{E}-05$ & $5.58 \mathrm{E}-06$ & $5.58 \mathrm{E}-06$ & $-6.61 E-05$ & $-6.60 \mathrm{E}-05$ \\
\hline 257 & 510.03 & $5.86 \mathrm{E}-05$ & $5.87 \mathrm{E}-05$ & $5.08 \mathrm{E}-05$ & $5.08 \mathrm{E}-05$ & $-2.89 E-04$ & $-2.89 \mathrm{E}-04$ \\
\hline 277 & 544.44 & $9.53 \mathrm{E}-05$ & $9.53 \mathrm{E}-05$ & $4.55 \mathrm{E}-05$ & $4.56 \mathrm{E}-05$ & $-4.71 E-04$ & $-4.70 \mathrm{E}-04$ \\
\hline 297 & 580.53 & $6.77 \mathrm{E}-05$ & $6.77 \mathrm{E}-05$ & $-2.07 E-05$ & $-2.07 E-05$ & $-2.86 E-04$ & $-2.86 \mathrm{E}-04$ \\
\hline 317 & 631.08 & $8.31 \mathrm{E}-05$ & $8.32 E-05$ & $-9.00 \mathrm{E}-05$ & $-9.00 \mathrm{E}-05$ & $-2.88 \mathrm{E}-04$ & $-2.88 \mathrm{E}-04$ \\
\hline 337 & 680.34 & $1.03 E-04$ & $1.03 E-04$ & $-1.14 \mathrm{E}-04$ & $-1.14 \mathrm{E}-04$ & $-3.55 E-04$ & $-3.55 E-04$ \\
\hline 357 & 727.44 & $1.02 \mathrm{E}-04$ & $1.02 \mathrm{E}-04$ & $-1.22 \mathrm{E}-04$ & $-1.22 \mathrm{E}-04$ & $-3.42 \mathrm{E}-04$ & $-3.42 \mathrm{E}-04$ \\
\hline 377 & 772.93 & $1.19 \mathrm{E}-04$ & 1.19E-04 & $-1.29 \mathrm{E}-04$ & $-1.29 \mathrm{E}-04$ & $-4.14 \mathrm{E}-04$ & $-4.14 \mathrm{E}-04$ \\
\hline 397 & 831.34 & $1.12 \mathrm{E}-04$ & $1.12 \mathrm{E}-04$ & $-1.12 \mathrm{E}-04$ & $-1.12 \mathrm{E}-04$ & $-3.96 \mathrm{E}-04$ & $-3.96 \mathrm{E}-04$ \\
\hline 417 & 894.09 & $4.79 \mathrm{E}-05$ & $4.80 \mathrm{E}-05$ & $-6.72 E-05$ & $-6.72 E-05$ & $-1.50 \mathrm{E}-04$ & $-1.50 \mathrm{E}-04$ \\
\hline 2132 & 925.08 & $2.35 \mathrm{E}-05$ & $2.35 \mathrm{E}-05$ & $-1.16 \mathrm{E}-05$ & $-1.16 \mathrm{E}-05$ & $-3.60 \mathrm{E}-05$ & $-3.60 \mathrm{E}-05$ \\
\hline 2122 & 935.67 & $2.38 \mathrm{E}-05$ & 2.39E-05 & $-2.10 \mathrm{E}-05$ & $-2.10 \mathrm{E}-05$ & $-2.64 \mathrm{E}-05$ & $-2.64 \mathrm{E}-05$ \\
\hline 2112 & 944.86 & $1.64 \mathrm{E}-05$ & $1.64 \mathrm{E}-05$ & $-5.73 E-06$ & $-5.73 E-06$ & $-2.66 \mathrm{E}-05$ & $-2.66 \mathrm{E}-05$ \\
\hline 477 & 968.95 & $1.76 \mathrm{E}-05$ & $1.76 \mathrm{E}-05$ & $7.07 \mathrm{E}-06$ & $7.08 \mathrm{E}-06$ & $-7.69 \mathrm{E}-05$ & $-7.69 \mathrm{E}-05$ \\
\hline 497 & 1002.45 & $5.64 \mathrm{E}-05$ & $5.65 \mathrm{E}-05$ & $1.03 \mathrm{E}-05$ & $1.03 \mathrm{E}-05$ & $-1.66 \mathrm{E}-05$ & $-1.66 \mathrm{E}-05$ \\
\hline 517 & 1042.45 & $1.40 \mathrm{E}-05$ & $1.40 \mathrm{E}-05$ & $8.75 \mathrm{E}-06$ & $8.77 E-06$ & $-4.96 \mathrm{E}-06$ & $-4.96 \mathrm{E}-06$ \\
\hline 537 & 1108.60 & $2.42 \mathrm{E}-05$ & $2.42 \mathrm{E}-05$ & $5.07 \mathrm{E}-06$ & $5.08 \mathrm{E}-06$ & $-7.85 \mathrm{E}-06$ & $-7.84 \mathrm{E}-06$ \\
\hline 557 & 1178.35 & $3.77 \mathrm{E}-06$ & $3.78 \mathrm{E}-06$ & $3.74 \mathrm{E}-06$ & $3.74 \mathrm{E}-06$ & $-1.83 E-05$ & $-1.83 \mathrm{E}-05$ \\
\hline 577 & 1227.20 & $2.37 \mathrm{E}-05$ & $2.37 \mathrm{E}-05$ & $3.79 \mathrm{E}-06$ & $3.80 \mathrm{E}-06$ & $-6.31 E-06$ & $-6.30 \mathrm{E}-06$ \\
\hline 597 & 1271.50 & $4.61 \mathrm{E}-06$ & $4.62 \mathrm{E}-06$ & $3.33 \mathrm{E}-06$ & $3.33 \mathrm{E}-06$ & $-1.87 \mathrm{E}-05$ & $-1.87 \mathrm{E}-05$ \\
\hline 617 & 1313.65 & $1.59 \mathrm{E}-05$ & $1.59 \mathrm{E}-05$ & $6.58 \mathrm{E}-06$ & $6.59 \mathrm{E}-06$ & $-5.03 E-06$ & $-5.02 E-06$ \\
\hline 637 & 1360.60 & $4.24 \mathrm{E}-06$ & $4.24 \mathrm{E}-06$ & $3.26 \mathrm{E}-06$ & $3.27 \mathrm{E}-06$ & $-1.52 \mathrm{E}-06$ & $-1.52 \mathrm{E}-06$ \\
\hline
\end{tabular}




\section{RPP-RPT-32239, Rev. 1 \\ M\&D-2008-005-CALC-001, Rev. 1}

Table G.18. BES-BEC Concrete Backed Steel Strain, Shell Bottom, Gravity Load Only

AP Backed Steel, Best Estimate Soil, Gravity Only, Best Estimate Tank Concrete, 460 In Waste Level at $1.83 \mathrm{SpG}$

\begin{tabular}{|c|c|c|c|c|c|c|c|}
\hline \multirow[b]{2}{*}{$\begin{array}{c}\text { M\&D } \\
\text { Starting } \\
\text { M\&D } \\
\text { Element } \\
\text { No. }\end{array}$} & \multirow[b]{2}{*}{ Path (in) } & \multicolumn{6}{|c|}{ Shell Bottom Surface (outside - away from waste) Gravity } \\
\hline & & $\begin{array}{l}\text { AP-460-BES-BEC } \\
\text { EPEL P1 Strain (in/in) } \\
\text { Gravity Bot Min } \\
\end{array}$ & $\begin{array}{c}\text { AP-460-BES-BEC } \\
\text { EPEL P1 Strain (in/in) } \\
\text { Gravity Bot Max }\end{array}$ & $\begin{array}{l}\text { AP-460-BES-BEC } \\
\text { EPEL P2 (in/in) } \\
\text { Gravity Bot Min }\end{array}$ & $\begin{array}{c}\text { AP-460-BES-BEC } \\
\text { EPEL P2 Strain (in/in) } \\
\text { Gravity Bot Max } \\
\end{array}$ & $\begin{array}{c}\text { AP-460-BES-BEC } \\
\text { EPEL P3 Strain (in/in) } \\
\text { Gravity Bat Min } \\
\end{array}$ & $\begin{array}{c}\text { AP-460-BES-BEC } \\
\text { EPEL P3 Strain (in/in) } \\
\text { Gravity Bot Max }\end{array}$ \\
\hline 762 & 67.33 & $3.81 E-05$ & $3.82 E-05$ & $-4.20 E-05$ & $-4.20 \mathrm{E}-05$ & $-4.64 \mathrm{E}-05$ & $-4.63 \mathrm{E}-05$ \\
\hline 782 & 105.04 & $3.90 \mathrm{E}-05$ & $3.90 \mathrm{E}-05$ & $-3.25 \mathrm{E}-05$ & $-3.24 \mathrm{E}-05$ & $-5.77 \mathrm{E}-05$ & $-5.77 \mathrm{E}-05$ \\
\hline 802 & 136.24 & $4.06 \mathrm{E}-05$ & 4.07E-05 & $-3.29 \mathrm{E}-05$ & $-3.28 \mathrm{E}-05$ & $-6.10 \mathrm{E}-05$ & $-6.10 \mathrm{E}-05$ \\
\hline 822 & 181.71 & $2.98 \mathrm{E}-05$ & 2.99E-05 & $-1.95 \mathrm{E}-05$ & $-1.95 \mathrm{E}-05$ & $-4.92 \mathrm{E}-05$ & $-4.91 \mathrm{E}-05$ \\
\hline 842 & 225.10 & $3.05 E-05$ & $3.05 E-05$ & $-2.08 E-05$ & $-2.08 \mathrm{E}-05$ & $-4.90 \mathrm{E}-05$ & $-4.90 \mathrm{E}-05$ \\
\hline 862 & 273.66 & 1.89E-05 & $1.90 \mathrm{E}-05$ & $-6.74 \mathrm{E}-06$ & $-6.74 \mathrm{E}-06$ & $-3.69 \mathrm{E}-05$ & $-3.69 \mathrm{E}-05$ \\
\hline 882 & 323.27 & 1.37E-05 & 1.38E-05 & $-9.72 \mathrm{E}-07$ & $-9.62 \mathrm{E}-07$ & $-3.07 \mathrm{E}-05$ & $-3.07 \mathrm{E}-05$ \\
\hline 902 & 369.20 & $1.40 \mathrm{E}-05$ & $1.41 \mathrm{E}-05$ & $4.12 \mathrm{E}-06$ & $4.13 \mathrm{E}-06$ & $-2.33 \mathrm{E}-05$ & $-2.33 \mathrm{E}-05$ \\
\hline 922 & 419.20 & $4.11 \mathrm{E}-05$ & $4.11 \mathrm{E}-05$ & $-1.17 \mathrm{E}-05$ & $-1.16 \mathrm{E}-05$ & $-1.33 \mathrm{E}-05$ & $-1.33 \mathrm{E}-05$ \\
\hline 237 & 463.02 & & & & & & \\
\hline 257 & 510.03 & & & & & & \\
\hline 277 & 544.44 & & & & & & \\
\hline 297 & 580.53 & & & & & & \\
\hline 317 & 631.08 & & & & & & \\
\hline 337 & 680.34 & & & & & & \\
\hline 357 & 727.44 & & & & & & \\
\hline 377 & 772.93 & & & & & & \\
\hline 397 & 831.34 & & & & & & \\
\hline 417 & 894.09 & & & & & & \\
\hline 2132 & 925.08 & $2.34 \mathrm{E}-05$ & $2.34 \mathrm{E}-05$ & $-1.89 E-06$ & $-1.89 \mathrm{E}-06$ & $-3.60 \mathrm{E}-05$ & $-3.60 \mathrm{E}-05$ \\
\hline 2122 & 935.67 & $5.46 E-05$ & $5.46 \mathrm{E}-05$ & $-2.61 E-05$ & $-2.61 E-05$ & $-9.89 \mathrm{E}-05$ & $-9.88 \mathrm{E}-05$ \\
\hline 2112 & 944.86 & $1.20 \mathrm{E}-04$ & $1.20 \mathrm{E}-04$ & $-5.54 \mathrm{E}-06$ & $-5.54 \mathrm{E}-06$ & $-4.89 \mathrm{E}-05$ & $-4.89 \mathrm{E}-05$ \\
\hline 477 & 968.95 & & & & & & \\
\hline 497 & 1002.45 & & & & & & \\
\hline 517 & 1042.45 & & & & & & \\
\hline 537 & 1108.60 & & & & & & \\
\hline 557 & 1178.35 & & & & & & \\
\hline 577 & 1227.20 & & & & & & \\
\hline 597 & 1271.50 & & & & & & \\
\hline 617 & 1313.65 & & & & & & \\
\hline 637 & 1360.60 & & & & & & \\
\hline
\end{tabular}


RPP-RPT-32239, Rev. 1

M\&D-2008-005-CALC-001, Rev. 1

Table G.19. BES-BEC Concrete Backed Steel Strain, Shell Top, Gravity Plus Seismic Load

AP Backed Steel, Best Estimate Soil, Seismic Only, Best Estimate Tank Concrete, 460 In Waste Level at 1.83SpG

\begin{tabular}{|c|c|c|c|c|c|c|c|}
\hline \multirow{2}{*}{$\begin{array}{c}\text { M\&D } \\
\text { Starting } \\
\text { M\&D } \\
\text { Element } \\
\text { No. }\end{array}$} & \multirow[b]{2}{*}{ Path (in) } & \multicolumn{6}{|c|}{ Shell Top Surface (inside - towards waste) Seismic } \\
\hline & & $\begin{array}{l}\text { AP-460-BES-BEC } \\
\text { EPEL P1 Strain (in/in) } \\
\text { Seismic Top Min }\end{array}$ & \begin{tabular}{|} 
AP-460-BES-BEC \\
EPEL P1 Strain (in/in) \\
Seismic Tap Max
\end{tabular} & $\begin{array}{l}\text { AP-460-BES-BEC } \\
\text { EPEL P2 (in/in) } \\
\text { Seismic Top Min }\end{array}$ & $\begin{array}{l}\text { AP-460-BES-BEC } \\
\text { EPEL P2 Strain (in/in) } \\
\text { Seismic Top Max }\end{array}$ & $\begin{array}{c}\text { AP-460-BES-BEC } \\
\text { EPEL P3 Strain (in/in) } \\
\text { Seismic Top Min }\end{array}$ & $\begin{array}{l}\text { AP-460-BES-BEC } \\
\text { EPEL P3 Strain (in/in) } \\
\text { Seismic Top Max }\end{array}$ \\
\hline 762 & 67.33 & $2.37 \mathrm{E}-05$ & $4.65 \mathrm{E}-05$ & $-5.00 \mathrm{E}-05$ & $-1.42 \mathrm{E}-05$ & $-5.76 \mathrm{E}-05$ & $-2.65 \mathrm{E}-05$ \\
\hline 782 & 105.04 & $3.16 \mathrm{E}-05$ & $5.71 \mathrm{E}-05$ & $-3.97 \mathrm{E}-05$ & $-1.16 \mathrm{E}-05$ & $-8.53 \mathrm{E}-05$ & $-3.43 E-05$ \\
\hline 802 & 136.24 & $2.67 \mathrm{E}-05$ & $4.97 \mathrm{E}-05$ & $-4.15 \mathrm{E}-05$ & $-2.67 \mathrm{E}-06$ & $-7.72 \mathrm{E}-05$ & $-3.12 \mathrm{E}-05$ \\
\hline 822 & 181.71 & $2.56 \mathrm{E}-05$ & $4.39 \mathrm{E}-05$ & $-2.74 \mathrm{E}-05$ & $-1.04 \mathrm{E}-06$ & $-7.52 \mathrm{E}-05$ & $-3.18 \mathrm{E}-05$ \\
\hline 842 & 225.10 & $2.05 \mathrm{E}-05$ & 3.39E-05 & $-3.08 \mathrm{E}-05$ & $1.95 \mathrm{E}-05$ & $-6.46 \mathrm{E}-05$ & $-2.27 \mathrm{E}-05$ \\
\hline 862 & 273.66 & $1.67 \mathrm{E}-05$ & $3.21 \mathrm{E}-05$ & $-1.50 \mathrm{E}-05$ & $1.68 \mathrm{E}-05$ & $-5.78 \mathrm{E}-05$ & $-1.46 \mathrm{E}-05$ \\
\hline 882 & 323.27 & $1.03 E-05$ & $4.60 \mathrm{E}-05$ & $-1.26 \mathrm{E}-05$ & $1.61 \mathrm{E}-05$ & -5.70 E-05 & $-1.25 \mathrm{E}-05$ \\
\hline 902 & 369.20 & $4.61 \mathrm{E}-06$ & $7.34 \mathrm{E}-05$ & $4.30 \mathrm{E}-07$ & $1.35 \mathrm{E}-05$ & $-5.01 E-05$ & $-1.05 \mathrm{E}-06$ \\
\hline 922 & 419.20 & $2.68 \mathrm{E}-05$ & $1.32 \mathrm{E}-04$ & $-1.26 \mathrm{E}-05$ & $7.35 \mathrm{E}-06$ & $-5.54 \mathrm{E}-05$ & $-1.16 \mathrm{E}-06$ \\
\hline 237 & 463.02 & & & & & & \\
\hline 257 & 510.03 & & & & & & \\
\hline 277 & 544.44 & & & & & & \\
\hline 297 & 580.53 & & & & & & \\
\hline 317 & 631.08 & & & & & & \\
\hline 337 & 680.34 & & & & & & \\
\hline 357 & 727.44 & & & & & & \\
\hline 377 & 772.93 & & & & & & \\
\hline 397 & 831.34 & & & & & & \\
\hline 417 & 894.09 & & & & & & \\
\hline 2132 & 925.08 & $2.51 \mathrm{E}-05$ & $3.78 \mathrm{E}-05$ & $-2.99 \mathrm{E}-05$ & $1.03 \mathrm{E}-05$ & $-4.95 E-05$ & $-2.79 E-05$ \\
\hline 2122 & 935.67 & $5.90 \mathrm{E}-05$ & $1.06 \mathrm{E}-04$ & $-2.28 \mathrm{E}-05$ & $5.30 \mathrm{E}-07$ & $-3.75 \mathrm{E}-05$ & $-1.90 \mathrm{E}-05$ \\
\hline 2112 & 944.86 & $6.05 \mathrm{E}-05$ & $1.26 \mathrm{E}-04$ & $-9.28 E-06$ & 2.69E-05 & $-1.98 \mathrm{E}-04$ & $-3.32 E-05$ \\
\hline 477 & 968.95 & & & & & & \\
\hline 497 & 1002.45 & & & & & & \\
\hline 517 & 1042.45 & & & & & & \\
\hline 537 & 1108.60 & & & & & & \\
\hline 557 & 1178.35 & & & & & & \\
\hline 577 & 1227.20 & & & & & & \\
\hline 597 & 1271.50 & & & & & & \\
\hline 617 & 1313.65 & & & & & & \\
\hline 637 & 1360.60 & & & & & & \\
\hline
\end{tabular}


RPP-RPT-32239, Rev. 1

M\&D-2008-005-CALC-001, Rev. 1

Table G.20. BES-BEC Concrete Backed Steel Strain, Shell Middle, Gravity Plus Seismic Load

AP Backed Steel, Best Estimate Soil, Seismic Only, Best Estimate Tank Concrete, 460 In Waste Level at $1.83 \mathrm{SpG}$

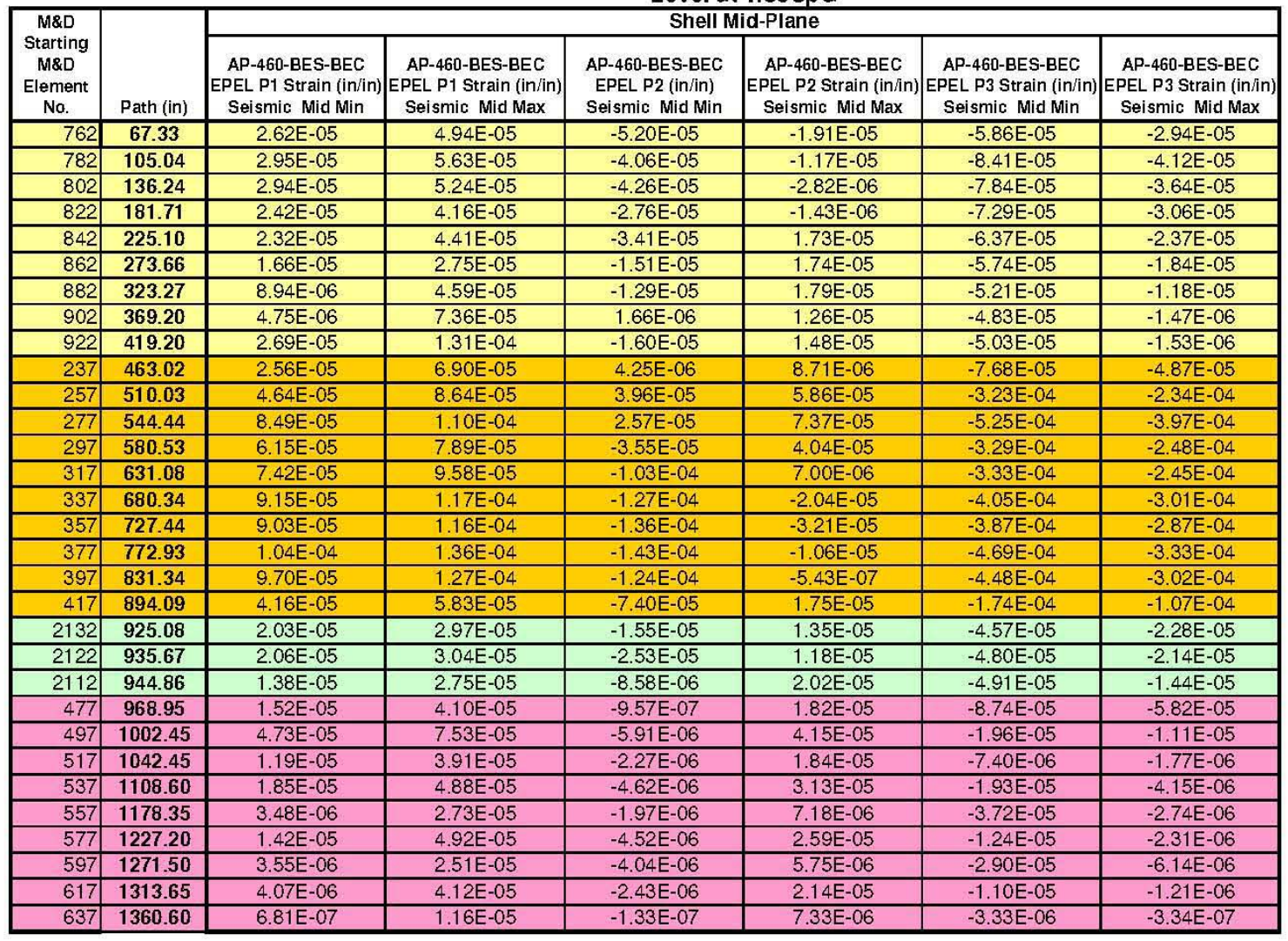


RPP-RPT-32239, Rev. 1

M\&D-2008-005-CALC-001, Rev. 1

Table G.21. BES-BEC Concrete Backed Steel Strain, Shell Bottom, Gravity Plus Seismic Load

AP Backed Steel, Best Estimate Soil, Seismic Only, Best Estimate Tank Concrete, 460 In Waste

Level at 1.83SpG

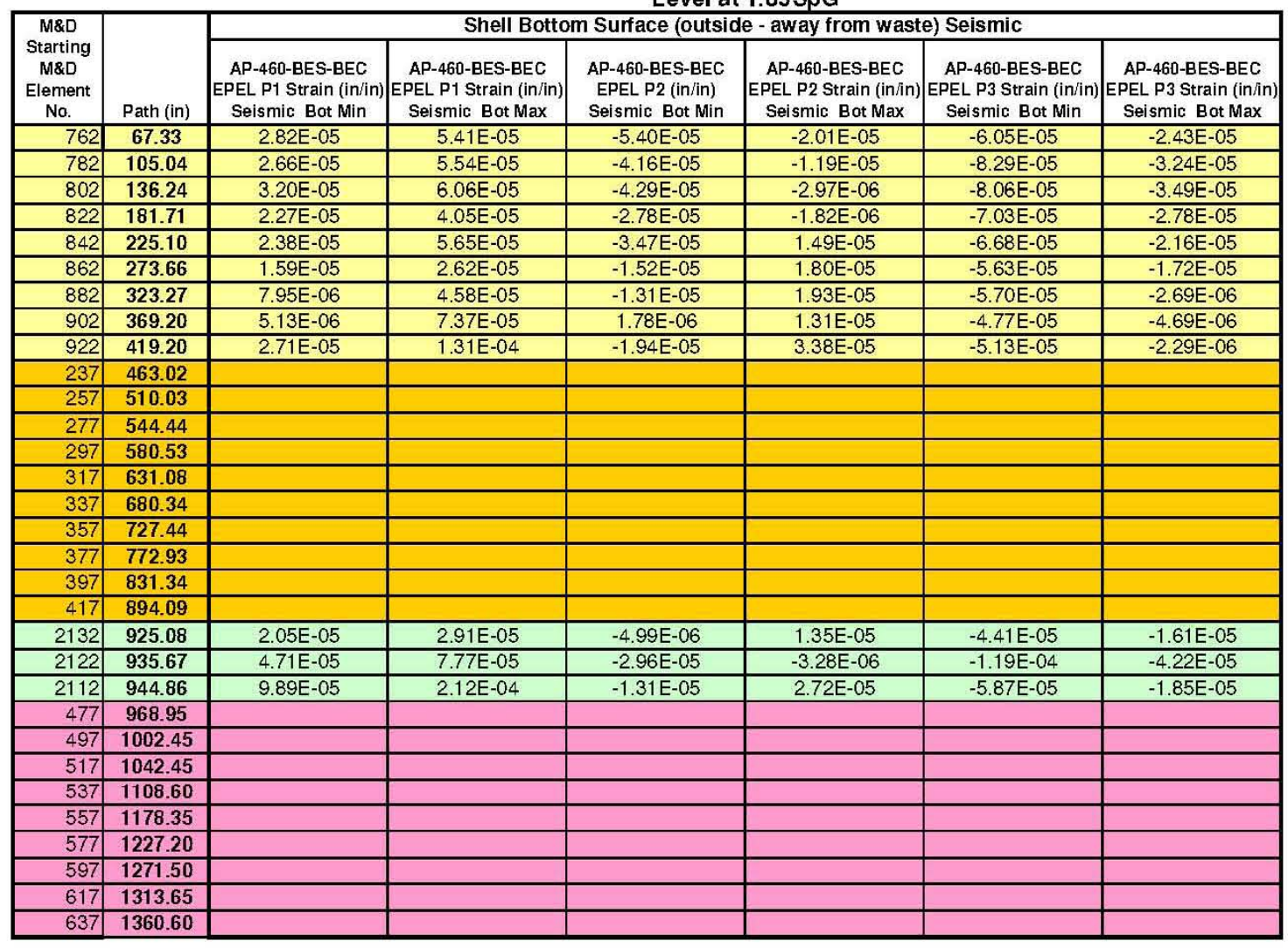


RPP-RPT-32239, Rev. 1

M\&D-2008-005-CALC-001, Rev. 1

Table G.22. BES-BEC Concrete Backed Steel Strain, Shell Top, Seismic Load Only

AP Backed Steel, Best Estimate Soil, Seismic Only, Best Estimate Tank Concrete, 460 In Waste Level at 1.83SpG

\begin{tabular}{|c|c|c|c|c|c|c|c|}
\hline \multirow[b]{2}{*}{$\begin{array}{l}\text { M\&D } \\
\text { Starting } \\
\text { M\&D } \\
\text { Element } \\
\text { No. }\end{array}$} & \multirow[b]{2}{*}{ Path (in) } & \multicolumn{6}{|c|}{ Shell Top Surface (inside - towards waste) Seismic } \\
\hline & & $\begin{array}{l}\text { AP-460-BES-BEC } \\
\text { EPEL P1 Strain (in/in) } \\
\text { Seismic Only Top } \\
\text { Min }\end{array}$ & $\begin{array}{c}\text { AP-460-BES-BEC } \\
\text { EPEL P1 Strain (in/in) } \\
\text { Seismic Only Top } \\
\text { Max }\end{array}$ & $\begin{array}{l}\text { AP-460-BES-BEC } \\
\text { EPEL P2 (in/in) } \\
\text { Seismic Only Top } \\
\text { Min }\end{array}$ & $\begin{array}{c}\text { AP-460-BES-BEC } \\
\text { EPEL P2 Strain (in/in) } \\
\text { Seismic Only Top } \\
\text { Max }\end{array}$ & $\begin{array}{c}\text { AP-460-BES-BEC } \\
\text { EPEL P3 Strain } \\
\text { (in/in) Seismic Only } \\
\text { Tap Min }\end{array}$ & $\begin{array}{c}\text { AP-460-BES-BEC } \\
\text { EPEL P3 Strain (in/in) } \\
\text { Seismic Only Top } \\
\text { Max }\end{array}$ \\
\hline 762 & 67.33 & $-9.92 \mathrm{E}-06$ & $1.28 \mathrm{E}-05$ & $-1.19 \mathrm{E}-05$ & $2.39 \mathrm{E}-05$ & $-1.77 \mathrm{E}-05$ & 1.34E-05 \\
\hline 782 & 105.04 & $-1.05 \mathrm{E}-05$ & $1.50 \mathrm{E}-05$ & $-8.51 E-06$ & $1.96 \mathrm{E}-05$ & $-1.92 \mathrm{E}-05$ & 3.18E-05 \\
\hline 802 & 136.24 & $-9.45 \mathrm{E}-06$ & $1.35 \mathrm{E}-05$ & $-9.68 \mathrm{E}-06$ & $2.91 \mathrm{E}-05$ & $-2.55 \mathrm{E}-05$ & 2.05E-05 \\
\hline 822 & 181.71 & $-6.68 \mathrm{E}-06$ & 1.17E-05 & $-8.55 \mathrm{E}-06$ & $1.78 \mathrm{E}-05$ & $-1.97 \mathrm{E}-05$ & $2.37 \mathrm{E}-05$ \\
\hline 842 & 225.10 & $-5.01 E-06$ & $8.30 \mathrm{E}-06$ & $-1.02 E-05$ & $4.01 \mathrm{E}-05$ & $-2.64 \mathrm{E}-05$ & $1.55 \mathrm{E}-05$ \\
\hline 862 & 273.66 & $-3.34 \mathrm{E}-06$ & $1.21 \mathrm{E}-05$ & $-8.78 \mathrm{E}-06$ & $2.31 \mathrm{E}-05$ & $-1.78 \mathrm{E}-05$ & $2.53 E-05$ \\
\hline 882 & 323.27 & $-1.85 \mathrm{E}-06$ & $3.38 \mathrm{E}-05$ & $-1.19 \mathrm{E}-05$ & $1.68 \mathrm{E}-05$ & $-2.98 E-05$ & $1.47 \mathrm{E}-05$ \\
\hline 902 & 369.20 & $-9.87 E-06$ & 5.89E-05 & $-2.67 \mathrm{E}-06$ & $1.03 E-05$ & $-2.87 \mathrm{E}-05$ & 2.03E-05 \\
\hline 922 & 419.20 & $-1.45 \mathrm{E}-05$ & $9.06 \mathrm{E}-05$ & $-3.73 E-06$ & $1.62 \mathrm{E}-05$ & $-3.51 \mathrm{E}-05$ & $1.91 \mathrm{E}-05$ \\
\hline 237 & 463.02 & & & & & & \\
\hline 257 & 510.03 & & & & & & \\
\hline 277 & 544.44 & & & & & & \\
\hline 297 & 580.53 & & & & & & \\
\hline 317 & 631.08 & & & & & & \\
\hline 337 & 680.34 & & & & & & \\
\hline 357 & 727.44 & & & & & & \\
\hline 377 & 772.93 & & & & & & \\
\hline 397 & 831.34 & & & & & & \\
\hline 417 & 894.09 & & & & & & \\
\hline 2062 & 925.08 & $-3.31 \mathrm{E}-06$ & $9.35 \mathrm{E}-06$ & $-4.02 E-06$ & $3.62 \mathrm{E}-05$ & $-1.34 \mathrm{E}-05$ & $8.11 \mathrm{E}-06$ \\
\hline 2052 & 935.67 & $-1.13 \mathrm{E}-05$ & $3.55 \mathrm{E}-05$ & $-2.87 \mathrm{E}-06$ & $2.04 \mathrm{E}-05$ & $-1.08 \mathrm{E}-05$ & $7.71 \mathrm{E}-06$ \\
\hline 2042 & 944.86 & $-1.31 \mathrm{E}-05$ & $5.21 \mathrm{E}-05$ & $-3.35 E-06$ & $3.28 \mathrm{E}-05$ & $-3.44 \mathrm{E}-05$ & $1.30 \mathrm{E}-04$ \\
\hline 477 & 968.95 & & & & & & \\
\hline 497 & 1002.45 & & & & & & \\
\hline 517 & 1042.45 & & & & & & \\
\hline 537 & 1108.60 & & & & & & \\
\hline 557 & 1178.35 & & & & & & \\
\hline 577 & 1227.20 & & & & & & \\
\hline 597 & 1271.50 & & & & & & \\
\hline 617 & 1313.65 & & & & & & \\
\hline 637 & 1360.60 & & & & & & \\
\hline
\end{tabular}


RPP-RPT-32239, Rev. 1

M\&D-2008-005-CALC-001, Rev. 1

Table G.23. BES-BEC Concrete Backed Steel Strain, Shell Middle, Seismic Load Only

AP Backed Steel, Best Estimate Soil, Seismic Only, Best Estimate Tank Concrete, 460 In Waste Level at $1.83 \mathrm{SpG}$

\begin{tabular}{|c|c|c|c|c|c|c|c|}
\hline \multirow[b]{2}{*}{$\begin{array}{c}\text { M\&D } \\
\text { Starting } \\
\text { M\&D } \\
\text { Element } \\
\text { No. }\end{array}$} & \multirow[b]{2}{*}{ Path (in) } & \multicolumn{6}{|c|}{ Shell Mid-Plane } \\
\hline & & $\begin{array}{l}\text { AP-46U-BES- } \\
\text { BEC EPEL P1 } \\
\text { Strain (in/in) } \\
\text { Seismic Only } \\
\text { Mid Min }\end{array}$ & $\begin{array}{c}\text { AP-460-BES-BEC } \\
\text { EPEL P1 Strain (in/in) } \\
\text { Seismic Only Mid } \\
\text { Max }\end{array}$ & $\begin{array}{l}\text { AP-460-BES-BEC } \\
\text { EPEL P2 (in/in) } \\
\text { Seismic Only Mid } \\
\text { Min }\end{array}$ & $\begin{array}{c}\text { AP-460-BES-BEC } \\
\text { EPEL P2 Strain (in/in) } \\
\text { Seismic Only Mid } \\
\text { Max }\end{array}$ & $\begin{array}{c}\text { AP-460-BES-BEC } \\
\text { EPEL P3 Strain (in/in) } \\
\text { Seismic Only Mid } \\
\text { Min }\end{array}$ & $\begin{array}{c}\text { AP-460-BES-BEC } \\
\text { EPEL P3 Strain (in/in) } \\
\text { Seismic Only Mid } \\
\text { Max }\end{array}$ \\
\hline 762 & 67.33 & $-9.67 \mathrm{E}-06$ & $1.36 \mathrm{E}-05$ & $-1.10 \mathrm{E}-05$ & $2.19 \mathrm{E}-05$ & $-1.63 \mathrm{E}-05$ & $1.29 \mathrm{E}-05$ \\
\hline 782 & 105.04 & $-1.10 \mathrm{E}-05$ & $1.57 \mathrm{E}-05$ & $-8.76 \mathrm{E}-06$ & $2.01 \mathrm{E}-05$ & $-2.21 E-05$ & $2.07 E-05$ \\
\hline 802 & 136.24 & $-9.01 E-06$ & 1.39E-05 & $-1.02 \mathrm{E}-05$ & $2.95 \mathrm{E}-05$ & $-2.20 \mathrm{E}-05$ & $2.00 \mathrm{E}-05$ \\
\hline 842 & 225.10 & $-4.85 \mathrm{E}-06$ & $1.61 \mathrm{E}-05$ & $-1.34 \mathrm{E}-05$ & $3.80 \mathrm{E}-05$ & $-2.01 E-05$ & $1.99 \mathrm{E}-05$ \\
\hline 862 & 273.66 & $-2.95 \mathrm{E}-06$ & $7.98 \mathrm{E}-06$ & $-8.62 E-06$ & $2.39 E-05$ & $-1.90 \mathrm{E}-05$ & $2.01 \mathrm{E}-05$ \\
\hline 882 & 323.27 & $-4.02 \mathrm{E}-06$ & $3.29 E-05$ & $-1.20 \mathrm{E}-05$ & 1.87E-05 & $-2.32 \mathrm{E}-05$ & $1.71 \mathrm{E}-05$ \\
\hline 902 & 369.20 & $-9.50 \mathrm{E}-06$ & $5.93 E-05$ & $-1.95 \mathrm{E}-06$ & $9.00 \mathrm{E}-06$ & $-2.60 \mathrm{E}-05$ & $2.09 E-05$ \\
\hline 922 & 419.20 & $-1.43 E-05$ & $9.02 E-05$ & $-5.64 \mathrm{E}-06$ & $2.52 \mathrm{E}-05$ & $-3.35 \mathrm{E}-05$ & $1.52 \mathrm{E}-05$ \\
\hline 237 & 463.02 & $-1.74 \mathrm{E}-05$ & $2.59 E-05$ & $-1.33 E-06$ & $3.14 \mathrm{E}-06$ & $-1.07 E-05$ & $1.74 \mathrm{E}-05$ \\
\hline 337 & 680.34 & $-1.14 \mathrm{E}-05$ & $1.35 E-05$ & $-1.35 E-05$ & $9.32 \mathrm{E}-05$ & $-5.00 \mathrm{E}-05$ & $5.38 \mathrm{E}-05$ \\
\hline 357 & 727.44 & $-1.16 \mathrm{E}-05$ & $1.37 \mathrm{E}-05$ & $-1.36 \mathrm{E}-05$ & $8.99 E-05$ & $-4.46 E-05$ & $5.53 \mathrm{E}-05$ \\
\hline 377 & 772.93 & $-1.47 \mathrm{E}-05$ & $1.66 \mathrm{E}-05$ & $-1.41 \mathrm{E}-05$ & $1.18 \mathrm{E}-04$ & $-5.53 E-05$ & $8.08 E-05$ \\
\hline 397 & 831.34 & $-1.45 \mathrm{E}-05$ & $1.54 \mathrm{E}-05$ & $-1.19 \mathrm{E}-05$ & $1.12 \mathrm{E}-04$ & $-5.14 \mathrm{E}-05$ & $9.42 \mathrm{E}-05$ \\
\hline 417 & 894.09 & $-6.37 \mathrm{E}-06$ & $1.03 E-05$ & $-6.74 \mathrm{E}-06$ & $8.47 \mathrm{E}-05$ & $-2.38 E-05$ & $4.35 \mathrm{E}-05$ \\
\hline 2062 & 925.08 & $-3.20 \mathrm{E}-06$ & $6.19 \mathrm{E}-06$ & $-3.89 E-06$ & $2.50 \mathrm{E}-05$ & $-9.65 E-06$ & $1.32 \mathrm{E}-05$ \\
\hline 2052 & 935.67 & $-3.27 E-06$ & $6.59 \mathrm{E}-06$ & $-4.31 E-06$ & $3.28 \mathrm{E}-05$ & $-2.16 \mathrm{E}-05$ & $5.03 E-06$ \\
\hline 2042 & 944.86 & $-2.58 \mathrm{E}-06$ & $1.11 \mathrm{E}-05$ & $-2.85 E-06$ & $2.59 \mathrm{E}-05$ & $-2.25 E-05$ & $1.22 \mathrm{E}-05$ \\
\hline 477 & 968.95 & $-2.36 \mathrm{E}-06$ & $2.34 \mathrm{E}-05$ & $-8.03 E-06$ & $1.11 \mathrm{E}-05$ & $-1.05 E-05$ & 1.87E-05 \\
\hline 497 & 1002.45 & $-9.10 \mathrm{E}-06$ & $1.88 \mathrm{E}-05$ & $-1.62 \mathrm{E}-05$ & $3.12 \mathrm{E}-05$ & $-3.02 E-06$ & $5.48 \mathrm{E}-06$ \\
\hline 517 & 1042.45 & $-2.07 E-06$ & $2.51 \mathrm{E}-05$ & $-1.10 \mathrm{E}-05$ & $9.62 \mathrm{E}-06$ & $-2.44 \mathrm{E}-06$ & $3.19 \mathrm{E}-06$ \\
\hline
\end{tabular}




\section{RPP-RPT-32239, Rev. 1 \\ M\&D-2008-005-CALC-001, Rev. 1}

Table G.24. BES-BEC Concrete Backed Steel Strain, Shell Bottom, Seismic Load Only

AP Backed Steel, Best Estimate Soil, Seismic Only, Best Estimate Tank Concrete, 460 In Waste Level at $1.83 \mathrm{SpG}$

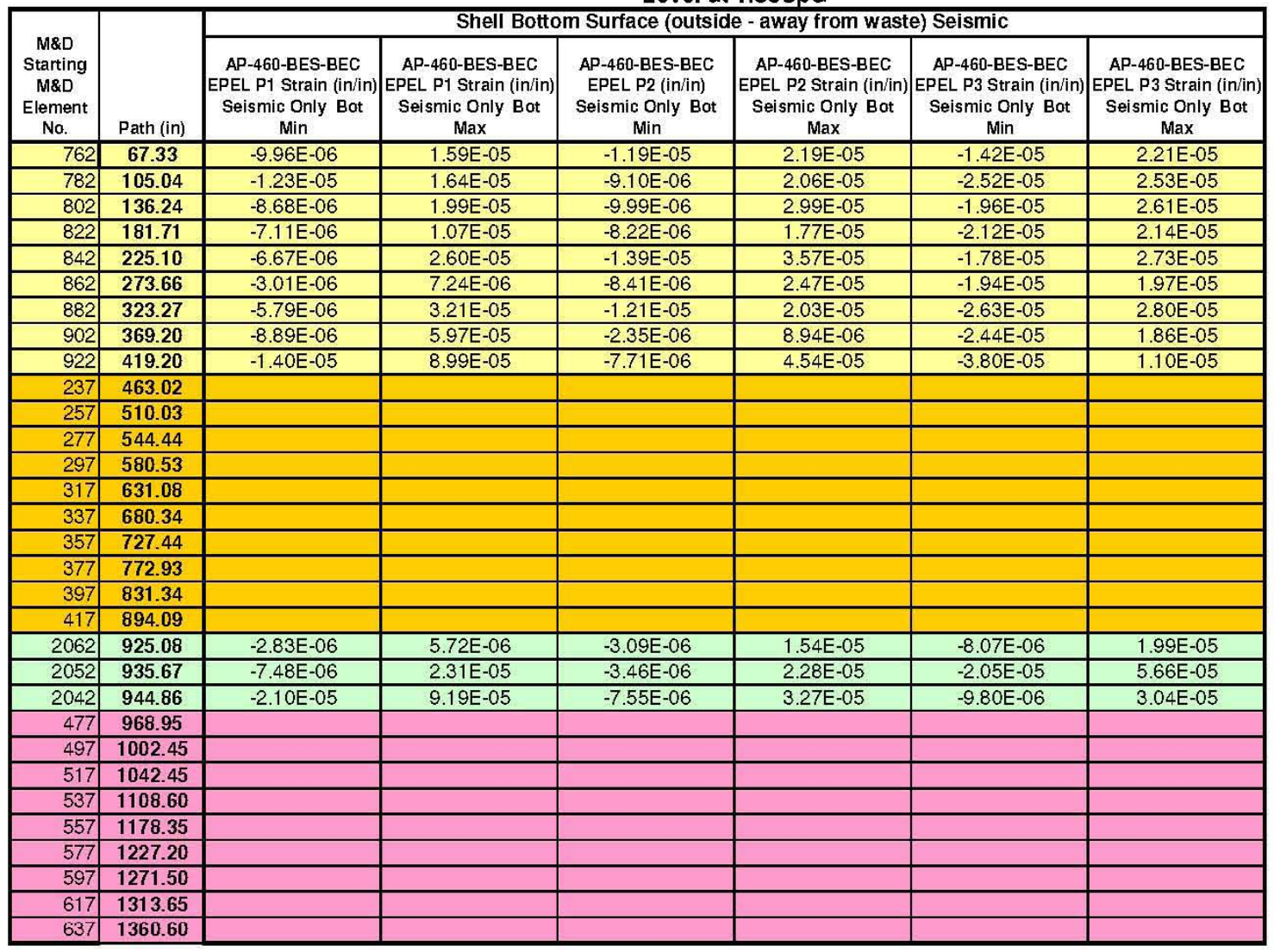


RPP-RPT-32239, Rev. 1

M\&D-2008-005-CALC-001, Rev. 1

Table G.25. BES-BEC Concrete Wall/Footing Contact Forces, Gravity Only

Tank AY, 460 Inch Waste Leve

$\mathrm{SpG}=1.83$

Best Estimate Soil

Best Estimate Concrete

\begin{tabular}{|c|c|c|c|c|c|c|c|c|c|c|c|}
\hline Angle & $\begin{array}{l}\text { Vertical } \\
\text { Min AP- } \\
\text { BES-BEC } \\
\text { Gravity }\end{array}$ & $\begin{array}{l}\text { Vertical } \\
\text { Max AP- } \\
\text { BES-BEC } \\
\text { Gravity }\end{array}$ & $\begin{array}{l}\text { Shear Y } \\
\text { Min AP- } \\
\text { BES-BEC } \\
\text { Gravity }\end{array}$ & $\begin{array}{l}\text { Shear Y } \\
\text { Max AP- } \\
\text { BES-BEC } \\
\text { Gravity }\end{array}$ & $\begin{array}{l}\text { Shear X } \\
\text { Min AP- } \\
\text { BES-BEC } \\
\text { Gravity }\end{array}$ & $\begin{array}{l}\text { Shear X } \\
\text { Max AP- } \\
\text { BES-BEC } \\
\text { Gravity }\end{array}$ & $\begin{array}{l}\text { Shear Y } \\
\text { Max AP- } \\
\text { BES-BEC } \\
\text { Gravity }\end{array}$ & $\begin{array}{l}\text { Shear X } \\
\text { Max AP- } \\
\text { BES-BEC } \\
\text { Gravity }\end{array}$ & $\begin{array}{l}\text { Shear } \\
\text { Max AP- } \\
\text { BES-BEC } \\
\text { Gravity }\end{array}$ & $\begin{array}{l}\text { Vertical Force } \\
\text { Max AP-BES- } \\
\text { BEC Gravity }\end{array}$ & $\begin{array}{l}\text { Vertical Force } \\
\text { Min AP-BES- } \\
\text { BEC Gravity }\end{array}$ \\
\hline 0 & -214.80 & -214.60 & 0.00 & 0.00 & -1.16 & -1.16 & 0.00 & 0.36 & 0.36 & -67.13 & -67.06 \\
\hline 9 & -429.60 & -429.20 & -0.44 & -0.43 & -2.34 & -2.33 & 0.07 & 0.37 & 0.37 & -67.13 & -67.06 \\
\hline 18 & -429.60 & -429.20 & -0.48 & -0.48 & -2.19 & -2.19 & 0.07 & 0.34 & 0.35 & -67.13 & -67.06 \\
\hline 27 & -429.60 & -429.20 & -0.75 & -0.74 & -2.09 & -2.08 & 0.12 & 0.33 & 0.35 & -67.13 & -67.06 \\
\hline 36 & -429.60 & -429.20 & -1.45 & -1.45 & -1.91 & -1.90 & 0.23 & 0.30 & 0.37 & -67.13 & -67.06 \\
\hline 45 & -429.60 & -429.20 & -1.64 & -1.64 & -1.64 & -1.64 & 0.26 & 0.26 & 0.36 & -67.13 & -67.06 \\
\hline 54 & -429.50 & -429.10 & -1.93 & -1.92 & -1.46 & -1.46 & 0.30 & 0.23 & 0.38 & -67.11 & -67.05 \\
\hline 63 & -429.50 & -429.10 & -2.03 & -2.02 & -1.08 & -1.08 & 0.32 & 0.17 & 0.36 & -67.11 & -67.05 \\
\hline 72 & -429.60 & -429.20 & -2.29 & -2.29 & -0.72 & -0.72 & 0.36 & 0.11 & 0.38 & -67.13 & -67.06 \\
\hline 81 & -429.50 & -429.10 & -2.17 & -2.16 & -0.44 & -0.44 & 0.34 & 0.07 & 0.35 & -67.11 & -67.05 \\
\hline 90 & -429.50 & -429.10 & -2.39 & -2.39 & 0.04 & 0.04 & 0.37 & 0.01 & 0.37 & -67.11 & -67.05 \\
\hline 99 & -429.60 & -429.10 & -2.34 & -2.33 & 0.42 & 0.42 & 0.37 & 0.07 & 0.37 & -67.13 & -67.05 \\
\hline 108 & -429.50 & -429.10 & -2.14 & -2.13 & 0.57 & 0.58 & 0.33 & 0.09 & 0.35 & -67.11 & -67.05 \\
\hline 117 & -429.60 & -429.20 & -2.10 & -2.10 & 1.14 & 1.14 & 0.33 & 0.18 & 0.37 & -67.13 & -67.06 \\
\hline 126 & -429.60 & -429.20 & -1.82 & -1.82 & 1.41 & 1.42 & 0.28 & 0.22 & 0.36 & -67.13 & -67.06 \\
\hline 135 & -429.60 & -429.20 & -1.62 & -1.61 & 1.74 & 1.75 & 50.25 & 0.27 & 0.37 & -67.13 & -67.06 \\
\hline 144 & -429.50 & -429.10 & -1.35 & -1.35 & 1.95 & 1.95 & 50.21 & 0.30 & 0.37 & -67.11 & -67.05 \\
\hline 153 & -429.60 & -429.20 & -1.06 & -1.06 & 2.10 & 2.11 & 0.17 & 0.33 & 0.37 & -67.13 & -67.06 \\
\hline 162 & -429.60 & -429.20 & -0.68 & -0.68 & 2.22 & 2.23 & 0.11 & 0.35 & 0.36 & -67.13 & -67.06 \\
\hline 171 & -429.60 & -429.20 & -0.32 & -0.32 & 2.33 & 2.34 & 0.05 & 0.37 & 0.37 & -67.13 & -67.06 \\
\hline 180 & -214.80 & -214.60 & 0.00 & 0.00 & 1.18 & 1.18 & 30.00 & 0.37 & 0.37 & -67.13 & -67.06 \\
\hline
\end{tabular}


RPP-RPT-32239, Rev. 1

M\&D-2008-005-CALC-001, Rev. 1

Table G.26. BES-BEC Concrete Wall/Footing Contact Forces, Gravity Plus Seismic

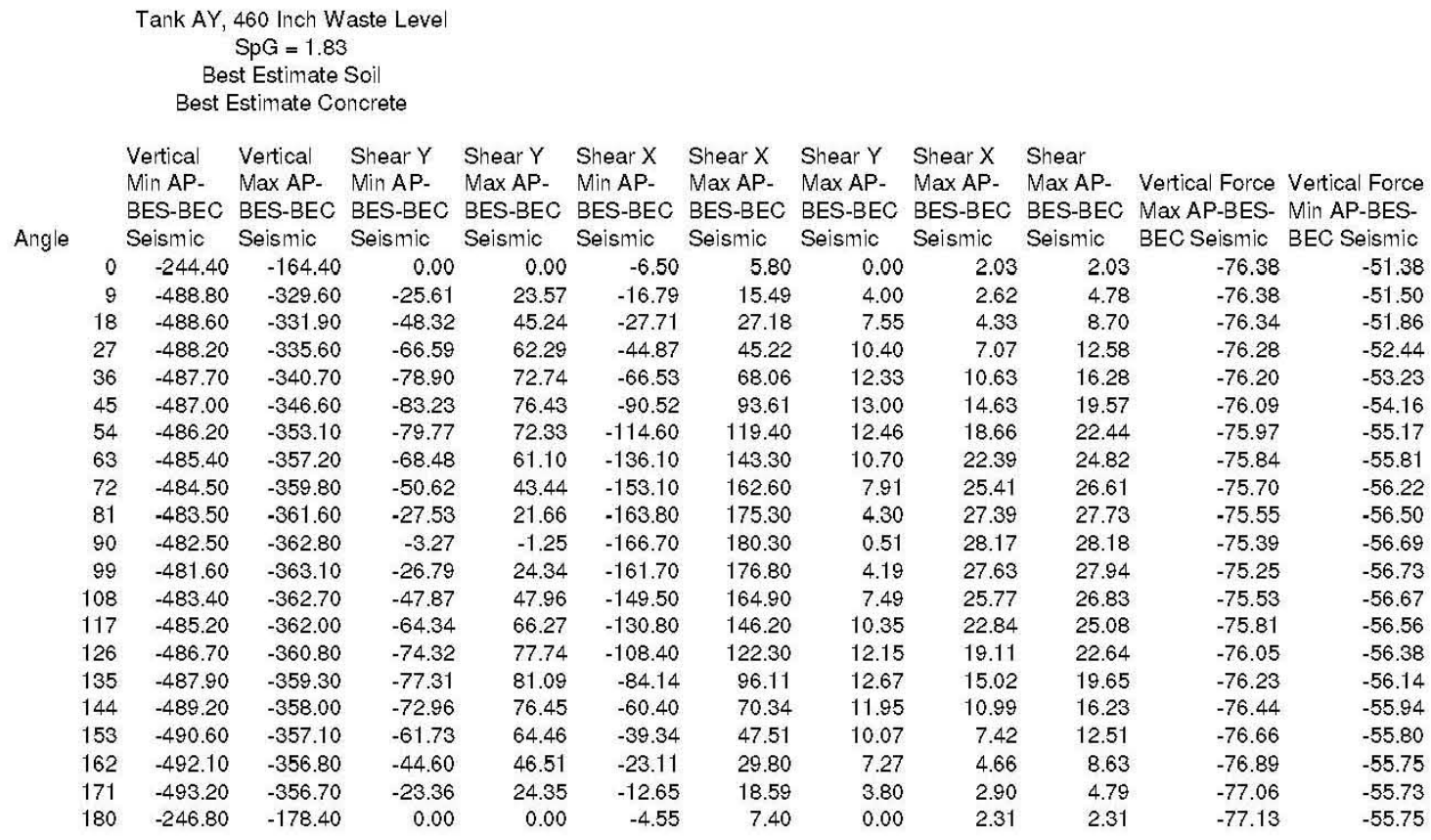


RPP-RPT-32239, Rev. 1

M\&D-2008-005-CALC-001, Rev. 1

Table G.27. BES-BEC Concrete Wall/Footing Contact Forces, Seismic Only

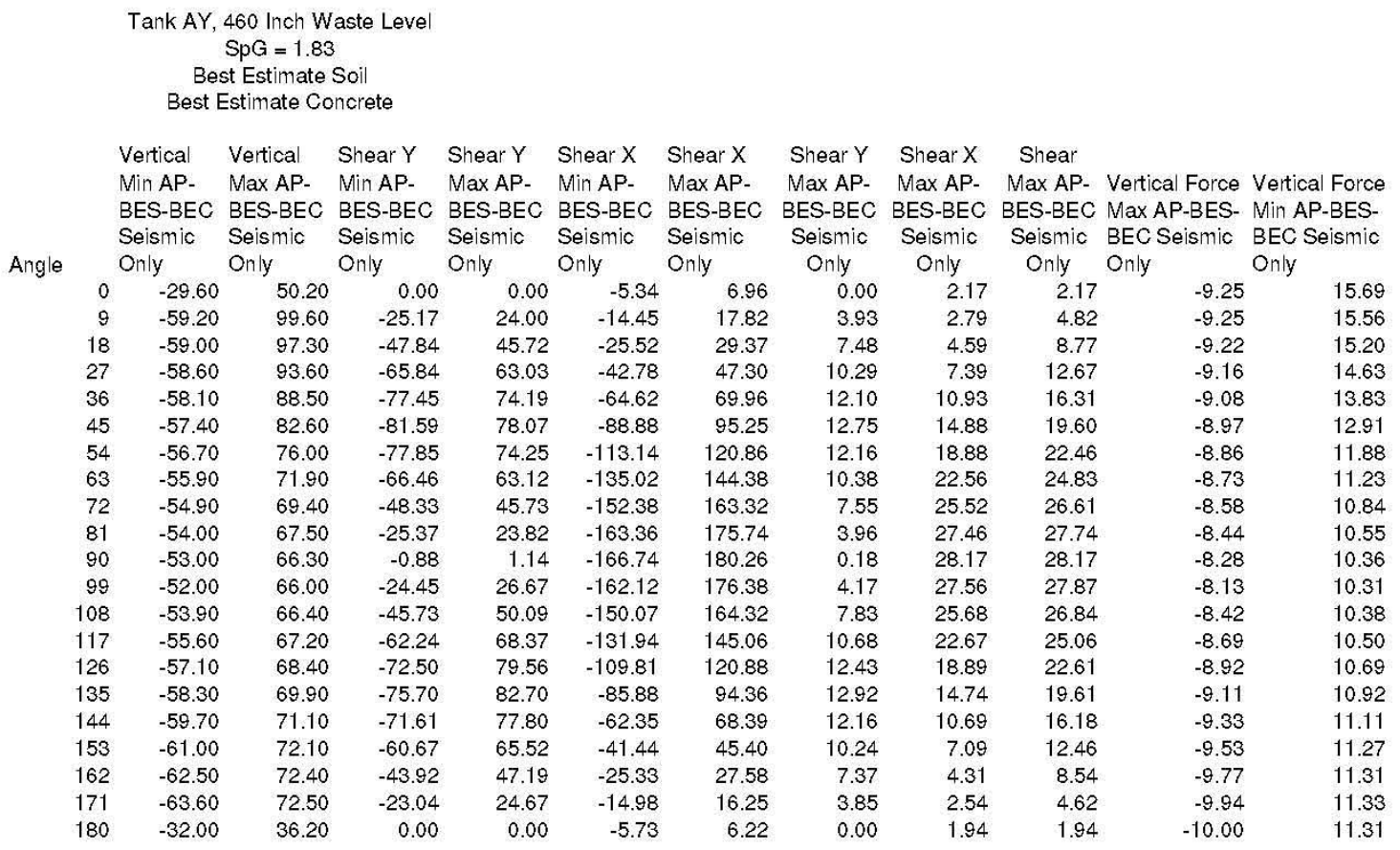


RPP-RPT-32239, Rev. 1

M\&D-2008-005-CALC-001, Rev. 1

Table G.28. BES-BEC Soil/Concrete Tank Contact Forces, Gravity Only

Tank AP, 460 Inch Waste Level

$S p G=1.83$

Best Estimate Concrete

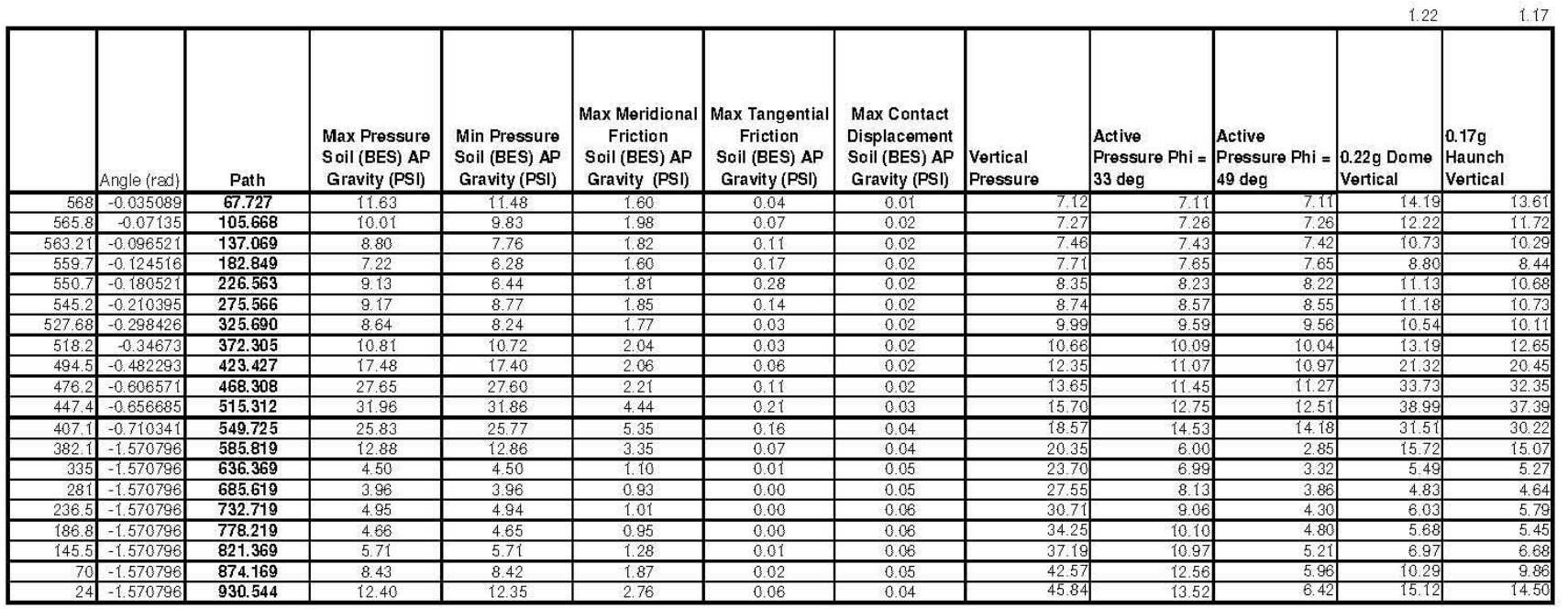


RPP-RPT-32239, Rev. 1

M\&D-2008-005-CALC-001, Rev. 1

Table G.29. BES-BEC Soil/Concrete Tank Contact Forces, Gravity Plus Seismic

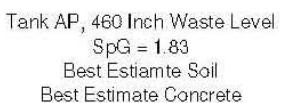

\begin{tabular}{|c|c|c|c|c|c|c|c|c|c|c|}
\hline & Angle (rad) & Path & $\begin{array}{l}\text { Max Pressure } \\
\text { Soil (BES) AP } \\
\text { Seismic (PSI) }\end{array}$ & $\begin{array}{l}\text { Min Pressure } \\
\text { Soil (BES) AP } \\
\text { Seismic (PSI) }\end{array}$ & $\begin{array}{l}\text { Max Meridional } \\
\text { Friction } \\
\text { Soil (BES) AP } \\
\text { Seismic (PSI) }\end{array}$ & $\begin{array}{l}\text { Max Tangential } \\
\text { Friction } \\
\text { Soil (BES) AP } \\
\text { Seismic (PSI) }\end{array}$ & $\begin{array}{l}\text { Max Contact } \\
\text { Displacement } \\
\text { Soil (BES) AP } \\
\text { Seismic (inch) }\end{array}$ & $\begin{array}{l}\text { Vertical } \\
\text { Pressure }\end{array}$ & \begin{tabular}{|l} 
Active \\
Pressure Phi $=$ \\
33 deg
\end{tabular} & $\begin{array}{l}\text { Active } \\
\text { Pressure Phi = } \\
49 \text { deg }\end{array}$ \\
\hline 568 & -0.035089 & 67.727 & 19.56 & 290 & 7.42 & 5.24 & 0.03 & 7.12 & 7.11 & 7.11 \\
\hline 565.8 & -0.07135 & 105.668 & 16.92 & 3.56 & 6.97 & 3.94 & 0.03 & 7.27 & 7.26 & 7.26 \\
\hline 563.21 & $-n n 96521$ & 137.069 & 13.97 & 2.25 & 5.64 & 3.20 & 003 & 7.46 & 7.43 & 7.42 \\
\hline 5597 & -0.124516 & 182.849 & 10.26 & 3.75 & 4.55 & 3.54 & 0.03 & 7.71 & 7.65 & 7.65 \\
\hline 550.7 & -0.180521 & 226.563 & 14.65 & 3.75 & 3.97 & 4.55 & 0.03 & 8.35 & 8.23 & 8.22 \\
\hline 545.2 & -0.210395 & 275.566 & 11.66 & 5.97 & 4.65 & 4.41 & 0.03 & 8.74 & 8.57 & 8.55 \\
\hline 527.68 & -0.298426 & 325.690 & 10.22 & 6.15 & 4.23 & 3.76 & 0.03 & 999 & 9.59 & 9.56 \\
\hline 518.2 & -0.34673 & 372.305 & 12.73 & 8.69 & 3.81 & 3.45 & 0.02 & 10.66 & 10.09 & 10.04 \\
\hline 494.5 & \begin{tabular}{|c|}
-0.482293 \\
\end{tabular} & 423.427 & 20.78 & 14.57 & 3.96 & 2.86 & 0.02 & 12.35 & 11.07 & 10.97 \\
\hline 476.2 & -0.606571 & 468.308 & 34.52 & 21.40 & 4.71 & 2.88 & 0.02 & 13.65 & 11.45 & 11.27 \\
\hline 447.4 & -0.656685 & 515.312 & 37.42 & 27.36 & 9.98 & 2.80 & 0.04 & 15.70 & 12.75 & 12.51 \\
\hline 407.1 & -0.710341 & 549.725 & 30.17 & 21.50 & 12.74 & 2.23 & 0.06 & 18.57 & 14.53 & 14.18 \\
\hline 382.1 & -1.570796 & 585.819 & 14.94 & 10.65 & 8.51 & 1.54 & 0.06 & 20.35 & 6.00 & 2.85 \\
\hline 335 & \begin{tabular}{|l|}
-1.570796 \\
\end{tabular} & 636.369 & 5.22 & 3.96 & 3.65 & 1.39 & 0.08 & 23.70 & 6.99 & 3.32 \\
\hline 281 & -1.570796 & 685.619 & 4.60 & 3.34 & 3.13 & 1.56 & 0.09 & 27.55 & 8.13 & 3.86 \\
\hline 236.5 & \begin{tabular}{|l|}
-1.570796 \\
\end{tabular} & 732.719 & 5.58 & 4.37 & 3.25 & 1.54 & 0.09 & 30.71 & 9.06 & 4.30 \\
\hline 186.8 & -1.570796 & 778.219 & 5.18 & 4.04 & 2.99 & 2.02 & 0.09 & 34.25 & 10.10 & 4.80 \\
\hline 145.5 & -1.570796 & 821.369 & 6.51 & 4.98 & 4.40 & 2.92 & 0.08 & 37.19 & 10.97 & 5.21 \\
\hline 70 & \begin{tabular}{|l|}
-1.570796 \\
\end{tabular} & 874.169 & 11.69 & 4.74 & 7.17 & 3.15 & 0.07 & 42.57 & 12.56 & 5.96 \\
\hline 24 & -1.570796 & 930.544 & 20.17 & 3.45 & 6.35 & 3.00 & 0.05 & 45.84 & 13.52 & 6.42 \\
\hline
\end{tabular}


RPP-RPT-32239, Rev. 1

M\&D-2008-005-CALC-001, Rev. 1

Table G.30. BES-BEC Soil/Concrete Tank Contact Forces, Seismic Only

Tank AP, 460 Inch Waste Leve

$\mathrm{SpG}=1.83$

Best Estiamte Soil

Best Estimate Concrete

\begin{tabular}{|c|c|c|c|c|c|c|c|}
\hline 565.8 & -0.07135 & 105.668 & 6.91 & -6.45 & 4.99 & 3.88 & 0.01 \\
\hline 563.21 & -0.096521 & 137.069 & 5.17 & -6.55 & 3.82 & 3.09 & 0.01 \\
\hline 559.7 & -0.124516 & 182.849 & 3.04 & -3.46 & 2.94 & 3.37 & 0.01 \\
\hline 550.7 & -0.180521 & 226.563 & 5.53 & -5.37 & 2.16 & 4.27 & 0.01 \\
\hline 545.2 & -0.210395 & 275.566 & 2.49 & -3.20 & 2.80 & 4.27 & 0.01 \\
\hline 527.68 & -0.298426 & 325.690 & 1.58 & -2.49 & 2.46 & 3.73 & 0.01 \\
\hline 447.4 & -0.656685 & 515.312 & 5.47 & -4.60 & 5.54 & 2.60 & 0.01 \\
\hline 407.1 & -0.710341 & 549.725 & 4.34 & -4.33 & 7.40 & 2.07 & 0.02 \\
\hline 382.1 & -1.570796 & 585.819 & 2.06 & -2.24 & 5.16 & 1.47 & 0.02 \\
\hline 335 & -1.570796 & 636.369 & 0.72 & -0.54 & 2.55 & 1.38 & 0.03 \\
\hline 281 & -1.570796 & 685.619 & 0.64 & -0.63 & 2.20 & 1.56 & 0.03 \\
\hline 236.5 & -1.570796 & 732.719 & 0.64 & -0.58 & 2.24 & 1.53 & 0.03 \\
\hline 186.8 & -1.570796 & 778.219 & 0.52 & -0.62 & 2.04 & 2.02 & 0.03 \\
\hline 145.5 & -1.570796 & 821.369 & 0.80 & -0.73 & 3.12 & 2.91 & 0.03 \\
\hline 70 & -1.570796 & 874.169 & 3.26 & -3.69 & 5.30 & 3.13 & 0.02 \\
\hline 24 & -1.570796 & 930.544 & 7.78 & -8.95 & 3.60 & 2.95 & 0.01 \\
\hline
\end{tabular}


RPP-RPT-32239, Rev. 1

M\&D-2008-005-CALC-001, Rev. 1

Table G.31. BES-BEC Primary Tank/Concrete Dome Contact Data, Gravity Only

\author{
Tank AP, 460 Inch Waste Level$$
\mathrm{SpG}=1.83
$$ \\ Best Estimate Soil \\ Best Estimate Concrete
}

\begin{tabular}{|c|c|c|c|c|}
\hline & $\begin{array}{c}\text { Max Pressure } \\
\text { Primary } \\
\text { Tank/Concrete } \\
\text { Tank Dome AP } \\
\text { Gravity (PSI) }\end{array}$ & $\begin{array}{c}\text { Min Pressure } \\
\text { Primary } \\
\text { Tank/Concrete } \\
\text { Tank Dome AP } \\
\text { Gravity (PSI) }\end{array}$ & $\begin{array}{c}\text { Max Gap } \\
\text { Lateral } \\
\text { Displacement } \\
\text { Primary Tank } \\
\text { /Concrete } \\
\text { Tank Dome } \\
\text { Gravity (in) }\end{array}$ & $\begin{array}{c}\text { Max Gap Displacement } \\
\text { Primary Tank/Concete Tank } \\
\text { Dome AP } \\
\text { Gravity (Inches) }\end{array}$ \\
\hline Radius & 0.959 & 0.916 & 0.003014 & 0.000000 \\
\hline $\mathbf{6 7 . 7 2 7}$ & 0.901 & 0.883 & 0.004594 & 0.000000 \\
\hline $\mathbf{1 0 5 . 6 6 8}$ & 0.263 & 0.245 & 0.002545 & -0.000011 \\
\hline $\mathbf{1 3 7 . 0 6 9}$ & 0.591 & 0.585 & 0.003366 & -0.000015 \\
\hline $\mathbf{1 8 2 . 8 4 9}$ & 0.843 & 0.805 & 0.004369 & -0.000124 \\
\hline $\mathbf{2 2 6 . 5 6 3}$ & 0.227 & 0.216 & 0.005150 & -0.000025 \\
\hline $\mathbf{2 7 5 . 5 6 6}$ & 0.659 & 0.648 & 0.006431 & -0.000623 \\
\hline $\mathbf{3 2 5 . 6 9 0}$ & 0.000 & 0.000 & 0.000000 & -0.001489 \\
\hline $\mathbf{3 7 2 . 3 0 5}$ & 0.000 & 0.000 & 0.000000 & -1.060800 \\
\hline $\mathbf{4 2 3 . 4 2 7}$ & & & & \\
\hline
\end{tabular}


RPP-RPT-32239, Rev. 1

M\&D-2008-005-CALC-001, Rev. 1

Table G.32. BES-BEC Primary Tank/Concrete Dome Contact Data, Gravity Plus Seismic

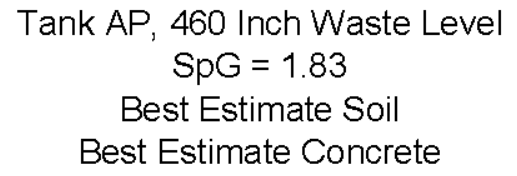

\begin{tabular}{|c|c|c|c|c|}
\hline & $\begin{array}{c}\text { Max Pressure } \\
\text { Primary } \\
\text { Tank/Concrete } \\
\text { Tank Dome AP } \\
\text { Seismic (PSI) }\end{array}$ & $\begin{array}{c}\text { Min Pressure } \\
\text { Primary } \\
\text { Tank/Concrete } \\
\text { Tank Dome AP } \\
\text { Seismic (PSI) }\end{array}$ & $\begin{array}{c}\text { Max Gap } \\
\text { Lateral } \\
\text { Displacement } \\
\text { Primary Tank } \\
\text { /Concrete } \\
\text { Tank Dome } \\
\text { Seismic (in) }\end{array}$ & $\begin{array}{c}\text { Max Gap Displacement } \\
\text { Primary Tank/Concete Tank } \\
\text { Dome AP } \\
\text { Seismic (Inches) }\end{array}$ \\
\hline Radius & 8.785 & 0.215 & 0.010040 & -0.000055 \\
\hline $\mathbf{6 7 . 7 2 7}$ & 5.176 & 0.043 & 0.010741 & -0.000074 \\
\hline $\mathbf{1 0 5 . 6 6 8}$ & 8.813 & 0.000 & 0.015468 & -0.000195 \\
\hline $\mathbf{1 3 7 . 0 6 9}$ & 6.749 & 0.000 & 0.022668 & -0.000867 \\
\hline $\mathbf{1 8 2 . 8 4 9}$ & 3.673 & 0.000 & 0.013956 & -0.002641 \\
\hline $\mathbf{2 2 6 . 5 6 3}$ & 5.413 & 0.000 & 0.017100 & -0.003173 \\
\hline $\mathbf{2 7 5 . 5 6 6}$ & 11.097 & 0.000 & 0.010916 & -0.003451 \\
\hline $\mathbf{3 2 5 . 6 9 0}$ & 6.685 & 0.000 & 0.052536 & -0.007267 \\
\hline $\mathbf{3 7 2 . 3 0 5}$ & 2.430 & 0.000 & 0.000000 & -1.071000 \\
\hline $\mathbf{4 2 3 . 4 2 7}$ & & & & \\
\hline
\end{tabular}


RPP-RPT-32239, Rev. 1

M\&D-2008-005-CALC-001, Rev. 1

Table G.33. BES-BEC Primary Tank/Concrete Dome Contact Data, Seismic Only

\author{
Tank AP, 460 Inch Waste Level \\ $\mathrm{SpG}=1.83$ \\ Best Estimate Soil \\ Best Estimate Concrete
}

\begin{tabular}{|c|c|c|c|c|}
\hline & $\begin{array}{c}\text { Max Pressure } \\
\text { Primary } \\
\text { Tank/Concrete } \\
\text { Tank Dome AP } \\
\text { Seismic Only } \\
\text { (PSI) }\end{array}$ & $\begin{array}{c}\text { Min Pressure } \\
\text { Primary } \\
\text { Tank/Concrete } \\
\text { Tank Dome AP } \\
\text { Seismic Only } \\
\text { (PSI) }\end{array}$ & $\begin{array}{c}\text { Max Gap } \\
\text { Lateral } \\
\text { Displacement } \\
\text { Primary Tank } \\
\text { /Concrete } \\
\text { Tank Dome } \\
\text { Seismic Only } \\
\text { (in) }\end{array}$ & $\begin{array}{c}\text { Max Gap Displacement } \\
\text { Primary Tank/Concete Tank } \\
\text { Dome AP } \\
\text { Seismic Only (Inches) }\end{array}$ \\
\hline $\mathbf{6 7 . 7 2 7}$ & 7.826 & -0.701 & 0.007026 & -0.000055 \\
\hline $\mathbf{1 0 5 . 6 6 8}$ & 4.276 & -0.840 & 0.006148 & -0.000074 \\
\hline $\mathbf{1 3 7 . 0 6 9}$ & 8.550 & -0.245 & 0.012923 & -0.000183 \\
\hline $\mathbf{1 8 2 . 8 4 9}$ & 6.158 & -0.585 & 0.019302 & -0.000851 \\
\hline $\mathbf{2 2 6 . 5 6 3}$ & 2.830 & -0.805 & 0.009587 & -0.002517 \\
\hline $\mathbf{2 7 5 . 5 6 6}$ & 5.186 & -0.216 & 0.011950 & -0.003148 \\
\hline $\mathbf{3 2 5 . 6 9 0}$ & 10.438 & -0.648 & 0.004486 & -0.002828 \\
\hline $\mathbf{3 7 2 . 3 0 5}$ & 6.685 & 0.000 & 0.052536 & -0.005778 \\
\hline $\mathbf{4 2 3 . 4 2 7}$ & 2.430 & 0.000 & 0.000000 & -0.010200 \\
\hline
\end{tabular}


RPP-RPT-32239, Rev. 1

M\&D-2008-005-CALC-001, Rev. 1

Table G.34. BES-BEC Primary Tank/Insulating Concrete Contact Forces, Gravity Only

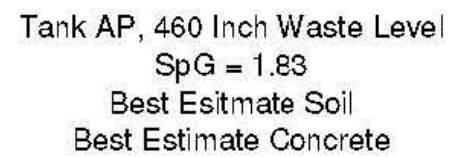

\begin{tabular}{|c|c|c|c|c|}
\hline & $\begin{array}{c}\text { Max Pressure } \\
\text { Primary } \\
\text { Tank/nsulating } \\
\text { Concrete AP } \\
\text { Gravity (PSI) }\end{array}$ & $\begin{array}{c}\text { Min Pressure } \\
\text { Primary } \\
\text { Tank/Insulating } \\
\text { Concrete AP } \\
\text { Gravity (PSI) }\end{array}$ & $\begin{array}{c}\text { Max Lateral } \\
\text { Displacement } \\
\text { Primary Tank/ } \\
\text { Insulating Concete AP Aravity (Inches) } \\
\text { Gadius }\end{array}$ & $\begin{array}{c}\text { Min Lateral } \\
\text { Displacement } \\
\text { Primary Tank/Insulating } \\
\text { Concete AP } \\
\text { Gravity (Inches) }\end{array}$ \\
\hline 424.00 & 72.708 & 72.639 & 0.008764 & 0.008744 \\
\hline 384.00 & 13.465 & 13.451 & 0.000326 & 0.000267 \\
\hline $\mathbf{3 1 7 . 8 5}$ & 33.285 & 33.250 & 0.002755 & 0.002741 \\
\hline $\mathbf{2 4 8 . 1 0}$ & 29.729 & 29.701 & 0.002479 & 0.002467 \\
\hline $\mathbf{1 9 9 . 2 5}$ & 30.750 & 30.722 & 0.001744 & 0.001735 \\
\hline $\mathbf{1 5 4 . 9 5}$ & 30.479 & 30.451 & 0.000997 & 0.000990 \\
\hline $\mathbf{1 1 2 . 8 0}$ & 30.444 & 30.417 & 0.000156 & 0.000150 \\
\hline $\mathbf{6 5 . 8 5}$ & 30.979 & 30.917 & 0.000304 & 0.000291 \\
\hline
\end{tabular}


RPP-RPT-32239, Rev. 1

M\&D-2008-005-CALC-001, Rev. 1

Table G.35. BES-BEC Primary Tank/Insulating Concrete Contact Data, Gravity Plus Seismic

Tank AP, 460 Inch Waste Level

$\mathrm{SpG}=1.83$

Best Estimate Soil

Best Estimate Concrete

\begin{tabular}{|c|c|c|c|c|}
\hline & $\begin{array}{c}\text { Max Pressure } \\
\text { Primary } \\
\text { Tank/Insulaiting } \\
\text { Concrete AP } \\
\text { Seismic (PSI) }\end{array}$ & $\begin{array}{c}\text { Min Pressure } \\
\text { Primary } \\
\text { Tank/nsulaiting } \\
\text { Concrete AP } \\
\text { Seismic (PSI) }\end{array}$ & $\begin{array}{c}\text { Max Lateral } \\
\text { Displacement } \\
\text { Primary } \\
\text { Tank/Insulaiting } \\
\text { Concrete AP } \\
\text { Seismic (Inches) }\end{array}$ & $\begin{array}{c}\text { Min Lateral } \\
\text { Displacement } \\
\text { Primary Tank/Insulaiting } \\
\text { Concrete AP } \\
\text { Seismic (Inches) }\end{array}$ \\
\hline 424.00 & 98.681 & 39.125 & 0.062712 & 0.004598 \\
\hline 384.00 & 24.521 & 7.299 & 0.306360 & 0.000106 \\
\hline 317.85 & 43.042 & 23.340 & 0.038640 & 0.000744 \\
\hline $\mathbf{2 4 8 . 1 0}$ & 37.042 & 21.035 & 0.020028 & 0.000514 \\
\hline $\mathbf{1 9 9 . 2 5}$ & 38.014 & 22.083 & 0.010837 & 0.000289 \\
\hline $\mathbf{1 5 4 . 9 5}$ & 36.465 & 22.764 & 0.006524 & 0.000288 \\
\hline $\mathbf{1 1 2 . 8 0}$ & 36.056 & 24.014 & 0.004350 & 0.000037 \\
\hline $\mathbf{6 5 . 8 5}$ & 36.465 & 24.431 & 0.003374 & 0.000234 \\
\hline
\end{tabular}


RPP-RPT-32239, Rev. 1

M\&D-2008-005-CALC-001, Rev. 1

Table G.36. BES-BEC Primary Tank/Insulating Concrete Contact Forces, Seismic Only

$$
\begin{gathered}
\text { Tank AP, } 460 \text { Inch Waste Level } \\
\text { SpG }=1.83 \\
\text { Best Estimate Soil } \\
\text { Best Estimate Concrete }
\end{gathered}
$$

\begin{tabular}{|c|c|c|c|c|}
\hline & $\begin{array}{c}\text { Max Pressure } \\
\text { Primary } \\
\text { Tank/nsulaiting } \\
\text { Concrete AP } \\
\text { Seismic Only } \\
\text { (PSI) }\end{array}$ & $\begin{array}{c}\text { Min Pressure } \\
\text { Primary } \\
\text { Tank/nsulaiting } \\
\text { Concrete AP } \\
\text { Seismic Only } \\
\text { (PSI) }\end{array}$ & $\begin{array}{c}\text { Max Lateral } \\
\text { Displacement } \\
\text { Primary } \\
\text { Tank/nsulaiting } \\
\text { Concrete AP } \\
\text { Seismic Only (Inches) }\end{array}$ & $\begin{array}{c}\text { Min Lateral } \\
\text { Displacement } \\
\text { Dimas Tank/Insulaiting } \\
\text { Concrete AP } \\
\text { Seismic Only (Inches) }\end{array}$ \\
\hline 424.00 & 25.972 & -33.514 & 0.054 & -0.004 \\
\hline 384.00 & 11.056 & -6.153 & 0.306 & 0.000 \\
\hline 317.85 & 9.757 & -9.910 & 0.036 & -0.002 \\
\hline $\mathbf{2 4 8 . 1 0}$ & 7.313 & -8.667 & 0.018 & -0.002 \\
\hline $\mathbf{1 9 9 . 2 5}$ & 7.264 & -8.639 & 0.009 & -0.001 \\
\hline $\mathbf{1 5 4 . 9 5}$ & 5.986 & -7.688 & 0.006 & -0.001 \\
\hline $\mathbf{1 1 2 . 8 0}$ & 5.611 & -6.403 & 0.004 & 0.000 \\
\hline $\mathbf{6 5 . 8 5}$ & 5.486 & -6.486 & 0.003 & 0.000 \\
\hline
\end{tabular}


RPP-RPT-32239, Rev. 1

M\&D-2008-005-CALC-001, Rev. 1

Table G.37. BES-BEC Insulating Concrete/Concrete Backed Steel Contact Data, Gravity Only

Tank AP, 460 Inch Waste Level

$\mathrm{SpG}=1.83$

Best Esitmate Soil

Best Estimate Concrete

\begin{tabular}{|c|c|c|c|c|}
\hline & $\begin{array}{c}\text { Max Pressure } \\
\text { Insulating } \\
\text { Concrete/Secon } \\
\text { dary Liner AP } \\
\text { Gravity (PSI) }\end{array}$ & $\begin{array}{c}\text { Min Pressure } \\
\text { Insulating } \\
\text { Concrete/Secon } \\
\text { dary Liner AP } \\
\text { Gravity (PSI) }\end{array}$ & $\begin{array}{c}\text { Max Lateral } \\
\text { Displacement } \\
\text { Insulating } \\
\text { Concrete/Secondary } \\
\text { Liner AP } \\
\text { Gravity (Inches) }\end{array}$ & $\begin{array}{c}\text { Min Lateral } \\
\text { Displacement } \\
\text { Insulating } \\
\text { Concrete/Secondary } \\
\text { Liner AP } \\
\text { Gravity (Inches) }\end{array}$ \\
\hline $\mathbf{4 2 4 . 0 0}$ & 86.458 & 86.250 & 0.003563 & 0.003527 \\
\hline 384.00 & 33.854 & 33.785 & 0.002846 & 0.002810 \\
\hline $\mathbf{3 1 7 . 8 5}$ & 27.736 & 27.701 & 0.002029 & 0.001997 \\
\hline $\mathbf{2 4 8 . 1 0}$ & 31.500 & 31.472 & 0.001470 & 0.001445 \\
\hline $\mathbf{1 9 9 . 2 5}$ & 30.931 & 30.896 & 0.000920 & 0.000905 \\
\hline $\mathbf{1 5 4 . 9 5}$ & 30.576 & 30.542 & 0.000659 & 0.000651 \\
\hline $\mathbf{1 1 2 . 8 0}$ & 31.215 & 31.146 & 0.000489 & 0.000487 \\
\hline $\mathbf{6 5 . 8 5}$ & 30.597 & 30.410 & 0.000165 & 0.000160 \\
\hline
\end{tabular}


RPP-RPT-32239, Rev. 1

M\&D-2008-005-CALC-001, Rev. 1

Table G.38. BES-BEC Insulating Concrete/Concrete Backed Steel Contact Data, Gravity Plus Seismic

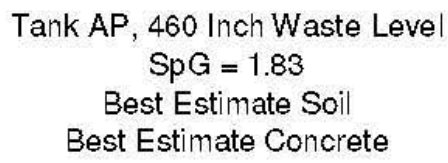

\begin{tabular}{|c|c|c|c|c|}
\hline & $\begin{array}{c}\text { Max Pressure } \\
\text { Insulating } \\
\text { Concrete/Secon } \\
\text { dary Liner AP } \\
\text { Seismic (PSI) }\end{array}$ & $\begin{array}{c}\text { Min Pressure } \\
\text { Insulating } \\
\text { Concrete/Secon } \\
\text { dary Liner AP } \\
\text { Seismic (PSI) }\end{array}$ & $\begin{array}{c}\text { Max Lateral } \\
\text { Displacement } \\
\text { Insulating } \\
\text { Concrete/Secondary } \\
\text { Liner AP } \\
\text { Seismic (Inches) }\end{array}$ & $\begin{array}{c}\text { Min Lateral } \\
\text { Displacement } \\
\text { Insulating } \\
\text { Concrete/Secondary } \\
\text { Liner AP } \\
\text { Seismic (Inches) }\end{array}$ \\
\hline Radius & 99.444 & 71.944 & 0.017964 & 0.000158 \\
\hline $\mathbf{4 2 4 . 0 0}$ & 42.083 & 24.590 & 0.016872 & 0.000273 \\
\hline $\mathbf{3 8 4 . 0 0}$ & 35.910 & 17.715 & 0.015096 & 0.000084 \\
\hline $\mathbf{3 1 7 . 8 5}$ & 39.340 & 22.556 & 0.014532 & 0.000060 \\
\hline $\mathbf{2 4 8 . 1 0}$ & 38.076 & 22.181 & 0.012588 & 0.000027 \\
\hline $\mathbf{1 9 9 . 2 5}$ & 36.625 & 22.806 & 0.010172 & 0.000031 \\
\hline $\mathbf{1 5 4 . 9 5}$ & 36.896 & 24.556 & 0.008530 & 0.000037 \\
\hline $\mathbf{1 1 2 . 8 0}$ & 35.951 & 24.250 & 0.007418 & 0.000060 \\
\hline $\mathbf{6 5 . 8 5}$ & & & & \\
\hline
\end{tabular}


RPP-RPT-32239, Rev. 1

M\&D-2008-005-CALC-001, Rev. 1

Table G.39. BES-BEC Insulating Concrete/Concrete Backed Steel Contact Data, Seismic Only

Tank AP, 460 Inch Waste Level

$\mathrm{SpG}=1.83$

Best Estimate Soil

Best Estimate Concrete

\begin{tabular}{|c|c|c|c|c|}
\hline & $\begin{array}{c}\text { Max Pressure } \\
\text { Insulating } \\
\text { Concrete/Secon } \\
\text { dary Liner AP } \\
\text { Seismic Only } \\
\text { (PSI) }\end{array}$ & $\begin{array}{c}\text { Min Pressure } \\
\text { Insulating } \\
\text { Concrete/Secon } \\
\text { dary Liner AP } \\
\text { Seismic Only } \\
\text { (PSI) }\end{array}$ & $\begin{array}{c}\text { Max Lateral } \\
\text { Displacement } \\
\text { Insulating } \\
\text { Concrete/Secondary } \\
\text { Liner AP }\end{array}$ & $\begin{array}{c}\text { Min Lateral } \\
\text { Displacement } \\
\text { Insulating } \\
\text { Concrete/Secondary } \\
\text { Liner AP }\end{array}$ \\
\hline 424.00 & 12.986 & -14.306 & 0.014 & -0.003 \\
\hline 384.00 & 8.229 & -9.194 & 0.014 & -0.003 \\
\hline 317.85 & 8.174 & -9.986 & 0.013 & -0.002 \\
\hline $\mathbf{2 4 8 . 1 0}$ & 7.840 & -8.917 & 0.013 & -0.001 \\
\hline $\mathbf{1 9 9 . 2 5}$ & 7.146 & -8.715 & 0.012 & -0.001 \\
\hline $\mathbf{1 5 4 . 9 5}$ & 6.049 & -7.736 & 0.010 & -0.001 \\
\hline $\mathbf{1 1 2 . 8 0}$ & 5.681 & -6.590 & 0.008 & 0.000 \\
\hline $\mathbf{6 5 . 8 5}$ & 5.354 & -6.160 & 0.007 & 0.000 \\
\hline
\end{tabular}


RPP-RPT-32239, Rev. 1

M\&D-2008-005-CALC-001, Rev. 1

Table G.40. BES-BEC Waste Contact Pressure, Gravity Plus Seismic

Tank AY, 460 Inch Waste Level

$\mathrm{SpG}=1.83$

Best Estimate Soil

Best Estimate Concrete

\begin{tabular}{|c|c|c|c|c|c|c|c|}
\hline $\begin{array}{l}\text { Waste } \\
\text { Height } \\
\text { Ratio }\end{array}$ & Waste Height & $\begin{array}{c}\text { Max Pressure } \\
\text { AP Tank, } 460 \text { in } \\
\text { Waste Level, } \\
\text { SpG }=1.83 \\
\text { Time History } \\
\text { (PSI) }\end{array}$ & $\begin{array}{c}\text { Min Pressure } \\
\text { AP Tank, } 460 \text { in } \\
\text { Waste Level, } \\
\text { SpG }=1.83 \\
\text { Time History } \\
\text { (PSI) }\end{array}$ & $\begin{array}{l}\text { Hydrostatic } \\
\text { (psi) }\end{array}$ & $\begin{array}{l}\text { Hydrodynamic } \\
\text { (psi) }\end{array}$ & $\begin{array}{l}\text { Theoretical } \\
\text { Min (SRSS) }\end{array}$ & $\begin{array}{l}\text { Theoretical } \\
\text { Max (SRSS) }\end{array}$ \\
\hline 0.99 & 454.35 & 9.264 & -8.222 & 0.37 & 1.74 & 0.00 & 2.12 \\
\hline 0.96 & 443.05 & 13.104 & -11.611 & 1.12 & 1.92 & 0.00 & 3.04 \\
\hline 0.94 & 431.7625 & 14.535 & -10.382 & 1.87 & 2.17 & 0.00 & 4.04 \\
\hline 0.90 & 414.125 & 12.028 & -7.035 & 3.03 & 2.63 & 0.40 & 5.66 \\
\hline 0.85 & 390.125 & 9.514 & -0.906 & 4.62 & 3.30 & 1.32 & 7.91 \\
\hline 0.80 & 366.125 & 11.271 & 0.116 & 6.20 & 3.94 & 2.26 & 10.15 \\
\hline 0.74 & 342 & 13.979 & 0.463 & 7.80 & 4.56 & 3.23 & 12.36 \\
\hline 0.69 & 318.325 & 16.167 & 1.108 & 9.36 & 5.13 & 4.23 & 14.49 \\
\hline 0.64 & 295.225 & 18.438 & 1.572 & 10.89 & 5.65 & 5.24 & 16.54 \\
\hline 0.59 & 272.125 & 20.757 & 2.526 & 12.41 & 6.13 & 6.29 & 18.54 \\
\hline 0.54 & 248.975 & 22.771 & 3.436 & 13.94 & 6.57 & 7.37 & 20.52 \\
\hline 0.49 & 225.825 & 25.306 & 4.401 & 15.47 & 6.98 & 8.49 & 22.45 \\
\hline 0.44 & 202.725 & 26.910 & 5.671 & 17.00 & 7.35 & 9.65 & 24.35 \\
\hline 0.39 & 179.625 & 28.771 & 7.035 & 18.53 & 7.68 & 10.85 & 26.20 \\
\hline 0.34 & 156.475 & 31.257 & 8.424 & 20.06 & 7.97 & 12.09 & 28.02 \\
\hline 0.29 & 134.075 & 32.653 & 9.958 & 21.54 & 8.21 & 13.32 & 29.75 \\
\hline 0.24 & 112.475 & 33.715 & 11.424 & 22.96 & 8.42 & 14.55 & 31.38 \\
\hline 0.20 & 90.875 & 34.958 & 12.993 & 24.39 & 8.58 & 15.81 & 32.97 \\
\hline 0.15 & 69.275 & 37.014 & 14.299 & 25.82 & 8.72 & 17.10 & 34.53 \\
\hline 0.10 & 47.738 & 37.903 & 16.264 & 27.24 & 8.81 & 18.43 & 36.05 \\
\hline 0.05 & 24.500 & 41.528 & 16.674 & 28.78 & 8.88 & 19.90 & 37.65 \\
\hline 0.02 & 7.755 & 46.472 & 24.743 & 29.88 & 8.90 & 20.98 & 38.78 \\
\hline 0.00 & 1.755 & 40.597 & 25.056 & 30.28 & 8.90 & 21.38 & 39.18 \\
\hline
\end{tabular}


RPP-RPT-32239, Rev. 1

M\&D-2008-005-CALC-001, Rev. 1

Table G.41. BES-BEC Waste Contact Pressure, Theoretical Pressures

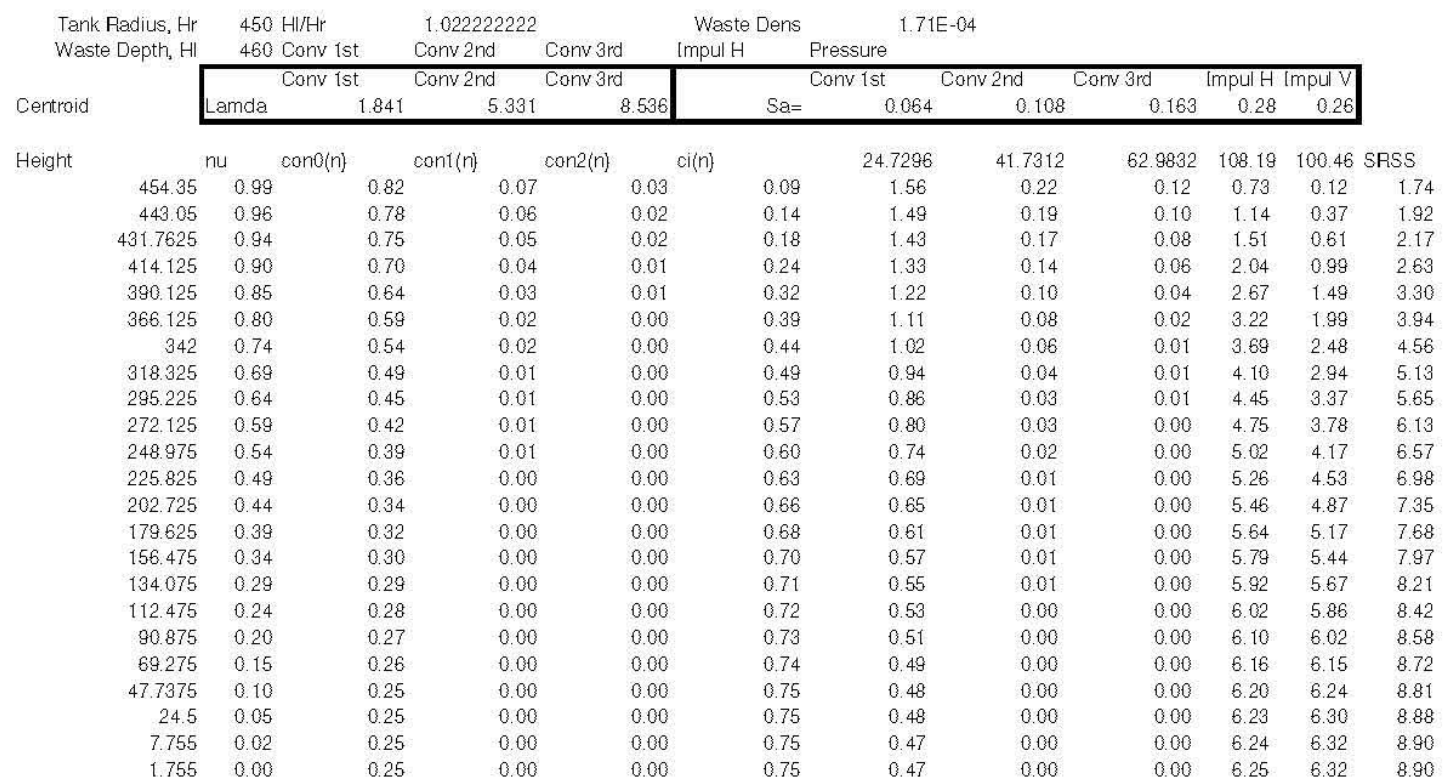


RPP-RPT-32239, Rev. 1

M\&D-2008-005-CALC-001, Rev. 1

Table G.42. BES-BEC W aste Surface Displacement, Gravity Plus Seismic

Tank AP, 460 Inch Waste Level

$\mathrm{SpG}=1.83$

Best Estimate Soil

Best Estimate Concrete

\begin{tabular}{|r|c|c|}
\hline & $\begin{array}{c}\text { Max Vertical } \\
\text { Displacement } \\
\text { AP-460-BES- } \\
\text { BEC } \\
\text { Time History } \\
\text { (in) }\end{array}$ & $\begin{array}{c}\text { Min Vertical } \\
\text { Displacement } \\
\text { AP-460-BES- } \\
\text { BEC } \\
\text { Time History } \\
\text { (in) }\end{array}$ \\
\hline 95.7 & 6.60 & -11.66 \\
\hline 129.9 & 7.52 & -10.69 \\
\hline 180 & 8.07 & -12.12 \\
\hline 218.5 & 7.39 & -13.09 \\
\hline 277.7 & 8.11 & -13.20 \\
\hline 358 & 8.58 & -13.24 \\
\hline 410 & 7.09 & -12.43 \\
\hline 450 & 5.02 & -9.41 \\
\hline
\end{tabular}




\section{RPP-RPT-32239, Rev. 1 \\ M\&D-2008-005-CALC-001, Rev. 1}

\section{Near-Soil-1.txt}

et, 8, solid 45

/input, soil-prop-Mean-geo, txt

$\mathrm{ksel}, \mathrm{u}, \mathrm{kp}, \mathrm{,}, \mathrm{k}, \mathrm{maxj} \mathrm{b}$

asel, $u$, area, 1, amaxjb

lsel, u, line, , 1, lmaxjb

vsel, u, volu, , 1, vmaxw
! Use Element SOLID45 for Near Soil Elements

! Read Soil Properties

! Unselect existing Keypoints

! Unselect existing Area

! Unselect existing Lines

! Unselect existing Volumes

/COM - Create Keypoints to match concrete tank profile

${ }^{*} \mathrm{do}, i, 1, \mathrm{bm}$ kp

$k, \operatorname{kmaxj} b+i, \operatorname{ctx}(i), 0, \operatorname{ctz}(i)$

*enddo

/COM - Create Keypoints above top of tank

$\mathrm{k}, \mathrm{kmaxj}_{\mathrm{b}}+\mathrm{bm} \_\mathrm{kp}+1,0,0,0$

! Keypoint at origin (surface)

$k, k \operatorname{maxj} b+b m-k p+2,0,0, \operatorname{soilz}(2)$

! Keypoint at to divide soil above tank

*get, KMAXtemp1, KP, 0, num, max

! Get maximum keypoint number for counter

/COM - Create Keypoints at outside of excavated soil

$\star$ do, $i, 1, \operatorname{tanksoil}$

$k$, kmaxtemp $1+i, \operatorname{soilx}(i), 0, \operatorname{soilz}(i)$

tenddo

${ }^{\star}$ get, KMAXtemp2, KP, 0, num, max

! Get maximum keypoint number for counter

/COM - Create additional keypoint in soil above tank

$k, \operatorname{kmaxtemp} 2+1, \operatorname{ctx}(2), 0, \operatorname{soilz}(1)$

k, kmaxtemp $2+2, \operatorname{ctx}(9), 0, \operatorname{soilz}(1)$

$\mathrm{k}, \operatorname{kmax}$ temp $2+3, \operatorname{ctx}(12), 0, \operatorname{soilz}(1)$

$k$, kmaxtemp $2+4, \operatorname{ctx}(2), 0, \operatorname{soilz}(2)$

$k$, kmaxtemp $2+5, \operatorname{ctx}(9), 0, \operatorname{soilz}(2)$

$\mathrm{k}, \operatorname{kmaxtemp} 2+6, \operatorname{ctx}(12), 0, \operatorname{soilz}(2)$

$\mathrm{k}$, kmaxtemp $2+7, \operatorname{ctx}(12), 0, \operatorname{soilz}(3)$

$\mathrm{k}$, kmaxtemp $2+8, \operatorname{ctx}\left(\mathrm{bm} \_\mathrm{kp}+1\right), 0, \operatorname{ctz}\left(\mathrm{bm} \_\mathrm{kp}+1\right)$

a, kmaxtemp $2+1$, kmaxtemp $2+2$, kmaxtemp $2+5$, kmaxtemp $2+4$

a, kmaxtemp $2+2$, kmaxtemp $2+3$, kmaxtemp $2+6$, kmaxtemp $2+5$

a, kmaxtemp $2+3$, kmaxtemp $1+1$, kmaxtemp $1+2$, kmaxtemp $2+6$

a, kmaxtemp 2+4, kmaxtemp2 +5, kmaxj $b+9, k \max j b+8, k \max j b+7, k \max j b+6, k \max j b+5, k \max j b+4, k \max j b+3, k \max j b+2$

$! a, 740,741,712,711,710,709,708,707,706,705$

a, kmaxtemp2+5, kmaxtemp 2+6, kmaxtemp $2+7, \operatorname{kmaxj} b+12, k \max j b+11, k \max j b+10, k \operatorname{kaxj} b+9$

a, kmaxtemp $2+6$, kmaxtemp $1+2$, kmaxtemp $1+3$, kmaxtemp $2+7$

a, kmaxtemp $2+7, \operatorname{kmaxtemp} 1+3, \operatorname{kmaxtemp} 1+4, \operatorname{kmaxj} \mathrm{b}+12$

a, kmaxj $b+12$, kmaxt emp $1+4, \operatorname{kmaxt} \operatorname{emp} 1+5, \operatorname{kmaxj} b+14, \operatorname{kmaxj} b+13$

$a, k \max j b+14, \operatorname{kmax} t e m p 1+5, \operatorname{kmax} t \operatorname{emp} 1+6, \operatorname{kmax} j b+16, \operatorname{kmax} j b+15$

$a, k \max j b+16, k \max t \operatorname{emp} 1+6, \operatorname{kmaxt} \operatorname{emp} 1+7, k \operatorname{maxj} b+18, k \max j b+17$

a, $k \operatorname{maxj} \mathrm{b}+18, k \operatorname{kax} t \operatorname{emp} 1+7, \operatorname{kmax} t \operatorname{emp} 1+8, k \operatorname{maxj} \mathrm{b}+20, k \max j \mathrm{~b}+19$

$a, k \max j b+20, k m a x t \operatorname{emp} 1+8, \operatorname{kmax} t \operatorname{emp} 1+9, \operatorname{kmaxt} \operatorname{emp} 2+8, \operatorname{kmax} j b+22, k \max j \mathrm{~b}+21$

cm, top-soil-area, area

lsla

cm, top-soil, line

type, 1

real, 1

/COM - Define line divisions to control meshing

lsel, s, loc, $z, \operatorname{soilz}(1), \operatorname{soilz}(2)$

lsel, $r, 1 \circ c, x, \operatorname{ctx}(3), \operatorname{ctx}(8)$

lesize, all, , 14

lsel, s, loc, z, soilz(1), soilz(2)

lsel, $r, 100, x, \operatorname{ctx}(10), \operatorname{ctx}(11)$

lesize, all, , 3

cmsel, s, top-soil

lsel, $r, 100, x, \operatorname{ctx}(2)$

lesize, all, , 2

cmsel, s, top-soil

lsel, s, loc, $x, \operatorname{ctx}(9)$

lesize, all, , 2

! soil above tank top, match tank meshing

! soil above tank top, match tank meshing

! Reselect lines in near soil

! Control vertical element size, above tank

! Control vertical element size, above tank 


\section{RPP-RPT-32239, Rev. 1 \\ M\&D-2008-005-CALC-001, Rev. 1}

cmsel, s, top-soil

lsel, r, loc, $x, \operatorname{ctx}(12)$

lesize, all,, 2

cmsel, s, top-soil

lsel, r, loc, z, ctz(2), ctz(12)

lsel, r, loc, $x, \operatorname{ctx}(2), \operatorname{ctx}(12)$

lesize, all, , 1

lsel,, , line, $, 1 \max j b+8, l \max j b+10,2$

lsel, $a, l i n e,, l \max j b+26, l \operatorname{maxj} b+28,2$

lsel, a, line, , 1 maxj $b+30, l \operatorname{maxj} b+38,4$

lesize, all, , 9

lsel, s, line, , 1 maxj $b+42, l \operatorname{maxj} b+42,4$

lesize, all, , 7

lsel, s, line, $l \max j b+9$

lsel, $a, l i n e,, l \max j b+25, l \max j b+27,2$

lsel, a, line, , lmaxjb+29, lmaxj b+45, 4

lesize, all, , 1

lsel, s, line, $1 \operatorname{maxj} b+6$

lsel, a, line, , $l \max j b+20, l \max j b+21$

lsel, a, line, , $l \max j b+32, l \operatorname{maxj} b+44,4$

lsel, a, line, $, 1 \max j b+31, l \operatorname{maxj} b+43,4$

lsel, a, line, , $l \operatorname{maxj} b+47, l \operatorname{maxj} b+49$

lesize, all, , 1

lsel, s, line, , lmaxjb+46

lesize, all, , 4

cmsel,s, top-soil-area

amesh, all

! Control vertical element size, above tank

! Control vertical element size, outside excavation mesh

! Control horizontal meshing in soil

! Control horizontal meshing in soil

type, 8

$\mathrm{ksel}, \mathrm{a}, \mathrm{kp}, \mathrm{r}$

ksel, a, kp, , ct_kps

vrotat, all, , $, 1,1$, ct_kps, 180,2

lsla

lsel, $r, 100, x, \operatorname{ctx}(2)$

lesize, all, , arcsize

lsla

lsel, r, loc, $x, \operatorname{ctx}(9)$

lesize, all, arcsize

lsla

lsel, r, loc, $x, \operatorname{ctx}(12)$

lesize, all, , arcsize

vsweep, all

aclear, all

cm, top-soil-vol, volu

! Control meshing to match tank

! Control mesh size at bottom of excavated soil

! Mesh area to develop pattern for volume meshing

! Select Keypoint for rotation axis

! Select Keypoint for rotation axis

! Generate Volumes for excavated soil

! Define meshing for slices

! Define meshing for slices

! Define meshing for slices

! Sweep pattern into volume

! Delete elements used for sweep

*get, VMAXtemp, VOLU, 0, num, max

/COM - Generate element above top center of tank

asel, u, area, all

vsel, u, volu, , all

a, kmaxjb+bm_kp+1, kmaxtemp2+1, kmaxtemp $2+4, k \operatorname{kmaxj} b+b m \_k p+2$

a, kmaxjb+bm_kp+2, kmaxtemp $2+4, \operatorname{kmaxj} b+2, \operatorname{kmaxj} b+1$

vrotat, all, $, 1,1,1$, ct $\mathrm{kps}, 180,2$

vsel, s, volu, , vmaxtemp +1 , vmaxtemp $+3,2$

vatt, 801,8

! Assign material properties

vsel, s, volu, , vmaxtemp+2, vmaxt emp $+4,2$

vatt, 802,8

vsel, s, volu, vmaxtemp+1, vmaxtemp +4

allsel

asel, s, loc, $z, \operatorname{ctz}(1), \operatorname{ctz}(2)$

type, 1

asel, $r, 1 \circ \mathrm{c}, \mathrm{x}, 0,4$

asel, r, loc, $z, \operatorname{ctz}(1), \operatorname{ctz}(2)$

cmsel, u, conc-tank-a

${ }^{*}$ get, atemp, area, , num, max

*get, atemp1, area, , num, min

asel, a, area, $1,22,21$

mshcopy, 2, 1, at emp 1

mshcopy, 2, 22, atemp

asel, u, area, $1,22,21$ 


\section{RPP-RPT-32239, Rev. 1 \\ M\&D-2008-005-CALC-001, Rev. 1}

vsel, s, volu, , vmaxtemp +1, vmaxtemp +4

vsweep, all

! Generate elements by sweeping area

aclear, atemp

aclear, atemp1

/COM - Assign soil properties by layer

*do, $i, 1, \operatorname{tanksoil-1}$

cmsel, s, top-soil-vol

vsel, r, loc, z, soilz(i), soilz(i+1)

eslv

emodif,all, mat, $800+i$

esys, 0

tenddo

cmsel, s, top-soil-vol

vsel, a, loc, $z, \operatorname{sollz}(1), \operatorname{ctz}(2)$

eslv

cm, excav-soil, elem

nsle

nummrg, node

/COM - Define component for excavated soil - tank walls only

cmsel, s, excav-soil

nsle, $s, 1$

nsel, r, loc, z, soilz(5), soilz(9)

esln, $r, 1$

$\mathrm{cm}$, excav-wall, elem

/COM - Define component for excavated soil - tank dome only

cmsel, s, excav-soil

cmsel, u, excav-wall

$\mathrm{cm}$, excav-dome, elem

csys, 1

cmsel, s, excav-wall

nsle

nsel, r, loc, $x, \operatorname{ctx}(14)$

$\mathrm{cm}$, excav-wall-n, node

esel, s, type, 8

nsle

nsel, s, loc, $x, \operatorname{soilx}(1)$

nsel, r, loc, z, soilz (1)

$\mathrm{cm}$, near-soil-face-node, node

*do, $i, 2,9$

esel, s, type, 8

nsle

nsel, r, loc, $x$, soilx(i)

nsel, r, loc, $z$, soilz (i)

cmsel, a, near-soil-face-node

$\mathrm{cm}$, near-soil-face-node, node

tenddo

esel, s, type, 8

nsle

nsel, r, loc, z, soilz (9)

nsel, $r, 10 \mathrm{c}, \mathrm{x}, 41,68$

$\mathrm{cm}$, near-soil-bot-node, node

allsel

*get, KMAXns, KP, 0, num, max

*get, LMAXns, LINE, 0, num, max

! Get maximum Keypoint number

*get, AMAXns, AREA, 0, num, max

! Get maximum line number

*get, VMAXns, volu, 0, num, max

! Get maximum Area number

! Get maximum volume number 
RPP-RPT-32239, Rev. 1

M\&D-2008-005-CALC-001, Rev. 1

\section{Run-Tank.txt}

! batch

! PNNL DST Seismic Analysis, Gravity Inputs, Best Est Soil, Best Est Concrete Properties, AP Primary Tank Geometry, Dome Friction=0.0

!

fini

/clear

/filname, AP-460-BES-BEC-Seismic, 1

/config, nres, 3000

/config, nproc, 2

! Increase allowable number of results to 3000

/ config, fsplit, 1024

! Activate 2 processers for solution

$/ \mathrm{prep} 7$

$g=32 \cdot 2$

! Split binary file at $4.2 \mathrm{~GB}$

$\mathrm{DF}=40$

! Gravity (ft/sec)

$\mathrm{ALPHA}=0.4$

! Factor for beta (stiffness) damping

! Alpha damping

lout, tank-out, out

/sys, "X: \07.00 - Quality Assurance $\backslash$ ANSYS QA \usrcfg. bat" > QA. out

/out, QA, out, append

/input, tank-coordinates-AP, txt

/ input, tank-props-bec-250, txt

Concrete Properties)

/input, tank-meshl, txt

/input, primary-props-AP, txt

/input, primary, txt

/input, insulate, txt

/input, liner, txt

/input, waste-solid-AP-s, txt

/input, bolts-friction, txt

/input, near-soil-1, txt

/input, far-soil, txt

/input, interfacel, txt

/input, interface-gap 1, txt

/input, slave, txt

/input, boundary, txt

/input, outer-spar, txt

/input, live_load, txt

/input, fix-soil, txt

/out

ALLSEL

lout, Tank-th, out

save

/input, solve-TH-BES, txt

! Run file defining tank coordinates (concrete and primary)

! Run file defining fully cracked concrete properties (PNNL

! Develop concrete tank

! Run file defining AP Primary tank properties

! Develop Primary tank

! Develop insulating concrete model

! Develop Liner model

! Develop waste model

! Develop J-Bolt model

! Develop excavated soil model

! Develop Far-Field soil model

! Develop soil and Concrete Interfaces

! Develop Primary Tank Interfaces

! Develop slaved boundary conditions

! Place base and symmetry boundary conditions

! Connect soil model to symmetry plane

! Apply live load over a loft radius over dome center

/input, post-tank, txt

lout

lexit

\section{Soil-Prop-Mean-Geo.txt}

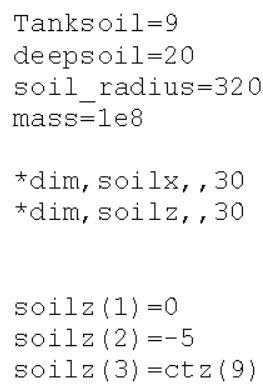


RPP-RPT-32239, Rev. 1

M\&D-2008-005-CALC-001, Rev. 1

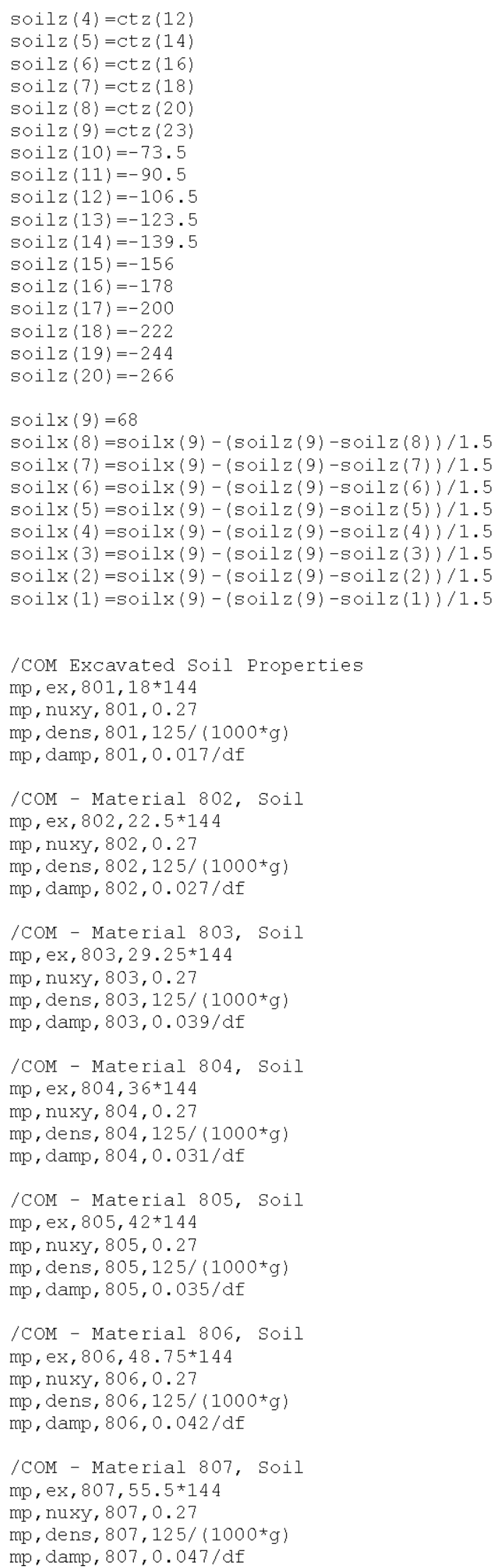


RPP-RPT-32239, Rev. 1

M\&D-2008-005-CALC-001, Rev. 1

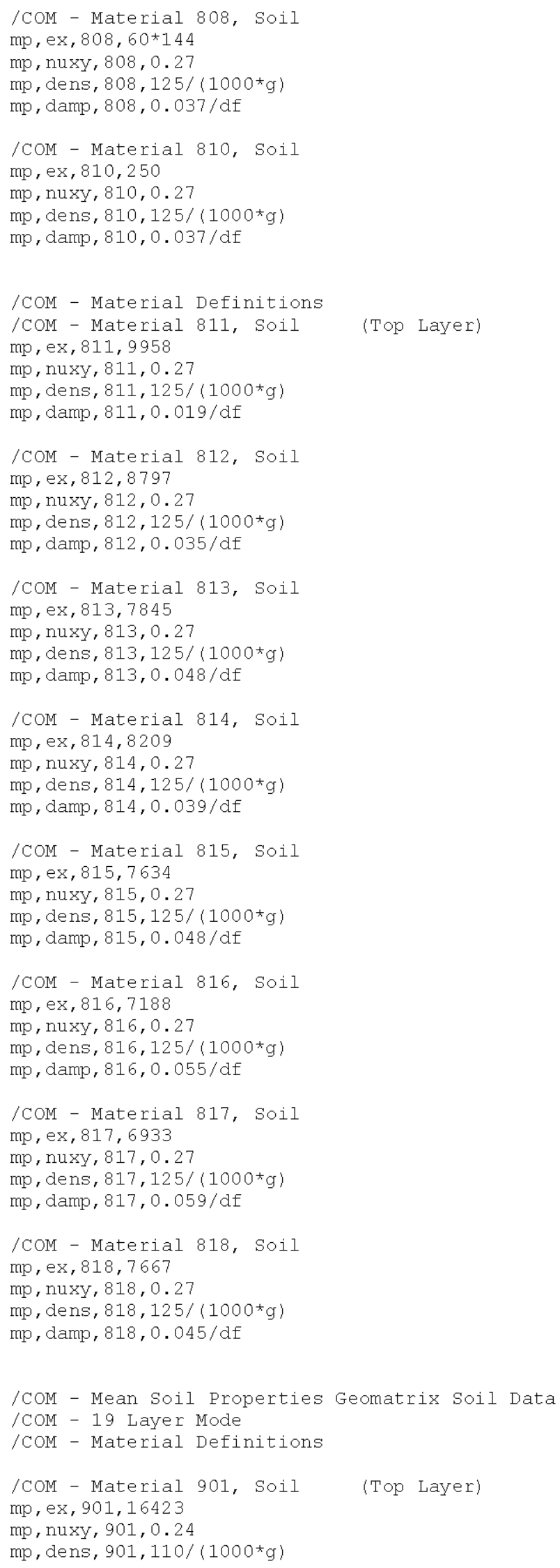


RPP-RPT-32239, Rev. 1

M\&D-2008-005-CALC-001, Rev. 1

mp , damp, 901,0.017/df

/COM - Material 902, Soil mp, ex, 902, 15479

mp, nuxy, 902, 0.24

mp, dens, 902,110/(1000*g)

mp, damp, $902,0.025 / d f$

/COM - Material 903, Soil

mp, ex, 903,14481

mp, nuxy, 903, 0.24

$\mathrm{mp}$, dens, $903,110 /\left(1000^{*} \mathrm{~g}\right)$

mp, damp, 903, 0.034/df

/COM - Material 904, Soil

$\mathrm{mp}, \mathrm{ex}, 904,14707$

mp, nuxy, 904, 0.24

$\mathrm{mp}$, dens, $904,110 /\left(1000^{*} \mathrm{~g}\right)$

mp , damp, 904, 0.028/df

/COM - Material 905, Soil mp, ex, 905,13625

mp, nuxy, 905, 0.19

$\mathrm{mp}$, dens, $905,110 /\left(1000^{*} \mathrm{~g}\right)$

mp, damp, 905, 0.032/df

/COM - Material 906, Soil mp, ex, 906,15456

mp, nuxy, 906, 0.19

$\mathrm{mp}$, dens, 906,110/(1000*g)

$\mathrm{mp}$, damp, 906, 0.033/df

/COM - Material 907, Soil

mp, ex, 907, 17532

mp, nuxy, 907, 0.19

mp, dens, 907, 110/(1000*g)

mp, damp, 907, 0.033/df

/COM - Material 908, Soil

mp, ex, 908,20972

mp, nuxy, 908, 0.19

$\mathrm{mp}$, dens, $908,110 /(1000 * \mathrm{~g})$

mp , damp, 908, 0.025/df

/COM - Material 909, Soil mp, ex, 909,23447

mp, nuxy, 909, 0.19

$\mathrm{mp}$, dens, $909,110 /\left(1000^{*} \mathrm{~g}\right)$

$\mathrm{mp}$, damp, 909, 0.026/df

/COM - Material 910, Soil

$\mathrm{mp}, \mathrm{ex}, 910,23138$

mp, nuxy, 910, 0.19

$\mathrm{mp}$, dens, 910, 110/(1000*g)

mp, damp, 910, 0.027/df

/COM - Material 911, Soil

mp, ex, 911,22753

mp, nuxy, $911,0.19$

mp, dens, 911, 110/(1000*g)

mp , damp, 911, 0.029/df

/COM - Material 912, Soil

mp, ex, 912, 22069

mp, nuxy, 912, 0.19

$\mathrm{mp}$, dens, $912,110 /(1000 * \mathrm{~g})$

mp, damp, 912, 0.033/df

/COM - Material 913, Soil

$\mathrm{mp}, \mathrm{ex}, 913,25780$

mp, nuxy, 913,0.19 
RPP-RPT-32239, Rev. 1

M\&D-2008-005-CALC-001, Rev. 1

$\mathrm{mp}$, dens, $913,110 /\left(1000^{*} \mathrm{~g}\right)$

mp , damp, 913,0.025/df

/COM - Material 914, Soil

$\mathrm{mp}, \mathrm{ex}, 914,25333$

mp, nuxy, 914, 0.19

mp, dens, $914,110 /\left(1000^{\star} \mathrm{g}\right)$

mp, damp, 914, 0.027/df

/COM - Material 915, Soil

mp, ex, 915, 35501

mp, nuxy, $915,0.28$

$\mathrm{mp}$, dens, $915,120 /\left(1000^{*} \mathrm{~g}\right)$

mp, damp, 915, 0.022/df

/COM - Material 916, Soil

$\mathrm{mp}, \mathrm{ex}, 916,39465$

mp, nuxy, $916,0.28$

mp, dens, $916,120 /\left(1000^{*} \mathrm{~g}\right)$

mp , damp, 916, 0.021/df

/COM - Material 917, Soil

$\mathrm{mp}, \mathrm{ex}, 917,38565$

mp, nuxy, $917,0.28$

$\mathrm{mp}$, dens, $917,120 /\left(1000^{*} \mathrm{~g}\right)$

mp , damp, 917, 0.023/df

/COM - Material 918, Soil

mp , ex, 918,37715

$\mathrm{mp}, \mathrm{nuxy}, 918,0.28$

$\mathrm{mp}$, dens, $918,120 /\left(1000^{*} \mathrm{~g}\right)$

mp , damp, $918,0.025 / d f$

/COM - Material 919, Soil

mp , ex, 919, 41496

mp, nuxy, $919,0.28$

$\mathrm{mp}$, dens, $919,120 /\left(1000^{*} \mathrm{~g}\right)$

mp, damp, 919, 0.024/df

\section{Solve-Gravity-LBS.txt}

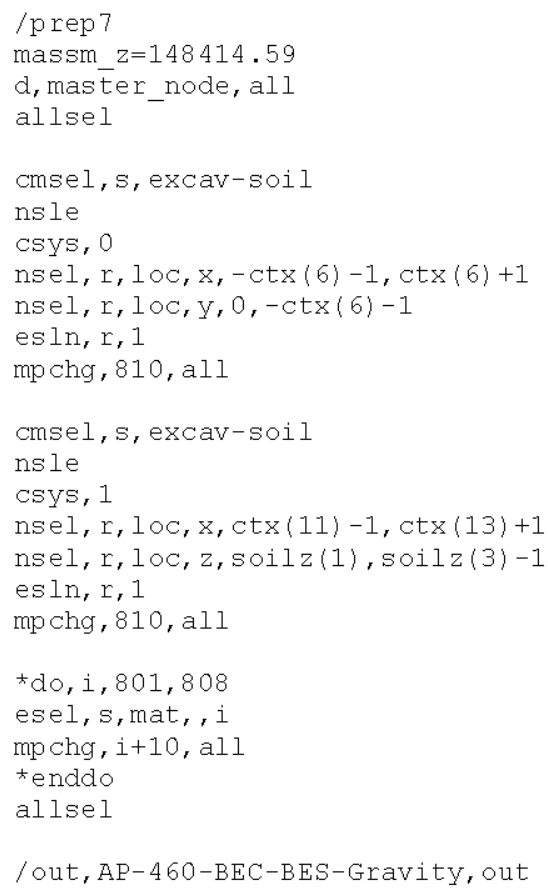




\section{RPP-RPT-32239, Rev. 1 \\ M\&D-2008-005-CALC-001, Rev. 1}

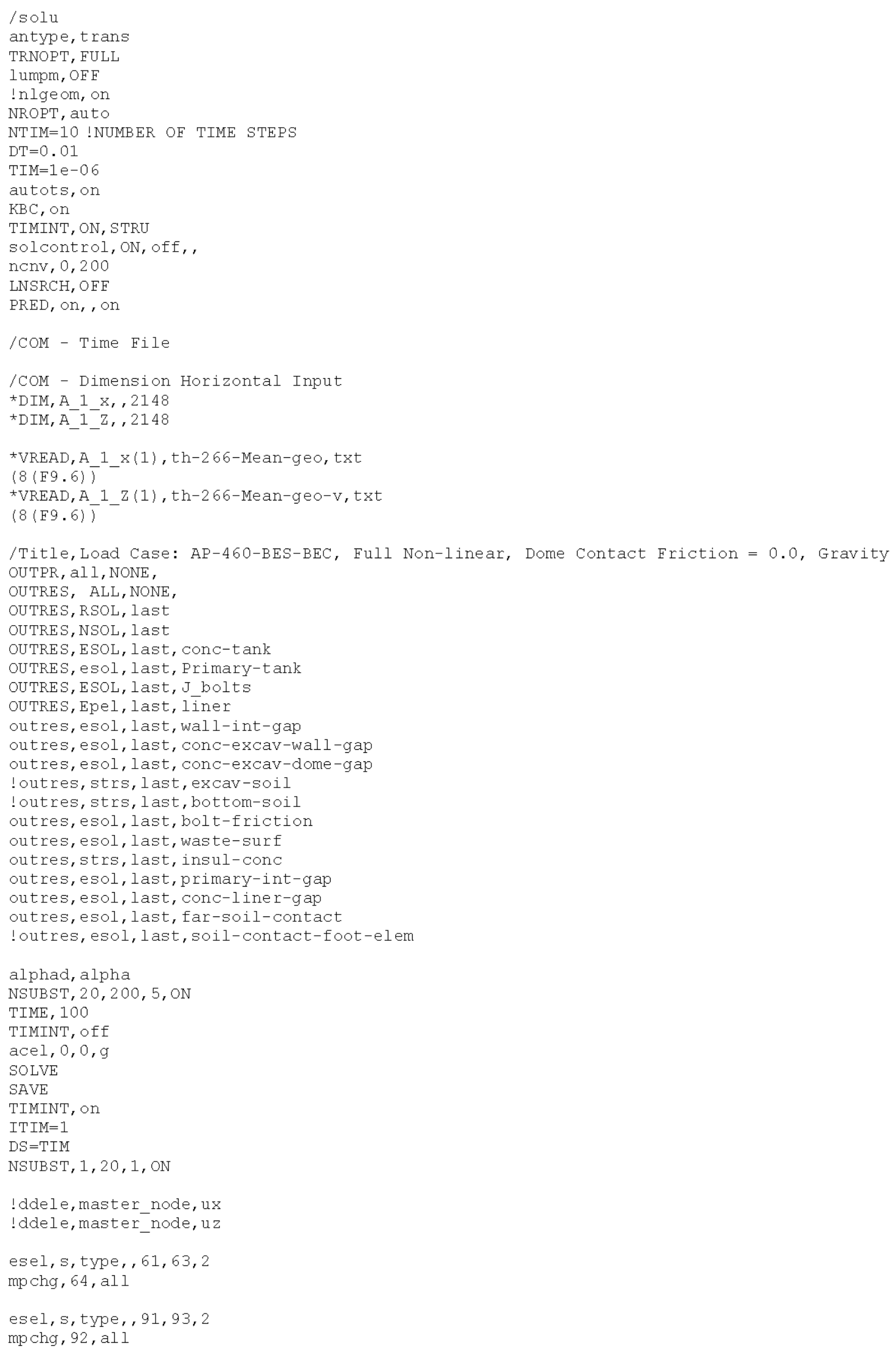


RPP-RPT-32239, Rev. 1

M\&D-2008-005-CALC-001, Rev. 1

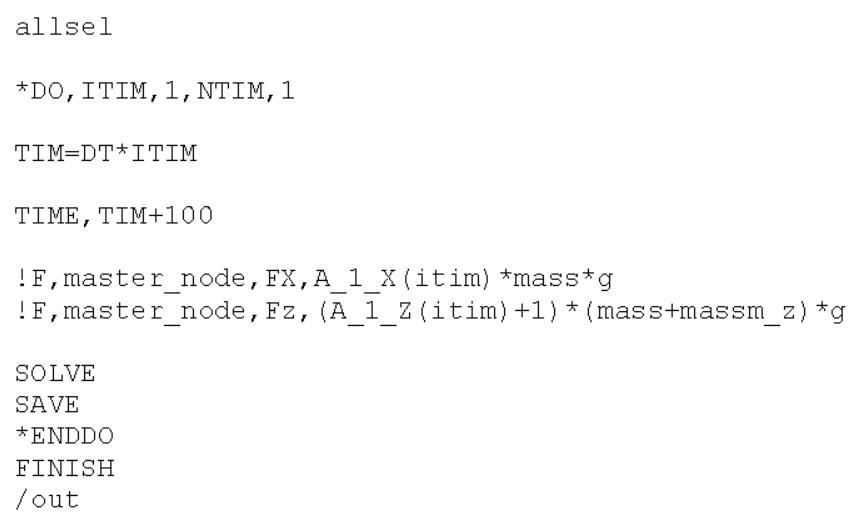

\section{Solve-TH-BES}

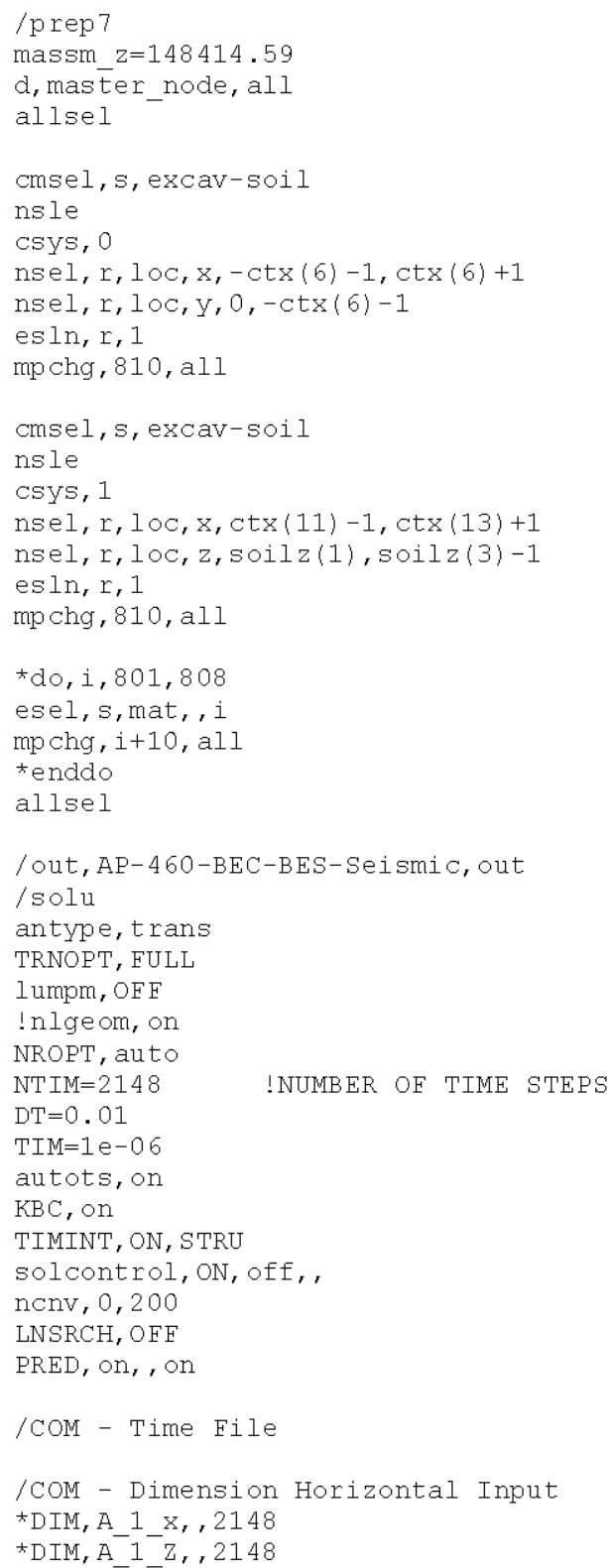


RPP-RPT-32239, Rev. 1

M\&D-2008-005-CALC-001, Rev. 1

*VREAD, A_1_x(1), th-266-Mean-geo, txt

(8(F9.6))

*VREAD, A_1_Z(1), th-266-Mean-geo-v, txt

$(8(\mathrm{~F} 9.6))$

/Title, Load Case: AP-460-BES-BEC, Full Non-linear, Dome Contact Friction $=0.0$

OUTPR, all, NONE,

OUTRES, ALL, NONE,

OUTRES, RSOL, last

OUTRES, NSOL, last

OUTRES, ESOL, last, conc-tank

OUTRES, esol, last, Primary-tank

OUTRES, ESOL, last, J_bolts

OUTRES, Epel, last, liner

outres, esol, last, wall-int-gap

outres, esol, last, conc-excav-wall-gap

outres, esol, last, conc-excav-dome-gap

!outres, strs, last, excav-soil

!outres, strs, last, bottom-soil

outres, esol, last, bolt-friction

outres, esol, last, waste-surf

outres, strs, last, insul-conc

outres, esol, last, primary-int-gap

outres, esol, last, conc-liner-gap

outres, esol, last, far-soil-contact

!outres, esol, last, soil-contact-foot-elem

alphad, alpha

NSUBST, 20,200, 5, ON

TIME, 100

TIMINT, off

acel, $0,0,9$

SOLVE

SAVE

TIMINT, on

IT IM $=1$

$\mathrm{DS}=\mathrm{TIM}$

NSUBST, $1,20,1$, ON

ddele, master_node, ux

ddele, master_node, uz

esel, s, type, $, 61,63,2$

mpchg, 64, all

esel, s, type, , 91, 93,2

mpchg, 92, all

allsel

${ }^{\star}$ DO, ITIM, 1, NTIM, 1

$\mathrm{TIM}=\mathrm{DT} \star I T I M$

TIME, TIM+100

F, master_node, FX, $A \_1$ X (itim) ${ }^{*}$ mass $^{*} \mathrm{~g}$

$\mathrm{F}$, master_node, $\mathrm{Fz},\left(\overline{\mathrm{A}}_{-} \overline{1}_{-} \mathrm{z}(\mathrm{itim})+1\right){ }^{*}\left(\operatorname{mass}+\mathrm{massm}_{-} \mathrm{z}\right){ }^{*} \mathrm{~g}$

SOLVE

SAVE

$\star$ ENDDO

FINISH

lout 
RPP-RPT-32239, Rev. 1

M\&D-2008-005-CALC-001, Rev. 1

\section{Tank-Props-BEC-250}

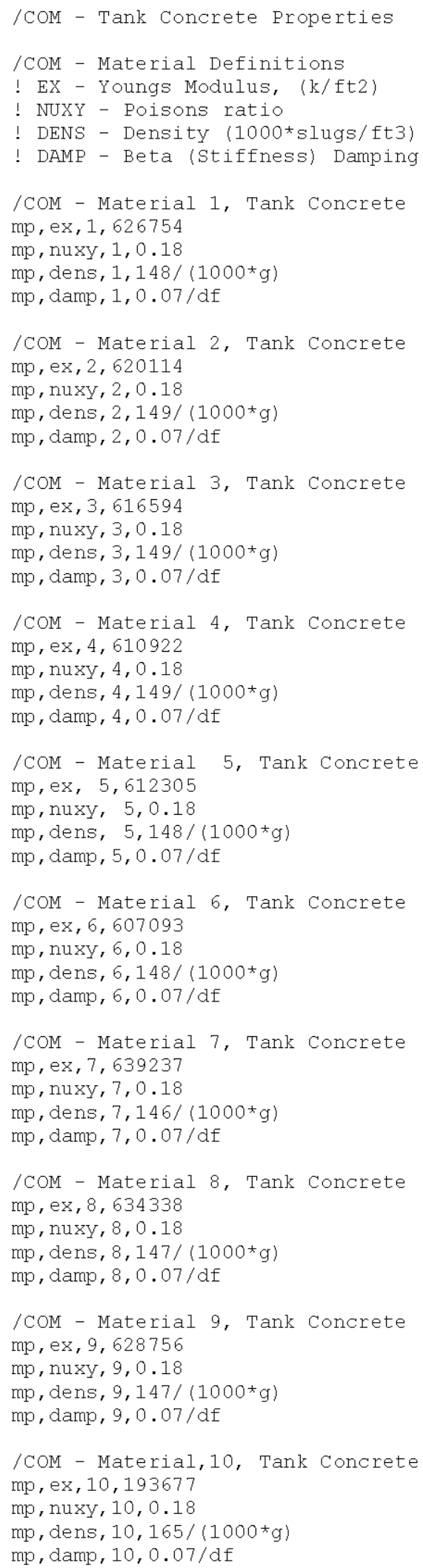


RPP-RPT-32239, Rev. 1

M\&D-2008-005-CALC-001, Rev. 1

/COM - Material,11, Tank Concrete $\mathrm{mp}, \mathrm{ex}, 11,575959$

mp, nuxy, $11,0.18$

$\mathrm{mp}$, dens, $11,144 /(1000 * \mathrm{~g})$

$\mathrm{mp}$, damp, $11,0.07 / \mathrm{df}$

/COM - Material,12, Tank Concrete mp , ex, 12,202953

mp, nuxy, $12,0.18$

$\mathrm{mp}$, dens, $12,159 /\left(1000^{*} \mathrm{~g}\right)$

mp, damp, 12, 0.07/df

/COM - Material,13, Tank Concrete $\mathrm{mp}, \mathrm{ex}, 13,157426$

$\mathrm{mp}$, nuxy, $13,0.18$

$\mathrm{mp}$, dens, $13,176 /\left(1000^{\star} \mathrm{g}\right)$

$\mathrm{mp}$, damp, 13,0.07/df

/COM - Material,14, Tank Concrete $\mathrm{mp}, \mathrm{ex}, 14,153784$

mp, nuxy, 14, 0.18

$\mathrm{mp}$, dens, $14,193 /\left(1000^{*} \mathrm{~g}\right)$

$\mathrm{mp}$, damp, 14,0.07/df

/COM - Material,15, Tank Concrete $\mathrm{mp}, \mathrm{ex}, 15,136651$

$\mathrm{mp}$, nuxy, $15,0.18$

$\mathrm{mp}$, dens, $15,200 /\left(1000^{*} \mathrm{~g}\right)$

$\mathrm{mp}$, damp, 15, 0.07/df

/COM - Material,16, Tank Concrete mp, ex, 16, 136651

$\mathrm{mp}$, nuxy, $16,0.18$

$\mathrm{mp}$, dens, $16,200 /\left(1000^{\star} \mathrm{g}\right)$

mp , damp, 16, 0.07/df

/COM - Material,17, Tank Concrete mp, ex, 17, 138084

mp, nuxy, $17,0.18$

mp, dens, $17,181 /\left(1000^{\star} \mathrm{g}\right)$

$\mathrm{mp}$, damp, $17,0.07 / \mathrm{df}$

/COM - Material,18, Tank Concrete $\mathrm{mp}, \mathrm{ex}, 18,123378$

mp, nuxy, $18,0.18$

$\mathrm{mp}$, dens, $18,209 /\left(1000^{*} \mathrm{~g}\right)$

$\mathrm{mp}$, damp, $18,0.07 / \mathrm{df}$

/COM - Material,19, Tank Concrete $\mathrm{mp}, \mathrm{ex}, 19,124633$

mp, nuxy, $19,0.18$

mp, dens, $19,190 /\left(1000^{*} \mathrm{~g}\right)$

mp, damp, 19,0.07/df

/COM - Material,20, Tank Concrete mp , ex, 20, 124388

mp, nuxy, 20, 0.18

mp, dens, $20,210 /\left(1000^{*} \mathrm{~g}\right)$

$\mathrm{mp}$, damp, 20,0.07/df

/COM - Material,21, Tank Concrete mp, ex, 21,548683

mp, nuxy, $21,0.18$

$\mathrm{mp}$, dens, $21,166 /\left(1000^{*} \mathrm{~g}\right)$

mp, damp, $21,0.07 / \mathrm{df}$

/COM - Material,22, Tank Concrete mp, ex, 22, 154870

mp, nuxy, 22, 0.18

$\mathrm{mp}$, dens, $22,184 /\left(1000^{*} \mathrm{~g}\right)$

$\mathrm{mp}$, damp, 22, 0.07/df 
RPP-RPT-32239, Rev. 1

M\&D-2008-005-CALC-001, Rev. 1

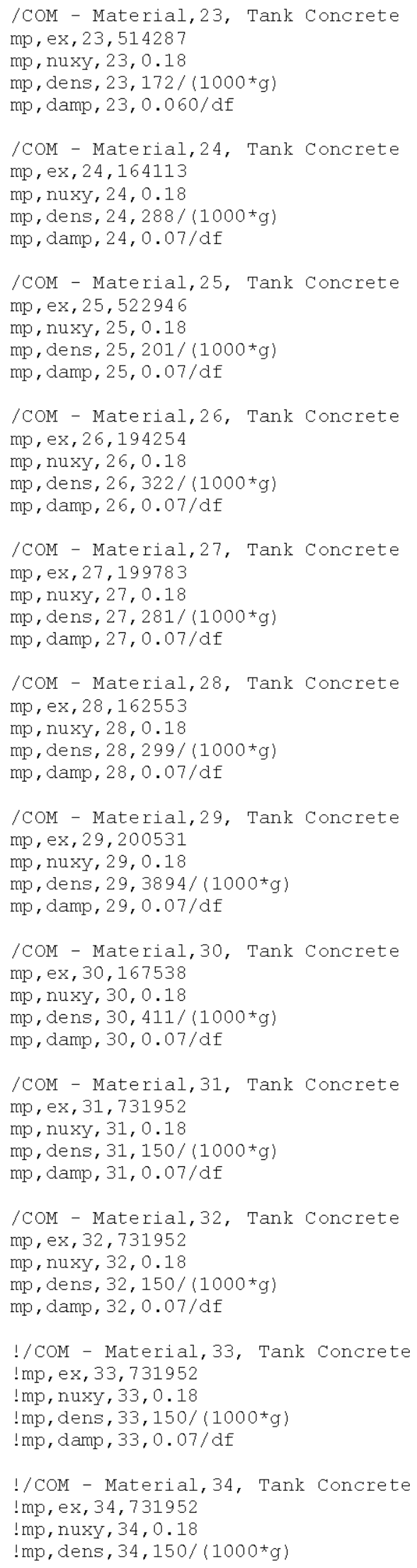


RPP-RPT-32239, Rev. 1

M\&D-2008-005-CALC-001, Rev. 1

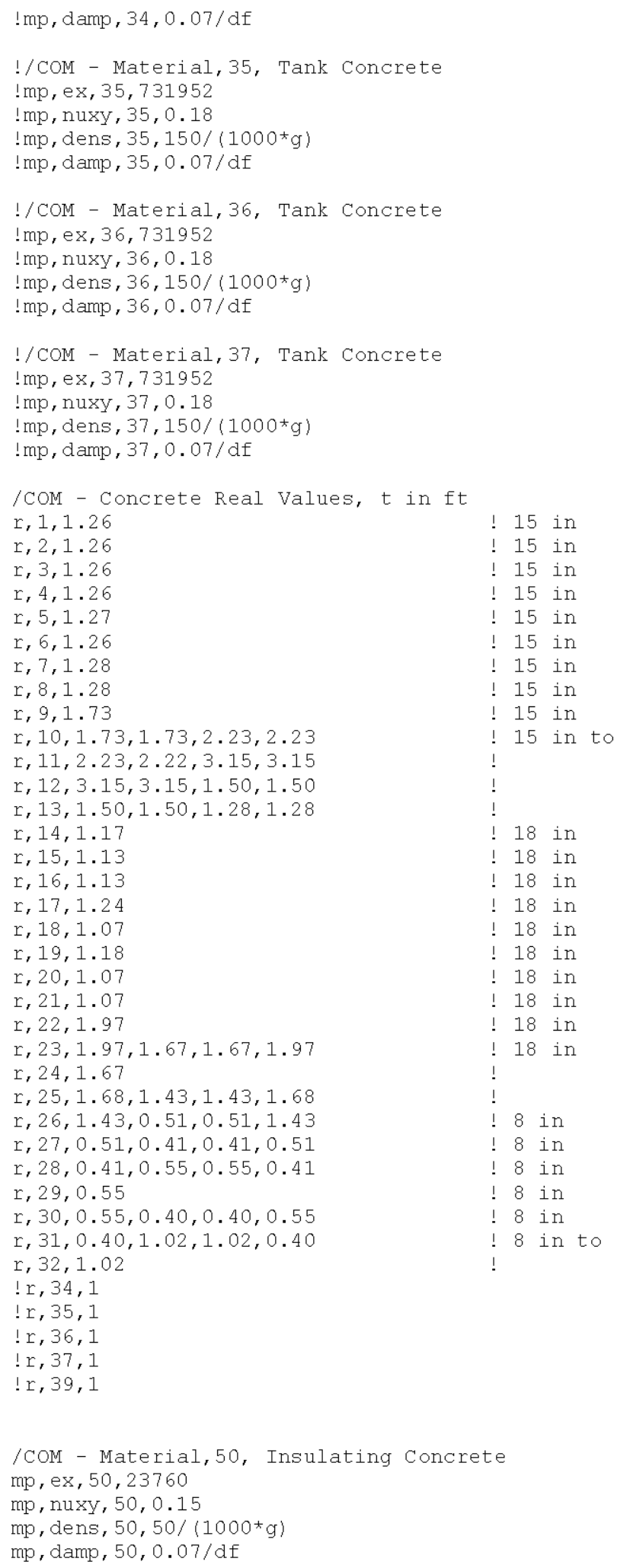




\section{RPP-RPT-32239, Rev. 1 \\ M\&D-2008-005-CALC-001, Rev. 1}

\section{TH-266-Mean-Geo.txt}

$\begin{array}{lll}-0.0000460 .000024 & 0.000044-0.000025-0.0000440 .0000240 .000042-0.000025 & 1\end{array}$

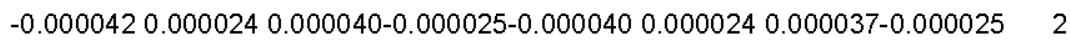

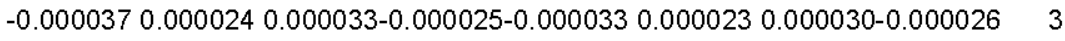
$\ldots \ldots$

$\begin{array}{llll}-0.000054 & 0.000023 & 0.000053-0.000023-0.0000530 .000023 & 0.000052-0.000023 \quad 510\end{array}$

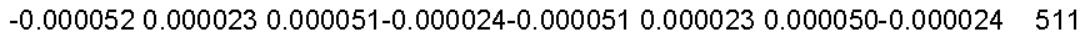

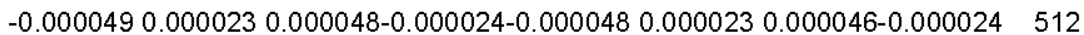

\section{TH-266-Mean-Geo-V.txt}

$\begin{array}{lllll}-0.000029 & 0.000124 & 0.000029-0.000125-0.000029 & 0.000126 & 0.000030-0.000127\end{array}$

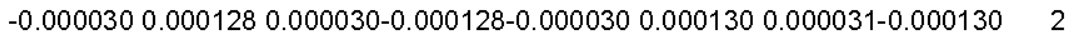

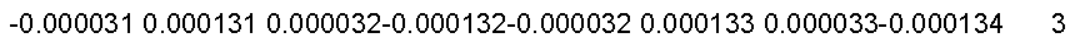

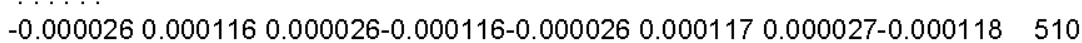
$\begin{array}{lllll}-0.000027 & 0.0001180 .000027-0.000119-0.000027 & 0.000120 & 0.000028-0.000120 & 511\end{array}$

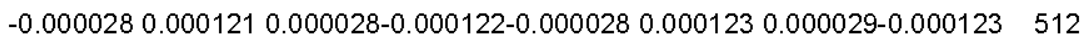

\section{BES-BEC Seismic File Listing}

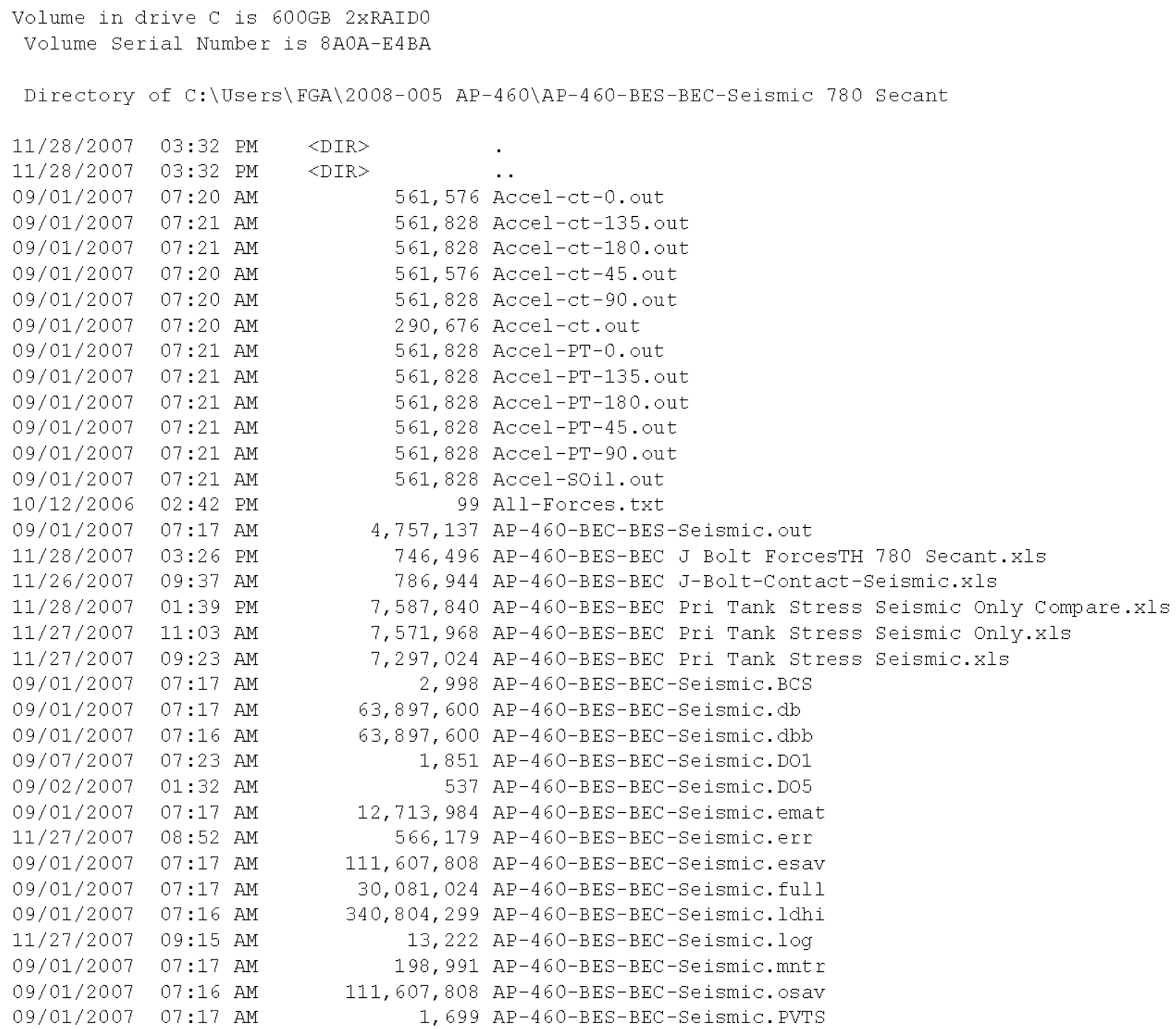




\section{RPP-RPT-32239, Rev. 1 M\&D-2008-005-CALC-001, Rev. 1}

09/01/2007 07:17 AM 08/30/2007 03:08 PM 09/01/2007 07:17 AM 08/31/2007 12:04 AM 08/31/2007 04:41 AM 08/31/2007 09:26 AM $08 / 31 / 2007 \quad 02: 19 \mathrm{PM}$ $08 / 31 / 2007 \quad 07: 19 \mathrm{PM}$ 09/01/2007 12:24 AM 09/01/2007 05:36 AM 09/01/2007 07:17 AM 11/26/2007 03:52 PM 11/26/2007 03:52 PM 12/22/2006 09:40 AM 08/15/2007 10:18 AM 09/08/2006 07:10 AM 08/25/2006 08:48 AM 08/21/2006 07:59 AM 08/25/2006 01:28 PM 08/25/2006 01:27 PM 08/25/2006 01:28 PM 08/21/2006 07:59 AM $08 / 21 / 2006 \quad 12: 44 \quad \mathrm{PM}$ 11/28/2007 03:32 PM 09/01/2007 07:20 AM 09/01/2007 07:21 AM 09/01/2007 07:21 AM 09/01/2007 07:20 AM 09/01/2007 07:20 AM 09/01/2007 07:20 AM 01/03/2006 11:17 AM 09/01/2007 07:21 AM 09/01/2007 07:21 AM 09/01/2007 07:21 AM 09/01/2007 07:21 AM 09/01/2007 07:21 AM 09/01/2007 07:21 AM 05/08/2006 01:31 PM 01/09/2007 06:21 AM 09/06/2007 09:16 AM 09/04/2007 08:26 AM 09/04/2007 08:03 AM 09/06/2007 09:16 AM 09/06/2007 09:18 AM 12/20/2005 04:49 PM 10/13/2005 06:54 AM 09/01/2007 05:46 PM 09/01/2007 05:46 PM 08/21/2006 08:00 AM 09/01/2007 11:48 PM 09/01/2007 11:48 PM 09/01/2007 08:03 PM 09/01/2007 08:03 PM 09/01/2007 11:59 PM 09/01/2007 11:59 PM 09/01/2007 08:14 PM 09/01/2007 08:14 PM 09/02/2007 12:10 AM 09/02/2007 12:10 AM 09/01/2007 08:25 PM 09/01/2007 08:25 PM 09/02/2007 12:21 AM 09/02/2007 12:21 AM 09/01/2007 08:36 PM 09/01/2007 08:36 PM
$112,656,384$ AP-460-BES-BEC-Seismic. r001 $43,974,656$ AP-460-BES-BEC-Seismic.rdb $4,294,967,296$ AP-460-BES-BEC-Seismic.rst $4,294,967,296$ AP-460-BES-BEC-Seismic.rst02 $4,294,967,296 \mathrm{AP}-460-\mathrm{BES}-\mathrm{BEC}-\mathrm{Se}$ ismic.rst03 $4,294,967,296$ AP-460-BES-BEC-Seismic.rst04 $4,294,967,296$ AP-460-BES-BEC-Seismic.rst05 $4,294,967,296$ AP-460-BES-BEC-Seismic.rst06 $4,294,967,296$ AP-460-BES-BEC-Seismic.rst07 $4,294,967,296$ AP-460-BES-BEC-Seismic.rst08 $1,388,445,696$ AP-460-BES-BEC-Seismic.rst09 513 AP-460-LBS-BEC-SeismiC.err 678 AP-460-LBS-BEC-Seismic. log 61,025 BES-BEC-SeismiC-File-List.txt 6,120 Bolts-Friction.txt 277 Boundary.txt 220 Contact-AP.txt 586 Contact-Footing.txt 704 Contact-Insul.txt 704 Contact-J-Bolts.txt 708 Contact-Primary.txt 742 Contact-Soil.txt

632 Contact-Waste-AP. txt

0 dir_listing.txt

561,576 Disp-ct-0.out

561,576 Disp-ct-135.out

561,576 Disp-ct-180.out

561,576 Disp-ct-45. out

561,576 Disp-ct-90. out 290,550 Disp-ct.out

1,616 Disp-J-Bolts.txt

561,576 Disp-PT-0.out

561,576 Disp-PT-135.out

561,576 Disp-PT-180.out

561,576 Disp-PT-45. out

561,576 Disp-PT-90.out

561,576 Disp-Soil.out

8,616 Far-Soil.txt

50, 902 File-List.txt

$43,843,584$ file.db

$43,843,584$ file.dbb

293 file.DO1

211,205 file.err

6,999 file.log

39,925 file.txt 562 Fix-Soil.txt

10, 342 Footing-Cont_max. OUT

4, 346, 248 Footing-Cont th. OUT 894 Force-c.txt

4, 996 Force-C 108 amax. OUT

2,905,500 Force-C 108 ath. OUT

14,716 Force-C_108max. OUT

$6,519,180$ Force-C 108 th. OUT

4,996 Force-C 117 amax. OUT

2,905,500 Force-c 117 ath. OUT

14,716 Force-C $117 \mathrm{max}$. OUT

$6,519,180$ Force-C 117 th. OUT

4,996 Force-C_126amax. OUT

2,905,500 Force-C_126ath.OUT

14,716 Force-C $126 \mathrm{max}$. OUT

6,519,180 Force-C 126 th. OUT

4,996 Force-C_135amax. OUT

2,905,500 Force-C 135ath. OUT

14,716 Force-C_135max. OUT

$6,519,180$ Force-C 135 th. OUT 


\section{RPP-RPT-32239, Rev. 1 M\&D-2008-005-CALC-001, Rev. 1}

09/02/2007 12:32 AM 09/02/2007 12:32 AM 09/01/2007 08:48 PM 09/01/2007 08:48 PM 09/02/2007 12:43 AM 09/02/2007 12:43 AM 09/01/2007 09:00 PM 09/01/2007 09:00 PM 09/02/2007 12:54 AM 09/02/2007 12:54 AM 09/01/2007 09:10 PM 09/01/2007 09:10 PM 09/02/2007 01:05 AM 09/02/2007 01:05 AM 09/01/2007 09:22 PM 09/01/2007 09:22 PM 09/02/2007 01:17 AM 09/02/2007 01:17 AM 09/01/2007 09:34 PM 09/01/2007 09:34 PM 09/01/2007 09:57 PM 09/01/2007 09:57 PM 09/01/2007 06:09 PM 09/01/2007 06:09 PM 09/01/2007 10:08 PM 09/01/2007 10:08 PM 09/01/2007 06:20 PM 09/01/2007 06:20 PM 09/01/2007 10:19 PM 09/01/2007 10:20 PM 09/01/2007 06:32 PM 09/01/2007 06:32 PM 09/01/2007 10:31 PM 09/01/2007 10:31 PM 09/01/2007 06:43 PM 09/01/2007 06:43 PM 09/01/2007 10:41 PM 09/01/2007 10:41 PM 09/01/2007 06:54 PM 09/01/2007 06:54 PM 09/01/2007 10:52 PM 09/01/2007 10:52 PM 09/01/2007 07:06 PM 09/01/2007 07:06 PM 09/01/2007 11:03 PM 09/01/2007 11:03 PM 09/01/2007 07:16 PM 09/01/2007 07:16 PM 09/01/2007 11:14 PM 09/01/2007 11:14 PM 09/01/2007 07:28 PM 09/01/2007 07:28 PM 09/01/2007 11:25 PM 09/01/2007 11:25 PM 09/01/2007 07:39 PM 09/01/2007 07:39 PM 09/01/2007 11:36 PM 09/01/2007 11:36 PM 09/01/2007 07:51 PM 09/01/2007 07:51 PM 09/01/2007 09:45 PM 09/01/2007 09:45 PM 09/01/2007 05:57 PM 09/01/2007 05:57 PM 11/19/2007 01:45 PM
4,996 Force-C 144 amax. OUT

2,905,500 Force-C_144ath. OUT

14,716 Force-C $144 \mathrm{max}$. OUT

$6,519,180$ Force-C 144 th. OUT

4, 996 Force-C 153 amax. OUT

2,905,500 Force-C_153ath. OUT

14,716 Force-C_153max. OUT

$6,519,180$ Force-C 153th. OUT

4, 996 Force-C 162 amax. OUT

2,905,500 Eorce-C_162ath. OUT

14,716 Force-C $162 \mathrm{max}$. OUT

$6,519,180$ Force-C_162th. OUT

4, 996 Force-C 171 amax. OUT

2,905,500 Eorce-C_171ath.OUT

14,716 Force-C 171max. OUT

$6,519,180$ Force-C_171th. OUT

4, 996 Force-C_180amax. OUT

2,905,500 Force-C_180ath. OUT

14,716 Force-C_180max. OUT

$6,519,180$ Force-C 180th. OUT

4, 996 Force-C_18amax. OUT

2,905,500 Force-C_18ath. OUT

14,716 Eorce-C 18max. OUT

$6,519,180$ Force-C_18th. OUT

4,996 Eorce-C_27amax. OUT

$2,905,500$ Force-c 27 ath. OUT

14,716 Force-C_27max. OUT

6,519, 180 Force-C 27 th. OUT

4,996 Force-c_36amax. OUT

2,905,500 Force-c_36ath. OUT

14,716 Force-C $36 \mathrm{max}$. OUT

$6,519,180$ Force-c_36th. OUT

4,996 Force-C 45amax. OUT

2,905, 500 Force-C_45ath. OUT

14,716 Force-C_45max. OUT

6, 519, 180 Force-C 45th. OUT

4,996 Force-C_54amax. OUT

2,905,500 Force-C 54ath. OUT

14,716 Force-C 54max. OUT

$6,519,180$ Force-C 54 th. OUT

4,996 Force-C 63amax. OUT

2, 905,500 Force-c_63ath. OUT

14,716 Force-C 63max. OUT

$6,519,180$ Force-C 63th. OUT

4, 996 Force-C 72 amax. OUT

$2,905,500$ Force-C 72 ath. OUT

14, 716 Force-C_72max. OUT

$6,519,180$ Force-C 72 th. OUT

4,996 Force-C_81amax. OUT

2,905, 500 Force-C 81 ath. OUT

14,716 Force-C 81max. OUT

$6,519,180$ Force-c_81th. OUT

4,996 Force-C 90 amax. OUT

2,905,500 Force-C 90ath. OUT

14, 716 Force-C 90 max. OUT

$6,519,180$ Force-C 90 th. OUT

4, 996 Force-C $99 \mathrm{amax}$. OUT

$2,905,500$ Force-c-99ath. OUT

14,716 Force-C_99max. OUT

$6,519,180$ Force-C 99 th. OUT

4, 996 Force-c 9 amax. OUT

2, 905,628 Force-c 9ath. OUT

14, 716 Force-C 9 max. OUT

$6,519,308$ Force-c_9th. OUT

135,680 force-j]̄.xls 


\section{RPP-RPT-32239, Rev. 1 M\&D-2008-005-CALC-001, Rev. 1}

09/07/2007 08:08 AM 09/07/2007 08:08 AM 09/07/2007 08:09 AM 09/07/2007 08:09 AM 09/07/2007 08:05 AM 09/07/2007 08:05 AM 09/07/2007 08:05 AM 09/07/2007 08:05 AM 09/07/2007 08:06 AM 09/07/2007 08:06 AM 09/07/2007 08:06 AM 09/07/2007 08:06 AM 09/07/2007 08:06 AM 09/07/2007 08:06 AM 09/07/2007 08:07 AM 09/07/2007 08:07 AM 09/07/2007 08:07 AM 09/07/2007 08:07 AM 09/07/2007 08:08 AM 09/07/2007 08:08 AM 09/07/2007 08:05 AM 08/21/2006 08:00 AM $11 / 28 / 2007 \quad 02: 54 \mathrm{PM}$ 09/01/2007 12:35 PM 09/01/2007 12:35 PM $09 / 01 / 2007 \quad 12: 37$ PM 09/01/2007 12:37 PM 09/01/2007 12:38 PM 09/01/2007 12:38 PM 09/01/2007 12:41 PM 09/01/2007 12:41 PM 09/01/2007 12:42 PM 09/01/2007 12:42 PM 09/01/2007 12:44 PM 09/01/2007 12:44 PM 09/01/2007 12:45 PM 09/01/2007 12:45 PM 09/01/2007 12:47 PM 09/01/2007 12:47 PM 09/01/2007 12:48 PM 09/01/2007 12:48 PM 09/01/2007 12:21 PM 09/01/2007 12:21 PM 09/01/2007 12:23 PM 09/01/2007 12:23 PM 09/01/2007 12:24 PM 09/01/2007 12:24 PM 09/01/2007 12:26 PM 09/01/2007 12:26 PM 09/01/2007 12:27 PM 09/01/2007 12:27 PM 09/01/2007 12:28 PM 09/01/2007 12:28 PM 09/01/2007 12:29 PM 09/01/2007 12:29 PM 09/01/2007 12:30 PM 09/01/2007 12:30 PM 09/01/2007 12:32 PM 09/01/2007 12:32 PM 09/01/2007 12:33 PM 09/01/2007 12:33 PM 09/01/2007 12:19 PM 09/01/2007 12:19 PM 09/01/2005 10:27 AM 07/20/2006 06:36 AM
$2,666,244$ Force-jb r10-th. OUT 5, 239 Force-jb r10 max. OUT

$2,666,244$ Force-jb r11-th. OUT 5,239 Force-jb_r11_max. OUT

$2,666,372$ Force-jb_r2-th. OUT 5,239 Force-jb r2 max. OUT

$2,666,244$ Force-jb_r3-th. OUT 5,239 Force-jb r3 max. OUT $2,666,244$ Force-jb_r4-th. OUT 5,239 Force-jb_r4_max.OUT $2,666,244$ Force-jb r5-th. OUT 5,239 Force-jb_r5_max. OUT

$2,666,244$ Force-jb_r6-th. OUT 5,239 Force-jb_r6 max. OUT

$2,666,244$ Force-jb_r7-th. OUT 5,239 Force-jb_r7_max.OUT

$2,666,244$ Force-jb_r8-th. OUT 5,239 Force-jb_r8_max.OUT

$2,666,244$ Force-jb_r9-th. OUT

5,239 Force-jb_r9_max. OUT

833 Force-j_bolt-milon.txt

661 Force-j_bolt.txt Gravity

4,024 Insul-Cont_108max.OUT

$1,738,448$ Insul-Cont_108th. OUT

4,024 Insul-Cont $117 \mathrm{max}$.OUT

1,738,448 Insul-Cont_117th. OUT

4,024 Insul-Cont $126 \mathrm{max}$.OUT

$1,738,448$ Insul-Cont_126th. OUT

4, 024 Insul-Cont 135max. OUT

$1,738,448$ Insul-Cont 135 th. OUT

4,024 Insul-Cont_144max.OUT

$1,738,448$ Insul-Cont 144 th. OUT

4,024 Insul-Cont_153max.OUT

1,738,448 Insul-Cont 153th. OUT

4,024 Insul-Cont $162 \mathrm{max}$.OUT

1,738,448 Insul-Cont_162th. OUT

4,024 Insul-Cont 171max.OUT

1,738,448 Insul-Cont_171th. OUT

4,024 Insul-Cont 180max. OUT

$1,738,448$ Insul-Cont 180th. OUT

4, 024 Insul-Cont 18max. OUT

1,738,448 Insul-Cont 18th.OUT

4,024 Insul-Cont_27max. OUT

$1,738,448$ Insul-Cont $27 \mathrm{th}$.OUT

4,024 Insul-Cont 36max. OUT

$1,738,448$ Insul-Cont_36th.OUT

4,024 Insul-Cont 45max. OUT

$1,738,448$ Insul-Cont 45 th. OUT

4,024 Insul-Cont 54max. OUT

$1,738,448$ Insul-Cont 54 th. OUT

4, 024 Insul-Cont_63max. OUT

$1,738,448$ Insul-Cont 63 th. OUT

4,024 Insul-Cont $72 \mathrm{max}$. OUT

$1,738,448$ Insul-Cont 72 th. OUT

4,024 Insul-Cont 81max. OUT

$1,738,448$ Insul-Cont 81th. OUT

4,024 Insul-Cont-90max. OUT

$1,738,448$ Insul-Cont_90th.OUT

4,024 Insul-Cont 99max. OUT

$1,738,448$ Insul-Cont $99 \mathrm{th}$.OUT

4,024 Insul-Cont 9max.OUT

$1,738,576$ Insul-Cont 9 th. OUT

1,664 Insulate.txt

4,030 interface-gap1.txt 


\section{RPP-RPT-32239, Rev. 1 M\&D-2008-005-CALC-001, Rev. 1}

$08 / 23 / 2006$ $11 / 26 / 2007$ $11 / 26 / 2007$ $09 / 01 / 2007$ $09 / 01 / 2007$

$09 / 01 / 2007$

$09 / 01 / 2007$ $09 / 01 / 2007$ $09 / 01 / 2007$ $09 / 01 / 2007$ $09 / 01 / 2007$ $09 / 01 / 2007$ $09 / 01 / 2007$ $09 / 01 / 2007$ $09 / 01 / 2007$ $09 / 01 / 2007$ $09 / 01 / 2007$ $09 / 01 / 2007$ $09 / 01 / 2007$ $09 / 01 / 2007$ $09 / 01 / 2007$ $09 / 01 / 2007$ $09 / 01 / 2007$ $09 / 01 / 2007$ $09 / 01 / 2007$ $09 / 01 / 2007$ $09 / 01 / 2007$

$09 / 01 / 2007$ $09 / 01 / 2007$ $09 / 01 / 2007$ $09 / 01 / 2007$ $09 / 01 / 2007$ $09 / 01 / 2007$ $09 / 01 / 2007$ $09 / 01 / 2007$ $09 / 01 / 2007$ $09 / 01 / 2007$

$09 / 01 / 2007$ $09 / 01 / 2007$ $09 / 01 / 2007$ $09 / 01 / 2007$ $09 / 01 / 2007$ $09 / 01 / 2007$ $09 / 07 / 2007$ $08 / 23 / 2006$ $11 / 28 / 2007$ $05 / 02 / 2005$ $09 / 07 / 2007$ $07 / 21 / 2006$ $04 / 20 / 2005$ $10 / 13 / 2006$ $09 / 01 / 2007$ $09 / 01 / 2007$ $09 / 01 / 2007$ $09 / 01 / 2007$ $09 / 01 / 2007$ $09 / 01 / 2007$ $09 / 01 / 2007$ $09 / 01 / 2007$ $09 / 01 / 2007$ 09/01/2007 $09 / 01 / 2007$ $09 / 01 / 2007$ $09 / 01 / 2007$ $09 / 01 / 2007$
$07: 55$ AM $08: 39$ AM $08: 45$ AM 02:03 PM 02:03 PM $02: 05 \mathrm{PM}$ 02:05 PM 02:07 PM 02:07 PM $02: 10 \mathrm{PM}$ $02: 10 \mathrm{PM}$ 02:11 PM 02:11 PM 02:11 PM 02:11 PM 02:11 PM $02: 11 \mathrm{PM}$ $02: 15$ PM $02: 15$ PM $02: 17 \mathrm{PM}$ $02: 17$ PM $01: 41 \mathrm{PM}$ $01: 41$ PM $01: 43$ PM $01: 43 \quad \mathrm{PM}$ $01: 45$ PM $01: 45 \quad \mathrm{PM}$ $01: 48$ PM $01: 48$ PM $01: 52$ PM 01:52 PM $01: 54 \mathrm{PM}$ $01: 54$ PM 01:55 PM $01: 55$ PM 01:58 PM $01: 58$ PM 02:00 PM 02:00 PM 02:01 PM 02:01 PM 01:39 PM $01: 39 \mathrm{PM}$ $07: 23$ AM $07: 47$ AM $08: 46$ AM $02: 19 \mathrm{PM}$ $07: 46 \mathrm{AM}$ 10:03 AM $01: 14$ PM $01: 29$ PM $01: 17$ PM $01: 17 \mathrm{PM}$ $01: 20$ PM 01:20 PM $01: 22$ PM $01: 22$ PM $01: 24$ PM $01: 24 \mathrm{PM}$ $01: 26$ PM $01: 26$ PM $01: 28$ PM $01: 28$ PM $01: 30$ PM $01: 30 \mathrm{PM}$
2,411 interfacel.txt

$116,224 \mathrm{~J}$-Bolt-Contact 0-90.xls

$116,224 \mathrm{~J}$-Bolt-Contact $99-180 . x 1 \mathrm{~s}$

4,519 J-Bolt-Cont_108max. OUT

$1,685,484 \mathrm{~J}$-Bolt-Cont 108th. OUT

4,519 J-Bolt-Cont $117 \mathrm{max}$. OUT

$1,685,484 \mathrm{~J}$-Bolt-Cont $117 \mathrm{th}$. OUT

4,519 J-Bolt-Cont $126 \mathrm{max}$. OUT

$1,685,484 \mathrm{~J}$-Bolt-Cont_126th. OUT

4,519 J-Bolt-Cont 135max. OUT

$1,685,484 \mathrm{~J}$-Bolt-Cont $135 \mathrm{th}$. OUT

4,519 J-Bolt-Cont $144 \mathrm{max}$. OUT

$1,685,484 \mathrm{~J}$-Bolt-Cont $144 \mathrm{th}$. OUT

4,519 J-Bolt-Cont_153max. OUT

1,685,484 J-Bolt-Cont 153th. OUT

4,519 J-Bolt-Cont $162 \mathrm{max}$. OUT

1,685,484 J-Bolt-Cont 162th. OUT

4, $519 \mathrm{~J}$-Bolt-Cont $171 \mathrm{max}$. OUT

$1,685,484 \mathrm{~J}$-Bolt-Cont_171th.OUT

4,519 J-Bolt-Cont 18 Omax. OUT

$1,685,484 \mathrm{~J}$-Bolt-Cont $180 \mathrm{th}$. OUT

$4,519 \mathrm{~J}$-Bolt-Cont $18 \mathrm{max}$. OUT

$1,685,484 \mathrm{~J}$-Bolt-Cont $18 \mathrm{th}$. OUT

$4,519 \mathrm{~J}$-Bolt-Cont_27max.OUT

$1,685,484 \mathrm{~J}$-Bolt-Cont $27 \mathrm{th}$. OUT

4, $519 \mathrm{~J}$-Bolt-Cont $36 \mathrm{max}$. OUT

$1,685,484 \mathrm{~J}$-Bolt-Cont 36th. OUT

4, $519 \mathrm{~J}$-Bolt-Cont $45 \mathrm{max}$. OUT

$1,685,484 \mathrm{~J}$-Bolt-Cont $45 \mathrm{th}$. OUT

4,519 J-Bolt-Cont 54 max. OUT

$1,685,484 \mathrm{~J}$-Bolt-Cont $54 \mathrm{th}$. OUT

$4,519 \mathrm{~J}$-Bolt-Cont $63 \mathrm{max}$. OUT

$1,685,484 \mathrm{~J}$-Bolt-Cont $63 \mathrm{th}$. OUT

$4,519 \mathrm{~J}$-Bolt-Cont $72 \mathrm{max}$. OUT

$1,685,484 \mathrm{~J}-\mathrm{Bolt}$-Cont $72 \mathrm{th}$. OUT

4,519 J-Bolt-Cont_81max. OUT

$1,685,484 \mathrm{~J}$-Bolt-Cont_81th. OUT

4,519 J-Bolt-Cont $90 \mathrm{max}$. OUT

$1,685,484 \mathrm{~J}$-Bolt-Cont_90th. OUT

4, $519 \mathrm{~J}$-Bolt-Cont $99 \mathrm{max}$. OUT

$1,685,484 \mathrm{~J}$-Bolt-Cont $99 \mathrm{th}$. OUT

4,519 J-Bolt-Cont 9max. OUT

$1,685,612 \mathrm{~J}$-Bolt-Cont 9 th. OUT

1,800 junk. out

1,971 Liner.txt

39,218 list.txt

667 live load.txt

5,542 milon.out

6,214 Near-Soil-1.txt

508 outer-spar.txt

147 Post-Tank.txt

4,024 Primary-Cont_108max. OUT

1,738,448 Primary-Cont_108th. OUT

4,024 Primary-Cont 117max. OUT

$1,738,448$ Primary-Cont 117 th. OUT

4,024 Primary-Cont $126 \mathrm{max}$. OUT

1,738,448 Primary-Cont 126th. OUT

4,024 Primary-Cont 135max. OUT

1,738,448 Primary-Cont_135th. OUT

4,024 Primary-Cont 144max. OUT

1,738,448 Primary-Cont_144th.OUT

4,024 Primary-Cont 153max. OUT

$1,738,448$ Primary-Cont 153 th. OUT

4,024 Primary-Cont_162max. OUT

1,738,448 Primary-Cont 162 th. OUT 


\section{RPP-RPT-32239, Rev. 1 M\&D-2008-005-CALC-001, Rev. 1}

09/01/2007 01:33 PM 09/01/2007 01:33 PM 09/01/2007 01:35 PM 09/01/2007 01:35 PM 09/01/2007 12:55 PM 09/01/2007 12:55 PM 09/01/2007 12:57 PM 09/01/2007 12:57 PM 09/01/2007 12:59 PM 09/01/2007 12:59 PM 09/01/2007 01:02 PM 09/01/2007 01:02 PM 09/01/2007 01:04 PM 09/01/2007 01:04 PM 09/01/2007 01:06 PM 09/01/2007 01:06 PM 09/01/2007 01:08 PM 09/01/2007 01:08 PM 09/01/2007 01:11 PM 09/01/2007 01:11 PM 09/01/2007 01:13 PM 09/01/2007 01:13 PM 09/01/2007 01:15 PM 09/01/2007 01:15 PM 09/01/2007 12:52 PM 09/01/2007 12:52 PM 10/12/2006 02:28 PM 09/27/2005 03:52 PM 08/30/2007 03:08 PM 09/01/2007 07:20 AM 09/01/2007 07:21 AM 09/01/2007 07:21 AM 09/01/2007 07:20 AM 09/01/2007 07:20 AM 09/01/2007 07:20 AM 08/28/2006 10:32 AM 08/28/2006 08:24 AM 09/01/2007 07:21 AM 09/01/2007 07:21 AM 09/01/2007 07:21 AM 09/01/2007 07:21 AM 09/01/2007 07:21 AM 09/01/2007 07:21 AM 05/22/2006 02:21 PM 10/31/2005 10:31 AM 08/23/2006 09:01 AM 11/27/2007 08:52 AM 02/11/2005 01:22 PM 09/01/2007 04:06 PM 09/01/2007 04:06 PM 09/01/2007 04:15 PM 09/01/2007 04:15 PM 09/01/2007 04:25 PM 09/01/2007 04:25 PM 09/01/2007 04:34 PM 09/01/2007 04:34 PM 09/01/2007 04:43 PM 09/01/2007 04:43 PM 09/01/2007 04:53 PM 09/01/2007 04:53 PM 09/01/2007 05:02 PM 09/01/2007 05:02 PM 09/01/2007 05:11 PM 09/01/2007 05:11 PM 09/01/2007 05:20 PM
4,024 Primary-Cont 171max. OUT

1,738,448 Primary-Cont_171th.OUT

4,024 Primary-Cont 180max. OUT

$1,738,448$ Primary-Cont 180 th. OUT

4,024 Primary-Cont_18max.OUT

1,738,448 Primary-Cont_18th.OUT

4,024 Primary-Cont_27max.OUT

1,738,448 Primary-Cont 27th.OUT

4,024 Primary-Cont $36 \mathrm{max}$.OUT

$1,738,448$ Primary-Cont_36th.OUT

4,024 Primary-Cont 45 max. OUT

1,738,448 Primary-Cont_45th.OUT

4,024 Primary-Cont 54max. OUT

$1,738,448$ Primary-Cont_54th. OUT

4,024 Primary-Cont_63max.OUT

1,738,448 Primary-Cont 63 th. OUT

4,024 Primary-Cont_72max.OUT

$1,738,448$ Primary-Cont 72 th. OUT

4,024 Primary-Cont_81max.OUT

$1,738,448$ Primary-Cont 81 th. OUT

4,024 Primary-Cont 90 max. OUT

1,738,448 Primary-Cont_90th.OUT

4,024 Primary-Cont $99 \mathrm{max}$. OUT

1,738,448 Primary-Cont_99th.OUT

4,024 Primary-Cont 9max. OUT

$1,738,576$ Primary-Cont_9th. OUT

6,028 Primary-Props-AP.txt

1,538 Primary.txt

450,096 QA. out

47,121 RS-ct-0. out

47,121 RS-ct-135.out

47,121 RS-ct-180.out

47, 121 RS-ct-45.out

47, 121 RS-ct-90.out

27,591 RS-ct.out

47, 121 R.S-OUT-Concrete.txt

34,101 RS-OUT-Soil.txt

47,121 RS-PT-0. out

47, 121 RS-PT-135.out

47, 121 RS-PT-180. out

47, 121 RS-PT-45.out

47, 121 RS-PT-90.out

47,121 RS-SOil. out

1,285 RS_FREQ-d.txt

1,108 RS FREQ.txt

1,816 Run-Tank.txt

0 scratch.hlp

1,053 slave.txt

9,896 Soil-Contact_108max. OUT

4,348,080 Soil-Contact 108th. OUT

9,896 Soil-Contact $117 \mathrm{max}$. OUT

4,348,080 Soil-Contact_117th. OUT

9,896 Soil-Contact $126 \mathrm{max}$. OUT

4,348,080 Soil-Contact 126th. OUT

9,896 Soil-Contact $135 \mathrm{max}$. OUT

4,348,080 Soil-Contact 135th. OUT

9,896 Soil-Contact 144max. OUT

4,348,080 Soil-Contact_144th. OUT

9,896 Soil-Contact_153max. OUT

4,348,080 Soil-Contact 153 th. OUT

9,896 Soil-Contact_162max. OUT

4,348,080 Soil-Contact_162th. OUT

9,896 Soil-Contact $171 \mathrm{max}$. OUT

4,348,080 Soil-Contact_171th.OUT

9,896 Soil-Contact_ $180 \mathrm{max}$. OUT 


\section{RPP-RPT-32239, Rev. 1 M\&D-2008-005-CALC-001, Rev. 1}

09/01/2007 05:20 PM 09/01/2007 02:34 PM 09/01/2007 02:34 PM 09/01/2007 02:44 PM 09/01/2007 02:44 PM 09/01/2007 02:53 PM 09/01/2007 02:53 PM 09/01/2007 03:02 PM 09/01/2007 03:02 PM 09/01/2007 03:11 PM 09/01/2007 03:11 PM 09/01/2007 03:20 PM 09/01/2007 03:20 PM 09/01/2007 03:29 PM 09/01/2007 03:30 PM 09/01/2007 03:39 PM 09/01/2007 03:39 PM 09/01/2007 03:48 PM 09/01/2007 03:48 PM 09/01/2007 03:57 PM 09/01/2007 03:57 PM 09/01/2007 02:25 PM 09/01/2007 02:25 PM 11/11/2005 10:36 AM 08/25/2006 08:47 AM 09/13/2006 06:12 AM 10/30/2006 03:57 PM 09/13/2006 06:07 AM 09/13/2006 06:08 AM 09/13/2006 06:09 AM 09/13/2006 06:08 AM 09/13/2006 06:08 AM 10/16/2006 02:18 PM 08/28/2006 09:38 AM 10/03/2006 02:02 PM 10/03/2006 02:04 PM 09/13/2006 06:15 AM 10/03/2006 02:03 PM 10/03/2006 02:03 PM 09/13/2006 06:15 AM 06/20/2005 09:04 AM 06/20/2005 08:52 AM $11 / 27 / 2007 \quad 08: 21$ AM $11 / 27 / 2007 \quad 08: 26$ AM 11/27/2007 08:31 AM $11 / 27 / 2007 \quad 08: 24$ AM 11/27/2007 08:29 AM 11/27/2007 09:15 AM 01/03/2007 03:40 PM 01/03/2007 03:40 PM 01/03/2007 03:41 PM 01/03/2007 04:02 PM 08/21/2006 08:02 AM 08/21/2006 08:03 AM 11/27/2007 09:10 AM 11/27/2007 09:10 AM 11/26/2007 09:54 PM 11/26/2007 06:09 PM 09/02/2007 04:12 AM 11/26/2007 09:54 PM 11/26/2007 06:09 PM 09/02/2007 04:12 AM $11 / 26 / 2007$ 10:06 PM 11/26/2007 06:21 PM 09/02/2007 04:27 AM

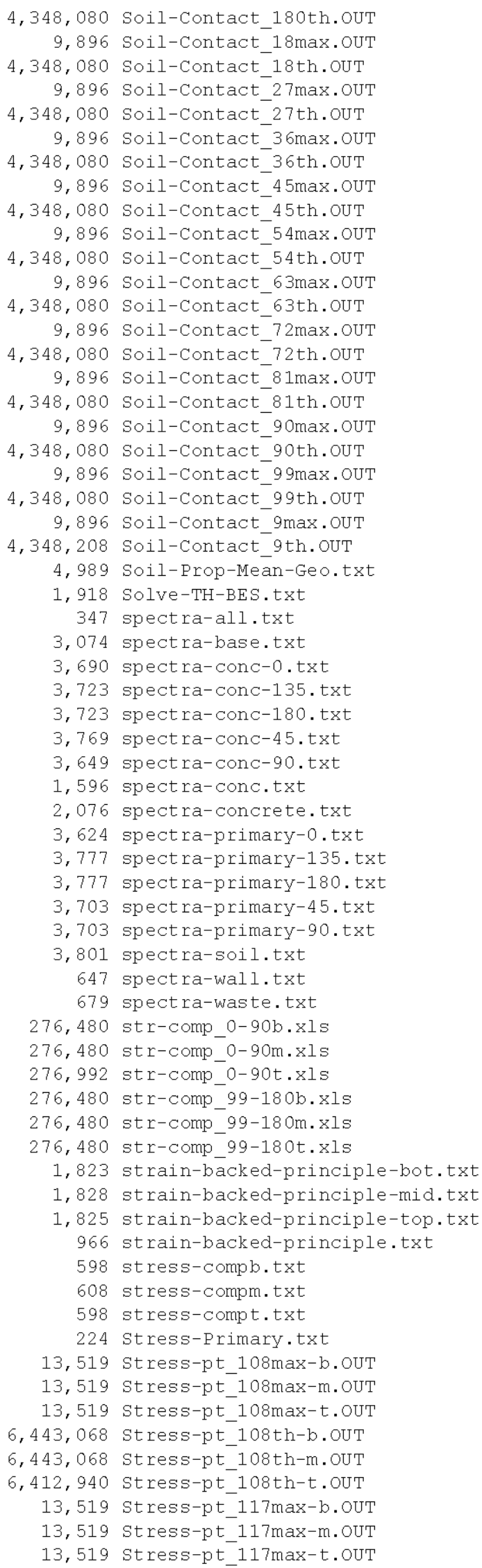




\section{RPP-RPT-32239, Rev. 1 M\&D-2008-005-CALC-001, Rev. 1}

11/26/2007 10:06 PM 11/26/2007 06:21 PM 09/02/2007 04:27 AM $11 / 26 / 2007 \quad 10: 16 \mathrm{PM}$ 11/26/2007 06:31 PM 09/02/2007 04:41 AM $11 / 26 / 2007 \quad 10: 16 \mathrm{PM}$ 11/26/2007 06:31 PM 09/02/2007 04:41 AM 11/26/2007 10:27 PM $11 / 26 / 2007 \quad 06: 42 \mathrm{PM}$ 09/02/2007 04:55 AM $11 / 26 / 2007 \quad 10: 27$ PM 11/26/2007 06:42 PM 09/02/2007 04:55 AM 11/26/2007 10:38 PM 11/26/2007 06:53 PM 09/02/2007 05:10 AM 11/26/2007 10:38 PM 11/26/2007 06:53 PM 09/02/2007 05:10 AM 11/26/2007 10:50 PM 11/26/2007 07:05 PM 09/02/2007 05:24 AM 11/26/2007 10:50 PM 11/26/2007 07:05 PM 09/02/2007 05:24 AM 11/26/2007 11:01 PM 11/26/2007 07:16 PM 09/02/2007 05:39 AM 11/26/2007 11:01 PM 11/26/2007 07:16 PM 09/02/2007 05:39 AM 11/26/2007 11:12 PM 11/26/2007 07:28 PM 09/02/2007 05:53 AM 11/26/2007 11:12 PM 11/26/2007 07:28 PM 09/02/2007 05:53 AM 11/26/2007 11:24 PM 11/26/2007 07:39 PM 11/27/2007 09:05 AM 11/26/2007 11:24 PM 11/26/2007 07:39 PM 11/27/2007 09:05 AM 11/26/2007 08:02 PM 11/26/2007 04:16 PM 09/02/2007 01:46 AM 11/26/2007 08:02 PM $11 / 26 / 2007 \quad 04: 16 \mathrm{PM}$ 09/02/2007 01:46 AM 11/26/2007 08:13 PM $11 / 26 / 2007 \quad 04: 28 \quad \mathrm{PM}$ 09/02/2007 02:01 AM 11/26/2007 08:13 PM $11 / 26 / 2007 \quad 04: 28$ PM 09/02/2007 02:01 AM $11 / 26 / 2007 \quad 08: 25$ PM $11 / 26 / 2007 \quad 04: 40 \mathrm{PM}$ 09/02/2007 02:15 AM $11 / 26 / 2007 \quad 08: 25 \mathrm{PM}$ $11 / 26 / 2007 \quad 04: 40$ PM 09/02/2007 02:15 AM 11/26/2007 08:36 PM 11/26/2007 04:51 PM
$6,443,068$ Stress-pt 117 th-b. OUT $6,443,068$ stress-pt_117th-m. OUT $6,412,940$ stress-pt 117 th-t. OUT 13,519 Stress-pt_126max-b.OUT 13,519 stress-pt_126max-m. OUT 13,519 Stress-pt_126max-t.OUT 6,443,068 Stress-pt_126th-b.OUT $6,443,068$ stress-pt $126 \mathrm{th}-\mathrm{m}$. OUT 6,412,940 Stress-pt_126th-t.OUT 13,519 Stress-pt_135max-b.OUT 13,519 Stress-pt_135max-m.OUT 13,519 Stress-pt_135max-t.OUT $6,443,068$ Stress-pt $135 \mathrm{th}-\mathrm{b}$. OUT $6,443,068$ stress-pt_135th-m.OUT $6,412,940$ stress-pt 135 th-t. OUT 13,519 Stress-pt_144max-b.OUT 13,519 Stress-pt_144max-m.OUT 13,519 Stress-pt_144max-t.OUT $6,443,068$ Stress-pt_144th-b.OUT $6,443,068$ stress-pt $144 \mathrm{th}-\mathrm{m}$. OUT $6,412,940$ stress-pt $144 \mathrm{th}-\mathrm{t}$. OUT 13,519 Stress-pt_153max-b.OUT 13,519 stress-pt $153 \mathrm{max}-\mathrm{m}$. OUT 13,519 stress-pt_153max-t.OUT $6,443,068$ stress-pt 153th-b. OUT $6,443,068$ stress-pt_153th-m. OUT $6,412,940$ stress-pt_153th-t.OUT 13,519 Stress-pt 162max-b.OUT 13,519 stress-pt_162max-m.OUT 13,519 stress-pt $162 \mathrm{max}-t$. OUT $6,443,068$ Stress-pt_162th-b.OUT $6,443,068$ stress-pt_162th-m. OUT $6,412,940$ stress-pt $162 \mathrm{th}-\mathrm{t}$. OUT 13,521 Stress-pt_171max-b.OUT 13,521 Stress-pt_171max-m.OUT 13,521 Stress-pt_171max-t.OUT $6,443,068$ stress-pt_171th-b.OUT $6,443,068$ stress-pt $171 \mathrm{th}-\mathrm{m}$. OUT $6,412,940$ Stress-pt_171th-t.oUT 13,521 Stress-pt 180 max-b.OUT 13,521 Stress-pt_180max-m.OUT 13,521 Stress-pt $180 \mathrm{max}-\mathrm{t}$. OUT $6,443,068$ stress-pt 180 th-b.OUT $6,443,068$ stress-pt 180th-m. OUT $6,412,940$ stress-pt 180 th-t.OUT 13,519 Stress-pt $18 \mathrm{max}-\mathrm{b}$.OUT 13,519 Stress-pt_18max-m.OUT 13,519 stress-pt $18 \mathrm{max}-\mathrm{t}$.OUT $6,443,068$ stress-pt_18th-b. OUT $6,443,068$ stress-pt 18 th-m. OUT $6,412,940$ stress-pt $18 \mathrm{th}-\mathrm{t}$. OUT

13,519 stress-pt $27 \mathrm{max}-\mathrm{b}$.OUT 13,519 stress-pt $27 \mathrm{max}-\mathrm{m}$. OUT 13,519 Stress-pt_27max-t.OUT $6,443,068$ stress-pt $27 \mathrm{th}-\mathrm{b}$. OUT $6,443,068$ stress-pt 27 th-m. OUT $6,412,940$ stress-pt 27 th-t. OUT

13,519 Stress-pt_36max-b.OUT 13,519 Stress-pt_36max-m.OUT 13,519 stress-pt $36 \mathrm{max}-\mathrm{t}$.OUT $6,443,068$ stress-pt_36th-b. OUT $6,443,068$ Stress-pt 36 th-m. OUT $6,412,940$ stress-pt 36 th-t. OUT 13,519 Stress-pt_45max-b.OUT 13,519 Stress-pt_45max-m. OUT 


\section{RPP-RPT-32239, Rev. 1 M\&D-2008-005-CALC-001, Rev. 1}

09/02/2007 02:30 AM 11/26/2007 08:36 PM 11/26/2007 04:51 PM 09/02/2007 02:30 AM $11 / 26 / 2007 \quad 08: 47 \mathrm{PM}$ 11/26/2007 05:02 PM 09/02/2007 02:44 AM $11 / 26 / 2007 \quad 08: 47$ PM 11/26/2007 05:02 PM 09/02/2007 02:44 AM $11 / 26 / 2007 \quad 08: 58 \mathrm{PM}$ $11 / 26 / 2007 \quad 05: 13 \mathrm{PM}$ 09/02/2007 02:59 AM $11 / 26 / 2007 \quad 08: 58$ PM $11 / 26 / 2007 \quad 05: 13 \mathrm{PM}$ 09/02/2007 02:59 AM 11/26/2007 09:09 PM 11/26/2007 05:24 PM 09/02/2007 03:13 AM 11/26/2007 09:09 PM 11/26/2007 05:24 PM 09/02/2007 03:13 AM 11/26/2007 09:20 PM 11/26/2007 05:35 PM 09/02/2007 03:27 AM 11/26/2007 09:20 PM 11/26/2007 05:35 PM 09/02/2007 03:27 AM 11/26/2007 09:32 PM 11/26/2007 05:47 PM 09/02/2007 03:41 AM 11/26/2007 09:32 PM 11/26/2007 05:47 PM 09/02/2007 03:41 AM 11/26/2007 09:43 PM $11 / 26 / 2007 \quad 05: 58$ PM 09/02/2007 03:56 AM 11/26/2007 09:43 PM 11/26/2007 05:58 PM 09/02/2007 03:56 AM 11/26/2007 07:51 PM 11/26/2007 04:05 PM 09/02/2007 01:32 AM 11/26/2007 07:51 PM 11/26/2007 04:05 PM 09/02/2007 01:32 AM 10/12/2006 02:29 PM 05/25/2005 03:32 PM 08/30/2007 03:07 PM 08/25/2006 07:52 AM 07/21/2006 09:41 AM 08/30/2007 03:08 PM 09/06/2007 10:14 AM 08/09/2006 07:43 AM 08/09/2006 07:31 AM 09/01/2007 07:20 AM 09/01/2007 07:21 AM 09/01/2007 07:21 AM 09/01/2007 07:20 AM 09/01/2007 07:20 AM 09/01/2007 07:20 AM 09/01/2007 07:21 AM 09/01/2007 07:21 AM 09/01/2007 07:21 AM 09/01/2007 07:21 AM
13,519 Stress-pt 45max-t. OUT $6,443,068$ Stress-pt_45th-b. OUT $6,443,068$ stress-pt 45 th-m. OUT $6,412,940$ stress-pt_45th-t. OUT

13,519 stress-pt $54 \mathrm{max}-\mathrm{b}$. OUT

13,519 Stress-pt $54 \mathrm{max}-\mathrm{m}$. OUT

13,519 stress-pt_54max-t.OUT $6,443,068$ Stress-pt 54 th-b. OUT 6,443,068 Stress-pt_54th-m. OUT $6,412,940$ Stress-pt_54th-t. OUT

13,519 stress-pt_63max-b.OUT 13,519 Stress-pt_63max-m.OUT

13,519 Stress-pt_63max-t.OUT $6,443,068$ stress-pt_63th-b. OUT $6,443,068$ stress-pt 63th-m. OUT $6,412,940$ Stress-pt_63th-t. OUT 13,519 Stress-pt_72max-b.OUT 13,519 Stress-pt_72max-m.OUT 13,519 stress-pt $72 \mathrm{max}-t$. OUT $6,443,068$ stress-pt 72 th-b. OUT $6,443,068$ Stress-pt 72 th-m. OUT $6,412,940$ stress-pt_72th-t. OUT

13,519 Stress-pt $81 \mathrm{max}-\mathrm{b}$.OUT 13,519 Stress-pt_81max-m.OUT 13,519 stress-pt_81max-t.OUT $6,443,068$ Stress-pt_81th-b. OUT $6,443,068$ stress-pt_81th-m. OUT $6,412,940$ Stress-pt 81 th-t. OUT 13,519 stress-pt_90max-b.OUT 13,519 Stress-pt $90 \mathrm{max}-\mathrm{m}$. OUT 13,519 Stress-pt 90 max-t.OUT 6,443,068 stress-pt_90th-b. OUT $6,443,068$ stress-pt_90th-m. OUT $6,412,940$ stress-pt_90th-t. OUT

13,519 Stress-pt $99 \mathrm{max}-\mathrm{b}$.OUT

13,519 Stress-pt_99max-m.OUT

13,519 stress-pt_99max-t.OUT $6,443,068$ stress-pt 99 th-b. OUT $6,443,068$ stress-pt_99th-m. OUT $6,412,940$ stress-pt 99 th-t. OUT

13,519 Stress-pt 9 max-b. OUT 13,519 stress-pt_9max-m. OUT

13,519 stress-pt 9 max-t. OUT $6,443,196$ Stress-pt_9th-b.OUT $6,443,196$ Stress-pt 9 th-m. OUT $6,413,068$ Stress-pt 9 th-t.OUT

4,009 Tank-Coordinates-AP. txt

2,512 Tank-Mesh1.txt 102 tank-out.out

5,450 Tank-Props-BEC-250.txt

5,591 Tank-Props-Rigid. txt

4,687 Tank-th. out 683 temp.txt

23,166 TH-266-Mean-Geo-V.txt

23,166 TH-266-Mean-Geo.txt

561,576 vel-ct-0.out

561,576 vel-ct-135. out

561,576 vel-ct-180.out

561,576 vel-ct-45. out

561,576 vel-ct-90.out

290,550 vel-ct.out

561,576 vel-PT-0.out

561,576 vel-PT-135. out

561,576 Vel-PT-180. out

561,576 Vel-PT-45.out 


\section{RPP-RPT-32239, Rev. 1 M\&D-2008-005-CALC-001, Rev. 1}

09/01/2007 07:21 AM 09/01/2007 07:21 AM 09/01/2007 10:43 AM 09/01/2007 10:43 AM 09/01/2007 10:55 AM 09/01/2007 10:55 AM 09/01/2007 11:06 AM 09/01/2007 11:06 AM 09/01/2007 11:18 AM 09/01/2007 11:18 AM 09/01/2007 11:29 AM 09/01/2007 11:30 AM 09/01/2007 11:41 AM 09/01/2007 11:41 AM 09/01/2007 11:52 AM 09/01/2007 11:52 AM 09/01/2007 12:04 PM 09/01/2007 12:04 PM 09/01/2007 12:16 PM 09/01/2007 12:16 PM 09/01/2007 08:42 AM 09/01/2007 08:42 AM 09/01/2007 09:00 AM 09/01/2007 09:00 AM 09/01/2007 09:11 AM 09/01/2007 09:11 AM 09/01/2007 09:23 AM 09/01/2007 09:23 AM 09/01/2007 09:34 AM 09/01/2007 09:34 AM 09/01/2007 09:45 AM 09/01/2007 09:45 AM 09/01/2007 09:56 AM 09/01/2007 09:56 AM 09/01/2007 10:08 AM 09/01/2007 10:08 AM 09/01/2007 10:20 AM 09/01/2007 10:20 AM 09/01/2007 10:31 AM 09/01/2007 10:31 AM 09/01/2007 07:51 AM 09/01/2007 07:51 AM 09/01/2007 07:39 AM $08 / 25 / 2006 \quad 08: 47$ AM 10/12/2006 02:27 PM 08/21/2006 08:03 AM 09/01/2007 05:24 PM 09/01/2007 05:24 PM 09/01/2007 05:35 PM 09/01/2007 05:35 PM 09/01/2007 05:36 PM 09/01/2007 05:36 PM 09/01/2007 05:37 PM 09/01/2007 05:37 PM 09/01/2007 05:38 PM 09/01/2007 05:38 PM 09/01/2007 05:39 PM 09/01/2007 05:39 PM 09/01/2007 05:40 PM 09/01/2007 05:40 PM 09/01/2007 05:41 PM 09/01/2007 05:41 PM 09/01/2007 05:42 PM 09/01/2007 05:42 PM 09/01/2007 05:43 PM
561,576 Vel-PT-90.out 561,576 Vel-Soil.out 10,180 waste-Cont $108 \mathrm{max}$. OUT 4,875,649 Waste-Cont 108 th. OUT 10,180 Waste-Cont $117 \mathrm{max}$.OUT 4,875,649 waste-Cont 117 th. OUT 10,180 waste-Cont_126max. OUT 4,875,649 Waste-Cont $126 \mathrm{th}$. OUT 10,180 waste-Cont_135max. OUT 4,875,649 waste-Cont_135th. OUT 10,180 waste-Cont $144 \mathrm{max}$.OUT 4,875,649 Waste-Cont_144th. OUT 10,180 Waste-Cont_153max. OUT 4,875,649 Waste-Cont_153th. OUT 10,180 Waste-Cont $162 \mathrm{max}$.OUT 4,875,649 waste-Cont_162th. OUT 10,180 Waste-Cont_171max.OUT 4,875,649 Waste-Cont_171th. OUT 10,180 Waste-Cont_180max. OUT 4,875,649 Waste-Cont 180th. OUT 10,180 Waste-Cont $18 \mathrm{max}$. OUT $4,875,649$ Waste-Cont_18th. OUT 10,180 Waste-Cont_27max.OUT 4,875,649 Waste-Cont_27th.OUT 10,180 waste-Cont $36 \mathrm{max}$. OUT $4,875,649$ Waste-Cont $36 \mathrm{th}$. OUT 10,180 Waste-Cont_45max. OUT $4,875,649$ Waste-Cont 45 th. OUT 10,180 Waste-Cont_54max.OUT $4,875,649$ Waste-Cont_54th. OUT 10,180 waste-Cont_63max. OUT 4,875,649 Waste-Cont_63th. OUT 10,180 waste-Cont $72 \mathrm{max}$. OUT $4,875,649$ waste-Cont_72th. OUT 10,180 Waste-Cont_81max. OUT 4,875,649 Waste-Cont-81th.OUT 10,180 waste-Cont_90max. OUT $4,875,649$ waste-Cont $90 \mathrm{th}$.OUT 10,180 waste-Cont $99 \mathrm{max}$. OUT $4,875,649$ Waste-Cont 99 th. OUT 10,180 Waste-Cont_9max.OUT $4,875,777$ waste-Cont 9 th. OUT

47, 317 waste-Reaction-460-SD3. out 340 Waste-Reaction.txt

10,266 Waste-solid-AP-S.txt 776 Waste-Surface-AP.txt 865 Waste-Surf_omax.OUT

534, 133 Waste-Surf Oth.OUT 865 Waste-Surf $108 \mathrm{max}$.OUT

534, 005 waste-Surf 108 th. OUT 865 Waste-Surf $117 \mathrm{max}$.OUT

534, 005 Waste-Surf 117 th. OUT 865 Waste-Surf $126 \mathrm{max}$. OUT

534, 005 Waste-Surf 126 th. OUT 865 Waste-Surf $135 \mathrm{max}$.OUT

534,005 Waste-Surf_135th. OUT 865 Waste-Surf $144 \mathrm{max}$.OUT

534, 005 Waste-Surf 144 th. OUT 865 Waste-Surf_153max.OUT

534, 005 waste-Surf 153 th. OUT 865 waste-Surf $162 \max$. OUT

534, 005 Waste-Surf_162th. OUT 865 Waste-Surf $171 \mathrm{max}$.OUT

534, 005 Waste-Surf_171th. OUT 865 Waste-Surf_180max.OUT 
RPP-RPT-32239, Rev. 1

M\&D-2008-005-CALC-001, Rev. 1
09/01/2007 05:43 PM
09/01/2007 05:43 PM
09/01/2007 05:43 PM
09/01/2007 05:25 PM
09/01/2007 05:25 PM
09/01/2007 05:26 PM
09/01/2007 05:26 PM
09/01/2007 05:27 PM
09/01/2007 05:27 PM
09/01/2007 05:28 PM
09/01/2007 05:28 PM
09/01/2007 05:29 PM
09/01/2007 05:29 PM
09/01/2007 05:30 PM
09/01/2007 05:30 PM
09/01/2007 05:31 PM
09/01/2007 05:31 PM
09/01/2007 05:32 PM
09/01/2007 05:32 PM
09/01/2007 05:33 PM
09/01/2007 05:33 PM
09/01/2007 05:34 PM
09/01/2007 05:34 PM
09/01/2007 05:25 PM
09/01/2007 05:25 PM
534,005 waste-Surf 180th. OUT
865 Waste-Surf $189 \mathrm{max}$.OUT
534, 005 Waste-Surf 189 th. OUT
865 waste-Surf_18max. OUT
534, 005 Waste-Surf 18th.OUT
865 Waste-Surf 27 max. OUT
534,005 waste-Surf_27th.OUT
865 Waste-Surf $36 \mathrm{max}$. OUT
534,005 Waste-Surf_36th.OUT
865 Waste-Surf_45max. OUT
534,005 waste-Surf 45th.OUT
865 Waste-Surf_54max. OUT
534,005 Waste-Surf_54th. OUT
865 waste-Surf_63max. OUT
534, 005 Waste-Surf 63th.OUT
865 waste-Surf-72max. OUT
534,005 waste-Surf_72th.OUT
865 Waste-Surf_81max.OUT
534, 005 waste-Surf 81 th. OUT
865 Waste-Surf_90max. OUT
534, 005 Waste-Surf-90th.OUT
865 waste-Surf_99max. OUT
534, 005 waste-Surf 99 th.OUT
865 waste-Surf 9 max. OUT
534,005 Waste-Surf_9th.OUT
642 File(s) $37,686,717,055$ bytes
3 Dir(s) $111,027,654,656$ bytes free 
RPP-RPT-32239, Rev. 1

M\&D-2008-005-CALC-001, Rev. 1

Intentionally left blank. 
RPP-RPT-32239, Rev. 1

M\&D-2008-005-CALC-001, Rev. 1

\title{
Appendix H
}

\author{
Upper Bound Soil, \\ Best Estimate Concrete
}

\section{Results \\ Load Case Specific Input Files}

File Listing 
RPP-RPT-32239, Rev. 1

M\&D-2008-005-CALC-001, Rev. 1

Intentionally left blank 
RPP-RPT-32239, Rev. 1

M\&D-2008-005-CALC-001, Rev. 1

\section{Appendix $\mathbf{H}$}

\section{Upper Bound Soil, Best Estimate Concrete}

\section{Results \\ Load Case Specific Input Files File Listing}

List of Tables Updated in Revision 1:

Table H.13

Table H.14

Table H.15

Table H.31

Table H.32

Table H.33 
RPP-RPT-32239, Rev. 1

M\&D-2008-005-CALC-001, Rev. 1

Tables

H.1 UBS-BEC Concrete Forces and Moment, Gravity Load Only ….................................... H.4

H.2 UBS-BEC Concrete Forces and Moments, Gravity Plus Seismic Load............................... H.5

H.3 UBS-BEC Concrete Forces and Moments, Seismic Only …........................................... H.6

H.4 UBS-BEC Primary Tank Stresses, Shell Top, Gravity Load Only .................................... H.7

H.5 UBS-BEC Primary Tank Stresses, Shell Middle, Gravity Load Only ................................. H. H

H.6 UBS-BEC Primary Tank Stresses, Shell Bottom, Gravity Load Only ................................ H.9

H.7 UBS-BEC Primary Tank Stresses, Shell Top, Gravity Plus Seismic Load.......................... H.10

H.8 UBS-BEC Primary Tank Stresses, Shell Middle, Gravity Plus Seismic Load...................... $\quad$ H.11

H.9 UBS-BEC Primary Tank Stresses, Shell Bottom, Gravity Plus Seismic Load .................... H. H.12

H.10 UBS-BEC Primary Tank Stresses, Shell Top, Seismic Load Only ...................................... H.13

H.11 UBS-BEC Primary Tank Stresses, Shell Middle, Seismic Load Only .................................. H.14

H.12 UBS-BEC Primary Tank Stresses, Shell Bottom, Seismic Load Only ............................... H.15

H.13 UBS-BEC Anchor Bolt Forces, Gravity Load Only .................................................... H.16

H.14 UBS-BEC Anchor Bolt Forces, Gravity Plus Seismic Loads …........................................ H.17

H.15 UBS-BEC Anchor Bolt Forces, Seismic Load Only ................................................... H. H.18

H.16 UBS-BEC Concrete Backed Steel Strain, Shell Top, Gravity Load Only ............................ H.19

H.17 UBS-BEC Concrete Backed Steel Strain, Shell Middle, Gravity Load Only ....................... H.20

H.18 UBS-BEC Concrete Backed Steel Strain, Shell Bottom, Gravity Load Only ..................... H. H

H.19 UBS-BEC Concrete Backed Steel Strain, Shell Top, Gravity Plus Seismic Load ................. H.22

H.20 UBS-BEC Concrete Backed Steel Strain, Shell Middle, Gravity Plus Seismic Load............ $\quad$ H.23

H.21 UBS-BEC Concrete Backed Steel Strain, Shell Bottom, Gravity Plus Seismic Load ........... H.24

H.22 UBS-BEC Concrete Backed Steel Strain, Shell Top, Seismic Load Only ........................... H. H.25

H.23 UBS-BEC Concrete Backed Steel Strain, Shell Middle, Seismic Load Only ...................... H. H.26

H.24 UBS-BEC Concrete Backed Steel Strain, Shell Bottom, Seismic Load Only ..................... H. H.27

H.25 UBS-BEC Concrete Wal1/Footing Contact Forces, Gravity Only ……............................ H.28

H.26 UBS-BEC Concrete Wall/Footing Contact Forces, Gravity Plus Seismic .......................... H. H.29

H.27 UBS-BEC Concrete Wall/Footing Contact Forces, Seismic Only ..................................... H. H

H.28 UBS-BEC Soil/Concrete Tank Contact Forces, Gravity Only ........................................... H. H.31

H.29 UBS-BEC Soil/Concrete Tank Contact Forces, Gravity Plus Seismic …............................ H. H H2

H.30 UBS-BEC Soil/Concrete Tank Contact Forces, Seismic Only ……................................. H... H3

H.31 UBS-BEC Primary Tank/Concrete Dome Contact Data, Gravity Only .............................. H.34

H.32 UBS-BEC Primary Tank/Concrete Dome Contact Data, Gravity Plus Seismic ................... H.35

H.33 UBS-BEC Primary Tank/Concrete Dome Contact Data, Seismic Only ............................. H. H.36

H.34 UBS-BEC Primary Tank/Insulating Concrete Contact Forces, Gravity Only ...................... H.37 
RPP-RPT-32239, Rev. 1

M\&D-2008-005-CALC-001, Rev. 1

H.35 UBS-BEC Primary Tank/Insulating Concrete Contact Data, Gravity Plus Seismic

H.38

H.36 UBS-BEC Primary Tank/Insulating Concrete Contact Forces, Seismic Only

H.39

H.37 UBS-BEC Insulating Concrete/Concrete Backed Steel Contact Data, Gravity Only

H.40

H.38 UBS-BEC Insulating Concrete/Concrete Backed Steel Contact Data, Gravity

Plus Seismic

H.41

H.39 UBS-BEC Insulating Concrete/Concrete Backed Steel Contact Data, Seismic Only

H.42

H.40 UBS-BEC Waste Contact Pressure, Gravity Plus Seismic

H.43

H.41 UBS-BEC Waste Contact Pressure, Theoretical Pressures

H.42 UBS-BEC Waste Surface Displacement, Gravity Plus Seismic

H.45 
RPP-RPT-32239, Rev. 1

M\&D-2008-005-CALC-001, Rev. 1

Table H.1. UBS-BEC Concrete Forces and Moment, Gravity Load Only

AP Primary Tank, Upper Bound Soil (Geomatrix), Gravity Only, Best Estimate Concrete, $460 \mathrm{in}$. Waste Level at $1.83 \mathrm{SpG}$

\begin{tabular}{|c|c|c|c|c|c|c|c|}
\hline $\begin{array}{l}\text { PNNL } \\
\text { Section } \\
\text { No. }\end{array}$ & Path (in.) & $\begin{array}{c}\text { Gravity Hoop } \\
\text { Force (kip/ft) AP } \\
\text { UBS-BEC }\end{array}$ & $\begin{array}{c}\text { Gravity } \\
\text { Meridonal } \\
\text { Force (kip/ft) } \\
\text { AP-UBS-BEC }\end{array}$ & $\begin{array}{l}\text { Gravity -In- } \\
\text { Plane Shear } \\
\text { Force (kip/ft) } \\
\text { AP-UBS-BEC }\end{array}$ & $\begin{array}{c}\text { Gravity Hoop } \\
\text { Moment } \\
\text { (ft*kip/ft) AP- } \\
\text { UBS-BEC }\end{array}$ & $\begin{array}{c}\text { Gravity Meridonal } \\
\text { Moment (ft*kip/ft) } \\
\text { AP-UBS-BEC }\end{array}$ & $\begin{array}{c}\text { Gravity } \\
\text { Through-Wall } \\
\text { Shear Force } \\
\text { (kip/ft) AP-UBS } \\
\text { BEC }\end{array}$ \\
\hline 2 & 67.734 & -69.410 & -74.460 & -0.072 & -8.576 & -5.449 & 1.759 \\
\hline 3 & 105.676 & -62.430 & -72.330 & -0.076 & -6.342 & -2.705 & 1.264 \\
\hline 4 & 137.076 & -55.370 & -69.950 & -0.118 & -4.600 & -0.353 & 1.449 \\
\hline 6 & 182.856 & -46.480 & -65.970 & -0.151 & -2.740 & 2.189 & 0.566 \\
\hline 8 & 226.570 & 39.590 & -62.720 & -0.045 & -1858 & 1.464 & -0.500 \\
\hline 9 & 275.574 & 33.840 & -59.530 & -0.072 & -1.692 & -0.047 & -0.579 \\
\hline 11 & 325.697 & -26.210 & -57.030 & -0.033 & -1.871 & -2.710 & -0.650 \\
\hline 13 & 372.312 & -16.800 & -54.780 & 0.072 & 3.958 & 3.227 & -0.209 \\
\hline 17 & 423.434 & -6.761 & -52.680 & 0.104 & -1.474 & -0.406 & 2.161 \\
\hline 20 & 468.315 & 24610 & -50.820 & 0.119 & -4.868 & 16550 & 7.303 \\
\hline 22 & 515.319 & 9.539 & -50.480 & 0.072 & 4.106 & 25.040 & -4.144 \\
\hline 24 & 553.722 & -2.727 & -47.960 & 0.040 & 1.371 & 7.485 & -5.798 \\
\hline 26 & 593.805 & -12.990 & -49.340 & -0.022 & -0.264 & -1.462 & -0.886 \\
\hline 30 & 644.355 & -19.210 & -50.880 & 0.011 & -0.250 & -1.389 & 0.687 \\
\hline 33 & 693.605 & -21.350 & -52.100 & 0.008 & -0.008 & -0.044 & 0.049 \\
\hline 35 & 740.705 & -23.900 & -53.400 & 0.006 & 0.024 & 0.132 & -0.021 \\
\hline 38 & 786.205 & -21.500 & -54.650 & 0.005 & -0.109 & -0.604 & -0.155 \\
\hline 41 & 844.605 & -21.740 & -56270 & 0.004 & -0.048 & -0.268 & -0.160 \\
\hline 43 & 901.355 & -11.290 & -23.860 & 0.002 & -0.212 & -1.174 & 0.202 \\
\hline 46 & 932.355 & -19.870 & -57.220 & 0.029 & -0.653 & 3.582 & -1.056 \\
\hline 48 & 1007.355 & -2.220 & -8.751 & 0.547 & -2.896 & 14.650 & -8.440 \\
\hline 51 & 1053.855 & -2.412 & -11.600 & 0.762 & -0.224 & 10.270 & 9.595 \\
\hline 53 & 1086.855 & -0.718 & -4.912 & 0.358 & 1.698 & 6.434 & -4.284 \\
\hline 55 & 1105.855 & 0.478 & 3.251 & 0.314 & 1.607 & 3.343 & -0.508 \\
\hline 57 & 1147.355 & 0.146 & -1.541 & 0.147 & 0.172 & 0.624 & -0.750 \\
\hline 58 & 1207.355 & 0.338 & 0.172 & 0.024 & -0.012 & -0.081 & 0.196 \\
\hline 59 & 1267.355 & 0.341 & 0.345 & -0.009 & 0.017 & 0.085 & -0.166 \\
\hline 60 & 1327.355 & 0.475 & 0.146 & 0.036 & -0.022 & -0.129 & 0.155 \\
\hline 61 & 1387.355 & 0.450 & 0.597 & -0.020 & 0.016 & 0.039 & -0.119 \\
\hline 62 & 1449.355 & 2.264 & 2.390 & -0.036 & 0.025 & -0.029 & 0.240 \\
\hline
\end{tabular}

Note: Meridonal/Hoop Forces and Meridonal/Hoop Moments are Reversed in Highlighted Sections. 
RPP-RPT-32239, Rev. 1

M\&D-2008-005-CALC-001, Rev. 1

Table H.2. UBS-BEC Concrete Forces and Moments, Gravity Plus Seismic Load

AP- Primary Tank, Upper Bound Soil (Geomatrix), Best Estimate Concrete, $460 \mathrm{in}$. Waste Level at 1.83 SpG

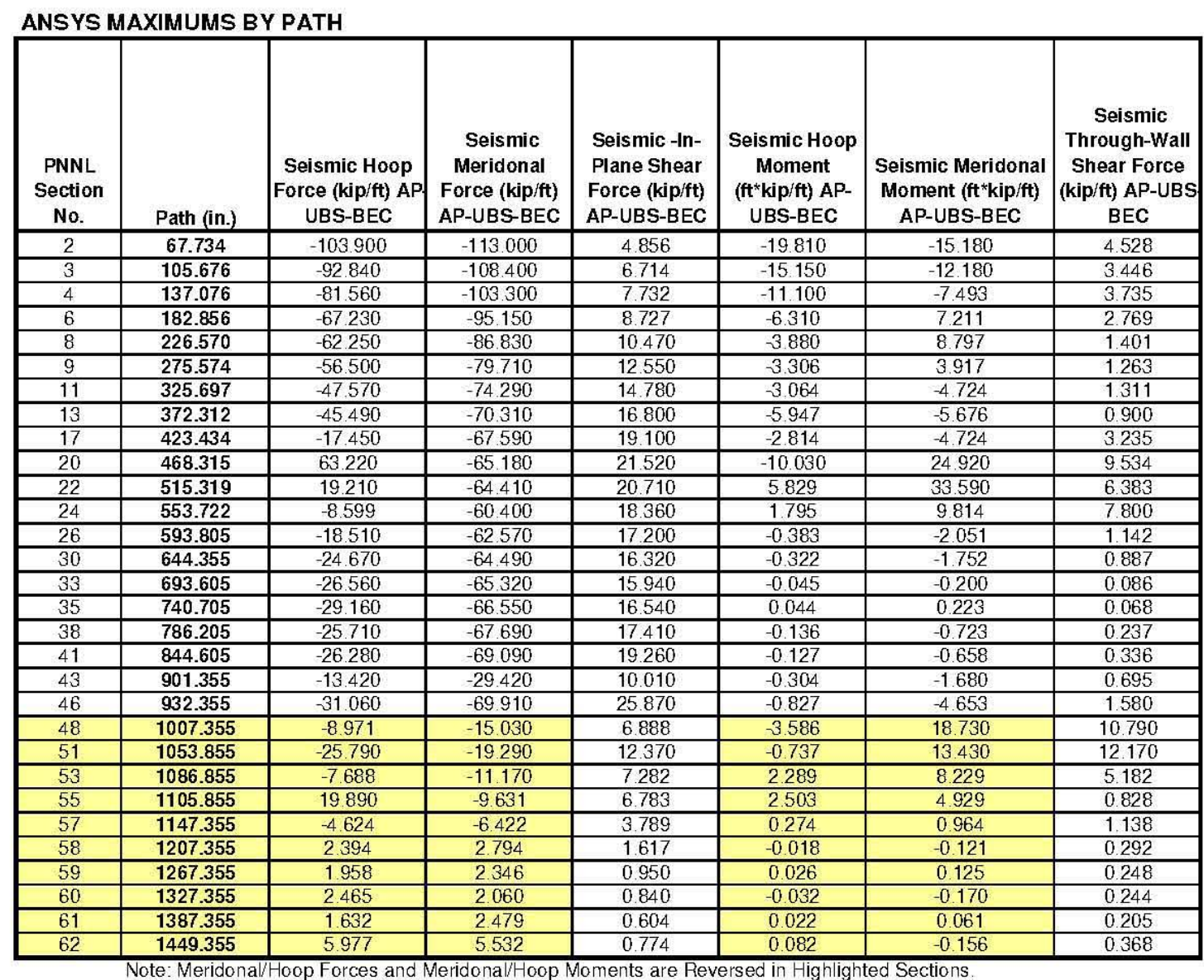


RPP-RPT-32239, Rev. 1

M\&D-2008-005-CALC-001, Rev. 1

Table H.3. UBS-BEC Concrete Forces and Moments, Seismic Only

AP- Primary Tank, Upper Bound Soil (Geomatrix), Best Estimate Concrete, 460 in. Waste Level at $1.83 \mathrm{SpG}$

\begin{tabular}{|c|c|c|c|c|c|c|c|}
\hline $\begin{array}{l}\text { PNNL } \\
\text { Section } \\
\text { No. }\end{array}$ & Path (in.) & $\begin{array}{c}\text { Seismic Only } \\
\text { Hoop Force } \\
\text { (kip/ft) AP-UBS- } \\
\text { BEC }\end{array}$ & $\begin{array}{l}\text { Seismic Only } \\
\text { Meridonal } \\
\text { Force (kip/ft) } \\
\text { AP-UBS-BEC }\end{array}$ & $\begin{array}{l}\text { Seismic Only- } \\
\text { In-Plane Shear } \\
\text { Force (kip/ft) } \\
\text { AP-UBS-BEC }\end{array}$ & $\begin{array}{c}\text { Seis mic Only } \\
\text { Hoop Moment } \\
\text { (ft*kip/ft) AP- } \\
\text { UBS-BEC }\end{array}$ & $\begin{array}{c}\text { Seismic Only } \\
\text { Meridonal Moment } \\
\text { (ft*kip/ft) AP-UBS- } \\
\text { BEC }\end{array}$ & $\begin{array}{c}\text { Seismic Only } \\
\text { Through-Wall } \\
\text { Shear Force } \\
\text { (kip/ft) AP-UBS } \\
\text { BEC }\end{array}$ \\
\hline 2 & 67.734 & 34.600 & 38.540 & 4.833 & 11.325 & 10.425 & 2.780 \\
\hline 3 & 105.676 & 30.510 & 36.090 & 6.735 & 8.886 & 9.536 & 2.460 \\
\hline 4 & 137.076 & 26.330 & 33.350 & 7.776 & 6.528 & 7.482 & 2596 \\
\hline 6 & 182.856 & 22.860 & 29.180 & 8.815 & 3.706 & 5.916 & 2.776 \\
\hline 8 & 226.570 & 24.180 & 24.130 & 10.491 & 2.109 & 8.946 & 1.086 \\
\hline 9 & 275.574 & 25.245 & 20.190 & 12.549 & 1.832 & 3.927 & 1.022 \\
\hline 11 & 325.697 & 23.465 & 17.260 & 14.785 & 1.485 & 2.367 & 0.729 \\
\hline 13 & 372.312 & 28.990 & 15.530 & 16.821 & 2.446 & 2.769 & 0.875 \\
\hline 17 & 423.434 & 10.780 & 14.930 & 19.127 & 1.395 & 4.407 & 1.112 \\
\hline 20 & 468.315 & 39.180 & 14.380 & 21549 & 5.322 & 8.390 & 2274 \\
\hline 22 & 515.319 & 11.178 & 13.970 & 20.727 & 1.732 & 8.590 & 2.240 \\
\hline 24 & 553.722 & 5.872 & 12.470 & 18369 & 0.447 & 2.360 & 2.011 \\
\hline 26 & 593.805 & 5.530 & 13.250 & 17.205 & 0.118 & 0.589 & 0.280 \\
\hline 30 & 644.355 & 5.460 & 13.620 & 16,322 & 0.072 & 0.367 & 0.200 \\
\hline 33 & 693.605 & 5.210 & 13.230 & 15.943 & 0.037 & 0.156 & 0.042 \\
\hline 35 & 740.705 & 5.270 & 13.150 & 16.540 & 0.028 & 0.096 & 0.047 \\
\hline 38 & 786.205 & 4.660 & 13.040 & 17.410 & 0.027 & 0.138 & 0.081 \\
\hline 41 & 844.605 & 5.220 & 12.820 & 19.259 & 0.078 & 0.390 & 0.176 \\
\hline 43 & 901.355 & 2.493 & 5.940 & 10.010 & 0.122 & 0.676 & 0.494 \\
\hline 46 & 932.355 & 11.260 & 14.380 & 25.869 & 0.182 & 1.073 & 0.897 \\
\hline 48 & 1007.355 & 6.779 & 6.282 & 6.378 & 0.792 & 4.080 & 2.353 \\
\hline 51 & 1053.855 & 23.498 & 7.690 & 11.631 & 0.566 & 3590 & 2578 \\
\hline 53 & 1086.855 & 7.008 & 6.259 & 6.949 & 0.593 & 1.803 & 1.005 \\
\hline 55 & 1105.855 & 20.194 & 6.382 & 6.491 & 0.899 & 1.589 & 0.474 \\
\hline 57 & 1147.355 & 4768 & 4.882 & 3.654 & 0.103 & 0.340 & 0.389 \\
\hline 58 & 1207.355 & 2.314 & 2.809 & 1.603 & 0.006 & 0.040 & 0.097 \\
\hline 59 & 1267.355 & 1.843 & 2.083 & 0.950 & 0.010 & 0.040 & 0.083 \\
\hline 60 & 1327.355 & 2.206 & 2.127 & 0.811 & 0.010 & 0.040 & 0.090 \\
\hline 61 & 1387.355 & 1.186 & 1.910 & 0.615 & 0.007 & 0.022 & 0.088 \\
\hline 62 & 1449.355 & 3718 & 3.144 & 0.766 & 0.057 & 0.134 & 0.134 \\
\hline
\end{tabular}

Note: Meridonal/Hoop Forces and Meridonal/Hoop Moments are Reversed in Highlighted Sections. 
RPP-RPT-32239, Rev. 1

M\&D-2008-005-CALC-001, Rev. 1

Table H.4. UBS-BEC Primary Tank Stresses, Shell Top, Gravity Load Only

AP Primary Tank, Upper Bound Soil, Gravity Only, Best Estimate Tank Concrete, 460 in. Waste Level at $1.83 \mathrm{SpG}$

\begin{tabular}{|c|c|c|c|c|c|}
\hline \multirow[b]{2}{*}{$\begin{array}{c}\text { M\&D } \\
\text { Starting } \\
\text { Element } \\
\text { No. }\end{array}$} & \multirow[b]{2}{*}{ Path (in.) } & \multicolumn{4}{|c|}{ Shell Top Surface (in side - waste side) } \\
\hline & & $\begin{array}{l}\text { AP-460-UBS-BEC } \\
\text { Gravity Hoop Stress } \\
\text { (lbs/in^2) Top }\end{array}$ & $\begin{array}{c}\text { AP-460-UBS-BEC } \\
\text { Gravity Meridional } \\
\text { Stress (lbs/in^ } 2 \text { ) Top }\end{array}$ & $\begin{array}{c}\text { AP-460-UBS-BEC } \\
\text { Gravity Stress } \\
\text { Intensity (lbs/in^2) } \\
\text { Top }\end{array}$ & $\begin{array}{c}\text { AP-460-UBS-BEC } \\
\text { Gravity In-Plane } \\
\text { Shear Stress } \\
\text { (lbs/in^2) Top }\end{array}$ \\
\hline 762 & 67.33 & -1502.08 & -166181 & 166181 & -2.88 \\
\hline 782 & 105.04 & -1497.92 & -213958 & 213958 & 2.76 \\
\hline 802 & 136.24 & -1302.08 & -2003.47 & 2003.47 & 3.59 \\
\hline 822 & 181.83 & -969.44 & -1763.19 & 1763.19 & 4.02 \\
\hline 842 & 225.10 & -704.17 & -1513.19 & 1513.89 & 1.37 \\
\hline 942 & 444.31 & -152.15 & -2658.33 & 2660.42 & -2.49 \\
\hline 962 & 458.66 & -1099.31 & 2782.64 & 3881.94 & 1.76 \\
\hline 982 & 473.08 & -1508.33 & 2658.33 & 4166.67 & -0.66 \\
\hline 1002 & 484.80 & -35.86 & -534.38 & 535.76 & -0.95 \\
\hline 1022 & 502.48 & 2752.08 & -272.15 & 3022.92 & -1.11 \\
\hline 1042 & 526.48 & 4727.78 & 298.89 & 4727.78 & -0.77 \\
\hline 1062 & 550.48 & 6309.72 & 136.32 & 6310.42 & -0.50 \\
\hline 1082 & 574.60 & 7881.94 & 356.18 & 788194 & -0.33 \\
\hline 1102 & 598.28 & 9569.44 & 83.54 & 9569.44 & 0.21 \\
\hline 1122 & 621.38 & 11118.06 & 280.97 & 11118.06 & -0.17 \\
\hline 1142 & 644.48 & 12687.50 & 154.79 & 12687.50 & -0.20 \\
\hline 1302 & 825.73 & 15770.83 & 93.40 & 15770.83 & 0.50 \\
\hline 1322 & 847.33 & 17180.56 & 474.44 & 17180.56 & -0.43 \\
\hline 1342 & 868.87 & 17416.67 & -2172.92 & 19590.28 & -0.80 \\
\hline 1362 & 892.10 & 12756.94 & -256944 & 15326.39 & 1.22 \\
\hline 1382 & 909.20 & 3725.00 & -7534.72 & 11263.89 & 1.19 \\
\hline 1402 & 918.38 & 3745.14 & 6644.44 & 6674.31 & -1.23 \\
\hline 1460 & 930.48 & 3176.39 & 8972.22 & 9013.89 & -459.24 \\
\hline 1442 & 949.48 & 102.92 & -761.11 & 872.92 & 68.54 \\
\hline 1462 & 990.98 & 599.03 & 913.19 & 914.58 & -25.53 \\
\hline 1482 & 1050.98 & 408.75 & 401.18 & 629.03 & 1.75 \\
\hline 1502 & 1110.98 & 454.03 & 628.06 & 629.03 & -15.15 \\
\hline 1522 & 1170.98 & 321.67 & 240.63 & 322.22 & 8.08 \\
\hline 1542 & 1230.98 & 39139 & 498.68 & 499.31 & -10.18 \\
\hline 1562 & 1292.98 & 294.65 & 283.19 & 295.21 & 3.42 \\
\hline
\end{tabular}

Note 1: Meridonal, Hoop, and Shear Stresses are Reversed in Highlighted Sections

(Floor) 
RPP-RPT-32239, Rev. 1

M\&D-2008-005-CALC-001, Rev. 1

Table H.5. UBS-BEC Primary Tank Stresses, Shell Middle, Gravity Load Only

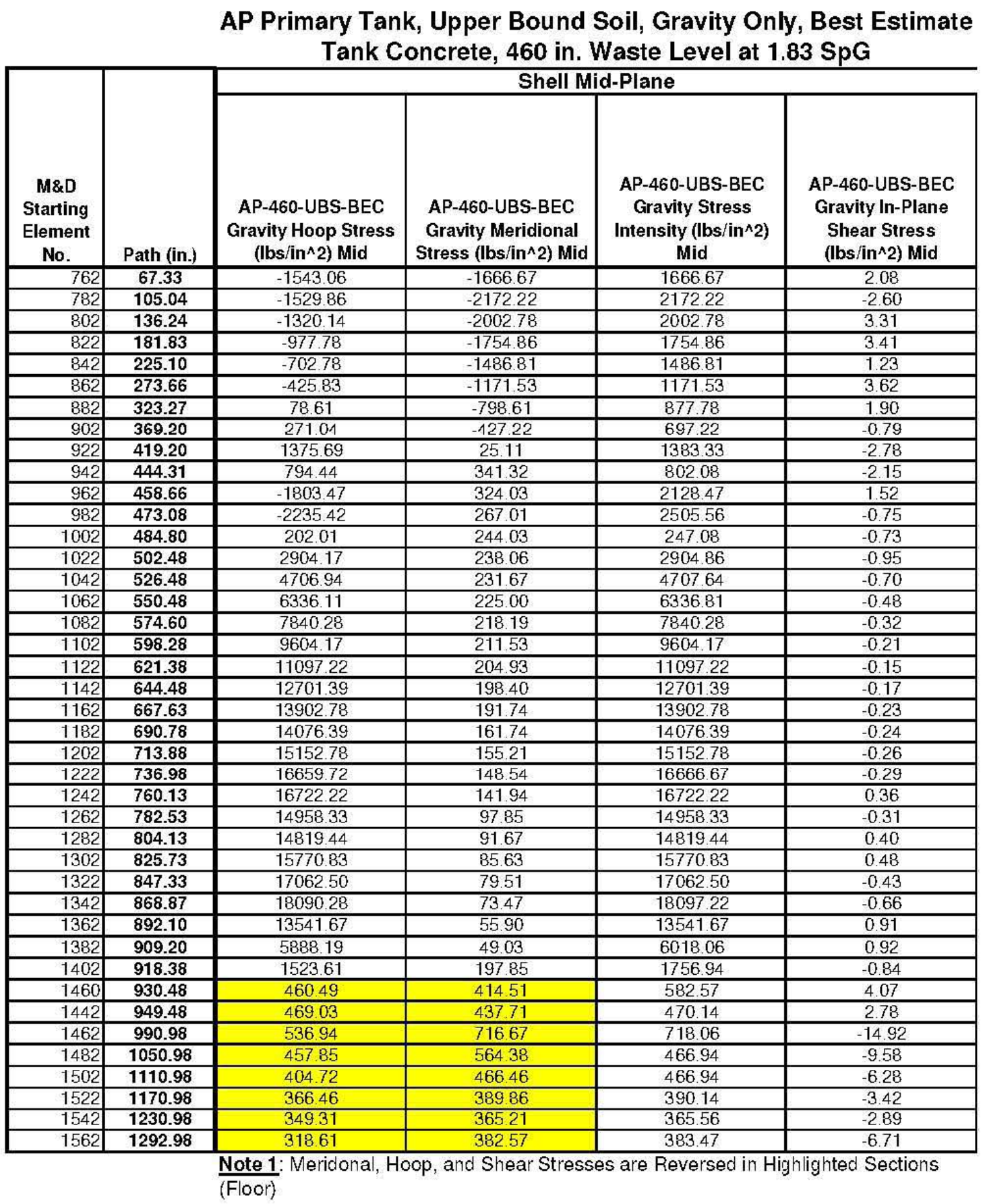


RPP-RPT-32239, Rev. 1

M\&D-2008-005-CALC-001, Rev. 1

Table H.6. UBS-BEC Primary Tank Stresses, Shell Bottom, Gravity Load Only

AP Primary Tank, Upper Bound Soil, Gravity Only, Best Estimate

Tank Concrete, 460 in. Waste Level at $1.83 \mathrm{SpG}$

\begin{tabular}{|c|c|c|c|c|c|}
\hline \multirow[b]{2}{*}{$\begin{array}{c}\text { M\&D } \\
\text { Starting } \\
\text { Element } \\
\text { No. }\end{array}$} & \multirow[b]{2}{*}{ Path (in.) } & \multicolumn{4}{|c|}{ Shell Bottom Surface (outside - away from waste) } \\
\hline & & $\begin{array}{l}\text { AP-460-UBS-BEC } \\
\text { Gravity Hoop Stress } \\
(\text { lbs/in^2) Bot }\end{array}$ & $\begin{array}{l}\text { AP-460-UBS-BEC } \\
\text { Gravity Meridional } \\
\text { Stress (lbs/in^2) Bot }\end{array}$ & $\begin{array}{l}\text { AP-460-UBS-BEC } \\
\text { Gravity Stress } \\
\text { Intensity (lbs/in^2) } \\
\text { Bot }\end{array}$ & $\begin{array}{c}\text { AP-460-UBS-BEC } \\
\text { Gravity In-Plane } \\
\text { Shear Stress } \\
\text { (lbs/in^2) Bot }\end{array}$ \\
\hline 762 & 67.33 & -1588.19 & $-1675,00$ & 1675.00 & -2.97 \\
\hline 782 & 105.04 & -156111 & -2205.56 & 2205.56 & 2.79 \\
\hline 802 & 136.24 & -1338.89 & -2002.08 & 2002.08 & 3.18 \\
\hline 822 & 181.83 & -986.11 & -1747.22 & 1747.22 & 3.05 \\
\hline 842 & 225.10 & -700.69 & -1461.11 & 1461.81 & 1.15 \\
\hline 862 & 273.66 & -442.01 & -1203.47 & 1203.47 & 3.23 \\
\hline 882 & 323.27 & 118.89 & -656.60 & 775.00 & 176 \\
\hline 902 & 369.20 & 227.57 & -552.57 & 779.17 & -0.79 \\
\hline 922 & 419.20 & 1462.50 & 319.17 & 1463.19 & -2.73 \\
\hline 942 & 444.31 & 1735.42 & 3340.97 & 3343.06 & -1.81 \\
\hline 962 & 458.66 & -2507.64 & -2134.03 & 2507.64 & 1.28 \\
\hline 982 & 473.08 & -2962.50 & -2124.31 & 2962.50 & -0.83 \\
\hline 1002 & 484.80 & 430.35 & 102153 & 1022.22 & -0.51 \\
\hline 1022 & 502.48 & 3056.94 & 747.92 & 3056.94 & -0.78 \\
\hline 1042 & 526.48 & 4687.50 & 164.79 & 4687.50 & -0.66 \\
\hline 1062 & 550.48 & 6363.89 & 313.82 & 6363.89 & -0.45 \\
\hline 1082 & 574.60 & 7798.61 & 80.35 & 7798.61 & -0.30 \\
\hline 1102 & 598.28 & 9645.83 & 339.65 & 9645.83 & -0.21 \\
\hline 1122 & 621.38 & 11069.44 & 129.10 & 11069.44 & -0.15 \\
\hline 1142 & 644.48 & 12715.28 & 242.15 & 12715.28 & -0.14 \\
\hline 1162 & 667.63 & 14020.83 & 576.46 & 14020.83 & -0.20 \\
\hline 1182 & 690.78 & 13958.33 & -231.25 & 1418750 & -0.21 \\
\hline 1202 & 713.88 & 15111.11 & 18.72 & 15118.06 & -0.28 \\
\hline 1222 & 736.98 & 16770.83 & 499.17 & 16770.83 & -0.31 \\
\hline 1242 & 760.13 & 16937.50 & 865.28 & 16937.50 & -0.34 \\
\hline 1262 & 782.53 & 14652.78 & -920.14 & 15576.39 & -0.30 \\
\hline 1282 & 804.13 & 14715.28 & -247.78 & 14965.28 & 0.38 \\
\hline 1302 & 825.73 & 15770.83 & 78.19 & 15770.83 & 0.46 \\
\hline 1322 & 847.33 & 16944.44 & -316.04 & 17263.89 & -0.43 \\
\hline 1342 & 868.87 & 18763.89 & 232153 & 18763.89 & 0.54 \\
\hline 1362 & 892.10 & 14333.33 & 2683.33 & 14333.33 & 0.64 \\
\hline 1382 & 909.20 & 8055.56 & 7638.89 & 8055.56 & 0.65 \\
\hline 1402 & 918.38 & -700.69 & -6249.31 & 6281.25 & -0.56 \\
\hline 1460 & 930.48 & -2259.72 & -8145.83 & 8187.50 & 466.46 \\
\hline 1442 & 949.48 & 836.11 & 1636.11 & 1640.97 & -63.61 \\
\hline 1462 & 990.98 & 475.14 & 521.74 & 522.08 & -4.35 \\
\hline 1482 & 1050.98 & 507.50 & 729.17 & 356.25 & -18.74 \\
\hline 1502 & 1110.98 & 355.90 & 307.29 & 356.25 & 5.27 \\
\hline 1522 & 1170.98 & 41181 & 54188 & 542.57 & -11.86 \\
\hline 1542 & 1230.98 & 307.92 & 235.00 & 308.54 & 7.65 \\
\hline 1562 & 1292.98 & 344.51 & 485.35 & 486.39 & -13.51 \\
\hline
\end{tabular}

Note 1: Meridonal, Hoop, and Shear Stresses are Reversed in Highlighted Sections

(Floor) 
RPP-RPT-32239, Rev. 1

M\&D-2008-005-CALC-001, Rev. 1

Table H.7. UBS-BEC Primary Tank Stresses, Shell Top, Gravity Plus Seismic Load

AP Primary Tank, Upper Bound Soil, Horiizontal and Vertical Seismic, Best Estimate Tank Concrete, 460 in. Waste Level at $1.83 \mathrm{SpG}$

\begin{tabular}{|c|c|c|c|c|c|}
\hline $\begin{array}{c}\text { M\&D } \\
\text { Starting } \\
\text { M\&D } \\
\text { Element } \\
\text { No. }\end{array}$ & Path (in.) & \multicolumn{4}{|c|}{ Shell Top Surface (inside - waste side) } \\
\hline 762 & 67.33 & -2245.14 & -2742.36 & 2742.36 & -201.11 \\
\hline 782 & 105.04 & -2256.94 & -3507.64 & 350833 & -348.82 \\
\hline 802 & 136.24 & -2132.64 & -3238.89 & 3238.89 & -386.18 \\
\hline 822 & 181.83 & -1668.75 & -2829.86 & 282986 & -418.40 \\
\hline 842 & 225.10 & -1895.14 & -2602.08 & 3173.61 & -559.03 \\
\hline 882 & 323.27 & 2020.83 & -1820.14 & 3844.44 & -1286.81 \\
\hline 902 & 369.20 & 2405.56 & -1342.36 & 3922.22 & -1927.08 \\
\hline 922 & 419.20 & 4272.92 & -113125 & 6597.22 & -3168.75 \\
\hline 942 & 444.31 & -5152.78 & -5706.94 & 6786.11 & -3086.11 \\
\hline 962 & 458.66 & -7756.94 & 7854.17 & 15576.39 & -305069 \\
\hline 982 & 473.08 & -8354.17 & 884722 & 1720139 & -3215.97 \\
\hline 1002 & 484.80 & -3935.42 & -2038.19 & 6749.31 & -336319 \\
\hline 1022 & 502.48 & 5833.33 & -976.39 & 7750.00 & -3288.19 \\
\hline 1042 & 526.48 & 10590.28 & 1439.58 & 10604.17 & -3028.47 \\
\hline 1062 & 550.48 & 13673.61 & 1465.97 & 13680.56 & -2744.44 \\
\hline 1082 & 574.60 & 16437.50 & 1953.47 & 1643750 & -2420.83 \\
\hline 1102 & 598.28 & 1929861 & 1600.00 & 19305.56 & 2075.00 \\
\hline 1122 & 621.38 & 21868.06 & 202778 & 21875.00 & 1718.75 \\
\hline 1142 & 644.48 & 24263.89 & 1914.58 & 24270.83 & 1396.53 \\
\hline 1162 & 667.63 & 25701.39 & -1625.00 & 25701.39 & -1136.11 \\
\hline 1182 & 690.78 & 25854.17 & 2385.42 & 25854.17 & -977.78 \\
\hline 1202 & 713.88 & 27097.22 & 1981.25 & 27097.22 & -927.08 \\
\hline 1222 & 736.98 & 28965.28 & -148681 & 28972.22 & -1095.83 \\
\hline 1242 & 760.13 & 28437.50 & -815.28 & 28437.50 & 1452.78 \\
\hline 1262 & 782.53 & 25715.28 & 282153 & 25715.28 & 1406.94 \\
\hline 1282 & 804.13 & 24597.22 & 1657.64 & 24597.22 & 1766.67 \\
\hline 1302 & 825.73 & 25604.17 & 1055.56 & 25604.17 & 2127.08 \\
\hline 1322 & 847.33 & 27638.89 & 1551.39 & 27638.89 & 2491.67 \\
\hline 1342 & 868.87 & 26895.83 & -293750 & 3100694 & 2922.22 \\
\hline 1362 & 892.10 & 17354.17 & -3022.92 & 21263.89 & 2857.64 \\
\hline 1382 & 909.20 & 5661.11 & -8923.61 & 17250.00 & 2781.94 \\
\hline 1402 & 918.38 & 6266.67 & 12805.56 & 12826.39 & 2710.42 \\
\hline 1460 & 930.48 & 6727.78 & 13368.06 & 1343750 & -309792 \\
\hline 1442 & 949.48 & 4522.92 & -159722 & 5188.19 & -2340.97 \\
\hline 1462 & 990.98 & 3940.28 & 166667 & 7062.50 & -3529.86 \\
\hline 1482 & 1050.98 & 2915.28 & 765.97 & 2761.11 & -2287.50 \\
\hline 1502 & 1110.98 & 2204.17 & 938.19 & 2761.11 & -1371.53 \\
\hline 1522 & 1170.98 & 1642.36 & 474.72 & 1673.61 & -813.19 \\
\hline 1542 & 1230.98 & 1189.58 & 734.72 & 1190.97 & -493.19 \\
\hline 1562 & 1292.98 & 755.56 & 495.83 & 756.25 & -239.65 \\
\hline
\end{tabular}


RPP-RPT-32239, Rev. 1

M\&D-2008-005-CALC-001, Rev. 1

Table H.8. UBS-BEC Primary Tank Stresses, Shell Middle, Gravity Plus Seismic Load

AP Primary Tank, Upper Bound Soil, Horiizontal and Vertical Seismic, Best Estimate Tank Concrete, 460 in. Waste Level at $1.83 \mathrm{SpG}$

\begin{tabular}{|c|c|c|c|c|c|}
\hline $\begin{array}{c}\text { M\&D } \\
\text { Starting } \\
\text { M\&D } \\
\text { Element } \\
\text { No. }\end{array}$ & Path (in.) & \multicolumn{4}{|c|}{ Shell Mid-Plane } \\
\hline 762 & 67.33 & -2385.42 & -2530.56 & 2530.56 & -193.61 \\
\hline 782 & 105.04 & -2297.22 & -3287.50 & 328750 & -341.94 \\
\hline 802 & 136.24 & -2281.25 & -3027.78 & 3028.47 & -379.58 \\
\hline 822 & 181.83 & -1618.06 & -266667 & 2667.36 & -414.72 \\
\hline 842 & 225.10 & -2095.83 & -2272.92 & 2548.61 & -558.40 \\
\hline 942 & 444.31 & 4818.06 & 1334.03 & 6265.97 & -3115.28 \\
\hline 962 & 458.66 & -9659.72 & 1285.42 & 10805.56 & -3078.47 \\
\hline 982 & 473.08 & -10673.61 & 1189.58 & 11881.94 & -3170.83 \\
\hline 1002 & 484.80 & -3440.97 & 1153.47 & 6676.39 & -3287.50 \\
\hline 1022 & 502.48 & 631111 & 127708 & 7319.44 & -3250.69 \\
\hline 1042 & 526.48 & 10590.28 & 1445.83 & 10597.22 & -3021.53 \\
\hline 1062 & 550.48 & 13777.78 & 1593.06 & 13784.72 & -2736.81 \\
\hline 1082 & 574.60 & 16395.83 & 172778 & 16402.78 & -2412.50 \\
\hline 1102 & 598.28 & 19409.72 & 1838.19 & 19409.72 & 2067.36 \\
\hline 1122 & 621.38 & 21888.89 & 1926.39 & 21888.89 & 1711.81 \\
\hline 1142 & 644.48 & 24347.22 & 1988.89 & 24347.22 & 1390.97 \\
\hline 1302 & 825.73 & 25625.00 & 1009.03 & 25625.00 & 2128.47 \\
\hline 1322 & 847.33 & 27479.17 & 905.56 & 27486.11 & 2499.31 \\
\hline 1342 & 868.87 & 28388.89 & 779.86 & 28388.89 & 2905.56 \\
\hline 1362 & 892.10 & 18548.61 & 556.88 & 18555.56 & 2761.11 \\
\hline 1382 & 909.20 & 8597.22 & 489.72 & 8875.00 & 2622.22 \\
\hline 1402 & 918.38 & 5717.36 & 637.43 & 6207.64 & 2606.25 \\
\hline 1460 & 930.48 & 4837.50 & 952.78 & 5327.78 & -2586.11 \\
\hline 1442 & 949.48 & 4585.42 & 940.97 & 5043.75 & -2431.25 \\
\hline 1462 & 990.98 & 3925.69 & 139167 & 7041.67 & -3518.75 \\
\hline 1482 & 1050.98 & 2916.67 & 960.42 & 2759.03 & -2297.22 \\
\hline 1502 & 1110.98 & 2197.92 & 734.72 & 2759.03 & -1363.19 \\
\hline 1522 & 1170.98 & 1643.75 & 610.42 & 1658.33 & -822.92 \\
\hline 1542 & 1230.98 & 118681 & 562.85 & 1188.19 & -485.14 \\
\hline 1562 & 1292.98 & 75139 & 577.78 & 751.39 & -245.28 \\
\hline
\end{tabular}

Note 1: Meridonal, Hoop, and Shear Stresses are Reversed in Highlighted Sections (Floor) 
RPP-RPT-32239, Rev. 1

M\&D-2008-005-CALC-001, Rev. 1

Table H.9. UBS-BEC Primary Tank Stresses, Shell Bottom, Gravity Plus Seismic Load

AP Primary Tank, Upper Bound Soil, Horiizontal and Vertical Seismic, Best Estimate Tank Concrete, 460 in. Waste Level at $1.83 \mathrm{SpG}$

\begin{tabular}{|c|c|c|c|c|c|}
\hline \multirow[b]{2}{*}{$\begin{array}{c}\text { M\&D } \\
\text { Starting } \\
\text { M\&D } \\
\text { Element } \\
\text { No. }\end{array}$} & \multirow[b]{2}{*}{ Path (in.) } & \multicolumn{4}{|c|}{ Shell Bottom Surface (outside - away from waste) } \\
\hline & & $\begin{array}{c}\text { AP-460-UBS-BEC } \\
\text { Seismic Hoop Stress } \\
(\text { lbs/in^2) Bot }\end{array}$ & $\begin{array}{c}\text { AP-460-UBS-BEC } \\
\text { Seismic Meridional } \\
\text { Stress (lbs/in^2) Bot }\end{array}$ & $\begin{array}{c}\text { AP-460-UBS-BEC } \\
\text { Seismic Stress } \\
\text { Intensity (lbs/in^2) } \\
\text { Bot }\end{array}$ & $\begin{array}{c}\text { AP-460-UBS-BEC } \\
\text { Seismic In-Plane } \\
\text { Shear Stress } \\
(\text { lbs/in^2) Bot }\end{array}$ \\
\hline 762 & 67.33 & -2561.11 & -2770.83 & 2770.83 & -186.94 \\
\hline 782 & 105.04 & -2372.22 & -3586.81 & 358681 & -335.07 \\
\hline 802 & 136.24 & -2429.86 & -3338.89 & 3339.58 & -373.06 \\
\hline 822 & 181.83 & -156736 & -2730.56 & 2730.56 & -410.97 \\
\hline 842 & 225.10 & -2295.83 & -2763.19 & 2763.89 & -557.78 \\
\hline 862 & 273.66 & -1268.75 & -1897.22 & 2204.17 & -769.44 \\
\hline 882 & 323.27 & 2579.86 & -1876.39 & 2833.33 & -1288.19 \\
\hline 902 & 369.20 & 2294.44 & -1256.25 & 3975.00 & -1927.78 \\
\hline 922 & 419.20 & 4662.50 & 1831.94 & 6484.03 & -3172.92 \\
\hline 942 & 444.31 & 5178.47 & 8368.06 & 8923.61 & -3144.44 \\
\hline 962 & 458.66 & -11604.17 & -5586.81 & 11611.11 & -3106.25 \\
\hline 982 & 473.08 & -13006.94 & -6466.67 & 13013.89 & -3125.69 \\
\hline 1002 & 484.80 & 3309.72 & 3699.31 & 6729.17 & -3212.50 \\
\hline 1022 & 502.48 & 6836.11 & 3530.56 & 7083.33 & -3213.19 \\
\hline 1042 & 526.48 & 10583.33 & 1451.39 & 10590.28 & -3013.89 \\
\hline 1062 & 550.48 & 13881.94 & 1720.14 & 13881.94 & -2729.86 \\
\hline 1082 & 574.60 & 16361.11 & 1502.78 & 16361.11 & -2404.86 \\
\hline 1102 & 598.28 & 19513.89 & 2076.39 & 19513.89 & 2060.42 \\
\hline 1122 & 621.38 & 21909.72 & 1825.00 & 21909.72 & 1704.86 \\
\hline 1142 & 644.48 & 24423.61 & 2063.19 & 24423.61 & 1385.42 \\
\hline 1162 & 667.63 & 26180.56 & 2627.78 & 26180.56 & -1100.69 \\
\hline 1182 & 690.78 & 25555.56 & -1560.42 & 25555.56 & -944.44 \\
\hline 1202 & 713.88 & 27048.61 & 1575.00 & 27048.61 & -897.22 \\
\hline 1222 & 736.98 & 29416.67 & 2315.97 & 29416.67 & -1088.89 \\
\hline 1242 & 760.13 & 29270.83 & 2925.69 & 29270.83 & 1434.72 \\
\hline 1262 & 782.53 & 24805.56 & -1659.03 & 25305.56 & 1383.33 \\
\hline 1282 & 804.13 & 24340.28 & -1076.39 & 24340.28 & 1764.58 \\
\hline 1302 & 825.73 & 25645.83 & 982.64 & 25652.78 & 2130.56 \\
\hline 1322 & 847.33 & 27326.39 & -925.69 & 27326.39 & 2508.33 \\
\hline 1342 & 868.87 & 29875.00 & 5667.36 & 29875.00 & 2888.19 \\
\hline 1362 & 892.10 & 19743.06 & 4586.11 & 19743.06 & 2664.58 \\
\hline 1382 & 909.20 & 11729.17 & 12472.22 & 12479.17 & 2463.19 \\
\hline 1402 & 918.38 & -6575.69 & -11659.72 & 11680.56 & 2501.39 \\
\hline 1460 & 930.48 & -7326.39 & -1227778 & 12354.17 & 2584.72 \\
\hline 1442 & 949.48 & 464861 & 308958 & 6072.22 & -2520.83 \\
\hline 1462 & 990.98 & 3911.81 & 1125.69 & 7027.78 & -3506.94 \\
\hline 1482 & 1050.98 & 2918.06 & 1175.69 & 2762.50 & -2306.94 \\
\hline 1502 & 1110.98 & 2192.36 & 569.72 & 276250 & -1354.86 \\
\hline 1522 & 1170.98 & 1645.14 & 804.17 & 1665.97 & -831.94 \\
\hline 1542 & 1230.98 & 1184.03 & 452.64 & 1185.42 & -477.08 \\
\hline 1562 & 1292.98 & 748.61 & 705.56 & 750.00 & -251.53 \\
\hline
\end{tabular}


RPP-RPT-32239, Rev. 1

M\&D-2008-005-CALC-001, Rev. 1

Table H.10. UBS-BEC Primary Tank Stresses, Shell Top, Seismic Load Only

AP Primary Tank, Upper Bound Soil, Horizontal and Vertical Seismic, Best Estimate Tank Concrete, 460 in. Waste Level at $1.83 \mathrm{SpG}$

\begin{tabular}{|c|c|c|c|c|c|}
\hline \multirow[b]{2}{*}{$\begin{array}{c}\text { M\&D } \\
\text { Starting } \\
\text { M\&D } \\
\text { Element } \\
\text { No. }\end{array}$} & \multirow[b]{2}{*}{ Path (in.) } & \multicolumn{4}{|c|}{ Shell Top Surface (inside - waste side) } \\
\hline & & $\begin{array}{c}\text { AP-460-UBS-BEC } \\
\text { Seismic Only Hoop } \\
\text { Stress (lbs/in^2) Top }\end{array}$ & $\begin{array}{l}\text { AP-460-UBS-BEC } \\
\text { Seismic Only } \\
\text { Meridional Stress } \\
\text { (lbs/in^2) Top }\end{array}$ & $\begin{array}{c}\text { AP-460-UBS-BEC } \\
\text { Seismic Only Stress } \\
\text { Intensity (lbs/in^2) } \\
\text { Top }\end{array}$ & $\begin{array}{c}\text { AP-460-UBS-BEC } \\
\text { Seismic Only In-Plane } \\
\text { Shear Stress } \\
\text { (lbs/in^2) Top }\end{array}$ \\
\hline 762 & 67.33 & 768.06 & 1093.68 & 1084.72 & 200.17 \\
\hline 782 & 105.04 & 762.50 & 1368,06 & 1368.75 & 349.46 \\
\hline 802 & 136.24 & 834.03 & 1248.61 & 1235.42 & 386.72 \\
\hline 822 & 181.83 & 70069 & 1066.67 & 1066.67 & 418.78 \\
\hline 842 & 225.10 & 1333.89 & 1222.99 & 1661.81 & 558.66 \\
\hline 862 & 273.66 & 1003.33 & 923.61 & 924.31 & 770.36 \\
\hline 882 & 323.27 & 1982.51 & 1044.17 & 2864.58 & 1286.68 \\
\hline 902 & 369.20 & 2091.32 & 1041.81 & 3309.51 & 1927.42 \\
\hline 922 & 419.20 & 2984.03 & 990.35 & 5038.89 & 3168.13 \\
\hline 942 & 444.31 & 5001.94 & 3237.78 & 4125.69 & 3085.34 \\
\hline 962 & 458.66 & 6659.03 & 5073.61 & 11697.22 & 3050.26 \\
\hline 982 & 473.08 & 6847.92 & 6190.28 & 13038.19 & 3215.90 \\
\hline 1002 & 484.80 & 3901.01 & 1504.86 & 6214.93 & 3363.30 \\
\hline 1022 & 502.48 & 3291.67 & 715.21 & 4727.08 & 3288.34 \\
\hline 1042 & 526.48 & 5924.31 & 1141.11 & 5877.08 & 3028.56 \\
\hline 1062 & 550.48 & 7363.89 & 1329.86 & 7370.14 & 2744.27 \\
\hline 1082 & 574.60 & 8555.56 & 1597.50 & 8555.56 & 2420.79 \\
\hline 1102 & 598.28 & 9729.17 & 1516.74 & 9736.11 & 2074.96 \\
\hline 1122 & 621.38 & 10750.00 & 1747.08 & 10756.94 & 1718.69 \\
\hline 1142 & 644.48 & 11576.39 & 1760.07 & 11583.33 & 1396.44 \\
\hline 1162 & 667.63 & 11909.72 & 1617.85 & 11715.28 & 1136.05 \\
\hline 1182 & 690.78 & 11659.72 & 1832.36 & 11659.72 & 977.70 \\
\hline 1202 & 713.88 & 11902.78 & 1689.79 & 11902.78 & 926.97 \\
\hline 1222 & 736.98 & 12409.72 & 1360.28 & 12215.28 & 1095.58 \\
\hline 1242 & 760.13 & 11937.50 & 1142.57 & 11354.17 & 1452.90 \\
\hline 1262 & 782.53 & 1045139 & 1706.25 & 10451.39 & 1407.04 \\
\hline 1282 & 804.13 & 9680.56 & 1227.36 & 9680.56 & 1766.71 \\
\hline 1302 & 825.73 & 9833.33 & 962.15 & 9833.33 & 2127.24 \\
\hline 1322 & 847.33 & 10458.33 & 1077.08 & 10458.33 & 2491.65 \\
\hline 1342 & 868.87 & 9479.17 & 1931.94 & 1141667 & 2922.35 \\
\hline 1362 & 892.10 & 4604.17 & 1607.64 & 5937.50 & 2857.70 \\
\hline 1382 & 909.20 & 1936.81 & 5631.94 & 5993.06 & 2782.01 \\
\hline 1402 & 918.38 & 2524.31 & 6163.89 & 6154.86 & 2710.47 \\
\hline 1422 & 930.48 & 3552.78 & 4402.78 & 4430.56 & 2639.51 \\
\hline 1442 & 949.48 & 4421.32 & 837.50 & 4318.06 & 2408.89 \\
\hline 1462 & 990.98 & 334132 & 1110.35 & 6149.31 & 3505.07 \\
\hline 1482 & 1050.98 & 2506.88 & 513.13 & 2133.68 & 2287.72 \\
\hline 1502 & 1110.98 & 1750.42 & 448.61 & 2133.68 & 1357.86 \\
\hline 1522 & 1170.98 & 1320.69 & 236.88 & 1355.07 & 819.62 \\
\hline 1542 & 1230.98 & 798.89 & 300.21 & 698.19 & 484.82 \\
\hline 1562 & 1292.98 & 474.24 & 213.47 & 461.81 & 240.60 \\
\hline
\end{tabular}


RPP-RPT-32239, Rev. 1

M\&D-2008-005-CALC-001, Rev. 1

Table H.11. UBS-BEC Primary Tank Stresses, Shell Middle, Seismic Load Only

AP Primary Tank, Upper Bound Soil, Horizontal and Vertical Seismic, Best Estimate Tank Concrete, 460 in. Waste Level at

\subsection{SpG}

\begin{tabular}{|c|c|c|c|c|c|}
\hline \multirow[b]{2}{*}{$\begin{array}{c}\text { M\&D } \\
\text { Starting } \\
\text { M\&D } \\
\text { Element } \\
\text { No. }\end{array}$} & \multirow[b]{2}{*}{ Path (in.) } & \multicolumn{4}{|c|}{ Shell Mid-Plane } \\
\hline & & $\begin{array}{l}\text { AP-460-UBS-BEC } \\
\text { Seismic Only Hoop } \\
\text { Stress (lbs/in^2) Mid }\end{array}$ & $\begin{array}{l}\text { AP-460-UBS-BEC } \\
\text { Seismic Only } \\
\text { Meridional Stress } \\
\text { (lbs/in^2) Mid }\end{array}$ & $\begin{array}{c}\text { AP-460-UBS-BEC } \\
\text { Seismic Only Stress } \\
\text { Intensity (lbs/in^2) } \\
\text { Mid }\end{array}$ & $\begin{array}{c}\text { AP-460-UBS-BEC } \\
\text { Seismic Only In-Plane } \\
\text { Shear Stress } \\
\text { (lbs/in^2) Mid }\end{array}$ \\
\hline 762 & 67.33 & 859.65 & 864.58 & 863.89 & 193.40 \\
\hline 782 & 105.04 & 772.92 & 1115.28 & 1115.28 & 342.35 \\
\hline 802 & 136.24 & 965.28 & 102569 & 1026.39 & 38021 \\
\hline 822 & 181.83 & 641.67 & 912.50 & 913.19 & 414.98 \\
\hline 842 & 225.10 & 1587.50 & 78681 & 1062.50 & 558.10 \\
\hline 862 & 273.66 & 940.42 & 69583 & 947.22 & 769.65 \\
\hline 882 & 323.27 & 2222.08 & 708.33 & 2309.72 & 1287.39 \\
\hline 902 & 369.20 & 2068.82 & 767.01 & 3252.08 & 1928.09 \\
\hline 922 & 419.20 & 3051.39 & 1059.11 & 5151.39 & 3170.21 \\
\hline 942 & 444.31 & 4026.39 & 992.92 & 5467.36 & 3114.62 \\
\hline 962 & 458.66 & 7858.33 & 96160 & 8679.17 & 3078.09 \\
\hline 982 & 473.08 & 8440.97 & 922.85 & 9379.17 & 317072 \\
\hline 1002 & 484.80 & 3634.79 & 909.65 & 6429.31 & 3287.56 \\
\hline 1022 & 502.48 & 3699.31 & 1039.24 & 4415.97 & 3250.81 \\
\hline 1042 & 526.48 & 5954.86 & 1214.44 & 5889.58 & 302162 \\
\hline 1062 & 550.48 & 7441.67 & 1368.33 & 7447.92 & 2736.67 \\
\hline 1082 & 574.60 & 8555.56 & 1509.86 & 8562.50 & 2412.47 \\
\hline 1102 & 598.28 & 9805.56 & 1627.01 & 9805.56 & 206733 \\
\hline 1122 & 621.38 & 10791.67 & 172174 & 10791.67 & 1711.76 \\
\hline 1142 & 644.48 & 11645.83 & 1790.76 & 11645.83 & 1390.90 \\
\hline 1162 & 667.63 & 12041.67 & 1834.86 & 1204167 & 1118.00 \\
\hline 1182 & 690.78 & 11631.94 & 1628.68 & 11631.94 & 961.04 \\
\hline 1202 & 713.88 & 11923.61 & 1622.78 & 11923.61 & 91170 \\
\hline 1222 & 736.98 & 12534.72 & 1588.40 & 12527.78 & 109142 \\
\hline 1242 & 760.13 & 12131.94 & 1526.94 & 12131.94 & 1443.88 \\
\hline 1262 & 782.53 & 10298.61 & 1063.96 & 10298.61 & 1395.25 \\
\hline 1282 & 804.13 & 9652.78 & 1001.39 & 9652.78 & 176460 \\
\hline 1302 & 825.73 & 9854.17 & 923.54 & 9854.17 & 2128.58 \\
\hline 1322 & 847.33 & 10416.67 & 826.25 & 10423.61 & 2499.26 \\
\hline 1342 & 868.87 & 1029861 & 706.94 & 10291.67 & 2905.69 \\
\hline 1362 & 892.10 & 5006.94 & 501.06 & 501389 & 276118 \\
\hline 1382 & 909.20 & 2710.42 & 440.75 & 2859.03 & 2622.30 \\
\hline 1402 & 918.38 & 4195.83 & 439.72 & 4451.39 & 260633 \\
\hline 1422 & 930.48 & 4378.68 & 547.01 & 4745.56 & 2589.66 \\
\hline 1442 & 949.48 & 4117.15 & 61132 & 4575.07 & 2433.77 \\
\hline 1462 & 990.98 & 3388.96 & 985.14 & 6323.61 & 3504.51 \\
\hline 1482 & 1050.98 & 2458.82 & 611.23 & 2292.15 & 2288.35 \\
\hline 1502 & 1110.98 & 1793.26 & 34972 & 2292.15 & 1357.86 \\
\hline 1522 & 1170.98 & 1277.29 & 232.29 & 1268.19 & 82105 \\
\hline 1542 & 1230.98 & 83750 & 19771 & 826.18 & 483.87 \\
\hline 1562 & 1292.98 & 454.58 & 195.28 & 372.01 & 240.25 \\
\hline
\end{tabular}

Note 1: Meridonal, Hoop, and Shear Stresses are Reversed in Highlighted Sections (Floor) 
RPP-RPT-32239, Rev. 1

M\&D-2008-005-CALC-001, Rev. 1

Table H.12. UBS-BEC Primary Tank Stresses, Shell Bottom, Seismic Load Only

AP Primary Tank, Upper Bound Soil, Horizontal and Vertical Seismic, Best Estimate Tank Concrete, 460 in. Waste Level at

1.83 SpG

\begin{tabular}{|c|c|c|c|c|c|}
\hline \multirow[b]{2}{*}{$\begin{array}{c}\text { M\&D } \\
\text { Starting } \\
\text { M\&D } \\
\text { Element } \\
\text { No. }\end{array}$} & \multirow[b]{2}{*}{ Path (in.) } & \multicolumn{4}{|c|}{ Shell Bottom Surface (outside - away from waste) } \\
\hline & & $\begin{array}{l}\text { AP-460-UBS-BEC } \\
\text { Seismic - Only Hoop } \\
\text { Stress (lbs/in^2) Bot }\end{array}$ & $\begin{array}{l}\text { AP-460-UBS-BEC } \\
\text { Seismic Only } \\
\text { Meridional Stress } \\
\text { (lbs/in^2) Bot }\end{array}$ & $\begin{array}{c}\text { AP-460-UBS-BEC } \\
\text { Seismic Only Stress } \\
\text { Intensity (lbs/in^2) } \\
\text { Bot }\end{array}$ & $\begin{array}{c}\text { AP-460-UBS-BEC } \\
\text { Seismic Only In-Plane } \\
\text { Shear Stress } \\
\text { (lbs/in^2) Bot }\end{array}$ \\
\hline 762 & 67.33 & 976.39 & 1095.83 & 1095.83 & 186.63 \\
\hline 782 & 105.04 & 817.36 & 1382.64 & 1382.64 & 335.23 \\
\hline 802 & 136.24 & 1095.83 & 133750 & 1337.50 & 373.78 \\
\hline 822 & 181.83 & 581.94 & 984.03 & 984.03 & 411.12 \\
\hline 842 & 225.10 & 1842.36 & 1302.78 & 1303.47 & 557.54 \\
\hline 862 & 273.66 & 877.50 & 760.83 & 1001.39 & 768.94 \\
\hline 882 & 323.27 & 2460.97 & 1221.18 & 2064.58 & 1288.11 \\
\hline 902 & 369.20 & 2067.08 & 751.25 & 3198.61 & 1928.07 \\
\hline 922 & 419.20 & 3200.00 & 1633.89 & 5020.83 & 3172.08 \\
\hline 942 & 444.31 & 3444.44 & 5075.69 & 5581.94 & 3143.90 \\
\hline 962 & 458.66 & 909931 & 350278 & 9105.56 & 310591 \\
\hline 982 & 473.08 & 10047.22 & 4645.83 & 10053.47 & 3125.54 \\
\hline 1002 & 484.80 & 3723.47 & 2678.47 & 5707.64 & 3212.51 \\
\hline 1022 & 502.48 & 4125.69 & 2782.64 & 4026.39 & 3213.29 \\
\hline 1042 & 526.48 & 5984.72 & 128708 & 5902.78 & 301399 \\
\hline 1062 & 550.48 & 7518.75 & 140681 & 7518.75 & 2729.76 \\
\hline 1082 & 574.60 & 8562.50 & 1422.99 & 8562.50 & 2404.84 \\
\hline 1102 & 598.28 & 9868.06 & 173729 & 9868.06 & 2060.40 \\
\hline 1122 & 621.38 & 1084028 & 169632 & 1084028 & 170483 \\
\hline 1142 & 644.48 & 1170833 & 1821.46 & 1170833 & 1385.37 \\
\hline 1162 & 667.63 & 12159.72 & 2051.74 & 12159.72 & 1100.64 \\
\hline 1182 & 690.78 & 11597.22 & 1425.56 & 11368.06 & 944.38 \\
\hline 1202 & 713.88 & 1193750 & 1556.47 & 1193750 & 897.12 \\
\hline 1222 & 736.98 & 12645.83 & 1817.15 & 1264583 & 1088.76 \\
\hline 1242 & 760.13 & 12333.33 & 2060.42 & 12333.33 & 1434.85 \\
\hline 1262 & 782.53 & 10152.78 & 739.58 & 9729.17 & 1383.46 \\
\hline 1282 & 804.13 & 9625.00 & 841.18 & 937500 & 1764.72 \\
\hline 1302 & 825.73 & 988194 & 905.00 & 9888.89 & 2130.73 \\
\hline 1322 & 847.33 & 10381.94 & 64181 & 10062.50 & 2508.49 \\
\hline 1342 & 868.87 & 11111.11 & 334583 & 11111.11 & 2888.34 \\
\hline 1362 & 892.10 & 5416.67 & 1911.11 & 5416.67 & 2664.65 \\
\hline 1382 & 909.20 & 3829.17 & 4840.28 & 4430.56 & 2463.28 \\
\hline 1402 & 918.38 & 5877.08 & 5413.89 & 5402.78 & 2501.49 \\
\hline 1422 & 930.48 & 5202.78 & 4145.83 & 4173.61 & 2539.44 \\
\hline 1442 & 949.48 & 381389 & 1528.26 & 4437.50 & 2457.90 \\
\hline 1462 & 990.98 & 3437.22 & 862.85 & 6505.69 & 3503.26 \\
\hline 1482 & 1050.98 & 2410.83 & 71357 & 240958 & 2288.99 \\
\hline 1502 & 1110.98 & 1836.46 & 279.60 & 2409.58 & 1358.33 \\
\hline 1522 & 1170.98 & 1233.96 & 319.10 & 1125.97 & 821.78 \\
\hline 1542 & 1230.98 & 876.11 & 22090 & 876.88 & 482.91 \\
\hline 1562 & 1292.98 & 434.93 & 283.96 & 269.51 & 240.24 \\
\hline
\end{tabular}

Note 1: Meridonal, Hoop, and Shear Stresses are Reversed in Highlighted Sections (Floor) 
RPP-RPT-32239, Rev. 1

M\&D-2008-005-CALC-001, Rev. 1

Table H.13. UBS-BEC Anchor Bolt Forces, Gravity Load Only

\begin{tabular}{|c|c|c|c|c|c|c|c|c|c|c|c|}
\hline \multicolumn{12}{|c|}{$\begin{array}{l}\text { AP Primary Tank, Upp } \\
\text { ANSYS MAXIMUMS BY RADIUS }\end{array}$} \\
\hline $\begin{array}{c}\text { M\&D } \\
\text { J-Bolt } \\
\text { Radius No. }\end{array}$ & $\begin{array}{l}\text { Mean } \\
\text { J-Bolt } \\
\text { Radius }\end{array}$ & $\begin{array}{c}\text { Radius } \\
\text { Incl } \\
\min \\
\end{array}$ & $\begin{array}{l}\text { J-Bolts } \\
\text { ded } \\
\max \end{array}$ & $\begin{array}{l}\text { Average } \\
\text { Bolts per } \\
\text { Element }\end{array}$ & $\begin{array}{c}\text { TVIn AXIaI } \\
\text { Force (kip) } \\
\text { BES-BEC } \\
\text { Gravity } \\
\text { Only } \\
\end{array}$ & \begin{tabular}{|c|} 
Max AXIal \\
Force (kip) \\
BES-BEC \\
Gravity \\
Only \\
\end{tabular} & $\begin{array}{l}\text { Shear } \\
\text { Force1 } \\
\text { (kip) BES- } \\
\text { BEC } \\
\text { Gravity } \\
\end{array}$ & $\begin{array}{c}\text { Maximum } \\
\text { Shear Force1 } \\
\text { Model Angle } \\
\end{array}$ & $\begin{array}{c}\text { Shear Force2 } \\
\text { (kip) BES- } \\
\text { BEC Gravity } \\
\text { Only } \\
\end{array}$ & $\begin{array}{c}\text { Maximum } \\
\text { Shear Force2 } \\
\text { Model Angle } \\
\end{array}$ & $\begin{array}{l}\text { Total } \\
\text { Shear } \\
\text { (kip) BES } \\
\text { BEC } \\
\text { Gravity }\end{array}$ \\
\hline Radius 2 & 44.72 & 22.36 & 67.29 & 0.55 & -0.005 & -0.004 & 0.001 & \begin{tabular}{|l|}
45 \\
\end{tabular} & 0.038 & 90 & 0.038 \\
\hline Radius 3 & 89.87 & 67.29 & 104.93 & 0.89 & -0.003 & -0.003 & 0.002 & 63 & 0.033 & 27 & 0.033 \\
\hline Radius 4 & 120.00 & 104.93 & 135.98 & 1.03 & -0.002 & -0.001 & 0.002 & 63 & 0.082 & 180 & 0.082 \\
\hline Radius 5 & 151.97 & 135.98 & 181.01 & 1.97 & -0.001 & 0.000 & 0.001 & 27 & 0.170 & 90 & 0.170 \\
\hline Radius 6 & 210.05 & 181.01 & 223.79 & 2.41 & -0.007 & -0.007 & 0.005 & 144 & 0.366 & 90 & 0.366 \\
\hline Radius 7 & 237.53 & 223.79 & 270.98 & 3.30 & 0.020 & 0.020 & 0.005 & 144 & 0.471 & 45 & 0.471 \\
\hline Radius 8 & 304.43 & 270.98 & 318.74 & 4.04 & -0.031 & -0.031 & 0.001 & 144 & 0.654 & 45 & 0.654 \\
\hline Radius 9 & 333.05 & 318.74 & 361.64 & 4.37 & 0.128 & 0.129 & 0.001 & 126 & 0.743 & 0 & 0.743 \\
\hline Radius 10 & 390.22 & 361.64 & 406.24 & 5.36 & 0.168 & 0.171 & 0.001 & 117 & 0.855 & 0 & 0.855 \\
\hline Radius 11 & 422.26 & 406.24 & 431.63 & 3.60 & 0.804 & 0.807 & 0.001 & 27 & 1.302 & 0 & 1.302 \\
\hline $\begin{array}{c}\text { M\&D } \\
\text { J-Bolt } \\
\text { Radius No. }\end{array}$ & $\begin{array}{l}\text { Mean } \\
\text { J-Bolt } \\
\text { Radius }\end{array}$ & $\begin{array}{r}\text { Radius } \\
\text { Incl }\end{array}$ & $\begin{array}{l}\text { Bolts } \\
\text { d }\end{array}$ & $\begin{array}{l}\text { Average } \\
\text { Bolts per } \\
\text { Element }\end{array}$ & $\begin{array}{c}\text { Bolt Angle } \\
\text { (Rad) }\end{array}$ & $\begin{array}{l}\text { Shear } \\
\text { Stiffness } \\
\text { (kip/ft) }\end{array}$ & $\begin{array}{c}\text { Axial } \\
\text { Stiffness } \\
\text { (kip/t) }\end{array}$ & $\begin{array}{l}\text { Shear } \\
\text { Displacement } \\
\text { BES-BEC- } \\
\text { Gravity Only }\end{array}$ & $\begin{array}{l}\text { Axial Min } \\
\text { Displacement } \\
\text { BES-BEC- } \\
\text { Gravity Only }\end{array}$ & $\begin{array}{l}\text { Axial Max } \\
\text { Displacement } \\
\text { BES-BEC- } \\
\text { Gravity Only }\end{array}$ & \\
\hline Radius 2 & 44.72 & 22.36 & 67.29 & 0.55 & 0.0351 & 780 & 780 & 0.00058 & -0.00008 & -0.00007 & \\
\hline Radius 3 & 89.87 & 67.29 & 104.93 & 0.89 & 0.0715 & 780 & 780 & 0.00051 & -0.00005 & -0.00005 & \\
\hline Radius 4 & 120.00 & 104.93 & 135.98 & 1.03 & 0.0968 & 780 & 780 & 0.00125 & -0.00002 & -0.00002 & \\
\hline Radius 5 & 151.97 & 135.98 & 181.01 & 1.97 & 0.1252 & 780 & 780 & 0.00261 & -0.00001 & -0.00001 & \\
\hline Radius 6 & 210.05 & 181.01 & 223.79 & 2.41 & 0.1825 & 780 & 780 & 0.00563 & -0.00011 & -0.00011 & \\
\hline Radius 7 & 237.53 & 223.79 & 270.98 & 3.30 & 0.2136 & 780 & 780 & 0.00725 & 0.00030 & $\begin{array}{l}0.00031 \\
\end{array}$ & \\
\hline Radius 8 & 304.43 & 270.98 & 318.74 & 4.04 & 0.3076 & 780 & 780 & 0.01005 & -0.00048 & -0.00048 & \\
\hline Radius 9 & 333.05 & 318.74 & 361.64 & 4.37 & 0.3613 & 780 & 780 & 0.01142 & 0.00196 & 0.00198 & \\
\hline Radius 10 & 390.22 & 361.64 & 406.24 & 5.36 & 0.5235 & 780 & 780 & 0.01315 & 0.00258 & 0.00263 & \\
\hline Radius 11 & 460.26 & 406.24 & 431.63 & 3.60 & 0.6938 & 780 & 780 & 0.02003 & 0.01236 & 0.01241 & \\
\hline
\end{tabular}


RPP-RPT-32239, Rev. 1

M\&D-2008-005-CALC-001, Rev. 1

Table H.14. UBS-BEC Anchor Bolt Forces, Gravity Plus Seismic Loads

\begin{tabular}{|c|c|c|c|c|c|c|c|c|c|c|c|}
\hline \multicolumn{12}{|c|}{$\begin{array}{l}\text { AP Primary Tank, Upper Bound Soil, Horizontal and Vertical Seismic Input, Best } \\
\text { Estimate Tank Concrete, } 460 \text { in. Waste Level at } 1.83 \mathrm{SpG} \\
\text { ANSYS MAXIMUMS BY RADIUS }\end{array}$} \\
\hline $\begin{array}{c}\text { M\&D } \\
\text { J-Bolt } \\
\text { Radius No. }\end{array}$ & $\begin{array}{l}\text { Mean } \\
\text { J-Bolt } \\
\text { Radius }\end{array}$ & $\begin{array}{r}\text { Radius } \\
\text { Incl }\end{array}$ & $\begin{array}{l}\text { f J-Bolts } \\
\text { Ided }\end{array}$ & $\begin{array}{l}\text { Average } \\
\text { Bolts per } \\
\text { Element }\end{array}$ & \begin{tabular}{|c|} 
Min Axial \\
Force (kip) \\
BES-BEC
\end{tabular} & $\begin{array}{c}\text { Max Axial } \\
\text { Force (kip) } \\
\text { BES-BEC }\end{array}$ & $\begin{array}{c}\text { Shear } \\
\text { Force1 (kip) } \\
\text { BES-BEC }\end{array}$ & $\begin{array}{c}\text { Maximum } \\
\text { Shear Force1 } \\
\text { Model Angle }\end{array}$ & \begin{tabular}{|} 
Shear Force2 \\
(kip) BES-BEC
\end{tabular} & $\begin{array}{c}\text { Maximum } \\
\text { Shear Force2 } \\
\text { Model Angle }\end{array}$ & $\begin{array}{l}\text { Total } \\
\text { Shear } \\
\text { (kip) BES } \\
\text { BEC }\end{array}$ \\
\hline Radius 2 & 44.72 & 22.36 & 67.29 & 0.55 & -0.138 & 0.124 & 0.730 & $\overline{90}$ & $\overline{c 0.760}$ & 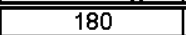 & 0.763 \\
\hline Radius 3 & 89.87 & 67.29 & 104.93 & 0.89 & -0.042 & 0.184 & 0.824 & 90 & 0.858 & 180 & 0.875 \\
\hline Radius 4 & 120.00 & 104.93 & 135.98 & 1.03 & -0.054 & 0.309 & 0.952 & 90 & 0.907 & 180 & 1.002 \\
\hline Radius 5 & 151.97 & 135.98 & 181.01 & 1.97 & -0.076 & 0.535 & 1.128 & 90 & 0.988 & 180 & 1.185 \\
\hline Radius 6 & 210.05 & 181.01 & 223.79 & 2.41 & -0.070 & 0.218 & 1.529 & 90 & 1.213 & 180 & 1.611 \\
\hline Radius 7 & 237.53 & 223.79 & 270.98 & 3.30 & -0.064 & 0.387 & 1.853 & 90 & 1.379 & 180 & 1.953 \\
\hline Radius 8 & 304.43 & 270.98 & 318.74 & 4.04 & -0.161 & 0.434 & 2.775 & 90 & 1.774 & 180 & 2.905 \\
\hline Radius 9 & 333.05 & 318.74 & 361.64 & 4.37 & -0.189 & 0.501 & 3.321 & 90 & 1.971 & 180 & 3.460 \\
\hline Radius 10 & 390.22 & 361.64 & 406.24 & 5.36 & -0.266 & 0.986 & 4.719 & 90 & 2.366 & 180 & 4.840 \\
\hline Radius 11 & 422.26 & 406.24 & 431.63 & 3.60 & -0.202 & 1.667 & 5.966 & 90 & 3.137 & 180 & 6.189 \\
\hline $\begin{array}{c}\text { M\&D } \\
\text { J-Bolt } \\
\text { Radius No. }\end{array}$ & $\begin{array}{l}\text { Mean } \\
\text { J-Bolt } \\
\text { Radius }\end{array}$ & $\begin{array}{r}\text { Radius C } \\
\text { Incl }\end{array}$ & J-Bolts & $\begin{array}{l}\text { Average } \\
\text { Bolts per } \\
\text { Element }\end{array}$ & $\begin{array}{c}\text { Bolt Angle } \\
\text { (Rad) }\end{array}$ & $\begin{array}{l}\text { Shear } \\
\text { Stiffness } \\
\text { (kip/ft) }\end{array}$ & $\begin{array}{c}\text { Axial } \\
\text { Stiffness } \\
\text { (kip/ft) }\end{array}$ & $\begin{array}{c}\text { Shear Disp } \\
\text { BES-BEC- } \\
\text { Seismic }\end{array}$ & \begin{tabular}{|c|} 
Axial Min Disp \\
BES-BEC- \\
Seismic
\end{tabular} & $\begin{array}{c}\text { Axial Max Disp } \\
\text { BES-BEC- } \\
\text { Seismic }\end{array}$ & \\
\hline Radius 2 & 44.72 & 22.36 & 67.29 & 0.55 & 0.0351 & 780 & 780 & 0.01174 & -0.00212 & 0.00190 & \\
\hline Radius 3 & 89.87 & 67.29 & 104.93 & 0.89 & 0.0715 & 780 & 780 & 0.01347 & -0.00065 & 0.00283 & \\
\hline Radius 4 & 120.00 & 104.93 & 135.98 & 1.03 & 0.0968 & 780 & 780 & 0.01541 & -0.00083 & 0.00475 & \\
\hline Radius 5 & 151.97 & 135.98 & 181.01 & 1.97 & 0.1252 & 780 & 780 & 0.01823 & -0.00116 & 0.00823 & \\
\hline Radius 6 & 210.05 & 181.01 & 223.79 & 2.41 & 0.1825 & 780 & 780 & 0.02479 & -0.00108 & 0.00335 & \\
\hline Radius 7 & 237.53 & 223.79 & 270.98 & 3.30 & 0.2136 & 780 & 780 & 0.03005 & -0.00098 & 0.00596 & \\
\hline Radius 8 & 304.43 & 270.98 & 318.74 & 4.04 & 0.3076 & 780 & 780 & 0.04469 & -0.00248 & 0.00668 & \\
\hline Radius 9 & 333.05 & 318.74 & 361.64 & 4.37 & 0.3613 & 780 & 780 & 0.05322 & -0.00291 & 0.00772 & \\
\hline Radius 10 & 390.22 & 361.64 & 406.24 & 5.36 & 0.5235 & 780 & 780 & 0.07446 & -0.00410 & 0.01517 & \\
\hline Radius 11 & 460.26 & 406.24 & 431.63 & 3.60 & 0.6938 & 780 & 780 & 0.09522 & -0.00311 & 0.02564 & \\
\hline
\end{tabular}


RPP-RPT-32239, Rev. 1

M\&D-2008-005-CALC-001, Rev. 1

Table H.15. UBS-BEC Anchor Bolt Forces, Seismic Load Only

\begin{tabular}{|c|c|c|c|c|c|c|c|c|c|c|c|}
\hline \multicolumn{12}{|c|}{$\begin{array}{l}\text { AP Primary Tank, Upper Bound Soil, Horizontal and Vertical Seismic Input, Best } \\
\text { Estimate Tank Concrete, } 460 \mathrm{in} \text {. Waste Level at } 1.83 \mathrm{SpG} \text { Seismic Only } \\
\text { ANSYS MAXIMUMS BY RADIUS }\end{array}$} \\
\hline $\begin{array}{l}\text { M\&D } \\
\text { J-Bolt } \\
\text { Radius } \\
\text { No. }\end{array}$ & $\begin{array}{l}\text { Mean } \\
\text { J-Bolt } \\
\text { Radius }\end{array}$ & $\begin{array}{r}\text { Radius } \\
\text { Incl }\end{array}$ & $\begin{array}{l}\text { J-Bolts } \\
\text { ded }\end{array}$ & $\begin{array}{c}\text { Average } \\
\text { Bolts per } \\
\text { Element }\end{array}$ & $\begin{array}{c}\text { Min Axial } \\
\text { Force (kip) } \\
\text { BES-BEC- } \\
\text { Seismic } \\
\text { Only } \\
\end{array}$ & $\begin{array}{c}\text { Max Axial } \\
\text { Force (kip) } \\
\text { BES-BEC- } \\
\text { Seismic } \\
\text { Only } \\
\end{array}$ & $\begin{array}{c}\text { Shear } \\
\text { Force1 (kip) } \\
\text { BES-BEC- } \\
\text { Seismic Only }\end{array}$ & $\begin{array}{c}\text { Maximum } \\
\text { Shear Force1 } \\
\text { Model Angle }\end{array}$ & $\begin{array}{l}\text { Shear Force2 } \\
\text { (kip) BES- } \\
\text { BEC-Seismic } \\
\text { Only }\end{array}$ & $\begin{array}{c}\text { Maximum } \\
\text { Shear Force2 } \\
\text { Model Angle }\end{array}$ & $\begin{array}{l}\text { Total Shear } \\
\text { (kip) BES- } \\
\text { BEC- } \\
\text { Seismic } \\
\text { Only }\end{array}$ \\
\hline$\overline{R \text { Radius 2 }}$ & $=44.72$ & 22.36 & 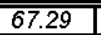 & 0.55 & -0.132 & 0.128 & 0.729 & 108 & 0.722 & $\overline{0}$ & 1.026 \\
\hline Radius 3 & 89.87 & 67.29 & 104.93 & 0.89 & -0.039 & 0.187 & 0.823 & 108 & 0.825 & 0 & 1.165 \\
\hline $\begin{array}{ll}\text { Radius } 4 \\
\end{array}$ & 120.00 & 104.93 & 135.98 & 1.03 & -0.053 & 0.310 & 0.950 & 108 & 0.825 & 0 & 1.259 \\
\hline Radius 5 & 151.97 & 135.98 & 181.01 & 1.97 & -0.075 & 0.535 & 1.126 & 108 & 0.818 & 0 & 1.392 \\
\hline Radius 6 & 210.05 & 181.01 & 223.79 & 2.41 & -0.063 & 0.225 & 1.524 & 108 & 0.847 & 144 & 1.744 \\
\hline $\begin{array}{l}\text { Radius } 7 \\
\end{array}$ & 237.53 & 223.79 & 270.98 & 3.30 & -0.084 & 0.368 & 1.848 & 90 & 0.908 & 135 & 2.059 \\
\hline Radius 8 & 304.43 & 270.98 & 318.74 & 4.04 & -0.130 & 0.465 & 2.774 & 117 & 1.120 & 117 & 2.991 \\
\hline Radius 9 & 333.05 & 318.74 & 361.64 & 4.37 & -0.317 & 0.372 & 3.321 & 117 & 1.228 & 117 & 3.541 \\
\hline Radius 10 & 390.22 & 361.64 & 406.24 & 5.36 & -0.434 & 0.815 & 4.717 & 108 & 1.511 & 0 & 4.953 \\
\hline Radius 11 & 460.26 & 406.24 & 431.63 & 3.60 & -1.006 & 0.860 & 5.965 & 108 & 1.836 & 0 & 6.241 \\
\hline $\begin{array}{c}\text { M\&D } \\
\text { J-Bolt } \\
\text { Radius } \\
\text { No. }\end{array}$ & $\begin{array}{l}\text { Mean } \\
\text { J-Bolt } \\
\text { Radius }\end{array}$ & $\begin{array}{l}\text { Radius } \\
\text { Incl }\end{array}$ & $\begin{array}{l}\text {-Bolts } \\
\text { d }\end{array}$ & $\begin{array}{c}\text { Average } \\
\text { Bolts per } \\
\text { Element }\end{array}$ & $\begin{array}{c}\text { Bolt Angle } \\
\text { (Rad) }\end{array}$ & $\begin{array}{l}\text { Shear } \\
\text { Stiffness } \\
\text { (kip/ft) }\end{array}$ & $\begin{array}{l}\text { Axial } \\
\text { Stiffness } \\
\text { (kip/ft) }\end{array}$ & $\begin{array}{c}\text { Shear Disp } \\
\text { BES-BEC- } \\
\text { Seismic Only }\end{array}$ & $\begin{array}{c}\text { Axial Min Disp } \\
\text { BES-BEC- } \\
\text { Seismic Only }\end{array}$ & $\begin{array}{l}\text { Axial Max Disp } \\
\text { BES-BEC- } \\
\text { Seismic Only }\end{array}$ & \\
\hline Radius 2 & 44.72 & 22.36 & 67.29 & 0.55 & 0.0351 & 780 & 780 & 0.01579 & -0.00204 & 0.00197 & \\
\hline Radius 3 & 89.87 & 67.29 & 104.93 & 0.89 & 0.0715 & 78 & 780 & 0.01792 & -0.00059 & 0.00288 & \\
\hline Radius 4 & 120.00 & 104.93 & 135.98 & 1.03 & 0.0968 & 780 & 780 & 0.01936 & -0.00081 & 0.00477 & \\
\hline Radius 5 & 151.97 & 135.98 & 181.01 & 1.97 & 0.1252 & 780 & 780 & 0.02141 & -0.00115 & 0.00823 & \\
\hline Radius 6 & 210.05 & 181.01 & 223.79 & 2.41 & 0.1825 & 780 & 780 & 0.02683 & -0.00097 & 0.00346 & \\
\hline Radius 7 & 237.53 & 223.79 & 270.98 & 3.30 & 0.2136 & 780 & 780 & 0.03168 & -0.00129 & 0.00565 & \\
\hline $\begin{array}{l}\text { Radius } 8 \\
\end{array}$ & 304.43 & 270.98 & 318.74 & 4.04 & 0.3076 & 780 & 780 & 0.04602 & -0.00200 & 0.00716 & \\
\hline $\begin{array}{l}\text { Radius } 9 \\
\end{array}$ & 333.05 & 318.74 & 361.64 & 4.37 & 0.3613 & 780 & 780 & 0.05447 & -0.00488 & 0.00573 & \\
\hline Radius 10 & 390.22 & 361.64 & 406.24 & 5.36 & 0.5235 & 780 & 780 & 0.07621 & -0.00668 & 0.01253 & \\
\hline Radius 11 & 460.26 & 406.24 & 431.63 & 3.60 & 0.6938 & 780 & 780 & 0.09602 & -0.01547 & 0.01323 & \\
\hline
\end{tabular}


RPP-RPT-32239, Rev. 1

M\&D-2008-005-CALC-001, Rev. 1

Table H.16. UBS-BEC Concrete Backed Steel Strain, Shell Top, Gravity Load Only

AP Backed Steel, Upper Bound Soil, Gravity Only, Best Estimate Tank Concrete, 460 In Waste Level at $1.83 \mathrm{SpG}$

\begin{tabular}{|c|c|c|c|c|c|c|c|}
\hline \multirow{2}{*}{\begin{tabular}{c|} 
M\&D \\
Starting \\
M\&D \\
Element \\
No.
\end{tabular}} & \multirow[b]{2}{*}{ Path (in) } & \multicolumn{6}{|c|}{ Shell Top Surface (inside - towards waste) Gravity } \\
\hline & & $\begin{array}{l}\text { AP-460-UBS-BEC } \\
\text { EPEL P1 Strain (in/in) } \\
\text { Gravity Tap Min }\end{array}$ & $\begin{array}{c}\text { AP-460-UBS-BEC } \\
\text { EPEL P1 Strain (in/in) } \\
\text { Gravity Tap Max }\end{array}$ & $\begin{array}{l}\text { AP-460-UBS-BEC } \\
\text { EPEL P2 (in/in) } \\
\text { Gravity Tap Min }\end{array}$ & $\begin{array}{c}\text { AP-460-UBS-BEC } \\
\text { EPEL P2 Strain (in/in) } \\
\text { Gravity Top Max }\end{array}$ & $\begin{array}{c}\text { AP-460-UBS-BEC } \\
\text { EPEL P3 Strain (in/in) } \\
\text { Gravity Tap Min }\end{array}$ & $\begin{array}{l}\text { AP-460-UBS-BEC } \\
\text { EPEL P3 Strain (in/in) } \\
\text { Gravity Tap Max }\end{array}$ \\
\hline 762 & 67.33 & $3.27 \mathrm{E}-05$ & $3.27 E-05$ & $-3.44 \mathrm{E}-05$ & $-3.43 E-05$ & $-4.15 \mathrm{E}-05$ & $-4.15 E-05$ \\
\hline 782 & 105.04 & 3.76E-05 & $3.76 \mathrm{E}-05$ & $-2.94 \mathrm{E}-05$ & $-2.94 \mathrm{E}-05$ & $-5.79 \mathrm{E}-05$ & $-5.79 \mathrm{E}-05$ \\
\hline 802 & 136.24 & $3.41 \mathrm{E}-05$ & $3.42 \mathrm{E}-05$ & $-2.41 \mathrm{E}-05$ & $-2.40 \mathrm{E}-05$ & $-5.53 \mathrm{E}-05$ & $-5.53 \mathrm{E}-05$ \\
\hline 822 & 181.71 & $2.82 \mathrm{E}-05$ & $2.83 \mathrm{E}-05$ & $-1.51 \mathrm{E}-05$ & $-1.51 \mathrm{E}-05$ & $-5.05 \mathrm{E}-05$ & $-5.04 \mathrm{E}-05$ \\
\hline 842 & 225.10 & $2.29 \mathrm{E}-05$ & $2.29 \mathrm{E}-05$ & $-8.47 \mathrm{E}-06$ & $-8.46 \mathrm{E}-06$ & $-4.46 \mathrm{E}-05$ & $-4.46 \mathrm{E}-05$ \\
\hline 862 & 273.66 & $1.60 \mathrm{E}-05$ & $1.60 \mathrm{E}-05$ & $-2.29 \mathrm{E}-06$ & $-2.29 E-06$ & $-3.49 \mathrm{E}-05$ & $-3.49 E-05$ \\
\hline 882 & 323.27 & $1.10 \mathrm{E}-05$ & $1.11 \mathrm{E}-05$ & $9.41 \mathrm{E}-06$ & $9.41 \mathrm{E}-06$ & $-3.27 \mathrm{E}-05$ & $-3.26 \mathrm{E}-05$ \\
\hline 902 & 369.20 & 1.39E-05 & $1.40 \mathrm{E}-05$ & $-4.62 E-08$ & $-4.19 E-08$ & $-1.36 \mathrm{E}-05$ & $-1.36 \mathrm{E}-05$ \\
\hline 922 & 419.20 & $4.72 \mathrm{E}-05$ & 4.73E-05 & $-1.04 \mathrm{E}-05$ & $-1.04 \mathrm{E}-05$ & $-2.26 \mathrm{E}-05$ & $-2.26 \mathrm{E}-05$ \\
\hline 237 & 463.02 & & & & & & \\
\hline 257 & 510.03 & & & & & & \\
\hline 277 & 544.44 & & & & & & \\
\hline 297 & 580.53 & & & & & & \\
\hline 317 & 631.08 & & & & & & \\
\hline 337 & 680.34 & & & & & & \\
\hline 357 & 727.44 & & & & & & \\
\hline 377 & 772.93 & & & & & & \\
\hline 397 & 831.34 & & & & & & \\
\hline 417 & 894.09 & & & & & & \\
\hline 2132 & 925.08 & $2.22 \mathrm{E}-05$ & $2.22 \mathrm{E}-05$ & $-1.96 \mathrm{E}-05$ & $-1.96 \mathrm{E}-05$ & $-2.93 E-05$ & $-2.92 \mathrm{E}-05$ \\
\hline 2122 & 935.67 & $6.32 \mathrm{E}-05$ & $6.32 \mathrm{E}-05$ & $-1.82 \mathrm{E}-05$ & $-1.82 E-05$ & $-2.21 E-05$ & $-2.21 E-05$ \\
\hline 2112 & 944.86 & $5.15 \mathrm{E}-05$ & $5.15 \mathrm{E}-05$ & $-4.28 \mathrm{E}-06$ & $-4.28 \mathrm{E}-06$ & $-1.14 \mathrm{E}-04$ & $-1.14 \mathrm{E}-04$ \\
\hline 477 & 968.95 & & & & & & \\
\hline 497 & 1002.45 & & & & & & \\
\hline 517 & 1042.45 & & & & & & \\
\hline 537 & 1108.60 & & & & & & \\
\hline 557 & 1178.35 & & & & & & \\
\hline 577 & 1227.20 & & & & & & \\
\hline 597 & 1271.50 & & & & & & \\
\hline 617 & 1313.65 & & & & & & \\
\hline 637 & 1360.60 & & & & & & \\
\hline
\end{tabular}


RPP-RPT-32239, Rev. 1

M\&D-2008-005-CALC-001, Rev. 1

Table H.17. UBS-BEC Concrete Backed Steel Strain, Shell Middle, Gravity Load Only

AP Backed Steel, Upper Bound Soil, Gravity Only, Best Estimate Tank Concrete, 460 In Waste Level at $1.83 \mathrm{SpG}$

\begin{tabular}{|c|c|c|c|c|c|c|c|}
\hline \multirow{2}{*}{$\begin{array}{c}\text { M\&D } \\
\text { Starting } \\
\text { M\&D } \\
\text { Element } \\
\text { No. }\end{array}$} & \multirow[b]{2}{*}{ Path (in) } & \multicolumn{6}{|c|}{ Shell Mid-Plane } \\
\hline & & $\begin{array}{c}\text { AP-460-UBS-BEC } \\
\text { EPEL P1 Strain (in/in) } \\
\text { Gravity Mid Min }\end{array}$ & $\begin{array}{c}\text { AP-460-UBS-BEC } \\
\text { EPEL P1 Strain (in/in) } \\
\text { Gravity Mid Max }\end{array}$ & $\begin{array}{l}\text { AP-460-UBS-BEC } \\
\text { EPEL P2 (in/in) } \\
\text { Gravity Mid Min }\end{array}$ & $\begin{array}{c}\text { AP-460-UBS-BEC } \\
\text { EPEL P2 Strain (in/in) } \\
\text { Gravity Mid Max }\end{array}$ & $\begin{array}{c}\text { AP-460-UBS-BEC } \\
\text { EPEL P3 Strain (in/in) } \\
\text { Gravity Mid Min }\end{array}$ & $\begin{array}{c}\text { AP-460-UBS-BEC } \\
\text { EPEL P3 Strain (in/in) } \\
\text { Gravity Mid Max }\end{array}$ \\
\hline 762 & 67.33 & $3.32 \mathrm{E}-05$ & $3.32 \mathrm{E}-05$ & $-3.59 E-05$ & $-3.58 \mathrm{E}-05$ & $-4.13 \mathrm{E}-05$ & $-4.13 \mathrm{E}-05$ \\
\hline 782 & 105.04 & $3.82 \mathrm{E}-05$ & $3.83 \mathrm{E}-05$ & $-3.01 E-05$ & $-3.01 E-05$ & $-5.89 E-05$ & $-5.88 \mathrm{E}-05$ \\
\hline 802 & 136.24 & $3.43 E-05$ & $3.43 \mathrm{E}-05$ & $-2.47 \mathrm{E}-05$ & $-2.47 E-05$ & $-5.51 E-05$ & $-5.51 E-05$ \\
\hline 822 & 181.71 & $2.82 \mathrm{E}-05$ & $2.83 E-05$ & $-1.55 \mathrm{E}-05$ & $-1.55 \mathrm{E}-05$ & $-5.01 E-05$ & $-5.01 E-05$ \\
\hline 842 & 225.10 & $2.26 \mathrm{E}-05$ & $2.26 \mathrm{E}-05$ & $-8.69 \mathrm{E}-06$ & $-8.68 \mathrm{E}-06$ & $-4.37 \mathrm{E}-05$ & $-4.37 \mathrm{E}-05$ \\
\hline 862 & 273.66 & $1.65 \mathrm{E}-05$ & $1.65 \mathrm{E}-05$ & $-2.53 E-06$ & $-2.52 E-06$ & $-3.58 \mathrm{E}-05$ & $-3.58 \mathrm{E}-05$ \\
\hline 882 & 323.27 & 1.09E-05 & $1.10 \mathrm{E}-05$ & $7.55 \mathrm{E}-06$ & $7.55 \mathrm{E}-06$ & $-2.82 \mathrm{E}-05$ & $-2.82 E-05$ \\
\hline 902 & 369.20 & $1.37 \mathrm{E}-05$ & $1.38 \mathrm{E}-05$ & $1.69 \mathrm{E}-06$ & $1.70 \mathrm{E}-06$ & $-1.74 \mathrm{E}-05$ & $-1.74 \mathrm{E}-05$ \\
\hline 922 & 419.20 & $4.71 \mathrm{E}-05$ & $4.72 \mathrm{E}-05$ & $-1.30 \mathrm{E}-05$ & $-1.30 \mathrm{E}-05$ & $-1.48 \mathrm{E}-05$ & $-1.47 \mathrm{E}-05$ \\
\hline 237 & 463.02 & $3.31 \mathrm{E}-05$ & $3.31 \mathrm{E}-05$ & $6.58 \mathrm{E}-06$ & $6.58 \mathrm{E}-06$ & $-6.11 \mathrm{E}-05$ & $-6.11 \mathrm{E}-05$ \\
\hline 257 & 510.03 & $4.47 \mathrm{E}-05$ & $4.47 \mathrm{E}-05$ & 4.16E-05 & 4.17E-05 & $-2.43 E-04$ & $-2.43 E-04$ \\
\hline 277 & 544.44 & $7.53 \mathrm{E}-05$ & $7.53 \mathrm{E}-05$ & $2.70 \mathrm{E}-05$ & $2.71 \mathrm{E}-05$ & $-3.61 E-04$ & $-3.61 E-04$ \\
\hline 297 & 580.53 & $5.36 \mathrm{E}-05$ & $5.36 \mathrm{E}-05$ & $-2.25 E-05$ & $-2.25 E-05$ & $-2.21 E-04$ & $-2.21 E-04$ \\
\hline 317 & 631.08 & $7.16 \mathrm{E}-05$ & 7.17E-05 & $-6.50 \mathrm{E}-05$ & $-6.49 \mathrm{E}-05$ & $-2.61 E-04$ & $-2.61 E-04$ \\
\hline 337 & 680.34 & $8.52 \mathrm{E}-05$ & $8.53 \mathrm{E}-05$ & $-7.75 \mathrm{E}-05$ & $-7.75 \mathrm{E}-05$ & $-3.11 \mathrm{E}-04$ & $-3.11 \mathrm{E}-04$ \\
\hline 357 & 727.44 & $8.20 \mathrm{E}-05$ & $8.21 \mathrm{E}-05$ & $-8.34 \mathrm{E}-05$ & $-8.34 \mathrm{E}-05$ & $-2.90 \mathrm{E}-04$ & $-2.90 \mathrm{E}-04$ \\
\hline 377 & 772.93 & $9.83 E-05$ & $9.84 \mathrm{E}-05$ & $-8.83 \mathrm{E}-05$ & $-8.83 E-05$ & $-3.60 \mathrm{E}-04$ & $-3.60 \mathrm{E}-04$ \\
\hline 397 & 831.34 & $9.35 \mathrm{E}-05$ & $9.35 \mathrm{E}-05$ & $-7.89 \mathrm{E}-05$ & $-7.89 E-05$ & $-3.47 E-04$ & $-3.47 \mathrm{E}-04$ \\
\hline 417 & 894.09 & $3.70 \mathrm{E}-05$ & $3.71 \mathrm{E}-05$ & $-5.25 \mathrm{E}-05$ & $-5.25 \mathrm{E}-05$ & $-1.16 \mathrm{E}-04$ & $-1.16 \mathrm{E}-04$ \\
\hline 2132 & 925.08 & $1.79 \mathrm{E}-05$ & 1.79E-05 & $-6.80 \mathrm{E}-06$ & $-6.79 \mathrm{E}-06$ & $-2.93 \mathrm{E}-05$ & $-2.92 \mathrm{E}-05$ \\
\hline 2122 & 935.67 & $1.76 \mathrm{E}-05$ & $1.76 \mathrm{E}-05$ & $-1.33 \mathrm{E}-05$ & $-1.33 \mathrm{E}-05$ & $-2.19 \mathrm{E}-05$ & $-2.19 \mathrm{E}-05$ \\
\hline 2112 & 944.86 & $1.11 \mathrm{E}-05$ & $1.11 \mathrm{E}-05$ & $-3.95 \mathrm{E}-06$ & $-3.95 \mathrm{E}-06$ & $-1.81 \mathrm{E}-05$ & $-1.81 \mathrm{E}-05$ \\
\hline 477 & 968.95 & $1.18 \mathrm{E}-05$ & $1.18 \mathrm{E}-05$ & $5.86 \mathrm{E}-06$ & $5.86 \mathrm{E}-06$ & $-5.07 \mathrm{E}-05$ & $-5.06 \mathrm{E}-05$ \\
\hline 497 & 1002.45 & $6.75 \mathrm{E}-05$ & $6.75 \mathrm{E}-05$ & $7.48 \mathrm{E}-06$ & $7.48 \mathrm{E}-06$ & $-1.96 \mathrm{E}-05$ & $-1.96 \mathrm{E}-05$ \\
\hline 517 & 1042.45 & $1.05 \mathrm{E}-05$ & $1.06 \mathrm{E}-05$ & $6.04 \mathrm{E}-06$ & $6.05 \mathrm{E}-06$ & $-3.63 \mathrm{E}-06$ & $-3.63 E-06$ \\
\hline 537 & 1108.60 & $1.28 \mathrm{E}-05$ & $1.28 \mathrm{E}-05$ & $4.14 \mathrm{E}-06$ & $4.14 \mathrm{E}-06$ & $-4.74 \mathrm{E}-06$ & $-4.73 E-06$ \\
\hline 557 & 1178.35 & $3.79 \mathrm{E}-06$ & $3.80 \mathrm{E}-06$ & $1.94 \mathrm{E}-06$ & $1.94 \mathrm{E}-06$ & $-1.05 \mathrm{E}-05$ & $-1.05 \mathrm{E}-05$ \\
\hline 577 & 1227.20 & $1.72 \mathrm{E}-05$ & $1.72 \mathrm{E}-05$ & $3.72 \mathrm{E}-06$ & $3.73 \mathrm{E}-06$ & $-4.75 E-06$ & $-4.75 E-06$ \\
\hline 597 & 1271.50 & $4.36 \mathrm{E}-06$ & $4.36 \mathrm{E}-06$ & $1.91 \mathrm{E}-06$ & $1.92 \mathrm{E}-06$ & $-1.21 \mathrm{E}-05$ & $-1.21 \mathrm{E}-05$ \\
\hline 617 & 1313.65 & $1.25 \mathrm{E}-05$ & $1.25 \mathrm{E}-05$ & $5.73 \mathrm{E}-06$ & $5.74 \mathrm{E}-06$ & $-4.06 \mathrm{E}-06$ & $-4.05 E-06$ \\
\hline 637 & 1360.60 & $4.01 \mathrm{E}-06$ & $4.01 \mathrm{E}-06$ & $3.43 E-06$ & $3.43 E-06$ & $-1.51 \mathrm{E}-06$ & $-1.51 \mathrm{E}-06$ \\
\hline
\end{tabular}


RPP-RPT-32239, Rev. 1

M\&D-2008-005-CALC-001, Rev. 1

Table H.18. UBS-BEC Concrete Backed Steel Strain, Shell Bottom, Gravity Load Only

AP Backed Steel, Upper Bound Soil, Gravity Only, Best Estimate Tank Concrete, 460 In Waste Level at $1.83 \mathrm{SpG}$

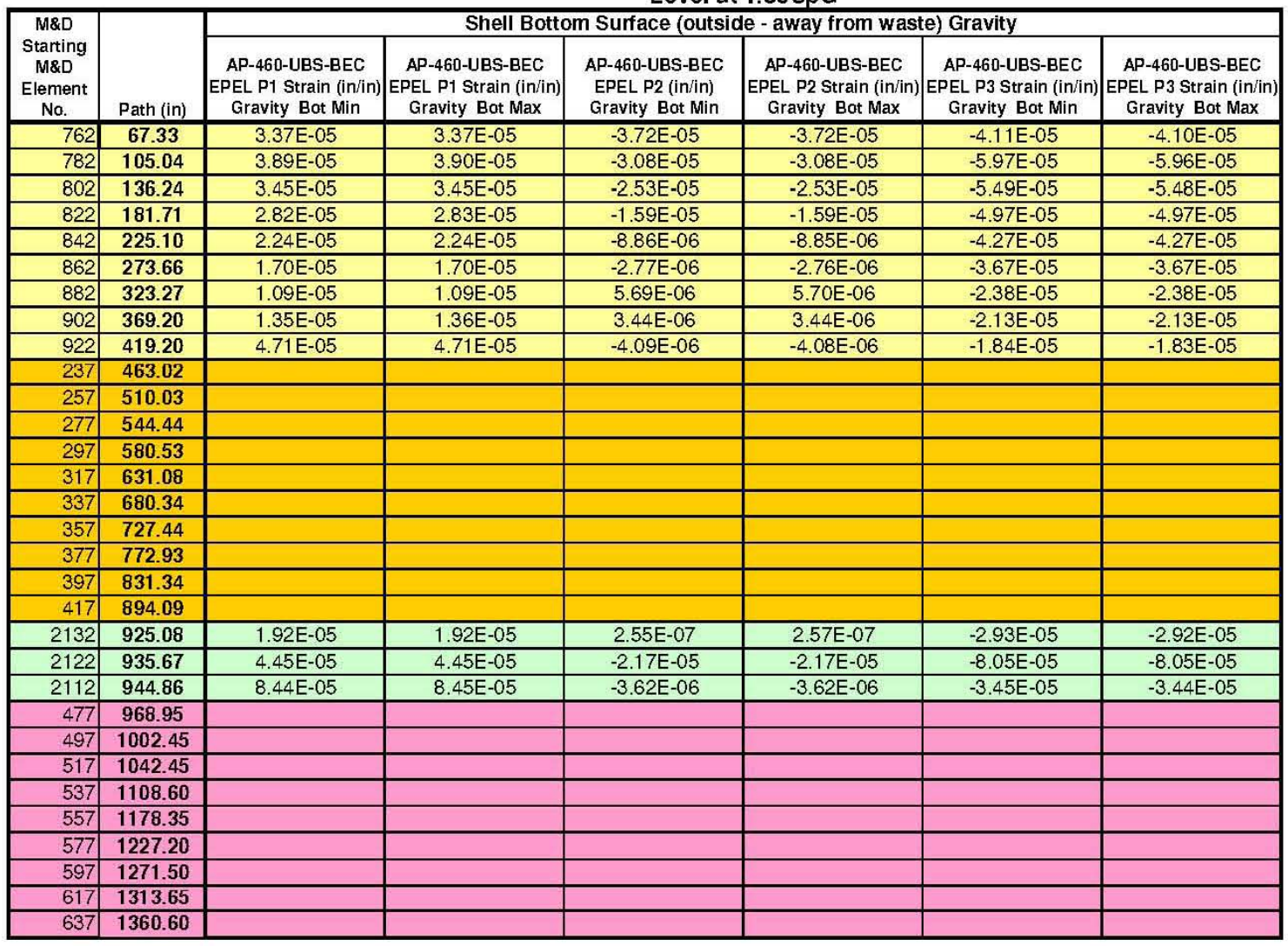


RPP-RPT-32239, Rev. 1

M\&D-2008-005-CALC-001, Rev. 1

Table H.19. UBS-BEC Concrete Backed Steel Strain, Shell Top, Gravity Plus Seismic Load

AP Backed Steel, Upper Bound Soil, Seismic Only, Best Estimate Tank Concrete, 460 In Waste Level at $1.83 \mathrm{SpG}$

\begin{tabular}{|c|c|c|c|c|c|c|c|}
\hline \multirow{2}{*}{$\begin{array}{c}\text { M\&D } \\
\text { Starting } \\
\text { M\&D } \\
\text { Element } \\
\text { No. }\end{array}$} & \multirow[b]{2}{*}{ Path (in) } & \multicolumn{6}{|c|}{ Shell Top Surface (inside - towards waste) Seismic } \\
\hline & & $\begin{array}{l}\text { AP-460-UBS-BEC } \\
\text { EPEL P1 Strain (in/in) } \\
\text { Seismic Top Min }\end{array}$ & $\begin{array}{c}\text { AP-460-UBS-BEC } \\
\text { EPEL P1 Strain (in/in) } \\
\text { Seismic Tap Max }\end{array}$ & $\begin{array}{l}\text { AP-460-UBS-BEC } \\
\text { EPEL P2 (in/in) } \\
\text { Seismic Tap Min }\end{array}$ & $\begin{array}{c}\text { AP-460-UBS-BEC } \\
\text { EPEL P2 Strain (in/in) } \\
\text { Seismic Top Max }\end{array}$ & $\begin{array}{c}\text { AP-460-UBS-BEC } \\
\text { EPEL PJ Strain (in/in) } \\
\text { Seismic Top Min }\end{array}$ & $\begin{array}{l}\text { AP-460-UBS-BEC } \\
\text { EPEL P3 Strain (in/in) } \\
\text { Seismic Top Max }\end{array}$ \\
\hline 762 & 67.33 & $1.98 \mathrm{E}-05$ & $4.96 \mathrm{E}-05$ & $-4.67 \mathrm{E}-05$ & $-5.69 \mathrm{E}-06$ & $-6.59 \mathrm{E}-05$ & $-2.34 \mathrm{E}-05$ \\
\hline 782 & 105.04 & $2.33 E-05$ & $5.90 \mathrm{E}-05$ & $-3.95 \mathrm{E}-05$ & $-1.17 \mathrm{E}-05$ & $-8.19 \mathrm{E}-05$ & $-2.64 \mathrm{E}-05$ \\
\hline 802 & 136.24 & $2.26 \mathrm{E}-05$ & $5.05 \mathrm{E}-05$ & $-3.73 E-05$ & $5.22 \mathrm{E}-06$ & $-8.91 \mathrm{E}-05$ & $-2.66 \mathrm{E}-05$ \\
\hline 822 & 181.71 & 1.97E-05 & $4.41 \mathrm{E}-05$ & $-2.68 \mathrm{E}-05$ & $5.38 \mathrm{E}-06$ & $-7.47 \mathrm{E}-05$ & $-2.35 \mathrm{E}-05$ \\
\hline 842 & 225.10 & $1.70 \mathrm{E}-05$ & $4.78 \mathrm{E}-05$ & $-2.37 \mathrm{E}-05$ & $2.49 \mathrm{E}-05$ & $-7.60 \mathrm{E}-05$ & $-1.97 \mathrm{E}-05$ \\
\hline 862 & 273.66 & 1.17E-05 & 3.36E-05 & $-1.33 \mathrm{E}-05$ & $1.91 \mathrm{E}-05$ & $-5.81 \mathrm{E}-05$ & $-9.51 E-06$ \\
\hline 882 & 323.27 & $7.55 \mathrm{E}-06$ & $8.86 \mathrm{E}-05$ & $-6.78 \mathrm{E}-06$ & $1.71 \mathrm{E}-05$ & $-7.30 \mathrm{E}-05$ & $-1.10 \mathrm{E}-05$ \\
\hline 902 & 369.20 & $2.17 \mathrm{E}-06$ & 9.39E-05 & $-3.49 \mathrm{E}-06$ & $1.54 \mathrm{E}-05$ & $-5.63 \mathrm{E}-05$ & $-7.98 \mathrm{E}-07$ \\
\hline 922 & 419.20 & $2.48 \mathrm{E}-05$ & $1.70 \mathrm{E}-04$ & $-1.52 E-05$ & $1.11 \mathrm{E}-05$ & $-7.03 E-05$ & $-1.51 \mathrm{E}-06$ \\
\hline 237 & 463.02 & & & & & & \\
\hline 257 & 510.03 & & & & & & \\
\hline 277 & 544.44 & & & & & & \\
\hline 297 & 580.53 & & & & & & \\
\hline 317 & 631.08 & & & & & & \\
\hline 337 & 680.34 & & & & & & \\
\hline 357 & 727.44 & & & & & & \\
\hline 377 & 772.93 & & & & & & \\
\hline 397 & 831.34 & & & & & & \\
\hline 417 & 894.09 & & & & & & \\
\hline 2132 & 925.08 & $1.90 \mathrm{E}-05$ & $3.28 \mathrm{E}-05$ & $-2.30 \mathrm{E}-05$ & $6.56 \mathrm{E}-06$ & $-4.18 E-05$ & $-2.16 \mathrm{E}-05$ \\
\hline 2122 & 935.67 & $4.94 \mathrm{E}-05$ & $9.48 \mathrm{E}-05$ & $-2.14 \mathrm{E}-05$ & $-2.19 \mathrm{E}-06$ & $-3.63 \mathrm{E}-05$ & $-1.44 \mathrm{E}-05$ \\
\hline 2112 & 944.86 & $3.60 \mathrm{E}-05$ & $1.02 \mathrm{E}-04$ & $-7.88 \mathrm{E}-06$ & $1.91 \mathrm{E}-05$ & $-1.43 \mathrm{E}-04$ & $-1.84 \mathrm{E}-05$ \\
\hline 477 & 968.95 & & & & & & \\
\hline 497 & 1002.45 & & & & & & \\
\hline 517 & 1042.45 & & & & & & \\
\hline 537 & 1108.60 & & & & & & \\
\hline 557 & 1178.35 & & & & & & \\
\hline 577 & 1227.20 & & & & & & \\
\hline 597 & 1271.50 & & & & & & \\
\hline 617 & 1313.65 & & & & & & \\
\hline 637 & 1360.60 & & & & & & \\
\hline
\end{tabular}


RPP-RPT-32239, Rev. 1

M\&D-2008-005-CALC-001, Rev. 1

Table H.20. UBS-BEC Concrete Backed Steel Strain, Shell Middle, Gravity Plus Seismic Load

AP Backed Steel, Upper Bound Soil, Seismic Only, Best Estimate Tank Concrete, 460 In Waste Level at 1.83SpG

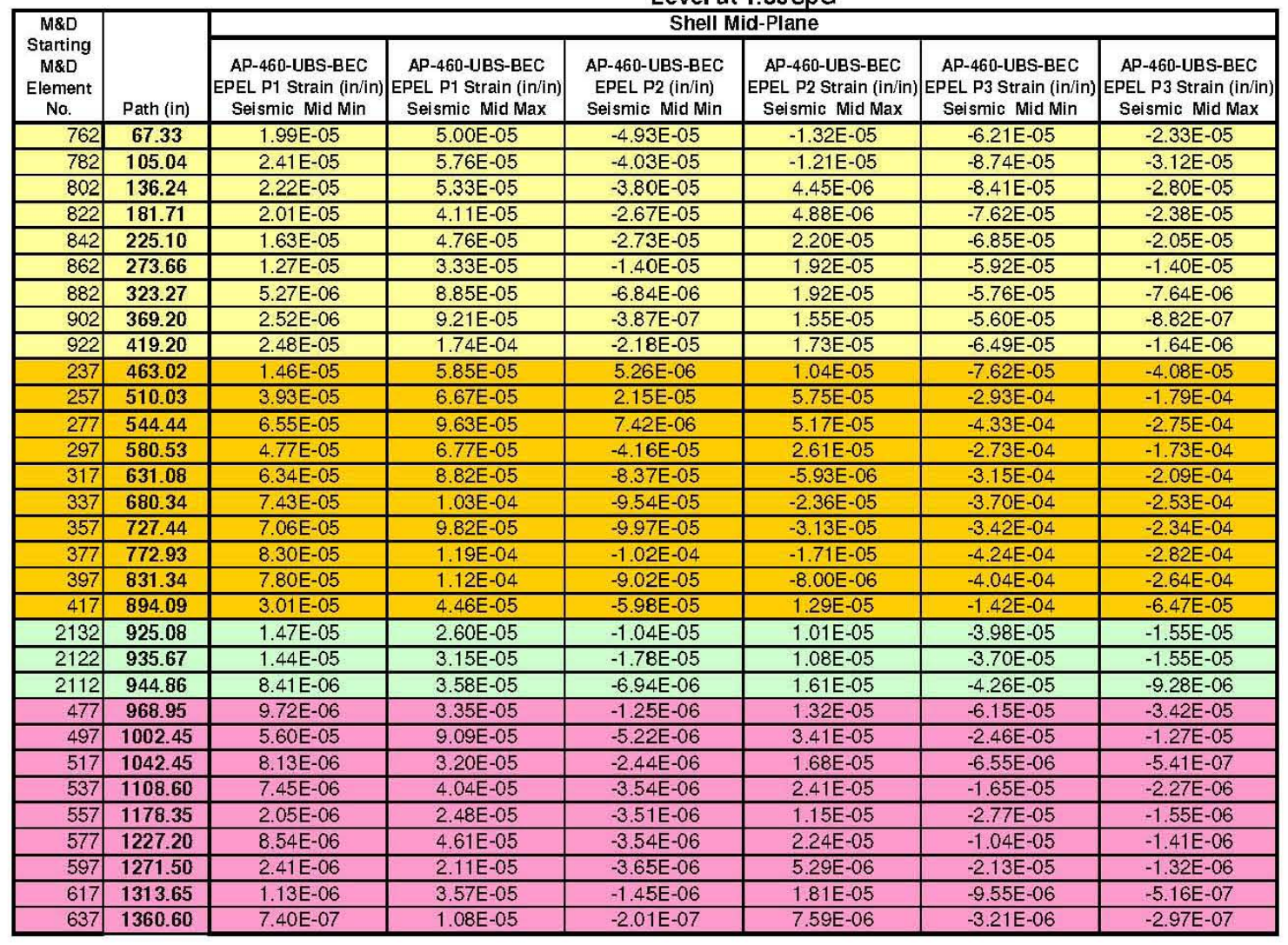


RPP-RPT-32239, Rev. 1

M\&D-2008-005-CALC-001, Rev. 1

Table H.21. UBS-BEC Concrete Backed Steel Strain, Shell Bottom, Gravity Plus Seismic Load

AP Backed Steel, Upper Bound Soil, Seismic Only, Best Estimate Tank Concrete, 460 In Waste Level at $1.83 \mathrm{SpG}$

\begin{tabular}{|c|c|c|c|c|c|c|c|}
\hline \multirow{2}{*}{$\begin{array}{c}\text { M\&D } \\
\text { Starting } \\
\text { M\&D } \\
\text { Element } \\
\text { No. }\end{array}$} & \multirow[b]{2}{*}{ Path (in) } & \multicolumn{6}{|c|}{ Shell Bottom Surface (outside - away from waste) Seismic } \\
\hline & & $\begin{array}{l}\text { AP-460-UBS-BEC } \\
\text { EPEL P1 Strain (in/in) } \\
\text { Seismic Bot Min }\end{array}$ & $\begin{array}{c}\text { AP-460-UBS-BEC } \\
\text { EPEL P1 Strain (in/in) } \\
\text { Seismic Bat Max }\end{array}$ & $\begin{array}{l}\text { AP-460-UBS-BEC } \\
\text { EPEL P2 (in/in) } \\
\text { Seismic Bot Min }\end{array}$ & $\begin{array}{c}\text { AP-460-UBS-BEC } \\
\text { EPEL P2 Strain (in/in) } \\
\text { Seismic Bot Max }\end{array}$ & $\begin{array}{c}\text { AP-460-UBS-BEC } \\
\text { EPEL P3 Strain (in/in) } \\
\text { Seismic Bot Min }\end{array}$ & $\begin{array}{c}\text { AP-460-UBS-BEC } \\
\text { EPEL P3 Strain (in/in) } \\
\text { Seismic Bot Max }\end{array}$ \\
\hline 762 & 67.33 & $1.94 \mathrm{E}-05$ & $5.52 \mathrm{E}-05$ & $-5.18 \mathrm{E}-05$ & $-1.38 \mathrm{E}-05$ & $-5.91 E-05$ & $-1.92 \mathrm{E}-05$ \\
\hline 782 & 105.04 & $2.30 \mathrm{E}-05$ & $6.08 \mathrm{E}-05$ & $-4.16 \mathrm{E}-05$ & $-1.24 \mathrm{E}-05$ & $-9.33 E-05$ & $-2.15 \mathrm{E}-05$ \\
\hline 802 & 136.24 & $2.20 \mathrm{E}-05$ & $5.92 \mathrm{E}-05$ & $-3.85 \mathrm{E}-05$ & $3.72 \mathrm{E}-06$ & $-7.92 \mathrm{E}-05$ & $-2.67 \mathrm{E}-05$ \\
\hline 822 & 181.71 & $1.96 \mathrm{E}-05$ & $4.04 \mathrm{E}-05$ & $-2.67 \mathrm{E}-05$ & $4.38 \mathrm{E}-06$ & $-7.79 \mathrm{E}-05$ & $-2.22 \mathrm{E}-05$ \\
\hline 842 & 225.10 & 1.39E-05 & $4.91 \mathrm{E}-05$ & $-2.90 \mathrm{E}-05$ & $1.84 \mathrm{E}-05$ & $-6.54 \mathrm{E}-05$ & $-1.50 \mathrm{E}-05$ \\
\hline 862 & 273.66 & $1.29 \mathrm{E}-05$ & 3.31E-05 & $-1.49 \mathrm{E}-05$ & $1.96 \mathrm{E}-05$ & $-6.19 \mathrm{E}-05$ & $-1.61 \mathrm{E}-05$ \\
\hline 882 & 323.27 & $3.03 E-06$ & $8.85 E-05$ & $-7.27 \mathrm{E}-06$ & $2.06 \mathrm{E}-05$ & $-5.49 \mathrm{E}-05$ & $-1.80 \mathrm{E}-06$ \\
\hline 902 & 369.20 & $3.65 \mathrm{E}-06$ & $9.08 \mathrm{E}-05$ & $7.64 \mathrm{E}-07$ & 1.78E-05 & $-5.76 \mathrm{E}-05$ & $-4.03 E-06$ \\
\hline 922 & 419.20 & $2.47 \mathrm{E}-05$ & $1.78 \mathrm{E}-04$ & $-2.82 \mathrm{E}-05$ & $3.43 \mathrm{E}-05$ & $-6.13 \mathrm{E}-05$ & $-1.62 \mathrm{E}-06$ \\
\hline 237 & 463.02 & & & & & & \\
\hline 257 & 510.03 & & & & & & \\
\hline 277 & 544.44 & & & & & & \\
\hline 297 & 580.53 & & & & & & \\
\hline 317 & 631.08 & & & & & & \\
\hline 337 & 680.34 & & & & & & \\
\hline 357 & 727.44 & & & & & & \\
\hline 377 & 772.93 & & & & & & \\
\hline 397 & 831.34 & & & & & & \\
\hline 417 & 894.09 & & & & & & \\
\hline 2132 & 925.08 & $1.65 \mathrm{E}-05$ & 2.89E-05 & $-2.10 \mathrm{E}-06$ & $9.30 \mathrm{E}-06$ & $-3.89 \mathrm{E}-05$ & $-1.55 \mathrm{E}-05$ \\
\hline 2122 & 935.67 & $3.73 \mathrm{E}-05$ & $6.96 \mathrm{E}-05$ & $-2.68 \mathrm{E}-05$ & $2.34 \mathrm{E}-06$ & $-1.07 \mathrm{E}-04$ & $-2.60 \mathrm{E}-05$ \\
\hline 2112 & 944.86 & $6.11 \mathrm{E}-05$ & $1.74 \mathrm{E}-04$ & $-1.59 \mathrm{E}-05$ & $1.95 \mathrm{E}-05$ & $-4.35 \mathrm{E}-05$ & $-1.07 \mathrm{E}-05$ \\
\hline 477 & 968.95 & & & & & & \\
\hline 497 & 1002.45 & & & & & & \\
\hline 517 & 1042.45 & & & & & & \\
\hline 537 & 1108.60 & & & & & & \\
\hline 557 & 1178.35 & & & & & & \\
\hline 577 & 1227.20 & & & & & & \\
\hline 597 & 1271.50 & & & & & & \\
\hline 617 & 1313.65 & & & & & & \\
\hline 637 & 1360.60 & & & & & & \\
\hline
\end{tabular}


RPP-RPT-32239, Rev. 1

M\&D-2008-005-CALC-001, Rev. 1

Table H.22. UBS-BEC Concrete Backed Steel Strain, Shell Top, Seismic Load Only

AP Backed Steel, Upper Bound Soil, Seismic Only, Best Estimate Tank Concrete, 460 In Waste Level at $1.83 \mathrm{SpG}$

\begin{tabular}{|c|c|c|c|c|c|c|c|}
\hline \multirow[b]{2}{*}{$\begin{array}{l}\text { M\&D } \\
\text { Starting } \\
\text { M\&D } \\
\text { Element } \\
\text { No. }\end{array}$} & \multirow[b]{2}{*}{ Path (in) } & \multicolumn{6}{|c|}{ Shell Top Surface (inside - towards waste) Seismic } \\
\hline & & $\begin{array}{c}\text { AP-460-UBS-BEC } \\
\text { EPEL P1 Strain (in/in) } \\
\text { Seismic Only Top } \\
\text { Min }\end{array}$ & $\begin{array}{c}\text { AP-460-UBS-BEC } \\
\text { EPEL P1 Strain (in/in) } \\
\text { Seismic Only Top } \\
\text { Max }\end{array}$ & $\begin{array}{l}\text { AP-460-UBS-BEC } \\
\text { EPEL P2 (in/in) } \\
\text { Seismic Only Top } \\
\text { Min }\end{array}$ & $\begin{array}{c}\text { AP-460-UBS-BEC } \\
\text { EPEL P2 Strain (in/in) } \\
\text { Seismic Only Top } \\
\text { Max }\end{array}$ & $\begin{array}{c}\text { AP-460-UBS-BEC } \\
\text { EPEL P3 Strain } \\
\text { (in/in) Seismic Only } \\
\text { Top Min }\end{array}$ & $\begin{array}{c}\text { AP-460-UBS-BEC } \\
\text { EPEL P3 Strain (in/in) } \\
\text { Seismic Only Tap } \\
\text { Max }\end{array}$ \\
\hline 762 & 67.33 & $-1.29 \mathrm{E}-05$ & $1.68 \mathrm{E}-05$ & $-1.24 \mathrm{E}-05$ & $2.86 \mathrm{E}-05$ & $-2.45 \mathrm{E}-05$ & $1.81 \mathrm{E}-05$ \\
\hline 782 & 105.04 & $-1.43 \mathrm{E}-05$ & $2.14 \mathrm{E}-05$ & $-1.01 \mathrm{E}-05$ & 1.77E-05 & $-2.40 \mathrm{E}-05$ & $3.15 \mathrm{E}-05$ \\
\hline 802 & 136.24 & $-1.16 \mathrm{E}-05$ & $1.63 \mathrm{E}-05$ & $-1.33 \mathrm{E}-05$ & $2.92 \mathrm{E}-05$ & $-3.38 \mathrm{E}-05$ & $2.87 \mathrm{E}-05$ \\
\hline 822 & 181.71 & $-8.49 \mathrm{E}-06$ & $1.59 \mathrm{E}-05$ & $-1.17 \mathrm{E}-05$ & $2.05 \mathrm{E}-05$ & $-2.42 \mathrm{E}-05$ & $2.69 \mathrm{E}-05$ \\
\hline 842 & 225.10 & $-5.95 \mathrm{E}-06$ & $2.49 \mathrm{E}-05$ & $-1.53 E-05$ & $3.34 \mathrm{E}-05$ & $-3.13 E-05$ & $2.49 \mathrm{E}-05$ \\
\hline 862 & 273.66 & $-4.28 \mathrm{E}-06$ & $1.76 \mathrm{E}-05$ & $-1.10 \mathrm{E}-05$ & $2.14 \mathrm{E}-05$ & $-2.33 \mathrm{E}-05$ & $2.53 \mathrm{E}-05$ \\
\hline 882 & 323.27 & $-3.48 E-06$ & $7.75 \mathrm{E}-05$ & $-1.62 \mathrm{E}-05$ & $7.71 \mathrm{E}-06$ & $-4.03 E-05$ & $2.17 \mathrm{E}-05$ \\
\hline 902 & 369.20 & $-1.18 \mathrm{E}-05$ & 7.99E-05 & $-3.45 \mathrm{E}-06$ & $1.54 \mathrm{E}-05$ & $-4.27 E-05$ & $1.28 \mathrm{E}-05$ \\
\hline 922 & 419.20 & $-2.24 \mathrm{E}-05$ & $1.23 \mathrm{E}-04$ & $-4.72 \mathrm{E}-06$ & $2.15 \mathrm{E}-05$ & $-4.77 \mathrm{E}-05$ & $2.11 \mathrm{E}-05$ \\
\hline 237 & 463.02 & & & & & & \\
\hline 257 & 510.03 & & & & & & \\
\hline 277 & 544.44 & & & & & & \\
\hline 297 & 580.53 & & & & & & \\
\hline 317 & 631.08 & & & & & & \\
\hline 337 & 680.34 & & & & & & \\
\hline 357 & 727.44 & & & & & & \\
\hline 377 & 772.93 & & & & & & \\
\hline 397 & 831.34 & & & & & & \\
\hline 417 & 894.09 & & & & & & \\
\hline 2062 & 925.08 & $-3.24 \mathrm{E}-06$ & $1.06 \mathrm{E}-05$ & $-3.45 \mathrm{E}-06$ & $2.61 \mathrm{E}-05$ & $-1.26 \mathrm{E}-05$ & $7.68 \mathrm{E}-06$ \\
\hline 2052 & 935.67 & $-1.37 \mathrm{E}-05$ & $3.16 \mathrm{E}-05$ & $-3.22 \mathrm{E}-06$ & $1.60 \mathrm{E}-05$ & $-1.41 \mathrm{E}-05$ & $7.70 \mathrm{E}-06$ \\
\hline 2042 & 944.86 & $-1.55 \mathrm{E}-05$ & $5.08 \mathrm{E}-05$ & $-3.60 \mathrm{E}-06$ & $2.33 \mathrm{E}-05$ & $-2.89 \mathrm{E}-05$ & $9.55 \mathrm{E}-05$ \\
\hline 477 & 968.95 & & & & & & \\
\hline 497 & 1002.45 & & & & & & \\
\hline 517 & 1042.45 & & & & & & \\
\hline 537 & 1108.60 & & & & & & \\
\hline 557 & 1178.35 & & & & & & \\
\hline 577 & 1227.20 & & & & & & \\
\hline 597 & 1271.50 & & & & & & \\
\hline 617 & 1313.65 & & & & & & \\
\hline 637 & 1360.60 & & & & & & \\
\hline
\end{tabular}




\section{RPP-RPT-32239, Rev. 1 \\ M\&D-2008-005-CALC-001, Rev. 1}

Table H.23. UBS-BEC Concrete Backed Steel Strain, Shell Middle, Seismic Load Only

AP Backed Steel, Lower Bound Soil, Seismic Only, Best Estimate Tank Concrete, 460 In Waste Level at $1.83 \mathrm{SpG}$

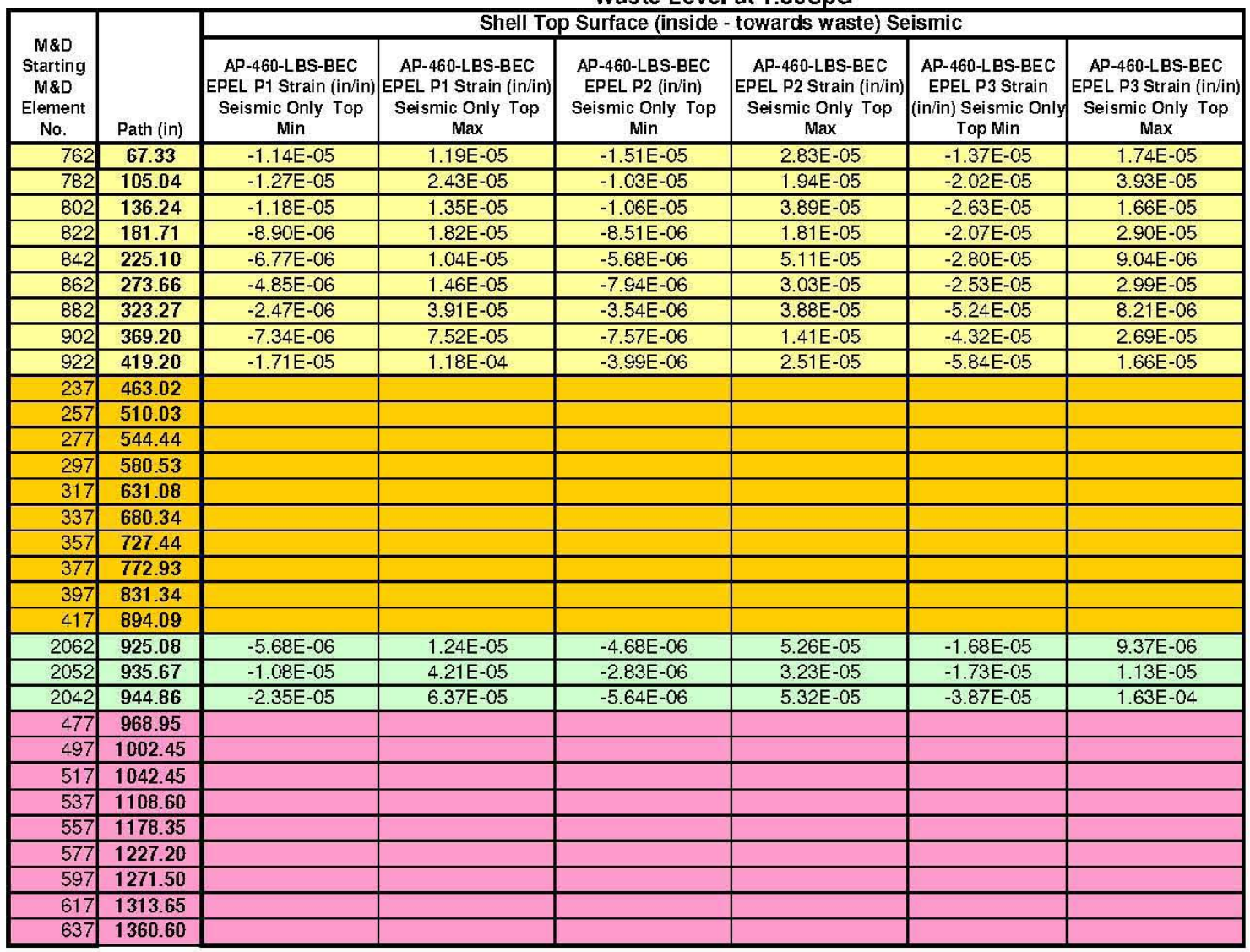


RPP-RPT-32239, Rev. 1

M\&D-2008-005-CALC-001, Rev. 1

Table H.24. UBS-BEC Concrete Backed Steel Strain, Shell Bottom, Seismic Load Only

AP Backed Steel, Upper Bound Soil, Seismic Only, Best Estimate Tank Concrete, 460 In Waste Level at $1.83 \mathrm{SpG}$

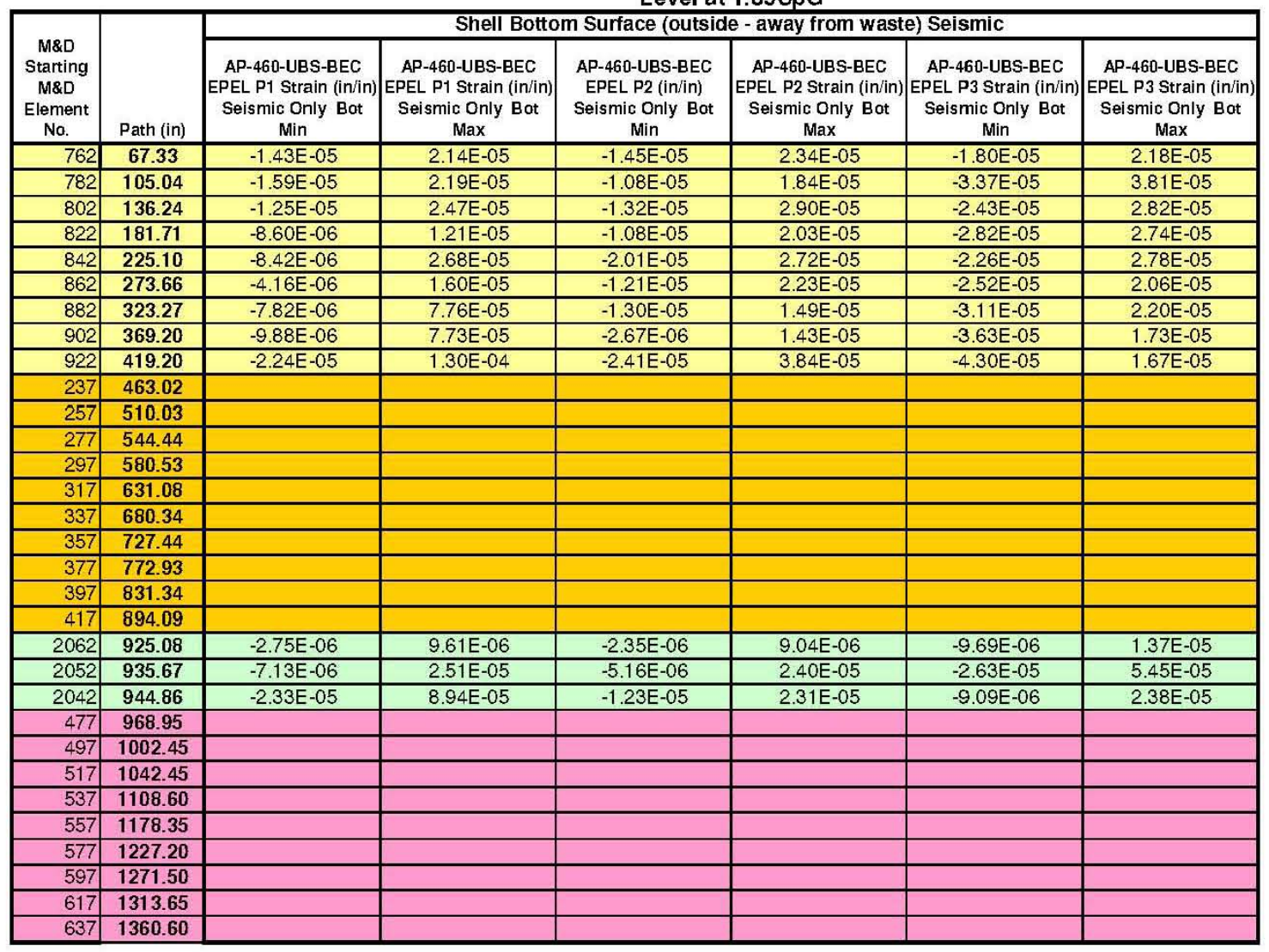


RPP-RPT-32239, Rev. 1

M\&D-2008-005-CALC-001, Rev. 1

Table H.25. UBS-BEC Concrete Wall/Footing Contact Forces, Gravity Only

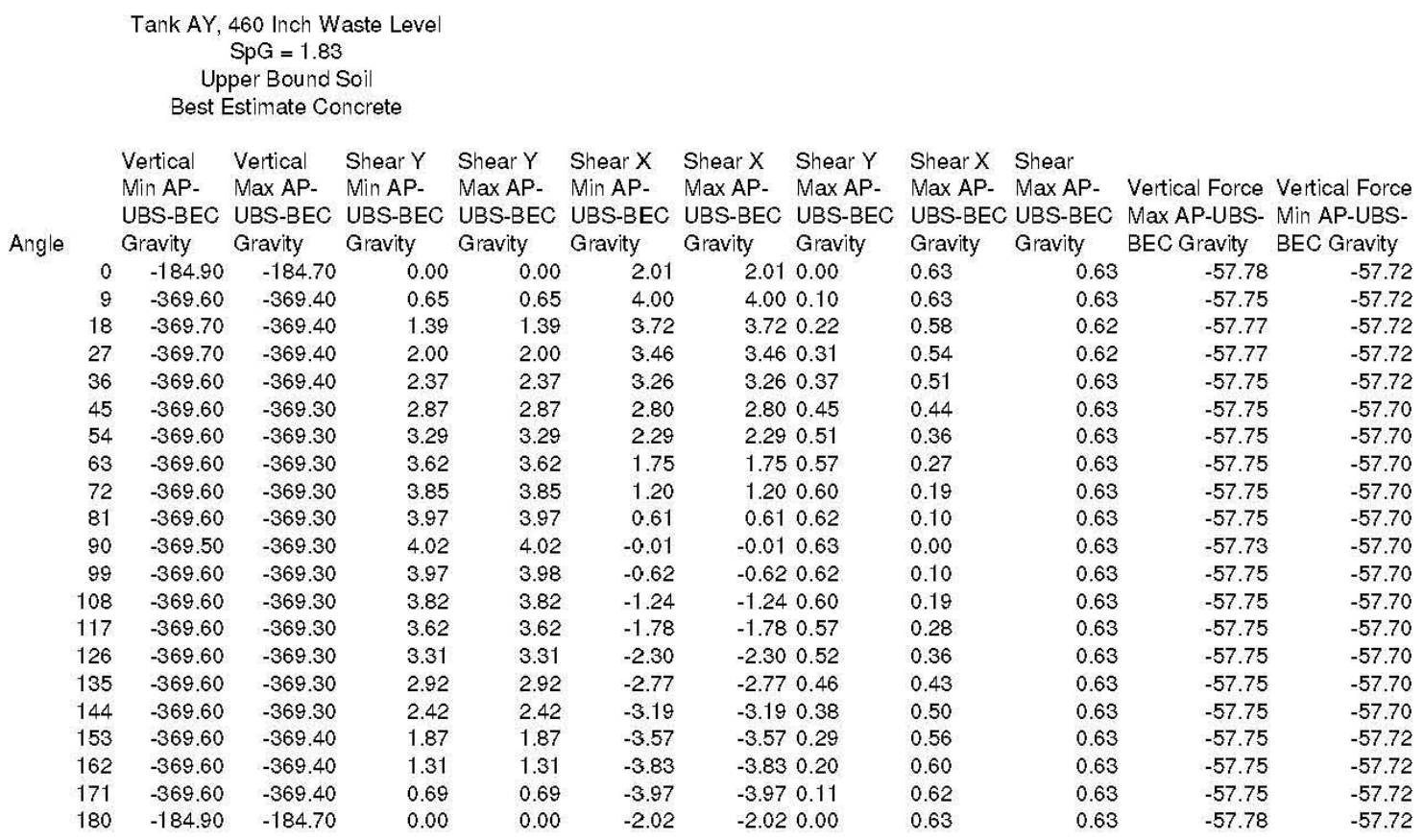


RPP-RPT-32239, Rev. 1

M\&D-2008-005-CALC-001, Rev. 1

Table H.26. UBS-BEC Concrete Wall/Footing Contact Forces, Gravity Plus Seismic

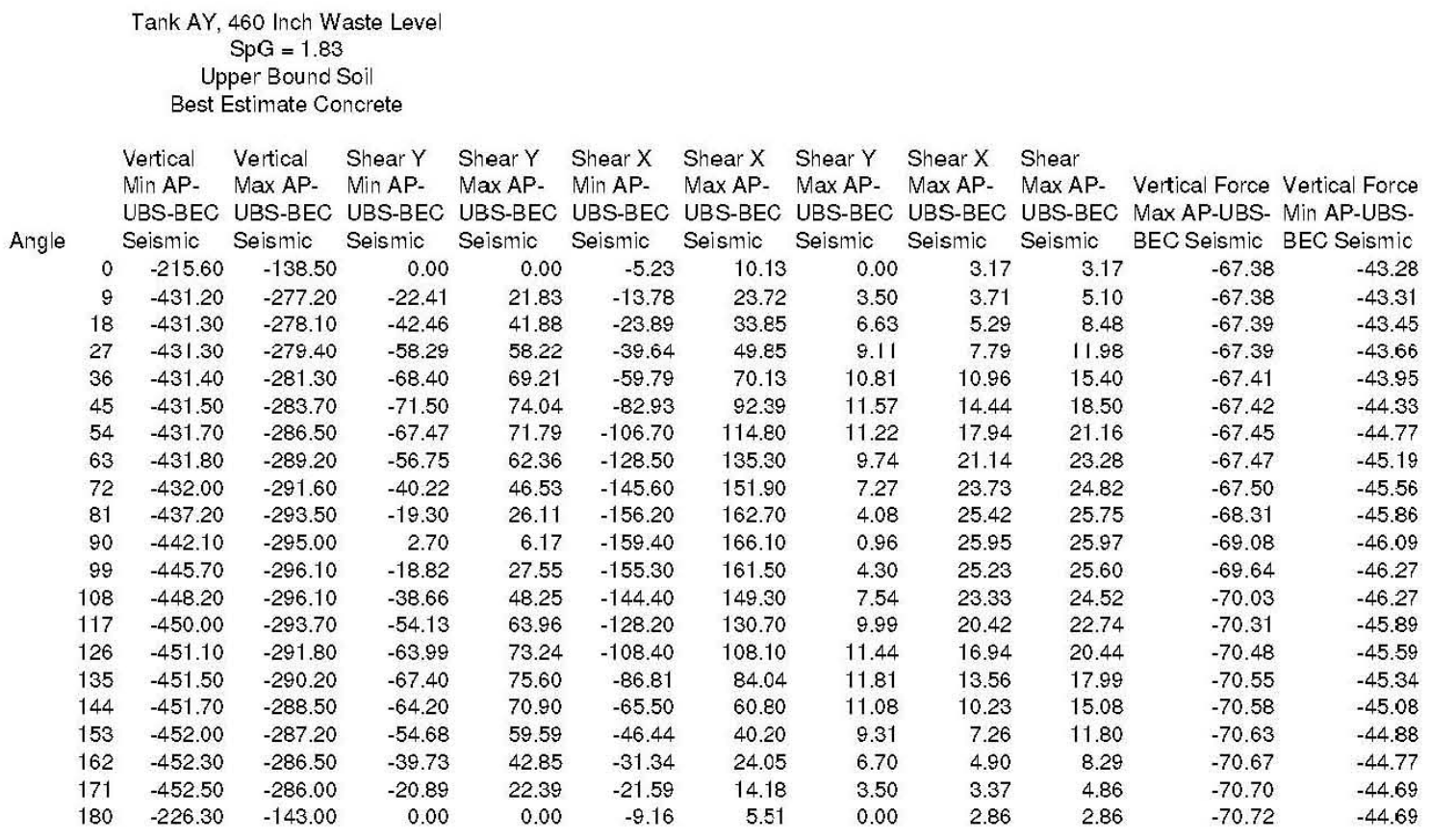


RPP-RPT-32239, Rev. 1

M\&D-2008-005-CALC-001, Rev. 1

Table H.27. UBS-BEC Concrete Wall/Footing Contact Forces, Seismic Only

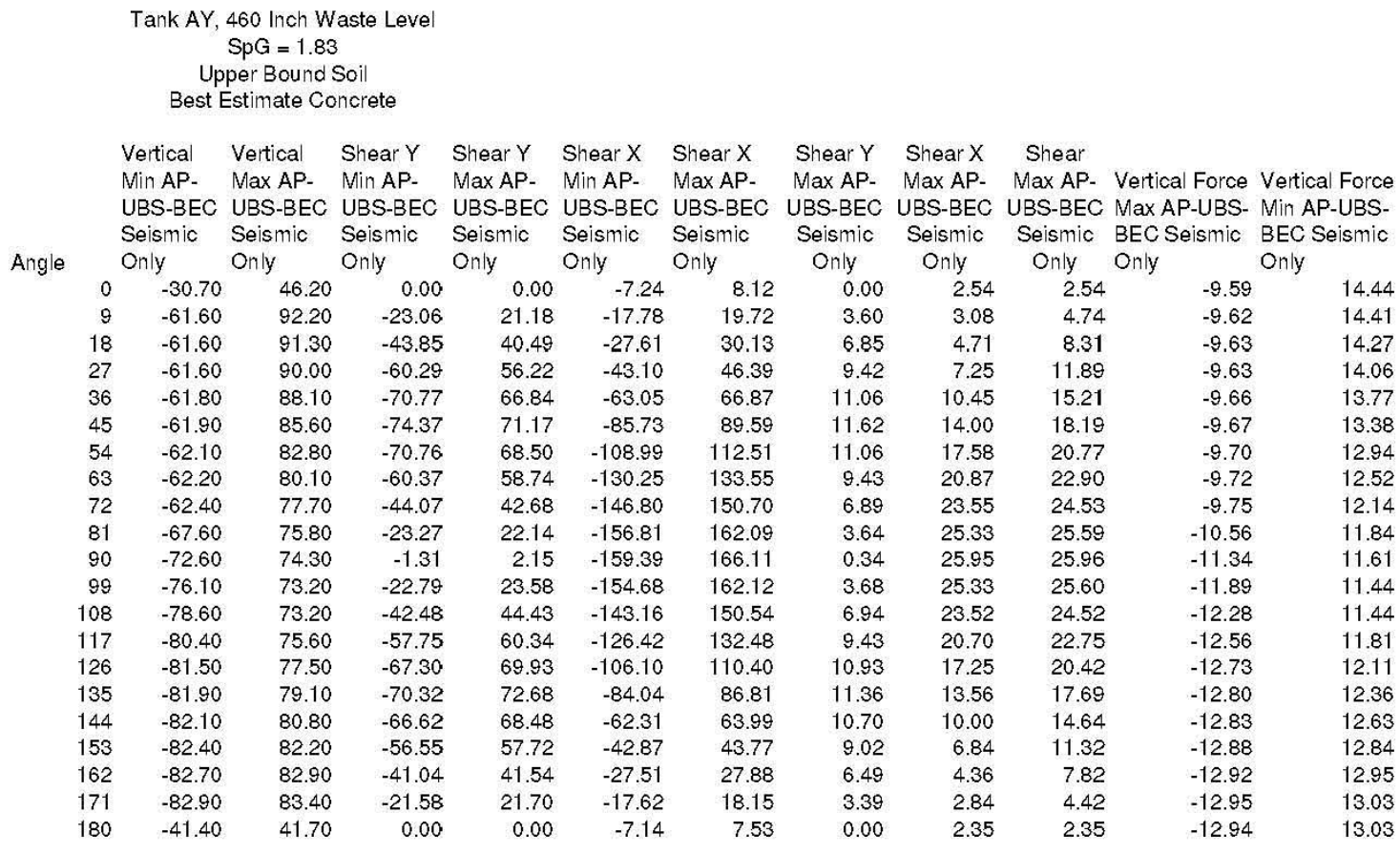


RPP-RPT-32239, Rev. 1

M\&D-2008-005-CALC-001, Rev. 1

Table H.28. UBS-BEC Soil/Concrete Tank Contact Forces, Gravity Only

Tank AP, 460 Inch Waste Level

$\mathrm{SpG}=1.83$

Best Estimate

\begin{tabular}{|c|c|c|c|c|c|c|c|c|c|c|c|c|}
\hline & Angle (rad) & Path & $\begin{array}{c}\text { Max Pressure } \\
\text { Soil (BES) AP } \\
\text { Gravity (PSI) }\end{array}$ & $\begin{array}{l}\text { Min Pressure } \\
\text { Soil (BES) AP } \\
\text { Gravity (PSI) }\end{array}$ & $\begin{array}{l}\text { Max Meridional } \\
\text { Friction } \\
\text { Soil (BES) AP } \\
\text { Gravity (PSI) }\end{array}$ & $\begin{array}{c}\text { Max Tangential } \\
\text { Friction } \\
\text { Soil (BES) AP } \\
\text { Gravity (PSI) }\end{array}$ & $\begin{array}{l}\text { Max Contact } \\
\text { Displacement } \\
\text { Soil (BES) AP } \\
\text { Gravity (PSI) }\end{array}$ & \begin{tabular}{|l} 
Vertical \\
Pressure
\end{tabular} & \begin{tabular}{|l} 
Active \\
Pressure Phi $=$ \\
33 deg
\end{tabular} & $\begin{array}{l}\text { Active } \\
\text { Pressure Phi }= \\
49 \text { deg }\end{array}$ & $\begin{array}{l}\text { 0.22g Dome } \\
\text { Vertical }\end{array}$ & $\begin{array}{l}0.17 \mathrm{~g} \\
\text { Haunch } \\
\text { Vertical }\end{array}$ \\
\hline 568 & -0.035089 & 67.727 & 11.63 & 11.48 & 1.60 & 0.04 & 0.01 & 7.12 & 7.11 & 7.11 & 14.19 & 13.61 \\
\hline 565.8 & -0.07135 & 105.668 & 10.01 & 9.83 & 1.98 & 0.07 & 0.02 & 7.27 & 7.26 & 7.26 & 12.22 & 11.72 \\
\hline 563.21 & -0.096521 & 137.069 & 8.80 & 7.76 & 1.82 & 0.11 & 0.02 & 7.46 & 7.43 & 7.42 & 10.73 & 10.29 \\
\hline 559.7 & -0.124516 & 182.849 & 7.22 & 6.28 & 1.60 & 0.17 & 0.02 & 7.71 & 7.65 & 7.65 & 8.80 & 8.44 \\
\hline 550.7 & -0.180521 & 226.563 & 9.13 & 6.44 & 1.81 & 0.28 & 0.02 & 8.35 & 8.23 & 8.22 & 11.13 & 10.68 \\
\hline 545.2 & -0.210395 & 275.566 & 9.17 & 8.77 & 1.85 & 0.14 & 0.02 & 8.74 & 8.57 & 8.55 & 11.18 & 10.73 \\
\hline 527.68 & -0.298426 & 325.690 & 8.64 & 8.24 & 1.77 & 0.03 & 0.02 & 9.99 & 9.59 & 9.56 & 10.54 & 10.11 \\
\hline 518.2 & -0.34673 & 372.305 & 10.81 & 10.72 & 2.04 & 0.03 & 0.02 & 10.66 & 10.09 & 10.04 & 13.19 & 12.65 \\
\hline 494.5 & -0.482293 & 423.427 & 17.48 & 17.40 & 2.06 & 0.06 & 0.02 & 12.35 & 11.07 & 10.97 & 21.32 & 20.45 \\
\hline 476.2 & -0.606571 & 468.308 & 27.65 & 27.60 & 2.21 & 0.11 & 0.02 & 13.65 & 11.45 & 11,27 & 33.73 & 32.35 \\
\hline 447.4 & -0.656685 & 515.312 & 31.96 & 31.86 & 4.44 & 0.21 & 0.03 & 15.70 & 12.75 & 12.51 & 38.99 & 37.39 \\
\hline 407.1 & -0.710341 & 549.725 & 25.83 & 25.77 & 5.35 & 0.16 & 0.04 & 18.57 & 14.53 & 14.18 & 31.51 & 30.22 \\
\hline 382.1 & -1.570796 & 585.819 & 12.88 & 12.86 & 3.35 & 0.07 & 0.04 & 20.35 & 6.00 & 2.85 & 15.72 & 15.07 \\
\hline 335 & -1.570796 & 636.369 & 4.50 & 4.50 & 1.10 & 0.01 & 0.05 & 23.70 & 6.99 & 3.32 & 5.49 & 5.27 \\
\hline 281 & -1.570796 & 685.619 & 3.96 & 3.96 & 0.93 & 0.00 & 0.05 & 27.55 & 8.13 & 3.86 & 4.83 & 4.64 \\
\hline 236.5 & -1.570796 & 732.719 & 4.95 & 4.94 & 1.01 & 0.00 & 0.06 & 30.71 & 9.06 & 4.30 & 6.03 & 5.79 \\
\hline 186.8 & -1.570796 & 778.219 & 4.66 & 4.65 & 0.95 & 0.00 & 0.06 & 34.25 & 10.10 & 4.80 & 5.68 & 5.45 \\
\hline 145.5 & -1.570796 & 821.369 & 5.71 & 5.71 & 1.28 & 0.01 & 0.06 & 37.19 & 10.97 & 5.21 & 6.97 & 6.68 \\
\hline 70 & -1.570796 & 874.169 & 8.43 & 8.42 & 1.87 & 0.02 & 0.05 & 42,57 & 12.56 & 5.96 & 10.29 & 9.86 \\
\hline 24 & -1.570796 & 930.544 & 12.40 & 12.35 & 2.76 & 0.06 & 0.04 & 45.84 & 13.52 & 6.42 & 15.12 & 14.50 \\
\hline
\end{tabular}


RPP-RPT-32239, Rev. 1

M\&D-2008-005-CALC-001, Rev. 1

Table H.29. UBS-BEC Soil/Concrete Tank Contact Forces, Gravity Plus Seismic

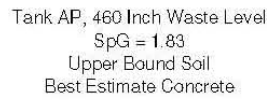

\begin{tabular}{|c|c|c|c|c|c|c|c|c|c|c|}
\hline & Angle (rad) & Path & $\begin{array}{l}\text { Max Pressure } \\
\text { Soil (UBS) AP } \\
\text { Seismic (PSI) }\end{array}$ & $\begin{array}{l}\text { Min Pressure } \\
\text { Soil (UBS) AP } \\
\text { Seismic (PSI) }\end{array}$ & $\begin{array}{l}\text { Max Meridional } \\
\text { Friction } \\
\text { Soil (UBS) AP } \\
\text { Seismic (PSI) }\end{array}$ & \begin{tabular}{|c|} 
Max Tangential \\
Friction \\
Soil (UBS) AP \\
Seismic (PSI) \\
\end{tabular} & $\begin{array}{l}\text { Max Contact } \\
\text { Displacement } \\
\text { Soil (UBS) AP } \\
\text { Seismic (inch) }\end{array}$ & \begin{tabular}{|l} 
Vertical \\
Pressure
\end{tabular} & \begin{tabular}{|l} 
Active \\
Pressure Phi $=$ \\
33 deg
\end{tabular} & $\begin{array}{l}\text { Active } \\
\text { Pressure Phi = } \\
49 \text { deg }\end{array}$ \\
\hline 568 & -0.035089 & 67.727 & 23.73 & 1.88 & 16.69 & 6.25 & 0.53 & 7.12 & 7.11 & 7.11 \\
\hline 565.8 & -0.07135 & 105.668 & 17.42 & 3.35 & 9.89 & 3.58 & 0.45 & 7.27 & 7.26 & 7.26 \\
\hline 563.21 & -0.096521 & 137.069 & 14.32 & 1.29 & 8.73 & 2.83 & 0.23 & 7.46 & 7.43 & 7.42 \\
\hline 5.997 & -0124.516 & 182.849 & 101,3 & 264 & $6,6 ?$ & 3.99 & 009 & 771 & 765 & 765 \\
\hline 550.7 & \begin{tabular}{|c|}
-0.180521 \\
\end{tabular} & 226.563 & 13.75 & 1.50 & 5.60 & 5.24 & 0.02 & 8.35 & 8.23 & 8.22 \\
\hline 545.2 & -0.210395 & 275.566 & 10.64 & 4.31 & 4.26 & 5.00 & 0.02 & 8.74 & 8.57 & 8.55 \\
\hline 527.68 & -0.298426 & 325.690 & 9.57 & 4.56 & 4.19 & 4.24 & 0.02 & 9.99 & 9.59 & 9.56 \\
\hline 518.2 & -0.34673 & 372.305 & 11.60 & 6.76 & 4.27 & 3.91 & 0.01 & 10.66 & 10.09 & 10.04 \\
\hline 494.5 & -0.482293 & 423.427 & 19.40 & 10.76 & 4.15 & 3.38 & 0.01 & 12.35 & 11.07 & 10.97 \\
\hline 476.2 & -0.606571 & 468.308 & 28.60 & 16.65 & 4.25 & 3.37 & 0.01 & 13.65 & 11.45 & 11.27 \\
\hline 447.4 & -0.656685 & 515.312 & 37.79 & 24.35 & 8.47 & 4.37 & 0.02 & 15.70 & 12.75 & 12.51 \\
\hline 407.1 & -0.710341 & 549.725 & 34.44 & 19.14 & 11.48 & 3.93 & 0.02 & 18.57 & 14.53 & 14.18 \\
\hline 382.1 & -1.570796 & 585.819 & 14.55 & 8.26 & 8.28 & 2.82 & 0.03 & 20.35 & 6.00 & 2.85 \\
\hline 335 & -1.570796 & 636.369 & 3.38 & 1.98 & 2.33 & 2.09 & 0.04 & 23.70 & 6.99 & 3.32 \\
\hline 281 & -1.570796 & 685.619 & 3.85 & 2.37 & 2.70 & 1.54 & 0.05 & 27.55 & 8.13 & 3.86 \\
\hline 236.5 & $\begin{array}{l}-1.570796 \\
\end{array}$ & 732.719 & 4.71 & 3.18 & 2.92 & 1.67 & 0.05 & 30.71 & 9.06 & 4.30 \\
\hline 186.8 & -1.570796 & 778.219 & 4.23 & 3.01 & 2.50 & 2.11 & 0.05 & 34.25 & 10.10 & 4.80 \\
\hline 145.5 & \begin{tabular}{|l|} 
\\
-1.570796 \\
\end{tabular} & 821.369 & 4.79 & 3.17 & 3.24 & 3.00 & 0.06 & 37.19 & 10.97 & 5.21 \\
\hline 70 & -1.570796 & 874.169 & 10.04 & 3.57 & 7.57 & 4.55 & 0.05 & 42.57 & 12.56 & 5.96 \\
\hline 24 & -1.570796 & 930.544 & 23.45 & 3.91 & 8.48 & 4.35 & 0.04 & 45.84 & 13.52 & 6.42 \\
\hline
\end{tabular}


RPP-RPT-32239, Rev. 1

M\&D-2008-005-CALC-001, Rev. 1

Table H.30. UBS-BEC Soil/Concrete Tank Contact Forces, Seismic Only

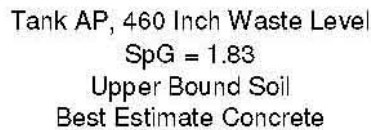

\begin{tabular}{|c|c|c|c|c|c|c|c|}
\hline & Angle (rad) & Path & $\begin{array}{c}\text { Max Pressure } \\
\text { Soil (UBS) AP } \\
\text { Seismic Only } \\
\text { (PSI) }\end{array}$ & $\begin{array}{c}\text { Min Pressure } \\
\text { Soil (UBS) AP } \\
\text { Seismic Only } \\
\text { (PSI) }\end{array}$ & $\begin{array}{c}\text { Max } \\
\text { Meridional } \\
\text { Friction } \\
\text { (UBS) AP } \\
\text { Seismic Only } \\
\text { (PSI) } \\
\end{array}$ & $\begin{array}{c}\text { Max } \\
\text { Tangential } \\
\text { Friction (UBS) } \\
\text { AP } \\
\text { Seismic Only } \\
\text { (PSI) } \\
\end{array}$ & $\begin{array}{l}\text { Max Contact } \\
\text { Displacment } \\
\text { (UBS) AP } \\
\text { Seismic Only } \\
\text { (inch) }\end{array}$ \\
\hline 568 & -0.035089 & 67.727 & 12.15 & -9.70 & 14.93 & 6.20 & 0.52 \\
\hline 565.8 & -0.07135 & 105.668 & 7.56 & -6.52 & 7.88 & 3.51 & 0.44 \\
\hline 563.21 & -0.096521 & 137.069 & 5.53 & -7.50 & 6.92 & 2.70 & 0.21 \\
\hline 559.7 & -0.124516 & 182.849 & 3.51 & -3.98 & 5.22 & 3.65 & 0.08 \\
\hline 550.7 & -0.180521 & 226.563 & 6.18 & -6.07 & 3.99 & 4.74 & 0.01 \\
\hline 545.2 & -0.210395 & 275.566 & 2.79 & -3.54 & 2.68 & 4.75 & 0.01 \\
\hline 527.68 & -0.298426 & 325.690 & 2.23 & -2.78 & 2.69 & 4.18 & 0.01 \\
\hline 518.2 & -0.34673 & 372.305 & 2.42 & -2.42 & 2.74 & 3.88 & 0.00 \\
\hline 494.5 & -0.482293 & 423.427 & 4.59 & -4.05 & 2.70 & 3.32 & 0.00 \\
\hline 476.2 & -0.606571 & 468.308 & 6.94 & -5.01 & 2.97 & 3.28 & 0.01 \\
\hline 447.4 & -0.656685 & 515.312 & 8.06 & -5.39 & 6.53 & 4.19 & 0.01 \\
\hline 407.1 & -0.710341 & 549.725 & 8.58 & -6.73 & 9.17 & 3.75 & 0.01 \\
\hline 382.1 & -1.570796 & 585.819 & 3.55 & -2.74 & 6.20 & 2.73 & 0.02 \\
\hline 335 & -1.570796 & 636.369 & 0.82 & -0.57 & 1.72 & 2.08 & 0.02 \\
\hline 281 & -1.570796 & 685.619 & 0.84 & -0.64 & 1.95 & 1.53 & 0.02 \\
\hline 236.5 & -1.570796 & 732.719 & 0.80 & -0.73 & 2.09 & 1.66 & 0.02 \\
\hline 186.8 & -1.570796 & 778.219 & 0.70 & -0.52 & 1.79 & 2.11 & 0.02 \\
\hline 145.5 & -1.570796 & 821.369 & 0.73 & -0.89 & 2.37 & 2.99 & 0.02 \\
\hline 70 & -1.570796 & 874.169 & 3.51 & -2.95 & 6.04 & 4.54 & 0.02 \\
\hline 24 & -1.570796 & 930.544 & 10.40 & -9.14 & 5.34 & 4.29 & 0.01 \\
\hline
\end{tabular}


RPP-RPT-32239, Rev. 1

M\&D-2008-005-CALC-001, Rev. 1

Table H.31. UBS-BEC Primary Tank/Concrete Dome Contact Data, Gravity Only

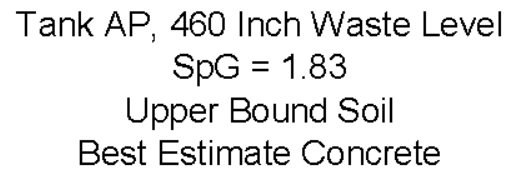

\begin{tabular}{|c|c|c|c|c|}
\hline & $\begin{array}{c}\text { Max Pressure } \\
\text { Primary } \\
\text { Tank/Concrete } \\
\text { Tank Dome AP } \\
\text { Gravity (PSI) }\end{array}$ & $\begin{array}{c}\text { Min Pressure } \\
\text { Primary } \\
\text { Tank/Concrete } \\
\text { Tank Dome AP } \\
\text { Gravity (PSI) }\end{array}$ & $\begin{array}{c}\text { Max Gap } \\
\text { Lateral } \\
\text { Displacement } \\
\text { Primary Tank } \\
\text { /Concrete } \\
\text { Tank Dome } \\
\text { Gravity (in) }\end{array}$ & $\begin{array}{c}\text { Max Gap Displacement } \\
\text { Primary Tank/Concete Tank } \\
\text { Dome AP } \\
\text { Gravity (Inches) }\end{array}$ \\
\hline Radius & 0.923 & 0.882 & 0.003043 & 0.000000 \\
\hline $\mathbf{6 7 . 7 2 7}$ & 0.801 & 0.782 & 0.004643 & 0.000000 \\
\hline $\mathbf{1 0 5 . 6 6 8}$ & 0.247 & 0.233 & 0.002581 & -0.000011 \\
\hline $\mathbf{1 3 7 . 0 6 9}$ & 0.473 & 0.466 & 0.003415 & -0.000007 \\
\hline $\mathbf{1 8 2 . 8 4 9}$ & 0.753 & 0.729 & 0.004411 & -0.000143 \\
\hline $\mathbf{2 2 6 . 5 6 3}$ & 0.211 & 0.201 & 0.010849 & 0.000000 \\
\hline $\mathbf{2 7 5 . 5 6 6}$ & 0.146 & 0.123 & 0.006404 & -0.000857 \\
\hline $\mathbf{3 2 5 . 6 9 0}$ & 0.000 & 0.000 & 0.000000 & -0.002717 \\
\hline $\mathbf{3 7 2 . 3 0 5}$ & 0.000 & 0.000 & 0.000000 & -1.062840 \\
\hline $\mathbf{4 2 3 . 4 2 7}$ & & & & \\
\hline
\end{tabular}


RPP-RPT-32239, Rev. 1

M\&D-2008-005-CALC-001, Rev. 1

Table H.32. UBS-BEC Primary Tank/Concrete Dome Contact Data, Gravity Plus Seismic

$$
\begin{gathered}
\text { Tank AP, } 460 \text { Inch Waste Level } \\
\text { SpG }=1.83 \\
\text { Upper Bound Soil } \\
\text { Best Estimate Concrete }
\end{gathered}
$$

\begin{tabular}{|c|c|c|c|c|}
\hline & $\begin{array}{c}\text { Max Pressure } \\
\text { Primary } \\
\text { Tank/Concrete } \\
\text { Tank Dome AP } \\
\text { Seismic (PSI) }\end{array}$ & $\begin{array}{c}\text { Min Pressure } \\
\text { Primary } \\
\text { Tank/Concrete } \\
\text { Tank Dome AP } \\
\text { Seismic (PSI) }\end{array}$ & $\begin{array}{c}\text { Max Gap } \\
\text { Lateral } \\
\text { Displacement } \\
\text { Primary Tank } \\
\text { /Concrete } \\
\text { Tank Dome } \\
\text { Seismic (in) }\end{array}$ & $\begin{array}{c}\text { Sax Gap Displacement } \\
\text { Primary Tank/Concete Tank } \\
\text { Dome AP } \\
\text { Seismic (Inches) }\end{array}$ \\
\hline Radius & 16.160 & 0.000 & 0.017004 & -0.000887 \\
\hline $\mathbf{6 7 . 7 2 7}$ & 5.399 & 0.000 & 0.018972 & -0.002879 \\
\hline $\mathbf{1 0 5 . 6 6 8}$ & 3.411 & 0.000 & 0.048360 & -0.002411 \\
\hline $\mathbf{1 3 7 . 0 6 9}$ & 5.190 & 0.000 & 0.037272 & -0.003506 \\
\hline $\mathbf{1 8 2 . 8 4 9}$ & 6.168 & 0.000 & 0.032880 & -0.002796 \\
\hline $\mathbf{2 2 6 . 5 6 3}$ & 7.368 & 0.000 & 0.032328 & -0.004583 \\
\hline $\mathbf{2 7 5 . 5 6 6}$ & 8.833 & 0.000 & 0.046980 & -0.005611 \\
\hline $\mathbf{3 2 5 . 6 9 0}$ & 8.757 & 0.000 & 0.035256 & -0.010124 \\
\hline $\mathbf{3 7 2 . 3 0 5}$ & 3.121 & 0.000 & 0.000000 & -1.073160 \\
\hline $\mathbf{4 2 3 . 4 2 7}$ & & & & \\
\hline
\end{tabular}


RPP-RPT-32239, Rev. 1

M\&D-2008-005-CALC-001, Rev. 1

Table H.33. UBS-BEC Primary Tank/Concrete Dome Contact Data, Seismic Only

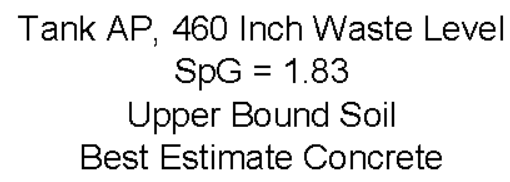

\begin{tabular}{|c|c|c|c|c|}
\hline & $\begin{array}{c}\text { Max Pressure } \\
\text { Primary } \\
\text { Tank/Concrete } \\
\text { Tank Dome AP } \\
\text { Seismic Only } \\
\text { (PSI) }\end{array}$ & $\begin{array}{c}\text { Min Pressure } \\
\text { Primary } \\
\text { Tank/Concrete } \\
\text { Tank Dome AP } \\
\text { Seismic Only } \\
\text { (PSI) }\end{array}$ & $\begin{array}{c}\text { Max Gap } \\
\text { Lateral } \\
\text { Displacement } \\
\text { Primary Tank } \\
\text { /Concrete } \\
\text { Tank Dome } \\
\text { Seismic Only } \\
\text { (in) }\end{array}$ & $\begin{array}{c}\text { Max Gap Displacement } \\
\text { Primary Tank/Concete Tank } \\
\text { Dome AP } \\
\text { Seismic Only (Inches) }\end{array}$ \\
\hline $\mathbf{6 7 . 7 2 7}$ & 15.237 & -0.882 & 0.013961 & -0.000887 \\
\hline $\mathbf{1 0 5 . 6 6 8}$ & 4.599 & -0.782 & 0.014329 & -0.002879 \\
\hline $\mathbf{1 3 7 . 0 6 9}$ & 3.165 & -0.233 & 0.045779 & -0.002400 \\
\hline $\mathbf{1 8 2 . 8 4 9}$ & 4.717 & -0.466 & 0.033857 & -0.003499 \\
\hline $\mathbf{2 2 6 . 5 6 3}$ & 5.415 & -0.729 & 0.028469 & -0.002653 \\
\hline $\mathbf{2 7 5 . 5 6 6}$ & 7.157 & -0.201 & 0.021479 & -0.004583 \\
\hline $\mathbf{3 2 5 . 6 9 0}$ & 8.688 & -0.123 & 0.040576 & -0.004754 \\
\hline $\mathbf{3 7 2 . 3 0 5}$ & 8.757 & 0.000 & 0.035256 & -0.007408 \\
\hline $\mathbf{4 2 3 . 4 2 7}$ & 3.121 & 0.000 & 0.000000 & -0.010320 \\
\hline
\end{tabular}


RPP-RPT-32239, Rev. 1

M\&D-2008-005-CALC-001, Rev. 1

Table H.34. UBS-BEC Primary Tank/Insulating Concrete Contact Forces, Gravity Only

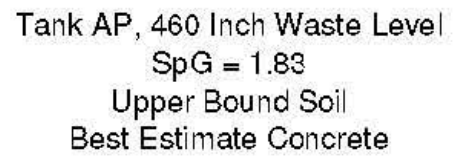

\begin{tabular}{|c|c|c|c|c|}
\hline & $\begin{array}{c}\text { Max Pressure } \\
\text { Primary } \\
\text { Tank/Insulating } \\
\text { Concrete AP } \\
\text { Gravity (PSI) }\end{array}$ & $\begin{array}{c}\text { Min Pressure } \\
\text { Primary } \\
\text { TankInsulating } \\
\text { Concrete AP } \\
\text { Gravity (PSI) }\end{array}$ & $\begin{array}{c}\text { Max Lateral } \\
\text { Displacement } \\
\text { Primary Tank/ } \\
\text { Insulating Concete AP AP } \\
\text { Gravity (Inches) }\end{array}$ & $\begin{array}{c}\text { Min Lateral } \\
\text { Displacement } \\
\text { Primary Tank / Insulating } \\
\text { Concete AP } \\
\text { Gravity (Inches) }\end{array}$ \\
\hline 4 (24.00 & 69.931 & 69.861 & 0.006617 & 0.006601 \\
\hline $\mathbf{3 8 4 . 0 0}$ & 13.882 & 13.868 & 0.000730 & 0.000654 \\
\hline $\mathbf{3 1 7 . 8 5}$ & 33.153 & 33.132 & 0.002825 & 0.002809 \\
\hline $\mathbf{2 4 8 . 1 0}$ & 29.764 & 29.743 & 0.002167 & 0.002156 \\
\hline $\mathbf{1 9 9 . 2 5}$ & 30.729 & 30.708 & 0.001478 & 0.001471 \\
\hline $\mathbf{1 5 4 . 9 5}$ & 30.486 & 30.465 & 0.000894 & 0.000888 \\
\hline $\mathbf{1 1 2 . 8 0}$ & 30.424 & 30.396 & 0.000110 & 0.000107 \\
\hline $\mathbf{6 5 . 8 5}$ & 31.056 & 31.014 & 0.000205 & 0.000198 \\
\hline
\end{tabular}


RPP-RPT-32239, Rev. 1

M\&D-2008-005-CALC-001, Rev. 1

Table H.35. UBS-BEC Primary Tank/Insulating Concrete Contact Data, Gravity Plus Seismic

Tank AP, 460 Inch Waste Level

$\mathrm{SpG}=1.83$

Upper Bound Soil

Best Estimate Concrete

\begin{tabular}{|c|c|c|c|c|}
\hline & $\begin{array}{c}\text { Max Pressure } \\
\text { Primary } \\
\text { Tank/nsulaiting } \\
\text { Concrete AP } \\
\text { Seismic (PSI) }\end{array}$ & $\begin{array}{c}\text { Min Pressure } \\
\text { Primary } \\
\text { Tank/Insulaiting } \\
\text { Concrete AP } \\
\text { Seismic (PSI) }\end{array}$ & $\begin{array}{c}\text { Max Lateral } \\
\text { Displacement } \\
\text { Primary } \\
\text { Tank/nsulaiting } \\
\text { Concrete AP } \\
\text { Seismic (Inches) }\end{array}$ & $\begin{array}{c}\text { Min Lateral } \\
\text { Displacement } \\
\text { Radius Tank/Insulaiting } \\
\text { Concrete AP } \\
\text { Seismic (Inches) }\end{array}$ \\
\hline 424.00 & 95.556 & 43.160 & 0.071064 & 0.002243 \\
\hline 384.00 & 27.160 & 6.400 & 0.369000 & 0.000574 \\
\hline $\mathbf{3 1 7 . 8 5}$ & 46.319 & 22.889 & 0.045408 & 0.000556 \\
\hline $\mathbf{2 4 8 . 1 0}$ & 40.931 & 20.604 & 0.024048 & 0.000414 \\
\hline $\mathbf{1 9 9 . 2 5}$ & 41.340 & 22.229 & 0.012828 & 0.000174 \\
\hline $\mathbf{1 5 4 . 9 5}$ & 38.618 & 23.271 & 0.007506 & 0.000200 \\
\hline $\mathbf{1 1 2 . 8 0}$ & 38.021 & 24.014 & 0.004883 & 0.000015 \\
\hline $\mathbf{6 5 . 8 5}$ & 38.486 & 24.563 & 0.003655 & 0.000092 \\
\hline
\end{tabular}


RPP-RPT-32239, Rev. 1

M\&D-2008-005-CALC-001, Rev. 1

Table H.36. UBS-BEC Primary Tank/Insulating Concrete Contact Forces, Seismic Only

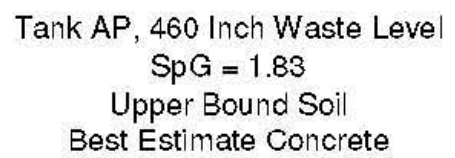

\begin{tabular}{|c|c|c|c|c|}
\hline Radius & $\begin{array}{c}\text { Max Pressure } \\
\text { Insulating } \\
\text { Concrete/Secon } \\
\text { dary Liner AP } \\
\text { Gravity (PSI) }\end{array}$ & $\begin{array}{c}\text { Min Pressure } \\
\text { Insulating } \\
\text { Concrete/Secon } \\
\text { dary Liner AP } \\
\text { Gravity (PSI) }\end{array}$ & $\begin{array}{c}\text { Max Lateral } \\
\text { Displacement } \\
\text { Insulating } \\
\text { Concrete/Secondary } \\
\text { Liner AP } \\
\text { Gravity (Inches) }\end{array}$ & $\begin{array}{c}\text { Min Lateral } \\
\text { Displacement } \\
\text { Insulating } \\
\text { Concrete/Secondary } \\
\text { Liner AP } \\
\text { Gravity (Inches) }\end{array}$ \\
\hline 424.00 & 76.458 & 76.250 & 0.002165 & 0.002129 \\
\hline 384.00 & 32.896 & 32.847 & 0.001609 & 0.001573 \\
\hline 317.85 & 28.125 & 28.097 & 0.001042 & 0.001010 \\
\hline 248.10 & 31.438 & 31.417 & 0.000724 & 0.000700 \\
\hline 199.25 & 30.917 & 30.889 & 0.000378 & 0.000363 \\
\hline 154.95 & 30.667 & 30.639 & 0.000262 & 0.000253 \\
\hline 112.80 & 31.118 & 31.069 & 0.000212 & 0.000211 \\
\hline 65.85 & 30.771 & 30.639 & 0.000041 & 0.000040 \\
\hline
\end{tabular}


RPP-RPT-32239, Rev. 1

M\&D-2008-005-CALC-001, Rev. 1

Table H.37. UBS-BEC Insulating Concrete/Concrete Backed Steel Contact Data, Gravity Only

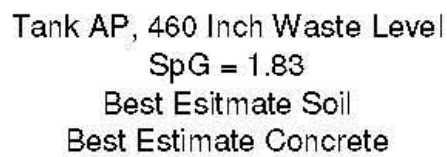

\begin{tabular}{|c|c|c|c|c|}
\hline Radius & $\begin{array}{c}\text { Max Pressure } \\
\text { Insulating } \\
\text { Concrete/Secon } \\
\text { dary Liner AP } \\
\text { Gravity (PSI) }\end{array}$ & \begin{tabular}{|c|} 
Min Pressure \\
Insulating \\
Concrete/Secon \\
dary Liner AP \\
Gravity (PSI) \\
\end{tabular} & $\begin{array}{c}\text { Max Lateral } \\
\text { Displacement } \\
\text { Insulating } \\
\text { Concrete/Secondary } \\
\text { Liner AP } \\
\text { Gravity (Inches) } \\
\end{array}$ & $\begin{array}{c}\text { Min Lateral } \\
\text { Displacement } \\
\text { Insulating } \\
\text { Concrete/Secondary } \\
\text { Liner AP } \\
\text { Gravity (Inches) } \\
\end{array}$ \\
\hline 424.00 & 86.458 & 86.250 & 0.003563 & 0.003527 \\
\hline 384.00 & 33.854 & 33.785 & 0.002846 & 0.002810 \\
\hline 317.85 & 27.736 & 27.701 & 0.002029 & 0.001997 \\
\hline 248.10 & 31.500 & 31.472 & 0.001470 & 0.001445 \\
\hline 199.25 & 30.931 & 30.896 & 0.000920 & 0.000905 \\
\hline 154.95 & 30.576 & 30.542 & 0.000659 & 0.000651 \\
\hline 112.80 & 31.215 & 31.146 & 0.000489 & 0.000487 \\
\hline 65.85 & 30.597 & 30.410 & 0.000165 & 0.000160 \\
\hline
\end{tabular}


RPP-RPT-32239, Rev. 1

M\&D-2008-005-CALC-001, Rev. 1

Table H.38. UBS-BEC Insulating Concrete/Concrete Backed Steel Contact Data, Gravity Plus Seismic

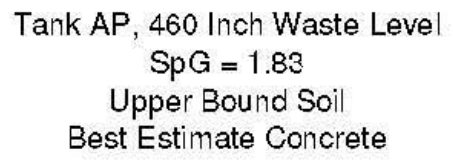

\begin{tabular}{|c|c|c|c|c|}
\hline & $\begin{array}{c}\text { Max Pressure } \\
\text { Insulating } \\
\text { Concrete/Secon } \\
\text { dary Liner AP } \\
\text { Seismic (PSI) }\end{array}$ & $\begin{array}{c}\text { Min Pressure } \\
\text { Insulating } \\
\text { Concrete/Secon } \\
\text { dary Liner AP } \\
\text { Seismic (PSI) }\end{array}$ & $\begin{array}{c}\text { Max Lateral } \\
\text { Displacement } \\
\text { Insulating } \\
\text { Concrete/Secondary } \\
\text { Liner AP } \\
\text { Seismic (Inches) }\end{array}$ & $\begin{array}{c}\text { Min Lateral } \\
\text { Displacement } \\
\text { Insulating } \\
\text { Concrete/Secondary } \\
\text { Liner AP } \\
\text { Seismic (Inches) }\end{array}$ \\
\hline 424.00 & 91.667 & 58.111 & 0.014472 & 0.000072 \\
\hline 384.00 & 45.764 & 22.153 & 0.013884 & 0.000181 \\
\hline 317.85 & 40.826 & 18.181 & 0.015360 & 0.000021 \\
\hline $\mathbf{2 4 8 . 1 0}$ & 42.938 & 22.174 & 0.015672 & 0.000029 \\
\hline 199.25 & 41.424 & 22.444 & 0.013560 & 0.000036 \\
\hline 154.95 & 38.924 & 23.410 & 0.010792 & 0.000017 \\
\hline 112.80 & 38.750 & 24.764 & 0.008864 & 0.000011 \\
\hline 65.85 & 38.194 & 24.222 & 0.007630 & 0.000014 \\
\hline
\end{tabular}


RPP-RPT-32239, Rev. 1

M\&D-2008-005-CALC-001, Rev. 1

Table H.39. UBS-BEC Insulating Concrete/Concrete Backed Steel Contact Data, Seismic Only

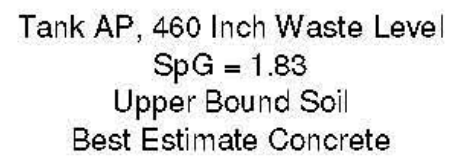

\begin{tabular}{|c|c|c|c|c|}
\hline & $\begin{array}{c}\text { Max Pressure } \\
\text { Insulating } \\
\text { Concrete/Secon } \\
\text { dary Liner AP } \\
\text { Seismic Only } \\
\text { (PSI) }\end{array}$ & $\begin{array}{c}\text { Min Pressure } \\
\text { Insulating } \\
\text { Concrete/Secon } \\
\text { dary Liner AP } \\
\text { Seismic Only } \\
\text { (PSI) }\end{array}$ & $\begin{array}{c}\text { Max Lateral } \\
\text { Displacement } \\
\text { Insulating } \\
\text { Concrete/Secondary } \\
\text { Liner AP }\end{array}$ & $\begin{array}{c}\text { Min Lateral } \\
\text { Displacement } \\
\text { Insulating } \\
\text { Concrete/Secondary } \\
\text { Liner AP }\end{array}$ \\
\hline 424.00 & 15.208 & -18.139 & 0.012 & -0.002 \\
\hline 384.00 & 12.868 & -10.694 & 0.012 & -0.001 \\
\hline 317.85 & 12.701 & -9.917 & 0.014 & -0.001 \\
\hline $\mathbf{2 4 8 . 1 0}$ & 11.500 & -9.243 & 0.015 & -0.001 \\
\hline $\mathbf{1 9 9 . 2 5}$ & 10.507 & -8.444 & 0.013 & 0.000 \\
\hline $\mathbf{1 5 4 . 9 5}$ & 8.257 & -7.229 & 0.011 & 0.000 \\
\hline $\mathbf{1 1 2 . 8 0}$ & 7.632 & -6.306 & 0.009 & 0.000 \\
\hline $\mathbf{6 5 . 8 5}$ & 7.424 & -6.417 & 0.008 & 0.000 \\
\hline
\end{tabular}


RPP-RPT-32239, Rev. 1

M\&D-2008-005-CALC-001, Rev. 1

Table H.40. UBS-BEC Waste Contact Pressure, Gravity Plus Seismic

Tank AY, 460 Inch Waste Level

$\mathrm{SpG}=1.83$

Upper Bound Soil

Best Estimate Concrete

\begin{tabular}{|c|c|c|c|c|c|c|c|}
\hline $\begin{array}{l}\text { Waste } \\
\text { Height } \\
\text { Ratio }\end{array}$ & Waste Height & $\begin{array}{l}\text { Max Pressure } \\
\text { AP Tank, } 460 \text { in } \\
\text { Waste Level, } \\
\text { SpG =1.83 } \\
\text { Time History } \\
\text { (PSI) }\end{array}$ & $\begin{array}{c}\text { Min Pressure } \\
\text { AP Tank, } 460 \text { in } \\
\text { Waste Level, } \\
\text { SpG }=1.83 \\
\text { Time History } \\
\text { (PSI) }\end{array}$ & $\begin{array}{l}\text { Hydrostatic } \\
\text { (psi) }\end{array}$ & $\begin{array}{l}\text { Hydrodynamic } \\
\text { (psi) }\end{array}$ & $\begin{array}{l}\text { Theoretical } \\
\text { Min (SRSS) }\end{array}$ & $\mid \begin{array}{l}\text { Theoretical } \\
\text { Max (SRSS) }\end{array}$ \\
\hline 0.99 & 454.35 & 10.694 & -9.875 & 0.37 & 1.84 & 0.00 & 2.22 \\
\hline 0.96 & 443.05 & 14.229 & -13.764 & 1.12 & 2.15 & 0.00 & 3.27 \\
\hline 0.94 & 431.7625 & 17.111 & -13.556 & 1.87 & 2.53 & 0.00 & 4.40 \\
\hline 0.90 & 414.125 & 16.431 & -10.236 & 3.03 & 3.19 & 0.00 & 6.22 \\
\hline 0.85 & 390.125 & 10.375 & -2.190 & 4.62 & 4.08 & 0.53 & 8.70 \\
\hline 0.80 & 366.125 & 14.229 & -0.505 & 6.20 & 4.93 & 1.27 & 11.14 \\
\hline 0.74 & 342 & 16.729 & 0.006 & 7.80 & 5.73 & 2.06 & 13.53 \\
\hline 0.69 & 318.325 & 18.889 & 0.908 & 9.36 & 6.46 & 2.90 & 15.82 \\
\hline 0.64 & 295.225 & 22.257 & 1.893 & 10.89 & 7.12 & 3.77 & 18.01 \\
\hline 0.59 & 272.125 & 22.833 & 2.556 & 12.41 & 7.73 & 4.69 & 20.14 \\
\hline 0.54 & 248.975 & 26.625 & 3.820 & 13.94 & 8.28 & 5.66 & 22.23 \\
\hline 0.49 & 225.825 & 28.882 & 4.864 & 15.47 & 8.79 & 6.68 & 24.27 \\
\hline 0.44 & 202.725 & 29.236 & 5.892 & 17.00 & 9.26 & 774 & 26.25 \\
\hline 0.39 & 179.625 & 31.549 & 7.188 & 18.53 & 9.67 & 8.86 & 28.19 \\
\hline 0.34 & 156.475 & 35.306 & 8.819 & 20.06 & 10.03 & 10.02 & 30.09 \\
\hline 0.29 & 134.075 & 36.264 & 10.250 & 21.54 & 10.34 & 11.20 & 31.87 \\
\hline 0.24 & 112.475 & 36.938 & 11.396 & 22.96 & 10.59 & 12.37 & 33.55 \\
\hline 0.20 & 90.875 & 39.639 & 12.507 & 24.39 & 10.80 & 13.59 & 35.19 \\
\hline 0.15 & 69.275 & 40.958 & 13.632 & 25.82 & 10.96 & 14.85 & 36.78 \\
\hline 0.10 & 47.738 & 42.993 & 15.139 & 27.24 & 11.08 & 16.16 & 38.32 \\
\hline 0.05 & 24.500 & 43.382 & 12.514 & 28.78 & 11.16 & 17.61 & 39.94 \\
\hline 0.02 & 7.755 & 47.694 & 23.021 & 29.88 & 11.19 & 18.69 & 41.07 \\
\hline 0.00 & 1.755 & 44.396 & 23.486 & 30.28 & 11.19 & 19.09 & 41.47 \\
\hline
\end{tabular}


RPP-RPT-32239, Rev. 1

M\&D-2008-005-CALC-001, Rev. 1

Table H.41. UBS-BEC Waste Contact Pressure, Theoretical Pressures

\begin{tabular}{|c|c|c|c|c|c|c|c|c|c|c|c|}
\hline \multirow{2}{*}{$\begin{array}{l}\text { Tank Fadius, } \mathrm{Hr} \\
\text { Waste Depth, HI }\end{array}$} & \multirow{2}{*}{\multicolumn{2}{|c|}{$\begin{array}{l}450 \mathrm{H} / \mathrm{Hr} \\
460 \mathrm{Conv} 1 \mathrm{st}\end{array}$}} & \multicolumn{2}{|l|}{1.022222222} & \multirow{2}{*}{$\begin{array}{l}\text { Waste Dens } \\
\text { Impul H }\end{array}$} & \multirow{2}{*}{\multicolumn{2}{|c|}{ Pressure $1.71 \mathrm{E}-04$}} & & & & \\
\hline & & & Conv 2nd & Conv 3rd & & & & & & & \\
\hline & & Conv ist & Conv 2nd & Conv3rd & & Conv ist & Conv 2nd & Conv 3rd & Impul $\mathrm{H}$ & Impul V & \\
\hline Centroid & Hydrodynamic & 1.841 & 5.331 & 8.536 & $\mathrm{Sa}=$ & 0.064 & 0.108 & 0.163 & 0.36 & 0.32 & \\
\hline Height & nu & $\operatorname{con} 0(n)$ & $\operatorname{con} 1(n)$ & $\operatorname{con} 2(n)$ & ci(n) & 24.7296 & 41.7312 & 62.9832 & 139.1 & 123.65 & SRSS \\
\hline 454.35 & 0.987717391 & 0.82 & 0.07 & 0.03 & 0.09 & 1.56 & 0.22 & 0.12 & 0.94 & 0.15 & 1.84 \\
\hline 443.05 & 0.963152174 & 0.78 & 0.06 & 0.02 & 0.14 & 1.49 & 0.19 & 0.10 & 1.46 & 0.45 & 2.15 \\
\hline 431.7625 & 0.93861413 & 0.75 & 0.05 & 0.02 & 0.18 & 1.43 & 0.17 & 0.08 & 1.94 & 0.75 & 2.53 \\
\hline 414.125 & 0.900271739 & 0.70 & 0.04 & 0.01 & 0.24 & 1.33 & 0.14 & 0.06 & 2.62 & 1.21 & 3.19 \\
\hline 390.125 & 0.848097826 & 0.64 & 0.03 & 0.01 & 0.32 & 1.22 & 0.10 & 0.04 & 3.43 & 1.84 & 4.08 \\
\hline 366.125 & 0.795923913 & 0.59 & 0.02 & 0.00 & 0.39 & 1.11 & 0.08 & 0.02 & 4.13 & 2.45 & 4.93 \\
\hline 342 & 0.743478261 & 0.54 & 0.02 & 0.00 & 0.44 & 1.02 & 0.06 & 0.01 & 4.75 & 3.05 & 5.73 \\
\hline 318.325 & 0.69201087 & 0.49 & 0.01 & 0.00 & 0.49 & 0.94 & 0.04 & 0.01 & 5.27 & 3.62 & 6.46 \\
\hline 295.225 & 0.641793478 & 0.45 & 0.01 & 0.00 & 0.53 & 0.86 & 0.03 & 0.01 & 5.72 & 4. 15 & 7.12 \\
\hline 272.125 & 0.591576087 & 0.42 & 0.01 & 0.00 & 0.57 & 0.80 & 0.03 & 0.00 & 6.11 & 4.66 & 7.73 \\
\hline 248.975 & 0.54125 & 0.39 & 0.01 & 0.00 & 0.60 & 0.74 & 0.02 & 0.00 & 6.46 & 5.13 & 8.28 \\
\hline 225.825 & 0.490923913 & 0.36 & 0.00 & 0.00 & 0.63 & 0.69 & 0.01 & 0.00 & 6.76 & 5.58 & 8.79 \\
\hline 202.725 & 0.440706522 & 0.34 & 0.00 & 0.00 & 0.66 & 0.65 & 0.01 & 0.00 & 7.03 & 5.99 & 9.26 \\
\hline 179.625 & 0.39048913 & 0.32 & 0.00 & 0.00 & 0.68 & 0.61 & 0.01 & 0.00 & 7.25 & 6.36 & 9.67 \\
\hline 156.475 & 0.340163043 & 0.30 & 0.00 & 0.00 & 0.70 & 0.57 & 0.01 & 0.00 & 7.45 & 6.70 & 10.03 \\
\hline 134.075 & 0.291467391 & 0.29 & 0.00 & 0.00 & 0.71 & 0.55 & 0.01 & 0.00 & 7.61 & 6.98 & 10.34 \\
\hline 112.475 & 0.24451087 & 0.28 & 0.00 & 0.00 & 0.72 & 0.53 & 0.00 & 0.00 & 7.74 & 7.21 & 10.59 \\
\hline 90.875 & 0. 197554348 & 0.27 & 0.00 & 0.00 & 0.73 & 0.51 & 0.00 & 0.00 & 7.84 & 7.41 & 10.80 \\
\hline 69.275 & 0.150597826 & 0.26 & 0.00 & 0.00 & 0.74 & 0.49 & 0.00 & 0.00 & 7.92 & 7.56 & 10.96 \\
\hline 47,7375 & 0.103777174 & 0.25 & 0.00 & 0.00 & 0.75 & 0.48 & 0.00 & 0.00 & 798 & 7.68 & 11.08 \\
\hline 24.5 & 0.05326087 & 0.25 & 0.00 & 0.00 & 0.75 & 0.48 & 0.00 & 0.00 & 8.02 & 7.75 & 11.16 \\
\hline 7.755 & 0.016858696 & 0.25 & 0.00 & 0.00 & 0.75 & 0.47 & 0.00 & 0.00 & 8.03 & 7.78 & 11.19 \\
\hline 1.755 & 0.003815217 & 0.25 & 0.00 & 0.00 & 0.75 & 0.47 & 0.00 & 0.00 & 8.03 & 7.78 & 11.18 \\
\hline
\end{tabular}


RPP-RPT-32239, Rev. 1

M\&D-2008-005-CALC-001, Rev. 1

Table H.42. UBS-BEC Waste Surface Displacement, Gravity Plus Seismic

Tank AP, 460 Inch Waste Level

$\mathrm{SpG}=1.83$

Upper Bound Soil

Best Estimate Concrete

\begin{tabular}{|r|c|c|}
\hline & $\begin{array}{c}\text { Max Vertical } \\
\text { Displacement } \\
\text { AP-460-UBS- } \\
\text { BEC } \\
\text { Time History } \\
\text { (in) }\end{array}$ & $\begin{array}{c}\text { Min Vertical } \\
\text { Displacement } \\
\text { AP-460-UBS- } \\
\text { BEC } \\
\text { Time History } \\
\text { (in) }\end{array}$ \\
\hline 95.7 & 8.49 & -13.15 \\
\hline 129.9 & 9.27 & -11.94 \\
\hline 180 & 9.83 & -13.40 \\
\hline 218.5 & 9.54 & -14.71 \\
\hline 277.7 & 10.19 & -14.76 \\
\hline 358 & 10.51 & -14.93 \\
\hline 410 & 9.13 & -13.92 \\
\hline 450 & 6.72 & -10.55 \\
\hline
\end{tabular}




\section{RPP-RPT-32239, Rev. 1 \\ M\&D-2008-005-CALC-001, Rev. 1}

\section{Near-Soil-1.txt}

et, 8, solid 45

/input, soil-prop-UB-geo, txt

$\mathrm{ksel}, \mathrm{u}, \mathrm{kp}, \mathrm{,}, \mathrm{k}, \mathrm{maxj} \mathrm{b}$

asel, $u$, area, , $1, \operatorname{amaxj} b$

lsel, u, line, , 1, lmaxjb

vsel, u, volu, , 1, vmaxw
! Use Element SOLID45 for Near Soil Elements

! Read Soil Properties

! Unselect existing Keypoints

! Unselect existing Area

! Unselect existing Lines

! Unselect existing Volumes

/COM - Create Keypoints to match concrete tank profile

${ }^{*} \mathrm{do}, \mathrm{i}, 1, \mathrm{bm}$ kp

$k, \operatorname{kmaxj} b+i, \operatorname{ctx}(i), 0, \operatorname{ctz}(i)$

*enddo

/COM - Create Keypoints above top of tank

$\mathrm{k}, \mathrm{kmaxj}_{\mathrm{b}}+\mathrm{bm} \mathrm{k}_{\mathrm{k}} \mathrm{p}+1,0,0,0$

! Keypoint at origin (surface)

$k, \operatorname{kmaxj} b+b^{-} k p+2,0,0, \operatorname{soilz}(2)$

! Keypoint at to divide soil above tank

*get, KMAXtemp1, KP, 0, num, max

! Get maximum keypoint number for counter

/COM - Create Keypoints at outside of excavated soil

$\star$ do, $i, 1, \operatorname{tanksoil}$

$k$, kmaxtemp $1+i, \operatorname{soilx}(i), 0, \operatorname{soil} z(i)$

tenddo

${ }^{*}$ get, KMAXtemp2, KP , 0, num, max

! Get maximum keypoint number for counter

/COM - Create additional keypoint in soil above tank

$k, \operatorname{kmaxtemp} 2+1, \operatorname{ctx}(2), 0, \operatorname{soilz}(1)$

k, kmaxtemp $2+2, \operatorname{ctx}(9), 0, \operatorname{soilz}(1)$

$\mathrm{k}, \operatorname{kmax}$ temp $2+3, \operatorname{ctx}(12), 0, \operatorname{soilz}(1)$

$k$, kmaxtemp $2+4, \operatorname{ctx}(2), 0, \operatorname{soilz}(2)$

$k$, kmaxtemp $2+5, \operatorname{ctx}(9), 0, \operatorname{soilz}(2)$

$\mathrm{k}, \operatorname{kmaxtemp} 2+6, \operatorname{ctx}(12), 0, \operatorname{soilz}(2)$

$\mathrm{k}$, kmaxtemp $2+7, \operatorname{ctx}(12), 0, \operatorname{soilz}(3)$

$\mathrm{k}, \operatorname{kmax} t e m p 2+8, \operatorname{ctx}\left(\mathrm{bm} \_\mathrm{kp}+1\right), 0, \operatorname{ctz}\left(\mathrm{bm} \_\mathrm{kp}+1\right)$

a, kmaxtemp $2+1$, kmaxtemp $2+2$, kmaxtemp $2+5$, kmaxtemp $2+4$

a, kmaxtemp $2+2$, kmaxtemp $2+3$, kmaxtemp $2+6$, kmaxtemp $2+5$

a, kmaxtemp $2+3$, kmaxtemp $1+1$, kmaxtemp $1+2$, kmaxtemp $2+6$

a, kmaxtemp 2+4, kmaxtemp2 +5, kmaxj $b+9, k \max j b+8, k \max j b+7, k \max j b+6, k \max j b+5, k \max j b+4, k \max j b+3, k \max j b+2$

!a, $740,741,712,711,710,709,708,707,706,705$

a, kmaxtemp 2+5, kmaxtemp $2+6, \operatorname{kmaxtemp} 2+7, \operatorname{kmaxj} b+12, \operatorname{kmaxj} b+11, k \max j \mathrm{~b}+10, k \operatorname{kax} j b+9$

a, kmaxtemp $2+6$, kmaxtemp $1+2$, kmaxtemp $1+3, \operatorname{kmaxtemp} 2+7$

a, kmaxtemp $2+7, \operatorname{kmaxtemp} 1+3, \operatorname{kmaxtemp} 1+4, k \operatorname{maxj} j \mathrm{~b}+12$

a, $\operatorname{kmaxj} \mathrm{b}+12, \operatorname{kmaxt} \operatorname{emp} 1+4, \operatorname{kmaxt} \operatorname{emp} 1+5, \operatorname{kmaxj} \mathrm{b}+14, \operatorname{kmax} j \mathrm{~b}+13$

a, kmaxj b+14, kmaxt emp 1+5, kmaxt emp $1+6, \operatorname{kmaxj} b+16, \operatorname{kmax} j b+15$

$a, k \operatorname{maxj} b+16, \operatorname{kmaxt} \operatorname{emp} 1+6, \operatorname{kmaxt} \operatorname{emp} 1+7, \operatorname{kmaxj} \mathrm{b}+18, \operatorname{kmax} j \mathrm{~b}+17$

a, $k \operatorname{maxj} \mathrm{b}+18, k \operatorname{kax} t e m p 1+7, \operatorname{kmax} t \operatorname{emp} 1+8, k \operatorname{maxj} \mathrm{b}+20, k \max j \mathrm{~b}+19$

$a, k \max j b+20, k \operatorname{kax} t \operatorname{emp} 1+8, \operatorname{kmax} t \operatorname{emp} 1+9, \operatorname{kmaxt} \operatorname{emp} 2+8, \operatorname{kmaxj} b+22, \operatorname{kmaxj} b+21$

cm, top-soil-area, area

lsla

$\mathrm{cm}$, top-soil, line

type, 1

real, 1

/COM - Define line divisions to control meshing

lsel, s, loc, z, soilz(1), soilz(2)

lsel, $r, 1 \circ c, x, \operatorname{ctx}(3), \operatorname{ctx}(8)$

lesize, all, , 14

lsel, s, loc, z, soilz $(1), \operatorname{soilz}(2)$

lsel, r, loc, $\mathrm{x}, \operatorname{ctx}(10), \operatorname{ctx}(11)$

lesize, all, , 3

cmsel, s, top-soil

lsel, $r, 100, x, \operatorname{ctx}(2)$

lesize, all, , 2

cmsel, s, top-soil

lsel, s, loc, $x, \operatorname{ctx}(9)$

lesize, all, , 2

! soil above tank top, match tank meshing

! soil above tank top, match tank meshing

! Reselect lines in near soil

! Control vertical element size, above tank

! Control vertical element size, above tank 


\section{RPP-RPT-32239, Rev. 1 M\&D-2008-005-CALC-001, Rev. 1}

cmsel, s, top-soil

lsel, r, loc, $x, \operatorname{ctx}(12)$

lesize, all,, 2

cmsel, s, top-soil

lsel, r, loc, z, ctz(2), ctz(12)

lsel, r, loc, $x, \operatorname{ctx}(2), \operatorname{ctx}(12)$

lesize, all, , 1

lsel,, , line, $, 1 \max j b+8, l \max j b+10,2$

lsel, $a, l i n e,, l \max j b+26, l \operatorname{maxj} b+28,2$

lsel, a, line, , 1 maxj $b+30, l \operatorname{maxj} b+38,4$

lesize, all, , 9

lsel, s, line, , $l$ maxj $b+42, l \operatorname{maxj} b+42,4$

lesize, all, , 7

lsel, s, line, , lmaxjb+9

lsel, $a, l i n e,, l \max j b+25, l \max j b+27,2$

lsel, a, line, , lmaxjb+29, lmaxj b+45, 4

lesize, all, , 1

lsel, s, line, $1 \operatorname{maxj} b+6$

lsel, a, line, , $l \max j b+20, l \max j b+21$

lsel, a, line, , $l \max j b+32, l \operatorname{maxj} b+44,4$

lsel, a, line, $, 1 \max j b+31, l \operatorname{maxj} b+43,4$

lsel, a, line, , $l \operatorname{maxj} b+47, l \operatorname{maxj} b+49$

lesize, all, , 1

lsel, s, line, , lmaxjb+46

lesize, all, , 4

! Control meshing to match tank

cmsel, s, top-soil-area

! Control mesh size at bottom of excavated soil

amesh, all

! Mesh area to develop pattern for volume meshing

type, 8

ksel, a, kp, 1

! Control vertical element size, above tank

! Control vertical element size, outside excavation mesh

! Control horizontal meshing in soil

! Control horizontal meshing in soil

ksel, a, kp, , ct_kps

vrotat, all, , , , 1, ct_kps, 180,2

lsla

lsel, $r, 100, x, \operatorname{ctx}(2)$

lesize, all, , arcsize

lsla

lsel, r, loc, $x, \operatorname{ctx}(9)$

lesize, all, arcsize

lsla

lsel, r, loc, $x, \operatorname{ctx}(12)$

lesize, all, , arcsize

vsweep, all

aclear, all

cm, top-soil-vol, volu

! Select Keypoint for rotation axis

! Select Keypoint for rotation axis

! Generate Volumes for excavated soil

! Define meshing for slices

! Define meshing for slices

! Define meshing for slices

! Sweep pattern into volume

! Delete elements used for sweep

*get, vMAXtemp, vOLU, o, num, max

/COM - Generate element above top center of tank

asel, u, area, , all

vsel, u, volu, , all

$a, k m a x j b+b m k p+1, k m a x t e m p 2+1, k \max t e m p 2+4, k \operatorname{maxj} b+b m k p+2$

a, kmaxjb+bm_kp+2, kmaxtemp $2+4, k \operatorname{maxj} b+2, k \operatorname{maxj} b+1$

vrotat, all,,,, 1, , ct kps, 180,2

vsel, s, volu, , vmaxtemp +1 , vmaxtemp $+3,2$

vatt, 801,8

vsel, s, volu, , vmaxtemp $+2, \operatorname{vmaxt} e m p+4,2$

vatt, 802,8

! Assign material properties

vsel, s, volu, , vmaxtemp+1, vmaxtemp +4

allsel

asel, s, loc, $z, \operatorname{ctz}(1), \operatorname{ctz}(2)$

type, 1

asel, $r, 100, x, 0,4$

asel, r, loc, $z, \operatorname{ctz}(1), \operatorname{ctz}(2)$

cmsel, u, conc-tank-a

${ }^{*}$ get, atemp, area, , num, max

${ }^{\star}$ get, atemp1, area, num, min

asel, a, area, $, 1,22,21$

mshcopy, 2, 1, at emp 1

mshcopy, 2, 22, atemp

asel, u, area, $1,22,21$

! Assign material properties

! copy mesh top match top of concrete tank

! copy mesh top match top of concrete tank 
RPP-RPT-32239, Rev. 1

M\&D-2008-005-CALC-001, Rev. 1

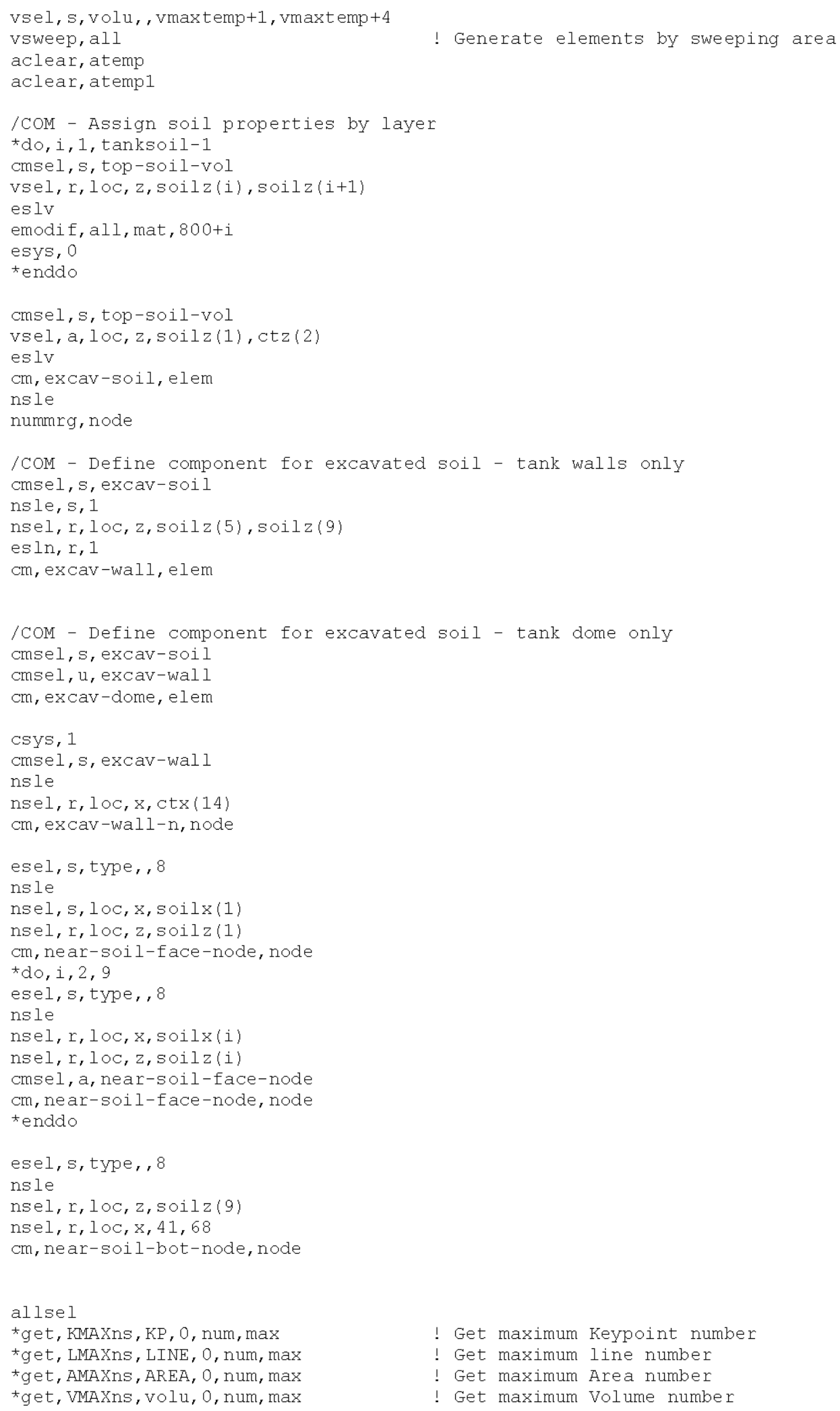


RPP-RPT-32239, Rev. 1

M\&D-2008-005-CALC-001, Rev. 1

\section{Run-Tank.txt}

! batch

! PNNL DST Seismic Analysis, Gravity Inputs, Upper Bound Soil, Best Est Concrete Properties, AP Primary Tank Geometry, Dome Friction=0.0

!

fini

/clear

/filname, AP-460-UBS-BEC-SeismiC, 1

/config, nres, 3000

/config, nproc, 2

! Increase allowable number of results to 3000

/config, fsplit, 1024

! Activate 2 processers for solution

$/ \mathrm{prep} 7$

$g=32 \cdot 2$

! Split binary file at $4.2 \mathrm{~GB}$

$\mathrm{DF}=40$

! Gravity (ft/sec)

$\mathrm{ALPHA}=0.4$

! Factor for beta (stiffness) damping

! Alpha damping

lout, tank-out, out

/sys, "X: \07.00 - Quality Assurance $\backslash$ ANSYS QA \usrcfg. bat" > QA. out

/out, QA, out, append

/input, tank-coordinates-AP, txt

/ input, tank-props-bec-250, txt

Concrete Properties)

/input, tank-meshl, txt

/input, primary-props-AP, txt

/input, primary, txt

/input, insulate, txt

/input, liner, txt

/input, waste-solid-AP-s, txt

/input, bolts-friction, txt

/input, near-soil-1, txt

/input, far-soil, txt

/input, interfacel, txt

/input, interface-gap 1, txt

/input, slave, txt

/input, boundary, txt

/input, outer-spar, txt

/input, live_load, txt

/input, fix-soil, txt

/out

ALLSEL

lout, Tank-th, out

save

/ input, solve-TH-UBS, txt

! Run file defining tank coordinates (concrete and primary)

! Run file defining fully cracked concrete properties (PNNL

! Develop concrete tank

! Run file defining AP Primary tank properties

! Develop Primary tank

! Develop insulating concrete model

! Develop Liner model

! Develop waste model

! Develop J-Bolt model

! Develop excavated soil model

! Develop Far-Field soil model

! Develop soil and Concrete Interfaces

! Develop Primary Tank Interfaces

! Develop slaved boundary conditions

! Place base and symmetry boundary conditions

! Connect soil model to symmetry plane

! Apply live load over a loft radius over dome center

/input, post-tank, txt

lout

lexit

\section{Soil-Prop-UB-Geo.txt}

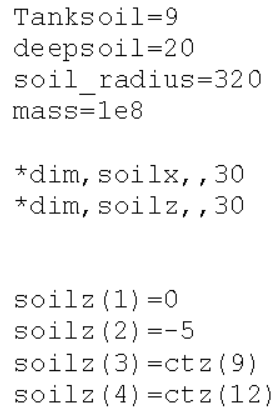


RPP-RPT-32239, Rev. 1

M\&D-2008-005-CALC-001, Rev. 1

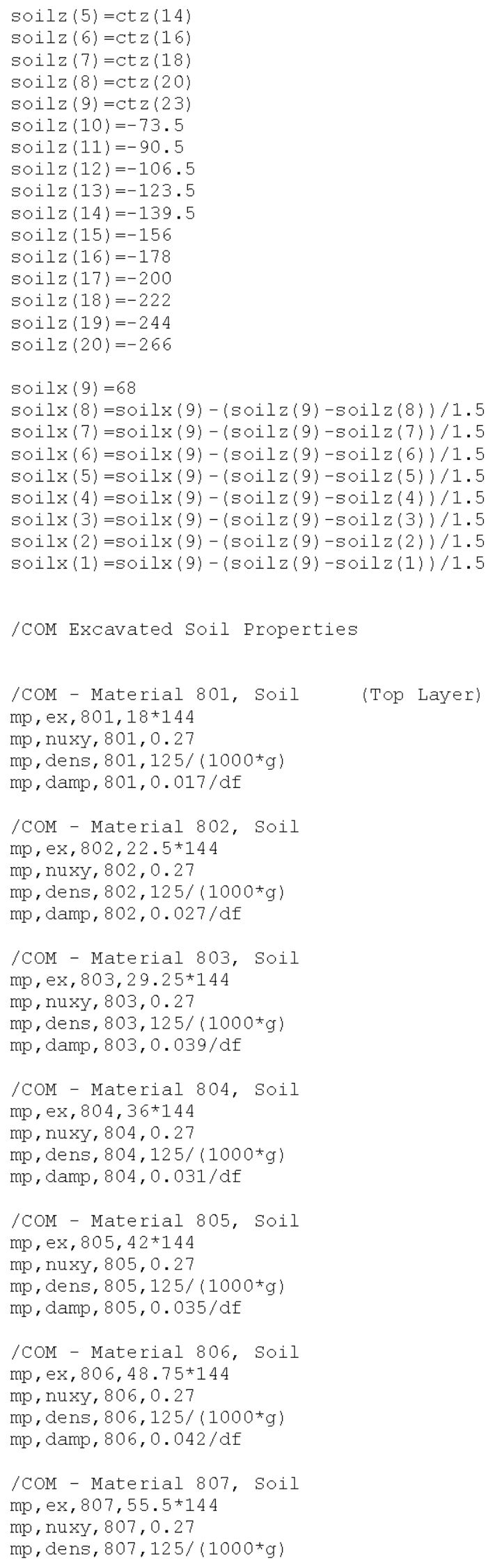


RPP-RPT-32239, Rev. 1

M\&D-2008-005-CALC-001, Rev. 1

mp , damp, 807, 0.047/df

/COM - Material 808, Soil

$\mathrm{mp}, \mathrm{ex}, 808,60 * 144$

mp, nuxy, $808,0.27$

mp, dens, $808,125 /(1000 * g)$

mp, damp, 808,0.037/df

/COM - Material 810, Soil

mp, ex, 810,250

mp, nuxy, 810, 0.27

$\mathrm{mp}$, dens, $810,125 /\left(1000^{*} \mathrm{~g}\right)$

$\mathrm{mp}$, damp, 810, 0.037/df

/COM - Material 811, Soil

$\mathrm{mp}, \mathrm{ex}, 811,15131$

mp, nuxy, $811,0.27$

$\mathrm{mp}$, dens, $811,125 /\left(1000^{*} \mathrm{~g}\right)$

mp , damp, 811, 0.017/df

/COM - Material 812, Soil

mp, ex, 812, 14108

mp, nuxy, $812,0.27$

$\mathrm{mp}$, dens, $812,125 /(1000 * \mathrm{~g})$

mp, damp, 812,0.027/df

/COM - Material 813, Soil

$\mathrm{mp}, \mathrm{ex}, 813,12816$

mp, nuxy, $813,0.27$

$\mathrm{mp}$, dens, 813,125/(1000*g)

$\mathrm{mp}$, damp, $813,0.039 / \mathrm{df}$

/COM - Material 814, Soil

$\mathrm{mp}, \mathrm{ex}, 814,13186$

mp, nuxy, 814, 0.27

$\mathrm{mp}$, dens, 814,125/(1000*g)

mp, damp, 814, 0.031/df

/COM - Material 815, Soil

mp, ex, 815, 12714

mp, nuxy, 815, 0.27

$\mathrm{mp}$, dens, 815, 125/(1000*g)

mp , damp, $815,0.035 / d f$

/COM - Material 816, Soil

$\mathrm{mp}, \mathrm{ex}, 816,12059$

mp, nuxy, $816,0.27$

$\mathrm{mp}$, dens, $816,125 /\left(1000^{*} \mathrm{~g}\right)$

mp , damp, 816, 0.042/df

/COM - Material 817, Soil

$\mathrm{mp}, \mathrm{ex}, 817,11562$

mp, nuxy, 817, 0.27

$\mathrm{mp}$, dens, $817,125 /\left(1000^{*} \mathrm{~g}\right)$

mp, damp, 817, 0.047/df

/COM - Material 818, Soil

mp, ex, 818,12357

mp, nuxy, $818,0.27$

$\mathrm{mp}$, dens, $818,125 /\left(1000^{*} \mathrm{~g}\right)$

$\mathrm{mp}$, damp, $818,0.037 / \mathrm{df}$

/COM - Upper Bound Soil Properties Geomatrix Soil Data

/COM - 19 Layer Mode

/COM - Material Definitions

/COM - Material 901, Soil (Top Layer)

mp , ex, 901,24801

mp, nuxy, $901,0.24$

$\mathrm{mp}$, dens, $901,110 /\left(1000^{\star} \mathrm{g}\right)$ 
RPP-RPT-32239, Rev. 1

M\&D-2008-005-CALC-001, Rev. 1

mp , damp, 901,0.016/df

/COM - Material 902, Soil mp , ex, 902,23826

mp, nuxy, $902,0.24$

mp, dens, $902,110 /(1000 * g)$

mp, damp, $902,0.022 / d f$

/COM - Material 903, Soil

mp , ex, 903,22996

mp, nuxy, 903,0.24

$\mathrm{mp}$, dens, 903,110/(1000*g)

mp, damp, 903, 0.027/df

/COM - Material 904, Soil

$\mathrm{mp}, \mathrm{ex}, 904,23271$

mp, nuxy, 904, 0.24

$\mathrm{mp}$, dens, $904,110 /\left(1000^{*} \mathrm{~g}\right)$

mp , damp, 904, 0.022/df

/COM - Material 905, Soil mp, ex, 905, 21584

mp, nuxy, 905, 0.19

$\mathrm{mp}$, dens, $905,110 /\left(1000^{*} \mathrm{~g}\right)$

mp, damp, 905, 0.026/df

/COM - Material 906, Soil $\mathrm{mp}, \mathrm{ex}, 906,24488$

mp, nuxy, 906, 0.19

$\mathrm{mp}$, dens, 906,110/(1000*g)

mp, damp, 906, 0.027/df

/COM - Material 907, Soil mp, ex, 907, 27725

mp, nuxy, 907, 0.19

mp, dens, 907, 110/(1000*g)

mp, damp, 907,0.028/df

/COM - Material 908, Soil

$\mathrm{mp}, \mathrm{ex}, 908,32629$

mp, nuxy, 908, 0.19

mp, dens, $908,110 /\left(1000^{*} \mathrm{~g}\right)$

mp , damp, 908, 0.022/df

/COM - Material 909, Soil mp, ex, 909,36376

mp, nuxy, 909, 0.19

$\mathrm{mp}$, dens, $909,110 /\left(1000^{*} \mathrm{~g}\right)$

mp, damp, 909, 0.022/df

/COM - Material 910, Soil

$\mathrm{mp}, \mathrm{ex}, 910,35784$

mp, nuxy, 910, 0.19

$\mathrm{mp}$, dens, 910, 110/(1000*g)

mp, damp, 910, 0.024/df

/COM - Material 911, Soil

$\mathrm{mp}, \mathrm{ex}, 911,35374$

mp, nuxy, $911,0.19$

mp, dens, 911, 110/(1000*g)

mp , damp, 911, 0.025/df

/COM - Material 912, Soil mp , ex, 912,35096

mp, nuxy, 912, 0.19

$\mathrm{mp}$, dens, $912,110 /\left(1000^{*} \mathrm{~g}\right)$

mp, damp, 912, 0.026/df

/COM - Material 913, Soil

$\mathrm{mp}, \mathrm{ex}, 913,40418$

mp, nuxy, 913,0.19 
RPP-RPT-32239, Rev. 1

M\&D-2008-005-CALC-001, Rev. 1

$\mathrm{mp}$, dens, $913,110 /\left(1000^{*} \mathrm{~g}\right)$

mp , damp, 913,0.020/df

/COM - Material 914, Soil

$\mathrm{mp}, \mathrm{ex}, 914,40076$

mp, nuxy, 914, 0.19

$\mathrm{mp}$, dens, $914,110 /\left(1000^{\star} \mathrm{g}\right)$

mp, damp, 914, 0.021/df

/COM - Material 915, Soil

mp, ex, 915,55863

mp, nuxy, $915,0.28$

mp, dens, $915,120 /(1000 * g)$

mp, damp, 915, 0.019/df

/COM - Material 916, Soil

mp, ex, 916,61211

mp, nuxy, $916,0.28$

mp, dens, $916,120 /\left(1000^{*} \mathrm{~g}\right)$

mp , damp, 916, 0.019/df

/COM - Material 917, Soil

$\mathrm{mp}, \mathrm{ex}, 917,60604$

mp, nuxy, $917,0.28$

$\mathrm{mp}$, dens, $917,120 /\left(1000^{*} \mathrm{~g}\right)$

mp, damp, $917,0.020 / \mathrm{df}$

/COM - Material 918, Soil

$\mathrm{mp}, \mathrm{ex}, 918,60224$

$\mathrm{mp}, \mathrm{nuxy}, 918,0.28$

$\mathrm{mp}$, dens, $918,120 /\left(1000^{*} \mathrm{~g}\right)$

mp , damp, $918,0.020 / d f$

/COM - Material 919, Soil

mp, ex, 919,66350

mp, nuxy, $919,0.28$

$\mathrm{mp}$, dens, $919,120 /\left(1000^{*} \mathrm{~g}\right)$

mp, damp, 919, 0.019/df

\section{Solve-Gravity-UBS.txt}

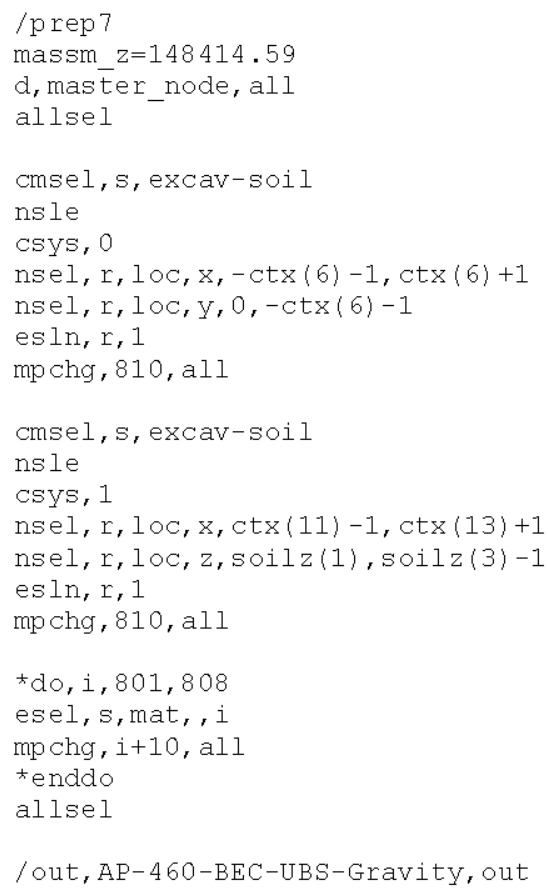




\section{RPP-RPT-32239, Rev. 1 \\ M\&D-2008-005-CALC-001, Rev. 1}

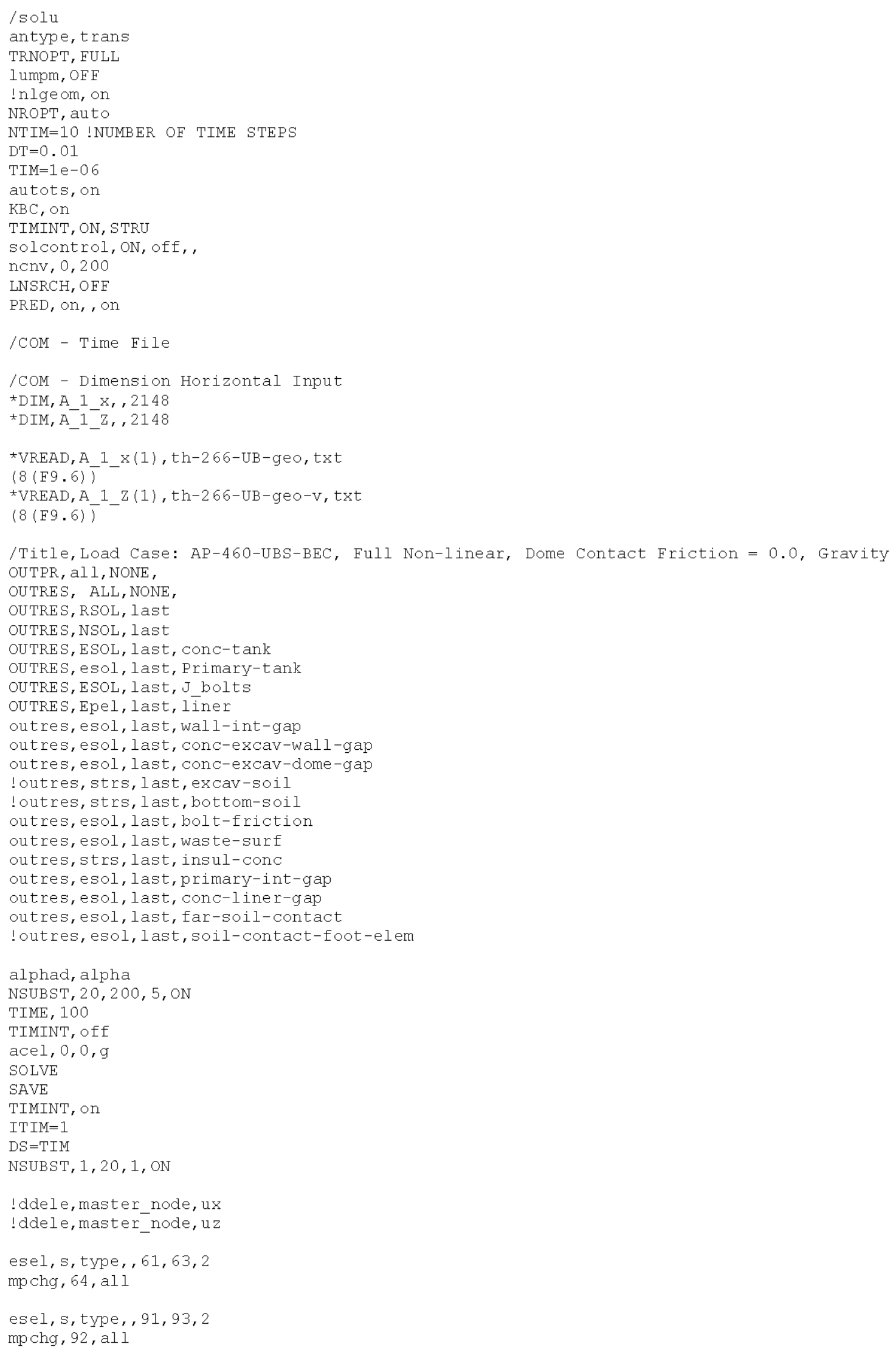


RPP-RPT-32239, Rev. 1

M\&D-2008-005-CALC-001, Rev. 1

allsel

${ }^{\star} \mathrm{DO}, \mathrm{ITIM}, 1, \mathrm{NTIM}, 1$

$\mathrm{TIM}=\mathrm{DT} \mathrm{T}^{\star} \mathrm{ITIM}$

TIME, TIM+100

! F, master_node, FX, A_1_X (itim) *mass* $\mathrm{*}$

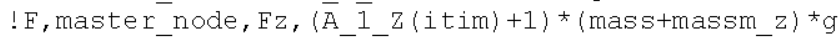

SOLVE

SAVE

*ENDDO

FINISH

lout

\section{Solve-TH-UBS}

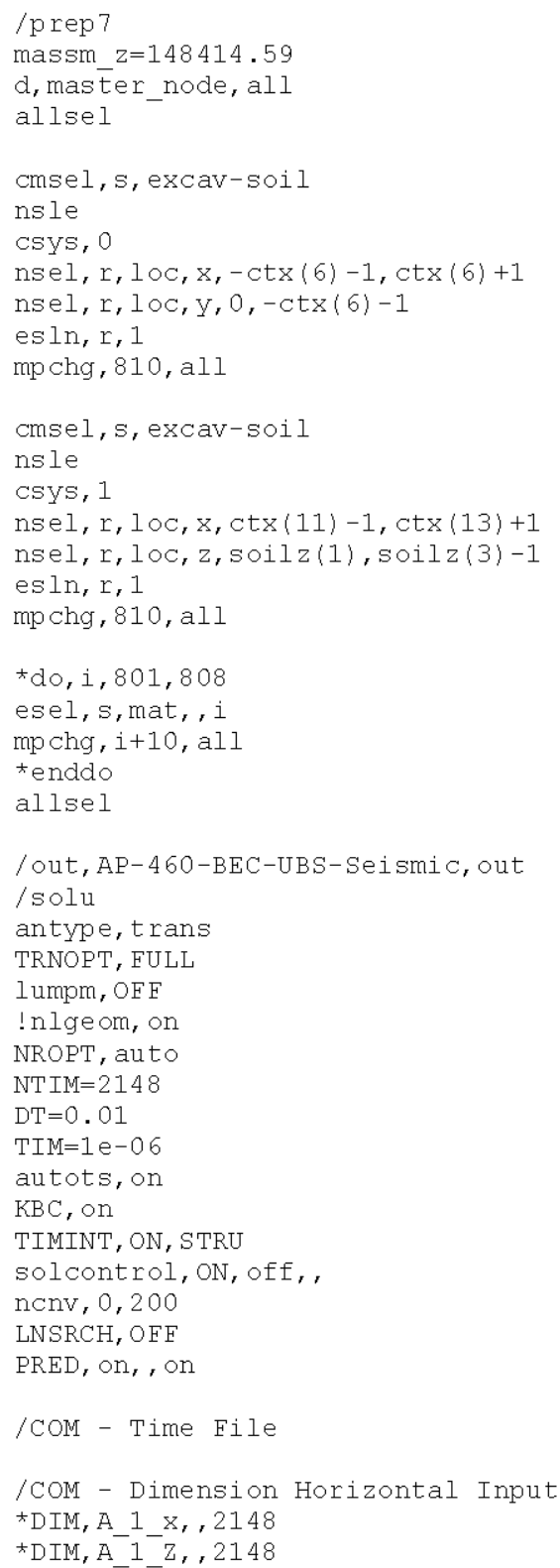


RPP-RPT-32239, Rev. 1

M\&D-2008-005-CALC-001, Rev. 1

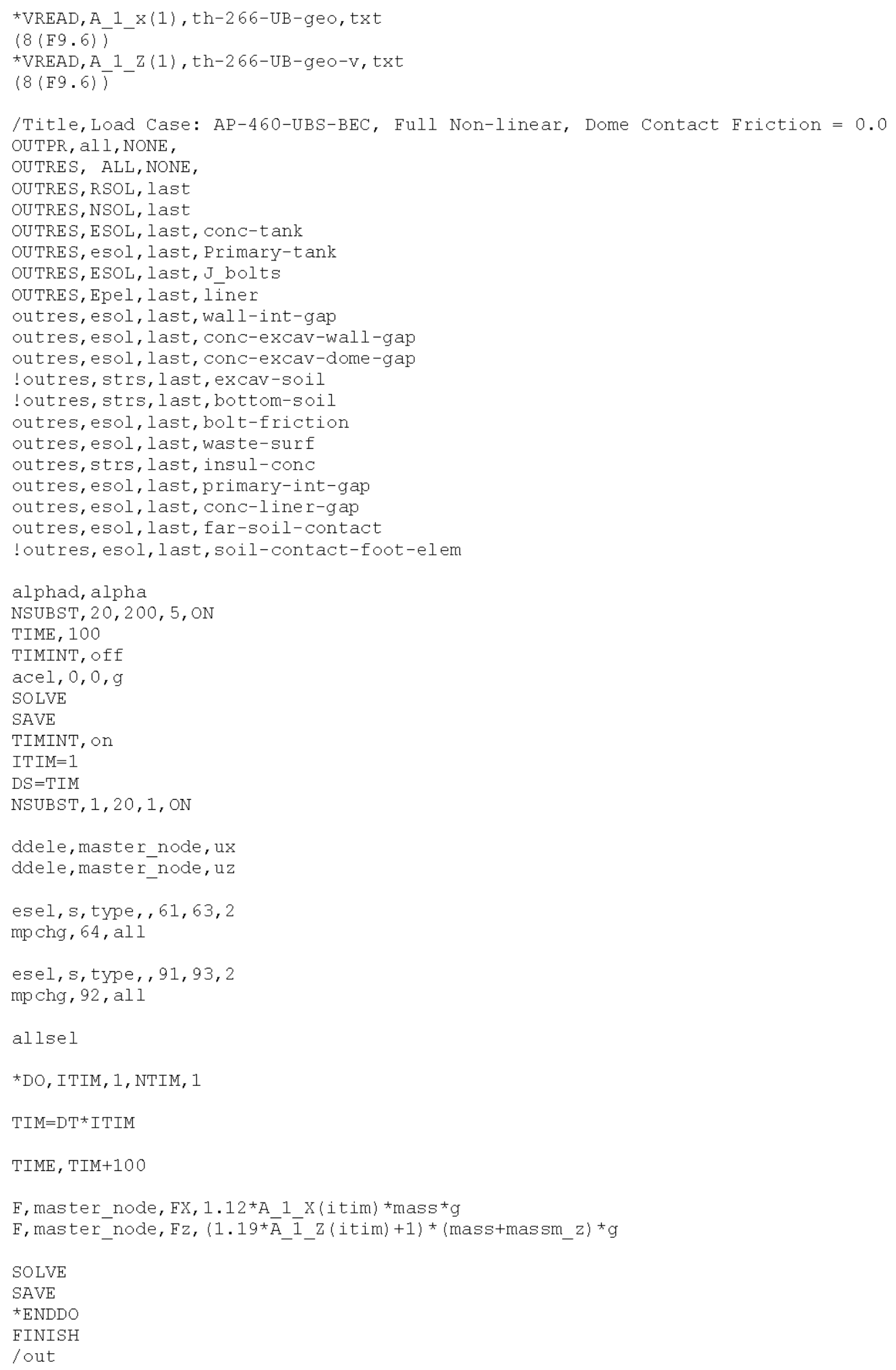


RPP-RPT-32239, Rev. 1

M\&D-2008-005-CALC-001, Rev. 1

\section{Tank-Props-BEC-250}

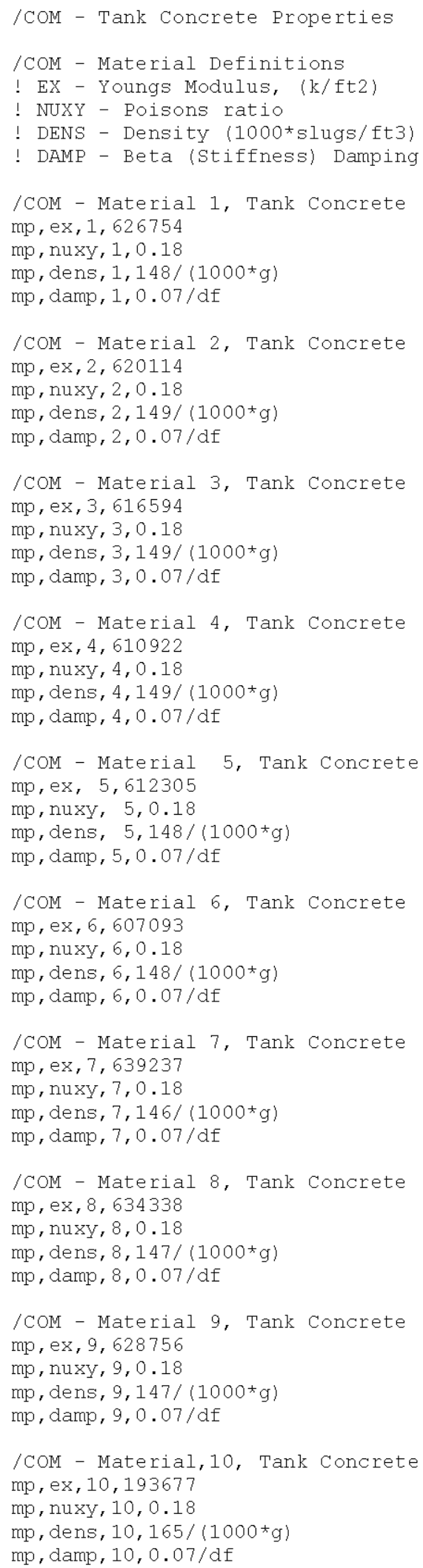


RPP-RPT-32239, Rev. 1

M\&D-2008-005-CALC-001, Rev. 1

/COM - Material,11, Tank Concrete $\mathrm{mp}, \mathrm{ex}, 11,575959$

mp, nuxy, $11,0.18$

$\mathrm{mp}$, dens, $11,144 /(1000 * \mathrm{~g})$

$\mathrm{mp}$, damp, $11,0.07 / \mathrm{df}$

/COM - Material,12, Tank Concrete mp , ex, 12,202953

mp, nuxy, $12,0.18$

$\mathrm{mp}$, dens, $12,159 /\left(1000^{*} \mathrm{~g}\right)$

mp, damp, 12, 0.07/df

/COM - Material,13, Tank Concrete $\mathrm{mp}, \mathrm{ex}, 13,157426$

$\mathrm{mp}$, nuxy, $13,0.18$

$\mathrm{mp}$, dens, $13,176 /\left(1000^{\star} \mathrm{g}\right)$

$\mathrm{mp}$, damp, 13,0.07/df

/COM - Material,14, Tank Concrete $\mathrm{mp}, \mathrm{ex}, 14,153784$

mp, nuxy, 14, 0.18

$\mathrm{mp}$, dens, $14,193 /\left(1000^{*} \mathrm{~g}\right)$

$\mathrm{mp}$, damp, 14,0.07/df

/COM - Material,15, Tank Concrete $\mathrm{mp}, \mathrm{ex}, 15,136651$

$\mathrm{mp}$, nuxy, $15,0.18$

$\mathrm{mp}$, dens, $15,200 /\left(1000^{*} \mathrm{~g}\right)$

$\mathrm{mp}$, damp, 15, 0.07/df

/COM - Material,16, Tank Concrete mp, ex, 16, 136651

$\mathrm{mp}$, nuxy, $16,0.18$

$\mathrm{mp}$, dens, $16,200 /\left(1000^{\star} \mathrm{g}\right)$

mp , damp, 16, 0.07/df

/COM - Material,17, Tank Concrete mp, ex, 17, 138084

mp, nuxy, $17,0.18$

mp, dens, $17,181 /\left(1000^{\star} \mathrm{g}\right)$

$\mathrm{mp}$, damp, $17,0.07 / \mathrm{df}$

/COM - Material,18, Tank Concrete $\mathrm{mp}, \mathrm{ex}, 18,123378$

mp, nuxy, $18,0.18$

$\mathrm{mp}$, dens, $18,209 /\left(1000^{*} \mathrm{~g}\right)$

$\mathrm{mp}$, damp, $18,0.07 / \mathrm{df}$

/COM - Material,19, Tank Concrete $\mathrm{mp}, \mathrm{ex}, 19,124633$

mp, nuxy, $19,0.18$

mp, dens, $19,190 /\left(1000^{*} \mathrm{~g}\right)$

mp, damp, 19,0.07/df

/COM - Material,20, Tank Concrete mp , ex, 20, 124388

mp, nuxy, 20, 0.18

mp, dens, $20,210 /\left(1000^{*} \mathrm{~g}\right)$

$\mathrm{mp}$, damp, 20,0.07/df

/COM - Material,21, Tank Concrete $\mathrm{mp}, \mathrm{ex}, 21,548683$

mp, nuxy, $21,0.18$

$\mathrm{mp}$, dens, $21,166 /\left(1000^{*} \mathrm{~g}\right)$

mp, damp, $21,0.07 / \mathrm{df}$

/COM - Material,22, Tank Concrete mp, ex, 22, 154870

mp, nuxy, 22, 0.18

$\mathrm{mp}$, dens, $22,184 /\left(1000^{*} \mathrm{~g}\right)$

$\mathrm{mp}$, damp, 22, 0.07/df 
RPP-RPT-32239, Rev. 1

M\&D-2008-005-CALC-001, Rev. 1

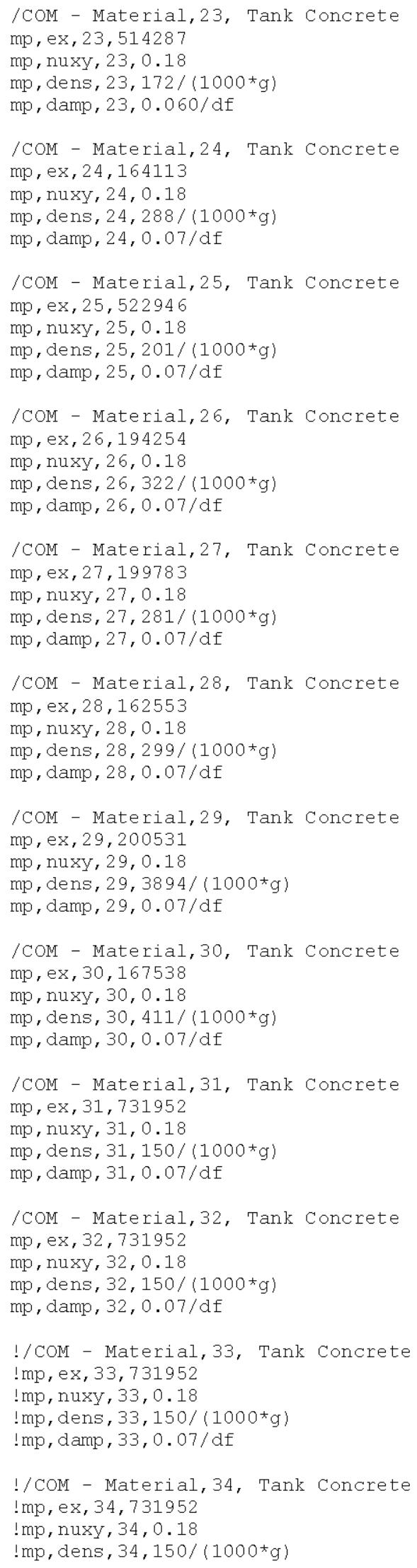


RPP-RPT-32239, Rev. 1

M\&D-2008-005-CALC-001, Rev. 1

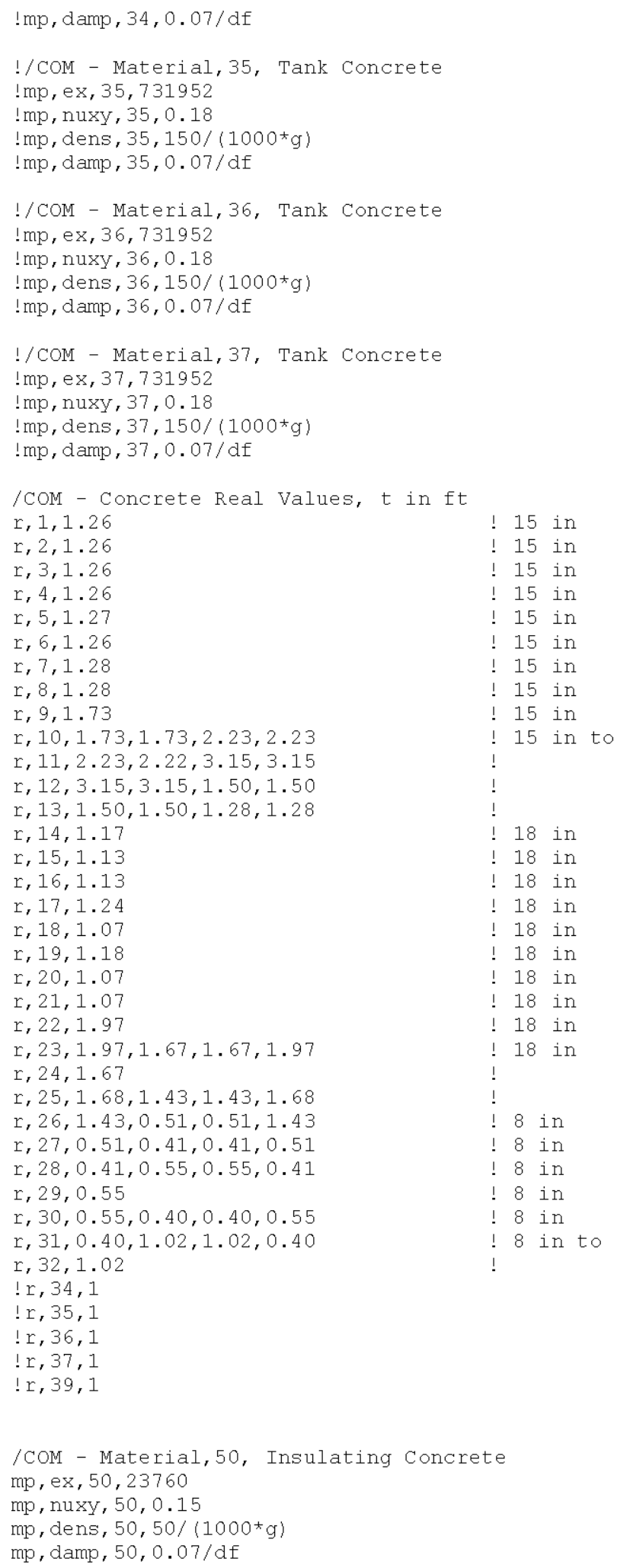




\section{RPP-RPT-32239, Rev. 1 \\ M\&D-2008-005-CALC-001, Rev. 1}

\section{TH-266-UB-Geo-V.txt}

$\begin{array}{llll}-0.000079-0.000134 & 0.000080 & 0.000135-0.000080-0.0001360 .0000810 .000137 & 1\end{array}$ $\begin{array}{llll}-0.000081-0.000138 & 0.0000810 .000139-0.000081-0.0001400 .0000820 .000141 & 2\end{array}$

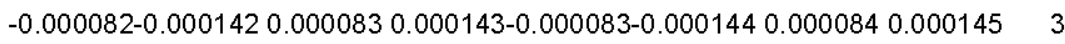
$\ldots \ldots \ldots$

-0.000075-0.0001250.000075 0.000125-0.000076-0.0001260.000076 0.000127 510

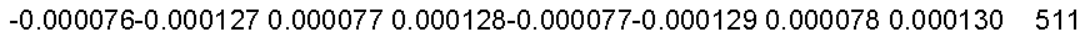
$-0.000078-0.0001310 .0000780 .000132-0.000078-0.0001320 .0000790 .000133512$

\section{TH-266-UB-Geo.txt}

$\begin{array}{lll}-0.0000210 .0000470 .000020-0.000047-0.0000200 .0000450 .000019-0.000045 & 2\end{array}$ $\begin{array}{llll}-0.000019 & 0.0000430 .000017-0.000043-0.0000170 .0000410 .000016-0.000040 \quad 3\end{array}$ $\begin{array}{lllll}-0.0000160 .000038 & 0.000014-0.000037-0.0000140 .000034 & 0.000012-0.000034 & 4\end{array}$ 10.000010

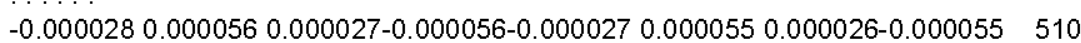

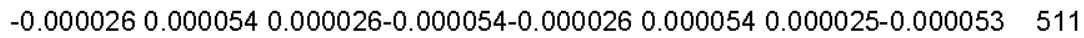

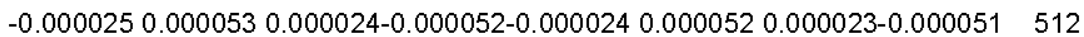

\section{UBS-BEC Seismic File Listing}

Volume in drive $C$ is $600 \mathrm{~GB} 2 \mathrm{xRAID0}$
Volume serial Number is $8 \mathrm{AOA}-\mathrm{E} 4 \mathrm{BA}$

Directory of C: \Users $\backslash F G A \backslash 2008-005$ AP-460\AP-460-UBS-BEC-Seismic780 Secant

\begin{tabular}{|c|c|c|c|c|}
\hline $11 / 28 / 2007$ & $03: 42$ & $\mathrm{PM}$ & $\langle\mathrm{DIR}\rangle$ & . \\
\hline $11 / 28 / 2007$ & $03: 42$ & $\mathrm{PM}$ & $\langle\mathrm{DIR}\rangle$ & . \\
\hline $09 / 16 / 2007$ & $12: 12$ & $\mathrm{PM}$ & 561,576 & Accel-ct-0. out \\
\hline $09 / 16 / 2007$ & $12: 12$ & PM & 561,828 & Accel-ct-135. out \\
\hline $09 / 16 / 2007$ & $12: 12$ & $\mathrm{PM}$ & 561,828 & Accel-ct-180.out \\
\hline $09 / 16 / 2007$ & $12: 12$ & $\mathrm{PM}$ & 561,576 & Accel-ct-45. out \\
\hline $09 / 16 / 2007$ & $12: 12$ & $\mathrm{PM}$ & 561,828 & Accel-ct-90. out \\
\hline $09 / 16 / 2007$ & $12: 12$ & $\mathrm{PM}$ & 290,676 & Accel-ct.out \\
\hline $09 / 16 / 2007$ & $12: 12$ & $\mathrm{PM}$ & 561,828 & Accel-PT-0. out \\
\hline $09 / 16 / 2007$ & $12: 13$ & $\mathrm{PM}$ & 561,828 & Accel-PT-135. out \\
\hline $09 / 16 / 2007$ & $12: 13$ & $\mathrm{PM}$ & 561,828 & Accel-PT-180.out \\
\hline $09 / 16 / 2007$ & $12: 13$ & $\mathrm{PM}$ & 561,828 & Accel-PT-45. out \\
\hline $09 / 16 / 2007$ & $12: 13$ & $\mathrm{PM}$ & 561,828 & Accel-PT-90.out \\
\hline $09 / 16 / 2007$ & $12: 13$ & $\mathrm{PM}$ & 561,828 & Accel-SOil.out \\
\hline $09 / 11 / 2006$ & $03: 21$ & $\mathrm{PM}$ & 99 & All-Eorces.txt \\
\hline $09 / 16 / 2007$ & $01: 36$ & $\mathrm{AM}$ & $4,705,103$ & $\mathrm{AP}-460-\mathrm{BEC}-\mathrm{UBS}-\mathrm{Se}$ ismic.out \\
\hline $11 / 19 / 2007$ & $04: 11$ & $\mathrm{PM}$ & 746,496 & AP-460-UBS-BEC J Bolt ForcesTH 780 Secant.xls \\
\hline $11 / 26 / 2007$ & $09: 49$ & $\mathrm{AM}$ & 791,552 & AP-460-UBS-BEC J-Bolt-Contact-Seismic.xls \\
\hline $09 / 16 / 2007$ & $01: 35$ & $\mathrm{AM}$ & 2,998 & $\mathrm{AP}-460-\mathrm{UBS}-\mathrm{BEC}-\mathrm{Se}$ ismic.BCS \\
\hline $09 / 17 / 2007$ & $12: 56$ & $\mathrm{PM}$ & $43,909,120$ & $\mathrm{AP}-460-\mathrm{UBS}-\mathrm{BEC}-\mathrm{Se}$ ismic. $\mathrm{db}$ \\
\hline $09 / 16 / 2007$ & $01: 35$ & $\mathrm{AM}$ & $63,897,600$ & $\mathrm{AP}-460-\mathrm{UBS}-\mathrm{BEC}-\mathrm{Se}$ ismic. dbb \\
\hline $09 / 16 / 2007$ & $01: 35$ & $\mathrm{AM}$ & $12,713,984$ & $\mathrm{AP}-460-\mathrm{UBS}-\mathrm{BEC}-\mathrm{Se}$ ismic. emat \\
\hline $09 / 17 / 2007$ & $12: 56$ & $\mathrm{PM}$ & 59,261 & $\mathrm{AP}-460-\mathrm{UBS}-\mathrm{BEC}-\mathrm{Se}$ ismic.err \\
\hline $09 / 16 / 2007$ & $01: 35$ & $\mathrm{AM}$ & $111,607,808$ & $\mathrm{AP}-460-\mathrm{UBS}-\mathrm{BEC}-\mathrm{Se}$ ismic. esav \\
\hline $09 / 16 / 2007$ & $01: 35$ & $\mathrm{AM}$ & $30,081,024$ & $\mathrm{AP}-460-\mathrm{UBS}-\mathrm{BEC}-\mathrm{Se}$ ismic.full \\
\hline $09 / 16 / 2007$ & $01: 35$ & $\mathrm{AM}$ & $340,804,299$ & AP-460-UBS-BEC-Seismic. ldhi \\
\hline $09 / 14 / 2007$ & $08: 50$ & $\mathrm{AM}$ & 250 & $\mathrm{AP}-460-\mathrm{UBS}-\mathrm{BEC}-\mathrm{Se}$ ismic. $\log$ \\
\hline $09 / 16 / 2007$ & $01: 35$ & $\mathrm{AM}$ & 198,991 & $\mathrm{AP}-460-\mathrm{UBS}-\mathrm{BEC}-\mathrm{Se}$ ismic.mntr \\
\hline $09 / 16 / 2007$ & $01: 35$ & $\mathrm{AM}$ & $111,607,808$ & $\mathrm{AP}-460-\mathrm{UBS}-\mathrm{BEC}-\mathrm{Se}$ ismic. osav \\
\hline $09 / 16 / 2007$ & $01: 35$ & $\mathrm{AM}$ & 1,795 & $\mathrm{AP}-460-\mathrm{UBS}-\mathrm{BEC}-\mathrm{Se}$ ismic. PVTS \\
\hline $09 / 16 / 2007$ & $01: 35$ & $\mathrm{AM}$ & $112,656,384$ & $\mathrm{AP}-460-\mathrm{UBS}-\mathrm{BEC}-\mathrm{Se}$ ismic.ro01 \\
\hline $09 / 14 / 2007$ & $08: 51$ & $\mathrm{AM}$ & $43,974,656$ & $\mathrm{AP}-460-\mathrm{UBS}-\mathrm{BEC}-\mathrm{Se}$ ismic. rdb \\
\hline $09 / 16 / 2007$ & $01: 35$ & $\mathrm{AM}$ & $4,294,967,296$ & $\mathrm{AP}-460-\mathrm{UBS}-\mathrm{BEC}-\mathrm{Se}$ ismic. rst \\
\hline $09 / 14 / 2007$ & $06: 03$ & PM & $4,294,967,296$ & $\mathrm{AP}-460-\mathrm{UBS}-\mathrm{BEC}-\mathrm{Se}$ ismic. rst02 \\
\hline
\end{tabular}




\section{RPP-RPT-32239, Rev. 1 M\&D-2008-005-CALC-001, Rev. 1}

09/14/2007 10:44 PM

09/15/2007 03:30 AM

09/15/2007 08:26 AM

09/15/2007 01:29 PM

09/15/2007 06:38 PM

09/15/2007 11:54 PM

09/16/2007 01:35 AM

08/15/2007 10:18 AM

09/08/2006 07:08 AM

08/25/2006 08:48 AM

08/21/2006 07:59 AM

08/25/2006 01:28 PM

$08 / 25 / 2006 \quad 01: 27$ PM

08/25/2006 01:28 PM

08/21/2006 07:59 AM

08/21/2006 12:44 PM

11/28/2007 03:42 PM

09/16/2007 12:12 PM

09/16/2007 12:12 PM

09/16/2007 12:12 PM

09/16/2007 12:12 PM

09/16/2007 12:12 PM

09/16/2007 12:12 PM

01/03/2006 11:17 AM

09/16/2007 12:12 PM

09/16/2007 12:13 PM

09/16/2007 12:13 PM

09/16/2007 12:13 PM

09/16/2007 12:13 PM

09/16/2007 12:13 PM

05/08/2006 01:31 PM

01/09/2007 06:53 AM

10/13/2005 06:54 AM

09/16/2007 12:09 PM

09/16/2007 12:09 PM

08/21/2006 08:00 AM

09/16/2007 06:58 PM

09/16/2007 06:58 PM

09/16/2007 02:45 PM

09/16/2007 02:45 PM

09/16/2007 07:11 PM

09/16/2007 07:11 PM

$09 / 16 / 2007 \quad 02: 58 \quad \mathrm{PM}$

09/16/2007 02:58 PM

09/16/2007 07:23 PM

09/16/2007 07:23 PM

09/16/2007 03:10 PM

09/16/2007 03:10 PM

09/16/2007 07:35 PM

09/16/2007 07:35 PM

09/16/2007 03:23 PM

09/16/2007 03:23 PM

$09 / 16 / 2007 \quad 07: 48$ PM

09/16/2007 07:48 PM

09/16/2007 03:36 PM

09/16/2007 03:36 PM

09/16/2007 08:01 PM

09/16/2007 08:01 PM

09/16/2007 03:49 PM

09/16/2007 03:49 PM

09/16/2007 08:13 PM

09/16/2007 08:13 PM

09/16/2007 04:01 PM

09/16/2007 04:01 PM

09/16/2007 08:26 PM
$4,294,967,296$ AP-460-UBS-BEC-Seismic.rst03 $4,294,967,296$ AP-460-UBS-BEC-Seismic.rst04 $4,294,967,296$ AP-460-UBS-BEC-Seismic.rst05 $4,294,967,296$ AP-460-UBS-BEC-Seismic.rst06 $4,294,967,296$ AP-460-UBS-BEC-Seismic.rst07 $4,294,967,296$ AP-460-UBS-BEC-Seismic.rst08 $1,388,445,696$ AP-460-UBS-BEC-Seismic.rst09 6,120 Bolts-Friction.txt

277 Boundary.txt

220 Contact-AP. txt

586 Contact-Footing.txt

704 Contact-Insul.txt

704 Contact-J-Bolts.txt

708 Contact-Primary.txt

742 Contact-Soil.txt

632 Contact-Waste-AP. txt

0 dir_listing.txt

561,576 Disp-ct-0.out

561,576 Disp-ct-135.out

561,576 Disp-ct-180.out

561,576 Disp-ct-45. out

561,576 Disp-ct-90. out

290,550 Disp-ct.out

1,616 Disp-J-Bolts.txt

561,576 Disp-PT-0.out

561,576 Disp-PT-135.out

561,576 Disp-PT-180.out

561,576 Disp-PT-45. out

561,576 Disp-PT-90. out

561,576 Disp-Soil.out

8,616 Far-Soil.txt

52,339 File-List.txt

562 Fix-Soil.txt

10, 342 Footing-Cont_max. OUT

4, 346, 248 Footing-Cont_th. OUT

894 Force-c.txt

4,996 Force-C_108 amax. OUT

2,905,500 Force-C 108 ath. OUT

14,716 Force-C_108max.OUT

$6,519,180$ Force-C 108 th. OUT

4, 996 Force-C_117amax. OUT

2,905,500 Force-c_117ath. OUT

14,716 Force-C $117 \mathrm{max}$. OUT

$6,519,180$ Force-c_117th. OUT

4,996 Force-C 126 amax. OUT

2,905,500 Force-C_126ath. OUT

14,716 Force-c_126max. OUT

6,519,180 Force-C 126 th. OUT

4,996 Force-C_135amax. OUT

2, 905,500 Force-C 135ath. OUT

14,716 Force-C_135max.OUT

$6,519,180$ Force-C_135th. OUT

4,996 Force-C 144 amax. OUT

2,905,500 Force-C_144ath. OUT

14,716 Force-C $144 \mathrm{max}$. OUT

$6,519,180$ Force-c_144th. OUT

4,996 Force-C 153amax. OUT

2,905,500 Eorce-C 153ath. OUT

14,716 Force-C_153max. OUT

$6,519,180$ Force-C 153 th. OUT

4, 996 Force-C_162 amax. OUT

2,905,500 Force-C_162 ath. OUT

14,716 Force-C_162max. OUT

$6,519,180$ Force-C_162th. OUT

4,996 Force-C_171amax. OUT 


\section{RPP-RPT-32239, Rev. 1 M\&D-2008-005-CALC-001, Rev. 1}

09/16/2007 08:26 PM 09/16/2007 04:15 PM 09/16/2007 04:15 PM 09/16/2007 08:39 PM $09 / 16 / 2007 \quad 08: 39 \mathrm{PM}$ $09 / 16 / 2007 \quad 04: 28 \quad \mathrm{PM}$ 09/16/2007 04:28 PM 09/16/2007 04:54 PM 09/16/2007 04:54 PM 09/16/2007 12:39 PM 09/16/2007 12:39 PM 09/16/2007 05:06 PM 09/16/2007 05:06 PM 09/16/2007 12:51 PM 09/16/2007 12:51 PM $09 / 16 / 2007 \quad 05: 19$ PM 09/16/2007 05:19 PM 09/16/2007 01:04 PM 09/16/2007 01:04 PM 09/16/2007 05:32 PM 09/16/2007 05:32 PM 09/16/2007 01:17 PM 09/16/2007 01:17 PM 09/16/2007 05:44 PM 09/16/2007 05:44 PM 09/16/2007 01:29 PM 09/16/2007 01:29 PM 09/16/2007 05:56 PM 09/16/2007 05:56 PM 09/16/2007 01:42 PM 09/16/2007 01:42 PM 09/16/2007 06:08 PM 09/16/2007 06:08 PM 09/16/2007 01:53 PM 09/16/2007 01:53 PM 09/16/2007 06:20 PM 09/16/2007 06:21 PM 09/16/2007 02:06 PM 09/16/2007 02:06 PM 09/16/2007 06:33 PM 09/16/2007 06:33 PM 09/16/2007 02:19 PM $09 / 16 / 2007 \quad 02: 19 \mathrm{PM}$ 09/16/2007 06:46 PM 09/16/2007 06:46 PM 09/16/2007 02:32 PM 09/16/2007 02:32 PM 09/16/2007 04:41 PM 09/16/2007 04:41 PM 09/16/2007 12:26 PM 09/16/2007 12:26 PM 11/19/2007 03:02 PM 09/17/2007 12:55 PM 09/17/2007 12:55 PM 09/17/2007 12:56 PM 09/17/2007 12:56 PM 09/17/2007 12:47 PM $09 / 17 / 2007 \quad 12: 47$ PM 09/17/2007 12:47 PM $09 / 17 / 2007 \quad 12: 47 \mathrm{PM}$ $09 / 17 / 2007 \quad 12: 48 \quad \mathrm{PM}$ 09/17/2007 12:48 PM 09/17/2007 12:50 PM 09/17/2007 12:50 PM 09/17/2007 12:51 PM

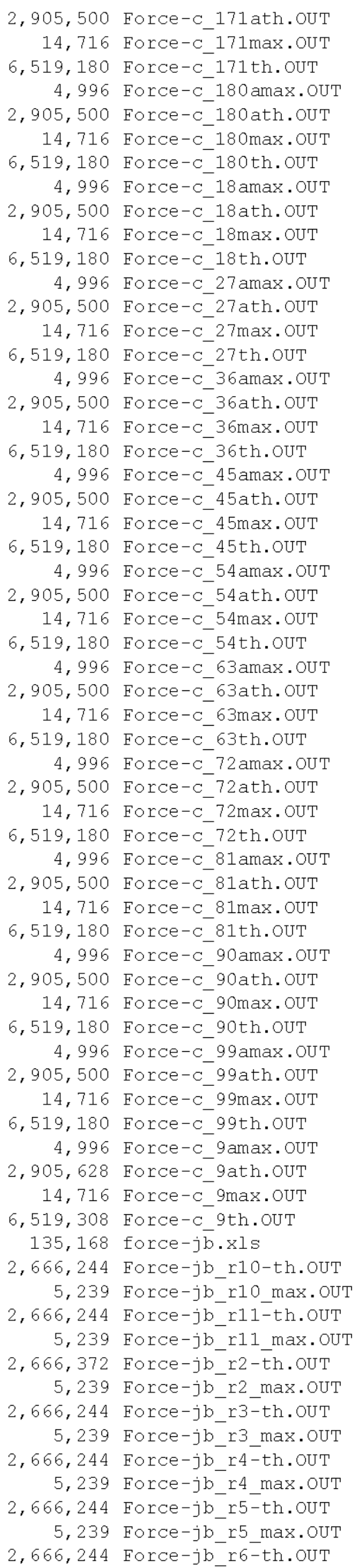




\section{RPP-RPT-32239, Rev. 1 M\&D-2008-005-CALC-001, Rev. 1}

09/17/2007 12:51 PM 09/17/2007 12:51 PM 09/17/2007 12:51 PM 09/17/2007 12:53 PM 09/17/2007 12:53 PM 09/17/2007 12:54 PM 09/17/2007 12:54 PM 08/21/2006 08:00 AM 11/23/2007 11:55 AM 09/16/2007 06:28 AM 09/16/2007 06:28 AM 09/16/2007 06:30 AM 09/16/2007 06:30 AM 09/16/2007 06:32 AM 09/16/2007 06:32 AM 09/16/2007 06:34 AM 09/16/2007 06:34 AM 09/16/2007 06:36 AM 09/16/2007 06:36 AM 09/16/2007 06:38 AM 09/16/2007 06:38 AM 09/16/2007 06:38 AM 09/16/2007 06:38 AM 09/16/2007 06:41 AM 09/16/2007 06:41 AM 09/16/2007 06:42 AM 09/16/2007 06:42 AM 09/16/2007 06:13 AM 09/16/2007 06:13 AM 09/16/2007 06:15 AM 09/16/2007 06:15 AM 09/16/2007 06:16 AM 09/16/2007 06:16 AM 09/16/2007 06:19 AM 09/16/2007 06:19 AM 09/16/2007 06:19 AM 09/16/2007 06:19 AM 09/16/2007 06:21 AM 09/16/2007 06:21 AM 09/16/2007 06:21 AM 09/16/2007 06:21 AM 09/16/2007 06:23 AM 09/16/2007 06:23 AM 09/16/2007 06:25 AM 09/16/2007 06:25 AM 09/16/2007 06:26 AM 09/16/2007 06:26 AM 09/16/2007 06:11 AM 09/16/2007 06:11 AM 09/01/2005 10:27 AM 07/20/2006 06:36 AM 08/23/2006 07:55 AM 11/23/2007 11:35 AM 11/23/2007 11:37 AM 09/16/2007 08:04 AM 09/16/2007 08:04 AM 09/16/2007 08:07 AM 09/16/2007 08:07 AM 09/16/2007 08:09 AM 09/16/2007 08:09 AM 09/16/2007 08:12 AM 09/16/2007 08:12 AM 09/16/2007 08:13 AM 09/16/2007 08:13 AM 09/16/2007 08:13 AM
5,239 Force-jb_r6 max. OUT $2,666,244$ Force-jb_r7-th. OUT 5,239 Force-jb $r 7$ max. OUT $2,666,244$ Force-jb r8-th. OUT 5,239 Force-jb_r8_max.OUT $2,666,244$ Force-jb_rg-th. OUT

5,239 Force-jb_r9_max. OUT 661 Force-j_bolt.txt

<DIR> Gravity

4,024 Insul-Cont_108max. OUT $1,738,448$ Insul-Cont 108 th. OUT

4,024 Insul-Cont_117max.OUT

$1,738,448$ Insul-Cont 117 th. OUT

4,024 Insul-Cont_126max.OUT

$1,738,448$ Insul-Cont 126th. OUT

4,024 Insul-Cont_135max.OUT

$1,738,448$ Insul-Cont_135th. OUT

4,024 Insul-Cont $144 \mathrm{max}$.OUT

$1,738,448$ Insul-Cont_144th. OUT

4,024 Insul-Cont 153max. OUT

1,738,448 Insul-Cont_153th. OUT

4,024 Insul-Cont_162max.OUT

1,738,448 Insul-Cont 162 th. OUT

4,024 Insul-Cont_171max.OUT

$1,738,448$ Insul-Cont 171th. OUT

4,024 Insul-Cont $180 \mathrm{max}$.OUT

1,738,448 Insul-Cont_180th. OUT

4,024 Insul-Cont $18 \mathrm{max}$. OUT

1,738,448 Insul-Cont_18th.OUT

4, 024 Insul-Cont 27max. OUT

1,738,448 Insul-Cont 27th.OUT

4,024 Insul-Cont_36max. OUT

$1,738,448$ Insul-Cont $36 \mathrm{th}$.OUT

4,024 Insul-Cont_45max. OUT

$1,738,448$ Insul-Cont $45 \mathrm{th}$. OUT

4,024 Insul-Cont_54max.OUT

1,738,448 Insul-Cont_54th.OUT

4,024 Insul-Cont 63max. OUT

$1,738,448$ Insul-Cont_63th.OUT

4,024 Insul-Cont $72 \mathrm{max}$. OUT

$1,738,448$ Insul-Cont 72 th. OUT

4,024 Insul-Cont 81max. OUT

$1,738,448$ Insul-Cont 81 th. OUT

4,024 Insul-Cont_90max. OUT

$1,738,448$ Insul-Cont 90 th. OUT

4,024 Insul-Cont $99 \mathrm{max}$. OUT

$1,738,448$ Insul-Cont $99 \mathrm{th}$.OUT

4,024 Insul-Cont 9max. OUT

$1,738,576$ Insul-Cont_9th.OUT

1,664 Insulate.txt

4,030 interface-gap 1.txt

2,411 interfacel.txt

$115,200 \mathrm{~J}$-Bolt-Contact $0-90 . \mathrm{xls}$

115, 712 J-Bolt-Contact_99-180.xls

4, $519 \mathrm{~J}$-Bolt-Cont $108 \mathrm{max}$. OUT

$1,685,484 \mathrm{~J}$-Bolt-Cont $108 \mathrm{th}$. OUT

4,519 J-Bolt-Cont $117 \mathrm{max}$. OUT

$1,685,484 \mathrm{~J}$-Bolt-Cont $117 \mathrm{th}$.OUT

$4,519 \mathrm{~J}$-Bolt-Cont_126max.OUT

$1,685,484 \mathrm{~J}$-Bolt-Cont $126 \mathrm{th}$. OUT

$4,519 \mathrm{~J}$-Bolt-Cont $135 \mathrm{max}$. OUT

$1,685,484 \mathrm{~J}$-Bolt-Cont $135 \mathrm{th}$. OUT

4,519 J-Bolt-Cont_14 4max. OUT

$1,685,484 \mathrm{~J}$-Bolt-Cont 144th. OUT

4,519 J-Bolt-Cont_153max.OUT 


\section{RPP-RPT-32239, Rev. 1 M\&D-2008-005-CALC-001, Rev. 1}

09/16/2007 08:13 AM 09/16/2007 08:14 AM 09/16/2007 08:14 AM 09/16/2007 08:17 AM 09/16/2007 08:17 AM 09/16/2007 08:19 AM 09/16/2007 08:19 AM 09/16/2007 07:41 AM 09/16/2007 07:41 AM 09/16/2007 07:43 AM 09/16/2007 07:43 AM 09/16/2007 07:45 AM 09/16/2007 07:45 AM 09/16/2007 07:49 AM 09/16/2007 07:49 AM 09/16/2007 07:52 AM 09/16/2007 07:52 AM 09/16/2007 07:55 AM 09/16/2007 07:55 AM 09/16/2007 07:56 AM 09/16/2007 07:56 AM 09/16/2007 07:59 AM 09/16/2007 07:59 AM 09/16/2007 08:01 AM 09/16/2007 08:01 AM 09/16/2007 08:02 AM 09/16/2007 08:02 AM 09/16/2007 07:38 AM 09/16/2007 07:38 AM 08/23/2006 07:47 AM 05/02/2005 02:19 PM 08/31/2006 03:05 PM 04/20/2005 01:14 PM 10/13/2006 07:45 AM 09/16/2007 07:15 AM 09/16/2007 07:15 AM 09/16/2007 07:17 AM 09/16/2007 07:17 AM 09/16/2007 07:20 AM 09/16/2007 07:20 AM 09/16/2007 07:23 AM 09/16/2007 07:23 AM 09/16/2007 07:25 AM 09/16/2007 07:25 AM 09/16/2007 07:27 AM 09/16/2007 07:27 AM 09/16/2007 07:28 AM 09/16/2007 07:28 AM 09/16/2007 07:32 AM 09/16/2007 07:32 AM 09/16/2007 07:34 AM 09/16/2007 07:34 AM 09/16/2007 06:50 AM 09/16/2007 06:50 AM 09/16/2007 06:52 AM 09/16/2007 06:52 AM 09/16/2007 06:54 AM $09 / 16 / 2007 \quad 06: 54$ AM 09/16/2007 06:58 AM 09/16/2007 06:58 AM 09/16/2007 07:00 AM 09/16/2007 07:00 AM 09/16/2007 07:02 AM 09/16/2007 07:02 AM 09/16/2007 07:05 AM
1,685,484 J-Bolt-Cont 153th. OUT

4,519 J-Bolt-Cont 162max. OUT

1,685, 484 J-Bolt-Cont 162th. OUT

4,519 J-Bolt-Cont_171max. OUT

1,685,484 J-Bolt-Cont_171th.OUT

4,519 J-Bolt-Cont 18 omax. OUT

1,685, 484 J-Bolt-Cont_180th.OUT

4,519 J-Bolt-Cont $18 \mathrm{max}$. OUT

$1,685,484 \mathrm{~J}$-Bolt-Cont $18 \mathrm{th}$. OUT

$4,519 \mathrm{~J}$-Bolt-Cont_27max. OUT

$1,685,484 \mathrm{~J}$-Bolt-Cont 27 th. OUT

4,519 J-Bolt-Cont 36max.OUT

$1,685,484 \mathrm{~J}-\mathrm{Bolt}$-Cont_36th. OUT

$4,519 \mathrm{~J}-\mathrm{Bolt}$-Cont_45max.OUT

$1,685,484 \mathrm{~J}$-Bolt-Cont $45 \mathrm{th}$. OUT

4,519 J-Bolt-Cont_54max.OUT

$1,685,484 \mathrm{~J}-\mathrm{Bolt}$-Cont_54th. OUT

$4,519 \mathrm{~J}-\mathrm{Bolt}-\mathrm{Cont}-63 \mathrm{max} . \mathrm{OUT}$

$1,685,484 \mathrm{~J}-\mathrm{Bolt}$-Cont_63th. OUT

$4,519 \mathrm{~J}-\mathrm{Bolt}-\mathrm{Cont} 72 \mathrm{max} . \mathrm{OUT}$

$1,685,484 \mathrm{~J}$-Bolt-Cont_72th.OUT

4,519 J-Bolt-Cont_81max.OUT

$1,685,484 \mathrm{~J}$-Bolt-Cont_81th.OUT

4,519 J-Bolt-Cont_90max.OUT

$1,685,484 \mathrm{~J}$-Bolt-Cont_90th. OUT

$4,519 \mathrm{~J}-\mathrm{Bolt}$-Cont_99max.OUT

$1,685,484 \mathrm{~J}$-Bolt-Cont_99th. OUT

$4,519 \mathrm{~J}-\mathrm{Bolt}-\mathrm{Cont}$-9max.OUT

$1,685,612 \mathrm{~J}-\mathrm{Bolt}-\mathrm{Cont}-9 \mathrm{th}$. OUT

1,971 Liner.txt

667 live_load.txt

6,212 Near-Soil-1.txt

508 outer-spar.txt

147 Post-Tank.txt

4,024 Primary-Cont_108max. OUT

1,738,448 Primary-Cont 108th.OUT

4,024 Primary-Cont_117max. OUT

1,738,448 Primary-Cont 117 th. OUT

4,024 Primary-Cont_126max. OUT

1,738,448 Primary-Cont_126th.oUT

4,024 Primary-Cont 135 max. OUT

1,738,448 Primary-Cont_135th.OUT

4,024 Primary-Cont 144 max. OUT

1,738,448 Primary-Cont_144th.OUT

4,024 Primary-Cont $153 \mathrm{max}$. OUT

1,738,448 Primary-Cont_153th.OUT

4,024 Primary-Cont_162max. OUT

$1,738,448$ Primary-Cont 162 th. OUT

4,024 Primary-Cont_171max.OUT

1,738,448 Primary-Cont 171 th. OUT

4,024 Primary-Cont $180 \mathrm{max}$. OUT

1,738,448 Primary-Cont 180th.OUT

4,024 Primary-Cont 18max.OUT

1,738,448 Primary-Cont_18th.OUT

4,024 Primary-Cont 27 max.OUT

$1,738,448$ Primary-Cont_27th.ouT

4,024 Primary-Cont 36 max.OUT

1,738,448 Primary-Cont 36th. OUT

4,024 Primary-Cont_45max.OUT

1,738,448 Primary-Cont 45 th. OUT

4,024 Primary-Cont 54max.OUT

$1,738,448$ Primary-Cont_54th. OUT

4,024 Primary-Cont 63max.OUT

$1,738,448$ Primary-Cont_63th. OUT

4,024 Primary-Cont_ $72 \mathrm{max}$.OUT 
RPP-RPT-32239, Rev. 1 M\&D-2008-005-CALC-001, Rev. 1

\begin{tabular}{|c|c|c|c|c|}
\hline $09 / 16 / 2007$ & $07: 05$ & AM & $1,738,448$ & Primary-Cont_72th.OUT \\
\hline $09 / 16 / 2007$ & $07: 07$ & AM & 4,024 & Primary-Cont_81max.oUT \\
\hline $09 / 16 / 2007$ & $07: 07$ & AM & $1,738,448$ & Primary-Cont_81th.oUT \\
\hline $09 / 16 / 2007$ & $07: 10$ & AM & 4,024 & Primary-Cont_90max.oUT \\
\hline $09 / 16 / 2007$ & $07: 10$ & AM & $1,738,448$ & Primary-Cont_90th.oUT \\
\hline $09 / 16 / 2007$ & $07: 12$ & AM & 4,024 & Primary-Cont_99max.oUT \\
\hline $09 / 16 / 2007$ & $07: 12$ & AM & $1,738,448$ & Primary-Cont_99th.OUT \\
\hline $09 / 16 / 2007$ & $06: 46$ & AM & 4,024 & Primary-Cont_9max.ouT \\
\hline $09 / 16 / 2007$ & $06: 46$ & AM & $1,738,576$ & Primary-Cont 9 th. OUT \\
\hline $10 / 12 / 2006$ & $02: 28$ & PM & 6,028 & Primary-Props-AP.txt \\
\hline $09 / 27 / 2005$ & $03: 52$ & PM & 1,538 & Primary.txt \\
\hline $09 / 14 / 2007$ & $08: 51$ & AM & 450,111 & QA. out \\
\hline $09 / 16 / 2007$ & $12: 12$ & PM & 47,121 & RS-ct-0.out \\
\hline $09 / 16 / 2007$ & $12: 12$ & PM & 47,121 & RS-ct-135. out \\
\hline $09 / 16 / 2007$ & $12: 12$ & PM & 47,121 & RS-ct-180.out \\
\hline $09 / 16 / 2007$ & $12: 12$ & PM & 47,121 & $\mathrm{RS}-\mathrm{ct}-45$. out \\
\hline $09 / 16 / 2007$ & $12: 12$ & PM & 47,121 & RS-ct-90.out \\
\hline $09 / 16 / 2007$ & $12: 12$ & PM & 27,591 & RS-ct.out \\
\hline $09 / 11 / 2006$ & $02: 59$ & PM & 47,121 & R.S-OUT-Concrete.txt \\
\hline $09 / 16 / 2007$ & $12: 12$ & PM & 47,121 & $\mathrm{RS}-\mathrm{PT}-0 . \mathrm{out}$ \\
\hline $09 / 16 / 2007$ & $12: 13$ & PM & 47,121 & RS-PT-135.out \\
\hline $09 / 16 / 2007$ & $12: 13$ & PM & 47,121 & $\mathrm{RS}-\mathrm{PT}-180$. out \\
\hline $09 / 16 / 2007$ & $12: 13$ & PM & 47,121 & $\mathrm{RS}-\mathrm{PT}-45$.out \\
\hline $09 / 16 / 2007$ & $12: 13$ & PM & 47,121 & RS-PT-90.out \\
\hline $09 / 16 / 2007$ & $12: 13$ & PM & 47,121 & RS-SOil.out \\
\hline $10 / 31 / 2005$ & $10: 31$ & AM & 1,108 & RS_EREQ.txt \\
\hline $08 / 31 / 2006$ & $02: 56$ & PM & 1,819 & Run-Tank.txt \\
\hline $09 / 14 / 2007$ & $08: 50$ & AM & 0 & scratch.hlp \\
\hline $12 / 29 / 2006$ & $11: 03$ & AM & 54,765 & Seismic-File-List.txt \\
\hline $02 / 11 / 2005$ & $01: 22$ & PM & 1,053 & Slave.txt \\
\hline $09 / 16 / 2007$ & $10: 21$ & AM & 9,896 & Soil-Contact_108max.OUT \\
\hline $09 / 16 / 2007$ & $10: 21$ & AM & $4,348,080$ & Soil-Contact_108th.ouT \\
\hline $09 / 16 / 2007$ & $10: 31$ & AM & 9,896 & Soil-Contact_117max.OUT \\
\hline $09 / 16 / 2007$ & $10: 31$ & AM & $4,348,080$ & Soil-Contact_117th.oUT \\
\hline $09 / 16 / 2007$ & $10: 41$ & AM & 9,896 & Soil-Contact_126max.OUT \\
\hline $09 / 16 / 2007$ & $10: 41$ & AM & $4,348,080$ & Soil-Contact_126th.ouT \\
\hline $09 / 16 / 2007$ & $10: 52$ & AM & 9,896 & Soil-Contact_135max.OUT \\
\hline $09 / 16 / 2007$ & $10: 52$ & AM & $4,348,080$ & Soil-Contact_135th.ouT \\
\hline $09 / 16 / 2007$ & $11: 02$ & AM & 9,896 & Soil-Contact_144max.OUT \\
\hline $09 / 16 / 2007$ & $11: 02$ & AM & $4,348,080$ & Soil-Contact 144 th.oUT \\
\hline $09 / 16 / 2007$ & $11: 12$ & AM & 9,896 & Soil-Contact_153max.OUT \\
\hline $09 / 16 / 2007$ & $11: 12$ & AM & $4,348,080$ & Soil-Contact_153th.ouT \\
\hline $09 / 16 / 2007$ & $11: 23$ & AM & 9,896 & Soil-Contact_162max.OUT \\
\hline $09 / 16 / 2007$ & $11: 23$ & AM & $4,348,080$ & Soil-Contact_162th.ouT \\
\hline $09 / 16 / 2007$ & $11: 33$ & AM & 9,896 & Soil-Contact_171max.OUT \\
\hline $09 / 16 / 2007$ & $11: 33$ & AM & $4,348,080$ & Soil-Contact_171th.oUT \\
\hline $09 / 16 / 2007$ & $11: 43$ & AM & 9,896 & Soil-Contact $180 \mathrm{max}$. OUT \\
\hline $09 / 16 / 2007$ & $11: 43$ & AM & $4,348,080$ & Soil-Contact_180th.oUT \\
\hline $09 / 16 / 2007$ & $08: 39$ & AM & 9,896 & Soil-Contact_18max.ouT \\
\hline $09 / 16 / 2007$ & $08: 39$ & AM & $4,348,080$ & Soil-Contact_18th.OUT \\
\hline $09 / 16 / 2007$ & $08: 49$ & AM & 9,896 & Soil-Contact_27max.ouT \\
\hline $09 / 16 / 2007$ & $08: 49$ & AM & $4,348,080$ & Soil-Contact 27 th.ouT \\
\hline $09 / 16 / 2007$ & $08: 59$ & AM & 9,896 & Soil-Contact_36max.ouT \\
\hline $09 / 16 / 2007$ & $08: 59$ & AM & $4,348,080$ & Soil-Contact_36th.ouT \\
\hline $09 / 16 / 2007$ & $09: 10$ & AM & 9,896 & Soil-Contact_45max.ouT \\
\hline $09 / 16 / 2007$ & $09: 10$ & AM & $4,348,080$ & Soil-Contact_45th.oUT \\
\hline $09 / 16 / 2007$ & $09: 20$ & AM & 9,896 & Soil-Contact_54max.oUT \\
\hline $09 / 16 / 2007$ & $09: 20$ & AM & $4,348,080$ & Soil-Contact_54th.ouT \\
\hline $09 / 16 / 2007$ & $09: 30$ & AM & 9,896 & Soil-Contact $63 \mathrm{max}$. OUT \\
\hline $09 / 16 / 2007$ & $09: 30$ & AM & $4,348,080$ & Soil-Contact_63th.ouT \\
\hline $09 / 16 / 2007$ & $09: 40$ & AM & 9,896 & Soil-Contact ${ }^{-} 72 \mathrm{max}$. OUT \\
\hline $09 / 16 / 2007$ & $09: 40$ & AM & $4,348,080$ & Soil-Contact_ $72 \mathrm{th} . \mathrm{OUT}$ \\
\hline $09 / 16 / 2007$ & $09: 50$ & AM & 9,896 & Soil-Contact_81max.oUT \\
\hline $09 / 16 / 2007$ & $09: 50$ & AM & $4,348,080$ & Soil-Contact 81 th.OUT \\
\hline $09 / 16 / 2007$ & $10: 00$ & AM & 9,896 & Soil-Contact $90 \mathrm{max}$. OUT \\
\hline
\end{tabular}




\section{RPP-RPT-32239, Rev. 1 M\&D-2008-005-CALC-001, Rev. 1}

09/16/2007 10:00 AM 09/16/2007 10:11 AM 09/16/2007 10:11 AM 09/16/2007 08:28 AM 09/16/2007 08:28 AM $11 / 11 / 2005 \quad 10: 36 \mathrm{AM}$ 10/13/2005 08:19 AM 09/07/2006 01:13 PM 09/13/2006 06:12 AM 09/13/2006 06:07 AM 09/13/2006 06:08 AM 09/13/2006 06:09 AM 09/13/2006 06:08 AM 09/13/2006 06:08 AM 10/17/2006 09:27 AM 09/13/2006 06:11 AM 09/13/2006 06:13 AM 09/13/2006 06:14 AM 09/13/2006 06:15 AM 09/13/2006 06:13 AM 09/13/2006 06:14 AM 09/13/2006 06:15 AM 06/20/2005 09:04 AM 06/20/2005 08:52 AM 01/03/2007 03:40 PM 01/03/2007 03:40 PM 01/03/2007 03:41 PM 01/03/2007 04:02 PM 08/21/2006 08:02 AM 08/21/2006 08:03 AM 08/24/2006 03:19 PM 08/24/2006 12:05 PM 09/17/2007 10:40 AM 09/17/2007 05:07 AM 09/16/2007 11:50 PM 09/17/2007 10:40 AM 09/17/2007 05:07 AM 09/16/2007 11:50 PM 09/17/2007 10:56 AM 09/17/2007 05:23 AM 09/17/2007 12:05 AM 09/17/2007 10:56 AM 09/17/2007 05:23 AM 09/17/2007 12:05 AM 09/17/2007 11:11 AM 09/17/2007 05:39 AM 09/17/2007 12:21 AM 09/17/2007 11:11 AM 09/17/2007 05:39 AM 09/17/2007 12:21 AM 09/17/2007 11:26 AM 09/17/2007 05:55 AM 09/17/2007 12:37 AM 09/17/2007 11:26 AM 09/17/2007 05:55 AM 09/17/2007 12:37 AM 09/17/2007 11:42 AM 09/17/2007 06:11 AM 09/17/2007 12:52 AM 09/17/2007 11:42 AM 09/17/2007 06:11 AM 09/17/2007 12:52 AM 09/17/2007 11:57 AM 09/17/2007 06:28 AM 09/17/2007 01:08 AM

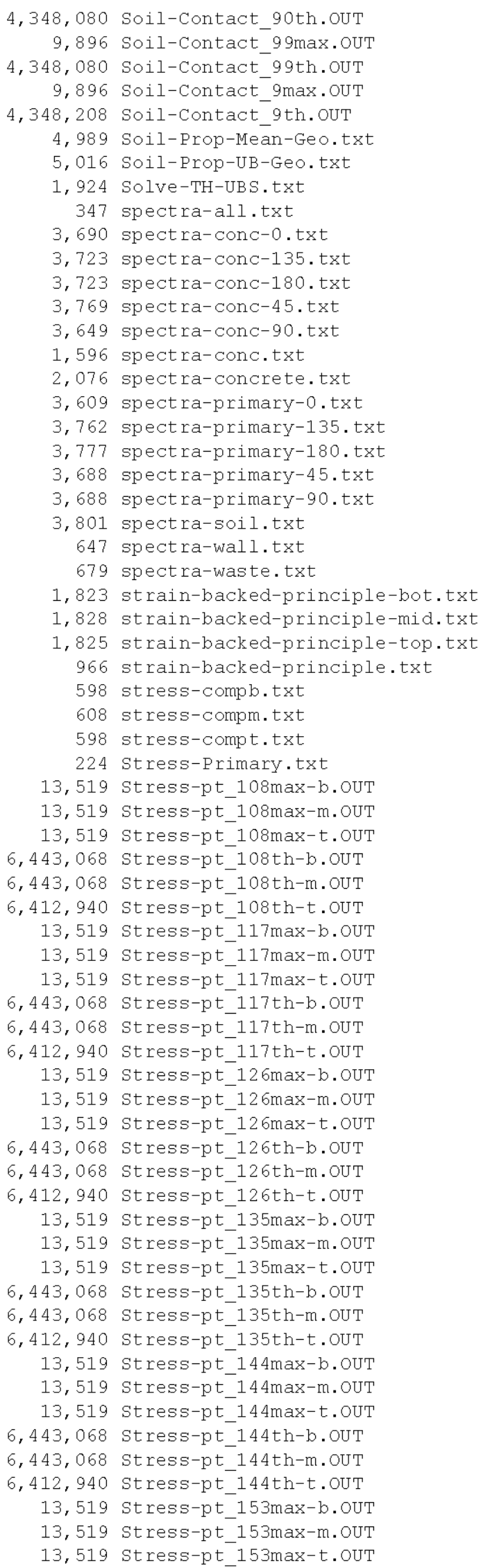




\section{RPP-RPT-32239, Rev. 1 M\&D-2008-005-CALC-001, Rev. 1}

09/17/2007 11:57 AM 09/17/2007 06:28 AM 09/17/2007 01:08 AM 09/17/2007 12:13 PM 09/17/2007 06:44 AM 09/17/2007 01:24 AM 09/17/2007 12:13 PM 09/17/2007 06:44 AM 09/17/2007 01:24 AM 09/17/2007 12:29 PM 09/17/2007 07:01 AM 09/17/2007 01:40 AM 09/17/2007 12:29 PM 09/17/2007 07:01 AM 09/17/2007 01:40 AM 09/17/2007 12:44 PM 09/17/2007 07:17 AM 09/17/2007 01:56 AM 09/17/2007 12:44 PM 09/17/2007 07:17 AM 09/17/2007 01:56 AM 09/17/2007 07:50 AM 09/17/2007 02:28 AM 09/16/2007 09:11 PM 09/17/2007 07:50 AM 09/17/2007 02:28 AM 09/16/2007 09:11 PM 09/17/2007 08:06 AM 09/17/2007 02:44 AM 09/16/2007 09:27 PM 09/17/2007 08:06 AM 09/17/2007 02:44 AM 09/16/2007 09:27 PM 09/17/2007 08:22 AM 09/17/2007 03:00 AM 09/16/2007 09:43 PM 09/17/2007 08:22 AM 09/17/2007 03:00 AM 09/16/2007 09:43 PM 09/17/2007 08:38 AM 09/17/2007 03:16 AM 09/16/2007 09:59 PM 09/17/2007 08:38 AM 09/17/2007 03:16 AM 09/16/2007 09:59 PM 09/17/2007 08:54 AM 09/17/2007 03:32 AM 09/16/2007 10:15 PM 09/17/2007 08:54 AM 09/17/2007 03:32 AM 09/16/2007 10:15 PM 09/17/2007 09:11 AM 09/17/2007 03:48 AM 09/16/2007 10:31 PM 09/17/2007 09:11 AM 09/17/2007 03:48 AM 09/16/2007 10:31 PM 09/17/2007 09:38 AM 09/17/2007 04:03 AM 09/16/2007 10:46 PM 09/17/2007 09:38 AM 09/17/2007 04:03 AM 09/16/2007 10:46 PM 09/17/2007 09:53 AM 09/17/2007 04:19 AM
$6,443,068$ Stress-pt 153th-b. OUT $6,443,068$ stress-pt_153th-m. OUT $6,412,940$ stress-pt 153th-t. OUT 13,519 Stress-pt_162max-b.OUT 13,519 Stress-pt_162max-m. OUT 13,519 Stress-pt_162max-t.OUT $6,443,068$ Stress-pt_162th-b.OUT $6,443,068$ stress-pt $162 \mathrm{th}-\mathrm{m}$. OUT 6,412,940 Stress-pt_162th-t.OUT 13,521 Stress-pt_171max-b.OUT 13,521 Stress-pt_171max-m.OUT 13,521 Stress-pt_171max-t.OUT $6,443,068$ Stress-pt $171 \mathrm{th}-\mathrm{b}$. OUT $6,443,068$ stress-pt_171th-m.OUT 6,412,940 Stress-pt_171th-t.OUT

13,521 Stress-pt_180max-b.OUT 13,521 Stress-pt_180max-m.OUT 13,521 stress-pt $180 \mathrm{max}-t$.OUT $6,443,068$ Stress-pt_180th-b.OUT $6,443,068$ stress-pt 180th-m. OUT $6,412,940$ stress-pt $180 \mathrm{th}-\mathrm{t}$.OUT 13,519 Stress-pt_18max-b.OUT 13,519 stress-pt $18 \mathrm{max}-\mathrm{m}$. OUT 13,519 stress-pt_18max-t.OUT $6,443,068$ stress-pt 18th-b. OUT $6,443,068$ stress-pt_18th-m. OUT $6,412,940$ stress-pt_18th-t.OUT 13,519 Stress-pt $27 \mathrm{max}-\mathrm{b}$. OUT 13,519 Stress-pt_27max-m.OUT 13,519 stress-pt_27max-t.OUT $6,443,068$ stress-pt 27 th-b. OUT 6,443,068 stress-pt_27th-m. OUT $6,412,940$ Stress-pt 27 th-t. OUT 13,519 stress-pt_36max-b.OUT 13,519 stress-pt_36max-m.OUT 13,519 stress-pt $36 \mathrm{max}-\mathrm{t}$.OUT $6,443,068$ Stress-pt_36th-b. OUT $6,443,068$ stress-pt 36 th-m. OUT $6,412,940$ Stress-pt_36th-t. OUT 13,519 Stress-pt 45 max-b. OUT 13,519 Stress-pt $45 \mathrm{max}-\mathrm{m}$. OUT 13,519 Stress-pt 45 max-t. OUT $6,443,068$ stress-pt 45 th-b. OUT $6,443,068$ stress-pt 45 th-m. OUT $6,412,940$ stress-pt 45 th-t. OUT 13,519 Stress-pt 54 max-b.OUT 13,519 Stress-pt_54max-m.OUT 13,519 stress-pt 54 max-t.oUT $6,443,068$ Stress-pt 54 th-b. OUT $6,443,068$ stress-pt 54 th-m. OUT $6,412,940$ stress-pt 54 th-t. OUT

13,519 stress-pt $63 \mathrm{max}-\mathrm{b}$. OUT 13,519 stress-pt $63 \mathrm{max}-\mathrm{m}$. OUT 13,519 Stress-pt $63 \mathrm{max}-\mathrm{t}$. OUT $6,443,068$ Stress-pt 63 th-b. OUT $6,443,068$ stress-pt_63th-m. OUT $6,412,940$ stress-pt 63 th-t. OUT

13,519 Stress-pt ${ }^{-} 72 \mathrm{max}-\mathrm{b}$. OUT 13,519 Stress-pt_72max-m.OUT 13,519 Stress-pt 72 max-t.OUT 6,443,068 stress-pt_72th-b. OUT $6,443,068$ stress-pt_72th-m. OUT 6,412,940 Stress-pt 72 th-t. OUT 13,519 Stress-pt_81max-b.OUT 13,519 Stress-pt_81max-m. OUT 


\section{RPP-RPT-32239, Rev. 1 M\&D-2008-005-CALC-001, Rev. 1}

09/16/2007 11:02 PM 09/17/2007 09:53 AM 09/17/2007 04:19 AM 09/16/2007 11:02 PM 09/17/2007 10:09 AM 09/17/2007 04:35 AM 09/16/2007 11:18 PM 09/17/2007 10:09 AM 09/17/2007 04:35 AM 09/16/2007 11:18 PM 09/17/2007 10:25 AM 09/17/2007 04:51 AM 09/16/2007 11:34 PM 09/17/2007 10:25 AM 09/17/2007 04:51 AM 09/16/2007 11:34 PM 09/17/2007 07:34 AM 09/17/2007 02:12 AM 09/16/2007 08:55 PM 09/17/2007 07:34 AM 09/17/2007 02:12 AM 09/16/2007 08:55 PM 10/12/2006 02:29 PM 05/25/2005 03:32 PM 09/14/2007 08:50 AM 08/25/2006 07:52 AM 09/14/2007 08:51 AM 08/09/2006 07:43 AM 08/09/2006 07:31 AM 05/16/2005 03:42 PM 05/16/2005 08:45 AM 09/16/2007 12:12 PM 09/16/2007 12:12 PM 09/16/2007 12:12 PM 09/16/2007 12:12 PM $09 / 16 / 2007 \quad 12: 12$ PM 09/16/2007 12:12 PM 09/16/2007 12:12 PM 09/16/2007 12:13 PM 09/16/2007 12:13 PM $09 / 16 / 2007 \quad 12: 13 \mathrm{PM}$ 09/16/2007 12:13 PM 09/16/2007 12:13 PM 09/16/2007 04:25 AM 09/16/2007 04:25 AM 09/16/2007 04:38 AM 09/16/2007 04:38 AM 09/16/2007 04:50 AM 09/16/2007 04:50 AM 09/16/2007 05:03 AM 09/16/2007 05:03 AM 09/16/2007 05:16 AM 09/16/2007 05:16 AM 09/16/2007 05:28 AM 09/16/2007 05:28 AM 09/16/2007 05:41 AM 09/16/2007 05:41 AM $09 / 16 / 2007 \quad 05: 54$ AM 09/16/2007 05:54 AM 09/16/2007 06:07 AM 09/16/2007 06:07 AM 09/16/2007 02:19 AM $09 / 16 / 2007 \quad 02: 19$ AM $09 / 16 / 2007 \quad 02: 32$ AM 09/16/2007 02:32 AM
13,519 Stress-pt 81max-t.OUT $6,443,068$ stress-pt_81th-b. OUT $6,443,068$ stress-pt 81 th-m. OUT $6,412,940$ stress-pt_81th-t. OUT

13,519 stress-pt 90 max-b. OUT

13,519 Stress-pt $90 \mathrm{max}-\mathrm{m}$. OUT

13,519 stress-pt_90max-t.OUT $6,443,068$ stress-pt 90 th-b. OUT 6,443,068 Stress-pt_90th-m. OUT $6,412,940$ Stress-pt_90th-t. OUT

13,519 stress-pt $99 \mathrm{max}-\mathrm{b}$. OUT

13,519 Stress-pt_99max-m.OUT

13,519 Stress-pt 99 max-t. OUT $6,443,068$ stress-pt_99th-b. OUT $6,443,068$ stress-pt 99 th-m. OUT $6,412,940$ stress-pt_99th-t. OUT 13,519 stress-pt_9max-b. OUT

13,519 Stress-pt 9 max-m. OUT

13,519 Stress-pt_9max-t.OUT $6,443,196$ stress-pt 9 th-b. OUT $6,443,196$ stress-pt 9 th-m. OUT 6,413,068 stress-pt_9th-t.OUT

4,009 Tank-Coordinates-AP. txt

2,512 Tank-Mesh1.txt 102 tank-out.out

5,450 Tank-Props-BEC-250.txt 4,687 Tank-th. out

23,166 TH-266-Mean-Geo-V.txt 23, $166 \mathrm{TH}-266$-Mean-Geo.txt 41, 472 TH-266-UB-Geo-V.txt 41, $391 \mathrm{TH}-266-\mathrm{UB}-\mathrm{Geo}$. txt

561,576 vel-ct-0.out

561,576 vel-ct-135. out

561,576 vel-ct-180. out

561,576 vel-ct-45. out

561,576 vel-ct-90.out

290,550 vel-ct.out

561,576 Vel-PT-0.out

561, 576 Vel-PT-135.out

561,576 Vel-PT-180. out

561,576 Vel-PT-45.out

561,576 Vel-PT-90.out

561,576 vel-Soil.out

10,180 Waste-Cont_108max. OUT 4,875,649 Waste-Cont 108 th. OUT

10,180 Waste-Cont $117 \mathrm{max}$. OUT

$4,875,649$ waste-Cont 117 th. OUT

10,180 Waste-Cont $126 \mathrm{max}$. OUT

4,875,649 Waste-Cont_126th. OUT

10,180 waste-Cont $135 \mathrm{max}$. OUT

4,875,649 Waste-Cont 135 th. OUT

10,180 Waste-Cont $144 \mathrm{max}$. OUT

$4,875,649$ waste-Cont 144 th. OUT

10,180 Waste-Cont_153max. OUT

4,875,649 Waste-Cont 153 th. OUT

10,180 Waste-Cont $162 \mathrm{max}$. OUT

4,875,649 Waste-Cont 162 th. OUT

10,180 waste-Cont $171 \mathrm{max}$.OUT

4,875,649 waste-Cont_171th. OUT

10,180 waste-Cont $180 \mathrm{max}$.OUT

4,875,649 Waste-Cont 180 th. OUT

10,180 Waste-Cont $18 \mathrm{max}$. OUT

$4,875,649$ waste-Cont $18 \mathrm{th}$.OUT

10,180 waste-Cont $27 \mathrm{max}$. OUT

4,875,649 Waste-Cont 27 th. OUT 


\section{RPP-RPT-32239, Rev. 1 M\&D-2008-005-CALC-001, Rev. 1}

09/16/2007 02:44 AM 09/16/2007 02:44 AM 09/16/2007 02:56 AM 09/16/2007 02:56 AM 09/16/2007 03:08 AM 09/16/2007 03:08 AM 09/16/2007 03:20 AM 09/16/2007 03:20 AM 09/16/2007 03:32 AM 09/16/2007 03:32 AM 09/16/2007 03:45 AM 09/16/2007 03:45 AM 09/16/2007 03:58 AM 09/16/2007 03:58 AM 09/16/2007 04:11 AM 09/16/2007 04:11 AM 09/16/2007 02:07 AM 09/16/2007 02:07 AM 09/16/2007 01:55 AM 08/25/2006 08:47 AM 10/12/2006 02:27 PM 08/21/2006 08:03 AM 09/16/2007 11:47 AM 09/16/2007 11:47 AM 09/16/2007 11:59 AM 09/16/2007 11:59 AM 09/16/2007 11:59 AM 09/16/2007 12:00 PM 09/16/2007 12:00 PM 09/16/2007 12:00 PM 09/16/2007 12:01 PM 09/16/2007 12:01 PM 09/16/2007 12:02 PM 09/16/2007 12:02 PM 09/16/2007 12:03 PM 09/16/2007 12:03 PM 09/16/2007 12:04 PM 09/16/2007 12:04 PM 09/16/2007 12:05 PM 09/16/2007 12:05 PM 09/16/2007 12:06 PM 09/16/2007 12:06 PM 09/16/2007 12:06 PM 09/16/2007 12:06 PM 09/16/2007 11:49 AM 09/16/2007 11:49 AM 09/16/2007 11:50 AM 09/16/2007 11:50 AM 09/16/2007 11:51 AM 09/16/2007 11:51 AM 09/16/2007 11:52 AM 09/16/2007 11:52 AM 09/16/2007 11:53 AM 09/16/2007 11:53 AM 09/16/2007 11:54 AM 09/16/2007 11:54 AM 09/16/2007 11:55 AM 09/16/2007 11:55 AM 09/16/2007 11:56 AM 09/16/2007 11:56 AM 09/16/2007 11:57 AM 09/16/2007 11:57 AM 09/16/2007 11:58 AM 09/16/2007 11:58 AM 09/16/2007 11:48 AM
10, 180 waste-Cont $36 \mathrm{max}$. OUT 4,875,649 waste-Cont_36th.OUT 10,180 Waste-Cont 45 max. OUT 4,875,649 waste-Cont 45 th. OUT 10,180 Waste-Cont $54 \mathrm{max}$. OUT 4,875,649 Waste-Cont_54th.OUT 10,180 waste-Cont_63max.OUT $4,875,649$ waste-Cont 63 th. OUT 10,180 waste-Cont_72max. OUT 4,875,649 Waste-Cont_72th. OUT 10,180 waste-Cont $81 \mathrm{max}$. OUT $4,875,649$ Waste-Cont 81 th. OUT 10,180 Waste-Cont_90max. OUT 4,875,649 Waste-Cont_90th. OUT 10,180 Waste-Cont $99 \mathrm{max}$. OUT $4,875,649$ Waste-Cont_99th.OUT 10,180 Waste-Cont_9max.OUT 4,875,777 waste-Cont_9th.OUT

47, 317 waste-Reaction-460-SD3. out 340 waste-Reaction.txt

10,266 Waste-solid-AP-S.txt 776 waste-Surface-AP.txt 865 waste-Surf Omax.OUT

534, 133 Waste-Surf_oth.OUT 865 Waste-Surf $108 \mathrm{max}$.OUT

534, 005 Waste-Surf_108th. OUT 865 waste-Surf $117 \mathrm{max}$. OUT

534, 005 Waste-Surf 117 th. OUT 865 Waste-Surf_126max. OUT

534,005 Waste-Surf 126 th. OUT 865 waste-Surf_135max. OUT

534, 005 Waste-Surf_135th. OUT 865 Waste-Surf $144 \mathrm{max}$. OUT

534, 005 Waste-Surf_144th.OUT 865 Waste-Surf $153 \mathrm{max}$. OUT

534, 005 Waste-Surf_153th. OUT 865 waste-Surf_162max. OUT

534, 005 waste-Surf 162 th. OUT 865 Waste-Surf $171 \mathrm{max}$. OUT

534,005 Waste-Surf 171 th. OUT 865 waste-Surf $180 \mathrm{max}$. OUT

534, 005 Waste-Surf 180 th. OUT 865 waste-Surf $189 \mathrm{max}$. OUT

534, 005 Waste-Surf 189 th. OUT 865 Waste-Surf 18 max. OUT

534, 005 Waste-Surf 18 th.OUT 865 waste-Surf $27 \mathrm{max}$. OUT

534,005 waste-Surf 27th.OUT 865 waste-Surf $36 \mathrm{max}$. OUT

534,005 Waste-Surf 36th.OUT 865 Waste-Surf 45 max. OUT

534, 005 Waste-Surf 45th. OUT 865 waste-Surf $54 \mathrm{max}$. OUT

534,005 waste-Surf 54th.OUT 865 waste-Surf_63max. OUT

534,005 waste-Surf 63th.OUT 865 waste-Surf $72 \mathrm{max}$. OUT

534, 005 Waste-Surf 72 th.OUT 865 Waste-Surf_81max. OUT

534,005 waste-Surf_81th.OUT 865 Waste-Surf 90 max. OUT

534, 005 Waste-Surf 90 th.OUT 865 Waste-Surf $99 \max$. OUT

534,005 waste-Surf_99th.OUT 865 waste-Surf 9 max.OUT 
RPP-RPT-32239, Rev. 1

M\&D-2008-005-CALC-001, Rev. 1

$\begin{array}{ccc}09 / 16 / 2007 & 11: 48 \text { AM } & 534,005 \text { waste-Surf_9th.OUT } \\ 617 \text { File(s) } & 37,554,084,805 \text { bytes } \\ & 3 \text { Dir(s) } 111,027,961,856 \text { bytes free }\end{array}$


RPP-RPT-32239, Rev. 1

M\&D-2008-005-CALC-001, Rev. 1

Intentionally left blank. 
RPP-RPT-32239, Rev. 1

M\&D-2008-005-CALC-001, Rev. 1

\title{
Appendix I
}

\author{
Best Estimate Soil, \\ Fully Cracked Concrete
}

\author{
Results \\ Load Case Specific Input Files
}

File Listing 
RPP-RPT-32239, Rev. 1

M\&D-2008-005-CALC-001, Rev. 1

Intentionally left blank 
RPP-RPT-32239, Rev. 1

M\&D-2008-005-CALC-001, Rev. 1

\section{Appendix I}

\section{Best Estimate Soil, Fully Cracked Concrete}

\section{Results \\ Load Case Specific Input Files File Listing}

List of Tables Updated in Revision 1:

Table I.13

Table I.14

Table I.15

Table I.31

Table I.32

Table I.33 
RPP-RPT-32239, Rev. 1

M\&D-2008-005-CALC-001, Rev. 1

Tables

I.1 BES-FCC Concrete Forces and Moment, Gravity Load Only ........................................ I.4

I. 2 BES-FCC Concrete Forces and Moments, Gravity Plus Seismic Load ............................... I.5

I.3 BES-FCC Concrete Forces and Moments, Seismic Only …........................................... I.6

I.4 BES-FCC Primary Tank Stresses, Shell Top, Gravity Load Only .................................... I. I.

I.5 BES-FCC Primary Tank Stresses, Shell Middle, Gravity Load Only .................................. I. I.8

I.6 BES-FCC Primary Tank Stresses, Shell Bottom, Gravity Load Only ................................. I.9

I.7 BES-FCC Primary Tank Stresses, Shell Top, Gravity Plus Seismic Load........................... I. I I

I.8 BES-FCC Primary Tank Stresses, Shell Middle, Gravity Plus Seismic Load ...................... I.11

I.9 BES-FCC Primary Tank Stresses, Shell Bottom, Gravity Plus Seismic Load ...................... $\quad$ I.12

I.10 BES-FCC Primary Tank Stresses, Shell Top, Seismic Load Only ...................................... I.13

I.11 BES-FCC Primary Tank Stresses, Shell Middle, Seismic Load Only ................................. I. I.14

I.12 BES-FCC Primary Tank Stresses, Shell Bottom, Seismic Load Only ................................. I. I5

I.13 BES-FCC Anchor Bolt Forces, Gravity Load Only …................................................. I. I

I.14 BES-FCC Anchor Bolt Forces, Gravity Plus Seismic Loads .......................................... I. I.17

I.15 BES-FCC Anchor Bolt Forces, Seismic Load Only .................................................... I.18

I.16 BES-FCC Concrete Backed Steel Strain, Shell Top, Gravity Load Only ............................ I. I.19

I.17 BES-FCC Concrete Backed Steel Strain, Shell Middle, Gravity Load Only ........................ I. I.20

I.18 BES-FCC Concrete Backed Steel Strain, Shell Bottom, Gravity Load Only ....................... I.21

I.19 BES-FCC Concrete Backed Steel Strain, Shell Top, Gravity Plus Seismic Load................. I. I.22

I.20 BES-FCC Concrete Backed Steel Strain, Shell Middle, Gravity Plus Seismic Load ............ $\quad$ I.23

I.21 BES-FCC Concrete Backed Steel Strain, Shell Bottom, Gravity Plus Seismic Load ............ I. I.24

I.22 BES-FCC Concrete Backed Steel Strain, Shell Top, Seismic Load Only ............................. I. I.25

I.23 BES-FCC Concrete Backed Steel Strain, Shell Middle, Seismic Load Only........................ I. I.26

I.24 BES-FCC Concrete Backed Steel Strain, Shell Bottom, Seismic Load Only ...................... I. I.27

I.25 BES-FCC Concrete Wall/Footing Contact Forces, Gravity Only ….................................. I. $\quad$ I.28

I.26 BES-FCC Concrete Wall/Footing Contact Forces, Gravity Plus Seismic............................ I. I.29

I.27 BES-FCC Concrete Wall/Footing Contact Forces, Seismic Only ...................................... I.30

I.28 BES-FCC Soil/Concrete Tank Contact Forces, Gravity Only ............................................ I.31

I.29 BES-FCC Soil/Concrete Tank Contact Forces, Gravity Plus Seismic ................................... I. I.32

I.30 BES-FCC Soil/Concrete Tank Contact Forces, Seismic Only ......................................... I. I.33

I.31 BES-FCC Primary Tank/Concrete Dome Contact Data, Gravity Only ............................... I.34

I.32 BES-FCC Primary Tank/Concrete Dome Contact Data, Gravity Plus Seismic .................... I. I.35

I.33 BES-FCC Primary Tank/Concrete Dome Contact Data, Seismic Only .............................. I.36

I.34 BES-FCC Primary Tank/Insulating Concrete Contact Forces, Gravity Only ...................... I. I.37 
RPP-RPT-32239, Rev. 1

M\&D-2008-005-CALC-001, Rev. 1

I.35 BES-FCC Primary Tank/Insulating Concrete Contact Data, Gravity Plus Seismic.............. I. I.38

I.36 BES-FCC Primary Tank/Insulating Concrete Contact Forces, Seismic Only ..................... I. I.39

I.37 BES-FCC Insulating Concrete/Concrete Backed Steel Contact Data, Gravity Only ............. I. I.40

I.38 BES-FCC Insulating Concrete/Concrete Backed Steel Contact Data, Gravity

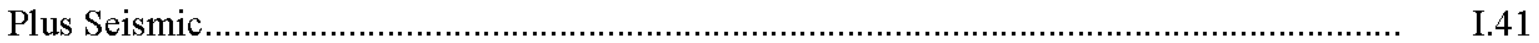

I.39 BES-FCC Insulating Concrete/Concrete Backed Steel Contact Data, Seismic Only ............. I.42

I.40 BES-FCC Waste Contact Pressure, Gravity Plus Seismic ............................................... I.43

I.41 BES-FCC Waste Contact Pressure, Theoretical Pressures.................................................. I.44

I.42 BES-FCC Waste Surface Displacement, Gravity Plus Seismic ....................................... I.45 
RPP-RPT-32239, Rev. 1

M\&D-2008-005-CALC-001, Rev. 1

Table I.1. BES-FCC Concrete Forces and Moment, Gravity Load Only

\section{AP Primary Tank, Best Estimate Soil (Geomatrix), Gravity Only, Fully Cracked Concrete, 460 in. Waste Level at $1.83 \mathrm{SpG}$}

\begin{tabular}{|c|c|c|c|c|c|c|c|}
\hline 3 & 105.676 & -42.100 & -59.650 & -0.060 & -4.301 & -1.047 & 2.463 \\
\hline 4 & 137.076 & -39.130 & -55.280 & -0.021 & -3.426 & 3.290 & 2.192 \\
\hline 6 & 182.856 & -32.560 & -51.110 & -0.063 & -2.003 & 5.501 & 0.494 \\
\hline 8 & 226.570 & -24.750 & -48.630 & -0.070 & -0.368 & 4.274 & -1.235 \\
\hline 9 & 275.574 & -29.800 & -48.550 & -0.032 & -1.001 & 1.605 & -1.101 \\
\hline 22 & 515.319 & 15.140 & -54.730 & -0.076 & 4.426 & 27.140 & -3.729 \\
\hline 24 & 553.722 & 0.176 & -54.420 & -0.043 & 1.691 & 9.244 & -6.579 \\
\hline 26 & 593.805 & -13.620 & -56.390 & -0.021 & -0.328 & -1.804 & -1.594 \\
\hline 30 & 644.355 & -24.390 & -58.230 & 0.008 & -0.478 & -2.651 & 0.820 \\
\hline 33 & 693.605 & -28.650 & -59.600 & 0.004 & -0.101 & -0.557 & 0.304 \\
\hline 35 & 740.705 & -30.420 & -60.990 & 0.003 & 0.019 & 0.101 & -0.026 \\
\hline 38 & 786.205 & -28.840 & -62.360 & -0.003 & -0.168 & -0.928 & -0.285 \\
\hline 41 & 844.605 & -27.080 & -64.140 & -0.004 & -0.164 & -0.907 & -0.265 \\
\hline 43 & 901.355 & -12.730 & -26.190 & 0.005 & -0.119 & -0.661 & 1.029 \\
\hline 46 & 932.355 & -16.040 & -63.150 & 0.026 & -0.582 & -3.062 & -2.114 \\
\hline 48 & 1007.355 & -2.505 & -7.697 & 0.430 & -2.083 & 8.061 & -4.653 \\
\hline 51 & 1053.855 & -1.606 & -9.120 & 0.603 & -0.577 & 3.855 & 6.516 \\
\hline
\end{tabular}

Note: Meridonal/Hoop Forces and Meridonal/Hoop Moments are Reversed in Highlighted Sections. 
RPP-RPT-32239, Rev. 1

M\&D-2008-005-CALC-001, Rev. 1

Table I.2. BES-FCC Concrete Forces and Moments, Gravity Plus Seismic Load

\section{AP- Primary Tank, Best Estimate Soil (Geomatrix), Fully Cracked Concrete, $460 \mathrm{in}$. Waste Level at $1.83 \mathrm{SpG}$}

ANSYS MAXIMUMS BY PATH

\begin{tabular}{|c|c|c|c|c|c|c|c|}
\hline $\begin{array}{l}\text { PNNL } \\
\text { Section } \\
\text { No. }\end{array}$ & Path (in.) & $\begin{array}{l}\text { Seismic Hoop } \\
\text { Force (kip/ft) } \\
\text { AP-BES-FCC }\end{array}$ & $\begin{array}{c}\text { Seismic } \\
\text { Meridonal } \\
\text { Force (kip/ft) } \\
\text { AP-BES-FCC }\end{array}$ & $\begin{array}{l}\text { Seismic -ln- } \\
\text { Plane Shear } \\
\text { Force (kip/ft) } \\
\text { AP-BES-FCC }\end{array}$ & $\begin{array}{c}\text { Seismic Hoop } \\
\text { Moment } \\
\text { (ft*kip/ft) AP- } \\
\text { BES-FCC }\end{array}$ & $\begin{array}{c}\text { Seismic Meridonal } \\
\text { Moment }\left(\mathrm{ft}^{*} \mathrm{kip} / \mathrm{ft} \text { ) }\right. \\
\text { AP-BES-FCC }\end{array}$ & $\begin{array}{c}\text { Seismic } \\
\text { Through-Wall } \\
\text { Shear Force } \\
\text { (kip/ft) AP-BES } \\
\text { FCC }\end{array}$ \\
\hline 2 & 67.734 & -77.070 & -90.430 & 5.360 & -14.710 & -15.710 & 4.795 \\
\hline 3 & 105.676 & -60.690 & -82.590 & 6.896 & -9.053 & -6.865 & 5.197 \\
\hline 4 & 137.076 & -55.760 & -76.170 & 7.419 & -7.270 & 7.907 & 4.812 \\
\hline 6 & 182.856 & -45.760 & -68.750 & 7.470 & -4.220 & 10.620 & 2.477 \\
\hline 8 & 226.570 & -36.850 & -63.210 & 7575 & -1.334 & 11.150 & 1.968 \\
\hline 9 & 275.574 & .48 .820 & -61.770 & 8.908 & -1.971 & 4.159 & 1.873 \\
\hline 11 & 325.697 & -38.750 & -62.480 & 11.360 & -1587 & -2.370 & 1.224 \\
\hline 13 & 372.312 & -37400 & -63.270 & 13.710 & -3.203 & -4.080 & 1.305 \\
\hline 17 & 423.434 & -30.800 & -65.750 & 18.080 & -5.077 & -4.595 & 2.320 \\
\hline 20 & 468.315 & 31.200 & -64.790 & 20.810 & $-3,356$ & 27.690 & 9.604 \\
\hline 22 & 515.319 & 31.480 & -65.430 & 20.700 & 5.888 & 33.940 & 5.434 \\
\hline 24 & 553.722 & -7.690 & -66.180 & 20.080 & 2.047 & 11.140 & 8.166 \\
\hline 26 & 593.805 & -19.030 & -69.070 & 19.950 & -0.484 & -2.626 & 1.913 \\
\hline 30 & 644.355 & -29.280 & -70.050 & 20.020 & -0.589 & -3.212 & 1.009 \\
\hline 33 & 693.605 & -33.380 & -70.050 & 20.250 & -0.156 & -0.787 & 0.354 \\
\hline 35 & 740.705 & -35.330 & -70.100 & 20730 & 0048 & 0.253 & 0.100 \\
\hline 38 & 786.205 & -33.280 & -71.650 & 21.270 & -0.217 & -1.152 & 0.366 \\
\hline 41 & 844.605 & -31.020 & -73.680 & 22.490 & -0.258 & -1.405 & 0.450 \\
\hline 43 & 901.355 & -14.410 & -30.180 & 10.860 & -0.240 & -1.331 & 1.632 \\
\hline 46 & 932.355 & -25.230 & -72.870 & 23.900 & -0.666 & -3.660 & 3.103 \\
\hline 48 & 1007.355 & -11.360 & -12.120 & 8.330 & -2.435 & 9.298 & 5.368 \\
\hline 51 & 1053.855 & -5.454 & -12.900 & 5.970 & -0.674 & 4.451 & 7.514 \\
\hline 53 & 1086.855 & 4.081 & -5.382 & 3.233 & 1.263 & 5.493 & 9.506 \\
\hline 55 & 1105.855 & 3.547 & -4.501 & 2.844 & 0.109 & 0.321 & 0.349 \\
\hline 57 & 1147.355 & 2.644 & -2.742 & 1916 & 0.021 & 0.057 & 0.055 \\
\hline 58 & 1207.355 & 3226 & 2.724 & 1.564 & 0.010 & 0.012 & 0.041 \\
\hline 59 & 1267.355 & 3.116 & 2.927 & 1260 & 0.024 & 0042 & 0.033 \\
\hline 60 & 1327.355 & 3.459 & 3.362 & 1.054 & 0.021 & 0.035 & 0.037 \\
\hline 61 & 1387.355 & 2.317 & 3.863 & 0.809 & 0.015 & 0.023 & 0.054 \\
\hline 62 & 1449.355 & 7.296 & 6.898 & 0.958 & 0.139 & 0.314 & 0.263 \\
\hline
\end{tabular}

Note: Meridonal/Hoop Forces and Meridonal/Hoop Moments are Reversed in Highlighted Sections 
RPP-RPT-32239, Rev. 1

M\&D-2008-005-CALC-001, Rev. 1

Table I.3. BES-FCC Concrete Forces and Moments, Seismic Only

\section{AP- Primary Tank, Best Estimate Soil (Geomatrix), Fully Cracked Concrete, 460 in. Waste Level at $1.83 \mathrm{SpG}$}

ANSYS MAXIMUMS BY PATH

\begin{tabular}{|c|c|c|c|c|c|c|c|}
\hline $\begin{array}{c}\text { PNNL } \\
\text { Section } \\
\text { No. }\end{array}$ & Path (in.) & $\begin{array}{c}\text { Seismic Only } \\
\text { Hoop Force } \\
\text { (kip/ft) AP-BES- } \\
\text { FCC }\end{array}$ & $\begin{array}{l}\text { Seismic Only } \\
\text { Meridonal } \\
\text { Force (kip/ft) } \\
\text { AP-BES-FCC } \\
\end{array}$ & $\begin{array}{l}\text { Seismic Only - } \\
\text { In-Plane Shear } \\
\text { Force (kip/ft) } \\
\text { AP-BES-FCC }\end{array}$ & $\begin{array}{c}\text { Seismic Only } \\
\text { Hoop Moment } \\
\text { (ft"kip/ft) AP- } \\
\text { BES-FCC }\end{array}$ & $\begin{array}{c}\text { Seismic Only } \\
\text { Meridonal Moment } \\
\text { (ft*kip/ft) AP-BES- } \\
\text { FCC }\end{array}$ & $\begin{array}{l}\text { Seismic Only } \\
\text { Through-Wall } \\
\text { Shear Force } \\
\text { (kip/ft) AP-BES } \\
\text { FCC } \\
\end{array}$ \\
\hline 2 & 67.734 & 24.120 & 24.670 & 5.344 & 7237 & 9.492 & 2.328 \\
\hline 3 & 105.676 & 21.600 & 23.110 & 6.878 & 4.916 & 6.361 & 2.734 \\
\hline 4 & 137.076 & 19.820 & 21.140 & 7.413 & 4.390 & 4.769 & 2.620 \\
\hline 6 & 182.856 & 13.370 & 17.900 & 7.480 & 2.785 & 5.119 & 2.353 \\
\hline 8 & 226.570 & 12.500 & 14.800 & 7.591 & 0.966 & 7.077 & 0.930 \\
\hline 9 & 275.574 & 19.080 & 13.790 & 8.918 & 1.137 & 2.738 & 0.885 \\
\hline 11 & 325.697 & 14.735 & 13.270 & 11.368 & 0.681 & 0.906 & 0.408 \\
\hline 13 & 372.312 & 19.347 & 13.150 & 13.725 & 0.912 & 2.052 & 0.646 \\
\hline 17 & 423.434 & 22.590 & 12.930 & 18.105 & 1536 & 4.168 & 1.065 \\
\hline 20 & 468.315 & 24.788 & 12.080 & 20.838 & 2.423 & 7.710 & 1.743 \\
\hline 22 & 515.319 & 18.530 & 10.760 & 20.721 & 1.678 & 7.040 & 1.922 \\
\hline 24 & 553.722 & 7.717 & 11.790 & 20.092 & 0.379 & 1.943 & 1.691 \\
\hline 26 & 593.805 & 5.521 & 12.690 & 19.956 & 0.156 & 0.822 & 0.327 \\
\hline 30 & 644.355 & 5.000 & 11.820 & 20.023 & 0.111 & 0.566 & 0.189 \\
\hline 33 & 693.605 & 5.270 & 10.450 & 20.252 & 0.055 & 0.233 & 0.062 \\
\hline 35 & 740.705 & 5.300 & 9.810 & 20.730 & 0.034 & 0.153 & 0.074 \\
\hline 38 & 786.205 & 4.550 & 11.740 & 21.272 & 0.049 & 0.224 & 0.083 \\
\hline 41 & 844.605 & 4.610 & 14.120 & 22.492 & 0.104 & 0.550 & 0.187 \\
\hline 43 & 901.355 & 2.320 & 6.300 & 10.861 & 0.134 & 0.769 & 0.669 \\
\hline 46 & 932.355 & 10.839 & 15.300 & 23.893 & 0.149 & 0.743 & 0.990 \\
\hline 48 & 1007.355 & 8.890 & 4.931 & 7.930 & 0.532 & 2.006 & 1.159 \\
\hline 51 & 1053.855 & 3.950 & 4.507 & 5.621 & 0.170 & 1.129 & 1.543 \\
\hline 53 & 1086.855 & 4.182 & 3.761 & 3.236 & 0.287 & 1.195 & 1600 \\
\hline 55 & 1105.855 & 3.456 & 3.801 & 2.901 & 0.033 & 0.121 & 0.258 \\
\hline 57 & 1147.355 & 2.340 & 2.441 & 1.981 & 0.009 & 0.024 & 0.035 \\
\hline 58 & 1207.355 & 2.453 & 2.293 & 1.588 & 0.004 & 0.015 & 0.031 \\
\hline 59 & 1267.355 & 2.102 & 2.066 & 1.264 & 0.012 & 0.024 & 0.028 \\
\hline 60 & 1327.355 & 2.224 & 2.047 & 1.046 & 0.009 & 0.021 & 0.031 \\
\hline 61 & 1387.355 & 1.426 & 2.206 & 0.747 & 0.007 & 0.015 & 0.043 \\
\hline 62 & 1449.355 & 4.294 & 3.861 & 0.947 & 0.104 & 0.098 & 0.120 \\
\hline
\end{tabular}

Note: Meridonal/Hoop Forces and Meridonal/Hoop Moments are Reversed in Highlighted Sections. 
RPP-RPT-32239, Rev. 1

M\&D-2008-005-CALC-001, Rev. 1

Table I.4. BES-FCC Primary Tank Stresses, Shell Top, Gravity Load Only

\begin{tabular}{|c|c|c|c|c|c|}
\hline \multirow[b]{3}{*}{$\begin{array}{c}\text { M\&D } \\
\text { Starting } \\
\text { Element } \\
\text { No. }\end{array}$} & \multirow[b]{3}{*}{ Path (in.) } & \multicolumn{4}{|c|}{$\begin{array}{l}\text { AP Primary Tank, Best Estimate Soil, Gravity Only, Fully } \\
\text { Cracked Tank Concrete, } 460 \text { in. Waste Level at } 1.83 \mathrm{SpG}\end{array}$} \\
\hline & & \multicolumn{4}{|c|}{ Shell Top Surface (inside - waste side) } \\
\hline & & $\begin{array}{c}\text { AP-460-BES-FCC } \\
\text { Gravity Hoop Stress } \\
\text { (lbs/in^2) Top }\end{array}$ & $\begin{array}{c}\text { AP-460-BES-FCC } \\
\text { Gravity Meridional } \\
\text { Stress (lbs/in^ } 2 \text { ) Top }\end{array}$ & $\begin{array}{c}\text { AP-460-BES-FCC } \\
\text { Gravity Stress } \\
\text { Intensity (lbs/in^2) } \\
\text { Top }\end{array}$ & $\begin{array}{c}\text { AP-460-BES-FCC } \\
\text { Gravity In-Plane } \\
\text { Shear Stress } \\
\text { (lbs/in^ } 2 \text { ) Top }\end{array}$ \\
\hline 762 & 67.33 & -6575.00 & -7423.61 & 7423.61 & -24.06 \\
\hline 782 & 105.04 & -5793.06 & -10395.83 & 10395.83 & -21.16 \\
\hline 802 & 136.24 & -4358.33 & -9152.78 & 9152.78 & -9.87 \\
\hline 822 & 181.83 & -2337.50 & -8104.17 & 8104.17 & 14.08 \\
\hline 842 & 225.10 & -1695.14 & -6069.44 & 6069.44 & -15.12 \\
\hline 862 & 273.66 & -756.25 & -4906.94 & 4906.94 & -5.95 \\
\hline 882 & 323.27 & -446.74 & -3163.89 & 3163.89 & -2.66 \\
\hline 902 & 369.20 & 610.14 & -2231.25 & 2836.81 & -3.28 \\
\hline 922 & 419.20 & 1733.33 & -81181 & 2539.58 & -5.73 \\
\hline 942 & 444.31 & 1458.33 & -2512.50 & 3965.28 & -4.51 \\
\hline 962 & 458.66 & 1252.78 & 1542.36 & 1542.36 & 3.46 \\
\hline 982 & 473.08 & 897.92 & 1145.14 & 1145.14 & -1.39 \\
\hline 1002 & 484.80 & 1605.56 & -359.86 & 1964.58 & -0.65 \\
\hline 1022 & 502.48 & 3093.06 & 6.49 & 3100.69 & -0.90 \\
\hline 1042 & 526.48 & 4690.28 & 92.64 & 4690.28 & -0.67 \\
\hline 1062 & 550.48 & 6314.58 & -57.52 & 6372.22 & -0.43 \\
\hline 1082 & 574.60 & 7881.94 & 173.96 & 7881.94 & -0.27 \\
\hline 1102 & 598.28 & 9569.44 & -104.10 & 9673.61 & -0.23 \\
\hline 1122 & 621.38 & 11118.06 & 96.11 & 11118.06 & -0.29 \\
\hline 1142 & 644.48 & 12687.50 & -32.22 & 12722.22 & -0.34 \\
\hline 1162 & 667.63 & 13791.67 & -381.04 & 14173.61 & -0.39 \\
\hline 1182 & 690.78 & 1420139 & 392.99 & 14201.39 & -0.38 \\
\hline 1202 & 713.88 & 1520139 & 129.86 & 1520139 & -0.37 \\
\hline 1222 & 736.98 & 16562.50 & -365.63 & 1693056 & -0.40 \\
\hline 1242 & 760.13 & 16500.00 & -746.53 & 17250.00 & 0.46 \\
\hline 1262 & 782.53 & 15270.83 & 1002.08 & 15270.83 & -0.36 \\
\hline 1282 & 804.13 & 14923.61 & 315.69 & 14923.61 & -0.45 \\
\hline 1302 & 825.73 & 1577083 & -45.97 & 1581250 & 0.51 \\
\hline 1322 & 847.33 & 1713194 & 33479 & 1713194 & -0.49 \\
\hline 1342 & 868.87 & 17555.56 & -191111 & 19465.28 & -0.83 \\
\hline 1362 & 892.10 & 13298.61 & -3065.28 & 16368.06 & 1.25 \\
\hline 1382 & 909.20 & 3745.14 & -9722.22 & 13479.17 & 1.54 \\
\hline 1402 & 918.38 & 3794.44 & 6022.22 & 6071.53 & -1.76 \\
\hline 1460 & 930.48 & 3545.83 & 10111.11 & 10159.72 & -520.56 \\
\hline 1442 & 949.48 & 193.68 & -44889 & 64792 & 50.92 \\
\hline 1462 & 990.98 & 575.35 & 866.67 & 868.75 & -23.83 \\
\hline 1482 & 1050.98 & 398.61 & 392.99 & 572.64 & 1.64 \\
\hline 1502 & 1110.98 & 434.24 & 57188 & 572.64 & -12.16 \\
\hline 1522 & 1170.98 & 331.94 & 282.29 & 332.29 & 5.38 \\
\hline 1542 & 1230.98 & 376.74 & 475.00 & 475.63 & -9.16 \\
\hline 1562 & 1292.98 & 285.28 & 284.72 & 286.32 & 1.95 \\
\hline
\end{tabular}


RPP-RPT-32239, Rev. 1

M\&D-2008-005-CALC-001, Rev. 1

Table I.5. BES-FCC Primary Tank Stresses, Shell Middle, Gravity Load Only

\begin{tabular}{|c|c|c|c|c|c|}
\hline $\begin{array}{c}\text { M\&D } \\
\text { Starting } \\
\text { Element } \\
\text { No. }\end{array}$ & Path (in.) & \multicolumn{4}{|c|}{ Shell Mid-Plane } \\
\hline 762 & 67.33 & -7006.94 & -7875.00 & 7875.00 & 16.08 \\
\hline 782 & 105.04 & -5915.28 & -10270.83 & 10270.83 & -17.90 \\
\hline 882 & 323.27 & -521.88 & -3386.11 & 3386.11 & 2.60 \\
\hline 902 & 369.20 & 614.38 & -2184.72 & 2793.06 & -3.25 \\
\hline 922 & 419.20 & 1716.67 & -845.83 & 2556.94 & -5.67 \\
\hline 942 & 444.31 & 2230.56 & 18.58 & 2267.36 & -4.02 \\
\hline 962 & 458.66 & 829.86 & 59.85 & 830.56 & 3.06 \\
\hline 982 & 473.08 & 570.14 & 60.53 & 572.36 & -1.58 \\
\hline 1002 & 484.80 & 1727.78 & 57.15 & 1729.86 & -0.43 \\
\hline 1022 & 502.48 & 3106.94 & 53.15 & 3109.03 & -0.72 \\
\hline 1042 & 526.48 & 4676.39 & 46.79 & 4677.08 & -0.61 \\
\hline 1062 & 550.48 & 6343.06 & 40.08 & 6344.44 & -0.39 \\
\hline 1082 & 574.60 & 7840.28 & 33.26 & 7840.28 & -0.24 \\
\hline 1242 & 760.13 & 16722.22 & -21.40 & 16743.06 & -0.44 \\
\hline 1262 & 782.53 & 14965.28 & -21.03 & 14986.11 & -0.34 \\
\hline 1282 & 804.13 & 14826.39 & -27.11 & 14854.17 & -0.42 \\
\hline 1302 & 825.73 & 15770.83 & -33.25 & 15805.56 & 0.49 \\
\hline 1322 & 847.33 & 17020.83 & -39.41 & 17055.56 & -0.49 \\
\hline 1342 & 868.87 & 1811111 & -45.38 & 18173.61 & -0.68 \\
\hline 1362 & 892.10 & 14208.33 & -44.51 & 14263.89 & 1.00 \\
\hline 1382 & 909.20 & 6527.08 & -54.41 & 6704.86 & 1.18 \\
\hline 1402 & 918.38 & 1690.97 & 115.21 & 2022.22 & -1.12 \\
\hline 1460 & 930.48 & 43972 & 380.69 & 571.25 & 5.28 \\
\hline 1442 & 949.48 & 454.72 & 425.21 & 455.49 & 2.70 \\
\hline 1462 & 990.98 & 522.01 & 702.78 & 704.17 & -15.01 \\
\hline 1482 & 1050.98 & 437.15 & 525.14 & 443.82 & -8.13 \\
\hline 1502 & 1110.98 & 393.06 & 443.47 & 443.82 & -5.27 \\
\hline 1522 & 1170.98 & 363.13 & 390.90 & 391.11 & -3.59 \\
\hline 1542 & 1230.98 & 343.06 & 366.18 & 366.46 & -3.25 \\
\hline 1562 & 1292.98 & 305.90 & 368.06 & 368.82 & -6.35 \\
\hline
\end{tabular}


RPP-RPT-32239, Rev. 1

M\&D-2008-005-CALC-001, Rev. 1

Table I.6. BES-FCC Primary Tank Stresses, Shell Bottom, Gravity Load Only

\begin{tabular}{|c|c|c|c|c|c|}
\hline $\begin{array}{c}\text { M\&D } \\
\text { Starting } \\
\text { Element } \\
\text { No. }\end{array}$ & Path (in.) & \multicolumn{4}{|c|}{ Shell Bottom Surface (outside - away from waste) } \\
\hline 762 & 67.33 & -7458.33 & -8361.11 & 8361.11 & -16.56 \\
\hline 782 & 105.04 & -6052.08 & -10166.67 & 10166.67 & 16.44 \\
\hline 802 & 136.24 & -4713.89 & -9506.94 & 9506.94 & 8.33 \\
\hline 882 & 323.27 & -597.22 & -3612.50 & 3613.19 & 2.56 \\
\hline 902 & 369.20 & 618,68 & -2139.58 & 2750.00 & -3.23 \\
\hline 922 & 419.20 & 1700.00 & -880.56 & 2575.00 & -5.60 \\
\hline 942 & 444.31 & 3002.78 & 2549.31 & 3003.47 & -3.53 \\
\hline 962 & 458.66 & 407.43 & -1422.92 & 1822.22 & 2.66 \\
\hline 982 & 473.08 & 242.57 & -1024.31 & 1260.42 & -1.77 \\
\hline 1002 & 484.80 & 1850.00 & 473.40 & 1850.00 & -0.71 \\
\hline 1022 & 502.48 & 3120.83 & 102.29 & 3121.53 & -0.54 \\
\hline 1042 & 526.48 & 4662.50 & -1.36 & 4669.44 & -0.55 \\
\hline 1062 & 550.48 & 6372.22 & 135.63 & 6372.92 & -0.35 \\
\hline 1082 & 574.60 & 7798.61 & -10965 & 7909.72 & -0.22 \\
\hline 1242 & 760.13 & 16937.50 & 706.25 & 16937.50 & -0.42 \\
\hline 1262 & 782.53 & 14659.72 & -1043.06 & 15701.39 & -0.33 \\
\hline 1282 & 804.13 & 14722.22 & -369.24 & 15090.28 & -0.40 \\
\hline 1302 & 825.73 & 15777.78 & -19.61 & 15798.61 & 0.46 \\
\hline 1322 & 847.33 & 16909.72 & -412.57 & 17319.44 & -0.48 \\
\hline 1342 & 868.87 & 18673.61 & 1823.61 & 18673.61 & 0.57 \\
\hline 1362 & 892.10 & 15111.11 & 2979.17 & 15111.11 & 0.76 \\
\hline 1382 & 909.20 & 9312.50 & 9625.00 & 9625.00 & 0.88 \\
\hline 1402 & 918.38 & -415.90 & -5792.36 & 5843.06 & -0.56 \\
\hline 1460 & 930.48 & -2672.22 & -9354.17 & 9402.78 & 529.65 \\
\hline 1442 & 949.48 & 716.67 & 1297.92 & 1301.39 & -46.47 \\
\hline 1462 & 990.98 & 468.89 & 539.58 & 540.07 & -6.23 \\
\hline 1482 & 1050.98 & 476.04 & 658.75 & 352.50 & -15.65 \\
\hline 1502 & 1110.98 & 352.22 & 317.01 & 352.50 & 4.11 \\
\hline 1522 & 1170.98 & 394.86 & 501.67 & 502.22 & -9.83 \\
\hline 1542 & 1230.98 & 310.14 & 259.93 & 310.56 & 5.51 \\
\hline 1562 & 1292.98 & 328.47 & 454.31 & 455.21 & -11.86 \\
\hline
\end{tabular}

Note 1: Meridonal, Hoop, and Shear Stresses are Reversed in Highlighted Sections

(Floor) 
RPP-RPT-32239, Rev. 1

M\&D-2008-005-CALC-001, Rev. 1

Table I.7. BES-FCC Primary Tank Stresses, Shell Top, Gravity Plus Seismic Load

AP Primary Tank, Best Estimate Soil, Horizontal and Vertical Seismic, Fully Cracked Tank Concrete, 460 in. Waste Level at 1.83 SpG

\begin{tabular}{|c|c|c|c|c|c|}
\hline \multirow{2}{*}{$\begin{array}{c}\text { M\&D } \\
\text { Starting } \\
\text { M\&D } \\
\text { Element } \\
\text { No. }\end{array}$} & \multirow[b]{2}{*}{ Path (in.) } & \multicolumn{4}{|c|}{ Shell Top Surface (inside - waste side) } \\
\hline & & $\begin{array}{c}\text { AP-460-BES-FCC } \\
\text { Seismic Hoop Stress } \\
\text { (Ibs/in^²) Top }\end{array}$ & $\begin{array}{c}\text { AP-460-BES-FCC } \\
\text { Seismic Meridional } \\
\text { Stress (lbs/in^2) Top }\end{array}$ & $\begin{array}{l}\text { AP-460-BES-FCC } \\
\text { Seismic Stress } \\
\text { Intensity (lbs/in^2) } \\
\text { Top }\end{array}$ & $\begin{array}{c}\text { AP-460-BES-FCC } \\
\text { Seismic In-Plane } \\
\text { Shear Stress } \\
\text { (lbs:in^2) Top }\end{array}$ \\
\hline 762 & 67.33 & -9194.44 & -10750.00 & 10756.94 & -1229.17 \\
\hline 782 & 105.04 & -8534.72 & -13909.72 & 13916.67 & -2013.89 \\
\hline 802 & 136.24 & -6736.81 & -12965.28 & 12965.28 & -1964.58 \\
\hline 822 & 181.83 & -382083 & -10840.28 & 10840.28 & -1596.53 \\
\hline 842 & 225.10 & -4153.47 & -9041.67 & 9451.39 & -1178.47 \\
\hline 862 & 273.66 & -2150.69 & -6397.92 & 6397.92 & -907.64 \\
\hline 882 & 323.27 & -2352.78 & -4977.08 & 6880.56 & -1013.89 \\
\hline 902 & 369.20 & 2184.72 & -335417 & 4807.64 & -1493.75 \\
\hline 922 & 419.20 & 4926.39 & -1785.42 & 6716.67 & -2691.67 \\
\hline 942 & 444.31 & 4811.81 & -5994.44 & 6659.03 & -2688.89 \\
\hline 962 & 458.66 & 6188.89 & 7062.50 & 12854.17 & -2684.03 \\
\hline 982 & 473.08 & -6897.92 & 7930.56 & 14833.33 & -2895.14 \\
\hline 1002 & 484.80 & 4293.75 & -1782.64 & 6194.44 & -3040.28 \\
\hline 1022 & 502.48 & 5191.67 & -895.83 & 6703.47 & -2981.94 \\
\hline 1042 & 526.48 & 9041.67 & 1228.47 & 9048.61 & -2763.89 \\
\hline 1062 & 550.48 & 11465.28 & 1237.50 & 11472.22 & -2502.78 \\
\hline 1082 & 574.60 & 13895.83 & 1667.36 & 13895.83 & -2198.61 \\
\hline 1102 & 598.28 & 16465.28 & -1360.42 & 16465.28 & -1847.22 \\
\hline 1122 & 621.38 & 18784.72 & 1751.39 & 18784.72 & -1456.94 \\
\hline 1142 & 644.48 & 21138.89 & 1609.03 & 21138.89 & 1083.33 \\
\hline 1162 & 667.63 & 22736.11 & -1730.56 & 22736.11 & -909.03 \\
\hline 1182 & 690.78 & 2313194 & 2106.94 & 23131.94 & -725.00 \\
\hline 1202 & 713.88 & 24298.61 & 1677.08 & 24298.61 & 810.42 \\
\hline 1222 & 736.98 & 25930.56 & -153681 & 25930.56 & 1062.50 \\
\hline 1242 & 760.13 & 2543750 & -853.47 & 25750.00 & 1432.64 \\
\hline 1262 & 782.53 & 23138.89 & 2392.36 & 23138.89 & 1365.28 \\
\hline 1282 & 804.13 & 22173.61 & 1331.94 & 22173.61 & 1670.83 \\
\hline 1302 & 825.73 & 23020.83 & 775.00 & 23020.83 & 1987.50 \\
\hline 1322 & 847.33 & 24701.39 & 1259.72 & 24701.39 & 2313.19 \\
\hline 1342 & 868.87 & 24791.67 & -2411.81 & 27590.28 & 2678.47 \\
\hline 1362 & 892.10 & 17451.39 & -3443.06 & 2232639 & 2589.58 \\
\hline 1382 & 909.20 & 5800.69 & -11597.22 & 19548.61 & 251389 \\
\hline 1402 & 918.38 & 6074.31 & 9166.67 & 9194.44 & 2449.31 \\
\hline 1460 & 930.48 & 718750 & 1557639 & 15652.78 & -2946.53 \\
\hline 1442 & 949.48 & 5072.92 & 1648.61 & 5079.17 & -2232.64 \\
\hline 1462 & 990.98 & 408750 & 1193.75 & 6394.44 & -3174.31 \\
\hline 1482 & 1050.98 & 3297.92 & 1097.22 & 2863.19 & -2131.25 \\
\hline 1502 & 1110.98 & 2479.17 & 684.03 & 2863.19 & -1418.06 \\
\hline 1522 & 1170.98 & 1974.31 & 80972 & 1975.69 & -946.53 \\
\hline 1542 & 1230.98 & 1347.92 & 521.39 & 1350.00 & -579.17 \\
\hline 1562 & 1292.98 & 929.86 & 700.69 & 938.19 & -308.54 \\
\hline
\end{tabular}


RPP-RPT-32239, Rev. 1

M\&D-2008-005-CALC-001, Rev. 1

Table I.8. BES-FCC Primary Tank Stresses, Shell Middle, Gravity Plus Seismic Load

AP Primary Tank, Best Estimate Soil, Horizontal and Vertical Seismic, Fully Cracked Tank Concrete, 460 in. Waste Level at

$1.83 \mathrm{SpG}$

\begin{tabular}{|c|c|c|c|c|c|}
\hline \multirow{2}{*}{$\begin{array}{c}\text { M\&D } \\
\text { Starting } \\
\text { M\&D } \\
\text { Element } \\
\text { No. }\end{array}$} & \multirow[b]{2}{*}{ Path (in.) } & \multicolumn{4}{|c|}{ Shell Mid-Plane } \\
\hline & & $\begin{array}{c}\text { AP-460-BES-FCC } \\
\text { Seismic Hoop Stress } \\
\text { (lbs/in^2) Mid }\end{array}$ & $\begin{array}{l}\text { AP-460-BES-FCC } \\
\text { Seismic Meridional } \\
\text { Stress (lbs/in^^2) Mid }\end{array}$ & $\begin{array}{l}\text { APन-460-BES-FCC } \\
\text { Seismic Stress } \\
\text { Intensity (lbs/in`2) } \\
\text { Mid }\end{array}$ & $\begin{array}{l}\text { AP-46U-BES-FCC } \\
\text { Seismic In-Plane } \\
\text { Shear Stress } \\
\text { (lbs/in^2) Mid }\end{array}$ \\
\hline 762 & 67.33 & -9812.50 & -10750.00 & 10750.00 & -1147.92 \\
\hline 782 & 105.04 & -8847.22 & -13923.61 & 13930.56 & -1940.97 \\
\hline 842 & 225.10 & -4612.50 & -8381.94 & 8680.56 & -1163.19 \\
\hline 862 & 273.66 & -2011.11 & -6186.81 & 6260.42 & -903.47 \\
\hline 882 & 323.27 & -2672.22 & -4445.14 & 6202.78 & -1013.89 \\
\hline 902 & 369.20 & 2097.22 & -3044.44 & 4691.67 & -1495.14 \\
\hline 922 & 419.20 & 5170.14 & -1575.00 & 6131.25 & -2693.75 \\
\hline 1022 & 502.48 & 5625.00 & 1070.14 & 6427.08 & -2948.61 \\
\hline 1042 & 526.48 & 9034.72 & 1213.19 & 9041.67 & -2758.33 \\
\hline 1062 & 550.48 & 11493.06 & 1345.14 & 11493.06 & -2497.22 \\
\hline 1082 & 574.60 & 13812.50 & 1466.67 & 13812.50 & -2191.67 \\
\hline 1102 & 598.28 & 16493.06 & 1568.75 & 16500.00 & -1840.28 \\
\hline 1122 & 621.38 & 18715.28 & 165139 & 18715.28 & -145139 \\
\hline 1142 & 644.48 & 21111.11 & 1710.42 & 21111.11 & 1072.92 \\
\hline 1162 & 667.63 & 22847.22 & 1743.75 & 22847.22 & -896.53 \\
\hline 1182 & 690.78 & 22881.94 & 1535.42 & 22881.94 & -715.28 \\
\hline 1202 & 713.88 & 24159.72 & 1515.28 & 24159.72 & 809.72 \\
\hline 1382 & 909.20 & 9166.67 & -370.97 & 9520.83 & 2366.67 \\
\hline 1402 & 918.38 & 6032.64 & 455.56 & 6497.22 & 2345.83 \\
\hline 1460 & 930.48 & 4924.31 & 746.53 & 5038.89 & -2390.28 \\
\hline 1442 & 949.48 & 4726.39 & 756.94 & 4807.64 & -2222.92 \\
\hline 1462 & 990.98 & 4134.72 & 1234.72 & 6393.06 & -318125 \\
\hline 1482 & 1050.98 & 3238.89 & 950.69 & 2859.03 & -2125.69 \\
\hline 1502 & 1110.98 & 2525.00 & 779.86 & 2859.03 & -1425.00 \\
\hline 1522 & 1170.98 & 1921.53 & 663.06 & 1923.61 & -940.28 \\
\hline 1542 & 1230.98 & 1390.28 & 587.36 & 1391.67 & -584.79 \\
\hline 1562 & 1292.98 & 885.42 & 557.99 & 886.11 & -303.47 \\
\hline
\end{tabular}

Note 1: Meridonal, Hoop, and Shear Stresses are Reversed in Highlighted Sections $\frac{\text { (Floor) }}{}$ 
RPP-RPT-32239, Rev. 1

M\&D-2008-005-CALC-001, Rev. 1

Table I.9. BES-FCC Primary Tank Stresses, Shell Bottom, Gravity Plus Seismic Load

\section{AP Primary Tank, Best Estimate Soil, Horizontal and Vertical Seismic, Fully Cracked Tank Concrete, 460 in. Waste Level at $1.83 \mathrm{SpG}$}

\begin{tabular}{|c|c|c|c|c|c|}
\hline \multirow{2}{*}{$\begin{array}{c}\text { M\&D } \\
\text { Starting } \\
\text { M\&D } \\
\text { Element } \\
\text { No. }\end{array}$} & \multirow[b]{2}{*}{ Path (in.) } & \multicolumn{4}{|c|}{ Shell Bottom Surface (outside - away from waste) } \\
\hline & & $\begin{array}{c}\text { AP-460-BES-FCC } \\
\text { Seismic Hoop Stress } \\
\text { (lbs/in^2) Bot }\end{array}$ & $\begin{array}{l}\text { AP-460-BES-FCC } \\
\text { Seismic Meridional } \\
\text { Stress (lbs/in^2) Bot }\end{array}$ & $\begin{array}{l}\text { AIP-460-BES-FCC } \\
\text { Seismic Stress } \\
\text { Intensity (lbs/in^ } 2 \text { ) } \\
\text { Bot }\end{array}$ & $\begin{array}{l}\text { ATP-460-BES-FCC } \\
\text { Seismic In-Plane } \\
\text { Shear Stress } \\
\text { (lbs/in^ } 2 \text { ) Bot }\end{array}$ \\
\hline 762 & 67.33 & -10444.44 & -11430.56 & 11430.56 & -1067.36 \\
\hline 782 & 105.04 & -9284.72 & -14368.06 & 14368.06 & -1867.36 \\
\hline 802 & 136.24 & -7486.11 & -12687.50 & 12687.50 & -1816.67 \\
\hline 822 & 181.83 & -3688.89 & -10277.78 & 10277.78 & -1513.19 \\
\hline 842 & 225.10 & -5071.53 & -863194 & 8631.94 & -1148.61 \\
\hline 862 & 273.66 & -1871.53 & -6234.72 & 6400.00 & -899.31 \\
\hline 882 & 323.27 & -3005.56 & -5159.03 & 5545.83 & -1013.89 \\
\hline 902 & 369.20 & 2045.83 & -3018.75 & 4856.94 & -1496.53 \\
\hline 922 & 419.20 & 5413.19 & -2303.47 & 5765.28 & -2695.83 \\
\hline 942 & 444.31 & 5428.47 & 8270.83 & 8270.83 & -2785.42 \\
\hline 962 & 458.66 & -9263.89 & -5260.42 & 9270.83 & -2778.47 \\
\hline 982 & 473.08 & -11118.06 & -5947.22 & 11125.00 & -2813.89 \\
\hline 1002 & 484.80 & 4102.08 & 2731.94 & 5839.58 & -2902.78 \\
\hline 1022 & 502.48 & 6057.64 & 3014.58 & 6247.92 & -2914.58 \\
\hline 1042 & 526.48 & 9027.78 & 1209.03 & 9034.72 & -2752.08 \\
\hline 1062 & 550.48 & 11520.83 & 1452.08 & 11520.83 & -2491.67 \\
\hline 1082 & 574.60 & 13729.17 & -1339.58 & 13729.17 & -2184.72 \\
\hline 1102 & 598.28 & 16527.78 & 1790.28 & 16527.78 & -1834.03 \\
\hline 1122 & 621.38 & 18638.89 & -1564.58 & 18645.83 & -1445.83 \\
\hline 1142 & 644.48 & 21076.39 & 1812.50 & 21076.39 & 1062.50 \\
\hline 1162 & 667.63 & 22965.28 & 2334.03 & 22965.28 & -884.03 \\
\hline 1182 & 690.78 & 22680.56 & -1590.97 & 22680.56 & -705.56 \\
\hline 1202 & 713.88 & 24111.11 & -1527.08 & 24111.11 & 808.33 \\
\hline 1222 & 736.98 & 26187.50 & 2019.44 & 26187.50 & 1060.42 \\
\hline 1242 & 760.13 & 26055.56 & 2418.06 & 26062.50 & 1415.97 \\
\hline 1262 & 782.53 & 22180.56 & -1588.19 & 23041.67 & 1341.67 \\
\hline 1282 & 804.13 & 21805.56 & -1063.89 & 21812.50 & 1668.75 \\
\hline 1302 & 825.73 & 22965.28 & 796.53 & 22972.22 & 1992.36 \\
\hline 1322 & 847.33 & 24256.94 & -856.94 & 24472.22 & 2325.00 \\
\hline 1342 & 868.87 & 26569.44 & 4100.00 & 26569.44 & 2644.44 \\
\hline 1362 & 892.10 & 20375.00 & 4975.69 & 20375.00 & 2417.36 \\
\hline 1382 & 909.20 & 12958.33 & 15159.72 & 15166.67 & 2220.14 \\
\hline 1402 & 918.38 & 5990.97 & -8263.89 & 8305.56 & 2242.36 \\
\hline 1460 & 930.48 & -8006.94 & -14625.00 & 14701.39 & 2381.94 \\
\hline 1442 & 949.48 & 4381.25 & -163472 & 5572.92 & -2213.89 \\
\hline 1462 & 990.98 & 4181.94 & 1375.69 & 6393.06 & -3187.50 \\
\hline 1482 & 1050.98 & 3180.56 & 859.03 & 2865.28 & -2119.44 \\
\hline 1502 & 1110.98 & 2571.53 & 92083 & 2865.28 & -1431.25 \\
\hline 1522 & 1170.98 & 1869.44 & 571.46 & 1894.44 & -934.72 \\
\hline 1542 & 1230.98 & 1440.97 & 73264 & 1441.67 & -590.42 \\
\hline 1562 & 1292.98 & 845.83 & 49160 & 847.22 & -298.40 \\
\hline
\end{tabular}

Note 1: Meridonal, Hoop, and Shear Stresses are Reversed in Highlighted Sections (Floor) 
RPP-RPT-32239, Rev. 1

M\&D-2008-005-CALC-001, Rev. 1

Table I.10. BES-FCC Primary Tank Stresses, Shell Top, Seismic Load Only

AP Primary Tank, Best Estimate Soil, Horizontal and Vertical Seismic, Fully Cracked Tank Concrete, 460 in. Waste Level at $1.83 \mathrm{SpG}$

\begin{tabular}{|c|c|c|c|c|c|}
\hline \multirow[b]{2}{*}{$\begin{array}{c}\text { M\&D } \\
\text { Starting } \\
\text { M\&D } \\
\text { Element } \\
\text { No. }\end{array}$} & \multirow[b]{2}{*}{ Path (in.) } & \multicolumn{4}{|c|}{ Shell Top Surface (inside - waste side) } \\
\hline & & $\begin{array}{l}\text { AP-460-BES-FCC } \\
\text { Seismic Only Hoop } \\
\text { Stress (lbs/in^2) Top }\end{array}$ & $\begin{array}{l}\text { AP-460-BES-FCC } \\
\text { Seismic Only } \\
\text { Meridional Stress } \\
\left(\text { lbs/in^}{ }^{\wedge} 2\right) \text { Top }\end{array}$ & $\begin{array}{c}\text { AP-460-BES-FCC } \\
\text { Seismic Only Stress } \\
\text { Intensity (lbs/in^2) } \\
\text { Top }\end{array}$ & $\begin{array}{c}\text { AP-460-BES-FCC } \\
\text { Seismic Only In-Plane } \\
\text { Shear Stress } \\
\text { (lbs/in^ }{ }^{\wedge} \text { 2) Top }\end{array}$ \\
\hline 762 & 67.33 & 3352.78 & 3381.94 & 3381.94 & 1219.64 \\
\hline 782 & 105.04 & 3484.72 & 3686.11 & 3678.47 & 2010.26 \\
\hline 802 & 136.24 & 2675.00 & 3881.94 & 3881.94 & 1961.98 \\
\hline 822 & 181.83 & 1639.79 & 2956.25 & 2950.00 & 1599.81 \\
\hline 842 & 225.10 & 265625 & 302014 & 3429.86 & 1181.72 \\
\hline 862 & 273.66 & 1612.50 & 1830.56 & 1829.86 & 909.85 \\
\hline 882 & 323.27 & 2345.07 & 1827.08 & 3730.56 & 1015.04 \\
\hline 902 & 369.20 & 1914.93 & 1737.36 & 234111 & 1495.04 \\
\hline 922 & 419.20 & 3193.06 & 979.86 & 4177.78 & 2690.08 \\
\hline 942 & 444.31 & 5153.47 & 3482.64 & 2695.83 & 2687.42 \\
\hline 962 & 458.66 & 7381.94 & 5522.22 & 11313.19 & 2683.31 \\
\hline 982 & 473.08 & 777431 & 678681 & 1368958 & 2894.91 \\
\hline 1002 & 484.80 & 4479.86 & 1423.40 & 4243.75 & 3040.32 \\
\hline 1022 & 502.48 & 2760.28 & 900.00 & 3604.86 & 2982.06 \\
\hline 1042 & 526.48 & 5182.43 & 1136.04 & 4358.33 & 2763.93 \\
\hline 1062 & 550.48 & 6232.71 & 1293.01 & 510139 & 2502.80 \\
\hline 1082 & 574.60 & 7299.31 & 1493.61 & 6050.00 & 2198.60 \\
\hline 1102 & 598.28 & 8420.83 & 1448.75 & 7140.97 & 1847.19 \\
\hline 1122 & 621.38 & 9265.97 & 1655.49 & 7902.08 & 1456.89 \\
\hline 1142 & 644.48 & 9982.64 & 163951 & 8527.78 & 1083.41 \\
\hline 1162 & 667.63 & 10235.42 & 1532.64 & 8957.64 & 908.94 \\
\hline 1182 & 690.78 & 9881.25 & 1714.17 & 8937.50 & 724.91 \\
\hline 1202 & 713.88 & 9862.50 & 1547.43 & 9097.22 & 810.40 \\
\hline 1222 & 736.98 & 10004.17 & 1282.43 & 900000 & 1062.64 \\
\hline 1242 & 760.13 & 9375.00 & 1129.03 & 8500.00 & 1432.77 \\
\hline 1262 & 782.53 & 8062.50 & 140667 & 7868.06 & 1365.38 \\
\hline 1282 & 804.13 & 7326.39 & 101639 & 7250.00 & 1670.95 \\
\hline 1302 & 825.73 & 7250.00 & 821.03 & 7208.33 & 1987.65 \\
\hline 1322 & 847.33 & 7569.44 & 943.26 & 7569.44 & 2313.16 \\
\hline 1342 & 868.87 & 7236.11 & 1528.75 & 818750 & 2677.98 \\
\hline 1362 & 892.10 & 4152.78 & 2436.18 & 5965.28 & 2589.26 \\
\hline 1382 & 909.20 & 2141.67 & 6054.86 & 6076.39 & 2513.89 \\
\hline 1402 & 918.38 & 3242.85 & 7231.94 & 3376.39 & 2449.30 \\
\hline 1422 & 930.48 & 3643.75 & 566181 & 5500.00 & 2426.94 \\
\hline 1442 & 949.48 & 4879.58 & 2092.43 & 4436.11 & 2283.08 \\
\hline 1462 & 990.98 & 3614.79 & 1355.28 & 5526.39 & 3151.20 \\
\hline 1482 & 1050.98 & 2899.31 & 706.53 & 229167 & 2131.65 \\
\hline 1502 & 1110.98 & 2095.42 & 678.54 & 229167 & 1407.20 \\
\hline 1522 & 1170.98 & 164236 & 532.29 & 1643.40 & 950.46 \\
\hline 1542 & 1230.98 & 1012.43 & 465,85 & 879.72 & 571.41 \\
\hline 1562 & 1292.98 & $644.5 B$ & 420.69 & 654.10 & 309.06 \\
\hline
\end{tabular}


RPP-RPT-32239, Rev. 1

M\&D-2008-005-CALC-001, Rev. 1

Table I.11. BES-FCC Primary Tank Stresses, Shell Middle, Seismic Load Only

AP Primary Tank, Best Estimate Soil, Horizontal and Vertical Seismic, Fully Cracked Tank Concrete, 460 in. Waste Level at $1.83 \mathrm{SpG}$

\begin{tabular}{|c|c|c|c|c|c|}
\hline \multirow[b]{2}{*}{$\begin{array}{c}\text { M\&D } \\
\text { Starting } \\
\text { M\&D } \\
\text { Element } \\
\text { No. }\end{array}$} & \multirow[b]{2}{*}{ Path (in.) } & \multicolumn{4}{|c|}{ Shell Mid-Plane } \\
\hline & & $\begin{array}{c}\text { AP-460-BES-FCC } \\
\text { Seismic Only Hoop } \\
\text { Stress (lbs/in^2) Mid }\end{array}$ & $\begin{array}{l}\text { AP-460-BES-FCC } \\
\text { Seismic Only } \\
\text { Meridional Stress } \\
\text { (lbs/in^2) Mid }\end{array}$ & $\begin{array}{l}\text { AP-460-BES-FCC } \\
\text { Seismic Only Stress } \\
\text { Intensity (lbs/in^2) } \\
\text { Mid }\end{array}$ & \begin{tabular}{|c|} 
AP-460-BES-FCC \\
Seismic Only In-Plane \\
Shear Stress \\
(lbs/in^2) Mid
\end{tabular} \\
\hline 762 & 67.33 & 3700.00 & 299375 & 2945.14 & 1143.22 \\
\hline 782 & 105.04 & 368681 & 3919.44 & 387778 & 1936.58 \\
\hline 802 & 136.24 & 2862.50 & 3566.67 & 3528.47 & 1888.40 \\
\hline 822 & 181.83 & 1538.89 & 2990.28 & 2970.14 & 1557.22 \\
\hline 842 & 225.10 & 3047.92 & 2383.33 & 2372.22 & 1166.35 \\
\hline 862 & 273.66 & 1484.03 & 1739.58 & 1738.19 & 905.41 \\
\hline 882 & 323.27 & 2699.86 & 1350.69 & 2824.31 & 1015.11 \\
\hline 902 & 369.20 & 1921.25 & 1313.19 & 1907.64 & 1496.36 \\
\hline 922 & 419.20 & 3453.47 & 1370.76 & 3574.31 & 2692.14 \\
\hline 942 & 444.31 & 3852.78 & 1135.35 & 3664.58 & 2736.24 \\
\hline 962 & 458.66 & 8477.08 & 1060.56 & 7978.47 & 2730.59 \\
\hline 982 & 473.08 & 9553.68 & 951.58 & 9462.99 & 2853.88 \\
\hline 1002 & 484.80 & 4127.78 & 916.72 & 4297.22 & 2971.50 \\
\hline 1022 & 502.48 & 3142.57 & 1017.22 & 3320.83 & 2948.70 \\
\hline 1042 & 526.48 & 5210.97 & 1166.64 & 4364.58 & 2758.39 \\
\hline 1062 & 550.48 & 6251.81 & 1305.33 & 5148.61 & 2497.25 \\
\hline 1082 & 574.60 & 7288.89 & 143370 & 5978.47 & 2191.67 \\
\hline 1102 & 598.28 & 8478.47 & 1542.50 & 7071.53 & 1840.26 \\
\hline 1122 & 621.38 & 9284.72 & 1631.67 & 7835.42 & 1451.34 \\
\hline 1142 & 644.48 & 10012.50 & 1697.27 & 8505.56 & 1072.98 \\
\hline 1162 & 667.63 & 10335.42 & 1737.19 & 8937.50 & 896.45 \\
\hline 1182 & 690.78 & 9831.25 & 1535.83 & 8798.61 & 715.19 \\
\hline 1202 & 713.88 & 9864.58 & 1522.26 & 8993.06 & 809.69 \\
\hline 1222 & 736.98 & 10080.56 & 1482.35 & 9298.61 & 1061.25 \\
\hline 1242 & 760.13 & 9506.94 & 1418.82 & 8930.56 & 1424.44 \\
\hline 1262 & 782.53 & 7923.61 & 977.15 & 7583.33 & 1353.59 \\
\hline 1282 & 804.13 & 7298.61 & 900.68 & 7062.50 & 1669.57 \\
\hline 1302 & 825.73 & 7229.17 & 813.09 & 7138.89 & 1989.74 \\
\hline 1322 & 847.33 & 7451.39 & 713.56 & 7416.67 & 2319.38 \\
\hline 1342 & 868.87 & 7548.61 & 588.26 & 7493.06 & 2660.75 \\
\hline 1362 & 892.10 & 4708.33 & 408.29 & 4673.61 & 2502.82 \\
\hline 1382 & 909.20 & 2641.67 & 404.91 & 2818.75 & 2366.70 \\
\hline 1402 & 918.38 & 4343.06 & 385.83 & 4476.39 & 2345.89 \\
\hline 1422 & 930.48 & 4486.04 & 567.43 & 4468.06 & 2394.72 \\
\hline 1442 & 949.48 & 4272.22 & 628.06 & 4353.47 & 2225.27 \\
\hline 1462 & 990.98 & 3612.78 & 979.86 & 5689.58 & 3166.88 \\
\hline 1482 & 1050.98 & 2801.81 & 582.74 & 2415.21 & 2118.67 \\
\hline 1502 & 1110.98 & 2131.94 & 337.78 & 2415.21 & 1420.95 \\
\hline 1522 & 1170.98 & 1558.40 & 273.89 & 1535.14 & 938.05 \\
\hline 1542 & 1230.98 & 1047.22 & 223.13 & 1028.19 & 582.94 \\
\hline 1562 & 1292.98 & 579.51 & 191.67 & 520.83 & 298.58 \\
\hline
\end{tabular}


RPP-RPT-32239, Rev. 1

M\&D-2008-005-CALC-001, Rev. 1

Table I.12. BES-FCC Primary Tank Stresses, Shell Bottom, Seismic Load Only

AP Primary Tank, Best Estimate Soil, Horizontal and Vertical Seismic, Fully Cracked Tank Concrete, 460 in. Waste Level at

1.83 SpG

\begin{tabular}{|c|c|c|c|c|c|}
\hline \multirow[b]{2}{*}{$\begin{array}{c}\text { M\&D } \\
\text { Starting } \\
\text { M\&D } \\
\text { Element } \\
\text { No. }\end{array}$} & \multirow[b]{2}{*}{ Path (in.) } & \multicolumn{4}{|c|}{ Shell Bottom Surface (outside - away from waste) } \\
\hline & & $\begin{array}{l}\text { AP-460-BES-FCC } \\
\text { Seismic Only Hoop } \\
\text { Stress (lbs/in^2) Bot }\end{array}$ & $\begin{array}{l}\text { AP-460-BES-FCC } \\
\text { Seismic Only } \\
\text { Meridional Stress } \\
\text { (lbs/in^2) Bot }\end{array}$ & $\begin{array}{c}\text { AP-460-BES-FCC } \\
\text { Seismic Only Stress } \\
\text { Intensity (lbs/in^2) } \\
\text { Bot }\end{array}$ & $\begin{array}{c}\text { AP-460-BES-FCC } \\
\text { Seismic Only In-Plane } \\
\text { Shear Stress } \\
\text { (lbs/in^2) Bot }\end{array}$ \\
\hline 762 & 67.33 & 4042.36 & 3132.64 & 3129.17 & 1067.49 \\
\hline 782 & 105.04 & 3890.28 & 4319.44 & 4284.03 & 1862.20 \\
\hline 802 & 136.24 & 3054.86 & 3406.25 & 339375 & 1815.51 \\
\hline 822 & 181.83 & 1438.89 & 3069.44 & 3056.94 & 1514.63 \\
\hline 842 & 225.10 & 3439.58 & 2552.78 & 2552.08 & 1151.66 \\
\hline 862 & 273.66 & 1355.14 & 1829.17 & 1825.00 & 900.96 \\
\hline 882 & 323.27 & 3054.65 & 2182.64 & 1938.89 & 1015.19 \\
\hline 902 & 369.20 & 1927.57 & 1030.56 & 2106.94 & 1497.68 \\
\hline 922 & 419.20 & 3713.19 & 2225.69 & 3193.75 & 2694.20 \\
\hline 942 & 444.31 & 2609.03 & 5722.92 & 5268.06 & 2784.37 \\
\hline 962 & 458.66 & 9649.03 & 3838.89 & 746181 & 2777.88 \\
\hline 982 & 473.08 & 11334.86 & 4924.31 & 9883.33 & 2813.54 \\
\hline 1002 & 484.80 & 3784.03 & 2258.96 & 4003.47 & 2902.67 \\
\hline 1022 & 502.48 & 3524.86 & 2912.92 & 3127.78 & 2914.64 \\
\hline 1042 & 526.48 & 5240.14 & 1208.32 & 4365.28 & 2752.15 \\
\hline 1062 & 550.48 & 6270.21 & 1316.88 & 5148.61 & 2491.71 \\
\hline 1082 & 574.60 & 7278.54 & 1373.68 & 601736 & 2184.74 \\
\hline 1102 & 598.28 & 8543.06 & 16.35 .49 & 7106.25 & 1834.02 \\
\hline 1122 & 621.38 & 9296.53 & 16.07 .82 & 7823.61 & 1445.80 \\
\hline 1142 & 644.48 & 10049.31 & 1755.72 & 8511.11 & 1062.55 \\
\hline 1162 & 667.63 & 10435.42 & 194139 & 8983.33 & 883.95 \\
\hline 1182 & 690.78 & 9781.94 & 1357.92 & 8613.89 & 705.47 \\
\hline 1202 & 713.88 & 9867.36 & 1496.39 & 8847.22 & 808.30 \\
\hline 1222 & 736.98 & 10156.94 & 1682.01 & 9416.67 & 1060.34 \\
\hline 1242 & 760.13 & 9631.94 & 1711.81 & 9125.00 & 1416.11 \\
\hline 1262 & 782.53 & 7790.97 & 673.68 & 7423.61 & 1341.79 \\
\hline 1282 & 804.13 & 7270.83 & 788.47 & 6722.22 & 1668.89 \\
\hline 1302 & 825.73 & 7243.06 & 815.57 & 7173.61 & 1992.53 \\
\hline 1322 & 847.33 & 7361.11 & 529.24 & 7152.78 & 2324.90 \\
\hline 1342 & 868.87 & 7972.22 & 26.02 .08 & 7895.83 & 2644.60 \\
\hline 1362 & 892.10 & 5263.89 & 2331.88 & 5263.89 & 2417.40 \\
\hline 1382 & 909.20 & 3652.78 & 5541.67 & 5548.61 & 2220.21 \\
\hline 1402 & 918.38 & 6404.10 & 6460.28 & 2893.06 & 2242.47 \\
\hline 1422 & 930.48 & 5704.17 & 5372.22 & 5305.56 & 2371.74 \\
\hline 1442 & 949.48 & 4430.56 & 2927.08 & 4278.47 & 2168.10 \\
\hline 1462 & 990.98 & 3713.06 & 839.24 & 5853.75 & 3181.86 \\
\hline 1482 & 1050.98 & 2767.71 & 948.82 & 2515.56 & 2104.99 \\
\hline 1502 & 1110.98 & 2219.31 & 608.06 & 2515.56 & 1434.00 \\
\hline 1522 & 1170.98 & 1519.86 & 512.26 & 1392.29 & 926.33 \\
\hline 1542 & 1230.98 & 1130.83 & 476.81 & 1131.11 & 594.46 \\
\hline 1562 & 1292.98 & 527.71 & 403.05 & 396.53 & 288.10 \\
\hline
\end{tabular}


RPP-RPT-32239, Rev. 1

M\&D-2008-005-CALC-001, Rev. 1

Table I.13. BES-FCC Anchor Bolt Forces, Gravity Load Only

\begin{tabular}{|c|c|c|c|c|c|c|c|c|c|c|c|}
\hline \multicolumn{12}{|c|}{\begin{tabular}{|l} 
AP Primary Tank, Best \\
460 i \\
ANSYS MAXIMUMS BY RADIUS
\end{tabular}} \\
\hline $\begin{array}{c}\text { M\&D } \\
\text { J-Bolt } \\
\text { Radius No. }\end{array}$ & $\begin{array}{l}\text { Mean } \\
\text { J-Bolt } \\
\text { Radius }\end{array}$ & \multicolumn{2}{|c|}{$\begin{array}{l}\text { Radius of J-Bolts } \\
\text { Included }\end{array}$} & $\begin{array}{c}\text { Average } \\
\text { Bolts per } \\
\text { Element } \\
\end{array}$ & \begin{tabular}{|c} 
Tiln AXIal \\
Force (kip) \\
BES-FCC \\
Gravity \\
Only
\end{tabular} & \begin{tabular}{|c|} 
vlax AXlai \\
Force (kip) \\
BES-FCC \\
Gravity \\
Only \\
\end{tabular} & $\begin{array}{l}\text { Shear } \\
\text { Force1 } \\
\text { (kip) BES- } \\
\text { FCC } \\
\text { Gravity } \\
\end{array}$ & $\begin{array}{l}\text { Maximum } \\
\text { Shear Force1 } \\
\text { Model Angle } \\
\end{array}$ & $\begin{array}{c}\text { Shear Force2 } \\
\text { (kip) BES- } \\
\text { FCC Gravity } \\
\text { Only }\end{array}$ & $\begin{array}{c}\text { Maximum } \\
\text { Shear Force2 } \\
\text { Model Angle } \\
\end{array}$ & $\begin{array}{l}\text { Total } \\
\text { Shear } \\
\text { (kip) BES } \\
\text { FCC } \\
\text { Gravity }\end{array}$ \\
\hline$\overline{\text { Radius 2 }}$ & 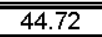 & 22.36 & 67.29 & 0.55 & -0.105 & -0.089 & 0.005 & 45 & 0.739 & \begin{tabular}{|c|}
90 \\
\end{tabular} & 0.739 \\
\hline Radius 3 & 89.87 & 67.29 & 104.93 & 0.89 & -0.081 & -0.073 & 0.015 & 63 & 0.834 & 90 & 0.834 \\
\hline Radius 4 & 120.00 & 104.93 & 135.98 & 1.03 & -0.018 & -0.014 & 0.023 & 63 & 0.458 & 0 & 0.458 \\
\hline Radius 5 & 151.97 & 135.98 & 181.01 & 1.97 & -0.051 & -0.048 & 0.024 & 63 & 0.248 & 9 & 0.248 \\
\hline Radius 6 & 210.05 & 181.01 & 223.79 & 2.41 & -0.044 & -0.043 & 0.009 & 72 & 1.299 & 90 & 1.299 \\
\hline Radius 7 & 237.53 & 223.79 & 270.98 & 3.30 & 0.042 & 0.043 & 0.006 & 144 & 1.852 & 90 & 1.852 \\
\hline Radius 8 & 304.43 & 270.98 & 318.74 & 4.04 & -0.104 & -0.104 & 0.003 & 144 & 2.133 & 45 & 2.133 \\
\hline Radius 9 & 333.05 & 318.74 & 361.64 & 4.37 & 0.056 & 0.057 & 0.001 & 126 & 2.256 & 36 & 2.256 \\
\hline Radius 10 & 390.22 & 361.64 & 406.24 & 5.36 & -0.223 & -0.219 & 0.001 & 63 & 2.434 & 0 & 2.434 \\
\hline Radius 11 & 422.26 & 406.24 & 431.63 & 3.60 & 0.658 & 0.664 & 0.001 & 126 & 2.659 & 0 & 2.659 \\
\hline $\begin{array}{c}\text { M\&D } \\
\text { J-Bolt } \\
\text { Radius No. }\end{array}$ & $\begin{array}{l}\text { Mean } \\
\text { J-Bolt } \\
\text { Radius }\end{array}$ & $\begin{array}{r}\text { Radius } \\
\text { Inc }\end{array}$ & $\begin{array}{l}\text {-Bolts } \\
\text { ed }\end{array}$ & $\begin{array}{l}\text { Average } \\
\text { Bolts per } \\
\text { Element }\end{array}$ & $\begin{array}{c}\text { Bolt Angle } \\
\text { (Rad) }\end{array}$ & $\begin{array}{l}\text { Shear } \\
\text { Stiffness } \\
\text { (kip/t) }\end{array}$ & $\begin{array}{c}\text { Axial } \\
\text { Stiffness } \\
\text { (kip/ft) }\end{array}$ & $\begin{array}{l}\text { Shear Disp } \\
\text { BES-FCC- } \\
\text { Gravity Only }\end{array}$ & $\begin{array}{c}\text { Axial Min Disp } \\
\text { BES-FCC- } \\
\text { Gravity Only }\end{array}$ & $\begin{array}{c}\text { Axial Max Disp } \\
\text { BES-FCC- } \\
\text { Gravity Only }\end{array}$ & \\
\hline Radius 2 & 444.72 & 22.36 & 67.29 & 0.55 & 0.0351 & $\overline{780}$ & $\overline{780}$ & 0.01137 & -0.00161 & -0.00136 & \\
\hline Radius 3 & 89.87 & 67.29 & 104.93 & 0.89 & 0.0715 & 780 & 780 & 0.01283 & -0.00125 & -0.00113 & \\
\hline Radius 4 & 120.00 & 104.93 & 135.98 & 1.03 & 0.0968 & 780 & 780 & 0.00705 & -0.00028 & -0.00021 & \\
\hline Radius 5 & 151.97 & 135.98 & 181.01 & 1.97 & 0.1252 & 780 & 780 & 0.00382 & -0.00079 & -0.00074 & \\
\hline Radius 6 & 210.05 & 181.01 & 223.79 & 2.41 & 0.1825 & 780 & 780 & 0.01999 & -0.00068 & -0.00066 & \\
\hline Radius 7 & 237.53 & 223.79 & 270.98 & 3.30 & 0.2136 & 780 & 780 & 0.02850 & 0.00065 & 0.00067 & \\
\hline Radius 8 & 304.43 & 270.98 & 318.74 & 4.04 & 0.3076 & 780 & 780 & 0.03282 & -0.00161 & -0.00160 & \\
\hline Radius 9 & 333.05 & 318.74 & 361.64 & 4.37 & 0.3613 & 780 & 780 & 0.03471 & 0.00086 & 0.00088 & \\
\hline Radius 10 & 390.22 & 361.64 & 406.24 & 5.36 & 0.5235 & 780 & 780 & 0.03745 & -0.00344 & -0.00336 & \\
\hline Radius 11 & 460.26 & 406.24 & 431.63 & 3.60 & 0.6938 & 780 & 780 & 0.04091 & 0.01013 & 0.01022 & \\
\hline
\end{tabular}


RPP-RPT-32239, Rev. 1

M\&D-2008-005-CALC-001, Rev. 1

Table I.14. BES-FCC Anchor Bolt Forces, Gravity Plus Seismic Loads

\begin{tabular}{|c|c|c|c|c|c|c|c|c|c|c|c|}
\hline \multicolumn{12}{|c|}{$\begin{array}{l}\text { AP Primary Tank, Best Estimate Soil, Horizontal and Vertical Seismic Input, Fully } \\
\text { Cracked Tank Concrete, } 460 \text { in. Waste Level at } 1.83 \text { SpG Seismic } \\
\text { ANSYS MAXIMUMS BY RADIUS }\end{array}$} \\
\hline $\begin{array}{c}\text { M\&D } \\
\text { J-Bolt } \\
\text { Radius No. }\end{array}$ & $\begin{array}{l}\text { Mean } \\
\text { J-Bolt } \\
\text { Radius }\end{array}$ & $\begin{array}{r}\text { Radius } 0 \\
\text { Incl }\end{array}$ & $\begin{array}{l}\text { f J-Bolts } \\
\text { uded }\end{array}$ & $\begin{array}{l}\text { Average } \\
\text { Bolts per } \\
\text { Element }\end{array}$ & \begin{tabular}{|c} 
Min Axial \\
Force (kip) \\
BES-FCC
\end{tabular} & $\begin{array}{c}\text { Max Axial } \\
\text { Force (kip) } \\
\text { BES-FCC } \\
\end{array}$ & $\begin{array}{c}\text { Shear } \\
\text { Force1 (kip) } \\
\text { BES-FCC } \\
\end{array}$ & $\begin{array}{c}\text { Maximum } \\
\text { Shear Force1 } \\
\text { Model Angle } \\
\end{array}$ & $\begin{array}{r}\text { Shear Force2 } \\
\text { (kip) BES-FCC }\end{array}$ & \begin{tabular}{|c|} 
Maximum \\
Shear Force2 \\
Model Angle \\
\end{tabular} & $\begin{array}{l}\text { Total } \\
\text { Shear } \\
\text { (kip) BES } \\
\text { FCC }\end{array}$ \\
\hline Radius 2 & $=44.72$ & $\overline{22.36}$ & 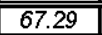 & 0.55 & -0.307 & $\begin{array}{c}-0.027 \\
\end{array}$ & $\begin{array}{l}1.302 \\
\end{array}$ & 90 & 2.184 & 180 & $\begin{array}{l}2.184 \\
\end{array}$ \\
\hline Radius 3 & 89.87 & 67.29 & 104.93 & 0.89 & -0.265 & -0.015 & 0.907 & 90 & 2.105 & 0 & 2.141 \\
\hline Radius 4 & 120.00 & 104.93 & 135.98 & 1.03 & -0.317 & 0.019 & 0.708 & 99 & 1.810 & 180 & 1.810 \\
\hline Radius 5 & 151.97 & 135.98 & 181.01 & 1.97 & -0.373 & 0.004 & 0.796 & 99 & 1.623 & 0 & 1.623 \\
\hline Radius 6 & 210.05 & 181.01 & \begin{tabular}{|l|}
223.79 \\
\end{tabular} & 2.41 & -0.127 & -0.012 & 1.200 & 90 & 2.238 & 0 & 2.238 \\
\hline Radius 7 & 237.53 & 223.79 & 270.98 & 3.30 & -0.028 & 0.088 & 1.510 & 90 & 2.827 & 0 & 2.833 \\
\hline Radius 8 & 304.43 & 270.98 & \begin{tabular}{|l|}
318.74 \\
\end{tabular} & 4.04 & -0.173 & 0.154 & 2.292 & 90 & 3.179 & 0 & 3.477 \\
\hline Radius 9 & 333.05 & 318.74 & \begin{tabular}{|l|}
361.64 \\
\end{tabular} & 4.37 & -0.102 & 0.341 & 2.790 & 90 & 3.451 & 0 & 3.948 \\
\hline Radius 10 & 390.22 & 361.64 & 406.24 & 5.36 & -0.567 & 0.513 & 4.047 & 90 & 3.786 & 0 & 5.014 \\
\hline Radius 11 & 422.26 & 406.24 & 431.63 & 3.60 & -0.059 & 1.863 & 5.081 & 90 & 4.418 & 0 & 6.064 \\
\hline $\begin{array}{c}\text { M\&D } \\
\text { J-Bolt } \\
\text { Radius No. }\end{array}$ & $\begin{array}{l}\text { Mean } \\
\text { J-Bolt } \\
\text { Radius }\end{array}$ & $\begin{array}{r}\text { Radius } 0 \\
\text { Incl }\end{array}$ & $\begin{array}{l}\text { f J-Bolts } \\
\text { uded }\end{array}$ & $\begin{array}{l}\text { Average } \\
\text { Bolts per } \\
\text { Element }\end{array}$ & $\begin{array}{c}\text { Bolt Angle } \\
\text { (Rad) }\end{array}$ & $\begin{array}{l}\text { Shear } \\
\text { Stiffness } \\
\text { (kip/ft) }\end{array}$ & $\begin{array}{c}\text { Axial } \\
\text { Stiffness } \\
\text { (kip/ft) }\end{array}$ & $\begin{array}{c}\text { Shear Disp } \\
\text { BES-FCC- } \\
\text { Seismic }\end{array}$ & \begin{tabular}{|c|} 
Axial Min Disp \\
BES-FCC- \\
Seismic
\end{tabular} & $\begin{array}{c}\text { Axial Max Disp } \\
\text { BES-FCC- } \\
\text { Seismic }\end{array}$ & \\
\hline Radius 2 & 44.72 & 22.36 & 67.29 & 0.55 & 0.0351 & 780 & 780 & 0.03360 & -0.00472 & -0.00042 & \\
\hline Radius 3 & 89.87 & 67.29 & 104.93 & 0.89 & 0.0715 & 78 & $7 \varepsilon$ & 0.03293 & -0.00407 & -0.00023 & \\
\hline Radius 4 & 120.00 & 104.93 & \begin{tabular}{|l|}
135.98 \\
\end{tabular} & 1.03 & 0.0968 & 780 & 780 & 0.02784 & -0.00488 & 0.00029 & \\
\hline Radius 5 & 151.97 & 135.98 & 181.01 & 1.97 & 0.1252 & 780 & 780 & 0.02498 & -0.00575 & 0.00007 & \\
\hline Radius 6 & 210.05 & 181.01 & 223.79 & 2.41 & 0.1825 & 780 & 780 & 0.03442 & -0.00195 & -0.00019 & \\
\hline Radius 7 & 237.53 & 223.79 & \begin{tabular}{|l|}
270.98 \\
\end{tabular} & 3.30 & 0.2136 & 780 & 780 & 0.04358 & -0.00044 & 0.00135 & \\
\hline Radius 8 & 304.43 & 270.98 & 318.74 & 4.04 & 0.3076 & 780 & 780 & 0.05349 & -0.00266 & 0.00237 & \\
\hline Radius 9 & 333.05 & 318.74 & 361.64 & 4.37 & 0.3613 & 780 & 780 & 0.06073 & -0.00157 & 0.00525 & \\
\hline Radius 10 & 390.22 & 361.64 & 406.24 & 5.36 & 0.5235 & 780 & 780 & 0.07714 & -0.00873 & 0.00789 & \\
\hline Radius 11 & 460.26 & 406.24 & 431.63 & 3.60 & 0.6938 & 780 & 780 & 0.09329 & -0.00090 & 0.02866 & \\
\hline
\end{tabular}


RPP-RPT-32239, Rev. 1

M\&D-2008-005-CALC-001, Rev. 1

Table I.15. BES-FCC Anchor Bolt Forces, Seismic Load Only

\begin{tabular}{|c|c|c|c|c|c|c|c|c|c|c|c|}
\hline \multicolumn{12}{|c|}{$\begin{array}{l}\text { AP Primary Tank, Best Estimate Soil, Horizontal and Vertical Seismic Input, Fully } \\
\text { Cracked Tank Concrete, } 460 \mathrm{in} \text {. Waste Level at } 1.83 \mathrm{SpG} \text { Seismic Only } \\
\text { ANSYS MAXIMUMS BY RADIUS }\end{array}$} \\
\hline $\begin{array}{l}\text { M\&D } \\
\text { J-Bolt } \\
\text { Radius } \\
\text { No. } \\
\end{array}$ & $\begin{array}{l}\text { Mean } \\
\text { J-Bolt } \\
\text { Radius } \\
\end{array}$ & $\begin{array}{r}\text { Radius } \\
\text { Incl }\end{array}$ & $\begin{array}{l}\text { J-Bolts } \\
\text { ded }\end{array}$ & \begin{tabular}{|c} 
Average \\
Bolts per \\
Element \\
\end{tabular} & $\begin{array}{c}\text { Min Axial } \\
\text { Force (kip) } \\
\text { BES-FCC- } \\
\text { Seismic } \\
\text { Only } \\
\end{array}$ & $\begin{array}{c}\text { Max Axial } \\
\text { Force (kip) } \\
\text { BES-FCC- } \\
\text { Seismic } \\
\text { Only } \\
\end{array}$ & \begin{tabular}{|} 
Shear \\
Force1 (kip) \\
BES-FCC- \\
Seismic Only \\
\end{tabular} & $\begin{array}{c}\text { Maximum } \\
\text { Shear Force1 } \\
\text { Model Angle } \\
\end{array}$ & \begin{tabular}{|c|} 
Shear Force2 \\
(kip) BES- \\
FCC-Seismic \\
Only
\end{tabular} & $\begin{array}{c}\text { Maximum } \\
\text { Shear Force2 } \\
\text { Model Angle } \\
\end{array}$ & $\begin{array}{l}\text { Total Shear } \\
\text { (kip) BES- } \\
\text { FCC- } \\
\text { Seismic } \\
\text { Only } \\
\end{array}$ \\
\hline Radius 2 & 444.72 & 22.36 & 67.29 & 0.55 & -0.202 & 0.061 & 1.298 & 108 & 1.445 & 0 & 1.942 \\
\hline Radius 3 & 89.87 & 67.29 & 104.93 & 0.89 & -0.184 & 0.058 & 0.892 & 108 & 1.271 & 0 & 1.552 \\
\hline Radius 4 & 120.00 & 104.93 & 135.98 & 1.03 & -0.299 & 0.032 & 0.685 & 108 & 1.352 & 0 & 1.515 \\
\hline Radius 5 & 151.97 & 135.98 & 181.01 & 1.97 & -0.322 & 0.052 & 0.772 & 108 & 1.375 & 0 & 1.577 \\
\hline Radius 6 & 210.05 & 181.01 & 223.79 & 2.41 & -0.082 & 0.030 & 1.191 & 108 & 0.938 & 144 & 1.516 \\
\hline $\begin{array}{l}\text { Radius } 7 \\
\end{array}$ & 237.53 & 223.79 & 270.98 & 3.30 & -0.070 & 0.045 & 1.504 & 90 & 0.975 & 135 & 1.792 \\
\hline Radius 8 & 304.43 & 270.98 & 318.74 & 4.04 & -0.068 & 0.258 & 2.289 & 117 & 1.045 & 117 & 2.516 \\
\hline Radius 9 & 333.05 & 318.74 & 361.64 & 4.37 & -0.158 & 0.284 & 2.789 & 117 & 1.195 & 117 & 3.035 \\
\hline Radius 10 & 390.22 & 361.64 & 406.24 & 5.36 & -0.344 & 0.731 & 4.046 & 108 & 1.352 & 0 & 4.266 \\
\hline Radius 11 & 460.26 & 406.24 & 431.63 & 3.60 & -0.717 & 1.199 & 5.080 & 108 & 1.759 & 0 & 5.376 \\
\hline $\begin{array}{l}\text { M\&D } \\
\text { J-Bolt } \\
\text { Radius } \\
\text { No. } \\
\end{array}$ & $\begin{array}{l}\text { Mean } \\
\text { J-Bolt } \\
\text { Radius }\end{array}$ & $\begin{array}{r}\text { Radius } \\
\text { Incl }\end{array}$ & $\begin{array}{l}\text { J-Bolts } \\
\text { ded }\end{array}$ & $\begin{array}{c}\text { Average } \\
\text { Bolts per } \\
\text { Element }\end{array}$ & $\begin{array}{c}\text { Bolt Angle } \\
\text { (Rad) }\end{array}$ & $\begin{array}{c}\text { Shear } \\
\text { Stiffness } \\
\text { (kip/tt) }\end{array}$ & $\begin{array}{c}\text { Axial } \\
\text { Stiffness } \\
\text { (kip/ft) }\end{array}$ & $\begin{array}{c}\text { Shear Disp } \\
\text { BES-FCC- } \\
\text { Seismic Only }\end{array}$ & \begin{tabular}{|c|} 
Axial Min Disp \\
BES-FCC- \\
Seismic Only
\end{tabular} & $\begin{array}{l}\text { Axial Max Disp } \\
\text { BES-FCC- } \\
\text { Seismic Only }\end{array}$ & \\
\hline Radius 2 & 44.72 & 22.36 & 67.29 & 0.55 & 0.0351 & 780 & 780 & 0.02988 & -0.00310 & 0.00095 & \\
\hline Radius 3 & 89.87 & 67.29 & 104.93 & 0.89 & 0.0715 & 780 & 780 & 0.02388 & -0.00283 & 0.00090 & \\
\hline Radius 4 & 120.00 & 104.93 & 135.98 & 1.03 & 0.0968 & 780 & 780 & 0.02331 & -0.00460 & 0.00050 & \\
\hline Radius 5 & 151.97 & 135.98 & 181.01 & 1.97 & 0.1252 & 780 & 780 & 0.02426 & -0.00496 & 0.00080 & \\
\hline Radius 6 & 210.05 & 181.01 & 223.79 & 2.41 & 0.1825 & 780 & 780 & 0.02332 & $\begin{array}{l}-0.00127 \\
\end{array}$ & 0.00047 & \\
\hline $\begin{array}{l}\text { Radius } 7 \\
\end{array}$ & 237.53 & 223.79 & 270.98 & 3.30 & 0.2136 & 780 & 780 & 0.02758 & -0.00108 & 0.00069 & \\
\hline Radius 8 & 304.43 & 270.98 & 318.74 & 4.04 & 0.3076 & 780 & 780 & 0.03871 & $\begin{array}{l}-0.00105 \\
\end{array}$ & 0.00397 & \\
\hline Radius 9 & 333.05 & 318.74 & 361.64 & 4.37 & 0.3613 & 780 & 780 & 0.04669 & $\begin{array}{l}-0.00243 \\
\end{array}$ & 0.00437 & \\
\hline Radius 10 & 390.22 & 361.64 & 406.24 & 5.36 & 0.5235 & 780 & 780 & 0.06563 & -0.00529 & 0.01125 & \\
\hline Radius 11 & 460.26 & 406.24 & 431.63 & 3.60 & 0.6938 & 780 & 780 & 0.08271 & -0.01103 & 0.01844 & \\
\hline
\end{tabular}


RPP-RPT-32239, Rev. 1

M\&D-2008-005-CALC-001, Rev. 1

Table I.16. BES-FCC Concrete Backed Steel Strain, Shell Top, Gravity Load Only

AP Backed Steel, Best Estimate Soil, Gravity Only, Fully Cracked Tank Concrete, 460 In Waste

Level at $1.83 \mathrm{SpG}$

\begin{tabular}{|c|c|c|c|c|c|c|c|}
\hline \multirow{2}{*}{$\begin{array}{c}\text { M\&D } \\
\text { Starting } \\
\text { M\&D } \\
\text { Element } \\
\text { No. }\end{array}$} & \multirow[b]{2}{*}{ Path (in) } & \multicolumn{6}{|c|}{ Shell Top Surface (inside - towards waste) Gravity } \\
\hline & & $\begin{array}{l}\text { AP-460-BES-FCC } \\
\text { EPEL P1 Strain (in/in) } \\
\text { Gravity Top Min }\end{array}$ & $\begin{array}{c}\text { AP-460-BES-FCC } \\
\text { EPEL P1 Strain (in/in) } \\
\text { Gravity Top Max } \\
\end{array}$ & $\begin{array}{l}\text { AP-460-BES-FCC } \\
\text { EPEL P2 (in/in) } \\
\text { Gravity Top Min } \\
\end{array}$ & $\begin{array}{c}\text { AP-460-BES-FCC } \\
\text { EPEL P2 Strain (in/in) } \\
\text { Gravity Tap Max } \\
\end{array}$ & $\begin{array}{c}\text { AP-460-BES-FCC } \\
\text { EPEL P3 Strain (in/in) } \\
\text { Gravity Tap Min } \\
\end{array}$ & $\begin{array}{c}\text { AP-460-BES-FCC } \\
\text { EPEL P3 Strain (in/in) } \\
\text { Gravity Top Max } \\
\end{array}$ \\
\hline 762 & 67.33 & $1.45 \mathrm{E}-04$ & $1.45 \mathrm{E}-04$ & $-1.48 \mathrm{E}-04$ & $-1.48 \mathrm{E}-04$ & $-1.86 \mathrm{E}-04$ & $-1.85 \mathrm{E}-04$ \\
\hline 782 & 105.04 & 1.67E-04 & $1.67 \mathrm{E}-04$ & $-9.13 E-05$ & $-9.12 \mathrm{E}-05$ & $-2.97 \mathrm{E}-04$ & $-2.96 \mathrm{E}-04$ \\
\hline 802 & 136.24 & $1.40 \mathrm{E}-04$ & $1.40 \mathrm{E}-04$ & $-5.50 \mathrm{E}-05$ & $-5.50 \mathrm{E}-05$ & $-2.68 \mathrm{E}-04$ & $-2.68 \mathrm{E}-04$ \\
\hline 822 & 181.71 & $1.08 \mathrm{E}-04$ & $1.08 \mathrm{E}-04$ & $3.43 \mathrm{E}-06$ & $3.44 \mathrm{E}-06$ & $-2.54 \mathrm{E}-04$ & $-2.54 \mathrm{E}-04$ \\
\hline 842 & 225.10 & 8.01E-05 & $8.02 E-05$ & $4.74 \mathrm{E}-06$ & $4.76 \mathrm{E}-06$ & $-1.90 \mathrm{E}-04$ & $-1.90 \mathrm{E}-04$ \\
\hline 862 & 273.66 & $5.84 \mathrm{E}-05$ & $5.85 \mathrm{E}-05$ & $2.50 \mathrm{E}-05$ & $2.50 \mathrm{E}-05$ & $-1.61 \mathrm{E}-04$ & $-1.61 \mathrm{E}-04$ \\
\hline 882 & 323.27 & $3.73 \mathrm{E}-05$ & $3.73 \mathrm{E}-05$ & $1.75 \mathrm{E}-05$ & $1.75 \mathrm{E}-05$ & $-1.04 \mathrm{E}-04$ & $-1.04 \mathrm{E}-04$ \\
\hline 902 & 369.20 & $4.40 \mathrm{E}-05$ & $4.41 \mathrm{E}-05$ & 1.69E-05 & $1.69 \mathrm{E}-05$ & $-8.30 \mathrm{E}-05$ & $-8.29 \mathrm{E}-05$ \\
\hline 922 & 419.20 & $6.80 \mathrm{E}-05$ & $6.81 \mathrm{E}-05$ & $-9.46 \mathrm{E}-06$ & $-9.45 E-06$ & $-4.57 \mathrm{E}-05$ & $-4.56 \mathrm{E}-05$ \\
\hline 237 & 463.02 & & & & & & \\
\hline 257 & 510.03 & & & & & & \\
\hline 277 & 544.44 & & & & & & \\
\hline 297 & 580.53 & & & & & & \\
\hline 317 & 631.08 & & & & & & \\
\hline 337 & 680.34 & & & & & & \\
\hline 357 & 727.44 & & & & & & \\
\hline 377 & 772.93 & & & & & & \\
\hline 397 & 831.34 & & & & & & \\
\hline 417 & 894.09 & & & & & & \\
\hline 2132 & 925.08 & 2.93E-05 & $2.93 \mathrm{E}-05$ & $-2.84 \mathrm{E}-05$ & $-2.84 \mathrm{E}-05$ & $-3.37 \mathrm{E}-05$ & $-3.37 E-05$ \\
\hline 2122 & 935.67 & $5.42 \mathrm{E}-05$ & $5.42 \mathrm{E}-05$ & $-1.68 \mathrm{E}-05$ & $-1.67 E-05$ & $-2.23 E-05$ & $-2.23 E-05$ \\
\hline 2112 & 944.86 & 9.37E-05 & $9.37 \mathrm{E}-05$ & $-3.39 \mathrm{E}-06$ & $-3.39 \mathrm{E}-06$ & $-2.12 \mathrm{E}-04$ & $-2.12 \mathrm{E}-04$ \\
\hline 477 & 968.95 & & & & & & \\
\hline 497 & 1002.45 & & & & & & \\
\hline 517 & 1042.45 & & & & & & \\
\hline 537 & 1108.60 & & & & & & \\
\hline 557 & 1178.35 & & & & & & \\
\hline 577 & 1227.20 & & & & & & \\
\hline 597 & 1271.50 & & & & & & \\
\hline 617 & 1313.65 & & & & & & \\
\hline 637 & 1360.60 & & & & & & \\
\hline
\end{tabular}


RPP-RPT-32239, Rev. 1

M\&D-2008-005-CALC-001, Rev. 1

Table I.17. BES-FCC Concrete Backed Steel Strain, Shell Middle, Gravity Load Only

AP Backed Steel, Best Estimate Soil, Gravity Only, Fully Cracked Tank Concrete, 460 In Waste Level at 1.83SpG

\begin{tabular}{|c|c|c|c|c|c|c|c|}
\hline \multirow{2}{*}{$\begin{array}{c}\text { M\&D } \\
\text { Starting } \\
\text { M\&D } \\
\text { Element } \\
\text { No. }\end{array}$} & \multirow[b]{2}{*}{ Path (in) } & \multicolumn{6}{|c|}{ Shell Mid-Plane } \\
\hline & & $\begin{array}{c}\text { AP-460-BES-FCC } \\
\text { EPEL P1 Strain (in/in) } \\
\text { Gravity Mid Min }\end{array}$ & $\begin{array}{c}\text { AP-460-BES-FCC } \\
\text { EPEL P1 Strain (in/in) } \\
\text { Gravity Mid Max }\end{array}$ & $\begin{array}{l}\text { AP-460-BES-FCC } \\
\text { EPEL P2 (in/in) } \\
\text { Gravity Mid Min }\end{array}$ & $\begin{array}{l}\text { AP-460-BES-FCC } \\
\text { EPEL P2 Strain (in/in) } \\
\text { Gravity Mid Max }\end{array}$ & $\begin{array}{c}\text { AP-460-BES-FCC } \\
\text { EPEL P3 Strain (in/in) } \\
\text { Gravity Mid Min } \\
\end{array}$ & $\begin{array}{l}\text { AP-460-BES-FCC } \\
\text { EPEL P3 Strain (in/in) } \\
\text { Gravity Mid Max }\end{array}$ \\
\hline 762 & 67.33 & $1.54 \mathrm{E}-04$ & $1.54 \mathrm{E}-04$ & $-4.34 E-05$ & $-4.33 E-05$ & $-4.59 \mathrm{E}-05$ & $-4.59 \mathrm{E}-05$ \\
\hline 782 & 105.04 & 1.67E-04 & $1.67 \mathrm{E}-04$ & $-3.30 \mathrm{E}-05$ & $-3.30 \mathrm{E}-05$ & $-6.59 \mathrm{E}-05$ & $-6.58 \mathrm{E}-05$ \\
\hline 802 & 136.24 & $1.43 \mathrm{E}-04$ & $1.43 \mathrm{E}-04$ & $-3.97 E-05$ & $-3.97 E-05$ & $-5.87 \mathrm{E}-05$ & $-5.87 \mathrm{E}-05$ \\
\hline 822 & 181.71 & $1.05 \mathrm{E}-04$ & $1.05 \mathrm{E}-04$ & $1.36 \mathrm{E}-06$ & $1.37 \mathrm{E}-06$ & $-5.57 \mathrm{E}-05$ & $-5.56 \mathrm{E}-05$ \\
\hline 842 & 225.10 & $8.40 \mathrm{E}-05$ & $8.41 \mathrm{E}-05$ & $3.93 E-06$ & $3.95 \mathrm{E}-06$ & $-4.40 \mathrm{E}-05$ & $-4.40 \mathrm{E}-05$ \\
\hline 862 & 273.66 & $5.67 \mathrm{E}-05$ & $5.67 \mathrm{E}-05$ & $2.45 \mathrm{E}-05$ & $2.45 \mathrm{E}-05$ & $-4.10 \mathrm{E}-05$ & $-4.10 \mathrm{E}-05$ \\
\hline 882 & 323.27 & $4.04 \mathrm{E}-05$ & $4.04 \mathrm{E}-05$ & $1.72 \mathrm{E}-05$ & $1.73 \mathrm{E}-05$ & $-2.90 \mathrm{E}-05$ & $-2.89 \mathrm{E}-05$ \\
\hline 902 & 369.20 & 4.37E-05 & 4.37E-05 & $1.64 \mathrm{E}-05$ & $1.64 \mathrm{E}-05$ & $-2.68 \mathrm{E}-05$ & $-2.68 \mathrm{E}-05$ \\
\hline 922 & 419.20 & $6.78 \mathrm{E}-05$ & $6.79 \mathrm{E}-05$ & $-6.27 \mathrm{E}-06$ & $-6.26 \mathrm{E}-06$ & $-1.97 \mathrm{E}-05$ & $-1.97 \mathrm{E}-05$ \\
\hline 237 & 463.02 & $5.70 \mathrm{E}-05$ & $5.71 \mathrm{E}-05$ & $3.43 E-05$ & $3.44 \mathrm{E}-05$ & $-7.06 \mathrm{E}-05$ & $-7.06 \mathrm{E}-05$ \\
\hline 257 & 510.03 & $8.28 \mathrm{E}-05$ & $8.29 E-05$ & 5.91E-05 & $5.92 E-05$ & $-3.34 \mathrm{E}-04$ & $-3.34 \mathrm{E}-04$ \\
\hline 277 & 544.44 & $1.16 \mathrm{E}-04$ & 1.16E-04 & $7.39 \mathrm{E}-05$ & $7.41 \mathrm{E}-05$ & $-4.83 E-04$ & $-4.82 \mathrm{E}-04$ \\
\hline 297 & 580.53 & $8.16 \mathrm{E}-05$ & $8.16 E-05$ & $-1.09 \mathrm{E}-05$ & $-1.08 E-05$ & $-2.47 \mathrm{E}-04$ & $-2.46 \mathrm{E}-04$ \\
\hline 317 & 631.08 & $9.16 \mathrm{E}-05$ & $9.16 \mathrm{E}-05$ & $-8.64 \mathrm{E}-05$ & $-8.64 \mathrm{E}-05$ & $-2.60 \mathrm{E}-04$ & $-2.60 \mathrm{E}-0.4$ \\
\hline 337 & 680.34 & $1.18 \mathrm{E}-04$ & $1.18 \mathrm{E}-04$ & $-1.12 \mathrm{E}-04$ & $-1.12 \mathrm{E}-04$ & $-3.23 E-04$ & $-3.23 E-04$ \\
\hline 357 & 727.44 & $1.21 \mathrm{E}-04$ & $1.21 \mathrm{E}-04$ & $-1.21 \mathrm{E}-04$ & $-1.21 \mathrm{E}-04$ & $-3.48 \mathrm{E}-04$ & $-3.48 \mathrm{E}-04$ \\
\hline 377 & 772.93 & 1.38E-04 & $1.38 \mathrm{E}-04$ & $-1.28 \mathrm{E}-04$ & $-1.28 \mathrm{E}-04$ & $-3.82 \mathrm{E}-04$ & $-3.82 E-04$ \\
\hline 397 & 831.34 & $1.28 \mathrm{E}-04$ & $1.28 \mathrm{E}-04$ & $-1.13 \mathrm{E}-04$ & $-1.13 \mathrm{E}-04$ & $-3.98 \mathrm{E}-04$ & $-3.98 E-04$ \\
\hline 417 & 894.09 & $5.95 \mathrm{E}-05$ & $5.96 \mathrm{E}-05$ & $-6.40 \mathrm{E}-05$ & $-6.40 \mathrm{E}-05$ & $-1.64 \mathrm{E}-04$ & $-1.64 \mathrm{E}-04$ \\
\hline 2132 & 925.08 & $2.92 \mathrm{E}-05$ & $2.92 \mathrm{E}-05$ & $-1.68 \mathrm{E}-05$ & $-1.68 \mathrm{E}-05$ & $-3.37 \mathrm{E}-05$ & $-3.37 \mathrm{E}-05$ \\
\hline 2122 & 935.67 & $3.01 \mathrm{E}-05$ & $3.01 \mathrm{E}-05$ & $-2.20 \mathrm{E}-05$ & $-2.20 \mathrm{E}-05$ & $-3.08 E-05$ & $-3.08 \mathrm{E}-05$ \\
\hline 2112 & 944.86 & $2.19 \mathrm{E}-05$ & $2.20 \mathrm{E}-05$ & $-3.62 E-06$ & $-3.61 \mathrm{E}-06$ & $-3.56 \mathrm{E}-05$ & $-3.56 \mathrm{E}-05$ \\
\hline 477 & 968.95 & $6.75 E-05$ & $6.75 \mathrm{E}-05$ & $7.27 \mathrm{E}-06$ & $7.29 \mathrm{E}-06$ & $-2.61 \mathrm{E}-04$ & $-2.61 E-04$ \\
\hline 497 & 1002.45 & $2.39 E-04$ & $2.40 \mathrm{E}-04$ & $1.64 \mathrm{E}-05$ & $1.64 \mathrm{E}-05$ & $-7.43 \mathrm{E}-05$ & $-7.42 \mathrm{E}-05$ \\
\hline 517 & 1042.45 & $1.47 \mathrm{E}-05$ & $1.47 \mathrm{E}-05$ & $9.76 E-06$ & $9.77 E-06$ & $-5.55 \mathrm{E}-06$ & $-5.54 E-06$ \\
\hline 537 & 1108.60 & $9.24 \mathrm{E}-06$ & $9.25 \mathrm{E}-06$ & $9.30 \mathrm{E}-07$ & 9.37E-07 & $-2.20 \mathrm{E}-06$ & $-2.19 \mathrm{E}-06$ \\
\hline 557 & 1178.35 & $1.04 \mathrm{E}-05$ & $1.05 \mathrm{E}-05$ & $5.65 \mathrm{E}-06$ & $5.66 \mathrm{E}-06$ & $-3.48 E-06$ & $-3.47 \mathrm{E}-06$ \\
\hline 577 & 1227.20 & 1.15E-05 & 1.15E-05 & $1.12 \mathrm{E}-05$ & $1.12 \mathrm{E}-05$ & $-4.93 E-06$ & $-4.92 \mathrm{E}-06$ \\
\hline 597 & 1271.50 & $1.25 \mathrm{E}-05$ & $1.25 \mathrm{E}-05$ & $1.10 \mathrm{E}-05$ & $1.10 \mathrm{E}-05$ & $-5.09 \mathrm{E}-06$ & $-5.08 E-06$ \\
\hline 617 & 1313.65 & $2.02 E-05$ & $2.02 E-05$ & $8.21 \mathrm{E}-06$ & $8.22 \mathrm{E}-06$ & $-6.16 \mathrm{E}-06$ & $-6.15 \mathrm{E}-06$ \\
\hline 637 & 1360.60 & $6.78 \mathrm{E}-06$ & $6.79 \mathrm{E}-06$ & 3.99E-06 & $4.00 \mathrm{E}-06$ & $-2.21 \mathrm{E}-06$ & $-2.21 \mathrm{E}-06$ \\
\hline
\end{tabular}




\section{RPP-RPT-32239, Rev. 1 \\ M\&D-2008-005-CALC-001, Rev. 1}

Table I.18. BES-FCC Concrete Backed Steel Strain, Shell Bottom, Gravity Load Only

AP Backed Steel, Best Estimate Soil, Gravity Only, Fully Cracked Tank Concrete, 460 In Waste

Level at $1.83 \mathrm{SpG}$

\begin{tabular}{|c|c|c|c|c|c|c|c|}
\hline \multirow{2}{*}{$\begin{array}{c}\text { M\&D } \\
\text { Starting } \\
\text { M\&D } \\
\text { Element } \\
\text { No. }\end{array}$} & \multirow[b]{2}{*}{ Path (in) } & \multicolumn{6}{|c|}{ Shell Bottom Surface (outside - away from waste) Gravity } \\
\hline & & $\begin{array}{c}\text { AP-460-BES-FCC } \\
\text { EPEL P1 Strain (in/in) } \\
\text { Gravity Bot Min }\end{array}$ & \begin{tabular}{|} 
AP-460-BES-FCC \\
EPEL P1 Strain (in/in) \\
Gravity Bot Max
\end{tabular} & $\begin{array}{l}\text { AP-460-BES-FCC } \\
\text { EPEL P2 (in/in) } \\
\text { Gravity Bot Min }\end{array}$ & \begin{tabular}{|} 
AP-460-BES-FCC \\
EPEL P2 Strain (in/in) \\
Gravity Bot Max
\end{tabular} & $\begin{array}{c}\text { AP-460-BES-FCC } \\
\text { EPEL P3 Strain (in/in) } \\
\text { Gravity Bot Min }\end{array}$ & $\begin{array}{c}\text { AP-460-BES-FCC } \\
\text { EPEL P3 Strain (in/in) } \\
\text { Gravity Bot Max }\end{array}$ \\
\hline 762 & 67.33 & $1.64 \mathrm{E}-04$ & $1.64 \mathrm{E}-04$ & $-4.67 \mathrm{E}-05$ & $-4.67 \mathrm{E}-05$ & $-5.21 \mathrm{E}-05$ & $-5.21 E-05$ \\
\hline 782 & 105.04 & $1.68 \mathrm{E}-04$ & $1.68 \mathrm{E}-04$ & $-3.36 \mathrm{E}-05$ & $-3.36 \mathrm{E}-05$ & $-5.59 \mathrm{E}-05$ & $-5.58 \mathrm{E}-05$ \\
\hline 802 & 136.24 & $1.47 \mathrm{E}-04$ & 1.47E-04 & $-4.01 \mathrm{E}-05$ & $-4.01 \mathrm{E}-05$ & $-6.84 \mathrm{E}-05$ & $-6.83 E-05$ \\
\hline 822 & 181.71 & $1.01 \mathrm{E}-04$ & $1.01 \mathrm{E}-04$ & $-6.38 \mathrm{E}-07$ & $-6.27 \mathrm{E}-07$ & $-4.94 \mathrm{E}-05$ & $-4.93 E-05$ \\
\hline 842 & 225.10 & 8.81E-05 & $8.82 \mathrm{E}-05$ & $3.12 \mathrm{E}-06$ & $3.15 \mathrm{E}-06$ & $-5.63 \mathrm{E}-05$ & $-5.63 E-05$ \\
\hline 862 & 273.66 & $5.49 \mathrm{E}-05$ & $5.49 \mathrm{E}-05$ & $2.40 \mathrm{E}-05$ & $2.40 \mathrm{E}-05$ & $-3.68 E-05$ & $-3.67 E-05$ \\
\hline 882 & 323.27 & $4.35 \mathrm{E}-05$ & $4.36 \mathrm{E}-05$ & $1.70 \mathrm{E}-05$ & $1.70 \mathrm{E}-05$ & $-3.74 \mathrm{E}-05$ & $-3.74 \mathrm{E}-05$ \\
\hline 902 & 369.20 & 4.33E-05 & $4.34 \mathrm{E}-05$ & $1.59 \mathrm{E}-05$ & 1.59E-05 & $-2.47 E-05$ & $-2.46 \mathrm{E}-05$ \\
\hline 922 & 419.20 & $6.76 \mathrm{E}-05$ & $6.77 \mathrm{E}-05$ & $-5.18 \mathrm{E}-06$ & $-5.17 \mathrm{E}-06$ & $-2.21 \mathrm{E}-05$ & $-2.20 \mathrm{E}-05$ \\
\hline 237 & 463.02 & & & & & & \\
\hline 257 & 510.03 & & & & & & \\
\hline 277 & 544.44 & & & & & & \\
\hline 297 & 580.53 & & & & & & \\
\hline 317 & 631.08 & & & & & & \\
\hline 337 & 680.34 & & & & & & \\
\hline 357 & 727.44 & & & & & & \\
\hline 377 & 772.93 & & & & & & \\
\hline 397 & 831.34 & & & & & & \\
\hline 417 & 894.09 & & & & & & \\
\hline 2132 & 925.08 & 2.79E-05 & $2.79 \mathrm{E}-05$ & $-4.91 E-06$ & $-4.91 E-06$ & $-3.37 \mathrm{E}-05$ & $-3.37 \mathrm{E}-05$ \\
\hline 2122 & 935.67 & $6.41 \mathrm{E}-05$ & $6.41 \mathrm{E}-05$ & $-2.17 \mathrm{E}-05$ & $-2.17 \mathrm{E}-05$ & $-9.95 \mathrm{E}-05$ & $-9.95 E-05$ \\
\hline 2112 & 944.86 & $1.54 \mathrm{E}-04$ & $1.54 \mathrm{E}-04$ & $-3.84 E-06$ & $-3.84 \mathrm{E}-06$ & $-6.32 E-05$ & $-6.31 \mathrm{E}-05$ \\
\hline 477 & 968.95 & & & & & & \\
\hline 497 & 1002.45 & & & & & & \\
\hline 517 & 1042.45 & & & & & & \\
\hline 537 & 1108.60 & & & & & & \\
\hline 557 & 1178.35 & & & & & & \\
\hline 577 & 1227.20 & & & & & & \\
\hline 597 & 1271.50 & & & & & & \\
\hline 617 & 1313.65 & & & & & & \\
\hline 637 & 1360.60 & & & & & & \\
\hline
\end{tabular}


RPP-RPT-32239, Rev. 1

M\&D-2008-005-CALC-001, Rev. 1

Table I.19. BES-FCC Concrete Backed Steel Strain, Shell Top, Gravity Plus Seismic Load

AP Backed Steel, Best Estimate Soil, Seismic Only, Fully Cracked Tank Concrete, 460 In Waste

Level at $1.83 \mathrm{SpG}$

\begin{tabular}{|c|c|c|c|c|c|c|c|}
\hline \multirow{2}{*}{$\begin{array}{c}\text { M\&D } \\
\text { Starting } \\
\text { M\&D } \\
\text { Element } \\
\text { No. }\end{array}$} & \multirow[b]{2}{*}{ Path (in) } & \multicolumn{6}{|c|}{ Shell Top Surface (inside - towards waste) Seismic } \\
\hline & & \begin{tabular}{|} 
AP-460-BES-FCC \\
EPEL P1 Strain (in/in) \\
Seismic Top Min
\end{tabular} & $\begin{array}{c}\text { AP-460-BES-FCC } \\
\text { EPEL P1 Strain (in/in) } \\
\text { Seismic Top Max }\end{array}$ & $\begin{array}{l}\text { AP-460-BES-FCC } \\
\text { EPEL P2 (in/in) } \\
\text { Seismic Top Min }\end{array}$ & $\begin{array}{c}\text { AP-460-BES-FCC } \\
\text { EPEL P2 Strain (in/in) } \\
\text { Seismic Top Max }\end{array}$ & $\begin{array}{c}\text { AP-460-BES-FCC } \\
\text { EPEL P3 Strain (in/in) } \\
\text { Seismic Tap Min }\end{array}$ & $\begin{array}{c}\text { AP-460-BES-FCC } \\
\text { EPEL P3 Strain (in/in) } \\
\text { Seismic Top Max }\end{array}$ \\
\hline 762 & 67.33 & $9.44 \mathrm{E}-05$ & $1.98 \mathrm{E}-04$ & $-1.79 E-04$ & $-5.00 \mathrm{E}-05$ & $-2.72 \mathrm{E}-04$ & $-1.09 \mathrm{E}-04$ \\
\hline 782 & 105.04 & $1.16 \mathrm{E}-04$ & $2.23 E-04$ & $-1.22 \mathrm{E}-04$ & $-3.62 \mathrm{E}-07$ & $-3.83 E-04$ & $-1.89 \mathrm{E}-04$ \\
\hline 802 & 136.24 & $9.56 \mathrm{E}-05$ & $1.88 \mathrm{E}-04$ & $-9.48 E-05$ & $3.55 \mathrm{E}-05$ & $-3.89 \mathrm{E}-04$ & $-1.46 \mathrm{E}-04$ \\
\hline 822 & 181.71 & $7.96 \mathrm{E}-05$ & 1.39E-04 & $-3.88 \mathrm{E}-05$ & $7.10 \mathrm{E}-05$ & $-3.34 \mathrm{E}-04$ & $-1.56 \mathrm{E}-04$ \\
\hline 842 & 225.10 & $5.91 \mathrm{E}-05$ & $1.20 \mathrm{E}-04$ & $-5.57 \mathrm{E}-05$ & $9.11 \mathrm{E}-05$ & $-2.84 \mathrm{E}-04$ & $-7.70 \mathrm{E}-05$ \\
\hline 862 & 273.66 & $4.61 \mathrm{E}-05$ & $8.22 \mathrm{E}-05$ & $-6.33 \mathrm{E}-06$ & $6.09 \mathrm{E}-05$ & $-2.00 \mathrm{E}-04$ & $-9.79 E-05$ \\
\hline 882 & 323.27 & $2.94 \mathrm{E}-05$ & $1.17 \mathrm{E}-04$ & $-1.58 \mathrm{E}-05$ & 4.47E-05 & $-1.54 \mathrm{E}-04$ & $-4.05 E-05$ \\
\hline 902 & 369.20 & $1.77 \mathrm{E}-05$ & $9.83 \mathrm{E}-05$ & 1.19E-05 & $3.37 \mathrm{E}-05$ & $-1.07 \mathrm{E}-04$ & $-1.60 \mathrm{E}-05$ \\
\hline 922 & 419.20 & $4.05 E-05$ & $1.88 \mathrm{E}-04$ & $-1.71 \mathrm{E}-05$ & $8.04 \mathrm{E}-06$ & $-9.05 E-05$ & $-4.41 \mathrm{E}-06$ \\
\hline 237 & 463.02 & & & & & & \\
\hline 257 & 510.03 & & & & & & \\
\hline 277 & 544.44 & & & & & & \\
\hline 297 & 580.53 & & & & & & \\
\hline 317 & 631.08 & & & & & & \\
\hline 337 & 680.34 & & & & & & \\
\hline 357 & 727.44 & & & & & & \\
\hline 377 & 772.93 & & & & & & \\
\hline 397 & 831.34 & & & & & & \\
\hline 417 & 894.09 & & & & & & \\
\hline 2132 & 925.08 & $2.57 \mathrm{E}-05$ & $3.66 \mathrm{E}-05$ & $-3.24 \mathrm{E}-05$ & $1.38 \mathrm{E}-05$ & $-5.21 E-05$ & $-2.75 E-05$ \\
\hline 2122 & 935.67 & $4.16 \mathrm{E}-05$ & $9.45 \mathrm{E}-05$ & $-1.85 \mathrm{E}-05$ & $1.09 \mathrm{E}-05$ & $-3.87 E-05$ & $-1.51 \mathrm{E}-05$ \\
\hline 2112 & 944.86 & $8.11 \mathrm{E}-05$ & $1.47 \mathrm{E}-04$ & $-7.06 \mathrm{E}-06$ & $4.22 \mathrm{E}-05$ & $-2.58 \mathrm{E}-04$ & $-4.86 \mathrm{E}-05$ \\
\hline 477 & 968.95 & & & & & & \\
\hline 497 & 1002.45 & & & & & & \\
\hline 517 & 1042.45 & & & & & & \\
\hline 537 & 1108.60 & & & & & & \\
\hline 557 & 1178.35 & & & & & & \\
\hline 577 & 1227.20 & & & & & & \\
\hline 597 & 1271.50 & & & & & & \\
\hline 617 & 1313.65 & & & & & & \\
\hline 637 & 1360.60 & & & & & & \\
\hline
\end{tabular}


RPP-RPT-32239, Rev. 1

M\&D-2008-005-CALC-001, Rev. 1

Table I.20. BES-FCC Concrete Backed Steel Strain, Shell Middle, Gravity Plus Seismic Load

AP Backed Steel, Best Estimate Soil, Seismic Only, Fully Cracked Tank Concrete, 460 In Waste Level at 1.83SpG

\begin{tabular}{|c|c|c|c|c|c|c|c|}
\hline \multirow{2}{*}{$\begin{array}{c}\text { M\&D } \\
\text { Starting } \\
\text { M\&D } \\
\text { Element } \\
\text { No. }\end{array}$} & \multirow[b]{2}{*}{ Path (in) } & \multicolumn{6}{|c|}{ Shell Mid-Plane } \\
\hline & & $\begin{array}{c}\text { AP-460-BES-FCC } \\
\text { EPEL P1 Strain (in/in) } \\
\text { Seismic Mid Min }\end{array}$ & $\begin{array}{c}\text { AP-460-BES-FCC } \\
\text { EPEL P1 Strain (in/in) } \\
\text { Seismic Mid Max }\end{array}$ & $\begin{array}{l}\text { AP-460-BES-FCC } \\
\text { EPEL P2 (in/in) } \\
\text { Seismic Mid Min }\end{array}$ & $\begin{array}{c}\text { AP-460-BES-FCC } \\
\text { EPEL P2 Strain (in/in) } \\
\text { Seismic Mid Max }\end{array}$ & $\begin{array}{c}\text { AP-460-BES-FCC } \\
\text { EPEL P3 Strain (in/in) } \\
\text { Seismic Mid Min }\end{array}$ & $\begin{array}{l}\text { AP-460-BES-FCC } \\
\text { EPEL P3 Strain (in/in) } \\
\text { Seismic Mid Max }\end{array}$ \\
\hline 762 & 67.33 & $1.02 E-04$ & $2.11 \mathrm{E}-04$ & $-1.93 E-04$ & $-5.38 \mathrm{E}-05$ & $-2.74 \mathrm{E}-04$ & $-1.24 \mathrm{E}-04$ \\
\hline 782 & 105.04 & $1.12 \mathrm{E}-04$ & $2.28 \mathrm{E}-04$ & $-1.27 \mathrm{E}-04$ & $-1.16 \mathrm{E}-06$ & $-3.95 E-04$ & $-1.81 \mathrm{E}-04$ \\
\hline 802 & 136.24 & $1.02 \mathrm{E}-04$ & $1.89 \mathrm{E}-04$ & $-9.76 \mathrm{E}-05$ & $3.09 \mathrm{E}-05$ & $-3.76 \mathrm{E}-04$ & $-1.65 \mathrm{E}-04$ \\
\hline 822 & 181.71 & $7.60 \mathrm{E}-05$ & $1.36 \mathrm{E}-04$ & $-4.03 E-05$ & $6.84 \mathrm{E}-05$ & $-3.30 \mathrm{E}-04$ & $-1.45 \mathrm{E}-04$ \\
\hline 842 & 225.10 & $6.61 \mathrm{E}-05$ & $1.19 \mathrm{E}-04$ & $-5.64 \mathrm{E}-05$ & $8.45 E-05$ & $-2.71 E-04$ & $-1.09 \mathrm{E}-04$ \\
\hline 862 & 273.66 & $4.36 \mathrm{E}-05$ & $8.19 E-05$ & $-6.89 \mathrm{E}-06$ & $6.13 \mathrm{E}-05$ & $-2.01 E-04$ & $-9.10 \mathrm{E}-05$ \\
\hline 882 & 323.27 & $3.21 \mathrm{E}-05$ & $1.17 \mathrm{E}-04$ & $-1.64 \mathrm{E}-05$ & $4.44 \mathrm{E}-05$ & $-1.48 \mathrm{E}-04$ & $-5.50 \mathrm{E}-05$ \\
\hline 902 & 369.20 & $1.74 \mathrm{E}-05$ & $9.80 \mathrm{E}-05$ & $1.30 \mathrm{E}-05$ & $2.79 \mathrm{E}-05$ & $-1.08 \mathrm{E}-04$ & $-2.38 \mathrm{E}-05$ \\
\hline 922 & 419.20 & $4.03 E-05$ & $1.88 \mathrm{E}-04$ & $-2.09 E-05$ & $1.52 \mathrm{E}-05$ & $-8.21 \mathrm{E}-05$ & $-5.19 \mathrm{E}-06$ \\
\hline 237 & 463.02 & $3.19 \mathrm{E}-05$ & $1.01 \mathrm{E}-04$ & $2.74 \mathrm{E}-05$ & $4.11 \mathrm{E}-05$ & $-2.42 \mathrm{E}-04$ & $-1.41 \mathrm{E}-04$ \\
\hline 257 & 510.03 & $5.32 E-05$ & $1.09 E-04$ & $4.06 \mathrm{E}-05$ & $6.97 E-05$ & $-3.87 E-04$ & $-2.57 E-04$ \\
\hline 277 & 544.44 & $8.74 \mathrm{E}-05$ & $1.16 \mathrm{E}-04$ & $2.68 \mathrm{E}-05$ & $8.86 \mathrm{E}-05$ & $-5.54 \mathrm{E}-04$ & $-4.03 E-04$ \\
\hline 297 & 580.53 & $5.34 \mathrm{E}-05$ & $7.07 \mathrm{E}-05$ & $-3.60 \mathrm{E}-05$ & $4.00 \mathrm{E}-05$ & $-2.89 E-04$ & $-2.06 \mathrm{E}-04$ \\
\hline 317 & 631.08 & $6.86 \mathrm{E}-05$ & $8.94 \mathrm{E}-05$ & $-1.02 E-04$ & $9.41 \mathrm{E}-06$ & $-3.06 \mathrm{E}-04$ & $-2.15 \mathrm{E}-04$ \\
\hline 337 & 680.34 & $8.51 \mathrm{E}-05$ & $1.09 \mathrm{E}-04$ & $-1.26 \mathrm{E}-04$ & $-1.80 \mathrm{E}-05$ & $-3.75 E-04$ & $-2.73 E-04$ \\
\hline 357 & 727.44 & $9.12 E-05$ & $1.17 \mathrm{E}-04$ & $-1.35 \mathrm{E}-04$ & $-2.60 \mathrm{E}-05$ & $-4.01 E-04$ & $-2.87 E-04$ \\
\hline 377 & 772.93 & $9.86 \mathrm{E}-05$ & $1.28 \mathrm{E}-04$ & $-1.40 \mathrm{E}-04$ & $-1.19 \mathrm{E}-05$ & $-4.40 \mathrm{E}-04$ & $-3.02 E-04$ \\
\hline 397 & 831.34 & $9.82 E-05$ & $1.28 \mathrm{E}-04$ & $-1.23 E-04$ & $4.95 \mathrm{E}-06$ & $-4.52 \mathrm{E}-04$ & $-2.96 \mathrm{E}-04$ \\
\hline 417 & 894.09 & $4.46 \mathrm{E}-05$ & $6.33 E-05$ & $-6.92 E-05$ & $1.36 \mathrm{E}-05$ & $-1.92 E-04$ & $-1.14 \mathrm{E}-04$ \\
\hline 2132 & 925.08 & $2.24 \mathrm{E}-05$ & $3.34 \mathrm{E}-05$ & $-2.48 E-05$ & $1.12 \mathrm{E}-05$ & $-4.88 \mathrm{E}-05$ & $-2.21 E-05$ \\
\hline 2122 & 935.67 & $2.37 \mathrm{E}-05$ & $3.43 E-05$ & $-2.62 \mathrm{E}-05$ & $1.11 \mathrm{E}-05$ & $-5.63 \mathrm{E}-05$ & $-2.41 E-05$ \\
\hline 2112 & 944.86 & $1.85 \mathrm{E}-05$ & $4.21 E-05$ & $-6.55 \mathrm{E}-06$ & $2.31 \mathrm{E}-05$ & $-5.57 \mathrm{E}-05$ & $-2.06 E-05$ \\
\hline 477 & 968.95 & $5.86 \mathrm{E}-05$ & $7.69 \mathrm{E}-05$ & $-9.78 E-08$ & $4.36 \mathrm{E}-05$ & $-2.96 \mathrm{E}-04$ & $-1.90 \mathrm{E}-04$ \\
\hline 497 & 1002.45 & $2.06 \mathrm{E}-04$ & $2.85 \mathrm{E}-04$ & $4.07 \mathrm{E}-06$ & $4.82 E-05$ & $-8.47 \mathrm{E}-05$ & $-5.53 E-05$ \\
\hline 517 & 1042.45 & $7.44 \mathrm{E}-06$ & $4.57 \mathrm{E}-05$ & $-5.72 E-06$ & $3.50 \mathrm{E}-05$ & $-2.73 E-05$ & $-9.66 \mathrm{E}-07$ \\
\hline 537 & 1108.60 & $3.11 \mathrm{E}-06$ & $3.55 E-05$ & $-4.13 E-06$ & $2.62 E-05$ & $-2.53 E-05$ & $-3.70 \mathrm{E}-07$ \\
\hline 557 & 1178.35 & $4.05 E-06$ & 3.39E-05 & $-4.06 E-06$ & $2.55 E-05$ & $-1.70 \mathrm{E}-05$ & $-2.54 \mathrm{E}-07$ \\
\hline 577 & 1227.20 & $5.07 \mathrm{E}-06$ & $3.31 \mathrm{E}-05$ & $-4.16 \mathrm{E}-06$ & $3.28 \mathrm{E}-05$ & $-1.12 \mathrm{E}-05$ & $-3.20 \mathrm{E}-07$ \\
\hline 597 & 1271.50 & $5.48 \mathrm{E}-06$ & $3.04 \mathrm{E}-05$ & $-3.04 \mathrm{E}-06$ & $2.93 \mathrm{E}-05$ & $-8.84 \mathrm{E}-06$ & $-3.05 \mathrm{E}-07$ \\
\hline 617 & 1313.65 & $6.31 \mathrm{E}-06$ & $4.59 \mathrm{E}-05$ & $-2.61 E-06$ & $2.17 \mathrm{E}-05$ & $-1.08 \mathrm{E}-05$ & $-1.13 \mathrm{E}-06$ \\
\hline 637 & 1360.60 & $2.93 E-06$ & $1.18 \mathrm{E}-05$ & $-1.13 E-07$ & $1.08 E-05$ & $-4.17 E-06$ & $-3.64 E-07$ \\
\hline
\end{tabular}




\section{RPP-RPT-32239, Rev. 1 \\ M\&D-2008-005-CALC-001, Rev. 1}

Table I.21. BES-FCC Concrete Backed Steel Strain, Shell Bottom, Gravity Plus Seismic Load

AP Backed Steel, Best Estimate Soil, Seismic Only, Fully Cracked Tank Concrete, 460 In Waste Level at $1.83 \mathrm{SpG}$

\begin{tabular}{|c|c|c|c|c|c|c|c|}
\hline \multirow{2}{*}{$\begin{array}{c}\text { M\&D } \\
\text { Starting } \\
\text { M\&D } \\
\text { Element } \\
\text { No. }\end{array}$} & \multirow[b]{2}{*}{ Path (in) } & \multicolumn{6}{|c|}{ Shell Bottom Surface (outside - away from waste) Seismic } \\
\hline & & $\begin{array}{c}\text { AP-460-BES-FCC } \\
\text { EPEL P1 Strain (in/in) } \\
\text { Seismic Bat Min }\end{array}$ & $\begin{array}{l}\text { AP-460-BES-FCC } \\
\text { EPEL P1 Strain (in/in) } \\
\text { Seismic Bot Max }\end{array}$ & $\begin{array}{l}\text { AP-460-BES-FCC } \\
\text { EPEL P2 (in/in) } \\
\text { Seismic Bot Min }\end{array}$ & $\begin{array}{l}\text { AP-460-BES-FCC } \\
\text { EPEL P2 Strain (in/in) } \\
\text { Seismic Bot Max }\end{array}$ & $\begin{array}{c}\text { AP-460-BES-FCC } \\
\text { EPEL P3 Strain (in/in) } \\
\text { Seismic Bot Min }\end{array}$ & $\begin{array}{l}\text { AP-460-BES-FCC } \\
\text { EPEL P3 Strain (in/in) } \\
\text { Seismic Bot Max }\end{array}$ \\
\hline 762 & 67.33 & $1.11 \mathrm{E}-04$ & $2.25 \mathrm{E}-04$ & $-2.10 \mathrm{E}-04$ & $-5.76 \mathrm{E}-05$ & $-2.75 \mathrm{E}-04$ & $-1.34 \mathrm{E}-04$ \\
\hline 782 & 105.04 & 1.07E-04 & $2.43 \mathrm{E}-04$ & $-1.33 \mathrm{E}-04$ & $-1.95 \mathrm{E}-06$ & $-4.04 \mathrm{E}-04$ & $-1.65 \mathrm{E}-04$ \\
\hline 802 & 136.24 & 1.07E-04 & $1.95 \mathrm{E}-04$ & $-1.01 \mathrm{E}-04$ & $2.63 \mathrm{E}-05$ & $-3.61 \mathrm{E}-04$ & $-1.76 \mathrm{E}-04$ \\
\hline 822 & 181.71 & $7.15 \mathrm{E}-05$ & $1.34 \mathrm{E}-04$ & $-4.16 \mathrm{E}-05$ & $6.58 \mathrm{E}-05$ & $-3.25 \mathrm{E}-04$ & $-1.32 E-04$ \\
\hline 842 & 225.10 & $7.06 \mathrm{E}-05$ & $1.24 \mathrm{E}-04$ & $-5.70 \mathrm{E}-05$ & $7.69 \mathrm{E}-05$ & $-2.61 E-04$ & $-1.30 \mathrm{E}-04$ \\
\hline 862 & 273.66 & $4.11 \mathrm{E}-05$ & $8.16 \mathrm{E}-05$ & $-7.45 \mathrm{E}-06$ & 6.39E-05 & $-2.02 E-04$ & $-8.10 \mathrm{E}-05$ \\
\hline 882 & 323.27 & $3.13 \mathrm{E}-05$ & $1.17 \mathrm{E}-04$ & $-1.69 \mathrm{E}-05$ & $4.73 \mathrm{E}-05$ & $-1.44 \mathrm{E}-04$ & $-5.57 \mathrm{E}-05$ \\
\hline 902 & 369.20 & $1.71 \mathrm{E}-05$ & $9.76 \mathrm{E}-05$ & $1.25 \mathrm{E}-05$ & $2.60 \mathrm{E}-05$ & $-1.11 \mathrm{E}-04$ & $-3.05 E-05$ \\
\hline 922 & 419.20 & $4.02 \mathrm{E}-05$ & $1.88 \mathrm{E}-04$ & $-2.61 E-05$ & $2.50 \mathrm{E}-05$ & $-8.82 \mathrm{E}-05$ & $-6.37 \mathrm{E}-06$ \\
\hline 237 & 463.02 & & & & & & \\
\hline 257 & 510.03 & & & & & & \\
\hline 277 & 544.44 & & & & & & \\
\hline 297 & 580.53 & & & & & & \\
\hline 317 & 631.08 & & & & & & \\
\hline 337 & 680.34 & & & & & & \\
\hline 357 & 727.44 & & & & & & \\
\hline 377 & 772.93 & & & & & & \\
\hline 397 & 831.34 & & & & & & \\
\hline 417 & 894.09 & & & & & & \\
\hline 2132 & 925.08 & $2.12 \mathrm{E}-05$ & $3.52 \mathrm{E}-05$ & $-1.71 E-05$ & $1.07 \mathrm{E}-05$ & $-4.62 E-05$ & $-1.55 E-05$ \\
\hline 2122 & 935.67 & $4.53 \mathrm{E}-05$ & $7.69 \mathrm{E}-05$ & $-2.66 \mathrm{E}-05$ & $1.16 \mathrm{E}-05$ & $-1.16 \mathrm{E}-04$ & $-4.05 \mathrm{E}-05$ \\
\hline 2112 & 944.86 & $1.31 \mathrm{E}-04$ & $2.47 \mathrm{E}-04$ & $-1.05 E-05$ & $4.18 \mathrm{E}-05$ & $-7.68 \mathrm{E}-05$ & $-2.71 \mathrm{E}-05$ \\
\hline 477 & 968.95 & & & & & & \\
\hline 497 & 1002.45 & & & & & & \\
\hline 517 & 1042.45 & & & & & & \\
\hline 537 & 1108.60 & & & & & & \\
\hline 557 & 1178.35 & & & & & & \\
\hline 577 & 1227.20 & & & & & & \\
\hline 597 & 1271.50 & & & & & & \\
\hline 617 & 1313.65 & & & & & & \\
\hline 637 & 1360.60 & & & & & & \\
\hline
\end{tabular}


RPP-RPT-32239, Rev. 1

M\&D-2008-005-CALC-001, Rev. 1

Table I.22. BES-FCC Concrete Backed Steel Strain, Shell Top, Seismic Load Only

AP Backed Steel, Best Estimate Soil, Seismic Only, Fully Cracked Tank Concrete, 460 In Waste Level at 1.83SpG

\begin{tabular}{|c|c|c|c|c|c|c|c|}
\hline \multirow[b]{2}{*}{$\begin{array}{c}\text { M\&D } \\
\text { Starting } \\
\text { M\&D } \\
\text { Element } \\
\text { No. }\end{array}$} & \multirow[b]{2}{*}{ Path (in) } & \multicolumn{6}{|c|}{ Shell Top Surface (inside - towards waste) Seismic } \\
\hline & & $\begin{array}{c}\text { AP-460-BES-FCC } \\
\text { EPEL P1 Strain (in/in) } \\
\text { Seismic Only Top } \\
\text { Min }\end{array}$ & $\begin{array}{c}\text { AP-460-BES-FCC } \\
\text { EPEL P1 Strain (in/in) } \\
\text { Seismic Only Top } \\
\text { Max }\end{array}$ & $\begin{array}{l}\text { AP-460-BES-FCC } \\
\text { EPEL P2 (in/in) } \\
\text { Seismic Only Top } \\
\text { Min }\end{array}$ & $\begin{array}{c}\text { AP-460-BES-FCC } \\
\text { EPEL P2 Strain (in/in) } \\
\text { Seismic Only Tap } \\
\text { Max }\end{array}$ & $\begin{array}{c}\text { AP-460-BES-FCC } \\
\text { EPEL P3 Strain } \\
\text { (in/in) Seismic Only } \\
\text { Tap Min }\end{array}$ & $\begin{array}{c}\text { AP-460-BES-FCC } \\
\text { EPEL P3 Strain (in/in) } \\
\text { Seismic Only Tap } \\
\text { Max }\end{array}$ \\
\hline 762 & 67.33 & $-5.02 \mathrm{E}-05$ & $5.32 \mathrm{E}-05$ & $-3.08 \mathrm{E}-05$ & 9.77E-05 & $-8.63 \mathrm{E}-05$ & 7.69E-05 \\
\hline 782 & 105.04 & $-5.08 \mathrm{E}-05$ & $5.61 \mathrm{E}-05$ & $-3.08 \mathrm{E}-05$ & 9.09E-05 & $-8.64 \mathrm{E}-05$ & $1.08 \mathrm{E}-04$ \\
\hline 802 & 136.24 & $-4.39 E-05$ & 4.87E-05 & $-3.98 \mathrm{E}-05$ & $9.04 \mathrm{E}-05$ & $-1.21 \mathrm{E}-04$ & $1.21 \mathrm{E}-04$ \\
\hline 822 & 181.71 & $-2.83 E-05$ & $3.09 \mathrm{E}-05$ & $-4.22 \mathrm{E}-05$ & $6.75 \mathrm{E}-05$ & $-7.94 \mathrm{E}-05$ & $9.79 \mathrm{E}-05$ \\
\hline 842 & 225.10 & $-2.11 \mathrm{E}-05$ & $4.02 \mathrm{E}-05$ & $-6.04 \mathrm{E}-05$ & $8.63 E-05$ & $-9.39 E-05$ & $1.13 \mathrm{E}-04$ \\
\hline 862 & 273.66 & $-1.23 \mathrm{E}-05$ & $2.37 \mathrm{E}-05$ & $-3.13 \mathrm{E}-05$ & 3.59E-05 & $-3.94 \mathrm{E}-05$ & $6.26 \mathrm{E}-05$ \\
\hline 882 & 323.27 & $-7.84 \mathrm{E}-06$ & $7.98 \mathrm{E}-05$ & $-3.32 \mathrm{E}-05$ & $2.72 \mathrm{E}-05$ & $-5.00 \mathrm{E}-05$ & $6.33 \mathrm{E}-05$ \\
\hline 902 & 369.20 & $-2.63 E-05$ & $5.42 \mathrm{E}-05$ & $-4.96 \mathrm{E}-06$ & $1.68 \mathrm{E}-05$ & $-2.43 \mathrm{E}-05$ & $6.69 \mathrm{E}-05$ \\
\hline 922 & 419.20 & $-2.75 \mathrm{E}-05$ & $1.20 \mathrm{E}-04$ & $-7.63 \mathrm{E}-06$ & $1.75 \mathrm{E}-05$ & $-4.48 \mathrm{E}-05$ & $4.12 \mathrm{E}-05$ \\
\hline 237 & 463.02 & & & & & & \\
\hline 257 & 510.03 & & & & & & \\
\hline 277 & 544.44 & & & & & & \\
\hline 297 & 580.53 & & & & & & \\
\hline 317 & 631.08 & & & & & & \\
\hline 337 & 680.34 & & & & & & \\
\hline 357 & 727.44 & & & & & & \\
\hline 377 & 772.93 & & & & & & \\
\hline 397 & 831.34 & & & & & & \\
\hline 417 & 894.09 & & & & & & \\
\hline 2062 & 925.08 & $-3.55 \mathrm{E}-06$ & $7.34 \mathrm{E}-06$ & $-4.01 E-06$ & $4.22 \mathrm{E}-05$ & $-1.84 \mathrm{E}-05$ & $6.15 \mathrm{E}-06$ \\
\hline 2052 & 935.67 & $-1.27 \mathrm{E}-05$ & $4.03 E-05$ & $-1.73 E-06$ & $2.76 \mathrm{E}-05$ & $-1.64 \mathrm{E}-05$ & $7.22 \mathrm{E}-06$ \\
\hline 2042 & 944.86 & $-1.26 \mathrm{E}-05$ & $5.29 \mathrm{E}-05$ & $-3.67 \mathrm{E}-06$ & $4.56 \mathrm{E}-05$ & $-4.63 \mathrm{E}-05$ & $1.63 \mathrm{E}-04$ \\
\hline 477 & 968.95 & & & & & & \\
\hline 497 & 1002.45 & & & & & & \\
\hline 517 & 1042.45 & & & & & & \\
\hline 537 & 1108.60 & & & & & & \\
\hline 557 & 1178.35 & & & & & & \\
\hline 577 & 1227.20 & & & & & & \\
\hline 597 & 1271.50 & & & & & & \\
\hline 617 & 1313.65 & & & & & & \\
\hline 637 & 1360.60 & & & & & & \\
\hline
\end{tabular}


RPP-RPT-32239, Rev. 1

M\&D-2008-005-CALC-001, Rev. 1

Table I.23. BES-FCC Concrete Backed Steel Strain, Shell Middle, Seismic Load Only

AP Backed Steel, Best Estimate Soil, Seismic Only, Fully Cracked Tank Concrete, 460 In Waste Level at $1.83 \mathrm{SpG}$

\begin{tabular}{|c|c|c|c|c|c|c|c|}
\hline \multirow[b]{2}{*}{$\begin{array}{l}\text { M\&D } \\
\text { Starting } \\
\text { M\&D } \\
\text { Element } \\
\text { No. }\end{array}$} & \multirow[b]{2}{*}{ Path (in) } & \multicolumn{6}{|c|}{ Shell Mid-Plane } \\
\hline & & $\begin{array}{l}\text { AP-46U-BES- } \\
\text { FCC EPEL P1 } \\
\text { Strain (in/in) } \\
\text { Seismic Only } \\
\text { Mid Min }\end{array}$ & $\begin{array}{c}\text { AP-460-BES-FCC } \\
\text { EPEL P1 Strain (in/in) } \\
\text { Seismic Only Mid } \\
\text { Max }\end{array}$ & $\begin{array}{l}\text { AP-460-BES-FCC } \\
\text { EPEL P2 (in/in) } \\
\text { Seismic Only Mid } \\
\text { Min }\end{array}$ & $\begin{array}{c}\text { AP-460-BES-FCC } \\
\text { EPEL P2 Strain (in/in) } \\
\text { Seismic Only Mid } \\
\text { Max }\end{array}$ & $\begin{array}{c}\text { AP-460-BES-FCC } \\
\text { EPEL P3 Strain (in/in) } \\
\text { Seismic Only Mid } \\
\text { Min }\end{array}$ & $\begin{array}{c}\text { AP-460-BES-FCC } \\
\text { EPEL P3 Strain (in/in) } \\
\text { Seismic Only Mid } \\
\text { Max }\end{array}$ \\
\hline 762 & 67.33 & $-5.15 \mathrm{E}-05$ & $5.67 \mathrm{E}-05$ & $-1.50 \mathrm{E}-04$ & $-1.04 \mathrm{E}-05$ & $-2.28 \mathrm{E}-04$ & $-7.84 \mathrm{E}-05$ \\
\hline 782 & 105.04 & $-5.50 \mathrm{E}-05$ & $6.08 \mathrm{E}-05$ & $-9.44 \mathrm{E}-05$ & $3.18 \mathrm{E}-05$ & $-3.29 \mathrm{E}-04$ & $-1.15 \mathrm{E}-04$ \\
\hline 802 & 136.24 & $-4.15 E-05$ & 4.57E-05 & $-5.79 \mathrm{E}-05$ & $7.05 \mathrm{E}-05$ & $-3.18 \mathrm{E}-04$ & $-1.06 \mathrm{E}-04$ \\
\hline 822 & 181.71 & $-2.86 \mathrm{E}-05$ & $3.14 \mathrm{E}-05$ & $-4.17 \mathrm{E}-05$ & $6.70 \mathrm{E}-05$ & $-2.74 \mathrm{E}-04$ & $-8.94 \mathrm{E}-05$ \\
\hline 842 & 225.10 & $-1.79 \mathrm{E}-05$ & $3.52 \mathrm{E}-05$ & $-6.03 E-05$ & $8.06 \mathrm{E}-05$ & $-2.27 E-04$ & $-6.52 \mathrm{E}-05$ \\
\hline 862 & 273.66 & $-1.31 \mathrm{E}-05$ & $2.52 \mathrm{E}-05$ & $-3.13 \mathrm{E}-05$ & $3.68 \mathrm{E}-05$ & $-1.60 \mathrm{E}-04$ & $-5.00 \mathrm{E}-05$ \\
\hline 882 & 323.27 & $-8.31 \mathrm{E}-06$ & 7.64E-05 & $-3.36 \mathrm{E}-05$ & $2.71 \mathrm{E}-05$ & $-1.19 \mathrm{E}-04$ & $-2.61 E-05$ \\
\hline 902 & 369.20 & $-2.63 \mathrm{E}-05$ & $5.42 \mathrm{E}-05$ & $-3.41 E-06$ & $1.15 \mathrm{E}-05$ & $-8.07 E-05$ & $3.02 \mathrm{E}-06$ \\
\hline 922 & 419.20 & $-2.74 \mathrm{E}-05$ & $1.20 \mathrm{E}-04$ & $-1.46 \mathrm{E}-05$ & $2.15 \mathrm{E}-05$ & $-6.24 \mathrm{E}-05$ & $1.45 \mathrm{E}-05$ \\
\hline 237 & 463.02 & $-2.51 \mathrm{E}-05$ & $4.39 E-05$ & $-6.90 \mathrm{E}-06$ & $6.72 \mathrm{E}-06$ & $-1.71 E-04$ & $-7.03 E-05$ \\
\hline 257 & 510.03 & $-2.96 \mathrm{E}-05$ & $2.65 \mathrm{E}-05$ & $-1.86 \mathrm{E}-05$ & $1.05 \mathrm{E}-05$ & $-5.27 \mathrm{E}-05$ & $7.67 \mathrm{E}-05$ \\
\hline 277 & 544.44 & $-2.88 \mathrm{E}-05$ & $-5.00 \mathrm{E}-07$ & $-4.72 E-05$ & $1.46 \mathrm{E}-05$ & $-7.07 \mathrm{E}-05$ & 7.94E-05 \\
\hline 297 & 580.53 & $-2.82 \mathrm{E}-05$ & $-1.10 \mathrm{E}-05$ & $-2.51 E-05$ & $5.08 \mathrm{E}-05$ & $-4.26 E-05$ & $4.06 \mathrm{E}-05$ \\
\hline 317 & 631.08 & $-2.30 \mathrm{E}-05$ & $-2.27 \mathrm{E}-06$ & $-1.55 \mathrm{E}-05$ & $9.58 \mathrm{E}-05$ & $-4.59 \mathrm{E}-05$ & $4.46 \mathrm{E}-05$ \\
\hline 337 & 680.34 & $-3.26 \mathrm{E}-05$ & $-8.40 \mathrm{E}-06$ & $-1.49 \mathrm{E}-05$ & $9.35 \mathrm{E}-05$ & $-5.16 \mathrm{E}-05$ & $4.95 \mathrm{E}-05$ \\
\hline 357 & 727.44 & $-2.99 \mathrm{E}-05$ & $-3.90 \mathrm{E}-06$ & $-1.36 \mathrm{E}-05$ & $9.50 \mathrm{E}-05$ & $-5.26 \mathrm{E}-05$ & $6.09 \mathrm{E}-05$ \\
\hline 377 & 772.93 & $-3.92 \mathrm{E}-05$ & $-1.00 \mathrm{E}-05$ & $-1.25 \mathrm{E}-05$ & $1.16 \mathrm{E}-04$ & $-5.79 \mathrm{E}-05$ & $8.00 \mathrm{E}-05$ \\
\hline 397 & 831.34 & $-3.00 \mathrm{E}-05$ & $-4.00 \mathrm{E}-07$ & $-1.04 \mathrm{E}-05$ & $1.18 \mathrm{E}-04$ & $-5.40 \mathrm{E}-05$ & $1.02 \mathrm{E}-04$ \\
\hline 417 & 894.09 & $-1.50 \mathrm{E}-05$ & $3.68 \mathrm{E}-06$ & $-5.20 \mathrm{E}-06$ & $7.76 \mathrm{E}-05$ & $-2.87 E-05$ & $4.96 \mathrm{E}-05$ \\
\hline 2062 & 925.08 & $-6.80 \mathrm{E}-06$ & $4.12 \mathrm{E}-06$ & $-7.99 \mathrm{E}-06$ & $2.80 \mathrm{E}-05$ & $-1.52 \mathrm{E}-05$ & 1.16E-05 \\
\hline 2052 & 935.67 & $-6.41 \mathrm{E}-06$ & $4.14 \mathrm{E}-06$ & $-4.21 \mathrm{E}-06$ & $3.31 \mathrm{E}-05$ & $-2.55 \mathrm{E}-05$ & $6.71 \mathrm{E}-06$ \\
\hline 2042 & 944.86 & $-3.45 \mathrm{E}-06$ & $2.01 \mathrm{E}-05$ & $-2.94 \mathrm{E}-06$ & 2.67E-05 & $-2.01 E-05$ & 1.49E-05 \\
\hline 477 & 968.95 & $-8.87 E-06$ & $9.31 \mathrm{E}-06$ & $-7.37 \mathrm{E}-06$ & $3.63 \mathrm{E}-05$ & $-3.45 \mathrm{E}-05$ & $7.10 \mathrm{E}-05$ \\
\hline 497 & 1002.45 & $-3.34 \mathrm{E}-05$ & 4.54E-05 & $-1.24 \mathrm{E}-05$ & $3.18 \mathrm{E}-05$ & $-1.04 \mathrm{E}-05$ & 1.89E-05 \\
\hline 517 & 1042.45 & $-7.28 \mathrm{E}-06$ & $3.10 \mathrm{E}-05$ & $-1.55 \mathrm{E}-05$ & $2.52 \mathrm{E}-05$ & $-2.18 \mathrm{E}-05$ & 4.57E-06 \\
\hline 537 & 1108.60 & $-6.13 E-06$ & $2.62 \mathrm{E}-05$ & $-5.05 \mathrm{E}-06$ & $2.52 \mathrm{E}-05$ & $-2.31 E-05$ & $1.82 \mathrm{E}-06$ \\
\hline 557 & 1178.35 & $-6.38 \mathrm{E}-06$ & $2.35 \mathrm{E}-05$ & $-9.70 \mathrm{E}-06$ & 1.99E-05 & $-1.36 \mathrm{E}-05$ & $3.22 \mathrm{E}-06$ \\
\hline 577 & 1227.20 & $-6.45 \mathrm{E}-06$ & $2.15 \mathrm{E}-05$ & $-1.53 \mathrm{E}-05$ & 2.17E-05 & $-6.25 \mathrm{E}-06$ & $4.60 \mathrm{E}-06$ \\
\hline 597 & 1271.50 & $-7.00 \mathrm{E}-06$ & 1.79E-05 & $-1.40 \mathrm{E}-05$ & $1.83 \mathrm{E}-05$ & $-3.75 E-06$ & $4.77 \mathrm{E}-06$ \\
\hline 617 & 1313.65 & $-1.39 \mathrm{E}-05$ & $2.57 \mathrm{E}-05$ & $-1.08 \mathrm{E}-05$ & 1.35E-05 & $-4.65 E-06$ & $5.02 \mathrm{E}-06$ \\
\hline 637 & 1360.60 & $-3.85 \mathrm{E}-06$ & $5.02 \mathrm{E}-06$ & $-4.10 \mathrm{E}-06$ & $6.78 \mathrm{E}-06$ & $-1.96 \mathrm{E}-06$ & $1.84 \mathrm{E}-06$ \\
\hline
\end{tabular}


RPP-RPT-32239, Rev. 1

\section{M\&D-2008-005-CALC-001, Rev. 1}

Table I.24. BES-FCC Concrete Backed Steel Strain, Shell Bottom, Seismic Load Only

AP Backed Steel, Best Estimate Soil, Seismic Only, Fully Cracked Tank Concrete, 460 In Waste

Level at $1.83 \mathrm{SpG}$

\begin{tabular}{|c|c|c|c|c|c|c|c|}
\hline \multirow[b]{2}{*}{$\begin{array}{c}\text { M\&D } \\
\text { Starting } \\
\text { M\&D } \\
\text { Element } \\
\text { No. }\end{array}$} & \multirow[b]{2}{*}{ Path (in) } & \multicolumn{6}{|c|}{ Shell Bottom Surface (outside - away from waste) Seismic } \\
\hline & & $\begin{array}{c}\text { AP-460-BES-FCC } \\
\text { EPEL P1 Strain (in/in) } \\
\text { Seismic Only Bot } \\
\text { Min }\end{array}$ & $\begin{array}{c}\text { AP-460-BES-FCC } \\
\text { EPEL P1 Strain (in/in) } \\
\text { Seismic Only Bot } \\
\text { Max }\end{array}$ & $\begin{array}{l}\text { AP-460-BES-FCC } \\
\text { EPEL P2 (in/in) } \\
\text { Seismic Only Bot } \\
\text { Min }\end{array}$ & $\begin{array}{c}\text { AP-460-BES-FCC } \\
\text { EPEL P2 Strain (in } / \text { in) } \\
\text { Seismic Only Bot } \\
\text { Max }\end{array}$ & $\begin{array}{c}\text { AP-460-BES-FCC } \\
\text { EPEL P3 Strain (in/in) } \\
\text { Seismic Only Bot } \\
\text { Min }\end{array}$ & $\begin{array}{c}\text { AP-460-BES-FCC } \\
\text { EPEL P3 Strain (in/in) } \\
\text { Seismic Only Bot } \\
\text { Max }\end{array}$ \\
\hline 762 & 67.33 & $-5.30 \mathrm{E}-05$ & $6.11 \mathrm{E}-05$ & $-1.63 \mathrm{E}-04$ & $-1.09 \mathrm{E}-05$ & $-2.23 \mathrm{E}-04$ & $-8.20 \mathrm{E}-05$ \\
\hline 782 & 105.04 & $-6.05 \mathrm{E}-05$ & $7.53 \mathrm{E}-05$ & $-9.92 \mathrm{E}-05$ & $3.16 \mathrm{E}-05$ & $-3.48 \mathrm{E}-04$ & $-1.10 \mathrm{E}-04$ \\
\hline 802 & 136.24 & $-3.97 \mathrm{E}-05$ & $4.80 \mathrm{E}-05$ & $-6.11 \mathrm{E}-05$ & $6.63 \mathrm{E}-05$ & $-2.92 \mathrm{E}-04$ & $-1.08 \mathrm{E}-04$ \\
\hline 822 & 181.71 & $-2.98 \mathrm{E}-05$ & $3.24 \mathrm{E}-05$ & $-4.10 \mathrm{E}-05$ & $6.64 \mathrm{E}-05$ & $-2.75 \mathrm{E}-04$ & $-8.24 \mathrm{E}-05$ \\
\hline 842 & 225.10 & $-1.75 \mathrm{E}-05$ & $3.60 \mathrm{E}-05$ & $-6.01 E-05$ & $7.37 \mathrm{E}-05$ & $-2.05 E-04$ & $-7.33 E-05$ \\
\hline 862 & 273.66 & $-1.38 \mathrm{E}-05$ & $2.66 \mathrm{E}-05$ & $-3.14 \mathrm{E}-05$ & 3.99E-05 & $-1.65 \mathrm{E}-04$ & $-4.43 E-05$ \\
\hline 882 & 323.27 & $-1.22 \mathrm{E}-05$ & $7.31 \mathrm{E}-05$ & $-3.39 E-05$ & $3.02 \mathrm{E}-05$ & $-1.06 \mathrm{E}-04$ & $-1.83 E-05$ \\
\hline 902 & 369.20 & $-2.62 \mathrm{E}-05$ & $5.43 \mathrm{E}-05$ & $-3.41 \mathrm{E}-06$ & $1.02 \mathrm{E}-05$ & $-8.61 \mathrm{E}-05$ & $-5.81 E-06$ \\
\hline 922 & 419.20 & $-2.74 \mathrm{E}-05$ & $1.20 \mathrm{E}-04$ & $-2.09 \mathrm{E}-05$ & $3.01 \mathrm{E}-05$ & $-6.62 \mathrm{E}-05$ & $1.56 \mathrm{E}-05$ \\
\hline 237 & 463.02 & & & & & & \\
\hline 257 & 510.03 & & & & & & \\
\hline 277 & 544.44 & & & & & & \\
\hline 297 & 580.53 & & & & & & \\
\hline 317 & 631.08 & & & & & & \\
\hline 337 & 680.34 & & & & & & \\
\hline 357 & 727.44 & & & & & & \\
\hline 377 & 772.93 & & & & & & \\
\hline 397 & 831.34 & & & & & & \\
\hline 417 & 894.09 & & & & & & \\
\hline 2062 & 925.08 & $-6.71 \mathrm{E}-06$ & $7.33 \mathrm{E}-06$ & $-1.22 \mathrm{E}-05$ & $1.56 \mathrm{E}-05$ & $-1.25 \mathrm{E}-05$ & $1.82 \mathrm{E}-05$ \\
\hline 2052 & 935.67 & $-1.88 \mathrm{E}-05$ & $1.28 \mathrm{E}-05$ & $-4.90 \mathrm{E}-06$ & $3.33 \mathrm{E}-05$ & $-1.62 \mathrm{E}-05$ & $5.90 \mathrm{E}-05$ \\
\hline 2042 & 944.86 & $-2.32 \mathrm{E}-05$ & $9.24 E-05$ & $-6.69 \mathrm{E}-06$ & $4.57 \mathrm{E}-05$ & $-1.36 \mathrm{E}-05$ & $3.60 \mathrm{E}-05$ \\
\hline 477 & 968.95 & & & & & & \\
\hline 497 & 1002.45 & & & & & & \\
\hline 517 & 1042.45 & & & & & & \\
\hline 537 & 1108.60 & & & & & & \\
\hline 557 & 1178.35 & & & & & & \\
\hline 577 & 1227.20 & & & & & & \\
\hline 597 & 1271.50 & & & & & & \\
\hline 617 & 1313.65 & & & & & & \\
\hline 637 & 1360.60 & & & & & & \\
\hline
\end{tabular}


RPP-RPT-32239, Rev. 1

M\&D-2008-005-CALC-001, Rev. 1

Table I.25. BES-FCC Concrete Wall/Footing Contact Forces, Gravity Only

Tank AY, 460 Inch Waste Level

$\mathrm{SpG}=1.83$

Best Estimate Soil

Fully Cracked Concrete

\begin{tabular}{|c|c|c|c|c|c|c|c|c|c|c|c|}
\hline igle & $\begin{array}{l}\text { Vertical } \\
\text { Min AP- } \\
\text { BES-FCC } \\
\text { Gravity }\end{array}$ & $\begin{array}{l}\text { Vertical } \\
\text { Max AP- } \\
\text { BES-FCC } \\
\text { Gravity }\end{array}$ & $\begin{array}{l}\text { Shear Y } \\
\text { Min AP- } \\
\text { BES-FCC } \\
\text { Gravity }\end{array}$ & $\begin{array}{l}\text { Shear Y } \\
\text { Max AP- } \\
\text { BES-FCC } \\
\text { Gravity }\end{array}$ & $\begin{array}{l}\text { Shear X } \\
\text { Min AP- } \\
\text { BES-FCC } \\
\text { Gravity }\end{array}$ & $\begin{array}{l}\text { Shear X } \\
\text { Max AP- } \\
\text { BES-FCC } \\
\text { Gravity }\end{array}$ & $\begin{array}{l}\text { Shear Y } \\
\text { Max AP- } \\
\text { BES-FCC } \\
\text { Gravity }\end{array}$ & $\begin{array}{l}\text { Shear X } \\
\text { Max AP- } \\
\text { BES-FCC } \\
\text { Gravity }\end{array}$ & $\begin{array}{l}\text { Shear } \\
\text { Max AP- } \\
\text { BES-FCC } \\
\text { Gravity }\end{array}$ & $\begin{array}{l}\text { Vertical Force } \\
\text { Max AP-BES- } \\
\text { FCC Gravity }\end{array}$ & $\begin{array}{l}\text { Vertical Force } \\
\text { Min AP-BES- } \\
\text { FCC Gravity }\end{array}$ \\
\hline 0 & -204.10 & -203.90 & 0.00 & 0.00 & -2.24 & -2.24 & 0.00 & 0.70 & 0.70 & -63.78 & $\quad-63.72$ \\
\hline 9 & -408.10 & -407.70 & -0.69 & -0.69 & -4.48 & -4.47 & 0.11 & 0.70 & 0.71 & -63.77 & -63.70 \\
\hline 18 & -408.10 & -407.70 & -1.20 & -1.20 & -4.15 & -4.14 & 0.19 & 0.65 & 0.67 & -63.77 & -63.70 \\
\hline 27 & -408.10 & -407.80 & -1.78 & -1.77 & -3.89 & -3.88 & 0.28 & 0.61 & 0.67 & -63.77 & -63.72 \\
\hline 36 & -408.10 & -407.70 & -2.63 & -2.62 & -3.69 & -3.69 & 0.41 & 0.58 & 0.71 & -63.77 & -63.70 \\
\hline 45 & -408.00 & -407.70 & -3.12 & -3.12 & -3.21 & -3.20 & 0.49 & 0.50 & 0.70 & -63.75 & -63.70 \\
\hline 54 & -408.00 & -407.70 & -3.63 & -3.62 & -2.74 & -2.73 & 0.57 & 0.43 & 0.71 & -63.75 & -63.70 \\
\hline 63 & -408.00 & -407.70 & -3.93 & -3.92 & -2.08 & -2.08 & 0.61 & 0.33 & 0.69 & -63.75 & -63.70 \\
\hline 72 & -408.10 & -407.70 & -4.30 & -4.29 & -1.41 & -1.41 & 0.67 & 0.22 & 0.71 & -63.77 & -63.70 \\
\hline 81 & -408.00 & -407.60 & -4.23 & -4.22 & -0.79 & -0.79 & 0.66 & 0.12 & 0.67 & -63.75 & -63.69 \\
\hline 90 & -408.00 & -407.60 & -4.53 & -4.52 & 0.02 & 0.02 & 0.71 & 0.00 & 0.71 & -63.75 & -63.69 \\
\hline 99 & -408.00 & -407.70 & -4.46 & -4.45 & 0.75 & 0.75 & 0.70 & 0.12 & 0.71 & -63.75 & -63.70 \\
\hline 108 & -408.00 & -407.70 & -4.11 & -4.10 & 1.27 & 1.28 & 0.64 & 0.20 & 0.67 & -63.75 & -63.70 \\
\hline 117 & -408.10 & -407.70 & -3.99 & -3.99 & 2.12 & 2.12 & 0.62 & 0.33 & 0.71 & -63.77 & -63.70 \\
\hline 126 & -408.10 & -407.70 & -3.53 & -3.53 & 2.69 & 2.70 & 0.55 & 0.42 & 0.69 & -63.77 & -63.70 \\
\hline 135 & -408.00 & -407.70 & -3.11 & -3.10 & 3.27 & 3.27 & 0.49 & 0.51 & 0.70 & -63.75 & -63.70 \\
\hline 144 & -408.00 & -407.60 & -2.59 & -2.58 & 3.71 & 3.71 & 0.40 & 0.58 & 0.71 & -63.75 & -63.69 \\
\hline 153 & -408.00 & -407.70 & -2.00 & -1.99 & 4.02 & 4.03 & 0.31 & 0.63 & 0.70 & -63.75 & -63.70 \\
\hline 162 & -408.10 & -407.70 & -1.32 & -1.32 & 4.26 & 4.27 & 0.21 & 0.67 & 0.70 & -63.77 & -63.70 \\
\hline 171 & -408.00 & -407.70 & -0.65 & -0.65 & 4.43 & 4.44 & 0.10 & 0.69 & 0.70 & -63.75 & -63.70 \\
\hline 180 & -204.10 & -203.90 & 0.00 & 0.00 & 2.26 & 2.26 & 0.00 & 0.71 & 0.71 & -63.78 & -63.72 \\
\hline
\end{tabular}


RPP-RPT-32239, Rev. 1

M\&D-2008-005-CALC-001, Rev. 1

Table I.26. BES-FCC Concrete Wall/Footing Contact Forces, Gravity Plus Seismic

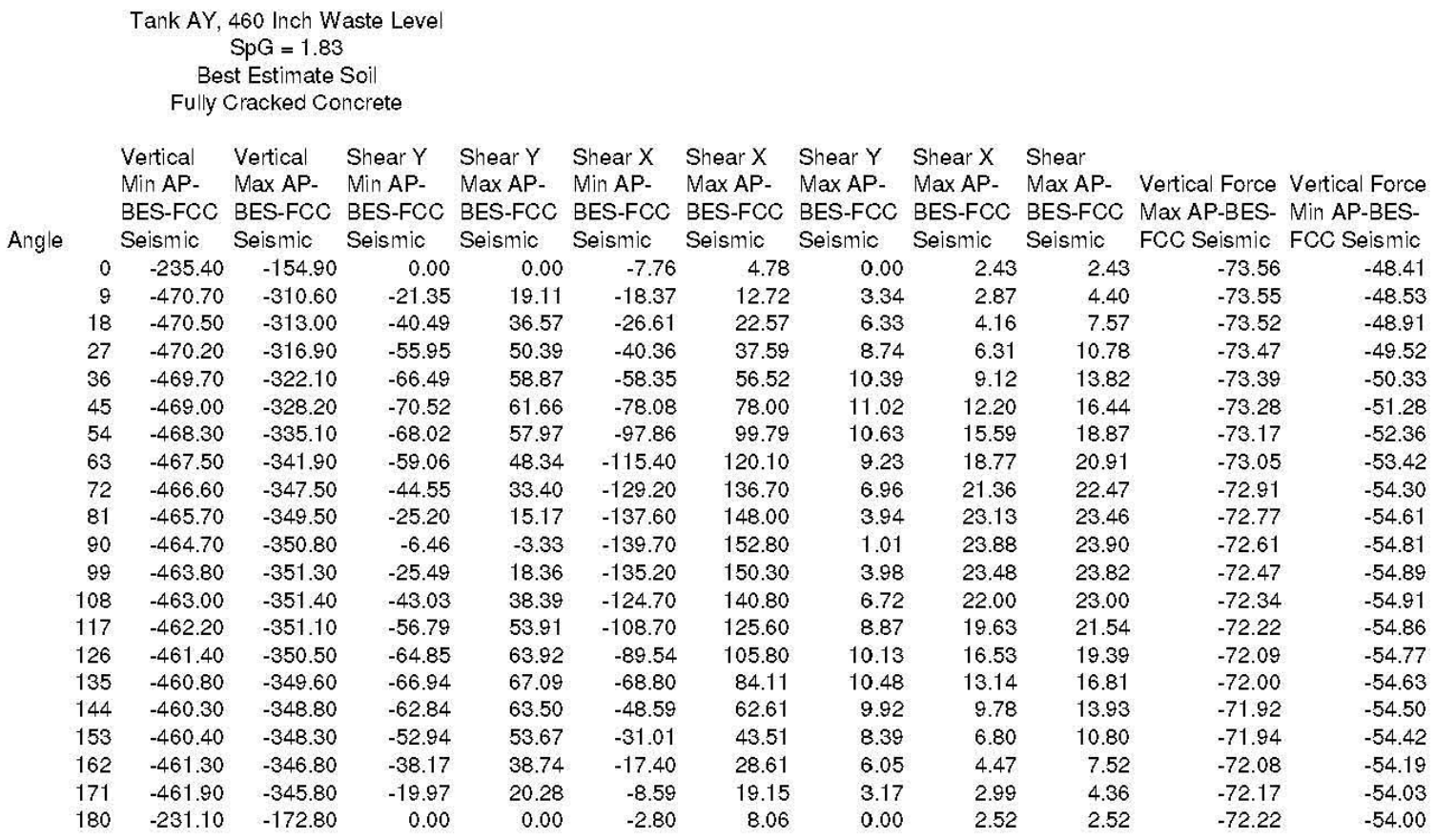


RPP-RPT-32239, Rev. 1

M\&D-2008-005-CALC-001, Rev. 1

Table I.27. BES-FCC Concrete Wall/Footing Contact Forces, Seismic Only

\begin{tabular}{|c|c|c|c|c|c|c|c|c|c|c|c|}
\hline \multirow[b]{5}{*}{ Angle } & \multirow{5}{*}{$\begin{array}{l}\text { Vertical } \\
\text { Min AP- } \\
\text { BES-FCC } \\
\text { Seismic } \\
\text { Only }\end{array}$} & \multirow{5}{*}{$\begin{array}{l}\text { Vertical } \\
\text { Max AP- } \\
\text { BES-FCC } \\
\text { Seismic } \\
\text { Only }\end{array}$} & \multirow{5}{*}{$\begin{array}{l}\text { Shear Y } \\
\text { Min AP- } \\
\text { BES-FCC } \\
\text { Seismic } \\
\text { Only }\end{array}$} & \multirow{5}{*}{$\begin{array}{l}\text { Shear Y } \\
\text { Max AP- } \\
\text { BES-FCC } \\
\text { Seismic } \\
\text { Only }\end{array}$} & \multirow{5}{*}{$\begin{array}{l}\text { Shear X } \\
\text { Min AP- } \\
\text { BES-FCC } \\
\text { Seismic } \\
\text { Only }\end{array}$} & \multirow{5}{*}{$\begin{array}{l}\text { Shear X } \\
\text { Max AP- } \\
\text { BES-FCC } \\
\text { Seismic } \\
\text { Only }\end{array}$} & \multirow{5}{*}{$\begin{array}{c}\text { Shear Y } \\
\text { Max AP- } \\
\text { BES-FCC } \\
\text { Seismic } \\
\text { Only }\end{array}$} & \multirow{5}{*}{$\begin{array}{c}\text { Shear X } \\
\text { Max AP- } \\
\text { BES-FCC } \\
\text { Seismic } \\
\text { Only }\end{array}$} & \multirow{5}{*}{$\begin{array}{l}\text { Shear } \\
\text { Max AP- } \\
\text { BES-FCC } \\
\text { Seismic } \\
\text { Only }\end{array}$} & \multirow{5}{*}{$\begin{array}{l}\text { Vertical Force } \\
\text { Max AP-BES- } \\
\text { FCC Seismic } \\
\text { Only }\end{array}$} & \multirow{5}{*}{$\begin{array}{l}\text { Vertical Force } \\
\text { Min AP-BES- } \\
\text { FCC Seismic } \\
\text { Only }\end{array}$} \\
\hline & & & & & & & & & & & \\
\hline & & & & & & & & & & & \\
\hline & & & & & & & & & & & \\
\hline & & & & & & & & & & & \\
\hline 0 & -31.30 & 49.00 & 0.00 & 0.00 & -5.52 & 7.02 & 0.00 & 2.19 & 2.19 & -9.78 & 15.31 \\
\hline 9 & -62.60 & 97.10 & -20.66 & 19.80 & -13.90 & 17.19 & 3.23 & 2.69 & 4.20 & -9.78 & 15.17 \\
\hline 18 & -62.40 & 94.70 & -39.29 & 37.77 & -22.46 & 26.71 & 6.14 & 4.17 & 7.42 & -9.75 & 14.80 \\
\hline 27 & -62.10 & 90.90 & -54.17 & 52.16 & -36.47 & 41.47 & 8.46 & 6.48 & 10.66 & -9.70 & 14.20 \\
\hline 36 & -61.60 & 85.60 & -63.86 & 61.49 & -54.66 & 60.21 & 9.98 & 9.41 & 13.71 & -9.62 & 13.38 \\
\hline 45 & -61.00 & 79.50 & -67.40 & 64.78 & -74.88 & 81.20 & 10.53 & 12.69 & 16.49 & -9.53 & 12.42 \\
\hline 54 & -60.30 & 72.60 & -64.39 & 61.59 & -95.12 & 102.52 & 10.06 & 16.02 & 18.92 & -9.42 & 11.34 \\
\hline 63 & -59.50 & 65.80 & -55.13 & 52.26 & -113.32 & 122.18 & 8.61 & 19.09 & 20.94 & -9.30 & 10.28 \\
\hline 72 & -58.50 & 60.20 & -40.25 & 37.69 & -127.79 & 138.11 & 6.29 & 21.58 & 22.48 & -9.14 & 9.41 \\
\hline 81 & -57.70 & 58.10 & -20.97 & 19.39 & -136.81 & 148.79 & 3.28 & 23.25 & 23.48 & -9.02 & 9.08 \\
\hline 90 & -56.70 & 56.80 & -1.93 & 1.20 & -139.72 & 152.78 & 0.30 & 23.87 & 23.87 & -8.86 & 8.88 \\
\hline 99 & -55.80 & 56.40 & -21.04 & 22.81 & -135.95 & 149.55 & 3.56 & 23.37 & 23.64 & -8.72 & 8.81 \\
\hline 108 & -55.00 & 56.30 & -38.92 & 42.49 & -125.97 & 139.53 & 6.64 & 21.80 & 22.79 & -8.59 & 8.80 \\
\hline 117 & -54.10 & 56.60 & -52.80 & 57.90 & -110.82 & 123.48 & 9.05 & 19.29 & 21.31 & -8.45 & 8.84 \\
\hline 126 & -53.30 & 57.20 & -61.32 & 67.45 & -92.23 & 103.10 & 10.54 & 16.11 & 19.25 & -8.33 & 8.94 \\
\hline 135 & -52.80 & 58.10 & -63.84 & 70.19 & -72.07 & 80.84 & 10.97 & 12.63 & 16.73 & -8.25 & 9.08 \\
\hline 144 & -52.30 & 58.80 & -60.25 & 66.08 & -52.30 & 58.90 & 10.33 & 9.20 & 13.83 & -8.17 & 9.19 \\
\hline 153 & -52.40 & 59.40 & -50.95 & 55.66 & -35.03 & 39.48 & 8.70 & 6.17 & 10.66 & -8.19 & 9.28 \\
\hline 162 & -53.20 & 60.90 & -36.85 & 40.06 & -21.66 & 24.34 & 6.26 & 3.80 & 7.32 & -8.31 & 9.52 \\
\hline 171 & -53.90 & 61.90 & -19.32 & 20.93 & -13.02 & 14.71 & 3.27 & 2.30 & 4.00 & -8.42 & 9.67 \\
\hline 180 & -27.00 & 31.10 & 0.00 & 0.00 & -5.06 & 5.79 & 0.00 & 1.81 & 1.81 & -8.44 & 9.72 \\
\hline
\end{tabular}


RPP-RPT-32239, Rev. 1

M\&D-2008-005-CALC-001, Rev. 1

Table I.28. BES-FCC Soil/Concrete Tank Contact Forces, Gravity Only

Tank AP, 460 Inch Waste Level

$\mathrm{SpG}=1.83$

Best Estimate Soil

Fully Cracked Concrete

\begin{tabular}{|c|c|c|c|c|c|c|c|c|c|c|}
\hline & Angle (rad) & Path & $\begin{array}{c}\text { Max Pressure } \\
\text { Soil (BES-FCC) } \\
\text { AP Gravity (PSI) }\end{array}$ & $\begin{array}{c}\text { Min Pressure } \\
\text { Soil (BES-FCC) } \\
\text { AP } \\
\text { Gravity (PSI) }\end{array}$ & $\begin{array}{c}\text { Max Meridional } \\
\text { Friction } \\
\text { Soil (BES-FCC) } \\
\text { AP Gravity } \\
\text { (PSI) }\end{array}$ & $\begin{array}{c}\text { Max Tangential } \\
\text { Friction } \\
\text { Soil (BES-FCC) } \\
\text { AP } \\
\text { Gravity (PSI) }\end{array}$ & $\begin{array}{c}\text { Max Contact } \\
\text { Displacement } \\
\text { Soil (BES-FCC) } \\
\text { AP } \\
\text { Gravity (PSI) }\end{array}$ & $\begin{array}{l}0.70 \mathrm{~g} \text { Dome } \\
\text { Vertical }\end{array}$ & $\begin{array}{l}0.19 \mathrm{~g} \text { Haunch } \\
\text { Vertical }\end{array}$ & $\begin{array}{l}\text { Active } \\
\text { Pressure Phi = } \\
49 \text { deg }\end{array}$ \\
\hline 568 & -0.035089 & 67.727 & 9.85 & 9.67 & 2.05 & 0.04 & 0.08 & 16.75 & 11.73 & 7.11 \\
\hline 565.8 & -0.07135 & 105.668 & 8.26 & 8.03 & 1.80 & 0.04 & 0.12 & 14.05 & 9.83 & 7.26 \\
\hline 563.21 & -0.096521 & 137.069 & 8.87 & 8.44 & 2.03 & 0.06 & 0.12 & 15.08 & 10.55 & 7.42 \\
\hline 559.7 & -0.124516 & 182.849 & 5.62 & 4.42 & 1.20 & 0.04 & 0.08 & 9.56 & 6.69 & 7.65 \\
\hline 550.7 & -0.180521 & 226.563 & 5.94 & 5.04 & 1.58 & 0.11 & 0.05 & 10.10 & 7.07 & 8.22 \\
\hline 545.2 & -0.210395 & 275.566 & 8.26 & 7.65 & 1.78 & 0.08 & 0.04 & 14.04 & 9.83 & 8.55 \\
\hline 527.68 & -0.298426 & 325.690 & 7.61 & 7.27 & 1.56 & 0.03 & 0.04 & 12.94 & 9.06 & 9.56 \\
\hline 518.2 & -0.34673 & 372.305 & 9.25 & 9.16 & 2.34 & 0.02 & 0.04 & 15.73 & 11.01 & 10.04 \\
\hline 494.5 & -0.482293 & 423.427 & 16.41 & 16.26 & 3.30 & 0.08 & 0.03 & 27.90 & 1953 & 10.97 \\
\hline 476.2 & -0.606571 & 468.308 & 28.08 & 27.99 & 3.18 & 0.12 & 0.02 & 47.74 & 33.42 & 11.27 \\
\hline 447.4 & -0.656685 & 515.312 & 31.94 & 31.77 & 5.02 & 0.21 & 0.03 & 54.29 & 38.01 & 12.51 \\
\hline 407.1 & -0.710341 & 549.725 & 25.44 & 25.38 & 5.31 & 0.16 & 0.04 & 43.26 & 30.28 & 14.18 \\
\hline 382.1 & \begin{tabular}{|l|}
-1.570796 \\
\end{tabular} & 585.819 & 12.38 & 12.36 & 3.23 & 0.06 & 0.04 & 21.04 & 14.73 & 2.85 \\
\hline 335 & -1.570796 & 636.369 & 4.39 & 4.38 & 1.06 & 0.01 & 0.04 & 7.46 & 5.22 & 3.32 \\
\hline 281 & -1.570796 & 685.619 & 3.84 & 3.83 & 0.88 & 0.00 & 0.05 & 6.53 & 4.57 & 3.86 \\
\hline 236.5 & -1.570796 & 732.719 & 4.74 & 4.74 & 0.96 & 0.00 & 0.05 & 8.06 & 5.64 & 4.30 \\
\hline 186.8 & \begin{tabular}{|l|}
-1.570796 \\
\end{tabular} & 778.219 & 4.41 & 4.40 & 0.92 & 0.00 & 0.05 & 7.50 & 5.25 & 4.80 \\
\hline 145.5 & \begin{tabular}{|l|}
-1.570796 \\
\end{tabular} & 821.369 & 5.67 & 5.66 & 1.31 & 0.01 & 0.05 & 9.64 & 6.75 & 5.21 \\
\hline 70 & \begin{tabular}{|l|}
-1.570796 \\
\end{tabular} & 874.169 & 9.10 & 9.08 & 2.04 & 0.03 & 0.04 & 15.47 & 10.83 & 5.96 \\
\hline 24 & \begin{tabular}{|l|}
-1.570796 \\
\end{tabular} & 930.544 & 12.02 & 11.95 & 2.51 & 0.05 & 0.03 & 20.44 & 14.30 & 6.42 \\
\hline
\end{tabular}


RPP-RPT-32239, Rev. 1

M\&D-2008-005-CALC-001, Rev. 1

Table I.29. BES-FCC Soil/Concrete Tank Contact Forces, Gravity Plus Seismic

Tank AP, 460 Inch Waste Leve

$S p G=1.83$

Fully Cracked Concrete

\begin{tabular}{|c|c|c|c|c|c|c|c|c|c|c|}
\hline & Angle (rad) & Path & $\begin{array}{c}\text { Max Pressure } \\
\text { Soil (BES-FCC) } \\
\text { AP Seismic } \\
\text { (PSI) }\end{array}$ & $\begin{array}{c}\text { Min Pressure } \\
\text { Sail (BES-FCC) } \\
\text { AP } \\
\text { Seismic (PSI) }\end{array}$ & $\begin{array}{c}\text { Max Meridional } \\
\text { Friction } \\
\text { Soil (BES-FCC) } \\
\text { AP Seismic } \\
\text { (PSI) }\end{array}$ & \begin{tabular}{|} 
Max Tangential \\
Friction \\
Soil (BES-FCC) \\
AP \\
Seismic (PSI)
\end{tabular} & $\begin{array}{c}\text { Max Contact } \\
\text { Displacement } \\
\text { Soil (BES-FCC) } \\
\text { AP } \\
\text { Seismic (inch) }\end{array}$ & \begin{tabular}{|l} 
Vertical \\
Pressure
\end{tabular} & $\begin{array}{l}\text { Active } \\
\text { Pressure Phi }= \\
33 \text { deg }\end{array}$ & $\begin{array}{l}\text { Active } \\
\text { Pressure Phi }= \\
49 \text { deg }\end{array}$ \\
\hline 568 & -0.035089 & 67.727 & 17.85 & 2.42 & 8.94 & 5.75 & 0.13 & 7.12 & 7.11 & 7.11 \\
\hline 565.8 & -0.07135 & 105.668 & 13.85 & 2.14 & 8.13 & 3.97 & 0.15 & 7.27 & 7.26 & 7.26 \\
\hline 563.21 & -0.096521 & 137.069 & 15.17 & 1.43 & 8.35 & 3.53 & 0.15 & 7.46 & 7.43 & 7.42 \\
\hline 559.7 & -0.124516 & 182.849 & 8.58 & 2.71 & 5.33 & 3.61 & 0.10 & 7.71 & 7.65 & 7.65 \\
\hline 550.7 & -0.180521 & 226.563 & 10.62 & 1.81 & 4.50 & 5.17 & 0.06 & 8.35 & 8.23 & 8.22 \\
\hline 545.2 & -0.210395 & 275.566 & 10.22 & 5.46 & 4.54 & 4.74 & 0.05 & 8.74 & 8.57 & 8.55 \\
\hline 527.68 & \begin{tabular}{|c|}
-0.298426 \\
\end{tabular} & 325.690 & 9.78 & 4.55 & 4.06 & 4.28 & 0.05 & 999 & 9.59 & 9.56 \\
\hline 518.2 & -0.34673 & 372.305 & 11.45 & 6.91 & 4.52 & 4.03 & 0.04 & 10.66 & 10.09 & 10.04 \\
\hline 494.5 & -0.482293 & 423.427 & 19.74 & 13.06 & 5.90 & 3.54 & 0.04 & 12.35 & 11.07 & 10.97 \\
\hline 476.2 & -0.606571 & 468.308 & 34.19 & 22.11 & 7.01 & 3.01 & 0.03 & 13.65 & 11.45 & 11.27 \\
\hline 447.4 & -0.656685 & 515.312 & 38.73 & 26.94 & 11.67 & 3.07 & 0.05 & 15.70 & 12.75 & 12.51 \\
\hline 407.1 & \begin{tabular}{|c|c|} 
\\
\end{tabular} & 549.725 & 31.28 & 20.55 & 12.78 & 2.56 & 0.06 & 18.57 & 14.53 & 14.18 \\
\hline 382.1 & -1.570796 & 585.819 & 14.84 & 10.34 & 8.19 & 1.80 & 0.07 & 20.35 & 6.00 & 2.85 \\
\hline 335 & \begin{tabular}{|l|}
-1.570796 \\
\end{tabular} & 636.369 & 5.12 & 3.74 & 3.33 & 1.42 & 0.08 & 23.70 & 6.99 & 3.32 \\
\hline 281 & \begin{tabular}{|l|}
-1.570796 \\
\end{tabular} & 685.619 & 4.52 & 3.17 & 2.89 & 1.36 & 0.08 & 27.55 & 8.13 & 3.86 \\
\hline 236.5 & \begin{tabular}{|l|}
-1.570796 \\
\end{tabular} & 732.719 & 5.41 & 4.17 & 3.09 & 1.39 & 0.08 & 30.71 & 9.06 & 4.30 \\
\hline 186.8 & \begin{tabular}{|l|}
-1.570796 \\
\end{tabular} & 778.219 & 4.93 & 3.75 & 2.92 & 1.61 & 0.08 & 34.25 & 10.10 & 4.80 \\
\hline 145.5 & \begin{tabular}{|l|}
-1.570796 \\
\end{tabular} & 821.369 & 6.65 & 4.78 & 4.36 & 2.57 & 0.08 & 37.19 & 10.97 & 5.21 \\
\hline 70 & -1.570796 & 874.169 & 12.31 & 5.41 & 7.36 & 2.75 & 0.06 & 42.57 & 12.56 & 5.96 \\
\hline 24 & \begin{tabular}{|l|}
-1.570796 \\
\end{tabular} & 930.544 & 20.06 & 2.62 & 6.52 & 2.84 & 0.04 & 45.84 & 13.52 & 6.42 \\
\hline
\end{tabular}


RPP-RPT-32239, Rev. 1

M\&D-2008-005-CALC-001, Rev. 1

Table I.30. BES-FCC Soil/Concrete Tank Contact Forces, Seismic Only

Tank AP, 460 Inch Waste Level

$\mathrm{SpG}=1.83$

Best Estiamte Soil

Fully Cracked Concrete

\begin{tabular}{|c|c|c|c|c|c|c|c|}
\hline & Angle (rad) & Path & $\begin{array}{c}\text { Max Pressure } \\
\text { Soil (BES-FCC) } \\
\text { AP Seismic } \\
\text { Only (PSI) } \\
\end{array}$ & $\begin{array}{c}\text { Min Pressure } \\
\text { Soil (BES-FCC) } \\
\text { AP } \\
\text { Seismic Only } \\
\text { (PSI) } \\
\end{array}$ & \begin{tabular}{|c|} 
Max \\
Meridional \\
Friction \\
(BES-FCC) AP \\
Seismic Only \\
(PSI) \\
\end{tabular} & $\begin{array}{c}\text { Max } \\
\text { Tangential } \\
\text { Friction (BES- } \\
\text { FCC) AP } \\
\text { Seismic Only } \\
\text { (PSI) } \\
\end{array}$ & $\begin{array}{c}\text { Max Contact } \\
\text { Displacment } \\
\text { (BES-FCC) AP } \\
\text { Seismic Only } \\
\text { (inch) }\end{array}$ \\
\hline 568 & -0.035089 & 67.727 & 7.99 & -7.43 & 6.89 & 5.72 & 0.05 \\
\hline 565.8 & -0.07135 & 105.668 & 5.58 & -6.12 & 6.33 & 3.93 & 0.03 \\
\hline 563.21 & -0.096521 & 137.069 & 6.30 & -7.44 & 6.33 & 3.47 & 0.03 \\
\hline 559.7 & -0.124516 & 182.849 & 2.96 & -2.91 & 4.13 & 3.57 & 0.01 \\
\hline 550.7 & -0.180521 & 226.563 & 4.68 & -4.14 & 2.93 & 5.06 & 0.01 \\
\hline 545.2 & -0.210395 & 275.566 & 1.96 & -2.80 & 2.76 & 4.65 & 0.01 \\
\hline 527.68 & -0.298426 & 325.690 & 2.17 & -3.06 & 2.50 & 4.25 & 0.01 \\
\hline 518.2 & -0.34673 & 372.305 & 2.20 & -2.34 & 2.18 & 4.01 & 0.01 \\
\hline 494.5 & -0.482293 & 423.427 & 3.33 & -3.35 & 2.60 & 3.46 & 0.01 \\
\hline 476.2 & -0.606571 & 468.308 & 6.11 & -5.97 & 3.83 & 2.89 & 0.01 \\
\hline 447.4 & -0.656685 & 515.312 & 6.79 & -5.00 & 6.65 & 2.86 & 0.02 \\
\hline 407.1 & -0.710341 & 549.725 & 5.84 & -4.90 & 7.48 & 2.40 & 0.02 \\
\hline 382.1 & -1.570796 & 585.819 & 2.47 & -2.03 & 4.97 & 1.74 & 0.03 \\
\hline 335 & -1.570796 & 636.369 & 0.73 & -0.65 & 2.27 & 1.42 & 0.03 \\
\hline 281 & -1.570796 & 685.619 & 0.68 & -0.67 & 2.01 & 1.36 & 0.03 \\
\hline 236.5 & -1.570796 & 732.719 & 0.66 & -0.57 & 2.13 & 1.39 & 0.03 \\
\hline 186.8 & -1.570796 & 778.219 & 0.52 & -0.66 & 2.01 & 1.60 & 0.03 \\
\hline 145.5 & -1.570796 & 821.369 & 0.98 & -0.89 & 3.04 & 2.56 & 0.03 \\
\hline 70 & -1.570796 & 874.169 & 3.21 & -3.69 & 5.32 & 2.72 & 0.02 \\
\hline 24 & -1.570796 & 930.544 & 8.03 & -9.40 & 4.00 & 2.79 & 0.01 \\
\hline
\end{tabular}


RPP-RPT-32239, Rev. 1

M\&D-2008-005-CALC-001, Rev. 1

Table I.31. BES-FCC Primary Tank/Concrete Dome Contact Data, Gravity Only

$$
\begin{gathered}
\text { Tank AP, } 460 \text { Inch Waste Level } \\
\text { SpG }=1.83 \\
\text { Best Estimate Soil } \\
\text { Fully Cracked Concrete }
\end{gathered}
$$

\begin{tabular}{|c|c|c|c|c|}
\hline & $\begin{array}{c}\text { Max Pressure } \\
\text { Primary } \\
\text { Tank/Concrete } \\
\text { Tank Dome AP } \\
\text { Gravity (PSI) }\end{array}$ & $\begin{array}{c}\text { Min Pressure } \\
\text { Primary } \\
\text { Tank/Concrete } \\
\text { Tank Dome AP } \\
\text { Gravity (PSI) }\end{array}$ & $\begin{array}{c}\text { Max Gap } \\
\text { Lateral } \\
\text { Displacement } \\
\text { Primary Tank } \\
\text { /Concrete } \\
\text { Tank Dome } \\
\text { Gravity (in) }\end{array}$ & $\begin{array}{c}\text { Max Gap Displacement } \\
\text { Primary Tank/Concete Tank } \\
\text { Dome AP } \\
\text { Gravity (Inches) }\end{array}$ \\
\hline Radius & 6.206 & 5.996 & 0.012252 & 0.000000 \\
\hline $\mathbf{6 7 . 7 2 7}$ & 3.552 & 3.466 & 0.020988 & 0.000000 \\
\hline $\mathbf{1 0 5 . 6 6 8}$ & 2.334 & 2.293 & 0.026196 & 0.000000 \\
\hline $\mathbf{1 3 7 . 0 6 9}$ & 2.368 & 2.323 & 0.030204 & 0.000000 \\
\hline $\mathbf{1 8 2 . 8 4 9}$ & 1.501 & 1.469 & 0.016440 & -0.000324 \\
\hline $\mathbf{2 2 6 . 5 6 3}$ & 1.645 & 1.626 & 0.036612 & 0.000000 \\
\hline $\mathbf{2 7 5 . 5 6 6}$ & 0.379 & 0.362 & 0.007492 & -0.000555 \\
\hline $\mathbf{3 2 5 . 6 9 0}$ & 0.684 & 0.666 & 0.020580 & -0.000059 \\
\hline $\mathbf{3 7 2 . 3 0 5}$ & 0.000 & 0.000 & 0.000000 & -1.054920 \\
\hline $\mathbf{4 2 3 . 4 2 7}$ & & & & \\
\hline
\end{tabular}


RPP-RPT-32239, Rev. 1

M\&D-2008-005-CALC-001, Rev. 1

Table I.32. BES-FCC Primary Tank/Concrete Dome Contact Data, Gravity Plus Seismic

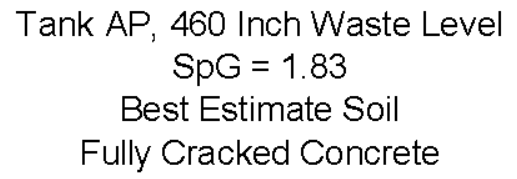

\begin{tabular}{|c|c|c|c|c|}
\hline & $\begin{array}{c}\text { Max Pressure } \\
\text { Primary } \\
\text { Tank/Concrete } \\
\text { Tank Dome AP } \\
\text { Seismic (PSI) }\end{array}$ & $\begin{array}{c}\text { Min Pressure } \\
\text { Primary } \\
\text { Tank/Concrete } \\
\text { Tank Dome AP } \\
\text { Seismic (PSI) }\end{array}$ & $\begin{array}{c}\text { Max Gap } \\
\text { Lateral } \\
\text { Displacement } \\
\text { Primary Tank } \\
\text { /Concrete } \\
\text { Tank Dome } \\
\text { Seismic (in) }\end{array}$ & $\begin{array}{c}\text { Max Gap Displacement } \\
\text { Primary Tank/Concete Tank } \\
\text { Dome AP } \\
\text { Seismic (Inches) }\end{array}$ \\
\hline Radius & 12.035 & 3.152 & 0.016296 & 0.000000 \\
\hline $\mathbf{6 7 . 7 2 7}$ & 11.729 & 1.253 & 0.027036 & -0.000006 \\
\hline $\mathbf{1 0 5 . 6 6 8}$ & 8.340 & 0.656 & 0.033300 & -0.000028 \\
\hline $\mathbf{1 3 7 . 0 6 9}$ & 6.250 & 1.116 & 0.037944 & -0.000001 \\
\hline $\mathbf{1 8 2 . 8 4 9}$ & 3.858 & 0.931 & 0.020532 & -0.000589 \\
\hline $\mathbf{2 2 6 . 5 6 3}$ & 3.751 & 0.673 & 0.045120 & -0.001006 \\
\hline $\mathbf{2 7 5 . 5 6 6}$ & 2.542 & 0.000 & 0.027684 & -0.002582 \\
\hline $\mathbf{3 2 5 . 6 9 0}$ & 9.563 & 0.000 & 0.035004 & -0.005564 \\
\hline $\mathbf{3 7 2 . 3 0 5}$ & 10.424 & 0.000 & 0.015444 & -1.069560 \\
\hline $\mathbf{4 2 3 . 4 2 7}$ & & & & \\
\hline
\end{tabular}


RPP-RPT-32239, Rev. 1

M\&D-2008-005-CALC-001, Rev. 1

Table I.33. BES-FCC Primary Tank/Concrete Dome Contact Data, Seismic Only

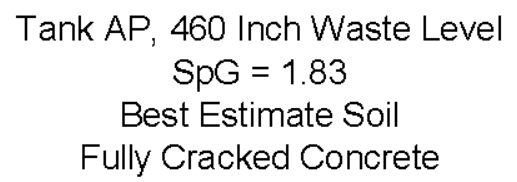

\begin{tabular}{|c|c|c|c|c|}
\hline & $\begin{array}{c}\text { Max Pressure } \\
\text { Primary } \\
\text { Tank/Concrete } \\
\text { Tank Dome AP } \\
\text { Seismic Only } \\
\text { (PSI) }\end{array}$ & $\begin{array}{c}\text { Min Pressure } \\
\text { Primary } \\
\text { Tank/Concrete } \\
\text { Tank Dome AP } \\
\text { Seismic Only } \\
\text { (PSI) }\end{array}$ & $\begin{array}{c}\text { Max Gap } \\
\text { Lateral } \\
\text { Displacement } \\
\text { Primary Tank } \\
\text { /Concrete } \\
\text { Tank Dome } \\
\text { Seismic Only } \\
\text { (in) }\end{array}$ & $\begin{array}{c}\text { Max Gap Displacement } \\
\text { Primary Tank/Concete Tank } \\
\text { Dome AP } \\
\text { Seismic Only (Inches) }\end{array}$ \\
\hline $\mathbf{6 7 . 7 2 7}$ & 5.829 & -2.844 & 0.004044 & 0.000000 \\
\hline $\mathbf{1 0 5 . 6 6 8}$ & 8.177 & -2.213 & 0.006048 & -0.000006 \\
\hline $\mathbf{1 3 7 . 0 6 9}$ & 6.006 & -1.637 & 0.007104 & -0.000028 \\
\hline $\mathbf{1 8 2 . 8 4 9}$ & 3.882 & -1.207 & 0.007740 & -0.000001 \\
\hline $\mathbf{2 2 6 . 5 6 3}$ & 2.356 & -0.539 & 0.004092 & -0.000264 \\
\hline $\mathbf{2 7 5 . 5 6 6}$ & 2.106 & -0.953 & 0.008508 & -0.001006 \\
\hline $\mathbf{3 2 5 . 6 9 0}$ & 2.162 & -0.362 & 0.020192 & -0.002027 \\
\hline $\mathbf{3 7 2 . 3 0 5}$ & 8.879 & -0.666 & 0.014424 & -0.005506 \\
\hline $\mathbf{4 2 3 . 4 2 7}$ & 10.424 & 0.000 & 0.015444 & -0.014640 \\
\hline & & & & \\
\hline
\end{tabular}


RPP-RPT-32239, Rev. 1

M\&D-2008-005-CALC-001, Rev. 1

Table I.34. BES-FCC Primary Tank/Insulating Concrete Contact Forces, Gravity Only

Tank AP, 460 Inch Waste Level

$\mathrm{SpG}=1.83$

Best Esitmate Soil

Fully Cracked Concrete

\begin{tabular}{|c|c|c|c|c|}
\hline & $\begin{array}{c}\text { Max Pressure } \\
\text { Primary } \\
\text { Tank/Insulating } \\
\text { Concrete AP } \\
\text { Gravity (PSI) }\end{array}$ & $\begin{array}{c}\text { Min Pressure } \\
\text { Primary } \\
\text { Tank/nsulating } \\
\text { Concrete AP } \\
\text { Gravity (PSI) }\end{array}$ & $\begin{array}{c}\text { Max Lateral } \\
\text { Displacement } \\
\text { Primary Tank/ } \\
\text { Insulating Concete AP } \\
\text { Gravity (Inches) }\end{array}$ & $\begin{array}{c}\text { Min Lateral } \\
\text { Displacement } \\
\text { Primary Tank / Insulating } \\
\text { Concete AP } \\
\text { Gravity (Inches) }\end{array}$ \\
\hline 424.00 & 76.111 & 75.972 & 0.011204 & 0.011182 \\
\hline 384.00 & 12.931 & 12.917 & 0.000215 & 0.000138 \\
\hline $\mathbf{3 1 7 . 8 5}$ & 33.451 & 33.417 & 0.003043 & 0.003030 \\
\hline $\mathbf{2 4 8 . 1 0}$ & 29.681 & 29.660 & 0.002262 & 0.002251 \\
\hline 199.25 & 30.764 & 30.736 & 0.000995 & 0.000988 \\
\hline $\mathbf{1 5 4 . 9 5}$ & 30.479 & 30.451 & 0.000732 & 0.000726 \\
\hline $\mathbf{1 1 2 . 8 0}$ & 30.451 & 30.417 & 0.000337 & 0.000330 \\
\hline $\mathbf{6 5 . 8 5}$ & 30.972 & 30.882 & 0.000346 & 0.000334 \\
\hline
\end{tabular}


RPP-RPT-32239, Rev. 1

M\&D-2008-005-CALC-001, Rev. 1

Table I.35. BES-FCC Primary Tank/Insulating Concrete Contact Data, Gravity Plus Seismic

Tank AP, 460 Inch Waste Level

$S p G=1.83$

Best Estimate Soil

Fully Cracked Concrete

\begin{tabular}{|c|c|c|c|c|}
\hline & $\begin{array}{c}\text { Max Pressure } \\
\text { Primary } \\
\text { Tank/nsulaiting } \\
\text { Concrete AP } \\
\text { Seismic (PSI) }\end{array}$ & $\begin{array}{c}\text { Min Pressure } \\
\text { Primary } \\
\text { TankInsulaiting } \\
\text { Concrete AP } \\
\text { Seismic (PSI) }\end{array}$ & $\begin{array}{c}\text { Max Lateral } \\
\text { Displacement } \\
\text { Primary } \\
\text { TankInsulaiting } \\
\text { Concrete AP } \\
\text { Seismic (Inches) }\end{array}$ & $\begin{array}{c}\text { Min Lateral } \\
\text { Displacement } \\
\text { Primary Tank/nsulaiting } \\
\text { Concrete AP } \\
\text { Seismic (Inches) }\end{array}$ \\
\hline 424.00 & 100.208 & 42.028 & 0.076152 & 0.002960 \\
\hline 384.00 & 25.951 & 8.104 & 0.162840 & 0.001160 \\
\hline 317.85 & 42.319 & 22.201 & 0.051528 & 0.000932 \\
\hline $\mathbf{2 4 8 . 1 0}$ & 37.611 & 20.722 & 0.032700 & 0.000779 \\
\hline $\mathbf{1 9 9 . 2 5}$ & 37.479 & 21.618 & 0.021708 & 0.000160 \\
\hline $\mathbf{1 5 4 . 9 5}$ & 36.361 & 22.431 & 0.015156 & 0.000171 \\
\hline $\mathbf{1 1 2 . 8 0}$ & 36.326 & 23.951 & 0.011286 & 0.000027 \\
\hline $\mathbf{6 5 . 8 5}$ & 35.500 & 23.681 & 0.009168 & 0.000037 \\
\hline
\end{tabular}


RPP-RPT-32239, Rev. 1

M\&D-2008-005-CALC-001, Rev. 1

Table I.36. BES-FCC Primary Tank/Insulating Concrete Contact Forces, Seismic Only

Tank AP, 460 Inch Waste Level

$\mathrm{SpG}=1.83$

Best Estimate Soil

Fully Cracked Concrete

\begin{tabular}{|c|c|c|c|c|}
\hline Radius & \begin{tabular}{|} 
Max Pressure \\
Primary \\
Tank/nsulaiting \\
Concrete AP \\
Seismic Only \\
(PSI)
\end{tabular} & \begin{tabular}{|} 
Min Pressure \\
Primary \\
Tank/nsulaiting \\
Concrete AP \\
Seismic Only \\
(PSI)
\end{tabular} & $\begin{array}{c}\text { Max Lateral } \\
\text { Displacement } \\
\text { Primary } \\
\text { Tank/nsulaiting } \\
\text { Concrete AP } \\
\text { Seismic Only (Inches) }\end{array}$ & $\begin{array}{c}\text { Min Lateral } \\
\text { Displacement } \\
\text { Primary Tank/Insulaiting } \\
\text { Concrete AP } \\
\text { Seismic Only (Inches) }\end{array}$ \\
\hline 424.00 & 24.097 & -33.944 & 0.065 & -0.008 \\
\hline 384.00 & 13.021 & -4.813 & 0.163 & 0.001 \\
\hline 317.85 & 8.868 & -11.215 & 0.048 & -0.002 \\
\hline 248.10 & 7.931 & -8.938 & 0.030 & -0.001 \\
\hline 199.25 & 6.715 & -9.118 & 0.021 & -0.001 \\
\hline 154.95 & 5.882 & -8.021 & 0.014 & -0.001 \\
\hline 112.80 & 5.875 & -6.465 & 0.011 & 0.000 \\
\hline 65.85 & 4.528 & -7.201 & 0.009 & 0.000 \\
\hline
\end{tabular}


RPP-RPT-32239, Rev. 1

M\&D-2008-005-CALC-001, Rev. 1

Table I.37. BES-FCC Insulating Concrete/Concrete Backed Steel Contact Data, Gravity Only

Tank AP, 460 Inch Waste Level

$\mathrm{SpG}=1.83$

Best Esitmate Soil

Fully Cracked Concrete

\begin{tabular}{|c|c|c|c|c|}
\hline & $\begin{array}{c}\text { Max Pressure } \\
\text { Insulating } \\
\text { Concrete/Secon } \\
\text { dary Liner AP } \\
\text { Gravity (PSI) }\end{array}$ & $\begin{array}{c}\text { Min Pressure } \\
\text { Insulating } \\
\text { Concrete/Secon } \\
\text { dary Liner AP } \\
\text { Gravity (PSI) }\end{array}$ & $\begin{array}{c}\text { Max Lateral } \\
\text { Displacement } \\
\text { Insulating } \\
\text { Concrete/Secondary } \\
\text { Liner AP } \\
\text { Gravity (Inches) }\end{array}$ & $\begin{array}{c}\text { Min Lateral } \\
\text { Displacement } \\
\text { Insulating } \\
\text { Concrete/Secondary } \\
\text { Liner AP } \\
\text { Gravity (Inches) }\end{array}$ \\
\hline Radius & 97.222 & 96.944 & 0.006835 & 0.006791 \\
\hline $\mathbf{3 8 4 . 0 0}$ & 36.493 & 36.410 & 0.005813 & 0.005773 \\
\hline $\mathbf{3 1 7 . 8 5}$ & 26.840 & 26.806 & 0.004486 & 0.004454 \\
\hline $\mathbf{2 4 8 . 1 0}$ & 31.514 & 31.486 & 0.003389 & 0.003360 \\
\hline $\mathbf{1 9 9 . 2 5}$ & 30.944 & 30.910 & 0.002450 & 0.002435 \\
\hline $\mathbf{1 5 4 . 9 5}$ & 30.806 & 30.764 & 0.001607 & 0.001598 \\
\hline $\mathbf{1 1 2 . 8 0}$ & 31.153 & 31.063 & 0.000703 & 0.000700 \\
\hline $\mathbf{6 5 . 8 5}$ & 30.542 & 30.306 & 0.000090 & 0.000084 \\
\hline
\end{tabular}


RPP-RPT-32239, Rev. 1

M\&D-2008-005-CALC-001, Rev. 1

Table I.38. BES-FCC Insulating Concrete/Concrete Backed Steel Contact Data, Gravity Plus Seismic

Tank AP, 460 Inch Waste Level

$\mathrm{SpG}=1.83$

Best Estimate Soil

Fully Cracked Concrete

\begin{tabular}{|c|c|c|c|c|}
\hline & $\begin{array}{c}\text { Max Pressure } \\
\text { Insulating } \\
\text { Concrete/Secon } \\
\text { dary Liner AP } \\
\text { Seismic (PSI) }\end{array}$ & $\begin{array}{c}\text { Min Pressure } \\
\text { Insulating } \\
\text { Concrete/Secon } \\
\text { dary Liner AP } \\
\text { Seismic (PSI) }\end{array}$ & $\begin{array}{c}\text { Max Lateral } \\
\text { Displacement } \\
\text { Insulating } \\
\text { Concrete/Secondary } \\
\text { Liner AP } \\
\text { Seismic (Inches) }\end{array}$ & $\begin{array}{c}\text { Min Lateral } \\
\text { Displacement } \\
\text { Insulating } \\
\text { Concrete/Secondary } \\
\text { Liner AP } \\
\text { Seismic (Inches) }\end{array}$ \\
\hline 424.00 & 109.931 & 81.319 & 0.024732 & 0.000354 \\
\hline 384.00 & 45.451 & 27.924 & 0.023232 & 0.000384 \\
\hline $\mathbf{3 1 7 . 8 5}$ & 35.563 & 16.368 & 0.020484 & 0.000331 \\
\hline $\mathbf{2 4 8 . 1 0}$ & 39.674 & 22.056 & 0.017304 & 0.000288 \\
\hline $\mathbf{1 9 9 . 2 5}$ & 37.660 & 21.903 & 0.014628 & 0.000226 \\
\hline $\mathbf{1 5 4 . 9 5}$ & 36.722 & 22.618 & 0.012288 & 0.000156 \\
\hline $\mathbf{1 1 2 . 8 0}$ & 36.931 & 24.375 & 0.010303 & 0.000174 \\
\hline $\mathbf{6 5 . 8 5}$ & 35.653 & 23.924 & 0.009026 & 0.000040 \\
\hline
\end{tabular}


RPP-RPT-32239, Rev. 1

M\&D-2008-005-CALC-001, Rev. 1

Table I.39. BES-FCC Insulating Concrete/Concrete Backed Steel Contact Data, Seismic Only

Tank AP, 460 Inch Waste Level

$\mathrm{SpG}=1.83$

Best Estimate Soil

Fully Cracked Concrete

\begin{tabular}{|c|c|c|c|c|}
\hline Radius & $\begin{array}{l}\text { Max Pressure } \\
\text { Insulating } \\
\text { Concrete/Secon } \\
\text { dary Liner AP } \\
\text { Seismic Only } \\
\text { (PSI) }\end{array}$ & $\begin{array}{c}\text { Min Pressure } \\
\text { Insulating } \\
\text { Concrete/Secon } \\
\text { dary Liner AP } \\
\text { Seismic Only } \\
\text { (PSI) }\end{array}$ & $\begin{array}{c}\text { Max Lateral } \\
\text { Displacement } \\
\text { Insulating } \\
\text { Concrete/Secondary } \\
\text { Liner AP } \\
\text { Seismic Only (Inches) }\end{array}$ & $\begin{array}{c}\text { Min Lateral } \\
\text { Displacement } \\
\text { Insulating } \\
\text { Concrete/Secondary } \\
\text { Liner AP } \\
\text { Seismic Only (Inches) }\end{array}$ \\
\hline 424.00 & 12.708 & -15.625 & 0.018 & -0.006 \\
\hline 384.00 & 8.958 & -8.486 & 0.017 & -0.005 \\
\hline 317.85 & 8.722 & -10.438 & 0.016 & -0.004 \\
\hline 248.10 & 8.160 & -9.431 & 0.014 & -0.003 \\
\hline 199.25 & 6.715 & -9.007 & 0.012 & -0.002 \\
\hline 154.95 & 5.917 & -8.146 & 0.011 & -0.001 \\
\hline 112.80 & 5.778 & -6.688 & 0.010 & -0.001 \\
\hline 65.85 & 5.111 & -6.382 & 0.009 & 0.000 \\
\hline
\end{tabular}


RPP-RPT-32239, Rev. 1

M\&D-2008-005-CALC-001, Rev. 1

Table I.40. BES-FCC Waste Contact Pressure, Gravity Plus Seismic

Tank AY, 460 Inch Waste Level

$\mathrm{SpG}=1.83$

Best Estimate Soil

Fully Cracked Concrete

\begin{tabular}{|c|c|c|c|c|c|c|c|}
\hline $\begin{array}{l}\text { Waste } \\
\text { Height } \\
\text { Ratio }\end{array}$ & Waste Height & $\begin{array}{c}\text { Max Pressure } \\
\text { AP Tank, } 460 \text { in } \\
\text { Waste Level, } \\
\text { SpG =1.83 } \\
\text { Time History } \\
\text { (PSI) }\end{array}$ & $\begin{array}{c}\text { Min Pressure } \\
\text { AP Tank, } 460 \text { in } \\
\text { Waste Level, } \\
\text { SpG }=1.83 \\
\text { Time History } \\
\text { (PSI) }\end{array}$ & $\begin{array}{l}\text { Hydrostatic } \\
\text { (psi) }\end{array}$ & $\begin{array}{l}\text { Hydrodynamic } \\
\text { (psi) }\end{array}$ & $\begin{array}{l}\text { Theoretical } \\
\text { Min (SRSS) }\end{array}$ & $\begin{array}{l}\text { Theoretical } \\
\text { Max (SRSS) }\end{array}$ \\
\hline 0.99 & 454.35 & 9.194 & -8.375 & 0.37 & 175 & 0.00 & 213 \\
\hline 0.96 & 443.05 & 13.444 & -12.167 & 1.12 & 1.94 & 0.00 & 306 \\
\hline 0.94 & 4317625 & 14.528 & -10.340 & 1.87 & 2.20 & 0.00 & 4.07 \\
\hline 0.90 & 414.125 & 11.938 & -6.713 & 3.03 & 2.68 & 0.35 & 5.71 \\
\hline 0.85 & 390.125 & 9.083 & -0.898 & 4.62 & 3.35 & 1.27 & 7.97 \\
\hline 0.80 & 366.125 & 11.708 & 0.095 & 6.20 & 4.00 & 2.20 & 10.20 \\
\hline 0.74 & 342 & 13840 & 0.489 & 7.80 & 4.62 & 3.18 & 1242 \\
\hline 0.69 & 318.325 & 16.056 & 1.160 & 9.36 & 5.19 & 4.17 & 14.55 \\
\hline 0.64 & 295.225 & 18.736 & 1.796 & 10.89 & 5.70 & 5.19 & 16.59 \\
\hline 0.59 & 272.125 & 20.646 & 2.802 & 12.41 & 6.17 & 6.24 & 18.59 \\
\hline 0.54 & 248.975 & 23.271 & 3.713 & 13.94 & 6.61 & 7.33 & 20.56 \\
\hline 0.49 & 225.825 & 25.979 & 4.672 & 15.47 & 7.01 & 8.46 & 2248 \\
\hline 0.44 & 202.725 & 26.688 & 5.980 & 17.00 & 7.37 & 9.63 & 24.37 \\
\hline 0.39 & 179.625 & 28.417 & 7.313 & 18.53 & 7.70 & 10.83 & 26.22 \\
\hline 0.34 & 156.475 & 31.889 & 8.653 & 20.06 & 798 & 12.07 & 28.04 \\
\hline 0.29 & 134.075 & 33.340 & 10.208 & 21.54 & 8.22 & 13.31 & 29.76 \\
\hline 0.24 & 112.475 & 33.208 & 11.694 & 22.96 & 8.42 & 14.54 & 31.38 \\
\hline 0.20 & 90.875 & 35.590 & 13.319 & 24.39 & 8.58 & 15.81 & 32.97 \\
\hline 0.15 & 69.275 & 36.382 & 14.660 & 25.82 & 8.71 & 17.11 & 34.53 \\
\hline 0.10 & 47.738 & 38.521 & 16.493 & 27.24 & 8.80 & 18.44 & 36.04 \\
\hline 0.05 & 24.500 & 41.014 & 16.910 & 28.78 & 8.87 & 19.91 & 37.64 \\
\hline 0.02 & 7.755 & 46.979 & 24.917 & 29.88 & 8.89 & 20.99 & 3877 \\
\hline 0.00[ & 1.755 & 40.417 & 24.736 & 30.28 & 8.89 & 21.39 & 39.17 \\
\hline
\end{tabular}


RPP-RPT-32239, Rev. 1

M\&D-2008-005-CALC-001, Rev. 1

Table I.41. BES-FCC Waste Contact Pressure, Theoretical Pressures

\begin{tabular}{|c|c|c|c|c|c|c|c|c|c|c|c|}
\hline $\begin{array}{l}\text { Tank Radius, } \mathrm{Hr} \\
\text { Waste Depth } \mathrm{HI}\end{array}$ & $\begin{array}{l}450 \\
460\end{array}$ & $\begin{array}{l}\mathrm{H} / \mathrm{Hr} \\
\text { Conv 1st }\end{array}$ & $\begin{array}{l}1.02222222 \\
\text { Conv } 2 \text { nd }\end{array}$ & Conv $3 \mathrm{rd}$ & $\begin{array}{l}\text { Waste Dens } \\
\text { [mpul } \mathrm{H}\end{array}$ & Pressure ${ }^{1.71}$ & $E-04$ & & & & \\
\hline & & Conv 1st & Conv 2nd & Conv 3rd & & Conv 1st & Conv 2nd & Conv 3rd & Impul H & רpulV & \\
\hline Centroid & Lamda. & 1.841 & 5.331 & 8.536 & $\mathrm{Sa}=$ & 0.064 & 0.108 & 0.163 & 0.29 & 0.25 & \\
\hline Height & nu & $\operatorname{con} 0(n)$ & $\operatorname{con} 1(n)$ & $\operatorname{con} 2(n)$ & $c i(n)$ & 24.7296 & 41.7312 & 62.9832 & 112.06 & 96.6 & SASS \\
\hline 454.35 & 0.98771739 & 0.82 & 0.07 & 0.03 & 0.09 & 1.56 & 0.22 & 0.12 & 0.76 & 0.12 & 1.75 \\
\hline 443.05 & 0.96315217 & 0.78 & 0.06 & 0.02 & 0.14 & 1.49 & 0.19 & 0.10 & 1.18 & 0.35 & 1.94 \\
\hline 431.7625 & 0.93861413 & 0.75 & 0.05 & 0.02 & 0.18 & 1.43 & 0.17 & 0.08 & 1.56 & 0.59 & 2.20 \\
\hline 414.125 & 0.90027174 & 0.70 & 0.04 & 0.01 & 0.24 & 1.33 & 0.14 & 0.06 & 2.11 & 0.95 & 2.68 \\
\hline 390.125 & 0.84809783 & 0.64 & 0.03 & 0.01 & 0.32 & 1.22 & 0.10 & 0.04 & 2.77 & 1.44 & 3.35 \\
\hline 366.125 & 0.79592391 & 0.59 & 0.02 & 0.00 & 0.39 & 1.11 & 0.08 & 0.02 & 3.33 & 1.92 & 4.00 \\
\hline 342 & 0.74347826 & 0.54 & 0.02 & 0.00 & 0.44 & 1.02 & 0.06 & 0.01 & 3.82 & 2.38 & 4.62 \\
\hline 318.325 & 0.69201087 & 0.49 & 0.01 & 0.00 & 0.49 & 0.94 & 0.04 & 0.01 & 4.25 & 2.83 & 5.19 \\
\hline 295.225 & 0.64179348 & 0.45 & 0.01 & 0.00 & 0.53 & 0.86 & 0.03 & 0.01 & 4.61 & 3.24 & 5.70 \\
\hline 272.125 & 0.59157609 & 0.42 & 0.01 & 0.00 & 0.57 & 0.80 & 0.03 & 0.00 & 4.92 & 3.64 & 6.17 \\
\hline 248.975 & 0.54125 & 0.39 & 0.01 & 0.00 & 0.60 & 0.74 & 0.02 & 0.00 & 5.20 & 4.01 & 6.61 \\
\hline 225.825 & 0.49092391 & 0.36 & 0.00 & 0.00 & 0.63 & 0.68 & 0.01 & 0.00 & 5.45 & 4.36 & 7.01 \\
\hline 202.725 & 0.44070652 & 0.34 & 0.00 & 0.00 & 0.66 & 0.65 & 0.01 & 0.00 & 5.66 & 4.68 & 7.37 \\
\hline 179.625 & 0.39048913 & 0.32 & 0.00 & 0.00 & 0.68 & 0.61 & 0.01 & 0.00 & 5.84 & 4.97 & 7.70 \\
\hline 156.475 & 0.34016304 & 0.30 & 0.00 & 0.00 & 0.70 & 0.57 & 0.01 & 0.00 & 6.00 & 5.23 & 7.98 \\
\hline 134.075 & 0.29146739 & 0.29 & 0.00 & 0.00 & 0.71 & 0.55 & 0.01 & 0.00 & 6.13 & 5.45 & 8.22 \\
\hline 112.475 & 0.24451087 & 0.28 & 0.00 & 0.00 & 0.72 & 0.53 & 0.00 & 0.00 & 6.23 & 5.64 & 8.42 \\
\hline 90.875 & 0.19755435 & 0.27 & 0.00 & 0.00 & 0.73 & 0.51 & 0.00 & 0.00 & 6.31 & 5.79 & 8.58 \\
\hline 69.275 & 0.15059783 & 0.26 & 0.00 & 0.00 & 0.74 & 0.49 & 0.00 & 0.00 & 6.38 & 5.91 & 8.71 \\
\hline 47.7375 & 0.10377717 & 0.25 & 0.00 & 0.00 & 0.75 & 0.48 & 0.00 & 0.00 & 6.43 & 6.00 & 8.80 \\
\hline 24.5 & 0.05326087 & 0.25 & 0.00 & 0.00 & 0.75 & 0.48 & 0.00 & 0.00 & 6.46 & 6.06 & 8.87 \\
\hline 7.755 & 0.0168587 & 0.25 & 0.00 & 0.00 & 0.75 & 0.47 & 0.00 & 0.00 & 6.47 & 6.08 & 8.89 \\
\hline 1.755 & 0.00381522 & 0.25 & 0.00 & 0.00 & 0.75 & 0.47 & 0.00 & 0.00 & 6.47 & 6.08 & 8.89 \\
\hline
\end{tabular}


RPP-RPT-32239, Rev. 1

M\&D-2008-005-CALC-001, Rev. 1

Table I.42. BES-FCC Waste Surface Displacement, Gravity Plus Sei smic

Tank AP, 460 Inch Waste Level

$$
\mathrm{SpG}=1.83
$$

Best Estimate Soil

Fully Cracked Concrete

\begin{tabular}{|r|c|c|}
\hline & $\begin{array}{c}\text { Max Vertical } \\
\text { Displacement } \\
\text { AP-460-BES- } \\
\text { FCC } \\
\text { Time History } \\
\text { (in) }\end{array}$ & $\begin{array}{c}\text { Min Vertical } \\
\text { Displacement } \\
\text { AP-460-BES- } \\
\text { FCC } \\
\text { Time History } \\
\text { (in) }\end{array}$ \\
\hline 95.7 & 6.59 & -11.64 \\
\hline 129.9 & 7.53 & -10.70 \\
\hline 180 & 8.10 & -12.12 \\
\hline 218.5 & 7.40 & -13.10 \\
\hline 277.7 & 8.12 & -13.19 \\
\hline 358 & 8.60 & -13.21 \\
\hline 410 & 7.10 & -12.44 \\
\hline 450 & 5.04 & -9.38 \\
\hline
\end{tabular}




\section{RPP-RPT-32239, Rev. 1 \\ M\&D-2008-005-CALC-001, Rev. 1}

\section{Near-Soil-1.txt}

et, 8, solid 45

/input, soil-prop-Mean-geo, txt

$\mathrm{ksel}, \mathrm{u}, \mathrm{kp}, \mathrm{,}, \mathrm{k}, \mathrm{maxj} \mathrm{b}$

asel, $u$, area, 1, amaxj b

lsel, u, line, , 1, lmaxjb

vsel, u, volu, , 1, vmaxw
! Use Element SOLID45 for Near Soil Elements

! Read Soil Properties

! Unselect existing Keypoints

! Unselect existing Area

! Unselect existing Lines

! Unselect existing Volumes

/COM - Create Keypoints to match concrete tank profile

${ }^{*} \mathrm{do}, i, 1, \mathrm{bm}$ kp

$k, \operatorname{kmaxj} b+i, \operatorname{ctx}(i), 0, \operatorname{ctz}(i)$

*enddo

/COM - Create Keypoints above top of tank

$\mathrm{k}, \mathrm{kmaxj}_{\mathrm{b}}+\mathrm{bm} \_\mathrm{kp}+1,0,0,0$

! Keypoint at origin (surface)

$k, k \operatorname{maxj} b+b m-k p+2,0,0, \operatorname{soilz}(2)$

! Keypoint at to divide soil above tank

*get, KMAXtemp1, KP, 0, num, max

! Get maximum keypoint number for counter

/COM - Create Keypoints at outside of excavated soil

$\star$ do, $i, 1, \operatorname{tanksoil}$

$k$, kmaxtemp $1+i, \operatorname{soilx}(i), 0, \operatorname{soil} z(i)$

tenddo

${ }^{\star}$ get, KMAXtemp2, KP, 0, num, max

! Get maximum keypoint number for counter

/COM - Create additional keypoint in soil above tank

$k, \operatorname{kmaxtemp} 2+1, \operatorname{ctx}(2), 0, \operatorname{soilz}(1)$

$\mathrm{k}$, kmaxtemp $2+2, \operatorname{ctx}(9), 0, \operatorname{soilz}(1)$

$\mathrm{k}, \operatorname{kmax}$ temp $2+3, \operatorname{ctx}(12), 0, \operatorname{soilz}(1)$

$k$, kmaxtemp $2+4, \operatorname{ctx}(2), 0, \operatorname{soilz}(2)$

$k$, kmaxtemp $2+5, \operatorname{ctx}(9), 0, \operatorname{soilz}(2)$

$\mathrm{k}, \operatorname{kmaxtemp} 2+6, \operatorname{ctx}(12), 0, \operatorname{soilz}(2)$

$\mathrm{k}$, kmaxtemp $2+7, \operatorname{ctx}(12), 0, \operatorname{soilz}(3)$

$\mathrm{k}$, kmaxtemp $2+8, \operatorname{ctx}\left(\mathrm{bm} \_\mathrm{kp}+1\right), 0, \operatorname{ctz}\left(\mathrm{bm} \_\mathrm{kp}+1\right)$

a, kmaxtemp $2+1$, kmaxtemp $2+2$, kmaxtemp $2+5$, kmaxtemp $2+4$

a, kmaxtemp $2+2$, kmaxtemp $2+3$, kmaxtemp $2+6$, kmaxtemp $2+5$

a, kmaxtemp $2+3$, kmaxtemp $1+1$, kmaxtemp $1+2$, kmaxtemp $2+6$

a, kmaxtemp 2+4, kmaxtemp 2+5, kmaxjb+9, kmaxj $b+8, k \max j b+7, k \operatorname{maxj} b+6, k \max j b+5, k \max j b+4, k \max j b+3, k \max j b+2$

$! a, 740,741,712,711,710,709,708,707,706,705$

a, kmaxtemp2+5, kmaxtemp 2+6, kmaxtemp $2+7, \operatorname{kmaxj} b+12, k \max j b+11, k \max j b+10, k \operatorname{kaxj} b+9$

a, kmaxtemp $2+6$, kmaxtemp $1+2$, kmaxtemp $1+3$, kmaxtemp $2+7$

a, kmaxtemp $2+7, \operatorname{kmaxtemp} 1+3, \operatorname{kmaxtemp} 1+4, \operatorname{kmaxj} \mathrm{b}+12$

a, kmaxj $b+12$, kmaxt emp $1+4, \operatorname{kmaxt} \operatorname{emp} 1+5, \operatorname{kmaxj} b+14, \operatorname{kmaxj} b+13$

$a, k \max j b+14, \operatorname{kmax} t e m p 1+5, \operatorname{kmax} t \operatorname{emp} 1+6, \operatorname{kmax} j b+16, \operatorname{kmax} j b+15$

$a, k \operatorname{maxj} b+16, k \max t \operatorname{emp} 1+6, \operatorname{kmaxt} \operatorname{emp} 1+7, \operatorname{kmaxj} b+18, \operatorname{kmax} j b+17$

a, $k \operatorname{maxj} \mathrm{b}+18, k \operatorname{kax} t \operatorname{emp} 1+7, \operatorname{kmax} t \operatorname{emp} 1+8, k \operatorname{maxj} \mathrm{b}+20, k \max j \mathrm{~b}+19$

a, kmaxj jo+20, kmaxtemp $1+8, k \max t$ emp $1+9, \operatorname{kmaxt} \operatorname{emp} 2+8, k \max j \mathrm{~b}+22, k \max j \mathrm{~b}+21$

$\mathrm{cm}, \mathrm{top}$-soil-area, area

lsla

cm, top-soil, line

type, 1

real, 1

/COM - Define line divisions to control meshing

lsel, s, loc, $z, \operatorname{soilz}(1), \operatorname{soilz}(2)$

lsel, $r, 1 \circ c, x, \operatorname{ctx}(3), \operatorname{ctx}(8)$

lesize, all, , 14

lsel, s, loc, $z, \operatorname{soilz}(1), \operatorname{soilz}(2)$

lsel, r, loc, x, ctx (10), ctx(11)

lesize, all, , 3

cmsel, s, top-soil

lsel, $r, 100, x, \operatorname{ctx}(2)$

lesize, all, , 2

cmsel, s, top-soil

lsel, s, loc, $x, \operatorname{ctx}(9)$

lesize, all, , 2

! soil above tank top, match tank meshing

! soil above tank top, match tank meshing

! Reselect lines in near soil

! Control vertical element size, above tank

! Control vertical element size, above tank 


\section{RPP-RPT-32239, Rev. 1 M\&D-2008-005-CALC-001, Rev. 1}

cmsel, s, top-soil

lsel, r, loc, $x, \operatorname{ctx}(12)$

lesize, all,, 2

cmsel, s, top-soil

lsel, r, loc, z, ctz(2), ctz(12)

lsel, r, loc, $x, \operatorname{ctx}(2), \operatorname{ctx}(12)$

lesize, all, , 1

lsel,, , line, $, 1 \max j b+8, l \max j b+10,2$

lsel, $a, l i n e,, l \max j b+26, l \operatorname{maxj} b+28,2$

lsel, a, line, , 1 maxj $b+30, l \operatorname{maxj} b+38,4$

lesize, all, , 9

lsel, s, line, , $l$ maxj $b+42, l \operatorname{maxj} b+42,4$

lesize, all, , 7

lsel, s, line, , lmaxjb+9

lsel, $a, l i n e,, l \max j b+25, l \max j b+27,2$

lsel, a, line, , lmaxjb+29, lmaxj b+45, 4

lesize, all, , 1

lsel, s, line, $1 \operatorname{maxj} b+6$

lsel, a, line, , $l \max j b+20, l \max j b+21$

lsel, a, line, , $l \max j b+32, l \operatorname{maxj} b+44,4$

lsel, a, line, $, 1 \max j b+31, l \operatorname{maxj} b+43,4$

lsel, a, line, , $l \operatorname{maxj} b+47, l \operatorname{maxj} b+49$

lesize, all, , 1

lsel, s, line, , lmaxjb+46

lesize, all, , 4

! Control meshing to match tank

cmsel, s, top-soil-area

! Control mesh size at bottom of excavated soil

amesh, all

! Mesh area to develop pattern for volume meshing

type, 8

ksel, a, kp, 1

! Control vertical element size, above tank

! Control vertical element size, outside excavation mesh

! Control horizontal meshing in soil

! Control horizontal meshing in soil

ksel, a, kp, , ct_kps

vrotat, all, , $, 1,1$, ct_kps, 180,2

lsla

lsel, $r, 100, x, \operatorname{ctx}(2)$

lesize, all, , arcsize

lsla

lsel, r, loc, $x, \operatorname{ctx}(9)$

lesize, all, arcsize

lsla

lsel, r, loc, $x, \operatorname{ctx}(12)$

lesize, all, , arcsize

vsweep, all

aclear, all

cm, top-soil-vol, volu

! Select Keypoint for rotation axis

! Select Keypoint for rotation axis

! Generate Volumes for excavated soil

! Define meshing for slices

! Define meshing for slices

! Define meshing for slices

! Sweep pattern into volume

! Delete elements used for sweep

*get, vMAXtemp, vOLU, o, num, max

/COM - Generate element above top center of tank

asel, u, area, , all

vsel, u, volu, , all

$a, k m a x j b+b m k p+1, k m a x t e m p 2+1, k \max t e m p 2+4, k \operatorname{maxj} b+b m k p+2$

a, kmaxjb+bm_kp+2, kmaxtemp $2+4, k \operatorname{maxj} b+2, k \operatorname{maxj} b+1$

vrotat, all,,,, 1, , ct kps, 180,2

vsel, s, volu, , vmaxtemp +1 , vmaxtemp $+3,2$

vatt, 801,8

vsel, s, volu, , vmaxtemp+2, vmaxt emp $+4,2$

vatt, 802,8

! Assign material properties

vsel, s, volu, , vmaxtemp+1, vmaxtemp +4

allsel

asel, s, loc, $z, \operatorname{ctz}(1), \operatorname{ctz}(2)$

type, 1

asel, $r, 100, x, 0,4$

asel, r, loc, $z, \operatorname{ctz}(1), \operatorname{ctz}(2)$

cmsel, u, conc-tank-a

${ }^{*}$ get, atemp, area, , num, max

${ }^{\star}$ get, atemp1, area, num, min

asel, a, area, $1,22,21$

mshcopy, 2, 1, at emp 1

mshcopy, 2, 22, atemp

asel, u, area, $, 1,22,21$ 
RPP-RPT-32239, Rev. 1

M\&D-2008-005-CALC-001, Rev. 1

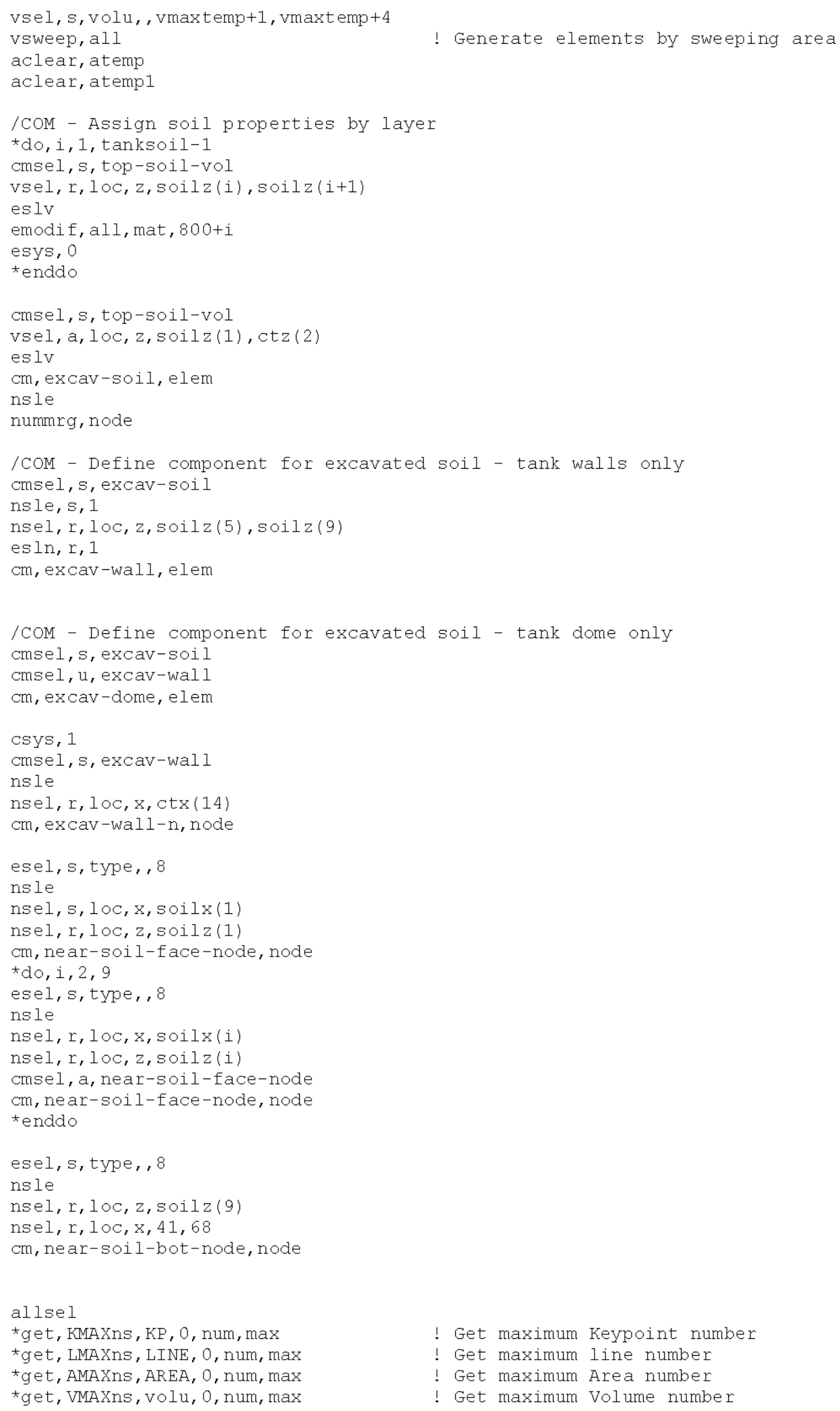


RPP-RPT-32239, Rev. 1

M\&D-2008-005-CALC-001, Rev. 1

\section{Run-Tank.txt}

! batch

! PNNL DST Seismic Analysis, Gravity Inputs, Best Est Soil, Fully Cracked Concrete Properties, AP Primary Tank Geometry, Dome Friction=0.0

!

fini

/clear

/filname, AP-460-BES-FCC-SeismiC, 1

/config, nres, 3000

/config, nproc, 2

! Increase allowable number of results to 3000

/config, fsplit, 1024

! Activate 2 processers for solution

$/ \mathrm{prep} 7$

$g=32 \cdot 2$

! Split binary file at $4.2 \mathrm{~GB}$

$\mathrm{DF}=40$

! Gravity (ft/sec)

$\mathrm{ALPHA}=0.4$

! Factor for beta (stiffness) damping

! Alpha damping

lout, tank-out, out

/sys, "X: $\backslash 07.00$ - Quality Assurance $\backslash$ ANSYS QA \usrcfg.bat" $>$ QA. out

lout, QA, out, , append

/input, tank-coordinates-AP, txt ! Run file defining tank coordinates (concrete and primary)

/input, tank-props-crack.txt ! Run file defining fully cracked concrete properties (PNNL

Concrete Properties)

/input, tank-mesh1, txt

/input, primary-props-AP, txt

! Develop concrete tank

/input, primary, txt

/input, insulate, txt

/input, liner, txt

/input, waste-solid-AP-s, txt

/input, bolts-friction, txt

/input, near-soil-1, txt

/input, far-soil, txt

/input, interfacel, txt

/input, interface-gap 1, txt

/input, slave, txt

! Run file defining AP Primary tank properties

! Develop Primary tank

! Develop insulating concrete model

! Develop Liner model

! Develop waste model

! Develop J-Bolt model

! Develop excavated soil model

! Develop Far-Field soil model

! Develop soil and Concrete Interfaces

! Develop Primary Tank Interfaces

! Develop slaved boundary conditions

/input, boundary, txt

/input, outer-spar, txt

! Place base and symmetry boundary conditions

! Connect soil model to symmetry plane

/input, live_load, txt

/input, fix-soil, txt

/out

ALLSEL

lout, Tank-th, out

save

/input, solve-TH-BES, txt

! Run solution Phase

/input,post-tank, txt

lout

/exit

\section{Soil-Prop-BES-Geo.txt}

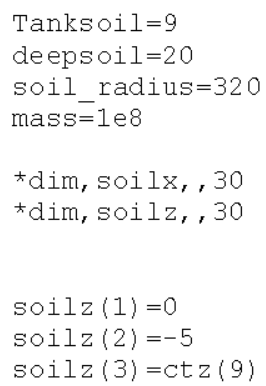

! Apply live load over a loft radius over dome center 
RPP-RPT-32239, Rev. 1

M\&D-2008-005-CALC-001, Rev. 1

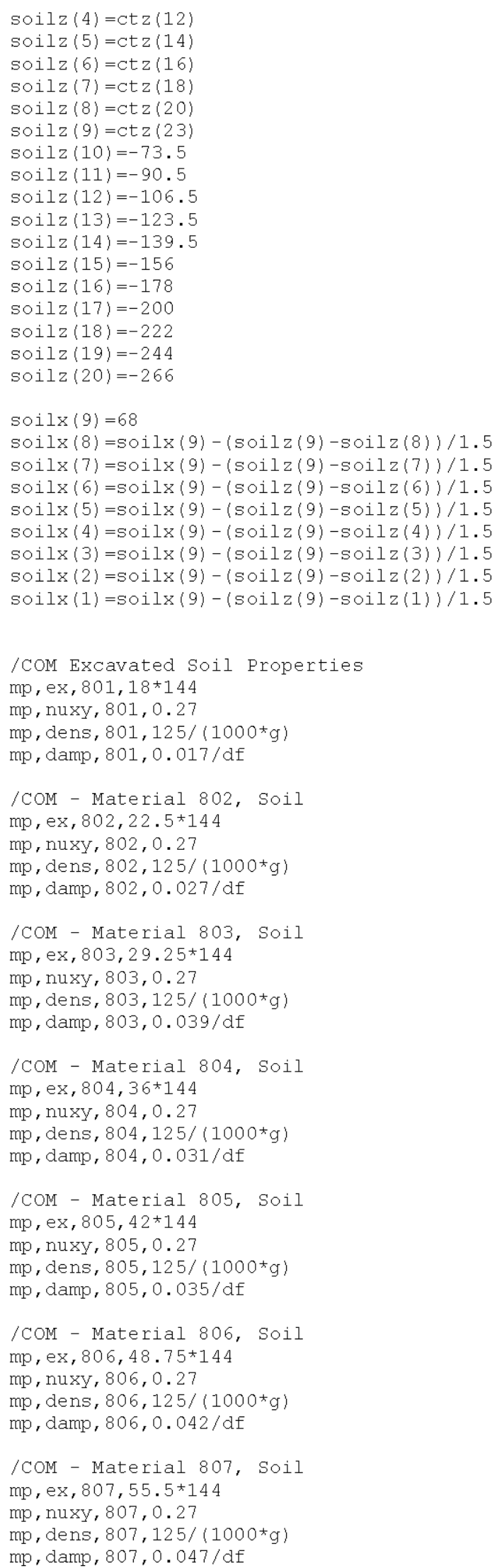


RPP-RPT-32239, Rev. 1

M\&D-2008-005-CALC-001, Rev. 1

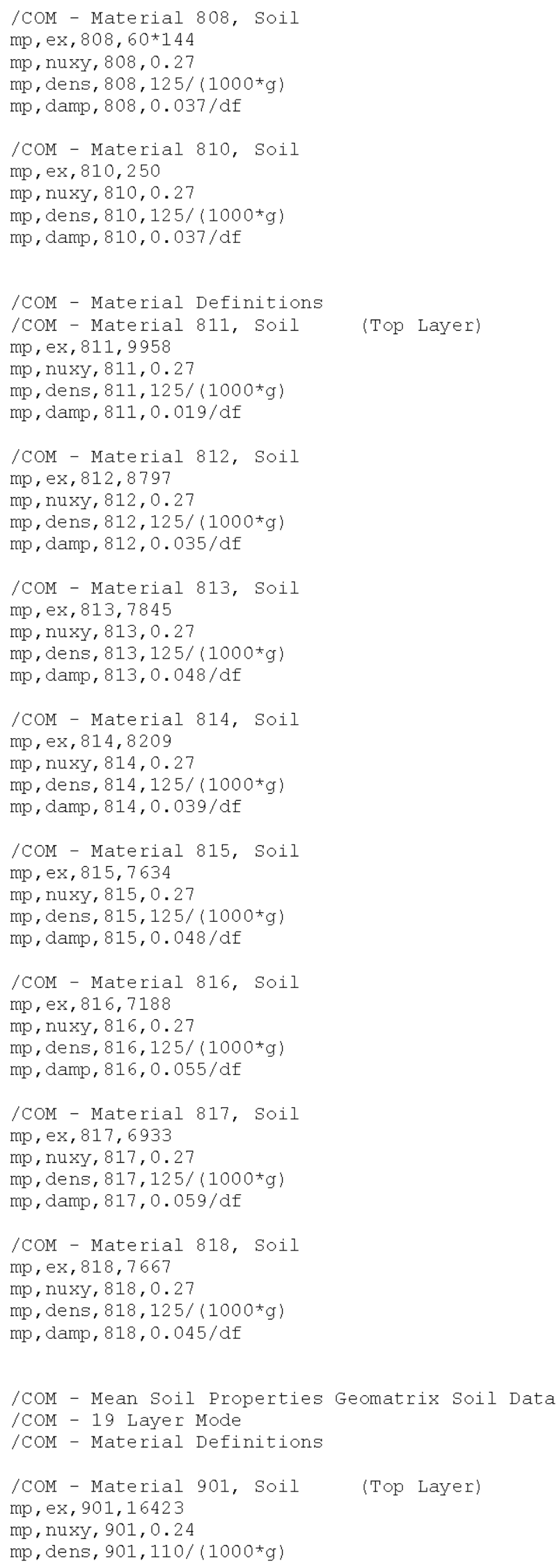


RPP-RPT-32239, Rev. 1

M\&D-2008-005-CALC-001, Rev. 1

mp , damp, 901,0.017/df

/COM - Material 902, Soil mp, ex, 902, 15479

mp, nuxy, 902, 0.24

mp, dens, 902,110/(1000*g)

mp, damp, $902,0.025 / d f$

/COM - Material 903, Soil

mp, ex, 903,14481

mp, nuxy, 903, 0.24

$\mathrm{mp}$, dens, $903,110 /\left(1000^{*} \mathrm{~g}\right)$

mp, damp, 903, 0.034/df

/COM - Material 904, Soil

$\mathrm{mp}, \mathrm{ex}, 904,14707$

mp, nuxy, 904, 0.24

$\mathrm{mp}$, dens, $904,110 /\left(1000^{*} \mathrm{~g}\right)$

mp , damp, 904, 0.028/df

/COM - Material 905, Soil mp, ex, 905,13625

mp, nuxy, 905, 0.19

$\mathrm{mp}$, dens, $905,110 /\left(1000^{*} \mathrm{~g}\right)$

mp, damp, 905, 0.032/df

/COM - Material 906, Soil mp, ex, 906,15456

mp, nuxy, 906, 0.19

$\mathrm{mp}$, dens, 906,110/(1000*g)

$\mathrm{mp}$, damp, 906, 0.033/df

/COM - Material 907, Soil

mp, ex, 907, 17532

mp, nuxy, 907, 0.19

mp, dens, 907, 110/(1000*g)

mp, damp, 907,0.033/df

/COM - Material 908, Soil

mp, ex, 908,20972

mp, nuxy, 908, 0.19

$\mathrm{mp}$, dens, $908,110 /(1000 * \mathrm{~g})$

mp , damp, 908, 0.025/df

/COM - Material 909, Soil mp, ex, 909,23447

mp, nuxy, 909, 0.19

mp, dens, $909,110 /\left(1000^{*} \mathrm{~g}\right)$

$\mathrm{mp}$, damp, 909, 0.026/df

/COM - Material 910, Soil

$\mathrm{mp}, \mathrm{ex}, 910,23138$

mp, nuxy, 910, 0.19

$\mathrm{mp}$, dens, 910, 110/(1000*g)

mp, damp, 910, 0.027/df

/COM - Material 911, Soil

mp, ex, 911, 22753

mp, nuxy, 911, 0.19

mp, dens, 911, 110/(1000*g)

mp , damp, 911, 0.029/df

/COM - Material 912, Soil

mp, ex, 912, 22069

mp, nuxy, 912, 0.19

$\mathrm{mp}$, dens, $912,110 /(1000 * \mathrm{~g})$

mp, damp, 912, 0.033/df

/COM - Material 913, Soil

$\mathrm{mp}, \mathrm{ex}, 913,25780$

mp, nuxy, 913,0.19 
RPP-RPT-32239, Rev. 1

M\&D-2008-005-CALC-001, Rev. 1

$\mathrm{mp}$, dens, $913,110 /\left(1000^{*} \mathrm{~g}\right)$

mp , damp, 913,0.025/df

/COM - Material 914, Soil

$\mathrm{mp}, \mathrm{ex}, 914,25333$

mp, nuxy, 914, 0.19

mp, dens, $914,110 /\left(1000^{\star} \mathrm{g}\right)$

mp, damp, 914, 0.027/df

/COM - Material 915, Soil

mp, ex, 915, 35501

mp, nuxy, $915,0.28$

$\mathrm{mp}$, dens, $915,120 /\left(1000^{*} \mathrm{~g}\right)$

mp, damp, 915, 0.022/df

/COM - Material 916, Soil

$\mathrm{mp}, \mathrm{ex}, 916,39465$

mp, nuxy, $916,0.28$

mp, dens, $916,120 /\left(1000^{*} \mathrm{~g}\right)$

mp , damp, 916, 0.021/df

/COM - Material 917, Soil

$\mathrm{mp}, \mathrm{ex}, 917,38565$

mp, nuxy, $917,0.28$

$\mathrm{mp}$, dens, $917,120 /\left(1000^{*} \mathrm{~g}\right)$

mp , damp, 917, 0.023/df

/COM - Material 918, Soil

mp , ex, 918,37715

$\mathrm{mp}, \mathrm{nuxy}, 918,0.28$

$\mathrm{mp}$, dens, $918,120 /\left(1000^{*} \mathrm{~g}\right)$

mp , damp, $918,0.025 / d f$

/COM - Material 919, Soil

mp , ex, 919, 41496

mp, nuxy, $919,0.28$

$\mathrm{mp}$, dens, $919,120 /\left(1000^{*} \mathrm{~g}\right)$

mp, damp, 919, 0.024/df

\section{Solve-Gravity-BES.txt}

/prep 7

massm $z=148414.59$

d, master_node, all

allsel

cmsel, s, excav-soil

nsle

csys, 0

nsel, r, loc, $x,-\operatorname{ctx}(6)-1, \operatorname{ctx}(6)+1$

nsel, r, loc, y, 0, $-\operatorname{ctx}(6)-1$

esln, $r, 1$

mp chg, 810 , all

cmsel, s, excav-soil

nsle

csys, 1

nsel, r, loc, $x, \operatorname{ctx}(11)-1, \operatorname{ctx}(13)+1$

nsel, r, loc, z, soilz(1), soilz(3)-1

esln, $r, 1$

mpchg, 810 , all

tdo, i, 801,808

esel, s, mat, $i$

mp chg , i+10, all

*enddo

allsel

lout, AP-460-FCC-BES-Gravity, out 


\section{RPP-RPT-32239, Rev. 1 \\ M\&D-2008-005-CALC-001, Rev. 1}

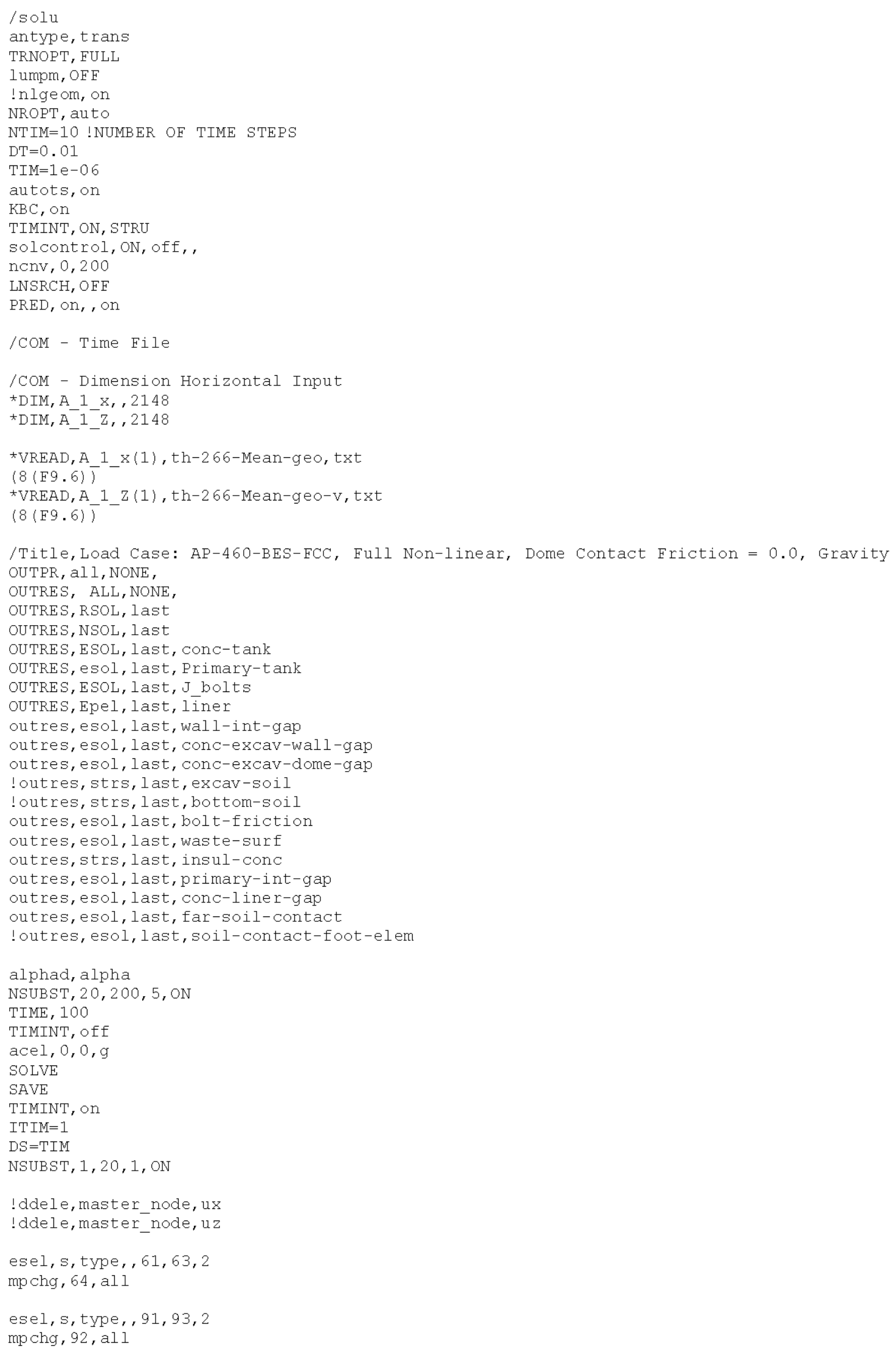


RPP-RPT-32239, Rev. 1

M\&D-2008-005-CALC-001, Rev. 1

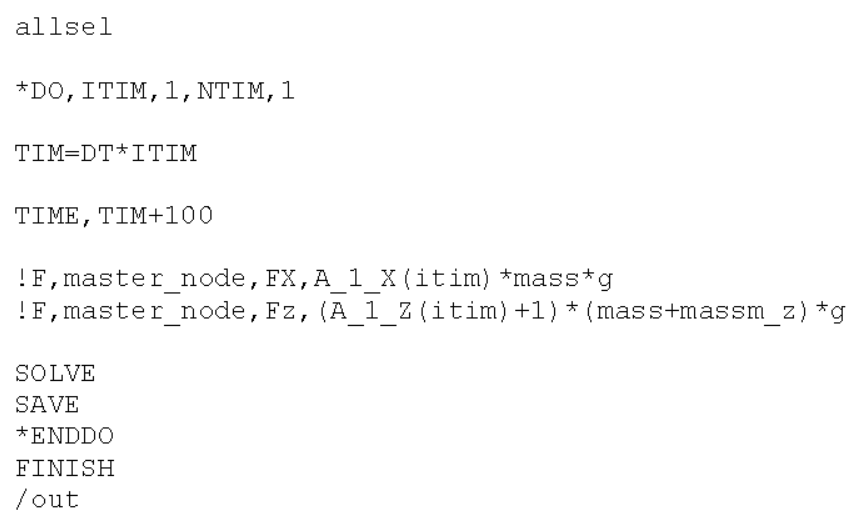

\section{Solve-TH-BES}

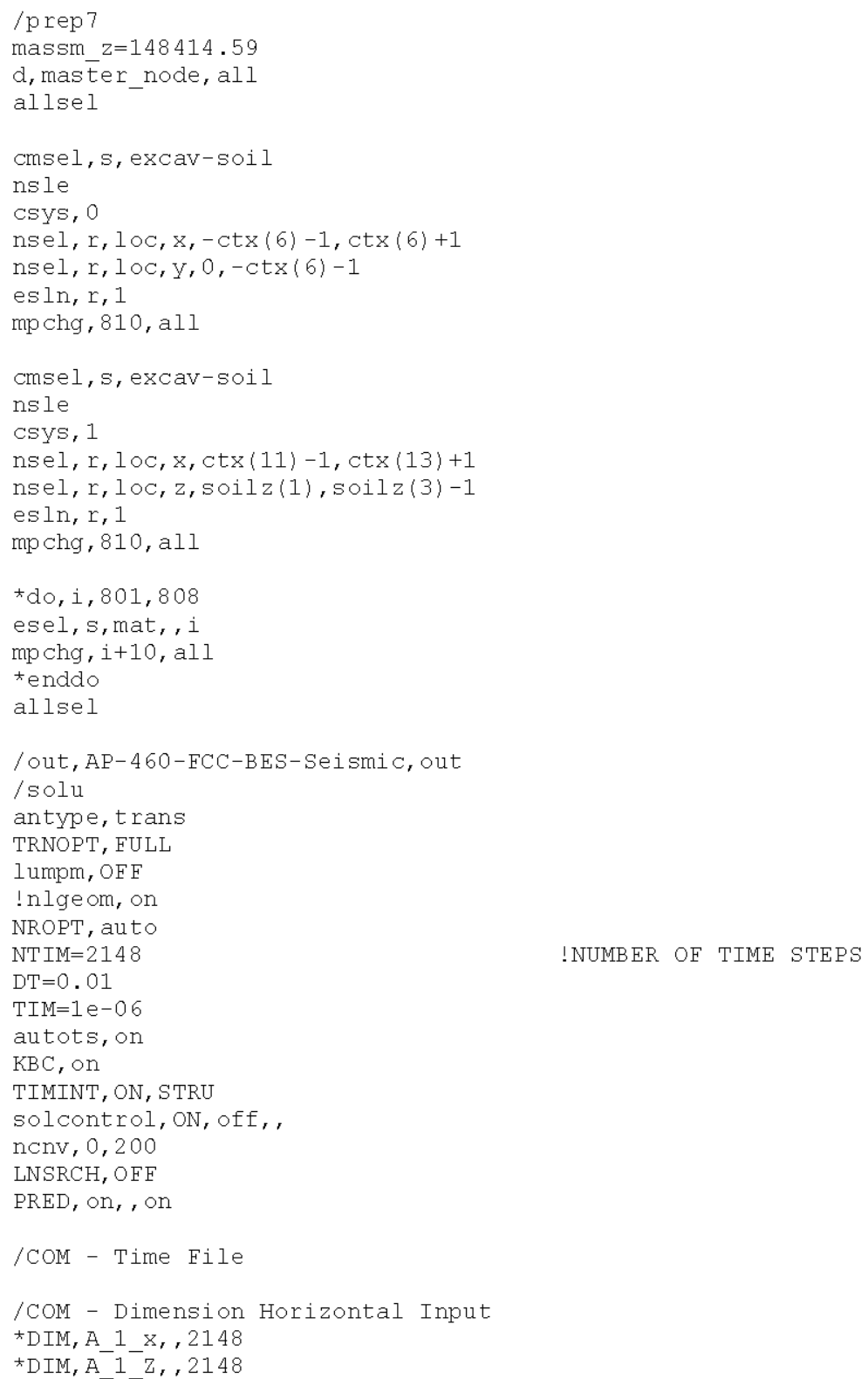


RPP-RPT-32239, Rev. 1

M\&D-2008-005-CALC-001, Rev. 1

*VREAD, A_1_x(1), th-266-Mean-geo, txt

(8(F9.6))

*VREAD, A_1_Z(1), th-266-Mean-geo-v, txt

$(8(\mathrm{~F} 9.6))$

/Title, Load Case: AP-460-BES-FCC, Full Non-linear, Dome Contact Friction $=0.0$

OUTPR, all, NONE,

OUTRES, ALL, NONE,

OUTRES, RSOL, last

OUTRES, NSOL, last

OUTRES, ESOL, last, conc-tank

OUTRES, esol, last, Primary-tank

OUTRES, ESOL, last, J_bolts

OUTRES, Epel, last, liner

outres, esol, last, wall-int-gap

outres, esol, last, conc-excav-wall-gap

outres, esol, last, conc-excav-dome-gap

!outres, strs, last, excav-soil

!outres, strs, last, bottom-soil

outres, esol, last, bolt-friction

outres, esol, last, waste-surf

outres, strs, last, insul-conc

outres, esol, last, primary-int-gap

outres, esol, last, conc-liner-gap

outres, esol, last, far-soil-contact

!outres, esol, last, soil-contact-foot-elem

alphad, alpha

NSUBST, 20,200, 5, ON

TIME, 100

TIMINT, off

acel, $0,0,9$

SOLVE

SAVE

TIMINT, on

IT IM $=1$

$\mathrm{DS}=\mathrm{TIM}$

NSUBST, $1,20,1$, ON

ddele, master_node, ux

ddele, master_node, uz

esel, s, type, $, 61,63,2$

mpchg, 64, all

esel, s, type, , 91, 93,2

mpchg, 92, all

allsel

${ }^{\star}$ DO, ITIM, 1, NTIM, 1

$\mathrm{TIM}=\mathrm{DT} * I T I M$

TIME, TIM+100

$\mathrm{F}$, master_node, $\mathrm{FX}, \mathrm{A}{ }^{1}{ }^{\mathrm{X}} \mathrm{X}(\mathrm{itim}){ }^{*} \mathrm{mass}^{*} \mathrm{~g}$

$\mathrm{F}$, master node, $\mathrm{Fz},(\overline{\mathrm{A}} \overline{1} \mathrm{I} z(\mathrm{itim})+1) *(\operatorname{mass}+$ massm_z $){ }^{*} \mathrm{~g}$

SOLVE

SAVE

$\star$ ENDDO

FINISH

lout 
RPP-RPT-32239, Rev. 1

M\&D-2008-005-CALC-001, Rev. 1

\section{Tank-Props-Crack}

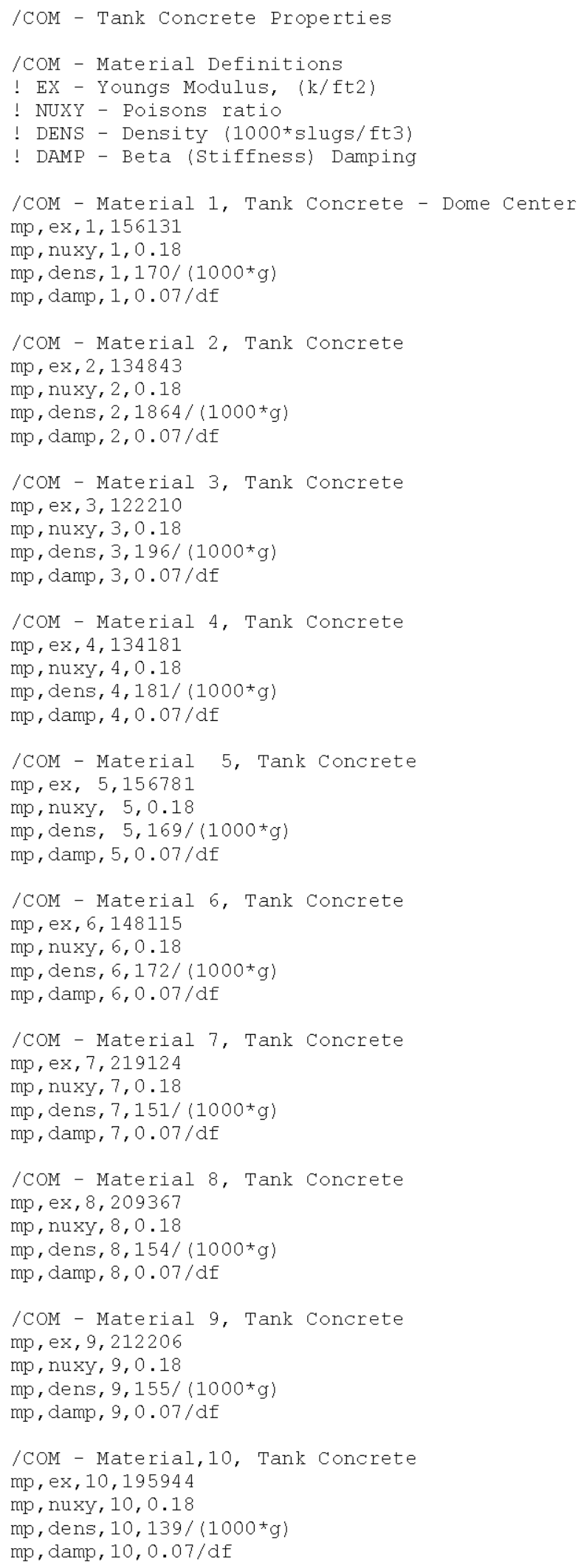


RPP-RPT-32239, Rev. 1

M\&D-2008-005-CALC-001, Rev. 1

/COM - Material,11, Tank Concrete $\mathrm{mp}, \mathrm{ex}, 11,182924$

mp, nuxy, $11,0.18$

$\mathrm{mp}$, dens, $11,138 /(1000 * \mathrm{~g})$

$\mathrm{mp}$, damp, $11,0.07 / \mathrm{df}$

/COM - Material,12, Tank Concrete mp, ex, 12,187438

$\mathrm{mp}$, nuxy, $12,0.18$

$\mathrm{mp}$, dens, $12,156 /\left(1000^{*} \mathrm{~g}\right)$

mp, damp, 12, 0.07/df

/COM - Material,13, Tank Concrete $\mathrm{mp}, \mathrm{ex}, 13,143402$

mp, nuxy, 13, 0.18

$\mathrm{mp}$, dens, $13,190 /\left(1000^{\star} \mathrm{g}\right)$

$\mathrm{mp}$, damp, 13,0.07/df

/COM - Material,14, Tank Concrete $\mathrm{mp}, \mathrm{ex}, 14,142377$

mp, nuxy, 14, 0.18

mp, dens, $14,172 /(1000 * \mathrm{~g})$

$\mathrm{mp}$, damp, 14,0.07/df

/COM - Material,15, Tank Concrete $\mathrm{mp}, \mathrm{ex}, 15,126463$

$\mathrm{mp}$, nuxy, $15,0.18$

$\mathrm{mp}$, dens, $15,178 /\left(1000^{*} \mathrm{~g}\right)$

$\mathrm{mp}$, damp, 15, 0.07/df

/COM - Material,16, Tank Concrete mp, ex, 16, 126463

mp, nuxy, 16, 0.18

$\mathrm{mp}$, dens, $16,178 /\left(1000^{\star} \mathrm{g}\right)$

$\mathrm{mp}$, damp, $16,0.07 / \mathrm{df}$

/COM - Material,17, Tank Concrete mp, ex, 17, 126463

mp, nuxy, 17, 0.18

mp, dens, $17,178 /\left(1000^{\star} \mathrm{g}\right)$

$\mathrm{mp}$, damp, $17,0.07 / \mathrm{df}$

/COM - Material,18, Tank Concrete $\mathrm{mp}, \mathrm{ex}, 18,113881$

mp, nuxy, $18,0.18$

$\mathrm{mp}$, dens, $18,186 /\left(100{ }^{*} \mathrm{~g}\right)$

$\mathrm{mp}$, damp, $18,0.07 / \mathrm{df}$

/COM - Material,19, Tank Concrete $\mathrm{mp}, \mathrm{ex}, 19,113881$

$\mathrm{mp}$, nuxy, $19,0.18$

mp, dens, $19,186 /\left(1000^{*} \mathrm{~g}\right)$

mp, damp, 19,0.07/df

/COM - Material,20, Tank Concrete $\mathrm{mp}, \mathrm{ex}, 20,113629$

mp, nuxy, 20, 0.18

mp, dens, 20, 205/(1000*g)

$\mathrm{mp}$, damp, 20,0.07/df

/COM - Material,21, Tank Concrete mp, ex, 21,134235

mp, nuxy, $21,0.18$

$\mathrm{mp}$, dens, $21,182 /\left(1000^{*} \mathrm{~g}\right)$

mp, damp, $21,0.07 / \mathrm{df}$

/COM - Material,22, Tank Concrete mp, ex, 22,139096

mp, nuxy, 22, 0.18

$\mathrm{mp}$, dens, $22,181 /\left(1000^{*} \mathrm{~g}\right)$

$\mathrm{mp}$, damp, 22,0.07/df 
RPP-RPT-32239, Rev. 1

M\&D-2008-005-CALC-001, Rev. 1

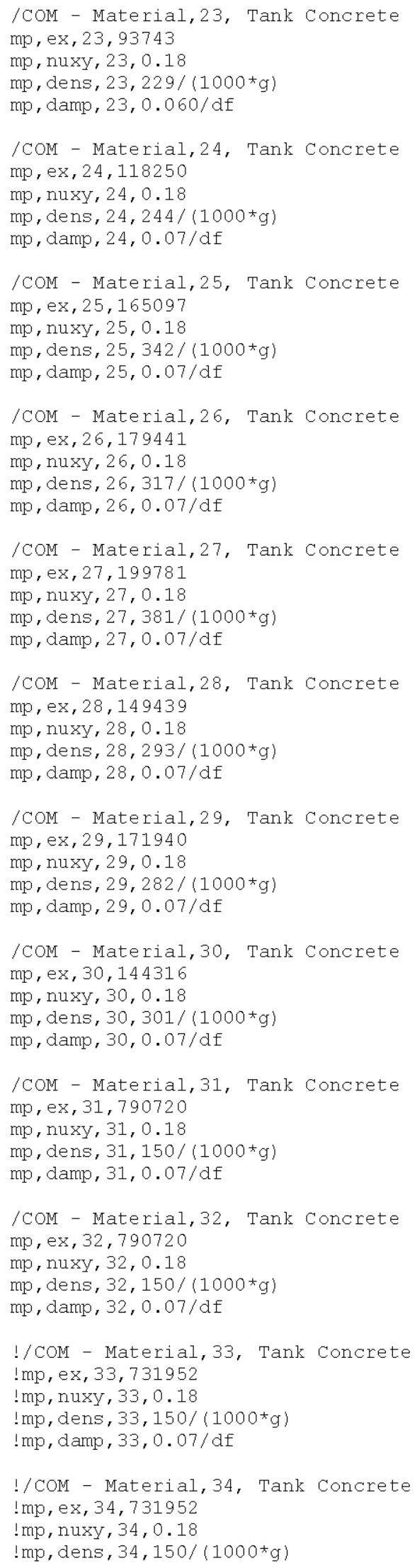


RPP-RPT-32239, Rev. 1

M\&D-2008-005-CALC-001, Rev. 1

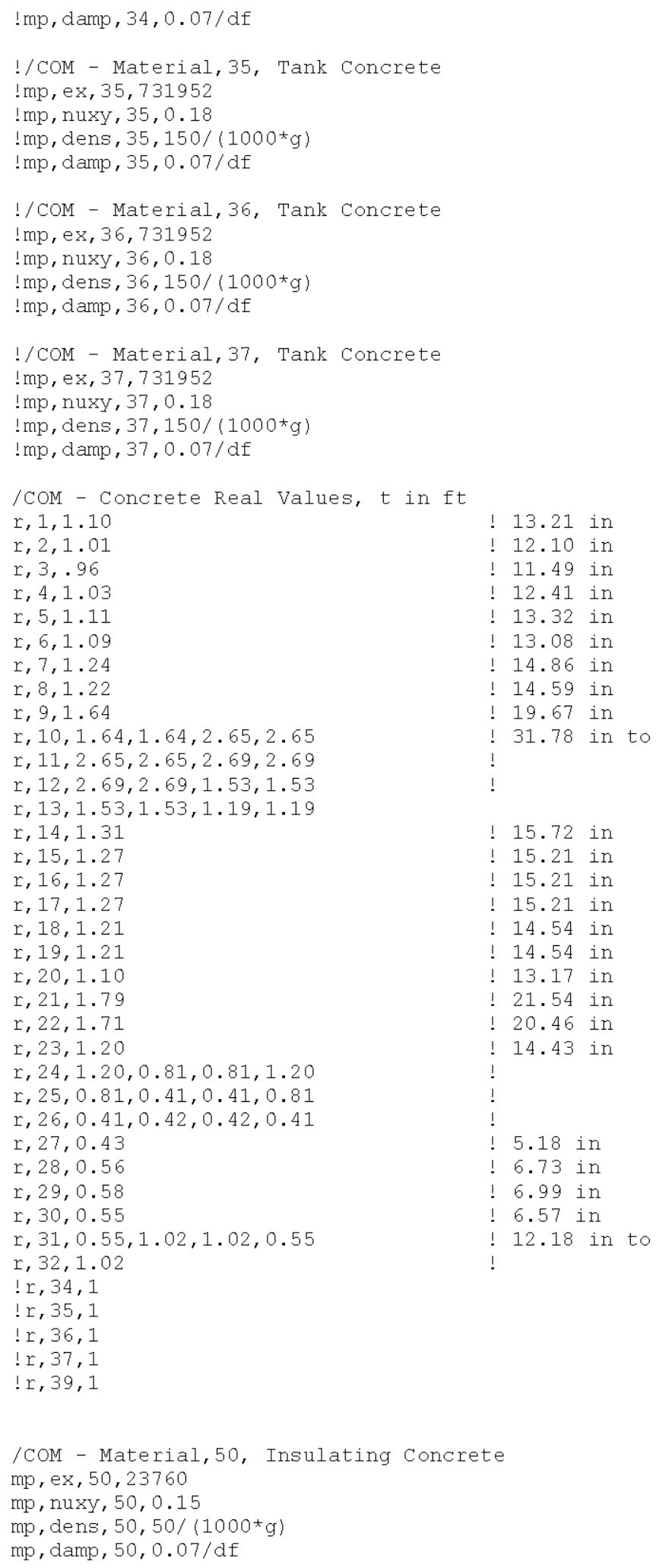

! $13.21 \mathrm{in}$

! 12.10 in

! 11.49 in

! 12.41 in

! 13.32 in

! 13.08 in

14.86 in

! 14.59 in

! 19.67 in

! 31.78 in to

!

!

15.72 in

$! 15.21$ in

115.21 in

$! 15.21$ in

! 14.54 in

! 14.54 in

! 13.17 in

! 21.54 in

! 20.46 in

114.43 in

!

5.18 in

6.73 in

6.99 in

! $6.57 \mathrm{in}$

! 12.18 in to

/COM - Material,50, Insulating Concrete

mp , ex, 50,23760

mp, nuxy, 50, 0.15

$\mathrm{mp}$, dens, 50,50/(1000*g)

mp , damp, 50, 0.07/df 


\section{RPP-RPT-32239, Rev. 1 \\ M\&D-2008-005-CALC-001, Rev. 1}

\section{TH-266-Mean-Geo.txt}

$\begin{array}{lll}-0.0000460 .000024 & 0.000044-0.000025-0.0000440 .0000240 .000042-0.000025 & 1\end{array}$

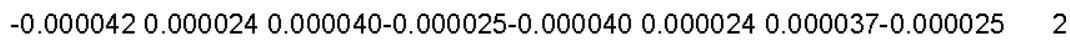

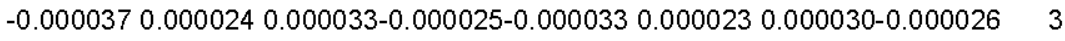
$\ldots \ldots$

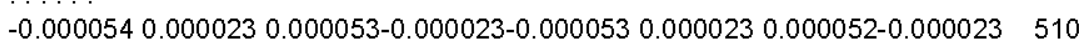

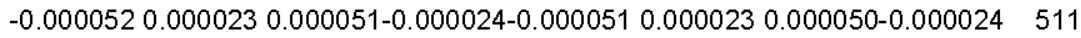

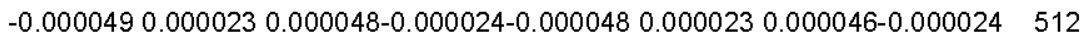

\section{TH-266-Mean-Geo-V.txt}

$\begin{array}{lllll}-0.000029 & 0.000124 & 0.000029-0.000125-0.000029 & 0.000126 & 0.000030-0.000127\end{array}$ $\begin{array}{llll}-0.000030 & 0.0001280 .000030-0.000128-0.000030 & 0.0001300 .000031-0.000130 & 2\end{array}$ $\begin{array}{lllll}-0.000031 & 0.0001310 .000032-0.000132-0.000032 & 0.0001330 .000033-0.000134 & 3\end{array}$ $-0.0000260 .0001160 .000026-0.000116-0.0000260 .0001170 .000027-0.000118 \quad 510$

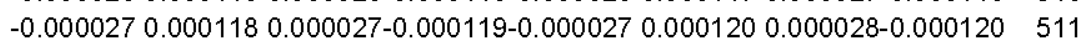

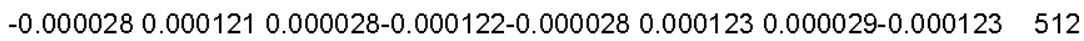

\section{BES-FCC Seismic File Listing}

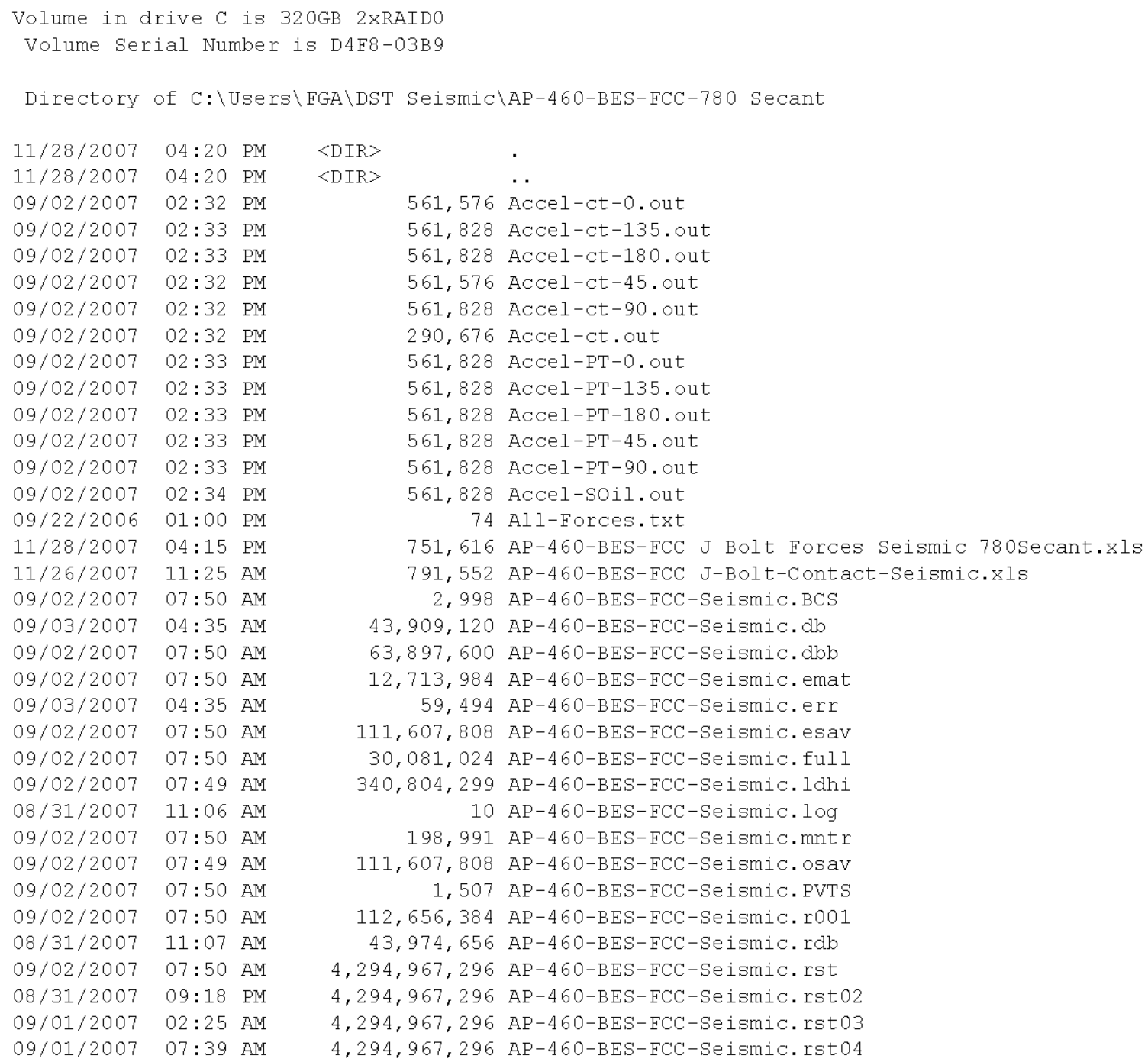




\section{RPP-RPT-32239, Rev. 1 M\&D-2008-005-CALC-001, Rev. 1}

09/01/2007 01:03 PM 09/01/2007 06:34 PM 09/02/2007 12:12 AM 09/02/2007 05:58 AM 09/02/2007 07:50 AM 09/02/2007 07:50 AM 01/02/2007 08:44 AM 08/15/2007 10:18 AM 09/08/2006 07:10 AM 08/25/2006 08:48 AM 08/21/2006 07:59 AM 08/25/2006 01:28 PM 08/25/2006 01:27 PM 08/25/2006 01:28 PM 08/21/2006 07:59 AM 08/21/2006 12:44 PM 11/28/2007 04:20 PM 09/02/2007 02:32 PM 09/02/2007 02:33 PM 09/02/2007 02:33 PM 09/02/2007 02:32 PM 09/02/2007 02:32 PM 09/02/2007 02:32 PM 01/03/2006 11:17 AM 09/02/2007 02:33 PM 09/02/2007 02:33 PM 09/02/2007 02:33 PM 09/02/2007 02:33 PM 09/02/2007 02:33 PM 09/02/2007 02:34 PM 05/08/2006 01:31 PM 09/04/2007 08:07 AM 09/04/2007 08:28 AM 10/13/2005 06:54 AM 09/02/2007 02:31 PM 09/02/2007 02:31 PM 08/21/2006 08:00 AM 09/02/2007 06:29 PM 09/02/2007 06:29 PM 09/02/2007 04:03 PM 09/02/2007 04:03 PM 09/02/2007 06:36 PM 09/02/2007 06:36 PM 09/02/2007 04:10 PM 09/02/2007 04:10 PM 09/02/2007 06:44 PM 09/02/2007 06:44 PM 09/02/2007 04:17 PM 09/02/2007 04:17 PM 09/02/2007 06:51 PM 09/02/2007 06:51 PM 09/02/2007 04:25 PM 09/02/2007 04:25 PM 09/02/2007 06:59 PM 09/02/2007 06:59 PM 09/02/2007 04:33 PM 09/02/2007 04:33 PM 09/02/2007 07:06 PM 09/02/2007 07:06 PM 09/02/2007 04:40 PM 09/02/2007 04:40 PM 09/02/2007 07:13 PM 09/02/2007 07:13 PM 09/02/2007 04:47 PM 09/02/2007 04:47 PM
4,294,967,296 AP-460-BES-FCC-Seismic.rst05 $4,294,967,296$ AP-460-BES-FCC-Seismic.rst06 $4,294,967,296$ AP-460-BES-FCC-Seismic.rst07 $4,294,967,296$ AP-460-BES-FCC-Seismic.rst08 $1,388,445,696$ AP-460-BES-FCC-Seismic.rst09

4,654,721 AP-460-ECC-BES-Seismic.out 59,216 BES-FCC-File.txt

6, 120 Bolts-Friction.txt

277 Boundary.txt

220 Contact-AP. txt

586 Contact-Footing.txt

704 Contact-Insul.txt

704 Contact-J-Bolts.txt

708 Contact-Primary.txt

742 Contact-Soil.txt

632 Contact-Waste-AP. txt

0 dir_listing.txt

561,576 Disp-ct-0.out

561,576 Disp-ct-135.out

561,576 Disp-ct-180. out

561,576 Disp-ct-45. out

561,576 Disp-ct-90.out

290,550 Disp-ct.out

1,616 Disp-J-Bolts.txt

561,576 Disp-PT-0.out

561,576 Disp-PT-135.out

561,576 Disp-PT-180.out

561,576 Disp-PT-45. out

561,576 Disp-PT-90. out

561,576 Disp-Soil.out

8,616 Far-Soil.txt

340 file.err

1,878 file. $\log$

562 Fix-Soil.txt

10,342 Footing-Cont max. OUT

$4,346,248$ Footing-Cont th. OUT

894 Force-c.txt

4, 996 Force-C 108 amax. OUT

2,905,500 Force-C 108 ath. OUT

14,716 Force-C 108max. OUT

$6,519,180$ Force-c_108th. OUT

4,996 Force-C 117 amax. OUT

2,905,500 Force-c 117ath. OUT

14,716 Force-C $117 \mathrm{max}$.OUT

$6,519,180$ Force-C 117 th. OUT

4, 996 Force-C 126 amax. OUT

2,905,500 Force-C 126ath. OUT

14,716 Eorce-C $126 \mathrm{max}$. OUT

$6,519,180$ Force-C 126 th. OUT

4,996 Force-C 135 amax. OUT

2, 905,500 Force-C 135 ath. OUT

14,716 Force-C_135max. OUT

$6,519,180$ Force-C 135 th. OUT

4,996 Force-C 144 amax. OUT

2,905,500 Force-C 144 ath. OUT

14,716 Force-C $144 \mathrm{max}$. OUT

$6,519,180$ Force-C 144 th. OUT

4,996 Force-C 153amax. OUT

2,905,500 Force-C_153ath.OUT

14,716 Force-C 153max. OUT

$6,519,180$ Force-C 153 th. OUT

4,996 Force-C 162 amax. OUT

2,905,500 Force-C 162ath. OUT

14,716 Force-C 162max. OUT

$6,519,180$ Force-C 162 th. OUT 


\section{RPP-RPT-32239, Rev. 1 M\&D-2008-005-CALC-001, Rev. 1}

09/02/2007 07:20 PM 09/02/2007 07:20 PM 09/02/2007 04:55 PM 09/02/2007 04:55 PM 09/02/2007 07:28 PM 09/02/2007 07:28 PM 09/02/2007 05:03 PM 09/02/2007 05:03 PM 09/02/2007 05:17 PM 09/02/2007 05:17 PM 09/02/2007 02:48 PM 09/02/2007 02:48 PM 09/02/2007 05:25 PM 09/02/2007 05:25 PM 09/02/2007 02:56 PM 09/02/2007 02:56 PM 09/02/2007 05:32 PM 09/02/2007 05:32 PM 09/02/2007 03:03 PM 09/02/2007 03:03 PM 09/02/2007 05:39 PM 09/02/2007 05:39 PM 09/02/2007 03:11 PM 09/02/2007 03:11 PM 09/02/2007 05:46 PM 09/02/2007 05:46 PM 09/02/2007 03:18 PM 09/02/2007 03:18 PM 09/02/2007 05:54 PM 09/02/2007 05:54 PM 09/02/2007 03:26 PM 09/02/2007 03:26 PM 09/02/2007 06:00 PM 09/02/2007 06:00 PM 09/02/2007 03:32 PM 09/02/2007 03:33 PM 09/02/2007 06:07 PM 09/02/2007 06:08 PM 09/02/2007 03:40 PM 09/02/2007 03:40 PM 09/02/2007 06:15 PM 09/02/2007 06:15 PM 09/02/2007 03:48 PM 09/02/2007 03:48 PM 09/02/2007 06:22 PM 09/02/2007 06:22 PM 09/02/2007 03:55 PM 09/02/2007 03:55 PM 09/02/2007 05:10 PM 09/02/2007 05:10 PM 09/02/2007 02:41 PM 09/02/2007 02:41 PM 09/04/2007 10:22 AM 09/03/2007 04:34 AM 09/03/2007 04:34 AM 09/03/2007 04:35 AM 09/03/2007 04:35 AM 09/03/2007 04:30 AM 09/03/2007 04:30 AM 09/03/2007 04:30 AM 09/03/2007 04:30 AM 09/03/2007 04:31 AM 09/03/2007 04:31 AM 09/03/2007 04:31 AM 09/03/2007 04:31 AM
4,996 Force-C 171 amax. OUT

2,905,500 Force-C_171ath. OUT

14,716 Force-C 171max. OUT

$6,519,180$ Force-C_171th. OUT

4,996 Force-C 180amax. OUT

2,905,500 Eorce-C_180ath.OUT

14,716 Force-C_180max. OUT

$6,519,180$ Force-C 180 th. OUT

4,996 Force-C 18 amax. OUT

$2,905,500$ Force-c_18ath. OUT

14,716 Force-C 18max. OUT

6,519,180 Force-C18th. OUT

4,996 Force-c_27amax. OUT

2,905,500 Force-C_27ath. OUT

14,716 Force-C_27max. OUT

$6,519,180$ Force-C 27 th. OUT

4,996 Force-C_36amax. OUT

$2,905,500$ Force-C 36ath. OUT

14,716 Force-C $36 \mathrm{max}$. OUT

6,519,180 Force-c 36th. OUT

4, 996 Force-C_45amax. OUT

2,905,500 Force-C 45ath. OUT

14, 716 Force-C 45 max. OUT

$6,519,180$ Force-C_45th. OUT

4,996 Force-C 54 amax. OUT

$2,905,500$ Force-c 54ath. OUT

14,716 Force-C_54max. OUT

$6,519,180$ Force-C 54 th. OUT

4,996 Force-c_63amax. OUT

2,905,500 Force-c 63ath. OUT

14,716 Force-C 63max. OUT

$6,519,180$ Force-C 63th. OUT

4, 996 Force-c 72 amax. OUT

2,905,500 Force-c_72ath. OUT

14,716 Eorce-C 72max. OUT

$6,519,180$ Force-C 72 th. OUT

4,996 Force-C_81amax.OUT

2,905, 500 Force-C 81 ath. OUT

14,716 Force-C $81 \mathrm{max}$. OUT

$6,519,180$ Force-c 81 th. OUT

4,996 Force-c 90 amax. OUT

2, 905,500 Force-c 90ath. OUT

14,716 Force-C $90 \mathrm{max}$. OUT

$6,519,180$ Force-C 90 th. OUT

4, 996 Force-C 99 amax. OUT

2,905, 500 Force-C 99ath. OUT

14,716 Force-c_99max. OUT

$6,519,180$ Force-C 99 th. OUT

4,996 Force-C_9amax. OUT

2, 905,628 Force-C 9ath.OUT

14, 716 Force-C 9 max. OUT

6, 519, 308 Force-c 9 th. OUT

134,656 force-jib.xls

$2,666,244$ Force-jb_r10-th. OUT

5,239 Force-jb rlo max. OUT

$2,666,244$ Force-jb r11-th.OUT

5,239 Force-jb r11 max. OUT

$2,666,372$ Force-jb r2-th. OUT

5,239 Force-jb_r2_max. OUT

$2,666,244$ Force-jb r3-th. OUT

5,239 Force-jb r3 max. OUT

$2,666,244$ Force-jb_r4-th. OUT

5,239 Force-jb_r4 max. OUT

$2,666,244$ Force-jb_r5-th.OUT

5,239 Force-jb_r5 max. OUT 


\section{RPP-RPT-32239, Rev. 1 M\&D-2008-005-CALC-001, Rev. 1}

09/03/2007 04:32 AM 09/03/2007 04:32 AM 09/03/2007 04:32 AM 09/03/2007 04:32 AM 09/03/2007 04:33 AM 09/03/2007 04:33 AM 09/03/2007 04:33 AM 09/03/2007 04:33 AM 08/21/2006 08:00 AM $11 / 21 / 2007 \quad 02: 57 \mathrm{PM}$ 09/02/2007 11:11 AM 09/02/2007 11:11 AM 09/02/2007 11:12 AM 09/02/2007 11:12 AM 09/02/2007 11:13 AM 09/02/2007 11:13 AM 09/02/2007 11:14 AM 09/02/2007 11:14 AM 09/02/2007 11:15 AM 09/02/2007 11:15 AM 09/02/2007 11:16 AM 09/02/2007 11:16 AM 09/02/2007 11:17 AM 09/02/2007 11:17 AM 09/02/2007 11:18 AM 09/02/2007 11:18 AM 09/02/2007 11:19 AM 09/02/2007 11:19 AM 09/02/2007 11:03 AM 09/02/2007 11:03 AM 09/02/2007 11:04 AM 09/02/2007 11:04 AM 09/02/2007 11:05 AM 09/02/2007 11:05 AM 09/02/2007 11:06 AM 09/02/2007 11:06 AM 09/02/2007 11:06 AM 09/02/2007 11:06 AM 09/02/2007 11:07 AM 09/02/2007 11:07 AM 09/02/2007 11:08 AM 09/02/2007 11:08 AM 09/02/2007 11:08 AM 09/02/2007 11:09 AM 09/02/2007 11:10 AM 09/02/2007 11:10 AM 09/02/2007 11:10 AM 09/02/2007 11:10 AM 09/02/2007 11:02 AM 09/02/2007 11:02 AM 09/22/2006 03:37 PM 07/20/2006 06:36 AM 09/22/2006 04:02 PM $11 / 23 / 2007 \quad 12: 35 \quad \mathrm{PM}$ 11/23/2007 12:39 PM 09/02/2007 12:02 PM 09/02/2007 12:02 PM 09/02/2007 12:04 PM 09/02/2007 12:04 PM 09/02/2007 12:05 PM 09/02/2007 12:05 PM 09/02/2007 12:07 PM 09/02/2007 12:07 PM 09/02/2007 12:08 PM 09/02/2007 12:08 PM
$2,666,244$ Force-jb_r6-th. OUT 5,239 Eorce-jb_r6_max. OUT

$2,666,244$ Force-jb_r7-th. OUT 5,239 Force-jb $r 7$ max. OUT

$2,666,244$ Force-jb_r8-th. OUT 5,239 Force-jb r8 max. OUT

$2,666,244$ Force-jb_rg-th. OUT

5,239 Force-jb r9 max. OUT 661 Force-j_bolt.txt

<DIR> Gravity

4,024 Insul-Cont_108max.OUT

1,738,448 Insul-Cont_108th. OUT

4,024 Insul-Cont $117 \mathrm{max}$.OUT

$1,738,448$ Insul-Cont_117th. OUT

4,024 Insul-Cont $126 \mathrm{max}$. OUT

$1,738,448$ Insul-Cont_126th. OUT

4,024 Insul-Cont_135max.OUT

$1,738,448$ Insul-Cont 135th. OUT

4,024 Insul-Cont_144max.OUT

$1,738,448$ Insul-Cont 144 th. OUT

4,024 Insul-Cont 153max. OUT

$1,738,448$ Insul-Cont_153th. OUT

4,024 Insul-Cont $162 \mathrm{max}$.OUT

1,738,448 Insul-Cont_162th. OUT

4,024 Insul-Cont 171max. OUT

1,738,448 Insul-Cont 171 th. OUT

4,024 Insul-Cont_180max.OUT

$1,738,448$ Insul-Cont 180 th. OUT

4,024 Insul-Cont_18max. OUT

$1,738,448$ Insul-Cont 18th.OUT

4,024 Insul-Cont $27 \mathrm{max}$. OUT

$1,738,448$ Insul-Cont_27th.OUT

4,024 Insul-Cont $36 \mathrm{max}$. OUT

1,738,448 Insul-Cont_36th.OUT

4,024 Insul-Cont 45max. OUT

1,738,448 Insul-Cont 45 th. OUT

4,024 Insul-Cont_54max. OUT

$1,738,448$ Insul-Cont 54th.OUT

4,024 Insul-Cont_63max. OUT

1,738,448 Insul-Cont 63th. OUT

4,024 Insul-Cont $72 \mathrm{max}$. OUT

1,738,448 Insul-Cont 72th. OUT

4,024 Insul-Cont $81 \mathrm{max}$. OUT

$1,738,448$ Insul-Cont_81th. OUT

4,024 Insul-Cont 90max. OUT

$1,738,448$ Insul-Cont 90 th. OUT

4,024 Insul-Cont 99max. OUT

$1,738,448$ Insul-Cont $99 \mathrm{th}$.OUT

4,024 Insul-Cont_9max.OUT

1,738,576 Insul-Cont 9th.OUT

1,672 Insulate.txt

4,030 interface-gap1.txt

2,411 interfacel.txt

$116,736 \mathrm{~J}-\mathrm{Bolt}$-Contact_0-90.xls

$116,736 \mathrm{~J}-\mathrm{Bolt}$-Contact $99-180 . \times 1 \mathrm{~s}$

$4,519 \mathrm{~J}$-Bolt-Cont $108 \mathrm{max}$. OUT

$1,685,484 \mathrm{~J}$-Bolt-Cont $108 \mathrm{th}$. OUT

4,519 J-Bolt-Cont $117 \mathrm{max}$. OUT

$1,685,484 \mathrm{~J}$-Bolt-Cont_117th.OUT

4,519 J-Bolt-Cont $126 \mathrm{max}$. OUT

$1,685,484 \mathrm{~J}$-Bolt-Cont $126 \mathrm{th}$. OUT

4,519 J-Bolt-Cont 135max. OUT

$1,685,484 \mathrm{~J}$-Bolt-Cont $135 \mathrm{th}$. OUT

4,519 J-Bolt-Cont $144 \mathrm{max}$. OUT

$1,685,484 \mathrm{~J}$-Bolt-Cont $144 \mathrm{th}$. OUT 


\section{RPP-RPT-32239, Rev. 1 M\&D-2008-005-CALC-001, Rev. 1}

09/02/2007 12:09 PM 09/02/2007 12:09 PM 09/02/2007 12:09 PM 09/02/2007 12:09 PM 09/02/2007 12:11 PM 09/02/2007 12:11 PM 09/02/2007 12:12 PM 09/02/2007 12:12 PM 09/02/2007 11:49 AM 09/02/2007 11:49 AM 09/02/2007 11:50 AM 09/02/2007 11:50 AM 09/02/2007 11:51 AM 09/02/2007 11:51 AM 09/02/2007 11:53 AM 09/02/2007 11:53 AM 09/02/2007 11:55 AM 09/02/2007 11:55 AM 09/02/2007 11:57 AM 09/02/2007 11:57 AM 09/02/2007 11:58 AM 09/02/2007 11:58 AM 09/02/2007 12:00 PM 09/02/2007 12:00 PM 09/02/2007 12:01 PM 09/02/2007 12:01 PM 09/02/2007 12:01 PM 09/02/2007 12:01 PM 09/02/2007 11:48 AM 09/02/2007 11:48 AM 08/23/2006 07:47 AM 05/02/2005 02:19 PM 07/21/2006 10:03 AM 04/20/2005 01:14 PM 10/13/2006 07:45 AM 09/02/2007 11:35 AM 09/02/2007 11:35 AM 09/02/2007 11:37 AM 09/02/2007 11:37 AM 09/02/2007 11:38 AM 09/02/2007 11:38 AM 09/02/2007 11:39 AM 09/02/2007 11:39 AM 09/02/2007 11:41 AM 09/02/2007 11:41 AM 09/02/2007 11:41 AM 09/02/2007 11:41 AM 09/02/2007 11:43 AM 09/02/2007 11:43 AM 09/02/2007 11:44 AM 09/02/2007 11:44 AM 09/02/2007 11:46 AM 09/02/2007 11:46 AM 09/02/2007 11:22 AM 09/02/2007 11:22 AM 09/02/2007 11:24 AM 09/02/2007 11:24 AM 09/02/2007 11:25 AM 09/02/2007 11:25 AM 09/02/2007 11:27 AM 09/02/2007 11:27 AM 09/02/2007 11:28 AM 09/02/2007 11:28 AM 09/02/2007 11:29 AM 09/02/2007 11:29 AM
4,519 J-Bolt-Cont 153max. OUT

1,685,484 J-Bolt-Cont_153th.OUT

4,519 J-Bolt-Cont $162 \mathrm{max}$. OUT

$1,685,484 \mathrm{~J}$-Bolt-Cont_162th.OUT

$4,519 \mathrm{~J}$-Bolt-Cont $171 \mathrm{max}$. OUT

$1,685,484 \mathrm{~J}$-Bolt-Cont $171 \mathrm{th}$. OUT

4,519 J-Bolt-Cont_180max.OUT

$1,685,484 \mathrm{~J}$-Bolt-Cont 180th. OUT

4,519 J-Bolt-Cont_18max.OUT

$1,685,484 \mathrm{~J}$-Bolt-Cont 18th. OUT

4,519 J-Bolt-Cont 27 max. OUT

$1,685,484 \mathrm{~J}$-Bolt-Cont_27th. OUT

4,519 J-Bolt-Cont_36max. OUT

$1,685,484 \mathrm{~J}$-Bolt-Cont_36th. OUT

4, $519 \mathrm{~J}$-Bolt-Cont $45 \mathrm{max}$. OUT

$1,685,484 \mathrm{~J}-$ Bolt-Cont_45th. OUT

$4,519 \mathrm{~J}$-Bolt-Cont_54max. OUT

$1,685,484 \mathrm{~J}$-Bolt-Cont $54 \mathrm{th}$. OUT

$4,519 \mathrm{~J}$-Bolt-Cont_63max.OUT

$1,685,484 \mathrm{~J}$-Bolt-Cont 63th. OUT

4,519 J-Bolt-Cont $72 \max$. OUT

$1,685,484 \mathrm{~J}$-Bolt-Cont_72th. OUT

4,519 J-Bolt-Cont $81 \mathrm{max}$.OUT

$1,685,484 \mathrm{~J}$-Bolt-Cont_81th. OUT

4, 519 J-Bolt-Cont 90 max. OUT

$1,685,484 \mathrm{~J}-\mathrm{Bolt}$-Cont_90th. OUT

$4,519 \mathrm{~J}$-Bolt-Cont_99max. OUT

$1,685,484 \mathrm{~J}$-Bolt-Cont $99 \mathrm{th}$. OUT

4,519 J-Bolt-Cont 9 max. OUT

$1,685,612 \mathrm{~J}$-Bolt-Cont 9 th. OUT

1,971 Liner.txt

667 live_load.txt

6,214 Near-Soil-1.txt 508 outer-spar.txt 147 Post-Tank.txt

4,024 Primary-Cont 108max. OUT 1,738,448 Primary-Cont_108th.OUT

4,024 Primary-Cont 117max. OUT

1,738,448 Primary-Cont_117th. OUT

4, 024 Primary-Cont $126 \mathrm{max}$. OUT

$1,738,448$ Primary-Cont $126 \mathrm{th}$. OUT

4,024 Primary-Cont 135max. OUT

$1,738,448$ Primary-Cont 135 th. OUT

4,024 Primary-Cont_144max. OUT

$1,738,448$ Primary-Cont 144 th. OUT

4,024 Primary-Cont_153max. OUT

1,738,448 Primary-Cont_153th. OUT

4,024 Primary-Cont 162max. OUT

1,738,448 Primary-Cont_162th.oUT

4,024 Primary-Cont 171max. OUT

1,738,448 Primary-Cont_171th. OUT

4,024 Primary-Cont 180max. OUT

1,738,448 Primary-Cont 180th. OUT

4,024 Primary-Cont_18max.OUT

$1,738,448$ Primary-Cont 18 th. OUT

4,024 Primary-Cont 27 max.OUT

$1,738,448$ Primary-Cont 27th. OUT

4,024 Primary-Cont_36max.OUT

1,738,448 Primary-Cont_36th.OUT

4,024 Primary-Cont 45max. OUT

1,738,448 Primary-Cont_45th.OUT

4,024 Primary-Cont 54max. OUT

$1,738,448$ Primary-Cont 54th. OUT

4,024 Primary-Cont_63max. OUT

$1,738,448$ Primary-Cont_63th. OUT 


\section{RPP-RPT-32239, Rev. 1 M\&D-2008-005-CALC-001, Rev. 1}

09/02/2007 11:30 AM 09/02/2007 11:30 AM 09/02/2007 11:32 AM 09/02/2007 11:32 AM 09/02/2007 11:33 AM 09/02/2007 11:33 AM 09/02/2007 11:34 AM 09/02/2007 11:34 AM 09/02/2007 11:21 AM 09/02/2007 11:21 AM 10/12/2006 02:28 PM 09/27/2005 03:52 PM 08/31/2007 11:07 AM 09/02/2007 02:32 PM 09/02/2007 02:33 PM 09/02/2007 02:33 PM 09/02/2007 02:32 PM $09 / 02 / 2007 \quad 02: 32 \quad \mathrm{PM}$ 09/02/2007 02:32 PM 09/02/2007 02:33 PM 09/02/2007 02:33 PM 09/02/2007 02:33 PM 09/02/2007 02:33 PM 09/02/2007 02:33 PM 09/02/2007 02:34 PM 10/31/2005 10:31 AM 08/31/2007 11:04 AM 09/04/2007 08:07 AM 02/11/2005 01:22 PM 09/02/2007 01:21 PM 09/02/2007 01:21 PM 09/02/2007 01:27 PM 09/02/2007 01:27 PM 09/02/2007 01:33 PM 09/02/2007 01:33 PM 09/02/2007 01:38 PM 09/02/2007 01:38 PM 09/02/2007 01:44 PM 09/02/2007 01:44 PM 09/02/2007 01:50 PM 09/02/2007 01:50 PM 09/02/2007 01:56 PM 09/02/2007 01:56 PM 09/02/2007 02:02 PM 09/02/2007 02:02 PM 09/02/2007 02:07 PM 09/02/2007 02:07 PM 09/02/2007 12:23 PM 09/02/2007 12:23 PM $09 / 02 / 2007 \quad 12: 29 \mathrm{PM}$ 09/02/2007 12:29 PM 09/02/2007 12:35 PM 09/02/2007 12:35 PM 09/02/2007 12:41 PM 09/02/2007 12:41 PM 09/02/2007 12:47 PM 09/02/2007 12:47 PM $09 / 02 / 2007 \quad 12: 52$ PM 09/02/2007 12:52 PM 09/02/2007 12:58 PM 09/02/2007 12:58 PM 09/02/2007 01:04 PM 09/02/2007 01:04 PM 09/02/2007 01:10 PM 09/02/2007 01:10 PM
4,024 Primary-Cont 72max.OUT 1,738,448 Primary-Cont_72th.OUT 4,024 Primary-Cont $81 \mathrm{max}$. OUT $1,738,448$ Primary-Cont_81th.OUT

4,024 Primary-Cont 90 max. OUT 1,738,448 Primary-Cont 90th.OUT

4,024 Primary-Cont_99max.OUT $1,738,448$ Primary-Cont 99 th. OUT 4,024 Primary-Cont_9max.OUT

$1,738,576$ Primary-Cont_9th. OUT

6,028 Primary-Props-AP.txt

1,538 Primary.txt

450,409 QA. out

47, 121 RS-ct-0. out

47, 121 RS-ct-135.out

47, 121 RS-ct-180.out

47,121 RS-ct-45. out

47,121 RS-ct-90.out

27,591 RS-ct.out

47, 121 RS-PT-0. out

47,121 RS-PT-135.out

47,121 RS-PT-180. out

47, 121 RS-PT-45.out

47, 121 RS-PT-90.out

47,121 RS-SOil.out

1,108 RS_FREQ.txt

1,819 Run-Tank.txt

0 scratch.hlp

1,053 slave.txt

9,896 Soil-Contact 108max. OUT

$4,348,080$ Soil-Contact_108th. OUT

9,896 Soil-Contact_117max. OUT

4,348,080 Soil-Contact 117 th. OUT

9,896 Soil-Contact_126max. OUT

4,348,080 Soil-Contact $126 \mathrm{th}$. OUT

9,896 Soil-Contact_135max. OUT

4,348,080 Soil-Contact_135th. OUT

9,896 Soil-Contact $144 \mathrm{max}$. OUT

4,348,080 Soil-Contact 144 th. OUT

9,896 Soil-Contact $153 \mathrm{max}$. OUT

4,348,080 Soil-Contact 153 th. OUT

9,896 Soil-Contact 162max. OUT

4,348,080 Soil-Contact 162 th. OUT

9,896 Soil-Contact_171max.OUT

$4,348,080$ Soil-Contact 171 th. OUT

9,896 Soil-Contact $180 \mathrm{max}$. OUT

4,348,080 Soil-Contact 180th. OUT

9,896 Soil-Contact $18 \mathrm{max}$.OUT

4,348,080 Soil-Contact_18th.OUT

9,896 Soil-Contact $27 \mathrm{max}$. OUT

$4,348,080$ Soil-Contact $27 \mathrm{th}$. OUT

9,896 Soil-Contact_36max. OUT

4,348,080 Soil-Contact 36th. OUT

9,896 Soil-Contact $45 \mathrm{max}$.OUT

4,348,080 Soil-Contact 45 th. OUT

9,896 Soil-Contact $54 \mathrm{max}$.OUT

4,348,080 Soil-Contact 54th. OUT

9,896 Soil-Contact 63 max. OUT

4,348,080 Soil-Contact 63th. OUT

9,896 Soil-Contact $72 \mathrm{max}$.OUT

$4,348,080$ Soil-Contact $72 \mathrm{th}$. OUT

9,896 Soil-Contact 81 max. OUT

4, 348,080 Soil-Contact 81 th. OUT

9,896 Soil-Contact_90max.OUT

4,348,080 Soil-Contact 90th. OUT 


\section{RPP-RPT-32239, Rev. 1 M\&D-2008-005-CALC-001, Rev. 1}

09/02/2007 01:16 PM 09/02/2007 01:16 PM 09/02/2007 12:18 PM 09/02/2007 12:18 PM 11/11/2005 10:36 AM 08/31/2007 11:05 AM 09/13/2006 06:12 AM 09/13/2006 06:07 AM 09/13/2006 06:08 AM 09/13/2006 06:09 AM 09/13/2006 06:08 AM 09/13/2006 06:08 AM 09/13/2006 06:09 AM 08/28/2006 09:38 AM 09/13/2006 06:13 AM 09/13/2006 06:14 AM 09/13/2006 06:15 AM 09/13/2006 06:13 AM 09/13/2006 06:14 AM 09/13/2006 06:15 AM 06/20/2005 09:04 AM 06/20/2005 08:52 AM 01/03/2007 03:40 PM 01/03/2007 03:40 PM 01/03/2007 03:41 PM 01/03/2007 04:02 PM 08/21/2006 08:02 AM 08/21/2006 08:03 AM 08/24/2006 03:19 PM 08/24/2006 12:05 PM 09/03/2007 03:16 AM 09/03/2007 12:16 AM 09/02/2007 09:16 PM 09/03/2007 03:16 AM 09/03/2007 12:16 AM 09/02/2007 09:16 PM 09/03/2007 03:25 AM 09/03/2007 12:25 AM 09/02/2007 09:25 PM 09/03/2007 03:25 AM 09/03/2007 12:25 AM 09/02/2007 09:25 PM 09/03/2007 03:34 AM 09/03/2007 12:34 AM 09/02/2007 09:34 PM 09/03/2007 03:34 AM 09/03/2007 12:34 AM 09/02/2007 09:34 PM 09/03/2007 03:43 AM 09/03/2007 12:42 AM 09/02/2007 09:42 PM 09/03/2007 03:43 AM 09/03/2007 12:43 AM 09/02/2007 09:43 PM 09/03/2007 03:52 AM 09/03/2007 12:52 AM 09/02/2007 09:52 PM 09/03/2007 03:52 AM 09/03/2007 12:52 AM 09/02/2007 09:52 PM 09/03/2007 04:01 AM 09/03/2007 01:01 AM 09/02/2007 10:01 PM 09/03/2007 04:01 AM 09/03/2007 01:01 AM
9,896 Soil-Contact 99max.OUT 4,348,080 Soil-Contact_99th.OUT 9,896 Soil-Contact 9 max. OUT 4,348,208 Soil-Contact 9 th. OUT

4,989 Soil-Prop-Mean-Geo.txt

1,922 Solve-TH-BES.txt 347 spectra-all.txt

3,690 spectra-conc-0.txt

3,723 spectra-conc-135.txt

3,723 spectra-conc-180.txt

3,769 spectra-conc-45.txt

3,649 spectra-conc-90.txt

1,590 spectra-conc.txt

2,076 spectra-concrete.txt

3,609 spectra-primary-0.txt

3,762 spectra-primary-135.txt

3,777 spectra-primary-180.txt

3,688 spectra-primary-45.txt

3,688 spectra-primary-90.txt

3,801 spectra-soil.txt

647 spectra-wall.txt

679 spectra-waste.txt

1,823 strain-backed-principle-bot.txt

1,828 strain-backed-principle-mid.txt

1,825 strain-backed-principle-top.txt

966 strain-backed-principle.txt

598 stress-compb.txt

608 stress-compm.txt

598 stress-compt.txt

224 Stress-Primary.txt

13,519 Stress-pt_108max-b.OUT

13,519 stress-pt_108max-m.OUT

13,519 Stress-pt $108 \mathrm{max}-\mathrm{t}$.OUT

6,443,068 Stress-pt_108th-b.OUT

$6,443,068$ Stress-pt $108 \mathrm{th}-\mathrm{m}$. OUT

$6,412,940$ stress-pt 108 th-t.OUT

13,519 Stress-pt_117max-b.OUT

13,519 Stress-pt $117 \mathrm{max}-\mathrm{m}$.OUT

13,519 Stress-pt $117 \mathrm{max}-\mathrm{t}$. OUT

$6,443,068$ stress-pt $117 \mathrm{th}-\mathrm{b}$. OUT

6,443,068 Stress-pt_117th-m.OUT

$6,412,940$ stress-pt_117th-t.OUT

13,519 Stress-pt $126 \mathrm{max}-\mathrm{b}$. OUT

13,519 stress-pt_126max-m.OUT

13,519 stress-pt ${ }^{-} 126 \mathrm{max}-\mathrm{t}$. OUT

$6,443,068$ Stress-pt_126th-b.OUT

$6,443,068$ stress-pt_126th-m.OUT

$6,412,940$ stress-pt $126 \mathrm{th}-\mathrm{t}$. OUT

13,519 Stress-pt_135max-b.OUT

13,519 Stress-pt $135 \mathrm{max}-\mathrm{m}$. OUT

13,519 Stress-pt_135max-t.OUT

$6,443,068$ stress-pt $135 \mathrm{th}-\mathrm{b}$. OUT

$6,443,068$ stress-pt 135 th-m.OUT

$6,412,940$ Stress-pt_135th-t.OUT

13,519 Stress-pt $144 \mathrm{max}-\mathrm{b}$. OUT

13,519 Stress-pt $144 \mathrm{max}-\mathrm{m}$.OUT

13,519 Stress-pt $144 \mathrm{max}-t$.OUT

$6,443,068$ Stress-pt 144 th-b.OUT

$6,443,068$ Stress-pt_144th-m.OUT

$6,412,940$ stress-pt 144 th-t. OUT

13,519 Stress-pt $153 \mathrm{max}-\mathrm{b}$.OUT

13,519 Stress-pt $153 \mathrm{max}-\mathrm{m}$. OUT

13,519 Stress-pt $153 \mathrm{max}-\mathrm{t}$.OUT

$6,443,068$ stress-pt_153th-b.OUT

$6,443,068$ Stress-pt 153 th-m.OUT 


\section{RPP-RPT-32239, Rev. 1 M\&D-2008-005-CALC-001, Rev. 1}

09/02/2007 10:01 PM 09/03/2007 04:10 AM 09/03/2007 01:10 AM 09/02/2007 10:10 PM 09/03/2007 04:10 AM 09/03/2007 01:10 AM 09/02/2007 10:10 PM 09/03/2007 04:19 AM 09/03/2007 01:19 AM 09/02/2007 10:19 PM 09/03/2007 04:19 AM 09/03/2007 01:19 AM 09/02/2007 10:19 PM 09/03/2007 04:28 AM 09/03/2007 01:28 AM 09/02/2007 10:28 PM 09/03/2007 04:28 AM 09/03/2007 01:28 AM 09/02/2007 10:28 PM 09/03/2007 01:46 AM 09/02/2007 10:46 PM 09/02/2007 07:46 PM 09/03/2007 01:46 AM 09/02/2007 10:46 PM 09/02/2007 07:46 PM 09/03/2007 01:55 AM 09/02/2007 10:55 PM 09/02/2007 07:55 PM 09/03/2007 01:55 AM 09/02/2007 10:55 PM 09/02/2007 07:55 PM 09/03/2007 02:04 AM 09/02/2007 11:04 PM 09/02/2007 08:04 PM 09/03/2007 02:04 AM 09/02/2007 11:04 PM 09/02/2007 08:04 PM 09/03/2007 02:13 AM 09/02/2007 11:13 PM 09/02/2007 08:13 PM 09/03/2007 02:13 AM 09/02/2007 11:13 PM $09 / 02 / 200708: 13$ PM 09/03/2007 02:22 AM 09/02/2007 11:22 PM 09/02/2007 08:22 PM 09/03/2007 02:22 AM 09/02/2007 11:22 PM 09/02/2007 08:22 PM 09/03/2007 02:31 AM 09/02/2007 11:31 PM 09/02/2007 08:31 PM 09/03/2007 02:31 AM 09/02/2007 11:31 PM 09/02/2007 08:31 PM 09/03/2007 02:40 AM 09/02/2007 11:40 PM $09 / 02 / 2007 \quad 08: 40 \mathrm{PM}$ 09/03/2007 02:40 AM 09/02/2007 11:40 PM 09/02/2007 08:40 PM 09/03/2007 02:49 AM 09/02/2007 11:49 PM 09/02/2007 08:49 PM 09/03/2007 02:49 AM
6,412,940 Stress-pt 153th-t.OUT 13,519 Stress-pt 162max-b.OUT 13,519 stress-pt $162 \mathrm{max}-\mathrm{m}$. OUT 13,519 Stress-pt $162 \mathrm{max}-\mathrm{t}$.OUT $6,443,068$ stress-pt_162th-b.OUT $6,443,068$ stress-pt 162 th-m.OUT 6,412,940 Stress-pt_162th-t.oUT 13,521 Stress-pt $171 \mathrm{max}-\mathrm{b}$.OUT 13,521 Stress-pt_171max-m.OUT 13,521 Stress-pt_171max-t.OUT $6,443,068$ Stress-pt_171th-b.OUT $6,443,068$ Stress-pt_171th-m.OUT 6,412,940 stress-pt $171 \mathrm{th}-\mathrm{t}$. OUT 13,521 Stress-pt_180max-b.OUT 13,521 Stress-pt 180max-m. OUT 13,521 stress-pt $180 \mathrm{max}-\mathrm{t}$.OUT $6,443,068$ stress-pt_180th-b.OUT $6,443,068$ stress-pt 180 th-m. OUT $6,412,940$ stress-pt_180th-t.OUT 13,519 stress-pt $18 \mathrm{max}-\mathrm{b}$. OUT 13,519 Stress-pt $18 \mathrm{max}-\mathrm{m}$.OUT 13,519 Stress-pt $18 \mathrm{max}-\mathrm{t}$. OUT $6,443,068$ Stress-pt_18th-b. OUT $6,443,068$ Stress-pt 18 th-m. OUT $6,412,940$ stress-pt 18th-t. OUT

13,519 stress-pt 27 max-b.OUT 13,519 Stress-pt_27max-m.OUT 13,519 stress-pt 27 max-t.OUT 6,443,068 Stress-pt_27th-b.OUT $6,443,068$ stress-pt 27 th-m. OUT 6,412,940 stress-pt 27 th-t. OUT 13,519 stress-pt_36max-b.OUT 13,519 Stress-pt $36 \mathrm{max}-\mathrm{m}$. OUT 13,519 stress-pt_36max-t.OUT $6,443,068$ stress-pt 36 th-b. OUT $6,443,068$ stress-pt_36th-m. OUT 6,412,940 Stress-pt_36th-t.OUT

13,519 Stress-pt 45 max-b. OUT 13,519 stress-pt_45max-m.OUT 13,519 stress-pt $45 \mathrm{max}-\mathrm{t}$.OUT $6,443,068$ stress-pt 45 th-b. OUT $6,443,068$ stress-pt 45 th-m. OUT $6,412,940$ Stress-pt 45 th-t. OUT 13,519 Stress-pt $54 \mathrm{max}-\mathrm{b}$. OUT 13,519 stress-pt 54 max-m.OUT 13,519 Stress-pt 54 max-t. OUT $6,443,068$ stress-pt 54 th-b. OUT $6,443,068$ stress-pt 54 th-m. OUT $6,412,940$ stress-pt 54 th-t. OUT

13,519 stress-pt 63 max-b. OUT 13,519 stress-pt $63 \mathrm{max}-\mathrm{m}$. OUT 13,519 Stress-pt 63 max-t. OUT 6,443,068 stress-pt 63 th-b. OUT $6,443,068$ stress-pt 63 th-m. OUT $6,412,940$ stress-pt 63 th-t.oUT 13,519 Stress-pt $72 \mathrm{max}-\mathrm{b}$. OUT 13,519 Stress-pt $72 \mathrm{max}-\mathrm{m}$. OUT 13,519 Stress-pt 72 max-t.OUT $6,443,068$ stress-pt_72th-b. OUT $6,443,068$ stress-pt 72 th-m. OUT $6,412,940$ stress-pt 72 th-t. OUT

13,519 Stress-pt $81 \mathrm{max}-\mathrm{b}$.OUT

13,519 stress-pt $81 \mathrm{max}-\mathrm{m}$. OUT

13,519 Stress-pt_81max-t.OUT $6,443,068$ stress-pt 81 th-b. OUT 


\section{RPP-RPT-32239, Rev. 1 M\&D-2008-005-CALC-001, Rev. 1}

09/02/2007 11:49 PM 09/02/2007 08:49 PM 09/03/2007 02:58 AM 09/02/2007 11:58 PM 09/02/2007 08:58 PM 09/03/2007 02:58 AM 09/02/2007 11:58 PM 09/02/2007 08:58 PM 09/03/2007 03:07 AM 09/03/2007 12:07 AM 09/02/2007 09:07 PM 09/03/2007 03:07 AM 09/03/2007 12:07 AM 09/02/2007 09:07 PM 09/03/2007 01:37 AM 09/02/2007 10:37 PM 09/02/2007 07:37 PM 09/03/2007 01:37 AM 09/02/2007 10:37 PM 09/02/2007 07:37 PM 10/12/2006 02:29 PM 05/25/2005 03:32 PM 08/31/2007 11:06 AM 12/05/2005 10:51 AM 07/21/2006 09:41 AM 08/31/2007 11:07 AM 08/09/2006 07:43 AM 08/09/2006 07:31 AM 09/02/2007 02:32 PM 09/02/2007 02:33 PM 09/02/2007 02:33 PM 09/02/2007 02:32 PM 09/02/2007 02:32 PM 09/02/2007 02:32 PM 09/02/2007 02:33 PM $09 / 02 / 200702: 33 \mathrm{PM}$ 09/02/2007 02:33 PM 09/02/2007 02:33 PM 09/02/2007 02:33 PM 09/02/2007 02:34 PM 09/02/2007 10:05 AM 09/02/2007 10:05 AM 09/02/2007 10:12 AM 09/02/2007 10:12 AM 09/02/2007 10:18 AM 09/02/2007 10:18 AM 09/02/2007 10:25 AM 09/02/2007 10:26 AM 09/02/2007 10:33 AM 09/02/2007 10:33 AM 09/02/2007 10:39 AM 09/02/2007 10:39 AM 09/02/2007 10:46 AM 09/02/2007 10:46 AM 09/02/2007 10:53 AM 09/02/2007 10:53 AM 09/02/2007 11:00 AM 09/02/2007 11:00 AM 09/02/2007 08:54 AM 09/02/2007 08:54 AM 09/02/2007 09:02 AM 09/02/2007 09:02 AM 09/02/2007 09:09 AM 09/02/2007 09:09 AM 09/02/2007 09:16 AM
6,443,068 stress-pt 81 th-m. OUT $6,412,940$ Stress-pt_81th-t. OUT 13,519 stress-pt $90 \mathrm{max}-\mathrm{b}$. OUT 13,519 Stress-pt $90 \mathrm{max}-\mathrm{m}$. OUT 13,519 stress-pt 90 max-t.OUT $6,443,068$ stress-pt_90th-b. OUT $6,443,068$ stress-pt_90th-m. OUT $6,412,940$ stress-pt 90 th-t. OUT

13,519 Stress-pt_99max-b.OUT 13,519 Stress-pt $99 \mathrm{max}-\mathrm{m}$. OUT 13,519 Stress-pt 99 max-t. OUT $6,443,068$ Stress-pt_99th-b. OUT $6,443,068$ stress-pt_99th-m. OUT $6,412,940$ stress-pt 99 th-t. OUT 13,519 stress-pt_9max-b. OUT 13,519 Stress-pt_9max-m. OUT 13,519 stress-pt_9max-t.OUT $6,443,196$ stress-pt_9th-b.OUT $6,443,196$ Stress-pt 9 th-m. OUT $6,413,068$ stress-pt_9th-t.OUT

4,009 Tank-Coordinates-AP.txt

2, 512 Tank-Mesh1.txt 102 tank-out.out

5,495 Tank-Props-Crack.txt 5,591 Tank-Props-Rigid.txt 4,973 Tank-th. out

23,166 TH-266-Mean-Geo-V.txt

23,166 TH-266-Mean-Geo.txt

561,576 vel-ct-0.out

561,576 vel-ct-135. out

561,576 vel-ct-180. out

561,576 vel-ct-45.out

561,576 vel-ct-90.out

290,550 vel-ct.out

561,576 vel-PT-0.out

561,576 Vel-PT-135. out

561,576 Vel-PT-180. out

561,576 Vel-PT-45.out

561,576 Vel-PT-90.out

561,576 vel-Soil.out

10,180 waste-Cont $108 \mathrm{max}$. OUT 4,875,649 Waste-Cont 108 th. OUT 10, 180 Waste-Cont $117 \mathrm{max}$. OUT $4,875,649$ waste-Cont_117th. OUT 10,180 waste-Cont $126 \mathrm{max}$.OUT 4,875,649 Waste-Cont 126 th. OUT

10,180 Waste-Cont_135max. OUT

4,875,649 Waste-Cont 135 th. OUT

10,180 Waste-Cont_144max. OUT

4,875,649 Waste-Cont 144 th. OUT

10,180 waste-Cont $153 \mathrm{max}$. OUT

4,875,649 Waste-Cont 153 th. OUT

10,180 Waste-Cont $162 \mathrm{max}$. OUT

4,875,649 Waste-Cont_162th. OUT

10,180 Waste-Cont $171 \mathrm{max}$. OUT

4,875,649 Waste-Cont 171 th. OUT

10,180 Waste-Cont $180 \mathrm{max}$.OUT

4,875, 649 Waste-Cont 180 th. OUT

10,180 waste-Cont_18max.OUT

$4,875,649$ Waste-Cont 18 th. OUT

10,180 Waste-Cont $27 \mathrm{max}$. OUT

4,875,649 waste-Cont 27th.OUT

10,180 Waste-Cont $36 \max$. OUT

4,875,649 Waste-Cont_36th. OUT

10,180 Waste-Cont $45 \mathrm{max}$. OUT 


\section{RPP-RPT-32239, Rev. 1 M\&D-2008-005-CALC-001, Rev. 1}

09/02/2007 09:16 AM 09/02/2007 09:23 AM 09/02/2007 09:23 AM 09/02/2007 09:30 AM 09/02/2007 09:30 AM 09/02/2007 09:37 AM 09/02/2007 09:37 AM 09/02/2007 09:44 AM 09/02/2007 09:44 AM 09/02/2007 09:51 AM 09/02/2007 09:51 AM 09/02/2007 09:57 AM 09/02/2007 09:57 AM 09/02/2007 08:24 AM 09/02/2007 08:24 AM 09/02/2007 08:08 AM 09/25/2006 10:41 AM 10/12/2006 02:27 PM 08/21/2006 08:03 AM 09/02/2007 02:10 PM 09/02/2007 02:10 PM 09/02/2007 02:21 PM 09/02/2007 02:21 PM 09/02/2007 02:22 PM 09/02/2007 02:22 PM $09 / 02 / 200702: 23$ PM 09/02/2007 02:23 PM 09/02/2007 02:24 PM 09/02/2007 02:24 PM 09/02/2007 02:25 PM $09 / 02 / 2007 \quad 02: 25$ PM 09/02/2007 02:26 PM 09/02/2007 02:26 PM 09/02/2007 02:27 PM 09/02/2007 02:27 PM $09 / 02 / 200702: 28$ PM 09/02/2007 02:28 PM 09/02/2007 02:29 PM 09/02/2007 02:29 PM $09 / 02 / 2007 \quad 02: 29 \mathrm{PM}$ 09/02/2007 02:29 PM 09/02/2007 02:12 PM 09/02/2007 02:12 PM 09/02/2007 02:13 PM 09/02/2007 02:13 PM 09/02/2007 02:13 PM 09/02/2007 02:13 PM 09/02/2007 02:14 PM 09/02/2007 02:14 PM 09/02/2007 02:15 PM 09/02/2007 02:15 PM 09/02/2007 02:16 PM $09 / 02 / 2007 \quad 02: 16 \mathrm{PM}$ 09/02/2007 02:17 PM $09 / 02 / 2007 \quad 02: 17 \mathrm{PM}$ 09/02/2007 02:18 PM 09/02/2007 02:18 PM $09 / 02 / 2007 \quad 02: 19$ PM 09/02/2007 02:19 PM 09/02/2007 02:20 PM $09 / 02 / 2007 \quad 02: 20 \mathrm{PM}$ 09/02/2007 02:11 PM 09/02/2007 02:11 PM
4,875,649 waste-Cont 45th. OUT 10,180 Waste-Cont $54 \mathrm{max}$. OUT 4,875,649 Waste-Cont 54th.OUT 10,180 waste-Cont_63max. OUT 4,875,649 Waste-Cont_63th.OUT 10,180 Waste-Cont $72 \mathrm{max}$. OUT $4,875,649$ Waste-Cont_72th. OUT 10,180 waste-Cont $81 \mathrm{max}$. OUT 4,875,649 Waste-Cont 81 th.OUT 10,180 Waste-Cont 90 max. OUT 4,875,649 Waste-Cont 90th. OUT 10,180 Waste-Cont_99max.OUT 4,875,649 waste-Cont 99th.OUT 10,180 Waste-Cont 9 max.OUT 4,875,777 waste-Cont 9th. OUT

45,117 Waste-Reaction-460-SD3. out 340 Waste-Reaction.txt

10,266 Waste-solid-AP-S.txt 776 Waste-Surface-AP.txt 865 Waste-Surf_Omax.OUT

534,133 Waste-Surf-Oth.OUT 865 Waste-Surf_108max.OUT

534, 005 waste-Surf 108 th. OUT 865 waste-Surf_117max. OUT

534, 005 Waste-Surf 117 th. OUT 865 Waste-Surf_126max. OUT

534, 005 waste-Surf_126th. OUT 865 waste-Surf $135 \mathrm{max}$. OUT

534, 005 Waste-Surf_135th. OUT 865 Waste-Surf $144 \mathrm{max}$. OUT

534, 005 Waste-Surf 144 th. OUT 865 waste-Surf_153max.OUT

534, 005 waste-Surf 153 th. OUT 865 waste-Surf_162max. OUT

534, 005 Waste-Surf 162 th. OUT 865 Waste-Surf $171 \mathrm{max}$.OUT

534, 005 Waste-Surf 171 th. OUT 865 Waste-Surf $180 \mathrm{max}$. OUT

534, 005 waste-Surf 180 th. OUT 865 Waste-Surf $189 \mathrm{max}$.OUT

534, 005 waste-Surf 189 th. OUT 865 waste-Surf 18max. OUT

534,005 waste-Surf 18th.OUT 865 waste-Surf $27 \mathrm{max}$. OUT

534,005 waste-Surf 27th. OUT 865 Waste-Surf $36 \mathrm{max}$. OUT

534,005 Waste-Surf 36 th. OUT 865 waste-Surf $45 \mathrm{max}$. OUT

534,005 Waste-Surf 45 th. OUT 865 Waste-Surf $54 \max$. OUT

534, 005 waste-Surf 54th.OUT 865 waste-Surf 63 max. OUT

534,005 waste-Surf 63th.OUT 865 waste-Surf $72 \mathrm{max}$. OUT

534, 005 waste-Surf 72 th. OUT 865 Waste-Surf 81 max. OUT

534, 005 Waste-Surf 81 th.OUT 865 waste-Surf 90 max. OUT

534, 005 waste-Surf 90th.OUT 865 Waste-Surf 99 max. OUT

534,005 waste-Surf 99th.OUT 865 Waste-Surf 9 max.OUT 534,005 Waste-Surf 9 th. OUT

615 File(s) $37,553,864,623$ bytes

$3 \operatorname{Dir}(\mathrm{s}) \quad 157,616,623,616$ bytes free 